

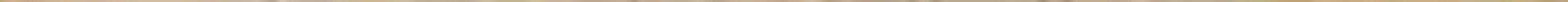




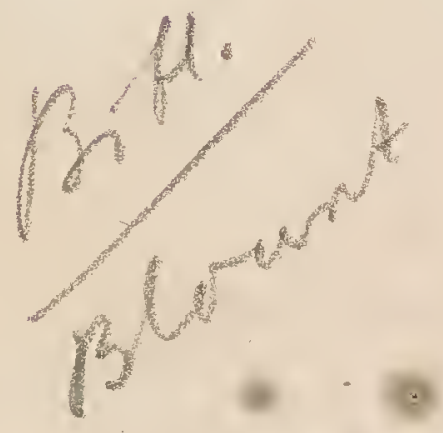

c 





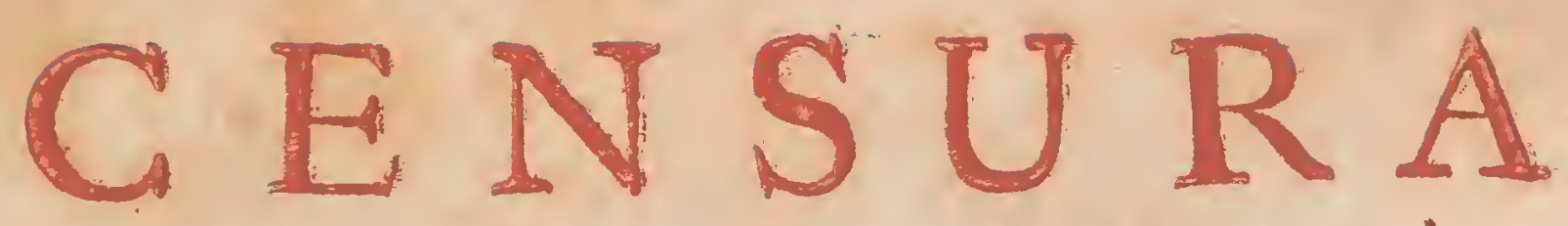

\section{CELEBRIOR UM}
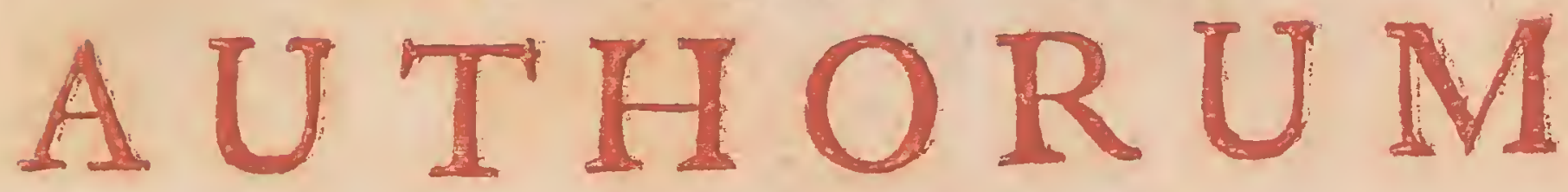

\section{SI T E}

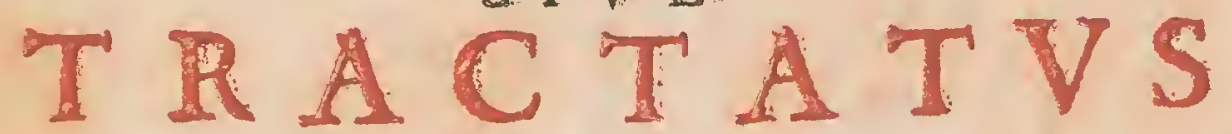

I.N: QVO WRIA VIRORVM DOCTORVM DE Clariffmis cujugaue Seculi Scriptoribus Iudicia traduntur.

IINDEACILIMO AEGOTIO LECTOR DIGNOSCERE quear quid in .ringulis quibufque Iftornm Authorum maximè memorabile fit, \& quonam in pretio apad Eruditos femper habiti fuerint.

OMNIA IN STUDIOSORUM GRATAM COLLEGIT, ET IN ordìzem digentit fecundùn feriem Temporis çuo Ipli Authoreffloruernnts

\section{THOMAS-POPI BLOUNT. Añglö-Bürizannus Bàronetzus:}

E⿱

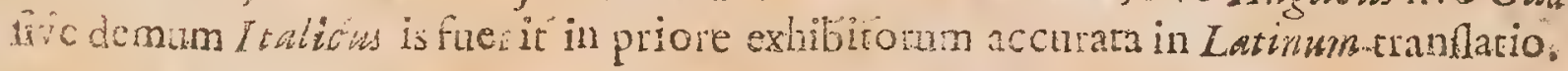

Curn INDD IC E locupléisisimo.

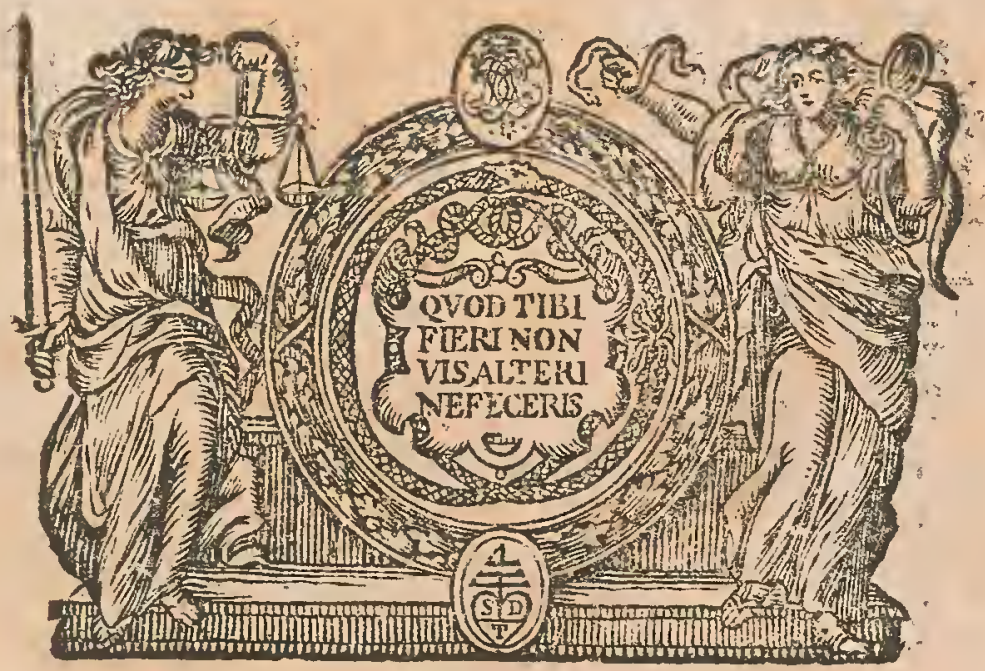

COLONIC AROOBROGYM.

Apud SAMVELEM DE: TOVRNES. 

PR EFA I IO

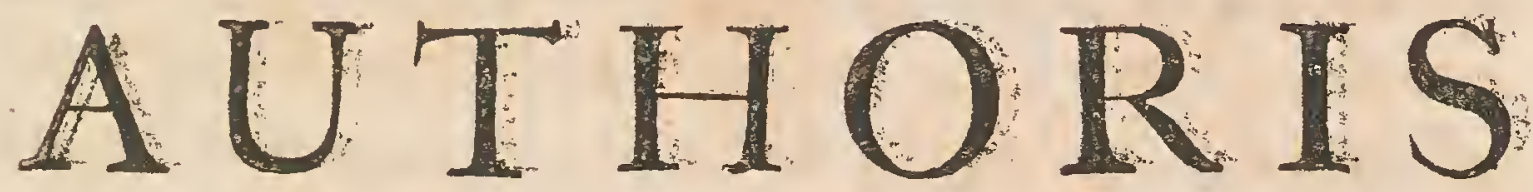

A: $D$
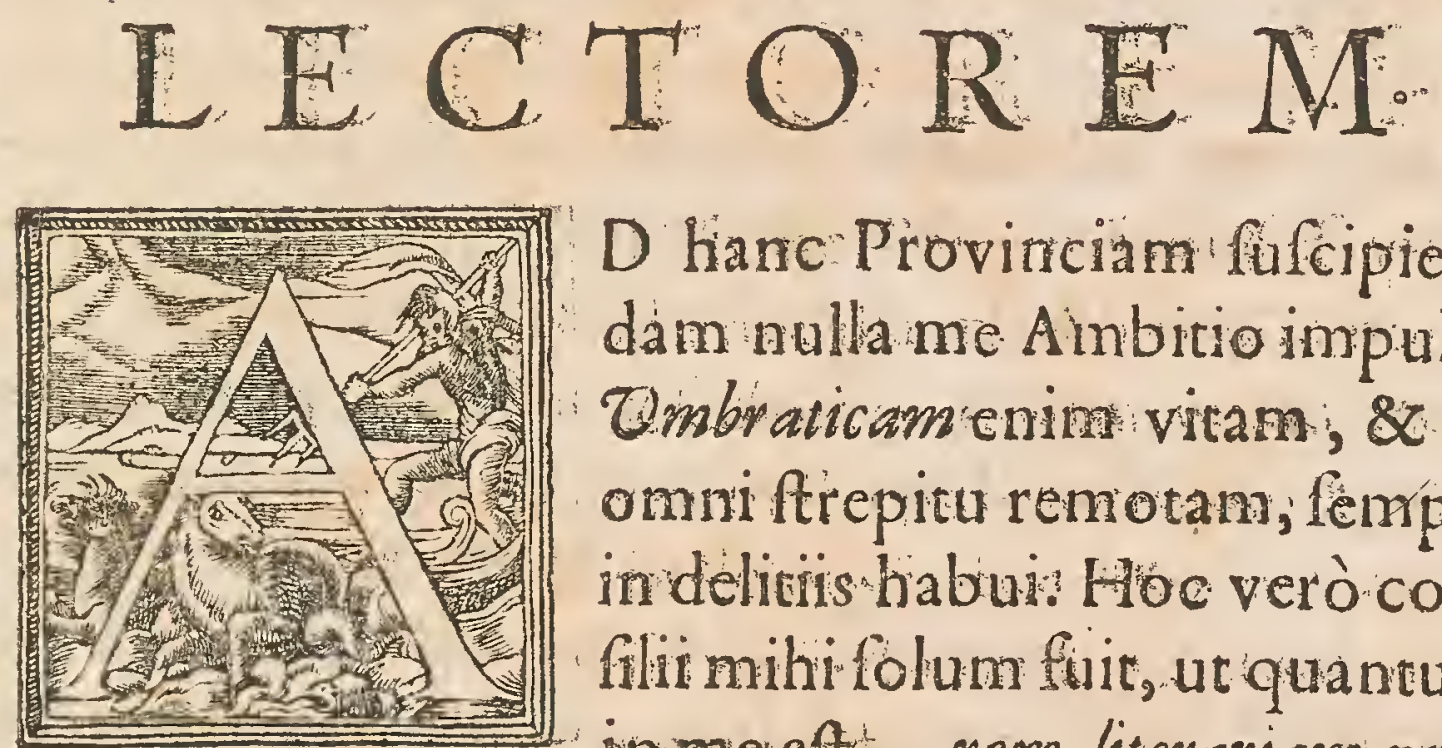

D hanc Provinciam fufcipiendam nulla me Ainbitio impulit; Umbraticam enim vitam; \& ab omni ftrepitu remotam, femper. in deliciis thabuin $\mathrm{H}$ loc verò confilii mihi folum fuit, ut quantum: in me eft, reme literariam pro.moverem: Qurum hoc Opus primùm occepir, itlud Orbi literario communicare haud mihi in animo: erat; ad meum ufúm folummodò congeffi : : Nunc verò, hortantibus viris eruditione claris, in vulgus: emitto. Equidem quum obfervarem quàm avidè: Acta Errditorum, aliofque id genus libros arripe- 


\section{PRAFATTO.}

rentHomines, non folùm qui infimum fubfellium occupane, fed qui primum inter eruditos locum tecent, non poffum non (perare hanc meam qualemcunque farraginem ipfis non omninò ingratam fore. Doctrina non finefummo Atudio \& vigilis paratur. Putare Homines Divino eAflatu doctos fieri, Fanaticorum eft ; etiam Poeta frufera nafcitur, nifi ad præclaram Indolem acceflerit Induswia. Acque hinc eft, quòd pauci revera docti fine [ quicquid crepent scioli ] quoniam laborem atque operam ferre nequeunc. Vt auter maximum, quantam fieri poceft, fruatum ex lectione perciperes, quendam tibi Authorum delectum, deque iis varia Doctifinorum Hominam judicia propofui; quge finter fe diligenter contuleris, \& tunm ipte judiciun acuere $\&$ confrmarepoteris, \& nunquan in nullius pretii Scriptoribus evolvendis oleum atque operan perdes. Quod enimad ipfras Operis rationem Pectat hôcle maximè nomine commendat, quòd inde tibi Biblosbecam intruere pollis; quam ad rem Notitia Aniorum apprimè utilis ac neceflaria; qua nifi adfuerit, rapè event, ut Homines in libris comparandis \& tempore fimul \& nummis fraudentur. Huic igitur incommodo ut occurrerem, hanc laborem exantlavi. Habes enim hîc quandam quali magainem cujulque Autoris: Vnde deprehendere poffis 


\section{$P R \notin F A T I O$ :}

poffis quando floruerit, \& plerumque etiam quando obierit ; quxnam fuerint ab ipfo fcripta, vel faltem qux primum obtinuerint locum; quâ valuerit $\mathrm{Au}-$ toritate in Orbe literario; num Tlagiarins fuerit, \& cujus Scrinia compilaverit; num prohibicus fit $/ n-$ dice Expurgatorio; Denique, quænam fut oprima cujufque Autoris Edicio. Omnia hac uno intuitu videbis, fi hunc librum evolvere digneris. Haud mihi eft in animo de omnibus eftroribus univerfm dicere, nimis hoc prolixum foret; fed de iis folum, qui apud eruditos maximi æitimantur. Inicium fumpli ab Fermete Trifmegifto; non illo quidem ficticio qui vulgò circumfertur ; fed vero illo, atque genuino, quem Shof coxvum fuife putanc; arque inde ad noftra ufque tempora defcendo. Autores, quos adduxi, funt propè fexcenti. Horum quifque juxta feriem Temporis locum habet. Hac mibi Methodus maximè placuit, quia tibi magis gratum fore putabam, fuxus \& refluxus Doctrins obfervare, quàm Ordinem Alphabeticum percurrere; Quod magis Dietionarii quàm Hiftoric Literarix fpeciem praberet. Miraberis fortaffe, Lector, quòd in tantâ præclariffimorum Scriptorum copiâ qui apud nos in Anglia floruerunt, tam paucos hîc attigerim. Si verò $x q u \hat{a}$ lance rem ponderaveris, me hac in re penitus excufatum habebis. Scriptores enim inti maximam par- 


$$
\text { P. R F T T : O }
$$

tem in vernaculâ linguâ: fcripferunt indeque factum

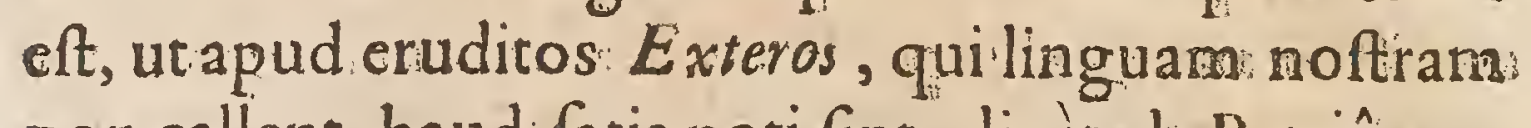
non callent, haud: fatis notifint, licèti de Patriâ now Arâ optimè meruerine, maximamque famam fibi domi comparaverint. Hocigitur incaufa eft, quòd de Scripiorsbus Anglicis judicia aliquot; cenfuras., five obfervationes inter literatos [ Exteros prafertim] seperire haud facile fuerit. Hócmodô Methodum bujus operis tibi explicuis Si diligentiam noftram in conquirendis reftimonils tibi probarianimadvertero, multùm mihi gratulabor ; fin aliter, pro hâc vice: milak veniam dabis, te iterum non interpellabo. 


\section{E D I T O R.}

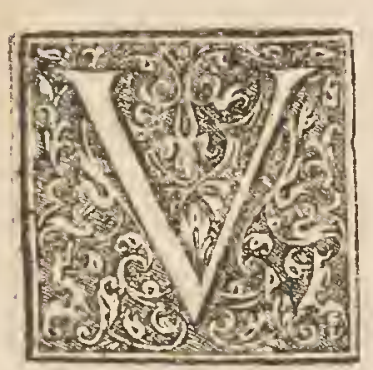

Is $\mathrm{M}$ eft milbi opere pretium fore, of quamplusima de Authoribus judicia, que Nobiliffmus Scriptor Thomas Pope Blowont, feve ut $\int e$ polyglotum proderet five potius ne cujupiam immulationis arguerctur, Vernaculà Erudito. rum é quorum foriptis ea depromperat lingud, hic paffim exhibuerat, Latinitate donari curarem; qui toti Literatorum vulgo, non femper omnium qua per Europam obtinent Linguarum Callenti, eximium iffud opus abfque interpretis ope conduceret. EDoc Volebam, Candide Lector, Vsere co fruere. 


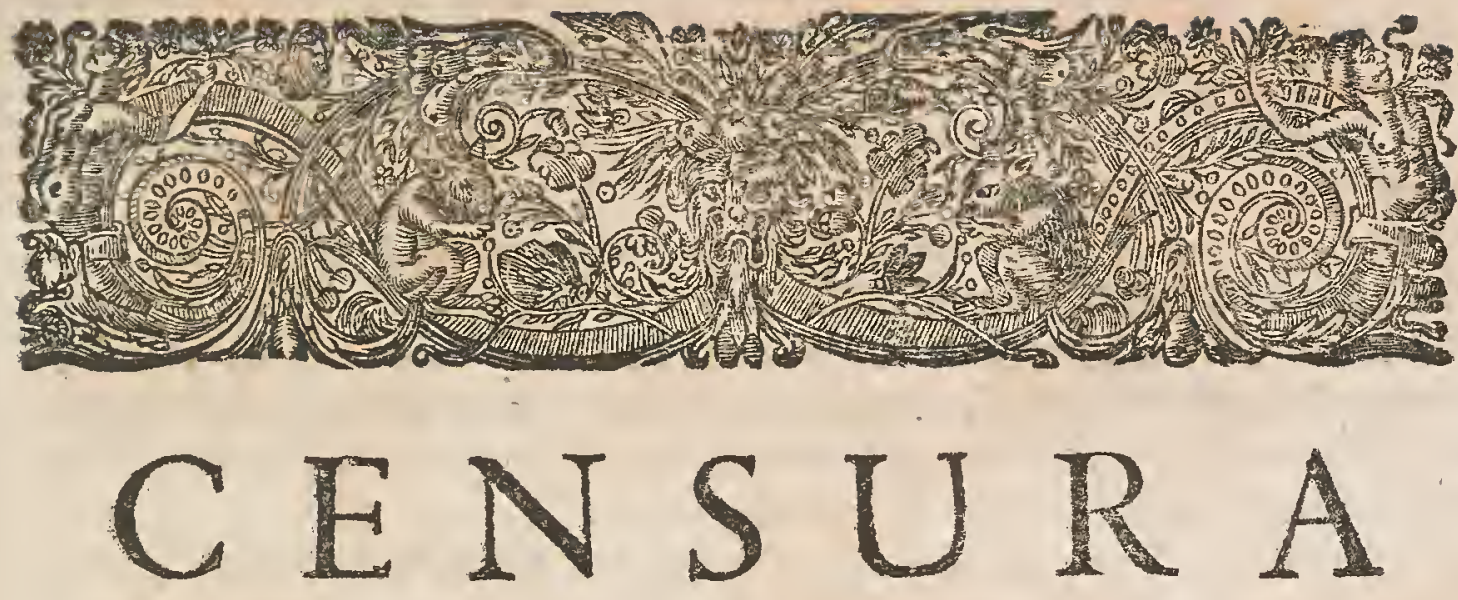

\section{E LEBRIOR V M}
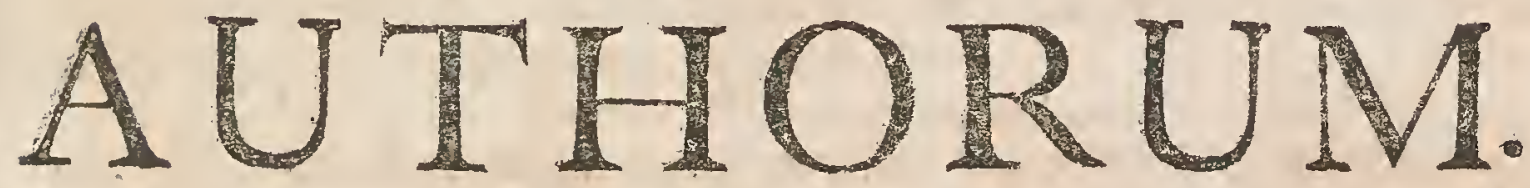

कोeg

\section{HER MES TRISMEGISTUS.}

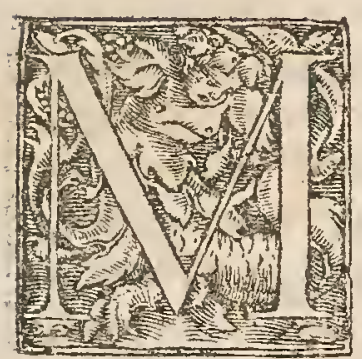

OS I S requatis fuilfe memoratur. Diodor. Sicul. lib. to Mercurium apud Ofiridem fummo in honore fuiffe, intimum cjus confliariusin \& \&acrum fcribam refert。 Juxta Eufebium esgyptiis Thoyth dictus erat. lamblicus de $M$ inAcr. Agypt. litcras a bo repertas, \& multa librorum millia confcripra effe memorat.

Atgytius fuit Mercurnzs, Grecè Hermes, qui ideò tero$\mu$ 'ylsos hoc eit, ter maximurs nuncupatus, quòd maximus Philofophus, maximus Sacerdos, maximus Rex exticerit. Nam. ut "laro fcribit, mos erat Egytiis ex Thilofophis Sacerdores, \& ex Sacerdotibus Reges eligere. Lil. Greg. Gyrald. in Dial.rr. de Poet. Hik.

Suidas rit, climforuiffe ante tharaonem, ac ter Maximumappellatum, quowỉam de Trinitate oraculum edidiffet : fed eA uguffin. de Civit. Dei lib. I8.cap. 39. cvincit Mercurium hunc vixifle etiam poft iptum Mofen, Deum Pharcanis, ut illum ex hoc haufite, qux dixit, fi qua ad rem dixerit, credendum fit.

Eufeb. de P'repar. Evang. 1.7. citat ejus librum de Origine Mundi. Illud quoque ex Ansignis conftat, eum doctrinam fuam, ne inundatione Nili peritet, columnis infculprife, quas fujo tempore adhuc extitifle, Procl.comment. in. Platon. seferto 
Artapanus apud Euseb. de Prepar. Evang. 9. 4. fcribic, Mofen Inventorem li= tcranm apud $\& g y$ tios fuiffe; ideoque ab illis divino Honore cultum, \& $\mathrm{Mer}$ curium appcllatu meffe.

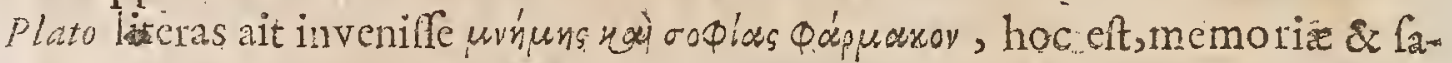
pientix remedium, in phedr. \& Pbileb.

Cicerv in lib.3. de Natur. Deorum dicit, Mercuriurn E Egypto prefuiffe, atque e Egyptiis leges \& literas tradidific.

Diod.Sicul libr. I. lefert, Mercurium docuille Grecos ted a tionem explicandi fenfa animi, ac proptereà épusiv, hoc ef, Interpretem ab illis dictum Iamblic auctor eft, Egypitos scriptores, putantes omnia inventa elle Mercuric fuos libros Meriurio infiripfife. Iarnbl. 1.1. de Myfer.

Qui tamế homo, fait tamén antiquifiraus \& inftuctifmus omni "gencre. doćtrina: adeo ut ei multarum rerum, \& Artium fcientia, Trifregifri cognomon imponeret. Hic feripfit libros, \& quidem multos, ad cognitionem divinnarum rerum pertinentes, in quibus Majeftatem fummi ac fingularis Dei aflerit : iildemque nominibus appellat, quibus nos, Deium, \& Patrem; ac. ne quis nomen ejus requireret \&́wupov cfie dixit; co quòd nominis propriétate non. cgeat, ob ipfam fcilicet unitatem. Laclant. lib. I. cap. 6.

Myferia in co [Mercurio] multa Arcana noftre legis; etri Egyptiurs fuilfe traditum fit, nec imbutum yeris facris Lipf, Epift. cent. I. Mifcell.Epilt. 90. Sed Prophanos ut omittam, Sacri Scriptores huc ctian eunt. Liceat Term. Maxum inter cos recenfere, cujus Philofophia valdè cun Mofaica ( in multis quidem) confentit. Lips: Phyjol. Stoir. lib x. Differtat. 6 ...

Librum integrum, qui łub no mine Trifrnegific circumferri ab aliquot feculis cepir, non veremur pronunciare, \& ommi affeveratione confirmare, effe

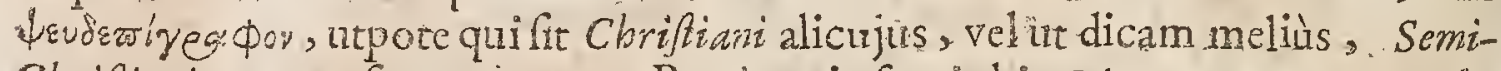
Chrifiant merum figmentum.-.-. Porrò quis fucrit hic Alercurtus, aut quandovixerit, omitto quarere. Confut literarum \&: omnium fciéntiärum inventionem ad itum referri folitam.Ca aub.Exercit.r.ad Apparat. Annal.Baron.Sect.ro.

Quodam tempore Hermes Trifruegifus, cum in e Aigyto Cacrum quoddam Animal, Serapi dicatum in totâ die duodecies urinam facere, parifemper temporis intervallo, obfervalfet, per duodecim horas Diem dividi debere conjecit. Exinde hic horarum numerus longo tempore cuftoditus, poftea in viginti quatuor hom. as divifus eft dies. Polyd. Verg. de Rer. Invent. 1.2. cap. 5:

\section{H ES I O L U.S.} Claruitante Omerus antè Chrifum 907. Hejzodus 37. annis Artis für fpecimina pu. Ann. II blicè edidit ante Flomerum. Ioan. Seld.Marmor. Arundel. De ætate verò - cccexs Homeri \& Hefiodi non convenit inter veteres.

Natus fuit in Afcra Boeotii vico unde \& Afcrous dictus. Hic milfus à Patre, qui Cumis pulfus Afcram concefferat, ad ovium cuftodiam, dormicins fomnia-

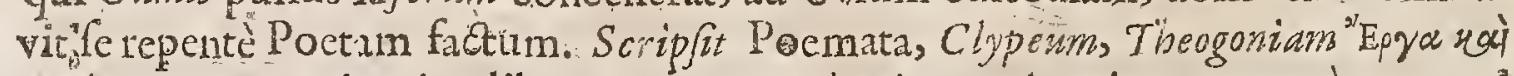

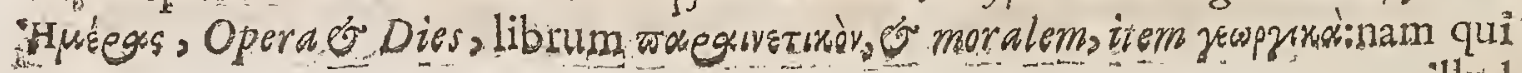
illid. 
"lfua unum \& idem opus elle cum Eprois putant. valde falluntur. Hofrn.in Lexic. Vir fuit perelegantis ingenii, \& mollifimâ dulcedine carminum memorabitis, otil quietifque cupidifrmus. Vell Paterc.lib. I.p.29.

Scriptor purifimus; \& qui optima virtutis continet pracepra.Dan. Heinfius. Illud certum eft, Homerum \& Hefodum parentes \& magiftros Græcæ Pö̈- eos meritò dici. Ioan. Andr. Quenft.

Major.finplicitas \& rudier antiquitas in $H$ efodo compare t, quàm-in Homero. Iifs: in Velleium Paterc.

Raro alfurgit Hefrodus, magnaque pars ejus in nominibus occupata eft, thmen utiles circa pracepta fententix lenitafque verboum, \& compofitionis probabilis: daturque ei palma in illo medio genere dicendi.Quintil.1.ro.Cap.r.

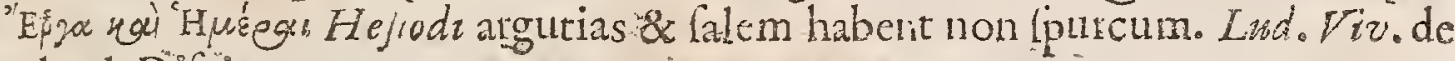
Tradend. Difcip.

Genealogia Deorum Hefrodi ad intelligentiam Poctarum utilis, catcra futilifima. Io. ibid.

Scribit $P$ anfanias, ejus carmen adhuc tuo tempore in plumbeis tabulis in Mufartun templo (cujus facerdos Hefiodu fuit) fervatum fuifl.

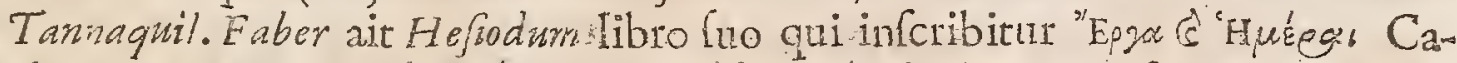
lendariorum autores noftros imitatum elle, qui fautos \& infaufos dies inter dum rotant:fed Opus illud, frattentius confideretur magni momenti non elfe. Epir. vit.l'oet. Gro Gallice.

Reliquifcriptores qui Mormm pracepta \& leges tradidere, propter infantiam \& fermonis inopiam, vim firtutis,ac formam germanam non potuerunt nobis ob oculos poiere. Ax Hefodus expreflam quandam imaginem, vivisillufratam coloribus, nec adfititio vitiatam fuco,planeque talem, qualcm Apellis color in

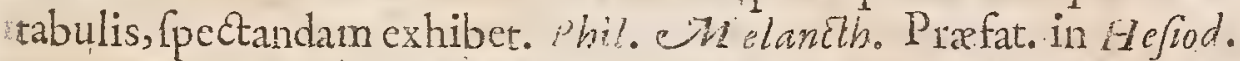

Genus dicendi medium \& aquabile amat, nec humilitate nimia jacens, nec fuperbè tumidum, quod probè obfervatum D. Halisarnafj. Opera cjus \& Dies adeò pruderter \& doetè fripta funt, ut hodieque ex lectione eorundem proficcre valeant non Ethrici cantum \& olicici, fed \& Oeconomi, Naucleri, Agricole. Quodad Theogoniarsin fpeciem quidem illa Deorum multitudinem infunuat, fed obfervant nature rerum ftudiof, fub inv olucris ift is fabularum (ape philofophicas collectiones recondi, quod \& jam olim Plutarch animadverfum. Unum profpiciendum juventuti chriftans, ne fidem illis nimium alliget,qux de difinctione \& obfervatione fuperfitiosâ certorum dierum admilect. Borrichide Poetis,p.ro.

Hefrodis multa ex Mufae deprompfit. Clem. Alexand. lib. 6. Strom.

Qui Theogoniam Hefzodi legerit, meminerit corum, quæ Epiphanizeolitra Valcntinianos five Gnoficos fcripft, qui, quod Theogoniam Hefrodiztrigintaque alla fecula funt imitati, in abfurdilimas Here es inciderunt. Et ô borun (exclamat Epiphanius) nugacitaken có tantam vanitatem, qui conjugârunt poeticis, \& gentilibus fabulamenis fuam ipforwm ingacitatem. Ac paulo poit idem Epphanius oftendit ex Hefiodo, Orpheo, ac Stefichoro innumeros illos" "qui apud iplos Dii nominantur, fluxille, id quod \& Irenens pradixerat ex Apofrolo, re 


\section{CENSURA}

prehendense cos, qui fermonibus fallis, \& Genealogiis van:s, atque intermo hatis futuri erant ut intenderent. At non ipf 1 tantum Chrifliane Ecclefie $P$ a tres, venum etiam ali habuere ubi Hefodum carperent. Extat etiam Luciani: Dialogus, quil Hefodus infaibitur, in quo Hefrodism de fe multa narrantem inducit, eumque iple, ut folet, irridet; extantque ideò Epigrarmata in $H$ eficdum plua. Praterquam quòd noctim Proverbium illudeft de iis quifuperfemefcunt, Hijodia Senedta de quo \& Pindari diftichon habctur. Ant. Pollev. Biblioth. Sclect.

Editio Hefioded latdatur H. Stephanis:Danielis Heinfi, \& G. Paforis, cui Lexicon Hefiodeurn adjunctum on Quas tamen amnes hauddubiè Graviana Guperaverit.

\section{H. O M E R U S.}

Clar. ante: Chrift Ara. Decceviro
A 7 ON minus obfcura fuit Homeri xtas, quàm aut illius Patria aut Parertes; de quâ erat olim quxtio \& vetutifima \& celeberrima, \&adhuc fub. judice lis effet, fin non auctoritare noftri marmoris dijudicata fuiffet. Floruit Homerws fub Diogneto Athenanum Rege, Anno Attico 676. Per. Iuliane $3807^{\circ}$ annis port Troja cladem 302. antequàm Olympia ab: Iphito \& Lycuigo inftaurata funt, anuis 23. antequam Corcebus ftadium vicerit, anuis I3I. De êे igi turre non eft ampliùs ambigendum. Ioan.Marsham. in Chronologia:

Apud Gracos nullum invenitur friptum, de quo confet, quad fit Homer: carminibus antiquius. Io eph. contra Appion. lib. I.

Hornerus quidem primus dootrinaram \& Antiquiratis parens. Plin. lib:25. c. 2. Honserus divinarm omuium inventionum fons \& origo Macrob. in fomn. Scip. lib. 2.c. 10.

Clarifmum deinde Homeri illuxit ingen ïm, finc exemplo maximum : qua: magnitudine operum, \& fulgore sarminum folus appellari Poeta meruit. In: quo hoc maximum eft, quod neque ante illum, quemille imitaretui, neque pof illum, qui eum imitari poffet, inventus eft. Vell.Paterc. 1. I. c. So:

Ut A ratus ab love incipiendinm putat, ita nos ritè copturi ab Homero videmur. Hic enim (quemadmodum ex Oceano dicit iple amnium vimfontiumque curfus initium eapere) omnibus eloquentia: partbas exemplam \& ortum dedit. Hunc nemo in magnis fublimitate, in parvis proprietate fupe raverit. Idem latus ac prefus, jucundus \& gravis, tum copia tum brevitate mirabilis : nee pocticâ modò fed oratoriâ virtute eminertifimus. Quintil. 1. xo.eap. I.

Homerus ille nofter divinx fapientia quidam Oceanus. Angel Politian. prefat, in Charmidem Ilatonis.

Homermx omniuri xtatum fapientes funt demirati. I aac Ca aub. in Epift. Qui Homerum contemnunt, vix illis optari quidquam pejus potefi, quàm ut Satuitate fuâ fruantur, Idèm in Differtat. de Homero.

Nemo tam confe tienti judicio fapientum omnis avi laudatus eft: \& id ab iiss 


\section{CELEBRTORVM AVTHORVM:}

Iis quipfilaudatimi. Abi igitur Imperititia aut I vor: tu capere, ta carpere non potes. immortalem hanc cceleftemque naturam, Lips. Animadverf. in. loc. predic. Vell. l'aterc.

T'luterchus lib. $2^{\text {? }}$ de Éomero, omnium artium, Pbyice; Medicine, Politice, Ethice, Eloguentir; reimilitarifemina Homero inefle affirmat..

Inter omues precipuè celebrata Ilias \& Odylea, in quibus totius Philofophix, \& artis Uatotis, necnon Paetices lumina confpiciantur. Lil. Gyrald. de Poetis.

AElianus fribit Agatbonem pictorem quendam Homerum pinxilfe vomen em, reliquos vero Poetas, ea: qux ipfe evomuiffet, exhaurientes.

Idem Author memorat Horrerum ab Indis in ipforum lingulam converfum affe. Ei etiam à quibuldam templium extructum.. Elian..in var. Hiftor.

In illo verò culpandus maximè Homerns eft, ( ut \& Hefrodus, Ovidiăs, ac: reliqua ferè omnis $l^{\prime}$ octarum Gentilium turba) quò deò dementiæac impietatis. proccllerit, ut non tantùm augeret mirum in modim Deorum numerum, fed \&: arpia quavis de Diis comminifceretur, illifque ftupra,adulteria, inceftus, contentiones, pugnas, cædes, homicidia, furtatribuerit, hoc eft, tales Dos Dea qu fingeret, quales cives honefta Refpublica nequaquam ferret. Ioan. Quen/t..

Alexander Macedo, ille orbis. Monarchas tanti fecit Homerum, ut ejus Mliam. da Divinum Poema a reimilitaris viaticum vocaret; imò Scriniolo, ex Dari fpolis auro gemmifque pretiofifimo, adfervaret, noctu cervicali unà ctum pugione fubjiceret, aum eo vigilaret, cumeo dormiret.

Baflins Magnus univerfam Horneri poefin laudem dixit effe virtutis..

- Duo fagaciores in Hornero folent improbare , unum, quòd otiofus Epithetis, \& aliquandoincptis, fepectiam digrefífonibus, \& colloquiis frigidis non abPinuerit; alterum quò impuraquandoque \& indigna tradiderit de Diis : pro mum excufabitipla tum artis nafcentis infantia, aut certè adolefcentia nondum confitmata; fecundum etiam cordatioribus antiquorum Ethricoram difplicuit: Quippe Hieronymus Philolophus apud Diogenern Laertium narrat; Pythagorian apud Inferos vidilfe animam Hefrodicolumna ærex alligatam, fridentemque. oppidò ; illam verò tomeri ab arbore fufpenfam, dirifque circumdatam ferpentibus, quòd tan foda uterque de narura divinâ prodidifet. Borrich. de Petis pag. 9.

Multa ex: Orpheo depromplit Homerus; Clem.Alex.lib. 6. Strom:

Homerus Iliadum librorum argumentum defumplit ex libris Corinni Poeta Epici, quiprimus Iliadem cripfit tempore Belli Trojani.Vide Suid. in voc. Corin.

Homerus omnem Poefm fuam ita fententis farfit , ur fingula ejus Apophtheg mata vicem proverbiorur in civum ore fungantur. Macrob. 1.5. Saturnal inG.

Editiones : Iomeri pluimæ funt, quas inter praftantiores habentur Romana? Stephanicna, Argentoratenfis. Nec damnanda ultima screvelii, quicquid etiam Moneadem defideret Lerisus Cajabonus peculiari Cripto.

$$
\text { A. } 3 \text { OCEL }
$$




\section{EN S V R A \\ OCELIUSS IUU C.ANUS.}

Quando floEurerit nonliguet.

A Níiquus Philofophus quo tempore foruerit, noudum confat inter erre L ditos. Libellum reliqüit de Vniverfinaturã : quem Latinè tranftulit Ludovicus $N$ ogarola. Hunc vero emendatiflimè cdidit vir doctiffmus Thonas Gale Contabr. An Dom. 1670 in opueulis.

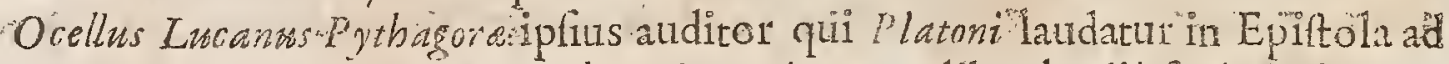
Archytam, nominatur Plizloni Iudao, \& Iuciano: \& liber hodie fanè doctus extat de Tniverfi naturâ. Iust. Lipf. mànduct ad Stoic.P.hrlof. lib. I. Dif. 6.

Cxterum funt qui tradunt opinionis huits [ de Mundo non intcrituro] non Arifotelern primum a storern, fed Pythagoreos quofdam fuilfe. At mihi Ocelli 'genere Lucaninfcriptum de Univerfi naturâ commentarium oblatum eft, in "quo quidem mustum effe ingenitum, "\& nunquam interiturum non folum proiulit, venum etiam exquifitifrmis rationibus comprobavit. Phil.Iud.inlib. de mundo an interitura.

Diogenes Taeritus quandam Archyta Tarentini, quxe eft ad Platonem, EpifoLam vita îlius inferuit, in quâ hunc Pbilófopbumnon Ocellurb fed Vcellum nuncupat, ac nonnullos ejufdem recenfet libros.

Dubitant nonnulli de libelli cjus [ de Vniverfân naturâ ] ingenuitate, non confideratè fatis, uc ego perfuafus fum. Nam \& brevitas \& gravitas illi leculo refpondet, ut de rebus \& fermone nunc nihildicam. Cafp.Barth. Adverfar.lib. 42. cap. I. pag. I867.

Ocellus Lucanus Liber eft admodum élegans. Scaligerana 2.

Plurima ex hoc libello De Vinverfi natura fumpferunt Ariftoteles Plato atque Philo Iudeus. Vid. Nogar. annotat. in Ocell.

Oceilus in rebus nature explicandis Atir fermone ufus eft. Nogar.

Omnia ferè Argumenta quiibus Ocellus \& Ariftoteles $M$ undi pioductionem eppugnant, hac Cuppofitione nitutur; Q iòd neceffe fuerit cum generari co modo quo res in Murdo gencrati videmus. Quis autem fane mentis hocita efle unquam afferuit? Verùm an ullo Argungontorum fuorum evincunt impoffibile chle ut Deus, cuius infunta potentia univerfum Orbem alio modo produxerit quàm

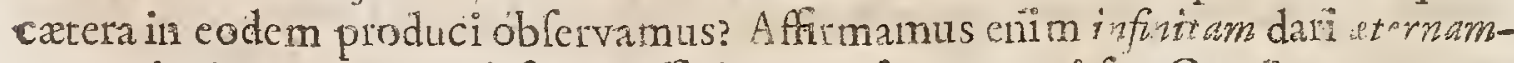
que Efentidm, qux Mundifuerit Efficicns caufa,quxq; vi fua Omnipotente eum ex milo produxerit, éique Existentiam contiutet. tulling f. Oryin. Sacr.I.j.cap.2n Sect 6. Anglicé.

\section{THEOGNIS.}

Claruit ante Oeta Græecus Olymp.jo.natus Megaris non Sicilie, 1 Platoputavit, led At-

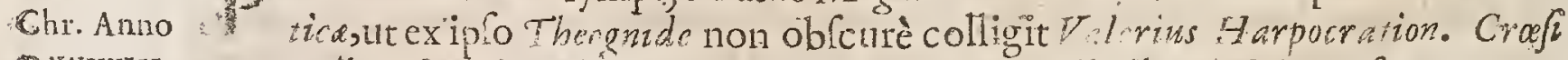
SXXYII. temporibus fuit, fed diu fupervixit nempè ad initium belli Perfoci. Hofman.

Theogni. Megarnfis Olympiade circiter feptuagefma znowis fuis \& Elegiis hiculentam famam adeptus eft,juventuti neceftarius fcriptor, \& qui morts pra- 


\section{CELEBRIORUM AUTHORIIM.}

vos corrigat à erapulâ., à turpibus abftrahats. ad honores reẤvia grallandum moneat, \& honeftatis curam ubique inculcet. Hac quidem de Gnomologiâ ejus: nama ar aize es ejufdem ut flagitiis hinc inde refperfas, monitore. Suidâ, averCantur boniomnes, \&eliciter tenebre occulunt. Dictio cjusfimplex, \& natin. va, latis tamen spportuna tum juventuti, tum webus, quas docere inntituit.Vid. Borrich. de Poet. pag. 20 ...

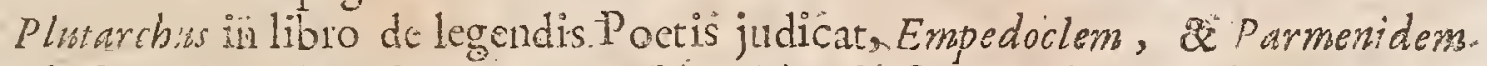
in Pbylcis, Nicandrum in Theriacus, Theognidcm in Sententils moralibus, carmen, non poema cendidiffe; nameros autem pro vehicalo mutuatos:elfe à Poetâ, quo pedefris effugercur / $t y / i$ humilitatem.

Si Fabro fit adhibenda fides, Theognis inter praclariores Gracia Poetas non cenw. febatur. Nihil inquit, pathetici necingeniofi continent ejus opera. Omnia in iis admodum fimplicia \& omamentis vacua. Non tamen diffitetur Etbicam ejus cum utilitate legi polfe, cumque Authorem in Gracia pucros memoriter: addifcere juffos fuiffe... Epit.Vit. P'oet.Gr.p.42.

Ex Suidî difcimus, \&alterum fuiffe Theognidem, fed Tragicum, qui ob friu. gida dramata Nix diccretur...

Theognis Doricâ ufus eft Dialecto...

Thengnis, Gnomicus princeps, moribus formandis unà cum Phocylide aptifin mus, \&vel Ifocrate judice, admodum neceflarius. Bonif. ludicr. Hift. lib. Is. cap. 8 .

Theogniden Suidas ait in ejus preceptis, non utique purum dfe, De inimicis: vindictam fumendam docet à Chrifianâ pietate remotus : Sed quid mirum cùm homo Ethnicus fuerit? Ex Etbnicis tamen nonalli, ut Socrates, nihil tale: confuluifent, ne precepiffent quidem. Claud.Verder. cenf. in Autores..

Inter cditiones Theognidis laudatur H.\& Fredericisylbu gii..

\section{S. S. C H Y L U S .}

$\mathrm{O}$ Lymp. -7r.ann.2. clatuit, ut ait Eufébius in Chronicis: co Anno ipfe in $M a-$ ratbonia pugnavit fortiter, ut eft apud Suidam. Primus hic (inquit Suidas ) reperit ut 'Tragici induerent perfonas terribiles \& frecibus inunctas, item Claruit anse Chritt. Anno Csce I XXXII ut Cothurnis, five grandioribus calceis uterentur. Cùm Tragodias fecerit 90. vicit vicies ecties, imò, ut alii ảunt, folum decies ter. Ex ejus Tragodiis fola fuperfunt feptem, nec.ex omnes integra, Promethens vinctur, Septern $D$ wces. ad Thebas, Perfe, Agamemnon, Choephori, Eumenides, Supplices...

Efchylu fublimis, gravis grandiloquus ufque ad vitium: fed rudis in plerifque \& incompolitus. Quintil. lib. Io. Infitut. O rator. c. I. laudantur tam men frequentes ejus Metaphora, laudatiores futura, fi in iis perfinteret, nec ante. expectatum ealdem abrumperet. Epitbeta ejus, ut militaris animi, plerumque. audaciora, conceptus immodici. Borrich. de Poct. pag. 29."

Is primùn in Scenam Hiftriones adhibuit duos, Ariftoletetefte ; habitum. convenicntem Principibus induxit, Pulpita infravit, ex Horatio; cxdes à: 


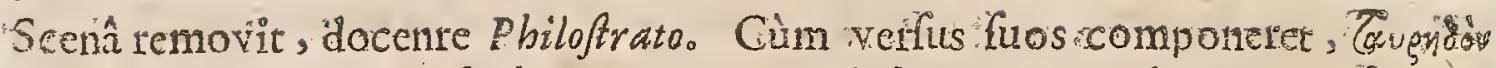

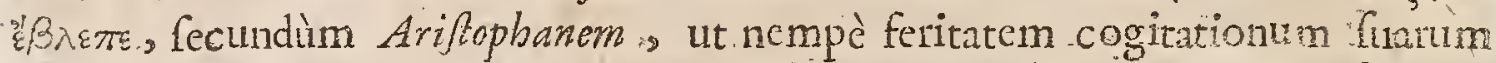
vultu quoque exprimeret. Quin repralentatio fabularum ejus adeo fubinde vifa eft teribilis:, tut memoret Scholiaftes ejufdem : cum primum ederet in publico Eurneaidas, puerorum multos a parentibus ad fpectandum admilfos prx horrore $\$$ metu fubito mortuos obriguille; quin $\$$ gravidas nonnillas imagine fealium larvarum conternatas periffe in Ineatro prater cxpectarionem.

lef. Rapinus ait e Efchylum nillo ferè principio fulcire mercs a decorum quibus Actores fuos onde; Fabulas ejus nimis elfe fimplices; Harum ordinationem lugubem clfe; brafin oblcuram \& intricatam; Agamennonifque Tragesdiaminter alias vix intelligibilem effe: Eum vetò, quia toum Theatriawanum 涼 grandiloquentia latere putabat, in vocibus omnem fuan artem poluifís praclaris, 1ententis infupet habitis. Sed addit Rapinus Poetam hunc felicis tamen effe ingenii fanique judicii., Dramatum in eo defignationes magnificum quid Sirare, eum in elocutionibus patheticum effe; cum denique cum Sophocle \& Euripide Tragcediarum exemplar exhibere. Rapin. Reflex.22. in Poet. par. 2.

Faber fcribit Poetam hyic amplx vatxque imaginationis fuilfe, Ced inordimate ac furiola :- Prodigiorumferax erat, \& weri-fimile ut quib nimis wulgare faltidiebat. Epit. Fit. Poet. Gr.pag. 54.

Hic Poeta intellcétu difficilimus eft. Särnafous præclarus Criticus, quique difficultutes apud intricatifimos autores accurrentes explanare dadeetabatur, earum fe pertalum profitebatur, quas apud exfchylum repetiebat, \& in quodam librorum fuorum ait. Poetam hunc S. Scripturâ oblcutioremelfe. Quxdam in hujus loetx Scriptis lectifima funt, \& Veteribuw Tragicis Gracia famigeratilimis accenferi meretur. Endito Ephernerid. Gallic. Mart. I 665.

Primus verò Alchylus grandiloquentiamaddidit Tragredic; ac fecituru verè ambulet Cotburnata. Volf..lib. 2. Inftitut. Poetic.cap. I 4 .

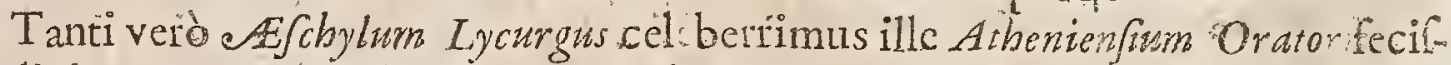
(ce dicitur ut Statuam illi abeneam poni curarit, \& alteram Sophocitamborumque Iragadias publicècuftodiri mandarit: publicum queque fcribam confituit. quii cos Hifrionibus lectitaret. Lilius Girald.

Afchylus Tragodus ób quoddam D ramaimpictaris damnatus erat. Quumque Abenien fes jam parati eflent eum lapidibus obmerc, Anynias Junior frater dejectî vefte, cubirum ofterdit manu carentem. Fuent aitem Arnynias unus ex iis qui fortifimè pugnarant in Salanine ubi manum amift, \& primumex omnibus Athenicnfibus fortitudinis premium confequutus eft. Ubi verò Iudices hominis animam \& miferationem intellexerunt. repetentes facinorum ejus memoriam, Af chylum abfolverurt, Elian. var. Hift.lib. 5. cap. I9.

Vino deditum fuiffe inde colligas; "quod Callutisnes apud Lucianum narret s Af chylum in vino folitum foribere Tragodias, una fenfus patet dictillius; $A \mathrm{f}-$ orylus cum foriberet, cirn:inzocafe magis Bacchum guam Apollinern. 


\section{CEIEBRTORIM AUTHOR UM.}

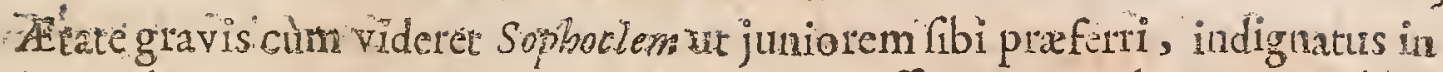
Siciliamad Hieronem Syracufanorum Regern conceflit, \& tandem Gele obiit, ¿quilâ in calvam ejus teftudincm ingenten demittente, de yuo Plwtarch. Pawsar. suid.

Inter editiones laudatur illa, qute è manu Henrici Stephan " \& Adriani Turnebi exit. Primum verò obtinet locum illa Thorne Stantai eruditis commentariis illuftata. Hanc editionen Stanleianam Ephernerides Gallica hifee verbis Iaudant. Omines ejus ediciones quas hactenus habueramus imperfectifime fuerunt. Hæc verò fumma cura \& diligentia procurata fuit, \& digna eft qux ir Bibliothecis reponatur, in is enim reliquz omamento clfe nequeant. Erudit. Epherner. Gallic。Tarm. I.pag. IIf.

\section{P.INDARUS.}

DOcta Thebame circa 76. Olympiadem claruit. Puetum à patentibus expofitum apes aluerunt, tefte filian. in var. Hift.l.r2.c.45.

De morte ejtis tradit Vulerius quod in gremio pueri adamati expirârit.

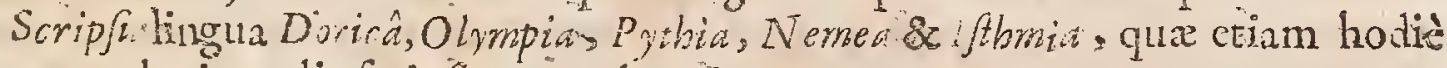
extant : plurima alia fcripfit, quir deperiertut.

Novem xcrò Lyricorwm longè Pindarus princeps, fpiritûs magnificcntiâ, rententis, figuris, beatifimû rerum verborumque copiâ, \& velut quodam Eloquentix fumine: propter quæ Horatius eum merito credidit nemini imitabilem.Quintillib. Io.¿. .

Corinna ể. m quâ Pindarustempeftate floruit, quem ctian, ut fama eft, in certamine quinquies vicit, quamobrcm Tanagrei cjus imagincm in gyran in loco illufri pofuchut, ut fribit Paufanias, caputque illi taniâ revinatum viCtoria caust̂. Quare autem P.indarum vicerit, duplicm idem atitor caufarm

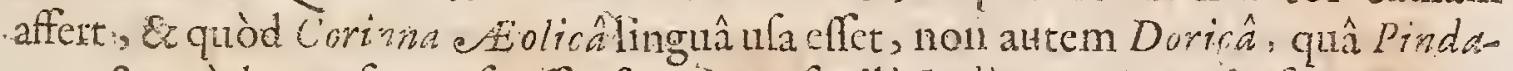
rus: \& quodcum formofa effet fomina, facile Indicurm animos in fe converric. ieil. Gyrald.

Pindaro illud peculiare eft, animos hominum inopinatò, fententiolâ aliquì mirabili veluti virgulî divinâ, percutcre. Bacon. Augm. Scient. 1.8.c.I.

Pindar nimis opintâ, pinguique elie facindiâ exiltimatus ch. Aul. Gell. Iib. I7. Noct. Attic. C. IO.

Pindarus eft oblcurus imprimis auctor \& scconditorum vocibtulorum

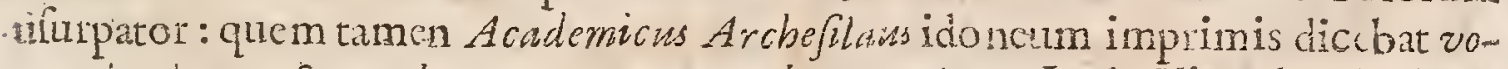
cem implere, \& verborum manam prebere copiam. Lud. Viv. de Tradend. Difcip. p. szo.

Lacedemonit in roliquam Mcotiam favientes Thebisin Pindarigratiam pepercerunt. Huic ctiam tantum tribuit Alexander $M$. ut cum Thebs severeret, ac ir omnes fune difrimine feviet, unius Pindari penatibus samilieguc parci jullivit.

Pindatu Thebanus Odogefimuin anam-complcvit : Pocta fublimis o cum

Caritit ante Chr. Ano CECGIXXVI: 
quadam novitare ingenii, \& multus in cultu Deorum. Bacon. de vitâ \& moréy ad artic. $\{, 6,7,8,9$ \& $\mathrm{x}$.

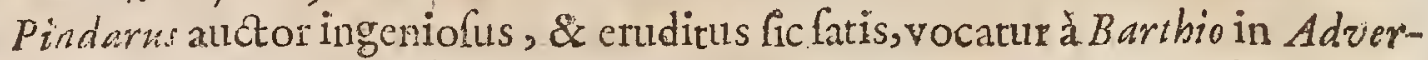
forit. Nec judicium hoc fummi viri difplicet. Voff. de Hilt. Lat.pag. 8Ig.

Fatendum eft Horatii judicium de Pinsaro Poemaribus, Dibyrambicum cius opus; q'ıd cum aliis pluribus nobis periit, unicè fpectare. Eruditor. Iudicia Parif: 1686 per D. Baillet. Gallicé.

Faber Salmurienfis air figuras à Pindaro ufurpatas nobiles quidem \& magnificas elle, fed Dibyrambicum tylum quandoque fapere, id ef audaciam \& remeritatem quandam is minime gratam cui caftigatum loquendi genus aliis anteponunt. A ddir eum cætera gravem ellè, fed paulò nimium iis quæ Apophthegmatwin nomine veniune delectari ; extrafuum argumentum ob dígreffionum fuarum prolixitareun, longe nimis identidem evagari' poftquam in nubes fefe fummovit fubitò iterum devolare cùm minimum expectatur; infalutatis altantibus iterum ingredi, id eft corum qux prius dixir connexionem cum xequentibus partin curare. Tan. Fab. Epit. de Vit. Poct. Gr.p. 65.

Etfi nevis non careat Pindarus, aliquid tamen habet quo Lectorem magis. capiat quàm Horatius, quodque Divinum quid magis fpiret, juxta $D$. Blondelli fententiam, Comparatione Pindari cum Horatio.

Dictio cjus fublimis, gravis, fententiis \& verborum copiâ frequens, Digreffionibus quandoque nimia, nonnunquam \& fine nexu abrupta, unde non rara oblcuritas. Figura ejus, ut magnifice, ita aliquando Ditbyrambica, \& pracipites. Hac audacia noftris moribusinter viria cenfcur: Pindarico ævo, Srfuccedentibus illi feculis haud dubiè inter virtutes numerata fuit, ita Antiqui Scriptores de laudibus ejus difertè perorant. Borrich. de Poer.p. 25 .

Quantus fuerit Platoni lindarus, vel ex co colligas, quòd alibi rọ́w

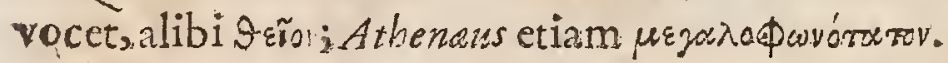

Horatius lib. 4. Od.2. Pindarzon cygno comparat, volatufublimia petenti.

Ptinius lib.2.cap.I2. Os. Pindari fublime prædicdt.

Quodad Editiones Pindari atrinet inter celeberrimas merito afimatue illa Erafmi Schrisidii ecuditis commencariis illuftrata.

\section{H I P O C R A T S.}

Claruitatite Chr. Anno CCCCIN

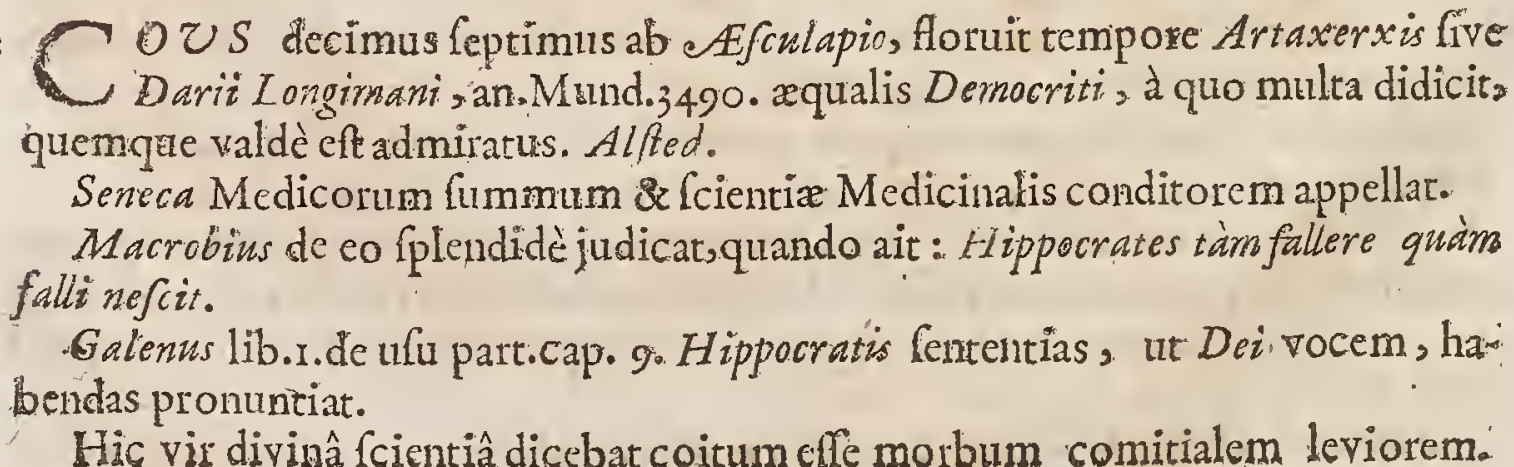
Ejus 
Ejus libri, tanquam divino cmanaverine ore, ubique celebrantur. Artem medicam in lucem revocavit, in quâ uque adeo enituit, ut venicntem ab llyrits peftiLentiam predixerit,nc difcipulos ad auxiliandum circa urbes dimiferit: aui ob meritum honores illos, quos Herculi, tota Gracia decrevit. Carol. Stephan.

Tanto vel difcendi itudio, vel in x.groscharitate fagrabat, ut eum non pusduerit vel retimenta guftare, ut inde morbi naturam perfentiferet. Unde Scatophagus per ridiculum vocatur Arifophanio Balthaff: Bonifac ludic. Hift. p. 592.

Verus medendi dictator habitus femper; hujus fcripta tanquam oracula, \& uon humane lingux verba, tota amplectitur antiquitas, tanquam duccm \& auctorem omnium diciplinarum. In hoc, verborum preff propietas, fententiarum concifa fubtilitas, fermonis venetanda antiouitas, artificii commendabilis dignitas : in cujus feriptis nihil fuperfuum, otiofum nihil, fed argutâ bievitate rorunda omnia, \& fignificantia, ita ut ubcrtas \& amplitudo rerum verbosum numerum longè vincat. Hewrn. dillertat. de ftudio Mcdicin.

Hunc tota pofteritas venerata eft tanquan medicorum frincipem. Volf. de Philofoph. p. Sg.

Tres funt quos admirari unice foleo, \& qui in hominibus exceffre mihi hutmanum faltigium videntur, Homerus, Hippocrates, Ari/toteles. Lip

Hippocrates Cou Medicus infignis, centum \& quatuor annos vixit. Artemque fuamtam longâ vitâ comprobavit, \&honêtavit: vir cum prudentiâ qua-a dam doctus : in experientiâ, 2 oblervatione multus:non veiba, aut methodos captans, fed nervos tantum fcientix feparans, \& proponens. Bac. Hiftoi. vit. \& inort.

Quanquam verò Dorica Hippocrati lingua foret nativa; Ionicé tamen fcripfit, a Derrocrito perfuafus ; nempe quia hac lingua fuavior clcgantionque habcretur. Elian. Iib.4.Hift cap.20.

Non à vero abludit corum opinio, qui Hippocratem Aphorifmos non fcripfifre, fed ab alio ex vari is $H$ ippocratis operibus bono judicio exceptos atbitrantur. Voff. de Philof.pag. 84 .

Preclarus ille vir cò pluris xetimandus eft quod doctrinam fuam froi foli deberet, \& quòd ab alis nihil mutuatus fr, alii verò omnes ab iplo multa do fumferint. Galents enim putat Platonem ex Hippocrais operibus pleraque omuia qua in illius Phil of ophi Scriptis miramu haufle, \& Pby/cos A ifoselis libros nihil ferè elle quàm ejufdem Autoris Phyfiologix commentarios. Erudit. Epherncrid. Gallicadie 1wn.22. Fetr. 1665.

Artis Mcdra poft Deum parens alter extitit divinus If ippocrates. Quamvis enim ance cjustempota e Afculapim Medicina inventorem agnofceret Antiquitaș, artem tamen Medicain luis temporibus fermè fepultam, aut faltem incultam, nullaque methodo difpoftam divinis planè fcriptis tantopere cxornavit, Eamplificavit Hippocrates, ut fub eo primum nata Medicina videatur. Zarnt. Ludtan. Med. in lib. de Medrc.

Onnium quotquot ante fe fuerunt Medicorum facilèpincéps Hippocrates.

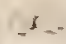


Primus ille laceræ luxatrque membra artis, folidiffmâ compage in unam elém gantifimi corporis molem redcgit, \& mirabili artificio confummatam pofteris reliquit Ioan. Wefterburg. in Epift. ad Ioan. Beverovic.

Quemadmodum Hippocratus fumma femper apud Medicorum filios fuit auctoritas : ita inter Opera, qure pofteritari reliquit, Aphorifini maximè aurei lanè illi, rotundi, \& ab omnibus Medica Artis cultokibus memorix meritò imprim. mendi, folent commendari: Acta Erudit. Ann.168-4.pag 29.

In divinis cjus fcriptis nullum eft verbum, quod non ex penetralibus: nature depromptum, \& profundâfapientia imbutum cllè videatur. Populares fuos. Gracos tanto elt amore profecutus, ut ad Artaxerxern Perfarum Regem, quamvis maximis donis ab tyftanide Helleppontiorum l'refceto evocatus, proficifici. noluerit. Gul. Rovill. in prompeuar.I con.llliftr.'Vir.

Hippocratis libellos legere fi defideras, yacet oportet à negotiis-, tr liberanimus fentiat vim concifi \& abrupti fermonis. Theod. Ianfon. Invent. nov. An-. tiq. p. I.4.1.

- Lippocratis opcra omnia Gracè \& Latinè , curâ operấque Iob: Antonide Vander Linden editafunt in 83.2. Vol. Lugduni Batav. 1665 . quam editionem pra cæteris valde laudant Ephemer.Gallic. die lun.22.Fcbr.1666.

\section{E U R I PII D E S .}

Floruit ante Ragicus. A.Gellius lib. 15. cap. 20. refert Euripidem, cum in Macedonic Chist. Ann. I apud Archelaum Regemeffet, noctu à conâ redeuntem à canibù per. ๔ccex r.rII. xmulum immifis, dilaceratum effe. Crudelitas fati ranto ingenio non debita, inquit Val. Maxmus, lib. 9. cap. I2. Emulumilltm Promerum dictum fuiffe, Swidas obfervat. Nivoguns ixuncupatus, vel quia caftus, \&ueneris expers, vet quia mulierum viriadeteftatus in eas fxpe invehitur. scrip/2t Fabulas 75 . ex quibis s. tantim victoriam reportarunt. Superfunt hodie ig. Mortuls eft amom atatis fure 79 .

Quanti verfus ejus fecerit Cicero, non obfcurè teftatus eft fic ad Tyronem.

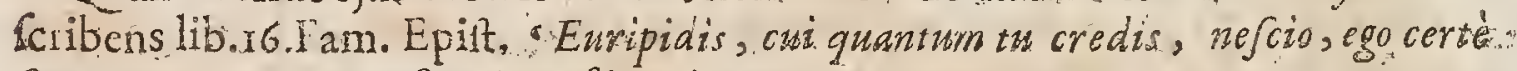
fingu'os ejus verfus, fingula tefirmonia puto.

Euripidem F abiss Sophocli praferens, uter, inquit, in difpar dicendi viâ fie Poëta melior, inter plurimos quaritur: Illud quidem nemo non. fateatur neceffe eft, iis, quife ad agendum comparant, uriliorem longe Euripidem fore. Namque is \& in fermone (quod ipfum reprehendunt, quibus grawitas , \& cothumus, \& fonus Sophoclis videtur effe (ublimior) magis accedit Oratorio generi : \& fententiis denfus, \& in is qua ż. apientibus tradita fint, penè ipfis. par, \& in divendo ac in refpondendo cuiliber cortum, qui fuerunt in foro diferti, comparandus. In affectibus verd cutu omnibus mirus, tum in iis qui mileratio we conftant, facilè pracipuus. Quintil. lib.ro.cap.I.

Sanè Euripides cum Protafi prologum ferè mif́ct eodem in multis filo:propter guod \& à Criticis damnatus eft Cafoscaliger de rePoetica. 45

Objecenp? 


\section{CELEBRTORUM AUTHORUM.}

Objecerunt Euripidi quid. fcelcfas atque inapuras fominas adduxerit in 'Sce-

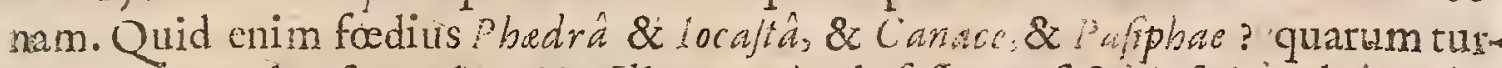
pitudine populus fieret zeterior. Ille contrà, ab fefe non fictas : fed juales quales fuerint, oftendife. Quin Hiftorta ipfas quoque abolendas effe, fr nequitix.null funt audiendx: quâ dề causâ etiam Comoedix in pretio fint, quarum cognitione damnentur vitia qux in eis recitantur: prefertim cum impurarum mulierum vitam mors iüfolix fit fecuta. Cof. acalig. de re Poet. p. 368.

Euripides cloquentix \& prudentix laude Sophoclt palmam dubian reddidit, finon plane eripuit. Euripides plus surx \& induftice adlibuit in diponendis verbis fuis \& fententiis, quam Sophocles; non tamen fatis appofite fabulam difponere putat Arifoteles, cui alioquin Tegyw dictio : redolet magis hominen rebus intentm quàm verbis, Euripidis Scholam plus fapit \& 8 verborum conquirit delicias. Itaque f manitudinem: \& fublimitatem Tragcedic infpiciamus vicent Sophosles; fi verborum nitorem; major erit Eus ipjes. Id in Euripide caftigant cruditio quod verifmite Poeticum rantoperè Arifroteli laudatum non ubique obfervet; ut cùm fubinde Princitibus alligat peram \& mendicitate $m$, neque enim id contingere unquam res lo qui-

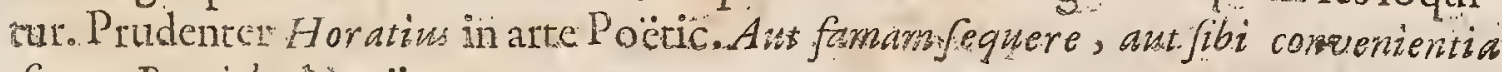
finge. Borrich. de poët.p. 30 .

D. Fabcrat Criticoum antiquorun acutiones cenfuile Euripidis ftylum Gris preflum non efie; Tragodias ejus Dialogum \& Socratis colloquia redolere,

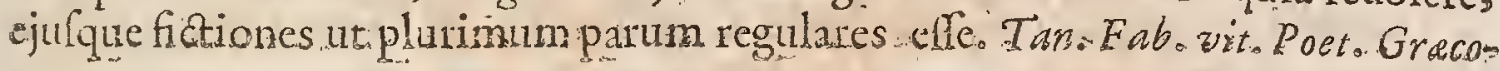
rum.

Ie foupinas ait Euripidis Tragcedias plis habere actionis, plus moralitatis, \& eventus mirabiliores quàm Sophoclis Tragcedia.. Sed laudabiles ejumodi quahates neu obftireunt quin plures in hujus loetx Operibus non mediocres nævos detexerit. Aferitillum in Fabularm furum ordinatione lat is accuratum non effe; ejus Charaderes variatos non effe; per eoldem calus ir ealdemfenten tras eumredite; fermones ejus fatis ardentes $\&$ fatis Patheticos non effe quo fit ut minì's quàm par effet moveat; ili ejus eventuum - inopinatorum preparatione precipitationem quandam obfervari; Dramaticonum denique nodorum fó litiones rerum naturæ minimè congruas effe, quippe qua totidem perpetux fint machina, id eft a Dis peragantur. Hac tamen non obftant quin Rapinus de eodèm poltér quemadmodum de" eAfchylo \& de Sopbocle fateatur, eum in fuis mo liminibus, fublimemeffe, in Fabulis judicio pollere, in elocutionibus patheticum effe: intritim illorum Poetarum operibus genium foelicem, preclaras naturæ dotes \& faniorem mentem paffm elucere; \& quanvis errores quoldam commiferint, eorumtamen Dramata omnia ut primigenia toridem Exemplaria proponi polfe. Rapin. Reflex.2r.G 22 in Poej.par. 2.

Cum aliquando fabulam recitaret Euripides, à populo rogatus ut fenten tiam quandam mutaret, infcenam progtelfits dixit, (e ut-populum docercts. non ut ab co difceret, Tragodias componere folere. Alcefidi poëza Tragico objicienti, cuòd triduo triatantum carmina compofuifet, fe vero centuma 
refpondit, Sedhoc interef, tuatriduo tantummodo, mea vero in omnetema pus fufficient.

Edidere hunc Trogicum plures quos inter laude fuâ non eft defraudandus Paulus Stephanus.

\section{SOPHOCLES}

Clartit ante Chrift:Anno $\operatorname{accxis}$.

Oetà tragicuss, patriâ Athenienís , tantâ orationìs fuavitate, ut vulgo

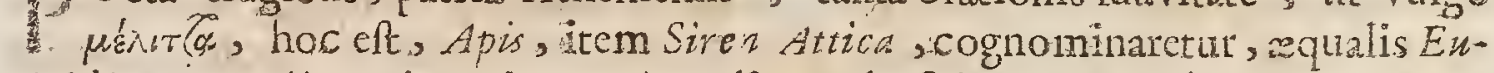
sipidis \& Pertclis, cujus ctiam collega aliquande fuit in Proturâ. Natus Olympiade 73 . ante Socratcm /ann. I7. Primus 3. Actoribus ufus eft, adjecto co qui vacatur Tritagonifa, hoc eft,terriarum \& ultimarum partium Hiftrio. Ijimus eriam Choros sx juvenibus is. "introduxit, cùmanteà I2. tantum introducercntur. Primus quoquctragicas contentiones \& compofitiones infituito Scripht ctiam Elegian, \& $P$ aanas atque Orationern prefarn, cùm de Choro adxerfus Thefor, \&C Carilur contenderct. Obiit autem 6. ann. pott Euripudis morsem, cui ftyli magnitudine prafertur, lice cjus fententiis inferior. Carol. Stephan.in Diction. HiRtor.

Tragodiam ad perfectionem perduxit. Styles cjus politicum fapit, \& fictiones admodum judiciola lunt. H of man.

Tragcedia princeps, cujus gravitas \& Cothurnus, \& fonus cateris multè fublimior. Quintil.

Sophoclis tragcedix graves, acutæ, fublimes; Divinum Pocian vocat Cicero lib.2.de Divinatione. Card. Loan. Bona.

Sophocles Athenienfis octogernum annum complevit : Poeta:grandiloquus totus in foribendo, \& familia negligens.Pac. de vit. \& mort.

Claruit ttylo tragico Sopbocles : Et quamvis Efchylus fuerit primus qui magniloquentiam docuerit, ut teftaeur Horatissin Arte Poeticâ in proverbium tamen abiit Sophoclens Cotbornbss, quàd Sopbocles cateros Tragicos dictionis gravitate longè fuperaverit. Laurent. Rarmir. not.in lib.3.Mattial. Epigr.20.

- Quanti sophoclem xftimarit Virgilius fatis indicatur Eclog.8. V.10. 'Sola Sopboclco tua carmina digna Cotburno.

Ejus tanta fuit induftria, ut cum ipsâ naturâ celtaffe videatur. Nam cuǹ effet annorum fermè centum, Oedipoderr Tragoediarn compoliuit. Oliver. in lib.8.cap 7. Val. Maxim.

Sophocles eft autor admirabilis ; primus Poeta Gracus, \& ferè Virgilium fupetat. Philoctctes quàm divina Tragódia! Tam fterile argumentum adeò benè amplificatur !\& Oedipus Tyrannus quàm paucas habet perfonas, quam puicherimus ! quibenè legerit, multum profccit in Grecifmo; quàm multa praclarx Sophoclis tragadix interierunt! Scaligeren.2.

Unus ex Yiliis Scpbocle jam grandævo, annos enim 85. attigiffe dicitur, Indioes adiit, rogatum, ut Patri curatorem contituerent.: Sed hoc partem Oedipi, 
quam tum forte pangebat, coram jutribss recitante, cum ignominin remiflus: eft. Exhibuir Fabulas I2j. quanquam alii dicant multò plures. Victorias autem: 23. repoitavit, quarum peftrema cum preter pem ill contigifiet, repentino gaudio dicitur expirafle, ut eft Authos: Valer Max.lib. 9. Luciamus autem grano uvæ ftrangulatum etim prodidit. Hofman.

Sophocies Tragicus, Olympiade 78 . clarus, Socrate paulò fenior, \& Luavitate dicenci, . Cententiartim, fchematumque frequentia, yuin \& dictionis perfpicutate Efobylo fuperior. In affectibus, fecundum Quintilianum, mirus s pracipue in iis, qui miferatione conftant. Borrich. de Poet.p. 29,50.

D. Eaber ait Soproclus fylum indolen omnino prodere \& animum fortem bellici viri qualis ipfe fuir : aitfylum illum politiorum hominum ufui prorfus. conformem efie, cum Euripides è contra in Scholx pulvere totus. jaccar; illum Efchylo longè accuratiorem in fuis fcriptis efle, quia polterioris hujus Fitziones monftrolx, incredibilcfque plerumque funt, Sopisocles verò exquifiti judicii \$egulatitatcincontinuófervat. Putatnihilominus aliquid ejus. Inventioni addi ejufque cogitationes paulòlatius enunciari polfe. Tan.Faber Epit. Poet.Gr.p. 86. 87.

Sopboclis fermones exactenimis ordinati funt. Artem fuam in quibur dam fuis Dramaribus fatis non celat; nimis affectata fublimitas obfcuritatem in co quan doque parit : \& elocutionis ejus nobilitas perfpicuitaris parten ei adimit. In Dramaticorumnodorum folutionibus non femper aque felix eft ac in Oedipo. Rapin. Refiex. in Poet. part.2. Refl.22.

De hujus (Sophoclis) furtis Philofitratum Alexandrinum juftum confecilfe opus fcripfit Enjebius.

Inter Ediciones hujus Scriptoris commendutur Illa;quam: Paulus Stephanus cum Scholiis Grecis 2. Notis. Is. Camerarii , atque H. Stephani, publio cavito

\section{HER ODOT U $S_{3}$}

A Niquillimis Grecorum Hiftoriconm qui hodiè extant: Floruit Olymp. deducendx in Thurios colonia prabuiffet. Condidit novem libros Hiforiarum, quibus Mufarum nomina impofuit, etf Lucianus affirmet, libios illos non abipfo Authore, fed ab aliis hoc nomine infignicos effe. Tullius. 1 . $x$. de legib: eum Hiftoria parentern appellat. Infigni injuriâ optimum Hiftoricum afficiunt, qui: patrem fabularum vocant. Quiod ipfum convitim facundiflumo Dialogo refutavit Hen. Stephanus. Nec fabula eft, quod Herodotus fcribit, formicas Indicas ovis magnitudinem aquare. Idem enim $B$ ub bequius tentarur, feque inter Dona Regis Perfarum Imperatori Turcico deftinata formicam Indicarn animal fevum \& mordax vidife affi mar, Konig. in Biblioth.

Sed utcunque de ifto eft, fatis liquet,non ita nuncupari eos libros ut mendacia: 
ciatitulo ipfo excufentur. Eft hoc commentumerudit Hifpani, Ludov。 Wivis in quinto de Tradend. Difciplinis:Led tanto viro minimè dignum.Vofjo Hirox. Grac.

Herodotus Gracus, ne quid omifite videretur, omina Gne delea congeffit, quoum pleraque non ab antiquis fcriptis, fed à vulgi fabulis accepit.Qui, quanųuam oratione concinnus fitsatque el cgans, corum tamen, qui fanè \& incorruptè judicant, avertit ab illâtam coaccrvatâ \& referta narrationum multindine, fí-

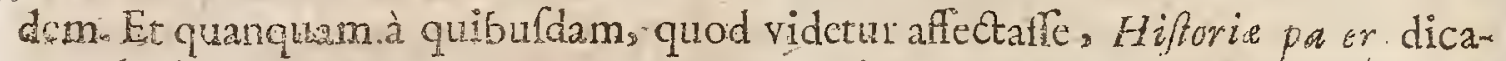
tur, ab aliis tamen Fabulurarb pater merito dictus eft. Parker. in $P_{x}$ fat. ad Antiquitat. Britann.

Miror Hunc unum Aifroria parentem à Ciceroneappellari, quem onanis anti-

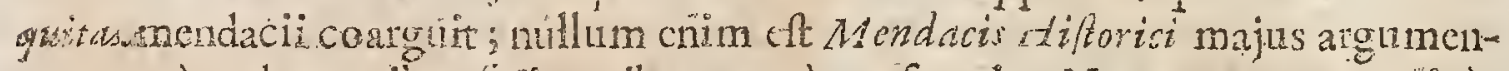
tum, guàm ab omnibus f́ciptoribusapertè confutari -: Nequetamen omninè rejiciendumputo. En enim in co,prater eloquentiam, \& liavitatis Iorice lepores plurima vetutatis inago: multa quoque in polterioribus libris verifinè ab eo fcripta memorantut. Bodin. in Method. Hift.pag. $55_{0}$

Magnus fanè Herodotur fcriptor, \& fine controverfia tiflorie Paterifed qui

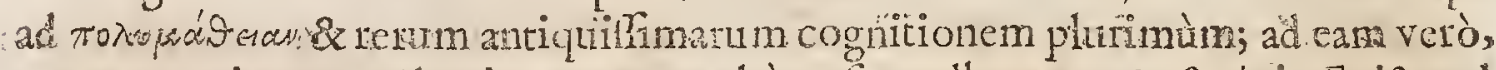
quam que imus pradentiam, non multùm fit collaturus. Cafaub.in Epif. ad Henro 4.pref.tert. Volum. Polyb. p. 52.

Hiforiam multifcipfere praclare fed nemo dubitatuos longè cateris prxferendos, quorm diverfa virus laudem penè eft parem confecuta. Denlis , $\$ x$ brevis, \& fempcrinfans fibi Thur wides dulcis, $\&$ candidus, \& fufus terodotas : ille concicatis, hic remillis affectibus melionille concionibus.s hic fermow nilus ; -ille xi, hic voluptate. prinil lib.ro.cap. in.

Oratortum verò numero hunc eximi,non finit fuadel dila, \& venuftas optima poefi Timilis:quam Orationi ejus incffe locuples teftis eft Halica naffeuc. Ac Plutarchus quoque, ctfi opufctilo eo, quod de malignitate Herodoininlcipfie, amore qrodam Patrix (ut magnis.ingeniis ufu venire folet) longiùs abreptus , maligniorem feipfe erga Herodotum prabeat : tamen agnofit in eo ditions fimplicem, \& abfque labore, rebufque facile fe applicantem. Ac libclli fin s, fic

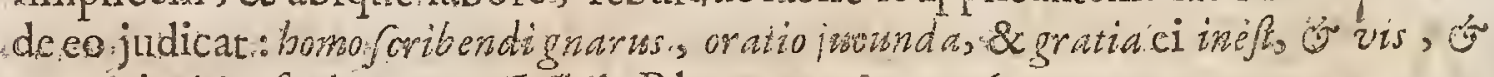
narrationi ineft elegantra. Vo/j. de R hetor.mattr.pag 67.

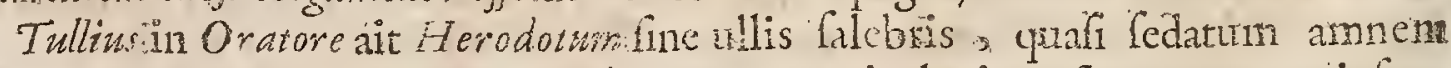
feri. Fabius fimiliter teftatur., cum in coomnia leniter fluan ', tum ipfam

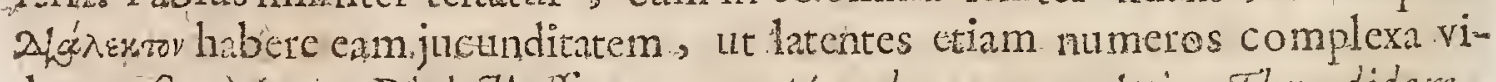
deatur. Sanc lonica Dialedtiefle normam Herodotum, ut Attice Thucydidem, fcribit:Dion. Haticarnaff.etimque fecutus Fbotizus.

Licet quafdam narrationes recitct Herodotusfibulis non ablimiles, totum tamen Hiftorix coupus fing uldtifidc, \& diligenti veritatis ftudio coagmen tatum eft. De aliis vero narrationibus plerunque prefatur ipfe, fe eas, non grod veras effe exiftimet, fed ut ab aliis acceperit, recisare. Whear method. legend, Hitot: 


\section{CELEBRIORUM A UTHORUM.}

Nobilifime huic fcriptori Perfeca imprimis debemus. Ioan.Ger.Voff. de Grac. Hift. p. :4.

Ablurdum ett in Perfcis o Babylonicis uni credere Herodoto, ignaro lingux Perfica, \& nullis Orientis gentium inftructo monumentis. Ifaac.Vof.de sibyll.

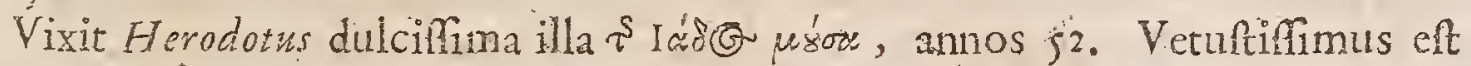
omnium folutx orationis fcriptorum, qui hodiè extant. Scrinium Originam Grecarum \& Rarbarartirs, Auctor à doctis nunquam deponendus, à femidoEtis, \& prdagogis, \& fimiolis nunquam tractandus. Sant. in animadv. in Euf. Chron.

Debebit \& nobis nonihil Herodotus, mel illud Misa unnectarmum, cujus quòd fabulofitatis arguantur: Canzosize, optimam mihi olim caufam dixiffe, videtur Ioan. Iovianus Pontanus; Ccilicet fummum \& antiquifimum foriptorem non ideò opas iftud gemineum promulgâfle, quòd fidem ommium traditom rum fibi conftare putaret, aut defendendam fulcipere vellet : led quòd in /onice. Diale $\{i$ Elegartiis regnum fibi pararct. Eo enim nomine \& fine infcripfife tituLos Mufarma frontificis librorum, ut quafiperludum nova tradere, hiltoriafe que jucundis fabulis condire cerneretur---Quem forip wrepris qui capere fatagdt, oportet fit fubactarum Idiatifno Ionizo aturian. Ludit fabulando Herodotus; ludendo docent Fabulá, fapientie pulcherrima gemme, Eufhat Svvart. Analect. lib. c. II 4 .

Herodotus in fecundo ex hiftoricâ Hecat. Milefin narratione quamplurime verbis totidem exfcripfife dicitur, pauca quædam leviter ementitus, cujufmodï

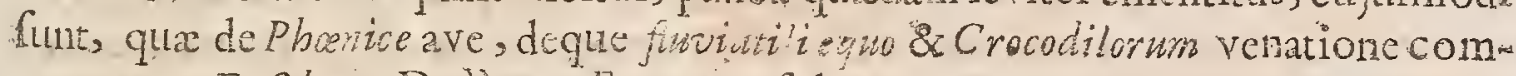
memorat. Enfeb.io. De liap. Evang. 3. fol. 466.

Suidas Hurpocrationem e Elizm quendam nobis memorat, qui deditâ operâ librum fcripfit ad falfitatem Herolotipropalandam. Notum eft quid libris fuis dicat Plutess bs de ferodoti malignitate feu invidia, fed occafio non minus parets quòd videlicet Herodoins Plutar bi pat iam parumofficiosè defcripfiffer. Strabo fimiliter tcrodotum nimix nugacitatis s arguere videtur, \& quòd prodigiofas fam bulas, hiftorize fux immifcuerit. Sed fateor, dum obfervo quibus de caufis in 'erodstams toties inychatir ${ }^{2}$ ' utarchis, me in hanc opinionem propendere, quòd plerorumque Grecorsm Scriptorum in ierodoturn acerbio inritatio indeorta fit, qued nimis multas fabellas ex Schola defumptas narraverit, Gracioque infantiam nimis detexerit, quantumq; ex Ateyptiacis fuperftitionibus Groci mutuati fint. Quamvis itaque Gerodotu in iis quorum à Gracis infmulatur. non multùn frt culpandus, quil tamenipfi maximè favent cjus in q̨uibuldam manifftas hallucinationes, in aliis verò ignoratitiam excufare non poffunt. 1o-

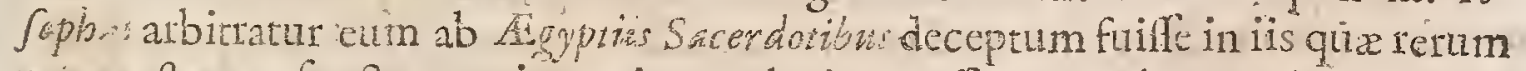
corlan ftatum fpectant, cujus raciones plurimas affert Iofepbus scaiger: Aut,

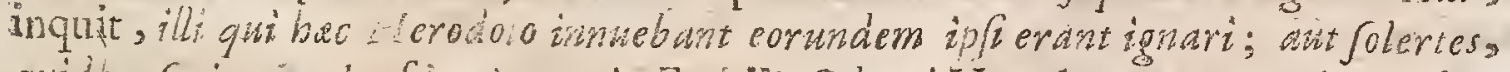
quidkm Saits, guales fuiernint veri Egytii, fed qui Hetodoto ut peregrino of fro-

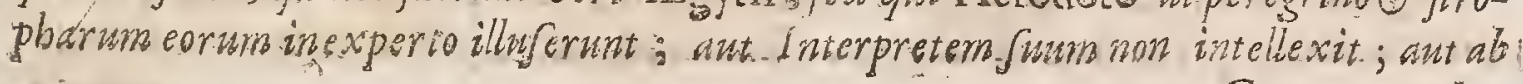


boc deceptus fait; an dsnique Herodotus ufque adéò Gracorum vitio laboravit wh veram Hiforiars Fabulis quibufdam proprio marte confictis adulteraverit on Qua propter Manethon potiùs quàm Herodoto, quoad \&gyptiacam Hiforiam adharet, Iofephos: Cum tamenalibil nefcio autem quomodo hac in parae fibi conftet) eum precla:o hoc Elogio dignetur, quod fit Scriniurs origiginum Gracarurr \& surbararum, auctor à Doct is nunquam deponendus.

Negari non poteft quin mulum utilifima Hiftorix ex ip fohamin liceat: Quis tamen ejus inciciam excufare queat, quinedum Oceani Continentem. ambientis exiftentiam negat, fed Geographos id afferentes damnat? Stillingf: Orig. Sacr. 1. I 6.4 . Sedt.10. II.

Herodoti varix cditiones quas excudebat \& recognovit - Hen. Stephan. I566. 3592. \& 1608. cum Expurgationibus permittuntur in Indice Madric. Edit. Anno. 1667.

1. Herodoti Hiftoriam Gr. Lat: edidit. Thom.Gale Lond: Fol: 1679. Accelfe-m runt huic editioni Stephani A pologia pro.Herodoto, item Chronologia, Tabu-la Geogroph.nec non variz lectiones \& notz ex Mf. \& Antiu. Scripta.

\section{H U C Y D.I D.E. $S_{\text {* }}$}

Clatuit ante Chritt Anno seccxxIx.

A Thenienfs, Hiftoricus, tempore belli Peleponnefiaci formit. Rictum Bch A lum Thucidides octo libris complexus eft. Multum verò fidei, fi yuis: alius, friptor hic meretur. Nam \& egregium veritatis in eo ttudium elucet, \& illa lcripft quibus interfuit. Threydides in octavo libroplane tenui dictione utitur, cùm in prióribus longè magis affurgat. Ac proptereà aliqui putaunt eum à filra Tin rdidis friptum cffe, vel à Xenophontes aut Theopompo, vel alio. Quorum fententiäm in vitâ ejú sejicit ch arcellimus: ac potins cenfét fuilfe fcriptim 2. Thucydide jam agrotante. Voff. de Hilt. Grae:

Thucydides aranes dicendi artificio meâ fententia facilè vičit, ntverborum prope numerum fententiarum numero confequatur: ita porro verbis aptus \& preflus, ut nefcias utrum res oratione, an verbafententiis illuftentur. Cic. lib.2a de Orat.

Denfus, \& brevis, \&emper inftans fibi Thucydides : aulcis, \& candidus, \& fufus Herodotn: ille concitatis, hic remiflisaffectibus melior : ille "concionibus, hic fermonibus : ille vi, hic voluptate. Quintil.1. 10.c. Ini

$I_{11}$ Thucidide, quem præcateris veracem exiftimavit antignitas, plúrima func ${ }^{\mathrm{t}}$ valdè digna $H$ ifforico; quippe cui etiam tria prudentiæ genera tributa funt: $C i$. vilis, Bellica, Hiftorice.

Demofthenes eumtanti fecit, \& ex illo fe tantum proficere putavit, ut ideo illum defcripferitocties, quemadmodum tradidit Lucianus. Cucero tanquam prudentem rerum explicatorem commendat. Poffer. Biblioth. Select. Tom. 2.I.16. Eap. 7 .

Qui res nec multas nec magnas nimis fcriplit, . Ced palmam fortalle proripuif omnibus, qui mulas \& magnas. Elocutione totâ gravis \& brevis, denlus.: 


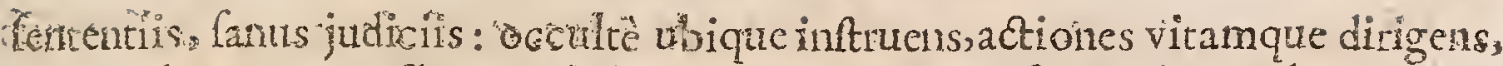
oxationibus \& excurfbus penè divinus. Qucm quo fapius legas,plus auferas: \& a tunquim tamen dimittir te fne Siti. Lipy. tot. da I. Polit.

Magnus eft vir \& lcriptor Thurydides; qui à gerendis rebus, ad eafdem nylo prolequendas quam fele contulillet; Hifloria ad ufum Foliticorum lcripta mor talium, credo, primus excmplum poft-futuris mirandum potius quam imitan- dum dedit. Scd vir maximus par ingenio argumentum nou habuit. I Jac Cajaub. praf. ad Polub.

Thuidides fanefidus omnino fcriptor, 8 quem principem fenarus Hitori fl mei arbitrii res foret, legere non dubitem. Si in fcriptis ejus veritarem habitare dixero, ipfan non dubito quin fuftagantem fim habiturus. In exilium eje. etus à fuis Abenienglus. (quod maximis ferè quibulque viris contigiflc dole-

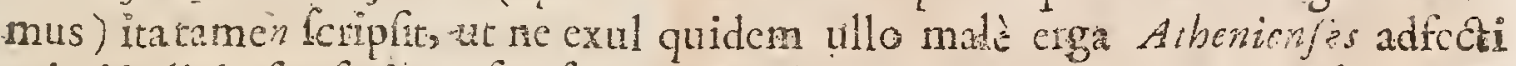
animi indicio fua fcipta afperferit, imò adeò veritatz: amans, ac morbus moderatus, ut ne Brafia quidem (qui calamitatis ator iph frerat)ufquam in fua Hiforiâ præ irâ aut odio máledixerit. Et inf ftifimum fibi Pericler, non fom Jun àcalumiis viudicavit, fcdprudentix diarumque vitutum nomine fincere commcndave Lan Bernar. de utilitat. legend. Hift p. 43 .

*Quod ad Tharydidem atrinet, eum lice octies fuâ inanu defcriplerit Demosthes nes; tamengravis mais itforicuscenferidebet, quam orator bonus. Eft enim fermo cjus durus, 2 yperbatis-implicatus: unde Cranppus orationes illius mom leftas atque odiofas elfe judicabat. Etiam Cicero aís n:c fe imitare enmpofje s vew. lit, nec velie fipo/fl. Fiflo de Rhetor. p. 68.

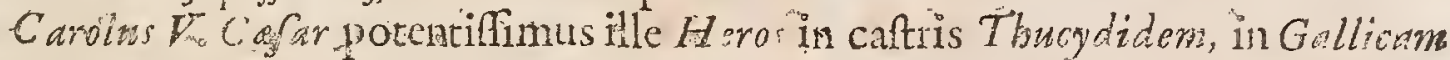
Iinguam à Claudio Ahaflienfi Epifcopoconverfum,ferrper fccum habuit, \&E Hunc autorem afidue magnâ cum voluptate legit, eumguc fuis intimis confilum riz, Silvagio, Mercurine \& Granclo commendavit, atque ex is quarere folicitus fuit, quid legillent, \& gua ipfe obfervalft, cum illis contulit. Camerar ho. ris fubciliv. Centul. 3. $6.67 \%$

Thucydides infuo [cribcheli generc accuratusef, fidelis in is qua dicit, fuw renus s ad id yood fua intererat minimè refpiciens. In cjusfylo fplondct magnificentiz nobilitas atque Majeltas; auterus ubique elt, fed aunteritate qua rihilnon magnificum fpirat. Verum quidem eft cum tractare algusnentum in omnibus exilias \& Jimitarius Herodoi argumento. Meso partium fuarum af fectu Herolotum Thucydidi, antcponit Dimy/us Halcarnajoms, quia fcilicet Herodotus ejus popularis crat: Sed quod ad me foetai, lanc Gracos omnes Hiforices fuperarecenfeo.Rapin. Reflex. Gallic.in Hifor.Sed. 28.

Hiftoriam Gracam Thucydidis of Polybii, Latinamque Salufii, \& Tiui Livis cateris omnibus praferendam clf cenfco; leu gravitatem in illis, ac majeftatcre operum fpectes, feu puritarenftyli judiciique integratem, feu denique om nes Hiftoria rectè confcribendx leges requiras. Quas ipfi adè concinuè feliciterque obfervarunt ut, ne tranfverfum quidem ungucm ab illis unquan deflexile, jure merito ab bitri polfut. Gr.Nand. Bibliograph. Politic.

$$
\text { C } 2 \text { Hiftoriarune }
$$


Hiftoriarm libri 8. gracè cum verfione Laur. Valle emendata \& fcholits: gracis, apud ten. Stephamum. Is98. in fol.

Hunc autorem in Anglicanim Sermonem accuratiffunè tranfulit Thoma. Hobbefins.

\section{Y I A S.}

Clar. ante Chrift Ann. C C C G.Y.

Cracufonns genere, Cephali filius, unus è decem oratoribús natus, A thenis qu ò. $\checkmark$ pater fe tranfulerat. Puer Thirion coloniam migravit, rediit annos natus 47 o interque principes oratores habitus. De quo Cicero in Bruto, Tum fuit Ly fas inquit, ipje quidern in caufis-forenfibus non verfatus, Sed egregie fubtilis foriptor, atque elegansoguern jam propè andeas Oratorem perfecturn dicere ac. Plurimæ ipGorationes tribuuntur; Apologia item Socratis; Precepta dicendi; Ex Epifole. Ferventibus Olympicis ladis, Olymp. 99. orationem çontra Dionyfum Tyrannwm, toties veteribu laudatam, confcripfit. Obiit Ann. xtat. 3r. Olymp; 100. Hofrnan.

Plutarchus 425 . ejus orationes olim numeratas fuilfe tradit, quarum 230 . gem muina tantum fuerint judicio Dionyfir ơ Cacilii. Ex. quibus non nifi triginat quatuor fuperfunt.

Lyfas fubtilis atque clegans, \& quo whil, fi oratori latis fit docere, quxras. perfectius. Nihil enim eft inane, nihil arcefirum, purotamen fontio quàm magnollumini, propior Quintil. Inftitur. Orat.1. 10. c. I.

Legi varias $L y /$ i orationes, qux dicuntur effe numero trecentze \& viginti quinque, quarum legitim funt ducenta $\&$ triginta tres. In quibus bis tantum folum diccndo vikus dicitur, cùn tamen frpiù cum Adverfariis contenderit. Eft in orationibus fuis brevilimus, \&ad perfurdendum perappofitus, \& fi quis alius graviter dicendi peritus, tameti non appareat. Etenim quanquana facilis videtur effe, nihilominus tamen imitatu eft difficilis. Magnam puitatem \& perficuitaten in rebus \& verbis etiam in principio orationis oftendit, ut in uarrando fine ambigibus, \& nihil externum aliunde adlcilcendo. Venuftatem autem compofitionis non quivis facilè animadvertit. Nam fimpliciter $d$ cafir ut res dat fe dicere videtur, affurgit tamen ornatu in immenfum, eftque oratio cjus \& propter fchemeta digna admiratione, \& propter fenfum \& verba, \& concinnam hor m compofitionem, \& inventionem, \& ordinem enthymema tum, \& Epicharematum. Phot.in Biblioth.Andr. Schot. interpret.

Lyflas propriis \& uftatis verbis utebatur; éque hoc affecutus eft, ut cùm loqueretux more confueto, novâ.tamen uteretur dicendi formâ, primufque in duceret recentiorem Atticifrnum. Non verumelle cenfeo quod Dionys. Halicarnafj. Ccribere non dubitavit, Lyfam videri res facere infignes, graves ac magnas. Nifi id ad unam alteramquc orationem reftringas: uti illam contra $M$ nefipolernurn, quam folito gtandiorem fuife Phorius ait. Cateras fifpectes; fubtilis potius orator eft, quàn fublimis. Teftatur autem icero non fuiffe verGatum in canfis forenflens: Ced aliis orationesfcriberc folere. Nempe quia ad 
minutarum caufarum genera fe demitceret, necelfario factus eft jejunior, a tenuior. Vofl. de natur. Rhet.p. 74,75 .

Inter plurimas vero orationer, etiam Socrati unam leripfit, cum is in capitis judicium vocuretur. Sed ille eam quamvis elegantem, tamen ut parum virilcm, velut Sicyorios calceos repudiavit: ut apud cicer. lib. r. de oratore.

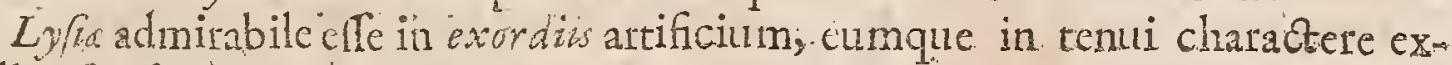
cellivife, fcribir Dion?. Halicamaff:

Favorina de Lyfin \& Pl:tone folitus eft direre, frex Platonis, inquit, oratione verbum aliquod demas mutefve, atque id commodiffmè facias, de elegantiâ. tantùm detraxcris : fr ex $L y$ jae, de fcatentia. A. Gell: Noct. Attic. lib.2o. eap. 5 .

Succinctus hic, fubtilis, elegans, fed tenuis, cui fr quid demas, fententia turbabitur. Audi Ciceronem in oratore: Dicat igitur Attice venufilfsrnus ille foriptor ac politifimus Lyfas. Ouis enimid poffit negare? durn intelligarms boc efle Atitu cum in Lyfianon quod tenus fat atgue inornatus, fed quod nibil babeat infolens at-. que ineptum. Ia . Oifel.comment. ad loc. predict. A. Gell.

Elegans inprimis fcriptor, atçue Attici fermonis tanquam norma quadam Ly fas. Petr. Victorius 1. 8. var. lect. cap.11.

Lyfix autem ipfus in primis acumen ingenii, inventioque landata eft ac fum mis laudibus ab cruditis friptoribus cel cbrata.Idem lib. 20.cap.16.

Lvfux triginta quatwor oraciones Iodocus Vanderbeidius Latinè vertit, \& notis. Politicis illultrayit Ann. 16 Ij.

\section{A R I T T P H A E} 10 Oeta comicus, Philippi filius, ex Lindo Rhodi oppido ortus, inventor
tetransert, in carpendis. hominum vitiis liberrimus. Cum Socrate inimisitias exercuit, quem in $N$ wbibus ut juventutis corruptorem egregium accerimè infectatur. Per excellentiam Corscedid Pocta ab ipfo etiam Perfarum Rege gognominatus. In eo funt omnia lingux Attice ornamenta, quem fub pulvinani fno, cum dormitum iret, fervare folitum ferunt: $B$. Chryfoftomnom. Comodix: qua magnâlibertate infectata vitia eft, princeps.longè, ficut Menander nova; fuit : Ita tamen, ut illiadjungendi Eupolis \& Cratinus funt, huic verò Pbilemon ąc Diphilus comites accenfendi. Carel. Stephan. in Diction. Hiftor.

Propter Ariflophanis maledicentiam in Proceres, Alciliades legem tulit, ne quis corricus nominatim aliquem in fabulâtreprehenderet. Ita factum, ut Arifom phanes induceret medium comcedix genus inter veteris maledicentiam, \& no

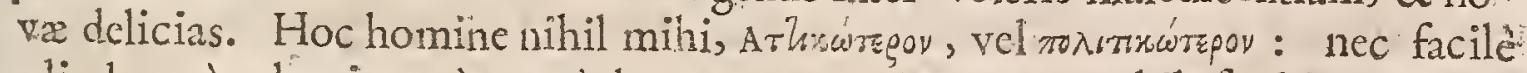
aliudxquèculparis quàm yuod nec pepercerit Socrati 2 philolophia parenti. Vofj. de Poët. G.ac. p. 34.

Nifi socratem hic impudentifimè fuis Nebulis profcidiflet, parentem fcilicet morum \& Philofophix,mihi in pimis fuerat colendus. Lil. Gyrald,

Saera hic oliva ramo coronatus fuit, infuper Athenienfium eloquentifiu C 3 . 므는

Claruit anse Chr. Anno C C C . 
mus habitus eft, ingenioque maximè excellenti in fententiis creber, inventione variâ \& jucandâ, arte fummâ \& precipuâ, ufque adeò utomnium jựicio poft fe reliquos ejus generis Poẻtas longo quidem intervallo reliquerito Stant qui if

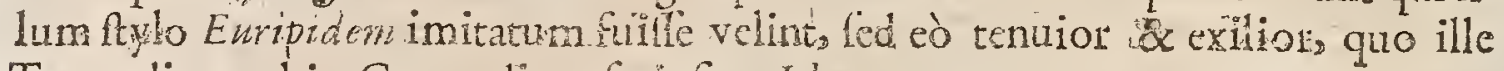
Tragcedian, hic Comediam fcripft. Idem.

Diminutivis vocrbulis, tefte Ariftotele in Rhetoriciss ufus elt, atque id qui- dem cum mordacitate, plerunque \& verutate, \& pracipuè in Babyloniz fabuqâ. Quales verò illius fnt fales \& argutix, nullibi melius elt legere quàm in libello Putarchi qui infcribitur Epitome Comparationis Aristophanis \& Merands: in quo de utriufue diffrentia multa.

Ex Poetis optimi, : quos operæ pretium lit lcgere, Attici Gant Euripides, Sophocles Arifrophane, \& quod Menundri eft reliquum. Arifaphanes elegians, \& Eftivus. LudVIv. Detridend. Difcipl.pag $475,252 \%$

Factifrmus quidem, fed \& obfcenifimus veteris comodiz fcriptor. Dilher. an Dilputat. Academ.

Pexpctuus Eur pipidis obtrectator, Comicus purè impurus. Heraldi. Animadzer. in Salmaf.oblervat. ad jus Attic. \& Rom. lib.6. cap. IO.

Alcous Ariftophanes conicus vine madidi pangendis invigilabant Pnematibus. Khodigin. Aib. 2 S. lect. Antiq. cap. 6. Dei.

Tomo qui per ebrietatem multaconferipfir. Ludativ. in Augnstin. de Civ.

Arifophanesbonusauctor Attîus \& primus legendus : nec le quifquam jaetet Attirifnum intelligere, qui hunc ad unguem non teneat. Certe nullus eft. quii melius apud Grecos loquatux iplo Arifrophane, ut nec apud Latinos, TEirentio. Scaligeranât I'pag. 23 .

Itra me Dii ament ut come plurimum ano, ubi hac Scatigerm dixilfevideo. Nam ego iple quidem huic Auctori intelligendo plus quind cin anm nos infumpli, neque me tamen operx ponitet. Tan.Faber in loc pradict. scal.

Singulare illi \& plerumque dillce reprehendendi, jocandique genus, doquentia Ática, quamnemo Gracorum fuperavit, Latinorum nemo. Legendistamen cum delectu Arifophanes ut ex eo, apum more trahantur mella won convitia non ols fecena. Olaus:Borrich. in differtat. de Poet.p.35.

Rapini de Aristophane judicium ct? quòd in Fabularum fuarum ordinatione aullam adhibuerit curam; quod ejus Fictiones à vero-fimili procul aimis abfint; quèd rufticè \& apertè nimis honines dudificetur, quòd ejus facetix holluonm mera imitatio plerunque effent; quòdque in quibuldam cjus Drama fum quadam apponanturcondimenta qux feculi nofti 1 alato parum laperen: Rapico Reflex, tarticularib. in Pocf.par. 2. Reft. 26 .

Idomate oblcuro, intricato, infmi trivialique Ryli quandoquentitnr; Infullis ef in frequentibus - -uis ad voces allufonibus, in fus verborum fibi invicem oppofitorum contradietionibus; in fuis Trasici cum Comico, facet cum ferio, gravis cum familiari Aylo permiftionibus; ejufque joci atrotiìs 
confiderantibus parum genuini non raro deprehenduatur. Rapin.ibid.

* Eim:lii Porti in Ariftophanern Epiftolx \& notationes, Aurelie Allobrogmm. fumptibus Calderane Societatis 1607 permituntur cum expurgationibus. Index $M$ adritien is Ann. $166 \%$.

Inter Editiones ejus commendatur illi, quam excudit Lugd.Batav. Io . Maire aum emendationibus Iofephi Scaligeri, \&alionum:

\section{L: O C R. A: T E: $S_{\circ}$}

A Thenien fis, orator, natus Archonte $N$ anfinaclos quinquennio ante Pelopon1 nefiarum bellum, minor. Lyfia annis 22. obiit Archonte Cheronide, paul sis diebus poft pralium ad Cheronearn, A.M.3FI4. Vixir annos nonginta:

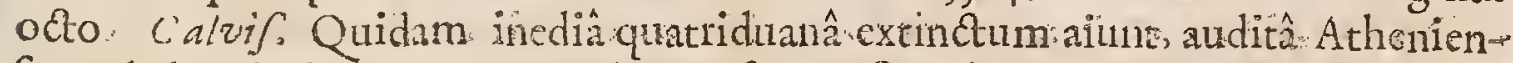
fumclade adicharonear accepoâ, cuifuperclfe noluit. Vitam ejus Plutarchus exaravit. Reliquit Orationes., quas uno volumine complexus eft Hieron. V.Volfo.

Ifocrates (cujus domus cuncte Graciä, qriafiludus quidam", pattit atque - fificina dicendi.) magnus orator, \& perfectus Magifter, quanquam forenf luce caruit, intraque paictes aluit eam gloriam quam nemo quickm, necjudicio, eft poftea confecutus : $\operatorname{xim}$ catera meliùs, quà m lüperiores, tum primus intellexî́, etiam in folutâ oratione, düm verfun iffugeres, modim tamen, à numerum quendam oportere fervari. Cic. de Bruto.

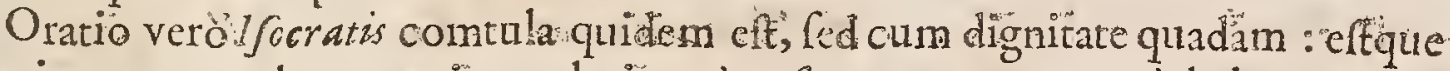
magis accommodata cotui populari, yù̀m foro: ornatum verò haber cum vî. बluadam. Pompatica eft, fed cum efficacia atque utilitate s ad Forenfia autem Certamina parum idonea. Dionyf F Falicarnafjo.

Ifocrates in diverfo genere dicendinitidus, \& comtus, \& palaftre; quà mugnx, magis accommodatus. omnes dicendi veneres fectatus eft: nec immerito : auditoriis enim fe, non judiciis, compararat : in inventione facilis, honeft: Atudiofus, in compofitione adeo diligens, ut cura ejus reptehendatur. Quintil. 1.50. C. Io.

Sermo profectò elaboratus, \& verborum diligentia, \& Splendor compofítionis in co apparent, vifque caftigata in numeros, ex fententia fententiam aquali bus periodisterminando. Pbiloftr. Quanti habins fuerit Ifocrates. vel ex co patet., quòd or ationem unam viginti talentis vendidit. Plin. lib.7. c.3o.

Ifocrates omnium Oratorum elaboratifimus: Iul. Scal. orat. I. cont: Er.afin. Tardus crat accuratufque in elaborandis fcriptionibus ufque, adeò, ut'

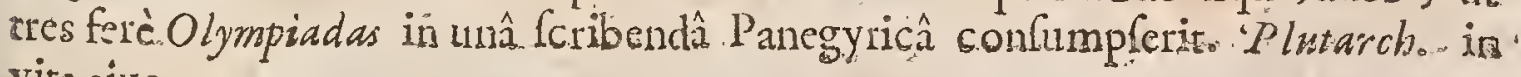
vita ejus:

I focrates umbratilis orator, affectatis ftructurze numeris ac periodis oratio uis, perdidit illam nariv dictionis gratiam. Erafm. Epift. 1 .28. epift,7. Imò \& Ifocrates hac parte ( viz. elocutione) erat nimis anxius. Itaque urfucatam \& calamiftris inufam, meretricifunilcm dicebat Cafar Scaliger: qui Platonican

Clartitatice Chrift. Ans ccécesty 
dictionem marronx gravi, ac decora: Ariftotelicam virgini honetta conferem bat. Foff de Ililog.p. 47 .

Quo fimplicilis ac purius cogitari nihil poteft. Lnd. Viv. de tradend. difcipl: 1.3. Tam diligens elt compofitio Jocrais, ut nonnunguam in verfum incidat. Turneb. not. in Quinit.

Quidam illum funt redarguunt, quod muita in oratione Panegyrica ex Epitaphis, fermonibus Archint, Thuydist, \& Ly fa fit mutuatus.

Hunc [ forratm] Theos fophifta, cum eadem [quoad fonfum] in ejus $P$ anegyrico inveniri air, que in Epraplsio atque Olymbrco Ly/2a, tantum abeft, ut vi"tuperet, ut inter exempla potius eloquentia fudiofs imitanda pofuifie centendus fit. Quamobrem dibcrandum amplins, an ea qux five ifocrater hic ab

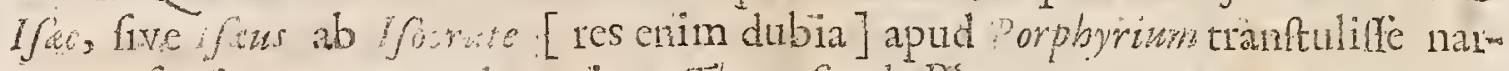
ratur, furtis anmumeranda veniant. Thomafula de Plag. num. 476 .

ljocrates vir à fummis vidis propter \& virtutis \& patria amorem ( qui ex omnibus ejus foriptis clucer) conflionmque gravitatem, \& orationis filendorem W firvitatem, fummè laudatus "Zicron. Wolph. 1rafat. fecund. prafix. Ifoc. operibus.

Ifocratis cditionem Wolpbianam longo intcrvallo poft Le reliquit illa Pauli Stephani edita $160_{4}$.

\section{$X E N O P H O N$}

Clar. ante Chinit Ann. acciXXXVI.

1 Thenicnas, Gryllifilius, tempore Artaxerxis Iongimani Perfarwm tregis Th claruit. Lacritus ait, eum obilfe An.z. Olympiadis 105. Erat : bilofophio, Hiforicus; \& bonus Strategus. Sub Cyro Artaxerxis frarre imperium in dccem hominum millia obtinuit. Ab Athenienfotrus pulfus, ad Lacedarontos fe contulit, qui exuli agrum dederc \& alia. Scripfit cómmentariolun de Repub.Lacedarn.

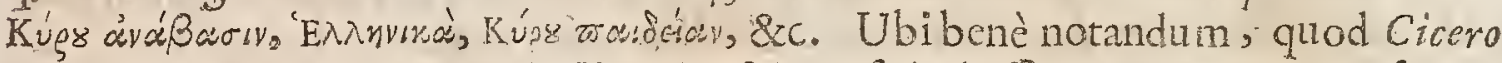
monet, Cyri Padiam non ad Hitorix fidem, fed ad effigiem juti impcrii fcrip. tam efle. Errant itaque quotquot inde Hiltorix veritatem petunt. Extat etiam Xenopbontis nomine libellus de Equivocis: verum ille ab Am. Viterbiengi confictus eft. Scriptor hic adeò eft dulyisut Gratzo ejus fernonem finxiffe videantur, queradmodum Eabius 1. 10. loquitur. Cicro in oratore ait, fermonem ei elfe melle dulciorem, Mufafgie ore ejus locutas videri. Et propter hanc fuaviaxem Musa Attice \& Apis Attica dictus of. Kunte.

Quid ego commemorem Xenoplsmits jucunditatem illam inaffectatam, fed quam nulla pofft affectatio confequil? ut iplo funxiffe fermoncm Gratis videantur. Quintil.1. 10. c. I.

Auctor ille (Xenophon) pra cateris decori oblervantifimus; \& quem non

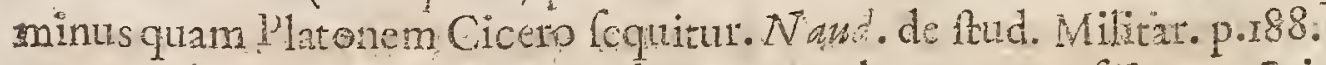

$X$ cophon purus in delectu verborum, \& clarus, ac perfpiculus, \& incompofitione furavis, ac gratiofus fuper Herodetur. In Hiftoriat tamen, flendor Xenophonti, ac majeftas deef; is , fi aliquando clowutionen conetur attollere, confertim 
confeftim languclcit, \& fublidit. Diony. Halicarnafs.

Xenophonters pratereo? abfit. Sed laudatifimus ille Cyrus ejus non habet hic locum, quem magis ad exemplum vitx, quàm ad fidem rerum fcripfit. In reliquâ Hiftori: (Gracanicâ, inquam, aut lerficâ). fané fuavișille \& fidus , certè circumfpectus fcriptor : è quo tamen haurias magis prudentiom. hanc civilem, quàm ut ultro eam propinet. Sententias quidem \& idogmata rarò mifeet. Sed juvir nos hic egregiè vî̀ aliâ. Cùm Thuryditem adhue latentem, \& in fû́ manu ut opprimeret, ( ô candidam, \&ab omni æmularione vacuam mentem!) primus iple protulir \& divulgavit. Liff. Not.ad r.lib. Polit. cap. 9 .

Luculentum X"enophntis elogium extat apud Dion. Chryfostom. in oratione de Dicendi exercitio, ubi mirè ad e, us lectionem adhortatur: arque inter alia aic, vel ijus folius lectionern Sifficere pofje bomini politice.

Sanè Xenophnon multum abfimilis ef Iulio Cafarn; uterque enim purus eft, \& clegans ac cum lenitatc quadam fluit : fed hôc differme, quòd liefar gravior, aliquantò, Xerophon fuavior eft. Illa Xenophontus laus eft, quòd cùm Thucy didem pofte fupprimere, primus ejus monumenta in lucem protraxerit. quemadmodum teftatur Laertius : quo vel folo nomine, quantum illi debeant omnes nemonon intelligit. De occultâ fimultate, qux inter nobiles illos socratis Difcipulos, Platonem \& Xenophontew fuit, nota resex Atbener undecimo, Laertic in l'latcnis vitâ, \& Gelio in dccimo quarto. Vollins De Hift. Grec.

$X$ enophon in dictione fua terfus eft; infua Scriptione minime fucatus \& jucundus; ingenium ejus eft facilc, copiofum, multarus rerum cognitione plenum; imagirutio ejus nitida, aptus ei dicendi modus : Ced nihil magnifici ncc fublimis habet; decortm in moribus non femper admodumfervat ejus Hiftoria; in qua ignaios \& barbaros Thilo ophorum inttar loquentes introducit. Cicerorefert cipionein illum deponere non potuiffe fi femel ad illius lcotionem animum appulifict Longinus characterem ipfir tribuit, quo in rebus cogitandis fclix eft. Lectilfmus denique Hiftoriu eft, \& ejurdem hiftorix lectione Scrpio \& Luculus tanti Duces facti funt. Rapin. Reflex. in Hift. Sect. 28.

$X$ erophon \& Polybins in morum documenta frequenter nimis incumbunt; fuifque reflexionibus iftoriaflum fapiù abrumpunt. idemibid. Sect.5.

Ioannis Lewnclarii in Xenophontis opera Greco-Latina annotationes, fi expurgentur, permittuntui. Vid.lndic. Madrit. Edit. Al1n. 1667.

Xenophonits Operum cditio optima eft P.arifienfls, in quâ Grecis Laina refpondent Levenclavii ex tralatione, Notis e Aril. Porti clucidata. fol.ann.I6r5.

\section{I $S$ E U S}

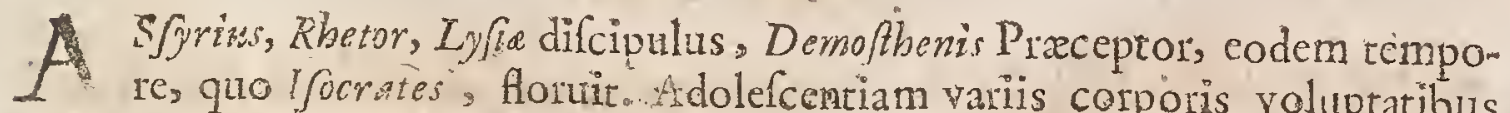
radidit; deinde vir factus, frugalifimus omnium fuit. Ex 64.orationibur, quas Clarnit ante Chrift. Anus. feripfit. Decem hodiè extant. I sui vitandefcripfit Plutarchi. Ejus orationes 
didit Abphonfus minintus cum orationibus Antiphontis \& Andocidisom

Legimus varias orationes Ifai: quarum numerus, ut femel dicam, fexagin a cquatuox: quarum germanx folùm quiniquaginta. Lyfiam autem potiffimùm: imitatus, cujus \& dilcipulus fuit. Imitatum verò illum fuifle arguit nominum concinnitas, \& rerum gravitas. Sic enim oratzones illins $L y$ /iam imitantur, uts. nifi quis diligenter attendat, utriufque ftyli differentiäm vix dignolcat, Schernaw ta fi excipias, Etenim primus If eus Schemata adhibuit, \& animum ad civilem artern convertit, quod maximè Demofthenes 2. illius Difcipuliss, imitatus ceft Phot. in Biblioth. Andr. Schott. interpret.

Primus, Plutarcho autotore, Schernatis uti cepit Ifaus, is a quo vim fuam anquàm àfonte hauft Demofthenes, quemque in órxovouía tam feliciter lecutus eft, ut eum devorafle dictus eft quemadmodum lozuplës reftis eft Diony. Halicarnafl. Equidem miti perfuadere non polfum, tam bardum fuiffe magnum virum, ut ignorct, ante Ifrum vulg̈̀े quoqne î̉ ufu fuilfe Schernata; verum id voluit, primum creditum I seum animadvertifle in vulgari fermone certas loquendi formas suas Schemata appellamus, eafque illum frequentafle, quibus locis dicendilimperiti fimplici oratione uri folent. Voff.1. 5. Inttitut. orator. pasgin. 263 .

Tribuit Ifeo Dionyfius Halicarnaffo. Dictionem puram puram, accuratam, propriam, evidentem, arconcifam.

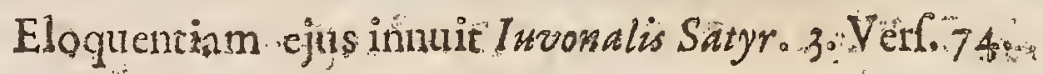

Ingerium velox, fudacia perdita, Serma.

Promptus, of If $x$ o tormentior o...-

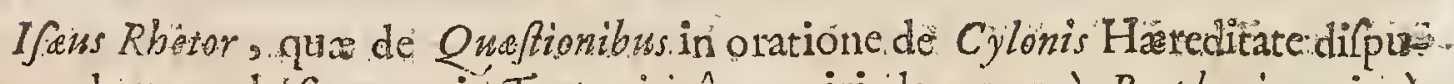
at, cadem apud lfocratem in Trapeziticâ reperiri docemur à Porpbyrio : imò Demof thenern etiam in eâ quam adverfus Onetorem, Vnde 6. habuit eâdem propé fententia differere. Ubilllud annotare vifium, quandóquidem I feum conftat, codem tempore quo Socratem Scholas habuife Rhetoricas, dubitari poffe, in utrunt ifta conveniats modò ipla per fe jafta eft accufatió? Nam de Demofthene, qui Difcipulus \& I fei fuit, \& Ifocratis effe potuit, ambigendi ratio celfato Thornas de Plag. Sect. $47,3^{\circ}=$

Demofthenes praceptore dicendi ufus eft I seo quamquam Ifocrate tùm docesp. 10. five quò propter orbitatem mercedem huic (decem enim a fingulis difcipulis exigebat minas, ) perfolvere non pofler, five quòd illius orationem ut hementem, callidimque usûs caufa prafexte Plutarch. in Demoftho

\section{P.LA T:O:}

Chanir ante Hilofophus infignis, SeEte Academica princeps, Arifonis \& Parectonia fiChr. Anno eccIXVI。

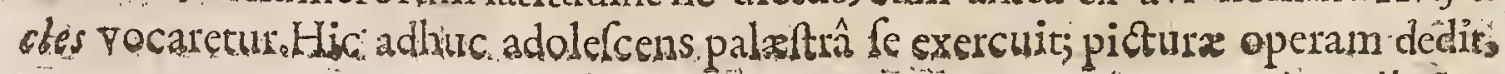
Iragediasgue 


\section{CELEBRIORUM AUTHORUM.}

Trage diafque \& poemata quedam firipfit. Poit hac ad Socratcm le contulit, Cub quo brevi tantum in Philosophiâ profecit, ut non immerito Divmus Plato, \& Philofophorum Homerus fuerit appellatus. Anno atat. 8r. placidifimo deceff obitu, die ratali, Olvmp. 108. ante G.N.347.vel 348. Hofmakn.

Plato ille fublimis apex Philofopborni \& columen. Arnob. lib. x. Plato ille Divinus, multa de Dec digna, nec communia Lentiens multitudini. A rmob. lib. 2.

Plato inter onnes Pbilesophos religiofifrmus, \& maxime fobrius. Calyin. inAtic.lib.r.c. 5. Sect I. Philofophorum Den à pluriris vocatur. Plato.

Philofopherum, ex quibus plurimum fe traxifie eloquentia $M$. Tullius conftetur, quid dubitat latumem effe procipuum, five acimine dilferendi, five eloquendi facultate divinâ quadam \& huñ ick? mulum nim fupa profam orationem, \& quam pedetrem Grari vocant, furgit: milhion hominis ingenio, fed quodam Delphico videatur ouaculo infinetus.Quintil.1. Io.c.I.

A istoteles longè omnibus, Platonem femperexcipio, proftans ing cnio \&

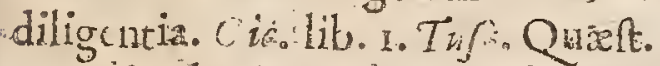

Quis uberior in dicendo Placone? Iovem fraudem aimit Pbilofophi, fr grace loquatur, fic loqui. I der in is rit.

Platonacars \& fublimitatem S latitudinem laudat Pinins 1. I. Epift. 10.

Ef profectè Plato non minor eloquentia, quàm Pbilorphia laude. Quiiß jure majori ctiam ejus eloquenciam admiamur. Nam de Phibophiá ejus now immerito dicere polfis., quod de efgypiis pharmacis fcribit Homerns:-....

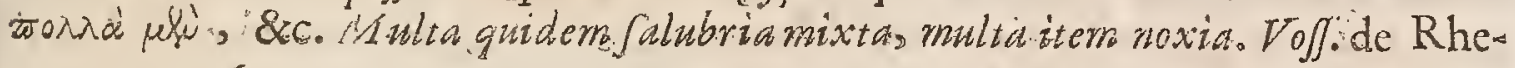
tur. pag. 76 。

Lictio Platonis minus eft idonca ad Thilofophondum peccat enim co (ignof

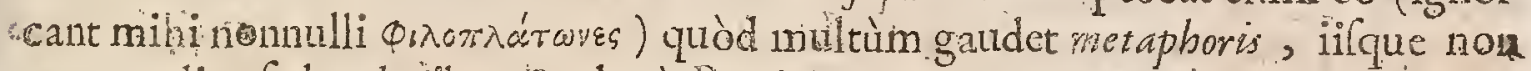

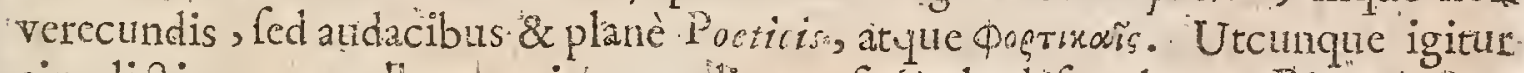
ejus dictionem extollant, qui lovem dicunt fi Colo defcenderet, Platonis Sermone ufums Philofophic magis convenit dictio propria, aut talationes receptex \& ufitatx. Voff de Philofoph, Sect.

Plato Lapicntia antiftes. Flan.lib.7.cap.30. Plato Homernis Plilofophorum, Plutarch de Homer.

Ob id Platomaximéladandus, quod proxime ad Chrifiam pietaten accefit. Beffar in calumniat. Plat.1.2. cap. 4 .

"lato 'brifricane, fi pauca detrahas, vel mutes. $M$ argl. Ficin in vit. Plat. Caycndum tamen admonet $F$ icus lis qui le dcentun Platoni, ne fuperfitiof fiant; at qui Arifoteli, ne impietatem hauriant. Ioan.Frano. Ficus ae rev pranot.lib. "T. cap. 4 .

Credidit Plato unum Deum, cui tamen Damones \& Heras aflociat: $\mathrm{X}$ dolet Tertulianuintractatu de Animî, omnes Hareticos à Dialogis ejus de Republiç \& Ideis fublidia errorum mutuatos elle; Heretica Idearum Sacramenta il-. las proptered vocans;additq; in I deis Platonicis Gnoficorum hreretica lemira reLucerc. Farendum tamen, primos Ecclefie Patres fere omnes Platonicos fuilfe. 
hujufque Philofophim reliquis omnibus ancetulife. Scribit quaque Angusts nus 1. 7. confeflior. libris ejus utiliter fe ad intelligentiam variarum virtueum Or thodoxarum ufum fuife, ibique fermè totum Evangelii loannis initium fe reperiffe. Imò Iufin. Martyr, Clerws; Alexandrinus, Eufebiussalii,iplum de Trinitate aliquam quo fue notitiam habuifle crediderunt, \& Mo fes Atticus à Numenio Pythagoricc, dictus cft. if ofman.

In Platone multum eft eruditionis fed recondite; ut cum ars occultatur in opere, eoque difcentibus non fátis congruens : doctis verò melior, er $G$ in ratura arbitrandâ non eft cum Ariftotele compaxandus, ut in præceptis morum excellat. Lud.Vir. de tradend. Difcip. p. 598 .

De Republic foripfit alim Plato primus : fecundum cujus inftiturionem tum domum vivent homines, quum aliqua exiftet civitas folis fapientibus habitata. Idem Vtopre coninget Thom. Mori. Legenda tamen ef Platon's Refprib. \& ejuf

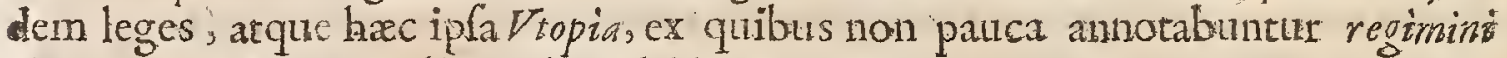
civitatum perquam utilia. Iderm ibid. 648 .

Plato Philofophus furti 'ex co infmulatur, quia ex libro five Timei Locrenfis de anund anima; five alio quopiam bilolai Pythagorici, Timenm fum concinnaverit ; quia multa fubduxerit ex rotagora libro de Ente, ex Ariftippiitem, Antifthnis \& Bryfonis Heracleote differtationibus; quia immortalitatern anime

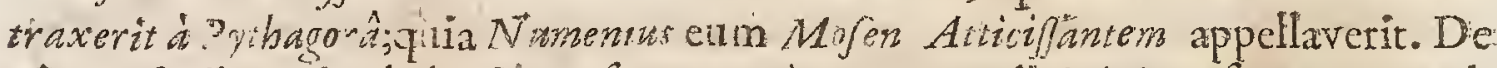
Tirneo facile patiar haberi excufatum, cùm non modò Dialogo fuo nomen ab eo indat, fed \& colloqueneen introducat. Quod idem de Protagorâ dieerem quoque, fi oftendi pollet, qux illi Philofopho Plato debet, ejufdem Dialcgo. nominis inferuilfe. De Philolao, Arifippo, Antishene, Bryfone deliberandum amplius. Pythagota verò olegiarium ideo facere Platonem, quxa de Immortalitate animu idcm. quodanteipfum $P$ th Cum Mofe denique minimè tanta illi fmilitudo intercedit, cux furti fufpectum eum faciat; neque verifmile eft, Numenum, qui Pysbagoricus juxta \& Platonicu fuit, Platoner illo clogiofuo deformare voluife. Thomas de Pelag.num. jo2, 2523 .

Nihil unquam inveni apud Platonem, quod deprehendere potuerim ex un Mofs Hiforia fuife expreffum: in multa verò incidi, ob que exiftimem, eam legute nunquam. Pául. Ber. I. 10. in Tim. Platon. p. 679.

Nullos habemus Platone \& Arifotele vetuftiores: excepto legiflatore fanctifmo, Mofr aut qui copiofus \& majori arte ac doctrina gubernande adminifrandaque Reip. formam nobis reliquerit librorum monumentis confrgnatam. Quare abuno Platone ftatim incipiendum eft, qui Dialogis fuis de Leqibus \& de Republìc $\hat{a}$, praclarè omninò regnum, \& Remp. inftituit ádeoque moribus \& Mafitutis Chriftiun fidei convenienter, ut Divus Thomas in opufculo de Regimine Principum, latonifinum in Republicâ defideret Ab illo verò licet omnia ferme mutuatus fuerit Ariftoteles; inefcio tamen quomodo, fic ifta fibi propria fecit, Magitrifui rationes pracipuas aut clarius ac facilius proponendo, alit Afbtiticer \& acutè refeliendo : ut non minus in intis quam in cereris operibus: 
Guĩs manifeftum feciffe cenfeatur, quantus ipfe Philofophus fuerit, quằn elegans fçiptor , quàrn acutus, quàm aptus ad docendum; qulàm copiofus, quàm rexum ominium cognitione refcrtus. Et verò lícet communi graviflimom rum virorum fententià, multa fcripfiffe dicatur, partion difficilia atque obfcuYa , partim etiam à noftris temporibus \& moribus aliena; nulla tamen mihì videtur effe in co difficultas, ‘ut obferirtas, qua non improbo labore, \& acri ftudio, ac cicbrâ le etione pervincatur.Gabr oN aud.Geog. Politic.

Platonis opertum editio optima eft Ligdunenfis Anin. 1590. in Fo k. cum Interpretatione Latinâ \& Comment. Marcellizi Ficini. \& cmend. Cafauboni.

\section{DEM OSTHENES.} Ivis Athenienfis, Grerorum omnuium Orator' longè elloquentiffimus, natus
eft tricnnio poft Arifotelem, ante Chrift nat. 379 .

Inclarefcerc copit decimo feptimo xtatis. Obiit veneno fibidato ante Cbriff. Ainn. atumi 320 . Calvilitiv.

Hic cùm ab xtatis initio eflet balbus, neque literam $R$ pronuntiare poffet, quibufdain calculis in os conject is propè maris litus declamans,narurze virium emendavit, ut poftè eloquentifîmus evaferir. Prærcreà ad ingons fpeculum perorarc lolitus eft, ut è̀accuratiùs gettum decorum tchere difceret.

Sequitur Oratorum ingens manus, cum decem fimul Athenis atas una tulevit: quorum longè prinecps: Demofthenes, ac penè lex ornand i. Fuít tanta vís in eos. tam denfa omnia. ita quibufdam nervis intenta funt, tam nihil otiofium, is dicendi modus, ut nec quod defit in 60 , nec quod redundet invenies. Qintit.

Leofthenern, proditum memorix eft, cum magnitudinem, vim atque filendow sem Demofthens in dicendofatis mirarinon poffet, (olum ex oratoribus dixiffe: animatas planě, non malleo culas, orationes exhibuiffec : quanquam non me fallit , M. Tullium quodam loco ita fibi faribere permifilfe, uf groe ec, inquite, difficiles a: morofis furmus 2 ut nobis non satisfaciat ipse Dernofthenes: qui quanguans unus eminet inter omnes in omni genere dicendi stamen non fernper implet aures: meas: itafunt avide, \& capaces, \&-empir aligrid imamenfum, aliguid infinituris defiderant. Sed alibi tamen füo teftimonio amplifimè Dermofthenems

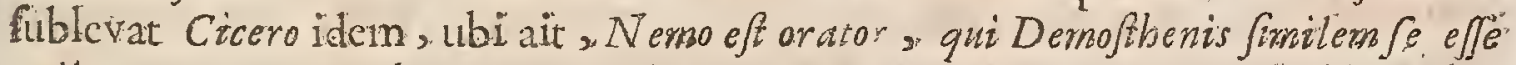
nolit. Quin propter bunc unum Atbenas żtern:mag is Atticas putat, Rbodig. in I. Io lect. antiq. c. 13 .

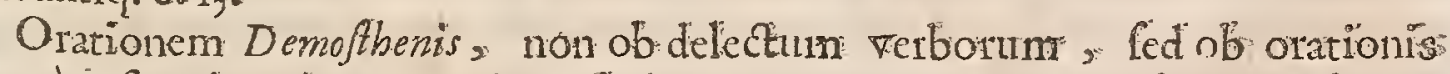

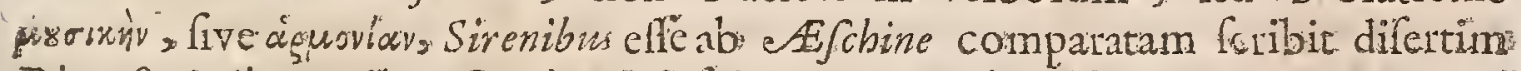
Diony. Halicarnaff:-..-Cerè \& in iplo Platone reprehendit Dyony. Halicarnaffor

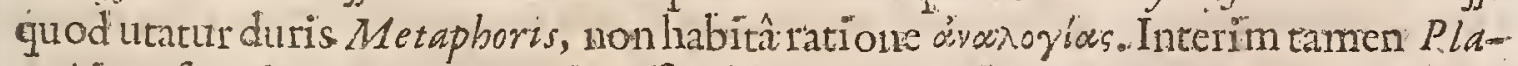
twi ignofendium putamus, ob dificultatem grandiloqui characteris,: quc ctiam ob callam ignofcendum Demafthenit, quod duriores interdum adhibeat tranflationes; unde inimicus ejus. AfCchines diccbat;

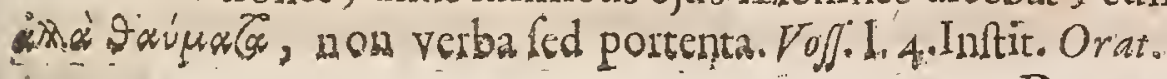

$$
\text { D. Demu僧henes }
$$

Clarritant: Chriftun: 
Demofthenes quafi populi robur. appellatus eam habuilfe vim dicendi prodt" tur,ur quicquid vellet id populo perfinaderet : difluaderetque quicquid nolleE. Nomine cujus commemorato (utaitValerins) eloquentix conummatio undientis animo oboritur. Franc. Sylv.in not.in I , . Ep1t. Polit.1. 3 .

Demofthenem autem inter Grecos Rhetores. fic effe primum, ut vixinvenias qucm cum illo pofis conferre, magnus exuditorum omninm confenfus eft patiar ut prer quidem eleguftet Dermofthenem, fed ad eum feriò redeat, jam factusoculatior, quo perficiat illam werè Atticarm. Venerem, illud cxcuffum judicium, illa funmo artificiocontorta Enthymemata, poftremo vim illam oin. nibus admirabilem, vix ulli imitabilem。 Erafmo Epilt lib. 28 . Ep. 26.

Non fatis repréhendi poteft infignis illorum error, quii pueris adolefcentum ilis orationes tinti Vili legendas proponunt, cùm tamen propter argı tmenti diff- cultatem à pancilfmis viris eruditis intelligi queant; pleraque enim earum fouenfes fint, ubi proteripfarn, ut dictum, materia difficultatem, multacx cete-

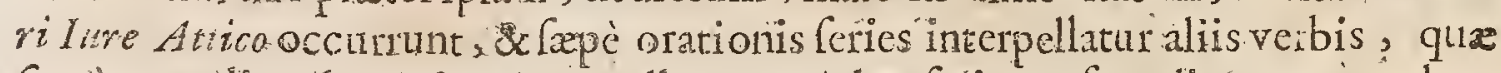
ffortè protulit, ubi Teftes interpellavere, Adverfarius refpondit, aut timultus aliquis copit oriri, aut etiam judcxiratum fe oftendit. Ne dicam de infinitis rebus aliis, quax vironmeruditifimo um conjecturis fuppleri vix polfunt. Fa*

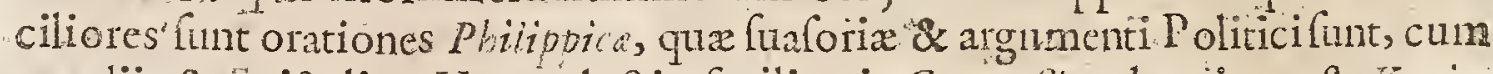
exordiis \& Epiftulis. Harumlectio facilius in Gymnafis tolerari poteft. Konig. in Eibliotr.

Pyiber dicere folebat, Demofthenis lucubrationes nimio plus lircermam olere; idemque cenfebat lutarchus, viz. quòd rmolhenis oratio videbatur immodicè uaborata. Hinc iğicur jactatum eftillud dictum, Plus olei guăn vini Demofthenem confumprife.

Desnofthenes.octies:iriè decies' (utait Turnéb. Iib. Adverfar. 28.c. 22.) defchipfit Thacydidem, utillu an in orationibus fuis meliùs imitarettir.

Legi omnes perè Orationes Demofibenis. Licuntur lllitís germanx fexaginra quinque : quarum ëlegantiores qua ad "opuhums quàm quie ad senatum habitæa à pluribus judicantur. Phot in cod. 265 .

Dicere polfumus nullum unquam Oratorem iras fuas, odia, indignationes, omnes animi fuii metus \& affectus tantâ wchementiâ concitaffe ac Demoflbenem. Et has decaufa dubio procul ait Demetrius Phalerait eum tanquan Divino numine afflatum concionati folitum clie; Eratothenes verò apud $P$ lutarchum afferit eum instar encrgumeni loguitume efe", "nflammabatur enitu loquendo tum fux abionis aftu tum ferventifina \& ardentiff ma, fi quis uns quam;imaginatione. Mira pariter facultate pollebat res accurate cuin omnibus circumftantiis exponendi; quod magni ponderis eft apud populum ut quis fideme ejus fibi demereatur. quippe cuî res è̀ veri-fimilior cenfetur, quò plura ejus adjuneta recenfentur. Faciltate queque pollebat ad vivum quicquid liberet ita depingendi, ut minima quas narrabat Fabulx multò magis quàm aliorum ran tiones peruaderent, "fimplicici minimeque fucato modo quodam quem in iis eloquendis adhibebat. Ejufmodi autem pictura vivis rerum coloribus expreffar 
morum in modum ipf fuccedebant: Rapin. Comparat Preclaror Firor.Antiquit. Tom. I.r. I4.

* Hieron. Wolphii in:Demofth. \& Efchin.opera Grac.Lat:verfo \& annotationes, cum expurgationibus permituntur. Index Madrit. Edit. ann...1667.

Ejus opera Grac. \& Lar.cum Comment. Gracis Olpiani Rhetoris in oratiomes quafdam, \& Hieronymi Wolphi annotat Geneva prodierunt an..16ه4. Fol. addita Sunt effchinis Declamationes...

\section{A. S.C.H.I N:E.S}

A Thenienfis orator, Demofthenis adverfarius. Hic a Demofthene victus in A illo de coronâ certamine, Rhodum difceflit, ibique docuit. Suidas auctor aft iplum, cùm in quadam causâ, I udices corrupiffet, in carcerem conjectum, hàufâ cicutâ obiifle. Scripfit oraizonesstres, \& Epiztolas novem. Orationes ejus monnulli Gratias, cum ob Sermonis fuavitarem itumànumero Chiritum; Epifolas verò $M$ ufas nominârunt: Konig.

Demosthene plenior e Efchines \& magis fulus, \& grandior fimilis, quo minus Atrictus eft:carnis tamen plus habet, lacertorum minus. Quintil.1.1o.c.I Inft. Oracon Efchines Atbenien fis, Atromet ifilits, in adolefcentia Tragcedias actitavit. Atque idem pofted concionibus \& orationibus tantum fibi romen comparavit

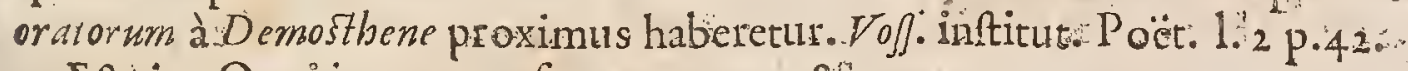

Eft ejus Oratio tanquam fponte nata, , \& extemporanea; non tantam artis: quantam ingenii ipfius admirationem concitans. Etenim cum grandia ommia in ejus or ationibus invenias , tum qux maximè natura preftantiam oftendant. In vocibus enim fumplex \& candidus, clerus.tamen, \& in orationum compofitióne, ncque valdè languidus, ur / focrates, neque contractus \&aftrictus, ut Ly fas : ipfo infuper fpiritu ac contentione nihil Demosthene inferior. 3 chematibus protereà cum fententiarum, tum verborum ita ufitseft; non tam nt ex arte, quàm pro fubjectx rei ac negotii neceflitate, dicere videatur... Quaz mobrem \& fimplex atque inelaboratu ejus apparet dictio; ac veliti popular orationi \& privato Sermoni maximè conveniens. Non enim vel in ratiocinat tionibus, vel in enthymematis multus, nimitumque coactus, Phot. in Biblioth. Cod.61..

Circumferur \& ejus alia oratio, Deliace Lex infripta; quam tamen Cecilins non recipit; fed ad altcrum 1 fchinem Atbenien fern ejus aqualem, hanc orationem, ut partum, refert..p bot. ibid.

Fuiff omnino e E/chines dicitur omnium horarum: Vir namque prater ejus verfatile ingenium, admodim etiam comis fuit, \&ad voluptates propenfior."

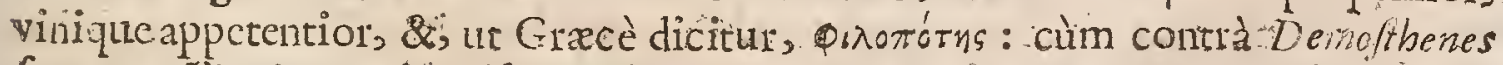
Ceverus effet, \& gravioris fupercilii vir, ac abitemius: quæ morum diverfitas in ter eos inimicitiarum caula fuilfe exiftimatur a Philoftro to: cum tamen plerique cos tamdiù inter fe amicos fuifle prodiderint donec ambo leg ati aby heirent fun Republica de pace mifl funt ad Pbilippurn Regem : tum" erin Claruit ante Chrift AnnoCCCLIJI: 


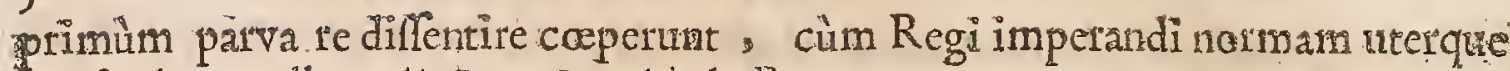
prafcribere vellet.Li!.Greg.Gyrald. de Poet.

Sunt qui fcribant, ab aliquo nunquarn magitto A Echinem didiciffe, fed cùm in judiciis fortè foriba officio fungeretur, nullo docente in tantam eloquentize attimationem evafffe. Gyrald. ibid.

Hieron. Wolphins A fohinis opera in Latinum Sermonem vertit, atque annorationibus illufravit, Baflees. An. 1972. Folio.

\section{A R I S T O T E L E S。}

Clartiot ante Chr. Anino. CecXIIII.
C Tagitita, Prilofophus, Peripateticorum princeps. natus eft Olymp. 99. A.M. 3670.U.C. 370 . Ante Chrift. Nar. 384 . Vixit annes 63. De mortis gem nere incerta circumferuntur quorundam narrationes. Hofman. Difcipulus fuit Platom, \& preceptor A lexanini.

Magnus \& admirabilis vir, quique ingenio diligentiaque vinceret plurimos nemini elfet fecundus; variarum renum cognitione Platone magifto fuperior . artificio verò omnes, quỉ ex omni memoria humanas tractaverunt artes, longo intervallo pofte reliquit. Fuife avidiorem gloria", avidiorem carpendi alios, adde ctiam non omuinò pecunix coutemptorem, fatendum eft. At dexteritatem in tradendis attibus nondum eft aliquis ab xvo condito affecutus. Utinam in refutandis alienis opicionibus induxiffet in animun paulè candidius agere. Arifoteles femper amavit brevitatem rerum, \& fententiarum, ne fi cxtenderet fingula, fuféque perfequeretur \& copiosè, res in infinitum traheren tur, $\&$ artis pracepta teneri dificile poftent. Itaque illud imprimis laboravit, ne fibi dictum ullum, ac ne verbum quidem ance fupervacaneum; quod dum confectatur, affcutus eft, ut nullus verbis, figurifque Græci Sermonis aptius magifque propriè fit ufus. Lud. Viv. in Augufrin. 1.8. cap. 12.

Ariftotelis ea laus eft. quod non Philofophia ufus Mythich, ut Poeta veteres non Symbolicâ, ut Pytbagoras, \&r Lepe etiam Plato; Ced apertâ,ut qux propricentc gaudeat verborum.

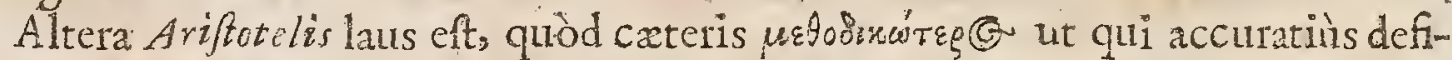
milat, ac dividats meliorique omnia ordine pertiactet. Tertia ejus laus ekt, quòd magis Platone excoluit fcientian natualem; in quâ quantum pị̂ltiterit, ino: numenta ejus docent. Prefertim qux de animalibus perfcripfr. Voffo de PhiloCoph. Sect.c. 17.

Quid multis? fron partem aliquam virtutum, fed totum Thilofophorum confrdcremus, unus ille ingenii acie, ac varictate doctrina, eorum, qui præcefferant, lumina tantum præltrinxerit, quanum Sol Lunx, \& iderum minomom. Idem ibid. In quem penè videtur efle collatum quicquid eft capax humanum genus. Rhodig. 1.23. cap. 22. Lect. A'ntiq.

Quid Ariftotelem: quem dubito Lcientiâ rerum an fcriptorum copiầ, an eloquendi 
elequendi fuavitate, an invertiontum acumine, an varietate opertum, clarioren putem. Quintil.lib.ro.cap.I.

Ariftoteles vir ingenio prxpotens, atque doctrinấ precipuus. Arnob.1.3. adverf. gent. Macrobin quoquenon veritus dicere nihil tantum virum ignorare potuilf. Eundem quoque finem humani intell câtus appellat B. Hieronym.primo adverf. Iovinian.

Ariftoteles Philofophorum, ne Platone quidem jtixta $M$. Tislium, excepto, citra controverfiam omninm doctiffimus - unus hic Pbilogsphiam, à divcrifis perfragmenta fparsìm mutilatimque traditam, in ordinem redegit, ac velut in - corpus compegit, ut qui à poëtis ac Rhetoribus orlus, ad Logicen deducit:- Aiunt illum fripfiffe libros plures trecentis. Diogrnes fiunmam aftimat veifibus fupra quinquies mille, trecentis $\&$ triginta. Nam prici folent verlium numero hignare voluminum magnitudincm, veluti notâ certio i, quod libri frequenter fint inxquales pro matciria copiâ. Erafrk. Epint1.28. Lipift. I3.

Inter Philofophos merito principem obtin t locum Arifítele' five tractandi - din $m$, five diftinguendi acumen', five rationum pondera confideres. Utinam tantùm principatus illle ab aliquot hinc feculis nonin tyrananidem abiiffet, ità ut veritas cui Ariftoteles fid:lem ravavit operam, nullầ jam re magis opprimatur quàm Ariftotelis nominc, ug Grt.in prafat.ad lib.de Jur.Bcllize Pac.

Ariftotelis Natur. ille Germanus Alumnus. Lips. 1. 2. Elect.c. 2. Tres.funt quos adninari unice foleo, $\&$ qui in hominibus exceffifle mihi humanum faftiginm videntur. Homerns, izippocrates, Arifoteles, idcmin contur. 2. mifcel. Epift. 44.

Termllianus Minutiloquium ejus taxat: Irenazs, Minutiloytrium \& fubtilitates circa qualtioncs: riteronymm, verfutias ejus:Ideo Sidonius; Explicat ut Plaio, implucat ut Arifloteles. At Gr gorius $N$ azingz.( orat. I. de Theol.) \& hoc

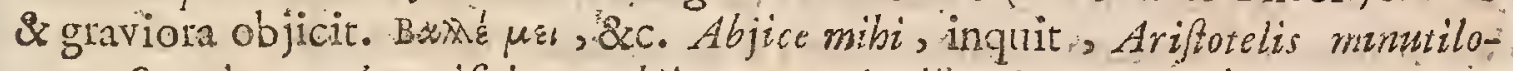
gram Sagacitaterro artificium, abjice mortuales illos Juper Animâ Sermones, \&. universe bumana illa dogmata.

A riftoteles-de Deo ipfe fecum diffidet, \& repugnantia dicit \& Centit. Lactan. 1.I.c. F. Arifoteles Deum nec coluit nec curavit. I dem de Irầ Dei. cap. 19. Ariffoe teles nunquam piè aut fanctè doctus. "bil. J udd.dc mund. incor.

Ariforelis confidentiam proinde fubit mirari, qui impetu quodam percitus. contradictionis, \& bcllum univcrfa aniquilati indicens, non folum nova artium vocabula pro lubitu cudendi licentiam ufurpavit; fed etiam prifam omnem fapientiam extingucte \& delcre annifus cft. A àeo ut neque nominet ufpiam. Authores antiquos, neque dogmatum corum mentionem ullam faciat, nifi quo aut homines peritringeret, aut placita redargueret. Sanè fi famam nomini fuo, ac fequacium tuiban affectavcrit , hoc rationibus fuis imprimis accommoda. tum. Cxtcrùm de viro tàm eximio ccrề, \& ob acumen ingenii mirabili, ArìAtotele, crediderim facile, hanc ambitionem eum à Difcipulo fuo accepiffe, quem fortaffe amulatus eft;it fille omnes nationes, hic omnes opiniones Gubigeret, -1 Monarchiam quandam in contemplationibus fibiconderet. Bacon. de. Ang. Cient. 1.3.6. 4 . 
Árifoteles, more Ottomanorum, legnare le had turó polfe putabats nifi fratres firos omnes contrucidâlfet.lbid.

Balous cent. I4. p. 220. in Appendice ad Jon. Majorem tradit, Colonienfes Theologos amumerâffe Divis Ariftotelem, \& librum etiam typis evulgalle cui: titulum feccint, De falute Arifotelis. Alium ctiam librum coldem confe ipfiffe De vitâ of morte Ariftotelis, in cujus calce concludunt, Arifotelern jic fuifje, Chrifti precurforem in naturalibus, quemadinodum fuit loano.Baptifta in Gra tuitis.

Ut Plato numeris fuis obfcuravit fuam Philofophiam: fic Ariftoteles multa Mathcmaticis collationibus reddidit obfcuriorn. Vid. Erafm. Adag. Rudius, ac Planiu.

Stagirite mortuo altare cum monumento cxtruxerune locumque "Aes 50 renêr. vocarunt, diemque feftum ejus memorix ftatuerune, idque fuo adhuc tem-. pore duraviffe, teftatur loan. Mandevilt. in Itiner. c. 2. qui circa an. Chrifto 322. illas regiones vifitavič, Konigius.

Compoluit A riftoteles plura quàm cateri, fed \&plura compilavit. In quo improbitatem ejus licetcognolcas, quod, qux compilat, non illis refert ac-. cepta, à quibus fumplit, fed libì vendicat; $\&$ coldem ubicunque peccalfe opinatul, cirius ardentem flammam ore continere pollet, quàm non nominare. Laur. Vall. in Prefat.in dialect.

Hic eft ille A rifoteles, qui de animá malé fentièns, lócum gaudii poft: mortem negavit, qui vetcrum dicta compilatus, malignéque interpretatus.

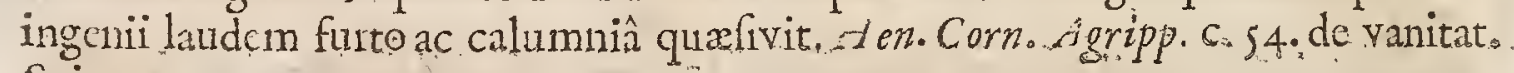
Scient.

* Theodori Zvvingeri Scholia in Ariftotelis Etbica. Ifaac. Cafauboni verfiones A riftotelis operum in Lat. frmonem : \& Daniel. Heinfir Paraphrafis in ejuf dem libros Politicorum permituntur, fi adhibcantur notæ Aučorum damnacorum \& operum pexmillowm. Index Madrit. Edit.An.I667\%..

Alexander Magnus quamdiu incorrupta \& integra ejus mens ab adulatoribus \& crapulit manfit's munificus erga Doitos, \&amator corum fuit. Imprimis hoc oftendit in-Arifotele fuo praceprore, quem, quoad animum utilibus prac. ceptis informandum, parenti fuo Pbilippo Regispræferre 110 n erubuit, donatis illi ob Hiftóiam Anmalium talentis 80 . qui faciunt coronatorum aureorum millia quadringenta odtoginta Alexandro enim inflammato eupidine Animdo. liz m naturas nolcendi; delegataque commcntatione. Ariftoteli, fummo in omni: Ccientia viro,aliquot millia hominum in totius Afre, Grecieque tractu parere julfa, omnium quos venatus, aucupia, pifcatufuuc alebant, quibufque vivatia, armenta, alvearia in curâ erant, ne quid ufquam gentium ignoraretur ab. $c o:$ qquos pexcunctando quinquaginta fermè volumina illi praclara de Anims. dious condidit. Pil. Camerur. Oper. fubcif. Pag. 237 . Centur. 2 .

Ferunt Ariftotclem moribundum dixiffe, Fade bunc mundum intravi:anxius wixi: perinkbatus egredior, canja caufarum miferere mei. Ibid. Centur.I.

Ariftotelis opesa omnia Grace \& Latine ini 4. Tomos digelta Gulielmus du 
wallius Regis Cliriftianiffimi Medicus \& Confliarits recognovit, difquiftioniWus is notis illuftavit. Parif. apud Ioan. Billain, Stmeonekn Piget, \& Fredericumbeonard.165.4. fol.

\section{EÜCLIDES.}

Cometra infigiils forilit tempore primi Ptolomai. Multa fcripfic qux ât Teometriam \& Muficam pertinent. Inter oueia verò ejus facilè palmàm obtinent libritredecim Elemientorum, magno Reipiblica literaria bono ạd Clarvit anite Ghirif. Amo noftrafque tempora confervati. Hem. Savil. lect.r. in Euslid.

Utcunque cnim multi antc aum Geometre fizeritit, non in : Eg gypto folim, fed ctiam Graciá; aliqui etiam quedan literis confignarint, hic tamen prime omnium Grecorum omniacoll git, collecta-digeffit, quaque negligentiùs probarentuix, accuratius demontravit. Opus Lum Eusides. Elcrentu inforibit. Conftant hac cleméita lib:is 15 . Nifi gliod de duobus poltermis res uon fit ita apcita. Pleriquc eos non Euclidis putant; led commentarios reppiclis Atexandrini. Alii \& ipfos libros Hypjerli tribuunt. Sanc̀ in Grarâ editione deciim s quartus prafationem habet proprian : quam nec primus habet Eucledis: non vano argumento, libros duos ultimos alterius effe, quàm Euclidis. Voffo de Marhemat. Cap. 15.

Due ferè anorum millia exiftimatur toto terranm obe ab omni reprehenfione liber \& Sacrofand:us fuiffe, \& fi quid port homines natos folide fcicitie comprehenfum \& animadvarfumeft, id Euclidi uni acceptum refertur. Rami Sichol. Math. 1.3.

Euclitcs laboribus, in Geometricis, hilihil additum ent à fenucntibus, quod -intervallo tor feculorum dignum fit. Bac. de Augment. Scient.1.3.

Euclides, Mathematicolum Pater, quo magifto non licet majorem effe difcipulum. Poflezrin. Biblioth. Select.1.15.c.r.

Euclides artís clementa continuo ordine \& magnâ folcrtiâ ita thadidit , ut à : quovis modiocris ingenii acumine pradito non dificulter percipi poffent. Tych. Bra. orat. de difciple Mathcm.

Inter Mathenatica monumenta primum eft Euclidis opus Elementorum, non rantum antiquitate, \&rdignitate, - yerùm etiam doctinx ordine; eft cnim totius Mathefeos bafis \& funciamentum Iofeph. Elancan. Sphar. Mund.p.207.

De Enclite, \& ejus Geometricis hifce verbis judicat Cardanus": Inconcujfa

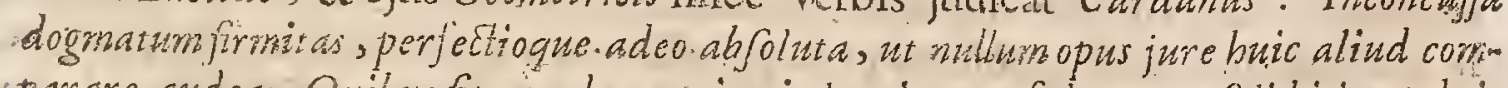
sparare audea. Quibus fit, ut adto veritatis lux in eo refulgeat; ut foli hi in ardnis

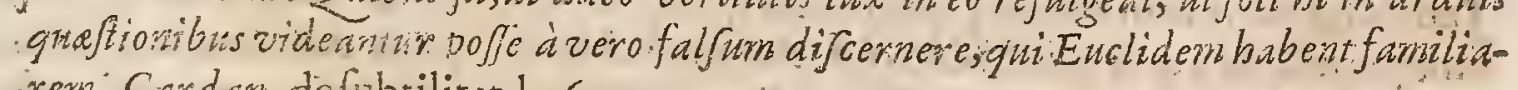
rem: Cardar. dic fubtilitat l.16.

Valdè autem ilind-commendat Scholam ab Euclide erectan Alexandrice, quòd non folùm mukos reliquerit Difcipulos; de quo anctor Pappus inf íptimo Collect. Marhernaticarum; icd abo cjus tespore, ufque ad tempora Sarracenica, vix.

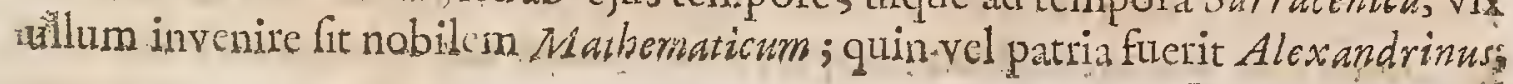

$$
\mathrm{E} z \mathrm{val}
$$


velfaltem Alexandria dederit operam Matbefi. Voff. de Mathem. $\mathrm{p} 533^{3}$

Enclides indigeftus eft \& incompofitus, cum enim ab univerfalioribus procelfus fièri debeat, ne vitiofa fiat repetitio, peffimè à Geometriâ aufpicatus cf: siirium, quam poft Aritbrneticam tractare oportuit. Oedipodem effe neceffe eft, qui hunc velicintelligerc:proponit enim fua problersata, nec manum ad circinum admovet: proponit quoque Theorernatanec ullum demonituat, Clawd.Verder. in airet. ccnfione.

Euclides veì̀ Geometra (quià civitate Tyro ortum duxit) Geomotrie peritiâ

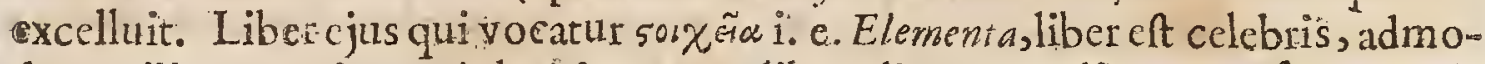
dumutilis, non eft Gracis hoc in genere liber alius generatis, ncque fecutus eft cum aliquis qui non veftigia ejus fectatus fit, idemque quod ille dixerit;nec inter tomines, qui preftantiam ipfus non confeflis fit, vel multiplici ejus doctrina ceftimonium perhibuerit: Gregor Abul.P bar. in Hift. Compend. Dynaft. Arab. Edit. Interpret.Edvv.Porork.

P'atc confultus de conftituendâ in Arce Palladis arâ, quis modüs, quxve illi. forma melior clfe polfet, quamvis Geometrix peritifinus effet, tamen ne alterius profeffionem fibi:ufurpare velle videretur, ad Evaidem, Geomeiram fuo tem. pore clarum, confultores rejccit: Oliver. not. in Val.Max.1.8.c.L.2.

Hunc Autorem notis eruditiffmis illuftravit IJaacus Barrowius.

\section{THE O P H R A T U S O}

Claruitante F Refus, Arifotelis difcipulus, tcmpore Alexandri Magni cläruit. Pritis. Chriftinn CCCIII: E Tyrtamus dictus erat, fed Arifotoeles ob diviniam eloquentiam eum $\Theta_{\varepsilon} \phi_{\text {eag- }}$

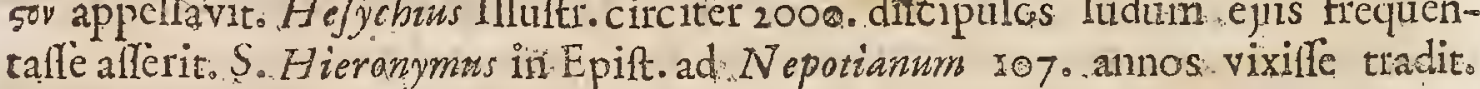
Scrip fit varia , quarum catalogum Iob. Mewr frus A. 1640. colleg it.

De Theopbraffi fiylo fatius eft tacere, quàm pauca dicere. Nam \& elegantia. ejus fatis ex tam multis perpicitir, qua ad nos, pervenernut: \& nemo adeò infanit; ut non magnifice de eo fentiat, qucm fummus fapiendi, \& dicendi ma-

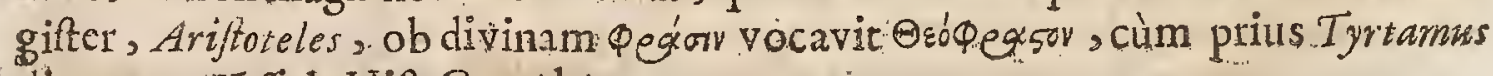
diceretur.Vof: de Hif. Grec.li.i.c 9 .

Theophraltus, ita aut diffufus eftsaut plènus: ut non modò mentis, quod eft omnibus commune, fed orationis quoque fux effe interpres videatur. Verbowum autem ità exquifitâ elegantiâ, ut cùmaliquid induftrix \& ftudii in illis. \& ỉn ipsâ compofitione agnofcas, plèraque effè tamen à naturâ libentiffinè credas. Jam fiargumentum videas ( quanquam quidnon perfecutus olim fuit? ?. ) alia funt popularia, qux plurimùm oblectant; ut cùm Stirpium naturam lciginutrs, ingenium \& morcs: quam Hifloriam dixere. Alia quix pofitum in arce veri animum, cognitione canfe fatiant atque explent: nec cujufquam tamen intellectum admodim excedunt. Quod ab co in pofterioribus fex libris (De canfis Planta rum) copiosè factum eft \& hiculenter - Quod fi quis.vulgaria hrc, \& infra cogitationes fuas pofita exiltimets nequte Horti suram aut Plantarum, fed quid 
vivitatem deceat ac fattum, munusfuum effe arbitretur, is non aliunde quàm è Theopbrafto, certius hoc \& uberius hauriret, nifi hanc foeticitatem nobis Fata invidiffent. Quis enim de Republucâ prudentius, quis melius, quis plura fcripfit? Nunc religuare char acterum extant, qua ad hanc Ehilofophix partem fpectant aliquatenus: quibus nihil elegantius, prudentius, ingeniofus, $a b$ ullo hactenus mortali Fama \& Pofteritati nincupatumlegimus. Dan.Heinf.in Dedic. Ordin. Holland. prefix. Theoph. Oper...

In Theophrafti librosfex. (de Canfis Plantaram) cùm Theodorus Gäza labbosaffet, fublecutus eft Iul. Caf. Scaliger, qui 'Theophraftrm cum aptiore genere interpretandi, Methodum fimul meliorem, quàm Theophraftus fecerat, fe oftendiffe profeffus eft. Id quod initio frribit, antequam primi libri primum caput exponendum aggrediatur.

Univerfus hic Theopbrafí labor ( de Canfiss Plartarum) maximè conducit ad Philofophix cognitionem, tum etiam ad ufun agrorum magnoperè confert, \& certè ad totrerum, \& fcicntiarum notitiam, ut omnibus libriś, Grecaque \& Latine lingux, ac.Medicinx.futurus frit utiliffmus. Ant. Poffev. Biblioth. Select.

Neget fanè Timens vir magnus Zalencum ullum fuiffe; \& Theophraftus tamen omuium fententiầ anctor haud inferior, ut ego autem judico, etiam fuperior, frpè \& in multis locis hujus Zalenci commeminiti Iuft. Lipf. Varo. Lect.1.2.c. II ...

Theopbraftus moriens accufaffe naturam dicitur, quod cervis \& cornicibus vitam diutumam, querum id nihil intereffet; Hominibus, quorum maximè inzerfuiffet, tam exiguam vitam dediffet: quorum fi xtas potuiffet effe longinquior, futurum fuife, ut omnibus perfectis artibus , omni doctrina hominum vita erudiretur...

Theophraftus, vitiorum pictor fimul ac cenfor egregins; Senecâ in omnibus libris commotiór.Gabr. Naub. Bibliograph. Politic.

Vir dignifinirus qui eo feculo viverct, quod tulit Socratem, vidit Platonem, Ariftotelem generi humano dedit, Trinmviros conftiturendx Philofopbie divinitùs fine dubio excitatos. Ifaac. Cafaub.

Theophraftus eruditushomo, gravilque Philofophis. Petro. Viotor. 1.Is. Vas. lect.cap.ro.

Divinâ vir eloquèntiâ. Theophraftus.Caf.Scal.dere Poet.pag. $53^{\circ}$.

Theophrafus fuavitate homo infigni lingua pariter atque vitz. Aml.GelloNorto Att.1..j3.c.5.

Arte, an forte datum Theophraft jut tibinomen: Nefcio: divino nomen ab elogrio.

Stcph. Pafchaf. Icon?

Mifterix plantarum Iibri so. Gracé \& Latinè , cum Iconibus plantarums E 3. prodicruns 
prodierunt Amftelod. 1644 . fol. cum animadverf. IoS. Scalig. Th ophiajti chave vacteres extant cum noris in opucculis vaiis à ThornâGale ciditis.

\section{TH E O C R ITUS。}

Clanit ante

Cluift. Anno clixxis.

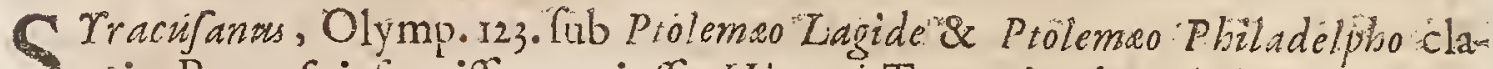
8. ruit. Pocta-fuit luavifimus : juffu Hieronis Tyranni, ob maledicentiam occifus. Scripfit Linguâ Doricâ, qua xtant, Idylha ;6. Quod fcriptigenus in Bw colicis Virgilius, imitatus eft. Unde Eclog.6.

\section{Drima Syracifio dignata eft Iudere:ver un - Noftra,s nec crubuit $\int y$ lvas habitare. Thalia.}

Admirabilis infuogencre Theocritus, fed Mufäilla rutica, \& paftoralis now forum modò, verùm ip [am stium urbem, formidat. Quïntıl.1.10.c. I. Infitut. Oratoriar.

Theocritus Syracufanus , fuavifima facilitatis Poëta, Ptolemeo Philadelpbo clarus atque familiaris, hit cujus laudes cultifimo etiam Pocmate, quod adhuc fupercet, exprelierit. Dictio cjus intelligcntibus facilis, fuavis, \& in fuo genere adnitiabilis.; quam imitandam frbi hine inde in Bucolicus propoluit Maro, fed ¿ ¿mmam ejus dulcedinem non potuit ubique exprimere. Borrich. de loct. p. I2.

Jam lis eft incer C'riticos uter utii preferendus fit Virgilino Gracusan Theo-

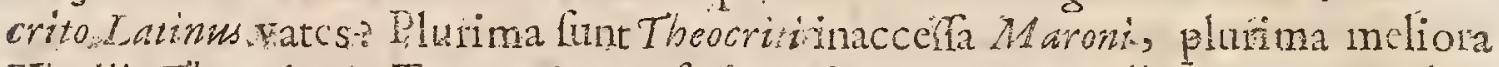
Firgilio Theocrit ch. Tamen Grecus feriptor immani intervallo Latinum relinm querevidetur. Illud quoque monendum videri mihi longè pauciora fcriplife Theocritum, \&x qux fub ejusnomine circumferuntur acervum efle congefto-

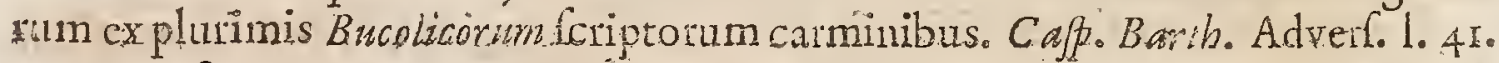
C. 26. P. . $86 \mathrm{I}$.

Dom. Faber Salmurionfis cribit Doricamillam dialeetum quatufus eft Theocritus multè fuaviorem effe vetenum Dorurridiomate. Dicit, quando quis Poetæ hujus Charaeterem examinare vult, magnam in co fecilitatem obfervari; cumque Authorcm quoad Rufticum. S Bucolicum tantùn Virgilio inperiorem effe

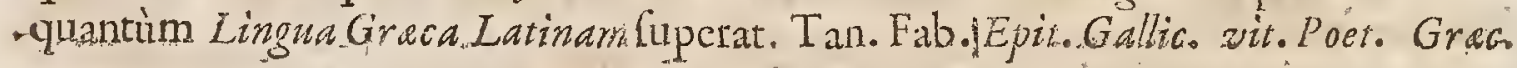
p. 134 .

Ief. Rapin. tentatur. Theocritum Virgilio, propter lingure Grecx genium, luaviorem, elimatiorem \& magis genuinum efle; In co lepores illos omnes qui ufitatam Poefews venuftatem conftitum frequentiores ell; Eum denique Exemplar imitandum effe, Virgilium vero Initatosem tantim. Ren.Rapin. Keflex.particularib. in Poef. Reflex. 27.

Theocrittas Buscolicorum peinceps, cujus.gratias \& veneres nemo fatis capita Dan. Heins.

Inter Editiones Theocriti pratantiores Heinfana eft \& H. Steplani. 


\section{A R A T U S.}

Deta Solenfis, tempore Ptolennai Philadelphi, in aula Antigoni Gonata, fit.

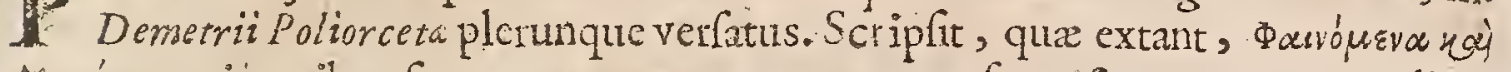
$\Delta v o \sigma h \mu e: \alpha$, in quibus fitum, motum, ortum, occafum \& numerum explicat: Claruit ante Chritt-Anno Aellarum apparentium. Quo libro adeò delectati fuere Claudius \& Germanicus $C_{a f a r}$, ut Latinum fecerit uterque. Vertit eum Latinè \& Cicero adhuc adòlếlens. Tace Rufum Eeftum Avienum, qui cundem Latinis verfibus eleganter. expreffit. Ovid.

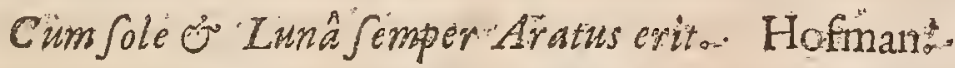

Conftat inter doctos homincm Aftrologie iğnarum ornatifimis atque opt mis verfibus Aratuin de Celo \& Stellis fcripipfife. Cuc. I. x. de Orator.

Aratz materia motu caret; ut in quanulla varietas, nullis affectus , nullia perfona cui ufyuam fit oratio: fufficit tamen operi, cui fe parem:credidit. Quntil.1. ro. c. I. Inftit. Oratoriar.o.

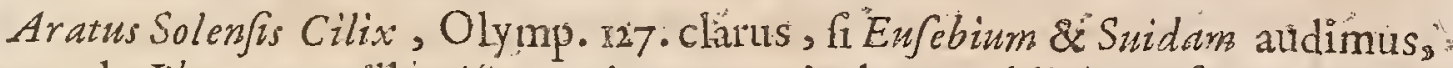
non mode P'banomena illa Aftronomica, quæ in luce publicâa verfantur, perféripfit, ficd \& Hymnos, ludirra, compofitionerm pharmacorum ad Theriacam, ortumb hominis, Epigrammata : folis autem P benomenis pepercerunt zvi dentes quibus latino verfureddendis \& Tullius adoléfcentiam fuam addixit, Cafarque.

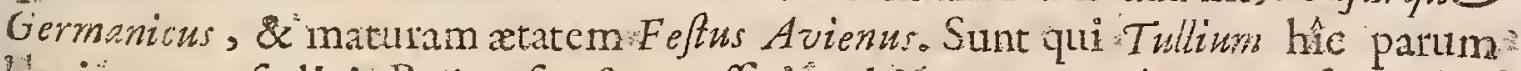
bioni', parum foelicis Poëtex functum offició arbitrantur, verùn excufar Arpinatern prima tum juventutis fax, à qua plenam operam expectare nimium ett.Neque defuiffe Tullic calorem Poëticum, fi hùcanimum duntaxit vertiffet, ved ex hoc fcriptoliquidum fuerit, ut rigidiores agnofamus fuilie, Martialers, $H_{\text {. }}$.

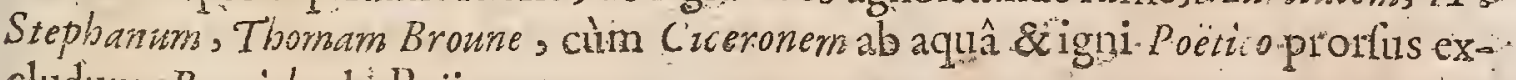
clidunt.Borrich. dè Poët: P.Tít

A ratus cultifimis werribus coeletia complectitur, \& Rellas. Rhodigin. lect. Antiq. 1. 7 . cap. r.

In ipfis Georgicis tempeftatisferenitatifque figna de Arati Pbenomenis traxis Dirrgilius. Macrob. Saturnal..1. . . c..1.

Arati autoritate S. Paniu:, Act.I7.verf.28.ufus eft.

Mirum quatum multos fuerititnoctus Interpretes : ex deperditis. (unt Ariftiry chiss. Samius, Aryfilli duo Geometre, Crates, Euxneti duo, Crates, Neumeniws Grammaticus; Pyrrbus Magnefous. o. Thales quilipiam , \&.Zeno. Vofs: de" Poets Grac.

Arati verò Seprolchrum celebrat Pomponins Mela. Iuxxta Solos, inquit, in parro tumulo Arati poete monumentum, ideo referendum, quia ignotum, quams.

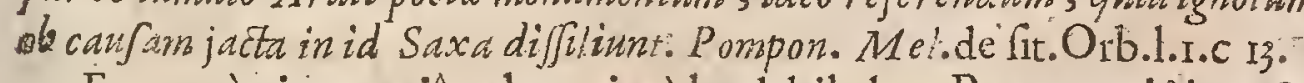

Ego verò cjus gratiâ ycl maximè laudabile hoc Poema exiltimo \& omnibus 
feculis commendatifimum fuiffe, quod minimum ampulletur, grecis vanitate fabulas inculcet, aut paratyagœdietu, $B$ arth. adverlar. 1. I. Cap.Is.

Edidit hunc Auctorem H. Stephanus, fed pra cxteris nitides, adjuncto etiam commentario, Hugo Grotius.

\section{B E ROS:US.}

Claruitante Chrit. Ann. COLVI.

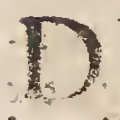

E retate Beroft nor conycnit inter omnes. Moff zquálem fatuii à nomntillis , ail Caff. Bartbius Adverfar. 1. SI. cap. 7. Quian fententiam jure ut

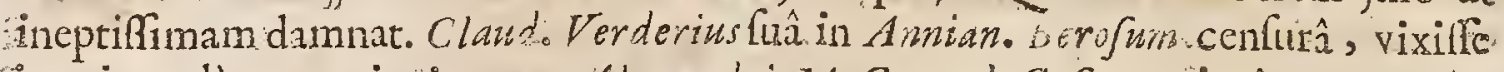
inquit paulò ante principatum Alexan tri M. Conrad. Gefnerus ipsâ Alexandri M. æat ite; adver(us uttumquc Gerard. Loan. Voffus de Hiftoricis Grec.1. 1. c.I3. oftendit foriulfe Berofiun fub Prolemas Pbiladelpho, Afgytiorum Rege, di-

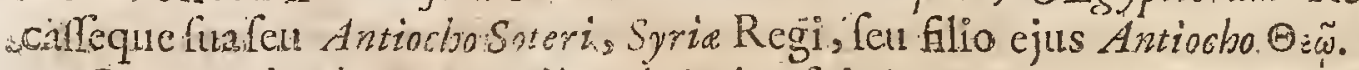

Genere Chaldens acpatria Babylonits fuit Berofics, Beli in Baby'one facer: dos: Aftrologus celeberrimus, \& Chaldixorum feriptor antiquifimus. Eum

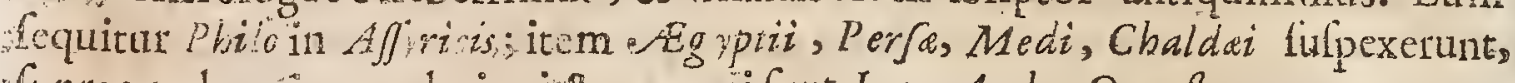
Supraque hominem admirati \& venerati funt. Ioan. Andr. Quenf.

Scripfit Babylonica, five. Chaldaica tribus libris; promilcuè enim his now minibus utuntur veteres. Ex eo opere praclara gurdam fragmenta confervavit nobis Elav. Io/ephus lib. piimo contra Apionem. Quorum aliqua luculentis notis illurtravit Scaliger.11 Appendice operis.de emendatione T mpuram. Habes

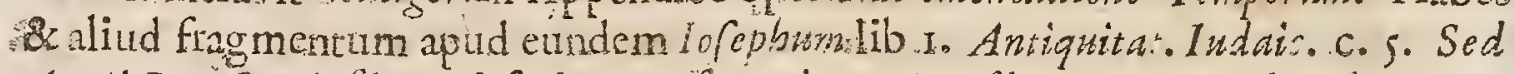
Anniz Berefus ejufdem eft fafinx, ac funt eins Megaftheres, \& Archilocbus ; ut infanum frt, velle ex quilçuilliis iftis, ac uugis mendaribus, metiri magnum illum Berofum: culi ob divinas prexdictiones ithenienfes publicè in gymnafio tatuam inauratâ linguâ pofuere, ut auctor eft Ptinius. Annianus ille Berojus multos comminificitur reges, qui nufquam extant: quod fatis docti viri oftenderunt. Ac vix quicquam eorum invenias apud hunc gux ex vero Berofocitat Iofepbus. Imò interdum pugnantrt habet, ut.cum ait, Babylonem à Semiramide conditam effe:cum Jofephus.dicat, à R, crofo feriptum fuilife, non effe cam à Semramide adificatam. Voff? de Hiftor.Grec.1.I. c.I3。

Libelluscircumfertur, cui titulus Berofin Babylonii Antiquitates ; fed commentum eft, quod indoctis \& otiefis hominibus milrè allifofcit, cujufmodi. funt Xenophontis xquivoca, tum Architocbi, C'atonis, Sernpronii, \& Eabii I'1ictoris fragmenta qux eodem frint libro ab Annio Viterbienfi conferruminata commentifque reddita mağis rìdicula: non quin infint quxdam in illis veras nam alioqui frontem non haberet narratio ; led ipfum hiftoine corpus commentitium eft, nec illius, sujus titulum mentitur. LudoViv. 1. g. de tradend. Difcipl.

Sub cjus nomine circumfertur viffgò libellus, in quo autem van funt pleram que omnia \& putida \& in ipfo Commentatore mendaciorum plauttra meraque Witerbienfumnugr. Rupert. in obferyat, ad Befold.capo.2. 
Plurimi veterum Berof memineres viz. Vitruvius l.g.c. . Tertulianus in Apologetico c. 19. Scriptor Cbronici Alexandrini, p. 48. Plin.1. 7 c.37. Clemens. Alexan 1.r.ftrom.

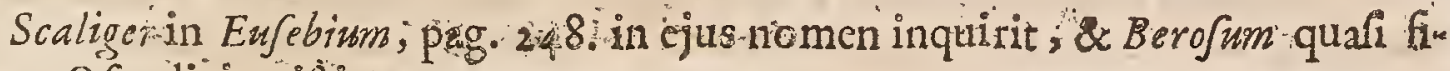
lium Ofea diçi exiltimat.

Iufimus Martyr affrmat Berofum fuiffe Patrem Sibylle Cumea.

Si omnir Berofl Opera extarent; quàm pulcra pro Sacris Biblis horumque antiquitate apuó ipfum reperiremus ! Eorm aliquid in lueem protuli, tanta tamen eft hominum malignitas at id agnofiere reculent. Scaligerana pofter. Gallic.

Aliqui extant libri füb Berof Chaldai, Maneibonis Egyptii, \& Metaflsenis s. smine; fed tantis illis Viris quorum nomine condecorantur indigni funt; eo" rumque fuppofitio eft maniferta. Omnes veri Berof quos citat lofephus contia Appionerr loci, in illo Scripto quod ipfi tribuitur, non reperiuntur, imò res eisadverfantes continet. In llo uros Lugduium memoraturs qué poft Cafarem demum nomen hoc fortita eft. Denique Hiftoria Berofi ad ætatem Nabuchodonoforis \& Nabopalafar is tantù extendcbatur ' hac vero infra illam defcendit.Ell.du l in. Nov. Biblioth. Awhor. Ecclefaftic. Torn. I. Gall.

Hic Berofus fuit, ùt alferunt Io ephus \& Tatianur, Beli Sacerdos \& Babylone natus, fed qui poftea floruit in Infula $\mathrm{Coo}$, primufque Attrologia Chaldaice apud Greros exiftimationem conciliavit; cujus nomini \& memorix Athenienfess "qui nunquiam fegnes erant in applaudendo iis qui magnum quid novi afferrent, $f_{2}$ prefertion cum corum fuperfitionibus affinitatem haberet, ftatuam linguâ deautata, erexerunt. Quod quidem emblemagcnuinum ejus hiltoriæ fuit, quix Apcciofam modò pompam oculis oftentabat, ced calis intus non erat qualis prima intuitu videbatur: Iis prefertin locis ubi veruftifumorum temporum compucumnobis tare pla fe fert duafute fuas Dynafias ante Beli teinpora reventet. Negari tamen nor poteft quin fragmenta quxdam Hiftorix ipfus, qux Io e o hi, Tatiani, Euf ebit \& aliorum curâ \& indúftrî ab interitu prelervata fune, litiliffima fuerint, non modò ab probandum Ethricis, Hiftoriz Scripturarum Sacrarum ve ritatem, fed etiam ad quorundam de Imperio Babylonico teftimoniorum illuftrationem; quippe qux $N$ abopolaffarem fuiffe Nabticodonoforis Patrem evincant; De quo Scaliger abundè Notis fuis in ejưs fraymenta . Ioquatis eft. Stiling flo Orig.Sacr. l.i. . c.3. Sect. 4 .

\section{A P O L ONIUS PERG EUS.}

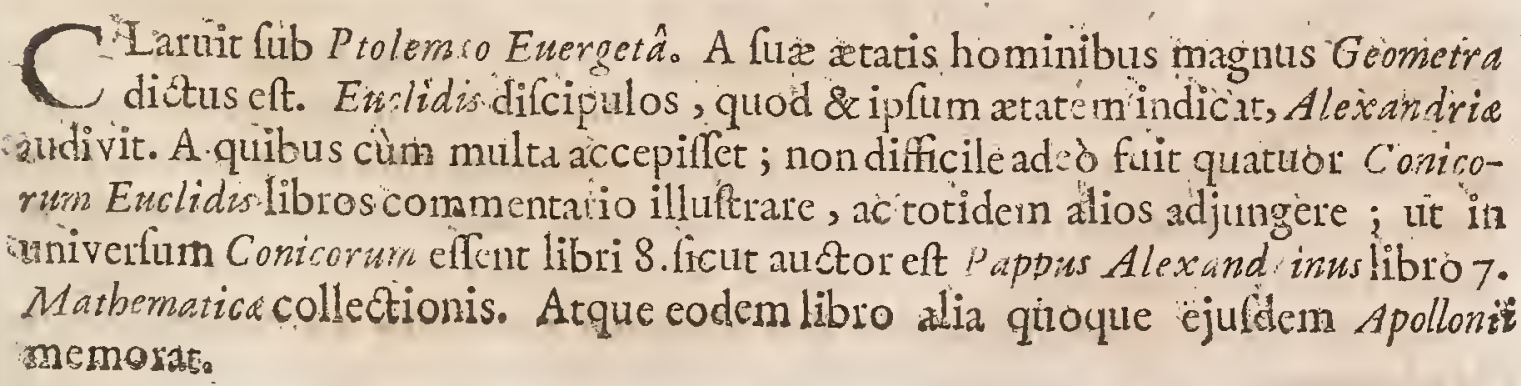
Clarnit ante Chritt. Ann. CCXL. 
Quatuor primos Conicorum libros tranftulit Ioan. Baptifta Mcommins; ficd in feliciter, cò quòd argumentum operis non intelligeret: unde non vidit fat manifeftas Graci codicis mendas, ac fxpè pueriliter hallucinatur ; ficut monitum à Francifco Maurolyco prefacione in C'ofrograpbiam fuam. Opere igitur pretium fecit Fridericus Commandinus, qui denuolatine vertit, Bononiegue. edidit An. I566: Tres verò alios Conicornin libros (quos ex oriente nactus (eft clarifimus iacobus Goluns) ex Arabice in Latinum (ermonem tranfutiti idem Golius. Qurerat aliquis quid facum fit de libro octavo?. Cognofimus de hoc ex codice Goliano: ubi ad calccm erat aplicriptum, è non fuiffé. Arabicé cranflatum; quia etiam liber ille defideraretur in codicibus Grae is, unde Arabes catera riantuliflent. Scd doctiflumus Merfennius prafatione in Apollonii Conica; qux

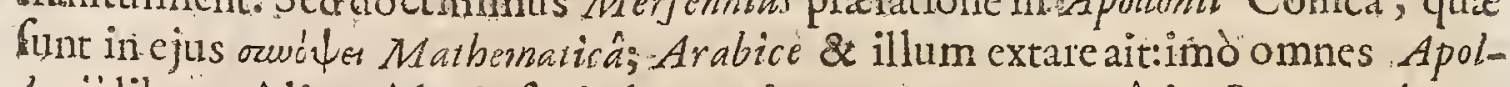
lonii libros ể linguâ legi ; fanè plures ctiàm, quàm enumerârit Pappus. Atque horum teftem citat Aben Nedir; qui libum contexuic de. Philofophis Arabicir, omnium que conm feripea memoravit, qui fuere à quadingentefimo pof $M u$ m bammedem anno. Interim (ut idem Mirfennius addit) Clandii Mydorgii, $\mathrm{P}_{\text {atrici? }}$ : Parifni, ea eft fufpicio,, tres illos Conicorum libros, qui ab Arabibus Apollonii crcdintur, non elfe genuinos; verum ab aliquo finppojitos, qui fub Apollonie nomine facere voluerit fucum. Atque hoc inde colligit quòd libro quinto: primâ propofitione in 6 . Apollonii non tantummodò in Cono recto, fed ini Scaleno ctiam quolibet, \& portionibus quibufvis, demonttret poffbilia quxque. Voff: de Scient. Matbern.

Meminithujus Auctoris Vifruvius l. I C.I. lọcum.

Cardanus in 16 . de fubtilitate e feptimum inter fubtilia orbisingenia tribuit

Fuere olim, qui Conica non elfe Apolloniz Pergai, fed Archimedis putarent. Exiftimavirhoc Herarlius ille, qui Arcbimedis vitam retulit. Ejus verba inde

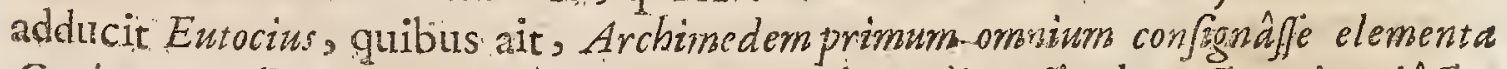
Contica: Apollonium autern cim ea fciret nec dum edita efle ab Auctore, inoolâfe in illa, proque fuss edidifle. Fortafe rudiones Archimedis Chartas nactuts fuit a pollonius, atque eas perfecit'. Utcunque eft', ante hac dc Conicis edita ab A pollonio imperfecta erat eorum noritia : ut tradir Eutocins Afcalonita initio commentarii fui in Conica Apollonii. Atque Ariftai judicio Pappi eadem mens suit. IJf. de Scient. Mathem.

Profefionem \& difciplinam hanc ad fupremm perfectionis perdixit gradim, oricorum componendo librum, qui Conicarum fectionum complcatitur proprietates qux fublimiorem, eminentioremque Difciplinx hujus fibi vendicant locum. Et, fane tot propofitionibus, totque figuris illum ditavit; ut admirabiles illæ nuncupari merueruit, è̀ quèd continieant lineas curvas; feu medias inter rectas ac cirzulares fefe invicem-fecantes;adeoque miros quidem fundunt fenfusis, \& proprietates. Abalphat.Procem.ad Apollon.Perg. Conic.1. $\uparrow_{2} 6,7 \cdot$

A pollonius Pergews, vit fauc in Matbenaticis excellens. Petr. Ram. Schol. inathernat: 


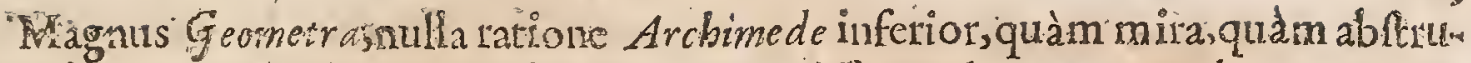
Cain Luis Conicis inlucem profert! Blangan.Diflertat.de-narur. Math.

Conicorum libri S. prodicrune cum Notis Claudii Richardi, Matbematum. Prófelloris Regitin Academiâ Mantuaria Carpetanorum Antvverpia apud ireron. Verduffen. fol.1653. Libri 3. defiderati haetenus cr. Aribico Latine redditi ab Abrabamo Echillenfi, cum Paraphrafi Abalphati Aphahanenfis, \& notis stphonfi Borelli, Elarentie fol.166r. Typis Jofeph. Cochint. Additus elt Archinnedis liber Afjurptorm è codice MS. Sereniflimi Ducis Hetruria,

\section{A POLLONIUS RHODIUS.}

ma Empore Ptolemes Euergetis Goruit Apollonins Rbodius, cujus quatuor ha- Claruit anté 1 bemus.A rgonasuticon libros. Sillei, vel, wt dir vocant, Ille filius fuit. Caldimachi difcipulus. Quanquam vero pacrâ eflet Alexandrinm, tamen-dictus fuit

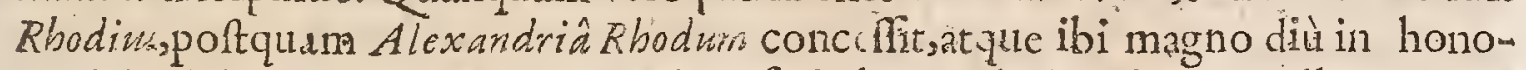
re vixit. Scio virum eruditum pro diverfis habere, Rhodiurn hunc, \& illum, quem Suidas vocat Alexandrinur, \& Eratof then in Alexandrine Eibliothece curationem fucceflife dicit. Sed cum idem Sizdas Fateatur Alexandrinum illum diu Rbodi efle commoratum, vel inde cundem effe cognofcimus. Tempora fane - convenimnt. Et auertè id, quod dixi, docet nos Anonyrmus q qui vitam Apollonib Ecripfit. Vug.De Hilt. Grac.1.I.c.I6.

Uno verò nomine Hiftoricus ifte \& Poeta audit peffimè. Siquidem ut Suidas teftatur,ingratus fuit ergapraceptorem fum Colimachum Grammaticum : qui sim hoc concoquere non poflet, indifcipulum fcripfit carmen maledicum, quuod ab Ave exgypti roftro ventrem puggante $I$ bin vocavit. Vof. ibid.

Hic cum xideretivenlia fua carmina, ut nondum fatis elimata, publicis Gnnis excipi, explodique, cafccelfi literato ica expolivit,ut omnium pofteà mererentur applaufum. Extat adhuc opus ejus 'Apzovashown, in quo dictio obfervan tur cafta, xqualis, fuavis, menbra probè diftributa, monita politica prudenter hinc inde adipería. Borrich. de Poët.p.is.

At verò corum, gure permulta fcripfit Apolloniustantùm, quod fciam,éxtants Argonautica, opus cuidem varium \& multis vigiliis clucubratum, durum tamen, \& alicubi ingratum nifi quâ parte $M$ edec amores dcfcribit,ubi \& Pub.Vir. giliijudicio ita excellere videtur, ut Virgilisus ipfe non aliunde plurain fuos Didonis amores tranfulifle facile vidcatur, quod nihilominus Grammatici ob* Ervant. Gyrald.dc Poct.

Apollonius. Argonautica edidit, non contcmnendum opus xquali quadam mew diocritare. Quintil. L.Io.c.I. Inftit. Grator.

Apollonius Rbodin, Poëta mirè difertus, recondita doctrina, argumentique adeò jucundi,ut cum Homericâ varietate fit confercndas. Hartung. Interps. Apolion.

Apollonii Rhodii Pocma, de Argonautarum expeditiöne, fimplicioris eft cohurni, qui cum nobili Homerica dicendi modo nullam affinitatem habet:

(n) Ans. CCXXXV. 
Fabula ejus ineptè confcripta eft; \& Argonautarum recenfio ili primo fation libro languefcit: Nihil enim habet varietaris illius qua ejulmodi argumento ufque adeo congrua fuiffet. Rapin.Reftin Poes.part.2 Refl.rs

Quam praclarus fit Poëta, (Apollonius) duo potifinum argumenita often-

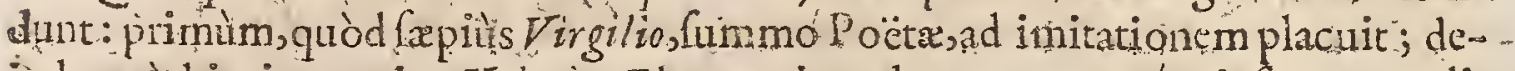

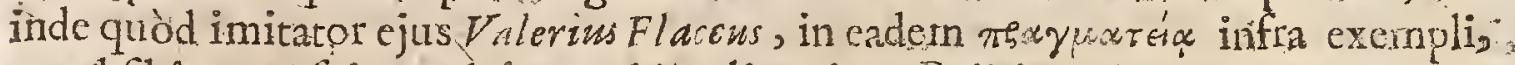
quod fibi propofuit; modulum yaldè relinquitur. Politicus de cxtero poêtas yua:les Epicos omnes efre decet. Tobias Magities in Eponymol. Crit.

Vix aliunde eftquod ex Afclepiade Myrlcano citat Scholiaftes Apollon $i$ ad lib.s. 1. arzov. quòd filicet Apollonus Grammaticus omnia fue ex Clcone trantulerito... Ionf. de fcript. Hilt. Philof.1.2. $c \cdot-17$.

Plater Pbilologicum fudium coluit Apollonius \& Poeticum, cujus hanc prie:dulcem pofteritatifngem ( $D e$ Argonanticis) admifit, nec tamen Ariparchus eum \& Arifophne, ricici nobiliores, in ordinem poetarum vcnire permiferunt:quò neminem fui temporis, ait $F$ abiw, in numerum redigerent. Vcl hinc feires polthumam effi G'ori poffefionem nec comitari viros, fed fequi. At ne mortuus quidem multitudini magis placuit" A pollonius, quàm fia quidem, ho-

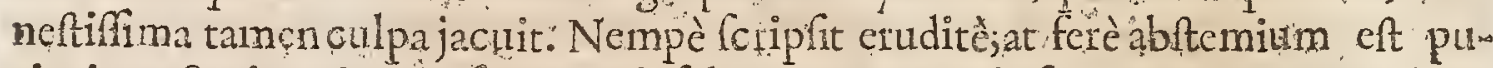
rioris nectaris zulgu, acferiptionis fubventanex magis face vappaque capirur. Quare \&hæc Argonautio Toefis mentim duntaxat altionm negale fut peculikm:cxtera hominum fectahic quoque fus m retinet ingenium.lerem. Hoelizlin. Proleg. in Apollon kbod. Argonaut.

Argonauticônlibri 4. cum vetuftis Scholits Grecis impreffifunt Florentix, fol. 1496. Qux cditio fi credendum fit Boeclero in fuo libello de foriptoribus edito ințcromanenta libliothecarum cuftoditur meritò. Iidem verò $G r$. \& Lat. cum

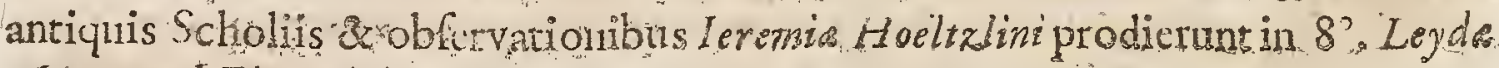
1641. apud Elizevirium.

\section{A R C H M E D E S.}

Clamberte ante Chrift. Ansa MCXXI.

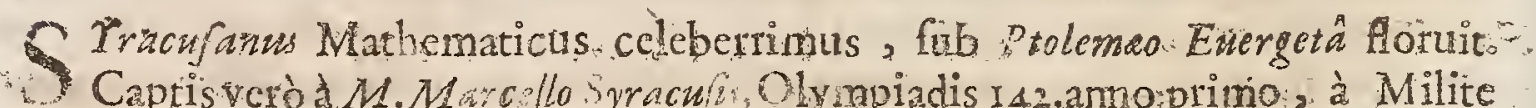
fuitinteremtus; fod contrà quàm interdixent moerator. Ejus fcripta plufcula

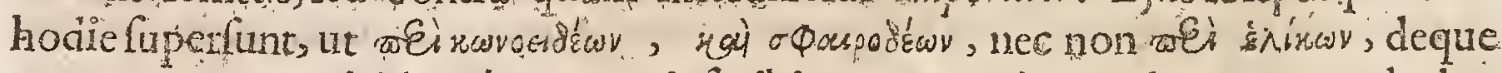

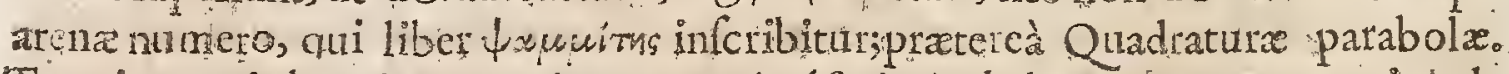

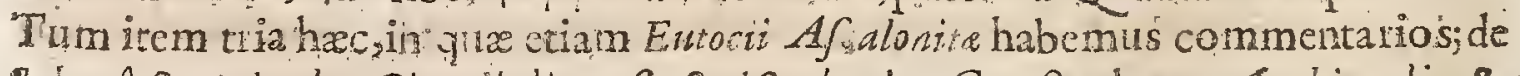

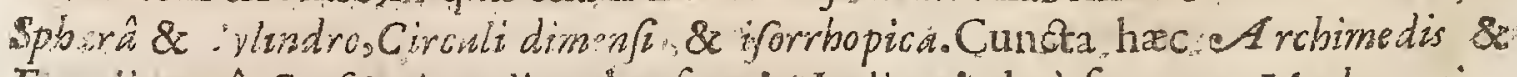

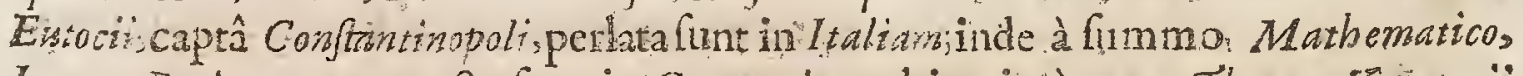
Ioanne Regiomenteno, veeta fint in Gerraniam;ubi primò cura Thome Veriatorie ob. Herveggio fuere excufa A.n. 1544.

Cardano l.1. de fubtilit.dicicur, Mathematices non tàm primus auctor, quà inimitabilis. Hoc multis videtur oftediffe. Patrix enim muros diu adverfus Roma-

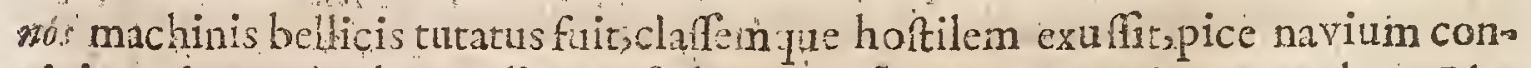
ipiente ignem ècalore radiotum Solaxirim reflexo per pecrula : ut radunt Liv. Fiber Plistarcho atque Galenwso. 
Id dexteritari ningenii illiuis alii attributunt:alii a laborem referendum putant porius indefarigatum, quo quidvis eum efficere verifimile frt facilè \& citra fudorem potuiffi. Nam fi quæras, per te non. inveniäs demonfrationem illius Quxhtionum: ubi didiceris, potuifé putes te eam vel tuâ fponte invenire, ad`ò Itraca eft via atque expedita, quas ad id, quod intendit Demonstrare, perducit. Plittarch. in vit. Marcell.

e Archinzedes diligentiffimè coelum rimatus eft, quâ ratione eurm vocat unicuñ sceli fyderumque (pectatorem Livius, \& fupremicouporis partes exactifinè me titus , Bpheram miro artificio compoluit David. Rivalto à Flurento in vito Ar rimed.

Exiftimabat:Ioseph. Scaliger. in cyclometricis, peceare in eo Archimedem;

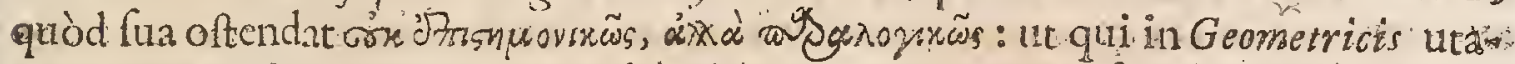
tur numeris. Sed pro Archimede luculentam Apologeticam Cripfit Adrianus Ro-

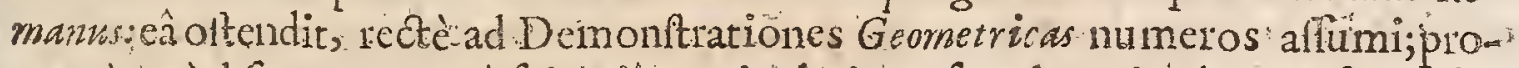
pțeręà quòd fic uon ex unâ fcicituia particulari tranfcendatur in alteram; fed adfumantur argumenta ex fcicntiâ univerfali, five Aritbmetice, \& Geornetriè , communisquod rectè fieri, abunde fuperiǔs oftendimus: cùm Mathefrn divideremus in univerfalem, five priman; \& porticularern, five fecundam: quarum prior trädit numéro, \&"magnitudini communia:poferior autem vel laumeri, vel magnitidinis, propria... Vigf: de Scientr Mathem。.

A rchimedes cùm Lunx, Solis, quinque errantium motus, in fphæràm illigavit', eff cit idem, quod illesqui in Timeo mundiam æedificavit Platozis Detis!'s ut tarditate, \& celcrizate, diffimillimos motus una rcgētet converfio. Quod fi in hö́c mundo fieri frne. Deo non potêt:ne in Spberâ quidem cofdem motus $A r c h i-$ medes fune divino ingenio potuilfet imitari.Cic.1. . I. Truf $c_{\text {. }}$ Quzelt:

Quantopere placuerint libù Archimedis de Spherâ \& Eylindro, doctunento illiud en it, quòdfepulchro ejus ambo fuerint incifi. Quo indicio Marc. Cicero.

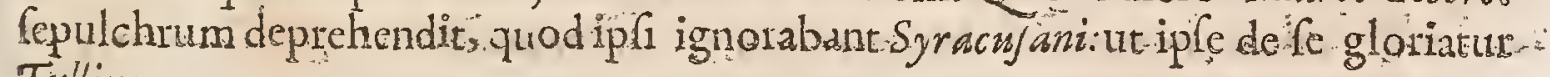
T.ülins.

E claris etiain Mathematicis fuit Archimeder, qui Gracus fuit,ät fcientiam ab A.gypriis haufit dicitur eum,qui aggeribus cinxerit terras plèrrarumque : Eg gpti villartum, \& fundamenta pofluerit poritizum, quibus à pago in pagum tranfitur, cum excreverir Nilus, Archimederr fuiffe. Sunt \& illi feripta multa; velüti liber de Sphará \& Cylindro, \& de reptanguto incirculo. Fertur Romanas è libris ejus quindecin geftamina combuffiffe.Gregor,Abul-P haraj。 in Hift.CompendiDynaftiar. A rab. Edit.ntetpret.Edvard. Pocockio.

Archimedem cùn nomino apicem quendam humanx fubtilitaris; totiufque Matbematzca Dilciplina abfolutionem animo concipio. Ejus inventa admitandaprodidềre. Polyb:P lutarch. Tretzo aliiquie Andr. Tacquet. Hiftor. Narrat. de ort. \& progrtl: Math.

Abfit , it divinifimum Arcbimedemalicujus parologifmi arguamus quem neque unquam decepiffe, neque uxquam deceptum effe cimus. bern. Varen. lib 1.Geograph. general.can. $3 \circ$

$$
\text { F. } 3: \quad \text { Extans: }
$$


Exant ejus opera Mechanica: circuli dimenfio; de lineis fpiralibus:de Qúadxaturâ paraboles: de Conoeidibus \& Spharoidibus:de numero arenæe, Grac.

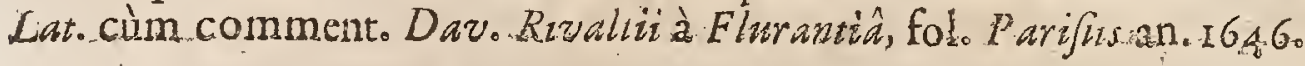

\section{O O I Y BIUS}

- Claruit ante Chrit. Ann. $C \mathrm{CX}$.

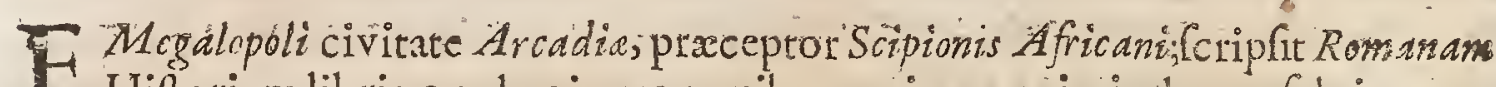
E Hiftoriam libris quadragintasex quibus quinque primi ad nus falvi atque incolumes pervenerunt: excreteîs folüm excerpta habemus.

Polybii in Philosopbrâ doctrinam, in Moribus probitatem, in Hifto iiâ prudentiam Cicero.s Strabo, Iofeppbrss. Plutarchss, (Deus:bone, qui quantique viri !) \& optimus quifyue vetenm, dilaudanto Cugous fidem T. Livius, ille Romann longè princeps Hiftoriz, tantoperè probavit, ut penè ad veibum libros illius.integroswcreret, atque iis profuis uterctur. Quem $\pi \%$. Brutus feverus ille morum feriptorumque confor, cuine ipfe quidem $M$. Tulliwa frtisfacit, adeò eft admiratus, ur ojus le ectioni propemoóum immorcretur. Ultimis certè huis temporibus, ililque adlictiflimis, ad folutum doloris pariter \& magifterium vitze Hiftoriam illius excerperer, atque in compendium redigeret. Quem denique Conftantinus Imperator, Corporis Historaci auctor., Senatoribus, Duccibus, 2 P rincipibu tam utilem judicavit, ut quil è Diodoro Siculo, Dionyso Haticarnafl: In fepibo, Dione Cocceio, \& aliis primæ notæ Hiftericis pauca admodun feligerct, qux in fum Pandectentransferret ; Polybium propè totum

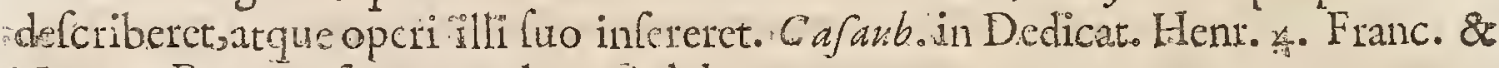
Navary: Reg.prefix.tert.volum.P olyb.p:24.

Eft utique proprium hoc exinio huic auctori, quiò ădo fimul pari ferè

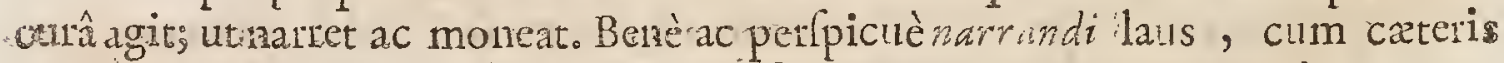
praftantibus Historicisilli communis ; fideliter monendi cum paucis: aut, ut verius äicam, cum ncmine. Nego enim ex univerfo numcro Grérorwin aut Romanorum generis hujus Scriptorum, vel unicum poffe reperiai , quîi pari fide acculâduo hac conjunxcrit. Quild mircmur? perfonam Hziforici icum alfumpit Polybius, nonin totum exuit 'philofophi. Philofophas chim erat; fcd vitâ, non linguâ:operibus,noufermonibus: rèbus'ipfis, non prefefrone, srinani fpecie Idernibid.p.27\%

Polybins non modò æqualis ubi̊que ac fui fimilis; fed etiam intelligens, gravis, in laudibus parcus, in reprehenfionibus acerbus, ac welut prudens legiflator \& bonus Imperator, multa de militari urbanâgue difciplinâ, multa de Historici officio difputat.Bodin:in Method.Hiftor.p. 58 .

Polybins.judicio \& psudentia Thucydidi hand difpar curaiz ftýlo folutior;qui excedit, äbrumpitt,diffundit, "\&c fepè mon tàm narrat, quàm ex profeffo docet. Sed recta \& Calutaria ubique ejus monita: $\&$ quem cgo, hos magis Principibuscommendatum velim, quiod anxiâ in cum inquifitione non opts; fed fuos 'fenfus ape-

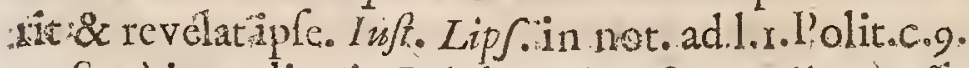

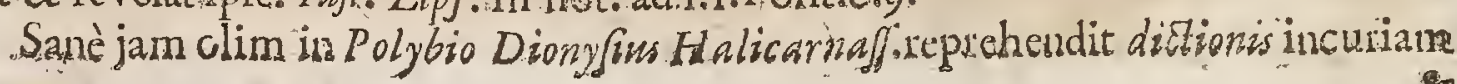


a quód utatur comprehenfione verborum mimis accuratâ. Polybio interim ignofci debet quia fieri vix potef, ut qui tantoperèsac ab eo factum., de rebus follicitus.fit, is de verbis adec̀laboret, quàm fortaffe rerum dignitas merebatur. Imò ea eft humani animi imbecillitasjut ingęntem illam verborum curam rerum incuria plurimù confequatur. Ita obfervatum et à viris doctis, Dionem multùm rhetoricari in praliorum defcriptione; fed corum, qux ad rem miliw tarem requiruntur, exiguam aftendere peritiam, propè dixerion nullam. polyo bium contra pigmenta illa oratoria afpernari'; fed tantam in eo militaris difcipline

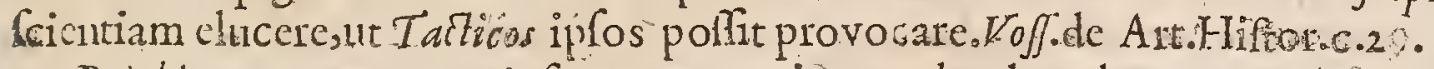

Polybins, nec amore cujufquam praterit, quod culpanduminec odio omitit, quod laudandum. I dem ibid.c.10.p.57.

Quatis quantufque vir fueric Polybius, ex eo promptum eft conjicere, quód tot fatuas ei erexerint Graci. ad Palantium, Mantinaam, Tegeam, Megalopolim \& alias Arcadic urbes. Paufan. 1. 8. Arcad. teftatur, tantum eum fuilie politi. urn, ut qurecunque monitu ejus gefferit Romants Imperator, omnia benèei evcnifent; in quibus verò minùs fe ejus viri dicto andientem prabuit, in iis offendiffet.

Xenophon \& Polybius in moralitatis döumenta nimis fiequenter excurunt, Gaifque reflexionibus Hiftorix filum abrumpunt: Rapin. Reflex.in Hi/t.Sect.5.

Profectò quicquid dicant qui Po! ybii partes... ufquequaque tuentur , . quod. fecir Cafaubonus; cum adco dilerta fint ejus verba, nunquam efficient ut zatis Gux Religioni valde addictus cenfeatur. Meoque judicio melius cum ipfo agerent, fr de co lit de ingenio Coelitus illuminato intra Etbricifyis tenebras, loquerentur , quique. Unicum Principium feu. Unicum Devor admittens, eos. omnes ridebat., quos Idololatria illinis ævi adorationis objecta conftituebat; requè ac Campos illos Ely fos, Cerberox, \& Khadamantos illos, quos Sectatoribus fuis ob oculos poncbat. Fr. Asthous le Vayer.Tom.r.pag.3I. Gall.

Polybius equodelapfus, cum ex fuo prædio Megalopolim rediret, morituran.

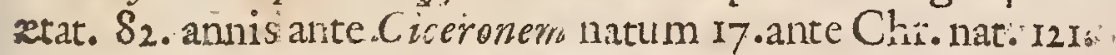

* Ifaci Cafauboni Commentailis in Polybium, cum expurgatione permirtín. aur. vid.indic. Madrit.1667.

Extant libri: Hifior. S. Gracè cum verfione Latina \& ex recenfione Ifaac. Cafaboni, Hanovia Typis. Wechelianis an. 1609 . fol. Prodierunt Iidem ex recenfione Lacobi Gronovit \&cumCaJauboni \& Palrnerii notis : addita funt excerpta de legationibius \&virtutibus ac vitiis per Confantinum Porphyr. Grac. \& Lat. omnia. Amitelodami An. 1670 in 8\%.

\section{POR CIUS CATO CENSORIUS:}

P Atrî̀ Tufculanus, civitate Romanus, Tribunus Milicum in Siciliâ \& Conful 1 Rernanus, natus eft An.U. C. grg. Mundi 37 r6. ante Cbr.nat.232.

Inomnibus rebus fingulari fuit prudencia \& indultria. Nam \& agricola Claruit anteg Chint. And folers, \&Reipublicx peritus . \& jurifconfultus, \& magnus imperater , \& 


\section{C.ENSUR A}

probabilis otator \& cupidifimusliterarum fuit. Quatum ftuäin etf fenio: arripuerat, , tamen tantum progreflum fecit, tut non facilè reperire polfis, ncque de Grecis, neque de İtalicis rebus, quod ei fuerit incognitum. Ab adoIefcentiâ confegit orationes fenex Hifori fcribere infituit, quanm funt libre feptem : : In quibus multa induftia \& diligentia comparct , multa:doctina. Cornel. Nepos.

Quis illo gravioi in laudando? acerbionin vituperando ? in Sententis argut tior? in docendo cdiflerendoque fubtilior? Referta funt orationes amplius centum quinquaginta, quas quidem adhuc invenerim, \& legerim, \& verbis \& rebus.illuftribus. Jam vero Origines cjus quemforem, aut quod lumen eloquentix non habentamatores huic defunt, ficuti multis jumante faculis," \& Pbilifii Syracu fo, $\$$ ipf Thucylidi. Attico genere dicendi fe gatidere dicunt. Sapienter id quidem;atque utrinam imitarentur, nec offa folùm, fed etiam fanguinem. Gratum eft

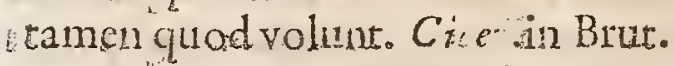

. M. 'Cenforiur Caro, idem Orator, idem Hiftoria conditor, idem Iuris idemrerum rufticarum peritifinus, inter tot aperas militia., tantas domi cont:nfiones sudi faculo literas Grecas atate jam declinatâ didicit , ut eflèt hominibus documento , ea guogue percipi polfe, qux fenesiconupilcent. Quintil.1.I2.6.II.

M. Cinforius Cato Hiftoricus eximius; \& alis quoque nominabus latratiffmus. Siquidem, ut Plinius Ecribitl.7.C.27. Tres furraras in bornine res praftitifje exiftimatus eft, Optimns Orator, Opinnus Imperator, Optnnus Senator.

Iftis Originibus, quas pro Catonianis obtrudere nobis voluit $A$ nnins Fiter bienfos, nihil profectöinficetius, Catoneque indignius, cam importuram, non multò poftquam in lucem prodierant, iabellicus vidit Enneadi is. Io.Iio. 2. item Faber Stapulenfis, Vives, B. Rhenanus,atque alii. Vofl.de Hiftor. Latin.

Iiludde $M$. Catone addesopus id, quod ejus nomine infcriptum circumfertur, ipfius Catonis gentinum non elle, quod his maximè argumentis demontrat poteft. Multorum enim autoritateconftat, Marcumillum catonern plura, quàm "nunc habcantur, Originum volumina confcripfilfe. Item non pauca carum

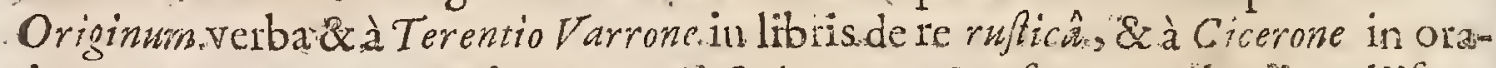
atone pro Cn. Plancio, \& in quarto Tuculanarum Queftronurn volumine, aliifque pluribus in locis cirari folent, qux nilihlominus in proviigato ifto Catone nufquam reperiripoflunt. Quibus rationibus lilud fatis inteligirir eos omnes aut tfalfos, aut commentitios, autcertè vanos efle libcllos, 'lllos imperfecto's, atque omíibus modis obtiuncatos, minimeque cum creteris conftantes. Onufr. $\mathbb{P}$ anvin. 1.r. Antiquit. Veronenf.c. 9 .

$M$. Carionem Cenforium moribus \& doctrina prattantem virum orationes multas fciptas reliquille $C i$ ero $\&$ Grammatici veteres tuartur:in quibus quar quam infignem illum Orationis nitorem dcfideres, tamen hominem incelligenren a a mantem antiquitations, fermonis elegantia, fententiarum acumen, \& ornatus quidem negligens mirificè delcetet. Lip/.1.r.variar. Lect.c. I3.

E活 Catone reperias qua nufquam alibi. Lud. Viv.de Trad.Dilcip.1. 
Cato optimus Aucorcum Varrone Præitaret nos amifile totum Ius Civile, ut th odie haberul, fneintegris Auctoribus, quàm Catonem \& Varronem. Scaligem rana I. p. 42 .

Ejus operum Fuagmenta ab Aufonio Popmo Frifio collecta \& notis illufrata Gunt. Acceffere loan. Meurfii obfervationes in Fragmenta de Re Ruficâ. Fra meker in- $8^{\circ}$. Anno 1620 .

\section{Q. $E N N I U S$ 。}

Talys, poeta antiquiflimus, Rudiis Catabrix oppido natus, Olympiadis iss.an.

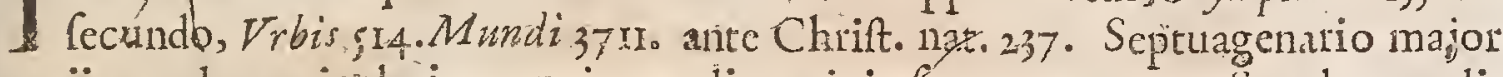
periit morbo articulari, quem immodico vini y.u contraxerat. Sepultus tradim

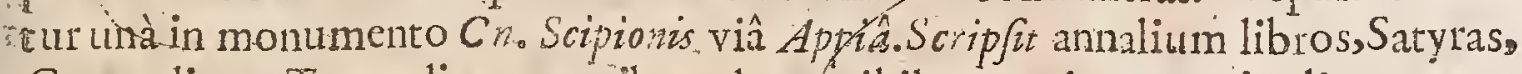
Comodias ac Tragodias, ex quibusad nos nihil pervenit, exceptis aliquot ver fibus à fcriptoribus veteribus palfim citatis.

Ennius, primus magni nominis Heroicorum, antiguitatis ftudiofus, interm -dumgenerolus. Thon.Demptter.

Pater cultioris \& elegantions apud Latinos Muse Q. Ennius. Paul.Merul. init. comment. ad Annal. Ennian. Hragment.

Ingenio acri fuit, atque ad fcribcndum promptifino, vehemens in fententiis, in verbis nudis, ut qui non difederet à communi more verborum. Lil. Gyrald.

Enrisus animam Homeri in fe immigrafle dicebat; unde Latinorum Homerus Cemper habitus fuit. Lavin. Torrent. not. in Horat. 1. 2. Epirt. 1. 4.727 .

Ennius primum inter Latinos Poctas Epicos locum obtinet; quem \& Virgilius fibi imitandum propeliit, \& M.Varro difcipulum Mufarum, quemadmodum M. Tull. Cicero fummum Esicorum Poetam vocat. P. fjevin. in Biblioth.

Eniz perfudiofus fuit Virgilius nam plura ex co fumplit; $\&$ in carmina fua traintulit; quorum partem notavit Macrob. 1.6. Saturn. c. I. Quum Virgilius aliquando deprehenderetur Ennii Poefin legerc, interrogatus quid ageret, ref pondit; Aurum re ex Ennii ftercore colligere.

De Emio itafcripfit Ovid daTrifib.

Ennius ingenio maximus, arte rudis.

Sicut \& rudem Ennii Mufam dixit Statius lib.r. ${ }^{2}$ Sylv. Ad nomen patrix Ru= dia nimirum alludens uterque. Car. Stephin.

Qui literarim jrcunditatibus infuructas habent mentes, non polfunt non in fuis pectoribus dedicatum habere, ficuti Deorum, fic \& Enni Poetx fimulacrum. Vitruv. 1.9 de Archited. c. 3. Habent Enniani verfus aliquid, quod prodeffe \& delectare poffit, \& orationem etiam, quod minin è quis exiftimaret, ex colere. Turneb. in Adverfar.

Enni verfus immortatitate omioum temporum digniflimi extant apud $A$. - G Gello 
Gell. l.r2. de Amiciv veri officio: qui \& à verbis cjufmodifunt, ut in iis vernar calusille, \& fine fuco ac cincinnis-nativus colok, hominem eruditum mirifice delecter: \& a rebus ira falubres., ut adolefcentium aures circumfonare ejufmom di, vocibus multò potius frt, quàm fexcentûn Philofophorum præceptis... Inft. Lipf.1. 2. Antiq. leet. c. 2:2.

Quemak:nodum eacft laus $N$ avii quòd primus carmine fignârit bellum Rom manm; \& luculentè quidem, ut ait $M$. Tuillius : ita Ennio. debemus, quòd non? paulò id politius fecerit, \& perfectius, idque verfibus Heroicis, ob quaruma majeftem ita cum colebrat. Luscret. in prim.

Ennins wt nofter cecinit, qui primus-amoeno

Detulit ex Helicone perenni-fronde coronamo.

Doffo de Hift. Lat:

Ennius Poeta antiquus s magnifico ingenio: utinam hunc habercmus ínte-.grum, \& amififemus Lucanum, Statiurn, Silium Italicurn s. omnefque pueriles. ejúmodi Postas, Scaligerana I. P. 7 8.

Fragmenta Ennit prater alios, commentariis adjectis, edidit Hieron Columna \& magis luculẹte $P$ aulus Meruha, Lugduni Bat. An.L595. in 4\%.

Hoc Q. EnnizPoeta Epitaphium : ur videre eft apud Philipp. Labbe in Thefauro Epitapho.

Afpicite ô Cives fenis Ennii imaginis formam::

Hic veftrum panxit maxirba facta Patrum..

$\vec{N}$ erro me lacrymis decoret, neque funer a fletw.

Faxit: cars solito vious per ora virumo...

Prior eAfricanus Q: Ennit, ftatam fepulčhro füo imponi juffi: clärumque: illud nomen, imò verò fpolium ex tertiâ Orbis parte raprum in cinere fuprem .

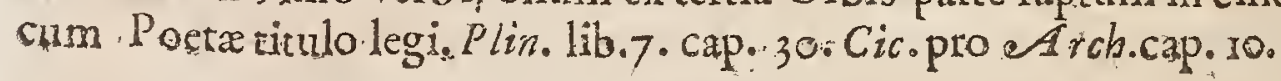

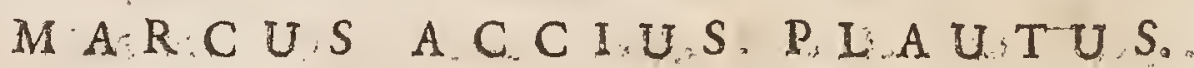

Claruit ante Chr. Anno C. I X XXI.

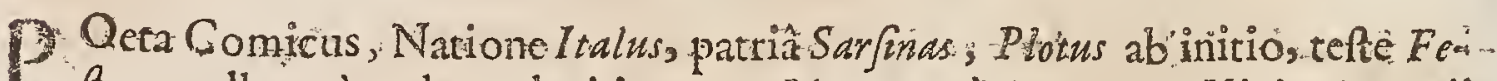
- Ato, appcllatus à pedum planitie, quos Plotos Vmbri, yocant. Vixit. Pacwvi Attitique zotate, nempe extremiśaliquot annisbelli. Punici fecundi, five Annibu. lici, ac proximis 17 . Vofl. de Poet. Lat.

Urbano,ingeniofo \& faceto genere jocandi refertum eum (cripfit Cicer. l. T. de Offic.

eAtins Stolo dixiffe fertur, Mufas Plantina Sermone louncuras fuiffe, fi Latir. sè loqui vellent.

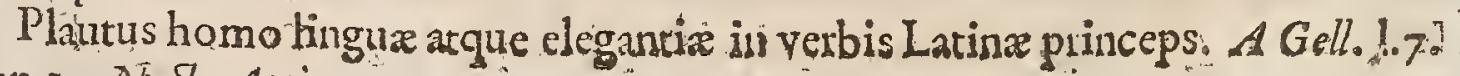
Sap.r7. Noct: Atticico. 
Quid hoc authore terfus? quid venuftus ? verbo, quid Latinius $A$ dco, ut

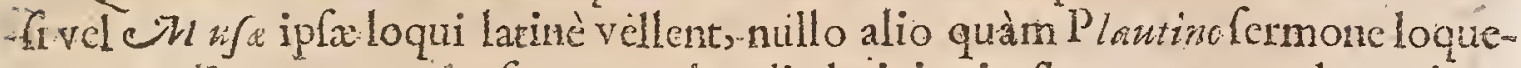
rcntur, ita omnem in fe comprehendit latinitatis florem, ac elegantiam. Plauti elegantias nemo capir, nifr emunctionis fot naris. Plautum latinifin. mum fcriptorem, nemo carpit, nifi plumbeis frt pracordiis. Unum tamer hîc te monco. Cave ita hos fcriptores (Plautur \& Trentium) legas,ut omnia tibi imitanda proponas, in que incideris. Habent enim illi \& obfolera,qua in ufu fuo, in defuetudinem \& oblivionem venếre. Qux Î vel peden - unum extra Theatrum feras, Ratim putchere. Iacob, Cruc. lib.3. Epift. Eran. Leewov.

Plautus lingur Latinadecus. Aul.Gell.1. Ig.c.8. Fons ille genuinæ puraque latinitatis, Pliwius Tanaq. Fai.I 2. Epif. 32 .

Quo poetâ.'( Plauto') nemo magis \& fur \& proximatatis hominibus pla cuit. Lwe. Viv. in Augutin. de Civ. Dei, l. 2 c.9.

Etjam primùm animadverto duos, quos loqueniflmos antiqua atas tulit, Comicum Plautrom \&e Oratorem Tillium, cos ambos etiam ad jocorum venuftam tem cxteris preftitifie. Macrob.1. 2. Saturnal. C. I Plantus decima Muga, Rornaze lingux lex, omnium lepôrum pater. loan. Bòn. Cardin.

Platuntanti omnis reasfecit, ut loquendi normam eum prefigeret velut. Barth.1.g.c. 2. Adverfar.

Optimum omnium Latinorum nominum eft Plantus. Scriptor, soul, quod Tilli argutantu1", qui omnem fapientian fuo nalo fuam debent, vulgo factus; fed

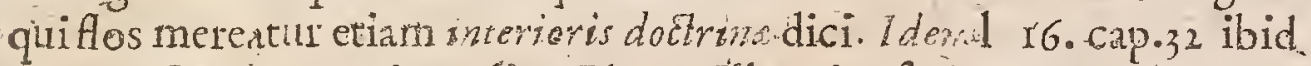

Inter Comicos quis melior Platso? llle cnim fciptor eft qui puritatem, qui proprictatem fcrmonis fuppeditet: ille qui ubanitatem, jocos, fles, $\&$ eam $4 t=$ ticoram Venerem fufficiat, quam frufta in reliquo Latio quaras Lip $\int .1$. s. Epitolic. Quzit. Epif 25.

Obfexni in lanto joci, mores molles \& lafcivi, Malfilia digni vel Tarento: Terentintotus pudicus, caftus, verccundus, \& quemà facris fais Vefta nonarceat. Iips.1.2. Epift. 18

Plautiquoque liccntia tibi notanda eft. Neque enim ille quicquam veritus ef, modò auditorem excitaret vel rilu, vel novitate tùm rerum tùm veiborum.

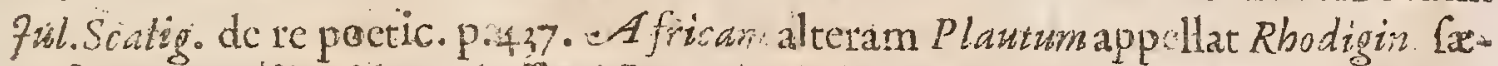
piffinè enim áliquid novi affert, \& maximè abundat rebus montrofis. Rbodigin. p. 694.

Plauti atate ne Oratorum quidem dedecebant Archaifni $\$$ voces illx antiquæ, quas apud Comicum hunc lcgimus. Sic cnim tum loqucbantur. Ciceronis werò xtate ca locum arkpliìs in Oratow non habebant.Vof.Intitut. Orat:1.4.p.29.

Audiant autcm illud hodie fupentitiof quidxm Plauti miratores, non femper, mon ubique inculcandos clle ejus Archaifros, neque jocos ejufdem in rous feris frequentandos; immó ne verba quidem illa, quie animi gratiâ , ut rifum captaret, procudit qquandoque-iple, fine grano falis admittenda efle. Berrich de l'oët. pag. 4 in 


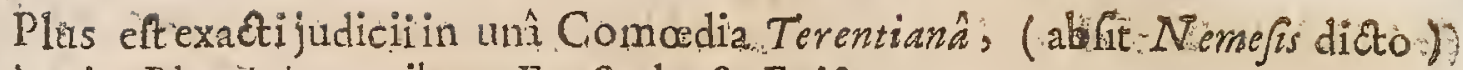
quàm in Plautinis omnibus. Erafm. 1. 28. Epift 20.

Plautrus quibufdam Comoediarum infcriptionibus minùs fatisfecit nobis.Nam: neque Rudens explet indicationem argumenti ejus Fabule, cuilid nomen focit :neque in totâ Trinunimo, verbum hoc eft nifi. femel: \& Truculentus fonum potius dat, atque expectationem futhinet, q̨uàm rem preftet. Longè commodiùs feciffet, fi pro Rudente, Terripeftatem; pro Iruculentc, Ruficum; pro Trinumano Thefaurum, infcripfiffet. 7ul. Scalig. de re Poet.16 6. pag. 766.

Plautus in Drainatum fuionum defignationibus ingeniofus eft, in fuis imaginationibus fcliciter audax, iil inventione fertilis, Infulfis tamen facetiis non caret, qux Caltem Horat ii palato 110 fapiunt, ejufque jocos, qui plebirifum movebant, quandoque miferabantur emunctioris naris homines: Verum qui-dem eft illorum quofdam fentivifimos elfe, fed quofdam fapiùs admodum inifiectos : Id autem ufu veniie folet quando quis in jocis nimiùm frequens eft; is fcilicet audacioribus enunciationibus \& t iyperbolis rifum movere conatur, quando id rebuls ipfis praftare non valet... Plantus Terentio non eft omninò. æq" iparandus in Dramatum fuorum eleganti ordiñatione neque in AEtwum fuorum diftriburione; fed vicifin in argumentis fuis fimpliciôr eft: Nodorum Dramaticorum folutiones apud 'Terentium natura' magis conformes lunt: quàm apud 'lautun ficut hac, in parte Arafophanem vincit Plautus.Rapin. Reflex. particul. in Poef.par.2.Refl. 26.

Hầc fanè parte videtur fuperiợr Plantus ; : uti \& variètate tum argumentorum, tum dictionis. Nam lautus femper fudet effe novus, fuijue diffimilis:feit rem fpectes, feu verbạ. In Terentio verò magnoperè conveniuntut argumenta fabularum : \& quando de eadem re, aut fimili, eft fermo, plurimum nec abfimi: lis eft dictio. Voffo inft. Poet. l.n. p. I2S.

Ex editionibus Plautinis Douzica \& Gruteriana Iaudantur. Sed preferenda: hiss Pareana cum Indice ampliffimo; itcem Taubroanniana \&:Gronoviana.

\section{P.UBLIUS T EREN.T IUS}

Clat. ante. Chrift Ann. CIIY.

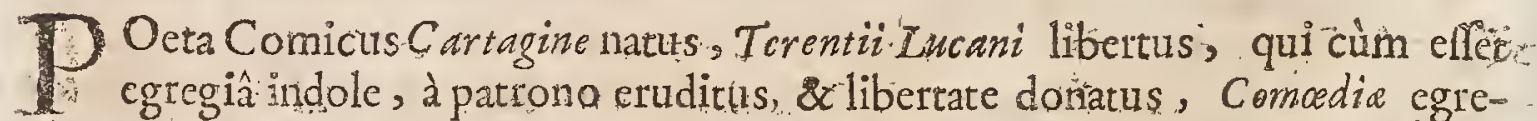
giararationem excogitavit', in Dramatibus fuis inimitabilis : Regula puritatis \& elegantiarum Latnii fermonis à Tullio habitus. Sic venit in amicitiam nobi-: lium, maximè Lalii \& Scipionis; quorum operâ adjutus in fcribendo fertur ob elegantiam fermonis, tefte Cicerone, çui adûtipulatur etiam Varro. Quid quòd eandemiple famam augere videtur, non enim nifi teviter fe tutari conatur Prologo Adelphorum. Sex ejus Comoedias habemus. Obiit in Graciam profectus, An。 595.U.C. 3. Olymp. Is5. Hofmun.

In Comoedia maximè claudicamus; licet Varro dicat, Mufas eAlii Stolonis. Plawtinofermone locuturas fuiffe; fi Latine loqui vellent: licet Cacilium laudiw. bus ferant : licet Terentii fcripta ad Scipionem, Africanum referantur: qux tamen 


\section{CELEBRIORUM AUTHOR UM.}

thint in hoc genere elegartiffina, scplus. adhuc habitura gratix., fi intra verfits trimetros ftetifent. Quintil.1. ro. c. I..

Terenti mira eft, ac propè ineffabilis amonnitas, elegantia, judicium, ac venuftas. Cujus incredibiles lepôres, ut Iofeph. Scaliger dicebat olim, vix centefi mus erudätorum quifque videt. Dan. Heinf. Differt. prefix. Terent.

Scriptor, ut ad nomen ipfum alludamuszerendus adole centix.10cu diuque. Vofi. de Philol. s. 7. Sect. 2..

illud inter-Terentianas virtutes mirabilè, quiòd jus F abula eo funt Tempera. mento, ut nequc extumefcant ad Tragicam celfitudinem neque abjiciantur ad snimicam vilitatem... Adde quòd nihil abltrufum $a b$ eo ponitur, aut quod ab Hiftoricis recuirendum fit; quod fepius Plantus facit, \&eo eft obfcuriorin plurimis locis. Adde quòd aryumentiac. ftyli itá attentè memor eft, ut nufquam non caverit, aut curaveritea, qua obeffe potuerant: tum quiòd media primis atque poftremis ita nexuit, ut nihil additum alteri, fed aptum ex fe totum, \& uno corpore vidcatur effe compofitum. Ewanth. de Tragced \& C Combed.

Non ex alio fcriptore melius difcitur Romani Sermonis puritas, nec eftalius. lectu jucundior, aut pteroru m ingeniis acco mmodation. l'lus eft exacti judicii ini unầ Comœdiă Terentian $\hat{t}$ ( abfit Nemejis dicto ) quam in Plawtinis omnibus. Erafm.1.28. Epift. 20...

Cafariatque Terentio ob propriêtatem ac nativam Roman Sermonis elegan tiam, proximum polt. Tullium damus lor.um. Voff.1. 4. Inftit. Orat.p.25. Obfaconi in Planto joci; mores molles \& lafcivi; Mafflià digni.vel Tarento: Tem rentius totus pudicus, caftus, verecundus, - Q quem à Sacris fuis Vefta ron arceat.Lip5.1.2. Epiftolic. Quxef. Epift. I8.

Scaliger fenex, poftquam omnium difciplinarum, ac fcientiaruma penè perlü ftraflet adyta, femper in manibus geftavit hunc Comicum, neque illius lectione: divinum illud pectus cxplere potuit. fac. Cruc. in Epift, p. 246.

Scicindum eft, Terentum, propter folam proprietatem, omnibus Comicis effe prepofitum; quibus eft, quantum-ad catera fpe etät, inferior. Serv.in illíd lib. Io. EEnerd.Talibis incufat.

Plautus \& Terentius optimi anctores lingure latina, quorum Phiafi loquent dum. Scaligerana I.

Utinam argumento meliori indiftriam fuam commodâffet, itá penè : omnia ejus compta funt, propria, pura; nil audix in tramflationiburs, nil futile ant fcurille in jocis, nil" dubium in compofitione. Borrich. de ' 'oct. pagin. 44 :-

Terentius vcrò ne ablcedéret ab illâ, quam affe tavit , puritate, difceflit ab ea, quan praftate oportuit, comitate. Ut rebus verba Plantus, hic res verbis accomodâffe videatur. F 7ul. Caf.Scal. de re poetic.lib. 6. cap 2. Sum mâ ille arte omnia, accurataque imprimis nitefcit oratione. Idem ibidem. lib. 6.c. 3 .

Terentius Comodiarum Prologos, Hieronymi verba funt, in defenfionem fui fcenis dabat. Urgebat enim eum Lufcins Lavinius, \& quafi publici æraria G. fareng 
Sot

Gurem Potam criminabatur. Quemadmodum verò fedefendat-s apudiplumi vide. Thomas de 1,ag. num.,554.

1. Husc auctorem recenfuit adjectis Commentariis, eslius Donatus; andidere Zindenbrogitus, Bondius, Farnabius, Daniel Heinfuts, alii Symbolam. ER "\& fua Laus Trentio variorum. Sed inter omnes praftantior habetur cditio Erancific Guieti, Bocleri。

\section{Hoc P.Terentii Epitapbium:}

Natus in excelfs tettis Carthaginis alte

Romanis Ducibus bellica preda fui. Deforips mores borinum, Invenumgrse, ferwmques

Qualiter fervi decioiant Dominos.

Quid Meretrix., quid Lenodolss quid.fingat avarus.

Hoc.guicungue legit, focs puto, cautus erit.

\section{Plillip. Labbein Thefaur. Epitaph. \\ C. L U C I I I U S.}

Giar. ante Chrir. Ann. CXXX.
\%

Etus \& venuftus Poeta, natione Italus, patria Auruncanus, natus ef Olymp. I53. Obiic Neapolí Olymp. I69. ac publico funere datus. Magnus fuit Magni Pompent avunculus. Bcllo Numantino fub Scitione Africano militavit. Primus Saţram induxit. In quâ eft magnâ ulus libertate, fi non uimiâ. riglede loet. Lat.

Frastyra quidem tota noftreft, "in qua primus infignem laudem aécptus eft Lucilius, qui quofam ita dcditos fibi adhuc habet amatores, ut eum non cjufdem modò operis anctoribus., fcd amnibus Paetis preferte non dubitent. Ego quantum ab illis, tantum ab Horatio dillentio, qui Lucilim fuere Lutulentum \& efle aliquid quod tollere polfs, putar. Nam \& eruditio in eo mira \& liber tas, atque inde acerbicas, 8 abunde Salis. Quintil. 1. ro.c. I.

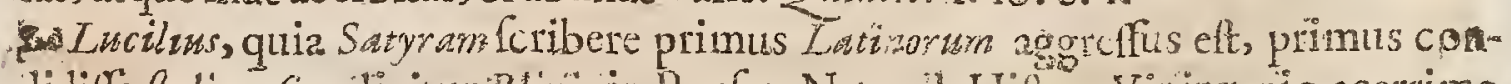
didife ftyli nafum dicitu Plino in Prafat. Natural. Hifor. Vir ingenio acemim a in fribendis verfibus feftivo \& urbano, optimis moribus, \& alicnx iniqu* tratis acerrimus acculator. petr. Crinit.

Lucilius homo doctus \& perurbanus. Cic.1. 2. De Orator. Vir apprimè lingux latimi fciens. Aul. Gell.in noet. Attic. 1. I\&.c.s.

Acerimi Poeca ingenii, miraque enditionis, atque urbanitatis Luciius. Po-

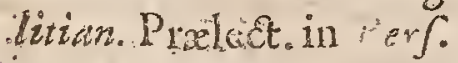

Zucriliw accr \&e violentus Poeta. ST acrob. 1. 2. Saturnal.c. T2.

Verfus T acil ipsâ laritate \& paucitate fuavitatem confequuntur; etf enim verfibur aliorum loetarum comparandi non funt: tamen quadam illeccbrâ, \& Inyitatione nos capiunt atque deliniunt. Turneb. in Advelial:p.992. 
Lucilins in Satyris interdum fe ad humilitatem I amborum demitrebat; Turneb:. in Adverfax; p. 586 .

Horatius Flaccus lutulentum vocat Lucilium , \& in fribendis carminibus incompofitnz. Scaliger illum ne fluere quidem ratus. vx. Poët.cap. 7.

Sunt qui in I wsilio id quoque vitio vertant, quèd Graca Latinis mifcuerit,ue finis in Epiğrammattís Pyiboleon Rhodius, qui proptereà ab Horratio irridetur. Ialem tamen fecit, fed parcifime Catullus, ut alios omittam.Lil. Gyrald.

E Latinis imprimis. Trmef gaudebar Lucilins: unde de co Aufonius: Lib. g:

Refciffo difces componere nomine verf fim:

Lucilii vatis ficc imitator eris..

Voff Inftitut: Orat:

Suavis quondàm \& facetus Poệa habitus fuit Lucilin, \&u imprimis dỏctus Hajus urbanitare delectarus, quanquam ejus fcriptorum pauca tantùm quxdams fragmenta reftant, foleo tamen ea nonnunquam relegere, ubi otilim cft; aus: animus feverióribus ftudiis farigăatus, amoenitate hac poeticâ refici portulat at que inftaurari: Iacob. To . Fortuit. P. 64\%-

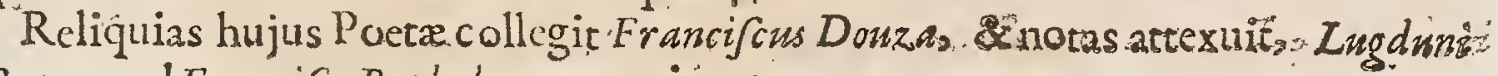
Bat. apud Francif $\hat{t}_{0}$ Rapheleng. $\mathrm{x} 997$. in $4 \%$.

\section{TIT US LUCRETIUS CARUS}

$P$ Oeta Synchronus Tullii \& Terentizttarronis, etfi paulo amiquior. De co ita Hieronymus: Olymp. 17r. Ann. 2. nafcitur. Titus Lucretius Poeta: qui poftè amatorio posulo in furorem verfus, cùm aliquot libios per intervallia Claruit ande? Chrift.Antro נinfanix fcripfiffet, quos pofted Cicero emendavit, propriâ fe manu interfecit , anno xtatis "quadragefimo quarto...

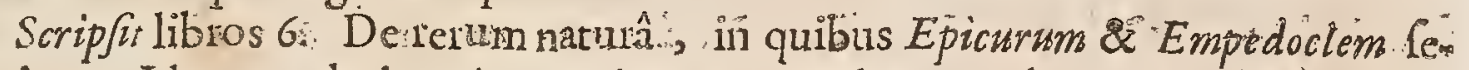
quitur. Id opus plerique à $M_{0}$. Cicerone emendatum volunt, quim:atuctor id ipfum imperfectum reliquiffet: \& quanquam Cicero fratris fententiam confirmans, non multa habere ingenii lumina fatetur " multx tamen artis esfe dicito. Quintilianus eti.tm in fuâ. naturâ.elegantem, fed difficilem effeteftatur..-

Itanc difficilis Lucretins, qui fumul.\& elegans? I tanefcriptor puriffmus, qui: fí quicquam poccavit, hec folum peccavit, quod-nimis populariter fcribit, dife. ficilis? Et is difficilis Romanx Eloquentix cenfori , qui etiam vulgo capiatur, qui àdeo omnem obfcuritatem fugiat \& effugiat, ut etiam Mufao Lepôre contingens omnia blanditiarum quarundasn merx latinitatis \& fuaviratum quidam : fit artifex ? Quòd fi adexamen hujus.fententix .venire velimus, nihil incort grumm magis dici potuife declarari poflit, cùm rebus ipfis nonnunquam fraus fiat, ut perficuitas fermonis fervetur. Nulle enim hic tranfationes; non fententix contoitæ , non tranfmarina Phrafis, non rertum unbibus involuta els quentia. Itaque quid difficultatis , ant quos nodos hîc reperit $F_{\text {abjus }}$ ego fateos me perfpicere minimè polfe. Caspo Barth, Adverfar. 1, 43:6. za... 


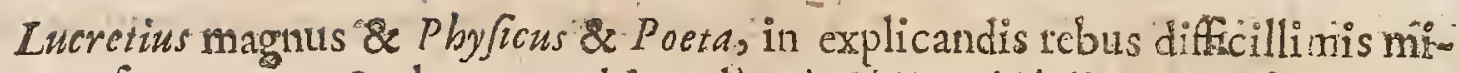
rus; terfus quoquc \& elegans, ubi paulùm à Philofophiâ divertens, fe Loetan profert. Balthaff. Bonifac.

Lucretius optimus latinitatis:auctor. VojJ. de Art. Grammat. Lucretius Poeta ingenio facundiâ praccllens. Aul. Gell. Noct. Attic.1. I....2I.

Neque mirari oporiet fi Lucretius verfus duriores interdum videntur, \& quafr - (rationi Coluta fimiles. Fuit hoc proprium illis temporibus, ut optimè teftaturapud Macrobiurn Fur. Albinus, cujus verba hac funt: $N$ emo debei anti yniom res Poetas ea ratrone viliores putare, quod eoriom ver.sbs nobis: cabri videntur. Ille enimftylus maxime turn placebat: diuque laboravit atas fecuta-, we magis buic molliori ftylo acquiefceret. Itaque minime defuerunt, Imperantibus etrarn Vepafianis, qui Lucretium pro.Virgilio, a Lucilium pro Horatio legerint. Petr. Crinit. De loet. Latin.

Nenini dubium efle potef, Lucretium intereos qui carmine de rebus $\mathrm{Na}$ iuralibus fcripfere, fubtilem, argutum, enucleatum, limatum, èlegantiflimum effe ; licet antiquum obtineat in verbis, quibus magnî ex parte exoletis, alia edeinceps mitiorafucceflerunt. Poffevin. in Biblioth. Select.

Quanti Ovidius Lucretiurs afimârit, his verfibus oftendi potef:

\section{Caxmina fublimis tunc funt peritura Lucreti. Exitio terras cisn dabit una dies.}

'Et "verè femel ( ut cum Lambino dicam') fciat Lector, nemincm in totî lingुtrâl latinâ Lucretio latinè meliùs elfe locutum: non M.Tulli, non C. Cafaris orationem effe puriorem. Gaßp. Scopp. de Arte Critic. p. 93.

Publius Virgilius non mod̀̀ verba aliquo taccepit ex poematis Lucretii, fed Iocos peneintegros ab eo trantulit: quod $\$$ Grammatici veteres accuratè notan rint. Crinit.

Lucretius bonus liber ef: nec melior alius audor lingux Latine. Tirgilius ab .co multa defumpfit. Scaligerana I. p. Io 4 .

In Lucretiv verfificatione tor ad eloguentiam difpofitiones elucent, ut fi $A$ w. gusfi tempore vixiffet cum Virgilio de Palma certare potuiflet.-.-... Sunt tamen Critici quidam qui Lucretium fupra omnes Latinos Autores extulerunt. Nimium hoc eft, fufficit illum inter bonos collecare. Novell. Gall.de Literar. Repubi. Itul. I695. pag. S12.

Dom. de Marolles ait Lucretii Poema quoldam admiratos elle, quoldam verò idem culpalfe, fed ferè univerfum in exiftimarione fuilfe apud omnes qui ipfum intelligunt. Mich. Maroll. init. Obfervat. in fuam Lucretii Verf. Gal触am.

Lucretiun virum Divinum atque incomparabilem appellat Iwl. Caf. Scal. Comment. in Arifot. Hiftor. Arimal.

Nos certè dignum cenfemus Lucretium mcliori fortunâ, quàm pracipiti ex amore infaniâ, 2 qui confecutus eft, interiru, cummon modo plurimum con-

tulesio 


\section{CELEBRIORUM AUTHORUM.}

aulerit \& lucis \& roboris Poefi Latine, fed vel maximè Latina Lingue. Non diffimulandum quidem, Verfus ejus fubinde-duriufculos efle, fed temporum ille genius erat, certè purifime latinitatis effe omnias in confelfo eft. Borrich. de Poet. pag. 45 .

Apparebat tamen doctiores paulo aliter fentire, atque affrmare id proprium efle Lurretio ut femper aliquid agat \& doceat : ac propterca docenti orationem illam aptifimam effe, corumque palato, Qusi Rimme Lapiunt, fuavifimam videri. Quod fi aut mäterix diffcultas, aut ftudium antiquitatis hominem non fefellifent, Lucretiano carmine nilil fane futurum fuifet perfecius. Farn. Sträd. Frolus Academic.

Exeditionious Lucretianis illa laudatur, que Paraicf cum adjuncto indise, item Oberu Giphanit: praftantion autem Tanaquili Es bri sum conjecturis \& commentationibus; pefima, licet fatis recens, Ioannis $N$ ardi, Elorenizn.

\section{TUL I I S C I C E R O.}

T Afciurz.nonas Januarii, A. Mund. 3843 . Antc Chr. natum rog. Inter. 1 fecit Ciccorems (An. Mundi 3907. ante C. N.41.) Popilius Cienturio, quem in causâ capitisolim Cicero defenderat, \& confervaverat. Calvif.

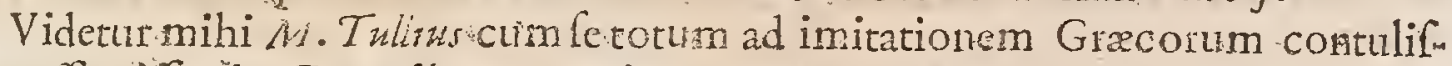
Cet, effinxilfe vim $\mathcal{D}$ emofhents, copiam l'latonis, Jucunditatem 1 Jocratis. Nec 'verò quod in unoquoque optimum fuit, ftudio confcclitus eft tantum, fed plurimas vel potius omnes ex fejofo virtutcs extulit immortalis ingenii beatifima abertate. Non cnim pluvins ( ut ait Pinán. ) aquas colligit, fed vivo gurgite exundat, dono quodam providentir genitus, in quo totas vires fuas eloquentia expireretur. Nam quis doccte diligentius, movese vehementius potef? cui tanta unquam jucunditas ahitit ? ur ipla illa quæ extorquet, impetrare eum credas, \& cum tunfverfum vi fuajudicem ferat, tamen ille non rapi videaturfed Sequi. Jamin omnibus yux dicit, tanta auctoritas ineft, ut differtire pudeat: nec advocatifudium; fed teitis aut judicis afferat fidem. Cum interim hre omia , qua vix fngula quîfquam intentifmâcurâ eonfequi poffet, fuunt il Jaborata: 2 illa quầ nihi pulchrios anditu eft, oratio pra fe fert tamen facilin ratem. Quare nonimmeirò ab hominibus fuxatatis regrare in judicios dictus eft: apud pofteros verò id confecutus, ue Cicto jam non hominis fed eloguentia nomen habeattr. Hunc igitur fpectemus: hoc propolitum nobis fit exemplum. IHe fe protecilfe fciat, cui C'icero valde placebit. Quintil.1. 10. Inftitut. Orator c.r.

Quoties inter legendum expubam in ftolidos itos, qui in ficerone nihil pracharum effe dictiant pixter verborum phaleras: Quàm, illic eft varia lection voluminum, qux doctifimi Greci de rectè beatéque vivenda reliquerunt? quanta vis? quantacopia falubrium ac fanctifimorum preceptorum? quanta cognitio, quantaque memoria prifcarum frmul \&recentium Hitoriaruin? Tum autem quàm altæ cogitationes de vera hominis folicitate, qua planè declarant 些 ylum 
illum hocegife, quod docebatm--Quid accidat, nefcio; me legentem fic af: ficere folet $M$. Tulliu, prafertim ubi de benè vivendo differit, ut dubitarc non polfim, quin illud pectus, unde ifta prodierunt, aliqua divinitas occuparit. Atquc hoc meum judicium mihi magis blanditur, quoties animo reputo, quàn immcnfa fit, quamque inaftimabilis aterni nu minis benignitas, quam quidem exingenio, opinor, fuo nimis in anguftum contrahere conantur. Erafm. Epif: 1. 28 . Epift. I.

Ciceronern femper mihi fuilfe in deliciis ingenut proficeor. Itaque fubiit fxpe mirarifultitiam noftorum hominum qui unicum germana latinitatis auctom rem fcholis prope jam expulent. Quin eo infanix multos veriife vidomus, ut ille cenfeatur difertiffmus, qui ab illo dicendi magiftro abfolutifrumo abierit

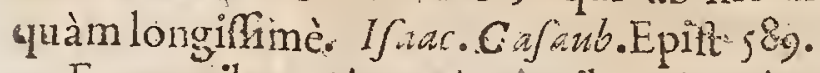

Ex omnibus Ciceronis operibus Orationes, libri de Officis, \& Tufculanarum Quftionum diligentifsimam acfapius iteratam lectionem merentur; Epifola ve. rò omnes, quis eas familiarifsimas fib reddideric, hoe preftant, ut ne fivelit quidem po[sit non eleganter fcribere. Gs.jp. Sciopp. confult: p.39. I. Vol.

Si quos Antiquorum libios ex iis, qui vel omninò amilsi lient vel certè non extant; vellem extare, funt iftifex Ciceronis de Republicâ ; neque enim dubito quiir opus fucit admiabile. Lud. Viv. in Angufin de Civo. Dei, lib. 2. cisp 9 .

Cicernis fcriptorum vix decimm partem reliquam habemus,eamque multis partibus man am \& mutilam. Inter amilfos libros refero-libros de Repuba. quos viri exuditi magnopere defiderant. $M$. Anton. Murct. l.rs. Var. lect:c.r.

Liber de confolnione falsò (ita fentio \& fenfi) Ciceroni infcribitur. Quid iă illo libillo re aurdictione dignum Tullio? vulgare aut frigidum totum negotium nec excufet vir doctus, quod in dolore. Ille verò faces ctiam admovet, \& faciéomnia magis excitata. Lipf. in Centur. Epift. ad Ital. \& Hipan. Epit. I4.

Nihil eruditius, utimam nec à mendis effet oblciuriùs, eft, Epiftolis ad Atticum $M$. Tullii. Quibus legendis neminem quemquam cordatum fatigati polfe arbitior. Adè nova femper infurgunt. Cap.B. Barth.1.39. Adverfar. C. 4 Cicerom nis ad Attrcurn Epifolx maxinème capiunt cum ob prudentiam politicam, qux: in illis ubique firat, tim quod fatun Reip. qualis tum erat, defcribunt, ita ut quemadinodum ait Corn. Ne pos guv eas legat, non multum eorum temporzm hiftoriarn defideret. Roland. Maref. 1. 2. Epift. Epift. I.

Liber cjus dé Offlizis omnium primus typis excufus fuit: dè quo rectè Mago. Grotiu Epift? ad Gallor, Liber non fwo pretio babritus sidco quod onnium manibus zeritur. Liber de Oratore pláne dignus quem tyrunculi habeant 2, ut Magni Homeri libros Alexander ille Magnus. Ioan.Bernart. de utilit.legend. Hiftor,p. I24

Cicero infeliciter $M u$ as poeticas cet aggreffas : ut videre ent apud Martialo. qui Gaurum commune hoc ait habere cum Cicerone

Carmina guod fcribat Mufes of Apolline nullo. Mat. Epigram. \$9. I: Imò ridet etiäm Iuvenalis illum Ciceronis verfum: O fortunatam natam we Consule Romam. 
in qquo verfu, quia natam natam inéptè iteratum videbatur, Cicero irrifis cett.

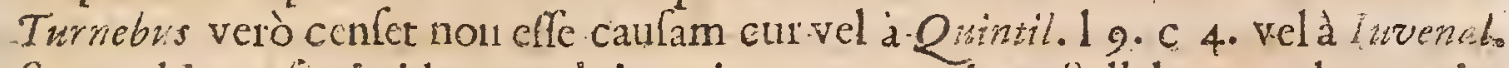
Sat. ro. hic verfus.rridcatur ob itcrationem eartndem Syllabarum: hoc cnim veteres in deliciis habcbant. Hanc figuram pofteritas faftidiit, \& ex.fito fartidio ea quæ de induiftriâ, ut vcnutta, affectaverant antiqui, afpemata eft : quar tamén multis in rebus ineptius multò \& putidius lafciviit \&-lufit, ut merito in quibus fe. citeumfpicit, interdum à feriis \& intelligentibus irrideri queat. Adrian. Ture neb.1.7.: dverfar.c. 19

Nonntlli etian feculi iftus; quod ficeronistempora cxcepir, "fummun. oratorem deridere aufi funt, quòd, ut aiuut, teriso, quoque fenfu, velur fententia loco poneret illud fum, eje siacatur. Voll lib.4. Inftitut. Orator. pag. 7.8 .

Augufinus Tulliurn Philoophattum vocat. Sed ni fallor hic aliquanto plus legerat.in Gracâ Philofophîa., quâm ille in libris hacris Erafm Epift. lib.2。 Epiff. 26 .

Libros omnes Pbilefophicos Ciceroniswihili facio; nihil chim in iis eft quod

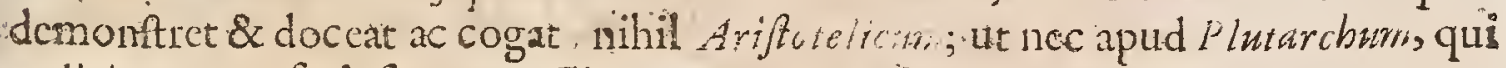
anlicis santum fcripfit non acoli.. scaligeran primap. 49 .

Cícero in Epifoins ad Atticum: fententias incerruptas habct, cò quòd arcanto fcribat; Authores omnes Latino iqui extaut elegantia liqperat: quam praclasa in illis occurrunt! Scaligerana ofterior.

Ejus Metaphra nec magno nitore fplendent, nce admodum atidaces funt: factlem \& genuinum orationi lux modum adlibet ; Conncxiones ejus nun quam corcte ncc affectatie funt; mnes tropi cateraque ornamenta debit!m locum in illa occupant: Ejus.cogitata ibi funt magnifica \& non facile quis dizerit utrum in îs feligendis an verò exprinendis felicior fuerit; nihil deni: que in cogitationum ejus cnunciatione quod ad delectandum aut movendum fit neceffarium difideratur. Rapir. Comparat. Pazclar. Viroro ontiquit. Tom. c. I 6. Gall.

Quodad riceronem attinet, judicium fequor quod de illo fert Sapientum vulgus, nimirum quod preter weientiam animus ejus aliis dotibus non multum excelluerit: Probus erat civis, mitifque ingenii, ut ferè funt obef \& dicaces homines qualis iple erat; Verum mollitic ambitiofaque arrogantia multum fane laborabat. Nec quomodo ipfum excufare valcam invenio, quòd Poefin fuam dignam efle qua publica luce frueretur exiftimaverit. Non eft magnus defectus verfus malé componere, fed defectus in co fuit quòd non animadverterie quàm nominis fui gloria indigni fueint. Quod ad cjus eloquentiam attinet prorfus incomparabilis eft non credo alium unquam Oratorem ipfi xqualem futurum.-.-.- Quod ad opcra Ciceronis fpectat, txdiofa milhi videtut cjus fcribcndi ratio: Ejus cnim l'refationes, definitiones, Partitiones, Etymow logix operis ejus majorem partem abfumunt. Quidquid vividi \& medutlofi continct prolixo ejufmodi apparatu fuffocatur. Mich.de Montagne, Experino. fusis lib. 2. cap. 10. Gall. 
Henricus Stephanus carplit Ciceronem quòd Convivit genuinam fignificatio nem ignoraverit, credideritque hac voce hominum fimal viventium fodalita- tem denotari, cùm potiùs fignificetur hominum lauto epulo fe invicem excipientium gaudiumq, fumul agitantium. Biblioth..Vniverf:orc. Hifor, Tom. s.p... i3. Gall.

OperaCiceronis omnia ex edit. Iani Gulielmi \& Iani Gruteri, Tomis duobus Mamburg1, in majori folio, An. 1618. qux optima Editio.

Hoc ejus Epitaphium, Auctore Euphorbo Scholatico:

Hic jacet Arpinas manibus tumulatus amiciso.

Quifuit orator Jummes ox exiritius,

Quem nece crudeli mactavit civis , of hoftis...

Nil agis, Antoni; fripta diferta manento..

Dristnere nempe wro Cičcronem conficis: at To

Tullius aternis uneribus lacerat.

Philip. Labb. in Théaur. Epitaphia

\section{MARCUS TERENTIUS GARRO.}

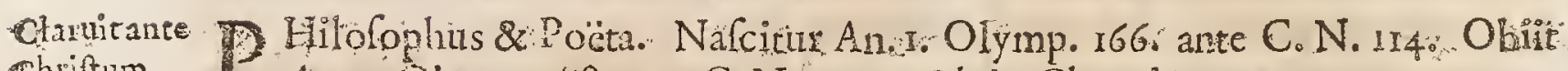
Shrift!m

Añ. An. Io Olymp. i8s. ante C.N. 26. En Jeb. in Chronic. Compofut 24 libros de linguâ Latina quos Ciceroni dedicaverat- Satyras Menippeas: Antiquitates rerum humanarum divinarumque : libros de vita popula Romani: Opus Hebdomadum, quod continebat imagines \& elogia doctorum vironum: Jibium de Poetis \& Scenicis originibus : \& 20 .

Varro Philofophus Romanorm plutima fuit in hiforâ lectionis Plutar. in Romul. Herman. Crufer interpret..

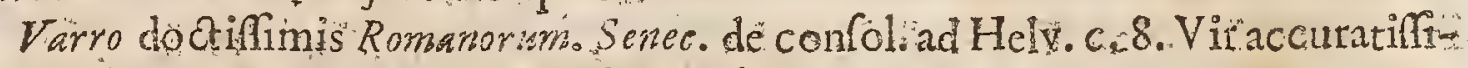
mc̀ doctus atque efuditus. Apul.in A polog.

Varro ille Romanus multiformibus eninens diciplinis, \&ü vetufatis indaga- ilone rimator: Arnob. adverf. Gent. 1\%5.

$M$. Varro, quo nemounquan doctiór, ne apud Gracos quidems. nedüm apud Latinos vixit. Laclant. l, x, divin. Inftitut. c.6.

Vir doctifimus apud cos ( Etbricos) Varro, detavifimx autoritatis.. Augiff.1.4. dc Civi. D : . c. I.

Quis $M$. Varrone curioflis int (de Dis Gentium) quafivit ? Quis invenit:doctilis ? Quis confideravit attentius? Quis diftinixir acutius ? Quis diligentitis pleniufque confripfit: Qui tametf minus eft fuavis eloquio, doefrina tamen atque fententiis ita refertus eft, ut in omni etuditione, quam nos fecularem, illis autem liberalem vocant, fudiofum rerum tantum is te doceat, quantumitudiofum verborum C icero delectat. I dern Ibid. 1.6. 6. 2 .

Ierentins Varro, vir Romanorum eruditifimus. Plurimos hic libros \& doctiflimos: 
'Aiffimos compoluit, peritifimus lingüx Latine, \& omnis Antignitatis, \& rerum Gracartirs, nottrarumque ; plits tamen . Ccientix collaturus, quàm cloquen cix. Quintil.1. 10.Infitut. co I.

M.Terentius Varro, fcriptor inter togatos fine controverfiâ. Longè doctiflimus. Ifaac.Cafaub.De Sinyr.Grac. Poet.\& Rom. Sat:1.2.c. I.

Terentius quidem Varro, vir cìm Graces literis perfectus \& Latinis, tùm Antiguitatis cumprimis imicator diligens. Lipf. 1. 3. Var. lect: c. 19.

Unicum Varronem inter latinos habemus libris tribus de Re ruftis. $\hat{z}$, qui" ve-

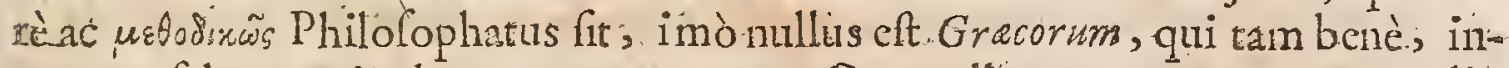
wer ens faltem qui ad nos pervenerunt. O excellens opus ex quo; qualia: ejus reliqua crane opera, conjectare quivis poteft? Sedquod mirum, non: minus in Poefivaluifle, frag menta Poermaturn indicanto.-Scaligerana prímas pagino. $146,147 \%$

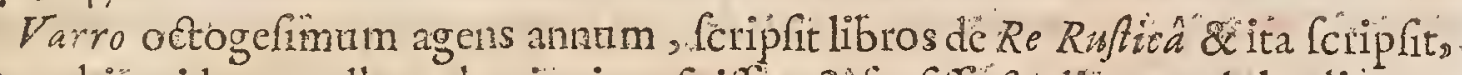
ut ex his videatur adhuc alaria animo fuiffe, \& fenfife ftudionum dulcedinero.

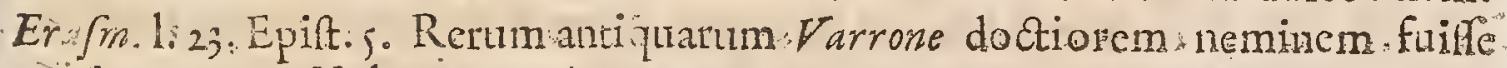
conitut:Barono. Vol r. Annal.p.35.

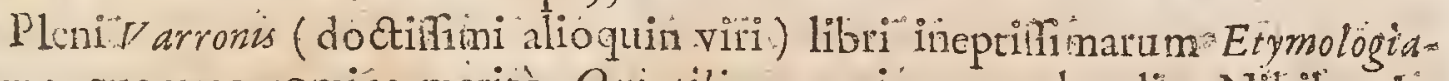
rum: quem co llomine meritò Quintilianus eciám reprehendito- Nihil enim plerumque infulfius.Mer. Cafaub. De quat linguisp.Iś. VelVarro iple quàm: interdu m in Vocabulorum Veriloguiis abfurdus eit? Twrneb. Adverfar. 1:3. C. 7 .

Varro morefuanxiè Etymologias comminifcitur. Iofo Scalo conject. in Varron. dủ ling. Lar. p. 90.

V.arro in Etymologiis Varro non videtur: itaque a Quintitiano ridetur merritò. Manut. 1.;. Epirt. 23 .

Docti haud ignorant; quid de Platonis Cratylo fit ftatuendum; quemàdmodúm \& de Varrinis Ó riginibuss, qui fxpè lilfuis de lingue Iatina libris prudens: fciens fallit, fallituique. Gerard. Lon. Voffo de Arte Hiftor. p. 2 .

Varronis de linguâ Latżnâ librì tres. intricati, ex illo dicendi more ipipi peculäari: Lud.Kive de Tradend. Dilcipl. p. 525 .

Vitruvius orationem peregrinitate \& plebitate, id eft, verbir loquendique gencribus infimx plébi familiaribus, aut ad tranfmarini Gracanici i ermonis confuctudinem incptiüfalè conformatis paffim infufcat. Qux vitia unà cum $A r-$

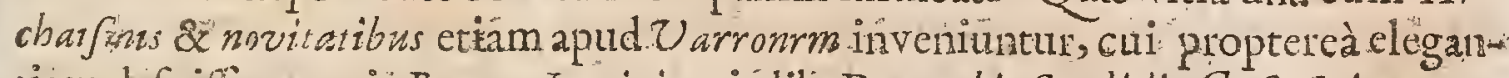
tiann defuifle notavit $P$ etrus Lavinius, in lib. De verbis Sordidis. Gafp.Scropp.cone. Sultat. p. 4I.

Magnam in Varrone Antiquilitatis do ctrinam; magnam Vèteris ritus, Sacrosrum $8 \mathrm{c}$ Cercroniarum cognitionem ; "eumque in Enkii lectione affiatum fuife obfervo. Andr. Schot.1. 2. c.24. obferv'Human.

In Plauto \& Lucretio pluna, in Varrone \& Terentio nomulla occurrunt Obfo-" leta, qua hodiè verius pro metallo adorande rubiginis, ut Juvenalloqui amats quàm puro putoque Obryzo habenda, utcunque fuerint id temporis latis clegantia, fatis aurea. Olaus Borrich: in cogitat.de Jariis Latin. Ling. etat. p:4.. 
Ejus operd five potiùs operum fragmenta, collectore Anfonio Popmâ Notis illuftrata funt, Lugdun. Bitav. in oficinâ Chriftoph. Plantini per Chriftoph. Ra phelengium 1601 . in 8 .

\section{DIODORUS SICULUS.}

Claruit ante - Clirift. Anh. TX.

\section{TIforicus, tempose I uliz Cafaris \& Angufi Oddaviani vixit. Narale ei fo- 1. I lum Agyrinm Secilice.

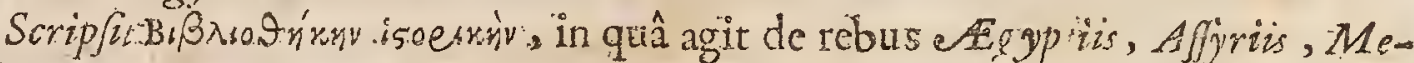
dicis, Porfecis, Grecis, Romanis, Punact, atque aliis. Confabat vero opus hoc libiis quadraginta, quorum argumcntum ipfe in prafarione recenfct. Sane multa adeò funt $\sigma \phi \alpha$ rewata Diodori in Olympiadum annis, Romanis Magifratibus, ut planè verifimile fur corrtptis ac mutilis faltis ufum elic. Sanè hoc irominc 110 à Pighio, \& aliis Chronographi fapius reprehenditus. Cetera fi fpectes, magna ejus indititria fut: ut qui triginta amorum operam in hanc fe hiftorinm impendille fcribat in prafatione lua. Ubi \&, quanto veritatis fudio laborârit. oftendit peregrinatione litâi in $A$ lấ atque E nis nullis teriitus fuit, quò minùs, loca ipra luftraret, de quibus fcripturus effct. Medò ufinam nobile.dè̀ opus.integrumad nos pervenifet. Nưcex 40 . Libris folum rj. cxtant, atque item pauca ex botio, \&aliis exccrpta. Equiori animo jacturain tantain ferremis, fi fupereflent Berojus; Theopompus, Ephorus, Pbilifus, Callifhenes, Timars, atque alii, cx quibus fua affiduoldbore congef[erat Diodorw. Vof]. de Hittor. Grac.

Sunt, qui Diodorum fuperionibus (Dioriz Cafjo. Armmieno, Plutarchs, \&c.) conferendum, plerique anteferenditm, putant: non video tamen, quid in eo tantoperè admirentur, five diccndi genus quo nihil magis vulgatc dici potelty live rarionem Hifto iarum fpectent. Rectè quidem \& o din propentea, qua initio cujufque libri dicturus eft leque ipfum breviter colligit; illuftium quogue Philofophorum, Hiftoi icorum, ac Pötarum atates lolus è veteribus ad Hiftoriam adjunxit. Camverò Univeritatis Hiftoriam fcribere propoluilCet, totus et tamcn in Hiftoriâ Gracontu. Quinetian prolixior cft in mins Gitippi Lacedarnoniticonciones (Laconicx bievitatis \& (ux in Thucydidern reprehenfonis oblitus) quàm in Hiftorià Bellorum, qux pcr Italiamgefta fume. annis ferè trecontis: cùm tamen longà digeffions de pelte Athenienfum \& cjus Caulfis difpuret. Omitto, quàmablurda lit cjus Interpretatio de Anno Lunaci, cum homines annos mille ducentos aliquando vixiffecrederentur, quafinon his quoque temponibus hanc xtatem mulci fuperarent. Scd chm annos zo in Hiftoria fcribendâ \& regionibus obeundis fe confumpfrfe fatcatur, mito quòd Italia fuitiflima Hitorias adeò negligeneer tradarit, pereferim cùm florente Romanorum Imperio, id elt, Crefare Dictatore, claruerit. Nam fiquis Livium \& Dionyfum cum Diodoro comparet, ubique ferè in Romadorum Antiquitate difcrepantes judicabit, maximè in ratione Faftorum \& 
Olympiadum, in quibus fxpiffimè labitur. Idque fortaffis imperitiâ lingux lutijix contigife puto:Quôd minùs Scripta Romanorum diligentiùs inquireret

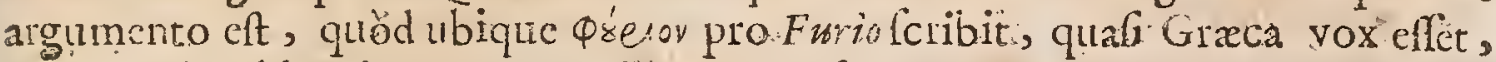
\&c. quod ut librariorum vitio tribuantr, fic enim opinor, non tamen-potef in Confulibus, Decemviris, ac Tribunis Militum confulari poteftate eadem. excufatio lockm habere, inquibus enurnerandis modótres, modò quatuor o mittit, totamque Faftorum Confulariwn rationem confundit:Bodin.meth. Hift. cap. 4:

Quantum folis lumen inter ftellas, tantum inter ommes, quorquot ad noftra: tempoa pervenerunt, -Hiftoricos (futilitatis potiùs, quàm voluptatis aurium: habenda fit ratio ) nofter hic Diodorus eminere dici potcito. Acquantò Univerfus Orbis civitate ac gente unâcen capacio: \& ampliọr, tantò major clt Scriptorum Dindori (frcorum argumentum (pectemus) quàm ulliis corum, qui extant, Hiftoricorum amplitudo . Henr. Stephanus in I ractatu de Diodoro, ubi \& Ludorici c.villis refpondst.

Nefčio cur Plinius dicat Diodoram Siculum défifife primum apud Grecos nugnri, quum nihil fit eo nugacius. An dëfendit eum titulus quòd libros fuos non illecebrosî. aliquâ nuncupatione invidiofos fecerit; Ced Bibliotheca Hiftoriàm: infcripferit. Lud.Viv. de caut..corrupt. Art. 1.2.p. iss:

Sed videamus (inquit Vollirts) quid movcrit eruditum illum cenforem, ut: iniquum adeò judicium ferret. Nempe unum hoc eum impulit, quòd primis. libris tradat $\mu v \vartheta_{\text {txy }}$ isopiay s. Hifforian fabularem. Atqui ipfa hac appellatione fatis fe purgat Diodorn. Adde quod ifte heroicorum temporum narrationes pro meris fabulis haberi minimè de bent. Nam verum iis argumentum fubeft, fed fabulosè yuædàn admifcontur.-

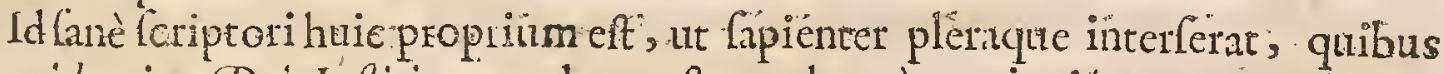
Providentiam Dei, Ir fitizingue demontet, dum à cogitatione Fortun homï. nes avocat : futmque effe dicitinfitutum, fortis alicujus viríi inorte narratâ. laudes ejusattexere. Modun interim tam in laudationibas quàm in vituperationibus tenct: ac non paluca intermifcet Divine Hiftorie noftræ veftigia; quam fi noviflet, chariora potuiffet exprimere, Poffevin. Biblioth. Select:

Infinus thartyr Diodorum celeberrimum Gracornm Hiftoricortun; Eufeöius Pamphilus illuitrem virum appellarunto:

Diodorus vir antiqux enditionis, in quo nihil culpes prater Epigraphen, a sorrupta.Romanorum nomina. Dempfter.

Laudatifimus cum primis Author Diodorus Sicutus; qui fumma fide, labore

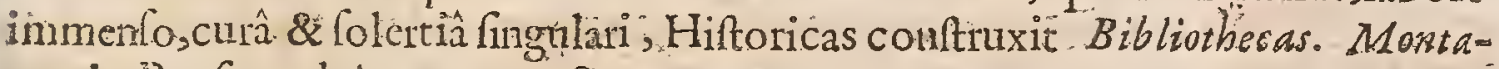
sut. in Præwat. ad Apparat: sect. 4...

Legimus Diodori Siculi Hiftoriarum libres quadiaginta, qui" univerfam quandam mundi continent-Hiftoriam. Eft Cephaitone longè ubetior, falterr cuimeadem refert; ut \& $\mathrm{He}$ efychio illuftri. Strlo utitur perfpicuo, nec affectato. fed qui hiftoriam maximè deceat. Neque etiam, ut fic dixerim, nimium Atticifat, aute Antignarius eft fupra modum; ;neque contrà ; ad bumile diceudi'ge- 
mus fe demittit, fed mediocri forma fermonis delectatur, figuratam orationem, aliaque vitans; nif quod de Gentium Diss; Heroibros, poctarum more fabula tur. Phat. incod. 70 .

Stylus Drodorinon adeò fluens, aut placidus atque Hcrodoti. Sed viciffim neque Herodotus nec This ydides, neque Xenuphon univerfalem. Hino iam fcripferunt. Fieri enim vix polfit, ut ii, qui tartam moliuntur molem, cum in varios auctores incidunt, è quibus colligunt permulta, ne variationen aliquam concipiant; certè dum intexendis rebus incumbunt, non adeo tantam verborum curam habere poffunt Pofjev. Biblioth.

Diodorus Siculusin Hiergglyphicis indagandis:non incuriolus fuit, tametf nonumquam fententiam ex.vulgo mutuatur. Ioan.Fier.Valerian.1.32. Hierow glych.c. In

* Henrici Stephani Annotationes, cum Prefationibus, in Diodorum Sict lwm pertittuntur, fi achibeaturnota Auctoris damnati, \& operis permifi. Index Nadrit. edir. An. 1667.

Extant libri Is. ex.40. reliqui, Grecè cum Interpretatione Laurentii Rhodomenni : addita funt Fragmenta coum, qui non extant. Hanovia Fol.1604. Tym pis. Wechclianis, apud Aubrios.

\section{SALIUSTIUS CRISPUS.}

Claruicante 1 Atus erat Amiterni Sabinorum ube Olympiadis $\mathrm{s} 3$. Amno 3 -qui eft Chr. Anno XIX.' A U 1 bis 667. Mundi 3S54. ante Chrif.nat. 84 . Ad pluresabiit quarto an-

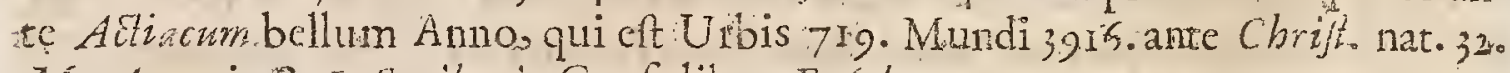
M. Anionio \& I. Scribonio Confulibus Enjeb.

Salluftium nobilitate veritatis Hiftorius. Augufin.1.1. de Civ.Dei, c.5. Elcclifimus verborum penfator. $l d \in$ t 1 . de wit. Beat.

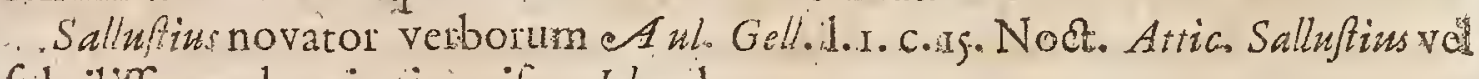
fubtilifimus brevitatis antifex. Idem I. Ir. c. I.

1. IO.C. 20 .

Salluftius proprictatum in verbis retinentinlmus confuetudini concefint.I dem

Quod ad dictionem Sallufir attinet, omnes antiqui judicant breven ac nervofam clfe, : Thucidydex.xmulam. Sanè füpeor ef planè Atticus, quâ laude D.mofheni provior eft, quàm Gicero ipfe, utbenè cenfet Tumobus in Adverfar. fuis. Sed ut Thucydiderr non omnes probarunt, ita nec Sallufitidictio omniibus probatur. Voff. de Hift. Lat.

Sallufitur, lerum Rornanarum forentifimusauctor, ut inculit Tacitus, frequens eft in manibus puerorum, fed mihi aptior videtur provectioribus. Tnimitabilis eft in illius fcriptis gratia: qua quotiefcunque repetita, tanquam tredium Lui, ant fatictatem le ctori afferant. Lud. Vio.

Vixtandem habitura ef quidquam egregium Latina Lingua quod non Sallw, Itianm Git. St phan. de I ipf.latinitat. Palaft. prim.

Si pauca excipias verba, qux partim notavit $\mathrm{jple}$, parim ex alicso fcculo, 
ac potifimùm ex Catonis Originibus, invidiosè decerpfit, genere diccradi brevifímo aptiflimoque dominari omnin $\mathrm{m}$ teftificatione temporu Strad. Prollus lor.3.Hitt.part.fecundà.

Fuere quidam Babani recentiores fupercilio non ferendo, judicio verò cos ruptifino, qui Salluft 7 dictionem idcircò brevem cenfuere, quía xem perfo-12amque nartet, Conflia atque deliberationes omittat:factum ipfum nudu in illico ponat. Quafi verò Cemmentarium feripferit ille, non Hiftoriam pleniorem, qui fit Hifzorze Pater appellatus. Ego verò contra holce Circulatores longè aliter fentio. Nonfolum quod negant, facere ; verùm śtiam apparatum addere, fpem, metu $m$, modum, crientum atcue alia pleraque ejufinodi adjungere, etiam excur* rere. intèrdum. Int.C.f.Scali 1.4. oêtic.c.24.

Brevitas Sallufiana proptereà vulgò jactata vỉdetur mihi, quìa tribu's yocibus integxas explt fententias:non ci cum.lucit, non interponit: afy zdetis utitui, - mittit verba, quemadmodum à vi is doctis oblervatum eft. Jem bid.

Brevis eft fed nilhil non ể brevitate comprchendit. ententiis gaudet, \& arrtiquilis verbis,acumine non inepro. …r. igo\%de Hift. Roman.

Crifpus Salluffirus ob elegantiam inimitabilcmque in fcribendo brevitatem -affecutus ent primas inter Hiftorices partes. Ita creber rerum frequentiâ elt, ut -veiborum propè numerum, fententiarum numcro fequatur; ita verbis, quorum novatoridictus ef , concinnus, ita elegans, ita preffis, ut nefcias utrum res verbis:san verba rebus illuftrentur. Pbilip.Beroald. in oratione quam Sallujt. exw plicat. habuit.

Non mihỉ Salluftiu videteur vitiis carullfe, \& gratix \& fimultatis. Certè cum de Cicerone fcubitsmulta filentio praterit, qua libsntifimè in aliorum gratiam setuliffet. Nalch.Camil.n libr.Theologic.c.6.

Objictantaliqui, quòd pravo loliginu fucco, pleraque ad Cïceronis laudem pertinentia, qux apudalios:legcre fit, praterierit. Verùm ea potius néglexiffe ego arbitror, vel ut fallasvil ut incerta planè, vel ut exigua \& minuta. Voff: de Hiit. L.

Salunfins homo nequam, fed graviffimus aliene Iuxurix objurgator. Lactant. 1.2.de Falsâ Rel.

Fuitverò criffus,lut ctiam Seneca, exhortator ad virtutes, vitiorumque accu* fator acerrimus, vitiofiflimus tamen. ipfe;coque nomine ab Appiano, ar. Dione fugillatus, quòd aliter fećrit, alitcr lcriperit, homo, ut cum Macedont toqual's \& Paruvia Galliano, ignava opera. Pbilosophâ fententiâ. Bonifac.l.ry. C. 7. ludic. Hiftor:

Greci cjus Hittoriam tanti fecere, wt eam Gracè tranfulerit Zenobias Sophifta,tefte Suidâ.

Alter efto C. Salluffitus, omnine primus, fi libros modò ejus haberemus. Sed Hiftoriarum corpus illud torum periit:\& ex his pauculis, admirari eum magis libet quàm anxie judicare. Illud video Thwcy didi fimillimum effe : $\&$ ided qua de illo dixi, dixiffe hic me puta. Lipf. not.in libr.r. Politic.

Saż Gracam Hiltoriam Thucydidis \& Polybii, Latinamgne Salluflii \& Tit 
Livii cxteris omnibus prxferendam elfe cenfeo; feu gravitatem in illis., ac majcftatem operum fpectcs, feu puritatem ftylijudiciique integritatem, feu denique omnes siftoric reetè confcribendæ leges requirns. Quas ipti adeo concinnè foeliciterque obfervatunt, ut, ne tranfverfum quidem unguem abillis unquam deflexilfe , jure merito arbitrari poflnt. Gabr. Nand. Bibliograph. Politic.

Extant Salluftii opera cum notis. variorum exrecenfione loan. Frederici Gronovii, Lugdrini Batavo,in. Officin. Hackianâ.An. 1665 . in 8o.

\section{J U L I U: $S$ C A $S$ A. R。}

Slamit ante Chrift.Anno X L V. I.

A Nte Chrifum Annos 98 natus eft. Varia admodum foripgrt, exs quibus I fola fixperfunt, quæ in re Hiftoricâ reliquit:nempéfeptem libri de Bello Gallico; quos Grece tranfulit. five Planudes five alius. Ad hac trés de Bello Cruili.

Scriptor eft purus \& elegans, inque verborum ftruchurâ accuratus, $x$ atque: - mnino placidi intar Auminis procurrens :intereà monitrùs àc gravis in fententiis, quo X'enophontem exfuperat: cxteroquin ei non diffmilis multum-Hxc. eò dico, ne Carionis, aut Floridi, aut alterius cujufquam judicium ab lectione Commentariorum Cefaris abfterreat juventutem. Qua pro pudor ! Satis infrequens eft in nobiliffimo atque adeo divino hoc Criptore , Aut fi quibus in manibus fit, haud alio legunt frne", quàmob eximiam Romanæ lingux puritatem, verborumque proprietatem fummam; fuper quo ante nos non femel fummiviri: funt conquenti. Sanè ex co haurife eft maximarum \& utilifimarum rerum copiam : quam quiverborum elegantia contentinegligunt, minus etiam pueris fapiunt, qui nunquam ita fe arboris frondibus oblectabunt, ut egregios ejus fru. ctus contemnant. Vofl: de Hilt. Lat.

C. Cefar laudatur in primis. Si ut difertus matrato r, libens affentio En enim ejus viri pura oratio fune fuco ac calamintiis ornata, vel Romanis vel Atticis Mum. fis digniffima: Sin utperfectus Hiftoricus; dubitare me dicam, cum \& non-s

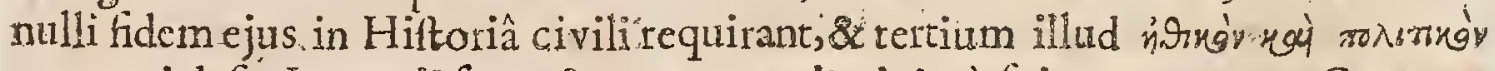
totum ei defit. Itaque ipfe Cafar, cateroqui minimè fii contemptor, Commenarios infaipfitnon Historias: \& hoc ipfolaudem veram meruit, quod falfam affectare contempfit Lipf. in Epiftad Maximil. II. Imperat.quam fuo in Tacit. Comment præmifit.

$C$. la far res luas ipfe digeffr:compofite fanè , ac pari modeftiâ ac libertate. Infolo funt, qux culpem, fine ejus tamen culpâ. Nam malam aliquam \& alienam manum accofflfe fatis, mihi liquet. Prudentiam non è verbis ejus hauries, fed è factis \& maximè militarcm: Ćormentarii enim funt., \& nihil pollicentur prater nudam; fumplicemque narrationem. Lips. in Not: ad Politic, Libr.x.c.g.

C. Cefar. fi foro tanetm vaciffet, non alius ex noftris contra Ciceronem. no. minaretur. Tanta in eo vis eft id acumen, ea contentio, ut illam eodem animo: dixiffe, quo bellavit appareat. Exonar tamen hacomnia mila fermonis, chjus 
proprie fudiofus fuit, elegantia.Quintil.t.ro.c.I.

Inter catera divini ingenii monumenta reliquit Cornmentarios reium Cuarum valdè probandos, qui adeò minditer, purè , eleganter confcripti funt, ut mundius, elegantius, terfus nihil quicquam reperiri pofft. In quibus fumma illa Oratoris virtus quam perfpicuitatem vocant, magno cum nitore confpicitur. Sunt enim, quod ncmo non videt, hucidiffimi planiffimique, in quibus omnia Alunt elaborata, ac foelicifimam facilitatem prafe ferentia, nec ullis recondirorum verborum, exolctaru que vocum fotoribus deformata. Pbilip. Beroald. in lit. ad Erneft. Schleinic. quas Cofar premifí

illud infuper addiderim, boram partem corum, qux his Commentariis fcripta funt, haberi etiam in Epiftolis $M$. Tullii ad Atticus, ; in quibus, cum quidnovi geftum erat à Cafare, fratim Atticum, Quintumve. Ciceroners fratrem aut $M$. Brutum ccrtioremfaciebat. Id quod maximo teftimonio eft, veriflima effe, quacunque his Commentaris fcripta habentur. Ald. Manut. in lit. ad $l_{i}$ t. quas Cajari pramifit An. Is 3 .

Scripht Cafar hos Commentariosin Caltris, a fuccifivis quidem horis, quibus herclèvel ob hoc major fides dibeter, quod rebus geftis, ipfe qui rcripfit, interfuit. Quàm veró reliquos autores in locis perfcribendis diligentia ac curavicciit, facilè videre poterit, quicunque vel apud Geographos aliquid laboris infumplerit, vel quil Galian ip fam viderito Genr. Glarean. in Annotat ad Cref. de Bello Gall. 1. I. c. I.

Pollio Afinius parum diligenter, parumque integtấ veritate, compoftos (á Carare rcrum fuarum Commentarios) putat:cùm pleraque, \& qux per alios. erant gefta,temerécrediderit : $\$$ quæ perfe, vế confultò, vel etiam memoriâ laphus,perperam cdiderit: exiftimatque refcripturum, \& correcturum fuiffe. Et prefecto (inquit Voffus ) qui cum $C$ faris Commentariis contuleritca, qua ab aliis, cùn Latinis tum Grar is, de rebus Cafaris fcripta fuese, negare non potew rit, cum, fr quid imprudentiùs, vel quomodocunque aliter fecilfit, quàm oporteret, hoc ferè vel planè præterire, vel ita referre, ut in alios potius conjiciat culpam. Vof. de Arte Hifter cap. 12.

Multi verò de Autore horum Commentariorum dubitarunt, \& Iulio Celfo, nefcio cui, temere infcripferunt. Certum quidem eft in quibufdam antiguis libris in fine Commentariorum legitur I tilius Celfus Confantinus legi Commentarios Cafaris. Ex hoc \& aliis atgumentis fatetur Lapfur Iuliunaliquem Celfum. manus attuliffe $C$ a fari, quxdam recidiffe, addidiffe, inteipolalfe, fed non immutaffe Cefarem, ut Infinus Trogum. Arnold. Montan. in Nor.ad Cafar..r. c.I.

Praclarifima, fi quis unquam; cogitata enunciandi facultate polluit $C_{a} f_{a r}$. Eruditi quibus fapit palatum cum non fine caufa mirantur ob inimirabilem ftyli puritatem: fedillum magis adhuc miror ego ob exquifutum cjus judicium; nemo enim fapientius unquam fcripfit. Solus fere inter autores nullas.ineptias dicit. De fe non loquitur nifr ut de homine indifferenti, \& quam femel induit fapientis perfonam egregiè femper futtinet. Verum elt eum non effe prorfus Eiftoricum. led verum quoque eft eum exemplar Hiftoria lcribendx perfectum fores 
fifylo minùs contracto fcripfiffet. Valde gloriofum eft Authori huic incomparabili quòd Henricus.IV. \& Ludovicus XIV. Hiftoria illius de bello Gallico vertendx operam navaverint, Rapin. Reflex, in Hift.Sect.28.

Cajar peculiariter dignus mihi videtur cujus ftudio quis vacet, non foh̀m propter Hiftoria notitiam, fed propter eum ipfum : ufque adeo cateros omnes perfectioncac excclkentiafuperat, ne Saluftio quidem exceptó. Profectò Alithorem paulò majori reverentia \& veneratione lego quam humana Scripta legi folent : modò ipfummet fufpiciens obejus geta \& magnirudinis ejus miraculum; modò ob lermonis pıritatem \& elegentiam inimitabilem, qua non folum ominibus Hiftoricis palmam praripit, ut ait Cicero, frd fortaffis ipfimet etiam Ciceroni. Tanta in judiciis fuis finceritate loquitur de hoftibus fuis, ut, exceptis coloribus falfis quibus iniquam fuam caufam, \&ambitionis fux peftilentis for des incruftare conatur, hoc unicumin eo reprehendi polfe putem, quid parcè nimis de fe ipfo locutus fit; tot enim praclara facinora fecifle non potuit quin de fuo ad ea unultò plus contulerit quàm fcribit. Mich. de Mont. Experim. 1.2. c. 10. Gall.:

Cafar in cujus fylo tot funt blanditix, tantaque nativa facilitas, quardoque tam obfcurus eit, ut fi quid fibi velit intelligatur, id minùs à verborum vi procedar quàm ̀̀ rei de qua agit confideratione. Novelt. dc Rep. Litt. Sept. 1686. Gall.

* Annotationes Ioan. Rliellicani; Toam.Glandorpii, Joacho. Camerarii, \& Franc. Hottomanni in $C$. I ulii Cefaris Commentarios, permittuntur, fi expurgentur. Index Madri. edit, An. 2667 .

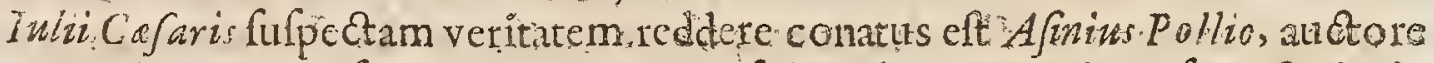
Swetonio. Ego vero nefcio an cum ratione; fed, ut dicam quod cenleo, fieri vix potuife vidctur, ut bello tantifque occupationibus detentus ( nihil atii fupereft iis, quibus cum Gallis dimicandum eft)religionem, ritus, ceremonias, \& mores hominum tam diligenter perquifierit:- verum ab aliis accepta refere eum facilè crediderim; habet enim absurda nonnula quale illud: Gallis morem fuifje, ait, wa

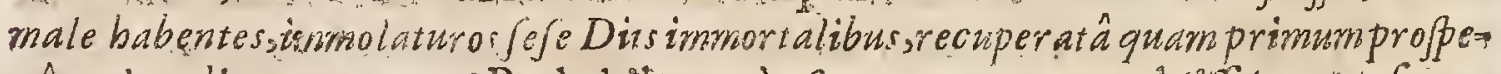
râ valetudine, yoverent. Probabile certè eft eos arotare maliillé quam Lanos factos in Vittemam enecari. Cirnd.Verder. Cenfon.in Auctorcs.

Extant C.Iuliv Cafaris Commentarii cum Notis Variorum, editore Arnolda Montano. Amfelodarni ex officinâ Elzevirianâ An. 167.0. in 80..

\section{A U L U S HIR R I U S}

Claruit ance. Chrittanno XIV.

A Landorpius. Aulum hunc Hirtium amicum \& familiaiem Casaris fuife 7 ait; \&Difcipulum Ciceronis, Confulemque à Cafare defignatum, proximo. poft credem ejus Anno. In ouo honore contra Antonium pro libertate pugnans ințeriit.

Commentarii ab Hirtio additi vel Oppio, planè funt alii quàm Cafaris; minus puritatis \& majeftatis habent ut Cafarianos à Principe feriptos appareat, alteros 
ałteros à privato: Ludovic.Viv. de Tradend. Difcipl.1. 4.

Inter Libellosqui adjuncti commentariis Inlianis, unus eft de Bello Africo: qui, me judice,non inter illos tantum cminet, fed inter pleraque Romana feripta. lta terfa in eo, \&ud comicum merem pura dictio; fimplex, cohærens, \& candida narratio;nihil quxfiti colorisaut fuci:omnia denique illo ipfo Cafare digniora (non tenebo veram vosem) quàm Commentaxii illi, qui feruntur. At neglectus tamen jacuit, imò.vix lectus is lib Hllus (adeò hic quoque præjudicia valent, \& traditx a tnug iftellis opiniones) quem fi feriô infpicis fatebere, non alium magis effé ad genium prici xvi.Puerisinter primos Autores formandx lingux fi quis proponat, nithil erret. Sanè hic:unus Commentarius inter omnes, nefcio quo fato, purus,nec interpolatus manfit, \& in fuo vultu. Excipio, quòd in partibus quadan labecula: è quibus paucas hic cluam levi manu. Irff.Lipf.1.2. Elect.c.22.

Hirtius terfifimo Belli Africi Commentariolo. Idem ad. Tacit. 1.2. Annalo. num. I2L.

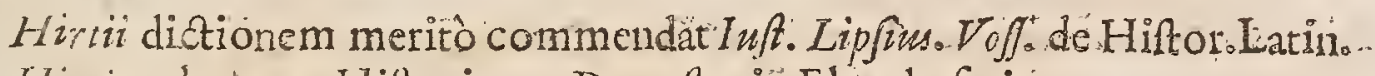

Hirtius eloquens Hiftoricus. Dempfter in Elench. Fripti..

Quis eft tain ingenio tardus, qui verbis Hirti optimi Lingua Latina ancto-

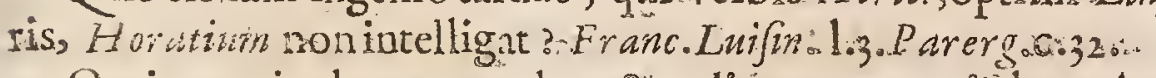

Omittam, inchoata quadam \& rudia occurrere iiihoc. AuEsore optimo(Iulio Cafare) fell partim mendofa, \&\& obfcura,partim ab. Hirtio, hoc eft, , nond as fcientiflamo Hifturico abfoluta. Paml. Ben. de Hiftor.l.11....

Hunc auctorem edidit Arnoldus Montanus cum Notis.Fariorum, illum. Car. faris Commentariis adjungens in $8^{\circ}$..1670.5

\section{V ALER I US C AT UIL US.}

T. Eronenfis trigefimo atatis Anno Rome moritur, Olympo -180. Ali. 4. Claruit ante nempe Lentulo \& Metello Coff. quibus Cicero ab exilio revocatus. Hieron. Eruditorum confenfi Docti cognomen accepit : ita cnim peculiari Epitheto Catullus cenfetur. Atque hunc quidem Ovidius Virgiliane majefati opponit. Tantum nominis apud eruditos, ac laudis eft confecutus. Sed \& verfus ipifus, quianquàm ut duriufculi notantur ( guoș uterque Plinius afferit) tamen. perrelegantes habiri funt, ac fectatores complures in his invenit. Petr. Crinit. de Poet. Latin.

Catrillo Dodti nomen quare fit ab antiquis tributum", neque apud alios comperì , neque dim in mcntem venit mihi. Nihil enim non vulgare eft in ejus libris. Ejus autem Syllabæe cùm durx funt, tùm ipfe non rarò durus: aliquando verò adeomellišs, ut fluar, neque confifat. Multa impudica, quorum pudet : multa languida, quorum miferet: multa coacta, quorum piget,

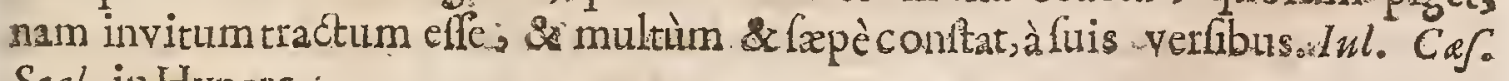
Scal. in Hyperc:

Catullus hunc Docti titulüm ab coxvis fuis non aliâ de cautsâ retulit , quàm quờ Grecoxum quainimitabilia putabantur; Latinis liseris exuditè exprefferit.

$$
\text { I } 3 \text { Neque }
$$


Neque enim puto meliorem Gracarum Venerum Interpretem ante Catulum fuif fe, qquàm illum ipfum, qui metrorum genera, qux illis folis data videbantur, incomparabili fucceflu primus Latinis tranfcriplerit. Quod non ignoravit Martialus cùm feripfit : Verona docti Syllabas anat Vatis. Barth.1 38.c.7. Adverfar.

Latinz puritatis cuftos fuit religiofiffmussuade \& Dodti cognomen meruit. Alioquilafcivus, \& fupra modum mordax;utpote qui ne Cefari quidem, jam rerum potito, pepercerit. Car. Stephan.

Unus amnium \& fuavis maximè \& Latinus Poeta Catullusef. Barth.1.8.c.2z。 Advirgar.

Poeta urbanus vocatur I wvenali Satyr.5.3. Poetarum elegantifimus , Gell.1.7.* Noćt. Attic.c.20.

Doctus, facundus,argutus, lafcivus. Ovid. A Mantiale Catulits cenfertur Maroni, eo difticho:

"Tantura magra Suo debet Terona Catullos Quamurn parya Suo Mantza Tirgilio.

\section{Mart.1.r.4.Ep.rgs.} tar.c. I:

Dulcillimus omnium Poctarum: politiffmus Catulu Turnéb.l. I2. Adver-

Tibulus ex Propertius locum $C$ atullo proximum in clegantiâ verborum, atque in fententiarum concinnitate obtincnt. Manut. Epilt.l.3. Epift. L 4. Muret.

Multa alia præter Epigrammatacompofuit Catullus, quæ vitio longæ vetuftatis defiderantui.

Qu.o Poetânihil ingeniofus, nihili eruditius, nihil jucundiıs excogitari poeeft Petr. Villor. 1.22.var.leat.cap.rs.

Catullus obfervantiffmus vel morofifimus oblervator puritatis Latine Lingua. Scaligerana.s.p. 47 .

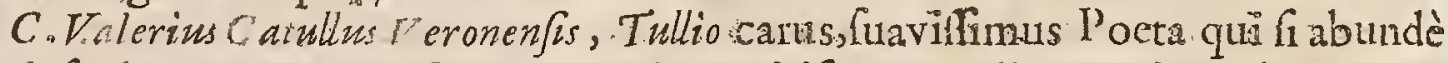
duriufculus appareat, prefertim in Epicis mirifica ingenii amo.jicate horrorem Illum abfterfit, '\& caftiflimâ Linguse Romani venuftate redcmit; dignus qui in arGumento caftiori occuparetur. Borrich. de Poet. p.49.

Habent Latini hujus generis auctorum nobilifimum par, Catullum \& Martialer. de quibus non ambigi placet, uter utri, \& quàm longè anteponendus fit: tantumne Catullu à Martialc quantum ingenuus aliquis \& honeftus civis ab alliberali importuno currâ de trivio dilcuepetat Antonio Mureto vifum eft: 2 Epigrammatum virtutibus fuperet $M$ artialis $C$ atullum,id quod Iuf ins Lipfius. cum Inlio Scaitgero fenfir. Multò etiam moror minus fuperbum $\&$ infolens $A n$ drea $N$ awger ii frftidium, qui ut eft relictum à Patsio lovio in vogis doctorum virorum, certo quotannis die confecrato infes, magnum numerum $M$ arti ilis librorum, quos coacervaffet ad eam rem, devoveret Vulcano, peffimuin, ut videbaturp Pocian praclarè execuatus. Meum judicium femper fuit, ita Catullun cum hartale comparari polfe, uterque ut vincat \& vincatur : Illurb quidem puro ac fimplici candore, \& nativâ quâdam minimeque adfcitâ exccllere ve- 
nuftate forme, qux accedat quam proximè ad Gracos; Hunc acumine, quod prom prium Latinorur: \& peculiare tunc fieri cepit, valeret: adcocue Catullum toto corpore Epigrammatis effe conficuum; Martialern claufulâ præcipuè atque ultimo fine, in quo relinquat cum delectatione aculeum, [pectari.Quodfi verfum \& numeros attendimus, Martialis bendecafyllabos", Scazontas, I ambor, prax Catul-

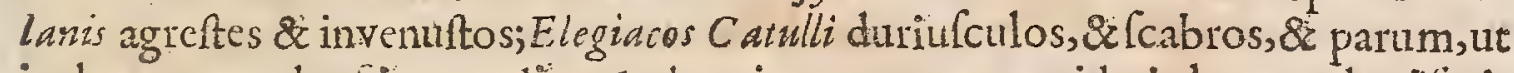
ita loquar,enodes: Si expendimus elocutionem, tantum videri alterum alterificriptorem preftare, quanto ex duobus, quibus Latina lingua maximè floruit, tem-

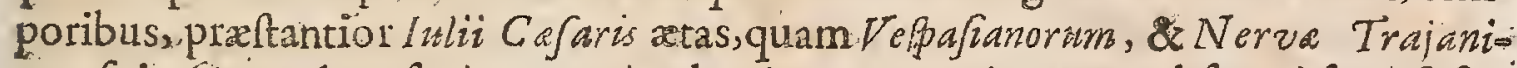
que fuit. Optandum fanè ut, quàm benè uterque tàm non obfcenè fcripfiffet: neve putaffet alter $V$ erfurulos tune denique habere falem \& leporem, fi funt molw Liuculi \& parumpudici : alter lafcivam verborum licentian linguam effe Epigram watum interpretatul. Vavaffor. de ludicrî Dict.pag.231,232.

Jef. Rapinus ait Catulium, quia Romanorurs primus linguam elegantix Venes wibus exornare cepit, nondum calluife magnum praceptum Horatio qui fermonem concilum \& breviloquentiam prefcribit. Rapin. Comparat: Ham. \& Virgil. cap. 10.

Author collectionis Epigrammatum, quam in aliis tam acriter perfrinxit Jefuita Vavafieur, non frne caula dixit Martialem \& Catulun impolita \& ruftica: ingenia fuilfe, \& Stationariorum militum quam pudicarum Matronarum collocutionibus congruentiora. Dom. Bayle Novell, de Rep.litt. Junii 168.4. paga 364. Gall.

Editus fapè Catullus eft,follicitè ab Gebharto \& Mureto; quibus adjiciendza:

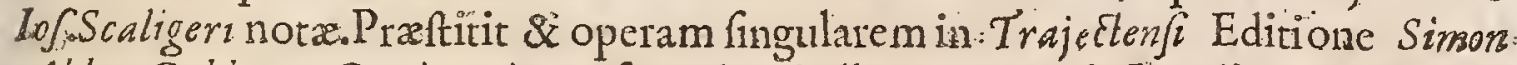

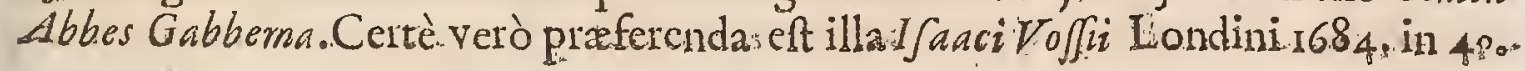

\section{O.R N. L.I U. S. NEP O S.}

TT Iftoricus. Veronenfirstempore Iulii Ce faris claruic. Hieronymus iñ Chronico

1 Euseb. vefert illum adannum Augufti quartum.

Scripfit libros illultrium virorum; ex quibus habemus 22. exterarum Gentium

Claruie ante Chrift. Ang Imperatores.Scriplit etiam de fcriptoribus claris, Catone, Terentio, Cicerone, $A_{t-0}$. tico, aliifuue as cripfit Chronicon rerum Romanarum.

Excerni Imperatores, quos habemus, Emili effe Probi, à multis creduntur. Qui eriorinde provenit quòd Librario id fuerit nomen, qui vitas eas partim Luâ. partim Patris \& Matris manu fcriptas Theodofio obtulit.Hoc ita effe, oftendunt:

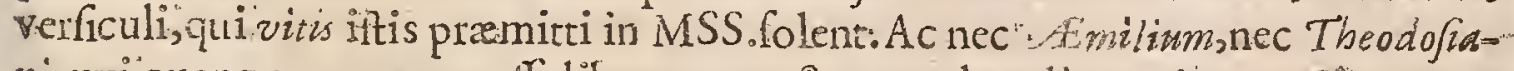
ni ævi quenquam, corum effe librorum auctorem, abundè arguit pura \&E Roman dictio. Upinetur aliquis ut Trogus ab Inftino, ita ab Exilio, qui Tub Theodofio vixit, in compendium eff redactum $N$ epotern.Sed aliud fuadet operis concinnitas,

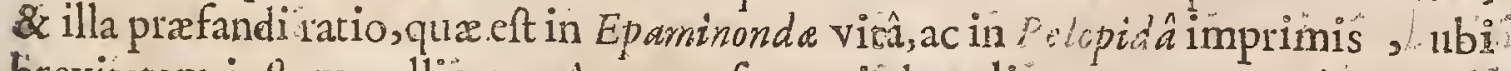
brevitatem juttam pollicetur. Attamen fententia hac licet crronea, minus periculi habeat, dummodò extracontroveríam maneats Amalium onnia de puriffi 
mis Nepotis fontibus haufiffe. Ger.Ioan.Vof: de Hift. Lat.l.I.c. I4.

Confantiflimo civitatis 110 fre tefimonio C. Conelium Nepotem, virum doctiflimum, \& Antiquitatum omnium peritifimum, Veronenfern fuife traditur. Cui in fummâ Curiâ cum reliquis Veronenfibus illutribus etiam Statua pofita eft ex publicâ auctoritate. Hic in Urbe, Ciceronis $\&$ Cafaristempore vixit, pervenitque ufque ad Augifit principatum. Scripfit difertifime 1lunftrium virorum vitas.Qunum tantù Pormponi Attici cxtat; qux catcrarum facilè specirnen indicare poteft. Scuipft accuratifimè rerum Romanarum Cbronicon, vel de Temporibuslibrum, in quo brevi explicarionc omis xii memorias complexus ent. Onuphr. Panvin. Catal llluftr. Scriptor. Veronenfo

Cornelius Nepos quàm elcgans fit fcriptor ex vitâ Pomponä Attici cognolcere licet. Dictio certe venuftifima \& Limplicillima:in difponendo nihil illo accuras ciussin fice nihil fanctius. Petr. Nani. de clar. Cornel.

- Limatifimus fcriptor, cujus judicium Cicero wevereri folet. Seiopp. de fylo pag. 5 :

Cupio purifimumillum Scriptoremaliquando caltigatiorem edere, quem tum docebimus effe Cornelium L epoterinon verò exirailium Equburn, ut vulgò putant. Obert. Gifari. Conject.in Lucret.

In Nepotivitas dubium non eft nonnullapofterioribus faculis inepfilf ab

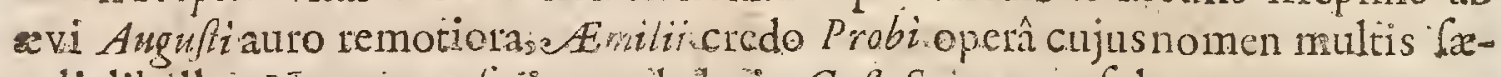
ctlis libchlis Nepgis prelcriptum liabuit. Gajp.Sciopp.confult p.4I.

Nepor,caftigatiflimæ moderationis anctor,cum abfinere illa orationum fplendidiore curâ, delcriptionumyue productiorc ambiru confituiret; quacunque a a ingenium, difiplinam,piivatam confuetudinem pertin nt, breviter ac veluti unâ congetioneablolvit: Catera âtionibus publicis earumque rationibus informandis bonâ fide attemperat.loan. Henr. Boecler. in co.nment.ad sernneg.

Neuter horum (de a fare \& Nepote agit) fatis nunquam laudari potelts prefertim ob feculi nottri confuctudinem, quo plerifque alia amnia faciliùs placent, qtàm id, quod in Cafare \& Nepote pracipuum judicant cruditi. Sed Nepotis quidem masis expofita dulcedo \& grati. elt : omnis cnim ejus friptio in moribus cxplicandis, qua laudi aut vicio dai merentur charrandis : (ententiarum civilitate \& Emilitudine, exemplorum quoque jucunda - varictate \& celebritatelectorem allicit: ipfaque dictio, qunvis fmplicitari futdere videatur, ddectu verborux, compofitione, fenfu ftatim aliquid fux fuavitatis, ctiam non aftimantibus aur intclligentibus, infunat: Dabimus hunc auctorem locoxum communium, ad quos refpiciat Civilis elo quentix fudiofus, guotiens mores Hominum publicaque \& privata confuetude vitx quadan frbtili elegantiâ, non citra gravitatem \& auetoritatem utentis, notari defiderant. Boecler.dceloquent. Folit.n. 43 .

Habemus etiam egregiam de vitis excellentium Imperatorum libellum, qua utalîs elfecredam, quam Cornelii $N$ epoits, animim inducere non polfum: quippè cætcra congruunt, fed pracipuè Infcriptio ad Atrichn, \& tcrum valdè. \& elegans f́cribendi genus, quod non alii faculo conyenit, quàm, ut ita di- 
ram, puro putolatino, quale fuit Nepotis。 Roland. Marefuns, Epir.lib. 2 Epilt.5.

Extant Corn. Nepotis vite excellentium Imperatorum eum Notis Variorum, Lugdini Batav. Ex officinâ Hackianâ An. 1675 . in $8^{\circ}$. Accelferunt huic edirioni pracipuorum Gracia Imperatorum Icones ære incife, ut \& Index Rerum \& verborum pracedenti multo anctior \& emendatior:

\section{P, U B, VI R GILIUS M A R O.}

N Pago qui Andes dicitur, haud procul à Mantuâ nafcitur, Cn. Pormpeio Claruitante Magne, \& M. Licinio Crafto Colfo Olymp.177 An. ini. Acronym. in Cbron. Chr. Anno Exaravit Georgica, Eclogas, Eneidem, Epigrammata.Virgilinus Brundufin moritur XXXIX. Olym. Igo. An.2. Vo\%.de:Poet. Latin.

Homericx perfectionis per uminâ imitator Maro : nullius difciplinx expers, \& quem nutlius difipipine crror involvit. Macrob. in fomn. Scip.1.i.c.7• 12.c.8.

Hac eft Maronis Gloila, ut nullius laudibus crefcat, nullius vituperatione. minuatur. Idem in Saturnal. 1. I. c. 24.

Fuit Virgilius ut fcrupulosè \& anxiè , itadiffimulanter \& quafi clanculò do. Etus : ut milta tranifulerit, quæ unde tranlata fint, difficile fit cognitu. Idemo ibid. 1.5.c. I8.

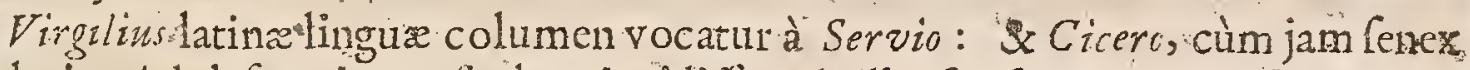
in hujus Adolefecntis opulculum incidifet, de illo fic fertur auguraffe: Magne Spesaltera Roma. Edra campran de Imitat. Rhetor. cap. 3. PI Iures hodie reperies quỉ Ciceronis gloriam, quàm Virgillí detrectent. Tacit. in dial.de Orat.

Virgilius, Vates fuaviffimus, Nitidifimuts, Pulcherrimus, Splẹdidifimus, Dulciffimus, Politiffimus---A-A pollo iplus cùm paftor effet, jucuidioribus aut teretioribus non cecinit numeris. - Ineft in eo Phrafis Regia, \& ipfus Apollinis ore digna -.... ic puto loqui Deorum proceres in Conciliis Cesle-

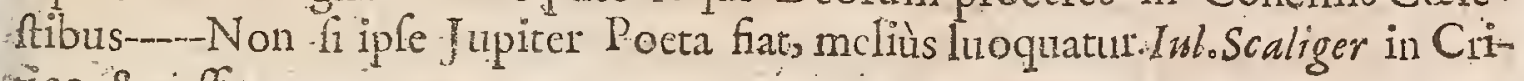
tico \& paffim.

Homerici verfus in terrâ, Virgiliani inter Mufas à Fhosbo facti videntur : ille Greculus Circulator, is Regix Orationis Auctor. Virgilius Magifter eft, Homerus Difcipulus. Hic Verus Poëta, ille Foraneus Narrator. Homerns moles quidem ett, fed rudis \& indigefta. Viroilius Matrona honefta. Idem.

Virgilins ampliffimum ubique fui præconium facit, modò ano judició \& non corrupto legatur. Ubique enim ille fibi conftat, idem Virgilius, hoc eft, ur planius uno verbo dicam, Postarum Deus. 'Sanè verò anìmo. \& ore verecundus adcò, ut ex moribus vulgè Parthenias cognomen invenerit, tanto étiam in honore habitus à Senatit Populoque Romano, ut auditis ejus verfibus in Theatro, univerfus populus illi affurrexerit, ipfumque, ut frribit Cornelius Tacitus, fortè prafentem fpe ctantemque yeneratus eft fic, quafi Angufum Cafarem: Ale 
xander Imperator \& Cafar eum Poetarum Platonem, ut Ceribit Lampridius, appellare folitus fuit, tametfi prapofteri in hoc judicii $A$, ranus, Ennium Virgilio. hoc eft, ftercusauro praponeret, \& fatui judicil Caliguld, qui eum \& damnares \& invefferêt. Lil. Gyraldus.

Virgilii verfus verè aureos jure appellare poffis, quòd ab Octavio pro viginti. verfictilis quinque aureorum millia receperit. Budaus de $A \int_{1}$. 1.3...

Auctor ett Donatus, Virgilio hunc morem fuiffe, ut horis matutinis plurimos. criberet verfus $:$ horis verö pomeridianis, ubi calot ille deferbuifet, coldem in cudiredderet, ac limaret: ac fapè ex centenis vix quaternos, aut fenos reliquilfe

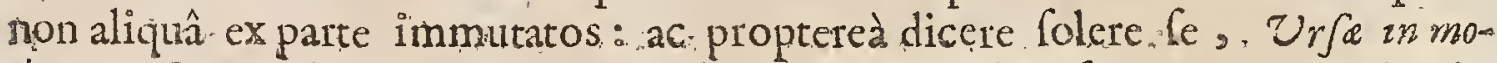
durn, foews edere informes, quos denique lambendo informaret. Donat.in vit.. Virgil.

Virgilius folts Poete nomine dignus eft. Iul. Scal. 1.3. Poetir.c. 2\%.

De Virgilio nunquam loquendum, nam omnes omnium laudes fuperat. Scaligerana I. P. I48.

Virgilii Giorgica fun admirabilia; haber ex Arifotele. exineis Virgiliz non eft correcta ut Gecryica, Berat compoliturus 24. libros ut Homerus. Omnes vem teres hoc dicunt, proptered juffit comburi illos libros. Ergaibit in ignes, carment illud quod polt Irgilimm additur, non eft antiquum. Scaligerana 2.

Duo illi omnis doctriixe apices Homerus \& Virgilius. Cafaub.praf: in Perf. Naturalis Philofophiæ non fuit Virgilàs omninò imperitus, Franc.Bacon.in HimStor. Vent. ad Artic. 27 :

Inftar omnium fit Virgilius, qui Topograptiatr Infernam accuratiflimè dcpinxit. Inferorum regionem in feptem Manfones dividit. 1. Infantum. 2. Falsò darnatorum. 3. Eorm qui fibi manus intulerwnt .4. Amantium. 50:Bellatorum.

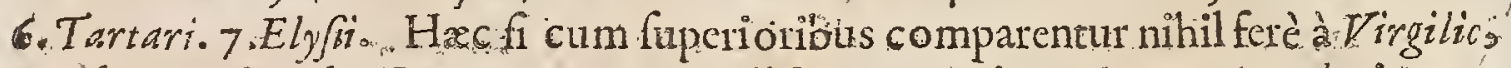
quod non prius ab Homero aut Platone dictum reperies. Ioan. Maxosho incan. Chron.

Virgilius inter Latinos princeps Poëtarurn ; - Bucolica fua annis feptem, fuam Eneida annisindecim elaboravit: \& primús ipfe fui rigidifimus cenfor ac: judex divinam friptionem adrogum damnavito Drexel par.prim. Aurifod. cap. 7.

Eneis virgiliz grande opus', \& plenum gravitatis', ac rerum bonarum \& quod liadi non concedat. Lud.Viv. de tradend. Difcip. 1.3.

In Bucolicis Theocritum Poctam eft imitatus, in Georgicis He fodurn quem fine

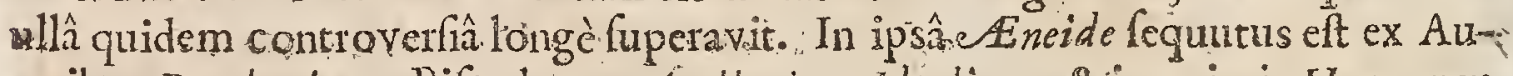
coribus Partbenium, Pifandrum, Apollonium, Kbodium, Simprimis Homerum: ex Latinis Q: Ennium, Livium Andronicwm, Navism, Titwm Lucretium, \& alios. complures. Petr. Crenit. de! Poet. Lat.

- Apud eminentifimum Poetanum nofrorum Virgilium nihil ferè pulöingeniofùs, \&erudititiùs dictum reperitur, quod non ad fiorneri imitationem fit confriptum, atque adeò " plenè ex Homero defcriptum. Quâ de re cùm ab xmulis aliquando Virgilius carperetur, dixilfe fertur: Non minus effe diffrile. 
rawmen ab Homero conmodè fumere, quidm Herculiclavam de manibus eripere. M. Ant. Majorag.prefat. in Homer. Iliad.

Fublius Virgilius non modò verba aliquot accepit ex Poematis Iucretii , fed hocos penè integros ab eo tranftulit: quod \& veteres Grammatici accuratè notềrunt. Petr. Crinit. de Poet. Lat.

Virgilius ex Xenophontis.libro Oeconomico multa tranfulit in Georgica, ut de - Georgrcis'Magonas Afri, Catoni, Varronis, Ciceronis quoque libro tertio Oeconomicorsm, qui Agriculturam continer. Serz. de Virg.Geors. 1 x. v. 43.

Inter editiones eminet Taubinanniana cum notis Servit, \& commentariis de la Cerća. Nec illatidata Petri Danielis, Dan. Heinfir, \& Thoma Earnabir;quibus adjungenda illa Cornelii Schrivelii.cum notis Variorw. Lugdun.Batav.exOC. Ginâ Hackíanâ Au. 1666. in 8\%:

\section{QUINT.HORATIUS。}

Tedcus, Lyricorum \& Satyrasum fcriptor, tempore Octaviani Augufi

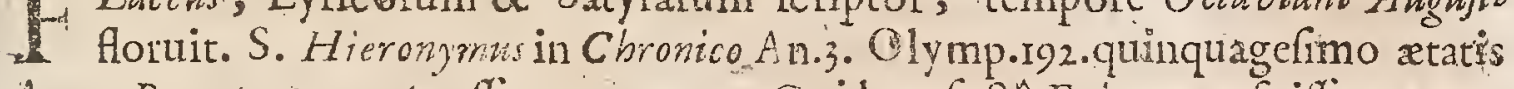

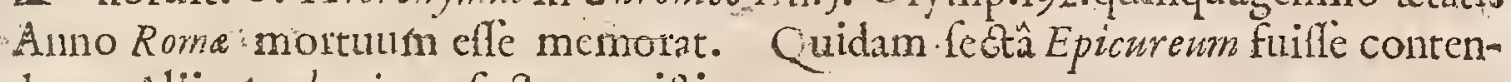
Claruit ante Crift Anne dunt: Alis Academicum, factum exiltimant.

Horatius ad notandos Hominum mores. precipuus s, purus imprimis \& ter-

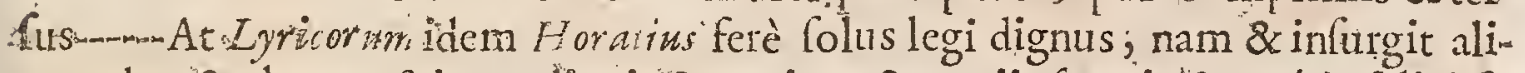
"quando, \& plenus eft jucunditatis \& gratiz, \& variis figuris' $\&$ verbis feliciff- mè audax. Quintil.1.1. ro.c I.

Quiin hoc proprium \& peculiare fuit Horatio, ut ridenti fimilis; \& quaf adiflmulans, imprebitatem ac vitia Hominum accufaret; quòd ea magis ur. geant, atque afficiant, qù fenfim ixrepunt, quàm qua apertâ fronte invadunt. Quod iplum \& P.oeta Perfins demonftrat:

Omne vafer vitum ridenti Flaccus amico

Tangit: \& admifjus circum pracordia ludit.

Callidas excufjo populum. unfpendere nafo.

Petr. Crinit。

Horatiuteft omnium Latinorum Gracorumque Poetarum elaboratiflmus. Scalig. Hypercrit. p. 867 .

Quis enim, qui de Poëtis modò judicare aliquid poffit, uni inter latinos omncs Horatio vel acumine ingenii, vel fententiarum gravitate, palmam non tribuit? Manat. Epif.1. 6. Epilt 7. Horatius emendatifimus autor, ut diccbat Augufus. Saligerana prim. p."gr.

Horatium in latinis fapientiorum Poétarum principem jure laudemus: in que penè tot vivendi documenta, quot verfus; tot Cententias, quot verborum fernlus , admircmur. Studiosè itaque \& fedulo fungula Horatii Poematalege \& per-

K 2 pende: XXXVI. 
pende : invenies non difputationes quidem fubtiles, aut ratiocinationum acumi na: fed plerague omnia qua ad rectè, fanctè, tranquillè, beatéque vivendum à prophano homine proficifci polfunt argutè ac graviter pracepta, excmplifuie Poetarum Hiftoriarumque \& vitx communis de copia depromptis explicata, confirmata, ac quaficondita. Hic enim mos, hæc ratio philofophandi unicè Horatio placuit: quo lenfilictiam in aureâ illâ ad Lollium Épiftolầ, Homericarn philolophiam Cbryfoppe \& Crantorea prafert. Mira eft \& in Odis \& carminis \& argumentorim varietas, fumma copia \& fuavitas: fententix graves, argutæ \& artificiofiffima: Digreffones oppido venufta. Corn. Scbrevel. Epift àd lector. prafix. Edit. Horat.

Unus \& unicus loratius in $O$ dis componendis regnat, \& omnes infinito inrervallo polt fe rcliquir. Baud. Epif. cent. 2. Epilt. 28.

Venerum ille parens Foratius ei profuâ clegantiâ \& ingenii urbanitate haud dubiè placet. Tanaquil. Fabr. Epift. 1. I. Epift: 57.

Iuvenalcm Poctam à Scaligero Patce, in Satyrâ prxpofitum Horatio, vidi quí jundignarentur. At ille, me judice, inter multa certi \& elegantis judicii, nihil verius protulit. I ip S. Epiftolic. Quxit 1. 2. Epift 9.

Horatzum poctam alioqui nobilifimum, libidine adcò prefervidâ fuiffe $\mathrm{fe}^{-}$ runt ut cubiculo ctiamnum uteretur fpeculato, quo fe cocuntem iitueretur. Col.Rhodigzn. Antiq. lect. I. I/4, C. 4.

Qu. Horatius Flaccus Ven:sib in Apuliâ natus, juvenis in bello meruit, tandemque Tribunus Militum conflicutus, re non fatis foeliciter geftâ, ad amœnum illum literarum poitum fefe recepit, \& primùm quidem elegantia carminum. Mecanati conciliatus, hinc per eum $O \delta t$. Augußo, zatatis reliquum fuaviter contrivit. Dittio ejus caftè latina, ipfe minimè caftus. In Lyrio à nemine Latinorum vincitur. Heroira Flacci, ut fapientix monitis abundant, ita numeris \& rotanditate amabili plerumque deftituuntur. Borruch. de Poct: $p: 49,50$.

Carminum igitur libri veljucundâ inventione, vel puritate formonis, vel figurarum tum novitate tum vaictate, majores funt omni non folum vituperatione, fed etiamlande: neque folùm dicendi genere humili, quemadmodum icripfit Quiztrlianus, contenti, verum etiam fublini maximè commendandi. Iul Scalg. de re poctic.p. 379 .

Horatius artem inverit combinandiomnes nervos omnemque fublimitaten Pinduri, cum tota fuavitate \& clegantia Anacreontis ut novum prorfus charact rem fibi efformaret daorum aliorum perfectiones coadunando. Nampra. rcrquamquò ingenium naturâ.jucundum habebat idem etiam vaftum, folidum \&. elatum erat; imaginationibus ejus nobilitas inef, in cogitatis \& fententiis fuis argutus eft : periti Artificis acumcn femper produnt illa Odxquas abfolvere vollit; fed perfpicacite non mediocri opus eft ad totum ejus ingenium penetrandum; nam arcanx quædam Veneres, \& elégantiæ quædam reconditxe paucifrmis obvia verfibus ejus continentur. Latinorum etiam folus ef inter Teteres qui in hoc fcribendigenere excelluerit, Rapin. Reflex particul, in Poef. Reflex. 30 . 
Cüm inter Satyricos prifci revi poctas rtes potiffimùm fint commendabiles, Ihvonalis, I'erjins atque Horatius; Horatius inter oratoxiam Iuvenalis dicacitatem, \& inter Perfii cbfcuram nimis adftrictamque brevitatem medius incedit, atque adcò inter Satyricos non minus, quàm inter Lyricos Lutinos, primum meretur locum. Alla Erwdit.Menf Jun. An. 1684. p. 26:

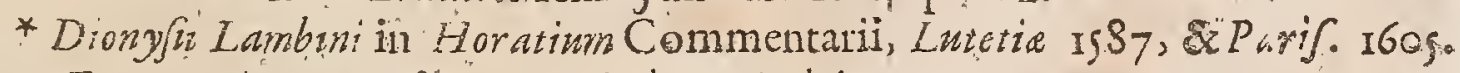
cum Expurgatione permittuntur. Index Madrit. 1667.

Prodicrunt opera Q. Horatii Flacci cum obfervationibus Petri Gualteri Chabotizà Goan iacobo Graffcro editis: Colonio Munatiane Ans. Irss. in foll, apuld Eudovicum Regen. Extant cum Notis Variornm, \& integris notis Ioamis. Bond. accurante Corn. Schreveliu, in S.. Lugd. Batav. ex officinâ Hackianâ 16.70 .

\section{M A N I L I U S。}

Ujus Aftronomicon habemus, extrema Augufi retate vixilfe creditur:
genti enim Manilium dentur convenire. Ger. Ioan. Vofli. de Poet. Lat.

Clartio ante

Chr. Anno

$\mathrm{XXX1}$

Fabius Quintilianus nullam mentionem de hoc Poetâ fecir: quocirca mixantur quidan, cur illum pratermilerit, præcipuècum de T. Lucretio, \& Etmilio Macro judicium fecerit. Studium fuum atque indufriam collocavit in Mathematicisartibus, tantumque in his profccit, ut maximas ingenio fui laudes tulerit: Scripfot libros quinque de Astronomicis, carmine He:vamin tro: in quibus magna ex parte Hipparchun, Eudoxum, atque Aratwin \{equutus traditur. De obitu ejus nihil à nobis compertum eft, l'etr. Crinitode Poëto. Lat.

De Mantionondum ftarui, magis optandumne fuerit, illum publicèin Scholi, legi, an dolendum, quod hactenus neglectus jacuerit, poeta.ingeniofiffimus, nitidifimus. friptor, qui obfcuras res tam luculento fermone, materiam morofifimam tam jucundo charactere exomare potuerit: Ovidiofuavitate par, majeftatefuperior; uno vincitur, quòd non poteft mantum tollere de tabulâ, \& (quodtam falsò quàm immeritò Ovidio objectum olím) nunyuan fcit definere: in quo peccat non judicio, fed fertilitate, indulgentiâ $j t y l i$ : quâa in re non judicium fed animum Ovidio quoque defuilfe, Quintilianus animadvertit. Eft \& aliud non leve vitium in noftro, quòd nimitus in verbontum iteratione, quum poffet aut parćus eadem, aut alia pro illis ufurpare. Itaque criticas aures offendunt, illa toties totiefque inculcata, Sidera, Coelum,. Mundus, \$er témpla,per fidera: \& alia non pauca, qua ter quater trinis quaternis con tinuis verfibus infulcit. Hoc ut non mediocie vitium eft in nitido fcriptore, ita puri funt ab hac labe Principes Poetx Virgilius \& Ovidius. Hoc uns excepto, nilhil ad perfectionem abfoluti Opet is in hoc auctore requiras. Imprimis omnia

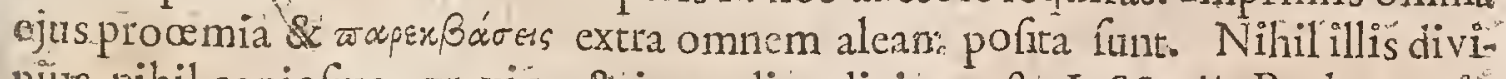
nuits nihil copiofius, gravius, \& jucundius dici poteft. Iof Scalig, Prolegom.in Manil.Aflronom.p. 20221. 


\section{$7^{8}$}

\section{EN S U R A}

Maniliz Aftronomicon multa habet de Chaldaich fupertitione ac vinitate infperfa: adeundum tamen non fine judicio $\&$ duce qui, qux devitanda fint,admokeat. Foan. Lud. Viv. de Tradcnd. Difcipl.1.4. pas53.

Imperfectum opus fuum reliquiffe Manilium, funt qui purent, cum de feptem Planetis nonnihilmominerit, \& de his max planè non eft executus. Latuit verò hoc ipfum Manilii opus per multa fecula. pirimus crim Pogius cum aliis libris in Italiam atulit. Martini; Pontifris Maximitcmpore. 'Gy rald. de Poëtis.

Quantus l'oeta quamque éloquens fcriptor fuerit, quantique ingenii ManiLiws licet vel cx Colầ defcriptione Andrornede perfpicere. Casp. Burth. Adverfar.L.S.c. 8 .

Opus Maniliz Afronomicon (At, \& Genetbliacon 1.5. verfu Fpico expreffum, Q ab e Egptimum difciplizis magnan partem decerutum. Dictio terfa, genus dicendi mediocre, judicium exquifitum, promptum \& facile eloquium, in an gumento latinis verfibus anteà intentato. Quin $\&$ Philofophatur identidem mon finiftè. Barrich. de peet. Lat.p. 54, 55.

$M$ anilium nillus fuit qui polfet intelligere freut cgo "; non enim ảefrribit Aftronorisarn hodiernam. fed veterem. Oportet benè legilfe authores ut intelhigatur. Funius quàm deliravit, qui voluit illum corrigere! Scaligerana 2.

Praclarè de hoc auctore meruit infigni cdirione \& commentario fof. Scälis ger, nec malè Fransifuss Innius Bitwrix.

\section{H. VITRUVIUS POLLIO.}

Clanitante Empore Augufi OAt viani Imp Alonit. Extant ejus libri decem de Arflarin. Ann. XXX. chitedturâcum notis Ioan.de Luet, Amfelodami Fol. 3649 .

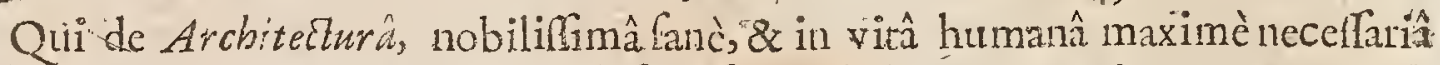
difciplinâ, inter Antignos è profelfo fcripferit, habemus neminem prater $V i$ truvium: qui methodo quadam peculiari \& commodâ procepta illits decem libris eft complexus : qux, ut apparet, maximam partem haulcrat ex aliorum fripterum monumentis, maxime Grecorum, (quarc \& Phrafis illius multis

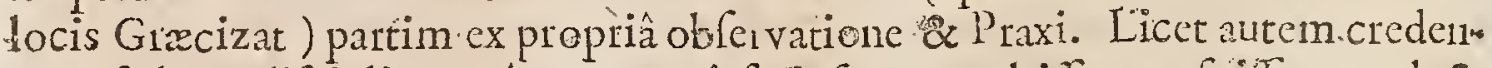

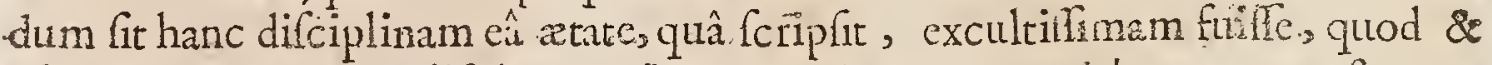
reliquix templorum, edificiorwirb, Pontum, Arcusn, :epulchrorurngue teftantul. a quibus exemplaribus hodiè precepta deducuntur; tamer ut in aliis Artibus arque Scienitis, multafuperioribus[cculis 8 noftro quo yne judicium \& indu-

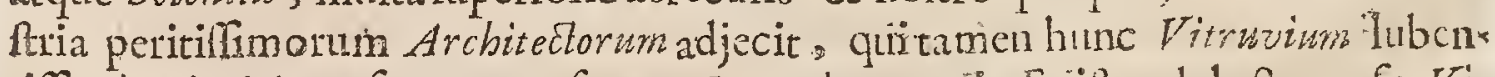
tilfimè Magistrarnifuum agnofcunt. Ioan. de Lact;in Epilto ad leato prafix Vitruw. de Arcbitedt: An.1649. Fol.

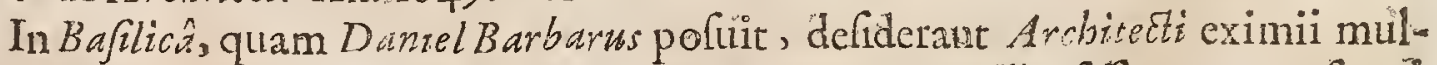
$\mathrm{ta}$ : qux abfolutiora fuiffent, nifi., mordicus Vitruvio adhxlifit, quem fimul fuige minus in inveniendo perfpicacem Chrifiani plerique omnes recentiones 
Artchitecii agnofcunt Anton. Poffer. Biblioth. Select. 1. 15. c. 17.

Archice ci qui v cram Architedturam callent, non omninò è Vitruvio, fed ex ratione, ex attentâ oblervatione, optimoque veterum modo pendent. Nam etfin Titruvins Architeiluram in unum corpus redegit; atque hujus leges, ac prem cepta egregiè tradidit , qux quidem omnia fatetur ab antiquis fe accepiffe, multa tamen putavit fe docuiffé, qux cùm ad rem venitur, \&usum, ncquaquam fuccedant nequid dicam de incommodis, \& futilibus menfuris Capituli Cuorinthii, \& bafinm omnium, atque coronarum quas ille attulito. Ioseph.Yalerian.vido Anton. Poffer.ibid...

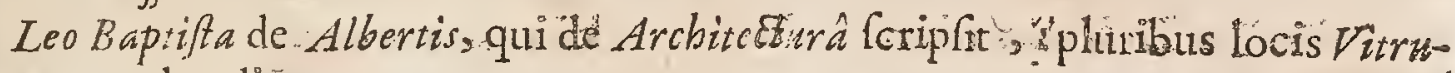
vium reprehendit.

Vitrtavi orationem peregrinitate \& plebitate, id eft verbis Ioquendique gcneribis infmax plebi famitiunibus, aut ad tranfmarini feu Gracanici fermonis confretudinem ineptinfculè conformatis paffim infufcat. Gafp. Sciopp.confuì sat.pag. 4 I. -

Sciuppin in Vitruvio optimi fcculi autore, aliqum plebiatem ac perigrinitatem agnovit; multa enim in illo funt fingularia , non tantum quod ad Voces fingulas fpectat, tam illas., quarum in Arte Architectonicâ ufus eft' quàtm alias, fed \& 1'brafes: forte quod familiarius ei loquendum fuit, ut populus, qux fribe-

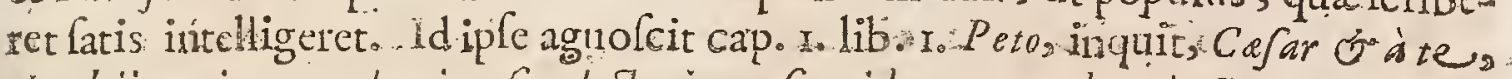
- ab iis qui me a volumina fint lecturi, ut fi quid parum ad artis Grammatica regularn fuerit explicatum , ignofcatis. Namgne non uti funmans. Pibilofophus, nes

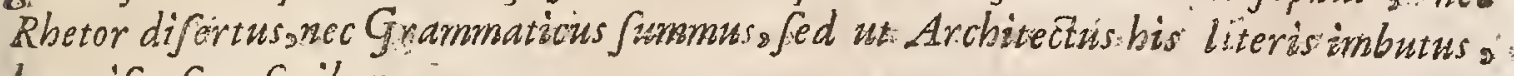
bec vifus furn. Scribere.

In illu hoc notavie Bartbius lib. 24. A düerf. cap I2. quòd plurali delectetúr. gum numero unitatis poffit effe contentus, quod \& fortè Romanum videri poffit, cum Idem lib.4.0.Adv. cap. I2. à Rom nnoran confuetudine provenire aum. sumet, quòd pluriwn numero unnm alloquañur. Romanus certè Sermo numerofam \& plenam dictionem requirito. Dan. Georg. Morbof. De-Patazin。 Liv.pago: 3) 86

Is fcriptor [ Vitruvnus] fux licet artis', Architecture videlicet, intelligentifli-: muss multa 'è vulgò haurit', qua elegantiores omnes refugerunt, i. quit Ger. Iowr. Volfus. Ineancem penè fententiam Scioppius : Vitruvins, iliquit, arationem peregrinitate é plebitate infuffcat. At peregrinitatem excufat, immò imperat argumentinovitas, quòd ex Gracis pene omnia fontibus haurienda: Plebrtas ( ue cum Catone loquar) ipfi neceffaria, \& (ine vitio linguâ uti cogatur Architectus. Quid quòd Plebs fape de rebus quotidiano opere fibi cognitis magis propriè pureque (. prafestim optimo illo feculo) loqua-

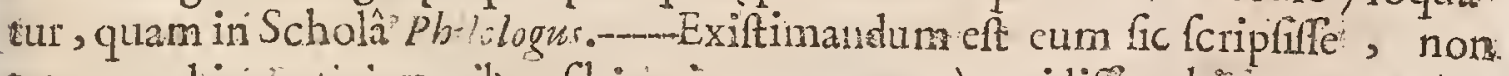
tam quod in 2 th tinis vocibus fibi quicquam temerè excidife arbitraretur, quàm quia cum fluxu, \& compofitione Gracortum vocabulorum penè-infinitorum liztandum fibi providebat, ut artem à Gracis hauftam commode explicaret; in ear

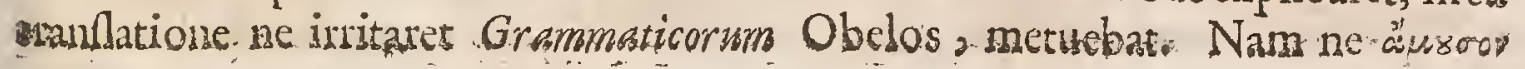


putemus Vitruvium, iplel.6. difertè tradit,imbutum fe à parentibus encyclio doetrinarum, omnium difciplinâ, e bilologis atque Pbilotechnis robus delecta tum. Ol. Borrich. cogitat. de var. Lat. Ling. xtat. p. s.

Magna Vitruvii authoritas non modò Antiquitatis venenfione nititur,jnec rationibus cateris quibus ad rerum cxiftimationem ex anticipati opinione movemur. Is quidem quo infignicbarur titulus, Architecti miminu I Saris \& Angufi, \& cclebritas faculiquo vixit, ubi ad fummum perfectionis culmen omnia perveniffe putantur, magnam de operis ejus merito opinionem animis ingenerare debent: Sed fatcndum eft magnam peitiam qua preclarus ille vir de innumeris divenfis rébus agit, curaque yuam cum judicio in easundem collctione adhibuit, \&in earundem collectione è magno numero Autom rur quorum fciopta pericrunt, meritò efficiunt ut librum hunc confiderent Eruditi tanquam opus fingulare \& thefaurum inaftimabilem. Dom. Perr.ult. Pref. in decem lib. Vitruv.Fol. Parif. I994: Gall.

Vitruvi liber de Hexagonis, Heptagonis, \& id genus, An. Dom.4494.inventusin Conobio quodam ad Bobium oppidum. Gcfner. Biblioth.

\section{DIONYSIUS HALICARNASSAUS.}

Clartic ante Chrift Anno X X V.I.

II Iftoricus, tempore Aurufti floruit. Ommin confeffione, fcriptor graw A I vifimus, \& in accuratiffmus perhibetur. Eum igitur agmen ducere volo, quippe ut liquidè liqueret unde genus funm hauferint Rornatir eaprimùm, qux de Aboriginum populo, \& prifcis Italia gentibus, non ex fabulis tantum \& vulgi rumoribus inaudiverat, fed ex libis etiam Portii Catonis, Fabii MI aximi, Valerii Antiatis, aliorumque plurium didicerat, refert": mox pertexit Hiftorian vigint libris, ulque ad primum bellum " mnicum, quod cœpit Anno tertio vel quarto Olymp. I28. An. U. C. 488 . Verum exîftis viginai libris, quos tefte $P$ b. ic , eliquit, undecina tantum ad nos pervenerunt; in quibus annorum tercenrum \& duodecim Hiftoriam, multâfide \& curầ defcriptam, habemus. Whear in Method.leg. Hift. Sect. I6.

Dionyfichuic landem eam tribbuit Scaliger in Animadverfonibus Eusebianis, quòd curatius eo tempora nemo oblervarit. Hac quoque parte Livio preferitur, quòd \& plura \& accuratius merlta tradat, que ad $R$, wh in is Aniquitates pertinent. Nec bonus tantum Hiftericus fuit, fed etiam $K b$ 'tor, ac Criticus nobilis: "quod oftendunt Rhetori \& Critica cjus epufcula, qux luperfunt" preter qua alia ejus generis fripfifle, cognofcimus inde, quod in iftis multa è fuis hujus. argumenti.citct, qux hodiè non habemus.Voff. de Hiftor. Grxe.

Diony frus Halicarnafjaus, homo Gracus, dc Rornanis multà veriùs iz meliùs Criipfit, quàm Fabruss, Sallufitus aut Cato, quỉ in frâ Repukflicâ opibus \& honom. ribus floruerunt. Ejus major fides eft în Hîftorinîn, quàm Livii, Trarquilli, Tacitis A rriani ; quòd de alienâ non de fuâ Rep. Fcripfit, '’ omnîum commentarios ac sivitatis arcana ex actis publicis collegit, prater moderatum dicendi. genus. 
sents, \& Atticampuritatem. Antiquitates Romanorum, ab ipfius origine urbis. eantâ diligentiâconícriplit, ut Gracos omnes ac Latinos fuperalfe videatur. Pofjér. Biblioth. 1.16.c.6.

Siquis veterem Imperii originem apud Dionyfum legat, ac cum Livianâ brevitate comparaverit, vidcbit opinor, nos haudimmeritò pratuliffe Diony fit curam ac diligentiam Livii feftination: : adco circumfpectè onnuia Dionyfins; adcò negligenter Livius ea tractafle videtur. enr.Glarean. ad Carol.j. Imperaror, Epilt. quam in Liv.annotat, fuis pramilit.

Dionyius Alexandri filius alicarnaffenfis , Kbetor in omniliteranm genere prieclarè verfatus. Suid.

Morum Romanorum diligentilimus Obfervator. Gro. lib. 3.de J. B. \& P. Gaudcamus (Dionyfi aliorumque fragmenta reperta, ) de Dionyfis \& 2 bio inprimis; quibus nil poteft in hiforia verius, prudentius Lipf. Epiltolic. Quart. 1. 4. Epif. 3.

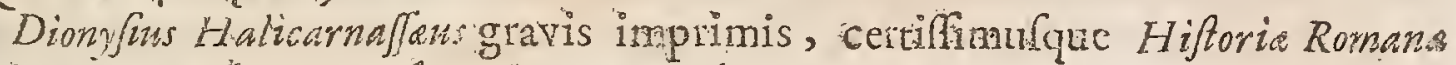
Criptor. Onuph.Panvin. 1.3. Comment. de Rep. Roman.

Vir imprimis gravis, \& nemini in vetufatis Romanormm notitia fecundus Gorop. Becan.l.4 Origin. Antverto.

Diongy ojus ( Herodoti) popularis, fummus dicendi magifter, \& fuavifimus fcriptot. Lof. Scalig in Animadv cuéb.

Dionysus Halicamafju diligens Antiquitatum inventigatorr. Rem Roma nam dilucidè ante oculos ponit; quibus initis, "quo ordine, quibus actionibus, quo confilio, quo cventu, fingula gefferit egregiè ratiocinando, recenfet. Car. Sigon. de Hiftor. Roman.

Stylus ejus atque Dictio, qux novatorem deceat; \& verò per infuetam vulgo viain orationem impellito At rerum fingularum minuta explicatio $\&$ fenfus illi quandam fimplicitatem adfert, \& ne ad ingratum fermonem atque afper sum abripiatur, vetar. Digreffonibus utitur non sarò : quare Hiftorix fam ftidium levat, reficitque lectorem interdum ac retinet. Ut autem verbo expedian, orationis elegantiâ, rerum particularium narratione 2 digreflom ne temperatâ, dictionem inalperitatem abituram Icnit. Pbot. in Biblioth $\operatorname{cod} \delta_{30}$

Donyfus Halicarnafjaus; vil ille quidem doctifsimus \& Rethor Criticus excellentifimus, fed profectò politicus intcrdum parum bonus, 2 cenfor alie norum friptortum alicubi morofus, ne dicam putidus. I faac Cafaub. Comment. in Polyb. Vol 3. p. 94.

Diony fus Halicarnaffum in fuo de Antiquitatibus Rornanis libro fensủs, fcientix 8 ratiocinationis profundinat $n$ non vulgatem patef acit; Accuratione, diligentia, jndicio, veracitate Ti to Livio pixpollet; magniq;ponderis eft: Sed hec omnia nó impediút quin admodú tadiofius Concionato: fit. $R^{2}$ apin.Ref.inHift.Sect.2S. * exeriliz Purtín Dionyfium Halicarnafjeum nota, cum qubibus circumferun. aur etiam Henr. Stephani of I ade. Cafauboni Nota.cum Expurgationibus permittuntux, Inder Madrit Edit. An. I66\%. 
Extant cjus libri undecion Hiftoria Romana Grace cum vetione Amitit Por ti : addita eft Glareani: Chronologia, Lugduni apud Francisgum. Eabrum Is92. Fol..

\section{SEXTUS: AURELIUS PROPERTIUS:}

Claruitanze Chrif..Ann. XIX.

$\int$ Talus, ex Mevaniânopido Vmbrie oriundus:. Celebritatem nominis Rom adeptus eft, cùn fummî ingenii comitate, tum elegantiâ carmilium Mecasnati \& Corn.Gallo maximè acceptus fuit. Ovidium quoque Tibullum, of Baflum inter principes amicos coluit,ad quos de fuis calóribus \& puelle ingenio fapius. fcriplit. In pucllam it ofiarm miro quidemaffcetu exarfit; quam, mutato nomine (ut eft autor $L$. Apuleins) Cyntbiam appellare maluit. Callimacburn pracipuè, Cyreneum, Minnermum, \& Pbiletam Græcos. Pottas in carminie fecutus. eft, quorum -manibus comitem fe profitetur. Nam ut illi apud Gracos in Elegia longè preftiterunt; ità Propertius apud Latirios corum imitatione primas videtur quorundam judicio confccutus Libros quatuor Elegiarum coinpofuit. L' etro. Crinit. de Poct.Eat.

Ovidiu: certè cùm frepède iṕpo Propertì agat, blandiom, tenérum, ac alulcem appellat, multumque illius Carmini femper conceffit.

Fabius Quintilianu cùm Tibullum maximè commendaverit, non deeffe tämen, inquire qui Propertium malint:-

Propertius, facili, candidus, verèelegiacus: terfior tamen quàm exiftima*.

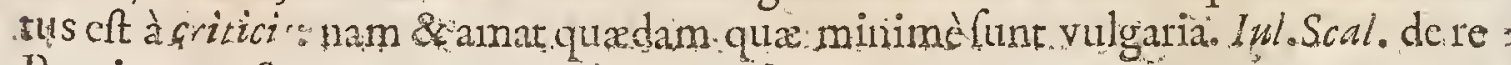
Poetic.pag. 8 .4.

Lepidilimus \& nitidiffimus poeta Propertins. Turneb. Adv.l.8. c. 2.: Tanta:

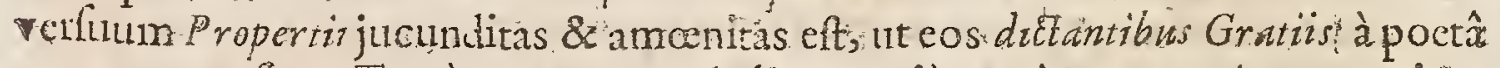
exceptos cenfeas. Tantùm optarem ad aliam potiùs, quàm amatoriam materiam beatam illam \&ecandidam ingenii venam contulifier: at .juventuti tutiùs.legi" polfet. Ider ibid. 1.11.c.is.

Dulcio i eruditione, \& entiriore dulccdine nemo Scriptor eittota Antiquitate ante "properitim, quem criptorem quo magis rimaberis', eòmagis ambis: qux enim primo intuiti obfcuriora videbuntur, ea fi penetraveriss omnium vide bututur nturali quadan Venere gratiofufima. Cafp. Barth. Adv. Io 9. Cap. $x$.

Ingeniofulimus \& limatiflimus, etiam - evuditiflimus fcriptor eft Proper. tius. Grecarum elegantiarum, fine pari gnarus \& amator. Idem ibidem. lib.; 32. cap. 9.

Vara eft in Propertic \& tecondita endiritio, \& preter fententiarum elegantiam \& acumen, multáili veróis quoque iplis, qux notatione \& laude dignen. tur. Illud quìdcm in co valdenovim, \& haud fcio an, facile apudalium scriptorem inventum, ut yerbis fimplitibus, utamur enim Grammaticorum vocibus ut res, poffrt intelligi,propriâ quadam \& fingulati ratione utatur pro connpofiri seam gate fignificationem, quam verba juncta habere debebant, nefcio quầ opiniones, elegantia 


\section{CELEBRIORUM AUTHORUM.}

alegantia": verbis fimplicibustion raro tribuat. Excmplis fict res manifertior: Sectari pro infectari, Teftari pro deteftarr, prater ceatcrorun foriptorum morem, apud hunc Poetam invenics, aliaque qua ipfe afferre polfum. Lipf. Var. lect.1. $3 \div$ cap: 7 .

Propertius Elegiacorum Roctarum omnium facile princcps. Hofman.

Properinin quatuor Elegiarum libros cultos: \& enuditos reliquit. Iil. Gyrald.

Propertium qui non amat, cum profecto $M u f a$ non amant. Tanta ejus verfuum fuavitas eft, ut quemadmodum Comicus ille ait, Nil nifimulsa loqui vidcantur : tanta eruditio, tut non nifi Phobo dictante eredamus exceptos. Lips.lib. z. Antiq.lcet.c. Lo.

Durum nihi quidem cit ab acis judicil Critico. [Quintiliano] difecderc, qui Tibullum vidctur pixferre. Sed tamen in is me effe fateor, qui / roperticm mathint. Quamvis enim Tibullus'mire fit jucundus, \& elcgans, Latina etiam proprica tatis amintior, quam alter, quilepè Greciffert, "\& in carmine exactior" \& rotundior: tamen Properitus illum cruditione, \& ingeniii fuavitate videtur fuperare, blandus ominsó, \& lenis in affectibus, in qubus etiam exprimendis nonnuquam, tancuam calidus amator, \& amoredeperditus, vehementior fuit Roland. Maref.1.2. Epint.6.

Tibullurr, ita ut erat, acccpimus, excultum atque expolitum. Eft Propertius -in manibus, \& oris blandi l'oeta, \&altioris fpiritûs, \& fabulis creber, \& ini tatione Gracorm coctior.Vuvaf de ludic. dict.p. 87 .

Propertius caftigatifimus Auctor, \& facundiffimus. Scaligerana r.p 47.

Qni omnium optimè inter Latinos s tylo Elegraco fcripferunt, funt Tibulluss Propertiur, Oviditus.T. Tullus, elegans \& politus eft; Properiaunobilis \& fublimis; fed utrique anteponendus eft Oviditi, quia fylus ejus magis eft nativus, magis moret \& affectusardentiores prodit, Rapin.Reflex.particular.2.part Ref. 29 .

Imparautem Tibl llo háberi poteft Pröpertins, 'licet Elegias aliquot pulchercherrimas nobilifimo ttylo elaboraverit: cim in multis varius, \& inconftans, languidior aliquando , 'ac humilis, aliguando inflatior, \& duriufculas A mpulLas, \& fefquipcdalia verba projiciatfreçuentiùs, quàm in Elegiis tolerati debeato Is c.Gaddius in Elogomnig. P.I 49.

Imitatus eft Propertius Scriptorés Grecos Pbiletam, Mimnormum, Callimachum [ ut fatetur ipfe] quos Latialicarmine ton infeliciter expreffit: uno partm nitmcrofus, qued poiryjllabo ifrequentifimè claudat l'entametrum. Quotics hic fcriptor ex Amoribus friis evigilat, non Itultè fapit. Borrich. de Poct.p. $\{2$.

Probertium edidere, \& illuftravere, qui Catullarn '\& Tibullum; in quibus regnat cditio Scaligerane, \& recentior illa inonis Abbes Gabems. Laudatur \& In: dex Tufcanclla \& Paferatit.

\section{AIBIUS, TIBULLUS。'}

A Ibius Tibullus, Romanus Eques, nutus eodem anno quio Ovidiu, \& Mef- Claruit ante A. Sala Corvino, Horatiogue familiaris, aे foro abitinuit, atque juventutem XII I.

$$
L \text { s fingendis }
$$


fingendis pingendifve Amoribus fuis impendens, res domefticas paututim attrivit : clegans alioquin, terfúque Pocta; $\&$ in exprimendis affectibus mirè felix $x_{2}$. infelix argumenti yanitate. Borrich. de ${ }^{3}$ oet. p. \$.2.

Troutu libros quatuor Flegiarum five Amorum compoluit: in quibus facile: probatlir ; quàm elogans \& candidum fit ejus carmen. : ut ejufmodicaloribus. defa ibendis Latino omnes videatur fuperaffe, cum aftectibus exprimendis,tum: elegantia \& fuavitate ingenii. Petr. Crini. de Poet.

Elegit mihi terfus atque elegans maximè videtur anctor Tibullus. Sunt quï Propertiurt malint. uninit.1.10.c. I.

Tibullo in Elegzis unanimi ferè Scriptorum confenfi palma defertur. Lil. Gyrald.

Durum milhi quidem eft ab acris. Judicii Critico dilcedere, qua Tibullurn vi-detur paferre. Sed tamen in iis me effe fatcor, qui Fropertium malint. Quamvis enim Tibullies mirè fir jucundus \& elegans, Latine etiam proprietatir amantior, quàm altris, qui lrep GrarijJat, \& in carmine exactior, \& rotundior: tamen opertiue illium ertuditione \& ingenii lizavitate videtur fuperare, blandus: omninò, \& lenis in affectibus: in quibus etiam exprimendis nonnunulam:tanauam calidus amator, \& amore deperditus, vehementior fuit. Roland. Marefo. I. 2. Epir. 6 .

Tibultu elegans cumprimis. Pocta \& in cujus puriflimis. fcriptisnativa qux dam \& vernacula Luina Ling mundicia relucet; de amoribus Sulpitix \& Ce

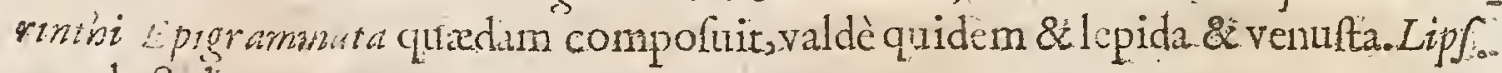
var. lect l. I. cap. 2.I.

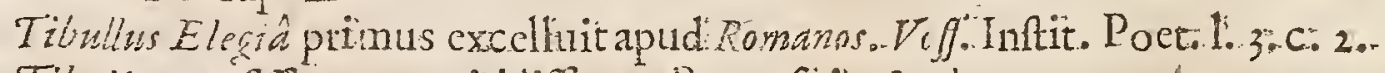

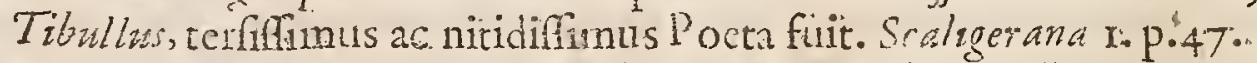

Antonio cM weto Tibullat cultisimus \& politifsimus Poeta plurimun de bet, cujus ille mulca incurabilia propè vulnera "coonia Chironiagu manu fana vit. Turneb.adv. 1.29. c. 30 .

Unifo mis ille penè totus elt: vixque difcedens abreipfo; codem pene" gyro. conclidituk :audis cnim cafas, foco, rum, nemora, prata, fpicas s: facra tum lagè tum multum : omnium verö culitilsinus, nec redundans in Elegia. In.fine quati: Epigrummata funt \& dura \& longuida \& infuavia. Elegiam quoque ad Iunonem non optîno conflio confsetum judices. Orat enim eam pro impudici-

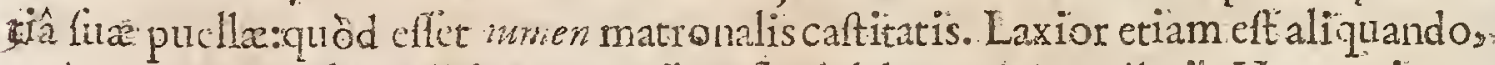
quàm quantum abertiditiorum auribus ferri debeat. Iul.Scalig. in. Hypercrit:

Vcteres f bilologi qui ibulli vitam fcriperunt, trestatum ab eo libros contiros autumants quorum nos ducatum fecutï, qua quartum hodic faciunt parw tim tertio anneetenda exiftimamus, partim vero ipfurs non effe. Barth.adverfar. a.c. 6 .

Albius Tibullus y Eques Romanus, in affectionibus exprimendis excellens, Elegiacos omnes mntec dere videtur elegantiâ, candore, numerofaque dulcedine carminum, qux delicata, venufta, culta in primis aures legentium animofque detinent canora jucunditate captos. Minimè redundans non parit fatietatems: 


\section{CELEBRIORUM AUTHORUM.}

wtí recentrores aliquot verbof longitudine puerili, ac penè intolerandâ. Dictiom nem ferpere humi, ac jacere non patitur, velut Ovidios aliquando, qui nonnulla excepfit è Tibullo, hunc tamen longè fuperavit ingenii tum acumine, cùm amplitudine, ac divite venâ, quam torrentis inftar exundantem fi cohibuiffet judicio imperfed excolente, majorem gloriam promeritus Tibullo praferendus effet. Par vero judicetur, vel major ob tot poemátia elegiacis numeris concinnata, in quibus pulchri, bonique plus eft: diffufum quàm in opere univerfo Tibulli collectum. Lacob. Gadd. in tolog. omnig. p. I4\&;. I49.

Tibullus cetera tam accuratis, tam elegans \& tam limatus in Elegiis fuis, non tamen admodum talem in fuo Mefale Penegyrico fe prabet: ufque adeö. arduum eft debicè laudace. Rapin. Refl. in Poef.par. 2. ReA. r4.

Scitus \& elegans tum in verbis, tum in numeris Tibullus: : Ced qui è Gracis; pleraque fontibus expreflcrit. Anár. Schott. 1:2.c. nz: Obferv. Human.

Commendatur editio Pafjeratii, nec minor hus Commentariis, Mureti, \& ficholiis. Iof. Scaligeri, Janique Douza.

\section{PUB. OVIDIUS NASO\%}

$\mathrm{N}$

Atione Italus, patria Sulmonenfis, nafcitur die fecundo quinquatraum; die 20. Martii, dicbus 262. ante Morten Ciceronis A. M. 3907. Ante Chrift.

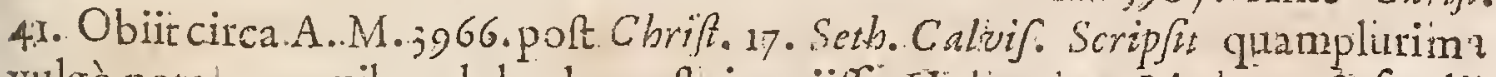
vulgò notal, ex:quibus dolendım eft, interiilfe Hulieutira. Medearn, \& fex. lï bros. Fifforum polteriores.

Inco opere, cui titulum fecit Mretarnorphofeon, fecutus eff: par bonium Cbiur Poetam, qui Græcè fcripfit preclanum Poema pari argumento \& materia fimili. Id.

Oviniz Opu in tantopretio habitum eff Gracorum ingeniis, ut illud converteriit in fuim fermonem : cttenim refertum varia atque inultiplicieruditione: quanquam ipfeautor inemendatum atque imperfectum reliquit, ut ipfe telfanur verfrculis additis. Nam ab́́cnte illo atque etiam nefciente editum ef in vul-

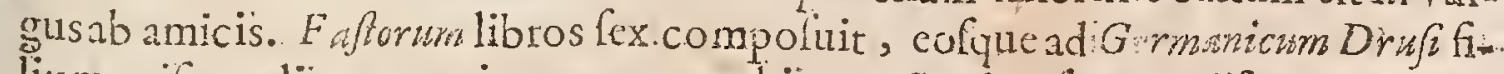
lium mift : rcliquos per importunum obitum, \& adverfam exilif fortunam ("ut" plerique putant) non potuit perficere; ipfe tamen alicubi afferit diodecim à fe. compolitos; opus quidem eruditum, \& plenum magnầ \& copiosầrerum ficintiâ. De Amoribus tres. libros f́ripfit, in quibus fub ficto: nomine: Corime maximè probavit ingenium fium Complures etiam Epiftolas, in quibus eft ufus mirâ. elegantiâ, \& artificio fungulari, ut Critici: áfEerunt.

In Elegia habitus eft paulo lafeivior, ut qui mimium quandoque indulferit in genio flio: Petr. Crivi . de Poet. Lat.

Tantafemper omnibus admirationi ovid ius fuit, ut non ingeniofus, 'fed ingenium ipfum:.ion latinus, fed ipfa latinitas : non Mufarum facerdos, fed

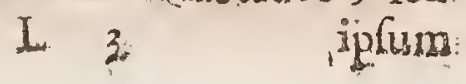

Clar: anteChrift. Anno VII. 
iphum Mufarum numen fit habitus. Quod ad liıguam latinam attinet, erudici omnes uno ore conftentur, fi funditis illa ellet amifa, unius autem Ovidif firir pta extarent, ex illis commodilimè polfc reftitu. Gifan. Apolog. pro 1oët. lat. pagin. $4^{8} 4$.

Opus ejus univerfum, ingenium potiùs refert, quàm curam. C. Barth. Ad، verfar lib.j8.9.

Lafcivus quidem in Heroicis quoque Oviàus, \& nimium amator ingenii füi: laudandus tamen iu partibus. Quintil. 1. ro.c. I. Inftit. Orator.

In carainabur non ignoravic vitia fua, fcd amavit. $M$. Ann Senec.l.z.declam. - declamat 1. Idern quinto libro Contraverfaram Battologiam Ovdio objicit. Oridius magnä in veibis novandis lic cntiâ utitur, ac neque humilia \& à plebe petita futidit; caque re nomemini vifus eft Argentex petius atati accenfondus. Gasp. sciopp. in lib o cui tit. conlultat. p. 4. I.

Oridius Roctarum ingenioffimus egtegiè illud pro mangitudine rei dixit: Ornia pontus evant: deerant qugat livor ponto; nifi tantum impetum ingeni waterix ad pucriles incptias reduxifet. $N$ at olupu inter owes fulvos o hi und $l$ ones; non eft res fatis fobria lafcivire, devorato orbe terraum. Dixitingentia (le tanta confufionis imaginem cepit, tum dixit; Expatiata ruzrs por upertos fumina campos---Prefleque labunt fiú gurgite turres. Magnificè hoc, fi Honcuravit, guid Oves \& Lupi faciant. Lo.AnnoSené.1ib. 3.cap.27. Natural. Qux?.

Jamverò ad eum pervenimus locum, in quo 2 ingenii magnitudo, \& acumen judicii exercenda funt. Quis cnim de Ovidio fatis dignè dicere poffit, neo dum ut eum audeat reprehendere? Faftorum feylus facilis, candidus: eruditio prifca \& multa: ac tametf matcrïa non Lemper admittat cultum, ingenium autem viri non fapè ; multis ramen in locis fipfo limatior atque teifrer eft. Minuslaborati libri Trifles; De Triftibus malè incribuntur: quemadmodum \& de Pentas mihilo majorecuracommendandi. Epifole omnium illius librorum politiffma. Nam \& fententix funt illuftres, "\&z facilitas compofita, \& numeri poëici. Iul.Caf.Scalig, in Hypercrit. p.854. 855 .

Uno vincitur [Manilizs] quòd noupoteft manum tollere de Tabulâ., \& (quod tam falsò quàmimmeritò, Ovidio olim) nunquam fcir defunere--.- Hoc at non mediacrevitium eft in nitido foriptore, ita puri funt ab hac labe (nima earundem wosmiteratione) principes Poetx, Wirgilius \& Ovidius. Iof. Scalig. Ploleg. Manilio

Omnes Ovidius tranfendit. Sive falfa prebabiliter, fiveobleura perfuicue. five utraque omatè, five omnia fimpliciter fint exponenda. Falfa., ut in Metamorphofi. Obfcura, ut Mathematica, \& antiquitatis atcana in $F$ afis.

Qux ad Mores pertinent, ubique. Etiam cum ludit aut lafivit. Idque ter bis \& oratione vulgari. Ut\& dicat qua velit, \& doceat qua quilque intelligat ; tam admirabili felicitate, ut cum quivis idem polfevideatur, nemo poffit: Nemo, rifi magni animi \& excitati tentare idem aufit: Sapientes etinm d:foe4cese Ubique sententie ubique loci commanes de ignavia de difciplinis 
Grevitatate forma; opum contemptu. Dan. Heinf. libr. de contitut. Tragod. Cesundum Arifoto.

Ovdii facilitas eft inimitabilis. Scaligerana 2. Poetarum Ciceronem vocat Erafmess in Ciceronianio p. 147.

Cum adeò facilis ejus dictio vidéatur, fubinde tamemos currit, ubi ob tra jçctionem verborum duinifculus videatur. VefJ.de P'oet. Lat. p. 30.

Ubique ingeniofus eft Oviaius, quod nemo unquam, nif qui, ipfe ingeniofus non effit, negavit: Ubique dóctus êt Ovidius, de quo non minus apud omnes conftat : fedhaud equidem feio an alibi doetion fat \& ingeniofior, quàm in fecundo Trifium. Neque adeo mirum elt :- callam apud Angufun agebat.

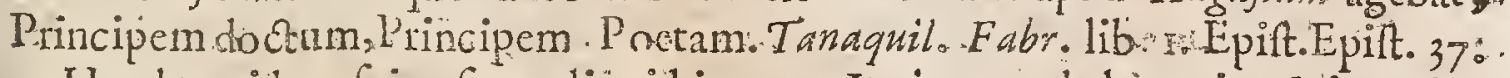

Haud equidem fcio, fitne alijuid in toto Laito, quod elegantius \& ingeniofüs fcriptum ab ullo Poëtn fucrit, quàm Elegia octava libri 2 , Ponticorum; ita.

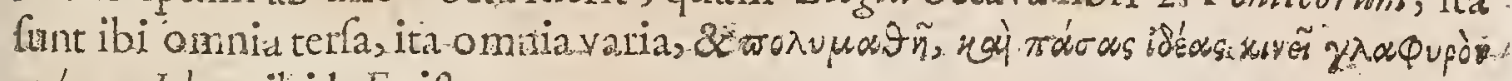

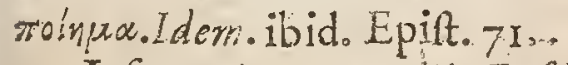

Jef. Rapinus Ovidii Faghis hane: gloniam tribuit", quod fit Opus omnium qux edidit placidifimum, quodune folidum judicium maximé prodit. Dicit infiper Poctam hunc tum de mum cum fencliceret Faftofque componeret attingew re potuiffe Prudentix ac:Moderationis perfectionem quae in hocpofita eft us: quis ea tantum dicat qure necuffriä \& convenientiä Cunt; Eum hoc tantùm lòco moderatum \&'circinnfpectum effe; Eumque alibi femper jułenilem animum exhibere. Kaprr. Comparat. Hom. \& Vingil. cap $*$ Ir:

Rapinus afferit Dvidism Propertio atque Tibullo in Elégiis anteponendüm effe, quia magis nativis seft ftylus ejus, magis movet, 80 ardentiores affectus pro dit; \&"yuiahoc paeto meliits quàm creteri Elegia Characterem expreflut. Rapin。 Reflex. in Poef. Ref. 29.

Optudum erat; ut extaret Ovidii Medea. Nam cum ingenüimejus viritale fit, ut penè modum humanz. Conditionis excedat; fi quo peccat,eapeccat, quòd $d_{2}$ magneru mo fliminum inftar, interdum redundcr. Quod fi it eo virium eff; tot

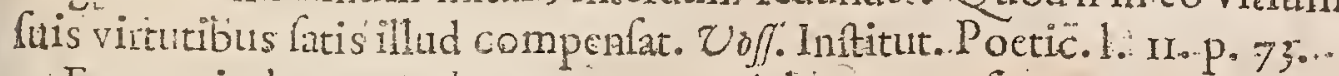

Ex omni choro Awhorum, quem unà legeremus fegtegavi Ovidium. Tor vum enim illud \& morofum Virciliane Majeftatis reveriti; incertum \& intricatum Papiniant tumoris abominati fumus. Et Horatiurs fapè fuaviter nequams. dictifque clëgantibus \& praceptis non rarò lafcivie ac intemperantix virus adł mifcentem refpuimus Quin \& ipfum preterire aufifumus Ciceronem, fubinde dum largo flumine verborum exundat, rebus \& fenfibm parcum Quidni igitur Ovidizin in manus fumerem? Ovidium dixi, imo potius Genium quendam ins.

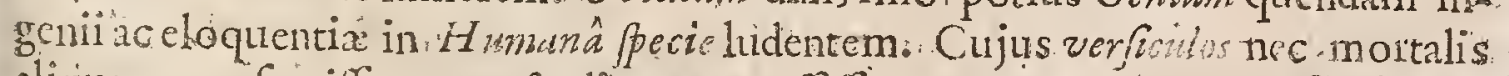
alicura cura finxiffe; nec ftudium expreffife; neque ars concinnaffe; fed $\mathrm{xe}$. natura ipfa fponte effudiffe, aut livino quxdam yhufa dictâlfe videatur. Oniditum, licteâ ubertate cloquii, facili proptîtate verborum, fincerà puritate ferz monis, fententiarum appofito lepore, utilique acumine; - xquali calore, 8 continuo fyli fpiriti cuivis conferendun; caterùg inexhauftâ. inventionis 
copiâ, candidâ fenluum perfoicuitate, lautâ fupellectile Hihoriaram : varietate ac divitiis omnigenæ doćtrinæ; \& mirificè fuavi,facili, lævi, ac rotunda compoftione camsinm cuivis longè praferendum vetermm Poetarum. Eui nihil unquam aliud vitio datum êt, quàm quod intemperancis ingenii fuerit, quódque vir amoribus alioqui nimium dedirus, fui quoque ingeniinimius amator extiterit. Laac Barrovo. Opuéc. P 120.

De Alio Vero Impcratere tradunt Hiforice Auguftefriptores, eum ufque adeò deamâfle librum ovidn de Arte Amanài, ut illum fxpiùs.in leato decubituius legerit, \& dormicurus pulvinari impolucrit.

Operum Ovidii cmendatifima eft editio, quam Nis.Heingus ad MSS.codiccs plures emaculavit \&in 3 "Tomos divifam, notifye Criticis illuftatam $\mathrm{Am}$ Aelodaritex officina Elqeoiriana Ann. 166 I. edidit: quam fecuta illa Burchardi Chippingizitidem Tamis 3. Lugd. Batav. ex Officinâ Hackina An.1670.3n. dim vilgata.

* In Ovid.Metamorph. libros commentaria, five Enarrationes Allegoricx. vei Tropologica, omino prohibcntur in Induce Tridentino; vid. Apper licern certor. Anctorum.

\section{Hoc Ovidii Epitaphium:}

Hic fitus eft Vates, quem Divini Calaris ira Augufti patriâ cedere jufjit burno.

Sepe mifer voluit patrits occumbere terris:

Sed fruftra: bunc illi fata dedere locume

Clar. paulò ante Chr.

\section{G R A T I S FAIISCUS.}

Tnegeticom fcripror Ovidi tempore vixit. Hunc auctorem primus "Actius Sannazarus è Gallits fecum attulit, \&cypis mandavit. Notis doetifimis eum illuftravit Ianus i'in An. 1645 .

Ecce antiquum Poctam Latinum Virgilio \& Ovidio Coxvaum qui celcberrimus fuit puro illo Seculo quo ampliflima Ingenia flomerunt, \& Poefis feveriffimorum ludicum cenfura obnoxia fuit, qui mediocribus elle Poetis non fonceffere. Stylus ejus ubique concifus, caftus \& foridus ett. Ejus compa ationem melius inftituere non polfum, quam fi $V$ rgtizi Gorgis requiparari polfe dixero. Idem fere Argumentum tractar, \& quanticare iplum ferè ddaquar quoad Carminum numerum. in hujufmodi comparatione noll :m videri Virgilium deprimeresui meritam exiftimationem nequtaquam doncgo: ed mens mihi tantì eft atury addebitum celebritatis gradum evehere apud eos quibus nondum innotuit quem Charactere t ibuere debeant huic Poetra qui hactenus parum tritus fuit apud nos: Noftum hoc judicium ni fallor ab is próbabitur fi opas ipfum perlegere non graventur, eujus ea eft brevitas ut diutúrnum otium ad ejus lectionem non requiratur. Ipfe Ovidins nobis hac in parte fuffagaretur. 


\section{CELEBRIORUM AUTHORUM.}

Poftrema quarri ejus libri de Ponto Elegia preclarum eft Opts in quo fingula feculi fui folertia Ingenia recenfet: Quoum nomen perennibus carminis ejus Monumentis durabilius evaft quàm li Annalibus in Capitolio aftectvandis infertum fuiffet. In hac Elegia Poetam hunc codem ordine cum Virgitio çellocat.

\section{Tityrus, antiquas for erat gui pafceret herbas: Aptague venanti Gratiss armadaret.}

Et reverà ætate frupar videtur illi fuife, ut \& argumento \& Rylo el parum siffmilem fe prabet. Et aufin afferere neminem qui acri \& Atudiofo ing nio praditus fit , ejus Melodia feu artc non delectatum ini, Et perfecti illi homines qui quodam quafi connubio binas hujufmodi dotes, tam rarò in eodem pectore fociabiles conjunxerunt dictionum ejus $\mathrm{Hc}$ trmoniâ intimè afficicntur. Cbritt. Vafe Iraf. ante Grainum de Venatione.

Due elcgantes Poeta venationis pracepta pocmate tractarune, Gratius \& $N e$ mefranus. Nemefiant ftyluscandidus, nec vulgare fonans: Gratius verò caftiga-

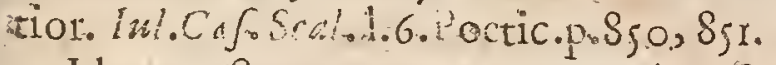

Idem trątat argumentum Grotius, \&. Nemefianus apud nos :Gracis Qppiamus: Magnus hic 1 'oeta, ficuti fapè à nobis dictum eft; quicum Grerorum nc* minem aulim comparare. Quariobrem noltros quoque duos holce ab illo puto longè Luperatos: quippe cujus unius Spiritu Virgigizunairs divinitarcm reprefentaram femper judicavi : tantum abett ut cum hujus numerisillonum verfus con* feni polfe rear. Atquc eos quidem ambos cum plebcios judicem, Grai ii puritam tem atque totunditatem, denique inventionem \& ordinem antepone. Id quod figillatim perpendenti omnia, fatis patebit. 7 der. ibid.l.5.p. 578 .

Felicifimum Latinoum feculorum facilè in Graiti poemate agnofcas, , nil chim vulgare aut ineptum ineft; o mnia codem filo gravitatem \& elegantiam fer-

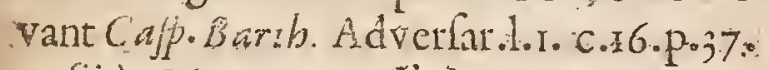

Si à Maront rectfleris, quem Gratio noftro preferre poflis Poetam toto Latio ne unquarn quidem habcbis. İem ibid.1.6.c.5.p.265.

Notamus in hoc fciptore eruditionem non ponitendam, judiciun acre,

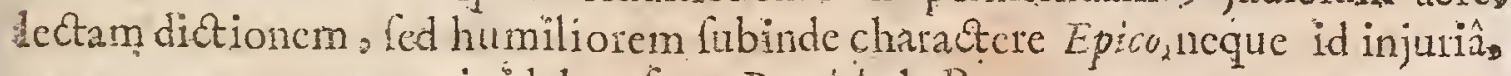
cum argumentum operis idd depofcat. Berrich.de Poet. P. 54 . lat.

Granitus anrei \& latiniffimi feculi Poeta. Ioan. Niefj.1. de ort. \& occaf. ling.

Gratium noftrum neque florentibus Romani adhue Imperit rebus magnoperc cognitum fuifle, teftari nobis abundè cum damno noftro poreft Nemefianus, quialiquot port faculis de sinatione tibrum feripturis, jactat primum fe. Romanorzm illud iter ingrdì , noun facturus fi foruifet nominis l'oetici g'oriâ tum Gratitu. Calp, B Brib. Adverfar.1.57.c.17. .

Gratzus, linculcntus Poëta, 2 in que meritò feculi felicitatem agnofcit Incomparabilis Cenfor caliger. Eruditifimum illius Poëmation, quod $C$ yegeticon unfcribit , primus ex carcere fqualoris \& fitûs vindicavit $C$, Barthius ; cuì M paffim 
paffim Pocta mullo poft Maronem inferior, cgregius \& flimmo proximus Vacest. audit : in cuocaftigata \& crudita Phafis preflaque \& Cemper fibi aqualis. To bias Magirus in Eponymolog. Critic.

Gratius Poëta cultus ac tẹllus. Derrofter.

De hoc Poetâ optimè meruit briftophorus Wafe, qui verfibus Anglicanis olegantilimè exprefic atque commentario illuftavit.

\section{J U.L.I U.S. H:Y G.I N U S.}

Elaruit Ann. Empore Odtaviani Auguft, cujus cxatliberus flouit. Scripfit librum de Dom. IV. Italicarum: comnentarios in Vhrglium: librum de Agricultura 2 . librum de Penatibus. Hodiè vero nihil H, givi habcmus, prater Foeticon Afronowic ad: M. Fabiw \& Mybologiam. Thomas Minckerus hxc edidit, commentariifque itlutravit: Anno 168 . Amifelodarni, in 8 ?

Eft hic auctor uEquidem non ita purus atque elegans, adeo ut in quibuldam patum etian Latims videri queat, ita vetus tamen, à reliquis dyginf faptis, qux quidem ad nos pervenere, non omnino abfimilis aut abhorrens, pracipue autem utilis iis, qui in bumanioribus hife ftudiis multum ac diligenter verfanwi. Ex hocenim non pawca, quze trm apud ovidium, tum aigud alios plerof que Poctas minimè hactenus, aut cerrè perperàm intellectafunt, intelligi 1 \& explicaritandem polic videntur, multaque híc plana jam atque expedita reperias. qux dudum magnos atque eruditos quoque viros variè ac miferè torferunt. Iac. Micyll. in Epif numcupatorio.

Et Augultales liberri, phadrus \& yginus etfi in hunc pofteriorem, quemadmodum \& in Afconin Pedianum, pofterioribus feculis nonnulla minus

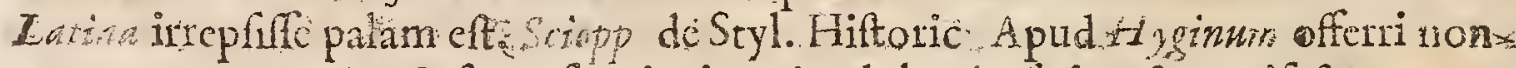
pauca parum $Z$ th $\&$ fresfequioris 2 vi redolentia faris cn manifeftum:tum frequente illum in narratione f. bularwo diffentirc à femetipfo, ac variare. Unde

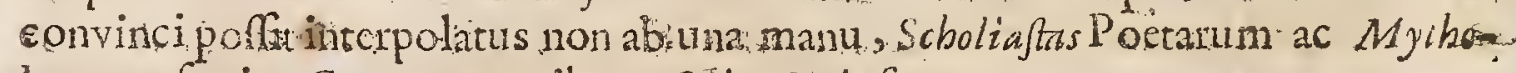
logos prefertion Grer compilante. Nic. Heinfur.

Eft fimilis fibilic fcriptor, licet minimè unitis a dotoris liber fit, fed Epitoma x y yin \& aliis contracta, $B$ er, b. 1.5.adverfar,c.2.

Hygini nomint proftatern libum ego bapjodiam ex omnibis hinc inde. Mythologorum lib is concinnatam effe arbitior. Nam apud Fulgentium inte- Tra periodi funt, qux hic extant, wifi tamenarrogans ille \&invenufus addo etiam femibarbarus \& fefquifolcecus feriptox. Hyginum potius exfcripfit. Barth. Adv. l.I. C. I2.

Qua phralis tylique facies in $H$ gein fabulis \& multa in co notanda funt ab:

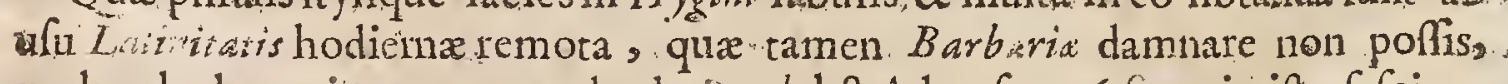
multa ob elegantiam commendanda.Barth.1.8. Adverfar.c.6. Sunt in ifto fafciculo : $A y g i n i)$, nomullasqa Metrp. 372

Jưdicition 
Judicium in Grammatico, qui fabularsm. librum capitum ducentorum feptua- gitca feptem conftipavit, \& prafixo Flygini nomine atatem mentitus eft \& auctoritatem, meritò requiramus mulcis de canfis. 1 dem ibid.c 8 .

Iuluws Hyginus.cripfit ad $M$. Fubium Quintilianum, cui familiarifimus fuit, De $M$ unde \& fphæræ ratione utile fanè Afronomicum. Pratercà de. Sugnis caleftibris opus, in quatuor libros diftinctum. Anton. Riccobonin fram.Hilt.

Nota magis 1ulli domus eft fua, quàm Hyino Cotum. Franc. Mod. Epift.9. Nivatig.lect.

Hic fabularum liber ad omnium poetaum leetionem mise necellarius. Ge nner in Bibliath.

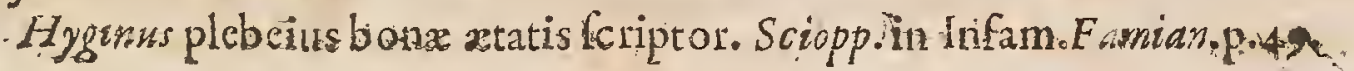

\section{T. LIVIUS.}

D) Atavinus, quarto obiit Tiberit Anno, atatis lux $>6 . q u 0$ or Ovidins de1 conit Torris. Ut de utroque Eufebizs in Chronicis t Rtatil. Scrip̧it HiftoriaClartit An xum libros 140 . is complect batur Res Ronnsas ab U. C. ufque ad ballum in $G e$ mun cunda periit $D$ cca:, \& quicquid fequcbatur libum 45. carero um nihil habemus prater argumenta, qua Epitome Liviana (fi argumntum libri 136:\& 337. excepeis contincntur, five ejus Florw, five alius eft autor.

- Eximius fekptor Livius:Patazznus, Romanx pater Fiftoria. Blond. Flavius It $a^{7}$. illuft principio.

Dilig ntifimus friptor, ad bene tum loguendum tum fercicndum in ncgo riis cum primis utilis. Lud. Viv de tradent. Dilcipl.1. s.

In Live libevas maxima, prudentia non parva, dicendicopia major, qudin diligcntiaideoque à leincipe an, tanquam verbofum is negligntem notatum fuilic crediderim. ar bron.

T. Livius Hiftoricon um princeps fuit. Scripfit Hiftoria Romana 1 40 libros artéac el'egantia tantä; prorfus ut nec xtasfuperior, neque tota pofteritas, now modò potiorem, fed neparem quidem ullum habucrit fcriptorem. Teard. Albertin Ital: defeript.

Non eft Antiquarius Livius, fatcor:fed nec omnia in co protrita , \& a face vulgi. Veturta dictionis plura haud dubièctarent veftigia, ablque correctorm

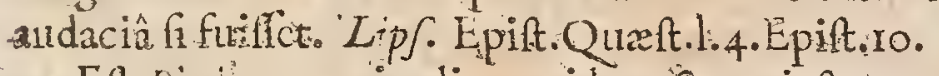

Eft Livius magnitudine quidem \& majefate opcris ante omncs. Diffufus alle \& placidus, in concionibris maximè dilertus ; \& talis o mninò, qualcm Faluius defcripfit. Patavinitas ei objecta ab Ajinio, id ett,nifi fallor, fermonis quadam peregrinitas nectam in veıbis qquam in ftylo toto. Nos quoque fupinum eum alibi, aut frigidum, imò \& Za ronó yov agnolcimus: derivatur tibenter tamen ir excriptores hanc culpam. Judiciis fententiifque bonus eft,etfi non frequens: quid refert? pro ipfo loquitur doeteque copia to cventurm \& exemplorum. Lipforor ad Poetic.l.I.c.g.

$$
\text { M Nihn }
$$


Nihilhoc fcripto eft grandius atque uberius. Defylo liem intentab tolin e A fritus folio. Patavinitotem in co animadvertere fe ai bat, ut F bius teftatur 1.8.c.I. Nimirum diclicum hominis palarum videbatur fibi aliquid fentite; quod non ufquequaque faperer genium Romeni fermonis. Atnon audiendus eft Keckermannu, quando hinc colligit, rejpehenfum áb: Afnio effe fublimem Lovii ftylum. Uti \&, cùm à Senecâ culpari putar l.I.de Irâ.c ultimo; \& de. Tranquillitate c.9. Nam longè aliua \& Fibiuris \& senecam relle, nemo diffitebiur qui verba cortum utrendut. Woff. de Hin. Lat.

Livit Patavintitem, quam guifabat pollio Afinius, nes non guttamus; fcilicet non habemus jam palatum ulque adeò cruditum, aut certè molofum. Livd: Viv. de Trad. Dilcipl:

Livius fermone illo, quem Pollio Patavinitatern dixit fapere, eloquentior fuit: multis Roma natis ; "\& fortalfis illo iplo Pollione. Idem. L. 2. De caul. Courupt: Art.

Quod fi Pollio fibifolus Romané vel loquir vel fribere vifus eft, cui Livius -let Pativinitatem, Virgilius Mantuanitatem, (iceronis dictio parum fapit, fanè fiis qua illius extait, non dixit melio : malim profecto cum hifce minus: Rcran: loqui, quàm cum illo eum ad modium, quem legimus ex fragmentis I. C. Scaliger li 4.C.I7: Poëtic.

I'bilippus Cominaus Livium vocabat Latinorum Polybinm, omnibufque fenacoribus \& reum publicarum gubernato ibus perlegendum dicebat.

Magnatibus vilis nulla eft lectio magis acconmoda quàm 'Hiforicorwm inter quos facile primas teuct T. Livins, de Latinis Loquor Erafm. 1. 28. Epiit. Is.

T. Livius non raro fecum iple diffidet in terum gefarm narratione, tantum abeftur nufquam aberret à vero. Idem in Ciceroniano p.Tog.

Lrvio non alius jucundior, etfi ad primum guftum Lubauterus fir I dem.1.28\% Epif: 8 .

Non movere debet Henricus Glareanus, vir varia cruditionis z cùm (prafátione Annotationibus in Livium pramilsâ $)$ Livi m bellicofa Gallorum gentis res gefas odio sè tradtre, vitutefque contum malignè elevare conquerimir. Quodeciart Bartibius facit Adverfariorum 1. 60. in Auguft: De Civitate Der L. I.C. G. Quàm cnim Livitus veritati Atuduerit, vel cx co conjecturam capere polfmus, quòd in defcriptione Bellicivilis, ne Augufto quidem in tantum voluerit gratificari, ut alitei res nariaret, quàm factum fciret. Voffo de Hiftor Lat.

Multi Livium improbant $x$ quod fuperfitiosè referat prodigia tam multa: ut boves.locutos; infantes femeftres. Triumplium clamafle: Qux fanè in: Gentili:

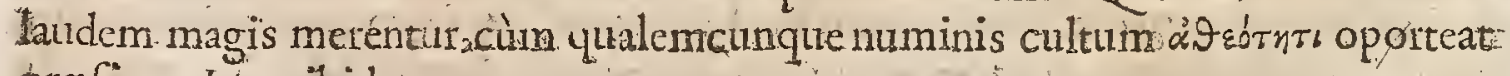
praferre. Idem ibid.

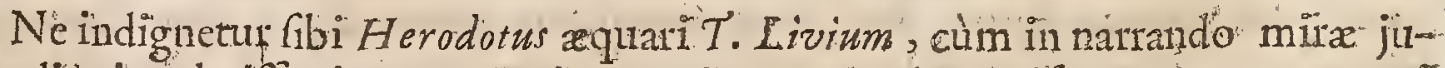
cunditatis, clarifimique candoris, tum in concionibus , fupra quam cnarrar: potef, eloquentem:ita dicuntur omuia cùm rebus, tùm peifonis accommodata. 
Eeel affectus quidem,pracipuè cos, qui funt dulciọes, ut parciffimè dicam, nemo Hiltoricorum commendavit magis. Ideoque immortalem illain salufint veloGitatem diverfis virutibus confecutus.ett. Quintil. I. IO.c I.

Magnus, Dest bone, autor T. Livius"; lacteâ quadum ubertate dictionis dí vinitus factudus, amans virtutum, ofor vitiorum, rectus judicii , retum tog rerum fagi, etfinon ex uftu,neque experientiì, egregiè tamen peritus: denique, fir quid judico hoc folum ingenum (de itforices lounor) populus Romanus par

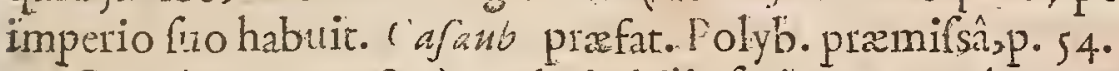

Carterù tantus \& tàm admirabilis. fcriptor, ut eloquentiâ. Polybium facile vincit, , quod ingenure fateor : ita aliis docibus à Polybio non obfcurè vincítur. $\mathrm{Nam}_{2}$ ut de libro fexto nihil dicam, \& id genus aliis Polybii digreffionibus; \& Tactica impcritiam selt, ubi deprehendas, , quod noftri commenturii Pólybiani docent : \& in cantis reitum affignandis, à fincero noltrijudicio, pra nithia fuperfititione non rarò deffectens, aniles ineptias folidis rationibus, \& certis illius demonftationibus ante ponit. 1la quoque tam frequens \& tam accurata portentorum enumcratio, annon eundem hunc animi illius morbum palam facit? Ut non abhorreat à veri fide, quod memorix proditum eft à nonnullis, Gregorium Magnum Pontificem Religionis Chriftiane propagande ftudiofiffmum, hae tanti Crriproris ridiculâ fupertîtione offenfum, ex omnibus Bibliothecis ejus Hiitorias curaffe tollendas. I dem ibid.

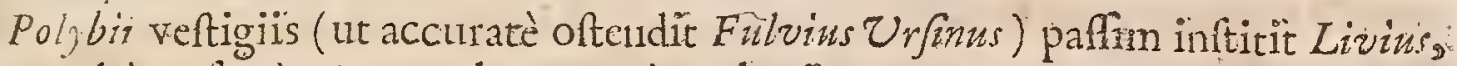
ufque adeo ut lapè ctian verbum penè verbo interpretetur. Iofj. Inftitut. Orator. I.I.P. 39.

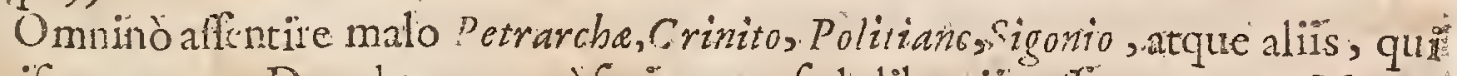
divifioncm cam Decadum, non àfcriptore, fed librariis effe, putant. Movet verò me illud, quod etinm iftos movit: nempe quòd C'enforinzos, Diomedës: ac. veterum alii, rilniquam Decadum, fed Cemper librorum meminere oroff. de arte Hit.c. 25 .

Neque partitiones. Decadum ab ipfor Livio funt,quod Profefforem Humanitatis ignorarc non decebat; antiqui enim Grammatzci non. Decades fed Libros agnolcunt. Laurent Pignor in Sym. Epiftol. Epift. 44 .

In Decades faftidiofam lcgentium ignaviam Liviicentum \& quadiaginta 1 . - Gros difpefcuiffe verofimile eft. Act. Erudit.Cal. Mart. An.1683.

Rufius Avienus, Servio tcfte, Livium carmine cxpreffit Iambico.

Elegans eft editio illh quz cum perpetuis. Ioan. Fried. Gronovii \& Variorum: motis in 3. Tomos divifa, Ainftelodam apud Ludvicum \& Danielem Elzevirios: an $8{ }^{\circ}$. Annis 1664 . \& 65.excufa fuit. Praferenda verò eft illa edirio, quix curm: notis Ioan. Doujatii prodiit, juffu C'briffianiflurit Regis, in ufum Delphini. Tomis: quinque, Parif. I679, 1680, \& 1681. in 4:

Hoc T. Livii Hiftorici Epitaphium in Palazio Patavino fub veteri Statua.:

Offa tmumque caput cives tibi , maxime Livis. 


\section{Prompto animo bic omnes compofuere twio. Iu famam aternam Rowas., patrieque dedift: \\ Huic oriens, illi fortia fact a canens. At tibi dat putria hac; ; so fuajora licerets Hoc toins. Jtares Aureus ipse loco.}

Armo Ceculi hujus decimo quiinto Bamberga, Hectore Cotzavio, Imperiáalis Ecclefia Decanc, Bibliothecan Public am recognolcente ac tiansferente, invertas

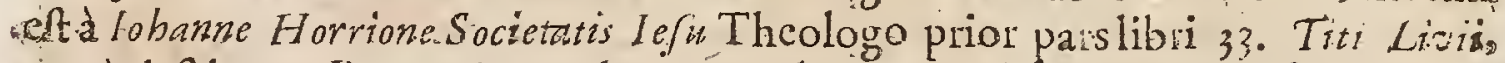
santeà defiderata. P'ratereà mombranam palmul x, quâ pila luditur, à fphrrifterii Magittro injunctam, deperditorum quippiam Livn continentem, $f$ vidiffe Dowjatzonarravit iobarnes Capellanus, vircel berïmus. In Regis etiam ijpariam rum Scoriale ẩ libliethecâ andum in vulgus editos quafdam Livit libros ha-

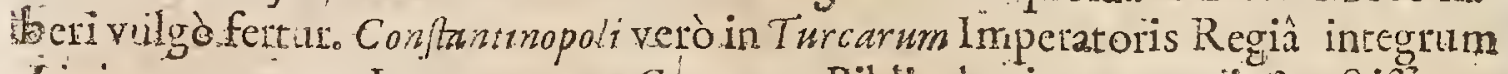
Livinm cxtare. ex Imperaterum Grecorum Bibliothecis, quas inftuctifims

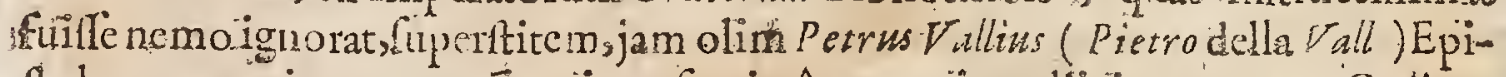
ftolarum exoticarum partîs piime feptimâ narravit : adjiciens, eum Codicem quinque millibus De catonis Magnum Hetruria Ducem aliquando redimere vo-

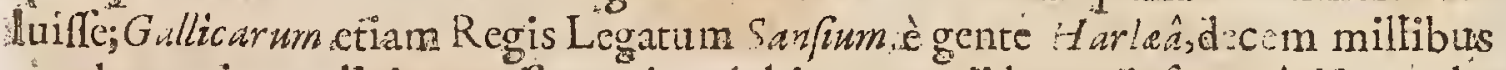
eundem nnimose. licitum effe, ac citra dubium grandi hac zrìs fummâ iftum ob-

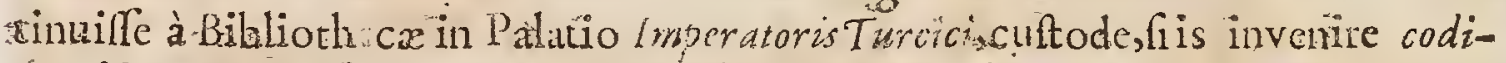
cer iftum patuifict, gucm disjectum ferebat, cùm cxhibere fibi eundem Legatus scuperct. Quo ipfo tamen vanitas narrationis hujus manifefta \& fides fubletta reddituk. Ut adeo qux nuper modo percrebuit fama de Livio integro, à $B$ aifja quodam Regi Gallice pro immensâ vi auti quàm poftulaverat oblato . eodem loco habenda Git. Act. Erudit. An. 168.3. Calend. Mart.

\section{$S T R A B$ O.}

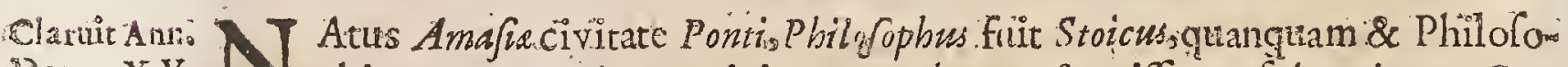
Dom. XV. graphia libri quos Tiberio Ca Jare rerum potiente confrripfit, etiamnum hodie extant. Scripfit \& alios, ac inter cos,commentarios hiftoricos utiles ad moralem ac civilem Thilofophiam: fesi ad nos non peivencrunt. Obiit circa annum. 12* Imperii Tiberii, extremx fenectutis. Hofinan.

Strabo wir profecto maximus. Extant ejus 17. Geograpbia libri; quos non unầ de causầ maximi facere opertct. Fuit enīim egregius l'hilofophus. Alterum etian eft, quod labores strabonis maximopere nobis commendat: fiquidem priorum Geographorum nemo plus terrarum luttravit. Geographiam fuam frribebat An. U. C. 77.1. quarto anno Imperii Tiberii Cefaris. Volf. de Hilft.Grac. 1.n.c.6.

Exhis apparet, quanto judicio ufus fit Strabo in Hiftoricis iftis:longè aliter ac

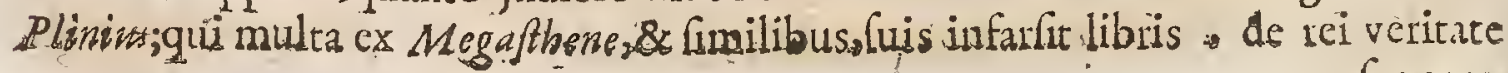
fecuruse 
propriè Spectant, quæ ad Regionis frum, longitudinem \& latitudinem pertinent peccat crò Strabo in hoc calu. in defcriptione Germanix multos errores commifit. Herman. Conring. in The faur. Rerump. Vol.r.p.27.

strabo Ama fenus Princeps Geographorwis, quem fruftrà contur de fui oper is poffeflone dejicere Franc. Patricius l.in 3.Peripatetic.Difcusfon.ut cuidam Stratorit tribuat. Caftigandus autem videtur Strabo, quòd fiftorias, $8 \mathrm{r}$ Phlofophicas Dilputationes Geographic milcuerit. Cardinal. Ioan. Bona.

* Ifacit afauboni in Strabonezy Commentarii, permittuntur cum expurgationibus. Vid. Indic. Madrit.cdit. Am. I667.

Extant Geographixlibri 17. Gracection verfone Guil. Xylandri oblervationibus /aac Casauboni \& Friderici Morelli. Lutria Pariforum An. I620 Typis Regiis in fol.

\section{P I E D.R U.S.}

Clar. Anno Dom. XX.

Trax Anguftilibertes, tempore Tiberi, claruit. Reliquit s. dibros Fabu larum e Efopicaruriverlibus Iambicis confriptos.

Dehoc lib llo idem egotecum \& cuin polititumo viro lacobo Bongar fo fen-

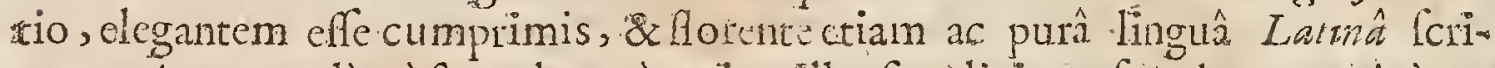
ptum: ( qux paulò pèf multum à nativa illa frmplicitate fua degeneravit) ac fupparem effe judico hunc pedrum Laberio, ac Publio Syr. Mimotraphis: abundare quoque optimis 8 ad vitam utilifinis fententils. Tantum vellem in numeris ac legibus caminis Tanbici palò accuratior fuifets in quibus "palam eft, eum fatis negligentem effe, ne dicam dilfolutum. Sed Corricorwm ille fortalfc hac in re licentiam imitari voluit, nihilque circa numeres penfi habuit, dum purè atque emendatè loqueretur: in quo ftudio nemini facilè ccdit. Hoc quoque nor fine judicio fecifé exiftimandus eft; quòd ad Fabularw deforiptionem rambu potifimum adhibere voluit: Hoc enim metri genus quam mininè à quotidiano \& naturali fermone recedit : adeoque ipfa $N$ isura. ( fi Arifloteli

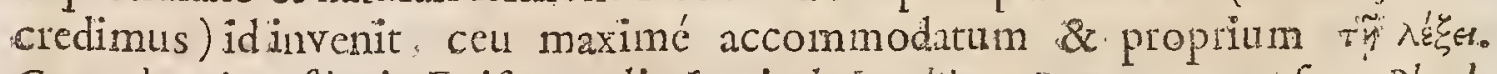
Conrad. Ritterfius in Epin. pradiminari ad Ioabion. Camerar. prafix. Phed. Fab.166\%。

De dicendigenere fi roges, quid fentiam, dicam equidem, \& quafi me Cenfor rogaret, cxanimi fententia; Neminem abitior à felici illa Tere tit fum plicitate propiùs abeffe-Nemo è veteribus ingenio firifle videtur ad illam Termit fempellenitutem magis facto, quàm budrus quod se necffe fuerat, ea en im eft Apologorum, atque adè Fabellarwo omnin natura, ut fermone non debeant, nifi facili placidoque tractari. 'Tanaquil. $F$ we. in Not. ad phadr.

T-bedrus fuavifimus ille Fabularor, \& urbuniortm hominum delicitum. Tan. Fab.1. r. Epint.Epint. 49 .

Phadrus Scriptor meo judicio politifimus. Cafanb. in Epift. 9.9. ad Petro pitberm. 
De Pbedri Fübulis ita judicant doctorum ple rique, effe ingenuz Latinitatis, areque mentirixvun Tiberit. In querum ego prorsùs opinione fum, licèr unam a alteram fubdititiam \& infititiam effe jain olin notarim. Gafp. Barth. Adver\{ar. $1.3 G . c .2 \%$.

Ingenuas Phadri fabulas à primâ pucritiâ in deliciis habui , \& immortali amore prudentiam in tam luavibus verbis \& fabulis abditam, dignam elle qu’h neget? Ldem ibid.1. lo.30.c. 22.

Phedrum \& Hyinum velut degantix minùs Atudiofos plebeia plufculur ufurpalfie apparet. G'a $p_{0}$ Sciopp. Confiultat. p 4 i.

Scripfit has far ellas ftylo longè optimo ac latinifrimo, ut plcrique dosti tradi" derunt. Nam quòd Schoppines in eo nefcio quid Barburi ac Thracici fubodorasur, id planè elt ejufmodi, quale ejus, qui in Tito Livio deprehendit Patavinitatern. Itaque hucufquenemini ex doctioribus flam approbare potuit fentent tiam, nec credo unquam approbabit. Ioan. Schoffer in Vit Pbedri.

Antigatitas nihil Fabulis ipfis elegantius habet. Eruditor. Diar. Gallic. 2. Febi. 1665.

Dictio ejus pura elt, \& emendata, nec indigna quam imitcntur lingux Latina candidati. Borrich. de l'oet. p. 56.

At verò Phedrmnofer illis (Plaw o \& Terentio) caftigatior eft, \& aditriEtior, fed ita tamen:, ut honeftâ quadam interdum libertate utatu1. Quod à nobis eâ gratiâ dicitur, ac quis omina cjus Carminàad mol. ftam illins purioris Iarbbici diligcntiam poftulet revecail. Nam qüuod fufpicatur $S$-boppins ignorâfe $\mathrm{Ph}$ arum leges metricas, cui, quafo,perfuaferit ? Eadem operâ P. Syrum, eadeng operâ Plawtum, Terentium, veterefque alios accufet, \& Virgilium iplum, fi Diis

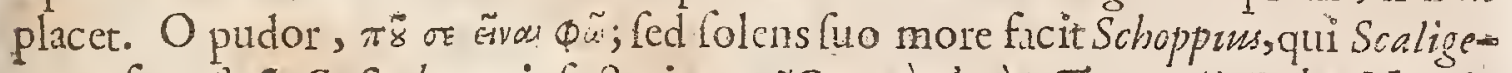

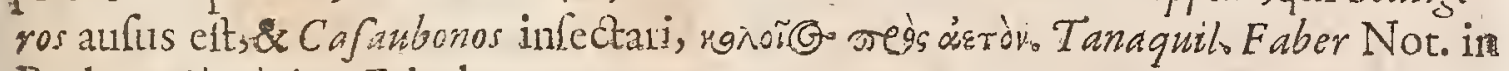
Prolog. Phed.l.a. Fabul.

Pbadrus Augufit vel Tiberii libertus gente Thrax, Efop: fabulas Latinis Verficulis defcripftadeò nitidis \& limatis, ut nil Romanius dici fcribique poffit. Dan. Georg. Mcrhof.de Patavin. Livian p. Is S.

Vavafjor de Ludicrấ Dictione p.206. Phedri dictionem ab omni peregrinitate \&infolentiân rcmotam judicat, naratque accepiffe fe à lacobo Sirmundo, cùm Petrus Pitbaus primùm mififlet Row dizh hos libros Lutetie editos, Romanos ut emunctxartis homines novitate voluminis percuffos non dubitaffe, quin atatem redolcret Auguffi, ac fummam illar facilitatem ftyli \& Scriptura repra fentaret. Id autem miraturV Vuvafjor, quî factum; quèd Seneca Afopios logos intentatum Romanis ingchilis opus dixerit, cum Phadrum hunc haberet, quem opponere poflit toti Gracra.

Editiones multx circumfenuntur;laudatior Rigaltii, Pithai, Schefferi, Tanam guilli Fabri, Holftii cum notis Freinshemii : Laudatifima verò ac emendatiffina of editio MarquardiGudit. 


\section{A N N S U S S E N E C A}

Clar. Anno P Hetor \& Declamator, Augufi \& Tiberii setate floruit. Idem tres filio: Dom.XX. I egregios reliquit, Lucium Annaum Senecam l bilofophum, M. Annaurn $N o$ vatum, alias funinu Gallionern dicum, \& $M$. Annem Melam, Iu ani poetæ patrem. Nobis ex fin evi Declametoribus excerptadedit, idque ftylo puro \& cleganti, nec minori acunnine judicií, quo egrcgiè ufus eft in ingeniis, dictifque corum, cenfendis, ex quibus laudabiliailta, fedula inftar apis, delibavit. Voff. de Rhetor.nutur.p. 106, 107:

Intẹ. Declamatores Ma.Seneca Rhetor infignis familiam ducit, five Suaforias ab optimis dicendi magiftris traetatas, five controverfias memoriâ reconditas. depromat. De cujus feriptoris Atylo ica judicarenon dubitem; nihil cfe in lingua I atri $\hat{a}_{\text {, }}$ cùm à Cicerone Fabioque dif́celleris, lcriptum purius aut elégantius. Judicium verò,quod femperifuit, eritque perpaucorum hominum, \& acumen in aliorum iingeniis dictifįue cenfendis, fummum ac proprium illius. Diffentio jgitur àviro do to, quìncmoriânorträ Senecam hunc Rbetorem levitcr doctum, ac quafi prolctarium appellat. Ana'r. Schott. de M. Senec. Declarnand. ratoprafix. oper. M. Ann. senec.

Ex deccmrontroverfarum libriš, quos vulgârat: Ann. Seneca, quinque vix fun perfunt: iique adeo mutili \& courupti, ut fragmentorum: potius congeriei, quàm alicujus integri corporis fpeciem referant. Graca cnim omnia quze notabilem operis partem efficičbant, penitus interciderunt. Latina verò manca, confufa, pe turbata, \& ubique tàm malè habitafunt, ut fi iple auctor rediret, fua clfe ejurarcr. Nir. Eat. prefat. ad M.Ann. Senec. libr.

Senecarn Rbetorem licebitcvolvere, à quo multum adjuvabitur verborum, \& propriorum \&e tranflatorumvi,tum copiâ \& veritate :ut rem candem crebrò \& The faftidio poffut exponere: multumque alere poteft facundiam Latinam, Metaphori potillimum, pre, cxteris S.ripioribus, dextrè accommoditis. Lud.Viv.l.jo... de Tradend. Di icipli

Lucius Ann. Seneca Pbilofophus patrem habuit nomine \& cognomine codem. Is domo Corduba fuit, profeffione Rbetor. Natus ante bcllum civile Cafarianur, fupcryixit ad Claudii circiter prificipatum:finc honoribus, \& non aliud quam Prozincialis Eques. Is jam fencx non dubie filiis fuis fcripfit, aut: dictavit. potius,illos, qui fuperfunt, controverfiarum \& fuaforiarum libros.. Sed ut in Plauifabula, iner duos Menachnos, fic inter duos. Senecas confufione-nominum ortus error. Tributa illi qux hujus crant : \& claritate nimiâ Fi ïi oblcurus. pater hodièimò ignotus. Memoüiam boni fenss fugitivam (impunè hoc dixerim ) primus retraham ego Ejus, inquam, Seneca hi Libri. Doceo ex atate, qux: pats convenit, difconvenit proli. Docco ex inforiptione qux in omnibus libiis, atiam fcriptis, concipitur: L. Ann. Senece ad Senecam. Novatun , is Melam fulios. vid. inft. Lips l.r.c.r. Elect:

M. Anmens Senequ Rhetor feu Declimator a Pater Philofophi ; extant non ipfius. 
ablus fed alien ab eo digeftr Declamationes : quas præloquis aut interloquiis diftinxit: $\$$ vel fic come atque amcenum ingenium fum fatis oftendit. Lipfins in vitâ Seneca.

Utile illud ad eloquentiam fcriptum eft; 8 quod in uno velut corpore pra ifert, tot membra vetciun oratolum. I 3 mipit. 4 . Cent. 4 . Mifcel,

Unicè me in Filio Sapientia delectat: in atrecomitas, lepos \& facundia quædam fimplex. Idern Epir.45.Cent.I.Milcel.

Opera M. Annai Seneca Khetoris prodicrunt cum integris $\mathrm{N}$ icolai Fabri, Andr. Schotti, Iob. Fred. Gronovii, \& felectis Jariorum Commentailis illuftata,

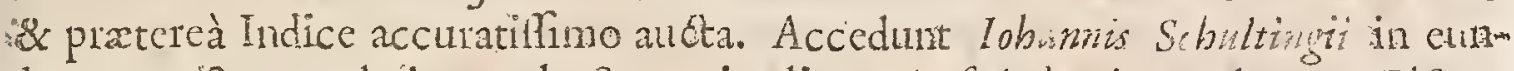
dem notx \&emendationes, hactenus inedita. Amfielodami, apud Dan. Elgevzrimm, An. 1672. in s?.

\section{Annai Seneca Epitaphium:}

Cura, labor, meriturn, Sumpti pro munere bonores.

Ite, alias pofithac follicitatc animaso

Me procul dizobis Deus evocat. Ilicet actis

Rebus terrenis hopitaterrawale.

Corpusavara tarnen follennibus accipe Saxis

Namgue arimam calo reddirnus, ofla tibi.

Pbil.Lab6. Thefam. Epitaph.

\section{VAIER I U S M A X I M U S.}

TT Empore Tiberii imperatoris claruit. Dictorum Factorumgue Memorabilium Iibros novem reliquit. Quidam ei libellum de Prenominibus quoque tri-

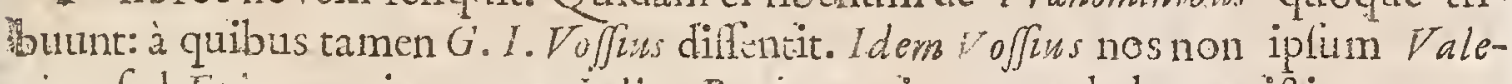
rivmsed Epitomen cjus quam Iulius $P$ aris concinnaverat, habcre exiftimat.

Stylus vix fapit tam bonum .evun:[ententias quoque nimitim affectat. Voff.de Hift. Lat.

Tam fimilis eft ficeroni, quàm tnulus homini, adco ut vix credas vel Italum fuifle, quilcriplit, vel hoc xtatis, quod pre fe fert, vixiffetam diverfum eft to tum dictionis genus: Afrum quempiam efle dicas, nec ullum carmen elabora; tiits. Erafino in C'iceronian. p. I 4 .

Vulerius Maximus, rerum varietate, eloquentix fpiritu, ac nervis incomparabilis, folû adulationis foeditate vilefcens. Bonif a 1 ig. ludic. Hilt.c. S.

Valerius kis ximus rerum varictate confpicus, in plerifque acutus, $\&$ fubtiis, in plerifque durus, \& abjectus, labe quoque adulationis vilefcens. Ioan. Cardin. lion.

M. Valerius $M$ aximus novem libros reliquit exemplorum, qux ex plerifque Hifrorits contulit in proprios locos. Sed \& ex omnibus elicit, quifepè inter fefe

Clar. Aning Dom.XXYI:

$$
\text { N } 2^{\text {varii }}
$$




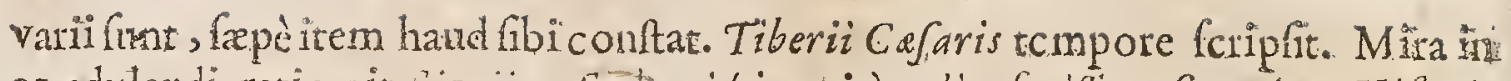
co adulandi ratio, ait Sigonitus; Sea qui (inquit)meliusfeciffet, finomina Hiftoricorum unde ille decerpfit, addidiffet. Poffertn. Apparat. Sac.

In pretio habentur Valerit Maximi libri noven Dictorum Factorumque Mesnorabilizm, qux ex praftantifimis utrinfque linguxe Auctoribus admirandâ induftriâ collegit, \& lingula ad certa capira virtutum \& vitionm revocavit, gravilimilque jententivi illuftravit c'onrad. Rittersh. Epift.ad cent.j.Meditat. Hilt. Carrierar.

Sententias habet initio \& fine cujufque capitis, fortaffis concinniores quà interdum deceret gravitatem exemplorum. Lud.T. vo de Tradend. Difcipl.

Valerins Maximus author propriè non eft Operws illius quod fub ejus now mine jampridem circumfertur. Certum eft jam Tib rii temporibus illuftem hunc Romanum, xquè infignem Patriciat ftirpe, enuditione ac militaribus geltis. quibus clarebat, in pluies libros congeffife magnum numerum Excmplosum feu memorabilium Geforum cùn Gracorurn tum Romanorum virorum: Veùm quia id cum magna prolixitate fecetat 2 Opus illud quamvis alioquicum: - fata faculi illius elegantia \& concinnitate confciptum, primo intuitu seglectam fuit penitulque interiffet non minus quam Hiftorix Trogi plureque Titi Livii Decades, nifi Africanus quidam $N$ epotianus, non verò quidam Iulizs P aris quod levioni fundamento nixus putavit Voffus illius Epitomen fub primi ejus Authoris nomine nobis. fupertitem, confeciffet: Quandoquidem hic Scriptor cum $V_{a} /$ erii Maximinec conditione nec dotibus gauderet \& verofmillimètrecentis aut circiter annis pof ipfum vixerit, rebus neque magnificentia neque elegantia Characterem quo fcriptæ fuerant, confervare nefcivĭ, multo minus de iifdem loquiftylo.illo elimato freculi Tiberii, quod ab illo Auguti: non Catis diftabar ut ab eodem valde differret. Erudit. Diar. Gallic. die Lun. 29. Jan. 1680 .

Valerius Max. ut Eg yptus Homerica, bonis \& malis mixtus ef: in plerifque enim eft acutus \& fubtilis, quod maximè vult videri;in plerifque durus, fubw oblcurus \& ad pl bcium fermonem abjectus, à puritate \& candore latini fermo nis longius dilcedit. Ext tamen in eo jucunchat thiforiarum quafi florum congefta varietas, \& brevitas narrationum, acuminibus fententiarum, non larò tam: aptè afperfa, utnibil videatur amonius.5. anjen lib. In!.de eloq. cap.I 4.

Valevizs Max. Hiftoricus, ineptus affectator fententiarum, quanquam non. inutilis propter exempla. Iofeph. Scalig. comment. in Catalectas.p.248.

Quovis $f$ damante durior, quovis in orationis ftucturâ faxeto alperior. Fr. Floridus.

Valerius Maximus invocat,ut Poetæ foleut, quodab Hiftoriâ alienum. Cland. Verder. in Autor. Cenl.

Valerii Maximi Exemplorum Memorabilium libros novem, Interpretatio ne \& Notis illuftravit Petrus lofephus Cantcl è Societ. yefu, julfu Chriftiam. Adifimi Regis in ufum Delphini in $4^{\circ}$. Parifis apud Viduam Thibout of $P$ e trum Efcladian. $167 \%$ 


\section{CELEBRIORUM AUTHORIIM. \\ C. VELLEIUS \& A TERCULUS.}

T Iforicus Romanus, imperante Tiberio floruit, Gente Neopolitanus. ExaraII vit duos Hiftoric libros à M. Vinteium confulem. Librorum Velleii bona Clas. A. D\% $\mathrm{XXVIL}$ pars deperiit.

Mco fanè judicio, nulli fccundus elt Velleius inter Latinos: tam eft caftus ae nitidus in diccndo, mirâ fyli jucunditate ac clariffimo candore præditus. Beat. Rbenan. in prolegom.ad Velle $i$

Vellei, Elcgantifimi fcriptotis, pauca admodim fuperfunt: atque eorum honorem fódâ adulatione in fui ævi rebus non leviter obfufcavit.VofJ. de Art. Hiftoric.c.32. Libronm Vell ii bona pars deperiit. Dittio ejus planè Romana atque elegans. Quædam etiam habet, qua haudalibi invenias. Sed in fui ævi rebus. nimis domui Augufte \& sejano adulatur. Idem de Hiftor. Lat.

Ut dicendigenus, quo nihil purius ac luavius Ruere potef, omittam; Antiquitater Romanornm ab ultimo principio tantâ brevitate ac perfpicuitate (fiquidem: integer extaret)comprehondit,ut nemini (ecundus effe vidcatur. Laudes etiam il to luftrium virorum cogregiâ quadam oratione, \& magno viro dignâ commendare folet,ut videre eft in laudibus Pornpeii, Cafarts . Ciceronis. Loan. Bodin. Method. Hif..c. 4 .

Extant libclli hiduo,nec toti, probi \& fidi,donec ad Cefarum res venids, ubi haud ufquequaquc veri. Per adulationem cnim multa celat,aut velat : imò \& palam alitcr narrat. Difcri camen ubique \& eloquentia quadam facili ac proy Aucute. 13.fF. Lipj.inproleg.ad Vell.

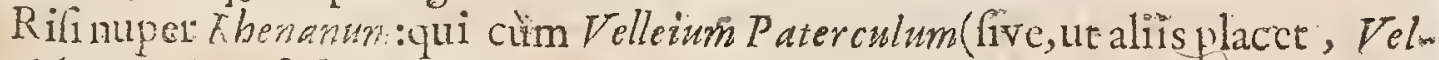
lium ). laudandum fufecpiflet;aut parem eum Cafori, aut certè proximo loco paHendum affirmat. Non pareo vero huic defignatori. Et næillc Vellcius in HiAtoricorum ordinc tantum abeft à Secundo, quantum Ca ar à prims. Melius Quintuliunu, qui in hiftorix Romana Catalogo hunc ne nominat quidem. Lips. 1. 3.; Epiftolic.Quxet.Fp.8.

Eft \& Velleizs P'aterculur, quí fub Tiberio floruit, infignis \& cloquens, cujus libcllus \& Epiphonemata habet praclara \& ingeniosc prolata. Sed \& hic Conales nor. fompcr enumerat, nce annos diftingut: certus igitur. $D u x$ hic nobis effe non:

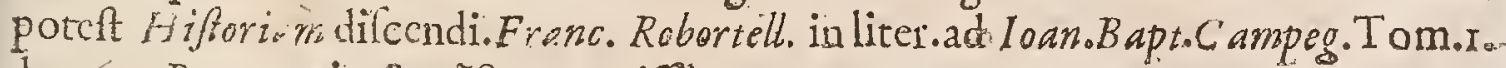
de póp Roman. vit. \& viot. præmiffis.

Heraque imò omnia placent, quodres îfx dignire fint, neque à melioribus confribantur. Tenuis alioqui verbis, neque fatis accuratus. Adulationis, fupra quamcredi potent, vitio laboravit; pralertim cum Augufi \& Tiberii Cafaris: geftanarravit. Sar. sigon. de Hith. Roman.

Vellens Paterculus tautum Prxconem Romani nonniris agit, uc co folo fine fcripfiffe videri poffit. Cap. Barsh. in Adverfar.p. 2878 .

Unum adhuc notatu digniffimum in ejus Atylo reperio. Quod fcilicetin ompihus quibus utitur Orationis figuris, Epiphomena cum tanta venultate adhibeats ut ipfinemo.fortaflis hac in parte fuerit unquam aqualis-Millo Critiorum

$$
\text { N 3. ancipiti }
$$


ancipiti judicio, conftanter tenesidum eft,circa genuinum Authoris hujus texsum, quòd exceptis errotibus iis qui poriùs à Scribis quàm ab ipfo, \& ab Apographis quàn ab Autographo Huxerunt, nihil in tota Larinitate purius nobis Cuppetat, nec dignius Auguffi Tiberique temporibus. Motbaus'le Vaver. Gall.

C. Vell. Patercuius, cxplicator veteris Hiftorialuculentus \& preflus $\&$ efficax. Ald. Manut. in Schotiis Grust edito adjeltis.

Compendium Vellejanmir laudabile fuit, Ced potior pars petiit; judicio \& ordinetamen feriptum:\& quod exemplar pleniovi Chronologix fit ad imitan dum. Lipjus Cent. III. Milcell. Epift. 6r.

C.Velleius Paterculus, vi: nobilis, cquiquc ficuti \& ejus Frater, primo anno Imperii Tiberiz fuit definatus Protor, cum \& alia munera in Kepublicâ obienit Jacebat fermè Cepultus uque ad Patrum nofrotum memoriam, cum ex Murbacenfỉ Bibliothecâ eft in lucem ed̆itus : quem denique Iuftus Lip, ins animadverGonibus illuftavit. Mutilus autem ch libellus hic, fed in quo diftineta antigue latmitatis lumina centuntur, ac ftydus preffus, fluens, idemque dilucidus:quamwis non defrt, cuivideatur cffe tenuis alioqui verbis, \& ordine non fatis accuram tus, vitio certè adulationis laborans dum Anguft \& Tiberii Cafaris getta commemorat. Ant. Poffevin. Biblioth. Select.

Extant C.Velleii Paterculilibri Hiftoriarum Romanarum due cum variorum motis exreccufione Antonii Thy fir J.C.Lugd.Bat.ex officinâ Haviancin 8:.1668.

\section{PH I L O.}

Clar. Anno Dem XL。

Rete Iudeus, Gente Alexdndrinus, familiầ Sacerdos, Schelâ Platonicus, Anno Cbr. 40. Princeps legationis Iudaice Roman ad Calizulam miflus eft; cum fecunda vice veniffec ad Clauditum, cum Peiro Apoftolo fermonem habuit, ejufque coluit amicitiam, tefte tum Hieronymo tum Photio. Subdit Photius, quâautoritate duAus non liquet, Pbilonem Chrifitanis ctiam facris initiatum, ab iis tandem defciville. Guil. Cuve in Chartoph. Ecclefian.

Phrlo vir à plurimis non modè nofrorum, verum etiam Gentilin in pretio 1abitus. - In divinis verò \& patriis diciplinis quantopcrè claboravit, res ipla declarat. Adhæc in Philofophiâ \& humanioribus lite is quantus fuerit, nihil atcinct dicere:quippè cùm in Platonicá \& Pythogorín Philofophia, quam pixcipuè fectatus eft, omnes fui temporis fuperafe memorctur. Eus.6.1.2. Filf. Ecclel $c$.interpret. Henr. Valef.

Philo verbis copiofus, fententiis locuples, 8 in divinis Scripturis explican-

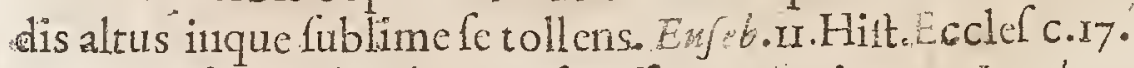

Acutiflimus fimul ac difertiflimus scriptor Lambec. I. prodrom. Hift. 1i. 6 .

Scripfit de Virâ Mojss, vir fecretioris Philofophix peritifimus, ex genere

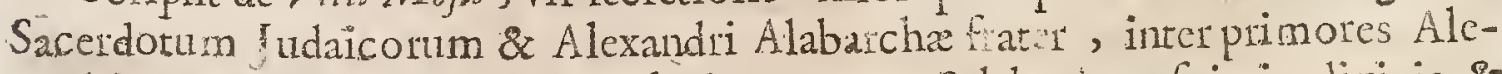
sandrinos meirò numerandus : plurimum cura \& laboris pofuit in divinis \& parris Inticutis percipiendis, itemque in Philofophicis \& extenze literatura diciplinis. 
imperitifinus. Atque adcò, ut timunculi Chriftianorum, nedum Indeormm; polfunt enm in paltes vocare. Tu miraberis, ego non miror. Ejulmodi crin cuant Alexandrini Indar \& reliqui 'Exyvisou: quo nomine diftinguebantur in Iudwis Hebraiftis, qui Biblia in Syagogis Hebratce \& baldaice legtbant. Itti verd Alexandrini, Graci tantum legebanr ea, qux hodiè extant, \& qui iple Plisto \& reliqui Indai fabulantur à 70 . Indais Hierofolymitanis juffu 'F tolomai verfa. Lof: Scalg. in Epift. 13. Gilló. Seguino.

Plerique veterum confuerunt, librum illum; qui in Bibfins Salomoni infcribitur Liber sapicnite, fcriptum effe à Philone; afcribi autem Salononi, ut libro conciliateturautoritas. Sed de hac re fic cenfet Vo/sus: Quicultus (de veneratio-

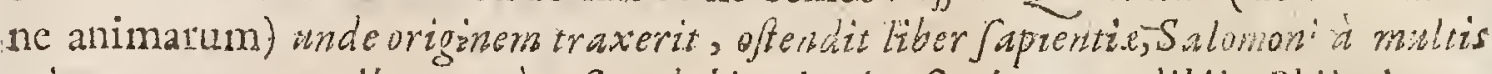

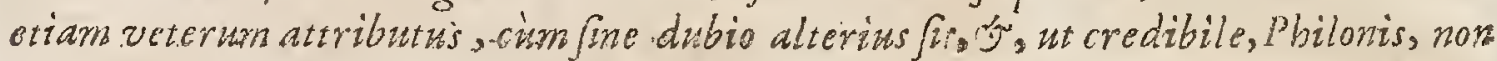

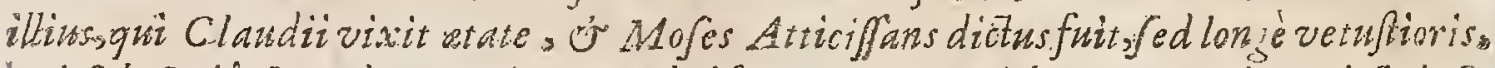
qui fub Oniâ facendote, amis ante Chrifmm 160. totpulchras fententias vel foripferit, vel congefferit. Vofl. 1. x.Idololat.c.s.

Infepbus \& T2bilo poít facrats literas de Indaicis xcbus optimè fcriplerunt. Marin. Ruar. 1. Cent.Epilt.p.gS.

Pbilo Platoni quam maxime par \& aliquando prio: $C_{*}$ arthius lib. Ix. cap.21. Adverfar.

Platonis amulius, magnus imprimis vir.Iof.Scalig.in conjectan. ad Verr.p. 72.

Philo eloqucntiâ Flatonis amulus, Thilofophus Practicus exquilite doatiniz, recti judicii, quotiens Allegorïs non immergitur; eâ enim Philofophì intenperantius \& audaciusutitur. Inter editiones preftat Parifienfis Graco-Latina 5640. Fol.Boecler.de Scriptor.pag. 52. feq.

\section{POM PONIUS MELA.}

Aar. Anno Wom. XI.V.

Eographus, cujus extat liber De futu. Orbis, Natione Hifpanus fuit, Clats*
diigue Imperatoris ternpoibus Aloruit.

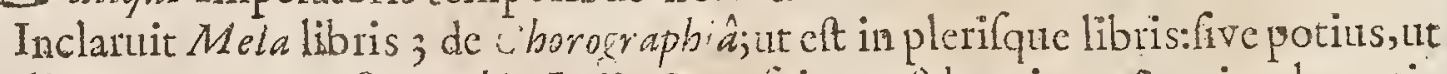
in aliis vocantur, De fitu Orbis. In iis, \& perficua elt brevitas, \& mira clegantia. Imò ut Strabo ab eruditione, à diligentiâ kiniws, ita ab arte commendaru1: Mela:quodjudiciument Alphonfi Garfie Mo amori in commentario de doctis Hijparza viris. Valdè autem ridiculus eft Clandius Verderius, cùm dietioné Mela - legantifimi fane fcriptoris, culparc non verctur. I lan.Gerard.Voff de Hiftor. Lat.

Pornponius Mela antiquas \& elegans Geographus, infigni opere De fotw Orbis toti orbi notus. Quenfiedt.

Cujus libellum de fut orbis, \{yli elegantia, \& brevitas toti orbi commendant. Cardinal. Bona. in Notit. Auct.

Pomponius Mela, probatiflimus Geograpbus \& diligens, fed nimis concifus. Baltbag. Bonifac. ludicr. Hilt.p.6ur.

E Latinis Geographes praftantilfini fun Pomponizs Mela, \& Plinims Secundus. Foff. de Philolog.p.5\%. 


\section{CELEBRIORUM AUTHORUM.}

Reliquit verc Melalibrestres De futu Orbis perelegantes, quibus nithil in eo genere praclarius: à quo Plonius, Solinus; certerique funt mutuati. Hifpanice Bibliothec.

Hipani qui noftro zo vantopexe in Pomponio Mela populari fuo Laudande Eutegerunt, non ebs judicio fecilfe putandi funt : eft enim omnino friptor verè Principibus Latinoruzh acesenfendus; in admirabilibrevitate niliil minus quàin obfcurus, quam ego fummam, fed nen folam ipfus laudem cenfeo. Bartb 1.150 c. 6. Adverfar. Licet denfis $\&$ concifus tomponii Stylos, minimè tamen obfcu* rus cit. Idem 1. I4. c. I7.

Pomponius Mela diligentifimus au民tos, quî́ nemo Latinorum accuratius de -Geograpbiá Ccripfit. If cia. Voff. ad Mel.p. 69.

Pomponius Mela Patarium, Bononiarn, Mutinamaue procult mari fepoflit.

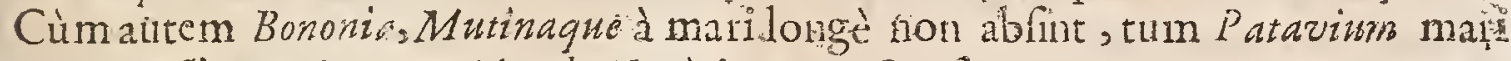
confat efle próximun: Claud,Vird. in Alu. Cention.

* Ioashim: Vadiani in Pomponium Melan Commentarii fi expurgentur, permittunturin Indir. Madrit. Edit. An. 1657.

Pomponii Mela liber De fru Orbis prodit cum Ifari Vojfi Obfervationibus

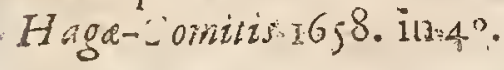

\section{AULUS TERSIUS FLACCUS。}

N Aturs eit Volaterris in Hetrurit Ans. Chr. 34 . obiit An. 62. Compofuit Claruit AnI Satyras mero lex, prafatus in his multum le labotis atque diligentix no Dom poluilfe, neque fe repentè poetam prodiiffe. Non defunt, quil cribant imperfectum fuilfe Hoc Opus à Perfor relicturn: quod mibi verifimile videtur propter immaturum illius obitum. Cùm publicarcitur Perfit Satyre, mirum eft quam fuerint judicio eruditorumappro Iucilium, qui accerrimus fuit in notandis, atque infectandis Romanorum vitiis. Petr. Crinit. De Poet. Lat.

Multum \& vera glorix, quiamvis-uno libro, Perfus mertit. Quintil.tib:זo. ceap. I.

Quanti Perfum xftimarit Martialis, oftenditur his verfibus:

Sapizs in libro memoratur Perfus uno, Quam leris in tota Marfus Amazonide.

$$
\text { Martiat. Epigr. 7. } 4 \text {. Epigr. } 2 \text {. }
$$

Perfiii faylus motolus: \& ille ineptus: qui cum legi vellet qux foripfiftet, intevligi noluit qua legerentu1. I $u l$. af. Scalig. in Hypercrit. p. 338 .

Qui liber etfi obfcuritate \& reconditis fenfibus éf plerunque refertus, nihiaeminus bonis eft annumerandus Authoribus. Litl. Gy rald.

Ignofecndum Perfis Satiryco, guòd \& crebris \& audacioribus utatur tran 
Aation:bus. Nam, utianimus, ita dictio nobiliffimi juvenis, grandia tantuma Givabat. Ger. Loan.Vo/f. 1. 6. Inttit. Orat. p. 454.

Perfus fruftra incricatus. Demspser. Perfuns, miferrimus Autor, oblcuritat: Atudet; : Hon pulchra habet, fed in eum pulcherrima pollumus fcribere. Scalim gerana 2.

Magna vis cftabftufaium rerum etian poftCommentationes tor doctiflimon. uum hominum apud $P$ erfum, ica ille farcicndis multis in pauca infauivit. Cafp. Barth. 1. I. Adverfar. c. 27 .

Longè falibus ab Horwtio fuperatur, \&̇à Invenale Perfius: quorum uterque

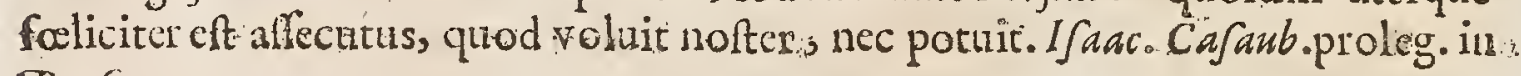
Pers.

Perfium digniffimum lcgiantiquitas cenfuit, he Quinilianus, Martialis $\& \mathrm{D}$... Hieronymus teftantur.

Perfins omnia qua de moribus differic, ex Platone excerpfit, Lud.Viv. in D. Angufin. de civ. Deil: 2 e. -6.

Perfins acutus Satyricus, fed obfciurus. Stylitm enim magnificum affectanso. crebrifqut \& audacibus tranflationibus utens, in obfcuritatem frequenter labitur. Nafcitui ctiam obfcuritas ex ignorantiâ. Scribit ittc qux fuo tempore fer vis \& abernariz notifima erant, qux quia nobis ignota nunc lint, plena myRcriorum arbitmamtis. foan.Bona. Card.

Cum Pocta nofer fefe Lectoribus intelligibilem prabere in animonon habuterit, afaubonus aliique qui ipfum commentari volierunt, contra mentem ejusivife videntur, coque culpandi quòd illum explicare tentarint; quando. yuidem juxta D. Godean indignus erat libore quo in hanc rem Enditi illi lefe fatiganut. Dici tumen poteft operam illórum nou omnino inutilem fuifer cìn ad hoc faltem ufuifucrit, ut Authoris exiguum meritum propalaretur. Jef. Vuafor monet nos, Jefuitam Petavium illum dimidiominoris facere quàm fecilfet fi abque interpretuionibus, giofematiš, \& commentaris reliAtus effe; quia cjus obfcuritas in hac faltem opinione nos tenuiffet, quèd my Mteria बluadam in ipfo-laterent. Erudit. Indic. de Poetis. Parif. 686 . Gall. Aulus Perfus Flaccus Jolaterranus, eques, oppidò juvenis fcribendx $S$ sio syra fore impendie, Nerone Principe, neque id infeliciter, felicins fi infitutumy. quod magno animoaggreditur, mordaci fale perfricans avi fui vitia, paulò clas riori dictione fuilfet prolecutus. Nune apud eos, qui' ininutiis Grammuticorum \& Aniguitatis innumiti non funt, obfcuritate nimiâ acumen fxpè perditó Quid quod intimorem nonnunquam atcollatur, Satyre utique non convenicntem: Obfouritatem fortalfs excufverint tempora : qux attingi ulcera fua mon pati bantur, nif tectiùs. Olaws Borrich. in Diffcrt, de Pö̈t. pagivaia 59,60 .

Miror equidem, quid ifti ( Quintilianss o Martialis) tale ac tantum (éx in fatyris deprehenderint, quod nos tam longo intervalló ne fufpicione quidem alfccuti fimus. Atqui majora nobis omnia in illo videri debent, quàm videri motucrijt Antiquis: proprerea quod ii plurima fui temporis nota habebant, 


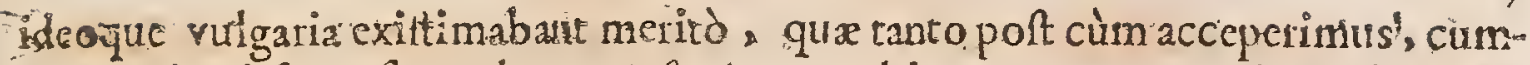
que annis obfcura fint, plena My/feriorum arbitramur: ut apud nos doctine interioris \& reconditx nomen \& infutr obtineant, qux fervis quondam ellent, \& Opifribus.3 Tabernarits notifima. Nec tamen occurrit quidquam Perjianum. quod laudem à nobis precipuam, nedum admixationem magnoperè efflagitct. Nam mihi quidem, ut vcrum đ̈icam, nihil fo offert infrgnius ipsâ obfcui itare fcriptoris, ex qua fortaffe nata eft opitio eruditionis \& doctina. Ac fapè Carming ut oracula vates, videtur fundcre qux opem conjceton is requirant: 'ic

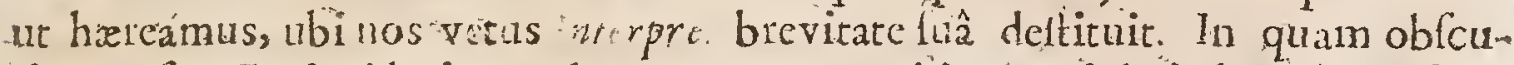
ritatem fiancto, incidat impudens : magmum vitium. i de indút ià quxfivit: mon apparce cur pleri jule fcipta mi-arentur, qux non intelligant; aut cur fcriptorem laudsnt, qui intelligi noluit. --.Defero Per/io, quantum defer-

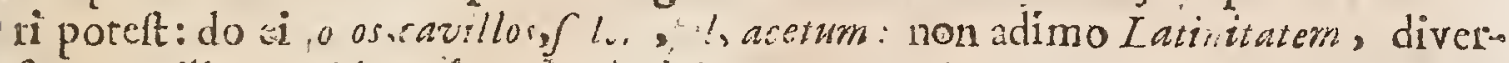
fam jam illam quidem ab optima, (ed tamen nondum corruptam. Frane.Vavaffo de Ludicr diat.p. 239 , \&6.

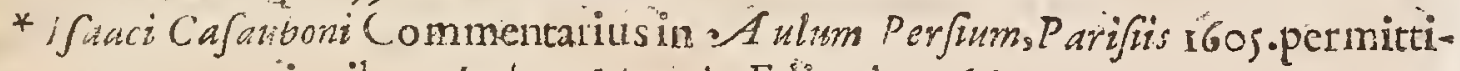
- vur cum expurgationibus. Lndex Madrit. Edit. An.16ri.

Edidit P'erfuns Eilhurdus Lubinus, itcm B'ernhardar, Autumnu, \& Claverius; laudatiffinè Ifacus Cofoubonus, qui \& commentaria lubjunxit, \& dilfertatio anem de fatyris Perfit; probanda ctiam induftria Thome Farnabii. quibrevio bus fed elegantibus fcholiis tenebras ejufdem abfterfito

\section{LUCIUS JUNIUS, MODERATUS COLUMELLA}

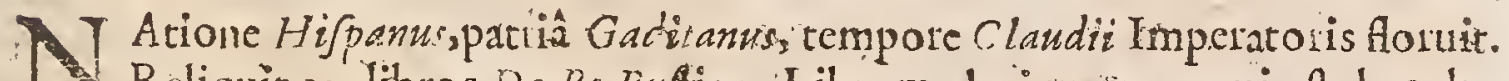
1. Reliquir 1-2. libros De Re Kaflica. Librum decimutio, qui eft de cultu Hortorum, veribus elaboravit.

Hipanus, literarun peritiffimus ac difertus, Gaditanu \& ipfe, ut fapius exellenti De $A g$ iculturâ opere tcitatum reliquit: quo à is in $R$ e Rufticu potifimùm oblervata quxid $I_{-0}$ Voluffo accepiffet, retulit. Claudii Principis temporibus flortit. Biblioth. is ispan.

Principibus Latina lingux fcriptoribus meritb accenfetur Columella; fermonis fuavitatc, politiâ, \& vi qun que, \& cruitione. Ejus Hortuitus purum \& vcrè Latinum carmen et, non tumidum, infatum, abfonum. Sed naturali vcnuftate cleg ans, nec adfeteans dcclanatorios flores,perpetux orationis dedccus $\$$ coru tionem. Barth. Adver 1.37. . . \%

$V$ cris defcriptio fimilem fibi habet placidifimis amoniffumis verfibus apud Columellam, untrm ex optimis Poctis, lib o illo untcalo De cultu Hortorum. Idernibid.1.20.c.19.

Sccipfit Columella De Re Rufrica minimè rufticè. Inter omnes crim qui cxtant Rei int fcriptores, soli inftar eminct ac elucet ; libris duodecim univerfan Ruris diciplinam as Agriculturam tradidit, temporibus Clandii Imperatoiiso Querentedivo

Clartic An no Dom. LVIII。 
In agris cxcolendis, in Apibus, in Columbis, nec non Pilcibirs alendis inte cateros Columella \& eEmilianus autores probabiles extiterunt. Sed Columella fedecim libris per diverfas Agriculture fpccics eloquens ac facundus illabiturs difertis potivis, quàm imperiris accommodus, ut operis ejus fudiof non folum communi fructu, fed etiam gratifimis epulis explcantur. Caffod. de Div. Leet.-. cap. 28.

Cumalios libros de culturâ, Agrorum tưm precipuè Catonis, IVarronis, Co-

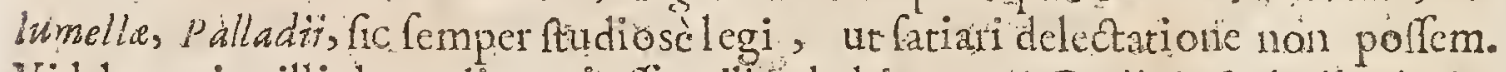
Videbat enim illislcgendis ruielfe, villas habitare, NA.Curi.L. Quintit Cincin nati felicam illam vitaindegere; quorum alter, cum de Samnitous ac Sabinis trimphallet, \&de Pyrrbo, in agris confumplit extremum tempus atatis: Ubi ad focum fedenti magnum auripondus Samnites chim attuliffents fprcto auro, magnificam illam voeem cdidit' Non aurum babere presl. rum fibi videri; fed cis, qui baberent aurum, inoperare. Alter DiElator factus, à willa in Senatum accer-

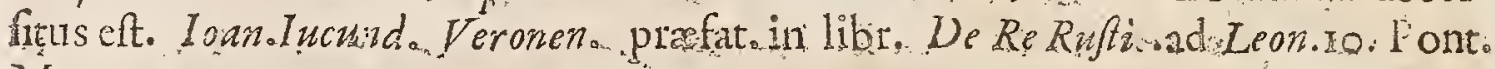
Max.

Magnus, utilis's, eruditus, cloquens auctor. Demp.ter. Ilacidiflimi \&amce. niffmi verfus apud Columellam, unum ex optimis Poëtis. Idem Dempfle..1.20. cap. Ig. lib 3 .

Columella elegantior \& terfor en Varrone. Lud. Viv. de Trado-Difciplo:

Columella utilis, clóquens \& politùs auctor qui de Re Rufticâ minimè rú nicè fcripfit tempore Claridi Imperatorisoloan. Card. Bona.

Claudii principatu inclaruit L.Im. Moderatus Colwnella, cujus non tantùm

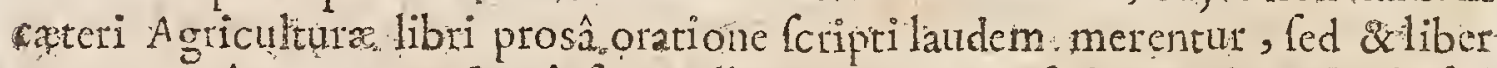
10. qui versî Hortum autor ipfe appcllat. Dictio ejus faris munda \& fuida, fed humilior, tut res rculues è convenientiùs exprimat. Is da $M$ alis Perficis, qula in perfide vencnata funt a fed trandatione in Europan rencuun omme: oxume, ita:

Mifera-Poma que Barbara Perfis
At nune depofiti parvo diferimine lethi.
Ambrofios prabent fuccos oblitanocendi.

Borrich.de Poet.p. $56^{\circ}$.

Libri ejus de Re Riffic inprefl fun Lrgduni apud Gryphium, Anno is 3 . an Gatonis, Varronis, \& Palladii libis ejuldem Argumenti in $8^{\circ}$. item Bas flex apid Hervagium. : ? 


\section{CELEBRIORVM AVTHORVM.}

\section{LUCIUS ANNAUS SENECA.}

(1) Ordubenfis Philolophus, Praceptor Neronis, jubente Nerone, periit venis incifis \& veneno haufto; Anno Dom.68. Scripjêt plurima vulgò nota.

Sanctus Jieronymus in catalogo Ecclefafiticorwm Seriptorum cum inter Sanclos. referre non dubitito...

Henris. 3ullingereus in cap. I. ad Romanos '́cribere aufus eft unum Senecam plus funcerioris Theologic poiteritati reliquuife, quàm omnes ferè omnium Scho=daficorum libios.

De Seneca Erafmus acutifimè fcripfit: f Chriftianus foripfit Paganè $;$ fo Paganus, Cbriftrane.

A nnaus Seneca frequenter milii in manibus eft : ue cgo fentio, non frie fruAtr. Sive cnim docerinam quaro, multa invenio in rieibus prifcis recondita: fve apicntiams Deus bonc, quid ad mores \& ad vitam, fcriptum unquam praclarius? Quails ille, \& quàm Romanur, ubique animus? qux tela adverfum cafus adminiftrat, \&iplim montcn ? Quomodo vitia eripit, inferit virtutes ? Farondum elt. In cacumine Olympi Montis conftitutus videos cum illum lego: fupra ventas \& procellas 's fuprd omnes res humanas... LipS. lib. . Elect. cap. 26. . .

Quanquam Oratiocompofità à Senecâ multum cultủs praferet, ut fuit illo viro ingenium amcenum, sctemporis illius auribus accommodatum. Tacit 1.13. Anna!.

Et cum Tullio Senecam pono, de quto plutarchns magnus vir \& Grecus ultero

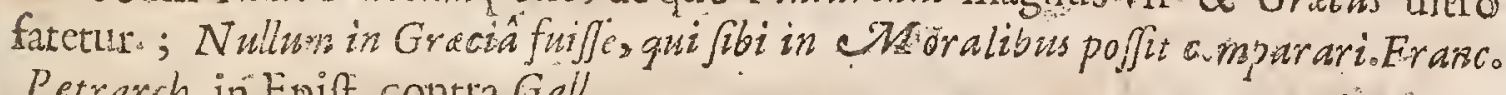
Petrarch. in Epift. contra Gall.

S.neca \& multa \& magnz virtutes fuerunt; ingenium facile \& copiofum, plurimum tutiờ, multarum rerum cognitio: in quâ tamen aliquando ab iis, quibusinquircnda quadam mandabat, deceptuseft: Tractavir etiam omncm ferè fudiorum matcriam.... Nam \& Orationes ejus, \& Peenato, \& Epiftole, \& Dialogi f:runtur. In Philofopbiâ parùm diligens, egregius tamen vitiorum inf etntor fuit. Multz in eo claraque fcirentix, mula ctiatn mrum gratiâ legen$d_{d}$ : Cedin eloquendo comupta pleraque, atque è perniciofnima, quod ábundant dulcibus vitiis. Velles enm fuo ingenio dixifle, alieno judicio. Nam fr aliqua contempfifer, fi parum concupilfet, fi non omnia fua amaffet, fi terum pondera minutiflimis fententis non fregiffet: confenfu potius eruditorum, quàm puerorum amore comprobaretur. Quintil.1.10.c.r.

Fuit Seneca vir cxcitati \& audacis ingenii", morum vitorumque publicos s. rum \& elcriptor yeriflmus \& aceulator acerrimus. Hornins lib. 4. Hiftor. Philol. cap. 6 .

Foret optandum, pares, aut faltem proximos illi viro fievi. Quintilian. Gap. 3.

Vir excellentis ingenii atque doctrina Colwmel. lib. 3. de Re Ruftica

$$
\text { Q. } 3 \text { - Prang }
$$


Omnes lüi xvi Romanos, multos verò \& alos, fapientian anteivit. Dis Iib. 54 .

Semeca tantus utique, quem Eronta, fcendum quo dam, nepos Plutarchiafferit, lic univerfos exterminare enores, ut when videatur Secula reformare, \& Deos ablhumano genere cxfulantes, ejus operâ revocatos, hominibus contraotâ. Socittate milccri. Iobnn.Satisbor. Policrat. lib. 8. cap. 13.

Seneca Princeps eruditionis ac potentix, qux poltemò nimia ruit fuper ipo Am. Flin. lib: 14.cap. A.

Parem ingenio non habuit, \& admirandus potius videtur quam laudandus. Corsfin:trI toloq. cap. 14

Quin ubique viditur plurimus jocormaffeator, ctiom in rebus maxime Ceriis, in quibus optâim illum aliquantò longius abelfe ab ineptiâ, obfconitzre, virioque fcurilitatis ac petulanix. Ex omnino liberale quoddam jocandz :genus, eft \& perpetwa quadam Orationis jucunditas, qua virum bonum non dcdeceat, fi in lowo adiriberatur at in Senech fapè cachinnos fcntias potius quìm rilum. Erajor.1.28 Epitt. E.

Ego Sencam universè, admiratione magis quàm laude profequendum arbitror: : in partibus aliquid effe quod.cenfeas, aut cuifurcenfcas, non nego Sance dcciditinterdum, aut à fe mutar. Ut in jocis aut tiElis, quàm ineptus alibi, five affectatus eft? in landions aut vituperie fine modo? exordin, aut tranforts.longin- qua, aut comica? Incuria etiom in Hifteris ? Inquilitiones alt differtationes in

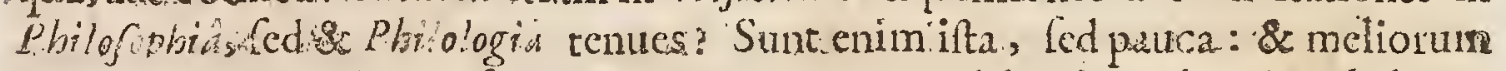
tatim interventu ita penfantur, ut momentum ad deprimendum non habeant in hâc juditii lance. Lipf. Judicium fuper Senec. cjufque fript prafix.I. Volum. Senec. Nor.Varion.

Scmperille mihi magnus vir apparuir: led ut folent verè magna, magis magilque inlpectus \& tractatus le approbat, \& credo polt Sacras Literas nihil in ullo orber in ullikinguâ, fcriprumutilius meliufque. 1 dem Cent.x. ad Belgas. Epift. 42. Sener Nu alis Philegopbia primastenet. Digniffimus qui femel atque iterum legatur, \& fidcli memoriz commendetur. Scaligerana. 1 .

Habet ille reverâ mutita eximia, urilia, fortia, fublimia, \& arguta, fubtiliaque complura eftquedignus admodum qui non áb Aumanion Literature tantum. Sed \&. Theologize eciam \{tudiofis fedulè quidem. [ed judicio atque examine jut adhibito, Zegatur. Venim noneft unius ejufdem que ubique colouis, nee per omnia conftat fibi. Gataker. Pralng. Anion. Pium.

In oetis ienecelocum dcdimus, non quafi omnium eum Tragedrarum paitcntem putemns, quas tiibui wulgò videmus: Ced quia noh dubium, quin in illis quiadam fint gentiini cjus foetas. Quà fpiflis verd conm error, qui propter Juppofititian illas Seneca \& $\mathrm{P}$ auli Apoftali Epijtolas judicarunt, fuifle hominen

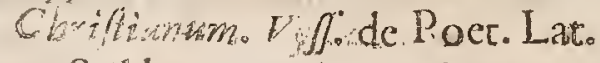

Sed heus, Fipiftolas ad Divurn Parium non memoramus ? qux nurc funt, wor

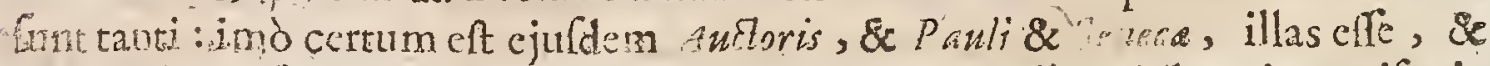
compofutas à Cemidoato indudibrium noftum. Tentatlatine loqqui, quifqujs 
auetor fuit. Ergo inter fe non feripferunt ? Hieronymus, (dë Scriptor.Ecclef.) Augufirius, (Epit. 53.ad Maced. \& 6. de civ. Dei C.IO.) atque eriam antiquior. utroque Linus Poinifex, (de paffione D.Panli ) alferunt \& paffiva opinio olim

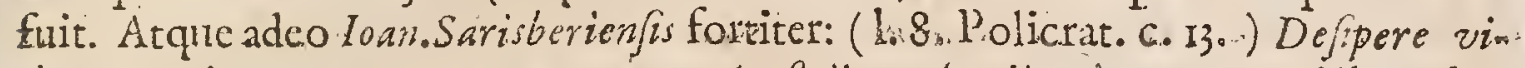

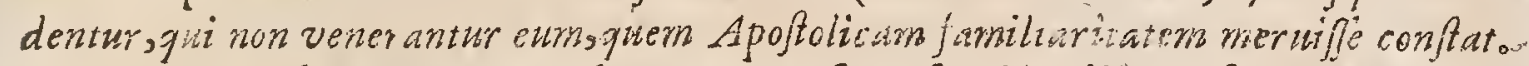
Iraque rejicere hoc totum \& calcare non aufim : fuerint aliquar, fedalix: fi ifta: requiro judicium optimorum parrum.Lipf. in vit. L. Ann.Sener.

Salmeron commentar. in bilipp.c. 4. \& Brnius Tom. 7: Bibl. PP.fidem harum literarum (viz.Panli ad Senecam, \& Seneca ad Paulum ) tucntur. Sed Eraf" mus fcholiisin Hieronym. De Ecclef. Scriptor. ait . Nitil in illis efje neque $p$ aul dignurn, neque Seneca.

Epiftola qux circumfertutut Pauli ad Senecam, \& hujus vicifin ad illum, non credo-ab illis effé fcriptas.Lud。Fiv. comment. in lib. G. Anguffrn. de C. D. cap. 10.

Sufpectranobis redduntur, qquamvis fciamus eas nen recền elfé excogitatas fed antiquitus fcriptas, \&ù S. Hieronymo cognitias-atque probatas. Baron. Yol.t. Annal. .

Seneca mores nequadquam intelligit; Eft elèganter loquax; qui venuftos fermones profurre indelinenter tentat : antivis non cft fylus ejus; \& illi yuos low quentes introducit Actores comicos femper refertut. Rapin.Reflex. in Poefin, Io par. Refli. 25 ..

Extan ejus opera cum Lipfir Gronovii \&alionm notis. Acceduut Liberto

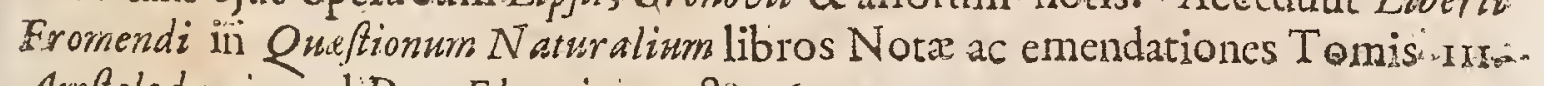
Amfelodami ap!d DanoElzcvirium, 8\%.1673..

\section{MAREUS ANNEUS LUCANVS:}

P Oeta Cordubenfis, natus eft tertió Nonas Növembias Anno Clbr.39."

In Piforianâ conjuluatione deprehenfus, à Nerone juffas mori, venis inci-

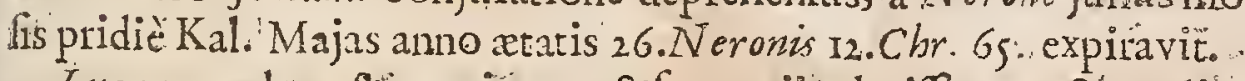

Lucanus audens \& concitatus, \& fententiis clarifimus; \&, ut dican quod fenuici, magis Oratoribus quàm Poëtis annumerandus. Quintil. 1..I@.c.I.

Lucanus ideò effe non meruit in numero Poetarum, quia videtur compo-

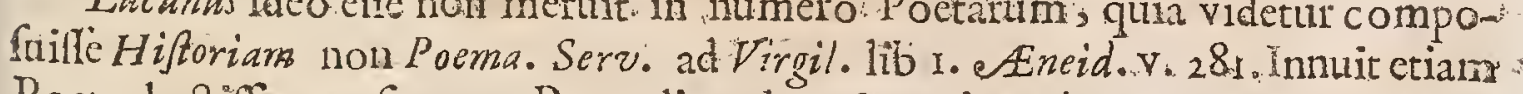
Poeta doctifirimus, fi tamen:Poeta dicendus eft; qui verâ natratione rerum ad Hiftoricos magis accedit. Ioan.Sarisóerienf.1.2. Lolicrat. G.190:

Altera (quieftio): An Lucanus fit-Poeta? Sanè eft. Nuganture etiám morefito Grammatio cùn objiciunt illum Hiftortarn compoluiffe. Principio, fae hiftoriam meram: oportet eum a zivio differre a differt autem verfu: hoc verò Poctre eft. Deinde quis' nefcit omnibus Epicis poét is Hiftoriam effe pro argumento, quam illiaut adumbratam, ant illuftratam, certè aliâ facie quum oftendunt, ex hiftoriâ conficiunt Poema. Nam quid aliuid Homerus? Quid Tragicis ipfis faciemus? Sic multa Luckno fiota: patria.inago, qua fele offexas Cefari: excita 
zbinferis anima, atque alia talia. Caf.Scalig. 1. r. Poétic. citp.z.

Lucanus Pocta magni ing enii, neque vtilgaris doctrine, fpiritus verò proirtus heroici, jam inde ex eo tempore, quôfloruit, maximâ femperfüiratoritate, pracipuè anúd Philofophos, propter grave, nervolum \& acutum, vibranfque \& penetrabilc fententiarum pondus, quibus univerfa cjus oratio mirificè flom ruit , adeo, ut in eo genere parem nunquam ullum habuerit. Barth. 1.53. Adver. far. cap. 6 .

At curnon potius mirari fubeat altam illius indolem; Tibertatis ufque accerximan propugnatricem, liquidum eloyuii fumen, materiam hatid fequacem puro carmine ducentis, quò voluit adeò ut non ruere immenfo fragore (quod de Nilo Plinius ) fed flue re vidcatur--Quid ego dicam acumen nobile \& divi* num fpiritum ardentem \& concitatum, Mufam mafculam, ac planè militarem, omia denique in illo alta, clasa, cafta? Thorn. Farnab. in lit. ad Lect. Lucan. pramifis.

Cit. Annaus Lucanus Neroniprincipi a milus ingenii glorix, nec multum Vrgilio infcrior. Dempf. in Elench. Script.

- A Stati 8 \& Martiule non lolum collutus Maroni, verum etiam prelatus.

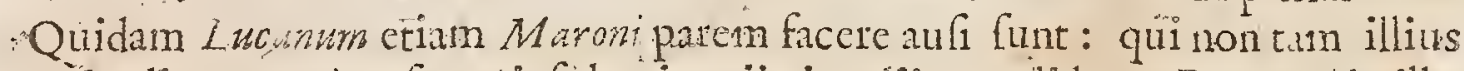
magnitudinem, quàm fuam infolentiam is incptiis prodidere. Fatemur in illo ingenium magum; equiden ctia m plufquam posticum condonabo. Effinis mens, fui inops, ferva impertus, argue idcirco immodica, taptacue calore fimul, \& calorem ipfum rapiens, hoftem maximum ejus temperamenti, quod in uno omnino Marone, \&admirabile et \& divinum. Proinde, uts nimis fortafsè liberè dicam, interdam mihi latrate, won canere vidctur. Cafar. Scalig. Poeaic. p. 844 .

Lucari,carmen plurimum habet vitium, te ctiam bellicis font prope pares, nec pralia vidcatur cancre, fed committere, \&intonare clafji um, eodemque ardore auma feribere quo Cofar tactavit ita ut ullum quorundam aures, tanquam fonum yafum, ac immodicum, non fernt. Lud.Viv. de Tradend. DifCipl.1. 2.

Lilius Gyraldws idem de Lucanoaffirmat, quod M. Tullius de Cordubcnfibus fuorum remporum Poetis, quii cos, neficio quid pinguc \& peregrinum fonate putabat. Quare Lucanum quidam, fanc̀ ingeniofus, indomito fimilem equo cffe dicebat s qui in medio prato, aut campifpatio curftet, \& acriter quidem \& animosè faliat, Léd inconcinnè \& incompofitè. Aliiillum expedito quidèm miWiti fimilem dicunt, qui amentatas qualdan velitum haftas aciat, potenti ac valido interdum brachio, fed parum plerumque confiderate ac prudenter. Lil. Gyrala.

Lucmas Poetact, fr modò eft, in quo quamvis quxdam reprehendantur. Longè tamen plura laudanda funt: tumidum, \& affectatum Cribendi genus, declamatoria rerum etiam minimarum ad oftentationem amplificatio, \& fiequentes is propofito excurfiones, ut omnilcius effe videatur, fortaffe in illoculpentur: at de rebus acres \& fanas habet opiniones, de virtute verò. mon fè̀ aliter are 


\section{CELEBRIORUM AUITHORUM.}

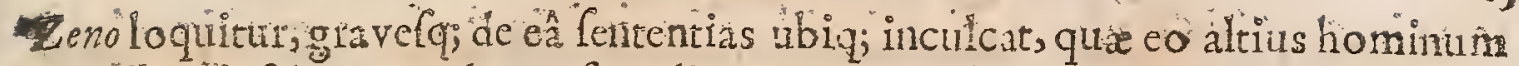
mentibus infident, quod nou fline aliquo acumine infguntur. Roland. Maref. Epir.1. I Epift.?.

Si propius totum Opus Lnani putare volieris, non folum nullam Afronomix peritiain in eo homine repcrics, fed \& importune femper interjectam rerum -Colefinm mentionem, \& levem, vanum, \& oltentatorem illum juvenem fuife deprehendes. 1of. Scalig. 1. I. Epil. Epilt.3.

Lucanus longus eft 8 tadit pater. Cef. Scalig:1. 3. Poetic.p. 288. Lucanioraw tióluperba, \& minax, anditorem invitum, atque alibi an mo harentem ubi vult tenere, aut trahere, abigit: Ty ranno haud abfimilis, qui mavilt metri, quam anari. Idemp.294.

Vxor Lucani Polla Argentaria poft excelfum mariti Tharfatiom ejus emendavit : imo 8 viventem in carmine dicitur adjutalic. Voff. de Poct. Lat.

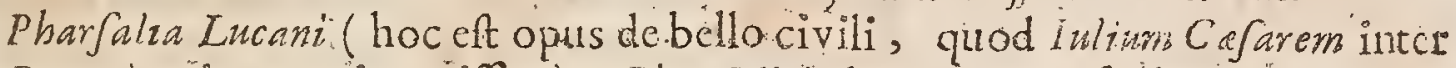
\& Pompeinm in campis potiffmum Pharfali is detonuit,) mafcula dictionis eft, fententiis, monitifue politicis id fatiem diftineta, durior tamen fubinde, "i horridula. Neque forfan à tumore femper abeft. Severior in eum scaliger, qui latrare Lucanum quandoque potius quameanere fcribit. Limaflet haud dubiè mufteum opus fi fata pracipitia otium indilffifent. borrz h.de Poct. p. 58 .

Lucanus ampli" \& fublimis ingenli cet; fed judicii non admodum fubacti : Argutias fuas oftentare tantum conatur. Et reverà nullum in fermonibus fuis mon dum fervat, in quibus Philofophum magis quam Poetam.fe prabere affectat. Rapir. Refti.in oct. 2.par. Refi. 5 :

De Lucamo universêtatuebant; ingeñum éi effe oppidò magnum, fed conrumacius, quam ut regi poffer; dictionem ingenio parem, animofam, peracutam, entitam: at indmonam, tragiccque feralem, \& quæ nefcio quas turbas amet fameque magne malit clfe quambone. Vnoverbo Lucanum elle, quin primus inclinaffe fylum aufus fit. $F$ amn. Strad. ! roluf. Acad.

Lucanus multum debet vulgatoribus fuis, G.Verfellano, Philippo Beroaldo, Iodoco Badio, Ant. Sabellico, plus etiam. Thome Farnabio, H. Groico, Corn. Schrevelio, ex quibus hic Variornin obfervationes addidit, ille Notas \& emendationes, ifte necelfariam Tyronibus interpretationem. Quin Theod. Hulmannus indicem Locupletem adjecit.

\section{TITUS PETRONIUS ARBIER.}

D Oeta, tempore Neronis claruit; qui principis fui vitam fub exoletorumo- Clar. Anto minibus defcriplit. Elegantic Arbiter Tacico dicitur 16. Anial.ac natrat, ut fe Dom.LXIV. erudito luxu perdiderit. Non minus nequi ie Arbitrum appellaris: Scriptorem, ut jamalii dixcre, puriffina impuritatis. VofJ. de Poet. Lat. p. $4 \mathrm{I}$.

T.Perr ins Arbiter Eques Romanus : inter pancos familiarium Neroni affumptus ef, elegantiæ A ibiter, dum nilhil amonum \& molle affluentiâ putat, ni= if quod eipetronims approbaviflet. Tacit. IG. Annal. cap. I\$.

P Scriptet 
Seriptor lepidifimus : immortalis Charitum pullus.C.Barthius in Racemat

Spurcus \&Obfcenus, fed ad piós etiam caftóque illuftrandós utilis Auctor. C:Barth. lib. Ir. Adverfar. cap. 20.

Scriptor terfus \& venuftus, \& nifi quòd in re illâ Voluptatum, nimis latiné interdum loquatur; catcra laudarus. Lipjus lib r. Antiq. Lect. cap. \&.

$N$ eronis \&aliorum procerum flagitia horenda, non minore flagitio publicavit. Ifaac CaJaub. lib.rr. de Satyrấ, cap.2.

Hic Satyricum opus varium, \&s ut fic drcam, mifcellum, compofuit. $\mathrm{Cu}$ jus licet fragyenta ad nos tantừm pervenerint, eddemque parum caltigata, multze tamen eruditionis hominem fuiffe facilè cognolcimus, nam in taxandis moribus cumacrem, tum feftivum maximè, \& jocis Leria mifcentem videmus... Lit Gyrald.

Confervarus eft elegantionum nequitianum curiofis Petronius Arbiter. Qund enim ex ejus Satyrico habemes, mera excerptant alicujus ftüdiófi, qui qua ad guftum fuum in illo auctore invenerat, eodem quo opus lcgebat ordine, adverfaris fuis commendavit. Qui putant àmonachis fic eviratum effe, vehementer errant. Qualis hæc caftratio forct, qux refectis areliquo corpore membris, vel potius ipfo corpore abjecto, folas pudendas partes relicuille videatur? Certè defidcrantur, vix videri polfunt falaciora ac nequiona fuilfe his, qua reli-

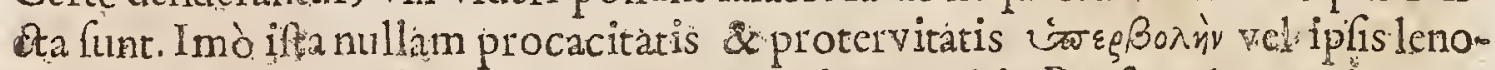
nibus ufurpandam reliquam faciunt. Claud. Salmas, in Prafatad Arspel.

Petronius candidas, terfus, fuavis, in omnibus, mirandus modo abfit oblcœnitas Thorr. Dempfto

Verfus fanè quam amconi \& elegantes extant Petrobia Arbitri de Ciconiâ. Adrian Turneb.118. Adverfar. c. 18 .

Elegans,profectò \& luculentus eft Scriptor Petronius a quemque non abs te santoperè amant vìri doctio GaJp. Sciopp.1. Terifmil.c:16. Phedribm \& 'Hyginum velut elegantiv minis ftudiofos plebeia plufculium ufurpaffe apparct: quo fermonis vitio neq; Petronius abotinere fepotuit, qui paffín etiam habet fingularia præter omnitun veterum \& æqualium confuctudincm: quætamen vitia aliis vitiis; fed dulcibus necpancis acutè, falsè \&eleganter dictisiedimit Ldem confulat.p. 42 .

Ut in vitâ fic in fùudiì juvat feveritàti àperfa comitâs. Eâ cansấ frequenter foleo a gravioribus libris, animum quafi in ludum mittere ad fcriptores amc niores. Quo in numero Petronium repono: quidquid dicant ifti frontis severa. Ettuâ fides Pytbee : vidintin quidquam venultius, argutius, poft natas Mufas? Non ego :abeffet tantùm nuda illa nequicià quâ tamen nihil offendor. Ioci me delectant, urbanitas capit cretera nec. in moribus meis magis labem relinquunt. quàm olim in flumine veftigium Cymba.Lips. lib.3. Epiltolic. Quzeft. Epiti. 2a. Petr.Pytbeo.

Petronius in brevi Poemate fuo de Romana Corruptione ino mnia qua ab iplo damnantur vitia labitur: Nemo unquam fanioris judicii precepta circa Poefin

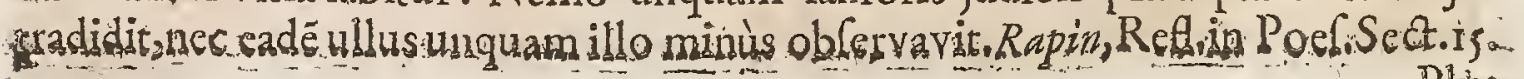


Plus qudin ofto roces apue Perronum leguntur, quarum ignoratur prorfus fignificario, ut Odopeta \&aliz. Scaligerana 2.

$P_{3}$ etronius Arbiter venufatem orarionis fux-inquinavit Cpurciffimis Amoribus. Adrian. Turneb. Adverfar.l in.c.6.

Utiuan vel folo hoc fcriptore abeffet oblconitas, nemo co unquam venwAtior manum ad fcribendum applicaffct. Barthius 1. 50. Adverfar.c 9.

Petronius carmen reliquit fani coloris, \& judicium de carmine ad Stagirite mentem accornmodatum. Borrich. de Poet. p. 58.

Petronium édidere vario, aeditis ctiam oblervationibus \& commentariis, quos inter Petrus Loticbius hodieque eminere videtur, \& Iof. Ant. Gonzales de Salas, cujus index Petronianuslaudatur. Nec ingloria hic Joh. Alex. Brafricani opera. Textum ctiam fic fatis -curiosè evulgavit Ioann. Bourdelotius, norifque critic is effecit, ut intclligenter tectitetur. De fragmento Petronii Traguriano hic nihil, de quo hodieque Hadr. Valefus, Chr:Vagenfiulius., Schefferus, Reinefiuso - Statilius inter fele digladiantur.

\section{LA JUS S ILLUS ITALICUS.}

7 Empore Neronis \& Domitizniclaruito Vitam inediâ abrupit Ano ata- Clar. A. D.

Toena elabonvit De Bello. Punco Jecundo libris s Gue ufyre ad tempora Concilit Bafleenfis conflictatum ent. Tunc fiquidem è lanebris in lucem prodire capit Konig.

Siliur Italicumlego, cujus ego lectione tum propter Antiquorum Poeta rum imicationem, tum Hiftoricarum rerum Pconicarurn narrationem, quam ad Liviz \& blybiz excmplar conformavit, mediocriter me capi fatcer. Eudow. Carr.1.2.emendat.c.I.

Etfiatem ad Maronis le exepplum componeret; nihil tamen ille ad divin Vatis Majêtâteñ imò carminurn gloriâ etiam vincitur, nen à Lucano modò fed ctiam Papinio, Valerio Flacco, \& juniorum aliis. Er tamen laudabilis indutrix fic quoque fuccelfus noninfelix fuit. Nec enim planè ei adulatur Martia-. lis, cum os ci tribuit magnurin, facundurngue. Quod fi depulitate etiam Sermonifque Romanicaftimonia certare lubeat; nulli illorum cedat, quos ca, vel proxima vidit ras. Imò portius eos exfuperet univerfos. Vofj. de Hift. Lat.

Silius I talicus tcribebat carrina majoricurâ quà ingenio. Plin.1.j.Epif. 7 .

Silius It ilicus conful. Orator verius quàm Poëta, nimius interdumque in- diccilus Virgilii imitator. Derapfer. in Elench. Scripto

Admagnemnemen ingenii pervenerunt, Silius Italicus, qui à natali folo \& patriâ germanâ nomen accepit, \& Valerius Martialis Bilbilitanus; quos in divinis Poetis habitos fcio : nam \& plurimum cos naturâ valuiffe, \& mentis folitos excitari viribus, \& quafi divino quodam afflari fpiritu, dum bella Punice alter ad Virgilii imitationem, cujus quotannis illuftres manes colebat, compolitus perfo 3 aret: ălter neque fermone inculto, neque aridâ venâ, falibus \& jocis 


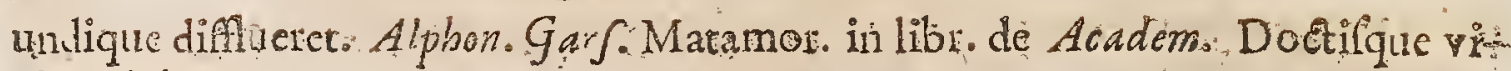
ris tispan.

Silim equidem poftrcmum bonorum Poctarum exiltimo: quin ne poctan q̨uidcu. Non nervos, non numeros, non firitum habet. Adeò yerò ab omni vencre alienus eft, ut nullus invcnuftior Gr. Totus haret, trepidat, vacillat: : ubi audet, cadit $I u l$. Cef. Scalig. in Hypercrit. p. $8+1$.

Licct omnium verè Latinorum Poetarum ingenio \& acumine fit poftemuss. prater dictionistamen puritatem non panca etiam habet, non iiffeliciter s sertodirifime dicta. Barth. 1.10. c:24. Adverfar.

Silius fralicus non bonus Anclor, legendus tamenut vetus Scaligerana 1. .

Extat Epicum illius carmen de Bello Punirofccundo, I7:libris expreflum quod jam fcnior compoluit, evulgatum demum primcipatu Domitiani- In quo feripto ita verfatus eft, ut parcè fingcret, veritati femper propiòr, non neglectis tamen coloribus, digicfionibus, fimilitudinibus, \& cateris Poetarum flofculis' Ingenioffimum nonfuife apparet, fed fi quid ingenio defuit, illud fallicudi-; ne, $8 \mathrm{c}$ advocato undiyue nitere rependit. Delituile autem in tenebris per mulra fecula hunc firiptoris arow mento fucrit irritus Francifiz Petrarche conatus, qui ignorato Silio, idcm bellum carmine aggreffits eft, fub titulo Africani. Vide Borrich. c. de Poct. p. 60, GI.

Méo quidem iudicio, ejusidcirco carminatalia funts. ut fint cognofcenda quidem, fed non ad imitationem, ea licct perpetuò victura Martialis vaticinetur, quem in Silit ludes omninò procliviórem fuiffe videmus. Urvervè inon fine infariaz noca fuit, quòd fponte quoldam fub Nerone accufaffe creditut; ita commendatione dignus, quod Virgi ium ante omnes coluille dicitir ?, cujus etiam natalem religiofius quàm fuum celebrabat. \& Neapoli maximèn,ubi monu mentum ejus adire, ut templum folebat. Coluit \& cicexonem, ipfufque Ciceronis manes. Iil. Gyrald.de I oet.

Jef. Rapinus eum quoad Poefin ufque adeo contemnendim non cenfuita Critivi cateri." Dicit enm in Opere fuo legum attis. Statio fuife oblervantiorem; juäicitm \& prudentiam in cjuftem operis defgnatione deprehendi: eum, finativis dotibus parum inftrocus erat. magna faltem animi attentione labow rallé, cjus verò clocutionem fliblimitate ac nobilitate parum commendabilen - Rapin. Reflex. in Poct. 2.part. Refl.13..

\section{VALERTUS FLACCUS:}

Alar. Anto Dom?

$2 \times x \leq 11$

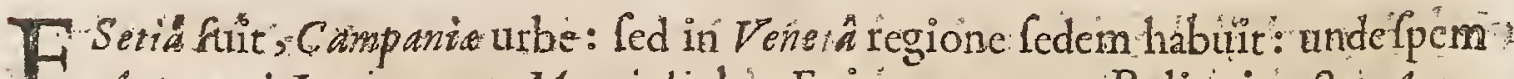
1. Antenorei Laris vocat Martialis 1.1 . Epigramm. 79. Reliquit odt Argow. natuticorum libros; fed imperfectes: unde, Quintilianus comqueritur in ejus obi-" tum multum fuiffe amiflum. Quàm Martials fuerit carus, liquet ex eo $;$ quòd ibidem vocet curarum pretium non vile fuarum. Pauperem fuilfe, ex eodem Epigrammate eognolcitu. Vid. Yods. de Poet. Lat. p. $46_{2}$ 
Hic cft Volerius Flaccus, cujus Argonauticon opus extat, Vespafiang patri inf eriprum, ut facilè ex ejüs carminis principio colligitur. Opus, inquam, quantnm per juvenem praftari potuit, cultum, eruditum, \& varium, led in quo plus eft virium, quàm virtutis, ut in co animos, 2y audaciam quandam juvenilem fa. silè offendatis. Gyralá. de Poet. Dialog. 4.P. 18 I.

Eft igitur Valeritus Flaccus excufarione dignus... Cujus sưm effit ingenium felix, judiciúm magnum ,o diligentia non vulgaris, immaturâ morte prevenets, acesbum item poema fum nobis reliquit,. Ef antem omnino dúriufculus: penitus verò nudus gratiarum comitate..Inl.Cafo.Scalizo. lib.6. Poetic. pepg. $8390^{\circ}$

Valerium Flaccum majoxis pretii Poetam, quàm quis prateriens cenfeat, effe, vel iğnoratio ejusapud vnlgum nobis perfuadeat. . Eit enim o mnitum veterum minimè tritus manibus hominum fchelaticorum aut litterionum, quod genus ab co vclut abhorret qui duriúcculus cenfeatur, \& minus gratiarnm amans. Sed nos generolum vatem, Qu quidvis potius quàm abfurdum cenfemus. Gajp.Bartho. Adverfar. l.I.c. 17:p: 3 \&.

Plurisomninò facicndum ego reor in numero Latihorumpotarum Valerium Flaccus, quàm vulgò faci int, imò non vulgò etiam eruditi. Sonus, firitus eruditio, gravitas, in co funt infignes,necdeen judicio; illud obfervavimus, quories per fe aliquid canit; longe faciliorem effe ,- quàm cum atpolloniun pede peflo imitatur. Nefcio quomodo enim gencrofusille animus flaccefcit; cum feipfum ad fecutilejas leges aliënarum.inventionum componit \& $\operatorname{cog}$ it, Bartho. ibid. 1.26. c. 3. p. 1259 .

Valerius Flaccus, fcriptor unicè milii carus obilinaffcctatam, genuinam, Romaw nam dictionis majeftatem.. Sane cgoeum anctorem, Argonawica lcribentem, ldgere malo quàm vel Ovidiun vel Papinium; quoum ille tenuem materian lifcivia utique violaffet aut deputicaffet : hic mayniloquentia contriviffet. Quow rum cum neutum Valerio objectari poflit , non video, quid in compofitione fermonis defidercnt. Nam de Gratis, quod: ait Scaliger. ncquaquam illi fure deeffè polfunt, qui atienas non affectavit, neque fprevit Romanas, neque tranfmarinas non expreffit. Vid.i'ompon.Sabin. Virgillo interpret, quem citat Konig. in Biblioth.

Ief. Rapinus feribit prióre parte Reflexionum fuarum, in languidum \& frigidu ftylum cum incidifies quòd grandiloquentiam ingenio ad hanc nato deftitutus af fuctaverit: \& parte polterioni ait Fabulam, ordinationem, Executionem ac reliquum Poematis ejus adinodum exiguo charactére ornata effe.

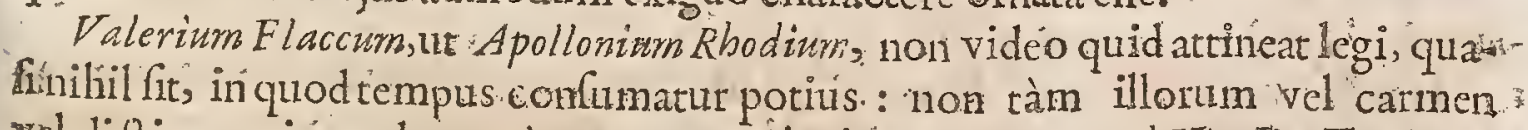
vel dictionem improbo, quàm argumenti levitatem.Loan.Lud.Yiv.De Tradenda:Difcipl.rnı... 541.

CáValerius Flaccus, Campanus, imperante Domitiano clarus, Argonauticalio bris 8. perfecutus elt, Orphcos \& Apollonii exempló. Dolét Eabio, quòdimmaturi morteinterceptus nequicrit affectum opus dédicere ad ufqueumbilicos. Agnofo:

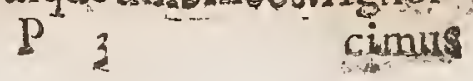


cimus fanè feliecm in illo, licet nondum exafciato, calorem, "imperus Poeticos hincindegenerofos, judicium plerumquefubaetu dictionem fic fatis floi:dam, fed aliquando inzqualem durifoulam guam emollinet dubio procul fi productius ei contigifer avum Borrich. De Poet p. Gr.

Publicavere hunc C.Val. Flaccum diveri, Bapt. Pius, Andreas Schottus Lud. Carion, alii; fed palman cateris preripiunt Lampert. Alardus \& Ioannes Weirzivs.

\section{CA JUS PLINIUS SECUNDUS.}

(Clar. Anno Dasn, LXXY.

$\sqrt{7}$ Eronenfi, dictus Senior, temporibers Vefpafiani \& Titi vixit, quolumnc. gotia adminifrabat :roctibus verò \& fucceffivis (ut ipfe inquit), tcmpo. ribus opus Hiftorie: Naturalis compoluit. Neronis quoque hiftoriam, vitam Fomponit Secundi, ảe Bellis Germenorurn, aliaque fripfit. Feriit in horendo, :montis $V$ efurtincendio, An.Chr.79 dum ejus caufam indagare vellet. Hofman.

Plinit Naturalis Hiforia, opus diffufum, eruditum, \& tum varium quàm ipfenatura.Plin. Min.1."3. Epift.

Plinivis mnium rerum memoribilitum collector, judex ingenioum fummus eftimaror acutus, admirator difertus. Angel. Politiar. in Epiftad Leonic.

Plinus yeitaris Antiftes senforquéliberrimus Budeude AJjL. Perfpicak cillimus Naturc Mýltes, Plinius. Drexell.in Aurifodin. p. 6.

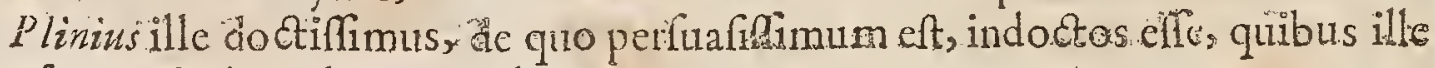
non fapit. Rhodigin 1. I 2.c. 3. le ct. Antiquat.

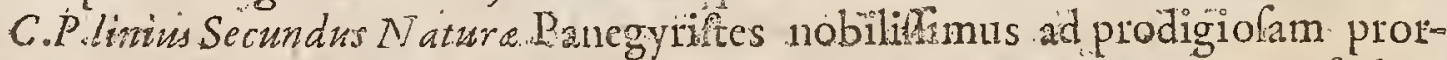
rus eruditionem pervenit hoc ano tramite excerptorm. Drexel.in Aufifod. p. Ir. Naturæ Bibliothecariusaudit apud Lanfum orat. pro Italiâ.

Plinii libros quii $P$ andectas appellaverit, me judice, haud erraverit. Omniat ille vir legit, vidit, fivit : \& in unum volumen Greciam \& Latium conclufit, paulò meherclèfeliciùs, quàm I brax ille Imperator veteres leges. Lipf.1.2. EpiAolic. Quraf. Epift. 13.

Pliniville diligens totius Antiguitatis perveftigator : qui nullam Bibliothecarn pratermififle videtur, quamnon exculfcrit, \&perluftrarit.Edw. Leigb de viw ris illutut.

Plinii. Hiftoriam $N$ aturalem opus eximium ac nunyum Catis laudatumyocat. Ger.Ioan. Voffoinl.de Hiftor. Lat.

Cardanus folum habebat pro Grarsmatice. Quonon tà Plinianodetraxir nomini, quàm fuo. I dem de l'hilofoph.c. 12. Sect. II.

Jan de $C$ ago P linio quid dicam ?Qui naturam Univerfam \& utrumque mundum planểurfratâ antè cateris audaciâ.s paucis voluminibus inclufit? Qui Imperio Romano, cui Univerfus terra Orbis conceffilfet colum quoque adjerit: Quodnonarmis aut vi bellicâ; nonariete ant baliftầ, fedfublimi animo, \& invactâ induftrî̀ expugnandum fuit. Heingus in Orat.pro Bibliorh. munanto pag. 320 
Plinius claffis Rom.Prefectus, naturalium rerum Scriptor diligentiflin mus, eloęuentilimus yeracilfmus, incomparabilis, unus omium infar. Dernpfter.

Plinius non ubique fui fimilis : pleraque enim acutè feripfrt, : \&. nonnulla neglecta \& inculta. Piniun defiderare videntur in Plinio.. Caufjin. lib.11r.de Eloq. cap. 14.

Pliniurn meritò nihil moramur, neque verbis ejus nifi ubi meliora nobis de" ficiunt, utendum putamus. Sciopp.de Styl. Hiltor. pag. I00.

Plinius fafciculariam facit; cunct d olfaciens, nihil deguftans, omnia glutiens, nihil decoquens, lerna mendaciorum, erroum Oceanu, in quem ingenti edito volumine invectus eft Leonicenus. Verder.in cenfur. Autor.

Scripta linii, Cardani, Alberti, \& plurimontum ex Arabibus, commentitis \& fabulofis narrationibus pallim fcatent; iifque non folum incertis, \& neutiquam probatis, Ced perfpicuè falfis, \& manifelto convictis. Fr. Bacon de Augm. Sient.. lib. I.

Plinius Hiftoriam Naturalem folus pro dignitate complexus eft, fed comple xam, minimes, ut décuit, imò potius indignis modis tractavit. Fdem ibid, 1. 2. cap. 2 .

Pliniustantus vir, ut non mirum fit, fi vulgus illim improbet, cum minime auctor vulgaris fit. Fo. Scalig. inter opufc.

Hoctenc, Plinium eruditiffmum fux atatis hom nem Latine elegantia ob Cervantiffinum, non mirum aliquando in vertendis Grecis hallucinari.Hoc non Solumilli, $\{$ ed 2 Ennio Attio, Ciecroni accidit. At quibus viriso qui funt colum minaprifce Latinitatis.Iof Scalig. ibid.'

Genus fcribendi, quod Plinius cecutus eft mihi prorus incomparabile videtui, medium inter frof $m_{3}$. \& carmen, qu@d de Platoris lermone dixit Arufoteles: breve, \& concifinm, foridum \& figuratum, ita ur fap̀ res viles \& humiles quales pleracue res natuales videntri yerbis grandioribus per trannationem exornct \& extollat Miror tamentam mattrum, \& gravem $S$ riptorem à quibufdam răquam exigui judicii hommem fugillari, ut qui multa ipfis ineredibilia, fibi non fatis comperta fide aliorum referat: cim eum mentis, \& judicii asumine mulcum excelluiffe, ex omnibus locis in quibus fententiam fuam de quacunque re Interponere voluit, manifefiffimè conftet quod pafim, fed maximè in præfationibus librorum guam breviter,$\ldots$ tam acriter façito... Roland. Mare $\int_{0}$ 1. Ir: Epift. 40 .

Maxima prifcorum negligentia. Dim rerum naturas profitentur, elenchis nominum tantùn concervatis, nobis plus inquirendum, quàm fi nihil prodisdiffent, reliquerunt. Inter quos princeps. Plinius, dum fudet nihil intactum re linquere, importunâfeftinatione praceps, pro epulis exponir titulos convivis. Iulis Scalig. de fubtilit. adverf. Cardan. exercit: 20 ;

Plinimm pauca lectionis virumappellavir Caf.Scalig. adverfus Cärdanum, exercit. 218 . Sect.I. Ubi ( inquit VofJus) nihil opus erat obtrectari Plinio

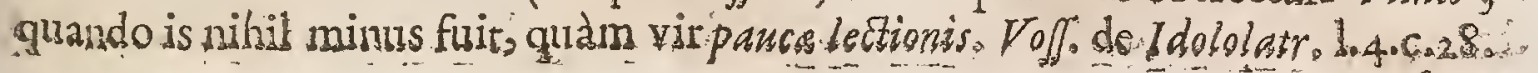


Hifforid Pliniinte pucherrimos libros cenfenda eft. Hinc etiam pauperm Bibliotheca vocatur. Si ei addatur Ariftoteles, numeris omubus abloluta erit illa Bibliothece. Si ad illos accedant Plutarchus i ieneca, tota familia librorum bonorumaderit, pater, mater, primogenitus, natu minor. Guido Patin Epift. 6. Gall.

Poferitas Plivio multum débet, quod'laboribus fuis confervaverit quicquid in Hiftoridm fuam $N$ aturalem congefit. Stylus ejus gravitate \& elegantia multa commendabilis eft. In Moralibus prafertim. excellit, tam rité. feleet funt ejus exempla, cjufque benè vive̊ndil Precepta animos adco movent: ut cor fuum ad propriarum lectionum norman direxilfe cenferi poffit. Difficile eft vitium acrius reprehendere $\&$ majoribus Ludibus virtutem extollere. Sed artium ac ćientiarum de quibus locutus eft tam parum gnarus erat ut finguhis palibuscefpitaveric, \& tam giviteridentidem laplus fat ut Dom. Salmafus alio Vetcribus illum accenfcat, qui fecure fe invicemtranfcribentes, libros fepiffinè de rebus fibi minime noris componcbant. Teftis eft Aratus qui Aftrologix prortus ignarus, librum tamen de Colurum motibus 2 Aftrorum curfu edidic. Plinius Operis füi proprie loquendo merus Architectus fliit, Ejus antem culpa eft quòd ex inepra materia illud conltruxeiit, quam ablque fufficienti peritia \& fagacitate coraterat. Vaituin itaque adificium exćitavit. fedparum folidum, quodque opificem viddeinexpctum fuilfe plus fatis comprobat. In co Symmetria parum obfervatur : ejulque partes innumera ornatu debito deftituuntur. Omnes ejufmodi defectus tribucndi funt praproperæ illius feftintioni continuifque avacamentis quious illum implì cabant functioncs. munerum \& favor quibus ab Imperatoibus Tito \& Vefp farm cohonetarus fuit. P inizis junior ejus Nepes refertillum inter conandum excerpta fua facere Lolitum ere. Vid. D. Beawdol. Hit. Operum Eruditorum Febr.i689. Gall.

Plinius quum multorum Átorum,nomina recenfeat, ex quibus libros fuos confecit, nullibi tamen Diof coridis, cujus omiila ferè fcripta luis intermilcuit, mentionem facit.Bilibald. Pirckbeim."in refponf.ad Oecolampad.de ver. Chrift. carne, A. A.

Ad Latinos trarifeo inter quos Cornelius Celfus Hippocratem ferè tranfulit. Plinius autem Diofcoridem, tametfipfe difimulaverit, \& Collenutius fortiter nem get. Georgius Agricol.in Dial. de re Mallicâ, c. Ig.

Pliniwrn Medicis aecenfemus, quandoquidem naturalis ejus bifforia magnam partem ex Medicorum libris compilatá : ejufdernque argumenti eft. Hunc multa fine judicio collegifle oppidò patet, præfertim ex re Aerbarin, cujus ntique fuit imperitus unde etiam lepe eandem terbarn diversä ejus appellatione decepaus viribus diverfam facit. vid. Sebaft. Scheffer. Introduc. in Art. Med p. s6.

Opera C. Plinii Sesundi edidit loann. Frid. Gronovius cum notis Variorum 3Nol.Leida.in 80.1669. apud Hachkiós. 


\section{QUINTUS CURTIUS RUFUS。}

$\mathrm{U}$ Nde oriundits fuerit, non conftat. I talum tamenfuiffe, fatis certum eft, id chim Azlizipfrus terfifima puritasad Romanum filum ad amuflim for- Ann. Bora. smata oftendit. Quinftedt. Quundo vixcrit variant eruditi. Quidam fub Augufto LXXX. vixiffe exiltimant, ut $P$. Pythens \& Bongargris Iipfints eum ilandio corvum judicat. Rittgerfius; ac ctiam Ger. Ioan. Voffins, tempore Vepafiant vixilfe, alfertunt. Alii ad tempora Trajani sum refenunt, Scripgt decem libios de rebus Alexandri.Magni, quorim due priores periêre.

Mattbans:Radcrus.in prolufionibus ad Hiftoriam Curtii C.I. non dubitat, Allum fummis rerum Romanaruy. Scriptoribus, Salluffio, Livio, Cafari, Ciceroni admovere; Tacito.verò, Suetonit \& Eloro praponere.

Rhetore fanè illuftri, vel Rhetoris filio dignifịma hac hiftoria eft. Ufque adcò auctor is verborum eft eligens; ncc perípicuè minùs quàm tersè fcribit; acutus ctiam eft infententiis sinque orationibus mirè-dilertus Inò vel $A$ ugguftá : evo digna cit dicti $; \mathrm{v}$ l proximè abit. Ut hiac quoque argumentu m capere poflimus, non vixiffe tempore Trajani; quod, plufculà affectarione acuminis, \& anxiâ brcvitatis curâ, ab hativâ illâ aurei ixvi fimplicitate magis receffit : utex Plinio juniore, Floro, \& aliis, non oblcurè videmus. Voff. de Hiftor.Lat.

Arrianu \& Quintus Curtives Go idus utcrque lid nitidior' artin, \& quovis imclle dulcior: : Totorem citius defatigatum quàm fatiatum dimittat: :ententiæe pafim dircta \& oblique, guibus mire illuteretur vita humana. Color in Epift. dc Atudio Peliric. p. $193^{\circ}$

Quintus Curtiws, me judice, probus ent legitimufque hiftoricus, fi quifquam fuit. Mia in lermone cjus facilitas, in narrationibus lepos:aftrictus idem, \&

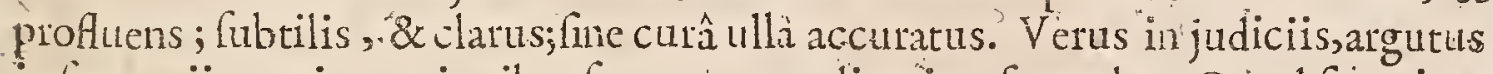
in fententiis, in orationibusfupra quam dixerim facundus. Quiod fi varium magis argumcntum habuilfet; fallor, aut varix prudcntix eximium magis fpecimen prabuiflet. Sed Alexander quid nifi bella 'Lipf. notis ad Io 'Libr. Politic.

Inter Hiftorices Ganè à nemine fibì plus actjumenti poieft promittere eloquentia Politica, quàm Livio \& Curtio. Sicut enim pofterior Livi Curtius Vefpafiani demùm temporibus, ut videtur, vixit, ita optimi avi Scriptoribus xquari \& foitaffe omnibus Ififoricis quodammodo anteferri potcts. Magnificentior Lrvit, Salufti gravior, Taciti profundior oratio. Curtii his omnibus fuavior, tcrfor,accuratior eft. Quod in moribus Livio tribuit Fabius, multo magis Curtio convenit; electiffima cjus verba, civiles \& apte fentcntix, expofitio mirifica, conciones expeditầ facundià inftructx: materiem fuan non magis promptè impletcoratio, ubi opus eft, quàm è pleno, prout decet, difpenfat. Livita cloquentiam fuam prolixiùs \& liberalius vel amare, vel imitari volentihus offert. Curitus haud paulo accuratior ąuabile politiffmi Ryli temperamantum non fimul \& femel, fcd poft iteratam fapiùs attentis demum intentifque 
conmendat. Livius, magnanimo quodim plenus candore, exponreêra fuavitate invitat fimul \& admittit lcctorem : Curtim per quædam admiffionis myfteria \&. gradûs in faniliaritatem adhibet erudiț \& decora ingenia, obviâ tamen fic. quoque \&expolitâ humanitute ftatim idoncus amari, nou enim abftudit graw

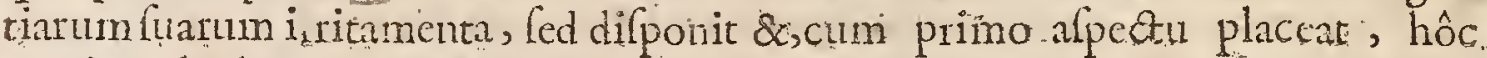
pictio vult placere, ut xelimetur. Seorfim laudarimeretur ( $C$ urtiw) quod non. minus utilen, quàm fubtilem obfervationem habet: rerum aulicarum elegantiam, ipfus Aulx genium, figuras, vultum nemo vel appofitè magis, vel magis ex decoro expreflit. Boecler de Eloquentia Politici:

Non alia, ciuàm belliça,nnrat; Politico tamen homini ipsômet Cafare tantò commodior , quantò difufuror eft, docens nón vincere duntaxat, fed victa ctiams, Ietinere. Termann. Cinrin.de Civ́.prudent.cap.14. pag.330.

Cafaricomitem do 2 . Curtinn, quem adeo inter felectosiecenfere non dum bito, ut inter optimos locumilli libcnter tribuam._Lan. Bernart. de ucilitat. legend. Hift.p.so,

Q. Curius rerum Alexandri $\mathrm{M}$. Latinus fuper omnes Greces diligens, verus, candidus \& profus integerrimus fcripror, fintegum. habcremus. Val. Acidal. in l'refat ad libr. quart.

Curiñ eft argutis, elegans \& nervolus feriptor. Dav. Cbytr. in Chronol: Herodot \& Thy:y".

Hifor icus catcis candidior eftscd Nihil,aiunt, ad Parmenonis jem. Hobet multas fermoris founulas à Ciceronanis diverfe. Erafn in Cireronian..

Indicare mili licet, quia totos 25 . annos in omnibus probatis Authoribus Latinis, Gracis Italis evolvendis infumfi; Totos quindecim annos in perula: Cicronis Oratorem geftavi: Omnium abjectifimus, eft Taciti tzylus, ominimque Eitoniographorum minimus eft. In quatuor aut quinque rebus verfatut totus ftylus ejus, in Antitbefous in Apofopefibus. Unica Qunti Curti pagina

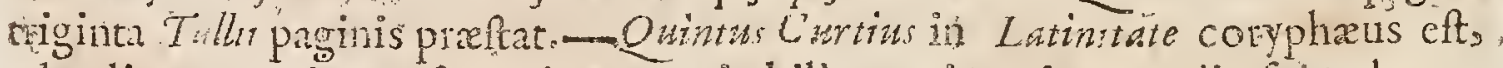
adco limatus, adeo terfus, adeogue mirabilis ut etiam in argutii fuis planus, perfpiculs \& intelligibilis fr. Florum in fupremo poft ipfum ordine faruo, totus . Horidus eft, quàm clegans cft! Dom. Tyronius viri praclarus ad Aylos dijudiGandos Q in o Cutio primas dabat. Perroniana pag.306. Gall.

Mirati fubit quòd primi ordinis Scriptor qualis fuit Q. Curtius Antiquitati kam parum notus fuerit ut nemó reperiatur qu ante modiù feculi XVI. Hiforicis illim anpumeravcrit. Ephemerid. Eruditordie lun. 18. April. I67\&, Gall.

Quintus Citrtiuc eft bonus Author. Jampridem interiat $Q u$. Curtius, quicquid illitus nobisfripereft ex unico Excmplari exfcriptum fuit, omniaque MSS. hova funt.

In Bibliothecat Sancti Victoris primus liber Q.Curtii eratfed deprehendig. effe compofitum à Petrarcha. Scaligerana.

Voluptatis illius, quam ex Hiforicis capere eft,illufte exemplum habemus in fapicutifimo Arragonie Rege Alphon Jo. Qui cum graviffmo morbo labora- 


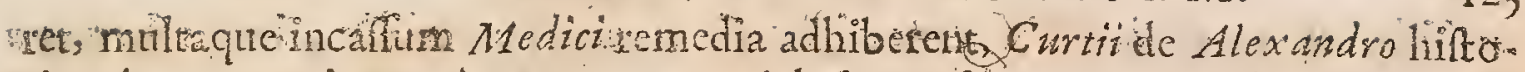
riam legere cœẹir o eâgue tantoperc delectatus. Fuir , ut valetudini refritutus dixiffe dicatur, Valeant Avicenna, Hippocrates, Medici ceteri : vivat Curtius fofpitator meus. Vof. de art. Hiftor. p. 30 .

Quintus Curtius ob finceritatem laude dignus eft. De Alexandro bona \& mala refere, Herois fui merio haudquaquam offufcatus. Si quidin ejus Hitofira rcprehendendum occurrat, nimia crit elegantia; Sed hoc non obstitit quin in umoribus jucundè ac genuinè deppingendis exccllichit. Rapin Reflex in Hift. Sect 28.

Unus Latinorum eft Q. Curtius, cujus fententiæ nec nimis difinduntur, aut difflunt: nec nimis in arctum compactio, aut conftictie negotiun lectoribus ifaceflint. Gafp. Sciopp de Hittorici offic.

Sunt qui Quintzm Curtium authorem fatis neotericum cenfent, putantque eum. -ad majorem authoritatem fibiconciliandam Antigue Roma Cafaribus coævum fe dixiffe. Hixc crat cujufdam cx Dom. Patini Gymnaftisopinio. Q. Curtii no-

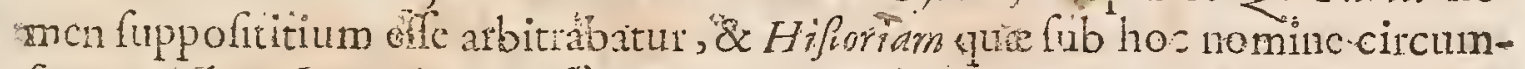
ifcrur, fictam Narrationem effe, quam I talus quidam ant: trecentos demum annos fabricatus fuccrit. Hanc opinionem his, inter alias, rationibus tucbatur, r. quia Aubscrem hunc veleres nunquam citant. 2. quia de Gange"\& In diâ, "\& quibufdam alìs regionibus loquitur, que ignorabaltur antequam aे Geographo Ptolcmeomemorarentur. Sed futtitra funt hace omnia. Quamvis validum \& mizrum quid fit Argumentum dófumptum ex co quòd à Veteribus nunquam citetur, nemini cui aci judicio pollcat $O$ pus hoc adco recens cife perfuadere quis poatcrit. Iam fupra mille quingentos annos nemo amplits Latine fcribit ur : tiftoricus ille, quifquis tandem is fit:Quamvis in Geograpbi is alicquando hallucinatus fit, inde non fequitur cum che neotericum; Hoc enim fundamento Titus Livius, Heradoutus omnefuc Veteres Hifto ici miftci cenferentur. Novell. de Rep. Liizeraria, Tom.2.p.25:, 253 .

Q. Curtii Kufi Hiftoria Alewandri M. prodiit-cum notis Variorum, Raderi, Ereinshemii, Loccenäi, Bilanchardi, \&c. Amftelodami ox officinâ Elzevirianâ 济 673 . in 8:

\section{EPICTETUS。}

D Hitofophas Stoicus, cr Hierapoli Phrggie urbe, Rome Epaphrodico cuidam Neronis familiari fervivit, atque ad Marci ufq̨ue Antonini tempora perveClar. A. D. LXXXII。 hilt : Domitiano autem impcrante ejus dominatu offenfus Româ Hierapolin migravir, ratus verum elfe quod eft Tragicum, Patriam effe cujufque, ubi quis stectè ageret. Tanta verò apud omnes homines ejus vitæ aủmiratio extitit, ut - Incianus Syms , lucernam ejus fictlem tribus drachmarum millibus, ob ejus authoritatcm, vaniffe tradat. Hofman.

De Senecá habes: clarum aliud lidus fe oftendit, Epictetus; ævo, non merito,

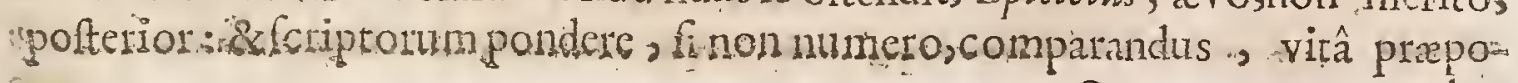
$\therefore$ $Q \Rightarrow$ nendus. 
mendus. Illc vir totus à $C_{e} \&$ à Deo, nihil à fortuna fuit. Origine vilis, \& inter Crvos; corpore claudus ac debilis; mente nobilifimus, \& inter omnis xvi lìmia refullit. Vita emendatifima fuit, \& planè alfcitum, quod in ore habebat,

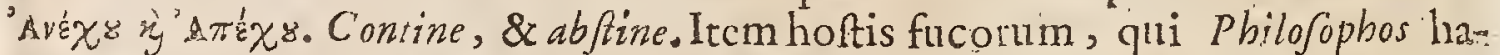
bitu \& verbis preferrent, vitâ dcgenerarent: quos ille appellare folitus Pbilofopiso fine factis, dictorum tenus. Lipf. in. Manuduet. ad stoic, Philoloph. 1. I. Differtat. Ig.

Scripta ejus pauca extant : Enchiridion fanè egregium, \& Stoica molalis Philofophix velut anima : item Differtationes, quas obiter in viâ, domo, Scholâ: habuit, ab Arriano collectre \& digcttix. Neque omnes ctiam extant: in Agellio \& stobeo reperies, qux hîc requitas. Sed, Deus bone,acrem \&altum in is fpiritum : accenfum animum, \& bonefti amore ardenrem! Nihil in Grecis, aut falo lor, tale extat: à duabis illis notís dico, Acrimonia \& ardore. Tironem aliquem \& rudem veræ I hilofophix vix afficiat auc tangat proficiëntem aut pror vectum incredibile eft quàm excitet, \& cùm pungat ubique, tamen etiam dem léctct. Genus ftyli concifum, fraetum eft, \& quod indolem fubitariffermonis habet: Sed docta interveniunt Lape, Smper. falutaria, \& non eft qui bonam Mentem magis aut trahat aut formet. Ego Smecionern illum nunquam lego. nifi cum interno animi inotr: $\&$ quod Hornero proprium, pluris facio cum relggo, fcmper ut novium, \& cum repetivi repetendum. Lipf. ibid.

Sermo in co omnitio efficax eft, atque energix plenus, \& in quo mila fit ad. promovendum vis.s. Stylus autem, qualcm res pofuliret, concifus eft, dilucidus, quique omacm refpuat ornatum Politian. iti Epict enchir.

Epicteti fungula voces Troclo; Simplicio, Luciano ipfi oraculorum inltar Cunt. Morneus de veritat. Rel: Chrifian. cr.30.

Epictetum magni xltimabat?. Angufinu:

Epictetus Philolophi famam minus aucupatur Philofophatur noliù Morno. de veritat, Rel. Chriff. co. 20 .

Eprizeti fcripta dürregimus iñ diverfos imò contrariós affeatus inpimur, ctiam nonnunquam inviti. Nunc enim gaudemus , fummâque perfundimur

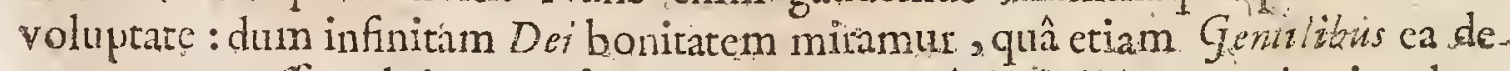
mo: thw nota efle voluit, qua fummam cum noftâ doctrinâ convententiam habère videntur; nunc rurfus contritamur maximoque afficimur dolore: quando cernirnus, quantò turpius in medio Chrifianifrno vivatur, quàm olim eftactum ab Epictcto, cique fimilibus alis : qui gratiâ tamed fpcciali Divini piritus (qux, nif nolentibus, nobis non deef) imbuti non fuere. Henr. Iul. Scheurls Bibliogr. Moral Impreff. Helmftad. in $8^{\circ} .1686$.

Unum hoc Enchiridium plus moribus hominum formandis valet quàm univerfa Artfotelis Etbica, imò \& omnium poft illum Philofophorum, qui Moralem Philofophiam magnâ.verborum pompâfcriptis mandarunt. Abrabam Berkel. in Epit. Dedic.quæ Epictet. Enchir. præmittitur.

Exiguum quidem eft volumen (Enchiridion) verùm non ex mole, fed pra

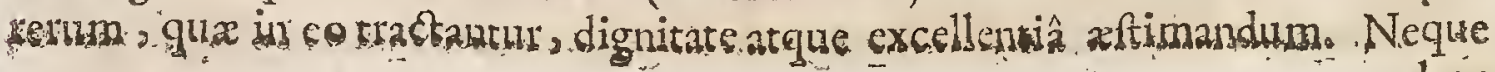


hoc latuit Antoninum Illuftriffmum, \& optimum Romanorum Imperatorem,

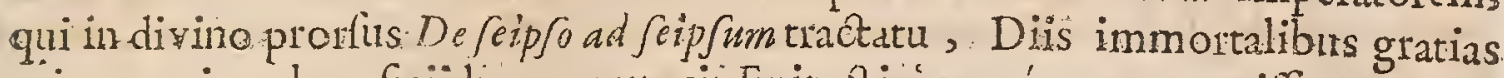

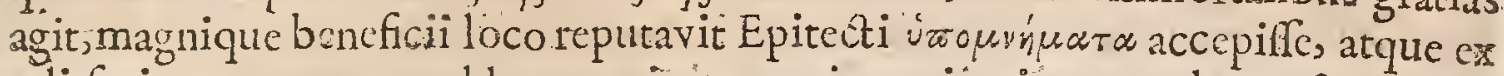
tali fcriptorumgenere ad beatam in tanto imperio vitam multum fructîs urilitaris percepille. I dem ibid.

Encbiridion illius fanè egregium \& Stcice Moralis Philofophia velut Anima. Lipfus. Gravis herclè rerum magis pondere, quàm mole magnus liber \& exofculandus., nocturnâ diurnâque manu verfandus. Remus ad Themift.

Epicterici Endhiridion moribus utile, differtationes graves prudentix plenæ. Dempfer.

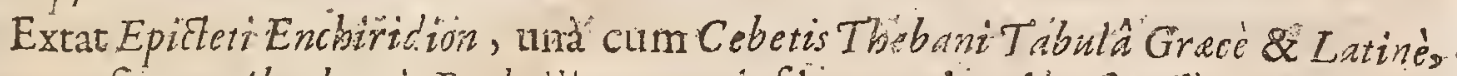
ex recenfione Abrabami Berkeliz, cum ejufdem animadverfionibus \& notis: quibus accedint notx Wolpbit, Cafauboni, Cafelii \& aliorum, cum Grack̂.P. rapbrafi. Lugd. Batav. Ann 1.670 . in 8 o.

\section{N. VA LERIU S M A R T I A I.I S。.}

T Ipanus, Bilbili in Celtiberia natus tempore Claudit Impcratoris : fub Nerone annos natus 20. Romam venit;atque annos iftic cgit 35. Tito, ac imprimis Domntiano carus fuir, à quibus \& donatus jue trium liberorum. Etiam Tribuns, Q Equefris dignitatis fuit. At non item hon hore fuit mortuo Domitiano. Inque fub. Trajano in patriam rediit: atque ibi confripto libro Epigrarnatum duodecimo, partim txdio patria, quianon in honore elfet, quanto. Fucrat Rome, partim etiam à civibus fuis fugillarerur, tredio vitæ. ut verifimile

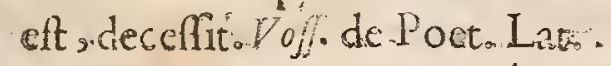

Libros I2 Epigranmatôn compoluit milo ingenio, \& fingulari urbanitate. quibus adjecit $X$ 'enic, a $A$ popboreta libellis duobus abloluta. In his fecutus ef Marfum Poctam, Pedonern, atque Getuli um, quorum exemplo Ceipfum tuearr, ac lafcivam verbortm licentian excufat: Petr. Crinit.

Erat homo ingeniofus, acutus, acer, \& qui plutimum in fcribendo \& falis haberet \& fellis; nec candoris minus. Plin. Epitt 1.3.Epitt.2r.

elius Verus Impcrator folitus ef fingulari affeceu profequi Lepótes atque jocos poëtx. Martzulis; fuumque Virgilinir vocare...

Jalerius Martia!'s artificioflfimus Eprgrammatum fciptor, ita in iis quidem jocatus eftur frequentiùs carpat, quàm delectet : tametfi è demorfione ipsâ delactatio quoque painur. Adhæc Dictis ejus partim oculatifima quadam infune fpicula; partim verba qua non folum à faceto fintaliena, verùm aut obfcon ipfa admodum furriliaque, aut maximè ampullofa, \& acida. Qu od quidem Hipparicum eft. Sunt tamen dicta ejus in univerfum arguta, fubtiliterque conquifita; abltufa fententix, exedemque rara, falfa; aculcata: inventiones verò maximè acuta: vcrba prxcipuè accommodata, quaque non primâ tantum fâ cie, atque in iplo explicatu, lectorem alliciant, atque auditorem:verùm "qua in ejus animorclinguan racitam quandam quafi fubtitillationem. Nihilo tamen 
minus iis, non pauca quidem alimadvertas, qux digna prorfus funt factis ac temperatis ingeniis : retincantque decorum illud, quod virtutis hujus, dequa pracipimus, maximè eft propiium. Locin. Pontan.1.3. de Serrione, cap I8.

Martalis unus Epigrarmatis Genium videtur polfediffe. Dempt.

Martialis ad Nafonis facilitatem plurimùm accedit, \& aliquid Ciceronians laudis illi potcrat tribui, in libros allugut Epiftolis prefatus ellet , Deum im mortal -n, quàm non Ciceronianis! Erafm. in Ciceranià p. I 47.

Maria islcpidiffmus Poeta:neo enim illis affentior, qui farram incptum

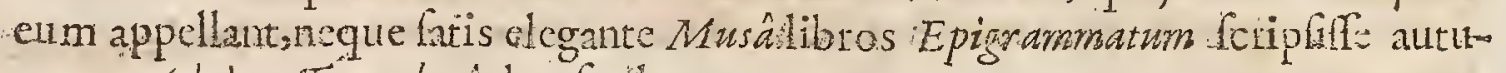
mant. Adrian.Turneb. Advcrfara.1.5.c. ig.

- Epigrammatis vintites peculiares, brevitas $\&$ argwia, hanc $C$ atesllus non femper ef affecutus; Martinlis poetzargutiflimus nufquam omifit. Inl. CefaScaligo loetic 1.3.c.126. Multalunt cjus Evigrammata divina,in quibus \& fermonis caflitas, \& argumenti fpecies luculenta eft. Verfus:verò candidi, numerofis pleni, deniyue optimi. Alia foed ne legerim guidem tantum abelt ut ad cenfuram vocem.Iderribid.1.6.p.838.

Quiid cenfestu.? non melius de $M$ artiale Scoliger judicavit , qui verius cjus candidos, numerolos slenos, Eptgrcmata multa divina dicit: guàm ille, quå Scurram de trivio appellat. Nollem excidifet viro magno hoc judicium judicii difimile. Nihil ad Catullum Martialis, Scio:fed \& hoc Ccio., Epigrammata illa necin trivio nata, nec ominia in triclinio. Multafoda, oblcona in Martiale: \& meherculcoin uno Catulh libello non pudiciora, fed pauciora. Ignorat fecim lum illud, qui hoc acculat. 1. Lipf. 1.r. Epift.Quxh. Epilts.

-Reliquit Epigrammatam librum omninò rejicicndum, quippe qui navie elegantixe latinæ neque maribus pioft. Raph. Volaterra\%. Comment. Urbarn ilib. I7.

Faceretë reliterariâ, fi guiis more vetcum Criticorum, delectum Epigrammarum ejus haberct, \& benis affigcret laudis notam, aliis culpr. Potuiffet hoc Douza nolter, qui Poetam iftum non folum feliciter exprefits fed ctiam correxit. Iuft. LipS. ut füpra.

Martialis iis, qui Epigrammata volunt Lcribere, \&legendus \& imitandus eft: nihil enim in tllo genere reperiri poteft terfus argutiufque. Et multa lunt ejus nonfpurca, quale illud de Santra.vid. Vol.4.Grot oper.p.74o.

- Epigrammata cjus myuta pleraque funt; 8 acuta, fed \& fapè pro obfcenitate purida, indigna qua oculis caftis obferventur: unde Ingo!fadienfis editio à Iefuitis procurata obfecena illa mcrito ampitavit ... Duo priores libri, qui $\beta$ pertaculoram nomine circumferuntur, alterius 'fcritois habentur fotus, venime Xenia \& Apopboreta communi confenfu cjus funt. Borrich. de Poet.p. 63,64 .

Martialern Bilbilitanwr quàm iniquè tractmunt nonnuli ! Hunc vilem è trinio Scurram pre Catullo vocat Mretm. Ejus Eprgrawmata. Afinis placere. aiebat Lil. Gyratias. Eorum cxempla, quot nancifci porerat , guotannis cum execratione Vimcano dicabat Andreas Nangerizs.

Martiolis Bilbilitanus atr ob peregrinitatem .Hipanicam nonntlis, fed 


\section{CELEBRIORLM AUTHORUM.}

malidicis cenforibus, vapulut - Laude tamen Elegantiarm Latinarm minimc̀ privandus eft Dan.Georg. Morhof. De Patav. Livian. p. 160.

- Latinum Eptgrammin, depravato judicio, quod graflari copit cúm pura Larinitu jam labafcerct, animos argutia aliqua, qux ancuminis nomen fortita eft. tirillare tcntavit. Marialis acuminuin in vocibus author quodammodo fuit, teminando nimirum vulgarem fententian alicua yoce inaudito modo ufuruata. Rapin. Reflex particul. in l'ocf. Refl. 3. par.2..

M. Fal. Martialis Epigrammata prodierunt cum notis Variorum accurante

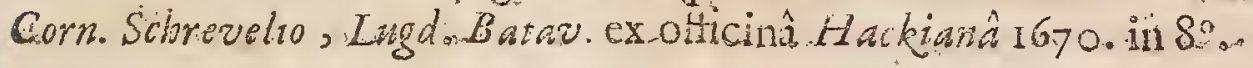

\section{A.R G S. F A.B I US QUIN.T. L I A N U.S.}

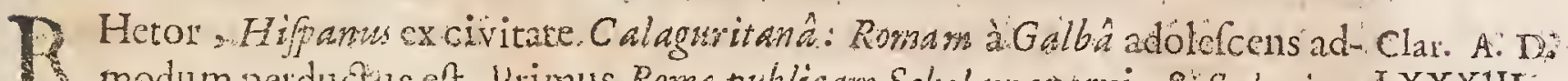
1. modum perductus eft. Primus Rome publicam Scholam ap ruit, \& Salarium IXXXII êffo tulit, eoque dives evife. Incidir ilius atas incatempora, quibus inclimatio quadam Scrmonis Romani ad barbariera fieri coperat Carol. Stephan.

Caceronis \& Qumiliani politifma funs foripta qua nihil fupervacui nihid impediti, nihil non ad Artem $x$ retoricam pertinentis complecuntr. Sanc̀ pervulgata quadam Rhetorurn pracepta negligens pracermilít, aut brevitevper-

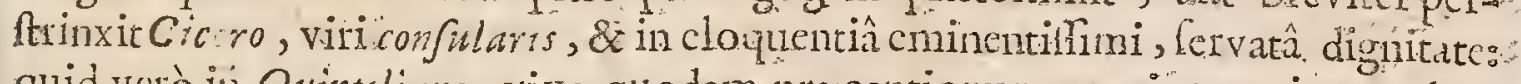
quid verò in Qumtrliano, vivo quodam praceptionum omnis generis exundante gurgite, quod velad mores, yel ad docentis dicentifue utilitutern pertineats defiderare poffis ? Quo magis Cicérons quibudam fmilis , nihil ejus pratel umbram \& larvam habenribus, infenfus fum, qui Quintilianum prolixum, \& nullo certo decentem ordine clamitantes, de muibus ftasi 2 forurn excutero meditantur. Cujtis mentem, \& fuceptam à principio ad finem infiruendi rationem, fintentis oculis acrius intucantur, facilcobltinatum in pravâ fententî̀ animum mutavcrint. Tuntà cnim facundià, diligentiâ, dextcritatc, induttriâ ab in is furdamentis ad fumma fatigia partibus omnibus expreffam hanc Elequentio Architeduram compcrient, ut pravisaffectibus depolitis, facilè confeluri funt, wihil in co generc ne mente quidem \& cogitatione perfectius concipi polfe. Petr. Galand. in Epift. Petr. Caftelinn.Fab. infitut.prafix.

Nemo potef Quntilianum intelligere, nif Cuceronerm. optimè teneat; neque: Ciceroner probé fequi, nifi Quintiliano pareat; necunquam fuit quifpiam eloquens pof Dimitianum, necelfe poteftnifi quife totumarti ejus formandums. imitationique tradiderit. Lawrent. Vall. 1.I. Antidot. in Pgg.

Nos quidem Quintilianum magnz cruditionis, \& elegantis judicii fuiltes agnofcimus; ac de quo ferio illud dici poffit, amalfe eum bonam mentem :'venrùmenimycrò dolcndum planè, quòd vir maximus totics re leviculâa deceptus : recedat ab Ariftotele Rbetore longè fe perfpicaciore, quifolus, non folù de arte, ficd etian ess arte, atque adeò artificiofifimè fcriptit, ac cui, ut omnium optimo, optimè optimam operam dari putamus. Vofj. de Rhetor. c.6.

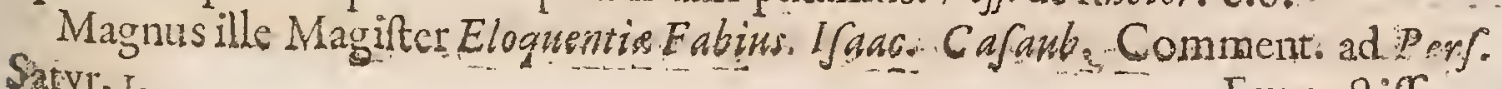
Satyr. I. EmHEtignas 

ling. p. 30 .

Emunctiflma naris \& judiciivil Quintilianus. Mer. Cajaub. De quxtc

Eabius: optimusinfituendx pueritix Artifex. Vojf. de Ant. Hin. p. 32. Gloris Romane Toga Quintilianus. Martial.1.2.Epigram.go.

Qui omnibus omninò Scriptoribus $M$. Fabium pratulit, non ille quidem abs satione audader judicavie. Nulla enim virtus Roxnani $S$ tyli eft, quam non expleat ; cìm quicunque ex cateris fummam attigêre, habeant finguli tamen in que vel abundent vel deficiant. Barth.1.31.c j.Adv.

Duntilianus omnium, qui unquan fcriplerunt, auctorum eleganrifimus. Barth.prafat. ad Gratium.

Cicoroni Quintilianumadjunxit Laurentivs Valla, tanquam comitem, aut we riùs focium, paremque, non omninò injuriâ, cùm verborum munditie, tum Erantationm, \& cotius dictionis acumine. Lud. Vives de Tradend. Difcip. 1. 3 .

Quintiliands affectavit Ciceroni diffinilis elfe. Cujus utinam extarent Declamationes; nam quas habemus, minimum habent Ciceronis. Erafm. in Cicerowhen.

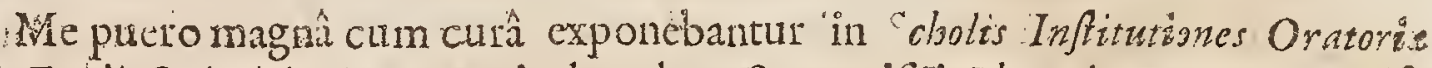
M. Fabii Quintiliani, accurari admodum \& exquiliti Rbitoris neque quifquam fatisbonus dicendi Magifter habcatux, qui non inillis vel precipuè aw ditores fuos exerccrefolitus effet. Marc. Ant. Mure - 1. I8. var. lect. co 20.

Miro quidem candore veterumingenis virtutefque omniumindicwit. Seneeam tantim damare, invilumque habere eft creditus: quod accidife fibi iple fcribit, dum coruptum, \& omnibus vitiis depravarum dicendi gcnus revocare ad feveriora judicia contendit. Nam cum folus ferè Seneca in manibus adolefcentium foret, non quidem ipfum omninò conabatur excutere, fed potioriBus praferinon finebat. Anget. Polition prafat.ad Quintit. Infitut.

Quintiliano nemo artem oratorianinter Latinoselegantius adernavit, annon Hifpanus? "Q hunc tamen, fi Ciceronemexceperis, omnibus proferre non dubitart nonnulli, etfi Pbolephus in illo $H$ ifpanitatem inveniffe fibi vifus eft. Dan. Georg. Alorbof. de Patavin. Live. p. 160

Extant M. Fabii Qnintiliani Infitutionum oratiaum libri duodecim, cum

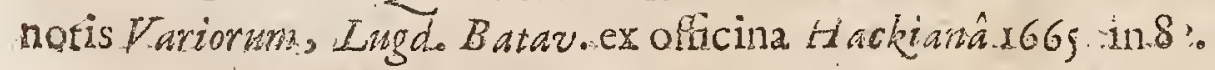

\section{SEX TUS JULIUS FRONTINUS.}

Cir. A. D.

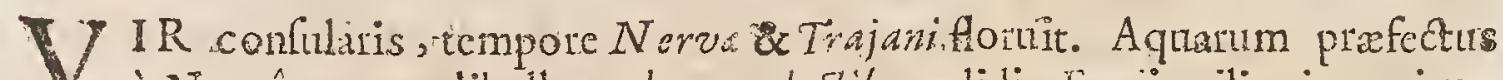

à Nervâcreatus, libellum de aquándibus edidir Etrei militaris peritus Trajano libros strategematicos dicavit. Moricns vetuit fibi fepulchrum conftrui. Ioan. Maria Latan. comment. in Epint. Pin.1.4. Epilt. S.

Inlius Erontinus maximus Geometia. Hieron. Mag. 1.4.Mifcell.c. 2. Serius \& minimè verbofus Autor. Barth.1.2.Adverfar.c.I.

Aulizs. Frontinas clegans \& difeatus fcripto: Ihom.Dempfter.in Elench Scripto 
Ipfa itrategcrata quibus Imperatores \& milites in bello, vel in ipfo pralio uti confuevere, \& at fuitutelam. \& ad hoftum perniciem, patum in operibus Luis (ii, qui de re Militariforipgerunt) attigiffe videntur, prater unum Fron'inkm, virum confularem, qui latis commodè , Catifque abundè ipfe defcriplit Strategemata. Iacob. comes $P$ urlitiar. in procm.libror.de Re Militar.

Inlias Erontinus ftategemata per Rornanorum hiforiam diffula, dictione facili, atque ordinatifimâ temporum ferie digeflit - videturaliquando Front nus non fatis elcgans, \& nonnunquam parum latinus fuilic, fi delication m quorundam aures coufulamus. Dilcrepat etiam interdum ab aliis fcriptoribus in rew rum gefarum narratione, dubium, errore, an conflio - ex quibus (Frontin Strategenatis) fane plurimum frugis percipere polfunt exercitum ductores, gııos ille acuit, cum ad infidias parandas, tum ad eas evitandas. Huic ctiam auctori debemus nonnullorum Militarium vocabulonm explicationes, quas abfque illo eramus, igneraturi. $B_{a}$ th balg: Bonifac. in excerpt. Rom. Hiftor. Script.

Scous Iulius Fronizus ftrategematum libros confcriphit in quibus ex omnibus Hitoricis exempla, in certos libros dittinata, cnumerat copiosè, \& magnâ. cum utilitate; licer pleraque, librariorum errore, ineptè fint repetita. Carol. Sigon. de Hit. Roman.

Iulius Frontunus de Agueductibus, \&ad locorum urbis notitiam valet, \& ad

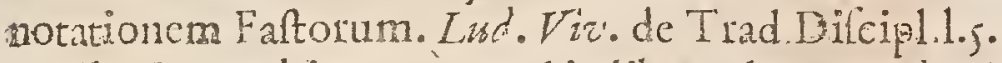

Elogium urbis Kona quod in libro de Aquedultibus leoimus; (Regina oم Domina orbis, que Terrarurn DEG Gentiumgue confifit, cuipar nibil, \& ibil fecundum) non Frontin effe fentir Lipgrus. Vereor (ipquit ut allitum adfíptumve aliena manu fit; \& gravis atque ertiditus reliquus Frontini ftylus non probat aut amat laciviam poetarum. Lipf.De Magnirud.Roman. l.r.c.2.

Extant Sexi Intiv Frontmi opera, cum notis \& emendationibus Roberti Kewchenii. Amftelodari i 1661 . in 80.

Vetuit fibi cxltui monumentum his verbis : Impenfa Monumenti fuperFacanca ef: Memoria nofti durabit, fi vitam meruimus.Erafm.lib. Apoph.

\section{PUBLIUS PAPINIUSSTATIUS.}

T Eapolitanus, fub Domitiano vixit : fed perperàm confunditur cum Statio - lioetâ, cognomine Surculo, qui claruit lub Nerone, ac Tolofen iss, in Galliis fuit. Reliquit quinque Sylvarum libros, I2. Thebaidos, 5. Achilleidos. Mirum verò Martialom, cum adeò celcbrat Stellam Poetarn, non meminife Stati, tainti amici Stelle, ut ei milerit primum Sylvarum. Nempe ab invidiâ id profectum videtur. Non ferebat Martialis Papinium tantoperè in gratiâ efle apud Domitianurm, idque ob extemporalem in carmine felicitatem, quâ Marialis longè vincebatur. Parum amicum fuific Papinio Martialern ex eo colligitur, quòd munquam æqualis fui meminerit : tum aliis qux legas apud Gevartium ad x. Sytzaruw. Yogl: de Poet. Lat? 
Velles Papinatur Stattum tam dextro ingenio Thebas fortiffinumque Acbitlem, quàm: Sylvas decantaffc. Sinon majus nomen, majorem certè gratiam inde: hauddubiè reportaffet. Nulli unquam Poetartum, quod fciam, magis prop rium fuit, Subito cettro incalefecre, atque ubri incaliuiffet, fortiǹs feliciúlque debacchari, ut quantumcunque $P$ bobum hauferit: acnefcionan etiàm majorem; odem. calore confeftion reddat. Cuperes, dixi, omneme ejus operam in. Sylvis locatam, nihil eft illis amabilius floridius, magifque poeticum. $M$. Anton. Sabellic.

Statiw: cultiffmus atque ingeniofiffimus, Poeta. Neque ullus veterum aut recentionum propinsadVirgilizanam Majeftatem accedcre valuit. Etiam propinquior futurus, fi tàm propè effe noluiffet. Siquidem naturâ fiầ elatus \% ficubi: cxcellerc conatus eft, excrevit in tumorem. At profectò Heroicorum Poetarum (fi:Pbanicerfillumnoftrm eximas) tum Latzinorum, tumn etiam Grecorum facilè princeps. Nam \& meliores verfus facit quàm: HEomerusidul.Caf. Soaligo de te. Poetic: 1. 6.p. $8_{4}, 8_{43}$.

Virgiliane Eineidos felix imitator Statius: Henr.Glarean.not. in Térent . fine: Eunsech.:

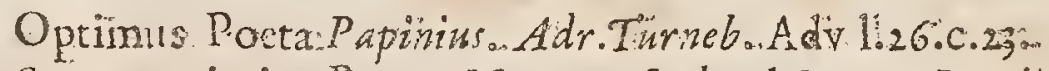

Statrus, eximius. Pocta: Ifaac. Ca aub.ad:Sueton.Domitian. Statins gerrerofus. \& fubitocalore admirabilis. Steph. Clever: adclandian.

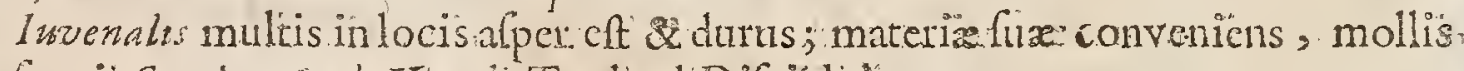
\& firavis.Statius. Lud. Tivo de Tradend.Difcipl: 1.3.

Papinius fublimis, \& celfus Poeta, non heralè tumidus. Lipf. Centur. so. Epift...3.

In Statio luxuriaingeniinou indecora. 1 dem ad: Anuali Tácit. 53

Statiws eruditus ii Sylvis, fublimis iil Thebaide, blandus in Achilleide. Thome. Dempti..

Papinius in libris Thebaidos ad bellumbellifimè defcripfit. Andt. Tiraquella. de Jure prinog nit.cin: Sedt.5.

Papinit Starit Syluzs, quò freiùslegas, càmagìs magifque \& admireris \& ames. Admireris firititum 'soericum; ames judicium \& floriditatcm charact co ris, du out fumma, ita ravilfina:vatum argumenta feliciortum. Bartbius Adv. Is. 12. C. 4 .

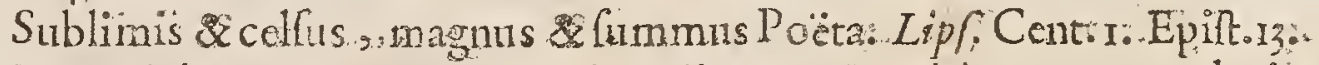

P.Papinins Surculus Stutitus . Neapolitanus, Domitiano gratus, plurima quiedem fcripfit, \&eruditènatque füblimi charactere omnia,fed quorum non pauca? interciderunt; etiam illutt is illa Agave, Tragoedia, quam egettate cogente Paridi vendidit; ut pro fuấpublicaret. Hodie V. Sylwarum ejus libros, 12 . Thebaidos, \& Achilicidos duos.numeramus, in quibus dỉctio ubique ferè florida, electias, magnificas in Sylvis tamen purior, \& magis nativa, in Thebaide calanittrata magis, in Acbilleide inequalior. Quxecaufa eft' cur inter. Poetas Statinm id effe prontncient nommulli: Criticorum, quod Alexander Magnus inter Heroes, hoc: êt, virtutes magnas magnis viriis mifcuiffe, \& modò Cotburnis aptiflimè ince-

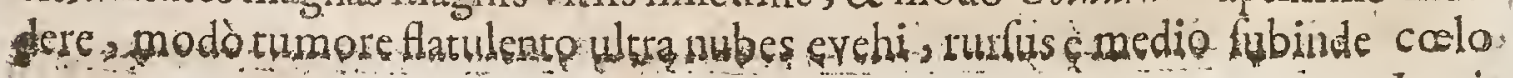
I. $\operatorname{car}$ is 
Ecariotaplu decidcre. Cerce Famianis Stradanon inepte fungit Statium in fun mo.cacumine eminentioris Parnafjucollis confidere, fedità periculosè , ut :Scmper videatur Iapfuro Timilis. Borrich de Poet.p.62.

Papirinm, vir doctifime, inagni feci femper, ut qui Virgilio omnigen ertuditione haud multumecda, (piritu autem Poctico certe quibufdam in partibus, fi percritco diccre lic at, dubiam eifaciat palmam. ing. Grot. in Epift. ad Granov. Lurct. 10. Decembr. 1637.

Jef. Rapinus cumpertringit quòd Poefeos elfentiam in verborum pompa \& magnificentia potius quàm in rebus pofucrit; alferit cjus carmina aurem quim dim implcre, cor yerò minimè penetrare; eum xquènfolentem feu ablurdum alfe in fuis ideis ac in earum cmunciatione; Duobus ejus locmatis ninil regulare -inelfe, fed omnia nimis yata, dcbiteque proportionis expertia. Denique Stetim pra Vireilio merum effe furiofum alleverar. Hat variis locis apud Rapinum legi pofiunt.

Starma publico donzvere plurimi; folficitè Io. Bernurtiw cum Cholis in Thebaida, \& Achilleida, notifque in Sylvas; in quas cxtant quoque Commentaria F. Morell 8 Frid. Tiliobroge, atquelectiones Papiniun Cafp.Gevaria. Notas adjecit Emmericus Crucen, \& diatribas Gronovin quibus Antidiatribat Crucens cppofuit Excuriofifris hodic ceitionibus illa habcur, qua è Bin

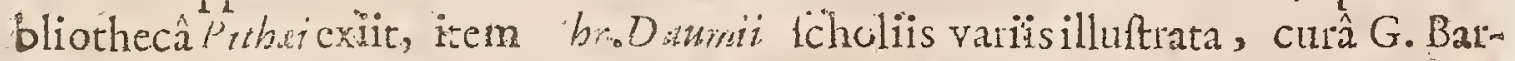
thii, \& deniqucultima, quam $I$. Veenbuy en cum notis variorum divulgaviso Lugd. Batav. ex officinà Hackianâ An. 167 I. 8:

\section{FLAVIUS JOSEPHUS.}

TH Xegio \& facerdotali fanguine editus, Matathic faccrdotis flius, ( quen Clar. A. D. I. Hieroigmus Gracnm Lizium appellat, recentiores verò Iudoi lofephin X CI V. Bengorion vocans, ) Hatione Hebrau, patriâ Hierofolymitanns, genere facerdos, in cxcidio Hierofolyma captus, Romam à Tito Is: peratore ductus eft; ibique propter ingenii excellentiam à Senatu \& populo Romano promeruit, ut eo vi-vente libri cjus publice Bibliothecx traderentur, ipli verò polt mortem enea

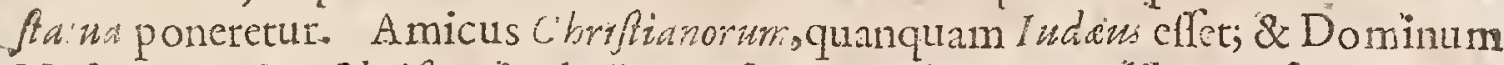
Noftum I efur Cbriftum in decimo octavo Antiquitatum libro infigni clogio celebravit: quâ de causẩ $D$. Hieronymu eum in catalogo Ecelcfiafticonm diynâ cumlaude recenlet. Sext. Senenf.

Scripfrt Judaicarum Anriquitatum libros 20-De Bcllo Judaico libros 7.-Contra Appionem libios 2.-D-De Maccabris-_-Vitain fuam.

Multa quoque alia adfert, quibus frdem hiftorix fuxconciliet : imprimis, quòd prope omnia oculis fuis vident: cxtera ab iis acceperit, qui ipfi rebus prafuevunt-m-mQuantum autem fidei mercatur, minimè nunc convenit inter enuditos. Sunt quibus ufque adcò fides ejus fuípecta fit, ut planè fufque deque habcant, quid Iofephm dicat, dummodo vel alterius qualicunque autoritate, vel.

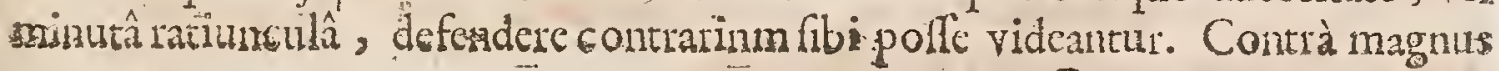

$$
\text { R } 2 \text { Sraliget. }
$$


Scaliger Prolegomenis ardui operis de Emendatione Temporum cenfet, ubique: elucere Iofephi \& erulitionem, \& fidem, in tanium, ut non folunt in rebus. Iudacis, fed etiam externis, tutiùs ei credatur, quàm omnibus Gracis ac Latiris. Iroff de Hiftor. Grec.

Flavius Iofephus, autor omni laude dignus, \& cui pof Sacrorum Voluminum: fcriptores prima effe debet fides, - etfi gravitatc fupra cunctos. Indoos eminet ramcn haud ubique à deliramentisabhorret popularium fuorum. $P$ etr. Cunens de Rep.Hebroor. 1. 3.c.I.

Cujus amor veri notiffumus, fites confantifima;nifi quid illi fortalfe huma. nitùs errare contingat; qux exceptio locum hîc non habct:cui ad penitus cognofcenda illa de quibus fcribebat, omnia prefidia abundè fupetebant. Nam aut ex actis publicis illa defcripfit,aut ex ocularấ fide. Cafanb. ad Baron. Apparato. Annal.

Nullam occafionem prætermittit Baronins, fve juftam, five injuftam, detra-

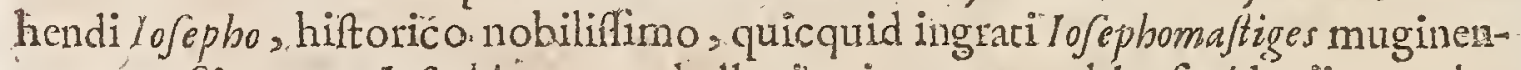

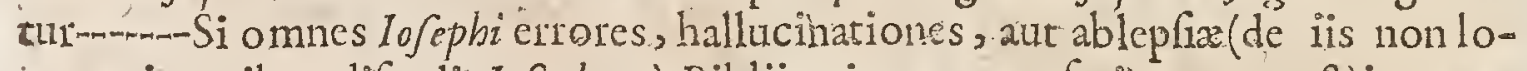
quor, in quibus difcedit 10 ephus à Bibliis : in quo excufari non potertin unam fummam contrahantur, vix centefina pars ea fuerit culparum ab uno Eu ebio admiffarum, frve in Cbronico, five in aliis fcriptis. Cur igitur tanta cura \& tanta c u iniquitate Iofepho infultabimus a cujus librosnifi providentia Dei fingularis ad oftra fervaffettempora, in quintis rerum I wdaicarum tenebris hodie verfaremur? quot fabulas, quot mendacia jubar. Hiftoria Iofephi difcutit? At errat Iofepbus interdum manifeftò.Sanç:homo enim erat.Idem ibid. Exercit. I2. Aun. 28. Num. 2 a

Is in omni Latinorum \& Grecorum Seriptorum genere verfatus, omnem Gentiliurn hiftoriam \& chronologiam excuflit \& perdidicit : ideoque ab iftoruma Hebroorum ineptiis.emotifimus fuit Poffevin. Biblioth. Select.1.2.c.25.

Miratur. Do Hieronymus in homine Indico tantum Grace, Antiguitatis fuiffe.

Si quid meijudicii eft, Io ephum habeo prudentem probumque Scriptorem: Lips. Holiorcetic. L.5.Dialogis 2o.

Inter omnes verò, qui fíftoriam Herodianam attigerunt, palma debetur. citracontroverfiam Flavio Io epho, homini quidem Iudeo, Hiftorico tamen. eximio, \& rara tum diligentiz, tum fidei, \& cui major adhuc xtimatio deberetur, frquidem temporum \& librariorum injuriis minus obnoxius. fuiffet, \& purus ac integcr ad manus noftras pervenillet. Frideric.Spanbem.par. 2. Dubior. Evangélic. Dubio 2.

Utinam diligentior fuiffer Io fephus \& religiofior in Sacrâ. Hiftoria Ccribenda: Gearg. Horr. not.in libr.2.Sulpit. Sever. c.8.

Iofephus multa, invidix declinandx ergô, ut gratioua ellent auribus Vepafiani \& Romanorum , prætevit. Catera ad pompam detorquet. Unde plurima habet. qux difcrepant à Scripturâ, \& ei contraria funt. Cornel. $A$ Lapide not.in libr. I. Sulpit. Sever.c. 42.

Deftylo ejus ita cenfer Photius effe eum candidum, purum, elegantcm, ac jirt. cundium inconcionibus etian difertum. 
Flaviz Iofepbi Ápologia, qua extatadverus Apionem, ufque ad miraculum eft erudíta.C'unazi de 太ep. Hebr.p. 2.

Quod Hebrei dicunt,teftimonim illud de Chrifo ư fuis libris non haberio. \&ideo videri fuperadditum à Chriftianis;acilè iefeli potelt. Nam Hebrei non habent lofephum filium Matathic qui Gracéfripfit libros Antiquitatum, de quo nos loquimur, fed Iofephum flium: Gorionis, qui aliquid fimile. fcripfit Hebraice: proinde noneft mirum, fi Indet in fto Iojepho hoc teftimonium non tabeant, cùm in no? ro habeatur, \& non fit fuperadditum; fed. verum \& germanum Iofepbitêtimonium:Certè fanctus Hieronymus \& Enfebins viri doctilimi: fuerunt, \&\& omnes penè libros vcterum fcriptorum legerunt, \& Tefimonium de Chrifto Iu ephotribuiffent, nif lcivillent vere ab illo auctore ita fciptum fuife. Bellarnin, de Scriptor. Ecclefiatic.

Dehoc lofepbi loco, gcnuinufne fit, an infititius, gravis nuper exorta eft controvcrfa. Hoc tefimonium cnervare nititur vir doctiflimus Tanaquillus Faber in cpiltola critica p. I:6. Confirmatautem.Ifaacus Vofjus, quem vide.

Iosephu in Hiftoria Indaica fupprimit miracula vera, zt Ethnicorum, qu: illa non credidifient, animis fefe attemperaret, \& eventus minus veros, fupponit quiahos illorum guftui \& ingenio convenientiores arbitrabatur. Rapin Reflexion. Hift. Sect. 27.

Mirabiles defcriptiones Hiforiams ejús onant, eloquentifimz Onationes, \& preclarifimafcutentiz: Narratio ejus perfpicua eft atque fidelis; Non modo lectores fuos delectat, fed ctiam trahit in optatam partem: Cupitos affectus in eis concitat aut fedat: Denique Hiftorici abfolutinumeros omnes continere dici. poteft, meritoque Grecorurn Titus Livius nuncupari. Tractatus de Maccabais ingenii ejus præclaras dotes \& ejus eloquentix magnitudinem prodit : Ejufquelibriadverfus Appionem quam acris judicii, profundeque eruditionis fucrit ma: nifeftat. Ell. du Pin. in Nova Biblioth. Author. Ecclefiaf. Tom.I.

Io fephiteftimonium de Ie u Chrifo refertur ab Eufebio;à Divo Hieronymo \& ab aliis pluxibus poft illos tang̨uam monumentum quod Religioni Iefu Chrifti non mediocriter faver: Scd atate noftra res exactiùs penderatz fuerunt, plurimi jam fuerunt \& adhuc funt cruditi viri qui hunc locum verè Iofepbi non elfe alfeverant: Et fatendum eft horum conjecturas non effe prorfus contemuendas. Ldern ibid.p. 67.

Laudatur inter varias Io Sephi Editiones.illa Genevenfss Grace \& Latinè in Fol:Ann. 16I. \& deinde Ann. 1634. vulgata emendata olim d Segifm. Gelenio.-

$$
\text { S. PO L Y C A R.PU S. }
$$

S Myrna àS. Ioanne Apoftolo \& Evangeliftá Anno Chrifi (ut čeditur ) 8. Clar. A. D. 1 Epifcopus ordinatus s Apoftolicus \& Propheticus Doetor, totius Afre prin- XCIY seps, nonnullos Apofolorum, \& corum, qui viderant Dominum, magiftros hat buito. Romam Yeniens. Cub.Imp. Antonimo Pio Ecclefram regente Aniceto, multos 


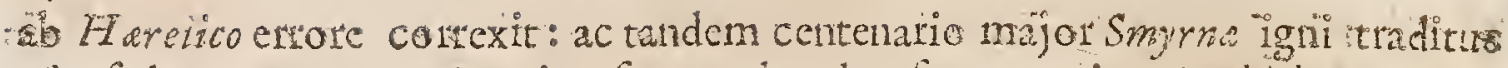
elt, fedente Proconfule \& univerfo populo adverfus eum in Awphibeatro perConante, die 26. Ianuarizex Martyrologio Kornano.A. C. 16\%. Libl. Deferiptor. Ecclefiaft.

Polycarpus Snymenis, circa extrema Neronis natus nonnilis clle videtu :

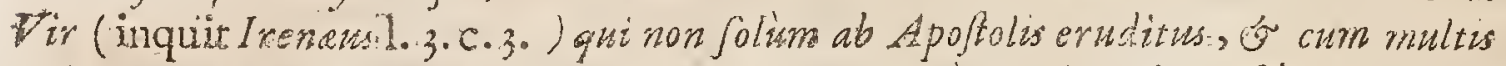

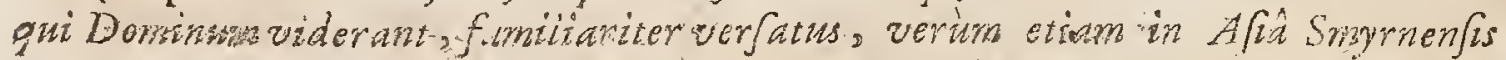

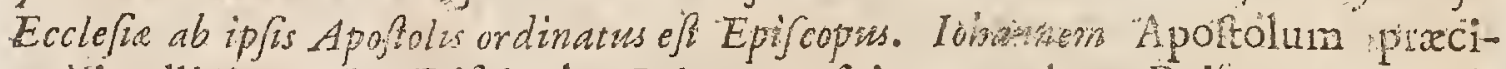
puè intclligge, cujus Difcipulus Polycarpus fuit, atquc ab co Epilcopus contirutus, idque factum clie circa An.94. vel 95. necelie eft; fi medo vera chiet dootifimi Ufericonjedura, cum che Smyrnenfis Ecclefu Angelum illum, cui Epiftolam fcripfrt D. Ichannes Apocal. IL Outâ gravi de Die Pafchatis controwerfia , Romartíc contulit, ibiquecum Aniceto Epifcopo (qui juxta Pearfori \& Dodoryellicalculum, ex Eutychio hautum; pontificatum init Án. I 43.) famidiarirerverfatus eft, plurimofque 1 arcionis \& Valentmierrore deceptos ad fidern seduxit. Demum fub M. Antomino, velut alii, Antonino $P_{i o}$, incalefcente Perfe-

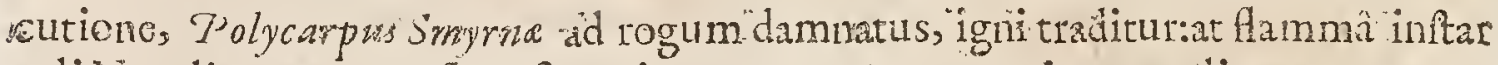
veli Navalis ventorum flatu finuatif corpus Martyru circumvolitante neque illud tangere ausâ, tandem gladioconfollus ent. Moutui corpus incincres redegerunt Etbaici, neabreptas ejus reliquias, divino honore C'brifiani profequerentur, veriti. Gul.Cave. IHiR. Itevas.

Scripfir ad Pbitippenfer valde utilem Epifolam, qux uque hodie in Afa con ventu legitur. Hieronymin catalog

Hanc Epiftolarm multùn laudant Augufinus Tertullianus Irenew, Bellarminus atque Baronius.

Hic docuit femper qux ab Apofolis didicerat; \& Eclejia tradidit a qux folm funt vera. Irenous.

Quo viro, poft Apoftolos, quorum familiaris fuit, vix ullus apud Chriftianos unquan fuit Sanctior ac Divinior. Dall.de P Cerdepig. Apoft. 1.2.

Polycarpus difcipulus Iobannis Evangelifa, \&eruditionis \& fanctitaris nomine percelebris, floruit circa I.40. anum Domini, aut paulè poft. Illyric. catal. Teft. Yeritu.2.

Irenaus dicit, Epifolans Polycarpiad Pbilippenfes perfectifimè effe fcriptam: ex quâ \& characterem fidei ejus, \& pradicationem veritatis, qui folunt, \& curam habentfux falutis, poffint difcere.

Polycarprepiffola ad Pilippenes multis referta of admonitionibus. cun

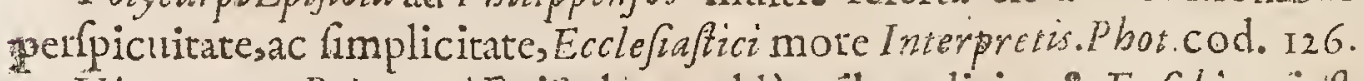

Hieronymus Polycarpi Epiatolam valdè utilen dicit \& Eu cebius inftuctiflmam,ut ex ế.fideicharacterem ac veritatis doctrinam cognofcere qucant in. qui falutis furationem habent. Magriam autem iftam utilitatem, in eâ quam Wunc habemus Epiftolâ non video Clariftoples. Sando de fcriptor. Ecclefiaft Inpxelt. Cogrnopoli I66g. 


\section{CELEBRIORUM AUTHORUM.}

Pólycarpo yenerationi fingularierat memoria S. Iobannis; Delectabatur reEre colloquia que cum ipionabuerat, $8 x$ cum aliis quile fum Chrifturn viderant : Narrabat qux fibie ejus doctrina $\&$ miraculis dixerant : Sï verò qucmpiam audiviflet, qui dockrinam Apofolica fidei contrariam atmuliftet, exclamalfet, O Deus, ad quanam tempore me refervaft ! E11. du Pä.. Biblioth. Nova Authorum Ecclefiatic.

Hec Polycarpi ad Prilippenfes Epiltola, magnam tum fylo, amm rebus ipfis. cum Epiltola Clementis ad Corintbios affinieatem habere videtus; cum \& identr. dem cafdem regulas fuggerat, iifdemque vocibus \& phafibus utattr :-adeo ut: nullum fit dubium quin ob oculos pretantifrmam hanc Epifolam fpecialiter. liabuerit, dum illam exararet. Et reverd pia \&ere Chritiana ef Epitola illas, brevibus \& utilibus Vitæ Præceptis Regulifque referta, eaque modeftia \& fim plicitate qua temporibus Apofolus convenicbat lcripta, proximè poft Sacre Canonis libros Veteribus in pretio habita. Cave in Polycarpi Vita.

Extat Polycarpi Epiftola ad Pbilippenfos Grace Latine cx editione: Prtri Hallois Duaci Aun. i633. cum verfone Iacchi. Uferit, Oxon. Annw. $164+4$. in: 4 .

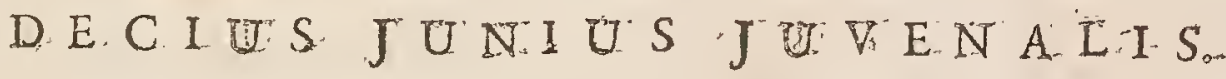

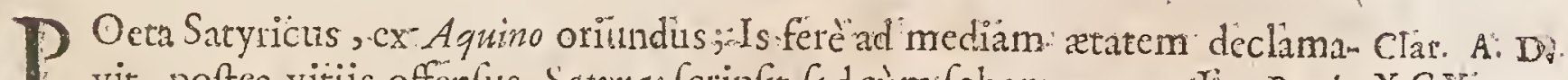
1 vit, poftea vitiis offenfus, Satyras fcripfit, fed cum fchemate notallet Pari- XCV: dem Pantornimum, jam octogenarius fpecie honoris, prafectus eft cohortis in: extimâ. Eggpto, inde I rali Hiftrionis exul vocatur à Sidonio Apollinari. Creditur vixife ufque ad annmmi2..Adrianio. Hofman...

Invenalis autcm candidus, ac:Satyrorurn facilè princeps Nam ojus verfits: longè meliores quàm Horatiani :. Sententix acriores.: Phirafis apertion.: Inlon C.s.S. Scalig.Poetic. 6. C.6..

Horatius eft imifor, \& ob id"Sermonum titulo contentus fuit, quí modo fententia lacertos expreffos oftendat-Scrmone vulgaro. , fed lccto tamen; parumculat numeros; \& defique, modò purè dicatet, nihil penfr haburit: In Invenale omnia contia. Hle ardet, inftat, apertè jugulat. Stylus waldè ariodet, in quo cum Romanâ puritate juncturas molles felicifimè confecutus eft. Uibana \& falfa multò plura I wenali attibuas - quàm: excipiàs ab: Horatio. Quibus lanè locis nequc temerè a neque fuftrà conterdemus I uvenalem long accuratioris Satyra auctorem effe : \& eum: tanto anteponere decet Horation quantò prelior Horitius I ulilio judicatur. Cum neque argumentorum varietate par fitilli 7 oratius, ncque dexteritatc tractandi, neque ubertatc inventionis neque crebritate fontentiarm, neque acrimonia. reprehenfionis, neque facetis \& urbanitate. Idem alio loco:

Invenalern Poctam à Scaligero Patre, in Satyrâ prapofitum Horatiós, viali quâ Sudignarentux. At ille a me judice, inter multa cexti \& elegantis judicii , nihil 
7erius protulit--.-De I Dvenali verò judicat. Ardore, altitudine, libertate, id ef. fuo quodam genere fupra Horatium elt;quod iplum maximè Satyre propriun videtur. Tangit vitia,objurgai, inclamurtraro jocos, fxpiù sacerbos fales mifcet. Qux omnia in Horatio contra; qui placidus, lenis, quictus, monet fapius quàm caltigat. Sed ita praclarè tamen hocipfum, ut in eâ parte $y_{\text {arte }}$ nihil polit fupra sum. Lipj. 1.2. Epift. Quate. Epift,9. Pulmanno.

Longè Calibus ab Horatio fuperatur, à Iuvenale Perfius : quorum uterque felicitcer ctt affecutus, quod voluit nofter, nec potuit. Excellunt igitur in eo Horatus \& I wenalzs, etfî ratione diversâ : nam illius fales plebeium aliquid ferè fapiunt hujus ornes joci quibus abandat, fic funt urbani \& falfi, ut acumen frpè atque eruditionem pra fe fcrant, \& ingenium longo declamandi ufu probe fubactum. Cafanb. Prolcgom.in Perf.

In taxindis motibus, nofirorim Patrum memoriâ, primum locum habere putabatur adeò, ut is tunc doction exiftimaretur, qui plures ejus verfus memoriter recitaret. Lil. Gyrald. de Poet.

Non fine causâ tanti femper ab omnibus habitus fuit. Nemo vitia feculi fui altiùs penetravit, nemo graviùs; \& cum majore indignatione perktinxit. Quod nullus differeri potêt, quil diligenter \& cam judicio legit. Marc. Zner. Boxhorn in Epit. Fincent.Fobre. p 35 .

Tuvenalis excellens, \& apud quem egregia quadam occurrunt. Satyre tragica. Miror antem cur fe dicar foripffe ftyle Lucilii, nam nihil eft difimilius, \& Phraf Horatiane. Scaligerana prima.

Iuvenalis argutusubique \&inventione \& difpofitiene, \& nexu dieteriorum, fed dum ad omnia confonda ttylum porigit:fape turpis, obfcenufque, utpro. indè quxdam catyre cjus rectiùs exularcnt. Nonnunquam ctiam philolophandi Atudio ultra Satyraintitutum exit, quo nomine memorabilis eft Saiyra Io. Borrich.p. 6.4.

Sed ne fiat lengius non necelfario, fic difinguemus : Horatium, placide \& leniter infuentem in animos, fuadere ridendo: fublannantem Perfum philofopharivelle : Iuvenalem, quaficrudum \& naufcantem, indignari omnia. Ut hic abundè faciat dicto fuo fidem, \& quem initio protulit verfum, totis Sam kyriscomprobet: Si natura regat, facit iizalignatio versum. Vavafj. de Ludicr. Dict. p. 242,243 .

Horatius optimè noverat ingenii futivitatem validifmis rationibus \& lententiofo quovis famone ad vitium derifioni cxponendum; efficaciorem eff: Qua in re Juvenalis quantumvis feriustarn agrè optatum cxitum alfequitur. Ex fanè violenti quibus ubique utitur Declamationis modi frè minimum efficacés funt. Nufquam ferè perfuader, quia femper ira commotus, nunquam animo tranquillo loquitur. Verum eft quod Moralis Pbilosophie locis communibus quibufdam utatur quivulgaria ingenia perftringere polfunt. Sed quantalibet vi polleat ejus dićtio, licet energicas voces ufurpet, ac eloquentix pompa in: ipfo fulgeat a parum tamen affectus movet, nihil in jpfo argutum, nihil nativum 


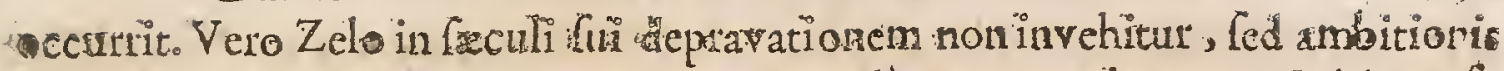
oftentationis ingenio; temperamento potiùs quam ratione ut Criticum le gerir. Rapinus Relex. particular. in Póé.par. 2 . Ref. $: 8$.

Profectò fermo Iuvenalis longè omnium ef Latinifjimus, \& purior quàr Horalii; numeri ctiam rotundi, concinni, \& Horatanis multo exationes; farrentix denique crobrimx, \&ad ftuporem ufque ingeniof $x$, ut nihil dicamus de Argumentorum nobilitate ac valietate, बূuz tantâ ingenii judicique dexteritate tractavit, ut affrmare nihil vereatur Lubinus, qui Sutyras luvenalis on nes profariâ ecphrafreddidic, in unâ Iuvenalis Satyrá plus doctina \& fapichcia ad vitars morcfgue regendos contineri, quam in 10 . Arifotelis ad filum it: bris. Alta erustit. An. $1686 . \mathrm{p} .407$.

* Eilharidi Lubini commcntaria in I wunalem \& Perfima, Hanovia, 1608. cum expryationibus permittuntur in Indice Madrit Edit. An1. 2667 .

Edendo \& illuftrande I ivenali manus admovit Eil. Lubinus, Fed. Ceratus, Scholialtes vetus, Grangaus, Autwomus, Caldermus, Ced diligentius in hac puLeftrâ verfatus elt pitheeus \& Thomas Farnabius Nec Cuá defuir indultra Schrevékio, qui uotas Variorumaddidi, Leida r66. . in $30^{\circ}$

\section{G A T I U S}

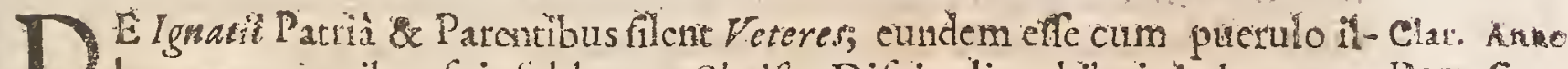
10, quem manibus fuis fublatum Chriftus. Difcipulis exhibuit indeque no- Dom. C.

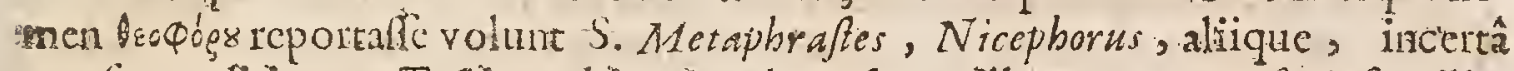
prorfustaditione. Teftis nobis eft Chryfofornus illum cum Apoffolis familiariter vixilfe, ab iifquctluenta fpiritualia haufile, rex p'

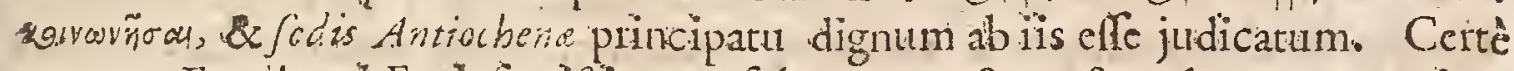
mortuo Euodic ad Ecclefix iftius prafulatum evectus eft : hancene gratian

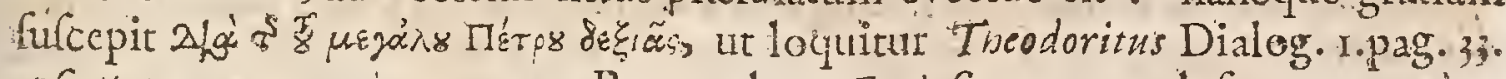
ap o l'etromanus er impo:erate. Rexerat hanc Eecl-giam annos plufquam 40 .eim Trajants circa An. 107. Partbis b.llum illaturus, Antiocbiarn venit, aे quo $S_{\text {. }}$ Ignativs ad beftias dananatur, \& Remone ad Martyriwn fubeundum vingus

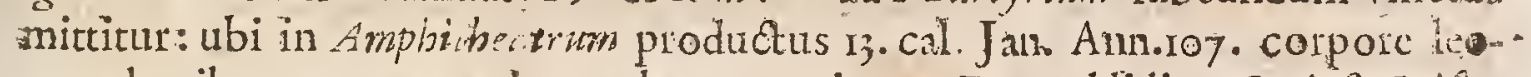
num dentibus mox comminuto, beatam animam Deo reddidit. Scripfit Epijtos laj quafdam. Gul.Gave. Hitt Literar.

Epitolas Gentinefuit: Ad Ephefros: Ad Magnefanos: Ad Tratianor: Ad Romanos: Ad Pbiladelphenos: Ad Smyrnoos: Dubium verò eft (inquit. Gal. Cave) num auctor fit Epiftolix ad Polycarpum. Epiftolx fuppofititie funt: Ad Alariam Cafobolitam- - Ad Tarfenges: Ad Antiobenos: Ad Heronem: Ad Philippenjes: Ad B.Virginem Mariam: Ad Ioamem Apofalum.

Ignatii Epiftolz, funt fanc primzva pietatis, doarinze Ecclefiaftica, \& regiminis Epifcopalis in ipfa Ap Ato'icá Ecclefia vigencis teftes luculentilimi. Hanc ob caufam astiter in cos infurgun Novitores totíquc viribus oppignaruat 


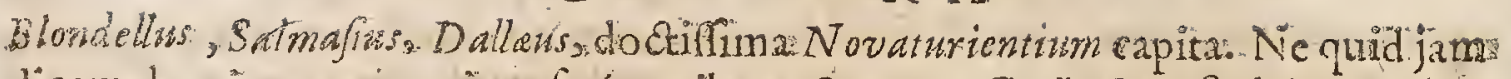
hicam de minorum gentium fcriptoribus ,Ovveno, Toetio, \&c. Sed inanes hotum impetus fortirer debellavit à́vu Harnmondus noftras, differtationibus:

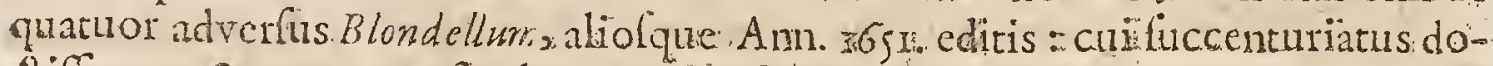

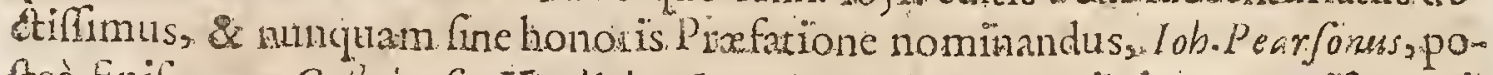
Ateà Epifcopus Ceftrienfis, Vindicias Ignatianas An. 1672. in lucem emifit ;:quibus obje ationes omnes fundìis adeo dillivit, \& caufam I gnatianam tot valiis, invictilqute argumentis munivit, ut mirum planè videri debeat, fi A dverfaria copias fuas tories devictas in asiem itcium proferre autdeant. Gub. Cave in loco. pradicto.

Ignatits, Patrarcha Antiochenus, vir quod in Orientis partibus penarum ent, fingulari eruditione. Scalig Canon. Ifag. 1. $z_{0}$.

Ignatii Epiftola merito dicuntur copiofa Apofolic ar mom maditionum apothea, fortifque adverfus hareticos armatura. Phil L Labbe.

Magnî quidem in primis Dei próvidcncia factum eft ut numerate omnes Epifolde abignatio foriberentur : Ced \& admirando platè divino conflio procitratu in, ut inter tot cantaque na fragia feripturatum, exdem ad noftiam aratem. incorrupte atque integra Cervatentur. In illis quippe ejus. temporis Orientalis Ecclefut facies propemodum viva redditur : atque adeo, ut non tantum res tunc: geftx, Cod \& Ecclefratica difculina, \& mores, \& Apoftolicz ipfe traditio nes Apoftolicarum Ecclefium velut in tabulầ quadanerudita manus peni cillo habeantur expreffr. Baron. Tom. 2 ad Ann. Chrift rog.

Ionati Epitolas Cemper Antquitds eft veneratx. Idern Tom. I. Qualis enims quantuve fuerit in Ecclefras. Ignatitu, quinonumi Ecclefie Antiochena, veliuni Trovincia Syrte prafectus Epifcopus videretur, fed tori penitus Orienti Epiftom

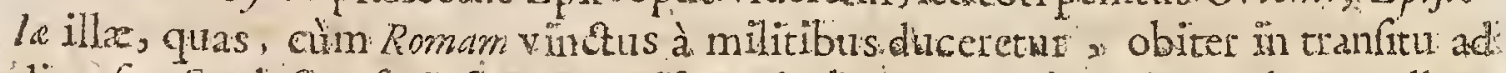
diverfas Ecclefas firipfit manifclè̀ declatant. Iplac enim, velut cxcellene quadampicturas vivan ipfus imaincm teprafentato Idem Tom.2. ad Ann. Cibr. sos.

Salrbafin in Apparatu de Primatu, pag, s6. Epiftolas Ignariz paflim in terpolatas efe conqueritui. In Bibliotrecâ Florentinâ yetuftiflimum exemplas extare dicitur, longè diver lum ab omnibus qua hactenus vulgata funt. Konigo. in Biblioth. fuâ.

Ignatius Antiochenus Epdcopus infituit primus, ut per Antiphonaratm xecjo procationem Pfalni cancrentur. Calvif, in Chronolog.

Omnes ejus Epifolæ peroum Galitaribus praseptis \& adhortaninibus utilifimisabundant. Viro C'brifiano Epifcopo \& Martzre digniflimafunt Unctiomis \& pictatis plcnifima. Nemo illas legat qui ubique non animadvertat San. Etum illum zelo prafus divino pro Animarum Salute pro legis lefu Cbrifit ob fervatione ejulque Doctrin confervatione, incenfum fuife. In omnibus que

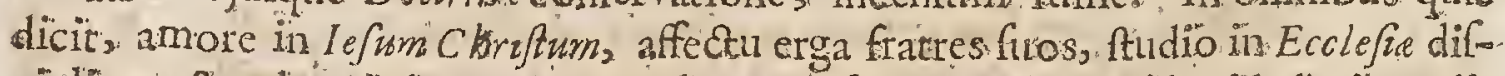
ciplinam \& ardore in bonmm pacis plenum lefe oftendit. Quidiuid denique di

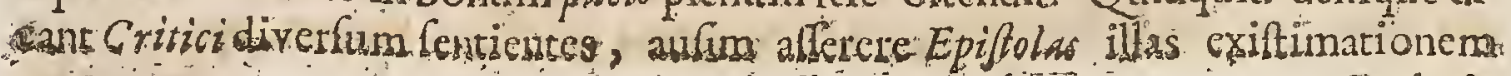




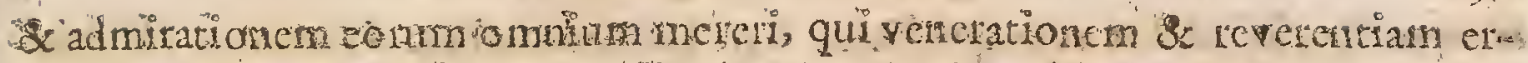
ga Pietatis librospreftentu E. El. dis Pin. Nova Bibl. Authorum Ecclefat. Lom.I. P. I33.

Ignaiti Epiftalas publici juris fecit lacobus Vferius Oxon if th 4 " annis 1642 . : 1644 demum Lonoini 1647 . Felix hoc quidem inceprum, quo vfierins le$1 \mathrm{ac}$, cum ingenii, judicii \& doctrinx fingularefpecimcn exhibuit, tùm Ecolefix utilifimam \& hife temporibus maxime falutuem operam praftitit. Cenique Ifaacus Voffus, aliquanto polt Ufferium, edidit Graci \& Latine lepecm purifr. mas eafdem S. Ignaizi Anio heri Epilcopi. Epiftolas, ex fide manufcripti codicis optima nota iz Bibliothecâ Medi éa Florentinéreperti. Editum opus Ann. 1646.21648 . Arifrelodami in $4^{\circ}$. \& poftea reculum Londini in $4^{\circ}$. Ann. 1630 : quorum diligentix vix quicyuam addi potelt, is qux fpectant ad lenatium ciufque Epiftolas. Cafzm. Ouán. in fupplement. De scriptor. Ecclefiaf.

\section{CORNELIUS ACITUS.}

7 Empore Trajani Imp. Aoruit. Struxit Hiftorias \& Annales. Annalibus clatuit Ans.

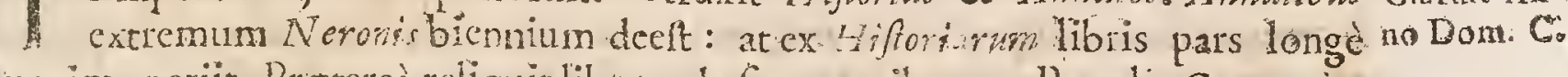
maxima pcriit. Proterè reli quit librum de fitu, roribus ac Populis Germania: jem de vitâ I $\mathrm{H} /$. Agricola, foceri fur.

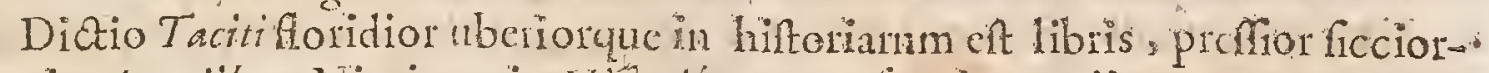
que in Annalibus. Ninirum Hin Hitoriá rem perfeyuitur ordine, nec cam intercidir robus aliis. In Annalibur fylum accommodat amis ac Coft. caque caufa ct, cur in Hiftoriâ caufas accuratius tractet : in Annalibuseas brevi ìs proponat:cur item in Hiffria uberior fit dictio, concifior in Amalibus. Interim gra vis utrobigne \& difera. Vofl.de Hifor. Lat.

Latmi Hiflorin fequuntur, quonmagmen Cornelius Tacitus mihiducat. Ante Livimm? inquies. Non eloquentia, autalis virtutibus: fed is, quasnunc conlidcramus, prudentia \& indiciinotis, Quis illo verius narrat, aut brevius Quis marando magis docet? In moribus quid eft, quod non tangat? in affe ot bus, quod non revelet? Mirabilis omnino fcriptor, \& quiferio hoc ipfum agit, quod non agit. Ncc cnim hiforia folum ent fed velut Hortis \& Sermina rism prxceptorum. Utii, qui veltes acu pingunt, ingeniosè geminas inferunt. fine confufione aut noxî formaran: Sic ifte palim fententias ferie narationis nihil omifsâ aut lassâ. Scaber tamen quibufdam \& obfcurus videtur: fuone vitio, an ipforun? Nam acutè argutéque feipfife fateor: \& tales efle daberc qui cum legent. Jaco confliarits magis Princepmoquam ipfis commendo : qui han beanthunc Sapientie frmul \& Prudentie vertun ducem. Lipf.in Not. ad Politic. 1. I. c. 9 .

Eft oratio Taciti minum in modum arguta \& prudentix plena. Quid multa: nullits profecto Hiforicus magiftratui ac Judici utilior videtur. Rudaus acerbè Tacitum Scriptorem omnium liceleratiflimum appcllavit: quod nonnihil adver. 4u6 Chrifianos fcripfit. Qux satio fecir, opinor, ut cun Tertullianus mendacif- 
fmun, Orofius adiulatorem appellaret: Sed cuemadimodum Marcellus I.C ne: retricem tupiter facere refpondit, quod fit merctix, non tamen turpiter accipere, cùm fit meretrix; ita quoque impiè fecit Tacitu, quòd non fuerit Chriftianus: Sednon impiè adverfus nos fripfre, cum gentili fuperftirione obligatetur Ego vero impium judicarem, nifi quamcumyue ueligionem veram judicatet; non eam quoque tueri, \& contrarias evertere conarctur. Bodin. MethodiHiftor. cap: 4 .

Hic magni \& acerrimi vir ingenils nova cujuldam, genvis, concif $\&$; finentiofre eloquentix gcnere eximiè prxditus; fi à fortunâ non effet defitutus, qux dignam ci tantî facultate materiam negavit; quemvis è principibus, five: Romanorum, five ctiam Gracorum Hiftoricorum videur poruilfe provocare. $C_{a m}$ faub: prafat.adl Polgbo.

Sumınum egoaucorem, \& fimmè uritem Corn. Tacitum femper judicavi cum privatishominibus \& optimatibus, tùm verò etium principibus ipfis atque Imperatoribus. Etenim cum ex religuis thiforicis alii res tantum domiforifque in repub. geftas prefcribune, ut Sallustius, Livius: alii Principum vitas. oftendillic contenti funt, ut Sue onius, lit. Plutarchus: hic unus utrumque munus: Grmmo ordine, diligenticurâ, magno judicio, multa concinnitate complexus

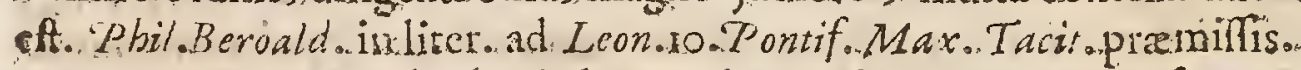

Tacius nunquam fune laude loquendus. Sidon. Carm. II. yerf 192.:

Non optimus ille quidem Latinitatis auct or fedHiforia Scriptor pndens. verus aruue acutus. Lamban. in Horat. lib. mu. carm. odi $27 \%$

Luculentus. Hittoricus ac vitx pernecellirius. Dermpfter.

Canjfins in plerifque adipalem cloquentia fuccum defiderat.

Cornelit Tacii A nnales \& Hiftorias quis non xttiinar? Eum omes, Ta bent pro Doctore Principum, pro Aulicorum Pragogo, Hitcricorum Antefigna no Pudentin Patre, Oraculo Cinilis. Difciplina, Coryphro Policiconm, \& G. Forftner. ad 3. Annal. pag; 260.

Ad Majeftatem ac feveritatem Taciti nonnifanimailluftes ac eximize affutgant. Heinf. Orat. in Obitum Phil. Cluver.

\author{
Quvenus in Libro $2^{\circ}$.hoc Epigramma Caripfit de Tacaio.: \\ Tieracem fecit probitasi, natura Sagacem \\ Obfourum breaitas te a gravitafgue Brevent.
}

Plimius abquentifimum fulfe ait, \& hoc eximium habuife Tacitum quods asurwis dicerct. Plin.1,2. Epint. I. \& II.

Acumen contracta dictionis, \& fubitiquidem ictus fententiarum, in quibus plis intelligendim plerungue quàm legendiun. fit. Strad.proluf.lib: 2. Hifto. part. 2 .

Stylus magis gravis, quam elcgans afjer enim parumque duriulculus eft, ato que dirtina Lingu candore difes dess Garolo Sigon 
Scio Cbriftianos eumalibi perftringere, \& deliria varia delirafTe, cửn de $I$ sdidir, eorumve ritibus acceremoniis fcribit, quo refpectu eum. Tertulliznus mendaciffimum vocitat: verùm ut vinum vinum non effe definit, fi guttulæ in eo aque, fic nec. Taciti liftoria proba, fi in ea hre macula ex ethnicorum maculis expreffix. Exrores fuere ignorantis, non mendacia fallentis. Quas fi tollas, prudens. ille certè, certerùm \& fuavis omninò fcriptor. Ioano Bernarto de utilitat le gend. Hittor.

M. Clandius Tacitus Imp. tanti eum fecit or ut inaginem illins in omnibus collocaret bibliotbecis; libros verò ejus decies quotannis defcribi, ,inque Archizis publicis collocari.juberet, ne perirent:

Atque hoc ett quod Tatito dandum vitio videtur: "quòd aliqua narrationibus. arcbrò inferat, non tam ad Hifforie curfum, quàm ad Hiforici acumen cognofcendum. Farn. strad.Proluc.Acad:

Magnis mentibus maximè convenit hie autor, \& precipuè nis s quĩ ad Reip:clavum. fedent :: fingulis frquidem penè lineis monirumaliqued Policicum consinetur, quoderucre non aujufvis cft: \& quodide: Thucydide dixit Cicero, ei: omniiò convenit, ita crebu me fé̉ rerum frequentiâ, ut verborwin prope numenum. Eententiäum numero confequatur. In judicando verò de iis rabus quas nartat, adè fagax eft, ut ad prudcutiam comparandam unus omnium inftar aucto rum efle peffit; quique non obiter fit legendus, fed penè ad verbam addi fcendus. Rolasd. Maref. in Epit. pag 23 .

Extunt C.Corn. Taciti Opera cum Notis J ariorum, accurante Iobn.Fred. Gronovio 2.V Vl. in \&; Amfelodami apud Dan. Elzivir. Ann..1673.

\section{CAJUS PLINIUS, CACILIUS SECUNDUS}

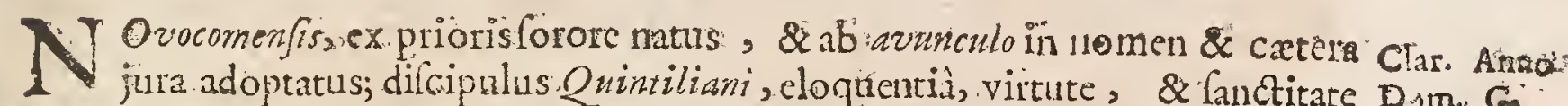
ge vitre ac morum, aut maximus ipfe, aut inter maximos fui feculi viros fuit. Floniti fub Trajano, cujus \& Paner yricum opuls infigne foripfit. Habemus cjus: Epifolarum libros, veriflinum Attice eloquentix exemplum ; exquibus vita. ejus $\&$ mores difcipolfunt. Ampliffimis muneribus défunctus "Prafecturam: quoque lithyno geflit in quâ. Chriftian rum moribus exploratis, non pepercicIllis Lolùm, iced \& cos per Epiffolam Trajano commendavit. Hofman..

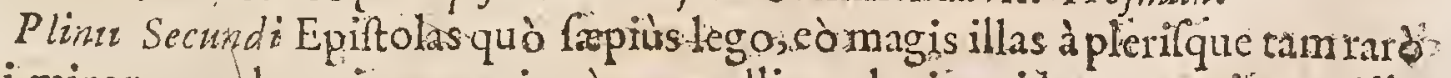
legi miror : milto ettant magis, à uonnullis ne legi quidem omnino--mll non folum aliquid habent propter quod tegi mereant!r, fed habent'o mnia, qua nos ad ...pistolarsm aut Grecarbm att Latinarum lectionem invitare \& poffint. \& d. beant. Nam five utilitatem; five delectationem, frve eriaun utrumque in iftanrumlection: fibi quis proponats eurn, quod abundè fio defiderio fatisfaciat, in venturum effe dico. Hcor. "tephan, prefar. in Plin. Epilt.:

Multx in Pliniz Epiffolis brensobferyationses ceditio antignitatis, mulex: S. 3 proseptionas: 
preceptiones Politica, iis fane, quiin Republicâ verfantur, non molò utiles, feat fummè neceflaria. Sed de earum pretio fupervacuum eft dicere, quum nerainem vel mediocriter doctum nòn earum elegantia derinciat 1oann. Vechlous in Dedicat ad Plin.Epilt cum Notis

Effe enim Epiftolicus Stylus fimplex dcbot ac vilut negligentiulculus. Name eft etiam quadamengligentia diligens; exemplo funt Plinit. Ceciliz Epiftolx acutx, eleganter exprelfä; in quibus nibil nifidomefticum, quotidianum, fed onm nia tantim latina, calta, ornataque leguntur. eumque fir ftylus ille multâ arte, arque ingenio, cultuque fubactus \& claboratıs, tamen peuć fubitis atyuc cxtem. poraneusidetur. Erajm. in brevifmân Epiftol. conficiend. formâ.

Accommodatior (Senea ) ad ufun lintus Cacilin, eorum praferim, qui de negotiis privatis aut Republicâ non Gribune. Nam hujulmodi mclior elt Cicero: ir inius vcrò fuccinatus, \& feftivus, \& facetus, \& acutus, \& ficqueins concinis lententiis, doctis atque acuris ingenis minifiee clt aptus, qui sc bolafito

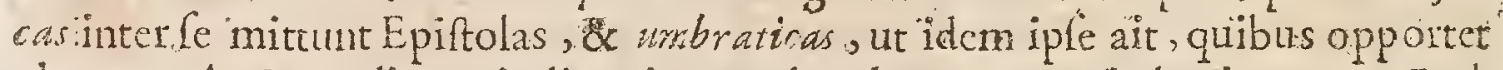
plus oruatûs \&condimenti adjungi, quando rebus non perinde niruntur. Lnd. Viv. de canlcibend. Epiftol.

ciśacrobiul. f. Sattrn.c. L. pinguc \& Rovidum ei dicendi genustribuit.

Plinimsterfis, candidus, in epiftolis alter Cicero, in Panegyrico gravis, orratus, difertus. Bonifac. in Hadicr. Hift. p. 600

Cujus Panegricuis Ep fole omnibus numeris abfoluta funt, mifcentes nite dulci. Sed in Panegyrico nimiâ quandoque prolixitate aggravat animum Iegentis. Joan. Bona. Caidinal.

Quin iphum Plinina, in fecunda hac clafe jure colloco, tcrfum, acuum,nitidnm : led non fine deliciis molliculum interdum, \& paum vinm. Lipf. Infti cut. Epiltolic.

Panegyricus, quem Plinius Trajanodixit, divinus planc libereft, \& novo Principi, DitBoni! quàm aptus. Lipf. Ccntur. 2.ad Belg. Epit. 3 r.

llinii Epiftolas quò magis legas, cò plus diligas. Sunt enim fuviffrme; \& gcnium inufitata alacritatis habent; fingulis periods amabili quedam acumine excitantis, Barth.1.29.c.15. Adverfai.

Quo [Panegyrico] eo in genere Romana facundia nihil habet digantius. Foffo. de Rhetoric.p. Ios.

Pliniani Panegyrici uncomparabilis facundialiquid luze vinutis gratiarumque in ominium qüdem animos immittere, paticorum tamencalano attingi poteft. Boccler. dé Eloquentiâ P.olitici th. 76

Male litunc \& altcrum $P$ li itum confundic Hieronymzis in Chronico Eufebiano, Num. 2125. \& ex duobus Plinis unum nobis, quantum infe fuit, concinnavit. Id quod dignum animadverfione fuâ exiltimavit Scaliger, quem ibi, fi Iubct, vide.

- * ConradiRittersbuficommentavius in Epitolas Plinit \& Trajani, cum expurgationbus permintur. Index $M$ adrit . 1667.

- Extant Cais Plinii Caciliifecundi Epinolarum libri so. cum Variorum Natis 


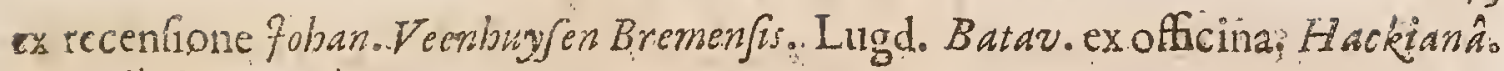
1669 . in $8:$.

Plinius Junior Anno Chrifti r oo . Fcripfit librum de Viris Illuffribus : dubitatur tamen, an ifte vite fint Caiv P linii Cecthi 2.junioris , qui Goüuit fub. Tram jano, Taciti Hiftorici amiciflimus. Quifquis tandem:fit Auctor, fanè propter argumenti magnitudinem utilis elt, etiàmfi nec accuratus in elegantiâ Romanâ,

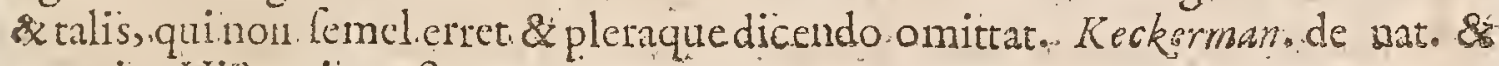
proprict. Hiftor. in auctar. cap. $\bar{z}$.

\section{P L UTAR C H. U.S}

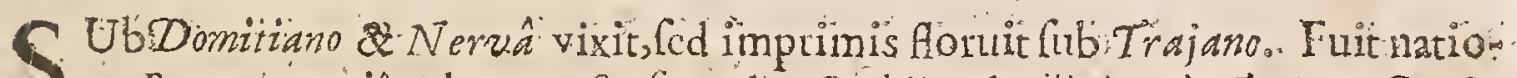

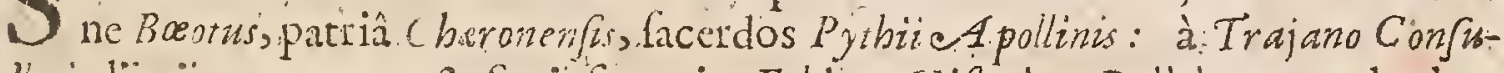
Clar. Annö lari dignitate ornatus eft. Scriphe varia, Erbica, Hifforica, Politicas qux duobus. Tomisinclitla:lunt.

Quis poft Plutarchum extitit, qui vereac folidx eruditionis copiâ \&: varietatc ita cum eo comparari queat, ut non.longifimo: intervallo abfuturus ab eo: fits. querncunque illi proximum elfe voluerìs ?. Quem ille Poetam. veterem, quem Oratorem, quem fiftorit Scriptorem non ita triverat, ut edidiciffe videucur ?: Quarn Philofophix partem non ita trautaverat, ut nemopoftea tan-

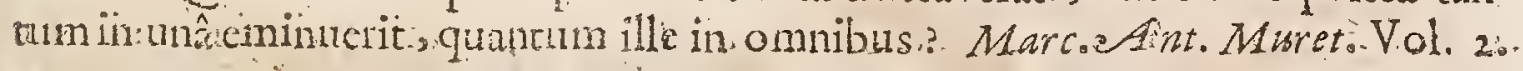
orat. I5.

Intcr: Gracos medios Plutarchus cft :quinøn: Hiftoriam proprie; fediparticum

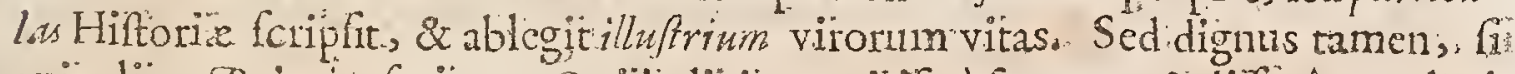

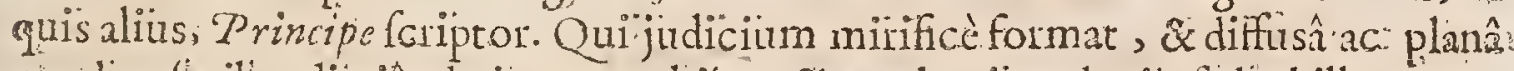
quadim fcribendi vila ad virtutem ubique \& prudentiam ducit, fed ad illam ma gis: : \&, niffallor, melïor omnino, quàm acutior doctor. Lipp, in Not. ad libr. T. Politic.c. g.

Quid!l lutarcho excogiraripoteft erudititius ?: quid firit uncuam pofthomines matos fapientius ?: Lacob. P'onian.annotat. ad:Voli 2: Progym. 44 :

Plittarcbus Cheronenfis, Trajani Principis educator, Hhilofaphus:Hiftoricus, Politicus., Antiquarius: fummi limatiflimique judiciio, Demppero. in Elencli. Seriptor.

Plenus of autor ille rerum, plenus monitorum:ad vistutem: $L$ d. Piz, de trat dend. difciplit 15 .

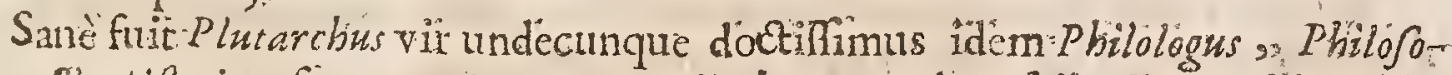
phiss \& tiftorious fimmus.-Magnam eniin horum triitm Cientiam undique ejis: fcilipta firant. Quin habitus: ctiam fuit or ntor bonus:- Tamen difimulate non:

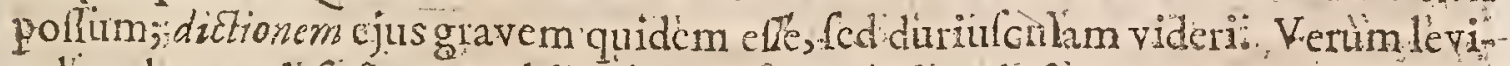
culim hunc defectum multijugâade cientia abunde fummus vạ compenfato. Voff: de Hiltor. Griec:

Cum Plutarchi oratio afjera mor of que fits pracipuè in his libris quos de

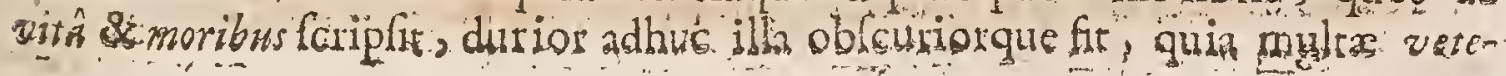




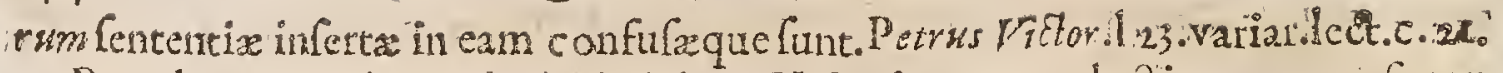

Populorum vero maximè illuftrim Hiforiam complectitur: tametínon perpetuam, Ced abruptam, \& ad Principum finilitudines accommodatam. Ef autem quodin eo miremur liberum de re quaque judicium, ut non tam Hiftoricus, quàn l'rincipura cenfor efle vidcatur : Sic tamen cxiftimo fi quis idoncus eft earum rerum Arbiter, aut lutarchum elfe aut nemincm; quid enim tartam fapicnciam latere potuit:? Bodin. in Methed. Hiftor. cap. 4 - pagin. 62 .

Illud tamen akimadverfone dignum elt, quod Gracos Principes cum Gracis, \& Romanos inter fe bonà fide comparavit: Graces verò cum Komanis non item. Idque facile intelligi poteft in comparatione Dcrrofibenis ac Ciceronts: Catoribs * Arifidis: Sylla \& Ly andri: Marcelli ac Pelopida: Quid denique aliud ef Ageflaum Pornpero quàn muscain elcphanto:conferre! Interdum criam in Roanorum Ankigutate labitur; quod in homine Graco, qui felinguam Latinam non fatis intellcxifle in vitâ $D$ erroflhenis confiterur mirmmiderinon debet. ldem ibid.

Plutarchus, feriptor alioqui verax, in rebus Grecorum illuftrandis, \& cxcutiFire, \& fingere interdum ctiam videtur. Melch. Can.1.Ir.loc. Theolog.c.6.

Plutarchus rerum Rowanarum notitiâ fxpelabitur. Paul. Manut. commento in Ciecron. ad Q.Eratr.1.2. Epilt. s.

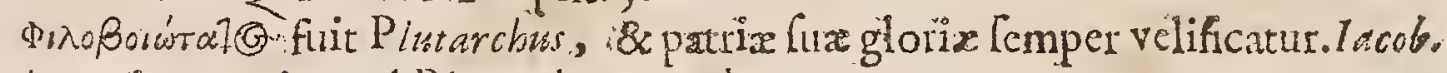
Palmer. in cxercitat. ad Plutarch. Lyfundr.

Ego quidem cum Theodoro Gazâ fentio, qui interrogatrs, fiommes libri perAendi effent, \&upfi optio daretui, quemfervatum yellet, 'lutarchusm dixit. ER suim vere Thefurus cortum, qua pixtantifima in omnibus aliis fcriptorbus Sparfminveniuntar, tive bilofophiam, \& alias diciplinas, ifve Hiforinm GreEam \& Romanam fpectes. Tanto vero judicio pollet, quod ubique, fcd maximé in comparandis inter fe Grect, \& Latinis limperatortbus, \& comm renfendis attis liquido apparet, ut hominem minime $B$ ootum in crafo jurases aere nitum. De moribus werdea paffm inculcat qux ignaviflimos quofque ad virutem ample. Ctendam poffint impellere. Denique omnia cjus opera quiferi exolverit, na is Ce pro doctiffimo venditare jure merito petef. Roland. March.L.I.Evilt. 24.

Plutarabus totius lapientix ocellus. Scaligerana prima.p. 124. Aulicis tantùm fcripfit, non doetis. Scaligeran a prima, pag. 49 .

Lycurgi vitam ex Antiquis Auctoribus Plubarchum compidalfe feribit Iaceb. Palmerius in excrcitat. in optimos a uctor. Grac. 1.9 .

Tantus eft amor $P$ atrie, ut nec anciquifimis quibufque, mulcifque ante fectlis vitâ functis parcat. Graris nimium favet Plutarchur, à reliquis ferè difidens air maxime ex Coriolan videre eft, fi cum Livio, aliffue conferatur: in Pbilo fopbicis multorum opiniones adfert nihil propemodum folvens. Claud. Verder. cenf.in Antorẹs.

Minus certè habet iple Plutarchus quipd de exmporis edacitare conqueratur: 


\section{CELEBRIORUM AUTHORUM.}

cum cjus precepta Politica ex illo tam infigni bonorum auctorum haufragio en atarint, valdè quidem illa fedatx ac, compoitre doctrina, ut genium auctoris gravifimo judicio, ac moderaticne temperatum, præle ferant. Gabr. Naud. tibliograph. Politic.

Extant opera Plutarchi omnia Grecé \& Latizè ex Interp. Herm. Cruferii \& Guil.Xytandri, Fiancofurti in fol. $x y_{20}$

\section{I O}

D Rufeenfis, cui facurdia Chry fofromi nomen peperit, tempore Nerve \& Tras Clar. Anno 2 jani claruit. Condidic orationes, qua cxtant: item octo libros de Alexan- Dom.CXI. dri virtutibus : ut \& librum, An $M$ undus fit corruptioni obnoxius. A pud Tra janum plerumque vixit; cujus familiaris fuit, eodemque curru dignatus ef.

Suidas tradit, cum magnificentiam adè affectâlle, ut Leoninar pellem ferén in publicum prodierit.

synefins in Dione cum Aquilarn frmul ac Cygnum, id ef, Philofophum \& ola torem, vocat.

Dio Prufiens ob auream facundiam dictus Chrofofomus, orator clariffimus. rehementia $\hat{a}_{\text {s }}$ ubertate, \& varietate preltans. Vid. foann. Card. Bonam in Notit: Aulorum.

Dion Prufeus, propter aureum elequentix fumencognomento Cbryfoftomus: fummus \& Pbilesophus \& Orator,cui ego quem præfelam nondun inveni.Nor fpino fa docet, aut injucunda, neque abruptis fententiolis rem obfurat, ut Arim ftotcles; neque abfurda atque communi fenlu abhorrentia tradit ut Platoneque. ut idem, longis perplexifque fufpendit lectorem ambagibus, \& difputatiunculis. fed plana \& aperta, veréque politica profert in medium. Docet tacilèsfficit mirabiliter, jucundifimè exponit, mira enim quxdam illi inct fuavitas. Attic ufus ent Dialecto felicinime, niff quòd longis interdum periodis molefus eft \& obfurior. At id Gracis câ tempêtate familiare erat, ut ait Plinius, extento fpirizu prolixifque periodis immenfam verborum fylvam effundere. Patria culoa \& amator, vitutis \& veritatis affertor, concordiz pacifque Rudiofus, nobilifimas Grecia civitates pervagatus, magnam ubique eruditionis, facundix, prudentix, probitatis laudem adcptus ct:. Thorr. Naogeorg. in Prafat. in Dion.

Dion in dicendi atte acutus ac folers eft habitus. Orationes conferipfiffe plurimas ieferunt, quarum octoginta in meas inciderunt manus: qua quiden oraiones Chryfoftomi [ hoceft, aurei oris] cognomentum illi apud ejus xtatis momines pepererunt. Cretùm plcreque Orationum ejus funt fuafori. Sed quando xquum ef deliberativo generi quiddam etiam judicialc permilceri pa. rem ipfe virturem in hoc quoque Orationis generc oftendit: \& inter omnes quidem maximè Rhodiace. Nam $\&$ acrius enthymematis inftar, \& brevem atq; contortam orationem (quod faltem ad charaterern) adhibet, \& vchementiacum ubcate abundat. Exemplis infuper maxime preftat; qux ubique multa è vatis $\therefore$ 
petita rebus, aptiffmènd propolitum argumentum accommodat. Libentilfire quoque fubulofas narrationes aliquas monitionibus intexit, ut eam etiam ob rem fimplex dicendr genus confectatus videri pofft. Rarius enim Platonis exem-

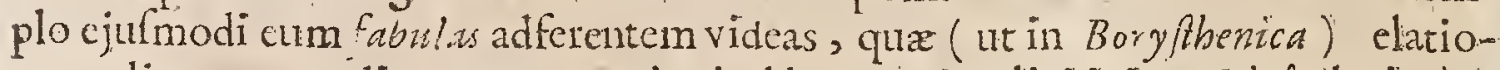
nom aliquam granditatemque orationi addant. Simplici igitur I deâ plurimùn eft ufus in fenizses, vocabulis item familiaribus, \& pafim obviis, nihilque compolitio habet aut liblimitatis oftentandasant captandx jucunditatis gratiâ. inno vatum. Pbo . in Biblioth.

Inte: omnes ejus Orationes copiofifina eft Oratio de llio à Grecis non capto.

Optima vesò ac ladatiflma cft in Dionis orationibus affectutm temperatio : quotics enim inpotentes, ac infolentes Respublicas increpat, neque contrmeliofus, neque importunus videtur (ed perinde carum, ac equorum ferociam fræno potius, quam Aagello compefcere. Sin ab optimis legibus infitutas civitare laudandas fe conferat, non tam erigerc, aut d fuperbiam excitare, quàm continere videtur, quafi citius intelituras fi alium in fitum degeneraverint. Sed \& reliquo quaque Pbilofophandi, inftituto fuir non omuibus expofito aut fimulitorio, fed ejufmodi ut gravitate quadam inftaret, non fecus ac condimento infita fibi humanitate temperata. Quàm porrò Eistoric fcribendz: aptus fuerit, argumento funt ab eo fcripta Getica Pbiloftrat de vit. Sophifar.

Extant Dioni, Chmfoponi orationes $8^{\circ}$. cum Interprctatione Thorne $N$ aom georgi, ex recenfione $\dot{F}$. Morelli, \& Notis Ifaaci Cafaubonis. Lutetio apud Clanodium Morellim in Fol. Anno 1604 .

\section{A U L US GELI.IUS.}

Clar. Anno Dom.CXII.

Q

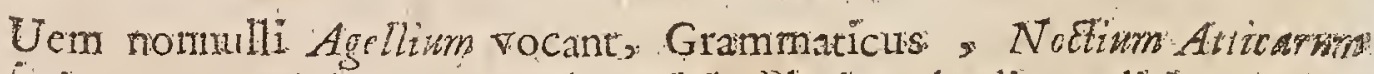

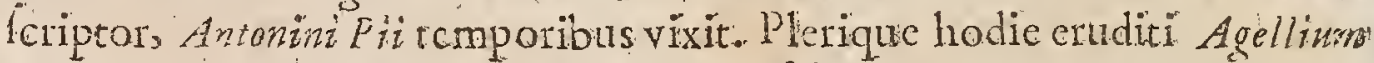
vocant, quamvis Salmafus, Volfius, alii promifcure Agelliwrn \& Gelliurn indigitent. Quod fi ex Gellià gente fit oriundus, mirum eft', cùm aliquloties Gelizos nominct, Ce non meminife ex eadem familiti prognatum. Annotat. in Prafato Ait.Gello

Ob citulun libri multi luccenfent Auctori, quoniam potius tempus quando feripfit quàm argumentum libriindicat. Hic verò tirulus multum placet $H a-$

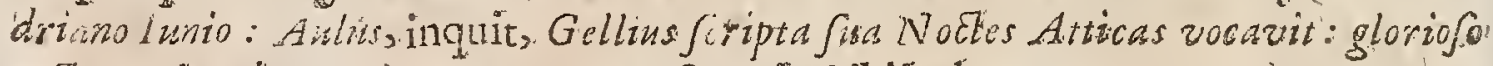
nocturne lumbrationis argumento. Gefner. in Piblioth.

Vinm clegantifimi eloquii, \& multex ac facundx f cientio appellavit D. A Am guftinuts, 1. 9.C. 4. de Civ. Der.

Huic judicio a ugufini, maxima, feu omnis potits Grammaticor wm nanus fuffagatur. Lud. Viq. in locum prediat.

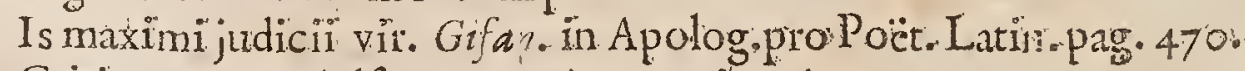

Criticorum Madulfa vocatur à $P$ ardo in 3 laut.

Aulus Gelius, cujus nomen C'ritici luxantes: Agellium vocant, Grammaticout gtm utilisimus, fubrilifimus, zscuratiffmus, Bonifac. Ludics. Hift. 
Agellinm Scriptorem ego habeo puriffimæ latinitatis, \& planè ad Comcediam antiquarr. Lips. cent. 4. Wiifcell. Epitt. 57 .

Aulur Gellizus publicus penè literarum cenfor, folertifímus verborum inveRigator atque ecnfor. Valla prefat. 1. 2.\& 1.6. . 23.

Vetus illa puraque Latiní Sermonis amabilitas mirum dictu eft quàm paucos habeat noftro wo amatores aut capaces fuarum deliciarum. Habut \& olim vix plures panciffamis. Poft primorum tempora vel folus eft feriptor Gellius, qui cam dilcxerit penitius, \& \&ecutus fit promptius. Barth. adver.. lib. 3 z. cap. 10.

Ejus Noctes maximé candidx. Politian. Milcel. cap. 13.

Agellius, Tertullianus, Arnolizs, Minutiur, \& Apuleitus propter eruditionis, varietatem omnino legendi funt, fed imitatio corum ftoliditatis opinionem conficir. Gaspar. Sciopp. confultat. p. 43.

Novaror non magni pretii. Scioppo de Atylo pag. 208.

Aulus Gelliur, homo rhapfodus planè, cong ftor potius", quàm digettor, \& oftentator quam peritus : loquaculus fine eruditione: in verbis ac fententiis putidulus- Que de fignificatu vocum differit, funt frivola \& pleśn que impesita, acfalla. Legendus eft quidem, fed ita, ut te rem levem fcias infpicere. Lud. Iiv.1.3. de Trad. Difcipl. Gollins durifimarum elegantiarem affectator. Lud. Viv. ibid.

- De Ciceronänis cùm dico, Agellium non excludo, cùm nemo feliciùs exprefferit Comicorum phrafin: ut de eo audiri non debeant doctifimi Hifpani duo Ludover.Vives, \& Anton. Augrifinus. Nempè concoquere" non poterant, quòd vituperâffet, vel faltem maligniùshuludafet. I. Senecam itidem hominem Hifpamum. V.Jf.1. 4. inftit. Orat. p. 26.

Agellizss fcriptor purus caftufyue, quamvis vir clarifimus. Ant. Augufinus 1.2. Emend.c.2.cum appellat non bonuin latinitatis ančtoré.I dem ibid.1.4.p.2rg.

Anctor eft doctifinus, \& excultifima cloqucntix. Rhodigin.1. 8. lect. Anriq. c. 13.

A. Gellii candidifimam phrafim mirantur eruditi : fed nec argumentun convcnit, nec phrafis, primum affectatá, \& verborum copiâ penè fuperfluers, rerum fupellectile frugalis. Erafon. in Ciceronian.

Scaliger ftylum cjus Antiquum cenfec; catera vcrò praftantiffimum Authorem effe, eum inuumera frag menta continere; ejufque bonitatem ac pretium in hoc prafertim confiftere; præclarum effe inter alia caputillud quo de Duodecine Tululis agieur : dolendum effe quòd ejus liber tot barbaris vocibus fcateat * quodque preterea integer non extet; totus cnim intercidit octavus cjus liber. Scaligerana 2.

Ncfas ct preterire hoc loco Aulum Gelizum, qui fexcenta Grammaticorums Poctarum, Kheroum, hilofophorum, Medicorum, Jurifconfultorum diata. facta, infituta ufque co non prateriit, ut unus firptor infur plurium haberi poffrt--Defe Gellitu dicit ipfe cùm multa paffim, tum vigefimo libro extrcmo, sequaguam, fe in feribendo \& commentando fccutum copiam, fed habuiffe T 2 delectum 
dclectum, eaque fola mandalfe literis, qua aut hominum ftudia commoveren ad dicendum, adjuvarentque non fine delectatione $\&$ animorum latitiâ,aut eos, aliis jam virx negotiîs occupatos, à turpi certè, aggrefique terum \& verborum imperititia vindicarent. Quod equidem verum puto, neque audiendum ullo: modo Gasparem Scioppium, præfidentem Grammu ticum, qui ex quatuor Laini Sermonis quafi atatibus, quas arbitratu fuo diltinguit aurea a argentea, onea, ferree: Gellium in viliffumâ, maximeque ignobilli reponat ætate, \& ultimis fcriprolibus annumeret. Judicium quantum exiftimare poffum , omnis judicii \& prudentix expers. Ut enim effe fatear hunc Scriptorem in frequentandis \& continuandis verbis ac locutionibus cornicorurs nimium, atque agete delicias ifto in genere putidiufculas, neque ulli temerè Scriptori imitandas : nunquam tamen dubitaverim, quin inultò ad fummos, quàm ad infimos Scriptores s: propiùs accedat. Ita diligens, \&accuratus, \& elegans, \& varius, \&amanus ubique. \& curiofus mini quidem videtur. Franc. Vawaff. de ludicr. dict. pagin. 268 . $2,69,270$.

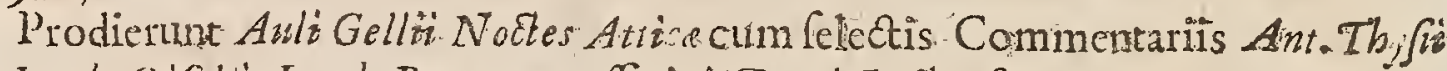

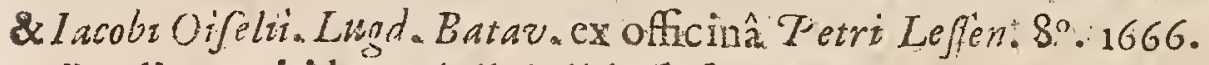

Prodierunt itidem Auli Gelli Nodzes Attice, quas notis a emendationibus: illutravit Iar. Pronft. Loc. Jefu, juffu Clurift Regis in ufum Dclphini 2 in $4^{\circ}$ a Parifapud CimonaBenard. An. 168 .

\section{CAJUS SUETONIUS TRANQUILEUS} Clar Anno. Tnpone Trajani Hadriani fluruit. Sub Hadrüano Epiftolarum magio

1 fer fuit. Texuit duodecin Ca farum vitas. Extat pratcirex ejus fragmen-

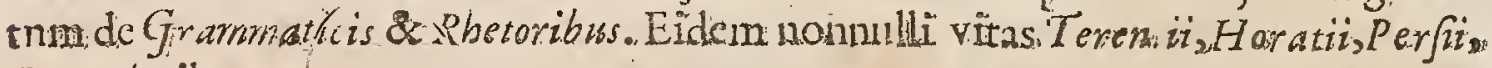
Lucaritribuunt

Atque hac fingukita Suetonitus hic nolter perfecutus în fuâ hiftoriâ eft, ut prater explicandi fcientiam, qua mirificè eft ufus, etiam diligentiam nobis fidemquc \& libertatem fuam plane probaverit. Nulla in his tibrï fufpicio eft gre tire, nulla fumultatis; nihit fudio dictum, nihik fuppreffum metus, rebus ip fre data omuia, veritati inpuinis fervitum eft. Angel Politian it prefato in Sueton.

Suetonius Tranquillus emendatifimus \& candidiffimus foriptor; cuifamiliare: fuit amare brevitatem. Flav.Vopif. in Firm.c. I.

lllud opinor apud eruditos omnes in confello.effe, quod'a dinarrationis fidem attinet, primas deberi Swetonio: quï, ut quidam non infeftiviter dixit, pron fus êt

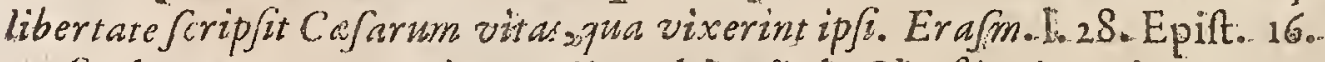

Scelerarus qunaque Tranquillus, ubi agit de Chraftianis: cujus tamen hiftorias santopere laudaruy, ut; qui æequì rerum xulimatores; nihil unquam accuratius. ab.ullo. Hifturico fcriptum fateantur. Non placet quibufdam. quod leviflima quxque perfequitur: $f_{\text {ed }}$ in Principundictis \& factis, nihil leve, nihil parvum rideridebet; proptereà quòd in vulgus manant, \& principis exemplo mores. 
Poprli ficmperreguntur. Hoc fortaffis improbari poteft, quòd faediflimas quafquc Principur. libidines nimis fudiosè confectatur, quas Cornelius Tacitus omiv fit. Bodin. c. 4. Method. Hiftoriar.

Sutonium Tranguillum non-injuriâ commendo fape Iuventuti. Verba vides? pura, tcrfa, propria. Filum totum orationis ? breve, nerwolum. Rem ipfam? utilis pariter \& jucunda Hifto ia eft: \&, quod mihi caput, plena moris \& dom arine an igua. Quis obfecro, ritus publicus olim privatufque fuit, quem velut de induftriâ non cangat? Quod munus, quils magiftratus, quem non libet? Tangat, \& libet, dico. Non enim explicet : quod infitutum ejus vetuit, \& ratio fcribendi. At viam tamen latam ftemit ad indagandum: \& aures atque animum imbuit audizionc aliquâ, imò cognitione. $\operatorname{Lip} f .1$. 2. Elector. c. 17.

C.Sustonius Tranquithus Hiftorucus prudcos ac verax : antiquitatis autem Ros. manorum \& Grecorurn petitus admodim. Pofferin. 1. I6. Biblioth. Select c. 7 .

Su-tonius Tranquillu: fcriptor (Deus bone) docus accuratus I faac Ca faub.in lit. Thuan. dat. Genev:13. Kal. Decemb, 1594.

Suetonius vitas aliquot defcripfit Anguftornm. Fielem fi fpectes, nihil certius. Acumen fcribentis fi confid res, \& prudentium, nihil acutsus, nihil prudenains. Verborum, qunntum fatis cft, adhibet, copiam autem rejicit. Formulas Fori \& Curic omne e fervat in loquendo. Mirificus plane vir, \& dignus qui ab omibus ameur \& legatur. Franc. Robertell. in lit ad Ioan.Baptift. Campeg. Tom. I. de Pop.Roman. vitî \& victu premill.

In Suetonio mirabilis dicendi proprictas, aftricta illa, \& qux plus habet ner *orum $\geqslant$ quàm corporis. Lud. Fiv. de rat. Atud. pucril. Epilt. 2.

Stylus ejus tenuis, \& qui Grammaticum magis, quàm Hiforicum fonat. $C a=$ rolus Sigon. de Hiftor. Roman. c. 14.

Adeö̀ tranyuillè \& zqualizer fluit, rebufque unicè addiczus; orationis orna mentanonnegligens fed lecurus preterit, \& tamen hunc iplum onatum velut umbiam (non id agens) trahito Eamian. Strad. proluf. lib.2,3. Hift. part 2.

Sed in: Suetonios quem hic fequitur Hieronyms, non pauca ejufmodi $\pi$ oboépaßc deprehendimus, eximio alioqui \& utiliflima friptore, cujus omnes li bros extaxe pluris intereffet Reip. Ezterarie, quàm multos quibus aquo animo careremus ; fillis poticemur. Iof. Scalig . Animadv. in Hieronym. Eufebian. Chronic. ad A nu. Abro.1960.

Ludovico Vivi l s. de tradend. Difcipl dicitur effe Gracorum \& Latinorum Scriptorum diligentifimus atque incorruptiflimus. V.crè quidem, fi de vitarum feiptoribus loqumur. Nam qui ic aco eum ívio, Salluftio:Tacito preponere: yclit: infignità, nco judicio a injuriâ adficiat tantos Scriptores. Vofjo de Hiftor. Lat.

Suetonius fic Ccripfit vitas Romanorum Imperatorum, ut nullum fibi præfcip ferit fervanditemporis ordinem. Baron. vol. I. Annal.

* ISaci Calauboni animadverfones in Suetonium, permituntur cum expurfationibus. Vide Indic. Madrit. $6667 \%$. 
Prodiernnt C. Suetonii Tranguilli vita 12. plimorum Imperatorum Romanoruph, cum Notis Variorum, accurante loanne Scbildio. Lugd. Batav. ex officina

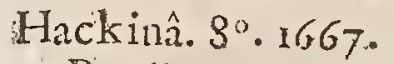

Prodierunt itidem cum paraphrafi Sabellici, ac Commentariis \& nocis $B e-$ roaldi, Glareani, Egn tiii, Pulmanni, Torrenti, Cafauboni, Urfini, Narciliz, ac Eipfiz. Parifiis lumptibus Hadriani Beys Au. rGro. in Folio.

\section{A P I A N U S}

Ciar. Anno Dr.Cxyind.

D Atria fuit Alexandrinus, Romecaufarum Patronus. Floruit Trajani \& Adriani remporibus. Hiftoriam Romanam complexus eft libiis 24. Orfus 'ab eAnế, \& Ilio capto, percurrit illa tempora ufque ad. Romulum. Inde accurariùs perfequitur omnia ufque ad $A$ igr fufm: quadam etiam carptim atc; obiter afyue ad Trajanum. Ex valto opere fuperfunt hodie Punica, Syriaca, Partbicas, Milbridaxica, Iberica; Annibalica, Illyrica, de bellis civilibusibri quinque, \& Celticorum fragmentum, vel compendium.

Stylus illi tenuis ac minime redundans; fed Hiftoriam, quoad ejus fieri poeft, veram texit, \& militaris difciplinx, fi quis alius, enarrator eft. Oratione dejectos militum animos crigere, \& ardentiores mitigare, affectufque exprimere ac fi quid aliud imitari dicendo licet, optimè novit. Phot. in Biblioth.

Scaligeri in Animadwerfionibus Eufebianis judicium eAt, Appianum ষel admolum un Hifloriâ effe infantem, vel multa ejus Syriacis elfe adfuta. Atcueidem alibi codem in opere vacat alienorum laborum fucum. Sanè malrùm Polýs debere, ac Iutarchum ad verbum cxfcribere folitum, viri docti jamdiu obfervaxunt. Vofl.de Hiftor. Grac.1.2.c. J2.

Baldvinusaliquet Plutarchin Crallopaginas de Bello Parthico,in libris quogue Appiani repetitas legi fitethr. Verüm id cfe factum fufpicatur, non ab ipfo

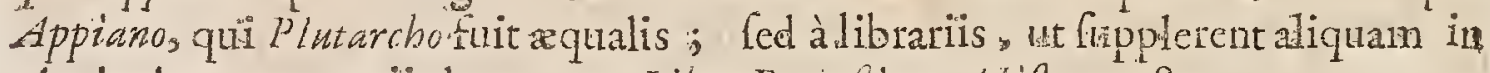
Appiani commentariis lacunam. Lib.I. De infium. Uifor.. p.87.

Necpraterendus nobis Appianus Alexandrinus, alicnorum quidem illé laborum fucus, ut meritò à magno viro appellatur: fed fcriptor utilis tamen, prafertim poftdeperditos non pauces corum, quos exfcriberc folet. Voff.de Art. Hiftor. c. 20.

Hiftoricus cximius vocatur Dempfiero.

Prudens lanè Scriptor. Conring. de Civ. prud. cap. 7.

Qua Appianus (de Pythagorâ eiugue Difcipulis, ant de Septern Grecia Sapienribus) refert, putidx funt cah humnix in viros optimos à Caufidico contra fidem veterum omnium monumcntorum, exemplo in Hiftoriarum Scriptore fanè non fcrendo, jactx. Corring. ibid.

Hiftoria ejus utilior eft viro Militari, quàm Civili.

Appianus Alexandrinus Gracus licèt Autor, fed quoniam extcrna \& civilia Romanabella memorix mandavit, in alienis "rebus mendax non fuit, futurus in

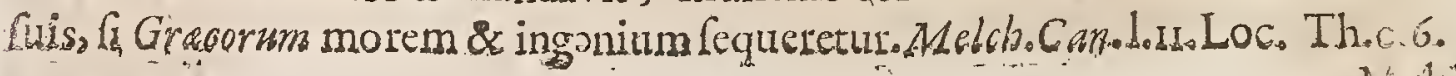


Multis in rebus levis, multactiam omittit: fed dilìgenter legendus, qưod pleraque ex Hitoriis his acceperit, qux perierunt. Sigon. de Hitt. Roman. cap If.

Non a Apiano de Romanis fcribenti ubique affentior, cùm in eorum antiquirate frepinfmè offendat. Iohan . Bodin. Meth. Hir. c. 4. p. 63.

Etri. in Romanorum Antiquitate Expe lapfus effe deprehendatur, unus ex omnibus Hittoricis eft , qui Romanorum provincias, opes, cxercirtus, totiulque Imperii deferiptionem proponit. Ant. Poffevin. Bibliot't. Select.

Etfurbit mirari, clam Appiano bellum Rhaticum fuilfe, cujustotante illung fcriptoresmeminexint. Livius copiosè defcripfrt, ex. Epitome enim cognofci-

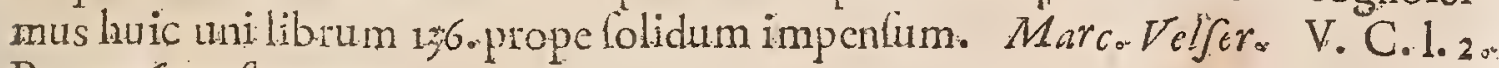
Rer. A inguftanar.

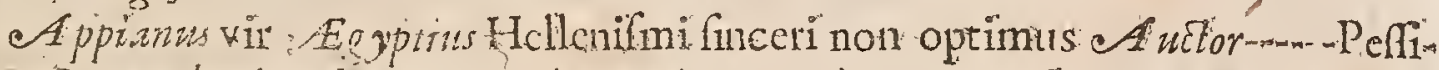
mus. Geograpbus in relsus Hipania Appianus, qui Saguntw inted Pyreneos \& Iberum flivium locat, qux omnium Geographorum confenfu fuit inter Iberum \& Sucronem, non longè à loco, ubi nunc Valentia. Iac. Parnel. Excrcito ad Appian.

* Henrici Stephani in Appianum Alexandrinum Annotationes permittuntur.

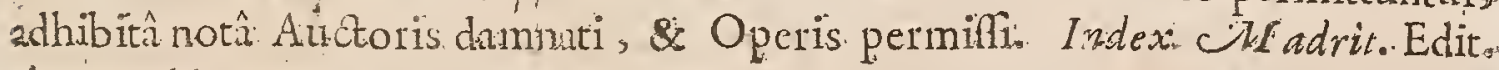
Anio 1667 .

Quie Appiani fuperfunt Hiftorica ex emendatione Henrici Stepbani \& Ale *andritiollii, prodierunt in $0^{\circ}$. 2. Vol. Ambelod. Anno $16 \% 0$.

\section{A QUI}

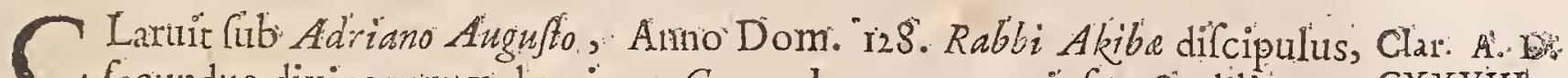
fectundus divinorum voluminum Gracus Interpres, curiofus \& diligens, Natione Ponticus, patriâ Synopious, vir utriufque mathefeos peritifimus, \& ob id Hadriano Auguffo charus: : à . quo etiam conttitutus eft prafectus opcrum ad extuluendam unbem Hierofolymam à Tito dirutam; Hic, inquam, cum urbe

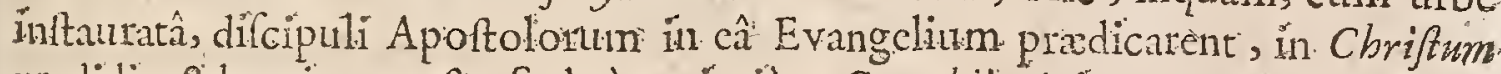
credidit, \& baptizatus eft. Scd cùm nimiùm Genethliacis intenetus, quotidic gcniturartm pofiriones, infpecto nafcentium horofcopo, defignaret'; atque ob id ¿ Patribus increpatus non defifteret, fed potiùs fefe illis contumeliosè opponeret, $a b$ ipfis de Ecclefà pulfus eft. Quam ille ignominiam ultrd quàm dicipo. teft: graviter molefteque fircns, abnegato Chriftianifino, Profelyens efficitur, \& apud fudecs circumcidieur, brevique edoctur Hebraorum linguam, interpreta tus cff $G$ racè divinas. Scripturas de verbo ad verbum, irruens in 72 . Interpretum tranflationem, ut nomullateftimonia de Cbrifo in Scripturís prolatay, \& ab cis stanflata aliter ederet, ficque acceptam confiffionem ulcifceretur. Sixto. Senen. in: Biblioth. lib. 4 .

Ea qua de Cbrifto in foripuris predicta fucrant, ut à Iratais gratiam inires Aqual laliter, quàm feptuaginta vertendo, fubdolî̀ obfcurizate involvit.Poffer\%. 1.2. Biblioth, Select. p. 173 .

CXXVYIII 
Aquila Prolelytus, \& contentiofus interpres, qui non folum rewba fedetymologias quoque verborum transferreconatus ef, jure projicitur a nobis. D. Hicronm.in Epilt.ad Pammach.de opt. gen interpr.

Valde accuratus interpres vocatur Bochario in Geographia Sacrâ. Aquila li-

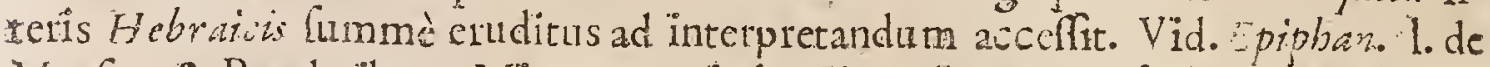
Menfur. \& Ponderibus. Miratur proinde Mic.Fullerss (Mifcellan. Theolog. 1. 4. C. 18.) Ivannis C'urterii maledicendi pariter atque mentiendi libidinem, qui eò infolcntie proceficint, ut patam affirmare non erubuerit ( prafat. in Procopit commcnt.in ifiam) Aquilarn Sinopitam, quum ipla vix Hebrxorum elementa didiciffer, Interpretationcm novam facrorum Dibliorum Adriano Imperante. molitum.

Alter verfir Graca crijus fragmenta tantum 1robis fuperfunt eftill Aquild, quỉ Adriano imperante vixit. Inierpretes, ille Chriftianam Religionem defewuit ut Judaifmum amplecteretur: Cumque Hebraice Linguz fudio fefe addixiflet, novam totius scriptwra trunfationem molitus eft, quam opponeret $V$ erm fioni LXX. Interpretum, qua frucuofifime adverfus Iudaos tunc utcbuntur Chriftiani. Sed cum fibi in has Verfione non omnino fatisfeciffet, ad incudem hane poftea revocavit, alteramque priori magis ad literam adomavit. Hinc fit ut Aquile Verfio, in eundem locitm diverfimodè citata quandoque occurrat. Fragmenta nobis refidua manifertè arguunt Interpretis hujus pracipuum ftudium fuilfe ut Hebraicum Bibliorum contextum verbotin redderet, \& Vocum Hebraicarum Lexicon potins quam vérfonem paligeret. Quapropter etiam adeo barbara eft Verfo illa ut pluribus locis fere intelligi non poffit: \& ha: de caufa Divus Epiphanius cam contemplut \& opus admodum inutile cenfuit. S Hierom nymus Aquilam tamen in quibuddam laudat ut accuratum \& fidclem interpretem, fed in alis eum refótit ridiculumque ac abfurdum appellat, quia voces interpretari non contentus harum etiam ctymologiam \& proprictatem notaverat. Caufa verò cur tam diverfa locutus fit D. Hieronymus de Aquile Interpretatione hac fuit, quòd fcilicet cin fe urgeri viderct cxprobrationc quòd $\mathrm{C}_{\mathrm{a}}$ tis accuratè Scripturarm Sacrarn non tranfuliflet, in fui Apologis refpondit hanc adeò literalem \& ex Grammaticali rigore vertendi rationem rejiciendam clfe, \& in ejufmodi Verfionum exemplum Aquile Verfronern adduxit, cujus nimiam fcrupulofitatem dammat. E contra verò idem Hieronymus dum agitur de prow pria \& genuina vocum Hebrairarum fignificatione exprimend, hanc ur orisium praftantifimam commendat, Authoremque ut accuratum \& fidum Inserpreterm laudat. Origines de Aquil Jerfone loanens Tudxos hanc catcis omnibus antepoluiffe teftatur, eandemque hac de caufa ufurpare folitos elfe in omnibus fuis adverfus Chriffianos difputationibus. Chrftiani vise verfa illan obedfem rationes, infanârunt adeo ut quadantenus tenerentur illam ut falfam \& ab Ecclefix Chriftianx infenfifimo adverfario concinnatam confiderare. Inrerea Patres fanum de illa judicium ferre non poterant; quia cum plerique Hebraice Lingux omnino effent ignari, cum Hebreo Autographn illam conferre nequibant. Jure tamen merito huic Interpretationi diffidcbant, \& credcbant Aguilam 
Aquilam, qui tantum adverfus Ecclefiam odium manifeftavelat, Iudeorum opinionibus favere, præfertim ubi voces Hebraica varium fenfum admittere potelant. Hæc tamen iphlaus jure debetur quod Hebraicum Textum, de quo etiam nulla erat controverfia, illibatum fervaverit. Quum verò. Patres criminantur Indcos qui Aquila Verfonern ulurpabant, quod Scripturam corruperint, id non de ipfo Contexu, quem integrum reliquit, fed de falfis Contextits Intcrpretarionitus folummodò intelligi debet. Cæaterum $P$ atres quibus hec Verfio dammata fuit, ad eam tamen quandoque confugerunt. Ricard. Siadn. Hift. Crit. Y. Teftrom. lib.2.cap.g. Gall.

Quo nemo unquam majori caftitate Ebraicam veritatem retulit, nemo fidem luam tam luculenter, yerbis etiam ipfis annumerandis praftitit. Petr.Das. Huet. declaris Interpret.

Aquilam verò agnofcimus exactifimum Interpretern, " in vocabulorsm propriisac rcconditis fgnifcationibu, \& cernendis oculatiffumum, \& confeetan-

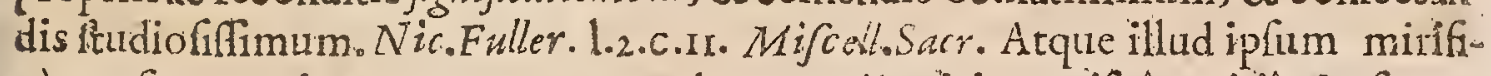
cè confirmatur interpretamento quodam Aquile viri exquifitâ peritiâ \& fingutari induftriâ. Idern 1.3:c.12.

Aquila proprictatis Aebraicarum vocum callentifimus. Sed fuperfitiofus ufque ad ineptias, in Etymologis earum exprimendis. Arnold. Boot. in Anirnadverf. Sacr. ad Text. Hebraic. V.T.

Extant Verfionis Aquile Fragmenta Grecasqua Flaminizs . Nobilus \& Drwfurs collegerunt.

\section{L A U D I S A I I N US.}

T Talus, fub Hadriano Cafare magni nominis fuic. Pranefte natus eft, fed Rome vixit, civifque Romanus fuit; unde $\&$ Ce in variis fepiùs Rornoma appellat. Scripfrt de Arimalibu, de Varia Hiftriâ, de Re milutari, que omnia ad nos pervenere. Catera ejus opera deperdita funt.

eElianu licctgencre Rimanu effer, non minus fcitètamen Atticè, quàm vel Mediterranci Aibenienfes, locutus eft. Et fanc laude dignus vir ille mihi videtur: primùm, quòd cùm habitaret in urbe, qux fermone prorfus diverfo ntebatur, Gracanice lingux puritatem fit confccutes:dcinde quod oblato fibi (ab iis qui hujufmodi titulos conferre folent) Sopbifta nomine, nullam de fe fiducian aut adulationem fui, aut fuperbiam ex tanti nominis honore conccperit : quip potilus cùm fuas ipfe vires experdilfet, eafque Declcmatoria Talefira impantes judicaffet, adfcribendum animum appulit, \& admirationem inde confecuts s ct. DiEio cjus eft omnino pura, fimplex \& inaffectata eft, ut Nicoftrati elegantiat lepôrem quendam adhibcat. Eft quando Dionern, ejufque dicendz genus \& tonum imitatur. Philofirai. de vit. Sophift.

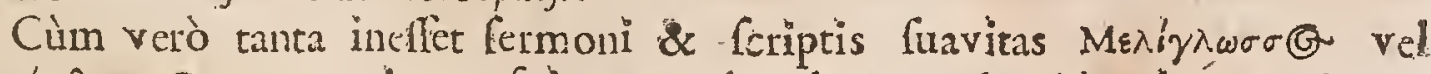

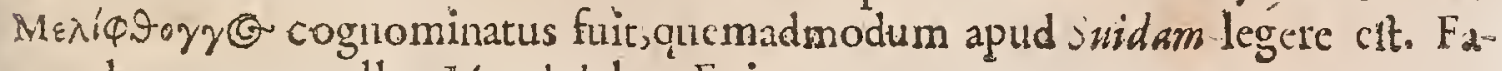
cundum cum appellat Martial. 1 12. Epigr.24. 
In libris de Animalibus præ fcriptoribus aliis laudem co meretur, quód ex mutis animantibus vitæexcmplum capere homines doeet.-.-.-Liber de Hifro-:riâ variâ minùs elegans eft, quàm libri de Animalibus. Sed planè mihi perfuadeo, non elfe extremam operi manum additamab Auctore, cò quòd fato pras veniretur. Namque ablque dubio aliter concinnaturus erat if:a capit i, qux ab ơ orditur. Siquidem fic folent fcribere, qui alicni operis excerpta folum nobis: dant : ut oftendunt Strabonis Epitome, Photii Bibliotheca, \& alia hujus monetæo Vofl. de Hijl. Grac.

Eli.znus, elegantifimus ille fcriptor, quique veteres Grecia heroas tam Itudiosé legerat. Tan. Faber. Epirt.l.I. Epilt.s.

Elianus, venuftus ille \& amabilis fcriptor. Idem 1.I.Epift.75.

In quo nihil non terfum, elegans, politum, plane ut Romanus Gracấ eloquentia multos Atherien $\int e s$ videatur excellere. Balth. Bonifac. l.15.ludic.Hift. C.3.

In dicendo apheliam maximè affectavit, quam nos fimplicitatem dicimus, quæque (uti prodit Fabius) fumplex \& inalfectatahabet quendam purum, qualis etiam in fominisamatur, ornatum.C al. Rhodigin.1.2r.c.32.Lect. Anriq.

Porro illud de efliano velut fuperpondium addamus, quod in co viro non parum admirationis habet. Quippe pradicare folitum ferunt, nunquam fe extra Italiarn pervagatum, navem nunquam infendiffe, mare ncc noviffe quidem, quo nomine in magnâ erat auctoritate, veluti patrii moris ftudiofus inprimis. Idernibid.

e Elianus de Hiftoria naturali, dumaliusab Ariftotele videri vult, a rei veritate recedit. Claud. Verder. cenfion. in Auctor.

Utinam fripta eAliani omnia ad nosillibata \& integra pervenillent ! certè quicquid ftylus fophifticus habet verbisnitidum, fcntentiis acutum, figuris jum cundum, tranflationibus floridum, inventione praclarum, compofitione elaboratum, id omne nofter ( $\mathscr{A}$ lianus ) velut quidam Eloguentice Inftitor nobis in tuendum \& senè contrectandum daret. Sed hîc Eliani opera vì temporum \& concurfu calamitatum partim labefactata \& convulfa, paxtim planè deleta extinataque meritò dole mus. Ioarbim. Kunius Prefar. ad Lilian. Var.Hif.

In ejus narrationibus quid non egregium,non preftans, non idoneum vel ad cognofcendum, vel ad imitandum fugiendumve? quid non in eo terfum, elegans, politum \& Atticum? Iufus Vultejus in Præfat. Hift.multifarix.

In Eliani de Antmalibus libris temperamentum quoddam \& Hasmonia utriufque Philofophix, Moralis, inquam, \& Naruralis. Gesner. de Elian. Hift. Animal.

Extant Claudii eAliani varix Hiftorix libri is. Grace \& Latinè ex emendarione Tanaquilli讠 Fabri Salmurii 8 . 1668.

Tactica Gracè \& Latinè cum Notis Sixti Arcerii \& Tabulis ari incifis, Lugd. Bat. 4\% apud Ludovicum Elzcvirium Anno 1613. 


\section{CELEBRIORUM AUTHORUM.}

\section{$P A U S A N I A S$.}

7 Empore Antonini Philofophi Imp. vixit, Difcipulus fuit Herodis Attici; Clar. A. D. CXXXIX. phiftas. Patria ci fuit Cafarea Cappadocix. Inde erat, quòd in Declamando, Cappadocurn more, corripiendas Syllabas produceret, producendas corriperet : ac proptereà C'oguo comparabatur, cibos bonos malè condienti. Jed \& stylus per Ce languidior erar. Declamavit non folum Athrnit, Led etiam Rome; ubi fenex deceffit. Extat hujus Scriptoris minùs quidem facundum, fcd èuditum opus de Graciâ, libris decem contans: iis \& fitum urbium ac locorum, \& Antiquitates Gracanicas; \& quicuuid penè memorabile Grecia habuit, magno Philologix \& Hiftoria ftudiolonm bono complexus fuit. Quod olim dicebat Dornitius Pifo, the fauros fribi debere, non libros, id à Paufanta verè fuctum dixeris. Quare non fatis concoquere polfum, quod excidit Cafari Scaligero commentario in priorem Iibrorum De Plantis, Arifoteli falsò infcriptorum; ubi dicitur, Greculorum ornnitum mendacuffrnus. Non fum ignarus, quàm multa narret fabulofa. Sed hoc Grarmaticum decebat. Nec fine fabularum iftulmodi notitiâ fatis intelliguntur veteres Scriptores. Utinam tantìm extarcnt ejus Afratica, frepiùs memorata Siephano in Etbrict. Voff. de Hift. Grac.1.2.c.14.

A utor ob variarum rerum copiam, \& Hiftoriarum jucundam diverfitatem utiliflimus, cùm exquifitam totius Gracre defcriptionem infituiffe, non folù locorum fitus, \& intervalla diligenter explotavit, \& accuratè annotavit, ventum etiam pracipua Regionum ornamcnta fudiosè cit complexus: Rerump. ftatus, Imperiorum fuccellus, Regur familiàs, \& res praclare geftas, fplendida Civitaturn \& fumptuofa xdificia; Eellorum dehinc caufas \& ambiguos exitus, Dum cum Confilia, Militum fortitudinem. Pacis item artes \& alia complura, quz adinfituendas \& confervandas Reff. multum hab nt adjumenti. Poft haz exhilarandi lectoris, ant omandi operis causa addit carum rerum defcriptionem qux multis decaufis aut voluptati omnibus fint, alut admirationi. Abrabain Loefcher. praf. in Piul.

Habuit fanè nihil'olim Gracia, quod fpectaretur dignum, vel ex are, Azro, argento, vel ex ebore, ligno, marmore factum \& elaboratum, quod hic nofter (Pausunias) non clegtnter atque intelligenter explicaverit-- In pervolutandis certè Paufanit libris, è Greci hominis facundiâ \& eruditione, non mediocrenn tum fructum,tum voluptatem capies. Rornil. Arrafens in Epirt.ad Alex. Farnef. Cardinal. Paufan. Defcipt. Grar. prefix.

Opus (DeGraciâ) antiquæ raræque eruditionis thefauros continens. Multa hîc invenies, I.eEtor candidiffime, recondita; multa Ccitu pulchra; nonnulla, q!æx alicubi nondum legitti. Admirabcris Autors accuratam \& exquifitam diligentiam, five narrationem rerum praclarè geftarum in fronte voluminum collocet; five Genealogias perfequatur; vel ab ovo (ut dicitur)ordiens, vel ad caput. ulque genedis fericm pertexens : Gye Statuarm rum Artifices commemoret: 
gum eos concelebret, quorum in honorem ereax funt. Ald. Minut.prefat.ing Panfan.

Paufanias minus quiden facundus feriptor, fed ob rerum copiam, \& Hiftoriarum varietatem utilifimus, Ioan. Cardin. Bona.

Auctor auro omni Antiquitatis Grace cupidis pretiofior. Barth ad: Nemefani lyneget pag. 234 .

Univerfa Greux provincias.Rerumque publicarum ftatus \& converfiones, populos, Urbes, caltra, fluvios, montes, vertices, fontes, fana, ftatuas tam curiosè defcribit, ut in co.genere omnium fuperârit Opinionem. Bodin. aap. 4. Method: Hifter.

Paufanias Gracus A uthor bonuseft. Scaligerana pofterior.

Extant Pausania Antiquitatum Grecarum libri 10. Grece cum verfione Romu. li Ainafei, 2x-exrecenfione Frid.Sylburgii.Francofurti, Anno 1583 , apud. hrese des. Wecheli in Fol.

\section{I A U. D U S T T L O M E U S.}

Clax. A. D. T Atione fuit Egyptiur, patriâ Pelufienfis, floruit Cub Marco Antonino ImCXI. peratore Rornanc, clarifimus artium liberalium, \&racarum literarum Atudiis Alexandria. Primus omnium apud Gracos. Coeli rationem accuratiùs di. ligentiúfque explicuit. Inftrumenta qua ab Hipparcho inventa crant, demontra-vit clariùs. Princeps itaque doctriiz: Mathematice jure fuir habitus, in Aftrolom: sice cnim fcicntiânullifecundus erat. Is monumentis ingenii \& doctrinx relictis: penè divinis, martuus etiamnum inter mortales vivit, xetcrnâ gloria laude viêturus perpctuò. Boiffard. in. J con.

Variis monumentis immortale fibi nominis decus peperit Clandius $p_{t o l o-}$ meur. De atate teftis Suidas. At nimium quantum errant, qui: Ptolomeum hune: arbitrantur fuifle unumex Regibus eAgyptii. Ut, yui cdidit eum, Srmon Grynaus, \& antehunc alii, Alburnazarem in cofecuri: Hic Prolomeus iil doetrinâ Siderum

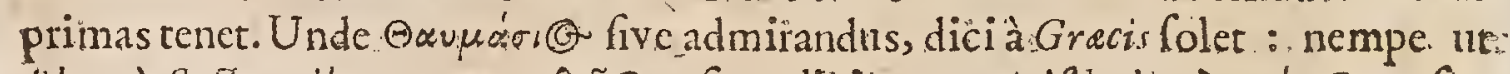

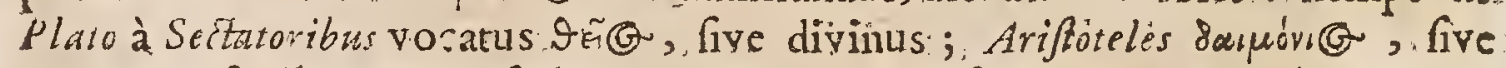
Demonum fimilis; quiquafi dii minorum gentium fortem excrdere humanam, diifque majorurr gentium vicini exiftimabantur, Vo]! de [cient. Mathemat. pag. I62..

Prolomatus Aftrologorum princeps, \& in Mathematicis vir ingenii eminentiflimi, Kbodigun.1.1.lect Antiq..c.16..

1-tolomats in $A$ rabic $i$, vir fane fide dignus.: quippe qui fcdulo hoc egerit , ut accuratè Ar abica traderet. Henr. Stephin in leriplo.

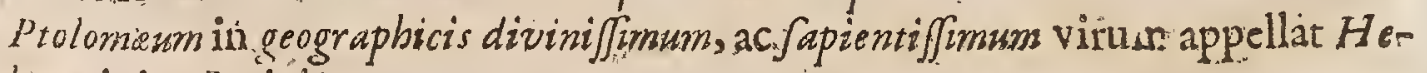
racleota init. Peripl.

P.tolomeus, fvir ingenio, induftriâ, eruditione, admilandus qü Hipparchion

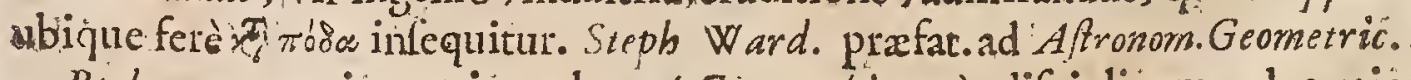

Ptolomews omnium primus hanc (Geographicam) difciplinam ad certiorem rationer: 
zationem redegit, commentus dimenfionem Latitudinis univerf Orbis a polo ad polusa, Longitudinis ab exortu ad occafum, adhibitâ.collatione terrs habitabilis ad coelum, ut jam nón.facilè quis, toto ( quemadmodum aiunt) celo poffrt aberrare. Erafm. 1.28.Epil.1.9.

Licèt Hipparchus primus omnum ex.collationc fuarum, \& Tirnocharis ob-

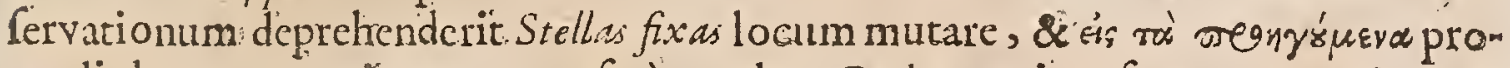
gredi; hoc tamen vix receptum ferò tandem $P$ tolomsus in ufum revocavit, \&

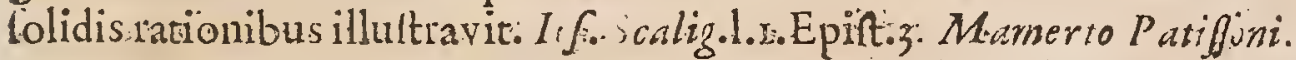

Ptolonno proximx poft Arcbimedern debentur ingenii. laudes; quia tam claras. fiterum rationesutin ateruum fufficerent, excogitavit; folufque divini opificii modum, \& fubtilitatem exprimere aufius eft; ut invenifle non dicam. Cardan. 1. 16. de Sitbtilit o.

Sed utcunque nihil, vel tantummodo minutum quid, defideres. in lis. qua: propria funt Matbernatici : in.llis tamen, qux Hiftoria fuppeditat Geugrapho

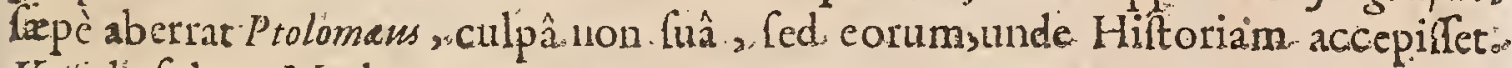
Volj. de fcient. Mathem. p. $247^{\circ}$.

P'toloneum frequentradibam; fed faltidium movebantnon pauca. Animadvertebam pluriona magno antori fcripta effe ab audítu, ex aliorum (qui fxpò fallunt, quorumque, cùm, quas vifa narrant, verbanonnunquaminon benè ca. piuntur ) fide :eamque ob caufam ipfius. Geographira, cxilieno concinnata rclatu, maleque \& inemendate fcripta, innumeris deformata effe erroribus; multaitem, quxaliis nominatifima, negligenter in iis efle omili ; mula fequiorem nacta efle ftationem, \& extra verum locata futum ; multa dubiam adepta nomenclaturam; infinita non fuis tributa populis, vel regionibus, plurima denique cùm ab aliis, rum ab feipfo, \& alibi-dictis, diffentientia.Panl. Merulo. fuâ in Geograph.prafat:

Ptolornci errores circa Stellarum motum; ip farumque \& Solis declinationent taceo : tacio quòd Sol m tardiorem quàm fic effecerit. Sedabfque racione pro fectò ait Quadripartit I. Planeias humidiores, ficciorefque effesprout amplis minufve ab afcondentibus è terrá vaporibus bumiditate afficiuntur: \& Luzam proptereà humidiorcm elfe quòd propior terre fit. Saturnum contra ficciorem quòd à terrâ.fut remotior. Cisud.Virder in Autor. cenfione.

Quin igitur quodres eft, $p$ to!omai peccatum agnofcimus libexè. Yolens liz

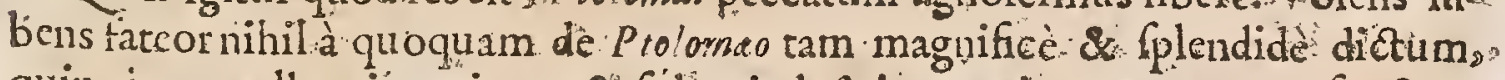
quin cjus exccllens ingenium, \& folers induftria omnia exuperet: perfpectum? tamen habeo:, multa hoc tantum ingenium latuife, multa induktriam: fubter fugille. Neque mirabitur, quicondirionem rerum quas explicandas fumplit Univerfi Orbi, tam univerlam, tum privatas defcriptiones, pofueritob oculos Si ipfe redivivus detur, cenfuram ultro agniturum, atque inconfideratam co. rum levitatem, fi quifunt, qui aliter fieri potuiffe perfualum habent, "rifurum exiftimo. Quor liceat illius crrores manifferos colligere, ab is qui Germanica, Gallica, Hipanica, Britanni, feripfere obfervatos ? Quoties hominem Ale*andrinwm in Italica défcriptione, quuâ unâ propter Imperii fedem nihil illuftrít 
Iugillant? Marc.Velfer.1.x. Rerum Augufanar.

Extant Claudii Ptolomer Geographix libri 8. cum Tabulis Geographicis reftitutis par Gerardum Mercatorers recogniti \& Caftigati à "etro Montazo, Amfelodami Cumptibus Cornelii Nicolai \& Iodoci Hondii, I6og. Fol.

Iidem Graè \& Latinè cuâ Petri Bertii Tomo Primo Theatri, Geographici Neteris Amfelodamis Anno 1618 . in Fol. ediri.

\section{DIOGENESLAERTIUS Give DIOGENIANUS.}

Clar. A. D. exL.

CIlix fuit, \&à Laerte Cilicie oppido Laertius five Laertienfis, appcllatus, fophorum - Librum Epigrammatum omni Metrorum genere fcriplit, quein idcirco $\pi \dot{\alpha} \mu \mu \varepsilon t$ gov vocavit - Timon is quoque Sillos commentario illuftravit.

Partm idone de hoc Autore judicat vir cæteroquin eruditus, fed novellorum fcriptorum, quàm Antiquit.tis ftudiofior, Bartbolomens Keckernamus.

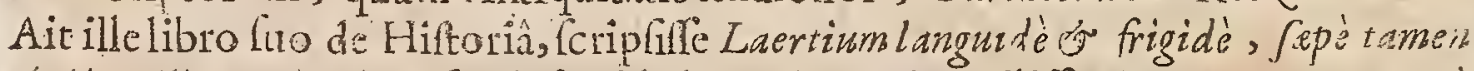
nón inutiliter. Qux profectò frigida laus eft operis utilifimi, \& auro contrd non cari. Quippè ex quo difcere fit, cum alia tam multaad hiforia m temporam pertincutia: tum praclara tot veterum Apopb begrn ta, quon Keckermanims malo fanè exemplo; Erafrnum laudare mavult autorem, quàm Plutarchum, Latrium, \& fimiles. Quin, quod caput eft, difcrepantes ex codem Laertio SEEarum Cententias difcimus. Voff. de Hiftor: Grac.

Extat magno commodo omnium literarum Diogenes Laertius: cujus RhapCodix', licet diligentifimx exactifimeque non fint, fummâ tamen utilitate $\&$ voluptate leguntur, ut multis vegrandibus carerc pro ifto velle fapientia fit. Barth. ad Claudian.pag. ro2.

Cafaubonu in vïtâ Diggenis cum Antiquitatis indagatorem Cedulum vocat, fed cui aut memoria firma, aut otium, judiciumve in digerendo défuerit. Diogenes Laertius unicum fere Philolophicx Hiltoricx columen eft:ablque eo eflits, suderafupereffent, atque cæementa difficulter in plerifque conjungenda. Ioan.Ionf. de friptor. Hiftor. l'hilofophic.p. $27 x$.

Diogenes Laertius Philofophorum vitas ad fœminam quandam compoluit. Magna eft in eo opere rerum cognitio', multoque eft legi dignifimum.Magnâ fide ac diligentià Philofophotum vitas compoluit. Lud.Viv. Be tradonde. Difipl.1.5.

Omnes illas Epiftolas, qua illis Philofophis (Democrito, Soloni, Thaleti, Pittaco, Mityleneo) à Laerio attribuuntur, multis argumsntis confictas à Grecis, quibus nunquam mentiendi voluntas aut facultas defuit, probare polfim. Ios. Scair . Epitt. 306.

the mili multis nominibus carifimus auctor. Ifaac. Cafanb. Epift. 18. ad lac. Bongarf.

Ip fe non indignus cft ut intex. Poctas conßumeretur cos qui Epigrannatis luGerunt, Lil Gyrald. 


\section{CELEBRIORUM AUTHORUM.}

Diogenes Laertius Ledulus indagator antiquitatis : ex cujus libro de Vitis Philofophorum multum proficere pollint ftudiofi. Sunt qui dicant eum plus fur dii in legendo, quàm diligentia in fcribendo adhibuilfe ${ }_{\text {I }}$ oan. Card. Bona.

Nullum au'nos librum Vetciestranfmiferunt qui uberiorem nobis dectrinam fubminiftrarit quam Vita Pbilofophorum à Diogene Laertio; fi modò fcribendi peritiam Argumenti quod fibi propofuerat ex æquo refpondentem habuiffet: Si enim de ipfrs tam erudite Orbi literato fcripfifet ac Gafendus de Peireskon quantislcientix divitiis fruercmur, quarum jactuam ob ejus impcritiam magna ex parte paffi fumus ! Cùm ab illo uno pendère cogamur, quia nullus alius aut faltem nullus melior Author nobis liupereft qui de illo Argumento cripferit. Doctoris Burnet. Prafat. in Vit.Dom. Matt. Halc.Angl.

In ejus Scriptis nufquam Secta cujufvis rigidus Affectator, neque Fautor deprehenditur. Si tamen de illa ex conjectura nobis opinari liceat, non abfque ra= tione putamus illum fuille fectatorem Potamonis Alexandrini, authoris Secte illorum quibus Eclecticorum nomen inditum eft, \& Vertatis Ariantiurn titulo preterea infigniti fuerunt; quir optionem faciebant è quacumque Secta eorum quibus tibi potiffimùm adharcindum effe arbitrabantur. Ejus doctrina ex ejus Scriptis patct; Si cuim ejus stylum obfervemus, concifum \& efficacix plenum iplum deprehendemus, voces ejus felectas, fermonem ejus facundum. Nec tam mon omni culpâ vacat, quod ad difpofitionem, fuperfuitatem aut defectum materix fpectat; quod quidam id memorix ejus libilitati imputantes excufant; alii multiplicibus ejus occupationibus id tribuunt, quibus ab eorum quæ fcripferat recognitione inhibebatur. Illis tamen accenfetur qui in omni doctina genere praftantiffimi fuenunt exiftimati; Itaut fi quod fentio dicere aufim nec Platoris Vita, nec Zenonis Dogmatum Epitome, nec tres Epicuri Epiftolx, ejus textura videantur. Diogenis Laertï vita 2 Verfoni Anglica pramilfa in $8^{\circ}$. Excufa Londiri An.1688.

Multaex hoc Laertii opere (de vitis Philofophorm ) fuis doctringe varia eclogis inferterat Sopater:tefte Photio Cod. I6.

Diogenis Laertiilibri 10 . de titis Philofophorumprodierunt Grace cum inrerp. Aldobrandine, cujus item notx ad vitam Lencippi ufque, nec non utriufque Cafauboni Ifaaci \& Merici, dcnique amplifimi conmentarii eAgidiz Menaoii ascedunt, curâ Ioann. Pearsonii. Londini apud Ortavianum $\mathbb{P}_{\text {ulleyn }}$ Typis Thom Ratcliffe in Fol. Anno. I66.4.

\section{JUSTINUS MART TR.}

T Atus eft Neapoli Paleftina, patre Prifco Bacchio : educatus eft in ftudirs Clar. An. Philofophize Platonica : ad Chriftum converfus eft, cum fidelium in perfe- $C \times \dot{L}$. aendis Martyrils conftantiam vidiffet:pradicavit Clriftum habitu Philofophico, (telte Eufebio) pro cujus etiam gloriâ mortem . quam fibi iple Apologiâ ad Antonium pradixit, gloriofiflmam perpeffus eft, Martyrii coronâ redimitus Aum.Dom.164 Circa an-Dom.I q $_{0}$ pro Chrifianis Apologiam obtulit. 
Operagenuina funt:Parrefis ad Grecos - Elenchus, feu Oratio ad Gracos-Apologid pro Chrifianis prima---.-A pologin pro briftia is fecunda-.--. Liber de Mondrchia $D \epsilon i$, forfan in fine mutilus.--.--Dialogus cum Tryphone Iudao--..--- Elitifola ad Diognetum.

Operu non extantia: Liber de animâ-..----liber Plaltes tictus-...--contrs omues Hxrefes-m---Contra Marcionem--...Commentarius in Hexameron-----De Refurrectione sarnisstefte Damafeno.

Opcia dubia: Arifotelicorum quorundam dogmatum everfio-n-.-. Epifola ad Zenam \& Serenum.

Opera.fuppofintitia funt:Quxttioncs \& Refponfiones ad Gracos--..-Quxfiones Græcanicx, de in orporco. \&c. \& ad caldem Chrittianx refponfiones---QuxAtionum I46. Refponfio ad Orthodoxos----Dubitationum adverfis Roligiotrem fummarix folutiones----Expofitio fidei de S. Trinitate. Gule ave.

Scripta Iütivi magnum in Ecclefiâ nemen confecuta funt. Abrabam. Scultet. in Mcdull. Patrum,p.I.

Reliquit núbis Iufinius puruima cruditi animi monumenta ac omnis gencis utilitatis plena. Eufeb.

Infinus Martyr vicinus Apoffolorum temporibus fuit: yuem tanquam Apoficolicum virum citant Eufebins, Bafilius, Epipbaniws, \& alii atres. Puffevin. Biblioth. Iuftino benè perfects erat Apoftolica doetrina \& confuctudo. Zanch. 3o volum.

Eit vir ille ad Philofophire tum noftre, tum potiffinum profane fummum evcctus faftigium, multipliciqque eruditionis, \& hiforiarum copiâ cicumfuens. Sed Khetorïco artificio, nativam Philolophix fux pulchritudinem colorare haudfudio habuit. Quamobrem ctiam oratio cjus, pollens alioquin ac valida, fcientificumque fervans stylum, Rherorica illa condimenta non (pirat, nec illectbris \& blandimentis vulgus auditorum attrahit. Phot.in Biblioth.

Libros enuditiffimos Infizus lcriplit adverfus Valentzianos \& Murionem, praterea de Harefibu: \& Hareticornm prafcriptis, quos fi quis legere non grava bitar rectiùs intelliget Irenai libros. Erufm. Epitt. 28 Epitt.5.

In rebus Hiftoricis graviter interdum hathucinarus eft infinus : Ut cum in Apologiâ fecundâ regnalfe dit Herodern in indáa, quando Ptolomens T Thiladelphres libros legis vertendos curavit: qui tantus eft five prochionilmus fivc metachronifmus ut oculis meis cùm illla lego vix credam. Cafoub. exercitat. I. ad Apparat. Annal. Baron. num. 69.

Omnium patrum antiquifimus cot Infinus, magni aptd ycterum Hiftorias nominis,non folum propter infignem rerum divina:um \& Philofophise cognitionem, fed ctiam propter zelum illum quem luculcntiffimè \& magnâ cum laude exeruit, cùm mortem pro Chrifto fortiter oppctiit. In hujus tamen viri operibus, quàm multa occurrunt vel levia vanaque, vel ctiam periculola? Manifeftè apparet ipfum cum Chiliaffis fentire, antequam Refurrectio penitùs perficiatur: Hierofolymis fiddes annos mille regnaturos. Alibi videtur Cenfille GIfentiam Dei effe finitam; probat enim adverfus I udawm o de Patre non fuiffe dictum, 
actum, Dominus pluit fuper Sodomam ignem ofulpbur, aliàs (inquit) in calis non fuerit. Quia habet de Ancelis, taneth iftis leviora funt, tamen \& ipla quoque abfudifima; Deus (inquit; horrinum ipforum, arque corum, qux fub colo funt, providcutian Angeis ad hac difpolitis attribuit: Angeli autcin ordinationem five difpofitonem eam tranfgreffi, cum mulieram concubitus cauf, amoribus funtvicti,tum filios procrearunt, eos qui Damones funt didi. Dalleus de ufu Patr.p.255.

Juftinus Martyr fimplex efo juvat tamen quid dicat infpicere. Scaligenand polterior.

Perfecta Pbilofopbic Etbrica cognitioni miran Scrinture Prophetiarumque, intelligentiam fociaverat, atque Kéligzonis noftre noticiam exquifitam; adeo ut Veterwin ferè nemo de omnibus Myperiv noftis accuratius differueric. Verum quidem eft eum circa Trmitarem ànobis diffentire vider"i, quod Hatonicorum Principiis infiftat: Sed qui ejus ac Vererum Doctindm ad amuffm examinaverint, cos nobifum in rebus confentaneos, $\&$ in fuos fenfus enuniandi modis a nobis tantùm difcrepantes animadvertent. Ell. du Pir. Nov. Biblioth. Authorum Ecclefiafic. Tom.x.p.x60.16I Gall.

Tatianus I

Epiphanius Sandum, \& Deiamicum vocar.

Philofophum Divinum I uftionm vocat Anaftatius, Bibliothec: in Hift. Ecclerafticâ.

Vir maximâ dignus admiratione. Henr. Ernft. de verâ Philol.n. 47 .

Vir vera Philofophia Atudio \& manyrio claro notatus ibid.12.54.

Gravis \& pius scriptor, quantâyis audoritate venerandus. Boecler. de Scriptor.pag. $6_{4}$.

Dionsf. Petwins Juftinum refentinter eos, qui idem quod Arius ante tradiderunt. ideoque rejicit Expofirionern Fidei, qux fub nomine Iuftini circumfertur.

Literarum Hebraicarum ruden penitus \& imperitum fuiffe, Iuftino vitio vertinon debcr, I', quia quamvis parrià fuerit Saratritanus, Grecis tamen paw rentibus natus fit ; deine quòd magnam vita partem in religione Genilium traduxerit; deindè quòd bilofophide Gracifque difciplinis fe totum dederit, qux a literarum Hebraicarm itudio immane quantum abhorrent. Hinc factum eft,ut in Hebrais adco pueriliter laphus fit.Gui.Cave. Hitt. Literar.

Opura I fixiz omnia prodierunt Grace \& Latine cum notis Sylburgii,Perionit. Billii, \& Petri Lauffeliz. Fol.Parifios An: 1636 .

\section{JUS T I N U S.}

F Iftoricus tempoie Antorani Pir imperatoris claruit. Sunt qui poft Impe- Car. A. 5 rium Confantisopolin tranlatum, eum vixilfe exifiment : quos Ger. Ioan. CXLII. Toffu redarguit. Pornpeii Trogi Hiftoriam in compendium redegit.

Studiolam verò juventutem, quxecognolcendx hiltorix cupida ett, hortor $\mathrm{X}$ etiam, 
etian, atque etiam, ut audorem huse, quỉ multis nominibus cognitu juctur ditfimus pai iter eftac urilifimus, nè poftremo loco ducant, fed affiduè diligenterque evolvant ad exemplum Auguttin, Orofit, Lfidori, alio sumque magni nom minis virortum, qui frequentieum lectione familiatem fibi reddiderunt adeo, 10 multa ex illo, prafertim Orofus, ad verbum tanfcribere, fuifque ipforum fcriptis infercre noin dubitârint. Theoph. Cangifer. Prafat.prafix. Infin o.

Eft I ffinu fcriptor terfus \& eligans : :ut de co fcribit Raimundus Lullus 1.7.de orat.cap. 4.Quàm tunpiter autem in rebus $L$ udaicis abertúrit , oftendit Benedictus. Pereruss in Daniel c. 40 . Vog: de Hiltor Lat.

Iuftinus Trogi Pompeii 2 Praceptoris fuiabbreviator, qunnum fiyli genus: patitui, difereus. Dempfter.

Voco ego cum delicias Hliftoricas, omniumque quotęuot: Epitornas confcripferunt longè principem facio. Bonifa". Indic.Hift. cap.s.

Trog iccrtè Hiftoriam I uftinus non folìn àdmutilavit, fed non uno ctian loco verbis ferrea demum xtate ufurpari coeptis.inquinavic. Ga/p. Sciopp. conzfulcat. P. 4. I.

Trog $i$ Pompeii compendium fecit I ftrnus quidam. Res casut fieriamat, dilpendio fuit Trogo. Nam ipfe quidem pra illo breviario Ceponi ac negligi cepie: atque interire tandem. Quenftedt.

Iufintus Hiftoricus Trogt Pampeii breviaror ftylonitidiffimus, eujus Epitome ipdi Trogo exitio fuit. Ioan.Card.Bon.

Iuftrmu qui Compilator evadit dun Hiftorici titulum affectat, licvia tantum excerpta Muteriarun tradit. Multanovit; , res.prudenter dicit ; non pauca geftas connfit quorum notitia aliàs. intercidiffet. Rapin. Refl. in:Hilt.Sect.2s.

Nullim cxvetuftis Scriptoribus, qui ex faedâ barbariei tempeftate, triftique: rei literarix nanfiagio quafi elictati ad nos pervencrunt, tyrociniis fudii Hi-

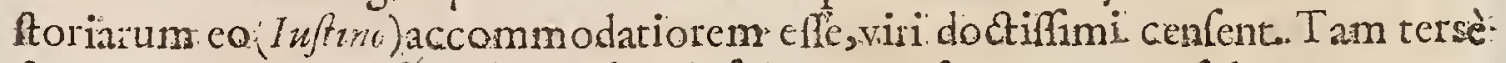
fane's tam emcndate fcripfit, ut faculi fui captum fuperare, nec folarum rerum, fed \& verborum flolculosex: Trogo, optimi avii Scriptore, delibafle videatur. Nec prater cum quifíquam amplius exrat corum, qü fecundümferiemtemporum res: plerarumque Gencium digefferunt, in iifque ordine pertexendis: elaborarunt: omnibus, five totis five maximam partem ablorptis, \& longâ fuperioris memoriz nocte, optimarumque Artiim fatalifilentio deletis. Aita erudit. Calcndo. Maii, Anno I683. p. I79:.

Nonperinde nitidus cft: I ffinus, ac Q. C.urtius: Lud.Tives Lib: 3. de. Tradend: Dicipl.

Quid de I uftino dicemus quí Trogi Epitomen fecit? qui eloquentiam penitiuls: fcrutantur, haurire polfunt inde aliquil è melioris feculi literaturâ. Fortaffe snim in plurimis non miinus Trogum exfcribit, quàm. Xiphilinus Dionem. Si candide \& citramorofam cenfuram agendium cft non video, quid repudiare in co polfit noftrifeculi. Politicus, vel in verbis, vel in. Cententiis, quatenus expofitioni rerum ferviendum elt. Nam elegantiam contexendie orationis aut ornandi Argumentialiundè rectiùs petiveris. Boerler.de eloquent. Polit.n.6g. 
Auputinur Iuftrim tant fecit, ut ex co non pauca in libios De Ciritate Dei ad veibumeranitulérit. Konig.

Sunt quihifteriam Trogi vidife fe ia Ituliafirmont: per quietcm puto. Lud. Tiv. in 1.4. Auguftrn.De C.D.C.6.

Quamvis Iuftinus fribendi genere adeo praclarus fit, ut Angusti potius quàm Antoninorum reculo dignus habitus fuerit, in aliis tamen ftylo ejus multò gravioribus cenfuram vitare non potel. Errorum plurimorum in rebus Iudaos ipectantibus cum convicit Pererius, Commentaris fuis in Danielem cap. $4^{\circ}$. Vopifcus eum Hiforicis illis annumerat qui mendacium vitare non potucrunt; fed levifima inde fit accufatio illa, quod illum Tito Livio, Sallufio \& Tacito confociaverit. Id in qun excufari nequit Chronologian lpectat, in qua tam cralsè hallucinatus eft, ut quilque fedulo carce dcbeat ne illim femper fcquatur. Eò atem graviores cenfentur llius lapfus, quòd Trogi Pormptit fama, cjufque apud $V$ eteres omnes exiftimatio, hanc opinionem indicant quod hujufmodi errores circa temporum Ceriem Apographo non autem Antographo, Ceu Epitomator potius quam Authori primitivo fint afcribendi. Eranc. Mothaus le Vayer. Gall.

Extat Infini Epitome Hiftorica ex Trogi Pompe Mittbia Berneggeri, fepiù Typis excufa, novifime Anno 1666. in $8^{\circ}$. Argensorati imprella.

Prodiic itidem cum Notis variorum accurante Schrevelio in $\mathrm{g}^{\circ}$. Amftelod. 3669.

\section{LAUDIUS.GALENUS.}

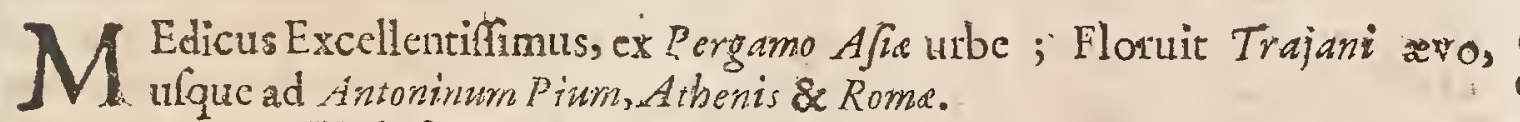

Clar, A. D.

CXLIII.

Hic cunetis Philofophis \& Philologis utilis, loquitur ubiyue puro, eleganti, timplici, \& nunquam affectuto fermone, non fine magnâ vocum \& fententiarum fupcliectile : adco ut nullî latietate lectorem offendat : Ced ubique progrediendi eupidum, rhctorico artificio demulceat, homo ad cloquentiam factus. In hoc pracepta quadam Philofophica rara \& eximia, magilque illufria quàm apud allum alium fcriptorem inverias. Nihil obtudir lcetori quod non frmis rationibus demonftret, ac ejus contrarium refutet; qui moralia habet perpulchra affectibus moderandis. Anbitionem \& avaritiam precipuè infectatur, \& de qualibetre doctè atque eleganter dille: it. Nullis non ad ingenii cultum ejus lectio utilis. Hewrn. in Difertat. de ftud. Medic.

Claudius Galemes, altcrum ab iplo Hippocrate Medicorum decus, \& quafi Lumen aliquod Artis Medicx, qui univerfam Medicinam veterem Hippocratr ă brevitate obfcuram \& Demonfrationum frmamentis orbam, mirâ ingcnii folertiâ, arduâ fc ibendi libeitate, ingenuo ac venufto in capita centa ordine difpotuit atque digeflit, \& adè purè,el gantcr,copiosè \& doctè omnia propofuit, rationibus atabilivit, eadim expolivit, locupletavit,atque perfecit,ut eum artem hanc primò inftituilfe ac genuiffe fit diccndum. Ioan. Andr. Quenß̧. de
vùis Doetrinâilluftr.

$\mathrm{X} 2$ Alexiand. 
Alexand. Tralkianus Galenuxn non nifi cum Epitbeto \& cognomine Diviniffmum vocat; telte Zicuto Lufrtano.

Francifc. Valeriolal. r. Loc. Comm.c. I. ipfum Heroa potius ac Demonem, quàm ioninem appctlandum cenfet.

Hoc nemo: plura,ac majo iundique doctrinâ fcripfit:ut de eo fatius fit taccre quàm plura addere. Vo/f de Philofoph c.r2. Sect.rg.

Galenus Criticonm non minus, quàm Medicorum princeps. Cajaub. in Atbsneum ad Lectorem.

Medicorum exprimoprimus. Dempfier

Pontifex Maximus Mcdicorum. Scalig. ex. 6r.

Mare eruditionis, Oceanus dilciplinarum, omnium ingenuarum Artium promus condus, \& quafi Bibliotheca quædam eft Galenus, è quo Medici cùm: omnia hauferunt, nihilo tamenminus, Criticoruminduftixe telinqunt. Heins: Orat. Ir. pie Eiblioth. mun.grat.act.pag. 3 \%

Philofophus \& Medicus fingularis, cujusfcientifima \& plurima cxtant in genii Monumenta, qux genuinam fapiunt eruditionem :- memo:ire proditur at monnullis, cibi \& potîs abitinentiâ centum \& quadiaginta anos vitam prorelâlfe, \& odorificumfemper anhelitum fpirâfic Unde adagium, ut Galeni vam let:dinem dicamus pro câsqua ultra humanum captum nümis fit profpcra, nï-

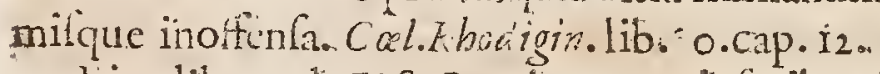

Ljus tibros de 7) J Partium auro infcribendos ait Cornel. Martini in Commpend. Theol.pag.22.4\%.

Galczus inter duodecim fubtilifinx orbis ingenia meruit locum, teftante

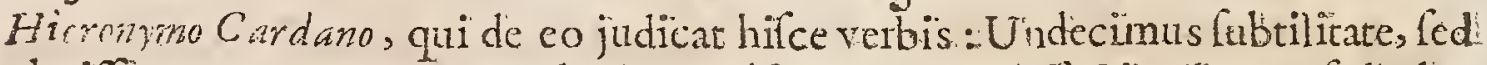
clarifimus arte $G$. lnu, Methodis, pulfibus atque dilfectionibus : fed adeo. verbofus, \& fudio contradicendi trdulus, ne alterum vix ferre: queas; in reliquo gravis jactura Artium pofita eft, quam noltte statis viri reftituere conati funt. ardan de fubtilitat.l.I6.

Qui Hippocrati Galenum parem cfe putant, neutrum eornm fe intelligere ea conf trione fitenrur. Mutto cnim plus H ippocrates à $G$ aleno diltat", quàm Galom nus à pucule quovis. Ider ibid:

Fufusct: Gilente, \& plenus verborum, nempe: Afianus, fed bonorum atque elegantium. Lnd. Viv de Tradend. Difcipl.

Galen liber de fectis Medicorm aliis omnibus cjus libris anteponendis: teftante Photio: Illud clurum, inquit, opus hoc inter creraartis. Medic fcripta omnibus praferri oportere. Siquidem difcere convenit, qua fecta inter omnes optima fit, ut cam deinde fecteris. Vidctur autem non propriè Medicus haben. dus liber hic', fed procmii vicem prxbere, arque adl' hilofophiam potius per tinere. Certum item illud ad dictionem quod attinet, atque compofitionem, purum eum effe ac venufum. Harum enim ubique formarum ftudiofus imm prim is $G$ alemus extitit, tametf in plerifoue fcriptis intempeftivis fuis fermonibus ac digreffionibus y. pralongifque periodis non fine moleftia lib̆ros commifceat, dictorum fenfum oblcuret, \& orationis feriem quodammodo abrumpat 
licetorem etiam ipfum longioribus hifce deliramentis in negligentiam abducens: equibus faltem vitiis vacar hoc de Seeit: Opur. Hoo. in Biblioth.

Malè quidam cum Chrifto coa vum faciunt, \& cum Magdalenâ collocutum effe tradunt, quos.rectë Glycas 1.33.Annal.p 323.\& ioh. Tzetzes in Cbiliza.p.223. redarguunt. V'ixiffe à quibufdam fcribitux annos centum \& quádraginta; $H$ ofmannus v.crò refert obiiffe $A$ nno D om. 140. xtato. 70. Ivdaorum \& Chriftiano rum holtem profeffum vocat idem: Hi ofmen. in Lexico.

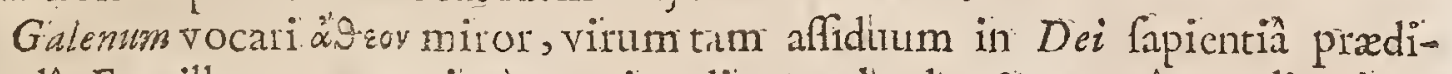
candâ.. Ego illum co maximè nomine diguum laude \& xternâ predicatione: femper judicavi..Cafaub. Epit. Dan. Tileno.

Gal raus inter M'dicos elozuentiffimus, inter eloquentes: Medicus acutifinmus, inter utrolque diligentifimus, inter omnes denique maximus. Gefner. prefit. ad Galent. Op..

Illud verồ ambobus ( Hippocrati \& Galeno) xternam laudenr consiliat, quòdinâ alterâque Saculorum dccade inferiores, illos pra cæteris, ubí none rectè valemus, confultores auxilintorefque non illubenter admittimus-_- Galenum verò pcritiâ vix quifquam fupcravit. Denique femper fummo ftudio in: curando fimul \& prelagicndo fefe exercuit, tantumque profccit, ut aliqui cum: Vatem elfe dicerent, tanquam divinatrice arte, non: Medicine Ccicntiâ. futuras prediceret. Ioan. Wefterbutg. in literis. Ioan. Beverowic.

Averroes in Sectionibus Collecttneornm, Galenum omnibus Medicis anteferre: non dibitavit.

Hic cft ille Claudiu Galenus Pergamo ex Afiầ orïndits, maximus vir mè dendique artis quafi quoddam $N$ umen. Quanquamenim folis ille nor omnia perfeceriti, neque etiam unus fit imitandus; ita tamen cateros preceffit, ut nullus fit hactenus inventus, qui tanto: ftudio \& indutrina Dograticaris hanc Artem excoliuerit. Iple quidem nulli uni Dogmatica fecta fuit addictus, nihilominus tamen maximè . ippocratem fétari viderí voluit, cujus ciam fummum egit enarratorem. Licer verè ita talis haberi volierie, fatendum tamen iin: phuribus eum non videri. aippocraticum, utpote qui" interdum plurimùm a Dogmatibus. H ippocratis ab̉eat, nunc apertè, nune clanculum: Nece cnim quæ* ille itippocrati tribuit, genuina femper funt: Hippucratis placita, fed fapè ipfurf mot Galeni Hippocratico nomine tantüm, majoris auctoritutis captanda caufa ftrcata. Sebaft. Ecbeffer. Introditct. in Artem Med:p.;6, $; 7$.

* Caffaris Hofmani Commentarii in Gaieni librum 17 . De uf partium Corporis Humani, prohibentur in Decreto 4: Febr.I G2\%.Index Roms Imprefizs An. 1664 . juffil Alexandri 7. Pont: Max.

Opera Galeni omnia Grece extant Baflec Tom. S. An: I538. apud! Andip: Cratandrum in Ful. Eadem Latine in $\%$. Tom. dintincta Venetiis 1625 . in Fol. Hafce editiones veluti preftantiores commendit: Bocclerus commentatione pofter thumâ de fcripror. Gracis ar Latinis p. S. $^{\circ}$

X 3; ARRIANUS. 


\section{A RRIA NUS.}

Clar. A. D. N T Comedienfis, Epicteti difcipulus, Hadriani \& Antonini Pï ac Marci Anto: CXLVII. Nini Imperatorumtemporibus vivens, a Confularem tandem dignitaterm. poftquam alios in Republicâ magintratus geffifet, evectus, excellentifimi Philofophi, infignis Hiftorici, praftantifimi (ut quidam arbitrantur) Tureconfulti, \& fortifini Ducis Militaris laudem fuftinuit. Quam non immeritò ipfifuife tributam, operum ejus oftendunt fragmenta, elegantià non mais renum quàm dulcedine fermonis (ob quam alter \& novus fuit dicus X'enophon, memorante Photi, $)$ qux (e commendant. Major autem longè ipfum manebar gloria, fi ad nos pervenifent a Photio indicati Paribicorum libri fepten decim, in qübus'bella à P'arthis \& Romenis ductu \& aufpicias Trajani Imp. gefta defcupfir: Bitbynicorarm item, in quibus patrix fux hiftoriam pertexit; \& Alanicorim commcntarii, qtas citat Photizs: tum vita Tillibori Latronis, Luciano in Pfeadom. feu Alexandrop. 474. indicata; nec nonde relsus, ionyiz Syracufarum Tyranii ; alius de Timoleontis Corintbii in Sicilit $\mathrm{gct}$ is, liber Photio citatus; \& decem de rebus polt Alexandrun geftis libii. Air Erudito Anno 1684 . p. I22.

Arriarinihil hodie habemus prater libros quatuor de Differtationibus Epidteti. Item Periplurisiweluftrationem tum Ponti Exxinisum Ponti Erythr.i: quod Hadriano Cafart dicavit Adhre feptem libros De expeditione Alcxandri: cos fcripfic exemplo Xenophontis, cujus toridem habemus librosde expeditione Cyri.

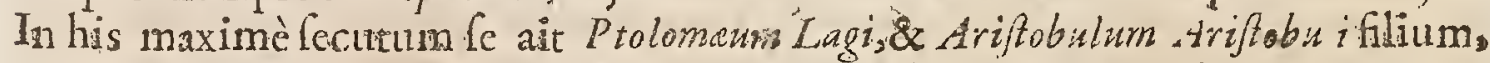
quorum uterquie fub Alexandro militârat. Superfunt quoque Indica Arriani.At plane ratio fugit doetifumum $G$ ir. Stuckitum,cum opus hoc ait temporum injuriis intercidifie. Nam Indica nihil aliud funt, quà m qui vulgo crediturliber Octavus de expeditione Alexandri. Quem feorfin à prioribus feptem feriptum effe, cùm ex Pbotio contat, tum ex fine feptimi de Alexandro ac vel maximè ex Indicorum, five ut vulgò vocant, libri octavi fune.Vo/f.de Hît. Grzec.

Huic auctori adfunt divina fermonis humäs puritas, perfpicuitas, \& cum ornatu decorum; omnia feliciter, ac velut fune curâ \& arte, licet plurimum artis cmineat, reprefentata. Nam \& proprictatis Grect lingua retinens eft, \& in brevitate apertus nufquam ordo vozum peruburus, aut invifa alieni copia. Iam affauum morumque imitatio, \& illud in apparatu admirandum; quin elegantia, narratio nec extans nec hians; figuræ non affe etat an non molefx; fermo cujufque forcunæ, ætati, aut ingenio mirè conveniens enitet undique. Adeò, uit cùm virtutes omnes Xenophontis, quem dulcedine orationis, \& quadam vitx fimilitudine cx-prefit, lectori fuo prafter; putes hune unum a naturâ factum, \& velut fato deltisiatum, quí Gruce nobis Alexandrum exhiberet. Nir. Elancard.in Dedicat.prefix $\hat{\imath}$ -Arriano.

Ef fanè fcriptor hic nemini cortum, qui hiftoriam optime contcxuerunt, poftponendus: Nam \& narrationum brevitate prattat, \& importunis digreflionib:1s 


\section{CEILEBRIORUM AUTHORUM.}

ant ćrebrầ Parenthcfi, rontinentem hiftolix tenorem minimè lradit. Decori inGuper obfervans, zhovâ orationis compofitioné magis quàm rocabulis ufque eo eft, planc ut alio n.llo modo neque clarior, neque dilucidior fieni. narratio poffit。 thot. de libr.decem Arrian.de rebus polt e A lexand. gettis.

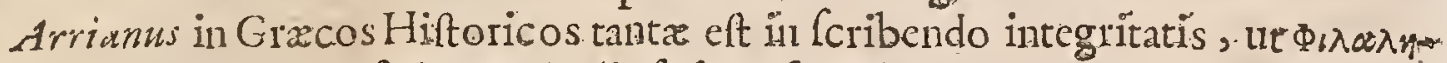

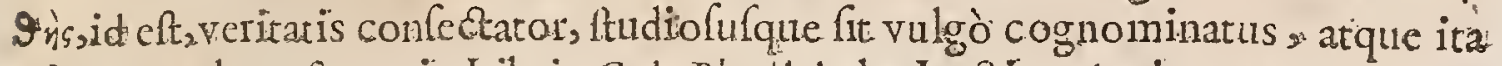
etiamnum honcftetur in Libris.Cal. Rhodigin.l.r.Leetion. Antiq. C.22.

A rri.n.s tanto fe reliquis. Hitoricis, "qui vitam Alexandre Magni foripfewant, fluperiorem putat, quanto reliquis I mperatoribus. A lexander fuit. Certè A rrianus fummo vir ingenio lummaque doctrinâ praditus, , ut planum fit ex. ejus Commentariis in Epizietum: pretereà ufum cum endínione conjunxit: ac propter fummam prudentiam ab $A$ driano \& A ughfo per omines honosum gra dus ad confulatum forente Repriblica provectus eft. Omitto flores. Attici lermonis, \& cloquentiam, "qua in co tanta fuit , ut alter Xenophon appellareturo Bodin. in Method.Hiftor.6.4. pag. 6o.

Eft in manibus etiam Arriani Epilletus, liber, ut noftì , verê aureolus, querm Jacobus s beg kiu s, magni apud Gios nominis homo, , fic Latinum fecit, quaft juraffet omnia non vertere, fed pervertere.I Ifac.Cafawb. Epit. G. Thuano.

Scionon alios èprifës magis confentire cuma Chriftianâ pietate quadm eos qui è Stoica â domo. In quo numeso exiam Arrianus eft, qui digeffit Gracè Diflertationes Epicteti, mihi valdè probatas.Lipf. Epitt.Cent.r.Mifcel. Epitit 33 .

Arrianus unum è pulchermis operibus. Antignitatis nobis reliquit. Eranc. Motbew le:Vayer.Gall.

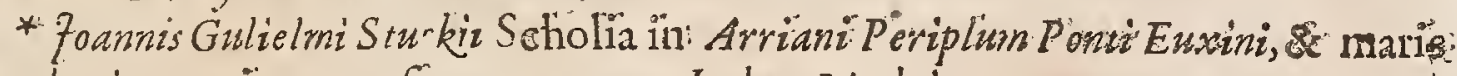
Erytbrai, permituntur,fi expurgentur. Indox IRadrit.

Extant Arriani libri 4. fupen differtationes Epicleti grece cum interpretatione Latinâ -tieronymi Woiphii \& annotationibus. Cantabr.8. Ann.165s:

Libri \&:dc expeditionibus \& rebus geftis: Alexandri M extant Grace cim ver fione Latinâ Bonaventura Vulcanii:editore Necolao Blancardo, qui recenfuit Thbros 8. Animadverfionum adjecit. Amftelodiani S . I668. apud W.aesberginm.

\section{A. THE E U S}

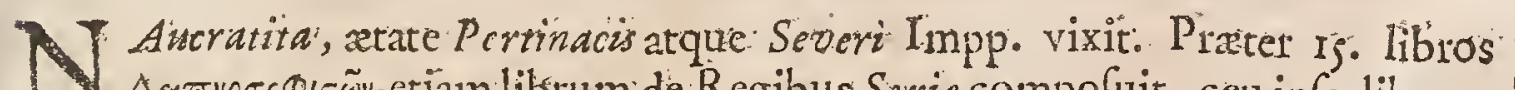

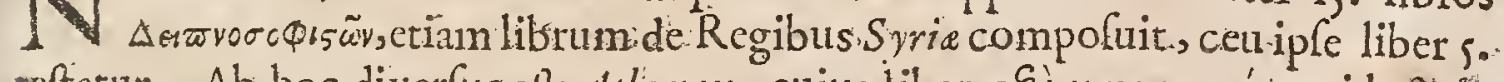

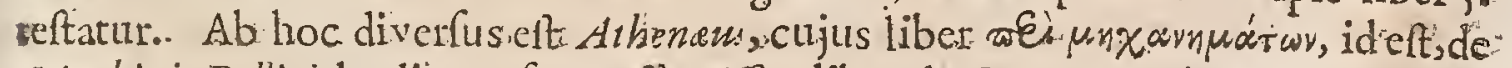
Macbinis Bellicis hodieque fupereft. Tofluns librode Scient. Matbem.p. 2go: eurn? Archimedi Syracufano aqualem ftatuito.

Ex omnibus illis quorum ad nos.Scripta pertenerunt, nullus eft, quafeam equidem memoriâ.repeto; qui à vetuftare pejus: aut crudeliùs fuerit acceptus,

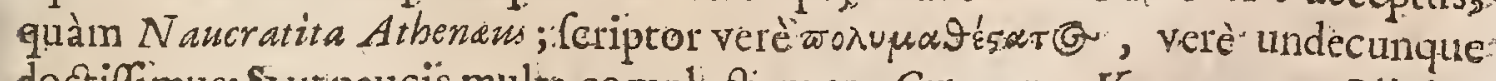
doctiffimus:\& utpaucis multa complectamur, Grecorun Varro "aut Plinins. Hujus igitur tam eruditi Auctoris luculentifima' Scripta, priorum feculortim barbasiesita vexavit ut nondum ftatuerim magis audendimne Studiof fuerie 
non penitùs illa intercidiffe, an dolendum, quò fic affecta ad nos fint tranimilla.

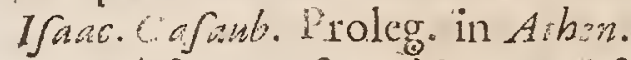

Quîfactum fit nelio, quod factum tamen fcio, It locis prope infinitis verba Ariftutelis \& Thoophraftidefcribens Athenats crraverit. Equidem yerumcenfeos hominem eruditiflimum non ex ipfis Auctoribus , fed cx fuis Adverfurizs \& Eclogis plciofque autorum quos laudat löcos deferipfife. Idem Animad. in Ather.1.2.c.20.

Sxpe fcriptorem huncpecare graviter, dum fuorum excerptorum fidem fequitur, neque ad fontes iplos abit, multis locis probatum nobis fatis fuperque. Idem ibid.l.s.c. Is.

Maximos ingenii doctrinæque fua fructus percipit à pofteritate quindecim

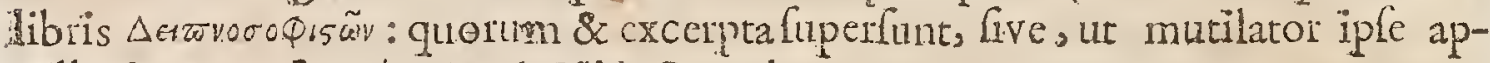

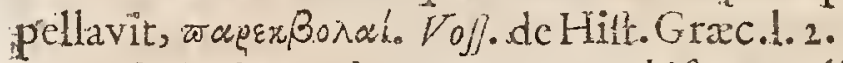

Quindecim Athenei Depnofophifarum libri innumeris indagationibus curiofis 8 jucundis referti funt, filicentiores illæ 13 . Libri excipiantur. Erudit. Ephemerid.Gall. 20. Maii 168 a.

Apud Athenæum intereffe licet præclaro cuidam non multorum dicrum, led multorum librorum convivio, in quo Pbilofophi convivantur, vel potius philoCophantur convive:Quos quidem convivas five hofpites, multi joci, multreque curiofitatis, nou multi cibì reperias, omnia jucunde, plurima abfenditè diffetentes Acutx interrogationes, feftiva refponfa, difputationes erudicx. Fercula ipfa materiam prabent Colloquiis mutuis. Utrumque fcriptoris narratio comm plcctituradcoque res propè totageritur Sermonc. Qui fcrmo non billacia , ut fieri folct, aut condimentum folummodo videri depet, fed caput omnino, aut fundus \& fundamentum Conæ. Verum quid facias? dcelt huic moivio extructifque menfis, lcpidorum noltratium pulpamentum, Ludicra dictio. Erane. Vavafj. de Ludicr. dict. p. 267, 263.

Atbenaus, Naucratita Grammaticus,tempore M. Aurelit,librum Deipnofophifarum compofuit: vatum opus, \& cutuditum, ut Pliniws 'alter Grecus ferè dici pofit:quod ad nos fanè haud integrum pervenit, cjus Epitome ab Hermolao Byzinino tantum relicta. H ofmarn.

Athenai Deipnolophiftican five Sermonum Convivalium Libri 5 . prodierunt Gracè \& Latinè ex recenfione \& emendutione I faaci Cafubboni : verfio eft facobi Dalechampir, cujus quoque note accedunt, apud Commelinum s6ri. Fol. Commentarius verò ejufdem Cafauboni in Aibensum prodiit Lugdunì apud Viduam Antonii de Harfy \& Petrum Ravaud. Fol. An. 1621.

\section{H E R M G E N E .}

Clar. A. D. T Arenfis, Cophifta,fub Antonino Pio Imp. inclarefcerecopit Eum r G.annos CLVI. oblicus ct:unde Antiochus fophifa dicebat:Hermogenes inter puerosfenex, inter Senes veró puer. Reliquit libros 2, de Ideis,doctos 2 tanto Rhetore dignos.Konig. Biblioth. 
Nunc videamus, quidfuper characterum numero, \& illis, quæ confiderari in iiis debent, fenferit feripleritulue is quil finomen fpectes, patrem merito vocet ipfum eloguentie prafidem Mercuriux. Hermogenes, dico, qui I dearum dodtinam duobus complexus êt libiis, doctis profectò, \& tanto Khetore dignis, utut cos videatur cxiguo temporis fpatio conlcripfifle. Voff. Inftitut, Orator.lib.6. pagin. 487 .

Ingeniorum illud pracox genus nontentere unquam pervenire ad frugem, dictum ct à gravifimis auctoribus. Id fir aliàs unquam, in Hermogene deprehenfum maximè eft. Cui vix dum pubefeenti vim ingenii miram \& doetrinam minus pervulgatam neque ex moi (quod aiunt) natura indagniadnexa cum riofori ing fit, adeo ut natus annos duodevigenti artem concinnatit Khetoricam, qua non-citra admirationem omnium atteritur manibus. Necindignum putarit 'Philofophus Mufonius Ieclamantem prafentia honefare. Immò velò nec Marcus Imperator, ad quen cxtant veiba illa; ficuti auctor Philottratus clt: Fenio, inquit ad Te Imperator pedagogo indigens Khetor, guem etiammur ctas znora-

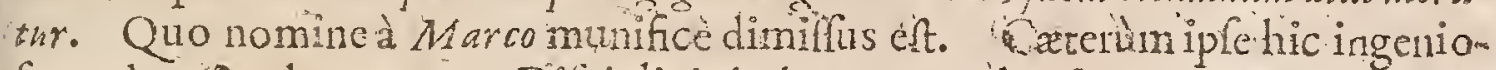
Lus adco, ultra xtatem Dilciplinis imbutus expolitufque agens quatum \& 'vicefimum annum mente lapfus eft, nullâ cvidenti causâ. Rhodiging. Leet Antiqg. 1. 21. ... 6 .

Hergngeni in Rbetorum claile poft A rifotelem princeps locus jure merito debetur, quippe qui ipr Ariftoteli palmam facere videtur dibiam. Quenfedt. de Vir. Docteina Hluftr.

Herrogenes Rhctor egregius ỏicitur Lilio Gyraldo.

Hermogenis ars oratoria prodiit Grace cum $\forall$ erfone $\&$ Commentaris Gafpo Laurentii-Genevaso. Annor6I4.

\section{AURELIUS ANTONINUS.}

F O pervenit cruditionis, conftantifimus Philofophire cultor, ut fuo merito F. Pofteritate dietus fuerit cognomine bilofophu. Deceffit An. Chr. ISo. Clar. Anne D. CLXI.

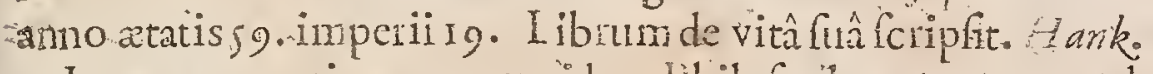

Imperator optimus, arque idem thilofophus tantus, tithoc meruerit proprium cognomer. Duodecin confripfit de officio fuo libros, maime pretan tis, humanitatis, temperantix, cruditionis, aliarim rerum præclararum teftcs pleniffmos: \& cum quibus multorum opcrofapracepta collata, merite fordere poffint. Gul.Canter.1.7. Novar. Leet. C.I.

Ominum fapientifimus atque doctiflimus M. Antoninus, quem propter affiduam operam Rudiis navatam, vulgò Hiftorici Philofoptoun cognominant, is libris aureis de vitâ fuâ. I Jaac Cafawb.ad Henr.4. Franc. Reg. Epift. quam pow lyb. pramifit.

Videcur autem fummus omnis memorix Imperator omnia Hominis, Pinci-. pis, \& ! hilofophi lia officia Monita, rationes, his libris complexus, nec maGnopere tamen ordini ctiam fuduife, aut cloquentiz. Caßp. Barth. Adverfar: 
1. 5.. p. 2412. Pulcherrimè Marcus Antoninus Imp. 1. 12. de vitâ fuâ; qui libelli̊ reverâ omnis humanæ fapientix funt apex \& fumma. Idem ibid. 1.60. cap. 8. pag. 2999.

Quem facilius eft tacitè admirari, quàm laudare, quòd oratio nulla hujus viri virtutibus exrequali poffit. Cùn enim à primâ xtate conftantem, \& quietam vitam fibi lequendam propoluifet, neque propter metum, neque propter voluptatem aut lretitiam, vultu mutato unquam eft confpectus. Philofophos autem Stoicos laudat. I uit autem illonm imitator non folum vite inftituto, fed etiam difciplinarum ftıdio. Suid.

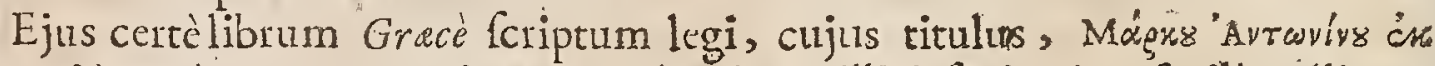

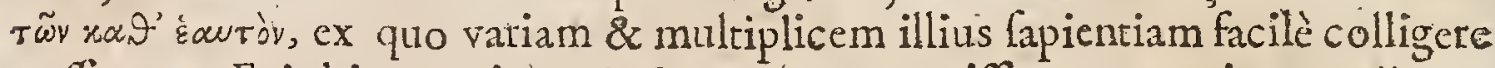
poffimus. Fut hic unus inter Ca fares omnes rquiffmus ac optimus. Lil. Gyrald. De Poct. dial. 5 . p. 203.

Antoninus tantum enicuit in Philofophia, ut iturus ad bellum Marcomanicum; timentibus cunctis ne quid fatale proveniret, rogatus fit, nou adulatione fed ferio, ut pracepta Pbolofophra cderet. Vulcat. Galican. in Avidio Caffio.

Opus hoc erutum è Palatinâ Bibliothecâ primus in lucem emifit Conradues Gefnerus: Latinè vertit Girl. X'ylander: ejus poltea tranlationem ad incudem vocavit vir clarifimus Mericus Cafaubonus, Ifaaci flius, eruditas præterea notas; \& emendutiones addidit. l'ofteà verò recenfuit, ac perpetuo commentario illuftavit Thomas Gatakerus, vir xpstiúralo, Cantabrig. Anuo Dom. i6s2.

Vita illa M. Aurelii Antonini, qux ab Antomino Gwevarâ, Mendonenf

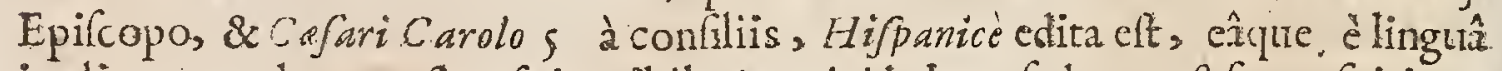
in alias permultas trandata fuit, nihil Antonini haber; fed tota ef Cuppoficitia,ac genuinus Gucvar. ipfus fotus; qui turpiter os oblevit lectori, planè contrà officium hominis candidi, maximè Epifcopi. Habet interim plurima lectu nec. injucunda: imprimis viro Principi : unde \& Harologiura Principurn infcribitus. Voffade Hift. Grece.

\section{LUCIUS APULEIUS}

Cia: Anne Adaurenfis Platonicus Philofophus, Gub Antoninis Impp. Marco D. CLXUI. Pbilofophotionit. Scripfit u. libros Milefiarurn, five de Afno Aureo: quod opus ex Luciano expreffr--n-Quxtiones convivales-m--librum de Proverbiis--..Epitomen Fiftoriarum--Libros Ludicrorum: aliaque qux partim à Servio, Nonio, ac Fulgentic commemorantur.

Barlbius in Notis majoribus ad Clandianum p. r259. Apuleium vocat fcrip. torem unum onnium maximè proplictatis amantem, \& veteris Latinitatis, fun. prà quàm vulgò credatur, coufervarorem.

In utraque lingûâ, Græcâ fcilicet \& Latinâ, nobilis extat Apuleins Afer, vir Magnus inplimis \& quivenuftate morum \& dicendi copiâ Socraticum fopten 
berrentem Platonicum facile redoleat vel tenuiter fapienti. Ioam Sarisberien. lib. $7 \cdot$ cap. 6 。

Saccrdotem areanx fapientix Aisfoniñ nutritum Sirene prædicat Epigtamma Grxe. 59.1.5. Antbol.

Proprictatis latine Scriptor optimus. Barth. lib. 55 . Adverf. cap. 2.

Mirifico acumine difertifimus Auctor.'Idem lib. 44. cap. 25.

Auctor cauta leationis \& periculol $x$ imitationis. Caufin.

Ineptâ dictione, rcbus cruditus. Dempfter. in Rofino.

Vil in ommi parte thilofophiz verfatifimus. Schoock. in fab. Hzmel. pa gina 27.

Omnigena vir Eloquentiz. Volateran. lib. 13.

In verbis novus, infententis crcber, in inventione acutus, in trandationibus audax, in elocutione varius Idemibid.

Stylum cjus ineptum effe volune: fatebor in parte (nec enim afperitatem illam \& horrorem quxitix dictionis ufquequayue exculo) fed tamen doctè ineptum, \& è quo multa bona felectaq̨ue hauriar bonæ felcetaque mentis lector. Lip. lib. Ir. Elect. cap. 2.

Cijus Phrafis docte inepta eft- $\rightarrow$ Apulciwar fane fcriptorem doailfimum, nimio Epithetorum ufu peccare, noil vulgus modò, ad cujus palatum is nihil $\Upsilon_{2-}$ pit, fed eruditi quoque confitentut--Neque folùm voces è tribus aut pluribus compofitas vitabit orator; fed nec eas, qux grandioris funt foni, cum laude uLurpabit, nifixçniam petat pudentem. Delinquunt hac in parte vegrandis \& affectatx cloquentia fcriptores, quos inter ducit familiam Apuleius. V cfi.part. 2. Orator. Inptirut. p. Ij 246,450 .

Aputeius non omnino tralus anctor, \& antiquarum vocum ufurpator. Tur *eb. Adverfar. 1.18. c. I.

Apulcins interdum non thalus Auctor, prefertim cum lácivix ingenii no indulget, neque ludum fibi pexmittit. $i d c \%, 1.29 . \mathrm{c} .13$.

Apulcis in $A$ f mo planè rudit. In aliis fonat hominem, nif quod Florida fut ridicula, Led excufat ca in 6 riptio. Lud. Viv. de Trad. Difcipl.1.3.

Librum ejus de awreo a $A$ ino cx Gra:o fino Luciani defcripfit, orationis genere tali, ut rudere veriùs quàm loqui, , ibi Apuleius viris eruditis videatur. Neand. Geograph. part. 3.

Ego verò Apuleiflectionem abhorrendam non cenfeo, quidquid ift de Arpinati Scholà inveltes pucri dicant: tumidus fortalle, vegrandis, \& adfectarx cleganitia fcriptor eft: at certè doctus literas \& morcs veteres, \& in fecmone ipfo Pian inptimis imitator. Staque ille nefcio quis Rhetorifta, qui "udere illum dixit, non loqui : probet prius de $\%$ lawto, \& credam de Apulcio Lips.1.2. EpifoLic. Quret. Epitt. 22.

Et quis non rideat, immò ringatur verius, fuper ftolidifrmo illo vulgide Apulfio judicio: Aint eum rider, quàm logui, maluilfe. Dii Deaque, \& quò non evadet denique projectifima illa hominum audacir! Tor jam \& frepe icis doctifmorum vilorum, adde, fira vis, Ciceronianorum, elogiis condc- 


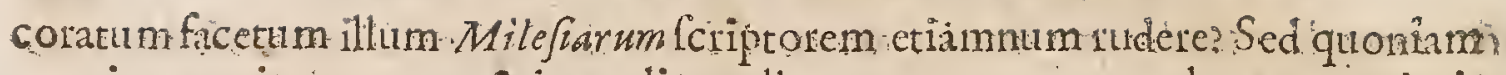
nequicquam invereratum $\mathrm{jam}$ olim radices agentem errosem hunc ex animis: volgi expectoratum imus, ferramus fanè yuz mutare nefas : : illud interim profeffi. malle nos illum rudentern frepe, quàm hos loquentes five latrantes audire. G.alp. Sciopp 1. I. fulpect. Lection. Epift: $4 \cdot$.

Id opus de Awre a fro lic latinum fecit Apuleins, ut ad verbum exprefferit pluxima, additis pleifque quo jucundior effet Lectio iis, qui Milefus fabulis delectantur, Econdivit fuâ illậ partim antiquariâ,, pairim nimis andaciternovatâ dictione remalioqui futuram fubinfulfam, atque fubfatuam. At ṇunc jưvat legere, quia thrafi illa complura dixit, qua nec appofitiù dici nec majore: cum gratiâ poterant: quem nonnulli quum imitari conentur, in ridiculas ineptias incidunt. Putocnim gratiam illam ellè propè inimitabilem indoViv. ir : Auguftin de Civit. Dei, 1.: 18.C. 18

Apulciu de Magicis artibus accufatus ctapud Claudium Maximum; Africt Prefectum, non Griftianum. Extane Apologie dux Apuleii de Magiâ, in quibus exuit nimiam illam fermonis lálciviam, \& antiquaria 8 audaciter inovata ver$\mathrm{b}_{\mathrm{a}}$ : accommodavitque fe forenfic dicendi generi; fed ita tamen, ut, nelcio quo; pacto, dpuleium interin of cas temporaria perfonâ contectum. Lud. Wiv ibid.io. S. C. 19 :

Calfodorius auter eft, eum primum Aritbmeticam Latinis literis illintraffe. Profelfis eft Carbagine, ubi publicè ciftatua pofita:

* Caftigationes I faci Ca aubon in Apule ii Apologiam, inter libros expurgandos locum habent; in Indice Madrit. Edit. An, 1667.

Apuleius libumfum de Salutaribus Rernediis ex Plinio toum compila-vit. Ioan. Budaus à Stap. in libr. I. C. 9. Theophraft. de Plant.

Quem locum [inlibro Dc Mundo ab Apuleio verfo, qui 1 riftoteli falso: tribuitur ] valdè indiligencer atuue impetî̀ vertit Apuleius, xquè ac tutẹm librim; cui fe, foedo ac milerabili plagio, non Interpretern fed Antorem incripft atcue multis etiam doctifimis vilis, quanquam in re manifeftifimâs, impoluit: Arnold.Boot. in 1.;2 c. 5. Animadverf facrar, ad Text-Hebraic.vet. Teftam

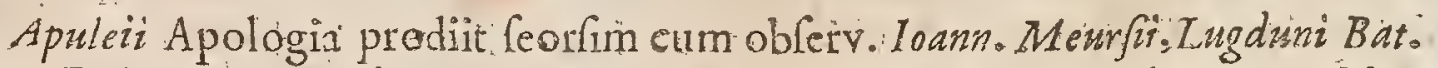
1607. Eadem cum Notis $10.2 n$. Pricei Parifis $4^{\circ} \cdot$ Anno 1635. Eadén 3 cum Nowtis I Saaci Cajauboni 4.1594 .

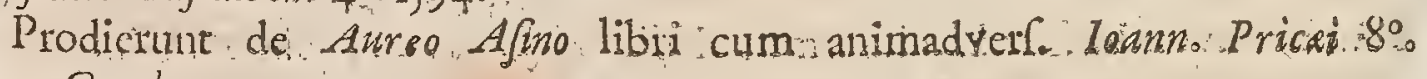
I65:0, Gonda. .

\section{LUCIANUS}

Clar.An.D: CI XX.

Amofatenfss, genere humili. Cùm hdartificium quoddam mechanicim ade 3 hibendus; nil proficeret, ftidia amplexus eft. Connio monitus: \& quidem forenfes rixas fibi ingratis deprehendens, ad Philóophiam fe applicuit, Declam 
mato infignis. Sub Marco Aurelio magni nominis, 2 eEgyptiis reditibus preepofitus..ucriptor praftantiflimus \& facctifimus, primùm braftianus, demum fidci defertor, fed tandem fux.improbitatis luit ponas giaviffimas, nam à cani-

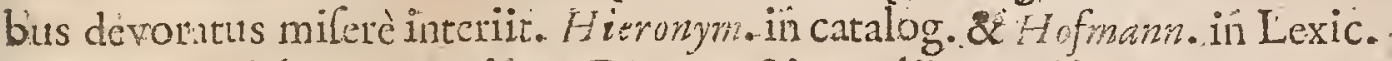

Scripfit Dialogos-.-.-vicam Demonactis --.-librum de Longrvis, \&c.Billiws eidem Epiftolas, que Ph L L ridis nominie circumferuntur, adlcribit:

Fuit huic Lucinnas Samnnatenus homo A hens, quippè qui premifcuè rifit omnem religionem; Gentilium Deos magnâ libẹtate exfibila it \& laceravit,ipfruge Chrifto mundi. (crvatori maledixit \& conviciatus eft', nominans èum Sopbi-

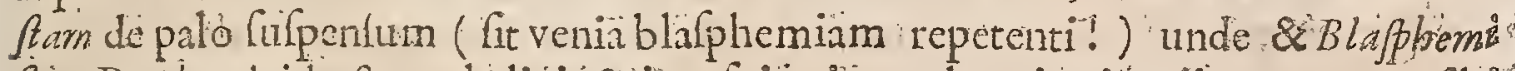
five $D y p h$ heri, id ift; maledici \& inaulpicati; vel potius impii cognomen fib: diabolicis fuis calimnies acquifivit. Simplicitatem doetrina coeleftis tifit hae voce, quam frepècontra pies ufurpavit, omnis doctrina ,: amnis fapientid veftro eft, Crede. Ioan. And . Quenfed to.

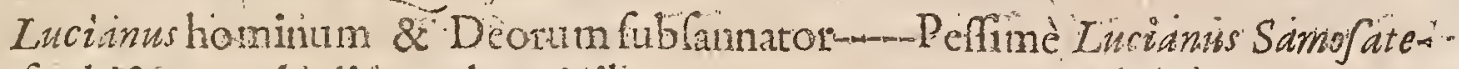
mus fophifà, qui' adimens hominibus veterem ac receptam teligionem", non faltem reponebar novam aliquam. Quod irideret antiquas dêmentias ac infaniàs, rectì id quidcm : led alia debsat fubitituere potiora. Sublatisenim profus religionibus, quid aliud quàm hominem frne humanitate relinquebato: Lud.Viu. de veritat. Fid. Chrifian. 1.2..p. 126..

Deorum Hominumqque Irrilor. Bartb. in Rutilo.pag IIT:

Lucianus nec diis nec hominibus pepercit. Laettant. de falsầ Relig. cap.go?

Lucianw, ingeniólus \& dicacitati aded devotus fcriptor, ut contra omnium: Deorum borsinumque fidem fuis ftrophis fe fare polfe exittinet. Barth. Adv. 1.. 2.cap. 8.

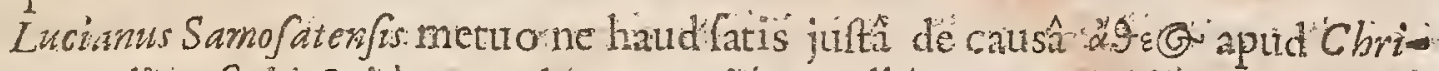
fianos audiat. Scio Suidam tradere eum ita appellatum, quod in Chrifum debachetur; verùm nufquam in elum maledicus ijvenitur, praterquan in. Perfonâ l'eregrini, ubi Chrittum appellit Sophiftam, quxe: Tox non folüm Impofforem fignificat, Gedetiam in bonam partem fumitur. Cbrifiani verò vocem illam

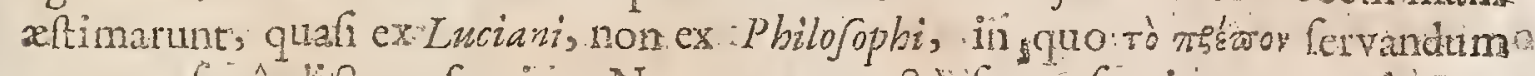
erat, perfonâ dictum fuerito. Non tamen rectè fccuxe fervitur, cum dè $D e$ a

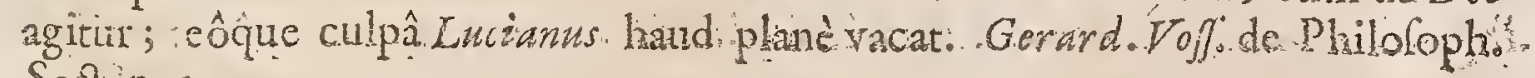
Sect. $p_{\text {: }}$. . . .

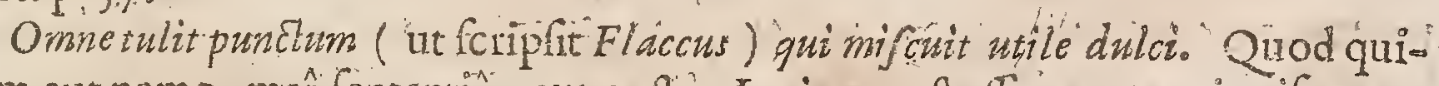
dem aut nemo, meî fententin s aut nofter Lucianus eft affecutus; qui prifcæ con's modix dicacitatem, Sed citra petulantiam referens', Deum immortalem, quâ. vafricicé, quo lepôte perftringit omnia, quo nalo cunctafúpendit, quàm omnia: miro fale perficat, tiihil vel obiter attingens, quod non aliquo feriat fcommatc, pracipue Pbilofophis infertus, atque inter hos Pythagoricis potilfimùm, ac Platonicis ob praftigias! Stricis item propter intolerandum fupercilium; ; hos: punctim, ac cæfim, hos omni telorum genere petit; idque jure optimo: Quid enim odiofus, quid minus ferendum, quàm improbitas virtutis profeffione probitas virtutis profelfione
$Y 3$
perfomato? 
perfonata? Hisc illi Blafthemi; hoc ent, maledici vocabulum addidere, fed hi nimirum, quorum ulcera tetigerat, Erafri. Epint. lib. 29. Epift. 5. In Luciani Somn.

Tantum obtinct in dicendo gratix, tantum in inveniendo felicitatis, tantum in jocando lepêris, in mordendo aceri, fic titillat allufronibus, fic feria nugis. nugas feriis mifect: fic ridens vera dicit, vera dicendo ridet; fic hominum now wes, affectus, ftudia, quafi penicillo depingit : neque legenda, fed plane fpeAanda oculis cxponit, ut nulla concedia, nulla fatyracum hujus Dralogis conferri debcat, Ceu voluptatem SpeEtes feu fpeaes utilitatem. Idem ibid.

Multa cloquentia \& varia eruditio ei ineß. Roecler de fcriptor. p. 62.

Lucianu fertivifimus \& politilimus f́ripter. Turneb. Adverf. $\mathrm{p} . \$ 42$.

Luciani verba funt tera, \& irafs dilucidd. Lud.Fiv. de Trad. Difcip.

Ad fylum quod attinet, longè optimus: dictione ufus fignificante ac propriâ. quz cficax dicendi genus dccet. Dittingionis adhæc, atque puritatis, xque utperfpicuitatis, \& apte magnitudinis, fi quis alius perftudiofus eft. Com pofitionem q̨uoque adeò commodè concinnat, ut lector credat, non fe orationes legere, fed jucundum aliquod carmen, fine manifefto cantw, audientium auribis infillari. Phot. cod. 128.

Luidum homo foediffimus, loquentia multa, at fapientia minimè. Calo Rbodig 1. g. lec. Antiq. c. I9.

Quid venuftius dici, aut fingi poteft? fed folens more fuo facit Lucianus. Neque enim temerè quenquam repefias terfiorem clegantioremque. Tanaquil.Fab. in Nor. in 1. 4. Hadri, Fab. 7 .

Lucianusy à Menzp non pauca effe mutuatum, \& in multis $x$ mulatum fuiffe, non dubito: fed facics orationis tota diverfa. Quin ipfe-gloriatü novum fcribendigenus fe invenifle : ac fub comicâ jocofrate gravitatem Philofophicam occuluilfc. IJaac.Cafaul. de Rom. Satyr.1.2.p. 268

* Lucian Samojatenfir Dialogi, viz. mors ellogrin, \& Pbilopatris, proh bentur in Indice Rome impreffo Anno 1564. jutil Alexand. 7 . Pont. Max.

Opera Luciani omnia prodicrunt cum Not is Thoot. Marcili, Gilb.Gognat \& Ioan.'Bourdelotii, Parif. apud Ludovi.. Grec. Lat. IGIs. in Fol.

\section{R E N E U S.}

Claruit A.D. T Jgdunenfs Epifcopus, S. Polycarpi difcipulus, Anno Chrifl. 202. martyCLXXIX. libri adverfus Vulzntimn, qui plenifunt doctrinâ \& pietate. Ambigunr nonnulli Grarếne an Latine feripferit; quoniam non inveniuntur ejus libi, nif Lacine confripti, \& tamen ipfe natione Gracus crat, \& Phalis ejus Gracifmum redolet. S. Hieronymus eum inter Grecos foriptores numerat. Bellarmin.de Script.Ecclefiaftic.

Erafruus verò Irenoum Latinè fcripfuffe putat, quo nomine vapulat à Beato Rhenano. los epho Scaligero, aliifque. 
Opera frenai qua non cxtant:

Libellus de fcicntiâadverfus Gentes---n-Demonftratio Apoftolicæ Plædica tionis, ad Marcianum Fratrem-- --Liber de Ogdoade ---Epiftola ad Blaftum de fchilmate---Ad Florinum de Monarchiâ, feu, Quòd Dens non fit conditor ma$\mathrm{li}_{2}$ Epiltala--AdViEtorem Epifcopum Romanum de Pajchate, Epiftoh---Ad varios Epilcopos de cadcm Re---Variortum Tractatum liber. Gul. Cave. Apofolicorurn tcmporum vir. Hieronym.

Doctrinarum omnim ascuratifimus explorator. Tertullian adverfus Valen. sir.c.s.

Irenaus in modici temporis fpatio pradicatione fuâ maximè̃ in intcgum Civitatem reddidit Chrifianam, inconculfumque annis circiter triginti $\mathrm{E}_{\mathrm{C} \text { - }}$ clcfaftici regiminis clavam tenuit. Blondel. Apolog de Epifcop. \& Presbyt.

Ephiphanius enm Apoltolorum fuccelforem, prifumquc Theologum nominat.

Magnus ille Ecclefa progugmator, ac pro fui nominis augurio Pacis EcclefulficeVindex Ireneus. Nam Eıyny Gracis pacenn fonat. Spirant illius: Scripta prifcum illam Evangelii vigorem, ic I hrafis arguit pectus $M$ artyrio paratum. Habent cnim Martyres fuam quandam dictionem fcriam, fortem, ac mafculamor Eloquentiznec ftudiofum nec peritum fefe fatenr iple prefans in primum libuim. Ejus fermo fuir dilucidus, digetu"s ac fibi cohærens. Erafin. Epint.lio 28. Epift. F.

Irenei variafcripta, \& Epiftole circumferuntur; etfi in aliquibus. Ecclefinticorum dogmatum certa veritas fpuriis. rationibus fucari videuni, quz obfervalle convenit. Fbo. in Bibliothec.

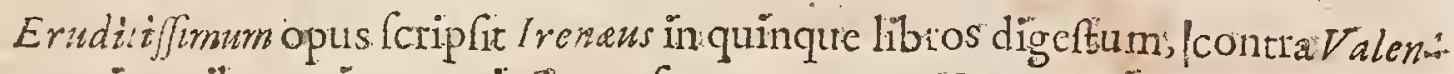
tinum, in quibus mire retegit \& confut veterum Harefccon impias ac portentolas opitiones. Gefer. in Biliothec.

Qux apud Epiphanium cxtant , Fragmenta, rertmpratered ipfius Irenei ges Aarum apud Eufroin Hiftoria, fatis convinc unt, \& hominem Grecun fuilfe \& Grace Lcripfite. Neque dubitandum.Lofeph. Scalig. in Epift. 239.

In ea fencentia videtur fuile Irenans aquè ar I ustims quòd anima cx Gratia immortales demum fint, \& quöd ill impiorum exiftere fut ceffature pof quam diu crucinte fuerint. Aliam adhuc fibi propriam opinionem habet, quodanime Corporum fuontum figuram accipint; fed figura Vox de qua litate quadam peculiari anima intelligi potê. Circa animarum à corpore feparatarum ftatum, Cenfrt illas in vifibili quodam loco fatuï ubïcorporum

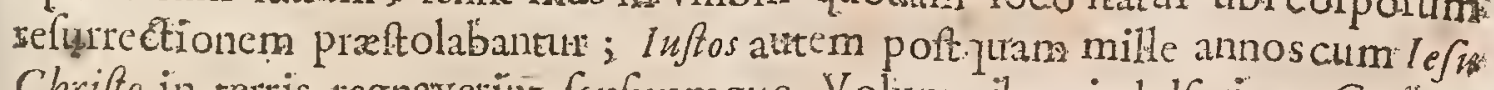
Chrifo in terris regnaverüt fcnfuumque Voluptatibus indulferint, Coelim ingreffuros ad xternam foelicitem polidendam. Crediditetiam Iefun Chrifturn: ad Inferos defcendiffe utibi Fidem Patriarchis \& veteribus Iuftis cum Iudeis um $G$ entilibus predicaret, eofque qui ejus predicationi crediderant de $S$ anctarum numero futnos effe. Qualdam preterea fungulares.alias opiniones fovet 
Opinatur verbi gratia quòd Iefus Cbrifun nltra anuos quinquaginta in terüs vixerit; cenfet illum qua homo eft judicii ultimi diem ignorafe $\$ 8 \mathrm{c}$. S. Infini fententiam approbat, quòd Diabolus ante adventum lefis Chrift condemnationis fux nefcius fuerit; Afreit Sanctos fenfim in altera vita notitian adcpturos rerum quarum ignail funt dum incipiunt Beatitudine potiri: Dewm âd Angelos Enochum delegaile fibi perfundet. Ejufmodi opiniones omnibus Chrifianifyri Vereibus funt condonandx cum eorum nemo harum fimilibus non fuerit inquinatus. Eludu Pin, Nova Bibl A A thorm EccleC. Tom. I. p. 197. 198.

Stylus S. Irenci guantum ex refoluis ejus fragmentis judicare poffumus, prefflis elt, terfus, nevolus, Ced parm fublimis. Lectorem erudire meg is quam delectre fatagit ; magis atrendit ad illum perfuadendum eis qua dicit quam mode eadem dicexdi. Dubitai non poteft grin tumin facris tum ï profanis confummate fuerit eruditionis. In Poetis \& Pbilosopis perfectè verfatus erat: Nullius Heretici doctinam \& argumenta ignorabat:- Scripturce Sacre callcntifimus esar $\cdots$ Innumerorum qua Apofolorwar difcipuli viva voce docueIant memoriam habebat; in Hiftoria Difciplinaque Ecclefiafica exercitatiflimus erat. Idemibid. p. rog.

Fatendum fanè ct, etiam in is Operibus qua fuperfunt, wevos queldam inelfe; qui fi defendi non poffunt, merentur excufar: : ex his maxime notai omeretur, quil 1.2. adv. Heref.c.39,40. reperitur: Cbrifum fcil non nifi ann atatis quinquagefmo munus Popheticum aggrelium elc: quique partim $\mathrm{cx}$ nimio difputandi fervore adverfus Gnofticos, quii Chriftuan expleto anno xatis fux tricefimo primo terris exceflile voluerum, ;orir potrit; partim ex malè intellecto S. 10.tn.8.57. loco; prafertim accedente traditione quadam falsâ; quam 2 apia magiftro, aut quovis alio enm accepille non malè forfan credi poffet. Phrafes quz apud ipfum:epiùs occurnut, duriufuliz, \& dictiones incommodiores, qua forfan Interpreti faris barbaro ut plurimùm afcribi debent, notare non eft opus; iple prudens leator facile animadvertet. Stylo ufus eft admodum fimplici \& inelaborato; nec cnim. quodde fe fatetur Profat. ad lib.r. verborum artificium, neque fermonis vim.; nec dictionis olnamentum s nec perfuadendi facultatem oftendit: utpote quæ nec didicit, nec affectavit. Adde, quod nativam dicendi fimplicitatem, Barbarorwm, inter quos degebat, linguam addifcendos plurimúm corrupit. Gul. Cave. Hifo Literar.

Extant Irenai epera adverfus Gnofticos, \& alia quxetam, Groc. Lat, unà curs fragnentis Graciso ex editione Franc. Fevardentit. Parif. Fol. I639.

\section{JUL I:US P:O L IUX}

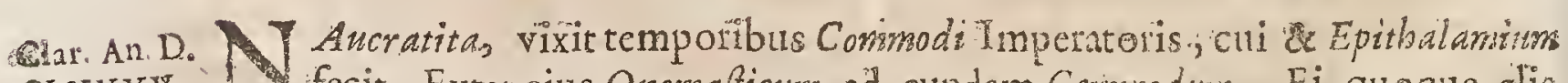
CLXXXY. fecit. Extat cjus Onomaficum ad eundem Commodurs. Ei quoque alio

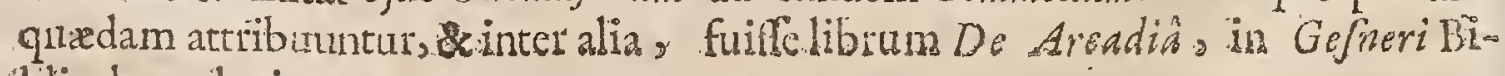
Whiotheca legimus. 
Pollucers $N$ aucratitern an doctum, an indoctum appellare oporteat, nondum atis compertum habco : five quod incptum fatumque effe videretur, eruditum fumul \& ignarum. At cnim vocabula ejus benè dignofcenti, conftar iplum admodum Attica Linguâ fuilfe cxecitatum : eỉatem yui Dectema io um illius genus perfpexcit, nihil melius aliis Attico fermone feripfilé vífus fuerit. Hec porrò fcire de ipfo opus eft. Pollux in Iudrciali genere fatis exercitatus fuit: quòd cum latre converlatus ellet, quicontroverfas forcnes percalluit. Sopbifticas -rationes magis audacter quàm artificiosè compofuit, luo frctus ingenio : fed enim optimâ praditus erat indele. Philositrat. de Vit. "ophift.

Inlius $P$ cl ux, mille antorm diligentifimus z eruditifimus, incomparabilis excerptor. Dempfter.

Contrade co pronuntiavit Athenodorus, Iulium Pollucern effe veluti Tantali hortos, rem videlicet leviculam, \& monenti non magni, quxque elle aliquid vidcatur, cùm fit nihil ferè.

Inlius Polluxvarietatem \& copiam verboum fuggeret : lectore tamen indiget:docidimo: nam innuit magis peritis, yuàm docet imperitos. Lud.Viv. De Tradend. Sifciul. 1.3.

Gaudeo fufcetam a Te Pollucis editionem, vir doctifrme. Neque enim dubito fore utilem Kcipublica Literaria, quam in copofuifti, operam. En fanè Pollubx, fi quid judico, friptor optimus, eruditifimus, utilifimus : \& co fecuto, quod totclaros in literis viros tulit, digniffmus. Ifaac. $C_{a f a u b}$. in Epift. ad Wolfgenc. Sebcrum.

Optandum effet ut aliquis eruditus novam Pollucis Editionem nobis procuraret :Quamvis cnim illa Seberi prioribus longè anteponenda fit, pluribus tamen locis deficiens eft ; Præterquam quèd Gualteri Verfio huic addita magni pretii non cft, ut ipfe in quadam ad Vulcanium Epiftola fatetur. Plura Pollures Manufcripta iu Bibliothccis habemus iis emédatiora \& integriora quibus ufus eft Seberus. Pantinus in spoftolit atdatiz p.370. Edirionis ternfrana memorat Pollucis Manufriptum quod ad Demetrium Chalcond, Lan focerum docti iani Parrbafi pertinuerat. CoS. ubonus Tractatu lino de ativic: Greromm Poefi p, Igo. loguitur de Pollucis quodam $M$ anu crupto quod in Regia Bibliotheca erat. Jefuita Henchenins aliud in Antuerpiana fodalium fui Ordinis Bibliotheca mihi oftendit. Voffizs inter Manuferiptafua Pollicis optima quoque fragmenta habet. Vulcaniu qui praclarus vir fuit, Prxfatione quadam in lfidori Hipalen/s.s tymolggias Pollucis editionem pollicebatur. Paulus Colorniez Biblioth. Sclect.pag. I05. I06. Gall.

Sub Commoto floruit Iulius Pollux Naucratites; cujus ceft Orationes perierint, eruditiffumum tamen Onomaficum remanfic. Voff. de Rhctor. Nat.p. 87 .

Extat Onomaflicunz Greè cum Interpretatione' Latinâ Rodolphi Gualteri, \& Anwotationibus Wolfgangi Seberi, Francofurti in $4^{\circ}$. Anno 1608: apud. Aubrinfo 


\section{CLEMENS ALEXANDRINUS.}

Clar. Anno A Lexandrini cognomen eidatum eft, quòd Alexandric diutiffinè docueD. CXCII. A rit \&ufque ad finem vitre commoratus fit ; cùm verò patrià Athenienfis. effet, hinc nonnunquam etiam Atherien fis dictus eft, ut fcribit Epphanius Ha$x \in \cdot 32$.

Alexandrine Ecclefix fuit Presbyter, Panteni difcipulus, \& Origenis Precep. tor, claruit fub Severo, Anno Dom. 20 4. Bellarmin. De Ccriptor Ecclefialt.

Opera genuina \& extantia funt : Protrepticon ad Gentes-Pxdagogi, libri

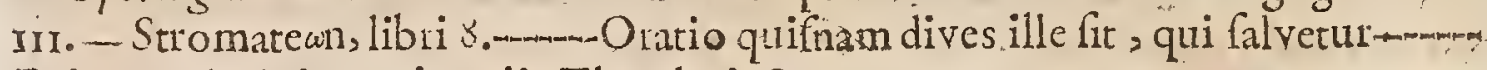
Epitome doctrinæ orientalis Theodoti, \&c.

Opera non extantia: Hyporypolewn, feu Inftitutionum, libri 8.m-m-Canon Ecclefrafticus -..-Adverfus Judaizantcs-D-De Pafchate--.-De obtrectation ne--Difputationes de Jejunio-n-... Dixhortatio ad atientiam, ad Neophytos. Suppofititici lunt commentariola in Prim. Canonicam S. Petri, in Epiftolan Judx, \& tres Epiftolas S. Iobannis Apoftoli. Gul. Cave.

Feruntur cjus infignia volumina, plenaque eruditionis \& cloquentix, tam de fcripturis divinis, quam de fecularis literatura inftumento. Hieronym. de fcripe Ecclefiant.

Hac autem mirabilis ille Clemens in exbortario ad Gentes apertè revelat, vir omnium rerenm experientiâ fcientiâque præditus \& ufu plurimorum negorio rum prudentiflmus, qui patrias nugas, à falutari \& Evangelicậ Doctrinâ monitus, citò contemplit. Eufeb.ad Prapar. Evang 1. 1.2.

Clemens vir difertus, \& plurimarum rerum cognitione preditus-m-Hujus hiftoria fepararim meminit Clmans in Stroriations, vir \& in primis ltum diolits, \& qui cortum qua apud-Gracos leguntur alritudinem curâ ac ftudio

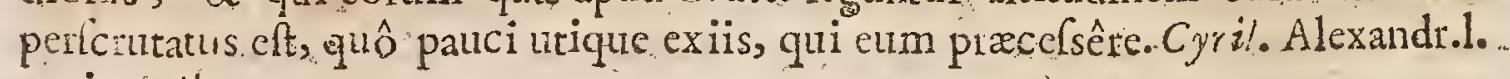
10. in Lulianum.

Cujus tot ugam doetrinam Ecclefia etiam nunc admiratur \& fuitur, in libris qui cxtant. Qui ipfe quàm fxpè Stoi:us eft, \& dogmata eorum facris noftris aptat? Lipf. 1. I. Manuduct. ad Stoic. Philof. Diflert. I7.

Inexhaufta doctrina virum vocat Cefasbonius exercit.I. ad Baron A ppar.p.2.

Clemens Alexandrinu, eruditione multiplici, etiam ad miraculum, inftue batur. Montacut. Apparat. I. Scct. 6r.

Elementis Alexandrini \& funma \& confummata fuit eruditio. Erataccr, vehemenfque \& fenfu fententiifque pollens. 1 dem Antidiatrib.3.

Is cùm omni facrâ \& exoticâ crudicione ad miraculum abundaret, præclara illa ingeniifui monumenta, qux fanè reliquit non pauca, folet multis divinorum Chrittianorum, philofophorum, etiam hareticorum fcriptorum literis,ac teftimoniis wariegare. Dallaus de Pfeudepigraph. 1. 2. c. 5.

Clemens Alexandrinus vir fanctitate \& omnimodâ cruditione praftans. Blondell.in Apolog profententiâ Hieronym. De Epilcop. \& Presbyt. p. 36. 
Clemens Alexandrinus fcriptor in primitivâ olim Eeclefiầ admodum colebrîs, tum pictatis tum eruditionis nomine. Iliyri . in catalog. Telt. Véritatis. Clem mens fanè doctus \&accuratus----Clemans ille, quem frep advoco, velut para* rium \& conciliatorem utiufque (Divine \& Humanx) Philolophix. Lips. dc Stoic. Philoloph.

Quid Stromaibus ( hac en cuim infcriptio) \& aliis Clementis Presbyteri Alew xandirini operibus variegatum \& ornatum magis? Textus eft cnim totus ille Scriptor ailufionibus ad iliforias, fententias, Apothegmata, \&adagia literarun tum facrarum, tum prophanarum. Hîs vividis carum colo ibus illuftratus affurgit, alibi umbris obicuratus quodammodo de liteficit. taque non elt quod fperent qui litcrarum humaniorum carent cultu, fe cum fructu \& intelligenti.in ejus Scriptis verfari polfe. Dulllaus de vero ufu Patr. C. . P. P. 39 .

Neque vero Clementis Aflexandrit qux fumma fuit cruditio obftitit quo minus in varios errores inciderct. Docet is vatiis in locis Gentiles ante Cbriffum natum juftificatos fuiffe per Philofophiam. Ccnfet alioqui Dewminjuttum \& perfomarum acceptorcin futurum, fidamnafet eos qui ante Chrifta adventum vixerunt. Clemen in eâ quoque fententia fuit, quiam ipflus difcipulns Origenes fequitur pafsìm, docens inferorum poenas omnes, effe purgatorias, non adeò aetcrnas, fed aliquando defituras, poltynan fcilicet, qui daminati funt, co igne fatis excocti \& purgati fuerint. Sed \& cum 7 uffrzo quidem docet Clemens Angtw los amore mulienum corteptos, iis arcana multa, qux tegenda fuerant, revelaffe. Ab Irenai verò fententiâ bominam ufque adquadraginta amos vitam in terris produxiffe fenticntis longifinc difcedens, tradit Chrifturs annum integtum in canc pradicafle, \& une \& trige hmo atatis fur anno mortum fuilfe. Dail. ibid. c. $4 . p \cdot 259,259$.

Clemens Alexandrinu, ô cruditum Scriptorem! Ethnicos optimè inc lligebat. Sic ctiam Irafinus Niarty, fed non tantùm. Præcl ros quibus caremus libros citat. Scaligerasa 2.

Dicamus nunc quodnam de S.Clemente Ales:andrino judicium fit ferendum; quin eruditionc conlummata ornatus fucrit ambigi nequit: S. H Heronymis haud

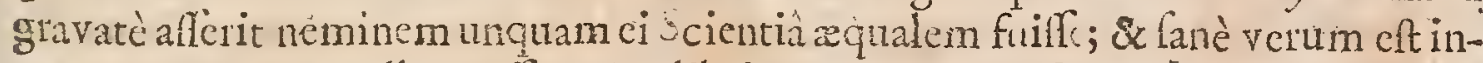
ter Veteres ornnes nullitm effe cujus libii cruditione profana zừ perferfi fint. Imò majorem ejus ubertazem propalat quan Scriptorem Chriftianum deceat, \& profiteri pollumus eum magis fuifre P'bilofophum quàm Thoolorum, licet Retiogonis noftra ignazus non effet, Sacramque Scripturamapprimè calleret. Sed Philon phix Moralis quàm Dograntum multò peritior eft, o inniaque fermè loca qua citat more Pbilonis Iudai all goricè explicat. Abfque ordine ac ferie pené fenper fcribit. Stylus \& cjus eft admodum incomptus, quod in Stronsatibus ejus imprimis obfervare licet: Nam in fua Parenefald Gentes \& in Pedagogo fuo Goridior eft ejus fermo ut obfervavit Thotius, imd ad nefcio quam gravitaterh non injucundam affurgit. Ell, du Pit.Nov. Biblioth. Author. Ecclefiaftic. pag. 234,235 .

* Nondefunt in hoc infigni Auctore fententix aliqux, qux errorem Gapiuns $Z z \quad$ qguas 
quas in libi is noftic Controverfarum notavimus, ob quas $G$ lafus $P$ apa in C'oncilio quodam Romano. Clementis hujus opufcula inrer aposypha retulit. Utrum auten fententix illæab. Haieticis inferta fint, ut ali yui pii credunt, an andoni mote humano acciderint, ignoramus. Bellornin. de Scriptoribus Ecclef.

Opcra cjus omnia extaut Grace cum verfone Frid. yylburgii \& ex emend.

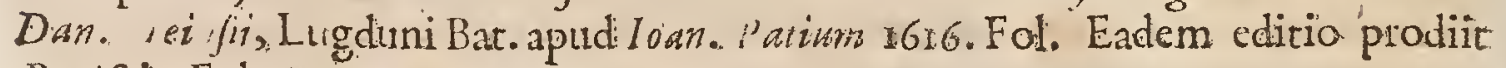
Parif. in Fol. Anno 164r.

Prodiit - Iormplia cjus de Divite falvando Grac. Lat. cum Fragmcntis nonnullis tum Grecis tum Lativis $0 . x_{0} \% 1683$. in 12 . Homiliam anted ediderat Combefis: in Auct. Gr. Lat. Par. 1.672. fol.

\section{Q. SEPTIMIUS TERTULEIANUS.}

Clap. Rnno D.CXCII.

1 Resbyter Carthagimienfis, circa Ann. 192. exeunte hoc facnlo ad Montan dogma prolapfus. Obieffe videtur circa An. 220.

Opera genuina funt: Apologeticus. Act Nationes, Libri: 2-DeTefïmonior Anima-Ad Seupulam - De locetaculis,-De Idololatrî̀-De Coronâ-De Pallio --De Ponitentiâ:-De: Oratione-Ad Mattyres -De Patientiấ-De cultu Fominarum 1.2._- Ad Uxorem, lib.2-de Virginibus velandis-ridverfus Judros - De rafcriptione Hereticorum - De Baptilino-Adverfus: Hermoyenem - Adverfus Valentinianos - De Animâ - De cane Chrilti - De Refurectione carnis-Adverfus Marcionem, lib. s-Scorpiace-Adverfus: Praxeam.

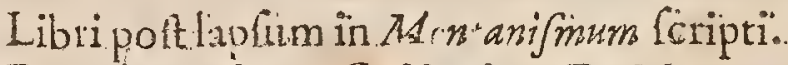

De exhortatione Caftitatis-De Monogamia - De Fugäin PerfecutioneDe jejuniis - De Pudicitiâ.

Opera fuppofititia funt:Poemata. Adverfus Marcionem, lib: s-De Judiso cio Domiui: - Genefis - Sodoma:

Opera nonexrantia: De Paradifo-Defpe Fidelium-De.Ectafl-Adverfus Apollonium - Adverfis Apcllicanos - De veftibus Aaron---De cenfu: Anima.

Libros de Corona: De Vitginibus Velandis; De Baptifmo Grecè Ccripfit. Gul. Cave.

Vir profecto acris ac vehementis ingenii, humanis non minüs quàm divinis: difciplinis imburus, fiorum quoupue temporum Rhetor proftantifinus, \& publicus cjus attis in urbe Carthaginienfi Pracceptor, multa Laino eloquio elegauter fcriphit, fedifylo ni miùm elaborace", ac diuro; \& propter inuftatam vocum novitatem obfeuro. Sixt. Senen.1. 4. Bibliothecre fanct.

Tertullianus creber eft in fententiis, fed difficilis in loquendo Hieronym: Epift. 2d. Paulin.

Septimius Tertullianus fuit in omnigenere literarum peritus, fed in loquendopar rum facilis, \& minus comptus, \& multum oblcurus. Lablant. li. s, cap. I. 
Seis quàm dur urs fir \& afper fermo Tertalliani. Certè ftrider magis, quàm loquitur. Cabvi in Epitt. 339.

Tertulleanus pertalbatifimè loquitur ut Afer. Lud.Viz. de Tradend: Difcipo. lib. 3 .

Inter Latinos Theologos multò omnium doctifimus Tertullianus, quanquam \& ipfe Philolophize cum primis callens. Erafin. 1. 29. Epitt.8. p. 1634.

Tertul want habet hoc virii quod in Origene damnat Hicronymus. Nonnum quam vim facit Scrizturis, idque impudentius etiam quàm Origenes. Nam hic: pletunque difputat \& inquirit 2 Tertallianus alfeverat ac pug!at. Erafm. lib 27. Epilt. 22.

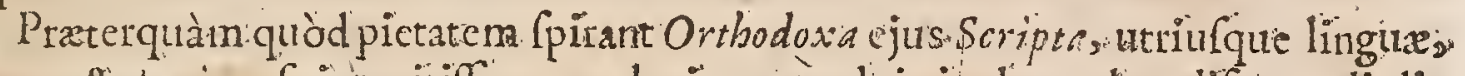
Gr.ce \& Latina', fuit peritifin nus; plurimumi valuit in docendo: difputandi, dicendi, fribendi copiâ \& gravitate maximâ fuit praditus : quod plerique ejus

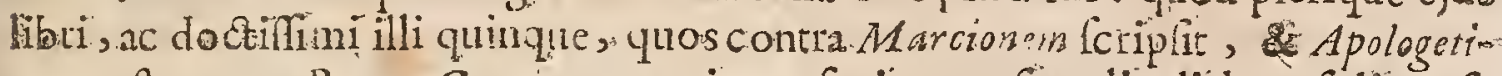
cus, teftantur. Bearus.Cyprianus tanti eumfecit, , ut fungulis dicbus. folitus fit eum lectitare, \& Magiftrum far Presceptorem appellare. Illyri... 1. 3. Catal. Tefto. Verit.

Tertvllianus diligentiffimus omnis Antignitatis fcrutator. Montacut Apparato, 11. Sect. 37.

Tertullianus vir in Romanis legibus exercitatus, \& pratereacclébris ctian:inter eos, qui Rome illuftres fictunt, Eufeb. 1. 2. Hiltor. Ecclef. c. 2 .

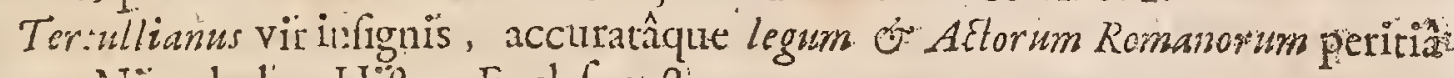
darus, Niceph. 1.2. Hiitor. Ecclef. c: 8 :

Andio. Te Clariffime Pameli, in emendando Tertulliano eff. Majors an utilio à Te res.ufceptawnefcio: Scriptorem plenumantiqux \& recondite: doetrine, corrigere ardutum : eundem eortectum dari, non lolum veftra.Theologorumb intereft, Ledhoftra omaium qui literas Gracas Romanafque tractamus. Tanta iiss

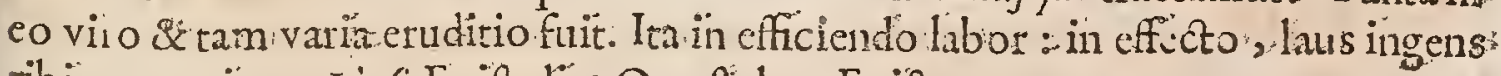
ribi ipropoinitur. LipS. Epiftolic: Quxft. 1. 5. Epift.9.

Scriptorum quantum ad nos venits erudition nemo eff; exque quo phira con-

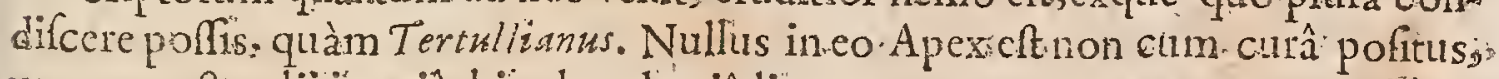
ut quo pacto alii inopiầ, hic abundantiâ litcrarum.peccare nonnunquam vílea aur. Barth.1. 19. Adverfar. c. I.

Tértulitenus femper in manibus habendis, accuratéque legendius eft'; tüm propter lingux. Rornane proprictatem, tum propter difćplinarumac líterartun?

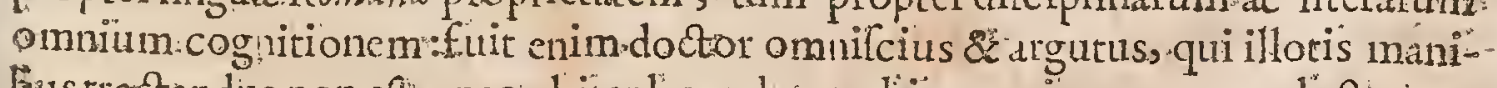
Gus tractandis non cft, nec obiter legendus; ubique enim remoraturlectoremo Tertullianu certè excellentilitmus auctor eft in omnibus. Scaligerana prima:

T.ertullianus pasdens \& fciens obfcuravit:malis, verbis bonas fententias, yell ipfo durior Apuleio. Erafin.ini Ciceron.p. Is 2 .

Septimins Florens erat ille quidem omni liberali eruditione imbutus, verùm: de indultriâ orationemalperat, \& horridum quiddam affectat, \& confecta tur : proinde quafi parum virilem eam eloquentiam putaret, qua concinnior. Z 3 \& elo. 
\& elegantior clfet. Turneb.lib. 7. Adverfat. cap. 20.

Ingenii acris, ardentis \& fubtilis crat, fed quod omnem illum concinnitatem. omnemque rectitudinem qua optari poffet non habubat. Ilus fape fictorum luminum quam verx foliditatis ratiociniis cjus incf ; percutit \& p:rftringitpotius audacibusfuis enunciationibus. quàm rationum pondereconvincit. Ejus fententia funt affectata' immò yuando que paulò inflat: modo fublimi cas exptimit, fed parum nativo. Mediocritatemin rebus fepius excedir; fere in omnibus exardefcir \& concitatur : Figuris \& hyperbolis totus turget. Ubere fcicntia \& - cruditione pollebat, quibus oppoituné uti noverat. In atya excellebar, joci ejus arguti func $\mathrm{k}$ mordaces. Adverfarios dexterc̀adovicbatur, colque tama rationum fe invicem fublequentium \& quaf concatenatartum profligabat. D:nique fi ratiocinilis luis non perfuadeat, aflenfum faltem verborum magnificâ pompâ extorquest: Concifus eft ftylus ejus, voces ejus energicx, ejufque Scriptâ tot fententiis ferè qu ot vocabulis conftant. Haec non obftrnt quir Lastantius tria vitia notatu dignain eis maitè carpat. Tertullianus, inquit, burnanio-

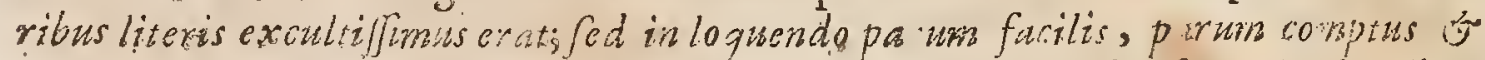
gmulturn obfizrus. Hxe quiidem tiia in loquendo vitia in plerifque Authoribus Africuis occurunt, fed illis in fummo gradu laborare Teriultianus dici potcit, nullumque Authorem cxtare cujus fylus durior, minùs conptus, \& oblcirior fit. Omria eivs opera tribus his vitiis obnoxia funt, alia quidem plus, alia minus. In Polernici. libris planior \& terfior, fed minus comptus eft; obfcuriot verò \& purior in Loris. Conamunibuts it in libro luo de Pallio, qui inter totius. Antiquitatis obfcurifimos libros cenferi debet. Ominim comptinimus cit Liber de Panizentiat. Praclariora ejus Opera \&utiliora fint ejus A pologeticus,

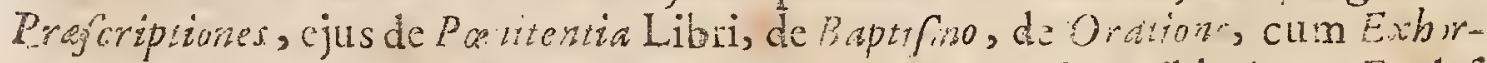
iationibus ad Paitentiam \& ad Martyriuri, Ell. du P'in. Nov.Eibl. Autor.Ecclef. T.om I. p 229, 229.

Expecto Tertullianum quem nobis mox evulgabis ut patienti urs quam prefcribit me doceat. Author eft cui me tua "rafatio reconcilizvillot fi inm averfatus effem, ejufque dictionis duritios \& ejufdum feculi viria me ab ejus Icctione deteruifent; fed illum jam pidem magni facio, mihique injucundus non videtur quantumvis fpinofis \& lugubris fit. In ejus Scriptis affulfit mihi Luxilla nigracujus meminit vetus quidam Poetı; nec cum mir no:i voluptate fpeculor cjus oblcuricatem quàm Eben nitidifini \& eliboratifini. Hacemper mea fuit opinio, quò quemalmodan Africunarum: formindtum pulcheitudo licet noftatium ycnuftei diffmilis, eas tamen amabiles reddit, \& quemadmodum Sophonifta pluium inticarum elegandian oblcuravit; fịc etian ejuldem Regionis ingeni. pl zecant fuâ illâ exotic tacundî̀; imò hunc etian pluribus iseronis initatoribus femper anteponm. Hoc delicatioibus fateamur, quòd ferrens quidem fre cjus $A_{1} l:$; fed nobis etiam vicifion fateantur illum ex hoc ferro drm.z preftatili na fabicavile, honorem-

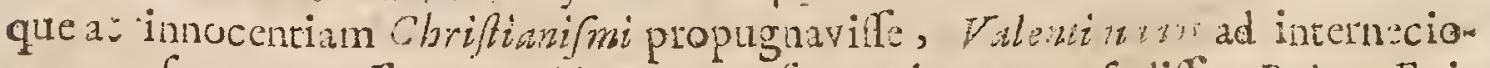

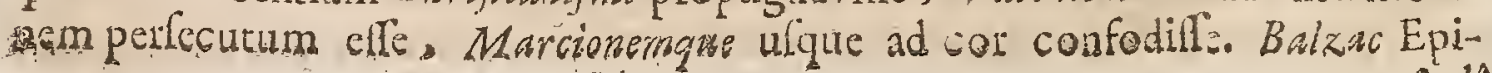


ftolâ ad D. Rigaltium, Epiftolarum Gallic. lib. 5. Epift. 2.

Tertulliani opera pro Apocryphis habet Gelafins.

* Beati Rhenani in Tertulitanum Annotationes, fi corrigantur, permittuntur. Index Madrit. Edit. Anno 1667 .

Sicut ille [Origenes] apud Grecos, ita hic [Tertullianus]. apud Latines noftrorum omnium facile princeps judicandus eit. Quid enim hoc viro doctius? quid in Divinis atque humanis rebus cxercitatius ? Nempe omnem Philofophiam \& cunctas ì' hilofophorunn fectas, Auctores adfertor efquie fectarum,om-; nefque corum Difciplinas, omnem Hiftoriam ac ftudiorum veritatem mir $\hat{a}$ quadam mentis capacitate complexus eft. Ingenio verò tam gravi ac vehemen ti excelluit, ut nihil fibi.penèad expugnandum propofuerit, quod non aut acumise irruperit,aut pondere eliferit. Jam porrò orationis fuxe laudes quis exequi. valeat"? qux tanta nefcio quâ rationum neceffitatc conferta eft, ut ad confenfumfui, quos fuadere non pestlerit, impellat. Cujus quot penè verba, tor lententia funt: quot fenfus, tot victoria. Sciunt hoe C'M arciones, Apelle; , Praxe.s. Her mogenes, Indxi, Gentzles, Gnoflici cxteriquue, quorum ille Plafphemias multis ac. magnis Voluminum fuorum molibus, velut quibuldam fulninibus evertit. Et tamen hic quoque poft hre omnia, hic inquam Tertullianus, Catholici Dogmatis, id eft liniverfalis ac vetufta fidci, parum tenax, ac difertior multò quàm fidẹlior, \&c. Vincent. Lirinenf. commonitor. I.

Habet Tertulliani ftylus majcftatcm quandam fibi propriam, \& grandem eloquentiam fale \& acumine plurimùn conditam , que fimul legentis ingenium exercet, \& animum fuaviter delectat, $G$ wl. Cave. Hift. Literar.

In Gripta Tertullianica labordunt varii, infigniores verò.funt, Beatus Rhenanus, lacobus Pammelins, Iown. Ludov.de la Ceerda Soc. I er. Nicol. Rigaltius. Hic. verò nèglectâ omni illâ divifione operum Tertrilliani in plures vel paucio res tomos, uti fecerant Iacabus Gammelius ac: Ludovicus Lacerdanus, fimpliciter. in uno volumine in Fol. edidit omnia Tertulliani opera Parifis An.1644. quiz. poftea impreffa $A n_{1}$ 1662: ibid apud Ioannem Dupuis , fub figno Coronæ aurex, lelect is ab illo variis notis cx auctoribus qui Tertullianum commentati fuerant, fed bevibus \& extra naufeam. Quifquis poft tantos; ac tam varios auctores, in Ter tullianumcommcntari tentaverit, ludere, opinor, atque olcum perdere apud prudentess exiftimabitur. Cafinir. Oudin in Supplem:de fcript. Ecclefialt.à Beh. darmin omifr.

\section{AEMILIUS PAULUS PAPINIANUS}

$\mathrm{J}^{c}$ Ctuss a tempore Severi Imp. claruit. Ssverus, quòd virum fummopere pron Clar: Rniris baret, Prafectum Pratorio fecit, , eique motiens Liberos fios commendavit. Dom. $\mathrm{CC}_{*}$ Interemptus eft ab Antonina Caracallâ, quòd parricidium ejus excufare nollet, cùm tricefimum-fextum annum vi $\bar{x}$ exegiffet. Tam miferè igitur interiit, vir omni aternitate a necdum terno illo Neforis feculo digniafi mus? 
mus. Guido Panciroll. de Reb. recens invent.

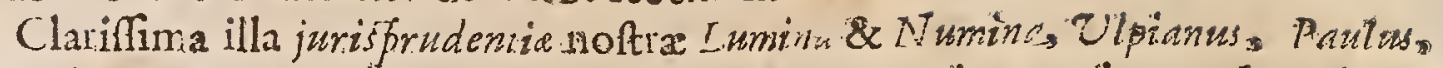
Scavoli, P'mponius, Iulzanus, Papinianus, ques quoticsnomino, tories miror, cotics ftupeo, meamque per tot vigilias infantim \& infcitiam deplo:e. sinton. Fab. in Cod. Fabrian.

Nemo unus unquan erit Papirianus. Cujac.1. r. Quaft. Paprnian Papinianos omiatum qui Gnt, qui ennt, quique fuerunt, juils pezitifimus. lidcm in Edit. Cod. Theod.in Epitt.

Eranco Baldvinut monct omnes ut revereantur Dei Providentiarn qui excitan wit fummosillos vicos, losepburtin in Egyto, Daniclen in Babylonia. Atbenis Tericlem, Rome Papinimum ad confervandam humanam Socieratem : I I stitice fplendorem. Baldrin. in comment.ad inftitut. in prafat.

Emilive Patus Fapini unus cgregium Afreacolumen, xvifuilumen, Vir excelf \& jufti judicii ac omnium JCtorum acutifimus. Qnenftedt.

Quem Flius Spartiznus Hilt. in Severo, Iuris Afylwm vocat, doctinæque Legalis tocraurum.

Wirum Juris experientilimum vocat Iobannes Sarisburienfis, lib. 4. cap. 2.

Tanto honore P'apinianwin affecerunt veteres, ut ab illo Legumftudiof, qui profecillent, Papiniawifte appellati fuerint, quemadmodum Irift inons in prafatione Digeftorumteftatur. Tanta ejus injure eft auteritas, ut fi difcrepantes fentcutia Iurifconfultorum occurrant, ca vedior exiftimetur, in quam $P$ upinianus inclinat, ut fancivit Theodofius in Cod. Tbeodofano.

Fapinianus fuit primus omnium in Conflits Severi, tum ob infignem pra reliquis omnibus luris fcientiam, tum quòd Severo ex fecundâ uxolc afinitate conjunctus effet. Arthir. Duck de Authorit. Iur. Civil. Rorrantor.

Interpretes noftri opiuantur, omnes conftituriones Severi $\&$ Antonini, qua in codice Infinianeo reperiuntur, à Papiniano multâ cum deliberatione confcriptas fuilf. Matth. We enbero in Papinian.

Romanarurn Lcgurn ufus \& excrcitium in Britanniâ evidentifimè confat ex co, quod fub Septimno Severo Imp. Emilins Papinienus Eborar I I ratecti Pratorio munus (quod in Imperio Romano frpremum fuit) gefferit \& jus dixciit: cujus ei fides tribucnda eft Dioni-Caffio viro Confosluri, qui fub Severo vixit, \& rcs geftas Severi fcripfit, licet à reliquis Rumana Hiftoix fcriptoribus omittazul. Arth. Duck. de Authorit. Inl. ivil. Romanor. 1.2. c.8. Seet. 5.

Fragmenta Papiniani recitantul in Pandecti?.

\section{IUCIUS ANNAUS FLORUS}

Clar. Anno Dom. CCI.

T Iftoricus, extremis Trajani temporibus foruit: Rerum Romanarum quaco proprior, adeo, ut ctiam Virgilii hemeftichia profundat. Et tamen è potifima eft F lori noftri laus, quòd fcriptor elfet elegans $\&$ difertus, \& fi pucula exceperis, qua frigidius dicta videntur. vere tloridus. Sed latx eft culpa 
reurs, quod in temporum ratione ulque aded negligens fit;ita uf non polfit non frpiùs hallıcinari, qui hunc ducem lequi velit. Valde autem falluntuit, qui eum putant in hiftoriâ fuâ Epitomen nobis livii dare voluifféfiquidem crebrò à $L i$. vio recedit. Voff. 1 . I. de Hiforic Lat. C. 30 .

L. Annaus Florus compendium nọ tam $L_{i}$ vi, à quo fepè diffentit, quà Rerum Romanarum fcripfit : fi quid mei judicii eft, compofitè, difertè, cleganter. Subrilitas quidem \& brevitas in eo frè mira : \& fententiarum quadam gemmula cum judicio inferte \& veritate. Lip S. lib 2. Eledt. cap. 5.

Habemus \& alterum Flori ejufdem opufculum de Romañ̂ Historiâ, "quo nihil poreft fingi in illo genere vel acutius vel lepidius. Lud. Vir. de Trad. Difipl. 1.5.

Florus quidem populi Romani, tanquam generis humani facta, 2 Romulo ad Cafarem Anguftum, pulcherrimo \& fimul abfolutifino enchiridio ablolvit, cum aliquo fortafie molis damno, null o veritatis. Eryc. Putean. in Prafat.quam Guis In ubric. Hift. libr. præmifit.

Qua ( Flori Epitome)declamatoris mihi,non hiftorici videru. Dum fingula bella deferiplit, in fingulis ineptus eft. Carol. ¿igon.

Miror autem ideò reprehenfum \& insptiz damnatum à Sigonio, quòd fingula bella fingulatim deferipferit. Quis enim meliore ordinc rem Rom wan digefferit, prafertim fi non utatu perpetua fcriptione, fed per fectiones, \& capita difpertita? Juftior multo illa fuerit accufatio, quod in temporum ratione ufque adeo negligens fit ut non polft non hallucinari, qui illum fequatur. Inclementior in illum Verderius: Lurits, inquit, Elorus brevitate fuâ $\int \mathrm{e}$ implicat potius, quàm explicat. Qurem cenforem nemo noncenfurâ dignum exitimet; perfuicuus eft enim ac dilucidus Florus, fi quis alius quolad ejus fieri maximè potuit , cùm fibi multa paucis verbis complectend proponeret. Balthaff. Bonifac. de Roman. Hint Script.

Lucius Florus ficuti nequaquam verbofus ant diffulus, ita neque, ut illi, qui Gumma rerum capita aut nuda Breviaria contexunt, in fe reftretus eft aut exanguis; fed Cóbriam \& verbis cultam orationem amat,denfus interim fententiis, \& rebus cum judicio prolatis, adè frequens \& foecundus,ut verborum propè uumerum fententiarum numero confequacur. loano Pontan. in Orat. Ifigogic. ad Lu. Flor.

Utinam Florus rontam brevis compreffuque effe ftuduifer. Lud. Viv. in $A u$ gufin. 1.4.c. 6.

Quas laudes Hipanie paffm tribuit ei exprobrant quil cenfent eum ex amore in Patriam cum quodam exceffufecundi libri fexto, decimo leptimo \& decimo octavo capitibus locutum efe ; pretef illa qua decimo tertio addit cùm Serzorii apud Hifpanos bellica gefta narrat. Franr. Mottbens le Vayer.

A Scaligero fuis in Eufebinin Commentariis jureculpatur, quòd à Cacozelia non temperarit, abjectoque ac puerili defiderio mirabilia dicendi veritatis difpendio fe abripi paffus fit. Idemibid.

Florw verè floridus, plus habet Paleftra declamarorix, quàm virium \& lacerterum. Canjsin. 
Lucius Florus otevitatefuâ fe implicat potius quàm e pliẹt : cujus operâ Eivii multilibriperiere Scelus laqueo digmu. Clam Verder. in Auctor Cencion.

Lucii Ann. Flori Rerum Remanawum libri 4. proderunt cum Notis Ioan. Carneris, editore I acobo Bedroto Pludentino : addici func Sextus Rufis \& Meffa. ba Corvinus. Bajile a I932. in fol: apud Hervagiurn.

Prodierunt itidem cum Notis Loannis Freinsbemit Argentorati 1669. in 80o apud Dolbophiurn.

\section{FIA VIUS PHILOSTRATUS.}

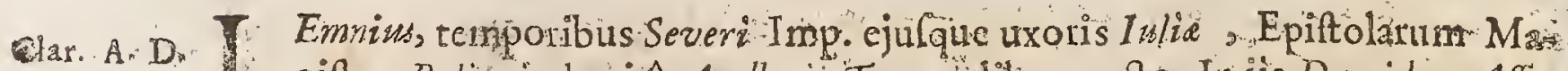
ECIY:

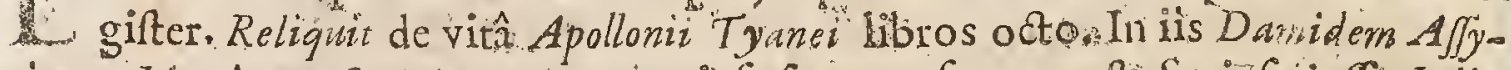
riurn, Maximum \& Merugencm, ut iple fatetur, fecutus eft Scripfit juffu Iulia

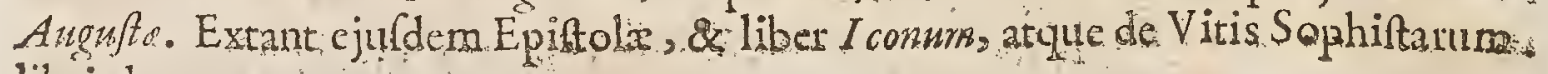
libri duo.

Phitofratus in Hittoricis magna Homeri mendacia majoribus mendaciis corrigit. LudaViv. de Tradend Difapl.p.625.

Liber Philofrati de Apollonis pene totus figmentum eft rabiolum, ac blafphemum hominis in fingendo nom inexercitati, quique hiftorias comminifcercur

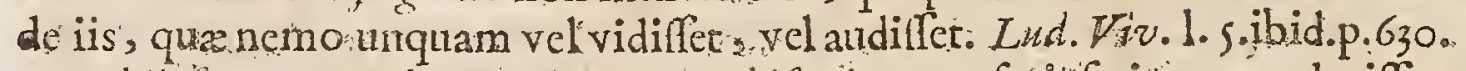

Philoftratus omniem, qui unquam hiforiam confcripferint. mendasifimusa Coel. Rhooligirid.17. Lect. Antiq.c.I3.

Pbiloftratum nugatorem ac mendacem frpiùs appellat Lipfiris.

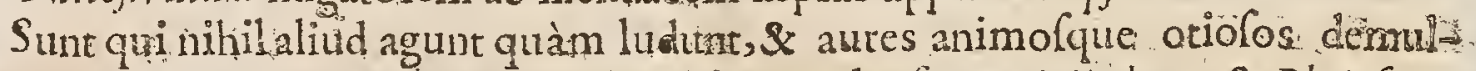
sent adductis tantum ad hoc narratitinculis : quales funt Heliodorns \& P brlofiratus, \&his vetuftiores, nihilo tamengraviores, Herodotus \& C.tefras, ob nimiam mendaciorm licentiam obliterati dudum in quibus vix quicquam preten fa

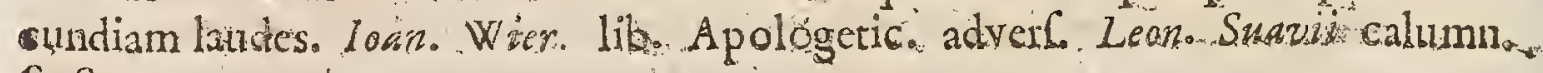
Sect. is

Vix quifum faris dignè valent unquamexpimere, quantum tümano generi

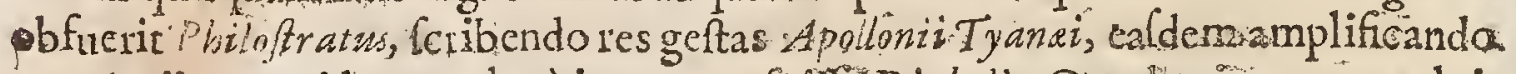

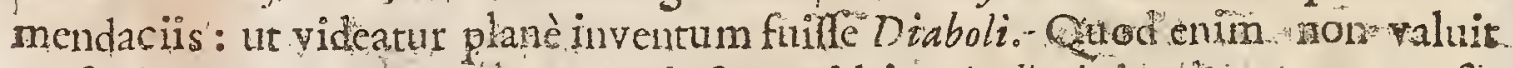
perficere in Simone Mago nuper extincto, id in Apollonio implereconatus eft: هuippe quixmulits Chrifit gloria; ficut fcipto jam Evangelio, longè latéque

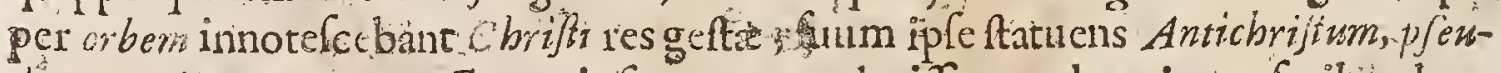
doevangelium quoque adtorum ipfurs per mendacifimum hominem feribendum curavit; cuifidempratantes homines, nihilo Cbrifo minorem fuilfe Apollonizm exiltimarent, vel, ficut iftum eaperfeciffe Magiâ complures compentun haberent, eâdem quoqué Arte chrifum ulum elfé falsò ac abfurdè effuticent. Commentario namque edito in Cbrifitiras Hierocles Philofophus, unus exAreopagi Judicibus, nihil magis monftrare conatus eft, quàm Apollonium agualem fuifechristo. Periè cjus inanias Eugebina adverfus cum fribens 


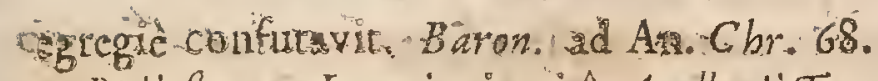

Pbiloftratus Lernnius in vitâ Apollonii Tyanai fabulater \& mendax, fed Cerme cius melte-dulcior fluit. Loan. Bona. Cardin.

Stylo ufus cft aperto, gratiofo, concifo,pleno etiam dulcedine a ac cum ex. aprifcis loquendi formis, tum ex receentioribus elegantiis laudem quxrito $\because$ Pbot.

Eunapirs ait, Philoftratum opus fuum non debuiffe infcribere Vitam Apollonit. Ced Accefjum Dei ad Homines.

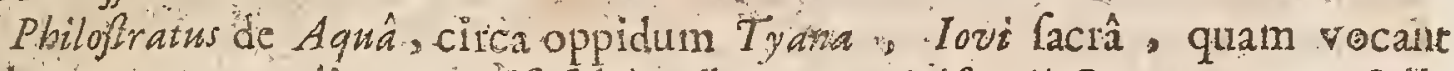
Asbanisam, ea prodit, qux, nila fal sò tribuantur Ariftoteli Græca, quæ poft li-

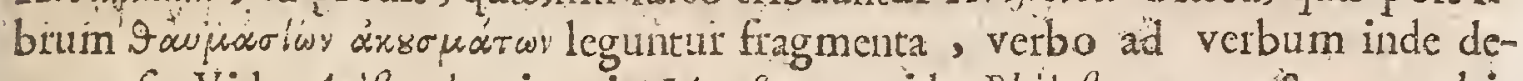
prompfit. Vide Arifrotelezn inquit Manflacus, vide Pbiloftratum , "\& apparebir facile furtum. Thornas. de Plagiu nuta. 518 .

"Philoftratus autem nullius eft apud ullum coldatun actoritatis, ita ut mirer - doctiffmum Bochartum tantầ cum fíducià ex hoc mendaciffimo fcriptore -quancunque conclufionem probare velle. In l'bilofrato Baronins, \& ex co Poffevinuserrores varios notat, fed multò plura craffinima mendacia atecntus - quiliber LeEtor obfervaverito Robert. Bail. in Op. fuo Hift. \& Cbronol. Impreff. Aimeftelod.2668 pag. 28 s.

Philoftratus hic immortalem eft nactus memoriam, libris octoniis de Apollozit vitâ. In eâ Te profitetur fequi,tum Darnidem Ajtyrium,tum alios duos, qui \& ipfip Piloftrai vitam fcriplerint; nempe Maximum \& Moerogenem. Sed, feu vanos - lequitur ducess fer iope multa comminifitur, magna Fomeri mendacia majoribus mendacits corrigit; ut de co refert Vives 1 s.de Trad. Difcipl. Ex tamen hujufmo- di commentis deceprus Caracalla Apollonio Hcioicum erigere monumentum non dubitavit; ut cf dpu Xiphilinum in vitâ Caracalle. Quin fuere Gentiles, quos ctiam Cbrifto comparare Apollonimmon puderet. Uti isierocles ille; ad-

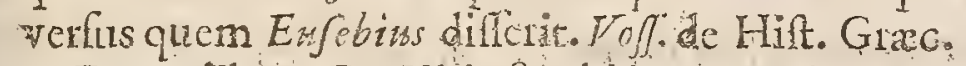

Extant libir 2.De Vitis Sophiftarum ad Antonimum Confulem Grecè cum

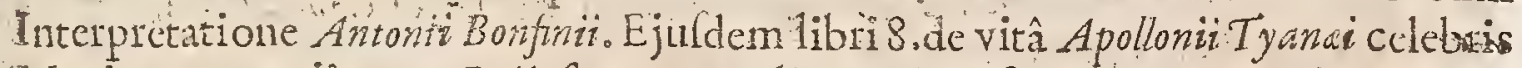
Magi,nec non aliorum Philofiratorum reliqua edita fuere curâ Frederici Morelli, Lutetice Pariforim Anno 160S. apud -laudo Morellimo

Prodierunt Epiftala i'biloftrati Gracè , editore loanne Meurfro, Lugd. Baw.

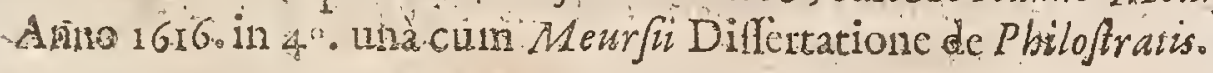

\section{O P I I A US}

Cllix, ex urbe Coryco, Grammaticus, \& Pö̈ta,vixir fub Antanizo Carlacalla.

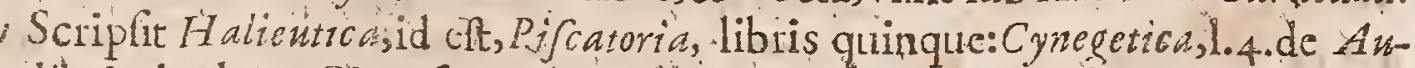
elas: A. B. CCXVI: cupio, libris duobus. Circa finem Imperii Caracalle lue exceffit . Anno Xtatis suicefimo.

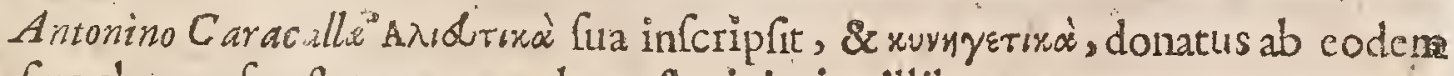
- bingulos verfus ftatere aureo, hoc eft, viginti millibus nummorum aureorum. A. 2 Suido 
Stid. Hinc Oppiani carmina à plurimis aike appellata funt

Oppianus quiden inter Grecos adeò fublimis eft,adè numerofus', ut eorrim unus adVirgilianarn diligentiam afpiralfe videatur. I wl.Cef.Scalig. ...5.c.9. Poetic pag. 664.

Oppianus Mufarum alumnus audít. Idem exercito, 2i 8 . Sect. I.

Idem tractat argumentum Gratius \& Nemefranus apud nos: Grecis Oppianus: Magnushic Pocti,ficuti fapè a nobis dicum eft: quicum Grecorum nominent aufim comparare. Quamobrem noftros quoque duos hofce ab illo puto longè fuperatos; quipue cujus unins ' (piritu Virgilianam divinitatem repralentatam femper judicavi: tantum abef ut cum hujus numeris, illorum verfus, conferri polle rear. idern 1.5. Poetic.p. 758 .

Oppianus fuavis, generofus inconparabilis Poeta. Dempfter:

Omnium cruditorum puncta hic unus abfulit, qutod certe onmi sevo pat: ciffinis contigit Conrad Ritterf, in proom. Oppian.

Dictio Oppien copiofa, haculenta, \& fententis hinc inde refplendens, non-

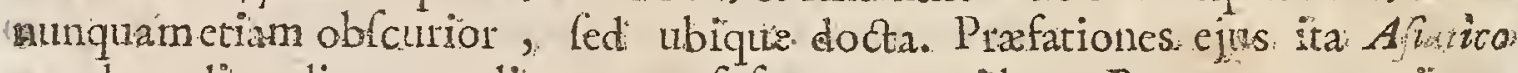
quodam dicendi genere climate, profufrque, ut totidem $P$ anegyrac orationes; videriqueant. Borri, h. De Poet.p.IG.

Dom. Crafja ait: Oppianum in Sententiis \& Parabolis prafertim excellere. Addit Oppanum rem admodum alduam preftitilfe, quod fcilicet: uniformitatem ubique fervaverit, quam etiam fermonis. facundia \& rerum de quibus: agit maturitari tam feliciter attemperare nowerit. Craff. de Poet. Grac. Italice.

Habet ftylum fioridum \& planum aum ficundiâ \& maturitate, \& in fententius ac Parabolis pracipuè excellit. Lac. Frifus Biblioth. Philor.

Oppianus Cilix,admirabilis ille, \& numquam fatis laudatus Pocta. Tan: Eab.Itro Epift. Epilt.63.

Oppianum tum fic expecto,ut dies noctefque de eo cogitem: amo enim allum Poctam utizquis.alius. f. Cafaub. in Epitiad Consad. Ritterf. Momp. a. d. 7 : Idus Sept 1597

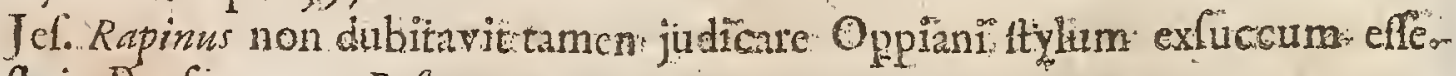
ReA: in Pocf: 2. part . Reflex..Is;

Oppianus de Pifcibus follutâ omatione Crihens, frepe pro aliis alio pifces aciö yit. Clind. Verder.in Autor. ceinfion.

Oppianus in defcriptione Equi Generofi pleraque è lobt c: 39 mutuatus eft,

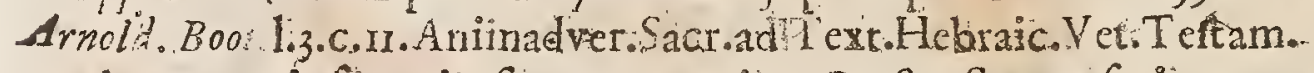

Anno atatis fux tricefimo quo etiam P erfus Satyra fcriptor acerrimus viwere defiit) peftilentî , qux tum A nazarbi gralfabatur, extinctus eft, vii \& poeta optimus, gratus omnibus gravis nemini. Mágnum igitur moriens: litctum \& ingcristui defiderium omnibus bonis taminter cives guàm apud exteros, quibulcunqŭ nominis ejus fuma innotuerat, reliquit: Nam à civibus quidem ejus \& Sepulchro

Sunt profecte Oppiani poemata fingularia ac divina, neminique Grew. 
corrm Poetarum poftponenda; plurimis verò etiam anteponenda, ut non temerè factum effe, videatur, quod fing zuli ejus verfus fingulis sutureì, fcu Stateribus æeftimatifuerunt. Neque mihi foli ita videtur, fed judicii mei approbatores \&

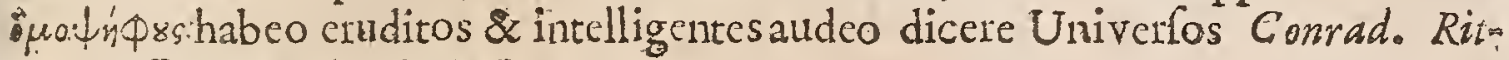
terf. in Procem. de vit \& Oper. Oppian.

Prodierunt Opera cjus de Venationc \& Pifcatu., Gracè \& Latinè , curế Conracikitter:hufin, cujus.Notie, iecm vetus. Scholiaftes Gracus, acceduntoEoydx in $8 \%$. Ano 1597.

\section{MIN U T I U S. FELIX.}

Minutius Felix, Gente, utverifimile eft, Afer, non ïgnobilem inter Clar. A. W M. Romanos Canfidicos locum tenuit, doctrinâ tamen ac pietate Cbristianâ $\mathrm{C} G \mathrm{XX}$. ipfe longènobilior. Dextate ejus quâ.vixit, nihil habeo, quod pro certoaffirmare aufim: fi tamen in re obfcurâ, dubiâque hariolari licedt, conjiciam illum, utpote Tertuitano fupparem, Cypriano antiquiorem, circa:Ann 220. claruife. Scripfit Roma libellum, pro octzvo, Arnobii libro aliquot retrò fcculis. falsò habitum, Dialogum, inquam, illum infignem, Octaviurm dictun:, inter Cacilium Natalem; Gentilem acerrimum, \& OStavium Ianudrintr, acutum Cibrifrianorum vindicem ac Patronum :: quos inter medius Cëdet bonus, Arbiter, Minutius Eelix. In quo Gane libello totumi Gentilinm cultum "Deornmque profapiảm non: minus ernditè qụàm: venuftè \& ingeniosè convellit, \& Chrissianos eorumque Sacra ab omnibus, Cacalii calumniis, atque objektionin Bus cleganter \& nervosè vindicat. Tandem manus. dans: Cecilizus gloriatur fe quidem ab:Octavio victum, de errore tamen triimphafle.. Gul. C'ave. Hift. Literar..

Minutius Felix, Romæinfignis canfidicus, feripfitDralogum Chriftiani Et brici difputantium, qui: Octavins infcribitur, fed \& alius fub nomind ejus fertur: de $F$ ato, vel contra: Matberaticos, qui cum fit \& ipfe difertihominis ; non mihì widetur cum fuperioris libri ftylo convenire. B. Hieronym de viris. lllufti.

Minutius Felix canfidicus Komani fori, in libro cui titulus: OCtavius ett, \&\& in? altero contra: Matbernaticos, fr tamen Inf criptio non mentituf auctorem, quite Gentilium Scripturarum dimilit intactum? I dem in Epift.ad Magnum.

Minutiani hujus libelli infcriptio, \& Dialogi forma s antiquum, eruditumquec feribendi morem refert. Genus dicendi eft argutum, acre, vehemens. Eft preflum ${ }_{2}$ ? - denfum, nerv ofum, crcbris lententiis compactum; omnitumque: Antiquitatum: atque Hiitoriarum memorî̀ refertum:\& in quo plurcsfententiassquan periodos numerare poffrs. Nam neque verbofi olim fucrunt Chrifiani, qui verba dares nondum didicerant: \& corum patroni exant homines docti', ac ut uno : verbo di"

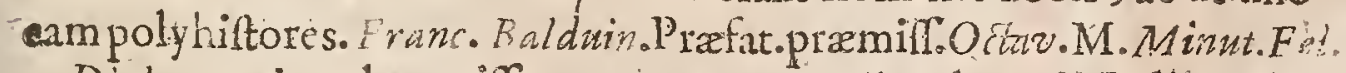

Diclogum ejus elegantifimum vocat $G$.calixt de verit.Relig. Chrift.11. I6. Minnitus Felix, Romantus Orator, reiChrifiame magnus Propugnator. Hies: - rexel. 0.3.Scct.30. Prodrom. Eternitnt. 
Caterum Minutius ( finon molc, fed ceapfe aftimes) magnalicrimpro Chriftiaris vincit volumina, cum rerum cepia tum dietonis venuftete A ubert. Mirans in Schol. ad Hicronym. de joript.Ecclef.c.58.

Minutius Eelux dialogun contra Paganos fcripfit, lactea Sermonis ubertate Lactantio nihil cedentem; mirabili ubiyue perfpicuitate, efiam in ncutè dictis: nihil argutiarum oblcuritate moleftarum, nihil intempeftiva eruditionis often- tatione infolens aut arcéftum: nihil verborum novitare aut transferendi improbitate;aut compontionis feabitudine durum, hótrens $\rightarrow$ abruptum. Monobibl. Ioan. Fred. Gronov. Obfervat. in Script. Ecclefiaft. c.7.

Minutitus Feix non ignobilis inter Caufidicos loci firt: Hujus liber, cuí Odtavio titulus ef, dcclarat, quà in idoneus veritatis allertor che potuifir, fi fe to Exum ad id fudium contuliffet. Lactanid.s.C.I.

S Tertulianicis comparentur Minutiana, fatim apparcbit, Minutium ab Terzulliano \& argumenta \& differendi ordinem, atque ipla plerumque verba fumplifRe. Nic. Rigali. Noto in Ninut. 1.2.

Equalem Tertulliano Minutium fuille, femper mili perfinal, \& qua in utro- 4 ue fciptere totides: verbis perferipta extant,uter ab altero mutuatus fit, dubi50. Iofph.Scalig. Epiat 375.Ioan. A Wonvr.

Dirlogus Minutiveficiselegans eft, pocabulis felectisconftat, Cententic ejus funt exquifita, jucundus eas eloquendi modus, jufque rationes magna lux argentiores reddit, multum eruditionis' in eadem obfervatux. Denique Tractaculus ifte, ut oblervat Lactantivs, demontrat Minutium Felicem preclarum Religionts ac Veritatis Patrontin futurum fuifle fad Kujulmodi ftudium totum animum appulillet. Sed $D$ :alogus çus Ingenii ab alintum muncrum occuparion nibus laxamentum captantis faxtus cf potius quàm opus cum affiduitate concinnatum. Leviter tantum res attingit non verò exhauito Majorem dat operam ut oftendat quam ridicula fint Ethnicorum opiniones. eafque propriis corum Autboribusimpugnct, quàm ut Chriftionortion Doctrinam explicet atque pro-

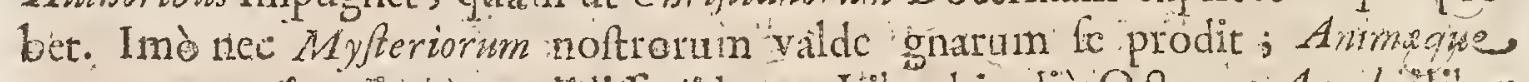
cum corpore interitum eredidife videtur. Liber hic diu O ctavis Amobil liber habitus eff; Repertus enim cumfeptem Authous hujus libris in veteri quoAam Vaticana Bibliothecæ 'Manuscripto, quater fub illo nemine typis mandaaus fuit, nemine verum ejus Authorem cognofcente. 'Eruditus Inrifconfultus Balduinus vulgarem hunc errorem primusanimadvertit, ac Heidelberge And. 560. Differtatiunculam hanc leparatim excudendam curavit cum docta Prafatione, qua vero Autorieam reftituit. Ell. du Pin. Nov. Biblioth. Author. Ecclefiaticor.p. 326, 327. Tom. I:

Certè in Cypriani de Idolorum Vanitate libello plurima funt qux totiden verbis in $O \&$ avio $M$ inutirileguntur, neceffe ut fir aut hunc abillo, aut llum ab thoc ea furrpfirc. Iof. Arn. Lexic. Antiquit. Ecclef.p. $88 \%$

Ejus Octavizs five Dialogus inter Ottavium Chritianum \& Cacilium Ethacum. prodiit cum Notis yariorum, accurante Iacobo Onfelivo Lagd.Bat. in $4^{\circ}$. 
Anno 652 apud loan. Marre qua cditio ibidem pulcherrimè repetita Anno 1672 in $S$. cx officinâ Hackianâ prodiit.

\section{U.LIUS A:FRICANUS。}

C Criptor Ecclefraficus, Claruit Anno:220. vixit Nicopoli, in Palaftinâ s erât-Clar.A.D. $\checkmark$ que Epifcopus Emans (fifides fit habenda Hebed-jeju Metropolite Sobenfi) C CXXX. obiit circiter anuum 232 . Chartoph. Gul. Cave.

Scripta cjus hxc funt: Commentarii infcripti de Ceftis-Epifola ad Origenem, de Hiftoria Sufunne-..---Anualium feu de Tempcribus volumina quin-

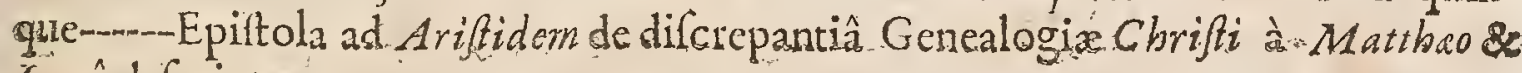
Lucâ defcriptra.

Zulius Africanus, accuratiffimus temporamobfervator. Chifitianorum pra

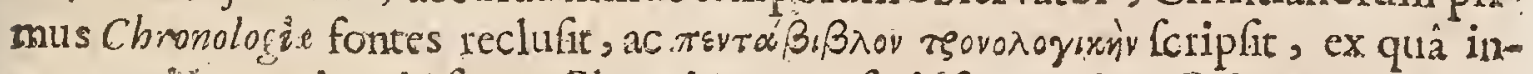
tegras etiam paginas in fum Chronicon tranfcriphe Eufebiu. Primus eas Grace publicuvitil ofephus Scaliger, qui nec dubitat Eufebii Chronicon vocare Africani Chronicon recodum. Aryule hinc detegitur Spiftus error Ioannis Bodini, quĩin Methodo. Hifteria fure Eucbio juniórem facit, arque addit, deduxiffe tempora: ufque ad annum 320 . Scribere debuit 220 ut ex. Enfebio fcimus, qui Africanum exlcripfit. Vofj. dè Hift: Grac.

Vir undecunque doetiffimus, Philofophis, Hiftörögraphus; \& Theologus: infignis. Suisfudis $\&$ fumptibus apud C'a farearn Paleftine infignem Bibliothecam condidit. Sciphit pratereà magnæu utilitatis plura opulcula: Tribeir. de Scriptor. Ecclefiaft.

Inlius Africanus, vir ingentis, variäque doctrina. VofJ. de Marhemato pag: 293. .

Doctum imprimis, \& antiquum Scriptorem, nuneupat Ifaac. Cafaub.initio Nor. in lactic. Enex.

Inmultis rebus non tan diligentiâ quàm judicio \& linguarum cegnition deftitutum labi probatu declive eft. Grot. ibid.

A fricanus fedulus potius friptor, quàm exacti pes: omnia judicii. I demo

Per idem rempus (viz. Ann Chrift.222.) Africanus librorum friptor quit.

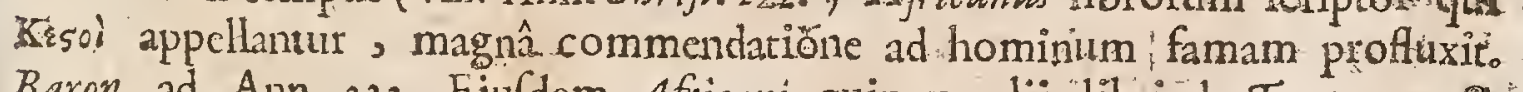
Baron. ad Ann. 222,. Ejufdem Africani quinque alii libri de Terrpornm A nnalium ferie, accuratá quadam induftía elaborati a ad nos perveneruut Iderribid.

Intius Africanus Chriftianorum, meâ quidem . Cententiâ, , doctiflimus $P$ aut Colomef. in Paralipom. ad Chartophyl. Ecclchiat. p.3.

Legimus, Africani illius Hiftoriam, qui $C$ eftns, ut nominant, libris quatuor decim compoluit. Concifus guidem ef o nihil tamen cognitu nfcellirum omittit. Pbot.Cod. 34 s 
Africanum noftum librum Suidâ ftatuiimus, ut de Voffio, Lambecio, Weftenio nihil dicam, quicquid dicant Scaliger \& Valefins, qui Africano cuidam Gentili, Sexto dicto, tribuunt. Giul. Cave in Chartophyl. Ecclel.

Eidem Anthori afcribitur praterea Differtatio qux infcribitar de C / Ris, quxque fub ejus nomine citatur, non tantùm à wida, \& à Sinsella; fed etiam à Photio; imò \&ab. Eufebio Hiftoria fur lib. 6. cap. jI fi modò afiatus non fit hiclocus, qui nec in Verfone Ruffini, nec apud D. Hicronymum legitus. Sed verifimilius eft id alterius cujufdam Africani opus effe. Ell. du Pin. Nov. Biw blioth. Author. Ecclefiafic. Tom. x. p. 3 I8.

Notandum à Snicha 24. numerari Ceftorurnlibros: Photio I4. aliis verò duntaxat novem. Labbe de Script. Ecclef.

Inlius Africanus quxdam praclariffima habeloat, fed lapfibus non carebat. Iid nobis conftat exiis qua ex codem tranfcriplit Eufebius. Quàm cximia ejus fragmenta traditurus fum! Scaligerana 2.

Accuratifsmacjus, quæ confecit fcripta, cum alis genuinz antiquitatis, inrerciderunt, præter frufula quædam, in Eufebiano Chronico, \& inter Bafilit. Origenifgue operaconfpicua.

* Iulit Afrucani Opera pro Apocryphis habet Gelafur.

Epiftalam ad Origencm de Hiftoriâ Sufanna Græcè edidit David Hoeschelius. Ann. 1602. Gracè \& Latinè unà cum quibuldam Origenis Opufculis Iob. Rod. Wetfenius Bafil. 1674 .

Extant Commentari de Cefis MSS. tum alibi,tum in Bibliothecâ Clarifimi Viri lsaaciVo/fii.

Chronicon Africani apud Chaldzos etiamnum extare Ccribit Hebediefus penes guem fides efto.

\section{HERODIA N U S.}

Clas. A. D. T Itoricus, tempore Maximini Imp. claruit, Religuit Hiforiarum liCCXXIV. 1 bros octo. Incipit à morte Aureiii Antcnini, \& delinit in morte Balbini \& Maximi. Eum in Latinum fermonem Angelus Politianus trantulit. Qûे de re ita Whear. "s Haud Ccio, uter majerem laudem mereatur Herodianusne, , quem în linguâ fuâ ubere venâ Guere non negaverim, an Politżonus, quĩ * Herodiani fripta tuntâ felicitate interpretatus eft, ut non tranfuliffe, fed iple "compoltifle videri poffit.

Artium minutiffimus fcifcitator vocatur Ammiano Marcellino lib. 22 cap. 42 .

Ad fidem pleraque dixit. Iul. Capitalin.

Scriptoris hujus dictio clara eft, at que perfpicna, quin jucunda:vocibus auxem utiturtemperatissneque fupra modum A tricis quibus nativa illa communis fermonis gratia quodammodo violetur,nec rurfus in humilitatem quandam ita demillis, ut artem omnem illæ fugilfe videantur. Adhæc nec fupervacaneis tumet, 
neque neceffariun quid omittit: Sed, ut uno verboabfolvam, omnibus Hitoria virturibus paucis fanè cedit. Phot. in Biblioth. cód.99.

Circumficere càpi quem potifimum ex omni Grecorum copiâ interpretändum fufciperem. Occurrit autem in primis Hero tianus hic, excellens ierum fcriptor, \&quidem in Palatinâ verfatus aulâ, affectrque jam zearis Hiftorium de fuis tcmporibus componere agg ruflus, neque eloquentix caruir laudibus, \& fidem in primis liberatemque retinuit--Copiotam quandam ad inftuendos mores fuppcllećtilem in hoc auctore inveniet lector, \& tanquam fpeculum hiumanitatis agnofcet, in quod infpicere omnis vita poterit, unde ea capere atque haurire documenta queat, per qux vel publicis vel privatis rationibus confulacur. Angsl. Politian in lit. ad nnoceni.8.P. M. quas jierodian primifit.

Herodianus perfmilis Thucydid: Nam elegainter Imperatorum res geftas ab Antonino \& Cornmodo ördiens, ufque ad Gordianum nepotcm defcribere cona tus eft, \& conciones äptè fuis locis etfinxit. Sed poterat, quâ in te culpầ non caret, hiftoriam fuam Confulatiburdiftinguere; quod in Hiftoriâ elt necefrarium. Franc. Reberiell. in lit. ad loar. Bap.z, Campeg.tom.x. de pop.Rom. vita \& vietu præmill.

Imperatorum fingulorum actiones $\&$ gefta diligenter \& certo ordine enumcrat. Concionibus gaudet, fed brevibus. A cumine, brevitate, \& fententiarum gravitate ailuffio comparandus. Si meliorum temportum rés tanto ordine \& câ copiâfcripfifet, intcr Grerns Hitoricos, qui Latina memorix mandartureprincipem locum proculdubio obtinuillet. Carö. Sigon.

Quod fi quis Dronen \& lerodianum velit comparare, Dio fanè amplitudine argumenti, copia expofirionis, frequentia pragmaticx informationis precelle-

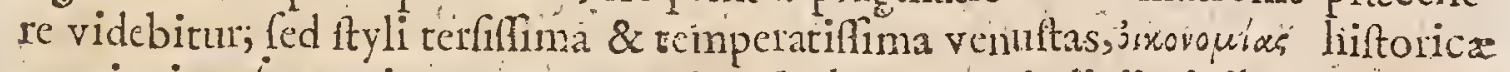
concinnitas, iententiarum opportunitus \& clegantia, judicii civilis gravitas \& xquabilitas, compoftionis univerfe competentia in Herodzatc loigè lateque emincbit--Quodnonnulli in Rebus Alexindri \& Maximini fidem ejus fulpectant, non magnisid videntur de caufis facere, ficut in notis ofténdimus. Ioan. Henric. Boello. in Herodian prefat. adle ctor.

Non idem fuic in Herodiane tudium veritatis inquirendx: nec ferè poreft ejufdem Principis virtutes ac viria rccenfere. Bodin. Method. Hirt. cap. 4 . de Suston. locutus.

Veritati criam ftuduit: wifi quod fides ejus nutet in Alexandro \& Maximno. Quod etiam obfervatim politin̂mo hujus S criptoris interpreti, Angelo Politino. Et ańfe cum Iulio Captolino in $M$ axininis duobus, ubi air : Herodianus $G$ ecus Scriptor, i guantion videmus in odium Alexandri plurimum facit. Simili- Trebellius Pollic in 30. tyrannis : ac Lampridius in Alexandro Severc, \& in $A n-$ sonico Diadumeno.Voff. 1.2. de Hift. Grac. c. Is.

Quanvis la erodionw hîc tantum fpectemus quatenus Hiftoricum fe profitetur ; cum tamcnacceperimus à uida cum plurima fcripfife. conjectarc poflumus, prater octo ejus Hiftoria librós nobis fuperfites, colque admodum breves, cum alia pluia opera concinnavifle, qua ad nos minimè pervenerint. 
Quam in rem obfervandum eft eum primitùs. Alexandrinum Grammaticnm fuille; xquè ac Pater ejus Apollonius cognomine Dyfcolus fẹ Morófus. Quapropter fortaffis etiam Artium minutifjimum fcificiatorem eum nuncupat. Ammianus Marcellinis. Ut ut res fit, meliorem xtatis fuz partem Romx in Aula Imperatorum traduxit, ubi ei facultas fuit, ea curiofitate quam in ejus libris cernerc licet, innumera preclara indagandi, qux alibi non docemus. Franc. Mothaus lo Vayer.

Hiftoricus elegans, copiófus vocatur Dempftero

Abfolutifimi ftyli \& judicii Hiftoricus, \& fune causâ ab Interprêtibus inter vitarum Scriptores repofurus. Bofuns de compar. prud. Civ. n. 29.

Herodiani libri Hiftoriarum 8. ab exceilu $M$. Iurelix Antonini Philofophi, ufque ad mortem Balbini \& Maximi,prodientun Gracè \& Latinè cum Notis \& animadverfionibus Ioan. H.Boeclerz Argentorati apud Iofarm Stedelinmin \&. Anno1662.

\section{DIO CASSIUS}

Clar. A. D. CCXXX.

Ui\& Coccius, frve Cocceianus vocatur. Nicea hic, Billynia urbe, natus: fuit, ac lub Comnodo, \& proximis mperatoribus, Senatorin gravifus eft dignitate: à Pertinace etiam ornatus, ab Alexandro, Marnmea filio, ad Confulatum fuit evectus, quem cum ipfo tmperatore geffit. Extremâ atate, cum bonấ ejufce Imperatoris veniâ, Nicean abiic, ut reliquum vitæempus in urbe pas tria vivcret. Hiftoriam ad hunc ufque Alexandrum libris So.perduxit. Ac olfits quidem fuit ab Urbe Conditâ. Sedprimi 34 . libri perierunt. Extant verò

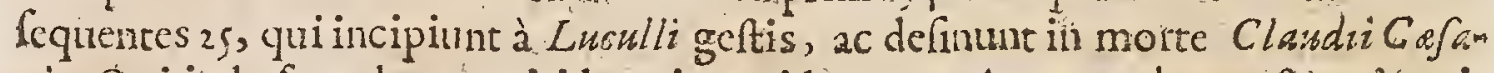
ris. Qui inde fequebantur, itidem interciderunt. Attamen bene elt, inquir Voffur', quèd hoüum excerpta faltem habemus.

Unius interim, fed latre admodum culpx abfolvere Dionem non polfim; quod quadam fetr judicii, fou morum pravitate, virtutes fuo pretio ærtimare nefcir; fed virus fum ejaculatur in optimos, \& praftantifimos viros ut Eicco ronern, Brutura, Caffunga \&.L. Senecam. Omnino hac aut infignem judicii defectum, aut malam mentem, argutunt. Tranftulir Dionern Caffurro Xylander: idemque à fe, fed liberiore tylo, factum ait, Robertus Conftantinus in fuo fcriptorum nomenclazore. Prater iftos 130. libros, q ui in decadas diftribucbantur, etiam prodidir Per/ica, 'ietica, 'Evobra five potius, ut Hieronyrn. VI olphius emendat, doosmá itineraria; ad hec res a Trajano geftas, \& Arriani Pbilolophi vitam; auctore Suidâ. Vof: de Hift. Grac. c. Is. 1.2.

Cum Dio totum vita fux tempus in Rep.gerendâ confumplerit, ac per ornes honorum gradus bis ad Confutatum evectus, deinde Proconful factus, $P$ rowinm cias fummâ cum laude gubernarit, magnam denique bonaum Artiwn fcichtiam cum ufu conjunxerit, Quis dubitet eum inter optimos icriptores cenfere? fectò Comitionm ac Magittratum Romanorum totiufque publici Iuris dif-

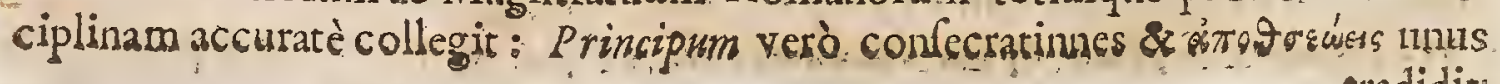




\section{CELEBRIORVM AVTHORVM .}

tradidit ; \&ca, qua Tacitus Imperii Arcanavocat, pené Colus crulgavit. Fuit enim publici confilii diligens indagacer:" Videtur tamen ubique partes Cafarix adverfus Pompcium, \& Antonii adverfus . icerones. datâ operầ tuerí voluiffe: illa verò portcnta. quie in Acie Maŕomanorum contigerunt. Arnulpho e Evptio. non Chrifianis tribuit, contra quam Tertullatus, Eufebins. Orofus, Iuftizu's Paulus Diaconus, ac MI arcm iple Aurelius in Guis ad Senatum hiteris teftarur. Bodin. in Method. legend. Hift. P. 64.

Hiftoricus diligentiflimus vocatur. Demp?tero.

Maximx fidei \& auctoritatis Hiftolicus, Rupert. ad lib: 2.ff. de O.I. sap. I.

Prudentiffmus profecto gravifimulque Scriptor, " nemineque utilitate "\& difciplina Hiftorica inferior. Boffin de Lompar. p'tid. Civ.n. 29.

Iplc ávтón inquifivit; pratcritorum memoriam ex publicis" Monumentis "recollegit s \& quia in clariflima luce Romanx Reip multos annos vixit, folus arcara Reip.intellexit, notifque confervavit, vetetes teges ac folennes formulas diligentiùs expreffit, ut in illo nihil poffit defiderari, Tilemo difcipl. Pbilol. pa pin. 202.

Inferior hôc ( Dionyfio Halicarnafenfí) Dio Caffurcet, ut tamen \&zipfe Po-

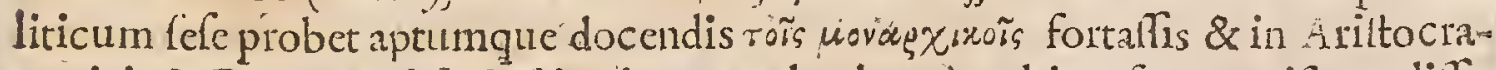
craticis \& Democratic. In Intituris parem laudem à nobis referens, nifi amplinimæHiftorie totos 34. priores libros, quibús res ab U rbe Conditâ ad Lucullum ufque tradidit, evi infolicitas detraxilfet. Infignes certe funt lupertites 25. libri, quamvis in morte Clandii dcfunant: \& nihil vulgare fapiznt ipfa reliqui Opcris-Xiphiliniana Excerpta. oming. de Civ. Pud. Cap.i4.

Judicii, quo praditus eximio fuit, \& prud ntix civilis, cùm alia licet opere toto fparfa colligere argumenta, funè quàm illuftria, tum ex illis, qua initio libri 42 de admiffis à pou polt cladem barfalican variis erroribus; qux libri hunc fequentis initio, de populari civitutis Rómanx fatu in urius imperium mutato; qua denique libro 47 . de dominatione uniss, excomparatone Trinnviratu, pre quo C. Cajfaris imperium fuit aureum, fapicntifimè dificruit Ex his enim, qua pauca producimus è multis, velut éx unguc teoncm, quodaitunt : ita, quanto Calfius nofter ufu rerum valuerit, facilè quivis agnó cet. Ioan. Letsritiv prolegom.ad Dior.

De Dione aliud eft; quem legendum cum judicio aio, nec fidei ejus ufquequaque frondum. Sxpè adulatur, fapé hallucinatur: utrumque ideo, quia Gracus, \& ingenii minimè conftantis Quxdam audaciùs in moribus extenis. quadam vaniùs affirmat. Iip $\int_{0}^{\prime} 1.4$. Epilt. Quant. Epift. 3 .

Summa eadem diviriarum Sene cxprefla à Dione: qui omnes res relictas habet prent culpet virum inculpatum. Ita adulterium ei objicit cum Agrippirs

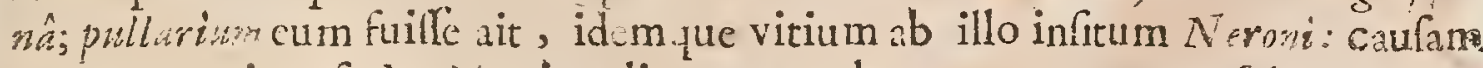
autoremque interfectx $M$ at: is: aliaque, qua homo vanus, prater fidem, prate que ovanium mentem conviciatur velut è platutio. Quibus odii caufis ? aut Bb 2 
qqo mendacii pretio ? Nam Seneca tanto anterior, non bencficio cognitus illi. Sed credo, judicii quadam morumque perverfitas fuit, qux eúndem illum in Ciceronem exacuit, qux in Caflum, Breturn, omnefque bonos. Caveat ab his , monco, juventus; \& è campis illis ita antiquitatum \& hiftoria flores legat, ut non colligat venena. Ídem commentar. ad Taci : 1. J3. Amal. hum.125.

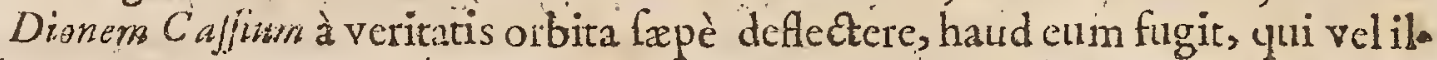
la legit, qux memorix tradidit de Cicerone, Caffio, Senecâ---Diu Caljius nu[quam ad minutias dilabitur; vel fi quid, quod levius videatur, minime pratcrire volet, excufrtione utitur, ut facilè liqueat, neutiquam imprud ntî̀, vel infcitiâ, peccare. $V_{0} \int:$ Dc Arte Hiftor. p. 49.66.

Ea eft humani animi I mbecillitas, ut ingentem illam verbortun curam rerum incuria plurimum confequatur. Ita oblervatum of à viris dactis, Dionem mulsum rheroricari in pralioum deficiprione; fed corum, quxad rem militarem requiruntur, exiguam oftendere peritiam, propè dixerim nullam. Idem ibid. p. 140 .

Grandis ejus fermo \& tumidus, cò quòd rerum ingentium fenfa adferat. Veteris item ipficonftuctionis Sermo plcuus, verborumque, quz rerum magnicudini refpondeant. l'eriodi parenthefibus trajecte, \& byprbatorum opportunus. ufus. Numcri orrò \& intercifio; ctfi accuratè adhib ita, ob orationis tamen perfpicuitatem, obiter legentibus non funt manifetta. In narrationibus pratered \& concionibus, Thucydidis maximè eft amulus ; nifi quòd ad perfyicuitarem magis rendit: catera ferè Thucydides illi norma eft, ac regula. Phot. in Biblioth. cod. 7r. Andr. Schot. Hoterp.

Nihil penè nos fugerer in rcbus Romanis (tanta diligentia \& accuratio fuit) S1 Scriptor ille tous cxtaret. Lip/. De Magnitud. Rom. I. 3.c. I3.

Dio Calfus apud plerofque authoritate caret, ob res infolentes quas fine judicio narrat; tantìm enim abeft ut veritati addictum le prabeat, ut potits à verofmili longè abcat; ut Hiforia fux libro 66 . ubi dicit $V$ efpafra zum fanaviffe crecum quindam Oculos ejus fputo fuo illinendo. Rapin. Retex. in Hiftor. Sect. 28. Gall.

Dio Caffus five Cocceius, Hiftoricus, plagii notatur ab Henrica Valefw, quòd è Sullâ Plüarchi capita non pacuca fua defcripleriz ad verbum. Henovales. Noto. in excerpt. Peirefian. è Dione p. or. Ed. Paris. An. I6 34.

* Ioannis Lemalavii in Dionis Cafjz Hiftoriam Romanam Notac Francof.r.592. Cum exprigationibus permittuntur. Index Madrit.

Dionis Cajli Hittoria Romanæ libri XXV. fupcrftes ex LXXX. quí incipiunt à Luculdi geftis, ac defmunt in mortc Clandii $C$ afaris, in luccm editi fun Gracè cum verfone Guilieimi Xylandri in fol. apud Henricum Stephanuma Alun. $159 x_{0}$ 


\section{$O$ O I G E N E S}

A Damantius dictus, ob indefatigabile ftudium, Alexandrie matus,ani.186. Clar. Anne A ibique Presbyter \& chola Carctheivce Magilter, Claruit anir. 230.à De- D.CCXXX: metrió ann. 233. Alexandriâ pullus, obiie Tyriann. 254: Gul. Cave.

Opera genisima ferè infinita funt.

Opera Suppofruiti funt : Libri Iob Tract. 111.\& comment.in endern-m.nommentarius in Evangel. $\varsigma$. Marci--.-Homiliz in divertos-m--De Sectis Philofophorum, \& Doginatibus-n-Lamentum Origenis-m-scholia in orationem Dominicam, \& in cantica'B. Virginis. Zacharix \& Simeonis. Opus Dubium eft Diulogus contra Marcionitas', de tectâ in Deum fúde. . Extat Grac. Lat. Gwl. Cave.

Negarinon potclt Origenem Krepius accufafe Judxos quod Scripturam Sacram adulteraverint, nec idem iis à S. Hicronymo crimen quandoque objectum fuiff." Sed fi duorum illoritum Patrum fcribendi modum attentè perpendamus illos, ut ad aliorum opinionem féfe accommodarent, contra fui ipforum fententiam frep locutos effe fat bimur. Ric. Simon, Hilt. Crític. V. T. lib. I. cap. 19. Gall.

Orizencs primus intcr Patres ad Librorum Sacrortam ftudium animum maximè intendit. Hinc eft quòd Mcthodo ab alins Patribus qui in: Cam precefferunt longè differat: Ac de illo dici poteft quod ne minis opera exlcriplerit, quamvis eerum legiffet Commentaria qui ante fe in Biblia Ccripferant; curm contra plerique cortum qui poft illum vixerunt, ferè tantùm libros upfius exfcripferint. Hac de caufa D. Aicronymus primum poft Apoftolos Ecclefiaruin Magifrum illum nuncupavit. Quia valde eruditus erat, fuis in Scripturam Commentaries fe in Librorws: Sacrorum \& profenornm Authorum ftudio xqué exercitatum oftendit. Allegorias prafertim in deliciis habebat, non modò quia Platonicorum Philofophorum Scripta legerat, fed etiam quia Scripture hac tatione fublimitatis famam conciliare putavit, que Ethricis fimplicior videbatur. 'Plutimi tamen. faciebat Literalexn Bibliorum Sen Jum; Ced Allegoriam utiliorem cenfuit ad Eruditosfaculi fui ad Religionem Chriftianam alliciendos. Ufque ad fexies mille Volumina feu charex Spiras intmerant, quas in Scripturam confcripferat. UE ut res fir, hoc faltem conftar, neminem unquam $x$ auc ac ipfum in Biblia labow raffe, five ad Textus emendationcm, five ad ejufdem explanationem. Si ejus Scholia feu literales Notul.t: in Sc ipture Textum \& verfornes haberemus, de piofunda ejus eruditione \& magna animi ad Criticam Librorum Sacrorum attentione melius judicare porfemus. Satis etiam in Hebraicis verfatus erat, ut àtudais. quos interdum confulebat facilè non deciperenur; ejufque ing enii vaftitas efficiebat ut multa detegeres ad Scripiurarurn elucidationem urilia. Ejus Ingeniet vis, Judiciique foliditas agnofcitur in ejus Hormilizs feu fermonibus quos ex: tempore dictabat aut pronuntiabat. Licet enim fingularibus fententiis creberrimus fittot tamen inutilitates \& digreffiones in illis non depreheinduntur ac in : $\mathrm{Bb}$ ? plerorumqus 
plerorumque aliorum Patrum Homilizs, Multò plus eruáitionis incrat Commentaritis ejus, feu Tratatibus, in quibus Scripinra fenfum profundius fcrutabatur; \& S. Hieronymus oblervavit illum in ejufmodi Operibu: ad Aebritum Textum confugiffe, ne quid negligeret quod ad Librorum Sacrortm elucidationem conducerepolfet. Nimium tamen enditionis admifcuife videtur fuis in Srip-

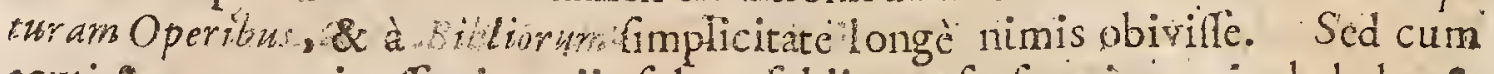
acuti \& penetrantis effet ingenii, folum fublimem fenfum in pretio, habebut \&

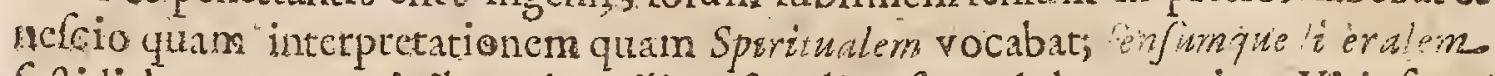
fartidiebat, yuem ni il non humilius fimpliciufa; redolere putabat. Vitiofatamen eft cjufmoäi Methodus; quia res non funt explic unde juxta ingenii nofti acumen \& ideas quas de illarum humilitate vel lublimitatc formamus' fed quales Tunt in le ipfis \& in fua natura funt confiderandx. In qfio hallucinati funt plarique corum qui Platonicorum lib os ut exemplar imitandim fibi propofuerunt. Si femel bec apcriatur fenetra, quifque fublimes \& fpirituales fenfus fecundum proptiam indolem finget; \& ita fordebit bitorian \& liceralis Bibliorum fenfu: Verum eft quod Origener in hoc exculabilis fuilfe videatur: quia experiontiâ didicerat Scripture literam ad inftitutionem parum conducibilem effe; contrà vurolitas Allegorias Auditorum fuorum animas excitare \& ad Lectiones fuas attentiores reddere. Idem ibid.1 3.c.9.

Orgenes Adurantius, pattiâ Al:xandrinus, Leonidx Martyris flius, Amomii prattantifmithilofophi in Philofophia, \& Clement: lexendrin in lacris dogmatibus auditor, ac difcipulus. Vir tantx fuit eruditionis \&ingeniii, "ut ei parem doctifima Gracic, felicifimorum ingeniorum parens, nninuám habuerit. Sixt.Senenf.

Athanafus eum fidci fux teftem locupletiflimum vocat.

Severus Sulpitius aflerit, eum in illâ patte, quâ probatuir, neminem poft Apon ftolos habuilfe zqualem; in eâ verò, qux jure reprehenditur, neminem deformius erraffe. Hieronymus, quanquam latis accrbè interdum in eum invchirur, tamen maximè admiratur ejus eruditionem; eundem que predicat facrorum orninin cxpofitorum victorem.

Origenes Adamantiu a D. Hieronymo Chalcenterus dictus, id eft habenstere: inteftina, rarum Gapientia fydus, atque utinam non caducum. Dum enim fartdit literam, Hiftoriam penè omnen in Allegorian vertit; \& dum fublimiora Cectatur, corruit in profundum, Iorn, Bon. Cad.

Certè magno fuit vir ingenio, atque excellenti eruditione Origenes : uti non immeritò fcientiam illins optaverit ficronyrazts, etiun cum invidiâ nominis. Fuit ille quidem penicioforum dogmatum author; fed tamen, quia preftntifi. mus erat Sarre Scripitre interpres, ita fpenendi $j u s$ errores fuere, uti nihil derogaretur fummis cjus vitturibus. Falli \& Hallucinari humanum ift. Solitudinem quarat oportet, qui vult cum petfectis viwce. Penfanda vitiisbona cujufque funt, \&, qua major pars ingenii ftetit, ea judicandum de homine en. I'ctr.. Cuneus de Rep..1 tevr. p. 294,295.

Quidaliis uLu veniat, nefcio: in me certếtomperio, quod dicam: Plus me docet: 


\section{CELEBRIOR UM AUTHORUM.}

docet Chriftianx Philofophire unica Origenis pagina, quam decem Augufini。 Erafm. Epift.1.2. Epit. 26.

Erat in omnidifciplinarum genere verfatiffimus adeò, ut ipfis Chriffiani nominis hoftibus admirationi fuerit. Porphyrius arcem totius eruditionis tenuiffe dicir. Rinir.

Ef certè hic Scriptor adeò omnibus modis impurus, five ita ipfe $f_{\text {uripfit }}$, five depravata pofteà fuerant ejus scripta, ut nullam in Eccléfiâ authoritatem in rebus controverfis mercatur. Throd. Beza in Epit. $2 \mathrm{~S}$.

Quamvis doetifimus fuerit, deceptus tamen ex Platonis Philofophiâ in multos errores incidit; S. Baflizus in libro de Spiritu Sancto c.2O. dicit Origenem non habuiffe fanas de fipirieu faneto opiniones: S. Epiphanius in libris de Herefa

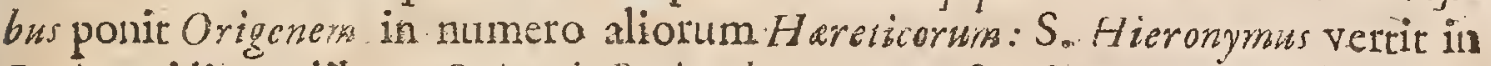
Latinum idioma libros Origenis Periarchon, ut oftenderet errores plurimos, quibus libri illi fatent. Denique in quinto Synodo generali, collatione 8. canon. 2. dicitur Anatberma Origeni, \& Scriptis ejus. Bellarmin. de Script. Ecclef.

Quntùm artinet ad Cypriani equalem Origenems ex quo uno fi Calvus perduraffet, plus lucis nobis a ced ret quàm ex reliquis aliis, \& à quo forfan potius quàm à creteis omribus habercmus in quo acquiefceremus, paucula funt, \& maximam partem, foedè lacera, \& milèè immutata quxefúbillius nomine feruntur. Magni enim \& mirandi iftius, viri monument, neyus temporum, neque hominuminjuriain fuperare potuerunt. Atque hand lcio annen horum invidia graviùs eแum afflixerit, quàm ipfa tot feculorum yetuftas qua ab ipfus morte ad nos flıxerunt. Dall. de ufin Patr.1. I.c. I.

Epiphaniu, \&:Rufinus eum fex.millia voluminum in facras Scripturas elaboraffe referunt. Vincentius Lirinenfis addit, neminem mortalium plura fcripfiffe. quàm Originem ; cujus Opera non folùm non perlegi, fed ne inveniri quidern polfibile eft.

Quidam inter fummos. Ecclefra Proceres dicere non dibbitabant, Malle fe cum Orizene errare, quam cum alvis verum flatuere.

Celebre de coveruftatis judicium eft, Origenes ubibenè,nemo melius; zubi-malè, nerso peju:

Origenes optimè fcripfit contra Celfstm, fèd réliqua nihil valent. Scaligerana 2. Inter: Origenis opera hoc opus contra elfam eft, meo judicio, longè pulcherrimum atque amplifimum. Tan. Fab. Epift. 1. I. Ep. 43.p. 140.

Hic amore caftitaris fe caftravit: Novum \& vetus. Teltainentum memorites novit: jam fenex Hebraicam didicit Linguam. Ioann. VVolf. centur.-3. lection. Memiolab.

Orzgenis libri contra Celfum vraftantiflimum opus. funt \& profunda enuditio: me refertum-Liber hic politiffmè , magna animi attentione exquifitaque methodo fcriptus eft. Non modò optimum Origenes opus eft fed etiam A Apolcyia pro Chrifitanis abfolutiflima \& elaboratiffima omnium earum quas nobis

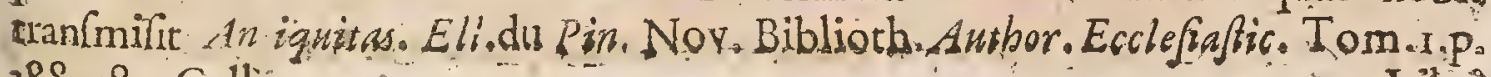
$3888_{2} 389$. Gall:

Libre 
Libri Principiorum magna cura foripti erant, \& utilifimi fuilfent fi Gatis habuliffet Rrligionir Principia ex Scriptura \& Traditone explicare, imaginationes fuas Philofophicas iis non admifcendo. Politioris ttyli funt tomiliis ejns Commentary in seripturam magnaque eruditione plena, fed accutatione debita carent, plurimaque inutilia, oblcura \& inticata continent. Sxpè polt explicationem aliquam inchoatam ad aliam fe confert precedente nondum abfoluta. Ejus Homilie fmpliciores \& intcllectu faciliones funt, fed harum fylus minus elegans eft. Idem ibid.

Extant Origenis opera omnia Graco-Latina Tomis 2. in fol. an. 1679. per Danielern Huetium. 'arifir apud Andr. Pialard.

\section{DIONYSIUS - LONGINUS}

Ciar.An. v. S Ophifta, tempore Severi Imp. Athenis docuit. Erat Porphyrii Philofophi cCXLVIII. D Precetor, \&Znobia, Palmyrenorum Reginx à Confliis. Occifus eft ab Aireliano Imp. co quòd Zenobia author fuilfet, ut komanis fefe opponeret, \& luperbiorem ei Epiltolam dietalifet.

Mulea admodum fripfit, quorum pleraque apud Suidam legi polfunt. Hodie nihil ejus extat, pretcr opufculum illud elegantifimum wei vै $\psi$ ss, De Cublimi

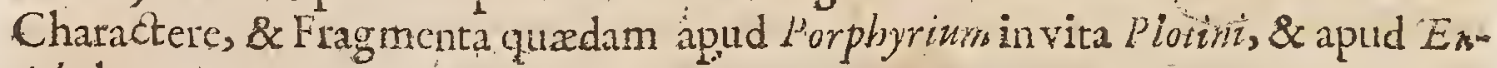
fcb.1. 15. Evangel., raparat.

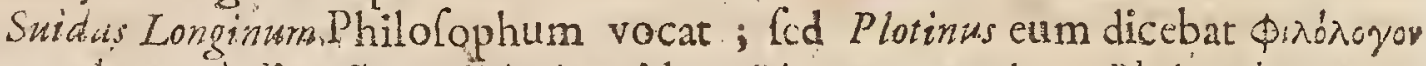

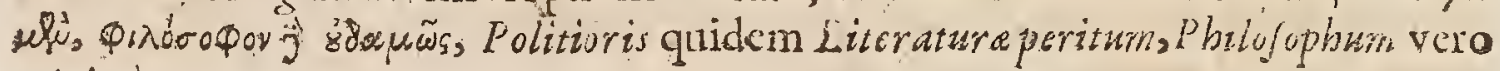
minimé.

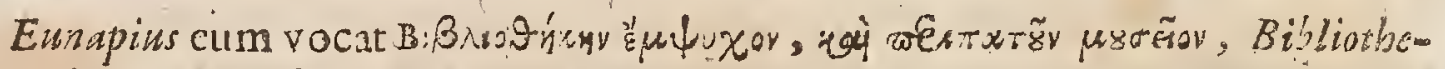
cam vivarr; \& arbulans Mufaum.

Dionyfus Lorginus Caffus, mordax Criticus, \& Rhetor preftantifimus,atque egregius thilofophus, Magifter loorphyrii, quem Eunapius in virâ Portby rii, \& ipfe Porjhyrius in vitâ Plotini valde commendant. Losn. Card.ionsa.

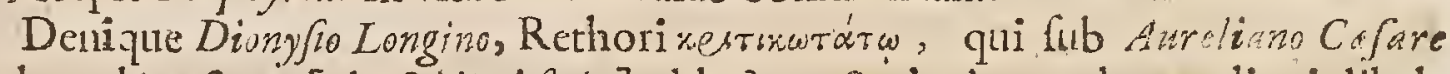
ac hoc charactere [ de futlimi f $y / 0$ ] ablectum \& planè aureolum reliquir libellum, appellatur v́\&@.Vof. Inititut. Oratoriar. 1.6 p.43j.

Ariforeler, Cicero, Outintlianus \& Langinus Rherorice, Tractatus Antiguitatis abfolutiffmos nobis.reliquentut. Rapin. Reflcx. in Eloquent, Refl. I.

Longinus magnus Magifter dicendi; nec minor exittimator fcriptorum aliemorum. Perr.Vidor.1.3-Var. Led.c. 11.

Certè Mofers, quòd de Deo magnificâ fit oratione ulus, laudat Paganifra deditus Longinus, impii illius orphyrii praceptor, ut Eunapius \& Suidas tradunt, ac Porpbyrius ipfe agnofcit. Idcreco (inquit Longinus) Iudcorum legifator, vir baud vulgaris, guandoquiteri divini $N$ uminis virtu ern pro dignitate cognovit ac

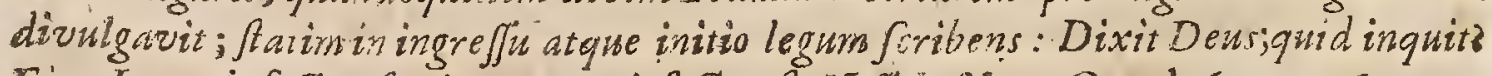
Fiat Lux, of facta eft; Fiat terra; of facta eft. Voft. Intitut. Orat.1. G. p. 446.

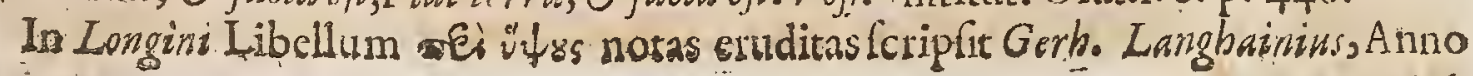




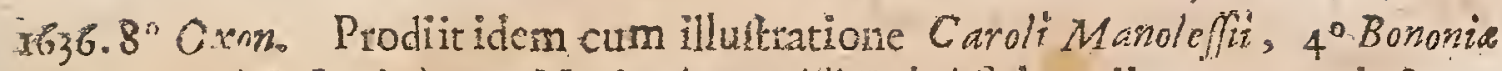
1644. Gracè \& Latinè cum Noris Tanaquilli Eabri Sakmurii anno 1663.1018 .

\section{CACILIUS CYPRIANUS.}

Arthaginienfis, ex Gentili Chriftianus, $\mathrm{ez}$, Retore prinùm Presbyter anno 247. deinab anno 248. Epifcopus Carthaginitn fre, capite damnatus, \& gladio animadverfus mno 258 . Chartophyl. EccleC. Gul. C'ave. Extant opera Part. 1666.3 Oxon.1682. fol.

Cyprianus Coribaginienfls Epifcopus, natione Afer, ante fufceptam fidem gloriosè Rhethóícam docuit: Scd luadente Presbytero Cacilio, à quo \& coguomen fortitus cR, ad C briflum convertus, omnem fubtantiam fuam pauperibus erogavit;ac polt non multum in ?resbyterum \& Epifcopum Cartbegnis elew Otus, multa piffima opulcula elegantifima Phraleos \& Cideroniono candori prom ximxad adificationem Ecclefa feripfic. In quibus, the fiteronymas ad Paulinum fcribens, ait, infter fontis puriflimi lenus inceffit s. placidur. Sixtus Senenf.

Unus igitur pracipuus, \& clarus extitit Cyprianus, quoniam \& magnam fibi gloriam ex artis Oratolix profefione quafierat; \&admodum multa conficripfit in fuo genere miranda. Erat enim ingenio facili, copiofo, fuavi, x ( qua sermonis maxima eft virtus) aperto; ut difcernere nequeas, utrumne ornatior in eloqucndo, an facilior in explicando, an potentior in perfuadendo fuerit. Lactant. 1. 5. Intitut.

Non alium video inter coss qui Latinè fcripferunt, qui ad Apoftolmi pectoris. vigorem propius accedat: ubique Centias Paftorer loqui, ac Martyrio deftinatum. Erafr. Epift. 1.2. Epitt. IS.

Non polfum equidem inficias ire, quin olim inter ortbodoxos Scriptores primas tribuerim Hicronymo: Verim ubi yprianum, quem prius \& carptim \& ofcitans legeram, propiùs fum contemplatus animi dubius reddor utrum utri praferam, adeò fuis uterque virtutibus fummus occurit. Quod fi hoc nomire jure prafertur Demofhenes, quod propiùs accefferit ad verum illud ac naturale dicendi genus, \& longì̀s abfut ab umbrấ Declamatori, longè pracellit hac parte Hieronymum Cyprianus: Magis ubique ferius, ac minus affectans; cum icronymus, quemadmodum \& Tertultianus, in rifu pene fit immodicus, ubinde defidens in expatiationibus, plurimum admifcens ex profarâ literaturâ: Qux dotcs, filaudi dantur, non tam defuere Cypriano, quàm vel fpretx funt, vel neglectr. Nihil in hôc reperies quod ad oftentationem ingenii videri poffit afcitum, aut quod ullo pacto vafriticm fapiat, qux non abeft Hieronymo. Idem ibid.lib. 23. ер. 6.

Cærerum cum Lucubrationes ab co relictz orc ominium in Ecclefia fint celebratx; quidnam autch cft quad Gelafus Papa in Rornarso concilio, itatuto Canone de libris Apocryphis, cenfuerit Cypriani Opufcula apocrypha effe $\vdots$ At per Opuculc certè non alia ab eo effe opera fignificata, quàm editos ab illo de rebaptizatione Harcticonm tradatus, exiltimamus; qui uno volumine opufulo- 
rum titulo infcripto, continctentur. Baron.2. vol.ad an. 26I.

Cùm ;an Cbrijtian Religionem amplexus eft, derifum à Gentilibu:, ac vilipenum, \& loco Cypriani, dictum Coprianum, , his, verbis teltatur Lactantius:

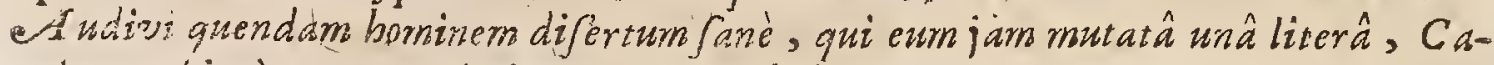
prianum (imò ut emendatiores codices habent, Coprianum, nempะftercorarium) wocaret: Quafi yuòd clegans ingenium \& melioribus rebus aptum, ad aniles fe fabulas contuliflet. I dem ibid. ad ann 2 go.

Cyprianur, virum fanctiflumum Carthagimienses ad unum omnes in primis colunt, cui templum planè memorabile extra urbem ad littus maris extruxesunt : cumque cùm aliis pietatis officiis venerantur, tum, feftum diem, quem Cypriana vocant, quotannis celebrant. Evagr. Scholafuc. 1. 4.c.16.EccleC.Hift.

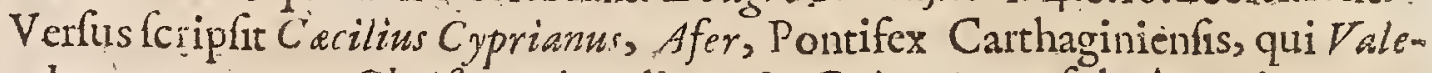
riano Imperatore pro Chrifto neci traditus eft. Cujus Opera folutî oratione omnibus nota, nec commendatione indigent. A verfus, quia parum cogniti vobis, tantum indicare volui. Sunt verò, quos ego lëgi, fexaginta novem Heroicis Defantle Cirucis Ligno, quos fi femel legatis, iterum \& frep legetis. Lil.Gyrald.

Tertuliani unicus admirator Cypriarius, ut etiam eum piopter excellentiam Magiffrurn vocitare foleret; illitis feintentiarum quafdamlibere fccutus eft,ac, inter cxteras, iftam de rebaptizandis Hareticir, quam mordicus tenuit-Idem bea. tus Martyr in fui feculi errore verfabatur, putans omnibus Baptizatis,ne pueris quidém exccptis, ucbarifiam effead falutemneceffariam. Dallode vera us is $P_{a}-$ triom, $\mathrm{P} 2 \mathrm{C}_{2}, 263$.

Quod de D. Cypriani Operibus nobis fupereft majorem ob anilfi dolorem in nobis cxcitat. Nulli enim libri utiliores illis ad yera Theologia folidam noticiam comparandum. In illis qux fuerit antiqua Ecclefa Diliplina cernere licet. Singularia quzdam ad ecclefaftice Hiftoria intelligentiam pernecelfaria hinc hatriuntur, \& plerarumque difficultatum in primis Concilitioecurrentium elucidar tio ibi reperitur, quarum foltitionem alibi fruftra quis quarat. Ephemerides Gallic. Enditor. v11. Febr. 1666 .

* Dejideriz Erafmi in D. Cyprianum annotariones, cum expurgatione permit. rumcu. Index Madrit. edit: Ann, 1667 .

Non meterret auctoritas yprian, quia reficit humilitas Cypriani; magnum quidem meritum novimus Cypriani Epilcopi \& Martyris. D. Augufin.1. 2.de Bapt.

Beatifimus C prianus velut oleum decurrens in omnem Suavitatem linguh cọmpofitâ: Declamator infignis, Doctorque admirabilis. Quantos enim ille

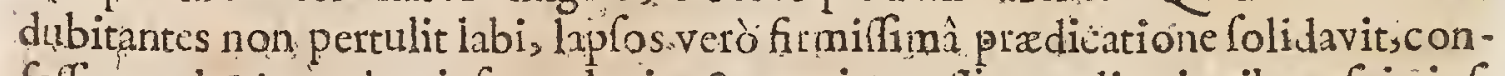
feffores ad Murtyriurn ipfe perduxit ? \& ne minor elfet predicationibus fuis;ipfe quo que Martyrii coronâ, Do mino præeftante, decoratus eft. Caslzodor. Divin. Lecto (4. 19 .

Omnia Sancti ypriani Opera edita in fol. Oxonii anno 1682 . cT Theatro Sheldeniano, cortecta ad Manufcripros Codices, qui fummâ cura allegantur,recognisa \& illuftrata per Ioannem Fell. Oxonienfem Epifcopum. 


\section{P:LOTINUS}

D Hilofophus Platonicus e Eyptius natione, è civitate Lyco, difcipulus Ammo nii, 1 hilofophi Chrifianispræceptor Porphyri, Galieni, Taciti \& i robi remporibus. Sul, Philippo Roma docuit, non Idololatras modò, fed \& Chriftianos habens Auditores, à quorum rcligione non multùm abhorrere creditus eft. Civiatern conditurus, ad $P$ latonis ideam, Gatien Imp opem imploravit, fed hic d Confitintiis fuis eft abiterritus. Fuit corpore gracili, tenui valetudine, morboque Sacro obnoxius. Siripfit de Rebus Philolophicis libros 54 . in Enneadas fex diftributos; quos Latine intexpretatus ent Marfilins Firinus. Porphyrius illum quoque contra Gizoficos Ccripfiffe addit. Doctrinam ejus Ficinur egregiè cxplicavit. C biit Amo 270. xtatis 66. Amelii Prxecepto t: tantâ virtutis veneratiowe fuperticibus relictâ, ut arx pafim ip

Plotinn: in difputationibus ftremus, ad inventionem folers, ad opportuna pcrcipienda promptifimus, foli tamen intelligentix ftudens, nihilide Oribogras pbria curabat. Qui ad hur lcgendum accedunt, hos mente fublimiore effe convenit, nam creteri homines animum habcnt, hic veiò not animum, fedintelleetum. Qux fcribere conccperat, ita animo difpofuerat, ut è libro quodam antè oculos polito exfcribere videretur: frque $a b$ aliquo interumpe batur, peracto negotio, non repetcbat ccripta, fed fequentia contexebat, quafi nihil ineermififSet. iorphyr. in vit. Ploir.

Ob vim ingenii coleftem \& dictionis obliquam, \& ab xnigmatum obfcuritate non alienam rationem, gravior \& à populari captu, disjunctior videbatur. Einapius in Porph.

Plotimus certè noftre momoria vicinus temporibus, Platonem cxteris excel-

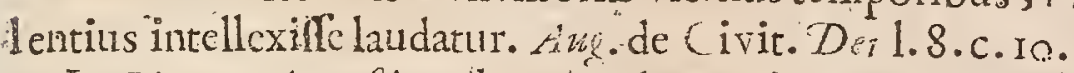

In Plotno Anguftrus 1.3. Acad videri Platonem revixulfe fcribit. Ita fuit ille os latonis in hilofophia purgatifimum \& lucidifimum, dimotis nubibus erroris. Macrobius quoque Principcun Philofophix facit iotinur cum Platore. Lud. Tiv commint i loc prædict. Auguft:

Qui hunc audit, Platonom audice fe putet: aut enim in Plotino Plato revixit, aut Dxmon idem prius Platonerm, deinde Plotinum afllavit Margl. Fitir. in Epitt.ad Lea.

Plotinus Platonicus profundifimus, \& à populari captu omninò disjundus. Genus dicendi fectatus eft horridum \& incultum, verborumque ac fentcntiaeum obfcuritate perplexum. Ioan. Card. 3ona. in Norit. Auctor.

Plotinus magis quàm quifquam verború parcus. Macrob. in fom. Scip.l.2.c.r2.

Vir fapicntia inclytus vocatur Lipfl cent. 4 Mifcellan. Epift. 39.

Philofophus maximi nominis, quique poiteris exemplum doctrinæ præbuit. Barth. ad Zach. pag. $2 S_{4}$

Ploimus Nuriberii inventa \& dogmata fibi tribuere a maledicis quibufdam di-

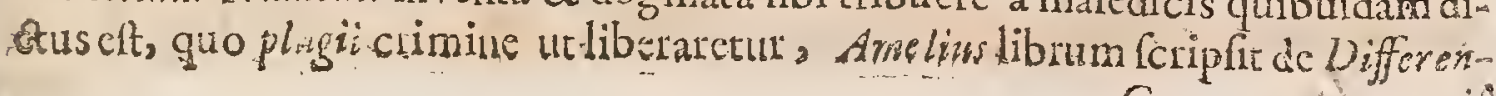
$\mathrm{Cc}_{2}$ tim

Clar. An D. CCL 


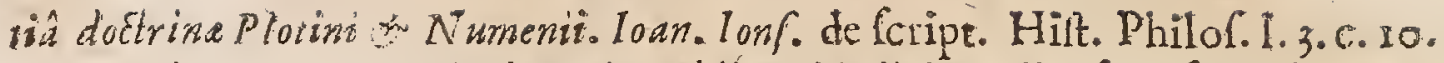

De Platonice, ut \& Pythagorice Philofopizir Principiis, fcripfere olim Numea. wim, Croniur, Moderatus, Ce Thrafyllus, qui Tiberiano avo vixit: Sed omnium ante Ce indufrian curîacurata vicis Plotinus.Voll. de Philof. Sed. p. 72.

Plotinu nou modò Habreorum Fatrum, fed lifcatorum aroque ac Salvatoris nofti perdockus traditiones. Theodoret. de curandis Aff. Græa lib.6.

sed redeo ad Plotinum, cujus monientis verba literis planè aurcis, fi quid aliro reperitur etiamum previofus, pericribenda : quia guid noftrûm cuíque meditandum obeundumque fie, fumma veritate prefcribune, non duxi per incuriam tranfmittenda. Nam cum jamjam force animam acturus, perrexit, ad es a invifendum Euflocbius, ficutiab eodem retatum fibi, Porphyrius icribit:habitabat is P'uteolus. A Adbuc (inquit Ploimus) te expedto, atgue equidem jarm adnitor: guod in nobis divinurn eft ad divinum ip furn quod viget in univerforredigere. Spi. rirumque his verbis emilit, Rhodogin. Leet. Antị. 1. zr. c. Io.

Plotini Philolophia Platonice libri 54 . in fex Enneades diftributi prodierune

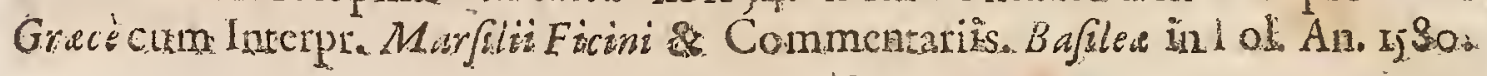

\section{G R E O R I U S}

Clas. Anno D. CCLIY.

A Ntế Theodoru diotus, Epifcopus fuit Neocafarienfis, à magnitudine:

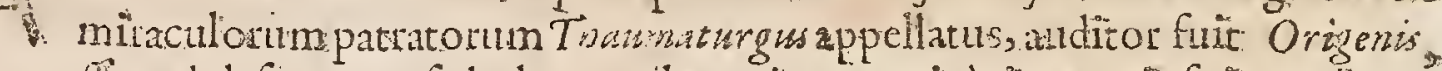
dum clet adolefcens; Ced ab erroribus cjus omnino immunis fuit. Bellarm o Obiitan Dom.265.

Swipa Genuina hac fune: Panegyricum in O igenem-Metaphinfis in Ec-

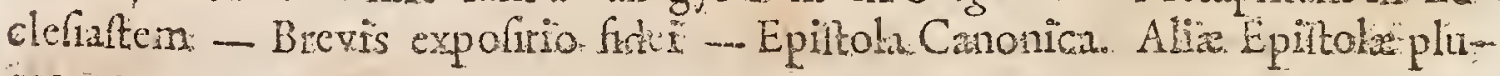
res qux non cxtmt.

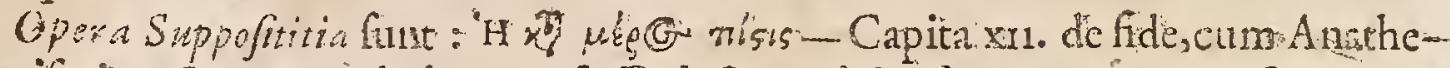
unatinis - In antuiciationem. $S_{a}$. Dei: Generricis Sermones tres -Sermo ing Sancta Theophania - Ad Tatianum de animâ difputatio, Gul Cave.

Ce tè-Ballius tuntam fuife mitaculonmejus preftantiamait, utab ipfis: etiam veitatis hofibus, Alier Moyjes appellareur. Vium Apcroliconum finorum \& vitucum vocat. Hieronywi

Vir doctus \& fanctusin \& multa foripfit, miraculis vivens corufcavito Tribern.

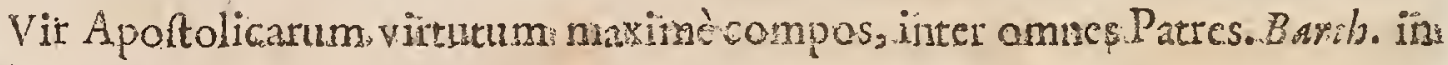
Adv. p. jG.

Gregoriurs Mignnu \& ilius yocenquo loco ponam a annon cum Apofolis: Prophetis, virum quieodem Spiritu, quoilli, verlatus eft g quique Sandorum veftigis per omem vitam inhalerit, quique Evangelicx conlervationis vigorem, quamdiu vixit,p pititeriț? Equidem illúd dixerim: profectò injuriâaffice-w remus veritatem, fi non animam illim annumeremus is yui Deo juncti funt: Qui velutinignis magnaque lucena.iu. Ecclefia Dei refpleiduit: Qui Spiritus: 
ope terrorem habuit adverfum Dxmonum poteftatem. Baflo de spir. Sanct. cap. 29.

De Gregorio illud confat : Quntumlibet in fude Chrinianâ Origenem habuesit Crtechifan atque Dotorem; tamen adeò omin penitus impuritate defrezram ab eo cognofcitur hatfec dockrinam, ut nullus unquam nec adverfariosum quidem fuerit, quivel levi fifpicione cum Origene conniventiæ eum in srimen adduxerit. Quod verò in ipfum aliquando fuerit inclanntum, fuis. fcriptis favile Sabellio : procul hxc abhorrebant ab Origenis Sententia. Baron.ad Ann. 266.

Contra Genites fcribens Thasmaturgus aliquibus vifus eft Sabcllio arma fub minitzâfe, quod S.Bafliw, Barcnins aliique purgant \& cxculant.

lite Gregoriu crcbià hominum celebratue fermone non A thenis folim \& BC: ryti, verum etrim per totan regionem 'Fonti, atque adeò per univefum ( prope dixerim ) arbem tcriarum : oc rat. 1. 4. Hift. Eeclef. c. 27\%

Ubicognovit fum infare obitum, totam diocefin ac civitaen fian perf

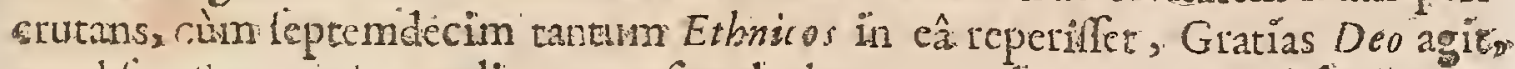

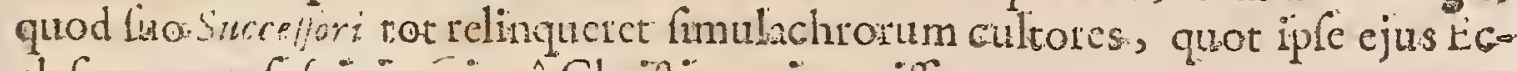
clefix curam fulciplens un ề Chrintanos invenifet.

Sicut de Moyse at criptura quoderuditus clec omni lapientia. Egyptiorum: Ita quoyue magnus inte vir [Gregorius Thaunatzargus] cum omnem Gentilium eruditionem atque doctrinam perfcrutatus effer, factoque periculo didicillet, quàm infurma corum opinones fut arque lententia, quàmque parum fibi cous ftcnt. Dilcipulus fit Evang lii, ac pritus quàm per mythicam \& incorpoream na

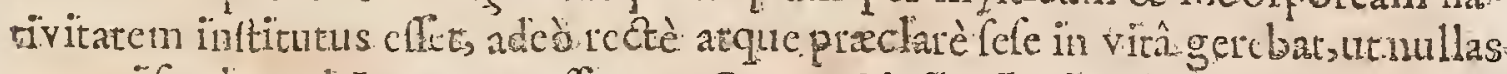
peccatifordes ad Lavasrurn afferret. Gregor. Nyjen. in vita ejus.

Gregorii Thanmaturgi Epifcopi Neocefarienfis opera varia, Grecè \& Latine fummî curâ comparata, Inerprete \& Choliafte Dodtore Gerardo Vo/fio colliguntur, oxn, ann. I.59 4 und clim variis Sancerum Patrune opufulis, qux anteà nunqurm prodicrant è pralis, codem Interprete \& Choliafte Gerardo Vofjio.

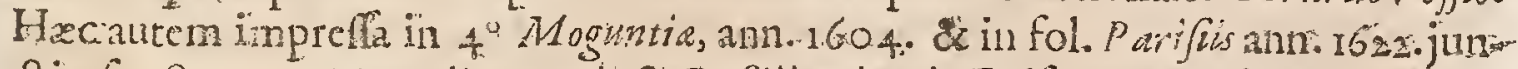
etis fanctorum Macarii Eqypiri, \& Baflii seleucia Epifcopioperibus, cum Zco. *.ru expofitione in aliquot canonicas Gracorum Epiftolas. De his operibus plene Pofierinis in fuo Apparutufarro, Bellarminus \& Labbeus De Scriptoribus Ecclefiafiriss, qui multis contendint ut magnam faltemeorum partem; finon omniajs legititram \& putent \& probent. Attanen ut cgo ingenuè fenfummeumaperiam, dicam valdè mihi fufpecta effe ca omia qux fub ejus nomine vulgatas

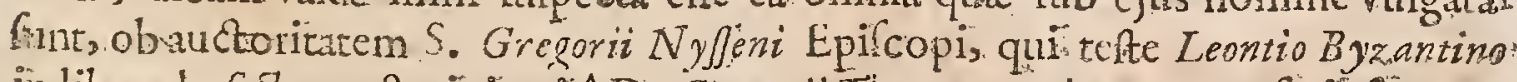
in libro de fétu, c. S. ait in vitâ D. Gregorii Thatudiugi quam conferiplit; cums wihil de scriptis reliquille potteritat : Quis enim hoc melius nofcere poterat ,

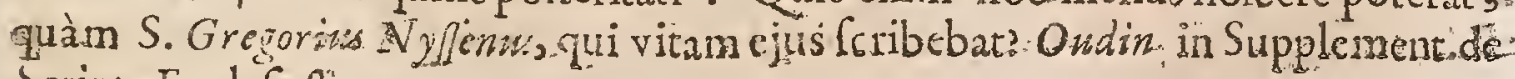
Seript. Ecclefiaft: 


\section{POR PHYRIUS}

ClartitA.D. D Hilofophus Tyrius, clarî ortus proLapiâ, prius Mr alchus vacabatur, dẹinCCLXX. de ob veftem regiam purpureasn, çuầ ob nobilitatem utebateri, Porphyrius à Sophifâ Longine, qui cjus in Rhetorici- Præceptor erat, di lus eft. Plotini füit difipulus, magifter verò Lamblici. Natus Aurelianitemporibus obiit lub finem Diocletinin.

Scrpta ejus hac funt: De divinis nominibus, 1 r. - De Principiis lib.2-de Mateiâ, lib.6. - Dc animî; 'lib. 5. -. De anmalium abstinentiâ., lib.4. De cognofcendo feipfum, lib. 4. - Quodunafuerit Plato is Ariftoteligques Ccat,lib.7 - In hiltoriam I ulani Chaldai Philofophi, lib.4. - Contra Chri-

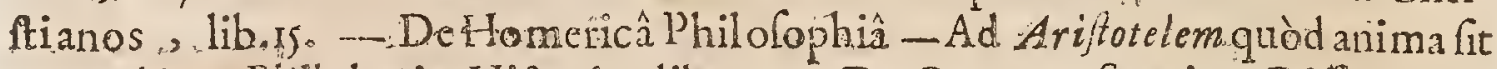
entelechia-Philologix Hiftaix, lib. s. - De Gencre, Specie, Differearia,s Propio \& Accidente-m-De-Dili fontibus, fecundum Pindarunz--De utilitate quam Reges ex 1ornero percipere polfunt, lib 10.---.-Mifeellanterum Qux-

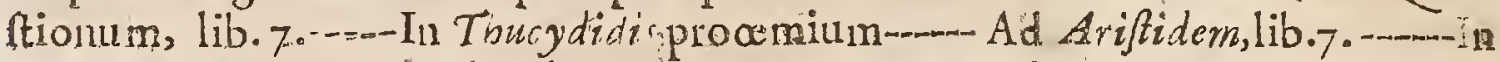
Minucianiatem. Itcm alia plurima, pracipué verò Aftrakomica.

Hic eft ille Porphyrius, qui contumcliofam, ac atrocium injuriatum plenam linguam in Chriftianos movit, \& quâ fuum pcttiferum veucnum in cos cftudit, ac ejaculatus eft. "uid.

Porphyrius, vit, fi quis alius fuit, Religioni Cbrifiane: \& ejus cultoribus infeAtifimus. Tanaquil. Fab. Epitt.1. 1. p. 145.

Rabidus adverfus Chriftum canis audit Porphyrius Hieronym. in procm. catalog. Sciiptor. Ecclef.

Porphyrius contra veritatem rabidà debacchatus eft inlaiaid. Theodoret. Serm.I. de Grac. affect. curatione.

Porpbyrius à polterionc gentilitate maximè cultus, \&inter Platonicos, ob exlentiam, Philofophus cognominatus; fed hoftis ille Cbrifti afophos vel milolophos potius appellandus. Hic habitus omnium Platonis myfteriorum confultifimus.VVier. de Mag Infam. c. z.

Ejus adeo cxolum \& ex crabile nomen, ut in Edictis Imperatorum profigan tilfrni quique Aderetici, Porphyriant diccrentur. Crakentborp. de Provid. Der.

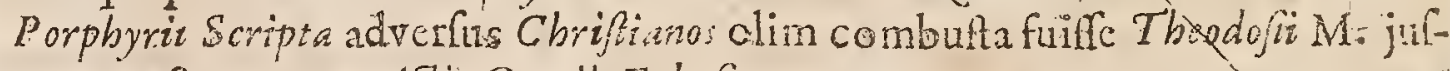
fu, anu. 44 S. patet ex Actis Conril. Eph: $=$ inr.

Lactanius duorum meminit Philofophorum, qui contra Cbriftiands feriplerint, quorum prionfine dubio hic porphyrus fuit. Defcribit eu nn velut fut velo Philofoptii omnibus vitiis coopertum, avarum fimul ac-luxuriofum quique opibus fuis'iplos ludices corruptos habucrit in potcftate. Jot $\mathrm{man}$.

Magnum hujus inter $P$ bilofephor, ac fopbifts, nomen fuit-m - orphyrimm primitùs fuilie Chriftianum, fed polteà a Religione hac refiliifle, Anguftinus innucre vidctur, 1. 1o. de civ. Dei.c. 28. Id ob auctoritatem tanti viri inficias ire non aufin : Sed hatenus tamcra nihil invenio, quo id vetismile fart,praterquam quò 
jünior familiarter ufins fit Origene. Ac longè etiam minùs affentire polfum dodifimo Anm.lium Ecclefasticorum Scriptori, [Baronio ad annum 325.] qui jam fonem denuò cx. Genili C briftianum factum putat Vof! dic Hift. Grac.

Ufque adeò vir ille [ Porpbyrius] in omni virtutum genere volutatus promifcuè fuit, ut nefcias quid laudes magis, Sermonis cl cgantiam \& nitorem, an verò diccndi acrimoniam. Videtur cxtremam fcnectam attigiffe; quo factum, ut multas relíquerit obfervationes, libris prius à fe editis repugrantes : de quibus nou polfum aliter exiftinare, quàm quòd xtatis progrefli fententian mucalit. Ennap. in vit. Porphyr.

Porphyrius tanquam Mercurislis quedam catena ad Mortales demilfa, omnigenæeruditionis beneficio ; cuncta apertè, dilucidè , claréque explicabat Plotini \& Philofophorum res, qui arcana fua obfcuritatis latebra, ficut l'oëtx Fabulis,

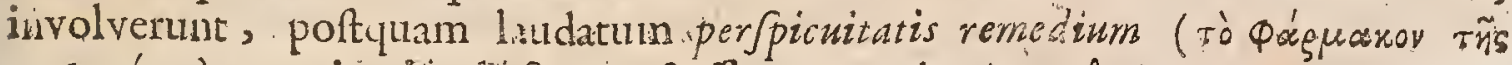
raథyrés ) experientici edoutus guftalfet. Eunapius in vita. ejus.

Porphyriurs Chriftiana fidei defertorem tanti fecit Libanius fophifta, ut euta pro Dco habuerit. IViceph. lib. Io. cap. 3 .

Julianum ejus mendaciis atque delirmentis tanquam divinis vocibus exul tafle, liquerex $N$ azian. orat. 4 .

Capitalis quidem ille [Porphyrius] fidci Chriftione hoftis, Philofophis tas mon infignis, \& vetcrum hiforiam fcientifimus. Nic. Fullo Mifcell. Gacr. 1.2. cap. 6

Optandum eflet nos habere libros quơs adverfus Chriffianos confcripfit :. Sü cos haberemus libros quos habebant $P$ atres egregia in iis cerneremus.

Ex Arr/fotelic libis Topicorum fumpfit, orphrius qux de quingue vocibus compcluit; opus; ut meầutique fententiâ utilifimum, ità longè ab utilitate traditum. Prætereo tauranoyíav, \& moleftiam Orationis. Lud viv. de caufis corrupt. rt. p. 18 r.

Jorpibyrius è facris I iterir, qua fibi collibuit fuffuratus, nomullis inde fententiis fur monumenta interfitis, pofthabuit veritater perdifcre. Simiufque duntaxat imitator permanfit, vel ut veriùs dicam, Graculus quidam fuit alicnis plumis excultis. Theodoret ferm. $7: \mathrm{p}-108$.

Quız verò caufa eum moverit, ut deficeret à fide \& libros in C Cirim thanos fcriberet docet Socrates 1.j. C. I 9 . Nam ifte Cafared Paleftina à quibufdam Chriftianis reprehenfus, cùm prregravi , quâ ardebats iracundia illud ferre non poffer, religionem Chriftianarn deferuit; \& pra odio illorum; qui ipfum coarguerant; ad libros confcribendos; quibus Chriftianos maledictis \& rontumeliis perftringeret, praceps ruit Eadem Nicephor. 1.1े.c.36. Lud.Viv. comment in 1.10.c. 26. Auguftin. de civ. Dei.

Porphyrii opera, viz. de Abtinentia ab animalibus necandis, libi. 40 cum veifone: I. Valen:ini : De vitâ Pythagora liber: Sententia ad Intelligibilia ducentes: De Antro Nympharum 's quod in Odyfed defcribitur Latinè omniaverfa funt per Lueam Holfeniwm; qui \& differtationem de Vitâ. ac Sciptis Porphyrii , nec non. Qblervationes ad vitam Pythagora adjecit: 
Cantabrigie in 80 Impenfis Gu\%. Morden. annos 1655 .

Libr: quatuor de Abltincntiâ prodicnunt Gracè cum Scholiis Michaelis Ephem fir anno 1547 . Florentia in Fol.

Scholia ejus optima ad lliada Enmeri fe hąberc, aliquando in lucem proditura, ait Ifar ns Voffin ad Melo lib. 1. c. 9. que cum alis commentatoribus Poctze ejus è Bibliothccâ Peirefcianâ acceperit.

\section{ALIUS SPARTIANUS}

19. Clar. An. CCXCIII.

$\mathrm{D}$ Iocleticni Imperatonis temporibus foruit. Vitas Adrianiz Elii veri,Didiz Iuliani, Severi \& 'efceis i' Nigri, Caracalla \& $G$ etd, literis confignevit.

eAlius Spartianus proftndifrmấf atet eruditione, non fine fui tcmporis eloquentiâ. Ioan. Bapt. Piur, c.57. annot. pofter.

E Spartianc, Latmpridio, Capitoline, 7 ulcatio, \& illis quali partium fecunda rim Hifforici, eloquentiaz non multum; rerum \& monun veterum inmenfam copiam eft haurire. Lipf.1. 5. Epift. Quaft. Epit. 21.

De Stylo res nota, uti \& aliorum, qui cum Spartiano conjungi folcnt. Ut funt Gallicanus, Trebelizus Pollio, Iulius Capitolinus, \& alii. De quibus fic Erafs mus in Ciceroniaso: In bis vite ef quad probes, prater Hiftoria fidem. Nam agrè tuentur Sernonis Latini caftimoniam. FofJ. de Hilt. Lat.

Rariflimos fupereffe, qui veritatem viderentur exquifitè fectari, \& fibi comperta fcripflfe, in catcrorum tamen copiâ non fpencndos, voluit divina beni-

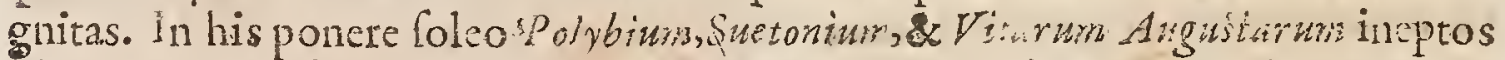
pleiumque confarcinatores, niff fi ita interpolatos; Taritum Ammianum $M a r-$ cellinum. Quibus etî diverfflimis Scripturibus, maximè omniun veritatis fudium cordi fulle Ccimus. Rarth.1.60 adverL. in Augufin. de C.D.l.r.c.6.

In partiano multa pluibus in locis deprehenditur earundem rerum repetitio, \& plurima ubique confufro. Nam quot:s Serviani cxdem legas in Adriano? incujus vitâ contcxendâ poterat fânè, debuerat certè Sparriumu vel temporum fervareferiem, vel perpares fic dicenda ditinguere, ut de publicè geftis, de peregrinationibus, deque privatâ caterâ ejus vitâ feparatim tractarct. Qui quidem ordo in aliis quoque Spa tiani lcriptis defiderarur. Bonifac. Ranan. Hift Scriptor.

efelins Spartiarus Hiforicus non magni ponderis. Demp/ter. in Elench. Scriptor.

Certum eft quod Spartianu, Lampridius cxterique qui quod Liforie Augufa nomen obtinere folct compofucrunt, tempora de quibus fcribunt mirum in modum illuftraverint, quòdque corum librorum lectio, quandoquidem melioribushac in parte deftitutifumus, abfque infigni difpendio negliginequeat. Sed totum illud ingens volumen qued ab illis habemus, frigidum \& exanime carlaver eft, potiùs yuàm Fifforicum corpus debitè animatum. Omnes Eruditi judicio conformes funt Authori qui,in fua Prefatione, Hiftorie debonefanenta cos nominat. Diciquc poteft nihil in conum lectione profici polfe, quod attinet 
adHiftorix regulas, nifi in contratium fenfum trahantur, quemadmodum in illorum imperitorum Fidicinirm cancu, quem Dícipulos fuos audice rolibat Ifinenias, ut ertores vitarent quos in illo animadvertillent. Francif. Mothetus le Vayer. Præfat. Lua.Gall.

Fulrus Capitolinus, \&huic xqualis Alins Spartianus, claruerunt ambo temporibus Diocletian, \& in gratiam ipfus \& ad iplum fcripferunt Vitas yuorundam Imperatorum; ut ex filisipforum fcriptis apparet: quamobrem cum fcirent ipfum Diocietianum immento odio in chrffianos Alagrare, \& ipfi cadem in eos invidiâ, qux de Chrifin fri fripta memoriâ digna reperiflent, ex compofito prætermiferunt: Adeo ut acerbifím in cos per imperatores $M$. Antoninum \& Lucium Verum excitat: perfecutionis ne verbum quidem fecerint : Sicut \& multa alia ab is obvoluta filentio relicta habentur, qux toto Komano orbi. perfpicua, publicis etiam teftata monumentis habentur. Baron. ad ann. Cbrix63.

Hiflorie Augufte Scriptores, licèt exili quide $\mathrm{m}$ ac levidenf teftimonio profe-

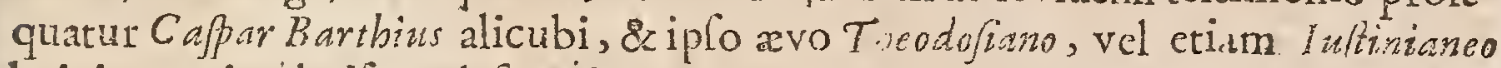
latinitatem in plerifquc deformiorem pronuncict : Nolim quifquam utilitatis parùm ex corum lectionc comparari polfe putet. Whoar. Meth. leg. Hift. Civil. Sect. 22 .

Hiftori: Augufu fcriptorum lectio cum omnibus \& Hiftorix \& Mozum all-' tiquorum ftudiofis neceffacia, nedum utilis; tum vel maximè iis, qui cognitioue Iuris Civilis Romanorum delectantur. Quàm multa enim toto fparfim opere invenias, qux ad Turifpudentix fudia propriè pertineant? quàm multis locis, aut novum Jus aliquod introductum, aut vetus antiquatum obfervacur ? ut taceam, çuod abfque his Tcriproribus fuiftet, plurimos prudentes, quorum extant in iandectic \& nomina \& Fragmenta, ignoraremus: Taceam item dictionis genus, in multis commune cum antiquis Jurifconfultis. Quid? tot Principum pulcherrimas Epiftolas tot gravifima Senatûs-ionfulta, tot alia publica monumenta, écciniis A uguftorum, Actis Senatûs \& populi, aut neficio unde exabdito cruta, quanti cenfemus faricuda? aut quem mihi dibis ex omni veterum Auctorum numcre, cui propter fimilem vel fiden, vel diligentiam tantum debeamus. Nec pratcrmiferim cruditas illas neque longè petitas, fed è ce natas digreffones, quibus hi Libri, tanquam fegmentis purpurxe veri luminis, variis locis lunt ornati. I Gaac.Cafanb. In Prolegom ad Hiftor. Anguft.

Alius Spartianns, Elins Lampridius, Inins Capitolinus, aliique Siftoria Augaffe Scriptores, in lucem emilfi funt cum integris Notis I aaci Cafubbri, Clawaii Salmafii \& Iani Gruteri, duobus Tomisin $8^{\circ}$. Lugd. Bat. ex officinâ Hackianâ, anno 167.1 .

\section{A I I U S L A M P R I D I U S.}

I

Mperarorum Diocletiani \& Conftantini Magni temporibus vixit. Nam ad illum quidem Antonini C'ommodi, ad hunc verò Antonini Heliggabalì ì Clar. A. D. CCXGVI: $\mathrm{Dd}$ Alexandri 
Alexandri Severivitasfcripfit. Gerard.Ioan.VoJius eundem fibi eLlim Spapis bianurn atque Laxnpridiun videri exiftimat.

Mihi quidem id animi fuit,ut imitarer Suetonium Tranquilluin, Fabium Marcellinum, Gargillium Martialem, Iuliurn Capitolinum, ALlium Lampridium, cxterofyue, qui hæc \&talia, nol tam difertè, quàm verè memoria prodiderunt. Flav. Vopifc. in Probo, c. 2.

E Spartiano, Lampridio, Capitolino, Vulcatio, \& illis quafr partium fecundarum Hiftoricis, eloquentix non multum; rerum \& morum veterum immenfam copiam eft haurirc. Inf. Lip J. I.g.Epiftolic.Quxef.ep.2I.

e Alius Tampridius Hiltor: cus futilis, fi Cribendigenus fpectetur, cæterùn necefrarius Polyhiftor. Dompfer in elench. Script.

Lampridizs Hiftoricus frigidus. Idem ibid.

Scylus Larapridiv pedefter ac humilis eft; dicio parum fincera, numerus plem. rumque fublultons; res null ferie digetre, ita relatx, ut in mentem veniebant; nullus verborum dele ens, nullus eloquentix apparasus. Baith. Bonifac。 in excerpt. de Roman. Hifer. Scripror.

De Iulio Capitolino e Alio Lampriaio. Trebellio Pollione, Flavio Vopifca, Alio Spartiano, Wulcatio Gallicano, qui uno Eerè tempore fub Diocletiano \& on frantiro Magno Imp. Rom. Principum vitas conleriplere, vix habeo quid dicam; adeò temporum injuriâ \& Librariorum indîligentiâ funt mutili, \& corrupti ; ex his tamen qux extant facile colligere poflumus, cos pro temporum conditione fatis diligenes in hiftoriâ conferibenda fuilte, fed rerum difpolitio, quâ uf funt. minus apta ,ftylufque tenuis. Pleraque etiam dicenda omittunt, multis in ptè, qua ad rem nihil vel parum perinent, additis, com brevitati ftudent, in Jimiam verbofitatem incidiunt, minuta qu -ffe debent, cùm corum temporum meliores Scripiores non habeamus. Car. Sigon. de Rom. Hift. Script c. 20 .

Illud opinor apud eruditos omnes in confero effe, quod ad narrationis fidem: attinct , primas deberi Suetonio : qui,ut quidam non infefiviter dixit, Prorfus ea

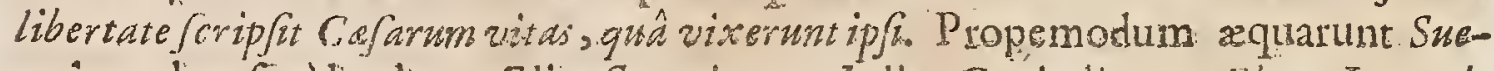
tonium, hac fanè laude, Elius Spartianus, Iulius Capitolinus, AElius Lampridius, Vulcatius Gallicanus, Trebollius Pollio, Flavius Vopifus, licet eloquentia: viribus fermonifque politie multò inferiores. Proinde mihi quidem diguividebantur, ut corum lucubrationesfudiofi fummâ fide fervarent, quorum fide: factum eft; tur tantarum rerum tan certa memoila duret in hanc ufque noltram: xtatem. Erafm. Epift.1:28. Epift. 16.

Romanorum Impp. vitzac res gefta, à fex.llis Hiftoric Amgufte Scriptori: bus, non tam difertè, quàm verè in literas, referuntur; quos accuratè emendatos, atque illufictos, I aacus $C_{\text {af }}$ aubonus, novifimi hujus feculi immortale decus, \& Chand. Sulmafins, rerum literarumque veterum ufque ad miracu. lum doctus. haud ita pridem nobis dederunt. Whear. Meth. legendi Hilt.Civil. fect. 22 :

IULIUS 


\section{JULIUS CAPITOLINUS.}

T Empore Diocletiani vixit. E Spartiano, Lampridio, Capitolino, Vulcatio, \& illis quaf partiumfccundarum Hiforicis, eloquentiz non multum; rerum \& morum veterum immenlam copiam eft haurire. Lips.1. 5. Epift. Quaft. Clar. A. 15. CCXCVIII: Epift.2I.

In his (viz. etlio Lampridio, Iulio Capitolino, Alio Spariano, Vulcatio Gallicane, Trebellio Polliane, Flavio Vopifco, Aurelio ViEtore) vix eft auod probes, prater Hiftorix fikem; tantum abef, uit cos (iceroniani cognominis honore digner. Nam xgrè tuentur Sermonis Latini caltimoniam. Erafm. in Ciceronionio.

Ex lis tamen, qux extant, facile colligere polfumusscos (viz. Capitolinum,

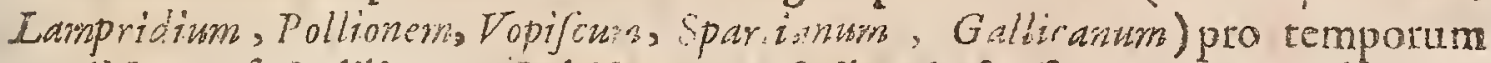
conditione, fatis diligentes in hiforia confcribenda fuife. Sed refum difpofitio, quâ hi uff funt, minusapta, ftylufque tenuis Plexaque etiam dicenda o mittunt; multis ineptè, quz ad rem nihił, vel parum faciunt, addiris. Et cùm brevitar fudete conantur, in nirniam verbofitatem incidunt, minuta quxque profe. quentes. Nobis tameu chari elfe debent, cùm corum temporum meliores Scripiores non habeamus. Car. Sigon. de Hift. Roman.c. 20.

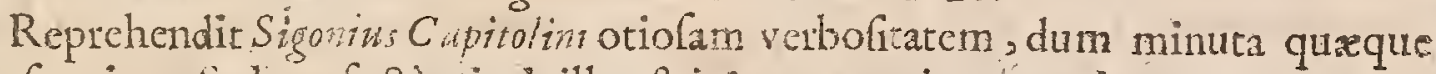
prolequitur. Sed profectò nimisille eft iniquus qui pró gratia, quam Srripior de nobis optimé merito dcbemus, reddit objurgerionem. Nam vel minimartum rerum copnitio magnam interdum affert utilinacm, prefertim li de magnis ggitur viris, quornm nullum eftam leve, tamque domefticum dickum ant factum, quin ohfervatione dignum videatur. Baishaf). Bonifac. de Roman. Hiftor. Scriptor.cap.2J.

Iulus Capitolinus, \& huic aqualis E Alius Spartianus, claruerunt ambo temporibus Diocletian, \& ingutiam ipfus \& ad ipfum lcripferut Vitas quorun dam Imperatorum, ut ex fuis ipforum Scriptis apparet: quamobren cum fcirent ipfum Diocletianur immenfo odio in Ćbrifianos flagrarc, \& ipfi eâdem in eos invidiâ, qux de Chriftianis feripta memoriâ digna reperiffent, ex compofito pretermifertint: Adcò ut acerbifimxin eos per Impp. M. Antonizum \& Lucriums Verw excicatx perfecutionis ne verbum quidem fecerint: Sicut \& multa alia ab is obvolutaflentio rclicta habentur, qua toto Romano orbi perfpicua, publicis etiam teftata monumentis habentur. Earon. ad ann. Chr. 163.

Vite nonnullx funt inter hos ( vit. Capitolinum, Lampridiusn, Pollonem, Spartianum, Galliconum ) quas jure dicas, centonum infar, è diverfi coloris pannis fuiffe confutas. Scriptorum alibi defideres judicium limatius, alibi diligentiam exquiftiorem; omnium maxime in Capitolino, \& in quatuor aliis. Balthaj:Bonifac. \& Roman. Hift. Scriptor.c. 26.

Iulius (apitolinus Eifforti nomine indignus, Dempfer in Elench. Script.

In Vopisio, prater exuditionem, illud, ctiam laudamus, quod omnia ordine $\mathrm{D} d 2$ rartat 
natrat meliori, quàm factum fuit à Spartiano, Capitolino, atque aliis Hifioria Angzafle Scriptoribus, in quibus pleraque valde tuibata. Vofj.1.2. de Hift. Las. c. 7 .

Omnium verò maximè inculiam fuam prodidit I wius $C$ apitolinus : Cuicongerendi tantum, non digerendi voluntas fuif( videtur. I áem de Art. Hift. c. 24. pag. 128 .

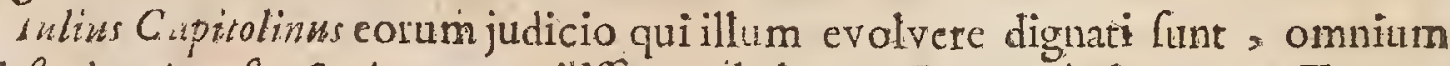
Huftorie Augufte Scriptorum viliffimus habetur. Fr. Moib. Le Vayer. Tom. I. pag. 412 .

* ifaaci Cafaubon Emendationes ae Notx in Iulium Capiolinum, inter libros expurgandos locum habent in Indice Madrit. edit.ann. 1667.

Side Alio Lampridro, atque Iniro Capinalino plurafcire defideres, vide in Elio Spariano judicia de hilce, aliifque Gifforie Augnfta Scriptoribus.

\section{H I E R O C L ES.}

Clar. A. D. C C CII.

1) Hilofaphus, an folum homo politicus non liquet. Claruit ineunte hoc Seculoci ca ann 302. Perfecutionis fub Drocletiano ferventis Auctor \&c:

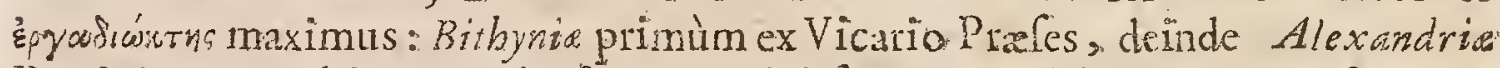
Præfectus. Utrobique in Cbrifizanos mìè defaviit. Ncc luôc contentus, Scriptís.

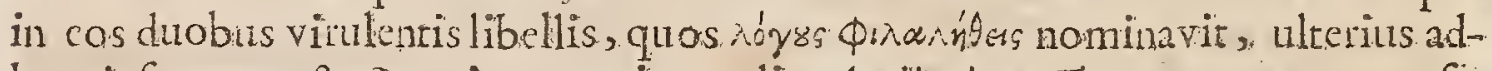
heic infecutus cfl. Quo in opere inter alia Apollonium Tyanewom, magum fa-

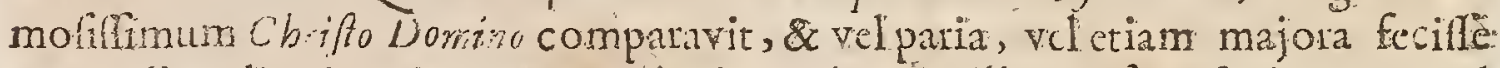
contendit. Alius à noftro, \& etate junior Hieroches ille, qui fcripfit de Fato apud Pboinan. Guil. Cave. Chartophyl. Ecclef.

Commentario edito in Chrilionos; Herocles Philofophus, unus ex Areo pege Judicibus, nihil magis monftrare conaturs eft, quàm Apulloniun xqualem fuife bristo. Porrò ejus infanias Enfebius adverfus eum feribers. egregiè confutavit : Qucm confulat, qui hæe pleniùs fcire cupit. Baron. ad ano. Dom. 68 .

De hoc Autore, tacito ejus nomi e, Lactantius hxe tradir : Alius eandem materiam mordaciùs ícipfit, qui erat è numero I útichis, qui audor imprimis: perfcutionis faciendx fuit: Qu o fcklere non contentus, etiam scriptis cos, quos afflixcrat, infecutus eft. Compófuit eniun libellos duos, non conira Chrifianor: ne ininicènlectari videretul'; fed ad C'bristzano. jut humanèsac benignè confulere putarc tur. n quibus ita falfitatem Seripture Sacra arguere conatus eft, tanquam fibi cllet tota contrania:Nam quxdam capita, qux repugnare fibi videbantur, cxpofiuit; adeò mulita adè̀ iñima cnumerans, , ut alíquando ex câúem difciplinâ fuiffe videatur. Lactant de Iufiriâ, 1.5.c. 2 .

ieroclem, Philofophum Alexañárinum, Raynaudus plagiariis accenfet, quo-

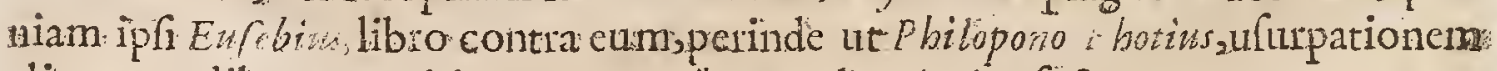
alienorum libiontm vitio verterat. Thomas. de Plagio, fed. 463.

Inter operaverò Philofophica. five Index 2. Jive alius fuerit, primum jure merito: 


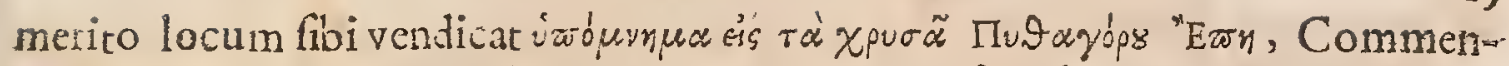
tarius in Aurca $P$, abagore Carmina, opus nunquam fatis laudatum. Neque enim carmina ifta tantum intcrpretari, aut Grammaticorum infar Scholia conficere in animo habuit, licd omnia $P$ thagorica difciplinx lineamenta brevi quafi tabulâ depingere. lon. :-enryor. in Prolegom ad itierocl.

Scicndum quòd ierucles, qui fcholam Alexandrinam fublimitate \& magniudine animi onnavit, prxter magnificentiam venerandam, \& conftantiam, ctiam ing nii ubertate admodìm affluebat; \& cim lingux præitantî̀, pulcherrimorumque nominum \& verborum facilitate ac copiâ exelleret, omnes ubique auditores in fui admirationem rapiebat, tam orationis venuftate, quàm fcientiarum varictare, cum Platone femper contendens. Darnafcius apud phot.

Ef autcm Phrafis Hierocit aperta atque pura, \& rebus Philofophicis apta, at non fupervacuis pulchrifque coloribus, \& Rhetorices variis pigmentis decorata. Phot.

Extant ejus Commentarii in Attrea Pythagore carmina, de Providentî \& Fato 2 \&cc. Gracè \& Latinè Londim in 8: an. 1654 .

\section{A R NOBIUS。}

A Fer, fub Diocletiano in ube Africa Siccâflorentifimè Rhe toricañ docuit. Clar.A.D. Elonit circa ann. Chr.303. Lactanti Praceptor fuit. Septem Libros ad- C C CII I verfus Genter edidit. Hâc ociafione hos libros feripfit: Cum adhuc Ethnicus ad Fidem Chrifit occultis infpirationibus vocăretur, \& ad crudelitarem quodammodò compellerctur,ab, Epifcopis Africa Sacramentum regencrationis efflagitavit: Quem cùm illi rejicerent, veriti,ne virfeculari cloquentiâ tumens, Religioni c. brifticine, quam femper oppugnaverat, illudere vellet, obtulít eis in argumcutum finc ritatis fux preftantifima adverlus prifinam Religicnem difputationum volumini, tanquam fidei lux obfides. Sixt. Senenf.

Amcbius ffer abltrufa eruditionis, fummique ingenii Autor adverfus Gente. libros feptem fcripfit. Rccondita hoc fapientiaxpromptuarium, gno fatua Gentilina Religio exploditur, vera confrmanur, omni lude majus eft. Quisi enim eloquentix nervos, rationum pondera, exquifitas fententias cuim pervolvit, non abripitur in amorem \& defiderium tanti auctoris?ubique triumphat florentiffima ejus dictio , atque ipfi adè Gentiles fuo jugulantur gladio: Calamus ille fimul omnes tacentes Gentilium Deor peifodit, confecit. Ipfi Dii , fi tales dii effent, erubefcerent, ubi audirent hic fua crimina, atque infulfas de fe confactas fabulas: Libro quidem fecundo Arnobius Groficorim fequitur opinionem de Immortalitate Animarum, \& aliis in Locis à veritate Chilfianầ nonnihil recedit. Sed hoc condonandum illi, qui ex Eth i ifrit tenebris.recèns ad veritatem Chrifitanam pervenerat. Idem huic autorievenit, quod is folet, qui ex carcere renebricofo in lucem percuctivifum adhuc dubium habent, in cateris fubtilis. difertus, ingenio \& facurdiâ pollens. Ethnicilai debellator fortifrmus. Ioan.

$$
\text { Dd 3. Mase }
$$


Maireprefat. ad Lect. Arnob. Impref. $4^{\circ}$, an. I $65 \mathrm{I}$.

Septem libros adverfus Gentes Arnobius edidit, totidcmque Difciptulus ejus Iactantius, quos fi legere volueris, Vivlogorum Ciceronis in eis Epitomen reperies, inquit ierony: in Epifolîad Magnwm.

Arnobio quis pof Tértulliantrinter facros Scriptores doctior? idcoque doAorum limâdigior? Tits. Cent.r. Milcell. Epilt. 42 .

Arnobit Chritini nominis Scriptorum quaf rarroeft. Antiqua \& recondita doctrinæ, quà in rcbus, quà in verbis.I derz Epiftol.Quxt.1.r.Ep.20.

Arnobut friptor endirifimus, neute magiftellorum auribus commendandus. Iof. Scalig. comment. in 'mapetro

Arnobium nemo tamindoctus elt quin eruditilimis fcriproribus accenfeat; nemo tals Cbritin $i$ dogmais ignarus, quinerrorés ejufdem facileignofcat egregiis illis \& eryofifmis inveativis, quibus vi quadam aut vibratione velue

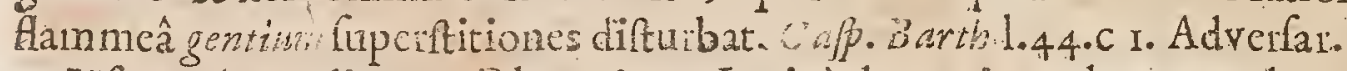

Ufque è cruditus, at Reto icam Latinè docuerit, multos præclatos difcipulos inftuxerit, \&dodtinâ xcconditâ atque fagacitate antiqux lectionis Varronurib \& Nigidionm fit fimilis, antiquifimorum moüu, titum, juris Pontificii vetuftifimi confultus, Theologorum \& initiatorino omnia Myferia do etus. Bartr.1.59-cap.10. adverfar.

Si non extaiet, denla nox foret in Superftitionibus Veterum. I dem lib. I8.cap. 14. Adverl.

Arrobim inzqualis \& nimius eft, \&ablque operis fui partitione confufus. Hieronym ad P.awlin. Lit. I Tom. I.

Reconditx enditionis, feyli afperioris. Dempler.

Cui Lucretii verbaab ufu remotiora milificc placuerunt, \& quafr in deliciis habita funt. Gifar.collectan. in Lucret.

Feruntur fub nomine Arnobit commentaria brevia in Pfalmos. Sed ea non videntur elle hujus Amobii, fed alterius recentionis:Nam in explicatione Pfalm. xo8. refellit hic Auctor harefim predefizatomingua tempore S. Ang tfini, vel poftea exorta eft \& in explicatione Pfalm Iog. nominatim refellit photinum harefis Ebionitarum Infauratorem. At Pbotzans tempore Fialsatiniani vixit, tufe Hieronyma, quo tempore Amobits fuperfes efle non potcrat-Feruntur etiam antotariuncula in varios locos Evangclii, cd parvi momenti, neque ccrtum eft, an fint Arnobiz. Bellarmin. de Scriptor. Sccl fialt.

Eruditiffimus Scultetza affirmare non dibitat, Arnobizm nil nif feptem il-: los libros adverfus Gentes fcripfiffe : Quibus (inyuit) eruditè, \& quidem rumido, elatoque orationis genere contra Gentes difputat. Sctzitet. in Medullâ Patrum.

Lactantius Ciceronem latis feliciter imitativ: Agellius, Tertulianus, Arnobius, Minutius \& Apuleir ,propter enditionis varietatem omnino legendifunt, fed Imitatio corum ftoliditatis opinionem conficit. Ca p.Siopp.confult.p. 43 .

Licet Arnabit facundifimos contra Gentes libios Hierongyzus ad Patulimus \&cribens, reprehendat, veluti fermone inzquales, \& nimios, ac fue ulla totius operis 


\section{CELEBRIORUM AUTHORUM.}

operís partitione confufos; aliàs tamen luculentiflimos $\&$ à florentifimo $R$ hecore feliciter elaboratos fatetur.

A Clemente Alexanairino multa Arnobius ad verbum penè mutuatus eft. Theod.Carter.ad Lect. Not. ad Arnob.

Septem Amobij libri eo dicendi gcnere fcripti funt quod Rhetorices Prom felforc dignum fit. Modus quo fua fenfa enunciat Oratoris eft, ftylus tamen ejus utcumque Africanus eft; ideft verba ejus. funt dura, perperam difpofita, parum polita, \& quandoque parum Latina. Liquet etiam eum Religionis noftra. Mystcriony perfectam notitiam nondum fuilfe adeptum. Multo majori folerria Ethnicorum Religionem oppugnat quàm Chriftienarn propugnat. Etbricifma ftultitian felicius propalnt, quam folide Chriftianifni veritarcm probat. Sed: mi um id viderinon debet; hoc enim omnibus recens Conver is folemne eft; qui ñelizovis fux adhuc plent ejus vitia \& debilitatem meliùs norunt, quàm argumenta \& proftantiam ejus quam nuper amplexi Cunt. Ell. du: Pin. Novo. Biblioth. Author. Ecclefiatic. Tom. r.p.557.

In luis cum Ethnicis altercationibus armis oppugnantibus folertiorem quàm oppugrantibus Athletam le prabet. Eò potifimum tendit ejus etuditio ut his. auxiliis Gentilum Caufa milerabilia fundamenta convellat. Non liquet eum; quo tempore fcribebat, multum adhuc è Bibliis legiffe, prater loca Evangelica Hiftorte magis obvia; aut eum Doctrinas \& Principia Chriftianilmi accuratè perpendiffe. Ncdum igitur æquè ac Catehumenus primis fidel Rudimentis: initiatus erat; Et idco cjus memoria tamquam erroribus maculacd traduci, non debet; ctianfi quedam in ejus Scriptis occurrant Catholicx. Doctrine haud itaAtrictè conformia ; potiùs enim mirari fubit quîin plures \& graviores. Errores non inciderit. Sxculai Eruditione abundè inftuctus erat, \& praclaris nature dotibus ad illam ornandam preditus erat. Stylus ejus quamvis jam olim à D. His ronymo perfrickus ut hxus \& inæqualis, fufficienter tamen elegans eft: Sapit quidem aliquando tancorem quendam Afrirane Dialecti, medium tamen Galcat tramitcm inter afperitatem Tertulliani \& lenitatem ac dulcedinem Cypriani: Nec ejus Opusadeo confulum methodique expers eft ac Pater ille viderur innuere, ut evidens erit cuilibet id attentè legere dignanti, $\&$ obfervant: quomodo inftitutum fuum defignaverit, Argumentum futm profecutus. fit ejufdem fingula partes ex natura fua convenienter fatis ab invicem dependeant. Liberè neminifque partium fudio ductus fcripft, $\$$ ut plcrique Scriptortum ejus conterraneorum cum infolito animi ardore ac firvore, Laconicís periodis nervofoque ratiocinationis acumine, multifque facetiffmis falibus, cujus occafio nem fufficientem ei fubminiftabat frgumentum quod pramanibus habebat. Prater feptem ejus adverfus Gentes libros diu fub ejufdem nomine Commentarii quidam in P fatmos circumlati fuerunt, quos ut ilius elfe probet, ac Atyli difcri men ac inæqualitatem concilitt multum laborat Erafmus.

Sed-fi eruditus.ille vir paulò artentiùs rem confiderâflet, aut fatis diù vixiffe ut Libros adverfus: (quos interiile concludit) in lucem egreffos vidiffet hui laboi pepercillet: Siquidem in hoc dudum ommes confentiunt, quod hujusmodi 
hujufmodi Commentaria foetus fint junioris Arnobii qui eadem Leonito Arslaw tenfi Epifcopo \&Rufico Narbonenfi, ambobus Augninino, vergente jam ejus xtate, contemporancis, nuncupavit: ut mittam quod loca quxdam in is occurrant Photi ianas \& Felagianas Controverfias frectantia, qua diu polt Armbit atatem cxcitara fuerunt. Quid de Arnobic poft ejus conveifione in factum fuerit, \& an $\oint_{d c r i s}$ Ecclefie Ordinibus fucrit inauguratus, nobis non confat. Si D. Kitronyrisis genuinum temporis ordinem defignaverit, quando eum collocat in Fronte Continuationis fuæ Chronici Eujebiáni, vivebat Anr. C br. 327 biennio polt Concilium Nicanum : fed an tunc tcmporis tantùm, an verò multùm diutius, me latet. Doctor. Willelmus Cave in Arnobii Vita. Angl.

Caftigatifima feptem illorum adverfus Etbnicos librorum editio anno IG I. prodiit Lugduni Batavorurm in $4^{\circ}$. unà cum Theodori Cantcri Notis, Godr chalci stcvoechii, Elcetis Gebharti Elmenshortii obfervationibus, \& collectancis variarum lectionum ac duplici Indice, nec non $B e$ fderii Heraldi animadverfronibus \& caftigationibus: Salmafani autem illi Commcntarii tam dii cxpectati, tam freçcjus anicorumque literis promifir atque jactati in fumum tandem ventof que evanuerunt. Labbe.

* Opera Arnobii Gelajins Papa Apocrypha declaravit.

\section{LUCIUS CELIUS LACTANTIUS FIRMIANUS.}

Ciar. A. D. Rnobii R hetoris quondam auditor atque difcipulus; vir in Cxcularibus liCCCIII. H teris abundanter doctus \& in divinis cripturis nobiliter inticutus, ita ut in arte Dicendi polt . iccronem facile obtinuerit principatum : Rhetoricam primùm Nicomedice, dcinde Romáfub Diocletiano ab eo vocatus glociosè docuit. Ubi cum psnưriâ Difcipulorum ad paupertatem devenilfict,ad extrcmúm C'a faris Criffifilii Conftantzin Praceptor jam fencx in Galliâ factus ett. Claruit fub Confintino Principe, cui amiciffmus fuit, Anno Dom.320. Tritbem.

Opera Genuina funt: Inftitutionum libii feptem - Inftitutionum Epitome

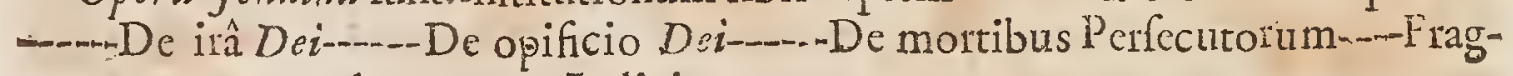
mentum parvum de extremo Judicio.

Operanon extanid: Sympofum---Grammaticus--O8ontoendy---Ad Afclepiadem 1.2.----Ad Probum Epiftol.libri 4.---Ad Severum Epif. libıi 2...-.mAd Dernetrianwm, Epil.lib.2.

Opera Sippofitrita: Carmen de Phonice--.-Carmen de Pafchâ-m-Carmen de Paflione Domini. Gul. Cave.

Lactatius Firmiantus fecutus Arnolii praceptoris fui exerplum, contra Gentes feptem voluminaconfcripfit élegantifima \& acutiflima,nec eft ullus - inter Chriftianos Scriptores tam vicinus dictioni Tulliand. Lud. Viv. comment. in Auguft. de Civ. Dei, 1.18.c.23.

Plus elocutioni, quàm Gruditioni, Atuduiffe Ladtantium, judicium eft Ant Galat. libro de Japigix fitu. 


\section{CELEBRIORUM AUTHORUM.}

Eufebius Cafarienfisu Chronico vocd cum virum omnim luo tempore eleguentifimum.

Hic elt Cicero Chriftianorum quemadmodum Cyprianus corundem Cafar. Alsted. Encyclop.1.32:c.7.

Firmianus à Patriâ vocabatur, Ced Lactantins' late cloquentix flumine, foLidiorique orationis genere. Wolf. Lekion. Meinorab. centur. 5.

Fluvium quafi quendum. Tutliance Eloquentia Hieronymus Lutedatiusz appelo lat in Epir. L⿳亠丷厂. ad Paulinum.

Lactan iz Cicero is ftylum effigiavit, aut, ut quibuldam placet, fipergrelfas eft. Mihi videtur rebus \& rententiis crbriö, nee numeris injucundior, nec fil xquabilitate, \&candore poltior: Has quippe vitutes maximis vilibus \& xmulatus, \& alf cutus eft; hunc nic a.jul s, nec polteri momordentunt, ne-

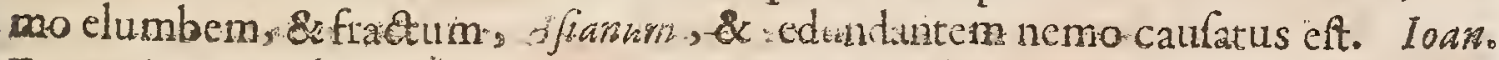
Frineje. icu, 1.3. Pilt. 10 .

- Maximè vero inter omincs, qui de Chriftianâ véitare friṕlerunt, longè cmiRet, \& excellit nitore quodam, ac copiâ L ctani $t$ irmizn vir omnem Chrifianorw proculdubio eloquentifinus,cujus libros lege, quefo, fil literas amas. Leonard. Areti.. in spilt. ad Coniza ram Sfortram.

Utinamtàm noftra confrmase potuillet \& quàm facilè aliena deftuxit. S. Hicrom mo Elit. I3. ad : asily m.

Flis ftudii pofuitin deftruendo Hellenifmo, quam in Cbriftiana Relisione

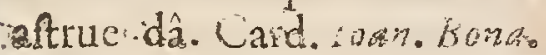

Quid verò, fi uliid tale Iattmio dictum effet? Quid fi dioum \& creditum Arigut ? dicam quod in animo eft, ncque ille tam validè peregrirarum fuperftitionum fundamenta convelleret, neque ifte Civitais Dei muxos tantâ arte conftueret. Franiff. Pet:arch. 1 r. Epilt. Senil. Epilt. 4. ad loan. Bo cucium.

Lactuntius Firnanus licct à vetcrum paucis de crroribus acculacus, $a b$ iis camen immunis non füit. Jamdudum Hieronymus gravifinum notavit. LaEtantius (inquit) in libris Juis, ut maxine in Ep ffolis ad Demetianum, spiritus

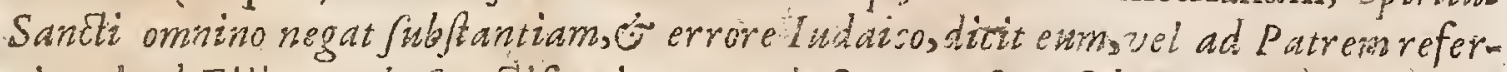

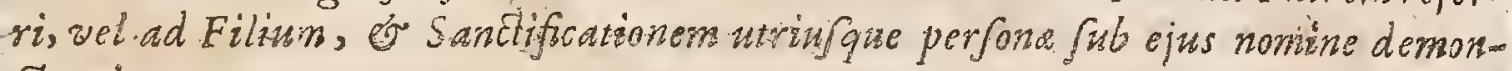
strari.

Cxteri funt leviores, eique cum multis altis $P$ atribus communcs: Ut qudd, *erbigratiâ, docet Angelos mulierum congrefibus inquinatos, \&inde nefcio quod genus $D$ monum terrenorwm natum. tem quò diffe: it omnes $A$ in unâ communi cuiftodiâ detioneri, donec tempus adveniat quo inaximus I udext meritorum faciar examen.

Chrisinn ante ultimum judicium in tertas ventum, os eos qui tum fuper Atites fururi funt non morituros, fed per mille annos infinitam multitudinent generatutos, vitamquein civitate ornatifimâ acturos pacatam, omnibufque commodis uberime aftluentem, fub Christo \& Sanctorum quorundam a morEus fulcitarorum regno. Dilleu de ufu Patrum, p. 266.

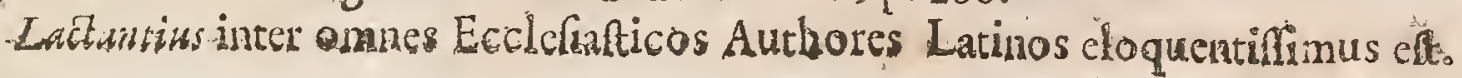
E C

Putús 
Purus; a aualis \& nativus eft ftylus ejus; denique Ciceroniano prorfits fimili, jureque optimo Ciceronis Chriftiani nomen meretur, ncdum ob vocabulorum: puritatem; fed etiam ob plinafews elegantiam \& faibendi modum, Ciceronisno ufque adco conformem ut vel emunctionis naris eruditi difcrimen aliquod vir:

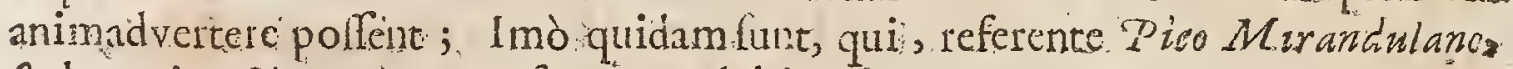
fylum ejus Ciceroniano preferre non dubitarunt.

Utut res fit, certum elt Lactantium (iceroni longè fuperiorem effe quodd fententias; quia Religionis materiz de quibus agit thilofophorum Axiomata. infinito intervallo fuperant, Gentium Religionem nervofifumè refutat; Chrifianarm folidè ftabilit; de Deo lublimiter loyuitur; modo maximé orthodoxo: Verbi divinitatem \& Incarnationis myfterium explicat; Vividifimor modo \&: areationem Mundi \& diem Judicii defcribit: Jis tamen falfa, incerta \& fabulofa quxdam admifect. Moralibus, exquiftis praceptis refertts eft 2, virtutes: perfpicue docet, homines ad earum exercitium potenter hortatur, juftitie: viam iplis monitrat, eofque ab iniquitatis devifs abducits. Deurn vero cultu homnorandi modim ipfis tradit, \& delictorum fuorum ponitendi: Fatendum t amen eft cum nimis, Philofophicè Theologiam tractare, omnia neftra Myfteria: non pener âfle, imo in plutibus erroribus verfatum ellè. Ell.du $P$ in Nov. Biblioth. Author. Ecclefiatic. Tom. I..

$V$ it fuit temperamenti ad gravitatem compofiti, vita fëverx, Zclo honoris: fua Rcligionis affectus, \&rin hac contra omnes adverfarios vindicanda inde-

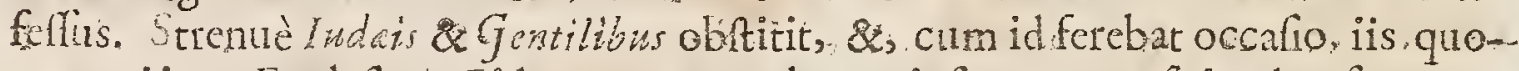
que qui intra Ecclefiam Fidem corrumpcbant, ipfique mens fuit adverfus omnes Seca \& Har fer ubertin Criberc. Prreditis trat dotibus promtis \& vividis, judicioque fagaci: Quodcumyue pra manbus habcret Argumentum id eo vigore eaque perfoicuitate tractabut at vidotiam facile. femper reportare. Ejus in pereguins 8 exoticis literis, in guibus prafertin verfatus enat; eruditio. cxquifitatuit, quo fiebar ut tam feliciluccella Gentiles propriis conm armis: proligatct, \& B. Jieronyzails de co diceret $\rightarrow$ Enmajori dexteritate illorwa

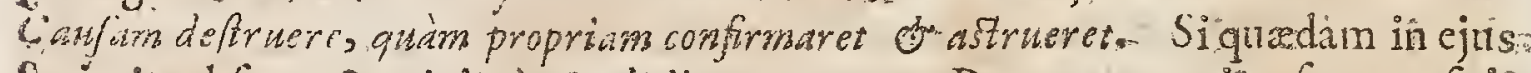

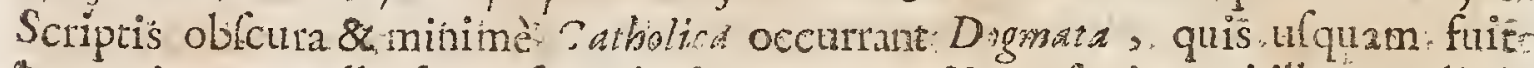
hortus in quo nulle ficcrefcane herbe noxiz-a. Si prafertim qui-illim colit $\mathrm{c}$ Thlibus $\&$ dumeris recèns prorepferit \& in fylvis ac defertis enutritus fuerit.. Pratrquan quòdpleraque nobis pateant qua apud Veteres in oblcuro late-

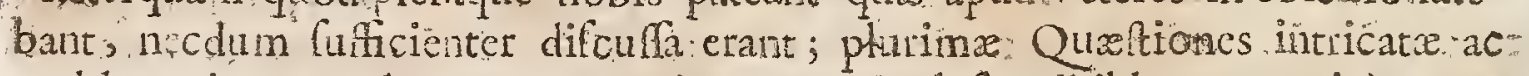
problematica manebant, utpore circa quas Ecclefia nihildum pracisè nequedogmatió determinaverat Dantur Errores qui Seculifunt navus potius: quam perone; plintimaque Humana infirmitati \&. hufficientis lucis defectui condonaridebent Notioncs ejus Chilisstica ipf cum plurimis Doctrinâ \& pictate clarifinis i Ecclefia Viris communes erant. Cave in vita-Lactanito. Angl.

Lachatius omnia ordine Temporis accuratiffmo difpofuit. Henr. Dodivello. difert. Cyprian. p. 305. in 8a... 


\section{CELEBRIORUM AUTHORUM.}

Lactantius guadam fuppreflonomine deferipfit ex Mercurii libro. Conring. *e Hermeticâ Medieinâ, c.s.

* Quemadmodum omıie ejus opera ad eloquentiam Tullianam proximè accedunt-, ita erroribus variis fic defor mata funt, ut non fune causâ Gelafius $\mathrm{P}_{\text {apa }}$ in Concilio Romano apocrypha cenferi voluerit. Bellarmin. de Scriptor Ecclefiaft.

Prodiertunt Lactantii operacun variorim Notis curẩ Servatii Gallai, Leida 2n. 1660 in 8 .qua pulchra eft editio.

Lactantiilibrum ad Donatum Confefforem de Mortibus Perfecutorum, per annos plus milie in obfcuro latentem, doctiflmus $B$ aluzius ex codice Manufcript. Wiblintheca Colbertine primum in Galli. edidit, 1679 . Parifiss. Hune LiGrum vir admadum Revelendus Gilbontss. Rum or in Anglicanum Sermonem elegantifimè trantulit.

\section{EUSEBIUS。}

$\mathrm{V}$ Ulgò Pampbillicognomentum fortitus ob initahn cum Pamphilo Mártyre Clar. Anko contubernale fuo fingularem amicitiam, Cafarec in Palafinat Metropoli- D.CCCXV: tanus Epilcopus por Agricolam, ab anno Chrifti circiter 3is.ad annum 340.quo -obiiffe perhibetur, Ariante Factionis fignifer, librorm omnis generis diligentif-

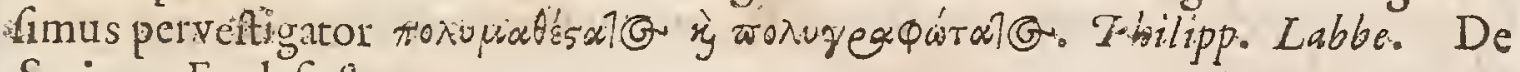
Scriptor Ec lefialt.

Scrìnit Eusebius. Chronica à Mundì fabricâ úque ad Confantini Magni vícennalia, qui eft annus C br. CCCXXVI. Horum priorem partem wavrodariv

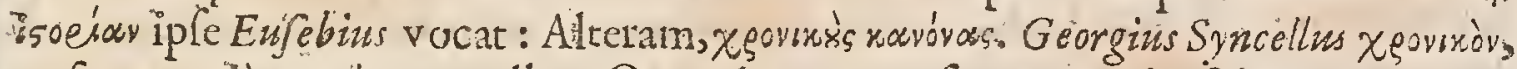
ac frequentiùs xav'vova appcllat. Opere hoc propofitum Eufebio fuit, monftrare, Mofaicas erigines tum iniris omnium dynaftiarum, regnorum, ac Rerump. tum natalibus fabuloforum Deorwir , longè effe antiquiores. Atyue ut hoc opere vetuftatem Doctrinx Molaicx; ita ejufdem, ac Christiane item religionis, veritatem adverfus Thilofophos tuetur aureis commentarilis de Preparatione Evangelica. Idem quoque elaboravit vigintilibros demonstrationis Ev ningolice: Quot olim fuilfe, auctores funt B. Ztieronymus in Scriptor. Ecclef.\& Photizs in Bibliöth. Sed hodie decem tautum fuperfunt. Arianism fuiffe, velfaltem ex= cidiffe illi Ario magis, quàm Nicene Synodo, conveni entiá,ctî veteres non dicerene, fatis ex hoc opere pateret: quemadmodum oltendit doctiffimus Bitm lius, lib. I. obfervationum lacrarum cap. 27. Ex Scriptis nominatis Cbronica

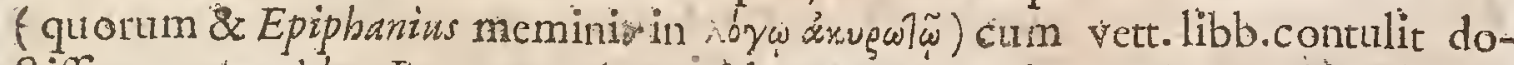
etiflimus d'noldus P'ontacu. Atque idem opus lo rebbus Scaliger caftigavit,notifque illuttravit, quibus nihil hic. fol videt eruditius: Ut omnino taccre de iis fatius videatur', quàm pauca dicere. Utinam aliquis tandem exfurgat quí in il-

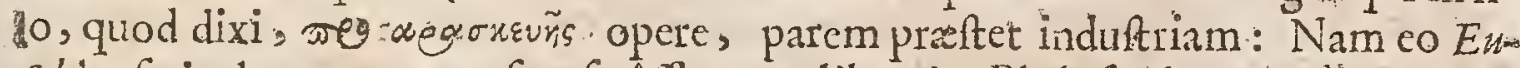

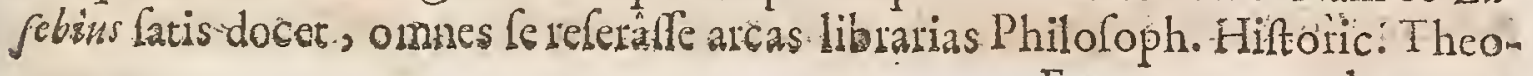


logorum, non Gracorum modó led etiam es gyptionum, ac Pbonicuso.. A rque hac quidem è fccit: Tum ut ex divina lege arguat Gentiles: Tum ut comprobet, multaillos de Hebreorum fontibus haufife. Condidit pretered Histcriam Ecclefiaficam libris decem, quibus initium capit à nato Chriftc, \&, pes tylannoum tempora accuratè progrclius ulque ad Conftantinum Magnurn, ea, qux ab illo in Ecclefia infiruta, velfaltem fub eo gefta diligentiflimè tractar. Mentionem facit corum \& F botius tmemate 27. edidit in fiper librum de $M$ artyribus: Ut conftar ex Hiftor. Eccl.1.4. c.14. \& 1.5.c. I \&.1. 4. \&20. Meminic ejus or qus quoque, cum Hieronymu in Script. Eccl,tum Gregorius Magnus ad Eulogium, Evif. 29.1.7. indict. I. Etiam de vita Pamphil fecittres libios, ac aliamulta; quorum titulos legere potes apud Hieronymwn in dicto opere. IVIinum.

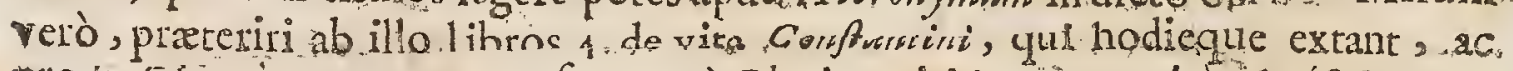

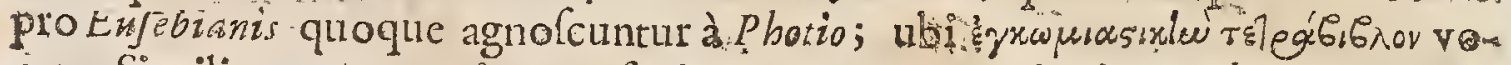
sat. Similiter nec mentionem facit Hieronymus orationis Eufebiand qux inf

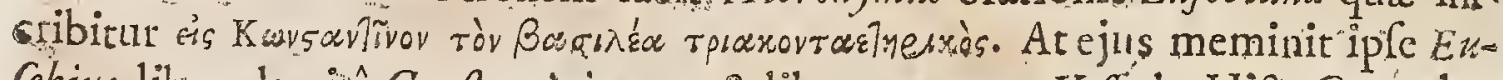

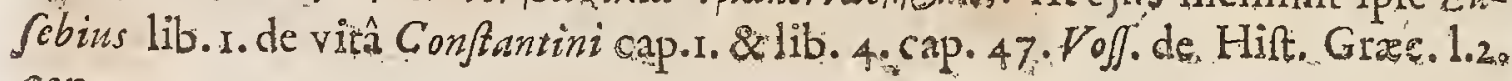
app. 17.

Primusimperante Confantiño Eufebius Cafarienfis, fui feculifine controd,

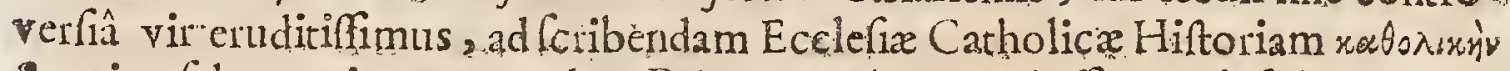
\&univerfalcmanimum appulit: Primuscerte quad affimat ipfe libri prim initio, manum operi admovit; \&orfus à nativitate Domini, rerum geftatum feriem ad fua ufque tempora fingulari diligentiâpertexuit: Cafawbin Prolegom ad Baron. Annal.

Invenire difficile eft, qui veritarem iromnibus fuerit affecutus. Ecceenim s Eufebins, qui in Hiftoriâ Ecclefiafticâ primas tenerc vid tut, Arianifmo femel

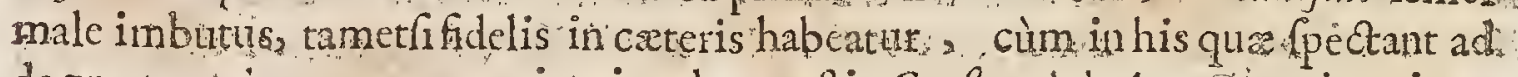
dogmata trianorum tum etiamin rebus geftis Confanini Augusti, cujus vitam. in gratiam Constantii Arianorwo Partoni, conferiplit, muld mentitus cft. $B$ ron. Prafat primi Voluma:

De fummầ-ẹus \&longè diffufiffimâ do ctrinâ, ut pluribüs agam, opus, non eft; cujus erudito nomini \& olim \& hodiè venerabundus affurgir totus penè or bis Lircrarius: Pictatc adeò venerabiliss, ut apud plurimas occidentis Ecclefias in Santarum numero haberctur, \& Sanci-Confefforis, \& Epifcopi beata recordationis, of egregie vite beaitfimi Sacerdot is women meluerit. Ar pro dolon! gravatur viri optimi memorianon apud recentioies modò, verum apud veterum. plerofque haretica pravitatis culpâ, quibus paffm Arianus andit, \& ( $1 \mathrm{ita}$ lon

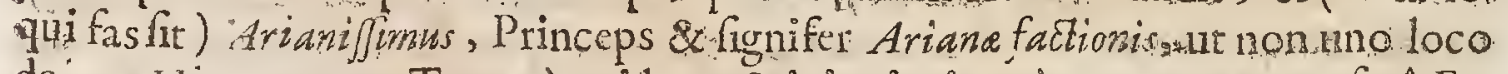
de co Hieronymus. Temerè quidem, \& iniquiori, quàm par erat, cenfurâ. Fasendun eft, illum in Rlatonicorum fcriptis, libififue Orgenis multum diuque. vefarum, exinde nova qurdam hauffe, \& Phrafes minus commodas, quandoque \&periculofas, in Christianam, Religionem induxiffe. Quod tamen illi cum inultis prateritomm Sæculørum Doctoribus commune fuit, fecuriù \& audacter nimis de jo loqutis 2 de quibus nondim fum Ecclefin tulerat judi- 


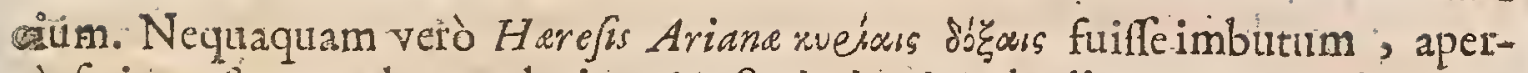
tè fatis teftantur loca plurima in Scriptis ejus hodiernum extantia, qua

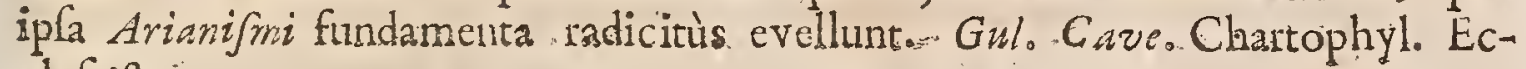
clefiat.

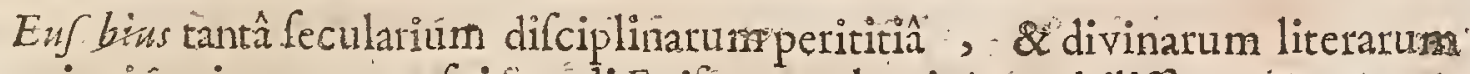
excrcitatione inter omnes fui Seculi Epifcopos claruit, ut nobilifimo Con tant ni Imper. elogio cclebrari meruerit. Is enim frepe de ipfo dicerc confuevit:Felicern Eufebium, gui non zsisus Frois, Jed orbis prope totius Episcopatu diginus. effet. Sixt. Sener. in Biblioth. lo. 4 .

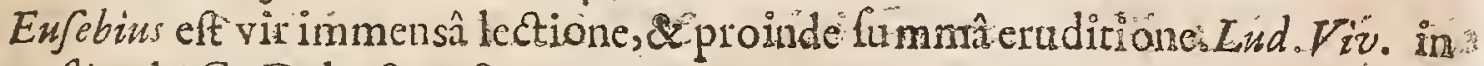
Augufin. de C. D. L.in8. c. 8.:

Cafarienfis Eufebius, vil longèdoctillimus, \&in omni Hiftoriarum genere exercitatiflimus. Ca ánb. exercit. ad A pparat: Annal exercit: I. p. rs.

Eufebins.Chronologus optimus; ulus autoritate Constantini Angusti in conquirendistoto orbe rerum geftarum Scliptoribus, utifristoteles Alesandri. Bonifac.Ludic. Hift:

Quô nullus Scholaticorum vecerum plura ad Hiftoniam Cbristianifmiconaatlit, nullus plura errata inferiptis fuis reliquit, nullius plures hallucinationes. extant. Scaliger. Elench. Triharel Serar. c, 28 .

Tota Eufebii Chronica nihil aliud funt quam centunculus ex panuis African mi confutus. 70. Scalig. Epift. Io3.

In rcbus Constantini potins eft Encomiafta, quàm Historicus. Baron.in 3. volo

Cardinalis ifte [Baronius] ubicue ferè fum in Enfcbium prodit odium, non atunde natum, quàm quòd Hiftoricus nolter, qui laudes \&.donatiónes ConStanini Ecclefiaftecas fusè perfecttus eft, Donationis Romanz non modò menriónem facitnullam, fed eam etian fictm effeinutit, dum Conftantinum non' Papâ Romano Rome fed Nicoderme baptizatum elfe fcribit. Abrabìn. Scnltet. in Medullâ Theolog:Pacrum p 756.

Emincutinter cripta Eufebii libri io. Hiftoria Ecclefraftica, \& libri is. de Prxparatione Evangelicâ : qui Thefautus funt omnis eruditionis veteris \& fa $_{-}$ picintis. Mich. Neand. in defcript. Obis.

Eusebii libros de Praparatione Evangelicâ, eximium opus appellat $C$ a $\int_{a} u b c$ nus ad Baron. Ann. 34. Num 129."

Euf bius Phrafi neque jucundus ufpiam neque perfpicuss" Homo tamera? multa doctrina eft: Tamet meutis acumine, dffectuumque conftantiâ, quan cod. I3.

Leguntur Eufebii Pampbili devita Gonfantini Magni Auguft. laudatorii libriquatuor. Eft porrò in hocopere fuifatis in dictione fim lis, nif quod nonnihil ad fplendorem magis trahitur oratio, vocefque ad foridum alicubi genurs tendunt:Etfijucunditatis, \& gratix in' explicando modicum adhibere, ut in aliis quoque libris, videtur. Adferuntur verò loca plurima in his quatuor libris ex universâ jus decem librorum Ecclefalticâ Hiftoriâ. Photius ibid. cod. 127 ? 
Eusebius inter eruditifimos Antiquitatis Viros eminuit, quod ejus Se cetatores \& Adverfarii communi c̀alculo agnoverunt: I mò \& dici potent ablque hallucinationis metu neminem extare inter noftros Authores Gracos quitantalectione tantaque eruditioneinfignis fucrit. Omnia fere Opera ab iplo concinnata tetim dem fotus fun Herculi laboris diutifnaque ac operofiffma díquifitionis. Fatendum tamen ef magno levamine ipfi fuiffe Monumenta eorum qui ante ipfum in eadem Argumenta fcriplerant, quorum etiam opera verbotim exferibere, nequaquam dubitat. Sermoni fue cxpolienda minime incubuit, quidefectus vulgails eft iis qui Scientiam \& Exuditionem operaprctium unice ducunt. Nec facundus neque jucundus eft ejus ftylus, quod fapius obferyavir Photibse Ell. du Pr, Biblioth. Nov. Aitthor. Eccleliafticorim Tom 2.p.26,27.

Si enuditifrmus vocandus, quiia multa legit, fanè remo illi hanc laudem invidere poteft. Sin antem is ertiditifimus $b$ qui judicium cum multa lectione conjunxit, alium potius, quâm Eufe bium producerc debuit. Iof. Scalg. in Not. ad Hieronymi prafat. in Eufebii Chronicon.

Per hac tempora (viz. Anno Dom.339.) mortus ef Eufelius Pamphili. Cafaree Palestive Epilcopus, \& Chronographorum Ecclefiaficorum facile princeps: Cujus indefello ftudio, incredibili diligentia, : vix fatis æutimandis Iaboribus pofteritati confecrata eltbona Historia Ecclefátice pars, quấ hodiè fruimur. Bucholcer. Indice Chronologico.

*Hiftotiam Eufebi Ecclefialticam Gelafins Tapa inter Apoeryphos libios setulit, fortalle ob nimias laudes Origenis. Bellarmin. de Ccriptor. Ecclef.

Hiftoria Ecclefantica libri ro. de vitâ Constantzi M. Jibri 4. Oratio ConStantini. Panegyricus Eufcbii. Omniacum MSS. collata, verfa \& Notis illufta-

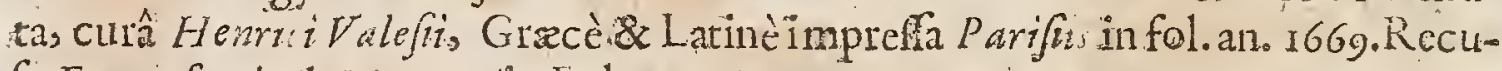
Sa Francofurti ad Moenuni in Fol. an. 1672.

Lclogarum ropheticarum de Christo, libri 4.inediti hactenus funt MS. in Bibliothec. Vindebonenfi. Vide Lambeciurs comm. de ea Tom. I. addit. 3.

De Preparatione Evangelicâ pro Chriftianâ Rcligione adverus Philofophos Commcntari: Demonftationis Evangelica libri decem prodientint Gracècum verfione \& emendatione Francrfoitigeri," Parafi I 228 . in fol additi de Thcolo-

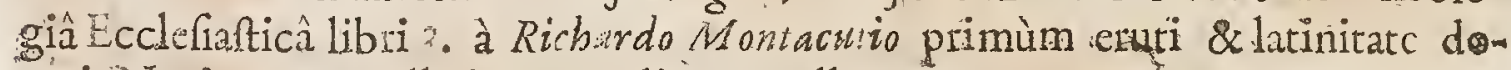
nati, Notis quoque illuftrati, \& alia nonnulla.

Hodiit expofitio in Canticum Canticorum Gracè , cum Oblervationibus Ioan. Mevrfi $4^{\circ} \cdot L \cdot y d a \cdot 1617$.

Prodiit Chronicon ab orbs condito ufque ad ann. Cbr.326. cum Notis Ar

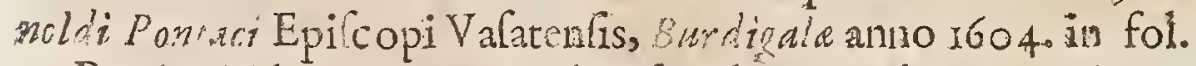

Prodiir itiden cum animadverfionibus lofephi Scaligrri, Lugduni Batavorum anno I 606. in fol. Auctius verò Amstelodami an.1653. accurante Alexandro ALoro Ecclefialte paryfiendi. 


\section{S. A TH A N A I US}

A Lexandrimu,ab anno 326. ex Diacono Alexandrie Epifc. Arianorm A odium fimul \& Aagellum; depofitus in fynodo Tyriâ anno 335. Treverim Clar. Anto D. $\operatorname{ccs} \mathrm{xP}: \mathrm{z}$ : in exilium milus anno 336 . Obiit in pace anno 371 .

Opera Genuin varia lunt.

Opera dubia: 'Synoplis facra Scriptura-Teftimonia ex S.Scripturâ de communi cllentia Patris, Filii \& Spiritus Santi -.Sermo in Paflionem \& CrucemiDomini.- Vita D. Antoni , prout extat hodie.

Opera fuppoftitia funt :- Difputatio contra Ariurs in Synodo Nicanâ-De Sanctifimâ Deiparâ Virgine - Symbolum Athanafit - Tractatu de Definitionibus,-DeS. Trinitate Dialogi.5.-Dialogus inter Otthodoxu \& \& Macedoniaisum continens 20 capitula - Quationes 135 . ad A ntiochum-Dicta \&: Interpretationes parabolarmm Evangelii , Quxf. I33-Quxfiones alix 20Difputationes cum Ario Laodicce habita-De unitâ Deitate Trinitatis ad. Theophilum, libri 7. Lat...-Ad Monachos. Exhortatio Lat... Epift. ad Marm cum l’apam, cum Rcfcripto Marci. Lat - De Paffone Imaginis D. N. T. Chrifti orucifixe in Beryto - Declaratio Levitici-Homilix $7 \mathrm{ab}$ Holftenio Latine edite - Expofitiones II. de Incdrnatione verbi - Orationes 4 , in Anchiurio $G$ r. Lat. à.Combef. cdit. Tom. I..-S. Syncletic vita. Lat.

Opera quanon extant : Commentarii in Ecclefiaften -Commentarii in Can-

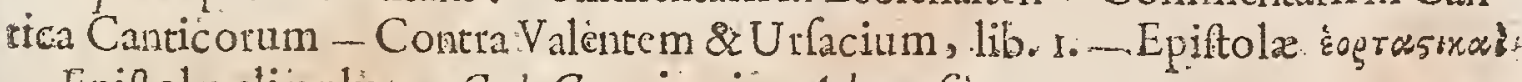
- Epifolwalix plutes. Gu'. Cave in vita A thanalii.

Malleus. Hæretic orum à plurimis vocatur. Theodoretus illum vocat af́gèoy.

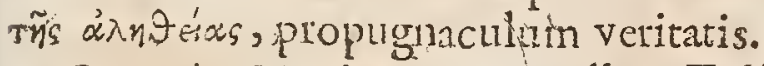

Gregorius Naziznzenus appliat, Tubam ingenten; \& columnam Ecclefia: Bater rectre fidci, voratur Epipbatio..

Athairafurn laudare, idem ct ac virtutem ipfam làdare, qưoniam virutes ampes in unum collcctas tenebat. Gregor. N azianz.

Magnus eruditione, virture, labore, paffionibus, fed fuperomnia, Symbolos: Andr. Vi int. Evif . oratione habitâ in Camerâ Stellitî.

Erat vir ille feculo tranquillifrmo dignus, dediflet nobis egtegios ingenil fa-

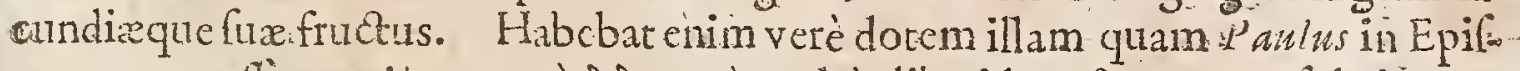
copo putat effé præcipuam, tò 818 axt tentus breviter omnibus modis, ad docendum appoficus. Nihil habet durum,

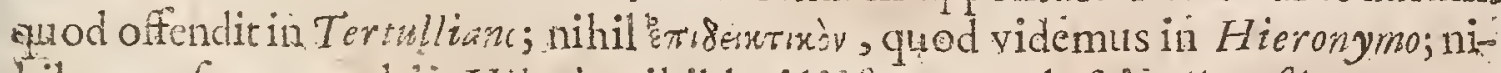
hil operofum, quod in Hilaric; nihil laciniofum, quod eft in Augufino, atque eciam Chrofoftorn; nihil Ifocraticos numeros, aut $L y$ fre compofitionem redolens. quod cft in Gregorio Nazianzeno, fcd totus, et in explicandâ re. Erajm. Epift. 29. Epirt. 89.

Excelluit polt Apoftolos in Perpicnitatis arte Athanaforts cui tribun quipo 
pe criditi, qudd acri nou tantum polluerit ingenio, fec \& fcribendi methodo ufus fit tam accuratâ, ut ne quidem ullum obfcuritatis veftigium in Scriptis ejus, quorum genuinusautor erat, appateret. Et ceitè Perfuadendi fngularis vis dictionis Scriptionifque facilitari ine? -Monachi varia A thanafu fup pofuemut upafcula, ut vino luo vel potius vappe, hoc ef, vitur fuis gratix \& nosninis aliquid conciliarent. Arque hâc de causâ celebri nobilifimi illiıs Patris Scripto (laltem adi ibi ipfe Colito) Syntugno $i$ i diato, Hederanimpri-

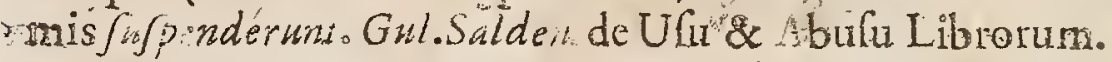

Adeò pofter tantaque cus pro reà fidc certamina, Athanafornomen poAteris doctrinx, \&: anctitatis fulgoribus clarum effullit; ut quaque ipfits fcripta non modò avidè legeteatu; ; Led froulari quadam reverentià colerentur. $B$ aropo

Praclarum eft illid Coğium Cojme, Abbatis Hirofolymingiquod apud So.

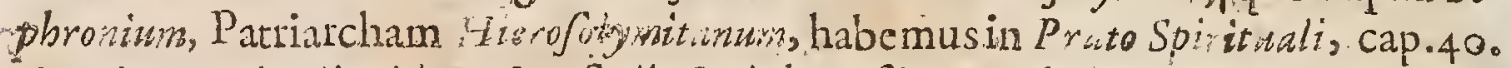
Curn inveneris aliguid ex Opufoulis $S$. Athanafii; nec babueris Chartas ad foribendurn; invefurs:ntis tuis fribe illud.

Atbanafitwon efle id Symbulur, quod ejus dicitur, probatur (inquit Vofime) primùmeo, quòd abhorruerit Ecclefia i atholica à novo Symbolo poft $\mathrm{Ni}$ cenum condendo - Deinde quia in veteribus Atbanafiz Codd. dendercturTum quianec Athunafusiple ejus meminerit; nec ejus vel proximi avi quifquara: Imò necillis memorari, qui vitam Atbanafialiquot faculis pofreà exararunt - Circa annum millefimum videtur hoc Symbolum jan in Ec-

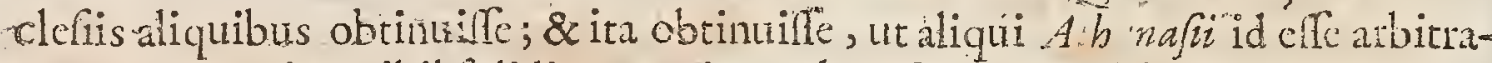
sentur. Interim nihil folidi ac certi pro hae Sententia adfertur. Poft annum verò millefrmum ducentefimum crevit hace opinio Athanufir clle; aliqui interim putabant Anaftafífulfe, ac ex fimilitudine eâ nominum hunc errorem provenife - Oriestales neque olim agnoville, neque hodie agnolcere $A$ tha

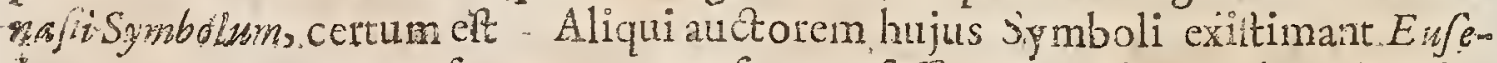
baum Vercellenfern, feu matryrem, feu confefforem potius, Athanafiz ipfus xqualem. Gujus fontentix etiam meminit Itsellns in Kefponfone ad Hardizgurn pro confeffione Ecclefix Anglicanx parte Cceundâ., cap.x. divifionex. Sym bolum illud, cui nomen eft $Q$ uicungue oult, ab Athanafio, ut nonnulli arbitrantur, confriptum; ut aliti ab. Eufbio Vercellenf. Alii veròcedune efle hominis Galli. Uti P.Pithares libro de Proceli. Spinit. Sand. Magai Athanáaii fymbolum, quamvis Treveris, ut plerique tradiderunt, idest, in Callia, is Tibe logo to meninter illos doetiffno, acutiffrnoque friptum. In Pitbeandwhanc fontentiam ( inquit Vo/fiss ) maximè inclinat animus : Nempè ut te Theologi $G$. $/ \mathrm{l}$ : faciléque mitii perfuaferim, conditum fiilfe Pipini, tol Karoli Mo temporibus oecafionem inter catcra piabente controverfía de Proceffrome Spiritûs andi : fuper guâ in Gallicistum ynodis agebatır. In mentem tamen venit, rideri etiam pof-

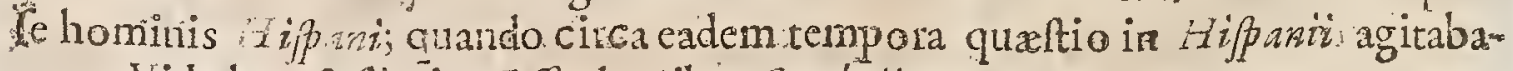
trur. Vide hxe fufuis in Voffo de tribus Symbolis.

Symbolum quod Athanafinomine infigniturdiy s memine contradicente 
Opas habionm fuit, cujus Pater ille verus Author eftet. Nunc tamcu convenit inter omnes id Patrisallius fotum none fie ; ced alicujus Authoris qui diu polt Ipfum vixerit. Ignoratur quis ille fit, quibufdam alicui $G$ allo ipfum thibuentibus, aliis, ut lef. Duejnellins, Vigilio Tapjens, quii vergente quinto Ecclcfiz feculo vivebat. Ut ut fit, certum eft poft Chislcedonenfe Concilium id adornatum fuill:; quuia tam difertè Neftorianorurn \& Eutychianorum errores reiicit, ut liouidò conftetid duas illas Harefes impugnare voluiffe. Ell. du $P$ in $=$ Nov. Biblioth. Author. Eccl. Tom. 2.p.rig.

Ejus Apolageticus ad Iraperatorem Confantinum of in eo genere Opus omilbus fuis abfolutum numeris. Nullum unquam Scriptum nativum \& fimplicente genium magis fpiravit, ner vilus unquam fermo, clegantior, figuris ornatior, \&ad perfuadendum efficacior extitit. Hac in parte excellunt omnia B. Athanafiz Opera. Simplicem \& fine fuco fpeciem præ fe ferunt, \& tamen fi attentius confiderentur artificio miro compofita deprehendentur. Verborum aptitudinem mirificam ubique in oratione fua fervat, thylumque fum Argumentis quæ tractat \& Perfonis quas alloquitur femper attemperat. Idem ibid p.I54.

Legi Magri Athanafin in Ecclefaffen, o Cantica Canticorum commeritarium. Dilucide dicit, ut in omnibus fuis feriptis. Ad earum tamen Epiftolarum gratiam \& venuftatem, quibus feceffum excufat fum exponit, neque hic liber, neque alus ejus, (qui quidem in meas inciderit $\mathrm{m}$ nus ) artingit. Phot. Biblioth. Cod. 139.

Leci funt eju/derm fancti viri contra Arium, ejufque dogmata libri quinque. Hujús dictio perfpicua, ut $\&$ in cateris ejus omnibus, fobria item \& candida vehemenfquue ac profunda, \& argumenta validè torquens: ejus verò ubertas in his, ac foccunditas admodum fanè fuit mirabilis. Dizle ticis aehæc ufus eft argumentis, non illis nudè propofitis, \& ipfinme ex eâ arte petitis vocibus (quod pueri, recentior fque difcipuli, juveniliter fefesac gloriose oftentantes, folent) verùm Philofophorum more, magnificéque prolatis, ac per nudas duntaxat notiones, \& has quidem benè ornatas. Sacree quoque Scripturæ teltimoniis, ac demonftationibus validè communitur : \& ut uno verbo abfolvam, folus hic liber ad Arinnifmum univerfum refellendum fufficere queat. Immò qui Gregorium Theologum, fanctumque Bafilium dixerit, ex hoc tanquam fonte hauftos egregios illos \& limpidos librorum fioram rivos contra cundem eirorem profudilfe, fanè àfcopo minimè aberrarit. Phot. ibid. Cod. 140. Andr. Schot. Interpr.

Naturæ dotibus acribus \&acutispræditus fult , cjus Ratiocinia vivida \& arguta fuerunt, judicium ejus fevertam \& folidum erat; qux omnia fi analogâ educationis felicitate exculta fuifent, cum efficere potuiffent unum ex erudicifimis viris qui in Ecclefia unquam claruerint. Sed a juvenilibus fuis condtibus $\dot{8}$ indagarionibus illicò abducebatur gravioribus \& feverio:ibus Itudiis qua ipfum in politioribus sculafis cruditionis partibus ninus eminentem reddebant, ob quarum defectum à Pbilostorgio perftringitux. Cave in. Aibanafii vita pag. 192. Anglicè. 
pbariniani Athanafio adeo infetti funt, ut eum Sathinafum vocare non vercantur: Konig. in Biblioth.

Cpera D. Athanafi in magnâ perturbatione funt, quàm multis ei aliorum Anctorum infcriptis. Hic primus eft, cui doctifimi hujus feculi Critici debuerant apponere medicam manum, ut S. Patris Scriptiones redderent puriffmas ab extrancis omnibus: fcd heu fupendam pariuntur confufionem! Oudin. in Supplem. de Script. Ecclefiaf. a Bellarm. omifis.

Prodierunt Opera Athonafiomnia Gracè \& Latinè ex cmendatione Petri Nannia Tomis 2:Parif Fol. 1627 .

\section{AUREIUS THEODQSIUS MACROBIUS.}

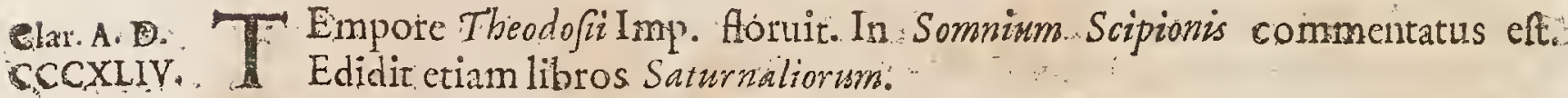

Macrobius Scriptor prettantiflimus; qui veterum Philofophiàm, non vanam illam, \& qux ad folam oftentatiónem pertinet, fed cordatam, \& malculam, altiffimè penetravit. Marc. Zuer. Boxborn. in Epilt. p. 17.

Curiofifimus in loquendo, \& recondiciffima Scientia: Macrobius. Laurent。 Vallaw

Ancorexcellentiffmus, \& vir reconditiffma lcientia.: Coet. Rhodigin. 1.I. C.I2, \& IS.

Macrobius, vir memolarum vetersm exfequentifimus non citia dicendi: mundicias. Idem 1.6.C.I4.

Mihiquidem in Platonicorum myteriis, in Mathematicis Difciplinis, in re Poëtica fatis cruditus, neque fuo feculo infacundus vidctur. Bonifac. Ludicra Fint.

Macrobii Saturnalia multum habent bonarum,ac yaiaum renm. Lud.Viv. . de Trad:Dific.l: 3 .

Macrobius melioreft his (Gellio ac: Apuleio) atque explanation , habee qux non tam vulgari fermoni.nut utilia, quàm Philofophix explicandx. Idem ibid.

Macrobius dapibus partim cmendicatis, partion fufturatis fuas omas in Aruxit. Politian. Epitt.1.12.Epif.22.

asopicam Coniculam Macrobizm appellat Erafrans a ex aliorum pannis fuos contexuit Centones. Itaque fuâ linguấ non loquitur, etfi quando loquitur, Graculnm Latini balbutire cicdas, Quod gcnus eft illud ex Commentario in fom

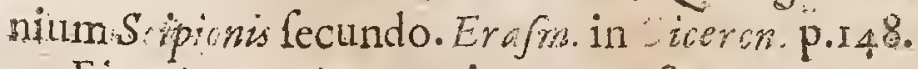

Ejus Saturnalua omnigena tractant argumenta. Critice \& Antiquitatum perjucunda \&eruditionis plena milcella cenfeturab Epilcopo Godeau. Gall.

Chriftophorus de Mile Awborem hine fingulari-Placonis fudio teneri oblerva vit; eltmque iis colligendisqux Authores in Virgilinm notaverant maximè ineubuiffe; ejus Satzrnaliz erudita effe fedfyli non laudabilis, quod freculo feripferit quo lingux Latina puritas jan altecata vel deperdita crat, ut iple $M a-$ 
repobius fatetur. Denique Ief.Vavafjor deprehendit illum totidem verbis Plum - tarchum innumeris in locis tranferipfife, ab Aulo Gellio plurima mutuatum effe: \&de Tuo tamen adcidille multa fingularia \& jucunda que ejus enuditionem \& Antiquitatis notitiam manifentant. Eruditorum Iudicia. Tom.2. Parif. 1695. Gallicè.

Macrobins Philofophus eximins, \& Criticus acuriflimus. Cardin. Bone Notit. Autor.

De Macrobio, quoniam Xylanderadco fprevit virum, erijus tamen nihil cognitum habuife videtur, hoc etimn dicam: fuife inter xtatis fure doctiff. mos fine controverfî cximiun quendam. Reine in Epift. ad Rupert. p.462,

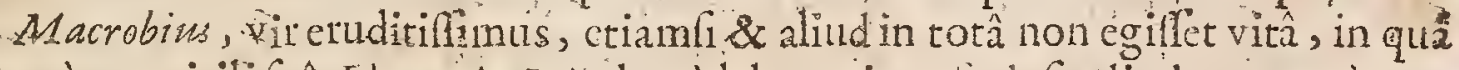
reverà pro virili fuâ Litexarie Rep benè laboravir : Scd fi aliud pretereà non cgiflet, quàm fervare nobis hunc omnis eruditionis thefaurum (Somnium, Scipionis) oprimè de ftudiis onnibus fuifet meritus. Lnd. Viv. Prafat. Vigilic in Somn. Scip.

Colium Rhodiginum optimorum Authorum fucum conviciantur quidam; ncc defunt, qui eodem crimine traducunt Macrobsum cum tamen illos omnes de bcnis literis benè mexitos fatcri-cogamur. Conrad Héresbach. Prafat. ad Lect. librorum de Re Ruftica.

Quod etiam Macrolizu (ut alia complura) è penu Gelliane enuditionis it fuasconas depromplit: homo fatis quidem enuditus, fed ingenio maximè ingrato; ac propè impudenti, ut qui tarkô xris alieni cımulô nufquam creditoris Homen profiteatur. Petr. Criniti. de Honeftâ Difcipl p. 534.

Totam hanc difputationem de Servis, num dominis beneficia tribuere pofEnt,partim ex hoc Seneceloco, partim ex Epit. 7 -partim ex Valerio confacinatam Macrobius la Saturn c -2.pro fuâ venditavit. Sed \& ex Agellio; \& Plutarchi Sympoffacis tam multa nullo pudore in feptimum librum Saturnaliorum Suorum trantulit, ut apparcat, cum facticâfe eandem artem, quan plerique hoc feculo factitant, qui ita humani nihil àfe alicnum putant, ut alienis æquè altantur ac fuis. $M$. Anton. Muret ad Senec.m. de Benefic.is.

Macrobiustianforiplit Alexandrum Aphrodifurna \& penè verbatim exprellit. Vlyfes Aldrovand de cuadripedo p. 394.

A Gellio ad Macrobium tranteo, ad cujus propofitum quantum faciat $V$ irgiliz werfus quidam quem citat, omnes viderint. Laudinti enim septcnarin numerum quid authoritatis adferre potef hic verfus? Talza voce refert, ô terque quaterque beat?. O pulchrum commentum ! non vidct Virgilium ternario numero unitatemaddidifle, quafi diceret ter imò quater laudandi. Non autem quatuor ut Septenarium efficeret: ut cnim recté Servins numerum fuitum pro infinito pofuit, de Septenario, opinor, potius quàm de alio numero nequaquam cogitans. In aliis linguam Iatinam pervertit idem Macrobius. Sed quid mirum hominem

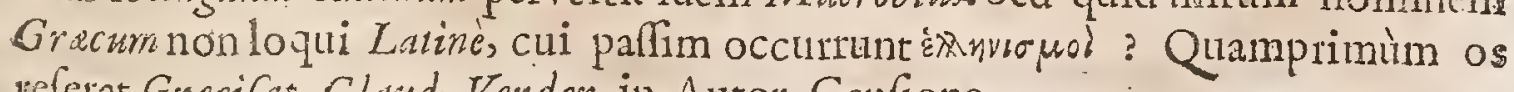
seferat Grecifat. Cland. Verder.in Autor. Cenfionc. 
Prodierunt Macrobii Opera,cx emendac Io an Rivii Reneti; Parifis apud Afcritum in Fol. isig. in 8 .

Prodicrunt itidem cum obfervationibus, I oan. Ifaaci Pontani. Lugd. Batods9\%.

Itidem Gum Notis vationm Pontani, Meurfit Loan. Fried. Gronovii, Gur Iracobi Gronowiza. Lugd. Bat.ex. Officina Arnoldi Doude,, 670 , \&:.

\section{J: $A M B, I C H U S$.}

ar. A. D. Orphyri Difcipulus, tempore Conftantii \& Iuliani Imperator. floruit. NaCecsive nes protrepticas adiPhilofophiam, quas primus Gracè edidit Iob. Arcerius: item, vitam I'ythagore, nec non libellum de Myfteriis Chaldaorum \&. Eg.yptiorum, quod pofremum opusprinus. Marfilius Ficinus edidit, poftea Nic. Scutellius Anno 15,5 . hifce verò duobus palmam praripuit vir ille doctrinâ celéberrimus Thornas $G$ ule, qui hoc opus, An.Dom.1678.in Latinum Sermonem elegantifime: mantulit, atque notis eruditifrmis illuftravit, in Fol.

His furcelfte amblichus, ut clariffmì nominis Philofophus, ita \& illuftris: generc, natus familiâ amplifimâ \& locuplete. Parria illi Chalcis 2. Syria, quam $C_{a}$ len nominant, civatas. Hic cuu Anatolio, qui à Forphyrio fecundüm locum obtinuit, confietudinem aluit, fed multis eum, modis fuperavit, \& ad: fummum Philofophix gradumafcendit. Ab. co conjunxit fe Porphyrio, quo gulli in re fui infcrior, praterquam in concinna orationis ftucturâ, dicendique facultate: Neque enim parivenere \& gratia abeodicta, inftucta fuere: Neque candorem habcbant, \&perfuicuitatem : Neque puritate Sermonis, exonare Scripta laboránt, quanguam nor omnino obfcuritate involuta fres att vitium: habede oratio: : ed ( quod de Xenocrate dictitabat Plato) Ynon facrificavit Mercurialibus Gratiis. Itaque lectorem non detinet, non obrepit illecebris quibuf: Wam, \&adlectionem invitat, quin potius avertere 3 obtundere aures videtur. Eunap. in vit. Iarbil. Tadrian.jun. Interpr.

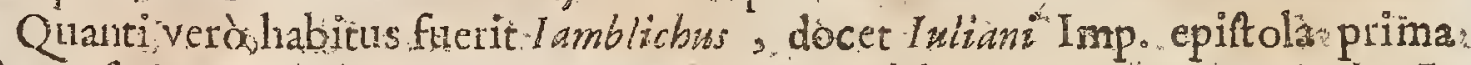

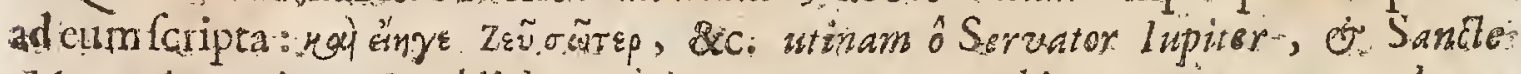
Mercuri, contingat, I amblichum opitimum, commsne orbis terrarum commodum

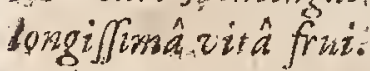

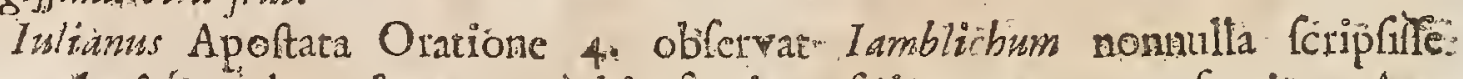

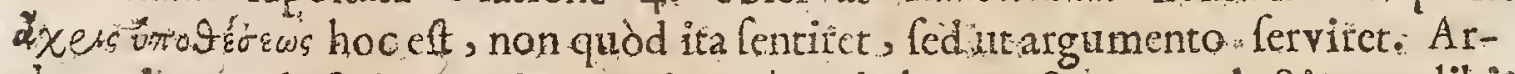
changelorum doetrinam, \& materix woin $\sigma$ w in hoc tractatu amplectitur, alibi aliter Philofophatur. Tho. Gale in Not in Tefimon. Anonym. Annotat. in Iamblir. de Myft. C'buldaor.

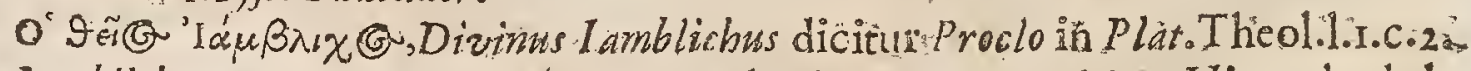

Iamblicbus, magna vit apudiGracos authositatis. Pier. Valer. Hicroglyph.1. 33. c. $4 \mathrm{I}$.

Inctâtat hoc argumentum ( de zìta Pythagora ) antsca Praceptor ejüs; 
Malchus, five Porphyrizs : ex eujus libro multa, vel ixfdem, velleviter immutatis verbis foripfie I amblicbus. VofJ. de Hitt. Grac.l.2.c.IS.

In vita $\ell^{\prime}$ ythagore mula furripuit ex eâ. $x$ quam fcriplerat Porpbyrius ejus Przceptor. De vitâ. Pythagor libros 7 . compofuit, quorum quatuor duntaxat: ad nos pervencrunt: Duo priores editi funt,duo pofteriores habentur MS. in Bibliothecâ Vaucanâ.loan. Card. Bona.

Alios duos libros de ejufdem vitâ:MS. habuit Lusas. Holftenins, \&e ditionem. promittit, cap.L.p. 4. vitx. Porphyrii.

\section{H E M I S T I U S.}

D Hilolophus \& Oracor, rempore Conftrnti, Ioviani, Valentis \& Valentiniasi Clar. A. D.

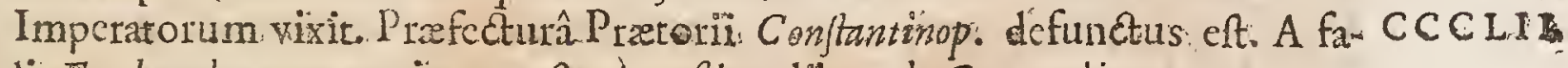
aundia Euphrades cognominatus ef, Angufinus libro do Categoriis praccptorem fium vocat: Scripfit Paraphrafin in Ariftotelis Phyficam libris 8 o o c. Praterca edidit fua, viz. de Interpretatione \& Infcriptione Predicamentorum ; Difputation resctiam qualdam Orationes ad Principes, fub quibus vixcbat.

Doctillinus is fuit Arifotelis Paraphraftes atque etiamnum magnæ: Autori. witis. Quenfedt.

Themiftim clegans nitidis Sariptor non: cantum doctus Philofophus. Turneb.adverf: I: I2.C.II.

Lecta funt civiles orationes Themifti fex triginta. Harum alin: ad Conftan-

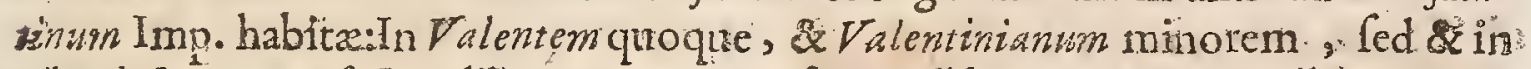
Theodofum Auguft. Laudibus eos encomiifque celebrantes. Sermo illi apentus; Cupervacancis carens, ac floridus. Verbis quidem ufus eft vulgaribus , fed in gravitatem aliquantum fexis. Hujus. Themifti in omnia fere Arifotelis foripta feruntur, non folum commentariased ctiam Metapora es, utiliter \& compendio

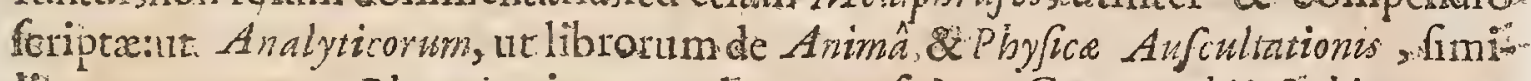
liumque operum. Platonir etiam quxdam expoluit: : Catcrap bilofoplite amans: insprimis, ac perftuaiofis. I hot. in Biblioth. And. Schotto Interp.

Hic licè Gentilis Valentem Imperatorem quotidie frevientem in orthodoxos: authoritace fuâ \& epitolis reddidit mitiorem. Vide fornen.\&. Suid.

Thernifium obfumman in Philofophia fcientian, Preture dignitate in fgnibus decorayit Conftantius Impcrator, Crakentborp. dè Provid..

Themifrii Orationes, quas dodiffmus Miræus antulit, vidi \& Cünmâ cam voluptate legi. Bcnè meretur de Rep. Literariâ, quiearun editionem parat. Sunt:

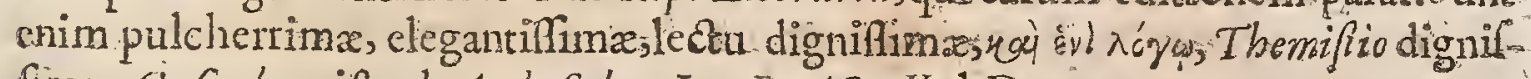
fimx. Cafaub. epintad And. Scbot.Lut.Parif.7. Kal.Dec. roog.-

Philofophis acutifimis fuo merito jam olim adfcriptus eft. Themiftius, ifque ox familiâ Ariftotelis, fr Hermola Barburo credas, oniundus. Egregium fua me moriâ Philofophum vocat Augufinu's \& Caflodorus diligentiflimum Scripto sem ac lucidum \&omnia ad facultatem intelligentix reducentem. Antonio $Z$ marra, qui I abulas fuper Ariftotelem edidit, creditus eft Alexandri Apbrodija E.f. 3 Abbresiator: 
Abbreviator; fed falsò, liq̨uidem ab eo diffentit haud timidè, oblervante codem Hermolao, cum colibuit, ordinemque ac Ceriem ejus variavit; veftigis tanen ejus infiftens Ariftotelis Pofieriora \& Pbyfica, item libum de Animầ, Mernoria \& Revanifcentia, Somno, \& Vigiliâ, In fornnis o Divinatione per Somnum eleganter \& perficuè explanavit, feque ipfum Paraphrafen Ariftotelis non oblcuic elt prò feffus. Hos libros Therriffii Parapbrafticos Hermolaus Barbarus Latnos reddidit, Venetzis An13.1570. in fol.edidit.Sed fi Voffum de Philofophia andire velis

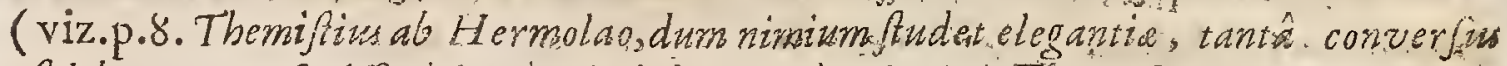

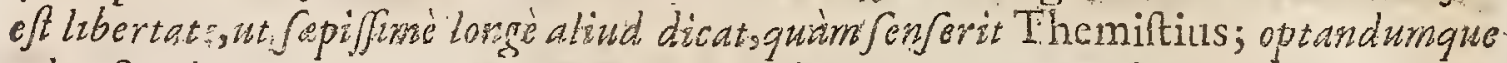

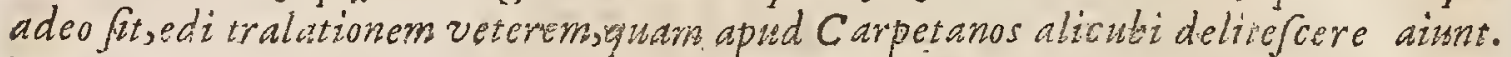
Fuitautem Therniftin, non infignis tantum Philofophus, fcu lucidiffrms Peripa. teticus, uti in titulo libii jam dicti falutatur, Ced \& Orator fine pari ; unde \&

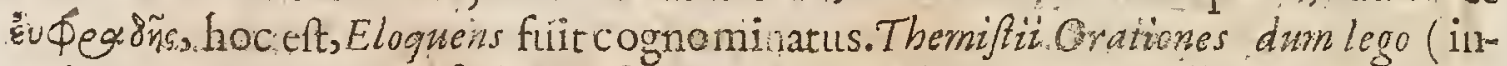
quit Muretus, orator ipfe difertifimus, L1.orat. 18.) nullum ei Sophiffarum, qui boc unum agchant, ut corrste ac polite dicerent, antepono. Nec mirum, cum,cum excellentis fuevit indolis, tam cellum fapientivatque eloquentic culmen attigifle. Patrem enim habuit Eugenium, Philofophix in Paphlagoniâ. Proferorcm fapientiffimum cumque fub difciplinâ ejus plurimum profeciffet, in Ponto $A$ far proclaris artibus fuitintitutus. His prefidiis inftuctus Commentarios foripfit in Arifotelem, qui tanti Sicyonio quodam livilolopho fuerunt æeltimati,ut Srbola fuâ derclictâ rectà Conftrmtrinopolm advolâtir, ferturque \&ipfe non minus quàm Soim crates ab Qracula à Difcipulis dubitantibus confulto lapientifimus omnium

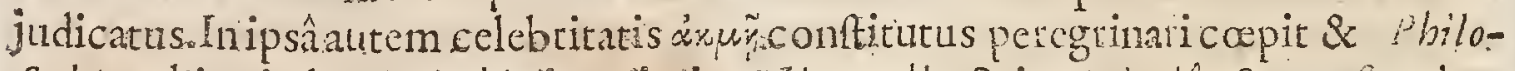
fophian hincinde, Antiochie imptimis. Nicomedice in Galation, \& onfantiropoli, \& Romxiprofitcii. Actr Eruai. Menfis O dob.i6s,

Chrifuanus nonnullis vifus fuit. Verum difcernendus omnino cit hic Thersio fius à Thersiffio alio, qui fectam Agnoetarumcondiditsproque Gentili habendus, .cum in Orationibus non alio, quam perpetuò Gentilisin more confuetudineque loquatur. Tametfi enim in orationbus illud in Sacro Codire obvium:Cor Regis in manu Dei eft, aliqueties afferat, affert tamen tanquam ex libiis peregrinis, atque Afyrits,jut vocat, arceflutun. Fuit interim cum Grogorio $N$ azianzeno familia riter conjunctus, teftibus Gregoriiad enm Lriptis literis. Bid.

Themitivis Paphlagonie Philofophus fuit, adeo doquen's ut Euphradis cognomine infignitus fucrit. In prima juventute Corrmentaria in Arifotelem evulgavit quæ tantifuerunt æftimata, ut quidam ex aptimis Greric Philofophis Scholam fuam: ad cum invifendum reliquierit. Tanta celebritate docuit Aniocbias Nicomedia, Romæ hilifue locis ut omnium Philefophorum fibi coxvorum faman obfcuraret. Romani ufque adeo ipfum demirati fun, ut ad Inperutorem, voros delegaverine qui procurarent ut illum apud fe remanere adigeret, fed hanc prarogativam adepti non funt. Confen ninopolin repetere maluit Ibernifturs ubi majorem vitæ partem traduxit. Sex Imperatoribus chatus fuit. Conftantius Protoris dignitatem ipfi contulit eumque xrea ftatua decoravit. Falens tantam ci reverentiam detulit us in ejus gratiam falfo zelo quo ad 
Ortbodoxorum perfecutionem ferebatur moderatus: fuerit. Nullum profecto Gignum exidentins exiftimationis cuiquam exhiberi poteft; Ex quo cnim Pinceps aliquis Religionem quampiam cxterminare in animum induxit, fupra modum grave ac molstum eft ei quicquid hujufinodi confilii progreffum remerarur \& nihil präter.Validifímas rationes hüjufmodi:remoram operari poteft: Interim tamen. Therniffri fermo mirum hunc effectum produxis in Iriperaw zorem ad exiritim Orthedoxomsm inflummatum quorundam: Arianornm Epifcoporum confilio, \& Imperatricis artibus. Philofopus ille Valentern admonuit quid: bonines frugi \& immeri os perfequeretur; Crimen non effe diverfun ab' eo credere or Sentire; banc opinionum diverfitaters mirum quid non effe;: Gentiles multo mais inter fe diffentire quim Chriftianos, Unwinguemgue veritatem diversa aliqua parte inineri, Deoque vifum effe hominum Supperbiam confundere Jégne venerabiliorers its reddere difficultate ipfum cognofcendi. Novellie Gall. de Literarum Rep. Menfe Decembr.1684.

Prodicrunt Themiffii Orationes 33.cum Notis Dionyfir Petavii ë Soc. Ief. arque. Iobannis Hardvini ex eadem Societate. Parifins $168_{4}$, in fol.

\section{H.I LAR I U.S.}

A Qmitanus, Epilcopus Pictavienfis, clariit anno 354. ob fidem relegatus: Obiit anno 369 .

Opera Genuina funt : De. Trinitate, libri I2.- - Adverfus: ConfanClár. A. D. CCCLIY: tium vita functum, liber ri-n-----Adeundem Imperatorem libri duonAdverfus Arianos \& Auxentium liber : Cuí fubjungitur Auxentii ad Imp: Epiftola----De Synodis, adverfus Arianos----Fragmenta ex opere Hiftorico

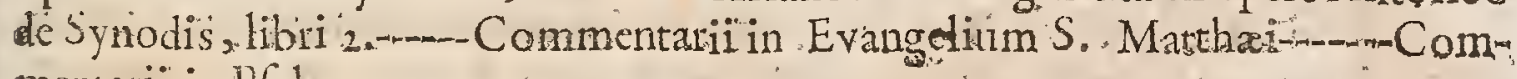
mentarii in Pfalmos.

Opera fuppofistitia funt:Epiftola ad Anguftinum mum-A lia ad eundem--C-Carmen in Gencfim---Epiftola ad Abran Filiam --- Liber de Patris \& Filii un tate---Liber de effentia Patris \& Filii.

Oprra non extantia: Tractatus in Job-w-Commentario in Cantica Canticorum---.--Hiftoria Ariminenfis \&. Sclucieinfis Synodi adverfus Valeintem \& Urfacium--n-m-Adverfüs Saluftium Prefectum. " feu Diofcurum Mcdicum---Liber Hymnorum ---Liber Myfteriorum--Epiftola plures. Guliel. Cave.

Quamvis jamprovectre atatis Chriftanus factus eft, tamen brevi in Ecclefia fticî̀ doctrinâ ita profecit, ut Doctor maximus, \& Ecclefix. Catholicx Colmmm m ritò habiuus Gt. Bellarmin de Scriptor. Ecclef.

'S. Hieronymus cum RomaniSermonis Tubam, Latinxque elóquentis Rho din mum appellat.

Hilarius difisilis eft \& obfcurts in loquendo: Et Gallico cothurno attolliturg 


\section{2}

\section{CENS U R A}

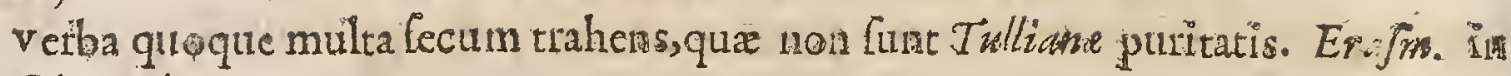
Ciceromian. P. Is.

Hebrxi Sermonis ignarus fuit, 2 Grecarum literamm vix quandam tentien auram accepit. Stylus ejus tam in paiterii juàm in Mathai Commentaris ent abque ulla artis affectatione preflus, folidus, interdum fuboblcurus, fed ab omni tumore faruque alienus : Tametf diverfum Lentire vifus fit Hieronymu, qui ad Putinun.fcribens, Filarius, inquit, Gallicano Cothurno attollitur, \&, cum $G$ ixcia fleribus adornatvr, longis interdum periodis involvirur; of ob id à finplicium Fratrum ledione procul efl. Qina fane Fieronymi verba refelenda funt ad Iibros duodecim de Trinitate; in quibus, ut idem Hieronymus in Epitola ad Magnum oratorem fcribit, Duodecim Quintilianilibros \& ftylo imiratus ct. Rumero. Sixtus Senenf. Liblieth.1.4.

Nifi Allarizs Pictaviengrs collegiflet Decreta Syrodorum Oricntalium, jan ahil fciremus; quia in Tomis Conciliorum, ficutnunc habentur, Geremoniz quadam in illis Synodis fancitx recenfentur, nihil verò de dogmatibus. Chernait. de lecturî Patrum.

Quia malculè Arianc impietati feleoppoluit Hilarius, Finc bereticorum flagellum \& Malleus, itemque Ariane pravitatis domitor palim audit. Quenftedt.

Hilarius Latinorum primus, eloqucntix fux gladium ftinxit in Arianos. Ea quaque res illi plurimum fama conciliavit,pracipuè quò reseffet cum hofte nobili. Nam noin dubito, quin apud Gracos,prater Aibunafurn, plures idem fe. curint. Evafrn. Epift.1.28. Epift.8.

Hilarius quàm egregius Author! de Trinitate benèlcripht. Scaligera.poferior.

In libris de Trintate vidatur totâ vi adnifus,ut in hoc opere diclararet atque exereret, quicquid ingenio, quicquid eloquentià, quicquid factarum cognitione Literarum poffet. Erajris. 1.28.ep.8.

Hilarius Pictavienfis Epilcopus Palmorum interpretationem \& Ho milias in 706 fcribens, è Græcis Origenis libris quadraginta fermè millia verfuum fic eranfulit in Luos Latinè,ut fenluum magis quà verborum curam habens, nonnulla etiam de fuo addens, non Interpres alieni, fed Autor fui operis ( ditimularo, viz. conftanter Origenis nomine) haberi voluerit; quod idem infitutum fuis quoque in Mathewr Commentariis profccutus elt. Eo fortafle conflilio ; ut Origeniani nominis invidiam evitarct.Quo pacto excufatum eum habere cum Erafino poffumus. Thom. de Plagio,num 466.

Hilarim, qui Origenis Homilias in Lob, \& libros in P falmor complures è Graco Latine vertit, 10 alfedit litere dormitanti, \& putidâ rufticorum Interpretatione fe torfit, fed quaf captivos fenfus Vietoris jure tranlpofuit. Hieronym. ad Pammach de optimo gen. intexpretandi.

B. Hieronymis $S$. Hilariwn vocat Latine Eloquentix Rbodamum, non modo ad Patrium ejus, folum alludens, fed etiam ad fyli ivius characterem qui violintus \& rapidus eft ficut Rbodani decurfus. Quemadmodum enim fumen illud aquarum fuarum impetu abftrahit quicquid earum torrenti oblutit, ita eriam $B$. Hilarius animum \&judiciumabipit \& fermonum fuorum, vi confenfum 


\section{CELEBRIORUM AUTHOR UM.}

excoryut. Modus quo resenun:iat. percutit, Anupefacit, dejicit $\&$ perfuadet. "Ejus Periodi prolixæ ac intricatæ plernnque funt, quod illum ubique obfcirmun xedit" \& quibufdam locis ferè intelligi nefcium. Barbaris frep̀ yocibus utitux. Z: in ajus Operibus loca occurrmut ubi conftructio ntilla ett. Figuris \& Antisthefibus creber eft; Ejus ratiocinia quamvis folida, admudum tamen fublimia - Gunt vivido illo \& urgenti modo quo illa contexit. Adverfariss fuos nnilo deLectu tractat, Ad Porentes:\& de lotentibus incơmparabili libertate loquitur. Nemini pafcite, norum rigidus Cenfo: \& Ceverus Fidei Defenfor eft. Elldu in Nov. Biblioth. Tom, 2. p. 281, 282 .

Ejus eruditio tanta erat quanta in his Mundi regienibus comparari poterat. Qued Hebraïcorum imperitus erat, qua occafione Hieronymo plus femel vapu* lat, minimè mirum elt, Indaica eruditio diebus illis infrequens erit, pralertin in Occidentalibus plagis. Sû́ in Oriente tot annos commoratione aliqưu-

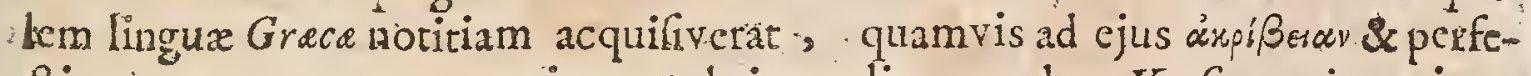
Ctionem nunquam pervencrits, qutod, inter alia exempla, Verfiones ejus etiamnum extantes comprobant. Ad ftudia Theologica prefertim animum appulit, \& ad examen Controverffarum qux temporibus illis agitabantur; in quibus, licet in fatuis \&: intricatis Spcculationibus fitze effent, magnus Magifer evafit,claruit que inter Latnoorum primos qui atholice Fidei explanationem \& Defenfionem fulceperunt. - Abfurdas \& fingulares ejus Notiones \& Opiniones plus fatis difcufferunt alii: Quarumcaufa parum zquum effer Memoriam ejus gravare, fi attendamus quồ : controverfa Dograta recèns exorta \& nondum fufficienter

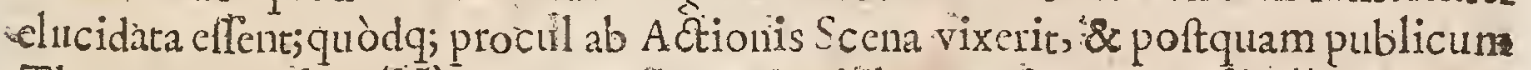
Theatrum confcendifiet, totam vitam Capitibus \& Controverfíisillius Sxculi fatigatns fuerit. Sed quid multa, Eruditus, Eloquens, $\$$ acris jndicii fuit Vir praclaris dotibus \& Cana mente preditns : Cathelicufque Epifcopus, \& quod caput rei eft, Vir pius \& bonıs. $D \%$. Cave in Vita Hilarii pagino 212.213 .

Notantur in Hilario voces nomnuilla, quibus preter loquendi confuetudinem videtir ulius, ut $\mathcal{D}:$ profofit, pro Degenerat, five in pejus proficit : Rheurnam dixit pro Rhetonate ; pajcham \& mannamirurfits Drapjalma Diapfalma, \& Diaps.al- ma Diapsalmatis. Zabulus pro Diabulo non apud ipfurn modò reperitur. Notanvar etiam aliquot Solocifimi - Porro quod attinet ad literas Grecas, eas tenuiter attigit. Iown. Gillot. in Comment. deS. Hilario.

* Defiderii Erafmi in D. Hilarium Annotationes, G expurgentur, permittua aur. Index Madrit. edit. anm. 1657.

Prodierunt opera ejus omnia Parifisis, ann.1605.1631. 16.52. Fol.

\section{I B A N I U S}

S Ophifta Antiochenus Ethnicus, floruir Iuliani Imp temporibus ufque ad Clar. Anno Theodofanm Seniorem. Hic Akenis audivit Diophantum Fhilofophum, D. CCCLX Gg deinde 
deinde in Declamationibus fe exercuit Conftantinopolim profectus ; ibidem lin dumaperuit, unde propter lafcivum in pucros amorem pulfus, Nicomediam venit, indeque eandem ob caufam rejcotus, in patriam reverlus eft: $\int$ cripfet Declamationes; Progymnafmata ; orationes, quafubobfcurr; \& Epiftolas, qua: laudatifima; item opus de Modis dictandi Epiltolas Hic etiam, argunentivi - mines Otationes Dernofthenis edidit. Qux omniadiligentixe Frederici Morelli; Leonis Allatit, Valcfir, \&c. debentur. Praceptor firit $B$ afilii, ab hocimpense Laudaus in Epit. \& Cbryfofonis oblatam à Iuliano Prafecturam Pretorii titula Soplitita polthabuit. Ho fran.

Iibri Libanii Catent gratiâ \& facetiis Comicìs, \& adfpersâ ubique unbanitate: \& argutiâ verbis fublervit ; afluit \& lepos ac grata jwcunditas, cunctis $S y$ y nictiou in vulgari colloquio peculiaris. (Attici nalum \& falem vocant) qux dos prater eruditionem peti ab eo potef - eruditionem magnam 8 multiplicem lectionem in Orationibus ejus invenias, \&didiones, gux illecebras meras, \& furavia firant. Eunap. in vitâ Liban.

Lecifunt Libanii Tomi duo. Is in fictis fuis, quafque exercitationis tantùm: causâ fcripft, Orationibus, feipfo eft; quàm in aliis preftantior. Nimiș enim diligens ac curiofus dum effe vult, nativam effufanque fermonis (utitadixerim). gratiam ac venufatem in illis alis corrupit, atque in obfcuritatem delapfus efts multa quidem interpoftionibus obfurióra leddendo, quxdam etiam ablatis ne. cellariis. Regula eftalio qui hố, in genere, ac norma Sermonis Attici. . Clarum item habet in Epifolis feribendis nomen : : Mulagte \& varia circumferunture ab co confcripta. Phot, in Biblioth. Cod. XC.

Philftrat floridusac picturatus: dilicidus magis eft \& fimplex-Libaniriso. Lud. Viv. de Trad. Difcipl.1.3.

Cbryfoform puer nondum Sacro Lavacro regeneratus, audivit ingeniólumb: Ged infigniter impinm Libsnium Sophifam Sic enim tum Rhetores appellabanMr. Erajm. Epin. 1.28. Epift: $4 \circ$

Zibanio do atorum hominum calculis, inter Atticifas priecipons locus tria buitur.-! dem ibid. 1 29. Epiftit6.

Libanius Sophifa Declamatoumirè difertus; fed dum nimis diligens effe: Yult, in obfcuritatem Cegè dilabitur :Ioan. Card, Bona.

Unus tantùm repertus eft Libarius Sophifta Antiocbenus, Iuliano magno amifitix vinculo adfrictus, qui funebrem in ipfus Imp laudem feripferit O ratc neyr, guâ etum pro arbirio laudibus in colum evexit, \&e inter numina collocávit. Baror. ad ann. 363 .

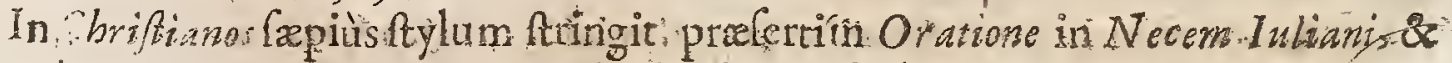
Oratione de Templis Gentilium, ipfi Theodofiv oblatâ.: Xonig.

Libanii 300. Epiftolas MSS. Regina, Suecie Chiftiana, habuifle tradieuro.

Legi heftenâdie orationem tuam magnâ ex parte ante prandium, pranfus चęro fine ullântermiffone reliquum abfolvi: O te felicem qui ita poffis diceaut fentirc potius! ô rationem 


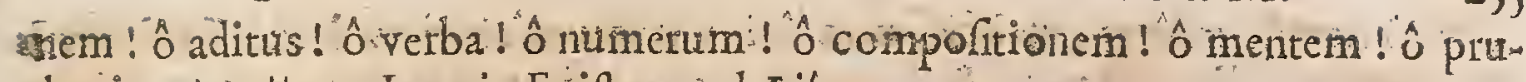
- dentiam ! Iulianus Imp. in Epift. 14 ad Liban.

Prodierunt Libanit Orationes, Declamationes, Dillertationes, \&c. Gracés, cum Verfone \& Notis Fed. Morelli-2. Tomis, Parifins I606, \& 16.27 .

Extant Orationes 5. Conftitutionum Imperatoriarum quales in Cod. Theodo:Jano \& Infinaneo occurrunt, Gracè-cum Verfione \& Notis Gothofredi. Genevie I63I. Fol.

Extant ejus Defcriptiones Grec. Lat per L. Allatiumb, Roma I G41:in 80.

$$
\text { JULIA N US. }
$$

A Poftáta, Imperator, inter viros dectrina elaros refertur. Elaboravit OraA tiones \& Epiftolas: Librum de Cafaribus: Mifopogonemadverfus AntioClarvitA.D. chenos: Hymnum in Solem, \&ce. Opera Iuliani omnia Dionyjus Petavius, $P$ a zrifirs. 1630 . edicuravit, in $4^{\circ}$.

Per omnia Philofophiz membra prudenter difputando, currebat Inlianus. Sed tamen cùm hace effectè , plenéque colligeret, nec humiliora defpexit: Poe:ticam mediocriter \& Rbetoricarn, (ut oftendit Orationwm, Epifolar:ungue ejus ecum gravitate comitas incorrupta) \& Noftrarum Extenarumque reium Hifroriam multiformem. Super his aderat Latinè quoque difrerendi fufficiens Sermo. Ammian. Marcellin. I. XVI.

Per univerfa hac ftudia animum fum diffuderat Iulianus Céfar : Magnus omninò Vir; fed major futurus, nifi Libaniun nimis aftimâffet. Giraci fermoinis ea eftilli elegantia, is nitor, ea facundin, ut omnes rapiat in admirationem Gui. Vof . de Philolog.c i. fect. 6.

Et genere nobilifimo, \& formâ liberali, \& ingenio ad literas \& ad arma accommodato celebris ftatim à pueritiâ finit. Chriftianos non tam violentis Perccutionibus, guàm dolis \& perfuafionibus à veritate fidei abducere conatus eft: Cùm oblata elfent eialfquando Scripta Chriftianorum, quibus defendeba-

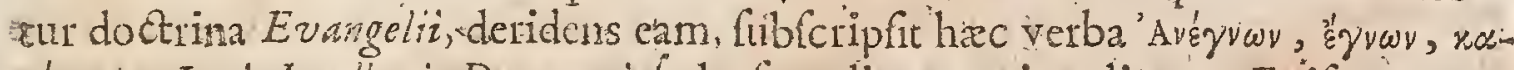

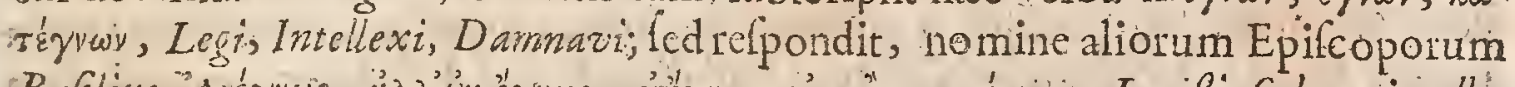

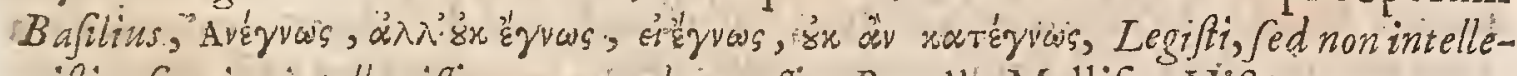
xifi, fi enim intellexiffes, non damnaffes. Pezell! Mellific. Hiftor.part.2. pagin. 273 .

Quồ [ I uliano.] tetrìus magifque Deo fimul \& Horrainibus exofum animal orbis vix vidit. Crakan horp. de Provid. Dei.

Inliunus, thaximis ille quidem preftans ingenili dotibus, \& eâ ftatione digniffimus; verùm eò mifer atque infelix, quòd in tuntorum munerum largitorem Deum, ingratus extitit' ac mox ab aguitầ veritate fceleftifimè defecit. I faac. CaSaub. Dedicat.prafix. Polybic, p. Iz.

Intuanus certera vir egregius \&laudabilis, nifi quòd ob fcelus defertæ Fidei Chriftianefordum Apoftatenomen ad Polteros tranfmifit. Bandii Orat. prefix. Plin. Painegy.s.

$$
G g \quad \text { Inlianus. }
$$


Iulianus Parabates, atrocifimus licèt Chriftiani nominis hoftis, vil tamea verè litcratus, literantuque \& libroum amantifimus fuit. Princeps, ut nomemo eum vocat, ad unguem factus, odiumin Chriftianos fi excipias. Gul. Selden。 de librorum Ufu \& A bufu.

Ccrtè I ulianum Iudaorum non minus quàm Chrifianorum holtem, Hiforiz. evidentia coegit fateri, \& viros divino spiritu afflatos vixiffe inter Iudeos, \&. ad Mofis atque Elic Sacrificia ignem coulitus , delapfum. Grot. de Verit. Relig. Chrift 1 r. 2

Etfi resgeftas \& exitum Irbliani Imp. Ammianus Marcellinus, \&aliicjus fautores, inter quos fuit Libanius, honotificè recenfent, \& fapientiam, pictatem atque ejus virtutes heroicas, prafertim continentiam \& cattitatem prædicant at-que commendant :tamen plerique alii Hifforici, de ipfus fe eleraris \& flágitiofis. aetionibus, \&horrendâ morte conveniunt. Scribunt enim; quumin prælio contra Perfas hatâ colitùs vulneratus eflct , haufum cavâ manu proprium cruorem versùs colum afperfulfe, cum hâc blafphemâ voce erga Chriffurb a a quo impic defciverat: Viciftitandem, Galilee : sicut commemorane Theodori-.. cus, Cajfiodorus in tripartie. \& Nicephoru, qui \& illud referts Julianum jam moriturum animâ fecedente à corpore, diviniùs quodammodò quàm prohomisum captu potuit, oculos intendiffe, ita ut Chriftum viderit, Sxexclamalle: Sam tura $T_{e}, N$ axarene Pbilip. Camerar. Oper. Horar. fubcifiv, $C_{n} L_{I}$.

Interdixit ifte Apoftata ufum Scbolarum Cbriftianis, ratus, nullam acerbiörem fore perfecutionem., neque cxpeditiorem viam evertendæ Religionis, quàn fi à: ftudiis literarum Chriftiani areerentur. Nimirum (inquit Volfiuss) acutus ac: peripicax Imperator faris videbat, quo pacto maximè pelfc nocere Religioni Chrintianx. Vofj. de Philolog.p. $70^{\circ}$.

Obiit Iunii 26. Ann 363 . Etatisfux Amo trigefimo lecundo cùm duos nondum integros annos reguâflèt. Princeps preclaris fanè Virturibus ornatus, Prur dens, Circumfpectus, Aquitaris a mans, ftcictè Juftus, Caftus, Temperans, in Laboribus paticns \& indefifus, in moliminibus ftrenuss, imo ulque ad temerịatem \& pracipitantiam : Ingenio erat, acer fed nimis Satyricus, Captûs facilitate \& Eruditione plerifque omnibus Principibus fuperior; De cxtero tamen Laudis \& aur $x$ Popularis avidiffinus; Qui dicacitate delect abatur, nec rarò cum wana fic fatis, gloria fe ipfum commendabat: Erat, fatentibus vel ipfis ejus Scripreribus, Superltitiolus potiùs quàm Religiofus; Immodic èamans. Ritum, Ceremoniarum \& Confuetudinum Ethnicifimi, quas tum gladio tum calumo \& reftauravit \& propugnavit; atque in quartm exercitio non parkas otii fui portiones infumfit, seque juratum hoftcm profefus eft eorun omnium qui ipfis adverfabantur. Denique, ne quod ei debrut taceam, fi ejus. Memoria, defectio ne aboptima qua unquam extiterit Religione, commaculata non fuifer, féque tam acerbo \& implacabilianimo erga C'briftianos non geflifet ; optimis Princi pibus qui unquam tenuerint tmperii Rorrani clavum accenferi potuiffet. Cave, ú fua introductione ad fuos: Ecclefrafticos.

Etfi Gdei Religionifque Chrifiane delertor turpilimus infenfifimufque ho: 
fis Inlianus elfét, Omnitamen doctrinæ gcnere excclluit, vitrque fur \& morum accrimus cenfor, bellorum ctiain in Germanos \& Perfas magnâ cum celeritate nec minori felicitate confectorum gloriâ inclytus, cam laudem apud pofteros meruit, ut; quod paucis contigit, \& armis ftrcnus , \& vitâ integer, \& literarum ftudis excellcns nof́catur : cùm qux:finguli Inperatores partitim proclara habuerant, ca unus hicanimo \& factis fit complexus univerfa. Igitur cumvitutibus maximis animum parem gereret; \&'laudes caterorum Inperato rum, ipfusctiamconfaxtini Magni, fuperaret; (quod adverfus Patres ipf iniquiores afferuit: $P$ eirus $C$ uneus, ringente $P$ etavio) iniquè tulit eorum vitia, ne cohibuit calanum, quin iftum in perverfos mores \& temeraria facta priöum Imperatonm ltringeret. Hïc natus liber, quem Cefarum nomilie:infignivit. quòd eorum, qui ante fe Romanis imperitavcrant, viria infectaretur. . Hic cum elegantia dictionis, \&argutâ dicacifate, rerumque variêtate infignis, rcliqua vel Græcorum vel ipfus etiam Iuliani fcriptafuperaretsè Graco fermene in Lati. mam à Carolo Cantoclaro Gallo, \& Petro Cunco Belgâ olim tralalutus efto AEa Eaditorum, Vol..2.j.j. 31 .....

\section{CHIUS:}

Sive, ut alii mulunt, Fabiuss,

\section{MARIUS; $\forall \rightarrow$ ICT.ORINUS。}

$M$ Arius Vidorinus perea tempora foruit, quibus Confantins Confantini flius Rornani Imperiihabenas elt moderatus, Afer quidem, \& ut plerique exitimant Cartbaginienfis. Qui verò $M$ afflienfern faciunt valdè falluntur. \& fallün legentes. Rome Fittorinus, ut Hierongmusprodit; Rhetorivam docuit, ubi \& ftatuam meruitin Foro Trajani, quo in loco \& plerifque aliis pofitas le gimus. Victorino operam dediffe in Rhetoricâ Hieronymun accepimus; 2 juvenem iplum fuife Gentilium Deorum cultorem, quos demum matriore atate abjuravit, ut Hieronymus \& Augufinus prodiderunt; quorum hic in libio Con feflomum, de eodem illud commenorat: quòd cùm aliquando Victorinus cum: Simpliciano viro fandiflno colloqueretur, feque Cbrifianum affereret, $\alpha$ id fe minus credere Sumplicianus refpondiffer, quoniam cum cateris Chriftianis illum in facris adibus concionibus intereffe uon confpiceret: tum viro fando per jo eum Vietorinus refpondir: An, inquit, Simpliciane Pater putas parietes Chrifianum borninem facere? Tandem verò cùm Victorinus ad templì devcniffet, \& velut homini verecundo, occulki Symboli liber oblarus fuiffer, ut legeret; ille pulpitum, quem Umbonem \& A mbonern Ecclefraftici yocant afcendit \& publicè clarâ \& altâ voce Symbolum prontınciavit; Quấ ex recunctispalam innotuit illum Cbriftianum elle. Sed enim prater Rethoricar \& Dialecticam, quas difcin ulinas in primis excoluit, (nam \& irutraque doctiffimè fciiphit) in Poeticâ tram illum floruiffe yidemus: Nam \& verfu Heroico feptem Maccaboorum $G, g$ frány 
fratrumacerbam cum matre necem lub Antiocho Rege defcriplit: Quod non multò antè Poema legi, parum licèt caftigatum .: Prxter enim functras, qux in co patentes pleveque exifunt, vacillant s quoque Syllabas \& pedes offendimus. Leguntur \& Iym quidam ejus nomine editi De anitiffmấ Trinitate. Extant \& ejus in l'oetica commentacii exquifita frugis, fi integri \& non mutili à Rudiofis thaberentur. Junt preterea in manu ejufdem commentarii in duos $M$. Tullit - de Inventione Libellos. Sunt \& quæ cx 'orphyrii Ifagoge in Latinum tranfulit. Lil. Greg. Grald. de Poct. Hif. Disl. s.

Victorini libios 4.adverfus Arianos S. Hieronymus tradit dialectico more fcriptos valdè elfe obfcuros, non nifi ab enuditis intelligi, ac cum judicio legendos, cumnonnulla contineant duriufcula s ab ufu loquendi Theologorum alicina.

Non quiia ignorcm Caium $M$ ariurn Villorinum, qui Romastreros Rhetoricam docuit, edidifle commentarios in Apoftolum; fed quod occuparus ille eruditione facularium licerarum, Scripturas omininò Sanctas ignoraverit: Et nemo pof fit quamvis eloquens, de eo bene difputare, quil nefcit. Hieronym. in Proom. coinmentin Epilt. Pauli ad Galatas, Tom. g.

M irius Victorinus Afer, Cenfu profundus, dictione obfcurus, durus in Cetentiis, \& Lepè Platonizans. Ioan. Card. Bona.

In Victorizi libris contra Ariurn pleraque obfcura \& involuta funt nexibus plicarum circumducta, qux ho minem doctum potius quàm difertum arguant \&capiant. Câp. Barbib. 42 adverf.c. 9 .

1 oema cM accabeormeft defriptio verfibus Hexametris Martyrii feptem Fratrum. Nihill non vilgare continetur in hoc Poemate. Nihil Poeticum habet prater Virgilii humilia quædam imitamina; \& pleraque ejus carmina Vilia lunt \& abjecta.

Commentaria Victorini in Apoftolum Pavilurs nondum edita funt. Jef. Sirm mondus corum Fragmenta quædam in nefcio que Manufcripto invenerat.

Sed dubio procul illa cenfuit indigna qux in publicam lucem venirent, quamvis in Admonitione fud dicat horum Commentariorum ttylum planiorem \& terforem effe quam s criptorum cjus Dogmaticorum. Ell.du Pin. Nov. Biblioth. Author. Ecclef. Tom.2.p.296.

Quæ fcripfit Vidtorinus cautè legenda monent ritic Sacri, quia magis Arti Rhetorica quàm Sacris Literis \& Thcologix eperam dcderat. Quoanno obierit, non conftat, hoc certum obilfe ante annum 37 . quo S. Auguftinus 1epudiato Manicheormm dogmate ad partes Carholicorum tranfit. Ejus opufcula new mo in unum volumen collegit. Philipp. Labb.

Stylus Vitorino paüm foelix, prefertim in Dogmaticis perplexus \& ingratus, \& qui vix uilla adeò decantatx eloquentix veftigiaretinet. In Commentariis verò ftylum planiorem \& apertiorem efle teftatur, qui lcgit, Doctifimus Sir mondus. Denique opufcula ejus attentum is oculatum lectorem poftulant. Cum in Fentilium eniim literarum ftudio longè majorem vitx partem tranfegerît nec nifi provectâ jam ætate Chriftianifnum amplexus fro non videturubique Fided 
dogmatz faris accuratè percepiffe, faltem non fatis foliciter expreffire.Gul. $C_{0-\text { - }}$ $v e$ in Hift literar.

Ejus Hymros tres de Fomoufio recipiendo Fabricius ametros notat \&anarythmos.

Libri quatuor adverfus Arium cum aliis quibuldam, extant Tom.4. Bibl. P.P. Pari, fol.

Librum adverfus Manicheos, \& alterum de Principio Diei., edidit Sirmones. dus in opufcudogmat. P. I53. P arif, I630.8?.

\section{E P I P H A N I U S}

F Leutberopolipaleftins appido oriundus, Conftantic feu Salaninis in $C_{y p r o}$ I. infulâ Epiféopus, Horuit fub luliano, Valentc, Gratiano, Theodofio, atque Clar. An.D; CCCLXX.

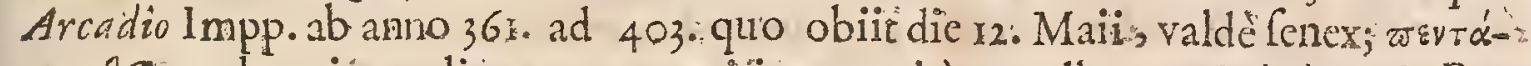

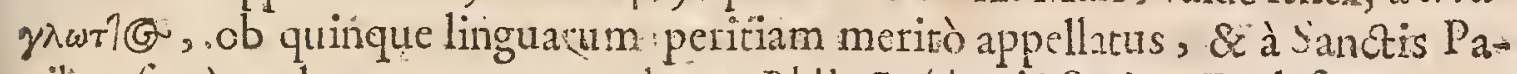
tribus Lxpè multumque commendatus Pbil. Labbe. de Script. Ecclef.

Sanctus tieronymu in Literis ad Pammach., vocat fummum Antiftitem 2:3 qư̂ nec xtate, nec fcientiâ, nec vitæe merito ; nectotius orbis teftinonio major extitit-Multa fripfit Epiphanius, quxab eruditis propterres, à fimplicioiibus: propter verba quoque lectitantur. Hieronym. de Scripr. Ecclch.

Cpera Genuina funt: Panarium five adverfus Harefes 80. - Ancoratus, feiz: de fide fermo-Anacephalieofis - Cu Panarii Epitome-De:Ponderibus \& Menfuris liber - Epiftola ad Ioannem Hierofolymitonum. Lat - Ad Hzerony. mum Epiftola brevis. Latinè.

Opcra Suppofititia funt : : Phyfiologus-De vitâ \& interitit Prophetarum De duodecim Gemmis in vefte Aaronis - Ejufdem libri Epitome-Orationes octo, viz. In Fefum Palmarum: In Christi Sepulturam: : In Chrifti Refur rectionem : In Chrifti Affumptionem : De Laudibus B. Marie Virguinis: In Fefto Palmarum - Denumerorum Myfteriis - De Chrifi Refurredione.

Opera non extantia :: De lapidibus - S. Hilarionis Encomium-Epiftolis plires. .Gul.cave.

Multa cum delêtu sudicio légenda apud Epiphanium. Cujus Panariumnos folemus vocare Christiane Antigutitis Scrinium: Et fanè praftantifimum eft opus, \& \&on omnitim hominum. Scalig. Elench. Trihæref。Serar.c.Ig.

Cum delctu ille uthor tractandus, optime alioqui de literis divinis deque Ecclefia meritus. Ider ibid.c. 2 r.

Fuit quidem Epiphnns virfandus, fed Grammaticx ac Rhetorice admo dtim rudis, ut fatis apparet ex Operibus, in quibiz, non foltum oracionis nitorem, fedctiam feriem \& fyntaxin, periodorumque ftucturam, orationis om-... nis lucem unicam, plerumque defideres; qux quidem viria varis multíque in : locisncceffaio obicuritatem pariunt, quod \& querunturejus Interpretes loan. Dallans de vero ufu Parritri C. $5 \cdot p \cdot 1.58$.

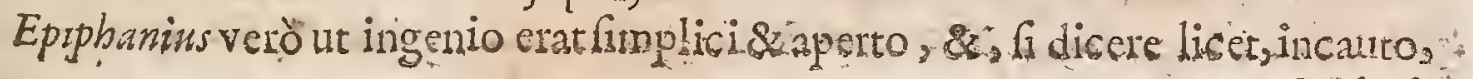
\& ninim 
\&z nimis credulo; fie aec fuit \& vehemens in is omnibus retinendis qute fatr cta \& vera effe in animum induxerat, ideoque faciliùs aboptus elt ad multa a\&mittenda tanquam folida, qua, utemel fufceperat non faciledinittebat, fed retínebat mordicus. Non exiguo yolumine 2 multo otio opus eflet, ad ea omnia recenfenda quæ notari ex co polfent. Si cui in ca inquirere cordi eftadeat Dionyfit Petami rccentiffini Interpretis Notas; caftigatcenim eum fapcnumerò, ac inenum quam quidem acriter. Dallows ibid.p. 272 .

In Haxefibus I udcormi \& Samaritenorum nop eft valdè acculatus Epiphanius. Montacut. Apparat.7. Sect. "o.

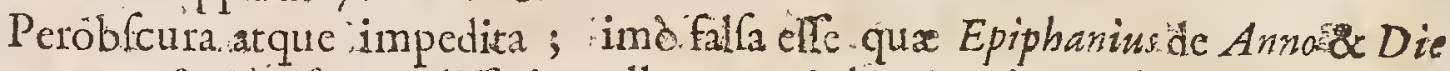
quo natus eft Chrifus, differit, nullumque Sphingis anigma ejus oratione pe. plexius cfe nondubiat pronunciare Petaviusin Epiphaniugn.

Cafaubonus.in exercitationibusad Annales Baronit, Epiploniumirum maximum vocat: Fed-credulitatis nimia cum frpius infimulat.

Epipbanius.Hiftoriaum diligentifimus Inquifitor vocatur Grotio.

Epipharius falla multacontinet. Bona quirdam habet, fed ignarus eft, atque smifellum"ingenium. Multa corrafit, \& Græcorum ac Hebraicerum nihil omnino callcbat. Antiquitatum Thefaurum habcmus apud Epiphanium, bonis enim ibris infuctus crats ex quibus quando defcribit, optimé; fed quando cx "Suo dicicaliquid miferrimus eft. Scaligerana pofterior.

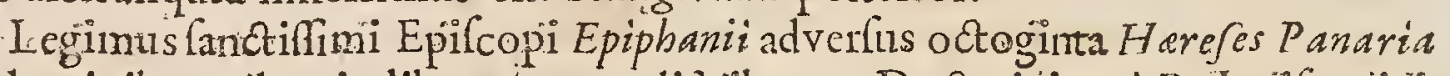
voluminibus tribus in libros leptem diftributa : Ducto igitur à Barbarifmo initio, tendit inde ufque ad Mefjallianos: Cxteris, qui ante.ipfum contra H.xeles fcripferunt, copiofor atque utilior; proptereà quòd guz reliquii:utiliacontinebant, hic nequaquam pretemifit: Sed quzcunque praxter ill fudiosè reperi: re potuit, adjunxit. Dictio ejus humilis, ac plane talis is qualem ejus cfie oportuit qui Atica elegantix rationem nullam diuceret.

Infirmus verò ut pluimum eft inconflictibus adverfus impias therefes fuf ceptis. Eft tamen ubi fortiter aggreditur, atque irruit, quamvis neque verborum ipfius, neque conftuctionis proprictas ullâ ex parte pratzantior efficiatus. Phot. in Biblioth. cod. 122 .

S. Epiphaniintylus omnis clegantix \& fublimitatis experseft;imo contrà fimplex, humilis \& abjectus cft afper eft atque rufticus, abfque ferie $\&$ connexione; multz lectionis \& cruditionis vir fuit fedin rebus difcernendis omni fagacitate, \& ingeniapolitie dentirutus. Falfis plcumque rationibus ad Harcticos refutandos utitur. Admodur credulus \& minimùm accuratus erat. Paffim hallucinatur Hi Hiforic factis notatu digniffinis; \& falfs monumentis aut rumoribus in certis nimisteme ć fidem adhibet; $Z$ do \& pietate áburdabar fed confilio prudenriaque civili deficicbat. Uh. du Pins Nov. Bibl. Author. Ecclefiaftro Tom.2.p.762.

Eruditio ejus contcmuenda non erat ratione cum lrophanorum tum Sacronum Scuptorum prafertim verè Eruditionis Ecclefraftice tramites emenlus crat; Omnes ufitatiores linguas mediocricer callcbat, fpeciatim verò Hebraicam

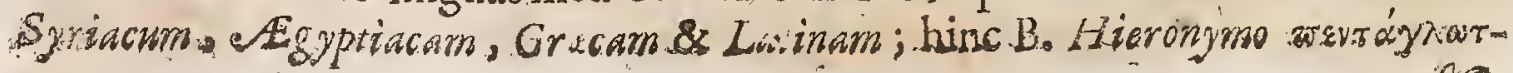




\section{CELEBRIORUM AUTHORUM.}

To denominatirs, quamvis Orientalium idiomatum notitia tunc temporis pas run frequteers effet. Verum eft quòd eiuditione multò magis quàm judicio polleret, ejufque Lectio diffurior quàm acuta \& nervofa ejus ratiocinia. Quandoque, ut obfervat Photius, Adverfarium cum acumine quodam adoritur, at enerves plerunque ac infulfi funt fermones ejus. Sed capitalis ejus defectus fuit nimia ejuscredulitas, cùm res plerunque referat alienam fiden lecutus, finẹns ut fibi imponatur ejufmodi narrationibus quas evulgaverat Patium altera, vel de propriis vel de Adverfarii fui actis, abfque debita inquifitione pravioqque exami. ne, quedin errores, contradictiones \& confufones innumeras etum conjecit; Quemadmodum evidenterpatet, ut alia taceam; cx ejus relationibus circa Arianos hijufque truici varios ramos. Vilis $\&$ infipidus eft ejus ftylus, nec ad Eloquentix confinia accedit; quem Characterem Scriptis ipfus jam dudum tribucrat bonus ejus amicus S. Hierorymus; Quod Jcilicet Viru Döcti ea legerent propter Matcriam ef Subftantiam, Simplices vero propter Stylum. Pracipuus librorum qui nunc extant eft ipfus $P$ enarion feu Tractatusadverfus $H$ ereses; In quo prater Argementum piincipale, multa Veterum Authorum Ecclefiafticorum Fragmenta notatu digna \& nufquam alibi occurrentia confervavit; Et non exigua Ecclcfiaftica Hiftorix pars itlo libro continetur. In preftantifimi \& utilifimi hujus Operis compilatione auxilio non mediocri fuerunt ei Veteres quidam qui in hoc fcribendi genere ipfi preluxerant, Iustinus $M$ artyr, Irenaus, Hippolytus \& quidam alii, quorum Sermones \& Relariones hic Author nofter autxit \& ampliavir, iifque integras addidit differtationes de Herefibus fri Tempore exortis; quod omnium turbulentifimum \& vexatifimum Ecclefix Sxculum fuit, Cave in Vita Epiphanii p.444.445. Angl.

Prodierunt Vita 2 Opera Epipbanii Grac.Lat.cum Notìs per Dionyjurm $P_{\varepsilon-}$ tavium, Tom. 2. in fol. Perif. 1622."

Auctior verò calitio qutix prodiit Colonic n682. in fol.2. Tomis. Sumptibus Beremo Schrey, \& Heinio Iobo Meycri。.

\section{S. B ASILIUS}

Appadox, meritò Magnus appellatus, per plures annos S. Gregorì $N a-$ Clar. Anno D. $\operatorname{ccc} L x x_{0}$ Cianzeni Aiberis, \& in Colitudine comes individuus, Cefarea in Cappadociâ, quæ prìus Mázaca diccbatur, Archicpifcopus creatus cft die Junii I4.Dominicâ añui 36g. Arianis, ipfique Valenti e A ugusto fapè reftitit, multifque exantlatis pro Fide Catholich laboribus , ad meliorem vitam tranfit Kalendis Januzriis anni 378. Pbil. Lab6. de Script. Ecclefiaft.

Opere Genuina funt: Homilia 9o in Hexäeneron--in--In Pfalmos Homi-

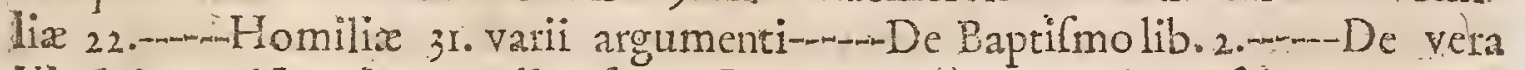
Virginitate ad Letoium Melitenf-- - Commentaril in I6:priora Ifaiz capita--.-m Adverfus Eunomium lib.s.----Ad Amphilochium de Spiritu Sancto-...-Sermo de Abdicatione rerum-ar-De verâ ac piân Fide-_-Procmium Ethicorun de H.h. judicio 
judicio Dei-Ethica feu Moralia_-Afcetica, feu de Inftitut: Monach.Serm. 2a - Regula fufùs diffutatx - Regula breviores - Conftitutiones Monaftic Epiftola ad Chilonem Anachoretam-Ad Monachum lapfum, \& Virgin. Lapf. Epift.3.-Ad Amphilochium Epiftolæ Canonica, 3. - Epiftola alia 428. Liturgia, fed incerpolata - Conciones Morales 24. Ex Bafilii libris ser Simeonern Logotbetarn felectx.

Opera Suppofittitia: Homilo 10.\& nn.î̉ Hëxämeron-De Grammaticâ eäer citatione Libsllus ( revera Mofchopuli) - De Confolatione in Adverfis, Lat. De laudibus eremi, feu vite folitaria ( fragmentum ex opere Petri Damiani) Admonitio ad Filium Spiritualem, Lat, - Precatio cüm facris operateturFragmentum Epiftola ad Julianum Imp.

Vir eloquentium preftantifimus , \&inomni doctrina genere fummus.. $D$ H ieronym. in catal. cripe. Ec lefiaft.

Fidei columen, veritatis norma, \& Eccléfre formas pléna prudentize canities, fidelis fervus \& magnus lontifex; Dei, hominifiue mediator; Spinitufque Sanci: Domicilium. Greg. Nazianz. in Epift 28.ad Sirnplicianum.

Vir divinus \& Sacrolanctur, orbis oculus, magna vox \& tuba,doctrinx $P_{a}$;latium, Sol inter Sidera. Greg. Nazian. in Epift. 10. ad Bafilinm.

Os Ecclefia, , aurea doctrinaluf́cinia vocatur Gregorio Nyfleno in Encomio, Ephrem.

Prefulgidum lumen orbis univerfi. Theodoret. $1.4 \cdot 4_{0} \cdot c_{0} \cdot 3$

Baflitus vir doctus atque fanctiflinus, tantie apud Grecos auctoritatis extitito ut ejus doct ina vel foriptis nemo unquam quantumliber fciolus in aliçuo conmadicere aufus fucrit. Trithem.

Baflius Cefarec Cappadocum Epifcopus is , re \& cognomine inagnus. Jure Ghrifianormm Philofophus \& Philofophorum Chritianigums dietus eft. Sixtus Seneyf. 1. 4. Eibliotha

D. Baflitus vir optimo jute dictus Aagnus, fed Maximi cognomine dignior - Equidem contumcliam elfe judico, Baflii facundiam cum quoquam eorum comparare, yuoum cloquentiam fupra modum admirata eft Gracia, juxta modum amulata I talia - In Bafilio nefcio quid morofulus ctiam lector polfit defiderare. Manat è fanctiffimo pectore, cunctifque humaniscupiditatibusj defacato, fimplex ac naturalis oratio. Preftuntur omnia qua poteft ars nec ulla tamen ufquam artis fignificatio: Agnofcas ibi fummam mundana Philofophice cognitionem, fednullam profus oftentationem. Sentias illim callere difciplit nas liberales, \& in his Matbernaticas omnes, fed fic alhiberi, ut nihil aliud quà ancillenturt pietati. Erafm. Epint lib. 28. Epift. $7:$

Opus Hexaëmeron dictum, afque adeò admiranda diction is curâ \& oratio ñis majeftate clabolavit, ut Gregorius $N$ azianzenus non immeritò dixerit tantum Baflii orationem onnes hominum Sermones antecedere, quantum divina vox bumanas. Rivet. Tom.2.

Hic plurima fcripfit:inter qux maximam admirationem hominibus movent

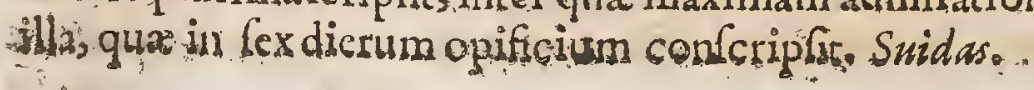


S. Bafilizes Sando Joanne Chryfoftorro fubtilior eft in Homiliis quas's in Cü Creationis Mundi dies confripfit., eafque in Eruditorum gratiam magis quàm ad plebis infticutionem adornafe videtur. Sxpius tamen Textus literam explicat, "\& aliquando ufque ad Grammaticum fenfum dsfcendit, precipuos notando modos quibus vocabula Graca \& Hebraica verti polfinte Graci patres hoc Opus mirati Cunt, Gùm ob Authoris Eloquentiam infignem, tùm ob eruditionem quandain quàm S. Bafilins affectâfle videtur. In illis Homiliis Orator perfectus, potiùs qutàn Sacri Textês Interpres obfervatur : Qua methodus plerifque Patribus communis eft, praefertin verò Gracis, qui in fuis Sermonibus catcris multò diffufiorés funt. Exundem ferè characterem fuis ila aliquot Pfalmos Homiliis fervat; ubi quídem tanta erudititio non clucet, fed frequentiona funt moral ia documenta, proptei Argumentum quod edifferit. Literalem fenfuum magis lequitur fuis in f faiars Commentariis, licet digreffiones quardam colsineant \& circamoralem ferrfum copiofiores fint. Faretur hic Patcrneminem Seripturam Sacram intelligere soffe viff plures antos imo totam vitam in cjufmodi ftudio fefe priùs exercuerit. Cxterum in hoc Commentario non apparet eruditio illa quam exhio bent ejus in Hexaemerum Homilia, quia gravius eft argumentum. Videtur è contrà meram affectâfle citationem vatiorum Scripin loco locom qui in xoto illo libro utramque paginam faciunt. R.P. Richard.Simon, Hift. Critic. Veteris Teftam. lib 3 cap. 10. Gall.

Nulli Authores cxtant quorum Scripta animos altius penetrent quàm $D$ Ba* filii. Omnia tam ad vivum defcribit, tanta vi rationes fuas explicat, tam horrendas vitii picturas dolineat, 'ejus ad virtutcm hortamenta tam efficaciter perfuadent, ejusdocumenta ufque adeò ampla \& utilia funt, ut ejus fripta legere nemo poffit quin fe erudiri \& perfuaderi de veritateperfentifcat, \& quin amorom erga virtutem \& adium adverfus vitia concipiat. Sermones ejus fententir's vacui, verbis vero pleni inonfunt, ut Oratorum plerique fermones. In illis eloquentia doctrinam comitatur: pariter erudiunt, delectant, \& movent. Dictio ejus rerla eft \& cmphatica Sublimiter fenfa fua enuntist. Stylus cjus purtus eft, elcgans:\& ad perfuadendum efficax. Ejus Oratio nativa, lenis \& inaffectata femper deprehenditus. Jucundè perfuadet, tam perfpicùè res explanat eafque aded verifimiliter enunciat, ut, cruditi Photii judicio, cum nobis proponere poffimus in Exemplar Demaftbene ac difertifimis Oratoribus Antiquitatis haud longe Inferius. Fmò, fi Erafino fides adhibedtur, Veteres Gracia Oratoresaitrecellit eorumque vitiis caret. Ad omnigenas compofitiones aptus erat. Ejus in :cripturam Commentarii maximè inftitutivi \& genuini funt. In $P$ ane $y$ yricis cximius eft. Ratiocinii ejus vis" \& acumé in ejus tractatibus de Controverfifis cernuntur. Ejus Morales fermones ad inftitutionem \& affectutum motionem apti funt. Denique licet ejus Afcetica ftyli æquè magnifici non fint ac alia cjus cripta, non illis' minùs tamen pura \& terfa dictio cis incef. Methodus tamen in qua ir ufus eft eadem fubobfcura quandoque reddit. Ello du Pro. Nov. Bibl. Aüthot Ecclefartic. Tom.2. p. $596,58 \%$ 
Baflius preftantiflimus eft in libris omnibus. Purấenim dictione "fignificante, propriâ, \& omninò civili ac Panegyrica, frequis alius, uti novit: fen fumque ordine ac puritate primus, \& nernini fecundus, apparet. Phot.in Bi bliorh. Cod. CXLl.

Vir fuit clara ac perfpic cis Apprehenfionis, promti \& acris ingenii , acute Colertis ratiocinii s profundi folidique judicii : Acquifitæ ipfus dotes oppidò adaugebant nativas cjus perfectiones, iifque fplendorem \& önatum incomparabilcm addebant. sicut ćducatio felix ei non defuerat, , fic nec indutria nec fedulitas ad ejufdem ufum eo defiderabatur : Herum ope Doctor eximius brevi evalit \& ad fummum omnis politici utilifque eruditionis faftigium brevi: cvectus cft, in qua nihil fibi impervium reliquit: \& tamen in fingulis ita verfa tus erar çcicntiis ut quifpiam alius in, harum nnica, ck̀m in qualibet Arte non: minù accuratus effet quam fi ei loli operam navalfet. Eminebat in Grammaticis, Rhetoricis, Philolophicis, Antonomicis, Geometricis Arithmeticis, Phy, ficis, \& quibus non ?. Omnes Gentilim Thefauros expilaverat, fearetionefque Philofophica fecularifque Doctriiz rccellis rimatus erat; Cujus refpectu, Philoforgius ait, \& forfitan verè, Athanalium pre illomerim infantern fuiffe. Ejus: fylus \& fcribendi modus mirifucus cft ac fere inimitabilis; proprius eft; perf picuus, emphaticus, dulcis, lenis \& facilis, \& tamen energeticus \& ad perfuadendum efricax, \& abiplo fluens cnm nativa \& inaffectata venuftate ac fuavi-

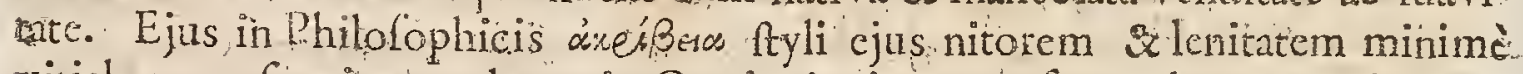
vitiabat;nec fuavitas ac elegantia Orationis cjus nervolum robur a evidentiam? Algumentorum infumabat. Cave in Vit. S. Bafilit p. 262.

Baflii Opera omniá prodierunt Grecè \& Latine, Tom is z. Parifis , Fol: ann. 1638 .

Adcommodiorem Operum: $S_{\text {. }}$ Baflit intelligentiam nonparum conferet Fro. Combefis Baflius refitutus, in quo ex optimis MSS. textum eaftigavit, auxit, ils.

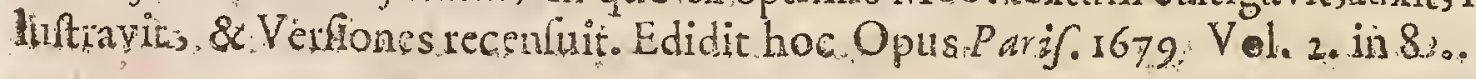

\section{S. GREGORIUS NAZIANZENUS}

Cax Ognomento Theologus, Nazianzi in Cappadocia natus, Atbenis operams Ces axx. dedit fub Libanio aliifque fophitis, cum Sancto Bafilio, circa ann. $354:$

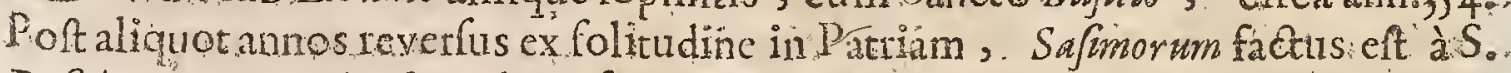
Bafi to tum Cafarierfi Archicpifcopo Epifcopu c, quibus relietis vivo adhuc patre adminiatavit $N$ aziaszenar Ecclefram, undé $N$ azianzeni cognomen ei adhæfit. Inde Walente Augusto Arianorur fautore mortio, Confant inopolim venit ann. 379. Ubi paftorali per aliquod tempus functus officio, occafione citatorum a Timotbo Alexandrizo Patriarchâ alifque pixfulibus tumultum in Concilio CF. Generali fponte receffit $N$ azianzum an 382 bi ique plenmque ruvi vixit, úf

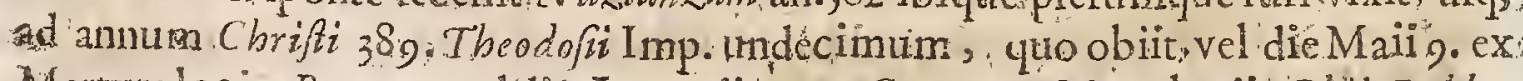
Martyologio Rosano, veldié Januarii zs ex.Gracorum Menologiis.Phil.Labbe. 
Opera Genuina plarima Cuut:

Opera Dubia funt:- Oratio feu Epiftola ad Evagrivan Monachum de Divinirate--.-fignificatio lin Ezechielem.

Opera Suppofititia fune: Metaphrafis feu Tranflatio in Ecclefraferem, quam Gregorii Thaumaturgi opus elfe conftat - Chrifus l'atiens, Tragcedia: quam ab: Apollinare Laodìno foriptam effe verifimile eft. Gul. Cave.

Vii fuit omnino divinis humanifque liceris folidiflmè imbutus, atque fi unquam apud homines talis exiftere debuit, effigies quædam atque omnibus vistutibus contans columna: Sim Metaphraftes.

Gregorizs os Christi \& vas Electionis vocatur Baflio.

Virper omnia incomparabilis, verbo \& operibus clanus Ruffin

Columna aured \& totius Ecclefie fundamentum. Eufeb.

Ab omnibus Grecis ob fingularem autoritatis fua excellentiam, primus polt

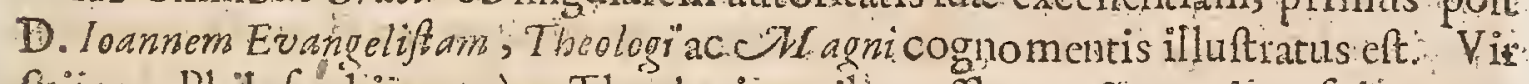
fuit tam Philofophir; quam T hcologixopibus affluens \& omnium fui tempom ris folutatane pedettri oratione eloquentilimus : quippe quil Polemonis Ladin ceni, Sophifte celcbratifimi, fublimem dicendi Cothurnm efictaflecutus. Hic

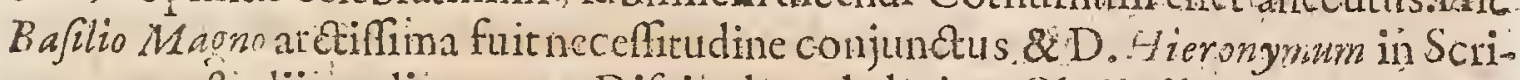
pturarum fudiis auditorem ac. Difeipulim habuit. Obtinuit etiam in Ecclefa Gracha, tantum authoritatis pondus, ut quicunque teftimonio ejus refragarianderet; ftation vel Hareticus haberetur, vel Horefeos fulpicionc notatetus. Sixt. Senenf.1.4. Biblioth. Sanctx: p. 209

Tanto attem tum vivens, tum etiam pof mortem nominis . Cléndose effulfit. \& gloriâ, ut tam Græcorum quàm Latinorum praconiis slebretur: quem \& reveriti Gunt \& laudavérnnt etiam Ecclefiz hoftes, wt inter alios Euforgizs, . qui Baflio atque ApollinariGregorium prafert: $B$ aron. ad ann. 389 .

In Gregorio Nazianzeno pietas propemodum ex a xuo certat cum facundia Sedamat fignificantes argutias quas co difficilius eft Latinè reddere, quòd plerąue funt in verbïs fre. Tota verò Phrafs nomihil accedit ad ftructuram I I ocraticarn. Adde quod de rebus divinis, qux vix ullis verbis hamanis explicari? polcums libenter ar frequenter philolophatur. Erasm. 1.26. Epift.33.

$G$ regorius multa feripfit, in quibus. fapientian cum Eloquentia minfice copuAvit: Bellarm, de Script. Ecclefiaf.

Gregorius $N$ azianzcnus dictus. Theologu, humanx \& divin: Sapientix The farus: Ioan.Card: Bona.

Pbiloforgins ait, Apollinarii Sermonem Conmentationibus effe aptiörem; Bafi lii in genere Pangyrico [plendidifimum; At Gregorii cam utroque comparata oratio, fublimiorem in feriptione locum obtinuit. Etenim Appollinario erat ubo sior in dicendo; Baflito verò gravior.

Ex Erafno, Billio, Baronio, aliifque retundas implamm os Martini Clemnitio Ientherani, qui up. 1r. Theol. J efuit. doblaterat $N$ azianzenum Apoftrophis fuis Horidis magis \& Retoricis, quà Theologicis, occafionem dediffe multis fuperititionibus. Labbe de Script. EccleGaA.

Hb: 3 Da 
De Facundire pixmio cum Authore illo difceptarenemo poteft. Pálmam dú bio procul omnibus fibi cozvis preripit., vocabulorum puritate, elocutionis nobilitate, fermonum ornamentis, finilitudinum concinnitate, ratiociniocum - prafantia \& fententiarum fublimitate. Sanctus Hzeronymus \& Suidas Veterum guendam nomine Polemonem illum fuife initatum tradunt; Sed afterere pofCumus ftylum ejus I focraticoproximum elre. Quantumvis fubliais s nativus tamen ef, lenis \& jucundus. Plenæ funt ejus periodi $\&$ ad fanem ufque fibi finiles. Verborum mira eft ei copias nec in elocutionis facilitate, modoque jucundo párem ullum agnoficit. Ejus Orationes arte ac methodo exquifita compofita funt: Character carum tum Argumento tum Auditoribus ejus conveniens eft. Deni-que cenferi potelt pexfectiflinis Gracie Oratoribus annumerandus. Nimium ta-

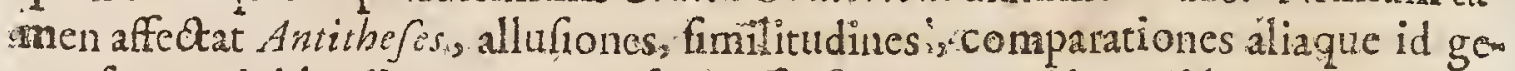
mus fermonis blandimenta quxipfum effominatum reddere videntur. Imo talfum ejus fententiis \& ratiocinis quandoque fuberte depichenditur, fed quod clocutionum ejus pompa velatur copiaque verborum ejus obvoluitur. Admodum prolixus eft \& pauca Periodis pluribus effatur. Eludu Pin, Nou. Biblioth. Author. Tom. 2. p. 655 .

Costeionitons ejus plures Philolophicx lententia admifcentur, \& Hiftoria $F$ a bulaguelocis referta funt. Moralem dodtrinarmeo modo tiadit qui Philosoph:rurr magis quam Populi captui accommodatus eft; verumin Mysteriorum

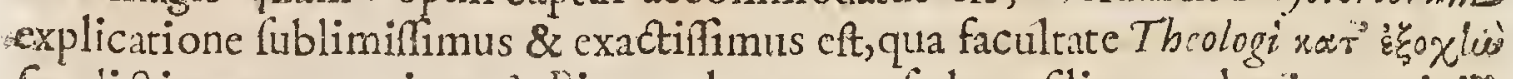
fic dictinomen meritus ett. Pietate clarus erat, [ed confilio, prudentiaque civili ad ies gerendas parum: álebat. I dern ibid.

Fuit (ne plura dicamus quàm de ipfo dicit Baflius Epirt. I 4 I. pag. I6j. $)$ dus \& Os Chrifi; jureque meritus eft Characterem quo Ruffnus ipfum inf-

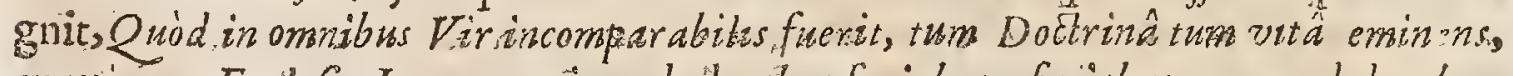
maximum Ecclefe Lumen qui quod docebat faciebat. faciebatque quod dor ebat. Divina hujufmodiac pratantes qualitates tipábantur Naturatibus Dotibus rublimis Ingenii, fubtilis Apprchenfonis, fani Judicii, facilis expceditxue Elocutionis : -Utrafque tandem ornabant torum ingens illud peculiam toraque praclara illa Lupellex Eruditionis humanx qua in Oricntalibus Schotis, cujufmodi crant Alexandrina, ipfaque Atbenienfis comparari potcrant - Omnes ejus Sermones mirificè fuavem quendan Gravitatis'\& Pictatis odoxem fpirant: Vixque dici potêt an ejus Eloguentian, an verò cjuś Santimoniam magis mirari quis debeat. Sttpendum modum argutx atopue Laconic funt ojus periodi ; Succinet $x$ ac expeditx funt ejus fententix, licet abundautem Sensûs incomparabilis copiampaucis verbis in fe contineant; Nec tamen aut Periodorum ejus brevitas Argunenticjus preftantix nocet, aut ejus Argumenti fublimitas Sermonc ejus obfcurum intellectudifficilem reddit. Quodcumque Themacdifferendu affumeret five in Perfuaforio, five Encomiaftico, five Forenfi gencre, mun muod-que perfectiffmè femper in fuo genere tractabat, raro aut nunquam infia folifam Sermonis Cui majeftarem \& Lublimirarem defcendeude. Hinc eft quod in alias 
alias linguas vix ac ne vix quidem verti poffint ejus : Tractatus, accuratione ali= gula quxe cum Autographo ullam proportionem fervet; Adeo ut Erafmus qui Occidentalem Ecclefiam infuitè fibi demeritus eft: fuis :Véterum Patrum Emendationibus \& Verfionibus, ingenue confeffus fit fe ab aggredienda Nazianzeni Translutione funul deterreri \& animum defpondere ob ftyli ejus acumen, Argun. menti :magnificeniam \& fublimitatem, eafque fubobfcuras allufiones quibus Scriptz. jus frequenter inserfperfa funt. C'ave in Vita Greg.Nazanz. pas. 334.335. Angl.

Prodiérunt:Gregorii opera omnia Gracè \& Latinè cum Commentar iis Græsørum Nicetx Serronii, Pfelli, Nonni \& Elix Cretenfis, ex Interp. Jacobi Bilt; Tom. 2. Parifis apud Claudium Morellium fol.an. 1609.

Brodietunt verò eadem Grac. Lat..Vol. 2. Par. 1630.

\section{AMBROSIUS}

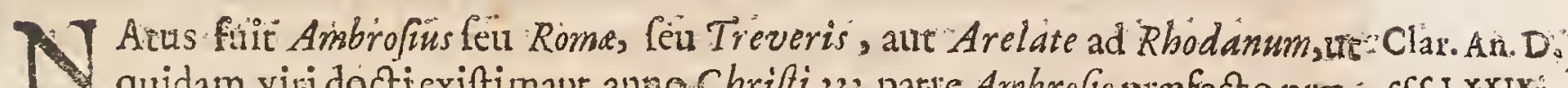

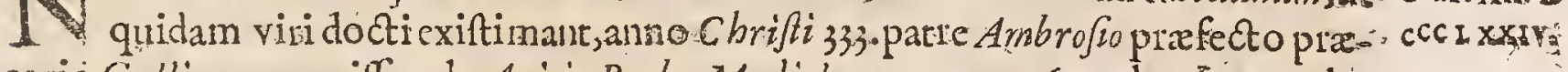
sorio Galliarum, miflus ab Anitio Probo Mediolanum anno 369 . ad gubernandas Infubriam ". Liguriam, atquere Emiliam o" poft mortem e A uxeniti Heretici" Ariani creatus conlenfu omninim Mediolanenfis Archiepilcopus \& confectatus: die 7. Decembiris anni $374.0 \mathrm{mnenr}$ ad fidem rectam convertic Italzam, utad annum Cbristi 375. Olympiadis 288. tertium, inquit in Chronico Saricus Hierco. nimu Ad Maximum tyrannum bis inGiallias legatus profectus eft annis $383 . \&$ 387. Dein, ne plúribus in percurrendis ejus praclarè gettis immorer, gloriofis pro Ecclefiầ Catholicầ perfunctus laboribus, fanctifime obiit die 4. A prilis Sabbato fancto fub diliculum; fetl, quod idem eft, pridie Pafchatis', quod. iii Nonas Aptilis incidit anno Chrifi 397. Cafario \& Attico Coff atatis 64. Epif copatus 22 cum quatuer circiter menfibus. PbiloLabbe.:

Opera Genuina plurima funto...

Opera hrec recenfentur inter Dubià : De Virginis formầ vivendi-me DeVirginis lapfu-Hymnialiquot--.-De-Diduis, liber...

Opera hac fuppofititia funt: Sermones de Tempore, \&e de Sanctis-m-Conció

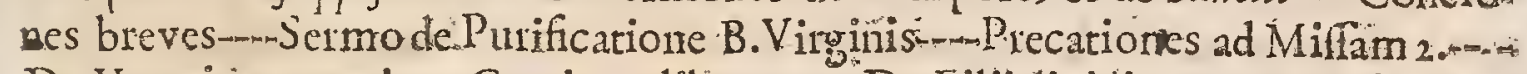
De Vocatione omnium Gentium, lib:"2.- - -De Filii divilitate, \& confub ftantialitate adverfus Arianos-In Epiftolis D. Panli commentaria-In A pocalypfim. B. Ioansis Commentaria - D.e vitionm virtutumque conflictu---Expofitio, Fidei fecundum Symbolum Nieranum - De Spiritu Saneto libeliti Erag-

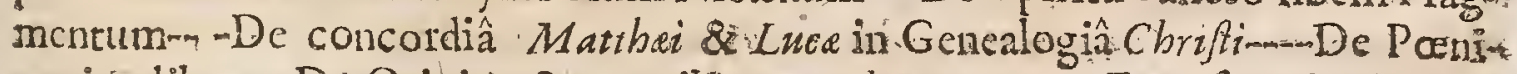
sentia, liber - De Origine \& noribüs Brachnanorum-Expofitio in Cantica Eanticorum-Epiftola ad Demerriadem.

Opera quanon extant : In Efram Commentarii-Commentari1-adverfus nonnullos Platonicos--Elucidationes \& Hornilix in Sapientiam - Expofitio îx.

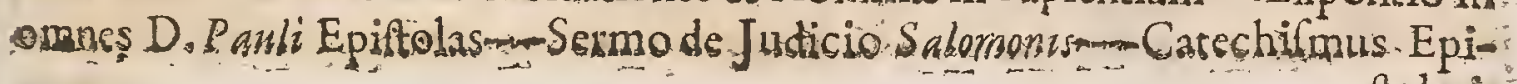
Atolu순 
Atolaris ad Eritigildem - De puerilis xtatis inftitutione ad Panfopliam. Gut. Cave.

Ambrofins Liguria \& Infubric primùm Prafes, dëinde verò Mediolanenfes Ecclefize Pontificatum divinitùs adcptus, ểinter fui temporis Epiifcopos: Fid ä Itabilitate, morum integritate, \& eruditionis admiratione excelluit, ut Imperator Theodofurs, virtutum illius celfitudine commotus, publice in fummo templo Conftantinopolitane Urbis exclamaveiit, Ambrofwirn novi unum quifolus dignè vocetur Episcopus. Sixtus Senenf.1. $4^{\circ}$. Biblioth.Sancta.

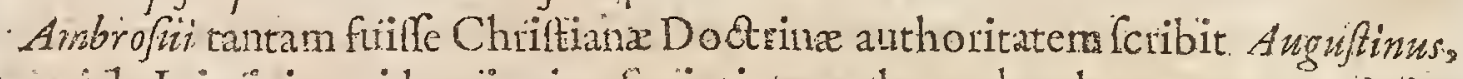
ut nec'ab Inimicis quidem in ejus Scriptis; quod reprehenderetur, potuerit inweniri.

Fuit veỉut Malleus Hzreticorum, conftantifimus impugnator, cujus Lingux in Fide C'brifil loquenti。 nulla potuit unquam auctoritus humana indicere filentitum. Trithem.

Adhuc audialium excellentem Dei Difpenfatorem, quem veneror ut Patrem: in Chrifto enim Iefis per Evangelium ipfe me genuit, \& eo Chrifti miniftro lavacrum regenerationis accepi : Beatum loquor Ambrofarum; cujus pro Catholicâ Fide Gratiam, conftantiam, labores, pericula, five operibus, five Sermonibus, iphe fum expertits, \& mecum non dubitat oibis pradicare Romanus. Anguftin lib. I. g. contraInizan. Pelag.

Inter prifcus Ecclefix Doctores Latinos, vix alium arbirtor effe digniorem, cujus extent integra Lucubrationes quàm D. Ambrofium. Hoc \& ex animo dietum videri vclim, \& citra cujufquam contumeliam. Sit Linguatum ac fcripkurarum peritior Hieronymu, fit elaboratioris phrafcos , tilaritu, fit in quattionum nodis explicandis argutior Angufinus, ałiis item dotibus excellue:int alii; fed quem mihi dabis, qui pari finceritate tracter facras literas, qui cautiùs vitarit -fufpecta dogmata, qui fic ubigue gerat Chriftianum Epilcopum, qui fic fpirct paterna vifcera squi fummam Prafulis Authoritatem cum fummầ manfuctudine conjunxerit? U Uique fentias hôc illsm affici quod loquitur, \& adert dictioni modefta qưædam ac pỉa jucunditas, grataque civilitas. Eft quem omninò fine cansâ Doctorem Mellifuum vocant. At hic, juxta nomen fuum, verè colefti manat Añbroffià, dignits qui fit, quod dicitur Ambrofint; hoc eft Immortalis, non folùm apud Chriftum, verùm etiam apud homines. Erafro. Epift. 1.28. Epift.3.

Hlid.confitendum, at non improbandum, quod pleraque qux icripfit Ambro fous, haufit è Graconum Commentariis, prafertim Origenis, led itas ut quod fa-m num effetexcerperet, quod à funceritate doctrine Catholicx alienum aut conxentiofum, difimularet, nec errorem proferens', nec atctore!n prodins, quorum alterum non crat tutum, alterum invidiofum Idemibid.

Dicendi cliaracternec flaccidus eft, nec humilis, quo riomine tarare videtur libellos.de Spryitu Sandzo Hieronymus, excufante Anguflizu, quò rem licèt grandem tameri fibtilem docenti, rion laudanti conveniret orario demiffior: Sed han bet interim fuos aculcés, ubi res poftulat, propiùs tamen accedens ad argutam.

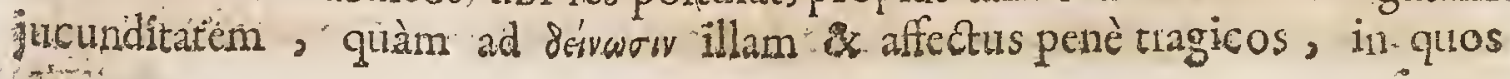
tr... interm 
interdum exardefcunt Hieronymus \& Hilarius. Ac plerunque totus fere Cermo ex variis fententiarum gencribus, velut ex teilellis, contextus eft, quo dicendi genere fupra modum delectatus videtur Seneca. I dern ibid.

Videtur nectarc \& Arnbrofia inuutritus. Tam fuaves habet s tam argutas ple-s runque orationis delicias, ut apes, qua infantuli cunas \& os circumfederunt. credas adhuc in ejus labellis feTrare. Nic. Canfin.

Arnbrofus firmiflimum Ecclefia fui temporis colinnen, ne ipfe quidem omni planè errore cartit. Cum Filario confentit omnes in univerfum ignis exament fubituros, juftos inde liberatum iri, infideles in eo aternum manfuros furtectionem verò mortuorum non fimul \& femcl futuram arbitrantur, fed paulatim longo \& ftatuto ordine, ità quicrediderunt primi refurgant, pro meritorum ratione. Dallous de vero ufu Patrum c.4.p.270, 27 r.

Arrbrofum Hieronymus multa palfim ex Oriqene, Hypolito, $B$ afolio, forfan $\&$ ex Didymo, Raymundus etiamex Philone defcripfirle produnt. Imo Sixtus Senen/is Anbrofii Hexä̈meron nihil aliud elfe ait, quän ipfur Bafilii Hexaëmeron Latinè verfum, iifdemubique fententiis ac verbis, tranjpofitô tamen linearum ac sententiarum quarundamordine atgue additis zel ex Hypolito of Origene, vel ex alio guopiam, vel de fuo fortafje nomullis digreffinculis. Thornas. de Plag. fect. 355 .

Ejus Eruditio plus elcgantiz quam profunditatis hab:bat ; quoniam aliqualem Platonica Pbilefothic peritiam juvenilibus annis ab ipfo comparatam haud mediocriter orabat Gracanicæ Linguæ \& Eruditionis notitia. Cùm Epifcopatum adcptuset, in Theologicis fpeculationibus parum verfatus crat, in quarum profecutione tam celerem progreffum fecit ut numine colitus afflatus videretur. Concionator apud alios evafit dum merus difcipulus in fe adhuc erat; Docere roicapiquodipjenon didici, hai ejus confffio fuit. Eodem tempore doccbat \& difcchar: Se ipfum infermabat, dum alios intitucbat. Quamviscum Grecorum Patnim fcriptis magnum haberetcommcrium, conumquc qui aum dacifimè \& fidentifimè locuti funt, omnia tamen fufpecta miniméque outhodoxa dogmat fedulo vitavit. Noxias prateribat herbas, Florefque folos colligebat, pretiofum à Vili leparans, Theologicalque doctrinas cum maxima mentis Scrupulofitate \& fincerifima reverentia erga notam \& receptam Ecclefix doetrinam tractando.

Varius eft Stylus cjus pro Argumentorum de quibus agit varietate, gencratim tamen concifus \& argutus, seneca ftylo valde fumilis, fed paulò mitior \& lenior. Sermones ejus conflati funt ex rotundis fententiis, argutis dictis, concinnis Tranfrionibus, \& Argumentum fum acriufcula quaquam claufula terminare folet. Verum eft quod ftylus ejus comptulus fit potiùs quam clegans. Peliodorum ejus brevitas \&acumen voluptatem afferunt, \& aliquid pungentis ac delicatifaporis in Lectoris animo relinquunt, imo femper aliquid intelligendum, quod aut verbis non expreffum, aut obfurè tantum infinuatum fuit. Operacjus ( ferè omnia manu propria exarata nifi fuperveniente invaletudine ipfrabducerentur) funt vel Trackatus feu libri in peculiaria quadam themata 
confcripti; vel Homilix; vel Epiftola;vel Commentani. Inter ejus. Traftatus quida: funt de quibus ei exprobratur quòd nihil fermè fine quàm meræe Tranflationes è Gracis. Sic B. Hicronymus dudum oblervaverat circa Librum cjus. De Spiritu S. ęuod fere omnia ex Didymi libro in idem Argumentum mutuatus effet \& in iis. vertendis detcriora feciflct; quòd frequenter $G$ racos Patres tranfcribat,prafertim Origenem. Non eft diffitendum quin Gracorum Patrum. Scriptis crebrò utatura Nec mirum eft quòd vif qui ad fudia:Theologica ferò fe accinxit, aliquantò magis folito in fubfidium advocet illos quî iplu in antecefferunt, \& quòd hic qui Ldiomatis Greci callentifrmus crat Orientales I hefauros in lagas Occidentales conveheret, non Cemper facta mentione peculiari Portûs unde cos aranfvexilfet. Nemo, quod in hanc rem optimè oblervat Erafrrus, Ciceronem culpat quodin Platonicis Libris adeò veriatus fuerit, \& in propria Scripta bonam I hilolophix fire partem hinc derivaverit. Notiones funt Plaronica I ullianis ornamentis comptx imò nec indecorum hoc eft plagium, fed defenfione non. indiga imitatio. Monendi etiam fumus quòd dierorymus non mediocri fimultate in Ambrofmm affectus fuerit, de quo etiam halid frequenter officiosè loquitur. Hieronymos impotentis animi vii fuit, qui multum fibi arrogabat \& qui rarò gloriofum Characterem tribucbat ils à quibus fe vinci putabat. Quamyis alibi honorificam ejus nentionem faciat, dicens quòd cum Mcdiolanenlis Epifcopus. factus fuilfer, univera i talia mox ad Latholicam fidem adducta fuerit cave in. Vita S. Ambr.fii p. 419,420 .

Ambrofun--..-Vir fummâx pietate, omnique virtutis genere verrerabilis; inyictianimi Prælul, qui Judæis, Gentilibus, \& cujufcunque generis Hæreticis animosè reftitit; literarum Græcarum xquè ac Latinarum peritilfimus; unde è Scriptis Patrum Grecorum, Origenis puta, Didymi, \&c. hortulos fuos largiter inrigavit: in hoc landandus, quod fuppreflis loliis lores decerpferit. Stilo ufus et concifo, arguto, teffellato; \& qui Senecx facundiam, molliori tamen ven $\hat{a}$ imitatur. Gul. L.ave in Hiftor. Literar. Script. Ecclef.

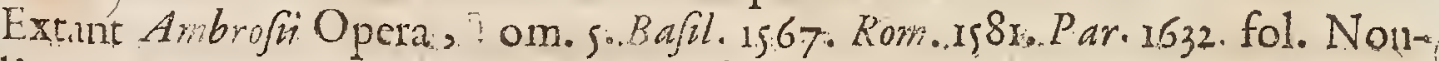
nullis etian videcur Arnbrofus effe auctor librorum De Excidio Iisdcorum, qui. fub Hegefppi junioris nomine circumferuntur, faltem fcriptor ifte crat Anbrofla. Júgxpov.G. Extant hi Libricum, Scholiis Gualteri, Col. 157.5 . in $8^{\circ}$.

\section{S. GREGORIU:S. NYSSENUS。}

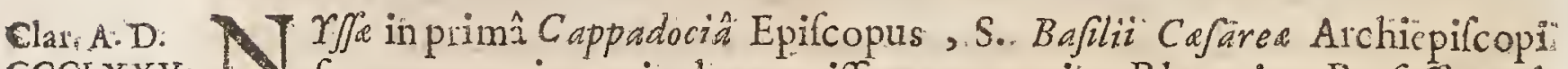
CGCLXXV: I frater natu mino",vir cloquentifimus, ut qui ex. Rhetorices Profeffore ad ad curam paforalem traductus fuiffet fub Valente Imp antequam S. Gregorins Theologus Safrnorum fieret Antiftes, ut ex ejus orationibus conftat. Interfuit Concilio Conftantinopol. Generali anno 38r.vivebatque adhuc anno 392. Theodofii Imp. I4. obiiffe tradunt alii anno Chrifi 39.5 alii lequenti, vel die 9. Martii, ut-Latinum Martyrologium, vel. g. Januarii,ut Faftis Gracorum adfcriptum legitur. Labbe de Script. Ecclefiaft. 
Opera Genuina varia funt.

Opera Spuria: In mulierem Peccatricem, \& eos qui durius alios judicant. de Penitentiân-Oratio in Principium Jejuniorum. Duas iftas Orationes Afterit Amafeni elfe patet ex Pbotio Cod.27-De Trinitate adverfus Judzos. ex Veteri Teftamento deleà Teltimonia-men-De Naturâ Humanâ libri 8. quí Nernefiifunt.

Opera Deperdita: Expolitiones in Proverbia-__-Contra Ablavirum de Patris, Filii \& Spiritus Sancti Divinitate; nifr quis forfan ex Argumenti affunitate furpicetir idem efle Opus cum libello ad Ablavinm, qui cxtat-m-Commentarii in Epirtalam D. Iauli ad Philippenfes. Gul. Cave.

Gregorius $N$ yfenus, quem Graci honoris cansî Patrean Patrum appellant. Academicis ac Peripateticis difciplinis excultus, vir clouguentix nervola ac prellix. Sixt. Senenf.

Gregorium veneranda Ecclefix antiquitas eximiè coluit laudibufque extulit, quem feyuentibus freulis Theologi , tam Graci quam Katini ad confrmanda orthodoxa fidei dogmata teftem certifimum adhibucrunt : Quippe qui in is qure ad fidem pertinent, nullâ in re à Baflio, ut inquit etiam Cardinalis Bellarminus, diffenferit. Oudin in Supplcri. de Script. Ecclefiaft: à Bellarmin. omiff.

Leo Imp. Confit. \&s vocat ipfum dulcem \& illuftrem Ecclefie fontem.

Suidas hominem eloquentifimum, \& multiplici eruditione præftantem.

Summus evafit orator, nec prifcis oratoribus inferior. Nimium tamen cjus cultum Rhctoricarum dilciplinarum reprehendit Gregorius Nazianzenus aure $\hat{a}$ planè Epiltolâ câ de re ad illum fcriptâ quæ clt numero 43. Intcrfuit Concilio Occumenico Confantinopolitano, inque co fcripflfe fertur à Nicephoro lib. Iz. Hiftor.c. I3. \&aliis, Libellum Fidei five Symbolism dictum Confantinopolitanum. Quenfedt.

In divinis $S$ cripturis admodum ftudiofus \& cruditus; provocatus ftudio fraEris Baflii. Tribibetn.

Sciunt omnes eruditi Gregorim Nyffenum inter Grece Ecclefa lumina cenfw tum cum paucis. Dignum Baflio fratiem: dignum fodalem Nazianteno. Montacut. Apparat. 9. scet. 10 .

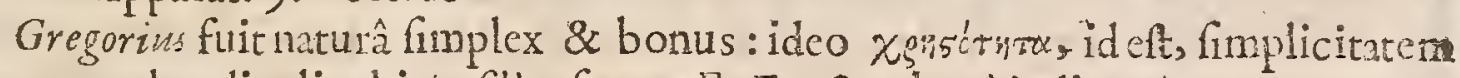
ejus reprehendit alicubi baflizu frater. Et Erafwa bonè judicat; in Stylo groque piarn firbplicitatern NVigerio placuifle. Abrabam.Sculter in Medul. Patrum.

Lcetus eft Gregnrii $N$ y Jja Epifcopi fmiliter pro Raflio adverfus Eunory tum liber. Stylus illi, ficui Rhetorm, illuftris, \& jucunditatem auribus intillans. Sed nce ipfe quidem, ordine Emnomii fcriptum reprehcndit. Quamobrem \& Theodoro concifior eft, \& Sophronio latior, abundat enim Entbymemats atque Exersplis. Illudautem vere pronunciaverim, quantum Gregorius venutate. fplendore, \& mirificâ jucunditate antecellit Theodoro, tantum etiam argumentorum copiâ \& ubertate eundem vincere comititur. Phot. in Biblioth.Cod.6.

Lectum cft alterum ejuldem Gregorii $N$ yfeni opus de eadem ipsâ re: in que 
rarionibus validioubus cum Eunornio manus conferens enm vĩ expughat;omnia impictatis frmamentalabefactans. Venultas verò Orationis, \& fplendor jucunditate mixtus, etian in hoc opere decenter fe oltendit. Phot. ibid cod. VII.

Quamvis S. Gregorius $N$ yjenus Rbetor trampublicè profefus. fit, \& Photius: afleverct fylum ejus fublimem \& jucundum efle; dici tamen poteft eum à $S$. Gregorii N azianzen eloquentia longè abelfe. Affectata eft ejus Scriptio, ejufque Itylus minimè nativus. Declarmatorun potius quam Oratoratm more loquitur. Allegorics aut abftractis ratiocinationibus femper immerfus eft Philofophiam. Theologic commifeet, $P$ bilofophorumque principiis tetitur tum in Myferiorum explicatione tum in Moralibus fuis fermonious. Quapropter ejus Opera Traitatatibus Ariftatelis \& Platonis quam aliorum Chrifianorum fimiliora funt. Origenem in allegoria Lccutus \& imitutus eftimò aliqui ejuldem Awiboris errores in ejus. Operibus occurunt, circa natum Aminarum \& circa terminationerr Ponx damnatorum; fed illos aliis locis difertè reiicit \& r feclit. Valdè igitur verifmile eft locos inquibus. Origeninn errores illi leguntur, additos fuife. Eli. du Pir. Nov. Bibl. Aithor. Ecclefaficor.Tom.2.p.682;,683.

Gregorius Nyfenus Epilcopus, Bafliti naturâ quidem futer, difciplinâ verè filius : qui unà cum Ralilio videtur ab Origenis de Purgatorio ipfus gehennzigne dogmate non admodum abhowuife; idique fatetur Nilus. Theffalonicenfis Archiepfrapus. Germanus Epifcopus Confanrinopolitanus * quĩ Ano Dom. 680 . Horebat, tres, $N$ if ni libros hoc errore infperfos conced bat; fedeos ab Hiseites vitintos.fuife hailolabatur, non ab ipfo auctore ita feriptos: ; quod: ultimum en cortum effugium, qui ftulta \& ablurda percinacia fibi perfuadent, nihil à veteribus feriptum efle à prefenti ipforum fide alienum. Caterìm tam: multafunt, \& totis $N y / f e n i$ arationibus ita penitus infixa hujus deliril venena. at parum fit verifmile ea ab alià cfie quàm $a b$. Aulloris mente $\&$ manu. In aliis Origenern fequitur. Ioan. Dalleus de ufu PP. p. $269,270$.

Vir fuit cum ob Syli perfpicuitatem \& elegantiam, tum ob eximias fuas: dotes vitrague pictatem requè venerandus. Hand parum idoneo fuit loco in: Confirntinopotitan Synodo, cum in maximi inomenti Cafbus cjus fuffragium plurimifccerint Collega. Quwpropter cùm recelfara puabatur expofitoria Confeffonis Idei perfcriptio, prafertim in Articulo de Spiritu ancto, , ejus. adornandx curaci demandabatur. Hoc autem eft Conftu unopolitanum, feu, wt valgò inter nos yocatue Nicenum Symbolum. Caue in vita: Gregorii Nyffani Epilcopi:

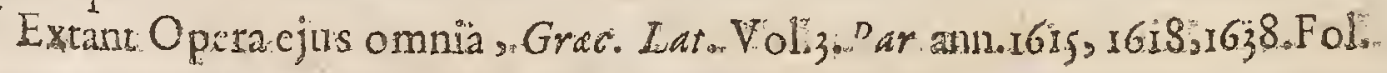

\section{S. HIE R O N Y M US.}

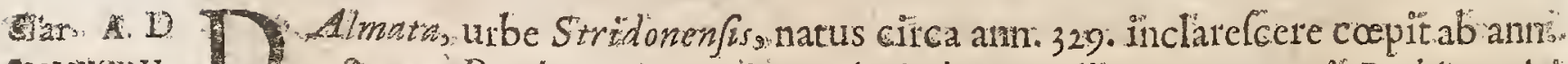
sens.XXY. 373. quo Presbyter Paulino Antiocheno ordinatus, cremi Beiblemetic inc ola factus ann. 383 . fcripgit catalogum 322, obiit Betblemi 420 . atat. 9 r. Gul. Cave, Chartophyl. Ecclef: 


\section{CELEBRIORUM AUTHORUM.}

Vii fuit in omni doctrinarum genere abfolutifimus. Quippe yui fplendore Cermonis \& eloquentix viribus, in quibus fub Donato Grammatico, \& Victorino Rhetore, clarifimis viris, profecit, omnes Latina Ecclefix fcriptores multo poft Ce intervallo reliquit. Linçarum qroque tantam habuit peritiam, ut Gracarn, Hebram, syam, Chaldadi Latinam omnes aquè ac Dalmaticam fibi ma vernam lingram tenere. Sed $\&$ in Scholis Fhilofophorum nihil de Arifiotelis, Platonic ac Zenonis, hoc cotade Peripatetucis, Academicis, Stoicis, reliquit inactum. Quibus inftu Cus apparatibus, contulit fead facrarum literarum Audia. ulus in his Apollinarz Laodiceno, Didymo Alexanórino \& Gregorin Nazianzeno præceptoribus. Sub quibus tantam fibi divinarum renm erudicionem, endior rionis.nomen comparavit, ut in obferis fanctorum voluminum difficultatibus: Komanus Pontifex Darnefu, doctinimus Augufinus, Paulinus, Chronatius $: H e-$ liodorus, multique aliipafim per Italiam, Galliam, Hipaniam, Africam, Palafinam Graciarn, eruditiaimi Epilcopi, ad huns unum confugerent, tantuam ad eum , quimultiplicilinguarum varietate adjutus, omnes legiflet divina: Scripturx interpretes, Gracos, Hebreos \& Latinos. Sixt. Senerfo Biblioth: Sanct.1. 4 .

Nec S. Hieronymim, quia Presbyter fuit, , contemnendum arbitreris $:$ qui: Grac \& Latino, infuper \& Hebran cruditus eloquio, ex.Orcidentali ad Oriene. talem tranfiens Ecclefiam, in locis facris atque in literis facris ufque ad dectepitam vixit atatem: cujus nobis cloquium ab. Oriente ufque ad Occidentem, inftar lampadis, refplenduit. S. Anguftin. contra Iulian.l. I.C.7.

Hieronymus Catholicomm Magifter, cujus feripta:per univerfum mundumi

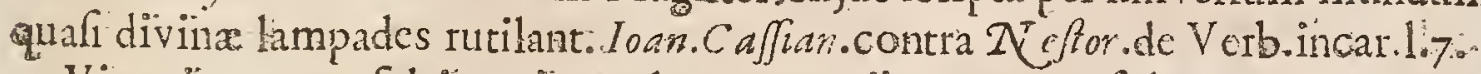

Vir enim prater fidei meritum, detemque viitutum, non folum Latinis atque Gracis, fed \& Hebrais etiam ita literis infitutus eft, ut fe illi in omni Scientia neino audcat comparare --.--Concivit odia perditorum. Oderunteum Haretzcis, quia eos impugnare non definit; oderunt Clerici, quia vitam eorum infectaturs, \& crimina. Scd plane eum boni omnes admirantur, \& diligunt" ; nam qui.eum Haretre:m elfe arbitiantur, infaniunt: Verèdixerim, catholica hominis Scientia, fana doctrina eft. Totus femper in lectione, totus in libris eft;non die, non nodte rcquiefcit; aut logit aliquid femper,aut faribit. Sulpic. Sener .in Dialog.x.de Viratibus Monachorum Orientalium.

Magnusmihï Auctor eft H ieronymus, vir in omnium temporum Hiftovii: Ferfatilimus.Grot.Vol.4?. Impreff.Lond.apud Mofern Pitt, in Fol.p. 489 ..

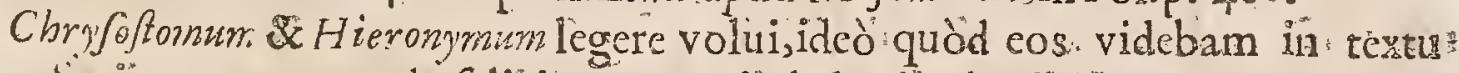
Grera Seripturae exponendo feliciores cæteris haberi. I dem ibid p.653:

Quantum in illo antiquitatis, quantum Gracarum literarum, quantum hiftoriarum ?:tum qu.x. Phrafis, quod dicendiartificium quo non Cbriftuanos modes omnes longo poft fe intervallo reliquit, verum etian cum ${ }^{\circ} f_{0}$ Cicerone certate videtur. Eraforn Lis. Epift so.

Hieronymum unum habet Ecclefialticus orbis,utrâque dọtrina Sacrâ \& Gentili, ut vocant.juxtd abfolutum, Idem l.q. Epift.1s.

I. 3 

Epit.8.

Quô virô nihil habet Orbis Latinus vel doatus vel fanctius. Idem lib. 28. His adde quèd confummatifimus erat Theologus, \& judice Erafrno' omnium Chriftianorum fine controverfiâ longè tum doatifinus, cum facundifimus, \& Theologorum princeps.

Caterum quod fanctifrmi viri pace dictum fit, prefervidi èat \& impotentis animi, qui affectibus fuis nimis indulgebut; femel laceffus , adverfa rios afperrimè traetavit, \&ab invectivâ ac Satyricâ fcribendi venâ vix ac ne vix temperavit. Teftes funt nobis fatis luculenti inimicitia, guas cum Rufino olim fibi necelfario, loanne Hierofolymitano, Ioviniano, Wigilantio, aliifque habuit. In hos arreptâ levi quavis occafione \& remetia omni pene gravitate, tota convitiorum plaulta evomit,nullâ perfonre, dignitatis, eruditionis ratione habitâ. Et quid mirumicum in jplum D. Paislum Apoftolum duran nimis \& planè infolentem cenfuram exercere folet. Quoties ipfum ad criticas Grammaticorum regulas anxiè expendit. Solnecifmor, \& vitiofarn elosutionern, \& quod fermone utztur triviali cbicicit, (ut Apologiam pro femetipfo hâc dere fcribere neceffe habuit: Nor, inquit, quotiefcunque Solocifrros, aut tale quid annotarns, non Apofolum pulfamus, ut Malevoli creminantur, occ )quod profundos fenfus aliena lingua exprimere non valeret, nec curabat magnopere de verbis, chin fenfum haberet in suto:adeóque non juxta bumilitatem, ut plerique afimant, fed vere dixiffe $P$ aulum Se fermone imperituri effe. Denique fultum cum fiultis Galatis fastum, fanpliciorio

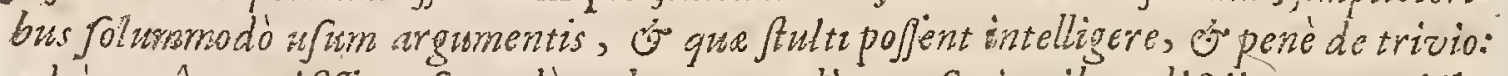

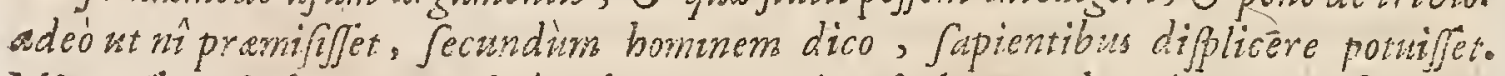

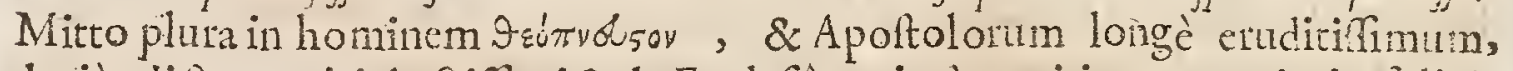
durius dictane viri doetiflimi \& de Ecclefià optimè meriti manes nimis folicitare videar. In hôc etiam reprehendendus, quòd dum Vhrginitutem immodicis prorfus laudibus efferat, de $N$ wotiis mints honeftè ac verecunde fentire videatur. Certè digamos tanquam fortis folummodò moliores facit, cum immundus Arcæ Nox animalibus \& ferpentibus confert, mulieremque fecundas nuptias repetentem,caniad romitum, fuique lotx ad volutabrum revertenti comparare non erubelcit. Sed quifque fuos patzmur manes. Gul. Cave, in Hiftor. literar. Script. Ecclef.

Latinos, Grecor, Hebreos, Chaldeos Scriptores plures evolvit,accurariùs excuffit,quàm eorum qui pof eum quifquan : nempe homo fummâ induftrià praditus, indefarigabili fudio \&r longâ vitâufus. Lud. Viv. de Caufis corruptar. Art. L.2.p.i31.

Hieronyras Doctor omninò Clarifimus, contra Hareticos leo rugiens, (hine juxta quofdan cum leone pingi folitus) \& commune totius Orbis ovaculum. Iob. Gottefrid. Olesir. in Abaco Patrum.

Nobis confat, Hieronymzsm omnium, qui olim interpretati facras literas funt, fuiffe eruditifimum, adeò penitùs pcrdidicerat Hebraijmman. Teir. Cunaw de Rep. Hebræor. p. 262.

Nihil illo viro eruditius vidit veterum atas, Idem $p_{0} 316$. 
Hieronymus, ut ubique vehemens ita in Eriftico contradicendi genere parum Interdum attendendus. Montacut. Apparat.9. Cect. 2.9.

Omnium traditionum curiofiffimus explorator. Idem.

Hic mos apud Patres frequens eft, maximè apud Tertulianum Ainbrofurn \& Hieronymurn, quicum ingenio fun fervido ac concitato, quam in partem propendent co tanto impetu feruntur, ut quos quidem laudant cos inter Angelos, quos verò vitupcrante inter Diabolos collocare videantur. Ita qua credenda pum tant non aliter commendant, quàm fi totidem effent Chriftianifmi fundamenta; quæ rejiciunc ac refutant, non aliter explodunt quàm fir merum. Atheifmum fpirarent. Dallens de uf! PP. $y$. I77.

Quicquid habemus in Daniclem, illud Hieronymo, debemus, hic verô: Porphyrio Chuiftianorum holti jurato. Hieronymus ron adeo doctus erat ac perhibetur; admodum ignarus erat; ad fuperftitiofas mulierculas fcribebat. Per nebulam tantùn Hebræa novit, quantùm edoctus à praceptore, nam Grammaticam nunquam liabuit, ufu didicit;-Hieronymus quamvis. Gracam Hebrai cam linguam bene calluerit, Biblia tamen fepius perperam interpretatur \& in telligit. lenaque illorum qua fcribebat non intelligebat, ut Serarius, fed bonus. eft quoad illa qua ejus revo gerebantnr-...-Melior est in iis quæ ad Ethnicos. fpectant quam in I heologicis. Nimis vehcmens, fuit, prefertim adverfus Iovinimmen \& Viglantium, quamvis immeritò, ut ipfe Erojmus id agnofcit-m-Quicquid dicat Hieronymus, eft Origeniftn or Miferrimè eft commentatus in Prophetas. rieronymu in Vettis. Teframentum multum laboravit \& non contemnanda dixit. Erat bonus Hebreus. Scaligerana polterior.

Patrum pott Origener doctifimus, eft dubio procul! S. Hieronymus, qui" Latinom Origenes quodammodo dici poteft; quia reverà eadem in Biblia Opera Ecclefie Latiria tradere affectavit, qua. Ecclefia Grace tradiderat Origenes. Imò in hos Origenem vince bat quòd $H$ ebraice $L$ ingue illo valde peritior erat, frequentiufque cum Indais fui temporis quàm ille commercium habuerat. $S_{\text {o. }}$ Hieronymus tamen adco fubtilis \& perfpicacis ingenii: non crat ac: Origenes. Unde etiam in allegorias \& in fpirituales fentus tam frequenter non excurrit; $\&$ : prætereacjus Allegoriz meræ interdum Etymologix meraque animi ex. allufone advoces oblectamcnt. Sed dici potefteum fupra creteros: omnes: Parres; ornatum fuilfe dotibus necellariis ad. Scripiuram Sacram xitè interpretandam; quia Hebraicam, Chaldaicom, Grecar \& Latinam linguam callebat: Non: modò legerat \& examinaverat Grecas Verfones qux in. Origenianis H $x$ a lis: erant, fed infuper cum doctiflimis fui temporis iudais fermones contulerat, nihilque ferè in Scripturam ipfis inconfultis faciebat. His addi poteft eum omnes Authores cum Grecos tum Latinos legiffe qui in Biblia ante fe fcripferant. Denique in profanorum. Anthorum libris verfatus erat; Adco ut dici poffit eum prax quocunque alio Patre iintructum fuiffe is omnibus que ad Sacrorum Librorum Interpretem efformandum conducere valent. Non eft tamen Semper accuratus., quia non fatis meditabarus 
batur \& quia plerumque Scribis Cuis tantùm dictabat, ut iple refert, quæ in aliorum Commentariis legcrat, aut quæ à I udais acceperat.Quapropter ipfr tribuenda non funt quxcunque in ejus Commentailis occurrunt, ejufque in Scripturam Oblervationes. In illis enim cxplicationes minime Orhodoxas affert o quas in Indeorum vel Hareticorttrib libris legetat, ut ipfe fatetui; traditis etiam Regulis ad ea in fuis Scriptis dit stinguenda qux vere fua erant, ab iis quix non erant: Diluit hoc pacto guod ci de ejus i conftantia \& opinionum diverfitate exprobrabätur.-..-.-Optandum eldet eruditum illum patrem tempus habuille diutius meditandi, 2 qua in Commentariis Juis fcriplerar relegendi ut ad fanioacs opiniones mentem dcterminatet. Caxterum nemo eft inter veteres Authores, apud quem Scraturx literalem fenfun melits quam apud $S$. Hieronymurs, edif́cere liceat qui tamen à plerifaue Theologis hodienis magni non aftimatur, quia nimis aridus \& nimis criticus ipfis vidctur. \& quia negligunt ftudium Linguarum Grece. \& Hebraice abfque quarum wotitia impolfibile tamen eft ejus Opera legere polfe. Et fane non femper fe in eadem lententia elfe oftendit, quodque uno loco approbavit, idem alibi reiicit : Eundem hominem laudat \& culpat pro variis rationibus ob quas de ipfo loquitur. Modo Septuaginta Interpretum Verfonem cateris omuibus prafert, cofque tanquam Prophetas fulpicit; modò ignoranriam eorum ipfis exprobrat, corumque $\mathcal{T}$ anflationern difpicit. $P$. Ki.hord. Simon. Hift. Cit. Veteris Teltam.1.3.c.9. Gall.

Quô tandem modô, aut quibus ego vâbis, tuam, maxime Hieronyrne, ingentcm fimul pietatem ac facundiam defcribam ? Quônam modô tot linguarum frmul \& totius própè antiquitatis ac Philöophiz admirabilem peritiam ? Quomodo Heroicum illum in fcribendo \& cœleftem ardorem tuum, quo imbille Hateticolum agmen, non fecus quàm mucrone quodam ftricto, perfecutus es ac proligâfti ? Qux omnia prophanos etiam in admirationem rapiant, \&c. Heinf.. Orat. 3. pro Biblioth. mun. Grat. act.

Hieronymus à Rufino furti accufatus, tum alibi, tum his verbis in Prologo 1.2. in Micbenth fe defendit : Narr quod dicunt, Origenis volumina me compilare, or contammare non dicere vetcrum Scripta: Quod ill maledicturn vebenens effe cxifimant, eandem laudern ego maximarn duca, cum illum imitarivolo, quem cuntispredentious or vobis placere non dubito. Si enim criminis eft, Grecorum bene dicta ransferre, accufetur Ennius of Mare, Plautus, Cecilius or Terentius, Tullius guoque coteri eloquentes viri: Qui non folwm verfus, fed multa capita of longiffmos libros, So fabulas integras tranfullerunt. Sed of Hilarius after furit reus. fit, quod in Palinos. quadraginta fermè millia verfuwn fupra dicti Origenis ad fenfurs verterit.

Extant Opera 4. Vol. Baf.1553. Antve. 1578. Tom. 6. Par.1643.fol. Francof. Tom. 
Tom. 12. 1684. cum omniumnotis \& Commentalis. Præfatiolibri, qui Cc mes.appellatur ap. Dacber. Spicileg. Tom. 13.

Vide Opera Genuina, Dubia, Spuria, \& Deperdita apud Gulietmum Cave in Hist. Literar. Script. Ecclef.

\section{AMMIANUS MARCELLINUS。}

TT Atione Grecus, patriâ Antrochenus, Honit Gub Gratiano ac Valentinano. 1 Libros fcripft 3 I. ex quibus tredecion prina deperierunt.

Clan. An. D。

Eft hic fcripror veritatis tudiofifimns, \& prudens, gravis planè ac ferius, \& dignus, qui ab omnibus, ac Germanis pracipuè amctur. Mirificè enim illuntrat Veteris Germania fitum. Eoquc majorem hac in parte fidem meretur, quia in hac fipendia ipfe meruelit adverfirs Gerranos. Dictio horridioreft. Sed virtutes Tujus Scriptoris funt tantax, ut hoc in rationem venire non debeat. Et quid mitu sum, fi duri militis phrafis quoque duriufcula fat, homoque Gracus Grecanicas fapiat loquendi formas. Vofj.de. Hift. Lat.

Mihi quidem Marcellinus fummis quibufque Fifforie Scriptonibus compa: randus videtur. Nam cum duo maxime in Hiftorico fpectanda fiat, Res Xerba; elocutio quidem haudquąuam rerum geftarum Scriptori negligenda eft, rerum tamenprima ac potifima cura cfe debct. Et Marcelinus quidemtum rgumento Operis, tum delcetu ac difpofitione, tum judicio ac fide ncmini cedic: In pralierum verò obfidionumque narrationibus multos longo întervallo Cuperat. Verba autem ipfa funt ea quidem Latina fere omnia: Sed confructio a collocatio verborum eft, ut ita dicam, ferè militaris. Nolim tamen omuinè megare in Hilteris Marcellini quadam occurrexe reprehendenda. Nam \& inter dum verbofior cit, quâm ut par fit, \& doetrina famamnimis affectat : Quod vi tium eft plenmyue corum, qui provectâ jam xtate ad fudia fe contulerunt: Hinc exceffus illi intempcfivi atque pucriles de terre motuum caufis de Cometis, de Iride. Pretcraumenm \& tonum Hiltoricum ravo fervat: Sed ferè Gothurnatus inecdit, cum Hifforico conveniat tracta \& leniter fluens Oratio. Henr.Valef.adlector. Epitt. quam Marcellinopramift.

Ammani Marcellini candorem ac fudium inquirende veritatis imitari debuifent. Is enim Principun virtuses ac vitia, ut optimus quilque Scriptor. fummâ fide notavit - Tacitur unum ex omnibus ad intuendum \& ad imitandum fibi propofuifle videtur. Hồc tamen ab eo differt, quèd Tacutus Romani Sermonis dignitatem, ut tempora fercbant allicutus e?t Ammianus verò latinis verbis, ac fepius ne latinis quidem, Greci feriplit, \& à re propoftâ longiùs àc frpius digreditur. Bodin. Mcthod. Hir. c. $4 \cdot \mathrm{p} \cdot 77 \cdot 78$.

Ubiad temporam fucrum Hiftorian, qua libris, qui extant, continctur, dc*enit, diligenterferipfit; fed ed, qux pertinent ad C'briftianos; traducons ac detorquens: Adeo autem duro ac afpero inepto \& planè turbato fermone, ut

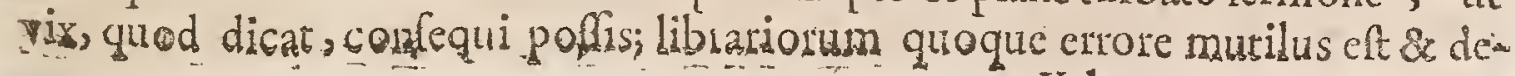
K $k$

pravatuse 
provatus; ntilis tamen eft, ubi intellexeris. Nam eaferibit, qua: ncliores anto res non habent. Ant. Pofevin. in Apparatu, Seet 3. c. Is.

Ammianus Marcellinus, homoquidem militaris. . Ced tam literatus miles, ramgue veterum literarum fudiofus, ut nihil non perveftiget. Unoverbo dicurn, Diligentifrmus Scriptor eft. Eft quidemfeabra cjus, hominis nempe. C, feantizopuliant, Oratio Latina: Sed rebus eft doctis referta, \& 2 variam, muliulicem, reconáitamque lectionem.includit, \& verò hiftoriam, quam alius non expofuerit, copiosè explicat. Franc. Baldvin. de Hiforiâ l. I.

De hoc Scriptore hoc dicari ; nullum neque apud Latinos 2. neque apud Gracos Historicurn cxtare, qui paucis plura dicat, ubires publicas \& virz munia tangit, nec ullum me unguan prodentiorem legille, Barch. 1. 45. Ada verfar.c. 2 .

Utilitate monitorum, \& veritate Hiftorich nefcio an quî́uam autor ullibi: Gt Lupra Anmiantim Marcellinum. Barth.ibid.1. 47 . c. I.

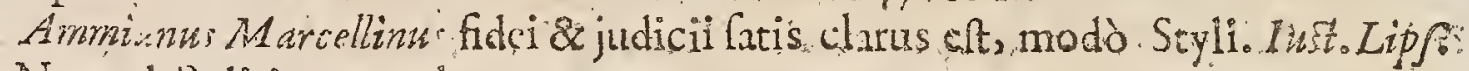
in Not.ad.Politicontm 1. r.c.9.

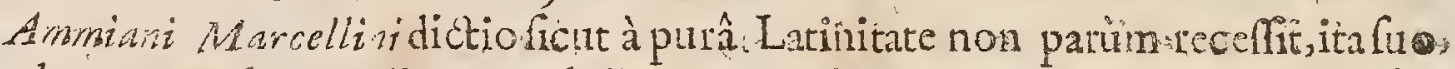
quodam genere loquendi rerum abdita \& negotionum naturas diligenter confequitur. Non poteft qudem, quod prudenter intelligit, civiliter \& venuftè clo. qui; fed oftendit tamen eximiè, fibi ineffe talis doet inx elemerta, fi velfeculi: facundioris exemplo velmaturiore difciplinâ licuiffer uti vio plerumque in militia \& negotiorm actu virlant. Certè compofitio is eloquentize fudiofox fepè poref fuggerere cogitationes \& fentcntias orationicivili profuturas ; \&f f-

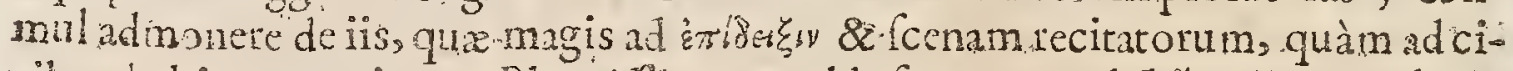
vilem habitumpertinent. Placuifle eum valde fuo xyo vel Libanii Epifola de eo \& ad eum docere poteft 1oh. Henr. Boecler. de cloquent. 'elit. n. 70.

Ainmianus $M$ the l'sut, Miles Graeus, antos habat plerumque Spiritus,ue qux bircosâ ( fi italicent appellare) Ininitate fcriplit, placere poffint inter wh

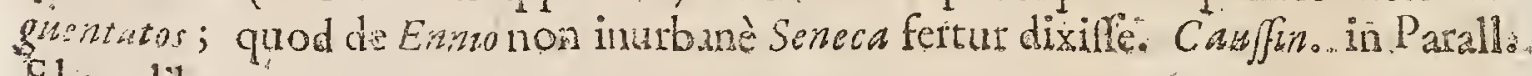
Eloq. lib.3.cap. 14 .

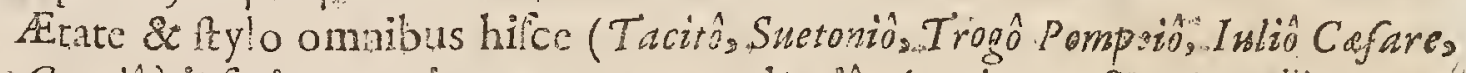
Q. Curitio) inferion netiquam tamen prudentiâ Anmianus eft Marcellinus pat cis bellique negorioum, eorumpreferim, qu in regnis folent venire ulu, preftans Narrator. Hermann. Conring. de Civ. Prud. cap. I4.

Tredecim priores libir Ammiani Marcellini quibus triginta ferè Imperatorum getta continebantur, \& quæeunque notatu digniountotis 259. aunis facta fucrant, a Nerva filicet ufque ad Conituntium \& Magnentii abium, ad:nos uque non pervenerunt ; Sed. Oatodecim libu nobis fuperfites, quorm quinque poftremos Accurfio debemus, ante quem detecti non fuerant, nos, circa jacturam illam abundèconfolantur, cùm preclatifrma , nobilifima \& maxima pars Hittoriæillius fint. In illis Armmianus omnes ingenii \& cloquentie fux vires adhibuic ut nobis ad viyum depingeret tum pace tum bello, fingula

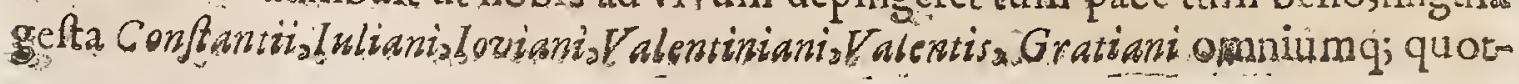


grot in Reipublice regimine partem aliquam obiverunt. Nihil neq;accuratius, ne"que frncerius, eo quod de is ic ribit, legete eft. Nihil ferè de fex illorum Impera torum Regno ablque A Amrniani libis nobis contaret. Unicus inter omnes $H$ in Atoricos, qui ad nos pervenerune, plene pertractavit qua alii obiter tantum petintrinxerunt aut prof fus omiferunt. Nam ut taceamus de Aurelio Victore, Eutro pio, Orofo ip jo, qui Hiftotias potials abbreviarunt quan contexuertunt, Zozimus \& Zonar as qui tribus illis alis prolixiores fuerunt, ad Amenianwm non ac cedunt, ejufque meram ferè Epitomen elaboralunt. Eruditorum Epheraerides Gall. diei Luna 28. Julii $688 \mathrm{r}$.

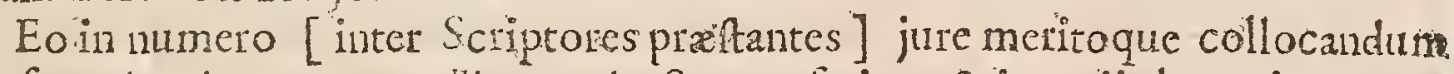
cenfeo Ammianum Marcelliwn, Auctorem Cerium \& ingenii elegantis: Quen non magis in manibus hominum verfari miror, immo indignor. Cujus fr înte-. gra hiforlia extaret, quam à Nerize principatu ad Valentiniani \& Valent is Impp. obitum perduxit, eflet profecto quî aliorum jacturam xquiore animo ferremus. De rebus fanè Majorum noftrorum à Tacti avo natum Scriptorem habemus neminem, qui memorix alt plura, aut exactiona tradiderit. Quippe nonalita nartat, fed vifa; nec ab aliis laltem acta, fed quibus ipfemet fepe interfuit, labo* rum parriceps periculorımque: Qui \& Atipendia adverfus Germanos meruit, $8 e$ pleralque Germaniarum partes luftravit: Quo nomine ut Germanus meritò illum amo. Prater omnifarium doctrinarum Genus quo dcliciatur, fententiis creber eft \& aptus; confliorum diligens obfervator : Nec publica tantùm \& cuivis in oculos incurrentia, fed arcana quoque $\&$ qux intra aulam, ut dicieur. notat, judicio minime vanus, nif quod in multiplicibus illis Regionum defcriptionibus, rerumaze Naturalium difquifitionibus penè intempeftivis in leges hi: ftoricas nemiinil videtur peccare: quorum alterum Philofopibi proprium; alterum l'eriegeticieft, \& orbrs frum narrantis. Deftylo ejus; quem nefcio qui Scholaftici vituperant, fic fentio. Durus ille quidem \& afper, fi cum Angufir *vo conferatur : At vero ornatus \& fuas habens Veneres, fi pofterina tempora \& faculum Auctoris, originemque ejus \& Sectam Cpectes. Qui cùm Gracus natione eflet \& Caferafequeretur, Cafrenfisimmò Aulicâ quoque dičtione ufus eft. Nam \& ipfí Imperatores, \& qui in comitatu eorum elegantiores videri volebant, ita tum loquebantur. Tamen ut in fenticeto rofx nonnunquan \&lilia fuccrefcunt, ita in ejus fly $i$ afpritic veilut flofculi quidam elegantiarum urbanarum apparent, qui curn Livianis de jure Latinitatis oppido certace poffnt: Unde neque Prifcramius Grammaticus vericus eft auctoritare ejus uti. Itaque in mints interdum placet, \& obfcurus effe vidctur, objcuritates non adjggremas culpe fcribentis, fed infcitien nor affeguentis, ut apud $A$. Gellium Sextuis Caciliut inquit. Frid. Lindenbrog. in Prefat. ad obfervat. in Ammon. Mercell. fol. $158 \mathrm{r}$.

Prodiit Ammianus Marcellinus cum Notis Valefii, Lindembrogii \& aliow rum, in fol. Parijgis apud Antorium Dezallier. ann. 168I. Differtationem de

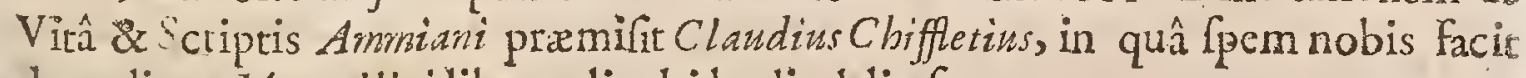
deperditos Marcellini libros alicubi hodie delitefcere.

KK 2 EUNA: 
Mla1. A. D: EECXXXX,

Ardianus fophifta, Medicus \& Hiltoricus, tempore Valentinianig Valenti 1. \& Graiani floruit. Reliquit de vitis fophiltarum: opus elegans ac venuRum, in quo paffim odium fuum (erat cnim Gentilis) erga Chrifianos prodito. Idem Cefarum res geftas, orlus, ubi Herodianus defierat, ad fua tempora ufque: perduxit. Extare dicitur in 'Bibliothecâ Venetâ. Konig.

Quòd Gentiurn dogmata fequeretur, non parum impius fuit. Quiergo pies ate fingulari imperium ornarunt, eos. omnino largiter vellicat atque traducit maximéque omnium Conftaninum Magnum; impios contràcextollit, ac pra: ceteris I ulianum Apoltatam, ur ferèd hunc laudandum, hiforicun hocm. ce opus elaboraffé visleatur Pulchra ejus dictio , fil quis ifta exceperit :

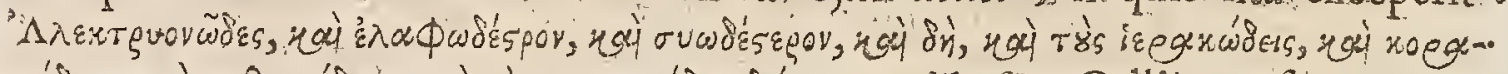

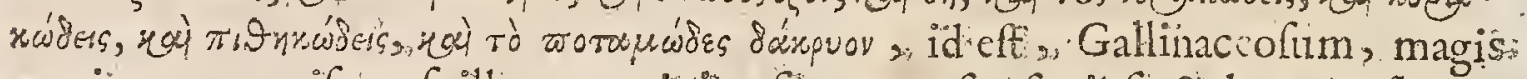
servinum, magifque fuillum, accipitrofi, corvofi, frmiofi, \& lacryma firminofa, \& id genus alia. His enim aliffque vocibus generolum dicendi'gentus cornrumpit, atque adeo adultcrat; Tropos adhec preter modun adhibet, quod: Hiftoria lex yetat. Eximit dutem moleftian ut plurimum dicendivis, atque arbanitas. Compofitione verò \& perfpicuitate ac periodis ad hiftoram accommodatè ac proprè utitur, nifi quò dinterdum juridacè magis, quàm Hiftoric implet, $t$ xitque orationem. Inrovat non pauca in conftuendo, verum id nots. ingratè, neque ut pcrio dis reprehendendis anfam prabcat. F́bot. in Biblioth.codi. 77. Andr. Schort.'nterprete.

Eunapium Grecum Scriptorem è tenebris erutnm, per otium vertendum?

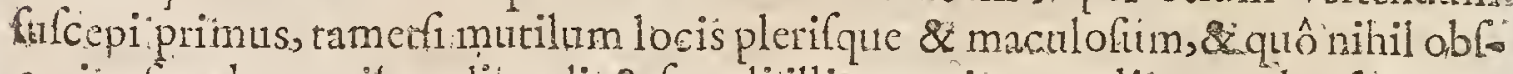
Gurius fit; ob concitan dicendi \& faculi illius genio pcenliarem thrafin; codem tamen pellacius nihil, quado altiorem quandsm doetrinx sirenem mentibus intillat, \& rerum alis scriptoribus omithrum, aut etianignotatarum, co-. gnitionem tradit: Hadrian I unius in literis ad Lect quas Ennap. xit. pramifr.

Dicendigenus non: $A$ foticum, quod redundante verborum copia luxuriats. fed nitidum \& picturatum, Sopbifarum genti tuncpeculiare $\ldots$ videtur fecutus quod res non adumbat, fed vivis potitus coloribus exprimit, atque ita ob oculos exponit, ut coram cennere videaris, concifus tamen $:$ Adde quod \& flof culos eruditos undecunque è Poctis \& 1 hilofophis delibat, orationique, cen ftel. las, afpergit..l dern in vitâ: Eunap..

Eo ex opere [de Rebus Ceflis Cefärum ] lolum de Legationibus fiagmentum. beneficio Viri Clarifimi Andrea Schotti, licem vidit: reliqun extare dicuntur. in Bibliothecâ Venetâ. Eò autem requiori animo iftis caremus, quòd:Zofrrmum. habemus, Nameardem res Eunapius, \& Zofinus, tractâtunt, \& ita taaçântunt, 1 t Zofimus Eunapium propè defcripfiffe vifus fit : 'ut à quo folùm differat, quòd non, MtiEunapius fecerat, Stelichontern conviciis profcindat: item quod bievior, \& planiox. 


\section{CELEBRIOR UM AUTHORUM.}

glanior Emapio fut, nec figuris, nifi raro, utatur. VoJf. de Hilt. Græc. lib.z. eap. 18 .

Librum de Vitis Philofophorum \& Sophiftarum, impulfuChrifantii, Eyl@ non omnino perfpicuo fcriplit. Loan. Ionfius, 1. 3. Hift. P'hilof. c. 27\%

Doetus, fed impius fciptor vocatur. Dempftero.

- Sic Monacbos pro ablurdis, avaris, \& incommodis ufui humano cavillansur cifdem cum Rutilio temporibus Eunapius 2 Zofrnus, rabiofi canes Diabolis grorum alter. Plilofophorum, alter Imperatorum vitas non alio fine fCripfit, quàm ut àlaudibus Idololatriam doctorum \& potentum hominum veritati ubique ef

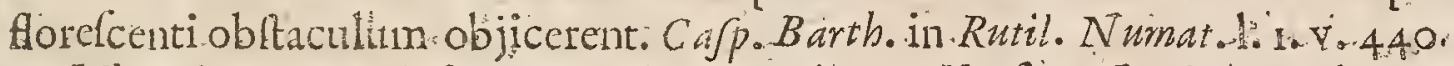

Liber de Vitis Sophifarum prodiit Grasè cum. Verfione Latinâ.Hadriani I w. nii. Colonite Allobrogum in 8. anm.1616..

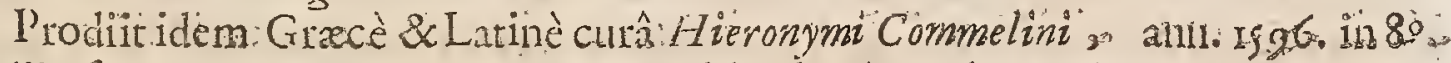
Addita funt Legationum Fragmenta ex Bibliothecâ Andrea Schottio.

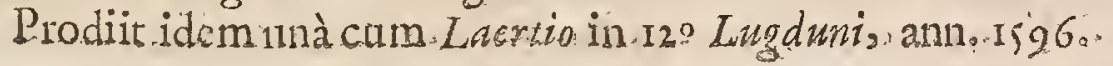

\section{Q. AURELIUS SYMMACHUS}

D Cma orimalus, cjufdemque urbis Senator, \& Prafectus, claruit pracipue clarntan

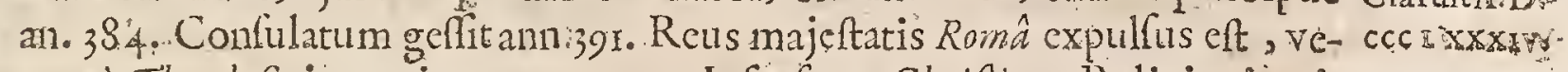
nummox àtheodofo in gratiam receptus. Infenfum Cbrifiand Religioni animum nbique prodit, imprimis in Relatione pro Arâ Victorie, quam Imp. Valentiniano obtulit; in quâ.Gentilium caufamitienuè \& exprofelfo agit .Gul. $C$ a ve.. Reliquitit dccem libios Eptfolarum.

Symmacbus Aproniano fucceffit, inter pracipuanominandus sxenta la dồ warum atque modeftix: Ammian. Marcellin.1:2S.c. $4: \cdot$

Symmachus ille, mirabilicloquio \& Scientiâ præditus proper Aquitan dé liromill: Dí part: $;:$

Nullo:veterum minor. Nhacrab. 1.s. c. I.

Symmachus inter: Senatores pracipuus habebatur y exatque Romani eloquil eruditione mirabilis. Cajsidor.Hift. Tripart. 1. 9. c. 23:

Symarnachis, Vir Confularis, \&Vrbi Prefeitus cloquentifimus \& dọiflimus

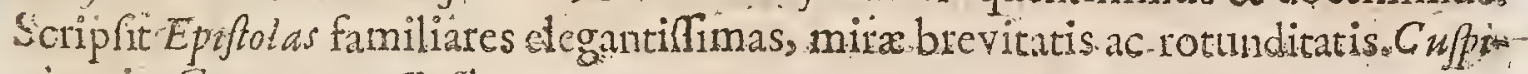
nian. in Comment. Coffo.

Fuit Symmacho vera facnndia; folèrs ingenium \& acum : par Cententiarum? gravitas \& veruftas: Si verba refpicias, brevitas grata: fur altius fenfum inveftiges, prolixa \& multiplex enudito:- Adde fapientiz Civilis Colidum atque abfrufam cognitionem. Adde raram fublimperatoribus fanctimoniam morum, $\&$ Romanar in. I ure fuggerendo libertatem. Non illic Rernmp. moderatoribus, aus Iure confulti, inprimis Magnorum:Principum Confiliaris, aut Secretariis, trat tandus levi manu. Iacob.Lectus

Dici non poteft, quanti merito fuo xtimändx fint-Symmacbi Epifolle. Non Gise ob accuratam illim, \& maximè ei generi fcriptionis aptam brevitatem K. k 3

Solumini 
folum, fed propter Cententias policicas tales atque eâ copiâ, ut vel inde pruden aliquis Reipubluce, cum gloriâ \& emolumcnto adminiftandx, ufum dilcere poflit. Nulla ex iis eft, qua non Lpire Genium quempiam, vin in rebus egregiv publicis procuraudis excitati : nulla Epiftola eft 2 qua non integrum $\operatorname{dog} m a P_{0-}$ liticialicujus Syntagmatispropagare queat. Cafpar. Barth. Ableg. lib. II.Cdpite 8.

In Epiftolis eloquens, in relatione wchemens. Dempster.

Symmachus in Epiftolis quotics fuo, quam Theodafuni faculi more ac modo loqui mavul, non multum optimis concedit. Sciopp. Confultat.p. 43.

Reinefus in Epift. 35. ad Hefriz p. 244. Epiftelas, quas habemus, non unius Symmacbi, unius tamen Saculi ellc judicat.

Iu Symmer bi Epifîles, qua fecébreves funt, \& publicas rés attîngunt, haud fcio quam Sidonius rotunditatem repererit : delectant tamen ob crebras argutas. \& concifas fententias, quod fortalle rotunditatem appellat; compofitio verò minimè rotunda elle videtur; \& ejus fermo qualis illo feculo exat, multùn à Gersmanâ ac purâ Latinitate defcilcit ac degcnerat. Róland. Maref.1. 2. Epift. I.

Symmacqum admirentur quibus ttudio eft moleftè poriùs, quàm benè dicere. Eragrn. in Ciceroniano, $9.1_{4} 8$.

Symrachus amat Plautina \& vetera infpergere. Lips. in Analect. ad Milit. Roman.

Symmachus nihil valet nifi pro Jurc Theodofano; Bonum of illum femel, nor ampliùs legeie. Scaligerana 2.

Prudenius libro t. corum, quos adverfus Symmachum feripfit : fic adverfarium compcliat.

O linguam miro verborum fonte fluentem;

Romani decus cloquii, cui cedat \& ipfe

Tullius; has fundit dives facundia gemmas!

Os dignum, aterno tinctum quod fulgcat auro,

$S i$ mallet laudare $D_{c}$.urn:

Quatuor funt genera dicendi; Copiofum in quo Cicero do minatur: breve, in quo Sallufius regnat: ficcum, quod Franton adfcribitur : pingue \& floridum, in quo Plinius Secundus quondam, \& nullo veterum minos nofter Symmachus Luxuriatur. Macrob. 1.5. Saturnal. c. I.

Haud quifquam ita nitet, ut comparatus tibi non fordeat; Quis ita $\mathscr{E} \int \rho p^{\circ}$ venuftatem, quis Sophificas Sucratis conclufiones, quis enthymemata DerngThenis, aut opulentiam Tullianam aut proprictatem nofti $M$ aronis accedat? quis ita affecter fingula, tht tu imples omnia? Quid enim aliud es, yquam ex omni bonarum Artium ingenio collecta perfectio. Aufon. in Epift. ad Symmach.

Illud pretioffimum generis hamani decus, vir tocus ex fapientiâ, virtutibufque factus. Boëth libr rr. prol. 4 .

De Symmacho MS. qui nunc Ingolfadii vinctus affervatux, literis Longobardicis 
dicis exaratus, nemo, qui verifimilis videnit, dubitare poflit, effé nimirum longèillım vetuftifiınum. Sciopp. de Art. Crit. in Prafat.

Extant cjus opera Geneve ijg3. in $8^{\circ}$. Parifis 1604 . in $4^{\circ}$.cum Notis Parai Neap. Nemet. I6r.S. S०。

\section{CLAUDIUS CLAUDIANUS*}

A Lexandrinus, magni (pïritûs Focta, fub Arcadio \& Honorio Imp.fforuit, A à quibus eti.tm ftatuam in foro Trajani meruit. Gentilis fuit (inquir) ac quidem pervicax : ut ex Auguftino \& Orofio eonftat." Nec obftat Carmen de Christo, quod in Editione Venetâ Andree Afulani, Clawdiani nomen praferto. In aliis enim libris adfignatur $D$ ama 0 Papa. Nec ignoro etiam in nonmulis $\mathrm{Ma}$ wufcriptis Clanditani nomen inveniri. Sedut Claudiani effet, non hujus fuerit . fed Clawdiani Mamerti, quifub Zenone vixit. Vof. de Poëtis. Latinis.

Clawdianus Poëta Agyptius genere, cujus hodiè Poemata extant, multa \& varia, nitidus \& ferax in fententiìs, majorque inventione, quàm figurâcarminis, fic quogue talis, ut fi in recentionum numero ponas, fit haud dibiè primus. ut veterum ultimus. Marc.Anton.Sabellic. Enncad. 7. Hitt. 1. 9.

Ad carmen natus fuit, quod elegantilfimè fcripfit, poetico wir ingenio; \&ad Cuperftitionem propenfior : tametfi de Chrifto extat carmenejus nomine infcriptum quad credo ab co in Honorii gratiam compofítum; , ut fuit alfertator maximus. Lud.Viv. in Auguftin.1.5. de. C. D.c. 26.

Ingenio excellenti fuit, niaximéque apto ad'carmen componendim: Nam affurgit feliciter, variifquc figuris ac fententiis mirificèdelectat, ut videatur 2 : naturâ ipsâ inftructus ad poeticam facultatem. Petr. Crinito.

Maximus Poeta Claudianus folo argumento ignobiliore cppreffis, addidic de ingenio, quantum deeffer materia: Felix.in eo calor, cultus mon invifus, temperatum judicium, dictio candida, numeri non affcetati , acutè dicta multas: fine anditione. Iul. Caf.5calig. de Re Poët: 1a G. c. s.

Nec equidem puer ego unquam Clandiant verfus contempfi :fed cum minimè numeros \&ì lineamenta variet, ïdemque fiu vabique, ab aliquibus eo nomine: in ordinem redigitur. At fi cuiforte illius numerifatis placent, placeant: ejus: certè faccelcis Inventio. Nam cum primo animi impetu", ut videmus s pulchrè. materiän apparet, \& animofiùs feratur, mox tanquam velntus hominem deficit, mec principirs fatis poftrema refpondent. Omnino tamèn, ut $P$ ifo dieebit, ef Poêta canorus, volubilis, \& valdè dulcis: : fed.ccrtè parum idoneus digunufque: ut tantoperè illum imitari ftudeatis. Sunt quidem in eo, fi cum delectu decerpantur, Aores, qui mirum dictu eft, quàm vob is prodeffe poflunt. Lil. Girald.de 1oct. Antiq. p. 193.

Elegantifimum Panegyricum Claudianus itr hune quartum Confulatum Ho norii fcripfit. Quem, ftudiofe Lector, acaratélegas, nt multas ejus temporis Hiftorias. Pleuss enim eft rerum \& Hiftoriarım, \& omnimodá fétet erudí tione, Joan, Cufpiniano in Commentar. ad ann. Uxbis MCLI,

Clar. An. D。 CCCLXXXYa 
Claudianus elegantiffmus Poeta, quåm præclarahabet in quarto Conf́latu

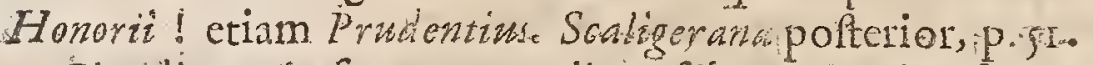

Claxdiams in Cexto Honorit confulatta oftendit, fe non ingenii folum viribus excitatum, fcd optimorum quoque Poëtarum lectione afiduân ad poc̈ticum decus \& gloriam pervenifle. Io seph. Cafalio var.lect.c. 37.

Claudius Clantranus Agsptins, omnibus Latinis rerumbertate prior, foll Homero, inventionis gloria , inter Gracosceflurus, poëtarum pragloriofffimits. Thom. Dempfter. in Elench. Script.

Tclem infuper dabimus non paulo auctoritate potentiorem : is critlaudatif

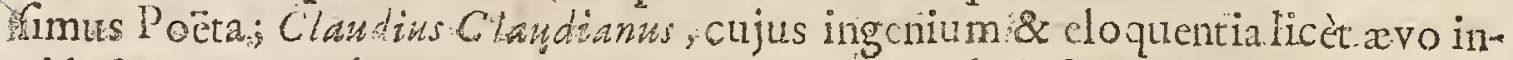
ciderint jam procliviouin vitum, neminitamen ab ipfo Angufteo avo puritare, candere \& magnificentiâ fermonis celfurus eft: quarum virtutum lic èt vulge non fun fatis xhimantes in fummo fcriptore; nos tamen eidebitum praconim non Iuvidebinus. Euftat.Svvart.1. I. Analedtor.c. T3.

Clawdianus Pö̈ta-et, quii non fabularum oblcuris ambagibus aures potius zitillet, quàm animum infruat. Nulla in co nugarum fcitè cogmentatarum ferics, qua blando errore à gravio ribus ftudiis ad sirenum:cantus mentes deducat. Gravifimus \& compoftxe ad Politicam doctritam nervofitatis Stylus.Boxborn. in M onument.

Legrimus hodic verfus ejus non fine veneratione tanti ingenii ; notamus didionem caftam, gravem, fublimem, \& nihilominus"s quod mirere, facilem. moralis \& Politica fapientia monitis intertextam ; fed ne quid difmuletur fubinde tumidiorem, penè juveniliter exfultantem, quod in Marone nemo jufte culpaverit. Borrict. de Pioet. p. $73^{\circ}$

Jef.Rapinwe eum nobis depingit tanquam Awhorem qui in fuis Poematio multum judicii non oftendit. Juvenilis indoles in omibus Clandiani Punegratis regnare confpicitur qua niihil habet folidi, quanvisingcrinm felix in iis rutilet. Infipides ablque ordine \& cohrentialaudes congevit. Ille Poeta pergit alibi, ingenio felicique imaginatione gaudet, fed ei palatum elt inertuditun quoad numeri delicias älas, carminumque madum illum quem in $V$ ir gito admirantur Dode. vefus \& verba ejus fimiliter contintò cadun; quo fit ut:vix abfque tadio legatur; nec in omni lua dictione ullatenus unquam afCurgit. Rapra. Reflex. partic, in Poetir part. 2. Refl. I 4.Ifo

Ciaudianum vero cum Tibullo fi conferrem in Elegits, carperer à nonnullis xamen is maximam meo judicio laudem promeretur in Elegia umeris omnibus abfolutâ, quâ labores Herculìr, obilque cantu Orpheo viduati calamitatem pulcherrimâ varictate, Aaridoque Stylo, velut endito penicillo exprimens ob oculcs ponit legentium. Facob. Gadd. in Elog. p.a tso.

Clandianus thon Latina fo' ùm, verum etian Gracalcripfit Poemata. Unde in veteri Epigrammate quod in bafiejus ftatux exat infcriptum, Virgilii fimu \&. Homeri animamin fe transfufam habuiffe dicitur. Latinum quidem carna primùm fcribere aggreffus ef Anno Chrift 395. quo Cofl. fuerunt Olybrius \&

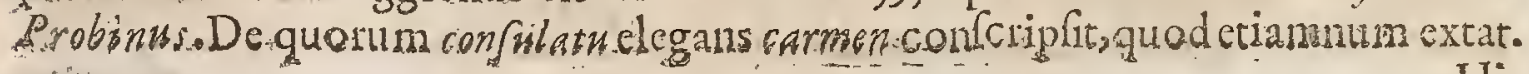


Hic conatus cùm feliciter fucceffifer Claudiano, animos ei addidit ad Latiua seinceps carmina confcribenda ; cum anted Græcos tantum verfus edidilfe: Henr.Valef. in Annotat. ad 1.r.c.Ig.Hift. Ecclefiaft. Euagrii.

De Claudiano interalios optimè meruit doctifrmis Commentariis Capar Barthius qui cum edidit Francofurti in $4^{\circ}, 1650$. feliciorem tameninemendanido textu fuifre Nic. Heinfum remo dubitat., cujus Notæ cum Commentaris Yariorum, applaufum provocant. Hac Heinfeiana Editio, accuratite Schrevelio, prodiit in 8o. Amfelodami ex officinâ. Elzevirianâ, anu. 1665 .

\section{TOR A I U S RUE I NUS.}

Desbyter, Bortit An D. 390. inter omites Monachos Aquileiex es , fecun dum Hieron. ep. 4I. juxta Bonofum \& Flarenitin, celebcrimus cum quiClar. A. D. bus hic Aquileic amicitiam init. In Agyptw profedus, dein Hicrofolymam venit, ubi an.25.commoratus eft, variis operibus in publicum edendis ibi intels-

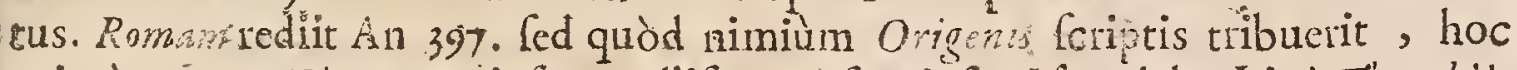
primùn cum Hierommo ipfum collifit, non fine infigin fcandalo. Lis à Theophilo utcunque compofita, paulò pof arriùs recruduit, cùm Rufbus Rorna librum Origens de Principiis ederer "in quo nomine fuo fuppreflo, Hieronym. pro Origene teftem advocalat, qui fic-infufpieionem venit Origenifmi : Hine acerbiffma utrinque invectiva. Tandcm $R$ afinos, ab Anaftafio Epife. condemnatus, obiit in Siciliâ, an. 410. E. Grecoweitit Iofephum, Eujebii Hiftoriam Eccl. $\&$ alia, illique duos adjecit libros, à S. Panlino rogatus. Scrippit quoque in Hofearn, loëlern, Amojum, \&c. Hofrnannin Lexic.

Rufinus, Aquitézenfes Ecclefia presbyter, apud multos olim magno loco habcbatur. Caffano 1.7.de incarnat.c. 27. vocatur Chrifiane Pbilofophia vir, baud conternnenda Ecclefiaficorum doctorumporito. Imò \& B. Hieronymus, ut ex -piftolâ ejus s.ad Florentiumconftat, fummis hujus fanctimoniam laudibus extulit. Sed intho fecit, antequam Rufinus Rnrnam rediens,trantlationelibrorum Origenis ér ủg w wr, crror s fuos detexiffet. Pofted fanè rnens longè alia beato patri fuit;ut advcrlaria amborum fcripta oftendunt. Atque hoc in causâ eft,cur $P$ alm ladius quoque gui Rufno erat addiatior, iniquior fit tieronymo. Set pro Hieronywo ftat Gelafus \& Concilium Komanum 70 . Epifcoporum: quo ltatuitur, multa in Rufino ad arbitrii libertatem pertinentia notata effe à B. Hieronymo: In quibus Hieronymi fententia fubfcribere conveniat. I mprimis Rufinu obutriufque lingu ac hiforiarumperitiam, magnifièri folet. Itaque \& cum Severus Sulpitivu rogâdfet Pontium Pablinurn, ut participem fe corum faceret, qua de antiquis temperibus obfervalfet : negavit hic, [e corum efle intelligentem; Rufnumgue Sulpitio, ut corum multis partibus peritiorcm, commendavit. Sic cnim inter alia ad Severum fcribit Epift. nonâ: Quod de me non babui, de fratris unanimi opulerit. tiore the fauro petni; or ip Samadnotationem, quarn commonitorii vice miferas,

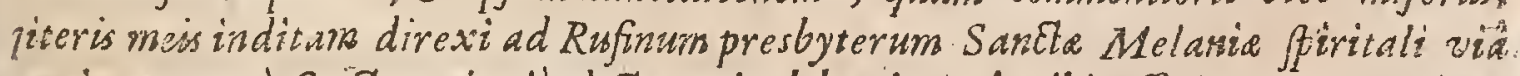

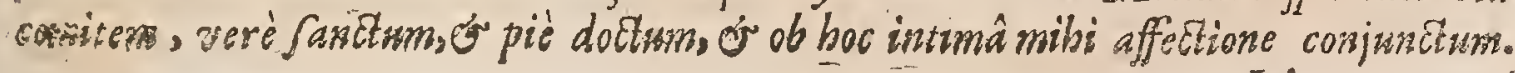


Sille bas, quse merito le promovent, de annorum, fove regnorw, non congruente: calculo, biantis Hiftoria caufas non ediderit ; qui Scholafticis, o falutaribiss literis, Grace juxta,ac Latine, dives eft: Vereor ne apud alium, in bis regronibus, fruftrà requiramus. Multum fanè operacontulit; $R$ uf frins ad Hiftoriam illuftian dam. Nam inter alia, qux Gennadiw, \& ex cor Honoriw commemorat, Clementis Komani recognitiones, \& Flavium Iofephum, Latine tranfulit.. Item decem lit. bros Eufebu hiftoria, Ecclefrafiçx. Quod ad Io ephurr, vcrfo illius, ut Cafanboni verbis utar ad Apparat. Annalinm fect. ulte multis locis eft ad infaniam ug que

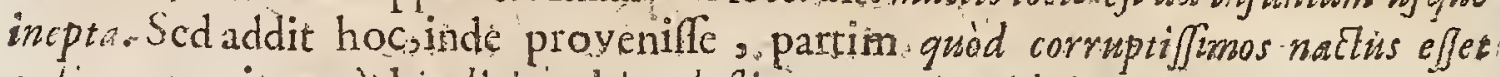
codices, partion quòd judicio criico deftiutus, quicquid inveniret, exprimeret... In Enfebio quoque nimium profecto libertate in vertendoufus furét. Sanè Eufe-. biana Tranfatio ne paraphrafis quidem dici poffit: Sed proprium opus, in quo

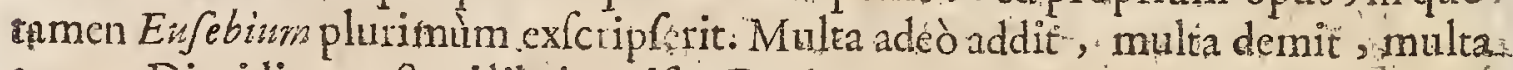
mutat. Dimidium octavilibri omift: Decimnm vix attingit. Atque hoc pactó ex libris decem Eufebiz fecit noyem:Quibus duos de fuo adjecita Scal quibus not: Cemper habenda fit fides; focrati crcdimus. Vofj. de Hitt. Lat.

Sanc futilifimum auctorem vocar etian Iofephus Scaliger, Appendice operis de emendatione Temporum:

Rufinus nihil unquam vertit bonâ fide. Erafm. 1.25.Epift.3...

Rufinus monarbus \& Aquileienfis ecclefie prébyter, vir eloquens, \& in divinis Scripturis valdè eruditus; Greco 2 tino peritus cloquio, inter Ecclefiafticos Doctores non parve opinionis fuit. Ejus fript licèt multa fint , tamen inter A pocrypha computantur. Is. dif. Sancta Romana; propterea quod in fanctiflmum virum Hieronymun fcriplerit invectivas Epiftolas;ficur ex earum lectione. intelligi porct, Sed polte⿳亠丷厂 in concordiam dilectionis fraternz redeuntibus, facta? funt opufcula Rufni authentica; in guantum Hieronymi dictis non fucrïut contraria. Tri hera.

Profẹtò, fi quifquam, Rufins is oft,qui Termpora Coleat confundere.Voff. de: trib: Symb. P. $43 \cdot$

Rufinus ex inflitia ubique errare folet Ca anb, cxercit. I6, ad Barons Ann:34a, Num.196*

Tantam habes Graci \&atini fermonis fcientiam,ut Graci te Latirum, \& Eatini Gracum putent. Hieron?m. A pol.z. adverf. Rufin.

Rufinus quamvis Grace loqucretur, non intelligebat tamen Graca qux légebat. Scaligeran polterior.

- Nec erit fortaffe piaculam fi nofter Lector Hiforiarum ftrdiofus inGper Rufrum habendo pratercat; nameorundem Temporum Hiftoriam ube rius multò \& accuratilis Socrates, Theodoretus \&: Sozomenus compofuerunt. Whear.in Meth. legendi Hiftorias.

Neque verò Hifioriam furm ( Socrates) negligenter ac fupinè "confcripfits. quemadmodum Ruffins Aquileienfis, qui duos libros Hiftorie Ecclefiatica, gatos Eufebii Cafarienfis libris attexuit, memoritcr mihi videtur. compofuilfe. Hen.Valef. de vitâ \& [cript. Socratiso. 


\section{CELEBRIORUM AUTHORUM.}

Dom. Gallois in ea ẹt opinione quòd a ofephi Verfo omnium ejus Tranflationumpeffima fit. Aliz taltem eloquentiam quandam redolent qua carum deffectus compenfat. Sew. Hla Iudaicarum Antiguitaturn adeo barbara \& obicura eft, ut niliil è Ruffino in ea deprehendatur prater ufurpatam ab illo interprete licentiam:introducendi is fepiszm ea dicentem qux in mentem ei nunquam veneinunt. Eruditorum Ephemerides Gallic. 10. Jantar.x667.

Rufnus, quamvis fenfum potiùs Eufebii fequatur quadm verba, terfus eft tamenac nitidus, nec legentibus injucundus: ac vel co nomine plurimùm lautdandus, quod Ecclefiajticans Fifftori:m primus Latinx linguxe hominibus dedit; cujus verfione ad noftram ufque ætatem ufa cft Occrdenzis Ecclefia. Herr. Valef. Prafat. ad Eufebiane Hift. edit.

Rufinus primus eft qui Euscbianan Hiftoxiam verterit, hed ie admodum licenter , de more fuo, praftitit. Totum decimum libtum omifit, duofque alios eiadjunxit qui Hiftorix feriem ufque ad Theodo/ii mortem complcetuntur. Ejus verfio pura, tcrfa imò \& Catis elegans eft; jucundè admodum Authoris fui Cenfum \& mentis ideas exprimit, imó fideliùs interdum quam Interpretes qui ipfum poftea verterunt. Authoribus Latinis auxilio non inediocri fiitit hine enim hauferunt quicquid.de primorum feculorum Hiftoin Ecalefiaftica fcriplerunt aut noyerunt.Ell.du $P$ in Nov. Biblioth. Authorum Ecclefiafticor. Tem. 2. pag. 9 .

Fatendum eft Rufinum, quamvis à S. Hieronymo accerrinè vapulaverìt, inter dectiflimos feculifui viros numerandum elle. Eruditione Sanctum illum foraffis non æquabat, fed pacatioris \& minus vehementis ingenii etat. Latinè non fcribit $x$ què cleganter, fed $x$ qualior eft Itylus ejus. Difiticii nemo poreft quinei multum debeat Ecclefia Latina quod pracipuon m Authorum Gracorum nozitiar ci gratificatus fit, preflerim verò Hiftorix Ecclefrafticà. Quamvis plurium errorum accufatus fiterit, nulfins tamen convictus eft, nec male crimina tiones in fe collatas diluit. Origenerm defendit, fed errores ipfi afcriptos repudiando. Id in cujus culpa elfe cenferi potelt, non quidem quod ex ejus feriptis liqueat., fed penesfidem Authorum yui de ipfo locuti funt, hoc unum efto quod Pelagii Praccptor fuerit. Sed fortaffis errores dilcipuli caufa fuerunt cur Magittro imputati fuerint quamvis eos ipfum minimè docueit. Utut res fit dici non poteft ab Ecclefia idco feceffiffe, nce illos errores pertinaciter propuguavife. Perperam itaque, mco quidem judicio, plerique recentiorum memoriaim ejus adeo contumeliosè infectantur, \& cum ipfo agunt ut cum Hærezicorum pernicioflffimov Non fúnt attendenda omnia convitia quibus à S. Hieronyzo, in mutux contentionis teftu, profcinditur, atque Gelafiz Pape modexamen imitarifatius ele, qui Sandi viri nomine ipfum condecorat: Rufsinus vir Religiofus, inquit, quamvis agnofcat eum ab Hieronymo jure reprehenfum circa ea qua de hominis libsrtate dixit. Ell. du Pin, Nov. Bibliot. Author. Ecclefiafticoi. Tom.3. Gall.

Summum quidem fuilfe Origenis admiratorem, \& cum Pelagì fectatoribus libero Arbitrio nimiun tribuife nemo prudens facilè negabit. Verùn Ll 2 annoin 


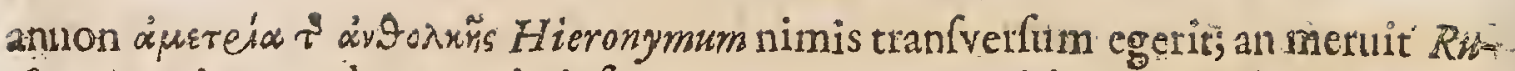
finus omnia, quxpleno ore in ipfum evomuntur, convitia, perpendent aqui re $\rightarrow$. yum aftimatores. Interim illud negari non poreft, Rufinum in vertendis è Græco Sermone aliorum Scriptis peflimâ fide ut plirimum egiffe, mutando,truncandos. addendo; ut nova potiùs quam aliena videri poffent; nec divinando quis aflequ: valeret quanam $R$ ufini, quanam infus Auctoris partes fueriut. Gul.Cave in Hif: Literar. Script. Ecclef.

Prodienunt opcra Rufni 2. Tom. Parif. Ifso. fol.

\section{DECIUS MAGNUS AUSONIUS:}

Glax.A.D. C.C.XC.

Dnere Gallus 2, patriâ Burdigalenfis fult. Valentiniano, Gratiana ox. Theoda- I fol Imperantibus, claruit. A Gratiano Difcipulo ad confulatum evectus eft: Rellarminus aliique eum inter Cbrifianos collocant, diffentiense $G .1 . V_{0} \int$ frog $_{2}$ gui Gentilem fuiffe afferit. Condidit varià carmina.

Aufonizingenium magnum, acutum : Stylus duriufculus:Mult fcripfit, non Colum varia, fed criam varie. Quare quid facere potuerit; non quid fecerit, pom sius judicandum. Utinam Epigrammata ne fcripfinct. Nam \& inculta funt pené ominia,\& omnia dura: Quxdam etiam inepta; aut frigida aut frivola, ut è Gracis fatis habuit qua exprimeret. Nonnulla verò adco foeda atque deteitanda, ut neque criptore, neque Auditore digna , nos in fpongiam incumbere merita Gut, fed Colis Aammis' expiari polfe videantur. San fibi mulum placuifle confat ex incuria criptionum futurorum faculơrum fecurum; cum fibi vide retur fui cle Princeps. Eum verò piguilfe Caftigarionis videmus in ipfis I ambr;, quos cùm puriores inchoaffet , lutulentos. Auere permifit. I ul. Caf, Scalig. 1. 6a Joctic. c. S.

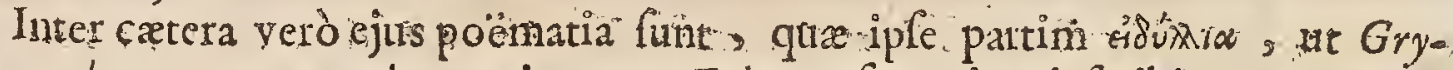
phum de numcro ternario, partim vocat Eclogas; fic enim infcribitur ea, quis vitx noftra miferias defcribit; valde fun bona, \& quovis magno Poct *na: Sed longè illuftrior illa, in qua Cupido cruciatur. Eft cnim docta, candida, neque carens numeris Mofellam verò adè̀ excoluit, ut ea fola magni Pö̈re nomen fibicomparare potteritá Ef enim in eâ multa ars tum difípolitio*is tum eloqutionisá Multa lumina figurarum; multum ingenii deprehendas. Idem ibid.

Multa in illo viro (Aufonio), verè Magno, tecum unà miror, multa fufpizio \&veneror. Ut pauca de multis, Illud imprimis apud me monftri inftar habet, hominem Chriftianurn, \&jut apparct, non nomine tantum ; fed \& pectore \& moribus, adè̀ fapélafcivaatqueimproba fcribere potuiffé, ut nifi nom n Aufonii effetadferiptum, Bilbilitanum Poëtam te legere putesSulpicio in hoc viro acumen, leporcm, ae rotunditatem, imprimis Epigrammatum, qubus (expleri mentem nequeo, ardefcoque legendo) veneror $\&$ eruditionem mulitiplicem de veterum fontibus haufam. Quid enim apud illos, frve Gracos, Gve Latinos, memorabile., quaे verborum, guà rerum ; quod 
non Anfonius delibaritio. Cunrado Rittershus. in Epift. ad Solononem Panthemurn...

Chrifianus quidem Aufonius fuit;ut ex ejus verfibus, \& item Paulini ejus difcipuli facilè colligimus : Sed petulantior tamen, 2 lafcivior quàm ut inter Cbrilíinos numerari dignus fit--n-In.Grypho quidem eruditio multa, varietas, \&'curiofitas; judicii verò, \& nitoris, ut quidem mihi nunc videtur, pamin. Sunt ejus quxdam, quxè Greco in Latinum tranfulit, in quibus argutire, falis, \& leporis fatis, qua legilfe aliquod ef opera pretium. Lil: Gyrald de Poët Dial.ío.

Doëmationcompoluit lepidilfimus Poecta Aufonins ad 'épotulum cjufdem

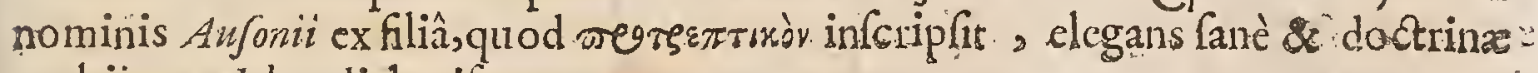
multijugx. Idem dialogifino 21.

In Nojellâ maximam laidem, ut eftantor Symmachus, jire optimo hbi vindicavit : Siquidem incredibili elegantiâ uritur in eo defcuibendo. Faftorum pra tereà libros abfolvit, opus magni laboris, ac multarum vigiliarum. $P$ etr. Crinit。 de Poët. Lat. :

Ingenium \&eruditio fuit in Aufonio malta, fed ltylus rempora illa, inquire? Erafirous in Ciceroniano, aula dclicias \& licentiam refipit.

D. Aufonius Burdegalenfis Pö̈ta cruditiflimus , licèt durioris ftylli. Thomo. Dempfer. in elench. Scriptor:.

Ausonius noftras. Poëta poft tempora Domitiani omnium enditillimus; in -

Aufonius non tam inclegars, meo judicio, Poeta; quâm volunt hi quil eum Ferreurn contumeliósè nominant. Ioann.Brodaus l.i. Mifcel.c. G\%:

Tam enditus.verò eft scriptor Aufonius, ut vix polfit alternm tertiumve verfum abfolvere, quin egregiam aliquam rem geftam alludat $C a p, B$ arth. $4.4 Q_{0} \cdots$ adverf.c. o

Nullam Aufonius difciplinam ignoravir: Ommés Latinos Grecofque Scripton res, quorum majorpars intercidit, ad ungucm novit. Hinc in ejus $S_{c r i p t i s ~ m u l t a . k}$ fe oftendit; $\&$ varia eruditio, nt cuivis legenti non hatim queant intelligi. Elias Vinet prafar. præénấ Aufon. Scriptis.

In Scriptis ejus oblita Tullianô melle feftivitas, merum gaudium. Symmach; lib. . Epilt. 30 .

"Oratio Atticis Salibús alperfa \& thymô odorata. Idem epint. $22 \%$...

IHe rexum eventus nequaquam eveniet, ut ingenium tuum dabor deterat: Be aigitatem cura fectat: Facundiam ufu's exhauriat. I dem ibid.

Tam fecundx (Anfonius) apud Aquitanos fuir farra, ur ab illis cum aiquo feptcm Sapientum contenderetur. Atque fcitum ejus in ore omnium : verfabatur: Besumefie non qui babet que cupit, fed gui non cupt' 2 que non babet. Atque deco jactabant Aquitani. Quemadmodum Aufonius neminem fibi propofuit imitandum : Ita Aufonium nemo nunc potef imitari. Eloquen : tixnon itaftuduit, cum hoc fapiùs diceret : Satius effo, fi moribus Antio. quorum prudentium yjueremus-' quàm fi eorum tantùm lingûa \& arte loL1: 
queremur. Iof. Scalig. Tib. 2. Aufonianarun led cap. ult. judicet.

Mofellamipliusita predicat Symmabus, ut Mibris Maronis adjungendam

Martialem Aufonius renovare vifus eftac refere fcribundis Epigrammsis. Iongo intervallo ent temporis ita dignitatis ac praftantix. Huic ego Poeta faveo libenter, cum homini Gallo, tum doceriná fingulari, \& fummâ ingenïi fliavitate pradito. Sea minus éi tempus profectè, quo vixit, favet. Quo quidemetempore infici jamdudum cceperat Latinus Serno, verbis \& parm Latinis. \& parum Latinejunctis. Poëricafacta ducior multó, quàm olim. Iravaffo de Epigrammate, C.IS.

Elegans \&acutum Aufriai Poëmation Grypheseft; in quo propter reconditam doctuinam \& occultos quefdam refpectus, ingenium poetåduclaravit luum. Andr. Schoti.1.2.C.33.oblerv. Human.

D. Magnus Aufonius Burdigalenfis, Imperatoris Gratiani Praceptor, ejul. quebcneficio Confultandem Romanuspanló ante initium Seculi s. obiit, Religione Ethnicusenque à Paulino amico, Ced Chrifianis' facris dedito identidem objurgatus, varia fcripfit, qua in luce publicâ verfantur:s omnia culta. felecta. jingeniofa,fed à fxecibus temporu m, quibus vivebat, non femper libera. Aden

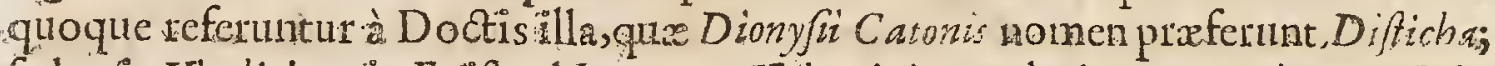
ICd quia Vindiciaus in Epift.ad Imperat. Valentinianum hujus Catonis meminit. alium cum elfe ab Aufonio credibile eft. Vivacitatemingcnii ejus ut ex aliis deprehendunt eruditi,in precipuè ex Centone illius $N$ uptrali, quo $M$ aron tatem in ruhorcm dedit, atgue utinam now lectorum hodiéque rentet pudicitiam. Borrich.de Poetis, p. 73 .

Aufonius editus ef Amfelod. ex recenfione lacobi Tollit cum Notis Variowim, in 8. Anno I67I. In Gryphurn ejus De Numero ternario commentatus eft Claudus Minos Divionenjs: In eundam de Urbibus Elias Tinetus:In Me Jellam Marguardus Foberus.

\section{S. AURELIUS AUGUSTINUS.}

Clar: A. D. CCCXCVI.

D Arre Parricio, Marre S. Monica, Tugafte in Numidia natus, Arbetion \& Lolliano Coll. Anuo Chrifti 35 s. Idibus Novembris, Romarn ex Africâ venir anu. 383. deinde Mediolanumann. 384 . ubi à S. Ambrolio Mediolanenf Prafule ad fidem Carholicam à Manichæorum hærefi converfus, \& baprizatus eft Pafchali ecmpore ann.389.xtatis 34. Poft fanctx matris obitum, ad Oftia Tiberina die 4 . Maì.ana. 389 . reverlus in Africam, à Vuterio Hipponen Epifcopo ann. 391. Presbyter ordinatus; dcinde Epif́copus ann 396. jubente eodem Valerio à Mregalio Calamery Epifcopo $\mathbb{V}$ urnidie Primate conlecratus novo moresut non fuccederet in Cathedtâ Epifcopali,fed accederet, commillam fibi Ecclefiam rexit per ann. 35 .ufque ad diem 28. Augufti ann.430.quo Vandalls Hipponem Regium jam rerium menfem arćtâ obfidione vallantibus,ad coleftem patriam evolivit, cùm

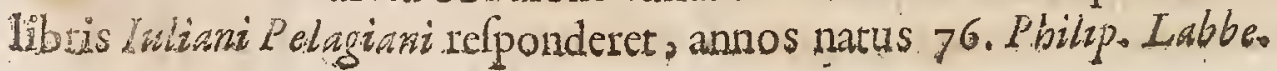


Vir supraomnes, , qui anté eum \& poft eum hucufque fucrunt, morta炡s, admirabilis ingenii acumine preditus, omribus liberalibus difciplinis inftructus, , Platom â Philofophî̀ plenifimè imbutus , Ariffotelice doctrinæe non ignarus, in divinis Scripturis longè omnium eruditiffmus "; \& in carum explanatione ultrà, quàm dici queat, incomparabili fubtilitatc fublimis; omnes

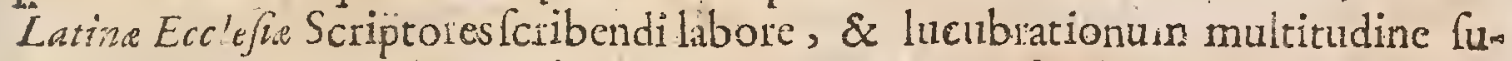
peravit, cditis plus quàm mille \& triginta exomni difciplinarum genere voluminibus Szxt. Senenf. Biblioth. 1.-4.

Orationis ejus, ac diationis genus frecundiffinum \& exuberantifmum eft

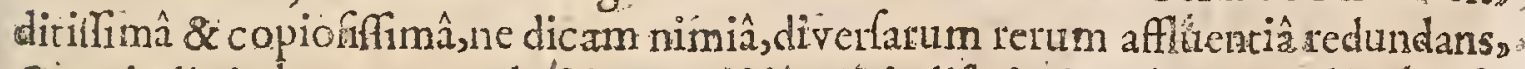
\& periodis in longun productis , miftim \& indifcriminatim quamplinima feo cum volvens ac. rapiens, digrefrionibus, excurfibus, \&ambagibus vagabandum ${ }_{2}$ quod ingeniolum, attentum, inemorem; \& patientem requilat lectorem;: quem ue mulciloquii trdio faftidiat, $p$ unicis quibufdatm argutiis recreare foles, ludensfepiffine in fimiliter progredientribus, \& fimiliter cadentibus fententis, aliifque. non injucundis Rhetormm figuris, quz longum \& implicitum prolixz lectionis iter emolliant. $l d c m$ \& ibid.

Auguffinu multum habet Africitatis in contextu dictionis, non perinde in verbis, prafertion in libris de Civitate Dei, quod unum ex cjus operibus-legenddum cenfeo philologo id enim bonâ ex parte in mediâ Philologiầ verfatur. Ludon Viv. de Tradend: Dicipipli.j.

Quia D. Angufinus omniğena cruditione preditus erat ${ }^{r}$ o dè :omnigenis: etiam rebus, \& pro omnibus hominum generibus fcripfit. Opernm ejus pluri-

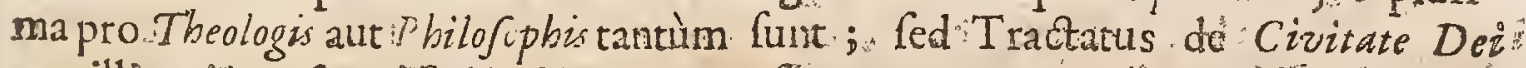
pro illisctiam eit qui Scientiam non proficentur, cumque illum infigni cuidam Dynafte Romano nulu upaverit, eum videtur præertim confcripflfe in gratiams. Nobilium ; cotumque captui attemperafe. Hum enim jucundum \&intellectı facilem elucubraccidelectatus eft" "ibique feryato filcndido illo igne qui in omnibusaliis ejus Operibus corufcat, iifque omnium admirationem conciliat, obforitatem vitavit qux in quibufdam ejus feriptis deprehenditury cujufque caula ab ipfo Hieronymo caftigantur. Unde etiam apud Maximos tetius $\mathrm{O}_{1}$ bis. Pricipcs in magno pretio fuit. Is ef liber sujus lëctionem, Eginardo tefte, Caroins Magnus in deliciis prafertion habebat Carolus, V. Regurns noftrorum fapientiflimus tanti.eundem aftimabat, ut virum cujps opera ad illius ver- fionem: Gallicam ufus eftremuneratus fit dignitatc Magifri Jupplicium libellorum. Henricus verò VIII. Angiza Rex Commentarios quibus Ludovicus Vives Authoris illiuis difficultates explanaverat, ut gratifimum munus omnium quz: fibi offeri polfent accepit: Eruditorum. Ephemerides Gall. dici luna. Is, Martia 3666.

Quid habet O rbis Chriftianus hồ Scriptore vel magis aureum, vel angufizus? ut ipfa vocabula nequaquam förtuito. fed. Nu minis providentiâ videantur indita viro.- Non arbitror alium effe Doctorem, in quem opulentus ille juxta ac benighus Spiritus Sanctus dotes fuas ømnes largitus effuderit guàm in Auguftinum 
quafí voluerie in unẩ tabulâ vividum quoddam exemplar Epifopi reprétentare - linguam habebat in tantum ab omni petulantià puram, ut etiam cum procacifimis Haretici, val fcripto vcl lermone difputans, mirè temperct à conviriis, fed Scripturatum modò têlinoniis \& argumentis veritatem allecit, impiet tter refellit, adeò ut ne laceflitus quidem regerat maledica. Erasm. Epift. 1.28 . Epilt. I.

Augafinus accuratiflimus in Fidei dogmatibus difcernendis; $\$$ in difputandis toletifirimus. Montacut. Apparat.1.fect. 70.

Magnus fanè vir fuit Auguftinus pietate \& doctrinâ adinirabilis Cafaú. Epir. 7 10. ad Perronatirn Ginid.

Unus Aurelizis Augujinus, vir tantus, Retractationum libros reliquir, fimplicirer ac bonâ fidesquem nullus cf ad hoc tempus initatus:videlicet manfueto vir Ingenio; 8 modice de feiplo fenticns. Lud Viv de Gaul. Corrupt. Art.l.I.

Hîc nobistotics occinuntur Aughlàni Reractationes. Atqui Retractatio nihil aliud eft quam recognitio. Neque enim eo titulo profiterul Lecaftigationem errom num fuorum, fed oatalogum \& recenfionem operum fuorum texere, ac fingulom rum velut argumenta, ò foectans, ne quid lucubrationum ipfus inercideret, aut

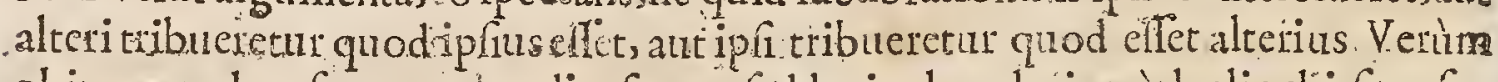
obiter quxdam fua reprchendit, fateor, fed levicula:veluti fuod alicubi fit ufus vocabilo fortivite, quò lapfus fit in nomine Medici. As plilia defendit,interdum - non fune tergiverfatione. Erafyrn:1.25. Epift. I4.

Ncc Hebraicé Sciebat Auguftinus , \& Grecéminus quàm mediacriter. Lud. Viv. in Augufin de C. D.1. I . C.1.3.

Nunquam infeliciù in Scripturis. Sanctis.verfatus, quiam" in Pfolmorum enar-

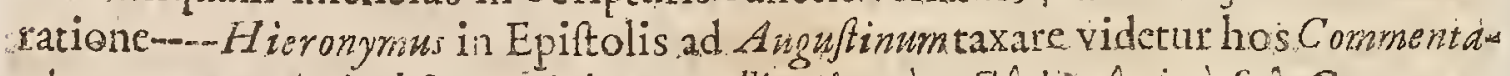

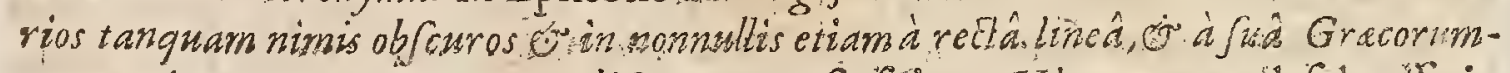
que ornium traftatorum mente difcrepantes. Sulpicor Hieronyman defideralle in his Enarrationibus explicationem $P$ falmornm juxta Hebraic vetitatis puritatem, \&. Gracerum Expofitorum fentcntiam : fed, cum Angufinus. Hebraici fcimonis effet ignarus, \& in Gracisliteris non fio effet inftuceusut Graca Comantaria liberâ manu poffer evolvere;necellc fuit illum lexpè ex inopia . literalis intelli-

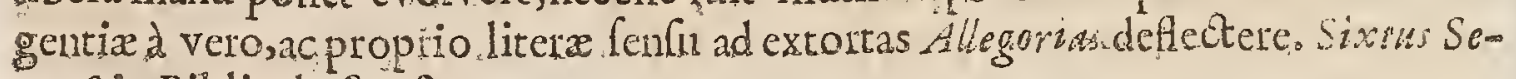
zenf. in Biblioth. Sanct.

S. Augufinu ingenio admodum vafto polito \& acuto pollebat. Ejus rafiocinia validè urgebant. Ufitata ejus Methodus cft preclara Principid ponere, ex quibus innumeras elicit confequentlas, adeo ut omnia Dootrina illius capita arctiflmam inter fe connexionem habcant. In piclaque My/feria magis ratioGinatus eff qutà ullus Author ante illum: plures Quzftiones priph non motas agitat, harumqueplures fola acuminis $\mathrm{f}$ (ui vi diremir. Longè fapius abivit ab corum fententia qui ipfum precelferum, ut novam prorfus viam .infiteret, five in Scripturarum explicutione, five in Theologicis opinionibus. Gitca res Theologicas de eo dicipotét quod de feiplo dicebat Cicero circa Philofophiam. quod fuerit Magins Opinator, id eft quod plurimas opiniones qua meram 
habebaut probabilitatem in medium protulerit. Sed id facit S. A A ugustinus admodum modeftè ac prudenter, non ea mente ut alios ad arbitrium fuum Cxcorum in morem fequendum adigeret. Contrà verò cùm agitur de Ecclefix Doctrina, eam cum animi furmitate proponit ac tuctur, eamque oppugnanates fortiter adoritur. Multo minus eruditione quam ingenii dotibus valebat; nam neque linguas callebat, nec Vcterum fcripta multùm evolverat. Multò faciliùs \&.terfús quàmpolitè ac eleganter fcribebat. Quamvis Rhethorican docuiffet, Oratorum tamen eloquentiam non poffidebat, àt illam faltem negligebat: Imònectemper in phrafibus fuis cafigatus eft ftylus ejus, vacabulaque impropria atque barbara quandoque ufurpar, argutis fxpius vocumque allifonibus utitur: Res eafdem frequenter repetit, cademque rario inia centies in' fcriptis fuis inculcat. Eidem mentis conceprui diutius haret, quem variis modis effatur, 2 in locos eommunes excurrere lolet. Argumenta innumera ex aliquo Principio edifferuit, Co:pufque I heologicum, utita loquar, Latinorum Patrum quil poft ipfum vixerunt efformavit. Hi frquidem ex illius libris medum hauferant l'rincipia quibus uff funt, fed etiam fiequenter eundem merè ranfriplerunt. Concilia in tuis Decretis condendis verba ejus adhibuerunt. Deniq; cum i ctrus Lombardus faculo Duodecimo Theologiam univerfam in Epitomen cogere volut, nihil fere egit quàm S. A uguftini locos exccrpere. Et quamvis S. Thumas cuterique Scholafici diverfam methodum fecuti fint, hoxum tamen pletique Principia S. Angufini amplexilun, iifque Opiniones fuas Theologicas fupcrftuxentint. Ell. du P ir, Nov. Biblioth. Author. Ecclefiaftic. Tom.3.

Origeni \& Sancto Hicronymo Sanctum Augusfinum à me fubiungendum effecenfui, qui eruditione prioribus aqualis quidem non fuit, fed hunc defectum ingcnii fui viribus, judiciique foliditate fupplevit. In fuis Libris de Dodrina C briftian pluimifque Operum fuorum locis optimè notavit dotes ad Scripturam ritè interpretandam necelfarias; cumque modeltus effet harum plerifque fe dcficere ingentiè fallis eft, adeoque nemo mirari deber fi ejus in Scripturam Commentary parum accurati quandoque deprehendantur: pretcrquam quodin eo Studii genere fatis cxcrcitatus nondum erat cum in hanc materiam Sctibere ftatuit, ut \& iple agnovit. Subtilioris quidem \& acutioris erat ingenii quàm Sanctus fieronymus; Eftque Origene ordinatior etiam \& verbis aptior in omnibus quorum inventor eft: led quia minimum Grecam linguam callebat, Hebraica vero prorfus ignarus erat, Opus quod in Genefirs lufcepie ut Manicheis refponderet, fupra vires ejus fuiffe videtur. Quapropter idem ad incudem revocare necefle habuit; imò nec erubuit ea damnare qux práipi. tanter nimis \& abfque auxiliis ad Scripturam bene interpretâtiam requifitis fcripferat - Cùm fubtilis \& acuri effet ingenii Scrpture falebras facilèdeprehendebat, imo quaddam fubinde animadvertebat is locis ubi plana vid-batur: Sed in co Studii genere fe ipfum fatis non exercuerat, ut aptas earum folutiones \& Lectoribus fuìs fatisfacientes affertct. Quiburdam pratereà Pbilufobicis Theologicifgue prajudiciis fcetus erat, qux Omnibus fuis Operibus interferit: 
Quaftionbus tamen fuis in feptem priores : Bibliorum Libros, oftendit fe Criti: $c e s$ infcium non fuiff, multóque felicius optarum exitum fe alfecururum, $\mathrm{G}$ Grat Hebratque idiomatis notitiam habuiffer; praterquam quòd totum tem. pus ad meditandum in tanti momenti materiam neceffarium ei non fuppetebat. Unde etiam fatceur fe Opus iftud Quastiones infcripfife, quoniam Dubia potiùs. propofuit quàm horum folutiones artulerit, quamvis tamen plurima enodaverit. Ejus in 'P Jalmos Commentarii feu potius Conciones nihil præter moralem \& allegoricum fenfum continent pratcreaque innumeris digreflionibus \& fupervacaneis fubtilitaribus fcatent. Ief. Richard. Simon。Hift. Criticâ V. Teltamenti lib.3. c. 9. pag. 297, 398. Gall.

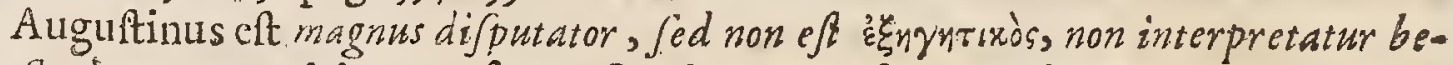
nè Scriptnram, eft ineptus frepe. Sancins Auguftinus in Sanctum Hieronymum tomachabatur, quòd Biblia vertilfet, qui optimè ipfi refpondit, adeo ut-Augum finus leniflimum refponfum repoluerit. Magnus Theologus fuit Sanctus $A u$. guftinus fed major adhuc fuiffet $1 \mathrm{Grecam}$ Hebraïcamque lingúam intellexiffer. Sxpe fatetur fe neque G, recè neque Hebrarcè quicquam fcice. Rhetorica, DialeEtice Grarnaticaque l'rofelfor fuerat. Veterum prattantiflimus eft Sanctus $A u=$. guftinur. Quàm mifellus Liber funt Sancti Auguttini Confeffiones! Scaligerana polterior.

Augustinus fuit utilis ad monita danda pia vitx, ad Interpretandas Scriptu ras fatis infelix, certè Gracis multis infcrior. Grotius in Difculf. Rivet. Apo$\operatorname{loget}$.

Angustinum fuos paffum effe manes nemo juxe inficiabitur. Ejufmodi ef quòd adversùs pueros ante baptifmum morientes, adeo immiferiéordirer proneinciat, non folim vifione $D e i$ privandos, qux fententia vulgo nunc obtinet, fed etiam inferorum igne in aternum cruciandos, qua fuit etiam fententia Grem gorii A riminenfis, doctoris Scholaftici non ignobilis, qui ob id Parvwlorum tormentum dictus eft. Statuit etiam Augufinus Eucharifiam pueris necellariam. Huic fubjicienda eft alia Opinio in quam evidenter propendet; Animam effe ex traduse, \& de patre in flium tranfire, \& ex ejus fubitantiâ non minùs quàm corpus progigni, minimè verò à Deo immediatè creari \& immitti, quæ hodiè nofra omnium fides ent. Nemo nefcit ipfum paffin Angelis naturam corpoream tribuere: temere itcm affrmare univerfum orbem momento creatum, \& Cex dierum intervalla, in crearione ad varios gradus cognitionis Angelice rem ferre. Cenfuititem cum veterum plerifque, Tempus quod inter hominis mo.tem \& ultimam refurectionem interpolitum eft, eA riwas abditis receptaculis contineri. Sed \& cum iifdem omninò videtur fentire fupremo olim die, omnium etiam fanctifrmorum hominum corpora, pof refurrectionem, igne luftratum iri. Illud fanè mirificum eft quod wir', alioyui cautus \& à temeritare alienus, difertifimè affirmat, LXX. Interpretes Prophetas fuife, \& \& $S$ piritu $S_{a n}$ cto immediatè afflatos in Scripturis vertendis; ita ut quæcunque apud hos alicer funt quàm in Hebreis fontibus, ea non ab Interpretum errore,

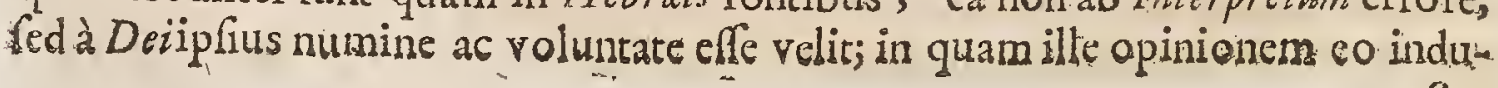


Qus eft, quòd vulgari, \&ab Hieronymo acriter caftigate \& irrifa, 'de Septuaginta diverfis ifforum Interpreturn cellulis fabulæ, nimiùm credulus fuiv. Dal laus de vero ufu PP. p. 280. \&c.

Angufinus defcripfit quxdam fuppreffo nomine ex libro Mercurii.Conring. Hermet. Medic. c. .

Extant cjus Opera decem Tom. Baf. rs29.1569. Antv. 1574. Par. 1585. Fol. Supplement 2 . Tom. Par.16 4 . Fol. Paratur à Renedictinis ! arifenf. acuratiffima Editio, cujus aliquot jan Tomi prodicrunt.

Vide Opera ejus Genuina, Dubie, Spurza, \& Deperdita apud Gul. Cave in Hift. litcrar. fcript. Ecclef.

\section{SEXTUS AURELIUS VICTOR}

U I beneficio Cl. Viri, Andree Schott', prodiit in lacem, stantir \& Luliani Imperatorum. De hoc Auctorc fic Ammrianus MarcelliClar. An. cecXevi. mins 1.2x. Imperator (Constantius ) revertitur $N$ aflium, copiofum oppidum: quiò inde expeditè cuncta diffoneret fuis utilitatibus profutura: ubi Victoreris apud Sirmium vifum, scriptorem Hiftoricum, exinde venirc praceptum, Panonix fecundæx Confularem prafecit, \& honoravit æineâ ftatuâ, virum fobrietaris gratiâ multilaudum, multò polt uibi præfectum.

Extant hujus Vietori is libii duo. Prior eft de Viris llluttribus a Procâ ufque ad Iutium Cafaremn: qui vel Cornelo Nipoti, vel Plinio Novocomenfis vel Suetonio etiam falso tribui foi et. Alter continet vitas Casarum ufque ad Inliani tertium Confulatum. His libellis pramittitur Origo Gentis Romana. Sed cur Commenratiuncula ithec minus credatur ejuldem elfe Vitoris, verifimile facit titulus ejus: quando ifthic legas, ex fontibus illis petitum effe, ex quibus fua haufere juniores ipfi, Livizs, \& Vilior Afer. Quis cnimfit Jidtor ille Afer, fi non eft hiftoricus ille Annziano memoratus, ac cujus duo funt libelli, quos dicebamus? Nec obftat Afri cognomen. Nam Aurelizm Victorem natione fuilfe frum, a vero non abhorret, quandoyuidem multus eft in eâ laudandâ, ac alicubiappellat terrarum Decur. Quamobrem ita colligimus, libellum de Origine Gentrs Rom mana congettum effe ab aliquo, qui fuerit poft Aurelizun Jictorem. Atque idem Ecripfit de Origine Gen, is $H^{\prime}$ at tovine: ut ipfe initio libelli de Origine Gentis Romaneteftatur. Vittorem fuife hominem Gentilem, vel inde conftat; quod in $H$ r.m driani vitâ cò inclinat, ut Antinoi Sacrificiurn res fuerit pia religiofaque. Voffo de Hift. Lat.1.2.c. 8

Hiftorix Romanx breviarium ex omni Hiftoriâ prif́corum digeflit, \& de viris Illuftribus urbis Romæ libellum illuftrem compofuit. Ecriptor praclari judicii, qui charactere cuiquevcrè Principi affingendo, paucos omninò pares habuit. Summa autoritatis Hiftoricus; A frum in eo acumen, \& denfitas fententiarum nodofa, \& fummo affectatoque ftudio difficilis. Barth. lib. 54. Adverfo cap. I3.

$$
\text { Mm } 2 \text { Inge. }
$$


Ingenium \& dictio Victoris Aurelii videntur fpeciem quandam referre Cort: Ta: iti , cui tamennihilo propior eft, quàm trannum argento. Laudandus: tasmen conatus, \& habenda gratia Vidloris induftrias qux cum multa undique delibaverit, cavi nobis, ne plurimarum rerum ignari eflemus quarum memoria cum vetytiolibus libris, unde erant execrpta, penitus interiifet $B$ alth. Bom mi,ac. de Rom. Hift. fcript.

Is ut elegantiẩ Romana haud mitabilis eft, ita propter magnitudinem materie: valdè nobis utilis, licet non femelerret, \& pleraque dicendo omittat.Car. Sigon. de Hiftor. Roman.

Durum hoc mihi ipfi viderctur; nifiVictorem cogitarem, reliquam ejus ad:fectata noyitaris Phalim. Lip $\int 1$, de Amphitheatro, c, 6.

In his, (viz eAlio Spartiano.Iulio Capirolino, exlio Lampridio a. Vuliatio Gallicano, Trebellio Pollione, Flavio Vopifca Aurelio Viltore) vix eft quod probes prater Hiftorix fidem; tantum abeft, ut $\cos$ Ciceroniani cognominis honore digner. Nam agre tuentur Sermonis Latini calimoniama. Erafm.in Ciceronicino.

Aurelius Victar, A uctor neque indifertus, nec inargutus: quem virum fobrie tatis gratiânulitaudum: dicit Amminnu Marcellinus: Q Ca faubonus Opufculim ejus de Vitis Auguforwr , elegantiffimum appellat. Whear. Method. Leg. Hift. Civ. lect. 22.

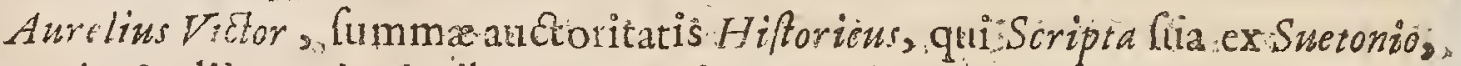
Eutropio, \& aliís antiquióribus contexuit: Ioan. Card:Bona.

Sextus Aurcliu Victor, vir Cónfularis, bueviter ab Augufo ad Thoodofia feuioris monem, fub quo vixit, Irmperntorum vitas mandivif memoria: Nonnulla alia praterita perfecutus eft. Corrigendus ent autem dum tempote Convenrus Medivlanen/is ambos Conftanini flius creatos fuife Cafares rtadit, cum

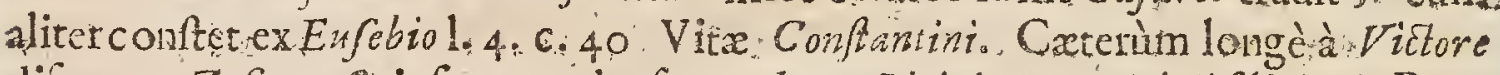
difcrepat:Zofmn, ipfe errore lapfus, dum Liciaianum Licinit fitum à Patre ereatum Cefaren dicit non ckm viginti menfum effet infans sedannos viginti watum. Ant. Poffer. Biblioth Sclect.

S. Aurelii Victoris Hiftoria Romana compendium Interpretatione Notis ils

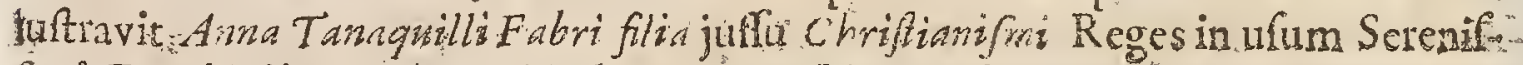
frmi Delphinin 4: A Parifychez Denis Thiorry 168 .

\section{S. JOANNES CHRYSOSTOMUS。.}

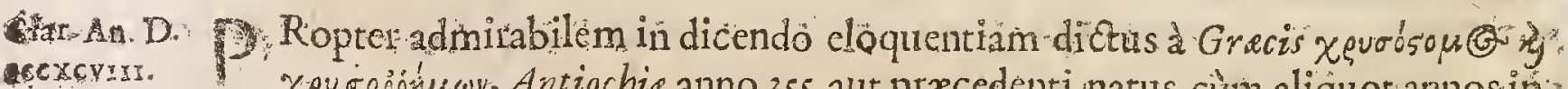
converfus, adverfus Gentiles $\&$ iddos anno 382 . fcipfit, rum amo 386 . aे $:$ Melétio Patriarchâ Antiocheno. Presbyter ondinatus,cum Marcuonitis non.femel dif Nutavit. Anuo Chrifti 39 8 Arcadii Imp. ab obitu patris quarto, poft Nectarium 
2dThronum Corftaninopol. Regix urbis evectus $\%$ ex eo dejectus eft anno 403. confpiratione Eudoxic Augufte, Theophili Alexandrini, \&aliorum Epifcoporum, \& in exilium ejectus, unde paulò poft revocatus anno feq. iterum deportatus eft Cucufurn Armenic oppidum, \& Arabijfurn, ac in villam, qux Comana dicivur, in Regione Pontzcâ, in quâ, cùm rediret, obiit die 14, eptembrts,anno $407 \mathrm{o}^{\circ}$ zratis 53. Pedis g. cum menfibus G. \& die 20. Phil. Eabbe.

Si: Plutarcbo fides fit habenda, -qui perficuitatem ac facilitatem germanum: Atticifmum elle cenfet, praclarus ac celebris loannes omnes fuperat, ut qui \& Atticum feverbis prabuerit, \& perficuitatem, qualem: haud fcio an alius:

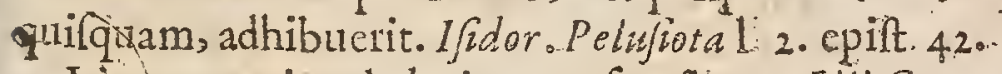

Linguam etiam habuit, qux fuo Guxu. Nili Catarrbaclas fuperabat. Nullus:

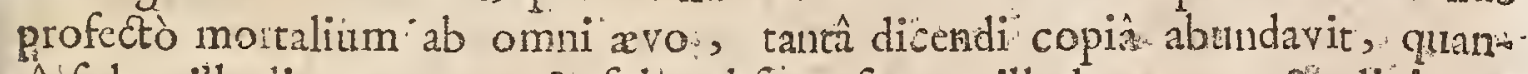
s' ' Colus ille ditatus erat, $\&$ folus abfque fuco, illud aureum $\&$ divinum [Ch, yfoftomi] nomen hareditario quafi: jure confcutus: cfio. Suidas in verb: I wóuruss.

Dictio illius de möre perfpicua \& pura; fplendida infliper, ac fltens apparet. . multam interin cùm fenfuum varietatem, tum gratifimorum exemplo rum copiam exhibens. - Quacunque auditorum captuia accommodata effent, atque ad corum falutem \& utilitatem pertinerent, ea neutíquam, ille pretermittebat. Quamobrem neque adinirari fanctiflimum virum fatis unquam poffum, quòd perpetuò in omnibus fuis fcriptisurditom ita utilitatem, tanquat fcopum prefixiffe fibi videatur, , ut catera , vel omninò neglexexit, vel leviffmè attigerit. Sed \& illud penitus pre: atulitorum utilitate contempfit, quod alicui vel fenfus aliquos ignoraffe, vel'ad profundion quædam penetrare refugiffe, vel id genus alia prateriffe, videri polfet: Phot. Biblioth: cod. 17.2 .

Quantum verö ad verborum rationem; \& genus Dictionis attihet; om ei tribumt nativam; nudam ac venuftam Atti:i Sermonis puritatem; admira bili docendi-facilitate conjuntam, qualis nulli unquam,..vel Grecorum elo

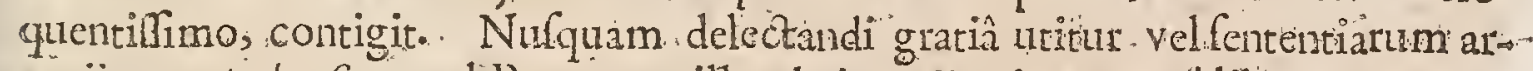
guntiis ut Ambrofius ; vel Poetarum illecebris, \& mimorum fálibus, ut Hierom nymu; vel facetiis \& jocis, quemadmodum Tertullianus: Sed iffectu porius. paterne Charizatis, \&spio quodam juvandi fudio mirificè delectat e A uditores; quos ut majori cum attentione detineat, orationis curfum frequentibus dialogifmis, percontatiunculis, \& cxercitatiunculis interumpere.folet... Sixtus Sem. nenf.1. 4. Bibliorh. Sancte;

Omnium ferè difciplinarum eùm Chryfoftomus fuerit exactè doctùs, nullan tamen ufquam prabet oftentatiönis fpeciern; féd'omnes humanas. Difciplinas

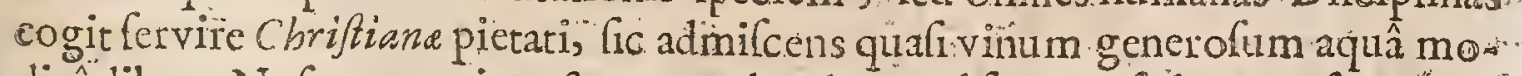
dicẩ diluas. Nufquam enim eft aqua vel color , vel fapor, fed tamen fentis vimun effe fuavius. Cumque tantus effer, tum eruditione, tum eloquentiấ; tamen incredibili quodam ju vandi ftudio, quicquid ferè fcriplit, accommodavit auribus populi, coque ad hujus captum demifit orationis habitum, quafi Praceptor $M=3$ cum 
cum puero difcipulo balbutiat. Metaphoris \& collationibus, quoniam pluri. mùm conducunt, \& ad lucem, \&ad jucunditatem orationis; frequenter utitur: in quibus inveniendis quidem mirus eft, fed multò mirabilior in tractandis. Erajr. 1.28. Epirt. 4 .

Mihi inter omnes Grecos placet Chryfoftornus lectus : quiieopiam, varictatem, figuras \& flexus Sermonis dabit; deñique \& ornamentum grande, \& quod plaufus movet, fimilitudines atcue Imagines, quibus fatet. Lips in Cent. 3. Epilt.ad Betgas, Epilt 49.

Pafchatiume feriarum, five religio, five otium, facile fuafit, ut veterum Greca Ecclefie Doctorum eloquentifimum, Chryfostornum, in manus fumcrem. Ejits enim facundia, eruditio \& facilitas, in causâ funt ut eum aliis: omnibus libenter praferam. C1.S.zrrav ad C. Salra of. Lut. Parif. 9. Aprilin644.

Ego ftudiofifinus illius Paris fum, tum quia nullus melior Novi Teft-menti lnterpres, "tum \& proptcr miram dulcedinem, \&amœnitatem dictionis, quam poftillum nullu; Eccleffaticus Scriptor confequi potuit. Iofeph. scalig. epift. 389 .

Verè dicam: Ego multùm faveo Chryfostomo, propter illuả flumen eloquenriæ, quod nunquám lutulentum fluit, fed femper fibi fumile eft. Hoc tamen non polfum difimulare, quod in co Scriptore deprehendi, quum ab illis difceflit, qua ad facram pagindm pertinent, nihil puerilius, ne dicam infcitius effe illo Iofeph. Scalig.epift. 84 .

Chryfostomus Patrusw Gracorum preftantiflimus. Si omnes S. Chryfoftomi lucubrationes typis mandentur, Ioo. florenis profectò valebit. Benè fcripfit, lce quando à Thcologia fua, fuoque textu digreditur, nihil nifi vilifimum preftat. Impuritatem fuperbix junxit. An decebat illum patrare qua patravit. Exilio multatus eft, idque jure merito. Infinita pulchra habet ot optima in Novum Teftamentum. Scalige rana pofterior.

Chry foftornum \& Hieronymum legere volui, ideò quòd eos videbain in textus Sacræ Scriptura exponendo feliciores cateris haberi. Grot. vol. 4. Imprefr. Lond. apud Mofern Pitt. fol. p. 6.53.

Poft Sacra Biblia 2 Paulinas in primis Epifolasnullum novi Ccriptum,in quo qui concionatores funt \& Grecenon nefciunt, majore cum fruetu verfeutur, quàm in $B$. Chryfoforri Homiliis, quas ita numetofas reliquit, ut nemo plures; ita bonas, tte nemo meliores; ita difertas \& dilucidas, ut nhil excogitari quidem poffit difertum atut dilucidum magis. Ioan. Boifus prafat. ad Notas in Tom. 3 . Chryfofiomi.

Iobame Chryfifturno, nemo Gracorum Patram ptura dedit, nemo meliora. five orationis ornatum fpectes, five gravitatem fententiarum. Subdas in omnes $V e-$ teris \& Novi Testamenti libros commentaria refert edidiffe complurimos prxrereà compofuilf Tractatus, ad multa ver fasm millin, quorum mumerum inire non bominis efle, fed Dei, rui notafint ornia. Georgius Alexandrinus quattor millia \& oetingentos ipfus Sermones, cum omues nou poffent, à piis quibuldam viris polt mortem ejus coacervatos fcribit. Porro in juterpretandis Scripturis ita 


\section{CEIEBRIOR UM A U:THORUM.}

felici,adeoque Divino fuilfe Ingenio conRtr, ut quamvis cateri Ecclefra $P$ atres, communibus fuffragiis locum aliquem Scriptura lecus quàm ipfi vifum elfet, interprctarchtur, contra omnes unius præponderaret fententia. Quam confuetudincm in Orientals Ecclefia, \& \{emper antea, \& fuo tempore obtinuilfe fcribit Author incertus vite Chryfoftorni, c.37. Quin \& in Occidentali magni fuille. ponderis cjus Interpretationes, tcftes funt locupletes-Hieronymiss \& A Asgustinus: ipfifque adeò Britume is Infulis folum cx omnibus Antiquis Interpretibus lecttatum, in fummâque hábitum ądmiratione multis ante fuam æatem feculis refert Georgiws. Nec minor in Dogmai ibus Itabiliendis ejufdem Auctoritas. Henr. Savil. in prafat. Loan. Cbry ost. oper. prefix.

Chryfoftomus licet pulchrè fuo cognomini refpondens, alicubitamen verbis redundat, \&in digucfionibus videtur immodicus. Erafm.1.28. Epif: .7.

Iobannes Chryfuftomus abfque controverfia doctiffimus ac facundiffimus fcriptor. Ei tamen multa excidif́c, velfalsò, vel certè incautiùs dicta; - \& veniam pofcentia quis neget? Quale eft quod fomniat $D$ avidem eos Pfalmos qui quinquagcfumum proximè confequuntur, humanâ fimpliciter intelligentiâ fcripfife, Spiritu Sancto vacuum: Idem peccarum originale videtur nefciviffe, nam \& peccat $\mathrm{t}_{\mathrm{m}}$ nobis naturâ ineffe negat, \& parvulos peccato carere ait, \& illud Pauli ad Romanos 5.19.:Per irobedientiam unitis bominis peccatores conftituti funt viulti, admodum dilutè interpretatur, ac fi Apoftolus vellet homines Ada fcele. lère, non peccaro quidem ipfin, fed morti fuife fubjectos" Eum quoque clarum eft juftorum animas coelo ante fupremam refureetionis dicm exclidere, \& preces pro ipfis damnatis approbalfe, ac velut utiles commendalfe; quod videntur quoque fentire Angufinus, Damascenus, \&alii. Dallaus de ufu PP. pag. 273.274 :

Extant Opera Chryfoftomi uracè 8.vol. Eton. 1613. (qux nitida planè eft \& accurata editio ) Grac. Lat. I. vol. Par.1609. \& 1636. fol. Orotio in Diodorwm Tarfenf, cum Palladio Gr. Lat. Par.1680.4\%. Horril. 6i ap. Combef.16j6. Ho milic 4. in P Jalir. \& interpretatio in Daniel. Gr. Lat. Par. 166., 4\%. Defideratur inter hujus $P$ atris inedita, celeberrima ad Cafarium Monachim adv. Apollinat rii. Hærefim Epiftola. Antiquam hujus Epiftola verficnem ( graca enim fuper. effe haud fperandum eft) ex codice Florentino à fé defcriptam Palladii Dialogo de vitâ Chry /of tom inuper fubnexuerat Emericus Bigotius. V crùm impreflone ad umbilicum perductâ,. Epiftolam à reliquis divulfam fupprimendam curarunt Cenfores aliquot Sorbonici. De quo meritò conqueftus eft ex Reformatorum gente Parifierfis Theologus. . Donec prodeat integra, liceat mitii hoc loco ad fragmenta qux extant, digitum intendere. Primùm habetul ap. Petrum Martyrom (qui Epiftolam hane ex codem Codice Florentino defcripferat, fecumque in Angliarm netulcrat ) in defenf. Euchariftix adv. Gardinerum Wintonicnfo Part. I. pag. 390. . Et iterum p.502.edit. ut: videtur. Tigur. 1559. fol. Et loc. commun. Claff. 4. cap. Io.pag. 603. nobile, fr quid alivd, adv. Tranfubrtantiationis dogma teftimonium. Aliud habet Damafcenus libro contra Acephalos ap. Canifo Antig. Dect. Tom. 4. Part. I. pag. 2Ix. Tertium Anonymus 
contra Severianosibid. p.238. Cave Chartophyl. Ecelefiaft.

Vide ibid. Fragmentum Græe. prædid.Epift a ex Biblioch. Artndelo antiq. MSS. defumptum.

S. Chryfoltori Epiftola ad Cafarinm apographam hatonit ex Bibliotheck Florentinâ Laurentius Panciaticbi, Cardinalis Medicæi Bibliothecarius, cujus copiam ab co impetrate non potuit Chrift. Sandius, ut iple tettatur in Appen-. dice Hiftorix Arianorur, cumque eum interrogaret quid Epifcola contineret, refpondit Panciatichi (e non andere id propalare. Chryfofrom: Homilio in to tum Pfalterium ( quarum partem tantùm habemus) ufus ef Wilbelmus Lindanus ex Cardinalis Granvellani. Bibliothecâ. Has in Latinum Sermonem verit Martinnus Duncanus, codem Lindane celte. Prafatione in Pfalterĭum vetus ab co caftigatum. Vcrim tralatio ifta nunquam prodiit. Veteris Teitamenti Synopfis, auctore Chryfostomo. MS. occurrit apud Cl. If. Voljum. His adde leremie explanation em. qua Gracè integra extat in catena Chilterianâ in hune Prophetam. Paul. Colomef. Paralipom.ad Chartophyl. Eccler. Gul.Cave.

\section{SULPICIUS SEYERUS。 \\ Vel potius, \\ SEVERUS SULPICIUS.}

6las. A. D. A Quitanus, Primuliacenfis in Galliâ Presbyter, tarffimi Sermonis Scrip CCC. Scripfit duos libros de Sacrâ Hiftoriâ -Vitam B. Marti i -Tres Epirolas - Tres Dialogos. In quibus fequitur eírorem Millenariorum.

Severus Presbyter, vir genere, \& literis nobilis. Gennad. in catal.

Severus, vir doctrinâ \& fapicitiâ pollcns. Augufin. epift. 205.

Dictione utitur tersâ, \& el eganti, adcò utt Ecclefanficorum puriflimus Scriptor à Iofepho Scaligero vocetur. Voff. de Hift. Lat.

- Elegantiâ Romani Sermonis vix quifquam Cbrifianus AuCtor extat praferendus Severo Sulpitio; ut cum legens videatur fantis Reipublice Senatorem ali quem de diuinis rebus differentem audire. Barih. 1. x2. adv. c. I8.

Chrifinnum Sallufium vocat Barthus 1. $49 \cdot \mathrm{adv}$.c. 4 .

Quô opuculo ( $\int c r \hat{a}$ Hiftoriâ) non fanè magno, aliud an ullo unquam feculo Reip.Chrifian urilius ac praftabilius editum fit, iis, quorum illudeft judicium, judicundum iclinquo. De clegantiâ verò prâtare aufim, \&affirmare me polfe confido, nulli idem omnium Scruptorum Ecclefaraficorum quicquam concedere; alia verò omnia, quxin codem genere verfantur, tanto intervallo omnimodis fuperare, ut ne fut quidcm ad hoc comparanda. Magnum eft quod dico, \& fortaffe plurimis incredibile: Sed ejufmodi tamen,quòd non tă dicenti mihi, quàm teftificanti pro me veritari creditum iri confidam, fi quibus opcræ pretium erit Orofum, Florum, Eutropium, aliofque Epitomarum autores cum hoc noltro 


\section{CELEBRIORUM AUTHORUM.}

omnibus partibus contendere. Victor Gifelin.in vita Sulpit.

Hortor omnes qui fe aut facris aut prophanis ftidiis dediderunt Adolefcentes. ut Severur: hunc eo animo lcgant, ut plutimùm fe non tam in prudentiæ, quan in religionis $\&$ innocentix fudio profecturos effe confidant. Addo criam Latina Eloguentix, quam ille tantâ induftiâ coluit, ut Salufianam dictionem nobis magnâ ex parte exprelfrit. Car. Sigor comment.in 1 I. Hift. Sacra.

Dignus fanc, qui val eo nomine legatur, quòd fupra faculi fui captum loquitur Latinè. Iof. Scalig. in epift. 305 .

Vir erat doctrinấ \& fapientiâ plurimùm pollens; fcriptor valdè politus. Whear. in Meth. legend. Hift. Ecclef.fect.

Sulpitius mollior quidem \&.jucundior \& dilucidior \& illaboratior Hilario, fed Phalis Gallum fuilfe declarat. Non deeft pictas, fed abeft vis \& gravitas, \& eft floridum dicendi genus magis, quam nervolum. Erafm. in Cictroni.no, pag 152 .

in Senectute vergente, à Pelagianis deceptus (Severus Sulpitius ) polted arroris fui ponitentiam egit; ac pcrpetuo filentio linguæ temeritatem expiavit. Stylus Severo clarus, facilifque; \& longè fúpra feculi fuigenium terius \& politus. Gul. Cave.

Hic Author (Severus Sulpi:ius) elegans elt. Admodum caftè politéque fcribit. Eximiam brevitatem frimma perfpicuitati conjunxit, in quo Salufium qucmimitatus eft antecellit. Hiftoria Breviarium ita concimum \& egregiè elaboratum nemo nobis cxhibuit. Non eft tamen valde acculatus \& in Hifto riam pluries pecsat, in Ecclefiafticam prafertim. Quoad Miracula credulus admodum eft, Vetertımque deliramentis fuffragatur, circa Regnum Mille als norum, circa Antichrifum quem putat $N$ eronem effe, circa tempus finis feculi, \& circa filios Dei quicum mulieribus commercium habuerunt. Admodum obiter perftringit Hiftoriam Ecclefix, à lefu Chrifo ufque ad Sxculum quarsum. Pauciffina de Arzanis memorat; fed de Prî́cillreniftis prolixè admodum differit, pluraque quam cateri Authores de' is nos docet. Ell. du Pin. Nor. Biblioth. A uthor. Ecclef. Tom. 3. Gall.

Quòd à Telagianis leductus inaliquo à regulâ Orthodoxe Fidei exorbitaverit vevern, nufyuam omninò, nifi in folo Gennadio legi, qui nefcio utrum hoc alicubi \&.iple legerit, an c $x$ folâ famâ, cuix facta infectaque loquitur, didicerit. Illud tamen fideliter credo, hunc ejus errorers gloriam fanctitatis ejus non oblcuralle ; cum autor idem qui refert, deceptum teftetur \& correcturn. Guibert. Abbas Gemblacenfis.

Malè verò Carolus igonius, Petrus Galefinius, \& Victor Gifelinus Sulpitiume hunc, cum Sulpitio, epifcopo Rituricen/l, confundunt. VofJ. de Hift. Lat.

sulpitiues Severus, vir fabulis addietiflmus, Henr: Dodvvel. dilfert. Cypr.p. 299. in $8^{\circ}$.

Severi Sulpitzi libri de Sacrâ Hiforia \& Dialogi de Converfatione Orientak lium cautè legendi funt. Bellarm. de Script. Ecclef.

* Ioannis Drusii Commentarius in Sulpitii Severi Hiforiam Sacram 
prohibetwr, donec cmendetur: Index Madrit. anno 166.7 .

Georgii Hornii Commentaria in Severum Sulpitium, amnind prohibentur in Indice Rome Impreffo 168x.

Prodicrint Opera Sulpriti Severi cum Notis Variorum, accurante Georgio Hornio. Amftelodami apud Elyivirios 1665 . in $8^{\circ}$.

De Severi Sulpitii laudibus \& Scriptis . Bellarminus \& Labbans in Opere fuo, De Scriptoribus Ecclefrafticis, Polfevinus in Apparatu Sacro fcriplerunt. Hujus operibus fapitis impreflis cum Notis ctiam \& Commentariós, addo duas infignes Epiftolas ad fororem Cuam, quas primus evulgavit Stephanus Baluzizus. rom.I. Mifcellaneorum fuorum p.j29. Itemque alias quinque in Spicilegio Luce Dacherii evulgatas ex MS. Cod. tom. 5. p. 532. niagnum veteris ac venerandi Scriptoris Supplementum. Cafmir. Ondin. in Supplem. ad Bellarm.

\section{AURELIUS PRUDENTIUS CLEMENS.}

clax. A. D. 7 Ir clarifimus, Hipanus, Miles Palatinus, (funt qui Virum Confulatrem $\mathrm{CecCV}$ atque urbi Romana Prafectum vocitent):Poeta Chriftianur, natum fecanieAnno Dow 348 Floruit Theodofi Magni \& Filiorum ejustempoxibus. De morte Prudentii nihil confat. Iuventutem incontinenter actam fibi faterur ipfe \& delet. Leguntur adhuc ipfus Poëmata multiplici ac vario genere carminum compofita:Quibus facile probari potefteum quidem pro conditione temporum maximè praftitife inter Chrifiaños Poctas, non modo eruditis verborum figuris fed etiam fententiarum gravitate. Sidorius Apollinaris haue omnino contemuendus autor in legendis atque obfervandis antiquis Scriptoribus, cùm loquitur dé Prudentio' Poetä, minime veritus eft,illum oratio adjungere fetr. Crinit.

Fuit homo multz quidem ertditionis ac varias, verim in Eloguentiâ ac linGur caftitate vel parùm valuit; vel potiùs neglexit, defiderio videlicet pietaris ac fide $i$ Quod ipfe innuik cum alibi, tum in Hymino octodecin Martyrmm Cefaraw guftrnorum. Lil. Gyrald.

Hifforiam Cbriftianari juvit iis, qux, inter alia, de variorum Martyrum paffionibusfcripfit:Carmine quidem; fed ex quo tamen petere rei gefta veritatem fo leant, qui hanc materiem prosâ prolequnntur. Volj. de Hift. Lat. .

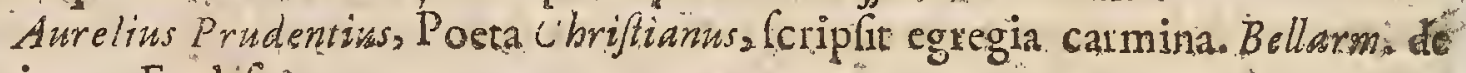
Scriptor. Ecclei.

Irudentius Pindarus Cbrifiranus dulcifimus, \& prudentifinus C Crifti vates. Ioann. Bona Card.

Senex yario metronm genere res Eccleflafticas ingeniosè \& eleganter tractavit. Illyricus Catal. Tefium Veritat.

Prudentius feptimum \& quinquagefimum anurum agens, ges Ecclefraficas vario carminum genere capit componere, doctè \& eleganter, nifi quòd interdum in vocibusperegrinis \& maxime Grecis, fyllabarum quantitatem neglexit; quum tamen Gracas illum Literas probè tenuife teftentur librorum ipfus In foriptiones Graca. Car. Stephain. in Dietionar. \&c. 


\section{CELEBRIORVM AVTHORVM.}

Prudentius fanè tolerabilis eft Poeta, fed aliàs xtatis confuetudine abripitur, Alìs prifcorum verborum ufui,\& Lucretizi imitationi nimium indulget. Cafs. Sciopp. in confultat. p. 43 .

In Prudentii carmine funt etiam qua defideres. Lud. Vivi de Trad. Difcipl. p. 520 .

Quô nemo diviniùs de Chriftianis rebus unquam Ccripfit. Barth. adv.1.8.c.Ir.

Eft cnim in co pectâ recondita enuditio, rarus in verbis lepor, in phrafi latinitas uon impura, nif quâ i mitatione facr $x$ loquelær, fregit volens regulam; \& quà à barbaric Menachorum exfcribintium fecus quàm voluit, non rarò fcribere coactus eft. Barth.1.2I.c.4.A'Ár.

Elegantium xcrum thefaurus eft Prudentim, qutem non debcmus inftar" Poetre vulgatis prixterire. 1 dera ibid.1.27.0.5.

P'ruderzizus bonus Posta. Scaligerana' $\mathrm{x}$.

Prudentius elegantiflmus Poeta. Scaligeranaj 5 .

Aurelius Trudentius Clemens, Theodofo Magne Imperatore clarus 's fupra genimm freculi fui facundiâ \& piầ eruditione alfưrrexit. Sunt inter manus opera ejus metrica pfychomachia, caibencirinos, apotheofis, hamartigenin, item de Coromis Martyrum, \& libelli duo adverfus Symmachism-cum hymnis aliquot. Verfus ejus, fi quantitatum vitia töllas, ferè fine Galebris, fonori,decori.Borrich.de Poëtis p. 720.

Prudentius non elt valde bonus Pocta. Barbaris fxpe utitur vocibus \& ab Auguftari feculi puritate longè remotis. Ejus fcntentix funt fic fatis concinnx \& vero Chriftiano digna. Quidam ejus loci eleganter'fcripti funt, quique cum jucunditate leguntur. Elles du Pin Nova Biblioth. Author.Ecclel. Tom; .

Prudentius omnium Chriftianorum Poetarum prudentiffimus \& exuditifimus. Taubrianir.

Tantum Ypirans tum fanctimoniix,tum facræe celuditionis, ut mereatur inter graviffimos Ecclefia Doctores annumerari. Defider. Erafrn.

Unus omnium inter Poetas Chriftianos Lectores fuos pafcerc fufficit lau-, tifimè, five pretiofiffimas panis cơleftis, hoc eft, verbi divini epulas efurias, five: efficacis eloquentix condimenta rèquiras. Petrus. Mofellanus in Epiit. ad Matth. Meiner.

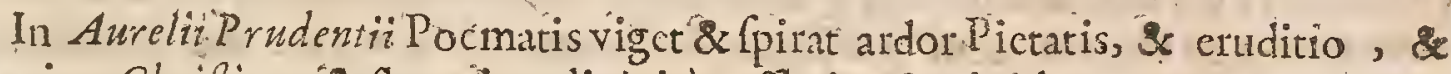
'gravitas Chriffiana, \& Alexanima divinitùs êflati pectoris to loquentia, ad ciendos in animis.legentium affectus pios efficaciillma. David. Chobtrans in Regudis ftudionum, P, I94.

Tamen in Prudentio verborum nontam acer delectus. Lipfo in 1. 2. Saturial. Sermón.c.2O.

Prodierunt opera jus five Poematacam Notis Criticis Nicolai Heingi it 32. Aimfelodam 1670. apud Elzev.

Libri 2. adverfus Symmachum cum Scholiis Ifaaci Grangai Gymnafiarche Vindocinenfis, ad ill. D. Crefarem de Vendogine, Vindocinenfem Ducem. Par.apud Rabertitum Fovet.1614. 8\%. 
Chax. A. D. ecCEX.

Enere Pentapolitanur, es Philofopho Platonico, Ptolemaidis in Thebaide:

I. Epilc. vivebat annum circ. 412. Gul. Cave.

Opera Synefir edidit Dionyfans Petavini, Ann. 1612. \& 163r. cum Notis. Inter qux liber de Regne: De Providentia libri duo: Epiffole Iss. Dio, vel, de vita ipfus inftirtto: Calvitii encomium: Cataftafis in Barbarcrum excurfionem Catafaffis in laudem Anyfii : De dono Aftrolabii : Homilia : Hynnni : De InSomniis.

Hic igitur Synefus, tum reliquis difciplinis excultus fuit, tum in Philofophin adeò excelluit, ut admirationi effet etiam Cbriffianis, his fcilicet qui neque odio, neque gratiâa adducti, de rebus.judicare folent. Perfuadent igituru illis, ut falutaris regenerationis lavacrum perciperet, \& Sacerdotii jugum fubiret. tametfr R.furreefronis doctuinum nondum fufcepilfet, ncque ita fentive velletz rectè o minò conjicientes, ad reliquas ejus viri virtutes ifta effe äcceffura, cùm Divina Gratia nihil imperfectum habere furtineat. Nec Lpes cos fefellit. Qualis. 'enim \& quantus extiterit, abunde tettantur,tum Epiffola poft frifceptam- Sacerdotii dignitatem eleganter \& doctè ab co confcriptz; tum Oratio quam dixic eidem 'imperatori Theodofr ; tum quicumque ejus libri admodum utiles circum: feruntur, Evagr. L.r. Ecclch.Hift.c.I5. Henr.Vales. Interprete.

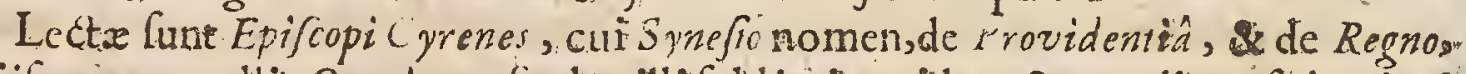
aliifque nonrullis Oratione. . Stylus illifublimis quidem \& grandis, fed quil ad popularcm fimul dictionem aliquantum inclinet. Lectre funt \& ejuldem Epiftols varix, venuftate ac dulcedine fluentes, cum fententiarum robore ac: denfítate. Pbot. in Bibliotl. Cod. 26.

Synefri Atyhus, Photii quidem judicio, grandis \& fublimis eft, feot Poefin aliquatenus redolct. In narrationibus prefertim \& in defcriptionibus exccllit.Pro lixis prafationibus crebrifque digreffionibus variat argumenta qua pertmetator Delectabilia reddit cadicm, praclaris Hiftorix fabuleque locis, infignioribufque Profanorum l'oetarum dictis. Nihil afperi nec tadiof habet ejus. Philofophiajeacft cjus indutria ut hanc gratam \& jucundam reddat;adifolam delectationem attcndere videtur, cùm præcipua fapientix capita tradit. Ad fummarum veritatum notitiam lectorem fenfim de ducit, dum feftivas tantum narrationes e $^{-}$ legere putent. In prima ejus Epifola duorum generun Opera illam feripfiffe: - bicrvat; a alia effe circa fublimiffmam P hilofophiam; alia verò Rhetoricas differtationes effe: Sed facile cognofei poffe utraque ejufdem ingenii foetus effe.s, modòres ferias. , mọà facctias meditantis. Et fane idem character ubique: Eonfuicitur. Opera ejus Philolophica Rhetoricis \& Poeticis figuris funeexornata; Eloquentix verò diatriba fententiis Philofophicis roborantur. In Plamtonieis criptis verfatiflimus erat, \& ex illo fonte hauferat quicquid maximi $\&$. celfffimi habct antiqua. Philofophia circafummi Entis \& Moralium Princijiorum cognitionem. Pauca de Religione noftrafcripfit, \& multum abeft quin 
in ea reque doctus effet ac in Platonis Philofophia. Liquet tamen ex ejus Epiftolis cum fuiffe fapientiflmum, prudentifimum \& optimum Epifcopum. Negotia quantùm poterat detrectabat ; quando tamen illis implicabatur dexterrimè fefe hinc expediebat eaque cautiffmè gerebat Magna finceritate cordil'que rectitudine utebatur, ncc tamen conftantia \& lenitate, datâ occalione deficicbat. Humilitatis feu modeftix ejus præclaram ideam mentibus noftris -ingenerant conatus illi quibus Epifcopatum reculavit, \& modus ille quo de fe ipfo loquitux. Ad puatum ufque annum vixerit ignorarur. Ell. du a in. Nova Biblioth. Author. Ecclef.Tom.3.

Synefius vir admirand $x$ fanctitaris \& doctrinz s eloquentiz tamen fudiis clarior, quam rerum Ecciefiaficarum notitiâ. Quenfledt.

Synefius Philolophortm omaium, uno Platore excepto, cloquentiflimus_.... Neque enim mihi animus eft, cloquentifimi juxtä ac fapientifimi Philofophi: (Synefri) laudes pertexere, aut orationis accuratifimx virtutesperfequi, aut reconditam philofophandirationem in lucem protrahere. Luc. Holffen. difertat. de Synef. \& de Fugẩ Epircopatû́s.

Phrafis cjus tanquam Attic baudatur. Gcfner.

Dictione ntitur gravi , \& qux exercitatum \& attchtum le etorem requinit. Neand. Geograph.

Synefus claboratus, \& tranflationibus paulò obfurioribus fiequens. Lud. Fiv. de Trad. Difcipl-p. 540.

Iounnes Maria Brajuchellanus in Romano Indice obfervat, Synefium, qui diutiù antè'Philolophus Ethricus vixit, Clatonica quedam feu Pytbagorica nonmunquam fuis a ymni, infertilfe, præertim, cǜn de Trinitute loquitur, víx Poëticis numcris potuiffe retinere exactam illam loquendi rationem,quam. Theologia irs Myfterio facra Triadis Lervandam prafcribit.

Reperiuntur in Scriptis cjus quædam E bnica opiniones, quales fum Opinio de Venere, quòd cjus indignatione mulieres $T$ ibyce grandes habean mammillas, pectosaque inconvenienter compofita, ita ut infantes non per alas, fed per hume ros lac lugant, mammâin humeros rejectâ, Epirt.4. Opinio de Foriunâ \& Famâs. quòd $D$ ea fuit, Epint.43, 4.4.

Vide plura /cj. Arndii Lexic. Antiquit. Ecclefiaft.

Synejius pius, doctus,argutus interdum, itylo amœno aque prosar.verfuque bonus. Balth. Rorifac. Ludic. Hilt.p.603.

Vir pietate \& eruditione inter primos fui ævi. Hofmän.

Vir fuit admirandæ fanctitatis \& doctrin $x$. Scripfit plurimas \& elegantiflimas; Epitolas. Bellarm. de Scriptor. Ecclef.

Synceri Epiftolas.admirandas vocat Gregoriur Gyrald ws.

Egregia in Synefii Epiftolis occurrunt. Scaligerana 2.

Synelius, patriam nactus Cyrenen, Pentapoleos in Libyâ Egypto groximân no minatifimain urbem, ab incunte atate, $u t$ ex epintolâsj. adverfus Andronicum, difcimus, Philolophia opcram dedit, Alexandria Magiftrâ imprimis: ufus. Hy

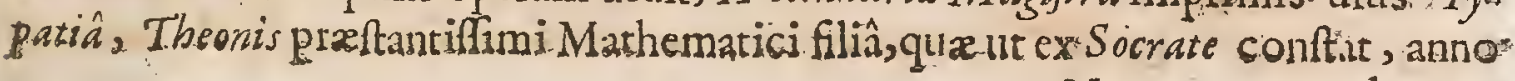


demum 4 Is. a populo primum teftis obruta elt, tum membratin difcerpra, fuitque inter fophifas fui temporis nominatifimus,uxorem d!nit, quatuorque ex ể flios fufcepit, Legatione propar iâ fuâ per triennium fundtus eft Co zlta atinopol.apud iscadium Imperator. circa annum too. ad qucm habuit ontionem de Regno: dein anno 410 . Epifcopatum Cyrenes feu Ptolemaidis patrix fux in vitus capelfere coactus eft, ordinatus à Theopbilo Alexandrin Patriarchâ fub

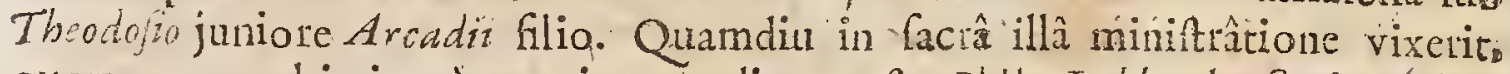
quove anno obierit, à nemine proditum eft Pbile Labbe de Scriptóribus Ecclef.

\section{TSIDORUS FELUSIOTES.} Cir. A. D. Resbytcr Agyptius fanctifimus \& magna in Ecclefi Christi glotiz vulgò Pelufota dictus, quò juxta Urbem $\mathbb{E g} y$ pti Pelufirm, quibuldam maodò C'elbeis vél Danniata appellatam, monalicam vitam exercuerit (Gunt \& quii Abbatem vocent Pelufaci montis in Egypto.) Fuife S. Ioannis Cbryo, ?ani difcipulum, floruile fub Arcadic ejufque filio Theodofo minore conftat. Obiit die 4. Februarii polt annum 45 : ncque cuimcertus montis cjus annus cognofci potert. Phil. Labbe de Script. Ecclel:

Angelicary in catne dégens vitam, multa feripfit varix utilitaris plena.s potif Iimùm autem Epifolarum omnis generis divinâ fimul \& humanâ gratià refertarum propè Chilizdes decem, frve decem milliain quibus omn ss divinas utriulque Teframenti Scriptuas expoluit, \& omnes omnium honinum mores infituit, ufus in eis dicendi genere maximè ad docendum azco mmodato. Vidumus in Bibliothecâ Marcianâ, Venctiis Volumen manu fcriptum , complectens hujus Cancti viri I 48 Epiftolas. Sixtus Sencnf. Biblioth.1.4.

Pelufiact in agypto montis Monachis prafuit Abbas, Tfidorus Pelufratd inde dictus, eximius I ahannis Chryfoforni difcipulus, vir doctiffimus, \& in Prophanis etiam Scriptoribus( Platone \& Plutrch) verfatus; qui propterinfignem vita morumque fanctitatem $A$ so $\phi_{g}(G)$ peculiariter cft appellatus, quemque Angelicam in carne vitam degiffe, atque Monatici Infituti vivum ac animatum exemplar fuille veteres affirmant. Plucuit ipf scripturam, \& alia qua occurrebant Dubia, Epiftolicafcribendigenore explanare. Scriplife autem ljadorum ad decem millia Epiftolarumatyue in his ter mille Scripturam Sacram expofinlfe, andot eft $S$ widas, vel quem Suidas exfcripfit. Hactenus verotriplici editione non plures inlucem pradierun, quàm bis milletredecim. Loan. Andr.Qunft.

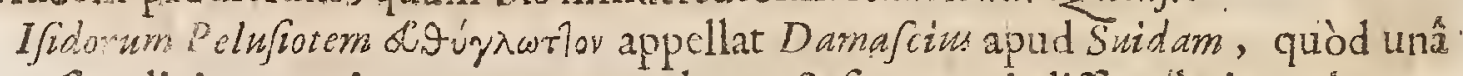
cum fimplicitate veritatem amaret,probaret, \& fine omii difinulatione lo que retur.

Quod fcribis de repertis B. Patris Ifidori Pelufota Epiftolis, \& tuâ curâ décriptis atque ad edendum paratis, beafti me, Mi Ritiershu/f, hoc Evangelio. Macte hoc fudio atque $Z$ errneo ifto. Multum quidem tibi jam Rep. Liieraria dcbet. propter egregia ingenii tui monumenta, quibus illam auxift, ornaft:Ced magnum cumulum 
camulum priöribus tuis meritis adjeceris, fram pium \& eruditum scriptorem

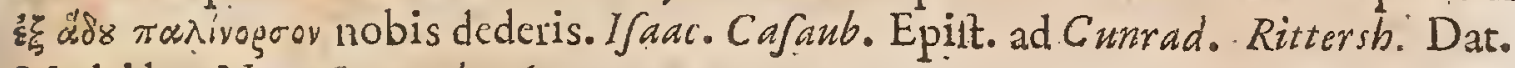
Madrid.3. Non. Septemb: 1604 .

Ifidori Epiftoli qux il publicum prodierunt, libris s.fuccinctx funt \& oppidò elegantes in quibus plurima Scriptura loca erudite enodantur. Hofrnan.

Ificorus i elufiota reliquit Epiftolás doctas \& pietatem fpirantes. Konig..

Ifidori Pelufiota Epiftola, bonus liber Scaligerana. $2 .$.

Origenifte Orthodoxos olim irridentes Pelufiotas per contemptum vocabant; ut docet Hieronymus ad Pammachium, de Erroribus Origenis.

Theodofio Imp.regnante, magno etiam in honore fuie Ifidorus Pelufiota, cujus gloria ob illius tum facta, tum dictalongè latéque pervagata eft, omniumque fermone celebrata. Ifte canem fic maceravit laboribus; ficque animum arcanis \& divinis dootrinis faginavit, ut vitan Angelicam in terris traduceret, \& vivam expreflamque effigicm vite $M$ onafica, 2 divinz contemplationis omnibus perpetuòintuentam proponeret.- Scripfit quidem cum alia multa opera perquam utilia, tum unum ad y rillum ex quo perficuum eft, eum iifem cum admira- bili illo Cyrille vixiffe temporibus..Evigr.1.j.c. Ifom.

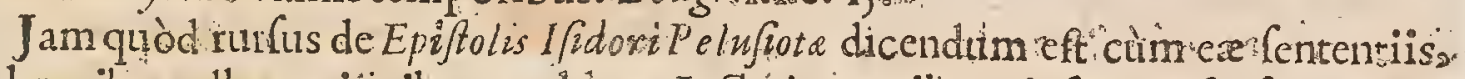
ac brevibusadhortationibus aculeum Lectori perntilem infigant, fuaferim proi bís, \& eruditis Gymnaflarchis, ne tantam finerent elabi occafionern, quâ cas: Difcipulis interdum pralegerent, ficque corum mores efformarent, diationem ac pies tatem eisinfillarent. Ant. Poffevin. Apparat. Sac.

Prodicrunt opera ejus omnia Graeè 8 Latinè in Fol Parif am. $638^{\circ}$

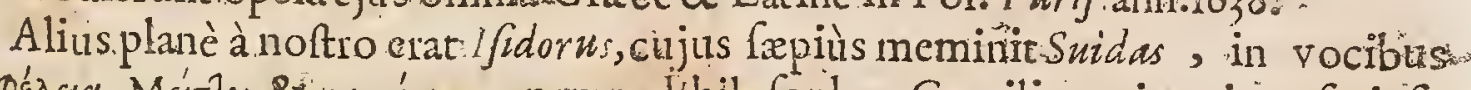

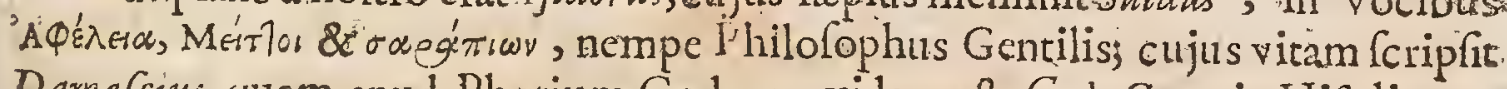
Darnafcius, quam apud Photium Cod.242. videre ef. G 1 . Cave in Hif.lirerax. Script. Ecclefo..

\section{S.CYRILIUS ALEXANDRINUS。.}

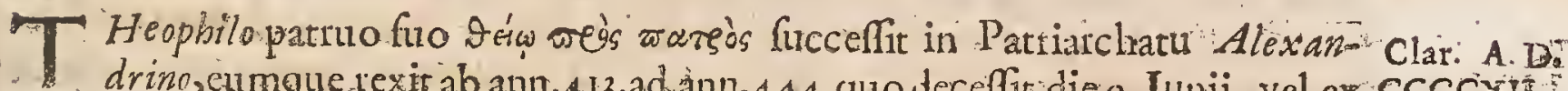

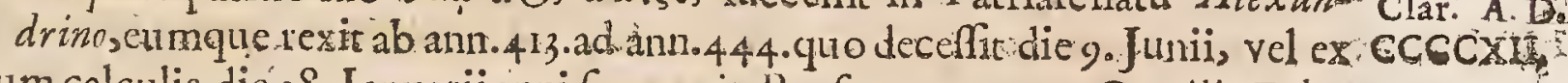
2hörum calculis, die 2 S. J anuarii anni fequentis. Præfuerat ann. 43 I. Concilio Ephefinc adverfus Neftorium, nomine Sancti celeftini Papa. Labbe de Script. Ecclef.

Cyrillus Alexandrinus Epifcopus, acumine ingenii, fubrilitate judicii, enu ditionis varietate, docendifacilitate, copiâque differcndicelebris, \& pietate fincerâ confpicuus, religiuit in divinas literas varios ac pene innumerabiles in- terpretativi gcnerisilabores, hoc cft Homilias valdè elegantes, quas olim (uE. Gennadius refert) Gmeciu Epifcopiad declamandum memoriz commendabant. Sixt. Senenf.

Cyrillus Epifcopus Alexandrinus, vir faictifimus, \&doctiflmus; ac prefeitim circa myfterium Incarnationis Deninica à Deo doctus. Bellarm. de Scrips? Ecclef. 
Cyrillus vir ingenii vehementis \& imperatorii. Mylterii Incarnationis acerimus Hyperafpintes. Hofman.

Cyrilus Epifcopus Alexandrinur, magis bonus Theologus, quam vir bonus, Iohannis Chryfortori vili innocentillmi difertiflunique in vità \& polt mortem holtis infenflf mus. He . Sav\%. Lect.uâ primâ in Euclid.

Co rill:s vir ingenii excellentifimi, $\&$ in omni do atrinaw inftituti, clectus ¿́pifcopus circa ann. $4 \mathrm{I} \xi$, per multos aniros tum vivâ roce, gregi fuo; tum variis fcriptis, quon nomulla extant, brifi Ecclefris eximiam operam navavit. iLyrir. in Catal. Teftum Vèritat.

In libris quinque adverfus Blaph mias Neftorit, fervat fyrillus fuum dicendi characterem, \& lermonis proprietatem. Clarior verò eft quàm ad : termia $n$. fcribcns, autin libis te Adorstiven in Spiritu. Sermo illi confictus, \& ad propriam dicendi formam coutortus, ac veluti folutum numerofque negligens metrum. 1'bu. in Cod XLIX.

Cyrili Thorauri, Epicherematis five Argumentationibus refertus elt liber, pugnarque validè ac variè cum Arï \& Eunornii furibundâ rabic. Etcnum \& Logicis argumentis fapienter illorum deftuit amentiam, quibus dum S. Scripture adnectir adtexit.juc tefimonia, quàm fit illa doctina futilis omni ex parte divulgat. Adhibet idem nuda quo que $S$. Scripturæ teftimonia, ut quò le. faftuofivertant, obfepti undique atque conclufinon habeant. Eft antem inter omnia ejus. fcripta liber hic maximè perfpicuus, is potifrnum, qui logicorum argumencorum fenfum capere polfunt. I dem in Cod.1j5.

Cyrillan ad certamina natum,nullam prorfus herefin graffari palfum finffe. Nicephorus ait I. XIV.c. I4.

Merito fortifinus Chrifti Athlata, \& Vefo iana Hxefios Averrun : dicitur: Multis, parfertim in Divinus Literas, editis Commentariis optimè de Ecclefa meritus eft. Q:zenftedt. de viris Illuft.

Cyri'tus Alexandrinu pietare, cloquentiâ, \& acumine infignis.' o.1. Ca:d. Pona.

Quod autem ad S.Cyrilum fpectat,obftıp fco quid:m,dum incredibilem \& planè incomparabilem animi ejus confidero manfuetudinem atque inodeltiam cum fummâ animi fummiffone conjunctan:quibus quidem omnibus virutibus, preter innumera illa Specimina edita , additamentum modò illud adjecit o mni lau de digniffimum. Baron ad ann. 432.

Hoc certe in confeflo eft, vix aliquem memorabilem nævum in Magno ithoc viro deprehendi, nifi quod Angelis nimium tribuere videtur. Olear. in Abac. Pl.

Ex yrilli Thefauro citantur featentix quadam pro Rornani Pontificis primatu, nempè:? etro ornes jure Divino caput inclinant, if Primates munditangrasm ip $\sqrt{z}$

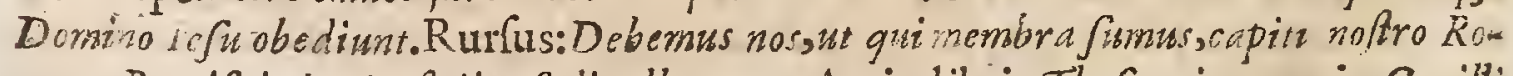
mano Pontifici, \& Apofoli a fediadberere. At in libris Th furri quos in Cyrilli operibus habemus,ne veftigium quidem horum teftimoniorú appret, qux conficta effe non dubitamus. Autor falf fuit Thom As Aquin in opulculo adverfus. Gracos, qui piimus ex Cyrilli The fawrorum libris Pontzici Romani tyraunidem affe- 


\section{CELEBRIORUM AUTHORUM.}

sere voluit. Bellarminus tamen quædam profert \& ex eo Pofferinus sx quibus ab eo crimine Thomam fum abfolvere conantur. Andr. Rivet. Critic. Sacr.

Sanetus $C$ yrillus fenfun: fublimcm \& allegoricum multò magis fequitur fuis in Es:odum \& Leviticum, quàm in Ginefin Commentaritis. Uno verbo, ad høec pracipuè collimat ut Iefú brifi \& Religionis noftre Myfteria notificet, hoc axiomato nixus, quòd Vetus Teftam. nihil fuexit quàm typus \& umbra corum qua in Novo futura erant. Itaque Domino noftro cjufque Myftcriis pleraque eorum qux in Exodo in Levitico léguntur, accommodat. Eadem mcthodo uti pergit in quofdam duorum caterorum Pentateuchi Librorum locos; Utque majori firmet authoritute hunc Veteris Teftamenti interpretardi modum relatè ad veritates qux in Now o continentur, fubjungir eos folos quibus perfectè nota funt Religionis noftrx Myfteria,capaces effe fublimium \& cellomm hujufmodi fenfuum. Ejus in Efaiam Commenraros filentio praterco quia Pater hic in fua Mcthodo admodum uniformis eft. Jer Richardwimon. Hilt. Crit. V. T.lib. 3 cap. 10. Gall.

Liber adverfus I udeos, \&breves illæ Anegoge haud fcio an Cyrilli fint. Sed es parvi momenti eft, cùm fint libelli breviffimi, \& leves. I ibıi fexdecim in Leviticun $C_{y}$ rilli non funt, fed Origcrits \& manifeftum hoc eft, tum quid aucor ubique fenfum literalem deftruit, tum yuia habentur ifti ipfi inter opera Origenis: ut mirum fit, cur Impreffores in omnibus Editionibus ifta opera auEtori non fuo attribuant . Cripfffe dicitur Cyrillus in dios ctiam Prophctas, fed non extant Commentaria cjus, nifi in 1 G ciam, \& Prophetas minores - Scripfit Cyrillus libros duodecim in loannem, fed quatuor intermedii perierunt. Sed Iodochus Clictovers' ad imitationem Cyrilli addidit quatuor libros intermedios. - Itaque Cyrili inon funt,nifi primi quatuor, \& quatuor poftremi - The fanrus creditur effe imperfectus, multa enim citantur à S. Thomâ in opufculo de erroribus Grecorurb ex The Gaturo Cyrilli, qua in libris non inveniuntur. - Liber de Sacrofanctâ Trinitate non videtur eflé 6 yrilli, fed alicujus pofterioris ; autor enim copiosè difputat de duabus Naturis in Cbrifto, \& de duabus voluntatibus, $\$$ operationibus, \& reddit rationem cur non repugnent iftis dogmátibus., qui aliquando dixerunt, in C brifo effe operationem theandricam, \& unam Veebi naturam effe incarnatam. Itaque videtur auctor fcripfiffe poft fextam Synodum. Bellarm. de Script. Ecclefiaft

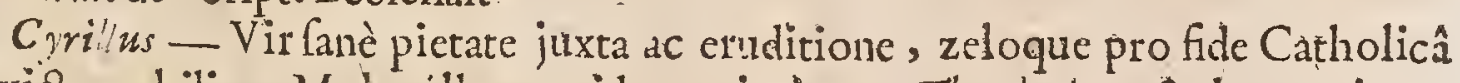
invicto nobilis. Multa illum quidem criminatur Theodoritu, \&ab co unicam in Chrifto Naturam pofitam fuiffe clamat. Fatendum quidem eft, eim frepiùs affirmare $\mu i \alpha v$ Ẽva $\phi^{\prime} \sigma_{w} \lambda^{\prime} \gamma_{z}$ : Sed xquè clarum eft, in omnibus his locis ipfum vocem $\emptyset_{\text {vor }}$ loco fet, fi modò hifce immolari vellem. Vitio infuper $C$ yrillo vertitur, quòd $H$ ypr.m tiam, celeberrimam illam thilofopham Alexandrinam, odio \& livore ductus, membratim à plebe difcerpi effeciffet. Verùm qui hanc in Cyrillum calumniam Rtingit, Damafciu, parum hac in re fidei meretur, utpote Chriftianz Religionis hoftis acerrimus. Id quid $m$ ab Alexandrinis, leviffino hominum genere,

$$
\text { O. factum }
$$


factum effe negari nequit: $C$ yrillo autem fatagente id eveniffe fpectata ilitis pros bieds credere nequaquam finit. Gul: C'ave in Hiqt. literar. Script. Ecclef.

* Ha varix Editiones Cyrilli Operum, viz. Bafilea $1524,1528,1546,566$, I576. arifís 1573 1605. inter libros Expurgandos numesantur in Indice Madrio tienf Edit. ain. 16197 .

Cyrillus eft cenfurân notatus, quàa mula habet contra Monachos.. Scaligerava.

Prodierunt Opera ejus omnia in 6 . Tomos diftributa Gracè \& Latinè,editcre. Ioanne Auberto Laudunenf Canonico. Parif. in Fol. ann. 1633.

Frodientun itidem Homilie XIX. in Leremiam è MS. Bibl. Scorialcufis Gra cè cum interpretatione Balthafaris Corderii Antwerpice 1548. apud Planto. num, $8_{0}$.

\section{PAUUS OROSIUS:}

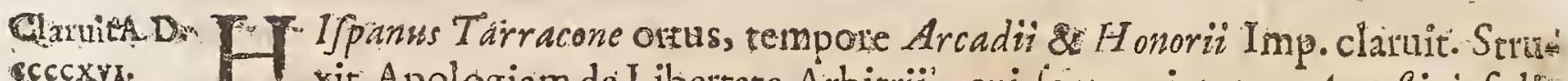
scccxvs. I xit Apologiam de Libertate Arbitrii, cui leptem intcgra Angutini folid cum parte octavi inferta funt, qua ex illo opufculo planè debent furcillari. Quñ de re G.I.Vofjbus, lib. 2, de Hift. Lat. cap. I5. \& 1. L. Hilt, Pelug. cap. 17. legi poterit.

idem Orofus, fuafu S. Anguftini, feprem libios Hittoriarum compofuit, quibus oftendit, ab Orbe condito ufque ad fuam ratem maximas femper atque atrociflimas calumitates paflin contigiffe. Hoc opus à quibuldam torme tes

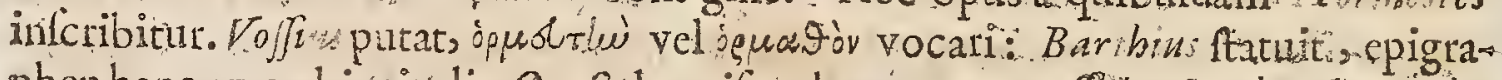
phen hanc ex verbis tituli, Orof de mifer hom natam effe... Steph. Iignandus Pighius in Hercule Prodicio, p ne verum \& genuinum titulum; Orchestram mundi, fuile exifimat. Pighis Cententiam ut rationabilem Reinefus ii Var. lect. 3.3.pag 396.amplectitir. Manufriptum ejus exemplax cum inforiptione Ormes fte extare etiam Oxonit in Bibliothecâ Balleolenfl, ur wit Thomas lamefius. Qui auctor eft, Cantabrigic in Bibliothecà Collegii S. Beriodidt Manufcriptum elfe exemplar Orofn de Viris Illustribus Quale opus (inquitVoflus ) videre nondum contigi. Sed fanè metuo ne nan Orofin verum Honoridillud fito. Qub norsina in

Adverfus Paganos.Orofus juifi Augufini feptem libros Hiftoriarum conf cipfit. De quibus selafus primus cum LXX. Epfcopis fententiam tulit, ejuf

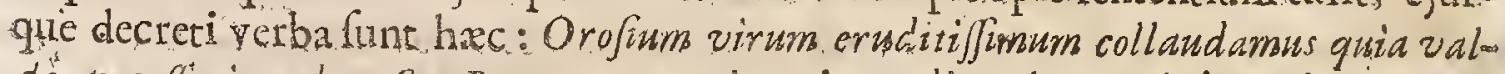
de necefjaria adverfiss Paganarmm calumnias ordinavit s mirâgue brevitate contexuit.

Angustini Conflio, ut ipfe ad Enodium fcribit, Orofins Betbleemum ad D. Witeronymurn profectus eft cum hac ejus commendatione, Ecce venut ad me Religiofus fuvenis, Catholicâ pace frater retate fulius, bonore Compresbyter, noster Orofuss vigil ingenio paratus eloguio flagrans studio, utile vas in domo Domini 
effe defiderans, ad refellendas fallas perniciofagque doctrinas, quie Animas Hifpa

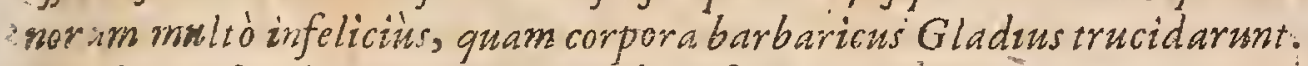

Eft Orofins Scriptor planè utilis : fed qui Scriptores Gracos non legenit: ind Gracarum literanum expers fuerit. Intemporibus etiam crcbeò fallitur: ut vel. Ulld oftendunt, qux in eo caftigavit Scaliger in animadverfionibus Eufebianis. $S_{æ}$ piùs ctiam *ulgares fectatur opiniones quàm hiftoricum accuratum fe probeat, crajus eft omnia ad veritatis trutinam expend re. Ita videmus eumlib.\%. tradere Drufum a Tiberio extindtum veneno, quam opinionem vulgi refellit Tam cinus in IV. Annal. Lustus Lipfins Commentario ad eumiochm loulpat hoc nomine Orofbum \&afpeciùs aliq̨uanto quàm vellem fủstexit: At me non valdè movent ejufmodi Soriptores legitima bistoria (dicambiratis guorundam curibus) debonew stamenta. Item in 1. 5. cùm quếfus effet-de magno Hiftorix hiatl ( nam trien: nii ferè gefta defiderantur) fubjungic mox: Adè bori: illis partibus cura otiurro-

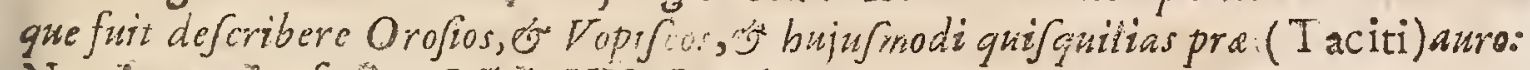
Nec inmerito lanè Voff. de Hift. Lat.1.2.c. I.

$P$. Orofus Hifpanus, in Hiftoritinterdum feetus veritatis aut inveftigator' wut enarrator. Dempster.

Paulus:Orofus xir indivinis Scriptuils "eruditus, in in fxcularibus literis pe Titifimuts. Trithem。

Paulus Orefus Nobilifimus ille rerum Cbriftianarum Historicus. Montacut。 Apparat.;. Sca. 4$\}^{3}$

Paulut Orofus, fcriptor ctique bonis adnumerandus y quamvis non quiden primis. Cafp.Barth.1.Adverfar.p.1661.

Barcrius ¿ Cafaubonus ffotem Orofo detrahunt propter nimiam credulita item : Rerumque Romanarum ignorationem ejus aliquando mirificam fuife dicuito Ifacc.Ciajanb. Exercittr. I. ad Baron.p. 8r.

Orcfi diligentiam, \& pietatem, viri quidamdoctiffrmi, fed importuni alieni judicii Cenfores, \& fuis affectibus, \& praconceptis opinionibus nimis interdum indulgentes, variè fugillant, \& criminantur : \& nimiæ levitatis, ut loquuntur, in Prodigits credendis poitulane: Zelum habuiafe, fed non fecundum difcretionem, pronunciant: \& rerum Romanorurn minificâ laborâfie ignorantiâ. Cujus viri pietas, eruditio, diligentia, canities nequaquam tàm acerbè, vel infolenter potius. tractanda fuxt. Coxtaneus erat Augustin \& Hieronyma; utrique familiaris, \&e multis nominibus commendatus。 Viderat ille, legerat, volutarat rerum Romanarum, \& noftrarum authores non paucos, qui à multis retrò fećulis defiderantur, quos de nomine Cenfores noftri vix noverunt: Quos, faltem, aliquos, Duces fequi poterat \& directores, in aliquibus hifce Prodigiis interprerandis, ne de fuo finxiffe, qquod multi folent, videatur. Montacut. Apparat. fect. 43 .

Scriptor hic acris judicii vir, brevi Hiforia ingenten rerum fuppellectilen continet.Qui tamen memoriâ lapfus videtur[inquir Baron. Card.Tom.A. nal.4-] cum verfus Claudiani de Victoriầ Theodofí contra Eugenium referens, non videaturconfuluiffe Clabdianum, qui aliter habct. Ant. Poferv. in Apparat. Sacr.

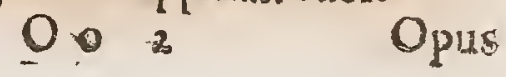




\section{CEN S V R A}

Opus cui titulus Hormesta Hiftoria quædam univerfalis eft in Ceprem libros: diftibuta, qux urilis quodammodo effe poteft. Non malè fcripta eft, fed parum accurata. Plures contra Hiftoriam \& Chronologiam craffi errores in illa: occurmut. Grxcos Hiftoriographos non evolvit Author; \& iis qua in rem. fuam facere poterant temerèadmodum fidem adhibct, an firmo nitantur fundạmento minimè perpendens. Ell.du Pin. Nov. Biblioth. Ant. Ecclef.Tom:3:

Paulus Orofus Hifpanis nonulla ex. Eutropio, \& ex.Floro excerpa collegit. Primx illi partes in Religione Cbriftianâ meritò laudantur uti \&in veterum fuperfitione explodenda. Vixit lub Honorio l'rincipe, Augufini, cujus difcipulus fuit, temporibus, ut hoc nomine, atque adeè brevitatis crijufdam facundx diguifimus fit, qui legatur. Anton Poffer. Biblioth. felect.

$P$ anlus Orofuns vir indivinis Scripturis eruditus, \& in facularibus liveris per tiflimus, vitâ \& converfatione clariffmus fuit. Biblioih. Hipan.

Fuit diferrus, ac multarum rerum verititiâ clarus. Ibid.

Oprima ejus Editio cl, qux cum Latini \& Andre Schotti-obfervationibus ac alioum annotationibus anso 1615 - Mogunita excufąeft.

\section{THEODORET U S five. THEODORTTUS.}

Clax.An.D. A Ntiochenus, Theodori Mopsusteni difcipulus, ab anno 425: Cyri Provinefcexxint.

ciae Euphratefun in Syriâ urbis Epifcopus, ob nimiam cum Nestorio anicitiam depofitus, in ynodo Chalcedonenfianno $45 \mathrm{I}$. reftitutus, vixif ufque ad ans num 460. feu; ut alii; 466. Extra controverfam fui faculi doctifimus erat: GH. Cave.

Aticâ vir eloquentiâ celébtis, \& fanitorum volimainum explanatiône clarifimus, Hereticormin quoque impugnato: accerrimus.. Sixt.Senen $\int_{\text {. }}$.

Vit in divinis Scripturis valdè doctus, \& in facularium literarum difciplinis fufficienter eruditus. Trithern.

Theodoretus Epifcopus $C$ yri, vir eruditione \& judicio inter prines. Patrias Antiochenu genere nobilis, difcipulus Chryfostomi fuit; domi parcus, urbem ma-

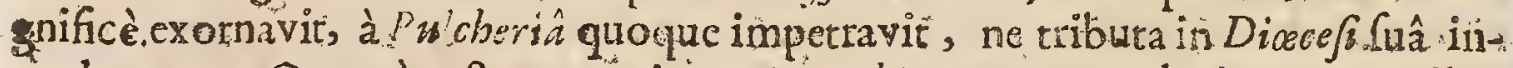
tenderentur : Qua cùm 800 . contineret Parocbias, quaru m plurima t1 erefobus variis infect $x$, omnes magnâ indufriâ \& felicitate prargavit. Ob eloquentiam, doctrinam \& pietatem Antiochic Prelulibus tantoperè gratus, utillum diu fecum retinerent, concionibus frequentibus ibidefunctum. In opere, cui Tituslüs, Medela P'afjionion Gracarum, tota veterum Philorophia \& Theologia latet. Hofrian.

Fuit autem Theodoretus in omni litcraturâ Grecâ eruditiflinus, fectator Màgui loannis Chryfostomi, illum enim fibi, quafi primarium exemplar, fit lo conformando propofitu ni habuit; id ò fluidus admodùm eft \& copiofus, in elocum tone facilis, \& Atticam gratiam redolens. Poffevin.in Apparat Sacr.

Sanetiflimum \& Sacrarum Literarm intelligentiâ pracellentifimum Theo 
logum eum rocat $D$, ufus obfervat. lib $3.6 .2 \mathrm{I}$.

Fuit ingenio excellentifimo: \& ad omnis generis difciplinas percipiendas capaciffimos Illyric catal. Teft. veritat.

Gernadius dicit, amnia. Theodoreti Scripta Colidis ac nervolis argumentis abundare.

Vir fuifeculî̀ eruditiffimus vocatar à: Dallao.

Virum planèdoctiflimum vocat Bellarminus de Script. Ecclef.

Clemens Alexandrinus, Cyrillus \& Theodoretus inter eloquentes fummè dow Qi, inter doctos fummè el oquentes. Nic.Canfin.

Ajunt virum hunc ii maximâ urbe Roman $\hat{\imath}$ ufque adeo clarum \& celebrem: extitife, ut etiam in omnibus officinarum veltibulis homincs parvas Imagines ipfi erigerent, hinc videlicet prefidium fibi $\&$ fecuritarem quandam comparang tes. Toban. Damascen. orat 3. de Imaginibus.

Libros plurimos compofuit Theodoretus, tum in Sacram Scripturam, tumadverfus diverfas. Hare $\int e s$, deque aliis Argumentis : quorum pleraque extant, mul. ta interierunt: Exquibus hanc ingenii ac judici doctrinæque laudem retulit, ut wemo Divinas Literas fidelius interpretari, nemo Hiftoriam Ecclefiafticam aptiùs illo texere exiftimetur. Stylivero is lepos \&elegantia yux \& lectorem fine faftidio reneat; \& perfpicuitatibrevitate non officiat. Iacob.Sirmond.in vitz Theodoreti.

De Stylo. Theodoreti ita cenfet Photius : Historice eummagis convenire, quadn iftum, quô vel Socrates utitur, vel Hermias Sozornenus, vel Evagrius Pónticus: alarus enim \& grandis eft, miniméque redundảns: Nifi quòd Trannationibus interdium andaciùs, penè ineptè utatur. Phot. in Biblioth. Codi 3 r.

Lectus Theodoreti Epifcopicyriliber contrax Harefes. Stylus huic perfpi:cuus, miniméque redundans. I dern Cod. 56 .

Superfunt Theodor tibri quinque Hiftoria Ecclefiaftic :" Quos ab Hereft Arrii incipit, \& deducit ufque ad temposa Theodofii Junio:is. - Secundx Synodi Generalis gefta fufius, quàm Hiftoricialie, enarrat... Apud Gennadium aus. sem legimus, continuafle eum Hiftoriam fuam ufque ad Leonem Imper. atque id alisis quinque libris, adjectis, Sed ifti perierunt. Voff. de Hift: Grae.

Theodoreti Hiltoriam Baronius fapiffine redàguit, uppote qua in Chrono:

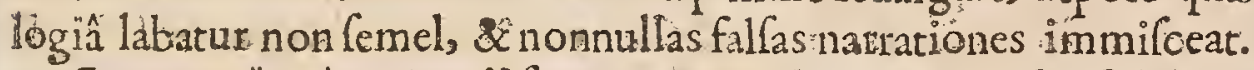

Errores Theodoreti varii lunt :- negavit ante Mofen fuilfe linguam He ebram: mulicres non effe ad I maginem Dei conditas : in Genef Mo en per Spiritum intel Iigcre Aerern, alia, quxide Centur. Magdeburg. 1.5. C. IO.

Laudat lobann:s Garnerius in Theodoreto piératem \& morum innocentiam :apum aliarumque rerum humanarum contemptam, ingenium capax, felicem memoriam, indefeffum literanm ftudium, ftupendam eruditionem, \& dicend facultatem, zelum adverfus Marcionitas, Apolinaristas, \& alios idereticos, alia. que domi \& foris praclàrè geft. Reprehendit contrà philautiam, nimium glöriæamorem, \& pertiliacilimum $P$ artium fudium. Arguit eundem, quòd non ram ex modeltiâ, quam prafe tulerit, quàm nobilionis Ecclefia defiderio, $C_{y}$ 
renfem Epifcopatum invicus fúceperit. Dolet,quòd cùm Magiftum Scretric "Theodorum, eloquentix Chryfoftornum habuiffet, Chry/oforni eloquentiâ ad tuenidos Theodorierrores abufus fuerit. Notat ipfum dum ad perfpiciendos tereticorum errores omnem animi acicm intenderet, id fuilfe paffum, quod aculi vehementer affeetifolent, nempe ut nonnuaquam totam ta ereforidere fibi vide"retur, ubi minima ejus fpecies vel umbra appareret. Deplorat, qued dè Nestorio, quen in Monaferio S. Eupreprii contubernalcm \& ftudion mó commilitonem hatbuerat, in graxidrmos errores abreptus., Cyrillum Alexendrinu impugnaverit, \& nanfolum in vivum amaiulenta convicia ore \& calimo congefferit; fed mortuo quoque infultaverit. eAtha Erwditorum Menfisfebruarii I 635 .

Theodorensi longe admodum abiit ab aliorum Patrum methodo. Non enim Homilias nec Commentarios in univerfam cripturam confcripfit, fed faris ipfi

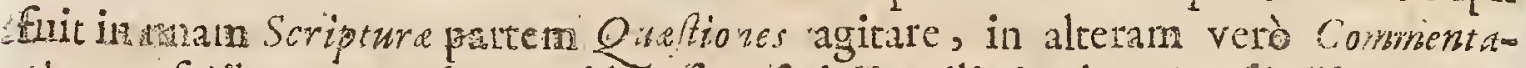
riosconfcirberc. Quxdnm quidem lunt fatis nutilia in ejus Quxtionibus., qux Tonge nimis accertuta videneur, Sedvice verfa ingens recondita Theologic con pia in illis conficicitur stylique Sacra Scripture notitia plufquam mediocris. Inter Gracosomnes Patres, thuic imprimis addicere fe débet quicunque in Biblics dootus evatere vult. Quandoque tamen, porius ad Semonis Gui ornatum gilatm ad explanationem argumentorum quæ pertractat, allegorias admifcet: Quod vitare debebar in Quxtionibus ubi resfimpliciter tantim propo neve paucifque veibis folvere requiritur. Catcros Græcos Patres fedulólegerat, prafertim yerò Libros Origenis : Sancti Iubanis Chryfofomi, quos Sepius fequitur. Veteres Gracos -merpretesidentidem citat, imo \& Textum Hebraicum, quem legebat in Origenis Hexaplis, \& in vocum Hebran in -

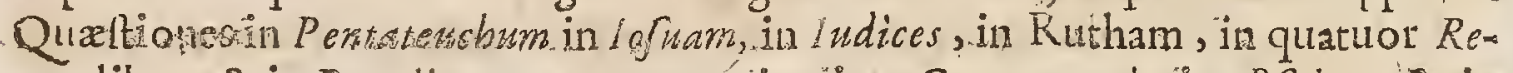
gum libios \& in Paralipornena conteriit etiam Comrnentariona P $P$ almos \& inplures alios Bibliorum libros, quos ad literan quammaxime poteft exponit. aliquas tamen moralitates iis femper admifcendo. Literam multò preffùs lequitur quàm cateri Patres Greci; Nee etiam vilde diffufus êt ftylus ejus. quanvis eum fimilitudinibus interdum exornet. Sxpiufculecitat Græcas veteres Verfones Aguile, Symmachi \& Theodotionisad Scripturatcxtûs amplioren elucidationem; Nec Septwaginta Interpretes femper fesuitur, cumprafertin infi perfuafum en Verfones a lias Scripine fenfum puriùs expumere. JcL. Richard. Simon. Hift. Critic. Vett. Teft.i. 3. c. Io. Gall.

Omnium Veterum preftantifinus eft Theodoritus quem mille Theodoreturn Yocant "hoc enim participium fignificat, itus verò nomen. Nulla ineft Allegis ria. Delendum ef quod omnia Greco idiomate non habeamus. Neminem Veterum nifi in patriầ ejus linguâ legam, licet babeatur tantim Latinè. Habebo Theoderitum in Canones Apóftolorum. Multafunt ejus in Bibliothecis Bavarî. Augustanâ, Papx. Scaligerana 2.

Certè dum TheodoretiHiltoriam in Latinum Sermonem converterem, verif:- 
ent me id quod de Metaphoris ejus dixerat Photins; nen fine faftidio deprehendi. Hujulmodi enim Figuras pracipuè in Hiftoriâ rerum geftarum, maximam moleftiam pariune Interpreti. Illud pratcreâ in Hiltoriâ Theodoriti reprehendendum mili videtux, ". quòd in toto opere nullam notam Temporum adhibuit. Nam neque Confules nominat, nec quo cujufque Imperatoris anno. res gefte funt obleryat, Hens.Vales. in Prefats prafix. editioni Theodor. 211. 1673 .

Extant Operaejus ommia in 4. Tomos digeftà, curâ-Iacobi Sirmondi Grecé 2. Latine, Purifilis apud Sebaftianum Cramorfi in folio anno 1642 ..

Prodiit. Tomus quintus cum Hiftoriầ Theadoriti, \& Differtatione de Libris ejus, aliifque Differtationibus Iobannis Garneri è Soc. Jef,-Partfirs: 1684 . in fol.

\section{PHILOSTORGIUS.}

FF Qualis Olympiadoro erar Pbilofiorgins Cappadox: Qui, Carterio, \& $E_{u-}$ I lampiâ, parentibus natus fuit, fub Valentiniann, \& Valentc, Impp. circa Clar:An D? $\operatorname{ccccs} x x_{0}$ annum $\mathrm{Cbr} .367$. Sed fub Theodofio juniore Eeclefiaftica Hiftoria libros edidit: 22, pro duodecim literis, quus habemus in nomine ejus, Ac prinus quidem lis

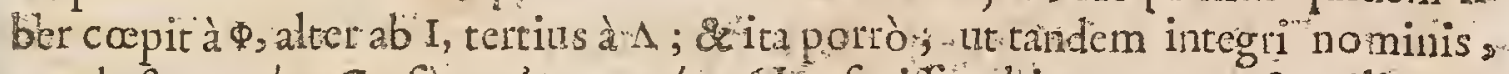

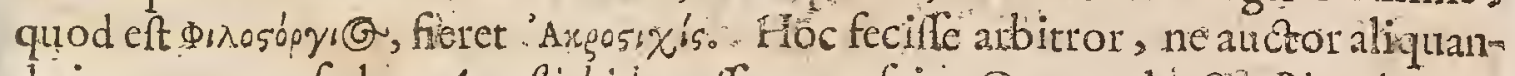
do ignoraretur: fed ex Acroffichide polfet agnolci. Quomodo \& Plautinarum Comodiärum nomen indicatur verfibus, qui cuique fabula pramistuntur.

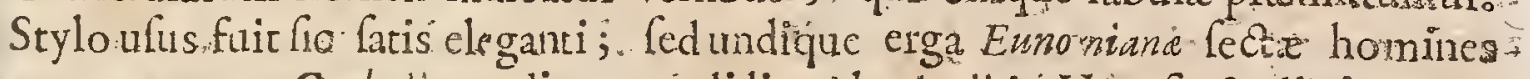
amorem, ergą Casthalicos odium prodidit. Ab. Arrii in Hicrefin ftudio incepit: ac defit in eotempore, q:10 Theodofros junior Imperii Cceptra Valentiniano minori, Flacidi, \& Corftantii filio patruelifuo , tradidito. Vof: de Hilt. Græc. lib. 2. Cap. 20 .

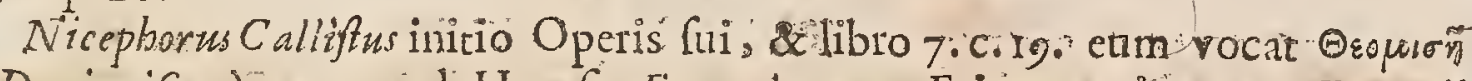
(Deo invifum) : nempe ob Hrefefin Eunomianarn. Etiam, ut lineptumi Eunomig lauditorem, taxat idem $N$ icephorus. 1.í2. c.'29:

Hoc Philoforgii opus Antiquitatis multa egregia referat. Nicephorns Callifus ex hoc Pbiloftar gio quem Deo invifum vocat, multa in Hiftoriam fuam tranftu lit. Hofman.

Sane artibus liberalibus apprimè fuiffe excultum liquidó conftat: Unde plurima in Hiftoriam fuam refert, qua non vulgarem Philofophid, tistoriague

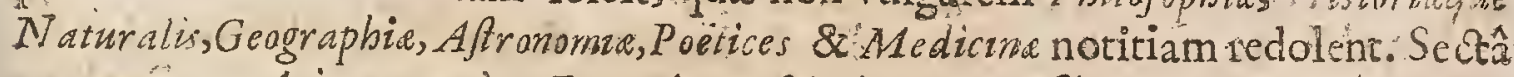

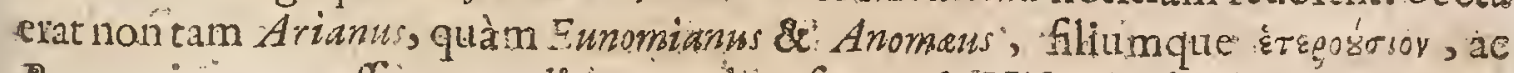
Patre minorem effecontendit; quod ex fexcentis Hiftorix locis parct: Un-

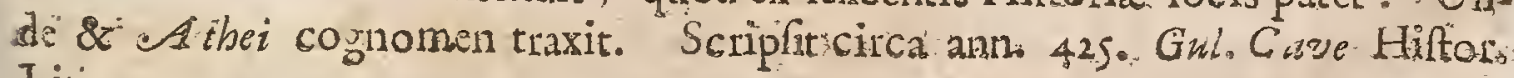
Literar.

Lecta eft Philostorgit Ariani veluti Ecclefustica Historia. Narrat aurem ferm

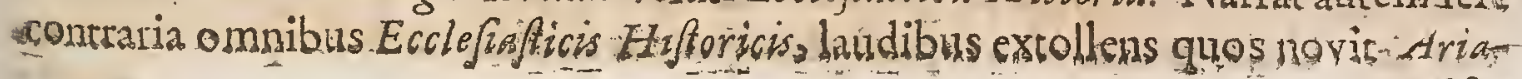

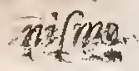


nifmo infectos, \& conviciis Ortbodoxos perfundens: ita ut hoc ejus opus nom tam! tiffora elfe videatur, quàm Hareticorum laudatio, cum nudâ \& mecâ vìtuperatione atque acculatione Catbolitcornm. Stytus illi comptior; \& poëticis fine tadio, miniméque ingratis vocibus utitar. Tropi quoque ac verbshignificantia gratiam ipfi cum jucunditate conciliant. Nifí quòd interdum audaciùs ipfis, xel nimitum detortis utendo, in frigidum \& importunum fermonem incidit. Ornatur ab illo variè oratio, vel aé latictatem, ita ut in obfcuritatem, nce eam femper gratam, occultè trahatur Auditor. Sapè etiam fententias aptè fuis locis inferit - Quantumvis autcm Philofforgins hic in Orthodoxos fureret, in Gregorium tamell cognomento Theologum, incurrere non eft aufus, cujus doctrinam vel invitus pladicat. $B$ afflio veris magno callamiliam texere aufus eft, quâ. illuftrorem eum reddidit. Vim enim 8 venufatem Sermonis in concionibus, ipsâ rei evidentiâ fatericoactus elt: temerarium tamen ỉpfum homo futilis appellat, nec in refutando xercitatum : cò quòd, ut ait, Eunomii libris refpondere aufus efret. Phot. in Liblioth. Cod. 40.

Suidas ex hiloftorgio non pauca recitat, variis in locis.

Putantur Fragmenta quadam Phrloftorgiana Hiftoria fuperelle inter libros Didaci Hurtadi, qui nunc scuriaci in Bäbliothecâ Regis Catbolici adverfantul. Aub. Miraus de Script. Ecclerial.

De Pbiloftorgio fcriptifque ejus fusè, ut folet, agit lacobus Gotbofredus prolegomenis in Philoftorgium, qui \& uberrimas annotationes adjecit, dodiffimo Valefio non femper probatas.

Hanc Pbiloftergin Hiftoriam eruit ex MS. Cod. Genevenfi Iacobus Godefredius doctifrmus Jurif́confultus impreliam in $4^{n}$. Geneve anno I $_{4} 2$. Sed \& illud procuravit imprimi iterum anno 1673 . Henricus Valefus, cum Hiftoriis Theow doritz \& Evagrii Scbolaftici in Fol. Parifo

\section{Z OS I M US}

Clar.An.D. Omes \& exadvocatus Fifci fuit, Paganorum religioni addictus: Theodofi cecexx. Junioris tempore claruit. Reliquir fex libros Hiftoriarum. Incipit ab Augufto, definit in Honorio. Paulò tamen (inquir Vöfuss) ulteriùs progreffum effe, verifimile eft. Nam quadan in fine declle, nemini puto elle oblcurum.Libros iftos Latinè vertit, atque edidie, Ioames Leun l sius. Henricus Steph.nus duos primos etian Giæecè cum Herodiano fuo excudit. Sed interpretationem efle Leunclavii, parùm candidè difimulavit.

Impiam hic Paganorum fecutus Religionem, in pluribus adverfus pios $x-$ pius latrat. Alioqui brevis eft, dictione perfpicuus ac purus, nec fuavitatis expers. Phot. in Bibliuth.

Ipfe totus in Chriftane Religionis pietate oppugnandâ: Principibufque Romanì, qui \& initiati fuerant, lacerandis verfatur. Ideò fapè falla fcribens indignus ef Hifforici Nomine, à quo amot $\&$ odium abeffe debent, ut veritati locus fir. Utilis tamen eft, quod pleraque aut ab aliis non fcripta, aut tem- 
porum injuria amilla perfepuitur. Car. Sigon. de Hift. Lat.

Zofirn, Ethnicus homo addi ctipanus, Ethnicigno, \& in Chriftanam Religionem infenfifimus, rum de $C b$ iftunorum rcbus agit, manifefus fapè convincicut

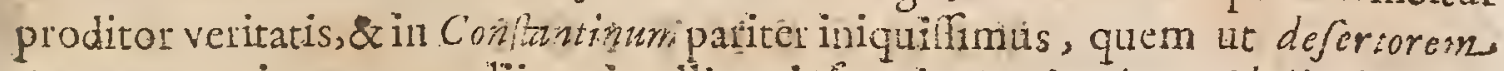
Ueorian exagitar contumeliis;ut inteligas ipfum in Conftantinn Phrippicas po-

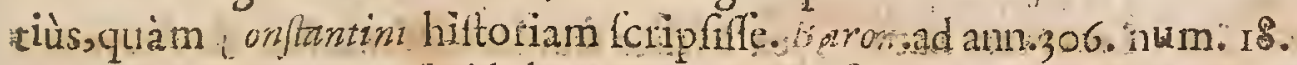

Zojmusconcs, vir idolomania addietifmus, inperio Romano ad veram Chrifi Religionem fulcipiendan felicirerinclinato, proviuciam hanc fulcepit

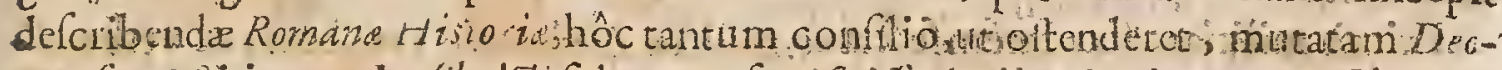
rur fupentitionem in (bristi fidem, cauram füf declinationis Imperit Plane tut

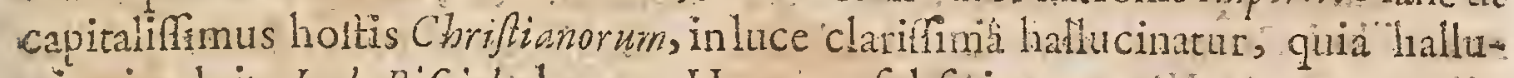
cinari voluit. Lol. Bifciol , 1.7.C.10. Horarum fubliciv.

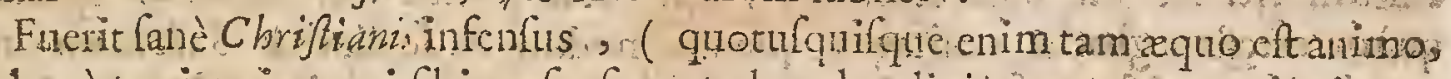

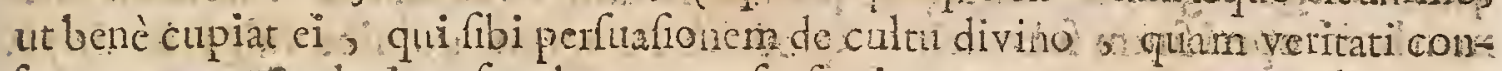
fentaneam, \& pluium feculorum confenfun nam putat sipere velit ? an

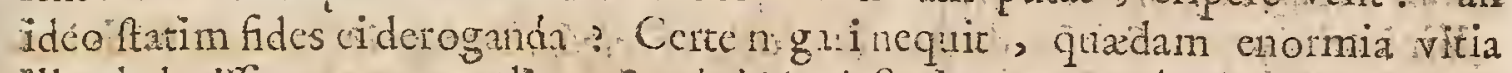
Illos habuife; quorm aliqua \& bristini Sctiptores notáment. Interpretazus foran aliqua fucrit paulò fecìs, odioléque traduxerit at fabulas exco: gitille, quibus plane nil verinctet, furquc fliforix infertilfesvix unquam oftendipoterit. Ioan. Andr. Bofin in Exercitat de Pontificat Max. Impp. Ro man c.6.lect: 4 .

Poflem, filuberet, velfopus elle ducerem, veriffinas hoc loco Zofmed Commentationislaudes explicare. Sedquando Vendibili, quod aiunt, vino, fulpensâ monopus eft harederá; mittamis itzanènec diutiùs ab elegantifi-

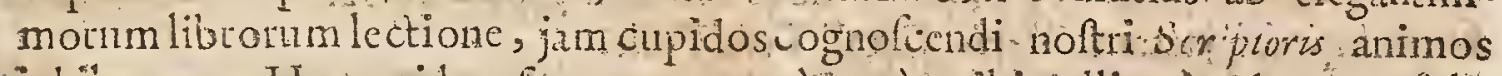
inhibeamus. Hoc guidem futurum, prope certo mihi polliceri videor, ut; folis

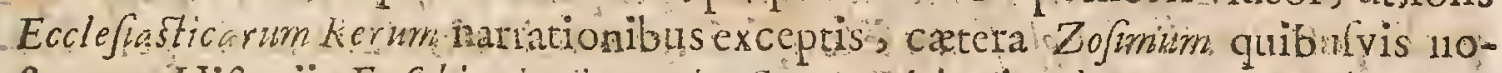
Arorum Hiftcris Eufebianis, So ratis, Sozorneniers, Theodoreteis crudicilectores non invitè prafuant: aut, fi hos,quaf majortim gontium Scriptores Ecclefafticos, animi quadam religione prapediti, Pagano poftponcre non audebuntiquin extra controverfiam in fuo genere parem his facturi fut, caterof que notros five Zonar five Cedrenosne qudem in comparationem cum hoc admilfirinullus equidem dubirabo. Joan. Leunclav. in Apolog. quan pro Zofirno contra Evagrium, aliofque fcripfit.

Henricus Stephanur in Epiftad Thilppum Sydneium, Zofmrum, veritatis \& eruendxe è tenebris, $\&$ in lucem proferendxe valdè fudiofum fuille air.

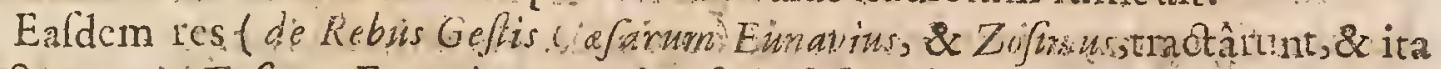

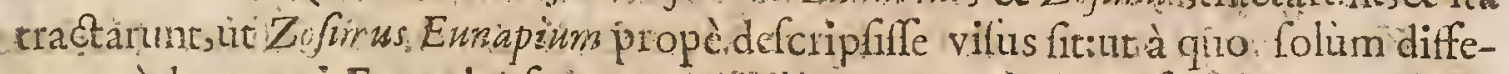

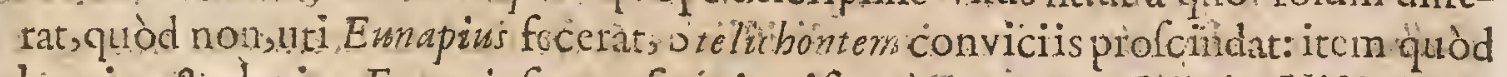
brevior, \& planior Ennapio fr;uec figuis, nifi rào, utatur. Vofj de Hif. Grac. tib. 2. cap 18

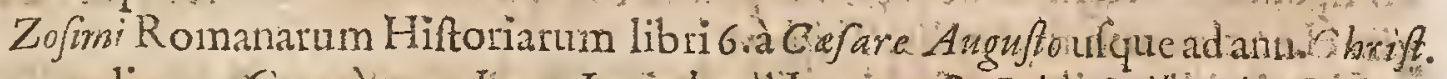

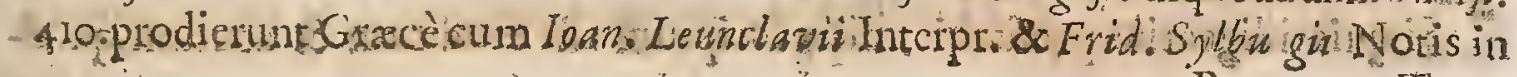
$2=13$ 
Tom.3.Hitorix Rom.Scriptorum ab eodem Sylburgio Franc. 590. in Fol.cdira: - Prodierut ixidem Oxinii 1680 in 8 .

\section{I N C E N T. I U.S.}

Clar. A. D Altus. Tull Lencormm natus, ex Militeleculari Monachus \& Presbyiter accxxxiv. Gu!: C'ave.

- Primò militian fucularem fectatus, militix Lirinen $f_{3}$ excubias; ut verbo Sidoniz utamur, polteà defudavit:ubi factus monachus \& Presbyter, elcgantiff. mumillud Commonitoriwm fcripfit adversùs Harefes, quod totiés bino publico rdirum eft. At Vir modcftifimus, utilitatem potius Cbriftianorum lpectans quam terreftris gloric vanitatem, quemadmodum de fe dicebar Salvianus, no. men huic operifum fubtraxit, quod fub peregrini nomine vilgavit. Steph. Baluz. Noris ad Vincent. Lerin.

Vir iu Scripturis Sandis doctus, \& Noticiâ Ecclefafficorum Dogmaturn fufficienter infructus compolitit ad evitanda Horeticorm collegia nitido fatis $\$$ aperto fermone validifumam difputationem, quam abfonfo nomine fuo, titulavit: eregrini adverfus $H$ arelicos. Cujus Operis, quia fecundi libri maximam in fchedulis : partem à quibufdam furatam perdidit, recapitulato ejus paucis fermonibus fenfu priftio compcgit, \& uno in libro edidit. Gennad de script. Ecclef.

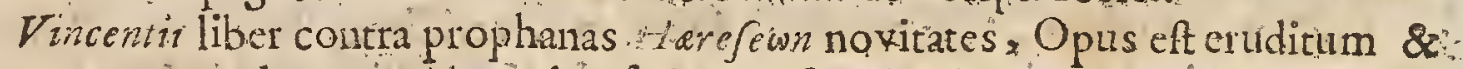
acutum, quodque veritains adyerfariorum fraudes detegat, atque impugnet. Pontiffii Dodtores de hoc Vincenti libro multùm gloriantur, \& Catbolicum illud fum fuperbè jactant. Illy ric Caral Teft. Verit.

Vincentivs Monafterii Lirinenfis Presbyter requalis Caffani füt, quippe qui :

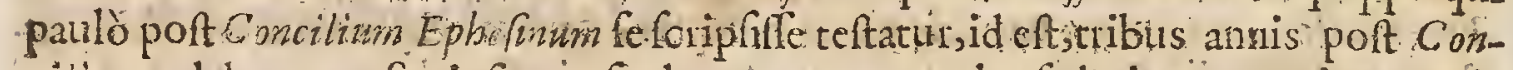
cilium celebratum. Scripfit opufculum parvum mole, fed virtute inaximum, de prophanis vocum novitatibus. Libellus extat: \&utilifine legitur. Bellarm. de Script: Eccler.

Hune Vincentii libellumpladulucum yocat Baronius Notis in Máryrol.

Idemque Baronith Tom. gonn. 4 - aitut vix fit reperire, qui paucioribus Chartismajora concluferit:

Comnonioriwn Vincentii Lirinenfis nunquam homini Chriftiano deponendum mainibus putem;imò inftar quotidiani Enchiridiz ciłcumferendum, ut folidum Bcatitudinis noftra documentum eleganter $\&$ nervofe literis ab eruditifimo homine fignatum; utimm non paulo copiofùs. Barth.1. 8 .adv. c. 7.

Vincentius Monachus \& P resbyter Monafterii Lerinenfis infula. Narione Gallus, vir in divinis Scripturis eruditifumus; \& fecularium literarum non ignarus, vitâ \& moribus clarus. Extat ejus infignc opus, quod fub Peregrini nomine. compoluit; à veteribus doctoribus percelebrè laudatum, de erroribùs \& Collegiis Hzeticorum fugiendis. Trithern.

Siguis diligentius perfitabit dices fcriptum effe eruditum \& acutum,guodgite 
que Har eticorum fraudes clace in apertum producat, detegat atque egtegiè im pugnet; quin \& prafens valdè rencdium \& antidotum quaf contra corunden venena miniltret : in quo ipfrus $S_{c r i p t o r i s}$ is ingcnii elucet, \& doctrinx magnitudo. Magdeburgens. Hirt. ent. V.c.io.

Vincentius Peregreni nomine Commonitoria feripfit, quibus nihil in eo genere majore judicio aut acutiore Stylo confcriptum memini Petr. Pitbeus prafat. in Salvitin.

Edo in ufis veftros duo cx Ecclefrafticâ Antiquitate Ccripta; unum S. Anguftini, libros vidclicet cjus de Doetrinâ Chrifianầ, quibus appendiecm addidi hibrum de Fide or Symboln; alterum Vincentii Lerinenjis: utrumque fieut celebritatis ita quoque titilitatis maximx. Complcetuntu enim Introductionem in univerfum ftudium Theologix, \& cum ad cripture Explicationem, tum ad tractationem controverfarum five confutationem Hareticortin viam muniunt. Gecrg. Calixt. in Procm.libris 4. Augugftin de Doctrinâ Chrift. \& Vincent. Lerin. Commonit. premiffo.

Vimcentius Monachus Lerinenfss jam ab annis plufquam mille ducentis vivebat. Intereatamen utait Card. Perronius, ejus feripta ex ufu concinno effe nunquam dc finunt. Et fane illis nonmodo avi fui Alevatores adoritur a fed "etiam atma miniftrat ad profinas Novitates oppugnandas, omnim Hereicorwo qui adverfus Ecclfferirinfurgere potuerunt vel unquam potcint. Eruditorum Ephem. Gall. Tom.1-2. pag . 335.

Laborat Vinetritus Lufpicione Serri-Pelagianifmi, qui tunc vigebat in illo Sonasterio. Unde \& nonnulli cenfent, eundem elle, qui objectiones illas propofuit, quas rosper appcllat Vincentiond \& refutat, ut funt Voffur \& Kiverus, ille Hift. Pelag. 1. 1. c. o. ifte 1. 4. Critic. Sacr. c. 24. Quodtamen Baroniu in Notis ad Martyrologinm dic 24. Mail prorfus impugnat. \& Tom.5. ann. 43I. Lerincnfein pro Catbolico \& holte Pclagit habendum opcrosè contendit. Novifimè tamen loannes Dalleus, c.2.lib. de Uju Patrur confirmat, \& Sanctum falutari admintur. Nam in Martyrologio Romano fic legimus: D. . Kal. I wnit in Mosafserio Lerinenfo celebraibr $N$ ata Lis $S$ Vincentip resbjteri, doctrinâ ô Sanditate conpicut Iof. Arudus in Lexic Antiquit. Ecclef. p. Iorr.

Extat Vincentii Lerinenfs. Commonitorium adverfus. Harefes, Parifis I6rg. $4^{\circ}$ \& cum Salviano ibid. 1669. 8. à stepharo Baluzio editum.

\section{$S$ O C R A T E S}

D. Atriầ ComRntinopolitans, officio Scholafticus, Helladi \& Ammoni in 1 Grammaticis Difcipulus Novatsans pailo faventio claruit \& feripht ann, Clar. A. D. CCCCXk 440. Extat Hiforia Ecciefrafica ftylo non admodum fplendido Gi. Lat. Parif. 1668. Fol. Edit. Waler. Gul. Cave.

Hiftoriam libris leptem condidit, orfus inde, ubi Ess ebius defit id eata Con Stantino, ufque ad Theodofurm Junioiem, perann, 50 . 
Novan partiblis etim faviffe pluribus è locis manifeftum ef. Nam (quod ob-

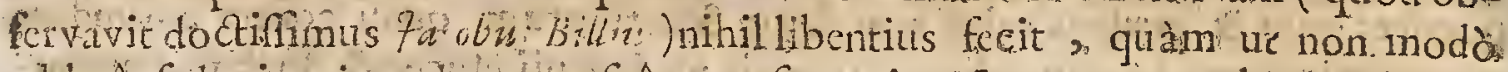
oblatî̀, fcd etiam interdim quizfitâ occafone in Novalianorkars haudem multa commemoret. Et fr quis pio,zclo incenfus Novatianos acriùs infectetur; hrjus. nomen exiftimationemque perftringere a labefactare fuduit. Sed ita obliquè, ut minùs perfpicaci leckori non tam dolori fuo arque irx oblequi, quàm veritaris rationem habere videatur. Fa ob. Rill. 1.r. Oblervat.Sacrar. c. 26 .

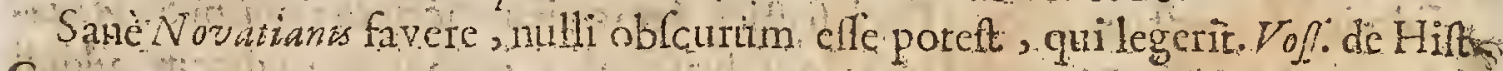
Grac.

Clandicat veritas in Socrate Secte Novatianorum addicto, \& in Sozomene eâdem tiincto fuligine. Baron prafat in Annal! Ecelć.p 2.

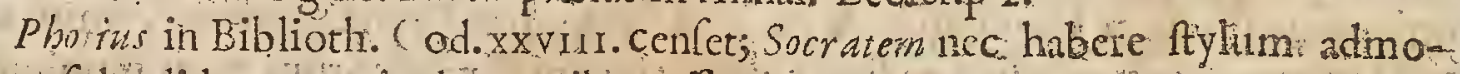
dum fplendidum, nec in dog matibus, efe accuratu $m$.

Tandem, verò (Socrates) abjectâ caufidicinâ, ad fcribendun Eccléfrafícam Hifrornam aninum füurn applicuit. Quâin re, \& judicio \& diligentîn ufus eft fingulari. $A_{-}$c.judicium quidem, declarant oblervationes ac fententize pafim inz libris ejus intexta "quibus, meo quidem judicio , nihil eft illuftrius. Diligentiam verò, cum alia rinulca teftantir , tum illud inprimis, quod temporum no-

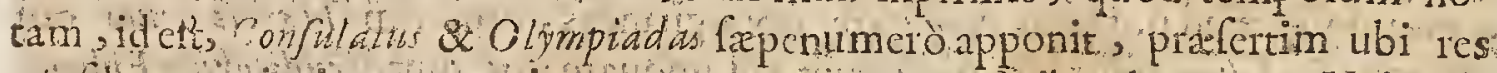

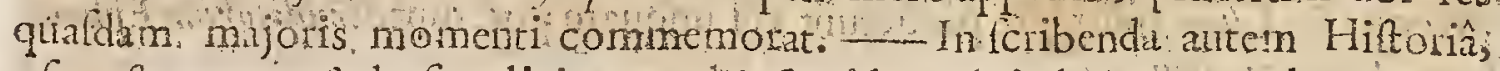
ufus cit orretes ftylo frmplici atque abjecto, idqune de indutt rá; quo ab omnibus

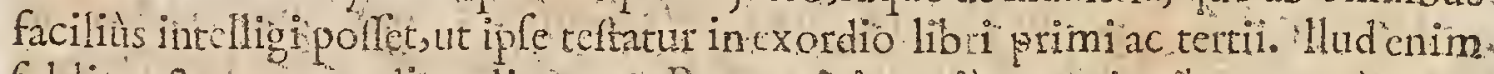
fublime \& onnatum dicendi genus, $P$ anegyricis pociùs orationibus, quàm re-

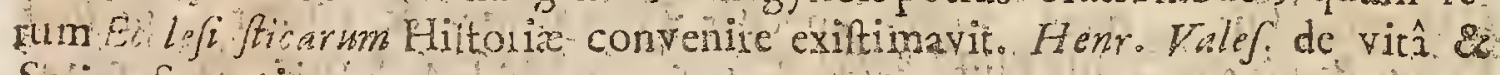
Script, Socratis.

-Potuifquidem Socrates nofter favere Novatianis , few quod necefirudine ac familiaritate ilfdem conjungens effer, feu quood corum díciplinain atque abitizensiam probaret. Fuitenim, quantum quadem $\mathrm{ex}$, ejus libvis colligere

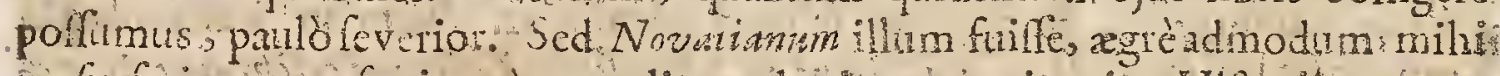
perfuaftim, prefertim cum cx aliquor locis, qua in ejus Hifbriâ occur-

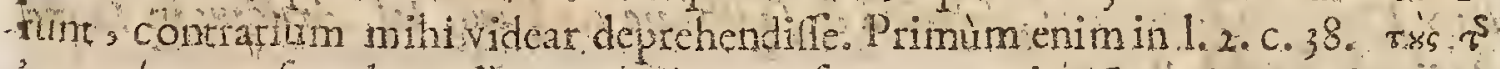

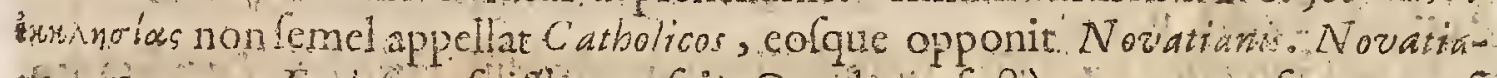

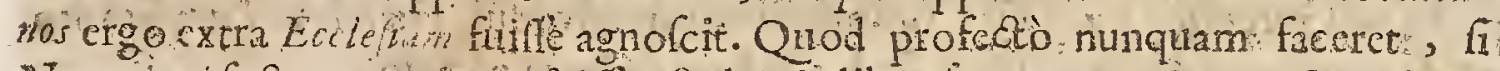

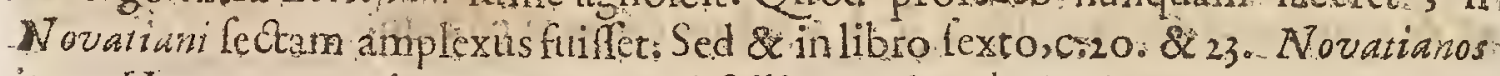

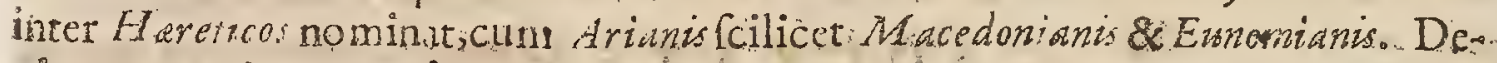
nique ex capife Ig, ejuldem libriapértè colligitur, s, Soratem Novalianum non:

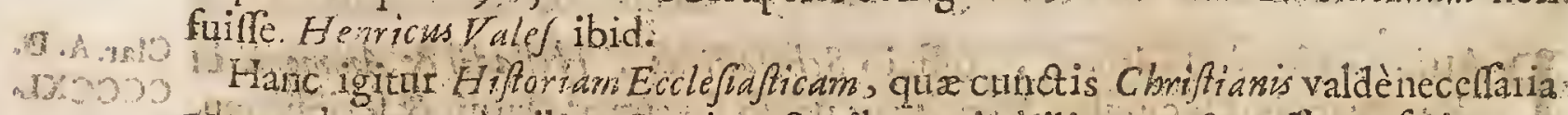
4omprobatur, a tribus Grecis auctoribus milidbiliter conftat effe confcriptam: tho fcilicet Theodorito o venerabili Epilcopo, \& dinobus diertiffamis viris, solow meno \& Socrate. Caffrodor. in Pref. Hift. Tripartit.

Socratem, Theodoretum, \& Sozomenum Epiptanins Scholafficus Latine tranfulit, Magno Aurelio Cajbodero id pótulante quiex tribus iltis unum coipus confecit: 
cir cididitque, unde tripartitarm Hiftoriam appellatam ex ipfo conftat. Whear. Sect. 34:

Socratern in re Chronologica aliquandò Trallucinarí, videtur Baronio.

Eranufous Turkianus ipfum mendacii accufat non uno in loco.

\section{HERMIAS SOZOMENUS.}

Reu, uevidetur, Palafinu, Advocatus Conftantinopolitanus, clarnit anno Clar. A.D. 4.40. Extat Grar.Lat. Hijforia Ecclefaffica, în quâ fapè à Socrate diffentit. CCCCXL. Par.1668. fol.cum Notis Vialefir. Hanc editionem ut \&i Socratis exprefferint Moguntint anno I677\% fol.verum longe infra $P$ arificnfers Cubfidet ifta editio. Gul. Cave in. Chartophyl.

Hiermias Sozornentis, dictus Scholaficus, Salaminiu! Scripfit Historiam Eccle-

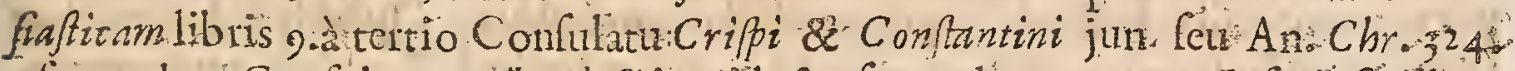
shique ad 57. Confulatum Theodofit junid eft, ufque ad ann. 439. Infcripfit illang Imperatori, fedpartem ejus, contineatem res geftas: Annorum 20: ab anino nemQe 400. amilumus: Nimuium Thcodoro Mopfieffeno tribuere videtur Gregorins M. nifihîfe fefellit, Socratern intelligens. fortè. Pcenitentix publicx gradus: exactè decribit. Novatianis quibuldam paulò xquior fuifte dicitur. Obiitanno? 450 Hefman.in lexic. fino:

Apud Gregorium M.1:6. Epift 95 hujufmodi de eo judicium eftsed ipsam quow que Sozomeni Hiftorizon Sedes Apoffolica recipere recuffat, quoniam multu mensitur:

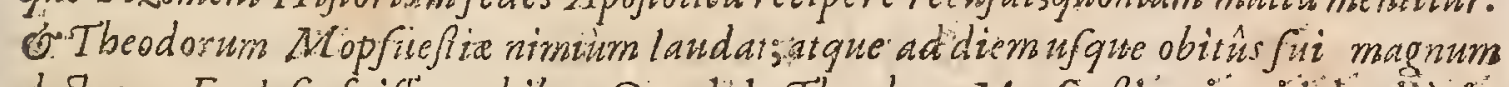
doctorem Ecclefne fuif'e perbibet. Quod de Theodoro Mopfitefie ait, id hodie in Socrate non legas; fed in Theodoretn. Quate videri poffit in Grcgorio mèmoria etror. Sed verifimilius efts feripfilfe lioc sozomenum in iis, qux deperierunt: Nam iple Sozomenzus refert in prufatione, fe Hiftoriamfuam produxife ufyue ad Confulatum Theodofit junio is feptimum decimum :ut pené:viginti amorum Hifto ria dcfideretur..Vofi.de Hirt. Grae.1:2.c. 20.

Cardinalis Baronius Tom.4. ad annum 4.39 hốc modo iherertetatus eft verba

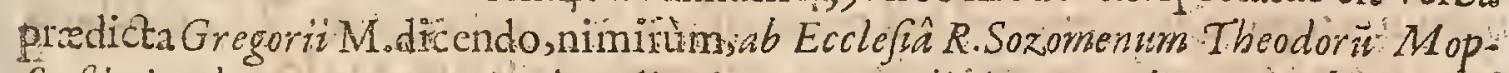
jucfir lawbdatorem non recipi: in reliquis que vera dixit, gquornodo potuit ab Ecclef fin non recipi? Pretercà à Gelaffo Papâ (cui nenro ob anckonitatem at âue dootrinam" refragari poteft juxta iptum $C$ ardinalem) conftat, Sozomenum non rejici, fed majoris fiect habcri quàm Eufebium Cafririenfem, cjufque Hiftoriam majoris aftimationis apud Pbotivm quàm Socratis fuilfe. Denique Melchior Canus ait, in Concilio F lor entino, cui interfuiti Imperarar Paleologus, teftímonium Sozomeni, non folim ufurpatum, fedetiam probatum. Whear in Merth. legendi Hift. Civ. Seet. 35 .

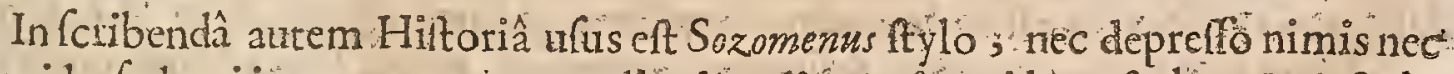
surgido, fed qui inter utrumque mediü incedit Qnif quidem ftylus 'Ecclefafficarrm rerum fcriptori optimè convenir. Et Photins quidem in Bibliothecâ, dictionem ozomeni grafert dictioni Socratis. Cuinos libenter accedimus. Sed

$$
\mathrm{Pp} 3^{\circ} \text { gthantum. }
$$


quantum elegantiâ diotionis vincit Sozomentos, tantum Socrates judicio vincit. Nam Socrates quidem tum de viris, tum de rebus ac negatiis Ec lefrafticis optimè judicat. Nihil ef in illo nifi grave ac ferium. Nihil quod tanquam fupeit tu mo pofis expungere. Contà verò in "n zomeno quadan occurunt levia ac picrilia. Cujufmodi eft in libro primo excellus ille de conditu urbis temona, \& de Aroom nentit, qui navem. Argihumeris fuis per aliquot ftadia tranlportarunt. Item de-

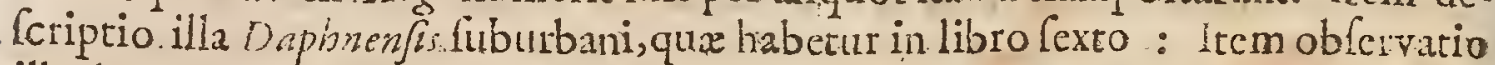
illa de pulchritudinecorporis, .ubi agit de Virgine. illâ apua quan diul latitavir Beatus Atbanafur. Denique liber nonus nihil ferè aliud continct quàm eventus Bellicos, quibus nibil communeelt cum ijilloriâ Ecclefraftica. Henr. Talef de vitâ \& licripris Sozomerit.

Sed \& dictio ipfa Cozoment quam Photius dictioni Sorratis anteponie, vitiis fuis \$1on caret. Obfervavi enim,periodos à Sozmmeno non aliter inter lec connedi quàm

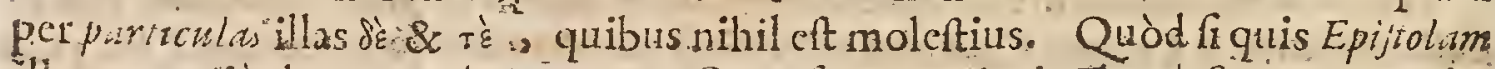
Illam attentius legerit quâ Sozormenus Opus luum juniori. T.Jeodofizo nuncupavit, inveniet profecto id quod dixi, Sozornenumnon magnum Oratorem fuille. I dem ibid.

Utcr plağiarius fit, Sogrates ne an, So zomenus, difficile eft dicere, cum ambo iifdem temporibus vixe:int, ambo princi atu Theodufir junioris, Hittoriam liam fripferint. Itaque in hujus Quationis difceptatione, utcndument conjecturâ. Idem ibid.

Sozornenumin Chronologiâ fepè erralfecenluit $B$ aroniefo

$$
S A L V I \cdot A \cdot U S .
$$

Clar. A. D. ececxl.

Ren Gallus, Presbyter Mafilienfis, claruit ab anno 4 o. \& deinceps magis magifque inclatelcere copir; in vivis adhuc erat anno 425 . Scripta ejus $P$ arifis exculd funt Anno Dorn.1669.8\%. Gul. Cave.

Salvianus plurima Operafcripfife fertur, fed nunc extant folum, quod cgo fciam libri očto de Providentiấ,\& Indicio Dei,\&libi quatuor de Ecclefiâ, lib nomine Timotbei, in quibus ita exaggerat vitas $C$ riftanoru $\&$ maximc $C$ cri:osum fui temporis, ut nimius videri polfet, nif ex vero zelo glorix $D ;$; \& Galutis animarum Oratio ejus proficilceretur. Bellarmin. de feript. Ecclef.

Salvianus humanâ.\& divinâ lițcraturâ infutuctus. Phil. Labbe.

Divinarum \& humanaium litcrarum Scicntilfimus. Hofman.

$V . i r$ in divinis Scripturis crudiriftmus, \& in fecularibus literis fufticienter inAructus.Trithern.

Salvianus Presbyter Mafflienfir, cultus ac pius Autorsnovus fui temporis Hieremias. Loan. Bona Card.

Nihil ci videtur ad abfolutam eruditionem deftrilfe. Et ut elt fanè mirus in caftigando artifex, ita en in docendo Magifter acerrimus.Centur. Mag '1.5.c. 10.

Sciipfit hic Latino, candido \& fuccinato fermone multa laudatifina opufcue L. Sixt. Senen 1. 4 . Bibliath.

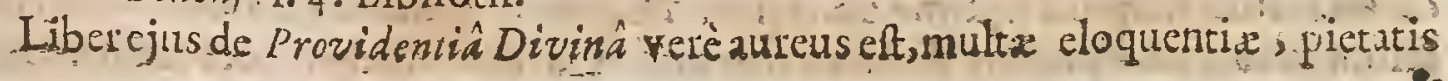


\& doctrina, merizoque omnibus legendus. Quenftedt.

Eximius fc:iptor Salvianus, fanè diligenti lectione dignus eft. Barth.1. 43. tap 16.

Iofephus Sicaliger Scriptorem Chriftianiffimum appellat:

Gallick Gentis Epilcoporum magiftum vocat Taubmannus Notis in Plautum.

Salviani Opera Conradus Rittershufus erudito Commentario illuftravit.Quo no nina gratias illieg it $C$ a aubonus hifce verbis: $S$ alvianum verò qui pluris faciat quàm ipfe facio ; non facilê invenias. Itaque pro eâ Operâ, quae illi optimo Scriptoli à te cftimpenfa,ago tibi pro mea virili grates gratillimas Ca anb. in Litter. ad Rittersh. Londini prid. Kal.Jan.16m.

Salvianus \& Vincentius Lirinenfis, viri, quantum fercbat mala feculi illiús foruna, \& cloquentiffini \& veræ pietatis ac linceræ religionis amantiffimi. Scripłcrunt enim illiadiò purâ ac tersâ Latinutate ut defiderari praterè nihil poffit in Criptoribus adè remotis à feculo Divi Augufti \& Titi Livii Res verò Religionis ac Morum coveri amore ac caritate erga miferrimos ataris fux mortales

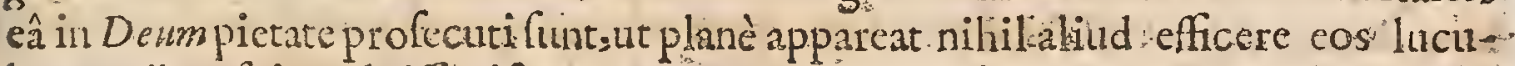
brationibus fuis yoluille nifit ut Hurnanum Genus adfanam mentem \& ad Divinnorumbeneficiorum agnitionem retrahcrente Steph. Baluz iil Epift. ad "Abbato. Iac. Nic.Colbert.dat .Lut.Parif:4. Kal.Jul.i669. Oper.Salvian. \& Vincerat Lirin. prixfixâ...

Salviauus quanrpulcher eft hic liber, \& quápulchira fimplicitas! Scaligerana z.

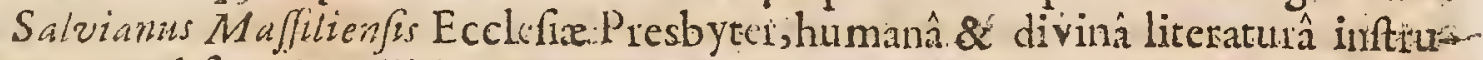
Atus, \&ćcut abfeque invidiâ loquar, Epilcoporum Sanctorum Salonii \& Verani magifter , fcripfit fciolatico \& aperto Sermone mula Genad de ScriptoEcclei.

Salvianws, magni nominis Epifcopus fui temporis fuit, laudatuque ab Eucherio Epifcopo Lutgdracnf fimul cum Vincentio, quos Sanctos viros elo juentiâ \& doctrina cmincnt suiffe traditin præfatione ad libros dé Queftionibus. Vereris ac. Novi Teftamenti, quos ad Salonium infcripfit,ad quem etiam Salvisinus cofm: uem fuos commentariôs dedit.: $B$ aron. ad ann. $42 \delta_{0}$ :

Salvianus Treveris oriundus, quem Mafflien fem Ep:jcopum pofferinins; Sixtus Senenfis, Bellarminu, \& cum iis alii è recentioribus multi faciunt, càm tamen Presbyterumtantim Maffli. fuirfe, ex incorruptis Codicibus Gennadii Maffi-

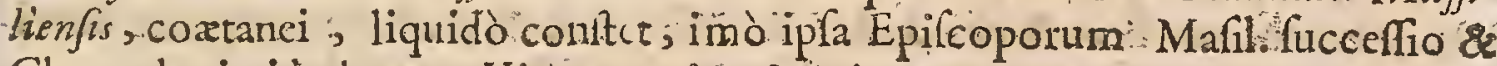
Chronologia idedoceat: Vivente enim Salviano, Venerius auno 428 . fuic Epifcopus, cui, Gennadio tefte, fuccclfit Euftachius, \& huic, Grecus, auctore Sidonio Apoll.tum Cannatus, \&c.referentibus Sanmarthanis, Tom:3. Gall. Chrift. f. 642. Major adhuc eft audacia Pbilippi Elfii, Ord. Auguft qui érenitam Salvianum, \& Anguffinianum facerc contendit; caltigati propterca aे Labbeo p. 322. de Script. Ecclef. Olearius in Abaco Patrum.

${ }^{*}$ Conradi Rittershufii Commentarius in Salviani Mafflienfis Opera, intex Libros cxpurgandos numeraturis Indice Madrit. impreflo Anno 1667. 


\section{I O PROSPER}

Clar. A. D. A Quitanicus, Valentinianitemporibus fuit, quem Burdigalenfen vacat ECCCXIVI。

Aoannes Aventinus: Leonis Papa primim Notarius ac pöf Epifcopus Rhegienfis fuit. Mululca preclara Icriplit pro Gratiâ Chrifit contra Pelagianos, Cefeque S.Angufini Difcipulum \& defenforem acerrimum demonftravit o utiloquitur Bellarminius de Script. EccleC.Chronologiarn fuan terminavit Anno 435. quo ircditur obille. Scriplit porro Pö̈ma,contra Ingratos; Librum contra Grollatorem, \&c.

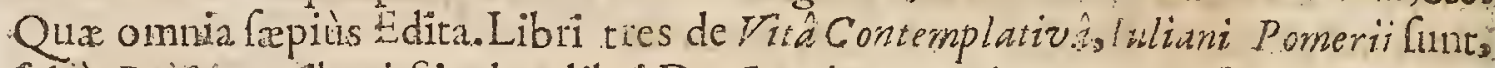
falsò Projpero tributi. Sic duo libri De Vocatione Gentium, nec Ambrofí, ncc hujus Pofperionce Troperi, Epifc. Anrelian cujus Sidonius Apoll meminit, in Epint. Mec Properi, qui An-527.Concilio Carpentoradtenflubfcriplit, led Africujulám Cunt, qui ad Demetriadem Epiftolam Ccripfat. Hofman.

Q:1o codem Leonis tempore in Italia Prosper claruit, qui ex Sîpaniâ origiaem duxit,vel (utrediùs alii tradunt)ex A puitaniâ:qui cù chlamydatus ko-, marm miles veniffet, à Leone Pont. Max. bcnignè fufceptuss, \& ad aliam militiam Iongê fuliciorem tranlatus eft, Leonifyue ipfus fcriba fuilfe creditur. Quin Ge im nadius, Epiftolas Leonis, ait, adverfus Entychern. quie adhuc legıntur, ab ipfo Properodictataseffe, funt quil credant. Certè ab iplo Lane non multò pòt Regii Lspidz Pontifex eftinftitutus, ubi cum doetrinâ, tum Sanctitate florait. Longior yobis videri polim, fi omnem cjus vitam percurrere velim, quam non contemnendo ftylo Flaminius pater complexus eft: ut mifrum faciam que in Ecclefâ legitur, \& quambreviter Gennadus in luo de viris illuftribus antigit. Poéticam ejus nune ego tantùm atringam, in quâ (ut ea fercbint tempora) cx-

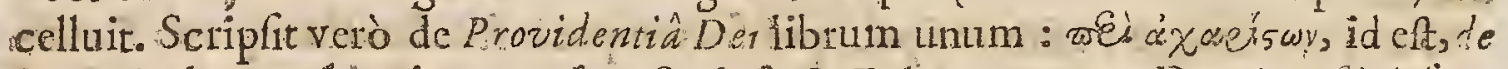
ingratis, alterum, heroico carmine. Scripfit \& Epigrammata ex D. Angulini lenrentiis, omnia qux leguntur. Item Iibellum altenm elego velfu de Diverfis Caufis: Odas infliper \& : ymnos,quorum aliquos citat Beda. Scripfit \& Proper alia pleraque folutâ Oratione, quorum magna pars extat, \& iple nonaulla legi, In Divorum quoque numero fuis meritis relatus eft , \& Regi I epidi maximè cultus Lit. Greg. Gyrald.

Vir in divinis Scripturis enditiflimus, \& in Cecularibus literis nobiliter dootus; carmine excellens ex prosâs eloquio difertus, fenfu profundus, ingenio fubtilis,alfertionencrvolus, vitâ \& convetfatione fanctilimus. Trithęm.

Vir acrisingenii, dictionis prefre, nerv of $\&$ elegantis, magnan cum vitx fanctitate divinarum \& humanarum rerum enuditionem habens. Sixt. Senenf. Biblioth. Sanct.1.4.

roper Aquitricus acerimus fidci defenfor, in fcrbeudo accuratus, five foluta, five ligatâ Oratione loquatur. Sirmundu in Notis ad Sidorium Apollow narerk contanter negat hunc Epifcopum fuife. Imo Laicur fuiffe \& Uxoratsm docer Pbilippus Labbe. Loan. Card. Rone.

O. Laudarur Gemadio Properidictio, utpote ( ut ait ) (cholutica atque nervola. 
neryola. Eadem de eo Marcellinus in Cbronico: Sed magno errore ibi, pro ner vofa habet verbofa Baroin. ad $A$ ann. 466 .

Vil cètè erat magn cruditionis, nec minoris pro fíde Catholicâ Zeli: adco ut Pelagiana Harelcos ruinam illi pra aliis acceptam referat Photiur Cod. 54 . Uxoratum fuifle argutunt verfus ad Uxorem fuam, qui à Beda in fne lioelli de re Metricâ adducuntur. Gw. Cave in Hift. litérar. Script. Ecclcf.

Profper Aquitanicus, Rhetor \& Pocti leculi quinti difertis, fenfu prófundus \& Cubtilis. Extat carmen ej!is adverfus Ingratos, irem de Providentiâ Deialiud; in quibus rarius impingit in Navos Profodicor, quàm vulgò vereres Ecclefum ficifolent. Confat elagianis infeftum fuifle, coque olim conmendatum. Bor. rich. de Poèt pag: 77 .

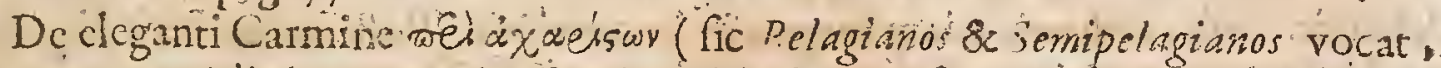
canquam ergidivinam Gratian ungratos ) quin cjus fit ambigit nemo. At carmen de Providenti hominis eft l'elaginnit cui illud Properide lygratis fubjun-gifolct, ut antidoti impleret vicem. Meritò verò judicium defideramus in $A n-$

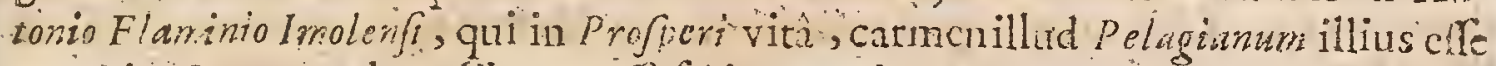
putavit: \& tamen ab colibrum effefoiptum ait contra ncfarian Caflanilasicfin Vigj:1. r.c. t. Hift. Pelagiana.

Dominns Godcau cenlet Pocria contia Ingratos Epitomen clfe omnium S.

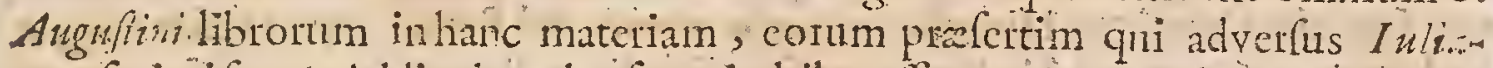
num Ccriptifunt. Addit e us phrafes mirabiles effe, mcritoque pluribus in locis non fine ftupore confiderail quomodo Sanctus ille verfifcationis pulchritudinem eum argumentifpinis confociare valucrit. Anton.Godeau Apurobat. Ver fionis Gall.! ocmatis hujus advarfins ingratos. Galice.

Quod fatis mirum in hoc adverfus Ingrato Pocmate occurie, juxta Anonymi Authois fententiam, ef quód ás $\beta$ e c circal idci dogmata in illo tain congruenter oblervatdeprehendatur, quantumvis reluctantious verfum coactione, genique Poctici liccutia; quódque ibi cemantur veritatescum hativis poefcos ornameitis, id eft cumblanditiis libcralique auducia rẹprafcntataqua amónitatem \& ingenium pariter fapiat. Anonymus Interpretes Operis hujus, in fro Prologo. Gallicè.

Gennadius in libro de Viris Illufribus : feribit Epifolam illam fclcbrem Sancti Leonis ad Flavinutr contia Euigchem, exifimari à Sancto Propero fuife fcriptam. At certe fr ull a Epittola $S$. Leonis eft, ill ommino eft, five frylum, Give doctrinam Leonis attendas. Libii de Vocatione Gentinyrtribuuntur ctiam S. Ambrofu, fed vere rosferifunt, non Ambrofir, ut fuprademonftravimus, cum de libis $A$ mbrolit ageremus. Liber de Providentia Di hon videtur profperi, led alicujus ex factione Gallorkm: gui Tempelagiant funt appellati. Legat piu-

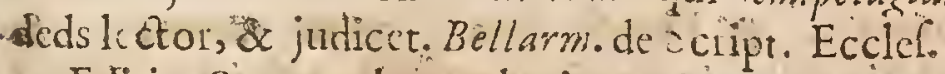

Editio Operum ejus probatior-Colonienfis, in $5^{\circ}$. anno I 630 . Chronicon inteStem edidit LabbeusBibl. Nov. MSS.T.-T.

$$
\text { Q...... EOL }
$$




\section{C.SOLLIUS APOLLINARIS SIDONIUS}

Char.An. D. D Atrem habuit, qui fub Honorio Imp. Fuerit Tribunus Notarius, Prafectis ceceisxir. Obilfe dici anr An. $4{ }_{2}$ xrr.Cal.Septembx.

Pratorio Gilliarum. Natus ipfe lub Theodofo juniore, \& Valentiniano 3 ... Ter utrilifque milikix Magilter fuit; quatęr Pratorio Prafectus. Muktum anctoritate valuit apudiduguftos Petronium Augufum, Avitum, Majorianum, Avito etiam gener fuit, ac perfamiliaris Theodoriro Gothormm regi : liter quem \& $M$ ajorianim, Sidonio conciliante, pactum initum eft. A Majoriano etiam Comitis honotc auctus. Sub Severo Auguflo Averniam adverfus iticurfus Barbarorum. defendit. Sub Anthemio etiam magno in honore fuit, Poft warias verè dignitates jum quadragenarius, factus efi Arvernorum Epifcopus: actum totum fo Sacris Studiis dcdit, rclictâ.Pö̈fi- Quantum autem, valuerit Pö̈f, partirn oftendit, quod in Trajari foro thatuam meruit cum Laureâ Apollinari: partin

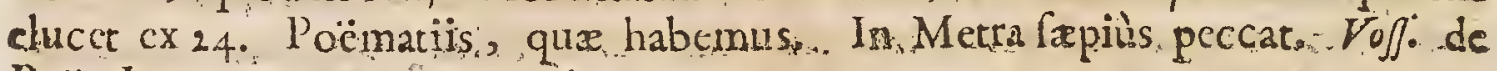
Pö̈. Lat.

Sidonius Arvernorm Epifcopus fcripfit vatia \& grata volimilia, \& fanz do at ina: Homofiquidem tam divinis quàm humanis ad integrum imbutus,acerque ingcnio; fripfit ad Diverlos, divcr fo metro, vel Prosâ compoftùn infigne Volumen, it quo quid in literis poftit; oftendit :-. Verim in Chrifiano vigore pollens, etiam inter $B$ arbar ferocitatis duritiem, qua eo tempote Gallo opprefCerat, Catbolicus pater \& Doctor habetur infgnis. Genmad.lib.de Viris:Illuftr.

In Sidonic, ingens, ut apparet, ingenii vigor... Magis ob multas vittutes admirandus quodpramortuâ $R$ manâ facundiâ hac criplerit quàm ob temporis vitia accufandus videatur, Cauffn.lib. 3. cap. I 4 .

Nemopof Claudianum melïor Poëta fuir; à guo deinceps cateri o mnem cloquentiam in affectatos illos Rithmos fregerunt, multa paucis includere, \& con: fonis fententarum claufulis velut harmonicum genus dicendi affectantes. Barth. lib. S7. cap. II.

Scholajliciffimus omnium Prafulim Sidonius. Wibert. Gernblacenfis.

Viriugeniofus \& Cothurnata Eloquentix. Vincent. Cpec. łib. 21.c. 46.

Vercris fudiofus elegantix , ita ut barburicis Incurfionibus obfoletx, \& penè antiquate ancigure facundia reductor of reparator habetetur. Savaro. in vitâ.

Apollinare opus, Mufs \& Apolline dignum Idem ibid.

In utroque dicendï genere Gallicum nefcio quid \& barbarum redolete vide rur. Lil. Greg.Gyrald. de l'oüt. Dial. s.

Verba Antiquaria, \& novata, \& Phrafis dura, atque novata, \& horrida, minùs multò notabilia funt in orationenumeris adftrictâ : quod eft animadvertere in multis veluc in Sidonio Apollinare; \&"Nartiano Capellâ. quorum Profa abfurdiflima eft Terfom nom penitus rejiçias.Lud. Viv. lib. 3. de ratione Dicend. co de Poëtic. 


\section{CELEBRIORUM AUTHORUM.}

Sidonats Apellinaris Arversorum Epifcopus, vir acris ingenii, \& Cothumatz

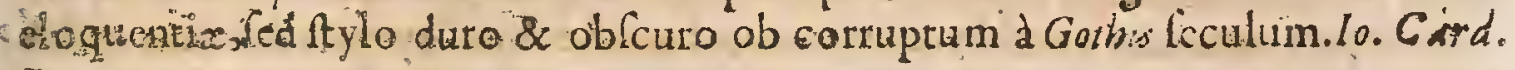
Bona.

Netamis hodieque non proletaram in Sidonï fcriptis eruditionem; \& locusples fanè ingenium. Non inficiandum tamen, dictionem cjus duriorcm fubide - effe, \& horridulam, immò quandoque tumidam. Ut taccam lapfus Profodicos, \& *erborum quandoque novitates. Borrich. de Pö̈tis p. 77:

In Epiftolis ac Carminibus fupra modum literatus. Rogn. Antiq. Rom.

Unice autrem laudo \&amplector stdoni modeltian, qui fe immetito a Arverne Ecclefie prepolitum efle couqueritur. Gener is fuit Aviti Imp.Virfummâ morum fanet titate, Rlictoricis \& Poëticis literis excultus. Greq, Turonenf. 1.2. C. $2 \pi$.

Sidonii Apollinaris, five Apollinaris Sidoni, ita enim milumus cum doctifimis vinis; ingenium magnum fyitit eloquentia in veriu non vulgaris co tempan re, nam de arten melius her exiftimo, cum infinti alis co tempore longè faciliùs fcriplcrint. G. Bartb: 1.49.c. 18.

sidonies accuratus, aliquando ctiam anxius; plcnus elcotorum veıborum \& fententialum, quas acuras brevi concludit gyro. Iul. Caf. Sculig. De Re Poüt. pag. $\$ 22$.

Ief. Rapinus ait illum in inproprictatem incidilfe, dun affectat grandilom quentiam nectanen Pocleos genium habet. Inò nce dubitavit alibi praterca dicere, sidonium fly lo admodum arido miniméque fapido fcriphre.

Apollinarius Sidonius à vitâ moribufquc Módesiznomen apud Librarios accepit. Barth. adver 1. 6. C.r.

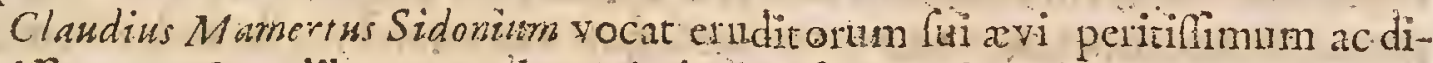
fertifrmun, cique libros tres de Anima adverfes Fanfum dedicavit. Labbe. de Sciptor. Eeciet.

Editio illa Opcrum cjus non faftidienda, qua Parifir cum Commentaris \&e caftigationibus lo m. Savaro is prodit, item $V$ overit, fed pexertur Hanovien os Elme borftirjprobatilima omnitim L.bbci cum notis lacobi Sirmond?.

Plura fi quis velit, confitat is loaninem Savaronem \& lacobum Sirmondum, qui sidonii noftri res gettas ftudiosè \& accurate co legerunt.

\section{MARTIANUS MINEUS FELIX CAPELLA}

14 Tatis dubire Auctor. Vir Proconfutaris, \& domo Carbaginenfis in vett. Clar. An. D. A dibris vocatir. Extant libri 7. De Nuptitis Pbilologie primum cditi Vicen CCCCXC.

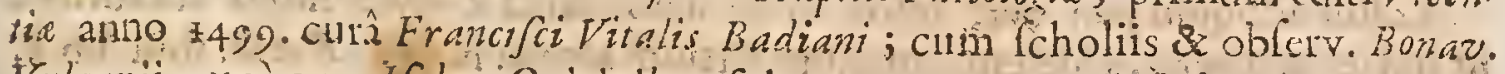
Yulcanii, unà cum Ifsdori Originibur. fol. ann. I57.7. emendati ab tugone Grotio Lugduni Bat anno 1599 in 9 $^{\circ}$. qux cditio relicuis pratantio:

Ut Petroniu", fic \& Marizamus Capella Satyre nomine opus fum infeipfit, stuod illius inftar hoc opus \& verfibus \& Prosâ fcripferit, \& utilc dulci 'mif- 
cuerit - Seyus Barbaries jpla eft:-tantầ audaciâ, tantâ figurarum infolentiâ, ut velin Poët omnium confidentiflimo non fercind fint: Stylus ctiam tam fpifsà saligine involutus elt, vix ut e plicari poffit:doctus alioqui, \& non yulgari cruditione refertus. A fric ainus fuilfe creditur; o non erat, effe debuit; ufque adeo horjido \& coacto fcribendi generc uritur. Incertum oft, quo tempore vixerit cer un tamen eft cum Instinian fuilfe antiquiorem, \& ad procon Julis crectum clfe dignitatem. L'etr.Dan.Hueto de Orig.Fabul. p. 79.80 .

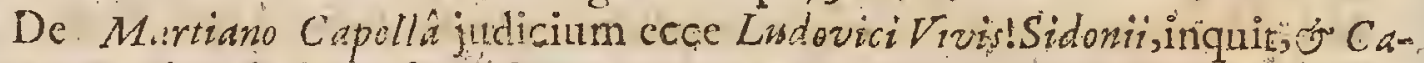
pelle Profa abfurdiflma eftaverfumnon penitus rejicies. Venum enim verò Scrip.

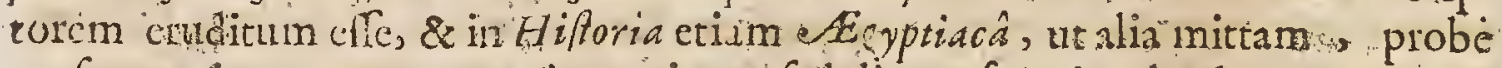
verfatum igno are non poteft q qui cum fedulo verfaverit; landatus propereà

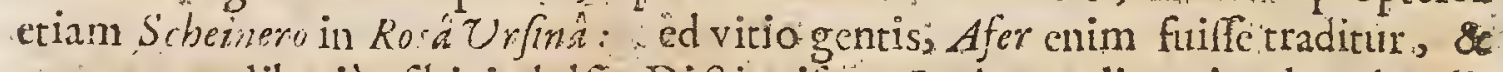
temparum, liberius fibi indulfi, Dietionifute Latina negligentior deprehenditur. Ol. Borrich, cogitar. de varis Lat. Ling. xtat.p. $2 \mathrm{I}_{\mathrm{b}}$

Martianus Fclix Capella, etfi Carthaginenfos fuit, Latinc tamen multa fcipiplit,

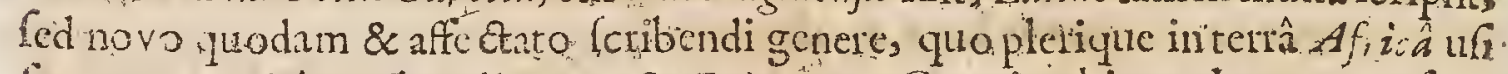
lunt, ut Apalen's Tertullanus, \& Fulgcnim. Carming hic multa compofuit, luis \& libris inferuit. Ejus verò Phlologit \&"Mercurii Nuptia non aliud mihi ele vidsutr, quàm figmentum quoidam Poëticurn, quod cum folutî oratione, tam pedibus altrictum confriptum fit. Parum ab alis friptorbus antiquis Aturinum, quod lciam, celcbratu, nifin eo qui de Difciplina Ecclefafficorum infribitur, qui à quibuldum Severino Boetio atrribuitur- Tameft multá variaque in co Tit \& exorica cruditio, nihilominus non eft pueris edicendus. Neque enim tenera xas eruditioni, ut mea fert opinio, fed lingur proprietati, \& clegnntia ftudere debet; \& Natur am imitari, qux nos quidem prius verba formare. deircum annis fapientizm alfeyui doect. Lil, Gyrald.

Sciptortm lunc. verè eruditum, tamen barbirum non planè immerito apm pellat 1.9 . Saliger notis in Cirn... Vof. de Hift. Latin.

Durum \& verè Latini Sermonis reftimantibus bubariorem fcripterem iefe Mariumum Caprllaim non imus inficias : Ex co tamen tot numero tantayue pondere difere poffs, quot quantaque $\mathrm{x}$ alic paris molis quovis. Tota fere ibi Cylupedist novem Chatis abfoluta eft, cum innumeris interionis fapicntiz Myfteris verfu atque Prosì oratione indieatis. \& propofitis. Barth.lig. adv. cap. 16.

Martranus Capella, auctor utilifimus ad veterum de fingulis artibus libera libus fententiam capiendam, nce dignus qui à Criticis adeo afpermabili titulo: proftituatur ludibrio Tulliaftrorum. Idem ibid:1. 7.c. IG.

Er fuit alioquin jam ante iplos mille annos tanta Capelle hüjus anctoritas, ut qui cum tenerct, videretur omnium Artium arcana nof Barth. ibid lib.8. cap. 23.

Qui dictionem ejus folutam in culpan trahit mitiù judicabit, fr temporum ealiginem intuetur, \& Afrum fuille fciat, cui genti, fi paucos excipias, lartago quxedam loquendi non erat infucta. Spargit autem Capella per totum opus fuum 
mctra varii gcneris, non optimi quidem illa coloris; (ed tamen néc.ubique peffl. mi. Borrich. dcl'oët. p. $\$ 0$

Ad ipfum Martianur te relego, in quo plurima invenies, quæ nec difcere tadebir, noc didicile poniebit. Neque hoc ipfos barbaid feculi homines latuit, apud quios quanti nominis fuerit. $i$ pella, .. vel folus Tironenfis fatis fuperque docebit, qui eum in fine libri non alizer nominat; quàm fi Arifotelern, civeronern, Jjarronem nominâffet. Hug. Grot.

Rebus Laribus, yerbis Africanus, durus inovator.Dempfter ow

$$
\text { G EN NAD I U S , }
$$

N Afrlienfis Presbytcr, vixit tempore Anaftafi Imp. \& Gelafii Papre:cui Clai. An B 12 \& opus de Fide dicavit. Epifcopum vocat Sigebertus: uti \& Platina in ceccxcs. Symmacho facit. Sed Presbyterdicitur è Wallafrido Strabone de divinis: officiis c. 2a. Imò iplefic Ccippellat infine libelli.de Illuft. Script. Ut verifimile fit, d Sigeberto eum confundi cum altcro.Gennadio, Constantinopolitano, qui Leonis fenioristemporibus floruit: ut ex.Mafjlienfi hoc Gennadio cogriolcimus, item ¿ Nicephoro 1.15. C. 22. \&23, Maffilienfis Gennadii duo libri extant: :unus elt de Dogmatious Ecclefrafticis; quıem falsó tribui Auguftino, jam ante amo's otingentos monuit Ecclefia Lugdunen/is in iis; quza de Godfcalci causâ adverfis Ioannem Erigenam Scotum fcripfit.: Alter liber, cujus unitis causâ hîc cjus memini mus, eft is, quem conferipfit de Illufribus Ecclefue Scriptoribu. Eum it Cafjodorns commendat libro de divinis lect. $c_{\text {. }} 17 \%$ Manufriptus cxtat ir Bibliothecâ publicû̀ Academix Cantabrigien/ scm ube: Reliqua Gennadii perierunt. Vofj. de Hift. Lat.

Gennadius Mafficnfis Presbyter \& poftea Epilcopus vixit tempore Gelafir Papx, circa an. Dom. 49. anmad iplum Gelafurn miffle libum fuum de Fide tcatrux ipfe Gennadius in extremo libro fuo deViris lllufribus, quamvis non in omnibus Codicibus liber Gennadii inveniarur completus: Scripfir librtm de Ectefiafticis Dogmatibus, qui éxtatinter libios S. Auguftini, \& hic effecreditur liber; quem ipfe mifitad Gelafurm.

Scripfit crian libitum de Us is Illuftribus, in quo fufpicionem non parvam reliquit fure non rectx fidei. Laudavit cnim Cafflanum, \& Faustum qui Semipelagranifuerunt; \& S. Profperum depreflit, qui progutiâ Deicontra Pelagizrn fortiflmè dimicavit. Scripfit pratcreà multa alia, qux iple commemonat in cxremo libro de Viris Illustribus: Sed ea non extant, aut certè ad manis meas non renerunt.Bellarm. de Script. Ecclef.

Gennadius Maftliengrs Ecclefix. Presbyter, vir in divinis Scripturis eruditiflmus \& lixcularium literarum non ignarus y Graco frmul \& Latino ad perfectum inftuctus eloquio, multa confcriplit opufcula \& de Græco in Latinum Sermo-, nem non pauca volumina Autiquorum Patrum traduxit. Trithem.

Hujus quoque [Symmachi Pont. M.] tempore Eeclefam Dei mulum

$$
\text { Qq:3 juyis }
$$


truvir Gennadius Maffilienfis Epifoopus, qui diligens Augufini imitator, "\& 1 brum de dogmatibus compofuit: \& quid cuique ad falutem neceffarium effet, - declaravit. Scripfit item de Illuffribus, Hieranymum imitarus, Platin. de Viris Pontif.

Nec verò poreft aur debet tanto cum fuftidio Gennadinsactoritas ideclinari, admittendo ejus lapfum. Nam A drianus Papa Epift; ad Carolum Francorum Regem de iplo perhonorificè loquitur, teftemque producit, \&cumlaude tarquan feriptorem ufquequaque Catholicum allegar in fux $c x u[x$ prefrdium pro veneratione reliquiaru in lanctarum, ubi etiam Ponifex titulo $S$ znditatis eundem honeftat. Unde colligit Suarez Gennadium numquam fuilfe Pelagitunen, quia fifuildet Hereticus; nontanto honore àb Adrizno Papâ ad fidei dogma confirmandum allegarcerur. Ioh. $B$ sp: Guefnatin fue Caffiano Illuftrato.

$\therefore$ ic iğitur conclüdimus, fatis gravem caulfam non effe, cur Gennadiun in $S_{e-}$ mipelaginnorum numcrum reponamus: Ut qui de ablolutà quidem Predeftina tione difenferit ab Auguftino., quod illicum multis Catholicorum communc fuifte, fuo loco comprobabinus; atfortafencecflatem gratix nonncgâ it

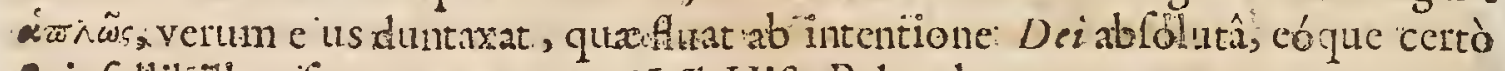
\& infallibillter (cmper operetur. Vof: Hift. Pclag. l.I 6 . Io.

Pelagianifni notâ eximunt libri ho eo contca Pelagiam fcripti : nec Gratire prævenientis neceflitatcmab eo Lublatameffe ( qua propria crat Semipengianifmi,nera) manifeftò liquet:: Adco ut Scriptoribus Catholicis jure accenferi queat. Gul.Cavein Hif Literar. Script. Eucdet:

Quamvis Gennadiurin Guo de Virisinitutribus libic non mediocri dilig ntia ufus fuerit, ơbervatur tamen eum minoricura exoticos $S$ criptores quam conterrancos perquifiviffe \& retuliffe, ac Authorum ejus plcrolque Gallos effe, put ciffimos verò ex aliis Imperii Provinciis. Eruditorum ladizin, Parifo $163 j$.pex Dorn. Baillet, Gälicè.

In Gennadizlabro de Viris Illiftribus nonnull: quxedam fuifle ab interpolato. re addita, ccnfet Labbeus.

Extat Liber de Scriptoribus Ecclefafticis Antvverpic1639. Fol.

(Integkior verò extarin Cod. Coxberenfi, cujus fpecimen dedit Mabill. Anal. T. I1. p. 42.)

Extant de Dogmaibus Ecclcfasticis libri duo cum oblervationibus Geverhar ti Elmenborsiti. Addita lunt Ci arialis. Lemouncenfis dua Epiftolx itamburgis : ${ }^{1} 4^{n} \cdot$ an. 1614 .

\section{滠 E S Y C H I U S}

Claruit An. A Zexandrinus, Grammaticus nobilis, \& fortè Chriftianus, ad Eulogiwm: Dom. D. A quendam Lexicon vocum Gracarum fcripfrt, in quô multa rarifimæe voces ac dificillimx phates cxplicantur, plurimis encomiis ab Eruditis commendàtum. Nitida ejus eft edirio qux nuperrimè an. 1668. .in $4^{\prime \prime}$.cum notis 1 atri, Scaligering 
Scaligeri, Salmafi, , palmierii, Grieti, Sopingii, Cocceii, Gronovii, Tanaguil. Fabri,

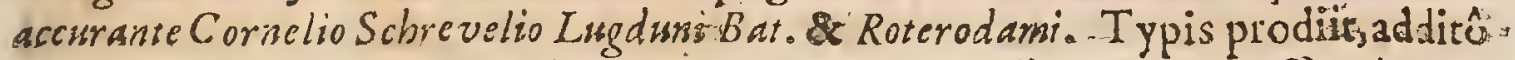
crân per Pricaum Indice anctorum omnium, equos ille citat, ex Officinâ $H a$ skigna. Ioan. Fiallervord. Biblioth. curiof.

Hefycbiw, do otifmusille Grammaticus, \& cujus liber p:o. Thefauro enudizis effe debet. Tanaguill. Faber l.i. E. Elifo.p. 10 \&.

Glolfographorum longè princeps. C af aub. in Athenarmo.

Grammaticorum Alpha. Montac. orig. Ecclef. Tom. I. part. pofer.

Equidem ita femper judicavi, omnitm veterum Criticorum, qui hodie es Eut, eruditiffimum illum effe. Cafaub. Epift.: Ig 8 .

Omniuin veterum Criticcrum, qutos habemus hodié longè, fi quid judico, doctifinus, \&ferio Grecautibus apprimè utilis. Ca Janb. Ep.265.

Ille verò omniumfui generis eruditione præcipuus, fed Glofjographus potiùs. quàm linguxu Ariftarcbus. Eufthat. Svvart. I.I. Analcct. C. I...

Inlius Scaliger in libode fubtilinate furilem \& planè Grammaticim astorems nominat:

Hefychii Lexicon Graca Lingua thefaurum ducebat $\Gamma$ raseptor in Gracis. mus BonaventuraVulcanius. Qui \& Gentilem non Chriftianum, fuifecicenfet Mihi ille, quem:Gentilem fuilfe Suidas putat, diviverus ab hoc videtur.: Sanè Lexui fcriptor tam multa admifcet è Scripturis, corumque Gracis Interpretio

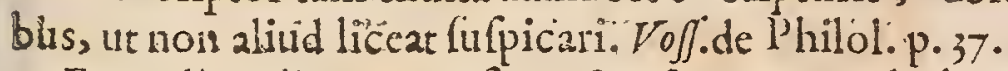

Ex nudà Indicas percurfione, ftructorem vocabularii illiuis ( $\mathrm{rem}$ nondum om-

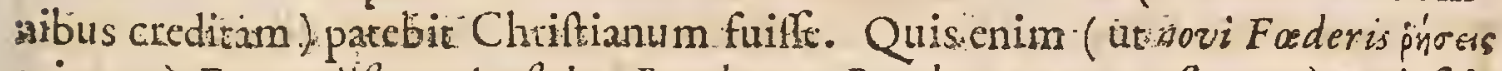

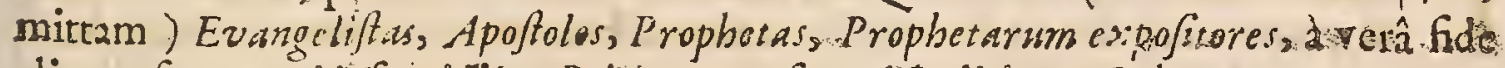
alienus fuo operi inferuilfet? Priceus praefat ad Indici Hefych.

Hcfycbio qui teftimonia Veterum Auctorum exfecuit, piaculum inexpiabilles fecit. Plurimaenim bonorum Scriptorum loca paucis verbis iluftrat doctifin, mus omnium Grammaticorum, qurnifi.coram Glaflis fuis videas, vin fentias: quàm fint eruditi..Cafpoliarth. ad Claud. p. I IO2,..

Vix centefmam Hefyrhi partem habemus, \& fapè pro gemmis, auro, algento, frape, inquam, meros carbones, \& lutum lutulentum imperiti homines fübttitucrunt. Tanaguil. Fab.1.2. epift. p. 58 :

Hefychitis optimus A Athor eft. Epitome nobis tantum reftat, citationes omitcuntur. Scalige rana pofterior.

Hefychii \&"Erotiani Léxica ad Hippocratem intelligendum maximo crunt ad jumento; quorum hic ex profeffo iplius Hippocratis dictiones exactifimè perpendit enarrarque..., ille yerò fuif optimus : Grammaticuses: Scaligerana. prima.

Hefychii Lexicon magni zeftimabant Heinfins atque Salmafrus.

Gracorum Lexicographormm par illud nobile, a e efychius \& Suidas, in Scho lis Grammaticis, auditu vix notum, nedum manibus tritum; \& Opera eorum (virorum clatiffimorum ) quamvis fandamenta futerint Lexicorums fublequen țum, is fuperitructorum; nihilominus tamen Latinge etiam seddica, adeò 
curta funt, \& abfrerfa; ut penè mexilum prorlus eflet, \& vix Operze prentium, tyronum ufii ea exhibere veftiganda. Gul. Rober:for.in $\mathrm{H}^{\prime} \mathrm{x} . \mathrm{d}$ Schrev. Lexic.

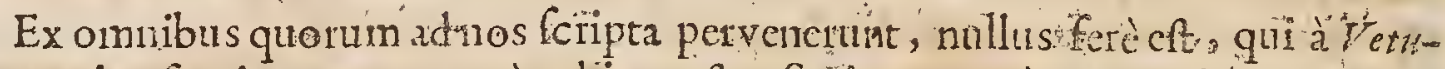
Rate pejus fuctit acceptus, quàm hic nofter Scripror, verè . o rè undccunquedoetiflimus, \& omüis Antiquitatis peritifimus ; cujus Lextcon

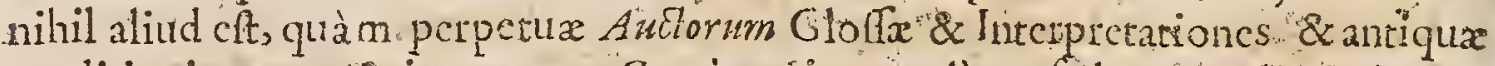
ertuditionis pcnu, \& in qun non Gracicitotius modò, fed ex parte \& Orienis., ut Dan. Heingusin Ariftarcho fuo ait sendititio conclufa jacer. Curnel. Scbrevel. in Prafat. ad Hefych. Lexic. 4 ". Impref. Lugd. Batav. I669.

Iulius Scaliger ait Hefyrbium efle Authorem frivolum, ablque cruditione ac niniméidoncum ad aliquid boni contundum, pertufoque canifuo fimilem.? Sed cum in hac fetcutia folum cfle atbitrot.

Lexici hujus cditio omnium abfolutifima eft Hollandiar anin i668. tota Grea cum Notis Variorum in $4^{\circ}$ accurante Schrevelio. Sed quonian hic Compilater mediociitcr celebris fir, potior, à Dom. J:Capparo Svvic rocxpecta-

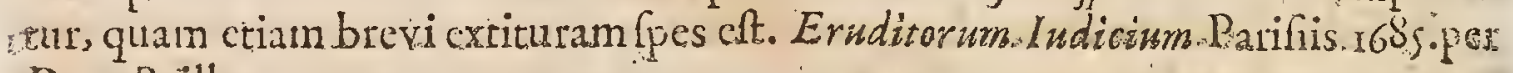
Dom. Baillet.

\section{TROCLUS.}

Clar. Ann. T Tcius, Plinlofophits, floruit Anno Christ. gno. Syriani difcipulus fuit: Dom. D. L Marinum verò dícipulum \& Luccelforem habuit. Sioeflerus atque Scbrekenfuch fins male in tempora Trajari collacant. Extant fex ejusilibri de Theologiâ Platonicâ, quii Hamburgi primtum pródicre an. 1618 . Item fuperfunt cjuf dem Commentalilin Timamr \& libros de Repub. Ccripfit quoque de Orphei, Pym. thagore \& Platonisconfenfuin Oracultsibros decem, aliague quæ Sxidas comincmolat. Koritig.

Hic effille Proclus (inquit Suidas) fecundus à Porphyring quii impuram fuam \& contumeliofam linguam adverfus Chriftianos: exacuit. Sed adverfus hunc calamum foeliciter itrinxit Ioan. Philoponus. Gul.Cave in Chartophylo

Circa Anu. Chriff. quiingentefimum memoriam fui nominis coníccrabat nobilis \& Grarmaticus, philofophus, "rochus Lycius acujus, inter alia multa, Spherarn habemus, imprimis agentem de $C$ irculis $C$ celeftibu. Sed menumentis aliis plus laudis meriit : quiia hoc opus exfcripfitex Ifagoge Gemini, Gcometræ '\&" Aftrologi; qui Ciceronis atate viguiit. Vertit Procli Spheram Thonas Linacer. Scholiis illuftravit Erafmus OSwaldus Schreckenfuchfour. Vofj: de Mathemat. p. IGg.

Mirari Gatis nen polfum malignitatem Procli, quando Scholiis in Cratylum Platoris, Ariftotchiexprobrat, guòd Analytice ejus à quovis non plune hebete. ac ftupido intelligi poffr. Nam nec ipfe, quii hoc culpat, quoties Commcutario in Euclidem aliquid ir Scriptorece improbat, ad Platonicas Methodos recu- 


\section{CELEBRIORUM AUTHORUM.}

rit, (cd omnia fccundum Arifotelis Analyticen expendir Nec fi tanta eft perfpicuitas Ariftotelis, it omnes non hebetes eum intelligant, Philofopho id vitio fed laudi duci debct. Quis cnim in tamenecellatio Argumento nen malit diCtionem perfpicuam, qualis Philofopho convenit, quàm Myfticam \& Symbolicam, cujufmodi corum eft, qui-noluntintelligi , ut magis fint admirationi? Quid quòd nec tam perfpicuz omnia fint in Analytitis, quàm videri vult Proclus. Quod veterwm plerique agnofcunt. Viff: de Natur. Logic. $\mu .70$.

Naturalis Pbilofophia adhuc funcera nou irvenitur. Ged infecta \& corrupta : i

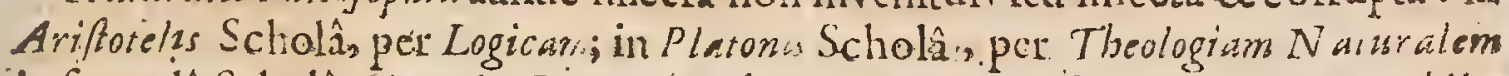

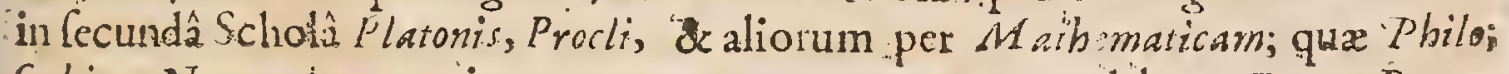
Sophiam Naturalemiterminare, non generarc aut prosiearc debet. Franc. BacorNov. Organ. 1. I Aphorifm. xcvi.

Proclus tum \& in Philofophia in Mechanicis florebat, neque Arcbinedis duntaxatcelebertimi Antificis cognônat omnia, fed \& ipfe nova quadam adinvenerat: ab eo facta eft Machina, quầ clafis Vitalictri debellara eft. Nam fpecula ex rac fabricalfé uftoria Proclus fertur, cactuc de muro è regione hoftiliuin uavium fulpendiffe, in gux cùm radii Cólares impegiffent; ignem inde inftar fülminis erampentem, caldiarios iplafque naves holtium combufilfe; quod $A r-$ cbimedern excogitalfe Ronsnis syracufás obfidentibus, Dion refert. Zonar. in Annail.

Proclusicum efret Olympiodori e uditor, hominis facundi i is cujus dicentis Orationen fluebat, fed torrentis inftar fercbatur, ut pauci dicta cjus affequercntur, folitus à recitationc omnia quae dixiffet Olymprodorus totidem atque iifdem vcrbis teddere. Cajatib: in Nor. Sfartian.

Licèt L.gizcâlevitcr inftruetus, attamen eximius Mathematicus fuit. Certè libris \& monumentis ejus recenfendis libro fuerir opus, ita multiplices unius hingenii. fortus momorantur; Georsetricarum vèrè in Eurlidem Expofitionum libri quatuor diligentiam magnam teftantur. A tque utinam, ut in primum $E_{u-}$ clidis librum induftrius effe voluit, fic in reliquos parem induftriam continutâffer : fed videtur aliis viam laboris indicare voluiffe, laboris ipfus parte contentus fuilfe. Petr. Ratm. Schol. Mathem.

Extant Procli Elementa. Theologica \& Phyfica Latinè reddita Francifco $P_{a^{*}}$ tricio, Ferraric in $4^{4}$. apud Dorninicum Mamarellum, ann1. 1583 .

Extant Theologix Hatonica libri G. è Bibliothecâ Gottorpianâ primùm eru:xi \& Grxcè cum lnterpretatione Latinâ E Emalii Porsi editi Hamburgi in Fol. ann. 1618 .

Extat Paraphrafis in Ptolemei de Sydertam affectionibus Tib. 4. Grecè cur Interpretatione Leonis Allatii. 'Leyde in 8'. an. 1635 .

\section{FULGENTIUS.}

A Fer, ex Abbate, Rufpenfas in Africa Epifcopus; claruitcirca ann. 508 . Clas. A. D. $\mathrm{R} x$ Calendis 
Calendis Januarit; atatis fure 65,Gul. Cave.

Omnibus quidem Patrum fcriptis ea dosinelt: ut non folo mentes Peritat is fulgore perftingant, fed fimul intimum quemdam pictatis fenfum cordibis lew gentium infelant: Haud fcio tamen an ullicus propria magis laus illa fuerięuàm Fulgentii; cujus ex Ccriptis is ćboritatis fpirat ardor, ea spirtus ubertas ex!ldat ut pectus Deo plenum non intelligas modò, fed fenti is.... e A uguftini difcipulum fcias, non magis ex confenfione dog gmatum, quàm ex fumilitudire virtutum, variifque ingeniiac morum onamentis , quibus ille totum Augufinum expreflit.

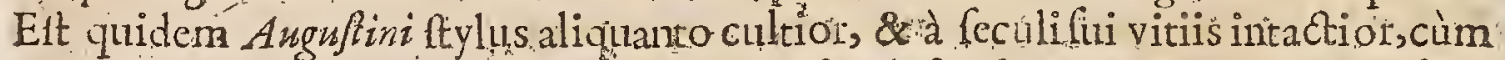
Fulgentio nunquam cura fuerit abtergere feculi fui frum, at idem in utrifque mentis vigor, idem acumen, idem fententiartum pondus; eadem iügenii felicitas; eadem in tractandis scripturis diligentin; dexteritäs, affluentia :eadem mon æquitas, fuavitas, manfuetudo idem Charitatis ardor ex Sority emicans,idem pro Veritate zelus. Nec dilpares utrique holtes. Nam \& Auguftino frequens cum Arianis luetario fuit, \& Fulgentium hac Hare is per totam vitäm exercuit : cum Serrip lagianis orientibus conflictus Angufino fuit, cum iifdcm adultis.Fulgentio: pariutrobique fuccefft. A neutro enim hice error in tötun compreffus eft, fic tamen ab utroque revictus \& depreffus eft, ut utriquite tota fe Latizorum Theologorum cohors femper, adjunxerit. Gul, Dejprez. Irefat, in Fulgent. Opera:

Fulgentius Afer, Ecclefiz Rulpen is Epilcopus, in confelfione Fidei clarus, in Scripturis Divinis copio sè eruditus, in loquendo dulcis's in docendo ac differendo fubtilis, Ifidor. Hijpalenf.

Fulgentius Rupenfis Epifcopus, in Gracâ \& Latinâ linguâ clatus., gemin fcientia fripfit multa. Claruir in Hornilitico dicendi genere Sigebert. Gerblac. de Script. Ecclef.

Vir erat \& eximiâ doctrinâ \& infigni pietate inter atatisfuz Epifcopos facilè princeps. Gul. Cave in Hift. literar. Script. Ecclef.

Pontif x Rupenfus dootrina \& vitx fanctimoniâ confpicuus, fummum ac penè ultimum Ecclefia Africane fidus. Drexel. cap, 2o Prodr. xternito fect. 46 .

Fulgentius Ruppenjes Epilcopus, incomparabilis vir, eujus ego admirator fum. Cajp.Barth. Adverfas: 1. $16 . c_{*} 8$.

Quem ego Scriptorem [Fulgentium] inter Patres Latinos fummoperè amo, Dónervas quibus praditus eft in peruadendo, \&vivam vin dictionis rebus maximis ubique parem. Ider ibid.1. 46. 6. 13 .

Fulgentius Rupenfis Epifcopus, Fulgentifinum Ecclefia fidis. Vofso Hift: Pelag.lib. I. cap. 2.1.

Hoc codem anno, ipfis Calcndis Januarii fummirm illià as penè ultinum Africane Ecclefra decus, Fulgentius Ruppenjes Epifcopus doctrinâ \& fanctitite mirabilis, optatum diu, ante pracognitum, prelenti vitx fuem latus impoluit. Henr. Spandan. ad ann. 529 .

In Antiquitatis notitia hofpitem admodifn elle oportet eum qui ignoratquan- 
rim dignitate fua, virtute, erviditione, Zelo \& ærumnis fuis pro Fide Catholica, in1 Ecclefiacorufcus fuerit Fulgentius, quem Tractatûscujufdam divi Auguftho ni lectio eripuit prefenti Seculo, \& muneri culidam primario in urbe Carthagine, cui natales debrbat è quadam Nobilifimorum \& illuttrifimorum conci-vium familia. Eruditoruxs Ephemerides. Gall. Tom:' 2. p. 216.

S. Fulgentzus Carthaginenfis, Epifcopus Rufpenfis, vir Ganctifimus, \& doctili 3 fimus, foruit tempote Tranfumundi Regis, àd quein feripfit libros. Obiit Ann: Dom. 529. vitxe firæ ann.65. Epifcopatus autem 25. ut Card. Baronius Annotat. Tom. 6. Anual. Scripfit plura, teite Ifodoro libro de Tiris illufribus, quorum -multa perierunt. Bellarm de Script. Ecclef.

- Quibus quidem apparet, quanta effer in Fulgentio cum ingeniiacumine facre Thcologiz eninens excellenfque doctrina. Videas miro quodam modo validâ fapè relponfione eriggere protritam ab hoftibus veritatem. fimulque proftcrnere policntem regiâ potenciâ, infilitantemque impictatem; tantâ tamen modeftiâ, ut ficutex co fublimis ipfus doctina intelligi polfit, ita cx hoc ejuf- dem intueri váleas fanctitatcm. Baron.ad Ann. Cbriff. 50:4.

Inter catera ante lpifcopatum compofuit 24. vel ut alii legunt 23-libros: quorum primus eft abfue $A$. hec eft, ne unam quidem literam $A$ habet. Secundus eft ablque $B$. T citius abfque C."\& fic dei ceps. Hujus operis Fulgentia ni cxcmplar M.. cxtat in Latienjiapud Hannones Coenobios tefte Auberto Miroo Bibl. Ec 空lef.

Extant ejus opera Antv. 1574.80 Lugd. K633,1653. Fol. cum operibus Ieonis M.'\&c. B.PP.' lom.9.p.16.

Poft varias Doctorum Virorum ad Opcra S. Fulgentii precuratas fuccelfu temporum Acciffoncs \& Commentarios, ea omvia ann. I684.cum optimo (inquit Oudinus) ordine \& chatactere imprella in $4^{\circ}$ Parif. apud Guzlletmun Defprez, vià lacobeâ, fub figno S. Prooperi, fuppofititì's fermonibus clemento minori ad finem adjectis.

Qvamvis verò qui huic Eulgentii editioni Parifíf 68 4. operam dederunt, nomina fuàlatere voluerint, de publicâ utilitate magis, quàm de fama foliciti $\&$ e: grcgii facti confcientiâ contenti, neminem tamen larcre volucruint, multum fe to Jeluitâ Chiffleió adjutos, qui variantes in omnia ferè Fulgentii operalcetiones, quas olim ex variiscodicibus Bibliorhecx Cartbufá ad Portas exfcripferat, be, nignifinè cum iis communicavit. Acta Eruditorum Menf. Septembr. An $=10168_{4}$.

\section{FABIUS PLANCIADES FUIGENTIUS.}

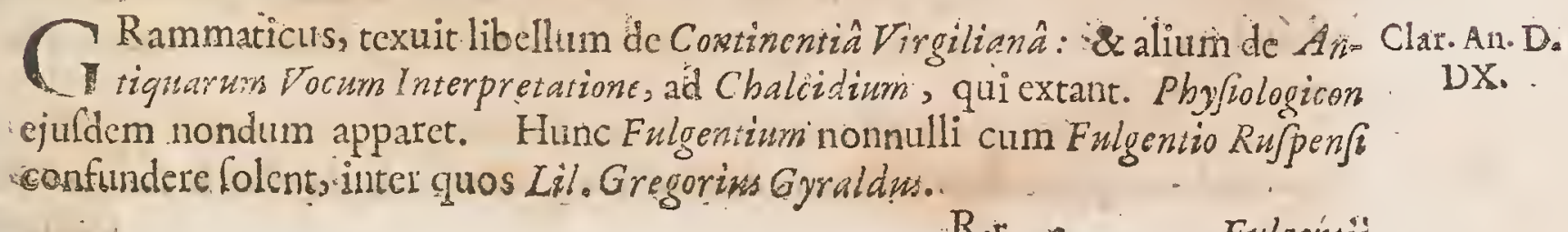

$$
\text { R.r } 3 \text { Fulgentio }
$$


Fulgentii Planciadis Grammatici Mythologiarum libutres, utiles quidem fed diotionis admodurn tumidx, \& verbis abotrufis , atque Poëticis abundantes.. Hoc opus editum olim fub nomine Fulgentii Epicopic arsboginengss. Bollandus

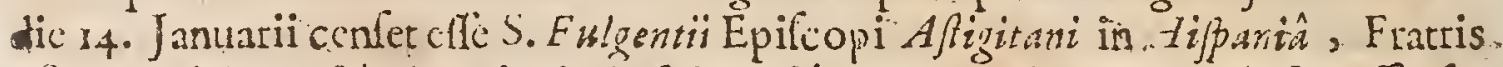
SS. L and :- \& ijdori, qui primo fuit Lilcopus Cartbage ine, unde fortaffis fuAum cet, ut Fulgentio Carth.ginenfi tribueretur, Sed hxc eft conjectura Biv.riti in Comment. ad bronicon Suppofititiver M. Maximi, nam Auctor Mytbologice rurn eft proculdubio Fulgentius Plonciades Grammaticus Afriganusaloan. Card. Bona.

Fulgentius omnium Scriptonmaudacifrimus, comptus. fermone, confulus. intellcotu, \& omninò quidvis pociüs quàm fapientỉ confultus. Casp. Barth. in 1. Sylv. Papinit, p. 8j.

Hæc Fulgentius : quem Scriptorem legendo mileratione temporumafficimur; tanta cnim jam ruditas à Græcâ literaturâ crat, ut fibï arrogantix fummr homo o mnin fcribere licere crederet, modò vel auctores Cracos vel voces ejufdem lingua per capur ped lique attr hlere polfèt in medium, ceind fum negosium curare. C. Barth. Comm.ad stat. Tom.3.p. 449 ..

Fulgentzus Planciades, fcriptor Mythologicus, utiliò quàn cloquentior: Se. mipoetans: A fer Affectator Barth.1:17. C. 7 \% Adverl.

Quò autem Fulgentius Planciades etiam Taciti Facetias citat, hôc inficeto adeo Grammatico plinè dignum eft, qui etiam Plauti Eucifion, \& fimiles laudet nugas, Vall. de Hilt: Lar. I I.c. 30.

Quod fignifer lovis fit Ganymedes, docet doetiflimus Mytbologus Fulyentiuss 1. Io Ioj. Sc.li. Comment. iil El: de Ob. Mac.

Auctor non contemnendus Fu'gentius. Turneb Adverfar. Li 16 . C. $3 \%$.

Eulgentius non contemuendus Grammaticus. Angel. Politian.

Expifati commodum expenario literaterio, cajus tu fuifti Condits, Mythologicon Placadern, fratrem, ut fertur, Caffirdori, hunc. Chalcirypis Officinatoribus tradendum cuavimus, nuncupatim tibi, dicantes fine provocarione electo judici aureum librum; quid libum? the fanrum potitus: quem Sidonius 1.3. eruillimum, \& ob ingenii merit، Questorium vocat, tanquam Quefturâ irjecte Epifo cop.tum Africa fimplerit Ioh. Bapt.Pius in Epift. Dedicat.ad Anton. Mariam Bestivolaum.

Fulgentii vetò paucos libros vidi, in quibuss de Christianâ Religione benè fentit: fed duriufculus in primis, \& affectrtion ftylo elt, adeò ut in fcriptis. fuis fpinas, \& verbonun afperitates, fi non aculeos potius pro verbis inferniffe videam zur : \& in primis in Mythologico : namaliz quidem piè \& Chriftiané friptanon tam horrida funt. Lil. Greg. Gyrald.

Ineptè luditille [Fulgentius] in Etymologiis ex Crecis fontibus derivandis, ut contrà M. Varro nimió feppè linggux Latina ftudio. Andr. Schotto. Obleiv. Hitman. 1:2. c. $17 \%$.

Fulgentii Mythologiâ quid ineptius? Brod.Annot. in Q Calabrum. p: 238 .

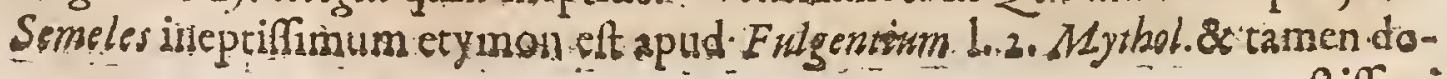


athimi viri cum $M y$ sbologum Dotiffsmi nomine commentane; qui totus nihid

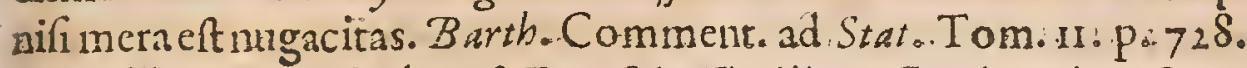

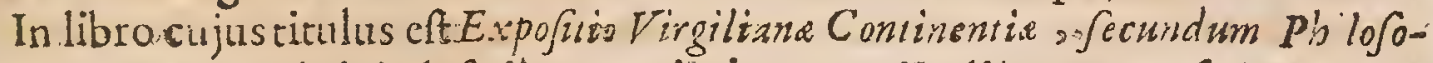

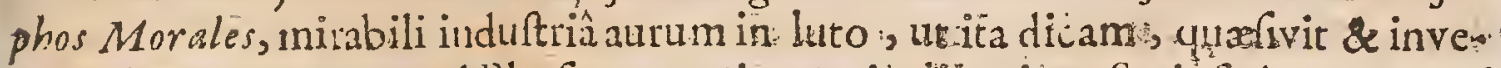
nit; dim opus, ëtx ad thyficam rationem inclinavit. Scripfishos:opus ad quendam Diaconum: Aliud verò Mythologiarum ad Catum Presbytertm Car thagingenferr o \& de abftrufis Auriquorum fermonibus ad Chalcidium Grammatioum, jan fenem, cumipfe adhuc juvenis effet, \& literaran: Humanitaris $S_{\text {chola }}$ Doctor \& Rector. Trizhem.

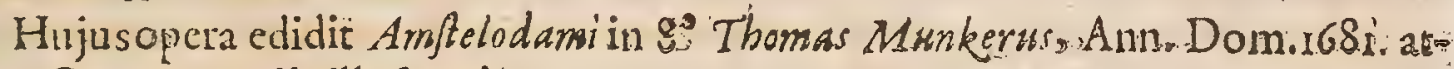
q̨ue Commentariis illuftravito.

\section{ANICLUS MANLIUS SEVERINUS BOE THIUS}

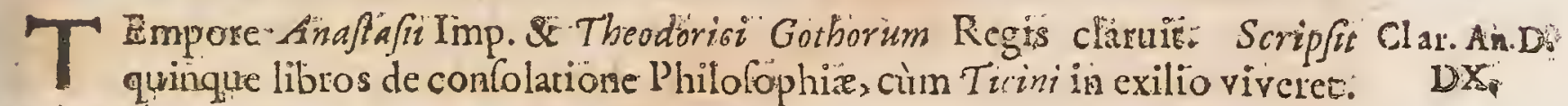
Cùin obbilitteras, ad $A$ raftafurn Imp. fcriptas, \& alia quredam fulpeEtus elferTheodorico Regi, quafretucteret recuperanda libertati , julliu cjus cum locero Symmacho,anno 524 . interemeus eft.

Certè hiter pofterioriē xui Scriptores, Grecos pariter ac Latinos, nenfo fulie in omni genere fapientiax: Boetbio noftro par. Nihil quippe ili eo non eft eximilum. Religionem lpectamus? Chriftanus eft, \& quidem inter Chriftianos fidei orthodoxafectator atque Adfertor: Patriam ? Romanus. Dignitatem? Patritius, exc onfulerdinarius, exmagifter officiorum. Familiam ?: Anicins : Manlius,

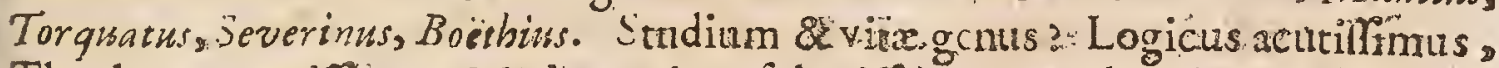
Theologus graviffmus» Mathematicus folertifinus, Mechanicus artificiofifimus, Muficus fuavifimus: adhæc Orator \& Poëta optimus.Dictionis modum? utroquc. in genere fufo pariter \& anmeris adtaicto, egregus, fed in hocpracipue exeellcuss.Boethii Petr.B.Bertbius prafatione prafixâ Boèthii libris de confolatione.

Sunt quidem omues:Boetbii libri.graves \& eruditi. Sed. in his, de confolatio ne Philofophixe, nefcio quomodo nofter Auctor feipfüm vicerit. Acputo, homines, quò funt morti viciniores, è̀ plus experiri in fe divinitatis; eóque communem vitze ordinem egreifos majora dicere, videre, cogitare, quàm in omna: vitâ actâ fecerint. Quxares ingens momentum habet ad probandam immortalitarcm animarum - Scripfit conlolationem iftam verbis fententilifue ita numesolam, ut nihil.pofit concipiele legantius. Idem \&ibidem.

Boëtbii Severini ingenium, erudirio, ars, Sapientia jo. frcile provocat omnes Awctores, five illi:Graci fint, five Latini... Saculi barbarie ejus oratio foluta

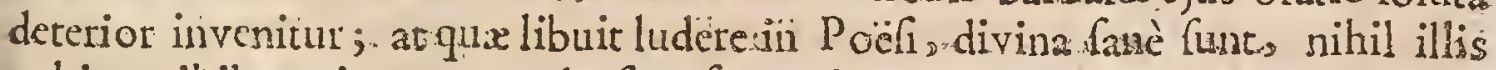
cultius, nihil gravius; neque denfitas fententiarum, , Venerem, neque acumen abftulitardorem. Equidem cenfeos paucos cum illo comparari poffe. Valla docet illıı Latinè Joqui ; at Vallam Bogthiusbene fapere, ful. Scaliger in Hypes* sritico, p.825.

$$
\text { R. Sinc }
$$


Sine dificulate profundus eft in Eciteniis, in reibis fine levirate confpicutus oratorvehemens, efficax demonftrator. Ad id quod lcquendum eft, nunc prolabitur fuadens, nunc quaft ftimulo necelfitatis impelicns. loamis Sarisberienfis Epic. Carnot Policratici lib. 7 . cap. is.

Fuit Bö̈thius in omni difciplinâ cgrcgiè doctus, quod liquidò ex ejus monumentis conftare potent. In pangendis verfibus mirâ ufus ent facilitate. Lilius $G y$ saldus de Poëtis:

Vir Latzic a Gracedoctifrmus, "in omni difciptinarum genere cxcellens, quôque Roma à Varonis temporibus non habucrit undecunque 'ćoctiorem. Quantum idem carmine valuerit, oftendunt libri s. de Confolatione Pbilojopbie, quos exul Trconi feripfit. Omnino nihil in poëfr venuftis habuit, vel illud avum, vel etiam quod proximè ancectit. Vofjus de Poëtis Latinis.

Severini Bö̈thii ingenium nequeante fe multos, neque poft fe iliquem toto Romani Imperii tempore habuit finilem. Bartbius adverfar. lib 57.6 .13 .

Quis Boètbio, vel in dialecticis acutior, velfubtilior in Muthemaricis, vel in Philofophia locupletior, $\mathrm{vel}$ in Theologia fublimior? Politianus in Mif cellaneis.

Bö̈biu egregius Philofophus., Poütarnon peffmus, Ciceronis dictione longè femotus. Erafmi.in Ciceroniano.

Be ëthins totus legendus eft, magnus quippe rivlofophus, Poëta eximius, phrafun Neronianitemporis imituns. Scaligerana primas p. 30.

Boeitus parvilas qualdam Odas compoluit, quas Operi fuode Confelationibus "Philofophicis immifcuit. Sed quantavis ingenii pólitic onatus effet, pravun fcribendi modum qui tunc vigcbat fuperare nequivit: Quod in illo pulcherrimum nitet, nitil ef nifi adulterina pulchritudo, genio lem culi quo fcribebat conformis. Rapir. Reflexionib. in Roeticarrin particulař Reflex.3⿻.

Extat Lugd.Bat. ex off. Hackiana.167\%.8 $8_{\cdots \circ}^{\circ}$

\section{AURELIUS CASSIODORUS.}

Clar,An.D. C Enator, V.C.\&illuftris, Exquaftor Palatii, Exconfil Ordinarius, OfficioDXIV.

- rúmque Exmagilter, Prxe. Præt. Prapofitus atque Paticius Romanus. Conm fulatum quidem ann. SI4. Colus geflit. Theodorico Oftrogotborum Regi carifimus cique à fecretis \& Epiftolis, ann.570. Adhuc vixit nonagenario major, anno werò 575 . obiit, Geut refert Lün.Henr. Vrfinus, 1. 4. de Stat. Anim. p. 544.

Quafi fidus quoddam inter Gotbici feculi barbariem cluxit, tandem Monam chus factus \&e Ravennatengis Conobii Abbas. Olear. Abac. Patrum.

Scripft plutima, hac verò primum obtinentlocum: Comment. in Pfalmos, \& in Cantica Canticorum - Epiftolarum libri $\mathrm{I}_{2}$. - Intitutionum Divinarum Iibri duo - De Orthographiâ ex Veteribus Grammaticis excerptâ_Chronicon,

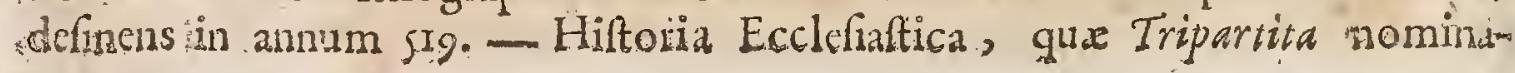


-ar; quam ex Gracis Auctoribus, Socrate, Sozomeni, ac Theodoreto per amicum fuum Epipbanium Scholafioum Latinè redditis concinnavit - Libri 12. de rebus geftis Gothorum... Eos Iornandes in Epitomen redegit - Liber de Animâ.

Imprimis verò A urelium Caftodorum Sevarorem, virum illuftrem, ac do ctum auxit dignitate Patriciatûs Theodoricus, de quâ eidem collatâdignitate extant ejufdem The dorici littera cum ad ipfum Caffodortim tum ad Senatum datx, in quibus magiftrarts tumab ip[o, tum à majoribus ejus benè perfuncti honorifica mentio habetur. Retinuiteum apud fe, cujus Conflio Regnum modem rariconfuevit, \& leges fancire populis; ufus etiam ejus Miniftcrio in conforibendis ad diverfos Epiftolis, ex quibus ipfius C C afodori libri variarum confe. cti funt. Baron ad and $: 493$.

Cafjodorus bonus Auctor, \& minimè fpernendus. Scaligerana $\mathrm{I}$.

Vir in divinis Supturis valde doctus, \& in fecularibus literis omnium fua rempore facilè eruditifimus, non minis fanctitate quàm fcientiâ clarifimus effulfrt Trithern.

Inter viros fuo tempore döiffmos citta controverfiam Principatum quents dam tenuit. Petr. Brofjeus in vicâ Cafjrodori.

Doctus, \&, utillatempora ferebant, eloquens.-Dempfter, in Rofin.

Virutique \& dignitate \& pietate magnus. Conring. de Antiq. Acad.differt.so

Magna Aureliz C'affiodori mens., quxinter hanc Gothri leculi barbariem quafi fidus quoddam eluxit; ftylo veniam deprecatur \& facile invenit. CanfJan. plura Valla lib. 4. Elogant: c. 88.

Cafjodorus Senator, \& Regi Theodorico abiepiftolis, polted Monachus, vil: gravis \& Colidè doctus, cujus facræ \& prophana lucubrationes plenz funt jucunditatis \& gratiæ." loan. Card. Rona.

Quingentefimns tertitis: Chrifi annus Dexecrato \& Volufiano confulibus notatur à Marceltino, ex quo librarii redarguas:errorem in: Calfodoro, apud? quem omilfus anni hujus reperitur horum confulatus. Actaautem Syno dália almi hujus, abfquecerto Confrle, poft confulatum : Ayieni notata leguntur: fed mile indictione nonâ cum undecima fcribenda elfet indietio: unde conjichis libraril crrorem ita exfcribentis Ix. locoxi. numeriliotas : fed \&nonnifilim brariorum vitio potuit accidiffe, ut ad finem Chronici Cafrodori aliquot defiderentur confulatus: omnis enim fufpicio of citantix procul ab ipfo abeft, qui fuoIum temporum fcriptor luculentifimus *accuratifimus extitit. Porto ex numero annorum Imperii Anafafii integrum \& Concinnum elfe $M$ arcellini Chro-' ricon, Caffrodori verò mutilatum apparet. Baron.ad Ann. Chr.:03.

Eft illud Chronicon [Caffiodori] non initile qnidim propter Confulum annos, quos digeffit; ut \& Sigebertus annotavit in Catalogo CXL. Sed tamen nec ni-t, miseft magnix rei. Sanè penè nunquam ei cum Eufebio convenit. Sed Cafjadori. Chronicon tantù marrago eft quam temulentia comparat Onupbrius $P$ anvinus, approbante etiam lofepho Scaligero in Animadverf. Eufebianis. Profecto in -:

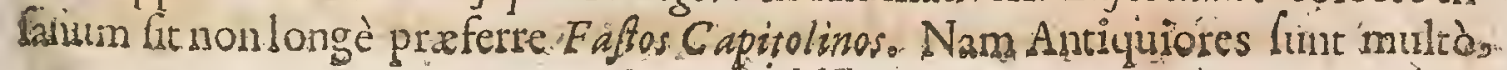
dongéque 
longéque florentioris avi: adhrec non Gonfulesimodò, fedetiam Cenfores, Ditatores nominant, cum fiis Equitum $M$ aigifris. pixterea prænomina exaet: magis pontut, quorum ignorantia facit, ueperfonæ confundantur, magnaque in Hiftoriis oriatur obfcuitas. Utinam tantum . Eafti illi non ad nos mutili perveniffent. Vof. de Hift. Lat.

Inutile etiam elfet heic examinate Cafiodori Commentarios in P almos, cum nihil perè aliud egerit quàm Divi Augufini Commentarios in coldem dibros.rcontrahere, ut id ftatim inieio Prafationis.fuxteftatur. Pratcr ejus Cormentarior, hujus Authoris praclurum habemus Tradtatum, cui titulus De Infitutione Divinarum Scripturarum, que le exercitatum in Scriptura Critica demontrat, Teque oblervalle que optima in hoc Argunchtum ap:id Vetercs Ecclefie Doclores occurrcbint - P'recipui ejus Authores funt Divus Hieronymus Divur Amgufinu; quibis accepras ferre tenctur plerafy; regulas aquas in Opere lito univcrio propoluit at S sripturarum interpsetationem. Plures memorat libios qui nunc defidcrantur, \& intcr; cateres Obfcryationcs qualdan Divo Hieronymo confcriptas, admodum concisè, in Prophetas, ut junioribils Scriptura fudia faciliona ferent. Novam $B$ cati Hierionymi Verfonem ex Hebreo canti atimats'tt aperte dicat vix in poltertan opus clle ad Hebraicos fontes confugere, cum tàmaccurata Bibliarum Ir anflatio exter. Rich. Simon. Hilt. CritV.T.ll. 3.cap.ID.

Omnia $M$. Auretii Caffodori opera imprefla lunt duobus Tomis in Fol. Rothomagi wno r679. impenfis Antonii Dezallier Bibliopolx'Parifienfi, \& col Ilata fuerunt cum MSS. Codd.curis Iobannis Garetii Monachi Benedifini Conregationis Cancti Mauri, premillì dicti Caffrodori vitâ,cum dillenatione de cjut Alonachifmo.

\section{SW STINIANUS I.}

ClartîtA.D. D Omanormm Imperatol, ex forore nepos 1 futini (en. à quo Nobilifimusprim 10XXVII. I mò, dein Cafar \& Augufus pronuutiatus, an. Chr.527. paulo poft ei fuc: celfit. Leges hic ftatim in hæreticos fevcras promilgavit. templa deftructa reparavit, Ecalcfix protcctorem fe fore profellus, dignum fe imperio oftendic. Hine per Belifarium contra Perfas Fantalof gues capto Gilimers, viator :s Africam rem cuperavit, Gotbos in Italia fubegit, Vitige R. inporeftarcm redacto, $M$ in ros fuperavit, Samaritanifgue fubjugatis priftinum Romano Imp. Cplendorem reddidit: poftąuan Hypalium Pompcium a 'rohur Anaftufit mper. nepo-

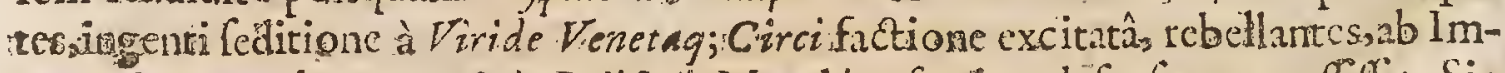
peratcicecorroboratus, \& à Boyifario Mundóq; forrirer defentus oppreffifer. Sic quicte Imperio partâ, I us Civule in eum ordinem redigendum curavit, quo nunc utimur, electis ad id negotiidecem viris prattantiflumis, qui Codices Gregorianum, Thodofianum \& termogeneum in unum contraherent, legclque per 2000. Libb. difperfasin quinquaginta faltem compingerent, unde Codex Digefforum 
vel Pandectarum ortus. Porro 4. Libb. Inftitutionum, qui texcum omnium lc. gum ruccinctè contincrent, \& Cod. Novellarurn, quibus novas à fe laras complexus erat, compofuit. consilio f. Oecum. Conjtantunapoli habito, priorum Concil fidemeonfirmavit , crrores damnavit, tria capitula rejecit, Anno $\$ 48$. dem Theudora Eutychianormi-commoda omaibus modis curaret, quie Epiphoznio Epilcopo urbis mortuo Antberium Eutych promovit ; doncc re à Marito cognitâ, huic.Menna Otthodoxus fibftitutus eft. F lix, ni paulo ante mortcna in Severitartum Herefin prolaphus effet, qui negaitunt Chrifti corpus coirtypti-

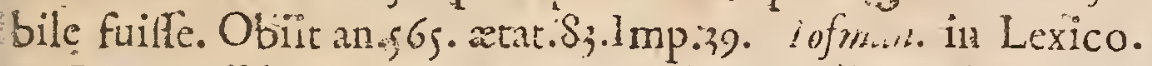

Quem quidem Imperatorcm tanti conftat ingenii, tantæque doctrinat fuiffe,

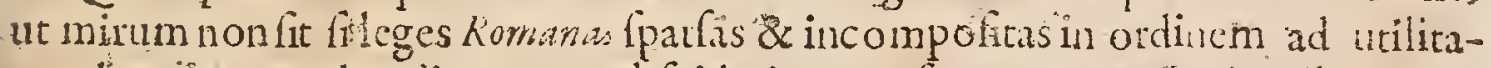
tem hominum redegerit, eaque abfciderit, qux lupcrvacanea \& inutilia vide-

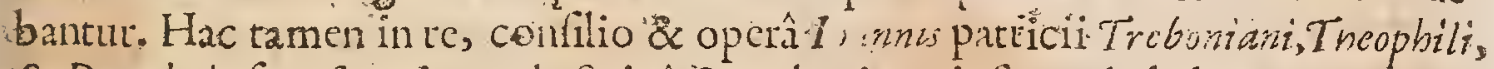
\& Dorotbei ufus eft, qui turn doctritấ i 2 authoritate infignes habcbantur. Immenfim namque illud librorum plagus ( ad duo enim fere millia libroum fuilfe confat ) coacervatis fumul ab urbzc conditâ ufque ad hac tempora tor judiciis, in quinyuagintalibros titulatim digcffre, quos nunc Diceftu, intunc Pandectappcilant: quod ornnem civilem doctinam contincant. Idem quoque legum Epi-

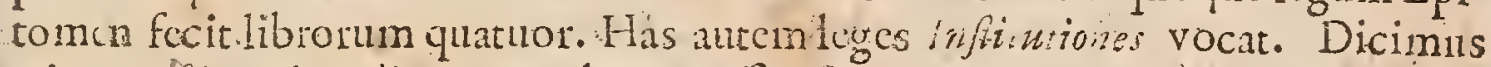
stian I uffitinui Codicem \& volumen cife. Sunt pretercà qui dicant Iufinianum plum libros de Incarnatione Domini cleganter fcriplifes temptumque in honorem Dei Patris (nam Filicis fapicntia cft) Sancte Sophit, quo nullum eft in orbe

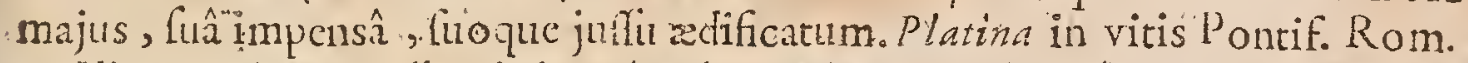

Vir magni \& excclinntis ingenii, locum inter Ecclefiafticos Scriptores memito acquilivit:- quòd prater plura, que five in ejus legibus, five in legum collectionibus tradidit ad (bijituntam pictatemfpectantibus, vindicem ic acerrimum Hurejintroqux cjustemperibus vigebant, 'oftendit; nimirum Porphyrit,

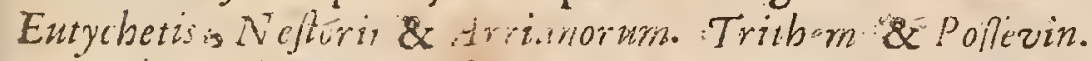

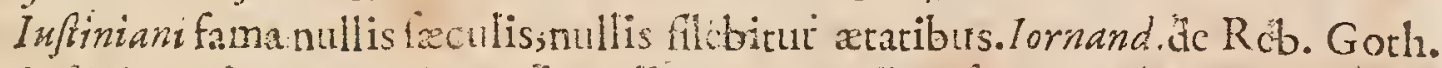
Inftinianu: Impcrateriner vites litcratos merito fuo reponicur.-Füit chim pprinceps, fi quiis alius, in hilofophicis Thcologicis, 2 Juridicis verfatiflimus, -adcò ut Sapientiffini P'rincipis elogitim à Theodabado, Gotborum Regc, obtinuerit. Konig.

Ipfus etian Infiniani induftix \& folicitudini debemus, quòd preclarailla vcterum Juifprudentum; \& Legillitorum monumenta fummo totius orbis bono habcamus concinnata. Alioquin nempe futurum crat, ut defudati illi ve-

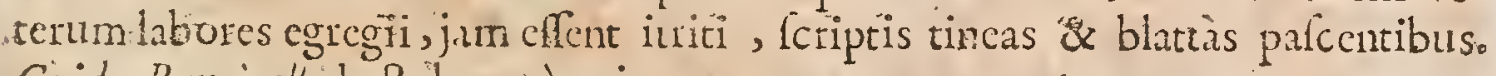
Guido Panciroll de Rcb. recèns invent. p. 2ro.

Triboniann: fagacis vir ingenii, \& ad fimulandum facti, impìus quoque \& Chriftiani zultûs ex profeffo holtis, avaritire cum primis mancipatus fic ut ad - mnemtucelli auram leges fixerit ac refixciit : hic fraudes firans, peftifero afflatu Iufinianum Imperatorem ira infcectat, ut nunquam mociturun perfuaderet, Cod vivum fentientcmque in collum tralatum iri. Hunc tamen Iufinia- 
num Gun, qui tradant, fide catholicum, rcctum in adminiftratione, judicitis juftum: unde lit factum, ut ex voto ccderent omnia. 'Rhodigin. Lect. Antiq. 16 22 C. 20.

Creditur Iufinianus protfum fuiffe literarum expers :- Erenim Infinus pater boves pavit, fed antea flucs, mox matcriarii fabri minifter vilis. Inffinianum Surdas ex impcritià ávan $\phi \dot{\alpha}$ b̈nov vocat. Idem ibid. 1.25.C.12.

Licèt aliquam infamiam paffis fit Iustinianu ex Suide tefimonio referentis eum fuifte rudem, litwarum expertem, \&emùm in amentiâ deceflife, quem \& aliqui viri docti fccuti lunt; tamen ejus famam defendunt longè pluies., majoribufque teftimoniis freti. Arth. Duck. de ufu \& Authoritate Jur. Civ. Rom.

Quidam tradunt Iustinuanum à̀ yerâ fide excidiffe: Suidas autem (qui aliis nominibus eum fortiter calumniabatur ) eum fatctir fuiffe omnium Imperatorum maximè or thodoxum; quod \&ipfus Proferfro Fidei Chrittiana in Codice Inftinianeo, \& Lplendsdifimum S. Sopbia Templum Confantiropoli ab eo coirftuctum adhuc dimonitrant. I mò etiam à plurimis afferitur ${ }_{2}$ eum fuille relatum in numerum S. netorum; novifrméque i ixtus Q Q sintus Pont. Rom. ejus cximiam pictatem celcb"avit. I derr ibid.

Non decrant olim, nec defure hodie, qui in facratifimum Principiem, non

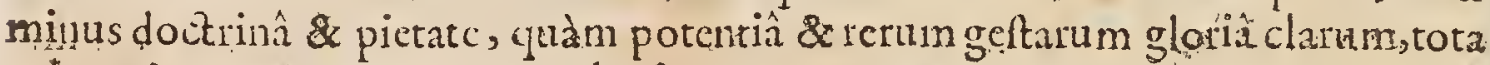
calumniarum \& convitiorum plaufta exonerant. Nemo verò unquam iniquiori cenfurâ, \& inverecundià longe infira lummi Principis fortem, in auguftifimos Iuftrituni mancs debacchatus eft, quàm Cald a Baroniu, omnes in hoc cloqucren tix nervos intendcas, ut ex Imperatore non bominem fed diabolum pobis exhiberet. Ut fid.m faciam, quxdam lectori ob eculos ponam. Fuit, inquit, borno penitiss illiteratus; adeo ust nec alphabetum aliquando aidiciffeta Sacrilegus Imperator a qui no: levemperfecutionem excitavit; furore percitus, mente dimotus, correptzes maligno piritu, agitatus à Satanâ, quique omnem in Ecclefía difjolvit ordinem, fecitque ex regno calcritm ergaftulum Inferorum. Infinitis effem, fiomnia percurrerem. Non mihi in animo cft,poft Grinetum, Giphanium, Truvorium, Rivinn noltrarcm, aliofque, egregii l'rincipis,vindicias agere. De eximiis I finizni virtutibus unicum aut alcerum. Veterum Teftimoninm profcram. De doctrinâ (jus \& pietatc hæc Procopitts, (De Bell, Goth. lib. 3. dc Adif. Tuftin. lib. 1. ) in Intinianumadhuc acqus. Solitum eum tum libros de rebus Divinis agentes pervolutare, tum de iildam colloquia cum Epifcopis. \&: Presbyteris in miltam noctem petrahere $:$ in more ei femper fuilfe multisante $P$ afchadierum hebdomadibus corpus vigiliis \& inediis plufquam afeticis macerare, femel in biduo cibum capere, vino, pane, aliifque cibariis penitus abftinuille, herbis tantùm falc \& aceto conditis, atque aquâ contentum. De egtegio autem illius erga fidem Catholicam ftudio audiamus Agatbonem Papam ex Epifcoporum I25. Synodo teftimonium ferentem. Et pre omnibus, inquit, crmulator ver $A$ Apoftolice Fidei pic memoric Juftiutus. Ang. cujus fidei rectiudo, guantum pro fincerâ

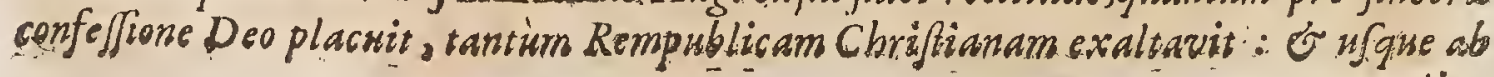
omnibiss 
mribus gentibus ejus religiofa memoriaveneratione digna cersetur: Cujwsidei reititudoper anguftifima ejus edictic in toto orbe diffufa landatur. Gul. Cave in Hit. litcrar. Script. EccleC.

Inftitutiones Iuftiniani multum laudat $C$ njacius: hunc librum omnium librorum In is cimilis nitidifimum, comptifimum, facilimum, nulloque penè $2 \mathrm{rm}$ terpreze indigenecm predicat. Cujac.1.2.obfervar. 3 I.

In Infiniani Infitutiones. Philippus Metnnthon hoc diftichon compoluit.

Continet hic tenuis Legum Precpta libcllus:

Primaque Romani femina Iurs habet.

prater Novellas, quarum plurimx funt fori Ecclefianici, cxtant Lat. Ep. 2d Synodum Conftantiropol. Concil. Tom. s. p. 119. Epp.'I. gr.l. ibd. p. 223 , 679 .

Tratatus adv. Origenis errores, ib.p.635. Confento adv. Tria Capitula,ib p. 63.. Comitutio 2dv. Anthimum, \&c.ib. p. 264.

\section{P.}

D Raslanm fub Isfinianonomenhabuit Procopius. Natus hic fuit Cafares Palestina. Fuir idem erator, ac Rheror fet profelfor, vel Caufidicus. Notarius erat, ac concs Belifurii cujus \& res geftas confignavic. Accuratè , ac

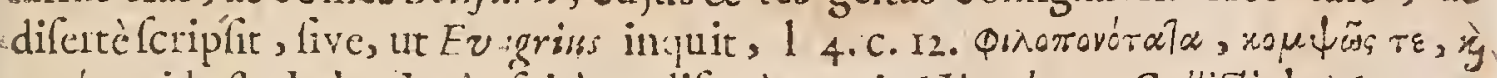

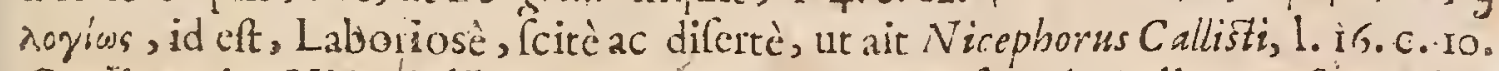
Gontiner ejus Hiftoria libros S. quórum duo primi funt de Bello l'erfico; duo fequenres de bello Vardalico: Quaruor poltremide bello Gotbico. Primos duos, quos de bello Perfero effe dixi, in compendium redegit Pbotiss in Piblioth Cod. 63. At onuium ouvow habes apud Agathiam in l'refatione : Qui Hitotiam fuam inde cepit, ubi Procopiss defit. Odo iftis polter non cit:arque eum, quiacomplecteretur res anteanon. ciatas ávérdo ro appellavit Suida tefte: qui ctiam auctor êt, libro hôc fuile-invectum in Iufinianum; \& conjugem Theodoram; item Belifariurn, \& uxorem ejus Antoninam. 'Avéroro ifta laudat Evagrius 1. 4. C 3r. Memonat quoque Nicephorus Callisti1. 17.C..10. Irem uidas; qui \& multainde variis cxicriplit in locis. Preter novem, .. quos dixi, libros, extat volumen Procopit de Infficiuni xdificiis in iex nurmationcs, Give, ut iple vocat, nógrs, divifum. Ex is clarèducet, Hominem fuille (bri-

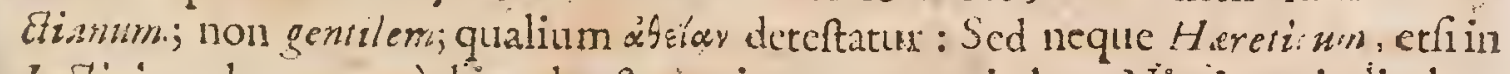
Iustinian damnet, quod in tales fatuerit ponam capitalem. Nimirum judicabat aliquas fidei controverfas tam effe difficiles penetratu, ut multi cas caperenon folint : eoque probare non poterat, fi propterea quis vitâ privarctur. Vofj. de Hilt. Grac.

Proconius Hiltorias optima fide Grace confcriptas nobis reliquit; ailigens in

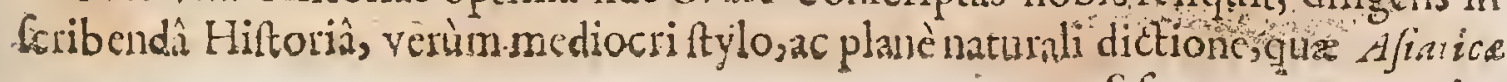
SI 2 propiar

Clar. A.D. DXXVII. 
propior eft, quàm Attice : ipfe enim Afratisus fuit. Conciones \& Epiltoln quaidam bicves interpoluit, haud prorfus in eogenere ineptas. Pofjev. de Hi itoric.

Procopius Hiftoricusinfignis, quique rbusà fe fcriptis interfuit, verax alio-

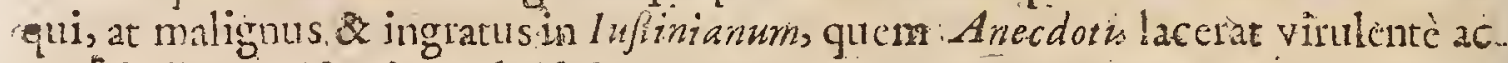
proficindit. worifac. in Lud: Hilt.p. Gor.

Certè quancum exipfus Scriptis perfpicere lijuet, veri non alifinil: mihi: videtur, "'rocopivan meque prorfus Gentilcm fuiffe, neque prorfus Chriftianum; cum Gentilibus Chriftianam non veram \& nnicam effe. Religionem credidilfe cum Chriftinis Gentilium ritus \& Cupertitiones ludibuio habuifescum urrifque fummum Numen cotliterıaque conditorem agnoviffe. Utut res fit, erat falt:m ? profeflone \& nomine tenus, chriftianus i. utque I ufinani gratiam è̀ facilits. captaret, quicquid in pectore clam fovebat, palan Chriftianum cultum prax fe

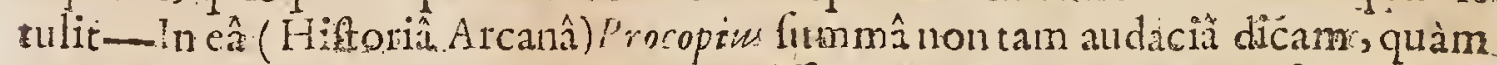
menticndi \& calumniandi prurigine tupiffuma \& ivaudīa hacenus , fcelera $I u-$

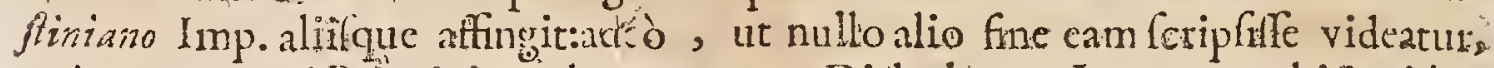
quàm ut optimi Principis sulam, tanquam Diabolorum Lemam, orbi invilam:

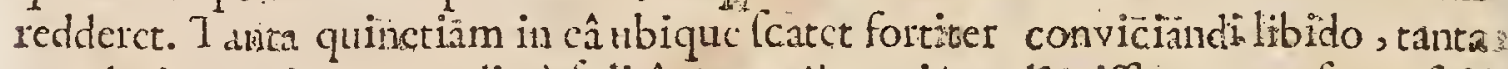

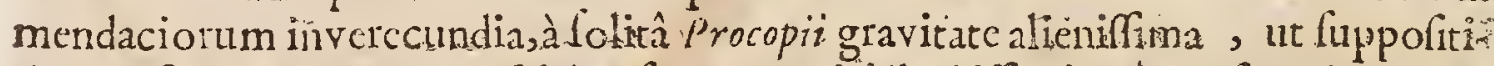
rium effe opus \& Procopi, falso infcriptum viri doctifrmi ophati fint. In excufis excmplaribus paginzenonull hourendas. Theodora Aug. impudicitias \& li-

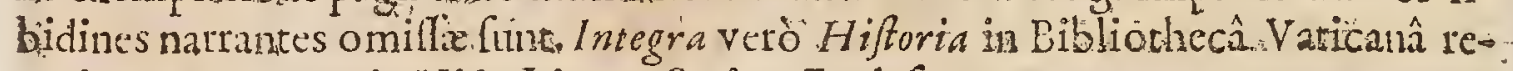
peritur. Gul. Cave in Hift. Literar.Script. Eccler.

Procopiu ornamenta Hiftorarun $\&$ Greci Sermonis putitatem att nefciffe: ant neglexife videtur : fed quread Hiftoriam pertinent.., fingula commemorat ac.res quoque levifimas magno ftudio confectatur. Et quoniam in rebus gercridis perpetuus Belifsurii comes, ac totius publici confilii particeps fuit, fapilis etiatn pro Republ. legationes obiit. Denique mediocriter eft à doct inấ informatus, ut non dubitem illum inter Selectós recenferc. Cùm verò fingulıs Epifolns, Decreta, Fodera, Conciones wario dicendi"genere ac Atylo deforibit, magntum verifint Scroptoris prabet argumentum : Nifi quòd fuum Bellifariur fupius, quim dccuit, e ineptis plèrunque laudibus oncravit: : incptiùs quogue cædem Conftrnt ani, qui apud luftrianum fabuli magiftum egit $\rightarrow$ Bellifarij juflu perpetratamita excufaxit, ut infatis effe diceret, Conftantranum fic mori debuilfe. Ridiculas quoque 30. porcorum \& tatua Theodorici conjecturas eximo,quodịne 7 bulen decies Britannia majorem facit, quatamen altero tanto. minor eft. Scdillud fidem omnium fuperat, cineres Vosuvii montis, qui citra Neapolim frus cot, Byzantium ulque vento delatos, ac populum ita exterritum, ut. annuis Trpplicationibus Deum placaret:quaxprodigia lapiunt Gracam vanitatem,

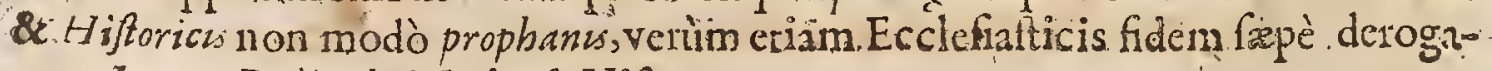
runt. Joann. Bodin. in Merhod.Hilt.c:4.

Procopius in iis qua fcribit accuratus eft, quoniam Belifarium in ejus bellis comitatus eft prachiorumque Geftorum ejụs teftis extitit , led in Hiftoria fua 


\section{CELEBRIORUM AUTHORUM.}

Ferfica nimis jejunus eft : Diarii enim potius quam: Fitforia fpeciem pref fert. Rapinus Kchl x. in Hiftor. Sect. 28.

Procopius. O egrcgium Hiftorianm! Uulcanius totis quinque vel fex annis meum fervavit, eltmque à me lacrymabundus efflayitabat, quoniam cum illi dare renucieam. Sculigerana 2. Gall.

Procopins onnibus iis dotibus eft inftuctus, quzad Hiforia pulcritudincm conduccre porlunt. Nam, Evagrio judice, accuratè , comptè ac eleganter feriprit. Nihil corum oblitus.eft qua ad Hiltoniam decomandam Ars conferre vam Iet Mirificx: funt ejus deferiptiones, ejus: Orationes vehementes's ejufque animadverfiones.fagacitatem Spiranto. Eruditorum Ephemerides Ciall. 26. Alto gulfti 5675 .

Paucis ut concludam, arbitror Procopium dignum effể qui attentè legatur, in primis propter ea quze folus cum accurara notitia tractat; Magna tämen uten-

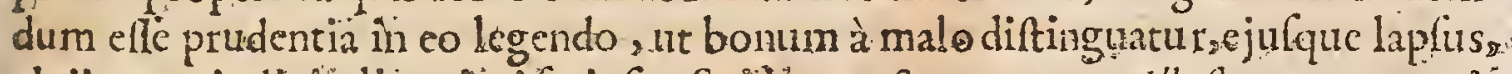
$a b$ iis quz-judicio limatiori fcripfit. Suidảs, poftulumenm Illuftrem cognominavit, Khetoris \& Sophifta nomen-ei tribuit, qualis revcrâ plufquàm Hiftorickm deceat fuiffe videtur. Diffulus ct , fed caubertate quæ potiús. Afratica eft gaù̀m Attica, feu quzefrequenter plis fuperfluitatis quàm verio ornatîs habet. Francifo. Mothaus le Vayer, Tom.1.0.363. Gall:

Leonardus Aretinus mortutus, quod ci nullo pudori fuit, furti dimnattis eff, quòd Gothicam hiftoriam fuppreffo Procopii nomine publicâfset, accufante CbriPiophoro Terfonâ, quialinidexemplar nactus, \& Gorbicam, \& Perfican fimul atque-

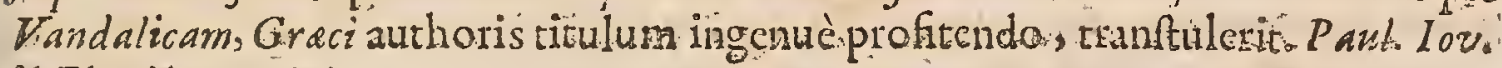
in Elogio Arcsini.

Fuit Procopius horum Romane Antiquitatis curiofiflimus', ut paffim in libris. de Bello Gotbico fingulari diligentia deferipferit urbis monia , portas ze cloacass vias, ædificia, fuburbia, nullufque illo exactiùs profequatur viaim Appiam, Enee navigia m, Manfoleum Adrazni, Bovis Myroniani fignum'in foro Pacis ; quaz: compluraque alia, athrecipfa de Domitiano uni Procopio debemus.Nic. Alemann. in Notisad cap. S.Procop.

Quoniäm altem Infiniantm omnis Literature imperisum frififse afseruimus non dcfucrit fortè, qui contra Suide teftimonium, P'rocopium Cefarienfem, BeliSariv fcribam, producit, qui inter varias nugas \& mendacia, quibus scatent cjus hiftorise (de his loquor oqua ad Iufiniani 7 ribonianique mores pertinent.) hune. Principers Theolngix operam dedifse, memoria predidit. Vide Franc. Florid. Sabin. ir lib. de Iurr. Civ. interpretibus.

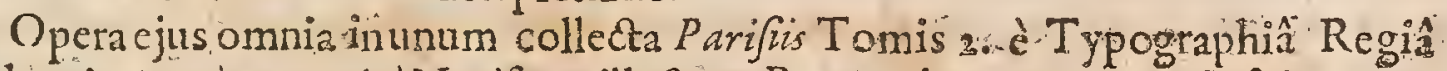
vulgavit Grace ac Latinè Notifque illuftrat P. Clandius Maltrait Jefrita ThoLofanus all. 1663 . fol.

Anecdota ftudio atgue cura Nicolai Alemanni Roma Lugduni $G_{33}$. Typis edita fiverunt in folo apud Andream Brugiot um.

Omniä verò Procopii Opera edía fuñ Grace \&u Latinè, inter Auctores Hiftorie Byzzantine in fol.24. Tomis editos, ex prolo Galliarum regió ab anno 1647. \& ad $3670 . \$ 3$ ultswa.

$S_{3}$ PRIS 
Clar. A. D. C effarien/es, claruit Atbeniscempore Infiniani Imp. Scripfit de Arte GrawiDXXVIII. U maticâ, ad Iulimum Confulem;ad Cbofrö̈r verò Perfarum Regem lib De Naturalibus Quafionibus. Convertit in Latinum Sermonen Dimyfii, de fitu , Orbisicarmina. Sunt quii fcribunt, hunc ab initio Chrifi tnum, deinde fidei $D$.ertorem fuilfe. Pars Operum ejus ab Eliâ Fineto aliifque cdita. Floutiit Conftantinopoli, Anno 525 . Nomen ejus,incodice Antiquifrmo \& cmendatifi:no Prafciat num effe, notat alicubi Hadrianus Valefuru. Hofman.

Prifcianus Ciafarienfos Grammaticus, omnium fui genelis. Princeps fcriptor. Foan. Card. Bona.

Prifcianus Prifcus \& nominc \& fide Grammaticus. Voff. 1.x. De Anal. c. 19. Magnus Grammaticonum Thalaffiarchus Prifciants. Barch.Adv.l.35.c.9.

Tres illi tanquan Trismviri, de quorum principatinter eruditos quxritur, Donatus, Servius, Prifiznus. Quibus ego tantum tribuo, ut poft cos quicung:te aliquid de Latinitate fcripferunt, balbutice videantur. Laur. Valla. P'rxfat. in Cecund. lib. Elegant.

Dixi promifouamveteres fripjiffe EI vel 1 , longum Prifcianu diter; qui veteres vule femper EI feripfiffe, fequentem rtatem, / productum. Errat iple, non . ego:\& refutant clatè xta \& $M$ armora vetufa, in quibus fere omnibus ( quafi a nihil interft) confufanca hac Scriptura. Putidum fit citare : cui mens aut oculi; legat. Illud non impertune moneo, foluife veteres Elillud licriberc, ceiam cum 1 brevi. Lipfusu de Rect. Pronunc. Lat. Ling. c. 8.

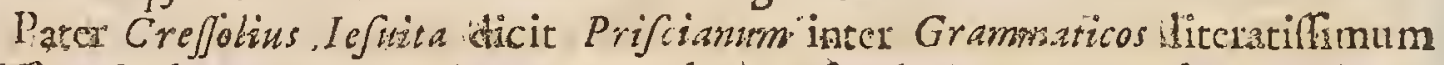
fuife. Iofias le Mercier eruditioncm multain ipfi tribuit. \& G.Voflus.cum limatioris judicii Grammaticum, ac in lingua verlatipimum confet. Srioppius tamen 1zon rarò in illum:invchitur, exigumm ci obiiciens judicium in omnibus qux Ecripfit, quamis non diffutiatu magna dexteritate \&e diligentiacum uti oporquiffe ad Operis fui executionem. Sed Bibliographus Anonymus oblervat Ciritichmipfumlegitimo in fuis Accubtionibus fundamento frepe detitutum effe.

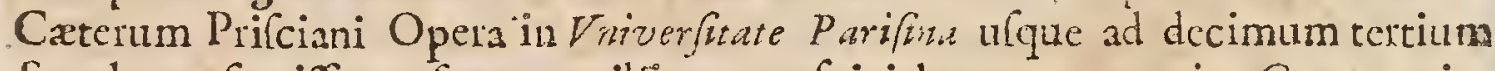
Seculum uftatifima fuerunt, ibique confpicicbantur parva ejus Grammatica \{cul ejus Rudimcnta,qux in inferioribus Clafribas A'babetum:vocabantu; ejufque major, qux Prifciznus Major in fuperioribus dic ébatut. $B$.illet, in Eruditorum Iudicis. Parif. 168, Gall.

Uulgò de incongrua Latinitatc dicimus quò Prifciano capost obtundatur, ac fi ritè loquiz fcribere, rpeciali jure, ad ipfum pertineret. (Anglica Authoris (ententia.)

Extan Opera ejus Grammaticacum expofitione loan.de Aingrëin Fol.Venetiis an. 1596 .

Extant etiam in Corpore vererum Grammaticonum à Prtshio evulgato. 
Thenetiis jam anno 4776 . excula tradir Folfus l.3.c.30. de Analogia.

\section{AGATHIAS, nomullis dicirur AGATHIUS。}

\section{$M$} Yrinenfis Pö̈t \& Hiftoicus celcbris, vixit lufiniani Imp. tcmporibus. Compofuit s libros de Imperio \& geftis I Iufiniani: : item Epigrammata Clar. Ai Do qux palfin in Anthologia leguntur. Surdas Scholafticum Smyrnasm appellat. Ve-

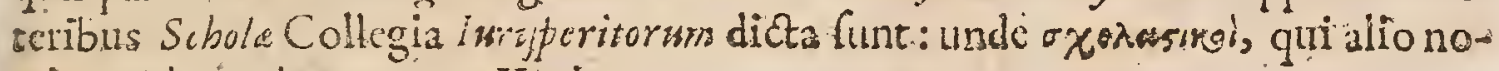
mine Advocati vocaneur. Konig.

Agatbius Srbolaficus Smyrnaus quinque libris res Iufiniani Principis, ejufque Ducum Belifurti \& Narfis in Italiâ, Africh, Tetfide \&apud Byzanizum geftas, poft Procopinm, fcripfit Rylo renui, \& crebris interpofitionibus confufo: $V$ erum utilis eft, quod ea profecutus fit, qua meliores fcriptores non habent. Car. Sigon.. de Hilt. Roman cap. 34:

Nune vero figathiam Hiftoricum Optimum quilufiniani lmp.res geftas poft Procopium Cafarienfem et perfecutus, Grece antehac nunquam typis edicum, in liccm cmito; Agahian, inquam, vinum fux atatis doctifimum, quique unus oëticen cum Oratoriâ iñ conjmuxit, ut dubium fit, in utrâ magis excelluerit; hin utrâque certènon dubiam de omnibus fui avi fcriptoribus victosiam reportavit. E cujus editione plurimum \& Hiftoria, \& Grece lingua incementi ornamentique eft accelfurum. Cùm enim vatia gravifimaque Bella adverfus populofifimas potentifimafque nationes, Francos fcilicet, Gotbos, Vandalos, $H$ unno', \& Perfas gefta defcribat; tum verò de corum moribus atque infi-

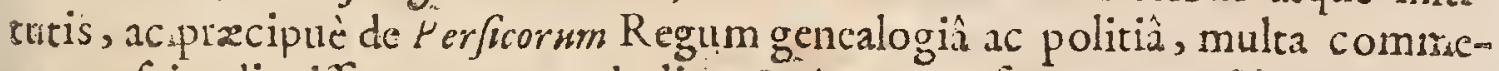
morat fcitu dignifima, qux apad alios. Scriptores nufquam reperiantur. Stylus ijfe planè cet foridus atque amœnus, multis fententiarum luminibus illuftracus. Verbis vero utirur felectiflimis, \& frequenter à communi ufu ac fignification remotis, adco,ut Suidas diligens GlojJographus potifimam Lexici fiti partem ex hujus Scriptis concinnârit. Bonaventur.Vulcan. in lit.ad Halland. \& Weffrif. Ord.quas Agath.pramifit,anno 1594. Ceriptiso:

Multum tempora illa ormbat Agatbias-_-Prater Epigramata multa; qua in 'Av9oroy'a habemus feripfit libios quinque delmperio, \& rebus oftis Iuftiniani. Nectamen ominia deco refert: fed inde, ut:iple ait, coepit, ubi defiit Procopius. Dictione utitur tersầ, \& Horidâ. Gentilem fuifle, pratcr alia oftendit illud $\phi_{x \sigma i r}$, quo 1. j. utirus, cum fermo fit deMartyrio B. Stephani. Voff. de Hift. Grac.

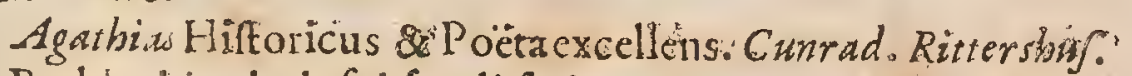

Probis inprimis fui feculi fcriptor. Olear. in A bac. PP.

Procopium fecuatur Agatbias, floridus \& non contemnende prudentix Scriptor. Whear. in Meth. logend. Hift. Civ. Seat. 24.

Agatbias ef multi nominis Hiftoricus \& Poèta. Dempfer.

Hic. Author tanquam unus è Seculi fui optimis Poetis celebratus eft. Credód cx cjus Poennis unum \& octoginta Epigrammata nobis, sautum fuperefse , in 
Mibris ejus Antbologic perfperfa, quxque Vuicanius in falciculum collegit, quem cum ejufdem Authoris Hiftoria evulgavit. Hec plurimi fecille videtur lojeph: Scaliger, cum ea in Latinosiverfus convertere dignatus fit, qua feptimo Anthologia libro occurnut. Idem de aliquot aliis priftiterunt Doufa \& Uulcanius. Poema quoddam infuper claboraveratcui ticulus Diphnici feu Daphniafis, quod rebus amatoriis unò ix pejoribus referum exat, fed utum in licem prodicrit ab inventa typographia, me latet. Eruditorum Indicia de Poetis Parifis 1686.

Sunt qui Agatbram exiftiment primum fuille, qui Grecorum Epigrarnmatum volumen collegeiit, in usumqu conjuxerit:alii Planudern $M$ axirnurn, Monachum, virum doctum. G,ruld. de Poetrifif.Dial.ro.

Vero propius elt, "lllum Ethiticum frifle, quàm Chrifi fílelem: neque tamen diverfa facionis lomines infectatur palamaut mordet, perinde ac Zofimus fecerat. Digtione ufus eit flởida ax tersâ; quam luo more,uti barbaram \& frecuLentam reprehendit Verderiur omni enimpotiùs omatu Scripta complit;nudanque Hiltoriam vetula rugis fcatenti perfinilem fibi viden dicebat:quodque gravifinos fcriptores feciffe comperetar, difceptationibus \& confliis judicium Eum interpofuit, \& quali Arbiter datus. Ecntcutiam tulit Balth. Bonifac..de Korn, Hift. Script. cap.24.

Zofinm, Procopius, Agatbias tantam redolent babaticm, ut ne eorum quidem meminiffedecear. Claud.Verder. in Autor. Cenfione.

Extant de Imperio \& Rebus Getis Infinioni Librig. Græcè \& Latinè cum Notis Bonazenture. Vulcaniz. Lugduni Bat. $4^{\circ}$. an. $1594_{\text {:3. }}$

\section{GII D A S.}

Clar. A. D DIXXXI.

Ygnomine Sapicns, \&ut à Gildâ Albanio dintinguatur., Badonicus dictus, gente Anglo Saxo,narus anno 520. ob pralium Badonzcum,claro (inde ei nomen)Iltuti Niorganen/ss difcipulus, Mcnachus Bannochorenfis, fcipitit an. $58 \mathrm{x}$. refte Radulphode Dicetonequid jam dicam de 'Tolydoro, Baleo \&\&E.quamvis alii, \& in his Rev. Ufferims libollum ejus ad an. 56.4. referant, ipfumque an. 570. obiiffe volunt. Gul. Cave Chartoph. Ecclef.

Scripfit Epiftolam frvelibellum de excidio Britannie, itemque Reprehenfionem acrem in Brtannix Clerum. Aliarum Gildalucubrationum ad nos pervenit nihil, prater Fragmenta quzdam, quz, veteri libro ;asonm titulortm 66. inferta, in Cottonanâ Bibiothecâ widimus. Nam ut cun aliis, qux inter Plañ inas Comodias habetur, Aululariam huic adfcribam, perfuaderi mihi nen patior: licèt è etiam politilfini virum judicii Ger. Ioannem Voffium propendere non ignorem. Iacob. Ujer. in Antiq. Britan. Ecclc. c.I4.

Iuftinianitcmporibus, atque ultrà. claruit Gildes, cognomento Sapiens, Iltuti Morganenfir difcipulus, \& Bannochorenfis cœnobii monachus atquc AbDas. Cujus tum libellum de excidio Britannic habemus, tum reprehenfionem accenin Britannia Clerum —Sanè ut fumma eruditionis vis, ita fidei, ac fanctimonix 
fandimonix' precelléntis fuit. Nec movere debent ridicula illa, atque inepta roracula, Gilda tributa. Planè enim funt nugatoris cujufdam commentum, qui auctoritatem aliquam quifquiliis fuis Gildx nomine voluit compararc. At verè Ecripfit Gildas librum antè memoratum, five ut ipfe vocat, cpiftolam de cxcidios\&cenqueftu Britannia. In qquâ refert, quàm atrocia fit pcrpefla Brisarni : Saxomom adventu ufque ad tempus illud, quo ifta traderet. Is liber primùm opcrâ Cuthuberti Tonftalli, Loidinerfis Epifcopi in lucem protractus;, ac curn prefatione Polydori Virgiliz çditus fuit. Meminit hujus Libclli eciang Venerabilis Beda hiftor. Angl. I. I. cap. 22. item Gulielmus Neubrigkn is in Prefat. Brevis eft in hiftoriâ : multus autem in caltigandis Britannorum viviis. Anteciam is lucem adfpexilfet, imponi fimplicioribus folec libillo dilio Gilda nomen ementicnte - Si quid Gildo, plezter epittolam, de quâdiximus, ac invedivamin

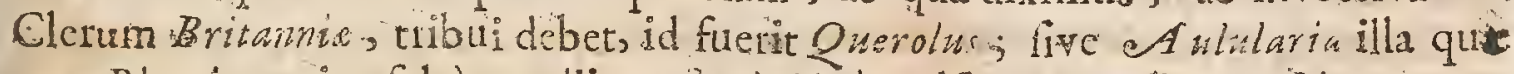
cum Plauti nomine falsò prodiit. Sanè Gidda adfigrnant codices quidam manu exarati : nce ftylus refragatur : nifi quod ille in Gilda Epiftola fit impeditior, iftricatiorq̨ué quàmin Querelr. Vofl. de Hift. Lat.

Hunc (Gildam) venerabilis Beda quafi, per Antonomafram notanter Britonum Hiftorictim vocavit.

Et fanè Auter Antiquus, \& Ccriptor non vulgaris. Pitfan。

Vil fuir fumme eruditionis ac fid i. Aub. Mirers:

P'x aliis Brit.n ia Scriptoribus, folus milhi Gildas (quotics eundem mate rix curfus intulerit) imitabilis effe videtur. Quia ea qux vidit \& ipfe cognovit fcripto commendans, excidiunnque gentis fux declararis potiùs quàm defcribens, vertm magis Hiforian texuit quàm ornatam. Sildam itaque Giraldus lequitur: quem utinam moribus \& vita fequi polfet; factus ejufdem plus fapientià quàmeloqucntin̂, plus animo quàm calamo, plus zclo quàm ftylo plus vitầ quàm verbis Initator. Sylveff.Gyraldidin priore l'rafat.pratix. Defcript.C ambrie fux.

Gildas homo Britamus : cui nihil remotius eft, qud mentiri,nihil propiuss, qquàm veritati inniti. Integritatis cjus non leve dockm ntum cft, quia in veritate promentâ, proprix gentinon parcit : \& cùn admodum parcèbona de fuis lom Guatur, multa in eis mala deplorat: nec veretur, ut yerum non taceat, Brito de Britonibus Icribere, ees nec in Bello fortes fuifie, nec in pace fideles. Polydor. Tirgil. l. r. Angl. Filt.

Legem imnocentix fibi conftitucns, vitam vixit integerimam Gildas, ut in

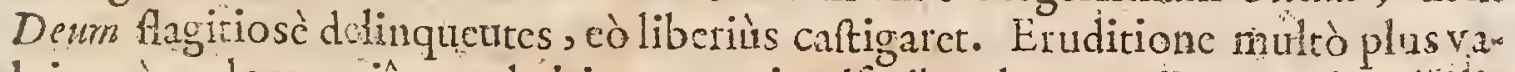
luit quàm cloquentiâ, quod vitio tcmporis adfcribendum modis omnibus jididco. Britanxice lilebis peceata \& ingruentem per Anglo-Saxones calumitatem, quotidianis deplorabat lachrymis. Impuros hominum mores, precipiè $S a c e-$ dotum \& Principum, non poterat in fuis Concionibus non improbarc. Loan. $B a_{-}$Leibs de fcript. Britan:

Hunc Gilda libellum de Exsidio Britannia, ob horridulum \& incom;tum Oratiginis Characterem, etiam à GulielmoN Nulbrigenfi in Anglicana fux Hiffom It 
risprocmio ita vituperatum invenimus : Cum fermone fit admodum jopobitus atque infipidus, pawis cum vel tranjcribse gel babere curantibur rard: irverilur.

Etfane (inquit Uferius Biblioth. Theol.MS.pag; Ir; ) Beda Britannorum

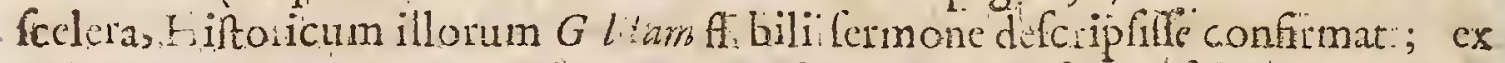
qujus ctim opere intcgras aliquando paginas Hiftoriz fure inleruis. Unde \& Prifens in riftor. Britann. Defenf. cap. ule rationem reddens cur a Bedâ preteritus fuit Ar/buru, ex hoc Gilda, inquit, id cronis hauferat quandonihil ex:

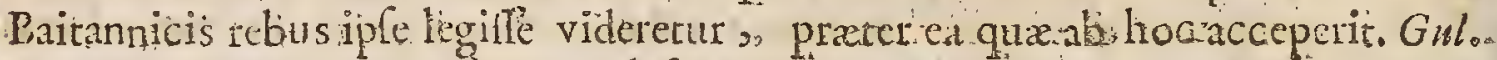
Gave in Hift. Literar. cript. Eccle.

* Hic Author inquibufdam locis desacerdotibus, cautè legendus Index $M a-$ dri: edit:ann. 1567:.

Extant Epiltola de Excridio Britanrie, Lond.1525.30.1568 I2? E E Ordinis

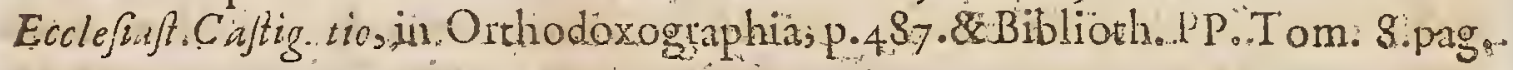
707 ; 7is.

Epiftoli te Excidio Britannic Manufripta affervatur Cantabrigia in Biblio-

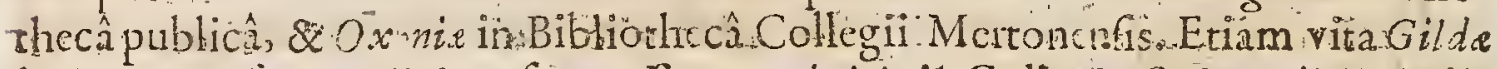
hujus Manulcripta dicitur fuperefe.Cantabrigia in Collegio S. Benedidi.Varia-

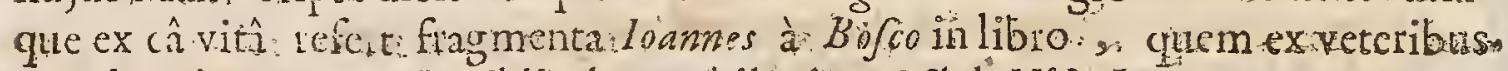
membranis Floriatenfis Bibliothececollegit. Vol de Hift Lat.

\section{S. G R E C $O R \perp U S$}

C QXC gro If. Romano lontifice S.R.E. Diaconus creatus mittitur CP.ad Mauriotium Imperatorem t pocifinrins ano 5 2. unde difputatione cum Eutychio $P_{0 .}$

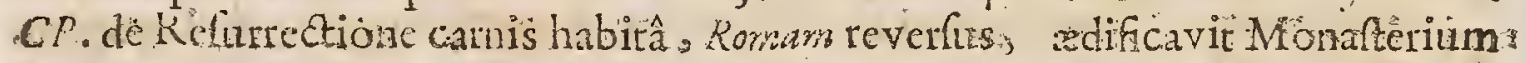
Sandi Andrea in Clivo Tami,ac pel gin lie extincto die 8 . Febr. anni ; 90 .iplo dectus, acespoque: Mauriiv Imp. confenfu confectatus eft die j. Scprembuis: ejufdem uni, tenuitque Pontifcatum annis 13 menfibus 6. diebus $10 . u$ que ad dicm I2. Marrit anni 604 : quo obit fub l'bo: Imp. Pbil. Labbe de ScriptoEcclef.

Gregiriu Papas Rornane Sedis \& Apoftolic Praful, compunetione timoris: Dei plenus, 8kumilitarefummus, tantaque per Gratiam Spiritis Sandi fcien-

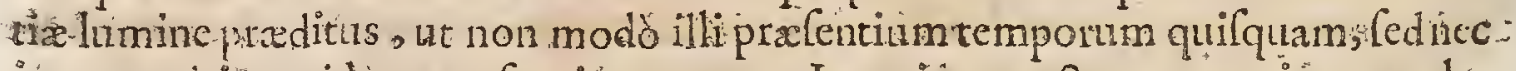
in prate iris quidem par fuerit unquam. Ita enim cunctorum meritorum claruit pcrfectione fublimis, 11 t, exclufis omnibus illuftrium virorum comparacionibus, nihil illi fimile demonftet antiquitas.. Vicitenim fancticate Antcvium, eloquentiâ Cyprianum, fapientiâ. Augufinum. Ildefor fo. Tolet dê Script. Ecclefiaft:

Gregorins Rornane Urbis Epilcopus , organnm Sancti Spinitûs , incompara- bilis. 
billis omnibus fuis pradccefforibus, multa pre fole praclara, ac pre obrizo auro preciofa Ccripfit. Honorius Auguffod, de Script. Ecclc.

Gregorins Primus, ex Moracho ordinis Sancti Benedidir.. Patriâ Romanu,

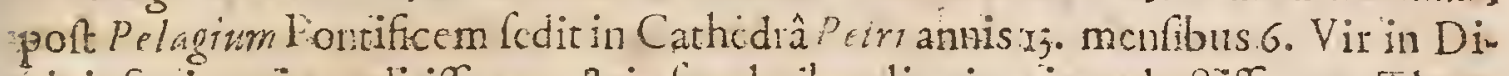
vinis cripturis cruditifimus, \& in ficularibus literis utiquedodiflimus, Theologorum l' rinceps, fplcnder hilofophorum, \& R hetorumlumen, vita \& conveifatione integcr atque far et:fim us, cui divinas Scripturas explananti Spinitus Sanctus aliquotics vifibili fpccicapparuit, cique arcana myfteriorum earundem invifbili magitterio referavit. Tribers.

Hic [ Gregurini] librum Dialogorur, quemcum Petro Diacone fuo de min raculis sancto um fui temporis habuit, Tendelinde Lmeabardorum Reginze, pro muncre mifit. Scripfit \& alia, qux d Remanis poft mo:tem ejus combufta funt, quile omnia opera cjus combuffifent niff etrus, diaconts ejus interve-

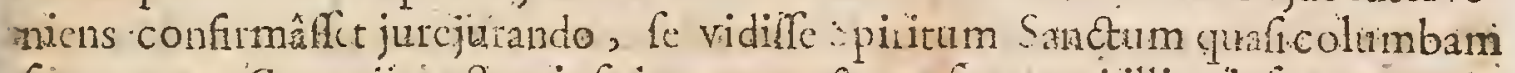
fuper caput Gregorii tractantis fodentcm, roftrum fuum ori illits inferentem : \& hoc ipfum Petrus hac conditione fecit, ut, fi.ple poft factum jusjurandum fta-

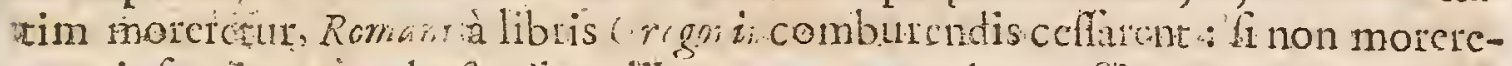
tur, ipfe ctiam combuftoribus libtorum manus daret. Sic Petris inter verba juramenti expiravit, \& Romanomm infania ceftavit. sigeber'. de Script. Eccled.

Alii quide m Pontrfices conftruendis ornandifque vel auro vel argento Ecclefiis operam dabat, hic autem totus crga animarum lucravauabat Beda Hift Ecclef. Anol.

Is ron fibi îpri, fed utilitati hominum, ac honri divino confulens, quem ccrtè ob Religionem \& pictatem rebus ommibusfemper attulcrat, fipretis opibus, poothabitis volutatatibus atque omni ambitione \& potentiâ, gubcrnacu1a. Chriftian Reipublica fufcipiens, ita vixit, ut ufque ad tcmporanoftya ancminem $\mathrm{ex}$ fuccefloribus parem habucrit, ncdum fuperiorem vel fancekitate -vita, vel.diligentià in rebus agendis, vcl doctrinâ \& feripris. Platina in Vit. Gregor.

Nullâ virtute major \&admirabilior, quàm quöd ambitionem illam contcmpfit, "quix maximes quofque Chrittiane confflionis antiltites'aflixit at Ejus Homilix mi ficè bonis rebus plenæ, \& exemplar fequentium feculorum doctoribus. In fumse pretio fucrunt, adeò, ut qui alionum librorum potiri mon pollcut, ex prifcripto, iftum fibi parare omnimodè oportuerit. C'app. Bartb. 1. js c.ult. Adverfariorum.

In Gregorie puram, nulloque fuco picturatam fanctimoniam agnofcimus. Erafriso in Prexat. Anguft.

Grparius Magnus $P$ apa morum inftuctor precipuus, \& ominim virtulum Magifter. Loin. Card. Bana.

Gregcrtem Romanum cjus nominis pritumagnofe virum pium, ea lo juchtem qux fentit. Et hic propiùs accedit ad M. Taltium, quàm Aribrofin : 1cid

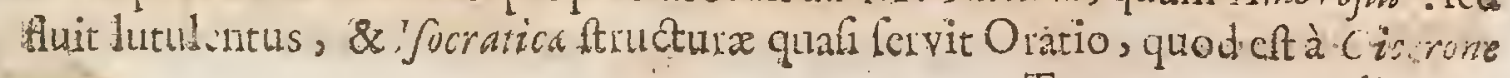


alienum. Sic enim puer in Scholis affueverat. Erafm. in Ciceron.p. $153^{\circ}$.

Verborum, \& Orationis genus in omnibus penè feriptis cjus continutum eR \& connexum, incifis quiburdam, \& membris fibi invicem correfpondentibus currens, \& juovorendirous, hoc eft, fimiliter terminantibus:fententiis furens, femperque ferè in abfolutis perfectifue finiens periodis, non affectatis tamen, nec quafitis, fed ex priftinâ fecularis eloqueniz exercitatione ultromanantibus, citra ullum accurate dictionis \& claborate texture artificium . Sixto Senens. Biblioth. Sanct. 1. 4 :

Sanctus Gregorius Papa prolixos in lobum Commentarios elucubrauit, ubi Iireralem fenfum tanquam parum utitem ad plebis infitutionem negligit. Hic Pater Santi Angufiti Opera fedulo legerat, quorum excerptis libros fitos referfit; \& in hoc fe judicio pollere demonf rat quod inomubis non fat fecutus vcterem Latium Verfonem quaad Grecam Septuaginta Interprecum factafuerat, quaque illo tempore Vulgata Verfoadhte erat; Verum ad Divi Hieronymi Tranlationem $x$ Hebraicis fape recurrit, iis ptafertim lecis quibus illam Vetẹi praftantiòm deprchendebar. Utraque hac Verfone fe utiprofitetur, quia Rome ambx tunc eraneinufu: Hac altem fuit occalio cur Nova hac Sancti: Hieronymi Verforeciperetur; qua tandem Veteri Vulgata fuccenturiata fuit. Jef. Rich.Simon, Hift.Critic. V. T. 1.3. cap. 10.

Hac carmina de Gregorio Primo, Leone Primo, \&Nicolao Prima compo fuit Stepharus Pagchatizs:

Bontifices quot Roma tuli celeberrima Sanetos:

Majores nullos Nicolao; Gregoriogue;

Sive Leone habuit: re funt ut nornane Primi:

Gregorius Magms -. Vit erat pietate infigin's nee ai illius ratioine habit:

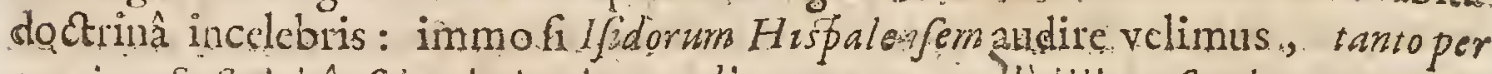
gratiam S. Spiritus fcientic lumine praditus, ut non modo.ill prafentium ternporum quifguam doclormm. fed nec inpreteritis quidem illi par fuerit tonguam. Sic quides 1fidorus: cujus zamen hac in re vaba cum grano falis accipicnda effe meminerit lector. Pictatis certe \& eruditionis laus ei ncutiquam êt denegunda, in hôe vcrò jure merito culpandus, quàd tefte Ioanne Sarisburienfi, de.Nug. Curial lib. 2. cap. 26 \& lib.8. cap. 12. non modò Mathefin ab Aula recedere jufferit , fcd quo major effet $S$. Scripturx autoritas, \& in ea evolvenda diligentia fudiofior, intempertivo nimis ac plane flagranti zelo nobiliflima Bibliotheca Palati$n æ$, in cuitis Archivis recondebantur tor vencrauda veruftatis monumentaz ignem admoverit, quo incendio perierunt.

\section{Scripta Palatinus quacunque tenebat Ajolto.}

In quibusinquit Sarisburienlis ; erant precipua, qua coleftium mentems Isperiorum oracula videbantur bominibus revelare. Gul. Cave in Hif. literar. Sript.Eccled on 


\section{CELEBRIORUM AUTHORUM.}

Anitoninus Florentinus, part. 4. Summe Confefjlonis, tit. II.c: 4. refert ; Gregin rivum omnes libross quos habere potuit, Tuti Livii comburi feciffe, quia ibi multa de Cuperfitionibus I dolorum narrantur.

Vniver Salis titulum penirisdamnavit Gregorius : \& primus appellari voluit Servus Servorum.

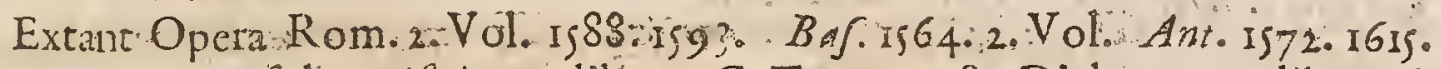
Par. 1605.1640. Fol Epifolarum lib.12.C. T.5.p. 1028. Dialogorum lib. 4. aे Zachariâ P.Gracè verfi habentur integti G1. Lat. edic. Par. I640. Tom.3?' Guppleris qux deerant ex Canif. Antiq. Leet. Tom.3..

Perpenfis ex utrayque parte argumentis reftat, ut hi Dialogi de $V_{i t a}$ \& $M i$ raculis P atr. Italicorum, of de aternitate Animarum, faltem fint dubix fidei; Gregario Mout videtur, Ccripti, iे recentionbus aucti \& interpolati. Ejus erge effe hard tiverion inficias. Interim in hoc opere concinnando nimiùm creduli-

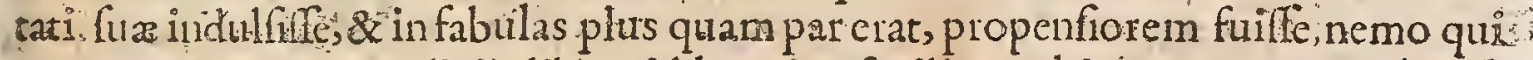
eque animo ac prejudiciis libero id legerit, facilè negabit. Gul.Gave iniHiffor. literar. Script. Eiscle fo.

\section{EVA GRIUS S CHOLASTICUS.}

Enere Syrus, domo Epiphanienfis , Advocaters \& Exprafectus natus anin I 53 r.guando obierit non liquet. : Gul. Cave Chartoph. Ecclef.

Evagriws Scho! afticus Epiphaniấ Syrix urbe oriundus, poft Eufebrum, Socratem Sazomenum, atque Theodoretum, libros $\mathrm{Eex}$ Ecclefiatticx confcripfit Hiftórix, ab anno circiter 431. quo NJ ffitoriana impietas in Concilio Ephefino damnata eft, ufque ad annum $59 \%$. Makriti Imp. 12.ut ipfe in fine narrat, ubi etra afferit fctiptum àfe aliud quoque opus fuiffe:, quod Relationes, Epiftolas, Decretas Orationes, Difutationes, relque alias ejufmodi comulectebatur: feque duos honoris gradiss confecutum : \& primùn quidem à Tiberio Conftantino ad Quz. fturam evectum tumà Mauricio munus adeptum fervandarum Tabularum, in quibus, non tam nomina, quàm ipfa Prafectorum acta infcribebantur.Pbil。 Labbe de.Hift. Ecclefiaft:

Evagrius, illuftri dignitate præditus, Hiftoriam alque ad: Iuftini atatem deAluxit, maximâ ex parte res prophanas tractans: quarum argumnenta, \& materiam, ex Euftatbio Syro, Zo Zimo, Prifco, loanne, Procopio Cafarienf, Agatbia, qui illis temporibus ordine infignes fuere oratores; \& pratereà exaliis, non poenitendis Hiftoricis decerpfit. Niceph. Calift. in Procem. Hift. Ecclefiat.

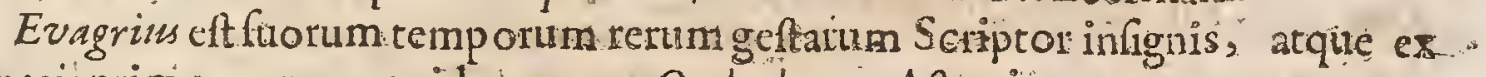
Gracis primus eorum, qui leguntur, Ortbodoxus. Aft enim vero magnam partem Scriptorum ftuorum Zacharie rhetoris, Eutichiani Haretici authoritate. confrinat Evagrius, undé ipjẹ haud immeritó Eutychionus à nonnullis dùcitur. Henr.Spondan. in Epit. Annal. B.aron ad Ann. 56 : num. II.

Zachariam Rhetorem, єujus anctoritate magnam partem Scriptonum fuorum $\mathrm{TE}-3 \quad$ con

DXC. $V_{2}$ 
confirmat, Eutychianum Hareticum fuille, plurimaque rerumbenè Catholicis gc ftarum flentio fupprimcre, atque ea qux Eutychinnerrorifavent; ad verbum recnfere conftat. Memincric igitur Lector Catholicus;ut cutè legat ea qux ab

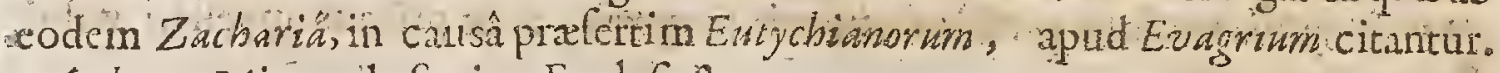
A ubert. Miraus de Script. Ecclefrait.

Laudanda ct in prinis Eugra diligentia, qui cum Hiforiam Ecelefiafican fcribcre aggrellis cffet, quxcunque ad id argumentum fpectabant, cx cotimis Seriptoribus collcgit, puta ex Prifen, Ioanne, Zuchari , Euftubio, \& Proropio Rh:toribus. Stylus yuoque ejts non improbandus eft: Habet enim elegantian \&veinuftem ut teftatur ctiam Photius. Scd quod pracipuêin Ev gro laudandumete exGrecis Eccleftétice Hiftorie Scriptoribus, folus liic redx fidei do Etinamintegram atque illibatam fervavit, ut poft Photium obfervavit Baronitis in Ainalibus. IHud tamen inco reprehenfionem meretur, quod non tantam diLigcntiam adhibuit in conquirendis antiquitatis Ecclefiafica monumentis quantaminilegendis prophanis Scriproribus. Certè totus ferè liber fextus in belli Perfecinarratione confumitur. Henr.Valef.in Prafat. adedit Theodoret \& Evagrit.

Evagrius Scholafticus Ecrlefiafice Hiftorix Scriptor, res potius profanas quàm racraspertractans. Loan. Card Bona.

Evagrius eft Scriptor à fabulolis narationibus, ut res arguit, non nimis alienus. Ifäac. Cafaub. exercit. I3. num. 31.

Lecta cet Evegrit S boluficiexprefecti, "nati Epiphania urbe Colefyria, EccliJiafica Hiftoria libris lex:Inchouns à fine Socrati \& Thodoriti Hiforiarum, pertingenfque ad Wh an anum duodecimum imperii. Stylus huic non ingratus, tametfi interdum redundare quodammodo videatur. Verum in Dogmatum veritate cateris Hiforicis accuratior ef. Phot. in Biblioth. Cod.29.

Qux quidem laus etfi ei non fit deneganda, in pluribus tamen fatis recenfendis nimisfuiffecredulum, \& in fabulas proniorem, ex îs quze dâa quâis occafrone de Cruce, Reliquiìs, fietifque Miraculis ( qux majori in pretio jam haberi coperant) refert, cuivis prajudi iis non occrcato liyuido patcbit. Gul.Cave in Hift. Litcrar. Script. Eccled.

Hiftoriam Evagrit pimus omnium Rabertus Stephanus Grecé edidit ex unico codice MS, Bibliotheca Rcgiz.

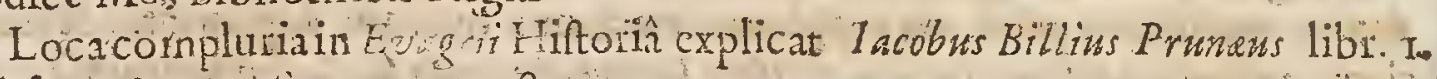
Obfervationim Sacrarnimc. 38 .

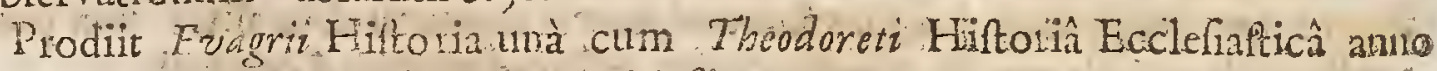
Dorn. I683. Fol.cum Natis Henritivalefi.

\section{S, ISIDORUS HISPALENSIS ARCHIEPISC.}

Clar An.D. Everiano Patre in provinciâ Carteginen/l natus, poft fratrem futum ZeanDXCV. drum Hifpalenfsin Botica Archiepifeopus finit per annos 40. ab anno Chrifi 


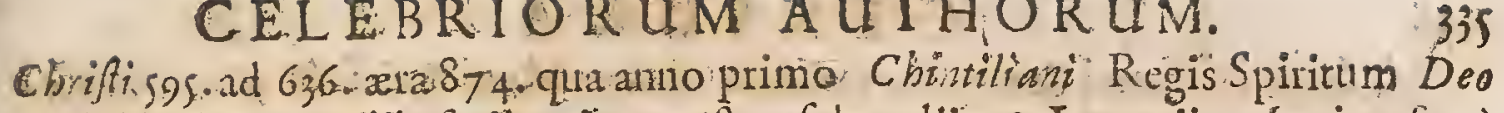
Ieddidit die 4. Aprilis, ferin quinta poft $2\{c h$ a alii $16 . J$ anuarii - / unior fxpè dicitur ad diftinctioncm alterius Ifutort Hifpan $C$ ordubengs Epifcopi qui $H C=$ norio 2 Theodofio in imperantibus $P$ aulo Orofio Hiforiurum Scriptori notifima

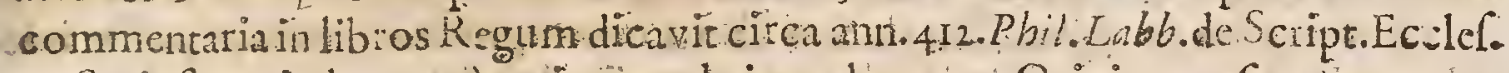

Scripht varia, hac vero primum obtinent locum: Originum, five Etymo:ogiarum libri 20. - Chroniconab intio Mundiuffie ad annum Cbrifi 626.Hiftolia Goboruris Vandalorum, \& : tevorum - Liber de Scriptoribus Ecclefiafticis - Commentaria in libros. Hiftoricos vereris Teftamenti.

Ifidorus vit egregius, Hipalen is Ecclefix Epilcopus : L antri Epicopi Succelfor Germanus, floruit à tempore $M$ auritii Imperatoris, \& Recired: Regis: in quo quiddam tibi Antiquitas vindicavit, in ò roftrum tempus antiquitatis in co fcintiam imaginavit $V$ in in omi locutionis geners formatus, ut imperito

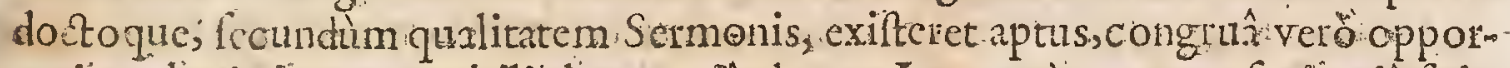
nunitate loci, incomparabilieloquentîa clarus. Jam verò quantus fapientiâ fuito ex ejus diverfis tudiis \& elaboratis opuculis perfacilè prudens leator intelligere

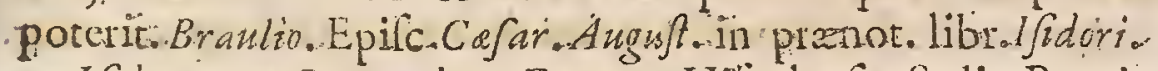

Ifidorus, poit Learidrum Fratrem Hilpalenfis Sedis, Provincia: Boetice, cathe dram teruit, vir decote fimul \&ängenio pollens. Nim tantz jucunditatis affuentem copian in eloquendo promeruit, ut ubertas admiranda dicendi ex eo in ftuporem werteretaudientes:: ex quo audita bis qui audifit, non nifi repctita $\mathrm{r}_{\mathrm{z}}$ piùs commendaret. Scripfit oper. eximia, non parva.Ildefonf. Tolet de Scripto Ecclef.

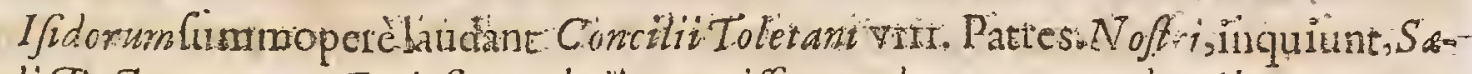
culi Dodtoregregin:, Ecclefie C'atbolica nowifjum decus, pracedonitibus atare por

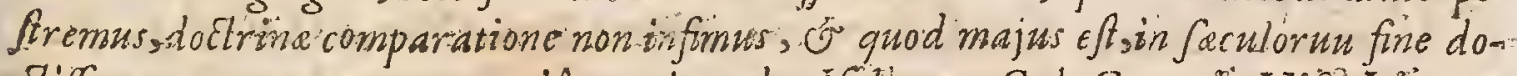

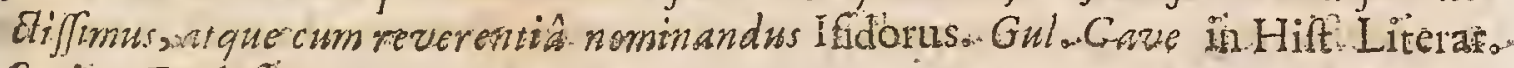
Script. Ecclel.

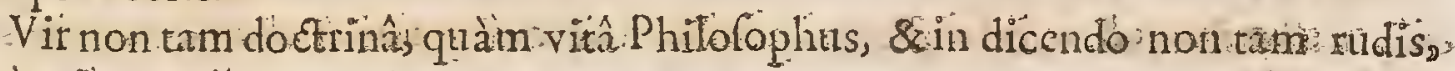
quàm inexercitatus. Volaterran.

Hifpanis Ifdarus Hifpalen is Fpilcopus Leandrifuccelfor multatum frip- fit qua fidem Chrtfianam mirifice juvant. De fummo enim bono; de virís illu Atribus, de vacabulis Grammarices, \& etymologils libros compofuit, Hiftoriam

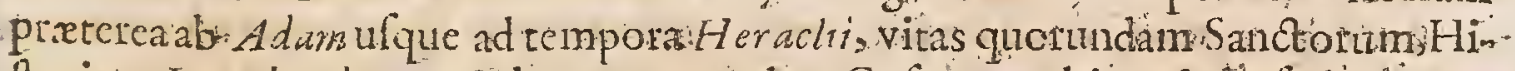
ftoriam Longubardorurim, \& brevem cuandam Cofnographiam fty lo fatis elegan- ti edidit. In eo homine pluris faciendid eft certe fanctitas, quàm ertadicio. Sunt: qui fcribant Ifodorum Germanum friffe, quanquam $y$ ispani hunc futur effe affi- ment : utcunque fit, Catis conftat; etum fuifle quavis laude digna m ob doctinam \& Canctitatem. Platina de Vit. Pontif.

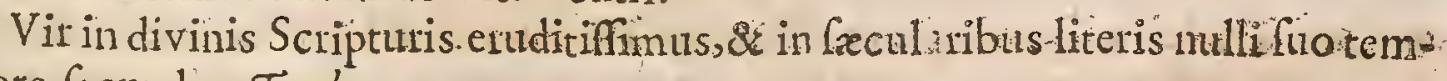
pore fecundus. Trubem.

Vir eximix fanctitatis \& eruditionis, divinarum Scripturarum peritiflimus. Sixt. Senens.o. 
$V$ ir doctrina frmul \& ingenio pollens. Baron. ad an. 636. Ced.g.

Fuit hic vir omnium literarum coguitione tinetus. Bibl. Hifpanic.

Qui unu s(1/2dorus Hifp) intcr omes Hifpanid Virćs, tum fanctitäe; tum literio

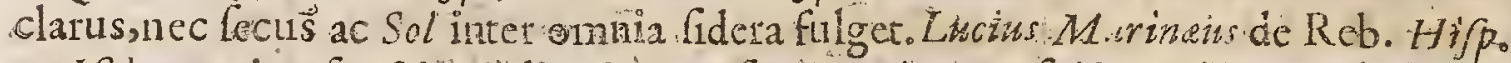
Ifidorus vita Canctitate, literis tam facris quàm profanis paucis æqualis, inferior nemini, quemque fatis fuperque doctum illud Originurnopus pofteris com mendat. iudovic. Norius. in Hipan.

Quem (Ifidorum.Hifpo) Hifpaniarum Doctorem nominat Rex Ferdinandus cognomento Magnus, quanquam fexpe etiam vanus (in opere Etymologico), dicatur Paulo Merula part.2. Cofmog.1.3.c.34.

Ifdorws Hipatenfr, Grammaticus noceffrius, in quo pleraque qua nufquam alibi, \& Hiftoricus non fatis cultus, nec diligens, " moribus tamen incorruptis, . E non ram doctrinâ, quàm vitâ Philofophus. Bonifac. Hudic. Hät. 1. Is.c. f.

Ijiderus Hifpatenjis. Grammaticus adfert nomulla ex antiquis haufta haud prorfus áfpernanda, prafcrtim quòd fontes illi non pervenerunt ad hanc atatem. Lud.Viv. de Traicnd. Difcipl. 1.3.

\section{Labbara.}

Eft quidem is Scriptor ncceflarius poriùs quàm doctus. Cajaisbep.307.Car.

Ioaxres, Gerundenfis Epifcopus, fic cenfer, in rebils Hifp inicis laudabiles efCe, Trogum Poinpeium, Orojum; \& Ifidorum Hifpalenfern : tolerabilem, Rotericum Toletanum icreros fomnia contcxere.

If dorus multa ex Veterun libis quibus hodiè caremus, eaque optima trantcripfit, ideo illum vclim häbere. Dootis utilifimus ef. Scaligerana prima.

Fratoribus Ifidorum Cemiprileis annumerat Ian. Douza 1. 3. pracido in Petros niurro, $0.9 \cdot 4 \cdot 355$.

Ifidorum centonum Sarcinatorem vocatidem Douz Not. in Salluft.p. 18.

If 2 dorus Hifpalen is Epilcopus firipfit Orignum librosxx. In quibus eum ex Servio $M$ aronis Interprete, Eefto, Nonio, Divo Augufinos caterifque meliocis now tx Auctoribus ad verbim: pleraque franferipfrfe, oftendit Petrus Ciacconius No. tis in I/iaror.

Talis fermè eft apud Latinos Ifrari Rhapjodia, qualis apud Graios Suide, undecunque à compluribus confarcinata. Best. Rhonan. in Tertullian. de Poni rentiâ, $p \cdot 47.1$.

Anctor Origirnm tive Etyrologiarum quibus tamen quandogue nil,nifinugas agit, \& rifum movet. Chrifian. Becman. de propriâ fignificatione vocum p. I3.

Ianus Don a centonum Sarcinatorem vocat I/fdorum. Quô tamen ipsô locê cum unum ălterumque Sallufit fragmentum haud mediocri acceffione augeat ex Ifforo, vellem parciusipfi probrum hoc, faltem dum ejus bencficio fruebatur, objeciffet. Thomas de l'lagio, num.474.

Catcum in facris quoquc.lucubrationibus cùn aliena conftipare , quàm fua dare idem Ifodorus maluerit, plagizm ipficum primis è S. Gregorio, cujus difcipulus fuit, objectum meminimus. Quod quidem crimen ab eo depellere qui *olet, nifi alian viam inftiterit, quàn Lwcas Tudengss, qui excraordinarium 


\section{CELEBRIORUM AUTHORUM.}

Spiritüs Sanciti influxum credi à nobis hic voluit, operam perdet. Idem ibid. muin. 475.

Miror fanè Bellarrninum in eâfuile fenteintiâ, quòd Chronicon illud decerptum fit ex libro s. Etymologiarum, cuin è contrà certo cerrìus mhi videatur, ex hoc Chronic delibafe Ifidorum aut certè Bratilionem qux brevi compendio. de ferie temporum traduntar ad calcem libri quinti Etymologiarum - funt qui

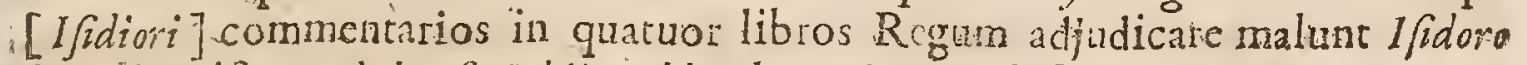
Leniori Epifc.Cordubenf. Thitl.Labbe de Script. Ecclefialt.

Ifidorus Hifpalenfis anno 6.9. prxfuit Syl10do Spalen fi quo modo vocatur Synodus Hifpalengs: Ur. Spalis pro Hifpalis,Spania pro Hifpania dixere. Item prefuir nobili illi lxx. Epifcoporum Synodo Toletand: que aino habita 6 3. ut. Manufcriptis Antiquis Garfazs Loaifa ob fervavit. Utrum autem Hifpalonfis hic fit idemille, qui Pontificum Epiftolas, \&: Conciliorum Canonas, sollegit, adhuc in Controverfià eft. Tofjode Hift.Lat.

Non polfum eladitum \& Ecclefiafic Antiquitatis frudiofum Lectorem hoc Loco gaudium meum calare: repertum nempe à ine elle fuperioribus diebus illuaste \&.bene longun If dori Hippalenis Epilcopi Fragmentum de Institutione 7.7unit Quadragefinalis, quod alibi, fi vitam Ders dederir, publici juris faciam. Boxborn.2d Hide Auguft.Script.p.999.

An Eragmentum illud e iderit Boxbornius, nobis incompertain; quod, aut egregie fallor, non aliud fuit ab 1 fadori 36. capite libri primi de Officits $E c-$ clefrasticis.Ifrdori operum editio $M$ adritenfis anno is99. rariùs proftat.in eâ $I o l$. Grial editoris \& aliorum Prafationcs legas, in editione Parifienfi Aul.1601. Typographorum avaritiâ expunctas. Paul.Colomes. paralipom. ad Chartophyl. Ecclel.Gul.C c.ve.

Opera omnia eum obfervationibus Garja Loayje Grialii \& I acobi du Breul Monachi S. Germani à Pratis. Pariffits in fol. apud Seb. Nivellium all.601. Editio bona.

Ppufcula noridum, anted edita vulgavit Constantinus Cajetakus, \& infcripfit Philippo ITI.Hifpaniarum Regi. Roma in 4. I6I6.

De ordine creaturatum liber ad Braulionen Epifcopun Cefarangufanumes primùmeditus à Dacherio Tomor.fpicilegii.

\section{THEOPHYLACTUS.}

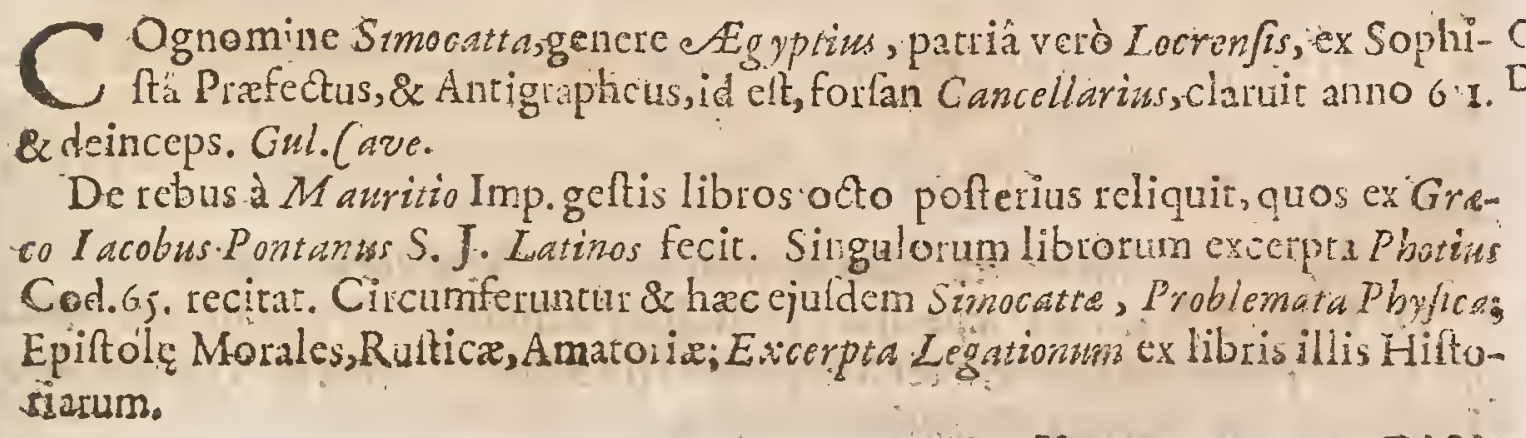

$\mathrm{V}$ แ

Didio 
Didio illus [in Hifuriarm Libris veneris aliquid habet, nif quod figurat. tis vocibus \& allegoricis fenfibus putide nimis ac frequenter ad facietarem ufus; in frigiditatem quandain ac juveniles ineptias dilabatur. Veruntamen \& Sentcnriarum illa interjectio minus opportuna, diligentiam arguit, \& curiolam, \& fupervacaneam, Cxerabonus, in reprehenfionem non incurit. Phot.in Bibliot: Cod.65.

Huic [ Pbotid de Simocatta] judicio \& nos fuffagamur, Dictionifque elegantian ex Tropis, um is, qui in uno verbo, tum is , qui in oratione.cernuntur, magnam partem à Simocattâ. qurfitam \& comparatum concectmus- Et eft aliunde parum nonnunquam dilucidas hic Autor, ut interpretem etiam me erudriorem puderenondebeat, id candide confreri, Quod de Sententis non opportunè infert s queritur Photius, id aliquando factum à Simocattẩ non memini. Curiosè quiden, \& foraffe plus fatis diligentem alicubi, non negaverim, \& in fententiis quoque crebrum elfe faceor: n.c ob id diem illi. dicendum puto. Invenitur pretereà aliquantò verbolion, quod photium preterilfe miror : \&xidem vel contincuter repétit, vel pluribus, quam opus eft, dicit_- Cenus fcribendi, fr torm frmul universe fpectemus, fanè elaboratum, prudens, grave, jucundum, diferum, planeque oratoritu_-_Nec lecto-. rem fun tantammodo meliorem, fid ctian doctiorem dimittere fudet; \&, cum alios ftmmi ordinis Scriptores, tum Homerm fe non of citanter legifle oftendir. Multa nihilominus particulatin landari in hac Hiftona Mawnitiana poffunt: ut defripriones Montum, Fluminum, Caftellorum, Locorum, puguarum, ritum : Orationespartion Sacra, partim Civiles, partim Militares, ienrentiis ornatinima ac robuftifnina, 8 omninò eloquentiffma: fimilitudines ad ilfufrandum accommodata: multa prudenter dicta: multa piè explicata. Si igitur Fistoria quoquo moto fcripta delectat; hec Hifforit fcripta ad hunc mo-

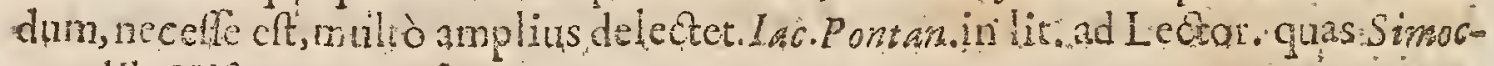
atte lib.Hitor premifit.

Ejarmodi elt, quod apud Theoploylactum Simsecatmm, foriptorm eximium inter Gracos recentio cs, oblervabamus. Cafaub. Noto ad Spartian. Fla drian.c.2i.

Theopbylattus Siribocatta, cujws prater Hiforiam exfant Quafiones Ployfice, \&. Epiftole agreftes, morales, amatorix: Stylum haber venufum, fed dum nimis elegantiam fectaturin cacozelon, 8 puerilem affectationem incidit. 10an. Card. Bona.

Qux, vero furùs Guis libris exponit Simocatta ea brevi s perftingunt T beophanes, Zonaras, Cedrenus, \& Nicepharm. Callifus: qui \& ex Simocattâ, vel is, qui Simocattam exfripferant, illa, qua de Mauritio fcribunt, hauferunt. Voff.de Hilt.: Grac. c.23.1.2.

Theophylactus Simocatta quàm mifellus Scriptor! Scaligerana poster.

De Rebus à Mauritiolmperatore geftis libri odo impreff funt in Fol. Pari-fais Grace pariter ac Latine, inter Scriptores Hiltosix Byzatine ex Typographio Regio, per Sebafianum Cramoijum an.16.47: 


\section{B E D A}

N Britanna ex Anglo-Saxonum genere oriundus, in Girvvenf territorio I non longè à Tine fluminis oftiis natus eft anno 673. à puero Monafticam vitam amplexus, in eâ per multos annos perfeveravit láb Bencdicto \& Geolfrido Abbatibus Monatterii BB.Petri \& Pauli ad Tinam, in Diocel Dunelmenfis, vulgò appellatus Presbyter Anglus ac Venerabilis, obiit anno 73). die 26. Mavii, five 7. Kal.Junii, quo Afenfonis Domini nemoria cclebrabatur. P bit. Labbe de icript. Ecclé. Scriplitpenè infinita.

Omnigenà lcientiarum eruditione infructus, Grammaricus Gracé non miuùs, quàm Latinè peritus, Pö̈ta, Rhetor, Hiftoricus, Aftionomus, Arithmericus, Chronographus, Cofmographus; Philo ophus \& Thcologus evafie in tantum itlis temporibus admirandus, ur apud cjus leculi doetio es proverbium de eo diceretur, Hominem, in extremo orbis angulo natum, univerfun orbem fuo ingenio perftrinxife-Opera cjus, adhuc co vivente, \& femper nova fcribente, tanto n pretio habitalint, ut ex ordinat one Épicoporum Britarnie in Ecclefiis publicè lcgerentui. Sixt.Senenf.

Fuir in. Gentilizm libris tam planè exercitatus, ut co feculovix parem hasbuetic. Physicen \& Mabefon, non à rivulis fordidis, lẹd expurifimis fontibus, hoc eft, ex Gresis \& Latinis authoribus primis haufit. Fidei yerò Cbristiane. Myfteria tam folidè, quantum ejus temporis dabat iniquitas, novir; ut ob cxaatan utriufque linguæ, Latina \& Greca peritiam, magno illo Gregorio à multis praclarior haberetur. Styli enim tuaviraic ac Dicendi copiâ,illum in plerifque exuperabar: arque utian Spiritualium Senfum puritare magis. Nihil ferèleatione dignum in omni reperitur vetuftate, quod luis locis non legatur in $B$ ed taméti Brituna limices nunquam fuerit egrellis: Si Angustinz, Hierongmi aut Chryfoftorni temporibus claniffet, non dubito quin potuilfer de paritate cum ipfis contendere: quòd inter tot fuperftitionum preftigia, tam caftos ediderit fœetus. Ioan.Baleus.

Et fanè nofter Beda vir omni eruditionis genere tam infigniter inftuctus, ur eo vix quenquam in omnibus fcientiis doctiorem unquam Europa protulerit. Pitferes de Script:Britann.

Qû̂ mortuô, fepulta eft cum corertm geftarumomnis penè notirin uf̣̆u ad noftra tempora. Cum enim pigro femper luccederet pigrior, multo tempore in totâ inlulấ ftudiorum detepuit tervor. Gul. Malmesbirs

Beda enim preter Grace atque Latina lingux doctrinam, quam non mediocricer tencbat, ob religionem etiam, atque mode?tiam, Venerabilis cognomentum adeptus eft. Scriplit cnimimulta in Actus Apofolorwra, in Lucam. Edidit \& librum de temporibus, \& homilias plerafque, quibus multum Gallici facerdores atuntut. Platrat de Vir.Pontific.

Obfervandum eft, festo, feprimo atque actavo feculo neminem ferè per Itas Harb. Galliam. Britanniam, Hifpaniam (uno verbo) in Occidenitalis Ecclefie i. 
toto orbe, nomen aliquod fripto libro inveniffe, qui nor in Monafterio edice tus fit atque inftitutus. Qui inter Britanmicos Monachos eminet Beda, idem omnium illius ternpetatis per occidentem Univerfum fuit doctifimus. Nos ipfi Germani prima Chriftane do.trinze exordia illis Conubitis debemus. Imo deb.mus illis initia omnis culture melioris, arque eruditionis : ficut \& Anglipe ac $S$ oti a Monacbis Romanis eam antchac acceperant. Hermann. Conring.tertiz Dillertat de Ánti. A cádem.

Vir moderato fermone fur gentis res geftas confribens : cui fanè ob id plurimum deber Polteritas, quòd plurima licitu dignifima literarum monumentis tradiderit, quorum memoria (fille non retuliffet) oblivionis nube tegerctur. Britannice Antiguit.

Viderur a tem quibufdam incredibile, quod in extremo mundi angula vir qui nunquam ma ia transfretaverit obaddifcendam fapientiam, fcholas Pbilojophorum non frequentaverit, tanti eruditione clareat, tantâ librorwm compofitione ubique mundo innatelcat : fed hoc non elfe mirandum ipfe docet, qui inter. DC. beate vita \& mirabilis fcientix Monacbos enutritus, quicquid feientix fin gul habuerant, onne hoc ipfe in unum fui cordis valculum Spiritu Sandio'illuminante concraxcrat. Simeo Dunelmenfin Epilt. ad Hugonem Deen. Eborac. de Archrep.Eboraci:

Beda Stylum habet nec omnino inelegantem s nec affectatze elegantia curiolum, fed temperatum; qui nec verborum multitudine faftiditim, neque pancitate obfcurizarem pariat, fed brevi facilitate currat gratifinè. Sixt:Senenf.

Quoram nos virorum ( Gregorii Turonenfis \& Beda) pietatem \& zelum promoyendx Religionis fulpicimus \& veneramur: at facilitatem in credendis multiș, qux priora lixcula non crediderant, admodum fufpectam habere profitemur. Ifouc.Cafaub.Exerc. 10 .ad Baron. Num.13\&.

Beda, optimi \& fanctiffini viri, a merito; fuo, ut vocatur, Fenerabitis, libro de locis Sacris, multa futilia aut palam falfa continerio ne Baronius quidem dubi. abat agnofcere \& fateri. Cajaub. Exere.-2. ad Baron. Num.4.

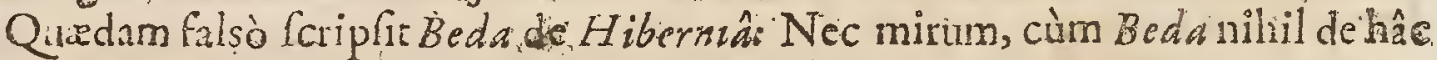
Infula oculatî fide cognoverit, fed per latoremaudiexit.Ioan. Bromton。 in Chronico, in Hen.z.

Seculi fui Omnigena Eruditione ornatifimus fuit. Incipiat ab ejus Axiomatiobs Soph:fa; ad ejus Metaphy:\{ca progrediatur Baccalawrens, ad ejus Mathematica Mayitter Arrium Ejus vero Controverfis \& in Scripturas Commentariz concludar Theologus : Et ilium finguli in guavis harum Artikm ac Scientrarmo quovis Scriptore Chriftiano.illius Seculi praftantiorem deprehendent. Univerfa ferme Biblia explanavit,in Anglicum idioma Pfalmos \& Novum Tefamentum tranftulit. Vitam egit qua Commentarius fuit in hec A poftoli verba. Ín medio Nationis'prav ac perverf $x_{1}$ fplendentes ur luminaria in munde. Tom. Fuller. Pr. reb. Angl.

Miratus fum non femel, cum tam multi Bede Codices in Anglîn reperian-

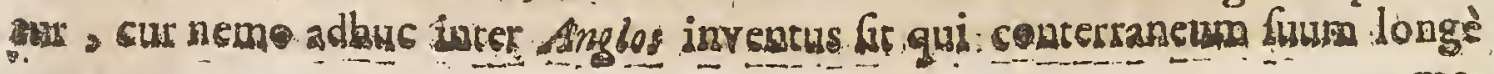


meliorem, quàm in eruditorum manibus verfatur, in vulgus emittat. Ego, quod folum polfum, in commune Reip.literarix bonum notabo, Beda Fragmentum ex libro de temporibus apud $M$ unfterum extare lib. 2 Cofmographic, quod in editis non comparet.Beda Hgmn aliquot occurrunt in collectione Cafiandridna. Obiter oblerva qua habet Ph. Melanchon in quadam ad 1 o. Cratonem Epifola:Narravit mibi Aventinus, inquit, $\sqrt{e}$ in Cadice Beda, qui est in Bibliotbecẩ Pafjovienfl, legiffe enarrationem verborum (Ccene Dominice) perfpicuarn, gue tota defit in libris editis. Quam BedéEditionem intelligut Aventinus, qui obiit Anno 1533. mihti non conftat, aili forte cjas in Evangelia Commentarios fepanas. tim exculos, quos videre nondum contig't. Genuinum Rede Mariyre? logiurn cum Flori Additamentis habetur in Ackis SS. menfis Martii Tom. 2.

In co enim invenias qux ex $B e$ de Martyrologio adducit Amalarizs de Of fic. Ecclé, 1.2.c.3 . \& de ordine Antiph. c.28. Quod minus animadverfum RR..Patribus Henfebenio \& Papebrochio. Panl.Colomes:Paralipom. ad Chartoph. EC. alef.Gul.Caye.

\section{Hoc Beida Epitaphium.}

Beda Dei famulus, Monachorum nobile" fidus .

Finibus è terrx profuit Ecclefix;

Solers efie Parrum forutando per ornia fenfum

Eloguio viguit, plistrma compoluit.

Annos bầ vitâ ter duxit ritè triginta.

Presbyter oficio, witis ingen:

Jani feprenis viduatus carne Kalendis

Angligena Angelicain commeruit Patriam.

Cricumfercur \& hoc vulgò monoftichon Epitaphium Leoninumo

Hâc Junt in folsâ Bedx Venerabilis Offá.

Rhil. Labbe. Théfar. Epitaphi:-

Extant Opera 3. Vol: Baf. i6s3. Col. 1612. fol. Hibtoria Ecclefastica uxd am Alfredi Regis paraphrafi Saxonica, doctique Abr. VVhelocz Notis Can-tabr. I6.44. Fol.cum Noris P. Chiffetii Par. 1685. $4^{\circ}$. Epp. Ir \& vira Abbatum Virernuthenfum \& Girvvic.Dublin.1664.80. Ep.ad Albinumap.Mabillon. Analect. Tom.1. Martyrologim Carmine Heroico ap.Dacher. Tom.10...

Opera Deperdita: Commentarius in Ifaiam 1 rophetam-Epiftolarum liber - Tractatus de Manfionibus Filiosum Ifrael--In illud Ifaia, G claudentur ibi in carcere, of Dies multos vifabuntur.-Epigrammatum libe:-- librum de vitâ \& Palione S. Anaffafit, malè è Græco tranflatum, \& pejus à quodam imperico emesdatum, Beda ad fegfum correxit, Gul.Cays: 
Clar.A.D. DCCLXXX.
$\mathrm{N}$ Atione Britannus, Eborace Civitatis Diaconus, offeio Scholatticus, Masgiftel Caroli Magni Francorm Regis, eique familiaris ac percaru , obiic

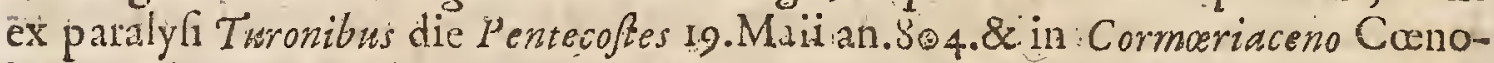
bio repultus. Venerabilis Bedie qui anno 73 . Fnem vivendi fecit, atque Egberti Archiepifcopi Eboracenfis dilcipulus fuilfe dicitur, evocatus in Galliarn à Carom lo circa annum 790. multifque Monafteriis prater Turonenfe S. Martini ab eoacm ditarus:Pbil.Labb.de Script. Ecclef.

Flaccus Albinus, qui \& Alcuinus. Diaconus cognominabatur, Anglus natione, ầ nonnullis $S$ criproribus Eboracenfis putatur, $\mathrm{ab}$ aliis verò Londino non procul oriundus ferrur. Hic Beda primum, Egberti Archiepif. polteà obfequentifimus olim Difcipulus, Theologorwm fux xtatis, inò omnium Anglorum ab initio, poft Bedan \& Adbelmum longè cruditifinus credebatut, ita ut elfet (aroli Magni Praceptor, \& Parifiorum Academiz. Inftitutor primus. Gymnafii Cantabrigien is Annales habent, guòd omnes illic. Libcrales Artes, publicè pont Bedam ducuerit, Latine, Gracè, \& Hebraïcé peritus: \& quod tandern Eboraci Gub Egberto prxlegerit, Philofephorwn fui temporis Antefgnanws. Ab Offä potentifmo Mercio rum Rege ad Carolstm pradictum,pro pacis fuedere confirmando, atque aliis regnorum negotiis millus: perfpecti ejus eruditione pene incredibili, it ex legato holpes, \& ex hofpite demum Magifter deliciolus : non aliter quàm apud Aibe nienses fuerit lim Gorgias. Deincepsiginur illum infructiorem pra aliis omnibus $C$ arolus $C$ efar habebat, in Rbetoricis, Diale Eticis, Mathernaticis ac Theologicis : qui \& fimul.computandi artem, atque derum curius varios, fub eo copiosè didicit:de quo Bebelius in quadam Prefarione hoc fribit: Albinus (inquit) atthor ubigue pius, wbigne doctur, succinetus, maturus, gravis, of ante multos alios pre-

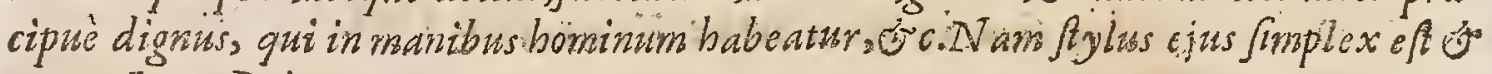
purus.I oan.Balous.

Carolus 11 agnus Francie Rex Imperaton eximian Alchuvin doetrinam ac fapientiam expertus, cun de remotiflimis Anglic finibus evocarum fibi totum alferuit, ac magnis in regno fue dignitatibus cumulavit---Albrovinus in celeberrimum hoc Gallice regnum alcitus unus è principibus Imperialis é.ulie comitibus fuit, ufu \& exercitatione rerum tractandarum, omnibuque artibus ac fcientiis adè infructus, ut prudent fimis ejus conflilis Rex Caroius femper uteretur---Poftemò beatos Alchivini manes honorificâ reeordatione profequitur Gallia, quod cum ob fingularem eruditionis ac fapientix famam apud Carolum $M$ agnum gratia \& auctoritate plurimum valeret, hac fortis benignitate non ad fui ipflus conmoda, fed ad commnnem Reipublice utilitatem ulus eft. Nam hôc potilimùm fuafore Rex ille gloriofifmus, qui quotidie eum de feientiis variis differentem libentifimè audiebat, litteras penè jacentos enexit, Scholas deftructas separa: 
reparavit, \& finonnulis reterwr habenda fides, $P$ arifenfem etiam hanc $A$ cademam primus infiruir. Andr.Duchefnius in Epiftad D. Gul. Warium, Franc. Procancell.quan pramifre Edit. Upp. Achuvini.

Erar ingenii felicilfmi, mitis animi, facundx lingux, mirx modertix, moderatæ gravitatis, maturi judicii, magna Pietaris, fingularis erud tionis, terfi fermonis, fyli fuccindi,fimplicis, puri. Politè tum verfu, tum Prosâ foripfit. Cum Latinorum literarum f́cientiâ, Gracarum etiam \& Hcbraicarum cognitionem conjunxit.Nam has linguas \& perfectè calluit, \& publicè docuit. Omnes denique fcientias Mathematicas, Philofophicas, \& Theologicas accuratè tenuit, atque etiam docuit. Demum teftimonio Vincentiz Bellovacenjis in Speculo Hiforiali, \& noltrorum Hifforicorurn, imà communi penè omnium fentencià, erat Anglorum omninim poft beatum Aldhelum, \& Venerabilem Bedarn planè doctifinus. Ad quas eriam laudes addunt quidam, tres antiquos Auctores fuille, ut ita dicam

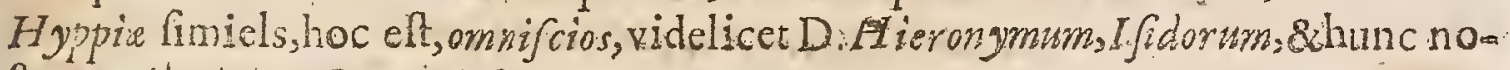
ftum Alcuinion. Ioan.Pitfous..

Temporibus Pipini; \& fili ejus Caroli-Magnt, Francortm Regum; clatuit Flaccus Alcuinus, cui cognomentum. Albinus fuit-.--Natione hic erat Anglus: a Bedâ primùn, hinc ab Egberto Archiepifcopo, eft inftiutus. Docuit Carolum $M$ agnum acieidem poftè ab elecmolynis, \& fantioribus confliis, fuit. Etiam confilio ejus Carolus inftituit Acudernaris. Parifranam. Latine, Gregé, Hebraciès call ebat:atque idem exat Rhetor, Philofouhus, Machematicus, \& Theologus nobilis. Voff.de Hilt.Lat.

Vir in Divinis Scripuris enditifimus, \& in Seculdriam Litierarm peritia nulli fuo empore lecundus, carmine excellens \& Prosâ.Trithem.

Virin omni lcientiarum genere fuo tempore celebratifimus.Sixt:Senenfs Arbinus Flaccus Alcuinus, abbas multa pietatis, \& fcientia Scriptor, quem Egmarthis ait Magistrum fuilfe Caroli $M$ agni. Liber antem de Divmis Offciis malè tributus ci videtur, quia in eo citantur verfus Theodulphi Epifcopi Aurelianenifs, qui vixit lub Ludovico Pio, quod etiam obtervavit P. Sirmondus in notis ad Theodulphidr. Ioan.Card.Bona.

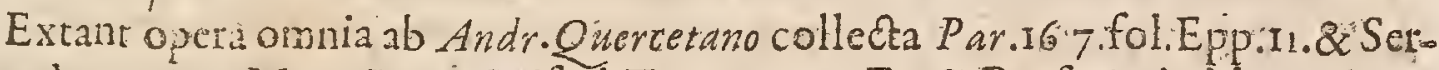
mo ad Carclum M.ap. Baluz.Mifcel.Tom.s.p.365. Ep. \& Præatio in lib.7.ad Fe-

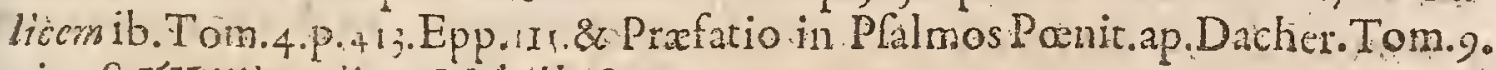
vita S.VVilitbrordi ap.Mabill. S.ec.II1. part.1.p.601.

Opera Deperdita: Commentarius in Proverbia_Commentarius in 4. Epiftolas S.Pauli,vizad Ephefios, ad Tirum, ad Philemonem, \&ad Hebrros-De Drthographrâ liber-De Muficâ liber.Gul.Cave.

Alchurini feu Albini Abbatis Epitaphium,ab iplo dum vivet dictatum, \& in laminâ æreà parieti infertum Turonis in D.Martini. Exrat quogue inter Epiśo phia Rabani Maurinum.7.

Hic, rogo, pauxillum viniens fubfifte, Viaros,

Et nea formtare peclore diclat two 
Wt Tua deque meis agnofcas fata figuris.

Vortitur en pecies.ut mea, ficaue tua.

Qwod nonc es, fuerarn fano res in Orbe Wiator,

Et quod junc egof furn, turisue futurus erès.

Delicias mandi cajo feitabar amore,

Ninc cinis, o puivis, vermibus atgue cibus.

Quapropter potius animam curare memento,

Qudm carnern: quoniarn hac manet, illa perit.

Cur tibi rur a paras? quarm parvo cernis in antro

Me tenet bic requies? fic tua parsa fiet.

Cur Tyrio contus inhias veftirier oftro,

Qusd mox efuriens pulvere vermis'edet है

it flores perewnt vento veniente minach.

Sic twa nangue caro, gloria tota perit.

Tumibi redde vicem, Lector, rogo, carminis bujws:

Et dic da veriam Chrilte tuo familo.

Obfecronulla manus violet piajura Sepulcri,

Perfonet Angelica donec ab arce tuba:

Quiz jaces in tumulo terka de pulvere Jurge.

$M$ agnus adeft $j$ idex millibus innumeris.

Alchvvin nomen erat Sophiam rnibi femper amanth

Fro guo funde preces mente, legens titulurn.

Phil. Labbe in Ther. Epitapho

\section{HINCMARUS RHEMENSIS。}

Cirr.A.D. F X nobili ortus Francorum familiâ, Monachum primo profelfus eft in Mo- ccexrv. I nafterio S. Dionyfir in Francia, fub Hildvino Abbate, tum in locum Ebbonis, ob conjurationem adverfus Ludouricum Pium Imperatorem depofiti, at- que ejecti, annitente Cotrolo Calvo Rege promotus in Archiepilcopum Rbemenfem menie Aprili anni : 45. in Concilio Bellovacenfa, ac deindeconfecratus Dominicâ die 17. Maii, cùm fedilfet annis 37. obiit die 21. Decembris anni 822 . Sparnaci, cùm metu Normannorum Duro Cortoro Rhemorum adillam Matronx -impoftam villem fecefrifet. Interfuit quamplurimis per ea tempora celebratis Conciliis, ac paulò ante mortem Cripfic Epiftolam menle Augulto ad Epifcopos Francia--Quanvis in quibufdam eum aberialie ut humanum eft, nemo negare polfit; conftat tamen inter atatis fuxeruditifimus ac fanctitatis $\&$ difiplina Ecclefrafticx tetinentiffmos vindices merito annumerandum effe. Pbilip. Labb. de Script.Ecclel.

Hincmari vitam Scripfit Elodoardus lib. 3. Rhemenfium Epifcoporum, 妾 gno ob Canoma peritiam, Theologie feicntiam valde commendatur 
Quem quidem etiam Nicolans I. Papa divinitùs valdè doctum fuilfe teftatur. Ae

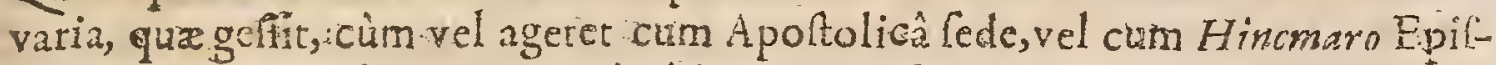
copo Laudronens altergaretur, vel aliis negoris fe inmilceret, fecerunt, ut non modò dubiam, verùmetiam conttancem de le relinqueret Opinionem, etum in plerifque haud rectè incelfile. Scriphit autem doitè contra Götheforalcum, \&rc. Pofferini Apparat.fac.

Non fum nefcius, dum tantis divinx gratix muneribus abundetis, ultrì vos cogitare apud Principem juvandi Bonos, facultatem divinicusaccepiffe, ut quod in fe non habent, in vobis polfideant, \& retnunerand $x$ vefte induttrix materiam prabeant. Nobilitatem veftrix gene ofitatis onnat enuditio falutaxis, altitudinem offcii conmendat Religio profchionis. Hac veftra Celfundini non arrogantia vitio, fed amicitix ftudio fer prat ut quoniam in vobis \& nobilitas \& fapientia convenerant, quantum hre locictas valeat etiam nolentibus emineat, qui ipfa quoque lumina Ecclefix obcurare contendunt. Lupss Abbas Ferrarienf, in Epit. 42.ad Hincmatr. Epif Rhemens.

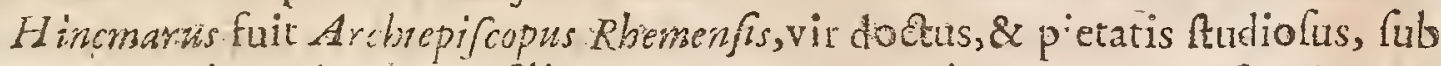
- Carolo Secundo Ludovici Pii filio, circa 87 . Domini annum: tametfi \& Magni Caroli tempera adolefcens attigerit.Is dum corrigere vitia morbolgie Clerico-

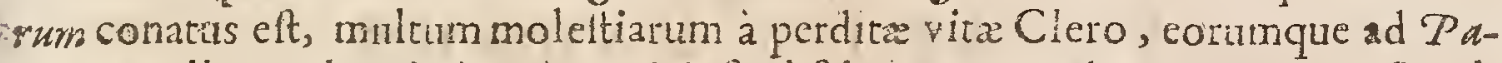
pam appellationibus, imò \& à Papis iphis luftinuit. $\mathcal{M}$ atth. Elacc. Illyric. Catal. Teft.Verit.

Iacobus. Sirmundus vir optimè meritus de omnibus literis jam inter oetuagenarium \& nongens aum medius non definit pofteriratem obligare. Librum nobis edidit ex Mandcripto qui fuit. Hincmari Archiepifcopi Rbemenfis fat is noti. Is l.ber oppolitus eft libro hominis lentientis cum Pradefinatis, id eft, ita tit nunc fentiunt qui Synocio Dordrectotane adharent. Eft autem friptus \& efficaciter \& eleganer, \& dignus qui leggurur non fuâ tantùm linguâ,fed \& aliis. Hug. Grot. Epifr.ad frarrem funm Lutet.10.0ctob.1643.

Hincmarus Khemen/s, Epilcopus doctus, fed dubizfamæ, dubio vitioum, ac virtutum temperanento Ioan. Card Bona.

Si de Hinomaro quid fentiendum aquo judicii librarento dicendum fit : quod ad fcientiam pettinet, fi agitur deperitia Caronum, planè dixeris eruditifnum, licet interdum nimis eis favens fuper Apoltol ca iedis Decreta cos extulerit. Si de Theologicis facultatibus, ipfum quiden invenimus excultiffimum, ut in his qua contra Gothefcalcum Pradefinnatianum Hæreticum anunde fripfit, adverfus quem pra cateris laboravir : In reliquis ecian talem exiftimatum anuem confuluerint plures diverfis Queftionibus, fed non in omnibus ita feliciter, ut ex répiponfionibus ad eas apparet. Baron. ad ann. 832 .

Vir in divinis Scripturis fingulariter doetus, \& in fecularibus literis nulli fuo tempore fecundus; fapienriâ \& morum honeftare confpicuas, atque eloquentiffmus; feripfit non contemnendxe auctoritatis plura - pufcula. Tribem. 
Er fane Ecclefix leges \& jura nemo meliùs intellexit, nemo animofuts defendit. Tandem ad ejus opera deveniamus, multâ quidem eruditione, doctrína, pierate, referta; \& qux Ecclefix Gallicane Hiftoriam mirè itluntant; de quiz

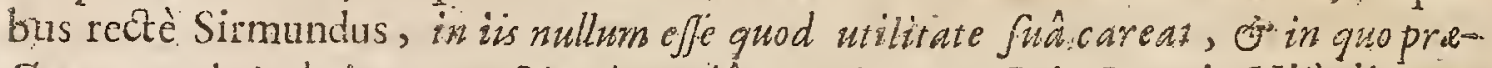

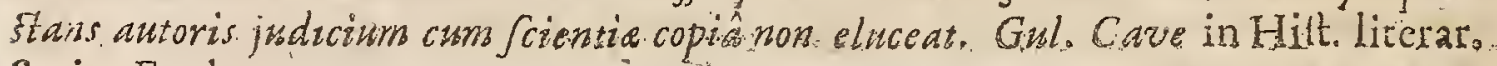
Script.Eccl.

Extant opera ejus omnia editore Io anne Cordefa Cänonico Lemoricenfis $P_{a}$ a ris.tors.in $4^{\circ}$.apuid Sebast. Nivelluwn.

Extant eadem in Tom. II.divifa cum obfervationibis Iacobi Sirmondi, $P$ axifo 1645 .in Fol.

Anno 658 . Parifs in 40.edidit Lud.Cellotius quatuon Hincmari opufcula do Ecclefraficấtibertate adverfus Hzncrarum Laudüno unà cum Concilio Duzian. cenfi, fuifque Notis eruditis, qua: ad Innocentiäm Hincmari Rhemenfis vindicandam plurimim conferunt, habentur etian Concil. Tom. VIII. pag. 1732. ibis que etiam pag.r-89. extant vir. ejus ad Hinemárum Laudun. Epiftola, ex Cor dice f'atic, delcriptx, \& tunc primùm editx, gura proinde in operibus Hincmasridefiderantur.

\section{$R A B A N \cdot S: M A U R \cup S$}

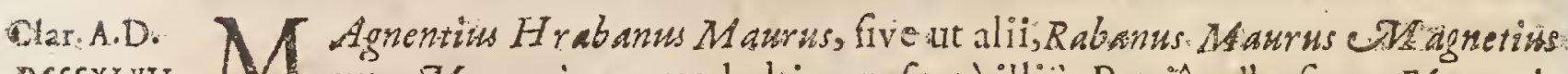

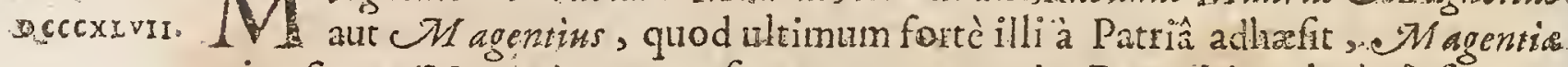
enim five $M$ oguntive natum fe atque renatum in Epitaplio clatè infinuat :deinde Eulda à puero Monachus, Alcuini difcipulus: \& pelt Egzlem ann. 822.defunctum ejurdem celebernimi in Buchoniâ flyà à S. Bonifacto xdificati Monalterii A bbas furo tempore eruditiffimus. Demum jam feniar poft Otgarinum diè Dominicâ 26. Jun ivann. 847 electus Mognntinns Archiepilcopus, obiit die 4.Febro ann. 856. Ludovico Lothariv filio imperante, regnantibus verò Ludovico in Germanii \& Carolo. Caitvo in Galliâ Ludorici Pii filiis, cumque ad S. Albanum Moguntix fepultus fuillet, tranflatus deinde fuit in Saxonidmo. Phit.Labb.deScript Eccle $\ell_{0}$

Juvcuis adkuc Benedictine Sectx monachüm induit, ac tam moribus quàrn feientiis mirabiliter profecit: \& omnium dicendi generım peritus, Parifienfem Scholann ab Anglis \& Scotis inchoat am, frâa doctrin celebriorem reddidit. Summus enim Theologus erat, Pbilofophiuss Aftronomus, Rhetor, ac Poëta fubtiliffimus: cui per eam xtatem, wit de ipfo fcribitur, nce Italia fimilem, nec Germania xqualem peperit Multa etiam in Bibliorum libros \& luculenter \& accuratè confcripo fit. Io. Balaus de Scriptor.Britan.

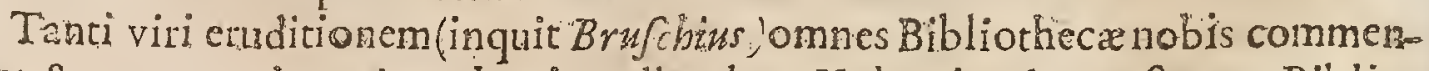
dant, \& quantum ingenio yaluerit; edita ab eo Volumina demontrant. Bibliathecam enim Füldénf $\mathrm{cm}_{2}$ tantâ librorum multitudine locupletavit, st dinumerari vix queant. Illum tamen Thorzas Waldènus in Epinolầ ad’ Papam Martznum Quintum;\& in libro fuo de Sacramentisisinter Hareticos sumerat; quòd Escharifictum 
riflicum panem, cibum digerendum elle dixerit, \& fecelfui obnoxium, Beriramignepartes foverit. Appendix ad Loc praxdict. Io. Bal.

$\checkmark$ ir in divinis Scripturis eruditifinus, \& in fecularibus literis nobiliter doctus ; Philolophus, Rheror, Aftronornus \& Poëta fubtiliffimus, cui (ut ab(que invidic loquar) nec Italia fimilem, nec Germania peperit xqualem. Trithem.

Vir omnium difciplinarum cognicionc abfolutifimus, Rhetor, Poëta, A ftroromus, Philofophus, \& Theolagus, cui nullum parem eo feculo Germania habuerit: Sirntosenenf.

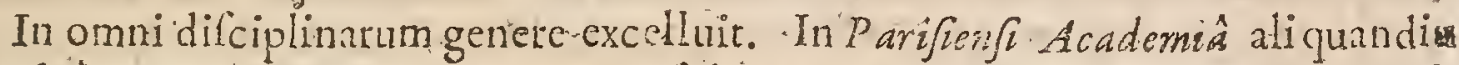
Profefforern egit, \& magno o mamento fuit Doctoribus Scbolaficis. Illyric. Catal. Telt. Veritat.

Dagnentus Rabanus laudibus Sancte Crucis, opere ingenii \& induftrix admirabili, Bartb.lib.29.Adverfar. cap.io.

Poëtarum fui Temporis nullis fecundus. Fincent. Bellovacent. Doctrinal.fui 1ib.I8.cap. 59 .

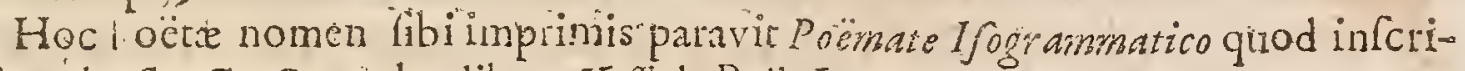
biturde Sancta Crutis laudibus. Vofj. de Poër.Lat.

Rabanus Maurusex Abbate Fuldenf Archicpifcopus Moguntinus, æquè do- Etus ac pius, ligatâ \& folutâ ontione excellens. Artificiofum valdè eft ejus Pö̈mation IJogxermatioum de laudibus Sancte Crucis. 10. Card.Bona.

Sunt qui fcribant rogatu Ludovici Gregorium IV. Santorwm onnizu celebrisatem Kalendis Novembris inftituille, eamque rem magnopere à Rabano Monacho, Theologo infigni, carminibus \& prosa laudatam fuifle. In his enim duobus dicendi generibus vir doôtus, ut illâ maximè tempeltatc, fatis valcbat. Platinis in Vit. Greg. IV.

Emicuit plane Rabanus ut wulgentiffmum'Sidus, cujus qure extant Scriptis tanquam lucis radii exccllentiam demonftrant auctoris; ut \& iildem illuftrata Gerrania glorictur fum haud adeo imparem magnis habuiffe-Doctorena : de quo Tritbemius tradit, ipfun prater Opuscula tam catmine quàm folutâ oram tiune confrepta, Scripiurarr Sandtam à Pincipio ufque ad finem omnem fclicirer explanafle, virum planè omni literarun genere egregiè e.cultum, triumque linguarum, Hebraice, Grack atque Latina peritum, Baron. ad ann.856.

Vertex fui temporis Theologo:um Rabanus. Idemad ann.8+7.

Rabanus Maurus Magnentius, Archiepifcopus Moguntinus, Scriptor feculi

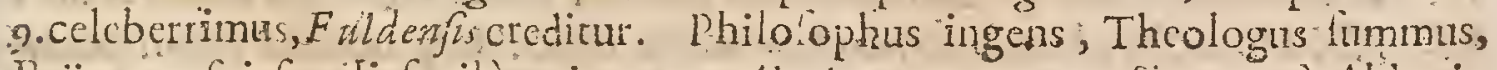
Ioërarum fui foctiti facile princeps. Alcuinopreceptore ufus, primò Abbatix Fuldenflidhibitus eft, cujus reditus cum ncgligentiùs, facris curis ftudiifque intcntior, culaffet, Monachorum importunis querclis cedens, ad Ludovicum Germanie Regem fe contulit, à quo Moguntina Infull ornatus eft antro 847. Synodos complures celebravir, Arbiter negoriorum fui temporis. Senscutix de Orali Manducatione Corporis Chrifitin Coen Domini, jam tum fpargi $\mathrm{Xx} 2$ cuptes 
coptx, acriter reftitit, diligens Augufinifectator, ejufque fententiam Bertramus Presbyter, jufli $C$ arola calvi, fcripto edito defendit:codem tempore \& Iobanne Scoto, de Eucharifíâ dogma Amgufini egregiè tuito, Hofpir.in praf.ad lib. Conc. fub co tamen Godefcalcus Monachus, quod l'radetinationem \& reprobationem dari,ucc Chriftum pio omnibus martuum ellè, ex Sacrâ Scripturâ, doceret, duriter h birus elt. Obiit ann.856. Hofman.

Anno 856.decellit Rabanus Hagnentius Maurus. Hic Albini Flacci auditor fuit, ac ex quarto Conobii Fuldenfts Abbate lextus eft factus Epifcopus: Moguntinus. Preter doctifimas in Scripturam Commentarios, inter alia compotuit Martyrologium, quod Manufcriptum in Monaterio S. Galli apud Helvctios adfervatur, atque exinde ab Henrico Camijo editum eft Tom. vi. Antiq. Lect. Fortalfe tamen non tam Rabanus id compoluit, quàm, multò antè Scriptum,tantummodo adauxit: quomodo, temporibus Othonis I I. Martyrologium Rabani locupletavit Notgerus Balbulus, monachus S. Gall;; qux \& Barthii fufpicio eft lib.33.Adverf.c.8. Liber ejus de Vitâ $M$ arta Magdalene Manulcriptus eft Oxonii in Bibliotheca Magdalenenfi. A it Poffevinus, Camine etiàn confignalie res geftas Lothari, Ludovici, \& C aroli Imp. Sed quo pacto Ludovici gefta panxcrit, qui primo ejus anno colis receptus fuit ? Ac quanto minus tradideris gefta Caroli Calvi, qui polt annos 20. Ludovico fuccellit Y Yitam Rabari tribus: libris complexus elt Trithernins: qui \& defcripfit tranflationem ejus in Saxoniam è Monnafterio S. Albani prope Moguntiam, ubi fuerat fepultus. Volo de Hilt. Lat.

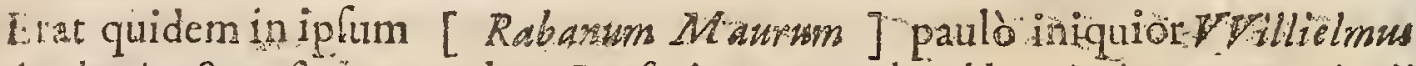
Alalinsbrienfis natter, quod ex Prafatione ejus ad Abbreviationem Amalario liquet, quam ex Bibliothecâ. Lambetbanâ nuper extulit D. Alix ad Tan $P$ ario ficnfems quâ non mod fententiam illius de Eticharistiá tanquam minù fanam, immò periculotam notą, ed \& 1 bros ejus velutiparum uriles traducit; quin 2 ingrgnis cujufdam $p$ tagi infinulat ; quafi duos de Officius Ecclefiaficis libros ex If doro, Angufino, \& Gregorii Paftorali ad verbum tranfcripfifet ; alia quadam Opulculuex I fidoro \& Beda compilallet; wit enim, inguit, vinille buic vitio pe-

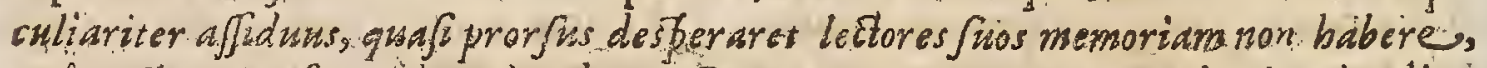
qua pojent ejus furia deprchendere. Quztamen non tam reiveritati quàm literatorum invidia, \& peculiari in Rabanifententiam odio funt afcribenda. Erat quippe Rabamus extra controverfiam inter feculifui doetrinâ claros facilè princ sps. Nec ipfe modò eruditifimus, fed folis inftar, doetrinæ radios undique fparfit. Erat fub eo Fuldenfe Monafterium publica virtutis of erud tionis Schola. CCIXX. Monachas habebat, quos non folum in SS.Scripturis, fed etiam fécularibus literis erudivit. Confuxerunt etiam ad eum aliunde Difcipuli, adeò urex cjus Scholâ prodirent, qui mox ad fummas in Ecclefiâ \& Republicâ dignitates evecti lunt. In fuorum ufum Bibliothecam Fuldenfem primus condidit, librifque ornaram reddidit; quin \& ipfe tor praclara feripfit Volumina, qua fola Biblio he cam infucuere poffent. Gwl.C awe in Hit. Literar.Script. Eccles.

Extant 


\section{CELEBRIORVM AVTHORVM:}

Extant opera ejus v1. Tom:Colon. 2627 . fol

Extat liber de Computo apud Baluz.Mifell.Tom.r.p.i.

Opera inedita : Commentarius in Acta A poftolorum. Extat MS. in Bibliotheca Collegii Baliolengis Oxon. volum.'s1.--Devitâ S. Marid Magdalens liber. Hubetn MS in Collegio Magdaleneng Oxon.vol. 166.... Expolitio de Pafchate \& Agnolpalchali. Extar MS. in Collegio S. Benodidti Cantab. volim. 1 12.-.....-Gloflarium Latino-Theorifcum in tota Biblia Sacra Veteris \&. Novi Tefamenti; cajus exemplar MS: venerandx vetuftatis' in Germaniâ repertum Bibliotheca Crearex intulic Lambecius, ur.iple prodit Comment. lib. 2.pag.46. En forlan alia alibi; de quibus videndus Catalogus., quem exhiber Serarius Rerm Mognntiac. lib.4. pag 6, I. Inter. Opera ejus qua hodic non fuperfunt geavi ( inquit Gul. Cave) Ecclelix difpendio; periit Epiftola ad Egilonem Abbatem Fuldenfem, quâ veram \& orthodoxam de Eucharifiva doctrinam alferuit, \& novam Raichafi fententiam tefutavit. Gul. Caye in Hilt. Literar. Script. Ecclet.

\section{JOANNES SCOTUS ERIGENA.}

Q

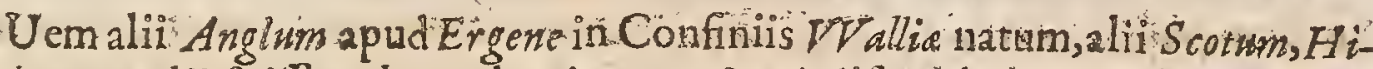
bernum alii fuilte volunt, claruit annor 58 .à difcipul is Monachis liberiùs Clar. A. D: i fe reprehenfis,anno 884 in Conobio $M$ almesburiens acutifque fealpellis interempeus eft. Seripgt malta, atque ex is libros quinque De Natura Divifones imprellos in Angliâ Oxonii anno 168 r. fol.

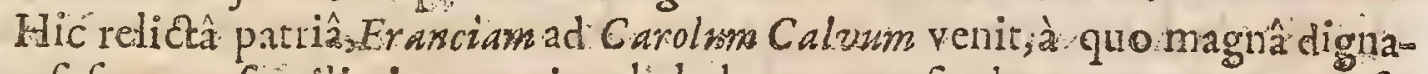
tione fufceptus, faniliarum partium habebatur, tranfigebatque cum co tam feria quarm joca, individuufue comes tam menfa, quàm Cubiculi erat: nec timquam inter eos fuit difidium, quia miraculo fcientix ejus Rex captus, adverfus. Magiftrum quamvis irâ prapoperwm, rec dicto infurgere vellet.Regis ergo rogatu Hierarchin Diony fi de Greco in Latinum, de verboverbum tranftulit quo fitut vix intelligatur Latina, qua volubilitate magis Gracâ quàm pofitione

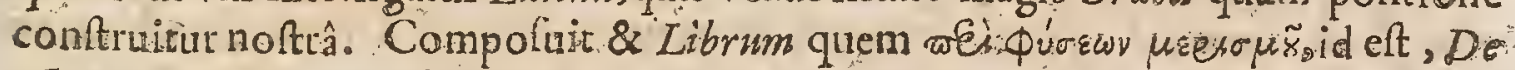
Natur Divijone titulavit, proptei quarundam perplexarum Quaktionum fo. lutionem benè utilem, fi tamen ignofatur ei in quibufdam, quibus à Latino rum tramitedeviavit, dum in Gracos nimium oculos intendit. Fuitmultr lectio. nis \& curiofa, acris fed inelegantis ad Ixterpretandum fcientia ; quod eum ( ut verbis A nafafii Romane Ecclefie Bibliothecarii loquar)non egiffe aliam ob caufam exiftimo, nifi quia cum effet humilis firitunon prafimplit verbi proprietatem deferere; nealiquo modo àfensûs veritate decider̃et. Doêtus ad invidiam, ut Gracorwm pediffequus, qui multa, qux non recipiant aures Latinia, libris fuis afperferit: qux non ignorans quàm invidiofa lectoribus effent, vel fute perfonâ Collocutoris fui, vel fub pallio Gracorum occulebat. Quapropter \& Hareticus putatus, elt, \& fcripfit contra eum quidam Florus. Sunt enim in libio wes 
申úras perplurima; qux multorum aftimatione à fide Cabolica exorbitare vio deancur. Willielm. Malmesbur. ex.Codice Thuaneo MS.

Anno 883.venit in Angliann Magilter Laannes Scotus, vir perficicacis ingenii. -Roger. Wendover in Chronic.

Vir fupra faculi fui captum doctus:Gut: Cavé in Chartoplugl.

Vir perficacis ingeniis multa doctrina. Ondin. de Scriptor.Ecelef.

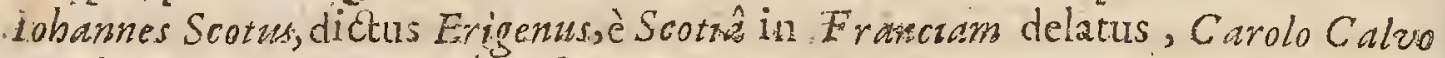
gratus fuit:Vir pufillo corpore, fed ingenio maximus, feftivus ac facctus, unde \& ménix \& cubiculi Imperatorii non raro particeps. Philofophus porro eximius, Theologus confummatus. Eodem tempore, anno 876.quo Raberizus Epifc. Mom guntinus, dil gens Auguftinifeetato $x_{2}$ in libb. de Infitut. Clericorum, figur arum locutionem; in werbis S. Cane agnofchat, a. Bertramo Presbytero, jwfil Caroli de-

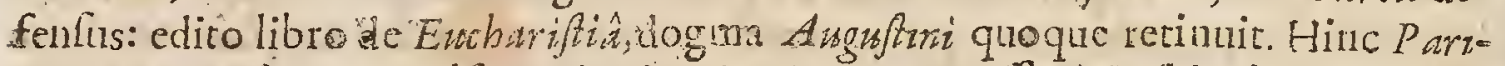
fis, Papx infligatu, pulfus, cum in Angliam pervenilfet, à Difcipulis, inftinctu Monthorum, graphis confoflus eft, Anno 834.4 . Opus ejus aliquor in $C$ onitits damuatum, \& Berengarius, qui ex illo falutarem doctrinam haufit, Rome an.10;9. frib Nicolao 2.in ignem conjicere coactus eft, quafi igni in veritatem jus elfet. Hofrinuth.

Caröus Tmperator ad quem pervenic Bertrami liber de Euchirifia,celebrem notrumpopularem in Aula fua tunc Labebat, cui nomén fobannes Scotzis; qui de codem Argumento librum confcriper \& ineundem finem in quem fcriplerat alter. Viriste ob minimè vulgarem ejus exuditionem, in Anglia, ubi magne apud Alfredum Regem in pretic tuit, fobannis Sapientis cogno nen adeptus eft: Er haud ita pridem in Ecclefu Rounanx artyrologizo locum occupavit, quamvis illinchodic ejectus fit. Reverâ cum ab Ecclefia Lugdunenf \& aliis codem tempore reprehenfum legimus, ob upiniones qualdmab iplo evilgatas circa Dei Pracognitionean \& Pradestinationern ante conditum Orbem, circulibermm hominis Arbitriurn, hujufquecum Dei Gratia in prefenti Seculo Concurfum. \& circa ganus Punitionis Reproborum Hominum \& Angelorum, in furtuseculo: Sed nufquam nobis contat lunc de Sacramerio librum fuille diannatum ante Lanfranci. tempora:Qui primus Anglicanim Ecclefian hoc comuptr boAtrinx de Carnati livefentia fermento deincepsinfecito. Eò urque Quxfio hæc -de Reali Prafentia problematica femper fuerat : \& perinde liberum erat cuique Rertrazin aut Johannis Seoti hac in parte Doctinum fectani, ac illam Pafcha fir Raberti, qux tempore folutionis Saibanes, fuperionevalit. Epilcopus Vjferius, Refponfonead Jefuit. Provocatione pag 76.77 .

Foannes dictus Erigena Monachus, in Divints Scripturis dostus, in difciplinâ franlarium Literarum erudiciffmu, Graço \& Latino ad plenum infuetus eloquio,ingenio fubrilis, fermone compofitus. Trithern.

Hoc viro eximio, tanquam Geniali quodam fidere, adornabat Alphredus Academiam fuam Oxoaii inchoatam. Erat ille primus qui publicèillic bonas artes profitebatur. Iofn. Balous.

Qua vero Balazs de hujus Patre Patricio, de Peregrinatione, quâ Athenas 
Aiberas petiit, de mirâin linguis Orientalibus peritià fcripfrt, nullam apud me fidem imperrant. Ediror Iean. Scot. Erigen. Lib. 5. de Divir Natusrx, fol. Oxor. $168 \%$.

\section{PHOTIUS.}

Ancti Tharafi P. CP. ex Corore nepos, vir doctiflimus, Imperatori $S$ primum a Sectetis, Protofparharius, atque urbis Senator, Eunuchus 2 Laicus, fedem CP. ejecto per Bardam Cafarem S. Ignatio viro fanctifimo. Clar.A.D. DCCCIVIST: invafit die zs.Decembris 858.vel uzt alii numerare malunt, omifsà duntaxat dietum ogdoade ut plenior computatio videatur a five ex familiari aliàs plerifque Romanis more, anno 899.tenuitque per fummam nefas ufque ad annum 869. quo in Synoda viIr. Oecumenicâ $C P$. celebrata reftituto S. Ignatio expullus elt deinde poft ejufdem Ignatii. mortem refticutus à bafflio cricacedone anno 878: perfeveravit thronum illum fanctiftmum foedare ufifuc ad annum 885 . quo d Leone Sapiente Bafliti filio iterum ejectus in lecellit Monafterii Acormetarum perilfie dicitur : Scd quo anno, quave die ignoratur. Phil. Labó. de Script.Ecclef:

Scripta ejus hae funt:Bibliorheca----Epiftolx---- Nomocanon Títulis XIY: compreherfus, hoc eft, Canones Apoftolorm Conciliorumque veterum cum le gibus Imp. Romanorum collati, 2 in unum digefti volumen---Adea Conciliorum feprem. Generalium in Epitomen-redacta---Sermo in Natalcm B. MHa

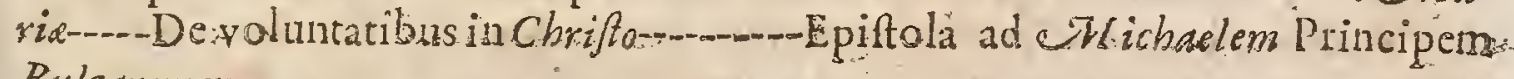
Bulgarasum:

Tandem Photitum Protofpatharium \& primum à Secreciss, Ratriarcham urbis: Regix defignant, heminem fanè minimè obfcurum \& \& $^{*}$ gुnobilem, fed claris \& illuitribus orimdum natalibus s. Irumque civilitim \& politicatum ufut prudeiz" tiaque \& fcientiâ clariftimumo... Grammaticx enim literaturx, \& carminis pansgcndi, dicendique laude, qự \& Philofophix \& Medicina, \& omnium propè liberalium difciplinarum externarum ftudio cognitioneque tantoperè flòrebatituts zvi fui facilè princeps haberetur, imò \& cum Veteribus certare poffet. Omnia quippe in illo concurrerant, aptitudo quadam \& naturx vis ac felicitas : , ftudium,opes, quibus librorum omnium copiam fibi comparabat, \&juod præe cunctis, glorie laudifque cupido; qua incenfus totas noctes ut lectioni affiduè va-

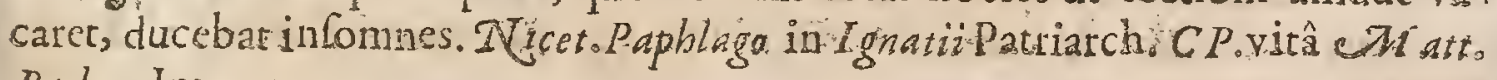
Radero Interpr.

Fhotiz Pleudopatriarchæ Confantinopolitani Bibliotheca, infinitam ejus. Téetionem, \& acerrimum judicium demonftrat: Sed hic homo perditus fuit, \& $\mathrm{pr}$. Mus auctor Schifmatis Grecorum: Ingsnii vafri, verfipellis, \& ambitiofi. foano Gard. Bona.

Photius eruditiflimus \& incredibiti lectione anctor, in co prafertim opere guod 
quod Bibliotbecam de libris à fe lectis nominavit, in quo tam accuratè, tam acri ingenio, tam confidcratè, tam doctè, tam diftinot̀̀, tam liberè de tantamulcitudine \& varietate librorum judicium facit, ut nihil animadverfone digntm pretermifffe videatur. Ita ferè cujufque libri argumentum, \& genus fyli,ac doctrnx difeernit \& notar, ut qui fursmas illas lcyat, totos libros \& ingenia anctormem noffe fibi videatur. Quis iginu noltrxatatis fe cum Plotio conferre audeat, five in-

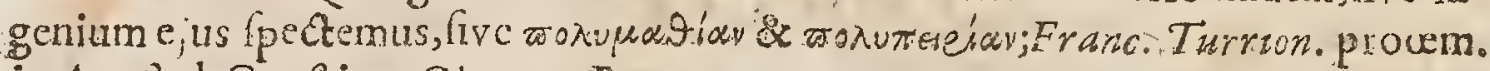
in Apoitol. Conftitut.Clement.Roman.

Photiz Bubliothecans laudat Andreas Schottus hife verbis:Non ex aliorum Sermone, vel obiter, \& tanquam per traniennam infpecto Opere, ut ferèhoc feculo: de toto opere judicium fibi ferendum cxiltimabat, fed a capitead catcen perleeto, libere judicat Cenfor of: Criticus gravifinus, fummi \& ingenii \& judicii de Scrptoribus ducentis amplius \& feptuaginta; Philologis, Poetis, Hiftoricis, Oratoribus, Pbilofophis \& Theologis : qui maximam partem, temporum ne.injurià, an $M$ ajonz incuriâ perierunt. Et quidem de ltyli charactere, fcriptorum numero, \&

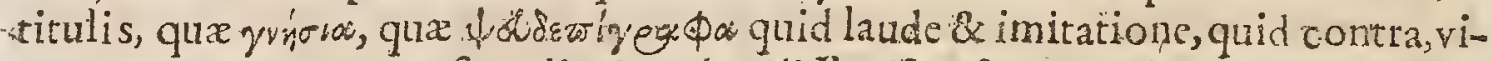
euperatione dignum in fingulis deprehendillet, fune fuco \& odio, more majorum pronunciat. Deni jue quâ quifique tempeftate Horuerit, cretera ue, longum effer enim ire per fingugh, audacter dijudicat. And.Scot.in Notad Chreftomaih. Procli.

Certè inter paucosille Scriptor ( Photins) meretur: Qui folus tot clarifimorum ingeniorum monumenta a fato eripuit: toto dico fato, \& laltem nomina, \& Scriptorum velut membra Cervavit. Quàm multosille legit, ex is clegit, \&, ut ficloquar, defloravit, quos nolfe nobis aliter nouefer ? Elacris prophrnis:; tractatoribus, Historicis, Oratoribus, Pö̈tis; \& nihil eft in Greca onni lireratmrà, aut, ut veriùs dicamo libraria, quod ille vir non libâtrit. Lipf. MI arc. Velfero.

Jtiam, mi Haefbeli, in Photii editione exomandâa te juvare pollem. Librum quidem totum in duos tomos diftinctum, manu Henrici Stephanz fcriptum, olim legi. Opus varium. Ex cujus editione incertum majorneredundatura fit in te, gloria, an in alios utilitas. Certè tam cgregium fcriptum non alio sditore dignum erat unam te, qui tot bonorum auctorum editione, \& eruditionem tuam \& propenium in literas animum teitari volueris. Iof.Scaig. David. Hoefoliol.

Photius acemimo vir ingenio perficacifimogue 2 in omni genere doctinarumpreflantifinus Scriproi. Fuller. Mifcellan.1.2.c.3.

Pbotius acerimi \& exquiftinimi judicii vir. Tanaguil. Faber 1. . Epift. ep. 43 .

Addu his temporibus editam, cum nullâ al â conferendam, Photii Patriarcbe Bibliothecam, in quâa vir ille Magnus Sentent am fuam de Scriptorum Ecclefaffi-

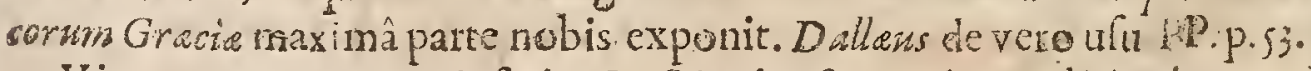

Vir,ut cætera taccam, infnita Lect onis, ftupendie eruditionis, omium non

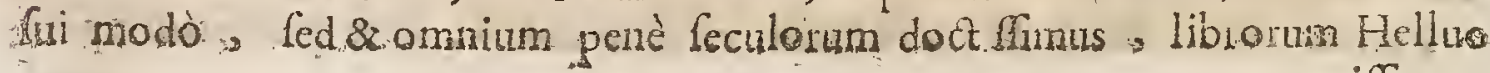
voracilnnus, 


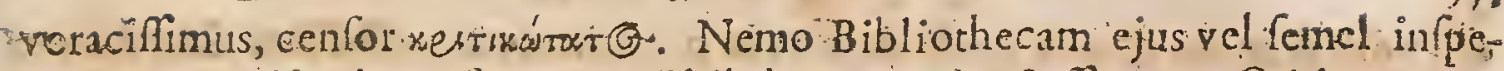
xerit, quin Hiftoricum fummum, Philologum inttuetifimum, Criticum perfpicacifimum ftatim dep:ehendet. Teftanturaccuratan Juris peritian to foleriia ad Interregationes propolitas Refponfa; prudentiam politicam liber $D_{\text {e }}$ Officio Principis, ut de Rebus Geftis nil dicam. Legantur cjus Epistola; videbis iplam Philofophica, Medica, Mathematica; Theologica, ad amurim tenuilfe. Verùm id apud omnes in confeflo eft, \& forté ílus ct Philippres Brietius. qui Photium literis frcularibus clarum, divinarum fuille ignarum affirma vit, reclamante totâ D. Ctorum caveâ, totque ejus Scriptis fummâ Sacrarum Litenam, \& Rei Theologica peritîn refertillimis:Gul. Cave in Hilt.Literar.

- Vides quàmmaláfide \& veiba 7 o ephi \& felitentiam Photiu recitet. Arque hoc non femel diligens lector, ireo preftantifimo Scriptore fi attendat, oblervabit. Solet enimnonamquam pugnantes invicem fententias diverforum alsetorumyni alicui tribuere, \&.integras narationes hoc pacto confundere. I Jasc. Cafaub.exescit.x.ad Baron.num.j.p. 3 .

Tumuluarium quidem Opts, ne quid tacitumitate prevaricari videar, Phow tianam hanc bibliotbecam extitile hec indicant:- eadem lepè repetita, hiatus interdum, atgue hiulca loca, iteglectus ftylus, rejecta denique in alteram Operis partem, libroum, quos jam recenfuerat, excerpta longio:a; prorlus ut credam Foutrum memori. luâ juvandâ potius, quàm ut cateris promifcuè pro effet, hoc opus confarcinallé, aut certè poftremam manum non adjecilfé, limâ nitidiori Opere futuro. Aulicis nimirum negotis, atque ambitione tranfverfim raptum, mentem aliò, aliò aures divifre. Andr. Schott. prefat. ad Phot. Biblioth.

Dom. Valois primogenitus probare decreverat hujus Bibliothecx plufquan guartam partem Pbotiz non clle, $P$ aul. olomef.in Opufc.p.97.

Onnibus, qui ante xtatem illam aut fuperiores extiterunt, palmam Patriarcha Photizs prarupuit. Quirde omnibus, imprimis autem fummis maximilque Chrifzanis fumul Prophanifque autorihus, Philofophis, Hiftoricis, Poëris, Oratoribus, fed naximè Theologis, ità accurntế ac exquifitè judicat, "ur unus eruditione variâ, cum omnibus, ques legerat, legendi diligentia, cum inaximis, qui ante exticerant, commirrus videatur: tam diffufo in his omnibus judic o atque accurato, ut non tantùm fingula, de quibus juđicavit, penetraffe, fed \&omnia, quize cciri pollunt maxime fucceltu didicilfe videatur; tanta autem fide, ut ron Criticum in Scripto, fed jumatum Judicem, in luce hominum de frngulis fentenriam pronunciace exiftimes. In quo uno homine ad univerfum lefe likerartum orbem circulamque Critice diffudit : ut, qui nihil in Grammaticâ, Rhetoricâ. nihil in mineribus feientiis ac attibus, Theologis ignofcat:; opiniones autem parum integras ac fanas, ut Theologus, profcribat; fic in omnibus ve.fatus parirer atque ablolutus, ut nec difiplinam ullam, neque partem ullam Critices inractam fibi magnus vir relinquat. Nam nec earn, quam emendat precermittit: gui noanulla, etiam in facris liccris à Scribis aut Hareticis cortupta eo tempore 
oflendir: \& in ea, qux ex genio \& ulu, de proprietate \& perfellóne fingulerm

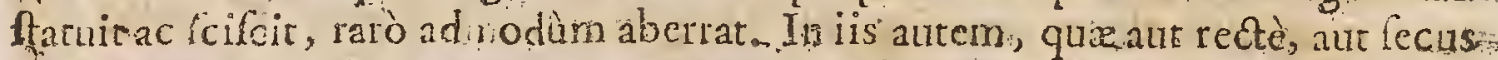
ab alis dicuntur, partem operis pracipuam confumfit. Dan. Heinf prolegom .in: Ariflurch.

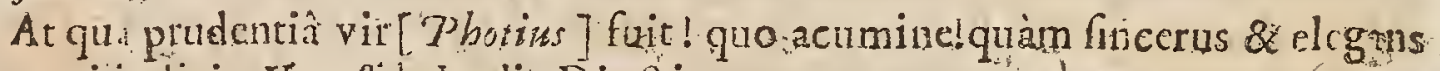
in omni judicio. Macaf.de Ludic. Dio tine,p 14 ?

De cujus [Pborit] infigni enditione atque exactoin cenfendis libris juditcio Catbolici aquè ac Heretici confcutiunt, Petr. Hallois de Diony. Areop. vitâ, quxft.1\%.

Pbotius latriarcha, in quô dubium, majorne leatio,an acrius judicium. Dempfto

Erudiriffmus Scriptor \& exactiffimi judicii cricicus photius. Ifaac. Ca aub. pronm. Notin Gregor.Ny/f.Epiftad Eustathiam.

Photium [ Bardas ] infignem doctrinât virum, cujus Bibliothecat thefaumm prabet adhuc prifce eruditionis, primarium tunc à fecretis, evexit in thronum. Io.Cluver. in Hift. Epitome, de Imp. Michaellit. iebus.

Photium acerbis paffin Bellarminus, Baronins, Labbeus s \& plerique omnes. Pontificii, ve bis dicteriifque petunt; Richardus Montacutius verò, Narvicenfis. in Anglia Epicopus, ex inftituto eum defendit:

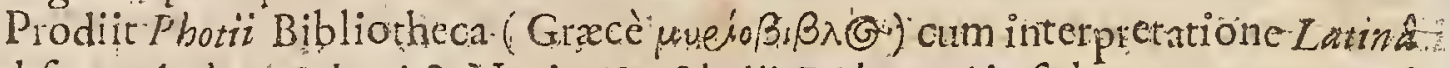

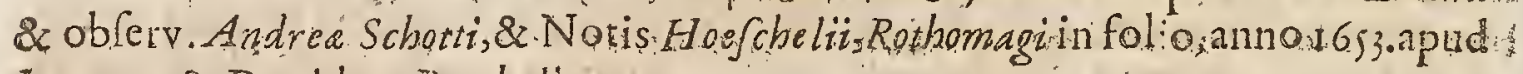
Ioannem \& Duviden Berthelinos.

Etymologicum ejus Manufcriptum fe apud Marcuardum Gudium vidife af w firmat Ez.Spanhemins de Numifn.p.358.

Epifolx CCXLVIII, prodierunt Grace cum interpretatione \& notis Ricbare. di Montacuiti, Eondini 6.5 i. fol.

Prodilit Nornocanon frve jus Pontificium Grace \& Latine, cum Commentario Balfarnonis, cujus reliqua feripta adjuneta funt parifis an 16,20 . in fol.

\section{ANA A TAS I US.}

Mar.A.D.

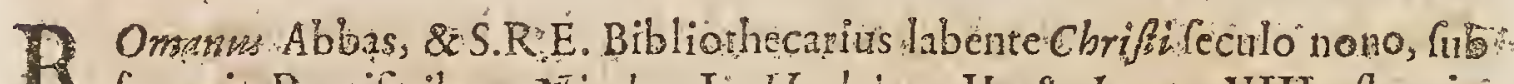
$\rightarrow 0 \operatorname{ccc} \times x_{0}$

ac fi vera elt Cardinalis Baronii Chronologia, ufqüe nd annum fermè 836 . vitam perduxi:quo verò asno obierit, ņemo affirmat. Errat $V_{0}$ ffús, \& fi qui alii- cum Anafiafio Presbytero Cardinale S.Marcelli, \& Biblicathecario Gregorii IV. Papx confundunt, qui à Leowe IV in Synodo Romana anno \&5. eft exalthoratus, è quòd courra Ganones Ecclefiam fiam quinquennio deferuifeto Fbil.Labb:de Scripr.Ecclef.

Multa fcripfut inter alia vitas Pôntifiçum Roman. quarum ultima ef Nicolai I. Compofuit.Mula de Grecis Latina fecit.

Anafiafuze Apofolicie Bibliothece cuftos \& inftaurator fagaciffimus, in Divinis Scripturis eruditus, \& in fecularibus literis nobiliter do Sus, Greco \& Latino multim peritus eloquio. - Trithem de Script. Ecclef? 
In Anafáfio (dicit nefcio quis Moguntinus haud indoctus) habemus fincece \& fideliter, exclufo omni veiborum fuco, défriptas centum \& novem RomaForum Pontificum vitas: hoc elt, quotquor à B.Petro Apoffolo, ufque ad anu. Dom. fere feptuagefimum fupta octingcncefimun Romanarn Cathedrars obisucrunt: vizà B. l'etro ulque ad Nicolaums I.qui anno S67.è vivis excellit. Whear.in Method.leg.Hift. Ecclef.Sect.41.

A naftafus in pretio erat Romane Ecclefie Bibliothecarius, vir fanè ita utraque linguâ doctus, ù è Greco in Lainum Peptimam univerfalem Synodur, \& Hierarchiam Diony fi, \& vitas multorum Sanctorum Caroli[Calvi]yratiâ in Latinuir, - eleganter \& doczè tranlulerit. Platin. in Ican.IX.

Anaftajus Bibliochecains, et rudi ftylo,fideliffinè tamen reium geltarum H ftoriam enarravit,immo in ţerum fui tempo is narrationc, nullum fidcliorem \& meliorem feriptorem habemus, apud quem magis cum fimplicitate veritas, quam cum fucomendaciavaluerunt. Baron.ad Am 752.84799.

Anaftatus S.R.E.Bibliothecarius, vin pio eorum ftatu Gracis \& Latinis liteis eruditas \& Theophane I Sauro, \& Nicephoro Patriarcha Conftantinopoltano Gracus Scriptoribus, inepto, ac planè barbare ftylo, verùm optimâ fide, \& diligentiâtHiforian deceptam, Latinéconfcriplit à Cbrifi natali ad Michaclem, ieniorem cognomine Rangales Conszantinopolitanumimperatorem: Nobis autem valde charus effe debet, quodea, qurnec meliores; nec pejores Scriptores habebant; literarum monmentis rradiderit. Ant.poferin Bibliot.fclect.

Anafafius Abbas, \& Biblioth carius Apostolicus Grace \& Lainè doctus;in Vitis Ponificurn plura lunt vocabula illius atatis quâ vixit, circa finem Lxculi noni, tunc omnitus cognira, nunc obfcura \& difficilia. Loan. Card. Bona.

Analtafus.-Vir erat pro evi lui genio nequaquam indoctus; qui utriulque

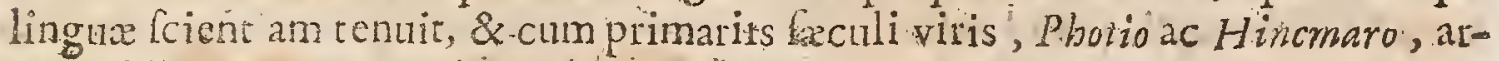
atam fatis amicitian coluit: Gul.Cave in Hittiteras.

Apud Anastaf frum multa de Sergio Papâ 11 defiderari videntur; fiquidem nulla ibi de clade zanta per Sarracenos illarâ mentio, cùm depredati funt Baflicas Apoftolorm: que quidcm haud potuerant à quov is etiam negligente fcriptore pretermitti, cujus cladis tantum eft mentio obiter facta apud Anaftafum ipfum in Leone, qui Sergiohuic fucceflit. Baron.ad An.Cbrift. 47 .

Multa ille [Anastafus Bibliothecarius ] Graecorum volumina Latinè defcriphit, at quamis non wis róds, fed bonà tamen fide fenfun retulife fe ipfe fcribat, in quibufdam rihilomin s boni interpretis numeros omnes abfolvit; \& tantâ quidem religione, ut præ fidi interprecis laude, puri \& cafti fermonis decus fir afo pernarus, \& vocabula Cethigis non exandica fingere aufus fit : juxta fandionem Hyeronimi, qui rebus novis nova fingere nomina interptetem jubet. Hut.. de Clar. Interpret.

Libri de Vis is. Pontifocum priorem partem Anaftafum parentem non agnolcere, inde probat Labbeus, qu d viderat MS.codicem optime norx rempore Caroiti Magni exaratum, in quo Vite 11 lix Damajo jam tum tribuebantur, antequam aut narus ellet Anastafins, aut falcem ex primis infantix crepundis cmerffet. 
Philip. Labb. de Script. Ecclef. Tom. Is p. 252.

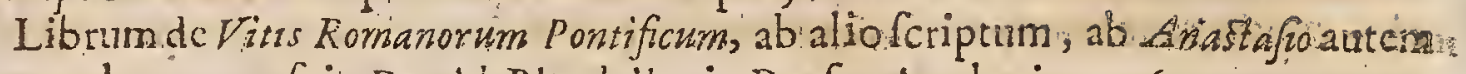
interpolatum, cenfuit David Blondellus in Prefat. Apologix p.2.6.

Extat Concilium Nicenum 11. ab Anaflafio Latine verlum, in Concil Tom.7o: pag. 29.

Extat Concilium Generale S. partim è Graco verfum, partim multis de fuo additis auctum ( hric cnim.Synodo: ipre prafens interfuit ) in: Concil. Tom. 3. pag $96 \mathrm{I}$.

Extat. Hifforia Ecclefaftica \& Vite P.ontificum, Parifis 1649 .in Folio.

Anastafiz: Collectane de Hiforiâ Monothelitarum edidic Sirmondus $P$ arijus $1620.8^{\circ}$.8 Biblioth.PD, Tom.12 p.831. Paffonem S. Demetrii. Mabillon.Anales.”. Tom.I.pag. 650 .

\section{$\operatorname{VEC} U \mathrm{M} E \mathrm{~N}$ IUS}

Clar A.D. C Criptoradmodtm incertx ataris, de quo altum apud veteres filèntium : ît accexc. $\int$ modo conftat, polt annum $8=0$ claruilfe. Olympidioro illum hîc adjungir. mus ad annum $920^{\circ}$ donec veram ejus atatem expifcasi liceat. Gul: Caue Chastophyl. Ecclef.

Oecumenius Gracus autor, valdè doedus, in explicandis Dovinis Seripturis bre-.. vis, apertus, \& clcgans, atque in veterum Commentariis evolvendisaffiduè verfar tus, collegit foletti curạa ex Dict pratantifimarum Grace Ecclefu Doctorum: nobiles A nunotationum Commentarios in Ostatestbram;uos ipfe in Commentariis fuis in Epiftolam ad Hebroos Capite fexto: fe fcripflfe teltatur. Collegit: etiam perfinili judultia in totum Novun Irfarmentum Catenam explanationum.Sixt. Senenf:1.4.Bibl ath:

Oecumaniz in omnes D. $p$ anli Epiffolas abfolutiflimi Commentari, cùm ex. aliis probatiffmis quibufque Cracis. Theologisi, rum pracipuè ex aureo illo. Chryfoflomo, divina brequtate colledi:ita utpolt hunc fupenvacaneus videri Theophylactss polit. Gefner.in Bibliorh.

Fronto Ducsus nolter apud Pofferinum in $f$ ppratat cenfebat in Commentariis feu Catenis Decumensi, in S. Paulum quxdam fuife à polteriore aliquo fcrptore admixta ; unde ridiculè promore concludere vifus eft Rober-

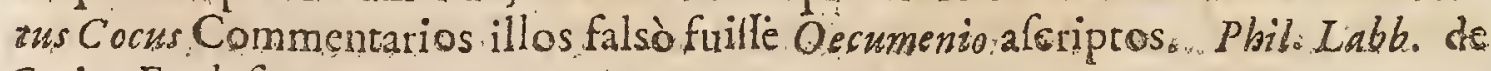
Script.Ecclee.

In Biblizotheca Patrum extat Catena in Epiftolam S. Pauli ad Romanos, fub nomine Theoduli presbytri Coles yria; qux tota ferè excerpta eft ex Oecumeniz: Caterâ. Aubert. Mircus in Auctar. de Script.Ecclef.

Plurima excerpfic Oecumenius ex C bryfoftomo, cujus tamen nomentunc folum addi curavit, quum ejus verba recenferet:nowautem cum ipfus fententiam conractioribus vebis refertet. Iopn. Henter. in Prafat ad Oecum. Comment. in. Act.Aport.\&

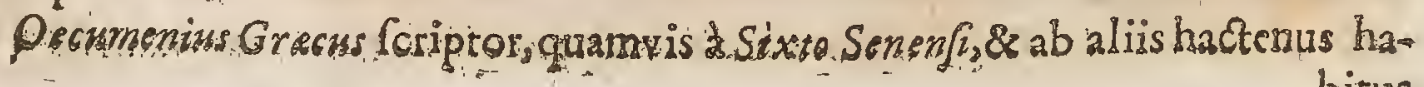




\section{CELEBRIORVM AVTHORVM:}

binus fit Auctor Scholioum and Epifolas D. Pauli, rectètamen mihi fcripfit Eronto Drickus nofter in Antiquis Grecis Parribus accaratus obleryator, ea non effe Oecumenii, nifi ex parte; neque vero Auctorem illius $C$ atena tan antiquum frilfe. Neque enin folet Auctor. ejus Catene aliquid fum interferere, nif rariffims. Ant. Poffev. Apparat:Sac:

Opera ejus Grecè \& Latine, edita Parifiss, duobus Vol.Anno 163\%r. Quibus adjuncta, qua Arete. Epilc. Cesar.in. Cappadocia .rribuuntur. Cuncta hac vertir Iornnes Hentenius, nempe Catenas in AEta Apofolorum; Commentarios in Epifolas S.Pauli: ịa Epiftolam S. Iacobijaliafque.Canonicas.

\section{AV. I E NNA yel ABOALI ABINSCENI...}

S Ub Conrado.2. \& Henrico 3. cläruit In Ballech oppidanatus fuit Patre Me- Crar.A.D.: $S$ dicorinfigni,anno. Hegira 37 - hoc eft anno Chrtfti 992. Vixit annos 58. ut MXI:mortuus fit anno CMAubanmedis 28 . five Christi rago. Atque hac cr gnolcere eft ex vitâ CAvicenne, quam unus ex ejus.d. fcipulis, \& iple eA rabs, icripfit. Quare toto fecula decepti funt, fecundìm quos (in iis eft $N$ eandor Bressenfis) Avicenna Cordube Averrbö̈n, Alexandrie andivit Rbifm in Adolefcentiầ. Multa quoque dè hoc ipfonarrant, mt qui rotx ab. Averroo fuit, impofitus. Ves rùm quàm hrecfint fallá, adparet ex fupradictis, \& præcipuè ex Scripto Leonis Africani de doctis Arabibus, ubi utriufque rita fus èdefcribitur. Voff. de Philom foph.c. I 4 ;..

Umnem mediciinam ordinie optimo complexus eft, ita ur hầc parte etiam exo fuperet Galenwm. Idem ibid.

Avicenna primus artem confcripfit, ccim anteà Galenus fparfim per occafio nem de diverfis Argumentis pro re natâ. differuiffet. Henr. Savil. Lectur; 2 , ì Euclid.

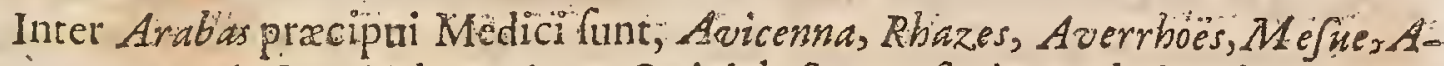
venzoar, Serapio \& Alfabaravius. Qui delectantur fusâ \& polydxdalâ yarietate. remediorum: Avicennam amplectantur: cuncta enim hujus ævi remedia ex eo manant, Eleurn.differtat. de studio Medic.

Avicenna, Medicus \& Philofophins infignis. Nondem decenni major literas humaniores \& quicquid fcientiarum ad Alcorani intellectum pertinet; calluife

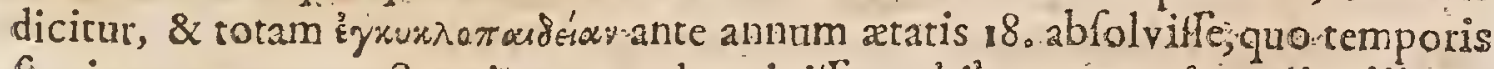
Patio nec unam noctem integram dormiviffe perhibetur anec interdiu aliis rebus quàm lectioni vacâfé; cùm aliquid illi intellectu difficile occurreret, ad remplum; nodi iftius folitionem à Deo precibus impetraturus, fe conferre foljnns.Edvr.Pocock. in Specim.Hift. Arab.p.,362.

De Religione fufpectns eft, quòd de rebus ad alteram vizam fpectantibus phislofophicè argutandi eafque aliter ac fonane verba interpretandi audaciam fibà Cumpferit: Ita, fi benè memini, à docto apud illos quodam, cui ejus iftis de rebus fententix mentionem injeci, refponfum accepi. Idom in Noris Mifcell. ad Portam Mofis c. 7 .

$$
\text { Yy } 3 \text {. }
$$


Multa in Philofophia \& Medicinâ compoluit. Ariftoteli ita addietus fuit, ute quidam referảnt, eum totam Ariftotelis Metaphyficam memoriâ tenuiffe. KGnig. in Biblioth.

Avicenna fingulari fcientiû̀ vir \& ingenio exactiflino, \& fubacto imprimis, id eft, ulu, auditione, lectione, ac literis perpolito at que culto, Rhodigin. 1.2. cap: 9 :

Cafar Scaliger Divinum virum appellat Comment. in primum Theophraft. Hiftllant.

I wius Scaliger Avicenna lectionem Medicis om ibus tanquam perneceffariam commendabat, nec quenquam in mangum medicumevadere polfe cxilimabat, qui tam doctum opiz non legilfet. Scatigerana r. p.18.

Fuit Avicenna vir lumni ingenii, magnus Philolophus, excellens Medicus, \& fummus apud fios Theólogus. Quum itaque tanto ingenio, tantà Phlóophiz cognitione, tant denique peritia Artis inftuctus elfet;rem hactenus Gracis ip fs intentatam aggrelfus cit. integram arten Wedicam in unum Sy/terna redigere conacus. Quanquam enim non negaveris, multa in illo Opere Canonis occurrere, qux corredionem mereantur; fatendum tamen eft, elle opus admiratione dignum. Leonardus fanè Funbuss, \& alii eA raburn. Wedicormo hoftes eximium illud opus damnando nihil egcrunt. Sebafi.Scheffer. Tntroduct. in Art. Medic.p.63.

Etri penè infuiti funt viri, qui Avicennam maximis encomilsaffecerunt, ta- men quàmabjectè quidam de eo fenferint, oftendir Zaannis $M$ anardi de cojudi-

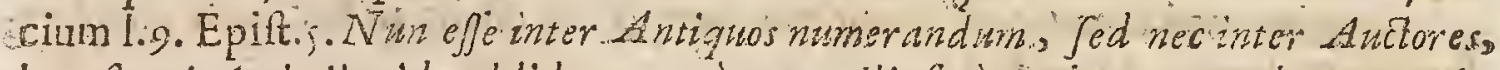
boc eft, qui Artialicuid addiderunt, curn ex alivs fere verbum ex verbo acceperit,

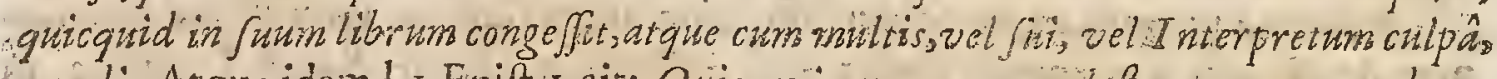
amendis. Atque idem 1. I. Epilt.I.ait: Quis avicennarn cen celeffe nismen non adora-

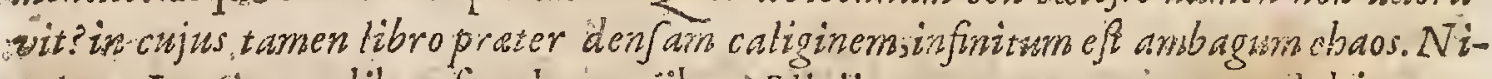
colaus Leonicenus libro fuo de erröibus' Pliviz, tyrannum vocare nou dubitat, variofque ei \& novios objectatertores Nec minus alii.infuliant.

Averrois doctina, \& Netaphyfica Avicennéminia denique illa Arabicamihi videntur refipere deliramenta Alcorani: nihil fieri poteft illis infulfus figidiufque. Lud.Viv l.s.de Cauf. Corrupt.Att.

Huic debenus cocturam Sacchari;item Caffam fiftularem, myrobalanum, tamarndam \& thabarbarum.

Natus in Arábia, vel Perfẩ, in villẩ Aufrene ad Bucharam, Patre Fali.Anno xtatis decimo tam luculentum ingemi fpecimen leceptoribus dedit, ut miraculo ellet: quippe Alchoranim; qui liber $M$ ahbonebi leges contincr,memoriâ tencbat. Nihil legere folitus fuit, quod non excerperet. Curavit aliquando adhucjuvenis Reois $N$ uch filium, fruftra frortum medicorum operam expertum. Idco ad regiam $B$ : Tio hecamadmilus, majori contentione operam ftudiis dedito Et cùm reliquim tempus difceldo abfunpfifet, anno xatis 27 . ad fcribendum animum appulit. Inplerifque $M$ efuem imitarus eft. Malus interdura fuit Evangelíta, quia fapè aberrat. Sed robufto corpore, \& valetudine pro perrimá uti 
potuiffet, nif nimià Veneris intemperantiâ \& alfiduâ libidine, in quam naturâ maximè pronus erat, eam labefactalfet. Floruit fub Conrado II I. Imperatore A.C. 1:45. vel, fecundum alios, fub Friderico Barbarofsâ. A.C. II6s. obiitanno xtatis fua 58 . Cepultus eft in civitate Chamedan. Ioan. Anton vander Linden de Scripr. Medic.

Qurdam Avicenne opera Latinè reddidit \& Scholiis illuftrata evulgavit Vopifcus Forituatus Plempius Medicus Lovanienfss. Lovanii in fol. 16,8 .

Extant Canonis Medrcine lib.j-Arabice: addita funt Oupfcula Logica, Phyg6a, \& Metaphyfica. Ronne in Typohraphià Mediceâ anno Ij93.in fol.

\section{MICHAE LA D S L L US.}

7. Atria Conftantinopolitarus nobiliprofapia onindas Micbaclis Duca Impe-Clar.A.D. rato is Preceptor, \& Senator CP. chruit anno 050 . tandem dignitatibus ML. exutus, habirum Monachalem induit.Latinorum in dogmate de Proceflone HoAtis ipfo fatente Allatio: feripfrepenè infinita, Philóophica, Mathematica, Me-dica, Hillorica, Theologica, guorum caralogum fatis amplum tam editorum

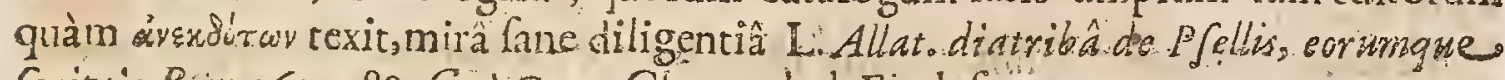
Scriptis Rom.1634.80. Gul.Cave Chartophyl.Ecclef.

Michael P fellus Philofophis Peripateticus, \&Medicus Gracus eruditus \& clarus \& in Theologia haud vulgaris. Iön. Anton. vander Linden. de Script. Mcd:

Deinde criam Michaeli P fello [ Toannes Tialus Pbilofophus] dedit operam illi latè inclyto, homini, non tam curâ Magiftrorum fapientum, quorum limina non multum triverat; quàm indolis prettantiâ \& velocitate mentis divinitus adjutx ( id videlicer impetrantibus per crebras vigilias contintatis matris ejus precibussin tomplo Cyrijad Sanetam Imaginem Dei Matris fundrolitis)in eminentifimum fapicntix atque enuditionis omnis apicem evceto; quippe qui ad Gracorum literas atque artes omnes, quas perfecte norat $C$ baldeorum Difciplinas adjunxerst; famanque merucrat doctifimi omnium, qui tunc ellent. Anna (omRena lib.s. Alexiados.

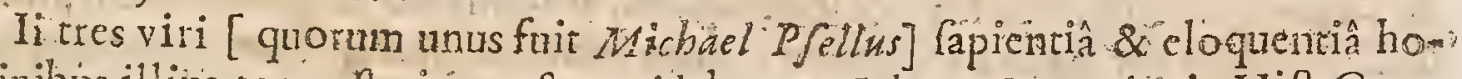
minibus illius tempetatis praftare videbantum. Iobann.C uropalat in Hift.Com pend.

Sapientifimus Pfellus vocatur MAich.Glyca in Annal.part.2.

Michae! fapientifimus P. Sellus, Thilc fophorum Princeps dicitur I0.Zona. in * Annal. Tom.in.

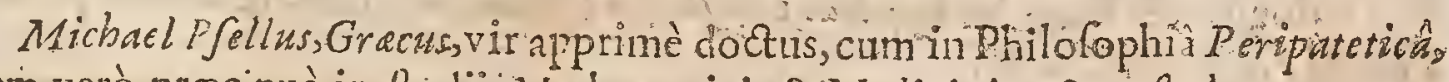
tùm verò prac puè in ftudiis Mathematicis \& Medicinâ. Quenftedt.

Michael P fellus, vir \& eruditione \& fam

Hujus quoque Confantini Duce tempore, vir cum in omnium libcralium Ar-s. tium Scientiâ, fed \& peregrinarum, floriit Michael P felliss, cujus innumerabiles 
pene libri curioforum \& Itudioforum manibus teruntur. Lil. Greg. Gyrald. de Poër.Dialog.s.

Vir planè admiradus, \& qui omes fere fccali fui cruditos dicendi copia ingenii acumine, doctrina profund tate, longo poft fe interw allo reliquit. Gul. Cave in Hift. literar. Scripr. Ecclef.

Aufim dicere, neminem eâ, vel fublequente ztate, Gracè vel invenilfe acrius, vel ordinalfe aptiús, vel tocutum eloquentiùs, vel profundiùs res, pertraccallé. Nulla fuit fcientia , quam iple vel notis non illuftrawerit, vel compendio non centaveri, vel optima Methodo non expedierit. Leo Allatur in Diätribà quan edidir de Pfellis, corumque foriptis, 1.42.

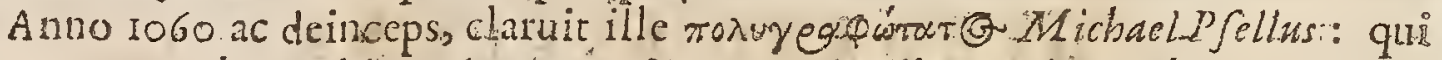
inter catera reliquit I bros dues, Confantino Duce dicatos, de VrEtús Ratione, deque Facultatilus ofucci-qualitate elementorum. Latine vertit Georgins. Valla Excudit Baflew Andr.Cratander anno is 29. Peffrmè trandatum efre, conquericur Litines Gyraddus:quia proptereà non multùm fuir adjutus eâ interpretatione, cùm verteret Simeonem Sethum, Antiochenum magiftum, de Cibariorum faculta-

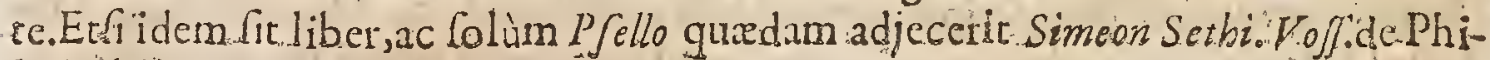
lo.ophia,ci2.

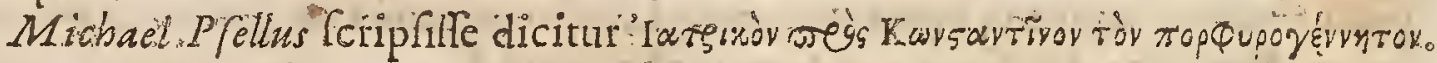
Medirale ad Confantinum Porpbyrogennetum. Lieotamen Allatius, differtatione de Pfellis,negat effe inclyti illius Wichaelis Pelti; quia neque ineo fit agnofcere $P$ felli in dicento acrimoniam, nec inte expediendà folertiam : ac tempora etiam obltare, five is Constantinus Porphyrogennetes fit primus, five lecundus, qui cum $B$ aflio imperium tenuit. Agnolcit interim librum effe non contemendum

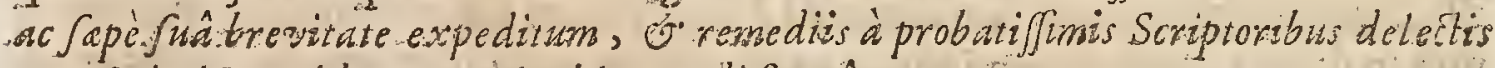
tranfcriptifque, idque populari logrsendi forma.

Seculo undecimo Michaelis P Jelli celebre erat nomen. Seriptit Lyra Pythagorace diagnamma, quod hodie mamufriptum fervatur in Galliâtefte thil Labb.

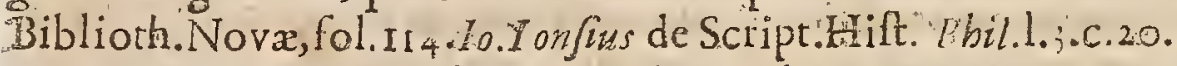

Michael Pellus Prafectus ftudiis Michaelis Dura Imperatoris, qui fuit ConAantini Duce flius, \& anno Ic71. Romano Diogeni fuccer in regimine Orienta Lis Imperiz. Floruit anno I071.20 fequencibus, infignis ob minam rerum philó fophicarum \& divinarum fcientian, quam probant plurima ejus Opulcula tang imprefla, quàm eriam Manulcripta adhuc latiantia in vanis Biblio hecis Oudr. in Supplem.de Script.Ecclef.à Bellarmino omili:

Extat Commentarius five Paraphatis in Cantionm Canticomum Grace editus à To. Metrio una cum Eufebir in idem Paraphrafr,anno i6 7.in $4^{\circ}$.

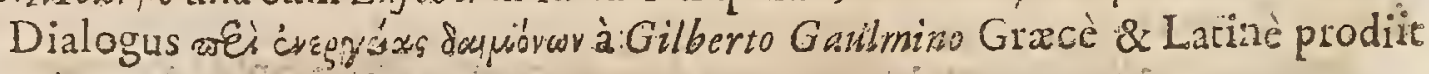
Litctic Parif. $16 \mathrm{I} ;$ in 80.

Prodiit de Virtutibus Lapiam liber ex Editione \& cum Notis Philippi Saci Tolose 161.81618 . in $8^{\circ}$.

Confer de ejus variis feriptis Leonis. Allatii Syntagma de Clo Pellis Roma apud Iac.Mascardwm anno $163+$ imprelium. 


\section{CELEBRIORUM AUTHORUM.

N Onachus, claruit anno 1057. Extant Greed \& Latinè Annales five Com11 perdium Historiarum ab orbe condito cum Notis \& Animadrerfionibus Clar. A. D. Xyland $i, C a r . F$ abroti, $L$ ac.Goaris, \& Gloftario inixo-barbaro, Par.1647. fol. ut olim:Bafil.ig6G.fol.

Totum Cedreni opus eft ftabulum Quifquilianum, \& Cento ex multis pannis Cordidis, purpureis, malis, bonis, integris, laceris confutus. fo. Scalig. Not.in Grac. Euselb.p.40.2.

Cedreni verò Synopjon arbitramur non multò polt cjus obitum mutilatam fuiffe atque ita ab illis librorum carnificibus, ur hodiè edita elt, polterirati tranfmiffam: quin ne a quidcm, qua breviatores collegerant, intęgra omninò ad nos pervenife: Nam Eomclavius vir doctifrmus in Notis ad males Turcicos fcribit, aliquor Cedreni fol a penes fe habuilie, qux in exculis defiderantur Nos verò apud Syncellum paginam integram reperimus, \& quxdam alia, qux in editione vulgata nom extant. I deen ibid.

Georgius Cedrenus in lcbus Byzantinis Zonarâpaulò a ligentior eft : In iis autem qux Cunftaninopolitanos Cafares preccunt, cedit Zonara: à quo \& Aylo vincitur, trivetiam à Nicetâ \& Gregorâ,\& aliis.Interim in Centone hoc,ac, penè - dixerim, Quifquiliis ittis, aliouos pupurx pannos reperire elt ex Africano ab Eusebio, indeque à compilatore hoc, fuo adlutos centoni. Nam ut Africanum Eu Scbus, Eufebium Georgius Syncellus;ica Syncellum, icemque Theophancm, qui Syn cellum continuavit, ad verbum exfcripfic $C$ edrenus. Voceavit verò hoc opus EúvoQWv'Isoes̃̃y. Sed ut ipfe mutilàrat priores, ita ejus quoque volumen mutilacunt junio:es: idque judicio nullo, fine ordine temporum, fine delectu rerum. Voff.de Hif.Grec.

Etfi Georgins Cedrenus fit quinen anilizm fapè fabellatym feriptor, \& veri incuriolus vel ignaras; Judicio legatur tamen, dabir quod juvet. Lips. Epift.Cent. 3.Mifel.Epilt.LXI.

Georgius Cedrenus Monachus Gracus, in cujus Historia fr quid boni reperitur, ab aliis compilatum eft. Io.Card $\mathbb{P}$ ona.

Cedreni porrè Hiforia à morte Nicephori ufque ad Imperium foaci Comneni,ctian legitur fü nomine $30 a n n i s$ Curopalatas paucis exceptis:quod Gefnerus. Fofjzs \& a lii molsuerunt. Aảeo quidem, ut alteruter Plagiarius fuilfe videatur. erubert. Mrraws in Auctar.de Script. Ecclefiat.

Cafrubonus quoque, Notis in lib. I7. Strabonis, refert, cù aे Graculo Hiltoriam Curopalate emilfer;eumque contuliffer cum Cedreno, deprehenderit eadem iifdem verbis ab iis dici, ut alterurer necellariò Plagiarius fit.

Hunc [Geogium Cedrenum]aliquando Wolpbius, fed quum fano judiciv? pratulcrat Zonara. Zonaras enim licè in. Hittoria poft Conftantinun Magnum jejunior fit, \& nonnili obvia quxque percurrerir, in his vero, qua ante Constantinus ad mundi exordia diligentiùs, ac copiofiùs verfatur. Sed quod lande dignum, eaque 
Gurnma ef; zonaras res de fuo componit, \& natrat, non alienorum fuxtis plaufum caprat, neque tractatus ilitegros exicribit. Leo Allat de Georg Diar:

Opus e vatiis Hiltaris, non lencentis lolm, fed verbo tenus confarcibanm abColvit. Qux fi ab Auctorbus repeterentur, nudus ipe, requènc comicula illa:

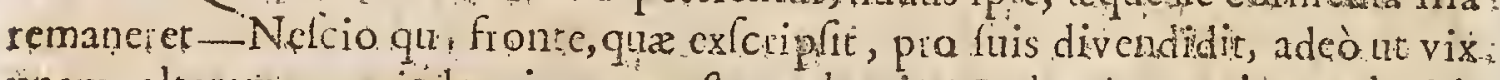
unam, alteratrve periodum in tam vafto volumine Cedreni propriam ac legitimam reperies: grat a tamen illi agendx funt, quod auctores nobis pracipuos, \& raros fuo ipfefurto conferyavit. Leo Allatius Diarrib.de Goorg. \& carum Serip. p. 334 .

\section{E A N N F R:A N:C U:S}

Clax...D. M LXX.
$\mathrm{N}$

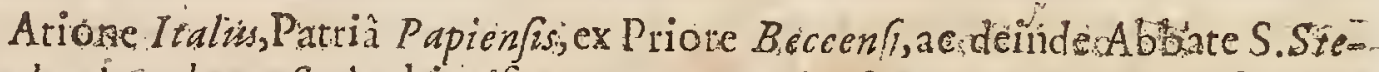
phavi adomenafis, Archiepifcopus Cantuarionfis \& Anglie Primas ab.anno. 1070.ulqui adianno 1088, quo mortius eft.

Stigando, serò fuccelfit Lanfrancus: Monachas, vir eleganter literatus; \& moribus mulk mudis onatus, qui inter cretera Magnifica Opera, librum com-

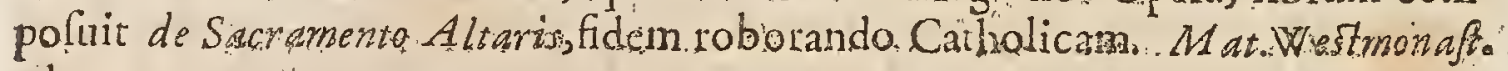
ad ann, 107\%.

Stigando lucceffit Reverendiffirans Patriarcha ex Abbate Ca domenfi omnium: liberalium Artium Doctor laudatifimus \& liculentifimus, \& in temporalibus: negoti is experientifinns, vitaque ac Religione fanctiffimus, Magifter Lanfranchis, in Archiept fopum Cantuarien fem Canonicè confecratusw Vide Rero.Ang lico. Script.Vezer.Tom. Impreff. Ox.on.1684. folsp.69.

Omnitim fui temporis in omni literarum genere tọ ctiffimus; 2 in Concilio, quod Roma adverfus Paerongariam Diaconum Ecelefix Andegavenfis. Hxreticum à II3. Epifcopis fub Nicoliao II. celebratum eft, longè clavifinus, inter alix prxftantis ingen i Sui Monumenta religuit pios., atque eruditos in totum P Palte. rium, \&:in omnes Paxli Epiftolis Commentarios. Sixt.Senenf.

Lanfruncus, vir eâ tanpeftate doctiffimus, errores Berengarit praclaro opuf

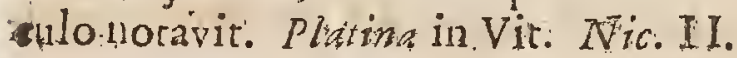

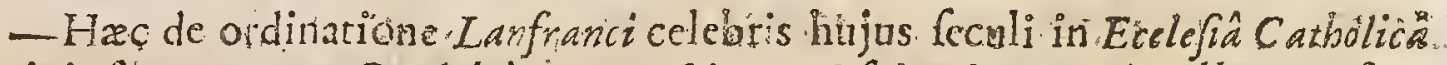

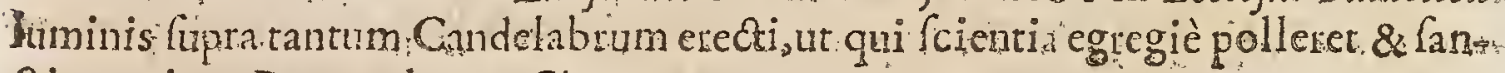
ctitate vitx. B aron.ad inn.Chr; 1070.

Lainfrancus Archiepifcopus $C$ antuarien fis vir Sandtis, \& dodus in Concilio Romano fub; Nicolao It. Pontifice anno: 059, difputaviticum Berengario:Hærefiarchâ:eumque ina convicit, ut: Berengarius librum futum in ignem ejecerit. Sed co ad vomitum redemte, , fcripfit idem Lanfrancus. infignem librum de veritate Corporis Domininin Eucbirifiâ. Bellarm.de Script.Ecclef:

Certè Eadmerus Lanfrancum de rebus Ecclefiafticis quxe fuo tempore geftre funt, veracifluno \& compendio fo calamo fcripfille difertè refert.Eadmer. lib.r. Hift.Nor. P. .

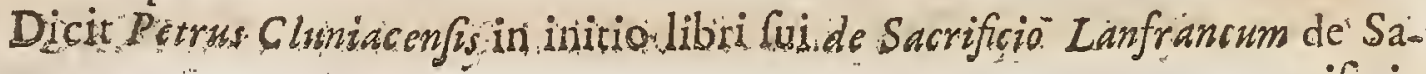
crificio 
crificio Eucharistice fcripfifè benè, plenè perfectè: Guitnwndum, incliùs, plenius, perfectiù: Algerum, opcinè,plenifinè, perfectiffinè.

Obiit,ut plerique tradunt, Jui.4.(ut Howedenus, \& Florentinus. ugorn.Maii 24.) 1089 febricula quod leppè opcaverat ab umptus, \& in Ecclefia Cantuarenf, quam nultum locupletarat, 2e edific is novis ornaverat, honorifice tumulatus. eft. Monachorum in co Cunobio degentium numerum è úque auxit, ut c m adveniens triginta tantum invenerir, 1,0 . deced ns.teliquerit. Manneria 25.per Odonem Epilcopum Banocenfern fratrem Regis urevinum erepta, Ecclefuerefttuenda.curavit. Balatium Arehiepifeopale quod eft Cantwarie fere totum conAtruxit. Xenodochia duo prope civitatem pradiotam infituit, unum videlicet apud Harbaldowen, alterum in Suburbiis quod S. Founzis: nom ne hodiè innotécit. Ad Aruoturam Ecclelia Cathedralis Roffenfis : agmam contulit pecuniams aut porius integram à fundamentis excitavit. In repuatione Cunobii S.Albari millc Matcas impendit. Manneriun de Redburn perinjurinereptum, illius - operî readitumelt: Ac deinde morens, mille libras nolt ate cidem Monafterio per teftamentum legavit. Franc. Goduvinde Prafiz. Angl.

Lanfrancus-Longobardus, "apiz oriundus, erat oph finarum frophis ac omni gencre Bialectices wate fua infructifimus-_-Cantuarie templum infauravit pratiofis ditavit ormamentis, Monachorum auxit pradia, Prebendas infituit, novos crexit cultus, adventantibuspergrinis Xcrodochia condidir, atque alia multa pio ampliando Papilmo fecit. Baleus de Script. Britan.

Vir juris Divini \& Humani fuo in avo fcicntiflmus acundequaque doctifimus, qui velut tertits è Colo Cato Monacho Malmesbuvenf, lib.j.de Gefis Regurn Anglia, dicitur, \& Archicpilcopus fuit Lub Wilbelmo Prino leu propè fexcentos abhinc (fil. 16,a.) annos Cantuarienfis. Selden. lib. ro de Synedr. Vert. Ebr. cap.r3.

In meno:iam Zanfranci Alchicp. Cantuarienfs hoc Epitapbium Ituxit Phis itepus Bone Spe:

Tixifi verferande Pater Capienter of equé,

'Vurfa vivens, mors guoque vita tibi afl.

Irter divitias pouper lanfrance fuifi,

Divitis manans pauperam arnator erax.

Per te florentes artes uatuere Latina,

Graria de vobis ecce trumphat owans.

Tu Latios ortu, Gallofque docendo levafib,

Te fob Primatem cardo Britanns babet.

In terrâ degens Calefina mente peicbas;

Exernptis terri fidera liber adis..

Sol Geminos denis ob federat igne diebus,

Prompjit Luna Dies, Nocite folutus abis.

Pbil. Labbe Theiaur.Epiraph.

$$
\text { Z } 3 \text { Plodicrumt }
$$


Prodierunt Opera omnia : Commentarius in Epiftolas $F$ auli : Libellus de S. Canâ.Notæ in aliquot CaJfrani Collationes:Decreta pro. Ordine.S. Benediet. Epiftolx. Editore Liucâ Dacherio Monacho Bened.Parif. in fol.1648.

\section{T HE OPHYLA.CT US}

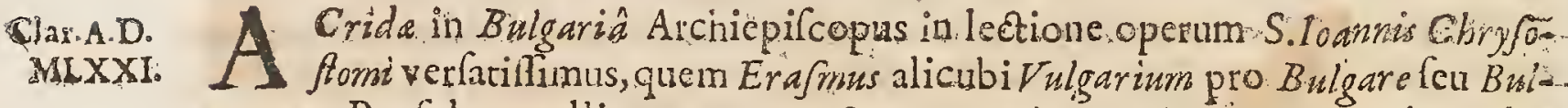
garoram Prefule appellitat, non anno 860.ut Pofjevinus, Perronius Card: \& plerique alii, fed circiter annum 107. . vivebat tempore fummi Pontificis A lexano. dri II. \& Romani-Diogenis Gracorum Imperatoris, ut ex cjus Epiftolis conftat. Pervenilfe quoque uique ad Pontificatum Gregorii VII. \& Imperium Nicephor: Botoniata mihi exploratum. Quo autem obicrit anno, profius ignoro Pbil. Labbe de Script.Eccled.

Theophylactus, Bulgarise Archicpifcopus, in Do Cirryfoftomi lectione diu multumque verfatus ac detritus, redegit in breve \& apertum compendium. juxta hiftoricam intelligentiam, quicquid admirabilis ille pater ex aurco fuo orc, veluti ex abundantifimo fonte, in exponendis Scripturis Sanctis effu. derat, pratermifus locis communibus, in quibus ille plenis eloquentix velis excurrere confuevit. Allegorias quoque cum ant nullas, aut raras apud CbrySofronum inveniffet, ez alion Commentariis fupplevit, \& fuis locis aptiflime accommodakit; Theophylatti in Oferm tiber unus, acephalus \&arelentus, boc eft: temporis injuriâ, inirio \& fine carens. Sixt. Serrenf. Bibl.Sanct.t.4.

Theophylactus in Commentaris, fuis in quatuar Evangelia, \&rinomnes Epit. ftolas S.P auli, ita Chryfofomum lecutus ett, ut Chryfoftoini Abbreviator dici pof fit. Porrò Schifmaticum fuille Theophylactum intelligi poteft ex Commentario in cap. 3. Toannis, ubi Latinos reprehradit quod credant Spiriturs Sanctum à Filio etiam procedere. Bellarm.de Script.EccleĹ.

Ubivis Theophylatam legeris, fenties S.I oannis Cbryofromi femper eructare fententias. Baron.ad Ann.Chr.1073. Lusc.

Scripturarum Interpretem, haudquaquam malum, cenfebat Erajrmus in capara

Hoc tempore forebat. Theophylactus Bulgarorm Archicpifcopus, folus ferè hoc feculo Theologix nomine celebris, qui fane in his verbis, Juper hanc Petram edificabo Ecclefiam meam, Evifcopi Roman nullam rationem habuit. P bil. CWh ormans in Myt.Inig.

Cautionem Theophylad hanc ad cripfit Poffevinus, erralle nimirum enaratione in caput 3. Evangelii S.Ioannis circa proceflonem Spiritûs.Sancti ex Patre ac Filio, quam Catbolici veterelque Patres colligunt ex iis verbis loannis 20. Infufflawit ac dixit: Accipite Spiritum Sandt. Idem monuit ab interpretibus ejus Hxreticis Ioanne Oecolampadio ac Ioame Lonicero falfatos fuiffe locos, qui ad poteftatem fummi: Pontificis fpeetant.

Prodicrunt Commentar. Theophylabi in Epifolas Pauli Grace \& Latine è Iodir: 
Zoann. Loniceri tranflatione \&' recognitione Pbilip. CM ontani, curâ eA wgustzmi in. fol.1636.

Prodierunt cjus Commentar, in 4 . Evangelia Grec. \& Latin. Parif fol. ann. 1635 .

Prodiit ejus Intirutio Regia curâ Petri T2ofjni $4^{\circ}$.Parif. IGgi.è Typographiâ. Regi

Integra Theophyladti Bulgarie Epifcopi Enarratio in duodecim Prophetas minores, Grecè MS extat in folio in Bibliothecâ Auguftanâ Codice 48.

Ejufdem quoquc colloquium cum quodam de Accufationibus Latinorum, \& Aratio in Alexitum Comnenum Imp.MSS. Grxcè in Bibliothccâ Serenifimi B. zarie Qucis Codice 116. Oudin.in Supplem.de Scripr. Ecclé.

\section{JOANNES: XIPHILINUS:}

C Onstantinopolitanus, tempore Conftartini Duce. Imperatoris clarnit, \& Dio- Clar. A.E. nis Caffi Hiftoriam in compendium redegir. Malè nennulli eum Parriar- MLXXIII. cham faciunt.Sic enim G.ül.Cave in Tab. Chronolog,ad Secul.s.s. Qui Dionis Hiftoriam in Epitomen redrgit , non fuit hic Patriarcha Confrantinopolitanus (quod ad unum ferè omnes Scriptores volunt; \& ini hì Andreas Schottus, I.Go Voffins, Lud. La-Gerda, \&sc.). fed ejufdem nepos. En ipfits verba, à nemine, quod

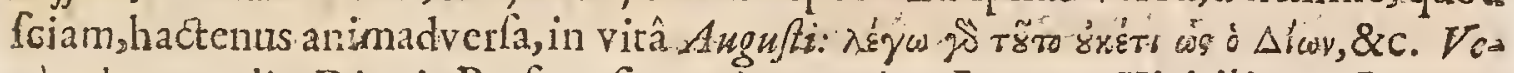
rüm hoc non dico Dionis Prufeenfiss nomine, fed ut Joannes Xiphilinus, Joannis Patriarcha fratris flitus, quitempore Michael is Impperatoris, filiz Ducie, hanc Epitomen comppofui: Gul. Cave Chartophyl. Ecel.

Sub Constantino XII. cognomento $D_{u c}$, ficujus uxori Eisdoxié tribuiriturf Cento Homericus de Chrifoo) claruit Ioannes, cognomento:Xiphilinus, VHI. ejus nominis, Ratriarcha Conftantinopolitianus, ordine in iis LXXVIIt. quâ dignitate functus eftannos:XI. menfes VIX. Antea fuit Monachts montis Olympi. Parrî. erat Trapezintizs D.e co fic Glycas. Annalibus parte IV: Conftantino Patriarcbâ mortuo, Joannes X philinus in ejus locum Suffecius eft ; vir omnino propter eloguen tian, doctrimam, pridentickn, virtutem admirandus. Trapezunre oriundris', vitam in Olympare ligiofis exercititis deditamagebat: undeavir perträctusest ad banc dim gritatem, tanguam inter alios eximins. Xipbilinus hic Dionis Hiftoriam in Coms. pendium xedegit: nificum nonnullis, nepotem ejus fuiffe, maliss. Sed priorem fententiam magis probo: uti \& Andr. Schottum facere video Prolegemenis is Photii myriobiblum.Vof. de Hift:Grac.

Xiphilinus, vir valde doctus vocatur Poffevino.

Xipbilinus, Epiromaftes Dionis adè fidelis, \& prudens, nt ea quidem, qux nimia elfe videbantur, refecearet, in -careris verò d̀ verbis, quibus $D$ ron, ufus fuerat, non difcelferit.Scripfit quingentis annis poft Dionem, Citichaelis. Imperatoris

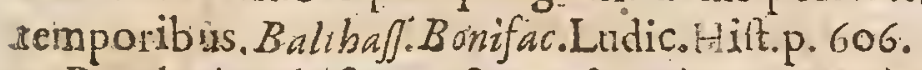

Preclarè rohifcum actum eft, quòd Ioarnis Xipbilini Confintinopolitani Mò. nachi Epitome; ex quadraginta quatuor porterioribus Dionis libris confecta fir

$$
\text { Ziz } 3 \text { perfis. }
$$


perfit, qux vitas I mperatorum omnium continens non modicum auxilium rebuss cognolcendis præltat. Car. Sigon.

Xipbilinus Dioneri Caffum in compendium redegit, magno Reipublicx Ma10: Dionis enim Commentarius ita excidit, \& Compendium rcentumeft. Calvif: ad ann.Chr.1066.

Mulcorum Dionis Scriptormm amiflonem prepoftero X iphilini confilio, vel aufui potius temerario debemus, qui dum fuas obtruft imperitis Eclogas, occaGonem prebuit, utintegri Dionis libri negligerentur. Io.Leunclav. Prxfat. in Dion.

Xiphilinus malitas pulchras \& uriles partes in Dione recîdit, têtante Iipfia qui in delcriptione Trajani pontis in Danbio, hilce verbis utitur : Defcribit graphicè Dia:Caffiss, \& gratia Sectori ejus Xiphilino efto, quò hanc partem non recidic.O quàm pulchras valentégue ille alias! Lip/. de Magnitud Roman. I. J.C.I:

Xipbilinus feripfit Commentarium in Matherm Gracè MS.apud If facum Vofjum, tefte Colomefio opufcul.c. 16.

Scriplit Sermones in Evangelia MS.in Scorialenja Bibl. Barvoëtius p.r33.

Scripfit Homilias in Evangelia Dominicalia totius Anni, qux MSS. Grxcè extant fub ejus nomine in Bibliotheca Sereniffmi Bavariz Ducis cod. 92. '\& in Vaticanâ ex MS. Colice H cidelbergeng Palatino, num.22. dignifimx (inquit Oudinus qux in publicum prodeant.

\section{IAMBERTS S:CHAINABURGENSIS。}

Clar A. D. T On at quidam Afchaffemburgenfs, \&conebii Hirsfeldenfis in Diceceli MLXXVI! 1 Moguntinâ ab anno rogs.alumnus, quo veftem Monaltican ex Meghinerì Abbatis manibus, at iplemet narrat, accepit, \& presbyter ordinatus, Hierofolymitanum iter infcio Abbate aggrelfus anno lequenti medio menfe Septembri a Monaferium fuum rediit. Is culco ac veraci ftylo fcriplit Hifloriarm ab orbe condito ad annm 1077 . qux hatetur in Collectione Rerum Germanicarum. Continuatio Monachi Erfurdenfis ufque ad amm 4 47. non accedir ad precentents Hiftoria diguitatem, fed haminem fapit parnm accuratam atque elegantem Pbil. Labbe de Script.Eccleliat.

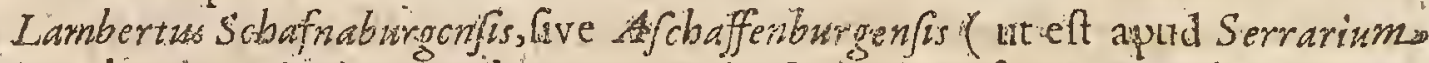
in Annal. Mogzistinis) monachus Hirsfeldenfis in diecefi Mogwntina. Hunc Trì

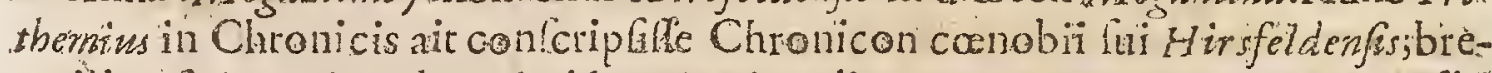
ve ithd, fed non intile. Id viderenondum licuit: Imprimis autem nomen fibi peperit Hiforiâ Germaniâ, quam perducit ufque ad an um Chriftż Io77.quó vivebar. Eum verò continuaxit Monadous quidam Erphorderfis ufque ad an. I 47 I. Ditio cjus elegans eft-Vix tamen pronare poffum, qu d Hiftorie quxdam admicceat privata, pofteritatis memoriâ minù digna. In rebus eriam pertinentibus ad controverfiam inter Henricum IV. \& Gregorition VII. fidem ejus claudicare, multorum judicium eft. Volf.de Hilt.Lat. 


\section{CELEBRIORUM AUTHORVM:}

Lamberto Schafraburgenfin nemo politiùs inter veteres res Gormania Literis commilit ...Barth.Adverf.1. $+9, c .4$.

Mirx avo fus Eloguentia Seriprorem vocat idem Bartb.1:45.c.23.

Infignis \& verax. Hiftoricus Lambertus vocatur Bellarmino de Ser ptor.

Chronographus doetilfimus \& accuratiflimus vocatur. Buchoicero in Ind. Chionol.p.3ro.

Pbit.ppus AXiclancthon de Cbronico Lamberti inter alia fic feribit ad Caparem Crugerum: Niondum widi, Germanis Scriptoribus eo argumento quicquam. diliggentius efle cornpofitumo. Ftedt.

Lambertus S.chafinaburaenfis; vir fupra faculim grudens, \& facunduss. Quen-

Equidem miror in Saculotam barbara tantam hominis 2 in loquendo pussitatem, \& in temporum putatione folenträm fuiffe, ut in Chronologis noftri temporis pudoren aliquem exprimere poffit, fis aliquem fenfum harum resum haberent.Jofeph. Scalig. lib. de emendat. Temp.

Lambertum Schafnabusgenfem haud planècontemno, in rebus Germanicts: ut: nec Rodericum Toletamam, in Hispanisss. Wrerque bonus, quantum potuit in tals. æro Lipf.Not.adir.lib. Roliticorum:

Henrice IV. Imp:coxvus \& rerum illius tempoxis diligentifimus \& judicio finimus Scriptov. Hen. Meibom. imn.in Epiff. de I.luffris gentis Heimburg. Orig. P.rogrefitio.

Sanè prudentix non minùs; quàm elequentiæ paliham (iut fileam accuratara semporum:rationem ) non fur tantum ætatis omnibus, fed \& difertioris ævi plu lu ribus preripuit. Caterum unius circiter decennalis hiftoriz.hoe preconium elt quà fcilicet Henrici I V: Gæatrisses nonnullas fuà atate geftas eft perfecutus: reliqua, qua: pracedunt, prorfus alia funt conditione, ut mirari mer itò fubeas: cur tam difininilia unôilli placuerit volumine comprehendere: Conring in Præ:fat.ad Tacit.de M.G. edit.primx...

Lamber it Hiftoriam Germanicam, opus infigne \& jucundi Icetionis v ocat: Trithemins.

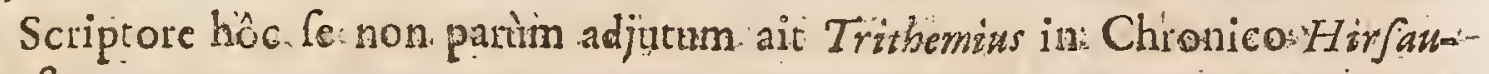
gien $\sqrt{2}$

* Hic Author inter Háreticos prima:Claffis rejicitan in Ińdice aldadritenfof sdit.an. 16:7\%

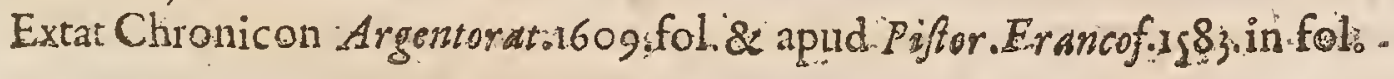

\section{S.U"I D A S:}

Cammaticus; Lexici conditor, vixille creditur circa ano o8i. 'Forfan antiI quior ipfe Sridas, multis qux. fequiora tempora fapiunt, à recentiori manu additis. Gul.Cave in Chartophyl.Ecclet:

Suidas junior, Grammaticus, Lexicon Gracum ex varis Scriptoribus collegit. De atate ejus alii aliter fentiunt. Hugo, Grotius in Epint 110 .ad Gallos, pi2 54. pant- - 
Lo polt Constantinum, Leonis filium, vixiffe autumat. Rationem addit. Nam, quancum memini, hic eft Imperatorum poftremus, quem in libro fuo nominat. Confantinus autem ille A. C. 9 12. regnare copit: Ciwverins in Epitome Hint p. 448 . fub Theophilo, qui anno 829. imperabat, collocat. Vofjus in tract.de Dhilol.p.37. art temporibus Alexii Cornneni ( is autem Imperioprafuit ann.1080.) aut Iuftiniani claruilie judicat. Ego aliquando exiftimaban, eum tempore $B$ afilis. I I. \& Conftantini VIIJ.vel A.C.976.\& deinceps vixille, motushac ratione, quöd in vo-

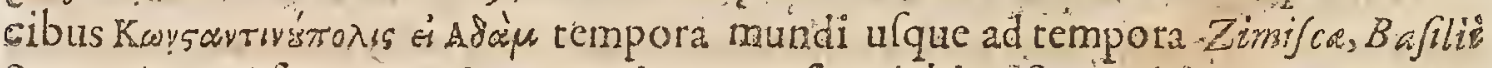
\& Constantini fupputet. Supputavit autern fune dubio üfue ad fua tempora. Kos sig. in Bitel.

Suidas Lexicographus, Monachus Byzanimus, admixabilis, incomparabilis: unus inftar omnium Grammaticorum. Io.Rofin.in Antiq.Roman. lere.

Carolus Pbilippi in Gufu Pbilologico vocat cum pecus cum aureo vel-

Sed admoneo, utcunque pecus Suidas eft, aureum tameri effe; 8 è meliore merallo vellus ferre. Carpfit \& fumplit ex optimis, qui fuerunt, \& plerique non funt;utinam judicio \& curâ,addo \& fide, meliori! Nam \& nomina fer élupprimit;\& intendere oportet quid ejus fit, quid alienum. Cxterum ctille Arcadicurn \& Midinum fapitjalios tamentectores fuos facit, qui curiol quidem fint \& intenti.Lip.de Milit.Roranâl. 4 D àlog. 'o.

Swidas Grammaticus nullius judicii, doctrinæ autem mediocris, qui Lacinirs andique collatis \& corrafis purpuræ interdum, non tarò tamen panni levidenfis crafto filo \& depexifartaginem illam coagmentavit. Montacuto in cxercitat. p.235。

Suidas in Grecis non contemnendus Author, rudem feprodit \& planè infarsrem in Latinis. Montacut. Apparat 3. Sect. to

Suidas (ut eft diverforum librorum è Centonibus confutus liber") fibi ipfi $f_{2}$ -iùs minus conftat.Iul Cas.Scalig.in Epif quadam.

Suddas autem more luo, id eft tivialiter (ut aiunt)interpretatur vocem $P$ arow dio. I dem de re Pö̈tic. p.I I4.

In hoc Auctore emendando mulurieft Pofferinus in eApparatzs Sacro, ubi inquit; In opere fixe Scriptis, qux. Suide nomen praferunt complitia funt qua ad Pbilologiam. ad Hiftoriam humanam, ad Poëfn, ad Philofophiann. fed \& ad divina Scriptwre, Patrumgue \& Hißoricorum Ecclefasticonum notitian fpeGant. Veruntamen etiam pleraque iifem fuetunt interterta, qua aut Evangelice veritati adverfantur,aut p:ocul abfunt ab Hiforicâ integritate. Hac Pofjévino in Apparat. Sacr.

Stidas homo ineptus, fateor, fed, incerdum, non malus compilator. Tan Faber. Not.in Prima Scaligerane,p.2.

E Scholiis Aristophanis, ut ex aliis Grammaticormm promptaniis in acervun fuum infinita congeffit. Defider. Llerald. Animadv ad Arnob. 1.3.

Sude rribuitur Lexicon, quod tamen multis auctariis à vatiis pofterioribus eft cumulatum, felicitate Lexicocraphis pecpetuá. Nam etiam e Ambrofiz 
Caleprini Dictionarium, quod ab Autore editum erat valdè jejunum \& ariUum, nunc accellonibus fubinde factis, \& Calepino femper tributis, clarum reddit artotorem. Raynand. erotemata de mal. \& bon. libris Partit.r. Erot.ro.

Nihil facilius fuciir, quàm cum anctorem (Suidar ) infinitis quibus lcatet mendis liberare : quod tamen miror nequiviffe videre virum cruditum ejus $I n-$ terpretcrin, cui,quum Suida fxpiffime integras Lärtii paginas defcribat, num: quam potuit hoc fubolere: quod Canè milor.Cafanb. in Not. ad Diog Laer.

Pauca legi apud $S$ boliafien Arifophanis, qua relata non fut in hoc Suide Dictionario, prodit $M$ aufJa us; qui \& fic judicat, vel scholizfrrillum à Suidâ, vel Suidam à scholiafle integras enarrationes defcripfile. Maufac. diflert. Crit.ad Harpocrat. p.37.4.

In Colleínness illis eruditos uno ore hodieque requirere, pleiaqque Veterum. Scriptorum, ut olybriac Dionis nomina temerè omilfit teftatur Andreas Schottus prafatione in Proverbia Zenobir.

Is mos inidi, adverbum priores exfcribere, neque metitione cos dignari. Ncfcio autem, quid in mentem veneiit do tifî́ no Arg 10 Politiano, ut epiftolâ ad Bernardum Riccium, qua leggitur libro undecimo, dubitaret, an ullus unguuam Suidas fuilfet. Fofl de Hift. Græc.

Eam abjicicndam prito, quàm Grammatifta quidam faciunt, duorum hujus unominis diffinctioncm, ut lcilicet ille antiquior tantùm. tiftoricus, hic recentio Grairmaticus Gyrald de leötar. Hift. Diali:3.

* Hierongmi Wolphii Annotat.in suidarn, fi expurgentur,permittuntur. Index Madrit. cdit. an. $166 \%$.

Prodiit Suidu Lexicon Grecècum'interp. Latinâ Amilii Porti Cretenjis \& Notis, Tomis II. Celunie Allobr. anno 1619. folapud Petrum Chovet.

\section{S. A N S E L M U .}

$7 \mathrm{~N}$ Augufa Salafforum iube inter Alpes fitânatus (Burgundum alii mints recté, ac Sedroniapud Rhatos natum, quidam Pedernonianum vocitant atque Italum, relicto Patre; quem nullo placare polfet obfequio, patriaque clan abfecdens, ad Laufrancuris venit Eeccenfis in Normannia celeberrimi Monalterii Priorem ac Magiftum, ubifactus Monachus, vixque clapfis tribus annis, de.. inde Prior per quilducim annos, atque $\mathrm{Abbas}$ ejufdem Conobii,cxatis in fupremo regimine totidem annis, Cantuarien fon adeptuselt $P_{1} æ$ fulatum an. Chrifti ro93. clectus die 6. Martii primâ Dominicâ Quadragefimæ. Multis pro Catholicâ Ecclefâ perfunctuslaboribus in Inalian, Galliâ, ac Britinniâ, Londini tandem obiit anno xtatis 76. Prrefulatûs 16. Chrifri r rog. die 2r. Aprilis, feriâ quartâ hebdomadx fandx, "\& in Ecclefia Cantuarienfrad caput Lanfranci predccelloris fuilepultus. Labb. de Script. Ecclef.

A felrnus Cantuarienfer in Angliâ Archicpifcopus ' Lanfranci Contuarienfis Archiepilcopi Difcipulus, ingentibus Dei bonis, doctrinaque \& fanctitate corutus, vakia Scripta, magno corum bono reliquit, qui ea voluerint attcnte A. 2.3 pertegere.

Clar: A. D. MXCII. 
perlegere. Ad quam Lectionem facilius allici potuerunt, $f_{1}$ intellexerint, ea non": folm effe fere breviffima, fed \& tanti fucci plena, ut vir inter alios productus A itonius Demochares Theologus Sorbonicus Epiftolâ Prafixâ Anfelmi opulculis, qux data anno 544 . edita eft 1550 . Parifirs, Cxripto fit teftatus, In Anfelmi iftius brevibus Opufculs penè ornia firmis rationibus demonftrari, que Petrus Lombardus Magifer Sententiarum, in quatuor plenis volurninibus,multis Sanctorum Doctoruriaulloritatibus poftè confirmavit. Ant. Poffevin. Apparat. Sac.

Vir in divinis Scripturis eruditiflimus, \& facularinm literarum peritiâ nulli Gro tempore fecundus. Trithem.

Vir magni ingenii \&acuminis. G.Callix in Apparat.Theolog.pag.532.

Vir tam Divinis quàm Humanis Difciplinis nobiliter excultus, ftylo mirè. fmplici \& puro,fed non injocundo. Sixt. Senenf.

Vir fuit ilatione Italus, profellione Monachus, ingenio acerrimo \& Canditate admirandâ cum maximâ prudentiân, \& humilitate conjunctâ. Ejus vita ab Edinero fideliter confcripta eft. Cum moreretur, dixit, optare fe adhuc modicum remporis, ut quiftionem obfurifimam de Origine Animse, quam coperat, abolveret:fed hoc tempus ei datum non eft, ntt majus bcnum ei in aternitate darctur. Bellarrin. de Script. Ecclef.

Illưtravit planè Anglicanam Eccléfam dobtrinâ, illuftravit \& fanctitäe, cæxteris Sanctifimis Parribus Chrifti Confefforibus, quos Ecclefia veneratur, minimè impar. Claruit miraculis yivens, atque defunctus, lucidum fidus Ecclefix Anglicane, multiplicifulgoreconufans omnibus intuentribus in tantâ noctis obfura caligine. Baron ad Ann. Irog.

Anfelmus, Vir Sanctimoniâ Vità, gravitáte eruditione eximiâ, aliifque virutibus clarus---In Synodo Barenfi coactâ, præclaram operam navarat : Jelmus, contra Gracos ibidem tunc pralentes, quorum crrores, ac illum pracipuè de proceffione Spiritus Sancti, doctifimè magnâque cum gloriâ prælens refutarat, inde poftmodum fumpta occafione libellum eâ de re edendisqui etiam. num apud doctos, in pretio eft. Cujus tamen certaminis non aliud tulit pramium, quàm quòd ipfi \&uccefforibus fedes affignata eft in Concilio generali prope dextrum pedem Pontificis, qui hoc ufus, elogio id conftituit, Irchidarnus (inquit) bune ir Orbe noftro tanguarn alterius Orbis Papam; alludens fortaflis ad illud colini, ubi Rritanniam noftram alterius Orbisnomine appellat-2-n-Quadringentis ferè polt obitum ejus annis, operâ Ioannis Moorton fucceflorum unius, inter fanctos relatus eft, fero fatis. Nimirum quia"non erat ad illum ufque diem qui rumeratá pecuniâ hunc illi emeret honorem; nec repertus. eft inter Pontifices qui ultrò \& gratis deferret vel huic, quo nemo ( fidenter dico) jam inde ab co tempore sandt elogio dignior in Divorum album afcriptus fit. Franc。 Godvvin. de Præful. Angl.

Ante anu. rro2. Cacerdotibus Uxores in Angliâ interdicta non fuerunt, tunc verò Anfelmus Archiepifcopus Cantuarienfis facris literis \& Naturx vim intum lit, \& Anglorum Gacerdotibus Uxores anted non prohibitas, prohibuit. Camder. in Britan. 
Anfelmus dicere Lolcbat, Se malle effe fine peccato in inferno, guatm in Coelo cum peccato.

Sixius Senergês in fuâ Bibliotlrecâtribuit S. Anfelmo explicationem in Genefirm, Exodum, Leviticuin, Nurneros, Denteronomitum, Iofue, \& Indices I. Sed unde hoc habeat, divinare non polfum cùm tanta opera Edinerum latterint. Bellaym min. de Scriptor. Ecclef.

Prodierunt opera cjus omnia in 4. Tomos diftributa, Atudio Theopbili Ray-

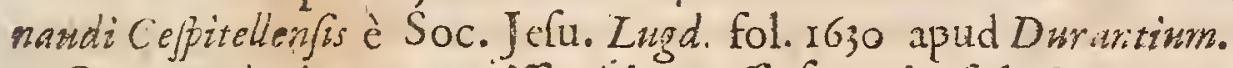

Opera vero ejus accuratifime impreffa funt in fol. Parif.apud Ludovicum Billaine ann.1675.curâ \& Itudio doetiffimi viri Gabrielis Gerberon Monachi Benedictini Congregationis'S. Muri.

\section{$S I G E B E R T U S$.}

CEmblacenfis in Brabantiâ Gollicanâ coenobii Mondchits, (errat enim MetI chior Goldaftus qui Gemblacenferm Abbatem cundemque Sànetum appellare Clar. A. D. $M C$ non eft vuritus) cum xtate flocens pueros in Metenfs S. Irinentii Monafterio diu docuiffet, Gerbbl «um reverlus, reliqu'um vite tempusibidem egit, Henricianis partibusadverfus Romanos Pontifices Gregorivars VII. Vrbanwm II. \& T afs chalem II. ad procacifinam ufque infrunitx mentis audaciam; atquc ut Catholici quidam fcripferunt, infaniam deliriumque addictus. Obiit die s. Octobris non anni Irrz. ut Mircus aliique plurimi fcripfere, fed anni Irns. proximè confequentis. Suum ipfe fibi texuit clogium c.I7r. libri de viris illustribus poft alia omnia opera compofiti;quem cum aliis fex, qui de Scripreoribus Ecclefiafticis ex profeffo trackarunt, recudendum curavit Aubertus. Miraus Antverpie anno 16;9. Labbe de Script. Ecclef.

Prre cateris ejus Scriptis xtetmantur libii de Viris:Illufribus, \& Chronicon ab $2 \mathrm{~b}$ anl.38I ad an.11I2.

Vir in divinis Scripturis à juventlite fuâ ftudiofifimus ' $\&$ multum cruditus, atque in fecularibus literis nullifuio tempore in Leodiensium teritorio fecundus, carmine exercitatus \& Prosî. Tritbern.

Poëta fui temporis cclebratiffumus; \& in divinis Scripturis à juventute detri"etus Sixtt. Seneris.

Cum annos religiosè piéque atate grandis apud fuos exégifet, an mam creatori fuo reddidit. Utinam ea æras tales multos tuliffet:certè non tam mutilam haberemus illorum temporum Hiftoriam. Franc. Sveert. Athen. Belgic.

Sigebertus, venerabilis Monachus Gemblacenfos Coenobii, vir in omni fcientia literarum incomparabilis ingenii. Monach. Angüffinian. Nuffenj, in Chron. Belg. Sigebertus visuemini luo tempore extditione inferior. Centuriator. Magde. burg. Cent. XIl.c. io.

Fclicia certe hre tempora fucre, quæ \& Sigebertum Monachum GemblacenSem virum fpectatre doctrine, \& Bernardum ex Caftilione Burgundie nobili genere ortum, protulere. Platin in Vit. Pajchal.II. 
Sigebertu vir doctus yocatur Lip 20,1 . 2. Var. Lect: $c$. 30

Sigebertus omnis divini humanique Iuris confultillmus. Ifyro in Catal. Tef. Ver.

Stylo utitur libero, \& neque Pontificibus, cum opas ctzparcit. Hofman.

Nortm probitate \& lcicintiæ nultiplicitate laudabilis, \& gratus lui tempowis fapicntibus. Voler. Andreas in Biblioth. Belg.

Sigebertw in computatione fapè libitur,têtantę Baronic.

Sigebertu Chronologus, in quo plaraque memoratu dignifima : quadam falf \& commentitia levia nonnulla \& futilia., Bonifac. 1.15. Ludic. Hilt.c.7.

Sigcbertu in luâ Chonologiâ iniquior fuit Gregorio Septimo ; ob fudium

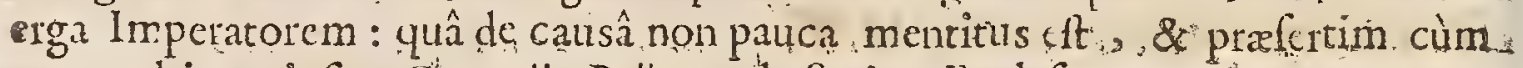
narrat obirum ipfus Gregorii. Bellarm. de Script. Eeclef.

Sigebertut Gemblacen/es Monachus,utiliss, \&laudabilis Hifroricus, nifi quòd Gregorio VH, iniquior fuit, \&ingratiam Imperatoris multi mentitis eft. Loan. Bona.

Quod ad, Sigebertum fpectat, Voffitis obfervat temporum feriem fapius ab. illo neglectam in ordine quo Scriptores fuoscollocart. Belluminus fentit etiam illum in fuis judiciis non effe fatis liberum, e eumque in ?aras propter. Imperatorcs animun nimis infenfum prodidile : fed hac ad Chionicon ejus potius quàm ad Viros ejus lllufres pertinct. Sigobertus in multos errores incidit nor minus quàm qui praceffermit accurationis defectu. Quidam vanz cujufdam. glorix illum ctiam infimulant, quod magna curra omnium fuorum Scriptorùm chumerationem Catalogo fuo attexuerit: Sed fi grave vitium haz fuenit, id Seculo noftio vulgarifimum evafit, neque hac fine exemplo fecit Sigebertus. Eruditorum Iudicis per Dom. B.tllet. Gall.

* Sigeberti liber contra Papam Gregorium, \& contra Epiftolam Pafchalis Pape, prohiberur in indie Korra Impreffo, $688_{\text {I }}$

Extat Chronicon ejus ab anno $3 \mathrm{~S}_{\mathrm{I}}$. ad annum III2.poftomnes alias Editiones Anberi Mirsi curâ à Mendis repurgatum Antu. I608. in $4^{\circ}$.

Extat liber de Viris Illuft cibiu Mirxi Notisilluftratus unà cum alis ejufdem.t. argumenti in Dibliothccâ Ecclefrafica Antv. 163.9. Fols

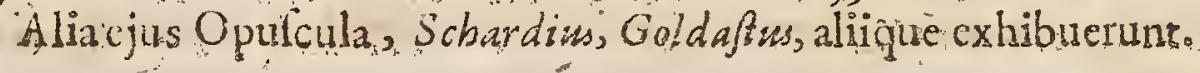

\section{S。 B E R N :A RDUS。}

Clar. A. D. Ncaftro Founanis prope Divionem in Ducatu Burgundia natus anno ragsz. MC Xy. I latre Tecelino, Matre Alethi, Ciffercium venit cum fociis circiter 30. anno Ir 3. ad Stephanum Hardingum tertium illius Monaftcrii anno rog8. primùn fundati Abbatem, à quo Claravallenf 2 Conobio anno IrIs.ad fluvio:lum Senzam in dioecefr Lingonen fi érecto datus Abbas, vixit ufque ad diem 20. Angufti anni irg3. quo ad colos evolavit Doctor Mellifluus", ac vcrè fui feculi decus fingulare, cujus vitam plures fcripfere. 2 Jil... Labbe de: Script. Ecclef. 


\section{CELEBRIORVM AVTHORVM.}

Vitæe fanctinoniâ \& preclarâ eruditione praftantifimus- Modus don cendi ejus in Lenfibus Mytticis indagandis, \& in moribus formandis ferè feraper verfațur. Oratio ubijue dulcis \& ardens, ita delcetat, \& ardenter iracendit, ut ex fuaviflimâ linguâ ejus mel \& lac verborum fuere, \& ex ard ntifimo ejus.pectore ignitorum affectum incendia erumpere videantur. Sixt. Sencnf.

Bernardo qui fuavius fcripfit? cujus ego Medirationes rivum Paradifi, A mbrofum Animarum, Pabuhim Angelicum, Medullam pietatis vocare foleo. Dan。. Heinf. Orat. In. pro Biblioth. mun. Grat. act.

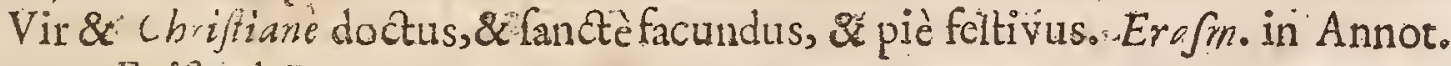
ad cap.r. Epiftiad Rom.

Birnardus, admitabili Religionis fúdio, eracrarum literarum peritiầ, quarum verba \& fententix dicentife fponte offerunt, in movendis ctiarm affictibus piis, non legnis,nec inefficax, fimul tamen feftivus o jucundus eft, ut $M$ ellifui

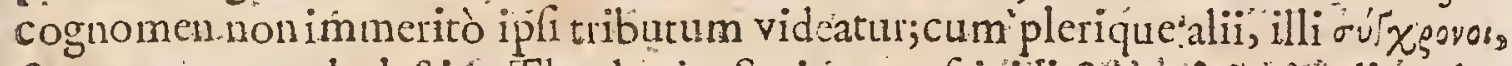

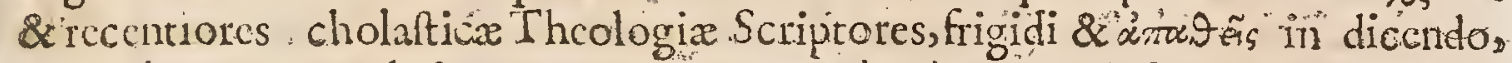
nnum hoc agaut,ut lectorcm doceant. David Chytraus in Oțat de Pho Melancthone, p. sog.,

Vir plane fincerx atque infucatx pictatis, inffigni in Deum amore, Angento adverfus corruptos Chriftianorum morcs zclo flagrans, multo inclior futurus, fi tempora, inquibus fors ipfi vivendi contigit, non prohibuifínt Literis humanioribus non leviter tincês, Scientiî 1 heologicâninttudiffinus, longè

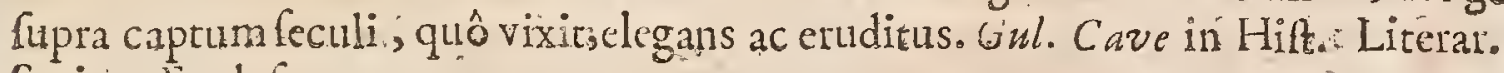
Script. Ecclef.

Bcrnardu vir mellex eloquentix, admirandx docktrinx pifque \& Cani fensûs fcriptor. In quo ita fumma Rclígio \& probitas cum fummâ ertiditio ne \& claquentra conjuncta fuit, ut à nonuullis Apoftolus XIII. appcilatus fito Quenfledt.

Nullos habuit: Praceptores prater quercus \& fagos Hinc :Proverbium ; Neque enim Bernaráus vidit ornia. Nec mirum, cum incidit in fatalia illa

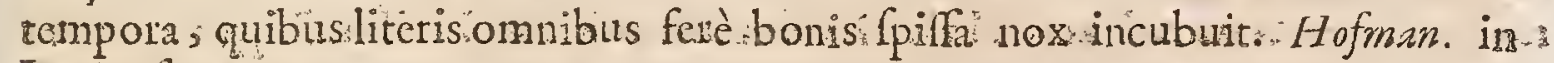
Lexic. \{tio.

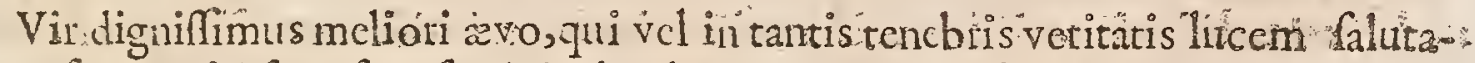
rem afpexit, vicefquc fuas fapè deplorabat. Morton. caufa Reg. C.33.

B. Lutberus nulltis dubitar illum omnibus Patribus anteponere, in Collo. Menfo cap. 30 .

Intcr Latinos, Bernardus me capit; \& "ulum habee excitändi, ob acrinoniam "s uhique \& calorem: tum etiam docendi atque imprimendi ; ob fcntentiarum acumen, quas crebrò \&" falubriter mifcet. Lipf. Êpint. Cent. Inr ad -Belyas Epilt. $4 \%$.

Utinam tales Papiflas multos, imò vel unum talem hodie habéremusin toto regno P. ontificio, qualcm Bernardwón fuiffe conftat. Ita fanè, ita folide difputat illè de fummis.fidei capitibus, de Scripturis, de Ecclefî̀, de Hominìs miériầ, de A 
gratuitẩ juftificatione, de gratiâ, de novâ obidientiâ, cum Catholicấ Ecclef̣ấ,conatra Tridentinas fabulas, ut uihil folidius quxri polfit. Num ergo Papilat fuerato qui contra Jefuitas, contra Tridentinos, in maximis fidei Articulis Ecclefarr. Catholicarr \& Patrum confenfum lequitur? Dicam apcitè quod res eft. Pernardus Romani Pontificis jurifditionem longè fupra omnes fuperiores - Patres extulit. Atque hinc eft quòd ?apift vocetuxà Bellarmino: Nam Cyprianus, Angiffirm, Ambrofins, aliique luperiores Romani Pontificis jurifdictionem cohibucrunt. Bernardus autemincidit in fatalia illatempora,ultra annum millefinum, $S_{2 z}$ tanâ jam foluto. Itaque quod cohibere non potuit, tulit ut potuit. Nam poft annum millefumum multi viri Sancti Romani l’ontificis jurifdiotionem in fpiritualibus, quam cohiberc noil polfent, patienter tulerunt. Georg. Carieion.in Confenf. Ecclef. Carhol. contra Tridentinor, lib. 6.

Librum ejus de Gratia \& Libero Arbitrio plunimum Laudat Vofjus Hif. Pelag. lib.1.cap.2I. Qui preconio (inquit) noftro non indiget, cum in delicis efje omribus foleat, qui cathoticam fentonitam fequuntur.

Hujus lectioni Carolus V. in feclliu fro pracipuè deditus, ejus maximè de Duplici Hareditate Cbrifi difcu Cu, in Agone mortis fe folatus eft. Thun. I.14.

Bernardi Sermones octoginta lex in tria prima Cantici Cancicortm capica eruditi omnes cateris ipfrus laboribus praferunt. Stxt. Senenf.Bibl. :antt.1.4.

De cjus ftylo ita Erafmus in Ciccroniano, Besnardumagnofco virum bonum; quz pars cft Oratoris, naturâ coinpolitum ad urbanitatem, \& ad dictionis 1 cporem:Ced adeo non Ciccronianus, ut è Scriptis vix fuboleat, unquam illi lcctum Ciceronem, pag. I53:I5:4.

Bernardus fuit autor Monafteriorum últra centum \& fraginta.

Refertur polt novem annos à morte inter Sanctos à loontifice Alevandro, quòd Apafolicam fedem adeò defendilfer, Calvifann.. I 53 .

S Brrnardus Abbas Claravallenfis, virplane Apoftolicus, \& non minus gloriâ miraculorum, quàm fapientix fplendore illuftis, florti maximè tempore. Innocentitilecsudi Pontifacis anno Domini millefimo centufimo tiigefimo, fed obiit anu.n53. ætatis fux f xagefimo fexto. Scripfit multa opera,fed multa etian illi tribuntur qux cjus non lunt. Opera qux fine dubio anctum Ber zirdum habent auctorem illa lua lint, qux numerantur à Gofrido ejus difcipulo, \& Alumo ${ }_{2}, 3_{2}$. vitx ipfus capite ultimo, vitam enim S. Bernardi primus feriplit eo vivente Gulielmus Abbas S.Theodorici, unico libro comprehenfam : deinde adjecit fecuntum librum $B$ crmardus Abbas bonx Vallis: tres ultimos addidit Gofridu Monachus Claravallenfr. B.llarm de Script. Ecclef.

Extant opera cjus omnia cum Notis loan. Picardi Mondaterii Parifisnfos ad S. KiEtorem Canonici. Antverpia apta Ioan. Keerburginm in fol.ann. IG G. chitî Edmundt Tiraguelli Religiofi Cint.

Extant eadem Audio \&labore Iacobi Merloni Horfii. S. Theol.Liccntiati,fol. Colonic 1642 . Tomis 5.

Extant eadem aucta'\&emendata à Domino foanne $M a b i l l o x$ Monacho $B e-$

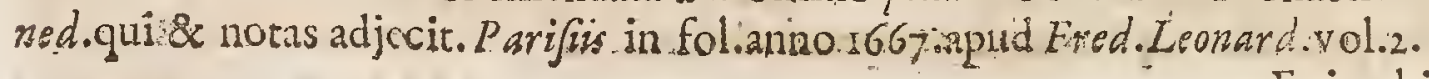


Epitaphium. S. Bernardi Clarevallis Ab. per Pbilippum Bona Spei Abbatem Ord.Præm.

Clatx fint Valles; fed claris vallibus Abbas

Clarior, his Clarumb nomen in orbe dedit.

Clarusavis, Clarusmeritis, \& Clarus bonore:

Claruit ingenio, Religione magis.

Mors eft Clara., cinis Clarus, Clarumque Sepulchrum:

Clarior exultat Spiritus ante Denmo.

Phil. Labbe in Thefaur. Epitaph:

\section{$A^{*} N$ N A C O M N E N A.}

A. Lexii Comneni Imp. filia, Nicephori-Bryennii Cafaris uxor, claruit Anna Clar.A.D. 11 mi8. Ccripfit an.Ir 48.Libros:rs. de rebus gettis Patris fui, quos Alexiada DEXVIIII vocavit.Horum ofto primos ex Auguftanâ Bibliothecâa edidit. David Hoefchelins Anno 1610.in 4\%. omnes quindecim Gracè \& Latinè prodierunt cum HoSt chelizi notis" \& Petri Poffini Glolfario, Parifiis, 1651 . fol. Notas. Hiftoricas \& Phi lologicas addidit. Carolus Dufrefnius, Parif. 1670 . fol. Foannes Bodinus falsd affitmat hoc opus Comnene conftitifle libris 20.

Erat autem \& ipfe ( Bryennius) ftudiis doctrinatum deditus, \&uxor ejus in iifdem operam nihilo minorem, ac potiùs majorem ponebat, exquifitè AtticifSans, ingenioque predita acutiflimo abftrufffimas contemplationcs, eam facultatem partin natur bonitate, partim induftriâ confecuta.Affixa etiam erat libris, \&'eruditorum confuetudine haud obirer utebatur. Ioan.Zonaras, Amnal, Tora, 3. Interp. Hiersn. Wolf.

Annam Cafariffarm fororem Imperatoris" (Ioannis Comnent) Nicephorus Briennius in matrimonio habebat,omnium difciplinarum parenti Philofophiz déditam , \&omnibus artibus erudizan. Nicet. Acominat. Choniates in Hift.de Ioan. Comneno, c.3.

Anna, Alexit illius filia, foemina eruditifimastanti dux fomina facti, libris 20. fux Alexzados paternam Hittoriam ita defcribit atque illuitrat, ur ejus æatatis, \& Imperii, \& orientis.tatum liquidò etiamnum confpiciamus. Eranc.Patrit. de Hift. Intitut.l.I.

Annam paulò pluris xtinimamus, quàm Aventinum aut Illyricum,cui quanta fuexit mentiendi facultas, docet ejus 'Alexias nuper Gracè publicata, de cujus dubiâ \& cufpectâ fide editor ipfe ftatim inlimine luculentum téftiñonium dedit. Et lectio ipfa docet, quot fallis narrationibus \& pfendologiis liber ille refer tus fit,prafertim ubide Latinorum rebus \& Gregorii VII. Robertique. Guifcardi Sermo. Iac. Gretfer. adverf. Melch. Goldaif t.1.2.c. Ig.

Hæc ipfa prenobilis foemina ad miraculum docta, in hac fuñ Hiftoriân, the amori ergafuum parentem nimium aliquando indulferit , nonnulli haùd levites fulpisandu: 
fufpicantur. Degor. Whear. in Method. leg. Hitt. Civil. Seet. 3 s.

Multa verò de parente fuo longè aliter narrat, quàm Latini folent: qui omos propè, fi unum excipias Albertum, Canonicim Aguen Sern, Cefarem cum defcribunt, tanquam hominem fraudulentum, acperfidum. Sed fatis verifimile eft, cum Latinos fuo erga Gracum Iriperatorem odio, tum fliam Comnenam amori erga patrem fuo, aliquanto amplius indulfile , quàm per-leges Hiforidiceret. Voff. de Hift. Grec.1.2.c. 27.

Comnena Alexiade luâsflve quindecim libris de geftis Alexii Comneni patris fui, doetrinam \& facundiam pariter comprobavit. Voff. de Philolog.

Quos quidem ( Alexiados libros) Anna Cornnenaraci profectó Cupra fexum judicio ac fingulari el gantiâ concriplit. Car. Dnfresn. in liter ad Lect.quas hitt. libr. Io in. Cinnarni pramifit.

Anve ea efornnen decima Mufarum, Pallas quadam Byza tie Grecie, cujus Porphyrogenituticet ac primogenitx moderantis orbem Principis, fi quils .ingenii opes aftimet, $A$ uqufornatales. atque illam Cunarum purpuram in minimimis ornamentis numerabit. Petr. Poffno.in lit. ad Petr.Segvierium, quas Anne Combene premifit.

Coninnitas qua libris quindecim Paternx vitx Gefa defcribit Anna Comnena, "\& elo quium quo eadem extollit, muliebre ingenium ufque adeo fuperare vifa funt.s ut an ipfa hiftoiam fuam contexuerit dubitatum fit. Verum eft : Bbi non poffelegi defcriptiones regionum, fluviorum, monti.m urbium, obfidionum, praliorum ; ejus in eventus quo'dam animadverfiones, judicium quod de humanis actionibus ab ipla fertur, ejusin plura argumenta digrcfioines, quin fateamur illam friffe perififfmam Grammaricx, Khetoric , Philom sophix, fcientiarum Mathematicarum ;imo nec Medicinz, nec Iurifprudentix, nec Theologix Sacrarumque Scripturarum prorfus ignaram : Quod ejus Sexui non eft valde ufitatum. Ephernerides Euditorum dici Lunæ 26. Augufti, 2167.5. Gall.

\section{JOANNES ZONARAS。}

Clar. A. D. T X Magno Drungario Biglx, \& Protoafecretis, Monachus ord. S. Baflin.

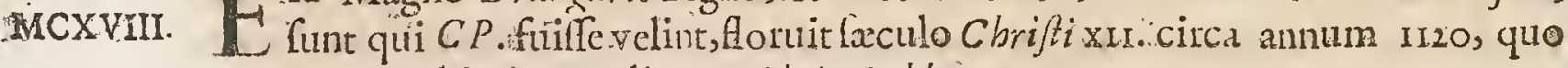
atrem anno obierit, nonliquet. Phil. Labbe.

Scripfit Annales ab Orbecondito ad Ann. xit8. Commentarios in Canoshes SS. Apoftolorum \& acrorum Conciliorum, tam Occumcnicorum, quàn Provincialium-..--Expofitionem Epiltolarum Canonicarum Ss.Parrum, Dio-

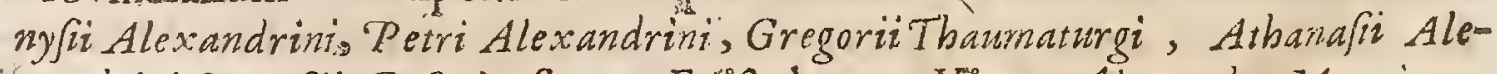

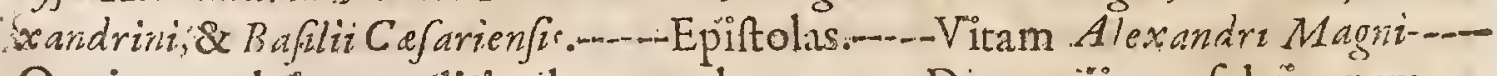
Orationem deimmunditic ob gonorthoam---De nuptiis confobrinorum--Poëma adverfus omnes propemodum Herefes.

De stylo quo incondendis. Annalibus ufus ent , iple ita pronunciat, od potits 


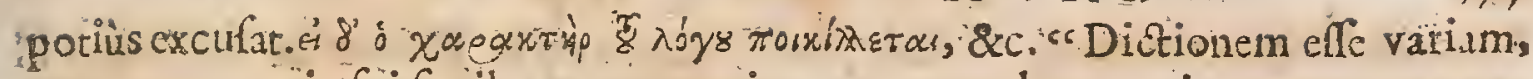
¿ nec per omnia fui fimilem, nemo miretur. aut culpet ovationem, aut me au$\because$ to:em illius. Cum enim hiftoriam ex variis Scriptoribus veluti ftipem colli" gere necelfe habeam, in multisillorum \& dictione \& compofitione utcndum "crit. sicubitameniple de mco aliquid interjecero, ac inferuero, fylus ad il "lius, quem fequar, nuetoris formam accommodabitur, ne Scripturà fefe dif cridere videatur. Annal. Tom r. p.

Extremis Alexitemporibus, item fub Ioanne Conneno, floruit loannes Zosaras; qui juftiùs inter Hiftoricos fibilocum depolcit. Hic priùs maximos in Confantinopoliano imperio honores geflit. Nam magnus in eo Drungarius, \&

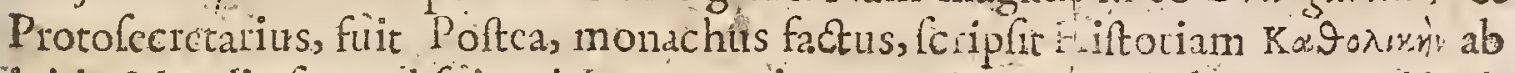

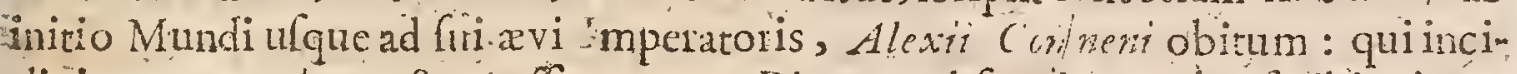
dit in annum ( $b r .118$ affm autem Dionem vel fequititur, vel cxfcibit: ita ut a $x$ pè quid Dio in lib is deperditis fenferit, e feripferit ex Zonará liceat cognofacere. Lincia fidi hiftoricum appellat eA lexand ll raficanus Juciconfultus, VirCl.prefutione in alwamm. Majorem tamencuram atque Induitian, mexitò in:eodefideramus. Scdillud maximè mirandum, virum ufque adeo experientcm, etiam in fui temporis rcbus, pleraque perfundorie tantum dicere: cum multa, magnaque iis tempo ibus getta lün, oricntali oibe cum occidenli quafi concurcente. anc pauca funt, quibus ilexiz comeris vitam perftinxit. Sedbenc eft, quod hunc Z naradefectum fupplevit Anexii Imp. flia, Anna Cornnena.Voffo de Hift. Grac.

Quinquaginta \& amplius annis pon Cedrenum loruit Iobannes Zonarar, nimirumc rca annum $112 \mathrm{c}$. Is Jniverfalern fciplit Hiforiam, quam in tres tomos partivit : quorum hoc in loco tertium prefertim Ledori noftro commendace placet. Siyuidem eo tomo, qua in Oriente à Confantino Magno, cjufque in regno fucceforibus, aqque ad fua rempora gefta fucrint, exactius defcribere laboravit, utpote paucis aliis tentata. Singulis Tomis retum aliis indictarum frè fit mentio (inquit vir quidam doctus) tertiâ verò Hiftorix rux parte, ea pleraque tradit de Rebus Byz zntinis, qux prater ipfum nemo alius, \& fine quibıs, nos bonam partem corum, qux à pofterioribus $1 \mathrm{~m}-$ peratoribus Orientis geftafunt, ignoraremus. Whear. in Mcthod.lig. diff. Civil. Sect. 36

Opus hoc Hiforiarum foannis Zonara, viri fua atate in Co ftantinop liteno Imperio clarifrmi, longo jain tempore à multis viris doctirnmis defikeratum, duplici potiffmùm noninc commendandum effe videtur: tum propter amplitudinem \& varietatem rerum, qua in co continentur: tum ob brevitatem, ho-

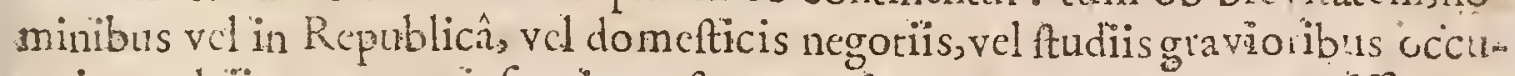
patis, vel is quorum infirmior eft memoila, gratar atque acceptiflimam. Hieron. Wolf. in Prefat. Ioan. Zonir. Annal.

Hunc Autorem adeo nihili fecit l faac Cafaubonus, ut ignominix causâ appelJarit Leciima itforic dehoneftame:tum.

in Bjbliothecẩ Baflieng? Codex habetur Canonum omnium Concil \& SS. $B$ bb 
Pp.cum Nomocanone Ph tii \& duplici Commentatio Zonare ac Balfamonts ubi longè plura, quàm in editione Parif cquo Corlice editionem nujeram $C a-$ nonwris omnium Conciliorum Oxonii in Angliâ accuratam, plurimùm juyit $C l a$ riffrrus Wetfenius jun. Oratorixin Acad. Bafll. Profelfor. Hofman.

Canonum porrò, \& reliquarum Epiftolarum Expoficio, qu apud Zonaram occurrit, eadem eft nará mutuatus cenfetur. Aub. Miraus in Auctar. de Script. Ecclef

Ioannes Zonaras in Tom. 2. \& 3. Annal res geftas ab Augufto ad annum Chr. m17. recunfer, ex quibus Cupinanus, \& $N$ icetas, alique rerum illarum def criptiones funt mutuati. Eufeb. Bobern. in Epitom. H.ft. Ecelef. p. 64.

In Scholits in Canones componendis, Zonara alintd atque Balfamoni propor tum fuit. Hic enim Civilis aquè ac anonici juris Confultifimus, utriulque concordiam perfequitur apparentes difcrepantias componit; \&Canonieas Quxtiones à fe motans multoties folvit: At Zonaras ècontra ipfis Canonum verbis: \& Cenfui interpretandis fricté. adharet, raroadmodum ad Civiles leges digrediens. Hinc fit, quòd Balfamon totum Zorare Commestaium toridem nonnunguam verbis tranfcribat; fuperflưm nimirum judicans, alia Zonare dictis addcre, cum nihilin tali $C$ anone occurrat, de quo exlegibus $P$ oliticis \& $\mathrm{mpe-}$ rialibus conftitutionibus difputatio inftituatur hoc eft nihil quod ad fuum pro $\rightarrow$ pofitum pertireac. Subinde etiam Zonar interpretationem celato nomine perftringit; neque ullibi" ejus mentionem facje; praterquam in Commentaris ad

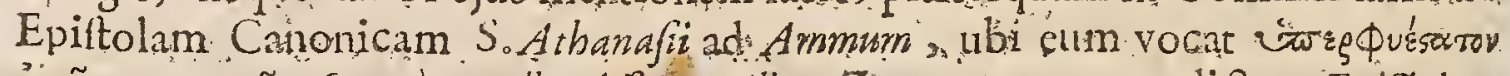

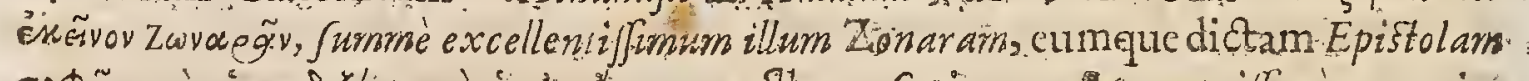

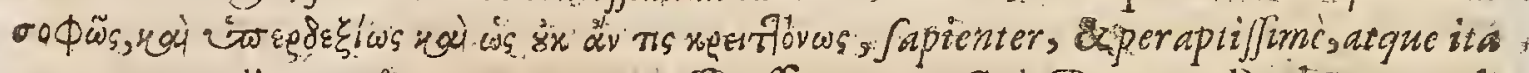
wt nemo melins, interpretattim elfe affirmato.. Gul.,Bevereg. Prolcgom. ad Canones.

Extat Hiftoria Catholica ab initio Mundi ufque ad Alexii Comneri obitum Gye ann. In 8. Græcè cum Interp. Hieron. Wolfy fol. Bajal apud loannem OporinHrn ann. I559\%

Extat etiam in Hiltoria Byzantina. .

Extant Commentarixil Canones Apostolorum \& Conciliorum, \&:in Epiftolas Canonicas SS.PP.Parif. I618.infol. Et cum Beveregii Annotationibus in Pan dect. Canon. Oxon. 1672. in fol.

Extat Oratio de immunditie ol Gonoriherm. Jur. Gri] Rom. lib. fa.. pag. 351 .

Extar de Nupriis Confobrinorum liber, apud Coteler. Monument. Tomön I. pag. $43 \hat{3} ;$

\section{GUILIELMUS MALMESBURIENSIS}

Glar. An. D. Ite, ur fapiù more antiquo fcribi folet, Willelmus Somerfet, Malmestriai MCXXX. rienfis in Angliâ Canobii Momachus, \& Bibliothecasius, noxellam fuam. 
3ur vocat, Hiltoriam anno Ir-42. tcrminavit : An utttà vivendo progreflus fit; prorlus ignora. Sunt qui hoc ipfo anno Ir42. mortum memorent. Phit. Labbe.

Scripfit librosy. de Rebus Geftis Regum Anglorum-Libros duos Hin ftorix Novcliz - Libros 4. de Rebus Geftis Pontificum Anglorum - Vitam Dunftani Archiepifcopi - Antiquitates Glufconie - Antiquitates Malmesberie - De Gente Wydenorum - Viram S. Aldhelmi Epifcopi Schireburgengss primi.

Hujus opera dim volvo, ix ex iis utilitatem cum voluptate percipio, nec hominis diligentiam pro merito laudare, nec ingentes labores fatis mirari pof. fum. Namadeo accurarè nôtras Hifterias tradzavit, ut vix quifquım in eo gehere fit illi-conferendus, nemo ariteferendus. Patfaus de Mlluftribus Angto Script.

Vir erat fuo feculo in omni genere bonarum literatum planè eruditiflimus, \& in eruendis Antiquitatabus ingenio, diligentiâ, \& induftiầ fringuluris. Anglice noftrx bationis ftudiefiramus illuftrator, 主 Primo Angl - axonum adventu in Britanniam, per P’ontifummac Regum fericm Historias ad fuatempora perduxit, elegantes ac pulcherrimas, ni quòd ex Cbriftiane Prudentic defectu, immode- xatè extulerir exccrabiles quadam fuperftitiones. Veruntamen in hoc nobis plurimùm profuifecum aliis multis creditur, quòd ejus ztatis naturam \& iniguos mores tam graphicè ac genuinè nobis depinxerito Balcus de Scripto Britan:

Inter retrnin Anglicarum Scriptores, " inamationis fide, \& judicii maturitate; principem locum teneat Gulielinu: Malmiefburzenfir, homo, ut erant illa temporn, literatè doctus ; guii Septingentorium plus minus annortum res tantâ fide,

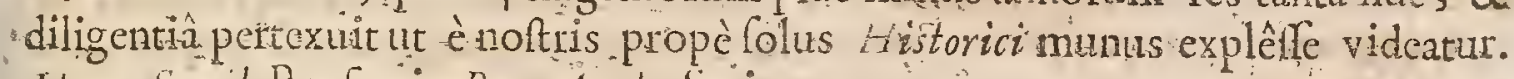
Henr. Savit. Prrefat. in Rer. Ang\% Scriptores

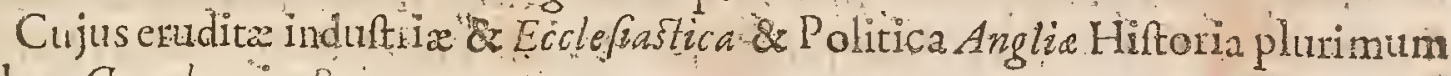
debct. Carrader.in Britan.

Mattb $x$ us Paris, vir ominum citimx tatis. Historicorum Anglorum (nificui placeat Wilielmon Malmesburiensemexcipere) eruditilfmus. Cafoub. in Epift. 624. ad Fronton. Ducaum, P. $74 \mathrm{r}_{0}$

In Anglorum Hitoria Gulielmus Malmesburienfis feriptor minimè ineptus. Barth. in Advert. p. 68.

Noftrorum Hiftoricorum polt Bedamprecipus Gulielmus Melnsesburien is Bibliothecailus. Lac.Vsher in Epit. Dedic. ad Brit. Eccl. Primord.

Gulielmum Malmesburienfen ante alios admittendum duco, idque moritrifimo fino: cum inter Hiftoricos nottos, \& narrationis fide, \& judicii materitate principom locum ten at. Whear. in Meth. Legendi Hirto. Civ. Sect. 28.

Magnam Hitorici fui Speculi partem ex Gulieimo hoc exfcripfit Vincert tiats Bclluvacenfis. Voffo de Hift. Lat.

Extant libris.de Rebus Geftis Regum Anglorum \& Hiftorix Novella libri $\mathrm{Bb} b^{2}{ }_{2}$ duo, 
duo, inter Scriptores Rerum Anglicarum abs Henrico Suvilio editos annis 1596. 196.1 ondiat, 1601. Franc ofurtio.

Vitam Aldbelmi Epifcopi Schireburgenss primi edidie Loan. Mabillon. fcculo 4. Sanctorum Ordinis D. Benedicti Tom. i:p.726. \& fequentibus. Ejuldem.

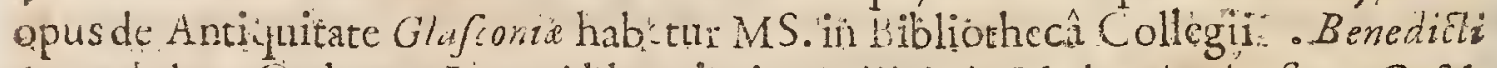
Cantabriun Cod:373. Item Abbreviavio Guillalmi Malmesburienfis cxi Geftis Haymonis de imperato ibus MS. in Bibliorhccî Colkgị Balliolenfis Oxonis Cod. 108.

\section{C.R A : T: I N U U S}

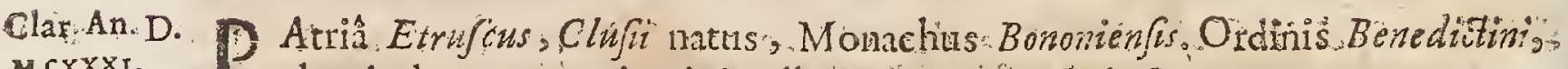
Mexxis: cluruitab anno rizr. in viy is adhuc ann. nij. Gul. Cave.

Decreta Pontificum in unum opus redegiț, juxta materiarum diverfitatem: digefit Hoc opusanthoritate Gregorii-Xill. ann. " 158 . à mendis purgatum, \&lua integritati refitutum ct:

Scripfrt Decrctum, fivc Concordiam Dilcordantium Canonum: Opus valde: labo iófirm in quo Canones plurimos collegit ex Refponfis Pontifum cx. Conciliis,, \& ex Patribus Et quanvis multi alii viri doeti in hoc genere. Sciptionis labonveriat, ut Diony aus exiguts, lifdorus, Cr fronu, Bur burdur. Ivo, \& fiqui alii funt:ipfe tamen folus obtinuit, ut publice in Gymnafis pralegeretur \& mulown doetifimorum virorum Commentaris ilhitraretur.. Gratiunu id unum thabet quodreprehendi polfe videtur, quòd non habuie delęetum Auctorum, ex quibus Decréa collegit. Bellarmin. dé Script. Ecclé.

Circa anum nistub Eugenio tertio Gratianss Monachus Bononenfir, Inris valde pcritus, compofuit librum Decreti prafurtim ex Canonibus Conc?-

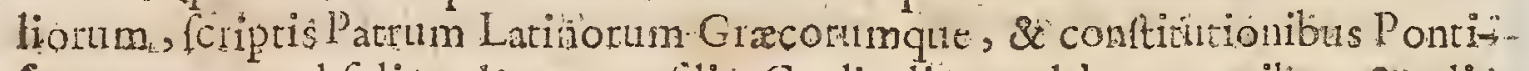
ficum, quas vel foli, vel cun contilio Cardinalum edabant; quibus \& aliquas lages Cof rca adjiciebat; \& prater hac ipfe Rubricas addidit, multaque dict funterferuit. Horum omnium Authoritas adhuc controverfa eft, cum Ga tum fapè errare deptehendatur, in rccitandis Canonibus Concilionm . Dicis Patr, \& ontificur conftintionibus, alierquelc habere plurina re petiuntur in ipfis fontibus è quibus Graianus hré defumplit .:. Dè Rubricarum verófide \& dictonm Gratiani omnes derogant" quod Gratianus homo priva-

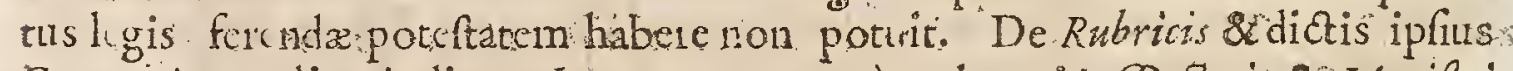
Gratininon aliter judicant Interbretes, quàm de unius Doctori \& Magiftri Cententiấ, ideoque in his fæè diffentitunt à Gratiano \&upofitentur Gratianwm erraffe, eique Iurus interpretandi tantum, non condendi poreftarem twibiunta. Pretcreà aliqua funt in Decreto qux $P$ alea dicuntur, nullamque I wris authorita- tem habsnt, five fuerint ipfus Gratiani, five alteritus; de quo varia tradunt $1 / \mathrm{s}$ sexpretes, cafque paulatim irrepfilfe in Codicem Decretz, \& paucifimas in libris. antiquioribus reperiri. Duck de Authoritat, Juris Civ. 
Anno ri 40.Gratianus compilat Decrete, \& Lombardus Sententias: quae dio fcripta Pontificiain omnipotentiam valdè promovent. Hine Graizanus Lombardwi, Fruncifius, or Doninicur, quatuor Evangelișta Antichristi vocantur. Alfsed. in. Chronol: fuî.

Gr. tranus totos ferè viginti quatuor annos in Opere fuo confarcinando infumfiffe putatur, id eft ab anno circitcr n27. ufque ad Injr. cùm id in lucem emifits.ntvulgò creditur. Morer. in MaioriDictionario. Gall.

Per idemetiam tempus Gratianus Decretum confarciliat; non feliciùs quàm Pandectas Iufinivinus; ; ex Canonibus \& Decretis antiquis quarquidem ipfe plüribuş locis ad temporis corruptelam accommodat, Komaile ambirioni prafertiin fervire cogit:"quamquam multa nobis veftigia rclinquit, quorum ope, antiquam Ecclefic \& Doetrivam \& praxim inveftigare- fedulo ouxentibus datur. P.bil: Mornew: in Hilt. Papat. P. 28,5 ,

Multa funt in libro; quem Decretorum Gratiani vocant, praclira ex Patri" bus collecta in quibus cernere eft' utcunque ftatum Veteris feu Primitive Ec-

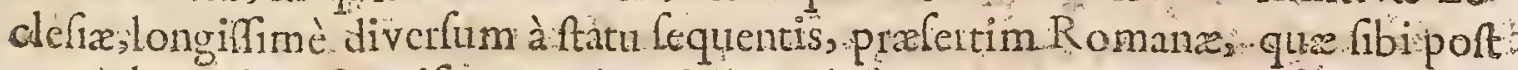
per Schariaticos Pontifices. Vrituerfalis Ecclefie nomen arrogavit ; fítamen $E$ co cle fram lice appellare, qua hoe facrilegum Idolum aufa ef -tatuere impudèntiflimâ facie. Sed Gratianus Pontificibus, jamt tunc tyrannidem in Ecclefia Ghrint fibi' vendicantibus, adulantion vel oblequentior, quàm oportuit, optimg? dicta \& decreta Patrum velantiquat, vel ad arbitrium Romanorum Pontificum depravat piâ (ut apparct) intentione, led peftilentiffmố exemplô. Nam indé

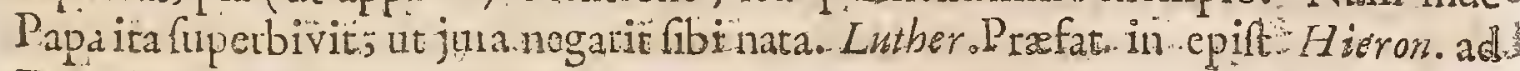
Evagriur tom. 4 : len.pag. 4.08 .

Cinonum concinnavit Decretum, iple concordiam difcardantium Canonum vor. cat; fed cujus maximam partem ex I Jidori quodam libro congeffilfe fertur: Thomaj.de Ilagie.

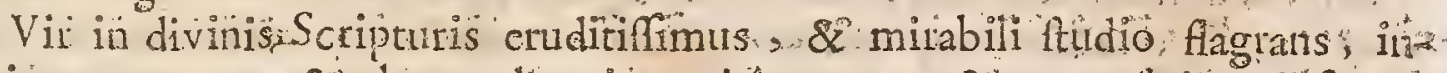
genio promptus, \& clarus eloquio s, vitâ quoque \& conwerlatione infigniso Trithem.

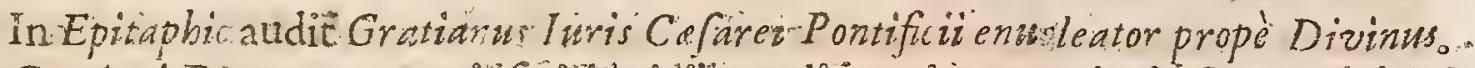
Grationi Decretum extat infinitis vicibuseditum, ir omini juris Cassonici culj-

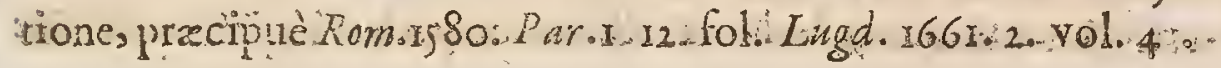

\section{PETRUS LOMBARDUS.}

NJ Atione Lombardus, patriâ. Novarien jas ab oppido urbi illi vicino"s quod? Th vulgò Lumen omminn diüitur, Mägifter Sententiarume vulgo dictus, . ex Clar. Anto E $^{*}$ Theologicr Scholx prafidente qui per ea tempora Srbol aicus vocabatui, Parifiènfis, non Archiepifcopus, ut alicubi Icripfit mints circumfipe ctè Blondellus, fed Epifcopus ab Anno C bristi ns g aut fequenti,quo ei ob eminentem doctrinam ceffit Philippus Archidiaconus ejufdem Ecclefix Ludovici V II. Regis Francie filius \& Lidovici VII. fratersufgue ad diem 20. Julii anni ir64. quo vibibb. 3 tam 
tam finit \& in fuburbana S. Marcelli Ecclefia conditus eft-- Quanquam Petrus nufter fuos nævos habere dicatur; rectè tamen Stancarus. libro de 'Trinitate dixit unum Lornbardum pluris fe facere quàm centum Lutberos, ducentos MeLandthones, trecentos Bullingeros, quadringentos Petros Martyres, quingentos Calvinos, ex quibus fi in mortario contundantur, utpote Hreteticis \& Hretico. mm Ductoribus Dotoribufque, expriminon pofit una meiaverx Theolow gia. Labbens de Script. Ecclef.

Hunc omnes Theologorum Schole finglari quadam vencrationis excellen

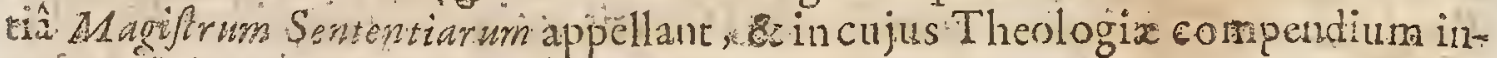
numerabilia difytationúm voluminn enditifini clarifimatum toto Chrifiano orbe Academiarum Thcologi clabơânrunt. Collegir in omnes Pralmos Davi-

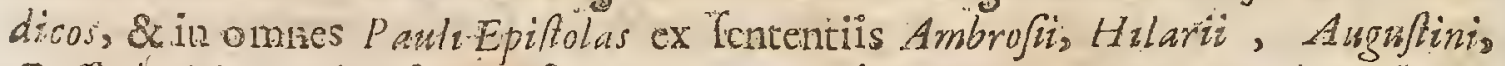
Caffiodori \& Exnigit fuppreflis eorum nominibus, Commentarios onni cruditione refertifimas; ing quibus etiam de fuo aliqua nonprorfus abjicienda interpofiit: Sixtus Senenfo. I. - Bibl. Sand.

Petrus Lombardws, Epifcopus Parîtrenjes ex Scluolaftico : vir in divinis Scripturis ftudioffinms, \&uobiliterdodus; ingenio fubtilis \& clarus elo quio nomen fum fribendo cum tantâ gloriâ tranlmifr ad polteros, ut ufque in hodiernum diem fuis opuculis Theologorum Schola ubique exercitata, fingulari ve

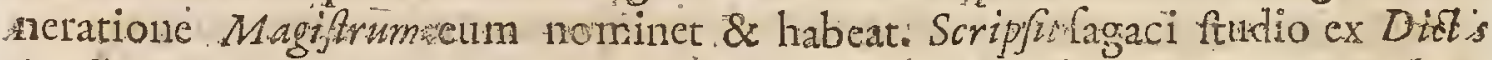
Sandonum Patrum commondabile opus, Sententzarum libros quatuor. Tribem.

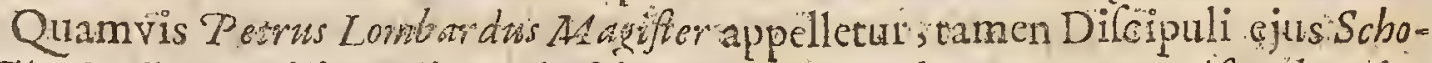
lastici Doctares, viri acuti ": docti non omnia probunt, qua Magiffer docuit:

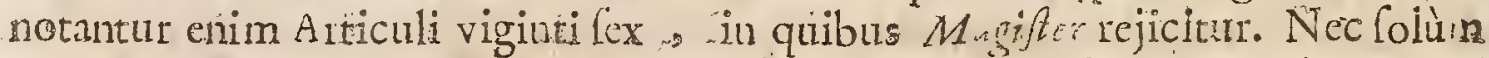
- epiniones ejus aliquando refelluntur: fed eriam non defuerunt, qui eum ad Alexandrum tertium Pontifisem detulerint, Harefis nomine quod docuilfets Chrifum, ut hominem non elle aliquid. Quam ejus Lententiam dumnatam fuif fe in Concilio quodam Parrfenfi, jubente Alexandro Pontiffes teltatur Matthaus Paris in Hiftoria Anglican his in Henrico II. qux damnatio contigitantis novemdecim polt obitum ejuldsm Petri. Non diu poftex accufatis fuit a loachimo Abbate quod docuillet, unam fummain rem elle Patrem, \& Eilizm \& Spiritum Sandturn. Sed Concitiurn Lateraneire fub Innocentio terio , Peri Lornbardi fententiam approbavir, \& contrailam Ioachimi Abbatis deprobavit. Bellarmin. de Script. Ecclef.

Eft \& alius feriptor preffis veltigiis Axistotelem lequens, illique tanquam rundamento invitens, qui noñ pauciores, opinor, emarratores habuit, Petrus Lombardus, ób hoc nobilitatus, quòd primus Thuologi mantea inerdinatam \& indigettam, in Methodum redegit, \& ad certa capita revocavit. Roland. Maref. Epif. 1.2. Epilt: 57

- $D$ : Lombardo Larbertus $\mathcal{D}$ aneus judicat, eum, fi in feliciora tempora incidillet, mi uifue corruptam fidei Chriftans doctrinam didiciflet, potuiffe multùn prodeffe Ecclefiz Der. 
Lombardus inter omines Papistas optimus \& doctiflimus. Rog. exfuluaro im Apològ. pro Con. Dom.:-

Gratianus, Lombardus, Francifcus \& Dominicus, quatuor Evangelifte Antichrifti vocantur Alffe dio in Chron. fuâ.

Quamvis in libro Sententiarum Papatum confirmetpro virili, multa tamen exciderunt, qux Pontificiós errores oppugnant. Ilyrir. Catal. Teft. Veritat.

Eadem methodus i'ctri Lombardi (is Gratiani frater) in 4 . Sententiarum lin bris, quas ex.Patrum locis hinc inde collectis, in certum ordinem compingit: quos 2 ipfe immutato, omilfo, addito interdum ali guo verbo, fcenæ fervire cogit, ad corruptam avi fui Theologiam inflectit. Mornems in Hift. Papat: pagin. 285 .

Lombardus facrofanct Philofophiz veritaten; fontemque puriffimum (ficut pltis millics à facobo Fabro, \& fodoco Clitoveo Praceptoribus meis ascepi is atque audivi) cono Quxtionum, rivulis opinionum conturbavit Ioan. Aver. tin. Anual.1.6.

Cerce ab hoc tempore ut lóquitri Trithemins, Philofophia fecularis, $S$. Theologiam inutili fuâ curiofitate foedare cepit, \& in diverfas fectas abiic.

Scholaftrcomm Pater fons \& lovis fatua Peirus fuit Lombardus, Epifcopus

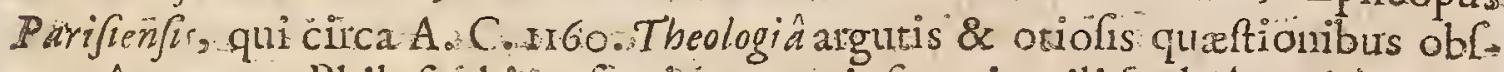
curatâ, aut per Philofopham fcculatem curiofrate inutilifoudatâ, vim Scripture elifit \& labefactavit atque à Chr ifte, à fide, à $D$ ei cultu vero, ad tricas inu riles Ecclefiarm abduxit - fermonemque purum \& proprium hourendâ barbarie deformavit Henn.Witten prefat. Memor, Philofoph.

Petrus Longobardus, Scholafticus Parifen as, poftề ejuldem civitatis Epif copus s magifiris fui temporis \& Scripturartim expofitaribus cò maximè prem ferendus judicatur; quod ingenio fagaci \& $u$ un affiduotantâ in exponendis $S_{c r i p}$ turis luce claruit, ut pend magifterio doctoris non egeat, qui gloflarum ipfins: lektioni animum intendere voluerit. Scripfit inter crtera magnum de Sacramentis Volumen, ubisprecedentium Patrum fententias eum fane intellexilfe planè expofuiffe manifêtum eft. Henr.Gandarerfor.

In condcndo.hoc Sententiarum opere non leviter adjutumeffe Lombardum Petri Abailard: Sententiarum libris,nobis auctor ef loannes Carnubienfis, iplus Lombardi difcipulis. Adduntalii. Lombardum magitti cujufam Bandini, obf suri \& penè ignoti Theologi, fcrinia infighiter compilafic.. Scripfr Bandinus Sententiarurn Theologicarum libros 4. qui curî: Bened. Chelidonii prodierune Vienna Igrg: Non ovum ovo fumilius, quà̀m: Bandiniano operi toriburdi Sententia, nif quòdpirolixior multà Lombardus fit, Uter alternm exfcrip ferits insertum, nec lisett facilè dirimenda) ffi non defunt, qux Lombardum fua ex Bandino deprompfiffe Luadeant. Gul. Cave in Hift. Literar. Script. Ecclef.

Libii Sententiarum IV prodierunt Rothornagi, an. 1653 . in $4^{\circ}$.

Extant Commentarii in Pfalmos, Parifis an: x541. 156r: in fol.

Extant in Epiftolas D. Pauli collectanea, Parifinsan. 1535 . I537. I55s, in fol. 


\section{A B E N E Z R A.}

Clat. Ari. D.

Ive Abraham EJdra filius natione Hifpanus, infignis fuit Grammaticus, MCXLV.

$\checkmark$ Philofophus, Aftrologus \& Theologus, qui commentaria præclara in tora Bibliia conleripfit. Commentarium fum in .12. Prophetas minores ablolvit in urbe Kbode, an. Dorn. II 4 S. Mortuus anno 75. ob infignem doctrinam \& fapien-

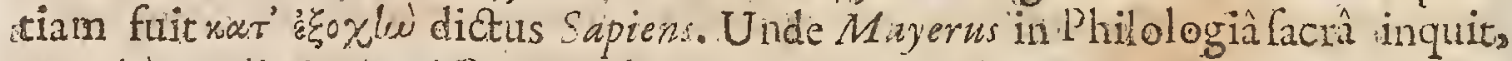

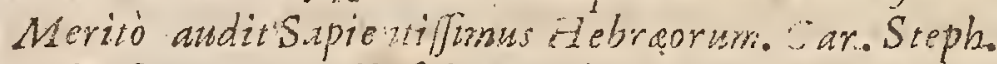

In Commentris fuis Aftrologiam \& qux inde pendent. Divinis haud fatis piè milcere folct. Selden.de Diis Syris \{yntagm. I. c. 3 .

Aben Ezra Judxorum Rabbinorun eruditifimus. Stylus cjus fat concifus unde interdum obfcurus. Rich. Sirton in Catal. Auth. I udeor.

Longè doctillimus Hebraorum Rabbi Aben Ezra. Iof. Scailig.de emend. Temp. P.27.I.

Aben Ezra, haud ex infimo.Dostorm fublellio vil-Spencer de Ur \& Thum. p.ro2.

Schikardus in libro fuo cui titulus Bewinath $H$ apperufchingtraduns quali honore Rabbi Sulornonem Iarchi profequantar Iudai, addit, "At fi me arbitro res sifta difceptaretur.palmam ego deferrem fequenti $4 b \%$ Ezre, quia non tantum - magisperfïicuus eft, methodiwus \& in ftylo multum degantion; fcupturaque “idiotifmorim teax, fed etiam prudentior: cautio, \& nigatum parcior: cum

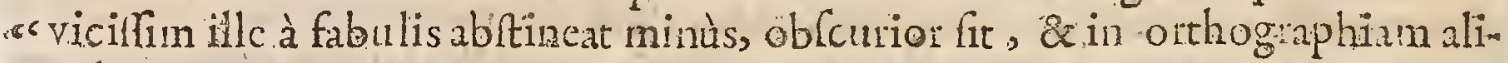
"cubi impingat; ut cum Kimchao interdum nò agat mitus, quàm noftrates «puéri cum Prifciano.

Aben Ezra Ceu potius Abrabam B "n Ezra inter cos qui apud Judxos, Doctifrimi Rabbini fuerunt eminct. In majorem Scripture partem Commentatios Cripfit qui in magnis Venetis \& Bafilien ibus Bibliis cxcufi repcriuntur. Styłum habet fatis concifum; qux caufa ef cur obfcurus interdum fit, preterquàm quòd imprefra exemplaria mendorum typographicorum haut omnino pura func. Extat Bibliotheca Patuin Orato hi Parifenfun Excmplar manufiptum Commentariorum cjus in Pentatcuchum. Pretcr fuos in Scripturarum Commentarios plures Grammaticos libros claboravit. Jel. Rich. Stmon.

Quintus denifue Scripturas interpictandi modus inter Yudacs, eftedulè perveftigare propriain cujufque vocis fignificationem, \& locis ad literam quoad cjus maximè fieri poteft explicare, non camen ferupulosè nimis adhrrendo Moffori, quia varie lectiones Exfcriptoribus plerumque funt afcribenate, non: verò $M$ afforetis. Aben ara hanc methodum fe fuis in Scripturam Comncntaiis fecutum efle profitctur. Et fruè nullus author Judæus à nobis legitur quu magis ad lireram \& meliori judicio Scripturam explicaverit. Crammatica tamen aliquanto plua quam par eft inteidum admifcet, \& optandum elfet ut cjus ftylus adco intercifus non effet. Quod ludxá alios impulit ad-Eiurim feu Commentariorum ejus clucidationes fcribendas - Ecce in ge- 


\section{CELEBRIORUM AUTHORUM.}

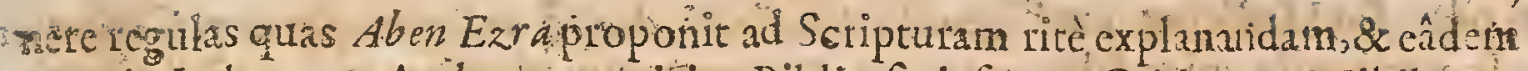
operâ Judxorum Authortum qui in Biblia fcriperunt Criticen. Nilil imco quiden judicio, rationi magis confentaneum eft quàm regulre ab eo prafcriptä,nec dubito guin à Chriftianis ad mittetur ejus methodus. Quanvis Patum fuorum Traditioni plurimum tribuat, non tamen approbat innumera delirasnenta quibus omnes cortum libri perfperf lunt ; $\&$ in fuis Commentariis fert fum maxime literalem \& genuinum quantum potelt exquirit. Jef.Richärd. Simon. Hin. Critic. V.T. lib:3.C.6.

LEE Eanè, ut dicis, multain Rabbinorum Seriptis occturtunt qux oftendunt judicii tenuitatem. Sed Lunt \& alii, yui lectis l'hilolophorum Gracorum \& Arabum libris nonnullis' \& Chrifianorium, accedente ingenii quadam bonitate, interpretationes adferunt non improbabiles, quos inter excellunt Aben E fra i

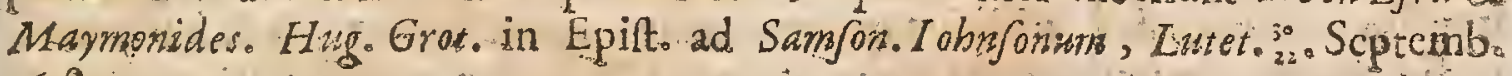
$x 638$.

\section{FVEROES, VCL AVEN ROES。}

A Rabs, in Africa educatus, naturali fcientî̀ vir pratentifluntis, omA niumque bonatum difciplinarum encycloprediam adcptus, feôâ MahoGiar.An

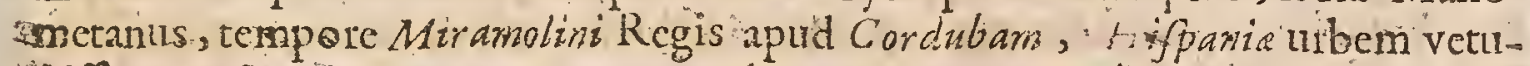
Hifinam, Goruitanno Dons. 1149. Multa ac variacompofuit. Librum (Colli$g c t$ ) dictum, totam ferè Medicinam complectentem, edidit. Avicenra rmulus \&inimicifimus fuile. Symplior. Campeg.libro de claris Medic.

Interprinos Arabumnon immeritò numeratur Averroës.Erpenorát. fcund de Ling. Arábicâ.

Fuit is Madicus celebris, at Philofophus acutiflmus, Maroccara Academize Profellor, religione Mulsammedanus. Magnus Aristotelis Zeloressutpote quem ut infallibilem propugnat, \& tanquatm Dewm veneratur. Medicoium ftimulus nonnullis dicitur Averrues, quòd Galenothon paucis inlocis contradicat, \& Avicenna mulus implacabilis fuerit. Locum fibi primuin inter expofitores Ariffotclis arrogavit ; Commentatorisgue vocabulo folus ferè -nuncupatur. Scrip? fre crimfuper uliverfun Arifiotelem Quenftedt.

Averroes Philofophorum Aceurfius; ut enim ifte apud Jurifconfultos, ita hic

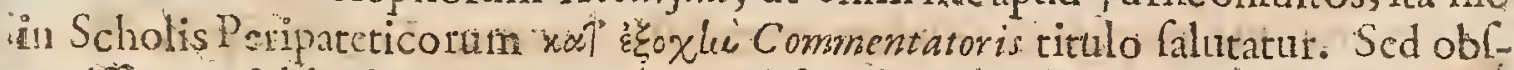

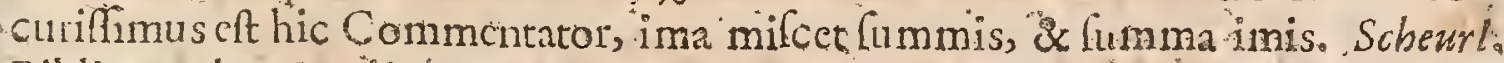
Bibliograph Morali, nimm: 6 ;

Inter Arabas Ariftotelis Inteforeces princeps locus debetar Averroi, unde

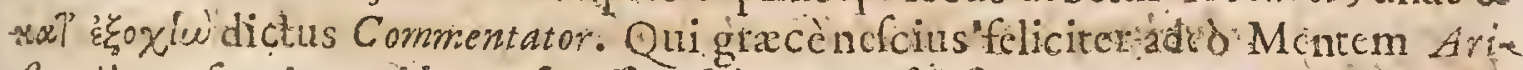
fotelis perfpexit, quid non feciffet, fil linguam fciffet Gracam? Nomenci fit $L$ ta

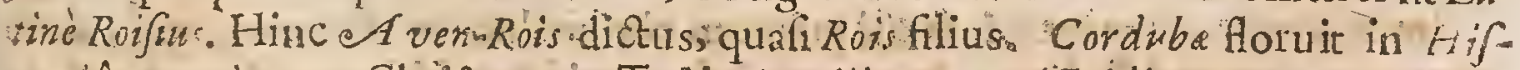
paniâ anno à nato Chiifto riso. Tettis Conciliator, ac EE gidius Romarns, qui \&

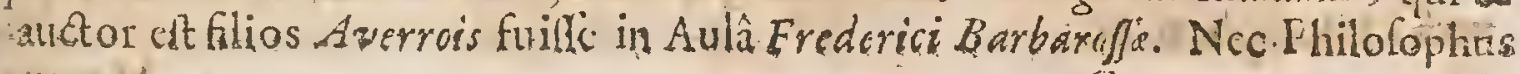
Wo, il

Cis mode. 
nodo. fed Medicint intelligentiflimus fuis: de quâ reliquit libros 7 . Coltige infc iptos, quia uniyerfalia pertractat. Quàm parum viderit tantus. Philolophus in vera \& unicâ falutis viâ, arguit illud, quod dicerct;. malle fe añmarn.

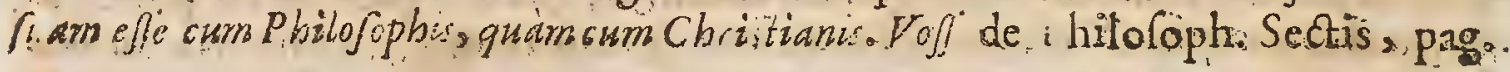
20.91 .

Ayerroë: Thilofophorum inter Arabes princeps, magni Commentatoris no mine fupgrbus (qucn, fi per Latina lingualicerergenium, Commentorem ant:

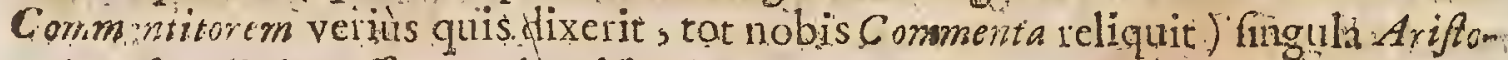
telis.verba divina effe oraculd arbitratus eft. Adr. Herebord epift. Dedicar ad Select. in Philof. Difpur.

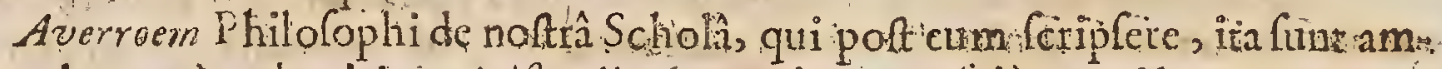
plexati utpenèathoritate Arifoteli adizquatint, nec follam gui longo polt iniervallo vixerune, fed qui ilius quaque tatate : - quod factum oft \& ignorantiâ

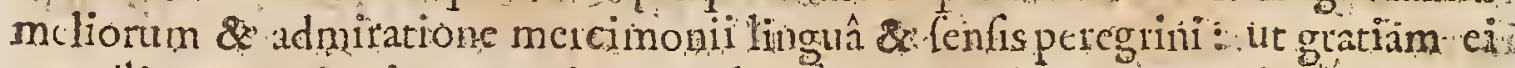
conciliarct apud primos novitas, apud polteros vetuftas, nomen eft C. ormentrom toris nactus, homo qui in A ristotele enartando nihil minus explicat, quàm eum jplum quẹm lirecpit declarandum. Sed necpotuilfet explicarc eriamfi divino. fuifet ingenio , quum elect humano, \& quidem intra mediocritatem. Nam quid tandem adfircbat, quo in Aristotele enarrando polfet effe probe linftuctus? non cognitionem veteris memorix, ronlcientiam placitonum prifce dificilim $n x$, \& intelligentiom Lectaium, quibus Aristoteles pafin fcatet- Itaque videas: cum peffinè Philofophos omnes antiquos citare , ur quinullum unquam lege: rit ignarus Gracitatis ac Latinitatis. Lud.Viv de Cauf. Cotrupto Artio 1., s.pago 296.227.

Cur autem Commentator (Averroes) am free ab Ariftctel is fui fententia víw deatue devius, inde factum volune, quod is in Hiffrkia uarus, \& Arabunn idio. mats imbutus, qum Grace literaturane apices quidemimbibillet. Anstotelis libies in barbanm fonm iton tranflatos quidem, fedmutilatos, decurtatos per

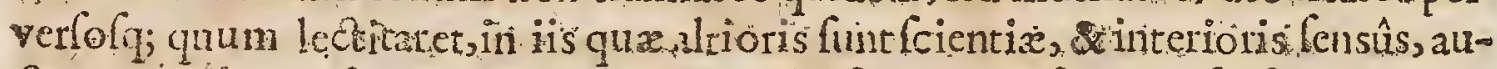
ctorem eminentifinum ftudio brevitatis ita frepe concifum, ut feifum aqummafudantes hilofophas, difineant diu multumque, minus minufque confequi valuit. Quod iti efle comprobat Plethon, \&indc argumentumevideiss, quód!

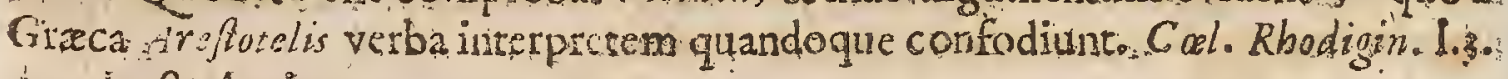
c. 2. Lect. Antio.

Averroès vir impius \& Auctor excerabilis vocatur Erafma Epift lib. 10 Epilt. 29:;

Aristateles vulgò habetur parum religiofus : Amemoës verò ejư Iriterpres. impius planè Phil. Mornass de verit, Rel. Chrift.c. 20 .

Iof. Differtat 4 .

Averroes vetut lymphitur in fristotelis laudes. Lips manuduct ad Stoic. Phis-i

Inter Aristotel is mancipia facilè prinum obtinet locum verrö̈s qui ; dim: nunquam eum errafle dicic, in errores iple manifeftos labitur, Henr. Ernft. de

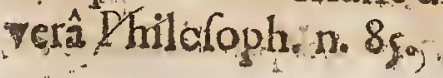

Magnus 

ifert. x.

Magnusille Ariftotelis Commentator. Conring. de Antiquitat. Acad. Dif

Philofophus \& Medicus non contemnendus. Tiraguell. de LL connub.

Varia ejus opera Manufcripta recenfet P'etrus Liambecias. lib. to Commentar.

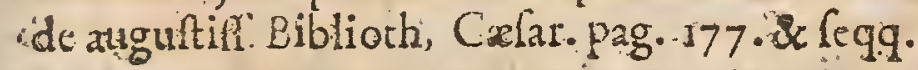

\section{HENRICUS HUNTINGTONENSIS}

J Icolatiflius, piius Lincolnienfis Ecclérie (anonicus, \& polt HuntingdoNenfis Arclidiaconus, flib Stephano Anglurami Rege claruit anno 158. ediClir. A. D. MCL.

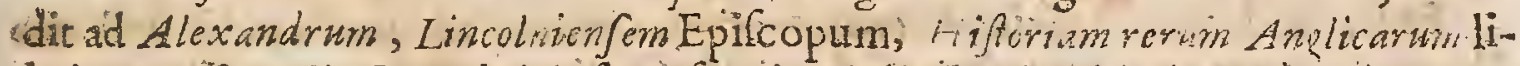
bris ro quì $M S i_{0}$. Cantabrigì Guperfunt in Bibliothccâ publicâ, \& pirivatâ Lumle-

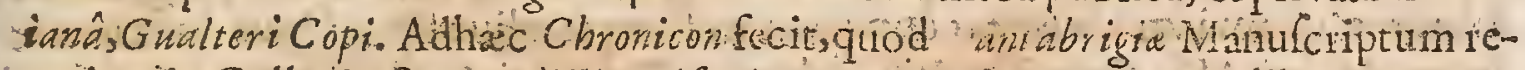
periturin Collegio S Benedilli. Fifforium quoque breviorem ano libro comprehendit. Item contexuit Seriem Regenn Orbis. Adhac Seriem Regum Britannid: qua Cantabrigie Manufciptacuifoditur in publicâ Libliothecâ:apud Th. Iamés

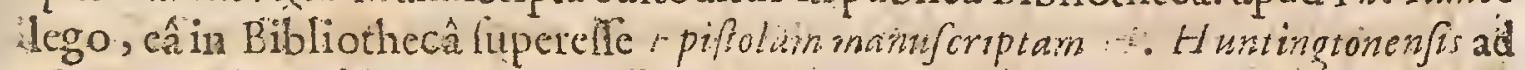
¿V Vurinum de Regibus Britunum. Poifcaqualeges apud eundem, apud Cantabrio gienfes etiam in Collegio S. Benedicti eaidem Epistolam cztare idcm opus videtur, ac quod voiaban Seriem Regum Brituninicortm. Item egit de Sanelis Anglie: tauod opus Manufciptum Antverpic extare fertur in Bibliothecà Societatis Iefu. Etiam expoluit Originem rerum Britannicarum. Bedum quoq; profecutus eft. :aliaq; nonnulla ingenii \& doctrinte fure reliquit documentit. Voff. de Hift. Lat.

Henricus Hunivigdonenfis patre $N i$. olit in Angliâ genitus, Fincolnienzis Ec- clefia Canonicus;\& Ales:andro magnifico illins ledis Epicopo mirè charus, â quo etiam piopter virtutes \& multiplicen eruditiónem, \& quia Roman cum eo profectus, in omnibus negotis ei fidditer adhatit, factus cft Archidiaconus Huntingdonenfls. Eratautem lenri $u$ à juventute poëta c egans, oratorfacundus, Hiftoriartim ailigens frutator, \& antiguitatum ftrentus inveftigaro: Quibus nominibus à Polydoro Vir gilic \& 'oanne Lelando mulcùm lauăatur. Albinum Andegavenfern Lincolnien fis ctiam Ecclefate Canonicum virum doctum, amicum \& familiarem habuit, cuil propter eximiam cruditionem, \& atem nonnihil provectiorem defert hunc honorem, it enm in feriptis fuis 'preceptoris thomine compellet Porrò accedente a elegantem doctrinam experientiâ rerúm, fimul y; crefcente maturitate tum ztatis, tum judicii, ad fcribendum (c contulit, \& maximè in Antiquitatibus perveftigandis, \& pofteritati mandandis fuam operam pofuit. Hiftorras edidit aetnâ laude dignas, in quibus \& fibi \& patrie fat ma no quifivit, quam nulla atas contiféfect, nulla obfcurabit oblivio. Hanc igitur faltem laboris mercedem accepit, ut dum aliorum res geftas à tenebris vindicavit, fulum ipfius somen'immortalitati confecralit. Loan. - i fens.

Cùm jam eflet experientia plents, ad Hiftoriam perferibendan totum fe

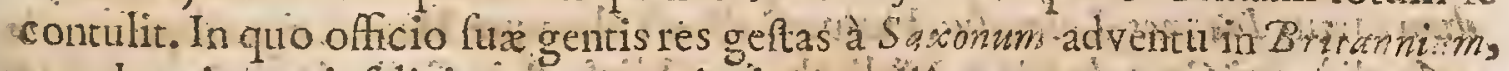

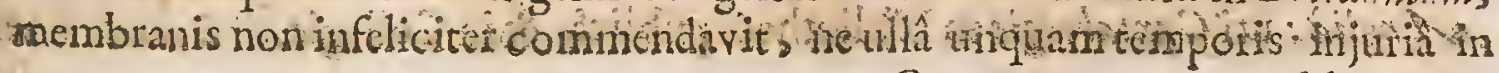

$$
\operatorname{Csc}_{2}
$$

oblivionem 
oblivionern irent. Cenfuit ad vita unftitutionem, pat Seripturarus Sacrarsan fudia utilifimas elfe Hiftorias : quòd rerum variarum exemplis bonos ad vintum tes accendant, \& malos à vitiis infamip metu deterreant. Interim fi quid addj scrit nugalium fabula rum, tempori imputandum, eft. Scripf reverâ Henricus leganter \& docte. Ioann. Balaun.

Henricus Huntingtonenfis Archidiaconis in Anglin vir eruditus, accclcbris fux xtatis Hiltoricus vivebatanno 11 4. Ant.Poffer. Appar. Sac.

Praclarè de hôc Autore fenfit doctifimus Henricus Savill; qui Prafatióne in rerum Anglicarum Scriptores etum, atque item Hovedenum, vocat, Auctores cumprimis bonos ơ diligenter 2 verifjimo qque Juperiorum temporim indices.

Exlibris decem Henrici Huntingtonenfis, omilfis eft nonus iim Collectione Veteri, quem quis unvenite poteft iñ $\mathrm{MS}$. Codice oprinna notx Bibliotheçe Thuanex, quam jam Colbertis comparavir furque adjunxit-Opus in criprum Imago Mundi MS. Oxonii in Biblióthecâ S. Trinitalis Cod 7 : in Magdalenenfa Cod. 17. Cantabrigie in Bibliothe Collegii S. Benedidi Cod .367. Oudin. in Supplem.ad Bellarm.

Oppidum Huningtonia abiplo plus honoris adeptum eft quam ipf retributer unquam valear - Q. Quandoquidem tot Exterorum nec ore tam celcbrata Huntingtonia, nec calamo notata unquam fuit quàm ob Saxonum Regurn prreclaram Hiltoriam ab hoc Henruco confcriptam Addamus quod futolida Superftrio fcculi quo vixit atrendaturs câ minus quàm ullüs cozvoum fuorum inquinatus fir; \& cum elfet Sacerdos Secularis, præflumtz Monaftic perfétionis faw 'tum paffum deprimat. Regnante-Stephano floruit; anno Domivi i I 4 . \&ci probabile eft eum anno circiter 1160 , diem obiifle. Thomas Fuller. in Preclaris An glia rebus. Anglicè.

Extant librirx. Hiftorie Anglorum cum alis e A nglicanaram rerum Scrip-

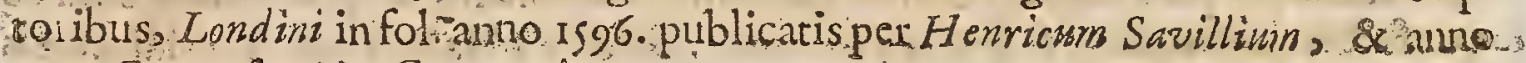
3601. Francofurti in Germaniâ.

Extar Epitolade Conemptu MundiapudDacher. Tom. vina:

\section{GALFRIDUS MONUMOTENSIS}

Mitic D.

D Egnance Henrico II vixit Gaufriaus, feu Galfridus, Monemutenfis Archi-

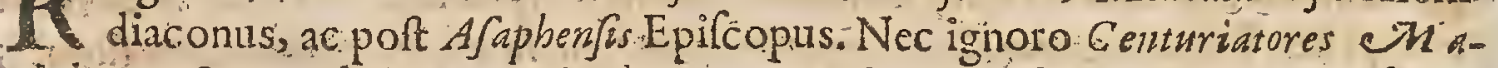
gdeburge fes aqualem putare Bede, atque ctiam Cardinalem fatuiab iiflem. Verum Lelandr, Baleo, Anglormane aliis, de Britannicis Scriptoribus magis credendum Ediditinter alia Hiftoriam Britanicam. Item Vitam Merlini Caledonii, \& Gefta ArturiRegis, Sed fides ejust multis damnatur Eofque inter Polydoro Virgilio ( qui tamen crebrò ejus auctoritarem advocat in Hiftoriâ fuâ:) item Alano Copo, loanne Molano, Baronio, Antonio Pofjerino, \&:Gulielmo Nen brigenfi. Adver(us Gulielmum Neubrigen fem, \& Polydorum Virgilium, Galfrim dum tuetur Toannes Lelandu. Hujus Galfredi pleraque Manufcriptafuperfunt in

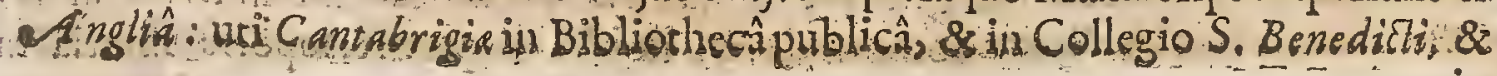

raghoxinge 
in:privatât. ibliothecâ Gualteri Copi. Vofj.de Hif. Lat.

Galfridus Artburius, Monernutbenfis Archidiaconus, genere Britannus, vif tam carmina quàm prosâ eruditus, quòd de clarifimo Britannorum Rege Arthurio multa conlcripferit; ab illius nomine cognomentum acceperit. Sune qui iftum plus jufto redarguant potifimum Guiliseimus Parvus $N$ ovoburgenfis, \& poft eum Polydorns Virgilius, quòd, ut ipls videbatur, importane Britannos extulerit... Solus tamen fuit, qui fuâdiligentia nunquam fatis laudatâ, bonam Bratannice Antiquilatis partem ab interitu planè vindicaverit. Illi certè non advertebant; communem cfé Antiquis Scriptoribus, tàm Latinis quàm Græcis, nimiüm làudanda latrix morem : imò nunc Adverfariis, iplis, eciam in meris adverfus Deum blafphemiis. Interpres ratum Galfridus erar non-fictor Hiftoriæ, \& vit per fum xtatem in omni fpeculatione doctiflimus. Benè igitur habet, quòd ejus defendendum fufceperit culam Ponticus Virumnins, Italus erudi ras; qui in gratiam Badoerce elarifime Kenetorum familia", qua ex Britannis olim fucrat, Hittoriam ejus Britannicam epitomavit, hoc teftimenium ferels: Galfridus (inquit); Hiftoricus egregins of Cardinalis angane vir autboritatis

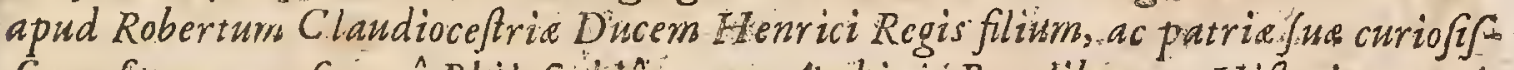

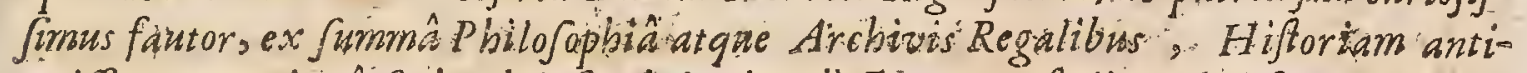

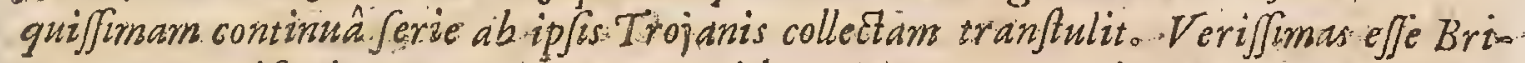
tannorum Hiftorias arguit Regum Occidentalium confuetudo que erat yecum Seriper habere cos qui veritate precipus coruri gefia notarent. Hæa ille. Sunt Galfrídi fcripta ab emulis frequentiưs ufurpata, etiam ab iplo Polydoro, nec hábent in Britannorwm Hiltoriis explicandis tettimonium majus. Si in annorum fups. putatione quibufdam aliis non refponderit, quod commume id fit Hiftoricorwra malum, facile condonabitur. Ioan. Balavis.

Vir in Ecclcfiafticis difciplinisingniterinfructus, do ctiis ctiam maxime il omni genete humanioris literaturæ, Chronographus ctiam non contemnendus. Quò fi in Hiftoriâ Britonum ficta nonnunquam faecis, falfa veris ; fabulofa finceris mifcuiffe videatur, id civitio vertendum non eft. Nam Hiforiam illam iple non compoftut . Ced exBritannico in Latinum fermonem tranfulit Interpres

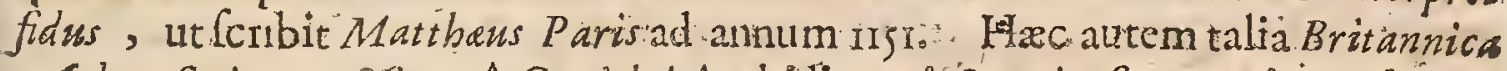
A dver Jaria ope \& opexâ Gualteri Archidiaconi Oxonienfs accepit Galfredus. \&fimpliciter vertit veritatem velfalfitatern, qux penes auctorem effe debet ne. quaquamexaminans. Certè go homini multum tribuo: Neque enim in Britannu is Hiftariis hốc teftimonio ejus, vix aut nevix yuidem aliquid antiguius, gravius, verifimilitis habemus: Si talisfabulator effet $G$ alfredus, qualem apuid Cefe fingunt eum quidam obttectatores, fanc̀ nunguam intuitu meritórum fuorum, \& imprimis laudatedoctriua, ad Epifopatum:AJaphenfem alfumptus füilfet. -loan. Pitfaus.

Ioannes Tuvinus eum Homerum Britannicum \& Mendaciorumpatrem appellac?

Sanè multa quidein fabulofa in co reperias : fed non tanta hîc Galfredi eft cul-

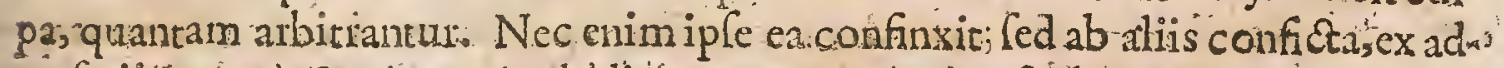

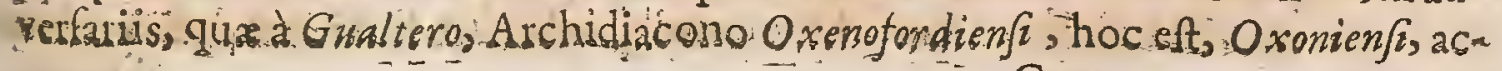

$$
\text { Cisc } 3:- \text { Eeperat: }
$$


ceperat, de Britannico fermone Latinè vertit; ut ipfe extremo Operis fui refert. Eâque in re fuit Interpres fidus : ut vacatur a Mattboo Parifiso ad ann.'IIj. Volf: de Hift. Lat.

De ecrto mortis ejus tempore non conftat. 'Galfridifidem in' Hiftoricis vellicârunt plures tum veteres tum recentiores, \& cenfurâ fatis iniquâ premunte Multa nobis incredibilia videntur, utpote à noftris temporibus longifimè re- mota, \& à feculigentifque notræ moribus aliena; multa, yuæetfi fabulofa elfe concedantur, non ftatim ipfe tamen ex proprio ingenio confunir, led ex.vetutioribus icrum Britannicarum monumentis haufit.

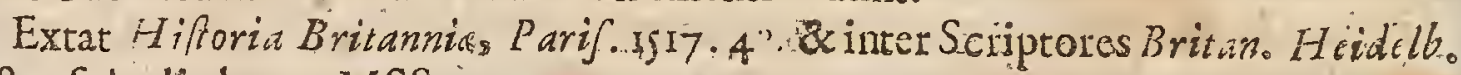
487 . fol. alialarent MSS.

\section{RAbbi MOSES MAIMONIDES.}

Clar. An. D. A Arus Corduba Ann. Chrift, I135. Septuagenarius obiito Ioan. Marh. in MCLX. I Canon. Chron.

In Agypto Scholam crexit: unde. nonnullis Mojes Agypizus adictus eft: ealluit linguan Hebraicarn, Chaldaicar, Arabicar, Turricar, Grecar, Philofophix etiam, Theologix., Turifprudentix \& Medicine peritifimus fuit : a Indais magnis laudibus afficitur. Quidam eum lucernam Ifraëlis aypollant:alii Iumen Orientis \& Occidentis: anemullis fapiens Hebruorum Araburn nuncupatwur. Elias in Thisbiaita de co fcribit: à Mofe Prophetâ ufque adbunc Mifen non furrexit fucut Mofos. Konig.in Biblioth.

Circa ann rí6o. effulfi inclytus ille Rabbi $M$ ojes $B$ en $M$ simor, quiab inirialibus nominis fui literis, Rambarn folet nuncupari. Fuit ille Mainonides in

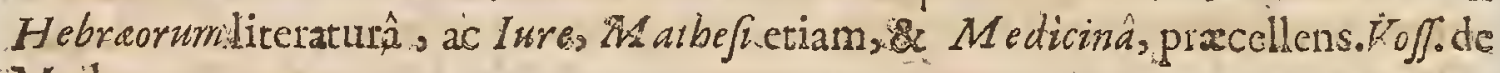
Mathem.p.370

Doctiflmus fuit inter Hebreornm Argiftos, unde Maximus Doctor dici

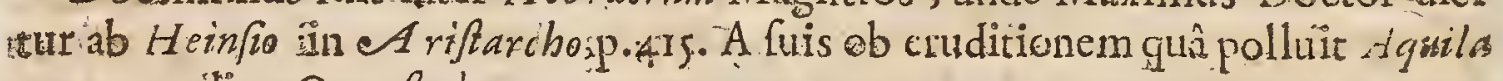
magna:audit. Quenftedt.

Maimonides Aquinas Rabbinorum à nonntilis wocatur.

Rabi Mofes Maironides ominum I ndcorum doctifimus \& acutifimus. Scalig. Canon. Ifagog. 1.3.

Inter Hebrousculebratifimus. Mercer. Prafat.in Iot.

Iudaorum jüris, quod tum tempoisin ufu erat, fcientifimus. Solden. ide Syned. Hebr. $1.3 \cdot c \cdot 3$.

Fut autorifte candidus minimequefupertitiolus. Pus certë veritati addi-

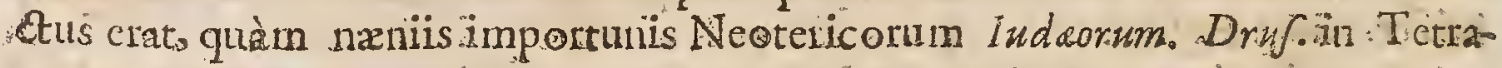
igramm.

Rábbi Mofes Ben Maimon Talmudicam doctinan fepolitis nugamentis felicitei compilcxus eft. Nunquam ita magnificè quiridquam de illo Autore dicemus quinid virtus fuperet ejus. Fato enim gudom \& forte nafcendi piimus 
foldfqưe in illâ gente rectè intellexit, quid hac Git non inepterce. Petr. Cumeus de Rep. Hebr. p.9.

Mofes Maimonidms (qui \& Mofos Azyptius dicitur) Colide atque ingentis doctrinx vili, de quo videor mihi poffe id verè dicere, quod Plinins olim de

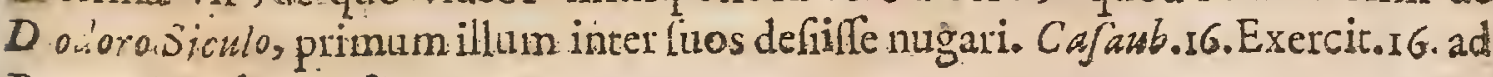
Barin. Annil : p.s.8.

Maimanidesadmirandie doetrinz Scriptor. Idem p. 5,33 .

Ex Fudeis Mainonides preftat \& Kinchizus quorum ille in fuo More Hanne:

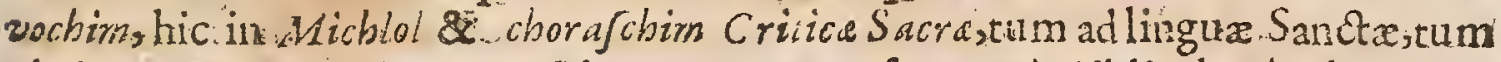
ad ri wu " \& ceremoniarum notitiam tantum confert, ut à Bibliothécâ Theologicâ non facile poffint abeflé. Hotting. Bibliothecar. Quadripart. po 175 .

His addendus inter indaos, quotquot à $M$ ofis atate flowerunt, doctrinæ \&: ingenii glo loiã longè praftàntillimus Rabbic Kr ofes Ben Mazmon; cujus partocinium fì quis meruerit, idem le Iudeorum omnium, quil illius effatas haud fecus

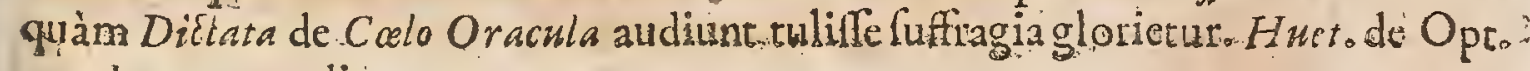
gen. Interpretandi:

Eximium do Atfimi Maimonida Opts Ductor perplesorum - Huet. de Clas. Interp.

Et fanè, ut dicis, multa in $R$ abbinorum: Scriptis oscurrune quze oftendunt jus dicii tenuitatem.. Sed funt \& alii, qui lectis l'hilofophorum Gracorum \& Ardw bum libris nonnullis \& C briftianorkm, accedente ingenii quadam bonitatc, interpretationes adferunt non improbabiles, qụos inter excellunt $A b e n$ - EZra \& Mazw monides. Hug.Grot.in. Epilt. ad Sar. fllobnfonum, Luteto... Septembr. 1638.

Ex quo livera: inter Iudaos Occidentales, Chriftianorum æmulos, explendefce-

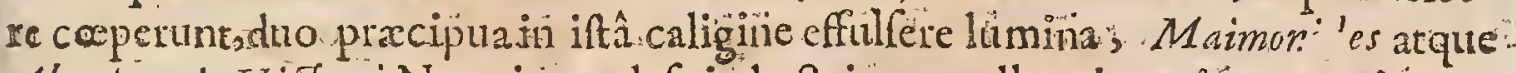

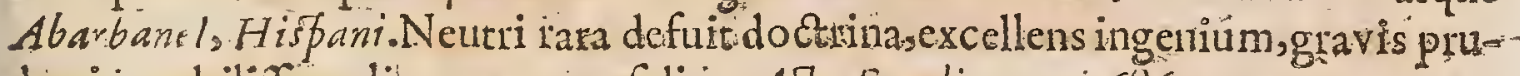
dentia, nobilifima literarum prefidia.. A Ala Erudit.ann.I686.p. 527.

Sicuti Rabbi Mufes Majemonides apud cives fuos tantam dudum adepetis eft

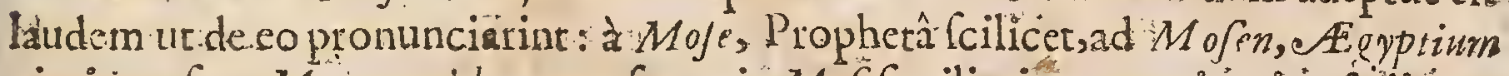
nimirum feu Majemonidem non furrex it $M$ of fimilis; ita now minoris eft dignacionis apud Chriftianos, quippe qui lolidx atque ingentis dootrine virum fuilfe unanimes affrmant. Hinc Philologi funmi magno numero fcripta ejus in liñ guam Latinam tranftulernut. ACa Erudit. Januarii 168 4. p. 10...

More Nevocbim Arabicì R. Mofe Ben Majemon conlcriptus lieerâtridaicu nondum editus, cujus Hebraicam quoque Interpretationem habemus liber ple-

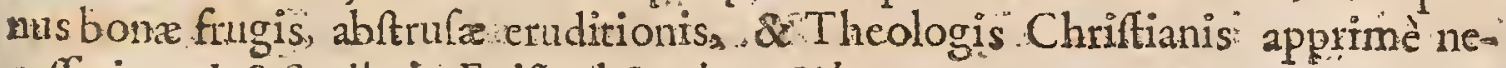
ceffarius. Iof. Scalig. in Epift.ad Stephan. Vbertum.

Rabbi Mofes cognomine M simonides feu Mainonis filius magnam exiftimationem fibi peperit. nedumapud Iudeos, . Ced \& apud Chrifianos, qui in fuis Opcribus unum ex cjus libris', cui titulis More Nevocbim frequenter citant: Hujus Authoris preciputus fcopus eft que in Scripturis difficillima infunt elizcidare, omniaque xquivoca in iiflem occtirrentia tollère. Plurimi Judxi in Methodim cjus. illico infursexerunt \& hoc Scriptum lamasyerunt; quiz 
fro ratiocinandi more Gentis fux Patrum traditioenm evertere vid cbature Ac fane R. Mofes Philofophum cculeri nimis affectavit, \& quoddam ex Arifotelis ac Scripture Principiis mifcellaneun ferculum paravit , quod omnirm palato fapere non potet. Ejus Metaphyfrca nimium fubtilis eft. \& in Gua plurimarum Hebraicarum vocum genuine fignificationis inveftgatione fatis peritus Grammaticus non videtur. Praterea fere - femper quxftiones decidit ex propriis prajudiciis qux quidem Religionis quam pro- ftebatur Axiomatibus yuandoque conformia funt ; fed lapits ctiam accidit, ut Arabum Philolophorurn "quorum libros evolverat, opinionibus mons cjus imbita fit. Jef Rich. Simon. Hiftor. Critic. V.T.1.3.c. \%o

R. Mofes omnibus delitamentis omninò vacuis noneft, licetalieveraverine quidam eum efre inter Iudres unicum qui dolitia nulla feripferit, Solus inter Iudeos nefcit delirare wabs ay fer. Verum eft pauciora apud ipfim ea occurrere guam apud alios Rabbins, fed eorum prorfus expers nou eft, aliàs genuinus Iuders non ell it. Idem. Supplemento ad Judaicos Ritus. Gall.

Extat Portac Troy is Arabiccicum Verfone Latina \& notis cura Edvarde,

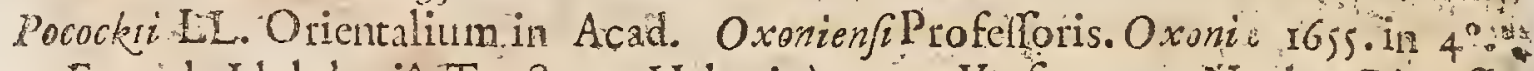

Extat de Idololatrî. Tractatus Hebraicè cum Verfone ac Natis Dionyfi Trofli. Amfrelodami $4^{\circ} \cdot \mathrm{I}_{4} \mathrm{I}$.

Librum, cui Titulus ef, Doctor Perflexorsm, ex Hcbrxo tranfulit Io Buxtorffus. Bafilex ${ }^{\circ}$. ann. I62\%.

-Extat de Ponitentiatractatus cum verfione Iodn. Tilpertr. Felmit. $4^{\circ}$ :an. ibito

Extat opus Manus Fortis infcriptum, Larinè redititum d Ludovico de Com. piegne natione 7 udeo. Parifapud Petrum le Mowneriniz?. ann. 1667.

Extat de Confecratione Calesdarum Tractatus. Parjfr.1669:in 12?.

Extat liber cui titulus Seplier Hainmizvos Amftelodami 1660 .

Extant Canones Etbrici Ebraice \& Latinc cum Interpretatione \&e Netis Geopgentii $4^{\circ}$. Arriftel. I ${ }_{40}$.

\section{PETRUS BLESENSTS.}

Crar.an. D. A Natali Gallic ad Ligerim oppito cognominatus, ex Canonico Bituricenfis MCLX.

A Ecclefie, Batbonitenfisin Anglia Archidiaconus, ac poftea etiam Londi-i nenfis, \& Cantwerienfis Archicpifcopi Cancellarius: obiiffe videtur (inquit: Labbe) circa annum r200. aut paulò polt. Scriprt multa, qua undique conquiifita evilgavit $P$ arijhis in folio apud Simeonem Pig?t anno $166 \%$ viâ lacobaâ Tibb ligno Prudentice, Petrus de Guffanwillz Carnotenfos. Presbyter doctifimus. cum Notis \& variantibus Lectionibus.

Vir indivinis Scripturis ftudiofus \&eruditus. atque in fxcularibus literis egregiè do:tus; ingenio acutus \& vehemens, quia viti. Principum \& Pralatorum non palpare fed arguere noverat: propter eruditionem \& vitx honeftatem apud Reges, Principes, \& Epilcopos in precio habitus. Trithem.

Vir lìnguâ difertus \& eloquens, omnigeno nitidioris doetinx honefámcatrobilitabatur. Non affentater Gnatoricus palpare : Ced teftis \& prece veridictis 
xeridicus, Pralatorum ac Principum vitia modeftè , redarguere non metuens, in Gratiam ita venit corain Henrico II. Anglorum Rege, ut primuta arelidiaconatle

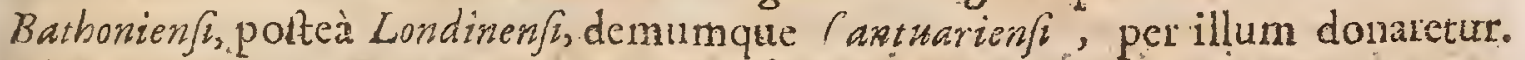
Thomse Becketi Cantuariorum Archiprafulis, quem pro raro numine tunc Clerse habebat, tumentem arrogantiam, in Epittolis ad Amicos'se in familiaribus collequiis folerter, fed religiosè, ftringebat. Clerumque ipfum à vero diffenticnrem, quafiimpetu quodam, frpiulculè vocabat Syriam, Edom, Vitulos Beibet. I dola aEg ypu, tingues Samarie, Sacerdotes Baal, Iudices qui coridunt leges inigruas, \& plura fimilia. Ioan. B zlem.

Inter dotes animi, quibus Blefenfis excelluit, prinipem ponn wry nem

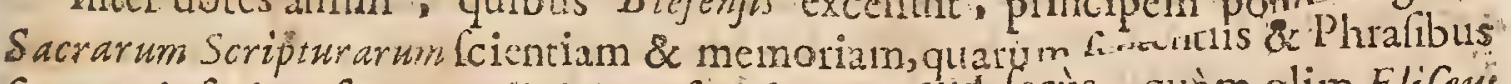
fic omniafcripta fua condivit $2 \mathrm{refperfir} \ldots$ r.. rauld lecus, quàm olim Elifaus

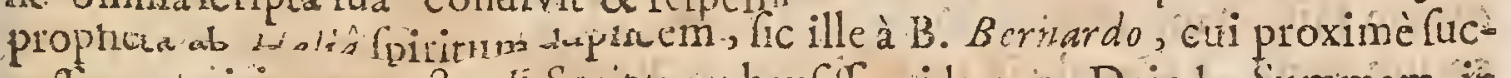
ccfit, siritum eructandi Scripturas haufife videatur. Deinde Summam th dictandis Epiftolis facultatem \& celeritatem. Ioan. Büfans in vit. Petr. Blesenf.

Petrus Bltesenfir, Archidiaconus Bathonienfis: vixit tempore Alexandri sertii Pontificis, \& Henrici fecundi Regis Anglorum, cuidiu familiaris, \& adminifter fuir. Scripfrt multa fapienter, \& cloquenter. Bellarmin. de' Script. Ecelch.

Tetrus Blefenfis Archidiaconus B.thonienfis, libertate fpiritûs in Ccribendo eximius, \& norman vivendi Ecclêfrafticis prefcribens. Loan. Card. Bona.

Primus fuit Petrus ille Blefenfiss, qui voccm Tranfubftaniationis adhibuit, - oblervante Calixto, tract. de Tranfubjt. th. 13 .

Quix ex ejus Enittolis nobis fuperfunt, totidem pro Ecclefra doctrina \& pro pictate funt Regula. Moreri Diction. Gall.

Ut Petri Blefenfl meritum innotefat, fatis eft dicere ettm fuiffe delectume ut unum è praclarifimis evifiui Politicis à Guliclmo II. Sicilie Rege, ad Sigillorum Cuffadix munus; plurimos illuttres Viros cjus operam quxfivifle tanquam eloquitentiffini in ejus feculo, al maximi momenti Epiftolas fuas fcri-

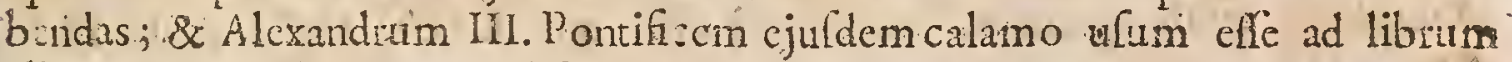
illum adornandum quem mifit ad potentem quendam Orientis. Principem qui Religionis noftrx Myfterit initiari cupiebat. Magni illius? Viri Opcra bis jam fub prelo fudavcrant. Sed nova hac Editio duabus creteris multò ablolutior cft. Nedumenimad plurium Manufcriptornw trutinam iterum cxaminata fuit, fed eriam I ractatibus afiquot hactenus ineditis locupletata. Conciones, quas P. Bufous ex focietate lefufub Pctri B lesenfis nomine typis malidari curavit , illi noin fint infertx, quia Petrus Comeftor catum gentinus Awbor nuper deprehchfus eft. Eruditornir Ephenerides Gallica, diei lu1ax 16. Maii, 1667.

Petri Btesenfis Continuatio ad Hifforinm Ingulphi primùm edita cum Insulpho, Oxor.1684. fol. p.ros.

$$
D d d \quad J O A N
$$




\section{JOANNES CINNAMUS。}

Clar. A.D. MCLX.

(Rammaticus, feu Notanus Imperatorims claruit anno 1160. in vivis adhin Tinno 1183. Gul. Cave.

Scripfir Hiftoriam, quâ compendio Ioanni Comneni, diffusc̀ verò Emanuelis Commeniflii res gettas depingit. Prodit Grace \& Laine 7.) lirajedti in 4\% anno

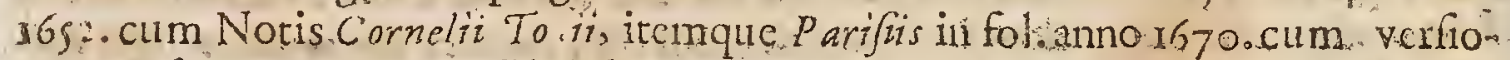
ne, notifque Hiftoricis \& $\mathrm{P}$ hilologicis Caroli du Frefr.

"aris mihi erit pro hac re fabiliendà elègantifini item ac prudentiflimi", lif

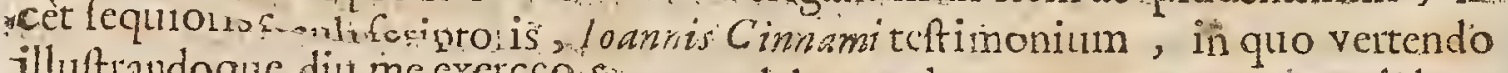
illutrandoque diu me cxecco f

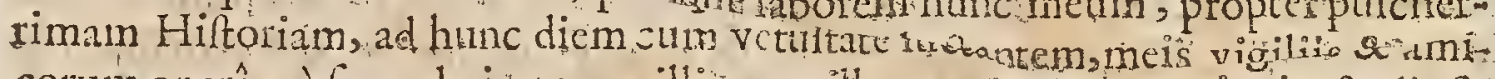
corum opcrî , é copulo in tranquillitatem illatam, Hijtorice veritatis foudiofis non ingrarum futurum. Leo Allat, in Dillertat. de P fellis.

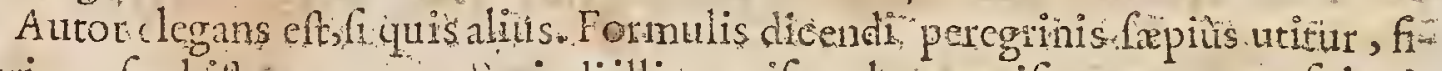
guris ex fophitatum pent. l'criodilli concifa, pletix s nifi cum compofitionis novitate afpcrantur \& oblcurantur. Totum fe,ut verbo extricem,ad Procopium. componit. Et mirum eftinter totalios ponteroris feculifcripteres, tumultuas. riè in dicendo fcibondoque delivantes, hunc tantum lapuifle. Nonnemo dixcrit, cum ninium foi indulfici in cnarrandis rebus Grocorum, quas majores cuàm erant, fcelit. His tamen répondebit Thucydides; carentis lunt tolckabiles alienz ląudes, yuarenus feipfum quoque parcm arbitantur alicui illarum allequendx. in quibus vero imparem, lis invident, fidemque non habent. In. Pentifices" Rcmatros, cim fefe tulerit occafo o femper \&acriter intemperans eft Idem in Diatrib. de Simeonibus.

Scdomninò modumexcefir in fuo Hudando Principe (Manuele Comneno) quem etirm, ubi vincitur, ut victorem nobis defcribit. Sedillud quàm vanum. quod eum folum inducit pugnancem: adverfus totum Saracenorum exercitum! Dictio ejus purior terfiorque, quam aliörum effe Graculorum folet. Inò Xenophontis ipfus, quem in Prefatione laudat, amulus eft Voff la.4 de Histow Grac.c.ig.

Virio ipfi vertitu, qerod in ladando Manuele modum excefferito Latray dat quidem, frd intranodeftia linités, nec adulatur; certè adulationis fufpicionem à fe longiflinè femovet, dum ex infita animi indole, atque ipio nature ductu fe ne verbun quidem ulato aut fcichtem, nifi verè perinde aci liberè proferre polfe profiteatur. Gul. Cave in Hift Literar. Scisipt. Ecclef.

Veftro dignum prafidio \&zutela habeatis maximis quondam Imperatoribus rarum loanntm huc Cinnarmum, Scriptorem iuduftiom, clegantem, magui Xenophontis xmulum, fatis ingenio fuo indulgentem, fatistemperantem; laildantem Comnenos Principes fuos, ubi latio, \& locus', \& merita poftulant, non res $\&$ fortunas eorum immodic è adulantem, omnibus denique, quæcunque jlo frculo viguerunt ingenia, Jumine ac claritate fuâ tenebras obducentem. 


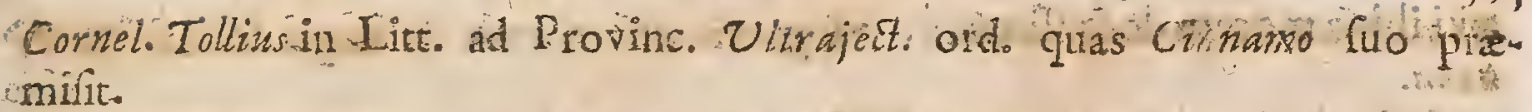

Fatendum eft. neminem fere alium juniokis Gracia Scriptorem aut totâ $H \dot{z}_{-}$ foria ferie verbis tam elegantem, aut in Or.tionibus tain bellum, tam argutur effe, atque hune noftrum. I dem in Not.ad Cimn.tri l.3.c.i 4 .

Cettè in ifto Opere, ut in enarrandis Grocorum gettis nimium fibi vidctur

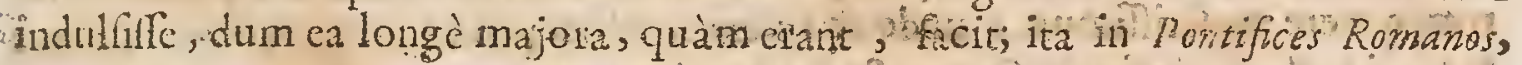
Imperatores Germanicos, atque adco in Ratinos omities, ex innato Grecanicis int geniis odio, feu potius invidiâ, parum xuus, imò femper \& acriter intempetans eft. Carol. Dufresn.in l'rolegom.de Cinnamo.

\section{JOANNES SARISBERIENSIS。}

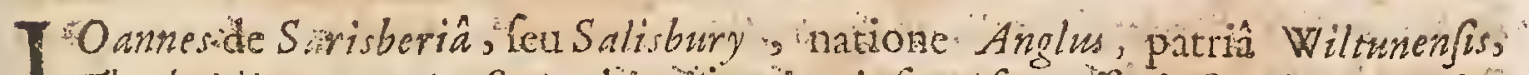
Theobaldi Cantuarienfos A rchiepilcopi, ejufque fuccelforis $S$. Thoma.Becket Clar. A. B. Martyris primùm. Clesicus, tum annoryj2. creatus Epifcopus Carnotenfis ceffione Wiltelmi dictiad Albas Manus, filli Theobaldi Comitis Campanic, qui ad Senonerfems ac dcinde Rhemenfern (athidram pro onotus, per biennium Carnotenferm Epifcopatum concefu Alevendri III. 1apx retinuerat. Interfuit Conci-

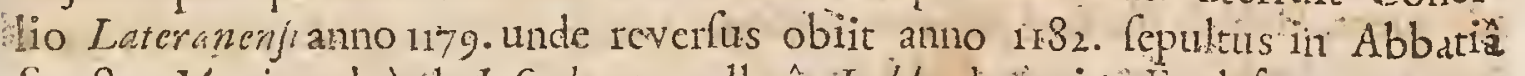
Sancere Maria vulgò deIofaphat appellatâ. Labbe de cript Ecclef.

Iosmes Saributienfis, natus in I'rovinciâ Wilcheric, qua alio nomine Wilugia dicitur, ex primis unts fuit, qui noltre $B$ ritannie poft Theodoritempora, Gr-curnci Latinamb Linguam , fure puritati ac dignitati reftituere laboravito Avidus bonarum litcrarum explonator a perceptis Artium praceptiunculis primis, trajuctoque mari, celcbrioia Gallorwm, Italorksm \&i Apulurum frequentabat ftudia. Dulce nimirum fempcr habuit, in libcralium Mufarurs Campis exercercludum, ingeniô ad iddextcrimo praditus. singulari per hos labores lingux beneficio atque entitione prattans, Engenio tertio, \& Hadriano IV.Rom.

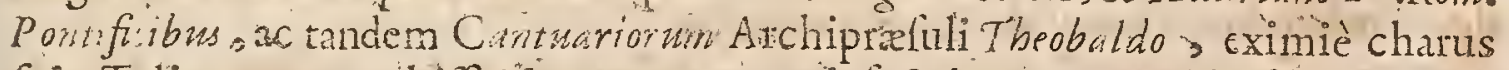
furt. Telis tamcin aceibifruisistonnunquam infectabatur Cleri abufús Scriptor

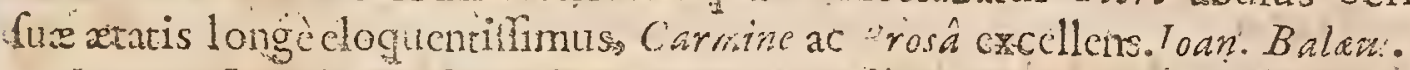

Ioames Sarrsburienfs Natione Anglus, patrîa Wiltunenfis. Vir ad bonas artes

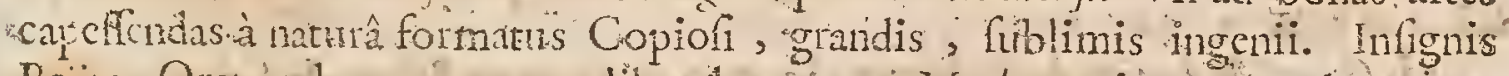
Poëta, Oratèrcloquens, mncs liberales, omnes, Mathemaricas artés ad ung iem calluito. In PhHofophia tum Morali, tum Naturali profunde eruditus. Groce Lingue perieffimals, Hebraica non ignarus. Denique in Sacris Scripititis omni-

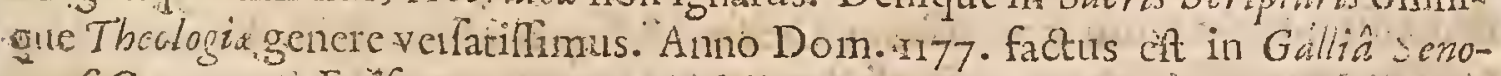
nenfiCarnotenjis Epsiscopus. Carnoti obiit an. Dom. 1182. dum in Angliâ regnam vit Henricus If. Pitserts.

Ejus Policraticon magni antimatur apuda Eruditos.

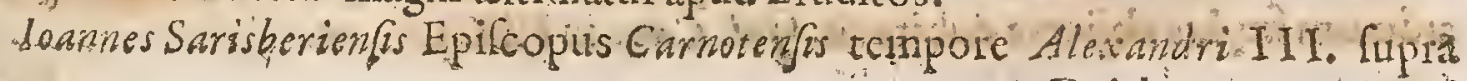
$<$ D.d 
zvillius morem doctifimus, vir gravis etiam cum de nugis fcribit. louts Bona.

Fuir vir Gracé Latinéque doctifimus: ac prosâ ïlem ac carmine pollens:

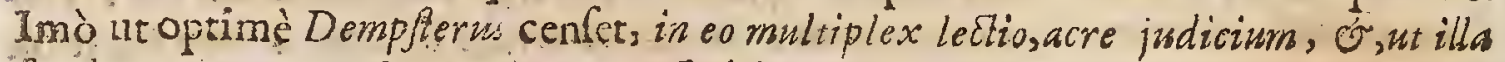
forebant tempura", eloguentic fatis. Voll de Hift: Las.

Io annes Sarisburienfis, vir, fupra quam barbaries feculiffercbar, in omni literamun genere verfariflimus, , unde \& Incomparabilis pio eâ atate Scriptor dicitur Rofino in Antig. Infignas Gracus \& Latinus, ita ut utramque linguam in Angliâ priftinz purisari reftituerit. Quenftedt. de Viris Doctis.

Dignus ille auctor, quí multorum manibus, teratur. Nzvi aliqui, fed illius avi funt: qui doctan Ccripti majeftatem non impediunt. Atque mores nottri ejulmodi quoque Cenforem merentur. Eryco.Pureañ cent.2. Epift $8_{4}$ ad Palthemivim.

Magnum ingenium, fumma prudentia , fingulàis eraditio füere ævo ultimo in Ioanne Saresburienfin Anglo, Ciarnotenfurn Epifcopo. Epiftole tanti Prefulis magno bono ližcrario muper memorixe reftituta funt. Bartb lar3.adv.c.12.

Quô ncfiò an ullun ex fequiòbus feculis literatiorem. Scriprorem habué ris. Ideris ibid.dis.c. 3 r.

Meritò Lannem Saresburienfem, Carnotenfum ante annos ferè quingentos: Prźluem tanti faciunt fummi hujus zvi viri", ut penè Romanis Scriporibus adxquent Habuit ille fane Scripiores, iifque dextrè ad res \& verba ufus eft quos nobis fata inviderunt. Idem ibid.1.57 C.8.

In quo Centone ( viz.Policratico lannis Sarisburienfis) multos pamos purpurxagnofco, \& fragmenta avi melioris. Lipf. Not. in $T$ icit.

Quamvis Expiufculè purpura thuic pannum affutum videas, non illicò tamen ex bonz notx Auctorum cenfu, exauctorari omninò merebatur. Enfías. Svvari.1. Analect c. 30

Ioannes Saresberien is, Cornicula vocatur à Iano Dousâ nomilie parum hoqefto, quodque faltem cô locô non merebatur, Scriptos aliö qui.non malignus, \& vel ex rvibabai moribus fi non ubique autores citat.s excufandus, neque tam. afperè habendus. Thorad de Plagio, num.53\%.

Joannes $S$ aresberienses multa ex Apuleio defampfit. Colvins in Notis ad lib.de: Dogm. Platon.

Videor mihi videre in hoc homine, prater raram quandam facundiam, omnis Seientix orbem. loan. Leland.

Vir Grare \& Latine doctilfinus, in quo matutinam fellam de fuis thefuuis Deum produxife ait Petr.Abbas Cellenfis, lib.7.ep.8.Olear in Abac. Patrum.

Vir atatis fux eloquentiflimus, \& reconditioris cujulvis Scientix genere inftuctifimus. Morum feveriffmus Cenfor, \& fi quis alius, rigid fervator Honefti:in carpendis aliorum, criamf Regum $\mathrm{v} \perp$ Pontificum vitiis parem adhibuit facundiam \&libertatem. Nec amicis pepercit, nec,inimicis.Quin nec ipfi Thrme; domino fuo \& familiari, obftinntum \& pervicacem in Regern clementifimum 2nimum fepius objicese disbitavit. $G$ wl. Cave in Hit. Literar. 
Hic, ut prophanis Scriptis autoritatem conciliaret, impudenter mentitus eft. Ernft de verâ l'hilor.

Plura de hôc Aurore memoratufanè dignifima, ex Epiftolarum:Thoma Becket collestione, non finc lectoris commodo peti poffint.

Extat Polycraticus Lugd. Bat.1639: 8 : ' in Biblioth.Patr.Tom. 23.

Extant E pirtolix: 303. in Bibliothecâ Patr. Tom. 23\%.

Epiftolarum aliarum liber prodiit $P$ ariflis. $1611.4 \%$.

\section{T. HIE O D O RUS BA.L.S A MON.}

D Iaconus, dein Nomophylax, \& Chartophylax, tandèm Parriarcha Antiochenm, eruditiffinus fui feculi. Spe fedis Conftantinopolitane, ab. Ifaace. Angelo Imp lactarus, in reefulum coetu,tranflationem ex unîfede in aliam Cam nonibus non effe contratram obtinuit, fed $D$ oft heo, qui Patriarchas Hier ofolymita nus fuerat, abimperatore promoto, deceptus eft. Scripfit notas in Nomocanonem Photit; \& Syllogen Conftitutionum Ecclefrafticarum; quorum ille in Bibl. I tiris C Canonici Iufelli, ha cum notis. Caroli A nnibals Fabrotti prodierunt. Sed Commentarius ejus in Nomocanonem, in Bibli:B aflienfislonge amplior extat., quàm qui $P$ arifirs habetur:Scripft porrò. Medikationes in privilegia. Patriarcharum. Refponfiones ad Murcum Parr. Alexandria : ubique acris contra Latinos, qui: sum: Antiochiam tencbant. Cbiit anno 1203 ; Hofman.

A Spondanu ir Epirom. Annalizim Baron. ad annum Is 3 . num. 4: vocatur. In rifconfultitflrmus, item legurn \& Canonum peritifimus.

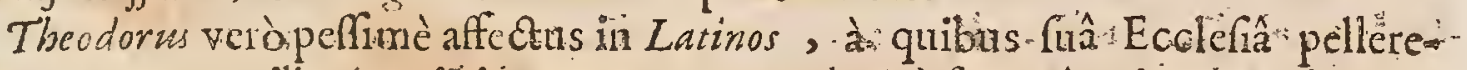
tue : toto opere illo (notis îl Nomocanonem Photii ) funmâ animi amaritudine à. fe confcripto, nilibilmagis elaboravit, quàm utinfamaret Latinorum Ecclefram principalem, Romanam Sedern, cujus auctoritate abr: Antiochenâ Eccleo fî́ fe excludi cognofceret: Arquàn calumniosè , aftutè, vafroque confilio id egcrit videndumeet: 'n primis vero homo vaferrimus confuetâ arte $P$ elafga apocrypha in fua collectione mifcuit cum authenticis arque probatis, nempe Canow nes Apoftolorum dictos, ab Ecclefiâ Catholicâ nunquam recepros \& probatos; itemque rejectos alios sappofitofy!e mentitos Canones ad fextam.Synodum, ex quibus tanquam è 1 hatret is Sagittas fumitcontra Colibatum Ecclefra-Occidentalis,jejunium Sabbari, \& alia id genus. Ite mque,quod nemo-aliüs Gracorum anted. fecerat, ex Astis Syluefri Pape, fub Eufebii Cafarienfis nomine falsò Grecè fcriptis edidit edictum Conftratini de Donatione, non ut rem "gxatam faceret $R o-$ mana Ecctefze, fed:ut Confantsnopolitarnm Patriarcharum oftenderez antiquiffrsum. Baron.adann. II gI:

Neque hîc omittenda cautio Ioannis Márie Brafóchillani lit expurgatione Bir WiothecæB: Bignaana veterum. Patrum: Memineris Lector Theodorum B.alfamonem

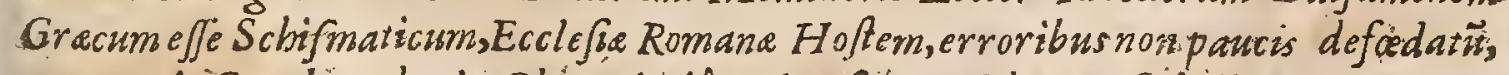

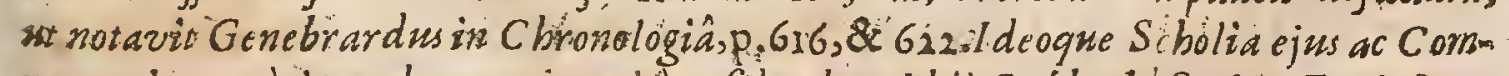
mentaria gatté legendasnec eir multum fridendumol' bilo. Labbe de Scripg. Ecclef. $D$ dd 3 Huxe 
Hunc Theodorum Balfamonew jure Canonico pariterac Civilrinfuctinimum fuife, non tam ex aliorum teftimoniis, quam ex fuis ipfus Openibus conftat. Multafiquidem compofuit, qua omnia ad juriprudentíum fpedtant-..-. --Intex omnia autem Opcra, qua illuftris hic in utrogue I ure princeps elabolavit, primum illud jure merito habetur, quo antiquos Conciliorum Patrumque Canones interpretatus eft. Gul. Bevereg. Proligom. ad Canones.

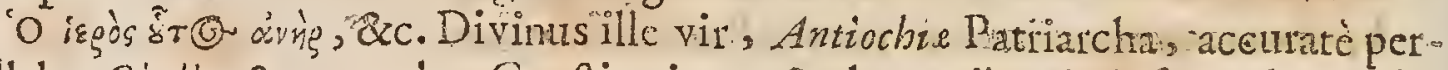
callcbat Civiles $8 x$ anonicas Conftitutiones, ab omibus in hifce rebus celem bratus fuit. Ejus autem feripta, qux ad Canonica \& Civilia.lemmata edita funt, non in omnibus, quod mirum eft,accurationem haberecenuntur; fed velut ex oblivione maximè inconfiderantiâ procedentia; alibi ctiam in feipfis divif. Nec de co dubitct qui dilig nter confiderârit, inveniens ëjus feripta fubtilitati viri non refpondentia. Ego aurem criam illo vivo multos audivi Conftantinopoli legifperitos, qui quafdam viri illius fententias reprehenderent, quòd non effent re É prolata in Canonum \& Legum "interpretationibus; \& aliis hujufmodi *oluminibus. loan. Epifc. Citri in Epift. ad Conftantinum Cabaftarn Archicpifc. Dyrrachit. Vide Gul B্Berer.ibid.

Vixit ufque ad annumi203. quo capta êt à Latinis Conftantìnopolis. De obitu. verò ejus nihil confat. Græcoim fui temporis citsinvidiam doetifimus, Juris Orientalis Canenumque Ecclefiaticorum, ominium quos unquam tulit ferax Græcia , perififimus. Elat preterca Fcclefiarum Orientalium ad- Versìs Larinos acerrimus propugnator, quo nomine convitia in illum pleno ore cffundunt Baronit. alique caula I'ouificio sectain. Gul. Cave in Hifto. Litciar. Scitipt. Eccle..

Extant Grac.Lat. Commentarii in Canones Apoft. Concilionm, Epi-

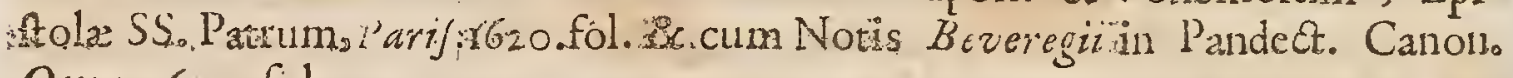
Oxon. 1672. fol.

- Verfo Latina Expofitionum Balfanonis.in Thotii Nomocanonem. Gentiano

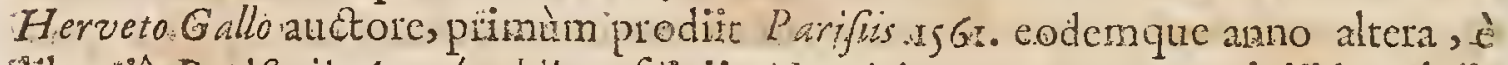
Nibräiî Bonifacii Anerbachii, aufpiciis Henrici. Agylai, Belga, qui itidem latinitate donavit, Baflea edita per loan. Oporinaza.

\section{Rabbi D A W I D W I M C I I}

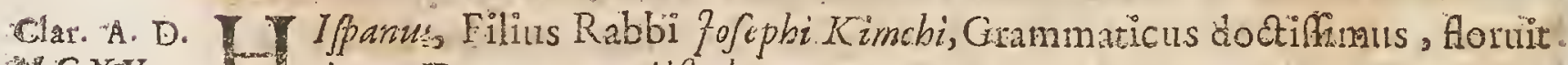
C $\mathrm{CN}$.

2.- Anno Dom.1igo. Alfed.

Scripti ejus hac funt: Mirblo, id ef, lumma parts dux; alteri Grammaticas" Regulas complectitur, iltera Dictionarium Talmudicum-Commentari: in libros:lofue, Ináicum, Samuelis, Hiforiam Regum;.in Prophetas, IJaiam,

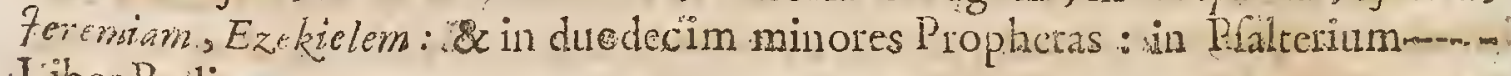
Iiber Radicum.

Nomen eft faniliz qua tres virosinfignes habuit; viz. 1ofephum Patrem, \& Daxidem, Mosemque. Filios: quonm uterque Granmaticam edidit, fed ille pleniflume 
plénifimè feripfit de hac arte, quịm Chrifiani Doctores plurimùm Cequuntur. Druf. Not. in. Tetragram.

Vir talis, qui quod liceram, quod Hiftoriam, quod denique Idiomata vocum aetinet, plurimum lucis ac utilitatis Veteri Teftamento adferat. Nonne ex folo iqfus lib:o Radicum Cole claviùs ipfus. Ebraica ertiditio follidifima refulgct? certè fuo Michol. omnem laudem elt fupergreffus. Dilberi Difputat. A cademic.

David Kirnchizs, authon, ut doctus,ita (nif ubi nimio in Cibrifianos zelo preceps rapitur: ) fobritis \& gravis. Pocork Nor: Mifcd in Port. Mof.c.4.

Magnus Crorifianorum adverfator, wocatur Grotio in 5. 1. Verit. Rel. Chrifl. fect:22.

ExIudeis $M$ aimonides preftat \& Kinchius, quorum ille, in fuo More Hannevochim, hic in vichlol \& Schorafchirn Critic Sacre, tum ad Lingux:" Sanctx, t!m ad Ritum \& Ceremoniarum notitiam tantum confert, ut à Bibliothecâ Theologicâ ion facilè polfun abefle. Hotinger. Bibliothecar .. Qua dripart.p. $175^{\circ}$

Multum laudat Kinchilibium Radicum Paulus Fagius : Nefcio (inquit.) an

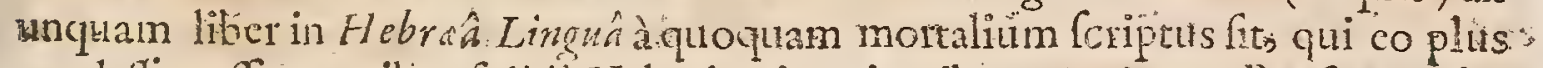
prodellic polfit o muibus folidé Hebraicari cupicutiburs. Faul. Fag, prefat.prafix.: Thisbiti...

Ut ex Rabbinis Hebreorum in Vetur Teftementrm noviffimus eftspreter Rabbi: Levi Ber Gerfon, ficetiam doatfimus, minimè fupentitiolus, \& Chrifianoam lectioni aptiffinus judicatur. Gefiner. in Biblioth.

R. Davidz Kim bi hon rificum vilim fuit à fuperioribus diffirere, nit: mam apud pofteros fibiconciliaret. Atqui hic fxpe dormit, magifque eft Grammaticus quàm heologus qui proinde I I dais negligitury \& tantum habetur pro Grammatico.Pofjevin.

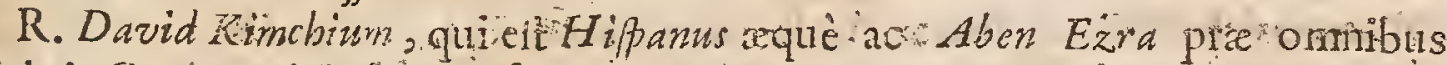
Judris Granmaticis fequitifunt Theologi, tum propter ejus methodum, tum propter Styli puritatcm: Ab illa familia prognari multum in Hebraicam liñ Guam laboraverunt. Mofis Kinchi fratis Davidis Grammaticam habemus

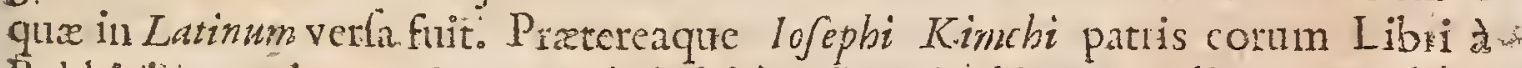
Rabbinis quando que cirantur. Scd qui. $R$. D. Kimchi omnes alios anteceluito cjis ferèfolius opera pofterioribus his feculis le eta funt: Chriftiani ea tranfulerunt prout eafibince flaria dcprehendetunt, imo ipfa tamquam . Cuarum Verfonum normam fibi propaluerunt. Rccntiones Judxicxteris omnibìs Grammaticisillos ctian antepontint: Et Aben Melech qai Grammaticalium interpretationum Rabbinicarum intotam Scripturam Synopfin confarcinavit, huic Authori præfertim adheret. De illo dicit neminem inter Judæos ci comparari polfe, tum quoad Mafjore fuidium, tum quoad honorum Exemplarium Biblit? corum qux: in Hispanta extabant perquifitionum. Interca tamen utcumque: fatis exacte Maffor arm [equatur Kimchi, ab illanihilo minus quandoque recedir, litèrafque in invicem permutat ut meliorem fenfum ertat.Jef Rich. Simon. Hifto Crit. Vt. l. I. C.3I.:

R. $D_{2}$ 
R. D. Kimchi ad Scripturarum fenfum literalem animum etiam appilit; Ejufque Commentaria minùs tædiofa forent, fi tor Grammaticis Gubtilitatibus non Ecatcrent. Idem ibid. lib.3.c. 6.

Inter Rabbinos quii excelluerunt in explicatione fenfusliteralis Scripetura $S_{a-}$ cræ, D. Kamchi pra catcris $x$ Rimatur. Ille eft qui graviores Grammatica difficultates cxplanavit. Ab illo P’agninus \& plcrique omnes creteri Authores quị Lexicis condendis operum navarunt Verborum fignificationem didicerunt. Ilii prefertim Recentiores Hebraica Lingue I diotifmorum netitiam acceptam ferre Eenentur. Epherzerid. Erudit. Gall. dici Lunx 6. Decemb. 1666

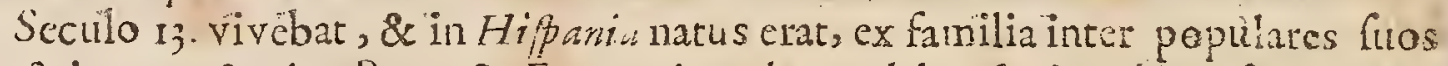
illuftri, cum \& ejus Patcr \& Frater ejus duo celcberrimi kabbin fuerint. In maximan Scripturx Sacre partem Cominentaries elucubaravit, qui apud Judxos in magno pretie habentur, fed quorum Chriltiani fufficienti noritia Careut, quia pauci reperiunturinter hos qui Hebraicum idioma fatis perfétè calleant ad Rabbinornm claram întelligentiam. Idemibid.

P falmos r vo. cum interpretatione ejus Hebraicâ, edidit Hebraicè cum verîo-

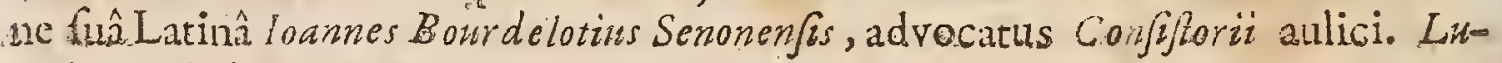
tetie Parif in $4^{n}$. anth. $16 \mathrm{I} \%$

Commentavii in omnes Pfalmos Dayidis ex Hebrao Latine redditi à Domino Ambrofiol lanvier Congreg. So. Mauri Monacho Benedittino. Parif.in $4_{0}^{\circ}$ apud Lud. Billaine ann. 1666 .

\section{ROGERUSHOVEDENUS.}

Clac.A.D. F Boraci.in Anglìa nobilibus parcntibus ortus, ac primarius quondam Theow s. tem anno defunctus fits, incertument. Inter domelticos Henricr.1I. Angli.e Regis aliquando fuit, quo defuncto, Hiftoriarn Give Annales Gentis Suc, dunobus elaboravit libris, eos aulpicatus ubi Beladefire, ab anno fcili:ect. Chrifti 731 perduxit autem ufque ad Lobannem Regem, qui anno IIg9. regnare copit. Extant Annales inter Autores Rerkm Anglicarum ab Henrico Savilio ediros,anne is) 6. Londimis iterumque Wechelianis Typis, Francofurti Anno I6or.

Dum egit in Aulì, folebant aliquii nomunquam ab eo confilium petere in Juris controverfiis diffciliolibus, unde vidit è re fuâ fore, fi ftudîs Cafarii vel Civili I I ris le dederet, ad aliquot igitur annes illi fcientix navavit operam. Deinde ctian ad Ins Pontificium vol Canonicumanimum adjecit, \& in utroque non contemnendos fecit progecffus. Hầc igitur doctrinâ \& in rebus agendi

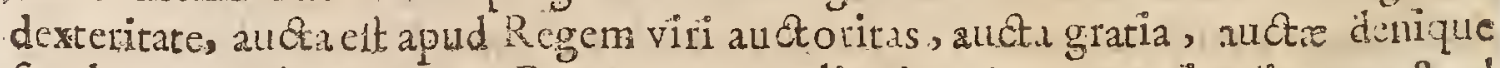
faculcates. Verùm Henrico Rege mortu, , reliquit anlarn, mutavit animum, \& ad Hilloriastum legendas, tum ctiam feribendas (c. contulit, fciipfirque Aninales gentis noftre longè accuratifimos, non folùm annos, fed ctiam menfes, dies, \& nonunnquam Ho:as diligenter annotans - Has Hiftorias Ann. Dom. I29I. omni diligentiâ, donec invenirentur , per Bibliothecas Anglia perquiri fecie 
Edvardus Primus Anglic Rex, eo tempore quo dubitari capit de Supremo Dominio Regum Anglia.în Rcgnum Scotia: de quâ controverfầ fcribit Raniulphus in Polychronicolibio feptimo, capite 39. Sed apud hunc \& alios plurimos Auctores res adeo clara inventa eft, uit pofteà nullis telictus fuerit dubitandi.locus, quin Rex Scotie femper fuerit Regis Anglic Vaffallus, tenueritque Regnum fum tanquam Anglicani Regni verum \& legitimum feudur.? onò Rogerus luis Hiforiis \& aliis Scriptis laudatiflmis nomen omni polteritati , imò potiùs im * mortalitati commendavit. Loan. Pitfeus.

Rogerus Hoveden, vel Hovedenus, Chronographu infignis, in Eboracenfi provinciâ, exîllutio Govedenorurir fumiliân natus plurimum apud fuos Anglos ingenii dexteritate valuit. loan. Baleus.

Rogerus de Hoyeden, infignis Hitoricus, fcripfit libros duos Annalium Anglicanorum valdè diligenter, \& pervenit ulque ad lobanmern Regen, qui regnare copit Ano Dom. irg9, Bellarm. de Script. Ecclef.

Vir clarifimus Henricus Savill, prafatione in Scriptores Anglia à fe editos Londini, vocat eun AuBtorem cum prinis bonum dilgentem, veriffirumque Superiorurn terrporum Indiccris.

Tantùn interim Lectorem admonitum volo, fuille quendam Rogeriuxn Hovedenum, hominem nan Hochum, qui eâdem quâ ille (Simeon Dunelmenfss) Cerie, Biftorians eduxit à Beda ad lobannis Regis Imperium, quem ob Hiftoriam avitam ut meritò probandum putem, ita improbandum, quòd, picta Simeonis prata, inulla cjus nominis mentione prorfus habitâ, compilaverit. Ioait. Leland. MS.de vitis Script. Anglie.

Hic mithinon placet Rogerius Hovedenius, vic alioquinlaudandus, qui Scrinia Simeonis, fupprefo ejus nomine, frence compilavit, \& aliena pro fuis, slorix avidulus, fuppofuit. loan. Leland. Comment. in Cyon. Cant.

Manufriptum hoc opus Cancabrigie adlervat Bibliotheca, qux eft in Col1egio S. Benedicti. Thorrats Iamesin Bibliothccâ câ S. Benediti exlure ait excerptiones de Chronicis Roberti de Hoveden. Uti quoque privatâ Baronis Lunlejanis, atque alia $G$ instieri Copi. Voj.

\section{GULIELUS NEUBRIGENSIS.}

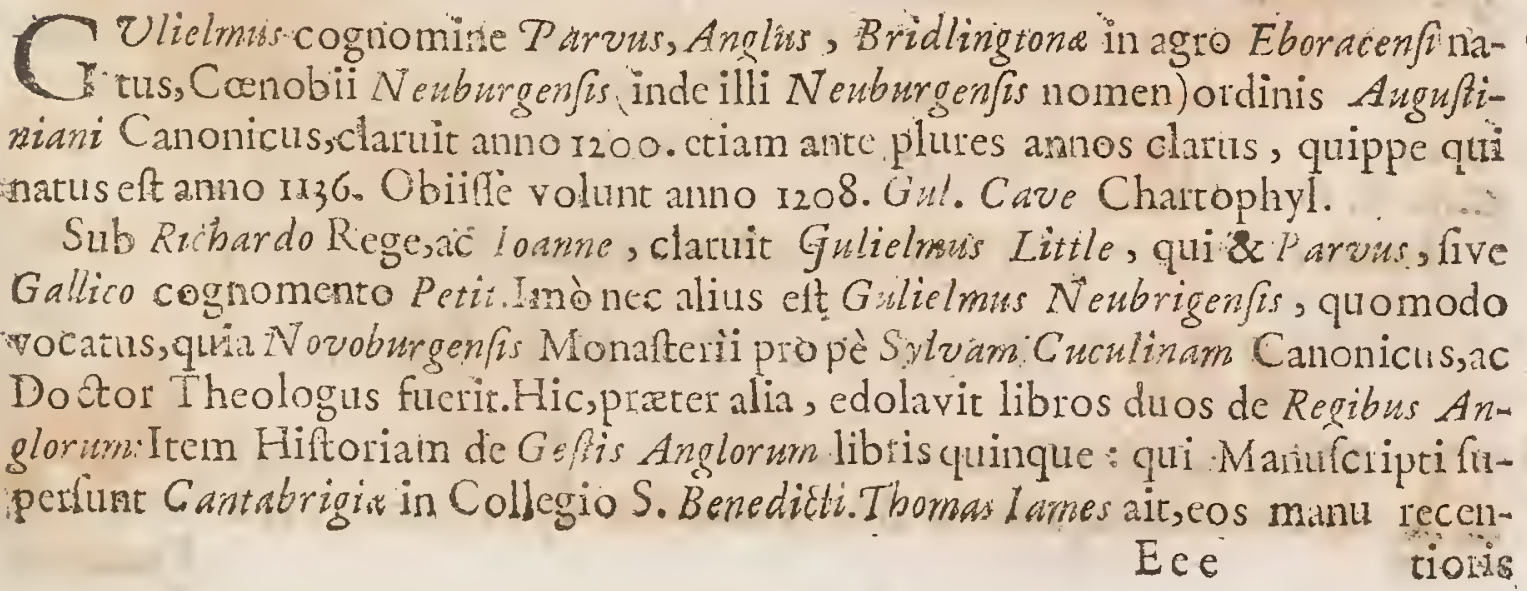

Clar.A.D. MCC. 
403.

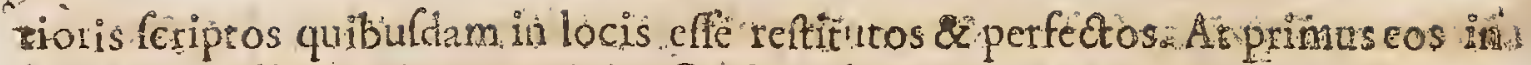
Inccm prorulit Guiliclmus Sylvius. Ordirur ab anno 1066.quo Guilizlmus cognomento N r thits, Dux Normannie, Haraldo Regi Anglurem, belium intulit: Hineautem paucis omnia perfringit, ufque, ad annum II 35 quo fe natum fuilde fcribic: : inde verò fusè omnia perfequitur, ufque ad annum 1197. oly doro Virgilio Veridisis Auctor nuncupatur. At à Guilialino Lelando non injuriầ reprelienditurs quòd modum non tenuerit in culpando Gialfredo A Monemuten 2 . Nam etfi multi fabu-. lôfa in co fnt; tameu non tam mulex quàm illè-videri vult. Nec iple effugere po-

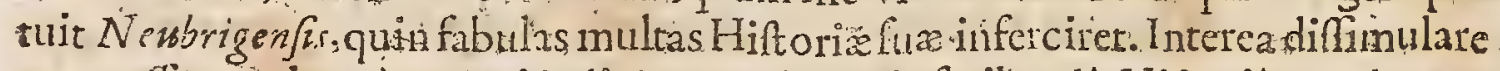

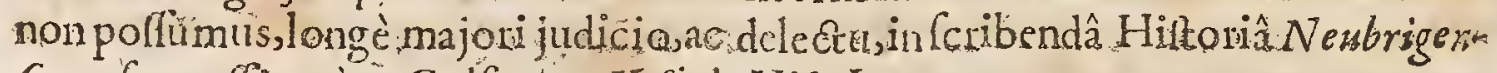
Serm uifum cife, quam Galfredurn Vofj. de Hift. Lat-

Is humanis juxtà ac Divinis Studiistantoperè adharebat utnullìn ferè horam rectècolloeatam purarê, nif in doctorumlibronm lectióne. A Polydoro Vergilio, Veridicns Author pronunciatur quèd Britannica Hiftoria fidem non

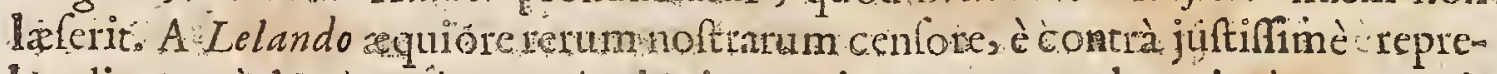
hendituri, q̨uòd Britannicarum Antiquitatum iğnarus, tam calumnosè cum Gatfrido Monernutenfi, lomine endito, \& mortuo, tam acriter in Chronicorum fuo rum Procmio decertaverito Arthurur quue fortiorem elfe, Lelandus dicit' quà ma qui Guprincrera à defide Monacho:ac alium fuife Merlinum, quàm putaret: fibjiciendum alicujus cucullatijidicio:quimeonm trontina medio tollere

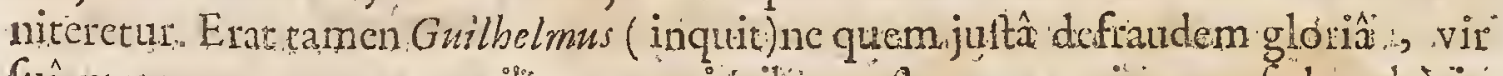
fuî xate, rerum remporibus recentiónibus geftarum ígnarus; led multò in Stripturarum Interpretatione, ut ex ejus facie apparec libris foulicioin Scripfir.ab * An.Dom. I066 ad all I97. Atylo fatisnitido. Ioan. Balus.

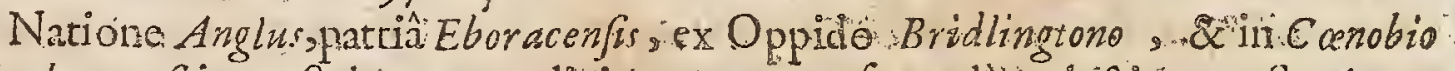
Newburgenfi juxta Sylvam qua dicitur Cuculina fecundun infitutum $S$. Augufini Hipponeings Epifcopi Canonicus régularis.S.Theologia Doctor, in prófanis. etiam literis benè verlatus. Viringenii, iut videtur, vafi \& aftuti, nomihil item ambitiofi. Magnatum adulator, \& (xeularis potentix nimitis fat tor: Undemihi de veritate in Hiltoricis narrationibus non parum fufpectus. A . Lelando certé nec immeritò reprehèditur, quòd Hiftoriam $G$ alfredi Monumeten fs tam rigida cenfurânotaverit;" Eratramen in Sacris Scientiis exuditus, \& in fuis Scriptis ubique fatispolitus loan. Pit fauso.

Stylus eft Gulielmo Gatis Latinus, fatisinicidus, Tôngè purior quàm qư Scria: ptores noftricoxtanei utilolebant. Ad Hiftorix cjus fidem non parum facita guod qux tradit, aut ipfe fuis vidit oculis, aut a viris fide dignis accepit: Gul. Cave in Hift. Literar.

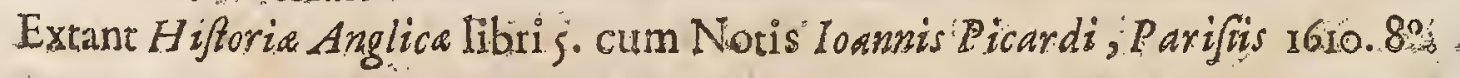

$$
\text { STEPH ANUS LANGTONUS: }
$$
M.A. A. D. A Niglus, primùm Gymnafii Parifrenfis Magifter fuit in Theologia, \& Trecula- 


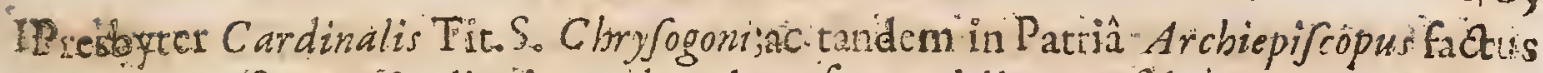
Cantuarienfss guain dignitate admodum fenex obitan fatitis 1228 .nonol $\mathrm{Re}$ -

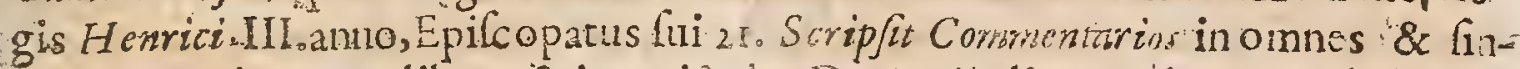
gulos Vet. Tefarnentilib osse in I pitolas D. Paulizaliaque pluta, qua habentur MSS.un Zibliothecis Anglicts, alibique.

Stephanus Langton. Anghus ad tirewas natus., Gymnafit Parifrenfis Maginter in Theologia, 湾 ad fanum $D$. Maria Canonicus Secularis, ac tandem fupremus

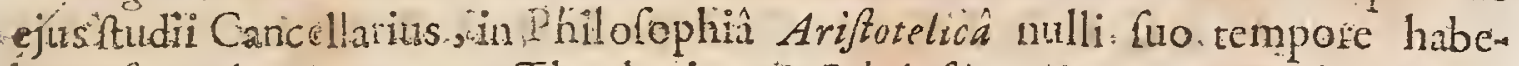
batur fecundus. Utramque Theologiam; \& Schlaftican \& interpretativarn inge- nio callidus:'novo pralegendigenere perfubtilitates docuit: Scripturafque a acras multis anuis quam fupetfitiosè per Allegorizationes ac Moralizationes expofuit. Qui mos diabolicus, unoquoquefere proliii ipfus interpretante commodo in maximum rei Chrifin na detrimentum , ad halic nottram etatem femperin deterius accrevit. His inieiis clarus , \& Romam à Pafire Innocentio III. accitusjinar $T$ alatinos, $P$ alainn $\&$ ipfe, Theologiumpublicè profitebatur: ad $S$ : Cbryfogonum Presbyter tandem Cardinalis effectur. Moituo interim Huberto Canimirienfi Archiepilcopo, idem Pontify (inquit Lel.indus) ad folitas artes recurrens callabatur neloio quid, ut Stephannifte fubftitucretur. Satis enim(ait) Gatis fcicbar illum in Angliâ magno ufui fabi futurum, utpote hominem a feiplo non ab Anglc, honoribus atctum. T annes verò Rex, ut erat animo excello ze iplanè invicto, tantam injuiam non ferens, Stephano ftatim regnofuo interdixit. 1oan. Balcu.

Nemo Scholafticas:fubtilitates frve in Theologia five in Pbilofophia clarius illo explicavi. Nemo sacre Scripture fenfum, tran allegoricum qiàm moralem ffeliciùs enodavit - Dum ellet Archrepifcopu ad re formandum Clerum, \& PopuIum Anglicanum, infignes Ecclefinfictas Conftitutiones numero quadraginta \& octo prudentifimè compoluit. Omnestum Veterit tum Novi Teftumenin libros ptimus omniumin Capita, uti nunc habemus, ad corum, qui Saclis Litecis ftudent, utilitatem, multo cum judicio diftribuir " $\&$ diftinxit:Quod ante illum fortè wix quifyuam unquam cogitavit \& in ispon illum nomo mutandum aliquié udicavit. loam. Pinferes.

Tborsas Waldenfis in Dotrinali mentionem honorabilem hujus viri non Iemel facit; 3 ejus argumentis atque autaitate nonnunquam utitu:

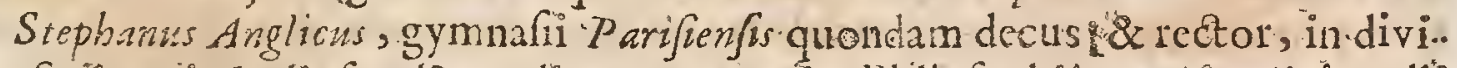
mis Scripeuis fudiolus, \& eruditus, atque in Philofophiâ Arifotelirầ nulli fuo temporefecundus theologiam mutis anis gloviosè docuit, \& primus Scriptum Sactammoraliter cxponere cepit. Et hinc mos inolevit, ut Magifti scholaftice Theo ogia divinos Tibros in Scholis lucidius \& facilius apen rirent:fcipfit ero in facrasliteras multas preclaras expofrioncs, fcd prafertim in Octarcuchum Commentariorum libres undecim, in fexdecim rophetas Iibios fexdecim, fylo \& affectibus non ingratos, ficut ex Fragmentis ejus, nuper à Tilmanno Carthufano in Tomis Allegoliarumpublicarisapparet.sixt.Senenfo Biblioth.Sanct.l.4.

Exe 
Homo egregiè doctus vocatur Francifco Godvvino in lib.de Prreful. Anglic.

Ob emincntiam fcientia morumque probitatem factus eft Archiepifcopus Canizrienfs. Oudn. in Lupplem, de Seript. Ecclc. à Bellarmin omiffs.

Extat Libellus de Tranfaione. B. Thom: Cantuarienzis ad calcem Epiftolarum: Thorne Becket nuper edit. Bruxell.1682.4\% ad R. Ioannern ap. Dacher. Iom. ILI inedita dabunt Balans, Pit fans, Iamefins, alii.-.

Clar. A.D. MCCIV.

\section{$N I C E T A S, A C O M I N A T U S_{0 .}$}

A Patria dictus Choniaters vir Confantinopolitano Imperio illutris, fortit A initio seculi dccimi tertii. Magnis muneribins fub Imperatoribus defunCtus, captâ à Latinis Confrantinopoli , Anno r204. Nicaam Bitbynie conceflit, ductâ ibi púllấqqum honibus eripucrat. Libris 2r. complexus eft Hiftoriam annorum $85 . n$ mpeabobitu Alexiz Cornneni, ubi deficrat, Zonaras sufque ad amnum $1205 \cdot$ quo:Baldvinus obiit

Zonaram tuum, vir ampliffme, Choniates fequitur, homo fuâ xeate non tan tùm magnis dignitatibus onatus, led etiam iugenio \& multiplici doctrinâ præ* ftans, \& veritatis Hiltorix, ut nihi videtur, ubique ftudiofus-Atque utinam alius Grecus extitiffet qui ab hoc autore \& Chalcocondyla pratermifa, pari facundiâ profccutus effer. Major enim eft Choniate copia diligentia lectio. que jucundior, yuàm Zonars. Hueronym. Wolph. in Epif,ad Ant. Fug ger quam Nicete pramifit.

Ex affectatione nefcio cujus infolentis elégantiæ \& Pöèticæ dictionis amulatione, in falcbras fxpe incidit: \& duris,ne ineptis dicam, utitur Metaphoris in Procemio prefertim, ubi cumprinis diértus vider cupit. Qued fi totam Hiftoriam frmili oratione involviffet, in Latomias ine quam moleftis converficnis confictari maluiflem. Sed quia tolerabiliter loquincipit;où ad rem iffam ventum eft, Hanc quoque operam tudiofs Hiftoriarum dare volud. Idem Procem A nuotat in Nicet.

Nicetas partum adhuc vulgo notus farcor fed digniflimus notitiâ : purum rectumque ingenium, fi aliud illo ævo. Stylus ejus operofus, Poïtas \& Homerum fapè refipiens : at res \& narratio ipfa difincta, compolita ; fine vanirate, fine incptiis, brevis, quodfatis fit, \& fida. Crebra apud eum \& oppor* tuna Monita:judicia non libera folum, fed fana. Adfummam, legite vos Politi i gratiam mihi aliquis pro indicio habebit, certè debebit. Inf. Lipf. I. I. Politic. c.9.

Qua (fimplicitatem \& elegantiam) cum polliceatur in exordio fuarum Tiftoriarum unà cum perfpicuitate-Hiftorix maximè neceffariâ Acorninatus - Choniates, \& nihil minus praftitcrit putidus Scriptor, verè in illim adnotavit A lexander fortaffe Chartophylax: Nefcio quid dicam, ô Choniata! Dicis, fapientix elfe, confcribere Huftoriam dilucidè \& perfpicuè ; deinde ænigmata \& obfcuriffima, fcilicet tanquam in Baratbro abdita, fcribis. Lisl. Bifciola Tom. I. Horar.Jubficiv.1.5.C.I5०.- 


\section{CELIBRTORIUM A'UTHORUM.}

Diligens fuit Homeri Lector ac initator, adeo, ut ob Poëticam atque infofentem Dictionem quandoque durior fiat:umprimis in Prafatione, qua fanè falebrofa : in cæateris molliùs fluit. Quod \& de le in Prafattone promittit. $U_{t}$ milìi quidem vidaatur Prafatione eầ oftentare voluiffe, quantus Logodedalus. foret:yuod fi fimiliter in Hiftoriâ feciffet, nx ille multò etiam minus laudis, quàm anunchaber', mereretur. Voff. de Hift. Grac.

In Nucete Thefauro fatis feliciter procedebam, quamvis in eo quoque libros aliquot,prafertim priores \& pofteriores non paucioribus falcbris fcatentes deprehenderim--m--nvicaam, qux Bitbynia Metropolis ct, [e contulerat, ubi, quod. Luperetat vita, fiterario otio impenderet. Quod quidem quantâ diligentiâ labow.

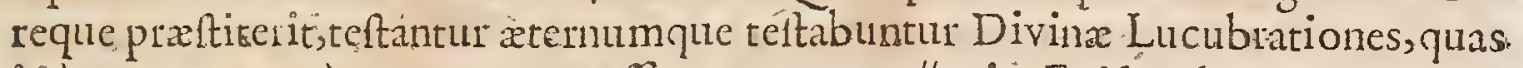
în hoc opus verè dureum congeffit. Petro. Morellus iñ Epift. ad Loann. Sanctan dreatem, quam Nicet. The auro premifo.

Hiftoriarum libros 2 r. vertit Hieronymus Wolpbius, e diditque Baflea, Anno" If57. dein Geneve prodiit, Anno 1593. \& Anno 667. Opus hoc inferterm elt $B i$ bliothece $\mathcal{B}$ yzantine...

Nicete The fanrus Fidei Orthodoxe prodiit Grace \& Latinè, interprete Petro

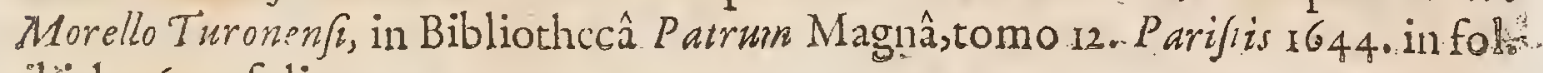
ibid. 1654 . folio 2 .

\section{RODERICUS XIMENIÜS.}

N Avarrus fuit. A mo Domini iro8. factuis ett Archiepifcopus Toletanus. Inde Rodericus Toletanus multis audit. Obiit amo 1245 ;

Multum glórix comparavit libiis 9 . de rebus Hifpanie ; quas" exorditur ab. Herculis in eas terras adventu;ac perducitufque ad tempora Ferdinandi III. Id t bievi, fed fuavi eloquio faccre, fententia eft Roderici Sanctii ,... Epifcopi Palentinio VofJ. de.Hift. Lat.:

Martinus Preful Toletanus obiit. Succeffit Rodericus Semenus domo Vafoo. Hominem externum, fpectate vitix probitas eruditioque, ut ea erant tempora, fingularisad eum honoris gradum prevexit. Ioan. Mariana l. xr. de reb:" Hijpan. C..2I.

Rodericus Ximenius, Archiepif́copurs Toletanus, dómo Navarrâ, literarum hü mauiorum, potifîmùm verò antiqquarum recentiorumque Hiftoriarum longè peritifimus. Multum huic,ut \& Luce Tudenfi Epifcopo ; meritòomnes debent, qtòd res prrelire geftas fitu ac fqualore obfitas?, peneque fepultas ab interitu vindicarit ad pofterofque tranlmiferit. Plurimarum hic rerum hiftorias, libis g. itemque Gotborum,atque Hunrorum res geftis eft complexus, refque quibus \& ipipe interfuit, memorix fideliter mandavit Andr. Schott.in Hippan.Biblioth.

Hippania (Roderico X’imenio) fummum beneficium debet, quòd res à fuorum temporum memoriầ, propecer vetuftatem abolitas atque remotas infigni opere pofteris tradidito. Verè is Hispanos, Hi ipaniâ in terrâ peregrinantes erransefque, quuod de $M$. Varrene Cicero commemorat, tanquam hof pites., quafi do Exe.3

mum

Clar. An do MCCVIIti: 
mum deduxit. Hieron. Surital.2.tenu ab Aragon. Reg. geftamum.

Foannes, Gerundenfis Epifcopus, fic cenfer initio Paralipomenorum :In tetes

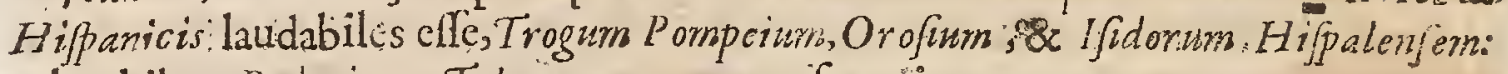
- colerabilem Rodericum. Toletanum: cercros fominia contexcre.

Lambertum etiam Schafnaburgenjern haud planè contemno in rebus Gormanzcis:uti nec Rodericum Toletanum in Hisponicus Utichue bonus, quantum potuit in tali xvo. Liph.in Not. ad L.I.l'olitic.c.s.

Anno millefimo ducentefima decimo quinto, peregrinatione fulcepta, Rodericm nofter Roman abiit \& Parrum Concilio, quod menle Novembi inchoatum eft in templo Lateranen $c_{2}$ interfuic. In eo convenu orationem ad latres habuit. Latrâ quidem linguâconceptain, cxtenumaliarum linguarum, quarum expers , non erat, Italica, Germatice, Anglice, Gallica, floribus omatam, Ccatentiifque diftintam:ut miraculi:infar Patribus effet, tantam Hipanum hominum linguzrum facultatem allectutum elle, quantumab Apoftolorwornate ulli homivi negaBant contigilfe. Aub. Miraus de Sciipt. Exclef.

Andreas chotusin Notis adillum, Epitaphium ejus annotar, unde frecili rudi-

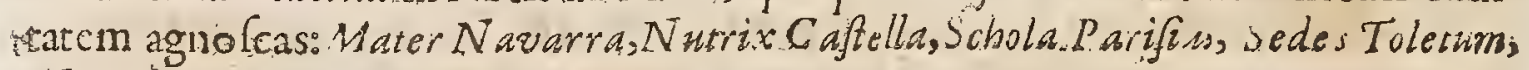
Hortus Manfoleztm, Requies Colurn.

Semper"in Fipaniâ vivet Auctoritas Roderici, memoria vigebit, cujus defuncti manibus in plunburs maximi Templi Toletani Sacellis ad hanc dicm parentatur; aliquot Sacerdotiis ejus juflu atque impensã, eam ob caufam conftirutis. Cafmir Ondin.in Supplem. ad Bellarm.

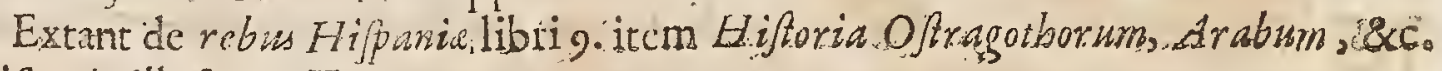
Hipanicillufratx Tom.2.

\section{TRANCISCUS ACCURSIUS.}

Clar. A. D. F Lorentinus, Jurifconfultus celéberrimus, mortums eft Bononic anno I2:2s: AfCCXXIII. Juxtaquofdam, Anno xtatis 37 . demù Legum ftudio vacareccepit, \& nühiDominus fummus Jurifconfultus evafit Is primus Jus Glofis. illuftrare aufus eft. Guid. Pancird. \& Konig in Bibl.

Vir magni ingenii, \& fingulatis inåtutiz, dicitur Boxhornio Monumentis HIIntr. Vir."

Francifcus Accurfur Florentinus, ferè quadragenarius, ad Jus Civile accefit, frib Arche \& Odofredo,in quo tantum profccit, Magintos longè fiperaret, retictaque profellione Turispublica in Colitudinem fe rcepit , in qua per leptcu-

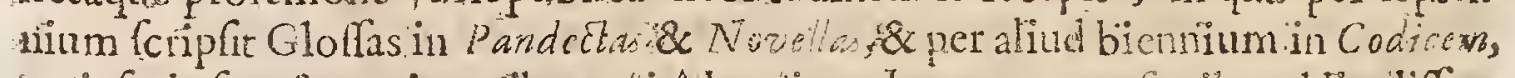
ut ipfe de fe teftatur, in quibus mirâ brevitate Lceges omes fmiles addit, diflenticnte conciliat; \& ex iis tantam indultix, judicii, memoriaque famam eft affecutus,ut nemo pof́ eum Juri Gloflas adjicere tcataverit \& intcrpietes pof cum "ex cjusadminatione, parem operam in ejus Glofis explicandis ac in verbis legum mpenderiut, quod fanè in is merito reprehendendin eft; adeoque eum inlecuti

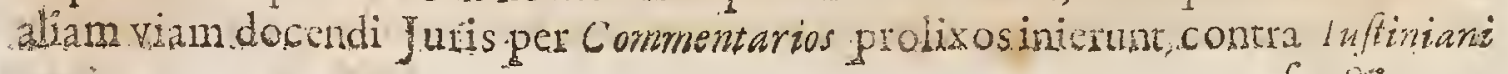


anctionem prohibentis Commentarios legibus fuis afcribi. Arth.Duck de Ufu \& Authoritate.Juro iv. Rom.lic.cos....

Tanta eft: Accurfoi Authoritas, ut ex ejus fententiâ caufa judicanda fit, quoties infiguis aliquis Interples ci adhereat. I deml.I.c. S.lect. 6.

Accurfurn vero ommibus Interpretibus Gracis \& Latinss anteponit Cujacius, 2.quo quicquidu $B$ artolus aliique aberiaveriat fomnia appellar. Vide Cujac. 1. I2. oblervat. I6.

Accurfores nofter, vir pland talis, ut cum, fi cum Latialis phrafis, tum pracipuè Antiquitaris magis fuifet peritus, omnibus tam Gracis quàm Latinis Interpreribus Juris, fi mci arbirriires fort, antcponere non dubitem, Sed hoc tumine deftitutus, mirum quàm ille fapiths, quafi in Cimmerios delatus effct, cacutiat, quàm frequenter ludos faciat equite adeo non plaudente, ut adolefentulis etiam fefe ridendim prabeat. Fonn. Bernart. de Utilitat.Legend.Hift.l.1.p. 3.

Magna dclinia delitavit magnus illc Accur/us, non in expofitione alicujus loci, fed totius tituli, De Orrgine I uris. profectò quoticícunque lego , in fomniantis hominis commento videor verfari , non vigilantis Commentario Idem I.2.p.I 4 r.

Inter antiquos Interptetes Acurfus \& Bartotus principattim tencint; de Cermone nonvaldè anxii, rerum quas tractant, chram folan habuerunt : quas cum nofent, quantum in ills barbarie, \& Codicum decavatione nolfe poterant, explicarenifrinconditè, \& barbarè nequiverunt. Quod non tam eis, quàm:

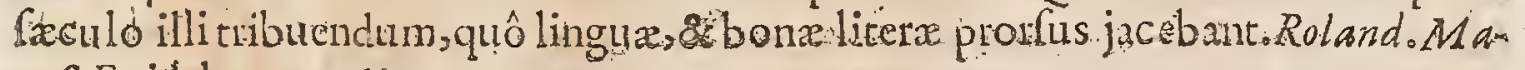
ref. Epitit.lus.p. $146 \%$

Accurfus Natione Italis, ex Florentian Civitate onindits, alditor quandim \& difcipuns Acconis, vir in utroque. Tuxe peritiffimus,atque in cxteris fxcularium litcrarum difciplinis noninfmè do etus, ingenio fubrilis \& clarus eloquio, ctijus quanta fit hoo tempore apud Legum profilores anctoritas, nemo eft vel modicè doctus qui nefciat. Scripfit multa praclara epufcula..... di primus totum jus Civile glolfavit. Tritbom

Tautaanderitatis fuitsut omnibus Interpretiliur auctoritate prefter, quippes quen Advocatorum Idolum appellare Cinus non dubitzvit... Guid. Panzirol. de Clar. Leg. Interpret. 12.0 .290

Nonlevi honore prolequendus, fi cjus remporum incorntnoda fpectes. Lelo. Taurell.in Tr.de Mili o.ex casubu \& Budxum Accur 20 implacabilem dicit.

Glolfatorum vetcium coryphzus, homo ingenii prorfus ftupendi,quin tantis difciplinarum tencbris ipfam difciplinarum diciplinam accuratiflamè intellexit:Cafp. Bartb.ad Claudian.lib.2.in Ruffin.pag.1201.

Ridicula ef: Accurfi glóriatio (in Gl.ad l.10.fect.2.ff. de T. ê 1. nihil opus: effe Theologix ftudio, ad cognolcenda divina , ut ąux ex legum Romanarum : libris affarim qucat pcti: Conring. de civ.prud.cap.3.

Docco Juris Civilis integrum, quem vocantstextum, omiflis Accurfu delirax mentis omnibus, \&ic. Braffican.inter Epiftol is Hel.Eob. He ef pag. 32.

Apollini cum Accurfio netantillim quidem convenit Ibid.pag.35: 
Acourfus eft Jurifconfultus vel quum interpretatur, whe, id eft, ir:ait, id cf: dixit:Sen,id eft, ant. Diligens \& acuraras Hiforicus, vel quum de Origine iz. abularum lepidam fabellam comminifaits aut de adoptione Gernanic Cafaris. Lud.Viv.de Cauf. Corrupt. Arti.I.

Extant Accurfir Glollix ad hufiniani Inftitutiones, Lugd: $1607.8^{\circ}{ }^{\circ}$

Extat Commentarius ad Corpus Juris Civilis, cum fuper commentario Gothofiedi, Aurclici I625.

\section{ROBER TOUS GROSTEST.}

Clar.An. D. T Incolnien/is Epiccopus. Quidam exm Teftam Groffam : alii Roberturn Capi-

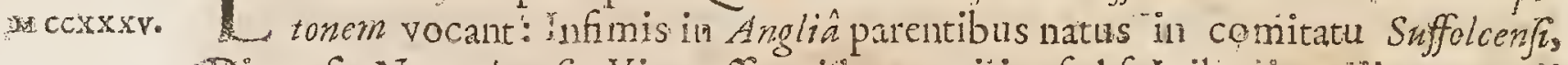
Diocefis Norvericenfle. Vir crafli quidem capitis, fed fubtilis ingenii ,., magni ecrebia mäjoris judicio. Pofteaquam humaniores litenas omnes ingenuas Artestam Principiis Pliflofophia percepiffer in Patiâ, fecundum morem qui

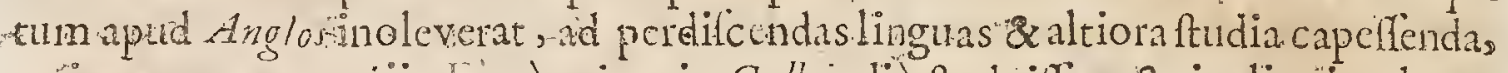
reğiones exteras petiit. $\mathrm{t}$ cum jam in Gallıis dit fuduiffer, \& in literis uberes progreflus fecillct, teverfusin Angliarn Oxonic fupremamin Sacrâ Theologiâ Laurean accepit. Nec immeritò. Erat cnim Latine, Grecè \& Hebraice infigniter eruditus, Philolophorum ctiam \& Thcologonm fuitemporis facile princeps; - denique, ut quidam lcribit , in feptem Artibus liberalibus vir præftantiflimus, S.verè Monarcha. Ad quam cminentem doctrinam accofit pictas, modeftia, prudentia, fobrictas, tcmperantia, omnefquevirtutes qua viros magnos \& decent \& faciunt. Quorum omnium muitus accedente Sacerdotali ordine, primùm ad Archiciaconatorn Leaceftren fem. deinde ad Epifcopatum Lincolnien fexn alfum. petus eft. Ioan, Piffeus.

Ipfis temporibus Epifcopus Lincolnienfls, Robertus, vir in I atino \& Greco peritiffimus, Teftarnentaxn. Patriarcharwide Greco fideli Interprctatione tranfulit in Latinum. Qux per multatempora incognita ac ubfcondita fucrant per invidiam Iudeorum, propter Prophetias ele Salvatori in eis contcntas. Sed Graci, omnium Scriptorum diligentifimi Invertigatores, pimum in notitiam illius Scripti devenientes, illud de Hebreo in Gracumatrantulerunt, \& penes fe ufque in noftra

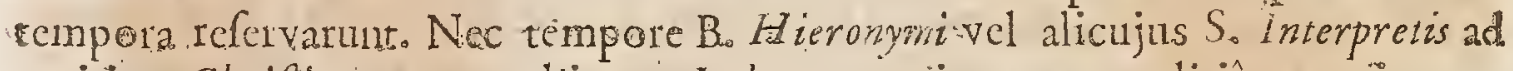
Motitiam Cbrifiznorumsmaclinante I udeorum antiquorum malitiâ. potuit quomodolibet pervenire. Illum igitur gloriofum Traitatum ad robur fidu Chrifiana \&ad majoem I udeorum confufionem, tranfulit plenè \& evidenter Epifcopus memoratus de Gracc,venbo ad vebum, in Liatinum, coadjuvante Mngiftro Nicolao Graco clerico Abbatis S. Albani.Matth.Paris in vitâ Hewr. Tertii.

Hoc amo I253.obiit S.Robertus dictus Grofteft. Epilcopus Iincolnienfr. 7.Idus Octobris. Qui in cunctis liberalibus Aribus excellenter crat crucitus prxcipuè in Logica \& Afrolngiâ plurima commentatus eft. Ad Innocentian Paparn mifit Epiftolam fatis tonantem, pro co, quòd Eccleflas Anglicanas iadcbitis, \& infolitis exactionibus gravare videretur,$\&$ quia $N$ epotulo fuo puero $P$ apa contuliffet 


\section{CELEBRIORUM AUTHORUM.}

Caronicatum cum proximà Prebenda vacatara in Ecclelia Liarolrionf i Quem tamen Robertus admittere noluit, referibens $P$ eps, fe lice velle, nec debere tales ad Curas Animarmadmittere, qui ie nelcirent, hec pontur regere Quà de causâ ad Curian vocutus, \& excommunicatus, appellavit à Curia Innocemin ad Tribunal Chrifi, undc-contigit, ut pott bennim mortis $k$ ber $i$ pparuit $p a p e$

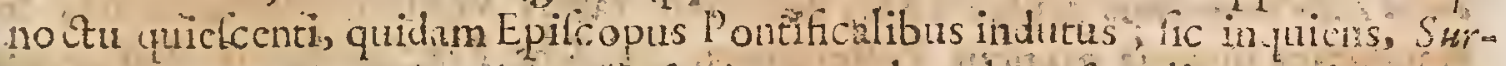

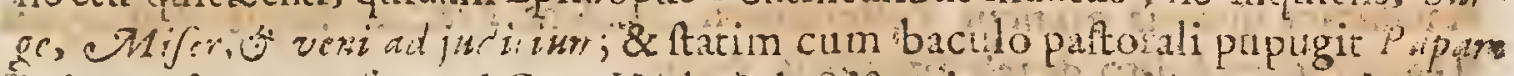

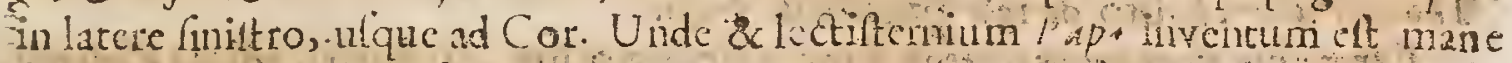
fanguinolentun ; iple defundus. Hâc de cuusân quam koberis perpicuis

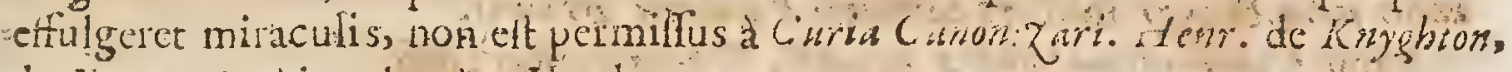
de Erealt. Anglin ienricolll. adann. 1253.

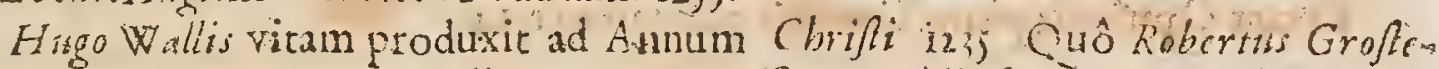
diss (quen Capitonar appellare Laine polfumus) illifurogarus, qui licet ef-

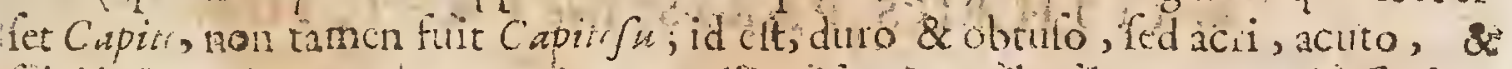
fubtili ingenio. Quangum in nonntlis vifus \& yubuldam $C$ apro fulle, fro. que nomini relpondere; qui chin ut homili m nonnuquandure, prafiact $\&$ pracipids Ententiz notant. Quod tamen (i aliquid id goms in co fuic) zeli in res honctas omnes mignirudo, \& fncen vite inculpate int gritus, (quam

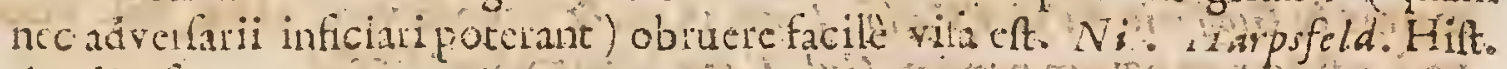
Anglic. fxc.13.

Riepertis I incolniente cognomento Grofa Tef, inter Ihilolophos \& Theologos lui fxculi primim locum adeptus ent. Ingenii a cuninc fubrilifimus, doquiobrevilimus, \& fentutiarm pondere copiofilimus. Six. Senens. Bibt. fanct.1. 4 .

Robertus Grofteft, vir in literis \& linguis, fapra quan cedi poteft in ill -atate crudatus, terificus $P$ ape redargutor, Rigis fui monito \& veritatis amator. Camten in firith.

Vir planè erat, (ut pietatem, vitx linctimoniam, reliquifque virtutes Chritiano Prelulc dignas pratemittam) ingentis animi, acris higenii, in re literariâ, quantum ea fercbant tempora, ad fummum penè apócen evectus, totum eir. cyclopxda circultum ementus in literis Geris parter acprophanis, ia lingui-

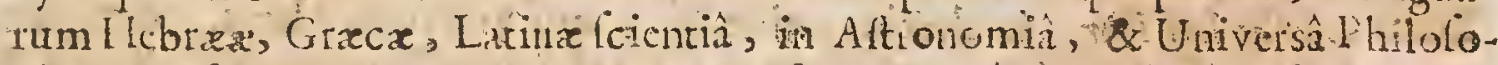
phiiladeo fupra communem Dodorum fortem cruditus, tr atris Magicx, \& excrandican cacodemone conforti apud fciolom vulgus teus perageretur:

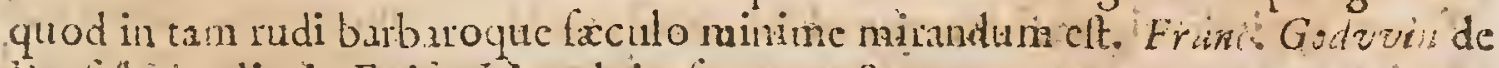
P'relia. Anglix in Epitc. Lincolnient. pag. $3+8$.

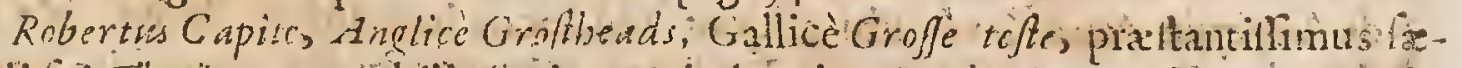

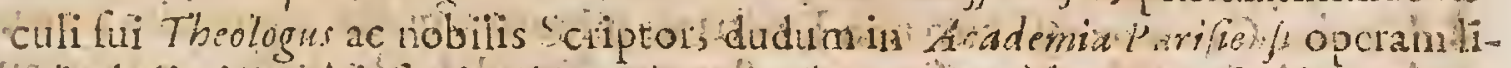

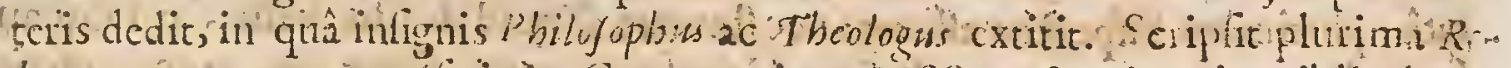
bertus, quocum pacafacis in Comparane MSS. refantium in ibliotheo is

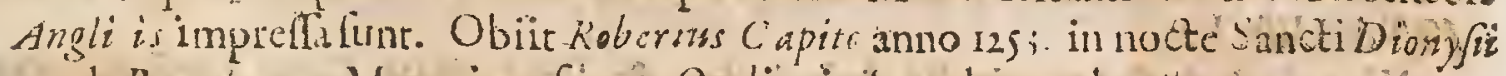
apud Bugedonuris Mancrium fum. Owdin. in supplem. ad "el'ar.

Scriplic non pauciores quàn treentos Tracatus quarum plaique omise

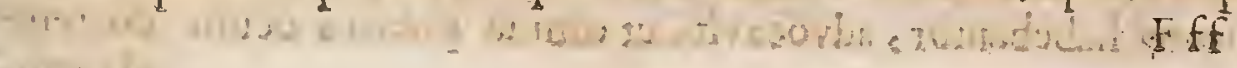
extane 
exrant Manufcripti in Bibliotheca VV efmonafteriensis, qualque Doctor VVilticl imus ejus in Sede Lincolnieng fuccelfor, Tribus roluminibus in Folie evulgare in animim induxerat, nif nupera turbida tempora ab incopto ipfum deterruillent, Ifta nimirum Civilia ngitra Bellos non modò Legronibus Mericarivm Libellorum nos repleverunt, fed etiam tantis Veritatis Thefauris nos defraudarunt quantis omnem Pofteritatem ditaflent Preclari hujus Viri opera. Thom. Fuller. Libio de reb praclesis Anglad.

Exta ejus commentuius in Libros Polteriorim Ariftotelis, edirus Venetiss anno 1504.81537. ibid. ex cdicione Pamphili Moniis:

Extat Compendium Sphare Mudi, Venetiirs, anno Is:8.

Extant Opufculaplura Texetivs edita anno is $4:$

\section{MATTHEUS PARIS, five PARSIUS.}

Clar An.D. A Nglus, Sancti Albani Monachins, Ordinis Berredrtini, claruit annow MCCXI.

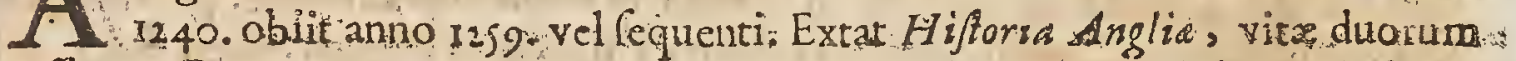
Offarum, Regum Merciorum; \& Xxun. Abbotum S. Albani, una cum addita-

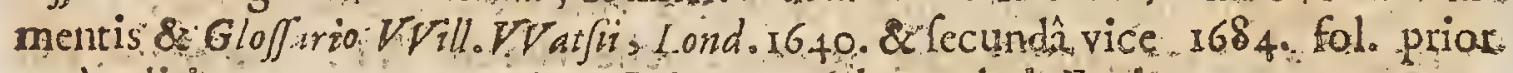
verò editió non parum præftat. Gul. Cave Chaitophyl." $c \mathrm{ch}$

Parzforun cognomen, olime apud Anglo's erat, quemadmodum: nunc. celcbre. Nif quis fentiat illum a yulgo parifren fern nominarum, quod aliquando Luteti. $P$ arifizrum ftudueric Sed in hac re urpote incertên niliil volo ftatuere Ioan. Leland. Tom. 4. Collectaneorum.

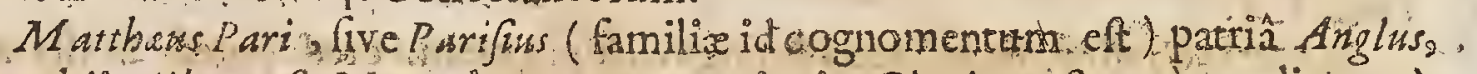
conobii Albanen [is Monachirs, congregationis Cluniacenfss, cù aliguantò antè,tum in primis ili pretio crat polt 245 , ufque ad annum 12.59 - quo migravit è vitâ. Hic ab oblivione nomenfum abundè vindicavic hiftoriâ majori : quam ferè omnes cenfent fuilfc olim bipartitam. Prior pars,ut aitunt,ab $A$ damo erat; uqque ad Guilielniz, Normannia ducem, Anglix regem, cognomine: Congrafairem. Addunt, eandem extare in Bibliothecâ Sidncian. Verum pars ifta, utừm fuerit Cir athei $P$ ar, an alterius, viderint, qui viderut A ltera autem parso quam hujus elfe $M$ itthai, certo conftat, Caniabrigia adfervatur in Collegio $S_{0}$ Beneditti: uti \&in Ribliothêâ Baronius de Lumleto: ac primum Londini, pof Tiguri, typis divulgata fuiratque id Gide bonâ, ur MSSi quos dixi, co dices cuivis fidem fecrint, Quanquam Coupulum injicere videatur Bryanus Tovyns low 3. de Antiquit. Acad Oxan ubi aliquot fibi locos in editione hijus ntathe - Mattbo Cantwarienf, viro non Doctrina minoris, quàn dignitatis, procurat $\hat{a}$, plurimùm fufpetos elle ait nectatuere aliquid de illis velle, priufquam fecundùm optimorum exemplatium Manuferiptorum fiden cos examinaverit. Fojl. de Hift. Lat.

Virtutis \& doctrinze titulis Principibus \& Proceribus Regni ; ipfrque-Regi Henrico tetio mirè charus erat. Rex eum ad maximas quafque folcnnitares, qua in Aula frequenter habebantur, advocavit, ur omnia prafens oculis contemplarctur, 
plaretur, \& poltea fecuits, atque fideliùs fcriptis mandaref friguld. Erat enim ad Hiftorias cribendas ingenio fatis accommodato. Quo nomine a fuis mul-

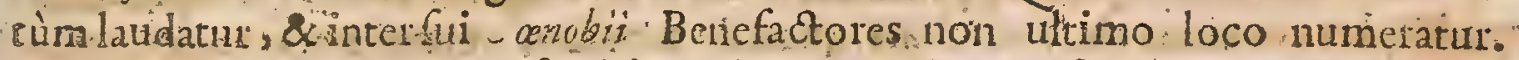
Sanc in ejus scriptis immenfos tabores incredibilem fedulitatem videre ef, quibus ctiam accedur ingenium \& judicium. - lown. Titjans de Illuft. Angl. Scriptor.

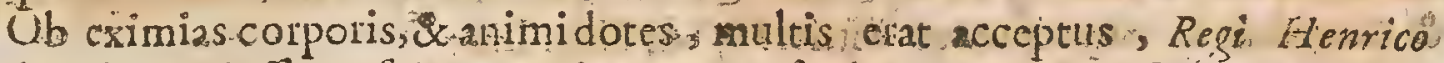
pracipuè, qui jufit ut futcmporis gata conferiberet, quod \& fecit. In quibus quorundam Rornanorum Pontificum avaritias, fiaudes, mendacia, dolos, pompas.jmpudentias, ty rannides $\&$ altes pellimas ita depinxit, ut nullus unquar Apelles melius. Io an. Balaus.

$M$ atibeus Parijus, vir imprimis cruditus fur qui \& fungulari fide \& dexte sitare Hiftoriam Anglorum concripht. Nagdeburg. Centuriator:

Vil omnium citima atatis ilifortcorum Anglorum (1uifcui placeat williel mum Malmesburienfem cxcipere) eruditilimus, \& Romsin Sedis acerrimus defenlor: Ifaac. Cápatib. Epil:62+f.p.74r.

Qưonnemo vixit unquam neque Paptrat fuperfitionibus addictior, neque rapinasum horribilium, quas 'Papa in Arglia excreuerunt,fdelior' téfis \& $\mathrm{cx}$ polizor. Idem in Prolegom. ad Exercitat. Luas Faron.

Alathaus $P$ arifienjis Hitoriam Anglicam fcriplit, induftic \& inquifite, $f$ non éleganter aut feiré. Sed milta in co bons-\& libera juảicia: nireris fi legas.Lipf: in Epif. $3.2 d$ Woverium Cent.5. Mifell.

Legi mula in vefto Monacho Mattbeo $P$ aris, qui quamvis Capenumero fit ineptus, tamen aliud agens pulchrè depingit rylannidem, quam Pontifices Romax: in Principesillius atatisexercuerunt. Non minus fuperbè vobis tunc imperabant, nec minus avare vos compilabant, quàm fi ab ipfis bello fubaati fuilre. tis. Hbert. Langwetin Epilt. Is.ad D. Pbil. Sydnewr.

De hoc andore tale cft judicium Baronit ad Annum 996: Quàm fuerit wimo unfenfinmo (inguit) is Apofolicam Sedem, quivis facile poreft intelligere: nifi probra illa fuevin additamenta ejus, qui edidit. Quz fi quis demat, aureum fane dixeris commentariums: utpote quod explablicis monumentis; totidemverbis redditis, egregiè contextutin, $\&$ coagmentatum inveniatur.

Magnâ prudcutiâ \& ufu rexumprævalcas scriptor Anglicus. Conrag. lib. I. de F. 1. cap.-10

Majorem ævô illoprudentiam oblervare eftin Matib. Parifi Anglicanarum renm hiftorià. Conring. de ir.prud.cap. I4.

Monachus Benedikinus, Augtor fummá fide a diligentiâ. Pet. Molinan cap.5. de Monarch.' 'ontif.\&c.p.75.

\section{VINCENTIJS, vulgo BELLOVACENSIS.}

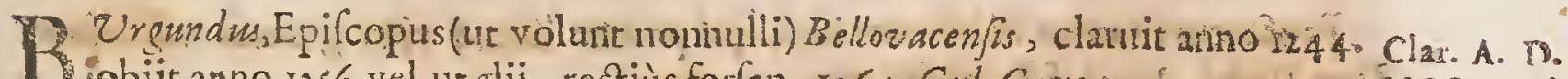
cobit anno $1256 . v e l, u t$ alii, rectius forfan, $1264 . G$ G. Cave.

$$
\text { Fff } 3 \text { Hic }
$$




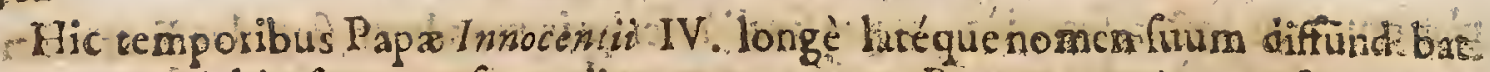
- Tncentiz hic, fumptus fippeditante Francorum RegéB. Ludovi co, fpeculum. guadruplex concinnavit Doctrinale, quod do omnibus scienciis tractat, Grammaticâ ordiens, ac in. Thcologiâ definens: Hiftoriale, quod Hiftorias comple ctitur ab Orbe condito ufque ad annum 1244 . Naturale, quodeft de naturâ rerum, futu locorum, \& ratione Temporum: Morale, quod eft de Affectibus, de Lege \& Gratià, \& de Virtutibus ac Vitiis. Voff. de Hilt. Lat:

Vincentins Gallus Natione Bürgindirs, Ordinis Pradicatorum, dictus Belwacenfis, vir in divinis $S$ cripturis tudiofus, \& exercitartis ac Veterum lectione dives, ingenio fubtilis, \& fermone compofitus; tantum literis ftudium adhibuit, ut nullis unquam haboribus, vigiliis vel occupasionibus $a b$ earum culturâ potuevit cyocai, quiu femper aur legeretsfriberet velpredicaret. Tantus itaque fuit, ut pofte necdum habuerit parem, fradua qux lcuipfit $O p$ phola ex multis laboriosè collecta xquâ lance cum cxtexis ponderemus. Tribem.

Vincenitus ejufdem Ordinis (Fratrum Predicatormin) dicitur fcripfiffe quoddam Opus magni ingenii, \& laboris, quod pratitulavit Traplex Speculurr, Hiftom riale, Allegoricurn, \& Morale. Iplun Hijtoriale non folum per Sanitarun Scripiurarum feriem; fed eciam per Secularium Hifiornarum ordinem, ulgute ad fua: deducens tempora, multaque hinc inde inferensfudiolis lectoribus profurura. Henrisus à Gairdavo c.42. Catal:

Vincentius Belvacenfis, vir omnifius, ac plurima lectionis, ut ex ejus quadruplici Speculu conftat. Ioan. Card. Bona.

Qui longè latêque nomen fum difudit vafto illo \& laboriolo opere quadruplicis speculi. Quenftedt.

Vincentium Beluacensem virum laboriofifina diligentia appellito Spondan.

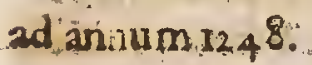

Vincentius Bellovacenfis Epifcopus s primus è luto aliquantulum emerfit. Fuit ille ordinis Dominicani, natione Burgund us. Ejus extant yuatuor Specula, viz.. Doctrinale, Naturale, Morali, \& fiftoriale. Vafti illi librifunt, \& non contemnendâ diligentia congcti'; fed ubique perlucet iftius feculi ruditas-Ejus in Hiftoriâ tion magna fides cett; nota enim et Monacherurn in illa genere induftia. Eft tamen nonnunquam ubi ii fterquiliniô hôc auri aliquid aplaret. Habuere illi nonnunquam libros, aur defcripfere a qui ad noftras manus non pervenerunt. In "peculo Morali habentur omnes illa Materix, qux) ad Philofophiam mo:alem sicivilem fectant. Varia Quztiouses circa hoc negorium, quafi per lancem facuram,è Scholatticis congelta, alique tamen ordine:sed de omibus illis libis hoc pronumciandum; quod Horatins de cujurdan Pọ̈ta carminibus: :

\section{Cikm fiseret lituleintus, erat guod tollere velless.}

Profuerunt tamen hi labores illis, qui portèa Libros cjus gencris ediderunt:-

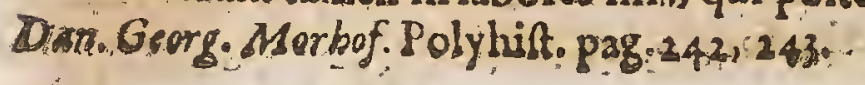




\section{CELEBRIORUM AUTHORUIM.}

Vincentii Speculum Hiftoriale multa continet alib: nufquam obvi.t : Prima ejus Imprefio polteriore praftantior cftiquia in Venetâ plurima dema funt atque immutata. Scaligerana 2.

Tritbernize in pradiandis Vincentii laudibus fortafle nimius, cum airpoft fe nondum habuilic parem - expectabit hic fortalfe Lector, ut vexatam toties. ab crudiris controverfiam, ip fe quoque pertractem, an à irincentio Bellovacen $/ 2$

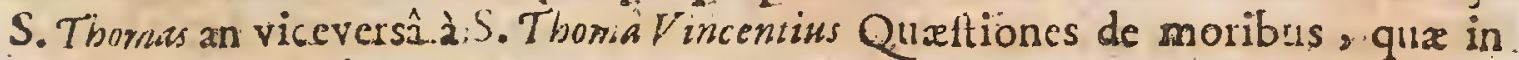
yrimâac fccundà fecundx, in Speculo Morali agitantur, mutuatus fit. Ego' fanè nullus dubico, quin ex Ingelici Dotoris fontibus fua hauferic Vincentiz.. Pbil. Labbe de scriptor. Ecclefiaft.

Magnam. Haforici fui Speculi partem ex Gulielmo Malmesburiens exforipfic Vincenizús Bellovacen iss. Vofj. de Hift. Lat.

Ergo.Vincentium Plagii damnabimus? Ne hoc quidem. Plagii cnim culpa folet ex eodepelli, quia iple in Operis totius prologo apertè fé profiteatur non: tractatorem, fed cxcerptorem. Quan excufationem \& nos utcunque admitimus: Thornaf. de. Flag. fect562,575.-.

Viricentius bellovacenfis, ufque ad Ann. Clirift. 1244 . deduxit Speculim Hiftoriale, in quomulix mug. Lo. Henr. Boecler. in Dillert de utilit. capiend compof. Hifto. Univerf.

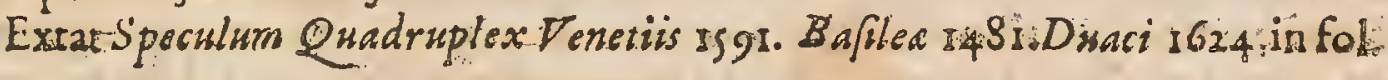

$$
\text { S. T H:O M A: S: Q U.I. N:A S: }
$$

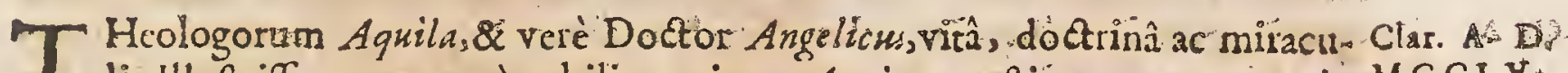
1 lis Illuftulfumus natus ènobili comitum Aquinatum ftipe an $122 \%$ in MC C L.V. caftro Lalii Aginino, ing elfus eft. Ordinem Sancti Dominict, milfufque Parifros: \$ Coloniam, Philofophicis Theologicifque ftudiis operam dedit, Magiltris prafantibus ufus Alexandro de Hales Angio, \& Alberto Magno Snevo. Inde ipre eadem dic cum Sancto Bonaventurâ anno 12ss: crearus ij facultate Parijien Docter Thcologus \&z ibider per plures anos ealdem difciplinas profelfus, fcriptis in Ariflotelen, S ripturaw Sacram, ac. Theologica Dograia quamplurimis do etifrmíque voluminibus, fanctiflime obiic die 7. Marrii: Ann.Chrif 1274 . 252 ris so.in Canobio Foljencva Ordinis Ciftercienfis prope Anafenum Carrpania fuvium, cùm evocatus a Gregorio X. Romano Pontifice ad Concilium Lugdumens $\mathrm{II}$. iter in Galliam meditaretur. Sanctorum Catalogo adfriptus eft die 18 ; Juliiamo 1523. A foanne Papa XXII ejufque corpus U rbano Vi. Rounamo Ponti fice anno 1368. Tolofarn delatum. P bil. Labbe de Script. Ecclef.

Thomas Aquinas ordinis Pradicatorum, ex illuftri Comitum Ágini familiâ. in finibus Campania fplendidiflimis parentibus ortus, Alberti Ratifponenfis Archiepifcopi doctoris cognomento Magni major ipfe difcipulus maximo a altifimo ingenio vii, cui ad plenam abfolutamyue totius tam divinia qudm humanx cruditicnis gloriam, folus defuit linguarum \& eloquentiz ufus, quem crudisi illius feculi, utpote fublionjoribus thdiis intenti, neglixere: Theologo-

$$
\text { Iff } 3 \text { RUII }
$$


rum furit, ac Philofophorum omnium, quos in háre uqque diem Scholatico: rum Academia protulit, fine üllâ controverfiâ princeps quippe qui primus omnium Latinorum 'hilofophorum non minus incredibili, quàm felici ufu omenem Ariftoteles Phil of ophiam Commentaciis Lucidifimis illuftrdvit. nacris verò fincerioris 'Theologix ftudiis ita fapientiflimo Auguffino praximus inceffit, atque ita mentem cjus, \& omnes teconditos fenfus introfpexit, extruffrque, ut

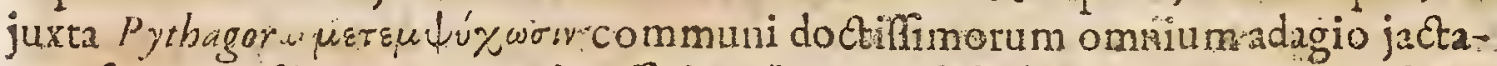
tum fit, Augufini animam migralfe in Thom. In Scholafticis quoque myitica Theologia difputationibus ita creteris Academiarum atucibus antecelluit ; ut univerfali fcholarum omnium confenfu receptum fit. Thomam, Scholaftica Theologia infauratorem, quatuor inter Ce implacabiliter purgnantia indirfolubili pac is fodere conjunxille, videlicet Copiam, Brevitatem, Facilitatem, \& Securintem; guas nulli unquam literaru in profeffori vélante, vel poit cum contigit fimul potuiffe connectere. Six s. Senenj: Biblioth.Sanct.1.4.

Thanas Aquinas Theologiam omnem in eum deduxir oxdinem, eâ perfudie Luce, iis locupletavitincrementis, ut univeda pofteritas illi quam plurimùm debeat. Compendio utendum eft in hujus viii elogiis, aliogui ea ad dicifnem non finiemus. Aguinas fapicntize ac fanctitaris magnum jubar, tamerf opem divinam fuis fe tiptionibus faventem habuerit, humanam tamen induftiam in fe defderari neutiquam pafius eft. Legit plurima, excerplit. Confidera leptemdecim tomos editionis Romane, quos Thomas potenis reliquit : imò vel tres folùm Tomos infpice, decimuni,undecimum, duodecimum, quibus tres partes fumma Theologixecomplexus eft. Quanta, Deus!'in his fcriptis, quàn varia, quàm fublimis crudieto, quot à prif́cis Patideus aliifque criptoribus teltimonia ? Hxc profecto Notas \& excerpta poltulant quàm maximè. Itaque non foTum innumera legitbeatus Thornas, fed\& exccrpfit, \&ua fecit. Drexel. in Aurifodin.6.7.

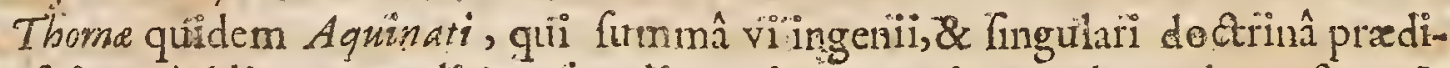
tus fuit, quòd linguas, politiorefque literas ignovaverit, condonandum cft, illius feculi, quod profunda Barbaries occupaverat, infelicitati tribuendum. Roland. Mares.1.2. Epilt.Ep Ar.

Thorbas Aquinas, vir non fuo taintum lec îlo magnus : Nam meo quidem animo nullus recentium Theologorum, cui parfit diligentia cui fanius ingenium, cuifolidior entitio, planéque dignus erat, ..cui linguarum quoque peritia , reliquaque bonarum literarum fupellex contingerets qui iis qua per eam tempeftatem dabantur, ram dextè fitulus. Erafm. in s. Rom p. 244.

In co culpandus maximè Thomas eft, quòd non tantùm Philofophica principir, fed etiam libilofophorum verba \& lacira ad conclufiones Theologicis atdacter applicat, quod veliph $P$ arifienfes Magifri in illo improbant. Quenfede. de Vir. illuer. p.389.

Scriptor de Scholà omnium fanifrmus ac minime ineptus. Lud. Viv. de Trad. Difcipl. 1. g. 
Tromas nimis eft Ariffotelicus, dires omnonrnatur vim, captumque exce-

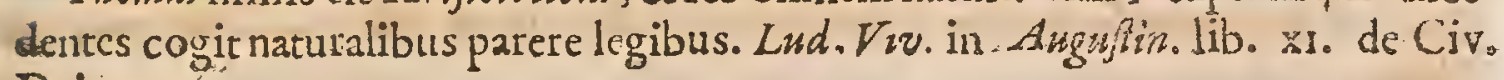
Dei, C. $34^{2}$.

Papiftartum Homerus vocacur Raynoldo.

Illum imprimis $P_{a p r l i a}$ obfuam quandam fanctitatem \& eruditionem , venerantur \& pradicant. Illyric. Catal. Teet. Verit.

Dici por ft quod Scliolaftica Philofophix fubrilitas, in fcientias ferc̀ omnes illo tempore intredücta, Scripturanm ftudionon parvum attul rit detrimentum. Sunt tamen Theologi quidam, \& interalios D. Thomas \& Thomas quidam Anglicus, cujus opera quredam in Ecripturam authores confudernnt cum operibus.S. Thome, qui foliditate \&udicio fuis in Biblia Commentariis admodum pollent. Sed praclara illa Ingenia inaufpicatò nati Cunt temporibus illis quibus fere nulla Humanion literarum notitia fuie, Jel. Rich. Simon. Hiftor. Critic.V.I.1.3.cap.10..

Thomas Aquimas Dominicanus : fír doctus, ingenio utcumqque tardus. Scaligerana 2a...

Ejus Lecliones Etbica Opussauro contra xflimandim, \& quố vix ullum ( $\mathrm{f}$ paucas hallucinariones circa homina propria \& derivationes Græcarum - vocum excipias) hoc tempore abfolutius exeare nobis perfuademus Henr.Iul scheurlo. Bibliogr. Moral. Impreff. in 8 : Helmftad. 1686.

Lurulentilis flüunt, \& Romuias atrres neglectâ dictione radunt, virí dúo proxclarifimi; Divus Thomas are Egidius Remanus, in operibus qlix de. Regimine Principum nobis reliquerunt. Sed in illis tameryminizmè, ut erat faculi fatums fomniorum montra aut nebulas pięas. fequuti funto Imò lectionis dirtunnâ ac fédulâ meditatione, ingenii ferum optimarum \& politicarum copiniluxuriantis argumentirm exhibincre; quo in concipiendo's nor magis indullerunt Genio potenti, \&ad grandia quaque \&edifficillima nato, quam . Trincipum Imperio. Gabr. Nawa. Bibl. Politic.

Ut, quod fentio, dicam, is ferè fuit mos Anitguitatis crudita ; ut librorim locorumve citationes pratermiferint, quod \& in Scriptis. B. Thome Aquinatis, qui Vitritro noltro pofferior fuit, videre licet bene octlatis Quamvis esim cos, à quibus aliquid promit', Crape laudat Auclores'; multa tamen in Argoto mentorum folutionibus aliilquı locis effert non fuat, fed alitinde furmpta, fuppeffis A A Elormin nominibus. Eranc. Mof chus pref.ad Lect. Hift. Orient. \& Occident. de Lac. Yitriato.

Francifrus Garcin tradidit, Moralid Aguinatem fita, qux in illius fummâs Theologia habentir, ex Vincentio. Be lllovacenfiaccepiffe, hoc eft, tantum non inregrum Vincentii Speculum Morale fibiftumpfife: Verùm probabiliats eft, Fincentizm è Thomà, è quo allia multa in Spcculo Naturali nomination tianfcribit, quàm hunc ex illo hanflfé, ligèt, in quo Garcia quarrit fux caula robur, s annis aliquot ante: Themam obierit Vincentius. Nam hounc,fi ipfe Speculi Moralis autor eft; à vivo, quibis uteretur, accepilfédicemus, prafertim cum per çuindecim annos integios ante obirum Vincentii Thomas ptimariam Gathedram rexeris 
Parifis. Bellarminu; certe negat ullo modocrcdibile offe, functum Thomano furnme fure partem fecundam, camque nobilifimam ex alio hatifi. Thornef. te Plagio, fect. 560,56 s.

Librum de Reginsine Principum. genuinum clfe negat Be'lerminun

Ifteauctor falum habse à ftylo jancti Thorna valdé diverfum : hic cnim prefsè \& beviter feribit, \& mulea paucis complicetitur; ille contra vabis aburdat, \& pauca multis explicat Adde, quod hic Austor non parcalevia profert de nominibus magiftratum libro 3. cap.22. \& lib.4.cap. 26. yule sancte Thorne nunquam cxcidillent, qux caulx fortate fuerunt, ut in editionc Loventenfs anni 1652 .libri ifti de Regimbe Principuminter opulcula 5 . Thom a dicripta nom inveniantur. Adde ultimo, cum Sandus Thomas feripleve feptem libios de eruditione rincipurs, plané utilifimos, qui habentur inter opulcula Rome edita, non videbatninecelatum, ut Lriberct ctiam de regimine Principum. Bellorm. de Script. Ecclist.

Extant-vira \& opera ejus omnia 5 . Tomis in fol.cum Commentariis partim Thome de Fin Cajetani, \& pattim Erancifer Ferrarienfir. Vonetiis, I594.

Sub cjus nomine citcumfertur Opufculum de Symbolo,eruditum quidem frum, licd non videtur elle Thome Aquinatis. Erafm.

Epitaphium S. Thome Aquinatis, in Monalterio Fofjanova defuncti.

Occidit bic Thomas, lux ut foret amplior Orbin

Et candotabrum for Nova Folli foret.

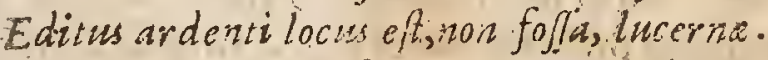

Hancigitur Follam quis neget efe Novam?

Pabil. Labbein Thef. Epitaph.

\section{A I B E R T S M A G N S}

Giar. A. O. MCC L X.

T Avinga apud Suevos cx nobililimâ D ynaftarum Bolftutenfum familiâ natus in Pradicatorum ordinem adfcriptus anno r221. difcipulos inter alios habute S. Thoram Aquinatem \& Thomam Cantipratenfer. Dein eccatus ab Trbano IV.

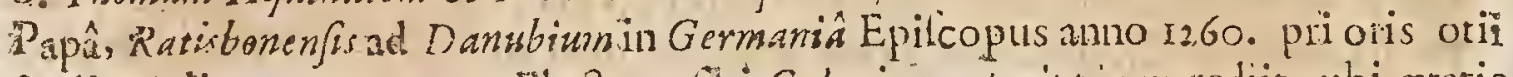
ftudio \& literarum amote dilectan tibi Colonian Agrippinam xedit, ubi xtatis -anno 87 . (qui ammo 1205. non Ir 93 . natum volunt anos duntaxat 75. vixille fatebuntin) Cbrafti 280 . is. Novenbris obiit cruditione ac pictate praftantilin "mus, ibialemque fepultus ete. Pbil. Labbe de Sulipt. Ecclef.

Vir cruditionis admirande, quem divinarum rcam pauca, humanam fortafie nulla d atuerunt, fublimibus ingenii ac memorix viribus ufque ad miraculumprotans, in divinis Rudiis longè exuditiflimis, \& I hilofophorum omnium, quos vel ante, vel poft eum univerfa Germania protulit, princeps : ob cientiarum ejus multitudinem, magnitudinemque, Magnicognomen, quod 
anillinguam erudironm contigit ante mortem adeptus. Sixt. Senenf. in Bibl. 1.4 .

Nonfurrexit pon enm (Albertum) vir fumilis ei:qui in omibus literis, Scientiis, \& rbus, tam do otıs, cruditus, 8 expertus fucrit. Quòd autem de $\mathrm{Ne}=$ cromantiáaccufaturinjuliam paticur vir Deo dilectus. Trithem.

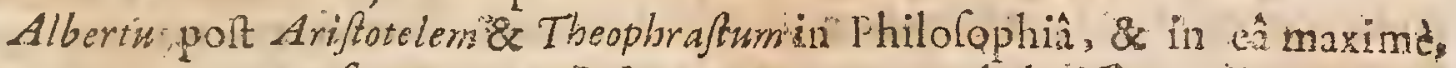
"qux retum naturam ferutatur, \& interpretatur, non habuific creditur parem: Quenfeds.de Script. Iluftr. \& Spondanus ad Annum r259.

Primus Latinorum, inquiutut Centuriatores Magdeburgenses , quicquid in sracis, Latinis, Arabibus, Ebrsis, Dhilolophis egregium firic , perferutatus eft Albertus Magnus.

Laudat Albertum impenffimè Aventinus: Germanum eum Farroners appel

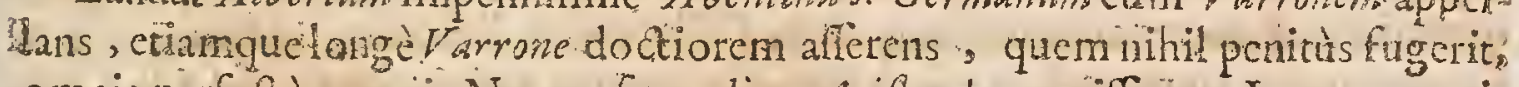
- omnia perfectè noverit, $N$ ature lecundum Arifotelem veriflmus Interpres extiterit; adcoque fngula, que de omnibusfcientis \& faculcatibus fcripfit,in fuo genere abfoluta ch: ac $\dot{G}$ uni duntasat operam navalfet, catera ne attigillet qua. dem. Ioan. Aventil 1.7. Amul.

Alberturille Magnus, profundâ rerum omnium divinartim \& humanarum contcmplatione, cur cues latentum recondirarumpue in natura potefatum in dagine hoc confecutus eftut verè magia miniferio, inferiona luperiorum dotibuscopulando, artemquc ad naturx commercium flectendo, fupenda fapè miracula ediderit: a prophanis cxtcroquin Diabolicx magia impofturis ali-nilitmus. Thom. I antius in orat. pio Germania

Eodem xerò propemodìm tcmpore, cùm exorta fuiftet Scholuftica doccndi methodus, muli etiarn hoc fribenê genere coldem Ethicorum libros explicarunt, aut potius inclimarunt, ut lib ner dicerem, frtes mihi exiplorum numcro excipere liceat, emni laude? ac commendarione majores, nemp. Albertum $M a=$ gnum, Divum Thomarn \& E Eidium Rornarum qui minus palo quàn cxteri inquinate locuti funt, judicio vero do etrinâ,fubtilitate, ad ò fupra morem \& fatum Sui fcculi excelluertnt,ut, fipacademas ex Alberit libo de tiforia $A$ ramaw

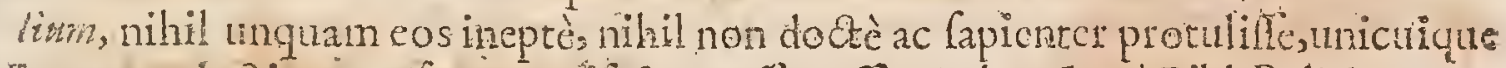
in earum lectione verfato, manifen m elle pofit $G .6 r . N$ and. Bibl. Politic.

Anno 1252. longè latéque radios fui nominis difpergebat. Albertus wagnus, Epifcopus katipoikenfls,nulli fuo zovo doctrinâ fecundus: jui emift monumcnes fui ingevii ac doctina permulta. Vofj de Scient. Marhemat.p.36z.

Primus omnium de $M$ etallis ac Lapidibus Fhilofophiam excolere copit ille ipfe Albsrue Magnus cujus hac ane reprectarum opus magno juáticio \& pari experientiâ conferiptum extat. Sebaf.Scbeffer.Introduct.in Art. Med.p.164.

In dicendo Goticum Lapit, \& baibarum; oratione fquarro sâ pro:sùm, \&e illepin

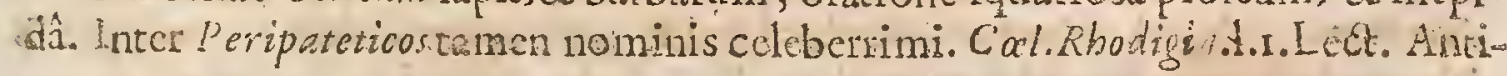
quarum c.ri.

Homo Grac doetrine ignans, in multis hujus ferentix videtin pecane Alberius.Idem in Var. Loc.Lect. Antiqg.

Ggg Infecibuntwat 
Infcribuntur Libri duo, mus de Mirabilitus, \&alter de Secretis Mulierm Magno Alberto.Sed uterque liber indignus eft, qui tanto viro tribuatuinam Gitro perfitiof. quadam continct, multa vana. Bellarm. de Script.Ecclefo...

Noram plerique Magno inufferunt Alberto, quod in libris de Mirabilibus Wh undi plurima congerat, qux vel doctifimorum captum effugiant. Ego verò multa reor opircula prafulgidun tanti viri nomen ementiri, ad legentium gratiam, qua nec fompiavit Albertw;nima quippe Scriptonm calfitudo $\&$ opinionum frmitas, in abditifimo rerum omnium examine, quam abineptis quo:rundam commentis, qua illi vulgus adfcribit, abhorrcant, cuilibet, yel of citunter legenti perfpicutum fit. Ioan.Imperial. in Mufxo Hiftorico.

Is Sedtam Alberiturum condidit, \& Ariftotelis Philofophian S. Scripturia xquiparavit. Ferdinandus Caftillus \& Ant. Poffevinus memorant ipfum quirs quennio ante mortem omnium, qua in Phitofophia didicerat, oblitum a $\mathrm{B}$. Virgine autem impetraffe, ne fe in Philofophormm opinionibus, fed fide Chri: Atianâ \&charitate mori funcret. Konig. in Biblioth.

* Alberto Magno falsò adfcriptus Libcllus de Secretis Mulierum, prohibstue in Edillo I6. Decemb.1605:

Extant Opera ejus omnia in 2x. Tomos digefta f fudiô \& labore $R$. P. . Fra Petri Iammit Ordinis Prad. Conventus Gratianopolitani. Lugduni fumptibus Cloudii, Proft, 2'erri \& Claudii Rigand, Hieronym. de la Garde, \&loan. Anto.

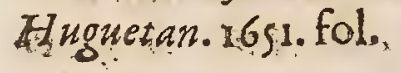

Epitaphium Alberti Magni, Auctore Iano Vitale Ranormitano:...

Natura has violas, Ratio bic tibi liliapaffim

Ad tumulum pargunt Teutone magne turmo.

Purpureis quarum tribulos arellis ab bortis..,

Et pulchris violis lilia mixta Serix;

Aviague abfrufa pandis penetralia camfe.

Vere igitur. Magni nomine dignns eras.

Phil: Labbe in Thel. Epitaph.

\section{JOANNESDUNS SCOTUS.}

Clar. An. D. T Oannes Duns, Natione Scotus, natus in vico Duns, oto mille paffibus ab $A n=1$
MC C.C. gliâ diftantelneque enim audiendi qui cum $C$ avello, Thadro, Wadingo, Arturn, \&c. Hiberum alferunt Duni in Vlioniầ natum, aut qui cum Carndeno, Balao, \&

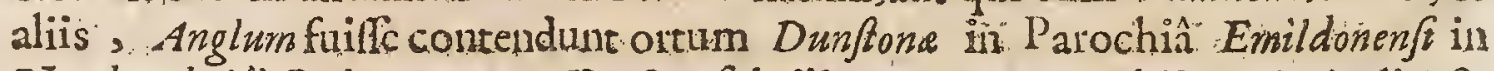
Northumbriâ) Ord. Minorum, Doctor fubtilis nuncupatus, obiit Colonia die 8. Novembris anni $308 . i b i d e m$ fepultus. P bil. Labb. de Script. Ecclef:

loannes Duns Scotus, ordinis Minormm, yir fuitacutiffmo ingenio præditus. Bellarm. de Scriptot. Ecclé. 


\section{CELEBRIORUM AUTHORUM.}

Vir admirandx cruditionis fubtilitate preditus.Sixt.Senen/ Bibl.S al:ct.1.4.

Fuit vir mediocri fortunâ, ingcnio ad litcras planè facto, 2 ad mirac ulum lubrili atque acuto, ut non tam hominem acic mentis ftupendum, quàm inter argutos 1 hilolophos quemdam dixetis Derm-----Nihil erat tam obfcurum, densâque caligine involutum, quod ille fibi faltem non rcddiderit perfpicuum \& clasum;nihil tam occultum \& abltufum, quad perfpicax cjus ingenium non penesraverit; \& è tenebris cruerit:nihil denifue tam nodolum, quadille, qualı quidame Oedipus,nondilfolverit. Pilsaus de Script.Britan.

foannes Scoinestulum Subtilis Doctorts, ob doetrinam, parque ubique acumen meruit. Cardan de fubtilitate, p. 80 ?.

loanmem Scotunilimam vexitatis appellat Iul.Caf. Scalig. cxercitat. 324. ad Cardan. de fubrilitat.

Ioannes Durs natione Scotws, Doetor fabtilis appellutus, poitcntofus Artifex, ac Uitigioran $P$ atriarcha, impolturam Labyrintbor ingcnio Dadalino cxcogitavit;contendendi formulas novas verbis intiécatis fubtiliter adinvenit, \& monftrifica conflictationum yacabula formavit, de Suppofrionibus, Obligatoriis, Infolubilibus, Hacceitatibus, Forrnalitatibus, Modis Intrinfecis, arque aliis Sophifarum. Chimaris, ut Chrifus incontentione pradicatctur, ac innumeris fuperfitionibus in Ecciefia veftirctur. Stultior chim cft ca Sententiarionum Papifítcorum Theolom. gia facra, ex Centaurorum biformi conflata gencre, quàm funt Scripta fabuloi Helnd: \& Orphei Theologoram Gentilium.Ioan.Balaus de Script. Britan.

Mirum auo fupercilio, 7 horne, $S c o t i, D$ urandi fimilinmque barbaicm excereto"tur:e tamen, fi res voccurad exactum judicium, illi quum fe nec cloquentes. acc Ciceronimos jactitent, mais Ciceroniani funt, quàm ifti, qui poftulant haber

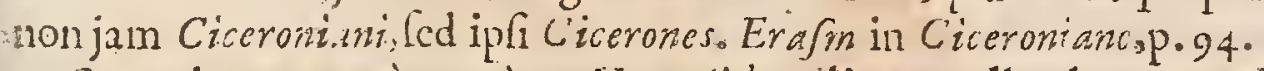

Scotusitem oxorics xcrè ueraclides olim appellandis, non in Dialectices tantum, fed in Philofophiâ \& Theoloniâ, in novis Qureltionibus non modò non necellariis, fedinutilifinis agitandis ita delectatus eft, utin eum illud feptimi

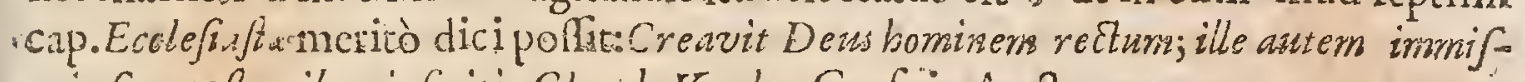
chit Se quafronibus infunitis. Claud. Verder. Cenl. in Auctores.

Yoannes scoms in Dialecticâ \& Spinosâ. Thcologîa ad miraculum doctifimus Subtilis Doctoristitulum promeruit; 2 wovam Scotzftrum fectam condidit; Homero major, utpote cum de eo nen Civitates, fed Regna contendant; Anglis verè. frum, Hiberni. fum, Scotis fum, fum quoque civen Sallis \& lialis adfeverantibus: Scd vita exitu infelix, quippe Apoptexiâ corrcptus, \& nimis fetinat funcre elatusscùm redeunte vitâ ferò moibi impetumnatura difcutcret, fruftra . miferabili mugitu open petens, \& diu Scpulchi Lapidem pulfans; tandem in appo [cpuilche felfum animam clifit. Thorn.Lanfins in orat.pro Britan.p. $47 \mathrm{r}$.

-Extant opera cjus omnias. Tomis, Lugduni 1639. in fol.

Epitaphium Ioannis Scoti, Auct. Iano. Vitale Panornataso.

Quod nulli ante bominum accidit, Fiator, Hic Scatus jaceofernel Sepultws

$$
\mathrm{Ggg} 2
$$


Et bis mortuns; ornnibus Sopbifis Argutus magis atgue captiofus.

\section{Phil: Labbe in Thefaur. Epirapho.}

\section{R A Y M U N D U S. L U L L U S.}

Clar. AD. $M C C G$

1 E hocingensinter Scriptores rixa: aliis cum inter Hereticos reccnfentibus ; aliis lufpectum de fide multifque implicatum erroribus, atque hi:ftrionem, perditxque memorix viruminfamantibus ; aliis denique, tion.tantùm ejus abfolutioni fubfcribentibus ; fed etriam ut Martyrem Doctoremque Illuminam tum depredicantibus. Obiifle dicitur in ora Mauritania lapidibus appetitus anno atatis 80. die 26. Martii anni 1315. unde potea delatus in Batearium primariams Infulam Majoricam, ut Saintus, \& pro fide Martyr colintr ab incolis, Pbile Labbe de Sciput. Ecclefiaft.

Raymundus Lulluzs, eremita, natione Hispanus, patria Majoricenfis, incivie

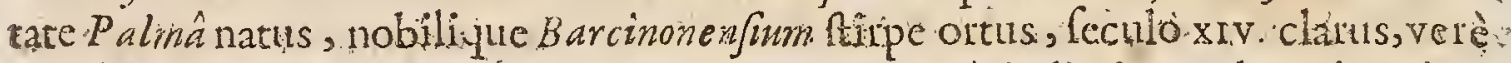
Protheus ingenio, Dadalus arte, â Polycletus normâ judicii ; ut de eo loquitur Mich. Majer. Symbol.aul. menfxl.g. f. 4 @s.

In icone quodam vocatur Pbilefophus, cum infcriptione Schedis in ore : Lex mea eft iffe Dominus; cumque difticho: :

\section{Dortrinampandż Rán mundis Lulliüsomnenso. Cui Dens, infudititscibile quicquid erat.}

Plura, quàm quatuor voluminum millia compofuiffe refertur Ephemerid. Gallos Erud.T. . Olear. in Abac.PP.

Elucubravit multa \& variain Philofophîn, Medicinî \& Theologiả is quaet apud multos in admiratione funt. Ab hominibus: fui zvi valdècelebratu t. Rabbimi dicebant, ei tantam fapientiam contigiffe, quantam Deus Salomoni concefferar. Apud Cives fros Majoricanos ranta ejus ent exiftimatio, nt Philofophia Lulliana ibi magno ftipendio loco Ariftotelica doceatur. Condidit peculiarem Sectum qux Zülliffurum dicitur. Eimericus memorat;, Lullum de plufiquam tre..

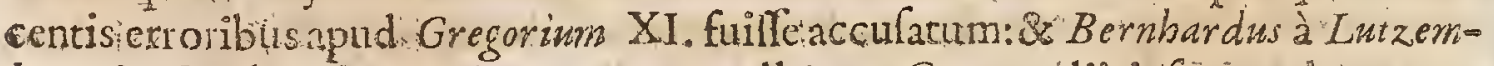
burgo in Catalogo Hapeticorum eum collocat. Contra alii ipfum vehementer defendunt, \&etanquan Martyrem ac Sanctum cxtollunt. Konig. in. Biblioth.

Raimundus Lullius, homo mirificiplanè ingenii. Huic debetur: Ars Al:bymiffica \& inventio Spiritûs vini, fcu vini ädufti. Quantuluam aurem ejus doctrina

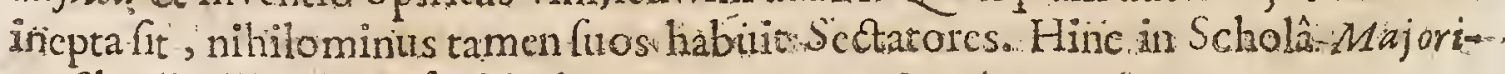
cenfihodiè illitis Philöfophia docetur. Herman. Conring.

Hoc autem admonere yos oportet, hane Lullit artem ad pompam ingenii \& doctrina oftentationem potiù's, quàm ad comparandam eruditionem valere ac longè plus habere audacixi, quàm efficacix. Henr. Corno.Agrip. de yanitat. Scicint. 
Neque tamen illud pretermätendum, quò nonnulli, viri magis tumidi, quàm wocti, infudantune circa Metbodum quandam, lcgitimx Methodi nomine haud" dignam, cum potius fit Methodus impofture; qux tamen quibuldam ardelionibus acceptifima proculdubio fuerit. Hac Metbodus ita fcientix alicujus guttulas afpergit, ut quis fciolus . Pp cic nonnulia - enditionis ad oftentationem polfit abuti. Talis fuit ars Lulii, talis. Typosofnia a nonnillis cxarata; qua nihil aliud fuerunt, quàm vocabulowm artis cujufque maffa, \& acervus; ad hoc, ut qui voces art is habeantin promptu, ctiam artes pipas perdidicille exintimentur. $B$ aco de Augment: Scient:1.6.c.2:

Miror autem, quid tibi, ihagne Dux, Princeps fagaciflme, venerit in men-. tem, He Raymundurn Lullum catalogo Doctorum, \& corum maximè, qui duces ae principes ordinum efle poflint non dubitaveris inferere, hominem: fultilfimè fubrilem; qui cum omnitim bonarum litcrarum effet expers, ac ne Latine fciret quidem, multatamen aufus eft patrio lermone evulgare, \& tali obfcuritate permifcere, ut doctinini licet, pauciadmodum ea caviant:quod incptiflima Scienthe certum cxiftimo effe argumentum. Ego Lulli Lapidern \& Doctrinam pari dignor pretio: \& cum Poetálic statuo: :

Qui. Lulli Lapidem quarit, quem quarere nulli

Profuit; band Lullis, fed mithi Nullis erito..

Laufus in ont contra Hijpaniam, es37\%

Raymundus Lullitis fuo cum Arabibus commercio in Medicina in $P$ by $f\left(c_{2}\right.$ ini Afronowi a doctifimus evafit. Ex illis verò tribus fcientiós quartam quandam Chymic fib confavit, quam Scientiam cenlerivoluit, cujus in Hi/paria $\mathbb{E}$ in Itrlia Reftauraton fuit. Ordinem in schola ftatutum evertere molitus eft; Philofophiam, cxterafque Scientias redigens in Methodum quandam cui nihil inef folidi ; quaque txntum abeft ut Eruditos faciat, quin potius Homincs ratione. rectè utcutes nunquam cformare potuerit. Rapin. Reflex. in Philof. Scet.:17.

Hunc ego inquirendo comperio; apud Anglos re quidem vera praftitife, quod fuis libris pollicetur. Et in Arce Londini jufu Reg is probatifinum aurum confecirle, mihique genus nummi oftenfum ett, quod adhü appellant nobile Raymundi auri, viz. puri, \& obtyzi, fummeque judicatura Robert. Conftantino in Nomenelat.

Extane cjus Experimenta Chemica, unà cum Georg. Hieronym. Velfkbigis

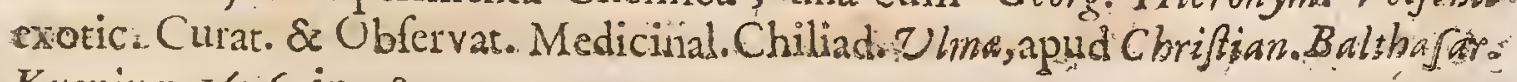
Kuenium, 1676 in $4^{\circ}$.

\section{DANTES AIIGERUS.}

1. Talus natione, patria Florentinus, nasus ef Anno 2265. oblic Ravenna antio Clar. A. D. Ggg $3:$ Scripto 


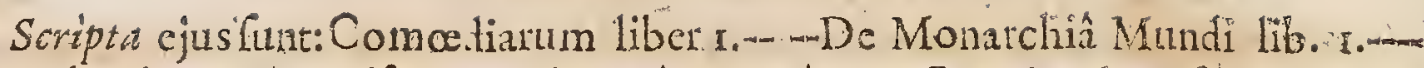
Epiltolæ plures-----Difputatio de aquâ \& terrâ-_-Catmina da Infeno, Pugà

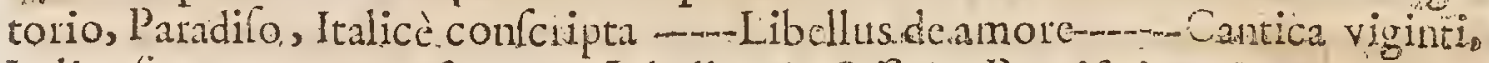
Italicolermone compolita- --.--Libellus de Offcio Pontificis \& Cafaris Konnani---De vulgari eloquentia libri duo, ctum tamen quatuor fe datuum polliceatur, fed hoc conflitum mois ejus interrupir.

Durantes ab initio vocstus, intercilo deinde, ut fit in pueris, vccibulo; Dances. Libcratibus Artibus in Patriâlegitimè enditus: poëtic x deditus àb ipsâ puctitiâ fuit. Scriphit opufculam do Monarchin, ubi ejus fuir opinio quod Imperium ab Ecleliâ minimè dependeret. Clijus rei gratiâ tanquam Hereticus poft ejus exirum damnatus eft, cum aliorum,tum Bartolz Juripheriri Sententiâ. Volatcran. Anthropoleg.

Fetrarch. \& Jatis l'oëmutailla Italica, quxe ftatun Ecclefse (ubiade atrin-

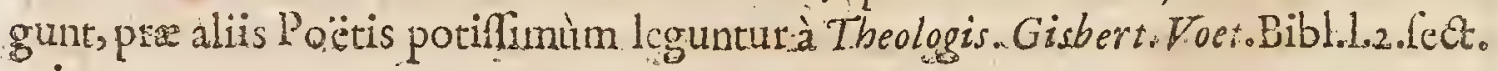
prior. cap.g.

Fuit vir pius \& doctus, it multi 'criptores, \& prafertim ipftus fcriptateftan5iti. Illyric. in Catal. Teft. Verit.

Maximâ vir laude \& autoritate, eruditionequc omribus cariffimus, veritatem magnâ ex parte agnofccus , regni Papifrici fraudes non ignonvit. Olear in Abac. PP.

Dantes Aligerus Pöeta Tui Teculi nulli fecundrs. Exat non tantùm Grece \& Latinè peritus, fed in linguâ Hetrufcá facundifimus:proptereà quoties ad colloquiia Principum admittcbatur, tantâ Cermonis elegantiì, tantî ubertate, \& cloquentix floribus omnium in fe animes convertebat, ut nemo illum non diligetet \& admiraretur. Boiffard. Icon.

In, qu qudem enditionem, \& multarum renm cognitionem offendetis, \& inprimis ejus theologix, qux Parifsonfbus atribuitur. In eo falis $\&$ mordacitatis ad fatidium interdum ufque. Cente in eo Paeticam difpoftionem majorem que diligentiam plerolque defidenare video, ejufque lingux nitorem $:$ quos Ioannes Stephanus cremita, \& amicus charifinus, \& municeps nofter , quá eft eruditione, \& quo à teneris erga $D$ antem fuit fudio, mirabiliter folitus ett refelJece. Lil. Gyrald.

Dantes Aligherius \& ipfe concivis nuper mets, vir vulgari eloquio clarilimus fuit, fed moribus parum per contumaciam, \&c oratione liberior, quàm delicatis ac fudiofis xtatis noftre principum autibus atque oculis acceptum foret. Francifc. Petrarch.

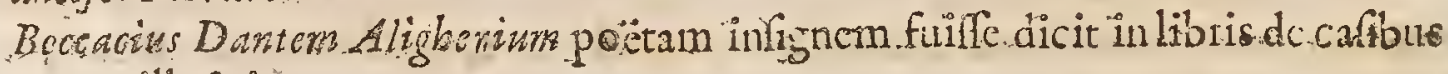
wirorum illuftrium.

Dantes vero Poëta non alpernabilis. Coel.Rhodrgin 1.r s.c.20. Lect. Antic.

Dantes Aligerius; vir aternâ dignus memoriâ, \& in Pö̈f kanaculâ excellendifimus. Boxhorn in Monument. vir. Illuftrium.

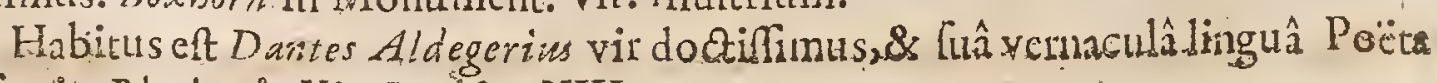
Snfignis. Platina in Vit. Bonifuc. VIIL. 
Dentes Algierius \& Erancifous Petrarcha, primi Philofophia , bonarum Artim, ominis eruditionis reitau ratores, Lacob. teerbrand. Epift. Dedicat. ad Díput. ex. Plikilor felect.

Primus Italururn Dantbes Aldigerius, non inftituto vetuftatis ordine tantum, fed precellentï gravis ingcnii fócunditate primum lacum inter imagines metiras, optimo jure conpicitur. Hunc Florentiu, factior co feculo. civitas protulit, ab altaque mentis indole cognitum oetovirali fupremre potentatis Magifratu infignem fecitut mox fatali converfa turbine \& fummum civem, \& Etru/ćting luz conditorem,tanquam frva \& ingrata patria profeciberet. Scd exilium, vel toto Etruris principatu ci majus, \& gloriofus fuit, quum illam fub amarâ cogita-

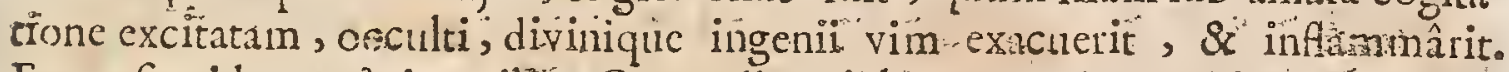
Enata frquidem eft in exilio Comadia triplex Platorece enditionis lumine

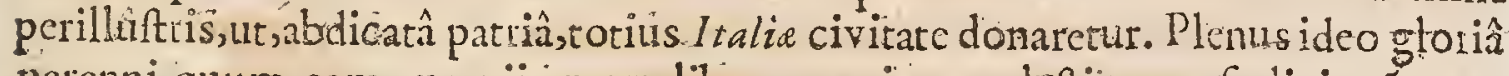
perenni,quum eam quæ piis mortalibus expetitur, crelêt is auxa folicitate tanto ore, tantoque fpiritu decantatam contemplaretur, nullî̀ adhuc obortâ canitic Ravenna morbo interiit, adeòmentis sompos, at fex verfus Cepulchro incidendos componeret. Nec Rauennates in apparatufuneris publico totius Italic civa defuerunt. Quum enim fepulchrum èmarmore condidiflent, non obfcurè exprobratâ Etrufcis acerbitate, novam fibi claritatem gloriosî pietate vendicarunt Paul. Iovius in Elog*:

Quis tam fui incius, qui advertens-Dantem Aligeritim factix Theologix implicitos perfæxè nexus mirâ demontratione folventem, non fentiat cum, non folum Philofophum, fed \& Theologum infignem fuilfe? Baccacius l.i 4. Gen. Dear.

lohannes Villani ipfi conterranets ac ferè contemporaireus' , afteverat nèminem adillam ufque ætatem, nec nobilius nec magnificentius tum verfibus, tum pedeftri fermone fcripfife : Sed cum panci ance ip fum feripfifent facili negotio celcbritatem hanc fibi comparare valuit-m--Re verâ Dantes inter primòs extitit, qui, referentibus Enditis viris P ortûs Regii,gloriam adeptus eft pofterioribus his feculis aggrediendi Poematum Heroicorum compofitionem; In quibus tam felix fuitut etiamnum apud Eruditos eorum refpectu admitationi. fit. Ita ut nemo hactenus extiterit;inquit Eques Salviati, quijplum hoc foribendi genere potucrit. vincere, ufque adco vocabulis \& elocutionibus fuis proprius eft quamvis infoletns quod fibi delegerat. Argumentum, agendo nimirum de Inferno, de Purgatorio, \& de Paradijo, eum liepe coegerit voces atque Phrafes fic fatis fingulares ufurpare. Sed unum eorum qua apudhunc Poctam majorem merentur exiltimationem, Praclarorum illorum virorum judicios eft quod ejus Opus quoad mom res.non mintis quàm quoad fermonem purum deprehendatur. Jel. Galluci habuth quod in ejusAllegoriis reprehenderet, quibus dicit illim totum intertextum effe; addensnihil ipfr reliquum fore eorum quorum caufa Poeta famam-fibi paravit, fiex ejus Scriptis exdem eraderentur. In hoc inquit tota ejus Inventro,tota ejus fetio confintit, qua in re longiffmè diftar à genuino Charactere qui in totis Virm

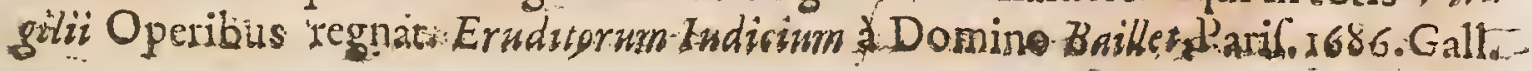


Vivens ipfe fibi hoc Epitaphiumfcipfr, cujus primis yctbis fgrnificat libellum de Officio Cafaris \& Romani Pontificis, deinde Canica Cua , nomea Exilium, patriam, epulturie locum,

Fura Monarchic, superos, Pblegethenta, lacugque.

Luffrando cecinio voluerunt fat a quon qub:

Sed quia pars ceffit melioribus bopita cafiriso Actorerngue fun petiit feticior affris,

Hic claudor Dantes, patriis extorris ab oris:

Quem genuit parvi Florentia mater amoris.

Eum tumulum Bembus civis Venetur, Bembi Cardialus parer cum Raven Prator ellet, refici ac refitui curaxit incifis his verfibus,

Exiguta Tumuli Duntes, bic Sorte jacebxs:

Sgurillenti nulli coginte perie fitu.

At niunc marnoreo fubnixus conderis arcks

Qmizibus of cultu plendidiore, nites.

Nimirum Benbus $M$ ib is incenfus Ethrufcis,

Hoc tibi, quem imprimis be coluere, dedit.

Jef. Rapin. dicit Poetahujus fententias ad e fere remper abtractas \& ade ardus effe, ut atte opus fit ad illius mentem affequendam : Dantis femonem won elic latis concitatum. Eum fatis modefum plerum que nen effe, \& in è nimis atidacem fuilfe quod proprium Animum tanquam Nınen fuum invacaverit.

* Dantis Aligeri ML onarchia omnino prohibetur.

Extant cjus Poëmata Italica cum expolicione Chrifophori Landini se Alex.

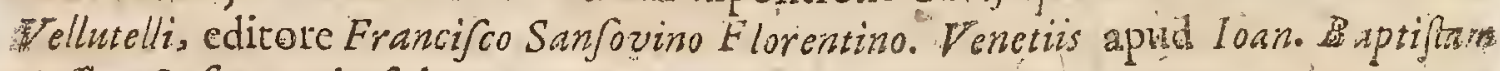
Seffarm \& fratres in fol. anno 156 \%.

\section{N I O L A S I Y Y A NUS.}

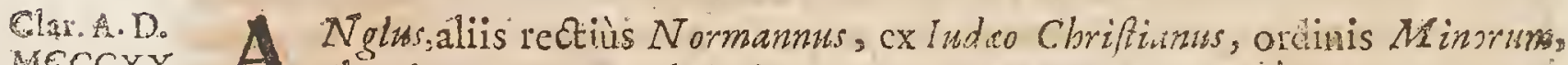
MECCXX.

- clartit Aino 1320. obuit Anno 1340. Git?. C.rve.

Scripfit Commcntarium, five poftillam in univerfa Biblia - Librum de Cor-

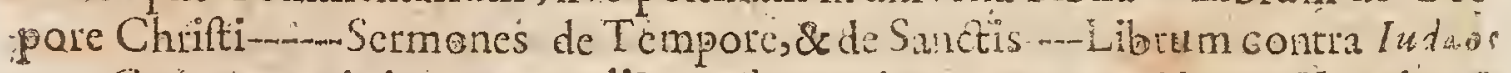
- Commentaria in quatuor libros Sententiarum---Quxtiones Vetris Novi Teftamenti-a-Tractatim de Vifronc Dei-...xpotitionem decem Pra-

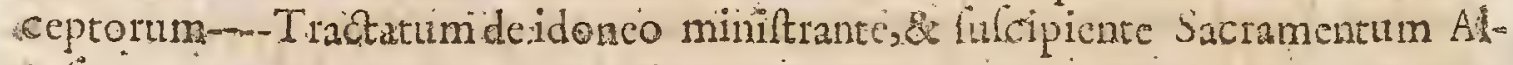
caris.

Scriptis fuis inclytus, in quibus futura Reformationis saninittris vium cgregie

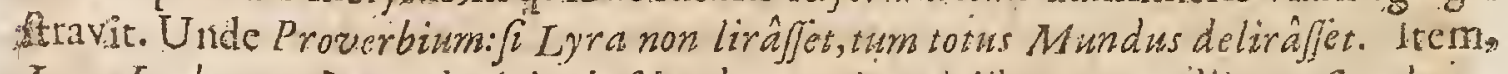

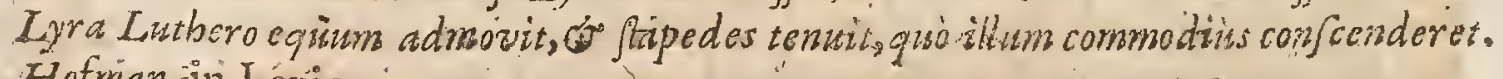
Hofrian.in Lexic.

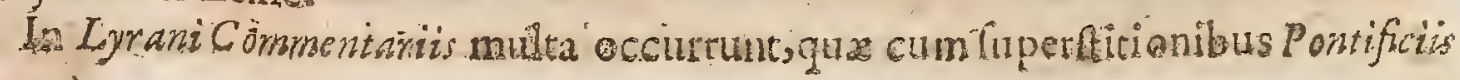


for confentiunt, atque demonftrant Lyranum multa commodiùs exprimere potuife, If feliciore teculo natus fuiller. Symbolicam \& Allegoricam illam

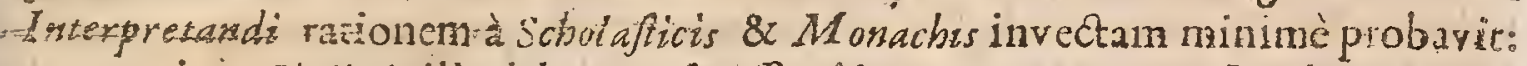
guam etiam Glojanioillo labore refutate videtur. Illyric. in Catal. Teft. Vecitat.

Vir if Scripturis Sanctis ftudiofinmus, \& longì exercitatione peritus ; Hebraich linguâ ad perfectum inftructus, ingenio promptus, lemone Scholafizicus. nec iminus converfatione quàm feientià venetasdus. Sunt qui eum ob eloquii finpl citatem xhiment contemnendum; qui mihi videntur \& vani \& imperiti. Tribem.

Nicolaus Lyranus, Scholaftice Theologice Profelfor, \& Sententiarum ejus expofitor non ignobilis, tanta quoque Divinarum Scripturarumb verà, purâ, ac germana intelligentia preditus, ut in eis exponendis, nullum eruditinimortm Theologorum fui temporis habuerit parem : Edidic in fingula tam Veteris quàn Novi Tefamenti volumina Scbolastica Pofilla libros 89. Atudiofis Sandarm Seripturartwr ac pracipuè Tyronibus ad majora properantibus non utiles folum, led valde ctram necelfarios. In quorum prioribus quinquainta libris univerfum Sancte Scripturæ corpus ablque orationis lenocinio \& verborum inwolucris brevi, nudo, \& aperto fermone expoluit, fumma in fingulis diligentia aperiens, \& elucidans literx fenfum cateris divinx Strintra fenfibus ut prattantiorem, ita dificiliorem, allatis in id non modò veterum Ecclefix patrum expofitionibus, fed Rabbirorum quoque fententiis, quarum apud Indeos precipua eft authoritas. Sixt. Seneng. 1. 4. Bibl. Sanct.

Ego Lyrarnidé amo, \& inter optimos pono, quod ubique diligenter retinet "\$ perfequitus Hiftoriam, quanquam alzhórirate Patrum fe vinci paxitur, \& nonnumquam eorum exemplo deffect to à proprictate fententia ad inéptas allegorias. Martin.Lutherin Annetat.in cap. 2 . Genef.

Bibliorum apud Pontificios Interpretes primarius Lyranus. Gomar. Anticofter. Literæ Hcbraice \& Hilloria Vetaris. Teftamenti doctilimus crat Lyranus. Cap. Molinazs Annotar.in Evangel.

Lyrants utrumque $D$ ei reftamentum d ligenti examine \& elucidatione cxplanavit. Ei in plerifụne, ut eì à multis imponitar, deliraverit, tempori eft imputandum, in quo ferè omnia crant Hypocritarum nebulis obfcurata. Meliorem certè cxeris omnibus per eam atatem navavit in Scripturis operam. De Verborum fimplicitate non eft quòd conqueritentur homines,

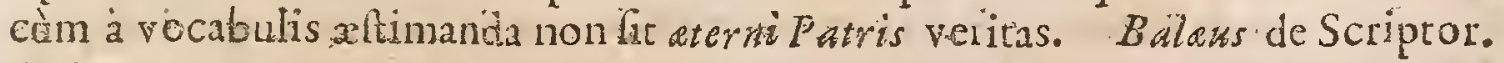
Britan.

Nicolatus de Lyra., qui è Lyra oppidulo in agto Perchiens nomen traxit, omnium Authorum in hacce Synopf compreheniorum doctifimus \& in Scripturx fylo verfatifimus eft. Pluros illum fuifle I udaurs, deinde Chriftianifmum amplexum efle contendunt. Ut ut res fit, certum faltem elt illum He+ traicam linguam calluilfe, imo fatis fuiffe peritum Rabbinorum Hebraica DiaHhis 
lecti,ut Iudkor.in Scripturam, Commentarios evolvere polfet, quod difficulter. occurrebat temporibus illis in Viris qui in Religione noftra nati fuiffent. Inftar

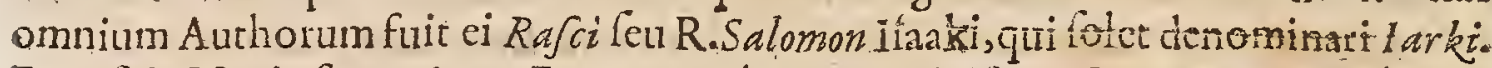
Eum fuis Notis fepe citat : Et eorum pleriq; qui in füos Commentarios al quid de I udatsa eruditione inftillaverunt, iplium tantummodo tranforiplerunt. Feliciorem multò fuccellum habuiftet hic Author fi Methodum quandam fecun dum Ariftotelis Principia philofophandi cjus ævo.ufitatam fecurus nan elfer, licer innumeris Scriptoribus fibi contemporaneis hacin parte cautiùs admodum proceflerit. Hocomari poteftelogia quod nemo ante ipfum Scripture fonfum literalem tam bene affécutus fuerit. Uptandum samen effet ut tot inutilia è: Rabbinis depromptanon permifuifet, \& ex eorundem libris en tantùm rétuliffet quead: Bibliorum Sac onm elucidationem faciebant.: JeC. Rith. Simon. Hilt.Crit.V.T.lib.3, cap.x

Hebraicarn linguam is perfectè calluit :- fuit ingenio prompto, nec minus. converfatione quàm fcientiâ venerandus. Ejus Opera omnibus S. Scripturam. difere cupicntibus, necelfaria efte, nemo melius novit, quàm quile in eorum lectone exercitavit. Sunt qui eum ob verbonum fimplîc tatem contemnerdum exiftimant, fed fi res ipfas, non verba ifti detrectitores fpectarint, non dubium eft quin ab eis maximè lauderur. Gul. Rowill: in promptuar. Icon. Infigno. Viror. fol.

Extant Commentaria in facra Biblia Lugduni I 50 ; If90. VI Tom.

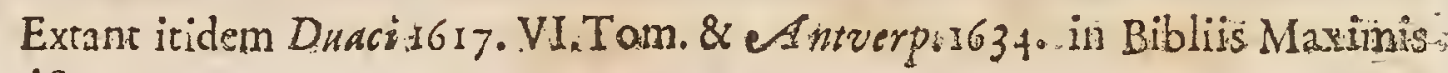
Parif. 1660

\section{GQATERUS DE HEMMINGFORD:}

Clar. An.D. A Nglws, regularis Canonicus Conobii Gisbumenfs, flomit fub Edvarweccxaxy. A dolII. Ingenii atque induftrix fux monumentum nobis dedit, Clroricon Edvoardilll, itemque Historiam. Anglorwm, ab Guiliclino. Normanno, hoc eft an.1066. ufque ad tempora Eduardi II. hoc eft, anno 1308. Quod opus ManuCriptum Cantabrigie adfervatu in Collegio S. Benedscti. Liber eft Chartaceus, nec valde antiquus. Incipit, Ne faftidiorus. Gisburne in Conobio fuo defunctus eftanno 13+7. Hunc Aut orem exfcribere folet Hiftoricus Monafterii de Abbington: ut obfervat is qui prafatur in CV atthoum Florilegurn. Vofj.de Hilt.Lat.

Gualterus de Hemmingford; canonicus Gisburnenfis Conobii, quod elt prope Cliviam Eboracenfitim Provinciolam, Thefi Alumini celeberrimo adjacentem, impendio ftudiofus erat literarum, quo tandem factum eft, ut in eruditum cvaferit, \& non levem apud fuos gratiam fibi pepererit.Ejufmodi enim res $L i$. teraria virtus eft, ut autori gratiam, honorem, gloriam etiam facilè conciliet. Quare virtutís pramio latior factus, quanquam ipfavirtus per fe fatis illufris aliunde emicantibus fplendoribus non eget, quâ copit, viâ, perrexit, magnis fa- 


\section{CELEBRIORUM AUTHORUM.}

neै pafibus ad extremam Sacra Theologia metam contendens. I In quo Audio quum jam non infeliciter curfun longum continualfet, ecce cupicio quxdam ejus occupavit animum, ut Hijtoriarn Rerum Anglicarum pofteritati dedicaret. Bonis igrur avibus ab ipfo Guilielmo Normanno exordium fumens ad tempora Edovardi cjus appellationis fecundi, hoc elt; ab anno Christi 1066. ulque ad annum ejus IjoS̊. Anglorum res geftas fummâ curâ perferipfit. Leland. MS. de Vir. Illuit.

Gualterus de Fernming ford res geftas Anglorum ftylo non inelegante , curâ magnâ \& fide pari defcribit. Gul.Horman.in fuis collcetan.

Amor Patrix eum impulit, uthiftorias Anglia legeret, \&exis notatu digniora Celigeret, atque accuratâ Methodo pofteritati traderet. Fiţaus de llluft. Angliâ Scriptor.

In Brigantum agro eft Gisburgh, wunc exiguum oppidum, cui magnæ ylorix fuit, dum Retit, Menafterium verpulchrum ó opulentum, quod Gualterum de Hemming ford, Hiftoricum non inerudium produxit. Quenfledt.

Hujus Hiftorix plura extant Exemplaria; duo fervantur in Collegio SS. Trinitatis apud Cantabrigien/es; tett um habet Officium Arnorum five Heraldorum; quartum Cottoniana Bibliotheca; quintum penes me eft; ied \& alia memini me vidife; quorum tamen domicilianune non veniunt mihi in mentem. ThomiGale.

\section{ARNOLDUS VILLANOVANUS.}

A Ragonenfos, fat ficio, Arnoldwm Villanowanum Cathalonia afferere Clar. An.D.

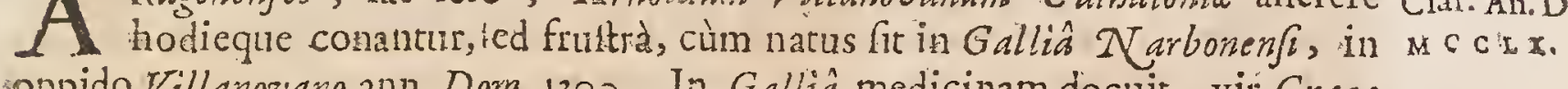
oppido Villanovano ann. Dorn. 1300. In Gallia medicinam docuit, vir Grace Lingux peritus, adde \& Hebraice, ut videre eft in explanatione libelli Tetragramnaton: Arabica ctiam haud ignarus. Porrò $N$ ature fecreta adeò rimatus eft,ut altiìs poft xtatem fuam nemò fermè penetrarit. Paul.Colomef.Gallia Oriental.

Arnoldus de Villa-Nova, rei medica eâ tempeftate peritifimus, majori tamen famâ quàm laude, qu' d nobile ingcnium, eruditionem maximam, pravis fuperAtionibuspravifque de religione spinionibus fedare vifus fit. Quo nomine aliquanto poft ab I nquifftoribus ignominiâ notatus eft, librzque quos magno numero ediderat reprobati. Ex humano femine quibufdam in vafe medicamentis hominis corpus efformalfe, qui affumer authorem habeo. Io. Mariana J eluir. I. I4.c.9.Rer.Hisf.

Arnoldus de Novavilla Hißpanur, vir exim è eruditus, linguarum, Habraica, Grece, Arabice \& Latine; Philofophix \& Theologix peritifimus, formit ante annos 300. Recenlecur à Papâ ejulque Spiritualibus inter Hareticos, quòd corum errores reprehendit-Habuit hic Doctor non paucos Audito. es atque Sectatores, etiam polt mortem, prixertim in Hifpaniâ, quos papiftr Arnoldiftas H.l $h 2$

yocave. 
vocavernint, \& tanquam Hereticos perfecuti funt atrociffme. Illyric. Catalog: Telt. Veritat.

Portentolo vir ingenio.Veterum $\mathbb{X}$ ovarorum maximus, Dogmatum raritate pcrcelebris, quem fibi civem Galii certatim, \& Hipani vendicant. Is licèr hue mili patriẩ, obfcurifque profectus laribus, tamen arcano impetu, ac excellenti mentis indagine, periciorum Natura operum fcrutator acerrimus, Europam ferè omnem fui nominis majeftate complevit. Hoc ipfi vel in fatis fuit, Medcinam Aftrologix, ac intimiori cuidam Philo ophix perpetuo jungere. I o. Imperial. in Minso Hist.

Ut erat homo multum deditus Rabbinornm \& Alchimiflarum deliramentis, ita nonnullorum Sigillowm compolitionem in fuà Medicinæ practicâ docuie Naud.de Stud.Militar.lib.r.

Nullum eft Natura arcanum quod libera, prudente tamen follicitudine cu $\Rightarrow$ riofitas ejus non, fcrutetur: Illì patent omnia ejus Penctralia, \& profundâ fuâ perquifitione vafti hujus Orbis thefauros omnes contemplatur. ILaacus Bullara Acat. Scientiarum \& Artium. Tom.2.

* Arnoldi de Villanova Dpera, nifi expurgentur, prohibentur in Imdice Tri dentino, vide Appendicem certorum Austorumo.

\section{JOANNES CANTACUZIE NUS:}

Clar. D. A Obilis Byzantinus, $S_{6}$. Cubiculi prapofitus, Magnus Domefticus,Thracia accosin. Prafectus, dsmum ab anno 134 :1 Imperator Conftantinopol: tandem purpus. ram deponere coactus, $M$ onacbus factus elt, Loa Saphus dictus, anno.1357. vel patzlò poft. Gul. Cave in Chartophyl.

Scripfrt Hiftoriam Ryzantinarm, quàm è Graco in Latinum fermonem convertit Iacobus, Pontanus, notifque explicuit, anvo.1645. Parif. fol. Itemque fcripfre Arationes tres; \& Apologias iv. pro Religione Chrifiana adyerfus Alcoranum: qux prodierunt Grace \& Latinè, Bafilee Is +2 . in fol.

Nec praterice fas elt Loannem Cantacuzenum, quiex imperatore Monachis facus, ac pro Ioanne Iofaaphus dictus, fub nomine Criftoduli luculentam condidr Hiftoriam de Imperio Andronicijunioris, \& fuon Conftat id opus libris Iv: cujus priores duo prrecipuè funt de rebus Andronici: polteriòres de iis, qua ipe polt obitum Andronici geffit. Factus-verò Monachus fuit anuo 1;60, cò autem majoris Hifaria ejus fieri debet, quia fcripta eft ab illo, non qui umbraticam f mper vitam egillet : fed qui primùm Magnus fuerit Dométicus: ac pof obitum Amdronicijunioris, liberorum ejus turelam obtinuerit:\& mox (ita valente Senatu, \& Imperii rebus exigentibus ) Imperatær creatus.fit, \& in eâdígnitate prudenter \& fortiter fe gellerit. His illud accedit, quòd non de rebus icripfr parum flbi perfpectis; fed quibus ipfe interfuit, arque adeò præfuit. $S_{2}-$ nè-inter recentiores Grecas non ei quemquam putopraferri oportere. Vofj.de de Hilf:Grac.lib.2,cap.28.

Inser recentiores quidem rerum Gracarm feu Byzantinarum Scriptores, ut Cนมเ 
funt Zonaras, Nicetas, Cedrenus, \& alii, meo quidem \& quorundam benè literatorum ; widiciohic primas tenct.; -videturque folus didicillè quô pàctô ad laudem accommodate contcxenda fit Hifloria. Mira, nova, inaudita, mulitata, occulcorum Deijudiciorum plena, grandia, illuftria multa hic recenfentur. Ee, fi Hifforna debet clle prudens, atque ornata rerum explicatio, neutra virtis in hac defideratur: qux mihi femper à viro nobilifmo, \& ingenio excellentiffmo fuaviflmog; vifa eft profuxilfe. Pudentia militaris atque civilis tam eximia hic clucer, ut civitatum Provinciarumque Rectoribus ac Belli Ditcibus majorem in modum commodaturam putem. Fac. Pontanin Epift.ad Lectorem, quam Hift. Cantacuz:pramifir -

Qux fierunt inter [Aridronicum Imperatorem ]avum, \& [Andronicum Imperatorern ] 1icpoten, eorumve occafione tam ab ipfímet, quàma à fuis amicis, cagitata, deliberata, gefta, profufflimè profequitus qui magna con pars fuit I. Gannes Cantacuzenus, illuftri urofapiầ ortus, magnus Imperiz Domelticus, \& Andronici juniorisamicorum \& confliorum particeps; \& terum Muderator, in Hifforîn, quam de is fuifque rebus luculentifimè confripfit fed ita : cas traetans, ut quamvis veritatem \& narrationis finceritatem continuò pricedicare non celfet, apertifimè tamen nepotis amicifimi fuicaufam adverfus avum agendana ac propugnandam fufcepilfe demonftret Henr.Spondan. in Annal. Ecclef.ad Ann. 1321.11419 .9 .7

Hoc loco Ledtotem monebinus; Hifforicum noftum [Ducari ] in enatrandis rebus, qua fub Imperatore I oanne [ Palcologo] gelta funt, donec Cantacuzenus: Monachis \& Anachoreta fieret; ab hoo non multùm difentire ex quo non param auctoritatis ac commendationis elaccedere deber: cum Cantacuzenus diligens ac judicio preftans Hifforicus fit. If mael Bulliald: in Notad cap.50 Duce Hift. Byzant....

Septimo volumine continentur libri tres hiftorix fenioris \& $x^{3}$ mioris An dronici à.Cantacuzeno confcriptx, qui \& ipfe fuif Imperator \& temporis illius rerum pracipuapars fuit. Aliquid heic de mirabilibus iltius magni Viri fam cinoribus delibandum ellet : Sed praterquan quòd in totius hujus Hiftori corpore fatis jam prolix $\vec{i}$ fumus, paucis dicere poffumus illum folum fuilfe dir gutum qui eafdem promulgaret, \& contra quam plurimis Principibus evenit ut iis honos ab hiftoria fua concilietur porius quàm eandem ipfilluftrent, Canta suzenus propriam hiftoriam ipfe illuftrat; quia non minore polluit cloquentia ad praclarorum fuorum gettorum confcriptionem, quam animo \& virture ad cadem patranda ; five in privata conditione ac Magni-Domeltici muncre, fiv poftquam thronum confendifer ubi neceflitas femel adverfus holtium viotertos impetus tuendi eum velut invitum coegerat oftendere quid polfet, frve denique in Monaferii folitudine in qua ultimos vitæ dies tranfigere voluit. Ofá vum denique volumen continet librum quartum ejufdem Hiftorix, ab eodern Cantacuzeno confcriptæ, \& hiltoriam poftremomm Imperatorum Conftantinopolews; cum ejuldem urbis invafione functa quam defcripfit Dricas; qui $C$ alchon dyli admodum et accuration \& folidioris judicii.Erwd. Epherner. Gall diei Lun 26. Aug. 1675 . Hhit? 3 IHOMAS 


\section{THOMAS BRADWARDNUS.}

Ular. A. D. T A tus fertur Hatfeldix in Comitatu Suffalcienf, 10 xomiz verò educatus: uccersvar I ubi cum bonarum literarum ftudiis aliquor annos inctibuilfet, Acaleanicorum fuffrag is Procuratorum unus creatur ann. 1325 polteaque Doctoris in Theologia: gradu honefatur, Mathematicus fuit infignis, Philofophus regregius, in Theologic vero. ttuáiis eoufque verfatus, ut apud Dootos illorum temporum Dodtoris profundi appellatione innotuelit ; eamque non immesito delatam illi fatebuntur credo, qui libros ab illo confcriptos perlegerint. Verùm in hoc hominc nili:l ent gued potius laudaveris, quàm morum vitxque

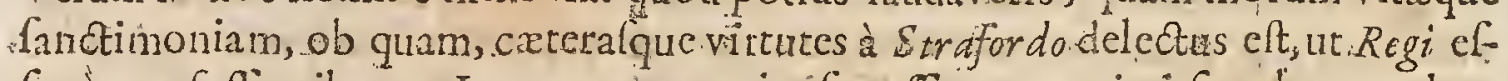
¿fer à confelionibus. In quo munere ita fe geffr, nt optimi frmul ac prudentifim viri laudem retulerit. Regem fiquidem à reato deAleatentem incrcpare confrevit audacter, eâtamen putudentiâ ve borumque lenitate, ut animum Princip's nunquam offenderit. Non defunt certè inter Scriptores qui infignes illas Edvoardi victorias, hujus potius lanctitati ac virtutibus acceptas ferendas exi-

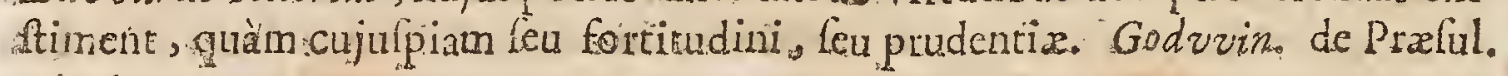
Angl. comment.

Quo anno hatus fit, quemadmodum nifhil pro certo affeweraverim, (nt funt magnorum (ape virorum principia obcura, quorum funt notifimi exitus) ita cum Procuratorexn fuilfe conftet 10 iverfatis Oxonienfis anno 1325 .circa annum Domini 12.90 natum crediderim, mediis temporibus $\mathbb{R}$ egis Edvzardi primi - In hoc curriculo Literario Colidan ex Arifotelis \& platonis fontibus haufit Philolophiam, fed in artibus egh atbernaticis ac Theologiâ ejus pertinmum eluxit isduftria; ac in Mathernaticis quidem ita excell hit , wt patcm illa xtas tuderit fortaffe nerninem- Thanas nofter cum fummus eflet Mathematicus, etiam in Theologicis tractandis nen recefft ab arte. Itaque primus, quad fciam. \& folus hanc viam tentavit in Theologicis, ut filo Adatbernatrco Theologica contexeret, ponendo fcilicet primo loco duas.Hypotbefes, quafi principia, \& ex is proxima quxque demonftando, \& corollaria dedicendo, petitis ctiames Euclide probationibus; deinceps ex Hypothefous, \& prademonftratis reliqua omnia perpetuâ ferie ad finem ufque operis attexendo, quô fit ut Conclwfines eju, cuipiam fortalle nimis altè petite vidcantur. Henr:Savil. in ["rafat. Bradvaardin. lib.de 'causá Dei contra Pelag.prefix.

- Ex Arifotele \& Averroe fedulâ inveftigatione pleraque haufit: Indeos, quos in lege péritiores feiebat, pro Scripturartm intelledione familiariter convenit. Unde ad tantum doltrîn incrementum pofteà perveniebat, ut in Oxonienfit. Academia fupremæ facultatis Magifter conftitueretur : egregiufque Raphaelis Volaterani, ac Ioanris Pici, hominum Italorizn, teftimoniis, Theologus fuerit. Cum Ioanne Baconthorpio Parifis olim reverfo, magnam de Prafcientia ac Pradeftinatione concertationem habuit, eique tanden in omibus confenfit, ut idem loames in quarto libro fontentiarum, dift. $t$.

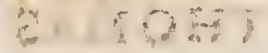




\section{CELEBRIORVM AVTHORVM.}

Quirt. 4. demonftat. Undeex Cancellario Londinenfi tandem Aulicus, atque ab optimo Rege Edviardo rertio ad confeffionem yocatus, Cantuarioram Archicpilcopus Ioanni: Offordio diem obeunti fubftitutus elt, Adverfis Hereticos arma lukcipiens. (verùm Fapiftas Papista non morder) in magno fpiritis fervore fcriphit, prafertim contra Pelagiasos. Sed prols dolor, Thomas longiori virâ dignus, exacto tantùm uno in Pontificatu anno, mortein obiit planè immaturam, anno ab-incarnato Dei verbo $I_{3} 5$. fub prædicto Rege Edvoardo tertio. Summa ejus Roma in Vaticana Pontificis Bibliothecâ extare perhibetur - Balarbs de Script. Ecclef.

Floruit hic longè-doctiflimus vir circiter 1330 . Domini annum, prignavit acerrimè progratiâ Dei, contra Liberum Arbitrium, \& Pelagienos ejus patronos, nempe. Scholasticas Theologos; idque nec fine approbatione multorum bonos rum,nec fine. multorum feductorum gravisàmâ offenfione, fuoque periculo: tamèn exoratus à piris doctifque viris, qux.de eâ controverfiâ in publicis Difputitionibus, differterar 2 tribus libris juft um volumen explentibus complexus eft。 Landatur hic Scriptos nomine eximis enditionis, etiam ab illuttribus wiris Raphaele Volaterano, \& Foanne Pro. Ellyric.Catal.Teft.Verit.

Nec minimum quoque auxilii repolitum eit in Libris de Proridentia Tho me Bradvvardiniqquoniam in illis pari fermè cum divo-Thomâ fubtilitate, \&: rationtum pondere procedis. Gabr.Nand.Bibl.Politic.

Thomas de Bradvisardina Anglus, ex ordine Eratrime. Minorum olarus ob doctrinam anno 1350. \& fequentibus., Scriphit nobzle Opus de causá Deí contra Pelagium, ơ de veritate Caufarum, variâ facre ac prophana; antiqua ac nova. Philolophixac. Theolog: $x$ doctrinâ locuples atque ornatum, quod manufcriptum affervabatur in Bibliothecâ Vaticanâ, cujus etiam manufcriptum codicem habuit olim in Germaniâ. Mattbias Flaccus Illyricus. Impreflum efte ex Manufcriptis Anglicanis, curầ \& Atudio doctiffmi viri Henrici Savillit, año

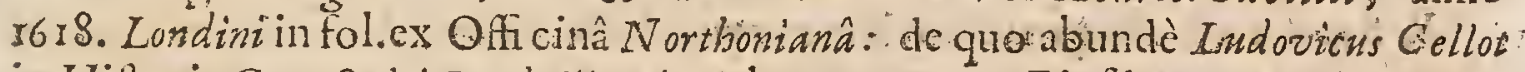
in Hiltoria Gotte Calci Predestinatian'1.5.C.19.P.390. Ejufdem Opus de Georne-

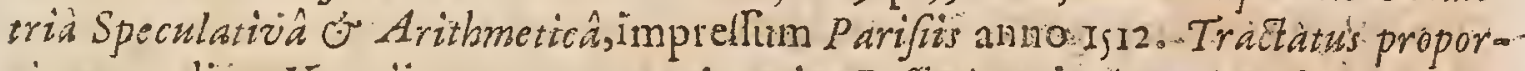
tionum, editus Venetäris annu I505. Antonius poffevinus in Apparatu Sacro mentionem illius habet, fed (quod mirum) de eo nihil habee Lueas Wadingus in Bibliotheca Scriptorum Ordinis Fratrum Minorum. Opus autem de caufa Dei conte-

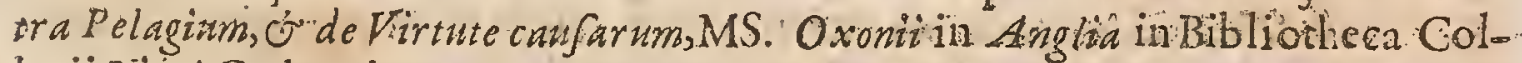
legii Novi Cod.22. in Orialenfl cod.5s.Mertonenfî cod.203. Cantabrigie in Col. legio Sancti Benedicii cod. 4 46. Domus Sancti Petri cod, 276. \& privatim in Bi.o bliotheed Baronis Lumleii cod. 267. Appellatur in nonnullis mantferiptis codicibus Cancellarins Londinenfis, quod an conveniat reckè Francifcanos, fell Conventuali ordinis M Tinorzom, mihi valdè füfpectum eft. Ondin, in Supplem, de Ecclef,à Bellarm.omill. 


\section{R A N C S C US P E T R ATR CHA}

Clar.A.D. MCCCL.

- Retiin Tufcia ex Elorentinis Parentibus, vel, ut alii quidamcum Gerardo A loanne Toffo, circa Ancifam L lorentini agti vicum majorum fuorum fedem, patre Florentino exule natis dic 20.1 itibi, teriâ Lecundi anno '304. Archi-

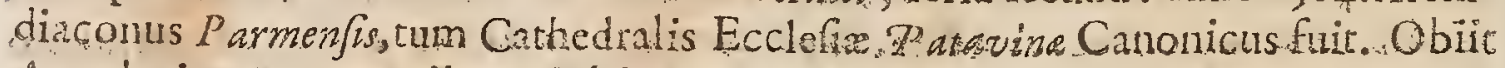
Apoplexia correptus dic . g. Juli, Anno Dom. 374 .

Scriplir plurima \& pedeltri \&x folutâtoratione.

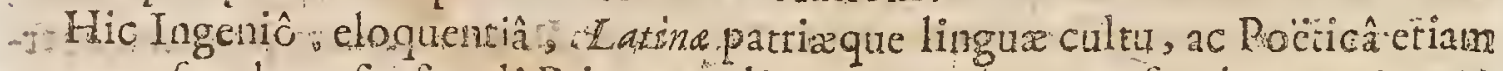
urraque facultate fui freculi Princeps, lireras multo avo fepultas, primus Gothicis tenebris cxcitavit Phil. Labbe.

Vir in divinis Scrpturiserudirus, \& in fecularbus literisoman fui remporis longè doetifinus, Philolophus Rhetor, \& Pö̈ta celeberrimus, qui literas Hamanitatis polt longa filcntia mortuas, ut ita dixerim, ah inferis revocavir ad fuperos, non mitus fantâ converfatione, quàm Scientiâ clarus cmicuit. Trim解e积。

Virundecunque doctifins, Latine Lingue mulis jam feculis extincte primus Instaurator. Hetruf ce Pö̈leos parens; \& ablque ull â controverfiâ princepsi inter Latinos quoque poëtas non jgnobilis, \& \&ob egregiam Latini"Carminic laudem in Capitolio Romano Lawream Coronam publico totius Italie favore confccutus sixt:Seneny.

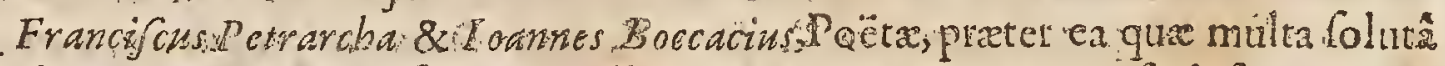
foratione uterque compoluirgonnulla quoque Carmine Latino firipfere, in qui. bus non multo pratatalter alteri. In his licer, quod temporum tamen vitio adferibendumputarim, judiciminus fot \& lime, multum tamen poetici fpiritus habere videntur. Lil.Gyralds.

Reflorefcentis eloquentix priaceps apud Itailos videtur fuife Francĩcus Pe- trarcha fua xtate celebris ac magnus, nunc vix eft in manibus : ingenium ardens, magna serum cognitio, nec mediocris cloquendi vis. Atqui clt, ubi defideres in co Lingux Latine peritiam, \& tota dictio refipit laculi prioris hororem. Erafm in Ciceron.

Primus omnium Erancijous Petrarcha magno viringenio, majoreque dili-

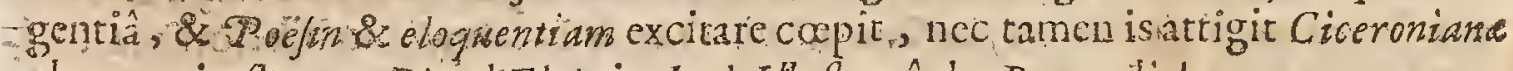
eloquentia forem: Blond. Flav in Ital.I Ilufratâ, de Romandiola.

Vir excellenti ingenio \& doetinà exquifitâ Francifcus Petrarcha. Pog gius in Hift difept de avaritia

Francifcus Petrarcha vir maxime doctinx, \& clegntifrmi (ut Lu tempor ferebant) Atyli. Lawnent Pignor 1. Symbol.Epitol Epift 3 .

Circa annum 1340 Patriarcha longè latéque difundere cepit ingenii divinio doct inxque mirandx varia monumenta. Voff. de.Poët.Lat.c.7.

Si inter Mortales unus eft tanto labori fufficiens, viribus praclariffmi viri.

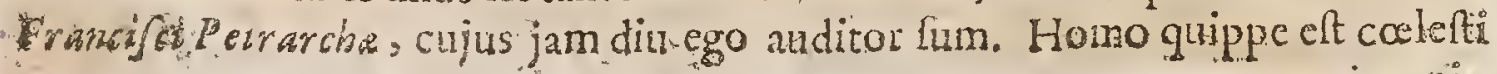
ingetisio 
sagenio praditus \& petemi mono îâjac ctiam facundiâ admirabili , cui famitiaili nx quarumcunque gentium Hiftorie funt, fenfus fabularum notifini, \& breviter, quicquid thilolophiz facro jacet in gicmio, maniriltum clt Loam. Boccat. in prafar. Operis de Gencalog. Deor.

Erancifcus Petrarcha poëta Sermonis Italici hodiemi omnium clegantiffmus, I atini veteris haud valde bonus. $P$ aul. Manut. comment. in C.ecron. I. I. Epit. ;.

Cui vix parem inveniremus, fi Latiza ejus Opera, his, qua Tufco Sermone confcripht xquari pollent. loan.Gobcllin. de geft. Pii II.Rom. Pontif.

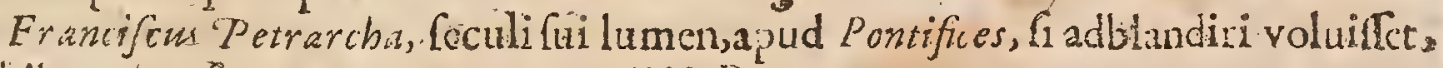
aihil nonconlecuturus. Mornens in Hilt.Papat.p.4:0.

Francifcus Petrarcha wir applimè doctus, dicete Colitus èt, nutlum cuiquams majus malun optari poffe, quam ut fuat Papa. Illyric. Catal. Teit. Verit.l.I8.

Francifous Petrarcha, thoebincetar, Mufarum cocculum, prifce eruditionis dccus, literarum delicium, omuium feculorn memorii dignts --.--Ea lcmperfuit Vatisnotri cel britas \& operum ejus fublimitas, ut è eruditorum omniumecohortes, veluti apes ad flores delibandos confuxerint. Quid dulcius, quid candidius hujus nofti fermone, qui in Latinis, Grects, dilertus, in Etrufcis lenior. Utrobique animos jam virtutum difciplina, jam verborum pigmentis ac leprefudvilimo attiahit, movet. Viget in lermone foluto nervus : carmen ejus plenuraz, terfum, laboriolum, omnium genio accommodatifinum. Ubique mira rerum fuavitas ac varictas, fontentiarum.lumina, verborum robora. lac. Phil.Tonafin in Petrarchâ redivivo.

Edidit hic coeleftis vir tam prosâ, quam metricè plurima opufcula. Qux cìm. fun lepốre fonantium verborum mellifua, \& fententiatum fucco mirabili fapidaspotius attificio celefti, quàm humano:ingenio judicantur fabricata.lac.phib. Bergomas in chronic.fupplem. ad Ann.CbrijizI.

Qrod ad doctrinas attinet, multarum rerum prudens doctufque fuit; imb veròntlla ef̣t ex doctrinis homine libero digna, in quâ vel audicns,vel per fe itthians non magnopere profecerit----Eloquio tuit claro ac potenti,nt ftylus librorum indicur, atque, ut vere dixerim, unicus fuit, qui per tot fecula exulantem, se $j . \mathrm{m}$ penè incognitam dicendi facultatem in noftra tempora revocatet. Strnmus vitâ, fummus doctrinâ, \& fummus eloquio fcriplit octodccim librorum volımina. Paul. Verger its vit. Petrarch.

Stylus cjus copiofus eft \& magnus, in confolando dulcis, \& in admonendo liber. Interdum jocatur: falibus, fed ubiquc reftrictus, ut ille, qui magis Senece dcnfitatcm, quàm Caceronis amplitudinem imitatur : und perfape ex hoc re-s centio:em Senecarn appellaverim. Hieron. Squardafichus in Petrarch. vit.

At lo. Boccatiu : Francifon Petrarcha, quorum praftantifimis ac prope divinis ingchiis "fermo Etrufr", ea vcrborum clegantia, iis ornamentis audus ac locupletrtus ct, ut fupra addi nihil poffit, propius ab antiquitate aberant; amis enim plufquam trcentis ante nos fuerunt; \& tamen nulla major ab tis oper data fuiffe vidcrur, quàm ut omnem prilcorum verborum facem aluis Scriptis 
removerent, ne purum ae limpidum ipforum orationis fumen aliqua ex parte: infufcarent. Quibus prafertim ob hanc caufam arbitror primas ab omnibus finecontroverfia deferri. Inferunt fe quidem inerdumin iplorum fermoncm vcrba. aliqua palo antiquiora; led ca miram habent venuftatcm; \&,quia loco funt: polira, adco omnium int lligentize funt obvia atque aperta, ut nullik ferè interpretis cujulyuam ope auxilioque indigeant. Idco nulla eft in Italiâ civitas, qua: ița barbarè, ita inquinatè loquatur, quin eos legat, intelligat, admiretur, edif́cat. Ian. Nic. Erytbr. linacoth. p. 219, 220.

Poltremò nunc tandem ad Africam \& librumiftum venio, quimihi vidctur inter pracipuos jure meritoque redigendus. Ef enim (ut res jp.a indicat) refertus hiftoriâ, documentis abundans, \& plenus poëticx fietionis. Magna eft in co volumine, \& vctufatis \& naturæ cognitio : magna eloquentix: vis; magna: precipiendi facultas - Quod fi ad extremam perdixifet atatem, quanto fururum fuerit excellentius, nemo ambigit. Scd tamen eft tale, ut dc eo gloriari juvenis debeat, \& pudere fenem non poftu.. Conftat autem elfe verfus aliquor: dimidiatos \& imperfectos, eft creberrimè apud $M$ aronem, aliquandè \& Enrentiam imperfectam. Sed hos defcetus acculent, qui nihil pati polfunt diininu-

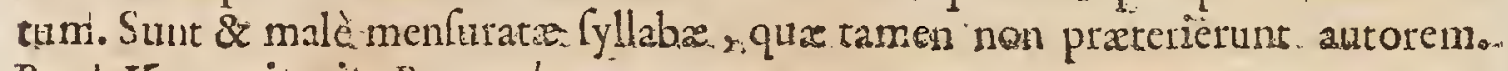
Paul Verger. in vit. Petrarch.

Sayjger ait illum perpicuè admodum Latinaque cum elegantia loquri: Eum guod ad Italica Scripta fucctat intellectu difficilem effe, propter voces plurimas è Provinciali vicina lingua defumptas $\& a b$ Italis minimè intellecas. Scaligerana poftrior. Gall:

Riftellu quodad ejus ftylum \& phrafes attinet ait illum lape interpretibus indigere \&c. Qurdam cjus Tetradecaftucha (Sonzetos vocant Galli \& Italipoematia $\mathrm{I}_{4}$. verfibus confantia) intellectu diffillima effe vel peririfimis ipfis hominibus. Roftean, Indiciis de quibufdam libris à fe lectis. Gall.

Jef. Rapin ait Petrarcham vernaculo fuo idiomate fcripffife; Scd Stylum ejus: nimis vaftum efle ut Herö̈ci Poeta nomen mereatur.

Francifcus tetrarcha in Hiftoria erraffè à quibufdam deprehenditur.: Quo ad? Ryi hisos vcrnaculâ linguâ confcriptos ternariìs quatetnos inconcinnè minufque antè interdum commifcet. Claud. Verder. iilccnl: Autorum.

Hieronyrnu Squarzáfichus in Petrarcha vita refert magnum illum Poetam nunquam afenfum dare voluilfe ut fua Soror preda fieret Bencoictixir. quis illus amore perditifimo captus erat, quique fratri Cardinalitium pileum in favoris remunerationem, pollicebatur. Tam nefarì commcrcii propofitionem: generosè repulit; Sed in falvo tamen non fuit ejus Soror, alius enim enat ei frater qui illam Papx vili pretio tradidit. Novellis Gallic. Reip... Literaria... Febro. 1686. pag. 14.4.

Extant opera ejts omnia Lugduni apud Samuelem Crisfinum, I 6ór. foll:

Extat liber de Vitêfolitariâ.MeGiolani in fold apud Huldericum Scinzenzeter. 2n. I.4.28.

Extans 
Excant Pö̈mata Hetrufca cum expofitione M. Ioan. Andrea Gefualdi Vienctitis apud Gabrielem Tolittum Ferrarienfem. 4. Is53.

Extant quxdäm Poëmata Italica antea inedita, qqux vulgavit Frederico Ubaldinus ex Auctoris Śchedis, unà cum cenfurâ \& cmendationibus fuis, Rome ano 1642.

Francifci Petrarcbe liber de cafibus virorum Hiluttrium MS. in Bibliorhecâ Colbertina, cod. 840. Itemque ibidem cjufdem Rerum familiarium Epiftolarum libri viginti quatuer Manufcripti cod.842. quorum novem tantùn funt imprefí. Oudin.in : upplem. ad Bellarm.

Hoc cjus Epiraphium oin viciniâ Patavitin Arquato pago marmorco fepulchro incifum

Erigida Francilcilapis bic tenet offa Petrarcha, Subfipe Virgo parens animam, fate Virgine parce.

Feffague jain terris cali reguiefcat in arcc.

$$
\text { Pbil. Labbe in Thefaur. Epitaph. }
$$

\section{B A R T O L U S.} D Saxoferrato (Uibs eft 7 mbrics quax Sentinum olim diccbatur) natus

Vir fuic ingcrio fubtili \&acuto, facundx eloquentix, \& multiconfliiiafliduus in fudio legum, fobrius in victu; memoria labili;cui defectui ut fuccurreret, guxcunque meditabatur, feripto ftatim mandavit. Ideo delitias omnes poltponens, Q libcriora corporis cxercitia negligens, totum fo ftudiis dedcbat, nul Lam fibi à Ccrioribus meditationibus relax tîonem concedens. Boiffard. in Icon.

Bartolus:ingens illud Juritconfultorum lumen ac ftella. Equi \& boni peritiffumus. Veritatis Magiffer vocatur Scurfo. Jurifconfultorum fignifer Mena. chio. Aliis Juräs lụccrina \& cacorum Dux, fpeculum ac veritatis pater. Tantâ cclcbritate jus civile profifits eft Bartolus, ut ad eum ob fummam eruditionis \& ingenii faman ac gloriam undequașuc Atudioforum turba conflueret. lpfir omnes falces porrigunt \& Cceptra Iurium C'onfulti fequentes. Quenftedr.

Bartolus natus anno rjo3. Ius Civile profeffus eft Prifis, polteáque Peruffi, quod tanto judicio aperuit in Commentariis fuis immenfis pro atate fuâ ( qux quadiaginta fex aunos non exceffat) ut longè primus Iufit itani Interpres poft Accurjium adhuc apud omnes celebretur, \& in eo fuiffe prac cateris admirabilem Jegumperitiam, ejufquc ingenio nomen adfuiffe Interpretes noftri tcftentur. serth. Duck. de Iur. Civ. I.r.c.s. fect. rs.

In ure primas, comparatus creteris partes habebir Bartolus. Andr. Alciat.

Ejus authoritas magna eratper totam Italiam propter foliditatem confilioaum quibus res Prinipum adjuvabar. Esat enim Caroli IV. Rom. Imper. confilii z liarius,

Clar. A. D. MC CCLa 
Hiabus, à quo nobilitate donatus eft: Boxborm. in Monumeit:

suprcmus Doctor, qui veritatem femper ante oculos habuit. Borcholt. de Tranlact.cap.r. n. 4 .

Jurifconfultorum diuPrinceps eft habitus. Grot. 1.2. de J.B. \& P. cap.22. Sect. 13.

Bartolus, non contemnendi Canè judicii, plurimúmque profuturus Reip. fi in meliora tempora incidilet - in diftinguendis factorum fpecicbus ut certum Jus colligatur, nulli fecundus eft inter Jurifperitos illius feculi. Oldendora. tr. de act. de formul. invertigandx Actionis.

Huic plus credendum, ur cenfet Angelus, quarm omnibus aliis, tanquam Magiftro omnium. Et Caccialupus refert. Regiô Edictô cuutum fuiffe , ut in Hifpania \& Lufitania in conflictu opinionum $B$ artoli obfervaretur fententia, ed quòd à femirâ veritatis \& æquitatis rarò judicatus fuerit aberuâlfe... Moller. 2. semeftr. 49. 11.12.

Bartolu fuit fubtilis Inyeftigator \& fuit Pater Juris, \&uris humani lumen ardentiffinum, in quo folct cle fubftntia veritatis, mihil boni ignoravit. Iob. Nevizan. Sylva Nuptial. lib.5.n.25..

Bàrtoius Sentini in J mbriâ natus, magno acumine perfuicacis ingennil 7 us $C$ in vile profellus, in omnibus I talia Gymnafiis exactxe doctrine documenta rcliquit---.-Equales fuos doctrinx firmitate, \& mirâ judicii confuntiâ fuperavir -.--Defuit ci Lariur cloquentix facultas, ne fummx glorix faftigin teneret. Et ramen eft quod maximè miremur, illum in perpectio doccndi muncre occuparum, tot \& tanta volumina perfcribere potuiffe , quum quadragcímo fexto atatis anno fato ercptus fuerit. Paul. Iov.

Inter antiquos Interpretes Accurfus \& Barialus principatum tenent ", de Cemone non valdè anxii ; rerum quastractant, curam folam habierunt:quas cùm noffcnt, quantum in illâ barbarie, \& codicum deprawatione noffe poterant, explicare nifinconditè, \& barbarè nequiverunt; quodnon tam eis quam feculo. illi tribuendum, quo lingux, \&bonx litera prorfus jacebant RoLand $M$ are 5 . Epilt.l.r. Epilt: $\times$ L.

Bartolus de Saxoferrato Mathematum \&: Hebraicarum quoque literarum peritus. Genebrard in Chronolog. Guâ.

Veruntamen Volfus in libro fuo de Pbilologiâ affirmat :...Bartbolum I urifcono. Sultum xatc Conili literis Hebraicis immortum effe.

Bartolus hiftoriarum ignorantî̀ denflfimis tcuebuis omnia involvit. 10.Ber-? 3zart d. Utilit. leg. Hift.p.Ir 9 .

Id ctiam fupraalios precipum habuit.ut in tot \&tam variis Commentarios, quæ edidit, rarò fibi contrarius reperiatur; mirä brevitate ufus plus taeendo quàm loquendo dixiffe fertur. Verona ftătutun eff, neminem ibi Jurifprudentum collegium poffe ingredi, qui $B$ artoli Commentaria non habuiffet, qua in decidendis canfis maxime neceffaria" elfe crediderunt. Panzirol. de Clar. Leg. Interpret.1.2.c.67.

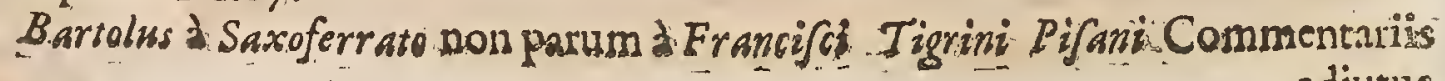
adjutus 
adjütus fuiffe ereditur, quxenim ab eo inordinatè fcripta fierant. Bartbolus digetta pro fuis publicavit. Idem ibid.

Nicolai quoque Mattrixelli atque alionum veterum fententias quandoque ad verbum defcriptas fibi impudenter attribuiffe dicitur. Ioan. Fichard. in Vit. Jun xifconfultorum, $, 2,24$ r.

* Procefius Sarana contra B. Firginem, auctore Bartolo de Saxa-Ferrato, prow hibetur. Vid. Indic. Madrit. p: $859 \%$

Hoc cjus Epitaphilim, Petre:Myrteo allctore::

Hic ef. Bartolis, ille Iurisingens

Lux', commodus explicator, bic eff.

Quem mors snte diemsäbfrultit maligna.

Heu morsinvida, G evo iniqua nofkro,

Rind Leges iterum jacere cogis...

Phil. Labbe in Thefaur. Epiraph

\section{J'OHANNES B OCGA TIU S :}

$\mathrm{D}$

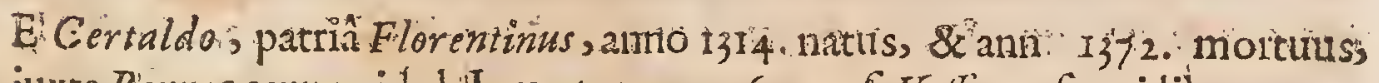
juxta Berneg.gcrum, idol:Lauret.pag, IIG. aut, fi Vofjim fequilibet, ann. Clar. A. D

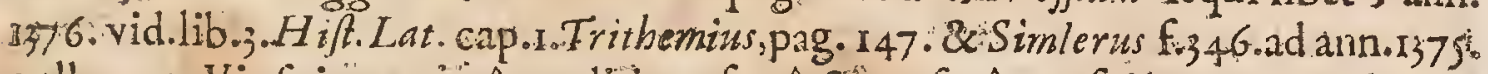
collocant. Vir fuit maximâ cruditione facrâ \& profanâ confpicuus, quod patet cx cjus yuæreliquitcriptis, ut funt, lib de faminis illutribus, quibus I phannam quoque T apifjarn amumenat; impreff. Berne Helvet.1539. Liber Italicus, Decameron five Princ eps Galeottus inicriprus, in quô fabulis, \& hiltoris cenrum $P$ apale regnum, Confeflonem auricularem, Sandtos, Lip fanolatriarn, Purgatorium, zic. acerrimè perftunixit', pexverfitatis. Papæz non ignarus. Vid. Bernegg. l.c.p.128. feq. Librum quoalue de Genealogia Deorum confecit, \&c alios plures. Olear. in A Bac.PP. Ecclefint:

Vir in feculăribus literis onnium fui temporis facile dediffimus, \& divinar rum Scripturarum non ignarus', l'ö̈ta, Philo'ophus, \&Aftronomus celeberín: mus, ingenio fubtilis, cloquio difertus. Trit hem.

Boccatzus multa reliquit Scripza, qux Autoris doctrimas \&laboriofas lucur brationes. faxis teftantur. Ioan. Boifferd. in Icon.

Non tamen cquidem inficias ierim, Ioakners Boccatium hominem fuiffe fuldiofiffimum, \& elegantis ingenii , ut ea ferebant tempora ; ingeniofum etiam \& eruditum, fed uon in Latinis \& eo minus in Cræcis is fuit, qui in proprio Idion mate, hoc.eft in Hetrufcisspatrio filicet \& vernaculo fermone, in quo folutîa oratione ommes ante \& poft eum qui fcripferunt, magno pofte intervallo reliquit, Lil. Gyrald, in Epift. Herculi Duci Ferrar. prafix. operibus Gyral. di. 
Magnam eruditionis \& indutrix laudem retulit Genealogiâ luâ Decram Vol! de Hitt. Lat.

Quamvis non defunt, qui. Genealogiam Deorum ex alio tranferiptam afferment, Konig. in Biblioth.

Francifcus Petrarcha, \& loanncs Boccatins, pretcr ea qư mulita folutâ ora rione uterque compofuit, nonnulla quoque carmine Latino fcriplere, in quibus non multò praftat alter alteri. In his licet,quod temportum tamen vitio adlcribendum putaim, judicii minus frt limæ, multum tamen Poëtici fpicitûs ha bere videntur. Lil.Gyrald de Poët.

Boccacius, Hetrufcorum Cicero, fabulator jucundus, \& cloquens ferinone patrio, fed Latini partu peritus, Theogonia non admod im accuratus, \& Mrtbologite non fatis idonetis charrater, in omnibłs oblconus, impius, verfificator incptiffmus, Bulthalf: Bonifac.l.r5.c.3. Ludicr.Hift.

Fomnes Bocracius Deorum Genealogias in corpus unum redegir, felicius quàm illo erat fculo fperandum; tametfi in Interpretandis fabulis lepe eft nimius \& frigidus - loannes Boccacius Petrarcha difcipulus nullà ex parte eft cuma Magiltio conferendus. La t. Vives de Tradeá. Difcipl.

Quenadmadum Petrarcha eloquentiam in Poëfr Hetrufcà à cive \& Magifto fuo, Dante Aligerio, inchoatam, perduxit ad marurutatem:ita iifdom temporibus Boccacins pedeftrem eloquentiam in fermone partio ( ut lovii de eo judicium eft) fimul \& inchoavit, $\$$ ahfolvit. Voff. de Hint. Lat.

Blondus ac Eocacius Francifco Petrarcha inferiores fuere, tumin dicendi viribus, tum in Romant fermonis proprictate. Erafm. in Ciceroniano.

Boccacii Oratio dulcis, copiofa, polita, orata, mollis, faccta, $1 \mathrm{em}$ ante ocuLos ponens, lit geri ca, quae legas, nen narrari videantur. Icb. de la Cafs in Vito Card. Bembi.

Author Biondo (fic It tis flavi crinis capita vocantur)ait illum Itaica fingua quam Latina facundiâ multo excellentiorem fuiflé. In quâ l'reclari Portus Regii Viri obfervarunt eum creris omnibus praftitife, inò \& feiplum fuperafle, juxta Bernbi Cardinalis fententiam, cum co majori clegantiâ \& puîtate feripfè rit, quà ab hujus nova lingux natalibus \& infantia jam longiori patio remorus erat. Judicio etian Equiris Salviati ejus Profa acurata \& nativa magis deprehcnditur quam ejus Carmina. Addunt Eruditi illi viri adventendum tamen effe quadam apud illum Authorem loca clace ontendere qued majori fcrupulo caveric puritatis Linguæ regulas ab hominum arbitrio ae voluntare tantum ortas violare, quam pracepta de norum puritate ab ipfomet. Dec nobis tradita. Erus ditorum Iudicia, per Dominum Pailet. Gall.

Jef. Rapin ait Boccatinin puriffmè vernaculo idiomate Cribere; Sed Charactem rem cjus nimiüm vulgarem \& familiarem effe ut Heroici Poetx nomen mcreatur. Idem Rapinus dicit alibi Boccatium aptis admodum verbis mentem fuam exprimere in Poènatis fuis, fed hanc non fatis altè penetrantem effe; Eum quoque *anx glorix nimium affectatx iafmulat, \&: qued-de feiplo indefinenter vantionem faciat.

Maximi 


\title{
CELEBRIORUM AUTHORUM.
}

Maximi inter ejus Compolitiones momentiett Decameron, quod Opus IraTh tota cum applantu excepit; Hoc pariter extrance Gentes adeo favorabiliter amplexx futu- tit ingulle idiomate luo legere hoc ipfum volucrint: Et co majori follicitudine hoc quilibet exquifivit quo majori. ftudio cjus fuppreflo tentata eft, \& icriori cinfuâ notatum, quod nimis licenter, \& in Monachos fatyricè uimis loqueretur. IJascus Bullart. Acad. feientiarum \&c. Gall.

* Bocatii Decades, fixe Novella centum,quamdir cxpurgatz non prodierint, Indice Romx imprelfo, 3.' annor68I. prohibentur.

Gloriam quoque meruit Boccacius compendio Hiforia Romane : item libris de illutribus viris, de charis inulieribus, de Bellis Inperatorum, de Florentinc runn Bcllis, de cáptî. Confantinopoli, atque aliis, commemoratís à Facobo Bergow mate ad aun. 365. Horum pleraque Manufcripta extant in. Bibliothecâ publicâ Acadcmiz. Lugdunen/is apud Batavos. Libri ejus novem de cafibus illufrium wirorum. Manufcripti adiervantur Oxorii in. Bibliothecâ Collegii Novi, tefte Thomâ Lamefio. Quí \& Oxonii in BibliothecấCollegii S. Magdalene, tum \& Lincolnienfi, extare ait Boccacium de cafibus illuftium virorum: fed neutroloco, opus illid quot librorum fit, addit. Voff. de Hit. Lat.

Extunt Genealogix Deorum lib̆ri xNo infcripti Hugoñ Hierofolymorum CypriRegi. Vincentice $1_{4} 87$. in fol. Et ltalicè redditx per Iofepburn Betufji, resGognitx à Gorgio Valentini in Venetiâ per Valcntinos in 4. anno 1617 :

Extat:Decarneron, cum Præfatione \& vitâ Boccacii, auctore. Francifso Sanfowino, Italice in $4^{\circ}$. 1549 . Idem liber Gallice redditus per Laurenizurn Premier..Parifis 1534 . in $8:$

Extat opus de cluris mulieribus Berna r539. in fol.

Extant de calibus illuftrium virorum libri Ix. in folio Parifis, apud Loannem Gormontizms.

Excenitèvitâ lexgefmolectudo xtatis anno. Sepulchrum ejts cum mat* morế effigị iniculprishis carminibus.in templo maximo Certaldi confpicisuls.

\author{
Hacjub mole jacent cineres; ac offa Joannis; \\ Meins fedctante Deum, meritis ornata laborum. \\ Mortalis vite genitor Boccacius illi. \\ Patria Celtaldum, ftudium fuit alma Poëfis.
}

\section{Panb. Iov. in Elog? \\ JOANNES WICLEVIUS.}

A Ngliss acer Papifmi oppugnator, claruit anno 1370. oblit 1387. Scriptä Clar. Al o. $A$ ejus penè infinita reentet Balews; plures ejus Tractatus tum Latinè tum Ncscusoj. Anglice fcriptos adhuc ineditos extare in Bibliothecâ Collegii Benedr

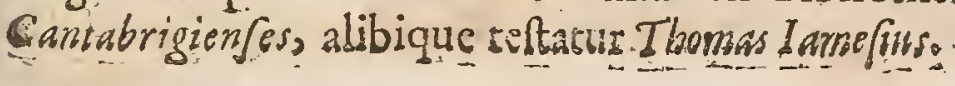


Vir magno \& excellenti planè ingenio preditus, Oxonir in Collogio Wr erto nenfî, omnes eruditas artes tantâ cum folicitate perdidicit, quantâ fui temporî́ nemo facile alius. Nam in thilofopliầ illâ Scholaftrâ, acuminis of ntatrice, principem locum obtinebat. Tum praxtcreà in Theologicurceflus penitiores, $*$ facrofanctos quidem illos, tam altè defcenderat w ut à Theologorwor vulgo pro Deo tantùm non habitus fit. Quo tandem calculo, (um mis honeribus infignibus, qua in ctuditos Acadernia conferre folet, donatus eft. llle rerò ut fe vidit ejufmodi audum titulis, fuamqueranti infcholis effe..authoritatem, ut omnia qua doceretrancuam è tripodedictactederentur: primum Fratercu! orum mendicitatem cutctenus ftingere copit, nec multo polt altis playig vilnerare. $U_{\varepsilon}$

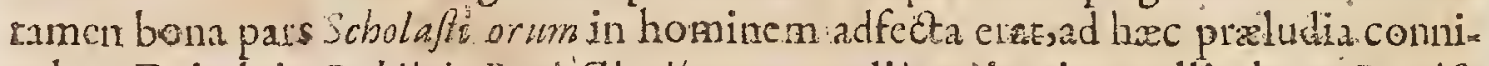
webat. Dcindein Publicis Pralectionibus atquealias privarim, vellicabat Pontifa cis Romaniaftum, avaritium ambitionem .ac tyrannidem:fic putans. futurum, ut Chriftiana Ecclefia cognitis erroribus refipifceret. Ioan. Lelarid.

Drater vitam quam verè A poftolican wiclevu duxit, ingenio, facundià, atque exuditione multiplici, omnes in Angli $\hat{a}$ commilitones longo intervallo fupe:abat. Unde iplum aternus P.ator, anno poft Servatortan 1360 .pcr fum Spiritum

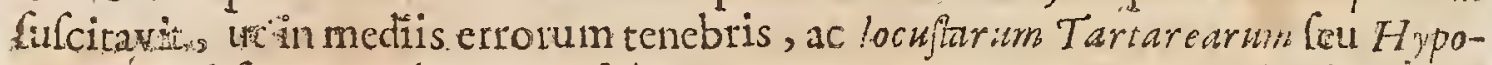
critarún oblcurationibus, pro fuâ yeritate ftaret, mananimus $C b$-ifi pugil: fiererque adverfus ejus infenfifimos hoftes, Antichryftos, infuperabilis Ecclifix columna. Loan. Balduss.

Ecclefiam de Astervvorib in comitatr Leiceftren $\sqrt{\imath}$ rexitille celcberimus Ioanses Wichliff, wir ingenio fubanto, \& facris literis verfatiflumus, qui cum calamum in Pontifuram Authoritatem, \& Romanam Ecclefiam Atinxillet, non lolum gravifime exagitatus crat dum.viveret; Ced etian alano polt mortere quadragefimo primo in corpus $\{x$ vitum füis quod Senengis Concrli mandato exhumatum erat \& exuftum. Canden in Britan.

Ioannes de Wicklffexercitatifimus fuit Thilolophus \& clatiflimus Theologus;rexcellentis \& planè Divini ingenii, immenla \& penè innumera Dootrinz monumenta poft fe reliquilt. Anton. à $v_{0}$ ood Antiquit. Oxvine

At hoc iplo tempore fub annum 1360 . caput exerit lo.znes Wiclefus ingentis angenii vir : in omnibus literis \& difciplinis Oxoni educatus, Philofophus \& Theologusinfignis, coque nominc omnibus facultatibus \& charus \& wenerandus. Hic fance Ecolefam Rornanamamni exparte ttrenitè adotitur.-Omitto Scriptorum ipfus eruåitionem, foliditatem penè inco mparabilem. Qux omuia Suyuis ferío artendcrit, feculo ahìa caliginofo, inter tot fulmina tam forrnidanda, quibus magni qui.jue Orbis Principes fuccumbere folitii,dubitare non poffit, quin ejus fpiritus cellitus lucem, robur, frduciam acciperct: quin Deus in eo \& per cum agerct, in imbccillitate homuncionis, fi mundum fpectes, abjectifimi, i mperii sutancruinatn moliretur.; plenitudinem illam poreftatis tantopere jactaitam, tanto temporc a Pontificibus affectatain jam aggredi occiperet.Pbil. Mornxi Myft. Iniquit. p. 4.452 .446$.

Loannes Wiclefusm---Vir erat, quô majorem non tulit poltremis hifce fcculis Chuifianus 
Chriftanus $\mathrm{Oubis}$; quique non minus fuprahudem quam invidian poftus viderur. Omnifarià rerum Theologicarum Scientiạ inftuctifroms, Lcgun Municipalium impcndid peritus, ratâ morum gravitate præditus, inprimis verd immenfe erga Denm zelo, erga proximum charitate Alagrans. Hinc nata puritatis prifinx in Ecclefam reducendacupido; quam tamen limites uque adcd egredinon permifit, ut omnia. Difciplinx Ecclefiafica jura illibata confervare rcligioni haberet. Eximiam cjuspietatem ne pellimi quidem advertarii in dubium unquam vocarc funt aufi ; praclatan certe dodtinam abundè teftati funt ex is quamplurimi. Sancin omnibus ferè, qux hodicnum ext.un, fuis ferittis acculatam Theologix notitiam \& climatum judicium prodit Wiclfus. Pretse ubiquc \& acutè difputat, egregiam fpirat pictatem, Gacram autem Scripturam fummâperfpicuitate ac Colcreiâ interpectari folet : Nil in co puerile aut otiofum (Sciptorbus iltius avifolenne vitium) deprehendi porct; ornnia gravia, fub. actir atque climata. Is denique eft, cui nihilad confummatam eruditionem defuit, nif fectum ferlicius. Difhmulari tamen non potelt, divenfálapè ac contram fria nonnunguam dogmata in illius libiis reperisi polfe : quod Wiclefo adco non detrahit, ut intaudem illi porius cederedabeat. Neque cnim prafervido quodam animi impetu abreptus., fed maturo judicio ac ratione ductus Ecclcfire Romana errores oppugnavit; quos unico ictu cum non detexifle nil mirnm eft. Henr. Wharton in Append. ad Hitt. Literal. Gul. Cave.

Acuratam Dogmatum Wictevianorzsn cum hodiemâ Ecclefia Anglicane doerrinâ concordiam fusè demơnitravir prolixâ Wiclefi Apologlì Anglico Ser-

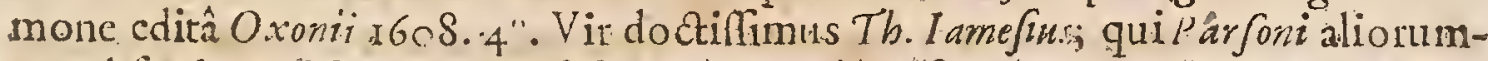
que abfurdas opiniones Wiclefo fummâ injuriâ, aflucntium, calumnias invictè diluit. Poftclarifimi Gonfelloris obitum, in Lanctifimos cjus manes maximâ infaniâ debacchat funt liontificii. Acrius tandem in Wiclefi memoriam nupe: invedus eft Varillafius, Hiftoriographus Gallus; qui priftinas calumnas renovavit, novas fubinde excogitavit; \& utrafque in Hiftoriâ fuâ Hærcfis in lucem dedit. Vevim taminfulsé ut plurimùn idumniatur Hiftoricus ille mendacifimus, adco omnem rerum geftarum Chronologiam perurbavit, tam crallos paritcr ac ineptos Errotes admifit; ut putidifimum Impontorem ubique prodat. 2. lifu potilis quàm refurationc excipi mereatur. I dem ibidem.

Conchufones cjus habentur inter Epifolas Gregorii XI: Conciliorum, Tom. II. Paut.2.p.2047. Ariculi ex ejus Tralogo excerpti, \& in Synodo Londineng damnati ibid. pag. 20 so.

\section{MATIHEOS WESTMONASTERIENSIS.}

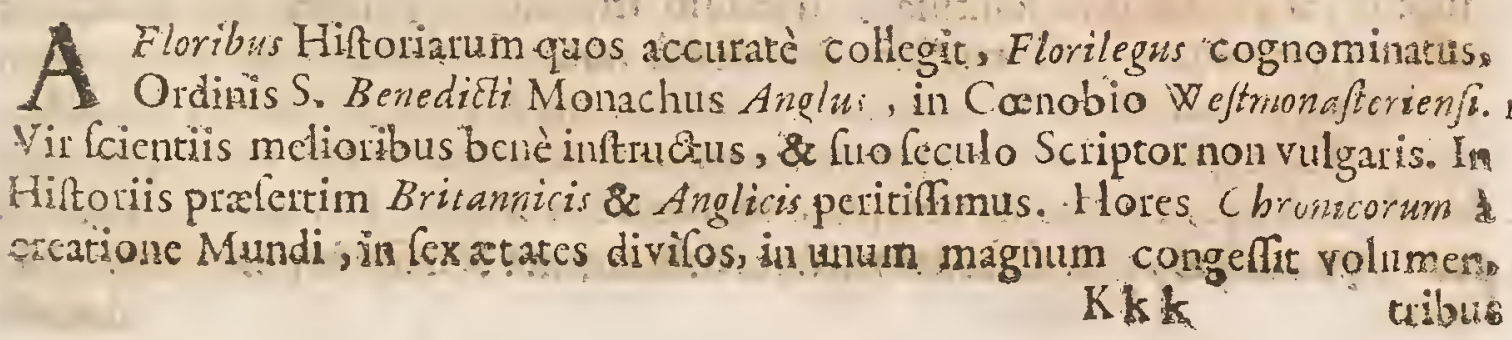


tubus libris ditinctum. In quorum primode rebus infignioribus agit ab orbe. condito ufque ad C brifturr natum. In fecundo à nativitate Chrifi ufyue ad Normannorum in Angliam advenum. In teitio agit de Imperio Norrsannorwn ina

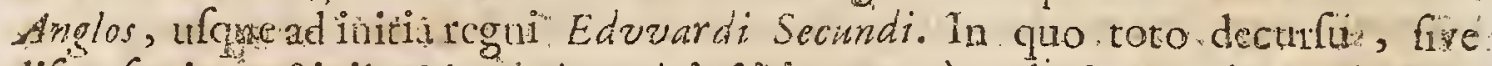
difcuru, ica veftigiis $M$ ath a paris inftitit , ueparum abejus Methodo deflexerit, nifí quòd in tertio libro multa ex fuo depromplerit, armario, qux vel ab-aliis . accepit 3 reliple vidit, quibus Hiftoriam fuam non pum ax onavit. Poftremòtes geftas leptuagintannorum défuo planeadjecit, deduxitque rerun feriem ufque ad $R$ cgis Edvourdi tertii mortem, ad annum videlicet Dorn 1377: poft quem annum nec iple diu fupervixiffe videtu. O mnia fuafcriplit

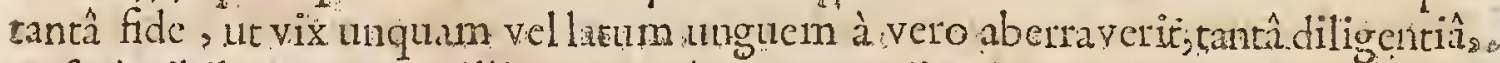
st ferè nihil cotum, qux illis temporibus notatu digna contigerunt; omiferit. His adde fummum judicum in rclaus feligendis, acumen in linveniendis, ordinem in diponendis, exactam rationem in temporibus calculandis, annis füpputandis.

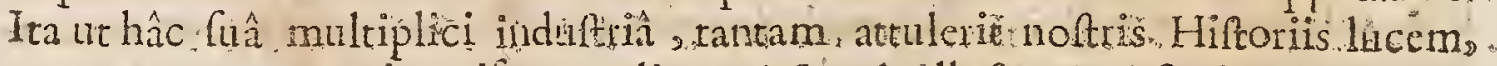
quantam ante cum vix quifquam alius. Pitféus de 1 luftr. Angl. Scriptor.

Scriptor xtate fuânon inclegans. Vii ipfe exat fuo feculo in omnigenere bonarum literarum planè enditus, \& in his qua ad Hiftoriam perrinent, po-m

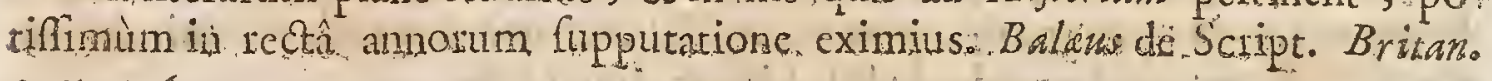
centur. 6.

Sciptor exactus, diligens, \& filelis vocattu Hofmanno:

Circa annum 1376 . vigere fama copit Mat hes Weftranafterienfis : gui Hilto: riarum Fores collegit ab exordio mundi ufque ad amum Dônini 1307 -Inde wulgò dictus cf Florilegur. n is fequitur impimis. Hifoxiam Matthai Paris majorein. 'olted autem, adjectis 70 annis, laborem hunc perdixit ad anm ufque $1377 \cdot$ Quod effrocis Biblothecarum repagulis, nunc per mans onnitim volitat, wathat Parkeri, Cantuartenfsi Antiritis, beneficium eft. Nec hic induftin We:tronafterien is Mattheiftetit: fed prateres duplici Chronico nomen fum extulit: unoquitem jatio , feu Wefmonafteriersin: altero autem funi $B$. Eadmutri. Porro Florilegihujus yefigiis inftitit Chronicon Roffenfe; imò vix "quigquam in colcgas Florizogo intactum; fr exceperis", quze propriè Monafterilim Roffenfe fuectaut. Voff: de Hift Lat:

Catertm ne Hitoriarum obtuanis multitudine, \& hinc ducaris in Confufio. sem: (Anglu, chim fis, \&2 Anglorum geftafcire defideres) Mat hei Paris \& Matthei Whrnonaflerit Ecriptis, precxteris incumbe: houm lectioni fi operam adhibeas, non folum qux domi fuis temporibus gerebantur, led qux tractibanur foris luculenecr addices. Babarosefle fateor, ncerenuo $f$ dicas varie cor ruptos, at proluminis fintillâ, quâtum fruebantur, utiles Dei miniftros aflero, quos è profundis tencbis \& obfcurí node fufcitavit, ad retegendam plufquam monttrolan Rornanor ur Pentificum vim \& tyrannidem, quâ detinebamur miferè captivi-.....Hoc jam reftat, cujus te admonitum effe velim, ne fcribientis barbarie, à lectionis voluptate immaturè avoceris. Neve attonitus admi.. * ris, gu animo, tam abfurdainterom deliamenta \&infpida phantafnata, hic 
Author (Matthaus Weftronefterien/s) Scriptis Cuis interpofucrit Poteris cquit dem ( 2 lubens fateor) tam incredibilim anmadverfone, ab omni, \& fpe boni, \& veritais opinione prorsus avocari. Sed fi \& temporum iniquiratem (in quibus is vixerat (erum omnium tumultuatum ordinem, diligenter confderaveris; nec tantum tibi mirari libierit, nec ita multum argucndus ille, culòd pro fectilifuivanitate cum alis in Religionis Cbrifiana myteriis aberaverit. Ift f non incogitanter pretericris, magnaz commoditatis particeps difcedes. Vid. Prafat. prefix. edit. Francofirt: $160 \mathrm{n}$.

* Flores Hiforiarum, per Mattherim Weftrmafterionsernediti anno 1573. Londini, mili emendentur, prohibenturin Incise Tridentin; vide Appondicem ccrtorum Auatorum.

Exrant Flores Hifforitruxs, Londinias 67. \& Eransof..160r. Fol:

$$
\text { Q ALFREDUS CHAUCERUS. }
$$

A Pud Wondfocknonlongè ab Oxonio in Anolis claris parentibus natuspa clar. A. D. eques. Virbolli pacifque aribus mitêlens. Antequam virilem æatatem attigif-

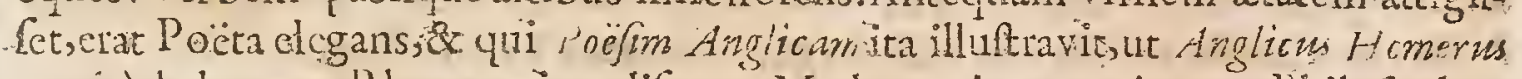
meritè habcretur. Rhotor etiam difertus, Marhematicus peritus, lhilofophus acutus, Thenlogus deniquc non contcmnendus. Maximè conatus eft, ut matena excolatur lingua, \& in Anglico fermone cloquentix Romane exprefia appareant *eftigia. IHi duo viri loannes Goverus 8 Galfredus Chawcerus attulerunt certe noltro Idiomatitantum Cpleneris \& onamenti ; quanttim ante illos prorlis nemo. Nan fibi mutuò calcar addidenunt, \&uter patria plus afferret honotiss; uterque vinci 2 vincerembiens, amanter contenderunt. Pitfers, de Illuft: Angl. cript.

Iucre \& in Britannorum idiomate $\&$ cortm vernaculo fermone aliqui Pötx ab eis fummo in prctio habiti, inter quos Galfredus C'bancerus vetuftior, qui multa fcipfit, \& Thomus Viatu, amboin fignes equites. Lil.G yrald. de Poëtis.

G. Ifredus ( baucerms Anglus loëta, linguam 'atriam magnâingenii folertiâ ac culturâp phumim ornavit ; interque alia, cum Loannos Mone poëma de Arte amandi Gullice tantim legetctur; Anglico illud metro feliciter reddidit. Voffurs Ac Hit. Lax.

Oppidum Woodfcek cum nihil habeat quod oftentet, Homerum noftum Anglicum Galfredury Chancerum alumnum fun fulfe gloriatur. De quo, \& noltris Poëtis Anglicis illud verè alferam, quod de Homero \& Gracis ille Italus dixit:

\section{-...- Hic ille eft cujus de gurgitef. icro \\ Combibit arcanos vatum ommas turb a furores.}

Hlecrim extra omnem ingenii aleam pofitus, Poëtaftros noftros longo poft fe intervallo relinquit. Camden. in Britann.

Galfridus Chancerus, Poëtarum noftrorum princeps, acris judicii, non lepidi K 152

tantam 
444

rantum ingenii, vir. Is Philofophicis, Theologicifque haud mediocriter ing in wis fuit. Hens. Savzl: Prefat. ad Bradvoardir. lib.contra Pelag.

De Chancero Leldadus ijter Epigrammata fua fic Cribit:-

Pradicat Algerum merito Florentia Dantem,

Italia o numeros tota Petrarcha tuos.

Anglia Chucerum veneratur noftra Poëtam,

Cuiveneres debet patria lingua fuas.

Ufque ad tempus Henrici VIIT. vix ullus Author qui Anglicè Cripfiffetiñ ald:qua fuit exiftimatione prater Chancerum; Necillo idiomate quiequam editum erat quod bis legere dignaretur prater quædam ejus Poenara. Scd lunc aliquatenus caput cxtollere coepit \& tolerabilem quendam fonm adipifci. Sprati Hiftoria Regire Societatis. Anglicè:

Dominus Gottefridius Chaucer Gentis noftra Homerus, quiqu now minù : duciloquam Mufam nactus eft in Wootfockic Nemoribus, quam Veteres in : Heluconis Collibus . Baker in. Hif. Regni:Edvvardi Tertii. Angl.

7) erfteganus damnat Chaucerum in ea quod Anglicum Idioma puritate fun Cpoliaverit, tot Gallicarum Latinarum vocum permixtione Anglicè...

Quxdam. Lectores monitos cupio ; ut, primè quod apud C haucerum occurrant quadam nomina propriaqux à Latinis \& à Gracis unde défumuntur procul abeunt; quatamen ut crrores in ipfo damnari non debent : Nam \& ille \& ali Poetx in ejulmodi:vocum tranflatione exuno idiomate in altenum fepe, ut $\&$ ipf Graciatque Latini varis utuntur Metaplafmis : verbi gratia Campanews pro Capaneus: Athecsppro Alteon: Adriane pro Ariadne: Quod in alis quo. que vocibus facit Chancerus: ut gon pro begon: leve probeleve : peraunter pro peradventure: loveden pro didlove : vvoneden pro did von : folet eriam Grecos imitari duas adhibendo Negativas ad fortiorem Negarionem, ut I ne faid none ill. Sic etiam fxpiffmè Verburn fub intellig endum omittit, ut I not vohat men bim call, pro I knovo not \&e. Sic denique loco Authoris aliquam Operum ejus partem nominat, ut Argonauticon pro Apollonius Rodius; idque interdum in Genitivo Cafu, Subfantioum pracedens fubaudiendo; fic apud ipfum legere eft Eneidos: Metamorphofeos, vice Authorum ejufmodiO perum. Vide Yrafationem in Opera Chauceri typis mandata in Folio. ann. I602:

Ex hoc malé fano novitatis prucitu, Belge Gallicas voces paffim civitate frta donando, patrii fermonis puritatem nuper non leviter inquinaverunt, \&: Chaucerus l'cëta, peffimo exemplo, integís vocum planftris ex eadem Galliâ in notram linguam invedis, eam, nimis anteà à Normannorzm victoriâ adulteratam, omni ferc nativâ gratî̀ \& nitore fpoliavit;pro genuinis coloribus fucum illincus, pro verâ facic larvam indurens. Vide Stephan. Skinner. in Prafat.prafix. etymologico fuo lingux Anglic. 
Zosdini Cénex obiit, \& apud Wefrmonafterium honorificè fepultus eft cum ha Infcriptione:

Quifuit Angloriam Vatestermaximus ölim.

Galfredus Chaucer, conditur hoc tumulo.

Annum fi quaras Dorrini, $f$ itempora mortis,

Ecce nota Jubjunt, que tibi cuncias notent.

23. Octobris 1400 .

\section{DETRUS de A.LIACO.}

fompendii ad Ifaram ex tenuilfime fortune parentibus ortuls, Doctor Clar. A: D.

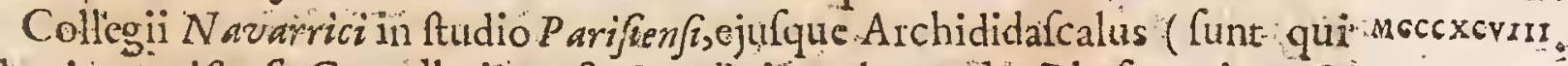
Academix. $P^{\prime}$ arifienfes Cancellarium;. . Capelle in eadem urbe: Thefaurarium $\&$ Magnum Francie Eleemo (ynarium præterea wocitent) Ioannis Gerfonis praceptor,

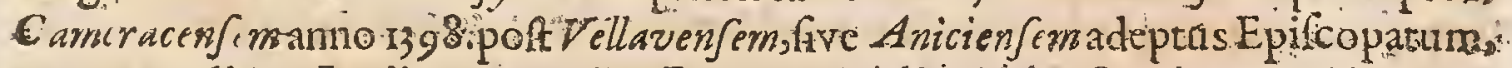
anno I 4Ir.die 6.Junilicrcatns eft S.R.E.Cardinalis titulo S. C'bry fogoni à Joame

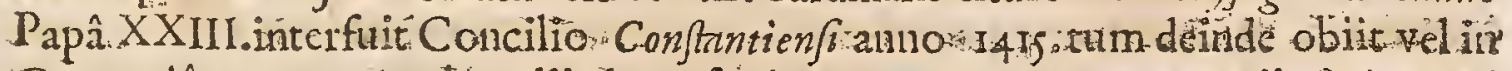

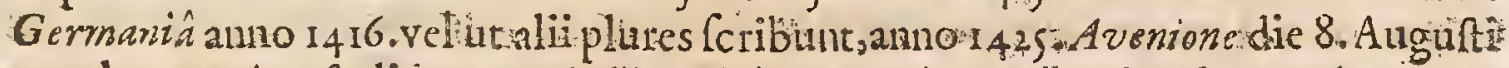
Iom legatus Apoftolicus per Galliam, dickus Aguila Gallia of aberrantimn ì veritate mallens indefefjus relätumque eft corpuse juis Cameracum, \& in Ecclefia Cathedialifepultum cum Epitaphio: Phil. Labbe dé Seript. Ecclé...

En habes inter viros egregios virum literis exuditiffimum, fide,prudentiâ, prow bitate, vigilanniâ commendatifimum, \& zelo nnitatis Ecclefaftice ardentifrmum, Petrum, Ciancellarium Exclefse Parifienfis, \& Regis Francorum Elëemolynze MiniAtum, virum utique, ut breviter dicam,te tuifque moribus digniffmum. Cujus. $_{\text {. }}$

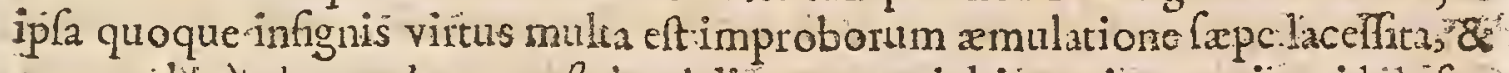
quem plänè alterum lumen noftri tevi dicere non dubitaverim, quicquid de fuo nomine detorquere maledicta perverlorum lingua ftuduerit. Huncin pacis cons? filiis adbibe participem;in laboribus confortem, \& in negotiis omnibus adjuto$\mathrm{rem}$ : Hunc dilige, cole, amplecteres huic alceri fiducialiter omnia committe, \& p; oculdubio non falleris,nec talem te Miniftrumelegilie pigebi. Nic.Clameng. in Epit. fecund. ad Benedictum.

Petrus de Alliaco Cardinalis, vir đooctrinâ \& moribus fpectatiffimus, non modò Galliam , at univerfum terrarum orbem radiis virtutum fpeciofiffimis: illittravir. Ioan.Ravif.Textor in lib.de Clar. Mulier.

Alliacus dum viveret dici meruit Aquila Francis, \& mallens àveritate aberrantium indefefus : quod praconium multis quidem explicari poten "Fed reli quum femper exit aliquid, quod àdìmerito poterit. Uno verbo; in Scholis \&in.

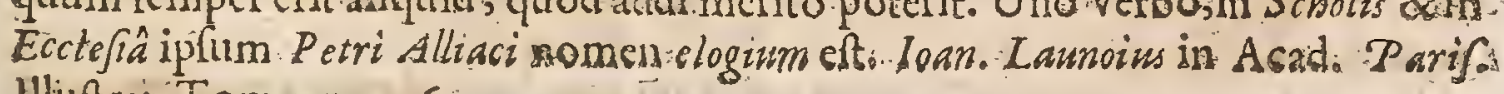
Illiftrat. Tom.2.p. 47.6 ?

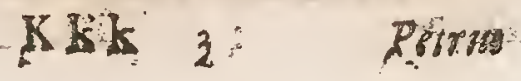


Perrus Alliacus, Epilcopus Cameracenfis, S. R. E. Card. Parifuenfs Gymnafie

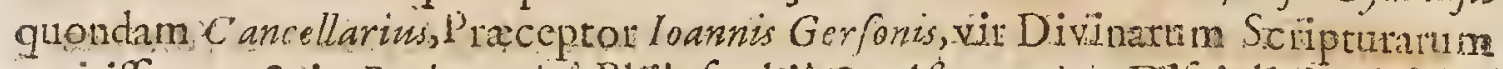
peritifimus, \& in Peripatetica Plilolophià A Atronomicis Difciplinis abfolutilfimus, cloquio elegans, \& Declamator facundessaggregavit ex Angufino, \& aliis Patribus plunima in Sacras Literas volumina. Drxt. Senenf.

Petru de alliaco Compendit ad l Jararn natus anno r35o ex patentibus ignobilibus quidem, fed probis, \& liberalibus, magnum familix fux honorem acquifivit obdoetinam fimul \& pictatem. Ondin in supplem. ad Bellarm.

Unum eft, in quo reprehenditur hic Auctor, quod videlicet fenfife videatur Chrifti nativitatm pranolci pothife ex Genethicis obfervationibus, atque ad hoc adduxenit apparitionen Stella, qua apparuit Magis Bellarm de Script. Ecclef.

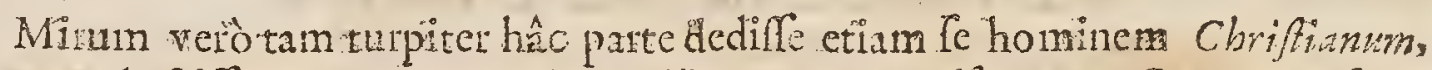

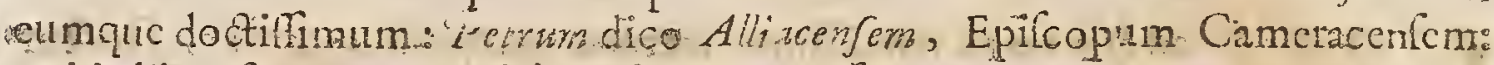
qui inlibro fuo de Concordiâ Hifurice, \& Aftrologra. Divinatricis, etian diluWitum Noë, Natalen Dornini, \& Miracula ciulem, omniaque Prodigin ex Afrologrâ prefciri, ac pradici potuire, arbitratux. Valdè ctiam futile cit fundamentum, quod arti itti ponit. A it, ab initio. Mundi ufque ad Diluvium Auxife annos

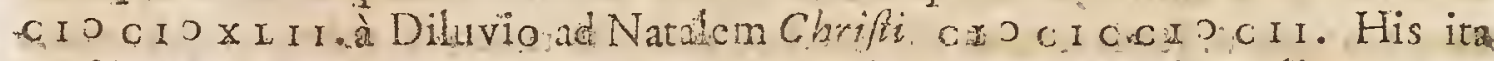

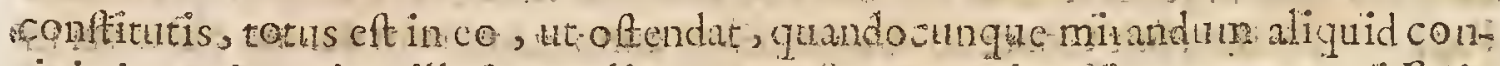
tigit in terris; etim illuferm aliquam Stellarum conjunctionem appartile in Colis. Atqui falfirmum er quod fibifumit de anno, vil diluvia, vel natalis. Domini: nec levis eft cror, fed fpififimus, in priori quidem numero annorumpene fexcentorum is in alteso autem patio paucionum. Quid mirum?

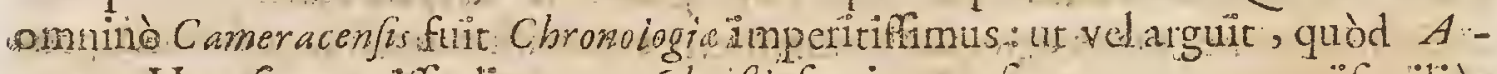
ramam Haerefn copific dicat an. Chrifi feptingentefimo : quam verifinilius aum penè extinctam dixifet: artam vero confat fere initio leculi quati. Voffo de Sciento 14 athemat p. 214 , $2 \pi$.

Tetrus de Alliaco Cardinalis, in Concilio Confantienf, jutîn Sioifmundi Cxfaris, obtulit articulos s fecundum quos putabat cartuptifinum fratun Ecclefize reformandum effe. Primum aurem ac pracipue curiam Romanam, corrigendam confuat totque ac tam vatias ei corradendx pecunia aites pracidendas, Epilcoporm Protitorkmque moresac vitam conigcndan, colque ad proprium eorum offecium recte obcundum cogentos. Deinde Pompan Ecclefarticam, fuperfua feft, jejuniortum abufum, prolixas battologias boatufques \& Sanctorum canonifationem efle tollendam Qün \& monahorm ordines minucudos effe. Danignc \& nimiam imagin templormmque curam \&2 copiam abogandam. Hre \& frmilia quadam alia in reformanda Exclefấ agenda putavit, acut fierent, in Concilio liaft, fed ninil profecit. lpfimet cnim quä emondariteformarioue debcbant, nempe Curifuni, Cardinales, Epifsopi, \& Monacbi, in Concilio regnabant, sad fuam libidinem jus falque infectebant. Ayrich Catal. Teft. veritat.1.10.

Hig Anctorir Landatione Theologir, didum hoc Superbanc Petram trahit ad aris Comitisurs. 


\section{CELEBRIORUIM AUTHORUM.}

Chriftum, \&e ejus Verbum. In fuis.conclufionibus difputat, Ecclefiam effe alligatain ad Scripturam: item, Papam non habere monarchian temporalem. Item, Romenam Ecciefiam errare polfe. Tranfubftantiationis Mifaricie dogma etiam improbayit, in 4 , entent. Idem ibid.

Scripta quamplurima reliquir, quxtamen in unum corpus nondum redacta, neque omuiatypis hactenus vulgata fucre. Potiffma, caque excufa, cnarrant $B$ ellarm' sus atque Labbews. Opera verò Manuferipta reperies in Ondino in Supplem. ad Bellaris.

Alliacus anno 4asfo-Aivenione moriens bibliothecam fuam legavit Nawarw reo Parifit. Collegio; quam ibi magnî cum volnptate aliquando vidimus.' Tu-

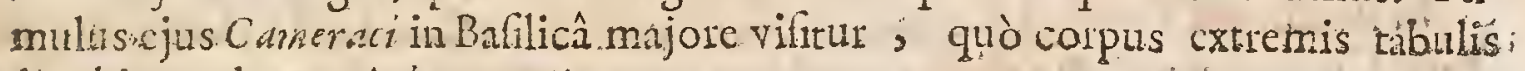
divehi mandarat. Awbert. Mirasss.

\section{Hoc ejus Epitaphium :..}

Thors rapuit Petrun, Petram fubiit putrecorpuss.

Sed Petram Clritum Spirituts ipfe petit.

Quifguis ades, precibus feropern, femperque memento.

Qutod prater mores orminia morte cadint..

Nam quid amor Regum, quid opes; grid gloria durents.

Aspicis; bec aderant nunc mibi, nunc abekkat.

Pibit. Labbe in Thefaur. Epiapho.

\section{B.A.D. U. U U B.A.D. U S.}

P

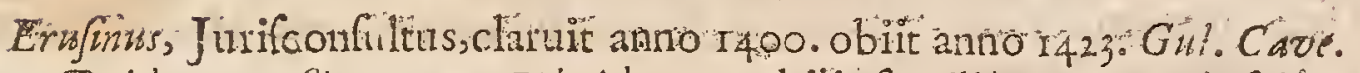
Baldus Perufii natus, cx Ubaldorum nebili familiâ:'s generis fplendori Clar. A.D. adjecit doetrinam excellentem in. Jurifprudentix. ftudio ; $2 x$ aliis liberdibus, diciplinis: auditor enim fuit Bartoli de Saxoferrato : praceptorigue non ceffirfcientiarum cognitione. In parriâ do uit limmâsum latde ${ }^{3}$ auditorum frèquentià, qui undiq̨e Perusium confluebant ad illum "audiendum. "Sed poft: yuam magnus ille Galeacizss Vicecomes. Mediolanenfis Acridemiám Ticinz erexiffet, \&e. Gholas ftudis bonarum liferarum flerentes excitaffer, accitis undique celeberrimis profefforibus, qui juventutem tam in Philofophiä, quàm in. Juilprudentiâ inftituerent; conftitutis unicuique pro ratione \& dignităte profêfronis, luculentiffmis ftipendiis, Baldum quoque Perufo evocavit, qui lummâ auditorum freqientiâ P’apie, quæe eft Tícinurn, jus aliquot annis publićé dó-

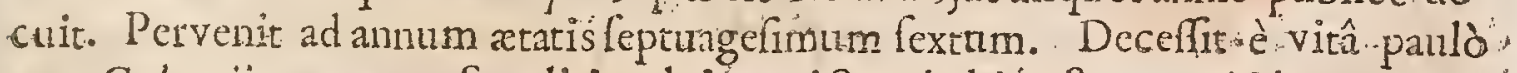
ante Galeacii mortem. Sepelini voluit amictus habitu S. Francifoi, ratus id? plurimum ad animx falutem conduccre: Quod etiám à Rodulpho Agriculo factitatum tradunt, \& ab aliis multis. Baldus florebat Anno 3365 . Sepultus anno 3400 . Biifgard. in Icon... 
Jus Civile profeflus eft Bononic Sx Ticiniper 5 . annos tanto cum ingentio acumine judicioque, at $B$ aldum nihil ignorare folcret fafon dicere, \& Philp $>$ ws Decius tefetur neminem mortalium authoritate Baldumadxequare polle. In his fanè ( $B$ artholo \& Balda) nihil defiderari poteft; quàm ut foliciore xtare vixillent, in iis enim feculis barbaries Gotbica \& Longobaráica Latinurn Sermonem \& literas ferè omnes extinxerat, \& ể ratione Antonius Contius cos Longobartizros DoElores appellat; ideoque $f \mathrm{in}$ is fermo $G$, thicks, hiftoriarum literarumque ignolantia reprehendatur, condonanda funt illis pro temporis ratione, ac compenfanda purâ exactâque Iuris Romani fcientiâ, quamimmenfo labone judicioque Pofteris tradiderc. Arth. Duck de Authoritate Jui. Civ.la. c. S. fect.15.

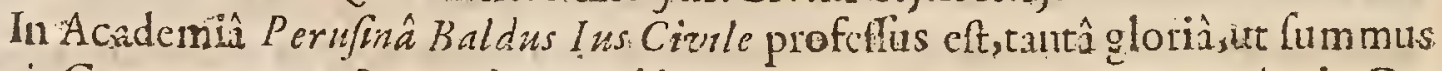
luris Commentator; \& terreltre quoddam numen vacaretul. Petr. Bertius in De. Ccript. Tractus Perufini.

Alcerum polt Bartbalum Romana pitidentia lumen vocar Quenfiedt.

Baldus Bartbolum prxceptorem fubtilitate ingenii \& varictate doctrina fupe-

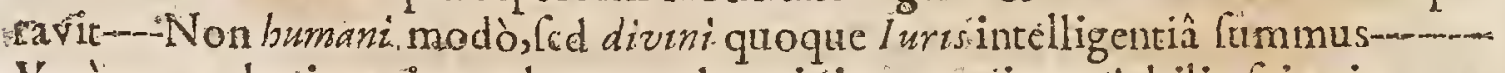
Verum præalto ingenio multaconvolventi, invertenti yue ltabilis cientix conintantia decrat. Paul. loz:

In $B$ aldo nihil prater Confantiain defidcrari potelt, frpè enim contraria alferite Arth. Duck de Authorit. Jur.Civ.1. I.c.8.Sed. 9.

Cùm parum fibi confans fepenumerò contrarites reperiatux, id tamen nor levitate, fed ingenii fubtilitate evenilfe Paulus Caftrenfis autumat.

Bartolo Preceptore action. of d nonita ventatis amator habitus ett. $P$ ancirol. de clar. Leg. Interpret.p. 204.

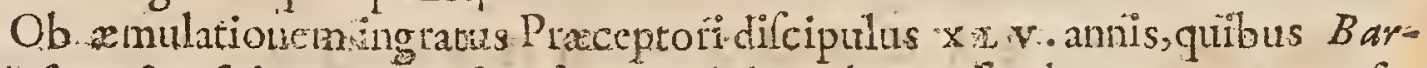
tholo fupentes fuit, conatus eft ipfus nomini tenebras offundere, quem ex profefo fepemordet, nec fue comemptu quandoguenominat, \& I dices eum fequenres $C$ acos vocat. Idem ibid. p. 202.

Ingenio acutifumus duabus tantum horis fingulis dicbus ftudiis operam dea diffe fertur, preterquam ubi rem dificilem aliquam pra manibus haberet, quod milî verifimile non videtur, crodendum chimnon cut tuntam leghm peritian paucis horis comparari patuile. I dern ibid.

\section{De hoc Auatore fic cccinit Poẹta:}

4. Baldum juri negat accendiffe Lucernam: Ille potefl medio jole negare diem.

\section{Alius:}

Nemo ( quod bunclatuit) Scivit, fi Jura monarchan Ferre quearit, tanto hic nomine dignus erato 


\section{JOANNES GERSON.}

CElebris Theologus. à nonnulis loannes Charlierius appellatur: Natus eit Clar. A. D: anno I363. obiit anno 14.21. juxta Tritberrium : juxta senensern vcrò A.nu. MC.DIV. R429.interfuit Concilio Conftartienfi. Parifins, Academix Cancellarii muncre ifunctus elt. Dodtor Cbriftianiffunzs audire Colet. Wimptelingus eum vocat sempiternam Parifienfum gloriam, $\&$ Confantienfis Concilvi colurnam. Opera ejus 4 . Tomis conizant. Koitig.

Ioannes Gerfon, natione Gallus florentiffinz Pariforum Academix CancelLarius, Theologix Scholaftice pericifimus, ?’ëta \& Ontor fuo tempore infignis, Caroli Francormanegis in Concilio Conftantrenfi Legatus, multa nobilia voluminaindivinas literas ftylo quidem Scholaftyo, led non prorfus injucundo, confripfit : in quibus ita cholafticas fubtilitates dulcibus My ftic Theologit affecibus mifcuir temperavirque, ut addubitandum fit, an enuditione pietatem, wel pietare etuditionem fuperaverit. ixt. Seney in Biblioth.

I oannes Gerfon, Cancdlarius Parifienfir famofifimus fuâ atare Theologus.

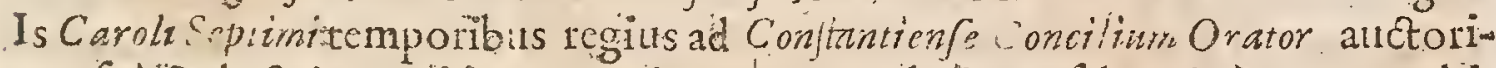
tate fuâ dia infererentur, indeque re benè ad Dez Gloriam \& Decus Rcgni geftà reverfus, Doctorir briftianiffrri nos folum apud nos, fed inter exteras Nariones fummo confenfu noinen merticiat. Thuan lift.1.137.

Furit omninè, meo quidem judicio, vir pius ac enditus:qui licèt mulis $\mathrm{Mo}$ anachorum \& Ephiftarum erroribus fuerit infectus., multos eciam nihilominus errores \& abufus $P$ apatus animadvertit, colque $\&$ taxavit, $\&$ tolli ex animo optayit, ut ex cjus friptis non uno in loco apparet. liquostamen proculdubio metu Phariforurbaut penitus diffunulavir, aut etian lenius, yuam tuntum virum decuilfet, \& resipla peftuliffet, reprehendit. Illyr. in Catal. Telt. Veritat.

loannes Gerfon Gallus, Cancellarius Parifzenfis,virdactus \& pinso Bellar. de Script. Erodel.

loaines Gerfon, fui feculi Oraculum. Hofman. in Lexic.

In Gerforii operibus nemo fine infigni fruet verfari poter. Gul. Cave.

loannes Gar fon, Theologus arifleinfes magni nominis sleidan. lib. I. Commental de ftaru Relig.

Vir fur tempetatis prudentiâ, pictare \& doctrinâ nemin facilè fecundus. Conring. indefer. Ecclel. Proteftant adversùs duo Pontific. Sophifmata.

Virfuîatate eximius, qui in mediis adulti Papatûs tenobris fui Eturas lucis \& vcritatis fepe vidit \& aliis candide commontravit. Georg. Calixt. in Apparat. Theolog pag. 143 .

Maximus 1 heologorum quos unctuam habuerimas in Gallia, Fuit Magifter Johannes Gerfon. Pafquic: lib.3.de Gallicarum reium Perquilitionib. Gallicè.

Inter Dodores Concrliz Cortantenfis quafilumen emicabat vir infignis Ioannes Gerfon, quem propter eluditionem \& animi candorem ac fervorem erga Ll1.

purtatem 
puritatem Ecclefia, nemonon laudat Adverfariorum, Claud. Sanctef: Ebroicenf: Epilc. in lib. de Eucbarift. repct. 10. c. 4 .

Foannes Gerfon fui faculi rarum lumen fuit omnium judico. Theoph. Raynaud. in vita ejus.

Foannes de Gerfon, natione Gallus, Cancellarius Pariflenfis, vir in divinis Scripturis eruditifimus, facularis Philofophix non ignarus, ingenio fubrilis, fermone Scholafticus, fci ntiâ certus ac ftabilis, conflio cautus, dubión clarifimus

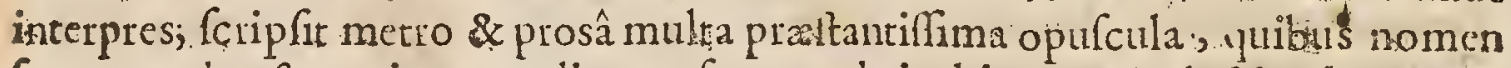
fum apud pofteros imm ortalitatem femper obtinebit:qucrum lectio devotis religiolis non minus utiliș quàm jucunda eft. Tritbern.

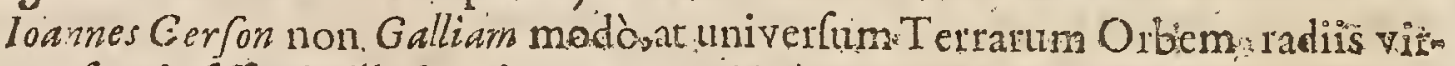
Eutum fpeciofiffimis illuftrayit Ioan.Ravif.T extor.in lib.de clar. Mulierib.

Audio loannem Gerfnem fuilfe virum Gumum atque eminentifinum. q̨uinetiam magnum Ecclefie Latine, nedum Facultatis Theologix Parifrenfis , hujus Regni decus \& omamentum. Claud. Espenceus in lib. 4. Apolog.c.7\%.

Loannes Gerfon Cancellarius Parifien/is, quad in Concilio Conftantienfa emendationem Ecelefia Romana plurimis rationibus propofuifet difoluto: Concilio, à Pontifice domo, patrî̀, dignitatibus, \&c. Ppoliatus, Lugduni confenuit, ibique mortus eft duodecimo Julii, Anuo Domo.1429, Calvif. in Chronolog.

Tribui folethuic Atedori praclariflinumopuculum de Imitatione Cbrifi, quatuor libris diftinctum: Ced nullibi inter ejus Opera numerattr, nec in Catalogo,quem fcriplit frater ipfus Gerfonis, nce in Tamis cditis Argentorati annow 148. Er tam planè cognitum eft, elle Thome à Kempis viri admodum pii Bcto. larm. de Script. Ecclefiafto

\title{
Epitaphium lommis Charlieri Gerfonir, Lugdwni in Ede D. Pauli circa. fepulahrum
}

\section{Paniternini, concredite Evangelio:}

\author{
Magnum parvatenet virtutibus urna Joannem \\ Pracelfurm meritis, Gerfon cognomine ditlum, \\ Parifis Sacre Profeffor Theologia.., \\ Clarnit eccleja qui Cancellirius anno \\ Milleno Domini centum quater atgue vigeno... \\ Nono, Iuce petit-superos Juliduodenâ.
}

Prodierunt Gerfoxis Opcracurâ Ioannis Geilèri Argentina 488.3 . Tom. 149\%"?

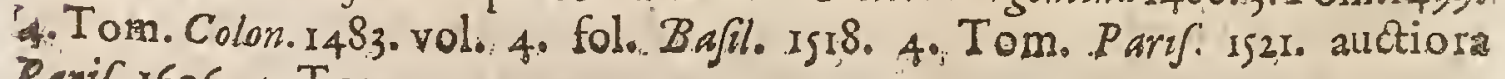
Parif. 1606.4 . Iom. 


\section{JOANNES ERANCISCUS POGGIUS.}

B Racciolinus, vel Brandolinus cognominatus: Florentinm fuit, natus in pago Terranova, territorii Aretini. Fuit à Secretis Eugenio IV. \& Nicolao V.quo Clar. A. D. cofficio lub octo Pontificibus fe defunetum elle iple Ccribit. Amo atatis 72. Ficreniam revocatus eft, ut Patriz Reipublicx candem operampraftaret. Erudicione infigni fuit, jrace imprimis \& Latine doctiflimus, Emanuclis Chryfolore olim difcipulus, Befarioni quoque familiaris extitit. Ob fales \& faciles jocos giatus omuibus, nifi quò Satyricus magis quibuldam videretu. Invectus. in Liur entium Fullan elt acritcr. Scripfit varia,lit de Varietats Foriund Epifolurum Aibros duos,in quorum illa,yuam ad Eeonbardum Aretinum feripferat de Hiew. ronymo Pragenfi,cum Johanne Huln, in Concilio Confantienfi, uftulato ob Rodigioncm, magnificelcntit. Forro Hiforium Florentinam, qux partm laudis habet. Alia quoque quxdam etiam minus probatasedidit, plurimóque auctores è Grecotranftulic. onftain, Concilio dinante, incidit in opera Quintilzani \&

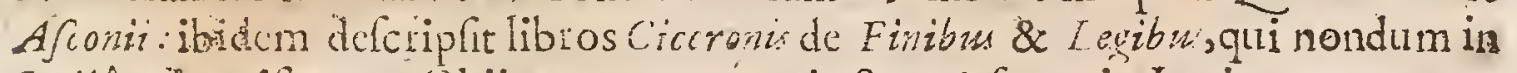
Italiâprius vifi crant. Obiitanno I459-xtatis So. Hofrnan in Lexic.

Erat Confliograyis, \&, quum lubcre, ficetianm fale perurbanus, ita ut mirâ, \& fape fibitâ varictate ad ciendum rilum modò pratextatis verbis utererur, modo gravibus \& malignis fommatibus atienz famx nomen perfringeret. Sed amarulcuto libcllo in Vallam importune invectus, ab codem pefrime andiendo cumulatas maledicentic fux panas luit. Quum Tall. fuo fulle turgidus, \& Facium \& 'Panormit.m, \& Raudenfern probrofis voluminibus jugularet. Erat quoque Poggins adco intemperans objulgator, ut quim in I heatro ${ }^{\prime}$ ompei, loco \& dic celebri, ubibullatorum diplomatum cenfura habebatur, Georgic Trapezuntio malediccret, ab eo aciiter duplici colapho caderctur. Tranfulit demum è Graco Diodorurn Siculm : Sed a ubiles aliquot libellos de infelicitate Principum, varietateque Fortuna \& de avaritia pefte. Orationes item plures compolıittantâ ingeniifoecunditate, ut facetias ctiam ad excitandam hilaritarem rgris arimis expetendas conferiberet. Sed quod gratum \& utile potteris fuit, Cuceronir libros de Finibu, \& de Legibus à le in Germanis defcriptos, in Italiamprinus atulit: ita ut $\&$ ei quoque $Q$ uintilianum in falamentarii taberhâ repartun dobcre fateamur. Paul. lov. in Elog.

Poggins, Florentinu, Philolophus \& Rhetorfacundus:, Greco \& Latino fermoncadpcreetum inftuctus, liccarum Apoltolicartim multis annis fcriptor difertiffmus. Spuxitiarum opus, quod freetias pranotavit, ab hoc illufrium xirorum catalogo meritò cenluimus repellendum, quoniam ejus lectio devotos offendit, incautis nocet, carnales inficit. Trithern.

Hiforiam fclipft Florentin.m : in quâ hoc à $M$ acbiavello merito culpatur, guòd pleraque ea omilerit, qux ad civiles difcordias pertinerent. Nimis \& $P a-$ triu faver: gुuó refpexit Actiws Sincerus epigrammate iftoc,

$$
\text { LII } 2 \text { Dum }
$$


Dum Patriam laudat, darnat dum Poggiüs boftem: Nec malus eft Civis, nec bonus Hiftaricus.

\section{Wiofi. déHif: Latr.}

Scripfit ctiam facetias Spurcitiarum, opus turpiffimum, \& aquis incendio qua dignum. Gc ner in Bibl.

sed qud hic ( $B$ rrgomas) facetiarum ejus libum vocat pulcherrimum, quil

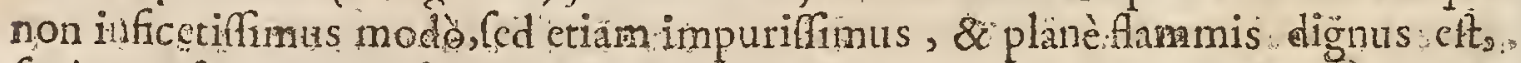
fanè rem facit ordine ftio erernitico, quem profitebatur, indignam. VojJ. de Hift. Lat.

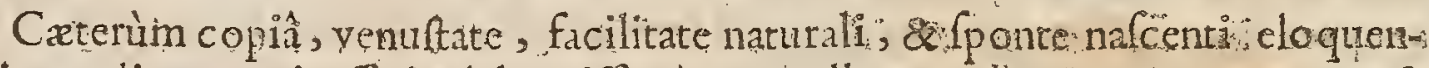
tiâ jucunditateque inaffectatâ longifimè pracellere Valla Poggium, non cet ambiguum. Poggi itaque eloquentiam probo : quamque negliọendam exis ftimo minimè.Henr. Bebelius ilit Lit. ad L:obard. Durrurn ann. I5. I3... Tubinge fcriptis.

Poggins rabulà adcò indoctus ut etiamfi vacaret obfconitarestamen indignus: effet qui legeretur; adè autem oblconus, ut eriamfidoctifimus fuilfet; tamen: effet a bonis vilis rejicicndis. Erajm. 1.4. Epift. Epift.7\%".

Erasmus in Ciceroniano p.x57.Poggus (inquit) Florentinus, vivida cosindam eloquentia vir - Naturafatis erat, artis of eruditionis non ita multum ...interim impuro fermonits fluxu, fi Laurentio Vallix redimus.

*.Poggi Florentini Facetix prohibcntur in Indice Tridentino

Ioannes Francifcus Pog gius, homo doctus \& admirandx facundià : vocatus: Barffardo in con. Idemųue Boiffardus hoc diftichon compoluit:

Felle armata tibi manus. ff: muitogue cachinno:

Finxifit andejcripta proterva $\int a l e$ :

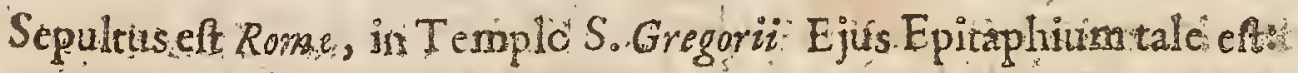

$$
\text { Deo Opt.Max. }
$$

Toami Francifco Poggio Florentino, cum virtute ac conftantiâ, morum gravia ? «ate, vira intcgerrime acti, paterna furque lande cloquentix, ac literarum, Juris" quoque civilis, ac Pontificii, divinzeque Scriptura cumulata doctrina, religiosè viventi, religiofuis fupremo die functo Kicentins Luce Maretinus, fratris ejus gener, parentis apud fe locum femper adfequuto optim. mern. pofuit. Boifjard. in Icon:

Yaria ejus opera variis locis atquetemporibus excufa hunt: 


\section{LEONARDUS BRUNUS, ARETINUS.}

A B Aretio, Tufcic oppido; ubi natus eft Aretinus cognominatus. InnoI centii VII. Gregorii XII. Alexandri V.Loannis XXIII. Pontificum, ufque Clar. A. D. ad Comfantiense Concilium, Secrctarius; pofted Reipublicx Florentina Cancellarius, per reliquum vita fpatium, fuit...

Leonardus Brunus Aretimu, Hiftoricus, Orator, \& Philofophus do etiflimus:Greca \& Latinx lingux peritiffmus:quarum nitorem retroatis leculis offuca-

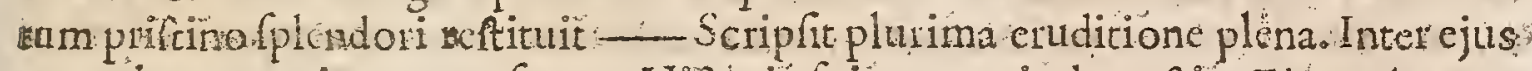
opera hac pracipua recenfentur. Hiftoria Gui remporis de geftis Florentinorum

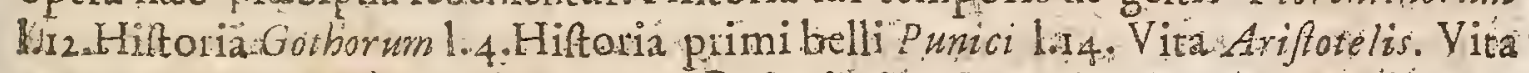
Gracchorum, Pauli Amili, Catonis Poferioris, Sertorit, Ciceronis. Dialogum do Moribus conicripfit, \&librum contra Hypocritas Commentarios in Occonomica: Arifotelis, Epiftolam Volumen Es ex Grecis tranfulie multa in La ainum fermonem. Boifjerd. in Icon...

Leonardus Aretinus fulici quadam \& focundiflimângenii vi atque bonitate. cloquentiàque pollebat. Franc. Philelph. I.r. Convivionum.-

Idcm $P$ hitelphus in Epifolà adeum Coriptâ anno:436.vocat eraditifinum, $8 e^{3}$ optimitm virumsatque cjus causâ air libenter f Clarentic vixite...

Vir doetifimus atque mnium eloquentifimus dicitul $P$ cogio Etorentino, fecundâ in Phitelphum invecivâ...

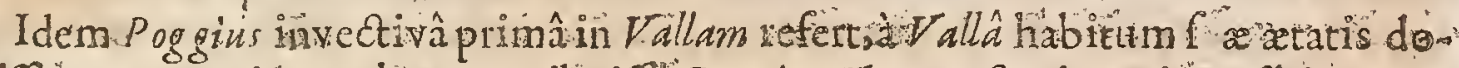
etifinum,proximun locum tribaife" Guarino Veronenfi, ux tertium fibi:

Leonardus Aretinus, multis nominibus commendandus, vin Phitofophicis xebus non infeliciter verfatus, in hiftoricis pro temporum ratione minimeafper nandus, \& facilis cujurdam natura (criptor; pluibus tamen rebus interim deft: tritur, \& quaradoque eum parum Latinè locutun contendas:quod fanè non eft mirandum. Namque ut nihil frnul 2 repertum \& abfolutum; ita unius Opera. Latinitas \& refticui, \& exactè excoli non potuit Florid Sabin in A pol advaJiimniat. Ling. I atin.

Lcouardiw Aretinus Philofophus, Hiftoricus \& Oratot elegantifimus prosbatufque - Certè inter viros difciplinis excellentes ob virtutem permaximam ac diceudi elegantiam omnibus praferendum efle putamus. Iac. Phil. Bergomenfis in * Chionic: supplem.ad Ann. Chr. 1456 ;

Leonardus Arctinus, Philofophus, Oratot \& Hiftoricus infignis, ac voun decunque doctifimus, Graci Latini lemonis peritus. Trithern.

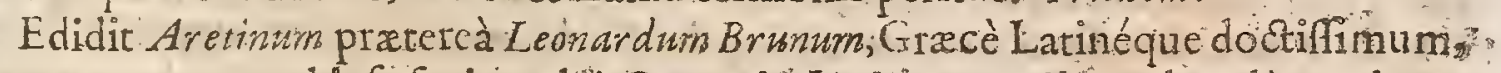
ut opera, qux vel ipfe fecir, vel è Gre in Latium vertit, abundè probant. Leand. Albert. in ltal.

Leonardum Aretinum ex te primùm fenfi obiifle : qui Latium ornavic literis, quố nemopolt Laítantiurn Ciceroni proximion fuit. 'Gandeo 'og ginm ejus losum apud Florentinos tenere: Sed maluillem potius locum non vacalle, ne tanto. L.113 3 Splendore 
Elendore caritfer Hetruria. Multos adhuc Gracos nobis Latinos dare potuiftet. Aneas Syl. in Epift.gr.

Legirnus Leonardum Aretinum Plutarcbiecleberimumintesprecm, magnầ doetrinâ. Lucius Ioan. Scoppal.1.c.j.Collcctan.

Andronici Thefjalonicenfis de Aretino judicium fuit:-Areinus adeo feliciter

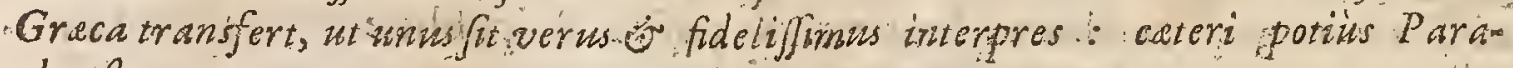
plsrafte.

Deftylo cjus fic Erafmusin Ciceroniano: Facillitate dictionis, ac pctipictiitate fatis accedic ad Ciceronem: Sed nervis, alifque vitutibus aliquot defttuitur :alicubi vix tuctur Rowanifrmonis caftinoniam : diogui vir doctus. juxta ac probus.

Idem aiunt, Grecè libellun fcripfiffe (Aretznum) de Republica Florentinum; ut Latini Hominis, nou âmodum indegantem. Compofuit quoquedebello

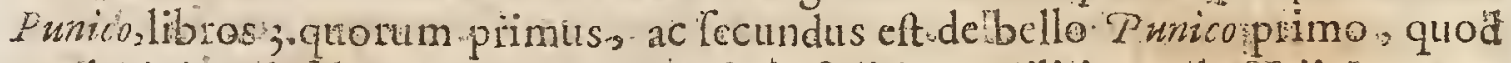
apud Livium delideraturercius verò eft de feditione militis conductitii; \& populorum Africe Carhaginen/ibus defectionejircmbello llyricu \& Gallice : qux ipfa etiamin Livio periertun. Ferè autem, quicquid habet, Polybio debctunde ct, quod in editionc Parifinfr,quam anteleculum Badius Afoenfudedit pojbit tromen in titilo exprimaturutculaqu in profatione 1 ple ncgetsmerum fe interpretem cgiffe. Praterea contexuit hiftorian Go horim : Ccd in quâ nitiil adferat.

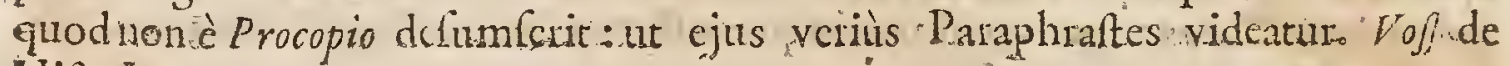
Hit. Lat.

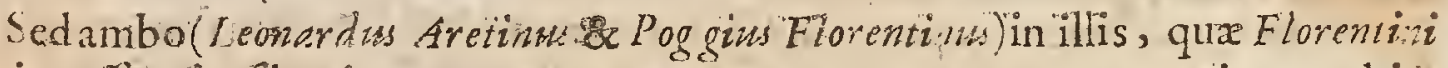
foris geffere, ita filentio pratcreunt magnam conm patem, qua pertipent ad in-

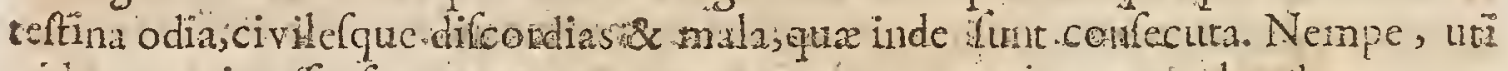
videtur, qua offenfan metuerent cokm, quoum majoses xeprehendere cogerentur. In quo neglcxere Hiftoriciboni otricium. Fo/jibidem.

Pïmusin Italiâ Ieonardus Aretiinatus, Grecarum Fitcrarum docus tे multis frculis Babarorum immanityrannide proculcatum ercxic,atype reftituit. Ejus enim incomparabili beneficio morales ariftotelis Librosoptimâ fide, traductos legimus. Fiftoris quoque ab co eleganter confcriptx, in manibus habentur. Hâc ingenii focunditate floventem, innocentius VIL quanjuam planè juvencm o grax

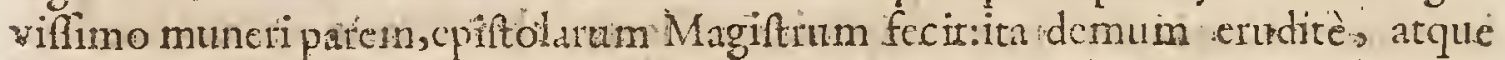
integrè officio functus, ut fuccedentibus quatuor Pontificibus amplificatî dignirate operam praftiterit. Sencfenti opes crewerunt cum alienâ libertate, tum fuâ trifi parfimoniâ cumulatx, adè ut Artottus, moldaci Tale perubanus in Fabellis ejus genium relicto corpore in fugẩ fitientem ridcuter expreferit. Mortuus, quod ei nullo pudori fuit, furti dumnatus et, quod Gotbrcam Hitoniam fupprello procopii nomine publicalfets accufante Chriffephore Perfona , qui aliud exemplar nactus, \& Gotbirarn \& Perfiram fimulatque Vand alicam, \& Graci autheris ticuLuming nuè profitendo tranfuleric. Paul.Iov. Elog.

Obiit fenex Florentic, divitiis \& glorin plenus, anni:Dorr.7443.ratatis 74. Cepulchrum masinoreum in Ede. Sancta Crucis fpectatus cum Infciptione: 


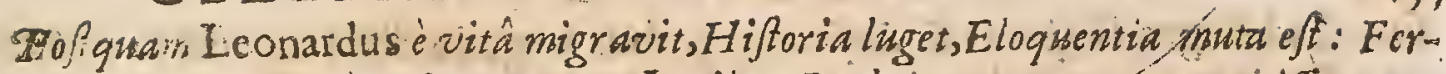
turgue Mufas cim Gras tum Latinas Licbrymas temerenon potuiffe:

Oudin. in Supplem. ad Bellarin.

Aluid Leonardi Aretini Epitaphium:

Amarus jacet bic, viater, bof fiss
Vivorum firnul atque mortworum.
Dits convicia nulla dixit, of $\int e$
Excufans, fibi cognitos negavito,

Extant libri rvide Bello Italico adverfus Gothos, $P$ arifuis an. Is 34. excufio.

Extant Dialogus de Moribus; \& Epiftolarum libri virr. Bafilex an. 1535.

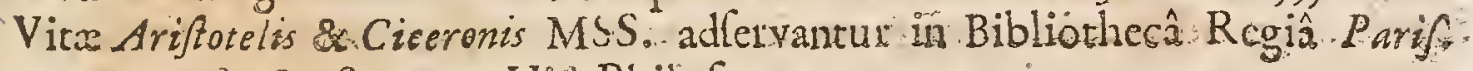
mam. 2155. tefte Ionfio, p.30g, Hift. Philof.

Tractatus de Republicâ Florentinorum MS. apud Leonem. Allatinum.

\section{G.UIIELM.US IYNWOOD.}

T Egum Doctor Oxonienfis (qui tamen in Aulâ Gonvilenfi Cantabrigic ad Clar. A. $\pi$.

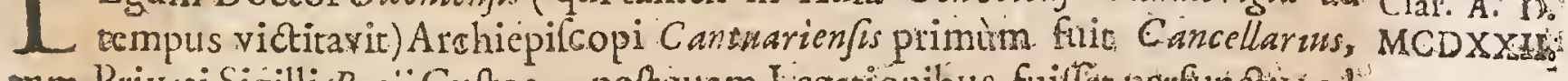
oum Privati Sigilli Regii Cuftos , poftquam Legationibus fuilfet peffunctus ad

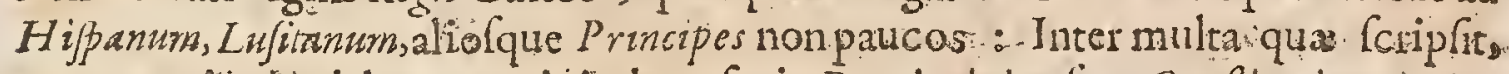
opuspræcipuécelcbatar, cui titulun fecit, Provinciale, leu Conffitustiones: $A n-$ glic;in qua redegit inordinem omnium Synodorum Canones à Steplaano Langrón ad Henricum Chichleium, Comtuariensem Archiepilcopum. Obiit an. Dom.1446. Henricı $\mathrm{Vl}_{225}$. \& in Ecclefia Collegiatâ S. Stepbani W-eftmonafterii jacet tumulalidus . Erancifc. Godvvin.in Comment.de PraGil... Angliie..

Gulielmus Landvvood, imperantc. Henrico quinto 'Menevenfa féde potítis 'eft. Fuit ille quidem vir Cafarei \& Pontifcii Iurisconfultiffimuss, qui Pontificias Cantuarien frum Sanctiones temerè disjectàs \& díperfas, \& in aptum ordinem di-

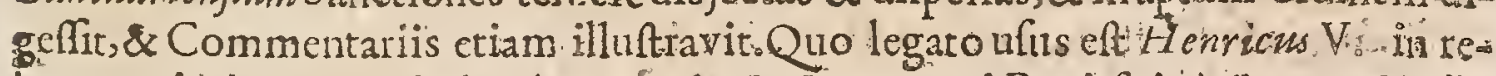
bus maxim: momentiad. Hifpanuin, \&, Lufitanum; cui Regi fuit à Secreto Sigillo:

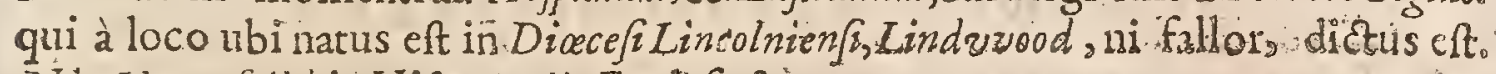
Nic. Harpsfeild.in Hiift. Anglic. Eccléfiaft.

Poft Ius Canonicum funt Conftitutiones Archiepifcoponm Cantuarienfisom in Conciliis Provincialibus editae è quibus eas,qua à stephano Langiono ad Henricum Chichley funt latre, ertditis Commentariis illuftravit Gulvelmos Lindarood, lcigum:Doctors Officialis curix Cantuarienfes conftitutus à Cbicbleio Archiepifcopo; (qui etiäm Legum fuit peritifimus) \& 'ingulariter eft commemo andus,cum Git primarius inter paucos Anglos, qui lukris Romani fcientiam in Scripris prodidesunt.llle yerò cùm effet Offecialis-Canturarienfis d.Rege. Henrico V. Legatus mif- 
- Lus eft ad Reges Hifpania \& Luftania;quibus" Legationibus defunatus poft Henrici Regis mortem redit ad munus Officialis $\&$ deinceps Cuftos Privati Sigilli ic Epifcopus Meneven/s factus eft. Artbur. Duck de Authoritar. Jur. Civil. Rom. 1. 2. c. 8 .

Guilbelmus Lyndvvode Horidiora ftudiorum fuorum tempora in lectionc juris Caforit \& "ontificii collocavit, doctulque non vulgariter in utroque evafit. Hinc famam, hine opes, hinc honorem, Officialis, ac Doctor, in : foro $C$ an $i_{\text {w }}$, fibicomparavit. Sed ur fortuna ampla aridere capit, relictis Clientibus.s foro illo utili quidem,at laboriolo, ad dulam fe contulit. Ioan. Baleus de Scriptor. Britan.

Guilhelmus Lindvvodus, Jurifconlultus Anglus. Vir in omni politions literathura genere ornatifi mus, ntpote qui felicis ingenii fui nervos in iis exercitiis per totam adolefentiam indutrix intcnderit. Cùm autem amad anos juveniles perveniffer,omem fuam forentem atatem ton milorecum fedulitate, $z$ longe majorc cum frudu; in juris tum Canonici,tum Civilis: ftudiis feeliciffmè eollocavit. Hac eniin ratione magnam doetrinam, célebre nomen acyuifivits s fibi ad funmos honores viam compendiofirmam munivir. Pitjens de Illutribus Angl. Scriptor.

Creterim tacerinon deber Lindvrodum ad Conciliam Bafileenfe ab henrico VI. Regelegatuminfignem Rggio nomine Concilii Paribus obtulire Appellationem contra Pontificum Romanorum fafum \& arrogantia n, RegemquenulHum in teris fibi in temporalibus fupcriorem agnofceic pradicâfe. Appeilationemiltam ab omnibus Concilionm Editoribus hucufque fummà fraude omiffamconquexitur Iamefurs Tractatu de Corsuptione Patrum, pag. 201. Henr. Whartonin Append. ad Hif. Literar. Gul. Cave.

Huyus Linvioodii Opera ( etiamfnanc confiderentur at Almanachus antiquatus ) apud cos qui judicio pollentin pretic erit, quamdiu viguerïat Ermditio \& Jrbanitas. Thorn, Eulter. in ejus Hift. Ecclef Anglicè.

Extat Provinciale Oxorit 679 . in fol.

Extat catdogus quorundam Archicpifcoporum Cantuarienfum, Londini is57.

Collectiones Confitutionum Provincialium gitatuordecim Archiepifiopo-

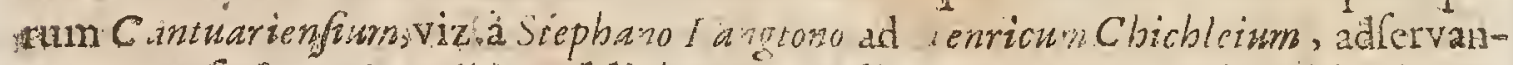

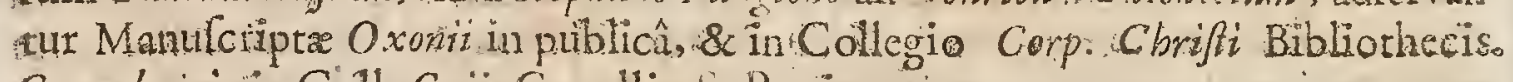
Cantabrigiain Coll. Caii, Gonclli, S. Petri.

$$
\text { JOANNES WHETHAMSTEDUS。 }
$$

Clar.An. D. A Liàs Frmmentarius à laco ubi natus eft, frc cogineminarus, ordinis. S. Bene-

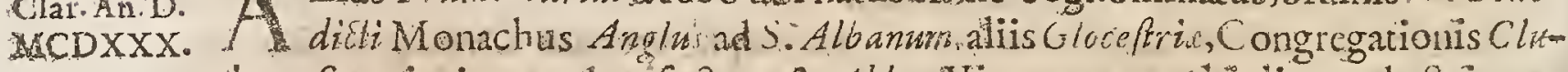
niarenfis qui etiam tandem factus eff Abba.'Vir propter multiplicem doctrinam, \& fingularem líguaru peritian, fuo tempore celeberrimus. Erat etiam ändufria mitabilis, aceni niangenii, folidiffrni judicii, \& incredibitis in rebus agendis prudentic. Propter quas infgnes animi dotes, dici vix poteft quanto fuerit in pretio apud viros principes \& magnates. Hurfredus Gloceftria Dux fingularis bonarum litcrarum \& litteratorum hominum fautor, 进um in deliciis habuit, \& 
mon ratò divertens de rebus variis familiariter cum eo contulit, ejufque confihio \& hortatu multa tantos Principe digna fecit In ejus denique gratiam Conobi Bibliorhecam, comptis variis, iifque felcetifimis libris liberaliter auxir \& ornavit. Abbas etiam bono Principi vicilin quoldam libros donavit, fuumque de viris illufribus elaboratum Opus ci dedicavit, \& exemplar unum fuâ manu pulchiè defcriptum ipfe tadidit. Hæc mihi Lelandus in firo Catalogo fubminiftiavit. Loan.Pitfeus.

Foannes Whethampstede, aliàs Frumentarius, in Albanifano Monachus, vit ad yariarum Attinm potiùs cognitionem, \& Antiquitateme tenebris eruendam. quám ad cloquentiam compolitus. Ioan. Balueus.

Dicitur in cantum ftudiis delectatus, tam impensè libris legendis atque et:am far bendis intendilie, tt aconomiam \& res fui Conobii penè neglexerit, ideoque sandem gravem Monachorum fuorum indignationem in fe concitalle $8 \mathrm{~kb}$ îs ( quad olim Hefrado, ob rem familiarein szudiorum -causâ neglectam, filios feciffe ferunt) in jus vocacum fuille.

Joannes Whetamstead natus eft in loco cognomine Comitatûs Hatforaicb, nan cam celebri ob Frumentum optimum a quo nomen mucuarur locus natalis, quàm obleannem iltum Whetamftead qui à Loco denominarus eft. Educatus fuerat in Prioratu Tinmouth provincix Nortbumbrice, quem Aureo Calice $S$ amo donavit. Fuit poftnodum $A b b$ as S.ALbani, atque fextus Cbriftiani hujus Nomin's. Taltisimpenfis hanc Ecctrfam adernavit, cùm fex millia Librarum ex*efferint. Duos Criticifmos omittcre non pollum circa ejus Adificia: Unume -quod ad Septentrionalem partem Ecclefie, cui novis feneftris majorem lucem conciliavit ) Statuas potuerit Etbricorum Pbilosophorum qui de Clorifi Incarnatione teftimonium culerunt. Aitter elt guod in exiguo $S$ acello (huic nomer Tittenbanger) Imagines crexerit omnium Sanctorum quorum Cbristiand Nonina fuerant Ioannes, cum Gui ipfius PiEtura-\& hac Precatiuncula Difticho comprehenla, Ut guarrais wignus propter momen fum in Calis locum babere pofiet. Propterea procuravir ab Humfredo Gloceftria bono Duce, magno fuo Meconate, qui apud S.Albanum fepultus fuit, yeftimentorum Synthelm pretii ter mille Marcartm; \& PembrokitDominium in South-Vallia.Plurimi funtLibri quos Po. fteritati reliquit, c.m non pauciores quam odtoginta \& ultra numerentur TraRatus. Diem verò obiir circiter anno 1440.Thom. Fatler libro de Viris l'reclaris Angtie. Anglicè

Hoc cjus Epitaphium, quodam Monacho S. Albani, Audore.

Contegit ifte Lapis venerabilis offa Joannis

wheihamftede, Abbas bic qui fuit ejus in anis:

Ter doctus, doctos of arnans, of eis miferatus.

Nec fraudes patiens curarum Presbyteratus.

In lubricos Phinees, in adulteriblque Joannes

Eartititi ymo Petrus in omnes Symonianos. 
Infuper in laceris domibus manfifque vetuftis s.

Sic reparator erat, fe reparando novabat.:

Quod fibi preteritus non fit compar $P$ ater ullusio

Sive coequalis manet impar rebus un ifis.

Marcas Millenas decies numero reperitas

Scripta fertint pof fe eque liquerat expofwiffe:

Pro dilectoris anima tui dulciter ora;

Albani Switi conwentus, gualibet loora.

Weaver's Funeral Monuments.p.56\%

\section{ALPHONSUS TOS TATUS}

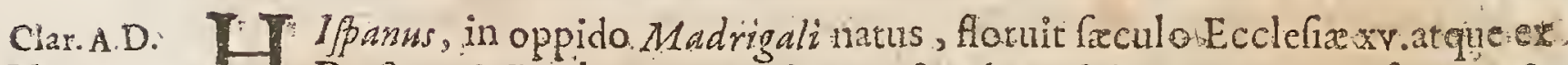
MCDXl. A Doctore \& Presbytero Salmanicenf. Abulenfis in Hifpania Epifcopus, \& Confliarius Reg:us, Majorque; ut vocant, Referendarius, obiilfe diciruranno Chr. If54.annos tantìm 40.natus. Concilio Bafleenfi interfucrat cum foanne. Capreolo plutibufque aliis viris do atis. Opora ejus valuminibus xxv11. Tenetiis edica, Anno 1596. Phibip.Labb.

Alphonfus Tofatus, Hijpams, ex oppisoinadrigali, propemodim puer Salmantica liberalibus Difciplinis operan dedit. In Collegum S. Bartholomai ad Latrumadicitus, facris Ordinibus primò initiatus, deinde creatus Epifcopus Abulengs. Cùm duo \& viginti annos explevifet, fientiäs, difciplinafque penè omnes clt allecutus, ut præer Pbilofophiam \& Theologiam, Pontificinmque \& $C$ afareum jus, in Grecâ, Hebraicâquelinguâ, in CHathernaticis item, atque Geographia, fed, \&in Hiforius excellueric. Vir memona mirabili, peracri in rebus publicis explicandis judicio, \& ( quod caput eft) magnâ fanctitatejquän jejuniis, vigiliis, orationibus, admodum forit \& ausit; virgo natus, virgo quoque (ut conftans eft fama) doceffro. Quamobrem quia in Ecclefia humatus eft,ibidem eximi veneratione colitur. Quadragjnta duntaxat annos vixit, quibus, 2 Salmantica publicè docuie, tr plici tipendio conductus è publico, id quod five anrea, five poft illum nemini contigit: Regis Confiliarius, Hifpaniarnquac Major Referendarius: deinde Epifopatús quoque munere fungens, tot, ac tanta duode. viginti annorum fatio fcripfrt, quot ne attentè quidem perlegere aliquis poffit. Sacrarum Literarum m nutiffma quxque: Noown autem Teftimentum admiran. dis Commencariis explicuit. Ant.Poffevini.in Appar.Sac.

Vir fanctirate \& doctrinâ celeberimus--.--de quo meritò friptum ett.

\section{Hic fupor eft mundi, quifcibile difcutit ome.}

Ex quod magis eft admirandum, tanta fcriplit bieviflmo tempore, cùm non

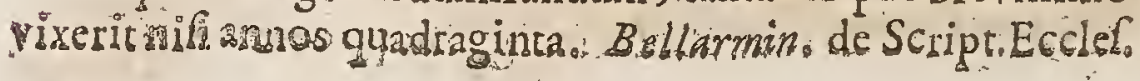


Ex tam infunitâ doctonım hominum multitudine; quantam hæc atas haBbuit, nemo citra controverfian ad Alphong Tostati, Epifcopi A Aulengss. laudem ad piravit: cui fialio, quam fuo feculo, vivere contigilier, neque Hipponief ng finurs, ne fue Stridoni Hieronymu, nec alium quempian ex allis proceribus Ecclefin antiquis, nuncinvideremus. Excellentis vir ingenia fuit, \& admirandx menorix; divinx etiam fapientia, \& antiyuitatis perit:llmus: dignus fortaffe, qui pont quatuor Ecclefie Dootores a cum 1 fidoro, \& Thom mâ, de quinto loco cerraret. Quod fi purior quadam, Splendidiorque confuetudo loquendi luis temporibus fuiflet: non dubito, quin ponteriores omnes in fui admirationem converfurus effet Aiphonf.Garfus Matamor. libro de Hifpan. claris viris.

clphonfus. Tofforus, Scriptorum mole, antiquitatis cognirione, eruditione multipliciad miraculum clarus auditor Olear.in bac.

Alphonfus Tofatus Epifcopus Abulenfis, vir ingenio, judicio, ac pietate exim. mius. Ioan.Card. Bona.

Tofati acumen placet; viri, fi in meliora fecula incidiffer, longè maximi. Caso Gabbiexcrcitat.ad Beron p.;2j.

Tanta retum factarum cognitione excelluit, ut co feculo doctior, ant fapien-

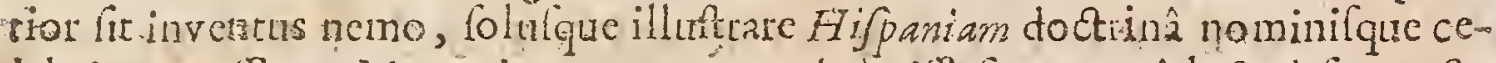
Jebritatapof́ret. Memoriam quoque cam habuiffe fortur, quâ lecta à fe cunets veluti Thelauro contineret. Laboris vero patientia ufque co cnituit, ut quod de Didymo Alexandrino jactatum ferunt, anea habuife intefina putarctur. Hripan. Bibliother.

Alphonfus Toftatus - Vir fanè Atupendx memorix, incredib lis diligentix ac rari planè judicii; qui non modò int ma Theologia Adyta penetrârat; led \& reconditiorem exterarum difciplinarum, Philolophie, Mathematica, Geographiæ, - Hiftorix ac Junis utrinfque fientiam toto, quod ainnt, pefore exceperar. Nec tamen pietate minus ac religionis zelo, quam doctrinâ infgnis; jejuniis, vigin liis, \& orationibus perquam deditus ; adeu ut deftncti meno ia apud populares fuos eximià veneratione colcretur. Diligentiam ve ò quod arrinct, \& indefefo fum legendi firbendique trudium; certè ominm non firi modo, fed cunctorum

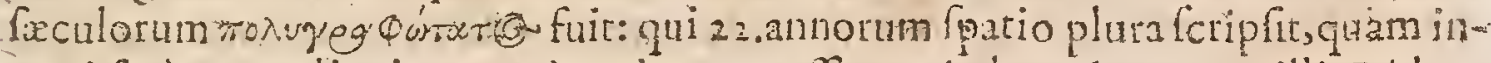
tegrâ ferè atarc aliquis attentè perlegere porft ; ut in hoc decantato illi Didy Alexandrino conferri foleat: quem admirandâ etian momorix folicitate ita cxaquavit, ut nil unquam femel perlectum oblitus feratur. Sanè ut immenfa, qu= typis excufa circumferuntur, taceam Volumina, quadringenti illius libri, dum ex Hifpantis in Italiars pralo deftinati a tveherentur, nanfragio interiife dicuntur. Ne tantas tamen dotes. labe aliquâ immunes cen eamus, nomulli in co debitam erga SS.Trintatzs mylteriam vencrationem, plures majotem erga Patres revesentiam, omnes Styli nitorem atque elcgantiam defiderantut Pontificiorum criminationes mittan, qui illum nimio placita fua à Card. Turrecrementâ impugnata, \& ab Eugenio Pontifice notata, defendendiltudio abreptum iplam Papalem

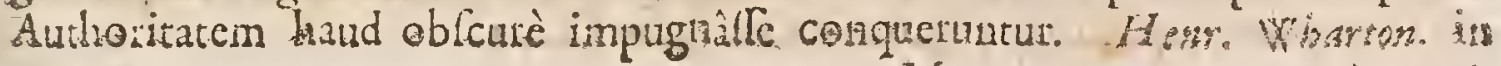
Mm m 
Append: ad Hift. Literar, Gul. Cave.

Quamvis Alphonfus Tofatus Hifpanus Commentariis fuis in Scripturam valde etiam diffufus fir, \& de illo dici foleat Qui fcibile difcutit ornne, felix tao. men eft in fuis digreffionibus; adeo ut ejus lectio utilis effe poffit, quia Doctus. eft ac in ltylo Bibliorum exercitatus. Quæftionum ferax eft; quas Textus fui oc- cafione movet.Sed Argumentum fepè longè nimis protrakit, bonaque interdum pars Commentatiorum ejus præfcindi pollet, licet idcircò minus accurati non effent reman'uri, quia nimium multis inusilibus referti funt. I el Richard Simo Hif.Crit.V.T.1.2.c.9.Gall.

Tor, tantaque funt ejus in Sacram Scripturam Commenaria, ut fi vel d primo. natali dies numerando, terna cuique folia artribuas, pluia fcripfilte comperias. Aubert. M1 iraus de Script.Ecclef.

De Tofati in Hebraicis ignorantiâ evolye Michaelem Ff avenanwrn. Theba gnof.p.\&I.,

In eodem majorem quoque erga Patres reverentiam defiderat Ioannes Lorinith Commintariis ad Pfalmos, p.83.

* Opera hujus Auctoris cautè legenda fumt . Vide Indic. Madrit. edito:667a.

\section{GEOR:GITS: TR:PEZUNTIU:S}

D. Clar.An。

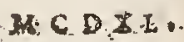

Rotenfis, natus eft anno 1396.obiit an. 4486 . Eugenii Pontificis temporibiz Romam venit, polteà à Nivicolao V. Scriba Pontificius factus eft.. Multad Gracistrantulit: Nec pauca ipfe Latinè compofuit. Scripfrt etiam Commentariotum, in quoafferebat, Koannem Evangeliftam nondum effe mortum. Platona: iniquior fuit, nec lawdem ejus ferre poruit, Ariftoreli unicè deditus . Plätonis tamen pares Card. Bejfarion tuendas fufcepit. Ad extremum Trapezuntius literasum prorfus oblitus eft. Konig.in Biblior lis.

Is Grecorum ferè primus Róne eatum fecularenalcentibus literis; qui Grace feliciore ftylo in Latinum verterit exiftimatus eft, uti liquidiffmè conftat ex: Arifotelis, facrifque Eufebiz Cafarienfis operibus, \& ex Rhetoricis preceptis. Hermogenis. Erat enim ingenio ad lucubrandum maximè valide, vehementique, fed uti mox apparuit, terici livoris pleno:nam cum fe Peripateticum profitereEurunumque Ariftotelem extollendo celebrarer, ufque adeo fuperbâ aure fuit, ut nec divini quidem Platonis ingenium laudari pateretur: cujus etiam dogmata. \& mores peracerbè ac infolenter ediro famolo volunirie lacesarst. Paul. Fov.in Eloz.

Virum egregiè doctum, deque re literaria pulchrè meritum, vocateum Eraft. mus in Ciceroniano; fed addit, abfolutiorem hû́c fuilfe Theodorum Gazam.

Profectò jultam laudem non ibo. Trapezuntio ereptum. Artamen nec tanta: ejus eft apud me auctoritas, ut ejus fententia apud me fit Minerve quidam calculus.Minimè profectò conferri meruit cum. Theodoro $G a z a ̂$, cui eum æquiparavit: Angelus Politianus:itaque jure politiflumi ingenii virum thoe nomine reprehen: dit Parrafous in Epiftolis. Voj:Inftit. Orateviar.1.4.c.3. 


\section{CELEBRTORUM AUTHORVM.}

Neque ignoro, Trapezuntum errores aliquot obfervatfe in tranfationibus $G a$ ze, quos hic monitus cortexistiti \& mèmorix prodidit Erafmus: verum \& illud fcio, longè plura elfe in Trapezuntianis, qux Gaza potuerit cullpare. Nam \& in eo defiderare posuit fidè plis in tranferendis è Greeco auctoribus, \& majorem $\mathrm{L} n$ gue Latina peritiam. VofJibid.

Sxpe labitur.\& hate fielem fe preftitit in transferendis è Graco auctoribus. Dallaus \&: Perronianai-

Nonnunquam Auttorem funm intra eas conchiodit anguftias, ut tora ejus membra recidat;quorum \& ordinem quandoque audet perverrere: Nativos præterea fenfus neque rimatur feliciter, neque politè reddir; $\&$ quibus fulis excufari poteft interpretationis licentias, vel a fpernatus elt elegantias, vel alfequi fe polfe-delpexavit. Huet. Clar.Interpas.

Georgzas Trapezuntius julfi Nicolai V.ita in Latinum vertit Eujebizlibros De Praparatione Evangelicâ, ut fentibus Arianorum amputatis, rofas tantùm homimibus Latinis obtulerit.Chriffoph.Chxiltophóri Sand. Nucleus Hitt. Ecclef.

In hoc omnes eruditi conlentiunt quod Trapezuntitis Eufệbiz Contextum ab 6 que fcrupula mutilaverit atque truncaverit, ejus fenfum perverterit 2 \& phrafes lăbefact:verit, plura ejus capita puflim preteriérit, tonmque decimumquintum librum intactum deferuerit: Adco ut vel ipf Eufebio fi ievivilceret fas non effet fe. ipfun apud Trapezuntizm revifere \& agnofcere.Eruditorum Indicia, per Do-

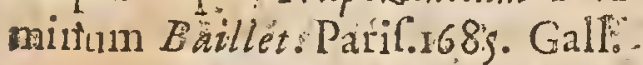

Arrogantia ftultitia quædâm eft", qux ultra modum ingaginationem infla quxeque arrogantem fupra vilies ingenii ejus ipfum impellit ad temete judicandum de aliorum agen đi ratione, \& 'apè damnandia qua laudet \& applaufu digna funt. Georgï Trapezuntii plenior fuiflet fama, ejufque Docttina dẹ (Plendore fuo nihil deceffiffet, fi in hanc mentis ineptiam nor incidiffet, qux vergente ejus atate in veram fulcutiam degeneravic. Ifaagus Bullarto A cad. Scientiaram \&c。 Gallicè:

De Trapezintio quidam memoria tradiderunt, exiremo fenio preffum \& mor bó gravi détentum, poitquan ad valetudinem redillfet, literarum omnium fuiffe oblitum; neque legere aut feribere poriuffe; quod ex dolore illi eveniffe ferunt: properea quòd ejus opera Ponififi Maximo oblata, centum ducatis antùn compenfata fuilfent, Is autem è Vaticano Palatio domum fe conferens ${ }^{2}$.. indignatione percitus ex ponte $\mathbb{E l i o}$ pecuniam ab ingrato acceptant in Tyberim abjecit, additâ exclamatione, Periere labores, pereat corsm ingrata merces.". Bioifard.Icon.

Quem ego fenem puer docentem audivi. In extremâ fenectute oblitus crat" omninò literarum, folufque per urbém baculenixus incedere malebar " Rapbaeb Yolaterran.liz.

Multa in geatiam Aula Romana peffimè corrupit. Scitite Medul. Ratró, g: 856.

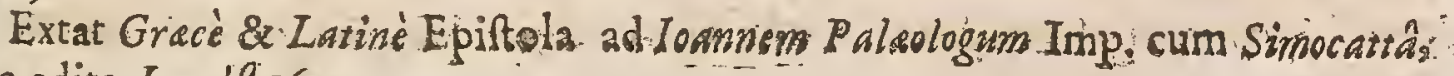
Lc.edita Ingolff.1604: 


\section{C.ENSURA}

Extar liber de Proceflone Spiritu S.ad IoamomC. uboclefum; \&e Epitola ad

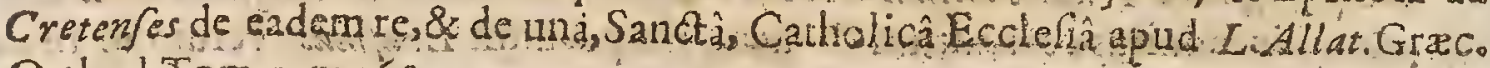
Orthod. Tom, I. Pi 469

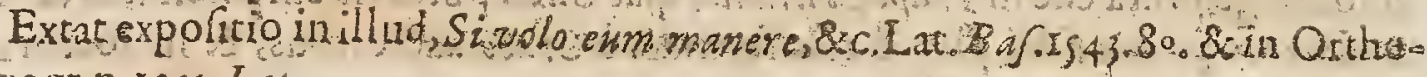
doxogr.p.1 231. Lat.

Extat CM artgrium Andres Chienfis apud Sur Mail 22.

Clar.A.D. 蛅 $C$ D $x \cdot x$.

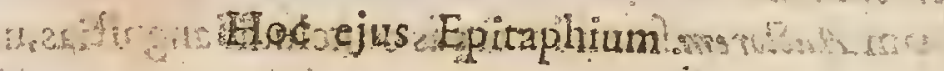

Fac urna Trapezuntif quicfomt

Georgil ofja, parm Deis amis

Quid acri, on nimiurn procace lingu

Platonem, fuperis purern petirize

\section{LAURENTIUS YALLA}

D Atricius Romanus, Canonicus S.Ioannis Laterani, Grammaticus, Rhetor \& Philofophus clarifinus, Theologix Doctor, Graca \& Latine Lingux peritifnus, Inimicifums fuit Pog gio, qui inoppide eitionis Florentinow rum natus, Rome fumma in authoritace vivebat in antâ Pontifici literam Apoltolicarum fcripror, vir quidem facetus, \& dictriis clarus paulogue amarior quàm par, fuit. Is in Vallam multa fcripfit accibiore fty lo, cui \& Valla refpondit non lcniori feripto. Scripfit praterà plurima alia erudirione plena at lunt Elegantiarum Lingue Latine libb.6. de rccipocacione fur \& funs in Antcnium Rasdensem: annotationum lib ad Alphonfum Regem Arragonism Epifo-

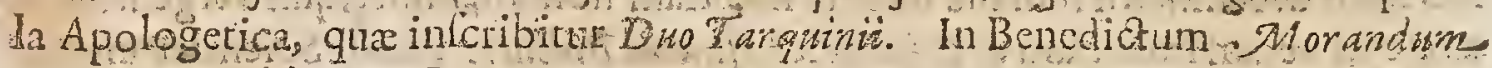
Bononienfern libr.2. In Bartolomatm F acium Ligurem, \& Antonitum Penhormitam recriminationum $1 \mathrm{~b}$.4. Ad Candidum Decembrem in Bartoli de armis \& infigniis. De Dialectica, lib.3.Apologia ad Engexivm Pontificem contraçalumniatores. Annotationes in Novum Teftamentum. De Volutute \& vero bono lib.3. De Libero Arbitrio ad Garfarn Epifcopum Illerdenfem. De geftis.Fer-

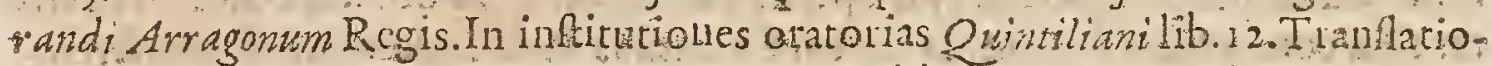
nem fliadis Homerice, Herodoti Halicarnaffei libios novem Hifforiarun Latinitate donatos: \& e Afopi fabulas. Scripfit \& Libellum peculiatcon contra Privilegium donationis Confentini Magni, quan fallam aldsrit, \& ementitam. Boifo fard.in Icon.

Laurentius Falla, Patritils Romanws, Grammaticorum huịs atats longè priti ceps, Philofophus, Rhetor, \& Theologus praftantifinus, ingenio fubtilis, acer \& vehemens, Latinam eloquentian Grece preferens, multa ad ejus ornatum compoluit, Greci \& Latini Sermonis peritilimas, edidir non pernendelection Opucula, quibus nomeu fumm ad notitiam folteritåj çum Laude tranfmifito Tritsem. 


\section{CELEBRIORUM AUTHORUM. 463}

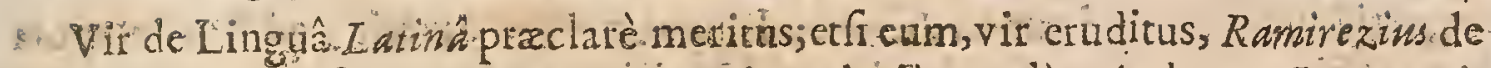
Irado Hifpanas, fuis in Martislên nơtis,audaciùs paulò Audacem Grammaticum;nti \& ejus libros in inelegantes elegantias appellat. Omninò enim illis tempo ibus Magnus fuit, \&sacutus Rcmani Sermonis cenfor:qui tamen non rarò के veritatis via defledts ; idque imprimis contradicendi morbo; quo veliementer laborabat: us non temerè omnino in eum jam olim dictum flt:-

Carpismajores, of te grogues Valla, minores.

Comperis, Carpis: Sic tisa fata ferunt.

Eof.de Confrucione, cir:

Unuius Zawrentiz mordacitas (fiquidem ita malunt appellare) non paulò plus conduxit rei litcrarix, quàm plurimorum incptus candor, ommia omnium fines: delectu mirantium, fibique invicem plaudentium, ac mutuma, quod aiunt, faben= tium. Erafm.1.+.Epilt.7.

Verim efto;mondacion aquo fuerit:num ideo fallum dixit; quía verum mor dacius dixit?ufqueadeonobis odio eft ifta mordacitas, ut cjtas odio, tan multa fcitu d gna,neceffariaque deteltemur ? Adeo nihil ignofcendum putamus ei qua tot mod's profuit? - Quis tam exigui animi eft, cujus pectus tantis invidia anguftiis concluditur, ur Fallam non \& magnificè laudèt, \& anet quàm maximè: qui tantâ induftriâ, tanto fudio, tantis fudoribus, Barbaroran ineptias refellit... literas penè fepultas abinteritu vindicavit, prifco eloguentid fplendori reddidit

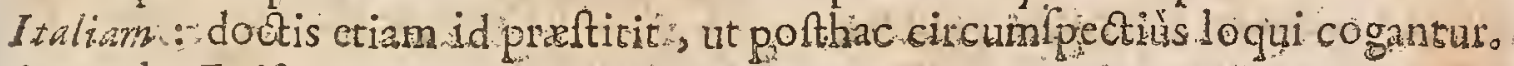
Erafor. 1:7. Epilt.3\%

Quòd verò Erafrnum \& Vallarn Clolos dixit Bellarminus id conviriumef fe, \& quidem impudens, omnes fent , quibus duo illi viri vel ex ungue nori funt; optinè luo leculo de literis facris, prophanifque meriti: \& , fi Bellarmini libri perennaverint, omnes pofteri os liominis mirabuntur; qui Sciolos cos vocareaufus ent, quorum axingenium planè eximium fuife, \& animum in inttan ndis biteris maximum, \&labores felicifinos; ac rerum denique Divinarnim atque FH uranarum ftupendam;pro illius prafertimtempatis captu, cognitionem, qu diutilnmè(f quid conjicere liceat) fupererunt, ipforum Opera loquentur. Sed viros egregios híc contumcliâ affici, à quoquam quidem indignum êt; à Bellarriz̀-s rovero indigniffinum; quem nemo opinor eruditus negaverit Scioli nothine multò efre, quam Erafmum; \& Vallari digni orem. Fa Dall de libr. fuppol Dionyf Areop. \&'Ignat.1.I.c.36.

Propitis accedit ad curam ac fubtilitatem Quintiliani, quàm ad illaboratam Ciceronis facilitatem, quanquam cateris (Leonardo Aretino, Pogyio Florentinos \& aliis ) elimatior \& purior. Erafm. in Ciceroniano; 5.157.

Laurentio Vallengî quemnam in hâc arenâ præponamus, non viđeo: Nemo

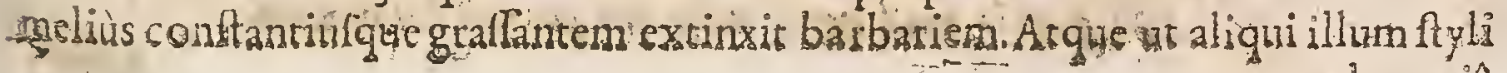
elegantia 
clegantiâ vicerint, qui tamen Latinam Linguam xquè juyerit, ad hac tempors non extitit. Franc.Florid.Sabin in Apolog. Ling-Latin.:

De $P$ andectis verò quid fentiam, malo alienis verbis, quàn meis diccre prodear igitur aliquis Latinorsm operum xitimator idoncus. Is evitiLaurentius. Vatlenfis, vir; certè cùm Latine doctifimus, tum verò alienorum Scriptorung judex;ut optimusfic ninimè anbitiofuś, lid quod invidiofum nomenejus vulgòreddid $r_{*}$ ut jam publico confenfu, Latieè ignorantium, tanguam iniguss Judex ferè rejiciacur. Gul.Budans. Annor.iu Pandect.prioribus.

Law entius? allenfis vir non minus de Rep. Literarân meritus, guàm Camillur olim de Roman $\hat{a}, V_{0} / j$. de Rhetoricâsp. $t^{8} 8$.

Proprictatis Latini Sermonis intellyentifimus. Scriver. "In Martidl.

Lawenizus Walla aggrefus eft reconcinnat:onem facerc Dialedice, in quâ dife Centi if Lristotele, \&Peripateticis veteribus, ac novis. Monet in guiloudam neutiquain prav è etf ea funt perpancain plerifque labieur, ut fuit vir ille vchemens, \& ad faciendumjudicium præcipitatus. Nec folum in re Dialedicâfalfus eft fedin Pbilofophiâ, nam hanc quoque attingit, \& quìd magremirere, in precepris Latine Lingux Lud.Y'iv. de Caul, Corrupt. Art. 1.j. (2.23\%

Yerbis cum puris tum etiam propriis uritur: qux ante Elegantias fcripfit ar de voluptate, minus funt accurata, quàm qua polt eas. Idern de Tradend.Difcipl.1.:

Annis abhine ducentis Herodotum \& Thucydidem Latinis literis exponebat Laurentius:Valla, in eâbene \& eleganter dicendi copiâ, quam totisvoluminibus explieavit, inelegans tamen, \& penè barbarus ; Gracis ad hoc literis leviter.tin-

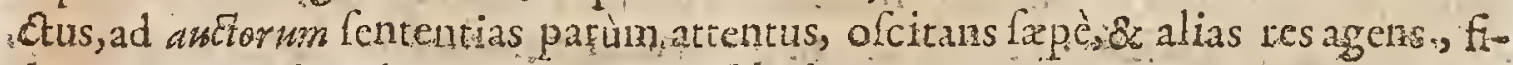
dem apud eruditos deconit. Huet. de Claris Interpret.

Paulus Iovius hoc judicium tulit de libris Laurentii Valla de rebus geftis Ferdinando, Arragonum Rege: "Opus loc eo Atyli charactere perfcriepfit ut ejus minime videri polfit, qui crteris elegantiararm pracepta tradideric.

* Laurentiv Valle Annotationes in Novum Tefamentum; \& liber ce Perfond contra Bofhrum, prohibentu, nificorrigantur: Ejuldem verò Libri de Falsâ.Donatione Constantini; de Libero Arbirrio, de Voluptatesomnino prohibentur. In, dex Roma-inaptellus Anno 168. julliu Innocentii XI.P.M.

Extant 8jus Annotationes in 2 ovum Teftamentum, Bafilea $1540, \& 1545$.

Extar liber de fictâ Confiantini donatione. Bafilea 1566. fol.

Extant libri 3.de Rebus geftis i. Ferdinando Arragonum R ege Franc.1603.

Extant Libri 6.de Elegantìs Lingux Latina, Lugd. I544. 80.

\section{Hoc Lamentii Valla Epitaphium.}

Obe! ut Valla filet! Solitus qui parcere nubli est. Siguris quid agat, nunc guogue marde bownw 


\section{CELEBRIORVM AVTHORVM.}

\section{Aliud:}

\section{Nune postguam Manes defunitus Valla petivito Non audet Plato verba Latina logui. Juppiter bunc cali dignitatus parte fuiffet, Cenforen lingria fed timet ipfe fus.}

\section{Phil. Labbe in Thefaur.Epitagh.}

\section{FLAYIUS BLONDUS}

7 Talus,Forolivii natus ot anno Dom. 1388. Eugenii.IV. Pontificis Romani Se1 cretarizs:aliorum quoque Romanorum Pontificum, in is Pii Secundi, SeClar. Ar.Do M c $\mathfrak{a} \times$. écctarius fuir. Obït Rome dic 4 Juni, Anno $1463 . x t a t i s .750$ - Blondus Elavins: Forolivien/is, ho mo multe crud tionis, Romam veniens proprer infignem quì pollcbat doorinam, ftatim omnibus innotuit:Er ut illo frectto fcientie rare erant, barbarie occupante omnes fere Chriftani Orbis Academias, quoticfunque ex illo ignorantix Baratho emergebat aliquis cognitiene bonarum dilciplinarum clarior, ftatim cxcipiebatur cum plaufu \& admiratiene omnium : Idem accidit Blondo poftquam Romam venit favore aliquot Cardinalium, qui apud Pontificem gratî̀ \& authoritate valebant, commendatus eft Eugenio P.M. in.cujus aulam rcceptrs, Epiftolarung Magifter factus eft. Uxorem habuithonefto loco: ex qua fufcepit quinque filios: qui omnespatcrne doctrin \& $\&$ virtutum, ficuti \& facultatum haredes facti funt. Pater licèt gravibus affièilque negotiis in auli Pontificiâ 'occuparetur, non tamen defiit multa fcribere, qux in lucem emiffa funt magno Reipublicx Literaria emolumento. Scripfit enim Becades tres de Geftis Romanerwm lib. 3I. Vel Decades tres. De Roma triumphante libr.ro. De Romá inftaurata lib. 3. De Italiâ illurtratâ lib.8. Prater hizc extant illius Epifolarum ad Diverfos lib.r. Orationum lib.1 \&alia plurima opufcula eruditione plena. Boiffard.ing Icon.

Flavius Blondus magno aufu, fingularique induftrîa,nec infelici eventu, multorum annorum intermoricntes res gertas è tenebris excitare orfus, Decadak confcripfic quibus ab inclinante Romano tmperio funetta tempora, ac idco veritat is luminc orbata, in lucem proferuntur. De vetuftate quoque collapfe urbis ac ejus demum refurgentis dignitate, erudico operofoque volumine publicato Guantam nec anbitiosè quzlitam exoptarit, in literis authóitatem adeptus elto Pawl.Iov. in Elog.

Blondus Flavius, vir in omni bonarum Artium difciplinà peritus, Phílofoglus \& Rhetor celeberrimus, \& Hiftoriographus infignis, ingenio execilens. eloguio difertus,\& dicendi gratia nulli fecundus. Trithem. 
Pra cateriș autem Flavius Blondus rariatque folicitiingenii homo, \& crim diligentillums antiquitatis inveltigator, rum Hiftoricus urbem hanc ortu illuAtravirfuo. Leand Allbert. in Ital de Foro Etvit.

Blondus Flavins, Hiftoriarum fcriptor egregius---Pracul 'Blondius ab elos

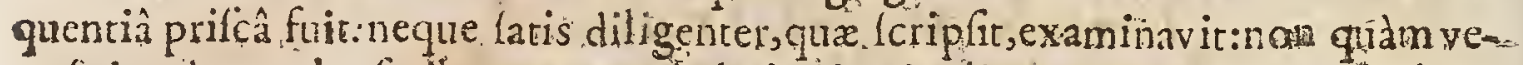
ra, fed quàm multa feriberet, curam habuit. Si quis aliquando vir dotzas, fribcndi peritus, Opera ejus emendare atque omare decreverit, haud parum utilitariss polterisafferer, \& feipfum clarum eficiet, multarum atum geftis, qua p opemodumfepulta funt, in lucem redditis. Io.Gobetlin. lin r. Comment.de Reb. Fu XI.nemorabilib.

Blondi. Flavii Forolivienfis hoc in negotia fummum ftudum amplectimur; quamvis in fribendo non admudum el egans habeatura-nec define, qui ab eo veritat is fidem mult is in tocis requirant: al oqui non paucis etiam. Intulentus Auere vilus eft Etorid Sabin.in Apal.adv Calumn:LL.

Ad honorem Blondiron parum pertiner, quod fripta illius in Epitomen contrahere dignatus fit Pirs Pontifex. D ctione eft nom admodum culta:: ur. etiam Volaterromus agnofcit, fed de Antiquitate tamen, utcunque interdum aliquid humani patiatur, fanè pra ærare quâ vixit, aptimèmeretur. Mofje. delift. Lat.

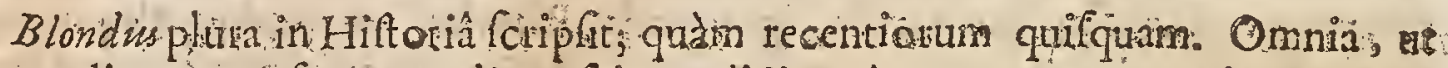
libere dicam qua fentio, meliare fide tradidit, quàm event utpote is quinona nulla; quibus ea perquirenddederat; temeré crediderit. Namper feomnia videre poruille, abrurdum eft credere : cùm nec ex autore una,j fed penè innumeris, atqueili is ipfis ambiguis \& variantibus, muta quxenda efent necipfa: dicendi figura multum el farois conciliat. Nam praterquam 3 quad ubique:

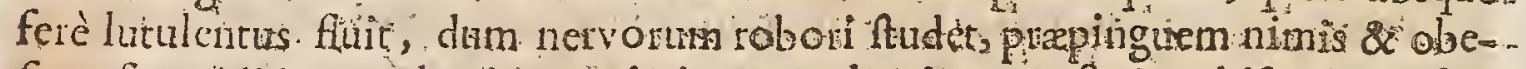
fum fe reddidit : ademitiqu nimia corpulentia venuftatem hiftorix. $:$. fne. qu prodelfẹuidem poteft, delecta verồminimè fed hxcille accuratâ narratione rerumque varictace compenfat: Hubert Gafard Obfervar fuis in Ling: Liz.p. 396 .

Flavius Blondis eft bonus, fed omnia qux ibi funt, funt \& alibi: Scaligerana: polterion.

Evane Opera Blondi Flavi-Baflea rss 2 alibi.

Manteriptus extat Cantabrigia in Collegio S.Beneditt: Oxaniz in Bibliöthecâ Balliolenfs efr Munufriptus Btondius de Cofmographiâ Italise. Blondus, an alius, fignetusinquit Vojfus, melius dicent qui vidate.

Obiit Rome, inque Capitolio jtixta Deipare. Templim fepultus eft: Nemepe in arâ coeli ante introitum Templi, ubi rale ejus Eptraphium, ut êt in $F$. britii Roma:

Blondo. Flavia Fonolivienfi, bifforico celebri,multorum Pontificum Romanorum Ses cretario, Blondi quirique fili patri bene merenti innanimes pofuere. Vixit annos

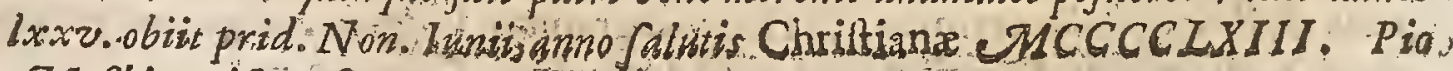
P. Mabinatigime fivente. 


\section{CELEBRIORUM ALTHORUM.}

Hoc ejus Epitaphium d fano Virale compolitum en

Eruis è tenebris Romam dum Blonde fepultam.

Es novws ingenio. Romulus atgue Remus.

Illi urbern forwwere rudem: celeberrima: surgit

Illa eadem studis, ingenioge, twis.

Barbarus illamibofis ruiturain evertit: at isti

Nulla urrquain poterunt tempora obefjectua.

I ure triumphalis tibi facta ef Roma Sepulchrum:

Illi ut tuvizas, vivat ut illa tibi.

Phil. Labbe in Thefaur.Epitaph.

NICOLAUS CUSANUS.

T I colaus, à vico, ubi in lucem editus elt dicecel Treviren 1 folle èrcyione Orficaftri, Cufanus vulg, five de Cusâ dictus, ex Decano S. Medxivira Fonini Constantren is \& Archidiacono Leodienfi Brixinen ins in Comitatu TiroLenjE E i coptis, \& S.R.E.Cardinalis titulo S. Petri ad Vincula a Nicolao V. Papa cratus 20 . Decenbris anno 1448 obiit Tuderti in Vmbriâ anno 1464 . die 11. Augufti natus annos 6\%Rome lepultus. Phil. Labbe de Script. Eeclef.

Vir in divims Scriptiris erueditilimus, \& Theologorum fuo tempore facile princeps, atque in fecularibus literis egregiè doctus: Philutophus, Rheroi \& Mathemaricus celeberimus, ingenio fubtilis, \& eloquio difertus, thum Linguas rum, Fetraice, Grece \& Latine peritus, vič \& converlatione integerrimus, \& fingulariter devotus. Circa Cufam nativitatis fux villam ad ripas Mofello in oppofito Vrficaftri hofpicale celeberrimum inhonorem S. Nicolai EpifcopiconAruxit: quodpradiis $\&$ redditibus copiosè ditavit, ac libris in omni Scientiâ plutibas exorndvit. Trithem.

Vir in ompi literarum genere adminandus, Mathematicus, Philofophus \& Theologus, fuprà quàn cuiquie credibile frt, endiriffmus, cui docta quadan tam in verbis quam in fententis amica fuir ob curitas edidit in principium Genefcos brevem dialogum tantie obcuricatis, ut vix a doctifimis viris pollin in selligi. Sixt.Senenf.1.4. Bibl. fanct.

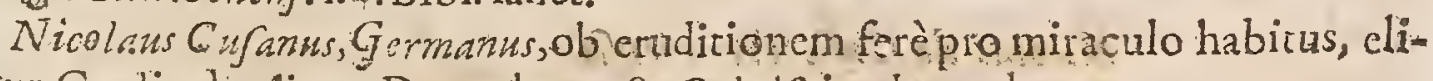
gitur Cardinalis die o Decemb, 14 8. Caluj. in chronolog.

Nicolases $C$ ufanus vit apprimè eruditus fuit. Primum reprehendit quoldam errores \&crimina Papx, poltca factus Cardinalis, cundem tueri expit. Extant tamen ejus coipta, quibus non paucorum Anticbristi mendąciorum \& crorum vanitaten refutavit. In libris de Goncordia Catholicâ refutat vanitatem Donatiowis Confantini,gua eft in Decretis \& affrmat libio 2.c.34. Vnivergale Concilium sit

Nin

2

fupre= 
Gupremam poreftatem in omnibus habere fuper ipfum Romanum Pontificem. In: libro de Pace Fidez probat, nos folâ fide juftificari, non ex merito, mul toque minus per. Truditiones burnanas, quas vehementer extenuat. Illyric. in Catal. Tef: verit.

In amni difciplinarum genere diligentiffimè verfarus, fcripfit preclasa opufcula, frepius typis admora, rribufque valuminibus diftincta. Nomenclat. Cardin. Roman.Eccler.

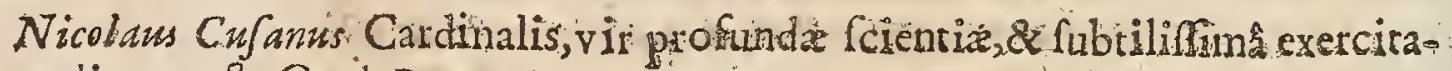
tione limata. fo. Card.Bona.

Vir fuit rquèpins ac doctus. Bchllarm. de Script. Ecclef.

Poffevinus in Apparatu Sacro virum eum vocnt, ir Scientiis penèmaibus excultum, ita peritia $C$ anonum eximium, ac reliquis vitæ donis ornatum.

Anno 4 $_{40}$ o.videlice tempore Nicolai V. \& Concilii Bafleenfis, ac.24. ann. fequentibus, magno etram ob Mathefin in pretio fuit Nicolars de C Csfa, Cardinalis titulo S.Petri: vir tantus,ut, quemadmodum de eo cenfer Faber Stapulera

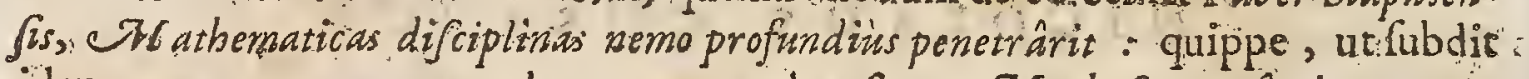
idem, que ante omne evum latuerunt, maxima sacra $\mathcal{X}$ athefeos myltexia aperverit. Voffius de Mat hem. p.62.63.

Nicolaus Cufanus, Card n. magni nominis, ex humili loco in id fâtigi eve ctus; Jurifonfultus \& Theologus infignis. In Germaniam miffus ann.I451.5 tuba.2

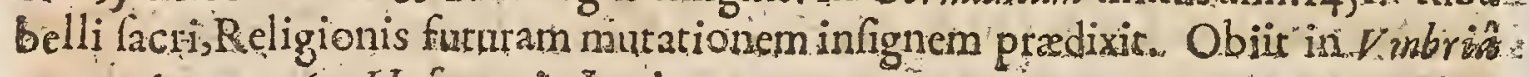
ant1. 464.xtat. 63. Hofman. in Liexic.

Cufor Germania Oppidulum: Molell 3 flumini Treverenfem DioecefintransAuenti proximè Gitum, Patria fimul \& cognomen fuit $N$ icola $C$ anonici Regu-. laris, \& Canonum Sacromm Doctoris ; Qui folertiflimè applicato ingenii fui excellenti acumine ad ferè omnes oprimas, fcientias, fpeciatim verò ad Theologiam \& deinde ad Leges Canonicas, in illa unus ex exuditifimis evafit qui feculo fuo yixerint, in his verò hulli omnium coxtaneorum ceflu, qui eafdem profiteretur. Vixit fexaginta tres annos, diefque fuos terminavit ad undecimum

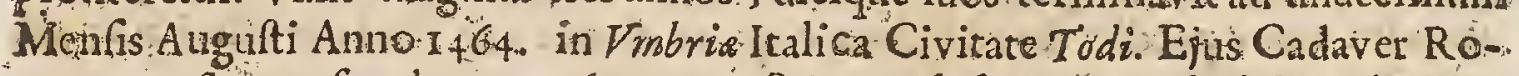
mam tranlatum fepulturam adeptum eft in Ecclefia ejus citulari Sanci Petri in Vinculis, ut ipfe Teftamento caverat, pro perpetua fua erga gloriofum il lum Apoftolum devotione : Ejus fepulcro infeulptum legitur ejufdem Epith phium Larinis yerbis heic ftatim fubjunctis,nimirum. Ital.

\section{Nicolas de Cufa Treverenfis".}

\section{S. Petri ad Vincula Cardinalis.}

Brixinenfis Epifcopus.

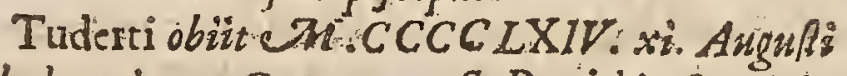

Ob devotionem Catenarum S. Petri bic Sepelini voluti

Dilexit Deurn, timuit, G veneratus est. so illifoliferwivit: 
Exrant opera omnia 3.Tom. Bas. 1564 a

\section{THOMAS A KEMPIS}

D

E Thoma patriâ Keèmpentritive d Campis modico in diecefi Colonienf oppido ad Rhenum, cognomento Hernercibin, hac eft. Malleolo, ordinis $C$ aClar. An. Dy grsnicorum Regularium S. Augufini Congregationis Windefimengss Rcligiolo in

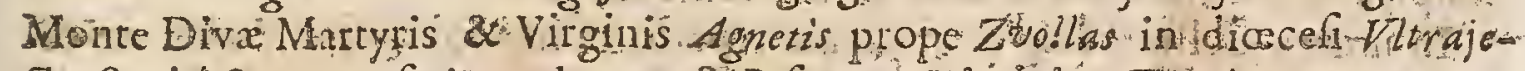

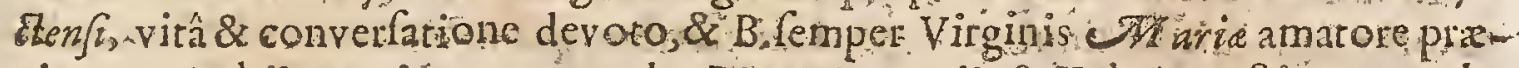

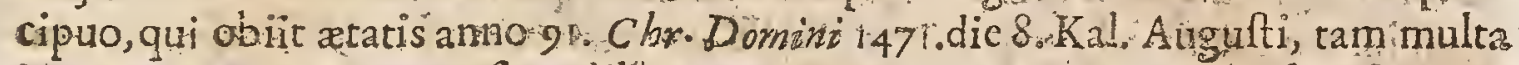
in utramque partem oocalione librorum quatuor de Imitatione Chrift hifce prow ximis annis icripta funt, ut non seceffe fit diutius in ejus pangendo eloyio im mosari. Pbil. Luable de Scaipt.Ecclef."

Varia confcripfit Orbis terra judicio, ac teftimono comprobata, a gubits illud mirandum, hortido illum colos ac folo natum cùm Latini Sermonis munto dities neglecta jaceret; tantum effe alfecutum himili illor, quod confectabatur dicendi genere.- Aureum illum de Chifti fintzatione libellum, \& non modò dèmanibus nunquam deponendum, \{ed \& ad verbum addifcendum, tanquarn piesatis Myrothecium (ut jure omnium-gentium ling nis hódie legatur) Gallia ali-

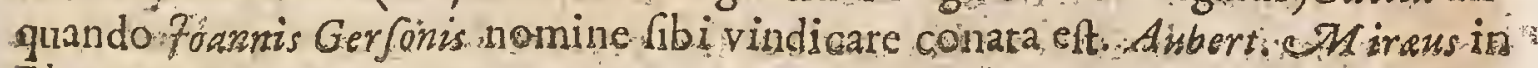
Elog. Belgic:

Hunc Libellum dé Imitatione Christi quidam fónni Gerfoni, alii Abbat Aeffeno Benedictino adfcribint: Bellarminus verò hac de re frc fcribit: "scrip-

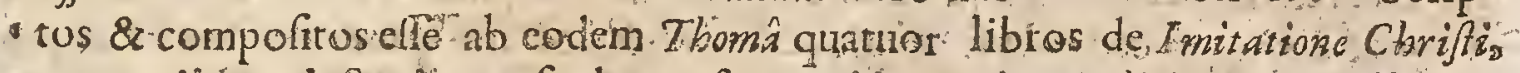

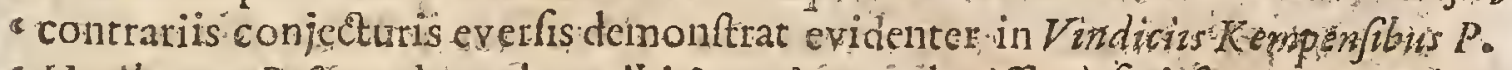
- Heribertus Rofinucyduis; cujus milhi \& rationes plenifimè fatisfecerune: \& Ten

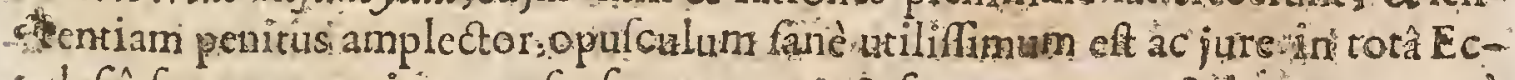
- clcfia fummo omnition confenfir receptum, \& frequentatum \& in omnes pend - linguas converfum. Ego certè ab adolefcentiâ, \& ufque in fenectam, hoc øpuf" cul um fapiffimè volvi \& revolví; \& femper milil novum apparuir \& nune stiam mirificè cordi mea fapit. Bellarm. de Script. Ecclef.

De auctore Librorum de Imnitatione Cbrifit mirè centant hô prafertim tempore eruditi, fed memet turbis hifce non immifeco $\mathrm{O}_{2}$ nec certè noftrum eft tantas -componere lites. Interim vide qux häbent Theophilus Raynaudas de Bonis \&

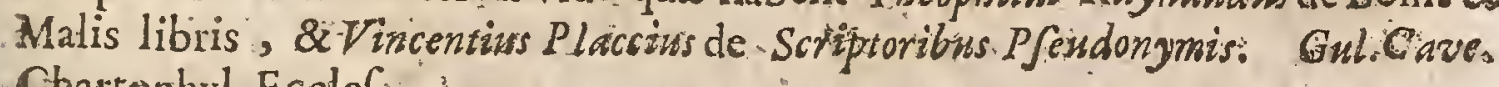
Chartophyl Ecclef.

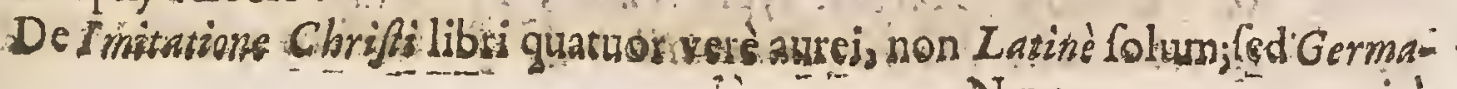
$\mathrm{Nan} 3$ juich MCDL. 


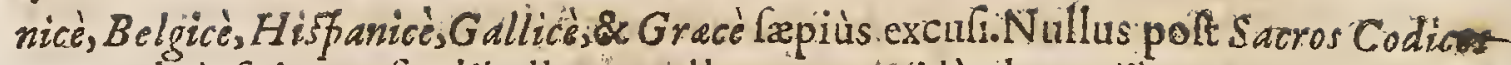
tam cuebrò fuit excufus libellus, nullus tam cupipiè abomnibus expetitus $\&$ leCtitatus, à fummis, mediis, \& infimis. Franc. Swuert.Belgicu. Athend.

Thome a Kempis exiguum libellum de Lmitatione Chrifi Lutherus in Prefarione omnium Antiquorum praterquan Augufini Sctiptis anteponit.

Comis \& affabilis omnibus,atque in primis viræ innocentià fanctimoniấa confpicuus erat; adeò ut pluimos lui vífendi \& audiendi causâ aả le attraheret. Sermo :illi omnis de Deo \& Sacrấ Scripturâ, cujus leationi mirè addictus, cellæxque fux ita amans fuit, ut hoc Symbolum Trai s ufurparet, dibrifque incriberet: In omribus requiern quefini, sed son inveni nifs in angello cum libello. Nunquan otiolus, femper vel leetirabat aliquid, vel in communem ufum feribebat, vel pro inftrictione Fratqum commentabacur. Obiir nenagenario major, 8.Kal.Auguiti; annopartz per Chrifurn inlutis 1 \% ir tofefronis 55 .

- In timbra Cellulx fulgidum atum reperio, In ima folitudine Viram qui to to or crinotuit fublimibus Ingenii fii foctibus, quil at Promethens alter celethem ingem rapuit ad cordanoftra Chrifiancerfectionis ardenti cupiditace inAammanda. Is eft cruditus ac pius ille Vir. Thomas Hamerken, Kempis vulgo diatu, ub is frat is in Colonienf Diocefnomine muture. In urbis D wentrix

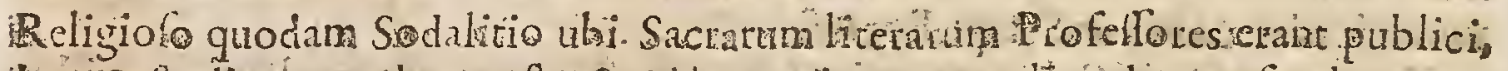

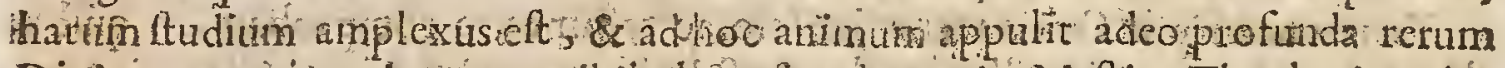

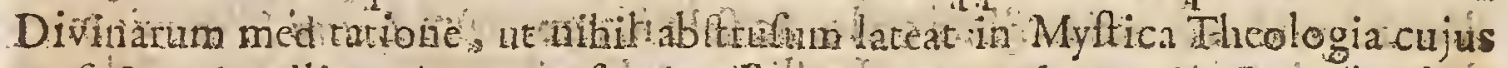

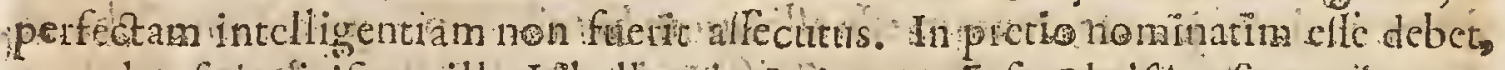
parvulus fed minificus ille Libellus de Initatione fefu Cbrifit: ufque adco puram \& fandam doctrinam is continet rám efficaniter movet corda logentium, ut nullo Volumin gennteliber molis fon fit comparabilis quemadmodum

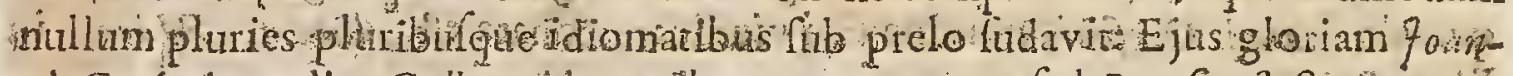
ni Gerfoni erudito Gallo qudam ribuere tentarunt, fed Paryben/is Senatus ato dacis \& temerarii hujusmolminis injutis Authoribus cognitis, Aos damnatorio Decreto ad defiltendum vano conflio fü; Gerfonern vero ad hanc palmam Thoma Kerpis cedendam adegitu Concigitut Patre quodan è Societate fe-

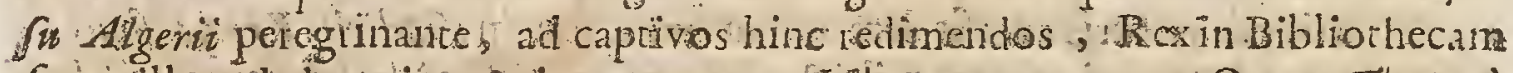
fuam ilhum deduxelie, \& inter magum Libronm numerum Opera Thorna

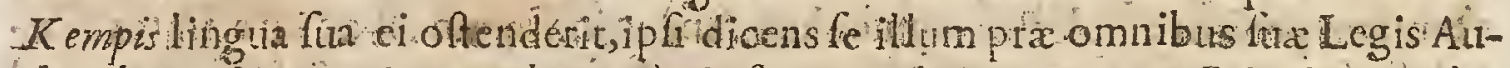

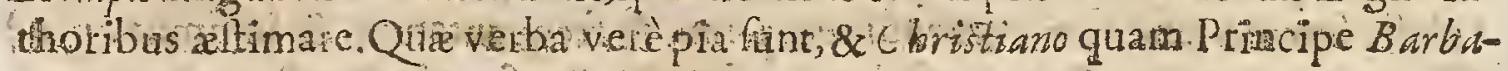
ro digniora Ifacicus zutlàt Acad. Scientiarum.

Scriplitide Imitatione Chrift libras 4 opus non tam mole; quàmufu \& famâ magnum: cujus admitadum, venufum tamenjaliotionum zelum, fententiarum pondus \& igneas pietatis fintillas multi multis depradicurunt.Henr. Wharton. in Append.ad Hift. Literateghave:

Mule fcripft, totius bibis judicio ac teftimonio comprobata, uno volumihe excuf , primum Normberge 494 fol. Deinde $P$ arif à Badio 1526. Penet. 156\%. \& 1569. Antver. typis Nutii, I574. \& 1580. 80 \& no-

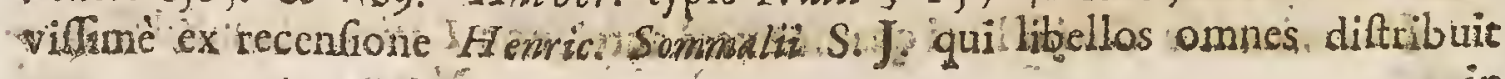


in: tres. Tomos, ibidi $1615.8^{\circ}$. Duact, typis Belleri $16355^{\circ}$. Valer, Andreas in Bibliah. Belgic.

\section{FRANCECUS PHILELPHUS}

N Arione Ytalus, patriâ Anconitanus, natus eft anno 398 s obititanno $148 \mathrm{r}$. 1 eques auratus, \& 1 oëta L aureatus fuir, Emanuelis $C$ bry $y$ clora gener, $P$ aleoClar.A.D: MGDL. gi Imperatoris Conflantinopolitani ad Pontificem, \& It alos Principes Legatus, Latinas Gracafque litcras docuit, Bononie, Romse, Médiolani, Florentze; atavii, \&: Mantude. Scrippft pluirima \& pedeftri \& folutâ oratione: mula etiam tranfrulit ex Graco in Latinum fẹtmonem:

Vir adea ftudiafus \& bonarum artium amator, \& cultor indefeffus, ut veluti alter Plinius, inter continuas bellorum occupationes femper aliquid aut legeres: fibijant dictaret alis. Trithern.

Ad omne genus feripti féfe accommodavit, ac ut de Vinicio dicit Angufus sind genium in humerato habebat:Grzca; Latina, Lyrica, Heroica, $D_{1}$ ofam orationem, ex tempore dictitabat.Volates an: .21. Ant hropol:

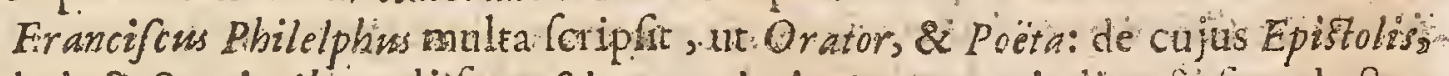
Dialogis, \& Orationibins, alit fue foluta orationis mionumentis diverfé funt doeto rum fententia: Phirimi enim judicium ei defuife volunt :- aliatumidum eum glenumque; alicubi exilem; perfapèaridhm, jejunumque arbitrantur, licèt fibì vel maximè plarentem; doctus tamon fuit \& magna aufus Elorid. Sabin. Apozlog, in Calumn asur. LL:

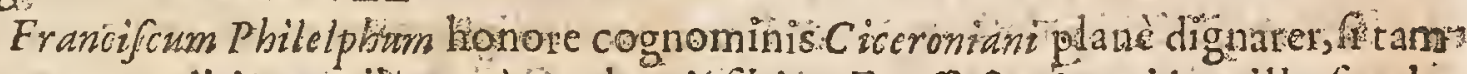

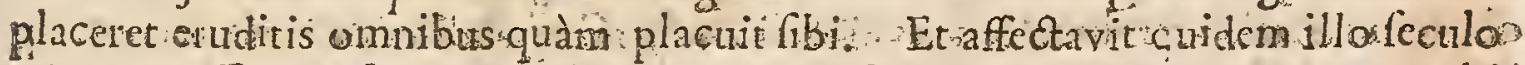

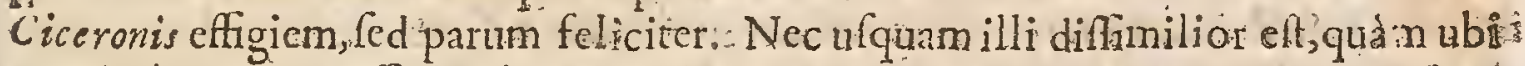
maximè aportuit effe frmilem, nimirum in Orationibus. Nam in Epistolis fatis's

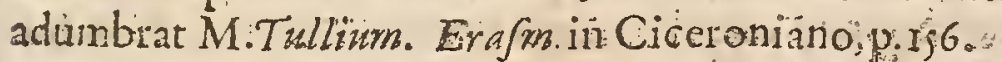

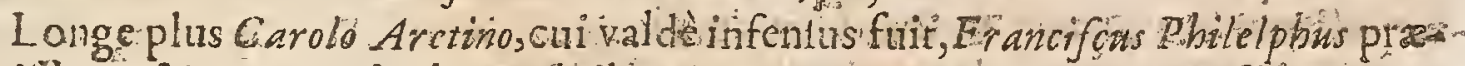

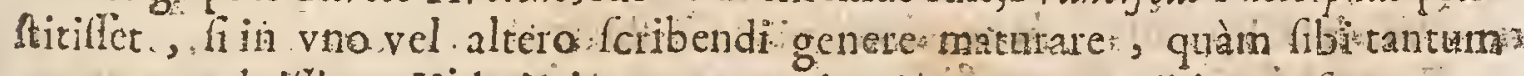
arrogare maluillet: Videtis in ê oratorios impetus", poëricum farrorem', variam \& capióam tum Graciarum, tum Latinarum rerum cognitionem;

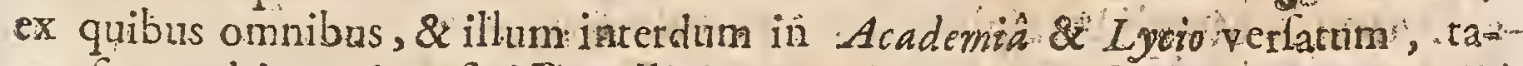
metfi non altius pedum fixiffe, colligimus: Dignus tamen fuiv multâa laude: Lil? Gyrald:

In Francifci Philelphi verbis planènibil defidéres:ejus tamen: lectio eft mo lefta, quèd motu ommi,\& quafi vitấ.caret: \& fortaffé is eft genius, quem in quoquec

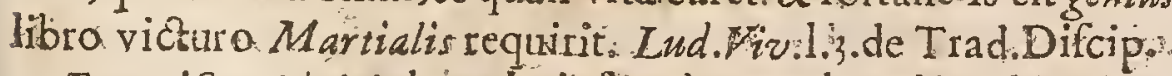

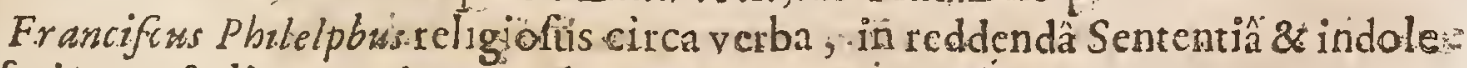
defecit: tranftulit Xenophontismulra,cumque videret verborum el cgantiam, verbum verbo reddere voluit, caterùm non potuit ex fide reddere, qux in Gracis r. periebat, quod mi un in homine Greco. Retr. Nann.in Horst. 
Ignófcendum feculo, quô vixit, quòd crebrò adeo in metrum peccat: Tojfrus ứ Poé.Lat.p.81.

Cùm de modulo fyllaba aliquando contentio è foretcum Timotheo Græculo : atque ita conveniffet, ut, fivinceretur, ipfe pecunia lueret erroten: fur vinceret, adverfarius barbam fibi totam frneret recidi:: Victor ufquc adeo fuit inexorabilis, ut barbam pecuniâ redini minimè pateretur, , fed milello Timothe o; non Gne ludibilo, cam novaculà abradi to tam neceffe forct. Konig.in Biblioth.

Scripfitinter alia duos Conviviorum libros, quos twdovicus Vives ab Hiporic \& Antiquitatum at uque item Phalofophia cognitione impensè laudat.

Franc, Philelphus, cques aurarus, circa principia feculi decimi quinticlarus, Ecriplit hecatofichorxm libros to. Engulis decem fatyras complexuseft, pro captu temporum eleganter, at yue nervosé. Legitur quoque epos ejus Sphorcias, item lyria \& efigrammata ; latis ubique expolitus.Borrich.de Roëris, 0.102.

Favêre ciantealios Eugenius, Pontifex,Rex A fonfus; \& qui fingtilarejuftitix \& bellic virtutís coronan eo feculo promeruit. Franciscus Sfortia, ab eo heroico poemate celebratus. Ing cnio enim in Endiis aftuate, vario, ambitiolo, quum

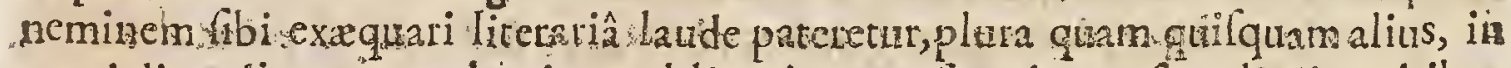
omni dicendi genere volumina publicaxit, prohtendogue fingulis in urbibus - crudicx juventutis acalemias excitavin, nullam fpem nobilioris glorie Latinis anulis de Romanâ facundiâ, nullam denique de Gracâ , wel ipfis Gracis relicturus, nifr tantus eloguentix Altviks. uti nullis moderati judicii ripis caftigatus, ninis latè-exundians, \& nutato fapè alveo, turbulentus \& incertus, dum feic di-

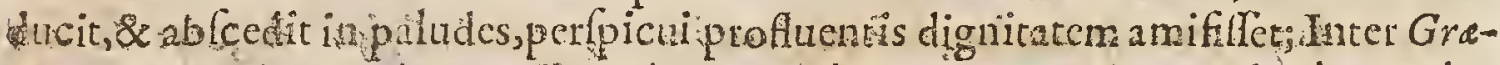
ca opera Latinitate donata, $x$ enophusitis Padia Cyri, \& ex Mhutarcho al quor borum vitæ, \& demum Lippocrates, Hon itzprobantur a Grecis, quim à Latiris perleguntur. Vixit ad exactam xtatem nonagerario proximus, periitque Bononie adeò dinfpatis teidomeftica copi is, ut ad efferendum funus \& cubiculi \& coquina infrumenta venierint. Panl.jov in Elog.

Philelphi Epiftola, bona. Scaliges ana Polterior.

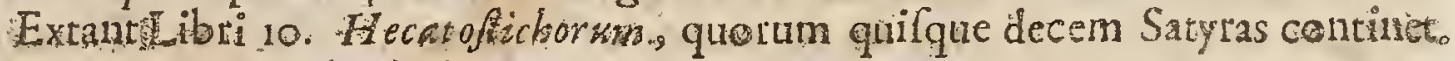
Mediolani per Clsrifophorum Valdarfer Ratïponenfom, anu. 476.

Extant de Morali Difciplinâ libri s:Venetiis $1552.4^{\circ}$.

Extant Epiltolarum Familiarium libri $16 .$, Venesisis 1498 ,

Hoc ejus Epitaphium:-

A bstulit infignis corpus fera Parca Philelple ingenio grafjans mors nockiffe negivi. 


\title{
CELEBRIORUM AUTHORUM.
}

\author{
Aliud Auctore Hieronymo Balbo:: \\ Itala Cecropix Pallas conjunta Minerva, \\ Et.fetit, if ceeidut morte, Philelphe, twa. \\ P. hil Labbe in The aur. Epiraph.

\section{THE ODORUS GAZA:}

(1) Atrià Theffalonicenfis, vir nobilis, $G$ rece Latinequelingux peritifimus;omnium fui temporis hominumdoctifrmus habitus elt. L"teras Latinas in ItaClar.A.D. MCDLV: 3la didicit, in quarum cognitione tantum profecit, ut fummâ felicitate \& omnium admiratione Lativia Griè \& Graca-Latinè exactiffimè verterit. Nonnunquam tamen Latina vocabula nova fecit. Stylo ufus elt non affectato, fed puro \& facili, veteres Latinos imitatus. Ejus doctrinam mirificis laudibus extol lit Hermolaus Barbarus. Beffarioni Patrarchx Conflantinopolituno, \& Cardinali Niceno familiaris fuit, \& amicus: $a$ quo mulis honoribus \& beneficiis cumulatus eft: ejufque commendacione Sacerdotium in magn Greciä adeptus, xatem allic ab Olvit feliciter, ftudis \& lectione bonorum autorum incumbens. Opera plurima eruditione plena reliquit. Obiit Rowne quiò ex Graciấ venerar; An.C brifti I 47 . Frederica III. Romanorum Imperatore, \& Sixto IV. fummum Pontificatum tenente. Quidam tra ideruntejus corpus in Greciam fuiffe tranfportatum, \& ibi tumulatum, ubi facerdotium obtinebat. Boifjard in Icon.

Theodorus Gas Theffalonica tonefto loco natus, Amurathe Greciams omnem victricibus armis quatiente in Italiarn venit, acumine, ferilitateque ingenii nemini lecundus, quum Grecus omnes lingux peritia, enditoque judicio fuperaret. Victorino autem Eeltren fe magiftro ufus, ulque adcò copiosè \& diligenter Latinas literas didicit, ut longè omnium Latiffrnè fcriberer, nec plane dignofci polfet, an cxactius, \&.ccrius ab co Latina Gracé, an ipha Graca Latine verterentur; Hiftorias enim A rifotelis de Animalibis, \& Theophrafide Plantis, ita Latinas fecit, tit Romanit Linguæ facultatem, quum nova vocabula folerter efingeret, andaci, fed generosa tranflatione locupleta-

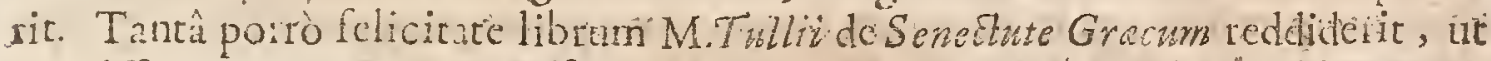
pericifimi preter adequatos fenfus, ipfam quoque Oiceronts elogientia-Majeftatem, icite \& gravite réprefcntitam adnitentur. Tranfulit etian Problemata Aristotelis, \& Hippocratis Apborifmos fpicuam fidem; nes oblurè ad flutem humani generis fua dignitas redderetur. Paul.fou.in Elog.

Omnium doctifimè hanc artem [Grammaticam] libris quatuor tractavit Theodorus $G$ aza: cujus operam ab ingenio doctrinâ he commendat Francifaxes Robertelius commentario de Re Pö̈tica, w Hulli veternan polponerdama

$$
000 \text { dicats. }
$$


dicat. Nec ei fe fimile qui cquam legille co in genere dictitabat Budans. Fofloge Arte Grammmat.p.I6,

Magnam incomparabilcmque jacturam jampridem fecimus ( Pontifex Maxime) in Theodoro Gazâ, qui vir Gracus Latinos omnes in hocmunere fribendi incerpretandique fuperavit. Is fi diutiùs vixillet, Linguam Latinarn hac quoque parte locupletalfet. Quod \& fecit in libris illis ablolutifimis de Animalibus Arifotelis, \& Theophraftì de Stirpibus. Hic unus mihi certare cum vetuftarc ipsâ vifus ctt: hunc mihi yuem colerem, quem imitarer propolui. Ab hujus Seriptis adjutum me \& fatcor, \& prodico : hunc ego non magnopere incuriofiùs legi,

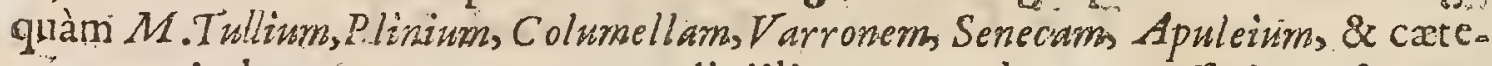
ros, quos in hoc genere commentandi diligenter evolvere necefarium eft. Hermol.B arbarus in Paraphrafin Themifiu pret. ad Sixtum 4.Pont.Max.

Gazam Pliniariorum verborum obfervarorem atque imitatoren diligentifimum appellat fovius I. I.de Pifibus, c. 4 .

Theodorus Gaza Ariftotelem, quam Ciceronem exprimere maluit, quonon alius felicior, five vertat Greca Latine, five Latina Gracè: Cùn fua loquicur, dwo. quxdam obftepunt delicato lectori, Philofophix fudium, in quo totus erat; \&

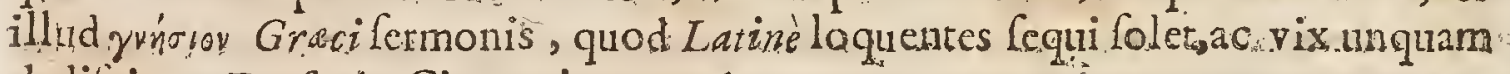
dedilcitur. Erafmoia Ciceroniano p. I60.s.

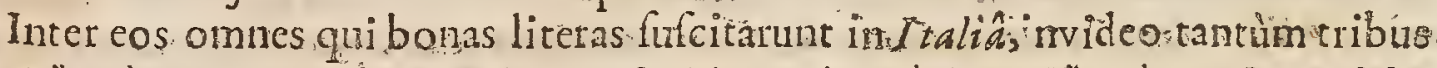
his, Theodoro Gara, Angelo Politiano, \& Pico Mirandulano. Theodorus Gaza, Mas马nus certè yir \& Doctus, gui tamen, in librorum Axistotelis de Anirnalibus VerWone lapfus eft aliquibus locis. Scaligerana prima.p. 102 .

Theodorus Gaza doctiffmus erat. Bona eft ejus Grammatica. Inter optimos è Græco in Larinum interpretes annumerandus: id luculenter demonfravit in Theophraftiverfone; vidir cx Plinio debere verti. Scaligerana pofterior.

Gerardus foannes Voffins 1. 4. Inftit. Rhet c.j.ipfinm Gregorio Irapezuntio longè praferendum elle, contra Angelum Politianum ftatuit.

Mili vero judicium placer Pomponiz Lati, qui rogatus ab ornatifino Equite, M. Antonio Mauroceno, quem fui ieyidoctifimum putaret? Theodorum Gazam répondit. Voffus ibid.

In Throdori Gaze Interprctationibus Grecis mulka efle, qua meliora fieri pof fint, quxdam etiam, qux omnino mutari debeant, I ofephi Scaligeri judicium eft, d quo quidem non recedimus: at ut meliora optavir ille, nos cupimus certè ne ab aliis interpretibus nobis deteriora contingant, paremque omaes fidem, perlpicuitarem, \& nitorem adhibeant. Huet. de Glaris Interpr.

-_uodin Theodoro Gazĥ longè diverfum fuit, qui Saturninâ quâdam iniquitate bonam fuorum foetuum partem abfumpfit. Tanta enim ille eruditionis vir, quanta multis abhinc annis nemo Gracormm, dicere aufim, etiam \& Latinorum fuit, cum divinas propemodum elucubrationes in Ariftotelis animalia, quam hiAtoriam Latinè legendam reprefentarat, Sixto IV. Pont.Max. nuncupalfet. fperans fcilicet Principis ejus beneficentiâ quafitum per tot dabores vitá fibfrdium non deparcum fe confecuturumineque tapen plures quàn aureos quinquaginta; 


\section{CELEBRIORUM AUTHORUM.}

qutalt magnum ab eo, à quo fe totum inauratum iri fperaverat, reculiffet; ftudiis indignatus fuis, quòd tàm parca-fibi laborum \& vigiliarum fuarum merces tribuia elfet,nummos eos primùm in Tyberimabjecit, mox ipfe hujus indignitate tei cxulceratus, infolabili.contabuit xgritudine. Fo. Pier.V.alerian. de Litcrator. infelic. 1.2.

Extant Grammaticx Græcx libri 4. Grxcè Baflea 1540.4\%

Extar L ber de Menfibus Grace Parifis I530.8.

Idemque Latinè per Perellum, Parifizs. I535. 80. \& Grec. Lat. Parifis 16 ja. octave. Toin. It.

Extat de Origine Tutrcarum Libellus'apud Nibufnum in Symwaitis à pag. $33 \mathrm{~s}$.

Hoc ejus Epitaphium: Ex Ch arulli libro r.Epigram.

Hic Gazes jacet, ơ Gazx Sophia addita mater: Altsritrum quoniam mors rapere haud potitito

Aliud. auctore LAngelo Politiano:

IFleus facrum caput occubuit Theodorus, ơ hora

Vinâabiere omnes religuia generis.

A ec tarmen boc guerrmsur, nimis eft potwiffe videri,

Non enim bic nofiro ternpore digmus bonos.

Hioc dolet beu? quod neutra Patri eft nunc lingua superfess.

pwe mittat juffas $M$ Manibis inferias.

Pbil.Labbe Thefaur. Epitaph.

\section{NEAS SYLVIUS}

POtea Piws II. Papa dictus, natione Thufcus fuit, patrià Sertenfes, fedit in Pon-Ciar.A.G:

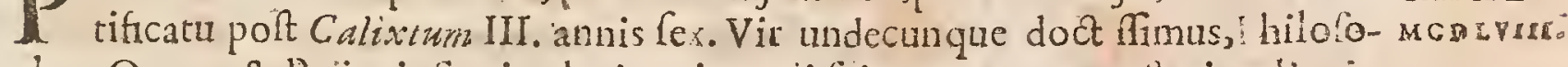
phus, Oraror, \& Poëra infignis plurima ingenii fui monumenta polteris reliquic. Hic quondam in Concilio Baflicenf cuidam Prelato fervivit pauper": deinde ia Scriban (anceillaria Friderici Irsperatoris HI. aifumptus, \& Poëta ab co Laureâ receptâ creatus eft: Primò Epifopus Tergeffinenfiss, pofteà Senenfiss, exinde Cardinalis, \& novifime Pépo omnium Sulfiagio elecus eft. Nortuis eit fub Friderico Imperatore anno Domini ${ }_{4} 64$. Ind ctione derodecinnâ, 19. Kalend. Septemb. xtatis fux anno 64. Fepultus Rome in Ecclefià S. Petri juxta altarc D. Andrea. Boijjard.inlcun.

Philelphus commendat eum ab ingenii acrimoniâ, dicendi lepore, ac moribas

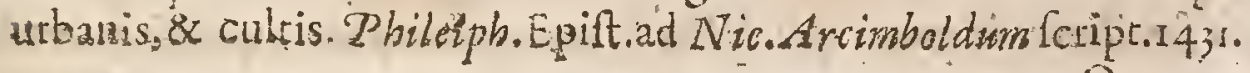


In Hiforiâ eft nonnullis ex recent oribus ordine poftponendits, Oratorargutus, vehemens, candidus, poëra itidem non vulgaris Elorid. Sabin. in: Apolog.

-Magna quidem in dicendo Pii laus fuit, quòd cum frepius iifdem de rebus lo. queretur, diverfa lemper vilus eft dicere: tanta erat in homine elcgantia \& copia:. Platina.

Eneas Sylvius, patriâ Senenfis, vir doctus,pludens, \&umagni animi Rellarmodè Script:Ecclel:

Mira in eo certè facilitas, \& fatis prompta factultas. Lil. Gÿrald. de Poët.

Literis, eloquentia, dexteritate, \& prudèntiâ hulli fecundus. Spondan ad Ann. 1458.

Scientiâ fane infignis, pari utinam \& confcientià Sed $P_{\text {appalts }}$ Cathredre vis in co ftatim enituit. UlLorneus in Hif. Papatus,p.525.

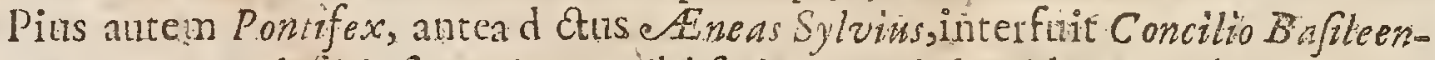
fl \& rem omnem delcriplit, \& decreta ibi faeta magnis laudibus extollit. Sed ad: fuimmun dignitatis gradum evectus, mutatâ fententi., Pontifuci Concilium debere fubefevoluic. Sleidan.1.2. Comment. Undeillud Quod Eneas probavit, Pius. damnavit.

Ejus voluptas quando à munere publica vacabat, in lectione \& feriptionc frequenti repolita crat Libros plufqum fapphiros \& fmangdos charos habuit, quibus chryfolitoum magnam copiam ineffe dicebat--Homo fuit werus, intcger, apertus, nil habuit feti,nil fimulati-CAdolefcens, \& nondum facris initiatus, poèmata edi dit lafcivia magis \& feftivitati accommodata, quàm prelfi \& gravia. Surgit tamen nonnmatam: \& dum jocatul, mordacitate non caret. Extant ejus Epignamata referta falibus. Ad tria millia varianm verfun fcripfife dicicur, quorum pars magna Baflea periit. Orationi folutre reliquâ vica fe rotum dedit. magnitudine rerum invitatus, delectatus eft eriammixto feribendi genere, \&ad: Philofophandum aptiore. Platiz. in vit. Pii II.

Vir fuit, ut dodiffmus, ita amantiffinus Poëtarum; fic tamen, ut poëtas fau-.. mel cos quandoque eluderer. Exemplo hoc fuerit Dilt chon:

\section{Difcite pro numeris numeros peerare Poete. ch ntare ej animus carmina, non emeré.}

Sedphileiphs ait liberalifumum fuiffe, atque in hunc fcripfife modum:

Difcite pro numeris numinos sperare Poete. Mutare eft animus Carmina muneribusa.

Tojle de-Mathemat. p:413\%, .

Ejus Epiftole faniliarcs in quadriplic Vita Statu ad diverfos tranfriffe, nume10432. 


\section{CELEBRIORUM AUTHORVM.}

ro.432.multâ.eruditione \& antiquitate refertæ, \& eximio autoris præconio infignitx (prefante Icilicer Nicoha de Vvile, Lateran. Palatii confitorique lmperialis L omite Poëtam quoque Laureatum eAneam Syiv dicit, ${ }^{\circ}$ ) impiella primò Aoriberg. 48 . impenfis Antonit Koburgeri.

Sedulus rerum vetuftate involutarum indagator audit Hieron. Balb. Epifcop. Gurzens lib.de Coronat.ad Carot. Quint.p. 49 cujus Scriptis Gerriban tantum tribuzine, quancum Lalladis fuffragio, juxra 70 . Bapt. Ennat.clar.vir. Epift.59. Bellarminus ac poftilum Nogrntini dicunt, mult eum audacion prius calamo fcripliffé, quira Pontifes factins retractaverit. Sed refelluntur à Crocios. Tom.t.vindic, Anti-Becani fui, f.470, ubi notabiles folculos promir,ab cjus,cim jam Pontifex elfet, ore prolapfos; vagum Monachum, Dirboli mancipium elf; fideli animo thefaurum nultumanteponcndum; lacerdotibus magna ratione fublatas nuptias, majori reltiuendas videri. Confer ejus iconem \& elogium, apud Boifjard.icon.illintr. Vir.P.3 pinifeq.Olearin Abac. PD.

* In Acis Aned Sylviz prohbentur ea , que ipe in Bulla Retractationis dàmnavit. Ladex Rome impreflits Anno 68 I.

Varia ejus Opera variis temporibus atque locis excula funt.

Hifturia Austriaca ad Ann. Chrits. 1458 .pertingens MS. hactenus inedita feviturin B biotheca Vindobonenfís unde ejus editionem pollicetur Petrus Limbecins in Catalogo proprionm Operum,p.s.

Omnia ejus Opera edita funt buflew ann. I 57 I. ex Officinâ Henricipetri:Fol.

Extat cjus Relponfio ad Orationem Oratotum Gallis in Conventu. Maniugno.apud Dacber. Spicit.Tom.8. \& Concil.Tom.xu1.p.177, confer.p.180r,\&c.

\section{NICOLAUS PEROTTUS}

C Entinum Imbrix oppidum, cui hodie $S$ axoferrato nomen ef, Burtholo Jure- ClarAD. Conlulto nobile, fecundam à Nicolao Perotto claritatem accepit. Hü , cum a $\mathrm{c}$ to $\mathrm{x}$ déefént opes, corporis vires municipali frugalitate, atque duritiâ confitutæ: perpetuis lucubrationm vigilis minimè defuerunt. Juvenis in ludo pueros honeftos docuit tanto concurfu, ut mox Latina lingux rudimenta, utili compéndio ad normam digetajob :dque facilè pueris perdifcenda publicarit. Exindé Rome Grecas literas pertinaci ttudio confectatus, fretulque Beffarione generofo Meconate a deò exactè, feliciterque profecit, ut ab co Polybiss gravifimus Hiftoriarum friptor, latinitate donaretur. Non defuere tamen ex æmulis, qui ejus auctoris traduct onem antiquifimam fuilfe , furtoque furcepram exiftimarint; quòd Thucydidern,Diodornm, Plustarchum, \& Appianum, clarifimo ingenionm Eertamine converfos, unus Polybius egregiâ Gde Latinus, xquabili, \& predulci Rornani fermonis puritate prorius antecedat. Co r pofuit quoque volumen Commentarii nonine in Martialem Cormcopice, ulurpato vetere Groso lemmate nuncupatum, perutile quidem, ac ob id fortalfe fempiternum : fed auftcro pudore fuppreffit editionem, quòd humili , \& parum pudico opere quefita laus dignitati minimè relponderet: partis enim opibus, Archiepifcopatum Sipontinur

$$
\text { Q00 } 3 \text { : adfea }
$$




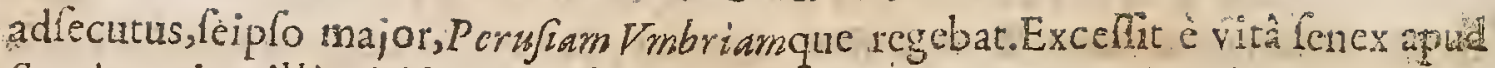
Sentinum, in villâ viridaris \& fontibus peramonầ, quan à pingui ocio Fngicuram appellavir. Paul.Iov.in Elog.

Nicolaus Perottus, Sipontinus Praful, homo fuit accuratoingenio, \& lectione multâ exercitus: eum Domutius, Calderinns, vir,ut in ea tempeltate, ,doctus, e

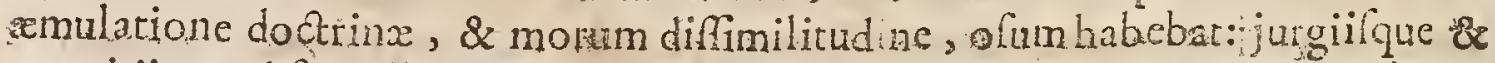
convitiis apud fuos fectatores plerunque incef ebat, xpiufore apud tudios in invidiam illum crimenque vocabat: \& ut funt ferèngenia, in explicandis $A$ w Etoribus fi quid in controverfam veniret, uterque porius., quo pacto diverius ab altero diffentiret, quam quid rerè lectionis effer, rimabatur. Alexandoab Alexax. lib.4.c,2I.

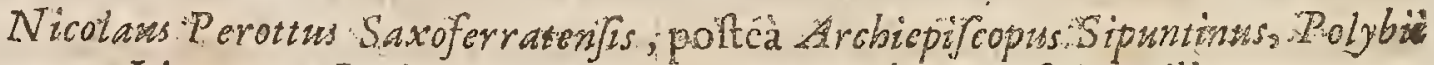
Interpres, Litcrarum Latinarum, quas, perdiu docuit, exquifitè, ut illa etant tempora, fuit peritus, \& cumprims curiofus : quod ingens iile in $M$ artialom Com-

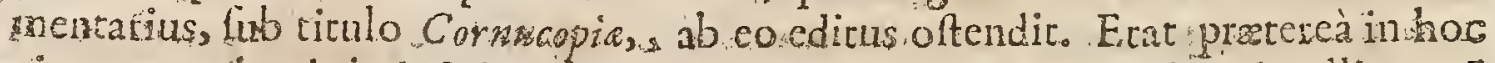
Firo non vulgaris instufrio in Gracis ita vertendis [ qua quidem intelligeret] ut nullum perfepè Graci Idionatis in Latina ejus Verfone veftioum appare-

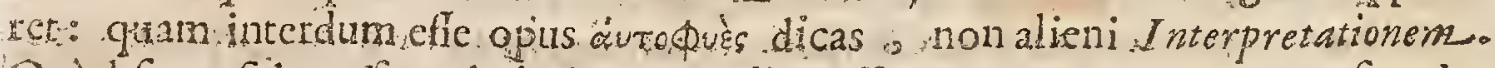
Quòd fipar fides, refponderic, inter excellentifimos Imterpretes poterat fine du-

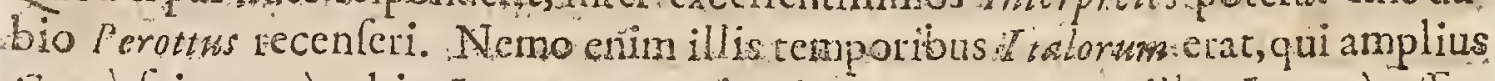
Grece fcitet, quàm hic I nterpres pauci qui tantum quantum ille $N$ os verò affrmamus. Perottum a fidel is I nterpretis laude tantum abeff, quantum qui longifimè. Nullo erim pacto ferendus atit excufandus eft hic Interpres, homo.Betlicarum rerum \& totizus. Tadlice adco rudis \&imperitus, ut gui in cateris par-

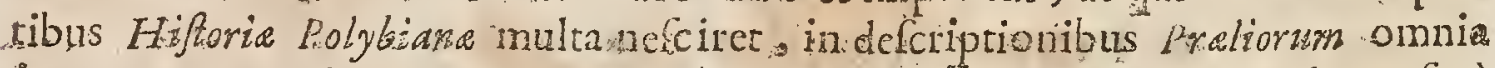
ignoraret, onnia peccarer; atque ếdem operâ tinto Scriptoni, quod erat ferè pracipuum ejus decus, adineret. Omninò praliumulum, facinus initare nullum, à Polybio fuctat paulo diligenciùs narratum. in quo gravifima \& momenti maximi peccata ab hoc Interprete non funt admill. I aac.Ca faub. de Po196.Interpret.

Nicolazs Perottus, natus Saxoferrati [qux \& Bartoli JC.patia fuit] Archiepilcopus Sipontinus, vir. Gracis Lativifque Liceris pereruditus ; ut de eo judicat Leander, \& monumenta ejus teftantur, claruit ann i460. Difertifimum virum

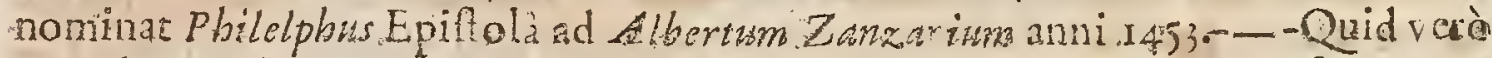
in co laudabile, quid culpardum $C_{1}$, optime dicet $C$ an awbonws Prefatione a Lectoren, quam Polybio ho de prioribus hiforic hujus interpretibuspram fat. Inter alias culpas eft, guiod fapè Livium exferibens dicar, qux Polybinsnon dicit Wog.de Hift Lat.

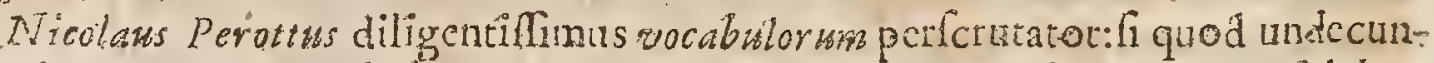
que incognitum audifet, neque dormitare, neque rerum aliquid gerere folebat, priufquan id inveftigâtct. Raph.Valeterran.1.21. Antropol.

Nicolat Perotti Cornucopiam fi vacet legere, non ponirebit collocat in co PI:era.Lud. Fiv.de Tradend.Difcipl.1.j. 


\section{CELEBRTORVM AVTHORVM.}

Perottus, qui fine mentione Audlorun exfcriberefolet aliena Martinius ii Lexic in voce Sarcina..

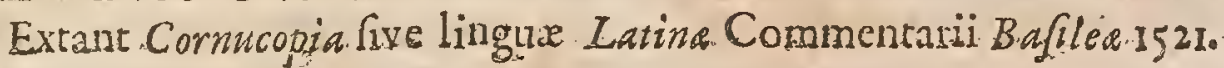

\section{K:ODOL.PHUS AERICOLA}

Roninganus;ibique Syndicus, Rétor Heidelbergen/s, claruit anno I474. D. Clar. An. obiir anno.r486. Extant. Opera ejus ormia 20. Tom.Col. I539. fol. Gal, MCDLxxrra Gave.

Quis non te Ródrilphse Agricola inufitato, \& planè portentofo confpirantium fyderum concurfu natum efle fateretur, fi vim coeleftis tàn varie radiofi" luminis , non fecus ac in aftris curfum cerrior difciplina deprehende-

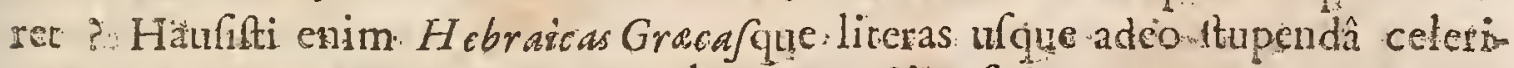

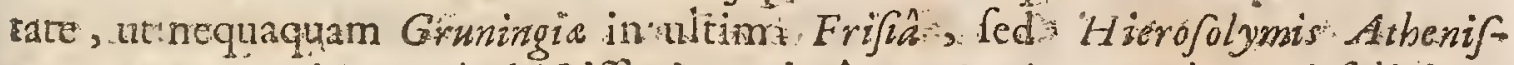
que natus ac educatus à doctiflimis crederếre... Lativias porrò tantâ felicitate

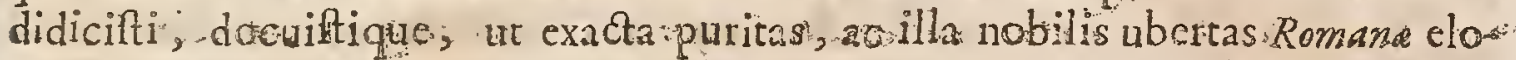
quentix, noftro cum pudorevin fquallenti asperoque Oceani-littore quarenda

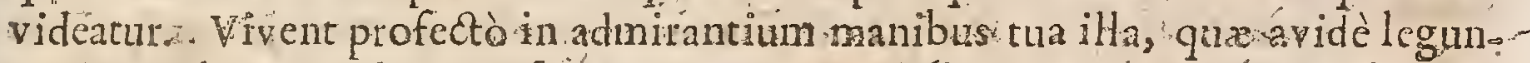
tur in Dialedicis Rhetoricifq; precepta, \& divini ingenni carmina, quibus vel

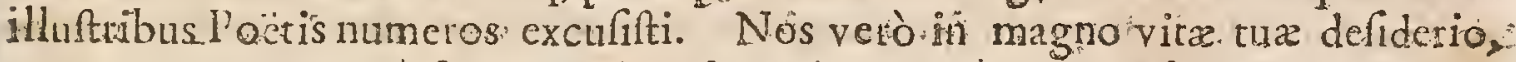
aut numinum.; cercè fiderum inconftantain indignanter ufqucquaque mirahimur, qua tantiscumularum muneribisstetris tantum oftenderint, graviore quidem in triẫ humani generis, cum ille coeteftr aurâ fortaffe dignion, in fecunditimo fuecunditatis curfu raperetur... Defunctum 'Heidelbergâ Germa-

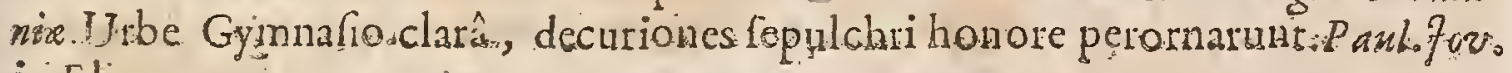
in Elog:

Vir in fecularibus literis eruditiffimus, \& divinarum Scripturarum non igna-" rus, Philofophus, Rheror \& Poëra omnium fin temporis celeberrimus; Griec \&: Latzinfermonis peritus, \& Hëbratce linguæe non ignarus; ingenio excellens, fermone difertus; Ioannis Camerariz de Dalburg Wormacienjis EpifGopí viri xquè doctianini quondäm Preceptor In Gymnafio Heidelbergèna \& fcribendo principatum faciè obtinuir intes omnes etiàm cujuleunque facul: tatis Doctores. Trithern.

Qucm ego virum totius curn Germanie, tum Italie publico, fummoque ho nore nomino illiús, qux gęnuer it, härjus, qua titeris optimis infituerit. Nihid. enim nnquam hốc Cifalpinus Orbis produxit omnibus literarîs dotibuis abfo. litius, abiticinvidia dictos Nulla erat tioneftà difciplina, in quầvir ille non po. terat cum fummis artificibus contendere:Inter Grecos græciffimus sinter Latinas latiniffimus, In carmine $M$.aronens alterum dixiffes: in Oratione Politianum qquendam lepûre teferebat, majeftate fuperabat. Oratio vel extemporalis adco para, adeo germana, nt non Friffurn quendam, fed Urbis Romana vernaculuma Loqui conteyderes. Eloquentix tam abfoluta parem adjunxerat eruditionem. 
Philofophix Myfteria omnia penetraverat. . Nulla pars mifices, guam non exactifimè callerct. Extremo vita tempore ad literas ffebraicas ac scripturas divinas totum animum appulerat. Atque hæc conantem fatorum invidia virum teris eripuit, nondum annos natum XL. Vide Erafm Adag Quid Cani o Balneo.

Vix \& hâc noftrâ, \& patrum Memorià fuit unus atque alter dignior, quỉ multùm legerctur, multúmque in manibus haberetur, quàm Rodolphiss Agricola lory. Jus, tantum eft in ejus operibus ingenii, artis, judicii, gravitatis, dulcedinis, eloquentix, eruditionis: at is pacifimis nofcitur, vir non minus, qui ut ab hominibus cogno ceretur, dignus quam Politzanus, vel Hermolaus, $\mathbb{B}$ arbarus, quos meâ quidem Cententi, \& majeltare \& luavicate dictionis non equat modò, fed terian vincit:Lud.Viv. Comment.in Cap.2 I. L.2.de Civit.Dei.

- Rodolphus "Agricala in luminibus tenebrofi hujus feculi jure cenfendis. Moro navis in Myfter. Iniqu. p.isz.

Rodolphi Agricole fcripta maximè omnium, qui ætatenoltrâ fcriplerunt, mihi quiidem probantur. Petr. Berrb.1.6. Epift.ad Erafrnum:

Rudolphus eA gricola Iacobo Bergomato in Chronicis vocatul Rodolphus a Chroningen, sempe quia in Bafion, pago juxta Choningam, principem Frifre Urbem, natus fuit: quod contigit circa annum 142 . Puer Lovani in Gymafio Falconenfe Philofophix operam dedic Et cum Thcologic rudimenta deguftârat

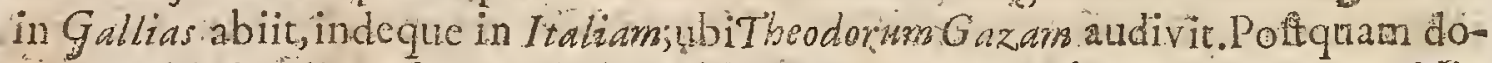
mum rediit Syndicus factus eft Reipublice. Groningana, ob cujus negorianillis in aulam Cxlaris Maximiliani, ubi cüm lemeftin hediffet, voti compos Groningam reverfus eft. Exinde à variis, cofque incer Antverpienfibusad Schola Prefeeturam depolcebatut. Sed protulit profellioncm Heidelberga; thil Philolophiam

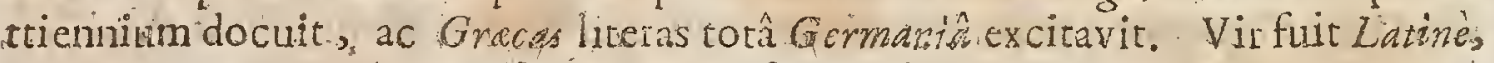
Gracè, \& Hebraice doctiffimus, phil fophus fummus, atyue dem ndmodum difertus, imò, \& Mufic , pictura, aliaumgue artium fudicfifimus. Vof: de Hift.Lat.

Rodolphis Agricola Frifus, optimus Magifter dicendi, imo fortaffis illorum Princeps. Scaligerana Prima.

Petrus Montanus; 1 hilokohus flatonicus, \& Poëta Satyricus de Agricolâ dicere folebat : Agricolar folum ex Germanis fcriptoribus infolenti Graciz, aut procaci I tatic o jicere poftumus. In orarione en th pedeltri mihi effinxilie vide-

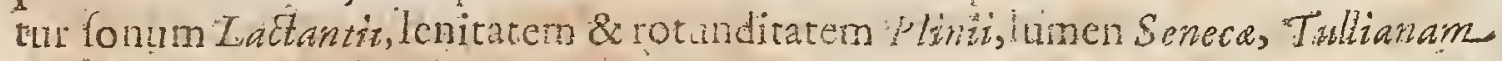
quóque redolet ubertarem, \& acumen oitentat Quintilioni, vehementiamque \& obliquitatem Cyprianireferte videran.

Ródolphm agnolco vitum divin pectoris, oraditon recondita, fylo minimè vulgari, fohdum, nervolim, claboratm, compoftum, fed qui nomih irefpiat \& Qwiztilianum in eqoquendo, \& Ijocratem in Ontionis thucurâ, urroque tamen fublimior, "Quintilano etian fufor \& dilucidior. Quod voWit, pirftitis; nec dabito, quin Ciceronis figuram potuifer, eflingere, filc vetifer anini ftudium. Et huic tamen ad fumman fanden quin alia quxans $x+2$ ? 
dam obtite re,tum precipuè regionis ac temporum infelicitas, quibus vis quicqua mono his habebatur titeris politioribus, \& nationis parum frutalis vita. In Italiâ fummus effe poterat; nifi Germanzam pretuliffet. Erafiñ. in Cicerons pag. 179 .

Rudolpbus Agricola primus omnium poft beata Gracia Italiaquetempora eximium illum Logicie facultatis ufum revocavit, ut Juventus à Poëtis. \& oratoribus difceret non folùm purè loqui \& ornate dicere , fed te propofitis rebus acutè cogitare prudenterque judicare. Vide Ranna Præfat.de conjungendâ Eloquentiâ-cum Philolophit.

Illuftres quoque interpretandi arte viros Belgium tulit, Rodolpthum in his $A$ gricolarn, in magnarun rerum fcientiàs ut temporibus illis, exercitatifimum, \& ex ¿ptimâ.Theodori Gaza diciplinà exortum:Latinè l quitur, fummo nitore foret; fed propter plenam \&diflucntem orationem, verborum \&indolis referendę laude caruit.Huet. de Claris Interp. fol.

Nperacejus omnia imprefia funt Colonia apud Gymnicum Tom. 2. anno 1539.

Extat de Formando.Studio Epiftola, (cripta ann.I484.Heildeb.621.80.

Obiit Heideberged anne is 85. atque in habiti. Francifcani apud Minoritas abidem, ur fracecerat, fepultus fuit. Epitaphium ei hoc condidit Hermolans Baxbarus:

Invida clauforunt boc marmore fata Rodolphum

Agricolam, Frifilpemgue decusque foli.

Scilicet boc vivo meruit Germania, laudis

Quicguid habet Latiuin, Gracia quicgnid babet

BARTHOLOMEUS PLA'TINA

7 El ut alii volunt Baptiffa Platinas Veronenfis Patria, humili loco, \& obfcuris natus elt parentibus : fed qui proper, eruditionem à doctis fummo hoClar. An.D. nore colebarur. Ma imè poftquam venillet Romam, à Pio. II. Pont. Maximo Gingulari fawore \& benevolentia exceptus eft, \& Sacerdotio donatus, \& multis muneribus locuplctatuis : Abbreviator enim A poftolicus factus eft; ut erat damo multre lictatura, Rhetor, \& thilo fophus acutiffmus. Tandem in odium P.anli I I. P. M. went, queod illins vitia non es ommi parte polfe ferre, per calumniatores \& invidos Y'qui peftes funt ordinarix omnium aularum i 2 pud Pontificem reddirus odiofus, ab eo primùm beneficio Ecclénaltico, bonils que omnibus fpoliarus eft : poftea in carceren:conjectus, \& equnleo adplicas auls, infunitis tormentis ufgue ad mortern cruciatus, \& excarnificatus efts 


\section{E N S VR A}

Extincto tandem apoplexiâ poft convivium Paitlo, Sixus IV: Lgur illi in Pon tificatum fuccellit, Ann. Dom $147^{\circ}$. Is Platinain vinculis liberavit prioribufque honoribus, \& beneficiis reftini, \& prater hac Bibliarhecæ Vaticand præ- fecit: in quât adminitratione egregiam navavit operam; doctorumque hominum exterorum benevolentiam acquifivit, omnes ad colloquia familiarifimè, \& humanifrmè admitrens, \&àd lectionem librorum, quorum curam gerebat. Botfardz. in Icon.

Scripta ejus funt: De Geftis Remanonum Pontificum-De Naturis Rerum -Epiftolæ ad diverfos - De honelta voluptate \& valetudine libri decemDe falfo \& vero bano Dialogi tres_Contra Amores Dialog. 1. Dialogus de Verâ Nobilitate- - De Optimo Cive Dialogi 2.-...-Panegyricum in laudenồ Befjarionis Cardinalis Niceni---Ad Paulurn II.P.M. de pace Etalia componendisatque de Bello Turcis indicendo, Oratio-.-.Hiftoria de Rebus Urbis Mantua ---De Arte Culinaria.

Platina, Apaftolicus quondám Abbreviator;vir undecunque dectillimus, Philopfophus \& Rheror celeberrimus, ingenio fubrilis \& vchemens, eloquio difertus : \& mulcens, animo confans \&rvalidus. Trithem.

Platinarn ab eloquentiâ, \& doctrinâa fingulari commendat Albert.Leander in Defcript. Ital.

Homo doctus \& antiquitatum fudiofus. Car.Stephan. lib.4.

Platina valide pronus ad potandas Pontificum maculas Genebrard. Chronol.

Etf Platina turpiter \& impudenrer Papis adulaturs fit: tamen nimiâ ipforums turpitudine ac malitià coactus aliquando, etiam tubindicat Babytonix Meretricis nefanda fcelera. In Marcellino quevitur $P$ aparum fcelera è excrevilfe, ue : vix apud Dewmifericordix locum reliquerint:avaritiam; fuperbiam, neglectum Doctrinie, \& Religionis fimularionem, mores etiam in prophanis deteftandos, propalam effe, ut inde laudem quxrere videantur.In Pontifribus poft millefinum. annum, fubinde repetit, Omnern pietatem or fanclitatem a $P$ apis ad Cafares migrafje. Tllyric.1.19. Caral.Tef.Verit.

Bartholomaus Flatina (id cnim pranomen ei ìidit Volaterranus; \& argumentis fatis liquidis probat doctiffimus: Vo Jjus, licèt à plerifque aliis vocetur $B$ apt

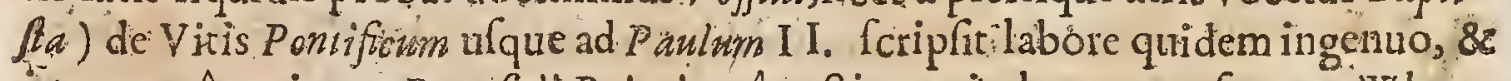
incorruptâ veritate, Pontificiz Principat ûs actiones in lucem proferens. Whear. Meth.leg. Hirt. fect. 4 I.

Inter cateros qui Pontificum res geltas memoriæ tradiderunt, facilè princeps eft B.Platina, non folù ob ernd tionem reconditam, \& 1 longum rerum Ecclefiatfticarum ufum, fed etiam ob amplitudinem \&plenitudinem ipfus operis quod edidit:Epif.Dedicatad Hift:Platîn.de Vit:Pontif.

Sacrati præfertim Ordinis, bonique mortales primutim Platine manibus debent, quando ejus ingenuo labore, ad exoptatam obfcur feculi, nec ideo perituram lucem, Pontificii principatus actionum incerrupta veritas nunciatur: qux procul eloquentix illecebris, uti pura \& incorrupra fidem prefert, \& cxteris claboras. 


\section{CELEBRIORVM AVTHORVM.}

elaboratis operibus auget dignitatem. Paul.fov. in Elog.

Platina imprimis innotuit Opere de vitis Pontificum ulque ad Paulum II. Vog. de Hift.Lat.

Summoram Pontifioum vitas eleganter fripht, eoque immortalem fibi gloriam peperic. Florid.Sabin.ita A polog.

Platira vir fuit gravis \& procul mendacio, coque admiratione dignior, quòd jam provectâ xtate,ac pofito tyrocinio, quod cotum militix priùs tradiderat, li teras didicit. Folaterran.1.2\%.

In Hiftoriâ valiturus erat Platima, fi nactus fuilfet argumentum felicius. In Optimo C. vallo, tut hoc cognamen non promereatur exuditorum calculis;alioqui vir doctus facundus, \&, ni fallor, bonus. Erasm in Ciceron.p.:61.

Quædan veròde Arte Cülinariâ fcripfrt Ptatina; qua ranti wiri autoriatem mon mediocriter minuerunt:mirum eit (inquit Jo Jaws jooft Pontificum vitas de re

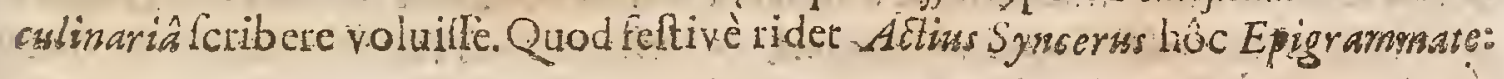

\section{Ingenia \& mores, vitafque obitufque notaffe}

Pontificum, argute lex fuit hifloria.

$T$ is tamen hinc laute tractos pulmerita $\mathrm{Cu}$ lind:

Hoc, Blacina, est ipfos pasceré Pontifices.

Extat Opus de Vitis Pontificum Chrifto ad Pailum II. cum Annot. \& Contimuatione Onuphrii Panzinit ufque ad Piusm V. \& cum Continuatione Cicarella inde ad lem.VIII. Col, $1600, \mathrm{in} 4^{\circ}$.

Prodicrunt de Falfo ore Bono Dialogi 3. Contra Amores Dialogus I. De Ferâ Aobilitate Bialogts 1. De Optimo Cive Dial.i.

Panegyicus in Beflationesn Patriarcham. Lovaniz. I572.

Extant de ratione victôs \& modo vivendi, feu de tuendà Valetudine: item, de

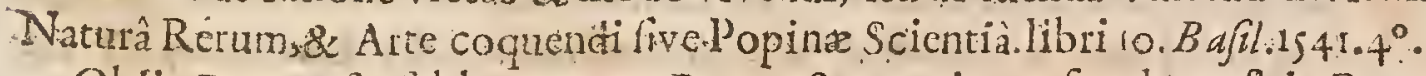

Obiit Rome pefte lublatms anno Dom.I4 8r. xtatis 60. fepultus eft in Exquiliis" in Tenplo S. $M$ aria Majoris, cum hoc Epitaphio:

Quifuis es (Jopius) Platinan, of fros ne vextes.

Angufte jacent, of foli volunt effe. Bemetrii alumin.

\section{JOANNES ANNIUS YITERBIENSIS}

T Atione Italus, natus en anno 1437. Oidinis Pradicatortans 3 Theolo1 gix Profellor, \& Cacri Palatii Magifter fuit. Roms obiit, fedente A-Car. A D. lexandro VI. anno 1492. Scripft varia Inter alia autem reliquit 17. Ant- XGDLX\%. quitatum libros, in quibus funt Fabiris Pidtor de aureo feculo, Myr/zhs Lesbius

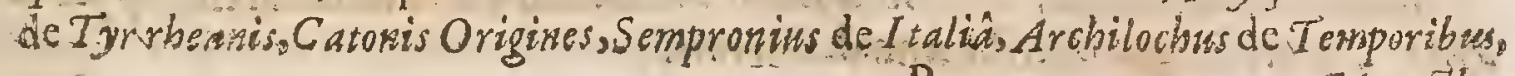

$$
\mathrm{PpP} 2 \text { Merasthe }
$$


Metafhenes, $P$ bito, Berofus, $M$ anetha: qux omnia fuis $C$ onmentariis illuftravit.

Fuit homo égregiè non folùm Latinis litcris, (ed ctiam Gracis, Hebrais, Ara

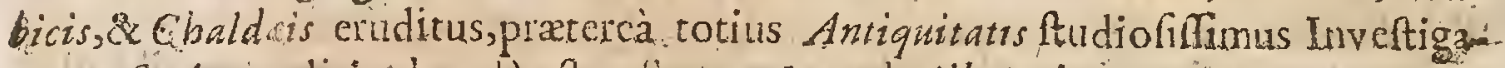
tor, ncr Scrptis editis abunde eft teftatus. Leand Albert. in I taliz.

Ioannes Annius Viterbienfis, homo, ut illa tempoda ferbant, \& diligens \& erudirus. Anson.Popma in Notad Catenis ex Origin.fragmenta.

Ioarnes Annius' Natione Italus patria Viterbienss, Tredicatorum Ordinis. Profeffor, Theologus eximins; hiftoriarum amnium, quor funt, quotque fuerunt;

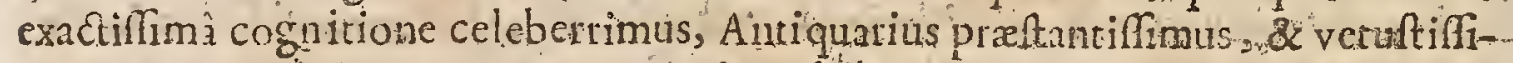
marum re rum indagator \& investor adminabilis, cujas in Berofom Bab, lonium,

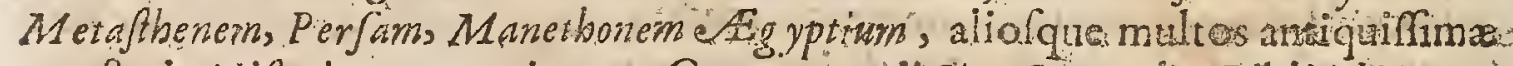
veruftatis Hiftoricos accurati cxtant Commentarii Sixt Senen/. l. A Biblioth:

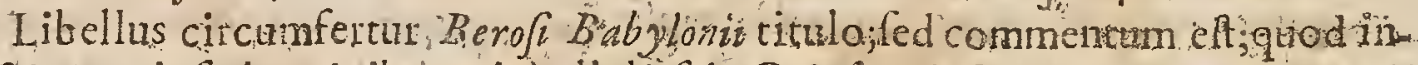
doct is otiofis hominibus mircallubefcit: Cujumadi fut Xenophontis a fequ voca,tum Architocbi, Catonis, Sempronit, \& Eabi Pretoris Fragmenta, qua codem funt libro ab Anno Diterbienfi conferruminata, commentique reddita magis rid'cula: non quin infint quadam in illis ven, nam al oxui frontem nontaberer nar ratio; ed iplum Hiftorix conpus Commentitimentinec illius, cujus titulum mentitur.Lud.Viv.de Tradend.Difcipl.lib.5.pag.624

Iftis Orglnibus quas pro Catonianis olstrudere nobis volinit Annius Daterbienfis, nihil pofecto inficetius, Catoneque indignius. Voff. de Hift. Lat. p.22...

Anmins ille, homa quiden dactus, fed rotus penè enendaciis ac fradibus confutus. Fo Jjus de Art. Graminat. 1.1.c.9.:

Annius in Commentariòs fuis pleraque omnigimpudentilime confinxis. Petr.Crinitide Honelt Difcipl. 1.24.E.I2.

Hucufque Nanclerus; penes quem fives elto. Nam Viterbiensis, quem laudats fidem non mereur apud me. Iar.Druf. I.de Henocho,c.n11.

Ut doction vidcatur, mendacia fua auctoritate prifconm Auctorum frmare: conatur. Propter à commentus eft Myrfilós, Xenophontas de esuivocis, MetaIhenes, \& alios nefcio quos, qui aut nou fuerunt;at ea non friplenun, qua pla. nus ille cos fcripfle menirur. Scalig Elench. Orat Chronol.Parei:

Quid igituthic mentis erat Baronio? Sed hac tolerabilia erant; modò ne ferium \& grve opus Annalium fabulis P feudophilosis è cloacâ Arinii Viterbienfis: contpurcaret iltud omninà ferrinon debet, zon potelt. Cafaub.ad Annal.Baran. Exercit.r11. Ann,II.

foanneswnius Viterbienfs reliquit Antiquitatum libros viginti feptem; frepiùs reçufos, fed nugis mendacibus plenos. Nam Berofris; Manetho \&alii Scriptores Veteres, quos fe producere licit, prorfus fun fuppofititi... Suis porrò nugis :

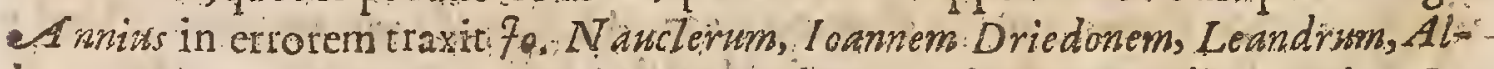
bertum, Valerium Anfelmum, Io annem Lucidum, Michälern. Me dinam, Sixt. Senenfem, \&alios. Aubert. Miraris de Script. Ecclef:

Annium Viterbiensern, improbifmum fabularum confarcinatorem, appellat Zfauc Cafaub in exercir in Anhal, Baranio 


\section{CELEBRIOR UM AUTHORUM.}

Prodiit Pitrum xvo cum magno primùm mul torum applauli, ex Annii Viterbierais. Monachi Bibliokeca Berofus Chaldaus; qui ante omnes Gracos in patria rebus geftis icribcndis egregiam operam navavit:unde Eunccius \& alii Chronologi multa ranģuam verithma tranfcriplerunt: fed polt propinquiorem oculatiorum infpectionem Itatrin The fauras Carbones. Quicquid cnim pixter antiqua fragmenta Berofoaddium erat,id toum ipfus Annii putidifima \& Nonasticainpoftura comperta, . \& ut hominis nequam impudens fraus ab omnibus doctis. mulris fibitis explofa eft. Rob. Bailius in oper.hiftoric.\& Chronol.

Non tam miror Italiam pieducere potuilfe tam impudentem Impoftorem, qui fub fictitio \% bilonis nomine infinita commenta Orbi aufus fuerit obtrudere. quàn repertos cffeviros doctifimos qui ejufmodi deliria patulis nimis auribus \& credulis animis haulerunt. Miferet Emafme \&almeronis Anmiaras nugas ex profello lectantium. Ibidem, l.2.p.57.

Erat qusidem ad manum Libellis, quem Birofi numine vendtun Bibliopolia:erant alia quxdam foannis Annii, qua non dubitoquin adiniranda fuilent vifa, fircutiltem; ne mpe portentola, \& vel folo audiu horenda. Sedab illis prorfus abftinui, ne de face, quod aiunt, viderer haurire, hoc eft, ex libellis friv olis, \& incertorum Autorum, quos ad ftupefaciendos imperitos lectores Greciadufit otiofa. Non quod fi Berofi fcirfem elfe, non ellemperquam libenter ufus; fed quod milii foeturam fubolebant Greci hominis, ut etiam Xenophontis eAquivoca, \& alia multa,qua illomm non fune, quorum tirulos pre.fe oftentant: Quod fi quis illis delectatu;, non procul fint petenda, amer, \& fitatur, fine me duntaxat rivali: Lud.Viv.init.l.18.deCiv.Dei; c.i.

Hixc Aimit fententia de Potefare Colligil fenommatum Anthore; tum ex ratione, non magnam meru fidem. Nam is auctor multa folet fingere, rreque: benè audit apud fapientes \& probos rerum fagrarum, \& prif cx. Hittoriæ: atinato:es.Io.de trnedal.3.c. 1.de Reb.S.slomonis.

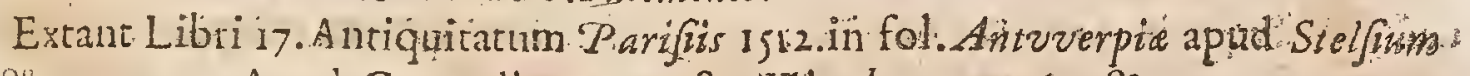
in $8^{\circ}$. anno I552. Apud Comaclinum 1592.8\%. Witteberg.an. $1612.8^{\circ}$.

\section{NICOLAUS, LEONICENUS}

17 Atus Ficentid Ital. A. C I42. Orator, Philofophus \& Medicus eximius: Graca. Galeni Volumina L atinè interpretatus eft; \& Commentariis illuftravit. Clar A D.: Cum aliquando ex co quær eretur, quonam arcano Medico uteretur, ut tanto cum

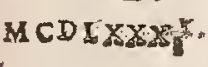
corporis \& anini vigore, etiam nullo ciborum habito delectu, fenecturis viria eluderet?vividum, inquit, ingenium perperuâ vitæ innocentiấ, falubre verö corpus hilari frugalitatis prefidio facile tuemur. Integris enim adhucfenfibus, memori : vegetâ, nec dum incurvâ confpiciendùs cenvice obiit Eerrarix A.C. 15240" atatis fux 96.I0.Ant.Vander Linden. de Script:Medic.

Scripfit varia, hæc verò primum obtinent locum: In Galeni opera Commensarii_-Notxin Diofcoridem -.... Ppufculum in guo omnibus aguis falutem \& 
vitam reftitui conciliarique polfe docuit---De Pliniv \& plutium alionm $\mathrm{N}$ dicorum, in Mediciná erroribus---Epiltolx.

Nemo profitentium Mcdicorum, Nicolao Leoniceno Ficentino crera falutaris fcientix dogmata puriùs atcue nitidius explicavit. Nemo errores Sophiltarum

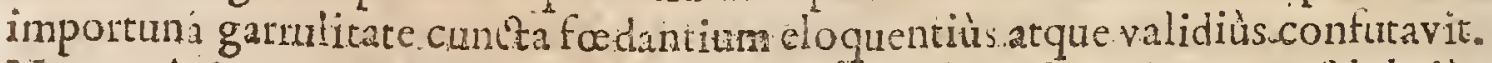
Nemo êc demum at illuftrem certioris peritix fidem longiùs atque falubriùs witam produxir. Primus enim Greca Galeni volumina. Latine interpretando ttudiofis perdifcenda demontravic, imperitorum latratibus, publicatis fummâ elo= quentiầ commentariis occurrerat, utpote qui do incunte atrate optimis litcris deditus, ingêtites opes capacis \& maximè conftantis ingenii, ad illuftrandam medicinameontuliler. Cibi enim \& vini maxime abftizens, fomnique mi nimi, prxfertim verò Vexerìs continentifimus, ufque adè nollioris vitx voluptates abdicavit, ut pecunias; luxurix intrumenta, nec agnita quidem mobetæ nota contemneret; oblatum, \& nullâ delęum curâ cibum caperet; nec unquam de fortunà quereretur, quòd unam vis acutus fudionm laudem refpiceret; nec opportuna mediocris vitz fublidia, benignitate Ferrarienfum principum 4 erculis, Alfonfque filii, fibi defuturaprofpiceret. Eum hercle perfectum Stoicum putalfes, nili hunefo ori.liberalis hilaritas affuifet. Edidit eruditum \& perelegantem librum; qui Romants Medirus a ntifophisto infcribitur, quim anteà de ordine triun doctinarum, \& de virtute formativà perutiles Libellos public ılet. Dionis quoque Hiftoria, \& Luciani Dialogi, vernaculà. lo-

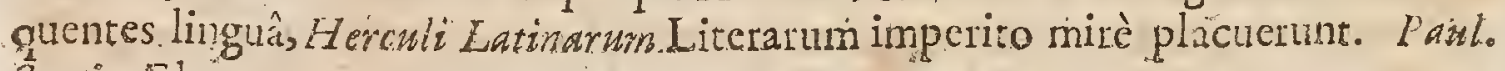
fovin $\operatorname{cog}$.

Leonicenus Medicus, vin ad atennitatem natus, quem ego ultimum freroum \& aurei Seciali reliquias appellabam. Erafm.1.20. Epift. 5 +.

Nicolaws, Leonicenus vir Grace ac Latine fcientillmus. Khodigin. 1.15. Leck. Antiq.c.18.

Vir hic Gracd \& Latint dodiffumus, à barbaric illorum temporum purgare artem 72 edicam conatus elt. Quenftedt.

Leoniceni Epiltoly maximam ejus doetrinam prafe ferunt, \& elegantiam. Gefne. in Biblioth.

De Leoniceno non nifi honorificè predicare débcmas, vel co nomine, quì primus Philofophiam \& Medicinam ipfam cum humanioribus literis conjunzit. Primus enimille nos docuit, homines, qui fne bonis literis medicinam tractant, effe frmiles iis, quíin alieno foro litigant. Et nirum pratcrea accepi de siro. A pueritiá, ímò à cunabulis îfs ad 30. annum morbo Cornitiali adeò rentabatur, ut, cùm ad fc redierat, pertafius vita penè fibi manus afferret, Sed poft trigefimum aninum planè co malo defunctus, omibus membrorum ac ferfium ofticiis integer, nullâ morbi fufpicione ad 94. annum pervenit. Et, Gi benè meministriduo, antequan decederet è vitâ, operam dederat lectioni. Felicem fáhè fenectam, qua prius portum apprehendit, quàm navigationis incommods fentiret. Iof.Scalig.Epif.: 9 .

Erat \& Leonicenns menito inter Poëtas collocandus, nam cum fenex optimos 
verfüs faceret, \& interdum è Graco in Latinum transferret, tum in juvenili fuâ. atate nan modò mediratos argutè, \& doctè compofuit, fed etiam, ut fxpè mihi memorare folitus fuif, extempore, \& impremediata carmina secinit..Lil.Gy rald.

Leonicenus à Parre femper imprimis commendatus, \& Medicorum fui temporis facilè Princeps judicatus. Scaligerana prima, p.97.

Oratione non valdè quidem fịlendidâ \& excultâ, fed perfpicuấ tamen, \& ad Grecurn exemplar affabrè compofitâ ufus eft. 2 jicolans Leonicenus. Huet. de Clar.Interpr...

Extat liber de Plinit \&alionm Medicorum errovibus de Hèbis \&Fruticibus; Animalibus, Metallis, Serpentibus, \&c. Bafil.1529. $4^{\circ}$.

Extat verfio aliquot Librorum Galeni \& Hippocratis, \& Quxftio de 3.Do: qriuis ordinariis fecund.m Sententiam Galeni. Venetits isa3.

Hoc ejus Epitaphum à Myrteo confectum

Cuineque Jat fuit, of terras cvolvere, of undas;

Quaque arcana tenent flumina, terra, Mare::

Dum rerum canfas lätè vestiggt, of agra.

Morborum resocat corpora cotluvit:.

Nunc Leonicenus tegitur parvo ag gère Terre:

Cujusutrangue valat fama per H esperiam:

Paulilov.in Elö:

HER M O L A ES B'A R BAR U.S

F X iluftri Barbarorum apud Venetos ortus eft familiâ: cujus nobilitas ex ${ }^{ \pm}$ E cellenti doctrinâ, \& rerum publicarum ufu zquata êt Exiftimatus enim ett fui fxculi ernditifimus, \& eloquentiffimus: Et hanc rerum fcientiam ornabat corporis vegeri preftantia, decor \& vivacitas in vultu, mores politi, gratia in omni actione, \& fuavis facilitas in converfatione, \& focietate amicorum: Hxtam infignes animi corporifque dotes illum gratum rediebant omnibus potifimum firis Venetis, quorum Rempublicam confiliis, \& prudentrâ plurimum juvit \& promovit; ; primum fomper locum inter fuos apud Principem obtinens, qui ejus familiaritate, \& confuetudine familiari mirum in modum delectabatur: Havirtutes illum commendarunt Alexandro. VI. Borgia P.M.z̀ quo hitcris invitatus eft ut Romarn veniret; \& Pontificis amicitî frueretur. Eò poftquam veu niffet, præfentia canti viri famam de co fparfam auxir: charus fuit Pontifici, charus toti-Apoftolico fenatui, charus omnibus extitit: neque mirum : Gloria enim erat Nobiliraris. Venetx, \& fü freculi fplendor: Ut igitur tanis animi dotibus; aliquis tribueretur honos; Alexandè Jum creavit Patriarchan Aguileien femb

Clar:A. O: AS C̈DLXXX: adproa 
adprobantibus hanc electionem omnibus Cardinalibus, \& Ecclelre Prxfulibus: apud quos ali . jua diu magnâ cum laude, \& admiratione verfatus erat. Sed now multo polt Rome, contagio peftis frviente, è vitá fublatus eft, ad collem hortulorum quò fecellerat: Sepultulque ad portam Flaminiam (quaert porta Populit) Anun Doin. +94 . Boifjard. in Icon.

Hermolaus Burbarus, Patricius Venetms,natus fuit anno 1454.21. Maii. Ob it 12. Kal. Jun.ann.Chr.1493. xtatis fur 9. Ab anno atatis vigefimo fecundo fcribere o:fus fuir:cumque ilia multa edidit, qux doctorum manibus.verfantur : tum etiam Plinitiveronen/s (non Novocomen/is, thi apud lovium eft) Hiftoriam Naturalem acuratè caftigavit. Idem Librum reliquit de Conferibendâ Hiftoria quem dicavit M. Antonio Sabellico, Hiltoriographo. Alia eriam ineditathactenus parabat, que cajumodi fuerint, cognolcere eft exprafatione ojus Caltigation num in Melam Proprietatis rocabulorum in utrầque linguâ curiofus erat, mo*ribus caftifimis, adcoque à faftu alienus, ut frè ficubi dubitatio oborta elfer, proximos, ac familiares confuleret, atque alleo à quovis difcere pararus elfet: quemadmodun de co Volatereanus tefami-Uti \& illud Volaterranus in eo reprchendic, quòd Pliniturn caftigandum fulceperit,opus, ut ait, impar dignitati, \& vitx fux infituto. Utinam fic à multis ejus dignitatis, atque inftituti, peccaretur. Et fanè cogitate debuerat Volaternumb jam antequam ä Epicopatum pro*etus ellet, parata majori ex pare habuille, qux ad iftud opus pertinerent. Neque proptereà Epifcopale munus, quod feu velens, feunvirus fufceperar, neglexit. Aliud fanè inter cetera argunn Conciones gus, qux Pataviz Manufcriptre iextant apud Ererritas. Viefj. de Hif.Lat.

Hermolans $B$ arbarus amices incus fummus, perquam fuit literis homo ornaxifimus, bonifque diciplinis \& ingenuis artibusexcultus, ac preter ingonii amonitatem, qux plurima in thomine firit, dedrua quoque curiosa \& eleganti. Alexander ab Alcxand.l.3.Geniat.Deor.c.I.

Vir omnium difciplinarmperitifimus. Nic. Leonicen sa Epintad Angel. Peditian.lib.2. Epilt.6.

Homo, ut mini quidem videtur,ex reliquiis aurei feçuli. Angel. Politian.lib.z. Epift.9.

Eratomninò Herrnolai, propter cjus fummam ân literaum, atque optimarum arrium ftudiis prattantiam, magum apud exteras nationes nomen, apud fuos quikem certè maximum: thatio ad doctinx fingularemopinionem etiam vitx peipetuam innocentiam abjunxcrat--.-.. Onnium ex flia civitate, qui ante illum nati elfent, Latinarum is Grecormm literis plane doctiffunus. Petr. Bemb.l.I. Hift. ejus reneta.

Habuit neftra hac atas bonarum literanmproceres dues, Hermolaum Barbarum, atque Angelum Politianum, Deum immortalem, quàm felici ingenio, quàm acrîjudicio, quantâ fachndià, quant ìnguarum, quantâ dicciplinarum onnium feienti preditos! Hi Latinam Linguar jainpridem $C_{\text {gulent }} \mathrm{m}$, \& mulra batbariei rabig ne exefam, ad priftinum revocare nitorem conati funt, atque ilhs fus profecto conatus non infeliciter ceffrt, funtque illi de Latinấ Linguâ 
ra $m$ benè meriti quìm qui ante eos optimè meriti fuere. Itaque immortalem fibi gloriam, immortale decus paraverunt, manebitque femper in omnium eruditorum pcctoribus confecrata Hermolai, ac Polttiani memoria, nullo ævo, nullo cafu, nullo fate abolendar. German.Brixivs in Epilt.ad Erafrnum. Vide Erafin. Epift.1. 4.Epilt.8.

Hermolaus Barbarts -- - Is vir erat, qui non folum I taliam furam, verum eiiam ome faculum hoc noftrum illulträrit ; cujus tanta eft apud omnes eruditos autheritas, ut inpudentiffmum fit ab illo diftentire : tam infignis in reftituendis literis urilitas, ut à literis omnibus alienithmus, aut certè ingratifinus habeatur, apud quem Hermolai memoria non fir facrofaneta. Erafm. in A dagion, Quid Cani cum Balneo?

Basbarix fuo tempore Victor, folidam fibi aptad eruditos glo iam peperit, \& vieturam omni ævonomen. Salmaf.Prafat.ad Plinian: exercitat.

Hermolans, ille omnium Skicnearum alumnus, dern ac parens. Inl. Scalig. - orat.ad Arnold:Perronum.

Erafmus in Ciceroniano eum vocat vere magnum, ac Divinum hominem, fed in dicendo Ciceroni difimillimum, \& ipfo, pene Fabio, P'inioque elaboratiorem; cujus eloquenire nonnihil offeccrit hiloio hix fudium.

Hermol sus Barbarus de elegantià follicitus, non tantum verbis, \& characteri,

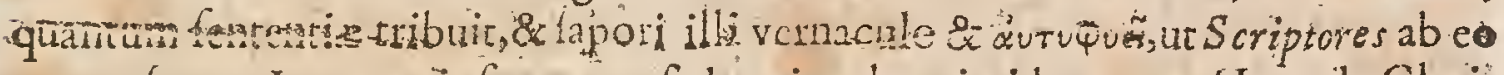
converf non Interpretis fermone, fed nativo logui videantur. Huet. de Claris Interpret.

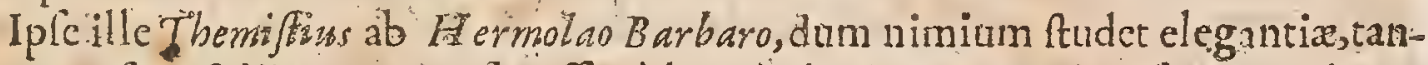
tâ convetfus eft libertate, ut lrep ffimè longè alitid dicst, quàn fencrit Themifius. Ur ominino optaindum fit, edi tralationem veterem, quam apud Carpetanos alicubi delitefcere aimant. Vof:de Philofoph. p.8.

Cui uni [Hermolao Barbaro] Plinius plus, quàm reliquis omnibus debet. Roland. Maref. in Ep.t.p. 83 .

Huic Pliniane verfioni multun deralit Paul. forizus.

Hermolazs Barbarus, Venetus Senator optimus, vir, quod omines fatentur, xtate fuâ lireratifamus, eo iplo tempore, quo aliquam ftudiis fuis quietem fe adiscutum arbitrabatur; dum Rome apud C Alexandrum fextum, Pontificem Maximum, Venete nobilitaxis nomine Oratorem agir ; fummifque vigitiis intermortuam bonarum literarum, neque non \& difciplinarum gloriam fufcirat; ob fúfceptum, inconfulto Senatu fro s. fuilegienfe facerdotium exul factus, \&de poffeffione ejectus vitam inopem aligeandiu traxit A lexandri Pontificis fummi fportủà quodanmodò fuftentatus; paucis verò poft menfilus peltilentiầ contactas; defertus ab omn bus, infelicifino mortis genere oppreffus ef; quique laudatione, \& eloquentiâ fuâ innumeros æatatis fua homines illuftraverar, \& funere, \& honore fepulchri defraudatus eft, ut ubi fepultus, quóve hominis cadaver conjectum fuerit, ignoretur. Fo. Pier. Falerìen de Literatorum infelicitate. 
Hoc ejus Epitaphium:

Barbariem Hermoleos Latio quï depulit ornnem, Barbarus hic fitus eft. Vtraque lingua gemito.

Qrbs Venetûm vitarn, mortem dedit inclyta Roma: Non potuit masci clarius, atque moris:

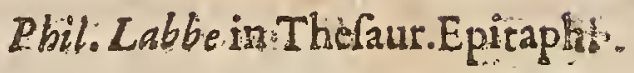

Paria ejus Opera variis temporibus atque locis impreffa funso.

\section{HIERONYMUS SAVANAROZA}

Clar.A.D. ACD LXXX.

T. Talus, patriâ Ferrarienffis, Ordinis Predicatorum, Florentie laqueo fuffocatusi: 1 \& crematus eft Anno Dom. 1498. atatis 46. ob zclum quô in corruptos EG: clefix mores invectus eft. Gul.Cave.

Scripta hxe reliquit: Qtradragefimale libs. Guper Pfalmos \& Prophetas. Compendium totius Phil ofophix tam naturalis; quam moralis. Opus de divifione, ordine, \& utilitate omnium Scientiarum. Triumphum Crucis:.Commentarius in Alcoranum, quod omniratione carere probat. Er Prophetiäm, in quâ.multa de hoc noftro feculo, \& Regrnorum commotione predixit.Expofitionem Orationis. Dominicz. Idem Italicé fcrip fit Libellum conera Aftrologian früdiciariam, quem Thomas Eraftus in Germanicam Linguam tranfulit. Scripfit etian. Sermones varios.

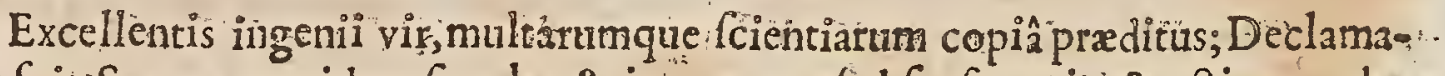
tor fuit; Sermone quidem fimplex \& incomptus, led fenfu acris;' \& actione vehomens. Sanetitaris yerò opinione ita omnibus admirandus, ut Elörentina Vrbis:populus ( apud quem feptem annis in magnâa \&afliduâ. Auditorum frequentiâ: Conciones habuit) exiftimaret eum cum Deo loqui; \& ab eo futurorum eventuum. prophetiam accipere, \& ob id nollet Rempubliciam, \& Communiatotius Civitatis : Imperiasnifi epus nutu, adminiftrari. Qux cùm aliqui bus Primariis $C$ ivibus non:

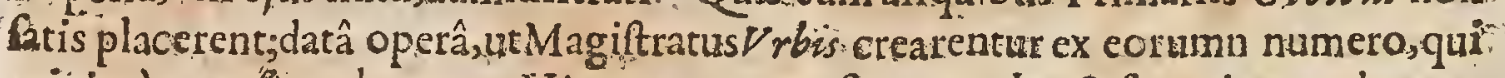
minimè eum ftquebantur, Hieronymus non fune tumultu \& fanguine multorum captus \& in Carcerem conjectus, \& ad mortem damnatus, paulo poft Sacerdotabi: honore exanctoratus, medio foro vions exuftus eft, cinerefque ejus, ne à fuis, qui jam eos colligere caperant, religiosè fervati colerentur, in profluentem $\mathrm{Ar}$ roum projecti funt.Sixt.Senenfil.4.Bibl.Sanct.

Prædicator acerrimi ingenii, fumm doetrinx \& Eruditionis. Vir aufteræ viזx, \& motum Sanctimoniầ omnibus admirandus : vehemens in reprehendendis vitiis, eloquentiflungus in Concionibius: tantâ vi dicendi, \& facundiâ pollebat, ut 
quồ vellet animos Auditorum perfuafos flecteret. Ideo quoties ad Populum verba haberet è fuggeftu, tantus ad illum audiendum confluxus crat, ur ampliffina templamulcitudinem capere nor polfent. Boiffardin Icon.

Vir etriditione ac pietate infignis. De Articulo gratuitze $7 u$ Rifficationis per fodem in Chrifum, rectè fenfit, ut apparet ex gjus Conmentariis in Plalmum gx. Humanas Traditiones elevavit. Communionem fub utraque Specie defendit. Indutgentias damnavit. Papa, Cardinalizumsomniunque Spiritualium turpem fceleratamqque vitam, \& officii neglectionem, gravifime eft accufare folitus. . Negavit quoque Primatum Papas. Claves docuit Ecclefix toti, non uni Petro traditas: Illyric.in Catal. Telt.Verit.

Hieronymus Saq anarola, Concionator percelebris, piètate, fanctimoniâ, do Etrinà ac̉eo clarus, ut à plerifque Propheta haberetur. Morsans Hift.Papat.

Ioanaes Picus Mirandulanus Comes Prophetam appellat, \& adverfus Papame Apologiâ in eam rem exprefsâ tuetur.

Triouit ei \& Marfüins.F icinus in quadan Epiltolà Propheticum Spiritum, \& alioqui eum magnificè celebrat.

Philipptas Comineus Gallicus Hifhoricus, quicum eo locutus eft, teftatur eum fuiffe virum fanctum, planeque Prophetici Spiritûs:quippe qui multa fibi pradjxerit, qux eventus comprobarit.

Moribus erat inculpatis, guantum quidem perípici poterat; \& dacendo mulo ros ad fanitatem; vitrqucemendationem perdu it. Comineus in vita Car.VIII.

Hierongrann Savanarala, vitx puritate, \& infigni doctrind fulgens. Spondan.in continuat. Baron.ad Ann.1492.

Hieronzynus Savanarola, eloquio, pictate, \& eruditione-nulli fui feculi fecunedus, atque ob has do:es cunctis gratifinas. Hofman.

Multa varii generis tatinâ. Linguâ compofuițnonnull a quoque Italico I diom mate, tam prosi guàm werfil. Ex.omnibus autem qua unquam cudcrit operibus, pracipum id certe fuit ustod in probationem Chriftiana Fidri cditum quatuor diftinctum libris, Triumphis Crucis inferibitur, atque cxteris prxponendum, non tantùm ftylo, quä certè cateris enditior eft, fed \&.ipfa, quam tractat, materiâ. Fo. Franc, Pic. Mirand.in vit. Hieron.Savanarot.

De fimplicitate Chriftiane vitx libri quingue digni qui ab omni Chriftians homine legantur. Gefner.in Biblioth.

In Pfalmum trigefimu primum \& quinquagefimum Medizationes, pridic antequam duceretur ad mortem, fcripfit inter metuendos carceres horrores, \& imminentis fupplicii anguftas Latino fermone, vivis verbis, animatis fenteatiis. \& Süiritûs.fervore Aagrantifimas. Sixtus Senenf.l. +. Bibl. Sanct.

* Hieronymi Sassandrole Ferrarienfis Sermenes, qui olim in Romano Indice. prohibiti fuere, non legancur, donec juxta Cenfuras latrum Deputatorum emen- dati prodeant. Ejufdem liber inferiptus, Dialogo della Veritu, omninò prohibe. rur. Intex Roma impreffus, $68 \mathrm{r}$.

Extat Trimphus Crucis, feu de veritate Fidei libri 4. Lugd. Eat.1633.8\%,

Extatede Simplicitate Chrifiane Vitalibri g.An.1615.8.

Q9 2 Exts 
Extat Compendium Philulophix Naturalis \& Monalis Wittebergor $96.8 \%$.

Extant Commentarij in Pfalmos 50.70.79. Tubing. 162 . in 12 .

Extat expolitioin Orationem Dominicam unà Cum Medicationibus ejess

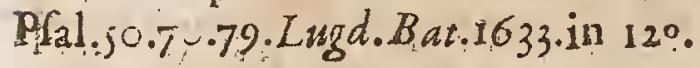

Hoc ejus Epitaphium :

Dum ferafiamma wos Hieronyme palcitur artosts,

Relligio fanitas dilaniota cornes

Elevit, of o, dixit, crudeles parcite flamon: ;

Parcite, funt isto vifçera nostra rogo.

Pbit tabbe in Tllefar. Epirapha

\section{MA:RSILIUS FICINUS}

Clar.A D. Arria Florentinus, natus anno 4333 Philofophix Platonica fun atate inftutu MCOLXXX:

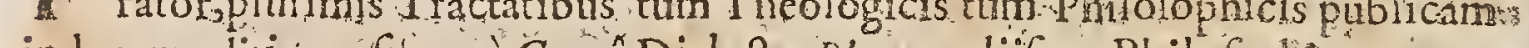
in lucem cditis, verfique è Gracá Dialcoto Flatone, alifque. Philofophis, momen fum pofteritati commendavit Obiiranno 499 in patria. Phil, Labbe de Scrigto. Eccle?.

Extant opera ejus omnia Fol: Parifis 164 ro

Marfalius Ficinus patrià Florentmus, Platonicu dactrinæ fummus admirator :\& cultor, Grecie \& Latina Lingux pertifimus:homo ingenii acuti, \& vigilantis: unicè adamatus à Cofmo Florentimoram Principe, propter exquifitam fcientiarum omnium, quâpollebat, cognitionem. Fuerat enim $M$ arglius cum Angelo lolitiano bonarum literarum ftudis excultus, operâ \& fumptu Laurentii Niétices, qui \& iple doctus; doctorum omnium Recceras vocatus eft, tantâqueautoritate, moderatione, \& pradentiâ Rempublicam Elorentinorum rexit, ut Pater Patrie dici jure mereretur.Pot cujus mortem, non minore apud $C$ ofmum gracia valuit; $\&$ ab a eo divitiis, $\&$ honoribus ditatus, otio literario vacans, Principis bene meriti fuafu, Latinos fecit Iamblicum, Synefium, \& P fellum, Platonicos autores, iplumque rotum platonem. Scripfit \& alia infignia Opulcula, qux do dotis cum fingulari: delectatione, \& fructu leguntur. Boiflard in Icon.

Vir in fecularibus literis enudiffimus, \&ed vinarum Seripturarum non ignazus, Philo lophus; \& Rheror celeberrimus, utrâque linguâ peritifimus; Platonice: Theologix unieum decas,; Ornamentum \& Corona. Scripfit urnato fermone. multa praclara Opulcula, quibus excellentis ingenii fui venam pofteris oftendit. Trithem.

Nature renm peritifimus." Tirag. de LL: comub:gli.1.p.19.

Omnium Academicorum peritifimus. Bodin. 4. de Rep.2. pagrag.;

Homo fumat ingenii \& inexhafti laboris.Daftliand.in Defcript. Urb. Ital.' 
Vit divinus \&fapicntillmus, quemfapientix \& integritatis decas rectifimè eppellaverim Leqin.1.Confil.s.n.ษ3.

Vic fuit peritus non vulgaricer, tum facra Theologix, sum etiam Platonice Philofophize. Bellarrade Scriptor. Ecclel.

Unus Latinorion Narfilizs Eistins divina Philofophra amore incenfus transfercndi Platonis negorium fufcep $t$, arque perfecit, $u$ qque adè feftinatà felicis ingenii focun ditate, ut pleriçue in pufllo cjus corpore, quod vix femihominem xquaret, tantam vim inufirati fuirichs, \& tantas utrufque lingtix facultares vigeremirarentur. Paul.fou in Elog.Doet.Viror.

Eo.falcm facto mericus; ut qui to clatorum virorum memoriam in occulto Latere pallis non eft, iple quoque oblivioni minimè fir tradendus. Meich. Ada mus iii ejus Vitâ.

Cujus longè felicior quàm Thracenfis Or phe Cithara, veram(nifallor) Eamydicen, troc oft amplicifimi judicii $P$ latonicam $S$ apientiam, revocavit ab inferis. Angel.Polition.Milcel.Gentur. I.c.roo.

Anno r +90 . longè latéque difundebatur nomen c Jrarfín Fisini : qui Apologia fir comprobat, Aftrologiam, \& Medicinam, ad Saccidotes pertinere. Eriam tres libros fecit de vitâ in quibus ex Aftologiâ divinatrice multa admifcuic fupertitiola.. Lecto tamen. Opere Pidi c M irandulani adverfus Aftrologos, vanitarem ejus feientia dicitur doprehendille, ac rejecilfe: Magnus omninòvir erat; prafertim in Philofophi platonica. Quatemirors fummum iridem virum, Ludovicum Vivem, cùm locutus efiet de Epiftolis eAn. geli Pôlitiani, Hermolái Barbari; atque aliorum, fubjungere deinde : Adnifcuis: fe bis Plitofophafter. Marflius Eicinus, ut oloribus gavia: atgue Epistolas compos-

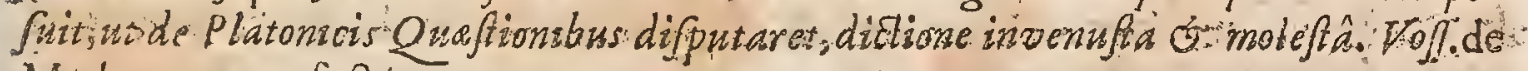
Mathemat.C.35. fecti.47:

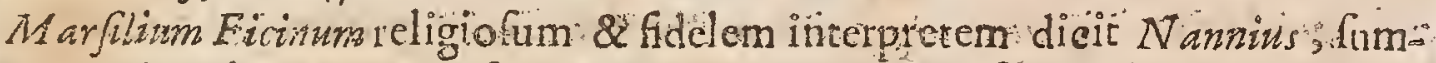
m que curà verbis infituilie, fententiam quoquereddiuffe, in indote verò defecille: Nos aliter judicamus; nam verborum curam negligit Ficinus, fententias

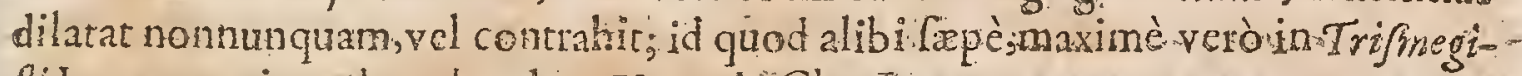
Ailnterpretatione deprehendas. Huet. de Clar. Interp:。

- Marflitu Ficinas Platonis Interpres, Sernano quidem fidulior \& purior eft Sed quinquam à flatonts mente difcedat rariffimè, it a tamen vertit; ut Platonem effe non judices. Vides quid $P$ láto dicere voluerit, fed guomodo dixerit, non habes: deelt Affectum vis, lepos, venurtas, clcgantia, arguties, acrimonia, dignitas, qux apprimè in Axiocho vertendo obfervavit Rodolph. Agricola. Clowd. Verder. in Auct. Cenfione:

Leonardus Le flus eum inter Magos retulit.

Ejus Opera fatis evincunt.Virim illum laboriofum ad compofitionem non minus idoneum fuife quam ad verfonem, nec propris bonis minus opulenmm quam Anriquitat is poliis. Quando fudii contentio ad animi relaxarionem aliquam quxendam illum adigebat; ejus oblectamentum erar cum honeAto \& jucundo fodalitio dulce vinum compotare. Tam brevis erat corporis 
ejus :tatura ut ad viros folitx magnitudinis lumbos vix pertingeret ; fed mas gnus erat illi animus \& conltans; ad Ixtitiam quam ad mororern propenfior. Sollicitè vitabat quicquid valetudini fux noxium elfe poterat; imò regiminis hujus aliis pracepta tradere voluit, libro two de Triplicitita: Septuagefmum tamen annum non exceffrt, Febrique anne I 99. abreptus eft, in fuz. Caregiana villa, quto tempore Ludovicus XII. Galliarum Rex, Alpes cum potenti exercitu fupergretlus bellum atque terrorem in Italiam inferebat. If. Bullarto in Acad.Scientiarum.

Hor ejus Epitaphium, Angelo Politiano Auctore:

II ares, Ingeñinom, Mufars Sophiamque fupremam. His atro dicam nomine? Marflius.

\section{JOANNES ANDREAS LASCARIS}

Clas:A: MICDLXXX.

T.

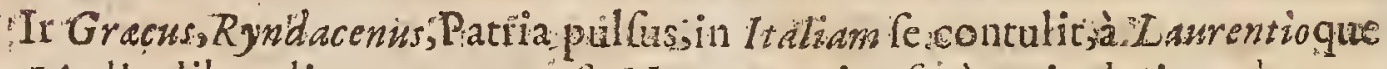
Medice liberaliter excepus elt. Nonagenarius ferè arriculari morbo perit circiter anum 15 s 3 in Polybio quxdam Latinè trantulit. Circumferunturs : eriam ejus carmina Greca.

Lafcaris mortm comitate generis nobilitatem prefe fert, acri judicio vir, multa in Epignammatibus argutix:poterat inter Ciccromian cognominis candidatos referi, nif erebra legationes \& Regum negotia revocallent hominem Mugis. Erafm in Ciceroniano, p.Iig.

Ianum autem Lafcarin in converfo polybin, exiguo quidem, at totius operis longè dificillimo fragmento lapenumerò demirari foleo, at cortun qua de eximiâ ipfus lucubrationc in Polybì noftro prafati fumus, minimè nos adhuc pigeat. Quòd fi hoc non fprevilfet Interpretandi mums, \& excuifo Veterno., quo penè fepultus vixit, plura ingeni fui monumenta reliquilfet, meliùs quippe nomini fui ; \& pofterorum ut litat confultuifet; at quantum conceffit otio fuo, tantum ex gloria dimintit. Huet. de Claris Interpr.

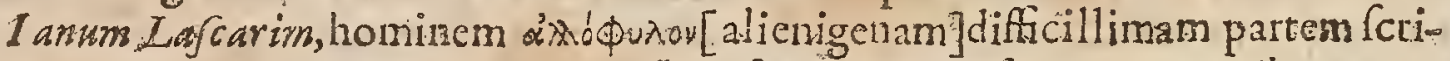
prionis Polybiana, facere Latisatm elle aulum, illis prafertim temporibus, magnum fuit; multumque veræ laudis eâ, quam vis brevi Opellà,preftantifimus ilLe vir, me judice, meruit. Qui fi in nonnúllis parum videtur caviffe; non tam ee nomine reprehendendus, homo enim erat; quàm admirandus quòd in plerifque

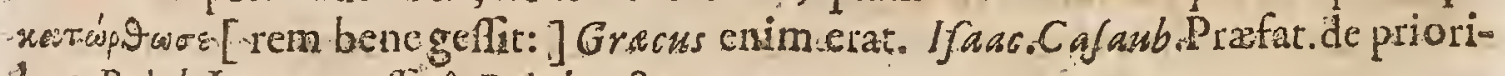
bus Poly6.Inteipr. afixâ Poly6.p.80.

Etfi Lanus Lafcaris homo Gracus aptè \& doctè pletaque jam verterat.: tamen reverâ alibi aliter, \& quod caput cit,non femper prelsè \& adatichè. Lip $\int$ de MiLit.Rom.L.I,Dial,2. 
Non afpernanda funt carmina Ioannis Lafcaris, fed qua tamen non augeaurs Firi nomen.Volj.de Poër.Grac.

Hic ergo Lafchares non folùm Gracè \& Latinè doctus, fed \& Regum, äc Pincipum agendis tractandifque negotiis fuit idoneus, \& vif Virgilium Epigrammate profcidifet ut artis ignarum, hic cum alio quocunque Grace nationis l'oürà fuiffet conferendus... Lil. Gyraid. de Pö̈t...noftror. Temporum, Dial.r.

Valebar Latina facundiâ, ita ut verfus qui extant perfcriberer; fed aded contumaci Rerilitate defidiefus erat; ut in vertendo Graca, vix Polybii Ca Arametationem efflagitantibus amicis exprellerit, quòd id ftudium recto an maligno judicio incertum; penitus dämnaret.- Verum egregit cum laude preftitit, lte Latini haberent emendatiora, qua -minore ipforum labore verterentur. Paul Lor:

Dominus Bullar dicit. Dootum she virnm verfonibus operam vavat: non fuilfe delectatum; quamvis Latini aque ac Graci fermonis callentiflimas. chet imo illumboc ftudi genus's opinione quadam fibi peculiari, damnass. Sed defeetum hunc penfavit, inquit, ingentibus fuis laboribus in Gracis Anthoribus emendandis, \& Latinis corum copiam faciendo on Orignali fua pul-chritudine genuinoque fuodenfu. If. Bullart, in Acad Scientiasum, libitar$2: 283 \ldots$

Hoc ejus: Epitaphium, Autoresangelo Colotio: :-

Dilleetris Mufis, ónrebus natus agendis;

Qucrngravita Iasperiis protulit alta dornus:

Toi freta dum curris, totque imvia regna pererras.

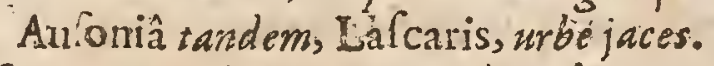

Sid futus in Patriâ es, Graio licèt Orbe remotus:

Virtuti nulla eft Terra alienaTHe.

\section{JULIUS POMPONIUS LATUSH.}

Aliàs PETRUS CAIABER dictus:

Talus, extra legitimum torm procreatus'; Anygdalariam natatem habuit. D.Clatina

Religionis Pagane admirator, Chrifiane contemptor fuit. Rome tanto cont MCDLXXX. curfu docuit, ut, cùm ante auroram docere inciperet à medià noete in auditorium, ad præaccupanda fubfellia, concurrerent. Septuagenarius obiit fub Aled sandro. ViI. Pontifice.

Scripfit librum de $M$ ahomete-Compendium Hifforia Romane-De MagiAtratibus Romanis - De.Arte Grammaticá-Epiftolas varias.

Sanè puræ crat didionis amator; \& Hifforia Veteris fcrutator diligens. Ith th sar lingux Grocr planè ignarus. Antignitases Jrbis Rome memoria rantù 
causâ conferibilafê videtur;non, ut publici eas juris faceret. Necenimea d di Etonis puritas, qux in aliis e us friptis elucet: ufque aded ut $B$. Rhenanus penè arbitretur alterius elle Auctoris. Vofj. de Hift. Lat.

Pornponius Latus Preceptor nofter, omnium, qui nôtrâ teftate fuere, omnis Vetuftatis peritifinus. M. Anton. Sabeltic. Schol.in Suetonit.Vitell. cap. I.

Pomponius,xir, ut in câ atate, veterum literarum impensèdodus, flext.ab $A-$ lexand.lib.j.Genial Dier.c. 11.

Pomponius Latus, vir Antiquitaris \& lierarum bonarum confultifimus. AnGel.Politian Mifcellanc. 73 .

Pomponius Letus, \& literarum, \& antiquitatis, ut Ccitis, benè peritus.Gyrald.de Antiq.loët.Dial.4.

Pamponius Latus exigur enditionis. Tota illa ejus celebris diligentia circa werba, \& Hiltorias aliquot, rum laxa enuta, a monumenta diruta conflimpta eft. Lud.Viz.de Trad.Difipl.

Pomponius Laius, Romana puritatis adeo ftudiolus, ut nec Grece quidem fcire Noluerit, ne quid alienum fonaret aut admifceret lingıæ illi. Ita $\mathrm{k}$ verba haber electa, \& dictionem fatis caltigatam. Lud. Viv. lib.extremo de Conferibend. Epilt.

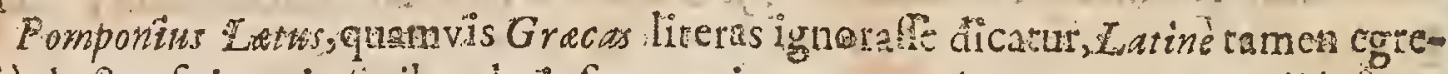
giè doctusfuit, in icribendo infra neminem recentiorum purus candidulque Eranc.Florid Sabin.in Apolog:

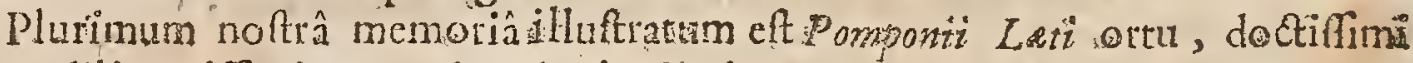
wiri, diligentifini ue totius. Antiquitatis \& Inveftigaroris \& Infauratoris uti Scripiorum jus monumenta tęantui, precipuéque Cufares. Leand. Alberto in Italid.

In hilce Cafaribus logas quix apud Fifforicos non reperias. Ea vere hauft (19agnam partem ex Panegyrigis veteribus. Voj]: de Hift.Lat.

Non pauca ejus Scrspta fuperfint magnam Hiftorie Romane corique Ant"gritatilucem ferentia. fo. Matth. Tofan. in Ital.peplo, c.:8.

Pomponizus Latus, vir funmâ evaditione, atque dicendi elegantia clarus. M. Ant.Majorag. Orat.X. quam de nutat fit homin is habuit.

Vir ille ('Pomponius Letus) caftum mayis, quamphalcram \& tumidum fernonem femper amavir. Romanam vetuftatem nemo un uam diligentiùs obfervavit, \& veneratus eft. Beat. Rbenan.in lit.ad. Theod.Gregrnundum, quas Pompon. Lati Antiq.pramifrt.

In fuggeftu fumman landen promeruit: quod eo magis mirum videtur, quin in familiari fermone hæátante ling ta balbutire folitus effer nec orintern demum ant clarâ voce lestitantern, ulla omnino oris titubancia deformaret. Paul. Jov.in Elog.

Pomponius , Laths elegantia Romani fermonis contentus, nihil affectavit ulträ. Erafm.in Ciceronianosp.16r:

Septuag narius exceflit è vîtâ, gum gelidiflumo vini potu ventriculi calorem $\therefore \sin 3$ oppreffilet. 


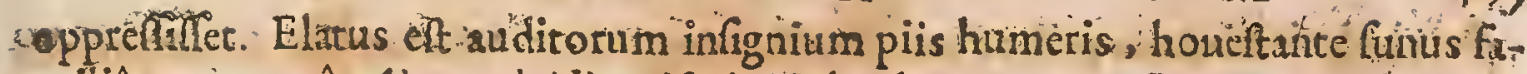
- miliâ purruratâ Alexandri l'ontificis, \& laudante Marfo Oratore. Quum variis autem el giis thmulus onarctur, hoc Epigramma Pontani, collculu putblico, locum obtinuit.

\section{Pomponi, tibi pro tumuito fot lasirea Sylva'.}

Ofja, Maris roress myrteaque inbra tegant:

Teque teganto artufque thoss violegue rof feque,

Veribubeat, Zephyros fi iret., Jo, ipfe cenis.

Stillet o ipse cinis, quas or Parnallus, of Antria

Thefpia, o ipfajuas Afcraminilfret aguas.

$$
\text { Paulolov. in Elog. }
$$

Woc alliuc Epitaphium, Autore Domitio Palladio:

Híc jacet ex, guâ:Lxtus Pomponit!ts Vrriâ,

Cujus honor werito pulsat utrurnque Polum.

Lierus erat Romevatis sublimis, ofideris

Rhetor nunc campis latior Elyfitis.

Rrodiit Iulii Pomponit Lati de Urbis Rome Antiquitatibus libélins ; "Tito

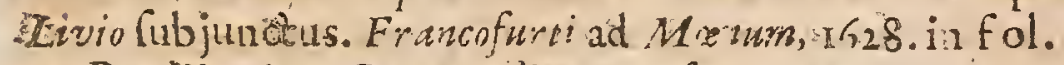

Rrodiit cjus Compendiuin Hiforia Romana, inquo de Cafaribus agit, Ve-

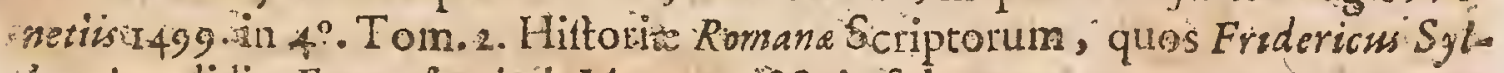
Shurgizusedidit, Francofurtiad Monumisos. in fol.

\section{OANNES I IUSS}

M Trandulá Dominus, \& Concordia Comes ac Princeps, ingeniontim fui Clar. An. B. magno omnirm meroese Florentie, die xv. Kalend. Decembris thivi I 494 . quo - die L a rolus VIII. Francorum Rex eandem ubemingrefus ofe. Aitas ejus 3 so duntaxat annorum fuit Phi?. Labbe de Scriptor. Eccler.

Scripta cjus hare funt: Heptaiflus de operc fex dierum Genefoos - Nongent* Condufiones Philofophica - Apologir - Tractitus de Ente \& UnoOratio de Hominis dignitate - Be Chrifti regno, \& vanitate hujus Mundi-

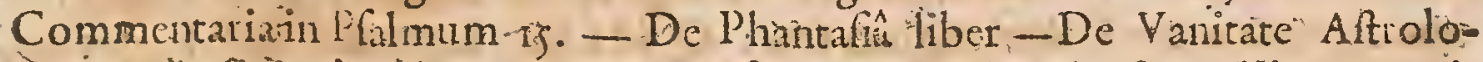
Gix, ale divinationibus qux per eam fiunt - Regule Cbrifiane Vite perutio les - in Contizium Platoris llibri tres. Elcgix - Epiftolx varix-Explicario Orationis Dominicas.

Vir fuit omuibus corporis animique doribus excultiflimus: Princeps formefus, comiss, facetus, mortmque insegritate \& gratii onnies.ad amicitiam, R:I 
\& fui admirationem pelliciens. Doctrinx enim erat admirandx, \& eloquentfa facundiaque primaria: in difputatiouibus fubtili ingenio, \& perfpicaciffima prudentia. Exactè tencbat linguas Gracam, Latinam, Hebream, Chaldaicam \& Sirabicam. Utque erat excelfi fpiritûs, ingenioque ad maxima quaque evecto, ardore juvenili impullus, Romarn venit, ubi Concliafiones nongentas, in omni fcientiarum genere difputandis propofuir; quarum quingentre funt in PhiloSophia Viterum, Mathemeticân, Cabbalâ \& Magî̀. In quibus invictum fe, \& admirabilem omnibus praticit, cùm omnibustanto ingenii acumine, , tantâ facundiâ, tantâ gratiâ refponderit, ut deomnibus triumphum retulerí Boiffardo in Icon.

Yiringenii penè prodigiofi, \& in omuitum attium, fcientiarum \& linguarum varictate ufque ad miraculum exculti, fcripfir admodum juvenis, \&ix tertium ac vigefimum aunum attingens ad Laurentium Medicem in primum. Genefeos caput brevem, Ced.admirandz audacize, \&. fupra adolefeentiae vires, ,.. Latinum Commentarium, Heptapli titulo pranotatum - Cærerùm de lioc opere varia funt doctortm hominum judicia. Quidaw ue endicum \& fublime admirantur; quidam contemnunt, ut juvenilisaudacix oftentamentum, extrinfecus tumidum, intus verò prorfus iuane. Memini me proximis annis, cùm Rorne effem, familiariter interrogalfe praftuntifimum vìum Aloy fusm Lippornanum, Yeroncn Sern Epifcopum, cui inter tot nobiles autores, are Catenæ. fux ilifertos,loannis Pici egregit viri nullam feciffet mentionem Tum ille ad me converfus firmma cum vultus ac verborum affeveratione inquit: Cum Catenam explanationum in Genefin contexerem, cos elegi criptores, qui mili kiderentui Mofss verba

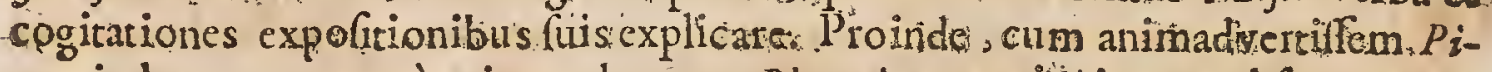
cum in hoc unum cantum incumbere, ut Platonicas cogitationes velfuas potius Phantafias verbis ac diatis Mofaicis exprimeret nilitil me ejus operâ indigere exiftimavi. Sixt. Senen S. Bibl:Sanct. 1. 4...

Phanix feculifui, illutris vir: Picus Mirandilanus, deditia M usarm, atque Alumnus Philolophix. Scalig. Comment in l.j. Manil.

Vidjplanè portentofingenii, \& pro xtate cruditionis laude nulif fecundus.. Gul.Cave.

Joannes Picus. Mirandulanus, Comes, verè mirandis, , feit profundam doctri-s. Mam, fei mam pictatem fpectès. Phil. Morn. in Hift. Papat. P. 554 L

Anno 1490. magni nominis famâper: Europam omnem volitäbat. Ioannes $P$ in rews. Mrandulanus; Doctorum nobilifinus, Nobiliim doctifimus, ac cum $P_{i}$ - cus diceretur, verè freculi fui Phonix fuit: Voffres de Mathem.c. 63. Sect.24.

Ioannes Picus Mirandule Comes, vir ingenio \& doctuinâ (pro xtate) maximus, vixit amos folum rriginta tres: Quid fi hoc ingenium aliis triginta anm nis excoli potuiffet omninö enim nihil ei defuit nifi maturitas. Bellarm. de Script. Ecclef:

Princeps hic nobiliffinus Ioannes Picus Mirandwin, vir unus, an heros potius omnibus fortunx, corporisanimique doribius cumulatiffmus utpotc formâ penèdi vinâ juvenis, \& eminenti corporis majętate perfpicacifino ingenio, 
memoriâ fungulai, fudio infarigabili, tum luculentà ubsti yue facundiâ : dubium verò judicio mirabilior, an moribus. Idem totius Philolophiz confultínfrmus, ctiamque variâtlinguarum literatura \& omnibus honeßtis attibus linpra veri fidem munitus, atque inftruetus: Denique ut Cemel complectar, nullo non praconio major. Angel. Politian.centur. r. Mifcell c. 1oo.

Polrtiano gravior loannes Picur, \& Catis caltigatus, wifi juo loco altcrcatur. cum Theologis Lud.Viv. de Trad. Difcipl. 1. 3.

Indoles loannis Pici Mirandule Comitis planè divina, ingenium ad omnia factum; led hujus quoque dictionem nonnihil vitiavit linguarum ac Philofophiz atque ctiam Theologia cura. Erafm. in Ciceton. p. is 3 .

Loannes Picus Mirandatu merito cognomine Phonnix appellatus eft; quòd in eum, Dii uperi, Cupra familix claitatem, omniscorporis, ac animi vel tarife Lmadena contulerint. Mita enim altitudine fublimis ingenii, deconâ facie, lectifimilque moribus, \& incomparbili quum difputaret, aut lcriberet, facundiâ, omnes ejus feculi fapientes in almirationem fui facilè convertit. Gravifimo autera opere, nec dum abfoluto, tanta cruditione, arque vehementiâ Atrologos totius divinationis valifatc-confutatâ perfecutus ett ut fubrilium difcipli-

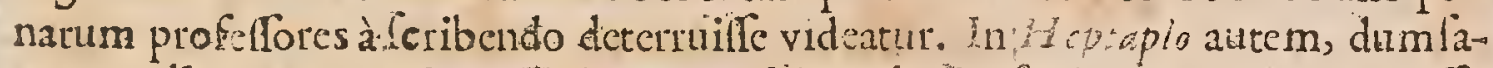
crarum literarum myfteria divino ore nobis recludit' " $\&$ in spologrtico gravifimus difiplinaram omnium rationibuspropofita ad difputandum, ingeniifui decreta deftendit, Ceipfum doctrinæ, atque memoia felicitate fupergreffus effe videtur. Paul. Iovin Elog.

- Perlutratis initur pumariis Gallie \& Italie Academiis, eruditifimos -utriufque Philolophiz l' ofellores ubivis conquifivit; - Philofophorum ferè - omnium fcripta pervolvit, remque fum tam indefollo animi fudio agcbat; ut Theologus fimulac Philofpphus omnibus numeris abfolutus, imberbis adhuc juvenis habetetur. Quod ad molliores verò literas attinet, is fanè erat,qui ferw monis elcgantia, facetiis, \& gratia; eloquentix viribus, difputandi fubrilitate. \& diffuf lirguarum fcicntia cmuibus fui frculi vitis palmam praipuit. Accu* ratx cnim linguartun Grecxi\& Latina notitix Hebream, Chaldaicars, \& Arsbicam adjeccrat dillcto, / talia anteane fama yuidem 2uditas. Henr. VTharton. in Append: ad Hift. Litérar: Gul. Cave.

Itali habucram Picum Mirandulanum, qui Miraculam quoddam fuit: Onuia feiebat, in omnibus linguarum generibus verfatus erat, qu odque infolite minim ef, adco juvenis ad tot fcicntia pervenerat ut anno atatis trigefimo fris ceflerit. Eximias feripfic Epiftolas, quarum ftylus non $\mathrm{e}^{2}$ quidem exquifitus. fed eloquentix corpus illis inct. Romx 900. Thefes evulgavit \& per totum Orbem emifit qua omnigenas Scictitias complcotcbancur halque adverfite quolvis preprgiare volcbat: Nequis autem itineris longitudinem caufatem. - mnes contrafe difputatum venturos ab omnibus fumtibus liberos partare pollicebatur. Perroniana p. 244.245 . Gall.

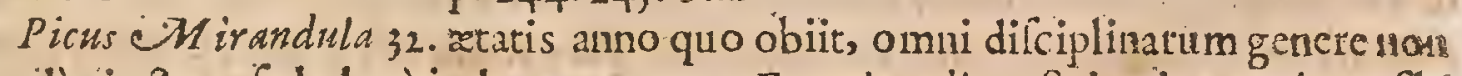
unodo tincus, fed plutè imbutus erat, ut Encyclopadiam Scientiatum jure fibo Rer 2 vendicat 
potuerir, longiove vita planè digniffimus Princeps, Scaligerana primas prosgin. 121.

Omnia loannis Piciopera Baflec edita lunt in fol annis 1573 , \& $160 \mathrm{r}$ in Off civia Henricpetrian?.

Hoc cjus Epiraphium Florentic ï̈ Edè S Marci: Auctore Hercule Strozho:

Joannes jacet bic Miraudula : satera norunt,

Et Tagus, Ganges: for $; a n$ Antipodessow

Aliud, eodem Authore s.

Hic fotus eEZ Picus : cujus ficunela periffent:

Virtutum ; septem vix fat erant tomuli:

Pbil. Labbe in Thefaur. Epitaphis.

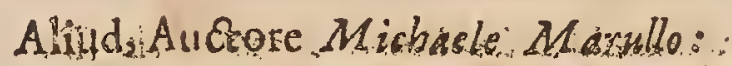

Accidis:etatis mediz quod Pice juventa

Viltina Socratica flenda ruina domus?

Niec vel Nobilitas, yel opes, vel gratia forma

Profuit aut anirni tot bona rara tuis

Non boc, crede mibi, natura injuri matris;

Larga vel imprimis, qua fuit sua tibi:.:

Sed vite documenta bornimum: quan fiux a fat ollis

Forma, genus, dotes ingenii., Imperia.

\section{JOANNES.JOVIANUS-PONTANUS}

Clar A. V. Freti in Umbxid natus: Obiit anno Dom ysos. xtatis 78 .

COZXXXV.

Vir ad omne genus eloquentix natus - Erat aufero fupercilio, a toto orishabitu fubigretis: fed ltylo, \& fcrmone perurbanus quum fapirinè vel in leris muto cum falejocarcur. Habitus tamen eft in omni cenfura quanquam abfolutè pius, fupra aqum mordix, vel eoquòd non homines modó fibi motos, fedgentium : \& nubium quoque omnium mores acerbà fcribéndi libertate perftringeret, ficuri ex vais Diologis Charonteque prafertion intemperan:rer oftchdit: Scd in pangendo carmine, quam texend prof cultior, atque fir-. blimior multis videtut: quandoquidem in Hiftoriznon (emper integra graviffimi inceffu's dignitate, ab ejus muneris difciplina defeciffe exiftimari pofft ; quu moftè ab Hefperidum Hortis eitriorum fuavilf misodores fpirans arque inde divino carmule in altum evectus, ad illa ipfa excelfo ore dccantata fidera pro-; pius accefferit: Paul. lov. in Elogo 
Eoram ( quiproximis disentis ant trecentis annis vixiffent) fummum clfe Ieamers lovianum Pontanum nemo indignatur: inquô cùm ornnia, tum duo preltantifima fucre, quòd talem in dicendo copiam, facilitatem, clegantiam, propictatemque fup prioribus anwis extinetà penè Latiba Lingua reddidit rentifimo Augufi ficulo narum confras : quodque \& carmine unus, \& foluta oratione tnutum verx glorix adupras eft, quantum vix in eorum unoquoque feparatimnon rzodòricentiores, Led antiquorum eam pauci fint affecuti. Nam quid af ejus Dialoge jueundius, doctius, fuavius? Sed non fugit tantus vir obtrectatores, quum fint \& ii non mediocriter doeti, qui enditionem Pontanc triBuant, judicium adïm unt Miremur, fi ron $\&$ $M$. Cicero Romanx elóquentia oceanus, exuccus languidus, enervis aridus, jejunas, ac diffolutus ab hujufcetnodicalumnartoribus dictus eft. Franc. Floria.Sabin. ii Apologia, \&c.

V́rania verò, Meteara, Hesperidurn hotri, ecloga,epigrammatas elegid a catc-

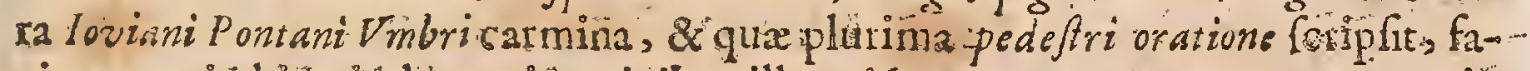
ciun, urin his tabularum imaginibus illum inter procere commemonem, quin acum omnifere antiquitate couferam; tametinon idem, , ur quiburdam vide-

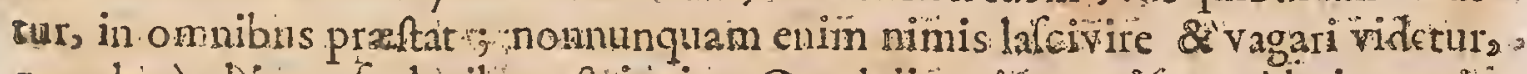

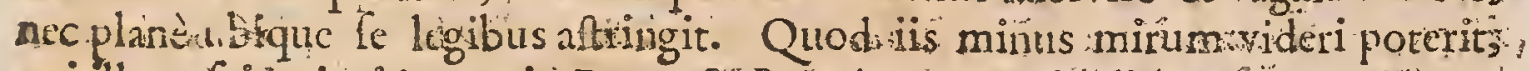
qui llum fciveriutin magnis Regum \& Principum negctisdiu verfatum \& mo-

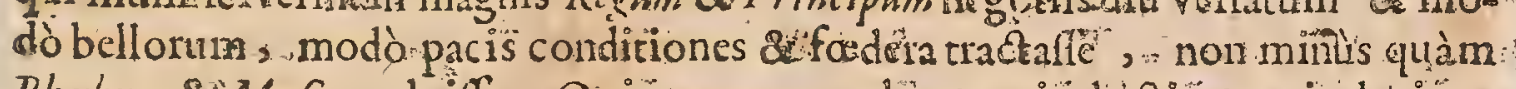

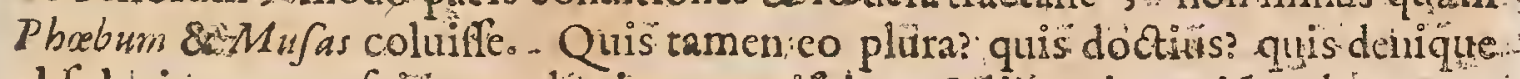
ablolutius compofuit? enuclêatius? exquifitus \& 1 ice ejus quidam hac tempore glorie parum xqui fine reftimatores, non illis tancn ipfe concedain; ni me-

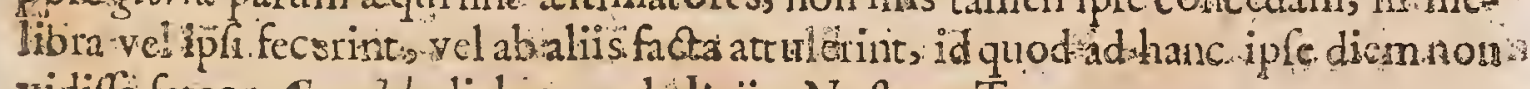
vidiffe fateor. Gyrald. dialog. 1 de toëe. Noftror: Temp...

Pontanur, cum illa quatuor complectifummâ curâ conatứ fit nervưn dico;? numeros, andorem venufatem, profecto ieft omnia confecutus. Q yintum autem Illud quodeft horum omuiün velitivita quadam, modurn intelligo, penitus igno avit:. Ailint Jircilium cùm multos verfus maturiso calore efudifet, pomeridianis houis ovo judicio folitumad palzonm numelum revocate. Con-

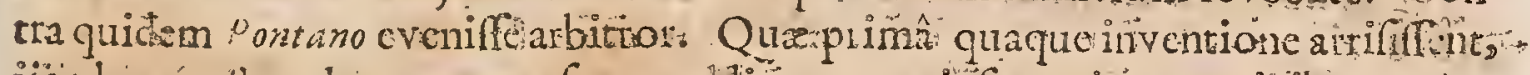

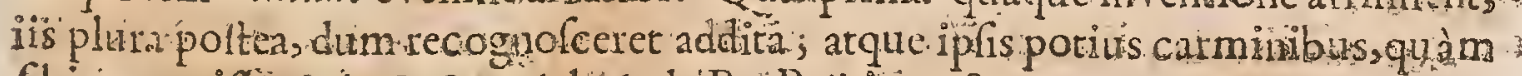

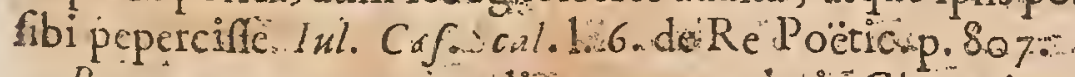

Pontanum uno ore predicant omnes; hilc $C i$ ercniand dietionis patmain tri-bitunt eruditorum centuria. Non fum vel tam hebess vel tam inyidus ht non. fatear Tontarum multis egregiis ingenii dacibus vium fuife fummum: A c me quoque rapit placido quodan Orationis haplu: - verbortm dulce quiddam refonantium ameno tinnitil demulcet antes denum Cplendore quodam perftingit dignitas ac majettas: Orationis. In Epigrammatibus plus tulifet liudis $\%$

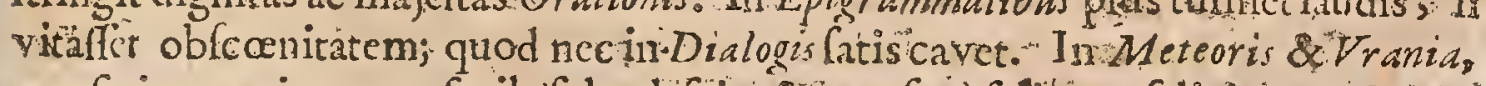
quxfivir materiam qux facile fplendefit, \& icm fane felicem feligiter tractavir. Erafir. in Civeroniano, p:203, 204\%:

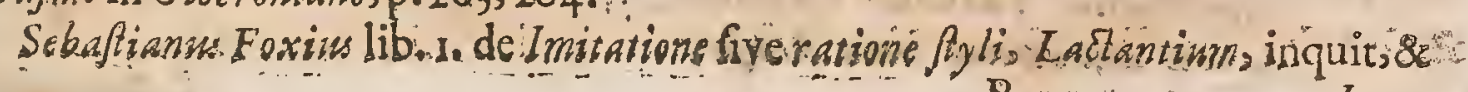
R-I $5: 3=\quad$ Jownt 
Iovianum Pontanurn ego maxime Ciceronianos puto.

Idem Foxiu lib. 2. p. 43.ait; Italiam hac Pontano cetrum prokimis annis mon habuifle doctiorem.

Iovianus Pontanus, vir memoriâ quidem neftầ omnibus bonỉs artibus, atque amni doctrû́ præditus : cui prateringenii manfuetudinem, qua plurima in homine fuit, munditiaverborum, \&x compofitus ille fermo, ad omnem ingenutacem plurimum accefronis faciebant. rilexund.ab Alexandr. 1. I. c. r.

Iovianus Pontanus, fuavis potta, acutus Ciriticus, Ethicus Hittoricus, Aftrologus doctus: 2 difctus: In quo illud imprimis admirabile, quod a nullo preecptore autad Carmen componendum, aut ad -bilofophrarn edifcendam, aut ad Celi, frgnificationesintelligendas infitutus fuerit, fed infitâ animi vi, lectioneque afliduî libi hæc omnia comparavcrit. Baltbaf. Bonifac.1. Is. cap. f. Ludic. Hilt.

10. Lavianus Pontanss "Politiano adhuc polition quod ex Vrani. cjufdem, Meteoris, Hesperidum bortis; lyricis, eclogis, Epigrammatis, \& pracipuê bendo cafyllabisfiquidum ef :in quibusad nitorcm, decufque veterum Poètarum afcendit proximè; haud dubiè tamen feipfo in geneve futurus fuperior, nif , lio cum evocallent Aulanegotia. Aphonfichim Inniori, Regis Neapol. Praceptor

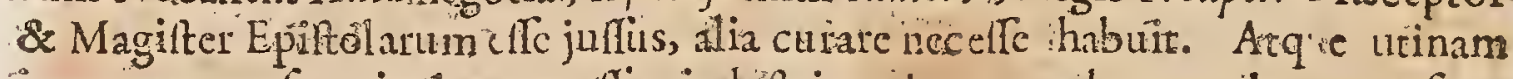
in argumente feveriori occupalfet indutriam ! nunc ad amatoria propenfior

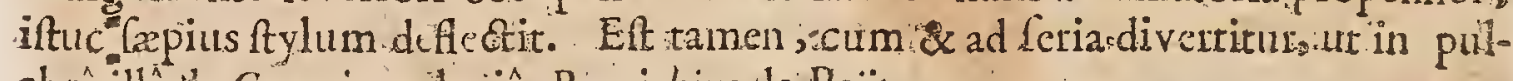
chrâillẩ de Creatione el cgiâ. Borricbius de Poët. p.10; 104.

Claruit Ano 1495. Inter primores frculil Hiftonicus, Poceas, \& Oratores habitus, mordaci tamen fylo.\& fubagrefti fupercilio plurimon odium \& inyidiam concicavit. Hinc nata forfancalumia, qua ipfo adhuc vivente in vil gusfparfa crat, illum volumina quadam Ciceronis, in vetufâ Monafterii affic

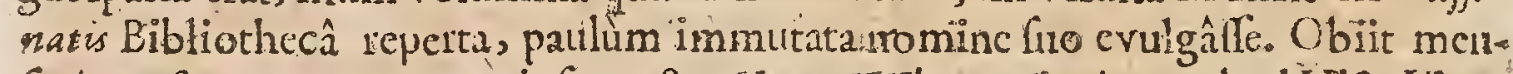
fo Augufto, anno rgoj.xtacis fux 7 \&. Henr. V Vharton in Append ad Hift. Liter: Gul. Cave.

Extant libri jus fóluto Ccrmone fctipti, \& in tres tomos diftineti, Baflee $1533.8 \%$

Pö̈mata leorfim excula funt.

Vixit annos feptuaginta lep:em. Fato autem functus eodem menfe, quo Alexander Sexius "ontifexwita excellerat: timulatus eit in Sacello ab fe fcpul chri causî extructo è regione Davalorum domâs tibi elogium áb fe comportuma in marmorea tabula fpectatur.

\author{
Vives domum banc:mibi paravi。 \\ In qua quiefcerem mortuis. \\ Noli objecro :injuriam mortuo facere: \\ Vivens quam fecerim nerrini. \\ Sum etenirn Jovianus Pontanus. \\ guem andwersut bone $M$ as.
}


$\operatorname{Sin}$ pexs:runt viri probi,

Honeftaverunt Reges Dominio.

S.cis jam qusi fun, vel gui potius fuerim:

Ego vero te, bospes, no tenebris noscere negueo:

Sed teipfwn ut nofcas : rogo. Vale.

Peanl. Iov.in Elog.

\section{JOANNES TRITHEMTOS.}

D Riùs Abbas Spanbeimenfis,poff Abbas JaVirciburgenfis ad S. I acobum, Iatur C fuic Anno Dom.I 462 .in pago Trittenteim ad $M_{0}$ ofellam. Obiit anno Is 16 . in

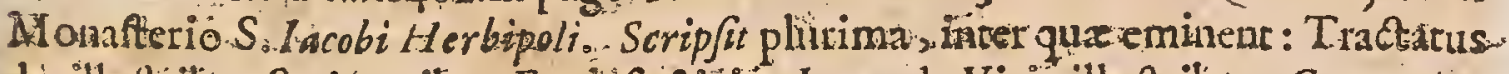
de illuftribas Seriptoribus Ecclériaticis : Item de Viris illuftribus Germania;

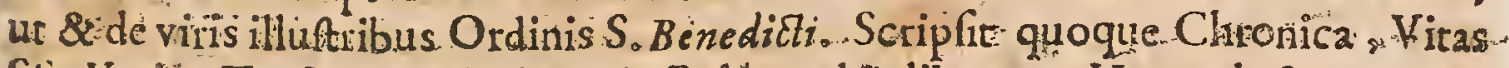
SS. Vaxios Tractatus \&Aficticos : de Polygraphüia libros 6. Unum de Ateganogran graphia ob quem librumad quibufatan cattigatur 2 prafertion di Carolo Bovillo.

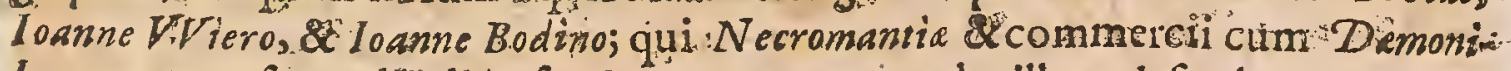
bus eumaicufant: alii aliter fentiunt, magnoque zelo illum defendunt.

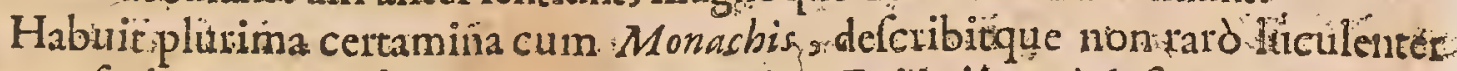

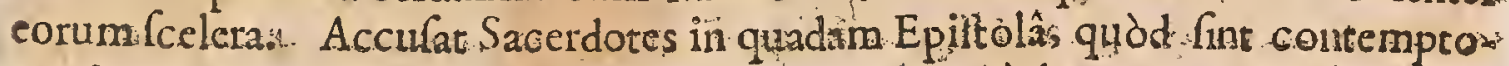
res Sacrarum Literarum.. In alia queritur graviter, quòd non tam Chriffus quàm Arifoteles, in fuggeftit pradiceruir... Dicit, non:Philofophiam, multo minus fábulass:fedlègem \& Evangelium Ecclefie Dei proponendum: Sic \& Patres foen

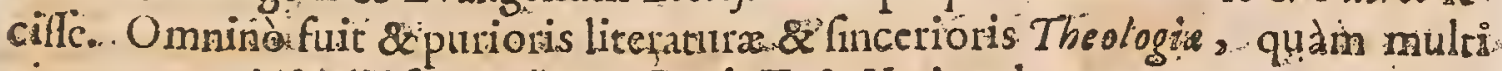

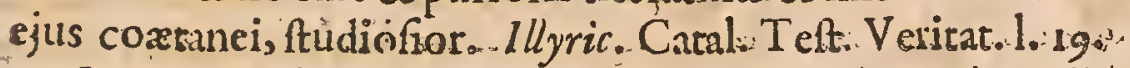

Ioannes Trithemizu - Homoquidem impensè eruditus quique inter fur feculi doctrint̂́cläros paucos habủit equalès; vix ullum fuperiorem. Nec vul gares modô trivit femitas, fed \& intina reconditioris entitionis penetralia referavit, \& forfan curiosè nim is rimatus eft : unde, ipfomet conquerente l.z.epift. 42. vulgò pro Magohabebátur; nee de crant qui ipfum fufcitalle Mortuos évo-

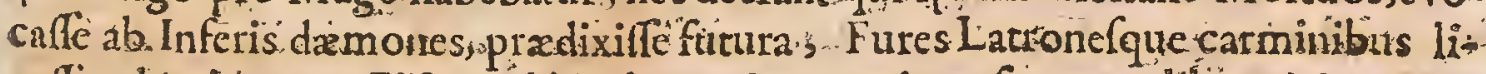
gaffe clànitarene- Ficta qujidém hrec , \& ementita, fe tamenlibros Magorum plerofque legiffe non diffitetur, quod \&" Steganographic Opus abindè teftatur. Nec fibi foltim Mufilque cecinit, fed \& plures dífcipulos in Canobie fuo me liobribus literis inftituite, adèo ut ad illum confluerent nom folüm ex Germaniâ

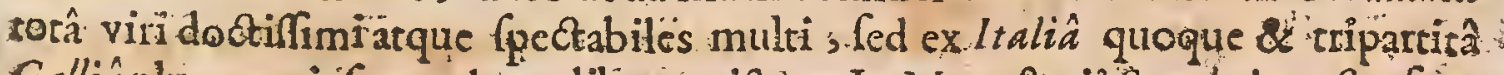
Galliâ plures, ut ipie nos docet lib 2. epint 3. In Monatterii Spanbeimenfis ufuim fimul \& oruamentum egregiam planè Bibliothecam plufquant 2000 . melioris: notze Codicum MSS. in quavis facultate, \& quavis feré linguâ, Hebraiç人

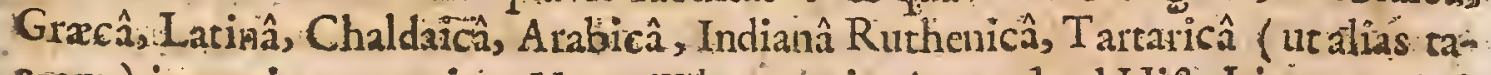

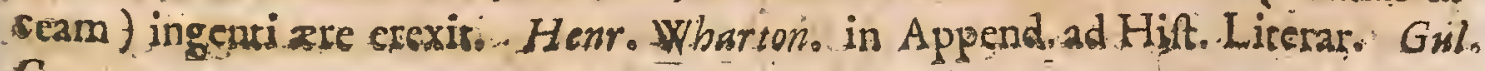
cave,

Jeiannes: 
Ioannts Trithemius, doctus, \& pius Auctor, fed in Hiftoria non fatis accula cus. Card. Ioan. Bona.

Gajpar Scioppius plus candoris, quam judicii Tribermio alcribit. Scicpp.de worig. dom. Auftriacc.

Ad Trithemium diverti, quen reperi Magum, nulla Philofophiz parte infgnem. Eus Steganographrarn evolvi velitarim nonnullorum capitum perlegcns initia. Vix horas ẩ librum in manibus hábui : abjeci enim eum illicò, quòd terrere.coperant me tantar adjurationes, actam.barbara arque infolita spiriunum ( ne fortè dican Demonum) nomina Univerfa veiò hujufrnodi nomina [ quoad videre vifus fum] ignotze lingure lint. Aut enim Arabica, aut Hebraica, aut Chaldarca, ate Graca: Latina, pauca, autfermè nullid Innumeri autem fune (Chàrateres, quibus adjurationes lingulæ notantur. Caro! Bovillus.

Quamvis Ṫithe rits nec adinvenerit neque confummaverit arcanum occultis Characteribus Scriocndi, (Steganographiam vocam-) certum tamen el eque Tritheminille de hac Artertadidt non mediocri atxilio fuillead illam de- duccodam at perfectionem quá hodie âtecuta eft: Cum enim maximè curiofa Ingenia fefe cxetcuerincin ocnetrandis Conjulationibus, of Silitum nomina quibus libum fum implexit taumg; myfterium illud velavit, uoir tantum ex-

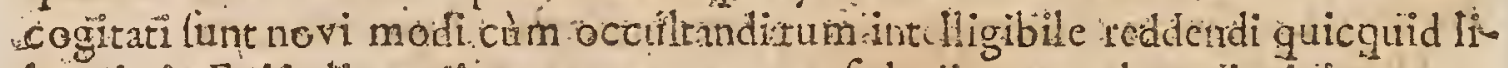
bucrit In Epiftolis, variarm notarum ope, fed etium regulas principiague traididerunt quidam at Griphos ejulmodi enodndos. Eruditorum Ephernerides Gallica 24. Jan.1679.

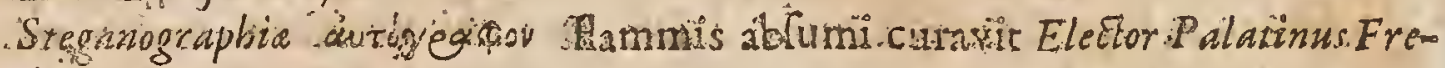
dericus II.

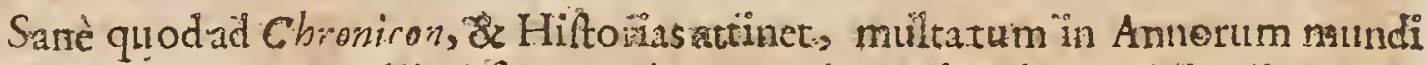

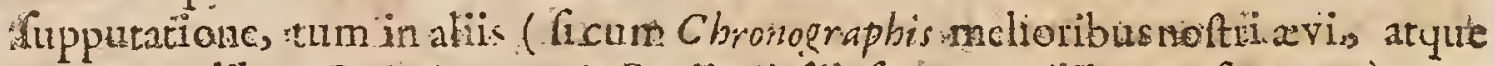
cum Annalibus Caf.ris Raronii Cardin. à (cip(o 1ecogtitis conferantur) cerahentur qux daudicent - Defexilibiis ejus Polygrophise. qua pluxes cribendi modos innuit, quos ltati Cifras, Agillius fcriptafurizu nominar, sum in is mentionem fccerit alteritus $\mathrm{O}_{\text {peris }}$, jued Steganographiam. quam nóminat or-

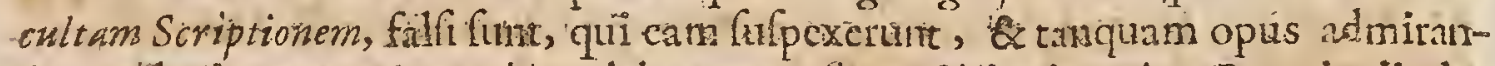
Atm. clavingure Polygraphiacelebratust. Supertitionis enim, periculi ple-

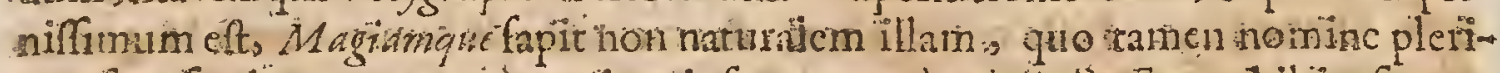

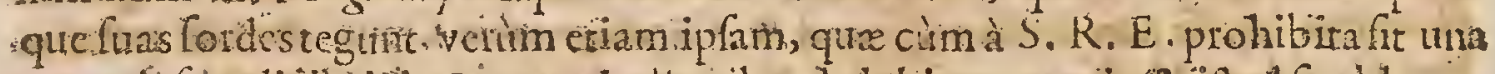

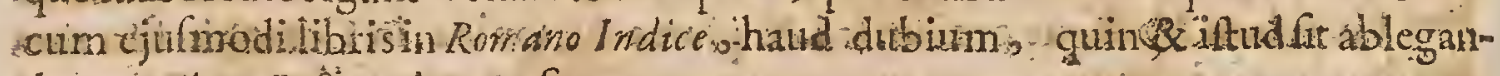
dum. Ant. Pofjer: Appar. Sac.

Stegancoraphian Trithemii (qua, cum clave, feorsm prodiit, Francof. .606.) adycifati funt multi, multi etiam benignius illam tractarunto Adarnus Tannerais

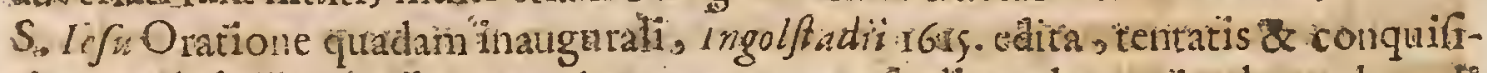
cis gux habuit, omnibus standem p. 20 . condudit: ab onniculpa, ob mati

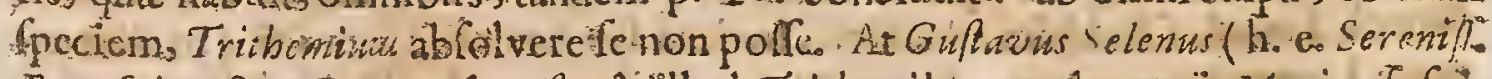

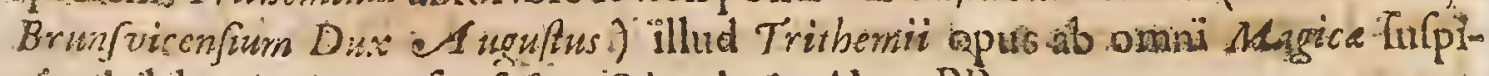
cionis labe purgne aufus fuit. Olearizsü Abac. Pl. 
Catalogns cjus de Scriptoribus Ecclefiaficis primum ad antum 4994 terminabatur; fed cxinde varia incrementa accepit. Platus vocat illum accuratum \& fedulum Scriptorem;nce de pofterio ti hoc capire quifquam litigaverit, quod in indefelfo labore confiftit, cùm revera laboriofifmus fuerit Tritherrius; fed in prius nun confentitur quod in difcernendis \& difcutiendis rebus majorem exigir fagacitatem quàm qua Trithersius in omnibns feriptis fuis urus eft. Judicium Eruditorum per Dom. Baillet Parif. 1685. Gall.

Extant Trithernii Opera Hiftorica, duabus partibus cdita per Marg. Frehed. arum, Francofurit 601 .

Polygraphix libri 6. excurifunt annossis. Fol.

\section{Hoc cjus Epitaphium:}

Hanc weruit fatuam a sermane Gloria Terre Abbas Trithemius quarn tegit ifla donn. Quam fuerit literis, finul of virtute celebris Admiranda Sui dant Monimonta ftyli.

Arguit boc etiarn multorum Gratia Regum, Ex quibus in primis 12 aximus eNEmilius. Maximus Amilius Romani Gloria Sceptri, Quifuit Autriacx clara propago dornus. Hujus Magnificâ fuit accepriflimus Aulâ, Et primurn tribuit doita catcrva locum. Abjitsufpicio de Drmonis arte Magia, Contra quan magnum fcribere copit Opus. Ut vivit fama ic vivat mente beatus, Et videat furmi Cailica Regna Dei.

Lorenzo Craffo.

\section{MARC. ANTON.COCCIUS SABELLICUS。}

Talus, Fabri Ferrarii filius, animum à teneris annis ad Andia applicuit, jü 1 ventutis per pagos inftitutionc aliquantillâ pecuniâ collectâ. Dein Pomponiu Lati Dornitti Veronenfer difciplinâ ulus, RomäVenetiifque, ubì humaniorcs literas profelfus eft, inter literatos inclytum nomen eft adeprus. Cbiit anno rso6: rurpi morbo confectus, atatis 70 . relicto flio notho. Hofman.

Illius epcra elegantillima \& eruditione plena hec extant: Hiltoria de Geftis

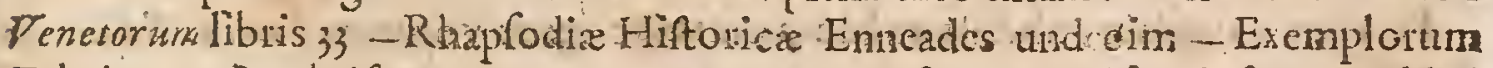
Ethricorum \& C briftanorum per omnes gentes factis dictive infignium libi 10. - Epiftolarum Familiarum lib. x2. - Orationes 12. De fitu Uibis Venete lib. 3..-De Vencris Magiltutibus lib, 10-De Pratoris Officio lib. 1s - De 
@ffiviis Scribx lib. x- - Genethitiacutn Urbis Venete - D; Appa ratu ejuf dem-De vetultate Aquileis - De ortu ix vctuftate Vincentie-- - De tur

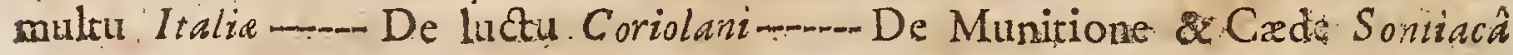
$\ldots$ De incendio Carniso - - De Barione Cymbà -....... De Origine $H$ ìnn

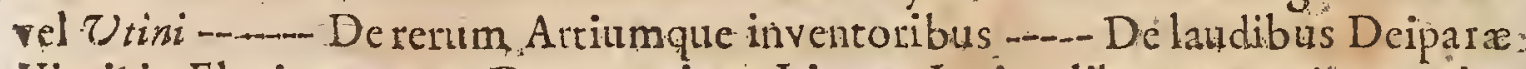

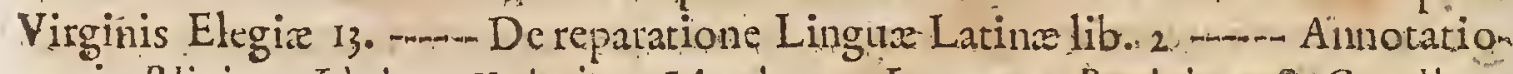
nes in Pliniun, Livium, Valeribm Maximn, Lucanum, Papinium, \& Catullum, quix priores dicuntui. Item pofteriores in Plinium, Ciceronsm, Lucanim, \& Argonautica Flacci, \& interpretatio Paraphraftica in Suetonium. Tranguillim.

Marcus Antonius Coccius Sabellicus ad vicum Varronis in viâ Valeria juxta Anienem Fabro Ferrario patre genitus, ingentem \& propè ferream vim ingenii: ad perdifcendas literas atculit, tanto proventu, ut plane imberbis apud Ty burtes ludum aperiret. Inde verò colle ctâ mercẹdé, \& togulầ carulêà excultus nobin lioris doeteinx cupiditate î̀ $U_{\mathrm{r}} \mathrm{b}$ am ad Pomponium fe contulit, à quo uberrimi : ingenii merito, in collegitum Șodalium folemni ceremonî̀ cooptatus, S Sabslici rognomentulit. Mutabat enim nomen, qui in Quirinali Gacta lau ro coronabatur. In ea chola, quòd cenfura lìteraum accerrimis judicum ingeniis ageretur, multum fibi de incondita, \&fubagrefti Latina Orationis exuberantia detraxife fertur. Nec multò poft; Roma excedens, Víno in oppidar non procul ab. Aquileia, nobiles regionis adolefeentes doctivo. Parta demmm nifigni nominis. fama, quum regionem vetuftatis authouitate percclebrem.lépidè décripfiffer, decantato ctian yerfibus Carnico incendio, \& deplorata clàdé Sontiacá : idcirco eum Vicentini celebritate nominis exciri ambitiosè duplicato ftipendio conduxerunt. Ncc ibi diu manfit; evocante Senatu. Veneto a conditione ur civitatis res geftas à finc Iufiniani confcriberet, \&trecentis aureis. ii gymnafio profiteretur. In hoc munere perutilem juventuti operam proftitit; quum in alkero. adulatione parum fobria rerum veritatem adumbraffe viderctur. Sed in Enneadibus omnium Temporum, ab orbe condito memoriam complexus, uti necefer fuit; ingenti operis inftituto feftinanter indulgenti tes illüftres praclara cognitio- digniffrmas perobfcura brevitare adeo vehementer offifcavit, us excitatam, uberrimo titulo legentium cupiditatem paffim eluferit, quum omnia in acer-

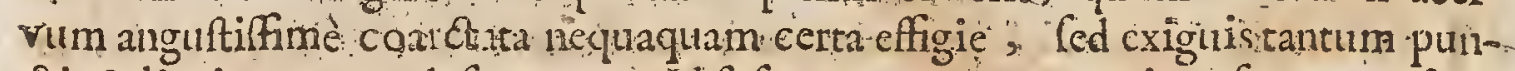
ctis \& lineis annotata defignentur. Id fufceptum minus gnaviter fecutus, icribendo ad Septuagefinum ferè anum pervenic;, Gallicá tabe ex vaga. Venene guxfita non obfcure confumptus. P a 10.700 . in Elog.

Marc. Antonius Sabellicus, vir undecunque do atfimus. Trithem.

Vir valde eruditus, Bellarm. de Script. Eeclef:

Fervida cujufdam, uberifque Eloquentia Scriptor vocatur, Florid. Sabin。 in Apolog.

Petrus Bembus in Epiftola ad ipfum Scripta vocat Doctiffimum, Eloguentiffzmum, optime da Republica meritum: atque addit s Septem Historiarum Ennea- 
dibus, quas nuper edidifi, uberrimum frutum propofitum video laudis o girm rate fempiterna.

Antonium Sabcllicum agnolco naturâ facundun,ncc artis expertem: Nec ịtfeliciter rethoricaturinterdum. In hiftoriâ fat fplendidè verfatus ; fed in hac tartùm, qux furum diccndi gcnus defiderat. Erafrn. in Cicerox. p. 164.

Antonus Sabellucus fuit quidem plenus, fed lutulentus quandoque fimilis ê Authori, er quo resdefumit: ut colorem videatur mutare cum Solo, perqüod bmnino tanquan Fluvius decurrit: quod non rarò ufu venit folicitis de re maigis, quàm de Verbis Lud. Vir. de Trad. Difcipl lib.3.

Hiftoriam Fenetorum Italice plines defcriplentunt, Latine pauci. Inter hos primoloco venit M. Ant. Sabcilicus, qui Latinè fcripfit. Probavit le egregium Hittoricum, \& qui meretur comparari cum Antiyuitate. Ridet eum quidem Bodints, quòd comparationem inftituat rerum Bellicarum stamanorum cum $V_{e}$ netoru in, fed immeritò. Habet enim fimilitudinem in Bellis cum Rornanis: in Pacis wero artibus cum Romanis. Coring. de Rep. Venet.

M. Antonius Sabellicus, verifus cum Elegos, tum Heroicos edidit, quos ego alluc Pucribenter legere folcbam. Facilis hic ubique, \& canous, nec injucundus, Ted minus omaino caftigatus, prosâtamen ubi intendit, plus preftitit. Lil.Gyrald. de Poët. 9.390 .

Sabellicus vir ille Ścriptorum copiâ, \& elegantiâ multo clarior, quàm meâ ullâ poffit commendationecrefcere. Ioan. Lier. Valerian. de Literator. Infelicit. L.x. vid. pluia ibid.

*. Antonii Sabelici Opera inter Tibros expurgandos numerantur in Indice Madritiens edit ann. 1667.

De fepulucho, vivens 2 incolumis, tempeftive fibi cavit, fcilicet degeneri flio diffítus, quem ex concubinâ fúccperat : compofitumque ab fé carmen lapidi infculpfit : infrgne quidem, \& meritum elcgium, fed certè horettius, fralica ingenii pictas infcripfifet:

\section{Quemnon reshominum non omnis ceperat atas: \\ Scribentern capit bac Coccion Urnabrevis. \\ Paul. Iov. in Elog.}

Opera cius 4. Tomis Bafilea cxcula funt Anin. Doin.1560. fol.

\section{ANGELUS POEITIANUS.}

A Monte Politiano (Hetruricoppido) loco natali; fic dickus, aliàs Bafjus, A Canonicus Florentinus, Iobannis'Pici Mirandula fudiorum comes, à Lan Clar. An. D: M csecexe. ventio Mediceo filiorum inftitutioni prapofitus. Gracè Latiréque plurima fcripfito Obiit Anno Chrifti i 494 . xtatis 40.

Is Cumptu, \& promotione Cólmi Florentinorum Principis, cum INarflio Fi: 
ciso bonis literis inflitutus eft: in quibus, tantâ felicitate profecit, ut brevitern. poris intervallo fui tempo is hornines doctos eruditione aut zquaret aut fuperatec. Grace Letinaque lingue peritifimus, Grammaticus, Otator \&: Poëtax: infgnis. Dictus enim eft communifui feculiconfenlu, Poëtariobilis propter exccllentiam carminis, quo commendabat11, dum illuftralfët Iuliani Méaicis ludos folemnes, vicilfer jue doctiffimo Poëmate celebrem illium: Pö̈tam Luram Pulcium. Gracas litcras Politianus doctit Florentia magno auditonm conflixu. Boiffird in Icon.

Fateor Ang clum prorfis Angelicâ fuife mente, rarum Nature miraculi mad quodcunque lcripti gcnus applicaretanimum. Erafin. in Ciccrón.

Marullus ridet Politianurib, vitum non folìm sê majorems, fed \& nullo no tix xtatis inferiorem.. Scaliger. ii) Caftigat. Catulliani.

Huic me puero àmultis prime deferebantu Mìra ejisomninò enditio vehemens \& paratum ingenium, jug is \& fecutens lectio. Sed calore potius quàm arte Verfus foripfiffe videtur, judicii utikuc parum cim in feligendo, tum: in caftigando habuilfe vifus eft: Lil. Gyrald. de l'oët.

Ablic verbo,invidin; habuit noftra hac atas bonatumliterarum proceres: duos, Hermolaum Burbarum, atque Angelum Politianum, Deum Immortalem !: quàm fẹcicingenio , quàm açijudiciò, quantâfacundiâ, quantânguarum, quantâ difciplịartum ounnium cientiâpreditos? Hil atinam linguam jompridem fqulcurcm, \& multa $B$ irbarici ubigine exefam, ad prittinum revocare nitorem conari funt, atque illis fuus profectò conatus mon infeliciter caffit: Guntque illi de Latinâ linguâtam bene meritiquàm quii ante cos optimè meritì fuere. Bristits in Epit Erafino.

Non poftremolocolinter omnia onnis rvi ingenia fuiffe Angelum Politianum ego Cemper perfiafus futi Stylus Latinita Romanos ip fosadit, Atticas Atbo nas, fi ita fari licets. Grecitate. Inventionam verò actrmine, lectionis vatictate. judicii dexteritate fingularis illius hominis felicitas fut ; caque quò rarior in utroque genere Orationis pari lade cui contingerefolect, è in ifto gratior. Bartio. 1.21 adw. c. 16.

Politimi vero literi quid politius dir oflit non video qui quot habet verba, tor illccbris, leporibulque abund,$\&$ Latrum illud vetus ita fapit-, \& Atticas Veneres, ut vel hic unus omnim infar elfe pofft, ei quil in Commencio hoc literario, ductorem defiderat. Iacob. Cruc 1:2 Epife. Theod. Beelio. P. $14 \div$.

Quanta fides, Dii Immontalès, in Politiano? Euivis intueri licet adhuc Florentia in Medicê $\&$ Martian $\hat{a}$ Bibliothecâ Manulcriptos libros, ubi publice affervantur, quibus ufus eft? Frano. Robertell. de Art: Critic.

Politianus, vit omni la ude majôr. Scropp. L. I.Verifim. c. I4:

Hăd fcio, uter majorem liudem mereatur Herodianus ne, quem in lingua fuâ ubere venấ: Huere non negaverim, an Politianus Herodiani fcripta

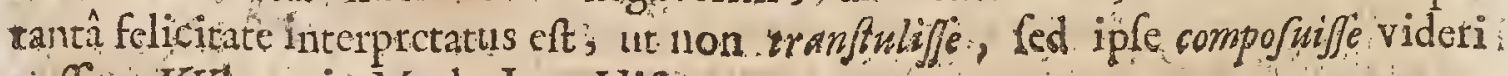
polfit. Whofar in Meth. Leg. Hift: 
Politioni Elevia pto Epicedio valdè bonaeft, ingeniofa, plena, numerofa, caneida,arguta,-cffieax.:-phanè digna tanto viro: \& quam equidem fcripfife malim, quàm quxe dicitur ab Ovidio in morte Drifi milfa ad Liviam. Epigrammata fibi. quifque examinct: Nam Elegiäizurs ad Lalagen optimum eft. Ip la quoque

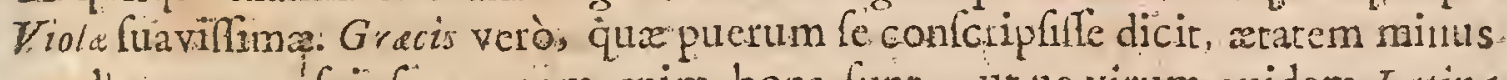
prudenter appófuit fuam : tam enim bona. funt, ut ne virum quidem Latina

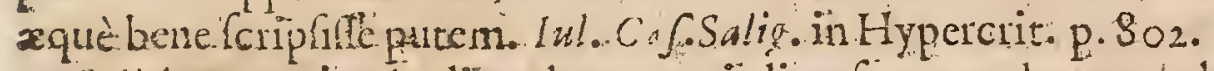

Policiarus varius in dicento, ut qui divcrfos quandoque voluerit effingere, exebrat tamen in eos, acutraque fententix; multâgue lectione \& eruditione non vulgarifias refercit opeia. Anton. Poffevin. Cicero, po. 26.

Yoli:ianus claboratus: verb̆a ejus bona, ac ufui communiapta, officiofis duntaxat:- nam gtavitatis minus habet quam vellem: \& dum felcceras qualdam vel rocnlas:vel dicendi formulas, quafi gemmas avet oftentare, longius circumdtleit lectorem, pluribus:tum verbis 2 thum fcufis Orationem oncrans, quadm erat? opuBu Ludoiviv. de Trad Difcipl.

Abthec vitio (dialectos commilccndi) nonfatis Politionus caverat etfi id oum ingentibus aliis. virtutibus redimesè fatendum eft. Scioppo.Grofipp.pa-

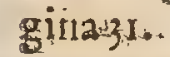

Angelus Politivanus miriffcè delectabatur Vocabulis Novis w ut quoque Ccribit: Grinitus. Voff. 1. 4: Inflitut: Orator. p..2\%

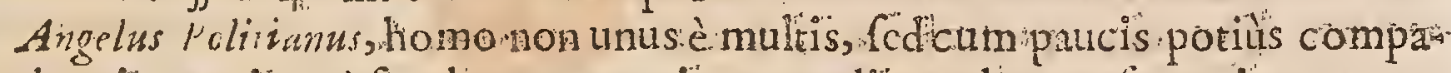
randus in ommi pené facultate, qua virum erudiet m deceat, fux princeps ata tis, in ferib ndo verö potiffimum. Nam quæ vcliOratione vorsấflidere, vell grosa commentari libuit, praclaris diftincta funt noris felicis \& elegantis ingenii", quod non ad alicniftyli exemplitu ferviliter compoftum, fedvelut jugum

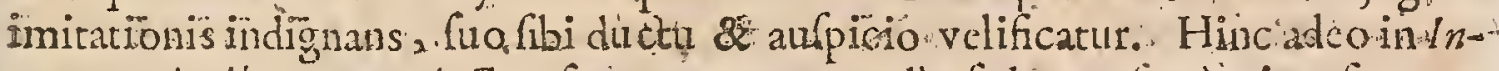

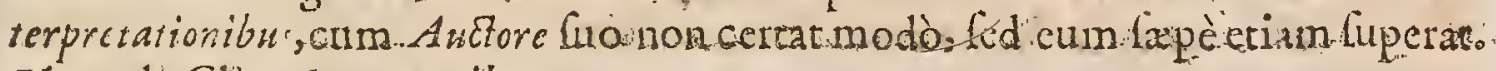
Hut ode Clar: Interpretibus.

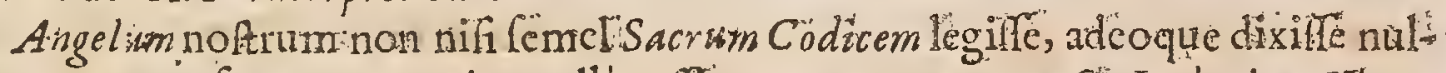
flim temptis. fs unquam pejus collocaffe, commemorat, ut \&e: Ludovicus Tives a

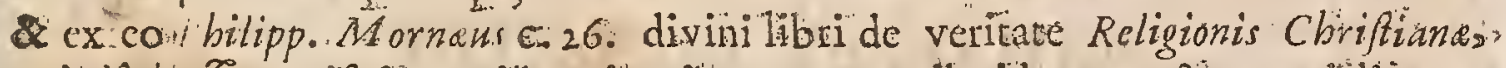
qui a'srómzo manifeftam eidem impingunt, nccullo idoneo tefte, quod dicunts?

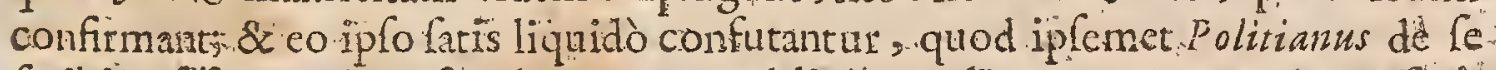

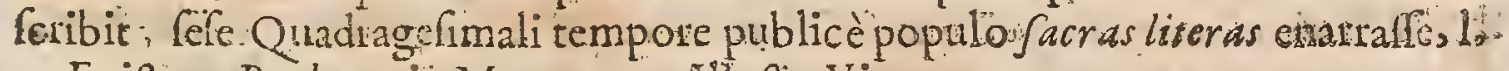
4. Epift x. Bos:born. in Monument: Illuftr. Viros.

Angelum Politianum excellentem Poëtam vocat Iofephius Scaliger; ffyltm? vero in Epiffolis nimis elatum \& oratorium munimè probat. Scaligeranầ I.pansii. 103. .

Angelus Politianus, vir undéquaque doctiffimus, ur operibus aliis, ita \& $i$ m rico, Elegiacoque, fed imprimis Epico illuftris. Sed \&epigrammata Politiani ple. sumque exafciata. Plus tamen furoris l'oeticiin illo, quàm artis; plus ingeniog. quàm jüdicii; ut jam olim rectè cenfuit Gyraldüs:Borrich. de Poët.p. IO5:

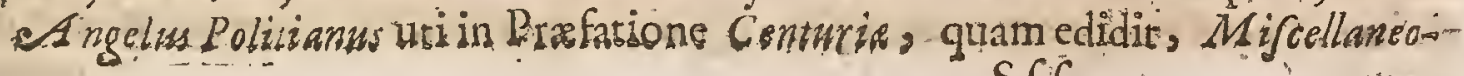
Sor 3

rums? 
rwm, plagiarios fuos increpat," vindiciafque adverfus eos minatn: fic in fine operis aliorum refpondet rumori, qui iplum in iltis $M$ ifcellaneorum capicibuse Nicolai Perotti Cornucopia pledam egilfe dilfeminaverant, fatumgue negat. Sced quomodocunque fe res d Z Politian Mifellaneis habeat, è lovio difco, żmulos ejus etiantranflationem Herodiani, quem ipfe Latinèloquentem publicavic, Gregorio Iiphernati tribuilfe; ‘’Budes Duareno, iplum :o quam de Homero habuit orationem propì totam ex ejufdern argumenti libello Plutarchi furripuiffc; ex Heresbacbro, Panepifernone aliorim non intellcatcongeffile, Thomas de Mlag. lect.525. 526 .

Heresbachius prafatione ad Lea. Librowm Tuorum de Re Ruficha funcifi. mum vocat Politianurn.

Opera ejus varia varis in Locis atque Temporbusifur imprefla.

Non fine gravi MuJaruminjuili, doleteque freculi, feftinate Fato ereptus fuit. Vix cnim quadragefmum quartum xtatis annum attigerat : Sed eo praspropero vitæe eiitu profeeto felix fuir, guòdimminentem convulfre Medica. Domûs ruinam effigerit. 'Tumulo autem hac carmen Crinitus Difcipulus aftixit:

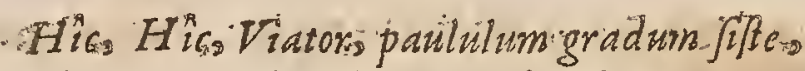

Tatem potentis Spiritus videsclarum:

Qui mente promptus acrik, of ardunuspirans

Ac Jumna quaque, of alta confequif wetus.

Is ille ego Arigelus Politionus $\int$ itm.

Fovit benigno me finu llora, of illic

In Eataceffi:, Parthenopceos Reges.s

Cirn Gallica arma irruerent rininabunda.

Iu vales of boc fis meriti mernor noftri.

Panl. Iov. in Elog

\section{DHILIPPUS COMINEUS}

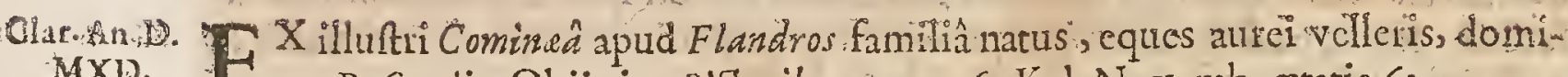
MXV. Cnus Rufcurii. Obiit in Filtonibus igog. 16. Kal. Novemb. 2atatis 63.

Ludovico XI. Francie Regi gratiflmus erat : cujus \& res geftascelobravit. orfus an. Cobristi 46 6. etiam pradidit res geftas filii ejus', Karoli VIII. Etfí autem non uno loco M jerus dicat, in plusibus falli : tamen Hiftoricus et verax ac prudens. Vof: de Hift Lat.

Scipfre Hiftoriam ita laudabiliter, ut nihil verear componere cum cum quovis Antiquoim. Incredibile eft quàm ille omnia vident, penetret, arcana confiliorum etuat, \& fubinde infturt nos falutarbus rarifque praceptis, \& id diffusè Polybiano quodam exemplo. Quanguamrexcda Polybium aut ralem ali- 
quem ille nec vidit: \& hoc y uoque laudem ejus anget; cuod tanta praftitit; lis: reratum omnium rudis, foloulu renm peritus \& naturali quadam j dicii bonitate. Ite nunc fcióli, \& linguarum aliquâ cognitiunculâ vobis pläcete. At Princeps nofter hunc legito, \& Enchiridium Cominaus illi clto. Dignus -Alexandris omuibus hic Philippus o.Lip. Not:ad r. lib. Polit:

Quem [Philippum Coninaum] Polybio comparavit Lipfus, non fine magna ratione: :uterque enim, obfervatione actrus, judiciô folers, prudentiâcopiopiofus, \&z quod omnibus careris laudibus fublimius, rarò apudalio deprehenditur, probitatis, conficientia, reverentix erga fatum \& farales eventus,perpetuis notis mixtiffinus. Illud quoque commune habert, quod, ubireidignitas, cogitationis utilitas, ust̂s \& applicationis dexteritas poftulare moram videtur, fublatunt letoremque Lumm; tanquam in re prafent, cum cura \& fide

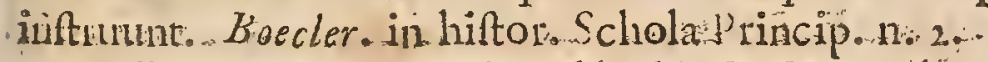

In Philippo Cominco depsehendet Lector dulcem arque jücunda m orationem, cum genuina fimp! icitate, narrationem puram, \& in qua foléndet cvidenter Authoris bona fides a vanz glonizaucupio cum de fe ipfo, 8 tum ab affectu tum ab invidia cum de aliis lozuitur, immunis: Ejus fermones \& hotamenta nagis comitantul ludabilis Zelus, \& Verac tas, quam ulla ingeniivis exquifita, \&ubique authoritas $\&$ gravitas virum non infimo loco natumac in magnis negotiis verfatum argununt. Mich. de Montagne T cus taminum lib.-2.c. 10... Gall...

Si quis autem eft omnitum vel holtia vel etiam paulo fuperioris atatis qui prudentiâ \& veritate proximè ad antiquos aceedat, is meo quidem judicio eft hic Auctor, quoniam graviflumas deliberationes habitas in ipfrs Regum penctralibus, antequam in actum venirent, ponitob oculos \& diligenter explicat, quod vix paucifeceruat, \& päuciores multò praftare poflunt, \& ut polfent vix tandem audent ne yuidóffendant. Ioan. Sleidan. prxfar. adicomm. Hit.:

Ludovici XI. Regis Gallis \& Caroli ejus filii res. bello geftas, quarum \& parriceps fucrat, Angeli Cathi Pontificis Viennenfis hortatu \& impulfu defcribere. aggreftis, heulcntam quatuor \& triginta annowm hiftorim, magnâ quidem fylifimplicitate, fed ner minori puritate, \& quod in rerum fcriptore fummum eft, fingulari apud omnes fidei ac veritatis opinione infignem poferitatitianfmifit $\rightarrow$ Nec eloquentià, prudentiâ, caterifque virtutibus ad fummas res! tractandas ¡doncis ulli hominum xtate fuâ concêfit. Eò majore omnium admiratione, quòd vix ullo literarum prafidio fretus, penè fola narura bonitate nitererur. S ca vol. Samarthan.in Elog...

Ludoviens Vives CaroliV. Praceptor Cominiun reprehendir, quod frepius ab Hiftoriâ propofrâ digrediatur, deque Principum moribus ac virtutibus, atque omninò de vita beata Philofophorum in modum difputet. Is tamen aliter atque Vives omne tempus in Republica gerenda, aut in bellis, aur in maximis le gationibus obenndis confumplerat, ut rectè, fr quis alius, judicium ferre potueri. Ioan. Bodin. in Meth. Hilt. c. 4. p. 53.

Corninans vir lectionis yaria, fudij indefent Unum dolebst maxime, quòd J. 
Gallicam, Hijpanicam, Germanican calleret linguas, Latinam Iolum ignoraretScripfit Gallice, quâ potifimùm linguâ excelluit, \& ad veterum Hiltoricortion gloriam venit. Valer. Andrcas in Bibl. Belgic.

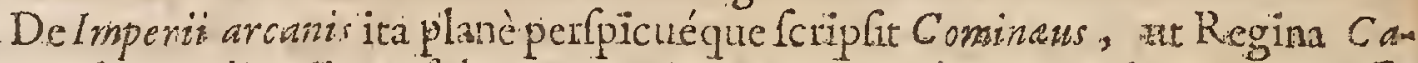
therina de Medicerdiccre foleret, Cominaum tot Hareticos in rebus poivicis effic cifle, quot Lutherus in Religione:

Nec me late plurimos hujus atatis Principes, infun in delitiis habere folitos, cen renum gerendarum, 2 policicæ negotiationis magiftum, ac pratered velut incorrupte veritatis integenimum afertorcm. Hinc in xtene literatorum Concilio fancitum, utficuti loviu in Hiftorica factorum narratione prieltat \& Guicciardinus indetegendis confliorum omnitim, alionumyuc caufs; itz Philippusin dirigendis ad civilem pretentam animis, fingulari quodam ingenii bono pracellat. Igitur quod fummè sreum à Phyficis exiltimarur, hic intelligendi vigorem cum agendi folertia conjunxit. Ioan. Imprialis in Milfo Hift.

Philippus Comincus cadem Libetrate Ludovicnm Sum depinxit, quâ iple vixerat: tantumquc fibi cxquifato judicio veræ gloria comparavit, quantum ille niumphis \& Imperio. Gabr. Nandias in Bibl. Polit

Ejus Hiftocia pixentim nominis illius memeriam commendat. Ansorum quatuor \& trigintalpatio maximè infignia gefta cópledtitur duoum poftremorum Burgundi. Dacum Ludovicz Xl. \& Caroli Vil. Gailia Regum: quamvis autem ingenii proprii facultatem ad illus conficiptionem adhibuerit ob fuam Latinitatis ignorantiam, hanc tamen adeo accuratè pertexuic ; tam perfpicuum ordinem, tantamquecon innitatem in ca obfervavit, \& tam ingenioséplu ib. Politica fententiis illam perfperfío ut abo mibus Europe Deatiscumadmiratione fuerit excepta, \& communibus fuffagiis gravi huic Authori tributus fuerit elogium Principis Hiftoricorurn fibi coxtaneorum - Poeta Ronfardus non dubitat illum Tito Livio aquipararcin Poersate quodin cjus laudem (criplit. If. Bullart. Acad. Scientiarum. Gall.

Cum pradirus effet acuro fublimique ingenio, id omni tudio appulit ad liberdes dilciplinas, \{peciatin vero adlleationem optimorum Hiftoricorum, quos cum impenfe diligeret fe quoque in compórendo excrcuir, ut liquidó conftat è luculento Hiforize illiustefimonio, qua Gallice Regum gefta narrat qui ab an. 1462. ufque ad initium Regni Ludoviri XII. clavum regni tenuerunt. Hac Hiforia ejufque in hujus Scriptione prudentia fingularis ad honorem \& celebre nomen veraciffmi \& fimplicillmi fui temporis Hiforici illum extulerunt; Quia tam abund fatisfecit corum muneri quifimilem provinciam fufcipiunt, ut im* nortalis futura fit cjus memoria, cim in ipfa Galla tum in omibus Europa Regionibus. Scripfir preterea Commentarios Caroli vlll. G illie Regi, belligue ab ipfo in Neatiolitanum Reg? immoti. Argentonis. Dynaft ille fuit, Vir magnorum negotiorum adminiftrations capax, magnxique dexteritatis; quod etiam cximiè demonfia it peiegregiis fuis Operibus qux omni refpectu Anumata dici debent, cum veracitatis an imam habcant, ob quam ab omnibus rerum publicarum Adminituatoribus honore:fummo cultus fuit: Quamobrem illa non citius 


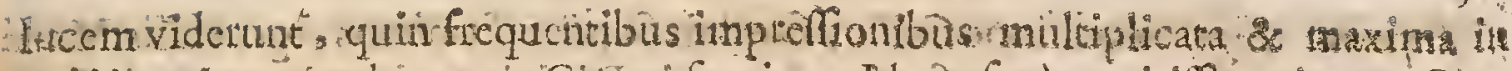

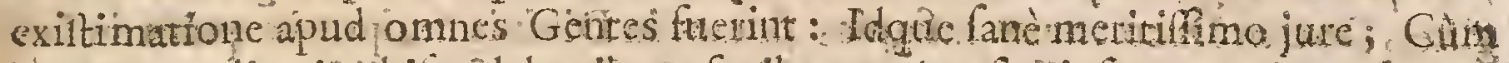

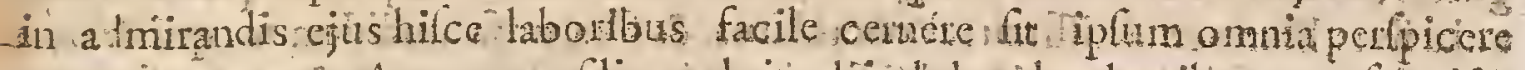

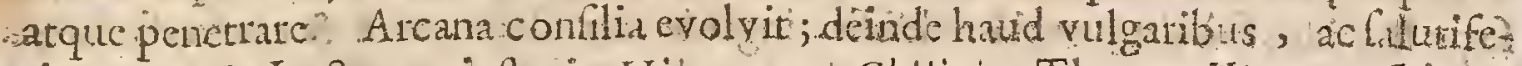
ris praceptis Lcetorem inftuit. Hièronymus Ghilini. Theatro Virorum Iiteras torum. Italicè.

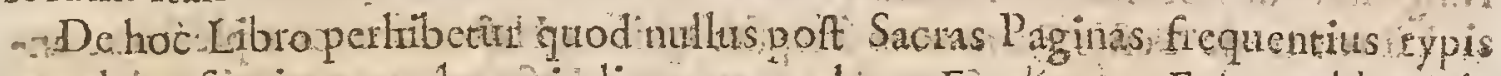

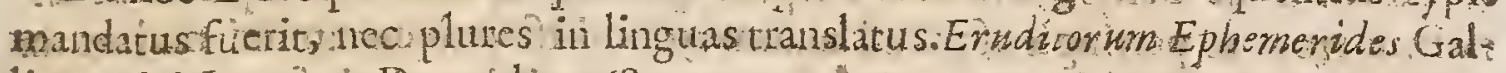

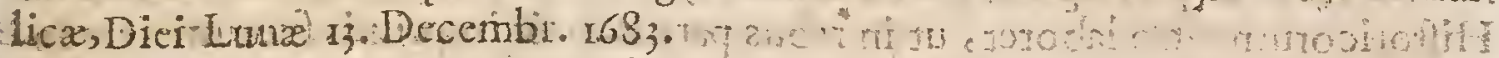
- In Cominao VValtonica mulk funt, qua non intelligimus, Iof Scalig. ia altrenis Scaligeranis; pag. 53 :

Annos ferè fexaginta quatuor tatus, obiit anno millefrno quingentefina no

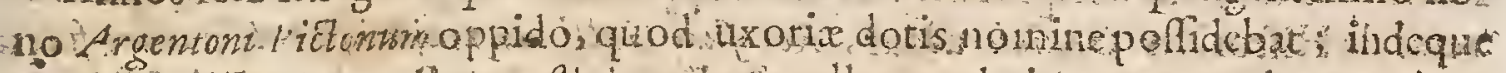

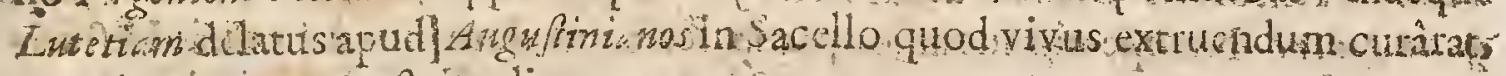

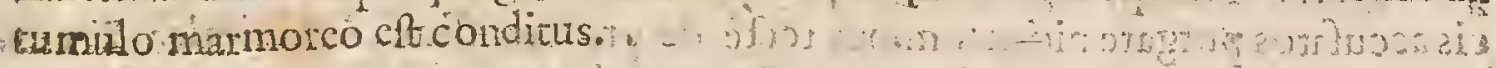

Hac cjus Epitaphium, Stephano Pajcbafor Authore.

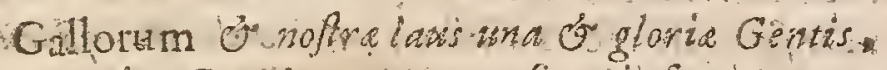

Hic, Cominae, jaces, fi mosito forts jaces.

Hiftoria vitan potziffi reddere vivus;

Extinclo vitam reddidit Hiforia.

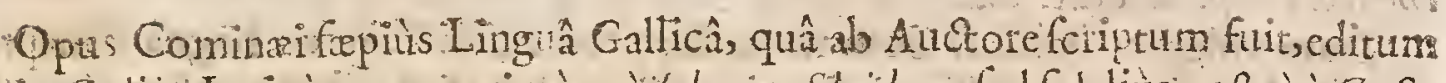

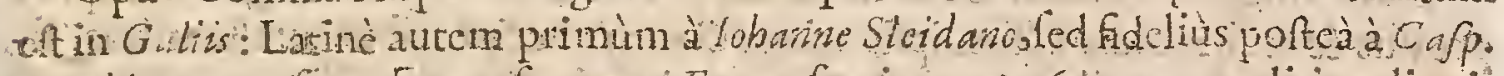
B. ribio converfum, excufumque Francofurti anno 1629 qua cditio religuis

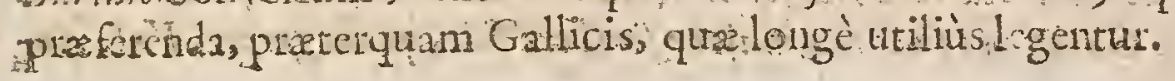

\section{ROBERUS G A GUINUS.}

\section{five, \\ RUPERTU GAGUINUS}

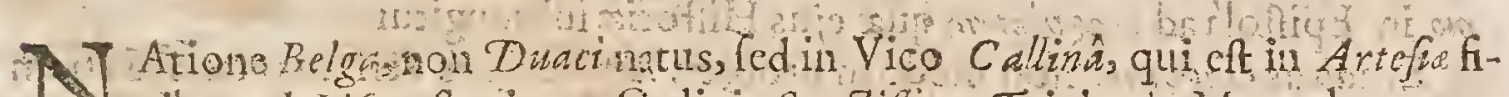
Clar.An. It. MXD.V.

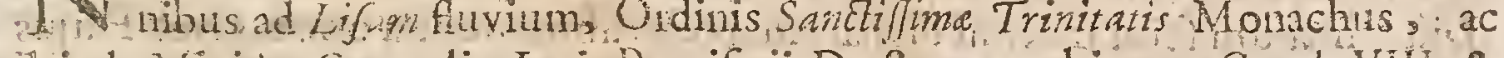
deinde Muitter Generalis Wuis Pontificii Doctor, nultis pro Gqrolo VII \&

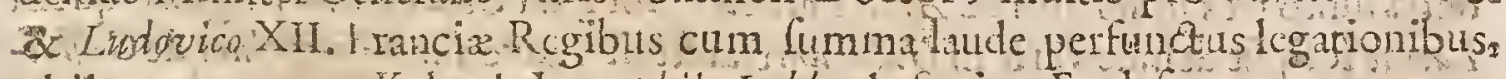
obiit anuro fsor rr. Kalend. Jun. bil. Labbe de Script. Ecclel

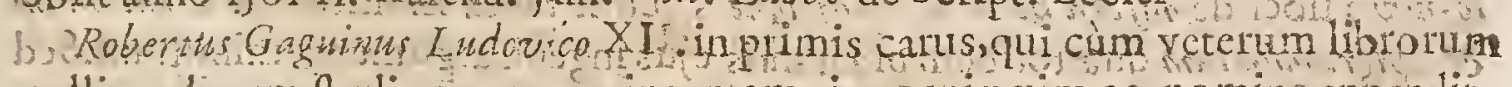

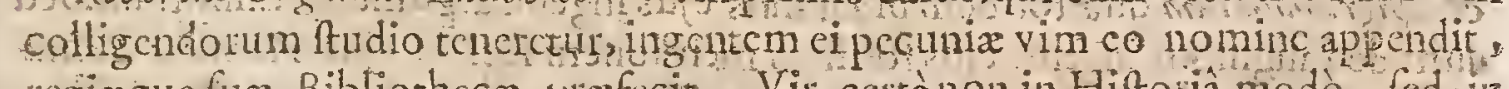

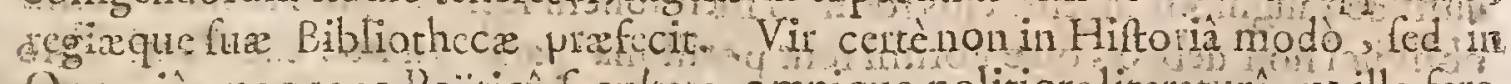
Oratorià quoque ac poẹtich facultate omnigye politionetiteratura 4 illa fere-

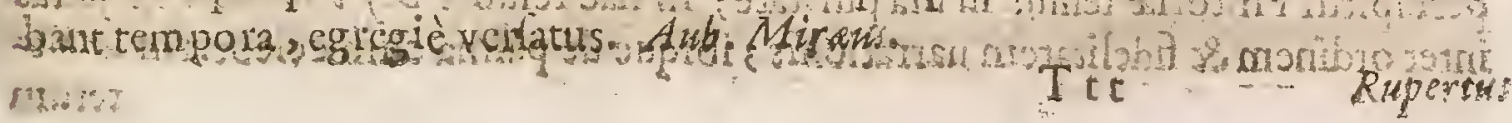




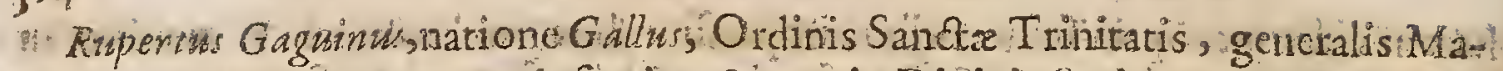
gifter, Doctor Decrerorum infignis, \& tam in Divinis: Soriptucis quam in fo

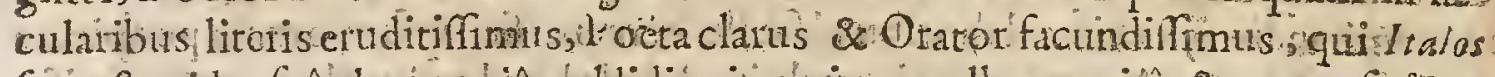
fxpe fup dos fua cloquentiâ redidit, ingenio excellens, vieâ \& conyerfacione devotus. Scripfit utroque genere multa praclara opucula qubus nomen tum longè lateque notificavit. Trithem.

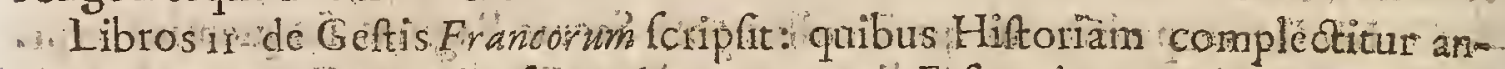

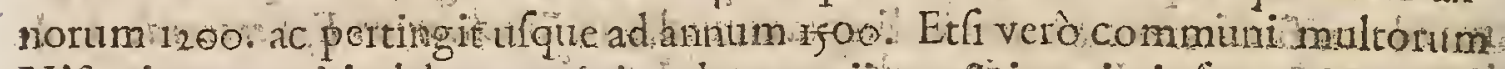

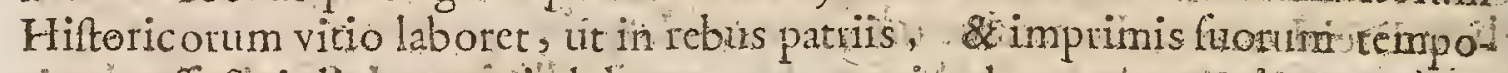
rum, affectu aliquantum indilgeat; quo nomine de eo conqueritur Ludovi

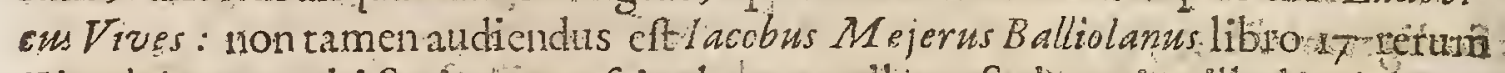
Flandricarur; ubi Scriptorem frivolum appelihto Scdgravins illad, qu do universè de Hiftoricis Gattic is! adidat, Res fuas Gallinon majori folent Jeribere fide,

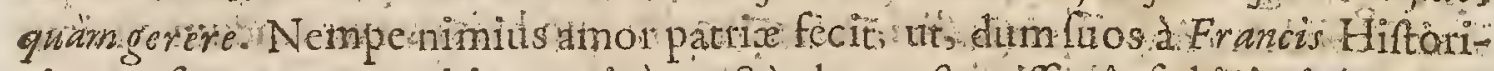
cis accufatos purgare nititur, minus rectè de praftantiffimâ, fed inimicâ, Erar. corum gente judicaret. Unde etiam eft, quod idem paullo ante Ludovicum; Gallie Regem, non dubitet diabolicum omnitum Difcordiarwin fatorem nuncuparc. Nec tamen in rebus externis nimiim Gagvino tribuendum videtur. De quio ita lovius in logiis s De fide (in rebus Gallicis) illi viderints guorsm intereft in corruptam rerurs menortian ud pofteros tranfmitti Nam in bis, quad Ialiam perinent bujus tempefatis ufquedeo infolenter, or pinguiftylo, cecutive folet, ut, qui nulla orationis ornamenta in e conf piciunt alfin in ejus imprudentiam fornachentur. Voff. de Hift. I at.

"T. Dum vilgares féquitur Commentariós provinciali friptos lingû̉, ineptos prorlifs \&multis locis falfos, ipfis etiam Gallicis Scriptoribus attefaintibits, frdes ejus fubirde vacillat. Itaf cè Mejerus Annal. Flandria lib I7 ad anum

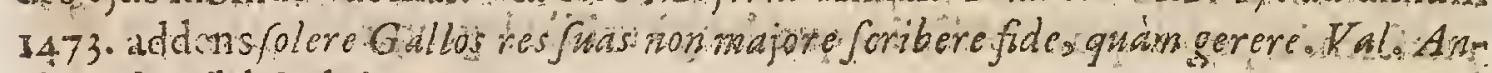
dreas in $\mathrm{E}$ ibl. Belgic.

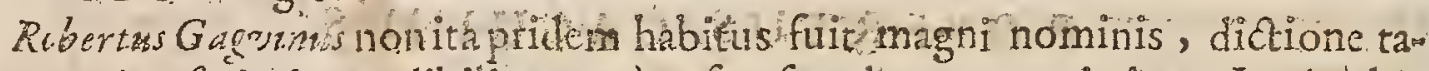
men, quàm fcriptis vendibilior: verum fro faculo: nunc vix inter Latine logluentes reciperetur. Erafin, in Ciceroniano, p. 167

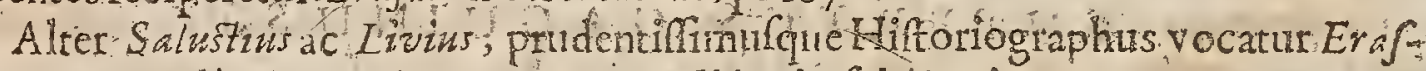
zan in Epiftoli ad Gagvinum, qux ejus Hitoria fubjungitur.

Eruditus Gagun non modo in probatis Authoribus kerfatis etat fed étiam Difciplinarum (citu maximé dignarumabfolutiflimanotita arnatus erat Híjus. teftes funto trcsillu libri de Arte Poetica. liber de Conceptione Iirginis quem

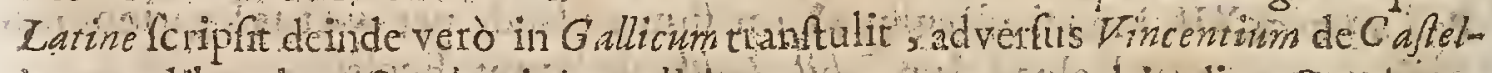
lo-nov; liber de mity era bornitis conditrone cum tanta multitudine Orationum \& Epgrarmatum qua totidem praftantis ejusingenii argumenta miniftrant. Sed - $u m$ de infignibus ingenii ejus faetibus mentionem facio, ejus Aninales Gallix oblivici non debeo, que cortm funt potiffima pars. In hoc excellenti libro

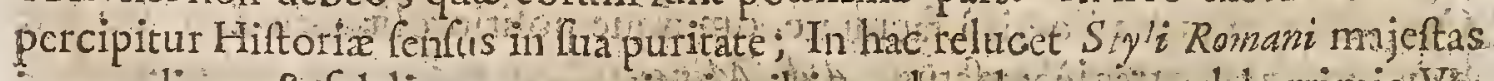
inter ordincm \& fidclitatem parrationis, ibique al palma cim eleberrimis W 


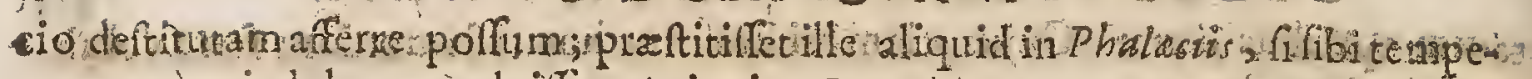
rare, quàm indulgere maluiffer. At junior Beroaldus promptam, ác paratam habet ubique facultatem, Sed Lyricis ille magris, quàm alio leribendi genere delcetatir. ex quibus \& laudem alfequitur, tamerf in his interdum for nomihil indulgere videatur. Lil. Gyrald.

Erafmu in Giceroniano fuo cum Patrem dixilfet hominem do literarum fudius preclarèmeritum; I wniorem tamen (uciñuit) in Ciceronianorum Camlogum citius receperit; quanquam is perpatica milit in literas. Sane filius non tantus crat Sectator reconditorum verborum,

Beroaldus homo, ut illa tempora ferebunt, neque indoctus, minùnè malus LipS 1. 3. Var Led c. 2 o.

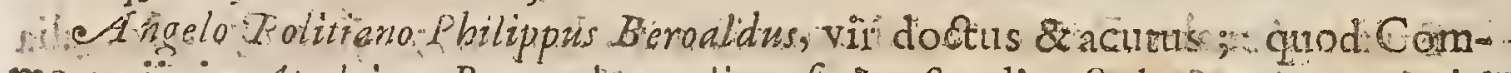
mentaiis in Apuleium, Propertum, alios, fatis oftcudit. Scd patum tamen viri illi, quamvis preftantinimi, ad penitis abolendam barbariem valierunt, do-

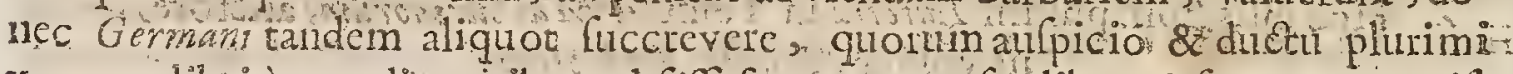
vetcum libri à mendis, quibus obfell fucrants proflus liberati funt. Nec quifquam, opinor, hanc $G$ enti noltra laudem ereptum ibis $G a j p$ Scicp.6. de Arte Citic. p. 6 :

Picus Miraraulanus ipfum Bibliotbecam vivam ambulans Mufaum vocare. non dubituit; quo elogio aliàs Longinuan Rhctorem Etinapies dignatus eft. Konig.

Pbilippus Beroaldus vir Diationariis quibuldam addictus fuit, è quibus fud equitomnia, fegnifrmus in Apuleiurn of citat. Hujus fi vellem enarrata omnia perfequi, magni voluminis liber emirtendus effet. Merasferipfit in Servium caLumnias, non Correctiones. Claud. Verder. in Autor. Cenfone.

Pbilippus Beroaldus Bononienfis, initio fccli decini fexticlaris sut varia omnino cuditione, ica quoqué poëticâ, chjus ctiam laudes Scripto explanavitIn Epiris minus afturgit Borrich. de Poct. P. 95 .

* Hic Aucto inter Hercticos prima Claflis rejicitu in Ind.Madritienfl elit. ann. 1667 .

* Opera ejus partim vinctâ, partim folita oratione de tariis argumentis ferip.

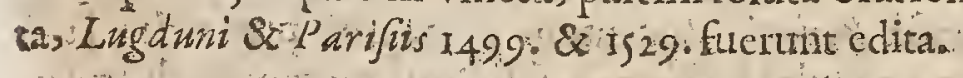

Obiit anno I504. Scpultus Bononic, ybi hoc ejus Epitaphium:

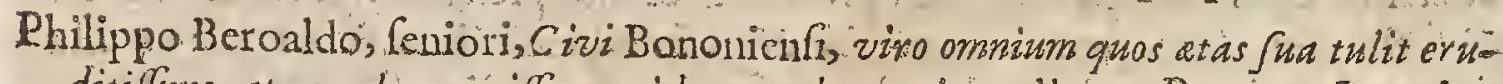

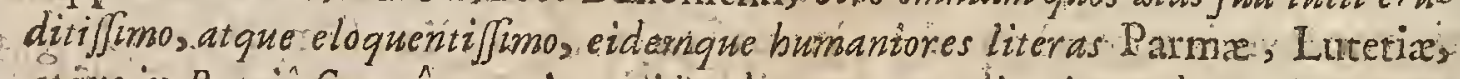
atgue in Patrî̀ Jummâ cum ingeniilaude, atque audientium admiratione pro-

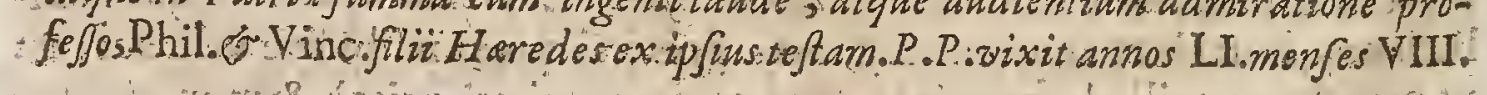

\section{ACCIUS SINCERUS, five,JACOB.SANAZARIUS}

Clar. A.D. Eapoli natus, patre equeftris ordinisiviro claro inter fúos \& luculentarum

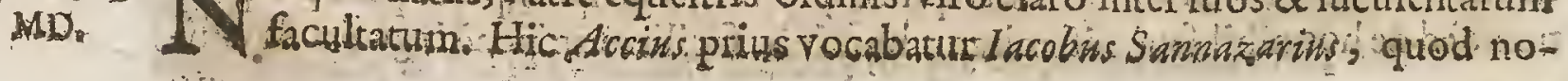




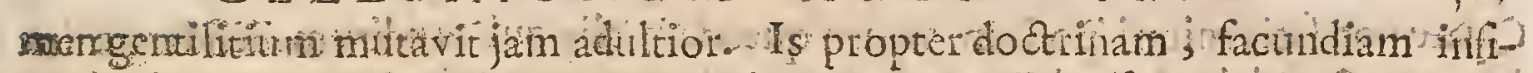

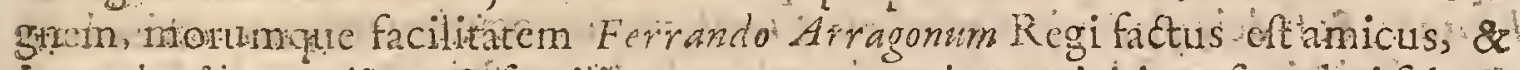
inter chariores anlicos \& fanithates receptus, cujus amicitian "fingulari fide \& confunià colu it quamdiu wix. Expulfun enim Neapoli Regen in Galliam uf que exulemfecutus ets: undê rewerlus abeo mulcis honoribus, \&o beneficiis affuctus cit. At inter aulica muniz ferialque occupariones, non defit bonas féqu

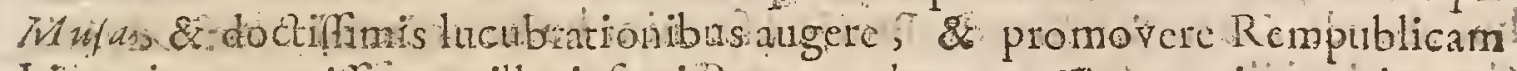

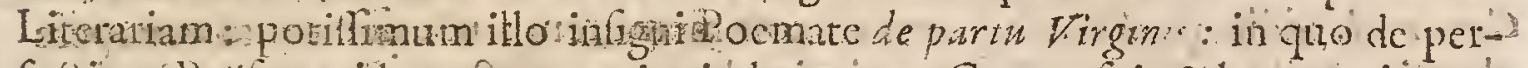
fectione Poefeos videtwe cumantiquis decerare. Compofuit \& lamentationem: de Morte Chriftr, Eclogas aliquot, \& Epigrammatm peifectillunorum librum. Boiffard. in Icono-

Adturs Syncerus Santrazariur Nieapolitanus, initio feculi decimi Cexti clarus,

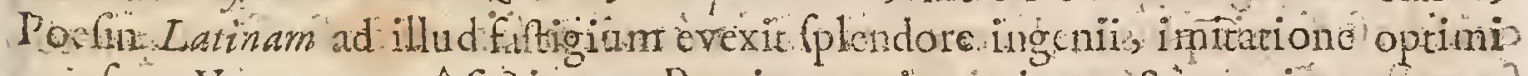

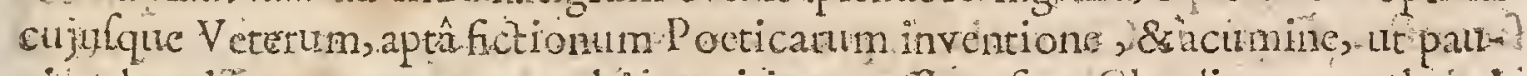
cis admodum ex eo temporealtús eniri concelfum fre Clauditur tumtio ad

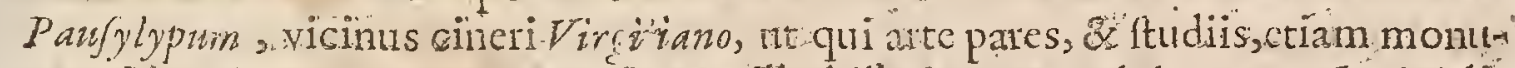
mentis conjungantur. Docet velEposillud illutre -quod de Partu Virginis libris tribus complexurs ch, nihilfere illius verbus invenil ealtigarius-Ad funmam, digna omina Sannazariz, qia Fockos Candidatis attente legantur, ita ubique in quocunquearguncrito regnat: cultre ejus Elogx faciles. \& numeroficlegi, arguta epigrammata, \& libera.BBorrich.de Poet. peros.

$S$ cripfr, tanquam ambidexter, Ethrufca firmul atque Latino carmina, pari leporc faléque, arridentibus utrinque Mufrs atum multo felle odii fubamarts" prapida jacula /anbis intorqueret; autamorum fuorum dubedine refolutus ,

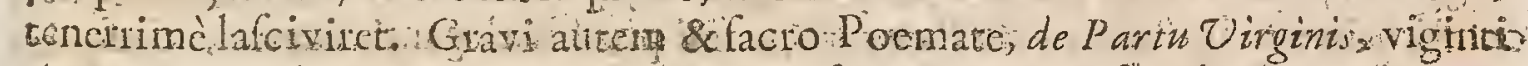

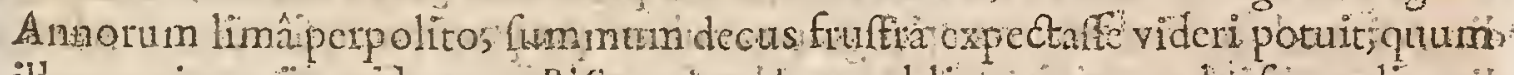
illa qua juyenij exciderant, Pifcatorte éloge publico cxcepte plutifi, reliquo:tum operim fumam oppefferint, ita; us campublici tanquam iniqui judici: querelâm aperto cum pudorésnce tamen fine tacitâ voluptate devoraret. Paula. Lov, in Elog.

A Pontano nonim proflixere tum in Portica, tum in Arte Dicendicelebres. Unde \& Pontani A cademia nunc nulgo ut Trojanus Equns, dicitur, in qua nume fenefeits ni potils floret, "ARtrus Syncenus Sandzarius, cujus urgenir exquifitax quædam monumenta legi, \& in primis Pifcatorias Eclogas nommllafque elegias. \& eptgramrnata, in quibus quadar funt om prater vernaculanou vidi, \& quoldam Jirginei Partus, ut iple appellat, Heroicos: Inquibus, ut fic dicam ftatarius Poéta videri poteft Nonewimiverborum volubilitate ferrur, fed limatius quoddin feribend genus confectatur, \& lima indies atterit, ut de illo non incleganter dictum illud Apellis de Protogene Pontanus ufupare folitus effet, eum rnanurn de tabulâ tollere nefcire. Præter diligentian curamque AClii, acerrimum quoque ejus.judicium. \& numcrornm fcientiam in poëticâ frcultate cognofcimus, quare ejus reliqua, qux condidít Cummopere defidesanus, qua longihs ille jam xtate provectus fupprimito $\Rightarrow h$ ? 
Quarenon fatis miraripolfum vium quendan alioqui enditum defierate in: Portano, \& fi deis placet in Sanazario Chriftianam elocutioniem, hoc eft barbarạm. Sed hic cum fuâ cenfurâ quâ homines ltalos pettringit; ronditüiùs perat mantbit. Lil.Greg. Gyrald.

- Pontonn Lucceflit Accius Sincerus, qui PartumVinginis matris mire felici car-? mine defcriplit, cuifupra modumapplaufum eft à Romano Theatro. Teftantur loc abunde Leonis \& (lementis Brevia (fic enim hodie Focant) num sudit Cardinal additaplafatio, ne catcros comnemolem inec finc causâtantopere

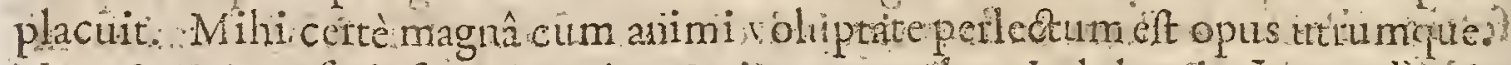
Nam \& Eclogat fcripht Lifcatorias: Quis autemedem Indolemin Tuvene Paticio non exofculetur? Hoc nomine prafuenduseft Pontanos què rem facram trabare non piguir, nuod ne do mitanteream, nec inamenè tractavit. Scd meo

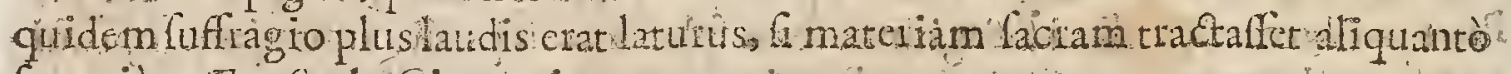
facratius. Erafim in Ciccioniano, p. $20.5^{\circ}$

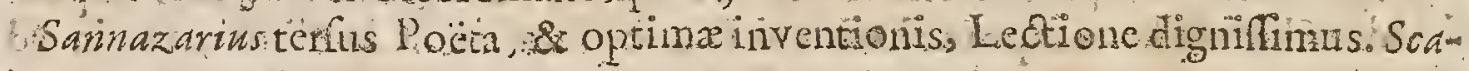
liger:.I. P.I3I: I32.

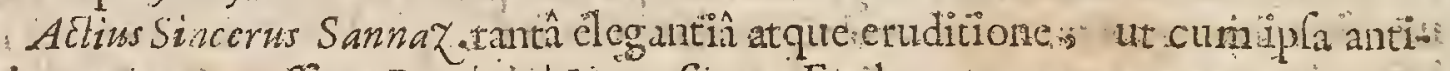
quitatecertale pollit. Barth.ad N emefoinum Eccl. $4 \cdot \mathrm{p}_{0.25} .5$

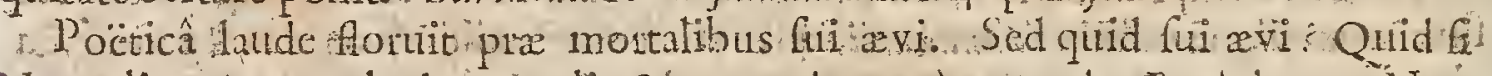
Neapoli majorem gloriam attulir Sannazarius, quàm tatius $p$ apinius Noh crit inquus cenfor qui hac cenfeat. Ludia de la Cerdin Zern.

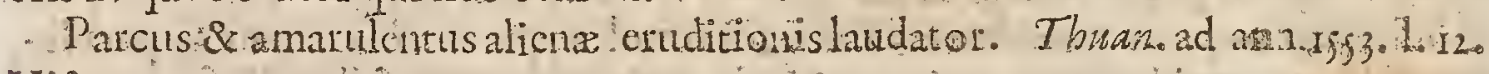
Hilt.p. $25 \%$

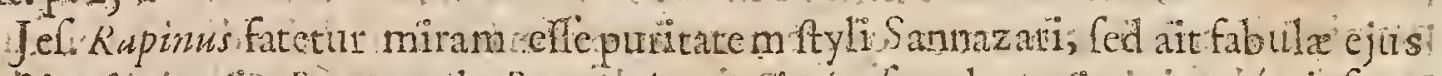

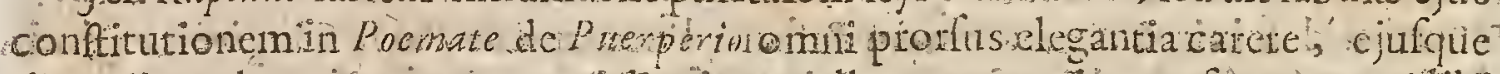
dicondi modum cum argumentidignitat nullam proporcioncmarvare Alibi

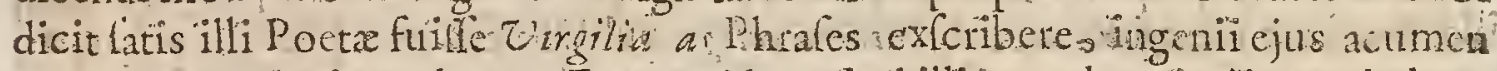
: aquaquam exprimende Eum quiden dati illits sothumi aliquos habere characteres fed non faris frequentes jum in proprium genium relabi, \& inter vanos fervilis imitationis condtus, nativi fuingeni paffin indicia pradere? Rat

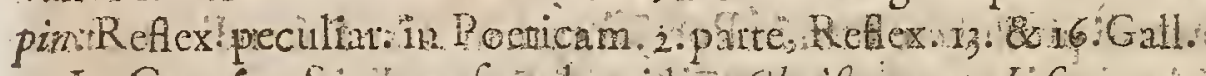

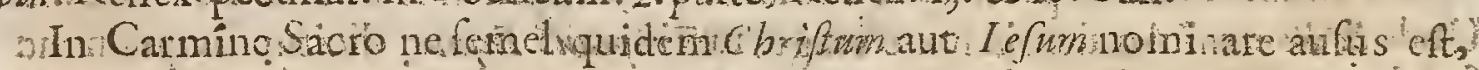

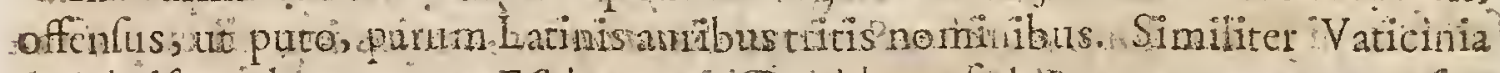

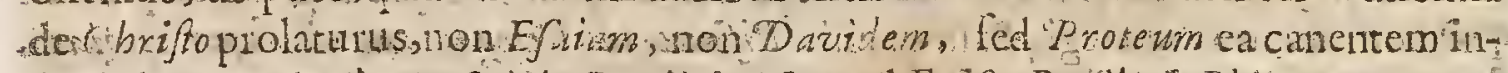

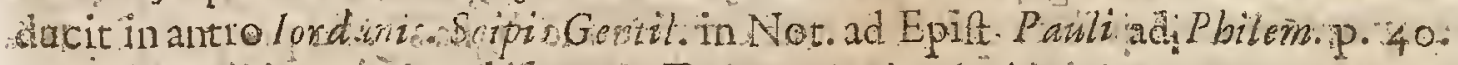

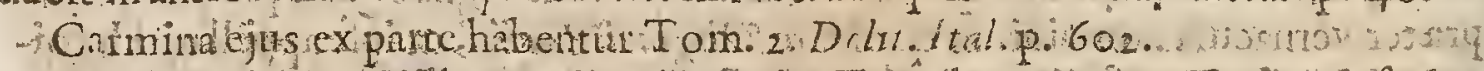

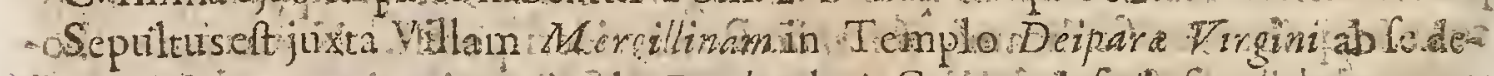

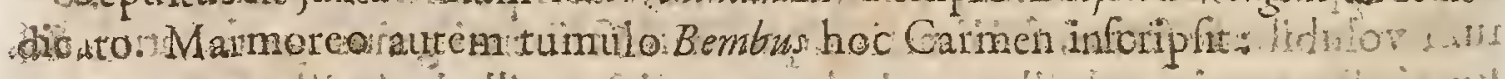

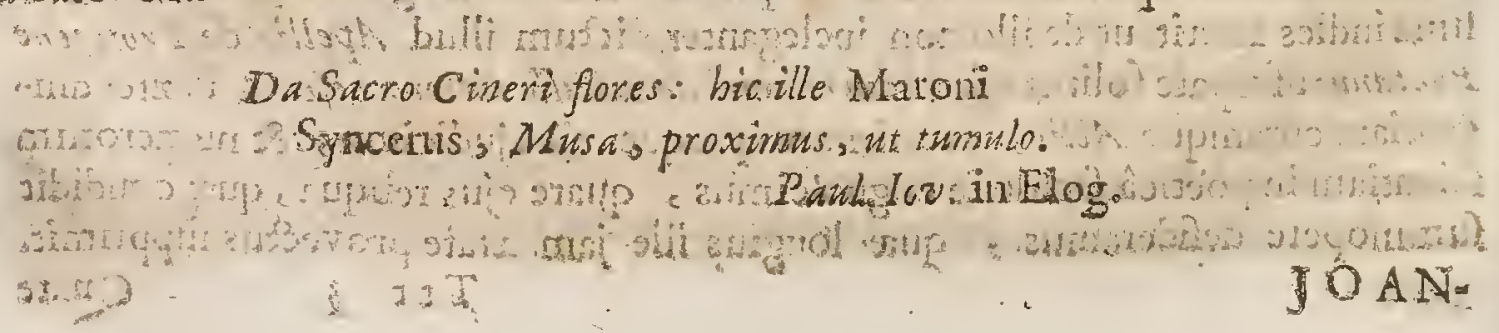



genitz. Praceptor datus eft. Verùm ob improbatum Regis divortinu, gium feceffit, C Cbit anno I53Gur Gul. Cave Chartophyl. Ecclef

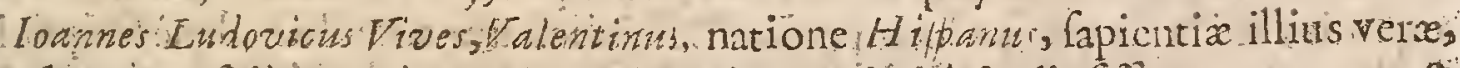

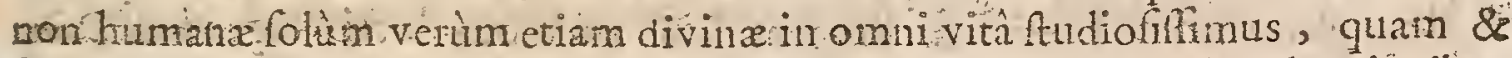
fummin.cum latde cloquentix \& virtutis plurimum illuftravit lucubrationibus de. eầeditis, \&゙ doctè pronfus \& accuratè conforiptis, probatus vir induftriâ, patiêntiâ, Labore, arimique magnitudine: Cujus immortalis famx gloria, idque meritò̀, quod ad fapientiæ cultum in omne axum vivet perpetnò' mağno fui defideriobonis ominibus relicto, obiit Brugis Elandrorum, an. 154 r. Boiffard. in: Icola

Ludwacus Vives, vir ut varix doctrinx, itafapientix? propè incomparabilis. Vof: Epiti piafix: Art: Grammat:

Ludovicus Vives, vir longc eruditilinns, ac praelarifimi judicilo Barthius in Adv:

Judicith ejus celebratur, quo inter III. viros illos R. P. contióttendx li teraric ejufdem tempeftatis excelluit, ut Budzo ingenium, Erafmo dicendicom pia, Viri judicium tribueretur... Teftantur id libri de Göripupis dafoiplinis, quibus in Arium abufus egecgie fylum ftrinxit: ut \& Epifola ad Forterrsbarbaros Sopbiftas exagitat. Ita Theologic ftudie fele dedidit; ut fui Kuenliritheologos adde-

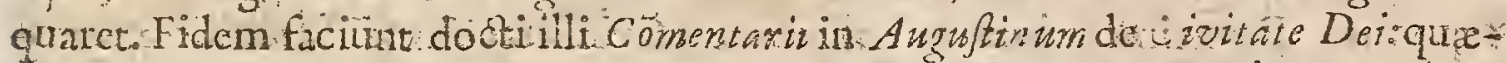

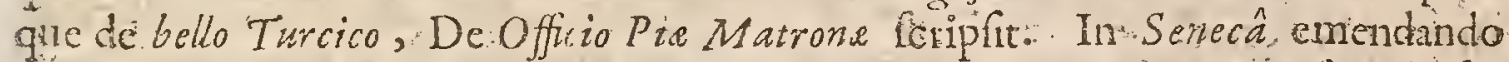

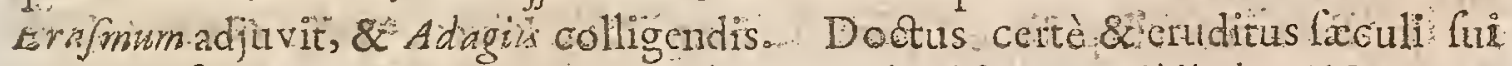
Criticu, fcriptis, Ze enditionis famâ perpetuo victurus. Biblioth, bijpan.

Eft apud ho's Ladovicust. Vives, Valentinu, nondum opinor vigefimum fextum egreffus annums.. fed in nulla . Philofophix parte non tupra vulgum, eituditus', tum in bonis literis, atque etiain in dicendi fcribendique facultate eò progreflus we hoo fectlo vix alitim norim guem aufin cuim hoc comnittere êf argumentuin iil quo won exercuit fylum.x. Nunc veterum exemplúm tefen rens dechamar; fed tantâ dexteritate, minti crede, ut fi titulìm adiónas, pures fem non liujus tegionis, nec hujus effe fxuli, magis autem feliciffimis illis Ciceron mes ac Senece temporibus natam, quibus Cognis \& Apiciis nliquanto plits erat Rloquentix, quàm munc eft is, qui videri volunt Orbis Magiftic Artis obfervalitiffrmus eft, fed ejus affectationem ita difimulat; ut negẹs remadirmbiatam agi. Eralm.1 rg. Epitainor:

Equidem nec ingenium nec eruditionem in lob. Lowd. Tive defidcro: adeft il liparata fententiarum ac verborum copia, cumque fuerit initio duriufculus, in dies magis ac magis in illo maturefcit eloquentia, quem fi nec vita nec fturdium defticuerit, bona: Ipes eft, fore us inter Cicerominnos numbetur. Sunt enin, qui 
bus feribendi conatus juxta $M$ androbuli morem, ut habet proverbium, fucce

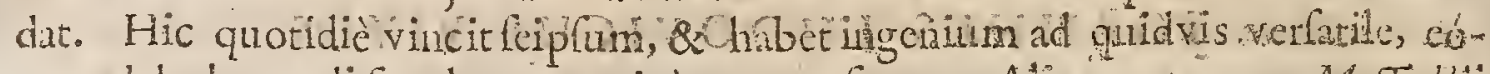
que de declamandi facultatem unicè compofitus. Aliquor tamen M. Tulliz virtues nondum ablolvit, prxcipué jucuuditatem dictionis a mollitudinem. Erajm. in Ciceroricano, $p$. $185_{0}$.

"Hacin re (de defect bu in infirmanda jwentute. of corruptelis fudionn)

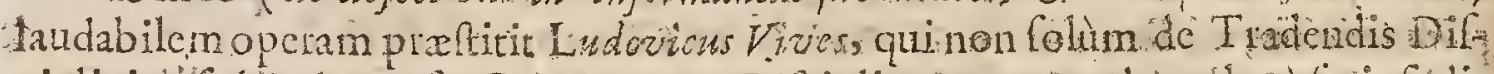

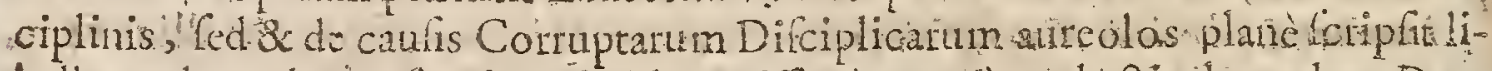
bellos plenos bonx frugis, ac diligentifrme omnibus doctis lggendos Dan: Georg. Morhof. Polyhilt. pag. 333 .

Ioannes Ludovicus Trues multas nobilifimas Incubrationes docteprontus 8 accuate confipfut ir: qubus fummam cloquentian cum abfolutifina cru

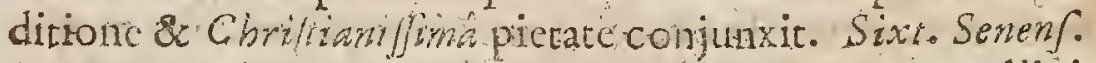

Quante datrina \& Ledion yir fuit, docentum alii jus libriplurimi tum

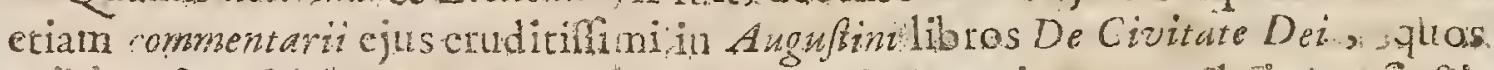

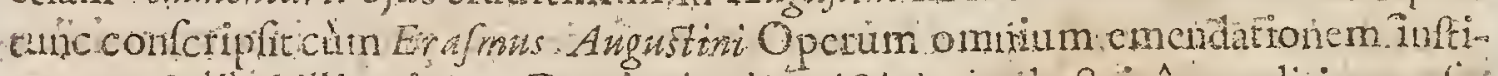
tueret; \& libi illi quinque De Tradendis Difeiplenis, doectina , cuditione, ta

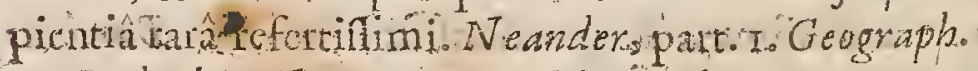

Ludovicus Frves, rarum Valenta decus propecera quod doclamator degrét

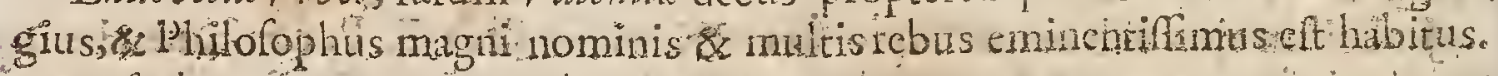
Quenfedt

Toannes Ludovicw Tives folicitatis d Cardinaliwolfeo, Angliam vilitavit?

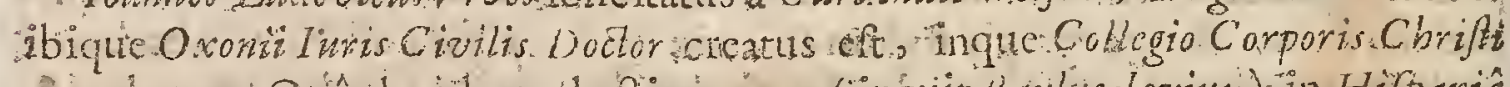

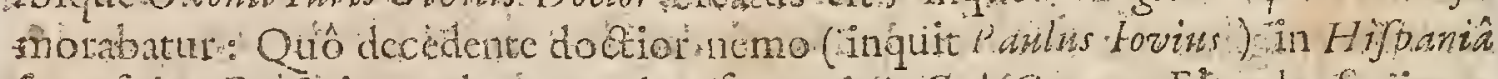

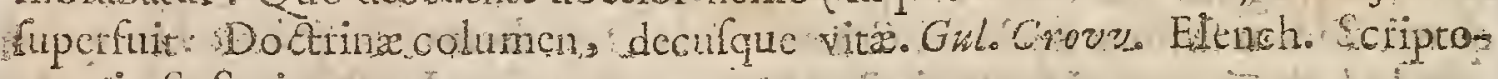
aumin S Script.

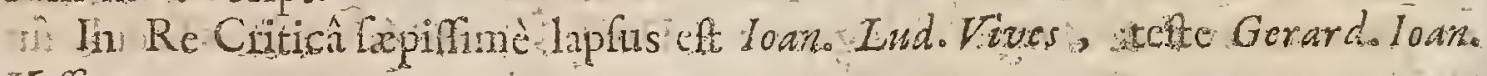
Ooff20.0.

Vives fillitur, dum in libllo quodam Lucanumirirgitio prafert;ndibrum

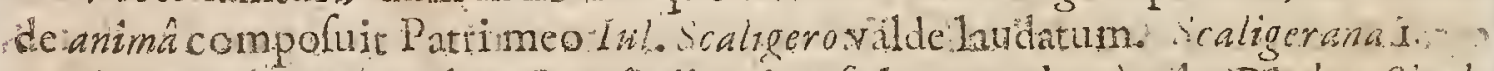

Vives, de Gelito malo animo judicavit, fed tamen bene; de Dipdoro Siento idem male judicavit. Vines frit do Aus: qux feripfic in Angufinum funt optima

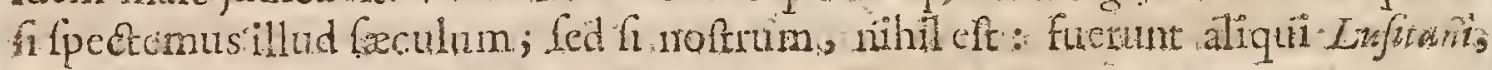
docti, pauci vijpani. Scatigerana:

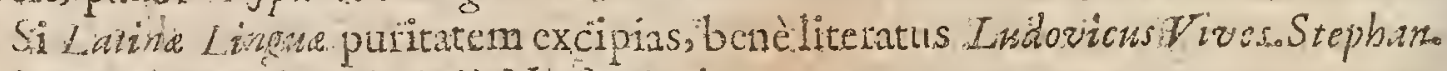
Epita. Dedicat.ad Am. Gell. Noct. Artic.

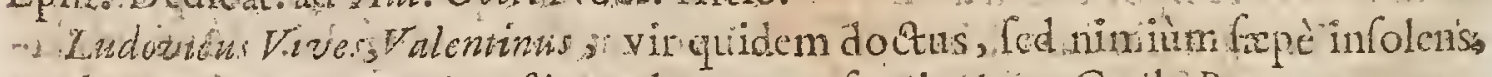
3 clatus, quippe qui Aupufinm docere prafumit Loan. Card. Bona:

A Natura judicio folido ing eniique vi mirifica inftuctusr praclaris hifce do ribus omnem arimi contentionem neceffariam ad felicem niliterarum frudio fuccefum addidit; quarum tam univerfalen notitam fbi comparavit, ut ma

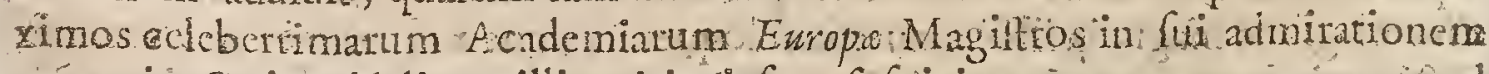

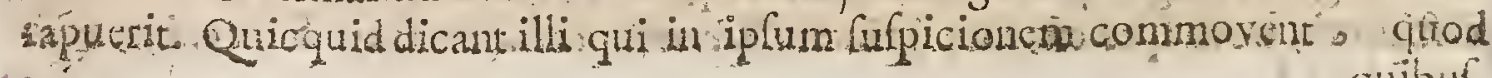


quibufdan locis magni illius Ecclefiæ Doetoris (nimirum D. Augutini) Centen tias altcraverit, difiten $i$ equeunt quin illis alibi fxpius lucem troneraverit, qux carum lanctitatem \& profunditatem conficliam reddit. Ifaacus Bullart. Acad. Scientiarum. Gall.

* Ludovici Vivis Valentini Annotationes in S. A ugufinmm, n'fic cxpurgentur prohibenturin Indice Tridentine.

Extant Opera omnia Brug.x5s3. Baf. I560.2. Tom fol.

In hune Autoiem Nichoiazs Borborinus hoc Epigramma Aruxit:

Ingeniurs, corpus, mores, facusdid, candor

Et frylus, invidto gino velit enfe, vales:

Hac pretiofa ut fint; tamen ifto nomine Vives:

Nil tibi tê dignum fata dedere magis.

\section{J A C O B US F A B E R.}

Tapulenss, vixit 1or. annos, purus ab omu contagione muliebri. Obiit an
no Donn. 537 .
Erat is ad Stapklas mairimum Picardre pagum ex ignobili familiâ natus, culzumque ingenii, quem illatempora ferebant, inter aniles lophiltarum nugas \& incptias apud $P$ arifios acceperat. Scd hanc fortuna tenuitatem gcnerosâ planè indole fuperabat. Cúmque pro falerti, quo pollebat, judicio aliquid in literis majus, omninò $\&$ praclarius elle fentiret, quàm quod antè à Barbaris illis \& imperitis praftitum cher; partimfuo impulfu, parim entitonm hominum, qui tum in 1 tatia forcbant, exemplo \& itmulatione incenfus, totum fe in illius boni cognitione \& fciontia collocavit; eo exentu, ut \& ipfe perfectifimè cioctus evaderet, $\$$ alios aptifimâ dinde incthodo facilitateque doceret : mon voce tantùm \& prelectionibus, verùn \& fcriptis, quibus ad univerfam Araftutelis doctrinam, Maheleolque partes omnes planum $\&$ facilem pofteris aditum patefacit. Scavol. Sariarthan. in Elog. Gallor.

Ab hoc hemunculo genere ftaturâue perhumili, fed ab ardenti ingenio cum Optimatibus haud dubièconferendo, totius Gallix juvcntus ad culatum licerarum ftudia alaciter excitata oft. Fuber enim 7 ngeniornm appcilari volcbat: quum in omni ferè doctrine genere ad docendum aprifimus haberetur. Defuit in eo, dum fcriberet, illa Lutini Sermonis puritas, qux diu, aut nglecta apud extcrnos, aut partum accuratè quafita, non magnopere fervida ingenia dele ctabat. Scripfit Commentarios in A/tronoviatus, juventuti perutilis, \& 5 cholia in moralcm l'bilofophiag perdifcentibus opportuna : xtate autem confectus, guum facras litteras atrigiffet, à $\tau u$ berana doctrinânon procul abfuit, ita ut in eâ fufpicione fenex moreretit $P$ Paul. $70 \%$. in Elog.

Iacobus Faber, celebcrimus noftrifeculiphilolophus, Belgice, quinimò tius Galla unum decus. Primus apud Gallos (ut Cicero apud Romanos) bhilolo-

$$
\mathrm{Vu} \text { u }
$$

phiam

Clar. A. D. MDIII. 
phiam rudem adhue \& impolitam cum cloquentil junxit. Ef in dicendo five blimis, in fententiis gravis, in atcentione exquifrus, in compolitione diligens: ac cuilolus. Trithem.

Vir probus cft Faber, eruditus, liumanus, dénique vetus ctiam amicns Erafmo. Epif. 1. 2. Epift: 24:

Vir . ius \& doctus, fed qui Theologicè dicere maluerit, quâm I viliar \& I cm in Ciceronianu p. 168 .

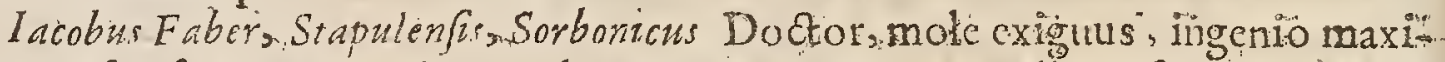
mus cx feiplo natus. Divinalum humanarumque rertm callentifinus. tofmun.

Eabrux literis renafcentibus facem pratuliffe ait I hatanus Hiftor. 1. r7:

Iacabus Faber tum in Arifotelcm fcriplit, tum Dialecticam iple compofuito. multaque ex receptis fue avo Opinionibus tanquam ex conotrahit. Lud . Vizo, de Trad. Dificipl. 4.

Anno 1503. magnum in Matbefr in Philofophia amen imprimis̀nomen fufinuit lacobus Fabir Stapulenfi. Vof: de Matliem.

Iaccbu Faber Stapulengr, Celcberrimus I hilofophus, ac literis Divinis a Humani apprime cxcultus, fced nunnullis novitatibus affcctus, quarum causấ refectus fuit à corporc Sorbond \&c. Spont an, ad ann. IS23. Numb. If.

Hic ille Faber Stapulen fos en, humili yuidem patrii ortus humili contempo

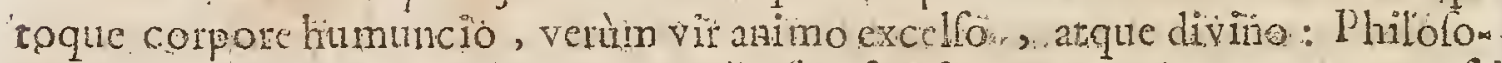
phus, non, ut iha atas volebat. tcnobuicolus, fed frincerus, tradens eacua perfpicuitatem lucemque adferunt in expliondis doctifimis. Philofophozum Sententiis. Null d bilofophre pars erat, quam ille probènen callcbat prompte \&. dcxtıe aliis non tradebat, barbaris illis verbis, fententils ac axiomatis, quanifi

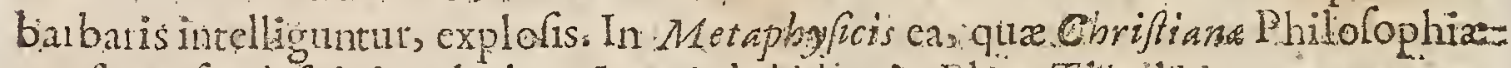
confona fape fuis inculcabat. Lar.Terbebiden. in Elög Theol

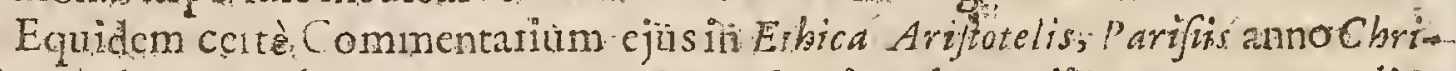
Pix 04 h. e. ante hos amos centum \& quadraginta dios editum pro endito agnolco : quippe qui optimis è "lutarcbo, P linio, therodoto, Halicarnafleo, Curtio

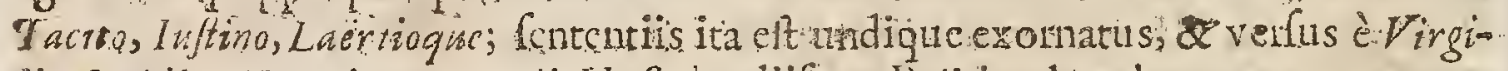

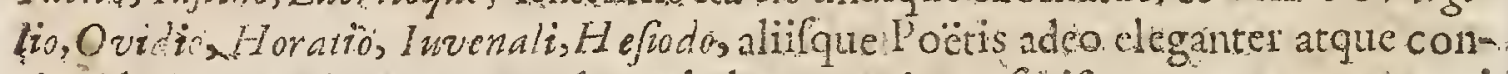
cinnè huic materiz accommodatos habat, ut mirum fit ifto, tam corrupto rei

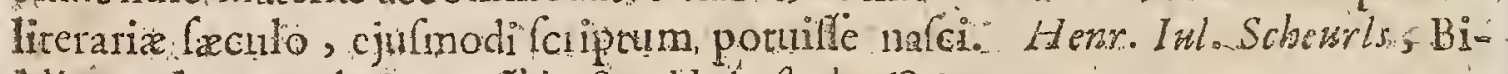
bliograph. Moral. Imprefl. in 9 . Helmftad 1636.

* Iacubi Fabri Opera féfuentia. Commentaria in Evangelia: In Epiftolas $S_{\text {o }}$ Paulf : In Epiftolias Canonicas: De tribus Magdalenis: Item in falmos ; tamdin prohibita fint, quamdiu abalicujus Vniverfita is Catbolica facultate Theologicâ, vel jufli Inquifitionis Generalis emendata in lucem prodieriut. Index Romaimprell: nno 169 i.

Extant in Epiftolas Canonicas Commentaria 8. Baful. $527.8 \%$ Antoerp:1540\% Iy 68.

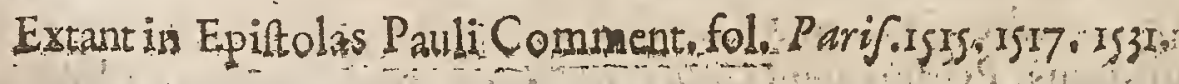


Extat Pfaltcrium quintuplex Latiné continens quinque Verfones Pfalteriu Davidis, Parif. rgog.

Hac cjus Epitaphium: Simone Vallamberto Autore:

HẤc quicunque urnâ Fảbrum putat effe fepultum.

Errat; coelestern non.tagic urna virum.

Aliud Georg. Bushanano Auctore:

Qui fudiis primus lucem intulit omnibus, artes

Edodum cunctas bac tegit usma Fabrum.

Heu tenebre tanturis potiere extinguere lurnen?

St non in senebris lux tarnèn iffa micet.

\section{RAPHAEL MAFFEUS VOLATERRANUS}

1

Talus, Volaterris Hetrurie Uibe natus eft. Obiit Volaterris Anno Dom. I52. anuos uatis plufquamfeptuaginta.

Hie Raphael primes atatis annos ftudiis bonarum difciptinatum impendens, in virum doetifimum evafit; quod cjus icripta fatis teftantur. Vir fuit habitu corporìs venutto, facundiâ elegante, \& morum gravitate vitieque fanctimoniâ clarus. Ejus opera pracipua hec citantur. Cominentariorum Urbanorum lis bri triginta @cto - Occonomicum X'enophontís ab eo interpretatum - De Prin cipis \& Ducis Officio lib. Io - Manodia feu funebris Oratio Gregorii $N$ an zianzeni latinitate donata - Intituta Monacherum - Procopii Cafarienfer de Bello Perfaco \& Vandalice lib. 2. - De fide Chriffranâ lib. ro. - Bafalii Orà tiunculr decem. Etalia quxdam ex Grecis Theologis, qux in Latinum fermonem trantulit, magnâcumlatde, \& reconditx eruditionis adprobatione. Vixit inter fuos quietè, \& pracipuâ admitatione virtutis. Buỉjard. in Lcon.

Fuit hic Vir infinira propè lectionis, quìppe qui dilciplinas ommes in acervum conjecenit, utili potius in alienâ defidiâ, quàm ad explicata doctrine decus nobili opere : non multo erim cum fal "' \& fine ornamento Lasine Orationis; cuncta altrieto ordine ita digeffr, ut alibi quxrendalegentibus indicare viden-

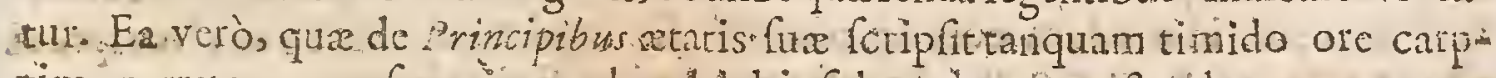
zim enarrata, rerum fupcriorum hauld dibie fiden clevain: conchiduntque ea omninò cerzâ yeritatis luce carere, qux inter adulationem $\&$ metum ncC prafentis nec fatura fpe land's, intermpeftive publicantur. Sed multum herclè debemus ingenuo gratuitonue labori, quo hic integritate vitz vir oprimus, delicaris rewum hofcendarum compendia demonftravit; \& Procopitum de Perfico, atyute Vandalice Bello, fincerè potiìs quàm fplendide convertit. Paul. Ior. in Elog.

Vir multa erat doctinze, \&induftrix : fed qui tamen non faris magnam

$$
\checkmark \text { UL } 2 \text { Grace }
$$


Grece lingux notitiam fuerit adeptus: quod multa adco perperam ab eo verfa oftendunt : ut omninò aberret lovit, cum ab eo P'rocopium de licllo P'erfico, \& Fundulico fincerè potiùs, quàm fplendidè converfum ait Praterea condidit Vrbanorum Commentariorum libros 38. quos. Iulio IT. Pontifici infcripfit, atque Urbanos vocat, quia in U rbe Româ confcripfit. Ex mille amplius utriufque lingux Auttorious cos fe congeflffe, ipfe ait. Tribus vero, Tomis difinxit, quorim primus Geographiarn veterem continet: alter Antbropologiam, five Viros illuftes : terrins Philologiam, five Artium rudimenta. Itaque in Prafarione ad: Iuliurr, opus hoc wav8oxeĩov appellat, quafi quo omnia comprehendantur.Vof: de Hift. Lat.

Bona cruditorum pars ei defert mediocrem cruditionem, cùm nihil, quàm aliena hinc. inde in fua immenf volumina tranfulerit: in Gracis vertendis velu pueriliter perfxpèlaplus. Florid. Sabin. in Apol. adv. LL. Calumniat.

In Graris parum verfatus Rapbaël Volaterranus, fucatam eruditionem oftentat, \& dum Interpretem fe gerens fuprafeipfum alfurgit, quafitâ laude ccciditi. Huet. de Clar. Interpiet.

Raphael Vulaterranus, varia vir eruditionis ac latè patentis-Author magnam: fane diligentix laudem meritus. Lud. Viv. de Trad. Difcipl.

Hic Vir quamvis admodu melebris nullius omnino artis valdê periuns erat, fẹd in Ttranflationibus miferandus etat, quia Graca linguæ ignarus erat.s adeo ut perpetuò totidem ill fre fint iidjgett farragines, in quibus tamenanimadvertitur oftentatio; infulfaque eruditonis fpeciolitas. Scriptorum peritia vel in ipforum erroribus agnofitur; Sed Volaterrani lapfits adeò pueriles funt, ut fimilis ferè cenfeatur pueris qui folent loqui neficintes quid fibi velint. Erum ditorurs Iudicia per Dominum Bälle t. Farif. 168 5.Gall.

Bibliographus Anonymus at in illo Opere (Commentariis nimirum) plurimum non ffe ponendum; inepriis \& quifquiliis referum eff; In illo ramen plura occurrere irca res It alicas quz $\vec{h}$ uthoris tempore contigerunt, prafertim verò in privaris familiis, qua fcitu digna funt, quaque nufquam alibi quam inilis Volaterrani noftri Commentariis occurrunt Baillet. ibidem.

Enditus vir \&: acerrimi Judicii. Baudius libro 2. Epist. \&.

Extant ejus Opera Lugduni I59?.

Conditus eft in templo Sancti Lini prope fummum A ltare 2 . arcu marmoré, ubi ejus Imago faxea incumbens arcx, qux olfa continet, pofita eft cum hâc infcriptione:" Sic itur ad aftra. Arca marmorea quâ"corpus clauditur, lauream in modum coronx triumphalis implexam habet, ubi fculptur :

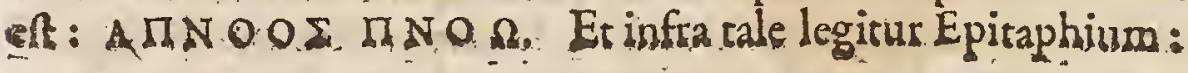




\section{Chrifto Serzatori:}

Raphaeli Maffeo Geardi Maffci F. Doetrinâ, Piétate ac Sanditate cum quovis aniquo comparando 2 st $\mathrm{\epsilon}$ jus indicant opera egregia, teftantur Miracula.Vixit annos LXX.menfoxx. di. VIII: obitit anno falut is M.D.XXI. viII.Kal.Eebruar. Marius : Mafeicus Epifcopus Cavalicenfis Fratrifandijfimo P.

\section{ERANCISCUS XMMENIUS.}

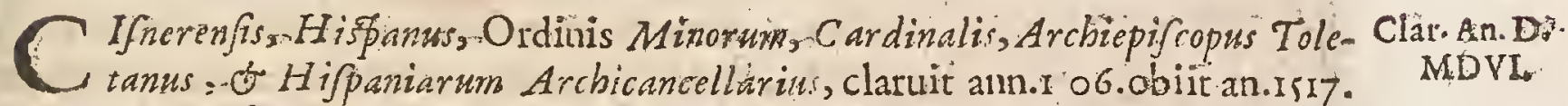

Hicuniverfum Vetus \& Novum T'eftamentum varùis linguis in $U_{1}$ be Comm plutenfi edidit; \& Leoni X. Pontifici dedicavit. Id opus Biblia Complutenfia vulgò appellans. Expreffim elfe dieitur ex caftigatifi mis \& veturtifimis e empla-

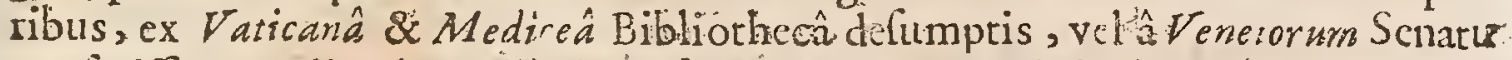

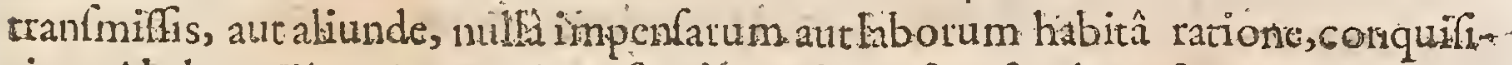
tis. Ab hoc Ximenio Complutenfis etiam Vniverfitas fundata cft: Konig....

Hic Ducatorum fexcenties millenis millibus impenfis fex tomos Ango is Is. emifit, itant ia Veteri Teftamento textum Hebraicum \& paraphrafin Cbaldaicam, cum duabus Verfronibis. Latinis, in Novo textum Gracum, cum Verfione Latinâ collocaret. Hocopus Leo X. magnificis privilegiis munivit, \& omutbus magnopere commendavit. Meritò autem mumeratur Opus inter. Inltrument-

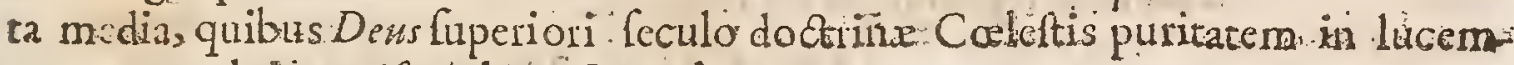
revocare voluit:- Alffed. 1. 32 : Encyclop. c. 7.

Fruncifcus Xinnenes Cardinalis, \& Archiepifcopus Toletanus, fümumus omninò vir, \&efelici fidere intis temporibus Hi/panà datus quibns finguläris quidam \& divinus in conftituendis Academiis artor agitaverat Magnatum animos. Ferman. Conring. de Hipan.

Dignus fane Francifcus Ximenius Cifnerus, qui doctos inter Hifpanos recenfeatur: qui ad funmun dignitaris faftigium ob infignem enditionem mer it eft à Regibus Catholicis cveaus. Hippan. Biblioth.

Francifcus Ximenius Cardinalis, cujus pietati \& animi magnitudiui tantum: Hipania debet. Throan. ad an.1552.1.1.1.

Illa ad onne revum duratura Bibliorum editio . Idem ibid.

Superius eculum Seriptura Sacra verfionibis in Occidentis Eceléfia fera cinimum fuit. Viri quidam Docti qui Hebraicam Linguain didicerane Bibliorum Tranflationemad Hebraïcum Textum fe adonare poffe rats funt accura tiorem veteri Vulgata I arina quam Beato Hieronymo alcribunt.. Hoc fuit in caufa cur breviffimo temporis fpario ingens vifus fuerit numerus Tranlatiónum abinvicem fatis diverfartmm licet Omnes fe ad Hebraum idem autographum Bibli interpretari contenderent. Jef. Rich. Simon.

Cardinalis Ximenius non fuit omino tane audix in novis fuis Alcalcin

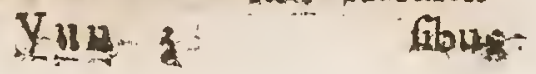


fibus feu Complutenfibus Bibliis, anno igx s excufis, in quibus Textum quidem Hebraicum conclufit, fidnullam Textûs cjufdem aliam Interpretationem adjungere aufus eft prater Hieronymianam, qux alias Uulgaid notrine venit. Vulgaria tamen Excmplaria pluribus emendavit locis. fecundum alia Latina Excmplariacaltigatioia, imo \& quandoque juxta Hebraictiratque Gracum. Collocavit inluper Vulgatam Verfionem inter Hebram Textum \& Septuaginta Interpreta. tioncm, hac ratione demonftrare intendens in Ecclefia Occidentali aullam aliam Scripturam ut normam agnofci quàm Verfonem illam Latinam intcr Hebratm atulue Groum à Ce collocatam., Confilium cjus quamvis bonum \& juftum fuiftrè tamen Theologicomplures inceppretati lunt, cuí cenfure anfan iple dedit, quia hac Bibliatribus columnis dilpefita cum Domino Noftro inter duos Latrones pofito comparivit; Textu Hebräico, ex ejus fententia pervarum Latronem, Verfion verò sracaprobum Latronem referente. Jefo Rh. Simon. Hilt. Crit. V. Tentam. Iib. 2.cap. 20. Gall.

Extant Sacra Biblia, Complutenfa didas 6. Vol. Compititi isis. Fol.

Hac ejus Epitaphium, An Academia Complutenfi:

Condideram Mufis Francilcus grande Lyceum

Condor in exiguo nunc ego Sarcophago.

Protextam junxifacces gaicaingue Galero.

Frater, Dux, Praful, Cardineulque Pater.

Ruin virtute me t juncturnefi Diadema Cucullo.

Cum unibi regnantipuruit Hefpecia.

\section{Phil. Labbe in Thefaur. Epirapt.}

\section{TESIDERIUS ERASMUS.}

Clar.An.D. J Atus Roterodami O dob. 28. Anno 467, Obiit Baflea Julii Anno 1536. MDX. 1. Cumanteà Gerardus Gerardi dicectur pof Defiderius Erafmi nocar maluit. Symbolo ufus ef: CedoN Nulio.

Spiritum \& yitam Erafino debent renafcentes litcta. Gratus \& acceptus Cummis lontifibus, Impcratoribus, \& Regibus "Propenfor natua fuit ad Jom cos quàm dcceret, quàm nonnunquam expediat, ut de fe pfe fatctur ad Barbim rium. Multa vir tantus fripfat qux ing. Tomos diftibuta, hodiecum fummo omnium fupore leguntar Inter alia plura non pofteman locum obinen Epistola Inis enim tor duce ejus vita in is ejufdem pate genins ingenium, mores eruditio animiquedotes vvertii Atbene Belgive.

Ut erat peregrimations amans plcrafque Cbristimi Crbis Acade ini ts magna celeritate famx, quadocendo, ytà fcribende, obivit major

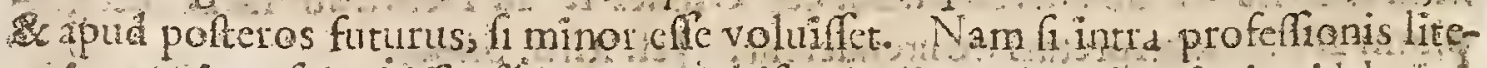
ariarminos fubnitilet, leque totum hife fudis quibus in pumis videbytur, sidt 


\section{CELEBRIORUM AUTHORUM.}

dediffer, paina fortaffe cum primis illis Latini Sermonis auctoribus faccre pow triffet.. Atverơ poftquảm Theologum agere voluit, ingenio fifis nimium fibi arrogavit, \&ein tractandis Sacris:Lie eris veterumque Patrum monumentis rigidum nimis cenforem fe prebuit. Aubert. Mirraus.

Neque ego video qux gratia abullo digna mériris ipfus haberi polfit. Cujis diligentiâ., labore, affiduitatè, \& Conffantiâ illius temporibus periculosî.

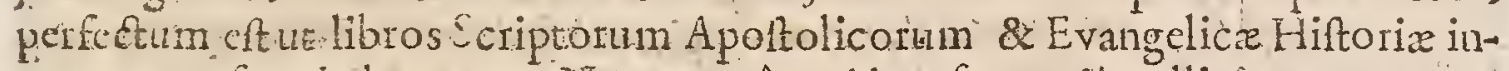
tegros purofque habeamus. Nequę mề quidem fententiâ, ullius operx, quæ: corrig ndo ultera. Erafmucas notationes progrediatur, locus eft r. in Nov. Faidis.

Notum enim divinum Erafmi Roterodami ingenium : nota incredibilis illius. viri a muitiplex eruditio; cum pari induftria de dexteritate conjuneta.. Gaspo. Sciopp. dé Arte Critic. p.G.

Erafmas ingeniofus criptorum cenfor. Lud. Viv.

Scd acumen E refmiana cenkirax \& certitudinem, quam in Latinis prattitut, in? Grecis prorfus defidero. Ioan a. Hales in Not: in Chrofoftom. Homilin Hebr.

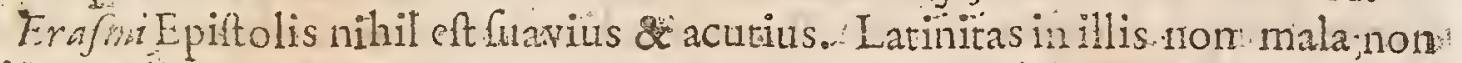
quidem talis, quam ad imitandum aliquis proponere fibid debeat (lic enim antiquii Scriptores ornne ferunt purattum) fed sativi, extemporalis, z interdum aliquem cxsebus colorem tratiens quod accidit interdum Scriptoribus doctifr. mis, Grotio, Salmafio ac.aliis, Illichim antores piout res funt; quas tradetnt,

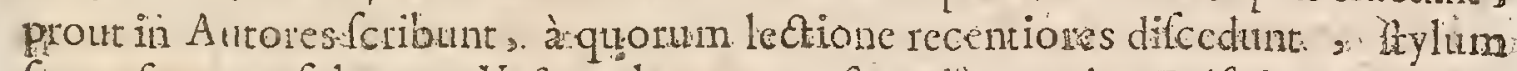
Guum formare folcut - Vartum hoc opus.eft variärum ejus. Epifolarum, nons

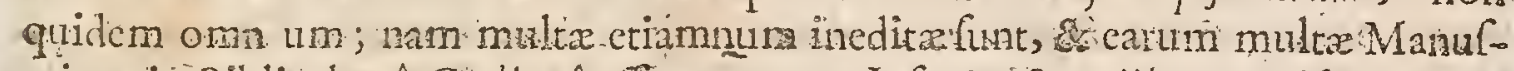

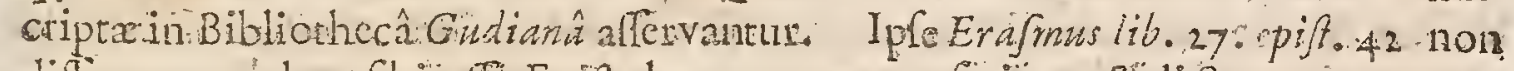

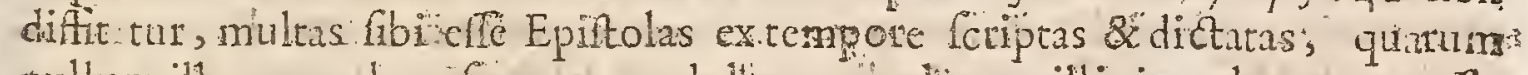
nullum ille exemplum fervaverat; dolittque multas ex illis in vulgus crnanaffe. Corincopia mcritò dixeris variarum rerum. Continentur in illo libro arcata? ftatîs, Civilis, Ecclefiafici; Literarii illorum temporum; facera nonnunquam? \& jocofa , ut ipfefuit ingenio mire futivo, e. g., alm movem ofculandi in

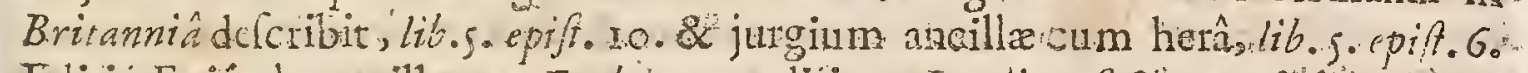
Editio Epiftolarum illarum Frobentana editione Londinenf \& careris langè me lior eft \& correctior : mulcisenim mendis hac poftente fcater; quanquam aliqua parte locupletior: Index huic operi fubjectus utilifimas eft. Lites in Theo logorum palaftris tum ventilaras, squicquid inillarum hiftoriam pertiber, il lic deprehendes. Quanquam Erafmus fe mediüm femper gefferit, ftudium ta merı partium non rarò deprehendès. Magna fuir ejus viri veneratio, \& me rito quidem, ingenium cxcellens, vaitum, diffifum, foccundum, acre, promptum, ad omnia paratum, in decus \& miraculum seculi natum. Triumphare duobus his civibus Batavia poteft, Erafmo \& Grotio, quibus pares poftera fecula non facilè datura funt. Dan. Georg. Morbof. Polyhift. pàg:282,283 .

Erafñns Roterodamus primus fuit inter Adagiorum Collectores, quod opus ipgis 
ipli fuo tempore profectò fuit difficillimun : Nam credoillum plus laboris operxque huic Scripto impendilfe, quam multis aliis. Liticulam illi a iquando movit Colizs R hodinus, quafi furripuenit Gbi aliqua circa Adagia moditata; fed non habct, quo jactet Ce Rbodiginur, qưod guttulâ unâ vel alterâ hunc fontem auxerit : paucula enim funt qux in opere iplius Antiquarmm Lectionum habcntir de quibudam dagiis. Etiam ${ }^{2}$ erdierius nugacifimus ille veterum \& recentiorum cenfor, pag.rs 8 ungues fuos in hoc opere figit, cui frmilem illéne paginam quidem fcribere poterat. Multa funt operis cius ediciones. Frobeniand elt emendatifima. Edidit \& Henricus Stephani è typographco fuo. Nova editio omnium eft corruptiftrma, I cèt ceteri s locupletior: nam adjecti Gunt Erafmi Chiliadibus

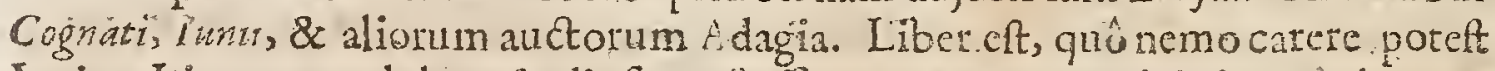
Latina Lingux paululum fudiofror. Sufficere tamen tytoni Epitomc cjus poreft, \& in Germania \& 1 mitelodaminitidior edita. I en, quod Adaginfitis fub titulis porantur, yuad non fit.in magno opere, nbi Index fupplet locorum communium titulos. Idernibid. p.:252.

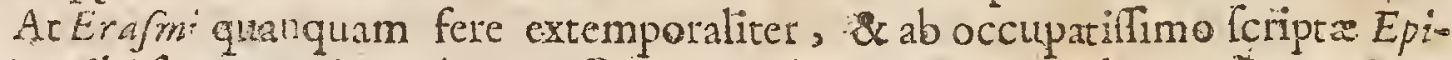
frole mihi. Cupra modum placent. Prater etudirionem enim, eloquentiam, \& tam in literis, quàm in quibulvis aliis rébus piudentiam, quam continent, Lutbcrane etiam fectxintia,aliafue restradunt : quas nefcio cur Aictor fecundum temporis ordinem, qui in literis edendis omninò neceffailus elt, nondigellerit: fod cjus rei caulos fe habuife dicit, Reland. Marefo cpilt. 1. 2. epift. I.

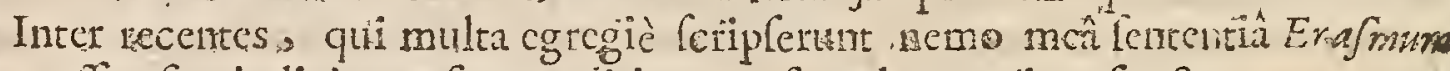
pracelit, frve judicium, five endicionem, five cloquentiam fpeets, quem non yerearcum quovisantiquerum conferre $=$ qui fi tor bufam \& Monachi, confictatus, non fuiffet, meliora etiam quam edidit, Orbi communicare potuiflet; \& fr tam mordax, autil quibufdan ttendis tam peritDax non fuift, nilsilinco viro illa ztas quod defiderater, habuiflet. Roland. Marcf.ibid. Epilt. 26.

Quidamimta Novifolius Teftamenti cancellos fuam in interpret ndo induAriam explicuerunt, quorum facilè, meo judicio, princeps ent Defaderiur Eraf a mus: is ê̂ fclicitate hanc omavit Spartarn, ut \& verba verbis, \& Contentias foncentiis, \& Gapo:em fapore exaquaverit; \& perfpicuitatem tamen cum dictionis caltitare, \& nativo illo colore obtinuerit, ya ad integram Interpretis laude unicè requirebamus. Quinctiam bi propter Latina Lingut indolem, quod uno Gracijidcm plurbus exponere verbis necethe habuit, afcititia verba vario \& infgnii charactere depingi curavit, quo fdeifux integritas palàm extaret. Huet. de Car. Incernese

Erafmo perfpicaciffmo vir ingenio, feipfo haud dubie futurus major ( quod fcribit lovins 1 andus fo Latine Lingud conditores imituri, guam petulantilingux indulgeremaluilfet. Erafmi Chiliades excellentifmum opus. Nimias tamca fuit, \& ytundo que fapit Germanws, videtur enim magnum numerum affectalfe . eadcm quater repctens. Scaligerena prima $\mathrm{p} .79$. 
Potifhma ejus opera.funt ejuldem Chiliades, ejus Epifola, cjufque Novum Teftaimentum, quod bonum eft: non paucis erroribus laborant quoad Lativitatem ejus Colloquia:Nimio habet in pretio Iatinitateri Hieronymi qui malè loquebatur-Erafmus meliùs quam ille loquebatur--...-Nullus unquam five 'Papaltas, five Lutheraniw, frve C'alvinjita prxftantiorem elucubravit librum nec èlegantiorem cjus in Novum Teftamentum L'araphrafi. Quamvis Parens meus adverfus Erafinum calamum ftrinxerit, magni tamen Erafinum facio, magnus fuit vi:. O quam praclara Epiftola in ejus spiftolarum fronte Ecipta eft. Erafrimus magnus Vir divinamedidit puraphrafin. Eralini Prefatio in Senccam eft prafanntafima: opteme de eo judicavit, malius al huc quaim Lipfius. Paenituir Patrem adverfus :illum Cripfiffe. Cullpam fuam agnovit ', fed fuerat irritatus cium vosaretur ab Erafmo Miles, quafi per contemptum, ut Amphitheatrurs vocat Dominos Pleffaum \& Lanovium, Milites per contemptum. In talia Adagia typis mandari curaiune, ac expunxerunt Erufani verba \& 500. inferuerunt Adagia qua talia non funt. Muretus illos redet. Erafmi Ainotationes in Novinn Tefarmenturn multa babent doctiffuna, \& ipfens Paraphrafis of inftar optimi Commentarii, quamvis in quibusdamerret....- - Oportet Magnos Viros in vita femel errare; of ille in Dialogo Ciceraniano augaciter laps su. scaligerana ficcunda. Gall.

Quibufdam vifus eft non fatis elfie Ciceroniants. ad ftructuram \& verba Tulliañ 'Ditlionis omnia feverè exigcntibus. ed ipfum itylum apertum, cxtemporalem, puxum, facilem, \& argutum femper amavit, vocabulis quibufdam aticoactus cft, Chriftiane Religionis marerix quam tractabat fervientibus. Beat. Khenan. Epift.ad 'arol. V.

Salibus, \& iis interdum aculcatis abundant nonnulla ejus Opera, in quibus craffos ercores, \& aniles quaddam fuperfitiones Orationis Libertate perftringit, unde orta eft Opinio contemptarum Religionum: Sed Norma Cbriftiane Charitatis fuadere debuit humaniorem interpretationem. Videtur autem Erafmus magis habuifle quid fugeret, quàm quid fequeretur. Unus omnia pervidere non poruit, \& rem hand exiguam prettitit, quòd in tantis ignorantiarencbris oculos astollere potuerit ad inveftigandaintuccm veritaris. Meticulofior fuit \& timens - offenfionum, atque hoc unicè in vitâ ftuduit, ut omnium ordinum \& generum benevolentiam colligeret. İ forfan impedimento fuir quo minus counicum oculos confingere aufus fucrit \& omnia iniquitatis mytteria vclo levato patefacerc. Multuin tamen, imò infinitum ei debet poltericas, \& forte nen habcrent reprehenfores cjus unde fanam confequi poruiffent,nifi ipfis dediflet quod reprehenderent. Dominic. Ban itu Epirt.Centur.2.Epilt. 27.

Pontificii Erafmo admodum infefti fint. 3cllarmin eum inter Semichrifitanos referre non erubuit. Poffevinus nomen ejus ex omnibus Carholicorum Scriptis expungi debcre affatur. Stapleton murem errantem vocat. Forerus in Araneâ dignumait, quiexomnium hominum memoriâ erafus effet. Quidaun erian Erafmo Ariarifmum objicere non verentur: non debuit autem vir optimus veni*e ản tam atrocem fufpicionem, à quâ faris fiiperque cum liberat explicatio prin capitis Evangelii focundùm Loannem. Konig. in Biblioth.

Xxx $\quad$ Vis 
Vir hic jure ubigue magnus. fed an tantus freric quantus $\&$ nonmullis exift satur, haud mihi parum liquet; certè inter.Germanos. Latinus, inter Latmos alio guaudo Germanus. Lil. Gyrald.

Erafrnus magnus certe opinator. Montacut. Apparat.x.fect:79\%

Varrofuifeculi, \& Cicero Germania vocatur Paulo lovio.

Magnum Batavia lumen vocar Vof! de Hilt. Lat. p. 713.

Admirabilem haber facilitatem ad Lucem. Lud. Viv. lib. 3. de Tradendo Dilicipl.

Vii magnôingeniô \& eruditione, neque minore judicio \& prudentiâ :... qứ: samen nelter profectò non fuit, neque ellè vel audire unquam voluir.G. Calix\%. in Appar. Thecolog. pag. I54:

Adagiorurn Opus ab Alóo imprefluman videris nefcio : eft quidem profamum, fed ad omnem do ctrinam uciliffmum mihi certe inzfimabilibus contitit: vigiliis. Erafm. in Epift. ad Servatium.

* Defiderii Erafmi Roterodami libri infra foriptzo Colloquia Moria, Lingua. Chriftiani Matrimonii Infirutio s. De interdicto efu carnitum, paraphrafis ina Ch attheum, qux d Bernardino Tomitano de Latino Sermone in Italicum converfa eft, prohibentur. Catcra vero opera ipflus, in quibus de Religione. axctat, fandiu prohibita finf quamdiu a Facultate Theologica Parifren/í, vel Lovanienfi expurgata non fucrivi Adagia, que non fint ex: Editione Pauli: M anutii, expunctis loeis fufpectis, judicio alicujus faculatis Theologice, Univerfatis Cakholicæ, vel Inquifitionis alicujus Generalis.permituntur. Ea verò qux funt ex edirione Parsit Manutii permittuntur. Index Romb Impres Anno: 168I.

Opera ejus, Impreffionis Frobeniane, 2: Tomis continentur.

\section{Hoc ejus Epritaphium::}

Fatalis feries nobis invidit Eralmum. Sed DeGdérium tollere non potuit.

\section{Aliua: :}

Terra Batav2 Jum cim miraretur Erafmum? Hoc majus potuit dicere, nil genui.

$$
\text { Aliud, Auctore Siepha Pafchafo: }
$$

Hic jacet. Erafmus, qui quondam bonus erar mus? Rodere grifolitus, soditur à Vermibus. 


\section{Aliud, Auctore Gilberto Cograto:}

Magnus Roterodamus ille nofer,

Hac quô Sacula neminems tulerume

Majorein, nequeprif ca clariorem

Norunt tempora, nec cui future

Parem pofteritus habebit: ecce

Sub bor marmore mortuns quiefcit.

\section{LUDOV. CEL。RICCHIERIUS RHODIGINUS.}

7 Talks, natus eft Anno 45 a. obiit anno Is:20.

Maximiliani Imperatoris temporibus, extremisimprimis, non parùm Hiftoria commadavit Lud. Coi.Ricchierius Rhodiginus, vir omnigenx doctkina, anteriorumautem literarum fčicntiâ nemini fui feculi fecundus. Nec modò varix lectionis, fed virum etiam pium fuitfc, ait in Citeroniano fuo Erafmus.

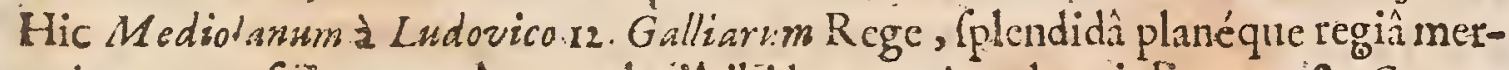
cede vocatus.füit:- inagnâ cum gloriâ ibidem Latina docuirfiteras, '\&e Grecas. Poftea eodem munere praclarè functus oft in illufti Gymnafio $P$ atavino. Immortale fibi nomen peperit Triginta Antiquarum Lcetionum Libris : quo mifcello Opcre, abftrufauthufque lingure vacabuhe enucleantur, in praftantinimis quibulque Scriptoribus loca oblcura explicantur, corruptacaftigantur, ad hac Hiforra recondite, 3 ritus voteres enarrantur:; ex intimà denique Philofophiầ,poîfimùm è "latonicorum penu, akcana multa promuntur. Itaque fxpenumerò miror, imò indignor, non magis hodiè manibus efle juventutis tanii viri labores, profectò auro contrà non caros. Qửppe \&.Thilologie ftudiofus, \& amator Hiftorra," \& Philofophia. feotaror, haurict inde, quod juxta profit, ac deIectet. VofJ.de HiR. Lat.

Rarum erat cotempore Tibilologie ftudium, ac foli penè Colio familiarę. unde cùm apud Aldum Erafmus Rotcrodamus in eum de facic fibi ignotum in cidiflet, habitis ultrò citróque fermonibus ille dicendi ubertate atque elegantia non ufque abviầ, C. Rhodiginum fỉbi adelfe fumınâ lillaritate agnovit. Tomajîn. in Elog.

Vir infinirelcationis., quem apparet nihil quod ufquam librorum eft latuille: Decujus integritate, " $\&$ in judicando gravitate, cò minus ambigendum, quod paffim in fuo Opere pium prefe fert animum, reverenter de Chri/to loquens. qux ci cum paucis doctis lialis, hoc prafertim xvo;communis eft virtus. llyyric. Caral. I ceft. Vcrit.pag. 4 .

Lividus in cum Delrius, hac in re delirts; More fuo Rhodiginus fhit alierad. inquit, vindicans, veterum errores fuos facit. Bonifac. Lud. Hift I.rs.c.4.

Coclizs Khodiginus, afperze dictionsis, recondita doctrinx , admixand $x$ exuditionis. Dempleter.

$$
X x \times \Rightarrow \text { Magnus }
$$


Magnus ille Rhodiginus, doctiffimus Præccptor nofter. Inl. Scaig 1.3 de Re loetic. c ult.

Khosimus vir erat pius, \& varix lectionișin eloquentix certam n hallquaquam afcifcondus. Erafre in C'iceroniano p. 167 .

Homo inexplebili legendi aviditate per omne genus autorum circumvolitans. \& cx retextis al orum fertis novas fubinde corollas concinnare gaudens ---.-Vir intcgritaris Chrifianæ, nullo ftudiorum labore farigabilis,cum ad extremam fenectutem pervenerit. Evaf $m$ in Adag pag.629..

Optimorum Autorum fucus, cujus affectatifima eruditionis of tentario non: poreft non habcrifufpeota. Eoban. in G oro.Virgil.n1. 47.

Ludevi-us Calius khodiginus vir fuic doctiffimus, rerum Naturalium \& humanioris doctrina peritifimus, \&, quod non parumad lades ejus facir, f.

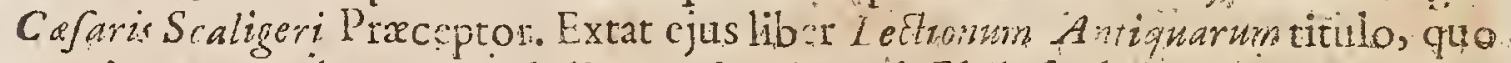
contincntur multa memorabilia tam in Narurali Philofophiâ, quám in Medicinâ, precipuè verò in humaniou i doctrinâ. Eft inter præcipuos Bibliothecaram thefaros, \& vario modo utilis: Quæenion per totam ille vitam collegie a. vel obfervavit, in hune, unum libum videntur congett ${ }_{2}$ ut non immerito $C$ ornuccompia vocari debeat. Dan G org. Morbof. Polyhitt.pag. 249.

Hujus multa volumina Lectionum Antiguarum, quum ingentes Vigiliarum, apcs oftentent, plerique admirantur: fed ea farago tanquam ex vetere horreo: ląboriosè affectatéque prolata, delicatis lectoribus quoddam / brancidum olere videtut. Nullus enion compolitiac illuRris fyli nervus, tantân compage confpicitur. Parl. Iov in Elog.

cali $L$ ctiones Antigna interdum vetultate horrent non tam rerum quàm: verborum. Lud. Viv. de Trad. Difcipl. p. 5330:

Calio Rhodigroid vitio datum, quod pafim difimulct fontes sunde veteres haufcrit narratione's Foff. de Idololat.1.3.c. 84 .

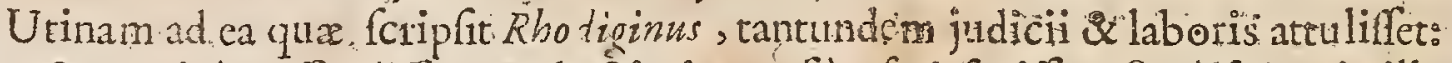
nam \& te minùs offendiffet, \& doctis impenfiùs fatisfeciffer. Sane fuit vir ille bonus \& verèchrifianus , \& multâ mihiamiciria conjunctus, utpotc cui anum etiam cx libris Antiguarum Ledionumbuncupatin dicaverit, fed quife unum habertin confilio, \& amicorum: admonitionibus xgrè manus darct: caterùm in ftudia $\&$ lucubrationes ad ponitentiam ufque affiduus. $C_{\text {al }}$. Calm. cagnin. Epift. Erafmo.

Calii quippe unicus fopus fuit intimiorem Vetermm fapientian prodere, 28 abltufos Auctorum fenfus eruere, non yerborum lénociniis auram captare : nec adeo culta fuit, quâ vixit', Latini Sermonis atas, ini quam pofteà bonâ fuâ fortunâ Iovius incidit: Torra/in. in Elog.:

Calium Rhodiginum optimorum authorum fucum conviciantur quidam, nec defunt, qui eodem ctimine traducunt $M$ acrobium, cum tamenillos omnes de bonis literis benè meritos fateri cogamur. Conrad. Heresbach prafat.ad Lector. Iibior. fuer. de Re Rufticâ.

Qui (Celius Rbodiginus) licètea Ce allaturum de hâc materiâ (de Paradifo) promittat 
gromittat (1.1. Lect. Antiq. c. ult. ) qua à nullo antehac fint animadverfa, pleraque tamen ex. Commentario Lud.Vivis ad Auguft. de Civ. Der 1. 13. C. 2I. rep tic. lobun. Gryphiand. in a boni"e H.i...

Atrigit hoc nihil non feicns Calius 1.I. Antic. Lcet.c.9.anctoribus non citatis, more fuo: Lel. Bifciol. Tom.r.Horar. fubcifiv. 1.r7. c. 23.

Hoc in Rbodigino aliifque reprehendit Voffins, quòd, $\sqrt{2}$ quos advocet Teftes, cos Kandat, qui depecierint, non appofito illius nomine, qui ea apud illos olim legiflet. Vofj.1.3.de Orig. Idololit. c. $\$_{4}$ :

In Colii Khodigini Lectionibus antiquis an non omnium fcientiarum quaf gemmuli eliceist? M. Ant. Majuragius Orat. 20.

Fatendum eft inta autorum; qui alioqui dubitantibus confuli poterant, occultatione peccaviffe $C_{\text {a liurr, }}$ magifque ǵlorix fux, quàm utilitąti public ftuduiffo Thomaf. de Plag. rum. 533 .

In Celio Rbsdigino, ctiam illud vitium eft, quòd omnia cùm moveat, nihil unquam folvit, contentis ferè aliorum teftimoniis :-nec fua capita claudit, fed fufpenfos lectores ubique is ipfitus pene Lectione confufos neferit, Claud. Verder. Cenf. in Auctores.

Calizs Khodiginus", non ignotus apud eraditos Scriptor, negat Halloixius plùimxlectionis varictate parem fcire. Ioan. Dallous de libr. fuppof. Dionys: Arcop. \& Ignat. Antioch.lir.c.36. fol.

Extant ejus Lectionum Antiquatum Libri:30. Francofurti \& Lipfa. 1666. in

Vitam uKuerad Aunum I520. duxit, quo Patavii mortalitatem exuit. In patriam tranfdte ejus exuvix in Clauttro $S$. Francifci conquicfcunt. Ejus Sepulchrum cùm poftinodum Germanus quidan fine hovore deprehendiffet, veluti indignabundus, \& civibus ignominiam exprobxaturus, extracto pugióne, ftrato lateritio infcripfit: .

Hic. jacet Tantus Vir..

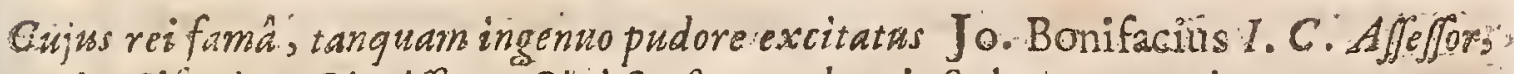
Hifioricus Clarifsmus Civifuoftatuam bac infcriptione erexit.

Ludóvico Calio Rhodigino:

Vt cujis animi Preclard monimanta

Ubique Mortales Suspiciunt:

Illiws etian gratum corporis monumentum?

In Patriâ conpiciant.

Joannes Bonifacius Iur. D. Sebaftiani $F_{0}$

Ere proprio P.

Pixit annos 70. Obitt anno M.D.XX.

Iac. Pbil. Tomafin.

$X \times 2$ Alist. 


\section{Altud, Autore Calio Calcagnine Ferrarien]f:}

Ludovicus ille Cxlius, domi ac foris

Grrecè Latinéque omniunn doctiffimus;

Vivet perennis: quodque paucis contigito

Vixit, Surque. aterivitati interfuit.

Hoc diftichon tumulo infrriptum legitur:

A druplici Patriên natlus cognamina bina,

Cxlius in Catlis, Hic Rhodiginus eris.

\section{THOM A LINACER.}

-Clar. A. D. A Nglus, Cantuaric natus, Medicus erat Henrici VII. \& VIII. Alique: MDX. A annis antequam obiret, facerdos factus. Cbiit Lordini Anno Dom. I5.24. ztatis $6_{4}$.

Scripra ejus funt :Grammatica rudimentaad Principem Marianm-..--De Structurâ'Latini Sermonis-.--Epiftolx-Multa Galeni Operain linguam L $L_{2}$ tinam vertit, \&c.

Thomas Linacer, Anglus, Artium ac Medicine Profeffor, utriulque literarture Latine \& Grece praftantifimus fimul \& doetiffinus, magnam icriptis Guis hadem \& gratiam apud entuditos mertit. Loan. Baleus de Script.Britan.

Erat tam infignis politioris literatulex cultor, \& amator, ut in clegantia Latini Sermonis, \& ftyli puritate, vix illi fimilem quenquam fua viderit æatas. Quo nominepcrè apud omnes ertdicos fiui,temporis admirationem concitavit, amorem, conciliavit. Grammaticus optimus, êlegans l'oëta . R hetor difertus,

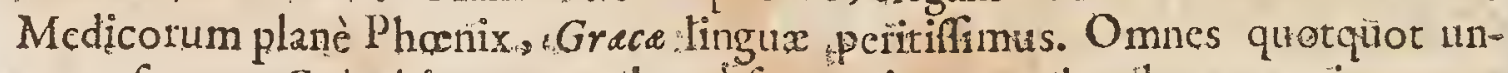
quam fuerunt Galeni anterpretesłlongé fuperavit., atque ita degauter ejus opcra plcraque Latina fecit, ut collatione utriulque textûs factâ, Galenus minus eloguens in Graco, quàm Linacer 'in Latino videatur. Cermene. Loan. l'it faus de flluitr. Angl. Scriptor.

A quo (viz. Linacro) milta funt Latina lingux mytteria oftenfa, actine impietate prodita. Lud.Viv. de Trad. Difcipl.1.3.

Magnam famam fịbi peperitex libris de Strulturâ Latini.Sermonis.Konig. in Biblioth. \& Voff: de Mathem.

Linacer Grammaticorum doctifimus. Bezo in Aet.ro:ver.y.

Linacrum novi, virum undequaque doetiffimum; led fie affectum erga Ciceronem, ut etiamfi potuilfet utrumlibet, prỉus habuiifict effe Quintzliano fimil is quam Ciceroni; noul ita multo in hunc æquỉor, quàm eft Grecorum vulgus. Urbanitatem nufquam affectat, ab affectibus abftinet religiofius quadm ullus Atticus, breviloyitentiam \& elegantiam amat,addocendum intentus, Erafm. in Giceroniano, p. 8;. 
Mitzo ribai déno libiros Galeni, opcrâ Thome Linacri mclìus Romanè loquen ecs, quàm auteà Grecc loquebantur. Erafm. Epift. 1.io. Epitt.27.

Ejufdem operâ fic Lati è loquitur Arifoteles, ut licèt Atticus vix in fuo fermone parem habeat gratiam. Erafrrs. ibid.l.15. Epift.17\%

Fecitin Medicinu tantum, quantumalius Latinus illius xtatis quifquam. Et quamdiu in Méivina fe continet; tamdiu laudem Gangularem habct: fin fords fcrpat, \&O Oratores carpat, videat ne ultra Crepidam progrediatur. Nam quanquam, in transferendis.Galeni libris, lisus ejus cfti propè fingularis: tamen fi de acumine \& celeritate ingenii difputatur, ante de rebus popularibus graviter \& difertè tractandis, in eo fi nunc viveret, aliis laudem concederet, Medicinam, ippe affumeret. Er tamen cur tam faftidiofus eflet in audiendo "Cicérone, nefció. Illud vid:mus, omnes yuosille libros de Latini Sermonis Strudturâ compofuit, excmplis Ciceronis abundare : ut nontam fortalie neglexerit, quàm aniini quâdam morofitate videri voluir neglexilfe. Ioan. Cb kus de Pronunciätione Gracâ.

Quzcumque fecit Linacer magno ii) pretio habeneur, fed pauca fcripfit. Sex ejus Libri de conftructionne Larinze Orationis , merx funt animadverfiones, fed erudita \& acris judìnii in optimos Authores. Magnam illi celebritaté pepereruns: \& de illis ut refert Lilins ab Erafino \& 2 Budao laudatur. Rudimenta Grammasicx cjus Axglice Latinitate à Buchanano donata fuerunt, \& cjufmodi litbor ue: teftimonium exiftimationis Aucheris reputatus eft. Eruditorum Indicizm. Parif. 1684, per. Baillet. Gall.

Quo (Linacro) nemo majorem Orationis nitorem, caftitatem $8<$ condécentiam ad Interpretationes contulit: quarum virtutum integritatem dum dili-

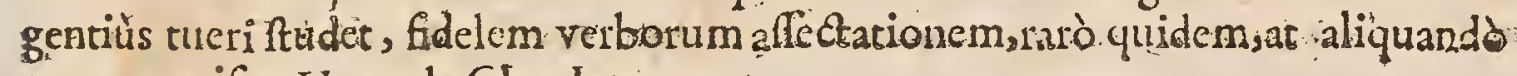
samen omifit. Huet. de Clar. Interpret:-

Thorsas Linacer Medicina Doctor, in Oppidó Derbia natus eft; Oxonie edua catus : Unde poftèa trans Maria peregrinatus eft, Roma prafertim \& Florentiz: moram trahens. In Angliam redux variis linguis inftuctus, primus - Eruditionis. apud Gentem noftrom reftauraror fuit: In dubium vocatur an Latinum an vero Gracum idioma ejus preftantius fit ; an peritior Grammaticus, an vero Medro cus; an eruditione, an vero probitate quoad mores infignior. Ejus operâs $G$ alenus elegantius Latinè in Tranglatione loquitur, quam antea in: Autographo Grazs locurus erat. Doctor. Thom. Fuller, libro de Rebus Praclaris Angliz. Angl.

Extant de emendatâ Structurâ Latinz Sermonis libri 6.P. arif.1532. 8 Col.15 43.9\%'

Extant Rudimenta Gramatices, ex Angl. ìi Lat. per Georg-Buchanansum s Parif. IS33, I5430

Londini Diem obiit die 20. Odobris, IS24. \& in Ecclefiâ Divi Pali Ca. thedralipropè portam magnam Borealem fepultus eft, cujus tumulum monu* mento dein confpiowo orsavit Jonmos Cains? Medicus Gantabrigienfiss, Apno. Bom.155.7\% 


\section{Hoc ejus Epitaphium:}

Thomas Linacerus Regis Henrici VIII. Medicus - vir of Grace ef Latinè atque in remedicâ longè eruditifflrnus: multos atate Suâlanguentes, of qui jam animam defponderant, vite refittuit Multa Galeni Opera in Latinam linguam

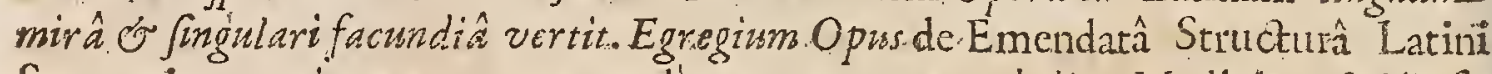
Sermonis, amicorum rogatu paulo ante mortens edrdit. Medicina Atidiofis Oxonia publicas lectiones duas, Cantabrigix unam in perpetunm frabilivit : In

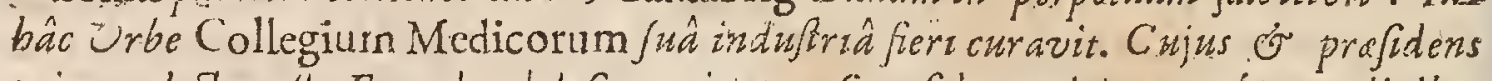
primus electus eft $;$. Frandes dolog gue rnire perofus, fidus amicis, ommibus ordinibus -juxta charus : aliquot annos antequamobierit Presbyter faclus: plenus annis ex "bâc ritâ migravit, multiurn defideratus, Anno Dom. Is24. die 7. OEtab.

\section{$S A N C T E S$ P A G N IN US.}

Clar.An D. J Atione Italus, Patriâa Lucenfis scujus extat Lexicon Ebraicum, obïit antro

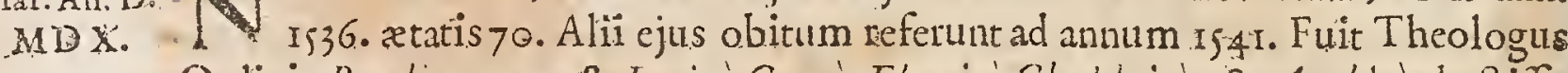
Ordinis Pradicatorumi \& Lutinè, Grecé, Ebraicé,Chaldaice, \& Arabice doctiffimus, ut Teftamenti utriufque.Verfio ex Graro \& Hebreo abuindè teftatur. Item ejus I Jagoge ad Myfticos Scriptura lenfus: Grammatuca item Ebraicu: \& Graca. Abrabam Bucholcer. Indic. Chronolog.

Sanctes Pagninus, Lucenfis, Predicutorii Ordinis, Concionator Apoftolicus, vir in divinis $S_{c}$ ripturis apprimè eruditus, \& triumlinguta:um, fed Hebree pow tifimum pcritifimus, cum animadvertiffer celebrena illam tieronymi Verfioinem temporum injuriâ \& hominub incuriâ vel magnâ ex parte inteccidiffe, vel magnâa ex parte fuiffe corruptam, tencavit \& iofe novam aggredi totius Scripture tranflationem, Leone X. Pont. Max. hoitante, \& Limptus operi neceffarios prabente. Collatis igitur hter fe mults , iifdemque probatifinis tebraorum exemplaribus; quantâ maximâ valuir diligentiâ ac fide, omne. Vetus Teitamen:tum ex Hebraicâveritate Latinitati donavit, \& Yebrai orum nominum multitudinem, quàm pricresinter pretes in Latiwas voces infexerant, Hebrazcw lingutre prolationi reftituit. Utque lector haberet restam rationem pronunciandi Hebraicè, accentus Hebrezs dictionibus fuperpoluit, addiểs quibaldam in margine totius voluminis numeris, qui indicarent, quot in fingulis. Hebraice Scripturx capitulis verficuli, quos $P_{c}$ fubin appellant Indai, continerentur. Quæ omnia tam folerti curâ executus eft, ut ejus cditionem peritifimi Hobreom rum Rabbini omnibus, quix nunc extant, tranflatien:bus praferant mulcis eame laudibus attollentes. Veutit queque non minori laude Novum omne Teftamentum juxta Grocum fidem:in quo, ficut \& in Veteri Teftamento, vulgatzeditionis authoritatem, manente Craci contcxtus fententiâ fequi conatus eft, pufque fuum Sclementi VII. Pont. Max dedicavit. Sixt. Senenf in Bibl. Sanct.1.4.

Sandes Pagninus virdinguarum Orientaliun peritilfmus, yui in Galliâ primus poft 
polt Hieronymum totam Hebraicam Scripturam Latine convertit, magnâ induftia ac fide. Ioan. Buxtorf. in Epitz. Dedicat. ad Lexic. Hebraic.

B. Lutberus Sanctern Pagninum amplinino celebravit clogio: Sancles, inquiens, Munferus vertunt Sacra biblic ftudio incredibitis diligentiâinimitabili.

Sanctes Pagninus vir ex D. Dominici familia ob infrgnem pietatem, facra Thcologiz cognicionem, \& fummam denique linguarum peritiam maximè confpicuus. Cujus viri Latina ex Hebraici veritate facrorum librorum Interpretatio, non parum candidis 'Theologis ad acra" Siripture atcane intelligenda adjumeneum attulit. Ar. Montan. in Prefat. ad Bila. Hcbr. Interlin.

Sanctes Pagrinus Dominicus Lexicon Hebraicuru edidit, tantâ enditione refertum, utcriam Rabbinos in co, argumenti genere vicrit, \& reliquos à praftantioic conficiendo detcruerit. Gilbert. Gen brart 1.4. Chronolog.

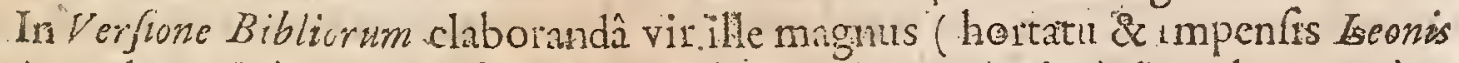
$X)$.25 filus minus annos firdavit. Verfionem hanc maxiute literalem, curn commode ficri poruerit, fidam, fingulari judicio atule periciâ concinatam,

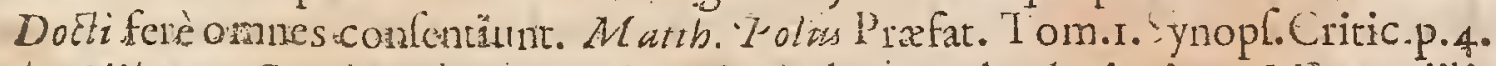

Gilbern Genebrardus PagniniVerfoncrn thoc medo depingit: "Minus dili"Gens, nimis ambitioh, nimis curiola, nimis Grammatica, nimis Cramma"ticarum minutiarum xmula" "quxque recentium preceptionum fubtilitate sc noxam funceritati \& Cententiarum \& rerum lepiufcule afferebat ande nec fatis "interdum cohærec cum Vecrum Hebreorum doctrinâ, neccum fidei Catbolice Mylteris. Gilbert. Genebrard. Prxfat. in Origen. Opcra.

Leonis Decimi Pontificis Maxim hortatu \& ope Bibliornm. Verfonem feliw ciffimoluccelfutentavit Santes Pagninus Lucenfis : Ebraice quidem Veritutis ubique ad veribum retinens, majoremque ejus quàm Latuintatis rationem habens. Perfectu proprmodum, \& abfolute Santiorum Voluminum Interpretationis exemplum dedit. Artamen ut punceum omne ferre difficle eft, quidam in eo nimiam diligentiam, ambitionem, ac curam; th morofam minutarum quarumque rerum ac levium affectationcm sinconcinnitatcm ctian, \& obfcuritatem culparunt relannatibus Ticè Ribbinorum peritifimis, quibus fummoperè probatui Interprctatio hac, ac reliquis anteponitur. Huet. de Clar. Interpret. pag. 144 .

Seriptura Inierpretande rationis utilc nobis exemplarpropoluit Sandtes $P$ agninus, yir cximiâ Ebraica linguxe peritiâ infignis; fic cnim Biblia Sacra tranftulit ut verba verbis quafi demenfa \& paria accuratè adfonent : quam ipfius. in Veteri Teftarnento operam, eruditorum quidem ftudiis accommodatam, led fi ad Tyrones intitucndoseconferre valles, aliquibus laborantem locis. 1dern de Opt. Gen. Interprot.

Fagnini verfo hoc infuper defequ laborat, quòd fapè obfcira fit atque barbara,imo \& Solocifrnis feeta. In hac fuit opinione quòd ad fidclem Scipturæ Trăflaw cioncm elaboranda litcram cractè \& ex rigore Grammaticx fequerdum eflets quod prafumptx huic accurationi édiametro repugnat, guialaium eft quod Yyy duz 
dux lingux in fuis loquendi modis conveniant; \& ita tantum abcftut Autogrä phum expri nat eadem puritate qua friptum eft, quin potius illid deformat omnibufque ejus ornauentis fpoliat-Novi tamen plures hanc Interpictasionem magri xetimace, eamque plurimis cxterarum Scripture Verfionum anteponere; fed illam dubio procul non Gatis examinarunt. Hift. Crit. Veteris. Teftama libi 2. cap.20.à Jef. Richard. Sirnon: Gall.

S.zntes 'Pagninu Biblia primus in Commata diftinxit; qua funt corum verficuli. Vetercs non diftinguebanted libum duntaxat citabaut. Hieronymus meminit. Capitum in verfis diftinctio recens eft. Oportet Pagnini Biblionum Verflonem efle bonam quia doctus fuit in lingua Hebraicas Scaligerana poferior. Gall.

Santles Pagninus, Lucenfis, Italius, Ordo. Pradicatoumm, Lugduni ad Rhodanum dic vixit", \& tandem obiit anno I541. ibidem in Templo Predicatorum conditus ante Odeium. Vir fuic ut Scripta ejus abunde probant, lingua H Hebraice peritifimus, \&laudariffimus orator: ut Symphorianus Champeins, qui homznem fapè dicentem audivit, teftatur,prafatione in ejus I Jagogen. Pagnini beneficium eft, quod Thomas Guadagnus, vil locuples, ad cateras impenfas in Dei hom. norem, \& publicum bonum, quibus Lugduni, Avenione, Florentie clarus erat. adjic eret adificationem Nolocomii Lugdunenfis ad excipiendespcite contactos, quod S. Laurentii vulgò dicitur. Scripfrt autem in Scriptaram Sactam quàm plurima, qux Sixtus Senenfis a Pofevinus, \& alii enumerant. Fateor quidem, nomulla apid cum, prxfertim quoad vulgatx Bibliorum editionis immutationem, merito improbari, qux Poffevinus annotavit, \& qux in polterioribus edirionibus expuntione damnata funtnon ramen omnia, quæapud pagninum, difplicent funt ab co profecta. Heraque enim Geneven fum inerpolatortin sequitia funt adfcribchda, tamctf ementiro loci nomine in lucem fint edita, \& mala fide pro Pagnini lucubrationibus publicata. Anb. Mireus.

* Thefaurus Lingux Hebinica Sanctis Pagnini, auctus operî. Ioannis Mercerii, \& Antonii Cevallerii, prohibetur, donec expurgetur. Vid.lis dic. Tridentio: nmm, in Append. Certorum Auctorum.

Extant. Hobraicarum Inftitutionum Grammatices lib.4.? ar. $15.49 .9 \%$

Extat Lexicon,Hebraico-Latinum, recognitum per Mercerum \&alios. Lugd. 3595 .

Epitome Lexici Hebraici Antvverp. 1s $87^{8} .8^{\circ}$. .

Extat introductio infacras Literas \&y Myticum S. Seriptura intelledum Col. 1563.

\section{JOAN.N.E.S GUS:IITANUSR.}

Clar.An.D. Ermanus, warus eft Svveinfurti anno 1473. Obiit amp:1529. A prilis 19.die; MDXV. U Vienne; quam codem anno Solimannus Turcarum Tyrannus, die 2.2. Septembris, obfidere copit.

Scripft de Confulibus, \& Ramanis Imperatopibusmom-Hiftoriam Aufriam- 
Tabulam Hungarie--.--De rebus Turcarum.

Optimus Imperator Maximzlianus eum in Senatum fuum adĆivit ; eumque in Hungariam, Bch-rnism, Poloniarnque Oratorcm mifit, annis duodecim continuis cjus conflio \& opeta in difficillimis rebus frepiffmè ufus. ( ùm nominis cclebritate \& tot peregrinationibus in maximorum Regum \& Principum notitiam peryeniffet; ut ab oblivione laboics fuos vindicaret, ad fcribendam Hiftoriam fe applicavit. Et quia în fummi Impcratoris aulà diwverfatus fuerar ; de Confulibur \& Ronanis Imperatoribss Icribendi argumentum artipuit: Ad quod inftitutum multam fupellectilem fuppeditavit rarifimorum librorum copia. Patebant enim ei cx Cófaris liberalitate \& beneficentià omucs undique vetuftio-

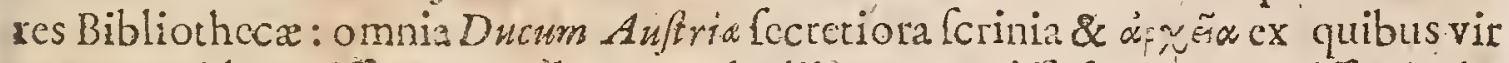
o mnium diligentifimus, multa, ब̨ure ab aliis pretermiffa funt, accuratifimè de promifit. Melcbior Adamus in vitacjus.

Potted Cefares \& Imprateres ufque ad Divum Maximiluanum perduxit. Quos morte preventus inemendatos, \& ob Scriptoris infciriam foedifimis erroribus depravatos reliquit. De dicendi genere aut clegantiầ, quibustanta Hiftoria omari \& illutrari potuiffer, non admodum eum folicitum fuiffe vidco. Forfan fi quid conjecturâ confequi pollum, fatisfakturum fe ingento Lectori atbitratus, fi que ipfe veriffina comperifet, fimpliciñmầ oratione mandaret pofteritati. Tolcrabiliorem hujus noftii dictionem facict ingenuitas \& fides, cum incredibili diligentiâ, \& ftudio perquirendæ veritatis conjuncta, Satis enim eft Hiftorico, ut preclarè dixit apud Cuéronem Cainullus, non cfie mendacem. Nic. Gerbel.in Litad Lectorem, quas $C$ ufpin. de Cxfar. operi præmifit, anl. 1540 . fcriptis.

Quod verólaude maximâdignum ent, nihil omifit , quod vifum eft illi ad -ordinem.retum, ad cognitionem antiquitatis, ad temporum rationem \& confe. -quentiam $\rightarrow$ ad morcs, ad fulcepta materix explicationem pertinere. Nam illud imprimisadmiratione dignum cenfebis; cùm de Latinis, Gracis. Francis , Germanifque Imperaroribus, quinctian de Turcis fcribendum cffer, adeò bellè, adcò aptè , adde, etiam diligenter fingulos fingulis temporibus adapravit, ut veluti uno in confpectu, fimul o omes fub oculis voniant. llud verò uno ore farentur estuditi, nihil unquam plus erroris, plus obfcuritatis attuliffe etıdiofis hominibus, quàm fi quis genealogiarum rudis \& ignarus ad fcribendam Hiftoriam accefferit : quâ in re, ut vcrè dicam, nullum adhuc cgo legi diligentiorem Cufpiniano.Idem ibidem.

Miramur queque diligentiam Jaboremque viro regiâ in aulâ e on(picuo longe honctiffimum Cufpiniani ITiernengis, à quô civili quâdam facundiâ Germanorum \& I'yzantinorum Cafarum Inpcria, propinquitates, ftemmata, moles, atque exitustcferuntur. Pathl. Iov.in Elog.

Cusfinianus Vir fimplicillima probitatis. Lipf. in excurfu ad 1.;. Taciti Annal. Ioannes Cuspinianus, vir eximia fide \& eruditionc. Ioj: Scralig. de Tempo: Bmendát.l. 5 .

$$
\begin{aligned}
& \text { Iodmes.Cufinianus Svvinfurterifss s. Mcdicus \& Maximaliani Imperatoris } \\
& \text { Yy } 2 \text { Otator: }
\end{aligned}
$$


Orator, atque diligentiffimus inquifitor Antiquitatis. Ioan. Gualter. im Chronic.

Hiftoriam Cafaream Ccripfit loannes Cufpivianus, folers Antiquitatis. Indag dtor, à Julio Caf are, ufque ad Maxiritiani I.mortem, Liculentum fanè opus, \& omnium lectione digniflimum : utpote quo, dum vitas omnitım ordïne $1 \mathrm{~m}$ peratorum defcribat, non tantum, infignin eontm exempla dicta \& faeta, quicquid in illis honeftum effet vel fecus, proponit : fed univerfam etiam temporum: feriem ( fupra mille quingentos \& viginti annos.) integram conncxamquc, 110 : intercifamaut muilatam, pofteritati reliquito. Whear. in Meth. lég. Hift, fect. 25 .

Tantapratcr eximiam facundiam in eofuit ptudentia \& fides, \& tenacitas Glcntii circa res arcanas, ut vigilantiffmus, Imperator Maximilianus I. fidelifimo illius pedori reconditifima quaque tutò committere potterit- Petr. Lambec. lib.2.Commentar.de Augufirf.Biblioth. Cafar

Ioannes Cufpinianus magnum fuo xvo Hiftoria lumen:Voff. de Hirt. Latap. 428 .

* Ioannis Cufpiniani Liber infcriptus, Imperatorum \& Cafarum vita cum Imaginibusad vivam effigicmexprefis, in Indice certorum Auctorum arohi; betur, donec conigatur. Ind. Trident

Extant de Confulibus Romanis, atoue item de Cafaribus Imperatoribus Commentavii, Defcriptio Aufric, \&alia quadam ctum Amotationibus Wolf:gangi. Hungeri. Erancofurti anno IGo1, foloapud Clawdiurn Ni arnium.

\section{A R T I: N U S L U: T L E R U S ...}

Citar. A: D. MDXVII.

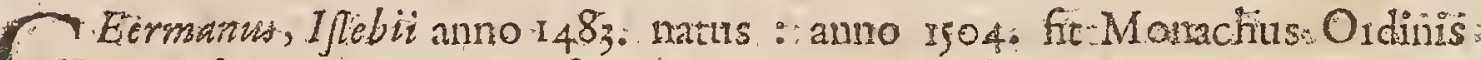
I:Augufiniani : anno 1517 . factus eft Religionis Reformats Dux atque: Ante-fgnants : obiit demum in oppido natali anno 546 . Wittemberga honorifice fepultus, Gul. Cave.

Martinus Lutberus, Scriptorum Ecclefiaficorum coryphaus, veritatis coem Heftis entheus planè \& imperterritus vijdex, Germanixque Helia, ècujus unico fcriptorum folto plus quàm ex omnibus Thoma Scriptis addifci polfe, Magnus quondam Erafmus ad Marinum Caracciolum Legatum Pontificium verifimè falfus eft. De quo Wolfgangus Severus, Auguftifimi Imperatoris Ferdisandi. I. quondam Pracepter, parrhefialticè cecinit:

Iaperi de firpe fatum Doetore Luthero. Majorem nobis nulla tropago dedito..

Et adde judicium Georgii Fabricizi ad Scrin. antiqg. notatum, p. 2xz:

Inter Theologos eft gloria prima Lutherus. Nam merito Chrifti nemo magis tribuit.

Olear, in Abac. Patrim. 
Quem (Lutberum) non:Cefares, non Reges, non fulmina ex. Arce Tarpeiá wibiata, non ullx.inumerabilium Sophiltarum Phalanges, vel tantillum teral: rune. Theodor. Beza.

Vir etiam hoftium judicio magnanimus, talia ecrtè aufus, qua totus mira tur orbis; \& unus ferme Orbi conjurato obnixus H of main.

Res \& verba philippus, res fine verbis Lutberus, verba finc re Erafrous. Edvv. Leigh. de viris doctr. illuntrib.

Pomeranus cat Grammaticus, \& verbonin vion explanat : Ego fum Logicus, monitro contextum lcrum \& argumenta: Iafius lonas eft Orator, copiosè \& arnate differit: Sed Lutberus eft omnia in omnibus, eft miracul m inter homines; quid zuid dicit, quidquid fcribit, id in animos pcactrat, \& mirifeèrclinquie aculeos in coidibus hominum. Phil. Melanethon.

Homo nudus onui prefido, non clam \& per cuniculos infidias ftuxit. (ue fraterculi folent vite Imperatorum \& Principum.) fed aperto Marte Monarchian aggreffus cft Pontificiarn, exercitatiffmos belli Duccs cajeranum, Sylvifrum teckinm, aliofque inftuctifimos ab omniapparatis genere profligavit, \& ingentianimo Heroicoque aufu, turrim atgolellus Babylonicam, penè jam, quod felixin pofterum faufumque fit, demolitus ct, Richard. Montacut. in Antidiat. g:

Lutberus Theologusconfummatts, profundus, incompatabilis, factam Theologiam ad Fontalem dignitatem, primævanque puritatem, necnon Evangelicam; finceram, fimplicemque fuam iltam inocentian, onni prorfus fecu1ari Philofophiâ explosî, revocare conatur. Paul Langizs, Cyrici: Monachus,? in chron...

Lwherum non novi, nec libros illius unquam legi,nififortè decem aut dù decim pagellas, cafque carptim. Ex his qua tum degutavi', vifus cri mihi probè compofitus ad my ficas literas veterum more explanandas, quandó noftra hrc aras immodicè indulgeat argutis magis: quàm necelfaris Quaftionibus. Erafin. Epift:li14. Ep. 5.

In Lubero demiror duas tam diverfas perfonas: quedam ita feribir, ut fuirare videatur Apofolicum Pedtus: rurfus in dicteriis, in fannis, conviciis", in falibus quem non vincit furram ? Magno animo contemnit $C$ efares $\&$ Pontifices, $\&$ dd levifimorum abjectifimonumque ho minum fufuros fic debacchaturin quemlibet, velut oblitus quam agat fabulam, \& quam pesfonam induerit. Erafm. Epif. I. 19. Epift. 24.

Lutherus Grac nihilpenitus noverat, quum adfcribendum acceflit", "Latine ? parum adinodum: \& qua tucnda fufceperat", dialecticâ, \&u argumentariunculis: autatus eft,non linguis. Lud. Viv. de Cauf. Corrupt. Art. p.I32.

I utherus Proteftantium primus fuit qui Biblia in linguam vulgarem ex $H$ ebreo Codice interpretari aufus eft; quamvisadmodum mediocriter tantum Hebraicum idioma calleret. Cum liberi \& audacis effer ingenii, Beatum Hieronymum accufavit quòd Hebraicum Idioma nunquam perfecte intell cxiffer. Sed fortion satione defectûs hujufe culpabatir ipe e \& quod in hujufmodi Opere pracipi

$$
\text { Yyy } 3: \text { savtes }
$$


tanter nimium procefferit, quod fpatium exigebat longe diutumius illo quod-at iplum infumfit. Unde etiam Verfonem fuamadincudem tevocarc caatus frit, ejufque alteram editionem procudendam curare. Sed hac revilio noin fecit to peritioresillius avi Protefantes utram defecus illarum, qui non pauci erant, notare non abfinuerunt. Jel. Rich. Sirron Hilt. Critic. V.T.1.2 c.23. Gall.

Sebafianus Xiunferus ablque dubio Germanicum Tutber:Verfonem indic are voluit, cum in una Prefationam fuarum fronti Bibliorum fuorum prefxarum, dixit fe potuific inumeros locos notare, quos perperam tranfulerint recentiores Interprctes, co quòdad Hebraicx Lingux ftédium non fatis appulcrint animum. Pratercaque idem Author fuis in lona cap. fecundum, Notis, L utberum nominare non veretu, illumque corripere quod negativè verterit, quod in $\mathrm{He}$ brá affrmativè enunciatir. Eadem illa Lutheriverfo publicè paticer rejeda fuitin Synodo Theologorum R. P. R. Dordiaci congregatorum, ubi caurum fitit novam Belgitam Vetfonem totius Seriptura ado rnandam efle, eò quòd vetus Belgica Verfio quiz"tunc in ufu crat ad Germanicams Verfionem Luberi exacta fuilet, quam crroribus refertam exifimabant. Zuingliani pridem antea novam rotius Scriptuæ Verfionemin funm ufim elaboraverant ob candem caufan Lutheranâ uți detrectantes, utpote quz, plurium Protefantium judicio, parum accurata crat, quæque ab audaci viro \& præconceptis opinionibus turgido fada fierat. Idcm ibid. Gall.

Lutbcro, Germanisorim Proteftantium atriarch $x$, non latis füit integrorum Biblionum ex Hebraicis Grecifque Codicibus Tranllationem in vernaculam (uam linguam exfculpfife, cenfuit infuper opus effe Verbum Jei fro modo explicare ut co ardius cohiberec corum animos quos in yates fuam pertraxerat. Scalle Pariarcha feliciorcm fucceflum fuis in Biblia Commentarits nachs non eft quam in Verfonc fua. Utramgue pracipitanter nimis praftitis \& plenmque anticipata judicia quoru m plenus crat tantummodo confuluit. Ut peritus cxiftimaretur, fruftra refpuit aliorum opiniones dum ei ridicula videbantu.- Commentaria fua Quaftionibus Theologicis innumetifque aliis à fcopo aliciis perfpergit; ita unilla frat potius Lediones Theologica vel Difputationes gnàn gemuina Commentaria. Id infun libri Genefeos expofitioncectnere eft; in qua digrtfionum:ingens numcrus deprehenditur, quæ judicium folidum parum redolent. Arbirratus eft, dum Leciones. Morales habebat so illos quil a fe differticbant Stentorcis clamoribus impitubat, magnas elucidationes Dei Verbo fe foenerare; fed vél ex ipfus libris judicari factlè poteft illim merum ardelioncm \& virum animimpotem femper fuific, qui fagacinate quadamingenii \& imaginationis fervoretantum valebat. Nihil neque fublimenequedoctum occurrit ejusin Etblia Commentariis; omnia ibi abje cta : \& frmplicia; "\&co griòd Theologix operam anaffet, Quixtionum Theologicanm Rhapfodiam potius compoluit quam Commentanimin Scriptura.contextum. Cui tei addi potat, illim cuaffinma Minerva loqui, Luofyue fenfus fapius quam rationem fuandequi. J cL Rich.Simen. Hit. Crit. Ysteris Tcrt. lib. jo cap. r. Gall. 
Luhberus Doctus vî̀ in Hebraicâ Liniguâ,ex quâ benè Biblia vertit; fed Cal vino inferior. Scaligerana prima, p. I04:

Nos Luthero caput \& fummapectoris, adde etiam media \& ima, denique ven. tem \& femus, id eft omnia in quibus vita Religionis confitit, deberi fatemur Martir. Kuaru in sis cent. Epitt.p.88.

Ingcnium nactus eft (: Martinus Lutberus) à Naturâ fagax jacice, præfervidum ad magn quxvis aggredienda factum, vir, fir quis alius, invicti atque imperterriti ani imi." Quoties veritatis agebatur canfa, laec amorem cujulvis curabat, nec odium; Pontificis fulmina, I mperaroris edieta, non minus quàm 1ebis convicia infuper habuit, \& fortier contempfit. Interim haud iverim infrcias, $L$ utherum affectibus liberiùs quàm par crat., fxpiùs indulafe, atque ctiam in majorum grtium Principes impotenti animo ftrinxiffe calamum. Verkm quifgue fuos pam

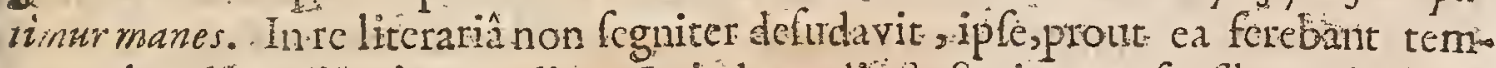
pora 2 haud mediocrier eruditus. In indagandis S. Scriptura ferfibus ftudium precipuè pofuit, ejufque bene-magnam partem Commentariis cxplicavit. Theológiam à multis retrò feculiscorruptam ad priftinàm integritatem pro virilirevocavit. Quâ:quidem in re fi minus forfanalicubi Orthodoxus videarur, virio non tam ipfi, quàm tempoi is, quô vixit, conditioni vertendumeft, ncc mirum, fi maculas qualdam contraheree, , qui Augia Atabultim tepurgire aggreditur. Primæxæ Antiquitatisnormamante oculos habuit, \& certè (ut in Epitola ad Cardinalem Albertum, rectè olim notavit Erafmus) multa in libris Lutberi damnantur ut Heretica, qux in Bornardi i Anguftinique libris ut orthodowa immò ut pialeguntur ; additque, Lutherum mulita imprudenter magis quàm impiè fcripfiffe. Nec preteriri debet quod in Lutberi vitû̀ refêtr M. Adàmus, Erafmum, Pontificis oratoribus ipfum ad Lutherum oppugnandum incitantibits, Iefpondiffe, Major eff Lutberus, quims ut in illawn foribam, imo tantus, ut ex"

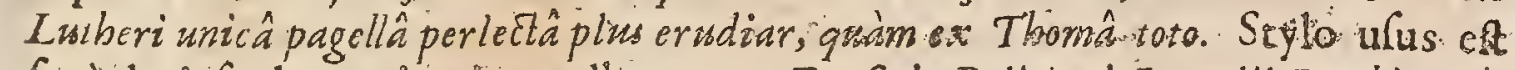
fanè duriufculo, wari quippe adhuc erant Erafmi, Politiani, Longolii, Bernbi, $S_{a}$ dolet', quị cum Cicerone, Livio, Terentio familiariter verfabantur. Utcumque. verò incompta \& inelaborata fít, genuinam cerrè pietatem, 2 ingentem ubiquse zelum fpirat vivida Lztheri dictio, nec tam verba, quàm ses fundere viderur。 Henr. Whakton. in A ppende ad Hift. Literar. Gul. Care.

Rex Henricus Vlil.ad famam fibicomparandam, \&ut Clerum fibi femper faventem haberent, hinnc non modò authorirate fua juvandurm effe putavit, fed etiam eorum propugnator fieri voluit, \&adverfus. Lutberum in Septem Sacramentorum patrecinium fcribere. Magnificis laudibus librum hunc extuleìnt Clerici tamquam eruditifimum Opusquod fub Sole unquam extitiffet; Rcgique Salomon omnibufque omnium xtatum Imperatoribus Chriftianis illum xiquipararunt; Pracipuumque hoc furt in plures annos a dularionis.argu mentum, prater gloriofum Tirulum, Fidei Defenforis quem hac de caufa Pontifex ipfie日tribuit。 Fatendım autem eft, fis Seculi conftitutio attendatur, quòdque Regis hoc Opus effet, aliqua id commendationc dignum fuiffe. Sed Lutherns tunc ne minimo quidem timore perculfus eft quin porius gloriam hins duxis, quod 


\section{4}

\section{E N S U R A}

tantus $R$ ex in arenam cum ipfo defcendifct \& ad ejus librum refponfum temifit. Hoc autem nen repoluit abfque acrimonia copiosè permiftâ, in quo univerfim culpatus eft tanquam oblitus magne venerationis qux Supremorum Principum perfonis diberur. Burnetti Hiltoria Reformationis lib.r. pag. 3 I. Anglice.

Lutherus fanè vir fuit fublimibus animi dotibus magnilque vitutibus ornatus. Vaftx erat intelligentix, qux cum evexit ad cacumen Dectrinæ Seculo tquo vivebat incognitx: Minifica erat cjus in Scripturis notitia, clocutio cjus erat malcula, cjulque ratiocinandi methodum comitabatur tota fubtilitas quam venerandx ac perfpicux veriates à fe rraditx ferre porerant. Ejus cogitationes ad magna copta iemper propend bant, ejufque confantia ad corum exccurionem fufficieus erat. Animi cjus fidentia nec concuti, nes fupefieri poterat: Ejulque illa tappprola ( Hec cnim id alio nomine cenfere pollm) coram frequentibus Wormatic Comitius illa non minor fut quauff funt olim Apofoli. Vita cjus fancta fuit, \&, dum ei per etium fecffum petere licebat, fevera. Ejus vintutes activiflumacum affabilitate non autem defidiolre atque terica quales funt Clauttrales. Nulla ipfum agitabat Ambitio prater ardorem in Deicultum; quod ad catcra pcetat, neque polfedit neque cxpetivit unquam nifi que ad meram vita fuftentationem funt ncceflata. Tompcramenti erat impiimis avaritiam aut abjectum quemvis affeotum werfantis; Beniginus crat ctiam in delinquentes, nulla proprii commodi ratione babita. Si in hane Virtuturn Congeriem atiqüs

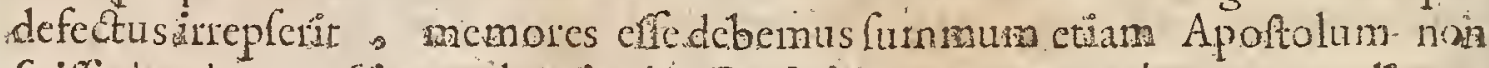
fuiffe inculpatum. Si quandam incjus Doctünx Corpore Labern ceinere liccato nec ctian maxima Ecclcix lumina \& vel in lajus purifina etate, ut novimus, in omnibus fuis Opinionibus fani fuerunt. Omnibus perpentis meriflimè profecto exumpere poffumus in hoc Prophetx dictum \& exclamare, Quam fteciof funt in monitbus pedes ejus qui leta fert nuntia. Repponfu ad quafdam Conjideraw tiones in $M$ : Lutheri Genum, Oxonii caculum amo $1687.4^{\circ}$. Anglice.

Opera ejus comprehenduntur feptem Tomis, fol. Wittebere. isgs Latiné.

* Martinus Lutbernsinter Hricticos prima Clafls sejicitu in Indice Tridentino.

\section{J OANNES OECOLAMPADIUS Aliàs $H$ A U S S C H E I N diatus.}

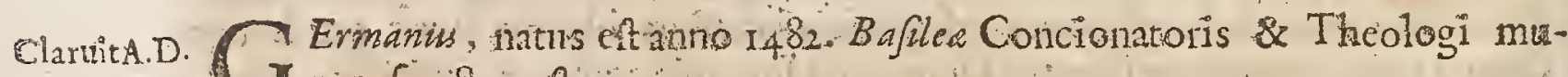
AXX. Inere fuid dus ef:

Siripji multa, valis in locis feparatim impreffa, qua diftibututur in Exrgetica, Didajcalica, Apologetica. Multa quoque è Graco in Latimum Sermonem tranftilir:

Pümus Reformator \& verus Paftor-Ecclefia Rafleenfus. Zwizglius \& ille eruditioné, tud diis, autonitate, loco, atate, pares crant: inter quos tanta aniñ orum conjunctio, utamicitia fanctior certiorque, quam vera conciliarit pietas, vix 


\section{ĆELEBIORUM AUTHORUIM.}

45

inter ullo surquam fuerit — In diffidiis Controverfifque componendis Fix admodum habitus. In fcribendo, commentando, docendo, confutando omus generis adverfatios, \& transferendo plurima, magnum fibi nomen, Licclefixine tu uetum comparavit. Cujus lucubrationes in Perophetas aliquet mirum in modum à viris doctis probantur. Lac. Verbeid.

Oecolarnpadius fatis novit Gracé, Romani fermonis rudior, quanquam ille magis peccat indiligcntî̀ quàm imperità. Erafra.1. Ig Epit. 23 .

Occolarpadius, vir obtilinguem eruditionem, ob doctrine fcientiam \&e ufum, antiquitatis denique Ecclcfiaftic exactan cegnitionem, fuâ xtate nülli Cecundus. Melch. Adari in Vit. Oecolamp.

Cùm in publicum prodillet libcllus de Eushariftia ; Senatus Bafleenfes rei inlolentia motus, cum tantifper apud fe vendi prohibuit ; donec à Cenforibus cxaminaretr, 8certius quippriam deccmeretur. Confuluit itaque Erafnnm Roterodarnum, Berum Propolum, \& Cantiunculam furifconfultum, quidia de feripto illo fentient? Erafmus senatui refpondit hifce verbis:S. P. Magnific Dornini celfundinis veftra hortatu, perlegi librum loannis. Oecolumpadii de Verbis cona Dori iz, meâ fententia doctum, difertum, of elaboraturn;adderem etiampium,

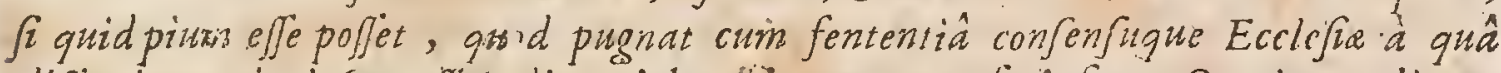
difjentire periculofum effe judiro. Ac anicos autem lcripfit : Oecolampadium emifife libcllum, tàm accuraté Criptum, tot machinis argumentorum, totque reftimoniis infructum, ut poflet vel clcetos in crorem pertrahere. Melich. Adan ibid.

Hic, quia vir erat finguliris enditionis \& magne antoritatis, plutimos seneno Zuingliano perlibros fuos infecit. Bohern. Epitom. Hift: Ecclef. pảg. 95.7.

Emicuit dudum perilluftris cruditio in Toanne Oecolampadio, fd profecto clariùs \& luminofius illuxiffer, nifi Chriftiand Hoftie facramentum repudiaffet. Paul. lov in Elog.

Foannes Oecolompadius Winfpergen is, cruditione \& pietate praftantifimits Theologus. Ge ner. in Wiblioth.

Ut doetrinấfic vitx. fanctimoniâ colendifimus fuit. Bòiffard.in Icon.

Hunc (Oecolampadiam) Erafinis Roterodarnus in edcudis Novi Teftamenti Annotationibus confulut, fieique adlibuit. Operá Subfidiariâ illius, non folim pietate, verum etiams trium peritia linguarum eminentis, adeogte veri Therlogi, ge adjutum efje ingenut ip fernet Er.finus fatetur.

Sub funcm Novembis anno 53 I. Oecolampadius èvitâ aleceffit. Ex interitu Zuinglimaximum animo perceperat dolorem, eaque res mobum ctiam -amxife putatur eran cnimconjunctifimi. Natus fuit amos 49. Extant ejus in Prophetas aliquot lucubrariones, quæ valdè probantur doctis. Ioan. Sleidan. Comment. lib.8.

Oecolarnpudium extinctum, utinam polfem dolere jure. 'ic enim litera \& doetrina hominis poftulabant, nificxtitifer ille in alio genere perniciofus. -Sadalst 1. 4.Epit ad Eragm. 
Deplorarunt hujus viri obitum prattantiffmi quique: inter quos Sebafivinuses: dAunfterus earmine Hibrao, \& Theodorus Beza Latino Hendccalyllabo.

\section{P.A U L U:S A.MIILIUS。}

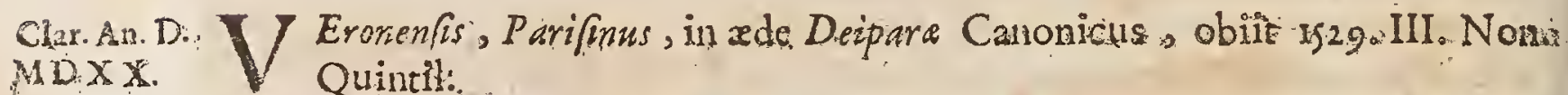
In Gallins retatis curfum fub Ludovico.XII. \& Francifco I. agebat Paulus $C$ milius. Magnum is fibinomen paravit Opere inclyto de rebus Geftis Francorum: cui annos 30 impendilfe dicirur. Ac libros quidem novem perfecit: decimum, morte praventus, reliquit imperfectum.Sed.eum propinquus illiis, Daniel. Zavarifus Veronenjis, ex fchedis difperfis, multâque liturầ obductis, collcgit, ac digeffit ita, uti nunc legitur. Definit E Emilius in anno quincto Carols Vill. qui C'brifti eft 1488. Laconzcam ei brevitatem adibuir Paulus Lovius. In hiltoriâ tamen belli facri, duce getti Godefrido Bullionio, luculentiùs fe diffuindere, mediamque ait viam liffiftere. Sec quicquid de cæterorum Laconfifmo dicat lovins omninò šcriptor eft elcgans, ac difertus s. Voff. de Hift. Lat.

Panlus etimilius in Gallics \&res quoque Gallicas fcripfitetrinion: Gallus. Ludozicus XII. decus hoc Italia abstulit, \& vindicavit fibi.: Ille, ut rem dicam, Penè unusinter novos, veram \& veterem Hiftorix viam vidit, camque frroo pede calcavit.Gsents fcribendi ejus doctum, nervofum,preffum; ad fubrilitáten \& argutias inclimans, \& relinquens defigenfque aliquid in animo ferii: Lectoris. Sententias \& dicta fape mifcet sparia antiquis. Rerum ipfarum. fedulus. fcrutatọr, feverus judex:néc leginoftro avo o quînag is liber abaffectu. Dedecus xvi: eft, quòd minùs ille placeat, quafi pauci fint qui capiant hec bona. In tantis ta-

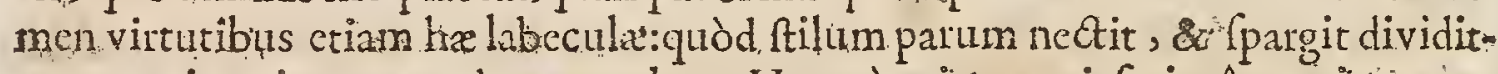
que eum in minuta quzdam merrbra. Hoc cùm in omni feriosầ orationie parum congruum, tum in Annalibus srinimè. Deinde, quòd innæăualis, alibî nimiùm anxius \&caftigasus, ideoque (ubofcurus; alibi(fed rarenter) laxus \& folitcus. Vetuftatis etiam nefcio quid affectat in nominibus hominum; locorum, urbium immutrandis, \& in veterem formam tedigendis:Lxpè enditè s, interdum vanè ; fed, ut ego judico, femper indecorè. In quibus.; fir refingere leviter eum. nobis fas? (audeo dicerc) virum daremus. fupra omnem hanc. novitiam, \&ad prifcam landem. Lips. Not.ad Lib.r. Politic.Ciga.

Paulus etmilius, cuide Scriptoribus Gallicis, plurimùm creditur, frepe hifforiam confundit, frèt:non ex terum fide, fed ex impetu calami interpolat, fing it multas ự animô concepit,non commemorat uf memoriis publicis ea de-ęre potuit.-Non parum adulari Pontificia surix doctus. 1ob. Henr. Boeclerm. ini:Præfat. Ser.Cærar. Germał.

Vir clarifimus, gravitate, judiciố \& clơquentiâ prêtans; obilit Anno Dom. 2529. Theoph. Daffiliand. in Defcript. Urb.Ital.

Si compendium rerum Erancicarum legere defideras, adi Hiftoriam Pauli Aznilii Veronenfiss Ltali, qui vixir Cub initiumfeculi Luperioris in Galliâ. Quemadmodum 
shadmodum Polydorus Virgilius, I alus, profequitur Res Anglicana: fie ille Galli Canas: defidero in co quòd dictio ejus nimis lit concila, \& affectatione Antiqui tcatis vocabula locormm mutet iu aliam Aexionem, v.gc. Geldriun Geldnarn vocar. Nac dubium, quin id verè dicat, Ced tamen pro tempore loquendum eft; Herman. Conring. de Regno Gal.

Pauli eErrilit \& rcconditam eruditionem, \& diligentiam, \& vitz fanclita-

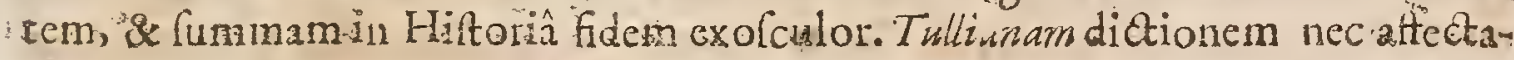
vit, nec habet, Erafm. in Ciceronteno.

Mcliori fide Hiftoriam fcribere, qudm Gaguixus fecit's qui affectus cuos mifcuit, Ludovici Tivis fontentia eft.

Eloquentifimus Vir, \& antiquarum originum vindex Panlus e Emilius Feronerifs. Ic. Scalig. Epitt.1.I. Epilt. I.

Paulus efinitive tam sanctus \& incorruptus enarator Hiftoria, ut jucejurando putes obftidenm; tam elegans,ut nif recentiona referiberct, videri polit haud iafirous Antiquorum. Thorn. Norus in Epift.ad Germanürn Brixium.

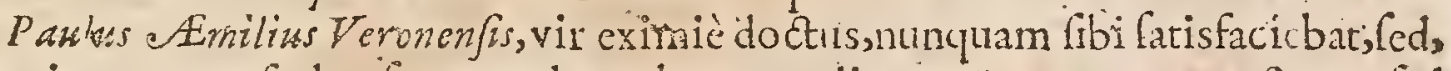
guoties recognofecbat fua, mutabut pleraque : diceres $O$ pur non correctum, led aliud:idque fubinde facicbat. Qux res in causâ fuic, ut citiùs Elephunt puriant,

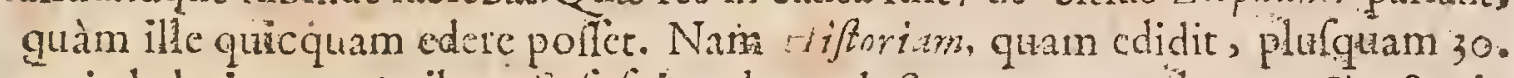
annis habuitpra manibus. Etfufpicor huc adactum, tit evulgaret, Erafor in Apothegrmb.6.p.58.

Paulz : Emiliv Veronenfis malignum filentum won fil bo, yui multorum non meminit qua ad Gallorum gloriampertinerche Nec ea ignoafle di-i poteft, qua nullusante iptum pretcriit,ut olemrillud ad metionem Regur calitus dernifum; \& litia fimiliter: quibus fifidem non adhibuit, cam faltem hominum mentibus opinionem infitam efle dicere oportuit.Ferder in Auctor Cenfionc, p. 88.

Clausi:Verderijudicium non moramuriqui ut dim terodotus Plutarchurn, ita Erilium ipe maligni animi reum agit. Et quo a:gumento?nempè quia vul-gata illa de Oleo ad Reges inungendos coelicus demillo, deque liib's, praterire maluerit, yuam ut lcutentiam de eo litam apponcre infimul cogerctur. Vo/]. - Ext Ent de Rebus Geltis Erancorum libri Io. Bafilea I GoI.apud Henricum $P_{\ell=}$ ri Addita eftcoitinuatio Araoldi. Ferroni.

\section{THO MAS de VIO.}

A Patciàdictusvalgò Cajetanus, ex Ordinis Predicatorum Gcnerali Magifró

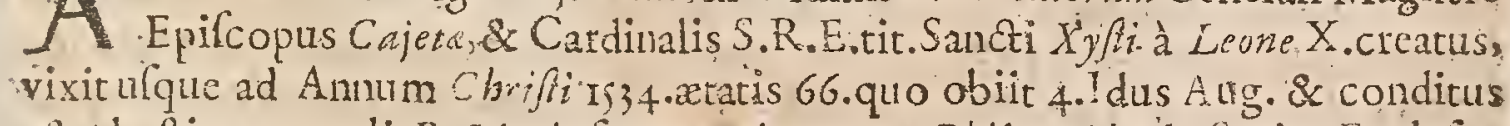
Ciar. A. D. elt ad otium templi B. Maria fuper Minervam. Phil. Labbr de Scripe. Ecclef. Scrop/ar Commentaria in totam fumman S. Thoma. Denique opufcula permulta, \& librum fcntacalorum, \& fummam cafuum confcicncix.

Sripgit etium Commentaria in omnem facram Scripturam, praterquam in Prophetas, -se in Apocalypfin, \&e.o

$$
\text { ZzZ Vit }
$$


Vir tam vitx fanctimonia , quàm ingenii praftantia illuftris, fubtillatmus Diakcticus, admirabilis Fhilolophus, Theologus incomparabilis, \& inter eruditilimos doctifrmi luifeculi lorigè ernditilfmus - Hic in extremâ fenecture fua,pof innumeras Iucubrationes in Arifotelis Philofophiam; \&in omnem D. Thum T hcologiam editas, totam Véteris, ac Novi Ieftamenti molem juxta.

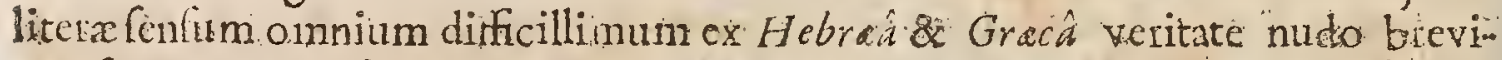
que fermonc expolitie, execptis Candro Canticorum \& Frophens, quos moricns

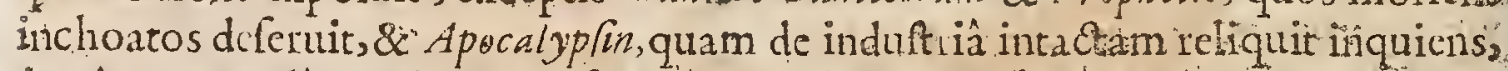
in exponendânon ingenio, fed divinatione opus effe. Sixtus Senenf.

Vir fuit fummingenii, nec minonis pietatis. Bellarm de Scriptor. Ecclef.

Cajetanus vir meo judicio, quanvis Papifta, tamen candidus-; plurimumque diftans ab ea pertinacin , quam in reliquis deplorare cogimur-..-Onnes Epiftothis Nou. Teft. \& Actorwon, librum reccnluit ad Veritatcm Gracarn Annotaicnibus illutravit infra fputium zirciter decem menfum. Dan.Chamier.

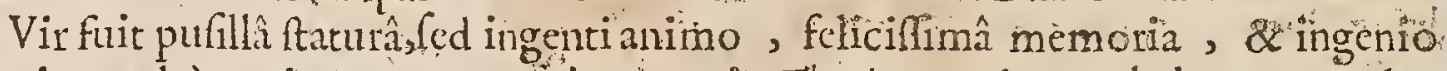
maximo:adè ut iitere omncs fui temporis Theologos princeps haberetur. AdoIjicens togam Predicatorum fumplit; in quorum cotu fic ad virtutis \& doctrinæ ftudia le compofuit, ut adolefcens, cum Generalia Ordinis Comicia Ferrarie celebrarentur, in publicit certatione, cum lacanne Pico Mirandulano congreffus, fpectante Ferraria Duce, totoque Ferrarienfe Sexatu inagno omnium applaufu; ipfoque Pico poftulante, pilam infignibus \& titido Doctoris onnatus fuerit. Aubert. Airu in Bibl. Ecclefialt.

Thomas de Vio, Ecclefix Romana nobilifamus Cardinalis,acerrimi vi judicio, Theologus in Scholà Latina longe ccleberrimus. Ioan. Dall. de lib. Suppof. Dionyf. Areop. \& Innat. Antioch. 1.1.c.36.

In Thcolögî S-bolafica tam infigniter docuts, ut nulli" ex his, quifuo temporefloruerunt, lecundus fuerit. Alphonf de $C$ aftro 1.2.adverf. Haref.

Cajetanus obfcurius loquitur more fuo, ut vix reatè inelligatur. Bellarm. lib. de Matrim. c. 10.

Majome Theologus an Canonifta, non facile dicas. Olear. in Abac.

Thomam Cardinalem Cajetanum malè de Trinitate fenfife probavir Archiepifcopus Complanws Ambrofus: inter Hzicticosetiam recenfetur ab Alfonfo de Cafro. Chriftoph. Sindius loz. Enucleat.Hift.fec.I6.

$C$ ardinalis $C$ ajetanus quamvis in compluribus facri Voluminis partibus $L a-$ tinè magnâ fidę convertendis facultatem fuam exercuerit, in obfcuro tamen jacuit -jus labor, nec fuffragiis doctorum comprobatus eft. Cùm enim Ebraica ac Grace linguxignarum fe profiteretur, viros utriufque peritos, non ad eruendos fenfus, quos apertè neglexit, fed ad verborum fignificationes cognofcendas quas fpectavit unas, in conflium adhibuit. Meritò itaque alieñ cruditiónis foetum exclubiffe creditu's eft. 1 tuet. de Clar. Interpret.

Cardinalis Cajetani hac erat prxconcepta opinio quod Bibliorum Tranflationes merè literales effe deberent, perfuafis neminem nimis ad literam Scripturam Sacram interpretari poffe, cum liac Verbum Deirfit, cui veliaddere vel detrahere 
vetitum. Hic Cardinalis Prafationé in Pralmos prolixè admodum explicat me thodum in hujus Libui verfione à fe obfervatam; atque profitetur quamvis He braica lingue ignarus ellet,fe tamen bonam Hibliorum partem verbatim jitxta Hebresun contextum vertiffe. Vitontm duorum hac in te operann adhibuctat hujus lingux callentium, quorumalter listens alter Chriftianis erat, quibus piafcriplerar ut voces Hebreas merè ad literam a juxta Grammatica regulas transferrent, quamvis eorum veriónull on fenfum fundere videretur-..-Interea Tranlatióipfius, ea prafertin quam Pfalmorum claboravit ad illum Grammatica rigorem prorlus exacta non eft, nce xquè babala ac "Malvenda \&" Ar i Montani Verfionés; \& quamyis omni Hebraici ldiomatis notitia deftitutus, de hoc tamen me lius differit quam plures Biblierum Interpretes, cjus mediocriter. zantum callentcs. LeS.Rich.simon.Hift.Crit.V.T.lib.2.cap.20. Gall.

Extar. Commentaria ejus in Biblia Tom. F. Fol:Lugd. 8639 .

Hoc ejus Epitaphium:

Hấc interiori folfulâ, quam lector anfpicis, felicis memorix Thome de Vio Ordinis l'radicatorum, Caddinalis Cajerani confervantur offa. Quii dum vixita itîx moribus, atque omni doctrinâ humano gèneri profuit, ite pro tanto benefiGio Dro-grarias agere , ac pro ejusanimâ meritò preces fundere teneamur. . Hic. quorundam aliorum inanem declinans fafut $m$, humili hoc fe coidi jufrt tumulo. Vixit annos-6j: dics 29. obiit Anno Chrift 1 1534. Thomas deV Vio Cajetanus Cards nalis S. Sixti Cacri: Ordinis Pradicatorum

\section{HENRIEUS CORNEIIUS AGRIPPA:}

Olonienfis, natus eft ann:3486.obiit ann.ry34. Non folum Juris Civilis, fed \& Medicina Doetor falutatus eft. Scripfit Comment:in Artem Lullii : libellum de nobilitate fexus forminei : de occultâ Philofophiâ five magî̀ : de Scicntiarum vanitate:de duplici. Coronatione. Carolz V. \$ec:-

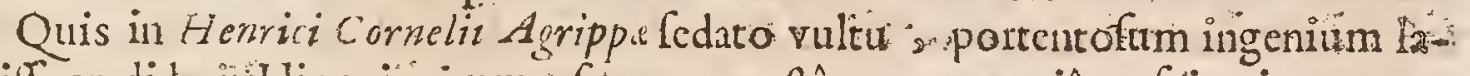
suiffe crediderit? Hic enim immenfo captu, vaftâque memoriâ ,, fçtentiarum artiu mque omnium rationes, arcanque intima \& fummos apices complexus, dif ciplinas convellit, teligioncs in dubium revocat;ftudiorumque omnium labores feftivâ declamatione deridet:eoque vehementiuis, atque validius ; quòd tantæ novitatis argumenta facrarum literarum auctoritate confirmentur; quafifeliciore opere illuàcntis ingenii tantas. opes oftentare nequiverit, nif vir edicatus in lin. teris, \& à Cafare eluditionis ergô equeftris ordinis dignitate honeftatus, impoltunos arictes inanis eloquentix, xternis optimarum literalum arcibus admowiffet. Sed ad hoc cum plaufu à multis exceptum volumen de Tanitate Scientiärum, alium addidit librum de Occultâ Philofophîa, curiofis admodtum peftilentem; quod opus, ex cenfurẩ Cbriffianâ, edicto vetitum; apud unos impios réperitur. Sed in utroque ferio, parier \& joco gravior, atque lepidior, ac ideo forfis ean xternus appareret; $;$ nifi puriosem eloqucntiam non fecús ac reliquas faculta-

$$
\text { Zzz: } z: \text { tes }
$$


ecs infelici vcl inepto judicio contempftfot. Excellit è vitĥ nondum fenex apud Lugdunum, ignobili \& teneb rofo indiverforio mulcis eum tanquan Necroman sie fulpicione infamem execrantibis squad Carodamonenngri Canis fpecic citcumducetet; ita ut quampropinqua monte ad ponitenciam urgeretur, cani collare loretm magicis per clavorum Enolicmata inferiptum notis exolverit, in hac Luprema verba irate prorumpens, Abr,perdita beftia, qua me toum perdi-

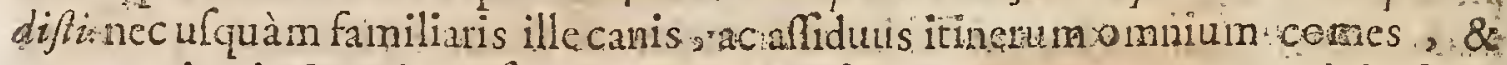
cum moricntis Domiai defertor, poltea confpedus ef , qum pracipiti fugre Caltu in Ararim le immerffec nec enatalfe, ab his qui id vidilie alfercbant, exiltimctur. Pult-Jov.

De Cornelio Agrippa quidam amici docti ad mefcripferunt è Brabantiâ, fed fic utne hominis violentiam probare, \& plus illi in colligendo fudiz, guam in deligendo judicii tribuere videantur. Erafir. Epilt.lib.24.tpift.s\$.

De Viro (Cornelso ygrippá) de quo suuid fentiam rogas, magnificentius cen feo quàm ut de ejus ingenio cenfukam ferre polfm. Ex ejus libii (de Incertitudine of Vanitate Scientiurum ) qualicurque $g$ fou deprehendi hominem efre ardentis ingenili, varixe letionis \& multz memorix, alicubi tamen majore copit quàm delectu, ac dictione, tumultuosî veriùs quàm compofitâ. In omni genere rerum viruperat mala, laudat bona. Erafm. in lit. Abcli Coljtero, dat. Friburg. 25 . April. $533 \%$.

Agrippa doctillimus Mathematicus à Patre exiftimatus eft, virque doctus. Scoligeranain.

Conclithomen ob multiplicem dodỉnam,non modò apud Germanos, red \& apud exteros culcbre extitit. Boiffard. in Icon.

Veneranduin Dominuin Agrippars , literanm literatorumque omnium miraculum \& amorem bonorum, appellat doctifinus Ludovicus Vive:

De Cornelio Agrippâ quid omninò fentiam, nihil habeo neceffe dicere n, nif quòd cummin literas declamitavit, videri volüt cgregiè literatus.: quanquan tamen non minus apud fanos videatur aucupio vanitatis delectstus, quàm otio sè Colers in vanitare Artiuminfectandâ. Claud. Ainosin Not.ad Emblcm. Alizati, pag. 63.

Teftem appelionon hunc aut illum emunctionis natis. Theologum, fed Cornetiumipfum Agrippam,quem in hife Myteriis(de Magin) norunt $\&$ agnolcune viri docti fuille Deliurn Natatorem. 10ant. Arrovvfrnitb Tact.Sac.p.87.

sixtsu Senenfis vocat Hareffos Lutherane Sectatorem. Sed quàm hoc fit at vero abnorme; patet excapite Cexto de Vanit Scientiarum,in quo B. Lutherum acrite perfringit. Quenltedt.

Quidam Magum fuifte, \& canis nig ri fpecie Cacodrmonem circumduxilfe, radunt. Scd-clariffinus fosnnes Wierus de P.xeftigis Dremonum 1.2.c. s. id merum Commentum enc affrmat.

Quidam Autores judic iis luis de cjus fama detraxerunt, eumque $M a c^{i}$ acculcamtunt : Alii vero ingentè profeff funt cos ignerantiâ \& affctibus inimicorum

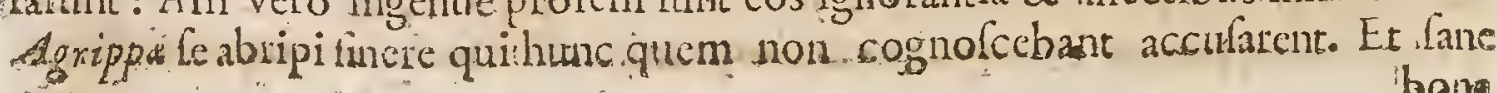
boun 
bona fide fatendum eft cum magnis \& preclaris detibus exornatum fuilfe; geninm ejus inter vaftiffimos \& luivientifimos eminuiffe; merizoque paffim nominatum fuiffe lui Seculi Trifsng giftzrm, ob eam qua polluit notitiam exi iniarum Th ologire sernm, arcanortm Medicine, \&'magnificarum Jurifprudentia Legum. Mioreri. Dictionarium Majus, Gallicum.

* Hic Author Komano Indice inter Hereticos primæ Claflis numeratur. Vid. Indicem Tridentivum.

Omnia ejus Opera, in dủos Tomos digeftasprodierunt in luçem Lugduni in $8: 1590_{2}$.

Hoc ejus Epitaphium lacobi Eatomo suctore:

Hunc tumulum haud Charites fervant, fed Erinnyes atre:

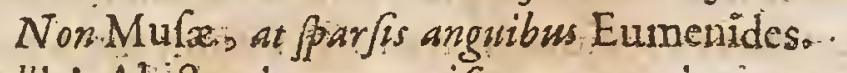

Colligit Al lecto cineres, mif Getgute aconito,

Gratague dat ftiggio liba voranda cant.

Qui quad erat vioun comitatis, atrociter Ore? i

Nunc quoque per cunctas raptats, agitgue vias.

Int wltatque adeo: \& Furias quia nover, at ornieis:

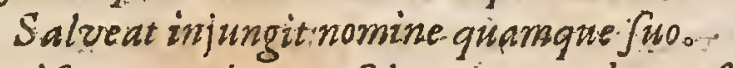

Omiferas arteis, qua fole ta commioda preftants.

Accedas Stygias notus ut boppes aquas.

\section{Rawl. Iov. in Elog:}

FRANCISCUS GUICCIARDINUS.

F Lorentia natus anno Dom. I480. Obiit 1540.

- Scripfst Hiftoriarum fui Temporis libros 20. ab ipfo Italicè conferiptos, 2xin Latinum Sermonem converfos à Calio Secundo Curione, Baflew apud Pex? nam, is 66. inf fols

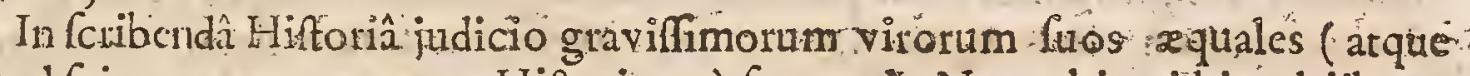
hand fcio an veteres quoque-Hiftoricos ) fuperavit. Nam ubi quid in . deliberationem cadit quod inexplicabite videatur, illic admirabilem in differendo fubtilitatem offentat, \& graves ubique fententias veluti fal accommodatè perfpergia.Mirum in eo ftudium veritatis inquirenda: Nihil enim temete red omnia neceffariis argumentis confrmat. Fertur enim Epiftolas, decresa, Foedera, collciónis exipfis fontibus haufiffe \& expreffife: Itaque frequenter occurrit illud, locutus ef in bac verba. Denique fuit \& rerum \& locorum, \& "perfonarum atque adeò confliliorum \& factokum tam diligens inveftigątor, ut omnes It:alia urbess. municipia, caftra, fluvios, quodque maxinuun duco, publica monumenta peni-: zùs infpexilfe videatur. Bodin. in Meth.Hift.p. $70,7 \mathrm{r}$.

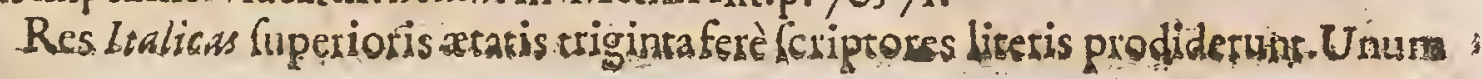
$M D X X$ 


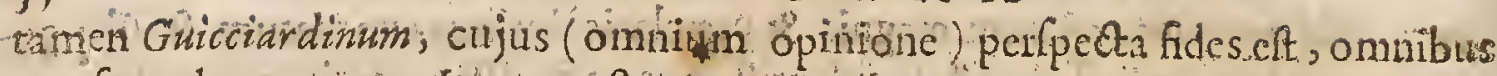
anteferendum putem. Ideri p. $79 ; 7,9$.

Francifous Guicciardinus prudens peritufque Sciipter a quitales lectores fubs facit. Liber eft \& verax: ab affectibus immunis, fitamen ab odio, quod retegere mihi non femel videturin Ducern 7 rbinatem. Sententias bonas utilcque

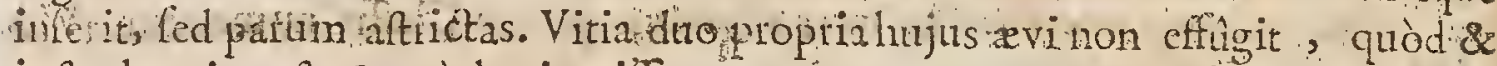
jufro longior eft, \& quòd minutilrma quxque narret, parum ex lige aut digni-

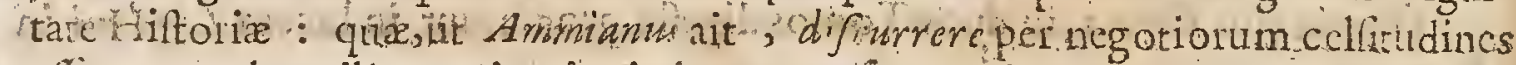
alfuetasnon humilium minutias indagare caufarum. Sed nec Orationes ejus fatis vegcta mili, aut caltigatx. Languent fxpè,aut folutè vagantui. Denique, une wcrbo, internoftros, fimmus ef Hiftoricus : interveteres, mediocris. Lips. in Not. ad r.lib. 'Politic.cap. 9 .

- Videtnritic Aucornulli vetenim pofponendus, nam fade diligentià, prudenriâ,cetcrifque vitutbus excellità in terum geftarum memoria, in confrlis explicandis,in hominumaturis notandis, in perfonis deferibendis, in Concionibus, Orationibuque referendis, plunina habet, qua in aliis, qux corundem tcmporum Hiftoriam fcriplerunt, defid rantur. Gefner in Bibliothec.

Vigetiphus nomen ad exteras quafque gentes Hiftoilc induftiacommeil-

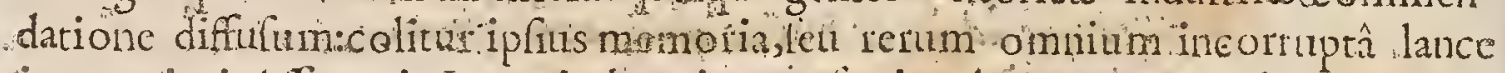
integerrimi Affertoris. Inerat in homine pratertim clatus a ac reconditus judicin vigor, Loan Imperial in Mureo Hitonico p. 98.

Francifcus Gucciardinus, Scitptor Hiltoriarum eximius, \& cum Thucidide

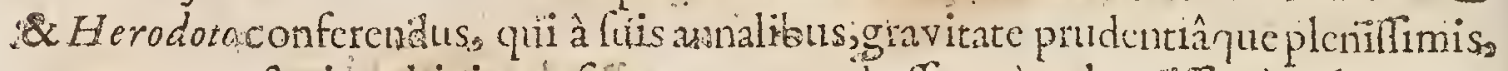
omnem vetufatis rubigiach frumque pracul effe quàm longifumè voluit, new que verbumad cos quodpiam accedere, quod putridam illam ac rancidam antiquitatem redolere Cut etam libris, quos érıditicujufpiam virilimâ perpolitos fuille contendunt, omnem Florentini Sermonis elegantiam, concinibaremque concedust; in creteris libris son ircim, quos, nullius cenfure, ut priores quinejue, fubjeccrut. Verè, anfecus, mihil ad hac tempus. Atque illius potiffinum firibendi rationem,utpote pudentem, feveram, gravem, ab incptisimprimis abhorrentem nilii videntur, in

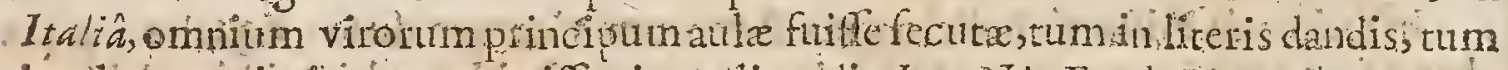
in rebus maximis atque givifunis explicandis. Ian. Nic.Eryth.Pinacotb $3 \cdot p \cdot 220$.

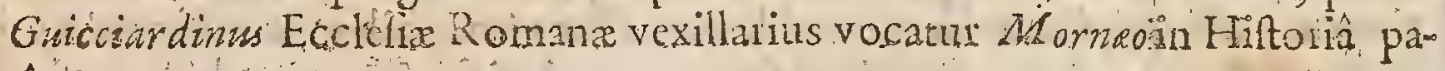
Satûs P.ss.

Acris judicinir, $\&$ ufus in publicis rebus adminitrandis. Pofevim in Biblioth. felect.

Nonne in omnium manibus ef Gucciarati Hiftoria, nec folum propter res quas continet, fcd etam proprer anetois cloquentiam, \& judicium in pretio Thabetur, \& prope atiquis comparatur ? Roland. M are A.1. Epirt: Epift.30.

Fracif cus Petri futhex antiqua \& nobili Guicciardinorum prefapia, primum obtinutitocum inter nobilifimos omnes Fiftoricos quìnquan feriplerint; quis

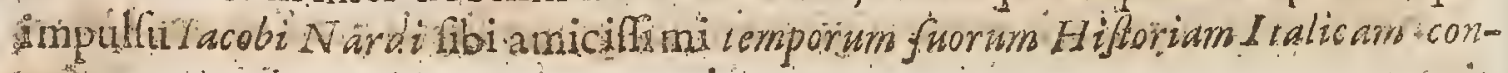
1 s.

sexwets 
rexit, non minori gravitate, ftylique elegantia, quam integritate \& eventutu h inarratione fideli, qux imprefionis ope apuld omnes Gentes in fummo pretio habetur, \& culciffmo cuilibet ingenio admi rationem movet. Ghilini Virorum Litseratorum Theatro. It talice.

Hiftoricus preftantifimus \& prudentiffmus, quamvis in Lutherum iniguior. G. Calixt.in Apparat. Theolog. p. 155 .

Guicciardinu quiburdan vapulat quod aliquibus locis Francific Marii at

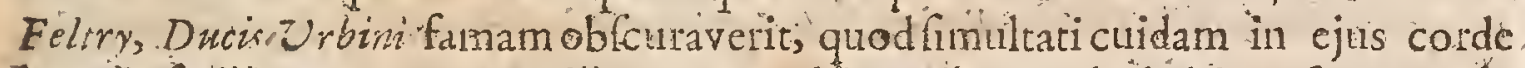
datenti afcribitur, cx quo ab illo Duce verbis ačribus male habitus fuerat, In quodam militari Conflio concto foederis illius occafione, quod ltalia Principes iniverant, ad ubem Mediolanum invadendam, ubi adcrat Guicciardinus q!atenus 'Generalis Trapalium Copiarum Imperator. Et fanè Guicriardinus plus ira-

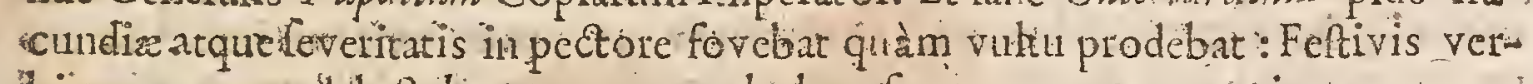
bis tamparum dolectabatili, ut ne verbulum fucctum pertotam vitam pronun-1 tiaffeccalcatur. Indolis cjus aufteritas in ejus Scriptis etiam deprehenditur : Qui

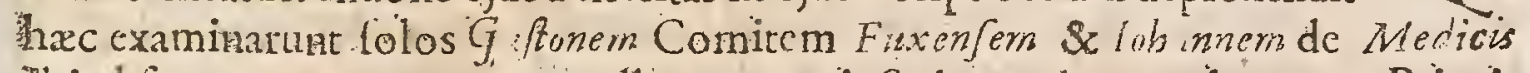
äbi oblervant, que rum naxvos nullilos notav erit; Sed cum duorum horumce Principum fola juventus calami ejus objectum fuerit, cenfuram ejus effugeruit. Cærerum venerabilis eft cjus memoria ut ingenui, minimeque fucati Scriptoris, - omina ad aquitatis trutinam ponderantis, cujus lances ab xquilibrio nullus odii vel faveris ventus dimovere poterat. Nihil feriptis confignavit quod vel non vidcritipfe vcla âb hominibus fide dignis relatum acécperit ; pura \& nativa eft ejus narratio, fed elegans \& cum judicio:Incipit ad annum 1490. ad Gallorum

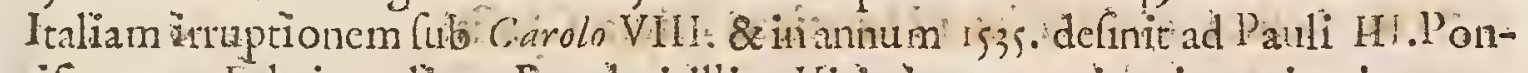
aificatum. Febris maligna Prxclari illius Viri vitam terminavit æatatis ejus anıo

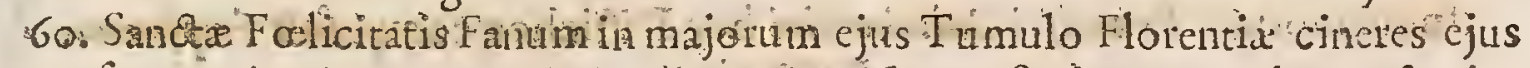
confervat; Angelm vero Guiscriardinu ejus Nepos Scriptorum ejus poft ejus mortem editer fuit ut in hominum memoria revivifceret; Tanco ctiam cum ap= plaufu excepta fuerunt ut ex Italico idiematc trandata fucrint in Gallicum, tipa nicum, Angli wm Belgicum at toti Europe cortim copia freret. Ifacus Bullart. Ac.d. Scientiarum Tom. I. Gall.

Guicciardinus fedufus êt Hilforlographus, à quo, mé quidem Cententia, tam accuratè quàm ab alio quovis Rerum ejus ævi notitia comparari poteft. Et fane harim etiam utplurimum, idque honorationi loco, pars magna fuit. Nullateinus verifimile eft quod vclex odio, vel ex favore, vel ex vana gloria tes nirriatas alteraverit;cujus fidem faciunt libera judicia de Proccribus ab ipfo latá;ilique inprimis à quabus honoribus auktus \& idmunera adhibitus fuerat, ut de lontifice Cles mente WL. Quod ad illudattinet cujus gratia potifimum fibiabblandiri videturs ejus niminum digreffiones \& fermones, horum plures boni funt \& acutè dietis ornai;fed his nimium delectatus eft: Nam ne qquid intactum tcliny!tat cum tamen amplifimum \&xpene infinitum arguimentum tracket, languidior quodammodo fit cjus orario \& Scholafticam garrulitatemfapit. Hoc etiam animadverti, quiòd cùm de tor Animis seventibus, de cam multifariis motibus \& con- 
fliis judicet, ne umm quidem eorum referat ad vitutem, ad Religionem ad corfientiam, ac fi harum nulla in univerlo orbe non jacerce extincta: Omniumque rerum gctarum, quantumvis in fe fpciofarm, caufam reiicit ad ali quam occaficnem vitiolam, aut ad aliquod commodum hinc Authoxi pro. venturum. Fingi tamen non poteft quin ex innumeris illis actionibus de quibus. Sententiam fert, nulla rationi fuam originem debcat Nulla corruptio homines tam univerfim invadere poult , yuir aliquis contagiun ejus effugerit. Quaproptcr metuo nc is feribendi chatracter guftûs ipfus vitio quadantenis fit trì buendus, imo fieri potuit ut aliosfuo pede metiri voluerita Wirbael de Morsragne. Tentaminum lib.2. Eap. Io. Gall.

Ex ltalis fupcreft Guicciardinus, qui(relinquo quod in quàn plinimis $H$ t. forici partes ignoravit) tam frigide 2 invitufque ( allormm victorias \& gloriam narrat, quàm accuratè lubenfque adverla quxque, quanturnvis mijimas fortis nx potentifimo belli numine ejaculata:quemad odum $S_{21}$ cilirum in alicujus fuminis trajectione Submerfonem perLequitur ateque dilatat. Dum videt Carolo VIII. totam Italiam ab filpibas ad Neopolin nemine penitus obgfente occupan ti, victoriam abfque fufpicione falf adiminon polfe, in Gallorum quorutam militum intenccione paucorumque, qua fine tiotorià obtineri non potuit,, totus eft, magnam camappclians ftiagem:-Carolo tomen agri dominium fuperfitiffe diffiter i non aufus eft. Sed qux de victoribus ftrages fieri potuit? f d duis Sermonem inftituit, eisfemper plus meritisattribuit, \& regionis laudes magiso : quàm luæ gentistes geftas perfequitur, unde maxima laus ducenda eft Claud. - Ferder. in Autor. Cenfion.

* Hic Author rejicitur inter Hareticos Prima Claftis

In memoriam Francifci Gricciardini hoc Diftichon compofuit Stephismest
Pafchafma.

\section{A Tito nullis, figuismibicredat, in Orbe" Clarior bio wna florwit Hifforiâ.}

\section{P. E R U S B E M U S} ar. An. D. D Atrivis Venetus, prater illuftem fuigeneris nobilitatem, illi acceffi,

Ioctrina fungularis, facundja, admiranda, \& fumma vitæ integritas. Qua virtutes illum patrix, totique I talie commendarunt: Romano potillimùn. Pon tifici : qui ut ejus nomen glorix fplendidi oris ritulo ornaret, \&'anguftis redde ret, Romana Ecclefix, Senarufue Apoftolici Cardinalem creavit amplifimifque beneficịs cumulavit. Is $C$ iceroniane eloquentize fedulus admirator, \& imicator extitit; Orator, Pö̈ta; \& Hiltorichs fuo tempore nulli fecundus, antiquis certè conferendus. Is plurimos ingenii felicis partus's monimenta pofteritatí xeliquit : inter qux hàc habentur prachipua. De Imitatione Sermonis lib.s. Epifo-

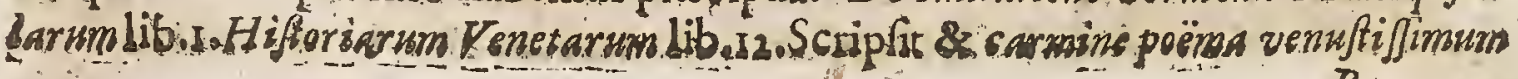




\section{CELEBRIORUM AUTHORUM.}

Beracum De Atná \& de Calice. Peivenit ufque ad annm Ceptuagefimun feptimum. Morti conceflit Anno lalutis I547.55.Cal. Februatii. Bo'gurd.in Icon: Fuit o mnino perpolitúm Bembringenium, perque acre, maximéque perfpicax, acutumque judicium, plurima in alios, ligendis, collocandifque verbis, multum ponebat operæa, atque in câ re magnam cùm prudentiam, tum verò ctiam diligentiam adhibcbát - Sulat praterea cjus verfus Latini multi, dulces elegantefque; ut me quidem zquè pi opemodum, ac vetcrum illorum l'oëtarum lcripta, delectent. lown.Cafa in Vit.Pex. Bernbi.

Petrus Bernbu; quem orbisecrarumcantat nec injulas vixit cnim, quancus en vitæcufus fuit, in virtute totus:iscumalias colut Philofophiz partes, tum verò Pö̈ticam arcem-anavit more quodam ardentiffmo, ejufque ltudium à primâ pueritia amplexus, nunquamenc in extremà quidem lenckute dimilit : feriplit autem erfus in omnixtate multos, \& Icripfit omnium elegantilinè,fic ut Apol 10 dictalfe vidcatur. Manumprafar.ad Torquat.Bernb. Petri filium in Virgil.

Uterque Petrus Bembu \& I acobus Sadcletus, verfu'\& pedetri oratione policifimus fcriptor. Yerum illius multalicentiofiùs (ut temporum nequitia, \& Domini cuilerviebat, mores fercbant) [cripta extant:Hujus contià fcria ferè omnia, \& digna perfonâ quam fuftincbat. Uterufque in difpari morum inftituto, for-

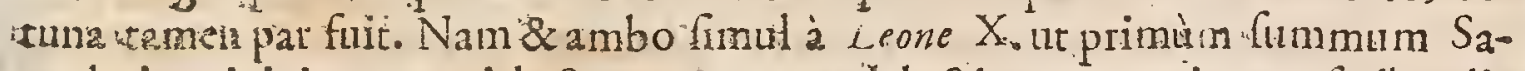
cerdotium inivit, ex omni doctorum numero delecti, quorum in conferibcndis Epifolis operâ \& ingchio utcretur: Dein \& in Cillegiun C'ardinaitiv codem anno \& Panio Ifl. allecti lunt; fub quo \& futis concelfere. Thuan ad Ann. I547.

Petri Berrbi mira illa fuit lemper in imitandis optimis auctoribus tam Latinis quam vernaculis felicitas, ut non $B$ embur plerumque loqucntem, fed quicr ille fibi propoluerit, vel audiie, vel legere videamini--ejus carmina vel Latina vel Veraculasdulcia, mollia, $\&$ delicata. Lit.Greg. Gyrald.

Petrus Bembu illutri dignitate \& famâ vir fuit:quameamen cliforiâ fûâ Vonetâ apud ine nen auxit. / acet in narrationibus, velfiget:in verbis affectatiunculas babet materic aut viro ferio parum dignas. Nulla vox nifi es Tuliano aut I niano penu:\& qux fic dicinompolfunt (quippe nova,vel iis ignota) miro verborum ambitu comprehendit. I pra etian tota fcriptio \& formula fic compofita, qual hæc omnia Roma gêta, \& Republicâ illâ ftantc. Sunt.in quibus rideam ; funt in quibus indigner. Et cùm tam curiosè à crbis fibi caverit, teperio alibi, qua, no: dicam Tulliana non funt, fed vix Latina. Lips Not.ad lib.x.l'olit.c.9.

Petru Bembus in illa puerili fuit haref, ut religio ipfeffet leribere aut dicere aliud, quam a Cicerone fcriptum aut dictum---Et advertite, Auditores, inepti Lominis impietatem cum parifultitiâ conjunetain. Is fiquidem Epiftolas omnes $P$ auli palam condemnavit, eafque deflexo in contumcliam vocabulo Epiftolac crits eft aufus appellare;cum amico auctor effet, ne illas attingerct, vel fi cœpilfet legere, de manibus abjiceret, fi elegantiam fcribendi \& eloquentiam adamaret. Atque ut creteran carminum ejus obfconitatern taccan : quid cjus Epiftolis ineptius, \& quidemillis, quas Pontificis maximi nomine, \& de rebus maximis frijplit\&ad vicosmaximos? Meuriar ego cum Scipione Gentili, \&luam gravi 
panâ, fr vel unam mihi in tor illis voluminibus Epiftolam oftendane amatores:

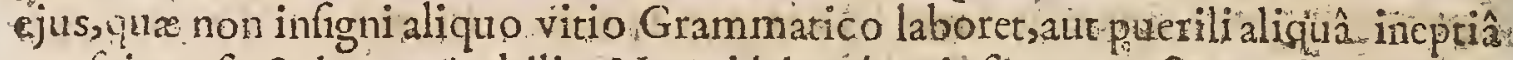
confpicuafit \& demonttrabilis. Ne quid de rebus ipfis atque Sententiam dicam rapicntix inanifimis, \& mirè languidis, \& (reptendum elte enim, quodejuspro prium maxime eft)ineptis. Thom. Lanfius in orat.contra I taliam, p. 736,737 .

Petri Érnbi nihil extat, quod fciam, prater aliquot epiftolas;in quibus exofcum lor non modò dilucidum quoddam, fanum, \& ut ita dicam, Atticurr diccudi genus; fed probitatem, humanitatem, ac fingularem ingenii candorem iñ Orationes veluti in Speculo, relucentem, Erafm. in Ciceroniano,p.20s:

Bernbu \& Sadoletus boni.Pö̈tx. Scaligerana prim.

Cultifrmis Elegis amores cecinit, fedialiquando infra dècormen, itbyp

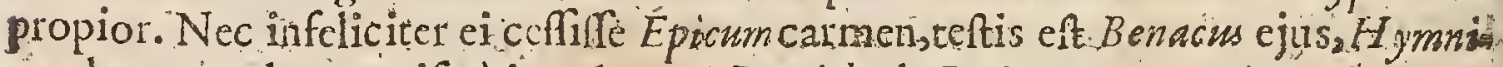
gue hcroo pede magnificè incedentes Borrich de Poëts p:94\%

Bcmbm nervis ferè lemper deltituitur-... Cùn Dominum. I efum Heroa vocat valiè me commovit Sanèvox impia \&utroque indignane argutetux quifpiam Heroem è femilfe benm, exaltero femilfe Hominem. Non polfunt monftronum figmenta vero Deo nofro convenire. Benacus cumad Catull lucernam vigitätus: videatur, profectò illius cxhibet tcnuitatem : ju lepore longè ab.ft. Extat \& Ara

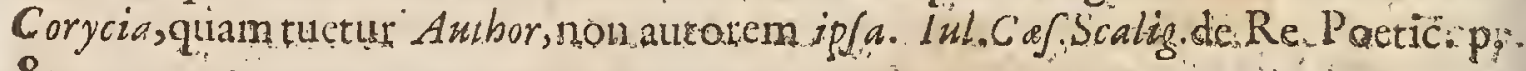
800.

- Eruditiflimus Heinfins Oratione ig. ait Bembiom folum propé eá tempeftate Latine fcipfilf; \& quod proprium tum Italorum eraspuram ac ingenuam nec calamiftis ullis aut pigmentís infufcatam atque inuftam exclüflfe. Orationem.

$B$ embus aut mulat in gratiam fuorum Civin aliter atque gefta fuat Scripfits: atut certè Guicciardinw Gepè mentitus eft Bodnn. Meth. Hilt.p.72\%.

Tanti afimabat átine fcrbendi facultarem qua polebatu proftereturtiane nequidem Manmano Marchionatui permutare voluilfe:-

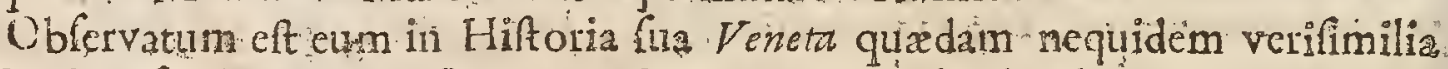

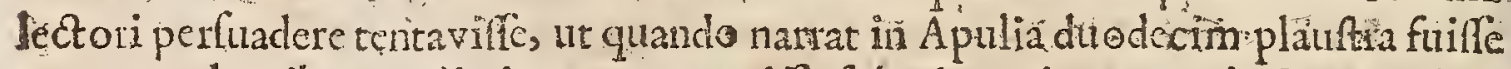
onerata volucribus.pralio in aere commilfo fe invicem interemptis.Feruntetiam eum in çadom hiforia plus amoris erga Patram quam erga veritatem demonAtraviffe Antonitus Teifier, Elogiis Viroium Eruditorum. Gallicé.

Ejus Eruditionem ingententam exquifitum de alionm operibus judicum: Atipabat, nt ex omnifere italia ad ipfum varia mitterentur Scripta, ut fuam de illis ferret fententiam:culis reiluculenti teftes effe poffine Sannazarius $\&$ Fra caforius, ambo inter primarios llius wi Poetas habiti, qui Poemata fua prelo. fubjicere noluennt, pritifuam ab ip fo luftata fuilfent. Ghilini. Theatro Lito satorum Virorum. Italice.

Opera ejus 13. 'Tomis diftuct, Angentime prodierunt anno $6090^{\circ}$

Sepultus eft Roma ad B. Mariam, fupra Minervarm poft aram fummam inter Zeonis X. cui a Secretisfucrat \& \& lementis VII. Monumenta. Ubi-hoc ejus; Epitaphium:

D. O. M : 


$$
\text { D. O.M. }
$$

Detro Bemboup atricio Vencto, ob ejus sngulares virtutes as Paulo III. Pont Max. in Sucrum Collegium cooptato Torquatus Bembus pos. Obiit 17. Calo.Febj. 547. vixitiannos 7 fr. M. T.D. 28 :

Hic Bembus jacet Aonidun Laus maxima Plicebig.

Cukn Sole, Lunâ vix periturus honos.

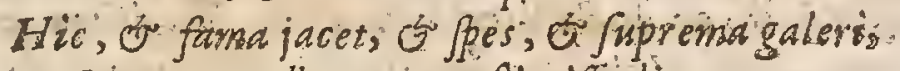

Quiam non ulla queat refitusiffe dies.

Hiz jacet exemplar vitá omni laude càrentis:

Summa jacet Jummâ bic crom pietate fudeso-

\section{Aliud Epitaphilum:}

- Tufce, ${ }_{0}^{A}$ Laria $M u$ se decus, optime Pates

of Veneta friptor nobitis Hifforia.

filens tibi purpureos forès, pargitgwe recentem

Adriácum Pelagus, Tybirs, Arnts aquam

Eit Nymphainf cribunt Ttumulo boc hiferabile cärmense".

Mors rapuit Bembun, deliciás Hominum:

Bobjfard. in Icon:-

\section{JOANNES ITERIUS VALERTANUS.}

$\mathrm{B}^{\mathrm{o}}$

Olzanus

Beluni in Venetive op

ppidó natus, anno isso. viviere defiito.

Clar. A

$\operatorname{Mox} \times$

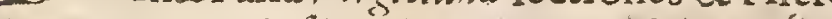
dảntur. Extat.cjufdem libellus de infelicitate Literatorum. Poemata ipfous legunsur T.2.Delit.itat.pag. II 93 .

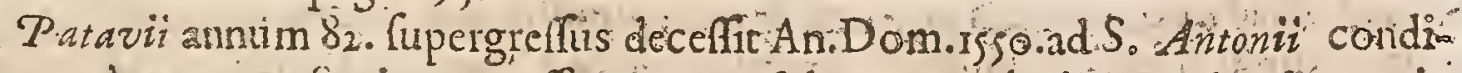
tas, quò vergente Senio concefferat, nt poft longam veluti peregrinatiónem in nidulo fuo, ex quo puer evolaverat, ad quiétem xteriam fe componerer. Is Vrbani partui Francifcani quil Leonis $\mathrm{X}$. przeceptor fuit, curâ in literis educaths: inter doctiffimos feculi fui mertuit recenferi, 2 Medicea Familie, cojus favorio

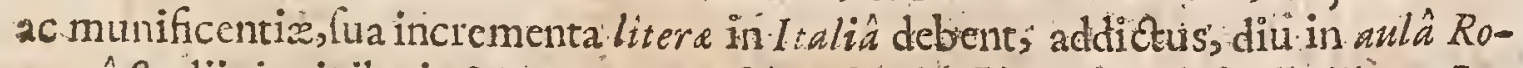
manâ ftudiis invigilavit \& magna negotia tractavit. Ejus inter alia Virgiliana Le-

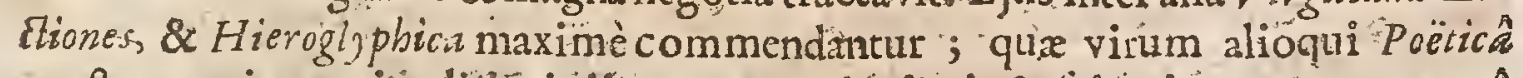
preftantem, in omni politióris literaturæ,antiq̨uitatis \& lcicntiarun genere torâ. yî́ầ verfatum oftendunt. Thuair. ad Ann. Isgo.

Picrius Valerianus vir tum probitate, tum literarum ftudio mihi chariff mus-..-. De Petro Pierinm fe fecit,juvenis multa Crarminum volumina edidits. multafupprimit,nunc preffiore pede incedit. Multam certè ubique exuditionem

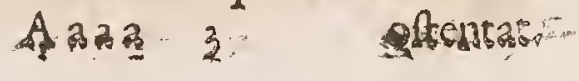




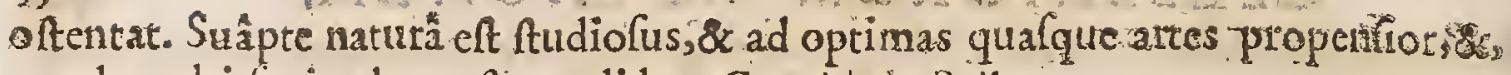
quod multi faciendum eft, candidus Gyrald de Pö̈t.

Pierius, Hieroglyphicorum polt Orum Lcriptor praftantiflimus. Bonifac..Lud. Hif. p. 600 .

Imprimis vide Pierii quinquaginta octo Hieroglyphicôn libros:- O.pus erudiditum, fed in quo illud probare nemo pofit, quod tam multa ut Hierglyjbica referat, qux talia olim habita effe,nullo ad ntuere poffit auctore. Voff. in Etymol. p. 248 .

Multa fides in fanctifimo illo ac doctifimo Sene, qui Virgilium ex Romano Codice emendavit, Ioanne Pierio.Valeriano, viro digniflumo gui ab omnibus ametur \& colatur. Franc, Robortell, de Are Criticâ.

Ioannes Pierius Valerianus Virgilium collatis variis Codicibus emendavit la bore profectò adlectionem præcipui Vatis perutili. Lud. Viv. de Trad.Difcipl.

Ejus Scripta cùm Poẹticatum P'hyfica; \&. Hiftorica, \& Oratoria,verantur jam eruditorum in manibus peracris ingenii adfcitâ laude, cùm verè in fingulilis folid nervos doctrine liceat agnolcere, vel id fummo tekante Scaligero, qui Pierium. Pö̈te nomine proffus dignum, non verfhficatoris affirmat. Vulgatifimum præc caEeris Hieroolyphicorum Opus, qu od arcanas éfgyptiorum refert notas, dum cutriolos Antiquitatis rcadit ábundè faturos,preclara mor alis, ac poltice documenta recolit, ad imitabilem non infipicntis populi normam congefta. Ioam Imperial. in Mufro Hito :

Valerianus wocábatur Petrus, verùm à M. Antonio Sabelliconomen ejus mucatum Picrius dictus eft. Patre orbatus anno xtatis nono, in tantam paupertatem fe redactum vidit ut apud nobiles yuoldam Venetos famulari coadus fucrit. Poltquam aliquandiu in ejufmodi mifeisa languidam egillet viram, Vrtarius Bolza:o cjus Avunculus in dom fuam illum iecepit, \& literis humanioribus imbut: Cùm autem Yiariss mirifico polleret ingenio, tantos in illis brevi tempore progreflits fecit, ut inter eruditifimos bi cocvos fama ejus increbruerit. $A n-$ smirs Teifser, in Erudicorim Elogio. Gallicè.

Tantaconftantia, tamque felicifuccellu literarum ftudium amplexus cft, ut tandem ad cognitionem pervanerit ravionm illorum arcanorum qux Seculis venturis pofter uofti allitic penctrabun curiolo fuo libro Hierogiphicorm, qua corrat è gravifimis Antiquitatis Authoribus, qui non minus eft commendabilis Eloqucntix Latinz ornamentis quàm Aigumenti luculentiâ....... n tota Ttalia eximio fuo ingenio, profundaque eruditione tantam celebritatem fibi peperît ut inter intimos ejus anicos recenferi polfcut viri illi Doctrinâ fuâ non minus quam Cplendida conditione infignes Andreas Gritti , Baptifta Egnatius, Marcus Antonius Sabellicus, Romulus dmazoses, Cornillius Muffo, Cardinulis Bembus, aliiquic complures; qui omnes certatim mortem ejns defieverunt poftquam eum totâ ejus vitâ fincriffrmo luo itudio colinilfent. I saacris Bullart. Acad. Scientiarum. Gall.

Pierius Hieroglyphica elaboravir, res eft haud magni momenti. Orús bonus art. Scaligerana 2. Gallicè. 


\section{CELEBRIORVM AVTHORVM.}

pievius $T$ ractarum in Dialogi forma confcripfitfuper Eruditorum infortuniis, que continuavit Tolliur..lllud Opus Pierii vocaturà Voffio curiofus liber \& egregius Sed ad nobis faftidum creandum unicè videtur laboralfe, vel faltem ut nos moneret profperx fortunx ufum einon effe fperandum qui eruditionem ftudis fectabitur. Imò unfelicium illonm rironm qui Literatonm nomine veniunt sumerum multiplicet, eorum calamitatesperfperfit yasiis naturalibus cafibus qui infortunio minimè funt ascenfendi. Et fic optandune effet tut majorit cum delectu folidionique judicio s ynopfis illa fuiffet elucubrata, eique illuftria tantum exempla fuiffent inferta qua lectionis locum tentre poruifent erga illos qui in profanum utam liberales difciplinas fe convertere poife putant, id eft is mon uti ad fuam probitatemaugendam, \& ad contendendum ut Eceléfizel Reipublicxutiles cvadant in Statione cujus tutelam Providentia in kujus vitie itinem

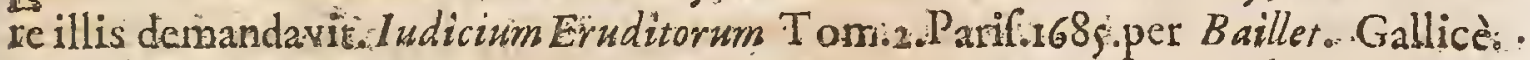

Ex Poeticis ejus. Operibus, qua liculentis argutiós, \& lo lo eleganti onnata: funt, caniicere licet, qùò, fi peculiarites corum ftudio fe fe addixiliet, unus du-

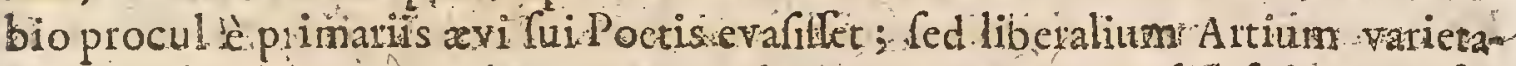
te impcndiö delectatus;ad rem tumam animumanquam appulif, fed mente fua ccleriatque vivida per optimas difiplinas tranfarrendo, yoluit potius-in fingur lis medroc iter enditus effe quàm unica perfeetè onnatus. Inter laudanda $O$ pe ra qua cjus. Ingenii foetus funt \& in lucem prodierunt, perelegans $\&$ magna . làde dignum eft Latınum illud de Hieroglyphicis - Liber ifte verè egregius \&: fuctuofus utilifimus eft quibullibet Literatis; cum innumera hinc haurire pplfint ad Scripta fua exornanda: Ghilini.. Theatro Vironum Litratorum.Italicè.

ExtantHicrogly phica : Pio facerdötum Barbis: De Literatorum infelicieate Libri Duo: Antiquitatum Bellunenfym Cermones 4. Francofurti ad M. auno i6.7. S. in $4^{\circ} \circ$.

\section{Hoc ejtis Epitaphium: :}

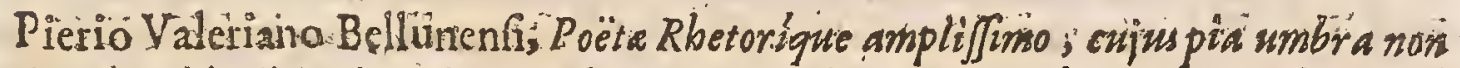

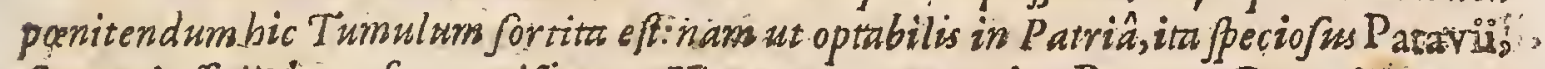

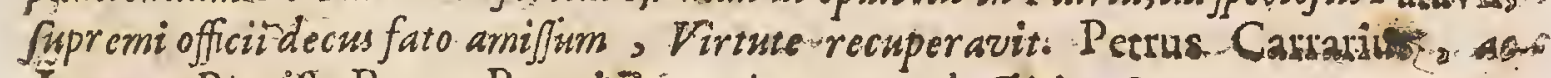
Joanues Baptilta Rota 2 Pacaviñ unamimes grato hosfiti poss.

Pieridas dum Pierius Sectatur, Orci

Nil timet infidias, bunc fera mors raprito.

Illa recem aterne, offentant hac monera vitax?

Hinc anedius vite Pieriurfoue neci.

Abjeflit has annos trifes: at promia lavidum

Atgue animam haseryant invida mors morititis 


\section{HULDERICUS ZWINGLIUS}

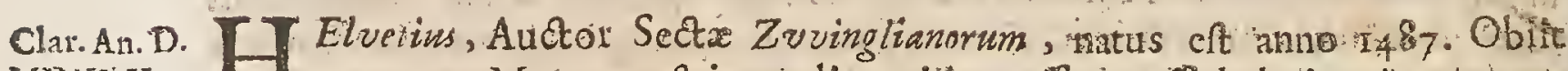

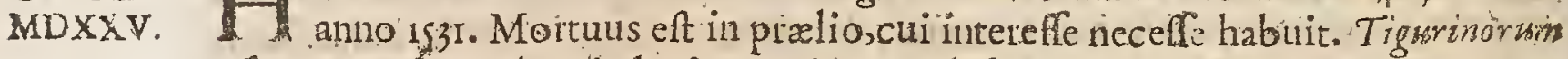
enim mos elt, ut, cưm in holtem exitur, Ecclefia Minifter primarius und prcice-

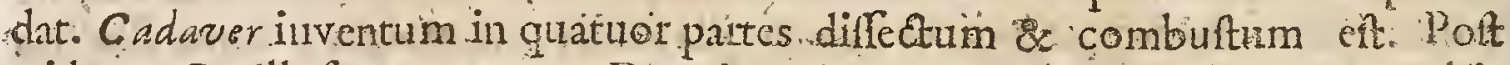
triduum Corillefum repertum. Docuit Glarone primùn, dein Tiguri. In vetbis S. Cone Metonymiam elle affirmare aurus eft. Konig.

Vir erat Zuinglizusin omni difciplinarum genere folidè doctus quii \& benefcio trium linguarum principum, quas calluerat, felicifimè Scripturas fcrutabatur ix tractabat. Idiomate fuo, id ent, Serrone Helvetico dil inifimus habobatur. Iacob.Verbeiden. in Vit. ejus.

Vir verè pius, \& folidè docus, cùm in omni litentrum genere, turì in Sacrâ

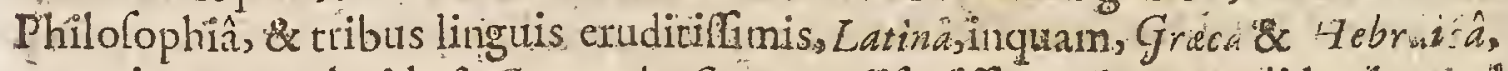
atque in vernaculo, id eft, Germanico Sermone difertiff mus,immortali daude apud omnemporticatcm dignus:quem addefcens olim Vetus T.ejtameizturn. Latine Tiguri enarantem, \& in Ecclejus Gernanice verbum Dei enucleantem andivi:Ced proh dalox nimium brevi tempore. Gefner in Biblioth.

O parnobile Synafpiftarum Hulrichum Zuinglium Tigurina $\$$ loannem Occam Lampadiurn $B$ afleenfis Ecclefiarum nobilifimarum anftatuatores : utrunque ex Antichrift faucibus omnipotentis Dei manu ad illum verbi Dei gladio jugulanAum erutum:quorum focundum Deum excellenti dootrinx, fumma fadei, laboribus incredibilibus, invista denique conftantix, tot ubique anime, ac prefertim Alpinarum Gentiumpars longè maima affertionem ex Antichrift tyranide ir Chriftanam libertatem dcbent: long iùs ctiam multò progrefíris, nffi, frc merentibus hominum peccatis, opus Dorrini à quibufdam(proh dolor)ejus ipfus architectis fuiflet impeditum. Theod. B 7 . in ! con.

Zvoinglius Sacerdos factus divinis fe fudiis totum devovit. Etbnica non magni fecit; prater unum Valeriun $M$ xximath, quem Eximplorum causî memorix mandavit-D-Dodrinam \& judicium ejustchantur S.ripta, vel ringcnte

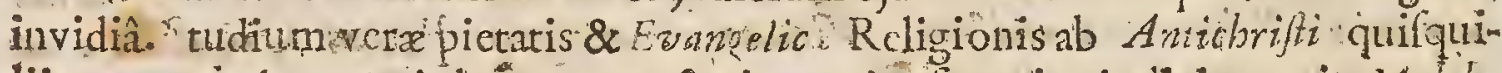
liis reparganda, omnis lo querur pofteritas;cujus funcerius judicium erit. $M$ clch. Adarn. in Vit. Zuingl.

Zuinglius qui Sectr nomine fuo infignitre Coryphrus fuit , fimplicen admodum fe exhibet fuis in Biblia Commentaliis, parumque in fudio Critices exercitatum: Qumvis modeftion fie duobus illis aliis proteftatrituri Patriarchis Lutbero \& Caluno ilden canen qubus ilti vitis laborat, fuafque projudicat tas opiniones fequitur. In hoc infuper elucet cjus modeftia quòd Vetercm Latr-

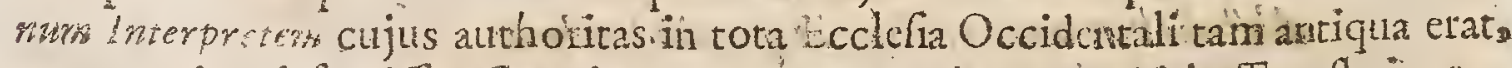
non omnino deferuiffet. Cum itaque novam Proplotiarim drice Tranflationem adoriaffethanc non evulgavit nificum Vereris illius Interpietis Verfone qux 
Zulgatadenominari folet. Novx huic J faix Verfoni ritulum dedit Complanatio I a ia Propheta. Cum verò tenertur nova hujus Transhationis A pologiam conatexerc, in ejufdem Profacine notat quos Authores fecutus fuerit tanyuam Di-

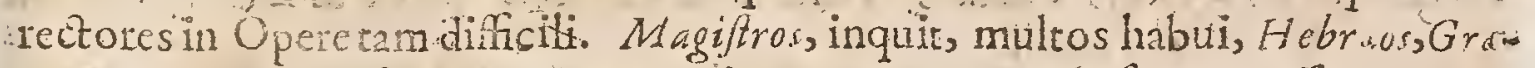
$\cos \approx$ Latinos, quafi veteres 8 novos interpretes ex zquo fecutis eflet: Unde - etiam paulo polt fibjungit, Invenicbam apud Septuaginta's que Hieronymus ignoralle vie plotur, of contra apsd Hieronymum multos gue ipi ignoraverunt. Hac fane genina Methodus ent, fed Author in Biblionum Critica non fatis edoetus clat ad coptum fun in tora cjus latitudine exequendum. Jef. Kich.Si. mon. Crit. Hift. Vecteris Tent. lib.3.cap. 14.Gall.

Icon.

Scripfit Eprfolas mulras, doctrinâ \& pietate mirâ refertas. Boifjurd.in

Statho confecit omia fuaftudia, certas eis vendicans horas, qux etiam non omifit, nifi feriis coactus. A fummo mane ad horam decimam lectioni, Interpretationi, doctina, fcriptioni dabat operam prout tempotis \& terum poltulabat ratio. Poftprandium audiebat vel narrantes, vel conflia rogitantes, aut confabulabatur, aut dcambulabatcum amicis ufque ad horam ficundam hine setiam reditus adlaborcs. l'oft conam ubi paulifper deambulâfer, ferè literis acribendis vacabat, interdum, a mediam ufque noctem nilit agens aliud. Pratcreà quoticfcungue negotia cogcbant, \& Cenatui fervicbat. Ofuvald: $M y$ conius in Vitâ ejus.

* Vlricus Zvvingliusinter Hereticor prima Clafis rejicitur.

Extant ejus Opera in 4 . Tomos digeta. Tiguri, 1544 . 15 I. I595. in Fol.

\section{T. HOM A S MOR U S.}

T Ondinenfr, Filius Tobannis Cancellarius Angliaprimus Minifter Juftitia, 1. Gub Henrico VIIT. Oxonii Thonse Linacri andicor fuic, tantumque in liberanibus tzudiis profecit, ut eruditione \& plurinarum Lingg. notitiâ multos fui fcculi longo poft fe intervallo rdinqueret. Ab Henrico hoc crebris Icgationibus adhibitus, Cameracenfe pacificationî, inter Francifcum I. \& Carolum V. Imp. interfuit. reverfulque Magni cancellarii axioma impetravit: Sed quod Regis divorium approbare nollet, menfes 44. .in carcere detentus pofmodum; cum conftanter in propolito perfeveraret, capite plexus eft, Ann. 1535. xtat.626 Hofran. in Lexic.

Scripta ejus funt: Vtopic Tibriduo, five de optimo Reip. Statu_-Epigrammata valia - Ex incino quxdam converfa Latine - Declamatio Thomse Mori Lucimica refpondens - Hiforia Richardi III. Regis Anglic imperfecta-Rew Sponfio ad convicia Martini Luheri congefa in Henricum VIII. Angine Rem gem - Expoficio Dominicx Paflionis imperfecta-Quod pro fide mors fugienda non eft - Precatio ex P falmis, '\&c.

Vir perficacis \& acuti ing cnil,acerimijudicii, memorix felicifimx, mul- 
re lectionis, fingularis enditionis. loan. Pit feus.

Fuir vir doctrinâ variâ excultus, \& ingenii amaniffimi, quippe Theolögus:Philolophus, Orator, Poẹta 2 Hiforicus, lingux uraca \& Latina perùtus. Bellarm. de Script. Ecclef.

Thoma Mori ingenio quidunquam finxit $N$ atwa kel molius, $y e l$ dulcius, vel felicius? Erafr. Epilt. I. . Ep 2.a.

Nonalium effe ćcio in Angliâ vel ingenio tali praditum zel virm ìcormptioribus moribus. I derribid. 1.26. Epilt 53. :

Non abirror levioris cffe operæ Morum effingere, quam Alcxandrum Ma gnum,aut A chillem nec illi quann hic notter inmortalitate digniores eraur $1 \mathrm{dem}$ bid. lib. so. Epift. 30.

Britannorum doctifimus vocatur Scevola Samartbano iii Elög. Germani Brisii. Anglicus ille Socrates appellatur Julio:Scaligero in Epiftolâ.

Thornas Morm: Anglus, circa annum IjI3. quo tempore etat Vicecenes civistatis Londinenfis confignavit Hiftoriam Kicbandi III Anglia Ricgis ; qua :il operibus ejus Lovanii editis reperitur. Sed ut fusè perfequiriur, quibus lcelćribusille ad regnum pervenerit: ita quomodo id geffecit, non exponit: Nempe omnino opus eft imperfectum: ac, uec eâ parte, quam habemus ultimam manum acs. cepit. Elegantiâ quidem Laini fermonis a aliis ejufee viri operibus longè vincitur. Sed Anglicano Cermoneab codem quà elegantifinc coarata integre in volumine, quod Anglica ejus opera continet, invenitur. Vitam prarereà $E d-$ vardi V.. Cripfr, tefte $B$ aleo - Profecto viromuinò eruditus fuit:; quicquid in fuo. Antimoro dicat Germanns Brixius, objectat quidem non pataca, quz eum fuggerint, pleraqu fanè minutai. Sed quis ca non condonet lubens viro o mni: penè virấ publicis muneribus diftento \& tandem per varios gradus ad cancella. rii munus evęo: Vof. Hilt. Lat.

Thornas Norus, vel co nomine magis laudandu's eft; quò Britannie Infula serminos vìx unquam egreffus, ẹruditionis famâ univerfarn Europam impleveric: Zondiri honeftâ familiâ natus, nullo magiltro puxeunte, ad exactam Lasinarum literarum cognitionem $G$ recas etiam adjunxit: Ab ils fudiis ad forenfes caufas

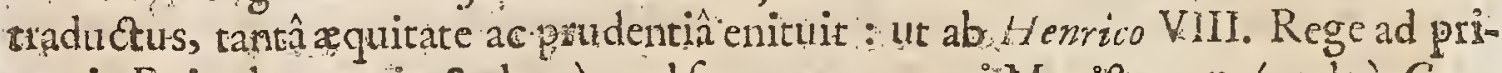
maria Reipub . muaia; \& demùmad fupremu m regni Magiftratum (vulgò Cancellariatur appellant) Colâ virtutis conmendatione vocatus fuerit Aub, Mi raus de Script. Ecclefraft.-

Fateor inoenium felicifimè natum, \&quod nihil non potulfet efficere, fi tosum his ftudiis vacare licuiffet. Caterum itto puero vix tenuis odor literatura melioris demigrarat in Angliam. Deinde F arentum autoritas,ad Leges ejus Genis difcendas, quibus nihil illiteratius, adegit $:$ mox in caufis agendis excrcitatus, hiuc ad Reip. munia vocatus. Vix: fuccifivis horis refpicere potuit ad Eloquenacix ftudia: Tandem in Regiam pertractus, \& Regni Regiormmquenegotiormm andis immerfus, magis amare potent fudia quim colere. Et tamen dicendi gewus, quod affecutus eft, magis vergit ad-ljocraticam ftructuram ac Dialecticam (4) 
cte aibilo M. Tullio inferior eft. Erafrn. in Ciceroniano, p. 174 .

Acutus Thomas Morus, \& plenus aculeis, ac ingenii. Lud.Viv. de Trad. Dilcipl.1.3.

De Republicâ Ccripfit olim Plato primus : Cecundüm cujus inftitutionem tum demum vivent homines, quum aliqua exiftet Civitas folis fapientibus habitata. Idem Utopia continger Thome Mori. Legendatamen \& Platonis Rejpublica \& cjuldem leges, atque hæc ipfa Vtopia, ex quibus non pauca anotabuntur Regimini $C$ ivitaturnapcrquam utilia. Idcrn ibid. 1 . .,

Vtopizer Mori, fi nondum legifti, fac requiras, fi quando voles ridere, imd ta fortes iplos intueri, unde omnia ferè Reipublica mala oriuntur. Erajgr. Epint. 1. r. Epit. 8 .

Vtopizrn hoc conflio cdidit, ut indicaret quibus rebus fiat, ut minu common dehabeant Respubtica, Led Britannicarn potifinum effuxit, yuam habet penitus: perfpectameoguieamque Secundum librum priù fripferat per otium, mox per occafionem primum adjccir ex tempore tque hinc nonulla distionis inaqualitas. Eraf. Epift. 1 10. Epilt, 30.

Primus qui talis imaginarix Rcipublic formam fcriptis confignârit, fuie doctifimus ille, ac omuium calculis fapicntinimus habius Thomas Morks Profeetus Saris scriniis, fet Princeps Scribarum in Angli. . Cujus Vtopia tamdiu vivet, \& habibiturin pretio per manus hominum quamdiu juftic ip a ac modrftia \& pictas non omninò ex ipforum animis \& affectibus exulabunt. Gabro Nand. in Bibliog. Polizic.

Sed quid Thomâ Moro Anglia Cancellario, in his criam faciis olim grandius, venutius? ipfe fibi premontiator, ipfe fibi in avi illus tercbris Dux \& Mawilter, irrifr Leonino', qui ubique tum invaluerant, verus, \& ad genium antiquitutis le luaque, qua plurina compoluit epigrammata accommodavit, major etiam in hoc gcnere futurus, nifr ad graviora ftudia pariatim inclinaflet. Noam hodicque lectiflimum epigramma ejus, datinatum Epitaphio Henric Abingdorii, quodcum Batava auris haredibus difpliceret, aliud pepigit ridiculè rhythmicum, placuitque fupra fidem, \& frmul gufum feculi cuilepidè ve prafentavit. Difplicuit illud:

Attrabat buc cculos, aures attraxerat olim Nobilis Henricus, cantor Abynodonius. Vius erat nuper mirâ gui voce fonaret.

Organa qui feité tangeret, unus erat. Vellenfis primo Templi decus, inde facellum

Rex illo voluit nobilitareforum;

Nune iilum Regi rapuit Deus, intulit aftris. Ip iss ut Rova ît gloria coelicolis.

Sed quod palatum excitavit heredum, itacopit:

Hic jacet Henricus semper pietatis ainicus. $\mathrm{Bb} b \mathrm{~b}$ 
Reliquias pre nafufean libet atrexere. Borrich dé Pöt p. Is 4 :

Pauca fané, fed ex quibus de frigulari ipfrus indufria exiftimati polit, con vertit Thomas Morm, jlanè optimis interpretibus æquiparandas : ad t. wue limata \& nativa Oratio, non isflatanon corrupta, quodcunque vult, facilècom-plectens, orace verò tam exactâ zquilibritate refpondens, ut, Qui utramovis re: ite norit, ambas noverit. H uel. de Clar. Intcrprct.

Dominus Thornas Morus. Vir fuit raris vituribus precluris dotibus onatus: Dum juvenis erat liberius de rebus fentiebat \& toqucbatur at ex ejus Viopia liquet fed poltea ufque ad fupentitionem !'ontificii:Cleri partibus 2 ftudis fefe devovit. Etficut cum juvit dum Autharitate pollebat jimo eidem in exercenda ejus crudclitatc opitulando ; ita etiancalamum furm ad candem Caufarm tuendam fteinxit ; tum adverfus omnes. Novas Opiniones in gencre fribendo,

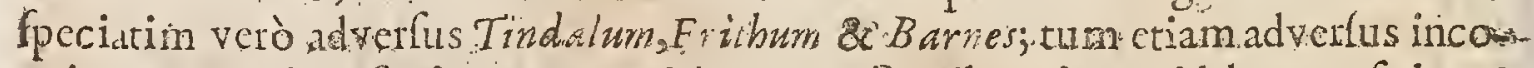
gnitum quemdam Scriptorem, quì neutris Partibus ftare videbatur, fed qui Cleri comptiones improbabat conumque crudelem geftionem damnabat: Morus minimégcntium. Theologus crat, \&uncuique. Scripta ejus legenti pater illum in Antiquitatc platac holpitem fuillc, prater citationes quas in Iure $C_{\text {ancm }}$ nico, \&'apud Mariftum Sentertiarum el occurrebant (1 cgcrattantum quofdam:

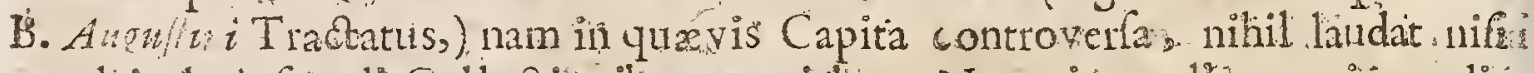
quod in hujufrodi Coldectonibus repericbat. Nec etiam allatenus in eruditione Critica circiscriptacas acras verfatus erat: Sed peculiaris ejus in foribjendo preftutia hec erat:s quòd naturâ fricilè fenfa fua exprimerer omrefque Papatus Opiniones quod fpcciofrorem faciem Lectori reprafentabat, arte c.alslidilfima latcris oppofri dr formitatem fucando vel occultando nec minori : fo- -

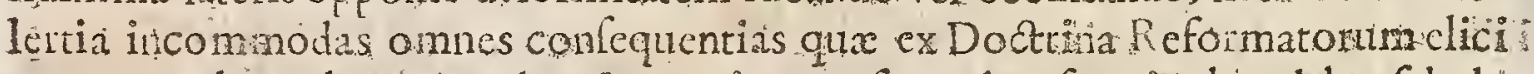
poterant ob oculos poncndo; \& quavis occafione data fucetis abindabat fabellis quas ad propoftum fum feite applicabat. In his itaque fitum erat totum robur criptorumejus, quortm fcopis crat Popellum potius guam Exuditos movere Verim quod attinet adiufitiam, Divitian coutemptum, modefiam feu humilitatem, finceramque generofitatem, rarum Seculo quo vixit Exemplumifuit Burneti Hiftor Reformat lib.3. pag 355-356 Fol. Angl.

D. Thomas Morus (qui, Henci V I I. litem adverfus Lutherumfuam fe cit, illumque adverfis itt m difendere voluit) Virerat, ut perhibent, adíno-

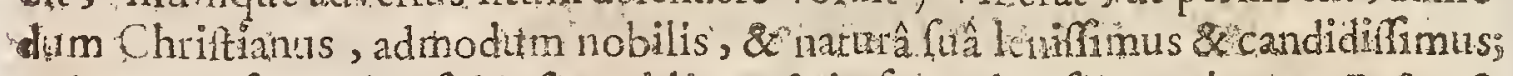

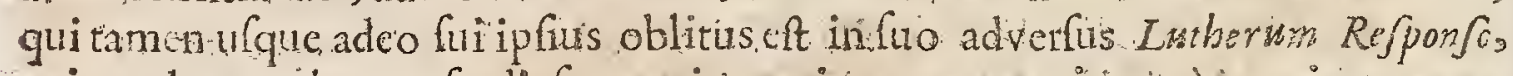
ut in codem majorcm fodi fermonis copidm evomuerit, ưuàn quis unquam fortallis confribcre potterita Liber totus quantus nihil" aliid eft quàm mera impuritas, ne, minimo adhibito tatócinii granulo quo virium aliquid haberer, null anque aliam Authori celcbritatern comparavis, sifi quò nemo in tota Europa majoris fuerit dextcritatis, in pravis vocibus cum bona Latinitate efunciandiș . Quanvis tanta quandoque fitanimi ejus impotencia ut vol amabilen fuam puritatem affectibus fuis immolet.- Héefl, inquit, Domin DoStoris Pofteriourices, gui curn Jibi jam privs fas effe Scripserit Coronam Regiam conpere 


\section{CEIEBRIOR UTM AUTHORUM.}

conspergere ed confpurare ftercoribus, an non nobis fas erit, posterizis bujus poste-

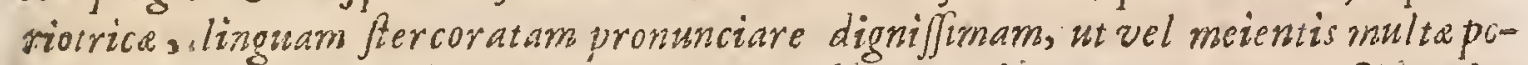
fieriora lingat Juis prioribus orc.p. $7^{2}$. Ab ulteriori citatione tempere : Si cupiat Lector Debacchatienem in fummo gradu pofutam confpicere', aliquas hujus hbri paginas evolvat, \& ad faftidium explebit defiderium. Refponfione ad Conm fiderainones quafdam in Martini Lutheri Genium, imprefla Oxonii $1697^{\circ} 4^{\circ}$. pirg. 41 .

Omnia ejus Opera uno Volumine in Folo comprehenfa Lovanii apud Ioana mern Bogardum edita funt anno 1566.

Hoc ejus Epitaphium, Airore Iano Trtale or

Dum Morus immerita fobmitit colld focuri:

Et flent occajurn pignora cara patris:

Imo, nit, infandi vitarn deflete tyrann:

Non moritur facinus qui grave morte fugits:

Alilid: Auscone Iacobo Escriclio Hifpano:

Henricus Monum gladis jugiläst iniguo.s.

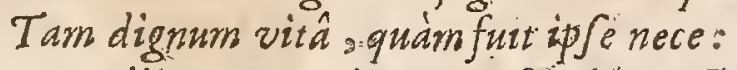

Mortwus ille tamen vivet per feculä cunctas"

Pof mortem. zirtus-orivere fola facito.

G ULIELMUS BUDAUS

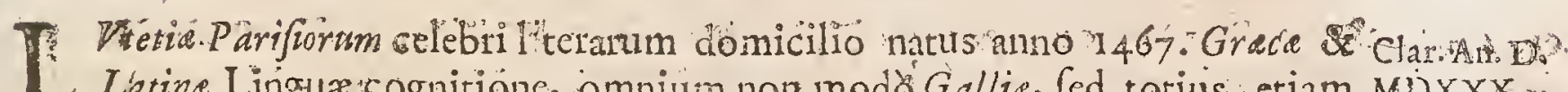
1 Latine Linguæcognitione, omnium non modó Gallia, fed torivis etiam MDXXX.-. Eurropa longe cruditiffmus eâ xtate habitus eft, civilis in primis fapientix; \& Juiprudentix latudel berimus; Senator Regius Supplicumque libellorum in Regir.Magifter: Is ctim perennem fpectaret laudem, \&u familiaris fortums honorefque aulicos ing cnio fuo \& fperatâ gloriâmultò arbínaretur iliores, Cexaginta amplius annis in ocio literario confumptis, ita ut fumma erudi-

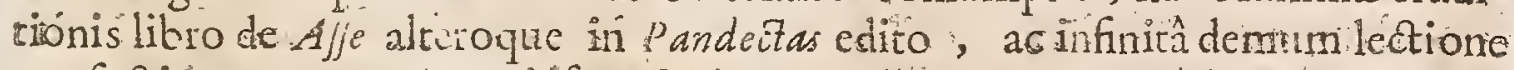
confectis onmentarits utiüque Iinguæ, nulli communicatâtaude, xquales omnes doctrine alto culpate infignis inuoc ntiâ, piè tranquilléque vitâ exceffit, abdicatis teftamento ptius omnibus proffus fureris \& tumulihonoribus : \& nodtu tumulatus ent anno is 4 Q. xtatis 75 die 22 . Augufti.: Boiffard. in Icon. .

Scrapfat Orationes \& Epiftulas Grecas, \& Latinas quamplirimas: Elegias \&" Epigrammata varia: Annotationes in Pandectarum feu Digeforum lib. De $A] \vec{b}$ \& partibus ejus. Et plurima alia.

Quodad enuditionem pertinet , mon video quâ in re Budaus Erafmo cedat: : $\mathrm{Bb} b \mathrm{~b} 3 \quad$ Grat 
fre hummiores, five Chrifiano dignas homine literas aftimare Tibeat. Quodrerb ad dicendi facultatem attinet, patem, meâ fententiâ, intam di éc fo dicendi genere laudem merentur. Bearifima in ambobus $\&$ rerum $\&$ verbo. rum copia: fed ita ut alter altius expatietur, alter augufiore quidem alveo, veàm altiore ingentem aquatum vim trahat: Auit ille plenios, hic fertur pidios. In Budeo vidcor mili agnofcere plus nervorum, fanguinis, , firitus: in Erufmo plus carnis, cutis coloris. In illo plus diligentix, in hoc phus facilitatis : creberi ithe lentcntis, hic facetiis : Ille omnia utilitati, hic plurimum dclectation tribuit. Chrifoph. Longol. in Epitt. ad 'acob. Lucam, Decan. fiureliancrf.

Guliclmus Budaus, Parifienjis, omnium qui hoc Patrumquc Coculo vixere, filic controverfia doctillimus. Cujus fama in excello $\&$ illuti l loco pofita omnes omnium nationum homines in adminationem fui quotidiè convertit : cóque magis, quòd in uifbe ab his fudiis id temporis abhorrente anter luxum \& opes ortus \& cducatus, nullo preceptore, nullo rivali, ad fupremum illud enditionis fattigium fuâ ipfus indu iî̀ confantî̀que penè incredibili provectus ett. Defuit quidemtanto viro perfpicuus ille venuftioris eloquentiz nitor guem re- centiores uni ( iceroni addicti majo:e ftudio \& religione coluerunt. Scid quid fo cxiftinabat (id quod res crat) ejus auctoritatis homini gravinatem ftyli magis quàm verborumkenočnia convenire? Certè voluntatem ëi nen facultatem defuilfe argumento efle poteft peuitifima illa illa totius Latinitatis cognitio, cujus in Pandectiv recenfendis \& Rornanorum I ure illultrando luculentum \& nobile $\int p c-$ cimen dedit. Scevala Samarthanuin Elog. Galiornm.

In Gracis autem quis non miretur eoufque progrefim, ut (quod nulli dum extra Graciart ato contigerat) ipfus lani Lafouris Grecorum doctillimi judicio *cterem Atticorum facundiam adrequaffe diceretut. Ideribidem.

Nunquam erit in Galliâ alser Budeus. Scaligerana prïma.

Budius qui dixit Gallicas vaces à Græcis originem duccresnon paucos errores commifit. Nihil nifi imitandi. Lcribere porcrat, Phrafeura locos communes ob oculos hăbens: Graca I:inguæe callentifinus in Europa füt. Per facilè potcrt hodie quis Greci \& Hebraici idiomatis peritus effes omnitum enim extane interpretationes; fed ut quis vim nativam $\&$ genium linguarum illarum noverit: diligentifudio opus eft, \& pauci co perveniunt. 10f. Scaliger in alteris Scali. geranis Gallicè.

Singulare hujus Utbis [ Lutet] ornamentum, eujus fi quando manum in aliquo loco cognofcimus, ita veneramur \& admiramur, ut çuodludens fcripferit. liorum feriis Scriptis anteponere non erubefamus. Turneb. lib. 9. Adverfas.

Incomparabilis Myfta Gracalitelature fuo zvo Guliolmus Budsus.C.Bartho 1. 2r. Averfar. c. 2 .

Græcarum literarum decus immortale. Merir:Cafaubin Epieteti Enchir.p.rss.

Tantum honoribus fuis promerendis impendit ftudium, ut nunquam ocio, nif

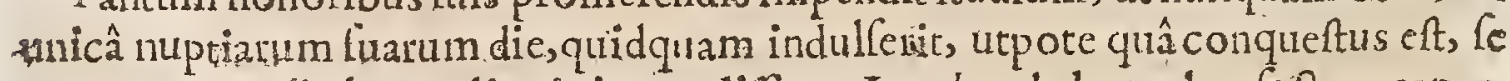
4. tantummodò horas litecis impendilfe. Lynaker de beneplac. fe 2. cap. to cum. 2. 


\section{CELEBRIORUM AUTHORUM.}

Ueroque Operc in Pandectas \& quinque libris de Afje plurimùm opitulatus eft rei Latina, elaboratâ il â fcrutatione rerumac verborum lingux uttiufque. Lud. Viv.libizm de Trad. Dícipl.

Tam abeft ab omni hæercfi $B$ uderss, quàm dulce ab amaro; vivit ne quifquam hodie utriulque lingux callentior. Luc.Viv. lib. 2. de cauf. corrupt. Art.

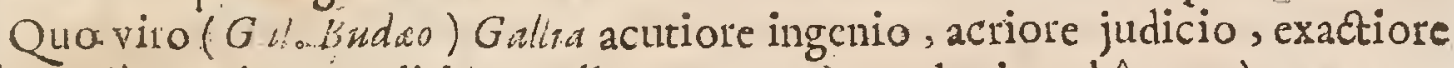
dil igentiâ, majọre eruditione nullum unquam produxit : hâc verò xtate nec Italn quidem Nihil eft ufquam vel Grecorums vel Latinorum Scriptorum, quod ille non evolverit, legerit excufferit', Graca â Latina jưtâ \& Cummècal

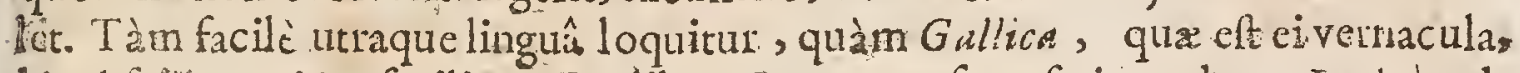
haud fsio an etiam facilius. De libro Groco qua fune fcripta, leget Latine: de Latino Gracè. Haxc qua videmus tam elaboratè, tam excultè ab co conferi pta: extemporali: furat ei facultate parcax. Faciliùs tìm Grocéfcribit sum Latiné quàm etiam carum linguxurum peritiflumi intelligant:- Nihil ef ram reconditum, tam abftrufum in his linguis, qued non perveftigarie, adierit, lifipexe-

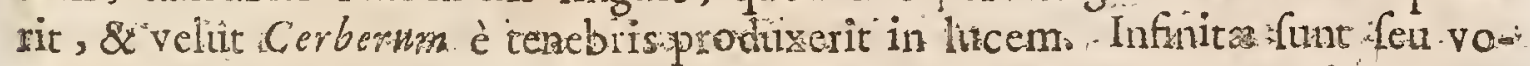
cum fignificationes, feu loquendi. figrarax ac proprietates' quas tuiús Budai Operâ feiunt homines ftudiofi prio ibus feculis ignatatas. Et hxa quidem oma nia tanta a tam admirabilia:iple per fe fune magittro ullo perdicit. Follixac fee: cundum ingenium $:$ quod in le uno invenit \& dactorem \& dicipulum, \&o do cendi viam, rationemque. Etcujus decimam partem alil fub magnis magia

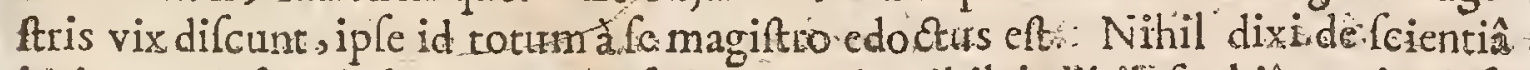
juris , per ipifum inetaurari eollapfa jam cepit, nihil de P'hilöophiâ, cujus ipfe in librisis de affe id fpecimen edidit, guod edere non quiviffet, nifi homo, qui in ominitu Philofophorum libris affiduò verfatus effer, maxîn. mofque in eis progreffus hakeret. Lud.Vivo in Augufino de C. D. Lib. 2a. sap. 7 :

Erafmus eum portentum Galli.e vocare folebat.:

Gülielmus Budans, hómo Gallicus, vir quidem dodtifimus, exuditionis non valgaris, fed quthantum inter Poëtas profecerit nefcio; ex ipfus, qua adhuc ego:

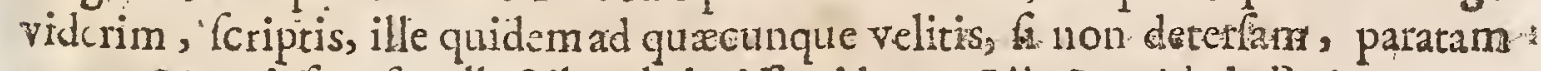
aanen \&copiofan fupellectilcm habuife videtur. Lil. Gyrald de Poët.

Quodad binas Lingulas fpectar, eas cum tanta facilitate poffidebat ut $\mathrm{Gr} z \mathrm{~m}^{\prime}$ cum librum malibus tenens Latinè ipfum legeret; pariterque Latinum Gracè legere potcrat. Ea celcritare urroque idiomate fcribebat; qure viri: Athenienfis aut Romanis potius videretur quam hominis in Gallix meditrillio nati. : Et farte poftquam falebras illas fupcraffet, quar vulgares animos frè tremorantur, duasum hujufmodi vix ducum auxilio ulfque ad intimk Antiquitatis. venerandx receffus penctravit: In ea nihil erat tam obfcurum quin in elacidaverit, nihil. samn occultum quin hominibus id revelaverie, medîis nemini prater ipfum cognitis. Hujus nullum aliud argumentum afferre volo quàm Epiftolas ejus Gracas \& Latinas, ejus in Gracam linguam Commentarios, ejufque Tractakum de Methodo facile addifcendi Ssientias. Lllius Ingenii fotus prathantes Erudia 
torum manibus quotidie teruntur, iifque clare oftendunt quantum debeat huic preft nti Viro, quod viam priùs inaccelfam \& obicibus plenam iplis aperuerit. Quis Notas cjus in Pandecta \& Digefturn legens inficias. ibit quin profundiffma Theri tis Mysteria fcrutatus fuerit, eaque eduxerit è tencbis quibus lub confufa \& informi Legum Romanarum mole obvoluta erant. Quod ad ejus Hiforiz notitiam tanto fulgoreconfp cua ct in ejus libro de Monetis Antiquis ut fub illo modefto titulo De $d f l i$ apertè nobis ob oculos ponat veterum Komanorum faftum \& Potentiam, nobilque thefauros à tot Sectis incognitos expromar, qui lub magni illius Imperii ruderibus forfan adhuc fepulti jacerents nifi ab Erudito illo Budeo effolfi fuiffent cjuqque labore in lucem educti. ${ }^{3}{ }_{1} x-$ clarum illud opus, non modo mirabundos fed 8 invidos reddidit, vel Doćtillmos in ftalia 8 in Germania: Imoquidam productionis ejus gloriam Budro cripere annif funt : Sed hre integra ipfr confervata fuit, quicquid captiofic ambitiol homines:illi tentaverinto Ifaac.Bullart. Acad. Scicntiarum, Iom.2. Gall.

Nullum eft dubium, quin Dotiflimus Gulliclmus Budaus Gallia ornamentum fuecit, \& coxtancorum Literatorum flos. Cumin illo fueritconcurfus omnium Ccibilium, quibus Homo perfectè lapiens evadere poten. Latis rentivis Crofjus. Italice.

Gultelmus Budaus vir ad feculi füi gloriam natus, laudibus literariis abundans, magnâque cum propter fungularem renm omnium fcientiam hominum admiratione affect:1s; tum abid potiflimum, quòd Gracas literas fuâ atateinter mortuas exfufcitarit. Huet. de Clar. Interpiet.p Is 6 .

Budazs opus illud luum in Pandectas eleganter compofitum aptè noninicripfit : quippe qui Legum quarundam voculas aliquot, cum fit interprctatus, int $P$ andectas fe fcripfrfe gloriosè ăi, cùm ne illius quidem Legis, non dicam tituli materiam attigerit. Claud. Verderin Auctor. Ccnf.

\section{Hoc Difichon compoluit Georgius Buchananus:}

Gallia quod Greca efloquod barbara non eft. Vtraque Budro debetwirumgue suo.

* Gulielmi Budai de Alle \& partibus ejus, Tibri j. cjukdcm Annotationes in $P a n d e c t a r$ cum cypurgationibus permittuntuin indice $M$ adritienfiedic. Asno 1667 . fol.

Opera ejus omnia tribus Tomis Impreffa, prodierunt Anno I557\%

Hoc ejus Epitaphium, Anctore fano.Vitale

Quifandtum furml o o fimul difertum

Exquiris fatientice metizltrum:

Vitra quid petis? bic jacet Buduews. 


\section{CELEBRIORUM AUTHORUM.}

\section{Alind ejus' Epitaphim:}

Badreus Columen decufgne Graition:

Bucksus Latic corona lingua:

Budźcus dubii lucerna lures:

Budzus pater elegantiaruris.

Et fons totius eruditionis:

Budzus patrie jubar corufoum:

Regis delicinim. Juit os Sugue

Tempeflatis bonos, lepor, violuptasis

Hic terre exurias religuit, Orbi.

Famam, Aftris Animam. Viatoris ite.

Ir Librum de Afe hoc Diftichon compoluit Theodorns Bezas

Quod fibi vitx multo malli peperere. labore,
Wno Buidsus comparat ARe fibi.

\section{MELCHIOR CA NUS.}

T Ipanus, interanfignes Francifividtoria difcipiles palmam facile Mel-Clar. A. D. - cbior Canus Provincix Cafsella obtintit. Qui \& Magittro pòtt in Aca- MDXXX. demia Salmanticenffluccedens, mox ad Canarientem Epifcopatum, qui Fortunam arum eft lnfularum, evectus, co fe paulò poft ábdicavit. Concilio quioque Tri-

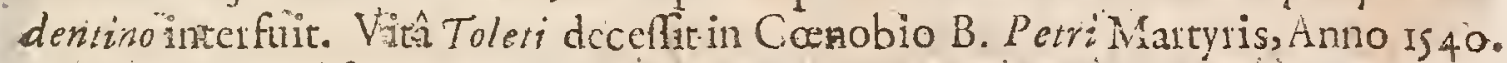
Scripfic autem difertoadmodurn fitylo de Lécis. Theilogicis libros duodecim, in quibus Ciccroniana dictionis amans.proemia attificiosè adhibet; Luxuriarique Atylo videtur. Brblioth Birpan.

Melrbzor Canus in Tridentino Concilio Theologuscelcberrinas. Quô nemo Facras literas pleniù \& planiùs docuit. Quenfed

Melcbior C anus magni fuit nominis apudi Ponificiss (nec immerito ) Theo. logurs. VVhear. in Method.leg. Hift. Civ. Cea. 33 .

Ejus loci Communes è foecundo, ertidito; \& facundo ìngenio prodicrunt, cò commendandi magìis, quòd ipfe noftrâ atate, primus eâ brevitate copiâ, difpofrtione, ac perficuictate de is pertutiliter egerit. Pofferin. in Apparat. Sacr.

Melchioris Cani Scriptum de Locis Theologicis multâ eruditione refertum eft. Voct. Piblioth. lib. 2. [ect. pofter. c. I.

Melchior Canus fummus Theologus, \& moderatifimus Vir. Montacut. in Antidiat.

Eruditione nulli in Ecclefî̀ Romanâ fecundus : \& quod rarum eft in Papist $\hat{n}_{3}$ *ingularis fuit candorisingenii Dr. Iack Jon in Symbolum.

Ex omnibus Theologis qui Concilio Iridentino interfuerant, hic maxima Crec clariflumseguse 
170

clufinmaque fama fuit. Nemo ab illius setate Myfteria Sacrarum Scripturarum melius explicuit. Pererius (efuita') Tom. in Daniel. 1. 12. c. 7 .

Criticus omnes fui Seculi foliditate judicii \& au dacia fuperat. Natus videbatur ad perftringendum omnes ani es fabulas omnefque errores populares qui in libros prafertim verò in Hiltorias irrepferant. Sufficit dicere C'rincam cjus apud Vofjium magno in pretio fuifle, \& Patrem Combeffinm illum vocafle C'enjorum

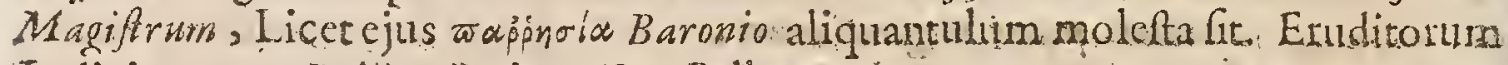
Judicium, per Baillet . Fris. $168 \mathrm{~g}$. Gall:

Utile erit Cafjandrum evolvere, quitot lites [ de Religione] apertequidem. somponere tentavit, licèt majori pittate quàm ingenio ; $\&$ Melchrorem Canum, qui hoc idem, led occulti conatus ęt, ingenio majori, quàm pietate ae propemodum admitabili judicio. Vixénim potef imaginatio confequi, quantum Auat orum ejumodi le étione, Politicortum mentes acuantur, excitenturque ad faluberrimè de rebus iftis confulendum, quibus non unitis aut alteritis. Hominis modò, fed univerfx plerumque Reipublice lalus ' \& belli pacifque momentá continentur. Gabr: Naud. Libliog: Politic.

Vir fuir politus \& elegans, atque in Hiftoriâ Sacrầ verfatiffinus. Aub. Mircus de Scripror. Ecclef.

Multa doctrinx Hifpanus. H. Conring. in prafat. ad Ciaffandr. \& V Vicel.

Extant ejus Opera Colo. Agrip.1605. in 8:

$$
S I M O N, G R Y N \text { I U S }
$$

D Hilofophus, a Theologus Bafteenfus.

MDXXX: Inotationi vite ejus, fum autem hi:

Quar is Simon Grymas ille quis fuit ?

Attende, dicam, magnus ille vir fuit:

Decreta Grammatices nibil novit monis

Quam Prifianus : tam prope eloquentä

Ciccronianze acceffit, ut nemo propius

Chryfippon exequarit in Dialecticis:

Non boc Jopas melius increpuit Lyram:

Numeri fcientia tै áurò rettulit:

Talis Geometra, quulis Architảs fuit::-

Cognitionem babuit ut Atlas iderum:

De moribus confmili Ariftoteli inodo

Difjeruit, of fapientia coelestium:

Non l'linio Pbyjece priores detulit:

Non re Jit Hippocrati medendi indagine:

Fuit alter Aurelius Sacris in Literis.

I.am quid Sacr a non attigit Poẹfeos?

Qwid ef relatu dignum in bitoriis nowis 
Et veteribus frnulgue miffellaneis

In lucubrationibus, quod nefoint?

Linguis Palxtinâ, Latinâ, Fitricâ,

Non aliter ac fermone plebcio ufus eft.

Sed quid opus eft multir, fuic plane Hippias:

Aut alter aut vel praferendus Hippia:

Grex difiplin.mum cuiparuit onnium:

Quern luget extincurn meritó Cyclopedia

Sui colit Gryna: qux tumulum fatrum:

Ut Apollini hujus nominis fum numus.

Enfi verò nithil addi polfer ad hoc Gryner Encomiun, nos tamen profequé

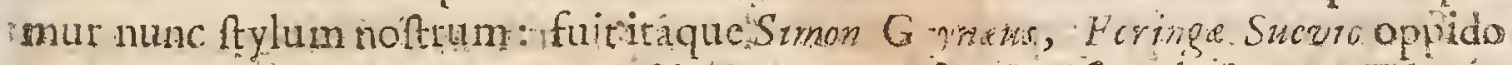
natus, ano 493. In quo modétia \& morum fuavitas fingularis, cum pietate \& difciplinarum omnium ex cti cognitione ccravit : magnillius Melanthonis in schola Porte Hercinid dicipulus. Thilofophix Mngifter Vienne Austria nuncupatus, modis omnibus villatide \& momortit ob Lingux Latine, Grace \& Hebraic peritian', omnifque Hilofoliz ad miraculum ufque cognitio nem; \& ob 1 heologiæ vera feientiam \& ufum dignilimus fempitenna.Quas ip-

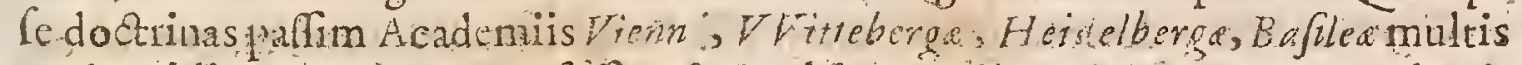
anuis publice privatimg; profelfus eft. Multis egtegie Latine \& Greris Authoribus fuo nitori \& lumini refintus. 'Tandem fibi ipli quidem fatis longrvus licet' vigente adhuc xtate mortu us, utpotecu nihil amplius juod dicerefuperetfe vi-

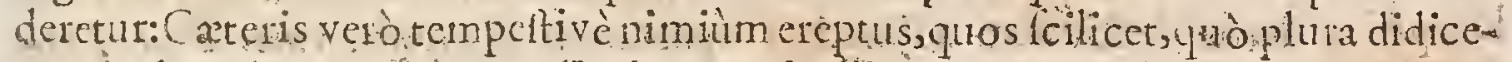
rat, eò plura docere, vic juvandis aliontum tudiis natus; potulfict. Obiit autem

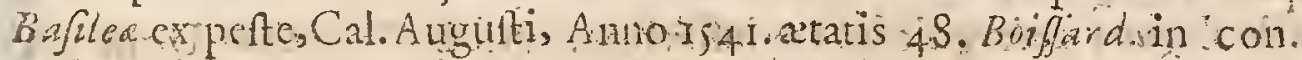

Scripfrt Epiftulas valias, - Commentarium in Odtavum Libum Topiconm Ariftetelis - Tractatum de urilitatclegendi Hifovias - De Ignitis Mcteoris, 8 de Cometarum ca fis ac fignificationibus-Prefationes varias-Commentaria itr? Epittolam Fali ad Rmano. Multà è Graco fermone in Latinum tranftulie. is

Incomparabilis Vir Sirnon Grynert, in quo pietatem Chriftianam, \& virtutest oinnes, \& Mufas atque Charites habuilfe domicilium exiltimo. Ribliand de Rat. Com. omn. Ling.

Simon Grynats ent hemo Latine Gracéque ad unguem doctus, in Philofophiâ. \& Mathematicis Diciptinis diligenter, verlatus, nullo fupercilio, pudore pene Inmodico. Erafm. Epin.1. 26. Epirt.39.

Vir in omni literarum genere citra Cupercilium eruditus, ita provehendis liberalibus Itidiisnatus. Eram.ibid.1.29. Epift. I5.

Vir inliberalibus Difciplinis atque Linguis chm optimè verfatus $r$ fet mulca rumque tam Gra.ur:rn, quàm La tinorum auctorum Lectione multa didicilfer; contigit ut judicium fepifime adhibuerit, quoties illo tempore utrufque Lingure Autores, quarumcunque $A$ vtium \& Facultatum libri, in lucem ederentur. Cujus \& confilio \& judicio ipf Typographi plurimum ufi videntur: quiin pro-

$$
\text { Cicc } 2 \text { rodendic }
$$




\section{$\$ 72$}

\section{E N S UR A}

rrudendis imprimendifque libris (quos Baflea, ut foecundiffima mater innuw. merabiles edidit) hujus judicium, tanquam Apollini Grynai Oraculum expe-tivere, utejufdem indicant t'r fationes ' 2 Epifold omnis ferè generis $A$ u cribus præmiffx : quß \& hâc ratione clarumapud pofteros nomen Grynai reddiderunt. Qui quidem fi longioni tempore fupervixilfet labore, indutria, enditione ac judicio Re Literaria Thealogicaque multum profuillet Lac. Verbiden. in Elog Theolog.

Erat Latine, Griace \& Hebraice dodiflimus., Konig. themat.

De fudionm omni genere praclare merebatur simon Grynaus. Fof. de Ma-

Vir Scientianm omium \& Linguafum eruditifimus ac ad promuxenda bonarum Artium ac Pietaris ftudia natus. Gefner.:

Simon Grynous princeps fui atatis Philofophorumae Philologonum addo etiam Theologorum - Fuit vitin tribus linguis \& universâ Philofophia folidè citraftupercilium eruditus; nec minus in Theologicis exercitatus : ut ve!bo di$c a m$, vera pietatis \& virtutis prif́x exemplum ferè fune exemplo: homo ad promovenda bonaum artium ac pietatis ftudia natus: mulkicute tam Latinis

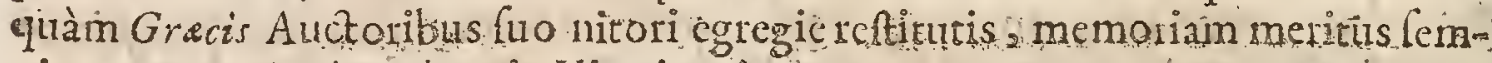
- piternam, Melet. Adam. in Vit; ejus.

Grynaus cùm videret magnum decus effe Ecclefar enditionem, magno labó rẹ accendereomnitm honefarum Artium fudia conabarur, optimos aurores veteres edebat ac enarrabat. Eratirigenium capax omnitum bonarum Artüm, fed hac majot hus êt, quòd non faftidit doctrinam Ecclefra, Cedemperad Philolophica ftidia lectionem adjunxir Prophetarum \& 4 pololorurno Pbil. Me-

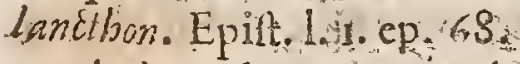

Andress de Laguna redatguitiplum infdelitatis infuis Verfonibus Dominus vero Huet ait ilhtm infignem garrulum ftife, e jufque, chnacerem ParaphaAtge potius quàm Translatoris clle? Pracipure ittiưs Verfiones funt quarundam. Mlutarchi Vitarum \&aliquorum ejufdem Opufculorum moralium, Varinum

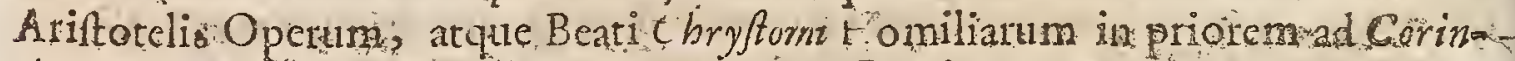

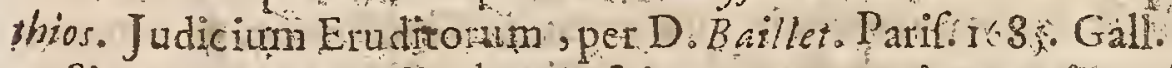

Simon Grynaus Vir elegans fuit, tam egregias concinnavit Prxationes in Pollucem aliof que Preftantes Authores. In i nium majorem yaldè laboraviti. Sacligerana prima. Gall.

* Simon Gryneur in Romano Indice inter Hareticos prima Claffis rejivitur.

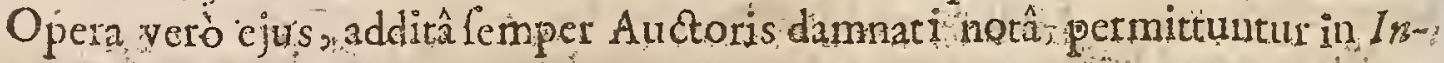
dice Madrit. edic ann. 1667 .

Extat Tractatus de urilitate LegendiHiftorias; Liviioperibus prafixus $B d-$ flece 1579 in $8^{\circ}$.

Extant Epiltolx aliquat \& Commentin Oetaym L Lum Topicorum Ariftotis Bafl. 1556 .in 80 . 


\section{JACOBUS SADOLETUS:}

N. Vina. Urbe.Italia natus eft parentibus nobilibus \& locupletibus, pri- Clar. An. D.
mâque auctoritate, \& gloria inter fuos praditis. Hic cum inter Italos fu- MDXXX! mâ fingt!laris doot inx quâ pollcbat., celebris eftet, à Leone X. Pontifice Maximo komam vocatus, \& Epifcopatu Carpentoraten fi in Gallia donatus êt: in cujus adminiftratione quum aliquotanuis integrè, \& fideliterfefe gellilet; pofcentibus omnibus Romani Senatûs. Patribus, à Clemente feptimo in ordinem

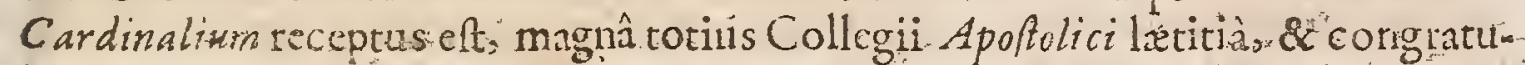
latione. Scripta reliquit plurima: librum de pueris tectè ac liberalietr-infta tuendis.. De laudibus PHilolophiæ. De Regno Hunarie à Turcis capto. Homiliam, cum Oratione exhortaroria ad bellum contra Tureas: Commentaria iq Epitolam Pauli at Romanos lib.j... Interpretationem aliquot Palmortm: Homilia aliquot \&Epiftolarum libro. Et duo Pömatia, Curtius \& Laocoon. Cum amum satisfeptuagefimum attigilfet, in febrim lapfus ; mano omnion bonorum dolore \& triftitia, diem poltremum obiit Romk nonflne dativeneni

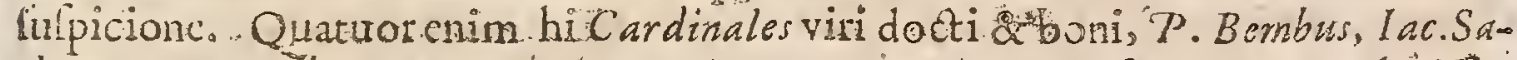
doletus, Cafpar Contarcnus, Campegius, propcratâ morte. ferunutr occubirife: caufar ignorant multís nifi quò forte cum iis q̨ui a Rornanâ Religione dilcordant, aliquan familiritatem habuilfec ctedantu1. Buifard. in Iconwi-

Commentarios in Epiftolamad Romanos ediditillid e imivm hujus atatis' deciss I acobus Sadoletws, admirabilifermonis nitore, \&copiâ plane ciceroni... $n \hat{a}$ nec deeftaffectus Epifcopo Chriftiano dignus: Fieri nonpoteft quin tale opus à tali.viro profectum, bonorum omnirm fufragiis approbetur, vercortanen se apud complures iple phrifos nitor nonnihil haberer aculeos ad pietatem. Erafin. Lis27:-Epift; 8 .

Librum de Laudibus Pbilofopbice valde laudat Peirus Bermbus in Epift.ad Carm dinntem Polum: "Equidcm (inquit) ab illis Augusti temporibus, qux profectò ss.maximè omnium fümis ingeniis \& praftantibus Scriptoribus claruentant; "yullum legi libum friptum, ut mihi quidem videtur appofticks, fpiendidius, "nullum melius, aullum Ciceroniano mori, Itilo, facundix denique icinitis.

Virgtavifmus, onnibufque virutibus omni diciphinam genere omn literarum cultu longè preltans lacobus Sadoletus Collega meuso.. Bernb. ad Budeur. .

Petrus Bembus \& Tacobur Sadoleturs uterque verfu \& pedenti oratione polis tifimus fetpton. Verun illits multi licentiofius (ut temporum nequitia, \& Domini, cui ferviebar, mores ferebant) Cripta extant: Hujus contrâ feria fer omnia, \& digna perfonâ quam fưtincbat. Thuan.ađ'Ann. I547.

Scribendi facultate nemo atare boftrâ ad illäm Antiquorum Scriptorum laudem propiùs accedere exiftinatu's eft. Anton. Florebell. in vit. ejus

Si poemata ipfius nomnulla, \& orationes varias, \& Epiltolarum Volumen, \& Commentatiunculas in.Pialmos \&.D.P.ainli Epiftolas, æquns rerum aftimator

$$
\mathrm{CACG} \cdot 3^{3}, \quad \text { alvertats }
$$


advertat, Colidam protfus eruditi, fufpiciendique ingenii laudem attigite fateatur. Ioan. Imperia!. in Mufxo Hiftorico.

Bembus \& Sadoletus boni P.ötx. Scaligerana piim.p. 27.

- Iacobi Sadoleti Pöëmata: Laocoon, Curtius, nec non Ocii \& Tranquilitatis carmen nirabilem illius gravitatcm ac fingülarem modeftiam declarant, qucm in hậc facultate auxerunt \& rcliquabonarum Artium \& fapientiz ftudia, qu ab unguiculis ille pleno pectore haufit: neque enim in prefentia cjus folutam, orationcm, in qua fupra cateros excellit, commemoro. Gyrald.

Cclebrior (Eaufio Sabco Brixiano) fama lacobum Sadolerum, Epifcopum Carpentoralcrem, fub initium fcculi decimifexticommendar, qui non modò aliis clarus operibus; fed \& infigni epica carmine de ftatuâ $I$ aoconini, atq;altero de Marco Curtio utrumq; enim maruri judicii opus. Borracbius de Poct. p.Io4.

Cardinalis Sadoletus vit erat qui cruditionem infignem virtuti non vulgari confociaverat; quique Catbolicurur \& rotefantiurn eltimationem ex æquo fibi

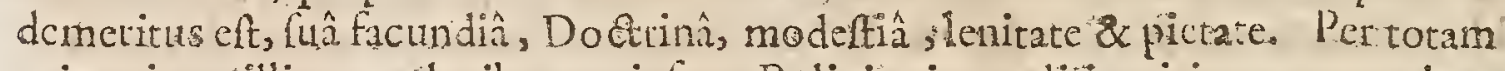
enim viramilli cum pluribus utrufque Religionis eruditis viris commercium interceflt, ejufque excellentes Epittolx ad Melandbonem \& ad Erafomm foriptx rifuntur, Antonius Triffler Elog. Viror. Eruditom Gälicè.

Jc. Rapinw fcribic Sadoletum Virgilii phrafes imicatum effe, genium tamen cjus non expreffife, \& inter fervilis imitationis conatus, ingenii proptii citeria ipfi excidille. Rapin. Reflex general: in loeticam, part. I. Gall

Iacobus Sadóletios tameti le ad Ciceronisimitationem formare fudcret, haud receptas-tamen Theologorum vocesufupat, \& Epifiopor, Provincinum 'Frafio des appellat. Clawdoverder. Auctor. Cestion.

Extant ejus Operán $M$ og. $16,07.3$.

Extant Obationes 2. five confilia de Bello movendo contia Turcas Ifleb.16o;.

Extant Epiftolarum Libri 16 \& ad Paulum Sadoletum lib.1.cum Ant. Flor:belli Comment. de vitâ Authoris. Culoniz Agr.'sg9o. 8a.

Extat de Liberis rectè inftitucndis. Arg.:1605.8\%.

Confolationes \& Meditationes in Adverfis. Eranc.1577.8\%

De Laudibus Philofophix. Ven.1539.3.

\section{Hor cjus Epitaphium.}

\section{O. M.S.}

Jacobo Sadolcto Epifcopo Carpentoractis S. R. E. Probytero Cardinali, Firomom

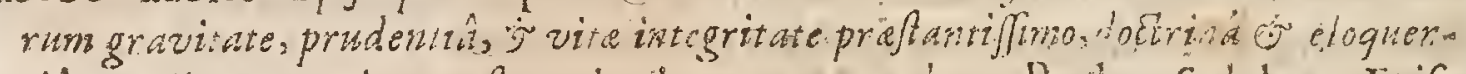
tia cum iis quos mira a eft antianitas comparando., Pat lus Sadoletus Epif-

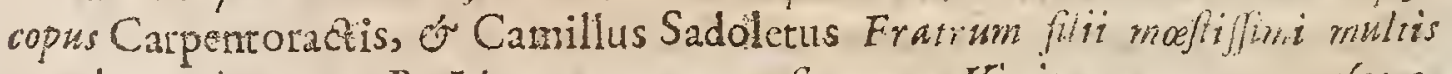
cumlacrymis Patruo B. M.protempore pofuerunto Viatit anzos 70 . menfes 3. dies 6. 


\section{CELEBRIORUM AUTHORUM.}

\section{MARTINUS, BUCERUS。}

Ermanu, Seleftadii natlis amo I491. Oddinem Dominicanorum, in quo Clar.An.D.

I vixcrat annos 15 . Evangelii doctrinam amplexus, reliquit, anno I52I.cum MDXXX: Petro Martyre, I'aulogue, Fagio, A rgentorato, ubidocuerat, ab Edvvardo Sexto invitatus, in Angliarr pervenit, anno r, 49 . ut ibi doctrinæ fux feme tem fac.ret, Cuntabrigz Profeftor: ubi obiit Anno Ijstoxtatis 6r. Ejus Oja Mariâ freviente, effolfa \& cremata, anno 1555. unà cum Fagri offibus : Sedambo, fub Elizaberhi,anno is 60. publicis laudibus ornati, honoribufque fuis reftitutifunt: Hofrnais.

Ingenio \& eruditione inclytus: Hebrea Lingux apprimè paritus fuir. Hof fran:

Eo eratingenio ut adverfarios patienter audiret, lenster refponderet; \& veritaris. poriüs quàm ictouiz curam haberet. Melcbior. Adam in vit ejus.

Cujus [Martini Buceri] \& eruditionem fingularem $\$$ minn, cum eximiaprudentia conjunetum omnibus feculis teltabuntur, tum doetifrma ipfus Lucubationes, \& in publicis comiris. Difputariones habit $x$; sum pro Eccl farum pace, quanvis non felici femper fuccelfi, labores exhau1ti. Buifjard. in Icon.

A convenut Ratisbonenfiloannes Gropperus A Archicpifcop "Colonienfis Lega tus, doinum reverfus, Bucerum minfice commendabat, \& interomncis idoneum

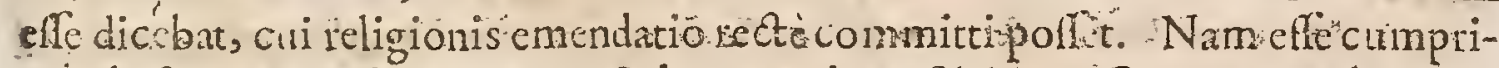
mis doctum \& pacis amantem, \& integravita. Sleidan. Commentar.1. If.

Cim Cardinalis Contarenus à P'etro Martyre interrogatus effet de Doctis Germanorum Viris; relpondit ille : Nibib attinet de Pbittppo, qui notus, dicere: $H_{a-}$ bent Gernani Martinum Buccrim : qui eavbernate dotrina Theologica $\sigma^{\circ}$

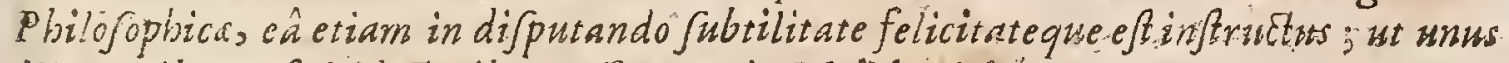
ille omibus noftris doctoribus poffit opponi. Melch. Adame:

De literis hocunum fummatim ponam: Quxin aliis finguli fingulis, ea in uno paritcr univerfa concidiffe: Augustini fuit in illo acumen. Fieronymi lingua

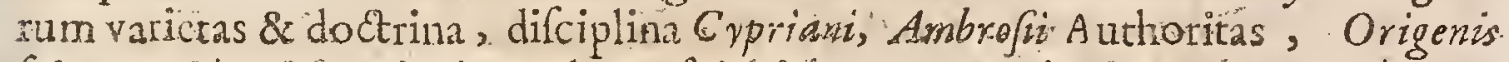
fcientia, Chryfoftomi in docendo perfuicuitas, Bernaräinegritás in vitâ: vel hac in illis prifcis Ecclefiarum theroibus uberiora fi fiediur (uti fuiffe confiteor ) tamen particulas ex omibus excellentilfmas nofter $B$ ucerus tanto fudio arcipuit, tot ornamentis perpolivit; ut fi non unus cum omnibus; tamen fepa-. ratin cum fingulis comparari pofft: aut in illo augufto veterum choro fo non prefideat, in hominibus noftri feculi, omnibus ex partibus interalios emineat. Gualt. Haddon. in Orar. Funcbri. vid. vitas $B$ atefii $\mathrm{P} \cdot 27.6$.

Quàm multiplicem in Bucero jacturam fererit Dei Ecclefa; quotics in mensem veuit, cor meum propèlacerari fentio. Calvin. Epift. adViretum.

Martinus Bucerus fummus Theologus; qui ut à viro quodam docto verè de 11 lo friptum eft, prxter reconditam eruditionem copiolamque multarum rerum coientiam, prater ingenip pafpicaciam, multam lectionem, aliafque multas ac 
varias virtutes, hane fibi propriam laudem habuit, yuod vix alius hấc memorla cxactiore diligentiâ in Scripture Interpretatione verfatus . Art. Iofus Simler. Orat.de Vit. \& O'bit. P. Martyris.

Martınus Bucerus vir fuit impense Doctus, limati judicii, pius \& modera tus. Inferior enuditione nulli forfan Reformatorum fuit: Sed quoad Zelum,veram pietarem, \& ftudium unitatem inter exteras Ecélefias forvandi, Melanchtom ni ac ipfrablque ulla caterorum injuria, peculiakis locus concedi potct. Cantabrigie moleftiflimos habuit adverfarios a atûs Sectatores, quilicet Legi oblè quentes loca fua retinuiffent, attamen five fub Argumentationis, pratextu., \& veluti ojcafione difputationis, five rffpectu Dogmatum nondum deteminatorum, jus exiftimationem minucre annitebantur. Nec enim natura ingenii é promptitudine præditus erat qux ad Difputationem requiritur, quo ábutic conabantur ad conditionem fuam medrocrem faciendam Qua decauif Perrus Martyr ad ipfum fcripfit ut à publicis omnibus Difputationilous abfineret. Burnet. Hift. Keform. pag.164. vol.2. Anglicè.

Buceri Commentaria in Pfalmos fub Aretii Fetini nomine in publicum emiffa, Romx magni aftimara $\&$ avidè quafita fuerunt aे pluribus Epifcopis \& Cardinalibuis. Sed ex quo ipfis innotiit eorum Authorem efle $B$ ucirum illud opus fupprimendam curaverunt, : tanquam pravum Jibrum wi-

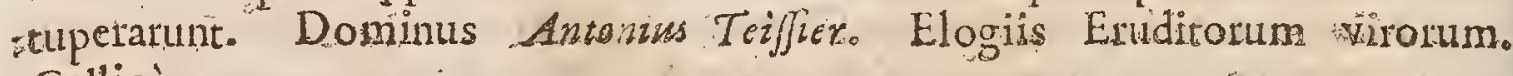
Gallicè.

Cuneta Buceri Latina \& Germanica Seripta in unam Ticonjungerentur, quod anti vifi Pictas \& eruditio merebatur, efficerent Tomos. IX. juite magnitudirits. Gefner. in Biblioth.

* Hic Author Romano Indiceinter Hareticosprima Claflis mumesatur; viet Inducem, Tridentinum.

Hoc ejus Epitaphium, audore Ioanne Checo:-

Wita gravis wijerois graviormors: Sed tibiranto

Mors nec vila pctefteffe, Buccre, gravrs. Titaf fuit Chriftus, mors lucrum; vivare ceffas

IVature, at Chrifti vitaperenis adeft. Alma fides Chrifi guan tu super aftra ferebas.

Te-super aftra eadern Suftulit alrna fides.

Cumgue twi Mores, Pietas, Dodtrina probentur:

. Nors twa non gravis eft. 5 gravis efi eadem.

Mors gravis eft Nhis orbatis lumine tanto:

Nongravis eft tibi, que vitabeata tibi est.

Doetrine fudium, Vite conftantia, mortis

Exitus, ô idem fut mibi, Chuifte precor. 


\section{IILIUS GREGORIUS GYRAIDUS}

Therariengfis, natuseft Anno 1479. Obit podagræ doloribus attritus Anno I 1552 . Opera ejus Voluminibus duobus Bafilex imprella : inter quæ Hiftoria Deorum Gentilium, libris ;7. De Poëris Gracis \& Latinis, libris 10. De l'ö̈is Lui temporis, libris duobus, erminent.

Vir memoria invicta, ingenio excellenti, erudicione in omni literarum genere eximia inclyus, Varro fui temporis dici meruit. Hofman.

Vir folide doctus, \& in lcribendo accuratus. Cafanb. Not. ad Diog. Laert. 1.8.

Litius Gregorius Gyraldus, utritzque lingux, \&omnis politionis literatura, $\&$ Antiquitaris (quam varis feripris illutravit)longe peritilimus: qui fortunx \& corporis adveritatibus, meliore atique fato d gnus, totâ vitaconflicatus elt. Thuan.ad ann.15s2.

Vir omnis eruditantiquitatis ac literate dootrine callentifmus, qui plerafque manufriptas Brbliotbecas Gracas in Italia excufrt, è quarum lectione confcripfre libros illos fuosendicos, \& varios de Dits Gentiurn; Opus admirandum, Hijorian veterum \& recentionum Pötarum, is cetcraplunina ex quifita fingula. Neanderin Geograph.

Scriptor diligentilfmus Gyraldus vocatur Montacutio A pparat.3. fect. 2.

Longe hoc (viz.Petro Crinito)doetior, \& diligentior Gyraldus. Vofj.de Hift. Lat.p.7;6.

Litius Gyraldu, optimus locorum coacervator \& judiciofus. Opera jphus omnia quàin optima. Scaligerana pofterior.

Lilius Gregorius Gyraldus vir totius entition gnarus--.- - Iongo fudio \& multis vigiliis elaboravit Hifforiarnde Diis Gentium, variam fanè, $K$ ad rotam antiquitatem nofcendam admodum necellariam.70.Bapt.Gyratd. in Epift.Oper. Gyrald.

In difertationibus a Poëtis tum Grecis tum Lativis, longè fuifem longion, nifi accurate de Poërarun fingulis diffruifet Lilius Gyraldus Ferrarienfss. Cujus extat Hiftoria dialogisdecem perferipta de Pö̈tis Antigubs ; duobus de fui temporis Poëtis. Opus licut magni ingenii, \& judicii, fre ingentis doetiñ, atque in-duftrix : ira ut expectandum non fit, nequis deincens hanc denuò provinciam fufcipiat. Eft ubi hujus, vel illius poëtre Hiftoriam, accuratius aliquis tractare valeat, \& fanc id in paucis : at ab aggrediundo iterum tam vafo labore non modò eruditorum vulgus, fed etiam fanos omnes deterruit. Videlicet poft meffer tam luculentam nihil fere nifi quxdam. Spicilegia reliquit. Vof. de Poët. ¿Lat.pag.

Lilius Gregorius Gyraldus, omnium fuffragio, unus fuit è praciariflmis ingeniis qux poftremis his feculis aluerit Italia. Tam mirificum in omuibus Scienriis fecit progreffum ut harum nullam ignoraverit. CMoreri. Diction. Galthico. 
Gyvaldum aftimo virum eruditiffmum, \& de omni Antiquitatum ftudic ap: primè meritum.C.Bartb.aniradv. Claudian.de Bello Gildon.p.368.

V.r non minoris judicii, quàm doctrinx. Vofjolib.r. Idololatr.c.29.

Vir omis erudita Antiquitatis ac likerarix doctrine excellentisimus. Dafjlbiand.in decript. Uib. Ital.

Magnæ lectionis, acris judicii criticus vocatur Demplero.

Certè hoc argumentum de Sibyllis multò dexteriùs \& diligentiùs, quàn Onw phrrus, vir doctiffmus Gyraldus perfecutus ent ; quamvis ille alter peculiari quodam tractatu rem fufceperit perficiendam. Kich. Montac in Analect. Exercit. 4. fect.6.

Sed fupra hos omnes [ Laurentium Gambaram, Poinponium Giduricum, \& Bapo iiftarn Giarinum] meritis cminct Lilius Gyraldus[Pico Mirandulano quondam familiaris] non tantum quòd varii generis, varii argumenti carmine fe Tatibus inferuerit, fed \& quòd Hiftoriam Počtarum Grecorum, \& Latinorum eruditè, \& magno judicio perfcripferit,adjecta \& de fuifeculi Pö̈tis cenfurân non minùs. liberà quain veraci. Borrith de l'oëcis; p.99\%.

Summa curâ fanoque judicio veterum Poẹtarum Græcontum \& Latinorum Hiftorian decem Dialogis contexuit, Recentiorum verò, aut fibi cortaneorum duobus aliis Colloquiis. Borrichins art non minorem libertatem quam zeritatem depreh nfam fuilfe in Cenfura quam in fui Saculi loëtas exercuit, ut illa quam exercet in Veteres crudicione referta eft, folidumque judicium fpirat, Nihilominus forephus Scaliger nobiš perfuatere tentavit niail effe giliu's nec mife abilius quam ejus judicia de Poëtiss, quamvis multum lectionis \& Doctrinx in is agnofat. Judicia eruditorum. Parnf. 685 . Gall.

* Ejus Opera, fr Expurgentur, permittuntur in Indice Mgadrit, editanno: 1667 .

Anno CIJIJXXXV. Lilius Gregorius Gyraldus magno in pretio ftetit apud eruditifimum quemque. Hic inter alia librum confcripfit de annis, \& menfibus, unà cum Calendario Ronano \& Grieco. Ac quia Eerrarien is effet, cpus hoc diczvit Renate, Galliarum Regis Ludovici XII. filix, Herculis II. Ducis Eerrarienfis., vidux. Natus Enit Anno. Chifti 1479. In pucritia audivit cum alios, tam Baptiftam Gnarinum, cel eberrimum fui temporis Grammaticum. In felicitatis parte erat, qudd, ad multijugam eruditionem parandam, polteavixerit apud Albertum, Pium Carporum, \& Ioannem Picum Mirandula Principes. Hîc enim ingenti Bibliothecâ frui, perque omne Scriptorum genus capacem diffundere animum dacum fuit. Mediolani à Demetrio Cbalcondylâ Gracas didicit literas. Multa Rome perpellus eft, cùm Uibs Anno CI J JXXVIl, diriperetur à Milite Imperatoris Caroli V. Poftea, in Patriamreverius, familiariter ufus eft foanne Manardo, \& Calio Calcagnino. Sex feptem poltremis vitæ annis manibus,pedibufque æger, ut ipfe de fe loquebatur, fpirabat potiùs quam viveliat. Nam, fine famuli auxilio, ne

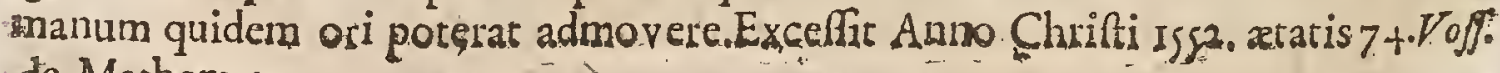
de Mathemat. 


\section{CELEBRIORVM AVTHORVM.}

Hoc ejus Epitaphium, Ferrarie in fammo Temple:

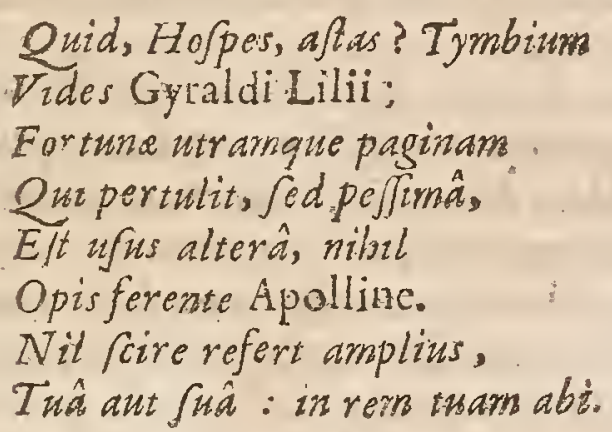

Ṕbil.Labbe Thefaur. Epicap.

SEBASTIANUS MUNSTERIUS

Ermanus, Engelhemistnatus Amno 1489. Olin Tubinge in Francry canoruste

I folidatio protellus, poftè̀ abjecto cuculio Proteflantium doctrinam amplexus. Baflea lingum fanctam profeffis elt. Erudicionis lixe plusina \& praclara ipofteritati réliquit monumènta. Pefte correptus eft Anno Ijs2.

- in unferus in Wathematicis multum profeccrat ; poftè verò fe totum Hebraica lingux \& facris libris addixit, multis edicis in utraque ficientia monumentis. De Republica optimè mecitus, adco ut Gernanus Erdras ac Strabo Thuan. appellatus elt. Thuan.

Vir cùn in variis linguis,tum 4 cbraicâ præcipuè doctus; \& variis Scientiis, maximèverò Weibernaticis praclarè imbutus : ingeniolis ac piis lucubratonbns Germanicés Latne' \& Hebraicé confriptis, de bonis liceris omnibus linguis, Philo.ophia 1 heologia optinc meritus. Gener. in Biblioth.

Sebafianus Munferas, duabus ebus multum laudis meruit, Hobràs literis \& Mathefi. VofJ.de Scicnt Mathemat.p. 189.

Dootus Lanè vir fuit Mimfterus, cui multum debent litera Hebraica. Iof.Sca tig. Elench.Tribaref. Serrar.c.4.

Hebrex \& Chaldaice lingua accuratà cognitione, plurimifque tum in lacras litcras, tum in warias Mathefeos partes editis feriptis, ac præfcrtim laboriofifrmo illo opere $C$ ofmographico nobilis, quo duce peregrinari terrarum orbem, dom ctiam manendo, licet. Theod.Bez. in Icon,

Cum Munferus fuam Germanographiam infcripferit Cofmographam; tocusett tamen in Germanormm \& Helvetionurn regionibus, oppidis, fitu, \& populorum origine ac defcriptione, quibus detractis, $n$ hil ferè Orbi Terrarum univerfo religuum fit.Bodin.Meth. Hilt.c. 4.p.76.

Sebafinanus Munsterus, Bibliorum Interpres fanè doctus, in Ebraicâ femper titylum collineans, ad éque nunquam non le componens; nec ideò tamen Latio 11. $\therefore$

$D$ ddd 2

Clar. An D

MDXXX. 
colo is negligens, in ejus quamvis lingux elegantis parum fet torferit: Quodf: quando obicuirs e planandis unam alteramve dictionem è propriopenuadiecito. certis illam notis homo religiofus infgnivit: quò adulteinis bector Germanafcponeret. Huet.de Claris Interpr. p.I44.

Hebraca non pauca Latinitate donavit Sebastians Mtunferens, bonis literis, \& fancta parifrmùm lingux cognitione fupra fidem exculus: quamvis autem in Interpretando verbum verbo reddere ftuduerit, Latinitatis tamen genio alferuit quandoque, \& Ebraifini fterilitatem uberion lermone explts nec religionem, quam requirimus, ubique curare fe profitetur, quòd ca dificentimu foveatur negligentiat reeto quidem \& laudabili confilio, modò ea in licsntiam fuam I nter pres non abutatur. Huet de clar. Interpr. p.187.

Sébaftianum Munferus [vir quantus \& qualis!in illa prafetrim temporum \& literarum caligine]prater ipfus Annotationes, quas in Criticis Landinenfis. habemus, Verfzonexn ex Hebrao textu adomavit, dostrinà non vulgari, ex fummo acumine; in quâ $H$ ébraica plerifque in locis fideliter admodun, nec minus perfpicuè reldit. Matth:Polu. Prefar. Tom. I.Synopl. Critic.p.4.

Atque hoc malimex Sebaftiano Munftero, optima virô, Artium Ndatbemathcarum \& Hebraic lingux doetifimo,quam ex me difat. Nic. Fuller. 1.r.c.16. Micell Sacr.

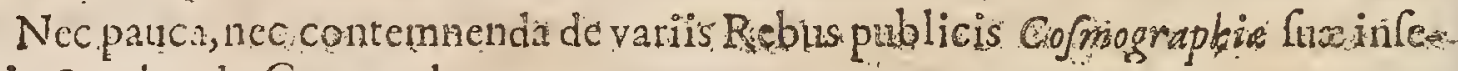
suit.Conring. de Cyy.prud.capia4. .

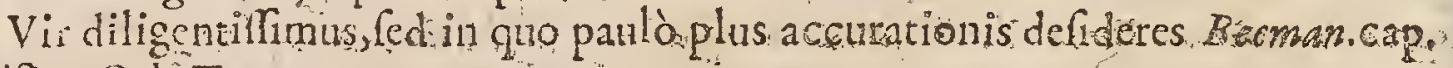
Hiftor. Orb.Ter.n.

Munterus omnia ex Prgnino hafuti quinon ampliùs reperitur aceid agnoa yit. Scaligerana polterio: Gall.

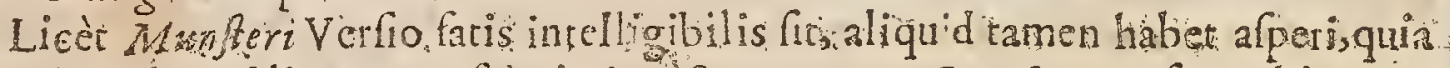
Texths. Hebraici hiteram prefse nimis iccatar, ut.c. r. Genefeus verf.2. wbi trans. fẹt Fructificate, or angefcite, or implete aquas in fretis. Vulgata, ut milii quidem. videtur, eadem verba per hac felicius exprefir , Crefice o multiplicamini to implete aguas maris. Uno verbo perfentor elTet cjus Intexpretatio fi a Latino Interprete tam longè non abiviffert. Carcum Genebrardu latis moderatus non vi detur in Critica quam in hanc Transhationem excrcuit; quando Authori exprom bravic quod parum accuratus fuerit, $\&$ Lutheronimis adbixferit. Armflerus,neglecta vocum propriotnotatione, fepe Luteranifabiat, of à fro D. Francif cinftituto "difcedebat. Contra enim afteri potet, 11 unferwo accuratifimum \&fidelifinum inter om nes Proteftantes in Bibliorum Vifróne fua fuife, imònec Lutberi Tram ductionem approbare potnit quia longè nimis à Literali \& Grammaticali fenfu recefferat. Dinuetius juftius de co judicitim tulit, dum Exactinterpretis el isgio ipfum ornat - Nota quas Munfterus Trandationi fuz annexuit eximix utiLiatis effe poftunt ad Hebraïa lingure \&: Scripturarum Styli cogaitionem: multogue utiliores effent fi plenaque minimè neceffaria non immifcuifret, qux que dẹfumfit à Rabbinis, qua ad Textûs fui eluciditationem nihil conferunt. Nimis ctiam affectay it famam Viri in corundem Rabbinorum lectione verfat ian Et 
tamen, fi excipianme libriquorundam Grammaticorum Rabbinorum, qui Scripouram cpmmentati funt, in hoc fudii genere non admodum exercitatus erat: Quod facile prabari polfet $e_{x}$ Latina Verfione quam elaboravit exigui Compendii Philofophici Rabbinico Hebræo confcripti: nulla enim ferè occurrit vox in hac Latiina Verfone circa quam hallucinatus non fuexit, imò ne prima quidem verba intllexit. In criptionis. Libri hujus. Liber hic afcribitur R.C.Coy/i Maimonis flio, quil huc Arabicè compoluerat ; Ille yerò contra in fua Interpretatione hujus Operis Authorem facit.R. Simoneris \& exinde has voces bilefcon araus. vertit in lingua favi, non advertendo quid Arabicoxidiomate frgnificent. Multò melius Grammaticos Rabbinos intellexit quia his legendis majowem navaverat operam, \&z hac re fuper confuluerat Eliam Lewitam Judroum Doetifinum

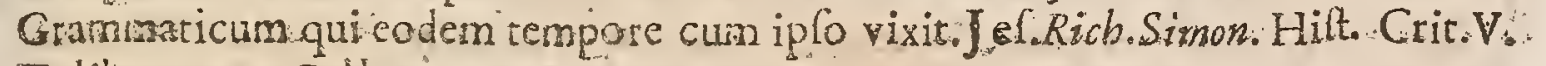
T. lib.2.G.2. Gall.

Ex recentiouibus chrüsterus, \& poleum Thuetus, \& Belleforestus, malè opera fua Cofmographiam infcriplerunt. Nam quemadmodum Gcometria Plátoni yedotar eft preat anis ridiculumitcm nomen naberi debet. Cland.Verder. in Auctor. Cenf.

Varia ejus Opera variis in lacis atqite temporibus impreffa funt.* Sebafíanus Munßerus inter. Hareticos prima Clafis rejicitur.

\section{IIIE RON O MUS FRA CAS TO RIUS:}

P

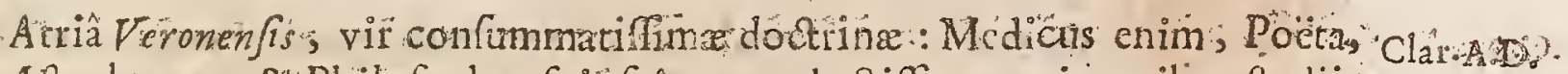

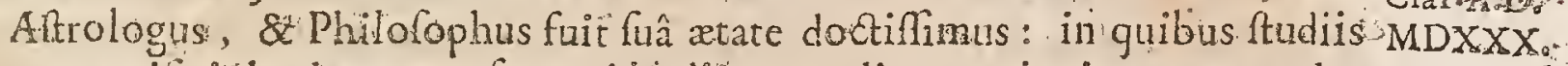
antam acquifivir laudem, ut ufque ad hodiernum diem antiquis comparandus. meritò judicenu. "Ejus Poëmata tanti fiunt aumdomnes literatos, ut illa confe-m rantur cum Vergatiazis: tanta in eis cloquentia, tanta dicendivis, \& facultas, fermonifqup puritas, ut aternâ laude non fine caus $\hat{u}$ ad colum evehantut, undé 2multis divinus vocatue Fracastorius Is cum totam atatem in arte Medicâ, \& in indagandâ rexim naturâ fedulo impendillet : in eo omnem movens lapideng, a ut literatos juvaret, \& omnibus prodelfe polfer, .. Pataviz a ubi tunc fummo in honove habebatur, natura concelfit : ann. Chriftiana falutisi-I 53 . ibique fepultus ; funus profequente publicoluctu totâ Academià, \& Civitate: Umnia. cjus opera tanta perfectione fcripta funt, ut in iis requiri ninil polfit. Boifjardo. ini Iıou

Scripta ejus hac: funt: Siphillis Poema, id eft libri tres de mobo Gallico: - Iofeph Comcedia - Homocentrica-De caulis Criticorum dierum, per ea qua in nobis funt-De Sympathià \& Antiparhiâ--.-De Contagione, \& Contagiofis Morbis, eorumque curatione---Naugerius, five de Poëtica dialogus----De Animâ Dialogus-_-De Vini temperatuxà Sententia-_-Caxninum liber unus--- 


\section{2}

\section{E NSVR A}

Alcon fiye de Curâ Canim Venaticorum---Turrius, five de Intellectione Dialogus ---Carmina fuper Genefin.

- Ad cxactam Philolophix \& Mathematicarum Artium, ac pracipne Aftonomix ( quam \& doctifimis fcripcis illuftravit) cognitionem, fummun judicium \& adtirabile ingenium attulit : quo multa ab antiquis ant ignorata, aut fecus accepta adinvënit, \& cxplicavit. Et medicinam, ut honeftifrmè-ac citra lucrum, ita felicinme fecit. Poëticam vero ita excoluit, ut ad Virgi-

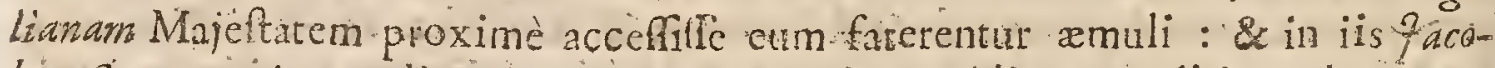
bus Sannazarius, alioqui parcus \& amarulcintus alienæ eruditionis laudator; qui, visâ ejus Siphillide, non folùm Loannern Iovnanum Pontanum, fed fe quoque iplum in opete accuratâ $x x$. annonm limà perpolito vicum exclanavit. Ei cerè hujus.feculi ingens iniraculum 1 ht. Cafar Scaliger tanqua in illarum, quas dixi, Scientiarum \& Poërices fummum faftigium confecato, Aras erexit. Totian ad anio $1533^{\circ}$

I witus Cafar Scaliger l. Gide Re Poëtica, vocat praftantifinum poft Virgilum Poëtarum. Syphillidem vocat divinum Poëma : in quo tamen nonnulla caftigat. Inter alia \& id reprehendit, quòd negaverit, cxtera animalia, prater hominem, morbo Gallico tentari. Teftatur Scaliger, vidifle fe cauem câ lae captum, cum Heri lui emplattra linxifet.

Hieronymus Fracaforius, Veronenfis, de morbo Gallico (quem iple à Barbarâ voce Syphillida vocat) libellos tres fcriplit, in quibus cùm antiquos confectatur Poẹtas, tum precipurè Pontrinum, quem celebrat, zmulatur; egregius certè in confikgendis fabulis, apta illi caminis ftucura, in eâ tamen quadam preli-

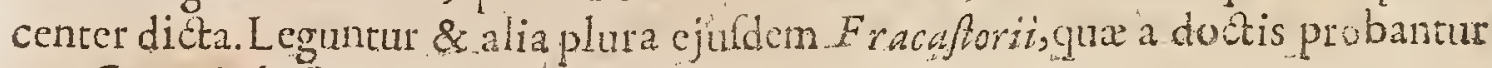
Lil.Gyrald. de Puët.

Anno' 530 .inter pracipua lecti deconat erat Feronyms Fracaftorins Veronenfis, Poëra idem, \& Philolophus, ac Medicus eximius. Cives fui Veronenfes defuncto, uti ante Catullo, ac Pliwio, ftatuam marmoream ftaticiunt Anno 555 . Vofj.de Mathem.

Fracaftorius qui tam felici fucceflu concinnavit Syphillidis fur Poema, Opus fanc pulcherrimun quod poltemis his feculis elaboratum fuecit, Latino carnine in Italia.; quodque feriptum eft ad initationem Geo gicôn Virgilii, non tam anpicato compoluit Pocma Epicum; quod aggrellus elt in Iofephnm Ag ypti Proregen, cujus fragmentum nobis fupereft:' Vulgarilimum enim genim arguit hujuf nodi locma, mediocremque characterem cxhibet. Rapir. Reflex.in Poëticam.Sect.14. Gall.

Hieronymu Frarastorizs excellens Pö̈ta in Syphilli. Scaligerana prim.

Alconem \& S phillider Epico camine e tulir, doctè fanè \& pudenter, immifis ctim fietiontbus poëticis"; licet aliquanto minus numerosc, gurppe docere femper ibi maluit, quàm femper delectate. Borâfchius de Poet.p.98.

Hieronymus Eracastorius filius Pauli Fhilippi, Civitati Veronenz natales debet, \& vel in ipfa puerili xtate future Clarieudinis \& in literis preftantix evidentifima figna dedit; quandoquidem, matre iplumbrachiis geltante, ful- 
men è colo vibratum, genitricem extinxit illafum relinquens in fantulum: Unde ipfuns fortune, \& tuturorum "in Difci plinis fuccelfum fauftiffimè conjectatum eft. Felicis Mediciticulum fibi comparavit, quoniam in Medicinæ exercitio magna utens dexteritate, \& egregia curandi merhodo, paucos habint pares, feque amabilem atcue mirabilem omnibus preftitic, prefertim vero is qui ob valetudinem ad iplum confug ebant. Adanimi vires recreandas in laboriola lina profefione tam fructuosè omnibus liberalibus Difciplinis lefe addixit, ut harum Arca locupletifima menitò vocari pollet ; cò ufque ut non modo fibi arrogaserit quorundam popularium fuorum Litcratorum exccllentium gloriam requare, fed \& omnes contemporaneos in celebrioribus lichenis vincete. Poêtcus amantifrmus fuit ; quàm excellenter autem fuc-" celferit ci fudium hwijmodi evidenter evineunt ejusopera, inter qux celebritatem adepeum eft illud quod è prelo in publicum prodiit Latinis verfibus de morbo yui Gallicus vulgo denominatur. Hoc igitur Poema cam Eruditorum fumma admiratione contexuito. Cùmquehocad Cardinalem Petrum Bemburn, literati fui avi gloriam, tranfmifflet, cujus conflio multum fideitribubat, ut de eo lum judicium fibi frgnificaret, Eminentifmum hoe ingcnium ad Sannazarium Neapoli refidentem idem deferi voluit, qui, coram Cardinale sippoly to Medico ut \&"Yoanne Baptifta Montanoipfrus Eracaforiz xmulos pluibufque aliis primaris Doctis, confellus ef feabalionemine in poefi luperarum fuife quam ab ipfo licèt totos 20 annos inlumpfiflet in corrigendo, expodiendo se elimando grave fum \& fachm de Matris Dei partu. Mathematicus excellens fuit, fudroque Cofmographiz infuper delectabatur, in qua quantum profeciffet mirabile ejas ingenium, clarifinè demonftant deferiptiones \& loca qux, a Portugallia in Orientem ${ }_{2}^{2}$ ab Hifpana vero ad Occidentem delineavit, in ligueis Spher is regulariter fabricatis a Gilni Thearro Virorum Literatorum.

Egre Eracastoria veniam concelferunt Docti circa Poema quod elaboravit in nefarium morbum quem Medice tantum pertractare debuifer.Si magnum fecifo fer lucrum in fanandis luxuriofs, dici porniffer illum voluife gratitudinem fuam conteftari, totam vim Cuam poëticam in Neapolitanamluem exerendo; \& in exemplum fortalic citarus fuilfet quavis data occafione loquendi de chirtrgo il10, qui reprehenfus quod ante Statwarn Caroli ViII in genua procumberer, refpondit fe optimè fcire cur id faceret, nullumque Sandortm elfe quem magis ve- ieraretur quàm Principem illum à quo indirectè ditacus-fuerat morb̆o nimiruman quem 2 (éapoli milites ejus contraxerant. Sed Fracaftorius gratis $\mathcal{M}$ edicinarm exercebat. 2Kovella Reip.Literarix.Febr.1687.p.191,192.Gallicè.

Præcipua inter Fracaftoriz dotes hxc fuit, quod in ingenium \& argumentum fuun dominium abfolutum exercuerit, Hine factum eft ut quantumv is fublimis. foret in ufitato fuo fcribendi modo, nullo tamen negotio potuerit defcendere feque deprimere quoties ipflibuit, ex D.Balzaci fententia. fudicia Eruditorum de Poètiș. Parif.1686.per D.Baiblet. Gall.

Carmina ejus ex parte leguntur Tom D. Delitoltal.pag.10, Opera ejus extans in Tomos audigetta.? 
Hocejus Epitaphium 736l. Gear Sealigero andtoce:

\author{
Hic fitus eft Fracaftoritus Hieronymus: urns \\ Quem capt t, bic cepit pectore cuncta fuo. \\ Sidera digefat : revocavit. funer as Rerum \\ Noture, imperiticonfcius, atque Dei. \\ Aut Hcliconiadum fontem fibi. fuffulit onnem? \\ Aut tumulus vertex bic Heliconis erit.
}

\title{
HENRICUS LORITUS GLAREANUS
}

Clar:A:D. MDXXX

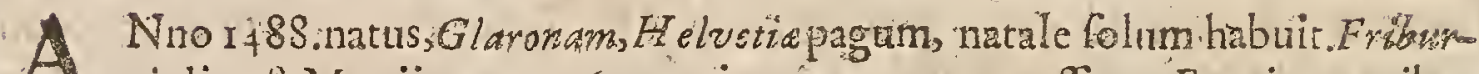
A gi, die 28.Mal tii, anno 1563.xtatis 75.naturx conceflit. - Erat in omniburs difciplinis verlatifimus. Domum ejus optimarum Artium Officinam diltan fuif fe memorant, ex quâ in omnes Germanix angulos viri doctifimi predierint. A Maximaliano I. Lauro poericâ \& eximio annulo donatus eft. Que ícivit, libenter i\& carididè aliis communicavit. Konig.

Scripta ejus hac funt:Ilagoge in Arthmeticen - Defcriptio de fitu Helwetia, \&vicinis gentibus - De quatuer Helvetionum pagis - Pro juttifino Helvetiorisn feedere Panegyricon, ad Maximrilianum Pugufterm, omnia Verilbus Heroicis. Ifagoge in Mulicam - De Geographin liber-Judicium in Terentii Carmina-Annotationes in Foratizism: in Ovidui Metamerphofes: in Ciceronis li- brum de fenectute: In Salutfirum: In Cajaris Commentaria: in T. Livium: In to-

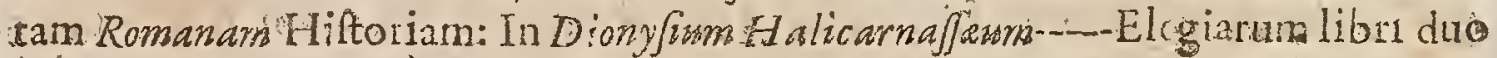
- De Arte Muficâ---De Ponderibus ac Menfuvis--Annotationes in Valerinm Maximum, in Suetonium, \& Lucanum-- Annotationes in Eutropizn---Epiftola ad Ioannem Hervagium--.-Brevis Ifagoge de ratione Syllabuum \& de figuris quibus Poëtæ uttintur--i-De Affe libell lus.

Eft apid nos Hearicus Glareanus Cafareâ Taureâ infignis, quọ equidem decus inter töt juvenis orriamenta maltó infimum effe duco. In omnibus difciplinis, quas Mathematicas 'vocant, eximiè doctus, neque vulganter exercitatus. In

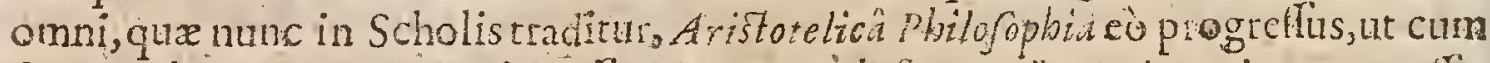
fummatibus eriam congredi pollet. Magnam infuper Theologice rei partem affecutus. In Gcographiâ in Hiltoricis abiolutus. Denigue nullum eft genus lite-

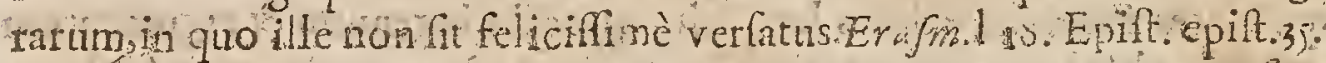

Henrucus Glarcanns, fummus olim Defid. Erafini amicus, Q Wulices fcientia clarus, rem literariam diin voce \& feriptis ( quantuin ea tempora fer ebant) jur vit.Thudis.

Multi judicii \& varix eruditionis vir nobis pueris floruir Henricus Glared-

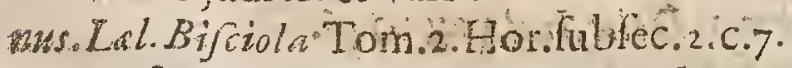

Vir fuit ingentis ac varix admodum eruditionis s etian criticus non patulò

melior, 


\section{CELEBRIORUM AUTORUM.}

Imelior, quàm multi perfuafum aliis volunt-a-A mo 1530 . laudem non exiguam meruit Henricus Glareanus. Helvetizs: qui permulta ad literas, \& Mathefin, pertinentia reliquir: In A richneticis, Mulicis, ingue Geographis, Aftrologis, ac Chronograph s, nomen eft confecutus. Nempe vir frait undequaque doctillimus. Woff. de Icient. Mathem P.96.423.42+.

Faciendum mihi elfe ftatui, ut ei hac loco refponderem, quàm planifimè, \&e quàm lenifimè polfem, non, ut Glareanum, doctifinum virum, quem mihi femtper, quem:omnibus hutgus memorixhominibus antepofui, oppugnatem, fed ut fententiam meam contra tanti viri opes in Liviantâ Antiquicate tractandâ munirem.Car.Sigon.1.1.cemendat.C. 5 .

Dedi etiam Operam,ut, quod-Glarearits ante me fecit, the hac quidem in parte Hiftorix Liviane deeffem, cujus quidem eruditifin viri labole facile ccontenrus elfe poteram:nifi ab co in totâ psà re diffenfifiem. Neque enim $L i-$ vium in numerandis ab urbe conditâ annis eadem rarione ulum, quầ creteros, efé reperiebann. Quit ille opinione dum eorum autoritatem ad Livianam Chronologiam cenfribendam adhibuit, in eam fape fe neceffitatem induxit;ur dum aliorum numeros fequitur, embinò Liviaitos aut tregligere aut immutare coactus fuerit. Qtod illi profecto in eâ Chronolagià committendum non erat, quam ipfe fe Liviano, stertim Hilkerix, comparare prefireretur. Accedit, quod dum ille nimium fuum volgrit in eâ re ftudium indicare,cogtromina multa, atque iteratorum \& multiplicatornm hono rum notas magittratibus ipfis afixit, qua non fo. lum ftudiosè 2 Livio praterita, fed ab ipfus etiam Livii lententià, atque adeo ab Apsâ Haftorix vericate remotxeffe videntur. Idemad Bernardinum Lauredanurs Epiftolâ, quam Oper. Livin premifit.an. 155s. Ccriptâ.

Henricus Glareanus maluit in Philofophia ac Mathematicis Difciplinis confenefcere, quàm remulari Phralin Giceronionam, cui v. $x$ convenit cum fubcilitatibus Aathenaticorum. Erafm in Cicerontano p. $3_{3}{ }^{\circ}$

Glarcanus non tam incptus Cenfor quàm quidam exiftimant. Lipf. Epiftol. QHeit.l.3.c.10.

*Hic, Authorinter Hereticos primaclaflis rejicitur in Indice Madriten edit.ann. 1667.

Carmina ejus leguntur Tomo 3.Delit.Germ p.128.

\section{GEORGIUS AGRICOLA}

Ermanns, Medicus, natus eft Clauchx, Mifinix oppido, vicefimo quarto clar.A.D. Martii, Anno r494. ob it vicefimo primo Novemb.1555.

Scripfit de re Metallicà---De Animantibus fubterraneis----De Menfuris \& Ponderibus---De ? elte---De Traditionibus Apoftolicis--De Bello adverfusTurcam fufcipiencho orationem, multaquealia.

Evolvi Georgii Dialogum de 鸿etallicicis: Nec fatis polfum dicere, majorene id veluptate fecerim an fruetu.M Mnoperèdelectavit $A$ rgumenti novitas, exhilararunt joci liberales obiter infperfi, nec injucunda fuit dictionis frimplicitass, Eee Atticum 
Attickm quiddam referens;precipuè verò me artentum habuit rerum fuboculos expoltarum energia. Vilus fum mihi valles illas, \& colles, \& fodinas, \& machinas non legere, fed fpectare. Nec multùm adfuit, quin ex tot venis argentariis de amaris conceperim aliquan ejufmodi rerum cupiditatem. Denique feliciter pralufit Georgizs nofter, nec ab illo ingenio quicquam expectamus mediocte. Erafrn.Epitt.1.28. cpilt.22.

Opus quod de Menfuris \& ponderibus habes in manibus, cupidifamè legam fimul atque miferis.Id auguror, mi Georgi, tibi magnx glorix futurum. Neceft quodinvidiam metuas, quum argumentum lit ejus generís, partim ob vetuftasem, partim ob regionum varias confietudines, partim ob ipfus mareria fubtilem oblcuritatem, ne quid, interimidicam de libris depravatis, ut nunguam fir exhaufti fatis. Idern ibid.l.i4.cpift.i8.

Georgius Agricola de re mctallica, foflibus, \& fubteraneis Animantibits ita accurate hoc feculo fcripfit, ut omneis antiquos in eo genere longè fuperaverit; \& exact ı non folum eorum, qux à veteribus prodita funt, explicatione 'sed \& multarum reum, quas veniens atas ind gavit, veftigatione, eam Hiftoriæ $\mathrm{Na}$ turalis parcem illuftrverit; additâ poft Grilielmurn Budoum, Eeonardum Portium, \& Andream Alciatum, de Ponderibus, Menfnis; de pretiis metallowm \&z monetarum diligentiffmâ rractatione. Thwansad Ann. $1555^{\circ}$

Metallicam difciplinam ita tractavit Georgius - Agrscola', homo Germanus, ut . Ariftoteles ac Plinius in eo genere nihil intellexille yideantur. Fo. Bodin in Meth.Hift.

Georgius Agricola, diligentifimus Natur, imprimis tei metallica fcrutator, Germanie no ture Plinius, qui meritò palmam refert inter cossqui de re metallicâ foriplerunt.Quensiedt.de Vir.Illuftr.

Equidem monumentis editis \& preclarè ipfe [Georg. Agricola] de re literariầ clt merirus; \& nomen lumm immortalitari confecravic Melch. Adam.in Vit. sius.

In Pontifuria Religione obiit. Ibid.

Ego omninò coniulo, ut legas fcripra Georgiv Agricole de ortu \& caufis fubterraneorum, \& de opificio $M$ etallico. Fuit praltantifimus Philofophus; \& tongè fuperavit omnes, qui ante ipfum de ijs rebus fcripferune. Hubert. Languet. in Epitt.62.ad D Pbil.sydreum.

Diligens \& erưditus Scriptor G.7.Vofjo in Theologyia Centili.

$S$ bterrance rei omnis Scriptor Incomparabillis. H. Conring. de antiquil. ftat.Helmft.p.p.34.

- Georgins Agricola,vir ernditione \& judiciô praftans.Fabric.lib.I.Oríg. Saxon. pag. 3.

Celeberrimæ famæ atque eruditionis Vir, quem in his Originibus habemus Ducem ac Principem.idem lib.3. p.368:

Georgius Agricola non minus eruditus, \& in cenfendâ Metallorum naturâ curiolus fuit, quam verè impiùs, nulli addictus Religioni, ut poft mortem vix fepeliri meruerit. Scaligerana prima, p.80. 
Port Albertum Magnkm hoc in Argumento [de Mciallis]nemo aliquid praAticit,ad ufque Georjius Agricolarm: cujus de re Metallicâ, \& oinnibus Subterraseis, Foffilibus, atque iis qux ex terrâ effluunt, Opera tanta induftriâ, doctrinâ. facundià, \& diligentià referta funt, ut non folùm ante fe natos longifinmo intevallo fuperaver $\tau$, vcrùm etiam exteros in fuporem rapuerit. Scbajp. Seheffer. inttroduct.in Art.Medic:p. 164.

Georgius Agricola Medicinam admodum gloriosè exercuit, totam induftriam fuam omnefque facultates fuas, in Natura arcanis $\mathrm{fcrutandis} \mathrm{infumfit,} \mathrm{\&} \mathrm{in} \mathrm{hoc}$ tam infolita fuerune cjus inventa, ut longifimè Plinium \& e A rifrotelem fuperaverit, quamvis ut polterior ifte in tanto molimine non adjuvaretur opibus tanti Principis quantus fuerat Alexander. Doctifinnorum feculi fui Virorum exittimationem meruit, inter cæterus autem Wolfgangi c MA eurerii, Georgii Fabriciis Valerii Cordi, Erafmi, Ioamis Driandri ' 2 Panlï Eberi. Cìm Aloiatis adverfus Agricelam fcripliftet in Pondernm \& Menfurarum argumentum;ei refpondit Agricola frripte ertuditionis rccondita pleno. Init io Reformat ands thancampleoti velle vifus aft hocque adverlus Indulgentias Epigramma compoluit.

\section{Si nos injecto falvabit cistula nummo, Hen nimizm infelix, tu inibi patper eris.

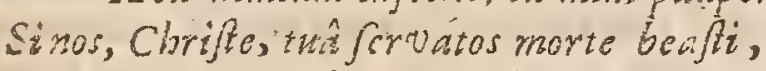 I arn nibil ingelia tu wibi pasper eris.}

Sed poftea Proteftantium Dogmata fe averfari profelfus eft, dicmque in Esclche Romana communione obiic. Antontus Teiffler. Elogiis Eruditorum Viro. rum. Gall.

* Georgii Agricole opera de Menfuris, Ponderibus, pretio Metallorum, Baji-

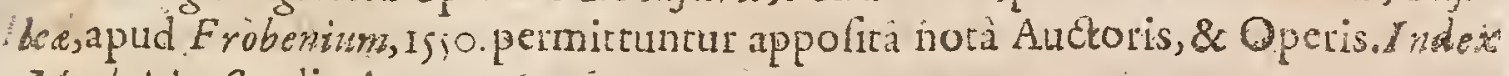
Madritienfis edit Anno 667.

Varia ejus Opera variis in locis atgue remporibus funt impretla.

\section{ANDREAS ALCIATUS}

T Talus, Jurifconfultus, Mediolanenfis, nobili genere natus A nno 1492. obiic Clar. A. D. Isso:Opera Alciati omnia 7. Tomis continentur. Primus omnium juris difci- MDXXXY plinam, nimiis difputationibus \& barbaro dicendigenere involutam, priftino nirori reftituere, \& ad veros fontes revocare conatus eft: Qúod quidem facere haud difficulter potuit, cùn Graci \& Latini Sermonis peritifimus eflet. Fuit folus inter Interpretes Juris doctiffimus, \& inter doctiflimos Jurecontultifimus. Falent. Forfter.in 1.;. Hift. Juris Roman.c. 4 r.

Andreas Alciatus hoc feculo non modo forris Cafarei, verum etiatn om num ftudiorum decus; nec minus fufpicicndus ob rarum quendam ingenix calndorem, quàm ob exactam omnium liberalium dif́plinarum perician. Erafm.

$$
\text { Eece }
$$


in Adag. Nibil adverfurn.

Andreas Alciatur, vir emmeta naris \& infonis eruditionis. 1o. Coraf lib r. Mifcell. Juris. c. I. fect.5.

Cujufmodiperitiam an fummo slciato dubitabimus concedese? Alciatos inquam, viro in omne avum memorabili, \& de quo nibil unguam tam magnifice dici poterit, illius adhuc quin longè latéque fuperet virtus, dötrina, atque induAria.NTam in Jurifprudentià vir quidem ille ficuti dicebar Homerusali is aquandus pluribus unus. I dem.1 7.c 7, lect. $2 . \& 3$.

In univerfa literarum doctrina elucct im pumis ea, qux ab humanitatenomen: fibi adcivit, Quan com coluent mali, qui juris cognitione, praltitere, $A n-$

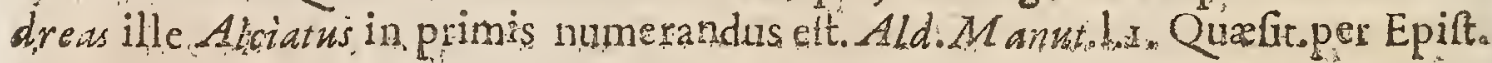
epift.7:

Imò \& Alciatus, vil fanè egregius, non dubitat affrmate, dicionem ejüs [Täciti] pra illa $P$ arli $70 \%$ elle lentreta. Condonemus tale judicium tanto viro \& coyicemus, ex amore fovii proficifci. Vofjl. x. de Hilt. Lat.c.3o.

Focundis, fi ad antiqua rempora comparatur, forfan, qux vinci pollet; fo dno

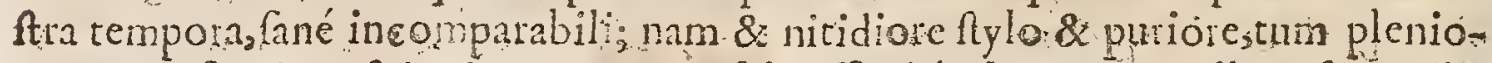

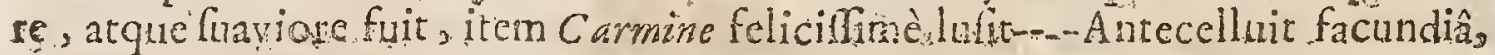
fientia linguarum, Hiftorize cognitione, Inerpretationis fubtilitate omnes, qui in ế facultate vixerunt. Quòd fivolumina cjus, quzextant, id non apertè teftarentur, fupicione adulationis carere non pallem: verum ipfares dicto mcomajor ef, quapropter id Horatianum proferam:Ornareses ipfa negat sontenta doceari.Hieron. Gardan in Andr. Alciat. Vit.

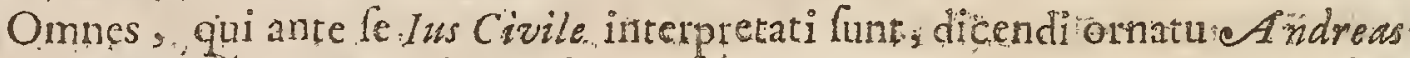
Alciatus cifediolunonjs. longe fuperavit:; qui candida Latini lemonis elom quentiâ, ac Gracis infuper literis imbutus primos noftos. Jurifconfultos Latiné loquidocuit, quos antereblaterifles non locutos fuillèdicebat. In omni denique Difciplinarum genere ita verfatus eft, ut abfolutam juriam ent-m

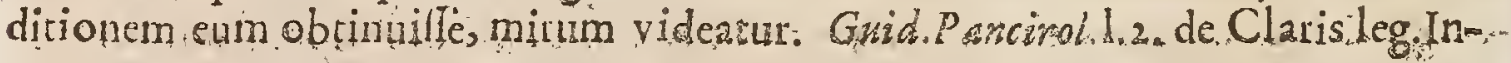
reprec. 69 .

Alciati prater Emblematan hil mihi vider contigit. Ea verò talia funt; ut cum quovis ingenio certare poffint. Dulcia funt, pura funt, elegantia funt: fed, non fine nervis: Sencentix vero tales, ut etiam ad afus Civilis Vira conferant. . Ful.Scalig;.6. de Re Toört.

De hacilludverifrmè dicipotef, quod elt apud Ciceronem de Scaulá, furif: peritorurs eloquentiffmu, eloguentium jurfprerivifuns : Addam \& ego, \& Polghis: Ftor, bonugue Pöta. Lil. Gyrald de Poër.nofri Temp. Dialog.z.

Ejus hodiequeleguntur: Emblemat ingenióa illa, atque Elegis nou poni-.. rendis exprelTa;nifi quod Pertametra fiequentius exeant in poly yllaba adeoque gratia non parum amitant. Ot. Borrich. de Poët.

Andreas Alciatus Mediolani nobili \& antiqua familianatus; eamfibi famam peperit, qua praclarifimis ingeniis qua ejus atate floruerunt accenfesesur, tum quoad decus omnium Difciplinarum quibus exomabarur, tum etiam 


\section{CELEBRIOR UM AUTHORUM.}

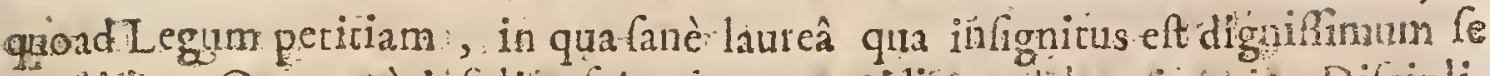
praftieiti. Quia vero infolita fcientiatum cupidine ardebat, in unica Difciplirha acuriffinum ingenium fuun exercere non latis ippl fuit, fed fcientias omnes erercurrendo, cx unaquaque, magno Litératorum ftupore, omnimodam laudem, s immortalem celebritatemadeptus eft. In omnibus qux fcitifinè lcripfir lucu-

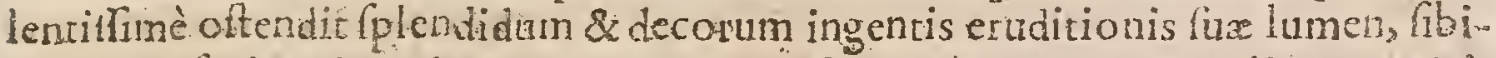
que apud fani judicil viros comparavit exiftimationem optimi politiorum literaxumprofelforis \& praftantifimi Juriconfulti temperis fui. Hifce aliifque infignibus dotibus, qux in ipfo mirificè reful gebant adeo comomozts fuit Senacas. Mediolanenfrs, ut iplum publica Legurn in. Ticinenfî Gymnafio Lecturâ conzdézoraverit : culuod munus aliquot annos obivit, cun magno concurfu Auditorum, quibus. egregia facilique far legendi merhodo fummoperè fatisfaciébatoHaud ita diu poltea: Imperator Carolns Quinius, folis tantivin meritis incicatus in earedolanenfum Senatoum album retulit ipfum; In qua Dignitate prusdentem fuam eruditionetn vita integritati femper confociande honoratiffmum: polt fe reliquit nomen meriti fui \& approbationis qua a jhem omnes dignati i eant Gibilini Theatum. Ital.

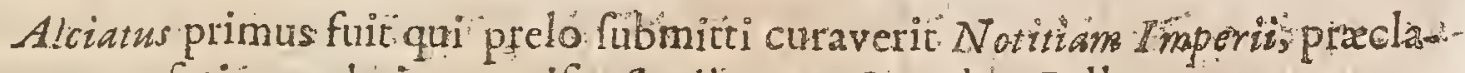
rainque prefationem huicpremifit; Scaligerana fectada. Gallo in

Stephinus Paquier affeverat Italos minoris aft inaffé Alciatum quàm Biartbo- Lomsum Socinim qui Bononire Jurifprudentiam docebat quo tempore eAlciatus: Mediolan Profeflór erat. Eorum autem hac erat rat o; quòd Socinus æratem fuam"

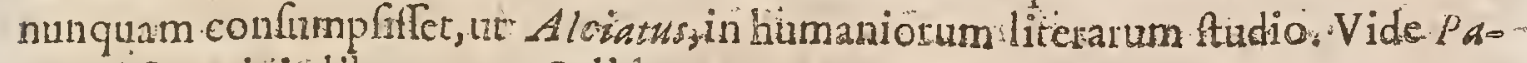
głeriz:Scrutinialib.9:c.29: Gall?

Andreas Alciatus ex Robertollo \& al lis. fua defumphiffe fertur:Car.Sigon c.680 p:33z. Tom 2.Lamp:Critic. p:186.243.

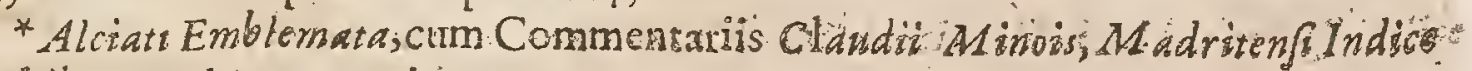
prohibenturdonec corrigantur.

Hoc ejus Epitaphium qül Cafar scaltger compofuit:.

Qidu fatis fuit invidis Juperfes:s

Puradictio, nobilis, diferta.

Compta carmine melleo Poëfes:

Ingens cognitio erudita rerum.

I hris regula justa, lexque legum

linmortalibus explicata pennis

Tirorum beat ors doctionum.

Nilfnit- catera gua capit' Sepulchrums:

Inmenfis meritis utergue utrigue

Ircumbunt drio, mutuegue certant."

Tix totus decus Orbis Alciati-y

Iotius decus. Orbis Alciatus. .

EFE 35 JOACHC. 


\section{JOACHIMUS CAMERARIUS}

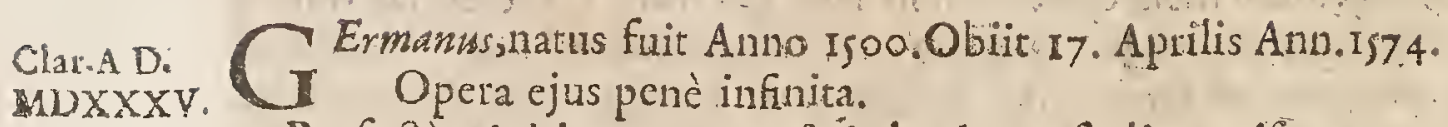

Profectó vir hic nunquam fatis laudatus, fralius quifquam, verè Germmio fux Phanix fuit; non gentis fuxjudicio folum, fed etiam exterarum. Quantis enim preconiis eum extollunt lovius, Turnebus, Lipfursacoptimus \& doctifimus quifque: Ufque adco, ut qui eum non maximi faciat, is certifimo indicio, vel inter indoctos, vel improbos, referi mereatur. Voff.de Mathe1n.p.377.

Cùn viram otio literaio confecrafiet Camerarzms, pof perceptam utriulque lingux cxactam notitiam, non folùm ad bonos aucoores interpretandos, tàm Poetas, quam Oratores \& Hiftoricos, fed etiam in folidionibus thilofophix, Mathematicarumartium, \& poftreno Theologix fudi s multa commentatus elt. Ad qua onnia ( quod pauci ante illum fecerant) politioris literatura or namenta femper attulit, variis in omni doctrinx genere lucubrationibus, aut dum vixit cditis, alt polt ejus mortem à tanto Patre dignis fliis publicaris: que lparfin \& diverfis temporibus ac locis per particulas edita (cum equfmodi fint, ut is ad rem literariam plurimum emolumenti fit redundaturum ) Cimul onnia aliquando edi Rcipublica maxime interct. Thuan. ad 2n1n:2574.

Studia nunguam remitebat, ne inter peregrinandum quidem; fed qua ablente Bibliobccâ vel inter v'as, dumequitaret, vel de node animo concepiffet, arrepo deinde calamo annotabat. Lingum Gallicam \& Italicam jam fenexattigit, \& Hebraicam etiam deguftavit. In Grach familiam duxit: in Latinâ ceffi nemini. Hiftoricos, Poëtas, Oratores, Medicos, Jurifeonfultos, Theologos Gracos \& Latinos excufrt. Melch Adam. in Vir.Carnerar.

Eò provectus eft eruditionis, ut, communi doctorum omnium confenfu, peritiorem lingux Grace nemincm, in Latinầ vetò linguâ difer tiores perpaucos, cxâctiorem autem nullum Seriptorem hzbuerit Germania, frcut plurima ipfus monimenta teftantur. Theod.Beza in Icon. Illuftr.Vir.

Vir inter eruditos magni nominis. H.Comring. de Official. Imp.th.Is.

Uriufque lingux hodie Princeps.

Ego o:O Deum, ut excitet Cangerarios in veftrâ Germaniâ, in noftrâ Gallin Scaligeros. Ifac.Cafaub. in Epiftad Georg. Remum.

Vivet vieillius, \& atatem florebit laus intemerata;nec quifquam erit, qu hoc

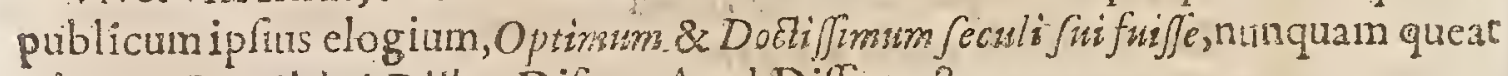
eripere. To.Micbel.Dilher.Difput. Acad.Difert:18.

Nonfux tantum Germanic, fedetiam torius nofra Emopa decus \& onna mentum,Ioachinas Carnerarius. Turneb T.4.adv.c.I.

Parens vefter xternum illud Germanice decus. Lipf.in Epift.ad Ioach.fil.

Grati mihi femper Camerarii, ob unum illum, Virum, quem Germania veftre habuir fine pari. I dem in alterâ Epitad cundem.

Nive 
Nota loachimi Camerarii innumera in rem literariam benè prómerita. Quem jue nequicquam ingtari luçmones rodere conentur. Sciopp. de Arte Critic.p.7.

Eft in celebri famâ foachimus Camerarius, Græcx atque Latinx lingux ita pericus, ut fcribendo pernobilis Ciceronis imitator evaferit. Taul. Iov. in Elog,

Camserarius vir bonus, qui non male Authores interpretabatur. Scalrgerana to

Camerarius fuit unus è maximis àtatis fux Germanis. Scaligerand 2 .

A quorum [ loachimi Camerarii, \& Zuingeri] léctione nemo unqüam nifi do Etior receffie--Camerarius \& Gipbanius nihil unquam ineptè moliti funt. Gabr. Naud.inBibliograph.Polit.

Toacbirmus. Camerarius reliquis: in juventutem Gormanicam meritis adjunxis \& Carminis gloriam, prifertim elegiaci, quâ parcis ade acedit, five inventionem confideres, five facilitatem, proprictatem, numerum. Ol. Borricho de Poèt pag. $127 \%$

Vir de politio literaturâ præclare meritus Ióchimus Camerarins, fuxqute adeò Germania fing ulare ornamentum. Caftus fermo; \& perfp cuins; quem ara cum Griecis contuleris, fincertmatque fanum, \& nunnif obfcurioribus declarand's, idque rarè \&.leviter, excurrentem agnófces. Hneto de Clars Interpret.

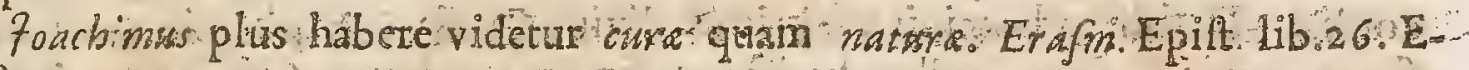
pirt.45.

Ad hanc autem in omnibus bonis difcipl his eruditionem acefferat pietas fingularis, prudehtialongo renm ufu confirmata s, quim étiam magno illi Philippo ctrelandhoni id ipfum effer quod eAtrious ille Ciceroni, tantum

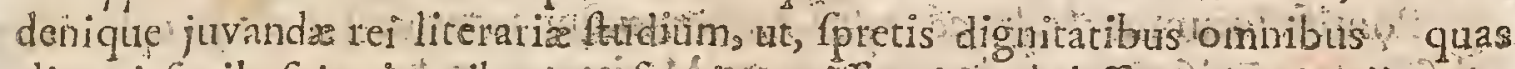

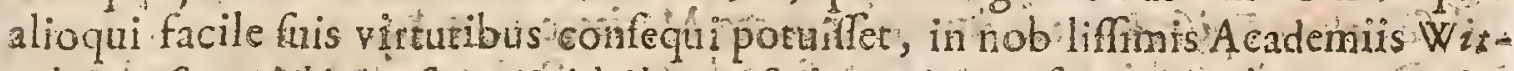
tebergenfi, Tübingenfo, Heidelbergenfi docendo confumptîs aliquot annis, - Lipfia tandem pofitis fedibus in extremâ fenecta fortiter idem munus obiens, lugenibus bonis filque omnibus, \& mox fequuturam rerum commutationem

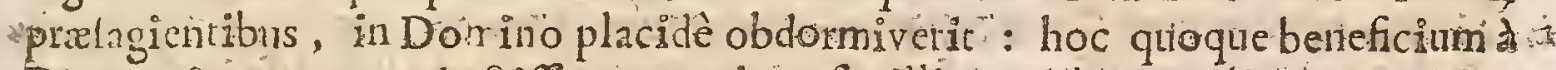

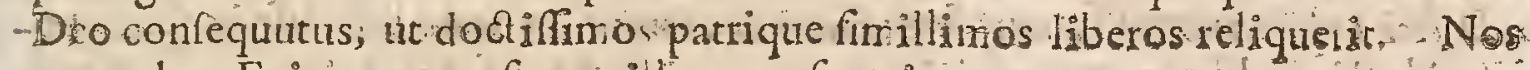
autem hoe Epigrammate fumus.il lum profecutio :

Extindtis olim; Mula, flevifis alumis.

Et vitam veftrâ reftituistis ope.

Nos contrà vobis, Joachisis in funere, Mufa

Has mileri exiingtis. Jolvimus exequias.

Namque ormnes teckm, teckim, Joachime, Camosase

dit vixere fomul, foc perieke fromul.

Bera:ing I6On. 
* Hic Author Romano Indice inter Hareticos primx Claffis numeratuo Omnia ejus Opera variis locis arque temporibus funt imprelia.

\section{ALBE R TUS PIGHIUS}

Clar. A.D. R Elga, Campenjes familiaris erat Pspx Adrarso, VI. quem etiam in MDXXXV. D Hilpaniam euntem, comitatus fuit: Ac defuncto Romx Adriano, amantiffmum fui lenfit Clementem VI I. Varias obiit legationes Romam, Wormatiam, Ratisbonam. In Mathefinftituit Paulwm III.à quo donatus eft duobus du-

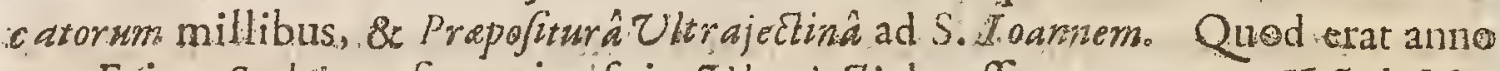
I535. Etiam Sadoleto ufus amico fuit: Ultrajecti decellit anno I542. Voffo de Mathemat.p. 7 \%

Scripia ejus hac funt:De ratione Pafchalis celebrationis: De refturutione KaIendarii.Ecclefiaftici-.-De Equinoctiorum, Solftitiorumgue Inventione-Apologia adverfus novam Ch arci Benezentani CK onachi Cocicfini Aftrologiam, atque Apologix defenfro--.-Afrologix Defenfio, adveríus 1 rognofticorum vulgus--Affertio Hierarchix EccleGalticx--Apologia indicti a Paulo III. Concili--Rario Componendomm diffdiorum, \& farcienda in Religione Con-

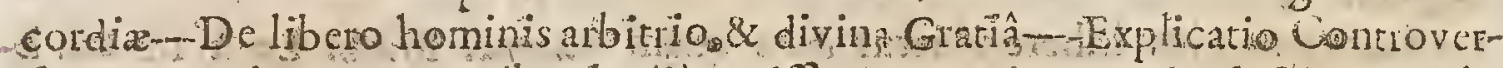
frarum precipurum, quibus hodie porilimum exagitatur Chrifífides \& Religio.

Vir maximus atque doctifrmus inter Pontifrios vacatar a Luello Epifcopo Sarisbur.

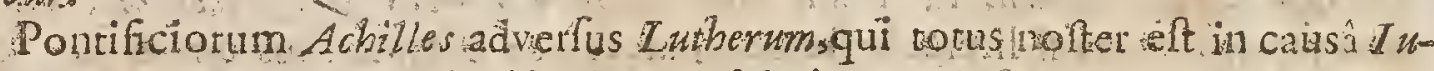

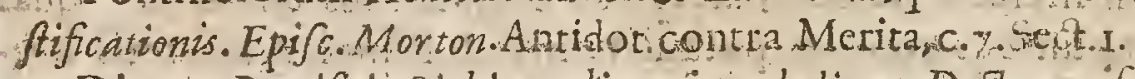

Dicunt Pontifici Pigbiumaliogu atbolicum Doctorem feductum ex Lectione librorum Calvini. At Pighius iple teltatur, fententian form fe cectione Scripturarum haufife: O Caivenum viel Adveriatiorum teftimonio beatum, cujus Script tantum cum Sacris Seripturis confenlum retinent, ut quod Pontificin Doctor celeberrimus fatetur fé Sacra Scripura lectione habuife, id alii Pontficii lectioni librorum Calvini tribuant. Profocto nifi Scholaficorum fententia cum manifeltis Scripturi pugnaffet, nunquam illam delenuiRet Pighius Epifo. Carleton Confenl. Ecclel.Cathol. contra Trident.c.3.

Albertas ? ighius vir multa ac varix lectionis, f́ientixque omingarix. Valar. Andreas in Biblioth Belgic.

Albertus pighius, vir actrifmi ingenii, Theologus, Philofophus, \& Mathematicus peritifirmus: fed liber ejus de Ecciefafticâ Hierarchấa cautè legendus eft, quod non lemper foliciam tradat doctrinam. Card.Io. Bona.

Libros thos de Hierarcbie Ecclefraftica Pincipatil cum legerem, plurimaque in illis invenirem, que tuâ curâ \& dilïgentià in lucem è tencbiris quafi vetutaris prolata funt: fcatereque ibidem omnia optimis \& fententiis \& autoritatibus cencrem: equidem ingenium, \& doctrissm, \& notitiam tuam xerum anti- 
quarsm fum armirarus. Sadolet. in Epift. ad Albert.Pigh.

Magnahercle Natura illadentis inverecundia, excellentem doctrinam cum illuftri eloguentiâ colijunetam, fi Cbristiani Scriptoris decus lpectetur, multa in- faceti Oris truculentia opertam, in Atberto Piglio conlpeximus. Is Campo Batavorm vico editus, lecutulque Adriani l'ontifeis fortunam qux ex difciplinis peregrè didicerat, Latini-fermenis elegantia feliciter exornavit; ita ur fubtitilifimarum fcientiarum placita, \& fi quid darum, atque difficile ex fa cris literis novitate rerum ac rominum fcribentibus offertur,prudenter ac molLitcrexplicaret.Sed in dilferendo vultus Scytbico more contufus \& enornis, \& afpero pientix gloviam deformabant. Adthirabili quoque cum ingenii, tum manuum - gutià excelluit, utpotè qui xrea intrumenta deptchendendis fiderum curfibus; exactilime fabricaret. Verum in libro de Hierarchi , quo veluti acutifimo gla dio Lutberi caufam jugulavit, ferè nemini conceffam pieraris \& doctrinz laudem adeptrs eft. Qumid volumen commentaretur, ut direptam ab impiis facio-fanetxpoteftaris thareditatem Romaro rontifici alfercticume fummo vitx periculo certifinum Dei maximi numen eripuir. Paul.fovin Elog.

Albertustpigbius felici ac xalarili vir ingenio, qui cum Theologix atque Aftronom congnitione naturalem quoque pudent am, rerumque publicarum ufum \& intelligentiam donjunxic, eximid-Latina dictionis elegantiâ, qux feribeage ageretvecomitante. Aubert. Mfireus in Elog. Belgic.

Immortalitate dignus fenex: plawe alter Livius, indeferf calami \& fyli.Lipf. cent.2.adBelg. Epift, 5 i.

Obfervet Lector, quadam $P_{\mathrm{g} g h t}$ Theologis Doctoribus difplicere, ut de Peri'

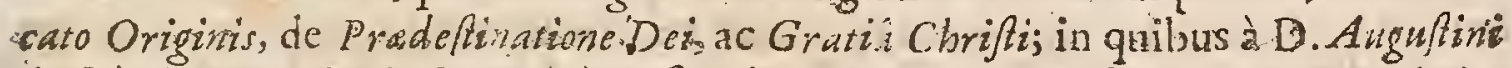
doctinâ, quan Ecclefia Gabilica fequitur, videtur recellffe. Anton. Pojevin. Apparat.

* Alberi Pigbii libri Accem de Libero Arbitrio contra Calvinum, ejufdemque Contraverfia de Peccato Originali, prehibentar in Indice Madritienfi edits inis. I667.

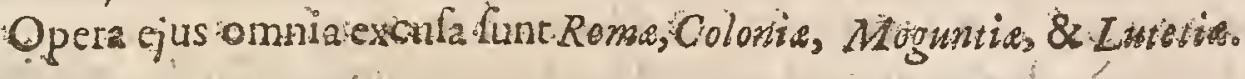

\section{Woc ejus Epitaphium:}

Ne worba Tiemultom tiator, iftum:

Sed adflareverenter, falutas

Sacrattom cinerem Virifacrati.

The ef Pighives, boc loco sipultiss

Aures qui Batavas it expoliat,

Ut dicas Japere Atricos lepores

Puare tarn bene dormiat precare,

Quarm docke, nitidégue:

Defendit Latix decus Trame. 
Et morem fartut pium Sacrorum:

Vtro ut nomine debeant Latini.

Pins illi addubitent:ustroque certé.

lngens promeritum Viri fatentur.

\section{BEATUS SIYE BILDIUS RHENANUS}

Qlar.A.D. $M D X X Y$
- Ermenus, natus ef Seleftadii Alfatia Oppido celebri, Anno Dom. 1489

1 mortuus eft dum rediret ex. Thermis Martiis, Argentine, Annous 47.

Scripfit Obfervationes in Plinium. Rerum Germanicarum Libros III. Annota tiones in Liviwn, \& Corn. Tacitum. Velleni P aterculi Libum refituit. In Tertul-: lianum Argumenta \& Annotationes. Prxfatus eft in Opera Senece, in Theophras firum Ener; in omna ferè Opera Erafrni, cujus Viram \& Mortem défriphit Duas Gregorii Nazianzeni Epiftolas vertit, \& alia quxdam.

Mulum illi fedulo \& pererudito Aritiquitatis obfervatori, omnes bonarum literarum ftudiofi debent, ut qui, etfi non omnia fit altecutus, pluxima tamen acu tè. ac diligenter animadverterit ; \& aditumad alia cognofendi multis ante tenebris obring aperuerit:quod \& illi-de Germanicis rebus libri, \& iftitum TertulLiani, tum etian Taciti, Plinii, Livii, Senece, Paterculi seconditi abunde demonAtrant. Beza in Icon.Vir.Illuft.

Beati vocabulum tibi non fortuito, fed divini nurniris conflio contigit. Ea rafm.1.29. Epift:3\%.

Omines beatitates noftum beent Beatum, quinobis Fertulkianum dederit, $\mathrm{il}=$ lum fic adanatum à Cypriano, fic laudatum ab Hieronymo. Sed ttinàm integrum \&e rendatum dare potuilfęt. Plurimum tamen debemas ilius indantrix 2 qua quod licuit praftitit. Idem l. I. Epitt.22.

Beatus Rbenanus, vir in humanioribus literis ; antiquitate, \& pia doctrinâ exercitatifhmus, ingenio miti, ut qui in cogitatione de conttituendâ ex omnium confenfu in Religione concordiá confenuerir:Summus Defiderii Erafmi obfervar ror, qui eandem viam in his turbis.infticit. Thuan.ad an.1547.";

Beatus Rhenanu, homo optimè de multis praclarifimis anctoribs meritus. Rarth.1.5. Adverf.c.I.

Magnam laudem debent exteri Eeato Rbenano, \& Tanni Rivio; quisfi, vel hodiè viverent, ubi poft cos hæ literæ mirificè excultx funt, principibus Criticis accenferi polfint. Et benè habet, quòd cos, qui juvcniliter olim Rhenani beatis manibus infultarant, pracipitate dicacitatis publice ponituit. GaJp. Sciopp. de Art.Critic.p.7.

Uno verbo dicam, fuit vir bonus \& doctus : imò optimus \& doctiflimus. Melch.Adam.in Vit. Rhenan.

Ingenii \& indultria laudem Rbenano libens do \& \& in inter primores eum fux gentis.Lipf.Not.in 1.3.Hilt. Tacit.Num.53.

Hiftoricus \& Criticus non costemuendus vocatur Demppere.

Flores 
Floret adhuc apud nos predulcis \& grata memoria Beàti Rberana : ex ejus ingenii liberalitate, officinaque libraria, optimarum literarum magias opes ad nos pervenifle conlpicitris Paul. fov. in Elog.p.221.

Ecatum Rhenanum ob fidelitakem, judicium, eruditionem, ac diligentiam lairdat Nic.Rigalt. Not.ad Tertull.

Rhenano Germania \& ros oinnes pluimum debemus, it Antiquitatis \& vete? rum Audtorum reftiturionc.-S Scaligerana prima.

Plurimi facio Argumente \& Notas quas - Rhentanus, qui fuit in humaniorib ros literis \& in Ecckfrattica Vetuftare doctiflimus, pretixit fronti omninm ferè Tertalliani Scriptorum; nec ullus mihi videtur uriliùs illo laboralfe ad hujus Authoris intelligent am, fapientifliméque a Bomino Rigaltio oblervatum elfé nihil Rhenano acfinile, ad abfolutum Opus faciendum, niff fuificientem Ma-

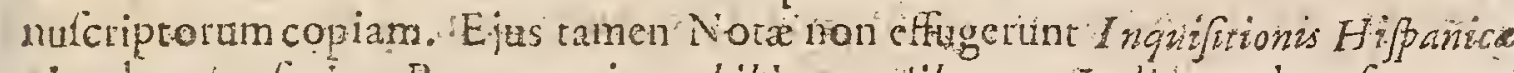
virgulam cenforiam, Romxque in probibitortim tibrorum Indicem relata fucrunt. proptore earum quafdam pauto liberiores in aliquos abufus que ejus feculo invaluerant: Verum id nilhil de harum merita exiltimatione decrahere debet. Ell.

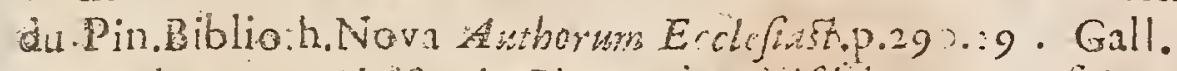

Stephames Pafchafins de Rberano hoc diffichon compolit:

\section{Qwi docuit quicquid Rheni concinditur Orbe, Annog Rhenailum dicere jure potes?}

Beatus Rhenanus filins fuit Antoni- Bildi qui poltquam Schickadum fe: secepillet Rheriani nomen obtinuit a Rberiacó nativitatis fine loco. Vir fuit enditione, modeftia \&eprobitate pariter infinnis. Accufatus fuir nimii terre-

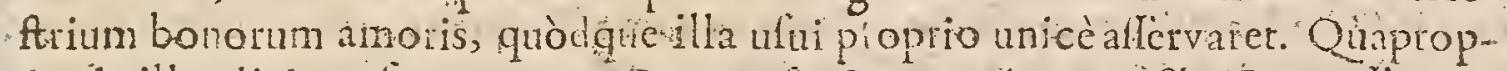
- eer de illo dici confuctumerats Beatus eft, Beatus Attarien fobr. Beza alleverat quòd Rbenanus licet Proteftaitium Relig'oncm approbaviffet, hanc ranen, ad Erafmi exenimplum, apertè nunquam profelfus fuerit. Alii frripferunt duos praclaros illos Viros diccre folitos finfle $L$ Lutheranos bonam quidem caufam tier is. fed íllam non bene propugnare, Zuttheranos bonam caufarm rialè agere, Ant.Teiffer. Elogiis Eruditorun Virorum.

Quamvis Rhenati Eufebius nihit hodie valeat, fuo tamen tempore Opus admirabile furit, pofico, ut ipfe arbitrabatur, gurod Grocum ejus Autographum reperiri nequiret: quoniam tolerabilem ei feriem dederat, prout cxigno exemplarum Latinorsm auxilio fubnixus fuerat, reliqumque vel propio judicio vel lectione propria ftepleverat. Quibufaram Rhenani fides fulpecta fuit, ob ejus aliqualcm libertatem fenfa fua pàllò nimia fimplicitate promendi, \& quia corum zelo non rgebatur qui volebant ut ferro \& igne in Sectarios feviretur; Sed nullatenus verolimile eft eum unquam Patrum fuorum Religionem deterüllfe. Judicium Eruditorum,per Bailletum Parif. 1685. Gall. 
Abfque reftamento deceffrt, licet apes 8000 . auceoum aftimationis Aro geninenfis paucis \& obfuris haredibus reliquifer. B bliotheca ramen iplus Senatui conceffa eft ex famuli Rudolphi Berzi reftimonio, qui Heri eam fuille voluntarcm extremam di it Cadaver Angertorato Seleftadizy afportatum, ibi fepulture tradirum eft. In Religione probavit Dootrino lucem, nectamen quid ipfefenciret, enunciayit, idcò timiditatis à nonnullis accufatus eft proptẹr nimian ipfus, erg? Pauperes tenacitatem de: co quidam dixerunt: tus eft quidem beatus, fed fibitoli. D. Pawl Freber. Theatr. Viron eruditione Clar.

* Beati Renani Scholia in Terullianmprohibentur in Indice Tridentino; vide Indicen Certerum Auctornm Ejus Epiftola de Primatu Petrix ubicunque re--

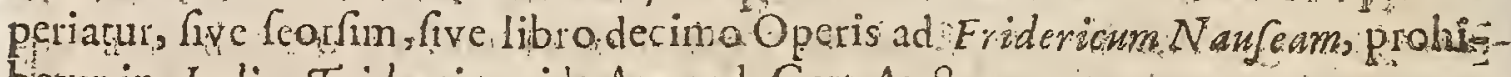
berur in Indice Iridentino vide Append Certo Auctorum...

\section{QABRIEL EALLOBIUS:}

Clas. Ak, U

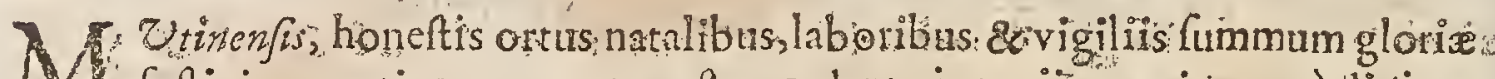
MDXXXY I I faltigim pertingere conatus ent, accedente ingenii acumiliepenè divino, [ nonenim continebatur inter conmunes intelligentiz limites] \& carporis va-... lido, \&ad mi abili temperamento., Qunre,ubi primum ad Medicamplenè capellendam factitatem, Simplicium Anatomicaque, \& Afrologici artis $\operatorname{Cog} n i t i o$ nem accepir; ratam, ferè Europan peragravit; ut, non tam abdita rerum cognolce-

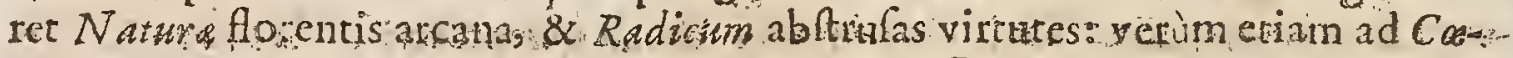
lefia penctranda pertingeret. Quorum notiram alTecutus,s eandem in curandis s morbis fortunato eventu adhibuit; His artibus inter Medicos fui ævi principatum facilè obrimit, communicuc platu in Lycea Patavino, à farenifima Vinetorum Republicâmaximis muneribus donatus, Anatomicam Artemexplicuit, nee

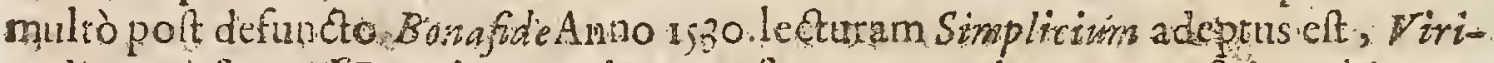

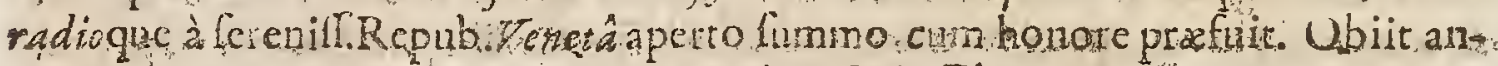

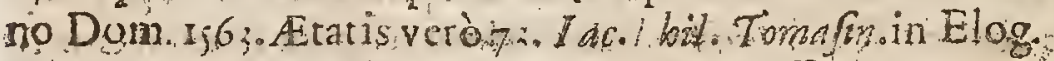

Fuit vir in perwolvendisilibris dihgentifmus, \& confcribendis miro lepốces

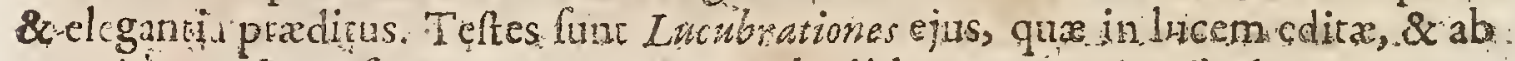

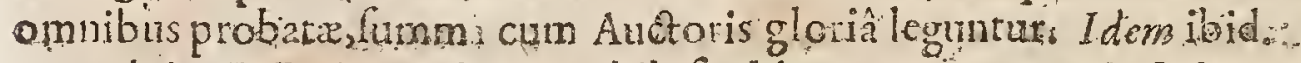

Gabiel Fallopius, vincum Fhilofoplise ac caterarum dactrinamesum rei. Anatomica imprimis, yaris obfervationibus locupletata: atque aeco urriugue

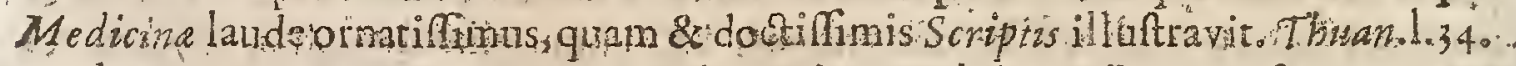

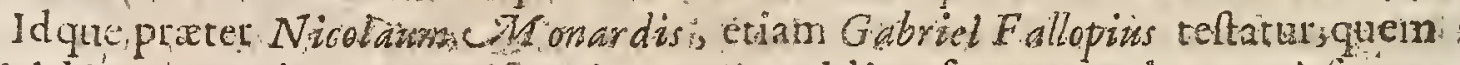

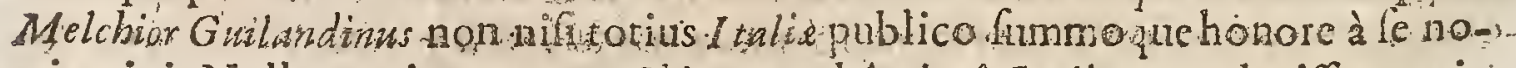

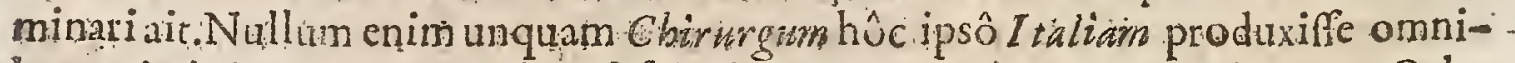
bąs anini ingeniique dotibus ablolutiorem. Guid. Pancirolo de Novo Orbe : Tition 
Gabisiel Fallopins, Anatônicorum fidus \& exemplar,vir admirandi fanè ingenii fómmique candoris, quique in omnibus $A_{r t i s}$ noftira parribus maximâ cum laulde fuit verfatus.Sskipfit auten inter alia: Obfervationes Anatowicas, præclarum atque infigne opus; in quibus mulea 跃 falio prarervifa animadvertit; nunquan tamen fine Pratatione éjus mentione facta, quinetiam Divini.titulo femper eum diynartus. Seb.Ssheffer:in. Artem Metic.p. 103 ;

l'rodit fub Fallopit nominc. liber Italicus rifcriptus Arcana varia of mira-

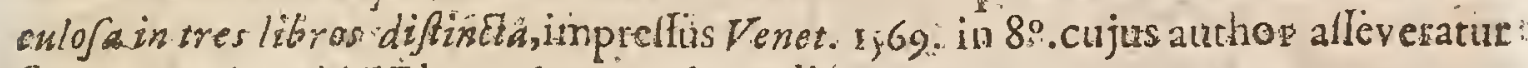
F. Bonac.Ant.Tezff. Eloge viror.erud. Gall.

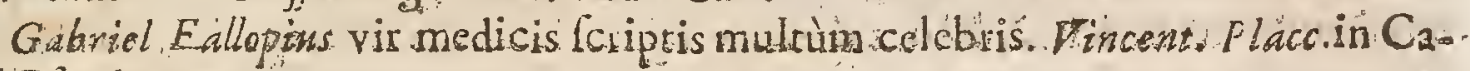
tal. Pieudonym.-

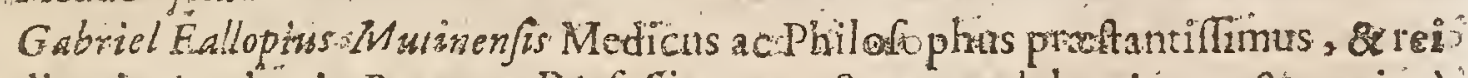
Medicæin A cademia Pataven Profefier, tractatun pulcherrimum \& maximè urilem edidit de Medicatsis Aquis, atque dorFo Julizbus. Gespers.

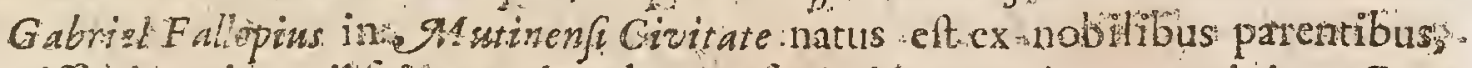
acutifinigue ingenii fui ope ad multarum fciéntian culmen pertigit ; Cum

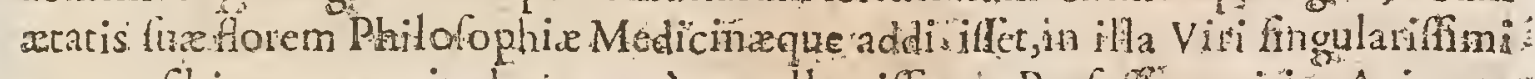

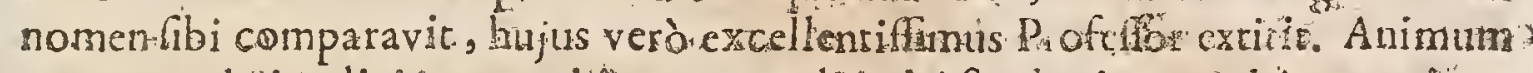
pretcrea ad Simplicitim cognitionem appralif, ad A fti ologiam \& ad Anatomiam, quarum Scientiarum openomen ejus gleïz famæeque rtcrniatem adeptus: eft. Toram fere luattravit Europam, non in alıun finem quatm of plura diflcerst; tan-s demque Patavium redux relumfit mmus wacandi rgyorum etrarioni, iti qua refopretu fuifelicifimos habebat fuccellis, hi verofalurare bencficiuminde perci-

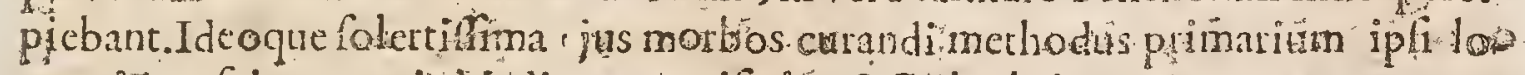
cum iñter fuitemporis Medicos aequifivie , \& Reipublice Vénete opportunam

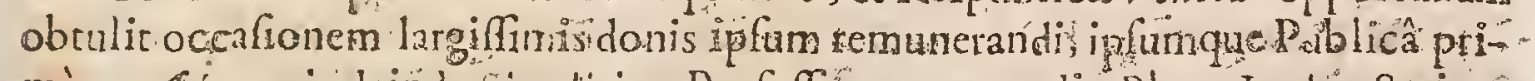

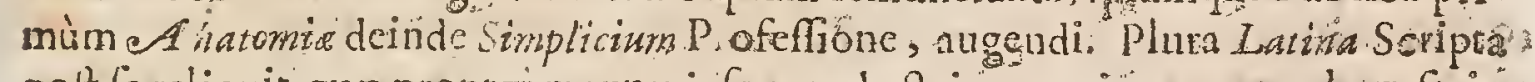
goit lecrcliquit, qux propter mytix ipforum doetrine merita cy portm beneficio in lucem cdita fint. Ghiliwi, Thearro Vironm Literatorum. Ital:

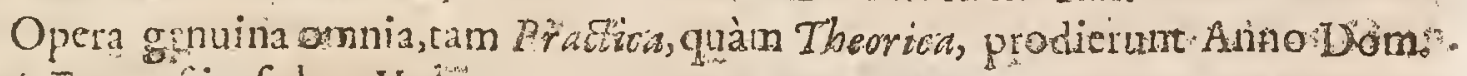
160'. Francof in fol: 3. Vol:

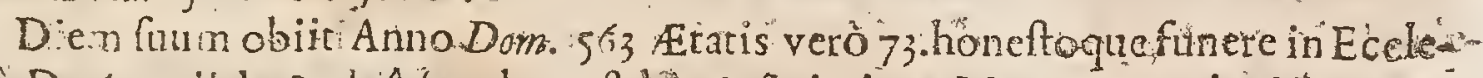

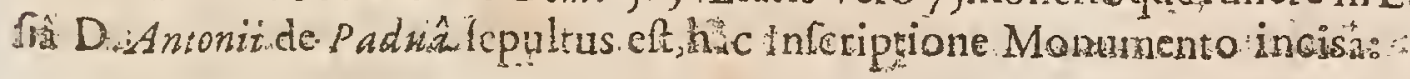
Fillopi bic tumbalof folus noncorderis; und :
Eft pariter tecuss nostra. Scpulta Domuss.
THEOPHRASTUS IMARA CELSUS? aliàs. B O M B A S.T. diôtis...

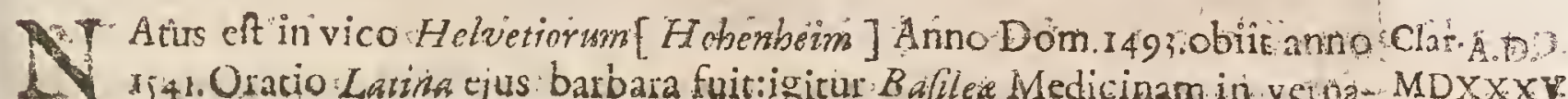

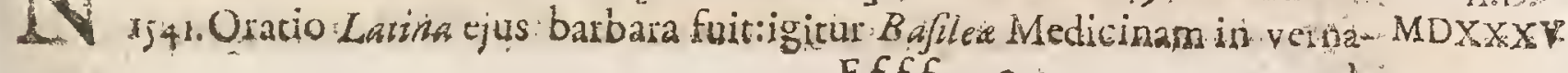
Fiffe 3 sula: 
eula lingua docere copit. Erat Arifotelis, Galeni; \& Avicesne maximus oon: temptor, quem poltremum etiam Bafzlea publicè conbuffit. Spiritu familiari ufus fertur, quem capulo enfis inclufum habuilfe putabatur. Scripfor libros 230 . in P. bilofophäâ, \& 46.in Medicinâ. Scripta ejus tanti.zitimara lunt, ut à nonnullis in Latinum, ltalicum \& Gallicumfermonem tranfata fuctint. Remdius etiam. $M$ edicos libros Crucé convertit. Konrg.

Patris auxilio primùm, deinde propriâ induftrấdoctiflimos viros in Germa-

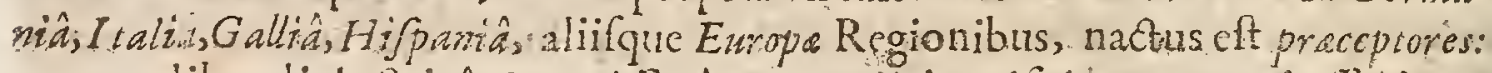
quorum libcrali do etrinâ, \& potilimum proprià inquiftione, tat qui ellet inge-

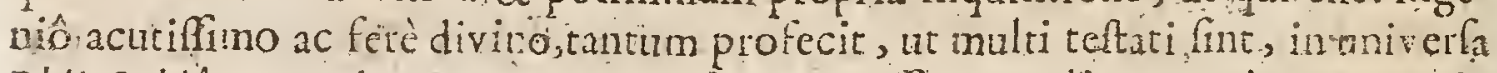
Philofophia tam ardun, tam arcana \&abdita cruilie mortalium neminem. Melch. Adarn in vita ejus.

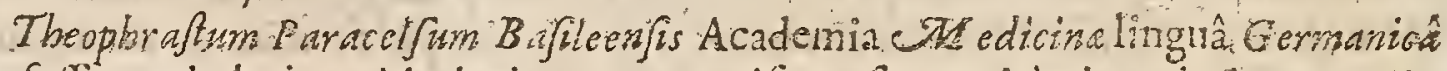
profellorem habuit; qu in intima nature vilcera fic penitus innoierit, is etallorum Stimpinquque vires \& facultates ram incredibili ingenii acumine exp!oraveIit ac pervideritad morbos omnes vel defperatos \& opinione hominnm infanabiles, percurandum;ut cum Theophrafto nata primum Medicina perfectaque videatur.Petr.Rarizus Orat.de Bafléa.

Ad Paracelasm vero quod attinet is equidem mini nequaquam propolui

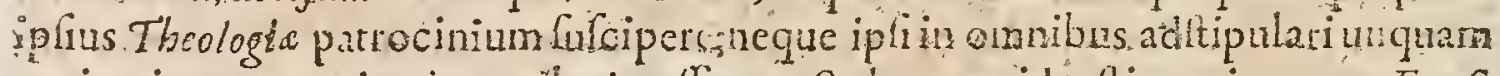
cugitavi, tanquam in ej is veloajur lem. Sed prate: id teftimonium, quo Eraf mus illum qưbufân Epiftolis ornavat, anfm ego dicce es cucri multa illum

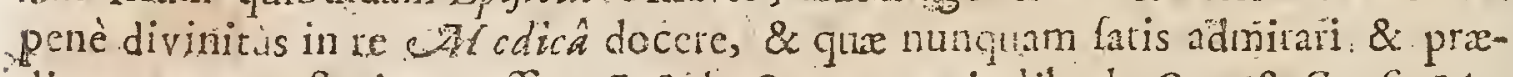
dicare grata polteritas polfte Iofeph. Quercetas. in lib. de Ortu \& Caufis Men tallorwm.

Principia rerum tatuic Paracelfosthxc tria Snlphtor, Salem, ac Mercuritum; quibus omnia corpora componantur, \& in qua tandem ctiam rciolvantur.

- Nec tantum nove Ficdicine, verum etiam nova Theologie autor ct Thesphraftus Paracelfus; ejus enim Scripta tanti,ercoribus, fuperlticionibus, \& diabolicis inventionibus funt teferta (puta in is quæ fidem conccmunc) ur vix cogitari, multo minus inveniri poffint deteftabiliora. Quenfadt. de vir.doct ina illuft.

Negabat $P$ aracelfus primos parentes ante laperm habuille partes gcaerationi hominis neceffarias:poltcà accenlife, ut Etrurnam gutturi. Aicbat Chriftum non cs Adama ortum, fed Abrabano, cui facta Piomifio. De Refurreftione ctiam mirifica fomniabat. Negabatenim:tibi placere rationem, quamprimi Ecclefice rum Reformatores hatenus iniifient, fanè felici's fe fuife Papan de folio detrufurum. Hic quilongevam aliss vitam pollicebarur; obiit anizos fol mnatus 48 . quod ci ̀̀ pluribus exprobratum. Quid fi dicamus, volnile. Dewm in co faftim retundere humanum Adhxe poctilis ( quod verifimum clt) mam gis indulfule, quàm conduceret longam fibi vitam promittenti. Vof: de liniloloph. p. $\rightarrow 1 \cdot 72$.

Theophraftrm Paracely wille, 


\section{CELEBRIORVM AVTHORVM.}

xile, fatecur Diniel Sennertus, negatque fe de Bernardo Penotio, varis, qux Paracelfus Foanni IJaaco Hollando , A rnoldo Rairnundo Lullio, Iöan$n i$ à Rupe Scifsâ,. Trithemio, Lanfranco fuerit fuffuratus, teftanti per omuia fidem habere, quod Paracelf 3 lcripta, autoribus iftis collara non ubique refpondeant : addictamen, non omnia elle de nihilo, atque hoc allegatos authores legenti patere: Mox loannis quoque Cratonis verba lubjungic leribentis, librum fe vidilfe, ante ducentos fcrè annos à Monacbo quodam Vlma friptum, in quo fparfa frultulatim à Theophraffo medicamenta perfoicuè deprchenderir. Qenique ex Bafilir Valentini Scriptis multa lupprefro nomine Paracellum in tira tranitulife clailfunum elfe ait celeberimus Conringius. Thomaf de Plag.Literar. fect. 514.

Paracelys qui Operntonis potius quàm Philofophi charancrem pra fe ferebat, Rayrnundo Lullio \& Cardano abturdior eft. Sibi cnim in aninum induxerar Pbilofophiam novam, novam Artem Crledicine, novamque Religínem conderc: Impulft proprio per ridiculam ncutialitatem, mediatorem te gerens inter Papam \& Lutherum ut ambos ad Axionata fua fequenda adduceret, Gobory priuns ejus in Gallia Sectator fuit; :Phy fun is erat adinodum fuperficiarius, fed dittillatarinlignis: Paracelsus profundieratingeni, dictionem habet moftam \&oblcuram: Omnir ejus verba totidem crant Anigmata, ejufy; formones Myftoria. Rullandus Germanicus Mcdicus Vocum cjus Lexicon contexuit, cujus ope nedun intelligi poteft $p$ aracelfus is fuit qui. Chymiam in Germaniateftauravit. Imperator Carolus Quintus aures ipfi prabcbat; fed Detirum iplum appellavit ex

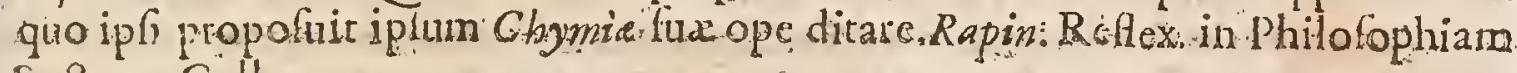
Sed.17. Gall.

Audivinine Paracelsm Genevemprimi quatuor Voluminibus folio Prof pudo:! quòd tam ineptus Liber prala \& operarios inveniat, quorum eft inopia ad aliquid optimi facicindum. Mallem Alcoranum impreftum fuile qui non cft xquè periculolus, \& qui faltem homines non xquè feduceret.Guido Patin. Sel Etoribus Epittolis.Epit.;8. Gall:-

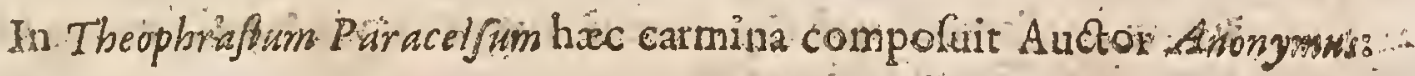

Si. foret Anttori conceffa facundia Lingue; Vidifjent F'byjscim fecula nulla parem!

Terba age flore carent : melle : sed undigue Rerwors: Mel redolet; Rerum flore refragrat opus:

Eloguium tulit ipfe Deiss, Natura negavit.

Quod non, cur pofcis, Zoile, Tantus babet."

Laurentius Craftua,

Dicitur fuiffe, animi integritate, pietareque in Egenos nulli fecundus. Guil. Dovil.in P, romptialcon.Lliütr. Vir.: 
${ }^{*}$ Hic Author inter Hareticos prima Claffs Romano Tndice locum bibet.

Extant Opera cjus Francofurti apud Palthenios, 1603. in 4. Vol.4‥

\section{JULIUUS CIASAR SCAIIGER}

Clar:A:D. N Acus cft in Caftro Ripâ adiLacum Benacum, A.C. 484.Patre Berredieto Scow MDXXXV D ligero:Bcllatore fortifimo, ex antiquifinấScaligerorum, Principum quon¿dam Veronenfurm, familia oriundo: in adolefentia Franctcanorum Monachorün . cœtu aggregarus, fed moxab ipfis ireum abtractus, guventutis anmos in bello tranfegic, inque eo Maginer Equitis titulum meruit.Tandem exiam milikia relib

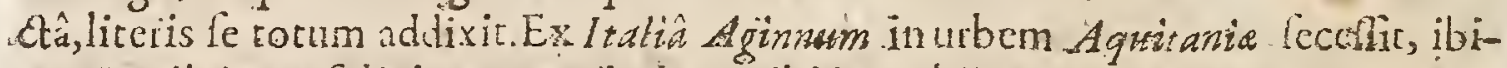
que Medicinam feliciter exercuit, donec ibidemobiit Grarmaticus, Criticus, $P_{0}$ öm

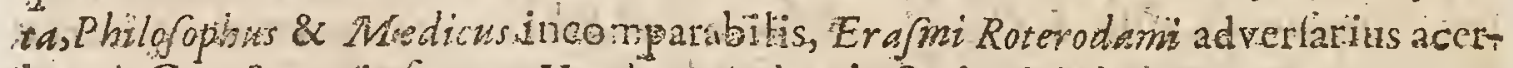

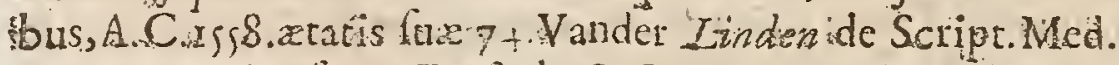

Seripta ejus funt : Epifold\&:Arationes - Commentaria in Hippocratem de Infomnis _Comm.in Arifotelem de Plantis - 1 :omm. in Arifotctis Hiftoriam Animalium-Comm.in Theophrastz Hiftoriam Plantarum - Doctrina vera Alchimis arque Auris Mecallicr-D = Sapientia, \& Batitudine-Oratio pro Citcerone contraciceroniannm Erafmi-De numer s Comicis, thbellus - locmara waria_-Dioblemata Ciceronamum Erafmi-De - Dumeris Comicis, libellus- Poemata varia- Problemata Gelliana-De Caulis Lingux Larinx-Dé Re Roeticâ-_-Exercitat ones ad Cardazwm.

lalius Cafar Scaligen, Sri icus, Grammaticus acerrimus, eeta excellens, Phi Lolophus erwdithmus, alter in Medicina efoulativs, \& quidem (dictu penè inacredile) hxe onnia, qum xtatis juenilis parte in armis confumptâ, fériù

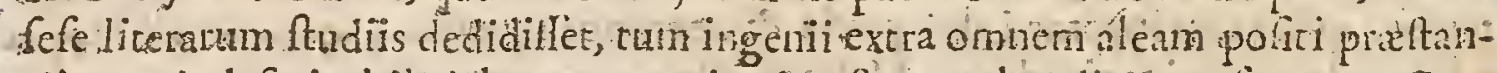
tiâ,tum indefarigabili lahore, quamvis adverfante valectudine, contequrus. Beza in Icon.vitullutr.

Quod de Tullio dixit vetus Magifter. Profeciffe multion chi is placeret: ego ve rius, Magnum elle cui I ulius ine magnus. Lipf.cent. Mifcell.epint $6=$

fulius Cof ar Scaliger, vir quô luperioren Antigttitas vix habuit, parem certè hac atas non vidit. Thuas.ach am. is 8 .

Illud Natura Miraculum Tul.Scaliger. Doff.Intit.Orat.1. c. 3.Seut.I.

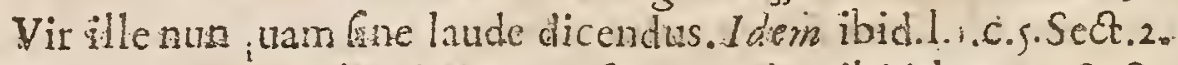

Iulius Scaligers vit ad unguem factus. 1 dem ibid.1.4.c.ai.Sect.3.

Magnus Naturx Myltes, Cafor Scalnger. Ideyn de vitiis ferm. 1.x.c.z8.

Iulius Scaliger, lummus prefectò feterum cenfor, ac delicix omnium, quorum intereft vacare $M$ hiss. Vofjolnftit. Orar.l.g.c.13 sect.

Divinum Virum Caforem Scaligerum gui non m tantur, 78 arrucinifunt. Ifo Cafaub.in Epiftad Thuanum, Momp.6.Kal.Jan.1598.

qulius Cafar Scaliger, vir ftupende enudirionis, \& quo fol doctiorem vix illucit alterum.Meibom. Mecenas. C.4.

Nevir fimego, fiacutius aut capacius ingenium inter homines fuit ab illo ists fuliano xvo, I ip S.Ac rect.pronunciat, Lat. Ling.c.7\% 
Tres funt quos admirari unicèfolco, \& qui in hominibus excefirfe mihi hi" anum faftigiam videntur, Homerus, Hippocrates, Ariftoteles : Ced addo hunc. quartum ( viz. Lulinm Scaligerum) qui natus in miraculum \& glorian nofti. xri. Idem cento.2.'ep. 44 .

Inter noftros Poëtas Latichium amo: Ianum Pañnonium xtimo : Scaligerunt. parrem admiror. Qui fi felix illud ingenium \& inventiontum iifvidendum acumen curâ temperaffet \& limâs, coronari-contra omnes Pöttas polfetáb illo ipfo xro prifco. Lipf.cent. 2. epift: 9:

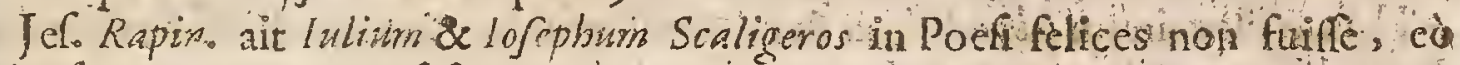
quòd ferò nimis ad eam fefe accinxerint. Ait titrumưte tgenii fui pertinaciam vincere non potuife, uspote qui aliò jam fefe convertecat, \& quamis Filius Patre foret excultior, parum tamen in fua Poefi venuthum fuiffe. Rapin. Retlex. in Poeticam r. parte Reflex.40. Gall.

Omnia cjus Poematadoctè \& laboriose compolita; fed in quibus fubinde horridulum quiddam, \&e hiulcum, atque à facilitate, \& ancenitate Poeticâ alienum offendas. Borrict. de Poet. p. 106.

Pater meus majoris quarm par eflet Mufeturn zeftimavit. Hutuc Homero anteponit. Grecornin Poefés's non Gatis peritus crat. Sraligerana-2. Gall.

later meis accuratè fcripfrt. O quàm egrcgius liber funt Excrcitationes ejus! Pater meus accencu nativo linguas pronunciabat quarum gnarus erat,non támen ritè pronunciare poterat e freminsm, ut in vocibus Perr, Mere. Pater meus quadrienuio ante obitum Semi-Lutbcranzs erat: Indies magis \& magis abufus obfervabar: Epigrammata in Monáchos fibi exofos fcripfit. Pater meis quando feftinanter Epiftolas exarabat, egregix erant; fed auando illas meditabatur Philolophum redalcbant. Pater meus licet veritatem Religionis plane non cogno-

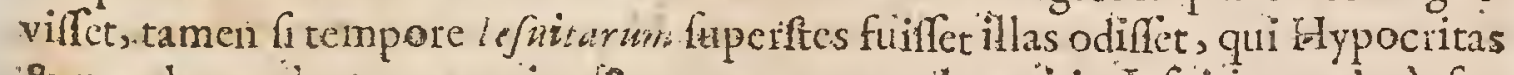
\& mendaces ederat canc pejus \& angue; quæ duo vitia Jchuitis maximè fregucntia funt. Nullus eft iefinta qui co modo feribere valeat quo l'arcns meus. fcripfit. Egregio pollcbar j!ldicio: O mnia legebat omuia examinabat. Iulium Cafar Scaliger femper dicebat fe meinfe Octobri moriturum, quod factum fuit. Scaligerana pelterior. Gall.

Dominus Cardinalis Perronim ait in genere eum infignes etrores commifile, eumq̨ue multa fivola leviaque Ccripfife. Additinter primos Gentis noftrix viros numerandum elfé lofepbum caligerur, quamvis requè praftantis ingenii ac Genitor ejus non fuerit o quị, inquiebat, magnus fuit Vir licet ferò ftuduerir; Eumque mitum in modum fcite fcriplife: J Julium ingenio magis quàm ftudio valere; contrariò autem c̀ diametro rem fe habere quoad ejus filium $I c f c p b i b m$ qui ingenio plufquam ftudio \& labore commendabilis erat: latii ftylum fuife elegantillimum, qui medium tencret inter Ciceronianum \& Seneca flylum; librum cjus contra Ciardanum pulchras obfervationes continere, multa vero leviffima, qua tamen tolerabilia funt quia elegantibus terminis exomata funt. Per roniana pag. 294.295. Gall.

Dominus Balzacius ait duos Scaligeros duo poftremorum temporum mira Gggg

cula 
\&ula fuiffe, eofque Antiquitari Doetiffmxablque favore opponere fas effeg Sed duos illos Heroas non minùs quàm duos çoum Patrueles Achillem $\&$ A jạccm partum annilos effe iram fuam cohibere \& min is animi impotentiis fele permififfe. Utrumque Hero plus femel levibus admodum occafienibus : Herculem furentern egifle . Contumelias quas in Erafmum fudit Pater miferationens mom vere, \& vel vilifimis halecum venditrices atque bajulos rubore luffufuras fuiffe; Filiumque Patrem adhuc luperofte ódcenitaribus quas modo ió hos, mo do in alios cvomuir. Bulzacius. Colloguies pag $208:$ Gall.

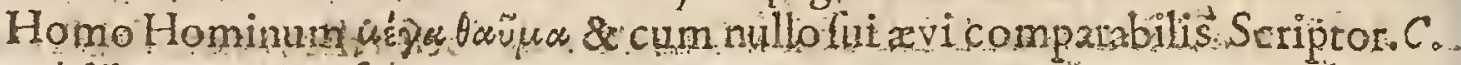
Barth.lib. 43 . Adverfar Gap. 5

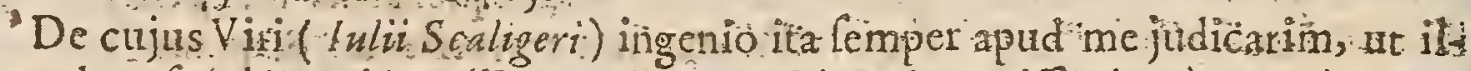
Inin dum fe bilofophis palliọ continut reetè ze decentifimè ; cùm verò 1 mperatoris paludanentum induit, futiliter omnia, \& vandocutum fuile iron dubi- tem afferere Gabr. Naud. de itud Militar. x! p x

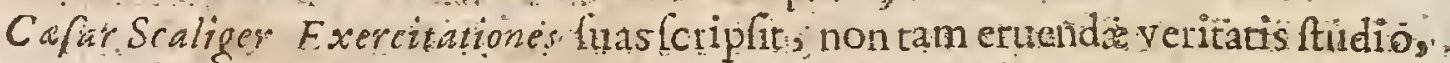
quàm ut effìni defiderio fuo farisfaceret, cum illis omnibus congrediéndi, quos: fuo tempote, literarum erudicionumque Rincipes haberi cognoverat: Gabro. Nand. de ciardan..

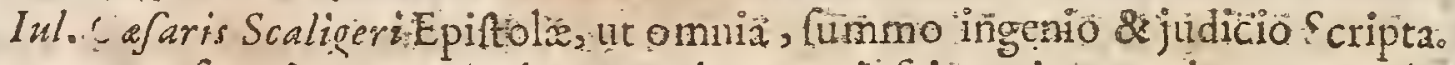
Totus, hervofitis eft \& rertm plenus, vehemens ipfin ingenilim, audax, acre,judicium penetrans, nonnunquam etiam cavillatorium, ut folcne viri etiam fum mi aliquâ inre labị, Adyerfus Cardanum \& Erofmum virulentum eribendi

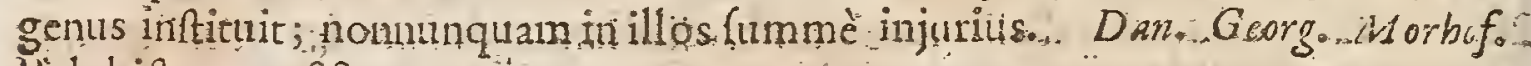
Yolyhift.pag. 299 .

Ho contradietionis fudium, quod ubigue in hife exercitationibus fe pro dit, Cophiftâ digniưs eft quàm Philofopho. Majorem etiâm modeltiam, dum

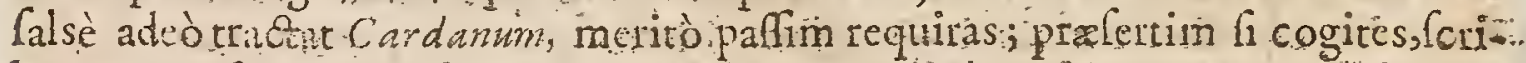
bere adyerfus virum fummum, trudis quidem bumanitatir $\$$ Metapbyfices, non paulo inferiorem a at non fcieiniaj nature, Matbefos auten omnibus difiplinis, in quibus parum omninò Saliger videbatzaltis quod dicitur equis pravertentem.V.J. de delololat 1.2.c..80.

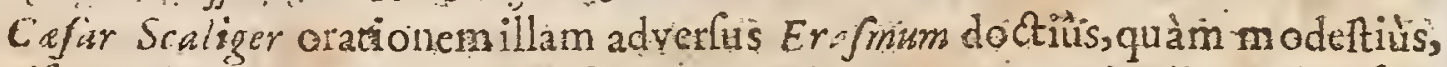
magifqueadoftchtationem, \& famxancupium, ex magnitudine Adverfari sudm veritatis ftudio, fcripfit. Sed hanc culpam heros ille polmodo pcenitudine duct!s quodammodo eluir divino Epigraminate, quo Erafmam ufque adeo

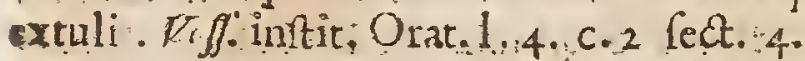

Latina !nili Cafaris Scaligeri Paetica, fpilfum fane opus, \& perfpicaciffimi ongenii atque ingemis in viro eruditionis argumentum. Toflevin. in Biblioth. feleat.

IH. Cafar Scaliger eruditonm maximus , fed uimium fibitribuens... Card. loan. Bona.

Cajpar Bartbius refert Cajarem Scaligerux Operis Poétices materiem EX 


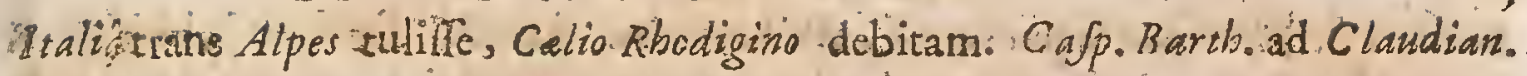
p. 972.973 .

Multumin Exercitationibus fuis debet Toanni Leonit utcunque nomen Scrip toris femper Cuppreffit Vofi. de Idololat .1. 3. c. 59.

Mirum aurem, non meminiffe cjus ( loanyis Leonis) Iul. Cof. Scaligerum, in opere Subralitatumadvarfus Cardanurrsubitam mudta invenias ex hoc Scripto re hauft. I dem.de Hift Lat. p. 676 .

Iulius Cafar Scaliger Lud.Preceptorem habuit Calium Rhodiginum. A quo won mirum, fircem queque illam, fontes, unde quid hauferis diffmulandi,

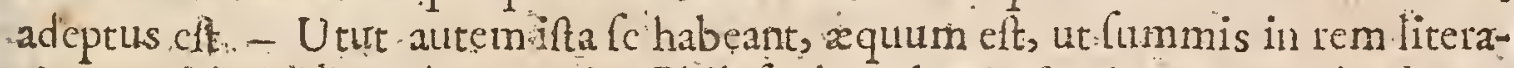
riam meritis Viri, quônec major Philofophus ab. Ariftele, nce major l'octa ab atate Virgilizinec major Medicusab jipparratg vixiffecenfetur, \& hic \& alii laplus à nobis condonentur Thomas de. Hugio:

Equatistemporum illorum Intius Cafar Scaliger, quem in ltalis natum apild Germu ino eductum, fibitandem Galliu windicavie: homo dilciplinas penè om-

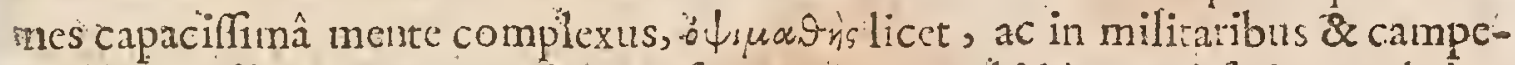
Atribus ftudiis toto juventutis decurfu exercitatus; ad id à naturâ factus, ut haberet noftra tas quo vetuftati invidiam faceret. Is cùm artes propemodum omnes ingenio fue it pervagatus, tum cam, qua circa uctorum interpretationem verfatur, lucubrationibus quoque fuis concelcbravit. At liber à religione verborum, fenfa lpcot:vir foluminodò, ur hunc ejus interpretandi modum lacobus Goupylus in omnipus non probaret. Hiset. de Clar. Interpret. Ital. .

Inter omnes qui ardentifimo defiderio moti ad nomen funm immortale reddendum, maxime affectu, ad Scicntias addifceridas animum appulerunt, anemo jucundis bonafum Literarum fudiis magis inferbuit, nec harum amore 'majoricaptus fuit quàm 17tzus af ar Scaliger Equçs Auratus;' qui poltea omnium hujus Seculi Doctrinâinfignium erthitiffimus evafit ; \& cognomentum Ariftotelis attatis fui promertit. G bilini, Theatro. Ital.

* Ejus de Supienti.. \& Beatituäne Libri octo prohibentur - Ejufdem verò Commentarii in Theophraftum funt corrigendi : Ejufdem I'oemata corrigenda。 Index Madrit. edit. An. 1667.

Opera cjus variis in locis atque temporibus funt impreliza.

\section{FRANCISCUS VATABLUS}

N Atione Gallus, Patriâ Ambianenfss obiit Anno Dom. is 47. Quem Hew 1 brat ipfi Lutctic Hebraicas literas profitentem admirati funt, C'hristiani verd maximo cum fructu docentem audiverunt. Is Grace lingure peritiffimus multa ex Ariffotcle in Latiram tranfulit: dein relicto Philofophix fudio ad Sacras Literas (e rotum applicuit; multaque hujus generis fub ejus nomine circumferuntur, ac Notatzones imprimis in Vetus Teftamentum ab Auditoribus ex. allius"prælegentis ore exceptæ. Nam ipfe five naturali pigritiâ (quiod illi expro-

$$
\mathrm{Gggg} z \text { bratum }
$$


bratum eft ) five morte preventus, nihil omnino fcripfit: (atifque habuit facre lirguc Arcana Difcipulis diligentioribus aperire, illuttri nominis fui famâ \& alieno prxconio contentus. Thuan. adann i 547 :

Ex Lutinis Francifcus Vatablus lector Regins, lingnam Hebraam cxm diligenetẹ docet, ut nil poffis merito requirere, Gulo ostel. ju Alphabet. 12. linguarum.

Non vulgaris judicii homo Fr. Vatablus, léctor Regins quo Przecptore literarum fieb. fum ufus, in quo admireris tam raram tamque exactam omniune difciplinarum atque trịm linguarum peririam, ut meritò addubites quam pues. primum didiceric Gul. Poftell: in libell de Affinitat. ling:

Vatablu iifignis doctrina viv, \& in Veteribus Hebreorum monumentis perquirendis diligentiflimus; cujus felicem \& fanctam recordationem nulla temporis vetuftas $\mathrm{ex}$ hujufce hingure candidatorum animis obliterabital oan.Mercer. lectori, in Tractar. R. Iuda Hilpan. de Accentibus.

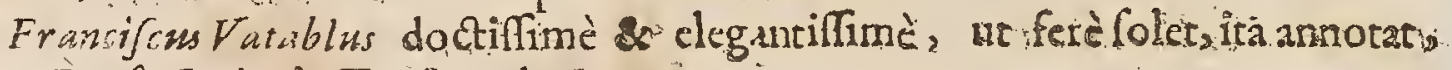
ac. Fauf. Socin. ii Tractar. de Servat.

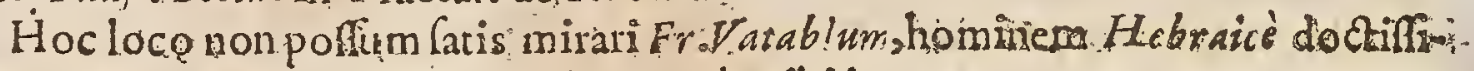
mum, \& acerimo judicio predirum. I dew ibid:

Vatablus Sarris cx Biblin Hebraic fide longè caftiùs quà anted tatiné converfis, nomeraretenitaticonfecravit fuim. Sravol. Samarthan in $\mathrm{Elog}$.

Vatablur feu potius Notx fub ejus nomine vilgatx tertium in hac Criticanum Synopfi locum occupant. - Admodum literales atque critica funt hujuf modi Notx; \& Author incumbit is yrafertim dificultatibus explanandis qua Textum intricatum reddere polfunt. Rabbinarum interpremationem plerumque Requitur, pracipuè verd R. Davidis Kimchi... Ejus Notx vocari poflun perpetua in totum. Textum Note $x$ qua pallea finte in illo qua nan explicet, admodum perficicuè ac line digreffionibus. Imo etiam rebus hatd in difilibus inmoratur, ut Lectoribus quibulvis podefte vatat an Denique in pretio habentur. Notæ illa in Scripturam quas Rob rtus Stephanus fub Vatabli Domine excudendas curavit, Gre Vatabli reverà fint, five varis ex Au houibus. excerpta fuerint, quod verofimilius videtur. Horum tamen nowina fuppreffit, pralertin verò Calvini , exquo quadam etham Noris fuis inferuit. Jef. Rich. Simon. Hilt. Crir. Veteris Teltam. 1.;, c. 15. Gallicio

Robertus Stephanur fumma cura collectis Notis quas Vatablus in Scrip. turan : Lectionibus fuis publicis tradiderat, illis evulgat anno is 45 . Non cisiùs in publicum prodierunt hifmod Notx quin Sorbons Th:ologi caldem canquam Hereticas infamaverint, omnefque conatus. adhibuerint ad Bibliorum Roberti Stephani venditionem impediendam.s Sed eruditus ille Typotheta Notas illas doctiflimè propugnaviti \& doctinam illis contentam fanam \& ortho oxam elfe demonftavit:. Anton. Teiffer. Elogiis Eruditor. Viror. Gallicè.

In co culpandius Iobannes Ruellius, quòd lobleurioribus quandoque locis vel perplexis afcititian commadet lucem, hoc autem explanatoris non Interpretio. 
Imterpretis effe demonftravimus. Idem peccat aliquando, raiüs licèt, Francifrus Vatablus, diligens exteroquin interprer, \& præ veritatis ftudio, el gantix \& ca-

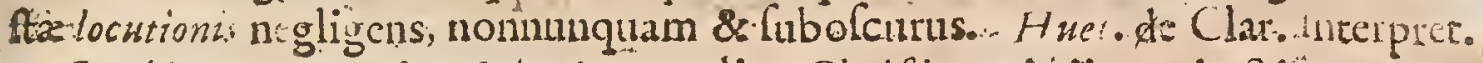

Vataúln s. Magnus in Hebrais, nec alius Chriftianus in iis eo doctior. coul gea ranci prims..

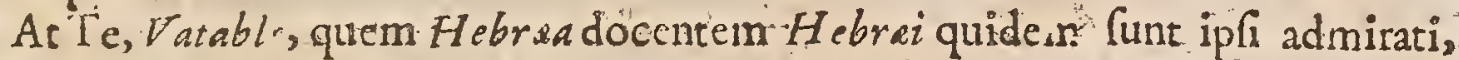
Chriftiani verd plurimi maximo cum fructu autierunt, quo tandem loco habebimus qui quodaliis facras literas. interpretando impertiebas. ; ufque adeò neglexeris, ut etinm cjuraris a ge tamen fumma eruditio, diligentiaque tua, lo. cum tibi quocule in hujus facrarii veftibulo compararint, quamwis quo alios inisroduxifti, nunquam ipre xideri poffis ingrefflis: $B e z a$ in con.

Francifous Vatablus, visut fummx eruditionis, fic acerrimi judicio. Petr. Pi cherel. in opufc. Theolog. p. $27 \mathrm{I}_{0}$.

Vatablus. Cartholicus fuiti fed ejus fcripta ab" Hareticis excufa \& depravata funt. Alioqui viriple fuit egregie doetus tam in Hebreis quatm in Greir. Acu. rè literum breviterque perflequitur, fed frè̀ à noftro interprete diverfus eft: $\mathrm{H}_{2}$ ber enimi iphe propriam verfionem vel potiüs verfionem IT igurinam Leonis Hen brei. Cornel. aे Lapide Prolegom. ini Epitelas Paulio..-

Ipfe Vatablus, quanquam in celeberrimo gymnafio plenis fublclis fuperbirs;",

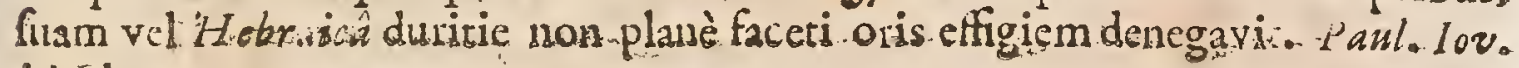
in $E \log _{0}$.

Quidam autumaverunt Rodolphum Gualterum Authorem elfe Verfionis Bi-: blionm qua Vatablo afcribitiur... Alii dicutut Bertinum qui th Hebraice lingux Profefforis:Regiimunere illi fucceftit, fibi laborem fumfufa eas fripto confagnandi.; prout e Valablo in Auditorio fuo pronunciabantur; esfgue non evalgaf-

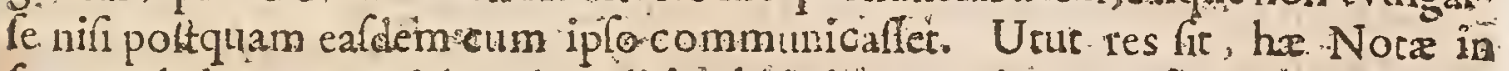
fummo habentus pretio apoud eruditi palati viros', quia paucifunt in textu loci qui os admodum mcthodicè non clucident. Anton. Teijfler. Gall.

Leodegarins a Quercu ad. Ioh. Fournium de Jatabli morte hasc carminat Conjipfit :-:

Dum fếrem Proceres linguc modò morte perempios:

Fleviferm Vatablum i modo flere Satis.

N:am jactura fuit gravior carwijle Vatablo,

Quam doclis squos me fleire dolenter ais.

Sed quoi ies volui flendo defcribere luctum

Tuim Vatablinimius me dolor impedivito

Sic etenim dolui, fe fletibus ara rigavi,

Vt minimum abfuerit quin ferem Niobe.

Pinapropter feci quod nobilis ille Thimantes,

Falarizi luthms pingere guem nequiz.

$$
\text { Gggg. , GASPAR }
$$




\section{GASPAR CONTARENUS.}

Clar. An.D. TJ I R Parricii Ordinis, infigni memoriâ, illuftrique doctritâ mirabilis MDXXXV. Reipublica Venete gravis ac prudens Senator, Philofophus ac Thcologus eximius, maximarum lcgarionum perfunctus muneribus, à punlo Ill in Senatum Ecclefrx Romanx lectus, purpurâque 1536 . ornatus füit. $A b$ codem ad comitia Imperii Ratifponenfa in Germariarm millus; ob vitutem ac doctinam omnibus admitationi flit. Laudantur ejus libri de elementis animonumgue zrmortalitate, adversus Pomponatium, quém praceptorem habuetat; item dera tione anni; de republicâ Venetorum; de feptem Ecclefie Sacramenits; de optimi Antiftitis Officio; Scholia in Epiffolas D. Pauli, Catechifrnus; Conciliorum magis illufrium furnm, Confutatio Articulorum Lutberi; de Potefate Pontificisde Prodeftinatione; de Iufification; de libero Arbitrio; aliaque egregiè lcripta volumina. Legatus, deinum Bononio creatus haud multo poft ardenti febre correptus,

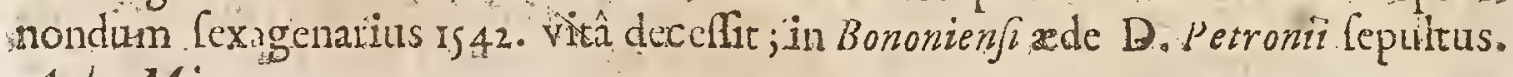
Aub. Mirazes

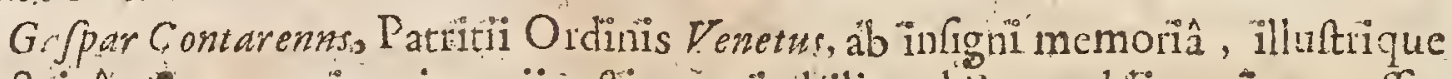
doctrinấ, corporis ac ingenii çaftitite mirabilis, ad Rempublicam ita accefirt, at gravirate judicii , confummatx prudentiz Senatoribus aquaretur: atque inde maturata maximarum legationtu munera capeffet, non ztatis guidem, ea dinâ vîtutis prerogativầ commendatus. Tuvenis enim, tanquam perfectus Peripateticus Arijtotelem à calumniâ dcfenéderat, quanquam modeftix causâ fuppieflo nomine adverfus iomponatium pracepterem, yuum ilte, finon infano, Impiotamen conatu Animas nottras interire cum corpore, ex Arifotelis fentensia perfuadere libro calito contendiff. Appulit exinde ingenium ad factas literas adeò diligenter, ut ad normam C brifiana difciplinæ librum de Optimi Antifi:is Officio publicirct.- In ipfo autem Civilium honorumcurfu, honefum, decorumque fibi, \& parrix de Republicâ Ver!etorum volumen colidito Paul. Lov. in Elog.

Memoriâ teneo me Romarn illis temporibus veniffe ; tantus, eat omnium, qui in eâ ubetunc aderant, de Contarin doctrinâ, prudentiâ, continentià,piewate, confenfus, tantaque admiratio, ut non amarent modò eum, quii tu1c erant Civitatís principes, fed etiam venerarcutur \& colerent. Ioan. Caga in Vita ejus.

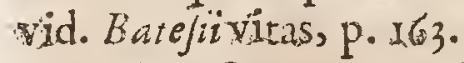

Gafpar Contareun, Nobilis Venetury opibus, prudẹntiâ literaturâ denique ofnatifimus. Excmlar ejus de inclytâ Republi: â Yrenetâ eft abfolutum, ex quo ceu Polyiteti canone quilibct ad fux Rẹpublica commodum aliquid excerpere poreft Herman. Conring.

Gafoar Contarenus, il hilofophus ingens, Crace \& Latine doctus adimedum.

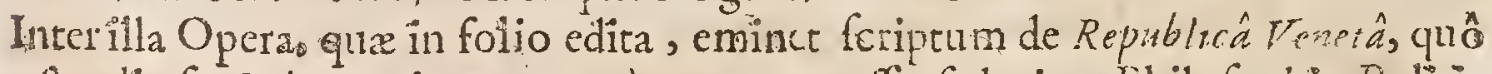
oftendit, fe. Reip. patria non tantù gnarum effe, fed etiam Philolophix Politica almodum peritum \& doctum Idern 
Contarenus erat $P$ atricise \& Senatcr Venetus, magni nominis propter doetriam, \& prater omnem expectationem dicitur, cum nihil ambivilfer, ad hunc faile gradum erectus. Ioban. Sleidan. Comment 1.2.

Quem vicum [Gajparem Contarenum] ingenio; doctrinâ clarifimum à primis adolefccntizannis afliduè colueram. Loan. Pier. Valerian. De Literator. Infelicitat:

Is legatione fua non bonam gratiam iniit apud Pontificers atque Collegim Purpuratorum, quafi non Catis acitice fele Lutheranis oppofuifft, \& quaf Rempublicam Romanam propè in difcimen adduxiffet. Cumablentem pleriquegraviter inculäent ab uno Eregofo Cardinali fuit defenfus. Mortus eftanno 1542. fubexitum A ugufti non fine venenifufpicione, cù paulè ante Fregofus quoque mortem obilifit Qui familiariter illum noverunt, de inffificatione $H$ :minis recte Scuffre dicunt.: Fuit vir cumprimis doatus a extat ejus de Magi. Atratibus atque Republicâ Tenetorwm liber. Sleid. lí4.

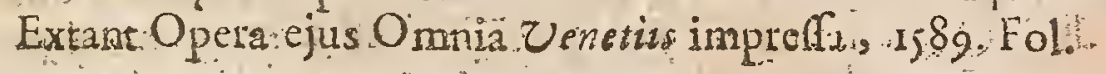

Hoc ejus Epitaphium Auctore Marc.Antotaninio:

Contarene tuo docuifti. Magne libello. Extinctis animas vivere corporibus. Ego jure tui vivuntmonumenia libellia: Et zivent Seclisinnwmerabilibus...

\section{Patul.1ov: in Elog}

FERDINANDUS NONIUS PINTIANUS:

I Llifri Gufmannorum gente oriund

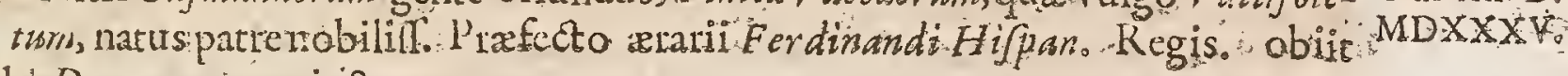
2ndo Dori. I55:2 xtatis So.?

Magntum Hifpinie lumen Ferdinandus Nonius Pisciâ Vacceormopido natus, atque inde nomen xulgò fortitrs quicum fub Alio Antonio $N$ ebriffen in patrià, in Italia Bononic fub Pbilippo Beroaldo literis humanioribus operam dediffet, \& Grecam lingtram, ad quam eofeculo ferè incognitam -incredibilí Atudio ferchatur, in Italia didiciflet, inde comparatis magno precio Exemplario bus Grucis, domum reverfus, primus lingux illits (qua omnis fere ertatio $\Rightarrow$ continetur) ulum in Hifpaniarn intulit, \& Ferdinandi Regis favore fubixixus,

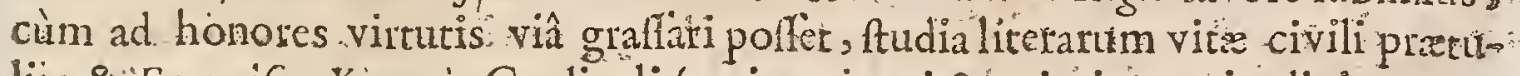
lit; \& Fran ifo Ximerio Cardinali (cujus pietati \& animi magnitudini tantum Hijpania debet) operam fuam \& induftiam in procudendà illâ ad omne xum duratun Bibliorn editióne addixit : almantic literas Gracas \& Latinas profté-. do confenuir; editis Hermola Barbari amulatione in Plinium, Melam \& Senecam populares fuos, Commentariis. Quowdad mores yir pius ac verax, fcd dicas 
\& áliorum acerrimus Cenfor. Thuan. ad An. rss2.

Pincianus, vir egregius ir doatrinâ minimè ventosà. Lipg.1.1. Elea. c. 16.

Pincianus, vil fidci \& judiciibonus. 7 dem Nor.ad lib. de Cruce, c.; 6 .

Pinianus, felcetus mihi cenfor \& 20 verbis modicus, re judicioque ingens, Iden Comment. in lib. I. Annal Tacit. Num 77.

Cui Senecaxternum dedebit. Lipj 1. 3. Epiltolic. Quxit. Epift. 9 .

Ferdinandus Pincianus, vir, ut verbo dicam, germana Critica exemplar cự maximam partem faitum Seneran meo qui quidem fuffragiostranifibas. Bonis in ispaná libris $\&$ benè eft ufu : non prxceps, non prepes, acutus tamen, fagacitate \& mod ftià pari. Sed ille in folo textu emendando fuit: fenfanon atrigit, neque aliter illuftravit. Lipf. Introdur. Leatad Senecam.

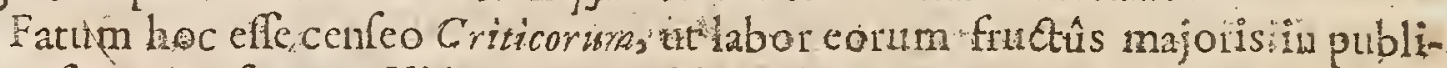
cun fit, qù̀m fams. Vide veteres, vide noftros, paucos reperies quorura nomen aut latè fufum, aut diu perenânit Velun Ferénando Pintian hodiè quàm indignior? Qưi reverâ vir eximius, vix tamen è vulgi tenebris fe exeniit \& paucis doetis in occulto laudatus, jacetetiam nunc ignoraturque inter fuos. At fi acuminis \& judicii aliqua hus en, huic eam reete tribues. Siflei modefix. magis. Non alium ego vidi, qui minu/s "adfeetate hoc egerit; ittam magis puriter coluerit, fine ambi/ione, frue fuco. "linius, Seneca, Mela rcites; fced piomus ille imprimis, per chijus lexcentas filcbras $\&$ zituantia vada pervafit felici quodam ingenii $\&$ judicii vento. Quamquam abrupta quadam in co ctiam nunc, non:ngo, quid mircmur.? aut guis Effulapinsipfe, fanandis tot plagis, unus fucrit ? Lif. 1.2. Elect. c.S.

P'intiani Obrervationesin Melarrac Plinirum, opus veñ cruditione refertum. Gefner in Biblicth.

Ex iis qui Caftigationes in hunc edidere Autorem [ Melarr] folus nobis profuir Pintianus. Virifte quantumvis nobili apud fuos oreus loco, plus ramen liretis, quìm natalibus debet IJuac. VufJ.præfat. Oblervat. ad Melain.

Miri acuminis homo Ferdinandus Pintianus. Barth.in Adverfar 1604.

Calebs \& abtemius femper vixit; frigida, jugis potio. Naturâ in omnes dicaffrmus, vitionzinque cenfor accerimus; fumma tamen fidei: nemo enim vanum deprehendit aut largè promittentem, 2 poit tergiverfantem - Objectanribus quibufdam nobilibus, quodin familix tamilluftis decora peccaret, qui in piftrinum literarium fe abdidiflet : fuas fibi reshabere juflit, \& fumefis imaginibus valere: Ceimmoutalia animo pixcipere, \& cum 'Dionyfo Syracufa' um tyranno inter difcipulos tanquam in regno verfai videii -.. Equidem iifi, cùm in Hieronymum Ramanum Hippanum Hilforicum nuper incidiffem q qui Reip. Gentilium lib. 9. cap. Il affirmat, Hermaphroduturb teu Androgynum fuille $P_{t h-}$ tienur; verum deceptus $M$ onachus eft, cum juveniles illiusin 10 . Menam poe* tam Corduberiferm commentarios, aliud agens legiflet. Hic enim de Luna orbe Garminc 76 agens. Anf nivillud Epigramma attulit in medium:

Nolo tamen veteris documenta arceffere farme.

Ecce cgo Jurn fartus fremina dephere. 
Converterar Hifpane Pistianus cedidit ofcitans lector ille de fe loqui Scholiaften:Sed quid mirum cumhujufmodi ineptiis referta furt illa chronica, cenLariâ notarionedigni. Ant.Schottin Bibliath. Hifpan.

Bibliothecam fuam, quam inftuaitfmam habebat, Academix Salmanticenfs Acgavit. Quatuor hxc, nec piura, verbarumulo infribenda curavic: Maximum Tita-bonum Mors.

Hoc ejus Epiraphium, auctore Andrea Schorto.

Barbarus Engancis illuxit lucifer oris, Barbariempepulit, Pbosphoras ut tenebras:

Pintia dives opam merito Se jactatalumo; Attica Mufa etenim lumen Hejperia.

Hic. Fredinande jaces; totus quen vitx capit orbis,

Salve ergo atgue vale: quadmirm: Vallifoletum Spirant. Suve rofe, ralliter ofla cubent.

Produxit forem bencolentern, ac inter acanthos

Sicraus? orien adeft: iares praftinguit uti flos.

Extant Obfervationes in loca Obfcura aut DepravataHiftorix naturalis Plï ai, cum ictractationibus locortum quorundam Geographiæ Mela. Salmantice apud loan.Gintam, I5 44. Fol.

\section{NICOLAUS COPERNICUS}

T. Orunum in Boxuffra patriam nactus, ans 147\%. in Mathematicis Pudiis aden excelluit, ut in fuo genere quo nimirum Ariftarbil aradoxa fecutus: Clar.An.D: $M D X X X Y Y_{0}$

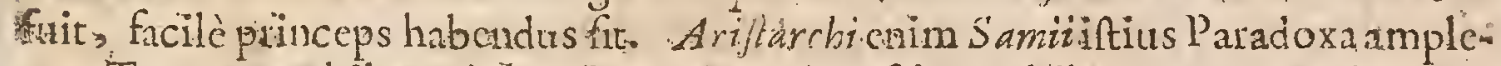

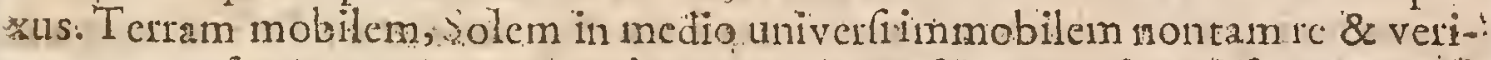

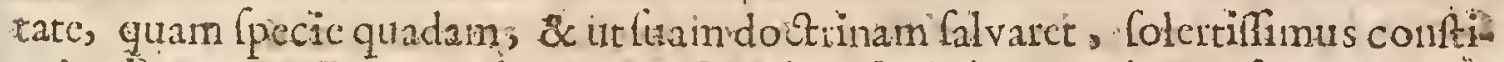
cuit. Pixter ftudium Marhematicesfuit virinfigni pietate, vitture fpectatâ , \& morum humanitatefummâ praditus. Is dum anıum jain feptuagefinum ageret, tandem fatur vitx laborumque ex hac mundi infabilicate, adimmotam illam coleftemque aterna lucis contemplationein volens conceflit anno is $43^{\circ}$ Scripfit Revolutionum libros, quibus terram moveri afferitur., Fecit \& Canonem triangulaum cum tabulâ, \&c. Boifjard. in Icon: :

- Anto C brifti 536. ac deinceps magnam fui admirationcm concivit Nicolas

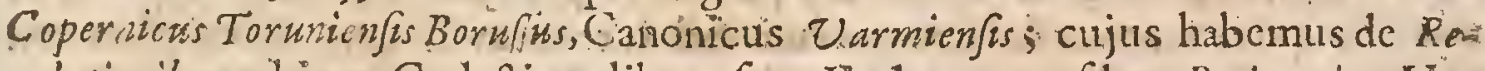
volutionibus orbium Coleftium libros. Cex. Iis docet, qualdam Ptolemaicas Hy. pothefes efre abfurdas, $\&$ axiomatis $M$ atbe maticis adwerfas. Item computatio nem Alphonlinam motibus caleftibus nen refpondere. Hypothefes igitur alited contituit: fedfic, ut inulta repugnent dogmatibus' Ariftotelicis per tot feculare-

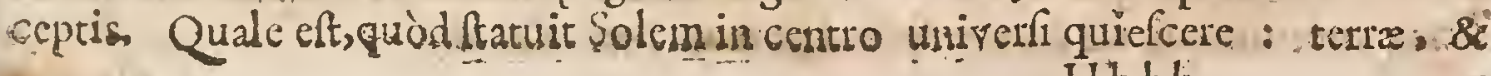

$$
\text { Hbhli 2qua }
$$


\& aqua globum, cum vicino äre, circa fslem motu tripl: ai moveri : o d vam fiphrem confittere inmotan. Vrff.de Maticm. p. 187 .

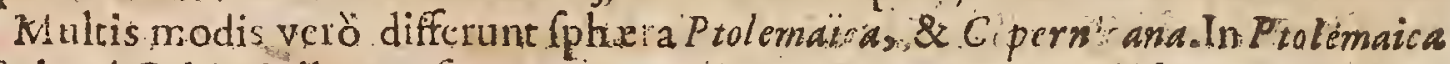
Sphrrâ Orbis ftellarmm fxarum dirno mo circatcram quicfecntem cricun-

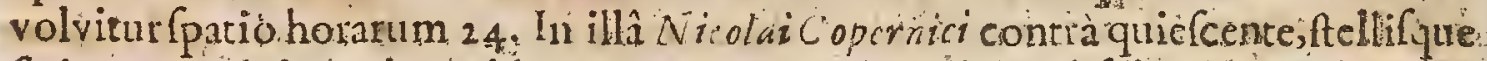
fixis, ter globus aboccidente in oxientem periodum abfolvic. In priori fol. terrâ immotîn, annu o fpatio permeat Zodiacum. In poltecioni tera moverur per Eclipticam, Fole immoto. Denique in P tolemuica, Luma mentruespatio tranfí Zoriacur. In Copernicanâ alutem, Luna circtinfirur Terra, proprianqueab folvit periodum. Nectamen Copernici opinionena prorfus effe novam putan-

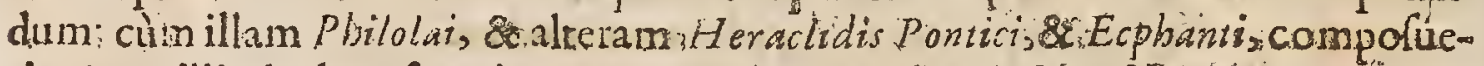

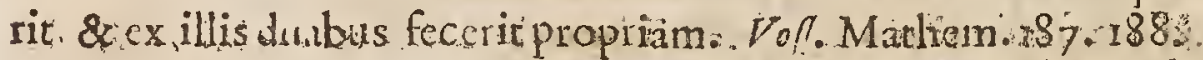

Nicolak Copernicus wh abfolutx fubtilitatis, non folum obfervatou fuit; fed etiam Hypo be feos Pytbagorica antioux Infauratos. Per eum enim ex humanis

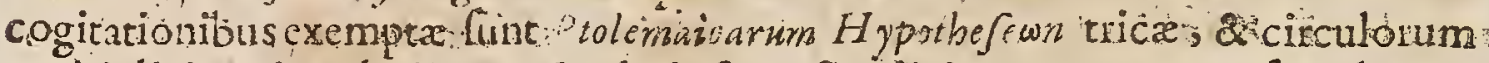
multipliciun involutiones: \&ad P by ficam fimplicitatem revocatx fune hominum mentes, Ifrnael Buliald. in Prolegom. Aftronorna Pbilotaica..

Hrec Copernicana Hyotbefi anfam prabuit Gulieim, Gillierto, Anglo, cuden dx atque invehendx Philólophix $M$ agne ica, quatenus Terram magum $M a-$

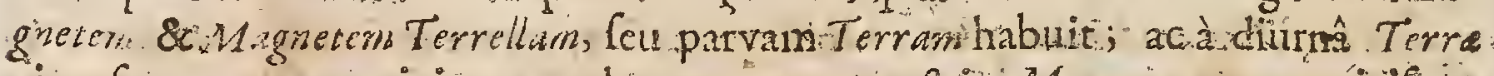
circafum axem verticitate pendere eam, qux efon Magnete, magnécicifiue corposibus fatuit. Petr. Gaffend. in Vit. Copern.p. 33\%

copericu viri (five ingerium fpectemus, five fulicitatem) plane inter fummos morthim (quantum $\mathrm{g}$ go judico ) pumerandus. Seth. V.Vurd. Prafat ad Aftronom.

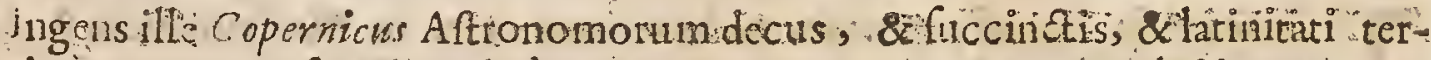
fori congruis, in fuo illo plulquam Atanico Revolvionum calcrium Operes ulus eft verbis Tych. Brib. Wrefat.ad Epif. Aftronom:

Gratias ingentes habemus Copernicin qui confititione Anin Siderei magnama

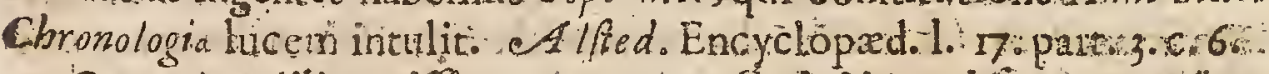

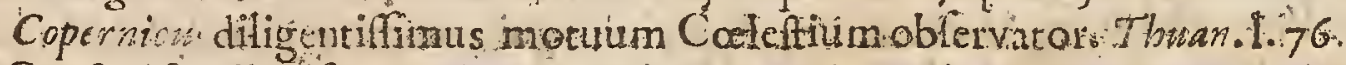

Confat finiliter fentuxiam opernici de Ratione Terra, (quanunc quoque Siviluit) quia henomenis non reptganat: ab Afronomicis Principis non poffe

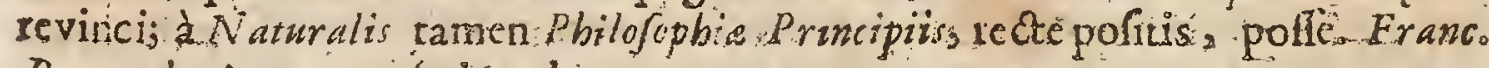
Bacono de Augment $\$$ cient d. 4 Cr.

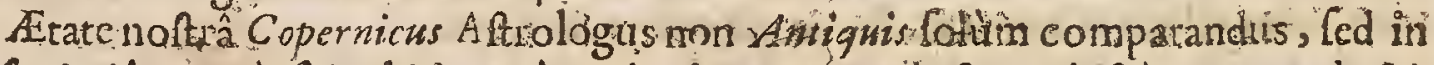

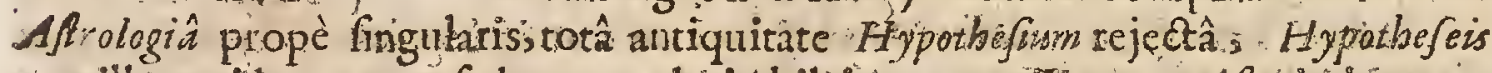
non illas quidem novas fed tamenadmirabileis revocavit qua Afrólogidm non ex Aftrorum, fed ex Terre motu demontratent-Atque utinam Copernicus iir ip fam Aftrologia abfque Hypothefibus confitinenda cogitationem potius ineubuiffet ! Longè enim facilins ei fuiffet Aftrologian Afronum fuorum veritati telpons dentem defcribere quàm gigante: cujufdam laboris inftar, Terrim movere, ut ad Terra motum quictas Stellas fpecularemur. Petr. Ramus 
Nicolai Copernici: nobilifimi Mathematici libros Coslefium Revolutionum. totius Aftronomia., renunque pulcherrimarum foitu diguifumarum locupletem

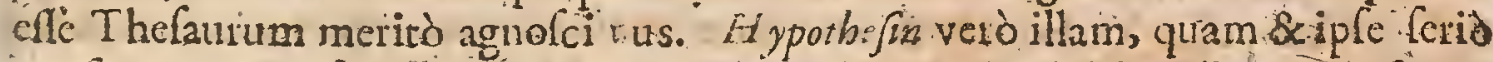
confirmat \& Difcipuliejus pertinaciter ttentur, Solts videlicet in Vniverfi medio quictem, \& Terreni Globi morum circularem non folum à communi hominum (cnti abhorrere, fed (quod multò mairnum eft) Scripibris Sancti-acerrimërepugnate certò tcimus. His fi quando premantur; illud unicum \& effugium, scripturas ex vulgail quadam horinum opinione loqni. Nic. Fuller. Milcell. Sact.p. 94.

Quis non judicavetit, Nicolan Cipernicnm ingenii dote fingulari, \& foelici Natura difpolitione, inter faculi lui perfieacininos Mathematicos excelluife.? Hllc qui Tormenfecivitate in Bormin oriundus, fub gelido limatc \& apud rufticam \& ftupidam Gentem cxquifita educatione carcbat : He inquam qui eo tempore quo hac Difiptina hominibus propemodi m incognitajacebat ; nullum habitit quo excitaretur excmplim, nec rivalem tillum giem æmuiaretur. Hujufmodi defectus, qui velui compedes Virum animi minus ardentis cohbuiflent, ipfum remorainon valuerunt: Contra vero in Italiam

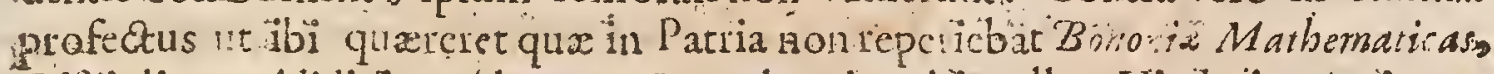
Difciplinas addidicit caldemque Romdocuit; ubi nullus Vir hujus Artis cupidus füt qui iplum ut vix Ducen \& facem non agnoferct. Verum eft tamen quòd omnes Doti veftigis c us autè non infiterint: Cum enim Opinionibus Ariftarchi profunde le e implicuiffer; imo \& caldem docere fufcepilfer,affirmando Soler fixum trate in univerfi orbis meditullio Terrengue ei creumvolvi; ejus Syftema Atupefecit aliquá ingenia, quæ maximæ Philofophorum 2artis Sententix cum adhrerent, hane novitatem admittere non potucruite, \& contratiam fententiam tenuerunt. Horum improbatio Copernici opinionem non mutavit: Ex quo primum hat propofuiffe eandcm non mino vigore quam peitinacia propugnavit, ac ufue adco plaufibilcm reddidit, ut etiamnum Univerfam Mathematiconm Echolam in partes adverfas dividat 8 perturbet. Eruditusillc Vir VVarmix Cononicus crat; inlolita huic enditioni úracalingux perfectam peritiam addidit, moramque innocentam qux omibus exemplo praite poterar. Ifar. Bullart. Acad. Scientiarum. Gall.

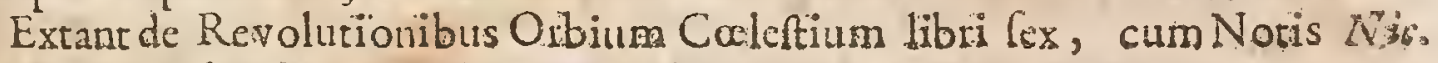
Muterii Amftelod. 1617.

\section{ELIAS. LEVITA ASCENAZ}

Ognomento Grammatic s, natus ef in nova Civitate Ey Ch haud procul - à Norimberga. Mortuks eft anno 547 cum paulo antè admonitu Pii V. Clax. A. D. MDXL. Pontiffis Romani Cbrifto nomen dediffet, adductis fecumaliis 30 . I udais ad fuf cipiendum baptifmum. Quod omue tamen Indei pernegant. Alfted. in Chroㄱolog.

Hhht 2 Omnia 
Omnia ejus Hebraica Scripta, qua Sebaftianus Munfterus Latina fecir , funt: Grammarica Hebraa-Hebrarce Inftitutiones - Vocabula Hebraica Iricgula: ria-Compofita Verbortum \& nominum Hebraiconum-Hebraicum Dictionarium Vocim rariorum \& peregrinarum, quod infcripfit: Tbisbites - Accentum Hcbraicorum Libex- Liluer Traditionum-Commentarium -in Granmaticam Rabbi Mofche Kimchi. Scriph eciam Lexicon Chaldaicurn.

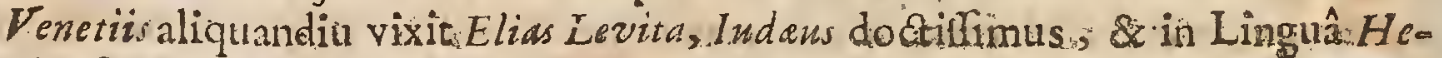
braica facundifimus, cujus extant in Lingnâ Hebrea \& Chaldea multa utilia Scripta d. Munftero \& $F$ agia in Linguam Latinam converfa \& expofita Ejus viri ftudio \& hboribus multum debent ommes $S$ anct $I$ ingux candidati; quòd in

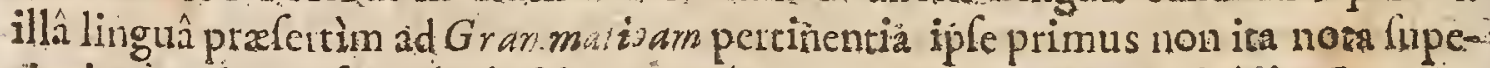
riori tempore, à fe multra lectione enuta communiçarit \& monftânic Neander part. I. Gcograph.

Doctiflmus hidus Elias Levita. Germanus; (cui gratiäm nonmedio.crem, debent $C$ brifieni, proper fricesum in Linguz Sancta cognitione iplos adju-

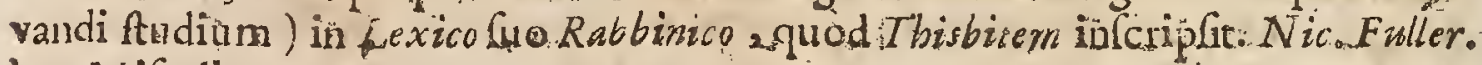
1. 2. Mircellic $\mathrm{c}$.

Incomparabilis Vir Elias I evios in aure lo fuo libello, quem inferiphit $M a f$ foreth harr Matoreth, Tradisioncm Traditionis, hoc, eft traditionem vil docti:nam excellentifinam, cognofcendi fcilicetinfinita Sacre Scripture Mytteria abftrufa: quem libcllum, annos anre paucos Latinè reddicum àclarilimo \& amicifima $B$ uxtorfio noftro iudiolis linguarum perconmendatum elfe velim. $K V$ as Ser. de Antio. Menfur.

Anno 1917: Elias Levita, Iudaus; Grammaticortm Hiebraorum fummus \&: facillimus, fux lingua dilcendx, Chriftianis Roma, Venetiis \& alibi in Italia, ît quam è Germani yencrat: copiam facit: ob quam rem magnas à reliquis I udeis calumnias \& odia fuftiinutit. Genebrard.1.4. Chronolog.

Elins Levita, unicus hujus xvicriticus, \& Aridtarchus Hebratfyi Iof.Scanlig. in Epilt. 62...

Elias Levita, Iudeus, in Germaniâ natus, Hebraica Lingura Grammaticus doctifimus Gef.uer. in Biblijoth.

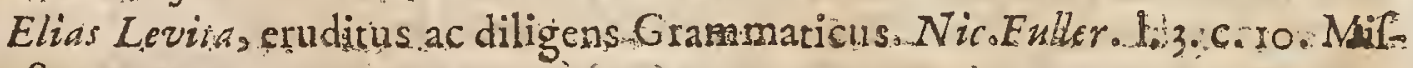
cell. Sact:

Elias Levita. Jüdxus Germanus qui ferè rotam in Iralia vitam egit, eft dubio. procul Iudcorrm Dodifirmus Criticus s, quos omnes iñ arte Grammatica fupe- ravic. Pratcr Notas quas in Libros Mojis \& D avidis Kimchi elaboravit, plura compofuic Operà Grammatica, qua Latino idiomate dönata furerunt: Ejuique in hanc Artem $R$ eflexiones utilifina funt ad Hebraica Linguaintimam notitiam comparandam. Munsterus Fagins aliique Chtiftani quidam iph con semporanei mágnam è doctis Rabbini hujüs lectionibus utilitatem perceperunt; qui. Judxis odiofus factus eft ob nimitim commercium oum Chinianis, quos breum docebat idioma. Romæ .Cardinal s \& hujus urbis primorés Difcipulos habuit. Munßtexus qui aliquot ejus Opera trantulit, profitetus, antequam 
Elie libros legillet, Ce Mágiftri nomen aflumpfiffe quamvis nedum Difcipulinomine dignus eflet. Aferi poteft virum hunc uricum iis ingenii viribus polluife quibus: \{e pra, udiciis abripi ngn Fateretur, nec Doctorm fuorum authoritati fumpliciter credcret: Res, in feiplis examinavit; \& mi-

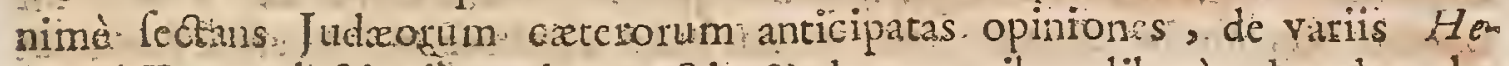
braici Texcus lectionibus, de punctis of de accentibus liberè admodum lo cutus eft. Legi deber imprimis . Tractatus excellens cui titulus $M$ afjoreth Hamousforeth, in 'quo ut Doctus Criticus Mafjore nodos Colvito Rich. Simon Hilf. Crit.V.T. lib. I. C. JT. Gall.

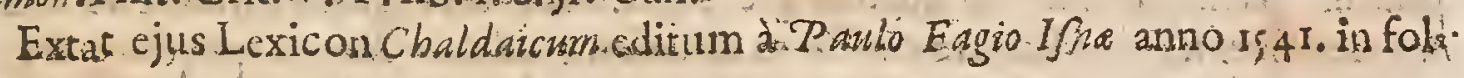

\section{RETRUS MARTYR VERMILIUS}

N Ains, eft Flörentia Anna rjoo. Obiit Tiguri Anno I562. prid. Id No1 vembir. Sacras literas magnâ cum laude docuit Argentorati, : \& Oxosii in. Clar. A. D MOXL.

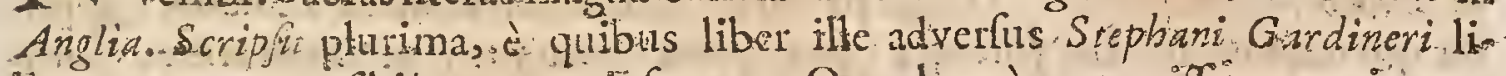

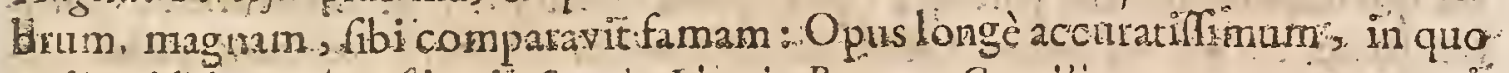
quicquid de Euchariftia, in Sacris Literis, Patrum Conciliorumgue menumentis; proditum fit, aєcuratè \& copiosè traethtur. Gefner. in Biblioth:

Abripla penè pueritia bonarum literarum ac imprimis Religionis ftudio in flammarus. sn pimùn fe. S. Augustini Canonicorum ordini addixit in Fafulino

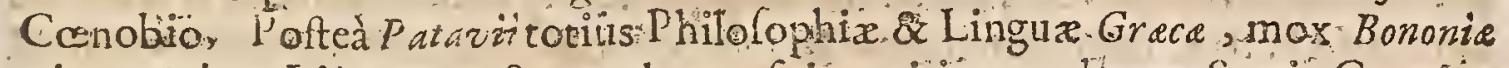
etiam Hebree Lingure exactam adcptns fuit nutitiam : ade ut Sacris Concio nibus hatendis omuium itlius ordinis per tom. Italian princeps habitus fuerit. Z3oiff ra. in Icono...

In dicenda werbis utebaturpuris, propînis, Latinis, compofitione pracerea tali, qux neque contractione. Orationis aut verboru ma mbiguitate obfcuritatem pareret, velinurfu's orationis longitudine fententiam fulpenderet, \& intellectum: ac memortam anditoris turbarct. Itaque non modo rerum ipfarum pondere, vem

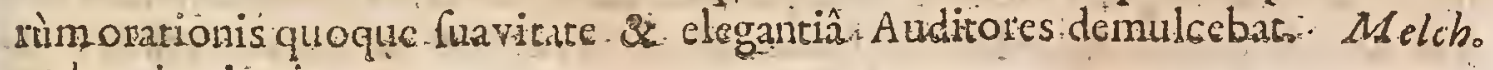
Adam. in vit. ejus..

Petrus Maryr, natione Italur ftaliam ob Evangelip Profeffonem relinques se coactus, multum valet eloquenti mes: Ger.

Petrus Marigr, ir illintris, nec frine fummilionovis prafatione nominandus? Ioann: Isel/. in Defenf. Apolog. Ecclef. Angl:

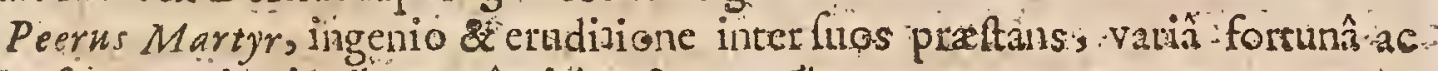
diverfis peregrinationibus torâ vitâ actatus. Thuan

Petrus $M$ artyr feliciter initiarus, bene fünditus in Philofophiâ, Hiftoriấ, Lin-

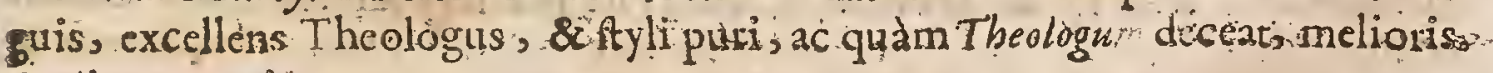
Scaligerana prima, $p_{0} 107 \%$

Sotrus ALartyr Florgmtimus quiin Angliann initio Reformationis frib EdvvanHhat 3 So YX 
do VI. accirus eft, quique poftea in Tigurinenfibus Scholis Scripturam Sacram docuit, multos etiam Commentaios in Hiltoricos Bibliorum libros contexuit, quir valde uriles effe nequeunt ad fenfus literalis intelligentiam, quia Lóc is communibus pleni funt \& Quættionibus quas occafione verborum Textûs fui movet Verofimile eft quia difertus crat hanc Methodum enmi elfe fecutum ut fuam facuidiam eo uberius propalaret imò \& eruditionem fuam; củmcontra if Textui preffius adhafifet eadem tam prolixè loquendi libertate potitus non fuiflet, nec diffolvendi tot curiolas Quxetiones à le in fuis Cómentariis motas, quibus etiam invedtivas quandoque addit. Sic, verbi gratia, ftatim ab initio Commentari fui in libum 1 udur, occafione Adoni-Bezeci quipedes \& manus ( pedum manumque pollices, dicir T extus (acer) 70 . Regibus vicinix lux abfridit, poftuam oblervavir illo tempore fingulas urbes fingulos Reges habuilli, prolixè digreditur in hodienorm Regum ambitionem s quorumunica eft follicitudo Subditorumumerum ampliares Tarita bodie, inquit, Monarchi flagrani ambitione, tut non quot poffint regere privideant; fed id unice fpeitom, ut quamplurimos regant. Déinceps vero candem refexionem Epilcopis applicat qui cupidifimè late patcntes Epifcopatus fectuntur, tat amplioribus reditibus fruantur. Epifcopi ornibibus modrs. id arbibunt ut Diceceses babeant quam annplifjimas, à quibus, licet riwngram eas infpiciant, uberrinos fructus rapiunt. Veibo ur abfolvam Petri Martyris in Biblia Commentarin longis digrefionibus crebri Funt \& ubique Virum eruditum fe oftendere afiectat. Exempli gratia cadern Iu dicum capitc; unius vocis occafione longum de Gigantibus fermonem texic ubi quicquid in hanc mateviain legerat ab ip fo refertur. l'reterea occafione vocabuli Hebraici Mar id en tributum quod freguenter codem Capite occurrit, proti am facit Differtationem dc Mifje origine, ubi omnes quibus contat partes explicat. Rich. Strmon Hilt.Cuit. V. T.t.; c. 14 . Gall.

1. Tanto fuiringenio, tam excellenti doce inâs, eâ pratereà pietare, modiftiâ, morumque facilitate, ut nen modò iis, quibulcum vixit, gratus, charus, revefendus fuerit; fed ab holtibus quogue \& advcrfariis inter fummos numeratus fit, \& admirationi illis fuerit - Nunquam dectior erar \& inagis admirandus $P C$ trus Martyr, quàm in publis difputationibus. Sive enim moderandi fflent concertantes alii, tam fe xqutim judicem prabcbat, ac rationibustartum qux ad perfuadendim valerent movebatur, ut nemo unquam fufpicaretur partibus cum fudere "non adverfarionum argamenta folida deprincbat non conivebat ad ami on errores \& fallas rations : fi extra fines dilputationis evagati vellent, cos manfuetè ad rem propofitam revocabar: fi varè res ad inxis vergeret, fuâ au-

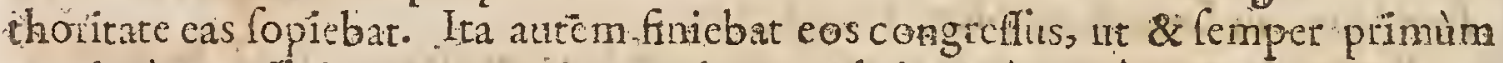
maximè neceffaria repeteret, \& tum demum de integ $\hat{i}$ calı sâ prŏnunciarer, quo \& Veritas vitrix fötet, \& inde non exigua ad Auditorés redundaret utilitas. Vid. Oration, de Vit. \& Obit.D. B. Martyr. prafix. ejufdem Lósis Commum nibus.

- Petrus Martyr fub Mcisfis Novembris finem an.1547. in Angliam transfretam

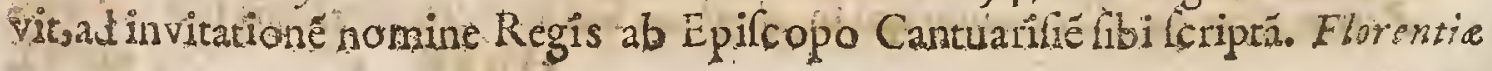




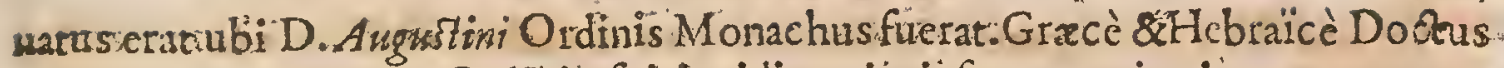
erat quos catcrorum Oxdinis fui invidiam in ipfum movit, in quorum mores fxpe ctiam invectinseft.: Ideoque cos reliquit \& Neapolin conciffit, ubi cartusn caegie: Hominum yui purè Deum colere delectabantur. Hoc cognitos lecum hune deferere coactus oft, \& prope Lucam fe recepit, ubi in 'iremellii atque Zainchii Cocítate moratus eft. Sed ibi quocque periculis expofitus Tiqurum ctum- Bernandino Ocbino petiit qur inter celebratiflimos italie Concionatores clàntuerat, $x$ anc verö pracidaneas fuas fupertitiones abdicavit. Tiquro Bafilearn profectus eft: Hinc verò Martini Buceri ope Argentinan

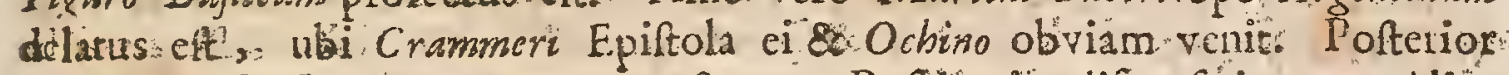
Gantuarienfss Canonicus creatns eft cum Refidentix difpenlatione: Alioque Diplómate quadraginta Marcx ipfi affignatx. fuctunt totidemque Petro

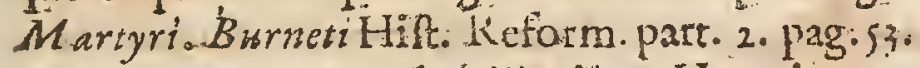

* petrus Martyr Vermilins inter: Harecicos prima clafis rejicitur in Indiceiciridentino.

\section{PHILIEUS MELA NCTHON.}

$C$

Ermanks, Bretta natts Ainno T497: Obiit VVitemberga a 60. Vi Titemberge

1. Philefophiam \& Theologiam-cum omnit madmiratione \& fruteta infigui Clär. An. B: MDXIL. docuit, frepe rernas \& quaremas tectiones tho die abfolvit. Auditores interduma mille quingentos habuiffe dictur. Korig. in Biblioth.

Apudexieros, eligionisetiam Adverfarios propter fuigulatern eruditionem moderationem, inque rebas agendis dexterituem. be nè audiebat cujus celé. britate acfamâmotus ịp̣e Eranicifcus I. Galliarum Rex: (cujus hones \&enomen

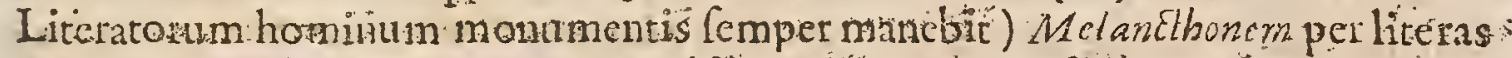

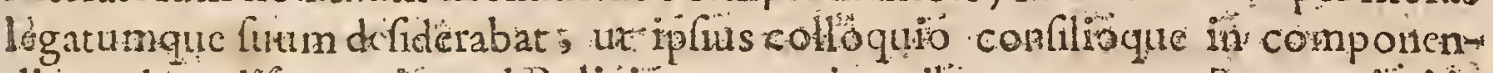
dis moderandifque rebus ad R eligionempertinentibus uteretur. I anta animi a in hoc homine elcmentid, monumque enarfacilitas, ut cam dof dariis congredicns landem ab ipfis ctiam papifis, aperto Marte rem gerentibus coufecutus: fuerit. Iar.Verbciden.

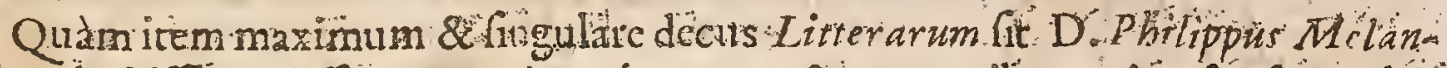

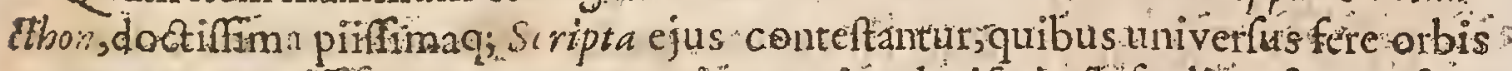

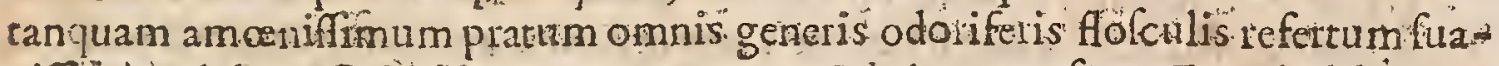

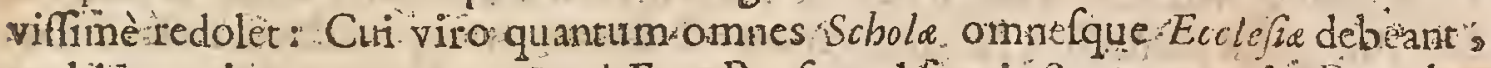

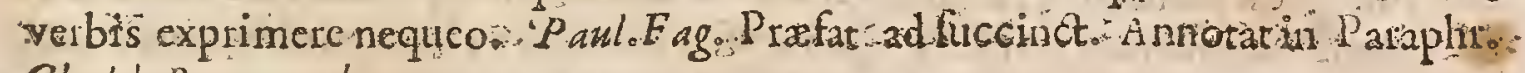
Chald. Pentateuch.

Melandhon literarum \& literatorum dectis. Henr. Steph. in Pindar.

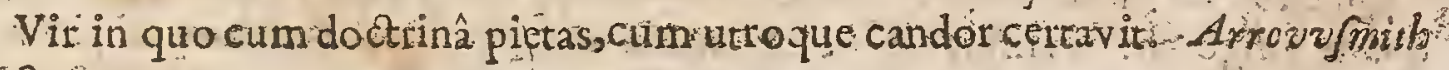
Tact. ?acr.

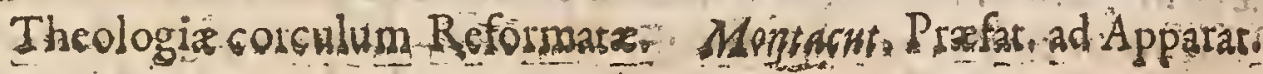




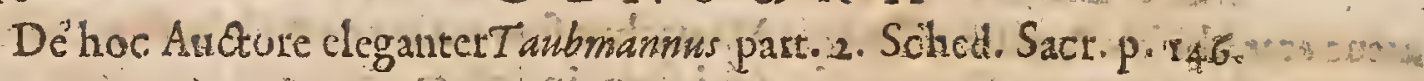

Hei graan mistorums lolio ferile cerer aroum.

$N_{i} i$ bove folerti Melanethonisitiud araffento

Illus ingenium magnum; \& ad omuia oomparatum. Iul. Cof. Sealig. de the 3.tic. p. 798 .

Communis Germanic Pixeceter, Germanie Phonix. Lipf.

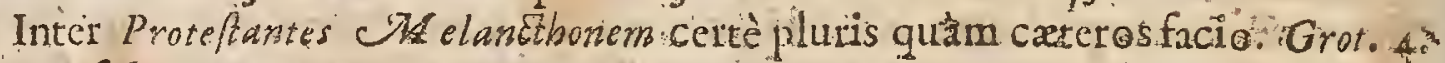
vol. in fol. p. $48 ;$.

Vir \&e judicio, \& pacis amare, \& eruditione multos fui: gregis frperans. Ibidem.

Philippus Th elanElhonprateringnem extitionem \& raram eloquentiam, haber gratiam quandum facalcm, quam genio fuo debet potius quam $i$ gonio o ut quam fit omnibus candidis grariflimus, neapud hoftes quidem habear quenquam cui Gt admodum exolits. Erafin. Epift.1. 27. epift. 2. .

Thuarzus 1 ibro 26 . animi cjus moderationem \& quictis fudium plurimum commendat.

2. irolao Gerbelio folus uns ferè omnia acute \& doctè brexiffmè agere wifus cft. Epift. Is." ad loannern Schruebel.

Philippus Melanthontoilu Germania fumman decas, uns ex primis pracipuis renafcentis freraria Reipublica, omnibufque fapientia revitcfcentis parentibus ac reftauntoubus atcun potteronm memoria dignifimes; multum eidebct Ecclefar multum quicunque bonas Artes \& fudia amplectuntur Gefner. in Biblioth.

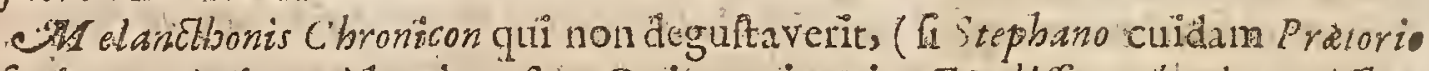
aufcultemus) is vcrèbardus eft. Quippe, inquit, Erudiffma ơ eleigantifirat Epitome eft ominin fere Hiffcriarum totius Mindio VIbear in Meth Leg. Hift Civil. feet. 6.

-Philippo Melantbone vix quicquan illo ævo enditius, facilius, difctius; non in aliis modò difciplinis, léd \& ipsâ Pö̈tice elcgantion. Dedatant id tot elegi cjus jam facti jam ex Gracis fontibus cadentes, jam farii argumenti. Borrib. de Poct. p. I3\%.

Nihil hoc ingenio felicius, fi totim vacaffet $M u f u s$. Nunc hane laudem leviter affeatavit, ac Narura felicitate contentus, nec artis, nec curx permutum adfcribendum adhibuit, \& haudfio,an ffectantem nervi fuerintdefe eturi. Ex-

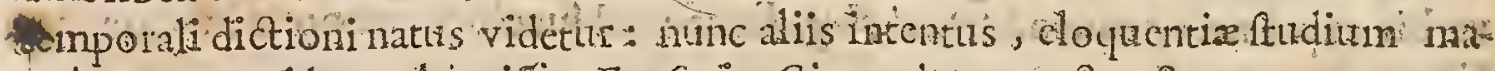

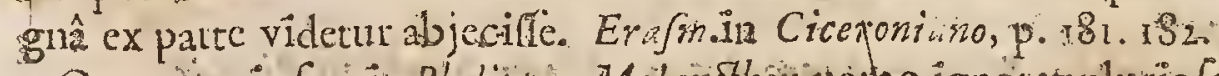

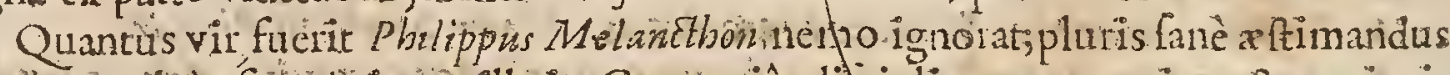
quàn vulgò fit. Primus ille in Germaniâ din iplinarum omnum \& purioris Theologix cum L mbere Reftitutor, nullum erditionis genus intactum. religuit, ut in frigulis habitate, non petegrinari, videretur. Nervos in illo \& impetum requiruat nonulli, fed tamen nec illud extra lauder ek. Ut enim tabuit 
habuit ingenium compofitum \& moderatum, \& ab affedtatione omni alienum, ira talem fe yuoque in omnibus vira actionibus \& feriptis exhibut. stylus ipfr - purus \& limpidus, nonnunquam humilis, nonnunquam affurgens:plena tanen ingenii \& prudentix omnia. Ejus viri vitam defcriplit toat brmms Camerariws, vir fuo tempore doctiflmus, \& intimionibus literis prae omnibus in Germaniâ exculturs. Mubta dilces cx illo, quxpetinent ad ftatum Liresatium \& Ecclefiafticum : omm enim fcen $x$, qux tum adornabatur s vel prafuit vel interfunt Melanethan, nomen omnibus Germanis meritè venerabile: Dan.Georg. Morhof: Polyhilt.p.2204, 225.

itylus in eo plants, liquidus, rec fuis deftitutus elegantis: quanquam non ampetus ille ac fervor fot, qualis in Fraf rizns, non tamen ideo culpandus: animi cnim elt character betmo, \& exillo idem in dictonem transfertur, huic ingenio-domefticam \& vernaculam. Ut cnim ipfe animus moratis eft, ita vel

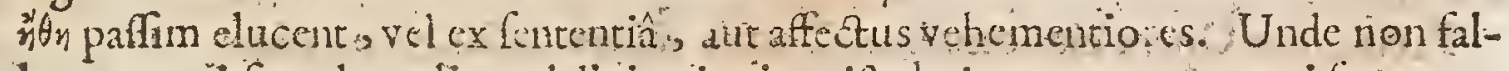
Juntur, qui ingulare aliquod divinationis epift ol ais genus commenti funt, tum ex iplo charactere fermonis tumliterasum, quod argumentum finguläi libro "tractavit Cantilus B lins idcm ibid. pag.28.4.

Et ô ridiculum !nc ad Ciceronem quidem feriò nos vocant : fed ad Melanethoncm fium, virum milhi, nifi z̀ Religione, haud afpernabilent; fed nec inter ducesaut antefignanos ad sloguenit : $m$ ponendum. De quo veriffumé Bonawirus in Italiánterrogatus dixit: Videri etm Latine loqui incipere, \& tentare. Lipf.

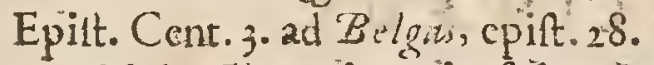

Melanthon pius vir frit , vatio dicciplinarum genere tinctus potiùs quàm cximie doctus \& dicujus. fcientie ad unguer peritus. Scaligerana piim.

Melanethan Lingux Latine peritus erat, fed Animus erat enervis, remiflus, mollis: Pacatus adinodum eiat. Magni hodieque apud Germanos aftinatur:

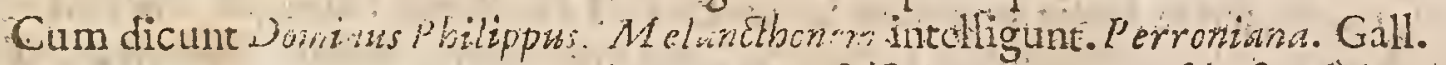

Melanchton ex omnitum eruditorum confeffo inter maxima fit feculitumina fplenduit. Humaniores in Germania literas reftauravits corumque omnium Preceptor fuit qui atate fua eruditionefuper vulgus ibi eminterwnt. Iplc Luberus dicere folitus erat Melanchtorseni ormnes Scripturarum Interpretes Doctrina Cuperare, \& quarv is ejus Magifter fuiffet, candore tameil laude digna fatcbatur fe ipfi\& ingenio \& cruditione inferiorem effe. Omnia éjus Opera profundiore Doctrina plena funt, perficuécute ac eleganterconleripta: Cum ramen illi non fuppeteret torum otium neceflarium ad ultimam manum ipfrs adhibendam, forfan non hab nt totain perfectionem ad quam eaperducere potuilfec. Anton. Teifler. Elog. viror. Eruditorum. Gallicè

Exquifitat Lingure utriufque facultate praditus ad interpretandum acceffit Hieronymus Wolftiis' - - Atque utinam parem vertendis Antiquis ftili moderarionem, \&, ut ita dicam, continentiam adhibuiffet Pbilippus 'Melunilthon! qux fuithominis facundia, \& egregia Latini Sermonis integritas, eruditos omnes, excufis de manibus veterum fcriptis, ad fui lectionem pellexiftct. Dicendi Iiji facultate 
facultate longè inferior fuit quàm Melanthon, diffundendâ licè oratione per fsmilis Nichael. Neander. Huet. de Clar. Interpret.

- Pbilippus timiduset, ita ut fepenumerò agat quz no probet Hieron. Zanchitus Epitt.1.2. ad Bullinger.

Dominus eum fortiore Spiritu intruat ne gravem ex cjus timidirate jactua montiar pofteritas, Calvin. Epift:183ad Ioan. Sleidan.

Ejus Locos Theologicos invictum libellum \& non folum immortalitate 2 fed quoque canone dignum dicit Lutberus in Epin ad Erafmum Tom.2. Witteberg. pag. 24 .

Pbilippus Melanthon, vir de Matbofeos fudiis praclatè merirus in Germaniâ. Fofl. de Mathem. p. Iri.

* Philippus Melanalhon in Primâ Clafe Hareticorum locum Habet io Indica Tridentino.

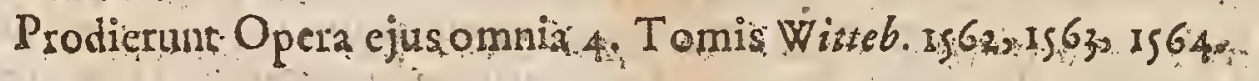

Sum ipfe Epitaphum pauld ange obitum hoc difticho promuntiavito

Ifte brevis tumulus miferi tenet offa Philippis.

Quiqualis fuerit; nefcio, talis enat...

\section{ROLU, S MOLINAUS}

$\mathrm{Clar}_{\mathrm{A}} \mathrm{A}, \mathrm{D}$ MDIX.

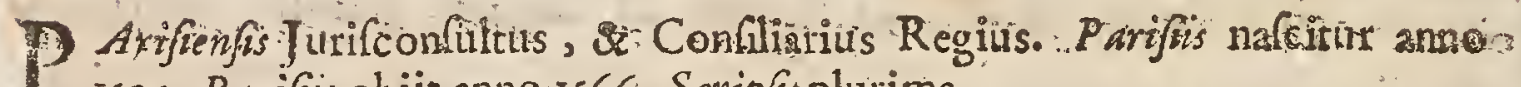
i500. Parifris abiit anno 1566. Scripfit plurima.

Carolus 1 tolinezs, Francie \& Germanix Juriconfultus, enuditione ac judicio . confpicuns, fedin Religione mire inconfans, a pontificiis enim ad Cal zinia-

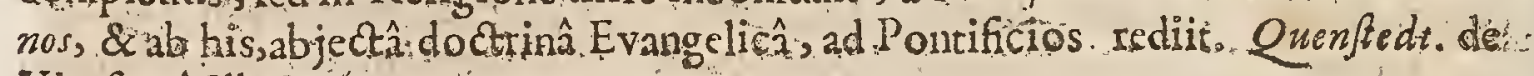
Vir. famîllluter.

Jurifconfultorum furo faculo doktifimus omnes fiprema Curix Patronos $\sqrt{1}$ non dicendo ( nam linguâ nonnunquam hrefitabar ) certè (cribenỏo refpondendóque facilè fuperabat-Parifiensum Leges Muricipales nom rulgati fubtilitäe interpretabitur. Scav Samartban.

Carolus Molineus Juris antiqui \& Galliciconfultrinmus: Cujus Nota in Jus Confuetudinarium noftum, \& alix doctifimx Lucubrationes apud nos pro ratis. I uris decifionibus habentur Confultationem in Concilium Tridentinum Lcripfr, qua \& illiperniciem creavit Vir bonusac fimplex, qui patrix Charitate, finpra quam dici potef, in Hamnabatur, cùm ernendationem in Religione, quam tautoperè optabat, in liccutiam \& factiones verfan videret, admodim indoluit; $a \epsilon_{;}$fi vita fuppeteret, religio se promifit fore ut exemplo fuo fcriptifque mulcos ab errore paffim graffante revocarct: in eaque cogitatione paulò poft aninam Deo reddidit anno.1566. Sexagenario major. Thuan. ad Ann. Is66.

Carolus Molinans: J. Co cam srudisioue ac judicio q quam probitate confpi-

cutse 


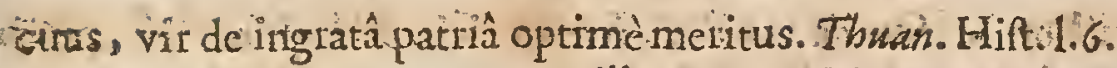

Carolus Molinaus, magnus ille Iurifconfultus, qui Iura Regum contra Papasum ufupationes fingulari ingenio \& eriditione vindicavit. GHb. Bates in Vit. Pet. Molin. pag. I.

Cùn adólefentiam attigiffer, expiffutue in Foro verfari; blafus elle; se impeditioris lingux deprehenfus eft, quod ci naturale vitiun initio obfuit, qui lites fatis exploratas difertè proloqui nullo modo polle videbatur. Itaque. \& litigantibus eoramque procurato ibus difplicebat, ineptis plerumque alienz induftrix judicibus, conemptuique illis potiùs, quam admirationifuit-.-Semel accidir ut à Chrffophoro Thuano Pxefide objurgaretur, quod cum arcidifet, prater Cpem; Collcgarum Seniores Advocaticoncurfu ad eun facto quod fé quoque violaros exiltimarent, per Francifum Portam batiquilfmum dici ei jufferum Can hodiè Molinam collegan qerbo $1 x$ feris, quid abste factum putes Lefifti cnim homitem doetiorem quàm unquam eris Poltridieque Chriftophorwos, quem Faei jam ponitebar, dixit, quod in Moli zurieffedilet, id calore fibi excidiffe: Tanta ille \& fummus \& dignifimus Pres humanitate fuit \& erga illos celcbres Patronos, inter quos etiam ipfe Hoructat reverentia. Papir. Mafjonin Elog:

E recentioribis unum tantummodo adjicio Carolwm Molinam, Galloum Jurifonfiltorum facile Plincipem; Hic, cum prater ingenì perennia monumenta plurima, tempore Henrici II. Libellum ctiam pro Parrie Ecclefieque libertate vindicaudî cdidillet, cog̨te l'ontificem, anteà infeltum, placâflet, eopfe libello-inmortilem fibi memoriam non meruit tantum, fed \& acquifivit. Audi lupereo exclamantem Antomturn Manbsum eruditione \& Scriptis non

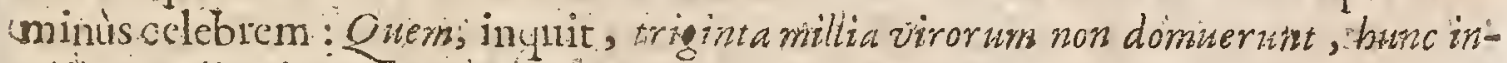
wictus Molinxi calanms expugnavit., O mernorabilem victoriam! O triumphum admirandim! Nunc tundernarma toga cedant. Nunc laurea concedat Stylo:! ba bent I wripperizi, quô ferorie wititur os occludant, quô togam à conturnelit fagi vindrare poffint. Hanc adeolasceantibi, Molinxe, debernis vivis vive que citento devo, of disjeltis ducumbtrophis, arente lauro, everfis ftatuis, tua Gloria in aternum virefet. Gxi. Salden de Ufu \& Abifulibrorum.

Dominis Salmafus fatetur Molineum preftantifimum leculi fui Jurifconfulrum fuiffe, tantaque dum vivcret authoritatis ut ci poft mottem eadem fupervixerit, cùm Omncs Senatusfupremeque Curia hunc ejus memorix honorem detulerint, ut Caufidicis indillerint illum cum Papiniakis, Jipianir cetcrifque Veteris Rome praclaris Jurifcentultis citant. Claud. Salmaf. Epiftola ad lob.Beverovicum. 7. Aug: 16:0.. Gill.

Ejus Commentarius in Parifinum Ufuarii Juris Codicem primus eft fudiorum ejus fructus. in mo $53 \$$. typis primum mandatus eft. Opus eft incomparabile fuifque tam abolutum numcris ut inimitabile fit ex Iuliani Brodeatifententia. Diony gus Godefridius ait hunc Commentaium quì Francici Iuris clavis verufque Interpres eft, ab omnibus Francix Tribunalibus cum applaufr exceptum fuidle, \& ab extraneis populis; qui cùn Caroli Molinei nomen non memorare

I iii 2 racra: 
facramento fe aftrinxiffent a fue ex invidia, frve ex odio Religionis ejus nec carere polfent ram eximio tamque celebri Doctore, eum tamen citant, imo quædam operum ejus cxcudi curàrunt lib ficto \& fuppofitio Gapari $C$ aballini no mine. Anton. Teiffer. Elogiis viror. Eruditoram (iallo...

* Libro cui titulus th tex Librorum expurgatorim, Gaparis Quiroga Cardinalis \& Hifpani Generalis Inquiftorir juffi cditus, referunkur. Opara Molinai, qua abfuc correctione legere nefas efticareraque, quowum correetio necelfaria fuit ab Hifpanica inquifitione judicata, ibi defignanur. Sed in I ndicc librorum a Concilio Tridentino prohibitorums: Molincus, citra ullam exceptionem atque limitationem, inter Authores prime Clafls collocatur; qua fuitunliuno Brodean - ccalio exelamandi. Tantente aninis colefibus ira! Ant. Ttiffer. ibidem Gall.

Quicquid ferèd difceptationes forenles quatiañas comminifici poteft hu-

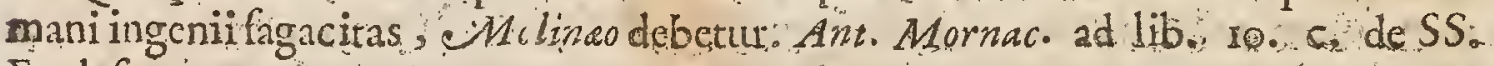
Ecclef.

Peffmus Theologus, nec-mulè melio Jurifconfultus. Ant. Faber de Error. Pragm. IQ: err.I.

Genebrardus ilfum igno rantia in fide. Hzereffeque accufavit:

Si cum Cujacio comparetur Molineus nullus homo-cet. Ant Faber de Error Pragmatic.

Qui verò de Harefibus egerunt , iplo etiàm Bucero in Teftimonitum ads vocato, eumdem Molinaum acculant, quòd unà cum loviniano cenluerit; ; Ie-

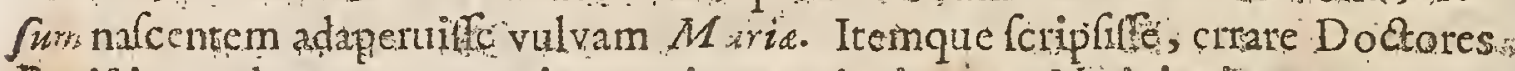
Papilticos, dum urgent merita tum incarnationis, tum Nativitatis, gtm tentaw rionum \&aflietionum Chrift : rihil enim hac omnia prodelte nobis , fed folam mortem Chrifti, folam à Deo acceptazm pro expiatione noftrorum pec-

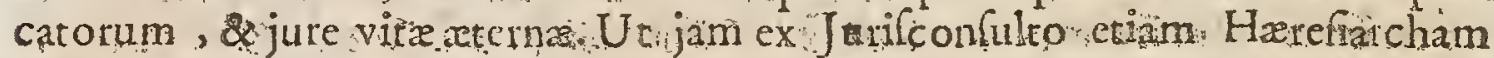
habeamus Quod planè ei non contigiffe, fi intra metas proverbii le continuiflt, Ne futor ultra crepidam. Nec mitum videri debtats fo tot exiftentibus ejus condemationis caufis, fuerit eju somen a Parribus Concilii Tridentini inter prohibitos Auetores pirna Claflis collocatum Quòd werò infuper , Peirwi Ruma nou fuifle, obftinte defendiffereperiatur; hoc quidem ci cum multis aliis commune exritit, xquè hallucinantibus. Ne verò illum; ficur vivum, ita \& mortum momino dạnnemus it tradit $M$ affon in cjus logio, ab eo lub mor rem vocatos fuiffetres pracipuos. Theologos, Clawdrum Efpenfaum, Curtium paforem s. Andrea, in cujus Parachià domicilitm habebat, \& Renatum

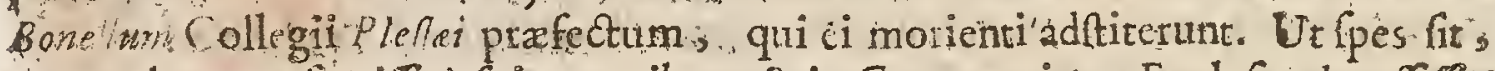
cum vel tunc telipuite à cuis erroribus, \& in Communione E-clefia deceffiffe. Hen. Spondan. ad an 1564:

Extant Opara Juridica, 3. Tomis. Parifis s6ri.

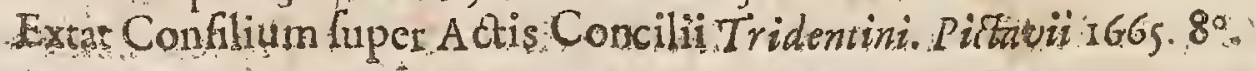




\section{W OLGANGUS M U CULUS.}

73. Ufanus, Lotharingus, natus eft Ani1497.obiit an.1563. Angufie Vindelicorum conciönatoris munere funutis eft. nitzà Bernam fe contulit, ibique Clar.An. D. MDXL。 Theologum egit. Reliquit locos Communes: Conm. in Gencín , Pfalmos, Efaiam, \& Pauli Epiftolas. Eisfebit, Sacratts \& Sozomeni Ecclefiafticam Hifto-

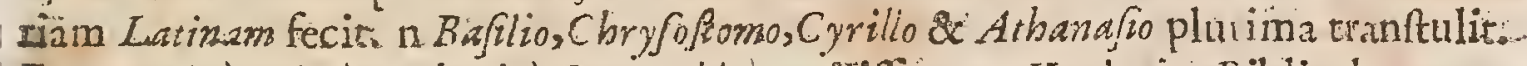
Erat Lstine, Gracè, Hebraice \& Arabice peritiffimus. Konig. in Biblioth.

Wolfgangis Mufculis, magni inserfues nominis.Theologus, qui Monaficam, dim, diein abjęcto cucullo Proteftentium doctrinam profulíus, vitam aliquando opere manuario textrinam exercens toleravit;pofted ferio animumad litcras jam atate provectiobr appilic: in quibus improbo laborc tantum profecit, $M$ artini? Buceri (quantum licuit)fectatov affiduus, ut famam Con:tonibus giuefitam, exiam liborioffrmis editis ir $S$. Scripturam Commentauis anxerito. Quem ad nomen ipfus altadens quidan, non Mufculum, aut ex Muriun famelicorum, qui: Fel.num ungues timent, numero elfe dixit;fed ex his potiüs, quil: Catos rapaces ter : ritarent:.Thum.ad An:IsG3.

Mi pater $M u f c u l e$, cgo omnes virtos dótos a pios obfervo \& colo:fed mihi

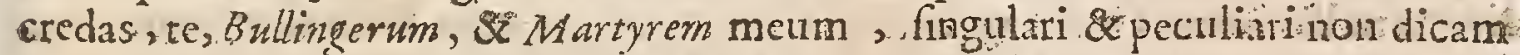
tantùm obfervantîn,fed amore quodzm tenero complöetorsut majoi etiam fi-

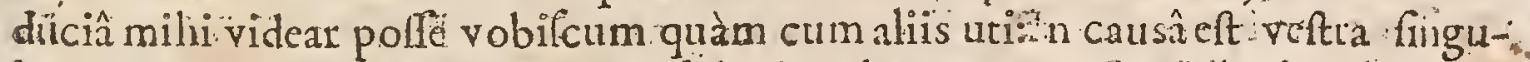

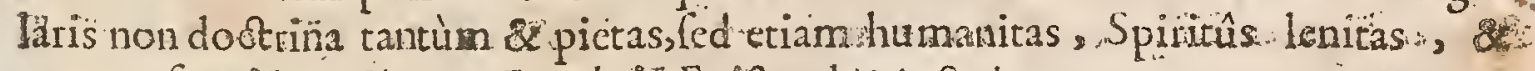
morum Luxitas. Hieron. Zanch. in Epit. ad Mufcul.

Ioi C Communes Mufculi opus planè divinum, qued foto decennio claboravito. it anno fexagefimo edidit. Melch. Adam. in Vit. ejus.

Natiria à contentiönibus femper abhorruit, neque fefe digladiationibus im maifcuit: Ubi verò in Controverfis Articulis ab aliis fortè dill untit, fine alionum

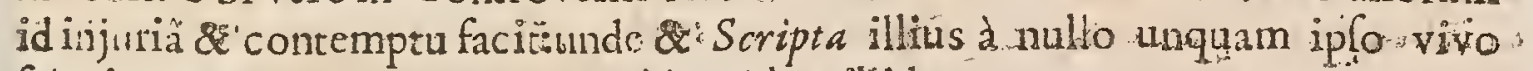
Gint impugnata, excepto uno Cochloo. Idem. ibid...

Wolfgangus $M u f$ culns Commentarium valde diffufum in Pfalmos compofuit: Berner/is Reipublice Magiftratibus abipho nuncupatum anno 1550 . Author ifte Prafationef fua proficetur fe totos 20 .circitcr annos in hac licubratione infumGillè, feque eos qui anteffe iii eumdem librum feripferuat confulutife, fed ex ve-w

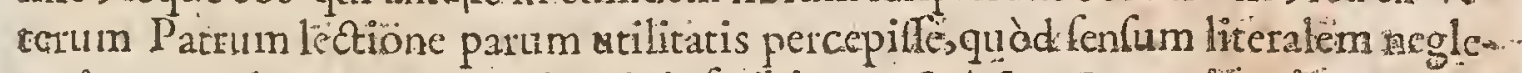
xerint: quod corum temporis meri afcribit. Verfati funt Patres, inquit; wn. ¿cri- -

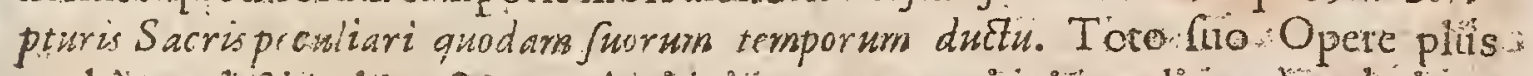

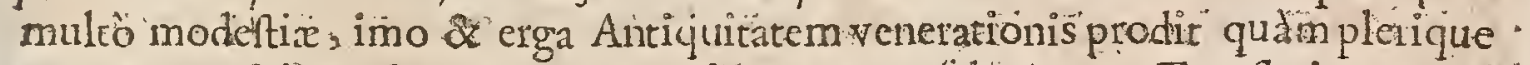
- mnes creteri Proteftantes. Et quamvîs novam Pfalmorum Tranlationem ad! Hebraum textum cxactam adornaverit, à.veteri tamen Interprete Latino quàm: minimè poteft rccedere conatur; imo \& addit optandum effe ut Vetus Larina : Verfio adeo conformis foret Hebraico Autographo ut per omnia confervati

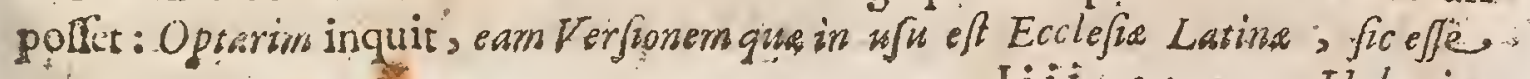
Ii int: 3 :

Hicbraice: 
Hèbraica veritati conformem untegra retineri queat. Denique eadem $P_{x e f}$ tione fibjungit Liberum cuique elle dèbere quem optimum iudicat fonfum eligete, temerariunque fore, juxta D. Augufinum, quempiam pertinaciter alloverare velle fe Authoris fenlum reetè affccutum effe. Haud imbierits, inquit:arbitratur Anguftinos adwodum temerarium efje in expafitione Scripin arum, de certitudigie mentis cjus qui fripfot pertinaciter contendere. Satis accurata eft $\mathrm{Mc}$ thodus quam in fuo Commentario fecutus eft. Primum affert diverfas Vccerum tum Gracerurn tum Latinorum Interpretum Traductiones, quibus \& neatericos quandoque adtit: Deinde veiba Textûs füi juxta. Literalem Cenfum exponit; Poftea vero Morales fins animadverfiones fubnectit. Be hoc Anthore dici potef quòd verum cognoveit modum Scripturam exponendi; fed non habuit omnia auxilia necclaria ad perfectumin co fuccelitum, quia in Linguarum \& Critices Atudio fatis cxcacitatus non clat. Veteres tamen 2 Recentiores Trannhtiones Gracas atque Latinas anino a prejudiciis libero examinat, fufficientique perfpicacitate preditus füt ad cognofcendum quod puncta qua hodic Hebraico textuR in fune, ei non inextiterint feculo Septuaginta Interpretum nec Beati Hieronymi atate: fed prorfus ignoravit qua ratione Arabica Plalmorum Verfic elaborata fuerit, quamvisillam Sepius citct. Miratur cur Arabs Tranflator Septuaginta In-

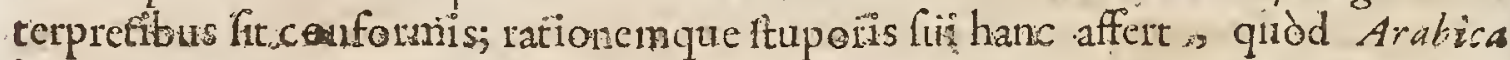
iingua nullamcum Graca analoginm habear, contra vero Hebraïcx admodum

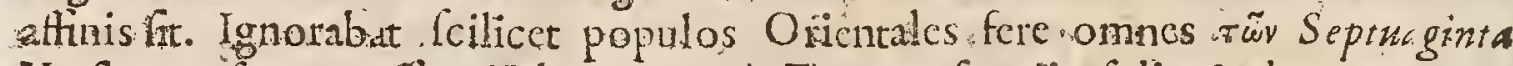
Verfonem fecutos efle, Hebrixum wero Textum fere in folis Iudcorum Symz-

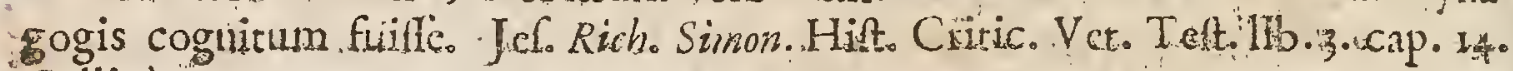
Gallicè.

Wolfgangus M w chilu: vir bonus, Ced lingne Gracmoticia imparatus, meque Iatinâ valdè inftrictus, brevitate \& nitore, fimplicitate ctiam ac fide commen-

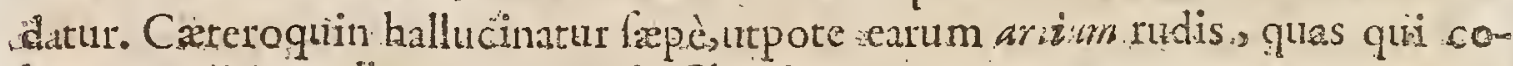
Ilunt, eruditiappellantur. Fuet de Clar. Interpret.

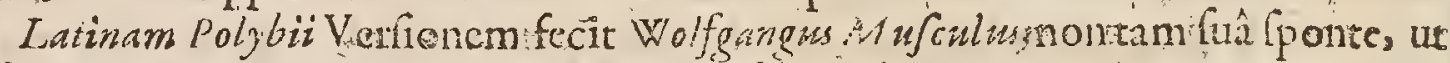
aple fignificat, quàm alieno rogatu. Non fuit in hac virosncque $Q$ : a a neque Latrne Lingux villa cximia peritia:crat chim älisdeditus tudies ; \&randi jan atate ad.capiendum ingcrii cultum accefilleiplum accéimus. Dcfiit etiam Mufculo illa, cuamin l"crotncommendabamus, induftia in Graris ita expos

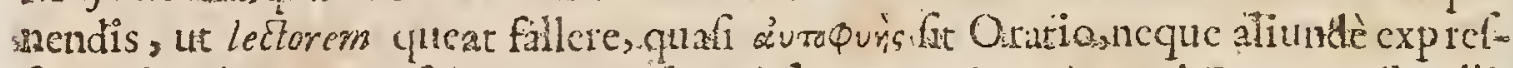

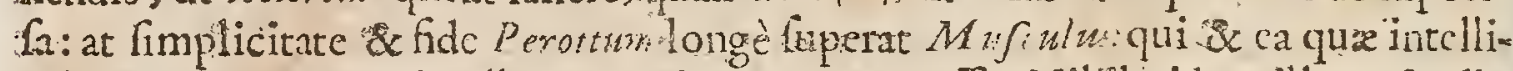
gebat, $\&$ ca qua nen intelligcbar, uti potcrat, expreffit. Nihil vidcas illum studio

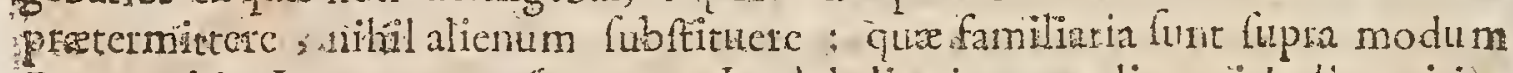
Perotto vitia. In utroyuc voluntatem benè de dite is merendi xquil Iu ice citius Laudaverint, quim effectim. I Juac.Cafaubonde pribibus Polyb. Interpret. alfix.

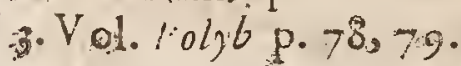
Eugéb.

Muculiverfonesnon magneperè probanturà Dodis. Her.Valef. Prefat. ad

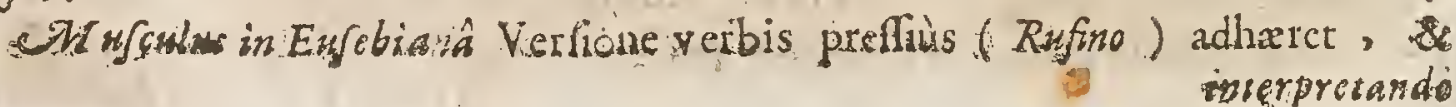


founnes Fernelius, Regis Archiatros, cum plures anmos in PhiloLophicis ac Mathematicis fudiis fummâ cum laude exegitfet, demum fe Mcdicinz totum mancipavit : quam \& felicirer fecit, \&e univerfam doctifimis \& poLitifimisfciptis complexus eft. Qux etfi morte praventus non edidic omnia, ( ut nec propriarum oblervationum defideratifimos libros) tantum tamcn veræ glorix iis, qux publicata funt , Europâtotâ eft adcptus, ut tanto vire difciplinæ fux alumno chol Medicina Parifenfis atemùn fic jure gloviutura. Thisan.

Verum eninver̀̀ eodem tempere fortiit loannes Fernelius, Ambianzr, Regis Archiater ; vir in melius promovendx Artis fudiofflimus, qui in amultis a Veteribus paiter recentioribufqu? diffidere aufus fuit. plurimis novis Dogmatibus in medium adductis; quique primus inter recentiores, morbos itotius lubftantix celebravir. In quo uti onninè fummè daudandus veriit, Univèrfamartem uno volumine ad modum Avicenne comprehendendi infignis conatus, gíódque Veterum expofitionibus-non femperfuperfitiosè inharendu exiftimaverit, praterca etiam mulla cirea molbos corumque caufas pimus obfervaveritita in fermone eleganiffifmo majus robur argumentorum merico d. fideravchîs. Et verò doquentiâ luâ incauto \& rerum imperito lectori palfin fucum facit potius, quèm ut frrmis argumentis eum inftruat \& convincat. Sebaft. Scheffer. Intreduet.in Art. Medic. p.73.

Longè majoren (Gulielmo Rondeletio) Jaudem meruit Ioannes Fernelius, vir experientinmus, \& magni judicii at,juc ingenii. Verum ille non tam fingulorum molborum curationem nobis reliquit, quàm methodum medendi generalem. Interim tamen libli Therapeutici de compofitione Mericamn-

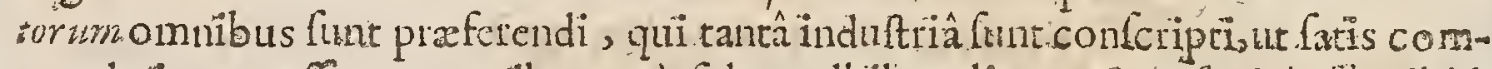
mendari non poffint; ut quibus.turo fidem adhiberediceat. Sebaft. Scheffer. ibid. pag. Ifto.

Fernelinsindufrius lucipera. quỉauthoritatem adeptus eft cò quod Regina Matris puerperio facilitatem attuliffet. Habuit falacillinam filiam cui dedir decem millia aureortm pro dote. Scaligerant prima. Gall.

Primarii, Excellentifimi \& eminentifimi Gentisnoftre vini fuerune $C_{\text {tojas. }}$ Ronfard, of Ferriel.

Tanta puritate Iatihè loquebatur ut fepe citatus funerit, ad hoc teftimonium opponendum Uiltramontanis qui nos in has lingua Barbaros vocabant. Moren Dictian: majori Gall.

Fabanni Fer elio un è primis locis inter eos qui in Medicina excelluerunt meritò concedi poteft ; cum urius celeberimarum Enrope Univerfuratum cáculis dignus, fuerit judicatus qui avi fyi. Hioporr ter dicerctur. Acutus 1 hilofophus Baffank preclaris ejus Operibus lectis ab his laudibus ei rribuendis

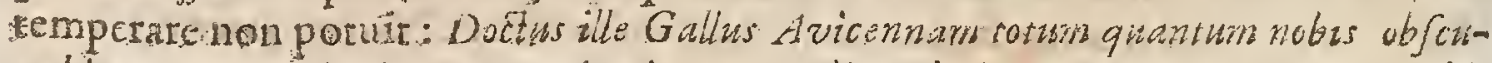

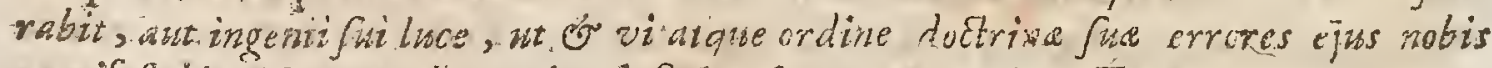
mainfeftabit. Ifaar. Bullart. Acad. Scicntiarum Artum Tom.2.

Omnibus noum eft Fernelii Pathologiam iner excellentifimos ejus Tractariâs 
Tracturts eminere, eumeqte omnium Authorum recention de moborum * caufa 8 natura optimè lexpfrife. Hujus amen Operis perfectioni aliquid deelfe pluresautumant, quia theoriam folam à praxi omnino lejunetam complctutur, mortiorumauc notitiam unicè doccido, tationem eoldem curaidi non tradit. Dominus Kutgerus Leoniz: defectum hunc fupplere molitus ct, huic Patholo. gix Tractatui Therapeuticen è valis ipfits Fernelir locis alio umque quormdain Authoium libris excerptam fubjungendo. Erwditorm Ephernerides Gall. diei luna 19. Aprilis 1656.

Nemofure cempetzaris medicorum loanne Fernel fpectibilior, atque illuftror fuit:nemo lubritis arcis ambigux fandiones ad folidiora natura parcntis cxordia revocavic; ut iccircò Gallorusn ipporrates, fublimi celcberima orbis Academie judicio vocaretur-Verè frcutinil dulcius ejus Oratione Tulliane propemodum dictionis amula, ita nil preclarius fontentis humana falutis prafidia inculpatè tuentibus. immenfa propterea eafdem fectantium cohors, per torem propè diffula O bem, vel ipfins interdum Galent vercndx univerfitaex preponderat si egregiam virtutis opinienem, licet ex inufitatâ lucri me-

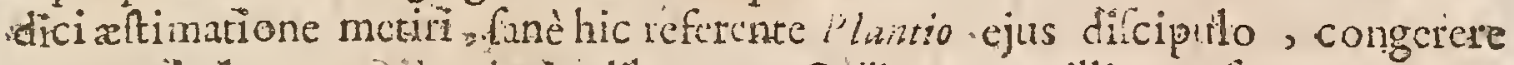
quotanis : cem, ac duodecim libarum Gallicarum millia conlueverat. Loan. Irrperis. L. Mul. Hift.

Jucundo Mathematicanum 足udio delectus eft, in quo ram excellentem fuccelfum habuit, ut nulli nifi huic Dicciplina operam unquam navafe vifus fit. Clatifinus \& fingulatis pariter fuit in Philofophia ut $\&$ in amenis \& humanioiteus lireris, adco ut meritifimo jure perfectima cientiarum omnium pidura nuncupari poftet. Cui rei confociara fuit vitz integritas exemplaris, quin in animo cjus fedcris ominis putifimo perpetuam ecd.m fixerat: ad tutum unica vitutis hajus prafidum compoluit actiones luas pridentiflmas ufque ad exirum virx, qua Chriftine excelic anno atatis 52. Aprilis die -26. anno 1558. Purifir, ubi in S. larobi Fano ejus exuvia condecoratx funt Sepulturatam celdori \& famigeraro viro digna, cjufque Tumulo tegitur Latina "unferiptio fequentibus verbis confans. bact. ltal.

Ioanni Fernelio Ambianenf Henrici II. Galliarum Regis Confliario, \& primo Medico nobiliffimo, atq̨e optimo reconditarum, \& penitus abditarum rerum fcrutatori, explicatori fibtilifimo, multoum falutarium medicanentorum unvento:i, veræ, Germanæque Medicinæ retitutori; fummo ingenio, ex quifit tque doct inẩ Mathematicà omni ingenere Philolophia claro, ommibufque ingenuis artibus intruto, temperatilimifque, fanetifin ifque moibus pritito, Socero fuo pientiffimo Pbilibertu B rcoizus fupplicum libellorum ì Regiâ Magifter magnique Regis Confilii P.refes, affuitate gener, pietate filius, marcns politit \$nno à falute mortalibus reftirutầ 2558 . Obiit 26. April. Anno 1558 . Vixit ann. 52 . Gbilivi Theatrum Italicè.

Extant Opeia ejus Medicinalia Genevie apud Samuelem de Tournes, 167.9. in Fol. $\mathrm{K} k \mathrm{k} k$

JOANNES 


\section{JOA N N S LELA N D.U.S.}

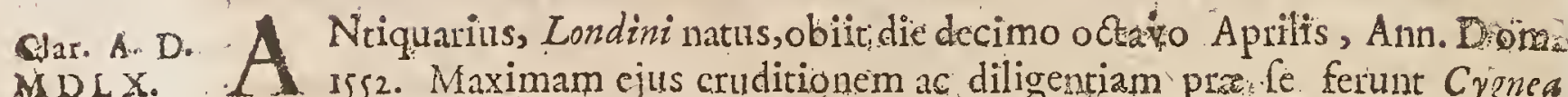
Cantio, \& liber de Scripioribus llumitribus Britaniia.

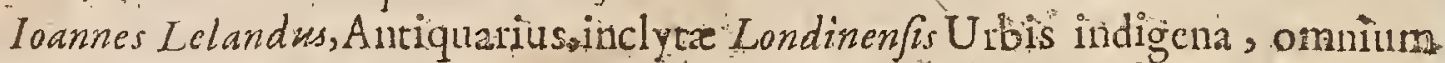
quos prateritî æatate Britannia nutrivit, lerum frarum ftudiofifinus , patriam omnem exquifitifimis laboribus adornavit De ejus ingenii \& doctrinx amplitudine, nou cft quòd hîc dicam, quịm opule ula plura, tam prosấ, quàn carmine ab iplo felicitcr edita, in omni difciplinarum genere Grace Latinè atcque in multis aliis linguis eruditilimum fulfe teftentur. Sub Sylvio quodam Lutetice Parifio rum ftuduit: Et alibil locorum, fub Præceptoribus femper optinis. Antiquitatis Britannice fervidusamator, ac diligentifunus perfcrutator, vetera totius Infula monumenta, magna ubique induftria \&cura perhuftavit, ac quafi ex Silice flamman difquifivit, ut ipfam illufraret. Incognita locorum \& rerum ex nimia vetuftate vocabuld prima,per antiquos ac fide dignos Authores revocavit : \& quo facilius intelligerentur,tam originalibus quàmunus ufitatis explicuit illa nominibus. Exoletos feurabufu remotos, atque adeo in Oblivioue penè fepultos, $B$ ritannicos Authores, hic folus refulcitavit, ut dignam haberentex fplendiais factis apfi memorian. Nihil praterea omift, ex aliąum Nationum fcriptis au linguis:, quod ad Natalis foli ormamentum yuoquo modo facerct:quafiad communcm ejus tum commodum tum decorem fuerit natus. Ioan. Balais de Scrip. Britan. Cent. vir.

Fuit non folim Urbis Londineñfs, verum etiam totius-Britannic limen, decus \& onlamentum fingulare. Regius Bibliothecaius factus. omnefum ftu dium eò convertit, ut $P$ atria laùdes [criptis celebraret, jufque gु loriam illuftrarets omnique pofteritati, imò, fi poffer, xternitati, commendater. Et quoniain non minus elegans Poëra, quà Orator erat facundus; \& verfu fcripfit, \& oratione folutâ. Antiquitates Britanniras fudioffrmè inyeftigavit, vethfillimos codices ubique perquifivit, plutimos invenit inventos curiolifrmè exculftex quibus res nimia rctuitate obrutas è tencbriseruit, acceptâ etiam ab iplo Rege Kononatâ Com milfione, \& largo vittico Ann. Dom. I534.totam Anglium peragrare incepit, celebriorcs quafque totius Regni Bibliothecas excuffit. In qua peregrinatione, ut ipfe in Strena fatetur, integnum Sexennium pofuit. Cum librorum lectione locorum infpectionem ità accurate conferens, ùt diligens \& perfpicax hominis ingenium nihil melioris notre fugere polfer. Super quâ re librum Anglice fcriplit, \& Regi Strence loco obtulit. Pit au de llluft. Angl. Scriptor.

Ego quidem ingentem numerum fcriptorum tractantum res Britannicas diligenier excuff. Leland. Comment. in C'ygn. Cant.

Lelandus genere Britannus in fux Gentis antiquioribus monumentis profem sendis homo apprimè diligens. Buchanan. Rerum Scotic.Hift.1.2. Jam praftiquod fum pollicitus, \& Commentarii qualcfunque mei in 
C Can Cantronem prodeunt, Opufculum ex peneralibus recondita \& SacroSancta Antiguitatis religiosè crutum, \& diligentia, curâ, fide quantd potui platie maximâ in lucidum ordinem redactum. Leland. Prefat. prafix. Comm. in Cygn. Cant.

Taulò ante obitum Pontifician deferuit Religionem. Quod multum deplorat Pitfereshis verbis:Illud fane vehementer dolcndims quod hio vir praclatus, \& optimè de Patiiâ meritus,perfidorum fuafionibus, \& Regis weltimore vel favore fuerit adduatus, ut pofremis ferè vite fux dicbus in fudt-cladicare ceperit. Quâ labcfada lunt neviflma hominis pejora plioibus. Nam confcientix remorfus felixiltud ingcnium tam infelicitcr torffr, ut id penitus extinxerit. Unà vidhlicetcum fide labefactatabefactavintedectum, \& paulat in delinim incidens, mífer planè mortuus eft amens.Quo triti exitu faetum elt, ut fua feripta pleragueimperfect religuerit. P itfons de lituit. Angl scriptor.

Iohannes Lelandas, re Hiforica \& Antiquitatum cognitione contun, quos Anglia watuan progenuit, facile Princeps. 1 t. W ot in Antiq. Oxon. p. 262.

Lelandruftepolt Regis HeririvII. bencfici ejus Patroni obitum mente motus eft, \& in hoc ftatu vitun fruit. Incertum eft an pre libois pondere, ar vero praftindii ceflarione trabum fuerie cjuscuebum; major in polteriori verifmiliudo; quir Henrico Rege fatis codinte, nulla pro laboe meredis proportio animos ei deinceps aiddidit. Thorita Fuller. Hifotia Ecclefiatica. An:glices.

Extat Cignea Cantio, \& in eanden Commentarii Antiquitat Bs Britannica locupletifimi. Iond. $16_{45} \cdot 4^{\circ}$.

Extant Principum ac llintrium Virorum in Angliâ, Trophar, Encomia, Ge methliaca, \& Epirhalamia, Londir. I58g.

\section{REGINALDUS POLUS。}

Ardinalis, \& Archicpifcopus Cantuarien/ss in Angli" natus, Parrem labuit Richerduin Regis Henrici VII. confobrinum, Inatrem Margariam. Clar.An D. $M 1 \times$. Comitilfam Sarisburien em Edvvardi IV. Regis Anglia ex fratre Georgio Claw rentie Duce neptem. Obiit decimo Ceptimo Novembris, Anno Dom. Ij58. atatis" j8. Scripfot varia.

Vir fuit polus egregiè doctus, modeftus, manfuetus, \& moribus fuapte natur placidiflmis; pr!ndens ctiam \& in rebus gerendis magnæ dexteritatis; ut nihil in . co defiderares, fi pontifria doctrina depravatus, ad crudelitatem in vere Religiow nic profeffores exercendam, quafin invitâ $M$ inervâ \& genio exclamante non deflew silfer. Godrvin. de Pralul. Angl.

Polux vir pietate, dodritâ, omnique virtutis genere tequè ac fanguine clarus. Eum ipfe Rex in deliciis habuit, non modò propter fanguinis propinquitatem. verùn ctiam propter virtutes ' $x$ cruditionem, quibus $S$ tirpern Regiam multùn -rnavit. Ioan. Pitjeus de Illuif. Angl Scriptor.

Panlus. M anutiws in I'rafatione Libui de Concilio Tridentino, poltquam RegiKkkk maldures 


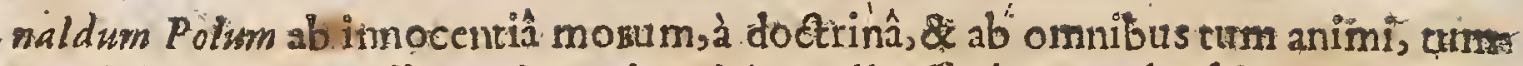
induftrix, rum ingcnii monimentis micè prædicallet, hæc verba fubjungit: Ilud certe conjat, qui val meliora, vel ornatiora foriberet, hac bominuin memoria extiviffe neminem.

Polo ut virtutis nitor, \& morum candor puspura. dignitatem adfeiverat, ita serum ingentium ufus, majorum claritas, cruditionis laus fingularem apud omnes gratiăm comparârat. Loann. Imperial in Muf. Hift.

Polz nofter, homo haud paule plus o mnibirs bonisartibus clarus quìm no. bilitate, cuae eft a . Britannia Regibus Petr. Bermb in cpilt.ad Sadoletum.

Supra familia fplendorcm (Regio enim fanguine natus erat) pietatis, pru-

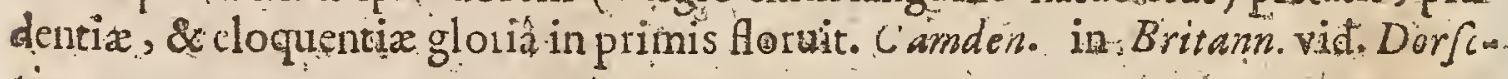
tiam.

Reginaldus Polus Anglus; vir eximiâ fanctitate, \&ario doctrinarum genere clurifinus. Onupbr. Panvin in vit. Pauli III. P. Maximi:

In quo fanguihis nobilitas ( uam proximâ cognatione Regem conting bat) morum gravitas cum eximî̀ doctrinâ conjunet î exritit. Godvein. Rer. Anglic. Annal. 1.2.

Reginaldus Polus Ciceronis admirator fummus, \& amulator non iufelix Erafm. Iil Ciceroniano, p. I7, 4:

Vir crat ernditionc, eloquentiâ,judicióque fummus,nection fi Scriptoribus.

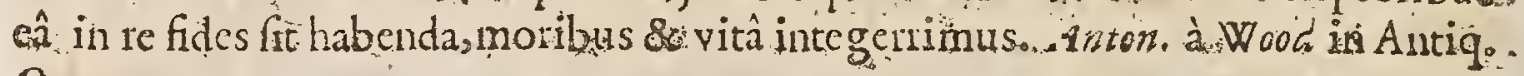
Oxon.p.ing

Cardinalis ad opes congerendas nullam habebat propenfionem;natalü mejus: nobilitas, praftantiaque virtutum cjus animum ejus fupa viles hafce cogitationnes attollebant. Vir crat eruditus, modeftus, humilis bonzque indolis; ejulque dotes \& temperamentum eum ad tam prudenter agendum moxebant ut fi Epifcopos ad fuimitationem aut lapam \& R eginam adtui approbationem inducere paruilfet, verifimile efteum valde promoturum fulfe Gcris iftis cum Roma㔖 Cede reconcithationem. Sed Deus huic Populo meliora definaverat : adcoyue Reginam crucneis Gardineri reliquique Cleri cruentis confliis permifit. In hoc mo. Cardinalis fuafionibus obfequi non potuit. Verum ejus hac in se opinionem alcribubar I mperamenti ejus maderation potits quam ejus prudcntix \& experientia: Ipte vero videns fenihil coum qua froi propofuerat in Anglia excuipolfe, in animi languorem primam incidir; quem fecuta eft valerudinis

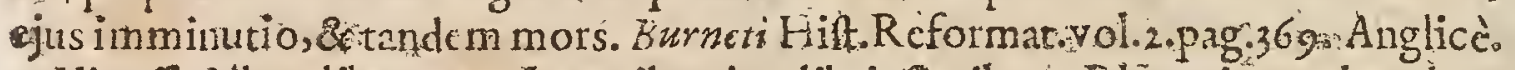

Vir ffectibus libar erat Juvenilcs ejus libri flöribus. Rhcroric $x$ admodum xornati erant; Illi vero quos xtate ad fene futem vergente compofuit aridi funt: atque languidi.Vitam terminavit pancis poft $M$ ariar. Reginam horis, 17. Novembris anno is58.Anglorum Speculum feu de Prảclaris Anglia Viris, Londini $3684: 8$ : Anglicè.

Slar. A. D.

$$
\text { J OAN NES: SLEI D ANUS. }
$$

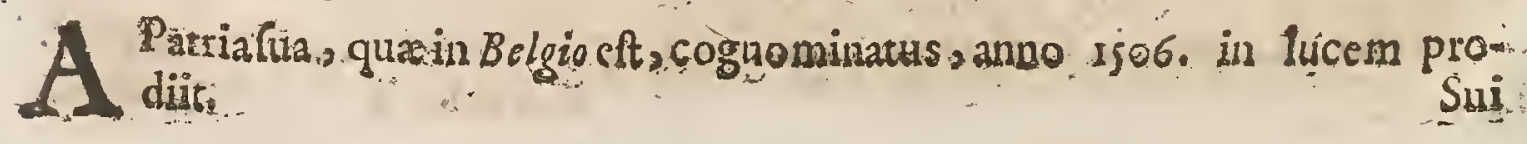


Suifeculi Hiftoricus facilè princeps, obiit Argentina ex Epidemico morbo, anno falutis is56. (quamvis non defit apud quofdan dati veneni filficicio, ob edenda quxdam Hif́torica, quæu tum ab ipfo ad huc premebantur) xtatis 50 . Cepulnfque ibidem quiefcit. In qua civitate multiplice \&eruditionis, Setprudenti atque pictatis edito fpecimine, fummo femper loco habitus fuit. Boifjard. in IEon. Seripjet Conmentarium de ftatu Religionis tempore Caroli V. Imperatoris Libellum de quacrol fummis Imperiis - Orationes duassunam ad Carolum V. Cafarer; ;alceram ad Germania Principes omnes ac Ordines Imperii, in quibus de Papatu \& caufa Religionis tractatur-Froifardum, \&u Cominessme é allic in Latinum tranftulit.

Bonus imprimis Scriptor loannes Sletandis, crijus frdem (pectatam \& gravisatem Lufpiciendain mecum alii inoverunt. Humfred. Jefuirilmi $z^{2}$. part.

loaines Sleidanus. Vir eruditione \& rerum agendarum peritia hoc feculo" clarus. Argentinenfi Reip. fuam operam addixit $\because$ in eaque iube tot rerum quas, gellerat aut à fide dignnis ace perat, notitià fretus, ammentarios feribere aggreffuls eft. Quos hucillucufque exattâ fide \& diligentiâ Thuar.

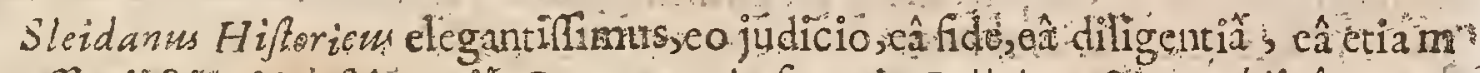

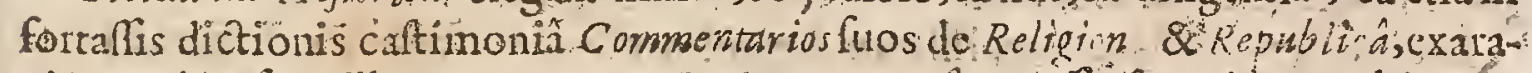

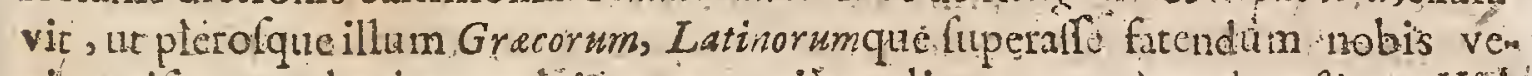
mint; nifi extera laudare vulgi more potius velimus s quan domefica. Vido. Conring. Prafat. in Taciti libell. de Mor. Germ.

Sleideni Iibellium de quatuor Monarchiis valde laudat Georotus Hornius hifice? verbis: Quanyuam pro magnitudine rerum brevior omninò \& contractior videatur autor, eatamen ipflus apuderuditos hactentus fuir exiftimatio, ut frequenṫifinè recufus,omniüm hodieque manibus teratar. Perfequitur cnim imanimè iarignes calus ac Imperiorum mutationes, \&oftendit fucceffionem poptortum acttemporum : precipuè ubi ad: Eccle fie recentiora certamina perventum, aperic : ex ipfis fontibus illis horibiles Imperatorum \& "Pontificum collifiones inde ufque ab if enri: $i \mathrm{IV}$. xevo ad Carolum V. in quo definit. Nam qux porrò fequuneurs in: peculiari De ftutu Religionis Commentario, copiosè \&"onatètradit, onanem nimi-

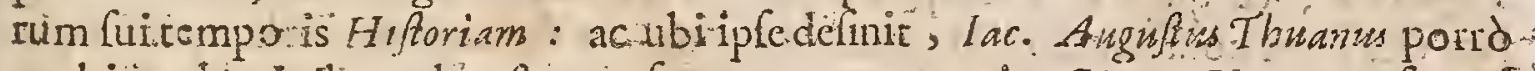
multis voliminibus ad hoftram ufque watem peitexit. George: Horn. prefat. ad: leict. Sleidan de quat. Monarch I66).

Eternum illius laborum teftimonium ef Hiftoria illa de Reip. \& Religionis iii Germania ftatu ab initio inftaurati à : Lutbexa Chrifianifri diligentifimè ginti quinque libis ( non hortante modo, fed etiam miteriam ci fluppedicante

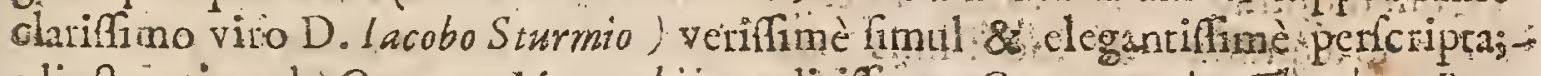
adjecto etiam de Quatzor Monarchiis cruditifimo Commentario. Theodor. Bez. Icont.

Sleidani Hittoria adinit milii fidem omnim fuperiorum Hittoriarum, inquit Carolcvitius. Vid. Matt.Drefferum in Orat. de ufu Hiftoriarum ( Num hifce verbic Caroloz:tius.Sleidanum laudet an vituperet in medio relinquo.) 


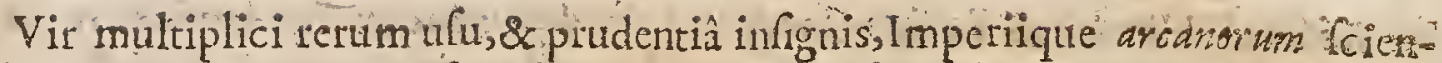
tifimus. In narrationibus fuis fepofito partiurs affectu, liber, gravis, operolus diftinctus, finc vanitate tamen, \& verborum ambitu; wa Lectorcm inftuens, \& actiones omnium vitamque dirigens. Verbo, SGiptor ad Hiftoria:sà nuturh factus, \& fi quisalius principedignus, quii judicium cgrégic format , \& ad civilemprudentiam ducit. Timantempictoremcelebrant, quod in ejus tabulis, plus lemper alicind iàtelligeretur quàm pirgereeur: Idem de Hiftorici hujus scriptione meritò dixeris. Quem (fi de tanto viro judicare milii fas ) ntinguam legeris finc fructù \& eto fepitis legas,plus auferas. Continua fertilitas eft:quaneum demis nalcitur, \&cum o mnia collegilete putes, plura telinquis. Iac. Crueins in Epiftiad latrem finn p. 6.

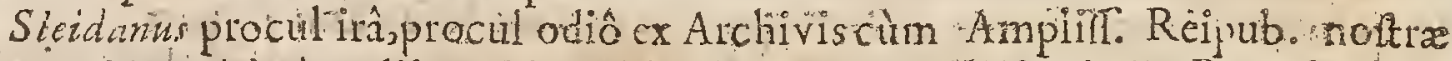
(Argentinenfis) tumalîs Actis publicis, ftatum Religionis \& Reipub. Cutdidè veréque défriplit, \& de quô, certis Auctoribus mihi.conftat $1 \mathrm{mp}$.

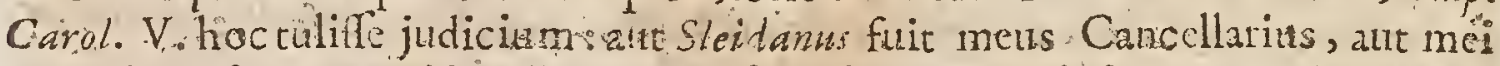
Cancellaii fuerume mei loditores : ejufque lectione déletatum, obltupuife Cecretifimarum reum narratione, commendalle ycricatem. Watth. Bernegger in Demolit. Idol.lautent.

Merito fuo 3leidanumplifima A rgentinenfum Reipublica Legatus integerrimis Hiltoricis debet accenferi. Tilerzannu in difcurfulehil $p .246$.

Sleidani Compendium de IV. Iummis Imperiis cl ganti, concinno, rotunto Orationis genere friptum, \& quod cx eortm numero ftatuere nos oportet, de quibus nos loëta:

\section{Finturns genium debet babereliber.}

Deg. whear.in Relee. Hiftor part. a.fed. b.

Gobannes Sleidanns vitam in Argentinenfis Rëipublica graviffmis rebus serendis tradixit. Tridentino Concilio interfuit , dignifimépue plures obivit - Legationes, Sed quod ei pretipuam peperit celebritatem:, Hiforia ejus, eft, tam deganter confcripta ut in pluribus Gymnalis, Prxceptoresillamdicipulis'

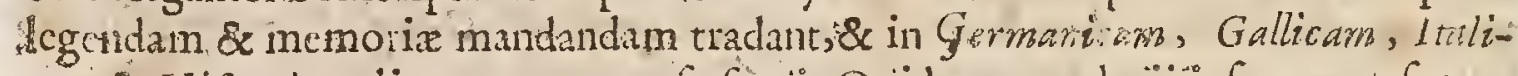
curvi $\&$ ispartcamlinguam converfa fucrit.Quidam nendacii ip lum accularunt Poffevinus Mafcardi \& alii quidam; eateinus ut Bartbolomens Latomus contcnderit evincere quod undecies mille falitatibus opus illud inquinatum fuerit. Verum hüjumodicriminationd iberatus fuit nedum à Domino Thwano, fcd

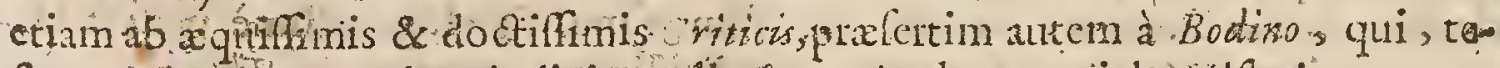
Rante Naudeo, accrimo judieio pollctinter A uthores qui de Hifforicorum merito judicium ferre fibifumplerunt. Anton. Teifler. Elogïs Viror Eruditorum. Gallice.

Sleidnins Hiftoricus elt fupra ornnem laudem pratans, fwe Argumenti five fyli cjus ratio habcarur. Argumentum guod perractat grave atque momeito- 


\section{CELEBRIORUM AUTHORUM.}

Cúm eft. Excutustrotabiles enarrat, Imperatoris illuftis res geftas, Difputationes, Controverfas, Bella qux Religio excitavit, fava qux Germaniam devaftaveruntpralia, Exilia,prócriptionefyue Principum, incredibilem denique cafum \& ftupendarum vicifitudinum multitudinem. Quod ad ejus ftylum attinet is purus. \& planus \&expolitus ct. Eloquentia Latime Patris Characterem feliciter amulatur. Elegantia robori conjundta inco confpicua eft, elegantefque phrafes confociantur jucundx varietati fententiaum \& Axiomatum qux Lectorem \& inftsuunt \& fimul delcetant. Qüod autem in co maximènfigne cernere eft, Verba ejus cum rebus quas feribit proportionem fervant. Hafque coloribus ita vividis depingit ut eyentibus ab illo narratis Lector interedefibi videatus: Ant. Teifler. ibid. Gallwo:

De Sleidano quid multa referam, aqui potiùs ut Lutheri Sectacoribus affen taretur s yuàm veritatis tudio permotus, fcripfife videtur Cland. Verder in Airetors Cenfion:

* Hic Author ince Hercticos prime Claffis rejicitur in Indiee Romass:

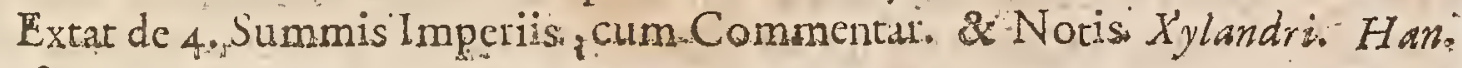
I6os.

Extant Commentarii de faru Religionis \& Reip Carolo V.Cafáce, libris 26. Franc. I610. $8^{\circ}$.

Extant Froifardi \& Pb Cominai Hiftoriz in Epitomen redacta \& illuftratz. Canjellis $1638.8^{\circ}$.

\section{FRANCISCUS RABELASU"S。}

F Allu, Chinonio Turonenfis. Incer D. Francifci cucullatos in PiEtoxibus pri

I mùm educatus elt. Sed impulfu quorundam Procerum qui urbanta cjus diClar: A. D.: $M D X \mathbb{0}$ cacitate plunimum oblcctabantur, monafterii Clauftajuvenis tranfliit, demumque in ridendis hominum actionibus tatus fuit. Cùm enim pro ễ qu $\hat{x}$ polkbat linguarum \& Medichine fichtiâ multa graviter \& erudite poffet fcriberesquod \& Hitpocratis Aphorifiniabillo cattí fide traducti, \& aliquot- Epifote nitido ftylo confcripta fatis indicant: Lucianum tamen amulari maluit, ad cujus exemplum ea

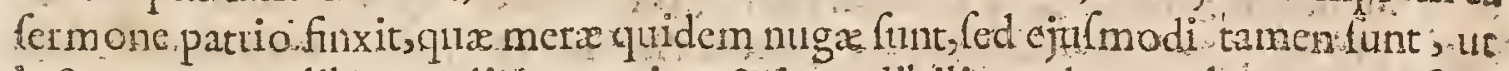
lcetorem quamlibit eruditum capiant \& incredibili quadam voliptate perfun slant. Nequefolim erat uifcribcndo falis \& fucctiarum plenus, ycum \& eandcm jocandi libertatem apud quemlibet, \& in omni Cermone retinebat;adeo ut Rornam cum Ioanre Bellaio Cardinale profectus, \& in Pauli III. confpectum venire ju $[-$ fus, ne ipf quidem Pontifici Maximo pepercerit. Atque hanc intemperantix fix caufam ingeniosè pratexebat, quèd cum fanitati confervandx nihil magis officing quàm morol \&xgrimonia pridentis Medrci partes fint non minus in mentibus hominum exhilarandis, quàm in corporibus curandis laborare. Scavol: $S_{a}$. marthan. in Elog.

Ecancifcus Rabelasus literis Grecis Latinifgue industiflums, \& Medicina. guast 
quam profitébatur, peritifimus , poftemò om ni itudio ferio omifo, Ce totus vita foluta, ac gula mancipavit, \& ridendi artem hominis (ficut ipfe aicbat) propriam amplexus, denocriticá libertate \& fourrili incerelum dicdcitate (criptuin ingeniolifimum fecit; quo vitaregnique cunetos ordiner quafi in feenan fub fictis nominibus produxit, \& populoderidendos propinavit. Thuan.1.6.de vit. fuâ.

Peffínè apud omnes bonos femper audivit Franof cus Rabellefius, Criptor vet. Calwinjudicio plane Atheus. Voctin Biblioth.

Nugdim l'atrom artificemque mirum, Rabeldfum vacat Stephanus Pafchafus. Nonnulli cum inter Atbeifas referume. Koriz:

Sparfit \& hine inde-verfus Gallicos per opera twa Gargantua \& Pantagruele foeta Erunc. Rabelais, fed otiolis tanum ingeniis \& potatoribus legendos. Borrich de Poèt.pitiz.

Rubeiafi Saryta quantumvis argutá , fylo tamen atieo fcurrili conferipta eft feculique nofti decoro tam parum conformi, ut illam hominibus lioneftis miniune dignam exitimem. Rapin. Reflex. in Lectic. parte 2. Reflex. 28. Gall.

Obiit an. Dorn sgraxtatis 70.apud Medonium, vicym agri Parifienfis ad quat-

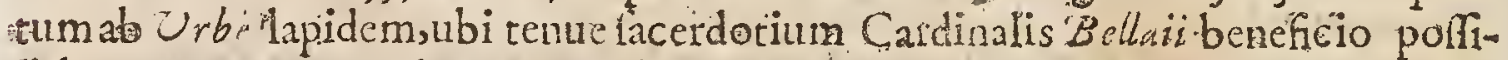
debat. Mortuus eft ridens \& jocatus:cum enim ut in Doraino moreretur adftantes hortarcntur, afferri fbi cuculli, quoddam genus, quea Dorrino xacant, jußte, illoque capiti inducto, in Domino Le obiterum dixit. Hufman.

Fcrunt poftquam Cancellacius da Prat Monpilienfts Facultaris Medicinze Plivilegia Senatufconftrto abroganda curaflet, Rabelxlii dexteritate hoc fuille revocatum, \& hac de caufa cos qui in illa Univerarace Doctoratu infigniuntur Indui folitos Rabelafii Togn, qua, ur viivis notum eft, magnx venerationi habetur-m-.-Ejus Epiltolx Gallicx teftatur eum terum negotiationi idoneum fuife, eumque plurimorum Cardinalium aliorumque i welum amicitiam Rome fibicomparalre. Dominà à Suntâ Martbâ Epilahas ejus commentari non funt dedignati. Carerum verò licet Rabelefins quoad mores admodum malè andiat, propter ejus rerum facrartm \& Monachorum profanas dilutiomes; fatendum tamen eft pratrantem illum fuife virum. Gallichitidioma, iralicum, Hispanicum, Germenicum, Latinum, Grccurn:Bebraicura callebat: Imo Arabicum nonignorafli perhibent, quod Rome à Cor then/s Epilcopo didicerat. Id laltem iple profectur. Eratpiaterca Grarmatious Philoforbus, Medicus, Iurifconfultus \& Afronomu, Calendingium crim extat in antum 1553 . ad Lugdan Latitudinem ab ipfolipptratum, \& in hac ube exculim. Buters eruatifirmus omnium $G$ allis fui temporis alumnorum Cracas o Latinas Epifom

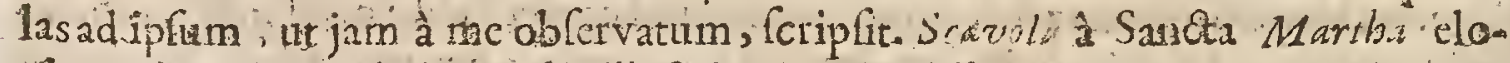
gium ejus adonavir inter alia illufti ium Gatine Virorum. Clemens $M$ arotus, Toarbirius Bellicenfis Antonius Baifenfis, Theotorus Reza, Prefes Thumus, Stcphanus Paquier orancifcus Baco Cancellainus Anglid, Andreas Du Chefniur, Crucaus Coriomanenfis : Antonius Verderins Valliprivasengis. Francifcus 


\section{CELEBRIORUM AUTHORUM.}

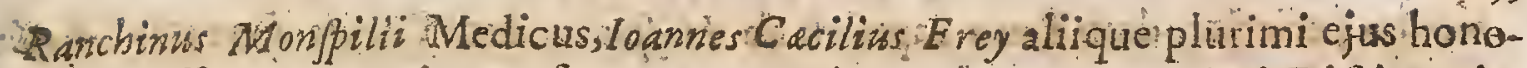
rificentiflmam mentionem fecerunt. Ludovicus Moreri, Majori Dictionario. Gillico.

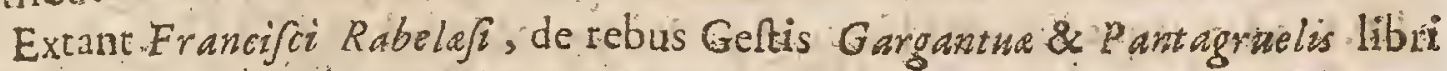
quatuor, Gallicè. Antvverpice anno 157 .

Hoc ejus Epitaphium Francifir Rabelefit Medici: fub Pamphagi Nonainq, anctore foachimo Bellato Andegavensa:

Hoc tumulo tumulus tegitur: miraris? at ipfe

Plus etian andito nomine credzderis.

Pamphägus bic jaceo, vafic crie mole gravatus

Pro tumilo venter fof guipedalis or rit.

Somnus, o ingluvies, Bucculque, Venulque, Joculgtie

Numina, dum vixt, Jola fuere mibi.

Getera gatis nefoit? Fuit ars mibi cura medendi,

$M$ axiria ridendi sed intbi cura fuit.

Tun guogue non lacrymas, fed rifurn bic folve, Viator,

Sigratus nofiris Manibus effe velis.

Pbil. Labbe in Thefaur. Epitaph.

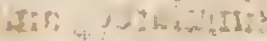

\section{PAULUS JOVIUS}

- Atione Italus, patrià Novocomen/zs:primò Medicinarn fecit, dein Epifcopus Nucerinus à Clemente VII. factuss hujus nihilominus, cùm Comenfém MDXL.

Epifcopatum dinpetrare non polfet, avariciam pafism perftringit. A Francifco I. znntấ penfione honorarus eft, fed polt hujus mortem a Conneftabile Montmorantivillâ privatưs's acriter in hunc invehitur : multum gratix, multum odio dans: Medicee Familize encomiaftes: El ofman.

Paulus Iovius Novocomenfss, vir mulra eloquentix, ingeniique acerrimi, Meticinam primò exercuit non fine felici fucceffu. Scripfirque librum de pif cibus-Romanis. Poftea ad Hittoriam fcribendam animum adplicans, aliquor

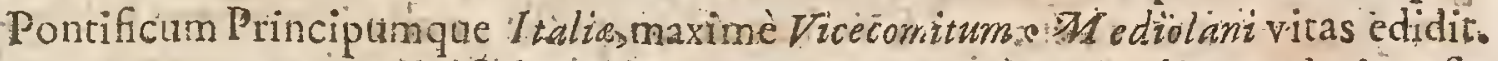
Elogiague, of 1 cones illuftrium Vironum, qui tam armis quàmliteris clarievafetunt, Scriptis fuis adjuixit; querum iple imagines ad vivum expreflas Comi in firo $M$ uf eo fervabat.Scripfit hiftoriam fui temporis, de rebus qua quiliquagintr

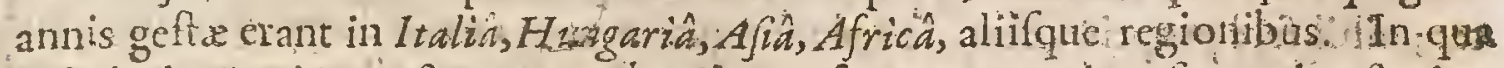
deferiptione mirinm eft quantum laudis, \& fanx promeritus fic apud polterita-

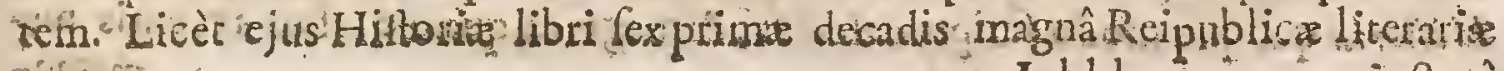
$-6.003$ In111 jactusà. 
- jauturâ perierint, dum Roma capra êt ab Hijpanis, duce Carolo Borbonio. Boifa Sards in Icon.

Paulus Iovius res Turritas accuratè \& onnatè perfequitur ; pracipuè yerò lib.12.ad 17.atque iterum al lib.32.ad 37. Whear.inMeth.Leg. Hif. Civil Artic.12.

Paulus Iovius luculentus Hiftoriarum fcriptar.Homa gratiolus fe paffum obnoxium prodit, eoque nomine ipfi in plerif fue rebus fides derogatur g quod ad gratiam, \&in odium lcripfille, \& yenalem calarrum habuifre ferè omnibus perfuaLum fit Thuañad Ann.is52.

Quô nemo in prophinis rebus plura fcripfrt, aut magis noftram xtatem fcriptis fuis illuftavit, felicifinn i rerum copiâ, ingeniique ubertate, ac ftyli fublimitate omnes profecto fuperaturus, nifi ingenio nimium indulgens, dum fcribendi imporentiavidirate velut rapidifimo xftu effertur, in fcriptis. fuis limandis ac poliendis fupinè negligens interdum fuifet, ut fluere lutulentus alíquando exiftmetur, qua res magnum de illius gloriâ cumulum dejicit. Hubers. Foliet Eloga Bendineli Saulii Card.

Quàm fluxa etiam fide patrum avo fuit Panlws fovins? qucm conftat in Aula Henrici I l. quibuique terre filiis benè de fe merentibus, generis clartatem, ace perpetuum nomen pollicitum: contraque maledice cos traduxiffe qui venali Hi. ftorico morem non gererent. $V_{0} /$.de Art. Hiftor.p.5o.

Imò \& Alciatus, vilanè egregirs, non dubitat affirmare, dict onem ejus ( Taciti) pra illi Pauli Iovii, ele lenriceta, Condonemus tale, Judicium tanto viro, \& cogitemus, ex amore lovï proficifci. VojJ.de.Hift.Lat. 1.1.Ca. Oo,

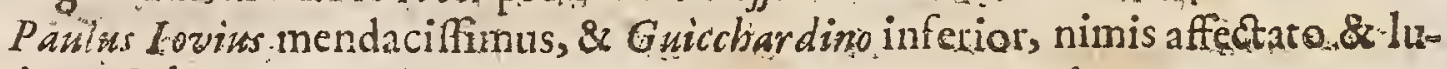
zuriante ftylo, poriùrs quàm caftigaro, utens. Scaligerana prima.2

Cùm antem rogatetur lovizs cur fimidaret falla vera difimularet; amis copuin gatiầ id a fe factum refpondit. Ac tametrifupertites intelligerct fuis friptis fidem derogaturós.; attamen intelligebat infinita pofteritati credibilia fore, qua fibi fui que popularibus laudem elfent allatura, 11 hd certe ad Compiternam memoriam teftatum reliquir Gorrous Pariengs, quiquas finxic Amadifa fabulas, non minus veras ac probabiles, quam lovii fripta tore con fidit. Ferendum quidem eflet, fi pro falute Rejpublic. mentiretur, id quod magifratibus Xenophon \& Plato permilerunt : lèd alfentationis causâ menciri c. om onibus turpe, tum verd Hiforicis tmpiffipum. Bogitio. Method. HiAtor.c.4.

Paulus lovius mihi nequaquam eà exiftimatione, đquam malgò habet, dignus efle videtur: Quantum enim fentio, non bonus eft Hiftorix Scripror, nec Judicio fatis valet: qui f Vernaculè Icripfifet, nullo in numero haberetur. Latinus enin fermo quafi fucus quidam labes illius multas contegit :. qui primâ fpecic elegans videtur, nam bellè fonat, \& quibuldam imponit, mihi nou in em Vix enim Latmus eft, certè minime purus, totufque idiotifmis fcatet; wihil ferè propriè affert, fed plertimque wres $\varphi$ egsixús loquirur, nec penè wlla vox eft fine epitheto. Id verò nominis ex hoc illi conciliatum puto, quòd firistoria quoquo modo fcripta delectat, \& magis ea qua de rebus recentis me menge. 


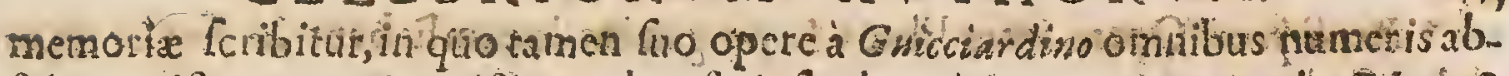

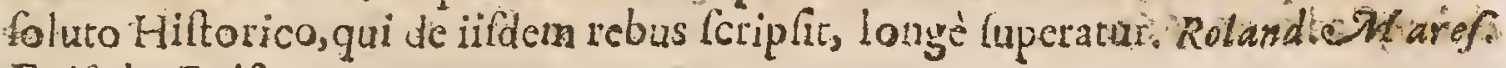
Epift.1.1.Epirt.4.

Paulus forus fernper habiru fuit Scriptor qui afectibus \& commodis fuis unicè obtemperavit.Rapin Reflex. in Hiftor.Gail.

Paulus lovius fe fe jactab, quod binis calamis, altero fcilicet aure $\alpha$, catero chalybco infruats elfet, ad Principes inzqualitce tracandos prout inzqual:ter in fe beneficos lexhibebant. Oforew in fua portugallis Hiltoria oblervat Pailum formm infignem tacuile Victoriam à Portugallis reportatam qui Rex corum annuam L'nifonem cimon concelferat. Anton. Tejjier. Elogiis Viror.Erud. Gall.

Panins fowius, multonm judicia magis acerba, quàm libcra experitur. Acrirer valde in virum cunt. Ego de co fre cenleo; Stylo, bonuri gravemque elfe, \& plane ad Fifroriam: judicio ac Gde, ambigum. Ubi afectus non diftrahun, restum; ulsi illi adfunt, obnoxium. Ad grariam feilicer fe dat \& auram. Laudationum nec caufam fépchabetnec modum, Genti fux. Faftio, Medicais, nimis ex profello addiatus. Oratombus quoqua aut frigidus interdum ant inep- rus. Laudandus anen legendalque ob multiplicem \& variam rerum feriens quas redeg icompofiè \& dilucide in unun Hiltonie corpus. Lipf. in Not.ad r. lib.Polic.

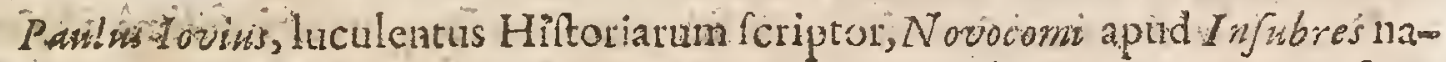
tus, 2 (temente VII. Epifcopus Nucerie Creatus, Conchio Tridentino interfuit, \&anno Ij52. exeunte, III. Idus Decembris, Florentile diem extrenum claulit; cum anno 69: \& menfes feptem vixifer; in Baflica S. Lauremiti ibidern iepultus. Scio equidem no deellè, qui lovï fidem in Hitoriâ vehementer elevent: fed dum rublta nitentin carmine, non egopaucis offendor maculis. Lipjus certè, magnus avi noltri. Criticus, in notis ad lua Politica, faris benignam de co fententiam pronuntiat: Unt firin Virormillufirium Elogits 1 ovius profectò triumphat ac rcgnat. Quod quidem genus feriptionis mult variartim nationum homines poReà xmulati finçin his Ubertus I ulius Folieta, Rofcius, Alfonfus $M$ atamorus Andreas Schottis, Ludovicus 2 Joniws, Scavole Sambarthanut, Simon Starovolfus, Cormetius Curtius, nos \& alii:fed nemo parem, meo quidem judicio, laudem has. etcnus eft adfecutus. Aub. Miraus.

Extant Opera ejus Omnia, 2.Vol.in fol. Bafilea $157 \%$.

\section{"3in: Hoc cjus Epiraphium:}

6.

Pauli Jovii Novocomenfis; Epifoopi Nucerin, Hifloriarwe foriptoris celeberr: mibic depofita funt oflajdonec eximiâ ejus virtute dignum erigatur fepuleruss.e. Vixit an12.69.menf.7.dues 12.06 iit 11.Decemb.1552.

Hic fitus eft Jovius, Romanx gloria lingus.

Par cui won Crifpus, non Patayinus erat. 
* Raulifovii Opera inter libros Expurgandos locum habent in Indice Nas Aritenfis edit. an. 1667 .

\section{ROBERTUS TEPHANUS:}

Cla*, An. D. D Arifienfis, Typograpbus fui feculi celeberrimus, tum impreffis nitidiffines, $4.5 \times 5$. 1 cum editis proprio Mate Jcriptis, de re literariâ preclariflmè meritus: Hebraice, Grace, \& Latinè doctiflimus. Auctar. Thefaurn-Lingtue Latine, Operis excellentis, Grammatica, \& Commentarionum in Evangelia: Novam quoque Bibliorum verfionem adornavit., Ob purioris religronis cultum, in Gallia parum tutus, Genevamfe recepit, ann . 1547, ibique obiit, anno 1559. xtatis 56. Hofmina:

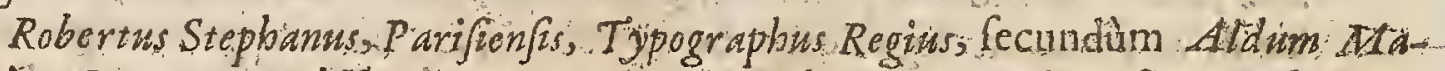

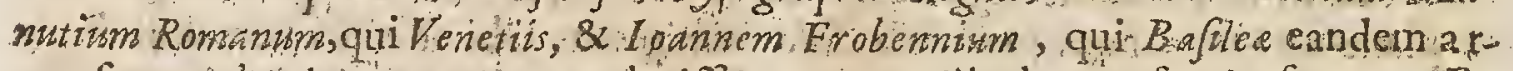
rem fummà laude' exercuerunt, clarifimus: quos ille longa fpario fupergreffus eft, acri judicio, diligentiâ accuratâ, \& artis ipflus elegantła. Cui ab id non foIụm Gallid, fed univerflus: Chuiftianus Orbis plus deber, quam cuiquam fortiffmorum Belli Ducum ob propagaros fines partix unquam debuit, majufquice ex: ejus unius induftrià, quàm ex tor preclarè Bello:\& Pace geftis ad Er ancifgum decus \& nunquam interitura glo ia redendavit. Thuan ond ann.1559.

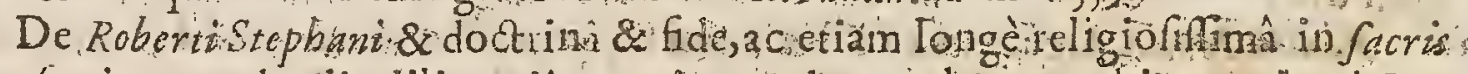
prafertim excudendis diligentiâs neminem phim ambigere atbitror. Theod. Bewza in yerf.2. C.2. Matt.

Vir bonus, honeftuss pilus, literatus, \& irduiftrius vacatur Stephanus a $I$ ăcobon Vierbeider.

Inter eas qui de re literariâ benè meriti funt, Roberti Stepläani Parifenfis Typographi folertifimi Plendidiffimique magna cum primis nec in tura laus fuit,yel ex illoamplifino Latinitatis. The foum, quemomnibus ejus: lingux ftudiofis plurimo lumptu, plurimo fudore, pluximâ diligentrầ deprompfir. Samarth. in Elog.

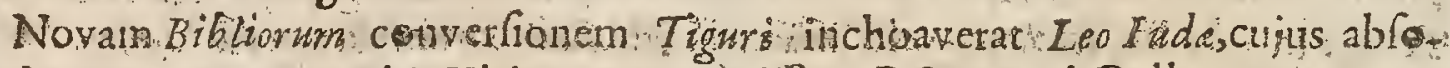
Jutionem quam repentina Viri mors peremiffet affecto operi Collegx, guorum fidei a moriente Lene fucrat religio ècommilfin; ultimam manum impóner-

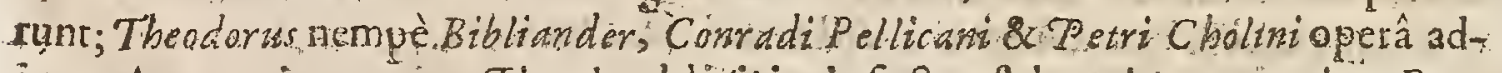
jutus. Anno primum 154. Tiguri publici juris facta eft hxe interpretatio. Eam vero biennio pòft edidit Robertus St ephamas; additis fris; fub Francifci Tatablis nomilre, Annatationtbus, Quanvis autem celato Auctore hanc interpretationem. fparfiffet Robertus item tamen fub odoratiTheologi E axifienfes acriter ip fum exagitare non defierunt, donec perpetua conflictarionis pertafus Genevarn conceffit: Caterum mitiù in interpretationem hane fe gellerunt. Hijpani Theologi, earnque secognitam non femel êdiderunt. Hutet:de Clar.Interpr:

Certum ef Roberbsims Stephanum in pletifque Bibliorum editionibus a fe erulgatis fincerè fatis non egife, eungue hac in parte Parifienfibus Thrologis ingo:- 
imponere voluife, nominatim Editione anni 1545 . Ex oppofito autem iidem Theologi Parifien fes videntur potuille majori cum lenitate \& charitate fe gerere relpectu novarum Bibliorum Tranhationum, quas cum Notis utilifirmis pralo fubmifrt, quamvis harum quædam damnari merercntur. Petrus Caftellanus primarius Erancic Elaemorynarius, qui Sanctioni Regis Confilio litem retulit, qux tune.temporis inter Parifne Eacultatis Theologos \& Robertum Stephanwm agirabatur, ab illorum Theologorum in quibuldam immoderatione culpanda temperare non potuit, quippe qui Hareles ubi nulla erant repererint : hujus autem caufa fuit, ut alleverat idem Caffellanzs., quòd co tempore Linguas Gracam \& Hebraicarm ignorarint: Sed verofimile elt Robertum Stepbonnum Obtrectaroris notâ dignum elle: cum iifdem Doetoribus exprobrat 2.. qùd abluctati fuerint eximix illi Editioni Grace Novi Teftamenti, quam tunctemporis publicam fecit cum Variis Lectionibus quas excerpferat è. Bibliothecx Regix manufcriptis Excmplaribus. Viritll Doefti, ait Robertus. Stephanus, cenfebant varias Lelliones gue funt in margine efje quafdam Annotrtiones prater Trextum additas. Sed hxc eft unanfefta calumnia, quä non pauci Parmina. Facultatis Dootores erant illo tempore, qui Graca Lingux ignaris non erant, imo qui hin ipfa Biblia erudite feripferunt... Robertas Stephanias vo:lait dubio procul odio exponere Parifienfes Theologos, fua cortum Cenfure Refiponfione, ut cum eodem loco refert hrea verba tamquam ab uno eorum-

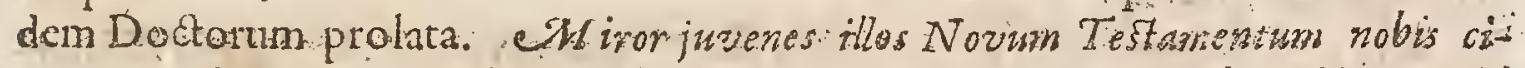
tare. Per. Deum ulira quinguagefirnum anmumb ageban cum nondum foirem quid

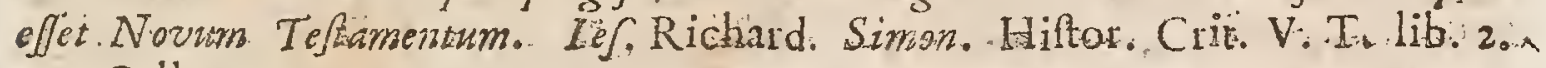
G.2I.Galli...

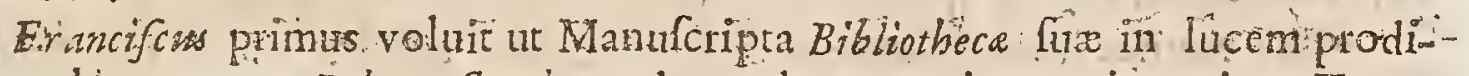
rent, bocmunere Roberta Stepliano demandate., quippe qui omnium Typographorun qui unquam fuerint diligentidinus erat; quique preter characterutn quibus iñ excudendis Libris utebatur elegantiam, conatus omnes adhibuit ut propria induttria \& incredibili labore eos quam maximé optari poutuit mendorum expertes emittcret. Et nifi a tam laudabile cœpto deftitillet Parifiorum Civitatem deferens ut extra Regnum fedes quareret, brevi: rempore Chitittianus Orbis plerifque hirjus Bibliotheca Aathoribus poritus effet iii quo immortalem gloriäm fibi paraffer. DetVerdier Præfatione in Bibliothecamfuam is8s. Gall.

--.-Ejurrodi fand fuit Venetris, patrum memoriâ, diligens fimul \& exaditus ille $\mathcal{A}$ ldus Manutius Romanus, aden quidem ur lummum in liac Arte [Typographici] gradum alficutus videretur. Ejus veltigịa Bafflea prefertim \& foannes Frobenzus \& alii aliquot fequuti funt, quibus res literaria plarimum debet. Sed quanto:illi ceteros antecelluerune, tanto majorem tibi; Röberte. Stephane, fuperiores omnes longè latéque fupergrelfo gloriam tribuendarn effe vel ipfa fremens invidia conficetur. Nam ut alii tecum nonnulli dè libtorum quorundam excufor um elegantiấ \& venuftate certent, nemo tamen vel in operofurfmis libris tecum in emendationis fide ac diligentià fuerit comparandus. Lill Tibi 
Tibi Linguam Hebradm magnopere illuftratam : tibi Gracortm Characterum fummam elegantiam : tibi partim in lucem revocatos, partim felicilinè refticutos, tum Grecos tum Látiros (criptores plurimos: tibi denique infinitâ quadam induftria \& inexhauftis laboribus ex omnium clafficorum autoium penu dèpromptum Latine Ling 1 he faurum debemus. Sed hæc tua precipua laus eft, quòd non inanis glorix, non lucri cupidus, offcinam tuam facris prafentim excudendis Biblirs conlecralti: quo in opere totie recudendo, emendando, modif que omnibus illuftando, teiplum quoque fuperalti. Bezä in Elog.

- Inter catcra tanti viri, Lingue Latina Thefaurum amplifimum habemus, à multis pridem taudatum, \& in xernum laudandum Coiomef. Gall. Oriental.

Tanta fuit in Opere illo [ Thefarro'] conftruendo diligentia, ut rem non folùm domefticam, fed \&curam corporis in totum fermè neglexilfe de le pradicet. Quid mirum, nec aliter fieri potuir; nam ảnobus annis fe Opus.illud ad Umbilicum produxiffe iple auctor ctt, de quo fxpiffmè egit cum viiis doctiflinis \& clarilimis quibufcum fuos laborcs communicavit, ut eo elegantius correctiufo que in lucem prodiret, quorum adhortationibus tanta ftudia, tantam diligentiam adhibuit, tot noctes diefque ei operi infudavitut nifi Ope Divinâ fuillet fultentatus, aut occumbendum ci aut fuccumbendum fuiltet Theod Ianffon. de Vitis Stephanor p. $43 \cdot 4 \cdot 4$.

Robertus Stephanus in Eluidarium fum Poeticumex Antbropologiâ Volaterrani pleraque virorum $2 \mathrm{c}$ mulierum nomina fic defribit, ut alieubi etiam cro. res ejus faciat luos, alibi novos à fe addat. Ignofcerem, fi lestorem fium appellans, Folaterrani fecilfet apertam mentionem. Tboraf. de Plag.num. 549. iño.

* Hic Author inter Hafcticos primx Clafls rejicitur in Indice Triden-

Extat Lingue LatineThefaurus,3.Vol.P arif.1543.

\section{POLYDDRUS VIRGILIUS, SEU Y.ERGILIUS}

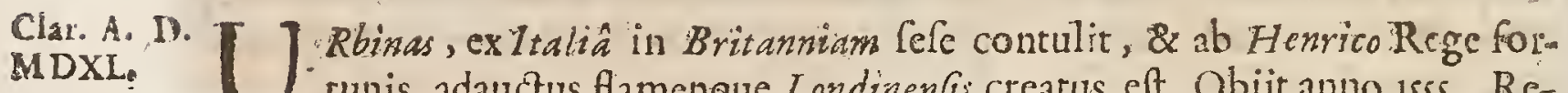
tunis adauctus flamenque Londinenfis creatus eft. Obiit anno 1555. Re= liquit Proberbia : Libellum de Prodigiis : Octo libros de Rerum inventoribus: Hittoria'n e 2 nglicanar, \&c. In Hitoriâ parum fidei ipli nonnulli tribuerunt. Notum illud Oveni.

Virgilii dwo Junt, alter Maro. Tu Polydore Alter. Tu mendas, ille Poëtr fuit.

Konig in Bibliort. 


\section{CELEBRIORVM AVTHORVM}

Poiydorus Vergitus, Urbini in Italiânatus, Romani Pontificis Qualtor, pro: colligendis D.Petri denariis ( nam fum quifque perfolvebat nummum, ad ficram Syoaxin admitlus) in Angliam primùm advenit. Ob infignem in omni bonarum literarum genecc.crudicionem, Wellengis Ecclefix Archidiaconus poftmodum factus, priori Officio Rontifici refignato, cenftituit Rornarn non repererc, fed deinceps in noftrâ permanere Inful.. Er licet in plerifque fcriptis luis veræ Religioni luperftitionem pratulerit, piè nihilominus Chrittianorum Miniftorum conjugia defendebat, pieque ftatuarum cultum damuabat, crim quibufdam aliis Romanenfurn Rabbinorumimpolturis. Quòd anticuitati Britannica in Anglorum Hittorià, quàm par eft, iniquior fit, ex veterum illius Gentis Chronicorum \& Historiarm ignotarione provenit. Quod pretered Reges aliquot ab impietate pios, \& alios è diverfo ab ipsâ xquitate iniquos etiam promulgaverit, communi ante agnitam veritatem per verbun, errori ac cacitati imputandum elfe judico. Galfridum Stonemuthenfers, wirm certe pro fuo fecula infigniter enditum, inconditè tam acriter morder; Novobuxgenfem $M O$.

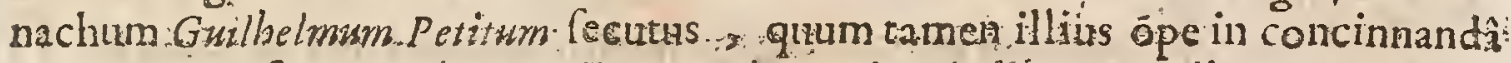
Hiftoria tam frequens utatur. Erat certè Poljidorus ob endita illa de Rerm In ventoribus, Sacrorm Ritibus \& Prodizizis Opulcula ab ipfis criam piis fulpiciendus. Föan. Baleus de Script.Britan. Cent.Xris-

Palydorus, ut homo Italus, \& in rebus noftris Hofpes; $\&$ ( quod captit eft) ne que in Republicâ verfatus; necmagnial aqui, vol judicit, vel ingehii ; pauca ex mulris delibata, \& falfa plenumque proverisample us, Hiftoriam uobis reliquit; cum catera mendofm, tum exiliter lanè, \& jejune confriptam. Hen. Samvii.Præfat.ad RenAngl.Scriptor:

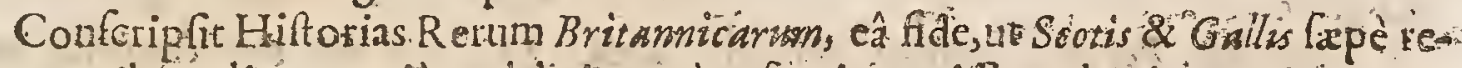
clamantibus, alieno potüs arbitrioj quàm fuo intexuife multa in gratian Gent tis exiftimetrr: quòdque in recenlendis minorum Durum nominibus tanquan gloria avidis plurimùm indulferit:Paul:for:ju Elogix.

Maximè erravit Polydorus.in defcribendis tempovibus Elentici VIII. num prętel quod lingux notratis prorfus ignarus, plurima conm tempouta nefcive habait necelfe:plurima etian, ut Marie Regina gratiam promptrus demereri pof

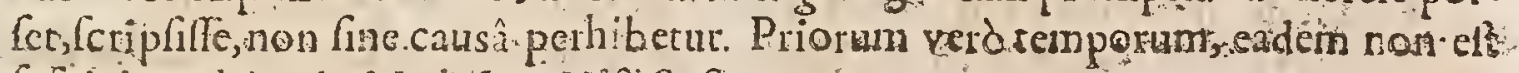
fufpicio. Whear de Meth.Leg.Hift.Sect. 30 :

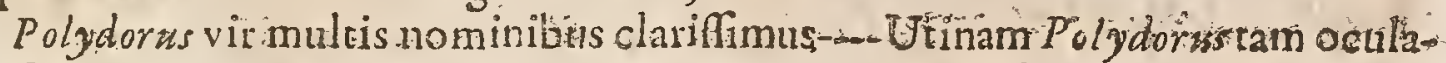
tus fuifiet reftis in rebus Britannicis, quàm interim eft terlus, nitidus, cl egans. Na

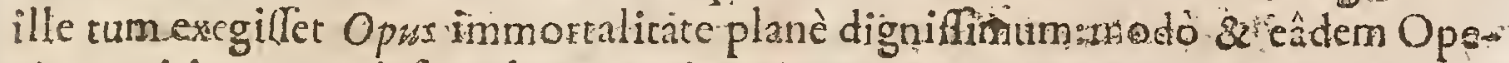
râ. $\operatorname{lognitionem~utriufque~lingux,~viz.~Britannice,~\& ~Saxonicatanquam~ád~coro-~}$ nidtem adjecifet. Lelaind.Comment.in Cygn. Cant.

Ad Artbirum remigro: cujus authoritarem fi quis elevare ftudeit, qut d Poly dorus Angl.Hift.l.3. vana elfe qua de Artburo fcribuntur aftrua, is non videtue mihi vetuntatis monumenta diligenter evolvilfe, fed de rebus ejus plané formnialle, cum de geftis A ritburi, de regno; decaftris, de regiis ; de conviviis; de legibus, de academiis, de virâ, de morte, de fepulturâ plena func omnia: adè̀ 
ut hic 70. Lelando de affertionc Arthuri magis accederem, fi nullum mihi devétuftate judicium effet, quàm Polydoro, qui ut in aliis, ira \& hîc licenter errat,ut pace ejus dixerim, etfi in aliis benè geftis commendarem. Quem, ne aliquando intelligerentur errores, fama percrebruit, atque etiam cognitum \& compertum certò eft, tot hiftorias noftras vetuftas \& Manufcripras immani feelere igni conmeridalfe, quot he plauftum quidem pollet capere atque fuftinere arbirratus, ut credo, fe ejus generis omnes folum habuife : aut veritus fibi vitio dan, quod fecutus legen jampridem librorum veterum caftigatoribus datan (ut iple de feait in prefatione in Guldam ) nonnulla refecuerit, qux Scriptores prodiderunt. Superfunt tamen Dco volente quampluximi omnis generis, \& illis Polydori multo pleniores \& perfectiores. Ioan Cains de Antiguit. Cantab. 1.r.p.5:-

Nominis Britannicigloniam non folum obfufcare; fed etiam Britannosip os mendicifimi, luis calumnits infamare, totis viribus conatur. Humfred.Lbayd. in defeript.Angl:

Polydorus Virgilius noin contcmendi literatur homo, fed in libro De Inventoribus Rerum fxpè futilis, \& mendax eft. Io.Card. Bona.

Hoc anno ijjo. Polydoriks Virgtizu, poltquan ad quadragefinum fere atat s annum in Anglia vitam perduxifer, veniam petît ad folem accedendi. Eam poftridie Kalendas Junii adcptus eft: Et quia de Republica bene meritus cenfebatur, quòd Genti noftrx utilem \& gloriofam hïftorian contexuiffer, ei conceffum eft Archidiaconatum fumm Wallie, \& Prebendam fun Nontingtonia retinete, hor obftante çus abfentia à Regne. Burnen Hilt.Reform. Vol.2.pag.154. Anglicè.

Plurimos Polydori entores detegit foam. Lelandus in declaratione antiquarum dictionum, qux occuterent in genethlize illutrifhi principis

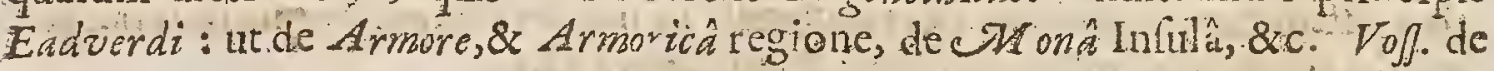
Script. Lat.

* Polydori Virgiliz de Inventoribus Rerum liber expurgatus, \& exculas Rome juff Gregorii XIII. is76 petmittiturin Indice Tridentizo.

Extane de Inventoribus Renm Libri $8^{-}$Argentorati in $4^{\circ}$. an. 1509 .

Extant Hiterix Angliz lib.26.editore Antonio. Thy lo. Lugd. Batavorim fumpribus fo.culaire ann. $16 \mathrm{~s}: .8^{\circ}$ : In Pyderum hxe Carmina compolut Sirnon Grynazs, libris de

Quimore of ritu argute apis

Campos Thefpiadim pervolat,

Anicis pajirn floribus

Carue os impreffus, infidet,

Succos miros, miras opes.

Genere 


\section{CELEBRIORUM AQTORUM.}

Genere omni anctorum convebit.

Divite mox alveario

Favos mella dulcia

Subinde prebet ornibus

Polydori non intellige

crito qui non Jummo $\sqrt{6} \mathrm{~b} i$

Noxnen venerandum vendicet.

\section{HIERONYMUS CARDANUS}

1

Talus, cur ediolani natus eft Anno 1501 , die 24.Septembris.

Soripgt varia, quorum Catalogum ip e contexil t.

Clar.A.D.

$M D \times L I r$

Non fure laude nominandus eft Hieronymus Cardanus- - Qui in Nature 'Scientià, ac Medicinâ, anififue' tot nova adfert, tut fummus vir Andreas Alciaatus eum vocare foleat Virum Inventionum. Quiin ingeninum profundiflinum, feliciffimum, \& incomparabile, ei tribüit, Cefar Scaliger:qux magna ct laus ab Adverfanoo tam gravi, \& acerbo.Voff.de Marhemat.p.4l.

Orban eft Refpublica Li craria yiro maxino, atque incomparabilli:eamque jacturam fecii, quam fortafe nullis pofthacfeculis reparare pollit---Cum in homine docto tres partes omninu excellere debeant, monum integritas atque civilitas, eruditio varia \& multa, ingenium fummum cum acerrimo judicio conjunctum, rria hac ille puncta adeo planè tulerat, ut ad unum modò tocus proffe, fo-

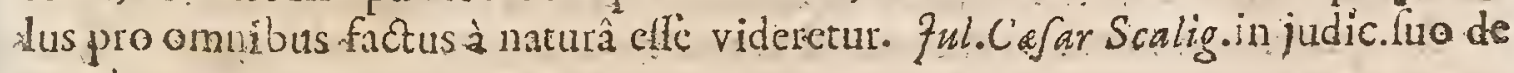
Cardano.

Quem [ Hieronymun $C$ ardanum ] cụm finguli, fuà quique in arte propriâ, preftantifimum fuifte non dubicent, ego certè primum eum \& unicum fuilfe exiftimo, qui fumlin omibus tam egregiè verfatus fit, ut videatur exemplun in co oftendere voluife, majoris amplitudinis \& immenfitatis doctrinx quam homini huc ufque concedere potuetit. Nam fi in religuorum ommiun dotes inquiramus, videbinus, multos humanioribus ftudis Theologica tantum fuperinduxilfe, nonnultos Mathematica etiam; quoldam Cll edicina \& Pbiloophie cognitionem; alios: Linguarum Orientalium, vel Juris utriufque notitiam; \& rurlum aliquos, paucis paginis, ut $P_{\text {icurn }}$ \& Fracaftorium, mirabilem ingenii fui preftantiam explicaffe: Sed qui plures fcientias in sumerato tabueric, qui altius in illas defcenderir, qui Commentarizs amplioribus illuttrarit-, alium profecto ab Hieronymo Cardaro inyeniemus neminem. Ut miraculo proxi-mum fit, hominem hunc, plus fermè in omnibus Scientils vidiffe, quàm fingthdi in propriâfuà requirerent,ant inveniri polfe fperarent. Gabr. Naud. in Hier. Cardan.vit.

Hieronymus Cardanus, magni nominis Give Mathematicus, five Medicus. Rome eum diverfo. ab aliis cultu incedentem paucis ante obitum annis confpicati \& adlocuti, ac fxpiù admixati Sumus; cum ecteberrimi tot \$criptis hominis recor$M \min$ an datio 
datio fubiret, neque tamen quidquam in eo, quod tantæ famx refponder ex; a mi madverteremus: cóque magis I ulii Ca faris Scaligeri accrinum judicium fufpeximus, qui divinum ingenium fuum in Opere de Subtilitate exagitandó præcipuè exercuit, inæqualirare illiłs ubique dligenter notatâ, qui in quiburdam inrerdum plus homine fapere, in pluribus minus pueris intelligere videarur. In Aribmeticis multaconatus eft, \& invenit: Iudiciaria, quam vocant, fidemapud multus adtitruxit, dum certiora per cam, quàn ex arte pofint, plerumque promeret. Verùm extremx amentix fuit, imò impizaudacix a Afrorum commentitiis lcuburs verum Aftrorum Dominum velle fubjicere. Quod ille tamen exaratầ Servatoris nofti geniturâ fccit. Tandem cum tribtrs diebus minus fepruagefmum quintum annum implevilfet, eodem, quo predixcrat anno

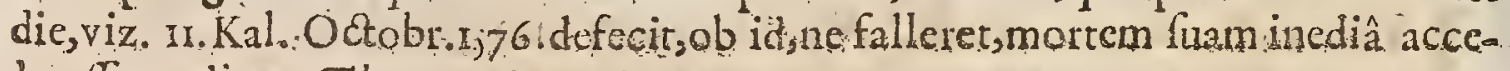
leralfe creditus. Thwan.

Hoc contradictionis ftudum, quod Scaliger ubique in Exercitationibus fuis ad Cardanism prodit Sophifta dignius eft quàm Philólopho, Majorem etiam modeftiam, dun falsè adco tractat Cardanum meritò pafim requiras : prafertin $E_{B}$ cogites, fribere adverfus. viium fummum, fudiis quidem bumanitatis, \& Metaphyfices, non paulo inferiorem: at non fcientia natura, Matbefeos autem omnibus difciplinis, in quibus parum omninò Sraligen videbat-, albis quod dicitur equis pravertentem. Quz à nè minimè dicerentur, nifi fecto loc viderem quoflam ion tam, yirtites ejus viri imitar guam unum alterthque [ homo enim erat] vitium morale; quonon mediocriter admitandas, planeque heroicas, ingenii doctrinaque dotes depreciavie:Voff: l.3. de Idolol.c.80\%

Et quidein eopredirns erar, animi acunine, ut magnus Philofophus fuifet, $f$ Peripateticus non effe aufus fuiffet-- tam vana-ubigue, cum in. Astrologia fuà,tum. in carer is fuis inanibus difciplinis; de Deo Divina gue providentia, commentatus:

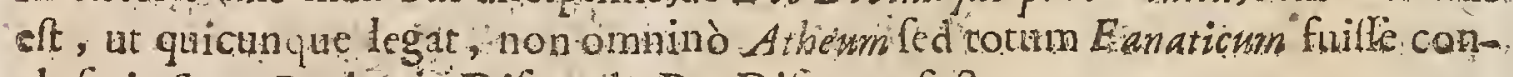
cluferit:Sam. Parker in Difput.de Deo Difput.1. fect.25.

Quod ad Cardanum artinet, Charaeter ejus vaftus \& inordinatus eft; in omnia rine delectu evagans, nec lllibi pedem figcns. Rapin: in philofoph. Reflex: 17. Gall.

Cardanus Vir eruditus erat; ex uft politiorum hominum vitam agere norat. De:maltifaria ejus experientia nullus dubito. Sed homo erat ventoli ingenii, opinionibus propris ultra moduin addietus, nec minus popularis aura cupidus : Nemo unquam veracius eft locutus quam ille qui puinus eum hac cenfura notarit; quilibet vel mediocri judicio pollens idem ex chus fcriptis atatim animadvertet. Homo denique fuit qui res infolitas enarrare affectabat;qua fcilicet admirationem parerent ut ipfe admirationi eflet, ias qui fidem ei adhiberent. Et fanè plura mirabilia refert de fe \& de Patre fuo., \& de quibuldam aliis cognatis fuis, quam quis ufquam alibi legere poftit." Verum non modò ventoLus erat, cujus nomine cenfuram aliorum incurrit, fed etiam mendacifimus, infignis mendax, quod \& agnof cit \& evincit amicus ejus conjundiflimus Nandens; ino ex ipfiufinct confeffo juxta ejus Horofcopium, $N$ uax, Religionis centemptors. 


\section{CELEBRIORUM AUTHORUM.}

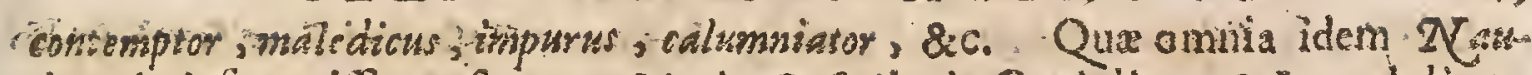
dans de ipfo veriffima facetur. Meric. Cafatib. de Credulitate \& Incredulicate 4p.s60. Here refert Author Anglicus innominatus, Anglicè.

* Cardani opera de Sapientiâ, de Varietate, de Subtilitate, de Confolatiene, Commentaria in Quadripartitum Ptolomai de Gchituris; \& reliqua omnia, qux de Medicinâ non tractant,prehibentur nifi corrigantur.

Extant Opera ejus omnia, Geneve: I624: in fol.in 10. Tomos digefta, per Care-n Itum Sponiamo

Hoc ejus Epitaphinm, quod fibi viveas feripfit:

Non me terra tegot, calo fed raptus in alto.

Illufiris vivam docta per or a virinm.

puicquid wenturis pertabit libabus in annis.

Cardanos nofcet, nomen to ufque meum.

\section{JOANNES DE CASA}

F. Lorenizms, patritio genete ortus, Archiępifcopus Beneventanus. Obiit deciI noo quarto Novembris is56.

Scripfit-cakalogum Hareticontum, cui refpondit Vergerius---Vitas Petri Bems-

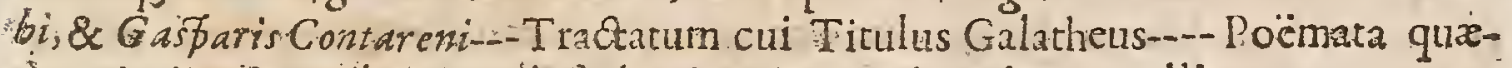
dam Italicas, in quibtis [proh feelus] Sodorniam lavidibus extollit.

Ioaines Cafa patritio apid Florentinos: genere ortins, eminet politions literatura faltigio, clapfi, ac prafenris propè faculi hominibus inaccelfojpraterquam guòdenim patrio, Latinoque carmine fuavifimè concinit, lolutâ utriufque irdiomatis oratione fic excellit, ac potifimum Itali, ut fincerx purxque Scriptionis excmplar ex ejus affatim optenlis defumatur. Ac profecto fi cejus tacteo cloquentix fonte, rivuli ad pofteritatis fructum manaltent uberiotes, nihil dubium, quin noltratioun angenia frequentifnuo haufu, itLos æquè ac nectarea Petrarcbe, ac Bocaccii \& aliorum hưu cenlus pocula - deguftaftent. At fato nelcio quo cecidir periniquo, ut longè pauciores exiAtant, quâm literatorum cœetus' exoptet. Yerè Libellus, in quo Gataibei nomine luculentam morum edocet rationem, fuperque teftetur unuึs perraram incomparabil is calami felicitatem, qıando 'brevitati candorem, etuditionem, fuadam, perfpicuitatemque ita connectit, tie inextinguibilis quidam ejus etiam, atque etiain legendi ardor cunctos abiipiat. Hunc proptereà Thuarus Gallicus anctor, veternm longè praftantiflmis requandum exiftimat. Hoc etiam intuitu vivens à Summis Pontificibus. Panlo III. MT arcello II. egregia munificentix retulic ornamenta, collato fibi nimirum Archiepifcopatu Beneventano, indeque gravifinarum Legationum munere aे P'aulo IV.pluries injuncto. Ioan. Inperial.ith MuliHift: 
De Clandio Ejpercao Parifienfi Theologo \& Foanne Cafa, qui Pontificiab Epiftolis crat, in Cardinalitum Collegium cooptandis tunc actum. Utrumque commendabat generis nobilitas \& doctrina, quamvis diverfa. Nam alter Theologicis fuidiis innutritus, in profeffione fuâ confenuerat ; alter eloquentiâ atque el ganter. Etrufcè ac Latinè fcribendi peritiâ vel cưm Antiquis comparandus, magna negotia fub Pontificibus fummâ folertià gellerat.' 'Sed longè dilpares utriufque motes erant, cùm ille fanctitate vitx ac morum caftitate praftaret; hic feculi licentiâ ac loci, in quo degebat, libertate ulus folutè ferè vitam egiffet. Itaque ab, amulis uterque apud Pontificem delatus; Espencaus quidem; quòd quxdam perperam inter concionandum de aire $\hat{a}$, quam vulgè appellant, legendâ locutus, cim ferrearm potiùs vocandam elfe contenderet polteà publicè recantare coactus fuilfet, quod \& à Ioanne Sleidano memaira proditum cf: alter's quòd etiam carmine rem nefandam in juventute laudâffe diceretur: ficque ob diverfas longè caufas uterqüe ab eadem dignitate fummotus eft. Thuan.. Thom.1.1.16.

Ioannes Cafus Elorentinus, Archiepifcopus Benerentanus, A poltolica Camerx Decanus, Sodomia laudes I talico carmine celebrayit :-in quo nefarius Cinœdus illud flagitorum poftremum \& Ipurcifumum aufis eft appellare divinum opus; teftatus prætereà, illo fe maximè oblectari, nec aliam venerem novilfe. Liber, qui unà cum Awhore Aammis debu flet aboleri. Herman Conring.

Quis ferat quod fuperioribus annis acc:dit, Eafalem quendam, fummum prospè dignitatis in Hiexarchî gradum obt inentem, carminibus turpiffimis infarda flagitia fua publicè predicare? En egreg um familix divina columen; cui turpirtudo latis per fe magna non c'ucitur, nifi ad eam impudentifima accedat glom riatio Gul.Carter. Prafat.in Propert.

fanus Rutgarfus, feuporius Io ephus Scaliger contendie quà Cafacarmine Italico minus felix fuerit, quòdẹte culpatus quòd Poëma ųuoddam idiomate vernaculo, contexuịtet, culpam amovere conatus fuerit; Tcuramen illud fecit Latinis fambis frigidiufeulis \&parum jucundis. Venum Dominus $B$ alzacius cenfet cosadhuc preftantiotes elfe omnibus Verfibus amborum Scaligerorum fi: mul fumptorum. Eruditor, de Poètis Judicium Parif.1686.per Bazllet. Gall.

Hic liber primum [ Galaté feu Ars placendi in civili convenfatione] parwi momenti ele primo intuitu videtur, quia $C$ ivilis Vitc prima tantum elemena fubminiftrat; fed omnia tam folido judicio ibi perractantur, tamque eleganter fcribuntur, ut excellentifimis Opexibus annumerari debeat. Unde etiam. propter illud fama Domini a Cafaejudem Authoris "quique inter cultifima Italic totius ingenia exittimatus eft, integra \& illibata etiamum perdurat. Erum ruditorum Ephemerid. Gall.diei Luna 3I. Janv.1667\%

Quodad Latinitatem Domini della Cafa tibi prorfus affentior. Cardinalis Bembi vita Scriptum elt terfffimum, in quo \& acerrimum judicium, eximiamq; Latinatatem obrervare eft. Vita Cardinalis Contareni prolix oceft, fed omnibus fuis numeris non fic abfoluta , imo ex ipfus Victorii confelfo, fecundis curis indigebat 


\section{CEIEBRIORVM AVTHORVM.}

indigebar ut ad perfectionis culmen proveheretur. Balżacius. Epift. 32.2d Dom. Ghapelain lib.18.Gall.

Prodierunt Latina Monumenta ejus Florent.1564: $4^{\circ}$.

Prodiit Galateus,feu.de.Morum elegantiâ, cum Notis Nath. Chytrai. Han. $1603.8^{\circ}$.

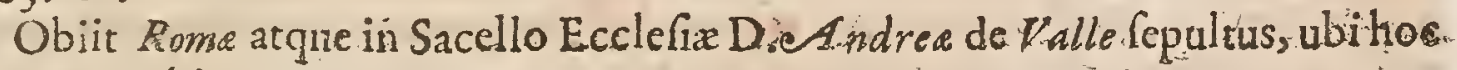
ejus Epitaphium.

\section{O M M}

Io difciplinarum genere excellentiam. Immortalibus illnftrem monumentis eAmula nequicquem pofteritas admiratur. Horarius Oricellarius avinculo optine merito . . . $^{2}$.

\section{IAULUS EAA.G.IUS}

T Abernis Rhenanis natus in Palatinatw anno 1504: Prima ftudiorum fündameinta. Heidelberga pofuit, deindé cum Sanctx lingux ftudio àrdetet incredibili, fub Eapnigne Doctore[ cui portea fucceffit]. Argentine ad miraculäm ufquie peritiffimus ejus evafit, ipfis. Indeis teftibus. Ifnx primùm Modelator Scholx, deinde Palton factas eft Ecclefix. Ufus autem Patronto incomparabili Petro Binflero ejus urbis primario Senatoren in Sanctâ Linguâ exornandì, uná cum Elia Levita Iridao Vene to doctiffmo, A A gentisam demùn vo catur : prius tamen urbe Conftantiä per biennitum reformatâ 2 Argentina demun munus Piftoris fimul \& Doctorís egregiè fuiftinuit anno IF- 4. Tandem periculofifrma Germanic tempentate, Cafare viclore, in Angliamabreptus cum Bucero Collcyân \& Synafpidé, Cantabrigiầvix falutatâ (heu) mortuns eft anno

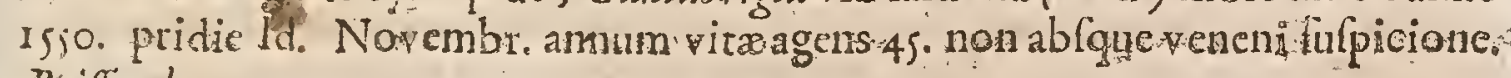
Bioifard.

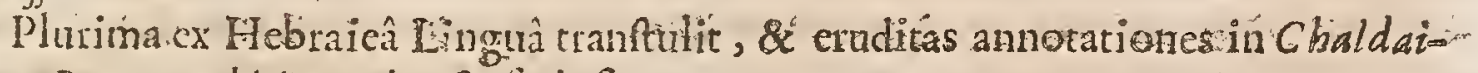
carn Pentateucbi "arapbraf fin feripfit:

Quô ion folùmfupèio i fectulo, fed \& multis retrò annis, nemo vixit no ftratium, Inguarum peritior: id quod \& in Colloquiis familiaribus, \& in difpuz rationibus crm Indasts, \& in explicatione Targuma", fêu Paraphrafeos librorum: Mofis Chaldaice liquidò demonltravit. Melch. Adarm in vit.Draconita.

Quâ in Lingû́ ( Hebraicâfc licete) tantùm profecerat, ut feculis abhinc ali-: quor doctio em $F$ agio creditum fit fuiffe nemirem. Facob.Verbeid.

Vir inter Chriftianos Hebraice doetiffmus. Fof.Scaliger. Elench. Trihiref.Sesar.c.r4:

Fagius in Genefin optimus: Scaligerana 2.

Paulius Fagius Germanus, vir de literis Hebraicis optimè meritus. Gefn. in B $\mathrm{bl}_{0}$ 
Homo facundus atque doctus vocatur Sleidano in Commentarionum l.18.

I udaos quod attinet, appello viros fide digniflimos \& in corum Scriptis verfatillimos, Paulurn filicer F agium \& Io. Merc. Io. Arrovysm. Tactic.Sac. 2.20.

Quemadmodum apud Indeos vulgè dicitur de R. Mofe. Mairsonide. $A$ UH. fe uggue ad Mofen non furrexit focut Mofes, viz. CHi aimonides: foc apud Germanos. meitito dici poteft de $P$ aulo $F$ agio, $A$ Paulo ad $P$ aulum non furrexit ficut $P$ aulus, viz.Fagius. Edvv. Leigh.dc vir.doctr. illut.

Paulus Fagius qui inter Cricicas illos fecundum locum occupat, in tora Biblia quemadmodum Munferus Notas non elucubravit, fed tantum in quinque Libros Molis; quinimo ejusmodi Notz fun in Onkelofs Paraphearn Chaldaicam, quam in Latinum tranfulit, non autem in Hebraicum Textum. Interca tamen non minus quäm ip a Paraphrafis Textum dilucicant. Methodus ejus eft juxt Critica regulas, quia totus fere tairim eft in tradenda fignificatione pio-

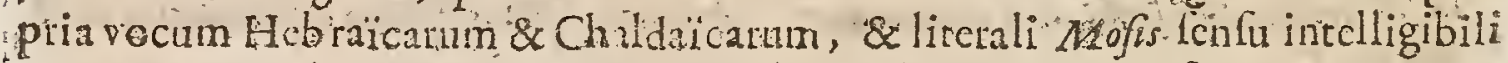
reddendo. In luis Notis Munfero pantò prolixior eft, preferrim in quatuor priora Genefeos capita; quxe feorfin \& admodum diffusè explanavit. Authore

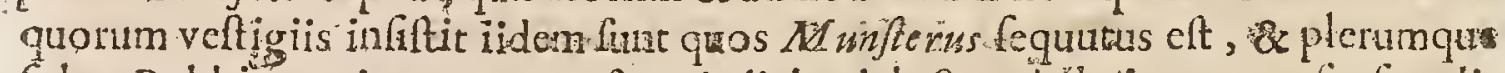
folos Rabbinos cinat, grorum fano judicio delectum habuit, ar qux fenfum lireralem fpectart tantummodo explicet. Pluribus locis Munfero felic or fuit feque Hebraicesingue eo peritiorem ibidem exhibuit. Jifden tamen defectibus labọnta duo illi Critici, quia Methodum eandem obfervarme; \& quia Rabbinorum Commentarits prorlus adhatene is Ex quibus, fateor, utilia quxdam quoad Scripture fenimin Literalem excerplerunt; fed etymologias fatis ridiculas penes corundem Rabbino:um fidem quandoque referunt, cum tamen ervori fun Qbnoxii.Ief.Rich.Sirkaz.Hith.Critic.V.T.L.3.c.15.Gall.

Complures I Ld doorwm Mngiftos Latinè loquentes exhibuit Parius Fagius, diligens Interpres, elegantiarim, pre veritatis fudio, negligens, \&., quantum fort Ebraicrelingux frcitas, fatis parcus. Huet de Clar. Intepr.

Cùm $P$ aulus Fagins, tum Bucertus Germanis folum verterc coacti, ob luterim negotium, Cranmero in Anglian trasfetare invicatisunt, \& Camobrigiam ablegati,ut Petrum Martyrem Oxonium prius miferat. Sed Fagio Calntare non fuit colum illud, unde brevi polt diem obiit, quii vir fuerat:Orientatium. Linguarum callentifimus, bonufque Scripturarum Explanator. Burnetti.Hilt.Refor.part.2. p.88. Fol. Angl.

Extant Capitula feu Apopbihegmata Patrum, Heb. Lat. cum Scholiis, If If.4I.

Extat Verfio ad Targum Orikelos, \& Notz in Pentateuchum. Arg. 54 G.fol.

\section{JOANES CAIVINUS}

Char.A.D. D vigermo feptimo Maii, Anno Dom.1564. Ecclefra Genevenf multis annis Soxb\%. prefuit. 


\section{CELEBRIORUM. AUTHORUM.}

Panè rii uniryerfam S.Scripturam Doctos Commentarios confecit. Opera ejus 8:Volumin:bus continentur, Genersa An11.1592.fol.edita.

Fuit ei ingenium vivaciffrmum, judicium fubactiflmum, memoria, tenaciff. ma, eloquetria doeta, rerumque \& lententiarum pondere conans. Unde MelanWho n de co:Nullius boc tempore oratio in difputando vel nervofor furt, vel plendi-

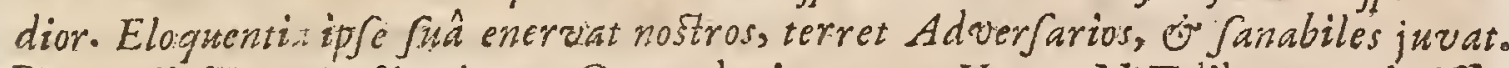
Pratct divinum lafitutionum Opus plurimos tum V.tum N.T.libros eruditifimis Commentari:s explicuit, aliaque ingenii fai monumenta edidit, è quibus $\mathrm{f}_{2}$ cilè pater, quicquid in ejus cincres convitionm congeritur, ail nifi prava loliginis nigum fuccum elfe. Hofman in Lexic.

In oratione gravitas \& majeftas fingularis eft: concinina, netvola prorsits, $\&$ wirilis compolitio, qux pondere fio penetret, moveatque maximè cum judicio legentium animos; quâi fribendi ratione vix ullum fibi habuit parem. Iacob. Verbeid..

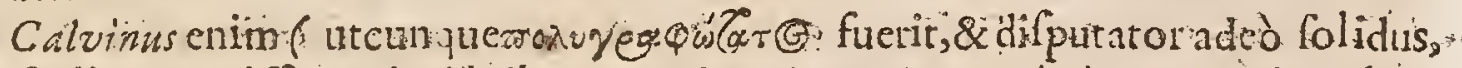
wh, filli, meritifimo ei adicribas, quodacrissceti. tupas baburit, quique bins omi jutce

\section{- toits dottror Orbis.}

Submiffess defert fascibus imperivion.

nunquam tamentherecicos, contra quos in arenam defcendit, totis argumentosum phalangibus eftadortus, fed diferto \& concilo porius acumine confodere: fudurt, imò \& confodir. Gul. Salden.de ufu \& abufi librornm.

Catarus illutris virgeo fine fummi honoris prefatione nominandus. Andro. Wintonenf.Epic.in libide Ufuris...

Calvinum \& Be:arm ctli onnes magnifaciunt veritatis amantes ; nemo taw men et paulò judex aquior, quí jurari ili-verba illorum poftuler Cajanba Epift.676:

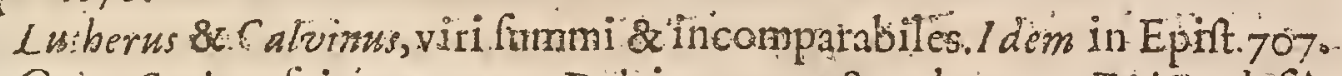

Cu us Scripta fpitant merum Dea timo:em; \& zclum pro Dei Ecclefiâ. NeG quifqum advafariorum, quos habuit innumeros, carpfer ejus mores prater Hieronymum Bolfectrm, Medicum, perdit fimum nobulonem, qui inttigatore Calvino pulfus Genevâ ob fcetera. Hic yitam Calvint confarcinavit, in quâ eftudit in virum fancum plauftra convition \& mendacionm: M olineus Hyperafpilt.L.I.C.I2i

Ioannes Calvinus, acri vir ac vchementi ingenio, \& admirabili factindiâ presditus, inter Protestantes magninominis. Thuan. ad an. $5 \sigma_{4}$.

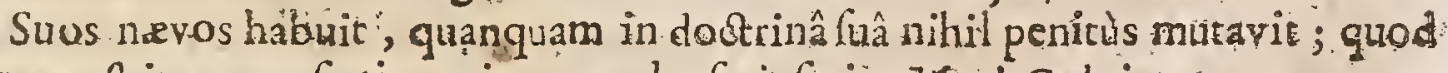
sorum eft,in eo prafertim qui tam multa feripferit. Mori-Calvinus.

Culvinus - quivir ob eximias animi dores [ ab Adverfariis quoque Portifi ciis admirationi habitas ] totque devoratos in Ecclefix bonum labores, fi, ut, fit Hominem fealicubi dtendji, meruic raltem ab umiaus, gui Reformat audir 
voluut, honeftiùs atque mitiùs tractari, tantique nominis carnificinam lanionibus potiùs Romanenfibus ( qui artem profitentur) relingui par etlet. Thom. Tullius in expolit. Precat.Dominice p, 188.

Author fum, ut Infitutiones Calvini diligenter evolvas, Plures darifcio magni nominis Thcologos, fed ille, tibi fit inftar omuium. Quis cnim co doelius, \& folidiùs fcripfit ? quis acriùs veritatem tuetur; validiùs criores \& Harefes profligat, confodit, jugulat? Controverfias tractar eruditius? Quis Sophiftarum ftrophas fubtilius deregit, eludic, elevat ? Nema. Unde \& à doctis cenfetur indôtus qui Caluinnm non legit ; indoctior qui lectum contemnit; indoctilimus, cui non fapit. Vide Zac. Crucii Epift. ad Iuf. Trotiurr.

Calvino credere non audeo,quum Cciam, quàm iniquè tractaveric \& virul. no tè viros multò Ce meliores, Caffandrum, Baldvinum, Castellionem, Hug.Grot.ad arr. Symb. Apofiol.

Calvinus ioldus Theologus \& Bocus, fyli fat purgati \& elegantio is quam Theologurn dcceat. Literas Sacras tractavit, ut tractandx lunt, vere, inquam, \& pure ac fimpliciter fine ullis argutationibus fcholaficis: \& divino vir predius ingenio multa divinavit, qua non nif à Lingux Hebraicaperitilimis (cujulimodi tamen iple nonerat) divinari polfunt. Scaligerana prima $p .39$.

- Calvinus omnium oprimè in 1 unielem feripfre fed omnia hantit ex B.Hicronymo. O quam bonus liber func Calvini Inftitutiones. Cal vinus \&Beza licta. - vii ambo I uris fudis operam nawarunt. Contius famæ Calvini conlobrini fui - acerbifmè obirectabat. Optimè fecir Calsinus in co quod mininè fcupie- nit in Apocalypin. Vir quidamerat Geneve qui in Calvini concionibus icri- bendis victum fibi comparabat. Afthmaticus erat, \& lentè loquebatur, ideo- que facile admodum erat fcubere qua pronunciabat. Multo masis mihi pla- cent Calvini Commontarii quàm ejus Conciones quas nunquam fcriplit. O quantus vir! Nemo Veterum eft ipf comparabilis. Tam bene Scripturam incel- lexit! Primarn, qux mihi prafens erit, pecuniam Operibs ejus omnibus coe- mendis infumam. Fratem habuit ipf per ominia fimilem. Solus Calvinus in - Theologicis: Nullas contexit Retractationes. tam multatamen foriptit: minum - illudeft. Arbitrio veftro an vir magnus fuerit judiciunj permitro.Hact. Gal.Cal- urmo Pontificii nen maledicunt rifi quando vident praclarm ejus ingenium. - atan praclarè interpretari Scripcuram, ut ipfi non poffnt çus preftantiam affequi. U quam Calvirus bene alfequitur mentem Prophetarum! nemo melius;erat

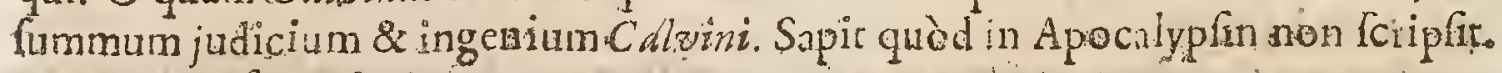
Scaligerana fccunda.

Unum dicam modé; Eorum omnium qui hodiè vivant, qui fe bellos homines, \& elegantes, \& difertos, \& eloquentes popelle faciunt, repeiri nemiacm qui ia pratare poffit, quod foonnes Calvinus in Epiftolà ad Francifoum I. Gallix Regem prafticit, crm egregium illud \& nunquam interiturum Inftiturio-

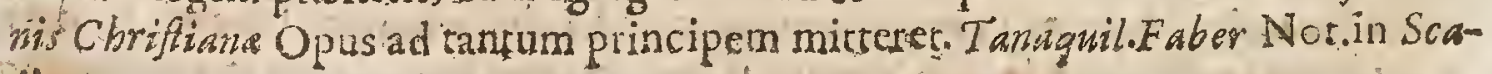
ligerana $\mathrm{I}$. 
Calvinus Protetantium Gallo rum Patriarcha plus ingenii atque judicii de- monftrar fuis in Scripuram Commentariis quam Lwatherus. Nimis tanen in fuis - ratic cinationibus fuletilis eft; \& Religio, juxra ejus principia,videtur magis niti - confequentiis quas è Bibliorum Textu deducit,quàm ip?oniet textu. Quoniam - allietus erar Moralia apud plebempredicare, Thcolog amque Lectionibus per- tractase, utrifque Commentaria fua referfit. Omina feréeiram accommiodat "prajudiciis fuis; \& Controverfis yuas cum diverfis hominibus a gitabar.In ejus - Commentario in Genelin id cernere éft, ime \& incateris cunctis, quonian - methodum fatis tiniformen fervat. Wuthero tamen circumpectior appa et, fit- bique cavet ne infirmis utaturargumentis , undê Adverfariis aliquod contra - ipfumemelamentum redire polfer. Idcoque non invehitar in 7 udeos \& 2 A niz"Strinitarios qui contendunt probari non polfe ex prinis illis" Genefews vocibus, - Creazit Dezas Mylterium Trinitatis, pratexende videlicet quòd'vex Hebraica Ëlobim, gax Deum fignificat, Fit pluralis tumeri, conjuncta verbo Creare in - fingulari. Quin contra lanc opinionem prolixè adinodum refutat \& prudenter

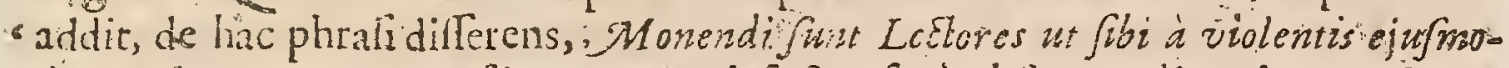
- di Glofjis carvedits. Eofdem tamen defectus ferc oblervare licet in ejus Com- mentariis, gui in illis Lutberioccurrunt: Nihil enim alind fibigropofuiffe vio

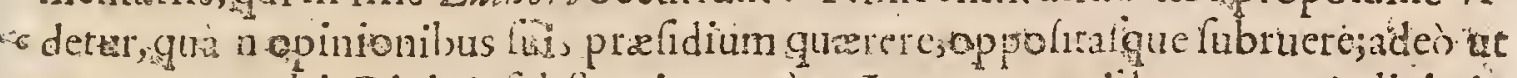
- non vam verbi Bivini fubftankian quäm Interprerum illorum prajudicia in

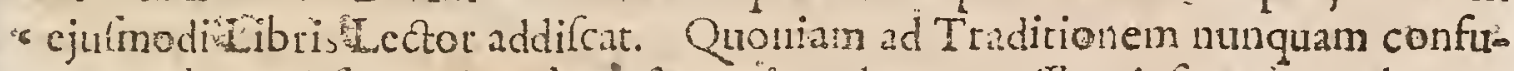

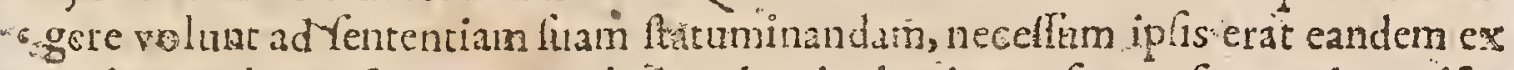
- Scriptura demonftraie actproinde ad ratiocinationes fe conferice, Id manife- ftum eft in Calvini Commentariis qui fcatent conlequentiis acutè dideductis ê - Scciptare Textu: Hoc autem prevertete potelt animos Lectorum qui Religio- nis principiafatis non penetranunt. Onamvis Luthefusin Hebraica Lingua "doctior effer Cálvino gitioujus ferè folos characteres no nat, pofterior ifte ac- curatior tameneft, qquoniam aptionis erat ingenii ad ea ritè perpendenda - quieapua alio; Anthores Ingebat. Cum tamen in itudis Critices \& Linguarum

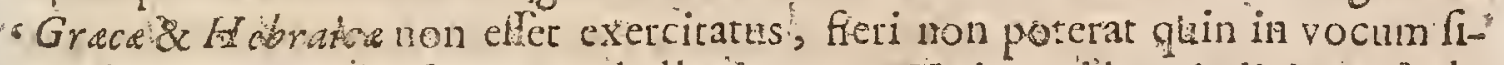
"gnificarione proptia frequenter hallecinaretur. Hujus evidens indicium elt ob- fervatio ill ius ftatimà principio Gené̂ềs in verbum Hebrärem baras, quod

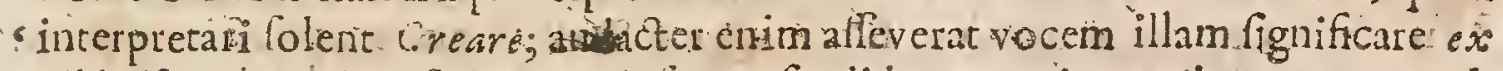
- nibiloffacere; tunde anfam arripuit fuccenfendi in eos qui materiam exernam ad-a -s mittunt, \& quodáamvveluri Chaos, ex quo Dens Mundum hunc alpectabilem ' produxerit. Venum cinim eft 1 eum ex nihilo Mundum feciffe, \& Clioos fer mas "s ceriam veterum Philofophortan meram elfe fabilam s, fed invidè probari nc - quit ex illo Genefews loco, nifi ci addatat-Traditio, quarm habemus a Mundi

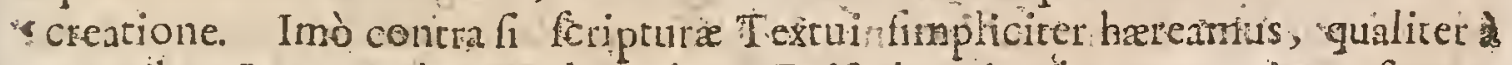
- vereribus Interpreribus \& ab Authore Epiftoliz ad Hebrazos verritur, fuppo"s nenda videtur materia quedam invifibilis, qux Creationi antecedancafuerits. r quemadinodum alibi ànobis obfervatum elt. Proterea Calvints dum interripetatur verfum vigefimum primum, capitis primi, Geriefés ubi accurcit vod. $\operatorname{Nin} n: 3$ cabulum 
- cabulumidem Hebreum bara confugit adalias nefcio quas fubtiltates, ad - primam fram Explicationem confirmandam. Quod ei frequenter contin- git fuis in Scripturam Commentariis ; quoniam hane fxpe fecundum pro- pria prajudicia explicat, non autem juxta propriam vocum fignificarionem, - quam intcrdum derorquet ur opinionibus fuis illam accommoder. Cate- rum quia fublimis admodum ingenii eft $C$ alrimus, in omnibus cjus Com- mentariis nefcio quid occurrit quod primo intuits placet \& queniam ad - hominem cognofcendum præcipuam animi curam adhibuerat, Libros Doctri- na Morali animos commovente replevit, imo \& conatur Ethicam fuam ju- ftam \& Téxtui fuo conförmem. reddere.' Si vanæ glorize adeo non litâffet - nec ambivilfet Sectza alicujus, Coryphrum exadere Ecclefra admodum utilem "operam commodare poruiffet. Ejus hace eft folertia , dienm, anmaliria - ut genuinum Textus fui fenfum detorqueat, ad hoc ut prajudicaris fuis opi - niouibus ferviat. Nullam preterea occafionem -negligit Ecclefia Romanz - hujufque ceremoniis obtrectandi, qun hoc intemperantec faciat: Hine efe - quòd bona Commentariorum ejus pars inurilibus declamationibus feta eft; - qux tameri runc temporis juvabant ejus incoptum, quod erat populos in le - gitimos fuas Principes excitare. Verto ut abfolvam nihil oblivifcitur eo- rum qux partibus fuis emolumento efle polfent, a ad hoc cumprimis ani- mum appulis; quapropter yeritas apud illum tam craffa mineryace in $L u$ - theri-libris non alteratur. Conatur faltem probabile reddere quicquid alfe* rit ; imà \& ftyli quamdam fublimitatem affectavit qux ad fententiartim fua- rum robur augendum non partum confert. Cui confiderationi bac addi po - teft, quod pauci Authores extent qui melius ipfo creatura niluilum port pec- catum cognoverint. Cum autem prefertim incumbate animadiverfioni de- fectum quibus obnoxii fun homines, cor movet : cim contra plerx- que Lutberi animadverfiones vanx tantum fint fpeculationes \& ridicula difa. - putariones. Hoc tamen vitio laboravit Calvinus in omnibus Scripris fuis, quod fupramodum honinis nihilum polt pecatum propalaverit, quòdque -illum Cemper in eotem, nihilo reliquerit, nullohabiro refpectis Statús gra-tix. Jef, Rich.Simon Hiz:Crit.V.T. lib.3.c. 14.Gall.

- Nemo hominum Calvini peritiam in Hiftoria Ecclefiatica ninquam æqua 4. vit. Annos 22 natus omnium Europaorum Dootiffinus erat. Aliquando in - quodam Doctoratum noltrorum convivio difcumbebam, ubi fénex Doctor - quidam notter Bafons nomine dicebar Caloinum totam Scripturam Sacram adulteralfe; fed bonum hunevirum cxcutiendum mihi fumplis quem adeori- diculum reddidi ut Dominus Guenaut junior qui mihi accumbebat, dixerir "mihi,quod ipfum vehemenzer nimis exagitarem, rogaveritque ut atatis \& - debilitatis ejus milererer. Joannes de CY onluc Valentinus Epifcopus folebat - dicere Caluinum torius orbis preclariflimum Theologum fuilfe Guido Patim. Epittolis felectis, Epiftola xxı.Gall.

- In hoc omnes confentiunt, guod operum ejus prxcipuum fit ejus Inftitratio , qux fumulfuir \& ingenii ejus, fpecimen \& inter ejus opera tuculentifo Gumum 


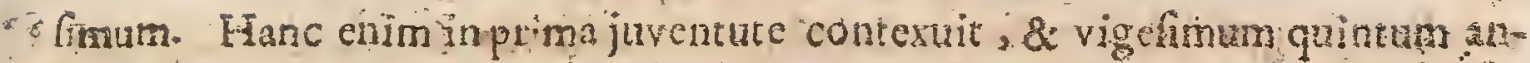
snumnonnum excedens evalgavir. Papirims chl afjo teltatur tanco applainu -illam ab omaibus publicè exceptam fuife, at brevi tempore plufiquam mille - ejus editiones prodierint. Anton. Teiffer Elogitis Virorum Eruditorum. Gallicè.

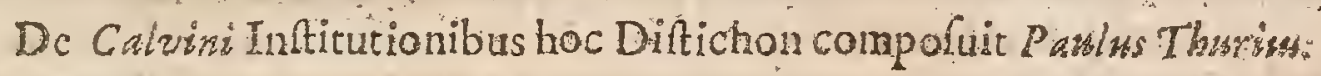

Prater Apoftolicas poft Chrifti terpopora Chartas Huicipeperere libro fectuta mulla parem.

"Hac Author Romano Indice inter Hereticos Primx Clafsis rejicitur.

\section{SIGISMUNDUS GELNIUS}

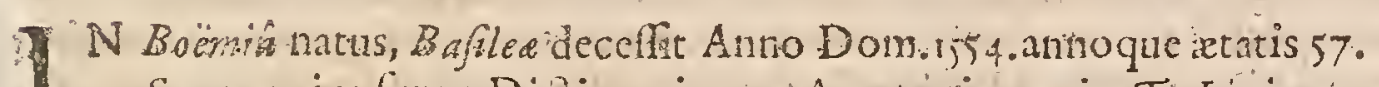

Scripia ejus funt: Dictionarium-Annotationes in T. Livium-AnnoClar.A. a siè tranftzlit Evagrium Hiftoricum : Origenem contra Celfum: Pbilonis Opera

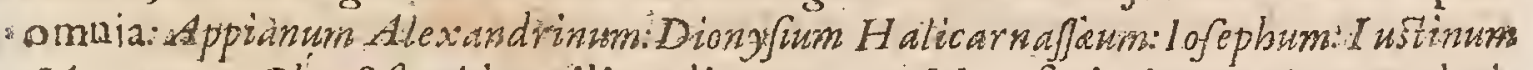
Martyrem: Cbryfoftomi homilias aliguot cum Manufcriptis Gracis exemplaribus contulit, emendavit, fupplevit-Edidit ctiam Epigrammatum Grecorum librum.Arnokium edidit, itemque :Ammianum Marcellinum.

Sigifmundus Gelentius, vir diverfis lingais, \& variarum rerum cognitione dodifimus. Gejner.in Biblioth.

Sigifmundus Gclenius, cum eg eftate totâ vitâ conflítatus, \& lautiore fortunâa dignus ab Erafrno judicatus : cujus induftria pracipuè in vertendis plerifque Scriptoribus Gracis \& Plinio ad vecufterum Codicum fidem emendando defudavit. Thuan ad ann.1554.

Sigifmundus torrm ferè vitie fux tempus in Authoribus Gracis \& Latinis emendandis infumfit, quos Erobenius \& Epifcopius typis mandabant. Fatis ceffit annos 57 : natuls, poftquam manifeftè comprobalfet in pluribus linguis fe verfariffimum effe, Dictionario illo à fe evulgato, quo concordantiam demontetrat, qua occurrit inter Linguas Griecam, Larinam, Germanicam \& Sclavonicam. Gelenius, inquit Erafinus quadam Epiftolarum fuarum, pro fura dodtrina non vulgari, proque morum finceritate dignus eft lawtiore fortwna. Ant. Teifleer. Elogiis virorum Erud. Gall.

In Gelenio major quxdam ingenii vis \& judicium acrius fult [ac in religuie foilicet Ammiani Marcellini editoribus ] quod cum multi præclari labores illius Wiri teftantur, tum maximè Interpretationes Latinx Dionyfii Halicarnafjei, Appiani, Philonis item ac. Iofephi, Origenis \& aliorum. Ex quibus apparet,eum 
excellenringeniô \& fingulati dootrinâ praditum fuifie Sed \& Ammin Mavcellini hiltorix ab co edire id ipfum abundè teftantur : in quibus plurima acurè \& ingeriosè emendavit, \&infignem paginarum manfofitionem qux in MSS. Codicibus omnibus reperitu, at in cditione extat Accurfizmirâ dexteritate reftituit. Quamobrem ejus viri nomini libenter hoc laudis teltimonium impert:mur, nepinem adhuc extille, qui de Hiftorià Marcellinimelius meritus fit. $H$ emr. Valefins in Prefat ad Martellin.

Qû́ [Gelenio]vix quilquam pluribus: hane artem [Intexpretand ] monumert tis ditavit: difertus imprimis habitus eft; \& elegans? ribus in unum periodis, vel disjungendis, fenlus fioi non femper intellectos ad libitum recoguit, Huet. de Clar.Interpr;

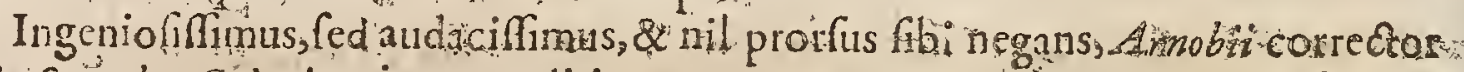
Sigifmundus Gelenizes, in cam editionecm quam totam ad luum captum reformavit, aut transformavit pointis, teftarus neminem hbi unquan auctorem tantum nego ii exhibuille. Barth.1.4. Adverf.

Arnobium primus Rome vulgavekat Francifcus, Prifcianenfostatorentims sed unà cum vereris. Manulcripti, quosulus fuerat, fodis admodum erraibus: Sigifmundws polteà Gelenins editionem hüc corruptam folo ingenio uti potuit réftiruit:Sed ingenii rlle frduciâ malo, exemploufis, conjecturas fuas textu inferuit;ntiquas lectiones fuo imperio ejecit, \& Arnobina nobis effinit, qui Aro nobii peciem non referret. Hanc audaciam merito reprehrndit Theodorns

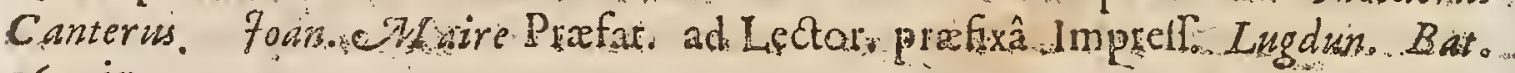
165 r.in $4^{\circ}$.

Buna fanè An Arnobio Opera Geleniw quangun interdum (Aquis non: Criticorum?) exeret pex acumen nimium aut calorem. Lipf. Epift. Cent. Mifcell.42...

Gelenizs yir acuminis; enditionis, Lectionis, Enshat. Sururt Analed. 1.2.c. C.

Qux principem locum obinent inter ejus Translationes funt Hra Dionyfiss Halicamalfi de Ramanis Antiquitatibus \& Jolephi de Antiquitaribus Judxorum Defuis tha inm fat is opinionem fovebar udicia Eruditorum Parifis 468.Gall.

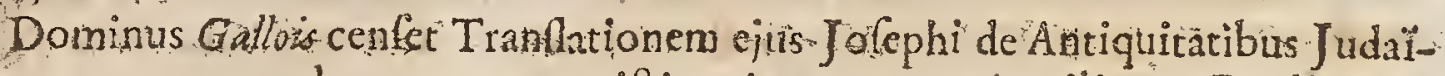
is earum autographo magnam exiftimationem non conciliate. Eruditoun Ephemerid.Gallic die 10. Jan.166\%.

* Sigifmundi Gelenii Epiltola ad Gilbertum Cognatum Nozorenum, prafixa libris Arnobii adverfus Gentes, ex Impreflione $B$ affled, 1560 .prohibetur in Indice Madriteng editianno $36.6 \%$

\section{H A DR I A U U S J U N I US}

Clar.A.D: Ome apud Batavos Anno 1513. ipfis Julii Kalendis natus. Obiit Arnempo MOXLV.

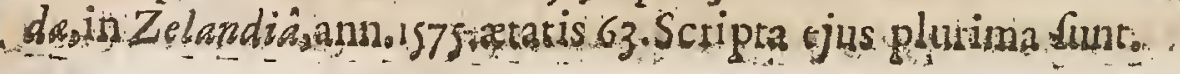


Medicus; Hiftoricus, \& Poëta doctiffmus, alterum a 5 Erafno Hollandia lumen dici meretur. Yir in quo omnia excellerent, Medicina; Hittoria, Antiquitam, sis peritia: ingenium ad toëricen factum. Linguas prater-vernaculam feptem

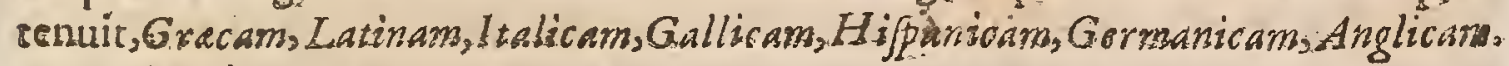
Meurfis Athen, Batarse.

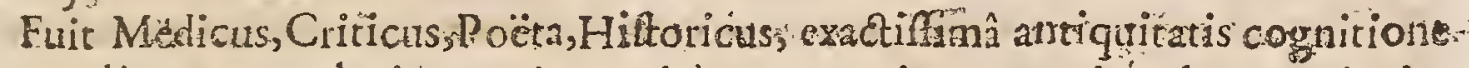
Clarus; linguarun plurim pe itus; adeò:ut non tria, quemadnodim Ennius ja-

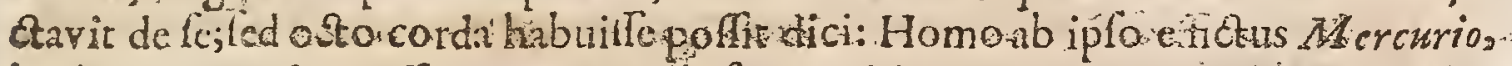
lepôre ac venuntate affluens:purus illi fermo \& expromprus. Eruditionem cjus.

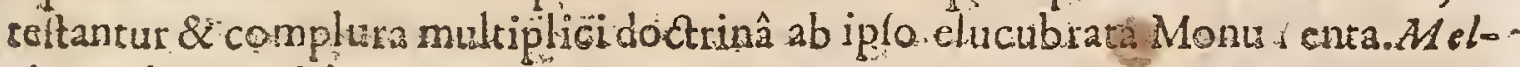
cbir.Adam, in vitấ cjuss:

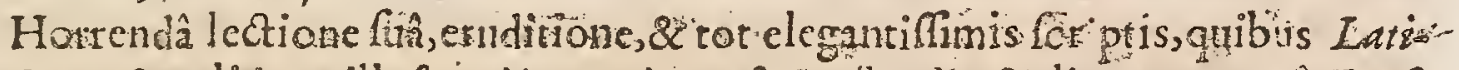
mas Gracafque literas illuftrayit, meritus eft Hollandia \&" lirerarum polt Erafo-

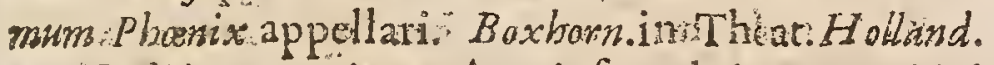

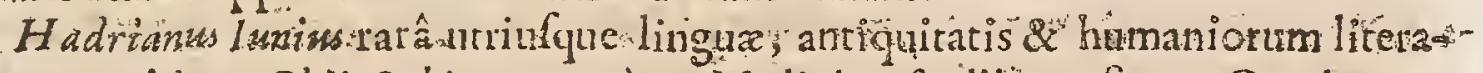
rum cognitione, Philofopbix pretercà ac Medicina ftudiis preftans. Quod com-

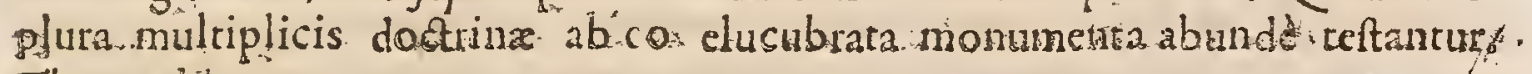
Thuan.adiann.1575..

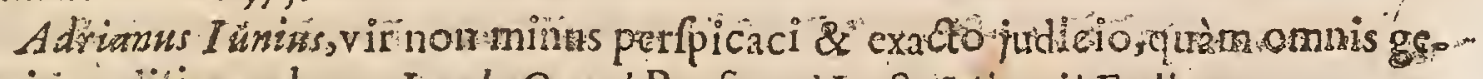
steris eruditione clarus. I acob. Onzel Perat.ad Lect. Minuti Folico.

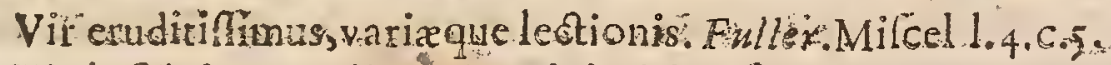

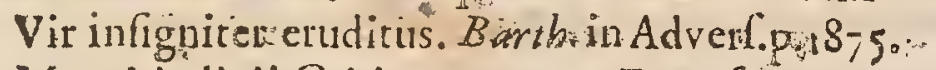

Magni judicii Criticus vocatur Dempfiero.

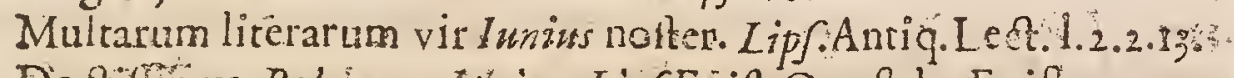

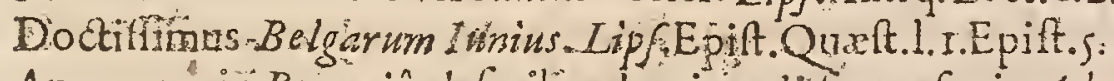

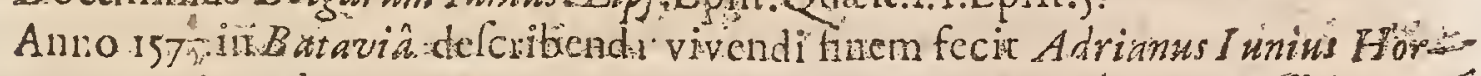

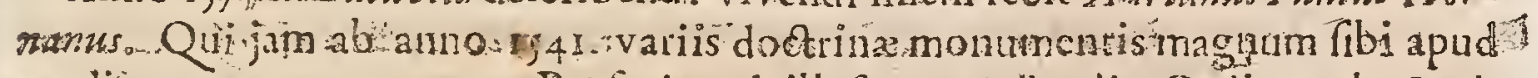
exuditos nomen pararat: Prafacio ad illuftes Hollandic Ordines ab I unio

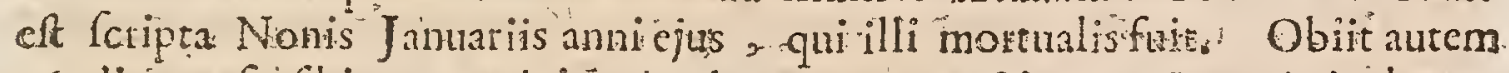

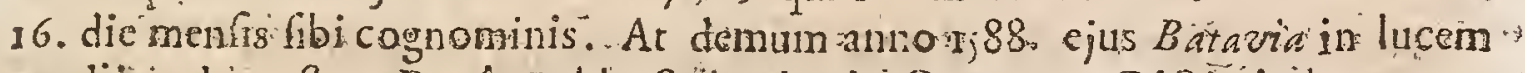
proditit, edente fano Duzâ, Leiden fss. Academix: Curatore. Didtio in hoc opere

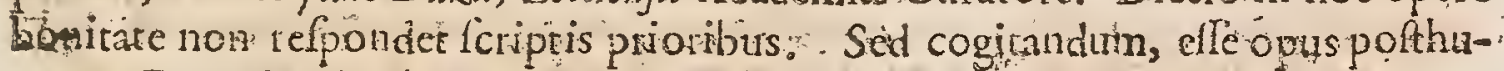
mum, Et credo, tenili xtate priltinus aberat vigof, Voff de'Scient, Ma themato P:259.

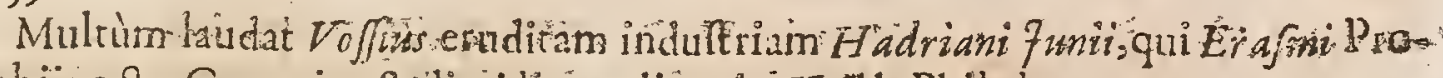
7erbiis octo Centurias, \& dimidiam adjünxit. Voff.de Phílolog pso.

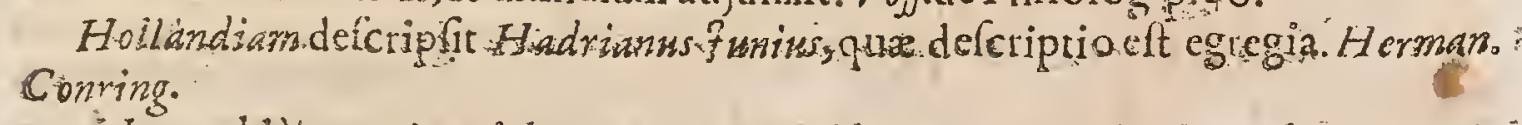

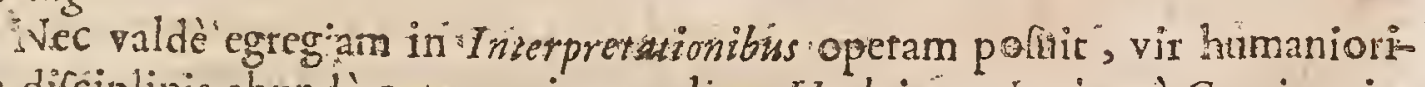
burs. difciplinins abundè care oquin expolitus Hadrianus I unius: à Gracis "quipor. pè abèrrat fæè è éque diftortâ \& falsâ Interpretatione adfring it : Sexcentis quidern locis in uno Eunapii libello Criticis debet fuppliciun. H Het.de Clar. Interpret.

Ning 3

Ferung: 
Ferunt foannem Sambuccum in Hollandiam de induftria profeotumat 7 mium inviferer, in fuo diverforió audiviffe illum cum Fourmannis id ef cum Rhedaris compotare; ex quo tantum celebris illius Critici conterntum concepit, ut illo inconfulto domum reperierit, Fmius audio Sambucci difellí, culpam à le depellere follicite comatus eft, dicens Rhedarios illos fe non convenille nif ut ab iis terminos aliquos artis corum edifceret quos in Nomenclatorem fum refere volebar. Ant.Teifler. Gall.

Hadrumus I unius in prinâ Claffe Hareticorum numeratur in Indice Romgaso.Ejus Anaftaurofis, five Pallio Servatoris Ghrifi, Jambico carmine confcripta, omninè prohiberur. Rcliqua cjus fcripta, cum expurgationibus permittuntur, Index Madrit.edit.ann. 1667.

Hoc ejus Epitaphium, Middelburgh in Zelanais fepulti.

Hadriano Innio Hornano, Philolopho, Medico \& Poëta celeberimo, Batavid Hitorico fidelinmo, cujus in omn difciplinarum genere exquifita entudio, - fingularis induftria, infinitr lectionis praftanta, nultiplex linguarum Scicntia pari conjunda comitate, doctorum omnium adnirationem laudemque mcrut : poft varia incomparabilis ingenii monumentaguibusaternam libi memorian comparavit, fub hoc marmore condito Pari-eprime de fe meri-

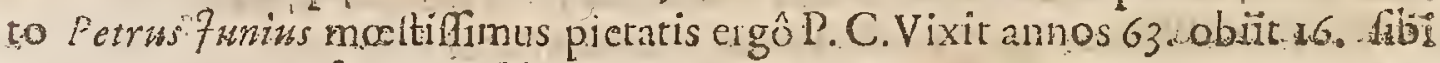
cognominis menfis. Ano falutis.Chrifinan MDLXXV.

Junius bic fotus ef: viltra ne quare, - viator,
Oculifgue fat debere te twis puta,

Tarn magni pectare wixi queis contigit urnam

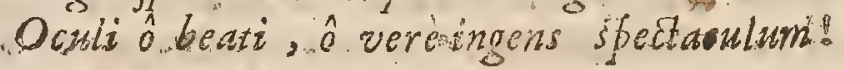

Yaria ejus Opera variis in locis atque temporibus inpreffa funt.

Clar. A. F. Cottusin Levinia natus Anno Dom. I5a6.circa Calendas Fébuarias. Obiit

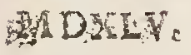

Edimbargit 18. die Septembris, Anuo Salutis 1,52

Scripta ejus hac funt: De Jure Regni apua Scotos, Dialogus - Rudimenta Grammatices Latine. Thome Linacriex Anglico fcmone in Latinam vera - :Rerum Scoticarum Hitoria - PS èjus Poëmatain unum collecta.

Vir' ingenii felicitate \& 'icribendi facultate [ quod ejus Scripta ad omnem zernitatem vicura, vel fatcnte invidià, teftantus] not trâ zate incomparabilis. 
Poft prima uriiufque lingux tyrocinia apud fuos facta , omnem ferè xtatem in Galliâ exegit: Lutetixe, Burdigala, \& pofteà Conimbrica juventutierudiendx on

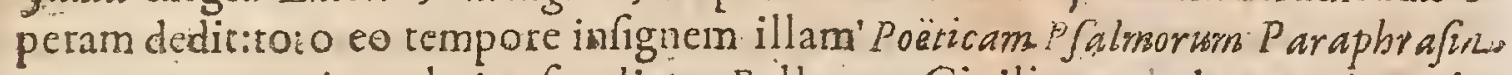
commentatus. Anno hujus feculi 60 . Bellorum Civilium apud nos ardente incendio od Patriam antiquam, aluma \& nutrice Galliâ. relictr, teverfus eft : ibi

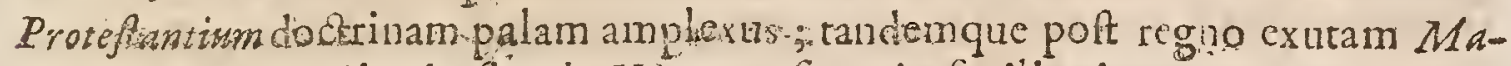
riam, Rearivam erudiendo ? acobo V lo appofitus, in fenili otio watriam Historiam

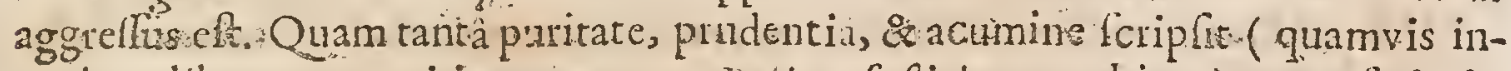
terdum libertate genti innata contra Kegium faftigin acerbior) ur ea (criptio non hominem in pulvere literaria veriarum, fed in media hominum luce $\&$ in

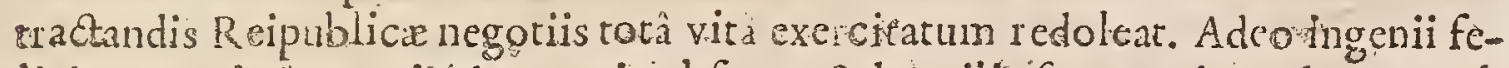
licitas \& anim magnitido omnia obfeurx \& hubilis fortunx impedimenta ab coremoverant , ut propteren non minus rectè de maximis rebus judiearc \& fcribére prudenter pollet. Thwan.ad"anm.15 8 as.

Sanè meminì P. Ronfardum virum acerrini judicii ( qui licèt in di parì for

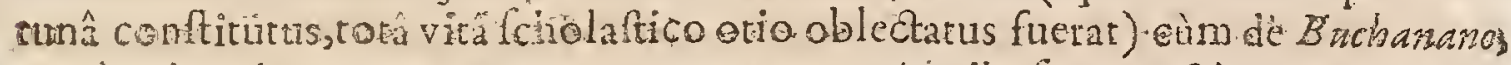
Hadr. Turneba; Ant Gooveano, M. Ant. Mureto ( quibufeumarctâ amicitiầ con-

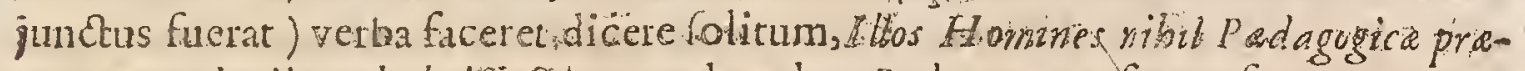

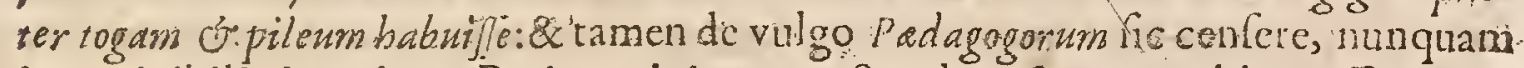

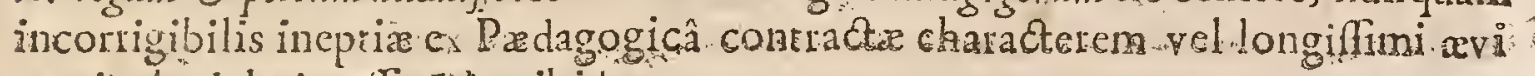
curricula deleri polfe.Idem ibid.

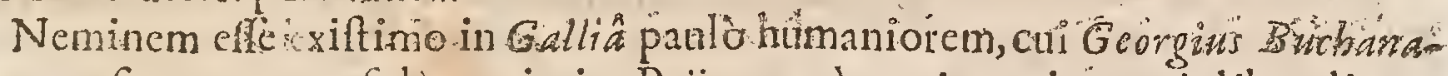
sus non fit notus; non fol im eximius Poëta, verùm etiam vir omni liberali era

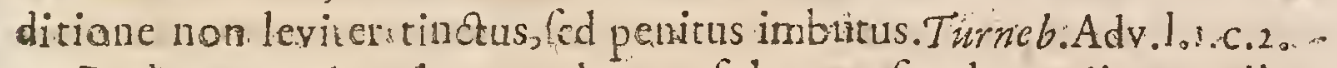

Bucbasanus vir qui nec cœlo, nce folo, nec feculo crudito, ntrille cecinit; $n_{3}$ tris, ad fummum tamen Poëtica facultatis culmen tam felicier afcendit; ut Pö̈tarum hitgus feculi princeps merito habeatur. Canden in Annal ad an. 19.92.

Qun nemo diligentius ant iquitates patrias eft perfcrutatus. Iacob. offer. Epitt. de Brit. Ecclef.primord.c.s.

Contra Bucbanani librum De Yure Regni apud Scotos calamum ftrînxit GuDielm. Barclaius.libro cui titulus contra Monarchomachos: interim nenter medium

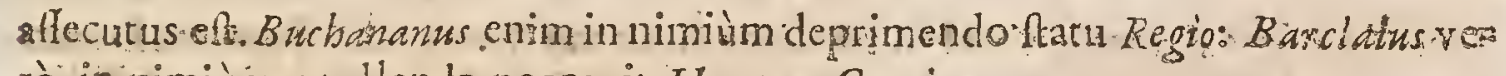
rò in nimiùm extcllenda peccavit. Herman. Conring.:

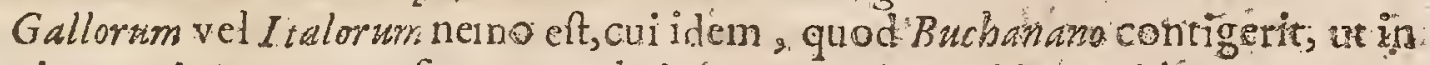
quovis carminum genere furmmam obtihérer., cujus quidem rei laude omnem. etiam antiquitatem $B$ webananus provocat; ut tanta illa ingenii, verè unici \& in " comparabilis, ornamenta adimpietatem converfa fuiffe yehementer non ipfius magis, quàm Reipublicx causà dolendumfit, Gafpar. Sciopp. in Palca. Grofipp. de Rluetoricîa.

Nemini pudéstiz \& eloqucntix laude cedens renum fuarum Scriptordignus; qui unus pro multis xiftimetur. H.Conring. de Civ.prud. c.r4.

Quem:m hiliceat omnis liberalioris eruditionis ac.prafertim Poëtices pareno sem appellare: Beiza in Epift, ad Iacob. Regem profix I com. Wir, Illuftr. 
Ego Pfalmorum ruorum lectione increditiliter delector, qui tales funt quan les à te uno proficíci potuerant.Eeza in Epift.

P Salterium verterunt Germani aliquot piè: Itati, ut folent, eleganter:Imprimis F laminius. Sed nunc omnium induftiam vicit Georgius $B$ uchananus Scotus, varietate fentenitiarum, \& puritate Sermonis.Georg.Fabrit.

In hoc argumento facilè omnibus palmam præripuit Buchananus.Iacob.D port.in Prxfar.ad Metaph.Pfalmor.

Georgii Buchanani Scoti. Poëmata varietare argumenti, dictionis nirore, fchemarum lumine, \& inaffétatâdecori cuftodià omnium fe è doctorum amosem, laudefque provocamne. Magnificèl ofeph. Scaliger. dum eum refpectat:

\section{Emperiu fuerat Romani Scotia finis, \\ Romani eloguii Scoria finis crit.}

Qu ùm religíofis, fed \& quàm puris manibus intendit Lyram Davidicam? quan fforet in elcgis: quàm plenus eft gravitatis in fephte, \& Baptiftâ Traguediis? quàm clarus in , illis de Sphera liberis epici ? quàm floridus in Lyricis, mifcetLaneis, epigrammatis? antum denique in F rancif cane, \& Eratribus vahemens \& aculeatus? Borrich.de Poëtis,p. 150 .

Buchananus unus eft in tora Europâ ommes poft fe relinquens in Latinâ Pö̈ f. Scaligerana prim. p. 370

Quoad ejus hoëmata Iosepibus Scaliger aitilla fuperarecomniaquatquot ab Augufti feculo in I lucem prodierunt. Hutenhovizs alleverar illum lioitas celes. berrimos Gallos \& I talos antecelluilie, ust ex boc difticho liguet,

Tres Italos Galli Tenos vicere; led unum

Vincere Scotigenam non poutere wirum.

Tres Galli fum CancellariasaHo pitalius, Adrianus Turnebius, Joantes Dorat: Sex autem Irali, Sannazarius, Fracaftorius, Flaminius, Vida, Naugerius \& Bembus. Ant.Ieifler Elogiis Eruditorum Vicital.

7ef. Vavalfor (Not s anonymis in Animadrerfones in ocicam p. 66.)

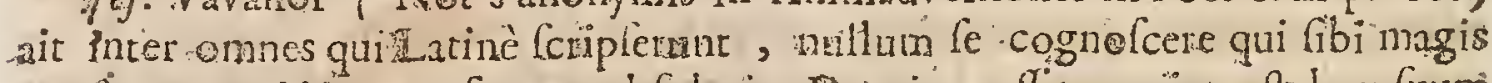
conftaret, quii idearum fuarumabfolut:or Dominus eflet, quique folum fum cogitationumque fuarum enunciationes quoguoverium pro Hibitu Hecterer quàin Buchonamar. Gaill.

Buchanarus ferviliternimis Titum Livinminitater. Quicquidhaber boni Veceribus fuffuratus elt. Sano admodum judicio fcribit, in lublime quoad fenfa parum atrollitur. Prolixz terti ejus libri citationes comibus non allebefcunt, ut nec diffufa quoad-omnia fingularia naratio ejus de Gente Regio- 


\section{CELEBRIORUM AUTHORUM.}

nis illius de qua ibiden loquitur. Rapzn. Animadverfonibus in Hiftoriam. Le 0 . 28. Gall.

Buchinanus $O$ das habet Antiquitate dignas. Sed inzqual is admodum ett ob

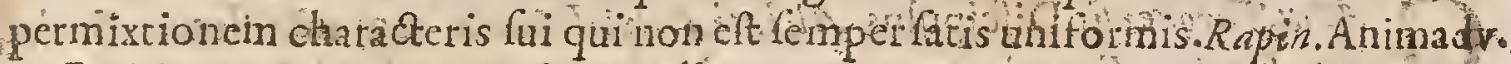
in Poëticam 2.parte, Animad.30:Gall.

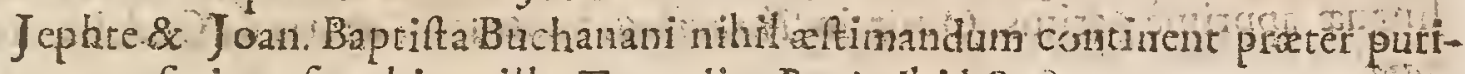
ratem qua fcripte fut binx illx Tragadiæ. Rapin ibid Sect, 2:

$\therefore$ Buchananis Hiftoriam \& libellum, cui tetaltis Detchto, portum ftudio,

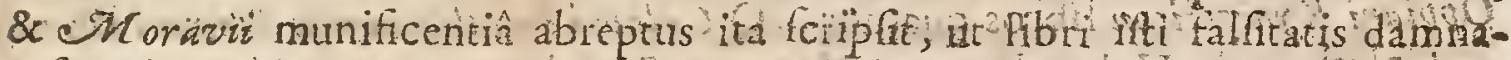

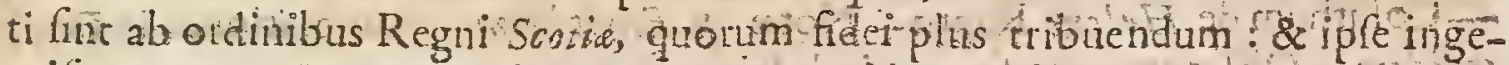
mifaens coram Rege, cui fuir Padagogus, Jubinde fe reprehenderit at ac-

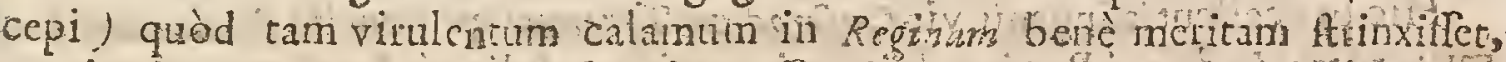

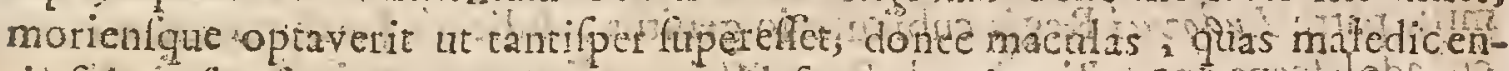

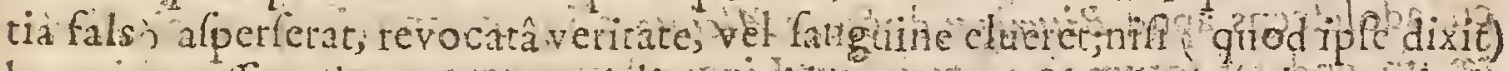

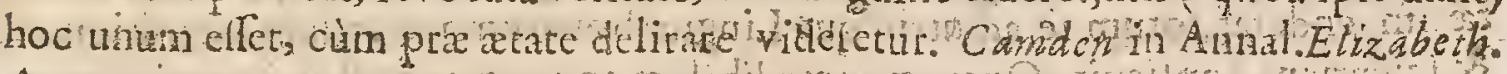
Anno 1567 .

Inter illos qui tunc tempons ( anno Is 4.) periclitabantur, unis erat Geogius Bucbanants. Cleus apud fe decreve ut utionem de illo funere

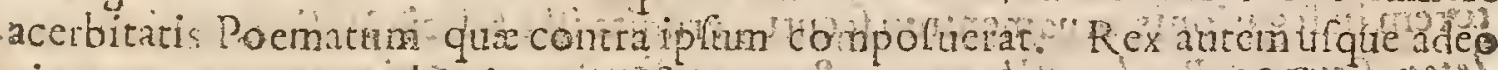

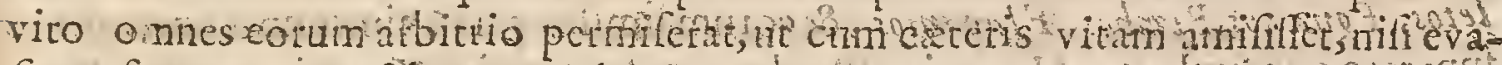

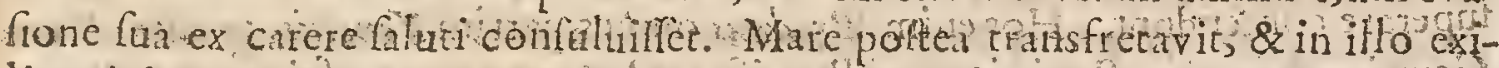

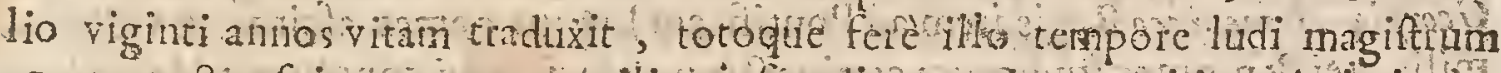

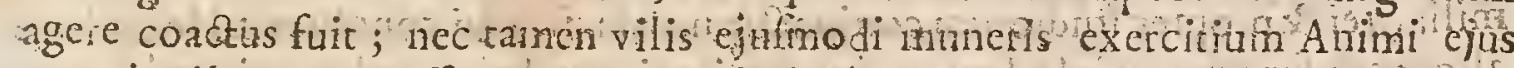
magnitudinem oppieflit. - In ejus Schiptis elecent nót rodo veneres \& lepố

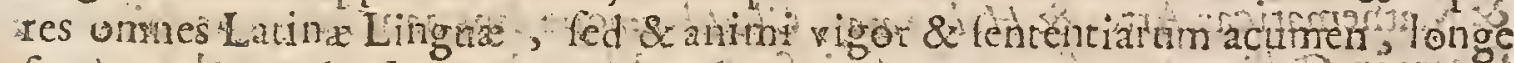

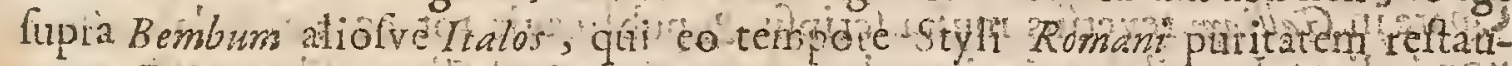

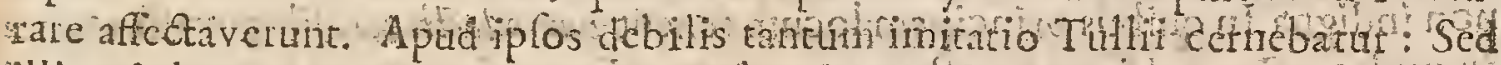

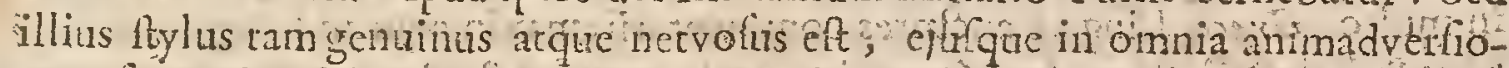
nes uf ue adeo folide, (prreter immortiatejuldem Poefnata, quibus manfe-

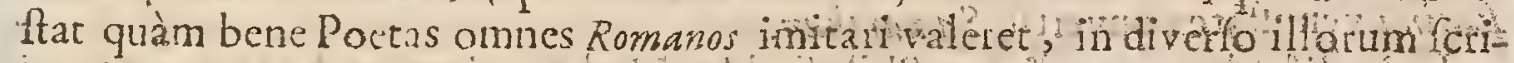

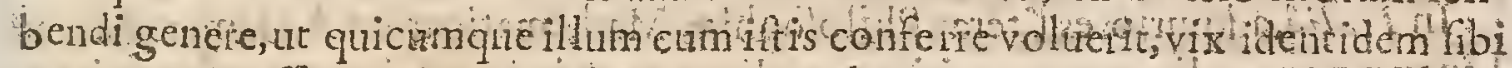

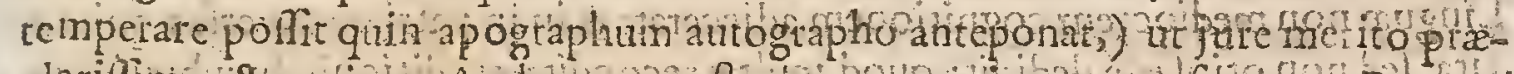

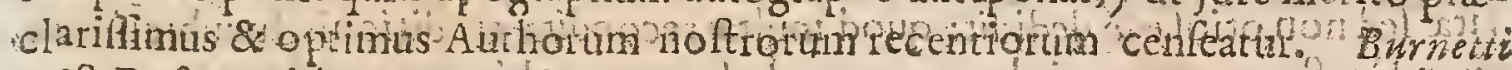
Hift.Reforith lib.p.in. Aingl:

Nec intactum abire patiar inter Scotre lumind lat poftremum,

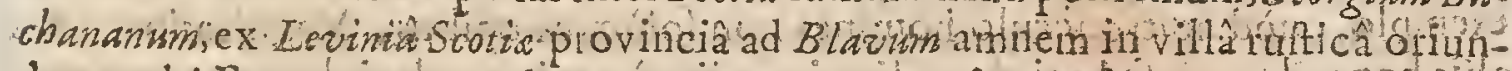

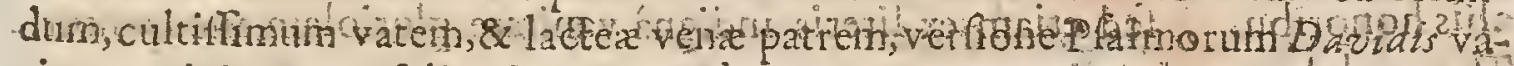

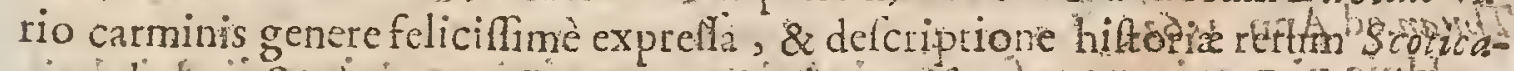

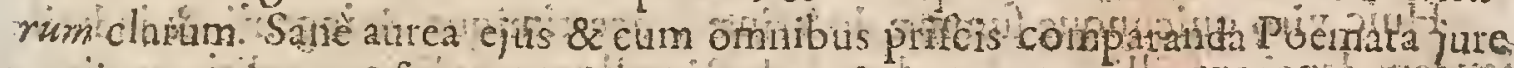
medito ornium y erfantur manibus. Quéraftedt.

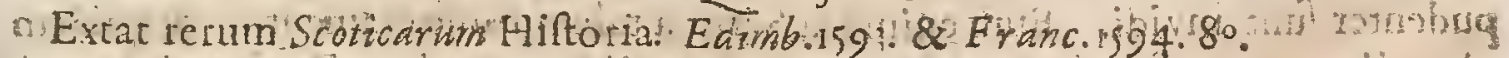

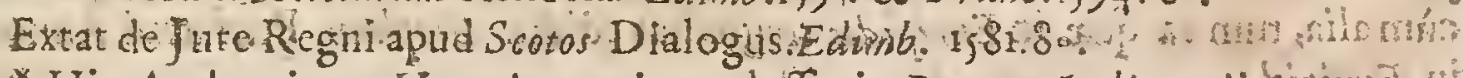
* Hic Author inter Hareticos prima claffs in Romano Indice rejictotit.

$$
0000 \text { JOANNES }
$$




\section{J:OA N N ES BRODAUS}

Car.An. D. Allu, Turanen 25 Difcrpulus Alciati, Petro Danefo conjunctifimus, Sida M D. .

I leto, Rembo, Egnatio Rome gratus, Mathematum, Chaldaice \& Hebraica lingux apprimè pericus. Obiit in Turonibus, anne 1563. xtatis 63. Colcbs.Hofnam.

- Scripta ejus hxc funt Commentarii in Epignammata Greca - Annotationes in - Oppian Kyngeticon libios quatuor-Q.CalabriParalipomenon Homeri lib. 4 - Coluthum de Helene Raptu-Nota in Euripidem-Annotationes in Dios coridem- Oblervationes, five varie lectiones.

Hic pracellent is ingenii vir Cofarod sni Turanum ex lioneftâ Brodiorum fámiliu patre Ludovici Regis cubiculario genituss, abdicatâ Junifprudentix curâ, cul adolefcens apud Bituriges, doctore Alctata, aliquor annos in fpem civilis vitx im enderat, totum (e ad utriugue Linguz bonarumque artium cognitionem \& fcientiam applicuir. Quarum incredibilem amorem jain olim apueritia con. ceptum auxit etiam \& infammavit ip?a P. Danefin Gallorum id xtatis doctifimi confuetudo \& familiatias, dum ambo Georgium Selvam Regis ad Venetos Oratorem in legationis ornamentum fecuti, erudita illa fel icis I talia ingenia $S_{a}$ dom letos, Egnatios, Bembos, Flaminios \& eorum fimiles pari animonum contentione fuperare contendunt Hos enin Brodaus omnes partim Tenetris partim Roma Grorgio Ampeniaco Regis iremad Pontificen Legato cones afcitus \&vidit familiariter \& propter fudio tum canjunctionem facile fibi conciliavit. Hoc etiam aliquan o juperior quòd ad eas, quibus pariter incumbebant, elcgantiores literas

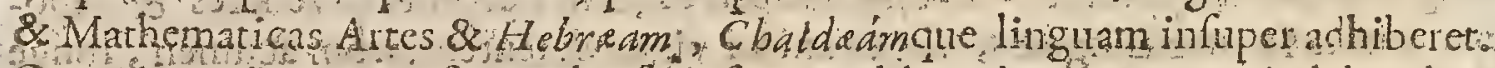
Quarcin, Galliam reverfas multa friplit \& publicavit rot as tantis labonibus non indigna In quibus principem locum tenent ver tediones, diligentiffimique in mulos Grace Lingux atctores commentarii, maximeque in Epigramma lar bore \& induftia Plandis $M$ onachi collecta, quorum \& Brodein bonam partem Eatina venutite copvertic Samartban.

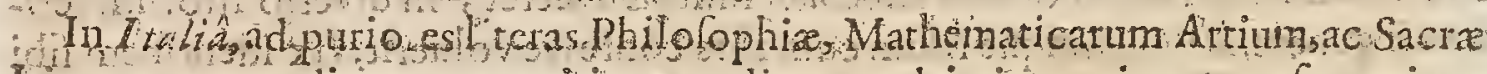
Lingua non mediocren cognitionem adjecerat dein in patriam severfus quietx

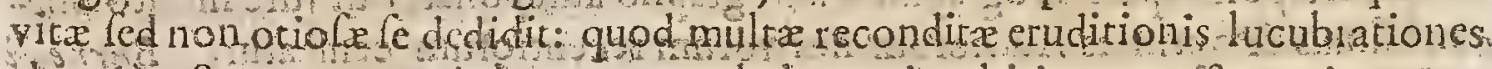
abunde teftantr, quas vir bonus procul ab omniambitione ac oftentatione pofitus alienispotius quàn fris atpicits pliblicari palfis oft co rariore nodeltix exemplo, quod nolto feculo homines nonfolù ex opibus, Magitratibus , \& alis honoribus fed ctiam ex literis indignâ vajitate gloriolam alicupantur. Thuanad Ang 1563 fin scint

Huic viro quicunque fun a Huic yiro quicunque fumma doctrina y acerrinique \& ingeni \& judici linudem denegant, illicertè aut planè indocti nulloque judicip prediti, ant impudenter funt invidi. Eum enim fua Scripta talem fuiltẹ clamnt , \& quidem cumalia, tun ea qux in Euripidis tragcedias edidit. Stephom. Pxafatiad Annot. in Euripid. 


\section{CELEBRIORUM ALTHORUM.}

Edecumati Judicii vir. Claud.Dausus in Notis ad Q.Calabrum.

Criticus magne eruditionis vocaturDempstero.

Brodaus vir tive Adolefcens potrus, àcris ingenii, piobi judicil, lectionis de : cit: de Moribserenara.cit.

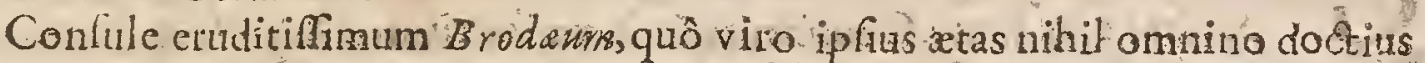
"tulit neque meliore judicio. Barth.advend.9.erto.

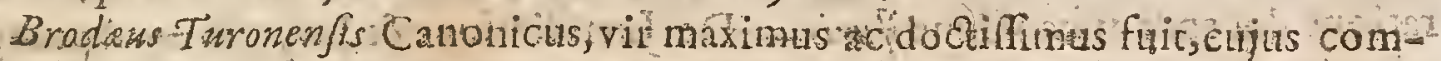
mentarios in Epigrammata Graccipturis fáció quanquorundam cripta plunima Scaligerana I.p.33. :

Vir egrcgire endicionis fo:Brodins Paul Colomes.in Opufc.p.rs.

Ioannes Brodaus Criticusmagna enditions. Thon. Dempfer. in Elench. Script.Romar.

Duo ctariftua Gallic lumina fo: Brodens \& Bodinu. Conrad. Rittershy. Prolegoni.in Oppian.

I vannes Brodaus, vit omnibus bonis literis inftuctilimus, Oppiano, Calabro, Colutbo, veluti triumvitis adjutrices manus adhibuit; candemque operam, quam elcgantiflimis nuper Grecorum Epigrammatibus impenderat, etiam in ho conculit Pätas: nihil conm omitcons; qua ad erudici doctique inferpyetis officium pertinere putavit. Veritimile eft, Brodaum diligentifimum hominem;Bibliothe? cas plurimas perluftrafle; in his quicquid rarum, quicquid oblervatione dignum animadvertit, id manâ ind Gerbel.Epint:Prafar.ad Hervag.in Brodai Norad Oppian.

De Strato non eft cur incomparabilis viri manibus Ioannis $B$ odat infultes. Habet enim ille Scotica Epigramasair qux tibi objiciat, \& cM wreto-Catullianjs Galliambos Fuitútem de bonishiteris oprime meritus, fi quis alius, ac ne I talos quidem tuos excipio / ofeplo.Scalig.in loc.controv. Rob.Titii,p. 38 .

Edidit fuperioribus Annis forn. Brodaus Turonenfis, Proful Amplifimes in Epigrarimatum Gracoum \& Oppiani de Tenatione Libios, Annotationes doctifimas, \& emni Scicntiarum genere refertifimas, qux illi nón mediocrem. landem apud Lireratos peperenut \& benevolentiam conciliannir Baptift. Sapo? Confl.Reg. Epift.Præat.ad. O. Fr.Mannium Burdeg.Archiep. in Brodici Not.lad Euripid.

Certè hòc ipfum $\alpha \xi_{10 \mu \alpha} \alpha \varepsilon \sigma^{\prime} \mu \varepsilon \vartheta \propto$, quod inepte alteri fubftituitur,profectum ab homine Gallo fuir, Brodoo nimirum Turonenfe, quem tamen ego, tantum abeft, ur infectari proptereà vclim, ut etiam verè lubenterque fatear multa fuiffe ab illo viro rectè non in uno authore reftituta. Nimirum aliquando bonusi dormitat: Homerus. To. Leunclav.not.in Xenopbon p.1068:

Foanin Brodei Commentarii in EpigrammataGraca, excufi funt Bafles Anno Dom.1549.in Officini Erobenianâ.

Extant.Notx in Martialem. Lug.Bat.1619.8०.

00002,2 ERAN 


\section{FRANCISCUS DUARENUS}

Clar. An. D MDL.

(Allus, Briacen fus Jurilconfultus celeberimus, obiit anno 1559 . xtatis 40 . Scripta ejus funt: Cammejtaria in varios titulos Digesti \& Codicis Difputanon Anniverfarianmbibriduo - De jure accrefendi lib.2.-.-De

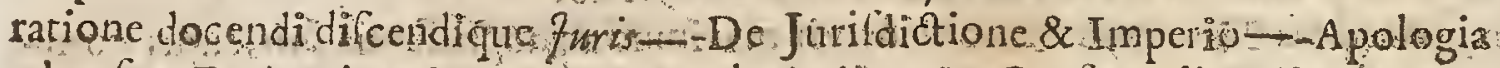
adverfus, Eguinarium Raronem-De Plagiari -In Confuetudines Eetdortum, Commentarius - De Sacri Ecclefix Minifterisis, ac Beneficiis-Dro libertate Ecclefix Gallicana adverfus artes Romanas defenfio-Epitola ad Sebaft Albefo. pinam Regis Gallia Qratorem Epiftola de Eranc. Baldvino-Defenfondverfus. Balbini Sycophanta maledicta.

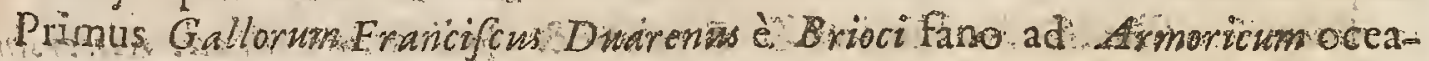
num genere nobili ortus explolis barbaronm glollematis puros \& limpidos. veterum I trifcoufultorum fontes. Juvencuti apentis tum vivi voce, dum apud Liturigas mag o nationam omnium concurli proficeter, tum Scriptis quibus: etamnum fibi ipfi fuperfes immortali cruditionis \& eloquentia bude commendátur Fuitacenimo quidem judicio, red memor iâ minus felici, neque unoquam nife exfriptopralegebat; coque factum eft, ur in Germanico irinere, cum a cel cbribus pafin A cademiis honcris causà̀t ferè fit ad pralegendum rinvitaretert, nec esum continu? voris \& precibus oblequeretur, à nounullis rerum imperitis \& in iquè judicantibus habitus fut iljdoction. Sed hoc inane vulgi da tanto vio judicium parta jampridem apud eruditos fama \& exittimatio tacilè

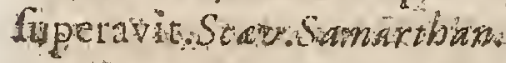

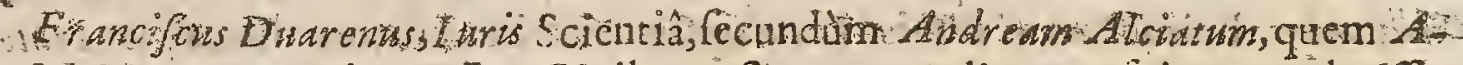

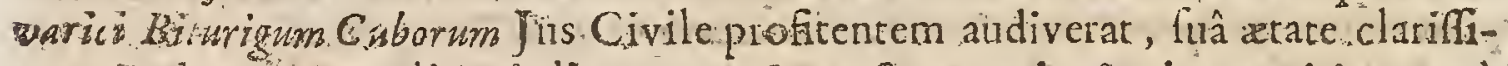
mus ad quam \& pulition literatua, \& exactam antiquitaris cognitionem d Magifro lio edoctus adjuxit. Duarerii nunc Opera in magno pretio, tati de-

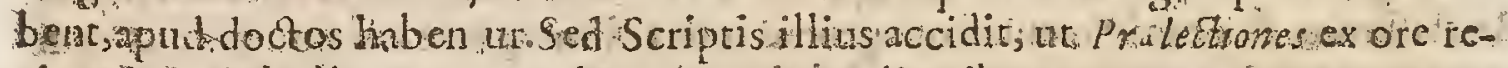

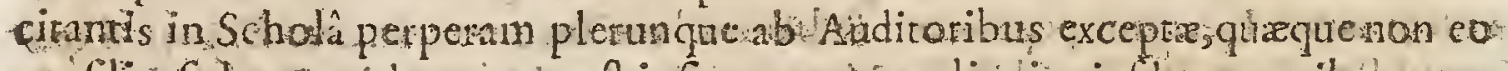
conflio frebantut ederentur, pof ipfins montem reliquis ejufdem operibus, qua

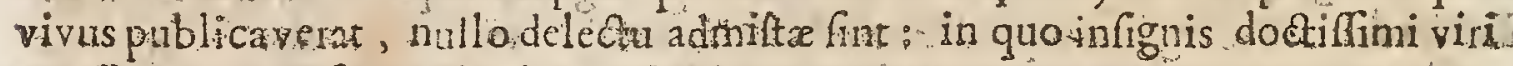
manibus injuria fata ett.Thran.ad A 101559 .

Hinc Autorem Cojacius ipfe plutimi lemper fecit; cum inter quattor Frant cifcos ( Franc Duarenum, France Conamum, France. Hottomannum, Franc. Baldrin*m. ) qui eâden arate earden feienniam profitebantur unum Duarenwn fibi placere $e_{2}$ ateros I th tantùm del gutirire diceret.

Dnarensis proterquam quòd eloquentià, dicendiquue genere fuavi \& facili omes fui temporis furifconfultos fuperavit, docendi ratione maximè antereffit. Primus enim diu astè Methodicam docendi rationem uon obfervatain iterum revocavit, reftituitque-Andr. Quensted.

Quantam coluerit Franciens Duarenus Iuriforwdentian , ejufque ftu- 


\section{CELEBRIOR UM AUTHORUM.}

dia promoverit, teftantut to ejus graviffmi viri opcra. Docuit in cele-

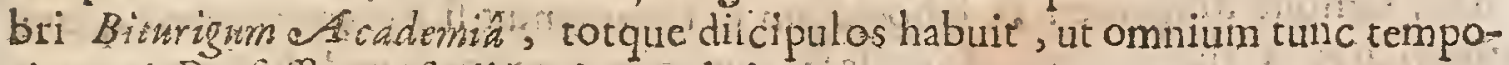
ris I uris Proferforum facile princeps taberetur.Gul.Rovit.l.in Promptuar, I con Illunt. Viror.

* Drareni libir de S.Ecclefia Minilteriis permittitur, fitamen corrcetus fuerit. Libellus verò eidem adjunctus, cui titulus eft: Pro libertate. Ecclefre Galli-

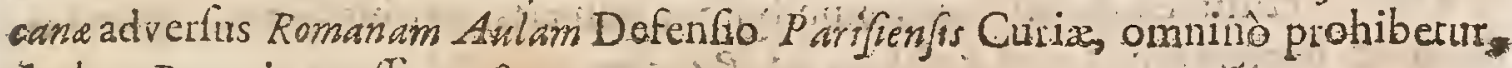
Lndax: Rarne impreflius $168 \mathrm{I}$.

Hoc ejus Épitaphim:-

Fiator,parge bismom floribus; Flos ille- - urifconfultorkm Francitcus Dunremus bic fatus eft, doctrinâseruditione, moribus clarus. In Gall.atque in Belg. Acadernits.

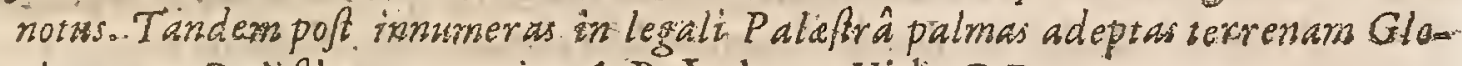

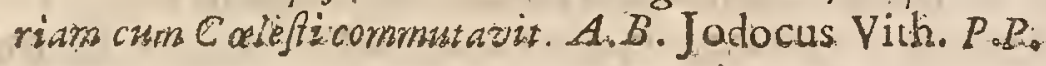

Opera ejus fimul prodierunt. Ijgżo.

\section{ONRADUS GESNERUS}

Edicus, Philologus, \& Polyhifor eximius, natus elt Tiguri Anno r516. Clar. A.d
Obiit.an.1565.

Vir pius \& omnigenere virtukum ornatifimus', omnia Natura arcana per ferutatus magis cogitans de aliorum utilitate promovendâ, guıàm póp ria: (âlutis rucndx curam rationemve fufcipiens, in omni literarum genere, prefertim vero

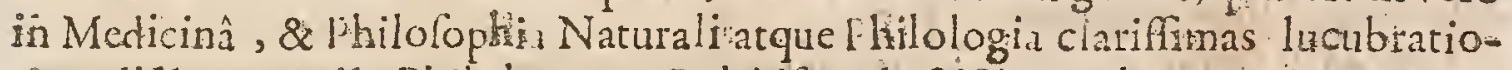
res edidit;exat cnim Philologus \& Polyhiftor doctinimus, lumen Germantd, \&

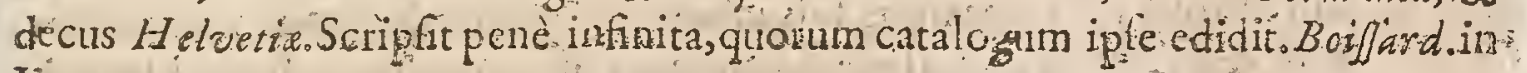
Ičon.

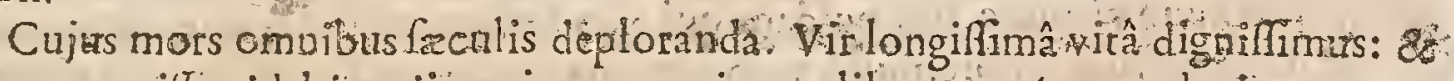
quam exegilfe videbitur iis, quirtatem ejus ex librojum (quos plurimos ac ut-

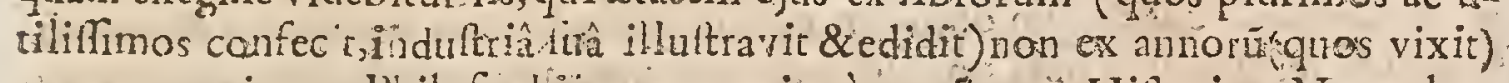

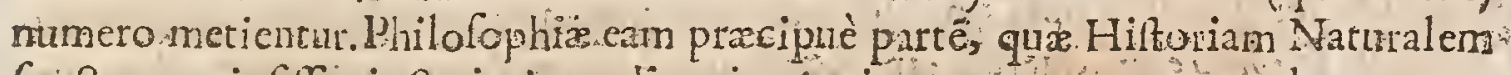
fpectat, copiofflrinis Scriptis explteavito Antiquorum quoque compluramonu-

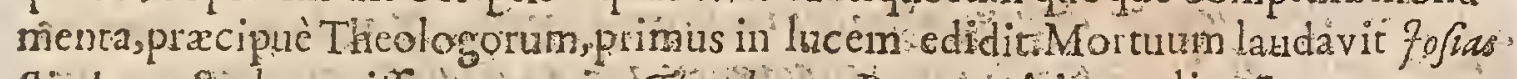

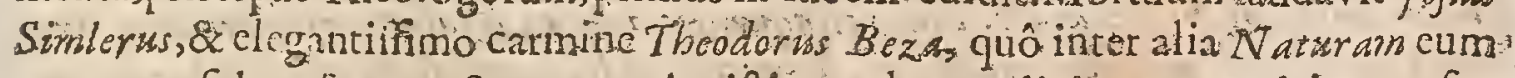
tanquam fidum firoum Sacrorum Antiftitem plorare dicit, mutan deinceps fls:turam, nifi ipfe mortius loquatur. Thusan.ad ann.1565.

Conradum Gefnerum, Tiguri honeftis quidem, fed tenuis fortunx parentibus nitum inter æatis noftrx clatiflimos homines fua tum pietas tum eruditio, probitas denique fingularis merito collócarunt ut plurimarum linguarum, ita 0000 2: omnium 
omnium Phyfices partium, \& intimorum Nature arcanorum uf uce adeo peritum, tamque diligentem ac laboriolum Scriptorem, fi ftylum excolere quàm fimpliciter ex aliis optimâ fide colledt pleraque proponere maluilfer, neq; mots jillum immatura fuftulifet, etas hac noltra in unico Gefnero cum Varronern alte- rum, tum Plinium quoque renatum fuerit habitura. Theods Beza in Icon.

Conradus Gefnerus Tigurinorum decus immortalc. Cafaub.in Athen.1.7.c.18.

Verè fanchifimus, doctifimus, omnibulque numeris abfolucifrunus, \& torius Europe ornamentam Zanch Epift.1.2.ad Bulzing.

Conradus Gefnerus erat homo Itrpenda eruditionis. Kong. il B Bblioth.

Nobilis ejus fama, quam praclaris Scriptis fuis fibi peperit, jampridem in omnes Orbis Provincias emanavit. Caßp:Wyer Comment.ad Mitrbidat. Gefneri.

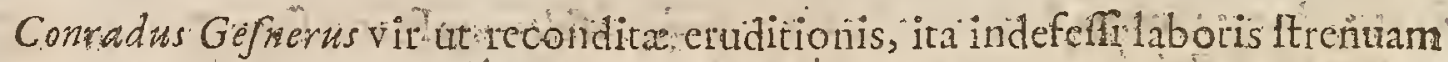
openm navavit in illutand a anmalis omnis fpirabilifque Nature Hiftoriàcui præcateris palman defera. Levin.Lemnde Miracul.occult. Natur.p.6.

Gefnerus verò ex Scriptis non tam ingenii, quàm laboris \& indultrì laudem culit, ut funt omnes Germani in ftudi is laboriofifimi : quippe tranferipfit qua priores dixerant \& ipfis corum verbis retulit. Roland. Maref Epift I.2. Epint. 26.

Gefnerus de omnium animalium Hiftoriâ fuftermè fcripfrt ; quam finiliter materiam Ulyffes Aldroadnus. immanibus voluminibus profecutuseft. Sed, liberè dicam, P linii paucos de Auimálibus libros pluris fecerim, guàm iftorum de iifdern infiniros. I dernibid.

Ut Icm in bonis Auto ibuis convertendis operam navâfent Conradi Clamerus, \& Gefierns Tigurini,nifi cos nimia ligentia extra metas abripuiffet. Huet de clar. Interpret.

Gefnerus milt ac varix lectionis, fummaque diligentix: Auctorminimè contemnendus. Scaligerana I ${ }^{\mathrm{a}}$ P.79.

Conridus Gefnerus inter Univerfales \& perpetuos Catalogorum Scriptores principatrm obtinet, virmaximis fuis laboribus optimè de Rep literariâmeritus.Fut enim \& vertendo \& colligendo ominum diligentiffimus. Injurii funt \& fugrati in bonum virum exteri guldam, gui ejus Scripta pafim traducunt ut non latis accurata, \& folô laborê nullô verò ing enio, fpectanda:Qrod familiare folet elle in Germanos convitium omninm exterorum; qui, fi non haberent à Germanis congeltas rei literanixopes,nnguftis certè fecum thabitakent. Adeo (quxVoffi Prafat in Theol Gentil.quecela eft lawdis nibil sperandum, guocungue etiarn ju-

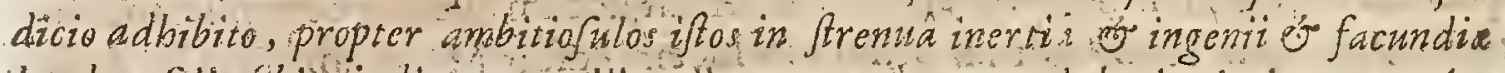

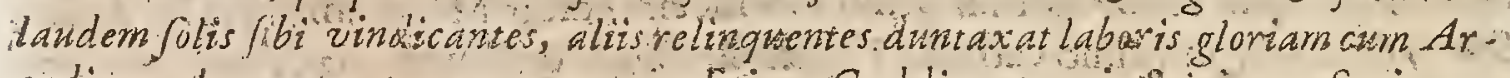
cadico, ut logunntur, pecore cormmuits. Etiam Gaddius, renuis \& jejunus Scriptor, minutam åitigentism in illo repreliendit, qui ipfe montes parturiendo non nifi mures parit. Rolandus quoque Marefins in Epirolis his Philologicis, opere doAto, Gefnerwn alicubi ut Locorum Cornmunim Scriptorem exagicat, cum Gefnerus \& Gefnero finiles inter cos fint, qui Sylvas ferant, ut babeant alii, quas cadang 
\& excidant. Non nego quidcm,nævos ineffe \& errores ejus A utoris Scriptis, fed illos facilè abforbet improbus labór ac infignis ejus utilitas. Aquiùs de viro ifto Ionfrus Hist.Pbilof.lib.3.c.20.\& Bailletus tom.2.pag.I5. judicat. Confiderandum enim, quot quantilque laboribus unus vit diftectus fuer $t$, Phy ficis, Medicis, Philologicis; quanta leculi iftius ob meliorum editionum defectum imperfectio. Quin potius totaipf pofteritas ob fumma illa \& Herculea in re literaria mcrita betricta eft. Infinita propemodum fun \& incredibilia, qux-vin ille nondum L. amos natus, cum moreretur, in omni fudiorum genere perfecit. Unnus penè Bibliothecan fcriphit, Quàm hönorificum Inliz Cafaris Scaligeri de Gefriero fuerit judicium, ex irs literis Sylvij,I.C.Filit,Scaligeri, colligas, que in Siberianis Epifolis p. 45 g.habentur, quihus illè Gefnerianicitiam ambit, eumque rogat, ut tio teftimonio paternorum Scriptorum Splentorem gloriamque angerat. Tuarn, fcribit ille, autoritatem tanti facio, at mullius arnicitian magis petam, aliun magis colam neminem.Dan.Georg: Marhof. Lolyhitt.p:199:200.

Dignus : quoquesuimemorenr Conradus Gofnerus anno 6 g. fiperionis feculis mortuas, qui inter Scriptores plurimos, quos in Pandectis \& Biblio thecâ recenfek Philofophorum quoque Poëtarum, Rhetorum, libros \& plerumque v tam exponit, idque iaduftrià quâ potuit, fummá. Quem ejuts labior crn fofas Simberus pari felicitate poftea awit. Utut veròmendis lcateat ifta Bibliotheca quàm plurimis; longè plus tamen laudis obea, qux benè dicuntur; quàn reprehenfonis, ab menda nonnunquam lev ia meretur: fo.fonginis de Script.Hilt. Philofip.3io.

Conradus Gefnerus vit fuit infignis non molo eruditione fua non vulgari, fed etian humanitate, integritate \& pietate quibus ornatus futit. In Theoria \& in Praxi Medicinzexcelluit. Hujus illufte dedit fpecimen faaatione maximi agrorum numcri qui incurabiles cenfebantrix; quippe qui diverfis Apoptexis , Hydropibus \& Epilepfis laborabant. Ingenten incomparabilium Scriptorum catcrvam polt fe reliquit; adeo ut : cum ratione dixexerit Beza, unicum Gefucrum tota clarulfe Scientia qux divifim in Plinio \& Varrone deprehenfa fucrat-_-Gefnerus contexuit iple Bibliosheca fua propriz vita Hiftoriam, in quanum abfervata dignm fcripfic. Ingenue nimirum fatetur Opeca fur tam accusatè \& tam diligentes elaborata non clfe ac exoptandum fcret, è quòd proptew fortis fux miferiam tenerctur libros at viotum fibi comparandum elucubrare, \& proinde eadem fine rora evulgare coactus a binis illis inexorabilibus Deabus paupertate videlicet \& nece/juten otio non frueretur fafficicnti wt eum perfectionis gradum attingerent ad quem illa perducere potniffer fr.folius gloria Ttimulis ad feribendum impulfus fuiffet: Feruntamen, addit deinde, ne confe/sio maea defpicabiles reddat libros mevuligatos, boc de me predicare anfirn quiod cmnes itlos. quodammodo fuperent qui in eadem argumenta que ipfe pertractavi:

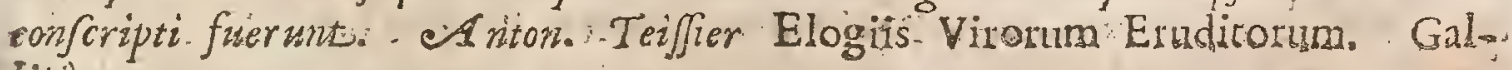
ficiè.

Ejus Opera omnia prodierunt Erancofurti Ann.:617: 
Hoc ejus Epitaphium Tiguni in Helvetia:
Ingenio vivens naturam vicerat omnem,
Naturâ vietus conditur boc tumulo.
Plinius bîc Jitus eft Germanus, perge, Viator,
Gefneri toto nomen in orbe volat. citur.

* Conradus Gefnerus in Romano Lndice inter Horeticos Prime Claffis reji-

\section{PETRUS NANNIUS}

Clax. Al. U. A Lcmaria Hollandie Oppido natus, Canonicus Atrebatenfor, comis \& blanMDL. munibus omnium votis luccenturiatus eft. Carus in primis, ob fingularem erudirionem, excellentibus in Belgio doctrinâ viris,fummâque diguitare pradiris;in his Nicolao Everardo Prefidi Mecblinienfh doctifinifque ejus libris; \&. Atrebatium Antiffiti Antonio P'errenoto, polt Cardinali, \& aliis: Famâ dcinde, ut fit, in-

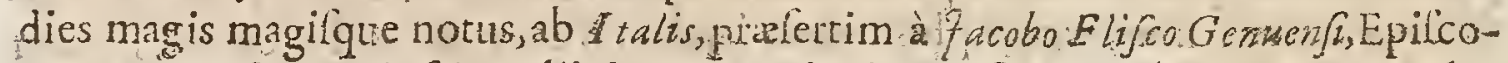
po Savonenfî, magn s. Atipendiișin Italiam invitatur. Cum jue linguâ utra que doCxiflimus, atque in Auctoribus tum facris tum profanis, egregiè verlatus eflet multas utruifque generis icciptorum veterum, Derrofthems, Plutarcbr, Synefir; \& de Christianis Aibanafin, ( bry oftoma, Bafliit, Athenagore, aliorumque lucubrationes Latina a civinate donavit. Sed \& e fuo iple peru plurima deprompfit, in his - Mifcellaneorum libros decem, Panegyricas \& Litzerarias Oniones totidem, quique prex cateris Scr ptis palmam ob:inent, Dialogitmos Heroinarum leptem. Nam in hoc genere regnaffe eum, preter Italos acuti judici homines memorat Cornelius $M$ ufins. Scripfit \&in Cantica, ac Salomonis Sapientiam commentarium. itemque Notas ad Arnbrofii adverfirs Symmacbum Relationcm. P fadmos quoq; Davidis plurimos non infeliciter verfibus reddidis: quos cum lacobi Latonit $\mathrm{P}$ falmis Plantinus evulgavit. Moritur Lovanivi 1.57 . ætatis 57 . pro fonere a fuccelfore Cornelio Valerio laudaur. Tumulum ipfi in D.Petribafilic: gratis difcipulus $S i$ gigimundus Fredericus Fuggerus poluit. Anb. Wiraus.

Conrado Goclenio virâdd functo, Närninu unus, qui fuccederet, dignus omnium. calculis eft judicatus. Vir fuit ingenio facili, ad quidvis prompto, \& ad lamanitatem omnem ac fertivitatem facto: viris in Belgica, dx extra, magnis carus ac grarus.Valer. Andreas.

Potrus Nannius, Lovanii dị in Bufidianẩ Scholà Gracam Latinaxique linguam magn erudirionis non vulgaris laude profelfus, multis ingenii fui editis monumentis; quibus rem literariam nulltùn promovit. Thwan.

Trrâque i. iguâ doctiffmus, atque in Autoribus cùm facris tam Prophanis eyregiè verfatus. Mctch:Adarm: 


\section{CELEBRIORUM AUTHORUM.}

Vir Gracé Latinégue perixiffmus, Franc。 Svoert.

Vit infigni literaturâ, qui utrâque facundiâ valet. Lil. Gyrald.

Critucur diligens vocatur. Deinotieri.

Viros aliquor infignes, \& Profétores habuit Collegium Buflidianm : inter eos $P$ eirum $N$ annium, qui alios poft $f_{3}$ ut mcum judicium eft, reliquit, \& fortafle relinquet. Iipf. Livanuwr 1.j. c. 4 .

Ubi in eas difficultates atque angultias incidimus, è quibus nos incolumes evadere polfe diffidebamus, doetifimonm yirorum, \& quarum in itteru magnum atque acte forcm effe judicium; auxilium experendum mihi elfe putavi:

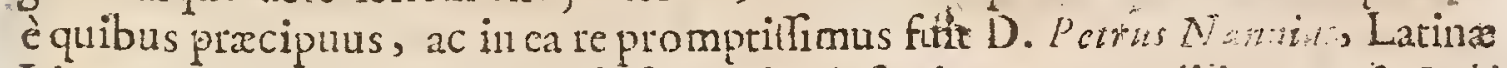
Lingur apud Lovanienf ' Profellor, cujus infignis-ac ara eruditio tam eft Orbi nota, ut me prxcone non egeat, qui inearrparabili fuâ humanitate egregiam mihi navavit operam; \& quem ego quoque ad hocimpuli, ut Ambrogenas En? las, in quibus permulta funt, que non omnibus funt obvia, fuis Scholiis illıAtrarct. Quod fà ab co factum eft rantà diligentià, tantâjue doctrinâ, ut fi non alias, vel boc flecm nomine, Ambrof hatc novam Edirionem plaufibiliom rem gratiorenquc futuram Lperem. Lan. Cofter.in Epift Dedic. Ambrof. Oper. prefix. An 5 ij.

Opera cjus teftantux eum fuilf bonm Criticur, excellentem Grammaticurn, peritum Oratorem, Theologix, Juris \& Mathclcwin gnarum fuiffe. Moreri Majori Dittionatio Gallico.

lauca in 'acris \& Profanisfublimia occutrunt, apud Grecie veteris \& antiqux Rnme Scripto:essadqux penctrans illud ingenium non pettigerit \& eximiis Cuis Operibus nobis non clucidaveric; Operibus inquam quibusinfigne $N$ annib nomen revivifeet vel invita anoum frric, qux non minori amore quàm veneratione à Doctis excipientur. Ifaa . Bublurd. Acad. Scientiarum. Gall.

Locum eriam fum in lnterpreibus tuetur Pctrus Nanins, fidus Senten-

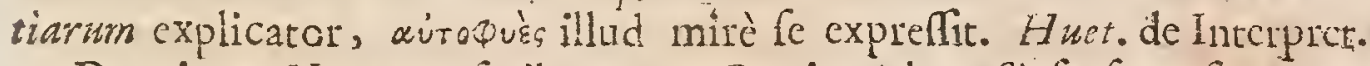

Dominus Hermant frib t eum Beati Athanafii ferfum fic pervertiffe. pluribus locis, ut cum nobis explanne debuiflet, qua obfura in Grecis: extabant, in plures errores impulerir Authores quii cjus verfionem fecuri funt, adeo tt hi, authoritate quam adepti erant, plures alios deinceps fefellerint. Godefrid. Hermant, Prafar.in Beati Athanafii vitam, Gall.

Eruditio fingularis in exquifitifmis fientiis, \& in omni politiorum lite: Larum Gracarum \& Lativ. rum gencre, Viri uque adeo dodi ac filit petrus Nannius Al:binariâ, Urbe matitima Septentrionalis Jollandi, oriundus, amplum temporis fparium exigeret, vel ad fimplicem ejus adumbrationem delincandam; utpote qua dignus evafit qui cenferetur inter primos Gentis Cux Literatos, \& iis requipararetur, qui inmortals fame pennis fub Eurom peo colo sloriofi volant. Vividiffmo \& ad omnia prompro ingenio valuit. Ghilini Theatio Virorum Literatorum Italice.

* Ejus Scholiain Sapientiarn Salornonis, in mulis locis expurgantur in Ino dice Madrit. edit. anu. 1667. 
Ejus Mifcellanea rom. y. Lamp. Crit:Gruteri contiventus:.

\section{Hoc cjus Epitaphium:}

Petro Nanno Alcmariano, Presbytero ph Canonico Atrebatenf, Viro Doeliffimo, Humaniores Luteras in Collegio Bullidiano annos xorit. profefjo: Sigifmun dus Fridericus Fuggerus, Baro in Kirchberg $\odot$ Viana $B$. M. \& Amico paterno Memor. virtutis ergô juflu parentis pofo Vixit annos LVII Obit CID. IDLVIT. XII. Kal. Augufti.

Nanni Caftalidum decus Sororums.

Quifguis te videat, tho gue foetus,

Hand Nanum vocitet; fed ô Gigants.

\section{ANTONIUS: GOVEANUS.}

Clar.An.B. MDL.

T: Vftanus, Ano I565. ex immodico peponum ufu obiit. Primim Tolorá deinde Divone Cadurcorum, postè Valentia \& Gratianopoli Jus. Civide profeflus eft.

Scripta ejus hac funt :-Varia: Letiones - Die fubltitutianibus Commen-m varius - De Turifdictione libri duto - Ad L.Gallsm Aquilium lib. x. - De Ture accrefcendi lib.r. Commentarii in titulum digefti ad legem Fabidiam. - A nimadverfonum liber unus - Caltigationes in Virgilium \& Tercnum -.manarrationes in Ciceronis Orationem contra Vatinium - Eritica Logices pars ectans cum Ciccronis Topicis-..-. Commentariius in Cicerone Topica,-...-.-Comment. in priores libros: Epiftolarum ad Atim cum, \& libros de Legibus -.....- Refponfo ad Petri Rami calumn as pro AriStotele--.-Eligrammata \& Epiftola-m-.Porplyyi quinue yocum Iradudio Latina.

Is genere Lufrtanus, fed adoprione, (ficut ipfe, quo eratanimi candore, par

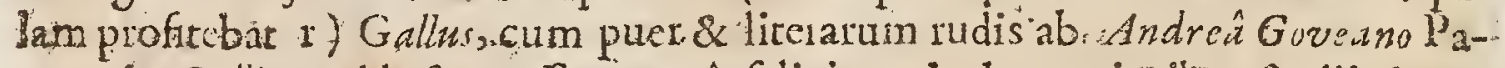

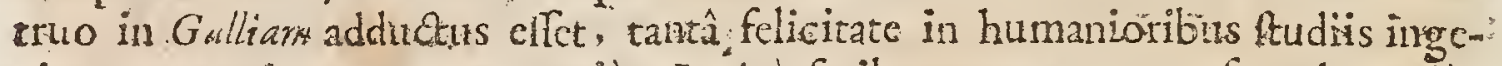
nium cxercuit, ut nemo puriis Latine feribcret, nemo verfus elegantius

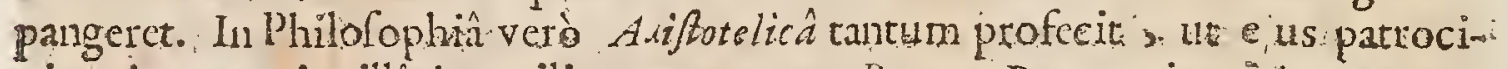
nium jam tum in illâ juvenili atate contra Petrum Ramum ejus impottunum oppugnatorem magnâ cum laude fufceperit : Poftè s, yuafi omnium foien

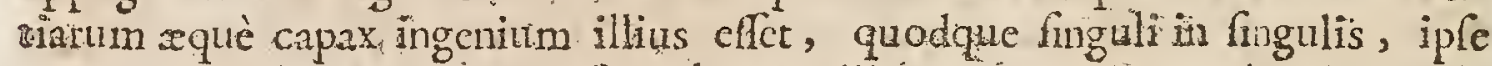
unus in omnibus praltare pollet, ab e Emilio Eerreto, qui Avenione jus Civile docebat, cim Lugduni privaris ftaduis intentus defideret, ad illius perpleæx ficntix profeflonem cvocarus cft; in quâ. rưfus cxiguo tempore tantos progreflus fecit; , rationem veram cnodandanm ex antiquitite fpinofa-

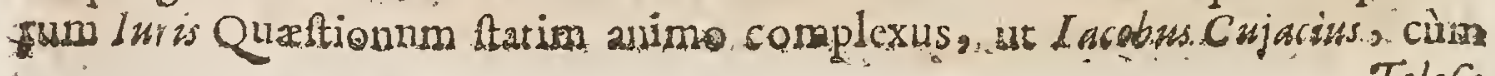


Totofa ante unde undccim anros in. Vipiani titulos fariberct, jam tum reftaw

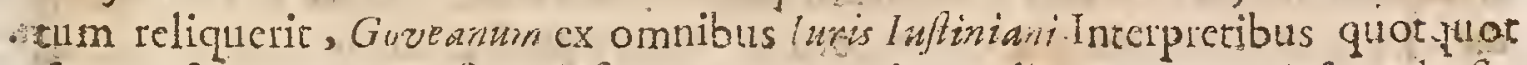
fint aut fuerc, untm offe, cui, fi quiratur, quis excellat, palma defurenda fit. -Thuan. ad an. 165 .

Goveanus cummuni doctorum fuffragio hac afficutus eft, ut \& Poüts elcgantifimus, \& fummus lhilolophus, \& prattantifimus I uris Int rpres haberetur: Konig. in Riblioth.

Auchor Biblioshece Delphinat $\hat{n}$ s affeverat illum fuilfe accularum, quid de Numine pesperam Yi lentic locitus effet adeo ut ipfi incubuctit cam culpam àfe depcldere; quod \& praftitit eximia oratione qux Manu-fcripta quondarn vifa fuit, in Bibliotheca Encmunai de Rabat primarii Prafidis in ذelatu, Gratianopolitano. Gallicis.

Adolefcens [larobus Cujacius] Antonæi Goveani hurilconfulti ingenium admirabatur, fed indiligentiâ hominis. notakâ, nihil deterritus elt, deterritum iri fe diccns Iure tractudo, fi homo Lufulmu: tanto ingenio, tamque fubtili, la-

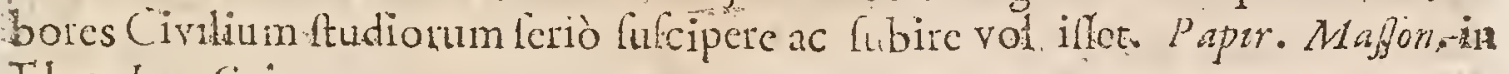
Elog. Iaic. Cirjar.

Govear: doct is elat vit, \&Valcns Dialicticus, optimus Poëta Gallicus:

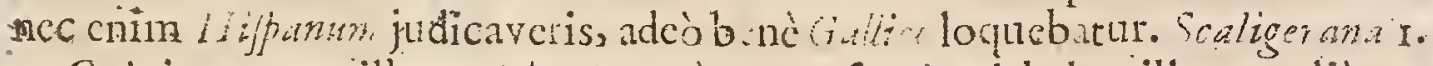

Calvinus vocat illum dibeum, cùm nen fucrit; dcbebat illum mcliùs noffe. Scaligerana pofterior.

\section{GULIELMUS POSTELLUS.}

$\mathrm{R}$ Arentonius Normanms,centcnario proximus anorgs. obiit.

Scripfit varia inter qua prinum locim obcinent: Tractatus de Repu-

Clar.An. B.

$M D$ L. blicâ Atbenenfun - Cofmographia S. Terre - Liber de Hetruria ... Clavis Abrcondirorum - Iinguarum duodecim differentium, Alphabctum - De Candclabro Moifes - De (rbis Terre conco:diâ.

Hic apted Butrentonium Normanie vicum obfcuris ortus parentibus cùm ingenium apprìnè capax \& ad concipiendas artes idonetz ì à Natura bonitate accepiffet, melioris difciplina fubfidio detititutus, câ nitidioniss cloquerixix facultate -caruit, qux una maximè doctorum hominum fcriptis dignitatem atque fplendorem afferre potct. $i$ dolefentiam vix attigerat, quando ipfe adhuc docendus difficile docendi munus aggreflus eft címque multos vitæannos in vicinorum liberis crudiendis ac perpetuo ftudiorum labore raduxilfet, tandem è Lndimagiftro Pagmo creatus a Rege peregrinarum linguarum profefter in unbemvenit, ediris locupletibus Commentariis, quibus d odecim inter fe difterentes \& varie linguz luperbâ doêtinx oftentatione explicántur. Nequle multò poft vilendi Orbis cupiditate incenfus reliquit $G$ alizan', confectaquefedecim annorum p regrinatione, Vevertir demum confedit: vibi nécio cujus mulicrcilse preltigiis abfurda quxdam \& impia de Religione commentus eft, qux deinde Lutetic frequenti auditorum,tubâ publicavit: cumfe morte obitâ revocatum

$$
\text { Ppp } 2 \text { ad }
$$


ad fuperós \& juvenili xtati reftiturum ineptè mcntiretur. Magna quidem fóli$d x$ i lebis admiratione, prefertim eorum ui ante profeetionem cum noverant. quodvid licet meminifint jam vetulum \& canefcentem hinc abiife, quem. longo poft intervallo reducem nigrantc barbâ \& xvi fore confpicuum cerıerent. Sic enim cos captibar, fmulatoque per pigtnenta miliaculo fidem lits nugis atque audtoritatem conciliare conabatur. Sed urgente magiftratu violatse perfuafionis reus alifugit in Germaniarm $\$$ in Ferdzandi Cafaris aula tamdiu fuit dum recantatis erroribus in patriam redeundi \& publice proficendi facultas 2. Principe reddita eft. At cum eodem recidere videretur, ex Senatus dccrcto in D. Mar. ini Monafterium relegatus eft: Quo in feceflu vinibus integris ad alterum \& octogefimum hujusfeculi pervenit annum csntenarióque proximus interiic. Samarthar. in Elog.

De Pofslli, Henricus Sicphani narrat introductione tractatús de Conformitate Miraculorum aniquorum or novorum, cap 14.p.g. 100. illim publice dixilfe quò, qui bonx R eligicnis fpecicm cffomarc velit, eam ex:tribus iftis Chri-

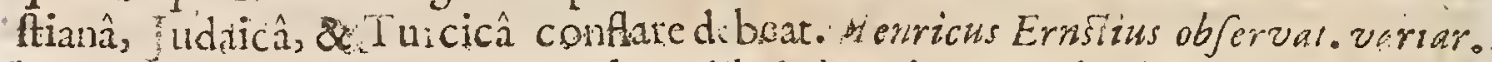
lib. 2. cap. 36. Pof tellura à quibuldam libri de tribus Impoftoribus autorem habe-

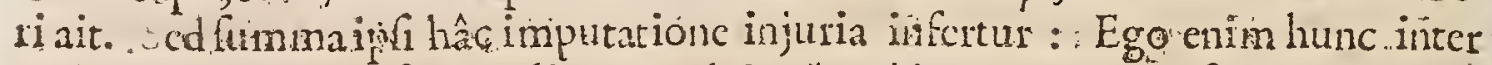
Aibeor vel Deiftas referre nolim, quod \& Theopbilus Raynaudus facit, qui $D_{c}$ cistarum parentem vocat, qui Deum wazbr admittere content cæetera Chrifiana Mýteria pro fabulis huberent: Nam onnia alie reftarm liber ejus de Naizvitate Mediciorisuliria, quem inter sinongmos relarum mirotapud T. Plucciwn, cum ejus nomen fronte libelli extet. Hune qui legerit, illum Chrifto \& Chriftanis Myfteriis univeriam rerum natuam quaf fufinendife deprchendit. Multa alioquin hab t, qua cum receptis in Ecclefa fententiis pugnant, errores quoque multos in Religione; paradoxa in illo multr funt

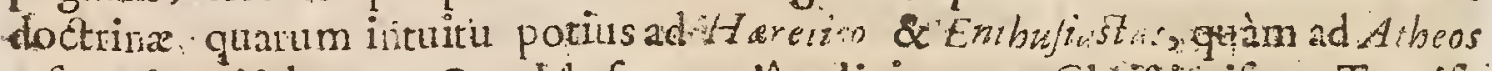
referendus vid batur. Quod de formandâ religione cx Chriftinimo Tunifmo \& Tudaifrno dixit, fortè co pertinct, qtod multa Chrifianorum monumontorum enqavè in ipfo Alcorano alifique, qui apud Oricntates \& Tudros extant, libris deprehenderet. In Tudrortin quoque vetuftionibus libis, quos

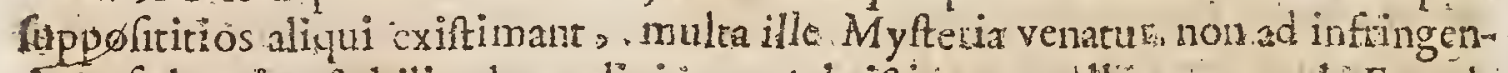

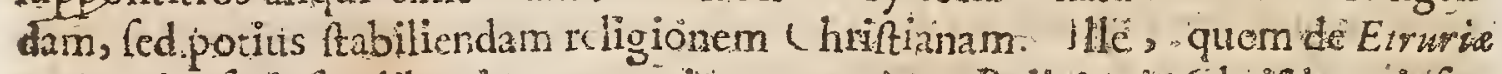
Orip?mbus feriph liber integra capita pro veritate Religionis Chriftianxinferta habet; ut mirari faris non poffim, quid in mentem venerit Rainatr, qui illum Religioni Chritianie adverfum faciat. Scdinulta funt in Rainasdo inepta \& falfa de Sciptoribis judicia. De. Zoftello legi amplius poteft $p$ opelinére in li-

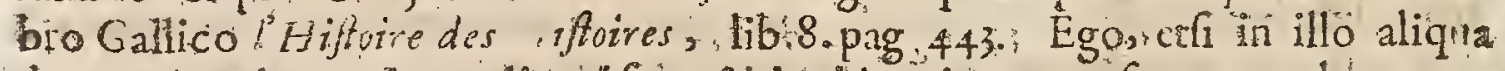

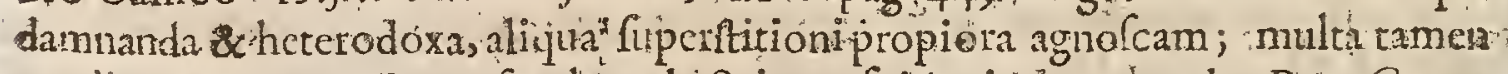
qutè excogitata, \& profundün acorinam. Cpirantia deprehendo. Dän. Georg. Mcrb.f.in Polyhift, p.75.74.

Poftellus, non fine lorore mili nominandus; quippe qui nobis Arabicalina gux praccptiones radiderir bibliand: de Rar. Commus omn. ling. c. 2 . 
Poftellus, Abyftir Scientiarum dictus; Polyglottus, Mathematicus, Cabbalifta infignis. Ejus, de Orbrs Concordiâ, liber prex teliquis laudatur: Hofmun.

Vir capite motus Postellus, \& non integre omnino thantafixe, magnus Peregtinator \& Mathematicus \& Hareticâ pravitate nonnihil adfperfus.t runc. Bacon. de longruit \& brevitar: Vit. in Hom. fect.19.

Gulie!rius oftellhs ingenii fuit admodum capacis, Lirguarum Orientis inel-

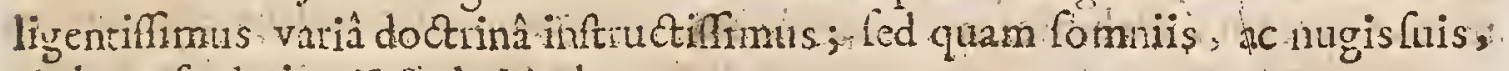
multum foedalit. Voff? de Mathernat p. 25.7.

Quidam d yrta noftris temporibus aufus eft fefe ipfum Tobanhon palam profireri, quem infants fed ni:ilominus ficleratus Poftelut fele animam Adama haberc jactians, fratrem fuum 1 utetze vocitabat, \& ille quidem. Tulef fuir crema-

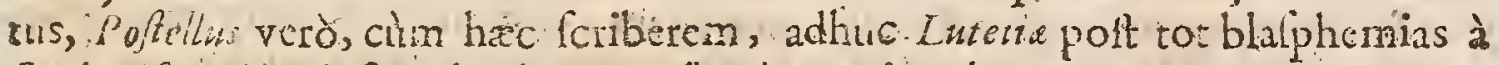
Sorbonifisctiam ipfis tolcrabater. Theod.Beza in Iob.20.ver. 22.

- Toffellus excellens thilofophis, Colmographns, Mathomaticus, Hiftoricus ftultuis. linguarum non ignarus fed nullius ad ung uem peritus. Invideo illi $A r k-$ bicam linguram Scaligeruint i. p. 125 .

Poftelimas Syru docuit, neminem vidi qui Pofello melius feriberet; füt verè ftultus, namalioqui fuiffet combuftus : per vicos curcbat Fecir libutun debere forminas per foeminain falvari, ut viros per Chrifurtu Poltellis erar ftultus; fuerat teceptus à le esittis, poftea fuit rejectus ab illis extra jocietatem.Scaligerand polterior.

Si quis Poftellum itèm commendare vellet ut commendari non poffet maisis. fufficerer ca notate quibus inftitutum de illo fermonem Iacobus: Gualteritus centcludit; ubi ( I thetik') \& ipfe anno-I578: docentem andivi, tanto auditorum-

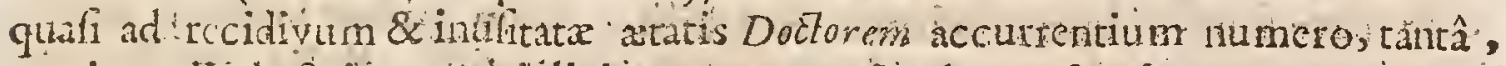

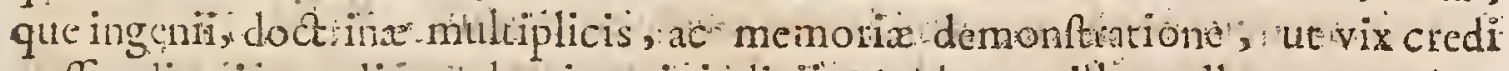

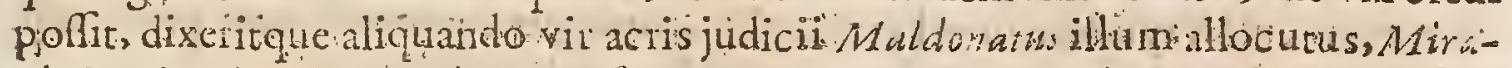
ri Se talcm in Mindo virum exifferes cujus utrque qutot verbur stot effent apopbibet

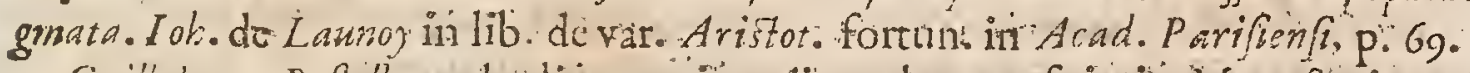

Guillelmus Pofellus ad reliquos vita dies relegatus fuit in Monafterium $S$. Marini Campontm Párifits, ubiob profundatn (quamvis confufan) ejus

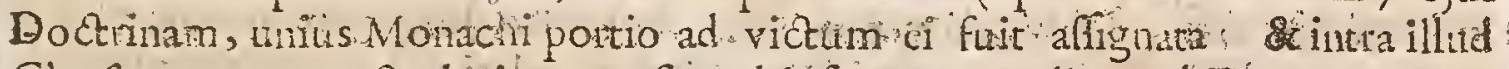
Clautrum antos octodicin manfit, ubi fupremun diem obiit, anno is $8_{2}$. plufquàm Cenum annos inatus: Eum illic inviferam ' concomitantibus Carolo \& arthol rn ao Maté, Pardicnfibus Bibliopolis, ad ipfo otendos libios quofdam manu exaratos Arabico idiomate, quos deinde excellêntififimo \& enuditif

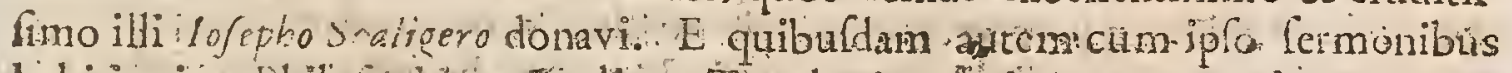

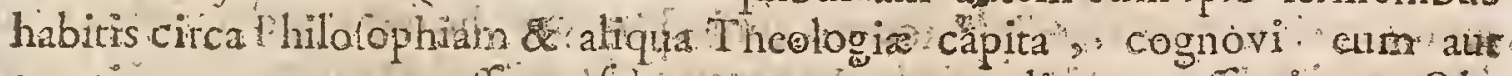
mentis compotem non effe, ant faltem nequam aut malisnum effe virum. $\mathrm{Ob}-$ fervavi prarerca eum ambitione \& arrogantia fumma turgidum ell $; \mathrm{Nam}$ pof plures chimxrios ermones in quibus nihil capiebam nec forfitan ipfe quid diceret intellig bar ( (inter quos imptiderrs ille alleveravit quemlibet qui eadem

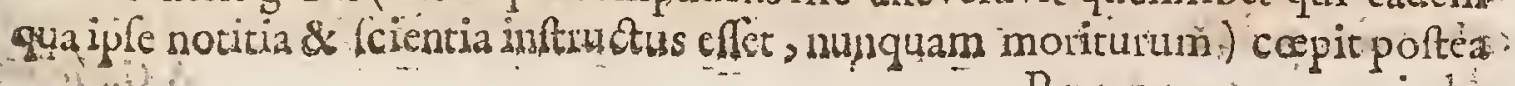

$$
\text { P.p.p } 3 \text { iade- }
$$


in "definotum "Reverendifimun Carolum Lotharingiw Cardinalcm on Jise convitia eructare, innumerifque ambagibus Prophctam quendam lefe venditare tentabat. Anton. Verderius Eibliotheca fua r, 95 . Gallicè.

Guillelmus Poftellur eo ingcni vigore, co acumice, caque memoria pollebat, ut prodigium quoddam scnleretur; Genius crat univerfalis,; qui nihil ignorabat, quique in linguan notitia cumprinis excellcbat: Preter Latinam, Gracam, Hebraicam, Chadaicam, Gyriacam, adco callens erat carum quarum hodie ufus eft, quas viventes dicunt, tht totum tcrartim orbem abfque inechrete fe peragrare polfe jactarct. Francifcus primus quiliteras amabat, \& Regina Navurra qua docta crat, Poftllum tanquam Muadi miraculum Culpicibunt Maximi Dynufx, \& interalios Cadinales Tumonerfi, ortarn:* gius \& Armaniarenfs cjus.colloquia quarcbant, enmque ut $\mathrm{P}$ incipem quadantenus colibant. Doérifmis adminationi erat, \& de ipfo dici folcbat tot Oracula quat verba ex iplus ore prodire. Sed erudians ille vir pra nimia $l$ abbinorum lectione, \& Aftiorum contmplatione, tim abfurdas opiniones aimo concepit, ut dicere aufus fit Iefurn brifum in Terram denuo venturum, \& hoc alveutu Monialen quandam Venctios fibi cognitam Fominaum Redemptilcem fore, quemadmodum lefu Chriftus Virorum Redemptor fucrat, Librumque de hoc argumcnto confcripfit, quem etiam infcripfit, De Virgine Veneta. Anton. Teifler. Gallicè.

Tales cfle poffunt 4.libíi de Orbi. Terra Concerdi Gul. Poftelli Barentorit. In quibus ferme folis niluil guod incptum aut lidiculum non effer immifür, fed univerfim religionum omnium informationcm infituit; noftranque prefertim rationibus tam propiiis, quàm ex aliarum confuräone defumptis, valiè quidem acutè fubtilicerque confirmat \& ftubilit. Idem A tuthor in libris de Rep. Turcarum, quos nondun paeiterlluxatà mente compofuit, Relig. Mabometi'a fummam, tiihil quiidquam vel minutiffmarum cjus ceremeni.rum pretcraitrens, complexus eft. Gabr. Nawd. in Irbliograph. Politic.

De Poftelli Grammatica Arabicâ penà cxciderat moncre enm cx wilgaribus Arabum Magiftronm praceptionibus collectam elle, lut non nifi Inte pre th vice functus:fit: quare cumbonam operam navalfe, deque Arabifino co nomine optimè meruifre, dubitandum non clt. Sed ke co hoc certó predicare poffum, eum Arali: angux non adco, quantum videri volebat; peritum fuife:

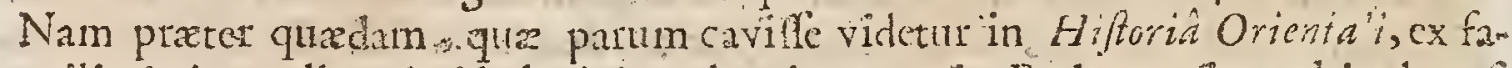
miliari ejus coliogrio id plane deprehcndere potui: Eodem cnim cubiculo uf fumus, \& meo lecto illicent, qum frerarem me cx ejus congreflu quotiditno aliqucm fruckm perceptum : Sed nond m hebdomadam integram mecum habitaverai, cum incurecere conjectus fuit, homo, quem infania als omuis malirix fufpicione vindicare poterat. Et qui aliter de eo judicant, longe decipiuntur. Impcritiam Arabifiri potes animadvertere, ex Inter pretatione primi capitis Alcorani quam $M$ fetrem vocant $N$ infiulmami, quam omnem preter triantt quatuor verba, infliciter reddidit. Iof. Saalig. in Epiit. j62. ad Seph. Feriwh, p. 648 . 
A Gulielino Poflello è variis linguis quamplurima Latine expofra funt. Fidam quidem \& preflim; doctrinx quoque, \&inigenii nötis diftinctam, at operofami anxiam interpretandi rationem eruditus ille vir executus eft. Hut, de Clus: Interpiet:

* Hic Aushor inter Hereticos prima Clafis locum habet in Indice Tridentino.

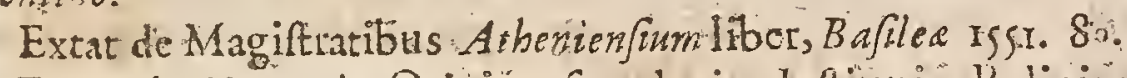

Extat de Hetruric Origines five de cjus Inftitutis, Kcligione ac Moribus vezuftis Opus Florentio Issr. $4^{\circ}$.

Extat abfeonditorum à conftitutione Mundi Claxis. Addirus eft Index ab eos confriptorum libromm Amflelod. $26_{4} 6.12 \%$

Hoc ejus Epitaphium Adriano Tartriero Med auctere:

Poltellus poftauam peragravit, plarimapajpus.

Propietate, polos Pariilis petitt.

Obiit fexto Septembris 15 SI. annosnatis 96 phil. Labbe in Thef Epit

\section{ANDREAS TIRAQUELLUS。.}

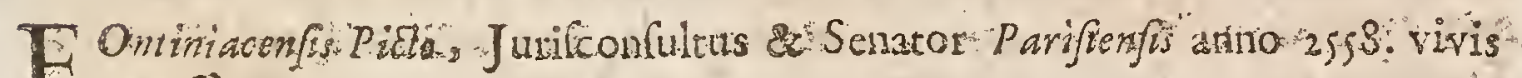
excefit.

Reliquit ampliffirmos Commentarios de Nobilitate : de PrimogeniClir.han MOL:

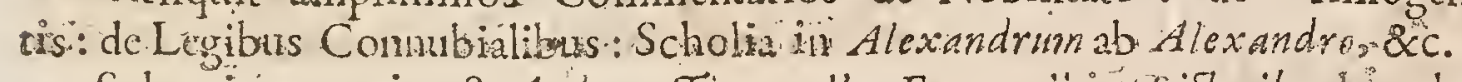

Sub cxitum anni 255.9.Andreas Tiraguellus Fontenait in Fittonibus loco how

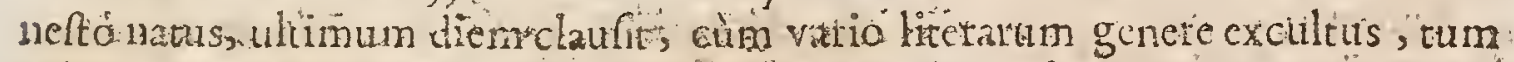

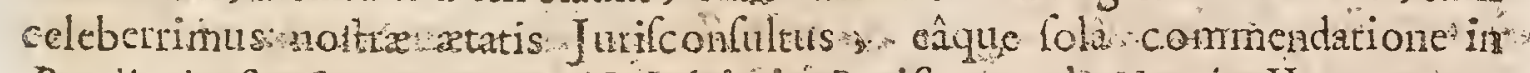
Burdigalenfem Senatum Francifco I.dein inis Parifenfem alis:Henrico II... coopta-"

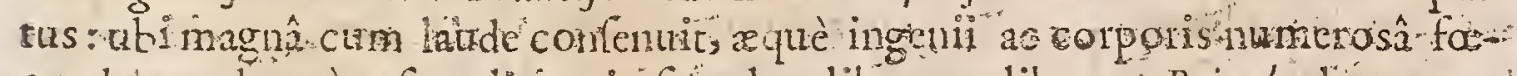
cundu's prole : cum fingulis annis fingulos libros ac libero $\mathrm{s}^{2}$ Reipub. daret; $\mathrm{ma}^{-}$

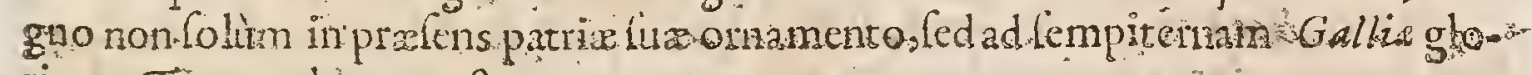
riam. Thuan.ad ann. xygs:-

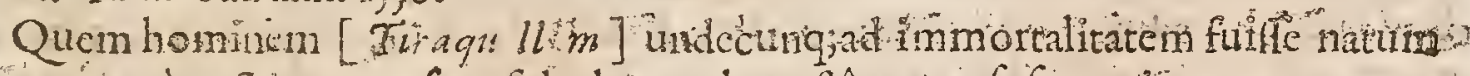
diceres : cùn \& humerolam fobolèn ex honeftà uxorc fuféperie , que genus propagatet, \&"ingentenn Iibrorum aumeram ediderit, qui nomen eternitat

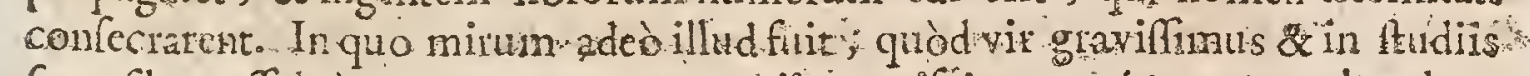

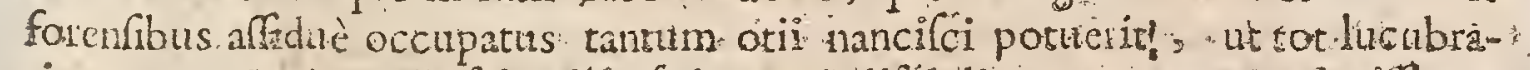

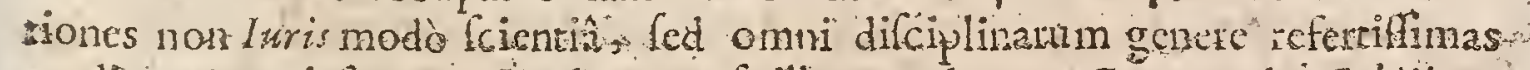
meditari hon defincret. Unde eperofa ills tum de'Retractur tum de Ne bilitate volumina, itemque de Legibus Connubialibus, \& allia quampluima inlucem exicrunt immortalitate digniffima : qux vir amplifimus Michael Hofpisalius ejus id temporis Collega perreleganti pö̈mate commendavis. Scevol Semartidino.?.

Tirraguellius. 
Tiraguellus, regilus Profeffor Lutetia celeberimus lurifconfultus, vir tantx ac tam varige lectionis, quantx nec fuperiori, nec noftrâ xtatcullus. Fulentin. Furfer. Hiltor. Jur. Civil. L. 2..... ult

Andreas Tiraquellws, Jurifconfultus, \& lhilologus diligentifinus omnifcius. Derspftor.

Floridiffmus Alexandri Alexandraischoliaftes, in libris da Nobilitat, de Primoge its deL gibus Connubialibu, iufuitâ multiplis cruditionis cong rielaboriofifimus. Eonfac.l. 15. c.8. Ludic. Hitt.

Unum hoc merico in Alexandro Alexandren improbari folct, quòd corum. und profeciffet difimularet autores. Sed huic vitio medicinan fecir doctiffimus Tir aquellu', qui digitum ad fontes intendens, unde quxque hauta elfent, indicavir Fof. de Hift. Lat. p.60g.

Quxhic in medium afferemus debemus cläiflimis viris Andres Tiraquetlo Turicontulto, rarolo Sigont, \& Barmaba Brifonio Jurifconfulto, qui tantâ induftrix lude ritus eos inquifiverunt, \& explicartut, ut nihil iftorum monumentis addi videatul. Rofl. de Antiq. Rom ubi de Nuptiis agit.

Accufatus fuit quòd nimia fcientia fur opinione tuigeret, quòd fupta modum gloriam \& honorem ambiret, quod cos defpiceret qui futentix fux obluckabantur. Veruntamen Tr alanelli libri tanto in pretio etant dum iple viveret, ut Bartholomens haffnem celebris Juifperitus corum plures payinas exfcriberc non dubitarit,quibus Opera fua exonnaret, de quo conqueritur Tiraquellus; Tractibus fuis de Ligibus Connubralibu: \& de Retractu, ubi \& Cui apologiam texit adverlus cundem Chaflaneum, qui iptum infimulaverat quòd pluta haufulet ex Colii Rhodigini veteribus Leetionibus. T'ijfier Elogiis Virorum Illuiftr. Gallicè.

Teruntur manibus Alexandri ab Alexandro Jurifc. Neapolitani Geniales

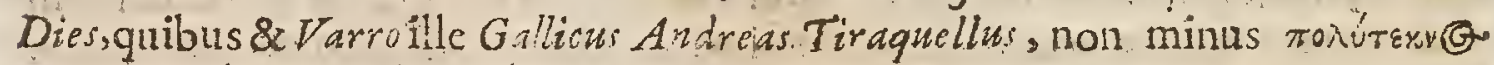

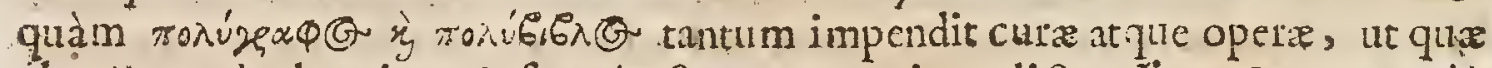
ab Alexandrubrevius, \& fine Auctoum mentione dicta. Rene, Comm nurivis illuftraretfuis. Co rad. Riterfonf. Epilt: ad Cent 3. Meditat. Hifor: Camserarii. Andreas Tiraguellus Iurifonfultus celcberimus \& Regius in Curià Parifenf 1 Senaror, jure omnium fiorum xqualiun doctiffinus crat exifimatus. Laboris ingentis admodum patiens, fcripfrt \& doctiffmè quidem eft interpretatus plures nobilifimos titulos Iurir. Inter alia, fcipint fuper tit. de Legibais Conrasbialibus, \& I ure maricali, magnum yolumen incriptun, deutroque Retrabtu municipali \& conyentionali, Opus maximi pretii \& monumenti. Gul. Rovil. in prompetar, /co\%, Infign. Homin

Theodorus Pez in Epigrammate quodam hunc Auctoremappellat, Alteriom seculi nof tri Varronem. Copiofofimus Calepinus luris vocatur Forftero de Succeft: ablnteft. 12 .

Non fine magna ratione dixit Dominus Thuanu $\rightarrow$ quòd quemadmodum Tiraquellus Reipublice pluimos tratiderat líbros, fic \& ingenti Civium numero iplam locupletaverat:afleveratur enim quod plufquam trigiuta liberorum parens fuerit 
fuerit ex legitimo connubio fufceptorum.Ant.Teifler Elog.Virorum Erud. Gall.

\section{In Effigiem Andree Tiraquelli hoo Hexaltichon compoluit Aucto: Anonymus:}

Iam nibil eft, vererarde fonex, guid pulla ferorum

Stamina, vel Stygias quiod verearis aghas.

Subirabet bec vultus morti pictura: perennem

Ingenio vitam tot tua fcripia dabunt.

Ergo ubi fatalem Lachefis tibi neverit boram, Magna tamen fugiet pars Aclieronta tui.

Extant Opera cjus Juridica 7. Tomis Francofurti 1616.

\section{FE.TRUS. VICTORIUS.}

F Lorentinus, natus eft anno 1499 . Obiit anno 1589 . Exaravit variarum Lectionum libros 39. Annotationes in Varronem, Clar. A. D.
Catonem, \& Columellam: Commentaria in libros Arifotelis de Arte Dicendi, MDL. de Poeticâ, de Moribus, \& de Republicâ: Cafígatzones in Ciceronem: Annotationes in Epiftolas Ciceronis: Scholia in eAfchylum: Orationes \& Epiftolas: libellum de Urbis Roma Regionibus \& Locis: Commentarios in Demetriz. Phalerai librum de Elocutione.

Petrus ViCtorius longavâ xtate id confecutus eft, ut literas in Italiâ renafcentes \& penè extinctas viderit. De quo pauciora eo mihi dicenda funt, quod ejüs pleraque monumenta extant, quibus bumaniores literas, \& antiquos Scriptores tam Gracos quàm Latinıos magnâ fide ac diligentiâ recognitos explicavit. Thuan. ad An. Is 85 .

Petrus ViCtorius, princeps ingeniorum fui temporis, judicio valebat acerrimo, ac eruditione magnâ, qux cum pari conjuncta erat modctiâ. Illi uni plus Cicero debet, quàm reliquis omnibus, qui in co perpoliendo tépus ftudiumq; pofuerunt, quorum plurimos fuperius illud felix feculum tulit, :Lialza præcipuè omnis eruditionis, quæ in illâ refloruit, parens: Hortum enim plerifque cultum quidem iefert acceptum, fed Victorio falutem. Non inficior alios etiam folertes \& doctos viros multos navos Tullio deterfiffe, fed Victorins tot gravia vulnera, tot latentia \& fuppulata, qux bonam valetudinem mentiebantur, in eofanavit ulcera, ut principem inter omnes locum obtineat. Ioan. Georg. Grevitus prafat. ad Ciceron. Epift.

Petrus fanè Vittorius, magnus cum primis vir, \& de quo illud Enmii proferre meritò pofim, Multa tenens entigua Seppulta: cùm in Gracis \& Latinis auctoribus partim caftigandis, partim interpretandisftudiosè verfatus fit. Lipf. 1. 2. Var. Lect, c. 25. 
Lavinius Torreniwad Sueton. Claud.C. 43 . vocat virum in emendandis $V_{2}$ teruris Scriptis rarâ religione \& fide.

Ex hac Erherdandi profeffione non tam doctrinx magnx, quàm magnæ bonitat is \& fidci laudem quxfivit. Fran. Robertell. de Art. Ciitic.

inftaurator non ultimus humanitatis. C. Baoth in Kutil. p. 186

Eruditorum Corypheus, quitam accuratè. vet: MSS. contextus obfervavit , ut communi omnium litcrntorum confenfu \& voce accuratius non potucrit. Riccobon. in lib. I. Rhetor Arift. c 2.

Neminem abbitror mcliori fide ac religione \& diligentiâ in antiquorum fcripcorum cmendatione verfatum elfe, quàm Victorium. Nam quandocunque ufpiam hæret, ne antiquitati prafcribat, veterem fcripturam velut fub fcriptâ teftatione reprælentat, \&rem judicio hominum relinquit : in quô eâ pudoris ingenuitate eft, ut de exiftimatione malit amitrere, quàm per fucum hominibus os fublinire, \& dum fame confulit, verum opprimere. Turneb.lib. Ig: Adverfar. cap. 28.

Victorius Italorum doctifimus, \& vir optimus ac fidelifimus, cui multum debemus. Scaligeran a prim.p. 47 :

Petrus Victorius, vir bonus, qui bene fcripfrt fed diffu us; infenfus milhi fuit quod in Varronén feripfifem ejuque Varrone ufus effem, qno ipfetam foliciter ut ego uti non poterat. Quàn milcra Kictorii Epiftola ad fuém Opeím de la $C$ fa circa Euripiais quendam lócum, cujufque criorem aniônadvertere nequit. In Italia maximi xitimabantur Vidtorii Varie Lediones. Dodkus erat fed vulgare ingenium. Immarito catpit illum Tutiu. Dum juvenis eram Varias Lectiones : ittorit in pretio habebam, fed hand magnifunt momentis mi feras fcribit Epiftolas cam magnis ambagibus. P. Fictorius dolebat me melitus Varrone uti potuiffe quam, ipfe, ideo mihi invidebat: In fuis variî́s Lectionibus non habetnifi verba \& paucas conjecturas bonas. Mulnm fecit it Libris conferendis, . Ced nonliabrbat genium Librorum: magni ficbat, quia Itali folent fuos magnifacere. P. Victurius bonus \& diligens, fed parvi judicis. Scaligerana 2: Gall.

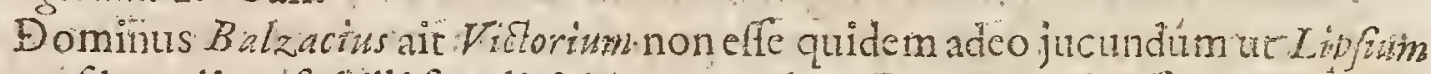
\& quofdam alios, fed illifimplicitatem quandam Romanam inefle qua maximè delectat, \& vel ipfam ejus negligentiam aliquam habere venulatem. Caterum claris ortum efre natalibus, Malxmonianque Sophiticem nobilitale. Nobrs tranfmiffe bonas \& Caifijudicii obfervationes in. Arifotelem, Ciceronem. Demetrium Phalereum \&c. de la Cafa illum tanquam Magiftum furm agnofcere; Annibalem Caro illum tanquam Patrie fuze: Oracalum confuluife: Scaligerum enm ut vinm eruditifimum fufpexiffe; àtrincipibus, Mediceis fape in proptios Lares conveniri folitum fuilfe; Regem ipfun Henricrm. III. ad eum - fcripfife petens in a micorum album fereferret. Balzac. lib.Ig. Epift.20. ad Capellanum 1638. Gallicè.

Nihilominusidem Author alibi dicit feftylum ejus atque Scribendi modos parvi. 
parvi facere, prafertim in ejus Epiffolis ejufque Orationibus: Balzacius lib. $\xi$. Epift.2I. Gall.

Summus A cademie Florentina parcus, concordi fuorum civium plafureft appellatus. Ita doctorum cohors omnium Italica Vnizerfitatis, ac ejus Orachlunn inita bunaniorum literarum diffidia deferebat. In quo tamen egregiam perpetuò retulit modeftix laudem animo potiùs amicon m ftudiis \& officiis, quàm: proprix glorix, ac inflationi prono. Neque pariter ullum vel emeriti lucri commodum fibi cordi effecunc oftendit, cùm bis aurcorum millia fibi à nobili quodam oblata 'Presbytero, ut Rbetorica volumen typis recufum ejus inferiberct nomini, conftantiffimè rejecit. Ioan. Imperial. in Mul Hiftor.

Eximia verò Petri ViEtorii facultas; ad ancloris abitciium ita fe componit, lit . mutatus, recoctus, penè alter credi polfit; aliẹno ore loqui, propriamque indolem exuiffe videatur. H uet. de Claris Interpret.

Petru Victorius ex eo genere Flagiariorum habetur s qui ambitione quadam accenfi deperditos, eoque nunquam fibi vilos citant autores, corum fuppreffo nomine, à quibus notitia talium ad eos pervenit. Thoma S. de Plag.num. 573 .

Author Bibliotbece Curiofe ait Perrum Victorium omnium Ariftotelis Inter: pretum praftantifimum effe, fed utcumque obfeurum. Gallicè.

In Petrum Victoriuni hoc diftichon compofuit Iacobus Boifjardus:

V.ictor es, o vincis Mufis o Apolline dextro:

Quin age, Parcarum vincere clauffra fudes.

Extant Variarum Lectionum libiri 25. Florentia Typis Laurentii Tarrentini fol. 1593 . Extant ibidern .1592.

Extant Notx ad Varronem, Dordsectiri6r9..8?.

\section{MARCUS HIERONYMUS VIDAS.}

D. Ariam häbuit Cremonam, Gallix Cifalpina urbem percelebrem, non pro-Clax. A. D.
cul à Mantuâ difitam. Hujus parentes non fuerunt ignobiles, neque te- MDL. nuium facultarum : qui filium bonis difciplinis inftitui fummầ diligentiâ cum raverunt, adhibitis ad ejus inftitutionem doctis, \& folettibus Praceptoribus. Cûmque effct in Plilolophix ftudio optimè eruditus tam in parria, quàm Th antua, P' atavium miffus eft, ubi fudiorum curfum abfolvit: \& Bononia, ubi facris literis incumbans, \&. Poëfi, tantum in iis profecit, utproximè ad Virgilianam exccllentiam illum perveniffe omnes judicent: cujus rei infigne te- fimonium prabet infigue illud, \& nunquam fatis Laudatum opus Chriftiados: Poema procild́lubio, quodram materiâ, quàm compofitione, \& fylo debet merito prefrericateris omnibus fcriptis, qux à noftri freculi poetis melioribus - Graditatunt : continet enim vitam Chrifi ac geftalibris 6. fcripfit \& eadem feliQqq 2 citate 
citate de arte Poeticâ lib.3. De Bornbycum curâ \& ufu lib. 2. De Iudo Scachorum lib. I. Hymnos, Odas, Bucolica, \& aliquot Epiftolas, quæ omnia hodie non fine autoris admiratione, \& xternâ laude à bonarum literarum fudiofis leguntur. Cujus vi tutem \& doctrinam ut aliquo honoris titulo, \& commoditate compenfaret Pontifex Maximus, Epifcopatum Alba illi detulit, donationem adprobantibus communi fuffagio omnibus Ecclefrafticis Patribus. Mortuus eft anno Dorn. I566. xtatis 59.M.V.D.X. Floŕbat in Italiâ celebris, anno Cbrifriana falutis M.D. XXX. Boiffara. in Icon:

Hunc unum hâc tempeftate meo judicio è perveniffe videmus, quò fine Gracis, duee cum primis Virgilio, pervenire poèr poteft. Vaftus illi animus atque poëtíus, præcipua verò ejus (ut mihi quidem videtur) virtus excellens ac mira quædam in poëticis materiis difponendis illuftrandifque felicitas. - Lil. Gyrald. de Poet.

Hieronyraus Vidas primus inter Italos poft I ac. Sanazariurn Poẹticam ad res facras tranftulit: \& verfibus elegantiflimis ac purifimis provinciam fuam excoluit. Thuat: ad An. is66.

Primus ferè omnium Latinorum Pö̈tarum vitam, mortem, Refurrectionem, aliaque ,alvatoris noftri gefta, ex quatuor Evangelius collecta, fublimitate carminis Virgiliane Majeftati proximâ, feliciffimè cecinit. Sixt. Senenf. lib. 4. Biblioth. Sanct.

Hieronymus Vida noftræ æataris, fcripfit carmen excultum fanc̀, \& mirè Virgi-

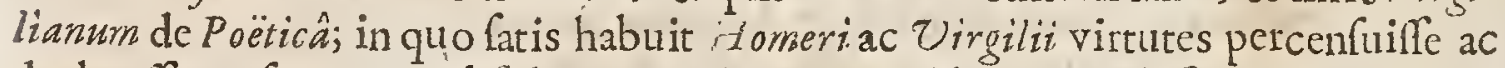
declaraffe, eafque pro ablolutis artis præceptionibus tradidiffe. Lud.Viv. de Caul. Corrupt. Art. 1. I.

M. Hieronymus Vida, etiam dum viveret, magini fuit nominis. Nuncillum audio à plerifque ftatui noftri temporis principem Pö̈tarum. Quo nobis acriùs laborandum eft, ut quæillius fint tot tantæque virtutes cognofcamus. Ab ejus igitur Poëticá initium fumere placet. Eft enim prxclarum l'oëma - tanto majore laude quàm Horatius dignus eft, quanto artificiofiù de arte agit hic quàm ille - Univerfum penè opus hoc eft quafi Parodia fumpta atque formata è Virgilianis. Non eas dico parres, in quibus apponit exempla; fed illa, quibus ipfe fua pracepta dat, ac leges fancit - Nunc ad Scacbicm tranfeamus. Inventio non inepta: juvenilis tamen, \& quæ interdutis officiat decoro. Rerum verò żupuvés feliciffmi ingenii eft; Stylus in Parodia Firgilian $\hat{a}$. Bormby $x$ caftigatior atque ela boratior, propiufque accedens ad curam poetices. Is enim liber rex eft librorum Vida. Nam H ymni \& Ëcloge puerilia funt aut plebeia. Catulli venerem dum vult affequi delicias lenociniis plebeias fecit. Chriftias verò meretur fummam laudem. Non enimnifi à viro pio atque etiam optimo proficifci illa potuere. Iul. Caf.Scalig. de re Poëtic.1.6.

$M$. Hieronymus Vide, difertifimus Poeta, dietione accuratus, diftributione \& difpofitione fabula concinnus, fpiritu \& nervis ubique plenus, robuftufque, etiam in minimis facundus, uber, floridus : id quod Jómbycum ejus libri dito; Latrunculorm, five Scaschormin opus, \& denique expictim illud ij. Italorum 
pugilum cum totidem Gallis certamen, non hebeti lectori facile perfuaferint. Laudantur \& Cbriftiados ejus libri s. Nec Ecloge ejufdem, atque Epicedia epica carent gratiâ, inferiora tumen cateris. Quin \& Elegr dulces, cultique. Borrich. de Poet.p.107.

Ief. Rapinus ait Vidam inter Neotericos ingenio maximè idoneo pollere ad

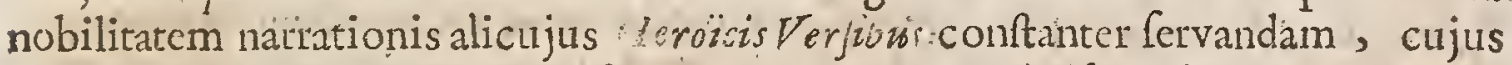
etiam indicia dederit l'oemate fuo in Mortem le U C Cbrifti. Jidem Rapinus ait, ejus ftylum incomparabilem fore, nifr quandoque vilibus utcretur phrafibus, \& afperitatibus Lucretianis fimilibus. Rapizus alio loco ait ftyli Vide puritatem mirificam effe, fed Fabulæ cjus difpofitionem nullateuus exquifitam elfe, ejufque Scribendi modum nullam cum ejüs Argumenti praftantia proportionem fervare. Rapin. Animadverfionibus in Poeticam 2. part. Animadv.Io: \& I6.Gall.,

$M$ arcus Hieronyrnus Vida, Cremonenfis, fummi ingenii vir funmaque do-? ctrina, poetaru Scholx Cbriftiane facile Princeps heroico firitu Maronem feliciter æmulatus fuit : quod fatis ipfe teftatum fecit illo infigni Cbriffiados opere, imunquam fatis laudato. Solutâ quoque oratione pollens, reliquit duos $D_{e}$ Optisno Keipubliceftatu dialogos, in quibus Reginaldum Caid.Polum loquentem inducit: ut utro dicendi Charactere magis excelluerit, ambiguum fit. Quod paucis noftra memoriâ contigifle memini, in his fortaffe $M$. Antoni Mi Mreto \& Petro Angelio Bargeo. Ciceronis carmina irridere nofter Vida certè non erubuit, in Saryrâ Iasvenalis ac Martialis. De Arte quidem Poëtì â Stagiritam \& Flacrum multa divinitùs obfervavit. Inventionis \& difpofitioniis tamen artificium ( quo in Chriftiados libris ufus omnibus xqualibus facilè antecellit) fcripto non prodilit, five quia priores tres illós de oeeticá libios dedit, five potius ftudio id texit ing niniofo Lectori obfervandum relinquêns: $\mathrm{Ex}$ Canonico Regulari, Congregarionis Lateranè ajs, Epifcopus Alba Liguffice creatus, meriti ergô \& virtutis doctrinæque fingularis, Concilio Tridentino interfuit. A A B. Mrens.

Si ordinem temporis fequamur, unus fe pofteà offert Averroes, cujus liber

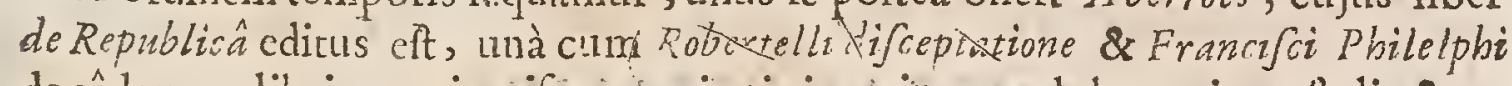
de eâdem re libris, qui prifčx gravitatis imaginem redolent, nitore ftyli, \& argumentorum præftantiâ; quodidem judicium ferendum eft de Republicâ elegantiflumi juxtà Oratoris ac Poetx Hicrorymi Vide; nifi quòd tantâ rerum copià ac varictate non lexuriat; diffulus in quarendo, vitâne publica piivata fit prartantion; in cxteris ficcior, ac jejunus. Gabr. Nandins in 1 ibtiograph. Politic.

Jef. Leonardus Frifo contendit fe in Vida Chriffiade gravem obferváfe lapfum, quem Iuilius Scaligger nón animadverterat. Quòd nimirum Vit S. Iofephur: \& S. Iohannemin illam introducat duas pronunciantes Orationes aque prolixas ac Enee Orationem coram D D n e e temporis intervallo quo

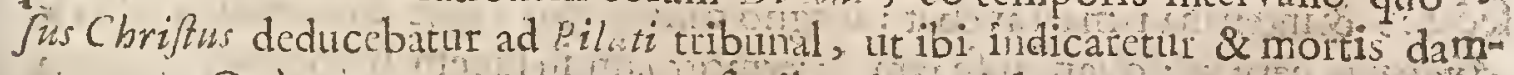
naretur. Quàm partum autem verofmile eft quod temporetam tumultiks=

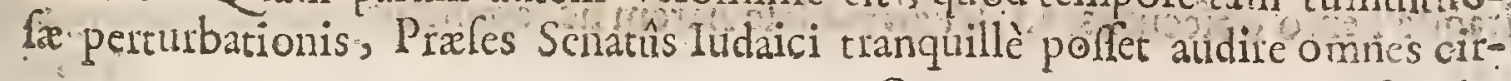

\section{Qqq9}

cumftantias 
cumfantias frigulares nativitatis s cducationis curriculumque totius vita

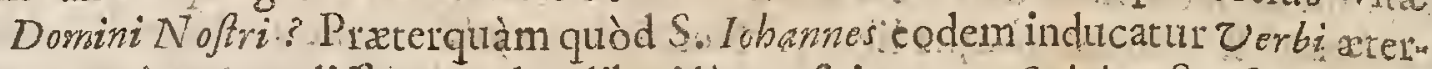
nil genctationem cdifferens adco dilucide ac fi jam tum Spiritus Sanctusaltum hoc Myfterium ipfi revelâflet, cujus tämen perfectam notitiam ante dicm Pen-

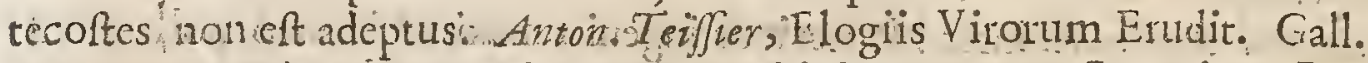

Marans Hieronjmus lida, Cremona Civitate ortus, Canonicus, Regulariss primum S. Marci, poftea verò Laterani, doctiflimus evafit in gravibus fcientiis, æquè ac in jucunda \& politiori literatura : Quia verò ex ingenita propenfone Sciendi, nimium avidus erat, aximum ad unicam fcientiam nunquam appulit, fedromnes, quafi librorum helluo, celeriter percurrens, nunquam ita confanter carum alicui operam navare potuit, ut illam è ufque addifcéret ut plenam liuden hing confequeretur Confat tamen mirabile ingenium ejus ad omie ficeracura ceptum aptifnmum fuiffe. Ghilini Theatro Literatorum Virorum. Italicè

- Garmina ejus continentur. Tomo 2. Delit.ital 1399.

\section{Hoc ejus Epitaphium:}

M. Hier Fida Albe Epifopo qucm probè omnes norunt, civitas Cremo na decreto Sepulchro fumptu pub. Civ. qui de univerfa Civitate B. M. ert arentavit V. A. N. Qui, cum quidquid in egregium hominem latis dici poteft, in eum bencficio nat fucrit collatum immortalit. erat dignus, nifi natura communis conditio obftirlfet. Vivit tamcil adlauc apud nos, vivetque atenum apud pofteros benef. jucundifl ac perpetuâ recordatione. Qui omnibus erga gregem fibi commifum officis funetus piet. charit. fide cont. praclarus omnibus carus, nemini noxits à bobis decelit fuo magis quàn alionm tempore, Qui non folúm piè, \& fanctè Deum coluit, fed ita etian cecinit, ut in colo locum, ubibeatus xvo fempiterno fruatur, \& in terri, ætenam fibi gloniam maximo onnium mortalium fructu compararit. Obijg anno M.D. LXVI. 27. Septembris: Gbilini.

\section{ANREAS VESALIUS。}

Clax.An. D. R Ruxellenfis, natus eft Anno 15 13. Obiit Anno r564. Baflec Anatomen exesMDL. $D$ cuir Inde in aulam CaroliV.adfcitus eft. Aulica vita pertælus, vifendaque Palastinaftudio ductus Hierofolymám adit : iu redeundo ortâ tempeftate in Zacynthum infulam ejectus eft, ubimorbo correptus in tuguriolo obiit. Inter Scripta cjus plurima. Libri ejus de $F$ abrica Humani Corporis primum obtiment locum.

Pincr etiamnum mures, talpas, glires, interdum etian canes atque feles dif Cecares. \& inteftin rimari avebat, magno omine ejus, qux in eo poftè eluxits Anatome peritix, quam iple jam intermortum in lucem revocavit. Nature jague geno oblecins, ad Medicinalefe Arem fic applicuit, ut in anatomit parena 


\section{CELEBRIORUM AUTHORUM.}

jarem vix ullum, ex: omn antiquitate; fuperiorem celtè neminem repererit. Metab. Adami: in vit. ejus:

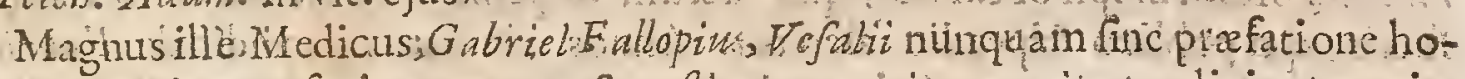
noris mentionem: fecit, parentem \&arefitutuoremb rei anatomica ; divinum quin-

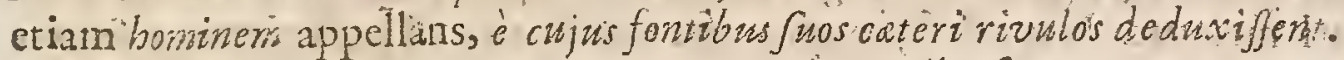

Andreas Te falius rem Anatomicam penitus collapham, atque ne quidem ab ipfo Galeno fatis accuratè traditametiamnum juvenis ita reftituit, ut jan fenibus omnibus hodieque fui admirationam reliquérit. Conring. 1.i2. de Scriptor.

Annos vix natus 28. Fcripfit illid optis admirandum De Humani Corporis

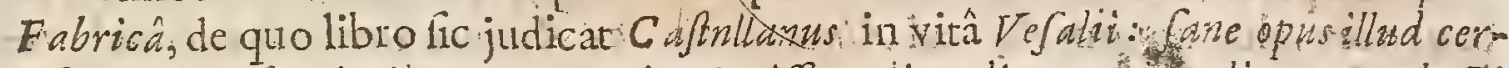

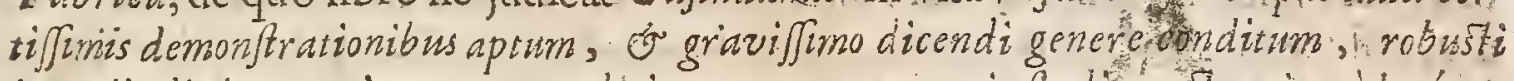

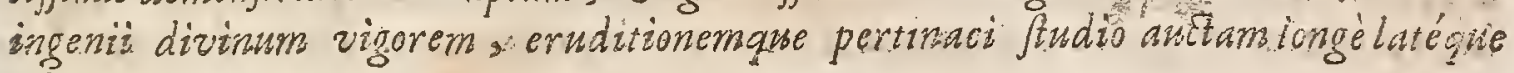
oftertat..

Andreas Vofativis, praftantiflimus Mecticus, \& Opere De Eabricâ Humani Corporis edito clatiffimus. Ibuan ad A nu, 1564 .

Præcluriflimüm illud De fabricâ Humani Corporis Opus, pofterisomnibus fulpiciendum. Boiffard. in Icon.

Vefalius Colertifimus ac diligentifimus Anatomes Corporis, Humani infturator, à Patre Iulio Scaligero non parum laudaur: Scaligerana prim: p. 1.47 .4$.

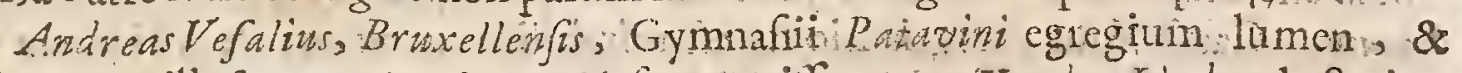
Anatcmes illuftrator omnium coufummatifinus. . Vander Linder de Script. Med.

Dominis Thuanus ait Te falitum larifis aliquando dègentem mirifunm peritix fur in Anatomica periculum feciffe: Oculis enim obductis, gloriatis ent fe à nemine circa offa humana decipi pófie, \& affeveravi fé quodibet os, fil bi oblasum defignatum ire, quod etiamprattiat. Gallo

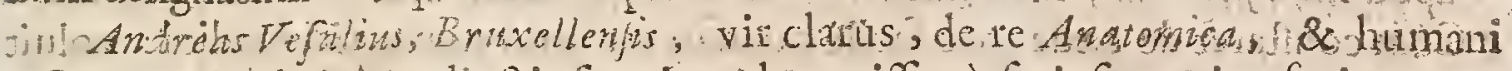
Gorporis Fabricha dicis. funt in na agno precio. utpotequa ad Medicina perfectam cognitionem ar

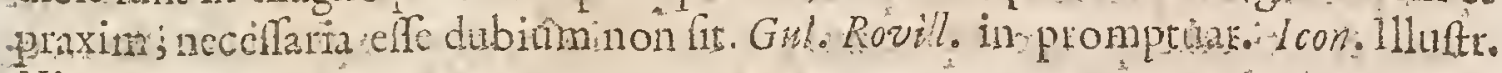
Vir.

Qunm ingenio penè unico immo divino nutus effet Andreastefefalius, cre- didit opere pretinn fe facturum, fi rei Anetomice fefe fuanique ftudium dica-

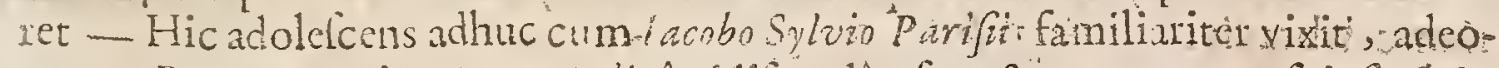
que eo Praceptore in Arte Medicâaddifcendà ufus eft: qquanquam, fi ipfi $V_{t} \in \int_{a-m}$ lio fides habenda, uti omnito habenda eft, à'Syluio in Anatomicis quídern nihil didicerit; quod tamen Riolenus non fine Ve falï injuriâ perfuadere hominibus voluit - Unum in Vefulio fortè jure reprchendas, qutòd in G Gle mo infectando modum nonunquam excedat, initatus tamenab imperitis $G$ alent admiratoribus, \&

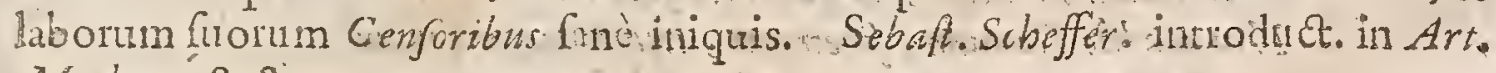
Mer. p. 99.8 ior.

Hic itaque Vefaizus tanto ingenii ardore juvenis viginti trium circiter annos

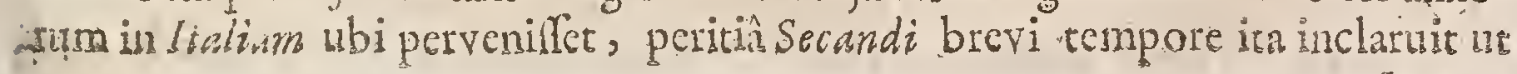


Senatus Venetus Secandi munus cum Chirurgia profeflone in Acadersian $P$ atavi nâ extra ordinem ipfiobtulerit; quò factum ut primus Anatomicus in Europà fuerit, qui publico ttipendio aleretur. Annos 28. natus, edidit de Fabrica Corporis Humani, fut grande ita regium profectò opus, cuique nullum aliud comparari meretur. Nam \& ftylo magnifico \& Latino eft perferiptum, \& tan'tam ipfus experientiam in Anstomiciis prodit, nt totus eruditorum $\mathrm{O}$ ibis ad extremum ufque diem nunquam fatis fit admiraturus, juvenem nullo Magittro ad illud faftidium cruditionis pervenifle. Sebaft. Scheffer. ibid.p. Ioo.

Huc alpiraverunt lacobus Sylviur, \& Andreas.Vefalius, quum alter $M$ efure libros tres, alter nonum Rafe ad Almanjorem, ex Arabum fontibus deduxiffe videri voluerunt, fed vano conatu, nam in Arabicis penitùs peregrini antiquąs interpretationes puriori duntaxat Latinitate expoliverunt. Huet. de Clar. Interpret.

Hunc [ Andreain Vefalium] Nicolaus Mafja tacitè perftringit, \& veluti Plagiarizem furtivis pennis inftar Cornicula e Efopica exornatum fugillat. Thomaf. de Plag. num. 571 .

Hubertus Languetus in Epiftolâ datâ Lutetie Calend. Jan. Is65. ad Cafparem Peueerum, hanc veram fuiffe causá peregrinationis $V$ e falit tradit. 'Fama cft, $V_{e} \iint_{a}$ c lium effe mortuum. Audivifti proculdubio, cum profectum effe Hierofolys. mañ. Caufa iftius peregrinationis eft mirabilis : ut ad nos ex Hifpania eft s perfcriptum. Commiffus fuircurae ejus quidam virnobilis in Hippania; quem - cum obilfe exiltimaret, nec fatis percepilfe caufam morbi fibi videretur; pec tiit à propinquis defuncti, ut fibi liceretcadaver diffecare. Concelfum eft $\in \mathrm{i}_{\text {, }}$ - quod petebat: cumque pectus aperuiffet, reperit coradhuc palpitans. Cogna- ti mortui nol contenti cum accufare factæ cæxdis, acculant etiam impictatis - apud Inquifitionem; exiftimantes, fe ibi feveriorem ultionem confecuturos. - Cúm conftaret de cade ; nec facilè excufaretur error tam periti medici : voluit omnino Inquiftitio de co fumere fupplicium : vixque potuit Rex. fuâ autoritate, vel potius fuis precibus eum periculo tanto eripere. Tandem conceflum eft - Regi-\& toti aulæx, pro eo deprecanti, eâ conditione, ut ad expiandum illudf́ce"lus proficifceretur Hierofolymam; \& ad montem Sinai. Hac Languetus.

Extantlibiri 7. De Humani Corporis Fabrica. Amftelod.1617. fol.'

Infortunium hujus Auctoris plorans Iustus. Ricquius, hifce verfibus memo: riam celebravic:

Vefalii cineres, venerandaque gentibus offa

Quifquis remotâ contueris Infulâ,

Quñ jacet incultis nemorosa Zacynthos arenis,

Gradum, Viator, of laborem fiftito:

Nature bic Genium, finemque, extremaque rerum

Vidife credens; catera infanus labor. 


\section{FRANCISCUS TURRIANUS, Soc. JC.}

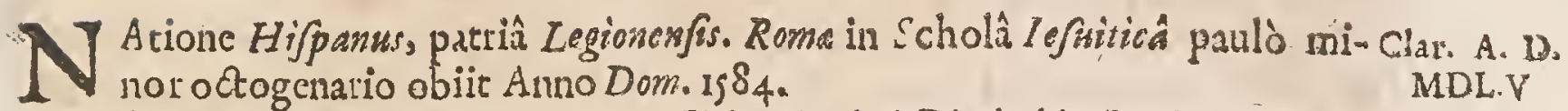
Multa Gracorum Theologorum, ut Nili, Maximi, Diadochi, Theodori, Abuen re Scripta inlucem protraxit. Contra Ant. Sadaëlem etiam Scriptis digladiatus eft.

Vir omni difciplinarum genere excellens; Philolophus, \& Thcologus eximius; Graca Linguæ perititiâ, atque exquifrarum \& reconditarum literarum cognitione cum paucis conferendus; curiolus Antignitatis indagaror; diligentiffimus in Bibliotbecis latentium, \& cum tine is blattifque luctantum Volurribrum SS.Patrum, atque acerrimus inveftigator. Aleganbe in Biblioth. Scriptor. Soc.Ief.

Cafar Cardinalis $\mathcal{B}$ aronius in Not. ad $M$ artyr. Roman. 26. Jahuarii, Doctiffimum paritcr ac religiofifimum appellat.

Stanifaus Cardinalis Hofius paffim ejus doctrinam \& eruditionem magnâ femper exaggcratione depradicat, oftenditque fe cum illo gratifimam \& fuavifimam habere familiaricatem.

Boëtius Epol.2.de I ure Sacro n. 52. appellat, Virum incomparabilis doctrinæ, fingularis pietatis, ferventiffmi zeli.

Turrianus erit Gracè doctus, \& in Antiquitate plurimùm verfatus. Konig. in Biblioth.

Erancifcus Turrianus rccum Ecclefrafticarum peritilfimus. Ioan.Card. Bona.

Erancifcus Turrianus, vir in Theologicâ Antiquitaté, \& Linguæ Grace \& Hebraa peritiâ clarus : cujus quo plura eruditi ingenii monumenta exßtant, co pauciora mihi de ipfo dicenda funt. lolt multa tum à fe, tum ex Antiquis $P$ raw tribus Grácis edita, contra Antoniurn Sadeelem pracipuè ftylum exercuit. Thuan. ad an. 1584 .

Turrianus utimmani erat Stomacho, nullo, aut perexiguo vel pudore, vel judicio, omnes Apoftolorum Canones pro veris ac genuinis agnofcit, libroque fin gulari Apostolicarn iis authoritatem adversùs Magdeburgenses Centuriaiores vindicavit; cujus infaniam fccutus eft Lambertus quidam Gruterus in prafation ne Clementis. Bellarminus paulo modętius quinquaginta duntaxat priores legitimos elfe cenfet, reliquos qui funt 35.vel, ut, alii numerant, 34 . non elle legitimos, quamvis à Gracis recipiantur. Dallaus de P Seudepig.Apolt:1. 3. c. I.

Homo quifquiliarum \& fabularum avidifimus Turrianus, cui fcmper preftó Cunt cateris pratcr ipfum mortalibus invifi \& inaudici $C$ odices, ex quibus fuorum apocryphorurn lectionem, quoties ea abfurda elt, pro fuâ libidine rcfingat. Dallaus de vero ufu Patrum, p. 26.

Turrianum novimus fuas de Conflitutionibus, \& Canonibus Apofolicis Cufpiciones ac conjceturas, omnes licèt fluxas ac evanidas, quafdam etiam furias \& ablurdas, pro totidem invictis Demonfrationibus Orbi Chriftiano magnâ

$$
\text { Rirr confidentiâ }
$$


confidcntiâ Gracè Latinéque oftentîlfe; nequetamen cuiquam ne fuarum quidem partium, cordato, id quod cupiebat, perfuafife. Dälaus de Libr. Cuppolo Diony. \& Ignat.1. 2. c. 36 .

Turrianus ex illo genere hominumerat; qui contra Novatores, ut ipfi appellant, nova dogmata, \& fabulas quoque novas defendere maluut, quàm veritati vel femel manus dare: homo, cujus eruditionem citiùs laudaveris, quàm judicium, Quid dico judicium? Appello confidenter omnes eruditos partium illarum viros; quos non dubito, Turrianum, habere oftentui, tanquam perféetifimum exemplai áxgroias, temeritatis, audacix \& inanifimx vanitatis. Cas Saub. ad Baron. Al1. 31.num: 26:

Cardinalis Perronius ait Turrianum bonum virum fuilfe \& ad Manu-scripta evolvenda idoneum, fed temporum mirè ignarum furfe ut \& Genebrardurn, \& judiciifolertiainferiorem effémnibus quotquot codem cum ipfo fecalo feripferunt. Perroniana. Gall.

Accipimus' Patre Paulo, lib. 6. Hiftorix Concilii Tridentini, Turrianum eidem Concilio interfuiffe \& in eos accerbifimè invectum fuille qui Corrinuniom nem fubutrayue fpccie de pofcebant, dicendo Dxmonium qui in Angelum lucis fe transfigurabat, Populum impellere ad peritionem Calicis venenati fub pratextu petitionis Sanguinis Iefu Chrifti. Gall.

Denique eruditio \& piobitas T urriani non obltiterunt quin apud polteros Eruditos infulfus admodum Criticus cenferetur; qui vana gloriaturgeret, \& pronus efferad omnia immolinda prajudicatarum fuarum opiniunem defenfioni. A quamplurimis vituperatus fuit, fed nemo ipfus faftum adeo deprefit ac Proteftantium Minifter Blondellus quando eum fibi fumplit exagitandun,

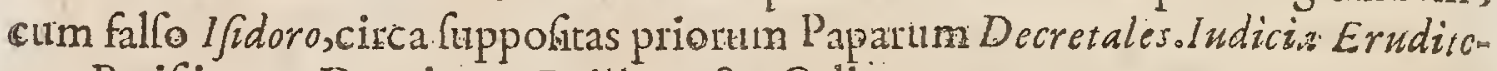
rum Parifis, per Dominum Baillet 168 ; Gall.

Dominùs Nicolairs Antonius conqueritur, quòd Dominus Huetius hơ honore ipfum dignatus non fit ut mentionem ejus faceret, libro fuofecundo de Celebribus Interpretibus, Et fanè omiflo ejufmodi finifram nobis opinionem: ingenerare potef depretio Translationum Turriani, qui catera Tranfator laboriofus magis :quam accuratus exiftimatur; etf diffiteri nequeamus quin $\mathbf{E} c$ alefix commodo hac in parte infervierit. fudicium Erudıtorum ibidem. Gall.

Plurafcripfit, qua Schottus in Bibl. Hifp.pag:255. Poffevinus in Apparatu pag.494. feqq. \& Alegarnbe in Bibliothccấ Iefuiticâ accurate fatis recenfent.

Optandum certè maximè aliquem exiftere Typographum diligentem, qui omnia Turriani opera ordine in claffes diftibuta, tomo tno \& altero, bono Ecclefra frmul evulgaret. Ea quomodo in Tomos 4. aptè diftribui poffrint, cxhibet A.S. Auctor Bibliotheca Hifpania. Tomo 2. qui videri poteft. Alegambe; 
P Atria Suffolcienfss, in Epifcopum Oforienfem Dublinii lacratus eft, unz1 cum Hugone Goodacro Archiepifcopo Armachano Februarii =. (ftylo Akm glicano) Iş2. İbi cùm nondum 6. menfes fediffet, Maria regnum adeptâ, profugere coactus, Dublinii aliquandiu delituit, fed è portu folvens, fub feftum S. Michaelis . I553. à Piratis captus eft \& venditus; lytro tamen foluto Baffleam in Helvetia profectus eft; unde poft quinquenuinm, reg!nante Elizabetha, in Angliam reverfus, \& Prabenda in Ecclefiâ Cantuarienfi contentus, fedem fuam repetere non curavit. Vir doctus fuit, in concionibus affiduus, \& anciquitatis ftudiofnfimus, in Scriptis verò (ut alibi dixi) effrenatâ ufıs libertate. Exceffit è vitâ Cantuaria MDLXIII. mẹnle Novembri, annos natus 68. \& in Ecclefîn Cathedrali ibidem fepultus eft. Opera edidit quamplurima, tam Latina linguâ quàm Vernaculâ, quorum:Catalogum iple in libro fuo de Scripw soribus britannie figillatim recenfct. Iacob. Waraus de Script Hiber. p. I35. I36.

Vir diligentiffimus vọatur Gefnero in Bibliothecâ.

Antiquitatum Britannicarum diligentiffimus perferutator: Godwv. de Converf. Britar.ad Chriftian. Relig.

Strenuilfimus propugnator fuit adverfus Romanam Ecckfiam., ut çx. Difticho illo Reverendiflimi Laurentïi Humfredi in vatiçinio fuo de Romá apparet.

\section{Pilurima Lutherus patefecit, Platina multa: \\ Quedam Vergerius, cuncto Balaus babet.}

Quod vekementius in Pontificium dominatum invehatur:Balaus, tanto minus fortè quilipiam mirabitur, quantò graviùs pra aliis regnis facram tyrannidem Anglia fuic experta. Ideóque acerbiona dícta ipfemet. excufat priefat. ad Leclor: in Acta Romanorum Pontificum. Tametf verò $B$ alaus adeò invifus fuerì Pontificiis, tamenn ipgenet $C$ atalogrom ejus de Anglicis Scriptoribus coguntur commendare. Valentin. Henr.Vogler. Introduct. Univerfal:in Notit. Scriptor.C.22.

Iobannes Balezs Covia in Suffoleia Comitatu, qux quinque milliaribus Don wice diftat natus, eft; cducatus verò Cantabrigie in Iefu Collegio; Cum prius vel

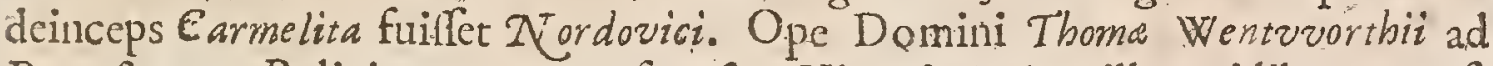
Proteftantem Religionem converfus eft. Hic eft Balaus ille qui librum confcripfit de Scriptoribus Britannicis, in novem Centurias digeftum, quem Lelant dus non magis fibi, demeritus eft, quàm me Balaus in hoc Opere \& in mea Hiftoria Ecclefiafticą. Mirum fubịc poffit, quọd cum is adẹo eruditus effet, . quiq; tot tantaq; pro Religione cgerat:\& paffus eiat, majoribus honoribus non fuerit,auctus, quandoquidem ineunte Regno Elizabethe Epifcopatus idoncis Yiris indigebant, qui cos adirent: Sed verofimile eft illum fuiffe virum magis Exnditum quàm prudentem; aptiorem ad frribsndum quam ad gubernandum;

$$
\text { Rrr a quippe }
$$




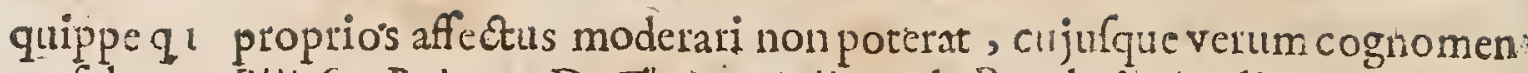
cenlebatur Biliofus Baleus. D. Thomas Fullerus de Praclaris Anglix Viris.

Impotentis lingur \& calami plerunque Scriptor, ,ed in multis non rejectitius. Montacut in Apparat prim. fect. 83 .

Ioannes Balaus, homo impius quidem, \& infamis Apoftata, nominari tamen hoc loco vel ided potuit, ut quis è fordibus gemmas legat. Valer. Andreas Præf. Biblioth. Belgic.

Hic Lelandi Catalogum non tam prolixè auxit, quàm prodigiosè depravavit. Omnia namque foedifimus fcurra mendaciis \& calumniis replevit, \& Opus Lelandi politifimum pollutifimo ftylo turpiter confpurcavit. Ioh. Pitsens.

Unum fcio, in prioru in feculorum Ccriptoribus non raro Balai fidem claudicare. Idem de Ioanne Pitfoo dictum velim, qui exfcribere Balarbm folet, præterquam in iis, qux ad diffidium in facro religionis negotio pertinent: ubi nihil anirum, fi pugnantiflima hi duo habeant. Vo/f de Hift. Lat. I. 2. c. I6.

Ajunt quoque Eluanum Avalonium doctrinam ab Apoftolorum difcipulis acceptam Britannis prædicaffe, librumque fcripfife de Origine Ecclefia Britan nic ${ }^{\prime}$; de quibus fides efto penes $B$ alaum: Multum enim metuo, ne ut in plerif que aliis antiquioris ævi fcriptoribus, ita hâc etiam parte fucum faciat lectori. Voffoibid. pag. 170 .

* Ioannes Balaus inter Hxreticos primæ Claffis Romano Indice numeratur.

Scriptor fuit impudentifimus ac maledicentiflimus adverfus Romanam fedem, Miffam, \& Euchariftiam, virus nunyuam non fpirans, nihil proptereà ex cjus: Operibus unquam permittendum. Vid. Indic. Madrit. fol. imprefl. Madrit.fol. impreff. Ann. 1667 .

Extant de Scriptoribus" Anglic \& Scotia Centurix XIV. ad annum ufq; Iss8. progredientes Tomis 2. infcriptre Elizabetbe Reginx Anglia. Bafiléa apud loan. Eporinurn anno 5557,1559 . in Fol.:

\section{CORNELIUSS JANSENIUS.} Clar.An.D. TT Vlpenfis, Flander, primus Gandavenfum Epif Copus, obiit Gandavi III
MDLV. April. 1576 . atatis 66 . April. 1576. atatis 66.

Scripta ejus funt : Concordia Evangeliftarum - Commentarii in Concon diam, ac totam Hiftoriam Evangelicam - Paraphrafis \& Annotationes in omnes Pfalmos - Comm in Proverbia Salomonis, \& Ecclefiafticum - Amnotationes in librum Saplentix Salononis-Brevis Confeffo Fidei.

Cornelio Ian fenio, fi cuialteri, fuit in primis preftans ingenium, exacta linguarum trium, Latine, Grare \& tebratce cognitio, finguliris prudentia, eximius rerum ufus, \& fummum religionis ac pietatis fudium...Hulftano in oppido apud Flandros honeftè natus, Lovanii Caftrenfin in Gymnafio Philofophica, dein facra fudia in majore Theologonum Collegio (cui \& magnâ cum laide poftè prafuit ) fummâ.animi contentione fectatus eft. lis decurfis, annos iple xIx.ijs Iungerloënfi Pramonftratenfum nobili apud Brabantos Abbatia profelforis 


\section{CELEBRIORUM AUTHORUM.}

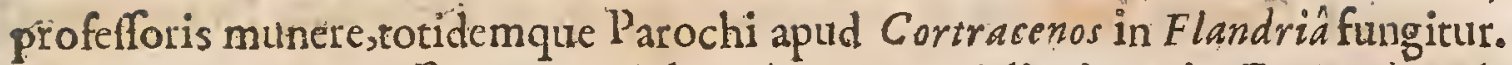
Inde Lovanium regrelfus, Doctoris laureâ, \& Decani dignitate in D. Iacobi æade cohoneftatur. Nemo fanè doetrinam facram aut in sholis doctiùs interpretatus eft, aut copiofius in concionibus explanavit : nemo in animis ad virtutem inflammandis, \& à vitiis ad frugcm revocandis acrior aut ornatior Orator fuit. Quò factum, ur ad facrum Tridentinum Concilium; "quò omnis doctrinx \& fapi ntixe Antiftites ex totâ Europa conveniffe feimus à Philippo II. Rege cum Mi baele Baio, \& Ioanne $H \in$ effelio collectis, miffus, tam excellenti de fe judicio abundè refponderit. Mox à reditu, peftiferx doctrinx lue in Flandria cref-

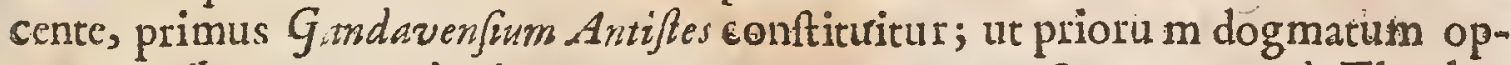
pug natoribus acer veritatis propugnator opponeretur. Quantus porrò Theologus fuerit, clamant doctiffimi in Concordiam Evangelicam, orbis judicio probatam, commentarii, quibis xquales aliquot, in his Alfonfum Salmeronem \& Thomam Beauxamum, in eâdem arènâ defudautes, à : fuis tunc edendis deterruit. Senio laboribufque confectus I576. moritur G,andavis, in fuâ Cathedrali fepultús; vel hoc nomine beatus, quòd iterum exortum in Belgio Calvinificum furo rem non viderit aut fenferit. Awb. Mirens.

Theologus apud Pontificios magni nominis. Quenfed.

Quantus Sol Coelo, tantus:I anjenius Orbi eft. Nic.Vernit. Defcriptione Acad. Lovan.

Vigilautiffinus facrarum literarum Interpres vocatur Montacutio in Apparat.

Interpres facrarum Scripturarum acciratifimus. Bellarmin.

Eruditus \& moderatus Interpres. C. hamier.

Theologus egregius, cui exácta trium linguarum cognitio. Svvért. Atlicno Belgic.

Pietarem certè ubique Scripta illius fpirant, qua plirima \& accuratifima \& doctifima reliquit: Vater. Andreas in Biblioth. Belgic.

Cornelius I anfenizs in omnibus qux fcripfit, prafertim in Concordiam Evan gelicam, \& in Proverbia dut etiam P falmos, fe magno valentem judicio, uti \& eruditum oftendit. Po fevin. in Bibliorh. Select.

Complurium recentiorum in eâdem re (Concordiâ Evangelicâ contexendâ) enituir ftudium, quorum pracipum fibi locum vendicare viderur eruditus æquè ac pius ornelizis lanfenius Epifcopus $G$ andavenfss; cujus frc nobis proponimus fequenda veftigia, ut tamen liberi interdum effe velimus, per aliam viam, qux rectior videatur, incedere. Cafar.Baron. Tom. 1. Annal. Ecclefiafto ad Ann. Dom. 3 r.

* Cornelius I anfenius vir fanè doctus \& Catholicus. Ejus Commentarii in Ecclefafftcum, atque Concordia Evangeliftarum, inter libros expurgandoslocum. habent in Indice Madritenfi edit. ad ann $16 \% 7$.

Edidit ad V. T. Cantica Paraphrafin, Luan. is7 accuratius ibrd. uj86.

Extant Commentaria in Pfalmos, prov. Ecclefraft. Cant. Sapientinan. Antyerp. 36i4. Fol. Lovan.1644. in 4 \&alibi feparatim.

$$
\text { Reri } 3 \text { Extant }
$$


Extant Comm. in fuam Concordiam \& totam Hiftoriam Evangelicam? Lugd.1597.

Hoc ejus Epitaphium, Auctore Maximiliano. Vrientie:

- Ef tumulus Sacer bic procul impic abefio,

Et Sacra depofiti ne quate membra viri.

Si nefcis, jacet boc turralo compoftus, avite

Nuper qui fidei musus ahenus erat.

Hic vere pietatis apes, 'or regula recit.

Hic Sacri Textus Harmonia una jacet.

An Satis hac? Patriamne mones ut of infuper addarn?

Et decora? \&o titulis nomina fulta fisis?

Hic fitus eft Præful Janfenius: baud pete plura:

Catera nam poterant bruta vel ip ja logui.

Phil. Labbe in Thefaur. Epitapl?

WOIFGANGUS, I ZIUS. Clar. A. 0. T Iennen is, medicus \& philologus, natus eft ann. I5I 4. obiit anu. 1559.
MDLV.

Scripfit duodecim libios Commentariorum Reip. Rom. in exteris pra vinciis: Commentarios rerum Gragarurn : 12. libros de Gentium Migratione: Chronographiam Pannonia \& alia.

VVolfgangus Lazius, iexum Gracarum fimul Romanarum \& Germanicarum no!n indiligens fcriptor; quod praclara ejus monumenta apud polteritatem teftantup Patria fux illuftracor, \& antiquitatis folers indagator. Thuan Hift:1.16.

Ad quas (cum Orientis tum Occidentis) notitias intclligendas pertinent Wolfgangi Lazii, hominis laboriofflimi, libri Commentariorum xrr. de Rep. Romana, in quibưs magiftratus urbanos \& precipue militares copiosè exponit, \& infcriptionibus vetuftis confirmat. Georg. Fabric.de Româ, cap.I.

Prxclaram in enodandâ \& eruendâ ludorum veterum ratione operam pofuit Wolfgangus Lazius in aureis illis Reip. Romana Commentariis, ex quorum leCione plurimum me profecille non nego. Sed multa adhuc ipfis declfe, neminem, qui rem attentius confideravit, puto effe dubitaturum. Ioan. Rofin. ad Godefrid. Henric. Hesbufios Epift. quam Antiquitat. Roman. libro s pramifit 1580. Ccriptâ.

Egó quidem, ut mihi ignofci cupio \& quandu in me eft , aliorum crorestego, aut ita detego, ut ulli injurius non fim. Quare lubens Lazii.in Romanâ Hiftoriâ lapfum filentio praterirem, nîtantus effet, ubi de prefectis pretorio loquitur, ut difimulari nullo modo poffit - Hxc quidem non Reip. Romana Commentaria, Ced xgri hominis commenta dixerim. Iacob. Guther. 1. 2. de officiis dom. Augutt. c. 7 . 
VVolgangus Lazius, homo rerum Germannicarum nefcio quàm peritus, noftrarüm certè imperitiffimus, ut qui alienâ fide fcripfit, non fuî. Dward. Non. Leo adverf. Teixeram.

Quem (Francifoi Guilimanni de Aufriacî Origine librum) cum legeris, Lazium, Eixungerum, ArnoldurnVionum aliofque id genus nugones cum fomniis \& Commentis fuis fratim, 'fcio; faceffere procul jubebls. C'afpo.Sciop. in lit.ad lector. quas Stemmati Auftriaco fubjunxit.

Verum prater alios, veri omnes limites exceffife videri potent $V$ Volf gangus Lazius, qui fudio in Patriam ductus quicquid in gente Germanzcâ laudabile, id penè univerfim è $P$ annoniis arceffère modis o mnibus fatagit. : Quo circa etiam Erancos, per multiplices nominum anfractuss, ac metamorphofes, modò $C$ inso merioss modò Cimbros, modò Brencos Sicambrof que facit'; eofque per P'annonias è Bofphoro quondam egreffos; latê per Europam fe fudiffe. Berojo pracunte, fabulatur. Ioan. Ifaac. Pontan. 1. 2. Origin. Francic. ..7.

Vir magne \& induftrix \& doctrinx fuit" " in quo tamen frepius plus judicii defideres. Voff. de' Scient. Mathemat? c.' 44 .

Vir multx induftrix, \& lectionis : judicium \& fidem eft ubi requiras. $L i p\}$. Lovan.lib. I. c.II.

Dacia non miror fi te trahit: me quoque, fi $D_{\text {ens }}$ meus pateretur, inprimis Nelectaret ea loca luftrare ; qux trita fcio veftigiis Romanis. Quot illic lapides \&

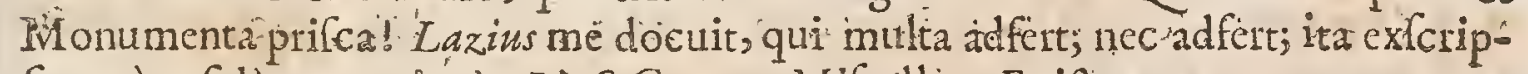
fit parùm fidè aut curiosè. Lipf. Cent. 2. Milcellantr. Epift. 24."

Auguffam L ruf ì St Strabone nominari urbem hanc Germanie fplendidiffimam, VVolfgangus Lazius fcribit 1. I. Reip. Romane, c.8. Sed de illâa apud Geographum niihil leges, \& Lazins, cùm in his, tum in citandis infcriptionibus antiquis multos interdum committiterrores." Martin. Opit. in Animadverf. ad irr-

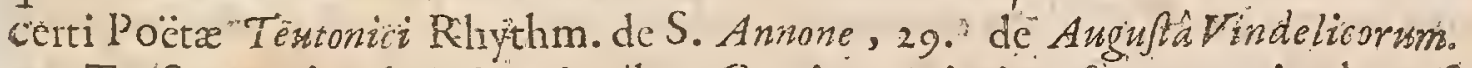

Tractatus ejus de Migrationibus Gentilmeximius eft, quamvis plures fabrilas eidem immicuerit, fi Reinerio Reinecczo fides fit adhibenda Maximi etiam xeftimatur' Libèr illius qui infcribitu Commentarii Rerum Grecarumb. Anto Teifler Elog. Viror: Erudit. Gall.

Magnus erat corrafor, omniatypis abfque judicio mandari cirabat, ut Gruteris. Scaligerana poltcrior.

Miracontentione allaboravit defriptioni contexendx omnium quibus Urbis Vienna \& Auftrix Hiftoria illuftrari poterat: ut Scriptis perennare faceyet glorianir Regionis cui natales fuos debebat; Quoniam vero plures aninos \& multam pecuniam in hoc opere infumpfit, id adeo perfectum \& adeo. snagnificum ieddidit, ut hic liber farnam ejus per univerian Europarn circumtulerit. Ordines Aufrix nobilem hunc labörém honerabili remuneratione dignum jidi-averent, quam etiam erudito huic Scriptori impertiendam etraverunt. Ifaacus Bullart Acad Scientiarum. Gall.

Chronographia Aufric hactenus inedita extat in BibliVindolo atitographa dédicata Ferdinando I. Imp.an. I545.

Prodiengnt 
Prodierunt libri r2. de Romanâ Republicâ in Exteris Provinciis Francofurt to ad Monum I598. in Fol.

Hoc ejus Epitaphium, Nicolao Renfnero Authore:

Wolfgangus Lazius Vienuæ Auftrix natus Anno rgo4. Patre Simone Medico

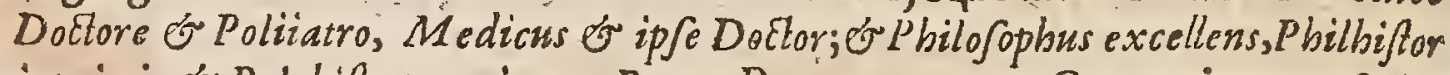
inprimis \& Polybiflor maximus, Rerum Romanarum on Germalicarum Scripo tor celeberrimus; Patria fua Vienne, of totius Auftrix Illuftrator fidelifirmus, totius Antiquitatis indagator folertiffinus: à Ferdinando Cxe. Aug. non modè

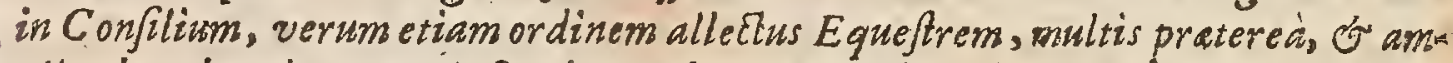
plis ab eodem honorum infggnibus nobilitatus: obiit diem furm quirquagerarzus in Patriâ An. Salutis MDLV.

Seu Romana placet tibi, fen Germanica fatta Nofcere, dulce leges me duce certus iter.

\section{ADRIANUS TURNEBUS.}

Clar.Aa. D. N Ormannus, fcripfit varia, inter qua eminent Adverfaria: Docuit Tolofe MDLY.

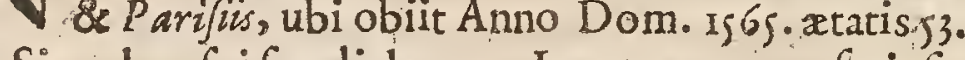

Singulare fui feculi decus. Is autem pauca fripfit fi hominis eruditionem Cpectes; totius enim Gallia doctilfimus merito luo judicatur. Sed ejus pracipua in docendo láus fuit, dum Ths lofâ, ubi profitebatur, Lutetians revocatus, \&e Tufano vitâ functo Succeffor appellatus difcipulis, qui ab ulțimis Orbisterrx parribus frequentifimi adillum audiendum concurrebant, recondita Antignit atis thefauros omues mirâ quâdım facundiâ depromit. Quanquam \& ea qux fcrip." "Cit ejufmodi funt, ut Auetoris decus atque dignitatem pra fe ferant. Nam in Poëmatiîs fublimis eft, atque acutıs, in Oratione folutầ terfus atque elegans. In Adverfariis verò tôt Veterum tum Grecorum tum Latinorum difficiles loc i aut emendantur, aut explicantur, ut dubium fecerit plufne in eo ingenii an di.ligentix admirari debeamus. Staturâ fuít mediocri, facie honeftâ, probis moribus, accedente ad cateras virtutes incredibili modeftiâ.: ut xmuli fubinde per opprobrium illi objicerent quòd vultum virginali pudore demiffum gereret. Cùm tamen fub verecundo ejus ore latentem generofi fipiritûs indolem ipfr quoque experirentur. Vixit annos 53. reliquitque motiens plutes filios paternaFum virturum haredes omnes certatim futuros, nif fata invidiffent, uno tantùm ex illis fuperfite: quem etiamnun graviffmo' Senatoris munere pari doctrinze probitatilq; laude fungentem Lutetia veneratur. Diem vesó fuum obii prid. Iḍ. Junias annos hujus feculi 65 . atque in Cometerio Scholafticorum juxta Silviz collega cineres nullâ funebri pompâ, fic enim jufferat fepultus eft. Scavol, Sarairthan. 


\section{CELEBRIORUM AUTHORUM.}

Nunquam fatis laudatus vir Adrianus Turnebus. Unicum Gallia nottre atque adcò totius Europe ormamentum. Iof. Scalig. Conjectan. in VAyrokerr.

Injuriam fecerunt manibus eruditiffimi \& maximi rini gui cjus abortiva quadam in Varronem poft mortem ejus ediderunt, quibus magis traduxerunt eum quàm ejus nomen commendârunt. Nam quid opus erat ea edere, cùm ipfe more fuo in Adverfarza fua qumultuatia Opera inferciffer? Sanè (ne quidamplius dicam ) indigna funt qua tanti viri titulum preferrent. I dem in Appondic. ad Conjectan. in Varronem de Lat.

Adrianus Turnebus maximum hujus atatis ornamentum. Vir omni virtutum omniumque literarum genere inftructiffmus: plurima rara eruditionis monamentâ edidit, \& præmaturâ tandem morte ftatim poft edita illa aternitate. digna e A dverfaria, fummâ omnium Ordinumb (an quos univerfos unilus mors. pertinere vifa ct ) meftitiâ, rebus hunanis exemptus eft. Thwan.ad ann. I5 65 .

A drianus Turnebus, magni ingenii \& doctina vir. Lips.1. I. Var. Lect. cap. 2 t.

Sol ille Gallic Turnebus. Lipf.1. 2. Elect. 20.

Poftremum Ciceronem Lambini vidi, \& in eo multa mutata; quxdam quod nollem, addita. Libertas fortaffe hæc vifa eft illi mihi acerbitas. Nam quale eft quod de optimo uno omnium quos fol vidit Turnebo fcribit, \& quidem variis locis ? quem difertè Plagit accufat. Momordit hominem, quòd Turn:bus aliquammultis locis incurreret in ealdem conjecturas. O I upiter, abdis hac? ut Plagiarivo fit Turnebus? non credam hoc fexcentis Lambinis? Idem 1. 5. Epiltolic. Qurettion. Epift. 77.

Inter Italos) C'riticos) Fulvius Urfinus, inter Hifpanos Petrus Ciacconius, inter Gallos Hadrianus Tuirnebus, inter Germanos Iustus Lipjus familiann ducito. Gafp. Sciop. Cenlultat.p. $39 \cdot 40$.

Antiquitatis verus Thefaurarius Adrianus Twrnebus. Barth.1.43. Adverfai. cap. 23.

Lux Criticorum vocatur Rofino Antiq. Rom.

Vir cruditiffimus \& de literis praclarè meritus. Petr. Faber l. r. Semeftr.

Infinita multiplicis doetrinx copia in T tornebo fuit $M$. Anton. Muret. lib. 18 . Var. Lection.c.rg.

Turnebus vir longè çoctiffunus, cujus Adverfaria opus omnig cnâa eruditione refertum. Gefner. in Biblioth.

Turnebus vir maximus crat, doctifimufque, cujus Adverfari:abortivumi fetum foleonuncupare; potuit enim melius fcribere. Agnofeas tamen genuinum partum Turnebr Scaligerana prima, p. I 45

Turnebus plura habetuno libro, quàm $V$ idtoriw: libris 37 Scalig rana pofterior.

Utinam non tantâ brevitate in fuis Adverfariorum lib is effet ufus. Paulò enim luculentior \& plenior quorundam locorum explanatio, \& majorem illi Operi gratiam laudemque conciliaffet, \& le etori multè magis fatisfecilfet. Henr. Steph. Ffelldo Cicero.

Utinam vir hic, fanè doctus ac multa lectionis, non tam cupidus undique $S \in \int$ fuilfet 
fuiffer omnia emendandi, melius nobis, melins exiltimationi fux confuluiffet. Petr. Victor. 1.36. Var. Lect, cap.ir.

Stephanus Pafquier ait Turnebiurn mirabilem fuife vitum, tum in Greca Las tinaque lingua, tum in totius Antiquitatis cognitione, ut nobis teftantur libri quos infriplit Adverfaria quod opus eft inimirabile quoad cruditionis diverffitatem. Addit quòd in pluribus Germania Univerfitatibus, quoties qui de Suggeftuloquebantur Turnebium citabant \& Cujatizm, fatim pileum deponerent ob reverentiam \& honorem quo memoriam ejus colcbant. Pafq. Perquifitionum lib 7.cap. 8. \& lib.9. cap. 29. Gall.

Adrianus Turnebus quamvis literas tantum profefius effer, in quibus, meo quidem judicio, palmam omnibus præripuit qui in is à mille retro anlis claruerunt, nihil tamen habebat quod magisftellum faperet, præter tøgæ fux geftamen, \& aliquem externum habitum qux aulico cultui forfan per omnia non erant conformia quxque flocci facienda lunt. Odi homines noftros qui obliquam togam difficilius quàm animum obliquum tolerant, \& ex faluțaroria flexione, geftu corporis, ocreis \& frmilibus, qualis quis fit pronunciare folent. Nam intus nemo ufquam terrarum excultiotis animi fuit. Sxpius datit operain fermones ab ejus ufu remotos ipfum dedixi. In his autem tam perfpicax erat, tam celeris apprehenfionis, tam fani judicii,ut bellum unicè per. totam vitam negotiaque publica geffiffe videretur. Genii funt ifti g gregii atque fortes.

\section{- Queis arte benignâ, \\ Et meliore luto finxit pracordia Titan.}

qui non degenerant, etfinon ita felicem inftitutionem fortiantur. Michael de Montagne, Tentaminum lib. I. Cap. 24. Gall.

Hadrianus Turnibus, literacifimus, \& omni laude ornatus Interpres; nam \& Graciluculenter fciebat, \& Latine Ccitiflimè convertebat : preffus ille \& adAtictus, ab autore nufquam digrediens; fuavis interim \& perlucens Oratio. Huet. de Clar. Interpret.

Hadranus Turrebus nobilis Criticus, maximas ingenii dotes poëtica facultam ie illuftriores reddere inftituit. Verfantur in medio Epica ejus, Califum Capium, Epithalarnium Delphini Erancifci, Pravotii turnulu, Parafitus Kegius, alia, in quibus tamen plus laboris cernitur, quàm fpiritus. Exaravit \& Lyr̃ica, \& elegos favente plerunque Minerva. Borrub de loet.p. Ing.

* Turnebi Operain tres Tomos diftributa, Argentorati imprelfa funt, 1600 . Tomus tertius inter libros Expurgandos numeratur in Indice $M$ adritenfi edit. Ann. 16:7.

\section{Hoc ejus Epitaphium:}

Turnebus jacet bic. Quis fit s guerere pergis, lam digrus es qui rieficias. 


\section{FRANCISCUS SIXTUS SENENSIS.}

I

Talus, ex Ordine Predicatorum, obiit anno Dom: I5 6g. Scripfit plurima; Bibliotheca Sancta maxino habetur loco apud cruditos.

Vir eruditæ diligentiæ, qui à $P$ io $V$. è tenebris enrorum (ut ip \{e dicere folebat) \& quafiab inferis revocatus, Sacre Militia nomen dedit, \&infigni Opert lib. 8. diftincto ( quo Sacrorum Librorum cenfuram fecit) gratum animum erga ipfum teftatus eft. Thuan. ad ann. 1569 .

Sixtus Senenfis vir plurima lcetionis, \& qui plurima aliorum Scripta evolvit, tum corum imprimis, qui ea tractarunt, qua ipfe ex profeffo tractat. Rainold. de Lib. A pocryph.

Theologus eruditifimus. Bellarm. 1. I. de Verbo Dei.

Doctorum Princeps; qui Sacras Scripturas accuratifinè tractavit. Stapleton. Doctrinal. Princip.

$S \cdot x$ us Seneñes vir planè doctifimus, \&fi quis alius, in $\mathbb{P}$ atribus verfatiflmus Montacut. Apparat. I. Sect. 68.

Neque Sixtus Senenfis recenfendus inter Hare ticos, fortaffis autem inter Criticotumentes Supercilio. Nam ad arcuna Theologie explicatiils enucleainda Cri-

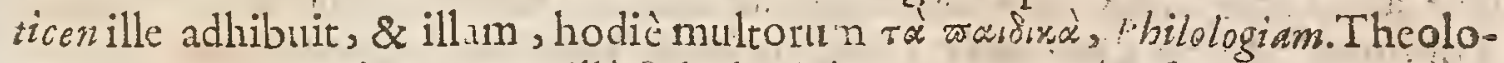
gus erat certe eruditus, \& in illâ Scholafticâ, acroamaticâ, Spirofiore Theolcgiâ verfatus, non tantùm exotericâ îllâ \& populari. Montacut. Apparat.I fect.86.

Sixtus Senea is immenfi laboris Scriptor, diligentix fupendæ, leetionis valix, \& eruditionis admiranda. Montacut . exercit. $5: c .3$. Softom.

Doctifimus \& Lagacifimus veterum Scriptorum Cenfor. Savil. Not.in Chry-

Sir:tus Serenfis migno valebat ingenio. Linguas, Latinam, ac Grecari Hebraicam exactè calluit. Poffevin. in Apparat.

Sixtus Denenfis homo cruditus vocatur Cafaubono ad Annal. Baron. num.22r.

Bibliotheca Sacra Sixti Senenfis, cateris, calculo meo, religionis fux fociis, ob valiam Scriptorumcopiam, \& erectu n in multis judicium, anteferenda. Hottinger. Bibliothecar. Quadripartit p. Ir.

Nihilominus quantumlibet erudita ac utilis fuerit illa Bibliotheca Sacra Six. ti Senenfis Inguifitio Romana non pauca ibi offendit qux palito ejus non fapicbant, quaque audaciufcula ipfr videbantur. Imo \& Poflevinus pro fua parteinnumeros laplus in illa obfervavit; fed dici poteft quod ipfe Critico atque Cenfore opushabeat pluvibus locis $S$ ynop $\int e w$ corum quam dedit nobis Tomo fecundo fui Apparatus Sacri. Non tamen diffitendum eft quin apud Sixtum Senensem lapfus quidam adverfus Criticen legitimam animadverti poflint, \& mi. rari fubit quod vir tam docti palari, \& tam acris judicii inciderit in abfurda de= liramenta, craffiorclque impolturas confratris fui Anni Viterbienfis. Indicia Eruw ditor, Parifies per Baillet, I685. Gall.

Clas. An. D. $M D L V$. 
Opus quod evulgavit Sixtus Senenfis, eui titulus Bibliotbeca Sacra multò utilius eft ad perfectionem allequendam in ftudie Librorum Sacrorum. Ejus in co fcopus fuit homines adducere in cognitionem Authorum ejufmodi Librorum, antiquarum verfionum, \& Commertarioum : Quamvis altem Scriptura Crivicam perfectè Inon calluerit, dici tamen porct pauca in hoc argumentum Scripta extare, in quibus tanta eruditio, tamque folidum judicium eluccant, imo frequenter animi fenfa liberè admodum promit. Primùm agit de I ibris Canonicis, quorum duas Claffes contituit; nomen Canonicorum primi Ordinis illis tribuens, qui in Ecclefiatanquam Divini femper agniti fuerunt; cateros verò Canonicos polterioris Ordinis appellans, quia de horum authoritate olim dubitatum eft, \& frmpliciter Libri Ecclefiaftici vocati confueverant. Poftea de unius cujufque Bibliorum libri Authoribus fingulatim loquitur fatis eruditè: fed quoniam utplurimùm fequiturfententiam Patrum aliorumque qui ante illum in eanden rem fcripferant, non eft femper accuratus. Collocat, verbi gratia, Ethere Volumen inter Libros Canonicos lecundi ordinis, quia Patres quidam Greri animadverterunt Additiones in illum infertas, qureque nullius erant authoritatis. Sed tencbatir, ut arbitror, potius confulere Canonem Indaicum \& Beatum Hicronymum quàm Patres Græcos ? qui de Gracis tantum Excmplaribus loqui potuerunt, quæ ab Autographo Hebreo longè abeunt.; 'Et lecundum hanc regulam Volumen Ẹther Canonicis Libris prioris Ordinis accenfendum erit, quamvis ignoretur \& à quo \&. quando fcriptum fuerit. In altera Operis fui parte Libros Sacros nimis multiplicat, quorundam nominum obtentu, qux in Scriptura occurrunt: Imó pluribus locis ejus Critice non eft accurata, ut quando loquitur de libris qqui Dionyso Areopagita tribuuntur, \&ducentørum quatuor Libiorim quorum Efdram Authorem effc vult. Quxeunque etiam codem loco refert de Cabbale Libris nullo fundamento nituntur. Iudai hac in parte Picum Comitem Mirandulanum fefellerant; Idemque Iicus qui nimis eredulus fuerat hujufmodi fraudum, in caufa fuit cur plures fidem adhibuerint quibufam Libris qui Cub ESdra nomine circumferebantur, \& in quibus reconditiflima Religionis arcana contineri plerique fibi perfuadcbant. Sixtus Sem menfis accuratiorem fe exhibet quarta Operis fui parte, in qua Patrum \& plurium aliorum qui in Biblia fcripferunt Analyfin facit. Richard. Simon Hif. CriticaV.T.lib.3. cap. 17. Gallicè.

* Ejus Bibliotheca Sancta inter libros expurgandos locum habet in Inzice Madrit. edit an. 1667.

Extat Bibliotheca Sancta ex precipuis Ecclefix Catholicx auctoribus in 8. Libros digeta, à Ioanne Hayo Scoto Soc. Iefurevifa \& Scholis illufrata.Coloni Agripp. ex officinâ Cbóninanâ tnuo I526. in $4^{\circ}$. 


\section{FRA NCISCUS ROBERTELLNS.}

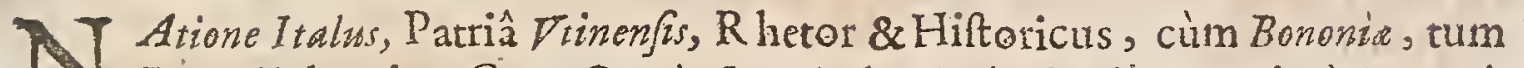
Patavii docuit. Cum Carolo Stgonio de Antiquitatibus maximè Romanis Giar. An D acriorem in modum certavit. Patavii obiit Anno Dom.1567. die 18. Martii, 1iatus Annos 50. Menfes 6. Dies 9. S6ripfit plurima quæ ad Romanas Antiquitates pertinent.

Francifcus Robertellus, vir doctiflimus atque eruditífimus, quem ego foleo in literis divinus hominem appellare. Frane. Luifnus 1.3. Parergon. c. IO.

Sigonius, Robertellus, Bonarnicus, lumina non Itala folum, fed etiam Europa. Lips. Cent.ad Ftal.\& Hispan. eqift. Is.

Averrois liber de Republicâ editus eft una cum Robortelli difceptatione, \& Francifci Philelphi de eadem re libris, qui prifcx gravitatis imaginem redolent, nitore Styli, \& argumentorum prattantiâ. Gabr. Nandkus Ribliogtaph. Polit.

Robortellus prazeptor mihi fuit, \& ego illi infantem ex facro baptifmate fufcepi; vir eft proculdubio fummx eruditionis, \& qui fcire optime poiftit, quid fit Hiftoria. Nolo tamen ad eum ingredi, ne hic meus animus irritatus, \& quafi extra C, me forte cogeret aliquid pronunciare contra "quam requitat amor" \& reverentia, बุuâ cum alioquin profequor. Franic.Patrit. de Hilt. Dial. r.

Francifcus Robortelius, juvenis ( eamenim in eo xtatem elfe audio, quod cum ipfus lande dictum velim ) mulrijugæ eruditionis \& generol $x$ indolis, fed tamen in Batavos homines ferocioris animi, \& importunioris maledicentia, quàm decet. Petr. Nann.18. Mifcellan. c. I.

Recte fentit Robortellius, laudemque acuminis non exiguam meretur, nifi illam corrumperet nimia debacchandi petulantia. I dem c. 2 I.

Quia de Robertello incidit Sermo, videtur mihi vir ille febriculofa eruditio. nis oftentator infignis, \& nullum ferre. Lucas Fruter. 1. 2.7) erifirmil. $1 \mathrm{c} .23$.

Francifci Robortelli fcientiam cùm multis aliis in rebus fingularem effe invenio, tum maximè in vi Grecorrm verborum intelligendâ, \& in Antıquitate Rom manâ contituendî. Carol. Sigon. l. I. Emendat. c. 32. per I"oniam.

Arecm nunc expugnemus Robortellian Scienitû́, quâ fe ille omnibus qui funt, qui fuerunt, excellere in tradendâ Roßsanâ Antiquitate gloriatur. I demibidem 1.2. c. 68 .

Inerat in homine peracris obtrectandi libido, fummaque in doctos omnes iniquitas, quos cùm pares ferre non polfer, continuis profcindebat convitiis: eximio fcilicet florens ingenio, fibique plus, quàm par effet, induigens procaciori ltudio popularium affectabat oblequia. Hinc igonio femper infenfus, ut quem acerrimum fortitus erat xmulum induftrix, laboris, ingenii. Cum Alciato pariter, aliifque clarifimis ejus ævi luminibus, internecinas propè fimultates exercuit. Ioan. Imperi. ? in Iuf. Hift.

Italis undequaque doctinimus \& ingeniofifimus. Sciop. de Art. Crit. 
Vir doctilinus \& difertriffimus. Riccobon. in Rhetor Arift.

Paucula illa, quæ Robortellus \& Scioppius de Arte Criticâ Cripfere, tumultua: ria funt, \& hujus rei fundum omnem non emetiuntur. Dan. Georg. Morbof.de de Polyhift.pag. 54 .

Carolus Sigonius hac in re, (de Romanorum nominibus) uti in aliis plurimis, Robortelium multis poft fe partibus reliquit : ut nos quidem Robortelianurn de Adverfarii fui Commentariis judicium parùm movent; coque minus quò non ignota fit hominis pompatici maledicentia, qui \& Erafmum imperitix imperitiflimæ infimulare, ac nequiffimum appellare non dubitet: Alciaturn nominet furem, expilatoremque fuorum Scriptornm: Vincentium Madiuris, hominem vanum, mendacemque : Paulum $M$ a zutiurn, Bibliopolam, hominemque ime peritum: M. Antoniurn Muretum, ludimagiftum : H. Stephanum impoftorem: fimilibufque elogiis, alios quolque preftantiffimos viros, \& Scripto, \& Sermone infignire confueverit: quo nomine reprehenfus eft jure fummo à doctiffmo quoque. Vofl: 1. I. Analog.c.7.

In Ltaliâ Francifcus Robortellus Vtinenfir, qui magno cum ftrepitu Bononic \& $P$ atavii profellus, cum Carolo Sigonio, fed impari ccrtamine frepius \& acerbius, quàm inter literamm profeflores decuit, digladiatus, in iifque contentionibus, Germanorum, qui \& ei mortuo honorificè parentârunt. femper præcipuo favore adjutus, tandem ultimum diem 15 . Kalend. April. claufit, quinquagefimum annum haut multum fupergrellus. Thuan.ad Ann. 1567.

Robortellus, afinus, beftia, magnus corrafor Scaligera $2{ }^{a}$. Gall.

Extant ejus novem Difputationes de Rornanorum Provinciis, Judiciis, \&c. Bo= nonia $5599^{\circ}$ fol.

Extat de Convenientia Supputationis annorum Liviane cum Marmoribus Capitolinis Libellus, Livio fubjectus, Francofurti ad Moenum I5 68. in fol.

Hoc ejus Epitaphium, in Clauftis Divi Antonii Patavii.

Francifco Robortello Utinenfi Rbetorice Artis, Moralifque Philofopbia profesfori clariffmo, qui in florentiffmis quibufque Italia gymnafis magna fama celebritate triginta totos annos publice docuit, Natio Germanica preceptori benemerito in perpetuam animi memoriam unanimis. P. vixit An. L. Menf. G. Dies 9. Obiit. Is.Kal. April. M.D.LXVII.

In hunc Auctorem hre Carmina compoluit Ioannes Plazzo:

Si qua recordanti veterum pracepta virorum

Grati animi semper maxima latitia:

Robortelle, tui tam cluri nominis, ornnis Gracia perpetwo ftat, Latiumyue memor. 


\section{GUILIELMUS RONDELETIUS.}

N Atus Monfpelti A. C. Iso7. Patre Iohanne Rondeletio, Cive Monfpeliens Clar. An.D. MDLV.

\& Mercatore Aromatarno: Difcipulus in Anatomicis fuit Guinter. Andernacz: tum Claremontir Medicinam tanto quafu excrcuit, ut paulo pònt adeptis fumptibus 1537 . Doctoralem Lanream impetrare potuerit. Anno is 45. in Academià Patria Regius Profelfor conftitutus elt. Ipfius potiffimim hortatu. Rex Monspelii Theatrum Anatomicum xdificari curavit. Anno I5sG. Academix Monjpelienjis Cancellarius declaratus, eoque munere ufque ad anmum is 6 . functus eft, quo nempe ip.e obiit, anno xtaris fure 59.

Scripta ejus hæi funt: Methodus curandorum Morboruu-De dignofcendis morbis - De Febribus - De Morbo Gallico - De Morbis Internis \& Ex:ternis - De Officinâ Pharmacopolarum - De Fucis - Methodus de Materiâ Medicinali, \& Compofitione Medicamentorum---.-Confilia Medica---De Urinis---De Ponderibus, five juftâ quantitate Medicamentorum-----De lifcibus.

Academia Monfpelienfs Medicinæ ftudio florentifima nullum unquam hum jus Irofefforem habuit Rondeletio alımno \& cive fuo clariorem. Multa quidem preclara molitus ef́, fed nihil memorabilius in vitâ perfecit, quàm quum magnifico eruditionis apparatu, nou fune Gulielvi Telizcerii doctiflimi quoque viri auxiliaribus copiis, valtum illud Neptuni regnum ingreffus eft, unde : ampliffimis ejus fpoliis onuftus dd nos rediit, Aquatiliumgue fpecies omnes tum fpectandas tum cognofcendas nobis obtulit. Quod enim attinet ad pofthuma cjus opera, indignum effe ea celebrare, qux ipfe elum viveret luci edere neglexexerit. Scavol. Samurthan. in Elog.

Idem hic Annus (1566.) nobis Gulielmum Rondcletium Montifpefjuli natum Medicinx arte pracellentem abltulit, à Francifco Rabelefo noftrate nihilominus contemptim appellatum in iis libìs, quos ingeniosâ magis, quàm omninò irreprehcnfibili jocand libertatefcripfit. Et certe ejus $S$ cripta ejulmodi funt, ut tanta de fe opinioni five excitate five fparfx non refpondeant. U, num eft quod hominis nomen maximè pofteritati commendavit, quod de Pifcibus edidit; fed cò minore laude, quòd illud potius aliene induftix quàm fux debuit ; nimirum, ex Gulitlrai Pclicerii Epifcopi Montifpefjulani, viri rarâ cruditionc ornati, Corrmentarius concinnatum; quod doctiffmarum Annotationum, quas ille in Plinium fcripferat, magno literarum difpendio amiffarum aut hactenusfuppreffarim pars erat, Thuar.ad an. 1566.

Guliclmus Rondeletius, doctifimus vir, \& natura Pifcium callentifimus. Ca Saubor. in sitbeneurn.

Rondelctiur, Gefnerui \& Aldrovandus, qui tres conftitunt trigam Hiftoricorum Phyficorum ablolutifimam. Alfted. Encyclop.

Eodem tempore Manfoeliuit Gulielmus Rondeletus nonnulla de re Anatomicá confcripfit quidem, verum mox vifo Vefalii opere, ue cumtanto viro in contentio- 
contentionem veniret, manus continere maluit. Majus autem nomen meruit, cvulgato de Pifcibus egregio opere; licèt illud Gulielmo Pellicerio Epifcopo Monfpelienfi per plagium Gurreptum effe Iof. Scalig. 2 ab hoc indu\&us Thuanus non dubituverint affrmare: nobis minimè perfuafis; cum non tantùm vivo \&e vidente Pellicerio opus illud prodicrit, fed \& Rondeletius poft libellum Pharmacentieurn in $P$ ellicerit nomen ediderit, illius operis de Pif:ibus luculenta fam ctâ mentione : quod fine fummâ impudentiâ fieri utique non potuilfet. Sebast. Scheffer. Introduct. in Art. Medic.p. p. 107.108.

In Gallia Rondeletius, Monspalienjis ( Eallopii rúyzpov(a) ) vir æquè doctiflmus, non parùm quoque de re Zootomica meritus eft confcripto de Pifcibus opere penc̀ incomparabili, utut, qua ibi traduntur, ad Philologrcam, Hifioricam \& Grammaticam peritiz humana partem Lpestent, præcipuè, \& iftis fudiis conducant. Loan. Dan. Majoris Chirurg. Infufor. edit. Kiloni 1667 . in $4^{\circ}$. pagina 236 .

Habitûs corporis plenioris erat, ftaturz verò infra mediocrem: Inlucem venit cum corpore tam debili tamque delicatulo, ut primis atatis fuæ annis ab omnibus morbis quibus obnoxii funt homines, fi lepram cxcipiamus, vexatus fuerit; fed poft infantiam omnibus illis agritudinibus liberatus eft, \& deinceps ejus valetudo in dies aucta eft, prout atate provehebatur. In juventute Vini ufum abdicavit ut arthritidem præcaveret, quæaliquoties ipfum perftrinxerat, Quamvis tamen meram aquam biberet omnis generis frum Ctibus copiofifsimè vefcebatur, cerafis prefertim, ficubus, uvis \& melonibus. Parum dormiebat, bonanque noctis partem in lectione \& ftudiis infumebat. Jngenio erat vivido, fubtili \& peracuto. Sed parum cauta erat ejus agendi ratio, cumque in maximi momenti rebus, non latis has perpenderet ante quam animum determinaret, confili plerumque iplum penitebat. Ufque ad excelfum liberalis erat, pecuniafque ade contemnebat, tamque profusè erogabat, ut quamvis latita elfent ejus ftipendia \& in exercitio Medicinæ mul-tum lucraretur, nulla ferè bona Cuis hredibus reliquerit. Magna contencione ad Anatomiam animum appulit, propriis manibus diffectiones fecit. Imo ut certum perhibetur ipfum corporis cujufdam è propriis liberis aperuifo fe, \&ob hanc operationem barbari patris \& inhumani nomine infamarum elfe. Difcipulos doeere ufque adeo deleatabatur ut quotidie tres quatuorve lectiones haberet, cùmque admodum feftivus effet, Cermones fuos jucunda aliqua fabella vel narratiuncula exhilarare Colebat. Affiduè legebat. Theologise libros: Sed ex quo incarceratus fuit Guillelmus Pelifjerius Monfpeffulanus Epilcopus, ut qui Protefantium opinionibus adhæreret, omnia Theolo. gica Scripta qua in fua Bibliotheca erant in ignem conjecit. Cum aliquid cómponebat adeo pracipitanter id faciebat, ut fripta nequidem relegere nec emendare dignaretur. Hinc eft guod ejus Opera non refponderint magnx celebritati quam eruditione fua fibi paraverat, ut optimcjobCervavit Dominus Thuanus, Amton. Teiffer, Elogiis Erudicoum Virarum. Gallice.

Extant: 


\section{CELEBRTORVM AVTHORVM.}

Extant opera ejus omnia Medica, Generve, apud Petrum \& Iacobum Choures, 1628.in 8.".

Extantlibri de Pifcibus Marinis. In quibus verz I lifcium Effigies expretre funt. Eugdwni, apud Mutthiam Bonhorme, as54. in fol.

Extat Uniwcrix A guatilium Hiftorix, Pars alterascum veris ipforum imagin wibus. lbidem, apud eund. 5555 . in fol.

\section{JOHAN NES MER CERUS.}

$\mathrm{U}$

Ticenfis, Jurilconfultus \& Philologus perctebris, Anno r570. Obiit, Clar. A.D.

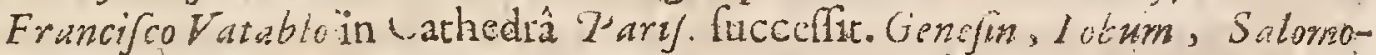
:ners \& lex minores priores prophetas enuditifimis commentaxis illuftravit: Pagnini quoqie 1 helaum recognovit, varifique anotationibus locupletawit. Trneftulit Harmenopuli Prochiron, \& Oxi foo lines Hieroglyphicon, cum obfervationibus.

Sublato ì vivis Francifco Vatablo Hebraicarum literarum apud Gallos ingltauratere, un"s in ejus locam luffici promeruit Ioinnes Mercris, cul primas in

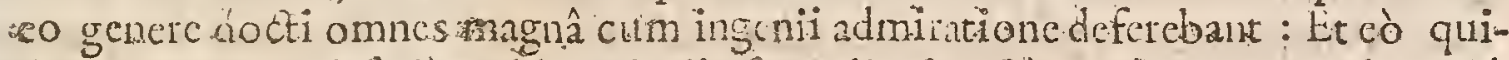
dem majore, guò feriùs ad hac ftudia fe applicuit. Cùm enìm, ut.erat honeftâ ortus familiti, in eam fpem à fuis educaretrtr, ut fibi ad Reipublicre Gubennacula ${ }^{2}$ dignitatcs viam pararct, Tui Civili operam adolefcens Averione Tholofa que primum impenderat, ejufque otii non leve documenturn ediderat $H$ armenopulo è Gracá linguâ fideliffumè tranflato. Scd longè graviera funt, \& homine Chrffian digniora, qux maxin iobum \& in omnes Prophetas magnâ diligcntiâ parigue judicio commentatus oft : plura etiam praftiturus, nifr Venetiis xediens, quò fe tumultuante ìtcum Gallia in Ferrerii Legati Regii comitaru contulerat; apud Aitiobriges patram furm Lethali morbo deprchenfus ante annos occieiflit. Corpore, fuit gracili, \& à Atudiorum laboribus macilento, fed voce robuftâ \& virili quz auditorivm probè impleret : temperantiâ autem, pudore, modeftiâ, '\& creteris animi boinis fupra variæ doctrinx laudem nulli fecundus. Cụi \& hac à luperûm indulgentiâ conecthum eft, ur fibi quodammodo fuperites non omino cum morke interiret. Uxorem enim duxerat Allerii 1 obilis viri \& Antonie Delonia fliam, Camille Morella virginis doetifime fororem, q110 ex connubio Iofiam filium tanto patre dignifimum fufcepito Scavol. Samarthan. in Elog.

foannes Mercirus apud Ocritanos honetto loco natis, quum utramque linguam adhuc adolefens didicirit, \& eoufque in Juris Civilis cognirione pro-

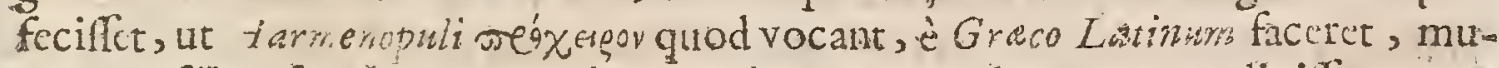
tato conflio, fimularque Vatablum Hebrea Lutetia docentem audiviffit, tanto animi ardore ftudium illius linguxe eft amplexarus, ut illo è vivis fublato, dignus unus videretur qui tanto viro in illius profeffrone fuccederet. Hî̀ verò quantum rele preftiterit adjuncto ad qutatuor Linguarum exactam cognitionem summamTrte que 
que diligentiam, ju dicio longè acenimo, doutiffinx ipfius Prelectiones partim: fam ediax, partim dinceps edendx fatis fupcrque teftantur. Accedcbane autcm ad hanc eruditionem fummum pictatis fudium candidum ingenium, modeftia fingularis, vita proifus inculpabilis, adco ut fervente civilibus ob rligionem bellis $G$ llin, quamvis facros libes non modò Grammatice , Cederiam ch-ifiane explic ret, lalvum tamen illum \& inxiolabilem amabiles ipfus mores fortiter in (uo munere perfeverantem pratiterint, \& ex cjus unius pene fcholâ prodilfe confet quicunque in Gallis hodio paulò felicius hebraiflant. Repetitis vero bellis Venetras ornatifumum quendam virum lecutus ibique Hebraorum doctillimis admirationi habitus, quum ad ftationem fuam ievertçns per Occituniam îter faceret intempentivâ planè morte Lublatus; maximum fui defiderium doctis piifque omibus reliquit. Theod. Beza in Icons.

Mercerus Vatablo in Ordinario explicaudx Sacru Lingue munce fiecenturiatus, vixcredibile eft, qualem, fe quantumque praftiterit; quippe qui quaruor linguarum peritifimus ad incredibilem diligentiam acerrimum judicium

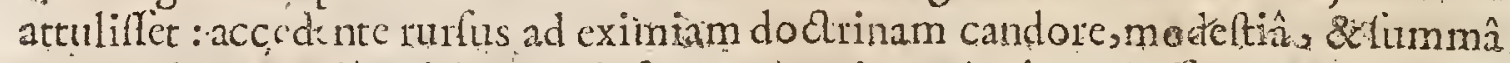

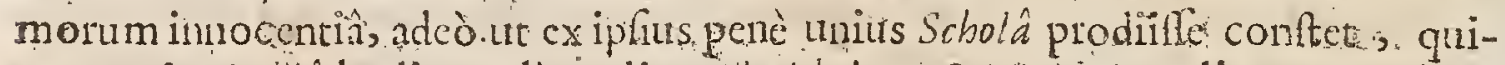
cunque rin Gallia hodie paulo mclius. Chaldaicam \& Hebraicam linguam callent - Poltmortem cjus publicata funt enditilima in Go minoress Prophetas priores, Iobum, Solurnonem, \&xpofteà iil Geneftr. Commentaria; qui fortus licèr pofthumi, accuratam Parentis fui diligentian produnt; ut vel ex is alis. (qux vivus publicavit) monumentis in confelfo fit , Nunguam quenguam Cbriftumurn filicius Hebrailafe. Thwan. adanp. I570.

Vir toticis humnioris literatura intelligentiflmus loannes Mercerus, Re-

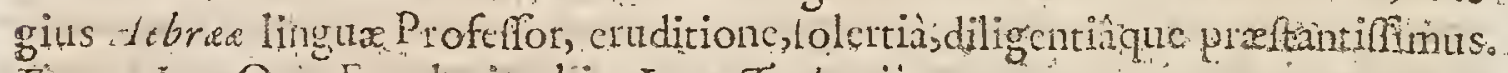
Franc. Iun. Orat. Funcirinobit: Luce Trelcatio.

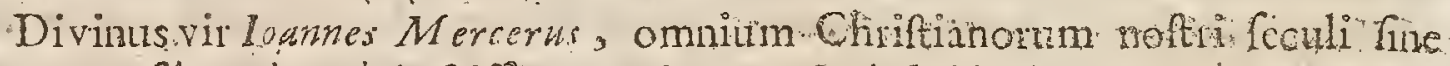
controverfin tebraxce doetiffimus. I faac. Cafaub. Epift. 28 I.

loannes $M$ ercerts profundx in Helraicis doctina vit. Idem ad Baron.p. 69.

loames Mercerus, fuperioris feculi lumen vivum \& clarum. Buxtorf. lib: de Abbreviatur. Hebroorum.

Ioanes Mercerus, yix cui in Ebrairis paren nunquam edidit Gatlia. Amana.

Parnobile Interpretum, Aercerur \& Luveleivs : quorum illenuper laudatns, \& (dum eruditioni atque pietati habetur honos ) femper laudandus. CW att. Polus.

Ioannes Mercerns maximi vir judicii, quilunus, optimè de literis Ebraicis meritus eft. Drufus in Obfervationibus Sacr.

Hujus Lententire merepptobatorem habeo Lobannem Mercerum, cujus viri jułlium femper feci pluimi, qui unus inter eos qui hac ftudia tractarunt, \& literas facras explicarunt, tantum eminet quantum lenta folent inter vibuma cuprefi. Druf:1.15. C. 25. ibid:

Mercerss Maxirnus Grammaticus, virpius, \& in exponendis facris literis excellentifimus Hebreus Scaligerana prima.: 
Mercerus Dotiffmus in Hebracis. Unde ctiam in Jobum optine foriaht. Quis hanc foriplerit librum ignoratur. Ich. Mercerns vir praclaus Orum interpretatus clt, Notafque in cum adomavit. Mercerms Juris piudentix operam navavit, Harmenopolumque tranltulit. Mercerus quando prælegebat Andi-

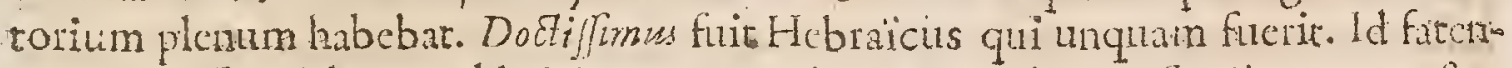
tur Indar. Laudabant valde Mercerum ginia elat maximus. Scaligerana polterior Gall.

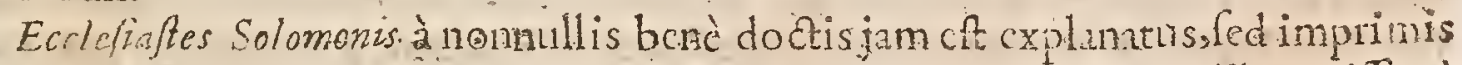
cruditifemi viri Ioanns Merceri pixe memorix Commentarius diligentifime

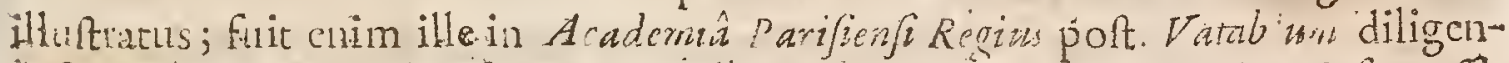
cilf nus famul \& cruditifimus permulitis annis Proffor, illo certe cui fucceffit doctrina non inferior, judicio ctiam fo taffe in difcenendis Rabbinorumaberawonibis.fuperior. Theod. Beza Epift. Prefat. in Ecclcliaf.1598.

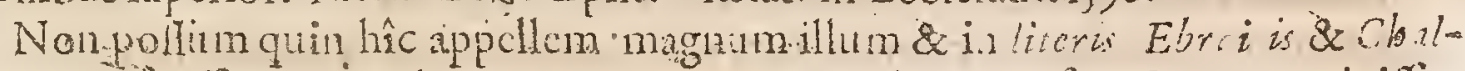
daich verlatifinum, lebannem $M$ ercertus, qui cum jam fincotutem attigifet,

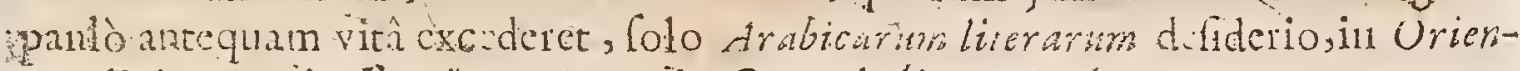
term dicitul cogitate. Than. Enprain Oat. de ling. Arab.

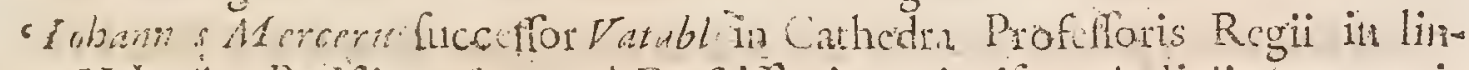
- gua Hcbratca Parifis, clt unus c̀ Do tilimis acriorifque judicii Interprcti- bus Sc. jpture, qui unquam fucrit inter Religionis Pretenfa reformata culto-

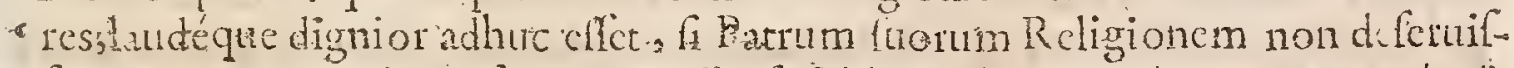

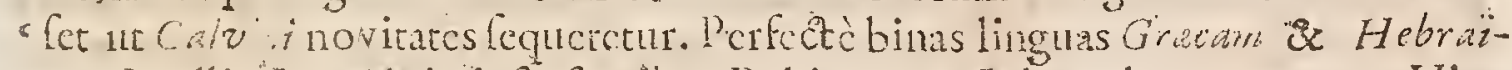
- camintelligebat, \& in ipfis fontibus Rabinorum Libros legere porerat. Hine - etiam ratio cxplicandi Biblia, gua ufus eft, multo magis Critica \& a curata eft " quàm plererunque catel orum Authoum quillum pracelferant. Totam ad" hibuit operam fonfil litcrili Textus lui, \& indagationi proprize fignificationis

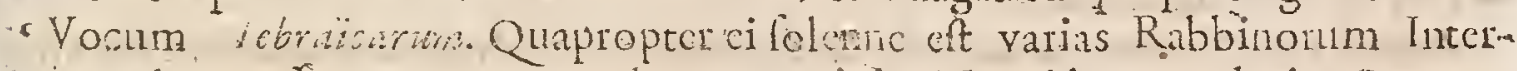
" pretationes afferre, quas quandoque corrigit. Nequidem neglexit Grecam * Verfonem Scptlaginta, nec cateros Bibliorum Veteres Interpretes; quod ta- men frequentus faccec potuifet. Confuluit ctiam Excmplaria debraica mana s cxarata, qux in Rcgii Bibliotheca erant. Veibo ut ablolvam, ornatus fuit s omibus dotibnsperiti Bibliornm Interpretis: meliufque adhuc dubioprocul - ei fucceffift \& labor, nifi xtatis qua vixit novitatibus fefe permififet. Optimi

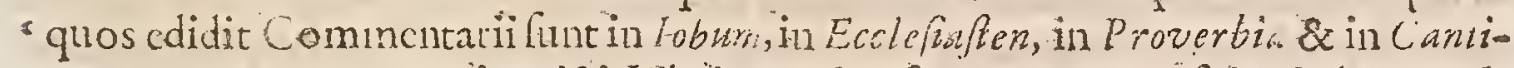
- cumb Canticorm. Quoniam ifti Libri carmine fucrunt compoliti, fyloque ad- modum intcrito, perdifficile verum cornm tentum eruere, nif cum perfecta "Hcbraic finglaz peritia, \& fummo ingenii acumine. Neutro antem deftiturus - fuit Merccrus, pcnitufquc examinavit ommes dificultates quz fibi objecte - funt.Quod a ejus in ferrefin Commentarios multa Judä̈ca eruditio illis inclt, - Ced latis caltigati non funt. Bera qui Authoris hujus Commentarios omncs "typis mandandos curavit, minutias cx illis non potuit cximcre;cx nltimis pre- fcrim qui non tint aquè abloluti ac cxteri. Cornelines. Bertranus, qui Beze - Collega fuir Genevx, quique Hebraam linguam callebat, corum evulgationem

$$
\text { Itrt } 2 \text { accuravit; }
$$


*accuravit, idque $f_{a}$ tis diligenter, quanvis errores quandoque occurrantsquot - tamen rariù contingit. Jel. Rich Simo z. Hift. Crit. V.T. lib.z..cap.I4, Gall.

Nec oblcurum eft in his Opificibus-loanmis Merceri nomen; cujus præcipuè laudatur remetiendorum pari numero, cum fententix; integritate verborum. follicitudo - Qui Vatablurn in Ebraicarurn literarum profeflone cxccpit loannes Nercerus, nonablurdèin Ori Apollinis \& Harmenopuli interpretatione verfazus eft; Latine faribendi dilig̈ens fine moleftiâ venuftas, non ubi hue tamen fatis: tenax, ncc qualem in Ebruis reddendis adhibet verborum parfimonia. Huet, de Clar. Interpret.p. 190.210 .

Ml ricrur in Geographiâ minimè verfatum teftatur Samuel Bochartus in Phaleg. p: 92 .

* loannes Mercerus inter Harcticos prima Claffis rejicitur.

Extant cjus in Gener. Pralectioncs, fol. Genev. I598:

Extant in Job. Prov, Ecclel.Cant Cant . Commentaria Amflelod. I6jo

Extant Commentariin 5. Prophetas minores, fold Genev. Is 65.

\section{SEBASTIANUS CASTALIO, frVe CASTELIIO.}

Claruita.D. Allus, Allobrox, cxcellèntilinguarum cognitione preditus, Bafflea Grace MDLV.

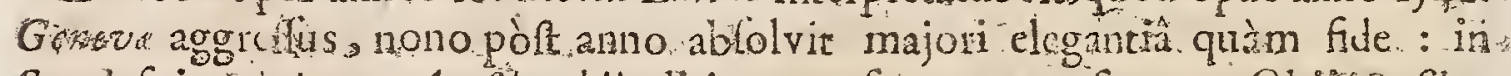
Sacris fuis Dinlogas, Arefdorphii editis, non ufquequaque fucerus. Obiit Baflex anno 1563. xatis 49. Prima Arninianimi Semin in Dialogis fuis fparfife videtrit. Hofrnan. in Lexic:

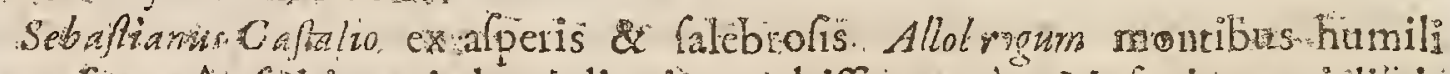
ortes fortuni, fed ingenio bonis literis excultiffmo, chm Mufas in omndiciplinanm gencre Latruloquentes viderct, tentare voluit num sacre Litera negligention hactents \& horidiore quodam fylo contentx his yuoque mun-m ditis xomari polfent \& expolin Foc itaque anino novam Biblionum erala tionem exousus omnes wriulque foederis libros raro \& admirabili nec ull dum: in his literis uffato puritaris 2 elegantiz nito:e exprefos intia decenniumado rnavit \& publicavit. Magnam poculdubio abcruditis omnibus \& pis gratiam Initurus, nif lacrolanctam rerum divinarum majeftatem vilus effet aliquot in

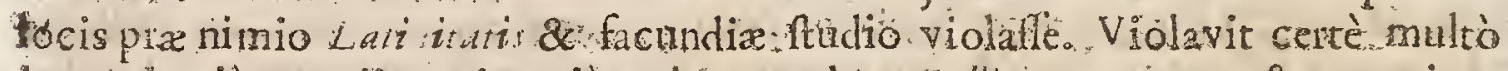
imprud ntius, ne dicam ineptits, dum eandcm Grlire operam praftare cupiens

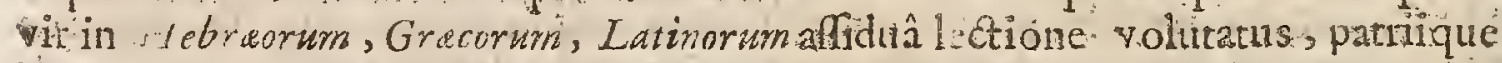
interim fermonis penè oblitus, aneptis è trivio ärinfima plebe voculis ac lomendi fornalis, adendum fe omnibus in re tam feria probuit atque conremnendum. Deberi tamen yidetur hoc ejus egfegix voluntati, fummoque labori, \& veterum, linguarum fuigulari peritix, ut unter doctifimos hujus atatis yitos yel cum primis enumerctur. Homo catcrogum fumplex \& ab omni. fartu 
faltu alienus, quifuburbanum predium fuâ ipfe manu quotidiè foderet, , fufceptamque juventutis exudiendæcuram alterno telluris colendx labore adsquaret. Exceffit: B. falca Rauracorum ex febre nondum fenex anno is63. scevol. Samaribain.

Quid verò de intemperantifimâ Sebafinani Caftalionis Converfione ftatucndum eft, qua res purifimas faftidiosâ venuftate oblimavit , \& omnem divini Verbi vim nimià curatuiâ elifit, \& verba à Patribus, \& toto:Cbriffianorum coetu recepta \& ufurpata inepriflimè repudiavit; homo cateroquin fimplex; \& ab omni faftu alicinls, ut de eo verè fcriplit Samarzbunus, \& eximiam in :Operts Gui Præfatione ing enuitatem \& candorem prefe fecens s, proptereaque a tnobis. frne contumeliâ dimittendus. Huet. de Clar. Interpret.

Sebafian.C' aftillon Allobrox Lugduni cum agerct adolefcens; accidit ut 'quidatm? errore rominis pro effellione, Caftalionem vocaret", quodaudiens à Mujarum.

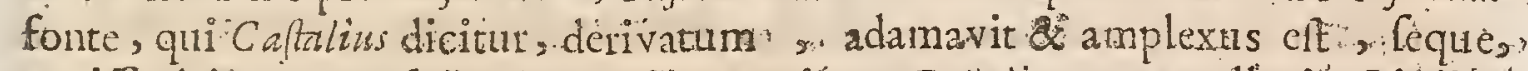
omiffo deinceps Cafellionis nomine patrio , Caltalionem appellawit. Id dicii ipfe in defenfione quadàn adverfus libellum: Loannis Calwinit...Scaligerana d: pag. 4 2:

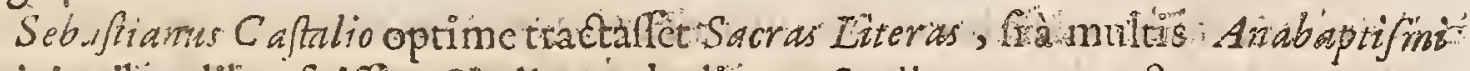
opinionibus liber friffet, Sadjutis abaliquno: Scaligerana I. p.28.

Sebuffianus Caftaliv Canticum Canticorum flagitiofuni effe librum dicebato.,

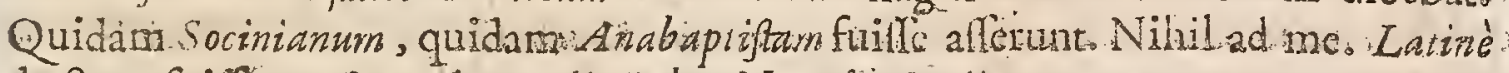
doctum fuiffe conftat. Tanaquil. Faber Not: in Scaligerana sus.

Caftrlio cum puriorem linguarum cognitionem ad Theologicam fcientiam? adjunxiffe fe putaret, impuras manus ( multorum. judicio ) ad facra tractarada. attulit, cùm à rebus ad tantum opus neceffariis homo imparatilimus navam.

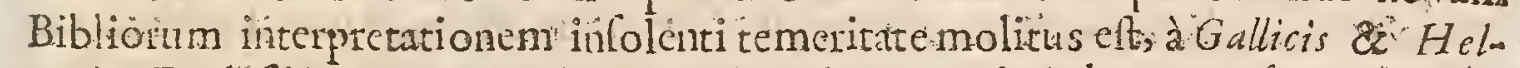
veticis Ecclefiis, quasum alioqui dockinam amploctebatus, lii quiburdam

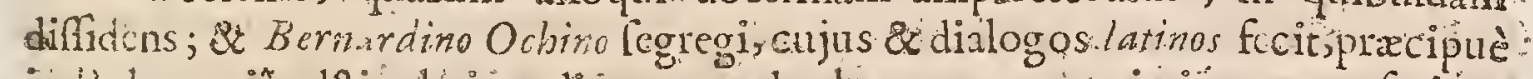

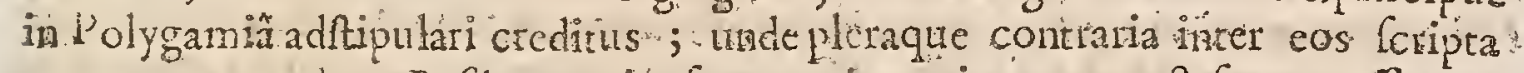

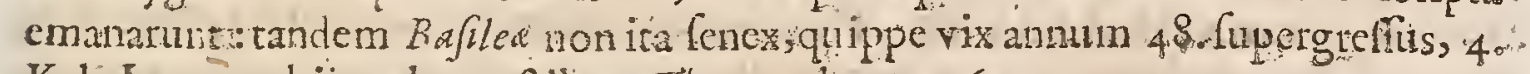
Kal. Jaudar.obiit ex lue peftilent. Thum. ad ann. If63..

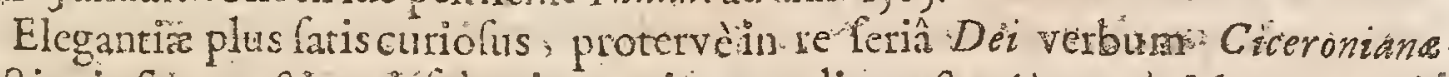

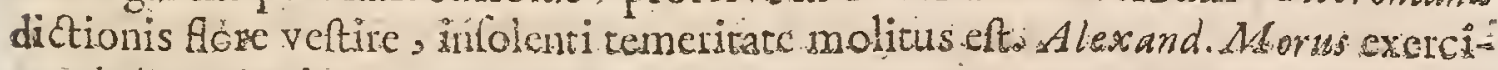
tat. de Sacr. ¿criptur.

Tranfiationera cjus Erbinicam appellänt I dem sbid。.

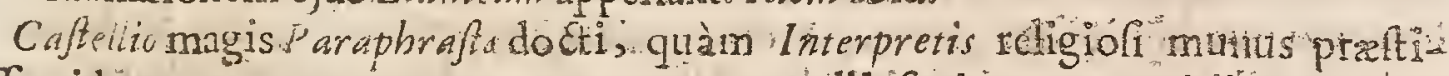
tilfe videtur : nccpropterea tamen, ut nonulli faciunt, convitiis exagitandus, cùm etiamfi verba non adhumerer, fenfum tamen ut plurimuin fidelifimè seddat, ut ab ils, qui Latinè tantum fciunt, intelligi poffat Martin. Kurarus Cento s. Epilt.p.97\%

Ciaftalio in verfione fuâ dé textu Hebraico ad verbum reddéndó nchadmodum laborat, at fenfumplurimis in locis perfpicuè, purè̀, eleganter, \& fideliter exprimit,

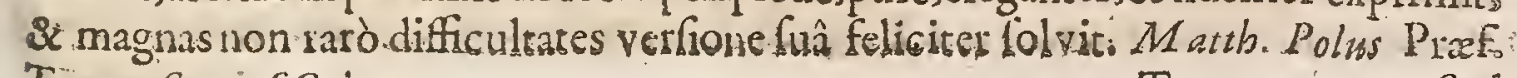
Tom.1.Syropf.Crit.p. So, 
Sed \& Cafrellionis verfonem, doctam fane; \& elegantem, \& multa in paucis complcetentem (quam etiam in Anionationibus fuis crcbrò citat nofter Hawmondus, \& aliis prafert ) haud raro mili uful\& auxilio fuiffe non inficior. Dr. Iacob. Duport Prefat. ad Metaph. Pfalmor.

Caftellio, homo meajudicio nce incruditus., nec malus. Hug. Grot. in Epitt. ad Nic. Reigersbergium. Lut.in Decembr.:4637.

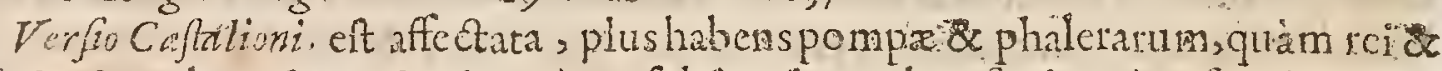
firmitatis, plus oftentationis quàm fubetantix., plus fuci quam fucci, plus hominis quàm fpiritûs, plus fumiquàm famma, plus humanarum cogitationam quàn divinonm fenfum. Gilbert. Genebrard. Prafo in Open Org.

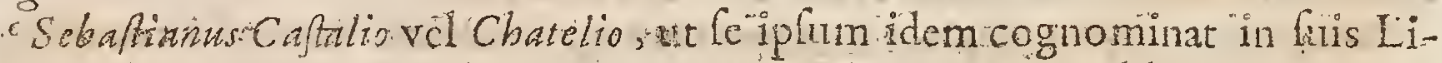
cbinis Gallicis, eft etian Author Ferfonis Lain integrom Biblionm, quam - fepius deincepsad incudem rexocrvit. Peima editio eft anui IjSI. Bafilez. - Onnium plurimizefimata ef illa anni 1573 . codem loco:quam tamencum rerepcire non poucrim, ulus fum alia catione anni 554 . qux Baflea ctiam prodiit - Notulifyuc quibuldam ftipatur. Geneve Doctorcs:s Theodoris $B$ cza cumprismis novam hanc Catalionis Trantationem accrbè admodum vituperartuts "s hincque hac occafiene ignarum \& emerarium vocaverunt, ci expiobrantes -quòd cripruram ludibundus tractaverit, quod prolixius alegere eft in Prefa- rione Gallica ad funem unius ex horum Verfionibus Gallicis Biblionumanii is.59.

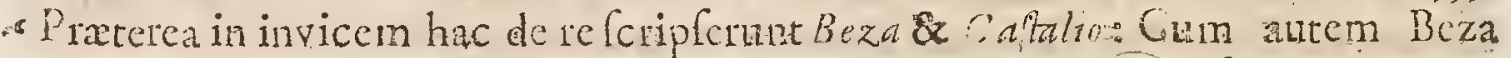
- Comonis Hebraciprorfusignaras cflet coactus fuit aliorum fententix itare, - qui affeverabant $C$ aftalionem idiomatis $H$ cbraici minimè perirum efe " afulio

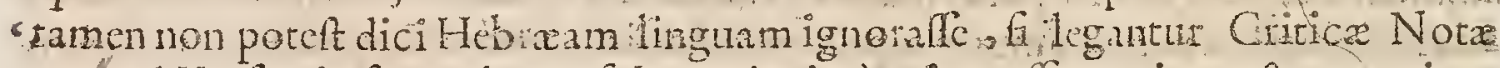
- quas ad Verfionis. fux calcem fubnexuit, imò etiam affunari potefteum trium

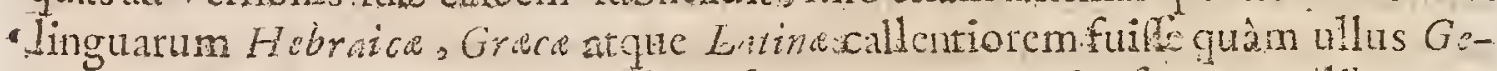
- nevenfum Doctornm. Sed non fatis fervavit Interpretis facrorum dibrorum "characterem; cultum \& lcgantem fyllim nimis affectavit, gua tatione Textus fui fenfum vidd debilitavit. Hujulmodi vitium Verfonis cjus totum corc pus infeftat, ut facile judicari poretir tatim à primis $G$ ecos verbis qux in - hunc modun trantulito Prineipo creavit Deus Colum of Tersan. Cum autem

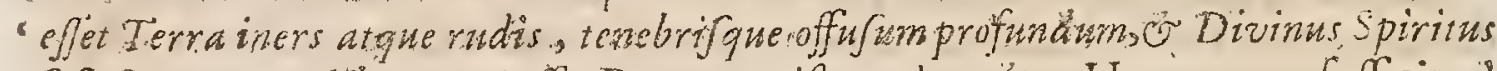

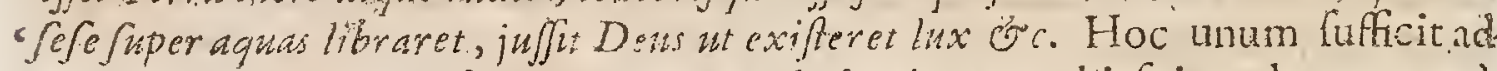
oftendendum fuod aftalio non contenderit Autegraphi fui vorba acculate - interpretai i, fd fenfum quanta potuit clegantia expinere, delexto in hunc. finem fylo cohercnte atque periodico. Uf fue adcopoliti icriproris charactem caffectavit, ut cjus lcume quandoque fut effomiantus, ut in libro Canticurum, "ubi abitratus ch, ad fervandum itylum quemargumentum ex exigcre videcbartur, Catulli diction m fibi imitandum elle, utendo vocabulis diminutivis; "quippe quatenerum affectum mais indicarcut ino diminutivis iftis voci* Epitheta diminttiva conjungit. Unde non contentus fumpliciter dicere Mea - columba, dixit Mea columbula. En quali diotione toto hoc libro utatur. Mea columbula 


\section{CELEBRIORUM AUTHOR UM.}

scolimbula oftende mihi tunm vuliculum: Fac utaudiam tudm voculam; nam

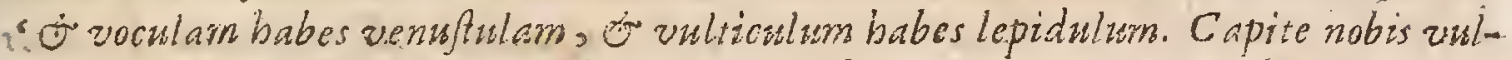
speculasparvas vinearum wafarricuiss. Jef. Rich. Simon. Hiltoria Crit. V. T. "lib:2. cap. 21. Gall:

- Tefobrion micus non eft quiprofelfus efCafalionis Verfonem in pretio - fehabcre; Andreas Hipperius alfeverat illam diligentifimè \& accuratiflumè -fcriptam elfa. Laurentius H.unfredus Anglus Caltalionery defendit adverfus eos ¿quicontcndunt ejus profcutionem cultionisfyli fulle in caufa quòd verum - fenfum neglexerit pliritm loconm in. Sacris Libils. Fredericus Furius Cerio- lanus hanc Tranfarionem fupsa cateras omnes cxtollito Ant. Tëejfer. Elogiis - Viror Eundit. Gallice.

Sebufitunus Cafellio fuấ quadain in Sacronum Bibliónmperverfonem $\mathrm{P}_{1} x$ fationepalatn verbi divini laris perfoicuam auctoritatem convellere thaduir fuifque in priorem at Corinth. Epifolam adiotationibus sut à arbo fcripto

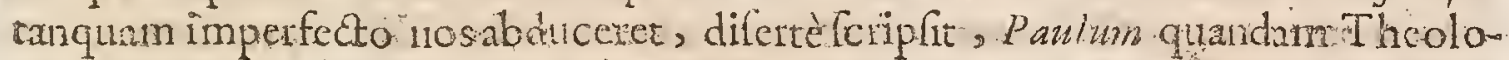

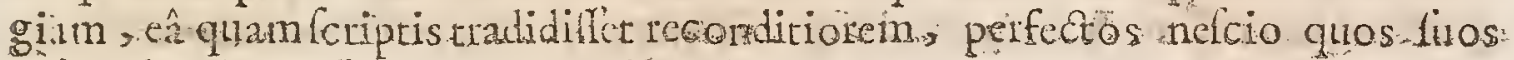
dilcipulos docuille. Theod.Beza in vitâ Calvini...

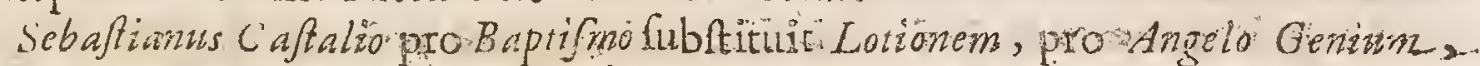
profide confidentiam, pro Ecclefin Rempublicam s. pro-synagogá Collegium, neque minus inepte in alis multis qua jure in Caltalione calpant Inelligen tiöres. fuf part. 2.Inttitut. Orator.9.6.

Caftalioni fecerunt injuriam, cum doctis clfet, faftum objecerunt, norturs eftex pupcratc. Scaligerana $2:-$

* Sebultianus. Caftalio Ronnano Indice inter Hareticos prima Clafjis ummeratug:oz

\section{A NDD R A S:M A S I G:S.}

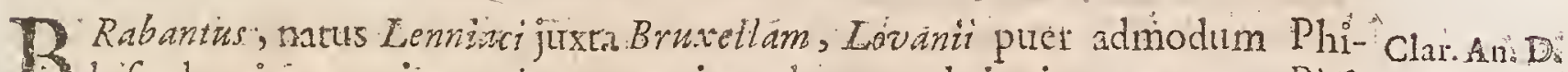
1 Lofophos iner, primum in piomotione locum obtinuit anno 1533 . Fòt MDL y. Juris utrifque ftudio operam dedit, lameaque: Doctocalinfiguirus, Cliviorurn

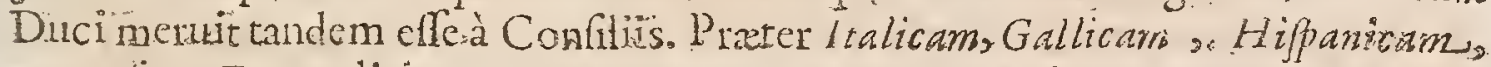
cateratque Enrofe linguas, ctiantatine, Grece, Hebraice, atguesyriace. cognitione non vulgari claruit; Mofern Mardenum, Ratrarcham Antiochinum,...

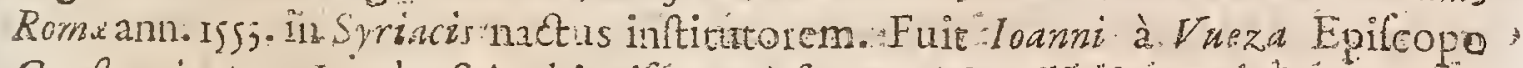

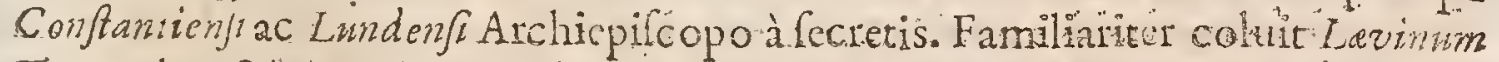
Torrentium \& Angerium Busbequinm, qui Mafi potifimum Confliofe dignin. rare crevileprofiteri ingenue Colcbat: Demum" à "philippo I I. Anuerpiam.

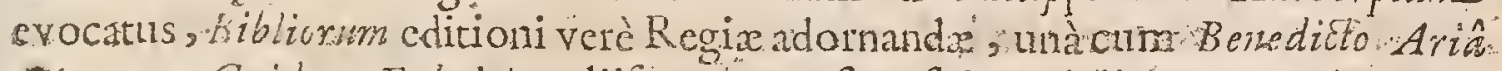
Montano, Guidone Fabricio, alifque prapolitus fuit. Edidir Grammaicurn Syriacarn, Syrorum Peculium, feu explicationem yocabulorum paftim apud Syridios ufurpatorm. Leguntur ita in Regionum Bibliorum Apparäu. Tranfur lit:è Syriaco Commentarium de Paradifo ante annos propé 1200. à More Bar Cepbes. 
Cepha, Syra, Ecriptum; item B. Baflit Liturgiam. Explicationem in Hifloriam 7o ue Imperatoris, in quâ tamen expungenda quxdam elfe monent Cenfores Romani. Difputationem De Cuenâ Dorrinicâ oppofitam Calviniftarum corruptelis ; \& alia. Vivere defit Zevenarie Cliviorum an. 5.73. Aubert. Atireus.

Vir fuit $\pi \lambda \epsilon \delta^{\prime} \gamma \lambda \omega \pi 70$ ': Nam prater Italicam, Gallicans, Hijpanicam, cxterafque Europelinguas, etiam Latine, Grace, Hebraica, atque Syriace, cognitionenon vulgari claruit. Habuit familiarem, uifdem ftudiis deditum, Sebaft. Munfterum, ad qucm frequentes dedit literas, \& Latinas, $\&$. Hebraicas; eafque tam doetas, Munfleri judició, ut illum velinter Latinos folùm; vel inter Iudaos folum educatlim teftarentur. Vater. Andreasin Biblioth. Relgic.

Vir fincero, calldido, \& aperto ingerio: A dhæc rarâ reconditâ doctrinâ

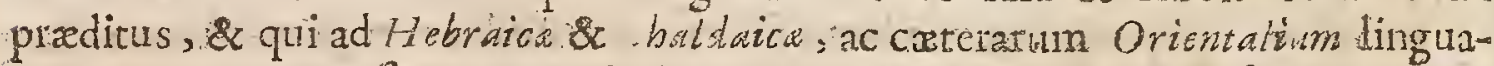
Ium cognitionem, fummam animi pictatem \& exactum rerum facrarum ftudium attulerat, variaque in eo gcnete commentatus fuerar; plura etiam daturus, fi viro bono per valetudinem ferè femper adverlam licuilfet Specinen corum prabont doctilimi \& accuratâ diligentiâ fcripti in Iofuam Comamentarïi Thuar. ad ann. 1573 .

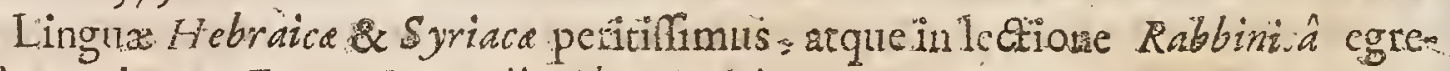
giè excucitatus. Franc. Svvertii Aiben. Relgic.

Omnium feculorum memoriâ dignifinus Andreas Mafins. 1 dem.

Andreas ML afius Papina quidem ar anior, \&exterimus Sacre Scripture interpres. Salon. Gliafins.

Andreas Mafins doetus fuit, \& bene feriphit in Yofuam. Scaligerana 2.

Doctiffimus iofuc interpres. G nebrard. Chronolog. 1. I.

Vir undequaque doliffmus, 2 linguarum peritillamus Andreas Mafus. loan. Wier. de Magis infamibus, C.i Cect. I.

Excellentis doctune ac emendatifini judicio vir Andreas Mafus. Paul. Colomef. Obfer. Sacr. p.IIA.

Furt virille( Andress Mafurs) nen folùm fugulari \& reconditâ eruditione. fed etiam candorc \& probitate fuprà exquifitam doctrinam longe magis mirabili, ideoque madcratis omuibus quibufcunque partibus addicti fnt, gratus \& acceptus, propter cxcellentes iftas dotes. Dallatis de ufu Patrum, pag. 67 .

Andreas $M$ afins vir peracri 8 limato Tudicio, quod teftari polfunt , quotquot ejus'segerut feipta: Eft author nnus inter paucifimos, dignuf que, cujus Cormentarin aternum cxcudanturac recudantur: qux tamen, fi Deo placet, jacent neglecta \& tantum non pro nithito penduntur, quỉa referra eruditione \& doctrina funt. Simen de Muis Tom.2.p.207.

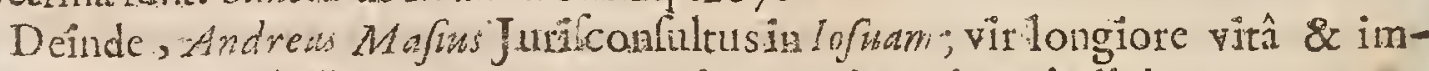
mortali memoriâ dignus; Interprescui parem ingenio, judicio, rerum ac inguarum peritiâ, candore \& modeftiâ, haud facilèrcperies. $M$ atth. Polus Prafat. ad Lector. t. Vol. Synopl, Critic. 


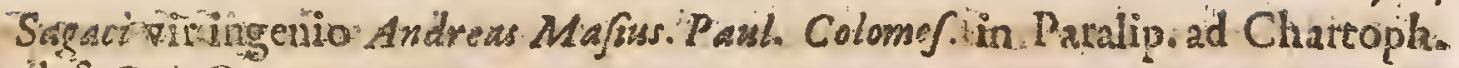
Ecclef. Gul. Cave.p.4.

Andreas Mafuns, vir nunquam fine laude nominandus. Idem ibid. pag.tr.

Or. P.r. Simon är paucos nobis extare Authores qui tam exercitati funt in Scris prureftylo, quique Bibliorum Criticen melius feiverint quàm $M$ aftus , \& ad veritatem hasc fibi perfuadendan funficere doctas $\mathrm{Pr}$ rationes legere, quibus atipatur ejus in lofuam Commentarium. Sed contendit in brevibus Notis eurdem Mafum diffufum quandoque paulo nimis elfe in Rabbinorum explicationibus.referendis, quibufdam locis ubi valde neceflarium fuife noii videtur. Verrum quiadem eft(addit idem Oratorii Pr.) quòd defectus itte non poffir.non placeare iis qui eruditione ludaica delectantur. Or. Presbyter Rich. Simon Hift. Crit. V.T.lib. 3.cap.rs. Gallicè.

Licet Mafus quidragefimum tantum watis annum attigilfet quando diem

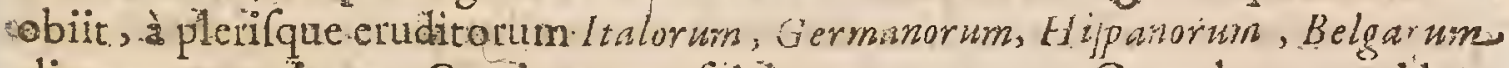
aliarumque variarum Gentum confulcbatur tamquam Oraculum quoddam. Tantakiim eruditione, tanto judicio pollcoat, ut quantumvis dificilia \& obfcuraclfent. quz ipfi proponibuntur, ea cxplanaret terfiflumè ac folidifimè. Durane morbo gio füblacus furit Commentarium fum in / Vuam impreffum videseperoptavit: fed hoc gaudio perfundi nequivit : Opus enim illud in lucer anora prodiit nifi anno uno poft obitum cjus, anno nìmirum 1574. Ant. Teifser. Elogits Virerum Erudit. Gutl.

Andreas Mafus vir perficicacis ìngenii, o doctrine fingularis, quen $M o$ is tbar Cephalibrum de Paradro, Iacobi arum I iturgian, aliaque multa è Syriaco Latine efferret, vesbonm religioni fefeadharere ipsâ interpretationum fuarum

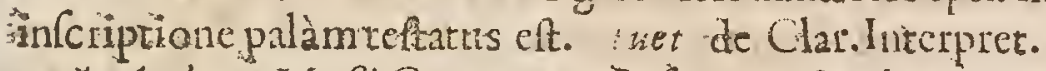

* Andres $M$ afil Commentaria felper Iofue donec corrigantur, prohibentur in Indice Tridentino app.ndicis Certorum Auckorum.

Extant ejus in !ofwerm Hilutrationes fol. \& octavo Antverp. $1574,1609.8$ inter Criticos per Corn. Bee, Lond. 1660.

\section{JOANNES JUELLUS。}

F Pifcouts Sarisburienfis, in Comitatu Devonic natus eft Anno Dom. is 22.24. Clar. A. D. E Maiz. Oblit 23.5eptemb. Anno Chr. 1571. Atatis 49. Sarisburienfi Divecefi per annos XI. menfes IX. fummâ fide \& integritate prafuit. Scripjăt f pologiam Ecclefra Anglicana, \& ddverfus Thomazis Harringumb.

Itvvellus Anglire fonat Germmam, vel potiùs monile gemaris confertum. Et certè qui in illo viro infrgnés animi dotes, quibus tanquam inmenfi pretii gemmis ornatus ef, fpectaverit; fareatur necceffeeft, rarò cuiquam no minis fignificata aptius conveniffe. Godvvin de Prefulib. Angl.

In hoc Autore nomenomen fulit. Thom. Fuller.

Inellus vir Gngulari eruditione, ingenio acutifimo, judicio gravifimo; Pietate \& Humanitate egregiè praditus, Theologiz cum primis cognitione $\mathrm{V}$ u u u infructifi- 
infructifimus, Gemma Gemmarum. Apologia ejus ab exteris piis fummopere in pretio habita eft, \& in varias linguas, Germanicam, H ippanic ann, Italicam, Galli-

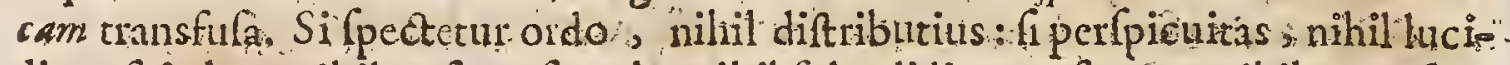

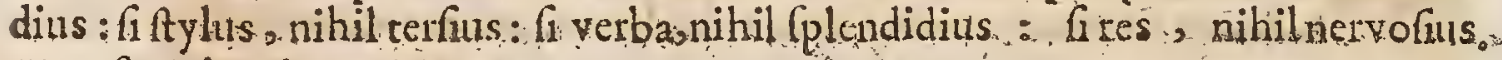
Hunfred. in vit. Inelli.

Theologorum quos orbis Chriftianu per aliquotannonum centenarios prom duxit Maximus. Rich. Hooker.

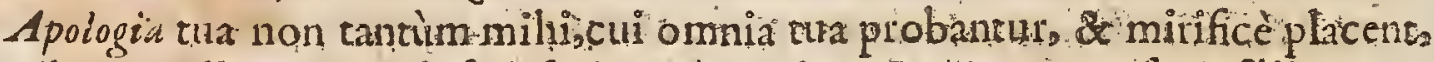
omnibus modis \& numer is atisfecit; verum etiam $B$ ullingero, ejufque filis \& $\mathrm{ge-}$ neris; nec non Gualtero $\&$ Wolphio, tam Gapiens, mirabilis, $\$$ eloqucns vifa clt, ut ejus laudandx nullum modum faciane, nec abitrantur hoc tempore quicquam perfectius edium fuiffe. Petr. Martyr in Epiftprafix. A poc. Inelli.

Erudirionem vęòincoinparabilem loquuntur, \& loquentur femper nun quam iutermoritura litcrarum monumenta ab co edita, ac illa in primis Ecclefre Anglicane Apologia, ourationis elegantiâs nervorum foliditate, fcntcatiarum mira bilis pondere; quấ Reformationem hî initirutamefugillantum ora conatus eft obturare. Godvvin.

Doctiffma illadifutatio Iuell contra Poncificium Hardingum, acenino jidicio Ccripea, variâque \& multiplici leotione referta Adam in vit W bitakeri.

Vir doctifinus vocatur levellus Candeno in Britanniä.

Vir fingula îng cnio; exquiftâ in Theologicis eruditione, \& fummấ pictate. Anton. a Wood in Hift. Anciquit: Oxon p. 235.

Tdiomatis. Graci callentifinus cratsnec hofpes inItalica lingua:Quod autem ad Latialem fermonem atrinct co tam eleganter loquebatur, tamque politès purè fựdéque, ling aavernacula loqui cenferetur Et fane rectà illuc tenden-

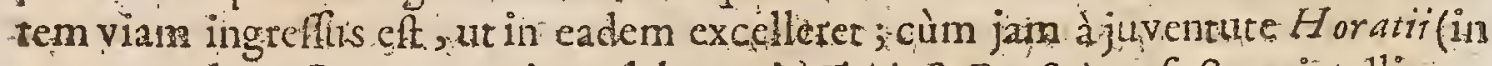
quem amplum Commentarium claboravit) Tulli is Erafmi perfectam intelligentiam fibi comparaveritstitpote quonm omnium diffifa \& exquifita opera perlegerit, excerpferit \& imitatus fuerit fingulis, vitz fux diebus, prafertin quamdiu Oxonii permanfat, quo rempore folcbar etiam ex tempore declamare Latinè

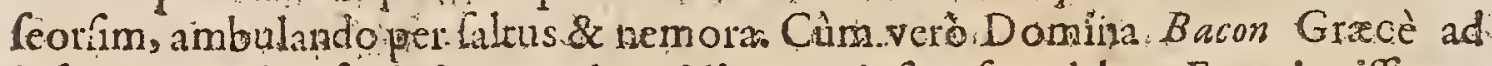
ipfum Epiftolas fcribebar , codem idiomate ipfi refpondebat. Exercitatifimus crat in omnibus Poctis Grecis, Oratoribus \&. Hittoriciss prafertim verò in Ecclefiaficis:Hiftoricis, fupra cxteros autem: Gregorium Nazianzenum amabat, eumque quavis occafione data citabat. In exilio fue exuditonis magntm incrementum ccperat, quippe quo, præter fuamcum Petro Martyre converfationem aliifue, Enditis: Argentinen fib \& Tygurinis, fumque confortium cum. Domino Sands, Eboracenfi poftmodum Archiepifcopo, qui ipfincontubernalis fuit pota ferètempore amborum exilii ; curiofitas ejus fecit ir fuperatis. Alpibus, in Italiam peregrinaretur, \& $P$ atavii aliquandiu fuduerit, fuaque cum Domino Scipione viro practaroinita familiaritate, in exiftimatione ibidem fuilfe videcur-Laboriofifimus fuit Concionaror qui Dicecelin fuim continud peragrabat, \& concionabatus quoliber loco ad quem appulerat, ubi llebis captui féfe attempecare 


\section{CELEBRTORUM AUTHORUM.}

semperare nnitcbatur, affectatos omes formones \& fonoras phrafes averfans, ut Sactis Dei' Templis indigtrum quid, quamvis tamen ibi etian verborum delectum follicite haberer, \& allaboraret Auditorum fuorum affeas movere pan thericis \& zelum fpirancibus applicationibus, tumidam omnem diaioncm defugicus, \&gravi fedatoyue potius quàm blando loquendi modo utens, nec unquam periculum faciens concionandi extempore. Vita Epilcopi luelli prefixa ejus Apologix Ecclefin Anglicanx, imprella Londini \$ . 168 5. Anglicè.

Talés fuerunt puecipu Eventus currentis anni 1562. quantum ad ea qua Ecclefiam \& Rempublicam conjunktim fpectant. Quod ad Ecclefiam fcorfim attinet, nilil memorabilius vid.tur quàm uvvulgatio clegantis Tractatus, cui ritulus spolugir Ecclefa Anglicana ; primum Latini confcripti ab admodum Reverendo Epifcopo Juello, munc veiò tranlatirin Anglicam, Gulicarn, ltalicam, Tcutotonicam linguam, \& tandem etiam in Gracam quam mirifice approbarlin omnes pii \& Lagaces homines, \& quam æortè tulcrun foli Angli fugitivi; cujufque tamen refutationem nemo ipforum molitus eff prater unicum Hardingum, quì priùs animo valde perplexo aliquandiu verfavic quomedo net Epilcopi provocatronem refponfum remitteret. Petrus Heylin. Hitt. Regia Fitabetba. Anglice.

* Hic Author in Rornano Indiccinter Hareticos prima Cafis reicitur.

Excant it it \& Opera levvelli, ex Angl.in Lat:per Gul. Whitakerum Geneve a gogo

In Ecclefin sarisburienfi in Chori Meditullio marmorco Lapide Cepultus ja eet, cum hac infcriptione lequente.

\section{D.}

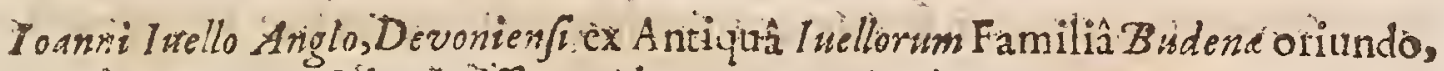
Academix Oxonienfis taudatifumo Alumno: Marianâ tempeltate per Germaniarn exuli: Prefiuli regnante Elizabethâ Regùầ Sarisburienfis Dicecefeos (cui per amos X1. menles IX. Cummâ fide \& integritate præfuit ) Religiofifimo i viro fingulari cuditione, ingcrio acutiffmojjudicio gravifimo, ictate, humaniate egrcyiè pradito, Thoologia cumprimis cognitione intruatilino; Gcmmx Gemmarumimiraturo faro Monker- farle prarcpto, Sarisburia fepulto: CaLorum Civi; Laurentins Humplodu, hoc Monumentum, obfervantiz \& Benc-

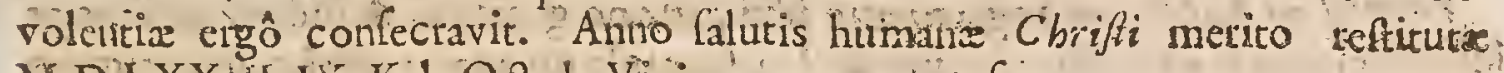
1.D.LXXill. IX. Kal. Oatob. Vixit aniros 49 . menles 4 .

$$
\begin{gathered}
\text { SAAL. CXII. } \\
\text { In memoriâxternâ erịtijuftus. }
\end{gathered}
$$

In mortem ejus loannes Wollèins in Linguâ Latinâ S. R. E. Sectetarius, hec, dermina compoluit.

Hei mibi quàn celeri fugiunt mortalia curfu, Quegue minus debet furripit atra dies. 
Piviere tu longo fussas dignifprinus aro:

Flende mibi wimism chare Jucllé jaces:

Moribus, ingenio, doclrinâ, 'pelligione', Nulla ferent talem focula longa virum.

\section{F R A N ISC US B:A D U INUS:}

Clar. An D. MLD.

$\mathrm{N}$

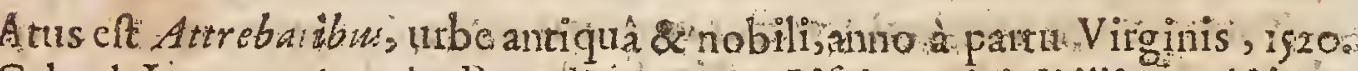
Calend. Januar Antonim Parer 'Procurator Fifci municipii illius, esint mastione magnâ in B̉elgia fuiti. Admodum puer Lovanii in gymnatia Latzinis Gracifque liter is informatus, peracri ingenio ad Juris Civilis ttudia conwerfo, arcana hujus fcientix complexus eft ufque adcò ftupendâ celcritate, ut admirationi cffet

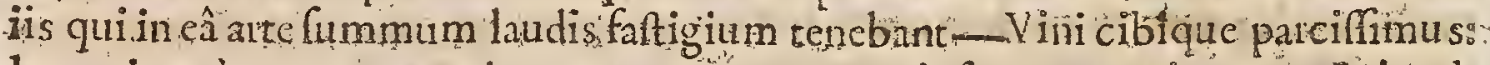
honoris quàm opum magis apperens:nünquan otioltus:magnanimus a in ad-

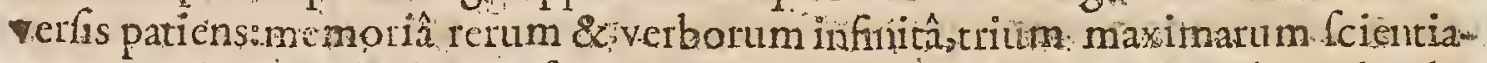
rum arcana , atout inți ma \& fummosapices complexus, Jaxis ( ivivilis Theolo-. gix \& Hiltoria. Dicere enim folcbat, Hiftoriam cum Iufprudentia conjungi opor

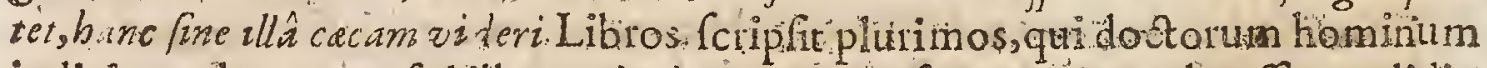

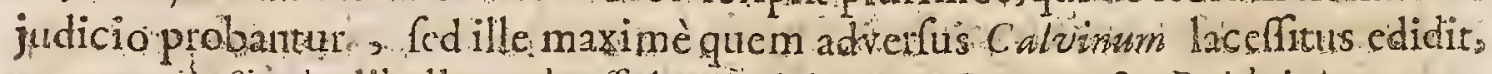
propter C afjind $n$ libellüa de officio piz, viri, quem Genevenfes Balduini partum

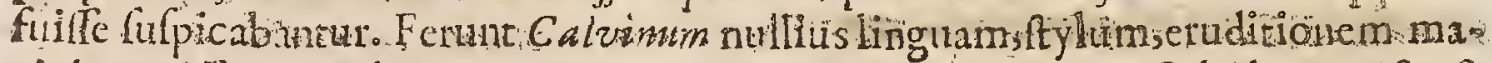
gis horrutfes quàm hujus Attrebatis familiais quondain fuiv Schola: Parifsenfis mortuo prolixe parcntavir: Aur utus poëra Epiraphiium, Papirius Mafionus grata animi anditor hoc elogium fcripfirac tumulum poluit cum hac Infcriptione:

\section{Qujaiv?}

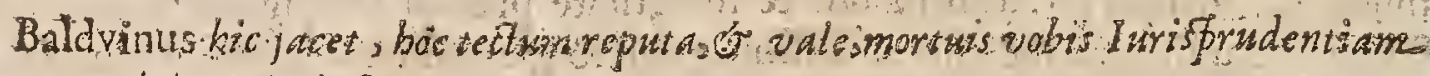
corripiet graris fopor:

Papir Maffor in Elog.

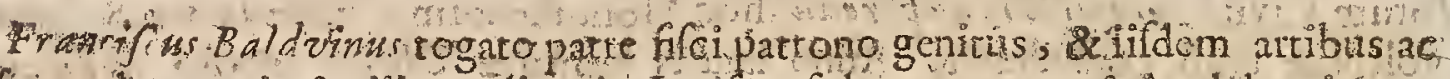
infuper eloquertia ftudis crudicts it fuifconfultum zetate noftrâ celeberrimum

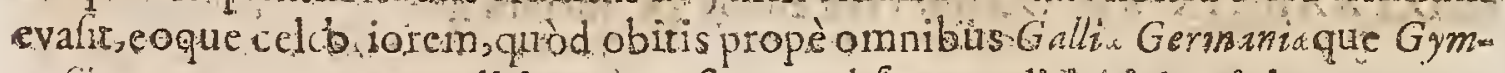
nafiz , guam cx operum editione quafiverat ablens cruditionis: opinionem pra-

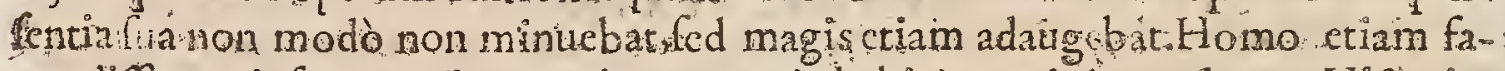
cundiffrous ipfoque oris ac totius corporis habitu non injucundus ex Hifto warum \& Civilis difiplina conjundione fingulatem fuis Pralectionibus gratiam

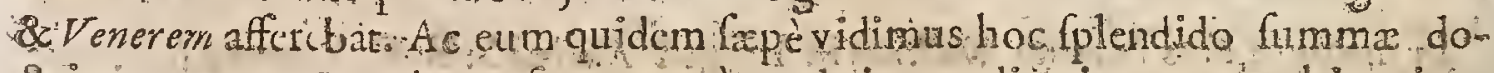
etrine apparatu Lu+etia profirentem, cün ad ejus auditorium permulti piima notx homines, Epif́opi, Senatores, Equitcs libenter \& maximầ trequentiâ con Aluerent. Scavol.Samarthan.

Francifcas. Balduinus, Juiffconfultus nobilissnon paxum luminis \& ornamenti 
thic noftre ztati artulit, Jus per totannos,tantâ cum laude profelfus in omnibus Eermè Gallia celeberrimis Academiis, maximè verò in illâ percelebri Anddga-

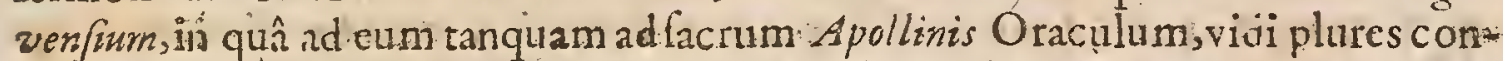
currcre, ut Juis difficiliores nodos folveret, dubiä elucidaret, \& fecreta panderet akque fummê facilitate referaret. Habuit is memoriam admodum fulicem; fuitque in dicendo gavifimus atque eloquentifimus. Gyl.Rovil. in Promptuar. Icon. Iflitut. Viror.

Vir fanè magnus. Lip 4 Mifcell. epift.33..

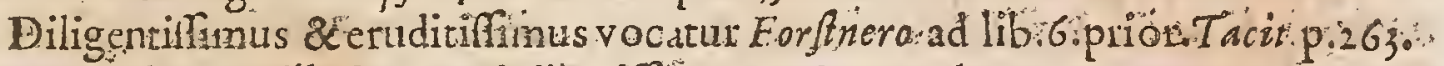
Antiquitatum illuttator vigilantifimus. Mi ontan de tut.cap.s...

Copioffinus \& fubrilifimus omnium Scripto rum.1.dem ibial câp.30.1n.75. Nova \& V creris jurifprudentia Princeps. Gentil. lib. 2 cap.4.;

Omnif ius \&:omnifinius. Idem lib. 3.cap.t:

Librumfe Confantini moratoris Legrbus Ecclefrafticis ac Civilibus Commentarios / fine exemplo multônditone a prudentia refertum dicir $H$. Conring de Anriquitat Academ fupplem.80.ad pag. 166.

Francifro Bulduino, Jurilconfulto egregio, pacis Ecclefiaftic $x$ Atudiofo magni facto àprincipe Aranfionenf Wilhelmo, aliitune Belgarmm Proceribus, qui \&s:

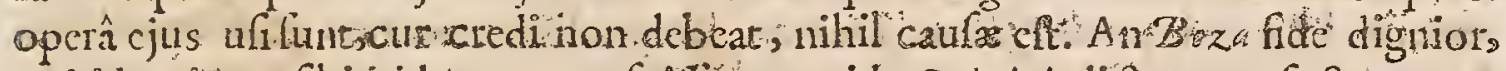
qui idunicum fibi videtur propofillé,ne quid : Calvini dicorum faotomve non defendereer. Hug. Grot. in Kivet. Apolög. Difculföne...

Hičcum puram religionem diu profellis.fuffet, tatuem turpiter rursus ad Papiftas defecit, \& quædam acerbècontra:Loannem Calvinum \&e Theodurum Bezar feriplit. Gejner. in Biblioth.

Eum ${ }^{2}$ roteftautes deferorem \& Ecebolum alterum vocubint.

Baldvi: suit A poftatasfedimmerifò Calvinus contra ipfum fripfit cerim non ellat Autoulibri quiipfi affingebatur, (ed. Cajfander. Calv. vidit quidem fe Tiallicinatum elle Scaligcrana: 2 .

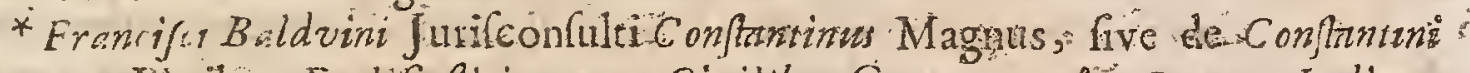
Imperat: Legibus Ecclifáficis, atque Cizilibus, Commentaia, Romano Indices prohibentur.

Varia cjus opera saris in locis atque temporibus funt imprerta.

Hoc Epitaphium Steplianses P afchafins Ccripgrat-

Francictus jactille Badvinuts:

Mirwor quam garins ; fub boc fepulchros

Narn quicquid tibi profercbat atas;

Qwirguid pagina facra, wel prophana,

Pukterè calluit.: unus inter ornnes:

Confultiffrius utriusgive I wris; Anceps ut patria bafitaret, illwom

Baldim diceret anne Baldvinum. 


\section{THE ODORUS BE Z A.}

Clas. A. D. N Atus eft 24. die Junii anno Dom:rgry. Vezeliis, veturto Heduorm op

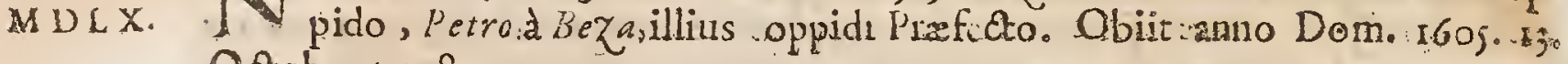
Octob.xtat. $\delta_{7}$.

Vir ingenio fummo, judicioaccurato, memoriố tenaciflemâ, facundiâ fingulari, affabilitate: comitare nulli fecundus:adcò ut, proptcricommemoratas dores adjunctầillis vitx longavitate (quæ tamen ommia erant inferiora fummâ doetrinâ \& pictate) quidam wocarent Bezam, atacis fur Pbonicem. Qui illum dente plufquam Th:oninc putierunt, fucrunt Pontificii dogmaris Propugnatores

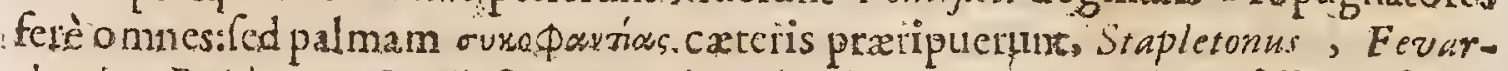
dentius, B. dvinus, Santiefous, Grssobrardus. Hunc tamentandem, felleum fuum amarom temperalle, intelleximus. Melich. Adam.

Tócodorus Bera ingenio hilaro ac clcganti \& longâ vitâ Gatis notus : quam Sexagintatotos annos în ftudiis \& lucubrationibus cxegit fâque tantùm pro. - wetus,ut, antequam moreretur, veris vitx qux eam defiderabilem efficiunt, tubridiis pre Cenio deftucretur. Siquiidem prefentum memoriam, debilisatâ quippe mentesevanidain amiferat, pratcritorum dum ing nio valcbat imprelfan lerYaverat. Itaque \& totos P. folinos. Hebratc \& quodcunque caput ex B.Pauli Epifolis propoluifles, integrum Grecé recitabar:necill iis, que alim didicerat, judiciocarebar, fcd qux dixevar Itatim oblivilcebatur. Thuan.ad atup. 160 g.

Verenandus Senex Theodorus. B zarcùn pelonginguitatem xtatis factus fie -bliviofusaded, ut polt frequentes ate novo Rege ig gic Kermohes libinde me rogaret de Rcginina an verum effer, quod fama, jaetaret illam fatis conceffil :idem tamen in literis vilus nobis is efe quem ante annos vigin $\mathrm{i}$ no varamus: Lo quitur Latine, interdum \& Gracè, ur anteà: audivimus de Hiftorî̀ vetcri differcnten è

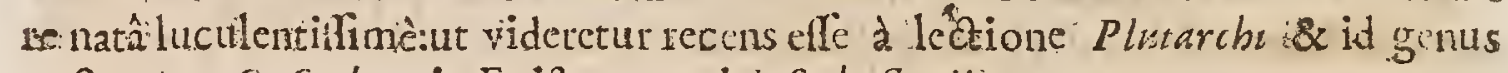
auctorum. Cafaubon. in Epift. 297. ad lofeph. Scaligerum.

Beza, vir non Grxcì zantù Fugilatiacumine \& I udicio ad Interpretationem plurimorum Scrïpturx locorum fcliciter adhibuit. Matth.Pclus pref.t. Tom.4.Synopl. Ciitic.

Ex omnibusejixs Sctiptis Annotatrones majores in Novam Tefamentum anaximè commendantur. Konia. in Biblioth.

Beza cruditionem, \& candorem; \& utiliffmosin Novum Teftamentum labescs o mues boni \& docti cum voluptate \& fructu lemper agnofceut. Frid. Spanbers. part.1. Dubiorum Evangel:p ist.

Inter catera $B$ eze opera in pretio cum primis habcntur ejus Nota in Navm Iefbumentum, in quas hac edit Latina carmina scaliget:

- Fotus Jupra caput estufitit ornes

Ille thorwm operum Juxnma, caputgue liber,

Quopeneirale Novi referatur. Foderis, of quo

Discafialucem nocle videre datur.

Anton. Tieiffier Elog. Author 
Author libir cujufdam qui infcribitur Iansenius Sufpectus, qui ut probabile faltemen, Eruditus aliquis lefuita eft affeverat totam fcientiam omnium Janfeniftarum frmul collectorum Calvini \& B Beza entitioni non effè comparabilem. Ant. Teijlier.ibidem. Gallicè:

Beza vir admodum celcbris, \& non folüm genere, fed \& doctrinâ imprimis nobilisj. deque literis tam facris, quam thilofophicis (fi quis alius hoc - ævo) preclarè meritus. Tycho Brabe de novâ Stella l.r.part.2.ci3o--

Beza aliquid fecerno in Teroullianum, lcid benè fecit quòd id non edidie. Diffici-

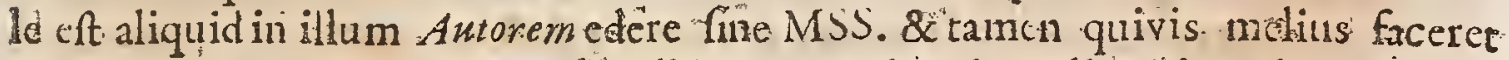
quàm Iunius. Beza nimis reprehendir Erafmum in minutul is, \&\& interdum injuntè. Beza crediditverfioni: Innii A ctorum ex Arabico, Ee interdum caufa fuir cur erraret.Rafelengius $\mathrm{P}_{\text {ater }}$ Céripferat ad Bezam errores propter illud Arabicum:non curavit Beza. In Hebraicisidocus non crar. Beza fuit valde preftanti forma; ut juidicaretur aliquis Princcps. In a fulit. Havef ut probarit novarn proitunciarionem Gracam. Dominus Beza multa léttionisvir nan fuit, quèd multis negotiis

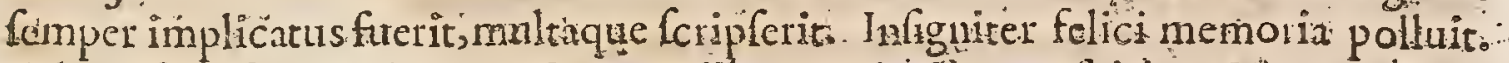

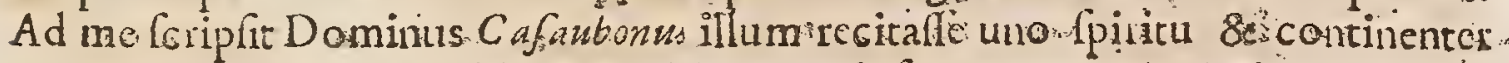
quatuor aut quinque capita Grsca. Non paucisicatent Gailrcifynis cjus carmina : scaligerana polterior. Gallicè....

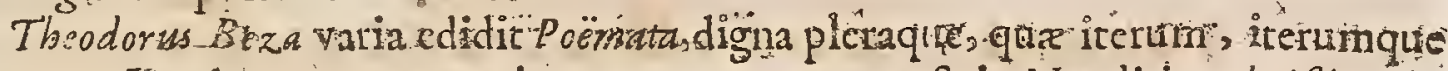
legantur: Laudantur precateris, que commentatus eft in-Natalitia Chrifti, in:

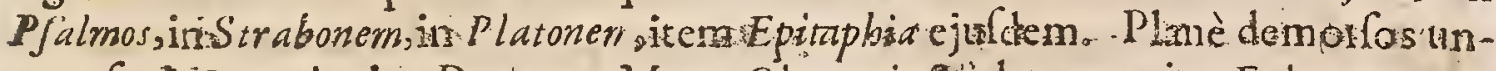
gẹcs fapit Devotio ejus Deciorum, Mors. Ciceronir, ae pleraque ejus Epigrammata.

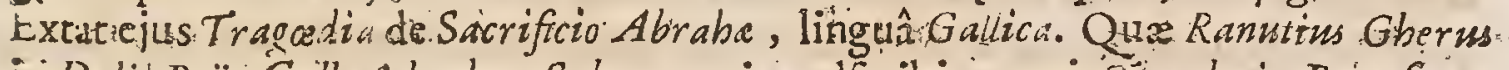

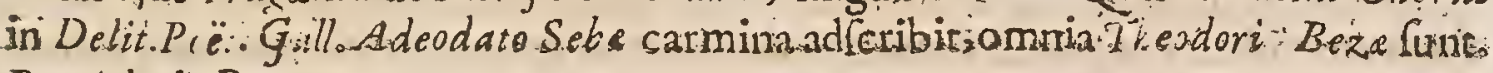
Borrich. de:Poët:p.I12, 113:

Indicatum quoque à Iosepho.Scaligero eft, acfejpe jactatuminter anicos; $G$ allisifmum ine fé it verfibis Theodori Beza perquam frequentem. Vidi ipfe priman edicionem corum verfuum, in quâ multa is contra rationem \& modum syllaba-

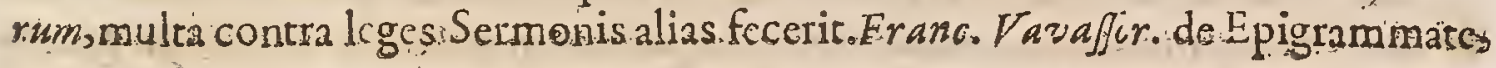
c. $22 . \div$

Qux porio minus nobis in Theodoro Bezâ placita ef nimin Latinitatis cura, qulum Sacre.Scriptura libros converteret; ea in rel iquis ejufdem Intetpretationibils, cum decentit temperatione conjuncta fe facilè probat. H. iet . de Clar Intergpret.

Circirer codem tempore vixis. Theodorus de. Beze egregius. Poeta Latinu \& Gallicus. Carmine Gallico compofuit Abrabami Sacrificium, tam graphicè de-

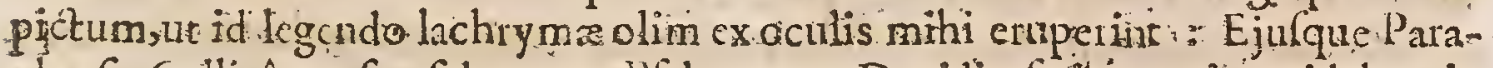

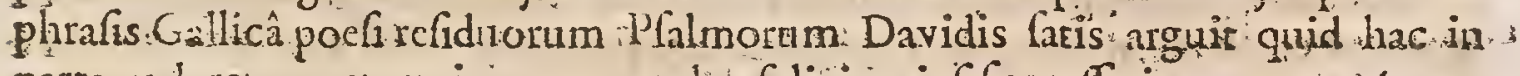
parte valeret, quamvis ea non adeo feliciser iphifuccelferit ac ansea wa a roto qui corum quinquaginta verterat. Stephanus, Peäquier. Perquịitionum lib. 6. cap. 7. Gallicè:

Vigneriw alfeverat Bezam in Eloquentia Gallica \& Latina nec pares. nec: qqü. illifecundi. Funt, habere. Vignierim in Biblioth.part.4.pag., 46 6. Gallo. 
* Theodorus Beza inter Hareticos Prima Claflis rejicinur Romamo Indice.

Extant in Novum Teltamentum Annotationes 2. Part. Gener.isog. fol. Camabrig 1642 . Gr. Lat.

Carmina cjus leguntur Tom:3.Delit.Gall.pag. 578 . nomine Adeodate Seka, vefalienfis, fub quo latere voluit.

Hoc ejus Epitaphium: Nicalao Rapino Audorc.

Beza fatis vixit, fif famam, of tempora pectes,

Caterafivite munia, acerbus obit.

Huns dilexere Aonides juvenilibus, anniso

Illum non etiarn deftituerefenem.

Nunc fama Gotur, or vita, tam cognitus orbi

Quarn fibi, Juprernum gandet obire diem.

Quod fi immortalen cuiguam fore fata dediferto

Debuerat nullo.tempore Beza mori.

At fo quid feclis dignurn eft disrare futuris,

Aternum in Beza nornine numen erit.

\section{JOANNES GOROPIUS BECANWS.}

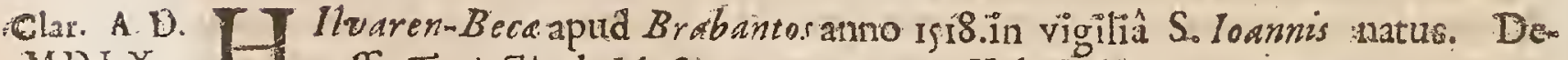
AD L X.

a celjt Trajecti ad Mofam anno 1572.4 . Kal. Julii.

Scripta ejus funt: Origenes Antzerpisina, quas ludens Becefellana appellavito futurum videns (inquit $A$ damus) quod eveniţut opus à mulcis tanquam vidicuLum contemnetetur. Poft obitum ejus curante Lavino Torrentio Antverpia a Plantino nitîdiffimè excula funt hxc: Hermathena: Hieroglyphica : Vertumnus: Gallica: Francica: Hipanica.

Hic paradoxum illud defendere conatus eft, linguam Belgic.rm, quam Cimbricam vocat,omnium linguarum effe antiquifimam, sante diduvium primis parentibus ufitaram. Hinc apud doctos pafim vapulat.

Quàm enim periculofa fat ca via, hodiernorum ingenionim luxuies quotidiana, \& inprimis Beccefelenica Ongines Goropiane me docent: quxe rillil aliud Cunt,quàm birundinum rafea. Ut ille vir nihil aliud oftendere allis fuis : criptis *idearur velle, quàm fibi otium fuperfuife çыo ad levia ingenia oblectanda abuteretui.. Iof. Scalig. 1.2. Epit. t pint. 146 .

Utinam verè, quod Critici defiderant, gravius, tantoque ingemio dignius argumentum tractandum fumpfiflet : Omme fane punctum tuliff $t$ utile dulci admifcuns, nec equalium cuiquam concefflfet. Sed nefcio quo vitio hanc in partcm ut plurimum ab eruditis pescetur: Dum vel humile nimis argumentum deligunt; ut qui quartanorb, calvitim, \& ejufmodi laudarunt; aut majus, quàm humeri ferre polfint. Melch. Adam in vit. ejus.

Crebri nobis fermones, atque etiam joci, de linguâ noltrâ \& Becano : Qui, ut fcis, 
fois, non antiquam \& elcgantem folum, fed primigcniam facit, \& cateras ex ế velut marrice cducit. Noftii atque exteri crecti-ftupucre omnes tentamina canta conarufưte novos:Multi \& iifere. Quid cgo ? Virum amavi, \& ingenium acre, facile, folix criam riratus fum: Felix, fi in aliam rem \& matericm vertiffer. Nam ifta quem fructum, imò quam fidem habent? Lipf. Epilt. Cent 3. ad Belgas, Epift:44:

Pariationes, aut Originationes, quas Becanus adfert, quis fäpefunc indignatiuncula aut rilulegat? Vix hoc Heracictus, fi vivat, aut Lucillionns ille Craffis. Lipf ibid.

Vil in Sermonibus, \& fubitis Differtatioulbus ad miracilum promptus \& facundus. Lipf. Poliorcetic. 1.4. Dialog.6.

Divino planè vir ingenio, qualem vix.fugula æates ferunt, feu Philofophiam, fcu P'hilologiam (ii utraque cnim ad miraculum ufouc cxcclluit) tractaret; tt Seculifui Varronomina i incrito potuerit. Aub. A irew.

Uti Ovidius ait,non omnia fingure Cretenfes: Ita Becanur dixero, non femper: angari; vimm judicii quidem modiocris duntaxat, fed magni ingenii, nec minoi is doctrinze. Vol de Origin. Idololat. 1.1.c. is.

Ut cnim fleam 站um inaniter fubtilcm \& opcrosè incutum 1o. Goropium Becanum, qui totum, qua latè patct, tcrarum orbem, imò Denn ipfum Tentonicè boqui cogit. Stcph. Skinncr. in prafat.ad Etymologic. Ing. Anglic.

Goropius Becanus homo argutior, \& in invenicndo, ac novas vias tentando, diligentioris Operæ $\$$ indaginis, quàm in judicando \& cligendo felicis -.. Mirabilis eft Goropius itte in $N$ omm norm notionibus inveniendis, concinuandis, compowendis, \& velint nolint, ad nem fuam allicicndis. Sanc illa nominum conjeature vix sunyuan folida. Pinea.de Këb. Salornon 1.4.c.7, \&\$.

Ioan e: Goropius, Hilvaren-Bera apud Brubantos,an.j5IS.in Vigilia S. Ioannis natus, divinam atquchumanarum rerum, bonarta mque Artium ac Linguantm, Latine Greca atquc Hebrai a pesitiflimus fuit. Nam in Philofophicis Lovaniz Atudiis ipfe unus cminuit: Exactidimamque deinde Medicine ac Mathcleos fcicn-

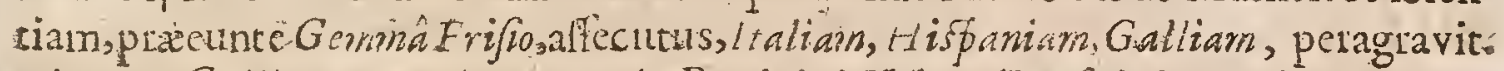
Eleonora $G$ ullic ac Marie Pannonis, Reginis a Valetudine fuit:in parriamque reverfus, annos multos Antverpie Medicinam factitavit. I.eodicicùm eliet apud Groesbequinm S.R.E.Card. Elowronurn Principem ingctâ forte fortun de Linguarum vetuftatc difputationc, patriæ linguæ (quæ illi Cimbrica) antiquitatcin. propugnandam fufcepit, fubtiliter certè atque ingeniosè̀nevoque doccndi genere demonftare conatus eft vecuftifimam illam Philofophiam ( quam olim Linus, Orpbeur ac Tham rias in Thracia docuere ab ipfo Noacho, ejufque fliis, Tapeto prafertim profectam cfle ac gentibus traditam, eamque cum $M$ oy $\sqrt{e}$, ac facrofanctâ cjus Hiftoriâ optimè convenire, quemadmodum eam in rem ad polthuma Goropii opera pluribus prefatur Lavinus Torrentius. Val. Andreas in Biblioth. Belgic.

Extant Origines Antvverpianc, quas Beccefelana infcripfit, Antverp. typis Plativing 569 . fol. 


\section{MATTHIAS FLACOIUS ILLYRICUS.}

Elar. A. D. MDLX.

A. Ibonálllyria oriundus, clarogenere, vulgo Francovvitz dictus : Narus A eft Annor520. die tertio Martii, obiit 5575, die undecimo Martii:Docuit Witteberga, Magdeburgi, I ena, Antverpia. Lutberi doctrinam amplexus cot.

Scripta ejus plurimasprecipua yero hae fune: Hiftoria Ecclefiafticx Commentani, Senturiarum $M$ agdeburgenfuin nomine celcbres. Cui Operi Ce Baronius oppoluit-Clavis Sacra: Scriptuba-Catalogus Teftüm Veritatis- Martyrologium - Libellus contra Interimiftas, \&ialios Chrifit Perfecutores-mmLibullus de veris \& fallis Adiaphoris.

Theologus, fuperioris feculi Origenes, qui non mediocres turbas in Republi-

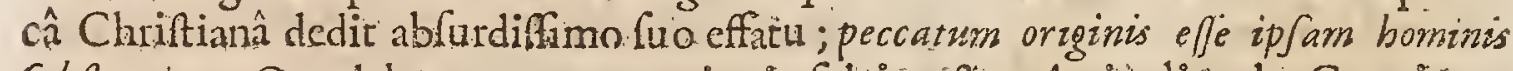
fubptantiarm. Quod dơgma cum pracipuis fidei noftre Arriculis; de Creatione Filii Dei Incarnatione, Redemptione, Sanctificatione, \&Refurrectione pugnat. Ncc tamen proptercd adfentiti poltim Gulielmo Budeo, quil Centur. XVI. Aaveranogias ad annum 1575. ait; Flaccium nequidquam rectifecilfe, niff cum moreretur. Tempore enim interimifico. Eccléfia Chrifli bonana \&idelem operam contra T'apaturn pugnando navavit:- Ip fi ctiam gutpote in Scriptis vcteribusEcclefialticis \& ad Hiftoriam facientibus yerfatifmo, infigne illid opus, \& quale prifina atas muquam viderat: Centuriarum Magdeburgicarum maximam partem debetus Liber etiam quem Clavern Scriptura, infcripfrib non caret fựa utilitate. Quenfted. De Vir̀. IHuftr.

Fuitingenium in hoc viro capax perinde \& inquies. Melandthonem, pacis futs:diofum, tộâ vitâ exagitàvit: Meich. Adam in vitâ ejus.. .

Homo wehemens, \& quocuxque locopedem figeret acerrimus turbànm incentor, Thuan. Hilt. lib. 38 .

Summus inter Proteftantes Pontificia andoritatis oppugnator, \&ob candem 3 vehementiam Philippo. Melandhoni preeptori olim fuo non Latis æquus. I hwan. ibid. 1. :6t.

Mr atthias Flaccius Illyricus, harefi infamis, -alioqui non male de Ecclefin: mericus, edico Catalogo Teffium Veritatis, \& adornatis fuâ.ipfus sobannis Wigandi, \& Matthai Tudicis operâ Centurizs Ecclefafacicis Magdeburgenfibus. Pezel. in Mellific. Hiftoric.

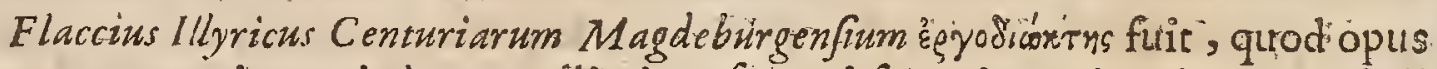
nen tamex nevis qui à nonnullis jam funt obfervati q quà inexpugnabili aftimari debet labore., \& inaudito anter conatu. Hotzinger. Biblioth. Quadrip. lib.3. cap. 3.

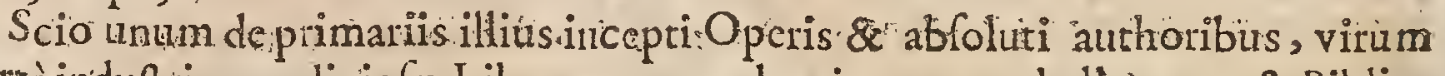
centè induftix prodigiol , Liblorum quendam immanem helluonem, \& Biblio-.

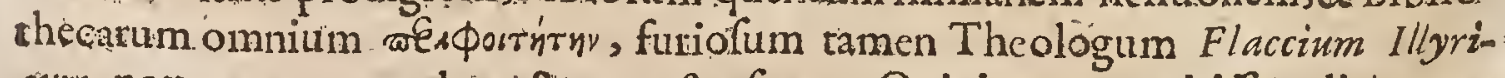
cum, novarum quarundam : \& monftolarum Opinionum extitide adinvento rem. Rich. Morbafut. Prof, ad Ecclefiaft. Exercitato- 
Tmpia dogmata, impiamque vitam Rom. Antichrifi defcribens, multis editis Mibris celebris faetus eft. Multa recondita ex Bibliothecis eitut , aliorumg̨ue Au corum fcripta in lucem protulit, qua nobis regni Tenebrarum Regis artes, mores, ftudia, tyrannidem atquc fcelera non fue ftupore proponunt. Qux latuifent fortè malè, fuifque tenebris fepulta fuillent, nifi abditos Bibliothecarum recelfus. atque finus penetraliet I llyricus. I ac. Verbeid. in Elog. Theolog.

Flaccius ifte, quamvis ab alia quadam cruditionis parte defitueretur, in Scriptis tamen veteribus Ecclefiaticis \& ad Hiftoriam facientibus fuit verfatilimus. G. Calixt. in Apparat. Theolog.pag. $18_{4}$.

Multas excitav it tubas in Ecclelis Protetantibus erroneis quibus implicar tus erat opinionibus;cumprimis autem fententia fua quòd peccaturn originale fit propria hominis fubltantia:tamque acerbè tantaque animi impotentia cítipfit adverfus Melanchionem, Praceptorem fuum, ut vit ille magnus., quantumvis ilenis 8 moderatus ingenio, non potuerit fibi temperate quin ipfum Ecbidnam Illyricam appellarct. Magnam fcriptis fuis famam fibi paravit, eoque prefertim quod Clav $S$ criptura incribirur;nam ille lib Proteftantibu \& atholicis æquè utilis eft, ut a.Fmat Rich.Sinnon.Hift. Viit. V.T.Ant.Teifler Elog. Vioum Eruditorum.Gallicè.

Si Autho ille Lutheranifni prejudicatis opinionibus adeo imbutus non fuilfet, qux ipfum guadantcnus adegerunt ad falfas cartm applicationes faciendas, multo clarierem famam fibiconciliâliet. Orat. Presbytcr Rich. simon. Hif. Crit. V.T.lib.3.c.13. Gäll.

Dencgarunt ecenam Minifti propter do drinam Depeccato originali : Ita Inne viatico., qüia abcriârat è viâ, abiit cx hac vitâ:Utinam pius \& bonus. Hie ron. Zanch. Epiftin.2.in Epir. ad Lavaternm.

- Ka hunc Anterem hoc diftichon compofuit lacobus Boiffardus.

$$
\begin{aligned}
& \text { Qudifcelus toms fis culpa, diferte Matlia; } \\
& \text { Incusare alios define. culpa tua eft. }
\end{aligned}
$$

* Hic Author inter Hereticos prime Claffis rejicitur in Romano Indice.

Yaria ejus Opera variis in loc is atque temporibus fun imprerla.

$$
\text { DIONYSIUS IA M I N US. }
$$

CAllus, Monjtrolin natus, anno 1572 . vivere defiit, arnoque atatis $56 . P$ arifis 1 literas humaniores, Grecamque \& Latinarilinguam interpretatus ef.

Clar. A. D. MDLX.

Scripta ejus hre funt: Commentarii in Horatium, Cornelum Nepotern, Plast1sm, Lucretium \& Ciceronem--.-Oratio de ltrilitate Lingux Grace, \& rectì Grem corum Latine interpretandorum ratione-_-n-Oratio de Philofophix Moralis laudibus----Oratio habita pridiè yuàm libros tres Ariftotelis De Republicâ expli-

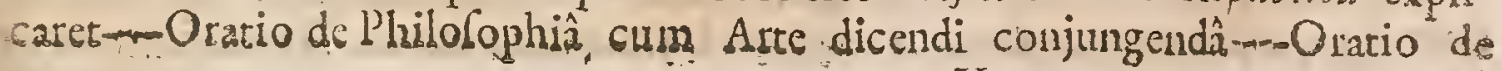
$\mathrm{X} \times \mathrm{x} \times \mathrm{X}$ 2. rationis 


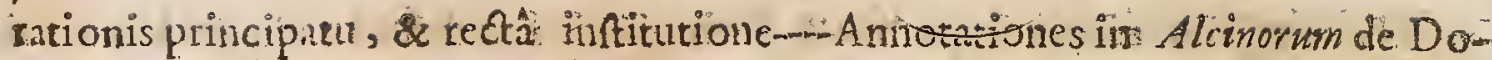
Arii ầ Ylatoni-n-ViraCiceronis ex ejus operibus collecta-_-Epiftolze Prafarorix - Epiftolix familiares---Ariftotelis politica, \& libride Moribus Lambino interprete-..-Advcularize Demafiben.\&Afchinis Orationes in Ling, Latinam tranflatx:

Diony/aus Lambinus . Monftrolii ad Oceanum quanquam Ccelo cralfo \& turbido,Mufis tamen ferenis \& faventibusnatus, ab earum dulci commercio quxfitas mulriplicis enditionìs opes tune potifimum difcendi cupidx juventuti explicuit, cum ex italiâ reverfus,ubiplures annos in Francifci Turnonii Cardinalis com mitaru vixerat, optimos quofque Grece Latind que lingureauctores Luteria in Scholâ Regiâ five prelcgendo, five commentando cxplanarct:Unde manarunt illi uberes in Lucretium, Horatim, lautum Commentariigui vice variarum Lectionum effe poffint: Nam de Ciceronis operibus, qua fummâ diligentia nec minorì fiduciârccenluit, alii judicabunt. Certè quàm fudiosè multumque fuerï in cjus: auctor is lectione verfatus documento funt advertaria Dernofbenis \& Afchinis Orationes, Ariftotel's poëtica, librique de moribus, \& quxecunque pratereàde Gracis Latin puriffimè fecit. Obeamque caulam \& àdoctiffimis visis, a quibus; Italia tuna afflucbat, magno femper in honore liabitus elt, \& omnibus. Mularum alumnis immaturo fato moricns acerbiffmum fuidefrderium reliyuit. Periit enim extemperum tadio fex tantum \& quinquginta natos. annos paulö poft indignam Ram i Colligre necem, telicto ex: Urfinà uxore nobilit matronâ. filio, doctina quoque hude pradito g qui prosuratấ polthumorur aliquot paris operum edirione non aburdè fanctis ejus Mavibus hoc erudirz. pictatis : officio parentavic. Scavol. Samarthan. in Elog.

Diony fus Lambinur, vil maximus, fupra omues Scioldyum morfis, Grace Latinz gque licematara foientifinus.Pareus.

Vir totius onbìsterrarum confenfu, in utrâque linguân valdè exercitatus. Car rio lib.i.cap.I7.Lect: Antrq.

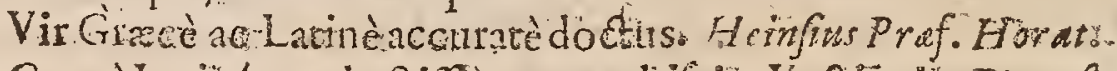

Græce Latinéque dectifrinus, milifire Leationis Demplter:

Vir doctrma mutriplicis, fedin variss lectionibus cnarrandis allquando vanus \& furilis; \& ad futidium uque fupertitiofus. Duran lib. 2.cap.15.

Dun. Lambinus, Monfroliiad Occanum in Pícudià, Gallia Provinciâ, natus, novâ. Arifotelici operis Politici verfione clarifimas. Tanticnim hae eft, ut jamdudum communi Doetorim Sentâs fuffagiô omniüm a liörum laboribus: pralata fucrit. Hinc forfin \& factam fuitsuteam editioni fuz Cafaubonus, gravis oppido verfonum \& Inxerpretum cenfor, infcruit... Verbô: Sit Atudiolo l'oli tices verfo Lambini pra:aliis omnibus comendatifima.G.Th.Mejer. in. Promfut. ad Polit. Aritin. 47 .

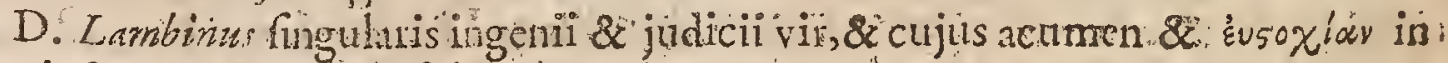

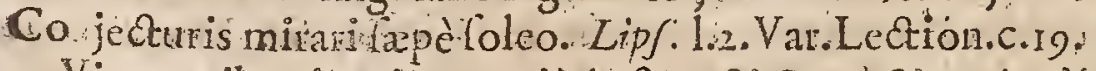

Vir omuibus literis egregiè doctus, \& Grace \& Latine imprimis enditus, \&: nunc. lingux Graca Profellione T.arifgenfe Gymnafum ordans.T urneb.in Adverfar. p. $351 \%$

Dionyjors 
Diong fus Lambinus magni ingenii vir, magnaque doctrinze. Petr. Vistor. $1.3 \mathrm{~S}$ Var. Lect. C. Ir.

Mulris ediris libris de Re literariâ benè meritus. Thuan.

D. Lambinurs multa pracletalcripta,utCicero, Horativs, Lueretius, Nepos, alique caftigariab; illo \& uberimis Commentariis illiftrati; in famx perennieatcon adferuerunt. Gajp. Sciopp. de Art. Crit. p.9.

De quo eanen Lambinus ne gru quidem:ut in omnibus feré folet paulo dificilioribus, catera faris verbofus \& ineptus. Sciopp. Comment. in priapei p.92.

Laybirus nufuam, atque in eo Combo (Planto) minore fritufus judicio. Idern de Art. Crit.p. 92.

Lambinus (farendum eft) non licem : fed umbram fapè facit nof tro Jmbro. Lipf. lib. de Amphitheatro, c. sx.

Lambi nus enat vii bonus \& doctus, qui Latine \& Romane loqucbatur, opriméque fribebat.Scaligerania 1 .

Lambinus in Horatium. Pleffens de Mifs. Tabula-Sancte Aldegonde. Mercenus in Job. Teftimentum Bcz.e. Calvini Opcra, preftantima Lambinus paucillimos habcibat libros Scaligerana 2:

Magnam criptis fuis famam fibi peperit; Vertum quidam judicarunt, nimis ferupulofam \& accuratam ejus lollicicudinem referendi varias. Lectiones, faftidium crare Cornmentariorum cjus Lectoribus. Ille quem in Horatium elucubrawie apudomnes Literatos eft inpretio: cumprimis alaten apud illifticm forephom Scaligerum. Res non fic fe habet quoad ejus in Ciceronis opera contectioues, nam culpatus ef in co quod Authoris illius Textum pro arbitrio mutare aufus fit mullis veteribus Manufariptis nixus, verbaque expungere in editio: nibus quar omnimmanibus teruntur; ut ils nova fubftitucret. Andreas scbottus at verat quories Lambinus poft correctum aliquem Ciceronis locum hree verba fubjungitoinvitis or repugnantibus libris ornibus, certum elle illum fallo" Ant. Tezjeer, Elog. Viior. Exuditorum; Gallice.

Quis autem non obfupefect quod Drony fus Lambinus Thofrolio prope Mare: Oceanum in Climate reveràcrallo collque turbidi; ortus, à Natutaingenio tam acuto \& cxcellentiprodigaliter donatus ficrit Arca enuditionis locupletifima: fuit; in omuifaris politioribus Literis Grecis \& Latinis doctiflimusevafit; Omn:que propemodurn alios fuperavit, qui in ejufmodi difciplinis ejts ate in fumrogradu excellere confebanur. Ghilin Theatro \&c. Italícè-

Copiofior paula Turnebo Diony ius Lambinus, dumquadiandx Orationi \&: daborata concinitatiftude, hanc Interpretationis falmbritarem haudquaquam obilinit. Huet. de Clar. Interpret.

Hac egoquondam Lambino : qui ea fromore ediait, longè alther " quàn: dicta fuerant, fupprelfo Auctoris nomine. Simeo Bo Jus Not.in lin.Cic.ad Attic. Epitt.3.p.8.

De Lambino nihil vidco caufe, cur ejus obtrectatio deterrerc te, aut abdicere Iftudio debeat. Ille in te fuit, qui in alios folet. Et ita mihi omnia, quæ ctupios aveniant, ut ego valdè misabas, futibi eum impune laudate licuiffet. Ità enima XXX: 3 homo 
homo elt: eis folis plurimùm invidet, quibus plurimùn débet. Quî̉ modố me acceperit, nofti: quantum autem mihi debeat, \& iple \& alii plurimi norunt: Muret.1.2. Epift.s.ad Giphainitur:

- Depreherdimus nos, eum (Lambinum) noftus emendationes in eum feriptorem (Corn. Nepotern) quas de veteri codice, quem habemus, defumptas, in Lucretiana collectanca conjectam, fibi lumpfife omnes. Giphan in Epilt. ad Muretum.

Poffum, mi Giphani oftenderetibi fi hic fistiteras ipfius (J ambini) manuferiptas, quibus mihigratias agit de locis quibuldam fibi explicatis, quos ipte poftè̀ quêtus eft à me fibifubrẹtos cle Muret.1. 2. Epift.7.

Carmina ejus habentur Tom.2. Delit. Gill. 385 .

Varia cjus Opera variis in locis atque tempo ibus fun imprerta.

\section{PAULUS K A N U I US}

Clamita. 7 Ypographus, Aldifilius, Calendis Quintilis, anno ist2. Venetiis natus 和D资。

- eft. Ubiit dic fexto Apritis, anio I574. ætatis 62.

Scripfin Anotationes in Ciceronem---Judicium de Poëtis legendis----No

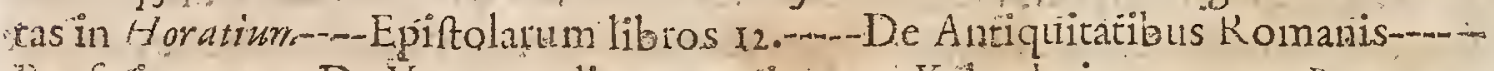
Præfationes-m--De Veterum dierum ratione--Kalendatium vctus Romanum, cum Commentario - Apophthegmata--Notationes in Virgilum -Orationcs 4. Demofthenis contra Pbilippum; Latinitate donatas-Adogiz collegit Hune laborem a Concilio Tridentino Manutio mandatum, Gregorius XIII.itacomprobavit, ut onnes Adagionum libras,unâ.cxceptâ Editione Manutianâ, prolibeat arque condeminet.

$P$ aulus $M$ anutius vir omnis elegantia, atque vintutis, \&zotius Antiquitatis tudiofirmus. Georg. Fabric. de Româ, c. I.

De quo fummo viro dico brevitur, quod lille in hoc doctina \& elegantix generenefciat, id alium fcire neminem. I dern ibid.

Paulus Manutius ho mo \& diligentiflmus doctifimus. Turreb. Advcrf. lib. 8. cap. 24 .

Paulus $M$ anutiurtranfacto feculo mertit Romani putitate Sermonis inter fer lectiffmos cooptati, quando lucem illam Titliane Facuid tic noftratibus propè invifam, ac fuperiorum obrutam xtatum caligine, folusipfe conlpexilfe, ac induftio calano Italis diffudife cenferetur. Foan. Imperial in Muf. Hint.

At praclarè , ut folet, $M$ arutius : de quo vito meritò dubirari poteft, plúne iple iceron, an ipfi Cicero dibeat. Nam \& ipfe tiactandis affiduè Ciceronzs

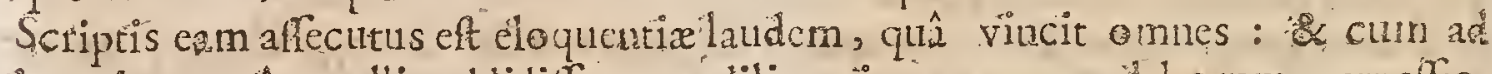
ingenium, quố excellit,addidiffet eam diligentiam. eanque laborum perpeflionem ac tolerantiam, quâ vires iplamque adeo vil tudinem fuñm, magno nottr ominum, quotquot eum, quia planè novimus, plurimi etian facimus, dolote proftravit; incredibile eft, quot ab errorum millibus cos libros felicilimè vindiGarit. M. Ant. Muret 1.I.Var.Lect.c.6. 
Manutius magnam affecutus eft in exprimiendo fylo Ciceroniano felicitatenn , cujuls Epintolx magnâ diligentiâ ac curâ confcriptx funt, atque, at Scioppus nobis narrat, tanto labore, ut menfes aliquer uni Epiftolx interdum impenderit. Scilicet, quem antea laudaverat, quod nemo sui fanus fit, ad puritatis \& elcgantix Latiizeftummam quiçuam Manutio defuifle dixcrit ; mox

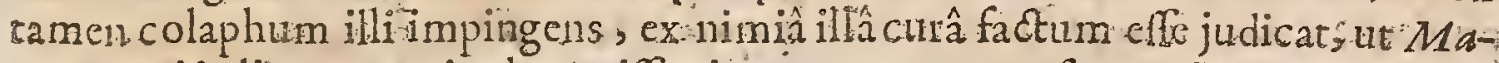
nimtii Epifrólis, quanvis elegantifimis, nequaquam ea fit gratia", qua hominem, nifí valdè otiofum; ad iteratam lectionem inviset. Pariffmus fanè autor

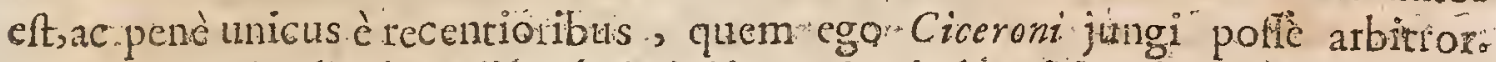
Quod scioppin dicit tredium lectionis repetitzinde oriì, li quid veri judicat, ex illo fortè eft, quòd plerumque de negotiis familinribus frribat: Sed nos. hîc de rebus non folliciri j, dictionis preftantiam commendamus. Aliquot ejus Epifolarum Editiones funt, quas receilet examinatque Thomafius in $>$ Prefatione novifima Editionis Lipfienfs', cui' fi verum fateri velingtss, non muls tum diligentix acceffie. Extantadhuc aliqux cjus Epiftolz. inedita apud viros doctes, atuuc unam ejus benellongann fervar Clavifimus Gudius, ipfuts $M a-$. nutii manu fcriptam, quam ipfe Epitolarum $M$ anutii Reginarn" pocare folet:-

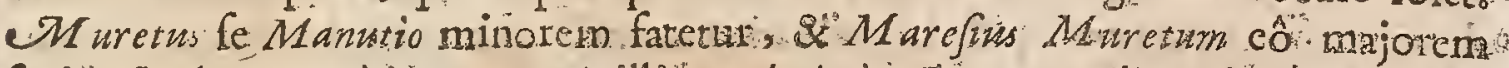
ficit. Scaltyer certè in Excerptis itlis Primis du Tanag: Fabro editis neminem magis Romane loqui ait:- Capacc. lib. zo. Elogiorum, bonx Latrinitatis amato-

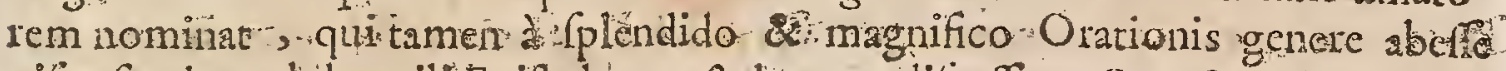

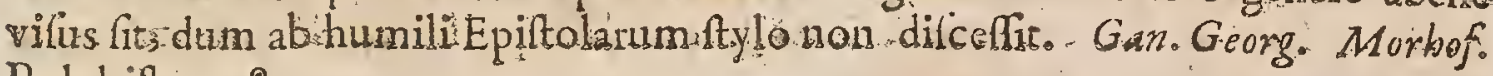
Polyhift:p. 2890.

OCtavianus Ferrarius in libro dể Sermonibus Eürotericis , p. 42. Edit. Vener. Magno inanutium elogio onnato. Vocat cun Virum acerrimi e elegantifimi judicii, qui Romarnat laudem eloquentia nobis ita veftiat bôctempore 3 ut prifcos illius au-

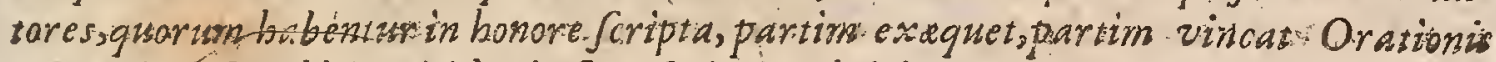
genercipfo fexrbili, nitido, so fine Satietate dutci:

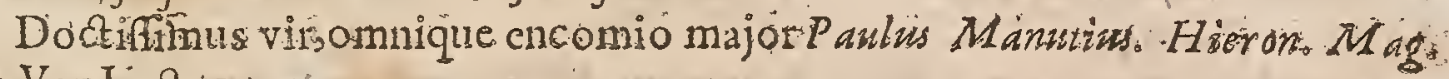
1.t.:Var.Lect:Crio:

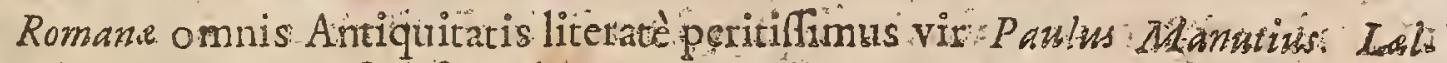
Bifciol. Tom:r.Hor. Subficiv. L.13.c:6:

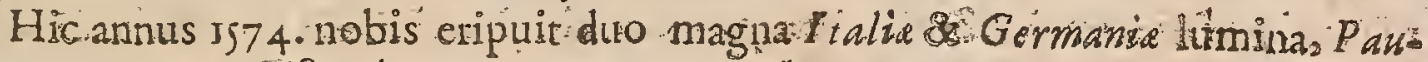
lim 'M anutium, \& foachimum Camberarium. Thuan:

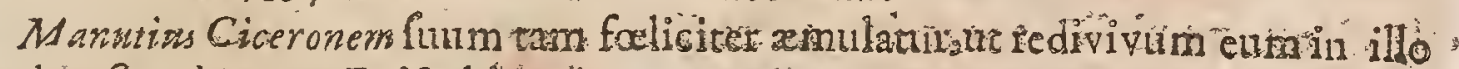
credis. Facob. Crus. Epiftol.1.2.p. 142 ...

Egone ut ad cujufq̨uam judicium in Ciceronis fcriptis appellem, quàm tüum

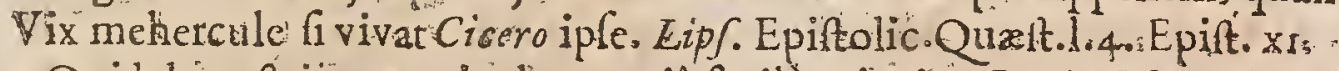

Quid de noftritemporis elogutentiâ facile principe, Paulo Manuio", Aldi filion lo quar?quô, fi Cicero ipfe ab inferiscxcitaretur, nefcio an Latiniüs, puriùs atque

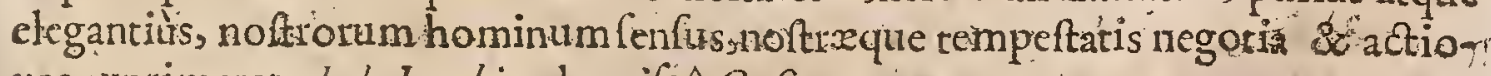
nes exprimeret. Iul. Lacobin de prifça Cafforum gente, cap. Xr.

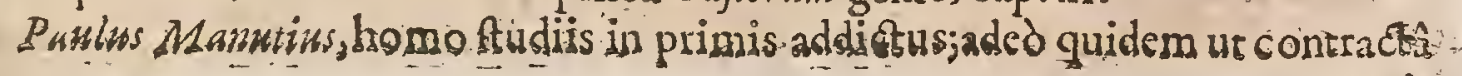


macie ac pallote, oculorumque dolore, lucubando olciplus quàm vini ( quod de Athenicnjium Oratore dim jactatum) confumpfifle videatur. In Epiftolis fcribendis, atque adcò Latino fermone fic regnat, ut ad veterum glorian propiùs acceffife crcdatur nemo. Aub. Miraus.

$P a u l u s$ Manutius, qui vî! quàm elegans ipfe in dicendo, quàm in exiltimando prudens? Ioan. Lucas in Epift. prefix.Perpiniani Epiltolis.

$P$ aulus $M$ anutius quicquid Cripfit bonum fuit, magno labore fcribebat EpiAtolas. $M$ anutius non poterat tria verba Latine dicere. Scaligerana 2.

Buneli \& Manutii Epiftolæ, licet primâfpecic Ciceroniane, tit libere loquar; mihi non ufquequaque placent. Nam illarum formo nimis laxus eft \& redundans: at preffus, ut + linic placet, Epiftolis maximè convenit. Tim Epittolas plerumque ad Familiares dandas, magno conati conferibunt, nace fectis verbis adonant, ac fi non effent Epiftolx, qua accurate quidem, at fue moleftâ feribi debent, fed Orationes de rebus gravifimis compofita. Manuio verò non polfum quin fuccenfeam, cùm in quadam ad Saulium Epítola lego predicantem, Se multum Bunello

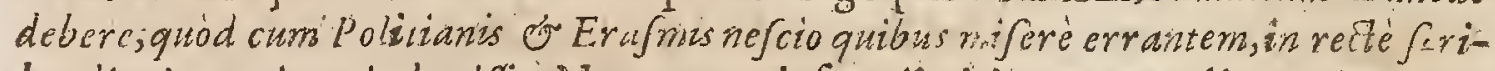
bendi viamprimus induxiffet. Nam cum ejufmodí viris errare malim, quàm cum Bunello fapere quorum Epiftolds non adco fortafic verbis attebus certe Ciceronianas longè pluris facio, quàm Bunelliana, aut Manutianas, icrum plerumque inopes, verbiscanoras. Koiand.Maref. Epitt.1.2. Epilt. 4 .in-

Certè Manutius antiquos Auctores non legit, nec evolvit diligenter : Ced, opiner, fapè ad Indices recurrit:in quibus fi quid non invenir, ftatim ait, nou clfe. Franc. Rubortell. de Ait. Critic.

A phrafibus, \& à lignificationibus novandis magno fudio ei, qui pura dictionis Latinc laudem affectat, cavendumelt: quod quidem fi $P$ anthis $M$ anutius feciflet; fcripta ejus cxterum cultifima fordibus quibufdam deturpata non haberemus, ut funt Ingrantudo, Speculatio, Contrarictas', Darmum pati. Difjuadere aliquem ab aligu Sciopp.in Grofip.p.22.

Quando componebat quatuor digitorum diftantiam inter lineas relinquebat, ut hoc intervallum aliis vocibus repleret, fr meliores fibi occurrerent illis quas ufurpaverat, Ut autem Epiftolx illx omncs cujủscapax erat perfectionem obtincrent, fub' fincm autimni demum abfolyebar quas 'ineunte vere inceperat. Anton. Teiffier, Elogiis \&c. Gallicè.

Paulur. Manutins.-. Libro:qucm uper compilatis Zafir, Gruchir \& Baldvini, de eadem te Commentariis, Ciditde 1 egibus Romants, \&c. Franc. Robortell. p.2s.part.2. Facis Critic.p.7r.idem p.88.

Exrat de Legibus Ronanes liber. Venetizs 3557 . in Fol.

Extat de Diexum apud Romanos vetereś latione Commentarius, unà cum Rofini Antiquitatibus in Editione Moguntinâ ann. 16.62.'

Extat de Senatu Romano Opus. Venetics $1581.4^{\circ}$.

Extar de Civitate Romanâ Liber. Roma $158_{4} .4^{\circ}$. 


\section{CELEBRIORUM AUTHORQM.}

\section{Extat de Comitiis Romanorum. Bononic.1585. in Fol.}

Carmina ejus extant T:om.2. Delit. Itai.p. 22.

\section{Hoc ejus Epitaphium, Hippolyzo Capilupo audore:}

Oui te, Paule, gemit, Linguamgemit ille Latinam.

Quos finul extinclos bic trevis or bis babet.s

Illa two fletitingenio, of praftantelabore,

Suftentata diu: teque cadente cadit:

Et rolwit, tecurn quia multos vixerat annos,

Tecurn etiam boc tumulo poft twa fata tegi.

Una fuit vobis fors vite, of mortis, of urne:

Unus of ambobus plangor, or ume honor.

Pibil.Labbein Thel.Epitaph

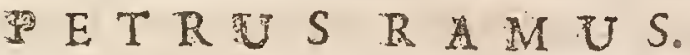

T Atioize Gallus, patriâ Veromanduns, netts clt anwo Dom. 1ys. interemtus Clar. An. D* hic vir fuit in Lanienâ Parizienf. An.Dom 1572 . inque Sequanam conjectus MD L X.

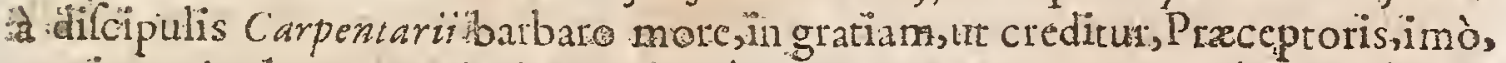

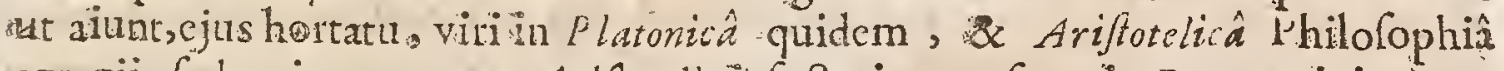
egregii; fed qui perpetuam Arifotelis infectationem ferre in Rarso minimè potuilfet: unde illud plufguam Vatiniantom adverfus eum odium cxarlat. Vojf. de Mathemat.p.67.

Réliquic 4. Lúbros de Relioione Chriftianâ: 27.libros Geometrix: 20. libb. Ariftotei arum Animadvexfionum:librun de Militiâ C.Iul. Cafaris : alium de moribus vett. Galloru\%, Kc.

Rermu ad annum nfque dccimum nonum, ne quiden primas notas didicerat, infervicbatque Dom.de la Broflc. Imeitam deductus tantum famulus profecit maximo dilcendi deficerio percitus, ut quamvis repugnante ingenio tarde, rudi \& ftupiảo sepugnante, quod majus cit, inftitutione ferâlabore \& diligentiâ in id litcrarum decus pervenerit, quò pervenifle vix credibile fit, ita ut anno trigefimo contra Ariftotelem fciipferit meliori ftylo quam pofterioribus annis. Bonus Orator, qui facultatem dicendínbi comparaverdt. "A $\mu$ '́lo8G planè o utpote qui aliud in difciplinis tradendis iter novamque viam inquirere voluit. Flumen verborum, guttula mentis, Religionis purioris quam profitebaturergo, mortuus eft anno Is 72 . in Lanienâ Parifinji. Scaligerana 1 .

Petru Ramu: yir omnium feculorum memoriâ dignus , qui necellariis hoc opus prafidiis aggreffus, pulcherrimam in hac Arte methodum aperuit. Is enim intempctivis tricis abjectis, utilia tantù documenta fectatus, Arithmetica elcmenta eâ folertiâ digeflir, ut quatotius partes, qux in ingulis generalia, qux fpeciaLia, antecedentia ircm, $\$$ conf́ quentia fint, facilè cernere, imò totam artem apodistico pinace dclcriptam, exhibere liceat. Chriftidn. Urftre.prxfat. Arithmet. fux. 
Ut virtus egregia nunquam caret invidiâ, xmulos, \& liz diligentix calumniatores acerrimos expertus eft ( Tetr. Rarnus) Petrum Galandium, Antonium Goveanum, Loa bimum Perionium, \& Iacobum Carpentariiom. Scd ante omnes infeltiflmos fenfit Sorbone Doctores, qui communi omnium fententiâ in Ramum infurgentes, illum hæreféos in Pbilofophiâa aєcufarunt, quèd in Ariftotelem Philofophorum principem aufus fuiffet Ccribere. Effecerunt liâ alltoritare ut Ramo fit interdictum iapofterum docere vel.fcribere in ullam Philo fophix partem. Boifjurd. in I con.

Petrus Ramu cùm diù bonas literas, philofophiam, \& poftremò Martiematicas Scientias in Praleâ Scholâ, cuipraterat, \&i pofteà in Regic auditorio docuillet: poltremò erroneam in Pholofopbicis doctrinaminvexit Ariftotelem voce \& foriptis importunè oppugnans. Tamen ex eo commendatione dignus fuit, quòd ingenio, diligentîâfafiduitate \& opibus etiam fuis ( quantum in iplo fuit) rem litcm rariam juvit,ac promovit; inftitutâ Matbematices profeflone, cuiannum vectigal D. librarum è facultaribus fuis attribuit. Thuan. ad ann.Is 72.

Etfi in nonnullis qua adnoftras literas pertinene valdè àte diffeutio,amotamen: eruditionem tuam, amo facundiam \& multas egregias viitutes, quibus tuum: hoc ingenium Dorrinm exounavit, nec optarim quicquam potius quàm \& tib gratificui, \& huic f holx frmul prodeffe. Beza in Epit.36.ad Petr. Ram.

Ne verò ( fili)cùm hanc contin Ariffotelem fententiam fero, me cum rebelle ejus quodam neoterico Petro Ramo confpirâffe augurềre. Nullum mihi:commercium cum hî́c ignorantix latibulo, perniciofiffima literarum tineâ, cornpendiorum patie, quicum methodi fua \& compendii vinculis restorqueat \& premat , res quidem, fiqua fuit, elabiturprotinus \& exilit; ipfevero aridas \& defertiffumas nugas fringit: Franc. Bacon. Impetus Philofophic.

Patrum noftrorum ævo fuit, quife iterum Arifotelem ex: Scholis cjivere, fuaque exilia \& frivola iis fubltituere polfe exiftimavit. Eft is Petrus Ramus, vir doEus ac difertus, fed quinon debucrit tam petulanter ingenio fuo abuti. Utmirer viros clie non malos, qui, fic in dcliciis habent ejus: Animadverfocnos, five. Scholas: quas ille, utadverfariorum aliquiacerbè fatisfcribunt, Oratorur \& $P_{0 \ddot{-}}$ tarmin Holculis exomavit;ut facilius \& certiùs inficeret juventutem : quo modo Athenienfes iis, quos capitis condemnârant, mifcebant cicutx pauxillum vini, id fua tenuitare cicuta craffitiem extenuaret. Ego autem, etfi in Rarro immodes. ftiam illam probare non pollum, benignius tamen cenfeo. Et cogitandum Arifor. telem ipfum non multò melius eos excepiffe, à quibus diffentiret. Hoc etià imminuit culpam, qteo quo tempore illa fribcbat Ramus, tanto in pretio paffim efiet Ariftoteles, ut non minus piaculare judicaretur, fi quis ab Arifotele difientire: 2ufus effet, quàm fi facrns negaret lireras. Vof. de Philofoph.Sect.p. 88 ;

Ramo non fuccellit feliciter confilium à le initum. Arifiotclis authoritatem fubruendi, juxta Valice \&Vivis documenta. I dea enim quam cfformavit nova Dialectič, nihil habet rationi confonu m præter id quod ab A A riftotelis Dialectica mutuatus eft, quam cum reformare voluit,ipfam destruxit. Rapin. AnimadverGonibus in Logicam , lect. 7. Gall. 
Ram unagmus fuit vir, fed magni nimis fir;ipfus $M$ athenatica fola bona. Sed ipic non elt Autor. Ramus male levibebat. Sealigerana 2 .

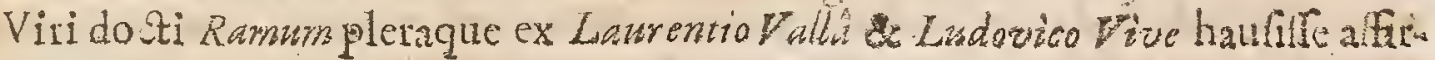
mant. Konig.

Juventus noftra à mc hoc audiat: Nunquam ille magnus exit, cui Raraus eft magnus. Lipf. Cent.r.Milccil. epift:89.

De Ramz Dialecticâ li vis dican quod confeo, pulchrum inucntum eft, magnumaic acumen, fed non ita magni momenti. Verder in Auktor.Cenf.

Vatti crat ingenii profundxquc eruditionis. Excellenti Merhodo Difciplinas - mnes pertiaztavit; Exiftimatus fuit Doctus Theologus, Infignis Math:maticus Philolophus acutus \& Orator celeberrimorum Antiquitatis $x$ mulus. Ominum fui feculi eruditorum cxiltimationem meruit, Gentefue exterx omnem movewunt lapidem ad Preclarum hunc virum $G$, this Lurtipiendum. Poft Rornuli Amafex obitu mononia Civitas mille Ducatos annuos ci obrulit, itlum in hajjus lacum pettraherct. Polonia Rex Cracoviam idum allicere conatuselt. loanizes H un

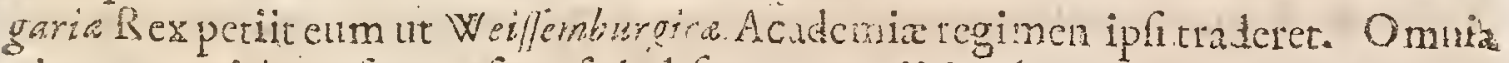
ejus opera ritè confcripta funt, fed obfervant cuttiti thyluin prioum qua adverfus Arifotem cm claboravit caeteris ab ipfo deinccus clucubratis multo praftantiorem fuiffe. Accufatus fuit quòd è Tractatu Vivus de caufis corruptarum artinu omnia excerpferit argumcnta quibus Ariftotele Virorum Eruditorum. Gall:

Extant Commentarii de R digione Chriftianá 8 . Francofurt.1577.

Extant Antiotelica Animadverfioncs "arifini $1558.8^{\circ}$.

Extant Infititutiones Dialecticx Parifis $1554.4^{\circ}$.

Extat Liber de moribus Teteriam Gallorizri Franco furti $15 \$_{4} .8^{n}$.

* Petrus Ratmis illter Hareticos Prime Clafis rejicirur in ladice Romano. Libri quatuor de Relipisse ( brifiana prohibentur:catcra ejus opera permittuntur cum expurgationibuis. Vide Indic.Madrit.edit. An. 1667.

\section{MMANUEL TREMELLIUS.}

W Olfurm paulò poft fecutus eft Immanuel Tremellius Ferraric patre Hebreo natus, Lingua Hébraica peritiffimus, qui cùm Lucan cum l'etro Marty-' Clar. A. L MDLX. reVermilio, \& aliis in occulto /'roteltantium doctrinz addictis concelfre, pofte-

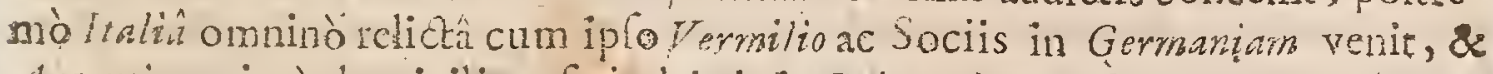
Argentine primò domicilium fixit, dcinde in Britanniam potiente reum $E d v v a r-$ do VI. tranímifiț yuố mortuo Germaniam repetiit, \& in Scholâ Hornabacbeñ fub duce Voifango Bipontrno, qui apud nos deceffit, aliquandiu docuit, unde Heidelbergam ad profefionem Hebraam evocatus ctt, ubi Syracam Novi Tertamenti interpretationem latinitate donavit, \& poltea novam veteris foederis ad Hebraice vecitatis fontes examinatam tranflationem molitus eft, focio tanti laboris alcito Francif co Innio Biturige, qui poft Tremellit obitum eandem cditionem n opere alieno plus jufto ingeniofus recenfuit, \&additis multis, auctiorem poXуу 2 tius 
tius quàm meliorem jỉdicio multorum reddidit. Relictâ poftremo Heidelberg Divistatum Medionatricum ubi olim cùm ex Italiâ veniret, uxorem dixerat; conceflis,unde Sedanum Bullionii principum fedem evocatus, ut in Academia novẩinguam. Hebraicam profiteretur,leptuagenario proximus tandem defecit: Tbuan. ad anum 1580 .

Domi in Lingux Arabice cognitione profecertut fama notifimi Emanuel Tremellin: \& trancifcus i unius, fummiviri, nec fine hortoris prafatione nominandi, qui quanti linguam A rabicam fecerint, quámque vehementer fudium cjus promotum volueriut, criptis fuis abundèfunt teltati. Thorn. Erpen. in Otat: de Ling.Arab.p.75:

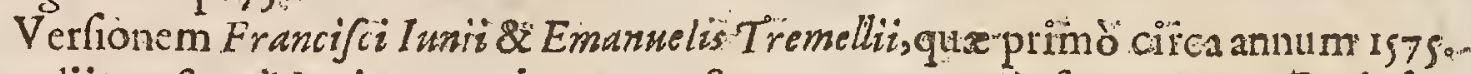
prodiit, pofte à 1 unio recognita.anno 158.7 magno cum Reformatarum Ecclefiarum plaufu exceptam fuiffe, \& confenticntia de ejus prættantiâ di vïorum ju dícia, \& Edicioner ipfus plinies repetitx, fatis docent. En licet nomullie verfiones propius in quibufdam Locis ab Hebrats abfint, nonnullex.ctiam fenfum \& difucidius \& cleyantiùs reddunt; confuderatis tamen 8 compofitis omnibusad accu-

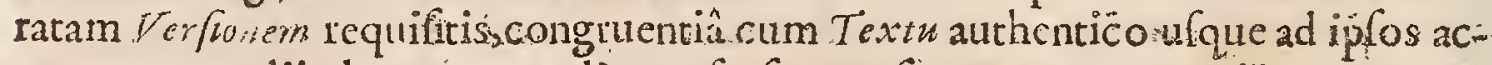
centus, quos alii plermque negligunt, fenfurnon fire magno acumine eruto., \& maximâ fidered hiro, verbis, finon fempcr politifr mis, at plèrumque propriis \& commodis " difichibus locis diligentilus expentis, doetius ar folidius cxpeditis: Hac Verfo primas forfan fibi vendicabit, \& apud zquas: Ludices reportabito Mattb: Polis prafat.ad Vol.r. Synopi.Critic.p.5.

Tremelliw vii fuit in Hebraicis mediocriter eruditus. Erat Iud Baptizatus: Ferranienfs. Hebren m fum cum Chuitianis didicit. Yerterat bene Bib̆lia. Adjunctus \&datus et ab Ecclefia I unius pro mere; Cum vertuntur Biblia., adjunguntur femper quidam: Tremellin obiit, Innius abfolvit; \& quando vult difentire à receptoe fuo maximè vidiculus eft: Scaligerane 2 ;

Supereft examinanda Tremellii \& Junitatina Verfo; qua naximi altimata fuit, fub initia prima inter Proteftantes, ii Anglia cumprimis. Orufins qui aprid Protetzantes inter criptowes fagaciffinos clarnitab illa pluribus in lôcis dänan-

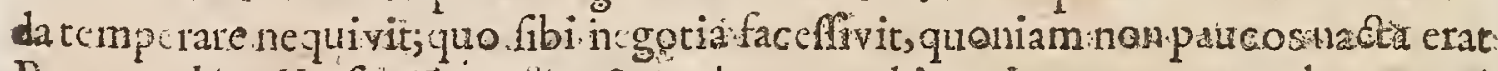
Pationos hroc.Verfio. Tremelliu \& innius eam adincudem revocare, altcramque accuratiorem claboritre coacti funt; fed quia quamfecuti lunt Methodus defectu: noncarebat, impoffibile fuit cos in fua $T$ randatione dcbitam perfectionemaffequi. Unde eriamaltera hac edirio à. 'ontantino l'Emperewr, qui ctiam Protckans

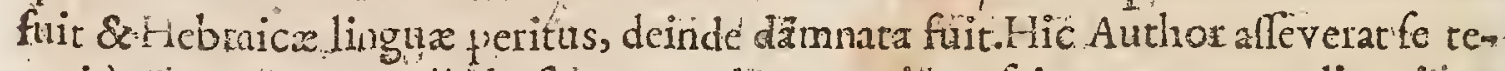
neri à ramelhn ac unit Verfione recedre, quiä nefcio qua vertendi ratione utuntur qua $f_{x p}$ in erronem conjiciuncut. Ctim Tremellius fuifer I udaus antequam ad roteftantes tranficet' nefcio quid fibi fingulare io fua Tranflatione feryavir, \& à vero fenfu frequenter recedit. Dictio ejus Latina eft parioer affectata vitiifqu futet; ubique ferè relativa pronomina, ubỉ nulla funt in Hebraicis, adhibet, ut cap.r.Genefeos verf. 4. ubi vertit, Viditque Deus lucem banc efJe bonam. o. diffinctionen fecit Deus.inter hanc lusem so. verfu 7: capitis ejuldem. Fecit 
orgo Derus bos expanfum, guod diflineuit inter bas aquas, qua funt ab inferiore

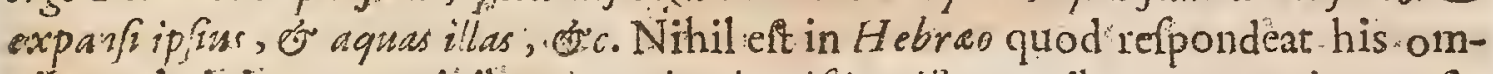
uibus relativis pronominibus hanc, boc, bas, iffius, illas : quibus tamen ejus verfio rota referta elt. Credo autem tunctemporis Doftorwn Geneven furm hunc ftylum fuiff; Eofl. $\mathrm{m}$ cnim defectus retinuit Beza verfione fua Novi Teltamenti. Orat。 Presb. Ki b. Simon, Hitt..Crit. V.T. libs.cap.2r. Galliçè.

Quicquid tandem dicat Fich. Simon certumeft hanc verfonem publico cum applaufu receptam fuile; $N$ am ab anno Is 8 - quo lucem vidit, cjus ulta feptem

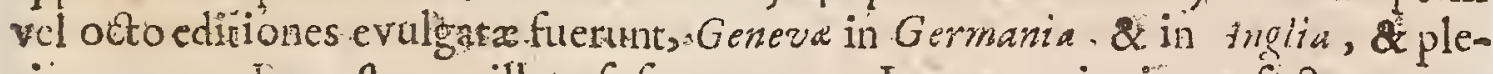
rique omnes Irocefantes. Illam fufpexeruntut Interptetationis perfect exemplar. Quicham Tremellium accufarunt quad somine fuo prafixo excudi curaverit Syriac IeftamentiVerfionem, qua Guidonem le Fevrede la Boderie Authorem. agnolcebat: Sediterancifus I wnu demontravie Tremellii Verfonem typis man-

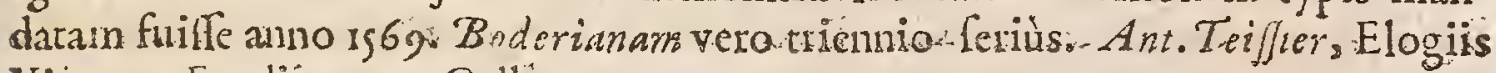
Virorum Erudiécum. Galli.

Emanuel Tremellius Novum Tefrimentum \&ingua Syriaca Latinè ab fe verfum $G e$ nov publicavit. In ea re, fil quod Raynaudus fecit, Genebrardo credimus, Guidonis Fabrui Boderiani laborem perplagium fibi vendicavii, qui illud ante è

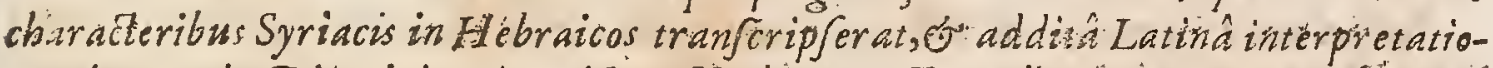
ne Antverpie Plantini typis emiferat. Verum pro Tremello jam moteu refpondit: Francifcus luniws, litem hancvel pueros exprima pagina in pectione dirempertros effe, cum Tremelii Interpretatio Anno 1569 . Fabricit tricnio poft in lacem prodicrititut in hunc potiks cadere debeat, fi forté fufpicio. Thornaj de Ilag.Hum. $566,5,57 \%$

* Immanuel Tremellius iner Hareticos locum habet in Indice Tridentitso: vide Appendicem prima:Clafis.

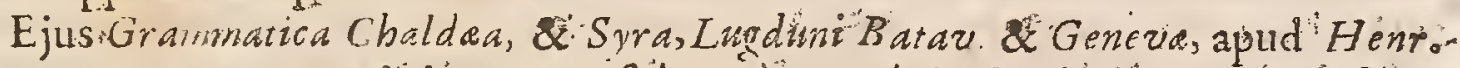
Stephanu\%, 1579 . permittitur, appofitâ täntum notâ Auctoris dảmnati, \& Operis peumifi, cum expurgatione, expunctâ videlicet. Epiltolâ dédicatoriâ. Inde Madrit. edit...ann $1667 \%$

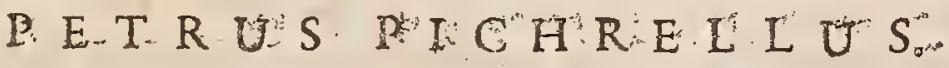

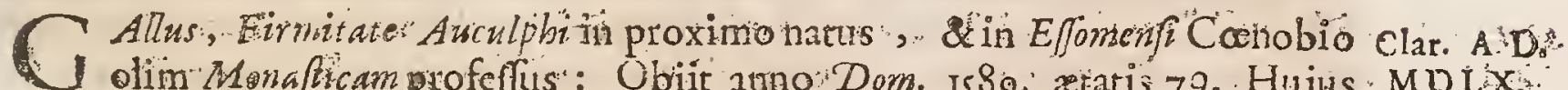
Opur cuia Theologica quax reperini potuerunt, partim anteàedita, partim manu: exalata, in unum collegit \& publicavit Doetillimus. Theologus Axidreas Rivetus, Lugduni Batavorumanno 1629 : in 12 .

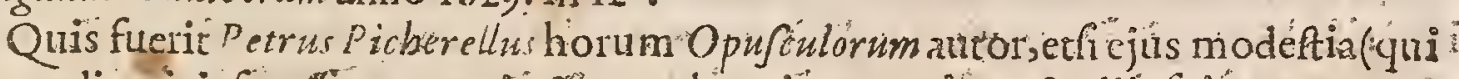
quamdiu vixir fcceffum amavit, extra hominum tubam fudiis fuis vacare posius elegit, quàm in publicum p,odire) mulcos celaverit: non pouit tamentanta eruditio ita in obfcuro latere; quin Scintila \& Igniculi Cubinde erumperent \& doctis viris innoteferet, qui fibi tautum \& $M$ ufis cancre voluifle videbatur. Nec fane ci fuir animus, talentum fibi a Deo concreditum condere, \& inutile ferva re in :

$$
\text { Yу.у } 3 \text { adventu }
$$


adventum Domini; cum perdius \& pemox in Sacris Scripturis verfandis \& interpretandis fudaverit, in quo ftudii genere; quàm exactam adhibuerit diligentiăm. quàm inftudtus fucit omnium bonarum Litcrarum fupedlectile, pauca quzdam qux vivens, potius fibi ab anicis furripi fivit, quàm fponte emifir, tertimonium reddiderunt. Habebat enim in animo, ut ab iis quibus nota erant iplus

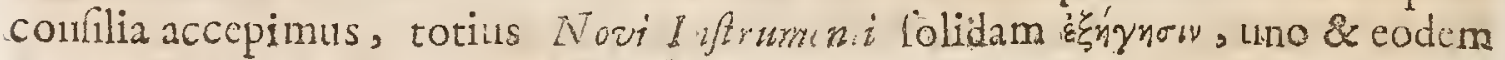
tempore, cum harum rerum ftudiofis communicare, quam unagno labote 3 induftriâ paraverat. Sed, chm dienum \& evi latur, ad miliores ledes revocarus fuilf $t$, nontales reliquit luredes, quos eadem cura tangeret; quorum five negligcntiâ, five alià culpâ accidit, ut vix fpes aliqua affulgeat, fruendi unquam canto thefauro. Indr. Rivet in Prafar. ad Lect. prafix. Opuf. Petr. Pi berel.

Magnum pichercli ingenium atque csuditionem oftendun libelli illi te Cana Dominic de Mafje Sucrificio, de Igne Purgatorio, de Inaginum Uf: icx quiibus Opuculirconteat, Picherellurb in fummis Religionis rebus haudmultum. Protelintinu doctrinâ alicnum.

Petrus Pi berellus homo trium linguarum peritifimus, \& acuriffmi ingenii. Thuan.ad Ann.r.s.8.

Petrum Picbereltum virum do otifimum Lapius appellat T beodorus Beza.

Judicium accuratum, di digentiam fingularem in l'ichereilo admiror, qui mihi videtur, fi quis unquam, veram ingrelius viam Sacras Literas interpsecandi. Hugo Grut. in Epin. ad 'sulielm, frartem, Anno 1620. Calend. Novemb.

His multa addidi ex Petri Picherelli Annotatis ad ria prima capita Genefeos; qui utinam fagax illud ingenium, \& graye judicii pondus, \& penitiorem linguarum notitiam,ad plura in S. Scripturam commentand adhibuilfer. Matth. olus piref. vol. L. Synopl. Critic.

Jam nomen Mifla hebraicum elle vel Chaldaicum, putidifumum commentum eft, hominum neque Hebreas neque Chaldaicas literas intlligcntium aut certe judicii prorfus nullius : quod ab etudirifinis viris luce clarius eft dew monfratum, in primis autem à viro longè doctiffmo Picherello Presbytero, in

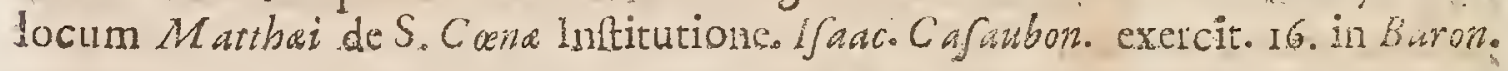
num. 590

Primus quem memorabo, erit celebris pichercllus, de quo Teftimonia Operibus ejus prefixa tam fplondidè loquuntur, ut mihi non opus fit quicquam dicere de exiftimatione in qua fuit apud Eruditos torius Orbis literarii. Totus ejus Tractarus mihi exferibendus elfet, fivellem îs omnibus infifere qua tradidit corum. Doctine de Tranfubirntiatione repugnantia. Hoc obferyaffe fuffciat, quod in fua expofitione verborum lafitutionis, Hoc eft corpus menm, hanc claran cortum interpretationem tradats bic parts eft corpus meur:; quod \& ingenue fatentur Papinte ipficum fua de hoc dogmate Fide contiftere non poffi; quodque hic prolixe demonttrat non "modò propiam fuam Cententiam effe, fed \& onfantem. circa hoc caput Dodrinam Patrum Primitisorum fuife.

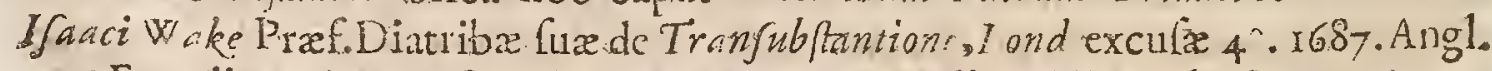
\& E vaiis 'icherelli Operibus in Soripturam nulla vidimus hactenus pretex 
- ejus Opufoula, collecta \& cvulgata ab Andrea Riveto Leydenfi Theologo, us id nobis aperit quodam loco lui in Exodum Commentarii. Sed vix damnum - corum carentia minuir eorundem copia qualium nobis ab eo facta ct, man- corum videlicet propemodum ubique ut authenticè id conftat ex Exemplari "quod me vidilfe memini apud Dominum Vofjum, in quo omnes lacunx - manu defuncti Domini Grotii repletz Cunt. Colonia Biblioth. Celect. pag. 22. - Gallicè.

- Ecce adhuc aliam Sorbone cenfuram, nihil nominatim defignantem, nulla - adhibita applicatione argumentis probata, Anni 1629. adverfus "etri Picberelli - Opucula, in Ecclclix Romana Communione defuncti in exiguo Prioratu Ab- batice Efjornenfis, inqua fine ulla peculiari defignatione Kalendis. Septembris. - Picherelli libaum damnant tamquarm impium \& abominabilem, putida Calvi. - niana lepra infectum, tanquam Tartari Cavernam foetidum. Volintque cenfu"ram hanc promulgari, ne Fidei Dornefici tanquum in procellofo mari Con- fcicntix fua navim ejus copulis illidant, \& fraudulenti hujus libri leetione dem - cipiantur. Authoris famæ injuriofa pariter efthac cenfura, qua ut Deferter \&e: - Perduclia pertingitur. Andrews Rzetus, Refponfione adiMileterij. Epiftolas "pag, 169. \&c. Gallicè.

\section{GEORGIUS CASSANDER} 1. Atus ct Brugis Flandrorum Anno Dom. Ists. Obiit Colonie die tertio Clar. A. D? cos \& Proteftantes controverfis. Opera ejus prodierunt, Paris. Anno I616。 Fol.

Literas humaniores Gandavi, Brugis \& alibi doculic:Pofted:Divinarum rerum fcientiam præcæeris amplexus, fufeptis indiverfa loca peregrinationibus, $C$ oloniam Agrtppinars, per omne reliquum vitx:fpatium, rebus luis invenit fedem: Ibi, quantum per valetudinem, quam depius adverfim cxpexiebatar alicebat Controwerfisis, quas eâ tempeltate Pontificiis, naximè in Imperio Romano, Theologi Proteftantes movebant, cum curâ perquirendis atque conciliandis intentus, elucentem ubique veritatem in l'rotejtantiurn Scriptis paffem animadvertit. Ab Imperatore Ferdinandol. ut de componendis inter Kamanam Proteftantium Ecclefinzrs diffenfionibus falutare confilium afferretsin Aulam vocatus"s,pertinace: Arthritidis dolore prohibitus venire non potuit:Cujns, \& Maximiliani II. - Lucn Eelforis, dcfiderio, cum prafens haud valeret;abens fatisfacere conatus; Librum fcripfit, quem de Articulis Religionis inter Catbolicos \& Proteftantes controverfis: Confultationem nominavit. In hoc aliilyue Libris fecurus odil", quemadmodim veritatis amorem, ita fibiregium,nonfervile judicium, fuille prodit. Hankus de Roman. Rer. Scriproribus.

Georgius $C$ afjander : vir utriufque linguæ peritiâ, \& antiquitatis cognitione, 
ac rerum poftremò facrarum diligentifcrutatione pracellens: rarâ hoc xvo modeftiâ: Et iis qui ingenium in contentionibu hodie exercent, ad vitandam acerbitatem in exemplum proponendus. Nam tot dotibus inftruetus, ille nunquam faftu intumuit: Contumeliis petitus nunquam paria reddidit, nullumque ullius arrogantia ferocis vetigium, velin moribus, wel in Jiripti, ejus deprehenfum fuit. Poft confulaitoners, de Controverfis Proteftentium Anticulis, jufu Ferdinandi Cafaris [criptam, \& ad Maximilianum milam,artbritidis doloribus confectus 3.Non. Fibr.pic defccit anno ztatis s2. ad B. Francifcifunus piofequcnte Magi-

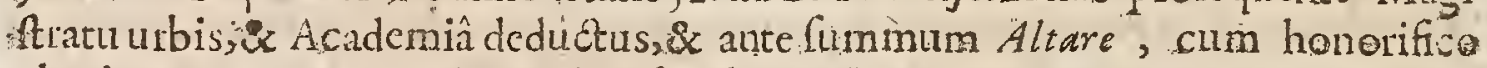
elogio à Galtcro amico individuo, fepultus. Thuan. ad annum 566 .

Utile crit Cafandrum evolvere, qui tot lites apertè quidem componere tentavit, licèt majori pi:tat = quàm ingenio; \& Mulchiorem Cianum, qui hoc idem, fed accultê conatus eft, ingenio majer q quàm pictare, acpropemodùn admirabili judicio. Vix cnim poteftimaginatio confequi, quantum auctorum cjurmodi sledione, Politicorum mentes actantur, excitenturque ad faluberimè de rebus iftis confulendum, quibus non unius aut áltevius Hominis modo , fed univer plerumque Reipublicxfalus, \& belli pacifque momenta contimentur. Gabr. Naud in libliogr. Politic.

Liber fpecialis Cafjandri de utraque pecie Sucramenti digniffinus lectu Grot. in Annotat.ad Confultat Cafjandrit.

Quò verè propter exiguam utilitatem \& multos abufus Cafjander mall ibltincli oltentatione \& circumgetatione Reliquiarum, in eo, ut in multis aliis rebus, piam oftendic prudentiam: sicut \& redèmener Ecciefarmon bafilicas

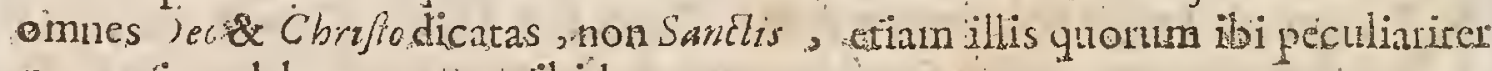
memoiia celcbratur. Grot ibid.

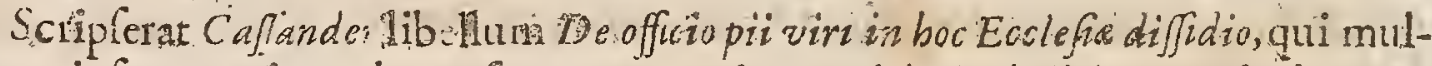
tis utriufque partis probatus fuerat; quamvis nec adè Catbolicis, omnis in Religrone:compolitionis inimicis acceptus; mulcóque minus Hareti is quiòd cortum damnatet novitates \& agendi mados. Adcò ur virulentifimus Calvinus, cxiftimans eum compofitum fuitie à Francijco Kaldvino, quem iole velementifimè

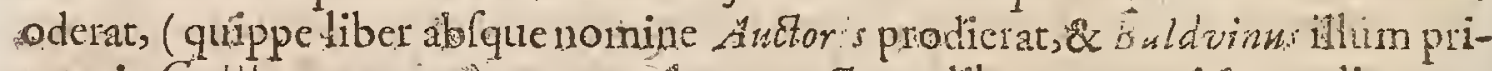
mus in Galliam avexcrat) arrepto calamo, unturem lib ru mque miris modis profcidit. Acclijus criminationibusfe Caflander ac vetcres Truditiones, Patrumque auctoratcm, prolixioni Apologin vindicavito pondar. ad An.r564.Seat.27.

Dum Paparum reformare Ginulat Georgius Caffander, stabilit \& commendat zequè, ac apecti hoites. Mclch. Adarn. in Vit. Zach. Zrinit.

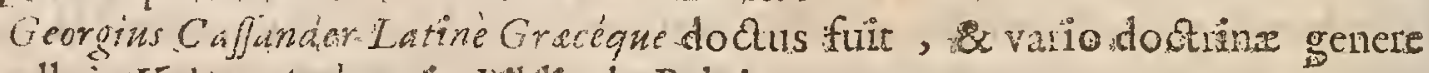
excclluit. Waler. Andrea Bn Biblioth. Bclgic.

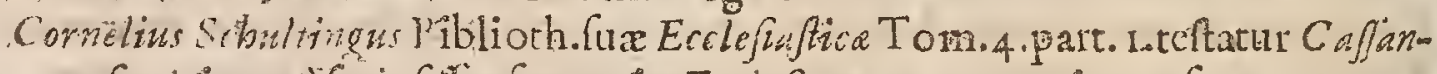

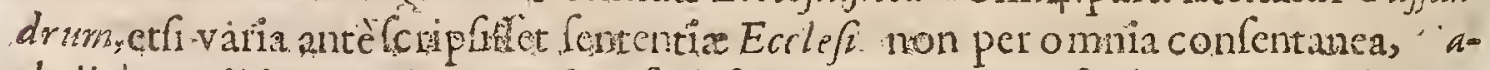
tholice ac pièin gremio Ecclefa effedefunctum. Itidem feuibit Bernardus Sutholtus J.C pluies fide dignos fibi Colanie atteftatos fuilfe, afjandrum morti vicinum, adiftente fibi magno teftumnumero, eadammafle, ac fribmifife fe $\therefore$ Leriptague 


\section{CEREBRIORVM AVTHORVM.}

-riptaque fua in omnibus judicio \& auctoritati Sancte Ecclefie.

* Scripta ejus pleraque Theologicia. à Patribus Concilit Tridentini, aut damnata, aut cenfurâ nutata funt.

\section{GEORGIUS FABRICIUS} pift. 52.

Ermanus Chemnicii, urbe Mifnie, natus eft die 24. Aprilis, Anno Domini-

1516. Obiit I $y_{0}$ Julii, Anno Dom.1571. Sehola Mijenenf2 26 annis prafuit. Car. $\mathrm{CD}$ MULXV. A Maximiliano Imp. fủ ipsâ fermè morte Laureâ Poeticâ \& Nobilitatis infigni condecoratus elt.

Edidit Ronam: SeptemLibros rerum-Mifnicarum: Annotationes in Terensum, Virgilium Horatium, Senecam. Multaque alis.

Georgius $F$ abritius rem literariam non mediocriter \& feriptis \& vivâ voce juvit \& illuftravit. Thuan.1.50.Hift.

Germania lumen \& onamentum Georgius Fabricius.70.Kirchman.1.3. de Funerib. Roman. C.i5.

Georgius tabricizs, vir politifimi ingenii. Tanaq. Faber. 1.2. Epilt. E-

Gcorgins abricius, wir judicil oprimi \& eruditionis egregix. Barth.Animadr. ad Rutil.lib. 2 . 327.

Vir lupra famarn fortunangue fuam laudabilis. Idem 1. I. Adverl c.io.

Ut menuie dect fimus miréque fagax friptor Georgizes Fabricus in aureolo sibello, quem Roman infriplit. I dem 1.2. Adverfar.c.22.

Georgius Fabritus, homo melms de human tatis litens meritus, quàm quifpiam facilecenkat. I dem ibid.1.4.c.1z.

Sicut mores ipfus [Georgii Fabricii] modefi \& placid fuerunt, ita \& dictio ejus, \& in carmine $\&$ in foluta orationc placida, luavis fine affectatione fuit. Excelluit ivitur in Attico dicendi genere, \& lectorem tewuit erudità brevitate. Hier. Weller, in judic de Geor, Fabric.

In carmine verò talat eft numerorum concinnitas, tantzs verborum delectus tantaque rerum fanctimenia, atque caltitas, ut non adxqualfe folum in hoc genere multos ex antiquifrmis; fed in aliquibus etiam fuperaffe videatur. Etenim in verbis eam curam adhibuit, ut ab i s, quæ ethnicam idolomaniam redolent, no-

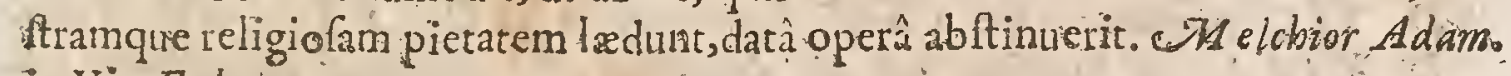
in Vir. Fabric.

Georgins Fabricius Chemnicenfis, exquifto verfu bexametro itcr futum Romas mum, Neapolitanum, Patavinum, Chemmicense, Argenioraten $\sqrt{6}$ rcmenfis eft: Nec elégis fuis, quibus calettes viarias perfcripfit, parumglorix confecutus. Bor- rich.de Poër.1 29.130.

Terentii editio Fabrigiana aliis omnibus ptxitat, \& fingularem laudem atque pradicationem meretu, teftante Ioacbimo Camerario in Epift. Terent.pra= ixân. 
Operam Fabrieit in Tragadiis Senece non multum laudat Lipfins: Georgin: - (inquic) Fabrici, Nihil tibi ego detractum ${ }_{*}$ co: Sed profecto non laudatifima - opera tua in hốc quidem Poëtâ : quem fxpiùs cura tibi innovandi fuit, quàm - in veteri nitore confervandi. Lipf:in:Agamemn.

Georgins Fabricius fuit unus ex ætatis fux praftantiffinis Poëtis \& celcbratiffmis Criticis;nec pietate minùs quam eruditione infignis, ut liquet ex his duont:bus qua ipfe compofuit Diltichiș.

\section{Fabricius ftuduit.benè depietate: mereri: Sed, quidquid patuit, gloria, Chrifte, twa efo..

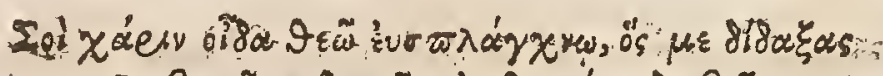 Ev B.}

\section{Ant.Teifferin. Elog Gal.}

* Georgius Fabricius Cbemnicen. inter Hereticos prinix Claffis numeratuxGeorgii Fabricir Cbemnicenfis Saxonie Illustrate libri novem in decreto 230 Aliz gutti 634 prohibentur.

Extat Rorna Antv. I657:8\%.

Extant Posmatum Sacroum libri 25. diobus Tomis Baj.:1567:80.

Hoc ejus , Epitaphilum: :

\section{CHISTO SACRO MAt}

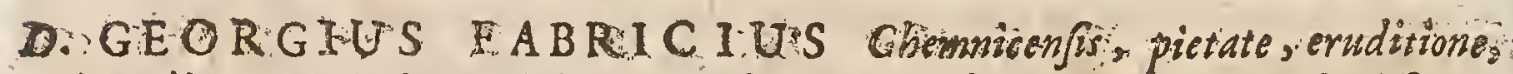
ingenii monumentis nominifque celebritate apud exteros quoque clariffrmus, Evangelii lucefcentis tempore Poëta excellens, Grammatiaus acutus, Hiftori-

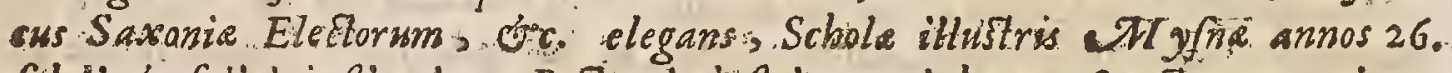
fideli of felici infritutione Retior indiaftrius , laborm Santorum pariens,

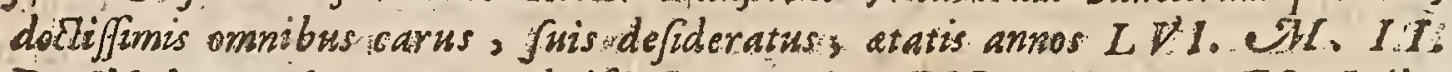
D. $X \perp X:$ complens anso Chrifi Servatoris $X I D L X X I$. Mr: I Ulio, $D: X^{\prime} Y I T$ in fundtione pia pie defundtis eft : quicguid mortalitatis babuit, in boc quietis. cubiculum pofteris memor. caufa venerand. depofitum aft. M. Magdalena Uxor, Georgius, Jäcobus, Henricus, Chriftianus,

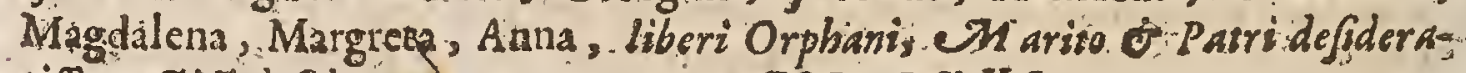

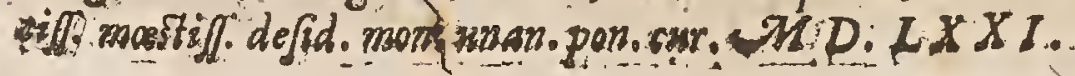




\section{O NUPHRIUS PANVINIUS}

D Eronenfis, Heremita Augufinianus: Panormi fato immaturo raptus eft Ants:

Dom.1568. die I6.Marti æratis fux.3.9.

Scripta ejus plurima nondum typis edica extant Rome, Verona, SM onacbi: MDLXY. \&a alibi apud eruditos: quorum, itemque exculorum, ferien qui volet, apud $A n$ -

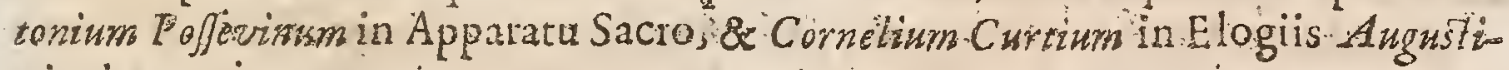
mianis reperiet.

Onupbrius Panzinius, vir \& doctrinâ \& fide fingulari prædirus. CAr. Sigon.l.x. Emendat.c.35:

Onuphrius Pawinius, Verokenjis, Ercmita A uguffinianus, vir ad oms. nes \& Romanas \& Ecclefiafticas antiquitates è tezebris eruendas 'ratus: quod preclara cjus \& ad omnem aterintatein victura mónumenta teftantur. Thuanit.44.

Sacrize prophanæ Hitorize peritifimus vis fuit Onuphrius Panvinius Verom

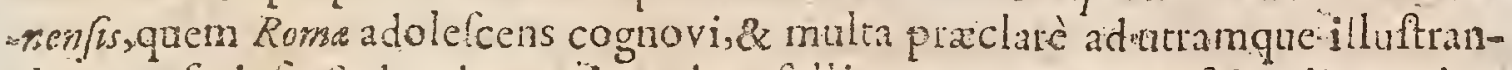
dam confcriplit. Sed, ut homo,i rerdum fallitur, \& peceat confidentil, aut imbecillitate protius memorix, quam ignorationc Hiftorix. Lalius Bifciol.Tom. I. Hor.Subfeciv.lig cila.

In Romanorum Antiquitaribus explacandis funtram ingenili laudem eft adcpsus. Bodin.Meth. Hiftor.c.4.

In partes Pạparum pronior multò, gużm Cafarumo Conring. de $\mathrm{O} . \mathrm{J}$. G. ap. 10.

Quod Conftantinus Maxentium VIII. Septembris viccrit, hariolatus eft amieus nofter Onuphrius Panviñtus, optimus vir, \& in cu, us ubitu omnes numeri Hiftor: $x$ collacrumarunt. 7 of.Scalig. de Temp. Emendat.l.s.

Onupbrius Panvinius, Parer Hiftorix. Idem lib.6.

Hac luculenta in coiptio effugir diligentiam oculatifimi \& accuratifimi viri, am:ci netri, Ontiphrii Parwiniti. I dern in Animadvad Eufcb. I.2. Chronic.annum M.DCCCCLXIX.

Onuphirius Panvinius vir ingenii maximi s imul, quod infolens, ftudii indefeff ; cui , quantum tota Refp. literaria debeat,memorari ex jufto nequit. Sacram omnem profanamque hiftoriam non modò evolvit accuratifimè , fed terum praterea feriem ac tempora diftinxit, exprefit, lumenque accéndit oimwibus, qui ad fcribendum poitea animum appulere. Cornel. Curt.in Elog. Vir.illuftr.cx Eremit.S.Angufinit Ord.

Onuphriws Panvinius, ille antiquitatis Telluo, fpectatx jivenis induft ix, \& ingenio, ut probitate, proftans, hîc eft, critque ut video, in aliquot menfes. Imprimit fuos $F$ affos cum Commentari s: \& interim adornat alia. Sxpè litig ?t obfcuris de rebus cum Sigonio noftro, fed utriulque bonitas, mutuus amor, eicellens ad cognofcendam veritatem judicium, facit, ur inter eos facilè conveniat. T'asto

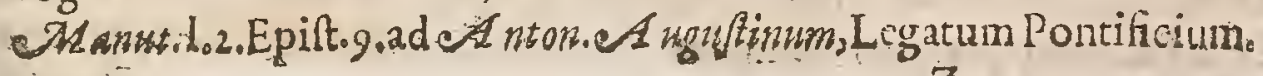


732

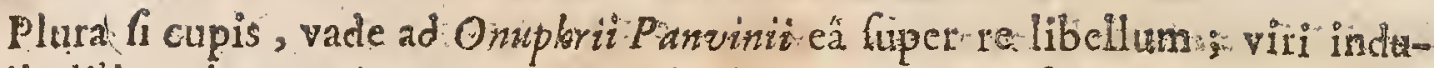
Arii, diligentis, \& cui Romanamemorix (curam tantum ferre potuilfet aut limam) debent debebinrque. Lipfin Commen.ad Tacit ol. Ir. Annal num 37 . de lud: Sacular.

Onuphius:Panvinime mona hus optimè de reantiquariâ meritus, faftis collatis,vetuftis marmoribus erutis. Thom.Dempfter.in Elench.Scriptor.quem fuo ad Io.Rafuit A ntiq aucturio addidit.

Onuphrius Panvinius. Teronenfs, Aughtinianus, vir diligentifimus, \& rerum: antiquarum indagator folertiflimus. Henx.Spondan. in Ecclefiattin anual, ad A.C 14; 1 ; num. 1 x.

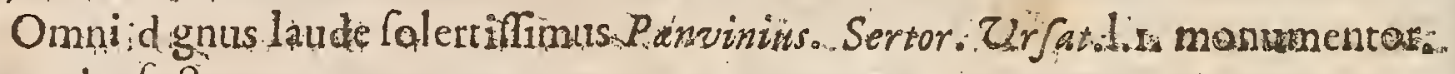
Patuvin. Tect,2.

Eximins ant quitatum caltor Pamoinius. 1 dem feet:7.

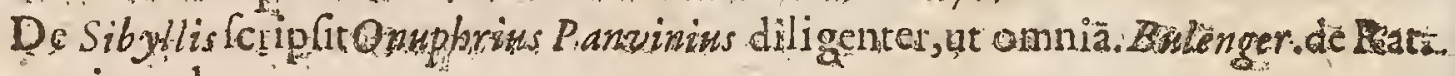
div nation $\mathrm{s} \mathrm{l}_{4}$. C. I.

Cer tè hac argumentum de Sibylis maltè dexteriưs \& diligentiùs, quàn Onsphrinsyir doaifimus Gy aldus perfecutus eft; quamvis ille alter peculiari quodam tractatu rem lufceperie perficiendam. Rich. Montacut. in Analect. Exerciro4. $\int e{ }_{0} 6$.

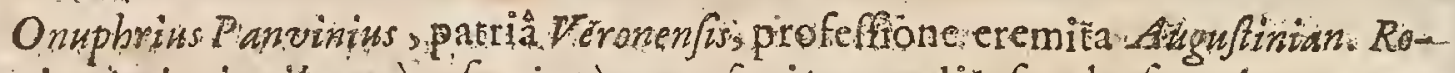
manis Antiquitatibus cum facris tim profanis ertendis. fecula fuperiore natus. Virgilianum illid Emblema, Ad utrumgue paratus, juce optimo ulurpavir. Qued quîtem Elogium non madò noftrarum, fed"\& adverfariarum í religione partum fudiali viro eruditifano, unamimi confenfu, stibunt Aub. Mirems.

Mulus eft Scaliger in refellendo erro: $Q$ nufriz de natafi Christi; demù verò inquit, Hxc ego ideo difcuff, ut navus ille de illo elegrnti libronmici nofu tollarur: qui profua fingulari eruditione, etiam imprudens faktem anno uno satalem Christintiquiorem ellefenft: fed quia characterems qua eft vera Helice in hac navigatione, nullum apprehendit, ide reesum curfam tenere non potuir. Honnes enim amns fumus, \& peccandi neceffrudinem non pollumus nifi cum Homine exuere Iofph. Scalig. do Emendat. Temp.1.6.p.530.

Tora illa Diatriba longa de $P$ a Jrone Domini Eastis infertas en pannus obre Setus pupura allutus. Scalig. ibidu

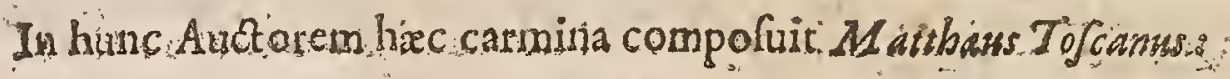

Roma Panvinius vigentis avtory

Roma decrepitos labantis annos: .

Romi nuwe iterum decus renafcens:

Doctis explicuit: fuis:libellis:

Ergo Panyinio peremps in aum

Gratias. 
Graitias aget annis Urbs Quititum

Vigens, deciepita, of fimul renalcens.

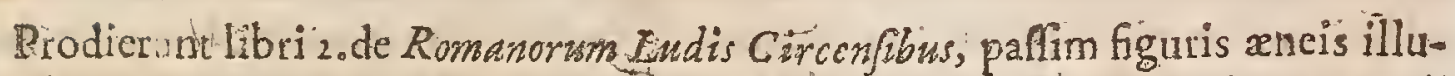
Prati, cum Ioannis Argoli nutis, \& in Ths Nicolai Pinelli additamentis, Fatavit $1642 . i n$ Eol.

\section{IATIN S IATINIUS}

$\sqrt{7}$ Iterbienfis, obit Romavicefimo prima Junurii Anno Dom. 1593. atatis Clar. A.D. 8. RomasadS. uAariain Viä latâ fepulcus. MDLXV:

In facris veterum Hatrum libris emendandis, imprimis in Tertulliano ad veteres codices recognofcendooperam impendit. Ejus Bibliothecam Sacram \& Mrofanm five Correctiones in Sacros \& Profanos Scriptores Dominicus M Matagrus Rospe ann.1677. Fol. in lucemprodire julfit.

Latinus Latinims, vir magnâueruditione preditus, Rome fummorum Pontifi-

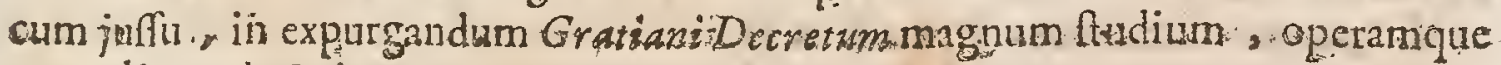
contulit.God. Watican.1num. 48,5 ;

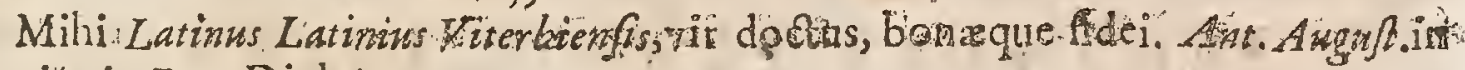
Aniquit Rom. Dialcg $x 1$.

Sed cim fecundam editionem noftartm Notationum medirarerjaccidit ut dè re tam ambigu i agerem cum naltro Domino Lutinio viro infiguiter erudito; \& in rebus Ecclefratticisadmodun verfato, quem ejafmodi reperisententia... CafoBaron.in Not.Martyrolog.Rorn. S.Jún.B:

Sed Listinizs nofter. . qui in mendis iftapfis cognofendis lymceos ha bet oeulos , fic jure putat locum elfe: reftiruendum, Iddem in Notato 10 Jill.G...

Roma eft Latinas Iatinus, famen vivit, probiflimus fenum quos ego novi: Q omni literaturâ.infuncus. Lip Sent.2.Mícell.Epift.3\%.

Quaremihi fuit gratifmum, quòd Domini Latini Latini emendationem mihi communicaveris, cujus ingenium in hocplurimi facio, quoniam ipfum fectandx enditionis virum cognofo ; frquidem inter nos aliquando fumus: collocuti, ejufque ingenii acumen ex. familianbus colloquiis facitèerfpexiquum unà cum Illufrilimo. Cardinale S. Angeli Epícopo Bononienspia memorixhîc ageret, quo tempore meum Náture. Theatrum peluftravit, quia rerum

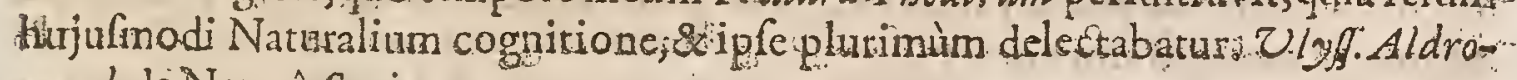
qand de Naturâ Sepió:

Latinus Latinius, magni ingenii vit, \& Grear wam Linarsm que literarum benè peritus. Petr.Vittor. 1.36 .Var. Lect.c.1 .

Adco peritus evafit in Veterume $A$ utborum Critices ut plerofque eorum quilin: hujufmodi Atudiis excelluerant fuperaverit. Cum omnibus avi fui eruditis commercium coluit.Ludovicns Morern Majosi Dictionario Gallico. 
Pamelius qui ejus doctrinæ luce felicite femper ufus eft in luis correctionibus \& Commentariis in Tertwlianum \& in Sanetum Gyprianum, non poteft affatim profiteri quanti facerct ejus doetrinam, ejufque Conjecturas \& opiniones ut ornnium folidifimas amplectebatur. Exculafint Latinii Notecum $P$ a melib. Commentaciis in hos duos Authores - Raimundus. Capifucóns, qui erat Sacri Palatii Magifter, dicebat le Gatis mirari non poffe laborem \& indefeliam contantiam qua Latinius legerat \& enoduvetat wat Authores , ut wec ingeni: ejus acumen \& penetrationem, incomparabilem ejus dexteritatem ad fefe extricandum è locis pexplevifimis, ejus folidam \& fagacem prtidentiam in ejus decilionibus; Ced fuper omnia ejus erga veritatem amorem mirificum, qua notus fuit ad omnia tentanda ut illam educeret ex Authorum tocis obforifinis tanquam è mediis kenebris. Iridicia Eruditorum per Dominum $B$ atllet, Pairifis ano 168 go Gall.

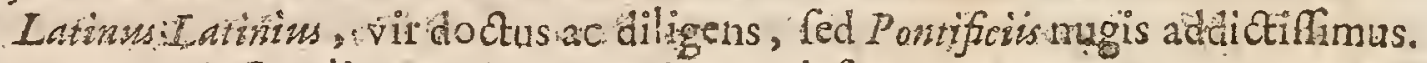
Raul.Colomef.in Paralipomad Chartophyl.Ecclef.p: 8 .

Extant Obfervationes \& Emendationes in Tertullianm in Edirione Parifienf Pameliz roos.

Extant Lucubrationes $4^{\circ}$.Rome $165 \%$

\section{TOANNES IEUNCLAVIUS}

Clar. A.

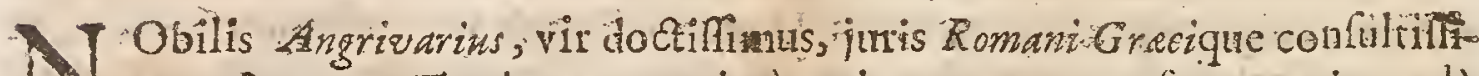
COLXY.

minor obitc. Eruditio ejus, ex Scriptoribus, gros-trantulit, eftimari poterit. Tranfulit autem Xenophontem $N$ Nazianzenum, Conftantinum $M$ a

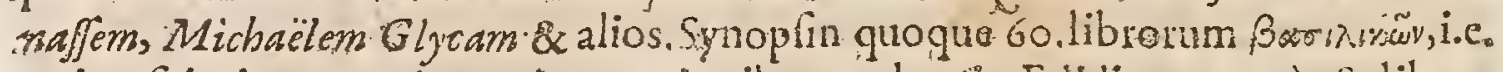
univerfi juris .Romani cum Annotationibus evulyavir. Edidit pratereà 18. libros Hiftorix Mufulmannice, quos è monumentis plorum Iurcarats excerpfit. Komigin Biblioth.

Toannes isenclavirs, juris Romani Gracique confiltifimus, 'B rerum Turcicartum apprimè peritus: ad quas lingure ipfus Byzantinâ petegrinatione comparatam cognitionem, exactam ulima Hiltonix Graca lectionem, \& acre ac admirandum judicium attulit. Quod non folum in feriptis ab iplo, dum vikeret publiblicatis, fed in iis, qua polt mortem cjus publicata funt, elucet. Non folum fui, fed \& Confaminopolitane Hiftorit, cujus fem feccat $\rightarrow$ incredibile defiderium reliquit.Thuan. ad annis9\%.

Amelbrariz in Wefpbalia nobili genere:ortus elt, nobilior eruditione rao

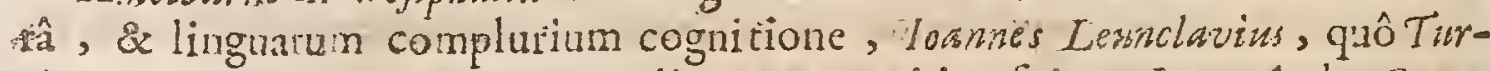
cicarum rerum, avoum memoriâ, nemo peritiof fuit. Ioan. Anár. Quen siced.

Pilmam omnibus rerum Turcicarum Latinis Scilpteribus rapit Joannes Le-

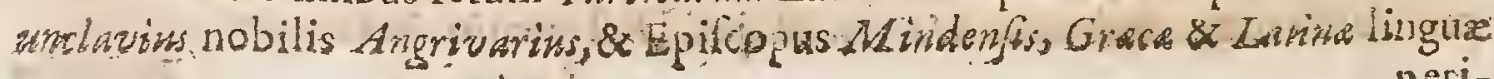
peri: 
perixifimus, \& varix etuditionis, qui-cum legato $C$ afarco Davide Vngradio prom fectus, mag os fecit progrelfus Conftantinopoli in notitià rerum Turcicarum. Va. luit ingenio, ac merito ommibus præferendus eft, quare \& Thuanus illum femper fequicuir. Hermari. Conring.

Scripfit \& Carolus:Sigonitus de Règno Italie, quod hat facit : \& fobannes

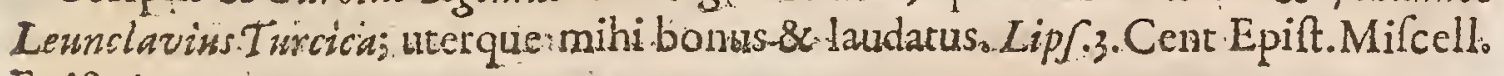
Epit.6r.

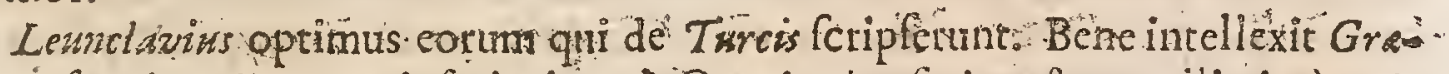
a Conftantinopolitana \& inferioris zui. Omnia ejus fcripta funt utilia inò neaeflaria. Graca Jürifconfuiltosum intellexit; fed autorun veterum non inrell exit, ut H.Stephanusi, qui paulò ante ebitum multa ferip fir ad-me contra Lewnclazùz edirionem Xènoptiontis. Scaligerana polterior.

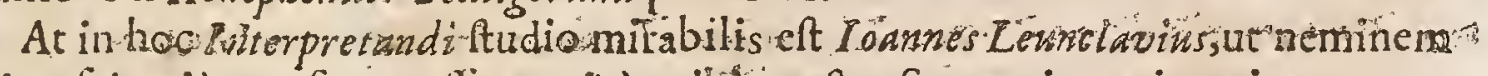
in ea dcientiùs verfatum elle omnino mibi cont et:Sententias quippe ita contor quet, ut nihill intercidat; coverboram namero circumplectitur, ut paria paribus

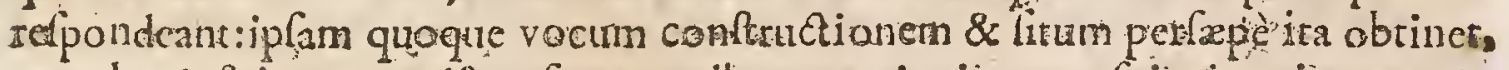
un coler ipfe integer exiftat: fumma adhixe concinnitas; perfpituritas, incortupta

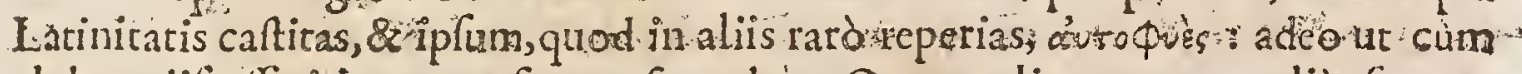
ab hoc difcelferitis, nemofit anteferendus. Quum reliquos autem aliàs femper

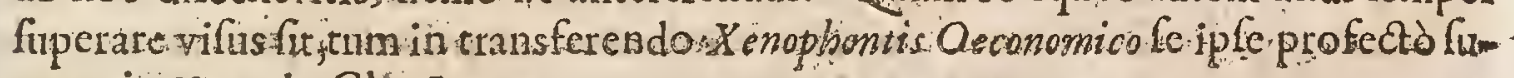
pẹrnvit. Hivet:de: Clär.Interpr. torio:

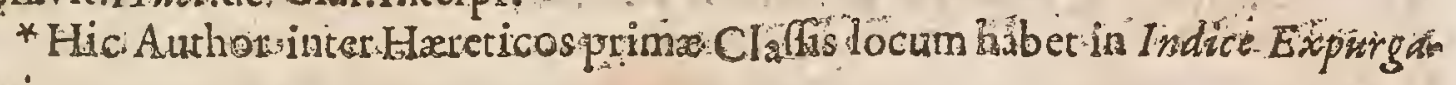

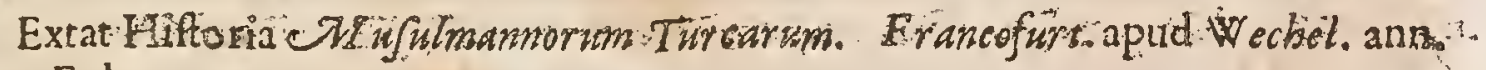
3591.Fol:

Extant Annales Sultänortum Otbónanidarum cx linguâ Turcicâ Luatinè redidith ¡bid.ann 1996 : Fol:

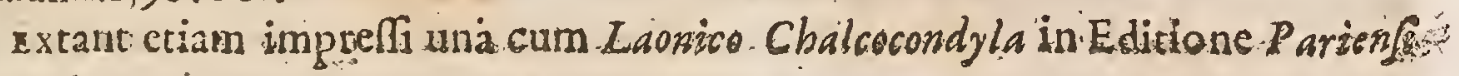
anno $16.50 \%$

\section{CA.SPAR DEV UCER}

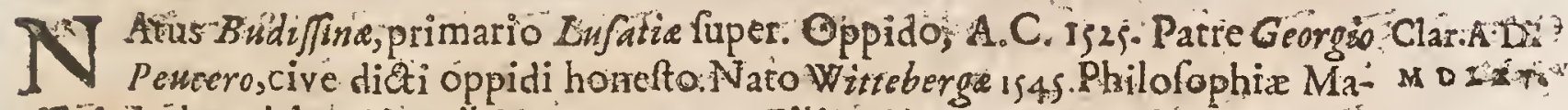

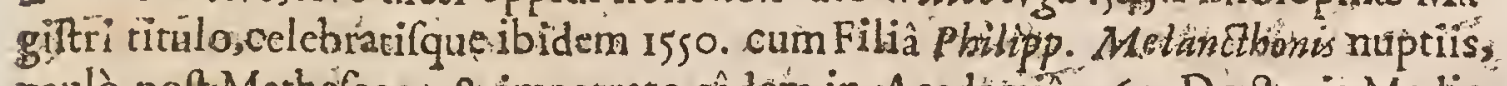
paulò polt Marhéfeos 3 \& impetrato eâdem in Acadèmiâ 1560 . Doctoris Medis Gtadú, Medicina etiam Profefore pubt. loco Iäcobi Milicbii conftitutis eft. Tum ob libros aliquot Theologicos editos de Religione fúfpectus $D r$ fd pria mùm, \& deinde $L$ ip seris 76 . carceri fqualido inclufus, in eo tempus omne à fomnolib'erum, precibus, lectione Biblior. \& verfibus fcribendis confumpfir; ubi chartam ipfifuppeditấrunt pargines \& folia yagua libri Concordis arsramen- 


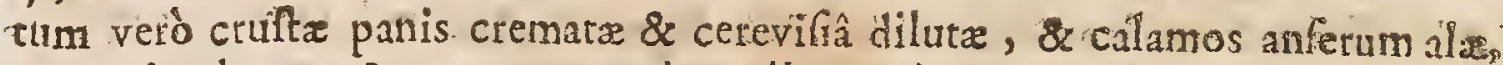
quas ad pulverem \& aranearum telas tollendas imperrârar A.C.i\$86.ircrum liber dimilfus ; abinde Servesta apud Principes Anhaltinos 16.annos valerudine multò, quàm anteà frmiore vixit; adeo, ut ig 7 .alteram uxorem duxerit. Tandem Defjavie nullo morbo, fed maralmo lenili obut Anno Chrifti 1602 , watus fux 78. Van der Linden de Scriptor. Medic.

Scriplit plurima, fed primo loco habentur: Commentarus de precipuis Divinationum gencribus - Elenenta doctrinx de Circulis Calejibus, \& primo ro tiu:- Hypotheles Afronomicx.

Gastar l'euceriss Budiffna natus, Philippi Melaribonis Gener, longân vitâ \& Ecriptis ac fottuna clarus. Thuanad ann.i6.02.

Medicus, hilofophus \& Hittoricus magni nominis, Arrifque Medicain Academia ittehergenfs Profetior, gui tum ob Socerum Philippum Melancthonem tum ob eximiam eruditionem Miedican \& Pbilofopbicam, addo etiam ob merita in Academiam non planè vulgariasmagnam fibi autoritatem concitaverat. Quenfled:

$\checkmark$ ir ad juvandas bonas literes natus AR elch. Adamin Vic. ejas.

Gafpar Pencer vir doctifimus. Fof.Scalig. in Epift.I.p.I4.

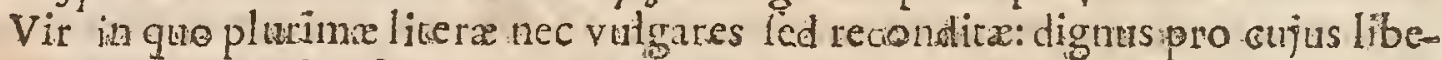
ratione apud illufriffmum. Saxonic Eleftorem Auguftum; omnes qui gradî̀ conGlio \& amiciriâ flurimùn polliut, intercedant. Gefrer. in Biblioib.

Gafer Peucer magne vir eruditionis \& minimè vanus. Bodin.Mcth. Hiftor. C.4.

Vir libro, quen de Divinationibus fcripht, fed decennali, quem ob conftantem veritatis de Perfonâ Chriftr, \& Canâ Domin profeffonem fuftinuit carcere longè celebrior: Scultet.de Curriculo Vit.

Variarum dizinationum magicarum monftrolas fpecies, prodigiolofgue mocos Satane artificio in aterram hominum perniciem dolosè confictos, in hittoriis annotatos, \& ab Ethnicis ufurparos, erudite in doctifimis fuis Commentariis de pracipuis divinationum generibus defcribic multigngx lectionis vir Cappar peucerus: Ubi plurimalectu dignifma comperies, Zoan. Wier de Magis Infam.C.12.

Capor Peucerus vir maximus, in cujus libris multa enditio elucet. Bibliograph.Curiof.Germanop. T667.

Magnx dectrina \& pridentix vir. Conring. de Utb.Germas.

Palmam inter ejus Scripta obtinere viderur Commentarius de Pracipuis D: binationum Generibus. inclch. Jidatn.

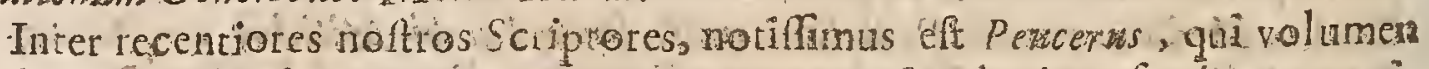

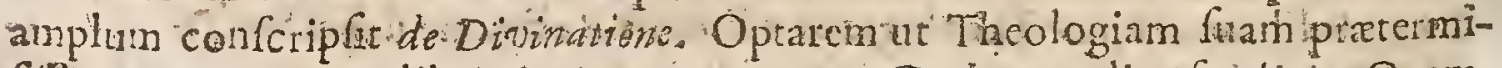
fllet qua magnam libri egas patem occupat: De hoc melius fentirem: Quamyis ne fic qu dem religutum mini adeo placear at ab endito viro expectavinem. Exempla enim probata vel expeimenta, qualiaeadem muncupare mini fas ef, - 
Parca vel nulla haber. Quia autem mens humaria in ratn abftufo argumento deprehendere poreft nifi qued experientia nicitur, excepta Scripture Sacre anthoritate ? Meric. Cafaub. de Credulitate \&.Incredulitatesp.134.135. Anglicè b Authore heic citatur locus. isino.

* Hic Auther inter Hareticos prime Claflis rejicitur in Indice Triden-

Varia ejus Opesra variis in locis at que temporibus funt imprefla.

\section{HUBERTOS FOLIETA}

Enuenfis Sacerdos, I talos inter'Scriptores mirè femper mihi placuir, cùrth I ob ftyli (iceroniani el gantram, tum ob xqua \& vera Hiforiarum ejus teftimonia. Patrem habuit Augufinum Folietam, qui Iulio II. Leoni X. CleCiar.A.D. MDLXV. monti VIII. Romanis exordine Pontificib s à confiliis fuit, \& ob lapientia atque proudentiæ præftantian longè gratifinnus extitit. Hunc Carolus V. Impetator, qu'd Leenem X. ad Fœdu cum Carolo adverfus Gallos. I talia incubantes in eundem impulifet, $M a z a r e n / i$ in Sicilin Epicopatui preficiendem curavit, \&2 quatuor in tiper millibus aureorum nummerum in annos fingulos auxit. Ubertus a Civibus lius miffus eft in exilium, quod feriptis luis vulnera Patrix ac remedia liberias indicare non dubiraverit. Ttaque pro Symbolo ipfi fuit tada fert fax ardens, hàc InfCepptione, Offcio mibi officio. Ad cxilii incommoda \& tadium fallendum, Hiftorix lcribendax tocum fe dedit,ut qui quas fyyli penas dabat eas nulla re convenientius quàm ftylo levari porfe exiftima er. Equro animo exilium tulit, \& à patria charitate eum nulla unquam inimicitia abduxermnt; imò fcripfir de parriâ. Exccpireum Hippolgtus Efrius Cardinalis. Ferrarienfiso Is eun it familiarium fuo um numerum amanter acceptum, omnibus commodis fovir-Obiit Rome exul,ann. 1.58. . 5. Septemb.annes circiter 6.3. Aub.Miz. rewr.

Scripta ejus lare funt : Hiltorix Genuenfurm libri 12._Claronm Ligurum Elogia_-Delaudibus Urbis $N$ eapolis-De ratiune fcribende Hittoriz. - De -caulis magnitudinis Imperii Turcioi-De lingux Latine ufr \&prattantià-De Philóophiz \& Juris Civilis inter fe comparatione-De nomullis in quibus Plato ab Aristotele reprehenditur-Conjuratio Ioamis Ludozitio Elifci--Tumoltus Neapolitani--C Cedes Petri Ludovici Farnefit----De facro foedere in Selimum---De ebfidione Melite--Nomina Polybianam-Opufcula.

Vir Latinè fcribendi facultate preftans, multa elegantifir mè \& acri judicio fcripfit : Quz limul edi publice intereft. Is unus noft to revo dignus furt, qui ficuti pem feccrat, Hiftorias fui remporis Pauli douii Veftigiis inf itens perfequeretur. Multa ex eo cum operi Hiftoriarum inferuerim, ac pleatumque verba ipfa ( nam quî meliora potuilfem ?) non folum ingentuè id pro fiteri, fed ejus memoniam dignâ recordatione hîc recolerc officii mei effe duxi. Thisan.ad Än.rigs. 
Ego tua fripta \& legeram ante multus annos, \& ita probaram, ut ex iis qu tunc excellere putabantur, tibi neminem anteferem. Hxc de tuis Liguribus illuftribus \& diligens, \& ornata commemoratio ita mi placuit, ut, qui conferri tecum hoc in genere poftr, prorfus neminem elle judicaverim. Paul.Manut in $\mathrm{E}$ pift.quam pramic.Folie. Elog. Clar.Ligurum..

- Hubertus Eoliet nobilis Genuenfis animadvertens Patrix fux Hiforiamab - A ugufino fuftiniano Nebii Epilcopo contextam cum applaufu publico le- ctam non fuiffe, idem argumentum tractandum fufceptr, "quod tam felici fuc- ceffuprafirit ut locum non afpernabilem occupare meritus fie inter Ita- lice Hiltoricos. Aceuratifinè ac difertiflimè Ligurum Virorum illuntrium - Elogia quoque confcripfit. Sed acris judicii è Criticis quidam hodienus, cen- fet illum in hoe Opere plus affe fibus propriis.quan veritati obfequurum effe, - eumque culpar quod Viros plurimos infignis meriti non laudaverit, hac unica - de caufr quod à partibus fuis adverfis Atarent. Ant. Teifjer Elogiss Viror.Erudioctorum. Gallicè.

Qui magis determinate de unjufcujufque Reipublicx Atatu cognoferè deliderat, is adire porcrit, quos audivi quondam à celeberrimis hominibus fummopere commendari, Vbertum Folietam. qui de Genuenfum, \& Nicolaum Contarenum, ac Donatum fanottium, qui de Venetorum Republicâ, præclaris olin Lucubrationes dedếre. Gabr. N and.ig Bibliograph.

Tu Gerna que Huberti Folieta natale folum fuifti, nobilis \& venerabilis tui Civis, honoribus aternis \& animo gratifimo maximoum ejus merirornm \& prifantifimarum ejus virtutum merroriam revereri teneris; quandoquidem labore diligenti, fudoreque multavelut è tenebrarum fepulcro glo:iolas tuas antiquitares eduxit, hafque huc illuc mille modis difperfas collegit \& in elegantinmum volumen cum exquifita distione multaque facundia redegit, quod in lucem editu m Eruditorum manibus evolvitur, cum magna Authoris laude \&legentium applaniu. Gbilini, Thentro Virorum Literatarum. Gaba.

Extant Hilorix Genuenfurm lib.:2, Genue 1585 . fol.

Extant clạorum Ligurum Elogia. Rom.1574: $4^{\circ}$. .

\section{GULIEIMUS X YLANDER}

Chr.A.D. DAXY

TT Ir doctiffinus \& clariffimus, natus eft Angufte Vindelicomm Anno Dom; I530. Obiit Heildelberge Anno 1176 . Heildelberge Grecas literas profeflus eft. Plutarchi parallela \& libros Moralium latinitate donavit : Cedreni hiftoriam itidem Latinè convertit, ut \& Strabonis Geographiam, \& Diophanti Arithmetica: Stephanum de urbibus recognovit: Polybrum verò in Germanicam linguam tranltulit. Scripfit \& Commentarios in Homerum:Libros variarum ledionum: Notas in Horatium, Esc.

Gulielmus Xylander Anguftanus, utriufque linguæ apprimè peritus, \& omnis antiquitatis ac literature gum paucis hujus xvi compatandus; adhxc Philolophicis 
phicis \& Mathematicis fudis clarus: Dum vixit, cum fumina egefate lichtutus, atque ob id faminon fama fcribcre exillimatus. Muita ille magno revititeraria bono vivus edidit;pluta quę promift, \& quâ erat ertiditione \& ingenia preftare potuit, publico daturus, uif immatura mors eum ( quippe tantum XI. amnos exegerat ) Heidelberge, ubi profitebatur, imemperantia vite accelerata oppref- fiffer. Thuan.ad Ann,ri76.

Futingenii fubtilitatejudicii perfuicacitate, memorix felicitate eximiâ preditus; raro opus ullum folitus ablolverc priùs, quàm tyographis tradcret: tancumque lucubrando femper promovit, quantum ill imprimendo ablolvedent. Melch. Adarsin Vit.X Xland.

Excellenti vitingenio, \& omni doetinà frc excuitrus,ut paucos fibi pares in Lieris Greces, Latinis, Lebrais, Chaldaicis, in Afronomicis, Gcometricis, iby/ficiss

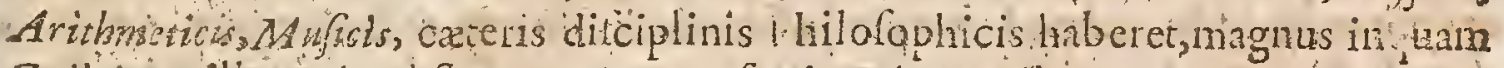
Gulielmus ille Xyland Fo. Leundiav prafat in Dion Aflumo

'Xglander, vir cuditirimus, beneque de Diopbanto, ac hoc nomine de ipsầ numeravidiate, co nmeritus. Vof.de Mathemat.

Sylander egregic utriulque lingue cognitione inftudus, variâque ac multiplice eruditione recfertus. Boiffard. in icon,

Ne jue rò faris pro merito \& virturbus laudari polfit Guliclmus X'ylander, qui quatuor licèt \& quadraginta vix confecerit anos, fummam tamen utriufque

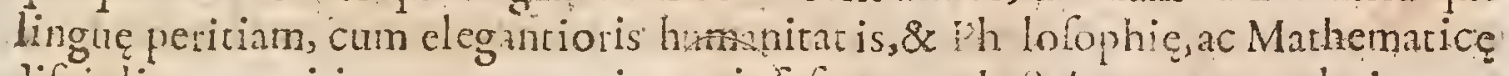
difciplinæ cognitione comparavit, preriolafque ror doct in tum opes huic propemodumuni lnterpretandi ftudio vilus ent confectalle; inde factum, it tam paucis vite fue annis, tot ac tanta Veterus Scriptorum volumina Lains verbis explanayerit: Nam que vix diutuno alii labore, intrepencas ille horas vivido meut is ammine \& lanata alacritate profligavit. Summa puxterea, que to:o vitę decurfu ho ninem mileve corlit, egeftas, foonte fuầ curtenten incitabar: Pracipiti autem fettinatione, id quod properantibus ferè contingit, aliquando laplus elt. Inet.de Clar. Ine rpece.

Catam X jindri hallucinationum nullam invenio praterproperantiam, Cui enimen familiariter noverunt, aiunt mercede àmercatoribus invitatum feripo fiffe, ut familiam áleret. Nam quemadmodum qui ejus eruditionem compertan habuerunt, per inlcirciam eim pẹccâffe nunquam concedent, ita qui teinuitatcm fortunarum ejus non ignorabunt, facilè illa $\pi$ apoéfuow exculabunt, atque coirdonabunt, quia ncminem latet eum fummam vigiliartum fuarum in celcritate poluille: que, fi intra modum fit, diligentia eft; fi fines migcet, elt precipitatio. Iof.Scâtig. Epilt. 247. ad Cland.Solmâs.

$\mathrm{X}$ ylander Anguftanus doctus erat, \& benè legebat : fed quoties érat cbritus: Scaligerana 2.

* Hic Author inter Hæreticos'locum' habet in Indice Tridentino.

Opera cjus cum expurgationibus permirtuntur in Indic. Madrit. edir. ann $.1667 \%$

A 22232

Varie 
Varia ejus opera variis in lacis atque temporibus funt impreffa.

De Gul.Xylandro.hoc diftichon campofuit 7acob. Boiffard.

\author{
Grecia Xylandia deberet plurimas ni jam \\ plutsirchus Latiam ferret ô ip $\int_{e}$ togam.
}

\title{
JACOBUS AMIOTUS
}

Clar.An.n. M D.I.X.

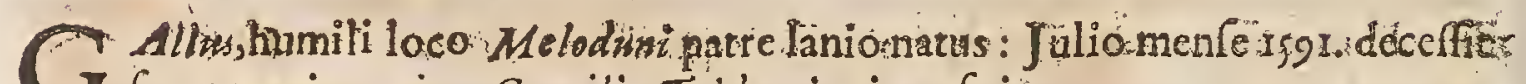
I fexagenario major, Concilio Tridentino interfuit.

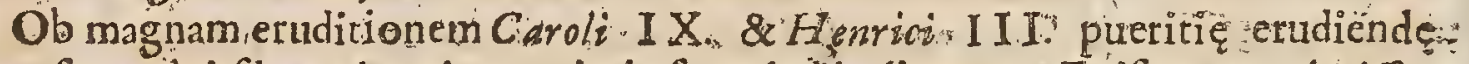
appofitus, ab i. fdem admodum opimis facerdotiis ditatus, ac Epilcopart Antiffro-

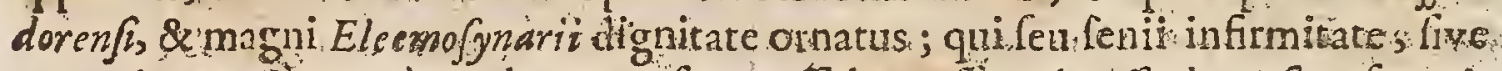

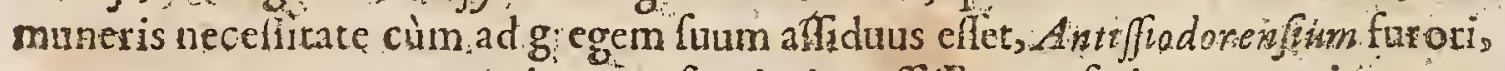
ut tunc tempora erant motigerum fe nimis geffilfe, nec fatis grato animo memoriam tor beneficiorum ab alumnis acceptorum confevvalfe plerifquexifus

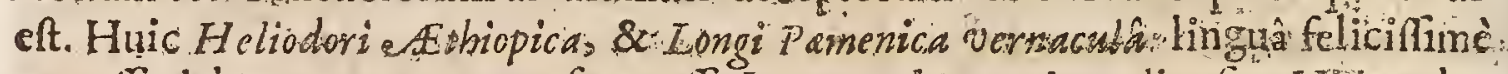
exprelfa debermus, quamquamfupprelfol Interpretis nomine edita. fint. His pratudiis periculum ingenii fecit, quod in majorum vigiliartum operibus poftè̀ exercuit, Diodoro, ac præcipuè Plutarcho, licet majore plecunque el cgantî̀ quàm fides. Gallicè redditis.Thiuan.ad Ann.15grs.

Egor verò de Ainiato zam honorificè fentio, ntomnibus quos hatènùs vides: rim, hiterpretibus, cujufcuaque fint.dingü, antefere non verear, \&unicuique pro normâ rectè lnterpretandiz proponere. Videtur enim expreffitte, quod $C$ ice

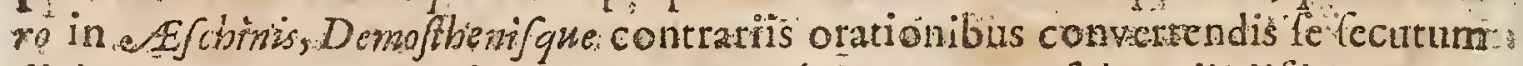
dicit: Quas non convertic ut, Izterpretes, led ut Orator fententiis ij dem, \& rum figuris: verbis ad Ramanum confuetudinem aptis, in quibus nour verbum verbo re didit; fed genus omnium verborum; vimquefervavié, nec ea annumetare Lcetpri voluit, led tanqquam appendere. In quo mihi fummo jndicio Amiotus ufus videtur, quòd ficiptorem diffcilem; 25 oblcorum, ad verbuns ( quod plerique nimiùm fidi interpretes faciurt) non reddidit; fed ezurs Sentfum fidelirer expreffit, Quam-licentiam non modeffam dicass, fed penè necelfa-

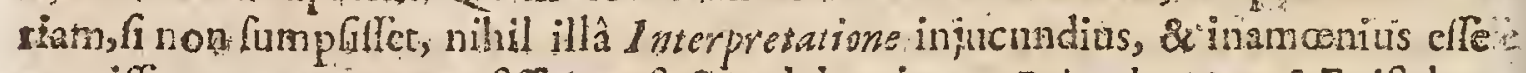
potuiffe, qux concra teviffima eft, \& pulcherrima.. Roland, Marefo. Epift.1.I. Epit:24.

Superiorum omnium diligentiam, meo indicio, vicir facobis Amiotus, Altijfo-; dorenfum Antiftes, liberali difciplinâ crudikus, ingegnio acutus, at oratione ita fubiilis \& timatus, in in co primum Gallica facundia vires fuas experta friffe vi

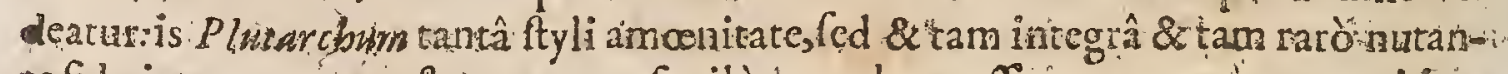
refide interpretatus eft, ut corum facilè querelas:poffit contemnère, qui inm- menfam errorum yim bonx frugi fuccrevife crininantuso. Huet de Clar. Irio. tarpret:

Domb:- 
Dominus Gadenu agnolcie ftylum ejus vetuftakum teverâ faperc : Addit tamer eum nihilo minus concinnum effe, pluribulque locis omni èxoptanda purirate gaudẻre:- Ferum quidem efle Lingux Graca Magiftros plures apud eum

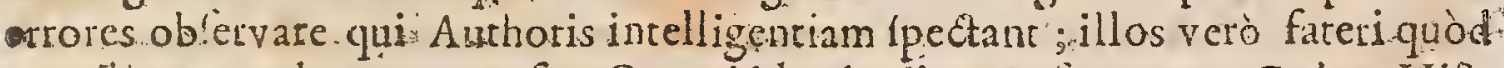
amnibus æqua lance perpenfis, Opus id laude dignum lit, Ant. Godean. Hilt. Eccleffiub tinem 2:feculi. Gal.

Quod attinet ad ejus Vèrfionem Operum Plutarchi, licet hö fir optsis excellsns, eique immortem famam paraverit, Dominus de Meziriac in politioribus literis eruditifimus, prefertim vero in Lingua Graca, frbilumebat dénon ftrandum; cam ad bis mille errores eraffinmos continere; Quamin rem Domimus Pe enffon praclaran fine fuam animadverfionem nobis tradidit, quòd quamvis juftifitna forer Critice Domiai de extezirinc, hoc exemplum à labore non tandererrere débeat quam ad eum excitare animos illonum qui Authoribus Intexpretandis incumbunt:- Nam, inquit, fi abenn partedeplorandum fie adeo prattantem Virum ac fuit A Aniotus, port tantum temporis tantumque laboris:ab ipfo infumptam in hocopere, ut cuivis notume en, anon potuife in bis mille docis non peccare; ab altera tamen parte; magno folamini elfe debet quòd duoilla errorum millia, quoniam mukd pluribus locis res.ilt feliciter fuccefferit, obftare non poturint quinammortale docus sibi acquifiverit. $H$ if Erancicie Acad Galo.

Amioti Tranfario ab omnibus nunc deferi videtur, non tantùn ob vocés obfoletassqua ibi occurunt; fed etian propter ejus Periodos, qua tam prolix funt tamque obfcurr, ut per nova membra iterum incipiant quando videntur ad finemperductix \& fape complectantur duas trefve diver fas res, que feorfinz

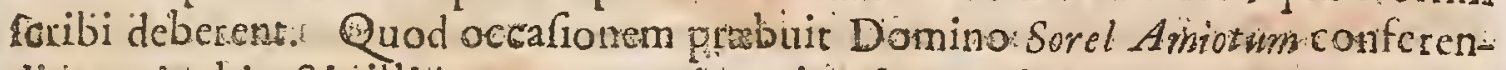
di cunt Atchitectis ill is parum expertis, qui port extruckan Domum in quà deeft? cubiculumaliquod vel conclave, eadëm fuperadificart; nutla fervàta fymmetria. Ephemerides Gallicxe Eruditorutro diei 15 . Aprilis 16,2 .

Laurgatius Boublel Celebris $1^{2}$ arlamenti Caufidicus Domino Patzin patri affeveraverât quèd Amiotus Plutaxcbi. Vitas tranftulerit juxta veterem I Ealiciams.

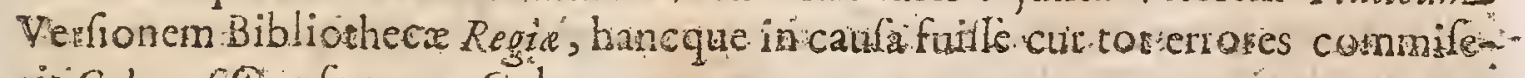
rixiColomef:Opulc.p.124.Gal:

Yaria ejus Opera varis in locis atque tempotiburs lunt impted $f_{f_{s}}$,

\section{A.TONIUS AUGU STINUSS}

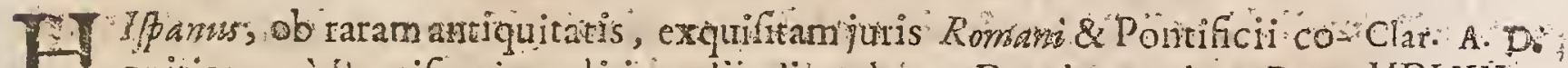

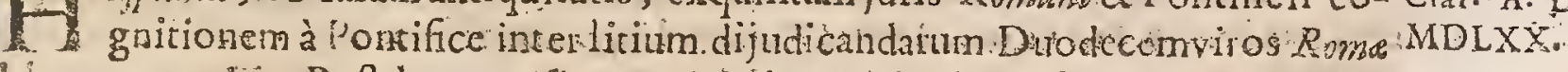

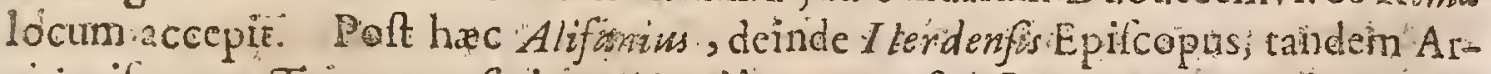
chic pifcopus Tarraconenfss in Hijpaniâ creatus eft. In apparata editionis tama Gracorsan, quàm Latinorum Conciliorum, annos LXX. menfes II. totidem

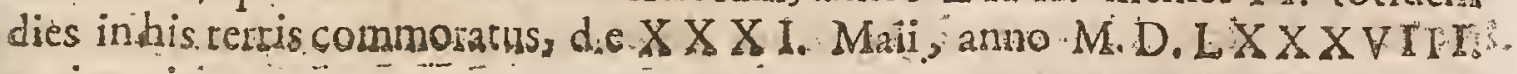
emiggavit:

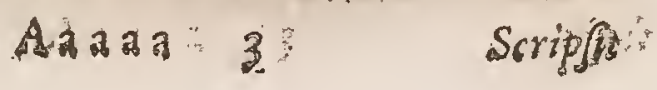


Scripfit varia, primum vero locum habent in Tarronem de Lingu? Iarim Emendat onum Notx: in Sext.Pornp. Eeftum Notx : Fanilix Romanortim XXX. Dialogi XI. Numímarum Griacorwin, Romanonum \& Hipanoritn Antiquitatum, item \& Scriptionum Veterum Hipano Sermone fcripit: Enenarionum \& Opin onum luris Civilis lib. f.ad Morefinm : Antiquz Collentiones Decretalium, cum Notis eruditis: Epitome Juris Ponrifici vereris, pas i.Concilia Graca \& Latina.

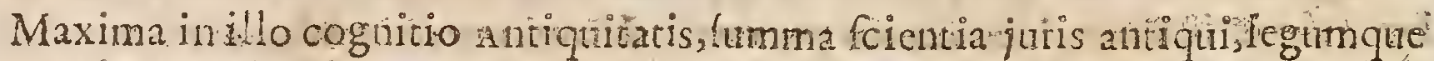
Romanarum, \& familiam : multe in co, ut Romenatus videretur, litere, \& elegantia Sernonis Latini. Ciceronem etiam fenex Iegebat afiduè tut eloquentia principem I uris xero tanta in co accuratio, ut *terum aliquis; preftantiono-

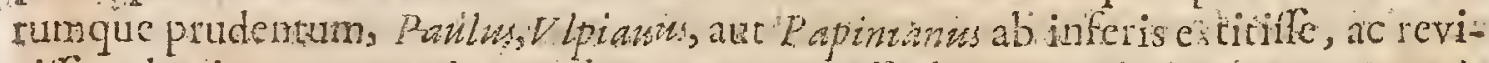
xilfe, vel animam ex $P$ y hagora lententia reccpille illonm videtur. Quanta porrò Hitoriam, antiquarumqua rem Gracia \& I talia explicata cognitio! Jus Pon-? rifín \& Civile ita lutrawithoc adolefens, fenex illud, ut Peincipen illum Juriconfutonm, notrifquc avi forem delibatum, uno ore gentes omnes praelicent. And Schott.in orat. Funebrofnt. Auguff.

Huic gravi malo renedium, quod poruit, adhibuit, doctiff us $\&$ optimus

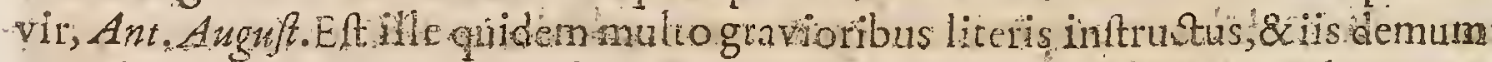
omnibus, que convcniunt perfonę Epicopi, quam fuft net: fed tamen has quoz guehumano es literas enixè adjuvit, ut notum omibus ftudiofis jplám. Retr. Victor.1.38. Var. Leet.c.9.

Antonius A A unfinus : Mignum Hifpanielumen; qui politioris lirerature

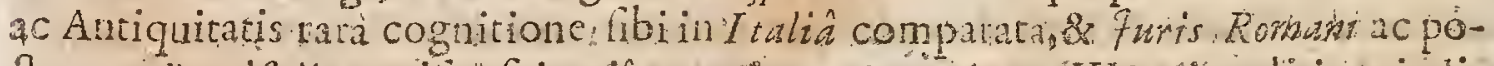
ftemo lentificiz exquilic fcientia meruit, ut Roma inter XI. viros litium judi-

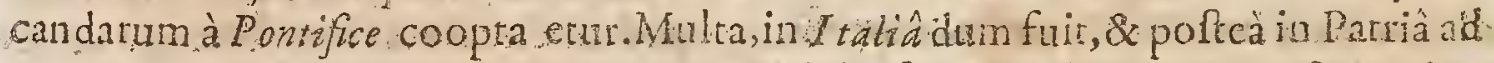

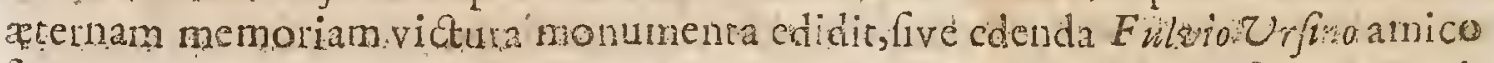
fuo \& in codem litcram senere, I wripprudentän excipio, veranti commiSit.T buan ad anno. 586 .

Vir Juris o omin Antiquitatis peritifimus. Conring.de O.J.G.c. 4 :

Vir illuftrifimus \& excellentifimus in omni generclaudis. BaluzinPefat。 adRegin.de Difcipl. Ecclef ;ect.3.

Benè eft, quodfummus vir Antonius Angufinus iplus Fefti Fragnentum ex Bibliothech $F_{\text {arnefan }}$ juris publici feccrit cum crudiris notis. Tojf. de Philo$\log _{\text {p.p. }} 35$.

Antorius Anguftinus, vir, \& eruditifimus, \& optimè de literis el gantioribus meritus $V$ ar ronis verò vindex, afferror, patronulque unicus habendus, inò verè ejus porius Afculatius. Adrian. Turnebdiz.3adverf.c. 17.

Accepi tum Varronem, quid quzeris ? the ghatis eft. Quod foperameandem pofuetis in Fefo, plutimum tibi Romana Liter debebunt. Aggredere. Quid enim tibinon, fuccedet quil, (ut omirtam illa qua pleno jam Theatro fpectnta lints ingenium, ju dicium, do orinam ) guantús quaneus cs, to us labor, tous indutria es! Paut. Manut.in Epin. 
Néque hoc dictus elim, tanquam ignorem, quantus vil fit Augustinus, quem ane etudirifmum ex fuis fcriptis expertus fum: fed ut fciant ifti, longè felicius enm potuilfe tractar e hoc negotium, 5 voluillet.lof. Scalig in Priafat.quam fuis in Darronern Libris præmifits

Ant.Augufinus, Hijpanns, tam cognitus eft \& inter homines doctos celebratus, ut non opus fic ejus fummam doctrinam commemorare, quam quidem ejus doctifrmi libu in Ins Givile \& Pontificinn editi, atis teftari mihi videntur. Gul.Rovill.in. Prompruar.Leon. Lllult.Vir.

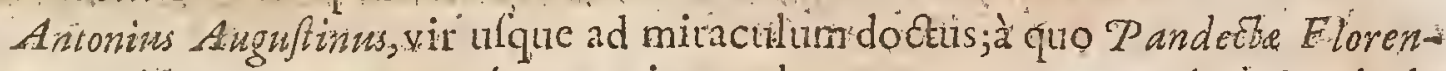
tine, Gratianm; \& utumque jus precipuam lucem acceperunt. Arth.Duck. de Aurhoric.Jür.Civ.1.2.c.6. .eet.31.

Qumm vix attigiflet vicefimum xtatis qunintum, 7 uris emendationes edidit:qui libellus, fr molem lpecte , in foecicm exiguus; (in rerum utilitatem, ponderumque momenra attimes, rnuaris aliorum yoltuminibus anteponendus. Andr. Schott.in: Orat:Funclo:

De numifmatum inferiptionumque antiquartum explantione librun ab" Antonzo Aigufino viro amplifimo \& undecunque doctilfimo, undecim dia

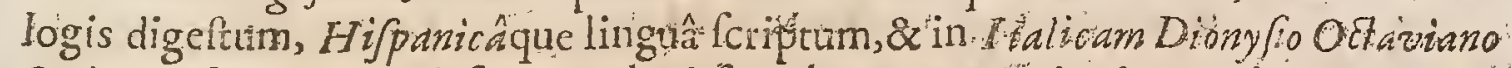

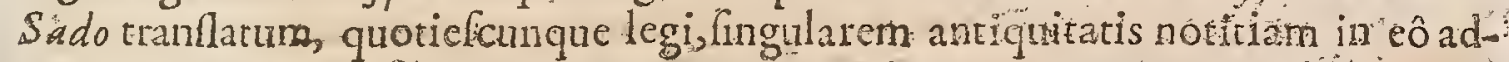
mirari fatis non polfum. Quidan tamen infurt nevi adco pecpufili, ut vel

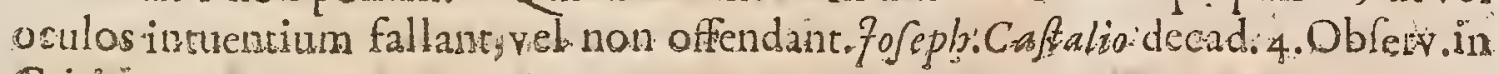
Critic.C.T.:

Tridentino Concilio interfuit, ubi totis viribus incubuit Ecclefiaficortin Reformarioni, oftendendo quòd omnia Ecclefię mala corum effreni dilfolutæ-

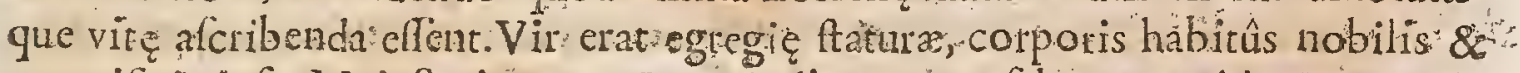
magnifici ${ }_{2}$ ejufq; Majeftatis quam I mperio dignam cenfebat Euripides In co cernebarur graviras lenitate temperata que ipfum omnibus: venerabiten \& ama bilem reddebant. Nemounquam toto viræ fux regimine majorem integritarem, conftantiam animique generofratem oftendre cum exemplari caltitate atque temperantia vivebat, tamaque liberalitate bona fua pauperibus dintibuebat, ut poft obitum cjurs in ejtriarcis pecunia non fuerint reperra que fifficerent ad ejus fepulturam congruenter ejufdem conditioni. Tam fublimis crat ingeniitam folidi judicii, tam dotus tamque laboriofus erat, at cotan fuccelfir qualibet opera potet aggredi: In obfurifran antiquitatis notitia verfatifr. mus erat, tantumque Dodtine thefaurum congellerat ut omnium in toto orbe ditillimus, ejufmodi falcem opibins, elfet. Excellis, inquicbat ipf Paulus $M$ anm tius in politiori litcratura, ita ut ficomparatè ad alios aliquid fom, comparate ad te nibil firn. Ant. Teifler "Elog. Vir. Erud.Gal.

Fertur Biblionecam omni librorum, \& antiquitatum genere inftructăm $P$ b:lippo Hifpaniarum Regi eam affectanti teftamento reliquife. Vir liberalis, humanus, $m$ tifque fuit", quem nerro domefticorum $\mathrm{X}^{-} \mathrm{X}$. retroannis iratum vidito Guid.Panzirol.de Clar.Reg. Interpret.

Extant ejus Dialogorum de cmendatione Gratiani lib.2. Tarraconia i $586.4^{\circ}$. 
Iidem ex emendatione \& Cum Annotationibus Steprsmi Bxiluzi, $P$ arivificis 16.72 .

Extant in Antiquas Decretalum colled ones Nota \& Emendationes. Parifirs apud Steph.Cramoifiz: 609 .

Extant Dialogi X I. de Numifmatibus prifcis Grecis, Romanis \& Hifparicis deque antiquitatibus qua in is occurrune, Hifpanice. Tarracona per Pbil. $M$ ey. .1587 .4 .

Iidem Italicè redditi perDiony) Ium OClavianum Sadam cum AuEtario.Rome fol.1592. apud Gul. Facciottum.

Iidem Latinè per Andrearn Schotturn, quỉ unum adjecit de prîfcâ religione \& de diis Gentilium: in quâ editione icones Numifmatum ì acobus Bizus æri incidit. Antorpia 1617 . fol. apud Henricurn eAntfam.

Extat Bibliotheca Latina, Graca, mixtojMSS. Tarracana in $4^{\circ} .0$ amo 1986.

Hoc ejus Epitaph:um::

D. O. M.

SS. Euchariltix $S_{\text {. }}$

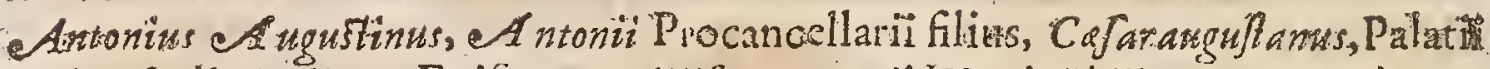
Apoftoli. Auditor, Epifcopus Allifanms, auli IV. ad Philippum \& Ferdzmandum Reges Legatus, Sicilic Cenfor, Ilerdenfs Epifopus, max mo plaudu Tridentino Concilio interfuit, inde ad Tarraconen fera Alchiepifcopatum trannatus Juris \& Humanitatis vindex clarifimus, elemofynaram largitor excellens, Oraculum Sapientixe terrette, ediris atrcis libris atque edendis relictis, hoc Sacellum Sancta Euchariß1x P. C. Chriftuxn ac Sanctam Iectam tutelaremexalfe heredes fasiuts. Obiit pridic Kal. Junii 1 s6.xtaris 69.

Petrus foannes Nunnefus: Valentinus Orator \& Philolophus hoc illi amicitix ergû Epitaphium compofuit.

\section{OANNES BODINUS} Clar. An D. AT Atrone Gallus, patriâ Andegavenfis, Jurifonfultus \& Politicus, anno alienus.

Foannes Bodivas in Andibus natus, \& puer, nt quidam certò affumarunt, in Carmelitarum Conobio vitam relyiofn profeflus, dein voto immaturâtate facto folitus, gnaviter literis operam dedit; lingunmmene non vulgari peritiâ fibi comparat, onniugn artum circularem anbitum animo ingenti comple-

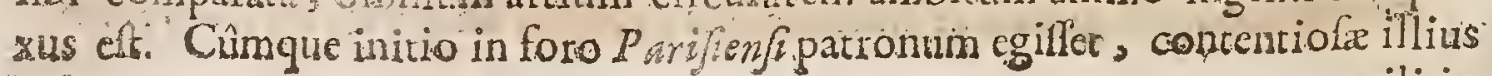
militiz 
militixpertafus, Seriptioni fe totum addixit, periculóque in Oppiani Cynegeticis ingen i facto; qua \& eleganter Latinè ac fcitè vertit, \& doctiflimo Commenvario interpretatus eft. Mox animum ad majora appulit, \& poft cKethodum.

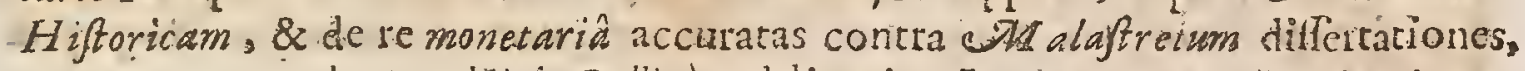
opus magnum de Republica Gallicé publicavit. In quo ut omni Scientiaum genere non theti fed imbuti ingenii fidem fecit, fic nonnul is, chi recte judicant, non omnino ab oftentationis innato Gentis vitio vacuum te probavit. Polteà \& Demonomaniam Gallice itidem fcripfre; in quà dum materiam ab aliis tantopere agitatam adverfus Ioannis Wieri plerumque fententiam enuclcatius -retractat, mayica rei ac vetitarum iftulmudi artium crimen minimè effigit-Demum A. 596 6.ineunte Maio feptuagenario major peftifer lue correptus, publicato prius Nature Theatro, quo rerum caulas \& affectiones ad pincipia faa - repetitas exequitur, quaf́ ( ygneâ cantione, vitam variis ftudiis fic \& fortunà agitatam Laoduni claufit. Thwan.ad an. 596.

Ioanis Bodini Andegaven ses felicillmum ingenium fuit. Qui cùm ab adolefcentiâ bonis omnibus literis egregiè imbutu, eflet, imprimifque Gentium onnium hiftoriam abolutifinè calleret, ilius l gendx methodum libei"o brevi quidem illa, fed fane luculentifno complexus eft. Fuit hoc illi fama furgentis aufpicium, quan editis de Republicâ fex libris varia muliplicique ecudicione \& Atupenda Exemplorum variecate referis abundè pofteà confrimavit aryue auxit. Neque verò quam Scriptis comparaverat exiftimationem prxentia fua minuebat, fi quando in familiari hominum congrediu de quacunque re propofitâ difertè copioléque difputarer. Scavol Samarthan.in Elog.

Affectui plus jufto eum indulfite, viri docti pridem obfervarunt. In gratiam popularium fapè fal fa alferere non dubitavit qualia funt, Imperatorem Romanum Turce tributarium elfe: Germaniam effe Gallix provinciam: Pincipes, Germanis Regni Gallici ligios efle valallos: taraens fecum, licitum fibi, fuorum popularium dignitatem honefto mendacio tueri. Konig. in Biblioth.

Bodinus homo temeratiu, \& infolens, falso adrnodum pro more fuo \& manifetta mendacia fcribens, propriaque libi convitia perperam in omnes effundens. Cujac.Obferv.l.13.c 38 .

Audirionibus \& incertis rumoribus nimium lerviens. Gu. Camden. in Hibern:fuâ.

Cumprimis legendus eft Bodinus in Methodo Hiftoriarum, qui doctè differit de Republ. Venetâ; quanquam Nicolaus Crafus quæratur quòd Bodinus fit iniquior. Herman.Conring. de Rep. Venetâ.

Pafim in Germanos tota mendaciorum p'auftra evomit. Quôd fe \& fua nimitum pradicare, alios veru infolenter conculcare, prater merirum foleat ac rei veritatem. Fo.Quenfted.

-1. Ingénium hominis ( fo.Bodin ) arridebat, placebat multa illa lectio, fed quoties attingebat res Germanicas, videbam hominem exarre turpiter, \& judicium paffim defiderabam---Erat mos Bodnni, quxcunque de exteris à circumforanco quolibet audiret, ea ab que aliâ curânotate \& publicare. Jim edidille illum le$\mathrm{Bbbbb}$

Ctiones 
diones Turnebi in Oppiamum pro fuis, nemonoftrorum ignorat: fed in libris de Rep.monitus, pleraque mutavit in melius. Ego primam tantim edicionem logi fccundam infpexi leviter, fit non inutilis ejus opera, ea certè non eft, ad quam deduci debeat adolefcens tanquam ad fontem aut purum rivulum, fac. Bongar/.in : Epirt.ad Conrad.Rittersbuf. Francofurt.4.April. 4600.

Bodinum exiftimavi femper, hominem rerum quàm verborum ftudiofiorem, Latinitare utentem haud planè niridà, metricarum Legụm pueriliter imperitum, Gracis literis vix imbutum, Hebraicorum morum ac lenrentiarum fatis gnanum non ex interiorc lingur illius cognitione, fed ex amicitiâ quam coluit cum do-

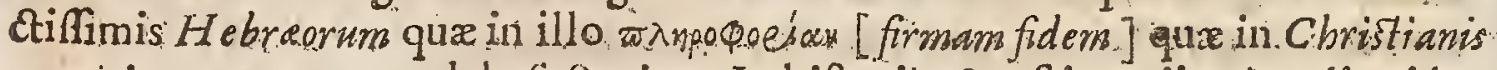
requiritur, non parum labcfactavit. In hiforiis \& reftimoniis citandis video eum à yerò fapè abire, neglectu malo credere, quàm dolo: quanquamisterdum : vix eft at doli fufpicionem effugiat.Grot. Epirt. ad föan. Corde efian, 19 Sepremb. 1634.

In Politicis nullus jaculum extra metam expedivit, excepto Io.Bodino, cui uni tantum cateri concedunt, quicunque unquam de Rep.Libros edidere,

\section{Quantum lenta falix pallenti ceditolixie.}

Nec immerirò fanè, cưm animum inquietum ac vaftillimum quemexceperat à naturâ, tam perrinaci ftudio, tam inexhaultâ doetrinâ, tam admiräbili judicio excultum, ad rerum omnium comprehenfionem attulerit, ut fuperatis linguram penè omnium ac fcientiarum difficultatibus, non modò Baturæ: Theatrum novis rationibus extruxerit, fed Regnorum quotquotin Mundocontitita fuere, fpecies, leges, inftiruta, arcanadenique \& virtures ac viria in ordinem fapienrifimè reduxerit, ac velut Phonix unicus fui feculi, feiplam tandem confumplerit in contemplatione altioris illiws fapientix, cujus fecreta revereti potius ac admirari debuillet, quàm ipfa in medium \& examen, velut reliqua, omnia vocare. Sanẹ quantum ad ejus Remp. fpectat, farendum elt opus elle elaboratumingenio, expolitum induftriầ, perfecum judicio, \& ità numeris omnibus abfolutum, ut qui ab ipfo difcelferit , haud diffmilis videri pofft nautis, illisantiquioribus, qui negleç vel ignoratâ Cynofure præltantiâ, navigationis fuæ curfum ad avicularum quarundam placitum dirigebant, frepiufque per caures \& faxa pracipiaes ferebantur. Gabri.Naudin Bibliogtaph.Polit:-

Joannes Bodinus Andegaven is $G$ allus, Jurifonfultus \& Politicis, quem fupra Aftra evehit $N$ audeus, nimio amore erga civem occecatus; celebris pra primis eft fex de Republica libris, in quibus varios locos civilés, yeluri eum, qui de Republica optimâ tractat te deinde ordinem \& demonftrationes, modeltiam etiam -rga A riftotelem aliofve defideramus. Sxpè nimis ad alia digreditur Bödinus, \& nimis operofus eft in Hiftoriis recenendis quę in fcientiâ politicấuno vệl alteroverbo erant tangendę, ati preclarè ab Ariftotele obfervatum . Plurima proterea, quę funt privari \& publici juris,admifcet; qu bus demptis omnibus, parum reManebit argumenti policici. Denigienon tam aliarum reum publicarum, quam 


\section{CELEBRIORUM AUTHORUM.}

Gallicanx peritiam habuit; hinc plurima ad farum Gallie pertinentia libris dc Rep.docemur. G.Th.Mejer.in prafat.ad Analyl.Polit.Arifot.n. 48:

Bodini Resp. magis ardua \& crudita. Non carct-carproribus. Mihi quog e nimis fe diffundere videtur. Sed facilè eft in operofo libro quod reprehendis-invenire. Christ.Colex.in Epilt.de Studio Polit.

Bodinus patrem 7 hil.Scaligerum falsò ignorantiz Mathefeos alguit, ipfe indoctifrmus valdéque jejunas, cum quicquid à mulris annis doctrinx coṇecutus elt, trancriplecitex aliorum laboribus, imo \& ex meo libello in Varronem de lingua Latinê, cujus paginas integras fuas fecit fur impudentifimus; $\&$ in unum velut chaos congenti, plurima leribens quęiphenon intelligit. Denique librum de Metbodo legende 1 ifforie inferipfit, in quo nihil minus quàm ea de re tractat, ut titulo fuo nullo mod's relpondear Oratio; quod quidem Verrius Flaccus notavic in Originibus Catonis, quẹ nihil minus inquirunt quàm $I$ talia Origines. Porto fi quis velit in illum fribere, fribenda ipf tradam neque enim mihihonoris loce ducam aliquid proferre quod mco no nine circumferatur. Scalig. I.

Ioamnes Bodinns. bonus Autor elt xtatis noftra, multòque folidiori judicio inftruetus quàmturba Scribillatorum Ceculi huij, dignufque qui ab aquis rerum judicibus exiftirctur. inontagne fuomm Tentaminum.lib. .c.32. Gall.

Criacin \& Pofjevinus aperrum illi bellum indixerunt: $C$ ujacius cnim vocat illum teinerarium, infolentem, mend $x e \mathrm{n}$; $10 \mathrm{c} q u \mathrm{c}$ angrammate nomen ejus defufit, fo. Bodinus, Andius fone Borro. Roffevinus veio, Opera cjus ingenti errorum, therefcon \&impietatumnumero referta efle contendit, nt cenere efti : celebris illius Jéfuitu Bibliotheca, e ulque libro cui citulus I udicium de quatuor Scriptoribus \&c. Boccalinus foripfit Bodinim igne damnatum fuilfe ab Apolline, co quod libris fuis alfeverare fit aufus, Principes libertatern Confcientia fubditis fuis concedere teneri. Mornacus libro fuo qui inlcribitur Feria Forenfes, quatuor thæe carmina in ejus laudem cecinit.

\section{Iani Bodini Gallicam Rempublicam \\ Qui viderit, majus nibil fatebiur, \\ In eruditâluce prifci feculi. \\ Gallus bicsolim quod Quirut Tullius.}

Quamvis tamen Bodinus eruditionis reconditz ac non vulgaris facundie vir fuerit, à Sammaribano \& Loif fuit oblervatum, eum inter Parif.Senatûs Gaufidicos clarefcere nunquam potuife, unde etiam cum $f e$ in hac arte minus felicem deprehenderet; Forum penitus defereme apud fe decreverit, Dicifque Andegavenfos minilterio fe feaddicere. Ant. Teiffer.Elog.Vir. Erud. Gall.

Illud velim ex te Ccire, quare Pontificii tam accrbè quotidie in Bodinum declament. Gertè quid mancipium ambitionis fuerit,ptopterea odio illis elle eum non crediderim. Aliam fubelle caulam necefle eft;quam ex te fcire velim. Hujus igitur tam inopinati odii caufam, \& quare hominem pridem mortuum canes ex sumulo eruant, neque cjus manes quiefcere finant,à vobis expecto. 7of:Scalig. Car.Labbro Lugd.Bat.4.Kal.Mart.1607. 


\title{
74
}

\section{E N S. U R A}

* Loanin Bodini Andegavenfes Demonomania, cjuldem de Republicâ, \& M Tethodus ad Facilem Hifforiarum cognitionem;jtem univerf $2 N$ atura Theatrum, änrer libros prohibicos rejiciuntur Indice Rome impreflo, 80.anno 168 I

Extat de Republicâ.Lit. F ar.1586. Fol.

Extat OpinionumIo. Wierii confutatio: Froncof. $1603.8 \%$

Extat. Juris Univerf dili ributio. Col. Agr.1580.8.

Exta univerfa Naturx Theatrum Erancofo. 1597.80.

Extat Methodus Hifturica. 1595.8: .

\section{Pauperrimus obiit; ideoque facetiflimum fuit Anagrammat:}

\author{
$7 O A N N E S: B O D E N O S$ \\ $A N D I U S S I N E B O N O$
}

Clas: D: MDIXX:
I NiBatavorum Urbe Trajęctenfi, ad veterem Rbentulveum, familia antiquâ

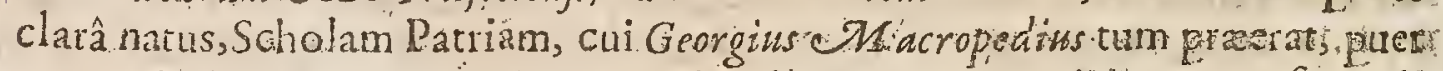
frequentavit Annos 12. natus Cornelio. Valerio, Laina Lownin in Cymmafio Trilinguiprofitenti,in difciplinam darur. Hujus Jater annos amplius quatnot adhatit, \& admadum adolelcens Tragedias Latize confcripfit o. Inde Iuteziam

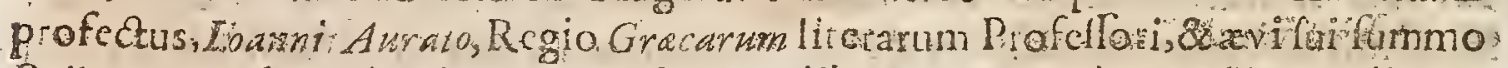

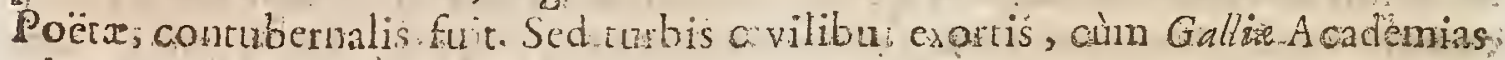
plerafque Juftraller, Italiam ingenion parentem aditi, Bononic Carolo Sigonio

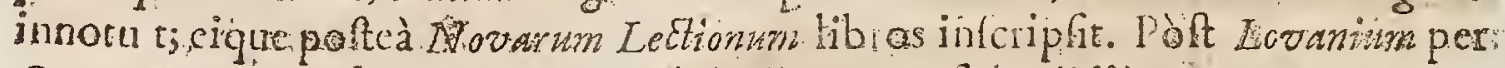
Germanizin reverlus, tam inmodice fudis totum fetradidit, un nortem properaffe credatur. In certas aperas dicn ita gariebarur, ut alia antenveridiem, pomeridianis horis alin ftudia tractarer. Simile de ayunculo fero Plinio foribir \& hactat alter Plinins: atqui ignavum acdefidem illum diveris, ficam toc aflduo arque indefello homine compares. Omnes non folum dies appendit \& numeravit ad ftudionm tractarionem, fed horas etiam fingulas ad cleplydram divift, \& atribuit huic lectioni, aut Huic Criptioni; quad n fipfe preftndo ia Stobia Eclogas à fe Latinè redditas, teltarecur, increvibile forcalle videri queat Argue his quidem coninuis laboribur culmen folidx eruditionis artigit, \&xin Gr eis Lid zinifquead fummam laudem pervenit : ut doctina aram tranferit. Bibliothe cam hubuit inftuctiffmam, collectis ex media Graciân \& Italiz libris calamo exaratis, quos extrudere aliquando decreverat. Seduc optima qreque iir terris diurnare non folent, longâ tabe $157 \%$. extinguitur Lovanit, cum tertium \& trice frmum xatis annum nondum attigifet. : in cujus, immaturo interitu magnum

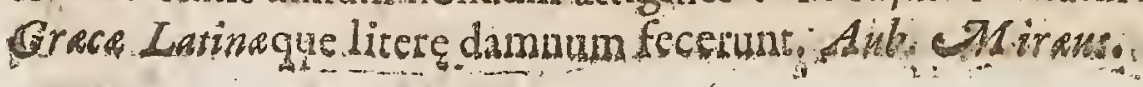

Gulielunus 


\section{CELEBRIORUM A UTHOR LM.}

Gulielmus Canterus primis utrufque lingux rud mentis fub lonn Aura* optimo Juventis Praceptore, Lutetix tactis, induftria propriât tantum profecit ut ediris quamplurimis Scriptis inter eruditifrmos lui fcculi numeraIi meruerit,plura usique praftiturus, nifi eum mars immatura eripuifect Thban. ad ann. L.7.

Scripia ejus funt: Novarum L ectionum libri 8. Syntagma de ratione emen-

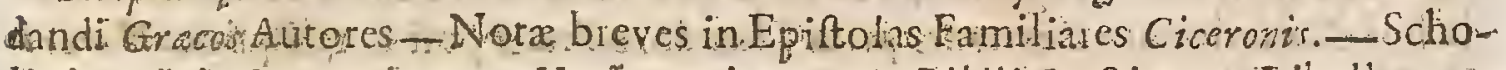

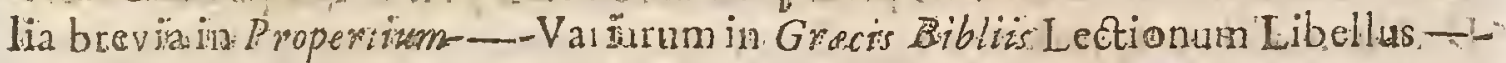
Anfoniz Epitaphia Hecoum qui Bello Trojano interfuerunt emendata:- Emendationes jin Euripidem, Sopboclem, \& e E f chylurm, oftensâ carminum ratione', anteà aut ignoxara pcritus, aut ob curiore, unà cuin leutentils infignioribus Latino verfu reddicis-Emenda iones \& Explicationess in Epiftolas Ciçeronis ad Atti-

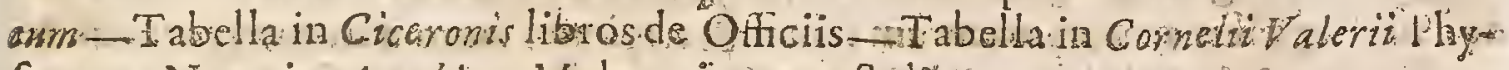
frcam-Noxa in Arnobium. Mutta ctiam tranftulix.

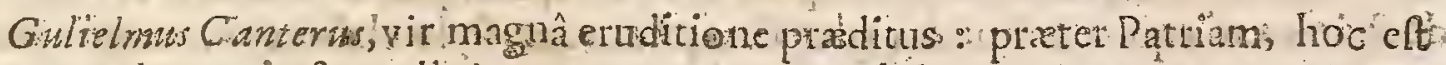
3elgicarm ling Germanicam, Gallican \& Italicam. Melch: Adam!

Studia calidè ille [Gul-Cantarus]; nimis habuit \& intentè Nunquam vidi:

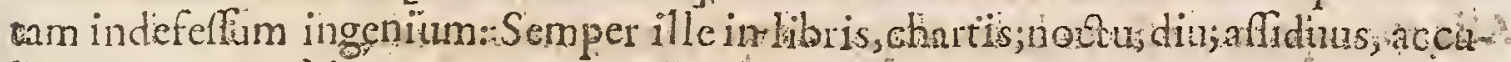
buus: nec des fol um omnes appenf \& humerariad hane curam, fed horz. Quas: fingulas ad clep 'ydran dividere, a attibuere ille folitus huic lectioni, ant huic fcriptioni. Lips.in Crntur.r.Mifgellain.EpiR Epilt.x.

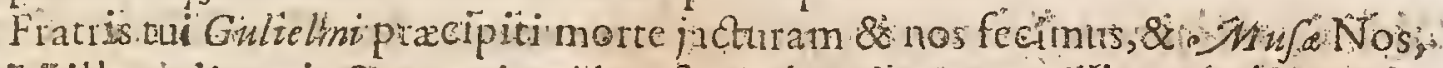

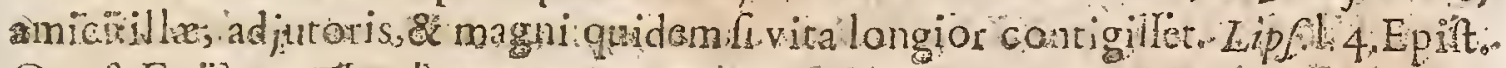

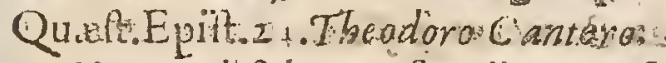

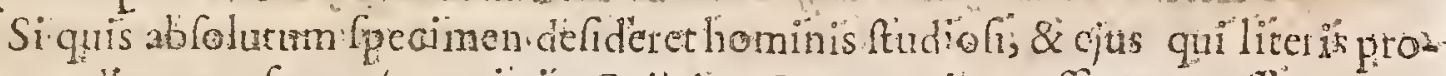
movendis torus fe conlectavit, in Gulielmo Cantero ad amufimexprefim repe-

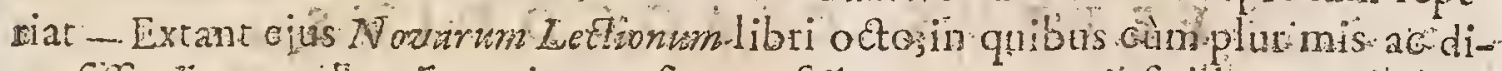
verfilmis anteribus integ tatem funmsefiduat, qualtus ip fel brorum helluo

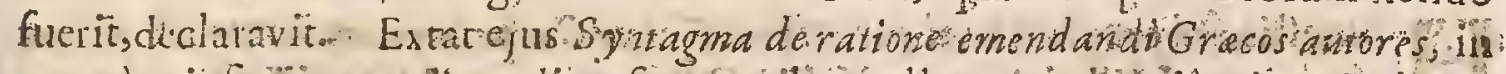

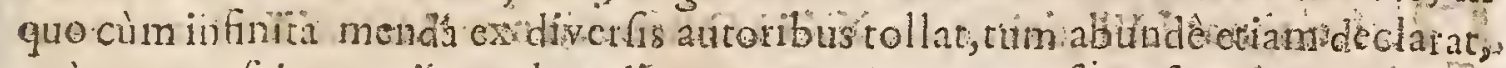
quam non ofcranter in evolvendis antorum Scriptis verfatus fuerit; tem opere fudiofs mulum dificutatis 8 impedimentiadinit. Confinilindur

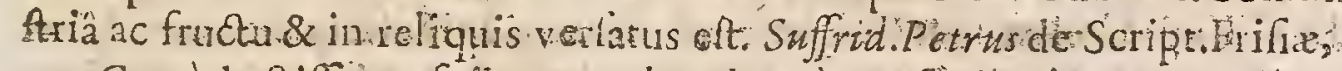

Grec doctifinus fuit, quemadnodum è tranflationibus, quas adonat it, ma-

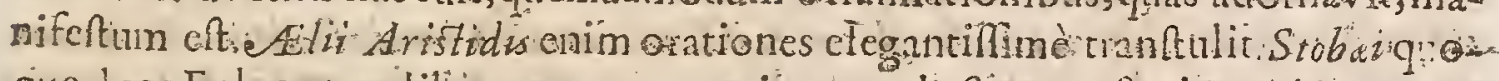

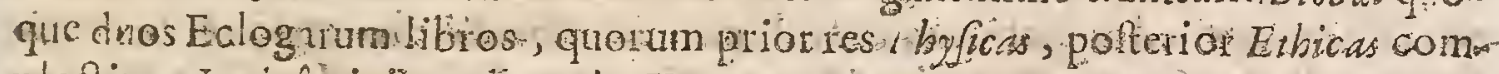
plectitur, Latinâ civitate donałit. Konig.

Hadriano funo felicior ab omnila lade Gul. Canteriss Ariftidem ita vertit, non fruftra fidem fuam in. Brolegomenis venditalfe vifus fit ; non plus frbi fumpfisLicentix, quàm dibat explanata Oratoris copia; Euripidem,ú infoctis fieri amat, de verbo ad verbum extulit; \& nifreycophronis obftitilènt angutix, \& quzfita

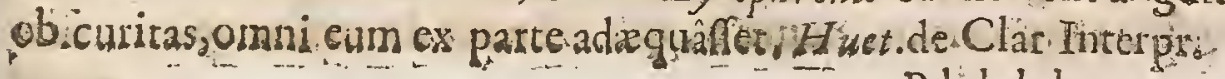

$$
\text { : }
$$

$\mathrm{Bb} b \mathrm{~b}$

3.

Quos 
6. Quoniam ad literas propenforis elletingenii, manumbrevi tempore pro- grelfum in is fecit, prsefertim ve ò in Veterum Authorum intelligentia \& $D_{0-}$ - EtarumLinguarm quas in Belgio didicit, \&poltea excoluit in fuis per Galliam, C. Italiam \& Germaniam pereg inationibus. Imo \& illis Regionibus Enditorum ' amicitiam adeptus eft in quorum cognitionean venit. Imprimisvero magni - fecit Aurati, 11ureti, Sigonii \& Fulvit Orfini familiaritatem. Splendidam ha- bebar Bibliothecam Canteris, quan Theodoro Fratri poo fe reliquite Moreri - Diction.Gallico majori.

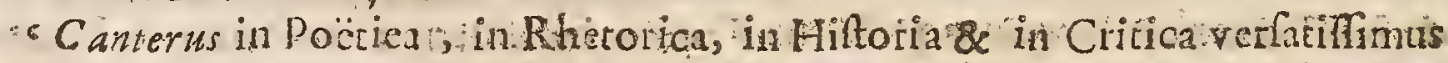
6.erat. Ejus Profa ejufque Carmina Latina nivabili concinnitate acelegantia -fpl ndent. Ant.Teaffer. Elogiis VironElog. Gall.

Quis hoc lcrens Elogium non thupécer, Quomod folicet Guliel. Canterus mondum egrelfins ataiem annorum trium e triginta, tanto ulus fuerit ario ut \& conlcribere \& in publicum exlerepotucit to opera, quas cum fret omnia bonx do etriaz varixque erudition is plena optimoque fylo elaborata, magno lunt emolumento toti Literarorun Républicx Gbilini Theatro Virorum Literatorum. Iralicè.

Odo ejus libri Nov. Lectionum To no tertio Lampadis Crieicx inferi funt. Alia ejus opera varis in locis atque tempo ribus funtimpretra.

\section{Roc ejus Epitaplium:}

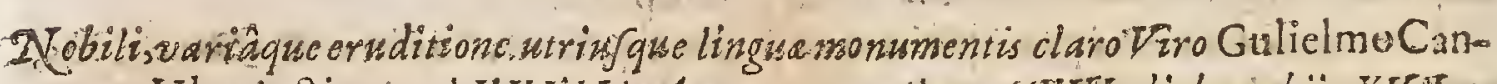
tero Ultrajectino, gui XXXII Annos natus, minus LXVI. diebus obiit XVIT siá, MLD LXXV, Fratri Ju Cariff.Theodorus Canterus pofuit.

\section{PETRUS CIACCONIUS} Clas.A.D. TI Oneftis, fed tenuiolis rei parentibus, Toletz Carpetanorum natus eft. Roma

\section{efflavir.} cùnanos LVI.vixilfet, die XXVI.Octobris,aino MDLXXXI. animam Scripta ejus hac funt:Kalendarii Romami Veteris explanatio - In Sallufium Nota-In Cafaris Commentavia Scholia veriera - in Infcriptionem columwe Roftrat C. Duilii Commentavius-DePonderibus \& Menfuris-DeTria .cinio Romano-Notad Arnobium \& Octarium C T inucii Felicis-In Ioannis Caffani opera Annotationes doctifinz--In Tertultianumiconjectura. Defderantur \&expectantur Notxin Marcum Varronem deltinguà Latinâ;\& Re RuAicâ:In Pomponizarn Melam: In Plinì Majoris Nacuralis Hiltorix libios docta Commentaria.

Ciacconius vir exquilitâ in omil feientiarmgenere, Antiquiratis \&:omnis politioris literature cognitione clarus. Et guem unum video ex omni literatonum, qui ævo noftro innoruerunt numero qui Asmaro Ranconeto noftro com- 


\section{CELEBRIORYM AVTHORVM.}

parari poffit. Thisans Iib:4.

Erat rara ad miraculumufque eruditionis, ut emendànd is antiquis Scriptoribus natum diceres---Side aliorum ingenis Scriptilque, que ipre improbarer, fententiam rogatus elfet, Criticus acer \& vchemens, nemo ut illi, ac ne fibi quidem ille fatistacerety Andr. Schott. in vit, Ciaccon.

Emendavit Petrus Ciacconius, cujus codex apud me eft fummo in pretio, ut debent effe apudiomnes bonos omnia viri illius, cum quo null us freculi noftri mottalis comparandus Lawrent Ramirez. Hypomnemat.ad Martialis lib. Spectaculorum, Epigram.22. fervis.

Petrus Cracconius. Hipanorum eruditifmus Laurent Pignor Commentar. de

Ciacconius inter fummos criticos, nifi fummus dies occupalfet. Lip Comment. in Senec.

Quem veterum invenias libtum, in quodoctrinavel etuditionis aliquid infit, quem non legendum, cxaminandum, caitigandumque fufceperit? --O Omninò

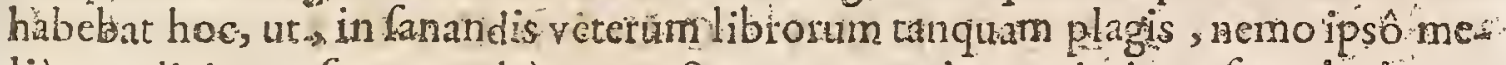
liùs medicinam faceret, adeè, ut anctorum corundèn animi, ue fomniavit $P y-$ thagoras; inmignalfe in iplum, fuanguc eidem, ete iis reburs qua enant in quxtio ne, fententiam quodammodo aperuille viderenturilanus $N$ icinis Erytbrapinacothec.

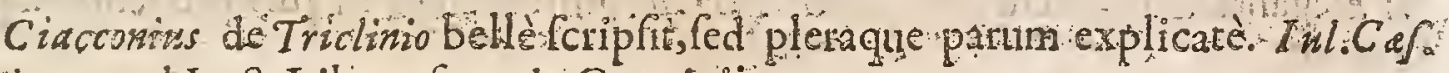
Builenger.ad Lect Libror: Luoride Convivilisi.

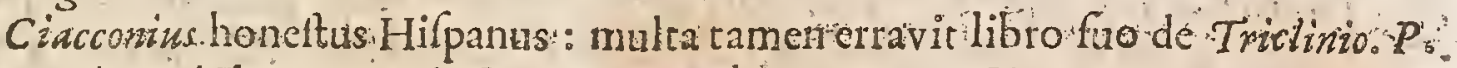
Ciacconius Hispanus erat doetus : erat presbyter Rome. Śćal. $z_{0}$.:

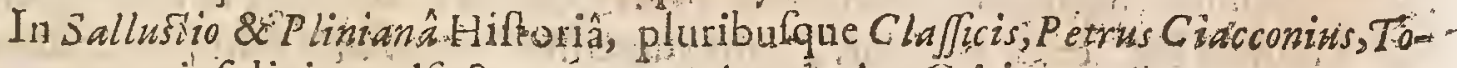
letanus, non infeliciter adfectav erat G.Sciop. de Art.Critic, p. 16:

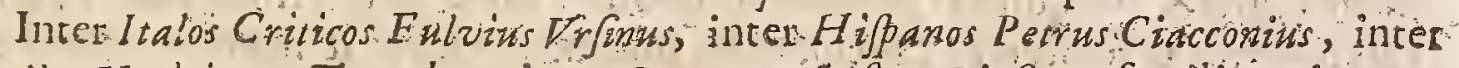

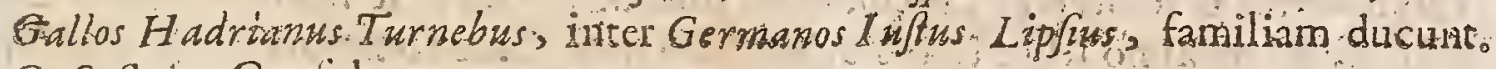

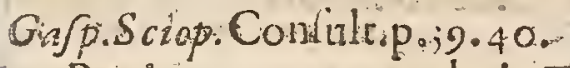

Patriam quoque prebuit Toletum Petro Ciacconio P Pes byt quem lantis Nicius Erytbraus in Pinacotbecat Cua plenum doetrinatum omnium thefaurum, el potius

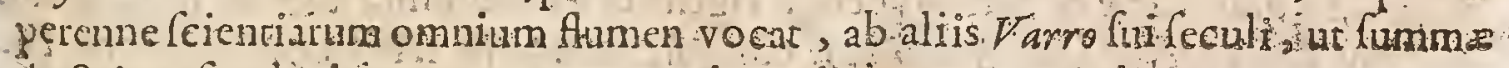
doctrinze, fic glonix contemptor acerrimus dicirur. Quensted:

In Petro Ciacconio Religiofo Feculari, honerandis parentibus orto, medio cris

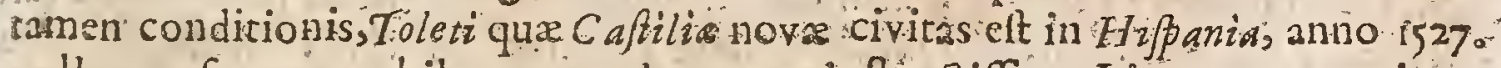
collocatæ furerunt nobiles amnes dotes que inftructifimo Liternto conveniunt, fublimis enim ingen $i$, tenaciffimæque memorie fuit. Linguntum Grece ac Latzne callentiffmus fuit, folitudinem amavit; librorum hellto fuit; dulcifima converfatio ejus in legendo \& componendo pofita erat ; nec ullam ambivit fortus: nam. Gbilini Theatro. Ital.

Liber de Romanorum Triclinio prodit Roma 1588 in 80 Geneva 1590 in $80^{\circ}$ Ariffelodami 1664 in $12^{\circ}$ cum Figuris.

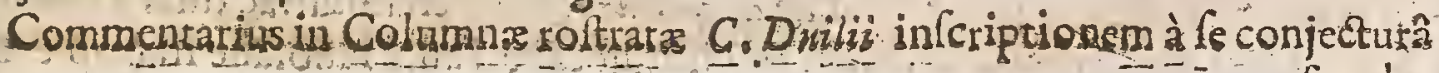
Cuppts- 
fuppletam: Prodiit Lugduni Bat.ex Offic. Plantin. apud Francifc. Raphelengizim 8.2597.

Prodit de ponderibus, menfuris \& nummis Opufculum. Additus eft Cóm de columnâ. Rórnáa ex Typogr.Vaticana 8:0160j. \& antéa ann. 1586.

\section{Hoc ejus Ep taphium in ade S. Iacobo Apostolo facrâ.}

Petro Ciacconio,presbytero Toletano, in guo multiplicis doctrine copia cum vite ac morum integritate certabatsqui à Gregorio XIII.S.S. Patrum libris, facrifque canonibus o Bibliis perpurgandis prapofitus, in co munere abendo eruditione, judicio, fide ac diligentî prufttit. Ecclefa $S$ Jacobi Hilpanonum, güi ur" bexn colunt, hares ab co inflituta, no nurnentum boc pofuit.Vixit annos s6.0biit aisno Ij81.VII.Cal.Novernb.

\section{J ACOBUS CU.JACIUS}

Clar. Aru. U. MDLXX. li elegantià,ad pofteros tranfmifit. Scripjet pluima qux ad Juripprudentiam pertinent.

lacobo Cujacio in Urbe Tettofagtrn genere humili nato pracelfum ac planie colefte ing cnium Natura concefferat, cujus uniss ope, nec ullis preterea- Magiftris adjurus, lupremum illum eruditionis gradnm attigir, quo larè confpicum \& nitentem hâc etate vidimus, dum incredibili narionim omnium concurtu intima juris \& antiquitatis penctralia, quorum aditus pehes illumerant, juventuti aperiret ac relolveret. Docuit enim pluribus in locis, ac prefertim apid $B i-$ "turigas ubi maxino illius $U_{r}$ bis oinamento long. fimè commoratus ef. Scevol. Samarthan.

Iacobus $C$ ujactus, Tholofe natus, raum non folsm Gallie, fed univerf Cbrifiani - Oibis, in quo literæ \& Jüiprudentia vigent, ornamentum, àmmis juris condi-

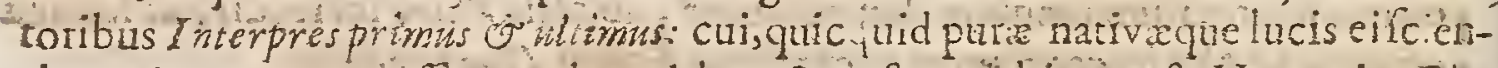
rix undecanyue accefit, ax hac debet, \& polteracbitura ct. Hac enim Elogialli àvic doctifimo \& gratifno T.P itbe meriò rributa funt. Huic rarâ feliate [quod vix alis poltrótem datur] contigit, ur vis videnfquelande,

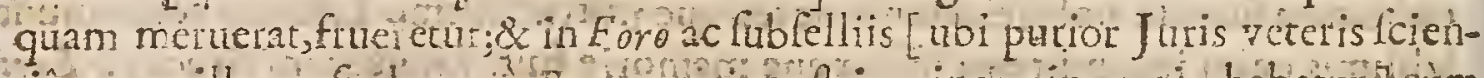

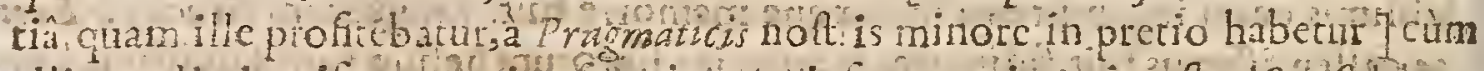

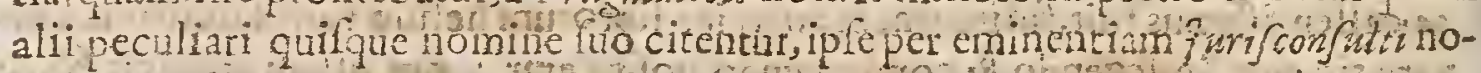
mine appellaretur. Thuan ad ann. 590 .

Tacobus Cujacius Tholg as, quod pofteri fortalis minbuthturefolum in Gro-

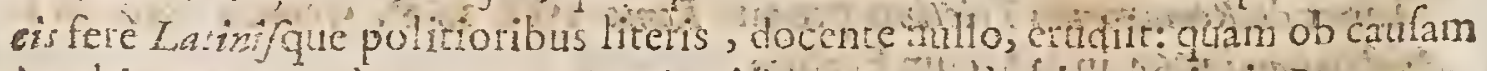

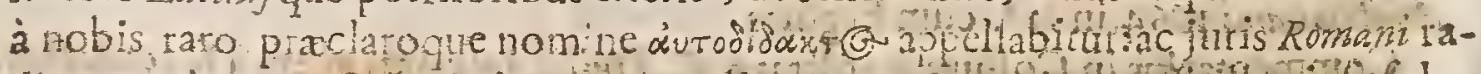

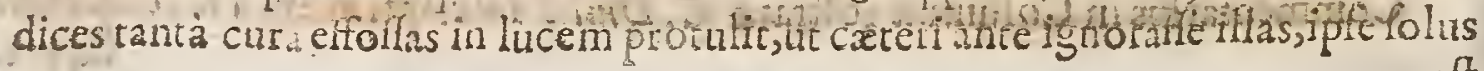


port multos iz quzefiviffe diligentiùs \& penitus inveniffe videatur. Sanè nullus hac ztate, five in Galliâ, five in verminiâ, at lialiâ, aliifve i rovinciis Juris interpres fuit, qui non deberi plurimum Cujacio putaverit, ob exponendi. Juris Komani folertiam-Scripfit, atque edidit quamplurima, quze \& ftylo \& gravitate rerum, Africanum \& P apinianums redolent, mentione in iis factâ amicorum per quos profecerat, quod magna ingcnia laudem ex alienis habitura perindè ac fuis fepec fecerunt - ut vcro Cujacii cætetas virtutes ac laudes, plenâ manu in aftra benevoli Auditores ferebant, ita mirandum in modum fufpicere ac prædicare foliti crant, '\& meritò quiiden, quòd, fcu difficiles, feu non ufque adcò obfcuras leges expofiturus elfet, continuas fe vel feptem aut otto horas fingulis dectionibus meditandis dirigendifque impendubat, antequam auditorii fuggeAtum confcenderet, ac fi quâde re vel tantillum non faris fibi liqueret, ullè ò comperendinabat, idà fe fíbi, furque exintimationi tribui predicans. Papir. $M$ aljoon.in vita cjus.

Cwjacius Imif:onfultorum Phøenix, doctor meus muleis nominibus de me optimè meritus. Iof.Scalig.in Varron. de re Rutí.

Cujacii Obfervationes. Divinum Opus vocat Clariflimus Thuanus.

Nullus shuc tam defertus in totâ Le gum viftitate angulus. fucrit, quem non

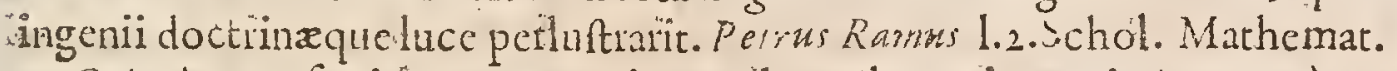

Catacist prafertim rovorth princeps legendus, vir non in jure tantùm, fed in o mnibus litetis apprimc̀ exercitatus : Quanquam meâ fententià magis aptus ei, -qui animi causâ, \& Romant tantùm Antigutrais nolcenda, jự operam dabit, quàm ei, qui in foro, te in litibus verfari volet; legendus tamen ob juris in doctrinâ excellentiam. Ruland. Maref. 1.r.epitt. epitt.40.

Quôdoctiorem, acutiorem autjudicii.fincerioris I urifconfuttum nulla ztds vidit, nulla opinor vid:bit. If. Cafrub. Not.in Lamprid.

Illa tua, Cujnct, velut propria laus, exacta certaque effe quæ femel ex adyto tui pectoris profufa. Liyf. Epift.C.cntur.r. Mifrell.t. pilt.67.

facobu C'macits, quanta mendarum millia ex lures Civilis libicis \& promifcuè *ariis Auctoribus exoneraycrït, oratione meâ haudqquaquam exponere queam. Sciopp. de Arte Criitic. p.s.

Primores, excelientiores eminentioreq; in Gente noftra Viri fuerunt $C$ ujaciuss. Ronfardou \& Ferralins. Cujacius preterquam quòdpraxtans erat Jurifconfultus, Hiftorix Ecclefiafticx fcientifimus crat. Delcetor Lectione Obfervationum Cujacii; qux fcripfit preffa funt atque folidiffma. Perroniana. Gall.

Cujacin eft Margarita Invefconfultorum. Scripfit fibi \& doctis tantùm - Non :omuibus datum, ctiam dodtis, fed rara cujuldam felicitatis eft, bonos auctores corrigerc, \& fux dignitati arque nitori reftituere : nec quenquam hediè novi qui id prattare poffit prater Dom. Cujacium, \& Dom. Auratum. Scaligeran. 1.p. $18, \& 67$.

Cujacius theoriam juris Veteris Romani calluir optimè, practicx non ignarus zantùm, fed, fr quid in eâ fciret, dedifcendi cupidiffimus, utpote quod ipfum à Jure Romano diverteret, Idem hoe obtinuerat,ne exploderetur, nam difceffiffet, 
fi vel minimum contra lubitum obfteperent Audirores. Dominus Cujacius tam bonus vir fuit; Difcipulorum Pater crat, \& plufquam quatuor millium librarum jacturam fecit, quod pecunias Dilcipulis fuis commodaffet. Scaligerana 2.

Addendus huc eriam facobu Cujaciu, xtatis noftra facilè confuleiffimus,

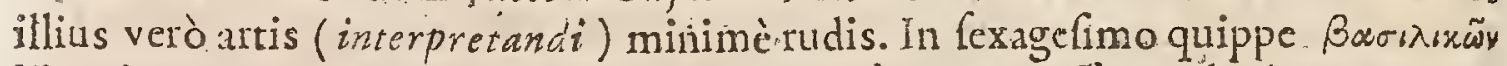
libro interpretando ita verfatus eft, lut fidej luz promiflum planè prafticrit;

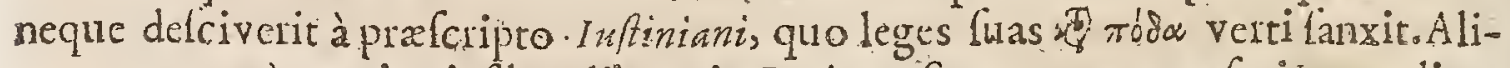
quos pratercà operis ejufdem libros in Latinurn Sermonem tranfclipros aditurum fe receperar ; verùin mors conflium ïtercepit. Miliimè autem iis alfentiendum, qui (ut videre eft in Cafaub. Epift. 263.) inarditâ mentiendi. Go falsa fun

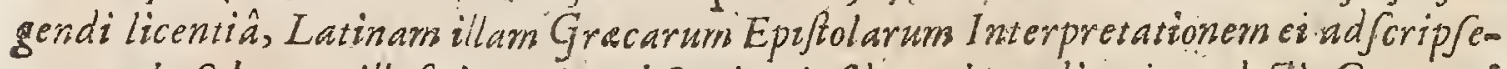
ront, of fub tam illufri nomine obfcuri cuiufdam er mediocriter docti Germani: verfonern, cateroqui non afpernandam, \& verborum ac. Cententiărum : Catis tenacem publicarunt; quurn Francifcus l'ithxus, à quo illi babuerunt, earn Japè

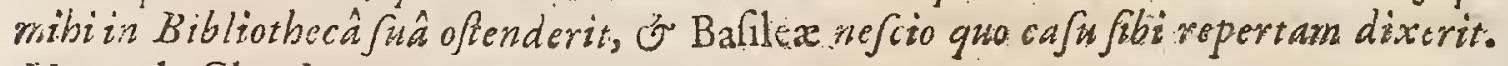
Huet. de Clar. Interpret.

Studcre folebat in tap te proftratus, pronus in ventrem, libris circa fe difpofitis. Difipulos fuos adeo diligebat ut pecuiam is dum illa indigerent commodaret, \& Ecaliger affeverat cum hoc pacto plufquam quater mille libras perdidiffe. Milfam 2 i roceffiones frequentabat; quià verò in partes. Henrict $I V$. coitra Fadionem ei adverfam tranfivit, Proteltanibus ipfum accenfendim effe voluit vulgus, \& pluries per frcarios cxdes illi fuit intentata. Teftamento fuo Ecclefiam Romanum uullatenus meminit, fed uxorem hortatus eft ut fliam fuam in $D$ ci rimore infitueres, Scriprure nihil addendo vel detrahendo. Veruntamen præclarus vir ille hac æumna excrcirus etsquod fliam genuerit tam nefaria profiturioni deditam ut de vitio fuo gloriaretur, \& alta voce pradicaret fe fibinon minorem famamex impudicitate qualituram, quàm parens fuus eruslitione illuftris erat. Ant. Teifler Elogiis Viror.eruditorum. Gall. fol:

Extant Opera omnia in Tomos V. digefta. Parifys apud Seb.Nivellium . I5 8 a

Hoc ejús Epitaphium:

$$
\text { Zac. Cujacio V.C. }
$$

Thölof a illius elum quondam $P$ alladia fuit alumno fubcinericio, hrededique ex affe Pofuno Rom rni l uris à Lummis conditoribus interpreti primo \& ultimo, cui quicquid puræ nativæque lucis \& fcientiæ undecunque acceffit, ætas fua debet, poftera etiam, fi qux Legum cura manet, debirura eft. P. Pitheu' P.F. Doctoribene de fe, bene delireris omnibus merito. 


\section{M.P.}

Vale, Cujaci, nos te ordine, quem Dest \& Natura jufferit, cuncti Cequemur. Decefirt IV. Non.Octob. Annos natus P. M. LXVIll. c I $0.10 \times x \mathrm{c}$.

\section{Cujaci Themidifane vides comarnure Sepilichrum, Conduntur fomul bic, gri periere fimul.}

* Ejus Opera $T$ ngduni, fumptibus Pillihote $\times 606$. cum expurgationibus permittuntur. Index Madrit. edit. an. 1657.

\section{HUBERTUS GOLTZIUS.}

TEnlow in Geldriz oppido natus, die 30. Octobris, ann. I526. Obiit Brugis Flandrorum, die 24 . Matiii, ann. $15 \%$.

Claruit A. M DLXX.

Erat Anti quarius eximius \& Numir natumindagator accrimus. Unde glo:irari haud d bitavit, à nemine tam multa tamque varia numilimata confectzas atcrectata, \& delincara elfes quàm à lé. Kontg.

Soripta ejlis hac funt I Imperatorum ferc̀ omnihum viva Imagines, à C. Iulio Cafare ad Caralum V. ex veteibus numifmatibus ... Fafti Magiftratuum, \& Trinmphorum Romanorum ab Urbe conditâ ufque ad Aingufl obitum - Ânimadverfiones in aliquot faftorum locos-Catalogus Confulum ab Auginti obituad Inftinanum-De Origine, \& utatu Populi Romeni--Thefaurus rei

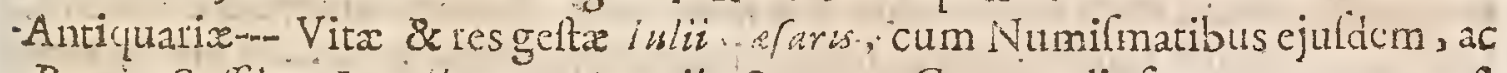
- Bruti, CaJfii , Lepidi, M.Antonii, \&c....-.-Compendiofa eorum qure poft crodem Iulii Cáfaris ufque ad Triumviratum gefta funt, narratio---.Fafti MagiAtratum \& Triumphornm Romanorum, qui ad lulii Cajaristempora pertinent, cum Animadverfionibus in coldem--..Vita, \& res geftre Angufti Cafaris, ex Nummis \& nfcriptionibus antiquis-.-.-Sicilia, \& Magna Gracia, five Hifto:ia Urbium, \& i’opulorum Grecia ex antiquis Numifmatibus--.-Itinerarium per Italian, Germsiniam ac Galliarn.

Nofter Goltzius, alterin Grecâ \& Romana Antiqulitate inveftigandâ Varra. Lud.Carrio Comment.2. Antiq.Lect.c.3.

Antiquitatum omnis generis altiff us Gurges. Had. I un.

Tua virtus, diligentia maxima, eruditio, induftria, tantarum rerum cogiatio, \& jndicium ita mili placent, ut vix ullius hominis amplins. Georg. Fabric.in hto. 2111. I573. Ceriptis.

Hubertus Soltzim; fulgidifrmum illud rei Antiquarix fidus. Abrab. Gorlems ad Lect. Lit.quas Dactylioth. fux prxmifit.

Golt in diligens \& utilis Scriptor. Thom. Dempker. in Elench. Scriptor. Hubertus Golizius, cui Antiquïtas Graca \& Romana, fecundum Onuphriums, Ccccc 2 Pention 
$P$ anvinium, Antonium Auguftinurs, Fulvium Urfinum, debctplurimum, ste cxlandi ac Ccriptis propriis ad utramque multum contulit. Thuan.1.78.

Magna profectò debetur gratia viro ingeniofifimo \& laboriofifimo, cui Germania parem, nedum fuperiorem, in hoc tali antiquitatis Pudio non habuit: quicue nullum ferè fpizicum tranquillum duxit, quò aliquid in. Reipublicx literarix conferret utilitatem. Melch. Adam in Vit.Goltz.

Vidi Faftos. Confulares tuos. Quid magis mirer ? diligentiăm in quxendis tot nummis ? felicitatem in reperiëndis ? an manum \& artem in exprimendis?: LipS.1.2. Epiftol.Quxeft.Epitt.21.

Goltzius nihil me docet, fcio omnia illa; fed eft bonus liber pro Tyronibus. Scaligerana polterior.

Hubertus Goltzius in Pictura, iil Sculptura \& in Antiquitatis cognitione ex celluit. Totam Germaniain, Galliam \& I Ialiam Equitis Marci Laurini Cumptibus perluftravit, follicitéque perquifivit ac folertifimè delineavit vetera omnia Nurnifinera, qux in Curioforum Conclavibus affendere potuit. Eaque à fe fculpta Doctis Commentariis explicavit. Anton. Teiffer. Elogiis Vir. Erudit. Gall.

Golizius adeo folerter parrallellifmum fecit inter Imperatorum Numifmata vetcres Hiftorias, ut plurima lace dièi digna dilucidaverit; qua: eatenus is obfuritate \& confufione delituerant, \& ad quæ fagacifimi Commentatores. pertingere nondum valuerant. Quoniam vercbatur ne illaberentur menda in Operum ftorum Impreflonem, quibus coumpretilim vilefcere potaifet, intra proprios lares infignern Typographiam ftruxit, in qua Editiones omnes manibus:ejus tractabantur, \& abillo folo corrigebantur: Quas etiam fuis omnibus num meris tam abfolittas praftitit in arte caland, in chanacteris munditie 8 in fermonis flegantia; nt per univerfam Europarn cum fupore confpectx fuerine; funtque etiamnum infigni ornatui intra celeberrimas Bibliothecas- Tam impensè Romanam Antiquitaternamabnt, ut illius in fû́ familiâ, vitamrevocare velle wideretur, nominibus Inlii, $M$ arcelli aliifquefimilibus qux liberis fuis imponebat. If, Bullart. Acad. Scicntiarum. Gallicè.

Nullus quoque pracerire polfum, quod micandum tamen eft , doetifimum exteroquin Huberturn Golvzinm, vium cui crudito Criptis non \& famâ cognitum, Martinit Smetii Infcriptiones Antiquas fuo nomine publicâfle; quod hifce. verficulis Hadrianus Damman Gand, ejưs operi prefixis, eleganter fanè defcri: bit:

Sed neque, te Goltzi decuit, qua Smetiüs olins:

Priva religuiffet vidux, twa dicere, cunctis

Vendereque: os boinini! pofflininióne putaffes

Findicias peterent Manes of polthuma pioles...

Janfon. Nov. Antig.p.27\%28,

Prodiitliberde Origine \& Statu Populi Remani, Faftis Goltzii Lubjectus Brugis Flandrorum, 1566 . in Fol: 
Prodiit vita \& res geftr. Cefaris Angufit, Foli Brigis Flandrorum rg8:0.

Prodiit. Thefaums Rei Antiquarix $4 \%$. Antverpic ig80.

Extant Opcraminias. Tomiso.Ant.1645.

In Effigiem Huberti Goltzii hac carmina compoluit Daniel Rogerins Anglus::

Goltzionarte parem pingendi cernis Apelli.

Sculpendigue parem, culte Lylippe, tibi:

Notitia limperii Grail pariterque Latini,

Varronifinritem, Paufaniague finnd.

\section{GUID.O. RANCIROZUS.}

J

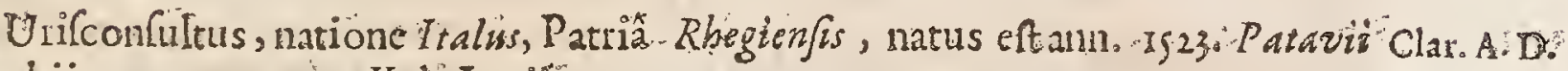
obiit ann. is.97. xvir . Kal? Juniî.

Scripta ejus hæc funt:De Rebus deperditis, \& de rebus recens inventis Commentarius in Notitiam Dignitatum utriufque Imperiz-De Magittratibus Municipalibus, \& Corporibus Artificum liballus-De quatuordecim utriü-

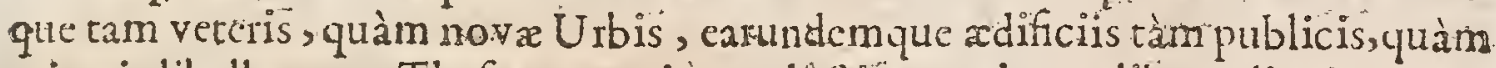
privatis libcllus--.- - Thefaurus variarum lectionum in tres libros digeftus-- -nRefponforum \& Allegationum in Iure volumen unum-_-De-De Origine \& AuEtoritate. Jurifcenfultorum, \& de viris illuftribus maximèn Iure-...De Origine \& Auctoritate Eytuitum--- De Iuris Antiquitate--De Numifmatis Aniquis--.-Comment.in Tertulliani Opera---Volimen, in quo plurima" nova.legum Explicationes continentur:

Guidus Panzirolus, Juvilconfultus doctiflimus, degantifimus, 2 non fow lum in Iure Civilh, fêd etram in omnibusbonis literis,nempe his; quas Fumaniores vocamus, optimè verfatus;necin Romanis Antiguitatibus mediocriter infleruStus. ConftantoLund. in Explicat. Nunifinat. Roman.

Guidus Pancirolus, praceptor meus, vir optrinus \& eruditifinus; cujus ea revcra laus fuit, ut, qui eun viderent, loquentemque audirent, redirent ferè dó stiores cultiorcfque. Laurent. Pignor in Commentar. de Servis.

Guidus T anciralius Jurifconfultus infgni doetuin âs \& Criticus exactus. Thom. Deimpter. in Elênch. Scripror.

Gui izs I ancirolius Juríconfultus, \& penitionis omnis antiquitatis ubérrimus promus Condus. Felix Ofun in Not.ad Alberrin. Mufati Auguftam Hift. 1.\% Rubricầ.

Supcreft tiber fcriptus feculo s. dickus Notitia utriufquc Imperii, ablque quo nemo poterit Codicern I uf tinianewn intelligere. Extat in illum doctifimus Com mentarius Pancirolli, Jưifconfulti Italicz, tantâ diligentiầ confectus, ut non poseris \& curam \& judicium viri fatis laudare. Herman. Conring.

Ue nos docet Notitza Imperii, \&adillam in nunquam fatis depredicandis. Commenedriss Guido Pancirolus. Herman. Conring. Differtat. 3. de Academicis Antiquit.

$$
\text { Cacec } 3 \text { Guidonis }
$$


Guidonis Pancirolli, magna gloris Jurifconfulti,operof funt Commentari in auguftifimum illud opus, inexhautum recondita antiquitatis Thefaurum, qui Imperti utriug que notitia infcribitur. Dou a Amal. Holland. lib.Y.p.220.

Jurifconfultus cluriflmus, fcrip fit enditifimum in Notitian usiug gue Imperii Commentarium, quem auro contra carum habent doctiores. $M$ aurit. de princip. jur.publ.c.2.n.36.

De ejus feftivitat:, quâ nulli cederet, \& multiplicidoctrinâ, quấfü Or dinis carcros lupetatet, multa etiam ex aliis audivimus----guis guantufque Pancirolus in difciplinì Juis fuecit, ipfus conflia teftatur. Cogel. in Polit. pag. 292.

Panciroli Notitia Imperitoptimus liber. Scaligerana.2.

Summi Romani Poniffes duo, Gregorius XIV. CLemens VIII. miro illum morc complexi lunt, \& ad Aula Roman limina, confultationis ergô, perhonorifice vocavere. At ille quictis amans, \& bonæ valetudini fuæ ftudens, lucubrationibus ctiara eruditifnis cvulgandisintencus, faftus hujufcemodi, \& honores omnes nihili ducens, Civitatem ("atavinm) \& Academiam noftram kome preferendam cenfuit, nec aliò, procul à Gymafio fui delicio, commigrandum. iac. Phil. Tornamint. in Vit. ejus.

* Henrici Salmutb in Guidonis Panciroli, rerum memorabilium jam olim depcrditarum, \&c. libros duos Notæ, 1607. cum expurgationibus permictuntur。 Vid. Ind. Madrit: Edit. ann. $966 \%$

Extantde Clatis Legum Interpretibus libri rv. Veneriis apud Marcum. Anron. Brogiclium $16377^{\circ}$ in $4^{\circ}$. \& ibielanno 1655 . in $4^{\circ}$. Editi ab Octavio Pancirollo Ftatris lilio.

Extat Commentafius in notitiam utiufque Iraperii Romani Orientalis \& Occidentalis. Venetiis ann. I593. \& Geneva, in Fol. 1623 .

Extat de Rebus memorabilibus mutatis, deperditis, \& noviter repertis, cum Comm. Henrici Salmuth Ambergenfium Syudici. Erancof. in 4.1660.

\section{JOANNES MALDONATUS.}

Clar.A.D. Oconobiliin Bxatia Hispantenatus, èlodalitio I efutico, egregièà teneMDLXX. ris annis omiliteraum gencre excultus; qui ad exactum Philofophix \& Theologia ftudium fungtharem piat ıtem, morum candorem \& accrimum judicium cum attuliffer, magnîcum laude \& frequenti omnium odinum concutfu totos 1o. annos Lureite Pariforurn ( Cluromontanâ cholâ profeflus cft; unufquein causầ cxtitifie metitò creditur. ut fodalitium îllud toti treademix valdèinvifum, \& alio qui jam prudentio ibus fuppesum, obtanti viri gratiam ac commendationem à cuatu, apud quem lis adhuc indecila pendebar, tandiu colcrareur, \& eo ufque dum robus fodaliumin ube confirmatis. Maldonatus polt concili tam infigni fuâ unius cruditione novo ordini c l. britatem à Gregorio XIII. Pontifice Kormam evocatus eft, ubi viraffiduus in ftudiis \&lucubrationibus fuis exactè digercndis intentus, ex 
nimiis vigiliis contracto morbo deceffr vis. Id Jan. cum paulum I Y I. arinum fupergrellus effet. Nihil vivens publicavit. Poft mortem ejus, operâ ac cur: Clementis utent ex codem fodulitio viri doetifimi prodierune eruditiflima Commentaria in rv. Evangeliftas $M$ usjponti edita, neliora \& integriora multorum judicio futura, fupertite altore cdita fuiffent; quibustamen fipari diligentia claborara in Acta Apolzolorum \& Apofiolicas Epiftolas interpretitiones, quas. Ccripfife illum confat, olim accedant, habebunt profuetè omnes docti \& pii opus pancisia hoc gencre comparandum, \&quodunum multorum intar elfe. polfit. Thuan ad annoirs 3 .

Ioannes Maldonatus, Homo difertus juxta ac dốcas, cujus cupidè legintur in xv. Evangeliflas Comantarii, variz pleni cruditionis. tifpar. Biblioth.

Maldonatus wir judicii cxafciati, \&z veritatis Hiftorica: Hyperafpiftes, fi quis alius. Thuan. ad ann. 158.4 .

Maldonatus, fcriptor fane ingenil atque eruditionis nomine laudandis, fed manifefto partium ftudio iń Cequiora non raro abreprus. Polus Prafat. 4 . Vol. Synopl.

Cujus in Scripturis explanandis folertiam ( nifi ubiamor infanus erga corum Ecclefiam iplum excxcavit) nemo Pontificionm, panci vero in Ecclifis no* Atris Liveraverun. Dom Lackson in Symbolum, Volin.lib.3. cap. 1z. Anglicè.

Acerimi judicit Explanator inter Jefuitas. Idem ibidem c. is . Maldnatus magni.nominis Interpies. Schlicbting in Hcbreos.

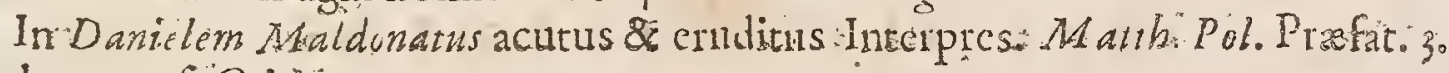
Vol. ynopl. Critic.

Cadinalis Perronius ait Maldonatum fuiffe proftatem virum, verumque Theologum, cuyis clocutiobona erat, qui Linguarum slialaticeque 'Theom logip peritilimus enat, qui enditus evat hilofophus, qui donique Patrum foripta diligenter evolverat. Perroniana Gallicè.

Malconatu in Evangclia maledicus, infignia tamen quxdam habet bona. Cum onnià Dom.Beza tranfcripferit, ei tamen obtrectat. Quandó aliquids habet boni, furatur à Calvino, \&ut agnofeas, maledicit ci, ut Eufcbius ex Africano. conatur furta fua tegcre. Maldonatus non poterat mihi verbim Hipinicum interprctari quod indaus potuit res conbsar. Solent Indai p afchate inin chbito Ics conftat: Scaligerana 2 .

Sanè etiam in " $M$ aldenati le fuita friptis, qux poftquam ipfe diem claufit fupremum, funt edita, nonnullautcoritate quâdam cenforiâ fuille mutata, \&̀ temporis prefentis opinionibus accommodata, audivi qui affirmarent, viros fide dig!ios. Ifaac. Cis cub. Epitt. 624. Frontoni Duceo, p. 727 "

Maldonarus, vir certe enditus, fed calami interdum intemperantionis \& litg!æ maledicentiffmæ; nifipotius, quod arbitror $¥$ male dicta, quibus à fe diflentien-

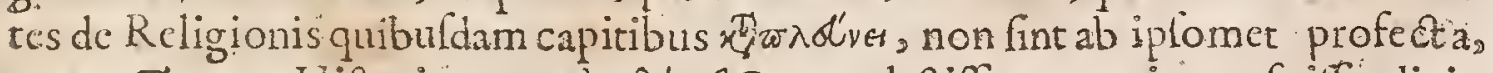

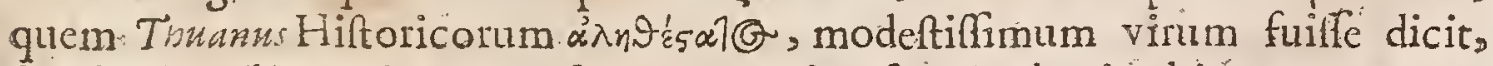
fed ab editoribus lefuitis Muffipontanis, polt ipfins Anthoris obitum, commentariis Evangelicis, sùm edereutur, interferta. Montacnt. Apparat.7 Sect.16.. 
272 aldonatus Pefuitarum virulentifimus, \& accrbus alienorum Scriptorum Cenfor. Cafaubon. ad Baron. Exercitat. 13. Anin-3r.Num. ir.

Quum ubique virulentus hic fcriptor in magnos viros profuâ modeftiá, pari spctulantiâ \& imprudentiâ dibacchetur; nufqum tamen maledicæ "linguæ fuz

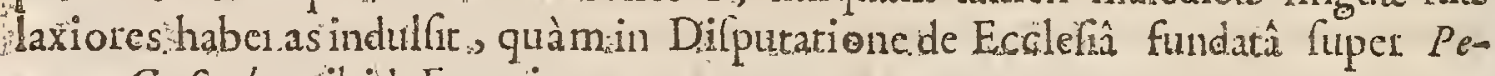
orum. Cafaubon.ibid. Excrcit. Is. P. 347 .

Maldonatus, acris \& magni ingenii vir; haffectibus, filingux, fi odio veriteatis, potüiffe modcrati. L dern ibid.

Maldona us in amplo Auditorio adolefentulis frequenti, acumine ingenii Numinis difpendiotudibundus abitens, duas fibi invicem contrarias lectiones habuit:Priore rationibus s̀ natura petitis Déi exiftentian evincere conatus cft; $P Q$ Aterioi verò quod nullus ellet Deus. Pagnier Catech.Jeluit.lib.2.cap.7. Gallicè.

lectionibus ejus nec ipf C'alviniftarum miniftri abftinebant. Dublus quotidie stribufve horisfubfellia certatimimplebane pritss quam ludum ille ingredereturs ne excludercntur. Sxpein aperto atque adeo in viis publicis docere coactus eft ob multirudinem auditorum, quos nulle exhedrx capiebant. Konig.in Bibliort.

Plutimi Proteftantes Lecturas ejus frequentabant, erataue fufpectus quod iis ¿nimium faveret. Edvoard. Eeigh. De Religione \& Eruditione. Anglicè.

Extant Maldonati Soc. Jef. Preśb. Opera variain Fol. 3. Tom. Parifis apud Andream Pralard. Ann. Dom. I678.

\section{CAROLUS SIGONIUS.}

Clar.An.D. T Atione Italws, patriâ Mutinenfir,obiit amo Dom.1585. xtatis LX. Primo MDLXX. Venetiis, deinde Patavii, tandem Bononia literas elegantiores doctuit. Cum Francifco Robortello \& Nicolao Grucbio, à quibus maximè dirca Romanas Antiquitates diffenfit, feriptis,ccrtavit.

Scripfit de Regno I talia-- Comment,in Faftos \& Triumphos Romanosum-- Natas in Scvernm Sulpitiurn--Librum de Rep. Tebreortin-m-Librum de Rep. Atbenienfium-.... Scholia in T. Livi Hittoriam;\&c.

Excellentis doctrina \& diligntia accuratifima virum appellar Lawrentus Rhodoman ad Ledor. Epint.quam Diodor. Sic.pramifit. Iral.

Vir do extina fingularis \& admirandx induftrix. Dafjeind. in defcript. Urb.

In Romanorum antiquitatibus explicandis fummam ingenii laudem oft adcptus. Boutin. in Meth. Hift.cap.A.

Marmora in for Romano effolla explicavit \& 1cftirtiit Carolus Sigonius in Faftis, fingulati induftrî̀, magnolabore, accurat $\hat{z}$ diligentiâ. Georg. Fabric. de Rom $\hat{\imath} \cdot \mathrm{c} . \mathrm{I}$.

Vir diligens \& eruditus Carnlus Stgonins. Monracut.in Analect.exercit.6. Sect. I.

Carolus ionisw oprimus \& praftantifimus Hifroricus. Nic. Reufuer. de Ital.

Vir do trinæ \& judicii magni Car.Sigonius.If.Cafaub. Comment in Strubonis iib. 17.

De Carolo Sigonio Mutinenfi, quem pofremum omnum Venetiis cognovi, Hon 
smon eft quoòd hîc multa dicam, cùm fuperiùs fxpe, tum ex'inftituto, tum obiter, de ejus diligentiâ, doetrind, \& probitate verba fecerim. Fateor autem, \& ex ejus lucubrationibus excufis, \& ex difputationibus, quas cum eo familiariter Venetiis habui, multum in totâ Antiquitate Romanâ me profeciffé, cujus ille mirum in modum peririfimus eft, Omuph.Panvin. Comment. ad 1.2. Fastor.ann. Urb. M.LXXXIX.

Carolus Sigonius . Mutine hatus perantiquo genere ac nobili multumque natura dotibus illuftris, floruit apud omnes fingulari doćtrinx ac virtutis opimione; prefertïn veró in vetuftatis arcanis exuendis, \& annalibus abditioribus - recolendis, caterorum fui temporis facilè princéps ett habitus. I Io. Imperaalin Mal.Hit.

Monumentis variis editis ad xternitatem viduris, antiguitatem Rorianam, iifdem, quibus Onuphrius Ranvinius, veftigïis infirens, \& pofecriora tesopora unus poft omnes maximèilluftravit, clarus.T buan 1.82 .

Carolus.Sigonius, wir doetiffinus, \& antiguitatis reftaurator omnium, quos Ito

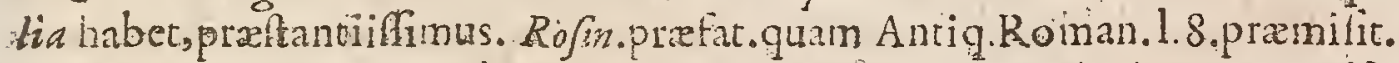

Quis non à Turnebo ali juodoctior redeat? Prudentior à Sigonzo?Difertior Mureta? Quorum ego non auditum fol im magno emerim, fed vifum. Lipp.Cent。 1.Mifcell Epit.22.

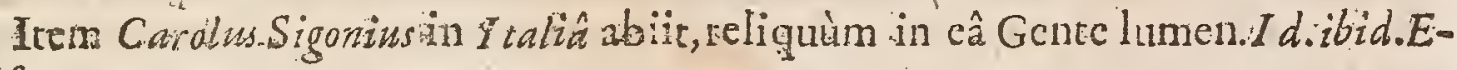
piff.7\%

Totius Antiguitatis (Sigonio) peritiorem nec noftra fecula, nec priora tuliffe, fi affirmem, facilè me is probaturum fententiam noftram confido, ad que:um manus latina ejus monumenta pervenerint, ut Faffi., \& de antiquo jure Romanorum, \& de veteribus Provinciis, foain. Matth. Tofcan.in Italix peplo, :. .183.

Sigoniur vir eximix \& fingularis do \&rine. Turneb.1.5.Adver!c.24.

Errovilaus Livii exhauriendis bonam fidelemque navavit operam vir eradifimus Carolus S'gonizu:quem ego \& antiquitaris peritifimum, \& bonorum Scriptorum intelligentifinum, \& erudiciffmun nominare meritiffimò polfun. Idem ibid.l.1.1.c.18.

Res in Occidentali Imperio, tam ad Eeclefiam, quàm ad Remp. pertinentes, qux comperiri diligentià polfent, fingulari curâ collegit, erndiciffmus Sigoninus; cafque, quàm veriffimè in maximà rerum obfcuritate, Scriptorum dilfenfione, \& temporum vetuftate potuiffer, luculento ftylo pofteritati mandavit: à Diocletiano \& Maximiano Augufis incipiens, anno 28r. \& in morte 7ufiniani definens, qui - biit an.Chr. 565. Whear.in Merh.Leg.Hift. Ecclef.lect.4'.

Bonus eft ejus Titus Livius Frobenianus multis fcatet erroribus Car.Sigonius \& P.Manutius. Optimè tractavic de Jure Ronanorum,\& de Româ omnium optimé : Eriam voluit dare confolationem Ciceronis, fed Itali reftiterunt. Scalig.

Qui penitius introfpicere cupient qux Populi Romani Comitia fpectant Sigonium legant, ejufque formidandum Adverfarium Grucchium. Formidandum (anc voco, quoniam aे Sigonio vehementer reformidatus eft:Dum enim fupertes $D d d d d$ 
fuit Sigonizs de ip fo nunquam nif cum elogio mentionem facere aufus ;eft, led ft tim acillum fatis ceffilfe novit, crudeliter ipfus famam laceravit. Novell.de Re pigbl.Literarum Tom.2.p.19. Gall.

Vir ingentis, \& doctrinæ, \& judicii, Caralus Sigonius, Vo/. de Arr.Pö̈t:p:33。

Patavino Hiftorico operam noftrà parentumque memoriâ, quà caltigando, qua Scholizs illuftrando, plurimi mavarunt feliciter.Ad veteres Codices.Calamo exaratos compararunt H.G lareanus ac Rhenanus, Giernani. Vicit verè omnium induftriam (fatendum eft enim) hîc, \& in omniadeo Romanầ Hittoria fumma Caroli Sigonii accuratio. Andr Schoti.1.3, c. 38. Obferv.Human.

Lireris Ebraicis nimium alienus, utcunque aliàs: vir doetifimus: Selden. lib.3o de Synedr. c.12.

Civitas Mutinenfis illuftium in qualibet Atre Virorum femper feraciffima, in Orbis lucem edidit Carolum Sigonium, co præcisè feculo quo: Italia fefe oftendebar Seminaritum præclarifimorum in Literis ingeniorum. Ufque adeò infudavit magnus: ifte Vir cruditornm libris evolvendis, ut gloriam fuam ad celfiflumum faftigium evchendo audiverit fe vererum monumentorum Refturatorem vocar1. Prater variam doctrinamadeo perfectè calluir Linguam Gracam \&: Latinam ur Seculis illis thatus videretur quibus Gracia 2 Latium Hominum in Scienti is celebentrimorum fecunditate claruenunt. Nec lucidioribus mentis habitibus deficiens fuit; quibus fplendide fcripta fua exornayit. Laurentius Crafo Jus. Ital.

Piodiit de Romanorumnominibus Liber, Tomoat. Hiftorix Romansę Scriptorum, quos Fradericus Sylburgins conjunxit; Francofurtiad $9 k$ conum, is 88 : in fol.

Prodierunt de Antiquo Civium Rómanoum Jüre libri ir. Demetius 1560 in 4 ? Parifis 1576 .in fol. Hanovia 1609 .in fol.

Rodienunt de Antiquo Italie jux lib.un.iifdem in locis atque temporibus.

\section{JOSI A:S: SIM L:ER:U:S}

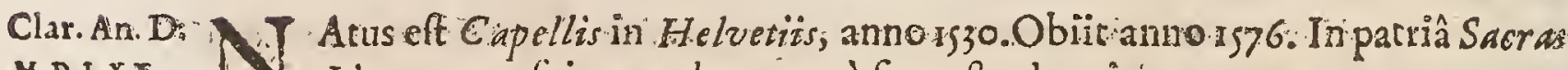
C D IXX. Literas expolivir,populumque è fuggeftu docuir.'

Scripst de Rep.Helueticorum---Notas in Antonini Irricrarium--Notas in

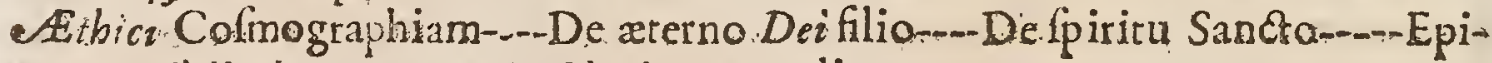
zamen Bibliotheca Gefneri. Plurimaque alia:

Fuit hic vir lon folum Theologia, fed \& aliarum axtium, qua Theologix ancillantur, apprimè peritus, imprimis Marhematum---Summo.iti Theologo. Petro Martyri fummè gratus \& acceptus fuit: A deo ut Simlerum fapè magno aliquando Ecclefix ornamento futurum prædixerit: Moriturus etiam vel hoc nomine plurimum fe fibi gratulari vehementerque gaudere, multis audientibus, affirmavit; qued illum,ralem \& tantum virum, fibi fuccefforem fore fperaret. Qux quidem 1 llius fpes vana non fuit, Melch. Adatm, in viriejus. 


\section{CELEBRIORVM AVTHORVM}

Tojess Simlerus, animi candore \& omnijugâ eruditione prætans; Petro

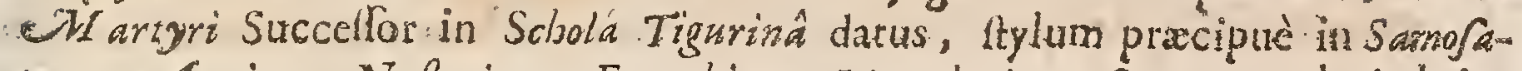
enos, eA rrianos, Neftorianos, Eutychianos, Macedonianos, \& nuper veluci ab inferis hoc ævo in Polonia excitatos. Tritheitas ftrinxir;aliis fcientiis egregie inftru- Eus, ac pracipuè Mathematicis , quas \& par le percepit, \& fumma cum laude diu profellus eit; $\&$ inftrumentis ingeniofifinèd de excogitatis illuftravit. In bonis literis \& excelluit,\& de Rep. Helvetior:zm. Commentarium magnầ prúdentiâ Thwan.1.62.

Quis enim in Mathernaticis difciplinis, \& quidem a'vro8:8a10, exriterit, non modo qui docenten illum audiverunt, fcd etiam \& libri \& Inftru mentanobilifina ab ipfo e ecogitata teftiscantur. Quantus aurem in $\mathrm{Hi}^{-}$ Storiâ fuerit, oftendunt Scripta, præfertim :quibus Patriam immortalitati confecravit. Quaim denique in Theologicis excellucrit (que fuit ipfius propria Profefsto) quantique in fcribendo tum acuminis , tum judicii, Veterum quoque Theologorum leatione conrfimati, fatis fuperque demonftrane Samojattiniani, Arriani, Nefforiani, Eutychiani, Macedoniani, Tritbeite donique noltris temporibus rurfim $a b$ inferis excitari, \& divini vcrbi gladio fortifimè Simleri manibus vibrato jugulati. Quid non igitur ab hoc ingen io potuit expeetari, fipaul. Grmius corporis domicilium habuilfet, \& nifi mors illum inmatura planè fuftuliffer Theod: Beza in Icou.

Homo ingenii doctinæque elegantifime, c M athernaticarum dicciplinarum Atudiofifmus, Hiftoriarum peritifimus Boiffard.in Icon.

Vir non minus pietate, quàm eruditione præatans. Humfred. part. 2. Jefuiifini.

Sprecherss in defcriptione Rhetice eum incomparabilis ingenii virum ap-
pellat.

Sinslerus magnam nominis claritatem editione illä librorum de Helvetiorum - Republicsî̀ elt adeptus. ̊̊acob:Verbeid.in vic.ejus.

Simlerus de Rep. Helvetionium, bon. Scaligeran.2.

Simleri Epirome Bibliotheca Ge fneri utilifinnum eft opus, quồ ftudiofí carere non polfunt. Voêt.l.2.c.t.Biblioth. Studiof. Theolog.

Quoad ad mores ejus attinet, honeftate, candoreac virtute ornati erant. Adeo bonus ac lenis erat ut nullo unquam ira motta abreptus fuerit, ipfique dolores quibus aftligebatur eum neque difficilem neque morolum redderent : Licet mediocriter tantum opulentus effet, impenfiffímè tamen in pauperes munificus; \&in amicos liberalis erat, ac fupra modum dclectabatur quibufvis hominibus præfertim verò extraneis benefacere. Confortium ejus gratiffimum erat fummoque gaudio perfundebatur fi quotidie aliquot horas in colloquiis cum familiaribus tranligere polfet. Tantis denique meritis clarus fuit vir ille ve null um eo illuftriorem nunquam tulerit Helveira. Ant. Teifier. Elog. Vis. Erudit, Gall. 
Theodorses Béd elegantifimo hốc Epigrammate Simlèrum arnavits.

Simlere - -mi Simlere, qua fuperstite:

Tot mortun revixerant:

Quos ira nobis numinis, tam pauculis

Ademit annisplurimos:

Simlere, quemotremuit renatus Arrius:

Tremuit renatus: Eutyches;

Viaftator illé P olonix, bic Germanix, as

Lafiflagella numinis.

Hen Jubita o immatura to mors sauferens i.

Quam mulia tecum fuffulit:

Lament amicis quanta, quot jugtiflimos.

Secum dolores attulit!.

Quos inter ecce Beeza quondam biand ut timbs

His irrigat to lachrymis.

Beza repetito vulnere ifto Jauciuss,

Communis ad tumulum Patris.

P. Candidus î cjus Effigiein hoc lưfit tetraftichon:

Quâ.tibi prefentat Simlens imagine vuitumg.s.

Afficit bac oculos pulchra takella twos.

Si queat excellens animi quoque pingier illa.

Gratia, nil oculi paldorizs a picerent.

Extat Biblioheca colleeta à Conrado Gefséro deinde in Epitomerr redacta novorum libion um acceffione locupletata, jam verò poftremò recoguria $\&$ in duplum aucta per Iafiam Simlesum . Trigurimuma. Tiguri in fol. apud Chrifopho Frofchoverum is74.

Extani ejus in Exoduin Commenticd, fol Tig is 89.16090.

Extat Resp. Helugtiorum Tigs!608.8\% .

J OANNES WE RUS; cogromine Pifciraritoss:

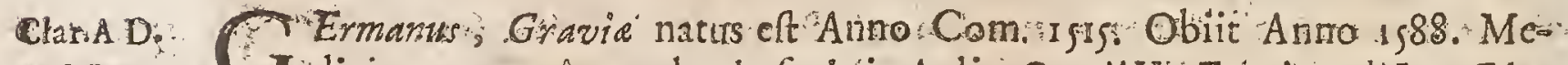

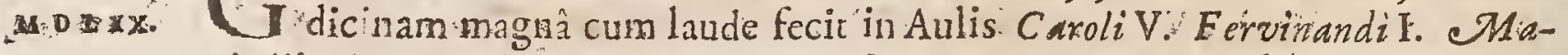
ximailiani I I. Rodolphi Ir.: Impp. Wilhelmi Clivia Ducis Archiarros fuit.'. In

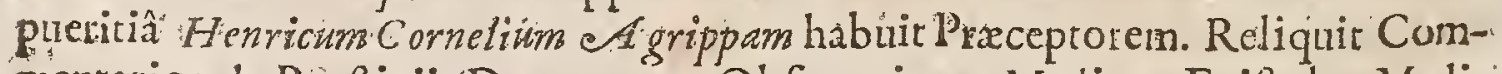
mentarios de Preftigiis Dxmonum : Obfervationes Medicas: Epiltolas Medisinales jerso. 
Vir benè de Repub. Literariâ, quin \& de Sagarum generemeritus. Nam apud: Withelman Clivide Ducem dum verfatur, non fine fifpiriis aliquoties vidit multos, Cbrifiani vulgi, prafertim verulas, ob veneficii fufpicionem.in ca.cers compingi ; Quxftionibus fubjici; Hammis exuri. Id cianram pexbeti, ur laudatum multis feripferit Opus de Veneficis \& Sagis : in quo quantuly in Theologià, in Jurifprudentia, Medicinâ, Philofophia pro feccrie, re ipsâdeclatat ; argumenta ex illarum difciplinarum fontibus de-fumpraadfercndo. Etfratem eo Scripto operam non lufit, cum ex Magiftratibus non parcico nomine gratias jp eger ne: quippe qui prudentiores cautio. refque co: Scripto facti ellent: non defuerunt tamen, qui in co \& reprehenderent non pacaj ix in certamen provocarent. Inter hos fuit Paulus Scalichizs, Ioannes Gampanus, Leo Suavins, nec Ioanni.Erentio ufquequaque fatisfecife videur.Melch. Adizro.

Promif me tranfmiffurum tibi librum clarifimi hominis, dotoris Ioannis Wierisante annos aliquar De Prefigies Dernomum, Incantationibus, ac Veneficiós. tam ingeniosè, acutè, \& doctè fcriptum, ut ab omnibus doctifinis viris in Burgundia \& to:o Belgio numinis loco habeatur. Capar. Borcholt in lir. Bartolo Richio, drit.7.Aug. 15640.

Qunntum voluptatis ceperim ex tuis libris De Preftigit Demonum, vix fat is: verbis explicare polfum. Video enimfingulatern in is prudentiam, judicium fow lidum, copiam reram neceffariarum, ordinem mirificum, fedulitatem inctedibi-lem, dëniqueanimi pietatem (abfe adulationis fúpicio) \& religionis Cbristian piritatem: eamque palfim propugnandi adverfus omnes impiorum hominum in.m

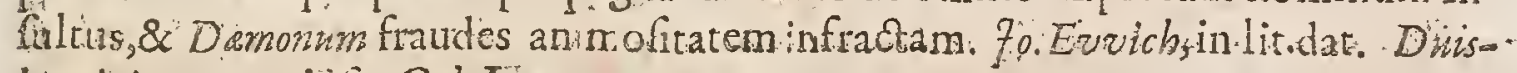
bergi, Ann. 156́.iplis Cal. Jinn.

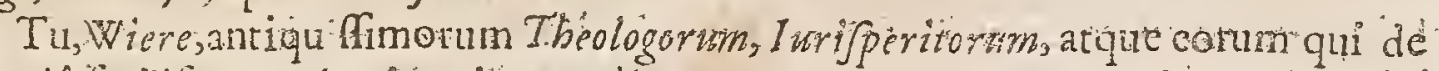
Magtâleriperunt (utinterim Medicostaceam) argłmentis irnixus; cum aliquid fe jam egille purant; nihil prorfus jam antum convincis; \& ut habet Gre-

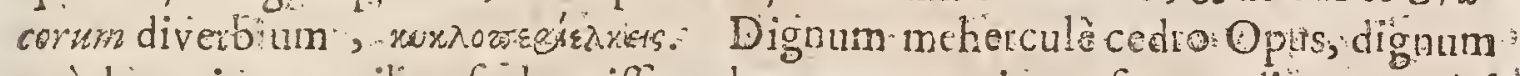
quòd omnium manibus fcelerarifimo hoctempore circumferatur, dignum quò d

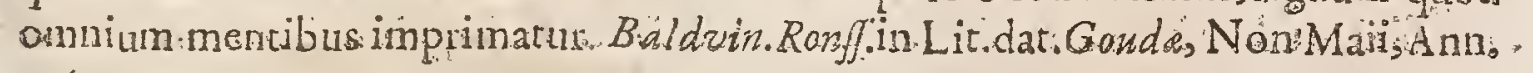
156;. .

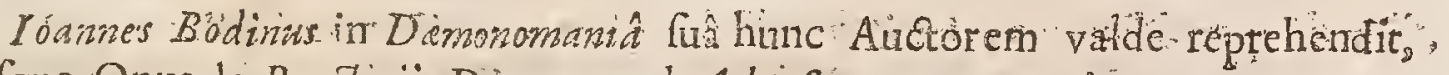
ejufque. Opus de Prastigitis Dimonum ad Atherfrimum vergere ait.

Wierins. Vir fuit enditus, Profeflone Medicus, nec ingenio nec experientia. deficiens. Quil librum ejus de Lamiis ( quemipfenunquan vidi) legerunt, ei exprobrant quod in. Opinione fua conftans non fit. Hoc milis: exploratum eft: cum libro fuo de rp restigits \&c. magnam inconfantiam prodere; imo \& quandoque non levem conflictum \& repugnantiam, ut homo qui in hò argunento

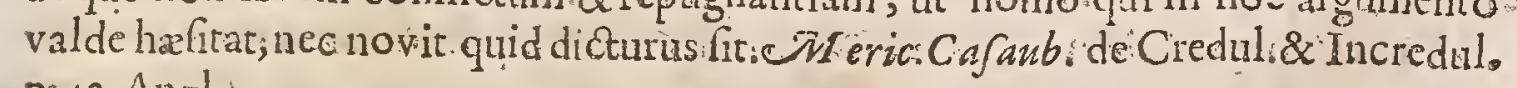
p:42.Angl.:

* Foannes Wierus inter Hareticos primæ Clafre rejicitur in Indice $\mathcal{M}$ adri senfi edit. ann.1667:

$$
\text { Qdddd:3: Ejis: }
$$


Ejus libri s.de" Pratigiis D.emonum, Incantationibus \& Veneficissprohiberttur in Indice Tridentino.

Extant opcra ejus omnia Amfélod.ap. Petrmm van den. Berge, 1660 . in 4.

\section{H I E:R O NYM US W:OLIIUS}

Clar. A.D. $M D L X X$.

C Ermanus, OEtingenfis, exactâ Lingua Graca cognitione clarus : qui perlu$\checkmark$ Itratis in adolefc ntia Gallix \& Italix Academiis, cùm fe A delieorum tanyuam in turiffmum ftudiorum nidum contulifer, eas maximè Scriptis \& induftriâ lu. illuftrayit, Fuggerorum libenalitate fublevatus:quorum munificentix Zonaram, Nrcetam, Gregoram, piimarios Hiftorix Confantinopolizana Scriptores ab illo fummâ. fide. Latinitute donatos debemus : ubi $\mathrm{Z}_{\mathrm{z}}$ Literas Gracus in Anna Scholà magno Auditorum,concur fu profeffus eft; tandemque chim xtatis anum fexagefimum quartum ageret; ex calculo literatis fè fatali, vir.Id Octobr.rsso.intempeltivâ magis Reipublicx guàm frbi morte ad Deum migravit. Thuan. ad Ann. 158.0.

Hierongrnus Wolpbins, Jurifconfultus \& Orator, vir Grace \& Latine deetifimus, qui plurimos Graces Authores, imprimis Dernofbenem \& Ifocratem, Tumina Gratorum Gracorurn, luculentè \& apte in Latinum Sermonem convertit, fcholiifque illuttravit. Augufte Vindelicorum Gymnafo \& Bibliothecex prafuit annos viginti tres. Quenfterid. de vir.Illuttibus.

Hieronymus Wolphizs OEtinge Rhetie Oppido natus, âm. I 16. pereruditus in omni fcientia genere ac Grecis pracipue literis deditus fuit. Acutus Rhilolophus, elegans Poëra, preftans Antologus, Philologus dcnique incomparabilis, plerifque Germaña ac Galli.s Academis perluftratis, Magifterii lauzeam sdeptus elt Baflea.

Redderet Aufonio qui redtius ore Pelalgos. Germanos inter Wolftius unzs erat.

Boiffard. in Icon。

Vir fuit valde diligens imò \& muiltre Lectionis ;: fed quii nec judicio admodum pollebat, nec ufque adeo accuratus erat. Quod in primis cernere eft duobus Tomis folio, infcripris De Lectionibus memorabilibus , qui. rariffrmi funt hoc tempore., imo \& in pretio habentur, licet in is multa inepta bonis permila occurrant. Indiczum Eruditoruxt Parif. 26.85 . per Dom.Bailleto Gall.

Exquifitâ lingux utriofque facultate preditus ad Interpretandum acceflit Hzeronymass Wolfurs: Sic autem de fuo hoc attificio, vir alio fui verecundus \& modeftus prædicavit, "Nihil ferè addidi,nihil detraxi, nihil immutavi; nec mire dò fententias appendere, fed penè etiam annumerare verba quatenus id divería 
"Latini Sermonis ratio finit, fum conatus. Nihilominus tamen Henrico Stephano neutiquam omni ex parte fatisfecit. Magna enimverò ars; \& hàud f́cio an omnium diticillima, quam acuto vir ingenio, elegantiosibus doctrinis excultif fimus, uno ferè hoc in ftudio tor annos pervolutus, cùm perfectam in fe, abfolutamque exprimere non potuerit; quodcunque illi defuit, humano id ingenio defuiffe credendum eft. Huet de Clar. Interpr.

Preclarè. iraque olfizus vixit, qui non folum profuit vivus omuibus, qui! $L i *$ teras Latinas \& Grecas amant, fed etiam nunc prodeft mortuus.. Reliquit enim ingenii fui monimenta literis mandata.;, quฺx erudire poterunt etiam pofteros. Melch:Adam.in vit.Wolfi:

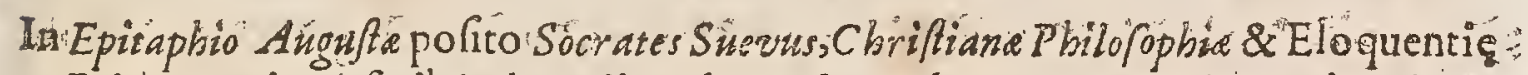
Prineeps, vir.ad fcribèndum; dicendum, daceudum natus, antiquz virtutis \& fidei Germanica exemplar appellatur. -

* Hic Author in primâ Claffe Hreticorum locum hấbet in Indice Trideñ tino.

Plurima ejus Opera cum Exputrgationbus petmittuntus in Indice MAdro: $\operatorname{sen} / \mathrm{i}$ editicann. $16677_{0}^{\circ}$

Varia ejus Opera varis in loxis atque temporibus funt-imprefta.

\section{HIERONYMUS ZANCHIUS}

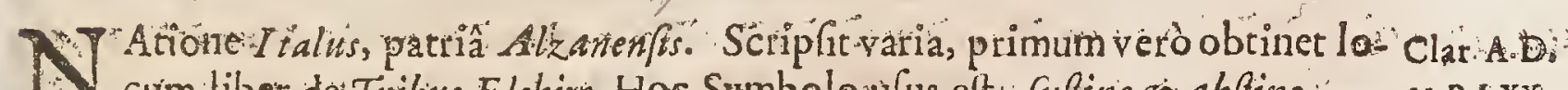
D cum tiber de Tribus Elobirn. Hoc Symboloutus elt; fufinie er abfine. Ex eadem Italiẫ prodiit Hieronymus Zanchinis Bergonias,qui paulo poft Petri Martyris Vermilividifcelfun ob eandém cauffam Argentinamsonceffit; 8 Vermi-

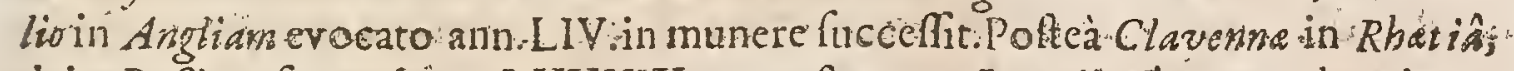

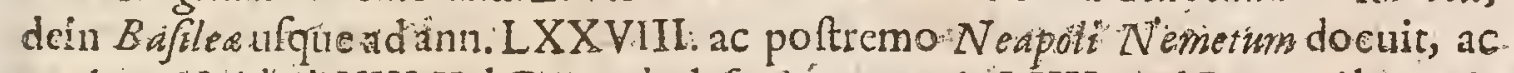
randem Heidelb:XIII.Kal.Decemb defecit an. xtatis LXXV.ad B : Petri honerificè fepultus:Scripjet.multa, qux profund $x$ in Theologicis Atudidis eruditionis: $f_{2}$ dem faciunt; quorum partem, ditim vixit, in licem dedit, partem flii, quos" plures. reliquit, poft mortem ejus publicarunt: Summamque in (cribendo moderationem fervavit, \& à foiffurà olim farciendìminimè fe alieñun ofteridît. Annum quappe agens 70 . Fidei confeffionemad Dlyxom Martineng ym comitem BarchenJein \& Patricitum Venetum fcripfrt, \& tam fuo quàm familie proprie nomine, $[$ fre

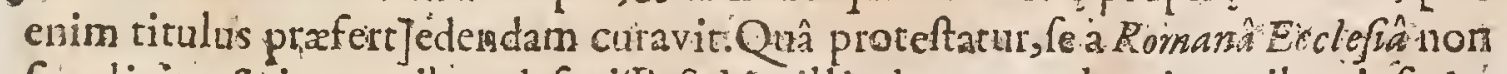
fimpliciter \& in omnibus defecilfé, fed in illis duntaxat rebus, in quibus ipfa de-

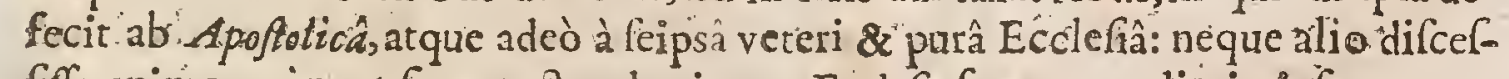
fiffe animo quàm ut fi correcta ad priorem Eccles fie formam redierit, iple quoque ad illam revertatur , \&" communionem cum $e_{\hat{a}}$ in fuis porrò coetibus habeat: quod ut.tandèm frat, toto animo Deum comprecario Quid enim pio civi opta- 
thus quàm ut ubi per Baptifmum renatus eft, ibi etiam in finem ulque vivati modò in Domino? Thman. ad Ann.1590.

Hieronymws Zanchiut multis in te Theologicâ fcriptis libris optimè de Ecclem fấCbristianâmeritus. Abrabars.Bucholcer Index Chronolog.

Vir fuit in Antiquorum Patrum \& Philofophorum Scripris verfatifimus, modeftix fugularis;pacis Ecclefiarum fudiofifimus. Melch.Adam.

Zanchius fubtilifimus fuit inter Protefantes. Labbe de Script. Ecclef.

Vir cruditione, modeltiâ,pietate paucis fecundus. Sanderfon.de ob ig. Confe Pralect.2.

*Hic Huthor Romano Indice inter Heretieos prima Clafls rejicitur.

Omnia cjus Opera continentur 3. Vol. Eol.

\section{A TINUS CHEMNITIUS}

Clar. An. D. Bfulit \&hic annus is86.qui fuit illi climadericus, Martinum ChemmMDLXX. A tiurs Britza, cui Eidelicognomencum, in Vandalia natum, quiliteias pïmas fub Phil. Melandbone \& Georgio Sabino Vitenberge \& Francofordice ad Oderam imbuit: dein fe totum Theologicis ?tudiis mancipavit, in quibus affiduo labore tantum profecit, at port philippi praceptoris.obitum Theologorum Augufta naconfeffo nis facile princepsinter inos babitus fit: Friderico II. Dania Rege, Ludorico Palatino, Angufo Saxone, Goane Geongio Brandeburgico VII. vir s Iulio Brunfuico, aliifque principibus ac civitatib is $\&$ od dinibus huic doctrine addictis in conflim fuper Ecclefranicis negotiis femper adthibitus, aut abfens confultus. Taudem Brunfuice, in quâ XXX. totos annos docuie, tor laboribus defunctis ac Scripris multis ediris V I. Id. April. debitum Narure perfolvir. Thuan. ad ann. 1586.

Brietza fibi egregium decus fut $m$, \& Ecclefia univerfe firmiftrmum fulcrum

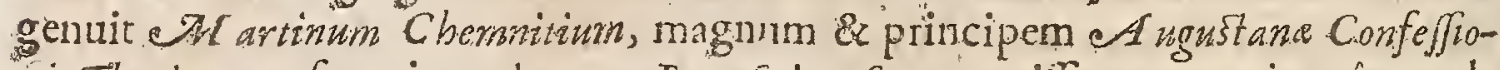
nis Theologura, fuperintendentem Brunfvicenfern graviffum, qui rará excelluit conjunctione fummi ingenii \& fummserud tionis. Utriufque condimentum fingularis pietas fuit \& morum gravicas. Non digrediar in contummati Theologi hujus commendationem, re lauabus tanci viri tenebras potius, quàm lucé affundere vidcar. Scripta ejus vim ingenii \& dotrinæ cum înfgni mo tefliâ teftantur. Fideliffmam autern operam fuam in confribendo libro Concordic praAtit Ecclefix Dei, multifue aliis eruditifimis de verà Religione editis operibus, 'imprimis Harmoniâ Evongelicâ., Examine Conciliz Tridenitn', De duabus in Chrifto aturus de S.C.ena to to terrarum obi celebratifimus elt. Quenfed. de Vir.lllutt.

Inter labores ejus primas facilè obtinet ille, quem dogmaribus, decretis, \& canonibus Concilii Iridentini examinandi \& refurandis impendit, urilem fanè comibus veritatem amantibus. Ip fe etiam inter prinos exti it, qui naturam artes, \& doctrinam Jefuitarum Germans, guantum illis temporibus patuit, detegere copicos 16 elich Adom. 


\section{CEIEBRIORUM AUTHORVM.}

Chemsititunon poftremus eft in Catalogo Hzreticorum; quia examen Tridentini concrliabuli non levirer ipfis dolet. Elias Hafenmull.in Hift. Ord.Jef.

Chernitius wir eximius, atgue acerimus Pontifiarum partium oppugnator. Gul.kivet. V.nd.Evang.part.3.c.6.

Ex. Lutberanis fatis commendari-nequit Harmonizà Chernizio ad Rnporem úque dexterrimè copta, la Polycarpo. Lyforo fideliter continuata, à Gerardo dexteritate \& fidelitate pari confummata; -ex.Pontificis I anferints, ex Calojinian Calvinus. Nic. Walter.in Öic. Biblic.

Gafmarus in virâ Chemnitii memorat, Cardinalem quendam "Tridenti ad Legatum Erici, Ducis Brinfvevicen/s, \& Lumburgenfis dixille, 'neminem in-

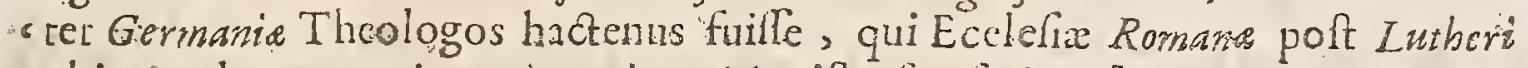
- obitum plus nocuerit, quàn Chemnitius ifto luo fcripto [eramine.Conciizi Tri- dentin. ] Hoc fe ingenuè confiteri, virum admirari, ei eruditionis palmam præ "omnibus Theologis Germanie tribuere, nihil magis optare, quam ur illum via defe aliquando, \& cum iplode toto Religionis negotio conferrepofit. Vid. retiam Konig. in Biblioth.

Examen Cbernnitii, quo Papifnai errores fel iciflimè refelluntur, magno certè Hoco habeadum. Hottinger. Biblioth. quadripartp.330.

$M$ artin Chemwitio, fi quid ego intelligo, inter omnes Theologos Lutheranos eruditionispalma debetur. M Mrtin.Ruar.Cent. I.cpif p.104.

* Mrartinu Chernnitius in Indice appendicis primx Clafis locum ha: Siget.

Georgius Calarninus hôc eum elogio decoravit:

Thagnum Terparum, magni poff fata Lutheri,

Si quern felici Teutonis orbe tulit.

Certe Chemnitius fuit is: monumenta librorum,

Hencule vel dignus quod labor ille probat:

Impia dum Latie decreta examinat Hydra:

Fata Tridentino que parit illa folo.

Entbea Syderei untans \& jura fenatus.

Pugnando Chriti proyrege viltor ovat.

Et bene babet: monftrurs vires quodcingue refumat,

Peftis Chemnitium vincere nulla poteft.

Ecquis erit Semper Martinus in arma paratus?

Alcidengue dabunt facula quaque jum.

Extat cius Harmonia Evangelica inchoata, à Polycarpo Lysero continuata, excufa fol.Erang.1622.\& Genev.1628. $4^{\circ}$. ibid. variis vicibus.

Extat Examen Concilii Tridentini, 4. partibus. Franc. $1596.8^{\circ}$. 
In effgicm ejus, ita Chriftianus Chemnitius:

Sculptum bis lineolis redivivum cerne Lutherum;

Quifquis Chemnitii fcripta verenda legis.
Non obrit primus, quoniam furrexerat alter
Martinus. T. Iures, dic, Bone, mitte, Deus.

\section{GERARDUS MERCATOR}

Clar.An.n. A Nrum 1594. ferè claufitmors Gerardi Mercatoris fuliaco oriundi; \& Ribs M. XX: A pelmonde in Pleumofis nati, qui Silva-ducis fub Georga Macropedio primis literarum rudimentis iniciatus, poftea Louanii philofophicis fudiis ac maihematicis dein artibus fe totum mancipavit, \& admodum juvenis ad fculpendas taburlas animum applicuit, Gemmâ $F_{r i}$ fro preceptore \& auctore, atque inde in familiaritatem $C$ aroli $V$. venit, inftrumentis Mathematicis mirâ arte cjus jufru fabricat is, qux Bello contra Proteftantes fufcepto, dum Cefar Caltra ad Ingolftadium haberet, forruito iucendio liquefacta ac confumpta funt. Pofteà Lovan. Dusisbure gurn cum uxore ac liberis migravit, \& in familia illuftrifmi Willelmi Clivio ducis honoraria ftipendia fecit, \& Cl.Ptolomei tabulas reftituit, ac elcgantifrmè defcripfit. Cúmque de edendis totius orbis tabul is jam a fe elaboratis cogitarets, cognico Abrabarnum Ortelium idem opus urgere, inchoatum laborem inhibuit, donec Ortelius exemplaria omnia fua diftraxilfet, ne aut induntix aut commodis viri amiciffmi precipitatâ fuorum edicione officeret.Poftè jam inclinatâ æxàtead Theologica ftudia animum adjecit, \& Harmoniam Evangelicam \& alia in facros libros confripfit, cum Cbronologian antea fcripfifet ad Solis \& L una curfum exactifinè puratam quam Onufrius Pamoinus harum rerum accerrinus judex tanti fecit, ut omnibis ab aliis ubicunque editis preferre non dubitaverit. Tandem vir to laboribus pro le literariâ exantatis benè meritus, tenio confe Etus Duisburgi, ubi Larem pofuécat, deceffic IV. Non. Decemb. cùmannos LXXXII.menles VIII. \& XXVIII. dies exegiffet.Thuan.ad Ann. 59 f.

Tantâ in $M$ athernatico artes propenfione præditus fuit, ut cibo fomnoque porius ipfi fudium elfet. $H$ ufman.

Matbeinaticorum fui temporis facile princeps, ac Geographorum notri feculi Coryphous audire meruit. Abrabam Ortel.

Mercator Pinacogtaphus accuratiffimus, idemque Matbematicis peritiff: mus: Nic.Fuller. 1.2.c.5.Mifcell.

Temporum emendatilimus Scriptor. Bodin. de Rep.I.4.c.2.

Nulli verò juniorum plus Geographia, quàm fummo viro Gerardo Mercatort, debet. Proxima diu Ortelio laus; quia tabulas ex Hitoriâ omnigenâ utiliterilluItravit; Matbefeos interim Icientiâ neuriquam cum M prcatore conferendus.Voffo de Philolog.c.XI. fect.28. 


\section{CELEBRTORUM AUTHORUM.}

Hoce ego palam de Mercatore, liberéque, profiteor; ex omibus Chronographis, qulos hactenus milhi videre licuit ( miverfos autem, qui extant, $\log i$ ) neminem exiltere, cui ego,jure fanè, Mercatórem tuum(live res (pętes, \&ordinem; five judicium, \& indultriam intueare; five notum coeleftum, quantum ad hæc artinet, animadverfionem confideres) longè non praferam. Onupb. Panvin.in Epilt.ad ho. Metellum praniff.Cbronotog. Mercator.

Chronologiam Mercatoris multum landat Io ephus Scaliger.

Cofmograpbus excellentifrmus vocatur Calvîjzo in Chionologiâ fuâ.

Cofinographus cxeicitatifimus, Mathematicorum fui temporis facilé pritrceps, qui glob:s artificiofis, radio dimenfis, coelum \& terram interius \& exrerius, quà licuir,demonftravit, \& editione Chronologie utilifrmam rei literarix operam prefticit. Abrab.Bubbolcer.Indic. Cinronolog.

Fuit infuper fingularis in eo pingendi,crlandi, fccibendique peritia. Valer. Andreas in Bibl. Belgic.

Verum quidem eft Librum Chronologicum fuille damnatum in Indice Librarum prohib torum à Pontifice., ut \& liber ejus cui titulus Atles Geograpbicus, ejufque Harmonia Evangelica, in quibus crro um \& herefewn ingens numerus occurrit, fi fefuita Pofjevino fit habenda fides, qui contendit omnia Mercaroris Opera plumbers perniciofis ductinis infecta effe; quia moricns confefionem \& communionem ex uflu Ecciefie $C_{\text {atholica }}$ ref puit, contentus confolatione cujufdam Miniftri.qui ad Deum praces pro ip?o fudit. Ant.Teiffer, Elog. Gall.

Gerardus Mercator quibufvis celeberrimis \& Veteribus Colmographis \& Mathematicis aquiparandus fuit, in bfervatio!c Polorum, Climatum, \& Regionum; eadem opera notum faciens memorandis fuis $\mathrm{L}$ abo ibus quot omifiones \& quor lapfus apud multos Profeffione illi congeneres Scriptotes incautos obfervari pofint. Laurenitus Crafjus. Ital.

* Chronologia Gerardi Mercatoris, qux à Sleidano, \& damnatis Authoribus fumpta eft, prohibetut, nifi. emendecur. Index. Rom $x$ impreffius anno i 681.julfu Innor.XI.Pont.Max.

Extatejus Harmonia Evangelica 2.Vol.4‥Duisburgi Cliv. 1593.160j.

Extat Atlas Geograpbicus Amftelodami, i607.16́11. \& aliàs.

In hunc Auvtorem hoc Diftichon compofuit Iacobus Boiflardws.

Hic adeo promptas merces Mercator babebat,

Totns.ut ex illis anserit orbis opes.

\section{JACOBUS BILLIUS}

Denaus, Ábbas Ordinis S. Benedicti, Theologus, Mathematicus, Jurifconful- Clar. A.D:

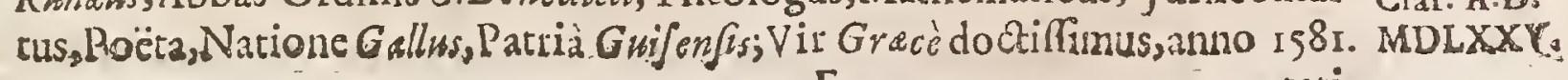
Eece 2 atatis 


\section{2}

xtatis 47 Parifin obilt. Multos vet. Gracos Patres eleganter tramfulit, notifque illuttravit. Edidit etiam formulas Gracarum Locutionum:item Antbologiann Sacram. Carmina ejus extant. Sacra Obfervationes.

Eos produxit ingeni fretus, quibus \& Cummo beneficio Rempublicam Cbri-

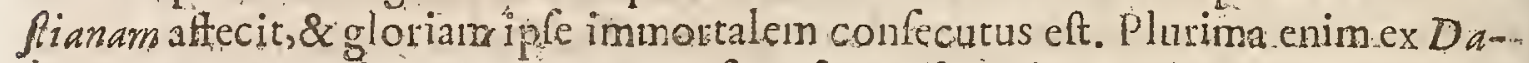

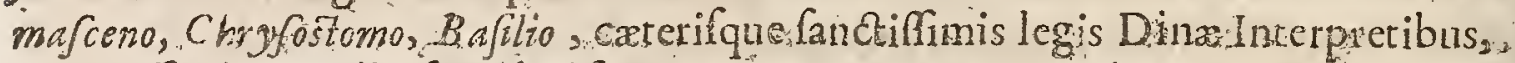
ac potifimum ex illo fingulari fcriptore $N$ azianzeno qui Theologi cognomen eft meritus, deetirimè fideliniméque tranfulit. Plucima \& fuo ipfeingenio meditarus eft. Cumquetous infribendi labore femper fuerit, tamen, que fuit ejus . verè (brifriana modefka, nullum unquam atrigir, ne tum quidem cum verfibus . Gallicis animi causíl luderet, quin ad pietatem \& Religionem pertineret. Catera omnia tanquarr Auxa \& caduca generó. quadam animi vigote contemnebat Utebatur faniliariter Gilberto Genebrardo, viro doetiffimo, cujus in xdibus Lutetia dum valetudine parùm firma hofpitatur, \& Gregorianaverfonis nuper à fe. recognitæ novam editionem urget, fub exitum anni is8r. palt longa morborum * tædia e phthifi randem octo \& yuadraginta natusannos interiit, elatufque eft ad Severini fanum \&i pis eruditoun epitaphiis confecratus. Samarthan.

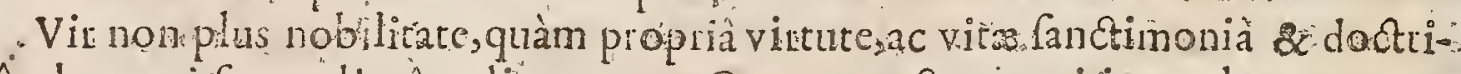
nầ ab omnifuco alienầ, linguxque Græcx exada cognitione clarus, quam in veteribus Parribus illuftrandis pxeipuè exercuit. Thuan. ad Auv. 591 .

Verbis ille paribus fententiäs aptè \& fideliter comprehendit; flylo certè non-

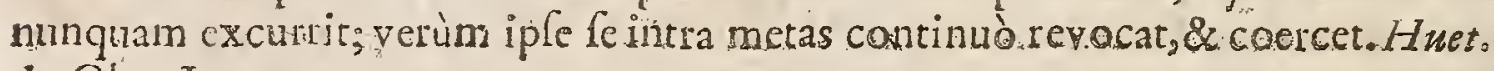
de Clar. Interpret.

Obfervationes Sacras elucubravit, qux manifeltant illum inter fui Seculi primos Criticos cenfendum elfe. Ejus Antbologia in pretiöadhuc eft. Pofferinus. air plufquam quinquaginta annos poft Doctum illum Abbatem nec vifum nec videndum fore virum yuemquam Graca lingux adé perium: Quodelogium aliquatenus immodicum videtur. Iudiciun Eruditorum per Dominum Baillets. 1685. Gall.

lacobus Billius $V$ ir fur honeftifimus; folida erat ejus fcientia, \& preter Dom Etorum Linguarurn perfectäm notitian, Patrum \& Theologid Doetrina inntuctus. erat Preterea nilhil erat ii Mathernaticis nequein I urifprudentia dificile, pulchrum \& fublime, uod ipf familiare non ellet. Erat infuper Poeta Latinus \& Gallicus, cujus inmictumargumentumfunt Poemata ejus qui nobis fuperfunt.. D.Moreri: Gall:

Billius fuit doctus. Scalig pofterion.

Exrat Antbologia Sacro, Octoltichis Verfibus; cum Scholiis. Parif: is750.80\%

Extane Sacraum Obfervationum libri 2. Parif 1585 .

Extant Norenin I fadori Pelufate Epintalas. 4eidelb. 1605. 2if

Extat Vita Gregorii Nazianzeni, cum Verfione \&Scholiss ad Opera ejus. P a FRAN 


\section{FRANCISCUS H.OTOMANNUS}

19 Arifis natus eft Anno Dom.1524. Obiit Baflex anno 1590..

Varia compoluit de Jure \& aliis ad antiquitatem pertinentibus; quæ, uti Clar.A. 0. ab" authore ante mortem recognita \& digefta erant, ita polteà facobus Loctius MDLXXY. publicavit.

Francifcas Hotomannus, Jurifconfultus clàrlfimus, Heftoriatungue \& totius Antiquitatis Coientifimus, clawit Geneva Allobrogumanno 1573 . quo 1 us Civile ibidem docuit. Multa ingenii fui reliquit monmenta, quibas in atenum victurum nomen per univerfum ubem obriner. Boiffard. in Icon.

Erat omnins ille vir [ Francifcus Hotomanrus] habili \& focundongenios. varique eruditione, acpotifimum esiniâ quadam în Rornanorim fure illuftran-: dofacundiâ confpicuus. Quod \& pofteris pluxima ejus Opera fptendidiflmè fripta magis ac magis indicabunt. Scavol. Sarnartban.

De quibus vide coum Commentavia: Hotsonanmm prefertim Jüifconful] sum eximiè antiquitatis gnarum \& Juifprudentix myltam ferè iccomparabilems. Gajpar.Barth.Animadv.ad Gratiz Cynegeticon, V:374.

Erancifcus: Hottomanustinter principes elegantiores Jürifonfultos ferè princeps. Idem l.zadkerfar. c.j.

Francifaus Hottomamus vir de Jurifprudentia fimul \& literarum omni genere benemerianmus I dem ibid.1.4 6. c. 9.

Francifcum Hotomannum, majorem Junifconfultum, ancriticm el egantio rem, dicam, nufcio. Videat mith quis obfervationes illius, in Ciceronis Oratio nes, \& Cafaris monumenta Commentarios: Sty fum ejus confideret; redivivum in Gallia Severum Sulpicium, vel cetam Ciceronem, veriflimè discrit. Gafp.Sciopp: de-Art.Crit:pre.

Policiflmus fuavifimaque" apud omnes dötos memoria vir, Erancifcus: Hotomanzus quô lol meliorem \& dostiorem non illuxit alterum. Galp. Sciopp:l.t. Verinmil.c.

Antiquartis eruditifimus vocatur Rosno Antiq. Rüm.

Hotornanma fola dictio Latina commendat ac eloquentia. Carara valuare ingenivin, Scaligerana r.

Hoionant Francro-Gallia bona eft" : in hac ipfum jur " Eft in Catalogo " Binum Fulmen, an fot Genevie, rolo, an fot bujus Vrbis, neemas Fulmon brutum, liber mifi donatus ab ip o Hotonanno, et praclarus liber, multa bona dicit; fed multa addita funt in editione Leydenji, proftat Genevenfis. Siraligerana 2.

Supe:eft ultimum eaput quod de Parlamentis jurididialibus Fottomannis dicir:\& quia ifto capite colophonem impofuit fuis conviciis, injuriis, \& famolo libello, qui Régibus, Reginis, Pontificibus, Ducibus \& hijufmodi non pepercit, noluit cærevis parcere. Et certè tam fpurcæ lectionifinis fpurcioraddi debinit : \& quia tam malè coperat,pejus us funiret, quum erat. Itaque plurimum afficior Ecese 3 cism 
cum videam egregium Jurifcon utrun unico libello nominis \& famæ jacturam \& natragium feciffe-- Plura ego, led quia non eft noftri inttituri, hec lufficiant. Ex quibus manifeltum efle omnibus exiltimo, ut fuperius diximus, totam Hotomanni orationem plenam elfe feditionis, fycophantia, mendacii, rebellionis: aihil in eâ pium, nihil homine Cbriftiano dignum, niril denique preter verborum fucum, Ant.Matharell.ad Hotomani Francogallo ann. $1575 \div$. primin editâ. relponfione,c.2o.

In famofo libello Erancifci Hotomanni plus iracun dix clt, quàm feientix: \& qui Juriconfultum fe elfe profiterur, graviter in co peccat, qu d jus fuum tribuit nemini: nifi fortè antiquato veteri jure, novum nomen, \& adhuc inaudicum Hotomannice fcientix civibus fuis exul mitrit. Exfulem ellet turpe.eft, \& patria nifilomints defiderio teneri, cujus motes, ritus, leges, intituta plnimum damnes. Multa \& annalium monumentis de Francis \& Francogalliâ ad mendacii fui defenfionem \& opptgnationem factolancte veritatis prof rt. Io. Papir. Majjon.in judic.de Hotoran. Francogal quod Ant. Matharelli refpontopramillepericui:

Velilli ipfi qui aduerfus ip.um feripferunt fatentur illum miltx lectionis \& recondira eruditionis virum fuillé. Anton. Teifjer Elog. Erudión. Gall.

Francifous Flotomannus ut alioum Plagio laderetur;ipfe fuis in BriffaniumTurneburn, Cujacium, Connanum, Corafum, Budaum, Ravardum, Petrum Fabrum, furtis meritus videfi queat, non obfeuce accufaris ab eo, quem hic ulimum nominabimus, Petra Fabro,ut de noftrâ in cum fufpicione nihil lầc dicamus Thomas.de Pilag.num. 469 .

Hotornannus cX Paf chaliz libro de Legato omnia furatus eft Scalig.2.

*. Huic Hotomanno nonnulli Sixti Y. Brutum Fusmen in Flenricum Regem. tribuunt. Hoc libro Hotomannus tantam apud Pontificios init gratiam, ut in primà clale prohibita fint omnia ip fus Scripta in expugatoriis ipforum Ind cibus. Konig.

Prodiit liber dePopuli Romani Legibus. Bafil. $5177^{\circ} 8^{\circ}$.

Prodilt liber de Populi Romani:Re Nummariâ. Genev. Ij8jo. 8 .

Prodiit Franco-Gallia. Francofurti 166 j. 8.\%

\section{BENEDICTUS ARIAS MONTANUS}

Clar. A. T. WDIXX.

\section{TI Ispalenfis, obiit ann. 159.8.atatis 71. Vir toto Otbe celeberrimus, qui 73 ibtits Regiis Antuverpia prefuit.}

Screppta ejus funt:De optimo Imperio, five in librum fofux Commentarius De variâ Republicâ , five Commentarius in librum fudicum -..In $3 \%$ priores P.almos Comment. - In 12.Prophetas Minores Comment. - In Ifaiam Comment.Elucidatiunes in 4. Evangelia, in Acta Apoltolorum, in omnia Apoltolica Scripta - Commentin 7. Epiltolas Canonicas - Comment. in Apocaplyfin- 
Antiquitates fudaica-Rherorica-Poemata Sacra-Comment. in Pfalmum ss.--Apparat.s in Biblia Regia.

Benedillus Arias Montanus lingux Sanctre apprimè peritus,ac fummè pius, Bibliis Complutenfibus elegaritiore formâ recudéndis à Pbilippo II. definatus, Pyregiam admodum operam in corum editione cum Fabritiis Boderianis F ratribus Falezianis Antvverpia navavit; unde fibi æmulos tanto odio accendir, \& in His Leonem Castrenfem, qui de Septuginta Interpretibus Commentariun fcripfit, ut ad caufam dicendam citatus Romarn, vix veniâ impetratà, pro tantotum laborum premio feceffum in Baeticâ. fuầ, in quo fe bonâ conlcientiâ fretus facrorum librorum lectione ac lueubratione folareur, acceperit., Thunn. ad ann. 1598.

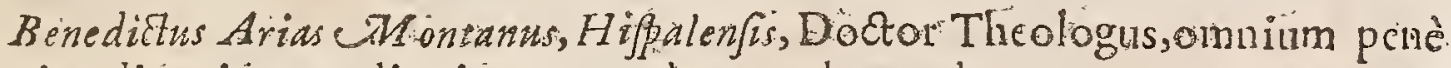
gentium lingulis atque liceris raro certè exemplo excultus, nomen cum omni poIteritate adrquavit: nam prater Graci ac Latini fermonis eleganciam, aliarum linguarum notitiam paraverat, ut Cboldai, Hebrai,Syri, Arabes \& his affines illo yel interprete; vel Magiftro uti potuiffent. Taceo omnis Philofophix act Thoo $\log \%$ cognitionem, vita que integritatem. Aub: Miraus:

Fatchdum eft, Arian Montasum fuilfe virum magnum, deque Eccleffä, Biblio. rum imprimis Regiorum opere[quorum illum curę.Pbilippus. II. ejus nominis Hipania Rex, prafecerat ] praclarè meritum. Voll.de.Scient. Mathern. pag 303.

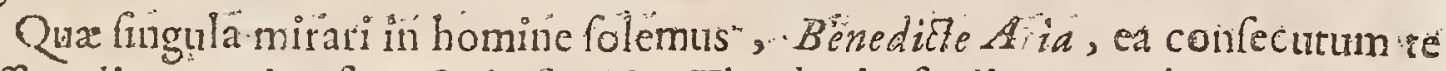
poftum dicere univerfa. Quid fan tius Theologix ftudio? at tu inter principes Theolog. jure cenferis. Quid in ipfo Theok rarius, quàm peregtinarum linguorum fcientia? at tu non dicam benè Grocè calles aut Latinè; fed Hebrai te, Syri, Chat-

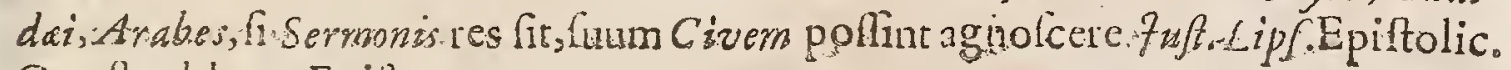
Quxtt. lib.4...Epilt.I.

Duplici dolore \& quafic ictu furn affectus, cùm tram Epiftolam accepi. Etra priorcm nou tam intulit ipłamihi, quàm illatum renovavit, mentione mortis Aria Móntani noftri, ômagni rarique viri, \& nobis etiam longinquis \&"exteris. ob virturem \& doctrinam chari! Lipf:Epift. Cent.ad Hipan Evilt.60,

De me, ac de meolatore \& induftriầ (quantulactuque eft) mhil proficeor? Hoc tamenumum recenlebo:me fcilicet, continuò immortales Deo'gratias agere,

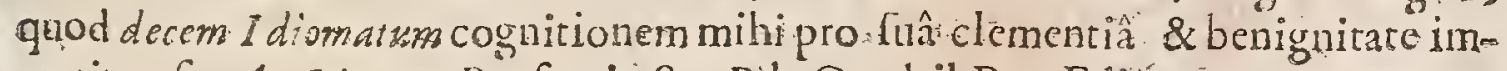
pertitus. fit.Ar.Montan. Prafar. in Sac. Bib. Quadiil.Reg. Edito.

Arits . Mn ontanus vir doetus erat, ejus Anti uitates Judaicas qua vilis pretiíoptss funt. Singularem habebat Religionem ut Rapbelengins Pater de Scaligero dixit: Impendiè laboravit in furis ad. Ancuerpiana Biblia majora Apendicibus. Scaligerana pofterior. Gall.

Poft $P$ agnini verfionis examen, colfentaneum eft ur heic fubnectamus judfos ciun gurod ferri debet de Arix Montani Trantlatione quxe in Bibli is majoribus Pbilippi II. excufa fuit, \& pottea denuò imprelfa in Polyglot is Anglicanis. Ei laris fuii Pagnini verfionem recognolćere, hancque reformare !ocis illis quos ad 
literam fatis non elfc.cenfebat. Sed meritò dictum fuit, dum fermo erat de Arice Montani correctionibus, Quot correctiones,tot corruptiones. Tantum enim abeft ut viria que plurima erant in verfione $\dot{P}$ agnini, abltulerit ut illa porius multiplicatverit. Ejus tamen methodu, vulg approbatur, quoniam inhoc opere esum tanrim particularem utilitatem refpexic qui Hebraar ligguamaddifcere cupiunt; Ideoq; alperintemin phrafibus anxiè non vitavit, quoniam ad Grammaticę rigorem textum fuum interpretabatur. Doctus jille vir qui fuperius Pagnini verfionem ut eximiumopus nobis commendavit, Conflium etiam Aria Montani ratum habuit, in ejus favoren dixit, illum fide, is Interprer is laudecontentum iíque proficui qui Lingux Hebrai rudimentäincipiunt, ignorantium obtrecta-

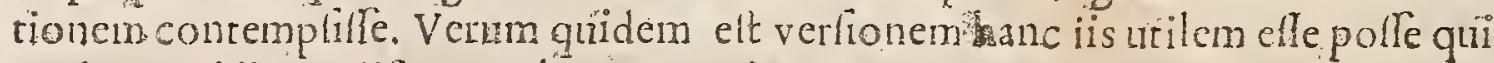
Hebram idiona difcere volunt, quoniam Hcbreum textum veibatim \& juxta Grammaticum fentum reddit; fed non tamencen'eo Lriam Nontanum Fidifsmi Interpretis Elogie infigniendumelfe ; contrà enim jure multò magis cum co agctur fi neptifirnus nterpres dicatur. An accarati antecpretis titulus ei concedi poreft Tranlarori, qui ferè ubique Testus fui lenfum evertie. Et re verä, omnis ejus cudirio verfatur in Hebreis vocibus ad literam justa ear um ufation fignificationem converterc, non atrendendo an locis ubi hanc ufurpatcongrua fit, "ncone. Cum L ebrea vocabula funt aqu wuca, rationem habere convenit, ut mihi quidem videtur, fonificationis prout aprahre eflocis in qubus occurrunt, \& ridiculumeft quamlibet fignificationem temerè ufupare, five confentanea five dillentanea fuerir. Hoc tamen vitumin tota Arie As on ani Verfone regnats in quo parum judicii oltendit---Verbo ut ablolvam, fi quis dignetur fingulas Aris Montan correctiones perlutrare, is deprehendet illum ut tywonem potius quam ut limati judicii virum Biblia cotavertife. Nec parum mirari fubit quòd Waltonus Verfiener ejus cxteris omnibus antepofueit , \&illam in Anglicana Relyglorta inferuerit, in quibus potiori jure locum obtinere debuilfer aliqua alia đqua vocum Hebraarum fenfum expreffillet, nec tamen à litera longè abivillet, Urat Presb.Rich.Simon, Hitt. Crit.V.T.l.c.20. Gall.

Bersedictus e rias M ontanus, inter clarifimos fippanos meritè repomendus, prater alia ingenii monimenta, ad $P$ oef frn quoque locupletandam fefe accinxit-a- Ecclefrastermeddidit Epicis, in quibus nihil otiofum, rumenfve, ninil

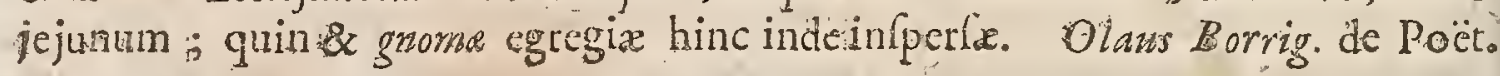
P. : 23.

Arias fapè Pagnini veranem temesè loco movet, \& pro bonis Pagnini prava ineptaque fublituit. eA rnold. Boot. in Animadverf. Sacr. ad Texr. Hebraic. Vet. Teft.

* Corrigenda in co funt pleraque tam in Commentatio fro in Efaiam, \& Comment in Prophetas minoves, yàm in Elucidationibus in quaruor EvangeWia, \&Acta Apoftolorum, \&in omnia Apoftolorum fripta, \& in Apocalypfin nec non in libro Generationis \& Regenerationis A darn. Index Madrit. Imprelt: A.4n.1667. 
Ejors Apparatrs in S:Biblia, extat inter Biblia Reg.Hiff.alia ejus Opera variis temporibus atque locis funt impreita.

\section{Hoc ejus Epitaphium:}

\section{Deo.Virentium S.}

Benedieti Arix Montani Hilpal. DoEtoris Theólogi, Sacrorsm librorim ex Deibeneficis Interpretis eximii, \& Tefinonii D.N. Jefi Chrift annuntiatoris Seduli, Diri incomparabilis, tisulis cunctis majoris, monumentis auguftioris, offibus in diem Refurrettionis I ustor un affervatis, cum honore D. Alphonfus Frontiberius Prior Conventüs S. Jacobi. Hilpalenfis, in Prioris quondam Jui opt.neriti memeriam P.C.anno R.D C.V. obiit anno C1310. XC III. atat. IXXI.

\section{MARUUS ATONIUS MURE'TUS}

CAllussex dicecef Lemovicenfí, eruditorum fui leculi facile princeps, frue

I Prec ptore, Latiné Gracéque doctifimús evalit. Parijais, in Collegio Cardinafis Thi onachi tertiam claffem rexit, cùm Buchananus fecundx. Tünebus verò primz preclfet. Hinc, fortunam magis optimam fectatus, in Llaliam abiit, \& Veretiis primò, dein Rome in pretio habitus, obiit anno is $85 . x$ tatis 37. Hofman.

Scripfrt Orationes: Varias Lectiones:Poëmata: Emendationes in Terentium, Horatiom, Catullum, Tibullum, Propertium, Tacitum, inque Senecam Philolophum: Epiftolas: multaque alia.

Marcus. Antonizs. Muretitus, magnum non folùm Gallie noftrx, fed ipfius Rome lumen. Thuan. Hif.l:So.

Ingenio præftanti \& ad-mnia nato prèditus; quod in politiori literaturâ pre cipuè exercuit, utrìufque lingux peritiâ clarus, \& Latine écribendi facultate intîn gnis,ad qux omnia acerrimum judicium attulit. Thuan.Hift.1.82.

Quis non miretur hominem Gallum \& quidem in Lemovicibus natum, fuo jpflus ingenio \& abfque ullà̀ Praceptoris operâ eruditum tantos in literis fecille progrefflis,ut prater exactam Grace lingua fcientiam ipfis etiam I talis peculiarem illam Latini fermonis laudem unus eriperet? Neq; verò id Auretus in Oratione folurâ folùm, fed in verfibus eriam aflécutus eft, in quibus tam erat Catallo fimilis quàm ipfe $C$ atullus fibi. Accedebat ade cellens \& divinum illud ingenium incredibilis morum candor \& urbanitas, qux mirificâ fuavitate hominum animos afficiebat atque attrahebar.Scavol.Samarthan. in Elog. Gallor.

Nihil unquam (mirumdietu) bis feribebat Muretus, vix adeo bis legebat id ipfum, quod féipferat; rarò interpolabat, non fxpè mua abat aliquid, rarius demcbar delebárque: ìta, cùm uno quafi tenore fluerent omnia, nihil nifi aptum \& accommedatum ad manum mentémque venicbar, ut multe meliora fortuitò illi Ffff exeide: 


\section{8}

exciderent, quam alii, qui candem incudem affiduè tundunt, excudant labore. Andr.Schott. in Vitâ Mureti.

$M$ arcus Antonius $M$ uretus, vir cumprimis eruditus, $8 x$ quin his literis nofris meo judicio familiam ducig. Lipf 1.2 War.Leet.e.

Vir in quonon eruditio. folùn varia, fed comitas etiam \& lepos multus.I dem: de Rect.Pronunc. Ling. Lat.c. I. Numr:33.

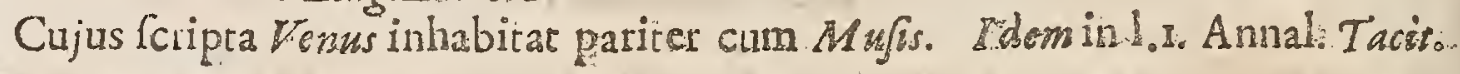

Niureturn ego novi,virum ingenio \& eloquio fuarem , judicio fapébonum, ambitioni, non lemper extraneum. Lip. Difpunct. Not. Mirandulani Cod.

Vir cùm omni liberali eruditus doctrinàgtum criam fingularieloquentiâ proaditus M.Antonius Muretus. Tirrteb.Adv.1.14 c.6.

Hic Latize. Orationis facundiâ tantam fibi apud omnes gratiam conciliarat ut ejus ævi quafi alter Tüllirs concordibus Italia. vocibus acclamaretur.Io.Imperial.

Edidit Varias Lectiones, quibus nihil uberius, nihil elegantius fingi poreft.Ko: nigin Biblioh.

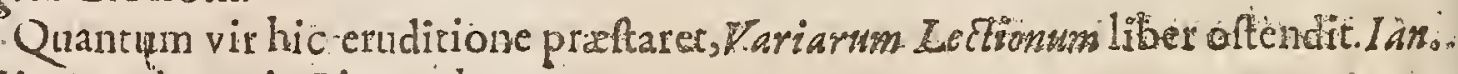
Nic. Eryibraus in Pinacoth.

Mureti-Epiffola lectu dignifima. Gefner. in Bübliorh.

M. Antonius M uretus Lemovix , eloquentiflnorum nofrar atatis hominum: numero jure adfcribendus eft, curi pura, nitida, \& el gans Oratio; æternam nominis gloriam peperit, prater ejus multiplicem eruditionem. Gul.Rovit.in promtom Icon.1lluftr.Vir.

.. Pauci funt in Mundo Aureti-; qui fi tam benè crederet in Deum quàm optimé perfuader er elfé credendum, bonus elfer Chriflianus. Doleo obiille $M$ ureturn, de cujus morte ad me fcripfit Cuiacirs. Animus erat eum reprehendere in muliös quæ pe optabam ab co videri. Scalig.r.

Muretus fcilbebat promptiffime, $M$ wretus etiam illam Italorum rationem Cribendi fufam fecutus eft: $M$ ureto nullus fuit poft Ci i eronem qui expeditiùs loqueretur \& fcriberet Romiané : Lip suts nihil pra illo, \& invidebat illi, furat eft emendationes Benè intelligebat Ariftotelis Rbetorica. Quid elegantius ejus Oratione de Tacito \& aliis ? Scalig.2.

De ip? tandem hoc jure:optino proditum z quod in pangendis carminabus Tibullo conferendus, in prola Oratione recentiorum cuilibet praferendus, fcientiarum porrò atque in primis Jurilprudentix gloria haud inter grcgarios colluw candus, Gallica preconia infigni, nec interiurá laude cumulavit. I oan. Imperial: iin Mur.Hift.

Jef. Rapinus eum in Odis fuis fatis liberum non elfe exiftimat hoc aurtem vitium inde obiri quòd elegantiori Latinitati nimis follicitè ftudeat. Rapinus, Generalibus ini Poeticam Animádverfroribus, Animadv. xxx. Gale. licè.

Balzacius CHuretum juremerito culpat, quod ea omnix eneratione \& ho neftate 


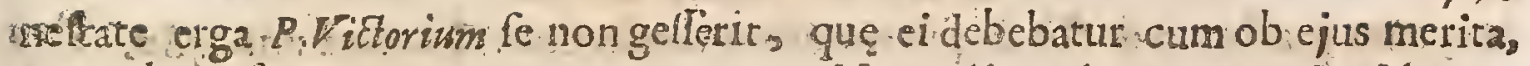
zum ob ejuldem provectiorem xtarem; Nam aliquod variarum Lectionum fuarum Caput exorditur eum mendacii quadantenus arguendo, Falfume est, inquit ginod aît Viclorius. Sed culpa multò dignior elt quòd $S a n-B$ artholomeanam. Bragcm laudawerits perinde ac fecit Oratione in laudem ('aroli I X. Rome prozunciata. Ant. TeâjfferElog. Gall.

Nom minù quidem ornatus [Dionyso Lambino] Thartinus A Antonius

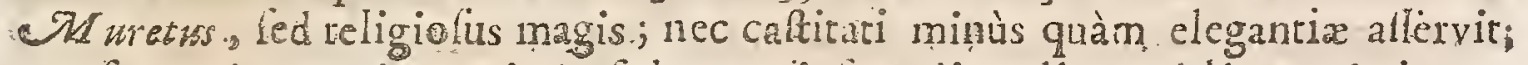
sec fententiam mod., exprimit, fed genus ipfum dicendi; quod licet, imitatur. Quòd fi plura inco genere elaberiflet, i. ter multos Interpretes propè fingularis extiriffet; fed tantum detra,it ex gloriâ,quantume, eo ftudio decerpfit. Huet. de Clat.Interpret.

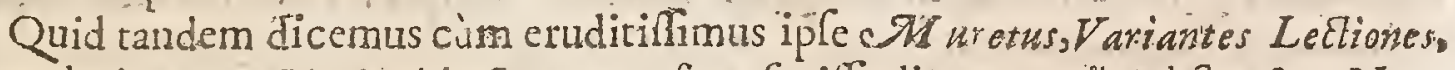

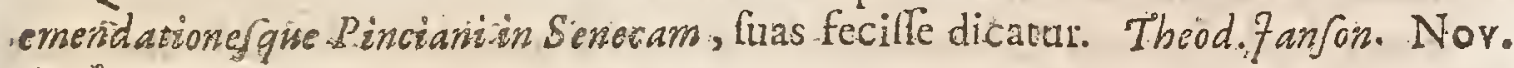
Antiq.p.27.

Varia ejus Opera variis in locis atque tempotibus funt imprella.

Obiar Rome, ac fitus in Sepulchro, quod in . Ede, Deo trino \& uno, in Colle fijortormm, dicatâ, fibi vivens extıuxesat : Ubi ejus Epithaphium pofuit foulius Rof of cins: :

Hic Marci caros cineres Roma inclita Serriats

Unod patria optaffet Gallia babere finu.

Stat calle Hortorum, tumulus stat proximnis aftris.

Que propitus puro comizit illo animo.

In facros latices lacrymans aperge, Viator.

Et dic, beu! lingua fulmina fracia jacents.

\section{JACOBUS PAMELIUS}

A Udornaropolitana Urbis Epifcopus, natus eft Brugis anno Dom.IS36. 3. Clar. A.D. Gili Baronum de Pamele Atipe.Montibus Hannonia obiit Anno Dom.1587. æta tis fure $52 \cdot 13 \cdot$ Kal.Oetob.

Scripta ejus hæc funt: Commentarii in Tertulliansom-Commentarii in $C_{y-}$ prianum - Liturgica Latinorum-Relatio ad Belgii Ordines de non admittendis unâin Republicâ diverfarum Religiontum exercitiis_-Micrologus de Ecclefratticis Obfervationibus-Caffodori divina leotiones_Catalogus Commentariorum Veterum Selectorum in univerfa Biblia -Commentarii in librum $I$ thdith_Commentarii in Epiftolam Pauli ad P bilemon.

facobus $P$ amelitus, vir \& facræ Antiquitaris peritifimus, \& cum multis fcriptiss, quibus eam illuftravit, tum uñ \& alterâ Tertulliani \& B.C.ypriani editione 
magnam gratiam 2 do ais \& piis omnibus confecutus. Thwar.ad ann.15:9;

De Tertulliani \& Cypriani Scriptis oprimèmeruit. Konig.in Biblioth.

facobus Pamelius, operibus fuis, Notis inprimis in Tertullianu \& Cyprin:num, nomen imnortale promeritus. Hofman. in Lexic.

Parnelii in jlluftrando Cypriano diligentia longè majaribus encomiis digna foret, fincerum \& sullis partium prxjudiciis addictum animum attuliflet, nec: primitiva Ecclefre.ftatum, invito Cypriano, ad hodienos Ecelege Romana mures. accommodace laboraller. Alta Eruditorum Vol.2.p.42.

Iacobus Pannelizis, vir cum primis eruditus-Ejus induftriam in difponendis Cypriani Epitto is cum magnoper commendemus, haud tamen pollumus cidem in omnibus affentiti:nam ad exactam rationem tempor wn hiftariam contextentes interdum aे pofito als co ardine cogimur refilire. Id iph viventi minimè difpli: cuit.Baron. Tam.2. Annal.

Tamelius doctus fuit \& bene fripfrt: fuit nobilis, valate modeftus in noftros:ita credebat ut fribebar : etiam Goulartizes in Gyprisno modeftè. illum tractat. Scaligerana 2.

Doctiflimus $P$ amelizss vocatur: à Lipjac.

Optimum officium ab co in Ecclefiam \& in rem Citerariam profectum, in Tertul.\& S.Cypr.editionibus pofem eft, quorum Opera novo ondine digeffr, iis 2dditis novis tractarib. anteanondum evulgatis. Dactos etzam commentarios in cadem elaboravit, ex quibus judicare convenit eum Antrguitatis Ecclefiaftica cognicionem amplam habuiffe, \& non mediocrem Critiens suiffe. Indicia Eru ditorum, Parif: 655.per Baill. Gall.

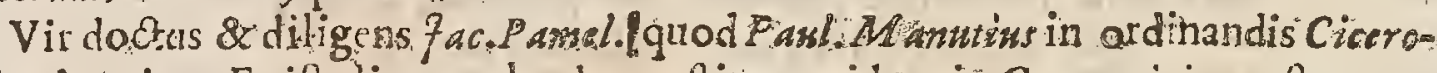
nis ad Aticun Epiftolis cum laude praltiterat, idem in Cyprsanicis praftare co. natus eft. Et huic Sparta, quam fufceperat, adomandę, magnam adhibuit diligen-

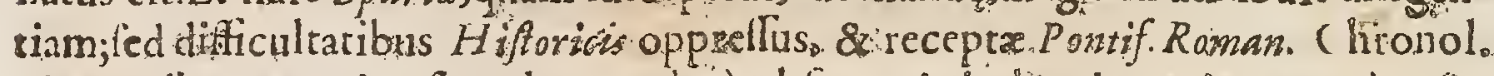
nimis adherens, etiamf multa preclarè ofervavir in hud paucis tamenà recto tramite abcrravit;quod in Vità Cypricini ab iplocollectâ clari s clucefeit. Ordinem a $P$ amelio edium aliquories corrigereconatus eft illintriffmus $C a r d . B a$ ron.fed non multum pretitit; \& Historiam pluribus erroribus maculavit; . Foan Pearfon. Epifc. Ceftrienf.in Prafat.ad Annal. Cysram.

Prodiit ejus Kitwale Sanct. Patrum Col.ann.5676.2. Vol $4^{\circ}{ }^{\circ}$.

\section{A B RA H:AMUS. ORTELIUS:}

Char. Ar.U. MDLXXV.

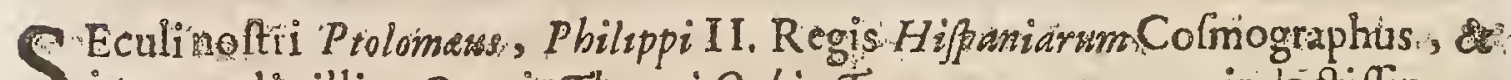
$\checkmark$ immonalis illus Operis Tbeatri Orbis. Terwarum autor, vir doctifimus, humanifimus atque integerrimus, natus, eft die decimo Aprilis, ann.1527: Anto verpia. Obiitibidem die 29. Junii. St. N 598 . xtaris 7 cùm fapè iu murbo. fuo

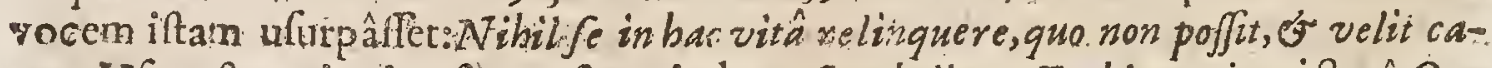

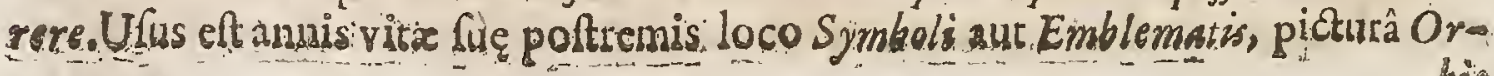




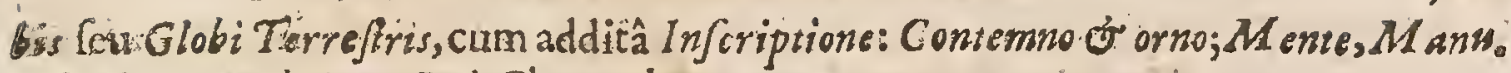
Abraharn. Buctolcer. Ind.Chronologen.

Scripta ejus hixc.funt : Theatrum Orbis Terrarum-Synonyma Geographica - Thefaurus Geographicus---Aurei feculi Imago, in qua Germasorum veterum vita, mores, Regio cum Iconibus - Itinerarium per nonnullas Gallia Belgica parres-Deorum Dearumyue Capica ex Ortelit: Mulro-Syntagma Herbarum encomiafticon, earum utilitatem \& dignitatem declarans.

Abrabarnus Ortelius, Cofmographus ad miraculum ufque politifímus \& laboriofigranus. David Chytraus, iu Paraphraf. Pfalm. Buchanan.

Ortelius in Theatro Terrarum Orbis, omnibus fitam probavit induftriam,

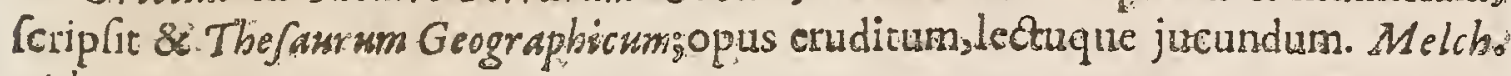
Adam.

Abrabarmus Ortelins rei Geograpbic ab ine unce atate fudiolus maximè eam partem nulli labori aut fumprui parcens illutta vit:neque of id percgtinationes longinquas kufcipere; ac multoties totấ wità repetere tecufavit : ediro pulcherrimo Orbis Texararm Theatro, \& renovatà antiquorumlacorum per Tábulás prow pria induftedã eleganter depictas memori ¿synonymorum que ingenti opere editos. Thrian.ad an.isgs.

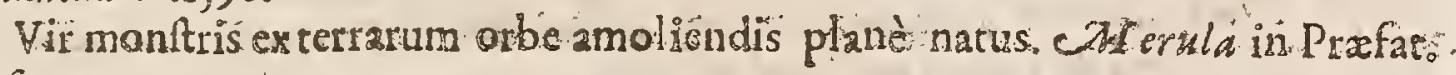
Colmogr.

Edidic etian Ortetins Theatrm orbis terrarm, librum, ut omnia ejus for

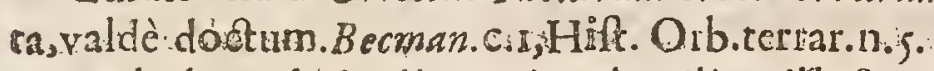

Tabulas ex hüftorià omnigenâ utiliser illuftravit, Marhefeos interim fcientiâ. neutiquam cum Mercatore conferendus. Voff. c.2.de Plitog, lect: 28 .

Arrio: 575 .clari erat nominis Abrabaynus Oritelius Aatuerpianus. Quod déinteps femper auxit: Pracipuènomen peperie Theatro Orbis Terrarsm, ac Parergo Give Tabalis Geographie vereris, \& Synonymis Geographicis. Etiam Antiguitatum earum valdè fuir ftudiofus, que ex nummis vetr. Gixacis Romanifque cognof cunsur uti quoque ex Saxir antiquis. Vof].de Mathem. Scient.pi2 ;9:

Vir erudit finus arque probatillimus, deque ftudis Geograpbicis oprimè meritus Abrabsenus Oxtelinis. Cafaubiad Bäron.Ann; 3 c. Num:68.

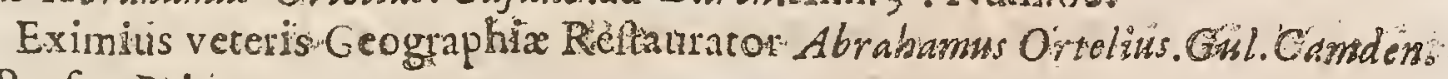
in Prafar. Britan.

Thefaurum abs Te,mi Ortelzyvidi \& in parte légìnverè Thefaurum. In eo habes quicquid Grecra aut-Latìim habuit, in eâ quidèn argụmenti parte: Place

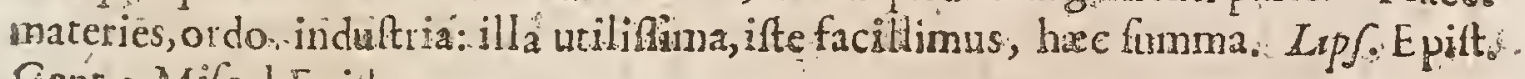
Sent.2.Mifcel.Epitt. 7 :

Theatrum tuum, Orteli,vidi: \& vis me verum dieere?nefcio an à multis annis cujufquam labor utilior fuerit in vulgus. A Abeant illa infinita Tabula Charta. Lipf.Epilt.Quaft.1.4.Epift. 4.

Ortelium ego non tam Reginm Geographim-; quàm'Regem Geographörum ap. pellare foleo: Marc.Veilfer.

Varia ejus Opera variis in locis atque temporibus funt impreffa. Efffi 3 
Hoc ejus Epitaphium, fouflo Lipjo Auctore:-

A Crabami Ortelii quem Uibs Urbium Antrerpia edidit, Rex Regum Pafilippus Geographum habuit, monumentum hîc vides. B revis terra eum capit . quîi ipfe Otbcm tertarumcepit, Atlo, \& tabulisilluefravit, fed mente contempfit , qua Coelum, \& alta fufpexit, çonftans adverfum fpes, aut metus, amicitia cultor, candore, fide, of ficis, quietus culter, fine lite, uxere, prode, vitam habuit quale alius votum; ut nunc quoque in ærennâ requiefcat, vo-

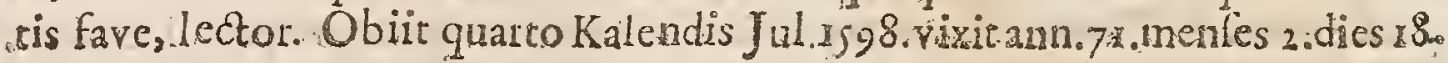

Ife Tepbus Scaliger in memoriam Orteliz hos Epitaphinum Ptruxit::

Quid primwom, Orteli, guid funmom peclore promam

Ruo poffincineri folsere jufta tuso:?

ExGiturus eram doclas in Carmana Divas;

Carriñna funt meritis inferiora tuis.

Impendendus erat musadus, Sed peictore mundum

Cepistiz laudes non capit ille twas.

Laudibus ergo tuis melius defifsere. Abunde

Laudatur, cur baus mulla, fat:effe poteft.

Aliud, Amkore Balduino Cabillavo S. Jo

Hic futus Ortelius. Buffi me fallst imago::

Qui jacet bic umbre vix leves umbra sus.

Vin noffe Ortelium? M undi decurre Theatrum:

Quantum opus eft Orbis's taitus \& ille Vir efk.

\section{THANNES SAMBUCUS}

Clar.A.D. 1 Arus eft Timawia, Fiungaria oppido A.C. 1531. Fuite ML aximiliani II \& 1 poltea Rudolpbi II. Imperatorum Confiliaitus \& Hiltoricus Cefarius; unáque Medicus elegans, Poêta cruditus , \& Antiquarius penè incomparabilis: necc noṇ sir adeo liberalis, ut omnem ferè fubftantiam fuarn conquirendis libris, monetis, \& ftudiis antiquis impenderit., Obiit.Vienne Auftr. Apoplexia A. C. 4584, xtatis fure 53. Vander Linden de Script.Med.

Scripta ejus propemodum infinita, guorum Catalogum habes apud f.ac。 Boiffardum.

Foannes Sambucus Tirnavis Pannonies oppido natus, anno I5310 in plerifque Italises. 


\section{CELE BRIOR ITM AUTHOR UM.}

Vtalie, Gallia \& Germanie Academiis cum laude verfatus eft : conjunxit autem cum literis hunanitatem; cum Latinis Graca: \& quod è fcriptis ejus facil èapparet, fientiam antiqua Philofophix cum elcgantia doetrina. Unde in Medicum olegantem, in Pö̈tam venuftum \& Ccitum, in Hiftoricum \& Antiquarium folertem evalut. Boiflard. in Icon.

I.oomes Sambacus, profeftione Madicms, cujus ea furt inveteribus libris colligendis diligentia, libèalitas in publicandis, ut principilaus viris, qu hâc tre

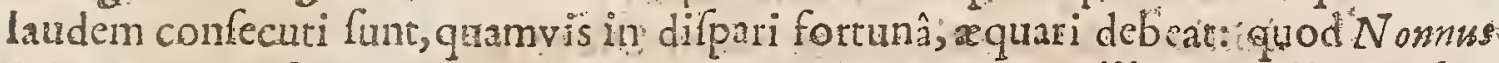
Dionyflacorum fcriptor, Arifuenetus, Emapius, Hefycbius illuftris, alii cins beneficio ediri abundè tetantur: aliaqui alienâ quàm fua induftiấclaxior. Thuan. ad ann. as 8.

A. Sarbuco heri ad me literx, fanè quàmamicx. Humanifrmum virum corà reperi, non pro opinione meà ( tecum hoc ft ) literatum Lipf: Cent. Mif." Epilt.2.

In te fingulareu humanitatem oum fingulari eruditione conjunotan dillexi, nel, ut magis propriè loquar, amavio Lips. in dedicat. 3. pofteriarum librorum Taciti

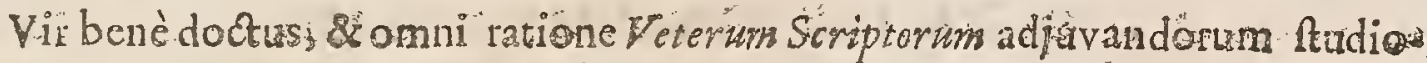

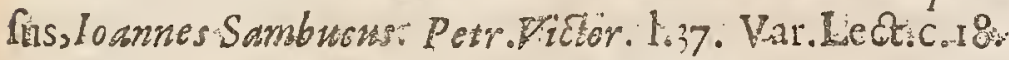

Accuratus homain legendo \& reconditæ doctrinæ, omni laude dignus vir ob: eximias fuas animi dötes, \&non minus quir al porum laudis valde liberalis eft. Petr.ViEtorod.37.Var.Liect.c.Ig.3.

Bonfini Hiftorix Hungaria addidit Sambiscus Appendicem, quâ res Hungarícas perfecueus eft ufque ad $F$ erdiandion I. qui fecundus fuit Rex Hungaria ex familiâ. Anfriacâ. Appendix quidem non refpondet endirioni Bionfiniane, meretur tamen fuamilaudem. Conring. de Hungaria.

foannes Sombucus vir clavifrmus, cum ipremulta eituditè elegantêr conto feripfit, tum etiam plurima fcripta rara \&inventi dificilia maximis labotibus $\&$ ? fumptibus collegit; quortm non pauca edita funt. Gefrier. in Biblioth:

Dominus Sambucus celebrior erat plutinorum Manu-feriptofumevulgàtione, quam propria cruditione. Paul.Colormefoin opufc.p. 13 . Gall.

Ag:è poterat Natura virum producere - Fo. Sambuco ad Sciestias propenfiorem

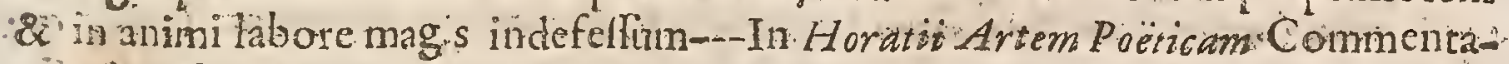
rios lcripfu, quibus manifeftifimum fecit in poefeos Eatinaveneribus fe nihall ignomalie-- - inter infigniora ejus Opera numeratur Hiftora cjus Hungarica quam non minori elegantia quàm fide contexuit. If. Bullart. Acad.Scienciaruin Tom.2.p.18:. Gall.

* Foamis Sambuci Opera non permittunturnili corrigntur. Index. Madrit. Imprell. Ann:1667.

Extant Icones Veterum aliquot \& recentum Medicorum acPhilofophorum, cum Elogiis Tetrattichis, Antverpic apud Cbrift. Plantinurn ann. I574. Fol. \& Lugd. Bat. ubi Vita fingulorum \& Scripta adduntur, apud Raphelenginmann. 16.0j.\& Amftelod. Fol.s6ij. apud fanfonium. 
Hoc ejus Epitaphium:

Sambucus linguas coluit qui docius, of artes. Cui nataiefuit Bannonis ora folmm:

Calaris historicus pramifle temporis acta.

Et dignosfcrippt: cognitione libros.

Aonios inter meruit grogue romen Olores,

Carmine jucundum qui cecinere melos,

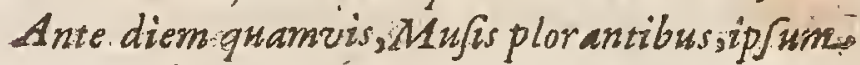

Emedio tulerit mortis avara manus:

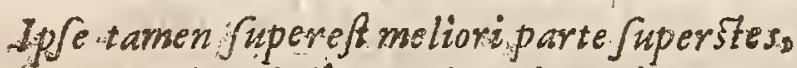

In coetis animina, nomine clarus bumo.

Nil in folertes $M$ M uf arumyuris alumnos

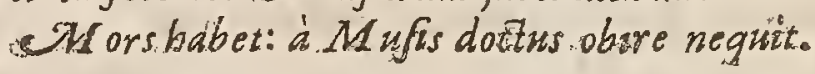

Obiit Id.J Juii MDLXXXIY. Atat. LEI.

\section{FUL IUS URSINUS}

Clar. A.D. P Atrî́ Romanus, nobili genere parcrno, fed minus jufto concibibitunatrsso MDLX. I Septuagenarius obiit Anno Dom.1600.

Scripta ejus fint: Nota in Ciceronems,Virgilium, Eutropium, Polybium, Terern tium, Dionem Caffum, Catonem, Varronem, Columellam de Re Rufficà, Salufium, Cafar.Livium, Velleium, Tacit. Suetonium, Spartianum, Fragmenta Diony, fi Halim. carnafjei, Appiani, \& Diodori Siculi: librum edidit de $F$ annil ries Romanorum: atque Apperidicem ad P. Ciaconisum de Triclinio.

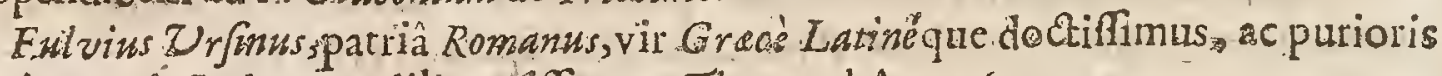
antiquitatis In dagator dil gentifrmus. Thuan.ad Ann. 1600 .

Earum ( nummorum for:zarum ) exempla paffim extant in eorwm libris., qui Antudiosè antiguitates ill as collegerunt. Inter quos Fuivio Vrrino \& Adolpho Occoni, dectiffimis viris s, palma confentuømium tribuitur. Franc. Hotoman. dePop. Rom.Re Nammariâ,, c. 5 .

Urfinus quidem doctifimus vir eft, \& de literi̊s, fi quis alïts;optimè meritus. Cafant, Ep $\hat{1}_{1}^{+} .12$ acab.Bungarfio:

Fulvius Vrfanus, vir preclarifamè de omni anciquitate meritas. David Foefchel.in lit ad Matth. Wackerum, quas Legationum excerpris præmifit.

Fulvius Vrfinus, hopso litgux utriufque omaifque adè antiguitatis benes peritus.Andr.schott.1. 2. Nodorum Cicexon.c.6. 


\section{CELEBRIORUM AUTHORUM.}

Vir illuftris \& infigniter eruditus. Fulvius Jrfinus, de Ecclefiaficis liceris ropt imè meritus. Baron.yol.2.Annal.

Amiciffimus meus Fulvins'Vrfinus , rerum antiquaruu folertifinus exiplorator; ad quem velut Lydirm Lapidm quxque vetera monumenta probanda selucidandague afferri folent, cujus \& apud me auctoritas plurimùm valet. Baron. ibid.vol.z.

Fulvius Vrfznus, vir infignis præclarâ exuditione \&e fincerâ fide omnibus noitus. Baron.vol.4.Annal.

Cujus nomine inter viros antiquarie rei ftudiofos nomen majus, celebriufque nullum eft: Gajfend.de vita Peireskii l.r.

Fulvins Vrannusoptimus fener optimè de omni meliore Antiquitate apud Bonos omnes promeritus. Fignor. Symbol.Epittol. Epift.18.

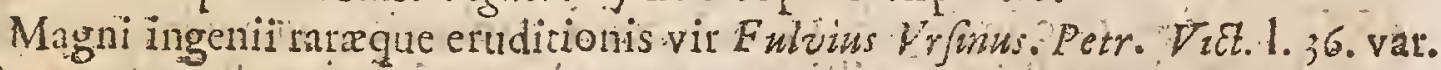
Leet.c.22.

1.1.cap: :3.

Inter I tulos Fulvius. Yr. nus familiam ducit Gap.Siropp. confult.p.:9.

Scripfit de Familtis Romanorum elegantifimè, enúdicifimum de Triclinio Ro-

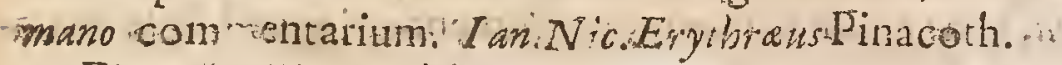

EjuS Trigtitum, \& librum de Familitis Romanornm quis non admiratur? Ioan. eNatib. Tofcanin Itallpcploscirg4!

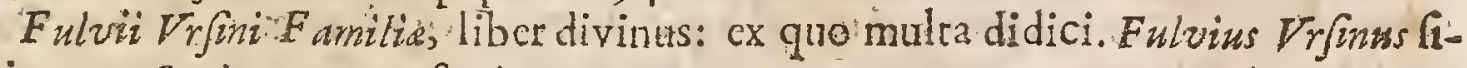
mia mea. Scaligerana poterior.

Eulvins Vrifnus plerafque retas in Tulium Cafarem Petri Ciacconiz, quas ipfe, qui fua ut parvi facere gloria contemptor acerrimus, fic libenter communicare folebat sum amicis, non ediderat, tacito ejus nomine fuis in $H$ iffo ticos Latinos notis adminifuit. Sed Ciacconio, chm notas eju; ab Andreâ Schotto áccepiffet, fua poitlininio reftituit,atque Fulvianis feparavit foannes Brantius. Thomas.de Plag. lect. 8:

In hunc Auctorem hxc carmina compoluit Ioannes Matthias Tofcaruss

Comprobet Antigua int dignum fe Fulvius urbe, Illits, extinctum fufcitat elogrium.

Roma licèt deprefa, tamen caput erigit, Hydre

In morem, ingeniis of rediviva viget.

Prodit 1 ber de Familius Romanis, cum ip nis numonum figuris, Rome is77.in fol. Parifis, editore Carolo Pantino, 663 . in fol.

Exant Imagines of Elogia illuftrin ac eld ditorum Viroum, ex Lapidibus Antiquis, \& Numilmatibus exprelfix. Rome anto 15.7 in fol.

Exrant Leges es Seratufconfulta qux in veteribus cùm ex lapide, tùn ex xre

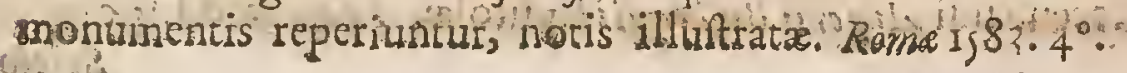
$(\cdots, \cdots$ 
Extat Appendix ad Petrum Cracconium de Trislinie. Rome Is88. in 80. Amfor logami apud Andream Frifum 1664. in 12\%.

\section{AUGERIUS GISLENIUS BUSBEQUIUS}

Clar. An. D.

R. Obili \& vetufta Busbequiorumapud Fldandros genere natas eft Comini a $\times \times \mathrm{Y}$ Anno 1522. Obiit Anno Dom. 1592.

Scripia ejus hec funt: Turctce Legationis Epiftola quatuor-..-Confilium de. re militari contra Turcam inltituend--..-Itinera duo, Confantinopolitanum \& Amafranum --Epiftolx Legationis Gallick--.-Liber de vera nobilicate.

Erate grandior à Ferdinando A Angstino Viennam Awfria cvocatus, \& ipfi \& Maximiliano filio in Repub. gerendâ ìta fe probarit, ut nullius ferè magis confilio \& virtute Principes illi niterentur: Hujus eriam Augurtos liberos Mat-. bhiarn, Waximilianum, Alberium, \&. Wencefaum, ephous prudentifimus, optimis moribus informavit. Cumque in omni adminiftrat onis genere excllerer, tum verò in legacionibus vintus ejus eniruir: quibus compluribus magnâ cum gloriâ. ad fummos principes allidue functus eft. Earum inggnes imprimis fuere Constansinopolitana \& Anafrana; quas etiam literarum monumentis eleganti fylo mandavit.Melch. Adarn.

Angerus Giflerius Busbequius, vir endirione, renmagendarum peritia, , candore \& probitate infignis:qui unam atque alteram Legato nem adi Portarn Otbomanicam lub Ferdinando Cafare inagnâ fuâ cum laude geffit, \&elegancifunis ae lectu jucundifmis Epiftolis explicavit. Ex quibus quamplurima in e Annetes meos me tranferiplife ingente piofic oc. Thuariad Ann. 1592.

Generoftimus paiter ac doctifmus vir. Lambec. lib r.de Biblioth Cafar.

Vir, quem iner æu i nottip primos verô elogiô eft pradicare. Lipf.cent. 2.ad Belgas epift 78

Vidinus nuper libellum diplicem Itineris \& Confibi tui, Libelum: fed meo animo, Scholás diflerrationefque fuperat multorum fapientum. Brevia omnia, facer: \& cò placent magis, quia inclufa prudentia,non oftenfa. Quin genus: ipfun dictionis ( etfi.jd minimè inter tuas curas) prifcum aditrictumque, fententiis occultum; \&; gnod verè invideo; fubtilis brevitas inuatatibi, aliis adfeetata. Lips.in Epif .and Busbeq.prafix. libb. Saturnal Sernon.

Non contemnenda ad rem Turcicarum cognitionem peti polfunt ex eleTantilfmis Augeri Busbequii Epiftolis de Legatione fuâ Turcicâ. Whear.in Meth. Leg.Hî. Civ.Artic. 12 .

Augerius Busbequius legationem fuam confripfit. Egregitis liber hiceft. Pulchra in eodem occurnunt. De Turcisbenè fcriplit. Scalig.pofterior. Gall.

Angerus $G$ Bufbequius , fummus omnibus laudibus \& meritis \& contemtis ir:Barth.Adv.1.i4 c.6.

Lynces AlJyrias ei ufuiadliuc hodie commendatas docent eximii viri, \& prinatibus onnisaviaccenfendi Angerii Bubeguii Ecillols. I dem ibid.l.15.c.13. 


\section{CELEBRIORVM AVTHORVM.}

scipio Gentilis in Apolog. Apuleii eum vocat eriditifinum elegantiarum ar. tbirrum.p.349.

Pofteritas confervat etiamnum ut pretiofas Retationes ab illo reliatas itineruin fuorum, tanquan fontem copiofum, ex quo experientiorcs Politici docementa polfunt haurire. In pretio cum primis eftegregia illa Synopfis ejus apord Iurcarum Imperatorem Legationis, quam thon minori clegantia quàm accuratione confcripfrt: quxquc citatur à Franci co Hotmanno Tract. fro de Logati M unere tanquam liber hoc charactere dignus, quique ampla precepta continet pro illis quorum opera untur Principes in praclaris illis functionibus. If.Bullart, Acad.Scientiatum. Gall.

Quamvis multùn pratereà juvari poflant rèlationibus epinolicis preclarifrmi viri A ugerii Bufbequii, \& libellis Ricoldifen Richardi Monachi, ac foannit cujurdam Andrea; qui proptereà in omnes linguas habentur tranflati : quoniam vel ipfus Pofrelli judicio cxreris omibus praferri debent, quicunque conati Hunt Turcica Religionis fundamenta validifimis rationibis convellere. $G a b$. A Avard. in Bibliograpli.Polit.

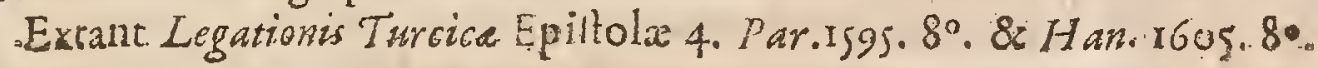

Hoc ejus Epitaphium 7ufines Richbius compoluit:

Busbequii asficiens Turmilum, corffidc, Viator,

Sta prope: non listum poficeris aut gemitum.

Dem quid cum tacrymis wirtuli? vita benorum

Vt nibil. infauffi, fie negue babet-Lachefis。

\section{ABRAHAMUS BUCHOLCERUS}

T Nago Schonau propè Dumam, qux fex paffum millibus Wittenbergả dir. Clar. An. D. I tat, natus fuit anno Dom. 1529. 1V.Kal.Septemb. Obiit Freiftadii Silefiorum MDLXXVt zuno 1594 .die 14.Junii ftyli novi.

Scripta cjus hae frint: Chronologia magna--Chronologica Ifagoge--Index Chronologicus-s--Catalogus Confinlum Romanorum---Epiftolx ChonologiCx---Admonitio ad Chronologix fudiofos de enodatione duarum Quxfionum Chronologicarum, annum $N$ ativitatis, \& tempus Miniferii Chrifli concernentium---Opufcula.

Mitto tibi dono Chronologiam Abrahami Bucholceri, qua meo judicie. omnes Chronólogias, quæ ad noltum ufquetempus prodiere ( lalvô temen pio \&x urili aliorum labore ) fiperare viderur. Idque non modò exactifimâ tẹmporum fupputatione, fed etiam corundem temporum collatione quadam myticû́ \& propheticâ, remotâ tamen omni tuperfitione:id quod in nuli Chronologiis tam dextrè factum mihi videre contigi---Quoties Sacra Biblia legun. sur, Cheonologia hac nen modò ntudiofis, fed ctiam is, qui fibi Doctores afte vi Gggg 2 deatur. 
aentur, latere effe poreft--.inimiabili penè brevitatefcripfit-.-Denigue Chro. noloyia hac loco multorum Commentariorum in Biblia Sacra, quibus multimagis impediuntur, quam promaventur, elle poterit; prafertim politicis hominibus, \& circa rerum gubernacula verfantibus, qui evolvendis multorum Scriptis vacare non pofunt. Wencef.Budovviz.,ji lit adeA damom Filium, amono 603 fcriptis.

\section{Abrabarnus Bucholcerus, opere Chronologicomagnam gloniam adégrus. Thuon. ad-Anum Is 34 .}

Cujus fe pectore tota vetuftas condidit. 70. Andr.Quensted.de Vir Ihuftr.

Eum virum magnum effe \& excellcniem ingenio, doctr nâ variâ, ace lectione multâ, docent tum, qux nuper edidit, Scripta Chronologzca valdèerudita, laboriosè \& accuratè cońcipia, țm etiam porrò melius docebunt, qux modò habet in manibus. \& de quibus fpem facit, fuperaturus fne omni dubio in illis amnium conars, labores \& fudia qui tactenus in funili argnmento valuerune; elle occupati, $N$ eand.Geogtaphpart.t.

Rucholceri Cbronologia magna omnịm eruditorum oculos \&admilationem in Ce convertit. Melch Adam. in vit. ejus.

Facundix Ėtholceriand vix parem reperiat Idem ibid:

Infignem illum reddiderun ejus eloquentia, modeltia, candör, affibilitàs... charras \& vite intcgritas. Adeo propiris non tudebat commodis ut, tantum ab. eft ut à Principibus yubus miniftrabat remuerationes peteret, quin eonú dona mirabili generolitate rejectit. In quo ilduftris Præceptoris exemplum imitatus-

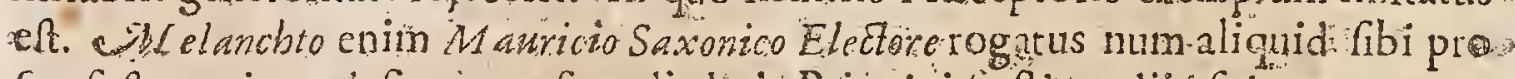
fua Cuftentatione deficeret refpondic huic Principi le ftipendiis fuis contentum elfenihilque prater ea capere: Cninque dentio urgeretur ab. Electore ut ci figni-

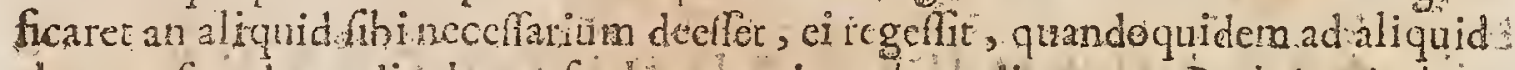
ab co pofcendum adigebarure ab co veniam abeundipetere. Bubbolzeri Cbro-

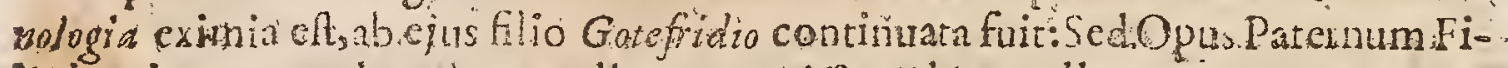
lôi lucubrat onem longè antcell t:Ant.Teijler, Elog Gall.

Sic Abrahame Bubolzerus Chonologus careroquin enditus hic impingit. In Ifagoge enim fil Chronologica annos diverlos $N$ atali Chrifti alignat 8 illis quas adhibet Epochis in diverfa abir, quippe qux Chrablexes diverfos habent -Qum sero facillinum fu cafpitare in talbirs, hadquaqua ob id convi-

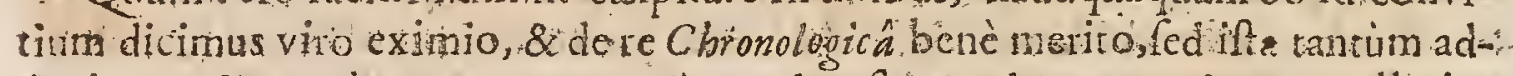
ducimus ad cantam, ut pat eat, quàm ardua fit Epocharum variarum collatio, \& quàm difficile fit hîc non quandeque impingere. Sichallicinatur idem vir enditus in applicatione Olympiadum ad annum Natichrini, dimmatalem Chritt refertad Gympindis OXCII pro Olympiadis CXEIV tertium, ubitamen fphalna Typographicum fuCpicari inalim, Erid.Spanbem part.2.Dit. Evan gelic.p.: 6.87

Ediât Ujagogen Cbronologicam anno I596. quam deinde continuavit filius, non tamerpar felicitate, ut mihimidetur; Parens enim guavis eft \& oblervar Hiftoria leges, nec intexit minuta ila \& quz publicè fciri parum interft ; ut 


\section{CELEBRIORVM AVTHORVM.}

quando inte. Paftor, in fioc vel illo pago fit natus vel mortuus; cquando hic Confuil, ille Senntor, quando hujus Academix Profeffor aut Rector, \&c. qux non nifi de tummis \& prantantifimis visis erant notandaz Kekerm. de natŭà \& prö prict. Hiftor. c.4.

Magn: diligentiâ.celcbrium Virorum memoriâm perfecuturs eft in Indice Ghronolugico; qui dein pi inùm a Godfrido filio, pìt ab altero filio, Patri coginomine, Abrabarai Sculteti operâ putifimum adjuto, deinceps ab aliis continuatus, novilq; acceffionibus fuit anctus, ita ut ante triginta holce ( forlicet ab anno1670. computandos) \& amplius annos jam quintum edius fuerit. Oblervavit atstcm Pater mens, Godfridus Voglerns, Godfridum in purimis ita non indul fifle affectibus, ficut in tertia editione fuit factum:utut illam alteram cditionem acerbè perftring? in dedicatione frater Abrabamus.. Po'teriores exiam cditiones hatud

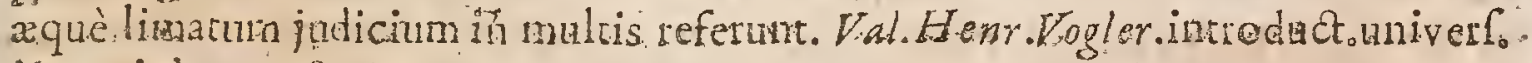
in notit.bonor.Script. c.2

Bulcboltzerns Vir bodaus crat, fed Jubilixis totor go. annes affignat. Scaliger! polteriol:

* Abrabana Bucholceri Index Chronologicus, atque Iragage Chronologica cum expurgat onibus permittuntur. Alia veru cjufdem Bitchoiceri Opera prohibita fugn in Fid. Madrit.

Extat I I ágoge Chronologica 8. Francof. $15: 7$.

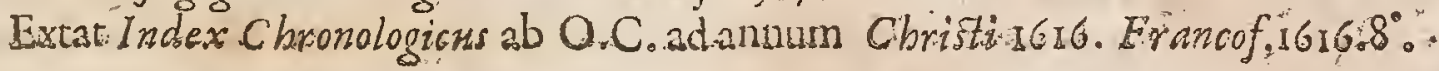

\section{EYCHO B R A HE}

$\mathrm{E}$

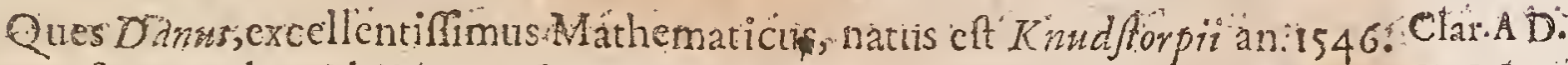

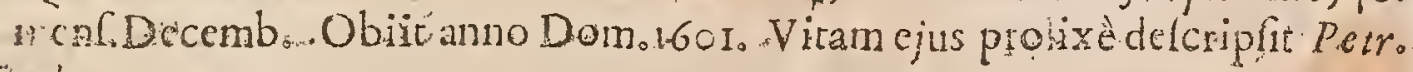
M. D.L.t. $x_{0}$ Gifjendus.

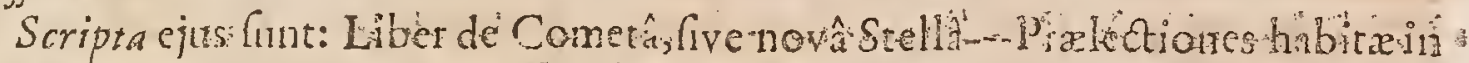
Academi Hafnemfor-Ontiohbitan Academithafnenfi--Progmnalmatum

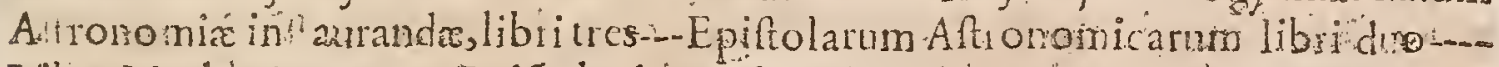
Liber Mechnicormm--Epiftal deconfectione Enixis-- Tabula Rodulpbina

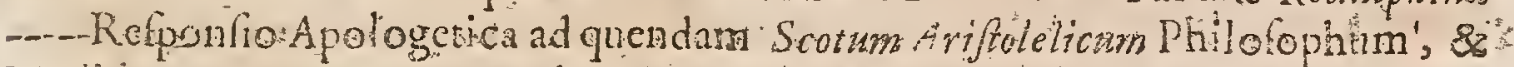
Medicum Galencum-Somnium, Lunanireaftronomia--Siellartan octavi orbis inematiun accurata reitutio--Epifolad GPewerm.

Poft Finellwh, commemoratus venit Tyobo Brabe, Eques Danus, An rorum verâ fcientia \& obfervationibis loigotempore in fu Tranopola, \& mangno fumPtu factis, omnium concordibustuffragis Principis Aftronomorum nomen pro incritus, Qui Ch ronefó Cimbrica reheta, cùm in Germaniam proximam fe recepillet, in Aula Rrólphi $C$ a faris aliquandiu Horuit. Cum Wultelrno Hefjo; qui \& in. eadem feicntiầ excellebar, arếa ftudiorum neceffitudine conjunetus : Q Prage hoc anno 1601. 9. Novembo decelat; chim vitzannos: 54 . menles 9.dies 19. tan-1. Ggggg 3 , tùm 
tùm exegiffet.Vir \& Scriptis à fe editis, fecundum ptolomeum, I oannem Regromo tanum \& Nicolaum Copernicum, imprinis clarus; \& poltea à loane Kepplero (cui praclaras ingenii fui reliquias, ne perirent, quafi teltamento legavit) ptblicatis, illuftrior. Thuen ad ann. 1601 .

Vir illutris, \& generoliffmus Dominus Tyşbo Brabeus, fingulare Naturæ Beneficium, \& liceraturx onamentum; quem non tam clara Patria., nobiles genitores, corporis, fontunaque bona dia; quàm excelf mens; $\&$ divinum ingenium, carm, amabilemque principibus, doctifque viris, adeoque nniveris, preftitere. 7o. fefen. in Funcbr. Orat.vid.Gafiend.in Vit. Tych.Brabe p.234.

Quinimò florente atace ad Cadarem accitus, honores ejtis anle frbi oblatos conltanter fprevir, fperatos refpuir, con athematicarum tudiis accenfus, ob qua abomnibus immortalicati nomen ejus metuit conlecrati. Ut enim Afronomia tot retro actis temporum curriculis penè oblivioni tradita, veris l thenomenis

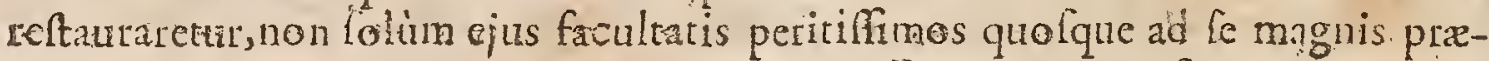
miis allexit, \& infignia, ut id iplum faciliùs allequeretur, ejufdem artis inftrumenta regiis fabrefecir impenlis; fed \& domos magnificas, ac turrès ingentes fundamentiserexityin quibus,varia per intervalla, Colum, Sydera, \& eorunden motus uno tempore, diverfis infrumentis $\&$ a pectibus fpectarentur ac.Pbilip. Zomafm.in Elog. Illuntr. Vir.

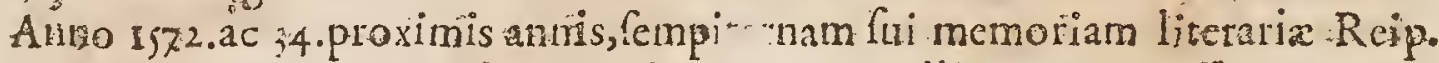
intulit Tycho Brabe, qui in fiderum oblervâ ne nulli priorum cefli; inque numero fixarum obfervando, non acuuievit Hipparcho ; imè P.olemsi, \& Alphon

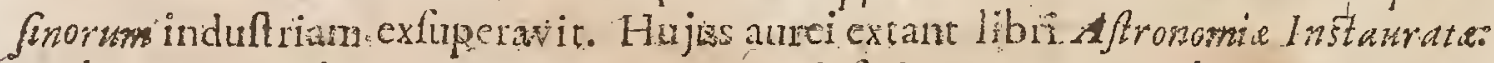
quibus, ut antea in Ptolemeo Copernicus, ica iple in Copernico multa correxit. It que exinde tres pracipuę fuerunt Aftrologorum Secta: quaruin Tychoniana forct media inter Pythagoricarn five Copernicanam, \& Arifoteleam five Ptoicmaicam. Woflue Mathemat.p.193.

Aftonomia \& Chyniç ftudiis maxime incubuit: cetera quidem non provsts

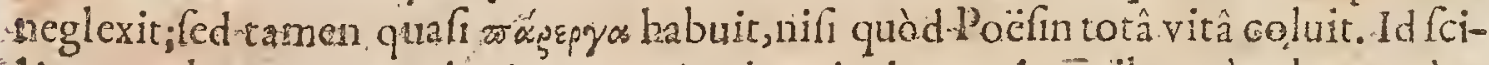
licet plobant, qua varia ejus Carmina interjecimus; in quibus cum bona, cùn mala, cùm mediocria fnt ( \& prater alia quidem, nonnulla, in quibus videtur non faris accurate fyllabarum quantitas obfervari) intelligi ficet fudifle cum illa nature potiis gen:o, \&oblectandi anini causầ, quàm contcntione animi, famxve aucupanda gratià. Petr.Gaffend.in vit. Tych. Brabe, L.6.p. $18 \mathrm{I}$.

Ticho Brabe luculentilimas in Aftrologiamobfervationes clucubravit pre

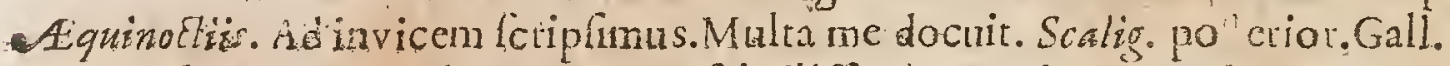

In Infiranenta Mathematica, gua fubtilifinè excogitaserat, ducenta aureorum millia infumfile dicitur.

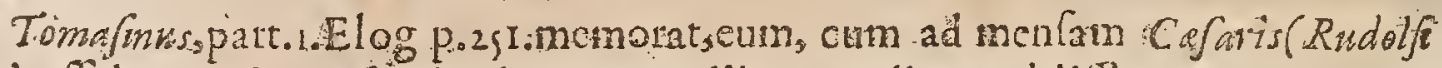
IY.) affideret, urîn effundend’x verecundiâ prapeditum obiille.

* Tychonis Brabe Aftronomix inftauratx Plogymnarmata; ejufdem Epiitole Aftronomica; atque de Difciplinis ARathematicis oratio, cum ex- 


\section{CEIEBRIOREM AUTHORUM.}

partgationibus permittuntur in Indice $M$ adriten $\sqrt{3}$ edit. Ann.1667.

Qpera ejus omnia prodierunt Erancofurti ann.I $6_{4} 8$.

\section{B.ARNA.BA.S BRISSONIUS}

(2) Alus, Fontanei in Pictonibus nafcitur. Tempore Iito, Parifis, à globo fediI diolorum fupendio necatus anno $159 \mathrm{l}$.: Hofman.

Scripta ejus hecc lunt:De Populi Romani folennibus Formulis \& verbis libri

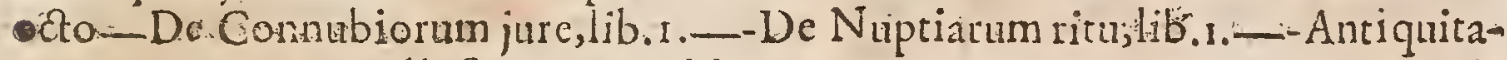
sum,ad I ur is Givilis illutrationem, libri quatuon-Dé Perfarum Regio Principatu, (eu Reguo, libri tres.

Barnabas Briflonius. Jurilconfultus magni nominis, excellentis ingenii, fol:dreque eruditionis laude, quan ligripta ipfus tefantut, charifimus, Gotofrid, $B$ w sholcer in Indic Chronolog.

Dignitate \& Doctrina eximius Barnabis B\%ifonius, Gallie, imo Europ , ma. gnum lumen: Lipf: 1.2 electi2. Is.

Quis Mufas nuvit, \& Riffonium non novit? Nec Dil firint, ur indictus nobis fis, clariflmum Gallix Lumen. I dem l.2 .Epilt. Qureft.epift. I7.

In Bxifjonio bonę omnes artes \& fapientia civilis magnam jacturam fecerunt, nec poft Cujacium ex noftratibus alter fuit, qui: Iuri Civili \& forenfibus formulis exuniverfali literatorum campo decerpris clariorem licen at tulit. Rom dolpli.Batorens 1.4. Comment.

Barnitbas, Briflonius, Jurifconfultus \& Criticus, judicio doctrinâque nulli fos cundis. Thors. Démpfer in ElenchiScript:

Equidon à Kège ( Gallorum Henrico III.) ipforudivi, cim diceret; nullum in Orbe christiono prin cipem offe qui haberet; quem Briffonio fuo in litesam glow ria opponeret. Saxvol.Samartban. in Elog Gallor.

Briflonius, venerabile omni avo nomen. Barth. Adr.l.If. C.t 8 -

Barnabas Briffonius vil Iurifprudentio in antiquam dignitatem reftituenda gatus SertoraV.rfat. 1.1. Monumcnt. Patav.

Exempla al ia paffim occurrunt apud atatores, quæ partim collegit magnæ dilim

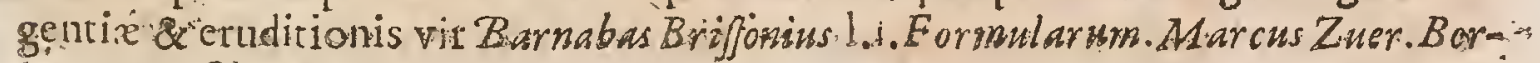
born. Quxft. Roman.I..

Quemadmodim in magnifico opere, Barnab B Biffonit librode Formulis:P.R.' abundè docetur. Frid. Tilernann de Hiftor. delect.

Barnabas Brifjonitus, fürifconfultus, Senatús Parifien fis Prafes. Optemirandum, de formulis of folemnibus populi-Roman verbis, ex ip Romanx Prudentia-: penetralibus magno judicio collegit. Tobias Magirus in Eponymolog. Crit.

Homo in litium tricis, quàm in Republicâ adminiftran dấ, magis verfatus-Felicilimo vir ingenio, five literarum ftudia; five negatia forenfia traftaret, ex advocato admodum famofo primùm Fifci patronus, poft Vidun Fabram, dein pot Pomponium Bellcureum Curieg Prafẹs greartus, non foum inter, literatos.

Scriprig

Clax. An. Dis MDLXXX. 
Scriptis plerifque editis, fed in Rcp. ac pracipuè in foro magnam lamen meruit. Thuan.ad ann. 591 .

Quæ ad Perfici Regni ftatum faciunt, operosè congefit Bariabas Briffonius, exiguv tamen politicæ Scientix fructu. Conxing. de civ.prud.cap. I to Pig. 309.

Qux hîc de DTuptiarum ritu in medium afferemus, debcmus clarillimis viris Andrea Tiraq. Juticonfulto, Carolo Sigonio, \& Barnaba Brifjonio Jurifonfulia,

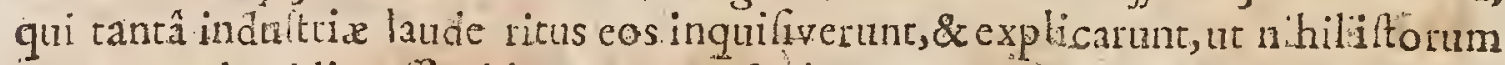
monumentis addi polfe videatur. [0. Ro/m.de.Rom. Antiq.

Libuma Briffoniz tomm perkgi, n guo, ut al tevis ad tc literis fcribebam, non eft difimilis Lui, cum tam in hoc de Regno Perfarum, quàn illo de Earmulis opere, nihil antiquius habuille videatur, quàm veterum telimonia congetere, ut volumen procudat, nihil tam metuere, quàm ne liber nimis.brevis. Gr. janc in re necelfaria, non folim prodelt hos facere, fed etiam negligentia elt non faccre. Rem verò vuly uifimam teftimoniis velle probare, hac verò eft, quod Gruci di-

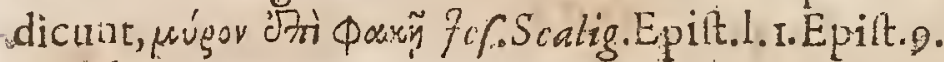

Liber cjus de Regno Perfarum ejus dignicati non refpondet,neque loco quem in Republica occrupabat, \& vidctur nihil tam anxiè timuitle quain ne l. ber fuus ad fatis amplam molem non excrefcetet; neficio guid in animo eju vetaretur cum lcribebat de Regno Perfarum, qui luccelinonis legem tam retigiose oblervant, $c$ mille inpattes illoum tranfiverit qui Corenam $R \mathrm{cg}$ luo legitino detrahere conantur. Munus fum confervare voluit inter homines qui illum tan-

se dem perdent. Ejus liber de eA dion bus formulis plus labo is habet quam indultrix. Guiforwom Factio Prafidis muntis in cum contulit. Liber cjus de Regno Perfarure eft labor Grammatici, non ejus qui remp.tractabat. Apud polteritatem benè fortalfe cedet prutitus glotiola, cum homines inceffet oblivio dignitatis ejus. Scalig.'. Gall.

Briffonii Formulx panca habent bona,nam maxima pars à Atudiofis eft coacervata. Doetus arat \& bene fcriplit; formulas non omnes col cgit; vcllem omnes colligi \& edi felectiores. Briffonius in two munere capiebat utrayue manu. Scaligerara polterior.

Barnabas B̈riffontus Jurifconfultus \& Criticus, virtute , judicio \& doctinâ eximius, certè alli fecundus, quamwis exitu infel cinimus. Nic. Hencl..i oti Vratiflatiengi, o.

De veteri nuptiarum apud Romanos ritu nemó, opinor, fide majoreque diligentiâ feriphit, quam vir doctiflumus ampliffmufune lires barnabas Brifonius. Idemibid.c.j.8.

Torques ergo bolenne regum apud Perfas infigne, quod minor a diligentifimo Briffonio in opere de Regno I erfarum pretermiffum elle. Io.Scheffer. de antiguor. Torquibus, $\$$.

Barnabas Briffonius i⿺ eruditis de Perfarım regno libris. Iidem ibidem 5.8.

Extant libri 8.de Populi Romani ́lelennibus Formulis \& Verbis. Parifis " per Sebafianum 


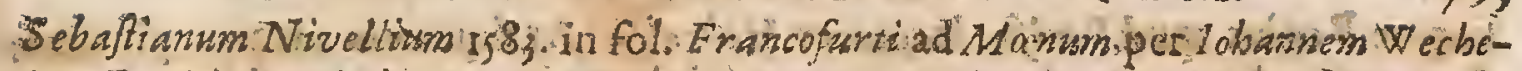
lum \& Petrum Fifcherum, isg2. in 4 . Moguntiestypis Nicolai Heylii, fumptibus P.hilippi Tacobi Fifcheri, 1649 : in $4^{\circ}$.

Liber de connubiorum jure prediit, Briffonit de nuptiatum ritu libello fulbgunctus: Parifirs, in xdibus Philippi Galteri Rovillit, 196.4. in 4". ibidem per ${ }_{2}$ Bartholomann Mackarn, 160 g. in $4^{\circ}$. Lugduni Batavorum per Francifoum

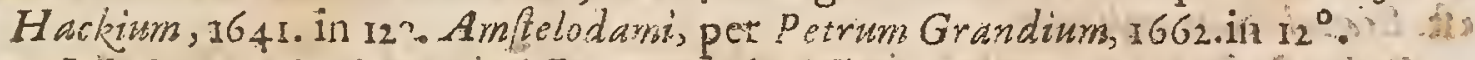

Libri 4. Antiquitatumad Juris Civilis illuftationem prodicunt Ligant,

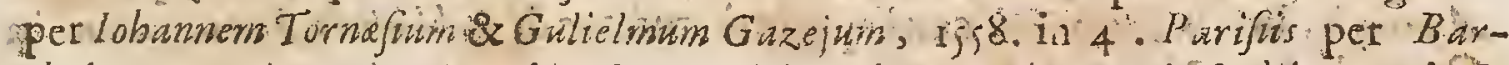

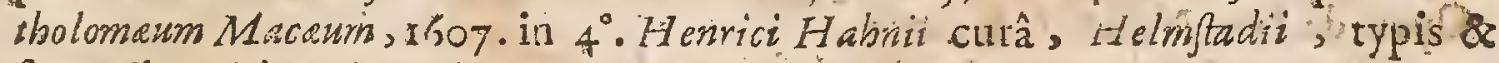
Sumpribus Tohannis Heitmilleri. 1663 . in $4^{\circ}$.

Prodiesunt de Pergarum Reght libri tres Parifis 1590 in $4^{\circ}$. ibidern, per $\mathcal{B}$ ar tholornam Maceum, 1600 . in 4 . Cun Friderici Sylburgit notis, Heidelburgid, un Hieronymi Commelini officinâ, 1595 . in 80.

Hoc cjus Epitaphium, auctore I ano Pafjeratio:

Lusrien Paifii unicum Senatîs

Extincturn feelere bîc jacet latrónum.

Damnate teriebris valtete leges:

Epitaphium Sibronii, five, inoldincm redactisliteris, Briffoniz, extat aptid. Barclai. Lib.1. Jatyric: h.m.

DEPOSITUM SIBRONII CONSULIS, QUILUTENTIUM BONO ACERRIMAM CONSECRAMERT MENTEM, DOMI FORISQUE CLARI SIMUS, OMNIUMIN IUVANDA PATRIA PRINCEPS. QUEM AMPLISIIMIS IN REAF. MERITIS CLARUM POPULUS INTERFECIT, NE DISSIMILEM EXITVM SORTIRETVR PRISCIS RERVM PVBLICARVM P ATRTBVS, QVORUM EXEMPLO SEMPER "VIXERAT:"

\section{G L L B R T US GEN E B R A DUS.}

CAllus, Ricomagi in Arvernianatis, Archiepifcopus Aquenfis in Provin- Clar.An. B. 1 cia , Semuri, Burgundionurn oppido, ubi facerdotiuin obtinitit, fat con-MDLXXX, cellit, annos natus 60. Anno Chriti isg7. Scripfot propemodum infinita.

- Diu literns Hébraic as magnâ frequentiâ in Regio Auditorio Lutetid docuit: inf foiptis fuis, qux plurima \& multijuga eruditionis plena evulgavit, iniquior \& acerbior \& vitâ quàm ftylo temperantior credicus. Tbuan. ad Aun. I597. - Arvernia bonis ingènis foecunda, cujus è grémio prodiere togati ordinis tot illiftes vin, hunc etiam edidit facrati ordinis eruditum virum, qui fancte

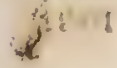
Hhhhh lingure 
lingua Regius apud Parifos Interpres Hebraica Antiquitaris arcana plinima, \& ea maximè qux ad rationes temporum fubducendas pertinent adhibito pcrfpiracis ing cnii lumine perquifivit ac in lucem protulit. Hoc enim ex fonte ottum eft c bronologicuri illid opus \& alii, qui nunc funt in manibus hominum frmilis Induttire foetus maxinnis ab co vigiliis \& laboribus elucubrati. Multa ille ex Hebrais \& Gracis accuratè tranfulit, multa recognovit, multa commentatis elt. Scavol. Sarnarthan.

Quin \& in hifce proivit fermè Gilbertus Genebraid dus , Archicpifcopus - Aquenfis, liecris Hebriv is certè apprimè erudikus \& Rabbinicis. Loan. Selden. in Oper. de Iure Natural. \& Gent.

Gilbertus Genebrardus, eruditum fcd petulancifima procacicatis animal =--.Qui Syntagma nobis quoddan Chronorhaplodicum male confutum, effudit temerè \& fêtinatò, de claacis Rabbinurum \& fimiceris, in rebus utriufque Teftamenti haufum \& effuticum, potius quam de Myothecî́s Ecclefiaficis derivatum : ut montes multo conatu parturientes, murem tandem ridiculum pem pererunt. Montacut in Prefat. ad A pparat. Sect.j6\%.

Riveru in If g ge ad S. Script.cap. 8. Sect 15. petillantifimum bononm omnium infcetarorem, ov veritatis hoftem acerrimum appellata:

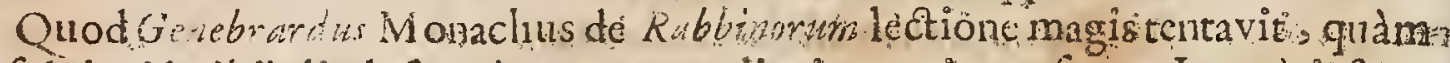
abfolvit, id nihitatid ct tquàn cento ex alienis pannis confurus Longè inftu-

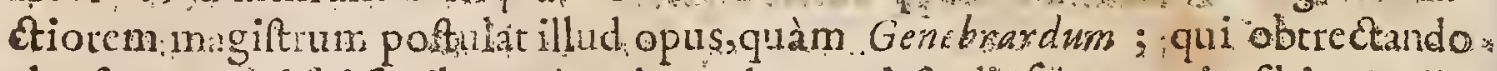

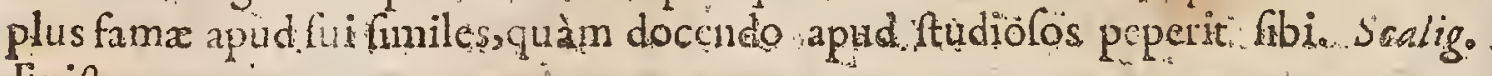
Epit. 243.

Ut dicam quod fentio, quando \& qui mecum fentiant habeo vitos optimos; Genebrardi Chronologiam ex iis, qua hactenus prodietust, integriorem puto atque abfolutionem; licet viri aliqui pix defreratlent, minorem Rabbinorum Iudaorurs in priore Veterie Tetamenti Chronolagiâ, in fecundâ verò Novi Teftamenti inullam quorundam Harcticorum fierimcntionem. Pofjerin. in Biblioth. Select.

Genebrardus, factanm literarumProfeflot parifienfis, doctits fane, fed pra fervidi \& acris ingenii vir. Iatc. Duport prafatad Metaph.P Calm.

Genebrardus, Hebraica linguz peritẩ clarus, qui; multa licè facre Scriprnre Commata, in gratiam Helena fuzqurpiter inflectar nomulla tamen 1101 - centcmnenda Interpretamenca habet. Matthe Pol. in Prafas. Yol. 2, Syuopfo Critici.

Genebrardus in Hebraic lingua \& in Seripturanm Critica Bellarmino doOiordubia procul erat; In ejus tamen Commentariis in Pfalmos omnis accuratio qux opeari pollct non obfervatux. Ejus methodusqua mandem haber cum Bellarmino, lude digna ett; quoniam plurimis locis vecfionem Septuaginta \& Vulgatan vindicat ab accufationibins recentionm Hebraizant inom qui a abbinoorum authoritâti nimis tribuunt : fed non femper moderationem fery at Intexpret mecefiariam, quifcilicet nullo partium ullarum ftudio duci debet. Pretrea laporsqui in ejus operibus vifunurevidenter arguunt illam in Hobraico idiomate 12013 


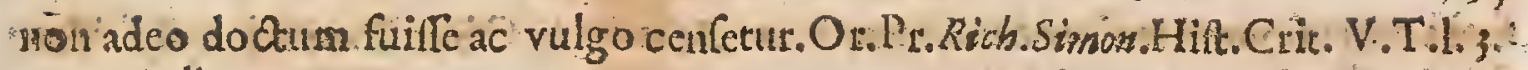
c. \2. Gall.

Plurinum in eadcm palæetrâlaboris fumfrt Gilbertus Genebrardus ; plunimo. rum fiquidem Rabbizorum libios vulgò ignorabiles Romanâ oratione non infelieiter expoliti, nam nif Latini fermonis indoli cum pertinacia lervillt, nec propterca Ebrai arationis feationes neglexiffer, nativanique illius b evitatem cxtendifer, ejus Interpretationibus poteramus acquilfcere. Huet ide Clar. Interpret.

Gilbertus Genebrardus, pracipitis vir in Tremellinm judicii, vicifim hoc

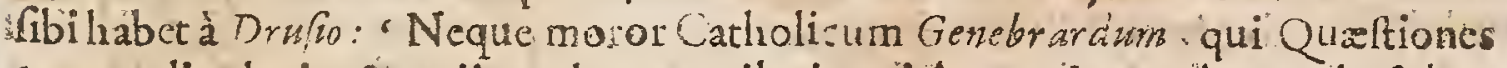
"meas olim legit, \& ex iis multá compilavit tacitô nomine mế, quod ent ho"minis minimè ingenui, fed is audic valgôplagrarius. Thonal de Lag.

Dorninus Genebrurdur Alch. quentis de cujus pietate \& doctinat tam in Graci \& Hebreis quam Latinisliteris totaglonitur Gulia, mean fimat Cententiam. Lud. Dorlian in Nov. Cogitat.ad Tezti p.388. Par rG 2z.

Vir faculorum memoriâ dignus, \& quo Gallia le jactavit dumno. I dem ibid. P. S10.

Annumero etian Chronologis maximis Cbronilnatarn Gilb.rti Genebrardis Galli, edican Amo rs 89 . Ced ità cditam, ut hiftorix 8 hiftoricileges in pluribus vialct,atque adeòimporentiamaffetuum effranem iftius viri demonftret. Keckeriann. de natur.\&proprict. Hittor.in Auctar.cap. 4.

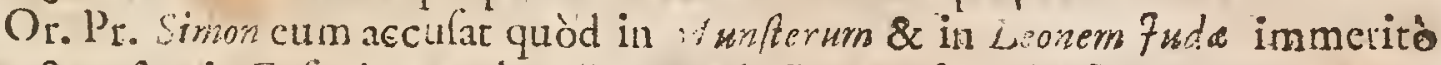
invectus fucrit. Etfanè nemo hominum à lonitate dilcipuli $7 \mathrm{efu}$ Chrifti Genebrardo alienio unquam fuir Ejus cnim Scripta detrectationibus \& calumnis in ejus adverfarios fcatent, \& plurescontunclias quam rationes ad illos op- pugnandos.infumit. Equioris animi crga Principem finum quàm erg. Ecclefie Romarind holtes non fuit. Nam toto factionis Guiforwm tempote infolito ardore Cumma vehementiarcbellium partes tuilus eft. Hac de caufa la[a Majeftatis reus pronutiatus eft 'snatus-Confulo quod primo Tomo probarionum Ecclejá Gullowane refertur. Ant, Teiffer Elog. Viror. Eruditow Gall.

* Gilberti Geneb ardi Chronographa in multis locis expurgatur in Indice Madrit. Quia in Fine ejufdcm Chronographia habentur nonnulla opufcula I isdaica, quz Genebrardus íatinita e donavit, \& ferè ad nullum ufum fidelinin... videntur quoque expungenda. Ind:x Madrit. edit.an.1667.

Variaejus Opera variis in locis atque temporibus fun imprefra.

\section{$M E I C H I O R$ G U I L A N I N U S}

Atus eft in Borufia. Non folim totam pene Europam, icd ctiam Afia clar. A. D:
Africe magnam partem, ipfamyuc Intiam perluftavit. Unde à Piratis MDLXXX captus catcnis ferreis ad triremium trantra alligatus aliquando fuit. Nihilominus reverfus in Eu.opam ob infignem fimplicium cognitianem tatavii Honto medico Prafectus, sxibidem Medicine Profertor conftitutins eft. Perpetuan $\mathrm{Hhbh}$

fex 
ferè contentionem reciprocavit cum Petr. Mathiolc. Obiit Patavit, 1589. Van - der Lindea de Scriptor. Med.

Scripta ejus hac funt: Commentarius in tria capica Plinii Wajoris de Papyro - Allertio Guilandin fententia in $G$ lenurn à fe pronunciatx--Apologix librum primum edidit, cui titulus Theon : fripfit etian duos alios, quorum ecundis, tattecion; tertius Bion infcribitur; qui, an editi funt, nelcio, ingut Gë fnem

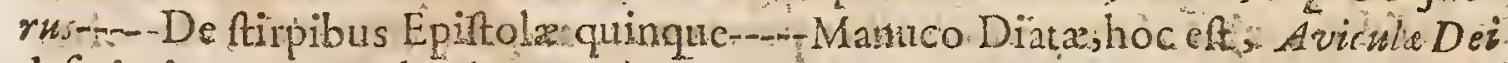
defcriptio--..-Epittola ad Conradum Gefnerum-.-Synonyma l'antaram, \& conjectanea.MS I Iornes Georius Schonck. D. Medic excudenda Ce Typographis. tradidiffe fcribit in fuis Bibliis Jatricis.

Melchion Guilandinu, Boruffus, Medicus, juvenis doctiflimus, cum aliàs in: re medicâ pracipuè, tum in Medicameñzofum fimpliciun cognitione, quám. multis \& longinquis per Europarn peregrinationibus, \& Mediterrane $\dot{M}$ Maris ad Africam trajectu fibi comparavit, exercitariflimus. Gefner. in Biblioth:

Virut in omni fcientitrum generc, fic in fimplicium Medicamentorum cognitione verfatiflimus. I ogn. Q ....hfted.

Vir fuit finc dubio literatilimus, qui infar Gorgid de qualibet: re propofitas copiosèatgue difertè poterát dilputxtẹ. Cafellan de Vir. Medic:

Hanc Srabo:ris fententian Melchior Guilandinus, vir multijugâ rertim plurimarum cognitione, eximiâ doctrina prec llens, wi wactatu de Papro (docto, I upiter! \& laboriofor) folidë confutat. Guda lanciroll. de reb. deperdit: p. $67 \%$

Melchior Guilandinus; cgregieliteris à puero imbutus, precipue in Hifforia Naturali ingenium excicuir, \& in Rei Herbaria ac Fofjlium oognirione excelluit. Pauca tamen, cum multa expectarentur, ejus extant foripta: Eft inter eas Commentarius de Papyro ad C. Plinum cditus, in quo tamenvifum tanta cxiftimationis multot s hallucinatm elfe, eruditifimus losephas Scaliger contrario fripto demontrivit. Thuan ad Ann. I.j89.

Gibiandinus pratcr A A dica Arm \& prafertim Botanica peritiam non vul garem, ne meliorum quuidem literarum notitià caruit. Iccirco, ubi primùm

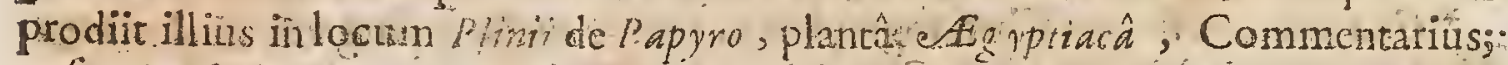
e fecuta eit doetorum aporobacio, un celebis nominis vio Dalecampius, in enndem locum pliziz pofteà fcribens, Guilandinum', propter iftud fcriptun maximè, miralaudatione aficcret -alii verò qui de Chartâ \& toto illo argumento fcripferunt, id demum apude Plinitum probarent, quod Melcbiori. clfet probatum. Adé fit fxpè in literis nu prosaureis vulgò habeantut 2. qua

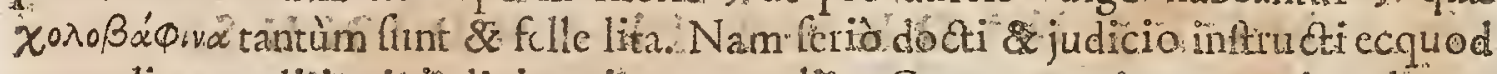
reconditx enditionis indicium in tam proliso Commentario potuerint deprehendere, sequidem fatcor me ignorare. Nulla quippé rei quâ de ag ebatür fungularis notitia, \& frultrà calcata Ág pturgnulla vctuftatis folida cognitio; Auetorum Latinorum intelligenria mediocris: Gracnum ne mediocris quidem.

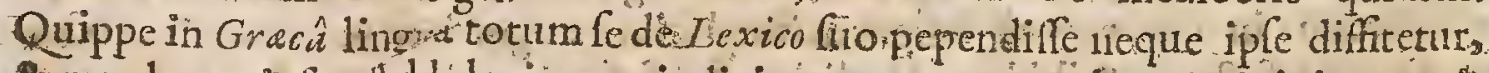
or clamat ipfa Addélevitatem judicionumut cum multa corrigit integerri- 
ma : Cim Auctores, profertim veteres, temerè \& fine ullẩ ratione reprehendit. Omitto planè defulroriam Scriptionem. Meritò igitur lofepho Scaligero dolurit, Guilandinum, quitam male liniwn acceperat, tanto cum plaufu paffim ab omnibis accipi. 1. Liafanb. In Epift.ad Tbuan prafix. Opufc. Iof. Scalig.

Matthiolus pafim in Epiftolis Guilandino varia impingit; arrogantiam, temeritatern, infériam in Arte Medicâ, ealumniandí libidinem; invidentiam; imò cò plogreditur, ut non dubitet Guilandinum alicubi nebulonum omnium principein pronuneiarc.

* Ejus Commentarius in tria Capita Plini de Papyro : Item ejus Affertio. Sententia in Galenum àfe pronuntiat: Item cjufdem Apologia adverfus $P e-$ trum Andream Mattbeolum: Item ejufdem, de ftirpibus aliquot, Epiftola quinque sermituntur, appofitâ nota Auctoris damnati, \& Operum permilfo Ium. Index Madrit. edit.ann. 667 ?

Extat Papyru, hoc eft Commentarius in tria C. Plinit Majo is de $\mathrm{P}$ apyro, Capita. Acceffit Hier. Merrurialis sepugnantia , quấ pro Galeno ftrenué pugnatur. Item Guilandini Affertio fententia in Galenum à .e pronunciatx. Vem netris, aptid Ant. J Jinurn 1572 , in 4".

Conjectanea Synonymica l'lantarum, operí Iob.Georgii Schenckii cdita:cum: Horit P'atavini Catalogo, fub anum If91. Francofurti, $1600 . \mathrm{in}, 8 \%$

\section{F R A N I S C U S A T R I C I S.}

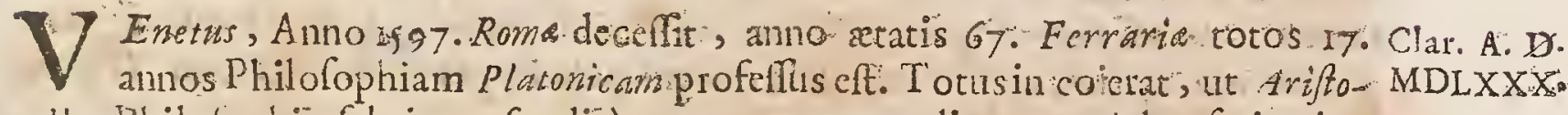
telice Philofophia fubricam fundirus everteret atque diruerct. Adverfarios ha-

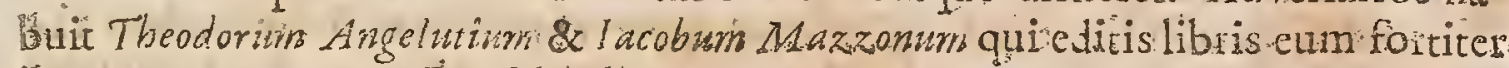
Impugnarunt: Konig in Eiblioth.

- cripta cjustunt- Paralleli Militares-.--Difcuffiones Peripateticx--.Nova: de Univerfis Philofophia--Nova:Geometria-Nova Rhetorica-.-Dialogi tés de fribendà Hiftoriâ, \& de atte poëticâtres decades--Commentarius in Homerm; quem infinito multoim annorum labore confecerat, fed non ediderat. \&c.

Francifous Patricius literis Gracis 2 Latinis egregie inftudus, ad Philofos phix ftidia animum applicuit: Sed dum ex ingenio fuo natas 2 à communi plem. runque fenfu abhortentes fententias in Scriptoribus interpretandis confectatur, d plerifque reprehenlus, \& in Peripateticis difcuffionibus, as novâ de Unver is Philolophia , complures adverfaros habuit. Et novars Pbilofophiam quidem cenfurâ notatam paulònte mortem retractavit. Alphonfo L.I. perauam familiayis, \& à Clemente VIII. qui ejus operâolim ufus fuerat g cum primum Pontifex renuntiatus eft, magno fipendio Romam evocatus Parallela militaria ftatim publicavit; multaque alia praterea fcripfit, qua in amicorum forinis inedita jacent: Thian. ad Ann. 1597 .

Frarcifcus Patricius Venetus, non hujus modè, fed longo fuperionis avi Hhah hallorim. 
Italorum ferè omnium multò doetifímus, in omni preftantiff narum arfịtum gencre; qui occupatiflimâ.in vitâ ac fummonum virorum negotiis penè omnibus, ac fere perpttuo itincrum laborc diftrictus, nunquam literaum ftudia inteımifit , \& egregia multa compoliit. qux fummis literatarum omium latibus efferuncul. I an. Nir. Exythr. Hinacoth. p. 20;:

Mulra hujus funt praclarè ac propè divinitùs fcripta q qux longum elfot omnia enumerare. Sed inter omnia ejuspraclariffma qpera, maximè placet

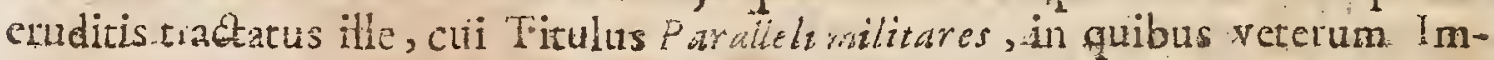
peratorum militaris diciplina cum ea comparatue atque confertur, qux notiis munc vigerin moribus; qui liber elt mole quidem amplus ac magnus, fed rerum, qux in co continentur, xftimatione $2 c$ pondere longè naximus arque graviffimus. Iderr ibid.

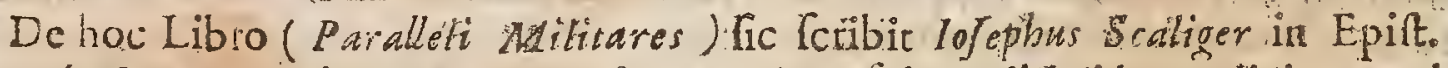

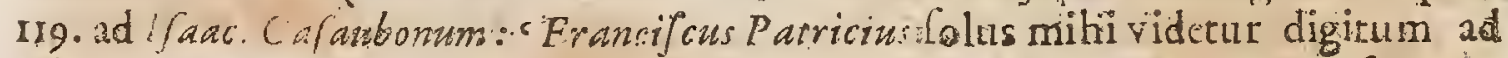
- fontesintendiffe: Qucm ad vebum alii, quai ftudiumtracàrunt, quam fequali t.eur, tamen cjus nomenne iemcl quijdem memorarunt.

Francifius Patricius, audacis homo:ingenui, ut nomen fibicompararet, Arifotetis Philolophiam refutandan fibi firmplie, Tomis eituatuor Difcurfonum

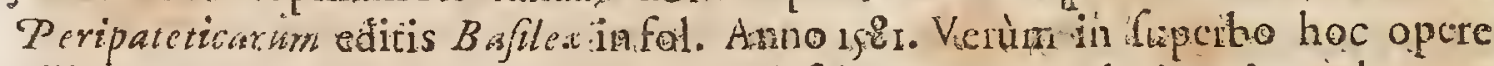
diligcntiam ejuslaudamus, judicium defideramus, audacian improbamus. Ionn. Ionfius de Scripror. Hift. Phílolophic.

Tamfelici fucceflu Dialogar fuos de rifariaconferipfrt, juxta $N$ audoi fen-

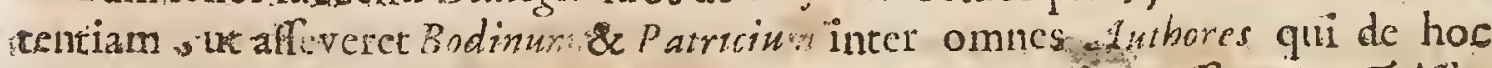
argumento egcrint, doctifimos \& acerrimo judicio pradicos elfc. Ant. Teiffier Elog. Erudit Viror. Gall.

Patricius:quantumvis doetus fucrit, \& licet ejus Ccripta immortalcm famam ei comparalfent, Tosflitamen gloriam invidebát; in hujus enim Hierofolywans:everam criticam exercuit, libio tatico cui titulus Iudicium S. Francifci Patricii in defenfonem Aroffi. Quapropter Dom. Chapelai arbitribatur T f fum in sminta Patricium per Mopjum depingere volliffe; it qui ibi defcibatne Iralicè tanquam vir chijushingua fermones incllitos loquirur, labiaque amicè : fubrident, fed qui fraudem pectore chit , ficamque fub pallio geftat. Ant. Teijfier ibid. Gall. \& 'tal.

Extat Magia Philofophica, hoc ct, Zorodfer, \& ejus 320. Oracula Chzidaica: Ayclepii Dialogus, \& Philofophia magna: Hermetis Trifmegifti Pymatrder: Sermo Sacerd. Clavis: ermo ad Filium.: Sermo ad Afolepinm: Minerva Mundi: Etalia Mífcellanea. Nunc primùm ex Bibliorhecâ Ranzorianâ è tenebis cruta is Letize reddita. Hamburgi, 1593 . in So. Extat ctiam cum a a diris Longini Tino Magico, five fecretorum Magicorum Opere. Offerbachii apud

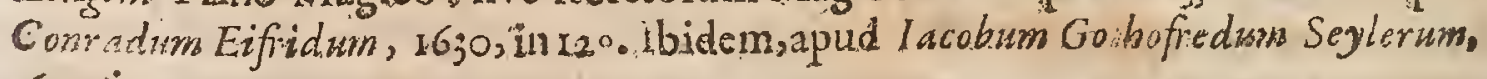
1673, in $\mathrm{r}: \mathrm{z}$ :

* Francifai Patritii nova de Eniver os Philolophia prohibctur, nifi fuerit ab Auctore 
Auctore correctá, \& Rome cum approbatione R. P. Magiftri. Sacri Pálatiz impreffì. Index. Tridentin. in Append. Cert. Auctor..

\section{J O A N N S HE UR R I U.}

$\mathrm{U}$ Litrajeclinus, natus eft anno Dom. I543. Primos pueri annos iis parriâ formavit Georgins Macropedius : Arnoldus Eyckines: Adolefenti McClar. A. B:

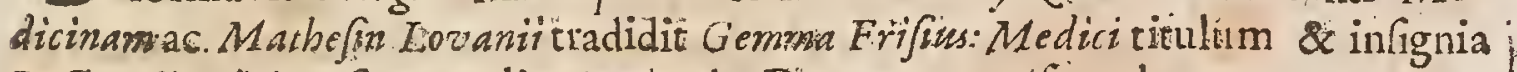
Doctoralia Tícinenfis conanlis Academiza. Domum reverfus s ab annorum i2. pe-

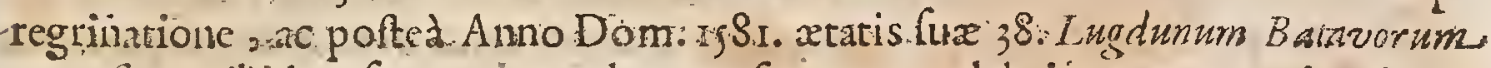
accerfisus, ibidemfummo cum honore famæque celebritäe, nec minori tum in docendo tum in fcribendo venuftate, . Medicinam aunos ipfos 20 . explahravie, feripfitque utiliffrmos in re Mcdicâ Tractarus: Vivere defiitis nno 160 r.atatis 58. die Ir. Augurti. Leida in Templo primario conditus.Valer. Andrears.

Elaboravit Commentaria in varios libios Hippocratis: item, Refponfum ad Supremam Curiam Hollandia, quốoftcudit, Nullum efle aquar innatationcm Laniarum indicium,

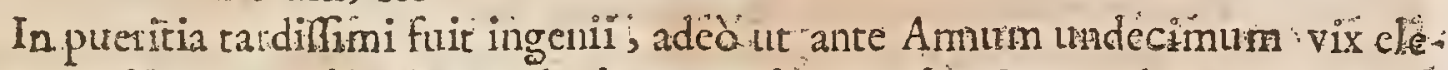
menta prims:tenuerit, \&ante decimum quintum vix Grannaticam perceperige. Poftè fummo imperu ftudia apprehenditradiebus nostes adjungens Acad. Lugd.

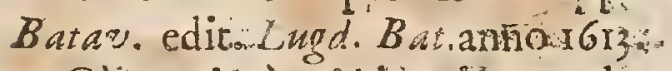

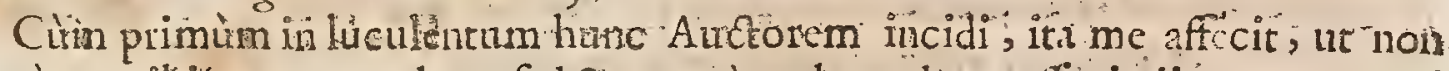

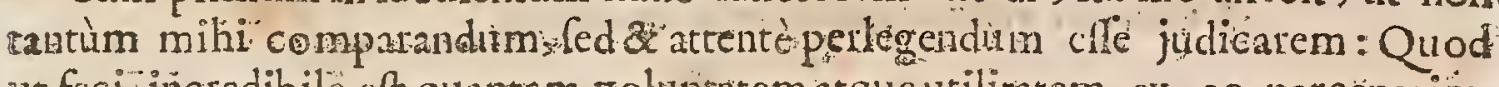
ut feci, incredibilê eft quantam roluptatem atque utilitatem ex co perceperion. Atq̨ue hre caufreft, cur libros cjus amem, a praftantiam corum expertus aliis. commendem. Audebo etiam obligare fidem meam, ftudiófe Lcetor,promitro ac

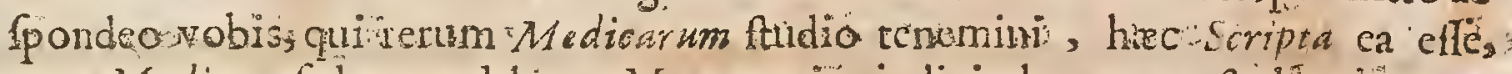
qux Medirum folentem dabint:- Magio enim judicio hoc opus eft clúcubiatum: àfummo Niro: Quipue qui per triginta annos Hedicâ exercicatione corrobora-

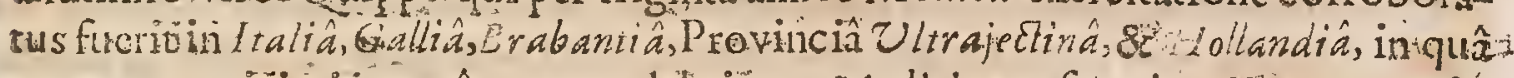
per annos viğinti quantâ: cun celebritate-Medicinam fecenis, Europa novito.

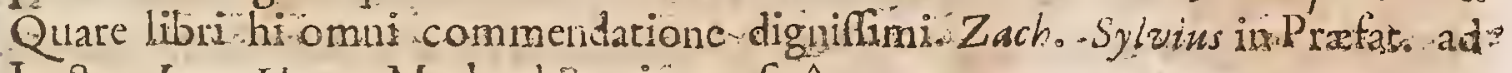

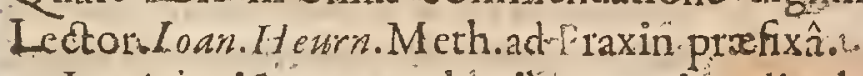

In Apiorifrsorum ambagibis extricandis plures cacuriunts si habiteris ocium :

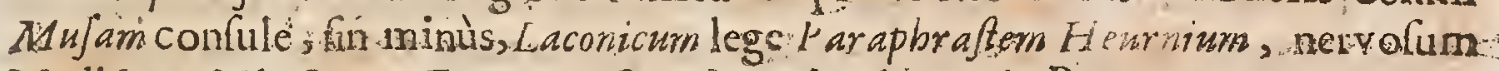

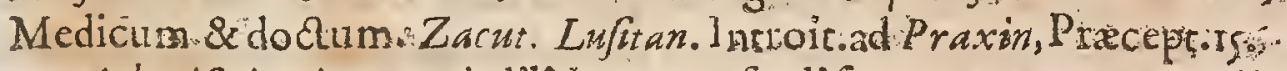

Aphorifni Hippocratis diligencer verfaudi fune cum Commentarizs Galeni \& Ho terii, aut Vallefir, Heurnii etiam accurati funtsfed pro Tyronibus paulo diffciliorts.:Albert. Kyper. Medi ritè dilcendi Metlod ip.:297.

Heurnius Medicus mihi in omni hoc morbo fidus, pericus; 2 (qux laus propria) cautus. Lipf: Cent.r.Mifcell.Epitt.go.

Primus in Acadtmiâ Leiden/ź propriâ manu Anatomiam adminifitavitie; cfflagitantibus id ftudiofis cum infolens hos exercising Patrie eo rempore effets Melch. Adam. in Vit, Heurno

Hunc 
Hunc ( Toannem Heurnium) Pedarium Iulii Alexandrin Senatorem non fune causâ vocavimus fuprà : deprehendimus enim, non pauca cum, uibi $M$ ediciñe ftudiofis modum difcendi pralcibit, tacitè mutuarum cffe fulio. Quanquam antem ita fibi caver, ut feif us ejus potitis, colque variè disjectos, inque compendium contractos, quàm verbalectori fuo appendat: eft ramen, ubi ungues Aqui ini promiccnt. Thomaf.de Plag.fect. $46 \mathrm{I}$.

Extant Opera cjus omnia, tam ad Theoriam, quàm a Praxin Medicam fpeEtantia, ab Ottone 1 eur, iu F. in duos Tomos diftributa ac edita, Lugduni Brtavorum, apud Raphelengium, $160 \%$. in $4^{\circ}$. Lugd apud 10h. Ant. Hignetan o Marc. Ant. Ravaud. 1658 . in Fol.

\section{Hoc ejus Epitaphium, Aluctore Dan. Heinfio:}

\section{H.te ille Heurniades, cuife tot maxima debent}

Nomina, cui debet fe Medicina, jacet.

Nature potius quarn morbic crimine reptus.

Quarn toties aliis fufsulit artis ope:

Ne turnulo quid defit, adeft fidrfjina conjux,

Et vite comitem, nunc guogue mortis babet.

Sic olim corijuncta Thoro, nunc junita sepulchro

Continuat pactam, nondurn aliena fidern.

\section{HIERONYMUS MERCURIALIS.}

Clas. AnD. T Atus eft Forolizi in Italia A. C. Isjo. Patre Iobanne Mercuriali nato MDLXXX. I Patavii I'hilofophix \& Medicinz Doctoris titulo, în patriâ tanâ cum famâ Medicinam exercuir, ut Mercurii filius faluraretur: hảncque 1569 . à Senatu Veneto Patavium vocintus, principem Medicina practice interpretanda

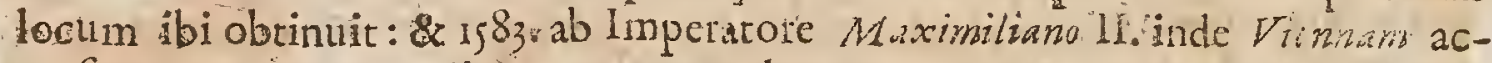
ecritus, magnis praniis, 300 . nempe ducaris, torque aureo, totidem ducatorum pretii, duobus cquis generofis, nec non Comitis \& Equitis anrati digni-

- tate, quod feliciter Imperarorem priftine refituerir fanitati, thonoratus eft. A. C:I587. Bonon amkeceffit, ibique per aliquot annos fofellorem egit, conductus annu ftipendio 1200 . duratorum. Abhinc tandem an. 1597 . contulit fe Pijas ubi initio 1200 . \& annis conlequentibus 2000. aureorum imperraro annuo falario, Mcdicinam finiliter publice docuit. Obit Eorolnvi, in Parria, in quam animi relaxandi gratiâ divertot, calculi dolore per 30 . dies victus 1606 . zatis fux 76 . Vinder inden de Script. Med.

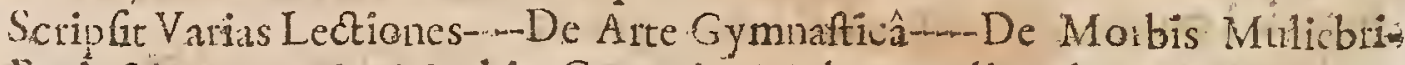

- bus Pratectiones-m--De Morbis Curaneis. Multaque alia ad rem Medicinam spectantia.

Heronymus Mercurialis Foro-Livii ü Vmbriâ matus ann.I530. antiquâ utrin- 


\section{CELEBRIORUM - AUTHORUM.}

guefamiliâ, secc modicis opibus; Patavii cum tyrocinium in Philofophix \& Mediciste ftudiis feliciter feciffet, à civibus fuis admodum juvenis ad Prum IV. legatus miffus cft, \& ex eâ occafione in familiam Alexandri Farnefât Carda:1alis literatorum fautoris eximii conccffrt, in quâ totum feptennium manfit, in illoyue orio primum ingenii fui foetum dedit Gymnaficam. Inde Patavinm ad. Medicam profeffịnem vocatus, jan famâ cjus inclarefcente, à Maximiliano Crfare, cum graviflime morbo laborarct, th aulam evocatus eft, à quo jerfanato multa honorifica munera accepit, \& Patu vium Gub anno 73. rejetiit. bi 18. annos Medicinam fecit \& docuit. Bönonie poltea aude ftipendio per quin-

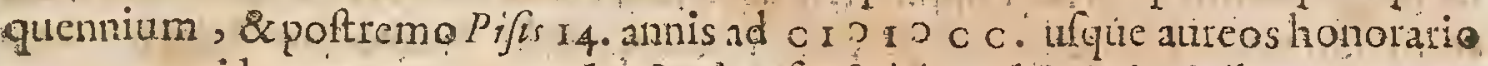
excurrente idem munus exercuit, \& cùm fruftrà à multis l'rincipibus evocatus effer, otium literarium vita aulicx femper pratulit, tandem ing ravefcente xtate, parriam répetiits ubi qui lemper valetudine profpcrà ulus fuerat, calculi morbo per xxx. dies acerbè vexatus, vitam de $k$ cp. oprimè meriran cum morte commutavat v. Eid. Novembr.ad D. Merrurralis in odeo à fe magnificentiflimè exeruéto fepultus, quo \& paulo ante.v. Kal. Dccembr. D. Mercurialus reliquias trainferri curaverat. Fuit cgregia corporis formâ, \& fanctifimis fuaviffmilque moribus, adhæc doctrinâ piafranti, 'quod multı cjus fcripta teftantur, à dilcipulis ferè publicata, ut fi quid in iis peccatum effet, ca citra faina \& exiftimationis jacturam cmendandi lumma prudentia ac modeftia libertatcm fibi ferrarer. Quxdam \& in, ippocratcm non omnino cdita, \& in Ariftoteles problemata reliquit. Thuan. ad ana, 1604.

Quxnam tanta cft vis ingenii, quod tantum Orationis flumen, qux tanta diccndi facultas \& copia, que Hieronmi Mercurialis Forolivienfis Medici ac Philofophil laudibus cx requo refpondeat ? Illud enim unicum rtatis noftre Jumen, illud eximium Medice facultatis decus, illud maximum acumen ingesiii, ad rerum caulas inveitigundas, ad Cođi converfionem ac motum, ad, fiderum ortus, occafus, adfpcetus, conpofiticnefque notandas, ad intimam ac reconditam ominum difiplinarum notitiam percipiendam, ritè à naturầ perféetum illud fummum cruditionis culmen atque faftigium, quis sonon modò laudibus efferre, verùm etiam diccndo allequi pofit? I an. Ni. Erytbr. Finacoth.

Hieronymu eN ercurialis, clariffmus Medicus, imò avi noftui primarius. Lipf. Epiit.Cent.2.Milccl. Epitt. 32 .

Hicronymus Mr ercurialis, vir probus, candidus,illutri doctrinâ \& famâ. Iders ibid. Epift. 39.

Hieronymus Merrurialis, Medicus excellentilimus. ommumque difcipli. sarum genere ornatiffimus: Boiffard. in Icon.

Dc Mercuriali quid quæris in ore omnium verfatur, aligitur, \& de fungulari ejus virtute \&loquuntur omnes, \& Sentiunt. Cambil.Paleot. in Epirtad Latinitum fcript. Non. Decem. is 87 .

Cum Mercuriali frequens eft mihi confuetudo. Quid queris ? Convivia, qux antea averfari folebam, nunc me magnoperè delc ctant; quoniam per ea commodè illius congreffu mihi frui licet. $Q$ quanta hominis eruditio, quàm 
fuaviflmi mores ! Camit. Palsot. Epilt. ad Latin. fcripr. prid. Calend. Febs 3538.

Hieronymus Mercurialis, magnus ille fine contioverfin latronices, cui $M e$ dica Ars ornarum deber flectum illum \& peculiarem, quo priftinam dignitatem nunc demum abunde teftatui. Paul. Guald in Vict incent. P inelliwidi $\bar{B}$ atefii Vitas p. 332 .

Medicinam tam eloquenter quàm erudite docuit, exiftimationemqua \& mirationem Doctorum Virorum innmeris puaftantibus fcriptis a fe compoftis fibi damentut. Sed non minus yirtute quam eruditione fura illuttris fuit. Cum enim non mùnor follicitudine perfectam fanitatem in Anino fuo ftabilire fatageret, quàm $x$ gris ad fe confugientibus valetudinem reftutuere, vitam, innocentia \& pietare corufam egit. Merita ejus fungutari, non modo magnam cclebitratcm ei pepererunt, fed etiam opes immenlas. Heredibus enim reliquic cẹntum \& viginti millia Scutatorum aurcorum , poltquam vixiffet honeftiflim \& folendidifimè \& infignibus liberalitatibus A micos affeciffet amplafque eleem of ynas pauperibus erogaffet. Paulo ante obitim Medicis dixiț fe geminos intra rcnes calculos habere, cofque rogavit utfatimac animam effiffet corpus fư aperiendu m curarent. Quo facto, juxta cjus votum, obfervatum ef illum

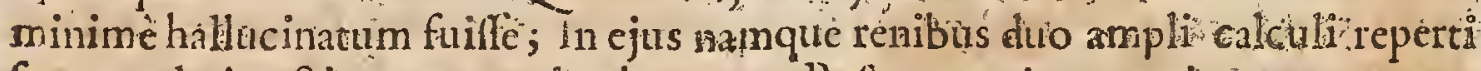
funt ponderis oftingentarum dià hmarum. Poftquam ejus concives eum magne pompa feptivilfon, ftatuam ei erigi curaverunto. Verba quadam fuperbia ac vanx gloria fucrunt ci exprobrata, dum enim de doctrina fua loquebatur folitus erat dicere neminem ab opinionibus fuis deflectere poffe quin in craffós, errores laberetur. Inter omnia ejus opera fingulatispretii cenlctur cjus Tractatıs de Arte Gymnafica qui dignus éft quem legant non mode Medici Ced \& quot* quot potioris literdura culcorss exiltunt. Ant. Teiffer Elog Vir Erudit. Gall:

Hieronymus Mercurialis Forolivienfss, vir clegantioni do Etrinâ planè imburus, in quo pracipuè omnis generis: Scriptorum Medicorum multiplex lectio cum acciurato judicio vix potel fatis laudari. Sebaft. Scheffer. Introduet.in Arto Med.

* Ejus liber de Hominis Gemorationc cum Expurgationibus permitritux, in Ind. Madrit. Edit. ann 1667 .

Extant de Arte Gymnaficâ libri 6. Amftelodami I675: in $4^{\circ}$.

Extant libri s. de Morbis $C$ utaneis, Bafilec apud Iuntas, 1601,1625 . in 40.

Extat Medica Practica Venetiis 162.7. -in Fol.

Extant Confultätiones \& Refponfa Medicinalia Tribus Tomis comprehen-

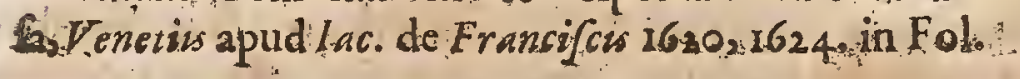

\section{STEPHANUS VINANDUS PIGHIUS.}

Clair. A. Do MOLXXX: gìs conftanter inftitit. Cujus quidem exemplo: 2 Rome fummos -inter do 
Orinâ viros diu multumque verfatus, Urbis, omnifque adeo Romana antiquaratis cam elt peririam conlecutus, ut ætas noftra paucos æquales tulerit, luperioren certèncminem. Quo factum, ut domum ex ltalia reverfun, Ant. Pereno: tus Cardinalis Granvellanus, acer preftantium ingeniorum xeftimator, in famiTiamadíciverit, \& fux, quam habebar copiofifimam , profecerit Bibliothecx. In cam fe abdens Pighius, ut -Atudiis jan inde à puer totus erat deditus, multa c̀ vetuftis calımóque exaratis codicibus cruit. Inde ad Scriptionem converfus, Valerium Maximum pariorc togâ donavit, "Ee Caroto Philippo Croyo. , primo

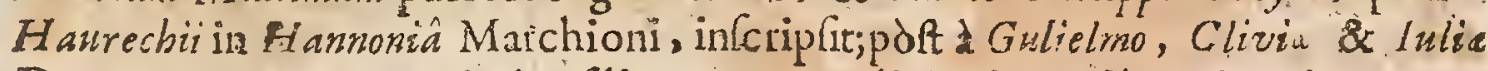
Duce, evocatus, Carolocjus filio, Ronan rcligionis gratiâ cogitanti, comes, vel potius Mercurius, vix que dux addicur. Quo ante diem, partique ac partia daboranti nimiscito è vivis ercpto, Vinandus, etii marore-confectus, tit ad poAteros faltem peregrinationis iftius manaret itilitas, Herculem Pradicium. ivelut boni principis imagiacm, evulgavit. Nam ut Prodicu Philofophus finxit Herculerr, cùn primùm pubefceret, cxirle in folitudinem, atque ibi confidentem diu multumque dubitaffe, cùtn duas cern ret vias, unam voluptatis, alteram virtutis, utram ingredi mclius foret; tandemque vincente atione, in virtutis

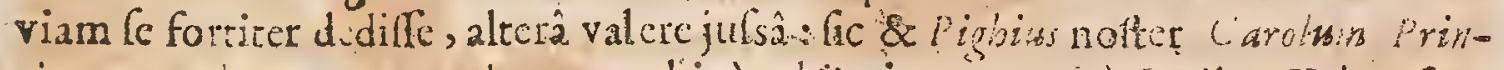
sipens, ut alterum, erculem, graphice cxhibuit, atque unà I tuliam Vniver a ams, velut in tabellì ob ocilos pofuit. Officiun porvò filio impcufum Gulielrmus parens agnovit, \& vicum lcuptis factifque benè meritum, apud Coloniam Trójanam (oppidum hodie anklenfe nuncupant, à Canctis Martyribus ex Legione Thebatâ, cò loci pro Religione crefis ) Canonicum \& scholacham renuntinvit.

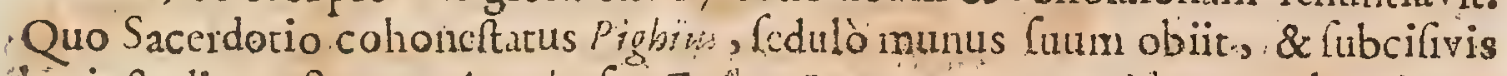

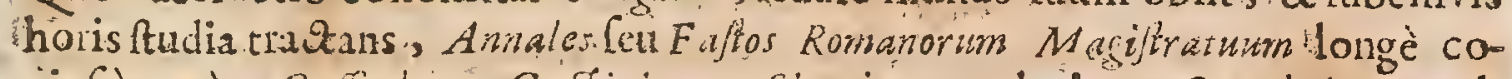

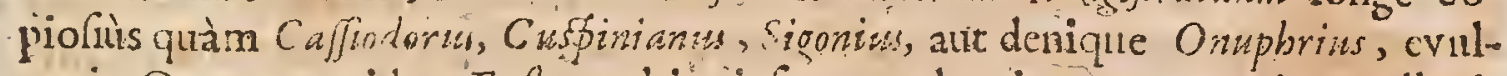
- gavit. Quorum quidem $F$ afs srum bina infuper volumina, qux moriens collegis fuis commendavit, Andreas Schottus typis Plantiaininis edenda curavit: ut alre-

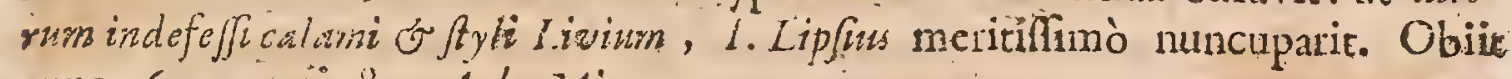
anno 1604 . atu is $\$ 4$. Aub. Mirsus.

Rerum ctt maximè Romanarum cam peritỉan ftudio diligcutià que '\& oblervatione âfidutuâ Fafforum Capitolinorum, marmorum, numif matum atque Inf criptio: num confecutus, ut quos comparem "sgonios atque Onuthrios (bone Dens, gualcs viros!) facriè reperiam; quos veró hoc in getiere illi antę̧onam (quod prafficine dictum volo) inveniam neminem. Andr. Schott. in $1^{\prime}$ rafat. quam Pighii Anual.Tom.2.pramifit.

Reaple comperi, aliifque, fpero, probabo; nullum aptioren Commentarium ad M. Tuliii hiftoricasad T. Livii Aunales, ad Dionyfum Helicarnaffenfem ac Dionern, ad L. Florum, ad Scriptorem de viris Urbis Rome illuftilbus, omnefque adeo Rom.narum rerum Scriptorcs, cxtra hos Pighii Annales, nec (perai, ac ane optari quidem polfe. Idem ibid.

Tempora cos refellunt, qui Augufino Eutropium faciunt juniorem. Ac mirum in itto eriam aberraffe virum temporkm bene grarum Stepharsm Pighitom Iiiii 2

Camperiene 
Campenfem in Annalibus Romanis. Voff. de Hift.Lat.1.2.c.8.

Stepionus Pighins vir de Valerio,imò Amnalibus luis Romanis,? de universâ. Antiguitate Romanâ praclarè merikus. Vofl. de Conftruct.c.25.

Valerium Maximum Stephanus Pighius nobis dedit peritè \& religiósè cenfum : \& illo modeftia excmplo, quod imitarivelim cos, qui hoc Ciriticum Stadium curnunt. Et validè valet Gane per eum Valerius. Lipf. 1.2. Elector. c.11.

Valerium $M$ aximum, fciolorum ftylis penè confectum atque exanimatum, Stepbanus Pighius in fanitatem, imò vitam, princeps reftititit. Gapp. Sciopp. de Art. Crit.p.t.2.

Extant Annales Magiftratuum Provinciarum Sènatûs. P.Q.R. ż. Tomis. Ant. 1615. in Fol.

\section{TOANNES VINCENTIUS PINETIUS}

Claruita.D. MDLXXX.

Rigine Gensenfss, Neapolinatus, optime meritam non folum de Italiz fuâ. fed de toto Orbe Chriftrno animam deo reddidit anno 16oj. cum ata tis ann. 6S. ageret, in cujuslaudibus commemorandis, "quas ahii fingularibus libi is fufùs pro merito explicarur funt he nimius frm anc. Tito Pomponio ipfum comparalc faris habebo, quippe quir Veneti; ut ille Attici, a fereniffima Kepublich, qua uplum impense dilexie, nomen pioncritus, $\alpha$ in privat vita pranobilis familix dccus fervansamicis cunct lamanitatis officia fedillo ac prolixè praftare, aliofque quampluimos, quos unutua virtutis opinione in

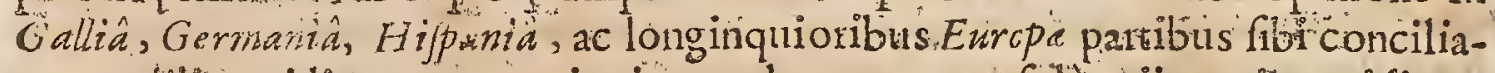
verat, diligcnti literarum mutitatione coleret, ut non follim iss, qui cotridiano eonvictu fruebantur, gratiflmus fedetian aliis paffim quampleirimis urilifimus effer. Bibliôtheca ejusiafignis tot annorum fpario \& folerti curâ collecta variam forturam pof ejus obitim fortita ef, $\$$ cum hricde conflictata, quod amplius ex $P_{\text {azulo }}$ Gualdr, Vincentino, qui ejus vitan certe dignam qua ab - mnibus legatur defcripfri, lector poterit cognofcere. Thuan. ad ann. Ifar.

fornnes incenius Pinellus, doctus \& probus fupra:omnia penè noftroram gemporum exempla Aens noftrabrorum tum veterum tum recentiortam oppidóferax, paucos viditin eo genere literaruin quas humaniores vocamus, quiburs non inferiptum allicubiclfet P inelli nomen: pellatielum, in cujus Eibliotbecâ viri doćt inaximaftudiorumáluorum prafidia collocata intelligebant. Paul. Ginald in Vitâ ejus.

founnes Vincentius Pinellits, vir plànè in omni fudiorum genere fingularisin ac propter eximiam humanitatem inte onnes maximè memorabilis, qui non: folum pretioffirmum ingentis fuz Bibliotheca thefaurem totum explicuit, fed: nullum etiam diligentix atque impenfa oficium in hoc:Opere provehendo- reliquir. Car. Sigor ad alcem libros. de Regn. Itat.

De $y^{\prime}$ inello, eft enim juwenis, preter antiquam generis nobilitatem, \& Gracis at Latinis literis impénsè eruditus, a cum liberalium artium ferè omnitm: cognitioncro. 
cognitionem profitearur, tum î̀ hâc ipsâ de frmplicibus Medicamentis Icientiâ plurimùm excellit, inprimifque in expendendis doctiffmorum virorum fententiis acripollet judicio, qquod \& tute ipfe fatebere, cùm illum intus \&e in cute. (ut dicieur) noveris. Barth. Maranta in Method. cognofcendorun fimplic.

Ioarines Vincentius Pinellus, immortalis memoriz vil, abque in omni opti-

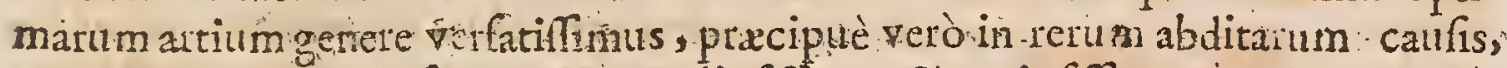
naturæ⿵⺆⿻ arcanis perfcrutandis, ftudiofilimus \& cui offrimus, cujus optimâ, * luaviffmầ confluetudine utinam mihi diutiùs fruilicıiff.t. sed hanc mihi felicitatem mors invidit, quxeum rapuit cum miram hominis eruditionem, morumque fitavitatem degultare vix coepillem. Horat. Cornacchin in lib.ejus de Logic. Prafatio.

Ioannes Vincentius 'Pinellus, vir maximi qquidem nomilis, fed mäjoris tamen,

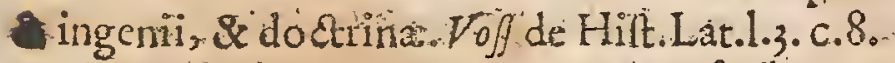

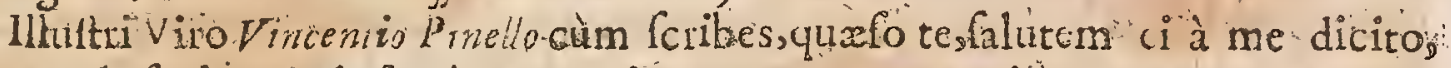
ignoto de facie, non dé famâ. A'mo virum , magnum merito apud omnes ima gnos. Eipf. Epift.Mifcel.Cent:2. Epift.24.ad $C$ arolum $C \ln f$ fum.

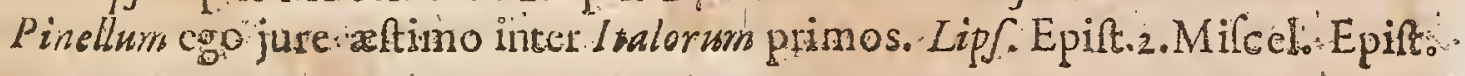
47.

Ovulitus, quod P inelli morte acecptum efte Abiit aternis ille vir, ipfend minis \& famx leetirus : fed nos in defiderio, \& dolore rcliquit, $M$ uf as in fqualore. Quis fuccrefcet, \& dotorem nobis demet, $3 /$ w fis fqualorem? Non, doctriliâ, fed opibus quoque opus. Eryc. Putean in Epiftad Petreskizm.

Ioannes Vincentius inellus, vir quamvis meritò abs omnibus aliquầ Laudè wignus plurimum lat datus ob multas \& magnas animi fui dotes, nunquam ta men Gatis laudastus. Peir. Victor. 1.26.Var.Lect:c.16.

Quamvis Pinellus doctrina tam infignis foret, plists tamen liotione quatm foriptione delétabatur. Nullum emifit opus. Ut certum tamen perhibent ât

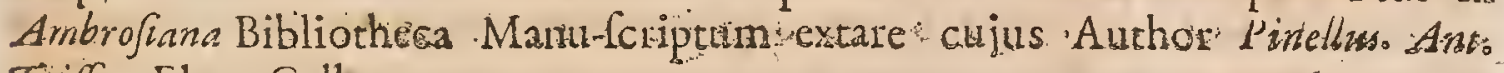
Tififler Elog. Galls.

\section{PETR USS PITER USS.}

(2. Alliss, Trecentas, Dilcipultís Turnebi \& Cujacii. Fato functus eft No

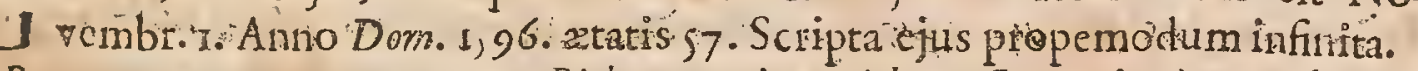
Petrus cognomento rour tam Pithaus, quàrn Pithius. Ego cnim à Gracâ voce Dea Pithus: nomen illi effe. fufpicor: Papyr. Mafjor.

Petrus Pithus omni liberati eruditone ornatus, antiquitatis ignorate quaf pitbius alter , oracalis fuis enarrator \&ulluiftator maximus. Turneb. Adverfar. 1.21.cap. 28 .

Pétrus Pitbasu, immortale illid Gallix decus, qnố viro digniórem omni laude alium ne Hiftorix quidem continent. Cafaub. Not in Capitolinum.

Petrus / ithous Juríconfultus rare cujufdam eruditionis virinatus ad eruenda Yetryfatis Monumenta, Gefner. in Biblioth.

$$
\text { Iijiil. Vis. }
$$


Vì fummâ próbitate \& eruditionc. Scalig. de Emendat. Temp. 1.6.

Petrus Pithiaus, vir præclarè de universâ metitus antiquicate. Vofj. de Philolog. c.Is.cet: 18 .

Petrus Pithaus, vir noftra atate maximus, five probitatem molum $\&$ veram nec fucatam pietatem, five ingenium excellens, exactamque omnium rerum, quas perfpectas habuit, ( habuit autem plus quàm adius quifquam multis retrò (eculis) reconditam cognitionem, \& tumin (üis tum inalicnis cernendis acre \& ab omni livore purum judicium fpectes. Nemo melius unquam unum quempiam Audtorer novit, quàipfe omnes" Antiguos uriufque ling thx Scriptores, quos ad unumlegerat, ad vetera contulerac exemplar is, 8 concozerat. Nemo privata 2 domentica negotia exactias tenuat=qudm ip fe Galicam

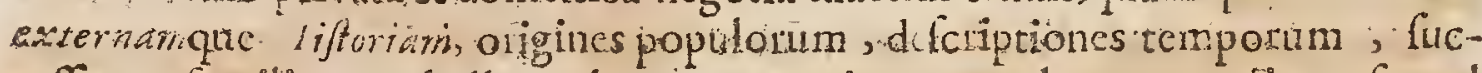
celfiones familiarum , bella, todera, conwentiones', vel exterorwincer fe, vel nobilcumgettes leges, mores, confuetudines provincianm, fingularumve $U_{r}$

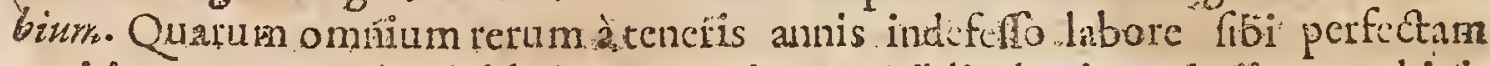
notitiam tun ex vulgatis libris, tum etiam ex Bibliothecis antiquis, archivis regiis, Schatûs, Rationalium, Uibitum, Monafteriorum comparavcrat. Intruinentorumque ipforum arque Actormabonam partem propiiâ manu defcriplerat. In jureautem Civili Rornarorumadillud fatigium pervenerat, ut de ce celeberímogne ejus $P_{1 z c}$ ceptore I acobo Cujacio dici jure peruerir: "Huncadicipt"Lo prariptiffe ne piimus Jurifcenfultus effet; illum Praceptori ne folus. es Thuan.ad Ann. I596.

Petrus Paibastin Ecclefa Pomane Communione natus, cducatus, mortuus: in quâ ille frc vixixt, ut non modò enuditione $\&$ literis, fed \& probitate, candore \& fapientiâ, cxterifque bonis artibus cxcelluifle exiftimatus fit. Ejusin eruendis entiquitatis monumentis fóletriam, judicium, ac fidem ornes laudant. Dallaus lib. de Imagin.p.500, 512.

Petrus ithaus, virimmortalitate dignus. Immortalis gratia debctur magno illi antigritatis yindici Petro Pi beo, qui $P$ hedrurn libertwin A uguftaleri non modè liberali manuiterum alferuit, íed ctiam vitâ redonavit:utinam verò ețiam vulnera ipfus perfanare omnia potuiflet! Conrad. Ritterstonf.in Epift. ad loach. Camberar. prefix. Phadrocum Not.

Immotalia,nullifque verborum pureconiis adfequenda funt in rem literariam merita Petri Pithei, quem virum fcculo nofto frit quodam peculini favore darum, cumpiocopialaudatura fitomis pofteritas, volenti nos animo frpè in ejus laudes divertimus. Calp. Barib. Advi.jo.c. 10.

Anto 1560 .ac deinceps, magnum apud omncs endidos nomen füit Petri $P$ irbai Iurifconfulti, viri optimè de Rip. lite ariámeriti, prafertim Scriptoribus antiquiso Vofi.de fcient. Mathem.p. $4 \mathrm{r}$.

Petrus Pitbeus, vir onnium predicatione major:cujus obitu mupro quanram Refp.jacturam fecrít, mecumlugere, quam multis commemorar male. Sciop.1.5 Sufpect. Leet.epift. 26.

Exincta eft illa feculi nofti lux periit illud Gallis noftre decus propè unicum? 
o.triftem a fortean fatalem noftiis $M$ ufis cafum ! nam ubi hodie Petri Prthai funt? Polt amifum Magnum Cizjacium ille fuit cum aliis oppidò pauci,, qui. dignitarem literarum in hoc regno tueretur. Eo extincto s ne bevi concidat $R$ erp. literaria metus cft. Cufaub. epift. I26. ad Iac. Gillotum.

Scaliger ait omnia opera Domini. Pithou bona effe; fedilli palmam afcribere videtur quod.iniccibitus Advexfaria Subfeciza fen Synopfes; deilide verò Annalibus Francorum in folio \&uin netâvo. Dicit tamen illum quandoque de. Antiquitate perperam judicares quoniam free ea rationd preferebat, ques in vêteribus exeaplaribus legcbat, quamvis illa contrarium ei fuggeffifet: Cateroquia attcm neminem illo meliüs. f́ire Hiftoriam, Confuetudines, legessinatiquitates : variarum Retumpublicarum quarumliber Regionum. Scaliger ana 2\%Gall:

Apud hune ( Petrum Pithaum) de pricis Gallorum I hilöophis ea lcgo, qua: rotidcm propè apicibus \& apud Gälbertum Cognatum, neurro interim alterius mcutionem faciente. Uter altertum vel anticipaverit fcribendo , vel defcribendo

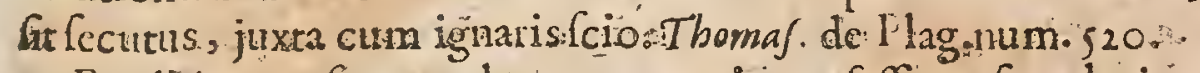

Eruditus erat fupra vulghis : tantam in profeffione fua gloriam adeptưs eft at frequentcr cx.Regionibus extranreis ad ipfum mitretenour lites ut jurdicium, a quo non licerctprovecase a de.iis ferret.'. Tam feliciter ipfr fuccedebant litium compoftiones ut:Arbitri Sapientis nomen inde meruerit: Erat prateica æaue modeftus atque doctus s omnilimque benev oléntiam incomparabili lenitate fibi conciliabat, \& ardenti affe etu quo cupiebar omnia procelara ingchia omnefque hönettos homines fibi conremporaneos`officis fuis fibi demereri. Ufquéadeo ab omni avaritia erat alienus \& iil egenos munificus, us pauperibus erogaretquicquid diebus.fettis 2 Đo miniticis lucrabattr. Proteftantium religionem profefis eft ufyue ad Parifnam Lanienam; fed metts morrisillum tunc adegit ad illitus

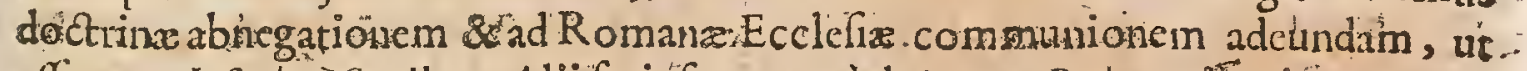

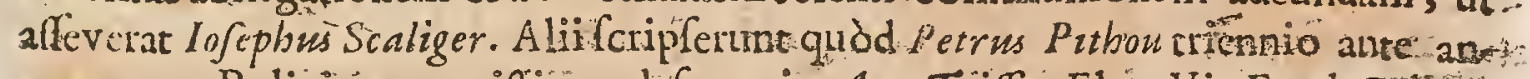

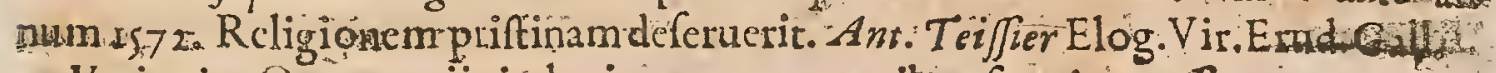

Varia ejus $O$ pera variis in locis atque temporibils funt impreffa.

\section{Hoc fibi vivizs Epiraphisum compofuir: :}

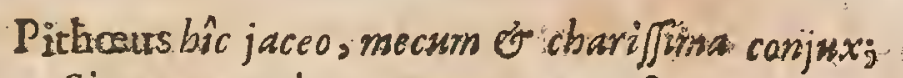

Sic compar vita, compare morte fruor.

Ininprobe, quid rides? caffi Sacra nefois amoris:

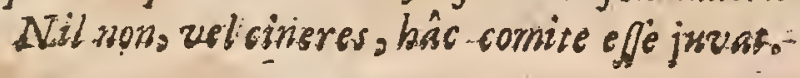




\title{
JOSEPHUS JUSTUS SCALIGER.
}

\author{
Hac ejus Symbolum: \\ EVIMVS TROES.
}

Alar. A. D. MDLXXX.

T. Vlii: Cafaris Scaligerifilius, Gallus, Agingi Nitiobrigum natus eft, die 4 . Augufi, Anto Dom. I540. Obiit anno I60\%. Menle Januaiii. Siripfit varia.

Daniel Heinfurabylfum eruditionis, cientiarum mate., folem to forum, divini Patric divinam fobolem, genus Deorum, perpetum iliccrarum dictatotem, maximum natura opus, ix miraculum ac extrcmum ejus canatum appellabat.

Is Juvetiis quantâ fit eruditione \& judicio, quấque in vetufis Scriptis conferendis induftrî̉, \& abftrufa fenfibus eruendis acumine, monumenta ab co cdita celtantur. Georg. Buchanan.in.Hift. Scot. I668.p. 77.

Senatuis Criticipinceps, I o ephus Scaliper. Vof]. Infitut Orator:1.4.1. Is9:

Praclarè admodum, fr quilquam àlius, de licerarum nudis merirus. Vuji tibiz. Idolol c.28.

Fulius Scaliger ir incomparabilis,nifi logepbum genuillet. Cafaub de 4 . ling. pag. 57 .

Nihil eft quad difcere quilquam vilet, quodille decete non pofiet:- nililegerat, (quid dutem ille non legerat:? ) quod non atim meminillet: nil tam oblcurum aut abditum, in ullovetere Scriptore Graco,Latino, vd :ebreo, de quo interrogatus non fation refponecrer : Hiftorias omnium populorum, omnium atatum, fuccelfones Imperiorim, res Ecclefue weteris in numcrato thabebat. Animaliums Plantaru in, Metallorufa, omniumque rerum naturatium proprietates, differentias, 8 appellationcs, quà vetcres, quà recentes, tunbut ac"Curatè. Locormm fitus, provinciarum fines, $\mathbf{x}$ vajas pro tempoubus illarum divifiones, ad unguem callebat. Nullam diciplinarum ficuriarumve gravionm reliquerat intactam. Linguas tam multas tam exactelchebat, ut velif hoc unum pe totum vitx fpatium egife, digntes miraculo potucrit videri. Omitto M atbematic ipfius tudia, \& nobilifiman Terntrom diciplinam: qua in pate, at non aficutus fir femper, quod quarcbar; ca certè prelticit, que jufam admirationem doctis xftimatoribus non pofint nen explimere. 4 . C a aub. ad Tbu.n.Lut z. Íl. Quintil. 1610.

Ex Iulri Cefaris Scaligeriliberis, ultimus hodie fuperat lofephur Iufus Scali$\mathrm{g}^{\mathrm{r}}$, qui fecundum Patrem minc inter lireratos $\alpha$ in re literaili principem fune controverfialocum tenet, vcrè eruditorum Pbobus, ut politifimi ingunii vir eum indigitavit. De hoc utplura dicnm, nec pudor ejus patitur, nec per ingentia ipfus erga me nerita licet; quanquam mini mè vereor, ne proptcrea minus vera de eo pradicare videar; cum quidquid dixero opinone omnium vero minus fit. 
Sed potius eftutranti virit tromen per tranfenuam appellaffe contenti, cultum quo divinum ejus ingenium cum rarâ morum probitate conjunctum pro jute amicitix, qux mihi cum illo intercedit:profequimur, venerabili filentio, ut in facris ficri amat, obfignemus. Thuan ad ann.1558.

Dii Beni! quàm multaille nova, quàm multa vetera, non lecta, non vila, non audita aliis'depromit! Dxmonium hominis. Lipf. epift. Quatt. 1. z. epilt. 20.

The unis eft, quem miramur, quem xmulumur,imòo, ne mchtiar, cui invidemus. Felicem Galliam hoc fol tecujus claritas non ad cos folùm qui nsme funt, sed ad poferos diffundetur, quamdiu quidem erir in Terris nomen ticerarum. Idem Cent. I. Epilt. 2I.

Literarum omnum Diftator perpetuus, \&e per on nia Diis magis quàm $H_{0}$ minibus comparandus, Iofephus Scuiliger. G.ilp.S iopp prafat.de $\mathrm{rt}$. Crit.

Ejus Scripta aure: tanquam encylia coelo dilapfa, cum honore \& religione -quadam $\odot$ mres eruditi tractarc folent. I dem de Art. Crit.p.10.

Fuit ille vir, quod etiam omnes invidi fateartur, inviti, ataris fure doctiffinus, cui nec fequentes omnes parem ferent aut videhunt, ut nec tule unt priorcs. $\mathrm{Cl}$. Salmaf: ad ano Beverovictim, eyda Non. Decemb. 1632.

Vir tantus,cujns nomen nunquam mihi occurrit, quin iltud venerer. Herald. Animadverf.in Salmal l.2.c.ro.

Scaligerama Manufcripta, curiolus admodum eft liber, fed aliquantum perieulofus. Trigefunas et annus ex quo illum exfcribendum curavi ex Autographo, quod mihi commodarunt Domini $d u$ " wै qui intimi Amici mihi fuernet \& honefti viri. En qua ratione compofitus fuerit: J Jucnis quidam nondum vige=

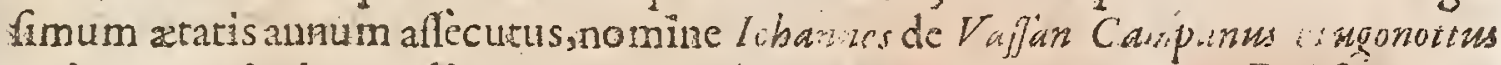
qui Geneva ftuduerat, literas commendatitias à magno Cafaubono Parifiis accepit ad Lefephum Scaligerum \& in Holland:am concefit. Iobenses ille de Vaffan nepos erat Dominorum Pithan Scaligcri amicifimorum, quem fingulis hebdomadỉbus viri Docti convenicbazat. Tohannes de Vallan attentèaudiebat \& feriptis mandabat quxcunque dicebat Sicaliger. Hunc ortum habuit liber ille qui hodie in Regia Bibliotheca extat. Iobannes de Vafjan è fua peregrinatione redux Minifter factus eft, deinde procurante $C$ ardinali Perronio \& amplix penfionis annux illectamento, Carholicam Religionem amplexus eft. Sed penfione portea non procedente, Fulienfis Monachis factus eft, \& antequam in Ábbariam illam fe reciperet , Domino dro Puy hoc Manu-Lcripun dono dedit.Grino Patin Epift.154. Gall.

Non minor Parente filius Iofephus Scaliger, cujus \& extant Epiftola. Ejus Viri maxima lunt in rem literariam merita, qui velut $l^{2}$ ater quidam literarum per univerfam Europars falutandus eft. Ex ejus ludo prodicrunt, quos B̈atavin ha-

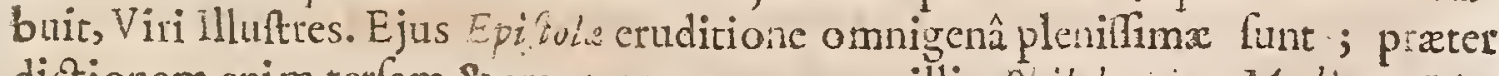
dietionem enim terfam \& argutam proponunturillic Pbiloloci:a, Medica, Mato thematisa, Chronologica, \& quie ad Orientalem literatwam pertinent ; judicia multa de viris doctis, de libris, qua legere, qua excerpere debent harum terum $\mathrm{Kkkkk}$ curiofi. 
auriofi. Dan.Georg. Morbof. Polyhift. pag. 288:

In Criticis omnium rectè æetimantium judicio princeps fine controverfatafine: xmulo ac rivali dominatur. Baud. orat. in obit. Scalig.

Quales olim fuere Reucblini, Merceri, Vatabli, Pagnini, \&c. \& non ita pridem magnus ille Scaliger, quem ultimum in feenam produco, quòd tanquam atquila in nubibus \& orbis literati Imperaror, ac eruditionis princeps, reliquis palmam præripere \& apicem fummzelaudis obtinere videatur, ita in Hebreis nou ad fuluporem, fed ad miraculum doetus. Iac.Cruc.ad Lud.de.Diem, Delpbis 8.KallSexto 1631.

Inter eos qui linguza Hebraica ftudio fummoperè dole ctàti funt fuite Ior. Scaliger fingulare I evden/is Academia hatd ita pridem decus, quĩ quantum ejus. cognitione \& fibi \& aliis profuerit , immortalitate digniffimo ejus Opere de smendatione Temporum, ut de aliis taceam, abundè teftarur. Thom. Erpessius Orate de Ling. Heb. \& Arab.

Cùm illuftrifrmum Belgii lumen \& Heros incomparabilis lof.Scaliger (ô qua: profuffifim $x$ lachrymx tantum literarum decus, tantam prudentix affluentiam morte in uno illo extinctam fatis dignè unquam deflerepolfunt)ad hane $H$ ebr. iff mi reftaurationem me pro illuttritua humanitate cohortatus fro débui tanti Herois judicium: magnifacere. Buxtorf.Pater.ad Holland. Ord.in Thef. Gram. Ling. S.1609:

Incomparabilis Scaliger, iīvidorzm fêpulus;criditornm Ccoptis ad cujus literariam qui proximè accefferit gloriam, ille caterorum fit cruditione Prificeps. C. Barth. in Clind.p. 77 .

Cujus incomparabilem eruditionem,iligenium fupra mortalẻs, priứs ảefeff: funt homines laudando (ufurpabo illud Salufii ad Cafarem) quù̀m ipfe gloriâ digna faciundo. I ch. Wouverius in $P_{\text {etron. }}$ pag. 375 .

Eo fuit ingenio, ut fücum fibi- fieri à quocunque tandem vetuftifimo veter2tore 8 mangone non facilè pateretur. Rupert.cap.2. Obferyat. ad - Be fold. hit.

Decus ærernum æyi fui: $V$ ir aut heros potiùs, \& quidem Heroe magno Gatus, in tantum laudandus, ili quantum virtus \& meliores liter poflunt intelligi: qua-

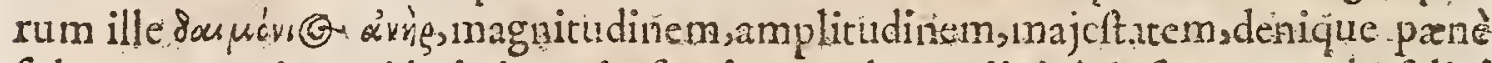
folus quun animo viderit, ingenio fueritcomplexus, divinâ \& f́ne exemplo fclicỉ : induftrià, per totum virz curriculum benè de îs mererinunquam ceftavito Ifade. Cafunb. in eEnea Tactica pag.9r.ubie jus obitum deplorat.

Eufebium Scaligeri legi, \& ita fum admiratus, ut nihil firmile putem me legiffe: 2f. Casaub. ad loan. Vajjunium epilt. 8 II.

Sanè unicus libellus contra Serarium tantâ doetriñx reconditze copiâ eft refertus, ut omnes inimici Scaligeri, fin unum conveniant \& capita conferanto parem librum nunquam funt daturi.:Iders L it.ad Thuan.

Author Novellarum Reipublica literarie Junii i684.arrepta occafioire abters soribus quos.in Scaligeri Catullo obfervavit: Dom.Vofins junior, ait illum nimis excelff effeingenii nimifque erudirum quàm ut bonum Commentarium elabom 2ate polfer. Nam ex ingenii acumine apud Authores quos Commentabatur plus artis: 
atis \& genii deprehendebat quam reverà $i$. inetret, \& profunda ejus literatura in waula crat, cur mille relarioncs videret inter $A$ uthorz quem legcbar fententias \& aliquod Antiguitatis reconditilime caput.Adeo ut fibi perfuaderer Authorem fuum ad cjufmodi Antiquitatis caputallufife, \& hoc fundamento fuppofito locum aliquem cmendabat. Fieri ctiam poteft ut cupido elucidandi M yturium aliquoderuditionis, cxteris Criticus ignotum, ipfum impelleret ad fupponendum quod id hoc vel illo Authoris loco lateret. Ut ut fit Corrrentaria ab co profecta - conjecturis audacibus, ingenións \& eruditifimis fcatent : fed parum verofimile eft quòd Aurhores de is omnibus qua iplis affingit cogitaverint. p. 532.353. Call,

Iofephus Scaliger, ut aliis in Republ. Literaria meritis clartus, ita non inficiandi nominis Pöre furt - - Equidem nubilus eftin affandratnubilus in Orpheo, fed fudio id factum,ut tciebricola Opcra Groca oftenderet reddi polle Latin a etiam caligine : in quât tamen multum anciqux lucis, fi quis intentiùs fpeculetur. Borrich. de 12oët.p.i18, 119 .

Jef. Rapirzureftatur nec Iulium nec lof phum Scaligerim in Poefi felices fuiffe, co quod ferè nimis inceperint. Dicit illos non potuifle vincere pertimaciam genii lui qui jam alionim feconverterdt; $\&$ quamis filits Patre cultior fuerit, nihil tamen illum in fua Pocf veinittim habuilf. Rapin. Animadv. general. in i'octic. Animadv.40.13.123.124. edit. in 4 .Gall.

Derifio \& Contradictio cjus elfentia pattem conftitubant: Nifi cnim in quibufdam fingularis fuillct, in omnibus vero peremptorius,neque Scaliger fuilfet, neque Iulin flius. Petr. levlin fua Cofmogtaphia : ngl.

Varia ejus Opera variis in locis atque temporibus funt impretra.

* Iofephi Sculigeriliber de Emendatione Ternporum prohibctur donec emenderur. Ejuldem Epiftolæe, donec corrigantur, non permitruntur. Index. Rom. imprefl: An. 168r.

\section{Hoc cjus Epitaphiurn.}

Eterne Memoria Jelephi Jufi Scaligeri Jul. Cxlaris à Burden Fil. Princiw pum Veroncrifum $N$ epotis, Viri, qui invitto aniwo una cums Parente Herce Max. contra fortunam afjurgens;ac I ns. Fum fibi perfequens, Imperium, Majoribus, erew tum ingenio excelfo, labore indefefjo, eruditione inuftata, in Literariâ Republic guafi fataliter recuperavit: fod prefertim ejus $M$ odefire, quod fierifibivetuit, iiders. gui in urbem banc evocarunt, Curatores Acadernic, as Vrbis Coff. Hoc Loco. Mow mumentum $P . C$. ipje fibiaternum un animis Howinum religut. Obiit XXY. Lanuariz M.DC.IX.

\section{HENRICUS STEPHANUS.}

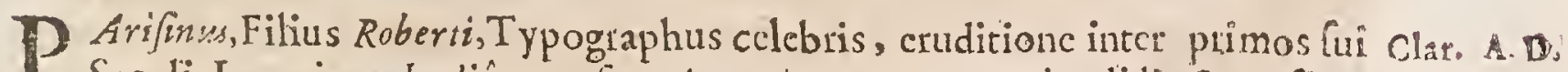
Seculi. Juvenis ex I taliâ reverfus, Anacreontem cum notis edidit, \& vcrfibus MDLXXX.

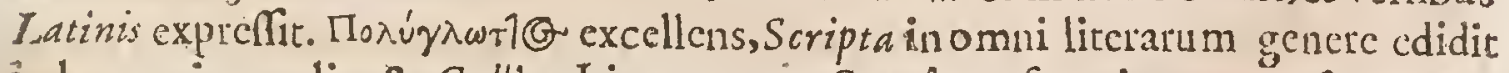

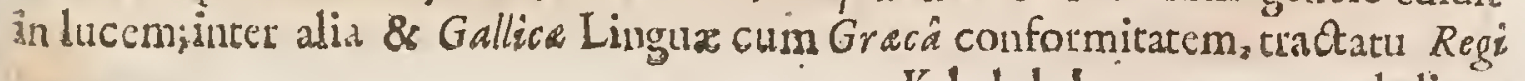
$\mathrm{Kk} \mathrm{kk} 2$ dcdicato 
dedíato monftravit:De publico impensè meritus. Apologia ejus pre. Herodaro quibufdam ingrata eft. Major is lecuritatis causâ Genevarm le recepic, unde frepe excurfiones faciens;anno 1598 : feptuagenarius ferè, $L$ ugduni obirit. Hofman.

Henricu tanto patre dignifimus filius. Typogmphicam non folum pofted exercuit, fed multa ad juvandam rem literariampropriâ induatriâ contuliţ inter alia edito, xmulatione patris, qui linguxe:Latina pen'Im olim condiderats Lingue Greca copiofifimo \& multorum Principum $G$ azis preferendo Thefauro. Thuen. ad Ann. I559.

Viti doctifimi, in cognitione Sermonis Graciplanefubacti, Henricus Stephann, Eufathins. Tanaguil. Faber Epit.l. Epit. IS.

Erat in co vito (Henrico Stephano) Tumma ingenii frocunditas, \& fivè Gract Give Latine $\mathrm{fc}$ ibrre, utriifque lingux ufus \& facultas omnium paratifima Samartban. in Elog:

Henricus Stephan inter omnes literarum principes ac. Heroas, qui lüperio faculo. Hellenifiri ftudio, Gracaque Lingux cognitione clarnerunt, ut in omni:

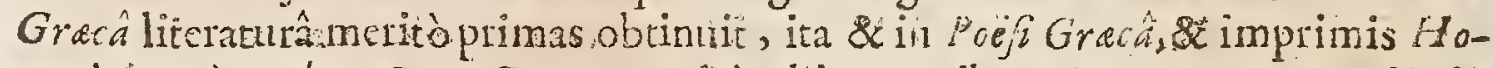

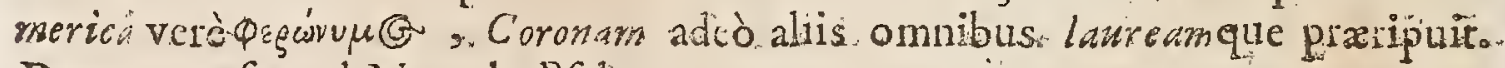
Duport. prafati ad Metaph. Falm.

Henricis Siepharius ex: omnium confeffo non modô inter cognatos fed ctiam inter omnes T yporhetas qui hactenus claruerunt eruditiffinus tuit. Fater. dum tamen cit Hebreonm illo callentiorem fuilfe Patrem cjus, \& Glii.imprefGones Paternistongè inferiores efficum quond characterum concinnitatem \& pulchritudinem, tum quoadaccurationem ipfam Cim enim velles ommes Authores, Gracus verò cumprimï àfé evulgandos, propriis fuîs manibus corre-

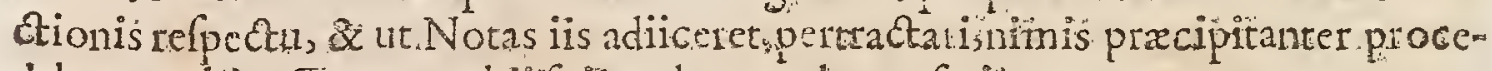
debat, nebina Typographifuiprala quandoque feriärentux : quapropter cxemplaria revifere examinare nulatenus ipfr vacaliato.r Iudicia Eruditorum pes Baillet. Parif. 168, Gall.

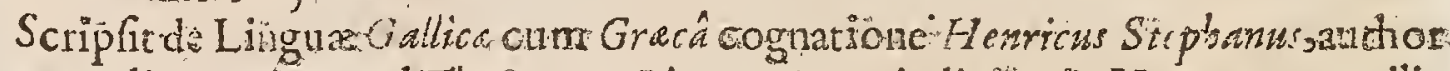
immortalis operis, quod The furum Iingtwe Grace indigitavit. Utautem erar ille vit in omni literatura meliorc confummatifinus lingua autem Grace vel ad mitacnlum perifus; ita hoc opcre defunctus eft. Meric. Ca ausb de 4. Ling.p. 1.92.

Fruftra laborane erionius, Herricus Stephonu, \& alii in Galli-a Lingux ex Griecâ repetendâ origine ac utiîifque cognatione probandâ, quafires.ita le ha-

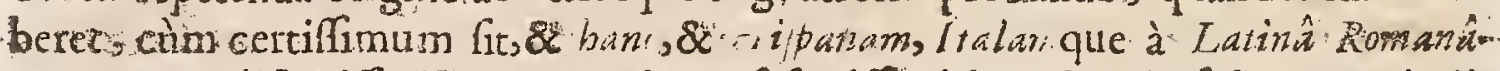
que corruptafuxillc. Hunc non mirum fr fapilfmè ineptiant in fuis Etymologiis frigidiflinis. Scaligeran. I. p.99:

Importunwm if um correctorim Scaliger appellat Henticum Stephanum, qui om nes quotquotedidir libros, fuo arbitrio corrupit. Scaliger ana ibid p.6.9, \& 8 I.

Henricum Stephanum planè Interpretern andeas dicere:cximia in reddendis verbis diligentidifumma in exponendis Cententiis accuratio; mira in Charactere exprimendo felicitas, infignis ad hac perfpicuitas a pari concinuitudine conjuncta. Huet. de Clar. Interpret. 
Mírificam de le famam admodium juvenis excitavit, cùm ex. Italià severfus Anacrenntem Poetam Gracum anno iss4. primus evulgalfêt. Acta Erradit.Kalend. Maii 684 .

Herricus Stephanus Rob̆erti filius, probus Adolefcens, ac liberali doctrina Gupra xtarem infftructus, Anacreontis C arrnets mihi dedit inventum à fe fortè( ut siebat) in antigui libri tegmine. Petr. Fictor.Var.Lcet.1.20.c. I\%

Dominus Colomies refertnobis, Scaligerwir habuife Anacreontern in quo propria manu notaverar: ; quod Henrochs Stephanus verfonis Odarum hujus Po.tre non fuerit,author fed Tohannes Doratus.P aul.Colomies. Opuilc.p. Iog. Sall.

Henricus Stephanus ediditemendationes Lud. Carrionis in Agellivm tanquam Gias. Pbil. Carol.Animadverf.in Agell. Yr.c.6. Animado 3o.

Nihil laborum unquam pejus cefit Henrico Stephasio, quàtm fctiptapro: Herodoto spoloora. Ifto quippe libro cùm graviffinè in facrum Cusullatorum ordi-

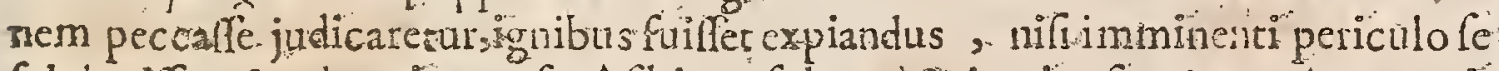

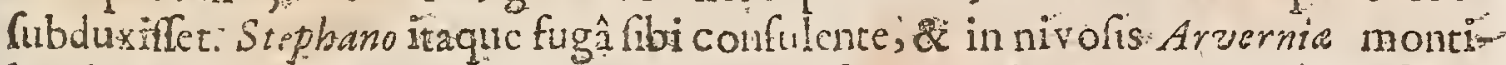
bus larizante i cremata àtortors, effigies pro ipfo poenas luit. Unde jocäbatur fapè̀.

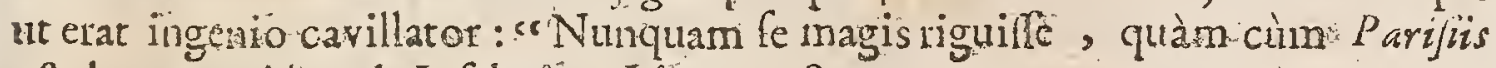
uft staretur. Tollizss de Infelicitat. Literat.p.87.

Henricus Stephanus Gatlicè, fi coævorum quifquam, benè fcribebat, ut illud comprobavit Differtatione de vita Catbrina Medica, quxperitum artis Magittum fapit juxt \&ententiam novis Tranflatoris Fratris Pauli.Linguam patriam tam eleganter loque batur, ux Henricus III. ipfi mandagerit Differtationem de Gallica lingue pracellemin confribere Noxelhe Gullice Reip. literatia Marti $1684,0: 923.93:$

Henricus Stcphanus non minus inordinatum in movibus, quatm eruditum in fériptis fuis fe pretebar - Morofus \& rufticanus erat, \& cum propriám filiam, tum gcherum füum do eum Cafánbonum averfabatur. Librunr contexuit dë Latinitate Lipfrana ubide bello adverfús. Turcas unicè loquitur, quod ita ridiculum: fuit cxiftimatnm uequidam feftive huicinforiptioni dwo vocabula attexuerint De Latinitatc Lipfiala adverfas. Turcam. Ant. Teifler Elog. Gall:

* Henricus Stephanus intes. Hexeticos prima. Claffis locum habet ili Indice Tridentino.

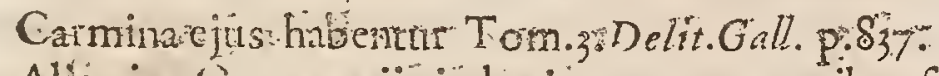

Alfa cjus. Cperavaiiis in locis atque témporibus funt ímptefä.

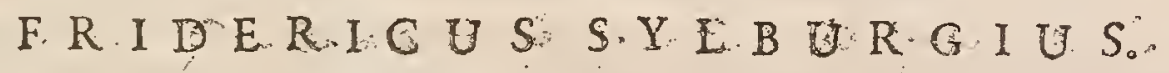

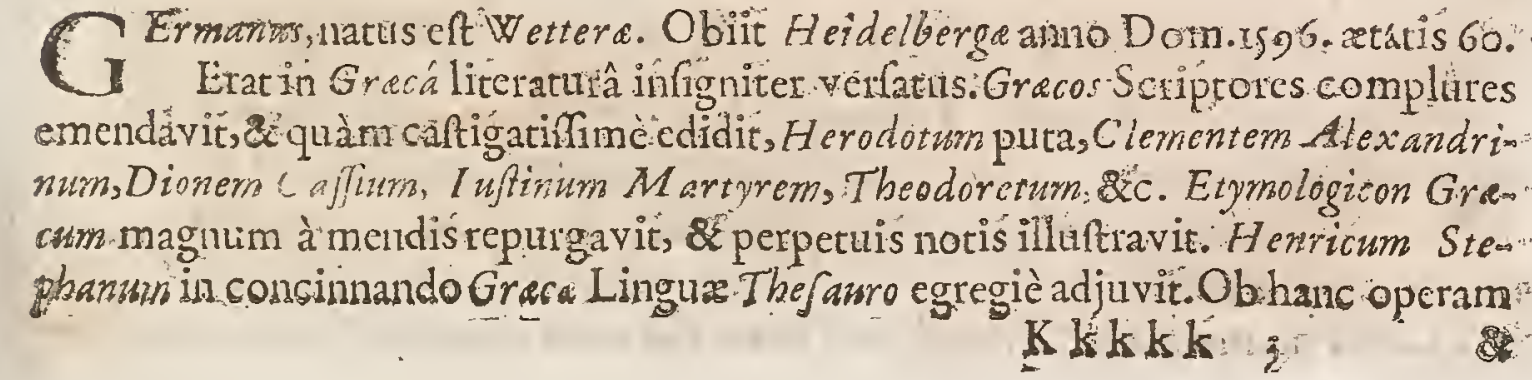
Clar. An.to? MDLXXX. 
\& alia merita à $M$ arpurgenf Academiâ annum ci tipendium, de Principum Hafju fententiâ, conftitutum eft. Konig. in Biblioth.

Vir optimus, doctifrmus, $\&$ de bonis literis benè meritus - Fùtverè vir eximius, humilis, indufti i incredibilis, candidus: \& apcrus. In Editionbu: ipfe ingenuè profchus femper eft, quorum operâ ac laboribus fit ufus, ad ditís etiam nominibus ad quorumcunque sy mbolas:ut fua cuique confaret gratia. Henricum Stephanur cgrcgie juvit incompartando The fauro Lingux Grece, adco ut potifinra pars ejus laboreconftet. $M$ clch. $A$ dam in vit. ejus.

Eriderucus sylburgin quàm plurima voterum, sprafetim Grecorum, Scripta partim jam edita, deino recognita, acivaris leationibus; Notis, Indicibúque il luftavir; parim primùn ipfe fummấcura adhibitâ publicavit :: eoque nomine magnam abommibus, qui rci literaria confultum cuprunt, \& a poitevitate non ing tatâinivit gratiam; coque majorem meruit lavdem, quòdin tam laudabili publicx utilitatis promovenda fudio affidus propriam gloriam contemnere vifus eft. Fhuan ad an.ijg6.

Fridericus Sylburgius, vil Grece doctiflimus. Meiborn.Meccenas:C.26.

Vir eruditionis ac induftiize fungulatis. Quenfed.

Sylburgii Grammaticam Gracarn.magni xetimat Voffus prafat. in Clenardi Gram.Grec.

Eniderico Sylburgio, Veterano, quanti auctores, qua Graci quì Latini, quà Sacri, quà Seculares, vitam fanitatémque dcbent! Decujus vini incredibili \& inde-

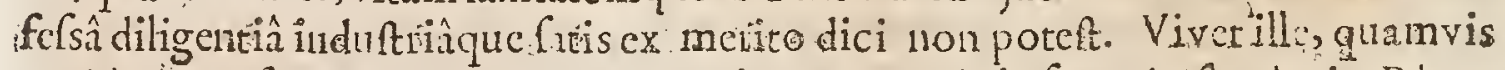
Hoidelbergafuperiore anno mortus, vivetperperuo, in fuo Ariftotele, in Dionyfo Halicarnafeo, in voluminibus Hifroricis in Clemente Alexandrino, in Iuftino $M$ artyre,in Theodoreto, in aliis. Sciopp. de Art.Crit.p.Tr, I\&.

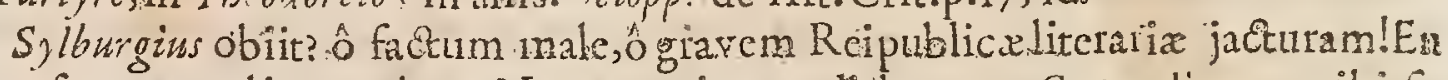
quo fpes ortalium redeant: $N$ am paucis ante diebus per Cormelinum mithi frgnificatum elat de multis ipfus.ceptis \& inchoat is laboribus. Habent Gracarum lirerarum amantes quod dolc.unt. Cafanb Epift.48.ad lacob. Bongarfurm.

Sylburgius Thefauro Grxco Henri-i Stephani operamcommodavit Sylburgia \& Cormelini editiones follicitè exquirentur. Scalig. 2. Gall.

Fridericus Sylburgins inter doctifinos feculi vilos cenlebattri quoad Gracarm linguim \& reliquas humaniores literas. Grammatica ejus Grac in magno pretio habetur, $\&$ Rawi,cujus Sedater erat, methodum in illa iervavit. Juaicia Erudicor. Pâril. 16895 per Bailletum. Gall.

* Friderici Syburgï Opera, fi expurgentuspermittuntu. Ind. Tíadrit. edito ant. $1667^{\circ}$

$V_{\text {aria }}$ jus Opera variis in locis atque temporibus funt impreffa.

$$
\text { FRANCISCUS TOLETUS. }
$$

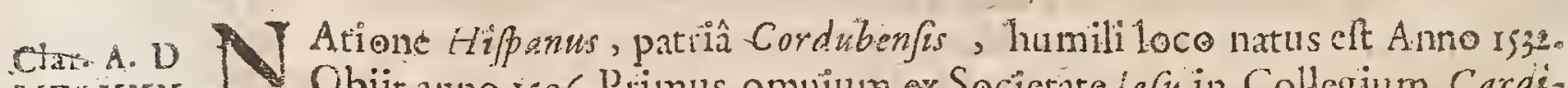
MDLXXX. Obiit amo i596.P Pimus ommium ex Societate 2 efu in Collegium Cardinalium cooptatus ent.

- Primus memolabitu Erancifcus Tolotus Corduba urrufque Seneca cunis no: 
bilifimấ-Bxtica civitate, cetcrum humili loco natus; qui animi virtutibus \& fédulâ infitutione, quod ipfi à natalibus deerat; fupplevit. Salmantica brevinomen adeptus magnum, ita ut philofophix profeflor prima adolefcentia fuerit, quod non nifi jam æatate provectâ aliiconfcquuntur. Poftea pietatis ftudiis cum fe rotum devovilfet, le futtzo lodalitio, yuod illo tempore paffim in Hispanzâ \& prxcipuè. Salinantica fiorebat,nomen dedit, \& Komarm evocatus gymuafio cùm:

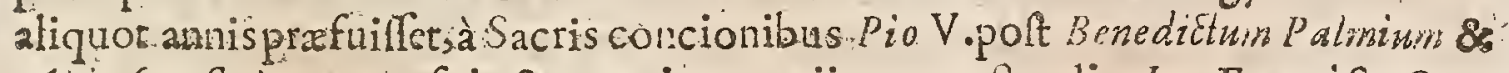
Aljonfum Salmeronem fuit, \& magnis negotiis pertractandis Io. Francifco Com mendono Cardinali in Germaniars ad Maxmilicinum Caratem; \& Sigifinundum. Augufum Polonie Regem,ut de Sacro foedere contra Turcas iciendo ageret; Iegato comes additus non minorem prudentix, quàm anted eruditionis ac pietaris laudem meruit. Dein fub :Gregorio XIII. magnis negotiis difceptandis adhibitus fuit, \& Lubsiasto V. Bibliis secognofcendis opcram navavit, ac tandem d Clemente Vult. prima exề Societate, in Collegium Cardinalium cooptatus eft' Ante

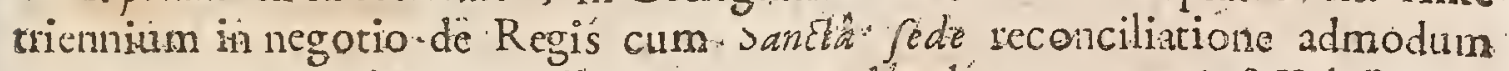
promptam \&ecgtegiam navavit operam, actandém hoc anno I596:18. Kal: Octob:

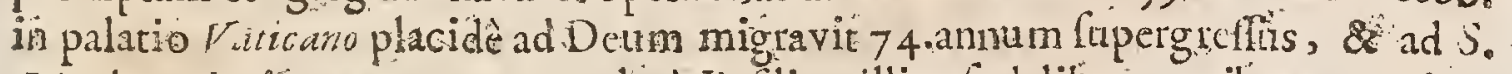
Mario majoris marmoreo tumulo a Bafilicz illius fodalibus, quibus pecuniam

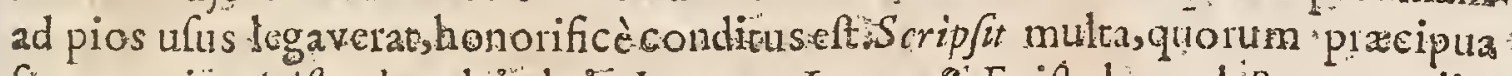
Thut, qux in Ariftotelem, dcinde in loannem, Lucam, \& Epiftolam ad Romanos edita

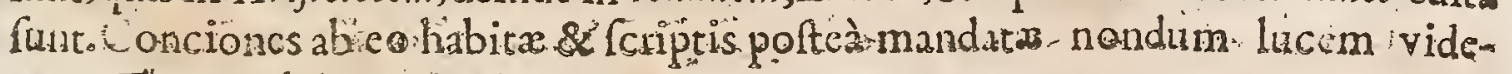
runt: Thuan. ad Ann.1596?

Vir fuit deetiflmus, \& curmaliis, tum terò Philolophicis ac Theologicis lireris omatifimus. Salmanticam à plimis annis cupiditate literarum profectus, Dominicum Sotum habuitinter cateres Doctorem- qui Toletum plopté ing enii excellentiam, Proáigium appellate confuevera. A. Pio.V. Ioltt. Max: anno falutis 1569. accerfieus eft, ut. rin facro Palatio Concionatoris munus obirct, : Quod tantîn cum laude prattirifyt per totos 24 annos apud Pium ipfum, V. Gregorrum XIII,

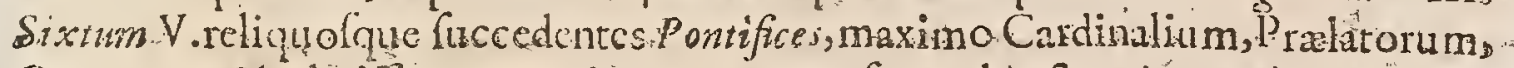

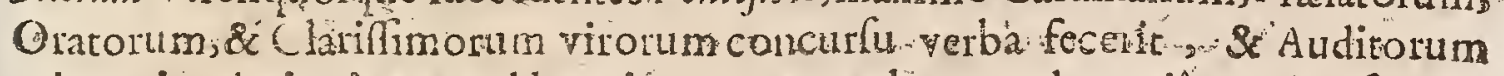
animos in adminationem adduxerit; riarum gravirate, recondirze do ctrinze excellentiâ, Ordinis difpofitione , ingẹnis a perficicuitate ac magnitudine. Phil. Alegambe de Scuiptorsoc. Itef.

Martinus Navarrus eum vocat, excellentem Sacrix Paginxe Dồtồrent" \& acerrimum Gymnaftam, Ecclefiaften-cum primis urbis \& orbis fufpiciendum Societatis Iefu ornamentum.

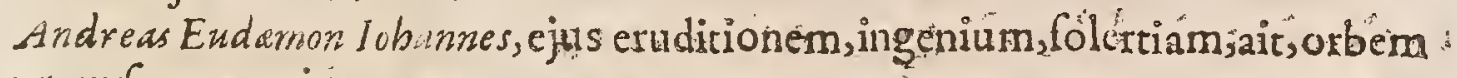
scriarum femper miraturumo:-

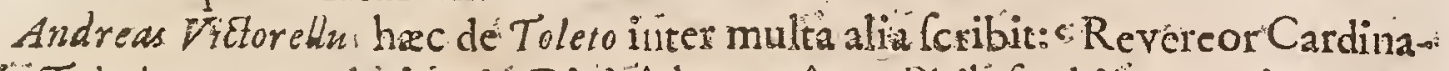
- lis Toleri nomen, adnìiror in Divinâ, humanâque Philofophiấ, atque in Sacran. - rum Licerarm, libris explićandis praftantiffimum viri ingenium, praftantifiri- mam eruditionem. Admiror aureum, facrumque, quale Veterum Sanctornm 3

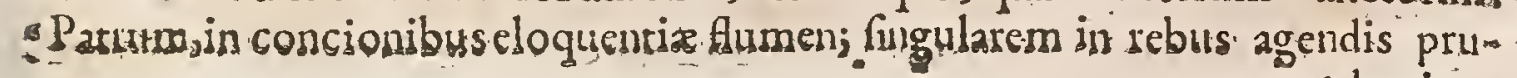


- dentiam, incorruptifimos benè inftituta vitx mores Cardinalis optimé de $C$ a - bolicâ Fiac \& Religione meriti.

Ferdinandus Ughellus eum appellat, virum ad Chriftiana Reip. beneficium natum, propter rcligiofffime vitæ exemplum, prudentiam, fimmamque doctridam longio î̀ yitâ dignum.

Eorum, qui de rebus divinis, \&ad xternam Calutem pertinentibus , ad fummos P.ont.\& ampliffimum purpuratorum patrum confeflum veuba fecere, Francifro Tole to Hi.jpano, è Sec. Jefu, omnium preftantium judicio virortam concelru, palmatribuitur. Nemo enim inventus eft adhuc co theatro dignior; nemo, qui aptius ad corum, quibufcum illi res erat, perfonas logucretur;nemo, qui illi prudentiâ doetrinâ doziuentiâque anteitaret, non hâc clegantulâ, \& in morem mulieris comptâs ad aucupium atrium, imperitorum pralertim accommodatâ., fed illà forti,ac vifili Ian.Nic. Erytbraus in Pinacoth.

Francifeus. Toletus, vir cateris honeftior, \& dignitate pracipuus,ac pracellens doctrinậ, omuiqure inter lefurtas exceptione major. Mo on ins de Monarch. Tempor. lont. Rom.6.4.

Multa Toletus feripta edidit, multos in Sacras Literas eximios Commantarios confcripfic, in quibus nullum, quod lciam, Doctrine Hildebrandice vetigium, nifi fortè lexiter impreffum, apparet. Memini cùm ante annos viginti \& quod excurrit, Toleti in Evangelinon Kobanmis Commentacii ad Thtodori Beze inanus primùn perveniffentquil tum forte eundem divinum Evangeliftam in 10 blicis Lectionibus exponebat; virum fllum,ut erardoctifimus pariter \& doctoru n candidifimus aftimator, impensè Toleti illudopus miní in privaro colloquio laudafle. Et merito. Nam in ejus Scriptis, qualegi,cum excellente rerum Philofophicarum \& Theologicarum notitiâ par certar modeftia; qua judicio meotum in alio quovis Scriptore, tum in Theologopotillimum, laus eft vel pracipua. Ac licèt noin negaverim. Toletum in ornando Romano Pontifice admodum liberaliter aliquandò agere:Nova tamen portenta Sententíarum, qualia Bellarminus è feecundo fuo pectore multa promft, apud illum non invenies. 1 f. Cafaub.in Epif. 624 . ad Frontonern Duceurn, 725 .

Toletas in Joannem bene fcipfit, nemini oberedat. Scaligerua pofterior.

Extat ejus in $P$ Jalin. 17 . Commentarius, Veir. 1602.0

Extant in Fatm 31. Scrmones Col.1600, $2.0 g .1604$.

Extat in Luce cap.I2.pr, Commentailus, fupplementum in reliquia dederunt Patresejufám Soc. fol. Rome $\$ 600,4^{\circ}$. Parif. $1600,4^{\circ}$. Venet. 1600 , fol. Venet. Ihor. fol.Col. I6II. \& aliis vicibus.

Extantin loan.Commentalia, fol.Rome 5988 , is $30 . L u g d .1599$. Col. I599, I6II $4^{\circ}$. Brixia 1604 . Lugd. I615, 4?. Venet. I589.

Extat in Epilt. ad Romanos Comment. $4^{\circ}$. Mogunt. $1604 \cdot 4^{\circ}$. Venet. 1602, \& Roin. Atidemo 


\title{
CELEBRIORTM AUTHORUM
}

Hoc ejus Epitaphium, Rome in S. Maria Majoris.

\author{
D. O. M.
}

Francifco Tolcto Cordubenfi S.R.E.Presbytero Cardinali, fummo Theotogo, Verbi. Dei Pradicatori eximio, in rebus magins agendis confilio of prudentîn. fingulari, gui ob excellentem virtutem is merita praclara Clementis VII $T$. Fortificis Max.judicio primus in Sacietatem Jefu ansplifiman dignitatem intulit. Dixit

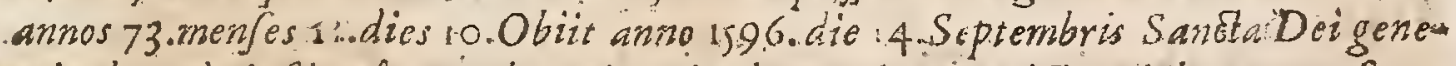
srice barede infitusâ, Presbyteris, qui ad ejus altare Mijjas celebrant, cenfum. perpetuo atrribui jufirt. Benedictus Juftinianus ef Petrus. Ald obandinus $C$ ardinales Executores Testamentarii College optino, Capitulum \& Canonici bujiss

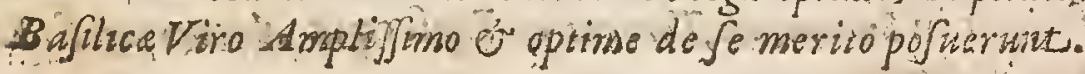

\section{LEVINUS T ORRENTIUS}

D Atriâ Gandavenfos, cùm literaram tyrocinium in plieritiâ Lovanii fecilfet, Bononia I wnis Civilis \& melioris Antiquitat is congitionem non vulgarem Clar. A.D. MDLXXX adeptus eft; dectiflimorum virorum, qui tunc in Italia florebant, Patavii,Rome, Tenetizs conluetudine ulias, ingeniumque in pangendis vertibus pracipuè exercuit : Domum reverfus ab Everardo M arciano Cardinali Leodicenfiepilcopo ob fingularem eruditionem cum funmâ mớm probitate conjunctarn in familiam afcitus, \& honorifico facerdorio donatus. Demun variis legationibus ftummà cum prudentix latide defunetus, poft Erancifoum Saknium,

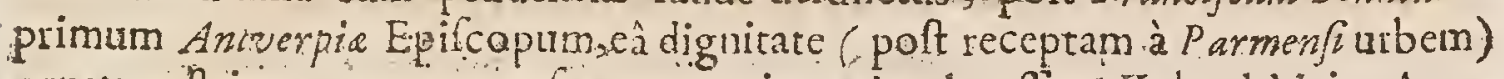
ornatus et, in coque munerc leptuagenario major decefirt 6.Kalend.Maias, Anno 1595:Thuan.

Scripfit Comment.in Horatii Opera---Comment.in Suetonii Cafares-n-.-Poëmata varia---De Bello Turcico.

Vir Sacrâ liberalique doctrinâ,ad miraculum ưfque excultus fuịt , ac Lyriç carminis poft Horatium, vel ipiorum Italorum judicio, princeps habendus. Hi- ftoriam Romanam mirificè illuftravit, \& commentarium eruditum in Suetoniz Cafares irerum evulgavit. Horatinm quogie infigniac copiofo Commentario ab ipfo illuftratum Andreas Schottus polt mortem edidit. Ant Sander de Gandav: Eride Clar.

Levinus Torrentius vir clariffumus, \& de Suetonzo nupertolim de universâantiquitate optimè meritus. Lipps.Elect.1.r.c.Ir.

Torrentius vir non in ounni re literarià folùm, fed in Poëfi ( quod mïhi quidem ëximiun eft : Qui fcio Poëtam prestantem neminem fuiffe fine parte quadam uberiore divinæ aurx / magnus, vel porius fummus. Lips. ibid.
2.l. c.17. 
Efferant Bembos, Pontanos, Flaminios Itali,attollant cxterifuos. Nos Torrena tum, yel iplorum I talorum judicio, Lyrici Carminis paf Horatium pincipem laudemus, qui perenn s perpetuique Torrentis inftar, facra carmina ad extremam ufque xtatem misâ ubertate profudit. $M$ irems in Elog. Belgó.

Endirio in Toxrentio elucebat varia, Hiftorię, Philolophię, rerum Divinarum humanarumque cognitio finghlaris : Eloquentia à narura fuens, fed aucta fudio \& uful legationum. Pö̈ta adhrc fuit excellens ; adcoque Catbolice fidicem \& princeps Lyra merito audiebat, Carmen quippe pangebat fonorum, purum, \& Horatio fumillimum Valer. Andreas in Biblioth Belgic.

Quem ego hominem (Törentium) ab egregiam doctritam, morumque prom. bitatem mirificè diligo. Latin.in lit.ad Anchiep. Sloguntinum, dat. I I.Kal. De. cemb.15.5.6.

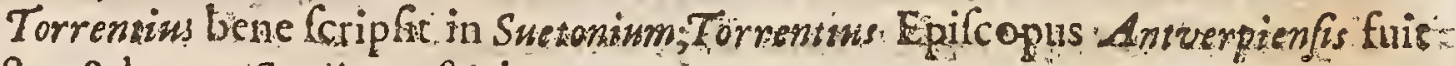
doetus \& bonus.Scalig. pofterior.

In Philolologieis quid pratteris Torrentius me tacente vociferatus: Suetonizs, ab ipfo editus \& Commentariis illuftratus. Sciopp. de Arr. Crito. pig. 15 .

A dolphus Occo fcribens ad A merbäcbium de illo verbis admodum in urbanis loquitur, quibus oftendit fe illum non cognoviffe. Cenfet illum ad Antiquitatum notitiam animum leviter appulife, in quo non minus hallucir. natur, quàm cim affeverat Commentarios quos in Stretonium nomine fuo excudendos curavit;abill o concinnatos non effe. 7 dicia Erudit:Parif.1685 per Baillexum. Gall.

Extan Poëmata varia Axtverpie ap. Plantinum 1594.80.

Extant Comment.in Suetonium ibid.1592. $4^{\circ}$.

Extant Commeatin Horarii opera. Ibidann 1607. in $4^{\circ}$...

Qbiit Anvorpire, ibidemque fepultis cum hâc infcriptionè

\section{O. $\mathrm{M}_{0}^{\circ}$ -}

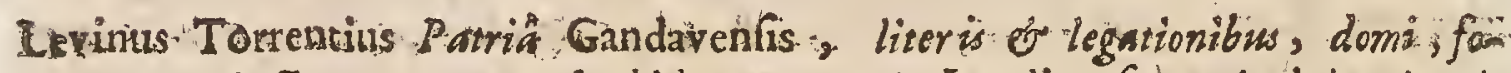
rifgue fpectatus, ex A rchidiacono or Leodicenfis principis vicario generali, 2 . Antwverpienfium Episcopus. -3. Machlinenfium Axcbieptfsopus, defegnatus, Collegii Soa. Jefu aprod Lóvanienfes fundator, ad rerumi Batus Belgici Concilium adfcitus, dum pracipitantem Remp. fraclis viribus, ani-

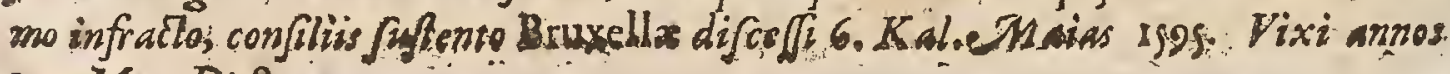
70.M.M.1.D.18. 


\section{CEIEBRIORUM AUTHORVM \\ MICHAEL MONTANUS}

C Allus, nobilis Petrocerius à Parce fummi curâ cducatus, Latinam linguram

I ante vernaculam, ab erudito quodam Germano, ipli à prima infantiä admoto, haufic. I ræecetores habuit Nicolaum Gruchium, quide Comitris Romano"rum Lcriplt, Gulielinum Guerentium; qui Commentariis Aristotelem illuftravit;" Geargium Buchananum \& 1 . Antontum Muretum. Grecam linguan per ludum addidicitinftrumentoram Mufico rum fono quotidie do fonno excitarus. Obiit an 1592. xtatis 59 . Hofman.

Th ichael Montanus, mihi ltudiorum \& voluntatum confenfione conjundif Imus, Vir libertatis ingenux: Quan conatus cjus [ fic cnim immotalia fui ingenii monumenta indigitavir $]$ ad omnem polterisarem teftabuntur. Thuan. ad ann. 1:92.

Thales ille Gallicus Michal Montanus Ecripfulibrum Gallicum $G$ aftum ticulo: probum, lapientem, \& valde a meum gultum. Lipf. Epif. Cent. . Mifcell. Epit. 43 .

Cum fide reminti Momanm meum,an no trum potius, quia vos quog; eum amais: Profcit, virille magnus elt, \& factus ad Mores judiciumque formandum, fed maxime ae robur animis ingigracndum, fine quo quid niff flectus thec vita? Afriduè in metu, fpe fumus, \& ab onni undà cipidinum rapimur : firmat hxe fapientic Anchora, guamille navigio noltro aprat. Idem Epitt. Cent. 2。ad Belgas, Epit.ad Rernattum Robertum

Magnam Montari eruditionem reltantur elegantes illi \& ingenuâ loquendi liberate non minus quàm do driax varietate amabiles Mfifcellancorum libriab

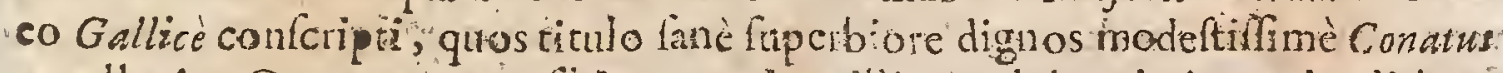
appellavit. Quantam porro fibi peperentex illits pulcherrimi operis editione vel apud exteras nationes eruditionis \& fupientix opinionem tum patuit, c m m ipla illa Roma, qux inter omnes totius orbis terrę Civitates pincipem fribi for cumvendicat eum ultrò in Civiurn luorum numerum allegit atque coopravit. ScaviSamarthanin Elog. Gailor.

Quanto in pretio femper habita fut Scripta $M$ ontari, inde judicium facere lices, qudd e rum Editio toties reperita fit : Malus enim liber vetuftaten noh perfert. Nec vero fine ratione, au felicirate quadam Genii folim; foriptor ifte rantam meruit famam. Nam prater alia multa, qua ex ejus lectione haurire licet. attenti lectoris judicium maximè format, \& inftruit.Quo nomine inter aliquot. Scriptores,quos Galla tulit,paxcipuè numerandus, \&, fi fas dicere,primatis ile lis, qui de moribus antiquitùs frriplere, quodammodo accenfendus venit.Roland: II aref.Epift. $\therefore$ Epilt. 2 2.

Dum M ontanum hîc fapientempradico, fimul recordor judiciorum, qua vehementer diverfa vel poitus adverfa patitur virille: Aliis ejus ingenium, ftyTum, judicium landibus ad colum extollentibus; quibufdam humilirer demimentibus \& pene nullo cenfu cenfentibus. Hoc in co putidum nimis. 
puerilis jastantia eft, quòd tories dèlamentatur ad nateam 8 irrifum legentis, quàn fit labili ac nullâa prarlus memoria : Cùm domeftico teftimonio ipfe fibi fidem demat, tot lectiflmis poëtarum verfbus, tar fapientum dictis velut ad nutum paraxis, tam aptéfcriptis fuis intar emblematum intextis. Uti \&ho in ea ambitialum, quod negat ferecordari fervam, nificas officiorum nominibus appellet Videor mihi in fcenâ audire Petronit Eumolpum, cui tanta familia fcilicer-enty Cartbotinem capere polfet Glaria nempe cupiditatem fpecic contemnentis manifeltiùs oftentat;quàm fi palam pare ferret. Thoono Lanfitas in Urar.p. 0 ;:

Equidem fi punctum omne fert fribendidicendigue recte qui facilline felicifirneque cogitata mentïs enunciare novit, vix quifquam hia facultate cum Montano: conteri poteft Senfus \& conceptiones ejus fummovent plebem : Sernone rum quidem humile aut abjectum quidum fonat, cum res minutas exfequitur \& pofrtas in quaridina confuetudinevivendö. Verbis:

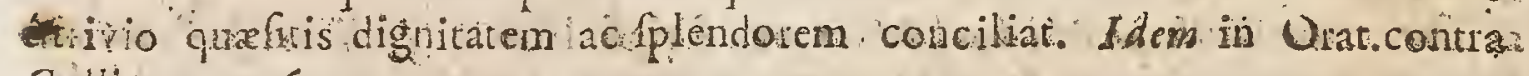
Galliam p. 06 .

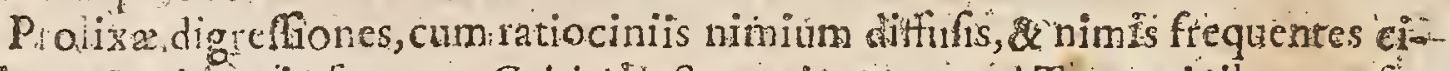
tationes $\mathrm{L}$ atinæ tria funt que Critici hactenus in Montane Tentaminibus cenfu-

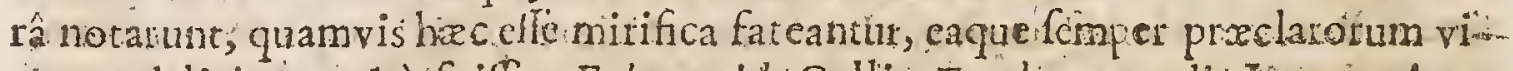

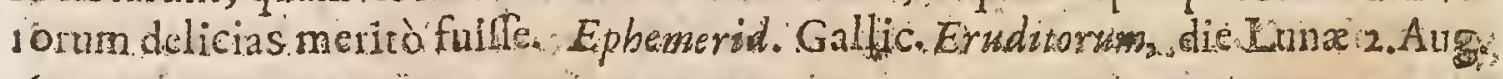
1677 .

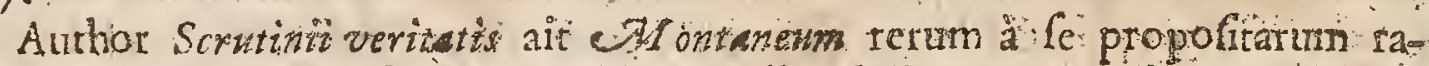
tiones ferèmmquan affere, aut faltem nullas ferè unquam ullatentis folida affere; eun quantum is liberalis ingenil quandoque tauen infulfam eruditionem affectare; human mentis mediocrem tantum cognitionem eum habere; vanam ejus glonam \& arrogantiam ubique in ibro fule féprodere; cum par am fe ipfum commendare; vanamejus gloriam nunqum manifeltius patere quàm cùn proprios nevos propalat: quandoquidem eos tautum memorat de: quibus Mundani gloniantur, fuperbiorem \& tamentiorem cum videri dum fe

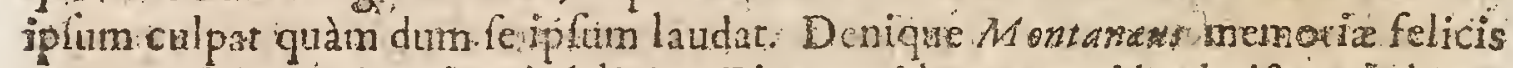
- non erar fed fudicio adhu infelicion. Ejus navi bonum quid admifum tabent-

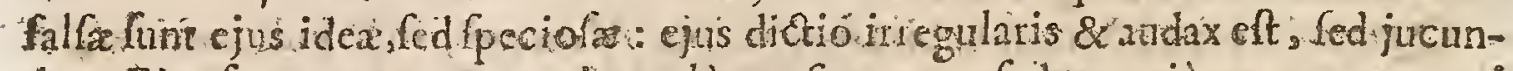
da - Ejus fermones argumentis malè confrmantur fed egregiè ment concepti funt. In toro ejos libro nativa folertiz lumen quoddamíplendet quod fummo pere delectat.Licet merus fit Exfcriptor, Exferiptorem tamen non redolet; yive

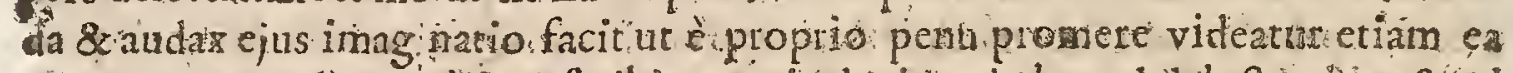
qüx tantummodo ex alis ex cribit, omnin denique habet ad delectandim \& illudendum requifita. Authon ScrutiniiVeritatis Tom 1. lib́. I1.c.5. Gall.

Prater U M ontandi Tentamina, extar ejus Interpretatio Gallica Dialogorm de Hominis Natura' 'Lacinè à Raymando Sebono Hifpano conferiptorum. Ibidem Gall. 


\section{CELEBRIORVM AVTHORVM \\ HRIST ORHORUS CLAYIUS;}

Societ. Jer.

N

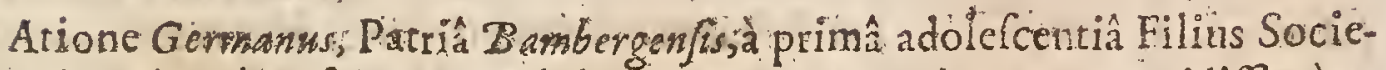
tatis; cumalias fcicntias imbibjt, tum vero Mathenzaticas avidifimè ac fludiofifimè didicit, \& magnâ com laudè diu Roma profellis eft ; tantumque felicirate ingen $i{ }^{2}$ arque labore affétuo profecit, ur non cum recentionibus tantum Mathematicis, ted eciam cum antiquiffimis illis \& peritifimis so comparandus. ex quo , factum ift, ut illum alii Markematicarum difiplinarum fcientia preftantiffini, Eucludem nottri feculi appellent; ; alii verò málle fe à Clavio viruperari", quàm ab aliis.laudai féritsant. Vir magnus, qui recudendis cous operibus noviffimè præfuit, nøn dubitat appellare, infigne Mathematico: um fedets, parrix fux: gloriam, focieratis noftra dectrs, Ecclefix Chrifiana ornazrentum; vlium denique maximarum virtuum \& endirionis lande celeberrimum, in quo illud maximè admirandum extiterit, qud cum tantâ erudit onis famâ, ac nominis fü clà-

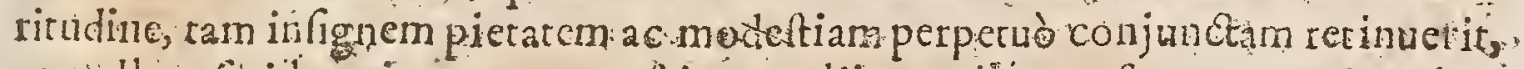
ut tiall un fibi hominem unquam feip um aliis omnibus po:tponeret. Tandèm

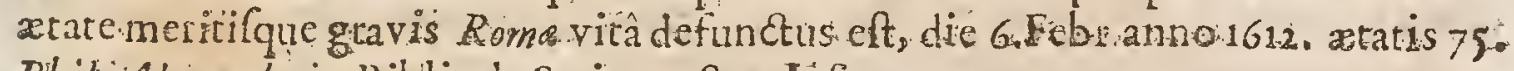
Pibil.Alegaxnbe in Biblion Scriptor.Soc.J ec

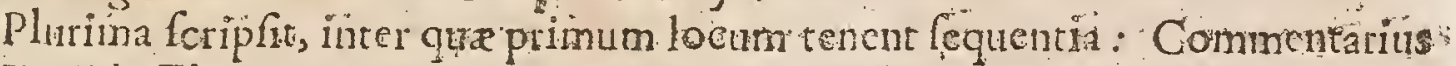
in Euclidis Elementa Geometrica. Item in Spheriea Theodogiz-Geometria Pradrica_-Comment in Spharam fornnis de Sacro-Bofco-Gromices lib.8.-Ro-

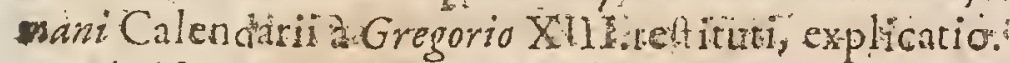

Cbriftophorus Clavias, Mathematicorum neltri xvi faciléprinceps-Nüllam

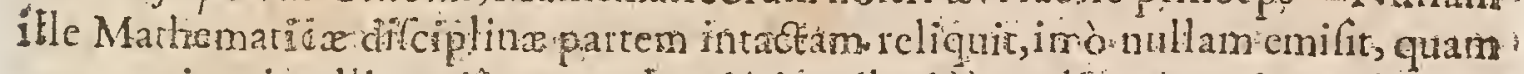
non penicas incelligentià comprehendèrit, dilucidè explicaténne dacuetit, do

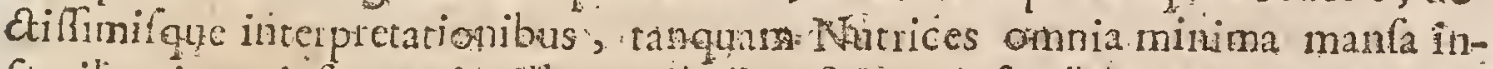

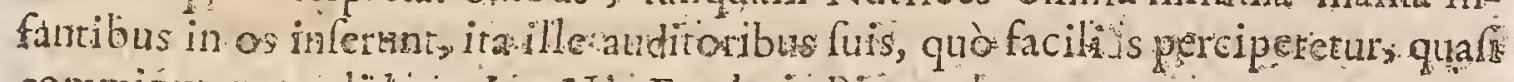
comminutaun tradiderit. Ian. Nic. Erytbr. in.Pinacorts,

Ex omnibas cjus lucubrationibor, quibus in lucem prolatis, nominis fur memoriam, omnium feculorum pofteritati conmendavir, Euclides, \& Sphra: Foankis de: Sacro-bofco, Commentariis illutrata, eft talis, ut in Arce poni pof-

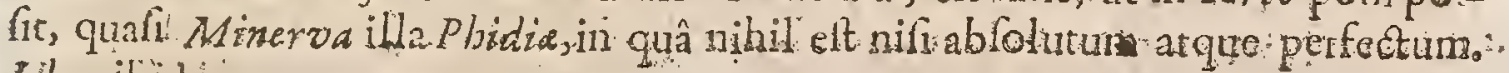
Idemibid.

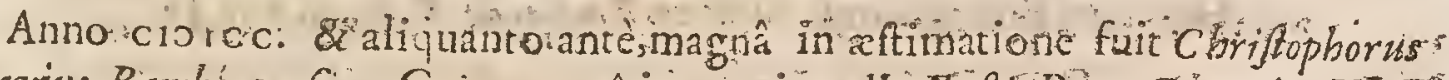

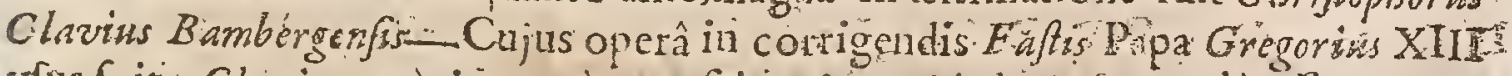
ufus fuit: Clavins verò ingenuè agnofcit, in Calondario fuo malè effe xquatas:

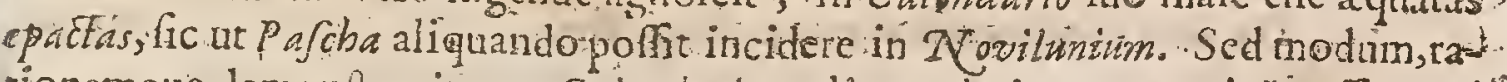
rionemque demont ravit, quo Calendaxium aliquando iterum corrigi polft: Voffo: dic Mathemat:pirg-, \& $38 \%$.

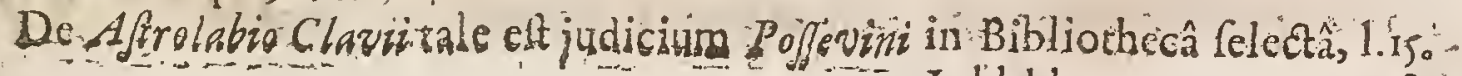
Lild! 3 
c.8. 'Aftrolabio demontrativo, fine Inttumento per folum Circinum, re'gulam, ominia, qux ad Primum Mobile percinent, isveniuntur certiffmè: ita ut - jam centies latiùs pateat, quàm antea. Opus à nemine hadenus tentatum, ac novilinè abriftophoro (lavio editum Rome crorcxcist.

- Certè no nideo quid- Mathematica ftudia Clavio contulerint, quihis adco infans eft, ut mediocúter literis thimanioribus tinctús, shæc meliưs. incel!igat, quàm ille qui toro vitx fux tempore niliil prater Mathematica tractavit.: Iofo Scalig. Canon.lfagog. I.i.

Infantiorem imperitiorem, \&magis riaiculum, reperies neminem[C briftophoro Clavio: ] fi quidem un us Geometrie Ccicntiamexcipias, [quam in co ctiarn if Rtipes efretpropter longum tempus quo illud faxum volvit, aliquam oportet ef\&c.Quinquaginta enim an os publicè. Euclidem lebit. Hoc unum excipe, tanrus

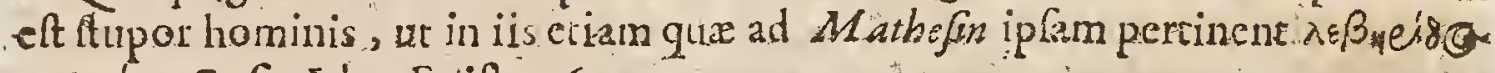

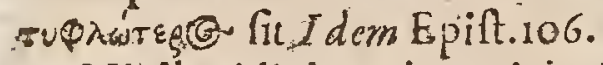

Nihil vidi incprius, jejuntus, falfus \& imputentitis libro:Clavii in Elenchum noftum de Anno I uirano--Sciro Librum Clavii in meum Elcnthum effe multornm. Neque enim Rilus Claviieft, nc gue unus. Idem in Epilti2g.

Clavius, quem fefuite tanki xltimant, ingeniumeft tardum, thebes, Lubrilitatis \& elcgantix expers, cralfus equus Germanicus. Rerroniana:Gall.

Calendarium Reformatum Cbriftophori Clav̈̈ ferè omnitum ingeniorum approbationem adeptum oft; y thidam alii ejus inftitutionem damnarunt. forephus Scaliger inter itos mum cx intelligentioribus, ? ad judicandum de eo msg sidoncis fe exbibuit: Sed Clavius illud rationibus adco luculentis adituxit. ut dotus ifte Criticus cjus opiniones impugnare deftiterit.; imo \& palam profelfus fuerit fe fibi gleriofum reputare Viro tanta celcbritatis manus dare. Facile pothac fuit Clavio aliorum Objectionibus afpondere introf fue seddere conatus corum quibus tentabant conftitutionem evertere tam validis argumentis fabilitam, fapienti nimirum explicatione ab ipfo evulgati. Q Q10 no minorem glotiam fibi comparavit quam liboribus quos ad hanc Reformatio-

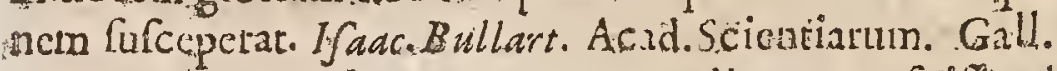

Sixius Senenf. 4. 4. etrm magno adjumento füfle ad seftituoncum Calenda- Grim Gregorianum memorat.

Extant Opera ejus omnia Tomoso impreffa Moguntic aunisu6u.\& 1612.

Hoc cjus Epitaptrium, Auctore Barnardo Babugio, Soc.J E.

Clavius è Terris cum jarn vix Sydera noffet:

Da Deus hac propius cerneres dixit: olid. 


\section{CELEBRTORUM AUTHORUM. \\ JOSERHUS A COSTA, SOC.Jer.}

T Atione Hispanus, Patria Methymnen/3s. Vir fuit ingeniu præftanri, acri judicio, labere indefefle, facundià dostrinâque praftans, qui omne difcit

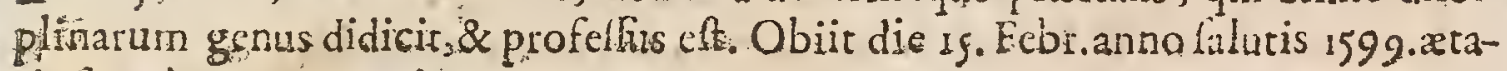
tis. fermè 60 . Alegambe.

Scripta ejus hac funt: Dề Chriforevelatolib.g:---De Tentroribus Novifimis lib.4.--Tractatus de procurandà Indorum falute--.-De Naturân novi Drbis.

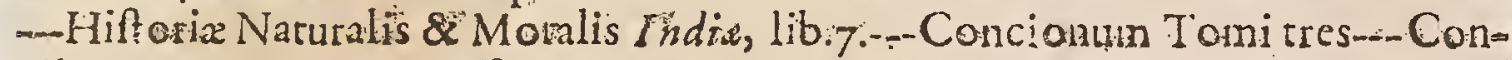
cilium Limenfe III. digeflit, \& Latime conlcrip Gat.

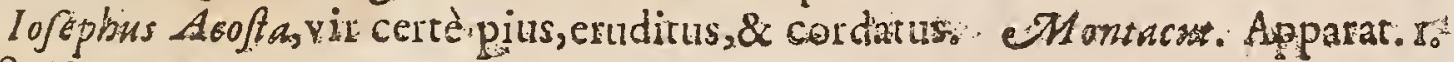
fett.88.

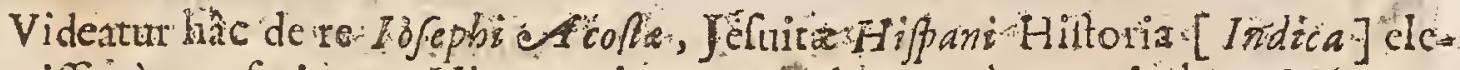
gantifinè confcripta. Hic omnix, quz nd naturalem, civ lem \& laciam

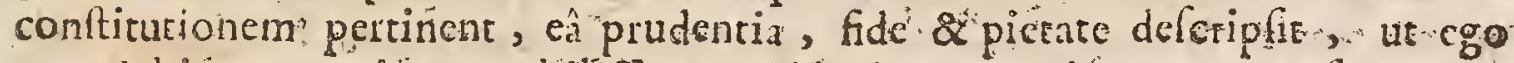
non dubitem eum inter mobllifimos Hiftoriarm Scriptotes recenfere. Hiftoria nondìn Latizè verfa cum magno literarum damno; certè, fr quis: liber its Latinum fermonem verti debet, hic eft. Egocercè illiüs hift odiam non nificum funmo ftupore \& admiratione legi. Scriplie ceiam idem Acofa alium quoque

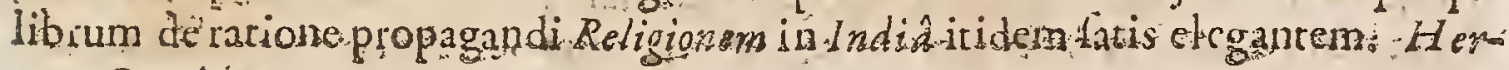
man.Conringo...

Iofepht Acofle Hiftoriam tamericanam valde commetidat Christ. Funcius in Breviario Orbis hadie Imperantis p.4 12. aitque 'Auctoren complexum elfe ( Hiftoriam: Amsericaizorum naturalcm, cixilem, \& Ecclefiafticam, et fide \& ac-

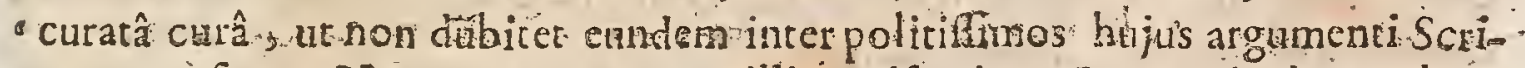
- ptores referre. Nunquam, nunquan illius Hiftotiam Noss Orbis.legerc lice - fine admiratione: Suntenim revera ibidem omnia Atupenda. Noniliarim "defcripfit vafta iltá regna, Ingarkn, Mexicasum of Pcruvidnum, quomodo" - fe habuerint anse occupationem Hifpanoranto Potuit autem nemo melius

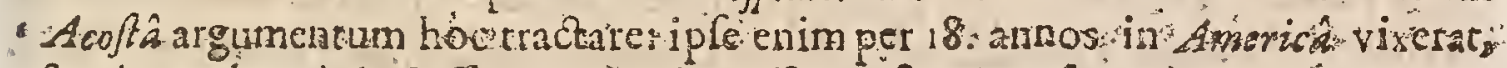
- fuerátque longè doctiffimas \& patientifimus fefuita, fincerè omnia cnărrans. - Prodeft igitur hoc Upus Acofta Théologis, Policicis, \& Matsematicis. ChrinRopph. Fincins in Brev. Orbihodimp. po +1 2.

Non fatis conftat fibi Acofia. Ait ad Peruviam, \& maritima Maris A aftralis

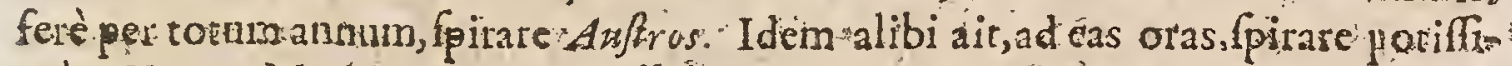
mùm Ventos Marinos: At Aulter illis terrelt ris eft, ur \& Boreas; \& Enpus, tantumque Zephyrus eit illis marinus. Fridna.Bacon. in Hilt.Ventorum.

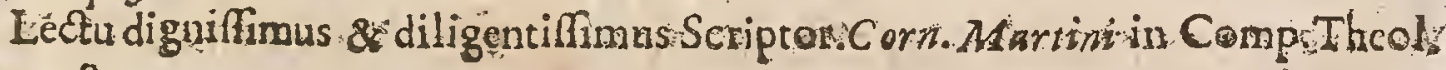
pag. 258 .

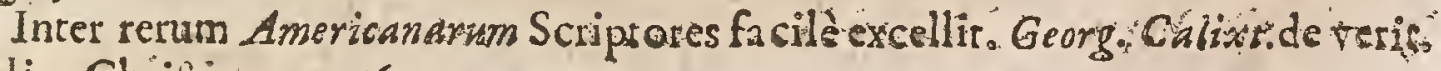
Relig. Chrillian numi6.

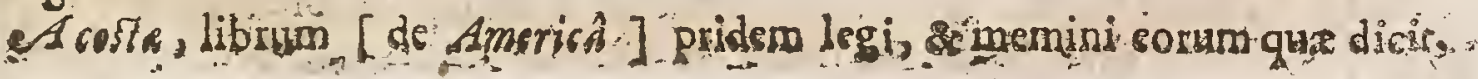


a mihi le nondum probant. Hug. Grot.in Epift. ad Fratrem, Lutet. Ir. Taw nuar.: 642 .

Vir fuir ingenio non vulgari, laboriofus, facundus \& prudens. Aub. Miraus in Biblioth. Ecclef.

Extant libri 9 . de C brifto Revelato, Lugduri 1592, in $4^{\circ}$.

Extant libri dato de Naturâ Novi Orbis, Colonia 1596. in $8^{\circ}$.

Libros 7.Hiltorie Naturalis \& Moralis India Theodoris de Bry.inferuit Pari9.4ux Hitorix Occidentalis.

\section{JANUS DOUSA}

Ciran. An. J Ordovicusnatus elt anno is 46. Obiit anno i604. Lugduneufis Academire HDIXXX:. L condendx antor, \& ejuldemper 29 annos Curator fuit.

Seripta cjus funt : Commentariolus in Q. Horatium Flacium--..Appendix Succidanea ad euidem-Epigtaminatum, Satyrarum, Elegiarum, Sylvatum Libri--Nova Poëmata Lugdunenfia--Epodôn liber ex puris Jambis --Oda-Britantica---No:z ad Salufitur-_-Centurionatus ad Plautum----. precidanea ad Petronium Arbitmo:Catullum : Tibullum.-Shediafma Succidatreum ad Tibullum---Epiftola Apologetica dna, una de Annalibus Batari s altera pro Pratore Nortvvicero, peregrinitatis reo---Annales HollandiarearmiAc---Eclos Sive Hialcedonia, carmine.

Multiplex erar in viro lectio, incredibilis pene memoria, Gracartum ac Latinarum literartm; Hiftorix Veteris ac novanhil erat quod plim fugerer; nibil de quo rogatus tion estempare refponderet. Unus ille Batrovix Varro, \& Academia Commine Oraculum. Melch. Adarm.

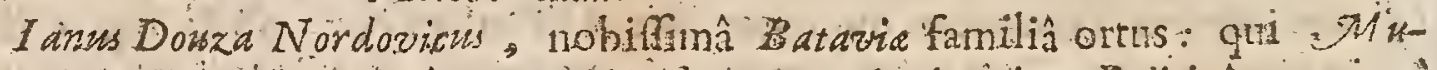

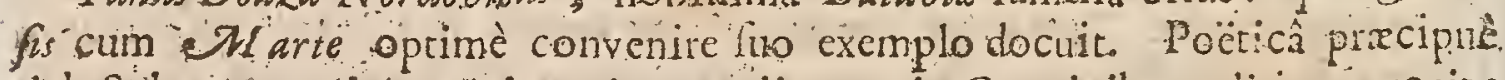
delectabatur in qui ingenim varii generis Carmiribus editis exercuit: etiam Patrie Amales fcriptit, multiplici lectione, \& admirabili metro î́ pró meritus ut Batavic Varro, \& 1 cadernia Cammune Oraculum vocaretur. Thuan. ad ain.160."

- Celebrant eum Monumenta fu nobilifima, inter crite fuatt, Nota ad Salufit Hiloriarum libros doctifrme, \& Pracidanea pro Q. Valerio Catulo, celebrant ctin ingeniofifma, polichmaque camina, gux totis Yoluminibus editab ipfo in publico proftan , quibus \& vivas fibi illufte decus comparavir, lnominique fui celebrarionem ad ominem polteritatem tranfmirtet Boifjard. in Icon:

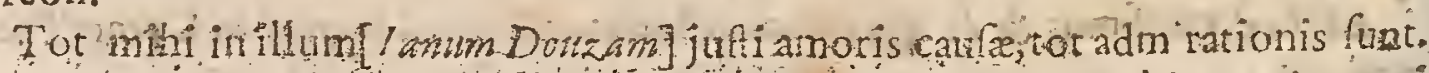
Othito Poefin, \& cum Noeff fupra hoc feculum doctrinam probitas, \& irgenti:

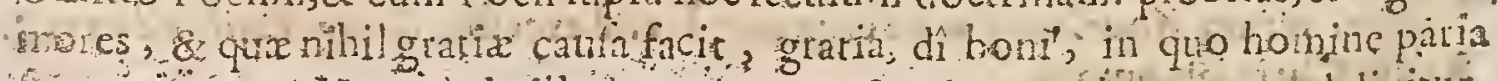
funt, aut erunt U vere de illo hoc elogium \& adptallabom, quod dicitur,

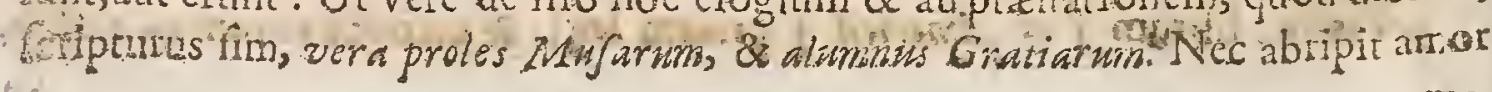


me. Judicio hoc foribo, fi quid unquam : \& peto quxfoque (vita tancum mili aut fama apud poftéros fit.) ita hac legant, no quar laudem ab anico; fed fententian a jurato refte. Lipf. Electorum l.r.c.5,

Douza, vir clarjllmus, magnus ille elegantix Plawtina fofpirator. Taraguit. Eaberl.2.cpilt.Epilt.; 6 .'

Horatius, Catullus, Tibullus, \& Petronius, operam Iani Douze Dominid Noortyvijk fgregiam expcti funt. Sciopp. de Art. Critp.i.7.

Quidam Autor Anonymus maximopere commendat operofifrmum illud Pö̈ma, quodin vocalemillam Nympharn, qux Echo dicitur, magno piritu lulerat: Cui co ingerere rmile aut ita copiofum literx aut ifthec fecula nondum afpexetant.Vide Karigin Biblioth.

I amus Donza, nobilis Batavus, Annales Hollandorum à multis fabulis liberatos collegit:alias etiam verfibus fus ita inclarut; ut magnum quoque inter Pö̈tas nofri leculi nomen invenerir. Conning. dillert.MSS. de Rcbulp. in defcript. Batar. Fueder.

Vir ut nobilitate inter fuos ita doetinâ apud omnes clarifimus. Groaitus.

Inter primos, quos curandis regendifque Rudiis Lugduni Batav. Jordines impoluere, farm Douza fuit, cuigenus, geftique honores, \& roleratum Lugduni obGidium apud poftëros carminumglarià prementur : in queis amen ejudem nominis filiusprecllit, idem Parri Annalibus Hallandia condendis focius \& par najoribus meditamentis, nì mors immatuta juyenem funma erudicorum expectarioni ablulillei. Grot.lib.j.Hiftor.

Qiii tàm felici confortiô doctrinam cum vintute \& onamenta licerarum cum infrgnibus nobilitatis conjunxit.

Jacundifunum erat bonififus viri conlotium, totas Propertiz Elegras lecitabat, larentis mei omkia carmina memo ia tencbat, ut \& Sanndzarii, Pontani \& aliorum. Solertia ingeniaimpensè ambar, ut Heinfus. Nemo fliorum ei fimilis eft. Omnes admołum fimplices funt, ut Parcntum uterque. Mifellus $t$ anus tam bonus \& ingenuus erat. Anum more cotum odidum morten ejus deAfevi.Scalig. 2. Gall.

Non poltum quin dicam Nobilem Douzaminxqualitare fyli \& intempefivis Digresjumibus mirum in modum Hiftorie majeftarem lafiffe. Dorzalius fupplere potuillet aliquando hunc defegum, nif eum immatura mors terris epipuifet.Dorninic.Bandius, Epit.Cent.2.Egift.71.

Laudibus quibus I anurn Douzam omnes cudiri Belge condccorarunt; aliàs splendidiores fuperadere cuperem; fed clegantes calamos fuos in tarin luculentum argumentum exhaferunt, adeo fue frulta fermonibus meis illum illufrioren reddere tentarem. Sipö̈ln cjus cum-Virgilana \& Tibuliana, \& eloquentiom ejus cum Ciceroniana contuleto, a a chajus inceptum racum pravertit, jufto illo Elogio parallelo quod de illa adornavit in fuis Epigrammatibus. Si Hollandici Frronis titulo illum nobilitem; hoc jam ante me in menrem renit is qui Polteritati notam fecenur ejus humanjorum liccarum pcri- 
tiam perfectam. Si gerfuadere velim euin. Provincix illius rariffimum ornamentum fuilfe; hac veritas fatis clucet in Elegiiis quas. Daniel Rittershufins \& Iofepbus Scaliger ad ejus jacturam Iugendam compofuerunt. Si denique dicere altfim eum Parnaffi filias in Leidenferm Accademiam introduxilfe, poftquam ejufdem inftitutionis inftrumentum principale fuifet, nihil novi proferam, nee ul10. Elogió ipfúm infigniàm, quod non occurrat iñ Oratione funcbri quam doctus Hernfus coram hoc cuetu in ejus honorem pronunciavit. If fac. Ballaxt. Acad, Scientiasum Gall.,

In hunc Auctorem hæc Carmina compofuic Stephänus. Pafchafins:
Auditit, Aonidum turbâ, admirante Dearum ...
Durfa, arte ingeni! Carmina fufa tui .
Carmina Selectis equantia fumen I ambis: Miratufque, Dex cedite, Phoebus ait?:
Dufa mibi Mufa est, sunt Mufica Dufica, Mufä, Qundam Heliconiades, fint madó Dufiades. bẹr.

* Hic Author Romano Indice inter Hxreticos prima Claffis locum kas

Yaria ejus Opera variis in locis atque temporibus funt impreff $\mathfrak{a}_{\text {o. }}$

\section{P:ETTRUS F.A B.E RE}

Clar. An D. A Ajoranus, virmaximus Fabrorum illtufte nomen raro \& admirabili dow MDLXXY.. S ctrine fux fplendore magis ac magis illututravit. Ut enim Cuiacius, Duare nus, Hotomannus, \& alii fi qui fint eorum fimiles, nobilium hic xtate Jürifconfulcorum familiam duxiffe non injuriâ prodicentus , in eotamen fuperioe quodammodo cenferi $F$ aber poteft, guòd non tranquillon tantum otio privatilque Atudiis, fed \& civilium rerum affiduâ tractarione urilem fe hominum focietati maximè praburexir. Ejus quidem judicium, prudentiam, fidem inconventu Rotomagenf Rex admitatus, non al um digniorem exiltimavit', quilpoft waria Togx muncra laudatiffinè obita prinarius tandem Præles, in Te étof a gum civiatate libinatali fupremo Senatui praficeretur: Sednon:longè polleà fuit cùm fexagenarius pro tribunali jus dicens xino. Kal. Jün. aimno 600 apoplexiâ repentè fuffocatus interiit; famà tamen aternum fuperftite poltquam eas de Ture publicavit Commentationes innumeris ingenil doetrinzque luminibus oraatas atque dillinctas. qux donec Romana loquentur litèra, maximo femper in honore \& pretio ab eruditis omnibus habebuntur. Seav. Samartban.

Compofiuit z, libros Semeftriuin : tres libros Agonolticon five de re athleticâ.' Yert. Commentasium in Tirode tegulis Juris; \& $c_{\text {. }}$ 
Ad clarum familiçin Noverspopiloniâ decus probifinos mores \& fingularem Antiquitatis omnilque divini \& humani Juris cognitionem attulit [ Petrus Fa-

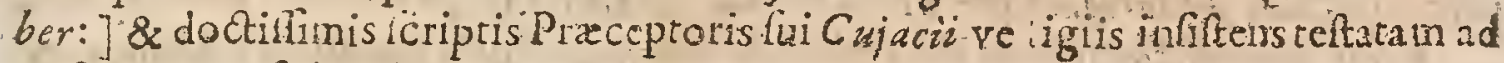
polteritatem fecir. Thran. ad ann. 1600 .

Quid egohîc dicam, aut fufpicer ramulationem cadere in illum virum?non xtas, non eruditio ejus permitunt:quarum ilh gravis \& inclinata, hxe me cemper judicio magna. Multa in viroillo variaque lectio, accurata collectio, \& in penetrando digercndoque judicium pariter \& acumen. Lipf.ad Belg. Cent.I.EpiRt.10.

Petrus $F$ aber in onni reconditarum litcrarum oficinâ affabrè perpolitus. Tac.Guther.1.2:de Offic.domûs Awgustajc.5.

P.Faber, vir undiquaque ad invidiam ufque cruditifimus, quad feripta-ipfus electifrma plus Gatis clamant. Ian.Gruter.part,2.Chron.

Vir rari,confantis, \& admirabilis cujuldum ingenijidudici, nodeftix. Dii faciant, utad id exemplum multiho dic fcribant. Lipf.EleQt. I.૯.22.

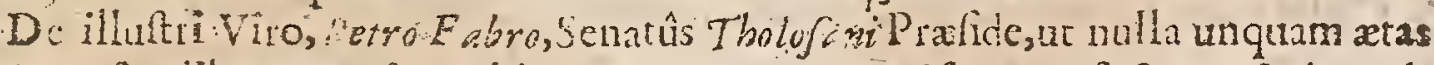
racitura fit, tribus Serneftrium libris \& uno cjus Agoriffico, perfectum elt: in quibus infrita, que omnes Critici dilcere \& admirari polfint, propoluit G Sp. Siop. de Art Cri...9.9.

Equidem lic cenfeo, cum hxe atas noftra, plurimos cruditione clariffiros viros tulerit,unum tamen extitilfe te qui Varro feculi noftri appeliari \& vir undecunque doctifimus audire poffs jure, imò debeas. Ignorans frm \& iniquis xtimator genii ingenirque tui, fi al iter fentiam, qui ex tuorum librorum lectione tantum quotidie \&honeftre voluptatis \& folidze erudicionis percipiam. Cafaub.Epift: it.ad Pabrum

Literx tux gratx mihi fuavelque fuerunt, quod in illis ingenii dexteritas, \& elegantioris doctrinx nitor cmicat. Ioann. Calvin ad 'l'et. Fabrum. Epilt.2:5:

Petru Faber Sanjorianus primarius Tholofani Selmatus Prxes, qui Senestrio of Agonifica friphe fuit unus ex doctirmis Gallice viris, fed merus eft compilato ${ }^{\prime}$, nihil dijudicat. In omnibus Gallic urbibus nulla eft antiquior familia jam à ducentis vel 300 .annis vel bello claruerunt , vel Judices in lupremis Francic Curiis fuerunt. Innumera fune Fabrorum familix. Scaligerana poftcriot. Gall.

Vir eminentilimaeruditionis. Grot.lib.2.de J.B. \& P.c.16.n.r.

Vir doutrinâ \& dignitatc clarifimus. Gudelin.

Petrus Faber, cùm legem quandam $P$ auli J vifconfulti emendâffet, in câque rc Brifjonizun qui jam anno 1588 . emendationem hanc iph præiverat, nominaviffet, non item Hotomannum, qui quindeccinio poft idem placuerat, ab hôc jdc acculatus Plagiific fe defendit, ut neget fe P'lagiarium, guippe qui fua Brifforis referipferit.De Hotomanniverò confenfrone nithil fibi tum ait confirifę:qquam fi maximè notam habuilfet, taciturum fe fuilfe tamen, ne fimul necelle haberct, ejus - Brifonio, qui prior Cripferar, Plagium prodere. Thomaf.de Plag. 


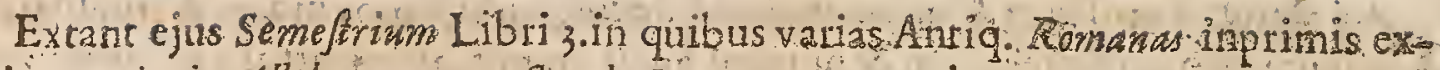
plicat. Colonia Allobrogum per Steph.Gamonetumus $6 ! 1$ in $4^{\circ}$.

Extat Agoniftican live de Re athlerica Vecerum . Iudis gymnicis, Muficis \& Circenfibus. Lugduni per Francifcuru Eabrum 1592. in $4^{\circ}$.

Extar Commentarius ad Titode Regulis I unis Ligduni apud Guiliclm. Rovile limm fol. 1566 .

\section{PHIL IP PUS: SYDNEI UIS}

Clar.An.D.

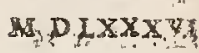

T. Iles, Patre Henrico Sydriey, Ordinis Aurea perifelidis Equite, Flibernios 1 Prorege, ac Wallic Prefrde, Matre vero Domina Maria, I Qannis Dudley. Ducis Nortburnbrien/is, Gli natu maxima , Penshurticin A gro Cantiano natus eft, fub exitum,anni ists. Elizabetha Regina oum fuo Cantionario oppidaVlifjinge \& Caftellode Rammekens in Zelandia prafecit. Sed (proh dolor ) in primo xtatis vere \& fore,immatura mors enr vits orbavit. Quippe, in quodam pralio prope. Zutphaniam in Geldrât, dum equm tertium / billos enim quibus vectus

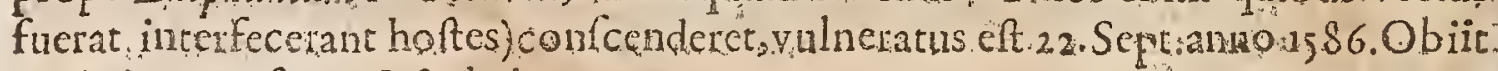
verò decimo fexto Qctobris,

- Stripjet eA Astrophel \& Stella. Apologiam pro Arce. Woëricà Pelmos Davidicos. MS. Wiltonia in Biblioth. Co bitis pembrochienfis. Anglice ex Gallico vertebat maximam partem libri a Pbilippo CMornoio exarat, infuiptique de Verime Chritiana Religionis Id operisabolvit Arshurus Golding, Generolus. Edit. Lond. 1587.

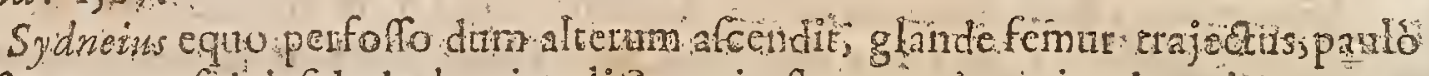
poit mano fir defiderio bonis relicto, in fore aratis expiravit yix quatuor

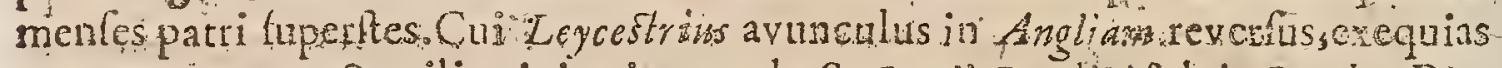

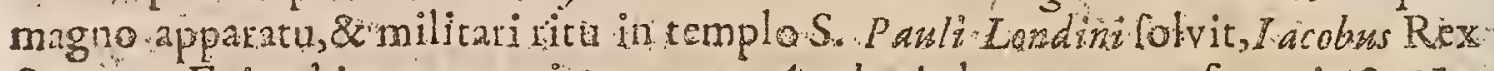
Scotorum Epitaphio parentavit; utraque Academia lacrymas confecravit, \& No-

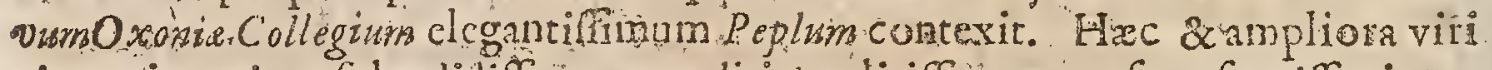
virtus, ingegium fplendidifinum, eruditio politifima, morefque fuavinumi me nerunt Gul.Camden.in Annal Elizab. Gu a nn 676 .

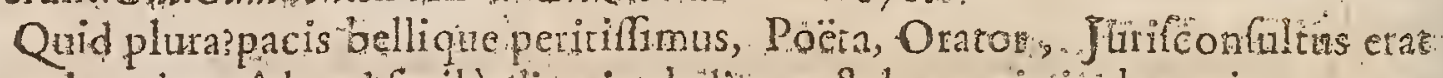
egregias; de quô hatr facile dicerisgladu an ftylo magis inclaruerit; quorum altero in erits altero in omne exum fuperfurus eft. Ant a Wood in Hilt \& Aniq. Univer. Oxon. 265

Corporis tu bona intueor? ad robur pariter factus ses; ad decorem. Animis cultifrmusille: \& ubetrimx in te ingeni judiciiquédotes. Externa? Rirpe nobiliffmus es, opibus fplendidiffmus. Nec quidquam facile tibi deent, quod $N^{\top}$ atur.e aut Fortuna adef. Macte his dotibus!co magis, quòd non adambitionem, ut pleraque if a nobilitas,aut ad pompam abuteris fed confers eas, quà potes, ad tuam \&publicatn folutem. Idque doni \& foxs, togà \& fago:cum vegeta illa animi vis 


\section{CELEBRIORVM AVTHORVM.}

ad omnia fufficiat: : \& M arti ita lites, ut Sacrum numquam deferas Sophic \& OM ufarm. Sed dibo hoc Laudum tuarum limen, non penetro. Quia ut facratum filcutio yotiùs, quàm plaufu fpectamus: fic tuas ego virtutes quas veneror, non exfequor, adoro prèédixerim, non adomo: Th tantum, ô Britannis tuxclarum fidus, (curtertatim lucem affundunt Virtus, Mufa, Gratid, Fortuna) tenuem obfcurumque hunc laborem àme libens accipe, \& paul ifper infar doni pendere parere in Eama templo. Inff.Lipf. in Epift.prafix.Dialog de Reat.Pronunciat.Lat.Lingov.

Naturate maximis animi \& corporis dotibus ornavit:Fortuna verò nobilitate \& opibus, ac folendidis neceffitudinibus: Tu autem à primâ pucritia animum magno ftudio excoluitti iis artibus, qua contendentibus: ad virtutem magno adjumento effo 1olent. Hublort. Eanguet. in Epift.72\%

De quo idem dicere poltim quod de Homero Angufiñus dixits earn fuavifin: mum \& jucundifimum elle etiam in fuis Vanitatibus. Sed Arcadiam fuam non tam deperibat , ut Epifcopus Heliodorts amatorium fuum librum; Optallet snim inftante morte (conlulto priùs fuper hac re Paftore quodam) eam fupprefo. file. Ecivu. Leigh de Ris \& Eruditis Yiris Angl.

Anglicre Aula ita effentialis erat ut mutila hoc videretur dum ejus confortio earebat; Cum \& inr rebús \& in verb s perfectus effer Magifter, ut es ejus Arca dia liquide conftat.Doctor $F_{u}$ llex de Rraclaris Anglize Vixis. Angl,

Der hoc Authore fic cecinit Poetas

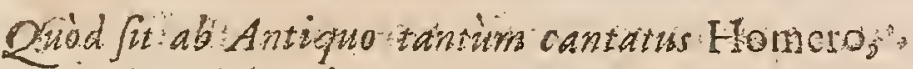

Felicern Macedo Rex vocat Alacidem.

Or me infeticams lquia tu Divine Philippe...

Felix carminibis non potes efle mets."

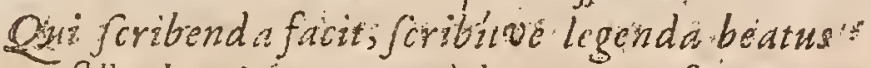

flle, beatior estus, quad at rumique facis:

Digna legifcribis, facis o digniffrna fcribi:

scripta probant Dóctum, te, tua-faita, probums:

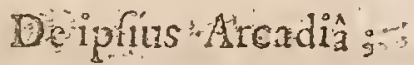

If fe tham moriens ( fed coninge tefe) jubebas

Arcadiam favis ighibus effe ciburm.

Si. meruit mortem, qui flathmam accendit amoriss?

Mergis non uri debuit ista liber.

In librum quecungue cadat Sententia: nullia

Debuit Ingenizam morte perirè turum.

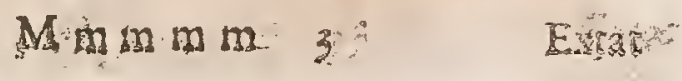


Extat Arcadia Comitilx Pexbrocbiensis vernaculá linguâ fcripta una cum Additamentis por W.A. \& R.B.Londini 1629.

\section{JANUS GULIELMUS}

Clar.AB. T: Ubece natus eft Anno Bom.15i5 Avarior ob it Anno is8.

IS DIZXXIV

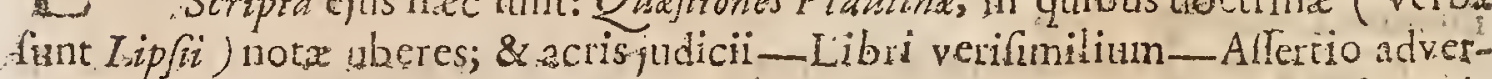
fus Carolurn Sigon. in qua erudicè demouftrat, non elle aut. M. Tüllit, aut fatis digram $M$. Tullio cam quęillius nomine veuditatur, Confolationem - Manes l'al meriani Poëmata. Vortic Euripidis Tragodias monnullas Latnè.

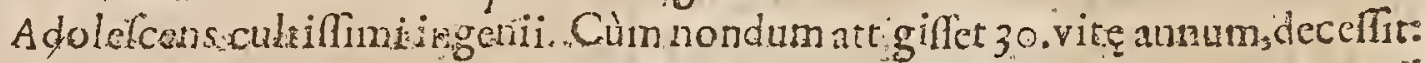

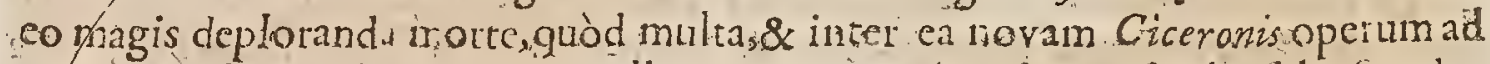
MS. ex cmplaria diligentinmè collatorum; \& anplius fexcentis claufulis fuppletolum Editionemparatam haberct:quam \& ego vidi, hactenus magnâ.rei literarixe pacturâ aut dilperditam aut fuppreflim. Cujus familiaritate, dum. Lutetia eflet, dius magnâ cum animi oblectatione ufus, hoc verè profiteri poffum, me lemper ab

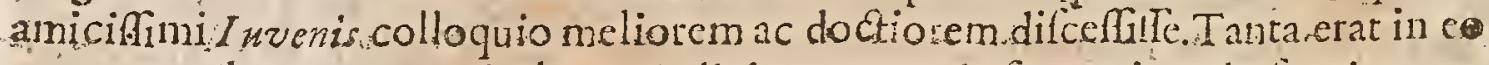
morum probitas, tantum in literis judicium, tanta in fermocinando fuavitas : ut alium vix meninerim (muitos autem audivi) qui Latiné limili cum facilitate \& puritate loqueretur: utomittam raram in Pö̈ticâ facultatem, Give Graca verteret, five verfusex ingenio faceret. Aniciétian non tam atatis limilitudine, quam ftudiorum confenfione contratam, immatura mo:s diremit, non tamen omninò

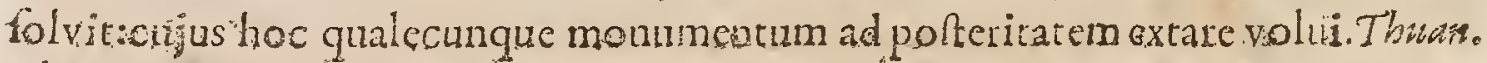
ad. Ann.1584.

Sanè amaban adolęfcentem infigni indole, magnâ fpe: nec facilè ing nium viderm (juvenile quidem) magis mili ad gnfum. Libelli judicio meu te"es. Quos in Critico iflo generepacos cdidit; led probos docko que, \& quos haud remere invidix dens atteret aut lima labentis avi. Iip/.clct.1.2. Epitt.16.

fani Gulielmi tireras accepi:pantò ancè etiam librum Quafionzm. Quem cgo ita probo, ut nçem aliquid melius in hoc genere vidiffe ab aliquor annis. Redam viam adolefcciss ille ingrelfus cft: \& ingenium in eo ac judicium pariter magna. Lipf. Epift.Cent. I. Milccll, Epift, 47 .

- In fani Grtieln morte valdè indolui. De vultu aut facie non etm noveram: oprimede anmo. Nec cenfeo melius aut rectius ingenium fuife hoc rvo. Sed Dro ita vifum opinos बrofque traducere adoprimamillam yitam. Idem ibid. Epiit. 38 .

Ex Scriptis limatifimis qux Gulielmi funt, fac lè apparet, ho ninem eum ac. Guratè erud tum fu fle. 1o. Pet. Lotich.

7anus Guliclmus, fos Germania ingen:orum Hlibatus. Caff. Barth. aniradv. ad Gratis Cyneget. 5. 1. 
Valde cgo, fiquilquan alius,amo \& colo elegant:fhitum Iani Guilelmi ingemitum:cui li lupertati effe diutius licuiffet, ne-nos Germani exteris nationibus unquam:invideremms. Gafp.Sciop:-1. I. frafpect. lectepit.8.

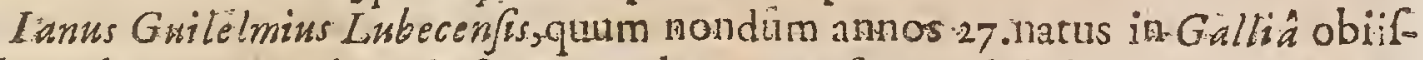
fet, hoc elogitun omaiun doctorum \& bonortum fecum abitulit,, Nullurn bôc-preclarius elegantius ingenium noftro arvo extitiffe: Sed de hujus Juvenis laudibus aliàs dixinus; quamvis Guitêtmus nullitis laudibus indigeat $\times 2$ omnibus verif mitium \& pläuinarum. Questionum fuarum lectoribus ex facili fe, , probica-

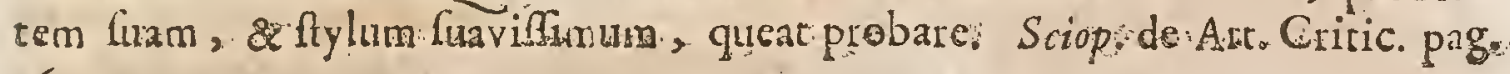
I6.17.

Nec fruftra cecinit Famus Guilelinus rofas ele egos, epigrantimata, manes-Pälmerianos;in unnibus enim vividus âvegetus calor: Borrich.de Toër.p. $33^{\prime}$.

Guilclmins juvenis erudicifhmus, $b$ ituräis obiit,ardente febre peren ptus. Die-

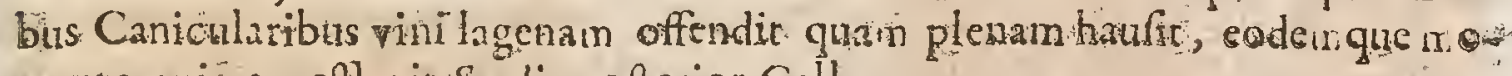
mento ani an eqlavit Scalig pofterio: Gall.

Carmina cjus habentii Tom.2.Delit:Germ.p.447\%

Extant Quaftiones Plawina in Leskap.Critica Gruteri, Töm.

I anus $G$ *aserus, polyhiftor hujus atatis incomparabilis, quanti fecentit $M$ w Jas Gulielinianas, integro Carminum Libello, Manibus Gulichmianis dicato, abunde ad pofteritarem teftatum reliquitsubi, inter egtegia alia Elogia, fthune defunteto. Literarium obelifcum, quowis matmore diururniercir, etexit:-

\section{Meiroriz. Sacro}

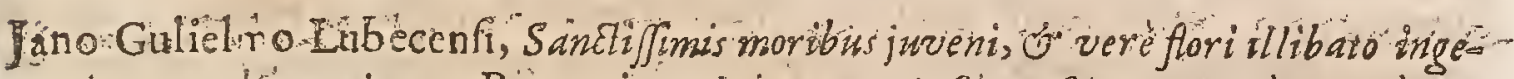

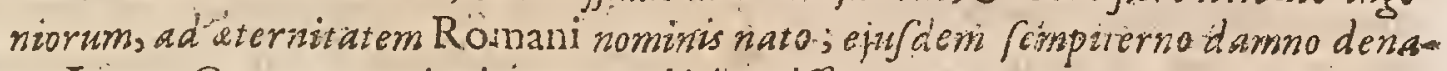

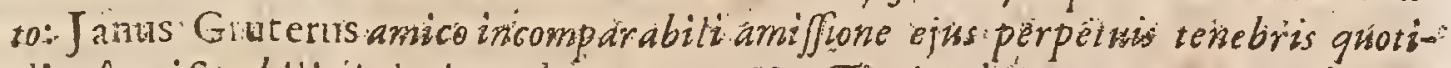

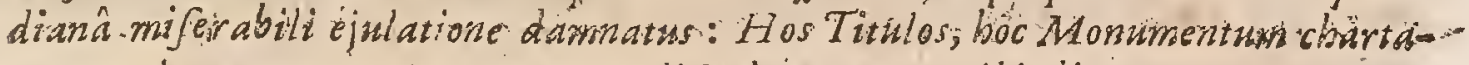

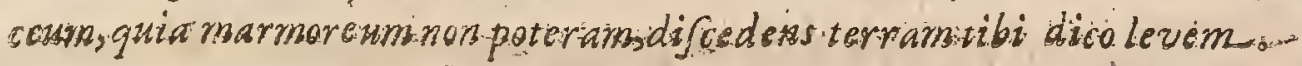

\section{LOANNES RASSEAATIUTS}

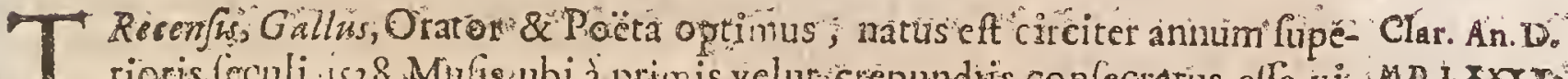

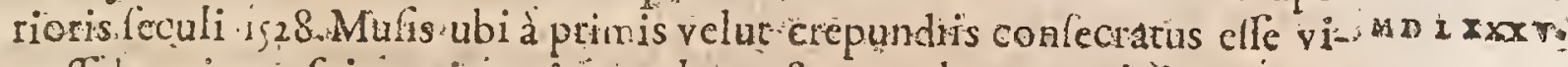
deretm $r_{2}$ affidaus in po fuit; ut ingenium cultura fupra valgat s ertid tionis con-

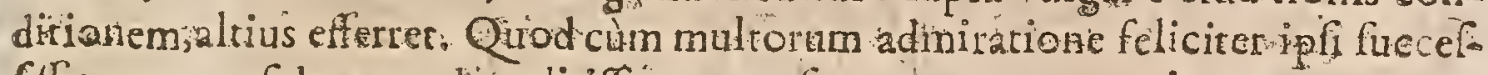

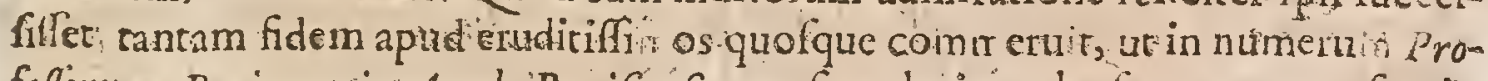

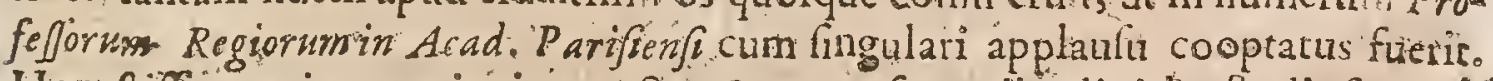

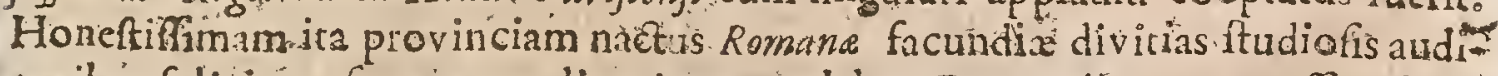
toribús feliciter ufquece explicavir, ne celebre Pafferatii nomen pafinn lateque in ore doct flmoram honorificentifimè vigeret, vigearque eriam nune.

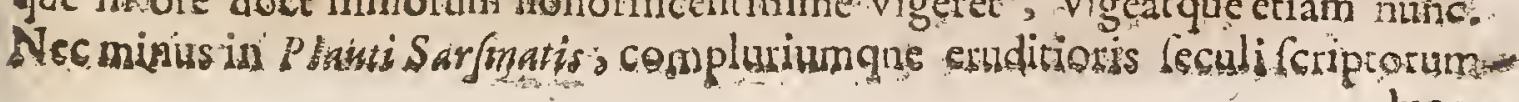


luculentâ interpretatione magnâ cum laude verfatus eft. Tandem cum doctifímarum lucubrationum [qux ipfi erant affidux] nullum modum, nullum finem faceret, ex continuis laboribus oculorum vitium contraxit, ut ab obiepente vifûs caligne a publicis pralectionibus, non fine gravi audicon dolore ferias facere cogeretur. Verumerim verò oculonm in ulaticoma accurata ingenii acies abundè compenfavit, Quxn igitur animis intus diu praviderar viræ melig ris beatitudisem, cam ex volo denum confecutus eft, antuorum 73 . Senex, poft-

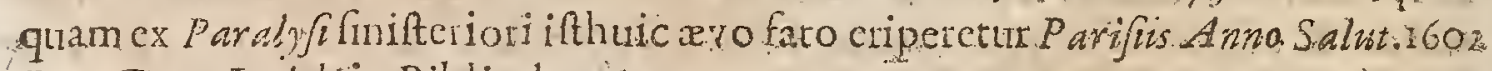
Ioan. Petr.Lotichin Biblioth p.69.

Scripta cjus Latrma funt: Orationes \& Prafationes-- Conjecturarum libei--. De L tterarm inter fe Cognatione, \& permutatione---Commentariiin Catut

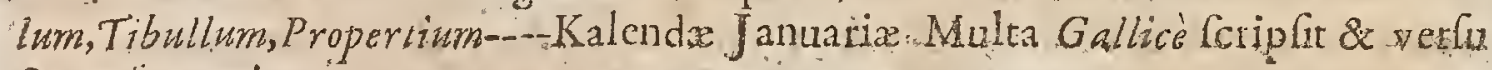
\&prola orationé.

Hic eft ille Pafferatius ougine Trecenfis, utrâque linguâ dofílfi us, quỉ primus apud Parfíos in Scholâ Regia recondicas verx. Latinitatis opes aliquantò majore cura \& . Ptudio peveftigavit, juventutique aperuit; cum I urnebus, Auratus, Lainbinus, catcrique priùs in eadem Scholâ jrofeff Grects potifimum interptetaidis operam \& indutriam impendilfent. Poterat guidem ex umbra \& fcholatico orio in apertam fori dicem predire, \& ad recum adminiltrationem fe conferre. Nec enim eiderantoportum civilis difciplinx prefidia, cul us puros limpidofque fontes aped Biturigas à diuturnâ dacobic inaci

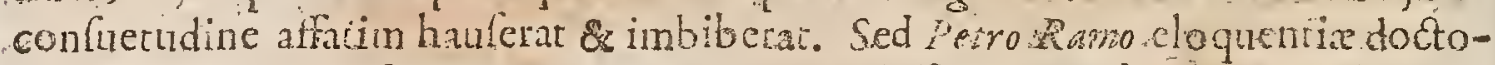
ri delesus a Rege fucceffor in ề demum profefione contenurt, nobilemque doetrinz fux famam vel apud remotiurnas orbis Terre nationes longè laté, ye propagavit : cum sihil vulgare, nithil è medio fumpum afferer, ob idquepolitifrmi quiqueliomines etiam cx ipfo Senatr celebre ejus auditorim frequentarent, ac velut cy nitidis \& fragranibus ejus hortulis lectifimos Romone elegantio fores.admirabili.sum voluptate excerpcrent. Scevol. Samarthan. in Elog. Gallor.

Iodxnes Pafferatus Latine Linguxprofelfor dignifimus: qui felicitate ver pangendi, ctiam Gallicos, \& folutâ oratione feribendi, ac bonos fcriprores ince:pretandi, diu magnam laudem in l'arifieng Academiâ meruit. Homo cmunctu naris, \& cui aliena pix placencht, ultimo dogio vovit, Be manes fir malis cormimibus onerarentur. Ita:yue pauci rrortum laudarant, dum verentur ne voto ejus minus refpandeant. Thuan. Ann.16r2.

lacob. Gillot in Senatu Parifenficonfiliaritis monet nos in guadam fua ad - Tof. Saligerwm Epiftola fe à Paferetio audivite, libum fuum de Cognatione Literarmb fibi adco placere, ut millum fum foriptun preter 11 ud in lucem venire vcller. Gall.

Accepi pufferatiilibellum de cognatione Literarum, maig utilcm mobis quan Authoiglofiofum. Rari erunt qui eo f́ciant uti. Nos quanti fit ex eo xltimare polTumus, quod paucorum hominum eft, \& pluce habebit qui non capiant qua 
qui co capiantur. Ego fanè in cenfum bononum cum dedico. Iof.Stalig.epilt. ad Car.Labbaum.

Pafjerat. valde ignarus erat; vix octo legerar libros : benè inftitucbat juventutem: duo verba Latiné fciebat, ornes reprebendobat, non erat tantus quantus habebatur. Tricafinus erat bonus Pedanus ad infituendam juventutem. Scalig. tofterior.

Fatendum eft omnium gui in Gallia Latine Lingue illuftrandre allaborarunt neminem majo:i gloria quàm Ioannempafferasium id praltitiffe. If:ZBal- lart. Acad.Scient. Tom.I.Gall

Difficndum non eit quiri Paferatius Latina camina fcitilimè componeret. Nihil purius,nec forfitam mag s nativum apud nos extat. Prater has duas infgnes qualitates, diccre polliumus ejus verfus multam eruditionem infitper conrinere, imò \& elegantiam quăndam, qux'à Vulgarium Poëiarum foribus eos difcriminat. Sed omnibus perpenfs, nihil ineft illis vigoris illius coleftis qui

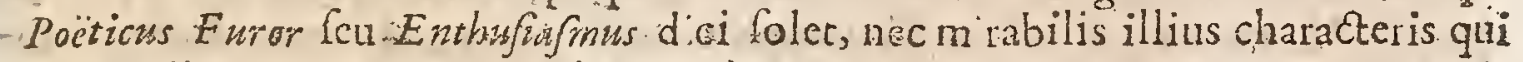
artis peritun Lectorem demulcet \& abripit. Iudicia Eruditorum per Dom.Bailletwin Paril.1686.Gall.

A noftris quo uc Regibus Carolo I X. " Henrico III. amabatur; illi quidem Fenationterupidilimo, libcllum de. Arte Venandi Gallico verfu friptum, obtulit, quen amici Ronfardus, Bellajus, Baifus, l'impontiúfque \&alii Poëte noftrates magnoperè probartnt. Latinus quoque fuit weximius, utoltendint 25. Pömatia cjus jam excufa, quorum quinque ad $\mathcal{M}$ emmum feripfit. Flestiz werò terti elogium edidit, veteribus conferendum.Ioan. Papyr.en affon.in Elogo loan. Pafjerat.

In huic Audorem hac carmina compofuit 7o.Pet. Lotichius:

Qui tenet arguti cognomen Pafreris, autor Arguis cantat carmina docta modis.

Hinc longevatratens disturna facula vite Dauliacas aulci carmine vincit aves.

Carmina ejus habentur Tom.3.Delit.Gal.p.1. Extant Orationes ac Prafationes. Par. 1606.8\%:

Hoc Epitaphium ipfe vivens Tibi compofuit:

Hic frus in parvâ Janus Palfertius ir rnâ,

Aufonii Doctor segizss eloguir,

Difcipuli memores, tumulo dace ferta CN agistri,

T.t-zavio florum munere wermet burnus;

Ning 
Hoc culta officio, mea molliter ofla quiefcent,

Sint modo carminibus non onerata malis.

Veni,Abii : Sic vos Venitis: Abibitis amnes.

\section{BENEDICTUS RERERIUS, Soc. Fefo.}

Clar. Ar.v. T Arione Hispannus, patriâ Falentinus, vix adolefcentiam ingrelfus, animum

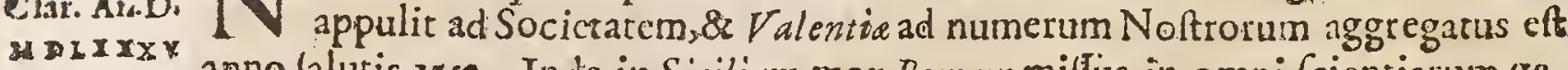
anno lalutis 1552. Inde in Siciliam, mox Romam milfis, in omni fcientiarum genere diligenter fe excrcuit, eximiamque eruditionem conlecuras eft. Dicendi artem publicé Rome docut, I hilofophiam Ariftotelis enarravit, \&e quatuor penè Artium curricula docento confecit; magnâ auditorum frequentiâ, atque applaufu. Ab humanis deinde ac thilofophicis difciplinis, ad divinas \& theologicas gradum fecir.D.Thomam per multos annos interpretatus eft : Sacras Lileras. explanavit, ubique doctus, ubique difertus, fuique fimillimus. Commutavit vir. maximè religiofus atque enuditus caducam hanc vitam cum xternà Roma, ubi perpetuo vixits die 6.Martii,anno falutis 1610 .xtatis 75 . focietatis 58 . ejus erudirionem nullus perè Scriptorum, qui ejus meminit, illaudatam praterit-In hujus autem Viri Scriptis tantum apparet ingenium, tanta doctrina atque eloquentia, tanta rerum onnium comprcherifio, ut fupervacaneum fit lucernam folis limini inferre. Alegambe.

Elaboravit Commentarios in Genefon \& Dasiclem:T D.4. Difpatationum in Genefon: Tomum 1.Difputaitonum in Exodum: Tomos. 2.Difputationum in Epiftulam ad Romanas, \& tres Tomos in Apocalypfin. Extant etiam.15, Iobri ejus Phyficotum.

Benedidus Eererius vir Sacris Literiu nobiliter imbirtus. Bhortacut. apparat. 11.5.3.

Beneditius Tererius vir Gracé,quod apparet, benè doctus, $\&$ in umnipolitioii literaturâ verfatus cumptimis. I dem Apparat. g.led.70.

Benedittus Pererius Sacrorum Librorum accuratus Interpres. Card. Fo.Bome Norir.Auetor.

Pererim eximià Hiftoriarkm peritià inftudus, magno etiam acuminesnec mi-

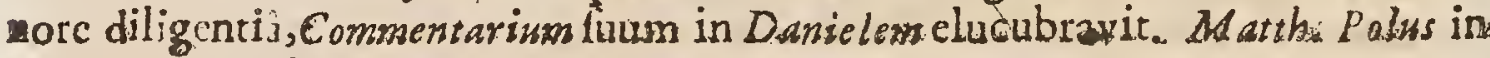
Prafat.ad 3.Vol.Synopf.Crit.

Magni nominis \& eruditionis Jefuita: Pererius. Commentaria ejus in Genefim ducta \& laboriola. Montac.

Beneditzs Pererius Philolophws, \& Theologus Socieiatis Iefu,edidit I V. Tom. Comment. \& Difputat. in lib.Genefeos, qui \& Roma \& Lugdrini \& Colonice excufi funt, referti infigni eruditione, ac perfpicuitate, quze illius iufcribendoeft propria-In Comment. fuis in Danielem materiam Chronographia corum temporum accusatè eft perfecutus. Ant.Pollevin. A pparat.Sac. 
Doctiffimus \& fidelifimus Geneseos explicator Lambec.prodr.Hitt.Lit.3.

Pererius Jefuita ingentem librum confcripfit Quaftionum in Genefm, cui multùm eruditionis ineft; \& quamvis omniun Textûs vocum explicationi non immoretnr, utiliffinus tamen eft; quonian folidè Quxftiones à le propofatas expedit, arduafque difficultates, qux occurrune in Scripturis dilucidat. Patrum ienfus quorum fynopfin congeffit, referre prefettim ftudet: Verum quia Pares Scripturę literale ni fenfum perpetuò fecuti non funt, potior Operis illius pars inutilis elt is qui Bib ioru v literalem feafum tantummodo exequilunt. Or. P. Rich.Simon.Hift.Crit.V.T.?.C.12, Gadl.

Pererius in Danielem afinus eft. Pefímus author eft, gravirer erravit: Danielem nequidem legerat nifi quando illum commentatus eft. Scalig. pofterior. Gall.

Quod autem ad Pererium (pectat, nullam vidco rationem cur in Celestes infuxus adeò infenfus effer, cim etiam admittat Qualitates occultas, iilque doctrinam fuam fuparftruat; qua non rarò è coléftibus inflw:vibus arceftintur, \& iifdem inconvenicntibus obnosia fant, \&, ut anter dictum fuit, à quibufdam, qui cateris homin bus oculatiores cenferi cuperent, Afnorum afylus nuncupantur. Meric. CaJaub.de C: edulitate \& Incredulitare Angl.

Opera ejus 2.Vol.fol.prodierunt Colon. Agrip.1622.

\section{TORQUATUS TASSUS}

D Oëra Italus celebris, Neapolitanus.Jam in pueritià. egtegio carmine edito, 1 furture eruditioni \& glonix pralulit. Nuntium!'apx in Galliam fccutus, Clar. A.D. Carolo I X. innotuir : Dein Ferrariam vocatus, ibi Hierofolymam Liberatam- MDLXXxi: edidit.Primuspaftores in Cenam introduxir, in Amyntâ, omnium Comodiarum Pastoralium principe. Litem cum dcademià Florentinà de Crufcâ, qux Hierofolymarn cjus fub cenfuram vocavit, nactus: Ferraride quoque nego:io adhuc difficiliori implicitus eft, à quo temporc omnia cjus retro fublapta lunt. Ticinum inde fe reccpit, hinc Neapolim profectus, andern, Card.Aldobrandino, nepote Clementis VIII.invitante Romarm pervenit. Obiit anno is95. xtaris jI. cùm. jamjam lauru cingendus eflet. Hofman.

Vir admirabili ac portentofo ingenio; qui infanabili in adolefcentiâ furore correptus, nihilominus per dilucida intervalla, tanto judicio, elegantiâ, ac caAtiffino ftylo plurima \& folntî̀ \& pedibus aftrictâ oratione feripfit ; ut mi Cericordiaun, (quâ plerique ejus vicem profequebantur) tandem in ftupo:en verteritidum furore 1110 ( qui in aliis mentes efferat aut heberar)ingenium ejus veIuti defacatum, in rebus inveniendis expeditius, inventis aptè digcrendis acutius, \& fententiarum gravitatc ac verborun delcetu ornandis copiolius à morbo furgir;\& quod fariffrmus quifque vix fummâ curâ ac labore per orium extunderet, ipfe poft violentam mentis emotæ agitationem ponte ac felicitate mirâ perficit ; ut non alienarione mentis percultus, fed aftro divino percitus vidererur. Thxan. ad Aun. 159\%.

Ialus multorum judicio aliguantùm ad Antiguos acceffilfe, \& corum artem Nnnnn 2 Gatis 
faris videtur fervaffe, nif quòd acuminibus fententiarum, \& argutio à recentioribus ulurpatis nimis indulite qua non fatis poematis gavitaten decent, quam ubique Cervare oportet. Rotand Maref.1.2. Epitt. Is.

Tajfus in Hierofolymâ fuâ Liberatề \& verbis magnificus êt, \&apparatu, [Cd rà

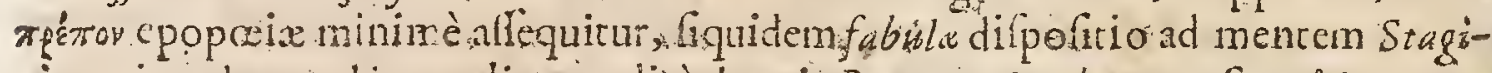
rita exigenda quod nter alios eruditè docuit Petrus, Mambrunus. Sunvis quo jue eft Talji Fabula, Amyntas. Borrich de Poet.p Io.

De laudatifimo ejus Hienafalem Liberate Pö̈nate guod ab Academicis Florentinis, \& alionun oblaterantium moribus, nuper Paulus Benins egregiè vindicavit, omnibus. Parnafs cultoribus ingenuè adtipulantibus, Sic Sancrmus... ipfum \& quod ad fabulam, \& mores, \& phrafm; \& alia, quibus Heroici Cnrminas ablolutus, effingitur Chatacter, Epica hilucufue Italici nominis omnia fuperafle. Fo. Imperialin Mul.Hift.

Tafjus Operum fuorum defrgnatione terforeft, in Fabulé fua difpolitio ne ad artis regulas exactiol, $\&$ in omnibus Poëmatis lil partibus catcris omnibus Italis plenior \& perfection. Sed tes totamatorias iis permifet, un intitur fui gravicarem \& charaderis lui dignicatem freguenter obliyifarti. Rapin. An:mady. in Poëricam part.2. Animadv.i6. Gall.

Annos oftudecin natus preclarum Poëma compoluie Rinaldo infripum, quod admirandi cjus genii quaf primus flos extirit, quodque ei conciliaxit exitimationem eorum omnium qui erudto palato ojumodi fripta devantant: Et fane fi de Ody fja dixit Longinus Senis quidem eam elle foetum, fed Senem illum.

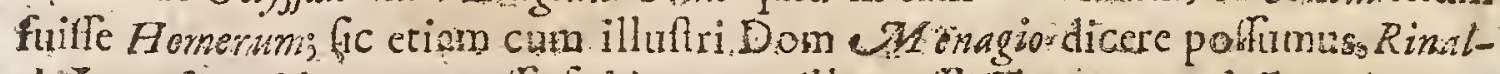

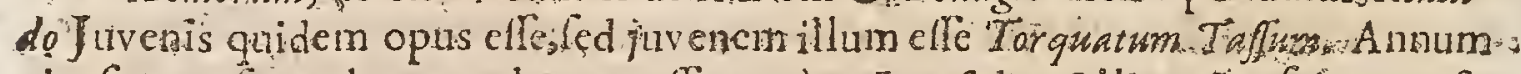
vicefinum fecundun nondum exceferat cim Itrufalem Liberata aufo catus eft, Po șmaillud incomparabile, quod omnibus fuis numeris" abfolutillimum eft omnium quosumque ab Augustifeculo in fircem venerunt, exomnitur fagacium Critịcersm fententia, cumprinis verò Domini Batraciò qui. cum multa. choquentiamultaque ratione dixit, Firgilum in caufa effe, Cur Tafjus in Epica

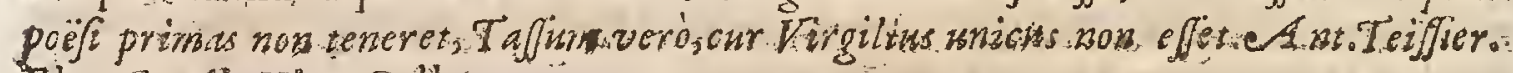
Elog. Erudi: Vir: Gall.

Extar Hierofolyma Liberata Itallè fcript fol:ann.1644.

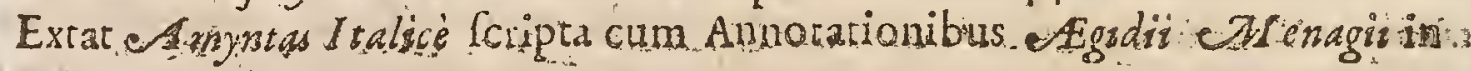
40.1655 .

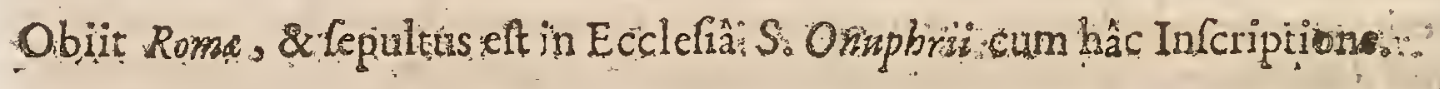

$$
\text { Holpes, }
$$

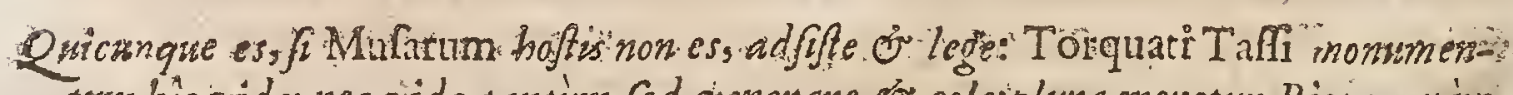

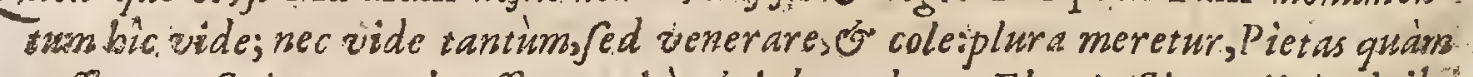

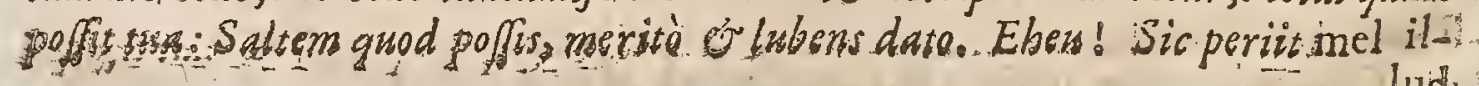




\section{$8 ; 8$}

\section{E N'S U R A}

apud alium officina, gummaribus, lachrymis, radicibus, hetbis, lapidibus, animalibus, gemmis, quàn qux in luis paratur libris;ut profectò admirabilem univerf referre videatur mercatum, dum incogniti cujufque climatis foctus, legentium mire fubjicit oculis, exprimitque vires. Dignus perrobili $V / y /$ / is nomine, qui frat è Graciâ fecedens totius propè orbis ambitum peragralfe fertur , ita hic generofo mentis impulfu, naruræ infrà cœlum ubique luxuriantis delicias collutravit. Fo.Imperial. in Mul.Hit.

Gracarum litcrarum ignorantiain in Aldrovando notat Ezech. Spanhemius in tractatu de Præetantià \& ufu Numilm. Antiq.

Vlyffes Aldrovandus multis in locis miram prodit Metrica Artis infcitiam: quod non à me dicitur, ut detraham nomini Aldrovandi,viri indưtriấfi i,polt doctifimum $G$ efnerum, in enarrandân nobis animantium naturâ, pulchrè de ftudiis promeriti.VofJ.de Idolol. 1.3.c.gI.

\section{Memoria n hujus Auctoris Cardinalis Maphers Barberinus, poftcà Vrbanus P.P. VIIl. hice verfibus celẹbravit:}

- Multiplices rerum Formas, quas Pontus of ather Exhibet, guidquid promit of abdit Humus,

Mens baurit, peitant oculi, dum cunila fagaci,

Ald ovande, turns digerit arte Liber.

Miratur proprios folers Induitria fretus, Quarngue talit moli fo negat effe parem.

Obfupet ip fa finul rerum frecund a Creatrix, Et cupit effe fun quod videt Artis opus.

Varia ejus Opera variis in locis atque temporibus funt imprefla.

\section{OBERTUS.GIFANIUS}

Clar.A.D. R Wrenfis Batavus, Jurifconfultus, natus eft Anno .1534. Obiit Praga, Anno

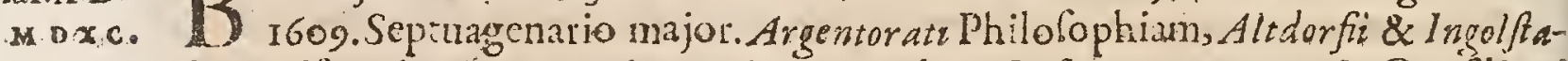
dii lurifprudentiam docuir. Tandem in Aula n. Caxaream vocatus, \& Confliari Calarei titulo exomatus eft.

Scripfit Comment in Ethicam \& Politicam Arifutelis - Collcctanea \& Indicem in Lucretiun-Obfervationes in Linguam Latinam -.. Comment. in InAtieaciones Juris-Antinomias Juris Civilis \& Juris Feudalis-Tractatus de Renunciationibus-Deconomiam Juris_-Notas in Corpus Juis Civilis Iechuras Altdorfinas - Scholiabrevia in Homeri opera - Comment. de Imperatore fustiniano - Indicem Hilloricum Rerum Rornanarum.

Is prima literarum rudimenta in Belgio fuo cum imbibiffer, indultriam fuam ptimumin T.Lucretio exercuir. Quem pol M.ichaẹlem Marullum Byzantïum, 
vera Religionis, quam vera Philolophix perpeiuus \& ftrenus alfertor extitit. Lauder hîc noftram merencur ejufdem nova Ver,oo Commentarii in Politica Arifoteit, quibus nihil; quam ultima \& pars \& ultima manus delint. Mejer in Pref.ad Analyí.Polic.Aritt.lect 47 .

-Huberius Gifanitus Juniperitifinus erat, in Philóophicilque \& politionibus literis enditifinus, Phara lcripta in publicum emifit, qux fagacium Criticórum exiltimationem prome uerutut Ejus in Ariftetelem Commentarii præftantiflmi funt, \&in Iufiriani Instituia omnium etiam qptime commentatuseft, Sciopiz quiden judicio. Quod ad ejus in zucretium Annotationes attinet, bonarum oblervationum, numero refertx funt; fed Lambinus iplum acculabat quòd seas frbi fuffuratus effet; quod fecit ut in Gifanium invehcretur, diceretque eum fuâ tanrùn importunitate, pertinacia, fuperbiajimpudentia, rufticitate infignem efle gut denique etian exprobrarce ei perfidian qua in L Fruterium ulus exat. Ant. Taifler, Elog.Viro: Erudit.Gall.

Obertum Gifantum fanus Douza Senior inordaciflnis carminibus, licèt non apertè nomiuans, fed alibi $F$ anmism, alibi Buranum appellans, perfringit, quòd fcripta Luce Eruteri, a moriente fibi,ut ederet commifi, in rem fuam verterit, \& ut prælo Fruteriana commitrecéntur,pugnantibus retiterit: quïn \& in ViEtorern Giselinum admiff. Plagir reum agit. Thomas de Plag. fect. 4.5 .

Obertus Gifanius in vertendo Homero indultriam luam conlumple; atque utinam lermenis caftitas fummx ejus. fidei refpondiffet, interpretandoitun Pö̈tarum egregium fpecimen haberemus. Fuet de Clar. Inteipret.

Varia cjus Opera variis in locis atque temporibus lunt impretra.

\section{IUSTUS I.IPSIUS \\ Hor, cjus Symbolum: \\ M ORIBVS CA NIIQVIS.}

Clar.A.13. T Atione Belga,natus eft in Ifcano municipio Anno 1547. die r8. Odrobris. MDXC.

Ligduri, \& Lovaniz.

Scrapfor permulta:omnia cgregia Imprimis lataem menenturejus Comment. in Tacium, Civilis doctina, Monita Pelitica, 'Manuductio in Philofopham Stoicrim, notein Sertecarm.

Iufus Lipfins diligentia, judic: o, multiplici lectione admiratsdus, Criticorum fuada, medula. Deripfer.in Elench Cript. Roman.

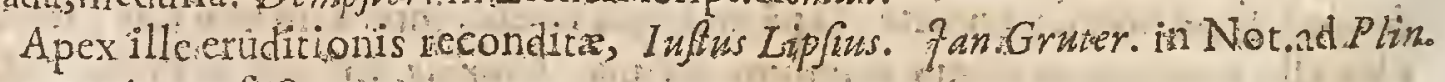
panegyric.c. 2. fect.j.

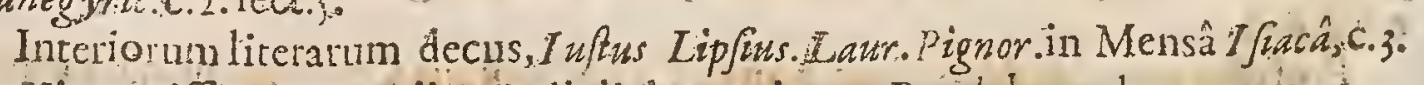
Wir acurifimus ingenii, \& judicil dexterrimus.Bartb, l.19.adv.c.15. 
Lipfur omnem gloriam nomine fuo concludit, vir famâ Orbi notus Occllus Belgii, univerfi thenix, Sol antiquitatis', Hiftoria omnis Promus \& Condus, fapientix \& prudentix anima. Nic. Vernulus.

Vir, frementibuis invidis, optimè de totâ re literariâ meritus. Band. l.2.Epit.2r.

Belgarum, dum viveret, doctifimus 7 ustus Lipfins.VoJj.1.4.Inftitut.Orator.c.s num.2.

- 7uffus Lypfus, victuris ad omnem pofteritatem Scriptis fatis fe illuftrem toto Orbe prebuit. Thuan.ad Ann.1606.

Lip̧rus, gloriofum ævi noltri fpecimen. Sciop.Sufpect.Lect.1.2.Epift.17.

Illius de Conftantiâ liber quàm diu vivet? Sciop.de Art.Crit.p.z.

Quem virum [1ustum Lipfium] per omnia diis, quàm hominibus ingeniô propiorem, uti lumen unicum \& numen ævi noftri colo \& veneror preter omnes; quós ille admiratores cultorefque ubique habet plurimos.Valent. Acidalins IC-s ction. in Patercul.p. Y. $2 .:$

Vit incomparabilis judicii \& ingenii admodum felicis. Barth. 1.56.adverfar. cap. 9.

Exactifinum illius divini ingenii judicium. Lud. Carrio lib.11. Antiq. Lect, cap. 4 .

Exquifti cenfor judicii. Conring.in Prxf.ad Tacit.

Ue æevo fuo Titus, fic noltro Lipfrus vierc Delicium Humani generis fuit. Aub. Miralus in Vira Lipjit.

Acre omino \& felix ingenium fuit f. Lipfro, in tollendis Veterum Scriptorum mendis, \& cluendis maculis, \& neminem habet fortaffe parem: Sed ut hominem fe noliet, aberravit interdum à fcopo. Lalius Bijciola lib.i4.c.13.Horar. Subleciv.

Lipfrus fuavifima quidem fed inimitabilis, \&, ut ipfe judicabat, ne tentandx quidem aliis eloquentiz vir. Dan.Heinf.Orat.1.p.II.

Romanos mores veterague tempora interpretando plurimum claritudinis $I$. Lipfuss fibi locoque addidit, amcina morum gravitate fupra profeffionem fpectabilis, \&luâ quadam eloquentiâ plerofque alliciens:nam cum floridum ipfi \&ptofluens Natura haud abnegaret,alterum maluit dicendi genus, concifum quidem, nec fine feftivitate, fed verè novum obtentu antiqui, quod cim imitarentur, quibusingenii judiciique non idem fuit, ad corruptiflina quæque deventum eft: Cùm verò Lipfrum metus publicus \& privata injuria mutandas ad partes impuliffent,accitur è Gallia Jofephus Scaliger., Grot.lib.5:Hiftor.

In Trafea (libro ab ipfo edito) multa infunt, qux non ad fanam magis, quàm ad publicum horiorem. Band. Cent...Epift.28.

CL.v. I.Lipfí Politica meô punctô, \& opinor, omnium rectè fentientium juU'ciô palmam obtinent inter onnia viri fummè de literis meriti monumenta. Baud.Cent.3. Epirt.;.

Lipfii Politicornin opus utinam tam completum \& omnibus Rerump. formis accoinmodatum, quàm elt accuratum \& planè è genuinis fontibus dedu-

$$
00000 \text { ctum. }
$$


Cum.10.Andr. Bofuts de Compar.prudent.Civ.n.I2.

De Lipfii noftri obitu non poteft te latere. Negari non poteft, in illius morte, \& literis jaeturam, \& amicis luttum fummum contigiffe. Amavi: hominem, ut amicum, colui, ut benè de literis meritum. Iof.Scalig. Epift.1.2. Epitt.cxx.

Audifti, ut opinor, V.C.I.ustum Lipfurm è vivis exceffifle; multum detrimentì cepit res literaria; \& magnum feculi jubar extincum eft. Integriore tamen famâ deceffifet, fi nunquam rem hâbuiflet cam divis illis fuis Kirginibus. Band. Epilt. Cent.2.Epilt.j9.

Quanquam in fummi illius viri judicio hâc quidèm in parte, -non ita multum præfidii ponendùm : cum nemo diffiteri pollit, eum rodum minimè tenuille in vocibus prifcis, Poëricis, duris : ut eruditioni cjus non" paulo amplius debeant literx, quam ftyli exemplo. Vojf. 1.4.Inftitut. Urator. num.7. cap. 6.

Nec probare illa Lip/ii polfum, viri ab ingenii elegantiâ \& variâ eruditione, quàm dictione laudatioris.Vof.1.1.de Hilt. Lat.c.19.

In Infi Lipfii ttylo, Scriptoris ærate noftrâ clariffimi, iftx apparent dotes: Acumen, Venuftas, Delectus, Unates vel nimius, cum vix quic quam propriè dictum ei placeat, tum Schemata nullo numero, tandem verborum copia: defunt autem Perficuitas, Puritas, Equabilitas, Collocatio; Juntura \& numerus Oratorius. It aque Oratio ejus eft obfcura, non paucis barbarifmis \& Solocifmis, plurimis verò Archaifmis \& Idiotifmis, innmmeris etiam Nenterifmis inquinata; comprehenfio oblcura,compofitio fracta \& in particulas concifa, vocum fimi-

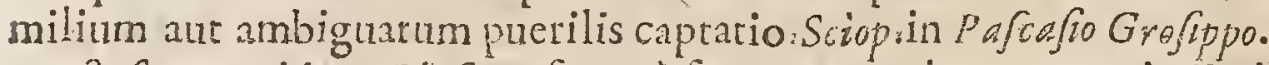

7 ufurs equidem Lip jum fummè femper amavi, propter eximias ingenii, doarinx, judicii, morum etiam integritatis, qua in eo enituere, dotes, ejufque pari ferè, ac Antiquorum Opera in honore habui. Verum maceror, \& doleo illum verba antiqua nimis frequenti in ufu habuilfe: Sed magis, eidem deelfe fermonem purum, \& merè Latinurb. Certé phralis qua corpus eloquentix facit, tota ab illo eft, \& in câ nullum, quem fequeretur, auctorem habuit. Quod utique in linguâ, qua intercidit, \& jam in nullius populi eft ufu, facere non licet. Natura quidem fure, \& genio vir ur doctus, fic nonnihil audax in fcribendo, indulfit: cui laxum, \& Auxum fcribendi genus cordi non elfer, concifa verò, \& adAtricta magis effent ad gufum, quique fracta \& elumbia, qualem elle Cuceronis compofitionem olim Brutzes judicavit, rcjiceret, atque alpernaretur. Inde Oratio ejus crebrâ Parenibefin intertumpitur, \& totainterragatiunculis fcatet. Roland. Mr aref.Epift.1. Epift.49:

Quod ad Insti Lipjâ Epifolas atrinet, ex mihi cúm Plinianis venuftate quodammodo certarurx videntur, nifi mala, cujus auctor efle ambiit, Latinitas, ut pleraque ejus Scripta,ita etiam eas corrumperet, \& infufcarec: tantum acuminis, \& arguriarum, tantum doctrinæ, tantum moralium documentocum iis paffim afperfumet.Maref.Epint.1.2:Epift.

Lipfii ad Polybium tandem vidi. Et vis dicam liberè quid fentiam ? Opus elt? 
eft, labore magno, judicio reato, ingenio denique talis viri conceptum feliciter ac formarum. Nemo negaverir unum illum hodiè re's veteris Reipublice Romana, \& nolfe eximic̀ \& explanare omnium elegantifimè. Veruntamen quod

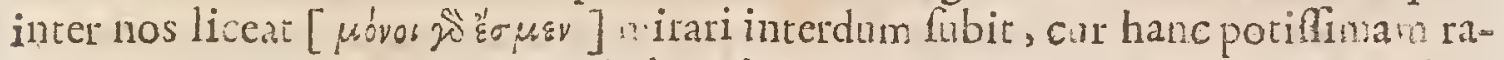
tionem tractandi ej s arg menti elegerit?Nam ad Polybii licem q id admodum att:Lerit fi $\mathrm{i}$, nond m videre potui. Multa ille quidem meliùs vertit q àm priores fecilfent Interpretes: Sed magnam eorum partem Turnebus, aliique fibi vindicant. De crtero, fi quid in Gracis illis obfen fuit, 1. cem id adh:ic defiderat. Non enim alluxit $F_{a x}$ Lipfrana illis locis. Cafaub. in Epilt. 2i.ad Bongarfaum

Noviffmus omnium qui ante nos in explicatione Polybii aliquam pofuerunt operam, fuit Imfins Lippins, vir clariffimus, \& de meliorum literarum ftudiis excellenter benè meritus. Hic fi integrum Polybium, aut unam aliquàm è tribus illius partibus Latine expreffilet ; atque ad hoc inceptum tantan Graces Lingux peritiam attulifet, quanta in eo fuit cognicio veteris fHistoria rotiufque Antiquitatis, \& Latina dićtionis facultas : polt Lipjam in eandem Palæeftram defcendere, hoc verò fuiffer, poft Refcium, in Scenâ geftum velle agere. Cafaub. Prafar.ad Polyb...Vol.p.So.

Infus Lipfrits in Libello de Confantiâ, tanquam in Darii Scrinio, res ipfas quas habebat preciofiltmas, elcgantian videlicet, \& omnes ingenii fui ac judicii gemmas, artificiosè conclulit. Gab.N aud. Bibliograph. Polit.

Multi conf esun librum ej is de Conftantia cateris omnib.s anteponendum effe. Quidam dic nt ftylum Variarum cjus Lectionum effe omnium purifimum \& elegantifimum, Quodad ej:s Tractatum de Politica, quanvis textuum variorum è plutibus lectis Authoribus excerptorum merus cento is fit, quen filo ex fro penta defumpto confuit, idque multò majorilabore quàm induftria, illum tamen in fuis Epiftolis iple commendat, eodem affectu quo Matres ardentius amare folent infirmilimos \& imperfectifimos fuos natos. Sed eruditi \& acris judicii viri non fi fragantur ipfi, nec fcriptum illud unquam magni xttmarunt, ut à SA otteo le V'ayer obfervatum ent. Ant. Teiffer.Elog. Viror:Eruditorum. Gall.

Tertia Centuria Epifolarum Lipfii omnium ejus operum peffimum eft: Optima autem funt ejus in Tacitum Commentarii, ejus Orationes de Concordia, \& in Ducis Saxonia obitum. Ejus Electa ejufque Saturnalia funt preclarifimi libri. Gracus tantum fuit quantum ad proprium ufum op's erat. Quam milcrandum Lipfí judicium de Seneca Tragico. Puëtices prorlus ignarus eft. Scalig. pofterior. Gall.

De Lipfí Epiftolis dici hîc multa poffent. Confiderari illæx vel ratione dictionis, vel ratione rerum poffunt. Vehementer fenex à juvene difcrepat. Cùm enim in juuentute fuâ Ciceronianam dictionem fequeretı.r, maturioribus annis penè novum eloquentix genus fibi finxit, in quo arg : tiæ, adagia, hemiftichia, Græcx fententix, quornm in familiaribus inter eruditos Epiftolis ufus effe potelt; $\mathrm{Ta}$ les enim Epiftolas illa ornant, in cateris locum non habent, ubi enthymemati- 


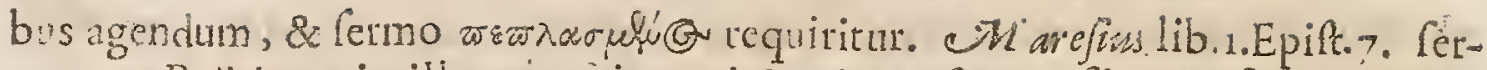
monen Poëticum in illo agno cit, qui Statiun "eferat, fibi profummo Poëtâ habitum, cujus feriptio valdè lit adtricta, \&zcrebrâ parenthefi interrupta. Idem ibid. Epitol. 49. ad Heinfarm in illo :epichenditantiquorum verborum nimium ufum, audaciam in fribendo, dictionem parcnthefibus \& interrogatiunculis interruptam. Refiondet illi $N$. Heinfius : Non defunt Lipfio Sue Veneres. Habet nefcio quid, quo lectorem trabat, of quod prorfus improbare non pofis. Vt non tam illi fuccenfeam, quarn ineptiffinis mortalibus, qui imitandumblibi illuorn proponwnt, idque tam prepofterè, wt vitia ejus exprirsant plerurngue, virtuies non afjequantur. I mitatus neminem Lipfus, ac proinde nemini initandus. CMernoriarn ego tanti viri fancte veneror. Nec negurimtamen, magnâ illi cx parte labem earn deberi, quam th Belgis noftris non immerito adfcribis.

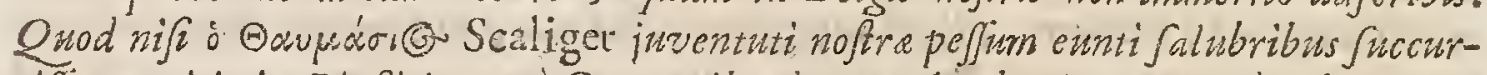
riffet monitis, in Lipfii locum a Curatoribus bujus ACademide opportunè Jubrogatus, futurum vis evat, ut tantam tot preclaroniningeniortim, que annis 50 . proximis in Bataviâ noforia eluxerunt, meffern mirarentur extéri. Nec labes tarnen illa folos Belgas \& Gernanos, fed Gillos etiarn vefiros, infeciffe videri poteft. Magnam partem dc illo vera funt, qua in Excerptis Scaligeranis dicuntur. Henricus Stephani Eatinitatcm $L i p$ fi fingulari libro notavit. Neque unquam cgo funferim, ut, antequam al iquis robur in ftylo acquifiverit, inexcrcitatus adhuc Lipfand Lediøni adfuefcat, ant cjus folculos in ufus fuos cxcerpat. Qui illum imitari funt, infeliciter rem fuam gefferunt : Namvel exfcripletun nomnlla, ac fententias quafdam compilarune, vel planè inepti funt, dum dictionem ejus exprimere tentane,perfe non laudabilem. Dan.Georg. Morbof.Polyhif.p.301.3C2.

Vide Patricium qui I talice fcripfie Parallela Nilitaria faris bona; ex quibus. Lipjâs'maginam partem corum, qux de Militiâ Romanâ commentatus eft, videtur hauflle. Salmaf. Epin.l." Epilt.93.

Lipfi Saturnalia Petro Fabio adfcribunru à Capare Scioppio, in. Not ad Prisip.p.1.4.

Iuftus Lipfirs à Mureto femel iterumque appellatus de Plagio, refpondit illi quidem, fed ita, ut certiùs nobis de improbis cjus quibufdam affectibus, quàm innocentia conftet. Thornaf.de Plag.

* Ejus Orationes odto falsò illi adfrripta, feneque poriffmum habita,prohibentur, cautè Legendus in iis, que de $F$ ato ubique dilferit. Index $M$ adrit. Edit.ann.1667.

Opera cjus omnia curâ Balth. Moreti fex Tomis diltincta, Antverpia Folio anno I $G_{37}$.

Hoc Epitaphium, quod fibi ipfe fcripfit, vifitur Lovanii in ade D. Francifci:

Quis bic fepultus, queris: Ipfe edifferam. AT uper locutus ơ filo of lingua fui, 
Nunc altero licebit. Ego Sum Lipfius:

Cui litcra dant nomen ơ tuus fävor.

Sed nomen, ipfe abivi, abibit boc quoque:

Et wilbil bic Orbis, quod perennet, pofsidet.

Vis altiore voce me tecum loqui?

HI wrana cuncta fumus, zornbra, vanitas,

Et fcena imago, \&, verbo ut abfolvam, Nibilo

Extremino boc te alloguor:

eEternitro ut gaudeam th apprecare.

Lapidis Scpulchralis Infcriptio in diotâ urbe \& $x$ de:

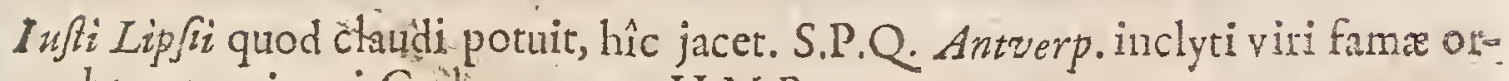
b1 note virturi Coslo receptx, H.M.P.

Ejufdem alterum Epitaphim : Anctore Anonymo:

Si fimplext animi candor; finefcia fuci

Integritas firsiles nos facit effe Diis.

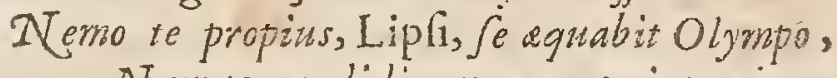

Nam te candidior nemo, nec interrior.

\section{Alterum ejufdem :}

Nemo te lacryzis, Lipfi, neque laudibus ornet.

Non lacryme, at plaufus funera Santio decent.

Ai gui te laudare volet velut Icarus alter

Nominis Oceano mergittur ille tui.

\section{RICHARDUS HOOKER}

T. On procul ab Exomia natus fub initium Anni 1554. Collegii Corporis Clar.A.D. A Chrifit Scholaris anno 1573. Socius \& Artium M: giter 1,77 . Rector de MDXC: Drayton. Leancamporim in Comitaru Buckinghamicinfubs Anno 1584. Ecclefixe Templariorum Londini Magifter is8j. Rector de Bofcum, juxta Sarisburiami 159 r. \& novifimè de Bishopsbourn, prope Cantuarian Amo I594. Hujus viri obitum, nec mciùus, nec digniùs exprimerc licet, quàm in verbis Gulielmi Land Archiepifcopi Cantuaricnfis. Qux in hujus Authoris libro de Ecclefrasticá Poltteià ad fe rum pertinente defcripferat (libcr autem ifte nunc penes eft Gulielmum Fuiman, Corporis Chrifti Collegii nuper Socium) vcrba hre func : Richardus Hooker vir Summis doctrina dotibus ornatus, de Ecclefin precipuè An-

$$
\text { O } 00003 \text { glican }
$$


glicanấ optimè moritus, obiit Novembr. 11. circiter horam Secundampoft CRC eridiem, anno 1600 .

Scrapfit de Ecclefiaficấ Politeiá lib.4. Lond. 1594. Angl. Quibus \& Quintum adșidit, feorfin editum Lond.1597. Angl. Tres illi, qui nunc cireumferuneur, poft obitum ipfus publicati, valdè mutili \& imperfect ( ne quid gravius dicam ) meritò habcntur. Scripfit etiam atque edicit Angice Iractatum de fuftifuatione, atque varias Conciones \& Refponfurnad Supplicationem Gualteri Trawers, ad Regum Concilium fatam.

Richardus Hooker Theologus, modefiâ, temperantiâ, manfuctudine, \& cateris virtutibus imitandus, \& fupra multiplicem cruditionis laudem celebris, quam libri de Ecclefafỉcâ Politeià, patria linguâ ediri, digniffimi qui Latinè loquantur, abundè teftentur. Garnden.in Annal.Elizab.fub an.1599.

Etfr vel fingula omnium totius Europe Academiarum Collegia perf́crutaremui, vix, aut ne vix invenire fas eflet, unumaliquod, in quo ejuldem fxeculi, ex eâdem patriâ, tres Theologi, quales erant Incllus, Hookerus, \& Rainoldus, omnis eruditionis Trunsviri,fimul flonere. Ant.à Wood in Antiq.Univ.Oxon.

De primis quatuor libris Ecclefiafica Politeia, audi qualem Clemens VI I I. Pontifex, cum corum partem aliquan Dr.Thom. Stapleton Latine interpretatus effet, fententiam tulerit. Credo (inquit) vix ullum doctrine genus reperiripofe, qudm non indagaverit Awthor iste; cujus ingenio onnia [quantwavis diffillima]cedere necefle est.Verè quidem Authoris nomine digniffrnus, cujus Operis quiomagis inveterafcet co major indies veneratio accedet; quippe in quo ea immortalitatis semina conduntur, ( $\int$ modì de toto opere, ex ejus parte conjcitare fas fit ) que pofteritas alet, quague semper adultior a ipja aternitas intuebitur.

Nonnemo Scbifmaticorum Malleum appellat.

Carolus I. Rritannia Rex, ejus lectionem liberis fuis, cùm eis valediceret, $\mathrm{Ce}_{-}$ niè commendabat.

Theologi noftri illum Venerabilis compellatione infignire folent.

Cum primum Rex I acobus. Regnum fuum adivilfer Archi-Epifcopum Whitgift percontatus elt de amico fuo D. Hooker qui libros fcripfit de Politia Ecclefiastr. cajad quod refpondit eum obille annum unum ante Reginam Elizabethan; qua triftem de cjus obita nuncium audierit cum stavi mœrore. Ad id r geffit Rex, Mihi verè non minus moleftus fuit ille nuntius, quòd me privari oporteret confpectu \& colloquio illius yiri, cujus libri mihi adco fatisfecerant: Et reverâ Domine mihi plenius fatisfactum eft unius folii imo yel unius paragraphi lectione in D. Hooker fcriptis, quamyis illa effent tavè̀m de Templorum ftructura, vel de Mufica Ecclefialtica, vel fimilibus, quàm lectione peculiarium Tractatuum quibus prolixè agebant alii Authores quamvis eruditifimi de unico iftiufnodi argumentortum; \& animadverto apud D. Hooker non occurrere fermonem affectatum, fed grayem, encrgicam \& evidentem rationis manifeftationem, eamque munitamauthoritate Scripturæ, Patrum, \& Scholafticorum, omnibus Sacris \& Civilibus Leg bus. Quamvis autem plerique alii benè fcribant, proximo tamen feculo peribit corum memoria; fed dubio procul in fingulis pa- 


\section{CELEBRIORUIM AUTHORUM. $\quad 847$}

ginis libri D. Hocker Animi D ivini effigies confpicitur, cjufmodi veritatis \& ram tionis imagines, tamque facmatis coloribus depictxi ut exolefcere nunquam poffint, led Authoris memoriam immortalem reddituræ fint. Vide If.Waltonum, in vita D.Richardi Hooker. Angl.

Epitaphium fequens diu poltea fuit evulgatum in D. Hooker memoriam ab Equite Wiliclmo Cooper, qui etiam fplendidum Monumentun ei conftruxit' in Bornens Templo, \& profitetur fe illum ut Patrem fuum Spiritualem revereri;. idque eleganis carmine anglico, quod hîc verbatim incepretamur.

Quamvis fagacis Hookeri famâ, vel pretiofi nominis memoriâ dignum quicquan eloqui nemo valeat : Quanvis hi fumptus fant in gratiam Viri, qui Monumentum ære perennius in fuis Libris ipfe fibi erexit : Aquum tamen eft ut Nos, fi non ejus Meritum, falrem noftrm ejus Venera, ionem palàm hîc faciamus: Ceremoniarun Ecclefrafticarum Patronus hic fuit : Quomodo igitur ablque omni ceremonia fepultus relinqueretur? An id fieret quoniam ejus Mors xquè ac ejus Vita, Humilitatis exemplar debeat efle ? An verò quiòd Defuncto magis gloriofum foret quarere, Cur abfque ulla pompa tumulatus fuerit? Verùm qui hîc obfourè tam dudum jacuit, ad altioies jam tonores evectus eft. $\mathrm{O}$ vos homines Ambitioli, difcite nunc moniti fapicntius vos getere. Humilitas vera eft exaltationis via. Hinc eft quid non fine Numine incitatus fuerim ad Virum hunc Humilem his Evangelii verbis compellandum, Amice, afendefuper *izs. Angl.

\section{JOHA NNES RAINÓLDUS}

A Pud Pinhovves propè Evoniam, in agro Devonienga natus, menfe SeptemI bri aut circiter, anino 1549. in Collcgii Corporis Cbrifi Scholarem, c̀ Coll. Mertenenfi electus anno 63. \& Socius probationarius 66. Lingua Greca in Collegio lub eodem tempore ProfelTor.S.T. Doctoratu infignitus Anno 85. Et? poft aliquor annos Decanus Lincolnien is ele Aus elt. Verum Academico vitx generc oblettatus, Decanatum fumm cum Dodore Cole pro munere Collegii Corporis Chrifti prefidentario permutavit.

Scripgrt Cenfuram librorum Apocryphorum Ver.T.contra Pontificios.DecaEeris qux publicata funt vide Cacalogum novum Bodleianum.

Tam admirabiles in pictate $\&$ literis reconditioribus, imprimis verò in Theologicorum Myfteriorum Scicntià progrefiones fecit, ut Acadennie lumen, Europe decus, Divine Glotie buccinator, Sanctitatis crimium exemplar, \& diligentifimus in Pontificios Scriptor fuerit. Cujus Volumina quotquor in lucem prodictunt extant omninò inconfutabilia: Sed in ipfo curfu, proh dolor ! Mors eum oppreffit. Nam ingratus Mundus tantâ ftellà fuit plane indignus. Vid.Herwolos givm Anglicam Imprell.ain.1620. fol. 
Rainoldo à Lingux Crece prælecturâ,nomen \& fama crevit. Author autem In quem legere fufceperat, iple Arifpoteles erat, cujus de Rbetorica eximios libros, pari Commentario illuftravit, in quo non minus, quàm in iplo libro tanquam gemino alveo decurrit, aureorum flumen rerum, \& verborum. Erat autem vir. ifte, memoriâ ufque ad ftuporem felici, in omni librorum genere,præcipuè verò S.eA ugufini Seriptis verfatifimus;adeo ut ipfe folus vel altera Bodleiana, vel tertia eAcademia non immerito dictus fit. Accepi, Doctorem eAlbericum. Gentilem in liâc Academiâ furis Civiizs tum Regium Profellorem, cum fortè Quxftiones quzdam in eâ facultate, inter ipfum \& Rainoldurm, ultro citroque commealfent difcutiendx, fateri non erubuife, hunc virum leges illas vel feiplo [quantus ille autem] perfpectiores habuilfe. Ant. à Wood in Hilt.\& Antiq. In verf.Oxon.p. 237.

Multa de eo dicenda nobis adfunt. Quandoquidem verì ejus \& jam facta eft, \& amplius à me fiet mentio, fufficiat imprefenciarum, hoc de illo affirmare, fuilfe Theologum in Patrum, Scholaficorum \& Rabbinorum Scriptis, verfatifimum, in Grecis \& Fbilologicis criticum cxactifimum, oratorem quoque facundifimumpium infuper, \& benignum, probum \& inculpatum. Literarum denique \& fudioforum indigentium faventifimum, \& in regendo Collegio, difciplina renacifimum. Ant.à Wood.ibid.

Vir celeberrimus Theol. Angl. longè doctiflimus. Dallaus de cultu Relig. Praf.p.8.

Rainoldus in eruditifrmo Opere Prælectionumi ad libros Apocryphos, quad citationibus omnis generis Autorum teffellatum eft. Voet. Præf. ad The fes.

Foannes Rainoldus Academiam in fino pectore geftalfe ferebatur. Sanè Scripta ejus onnigenan erudirionem, antiquitatis fummam notitiam, imprimis Colloquium cum Harto Jefuitâ arguunt. Leti Compend. Hit. Univ.

Viri pereruditi Ioannis Rainoldi excelfum ignoravi hactenus; qui magnâ, ut tu. quicem ais, Anglicana Ecclejar, ut ego judicio, omnium Ecclefarum, jacturâ contigit. Quanti ego Doctrinam cjus fecerim, non femel ex me audire pocuifti: \& certè, vicem potiùs noftram, quàm illius dolco; qui ad portum quietis delatus, nos in tempettatibus reliquit; quas evadere facile effer, fillis lectifimis plantis excifis, alia meliores, aut certè non deteriores, fuccrefcerent.I of. Scalig. Epift.1.4.epiit. 446 .

Fobannes Rainoldus eruditus \& pius Oxonia Doctor, cujus nomen non minùs ultra mare quàm hîc celebratur.In hoc folo continebatur locupletifima Bibliotheca: omnibus Facultatibus, omnibus Studiis, omni Doctrina refertus erat:Memoria, \& Lectionis copia hujus viri ferè Miraculum erant. Doctoris Hall Decad.Ep:ft.ep.7. Ang.

Ad parietern Borealem Sacelli Corporis Chrifi, fub humanâ Efigic, habitu Doctorali ad medium ufque veftitâ, hæc legas:

Jo.Rainoldo S. Theol.D. eruditione, pietate, integritate incomparabili, bujus Collo.

Pras.qui obiti Maii 21.anno 1607.etat. Sua 58. Jo. Spencer Auditor, Succefor, Birtutum er San Zitatis adrnirator H.M.amoris ergô pofuit. 
Hic Antor inter Hæreticosprimæ Clafis rejicitur in Indice Expurgatoniq.

\section{A NTONIUS POSSEYINUS Soc.lés.}

T Atione Italus, pariâ $M$ antuinus A Gregorio XIII. gravifinis, negotiis A \& legationibus adhibitus ent. Bis ad Mofcormm Principem abiit, \& inter

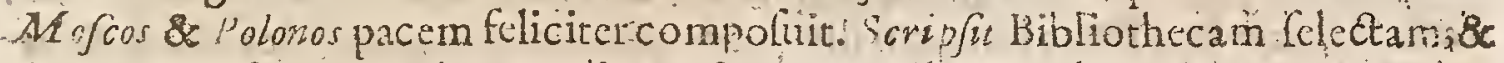
Apparatum Sacum tribus ronis confantem:mulaque alia. Obiit Eerraria die vicefimolexto Pebruarii, Anno Dom. 6 rr. atatis 78 .

Aintonus $P$ afjevinus, ut crat magnà variâyue crudicione multarunque rerum expcrientiâ inttuctus, \& pretereà fummèindnttrius ac laboriofus (adco quidem ut 110 ctu pedem campanule adligaret, ut ftatim atque obdormillet, à fom-

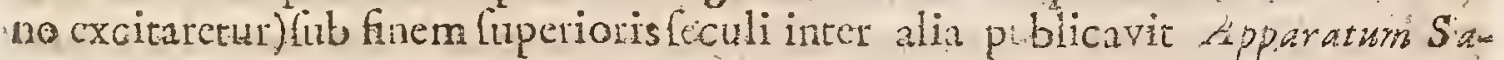

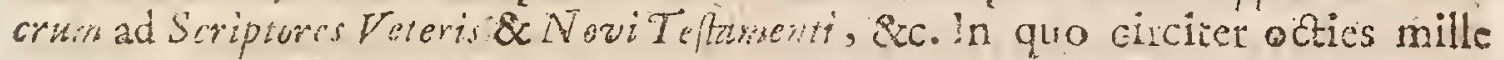
Auctores partim indicartur, partim expcnduntur : additis palim cenfuris o expurgationibus, emendationibus, correctionus Verionum alifque. Prodiie valtum hac opus primo Veneitis amis leculi hujus III. \& VI. Ced mukò locu-

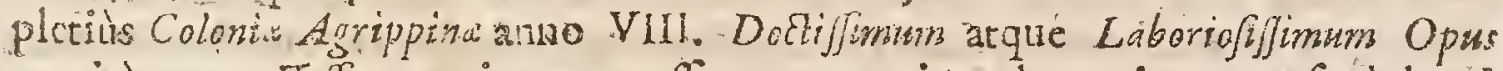
mericò vocat Voffus : qui tamen paffim erro:es cjus achotavit: quos fanè haud paticos admifit. In Protejuntes etiam fapius invehitur. Bellarritio tamen non tho nomine praferri merctur. Ioan. Andr. Bofus Introduct. in Norit. Scriptoi. Ecclet.cap. 2.

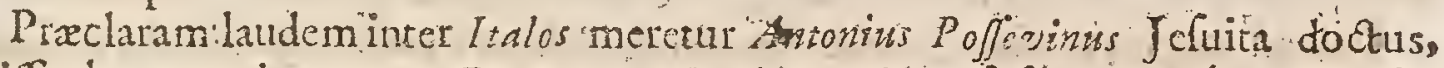

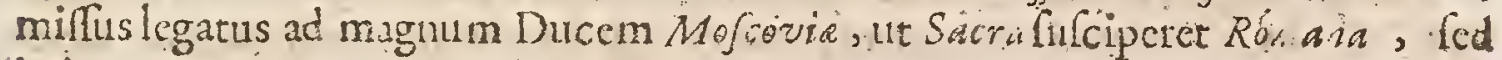
irrito conara. Herman. Conring. de Mnfoù Imper.

A toniu Poffevinus fuit vir miltre cruditionis \& magna dexteritatis in rebus perficiendis. Idem de Repub. Succica.

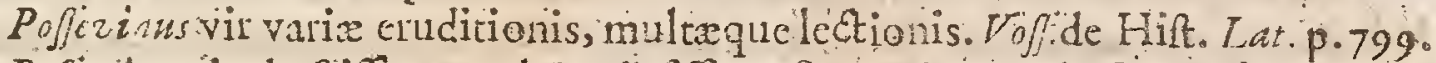

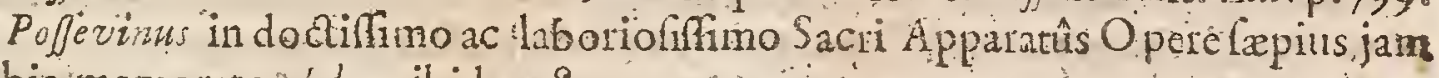
nobis memorata: / ders ibid. p. 813 .

Dominus Naudzus fcribic quod in hoc Aptratu nimia fucrit ejus facilitis \& negligentia; quaptopter medioctibus tantum Genirs placese pofft. Ke exmanru ficibit eum in fcribendo nullam fervare methodum; quacumque fecic meras cflelacinias \& rhaplodias malè contex as, \& indigctè congetam molem conftitucntes, adio ut vix ullis corum ufus cile poftit, wifi cum multo judicio multaque prudentia legerit ipła. Germanus quidam anonymus, divit eum, cemibi quandoque judicium fuum de Authoribus fubiicere fibi fumferit, in hac tadiofum effe, quòd affectibus Gatis lib rum fe non exhibucrit; cum crfe plenum prxjudiciis quibus Patrix Profefronifque fux homines moveri confite verunt; cjufque Critisen, dum folus \& fine duce ambulat, nonadmodum elle tutam cextam. His addi poteft quòd malè Latinè loquatur, nec Solocifmos.

$$
\text { Ppppe anxiè }
$$


anxiè pracaveat, quól prolixis digreflionibus fiequenter abducartr cxta furm argumentum, Hiftorias in verbi gratia Populonm, Loconum \&c. adbibenido. Caterim tamen nemo difficeri debet, quin cjus. Bibirotbeca cjuque Apparatus Herculei labo is fruetus fine, ingenfque utilitas ex iis percipi poffit, fi aliquis, Vir idoneus \& li natid judici es ad incudem rcvocare dignaretur, addirioncíque ac correctiones iis necelfatias elucubrare. Judicia Eruditoum per. Bailtetwin Paif, 168 , Gall:

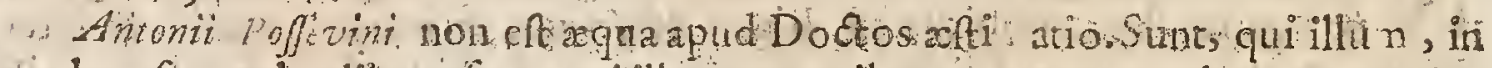
colu ferunt ladibus, funt, quillu coj pilatorem, non ultre-cur $\&$ judicii habot. bibliotbera Selecti is. libris conttat. Multa hic pertientia ad ratio-

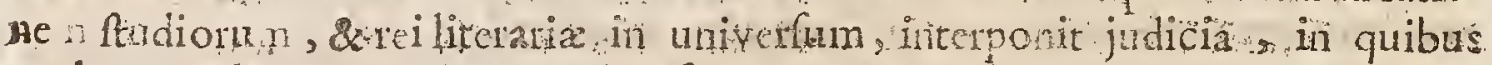
multa reprehendit lacobu Gaddizx. fed non magni faciendum ef ejus judicium.

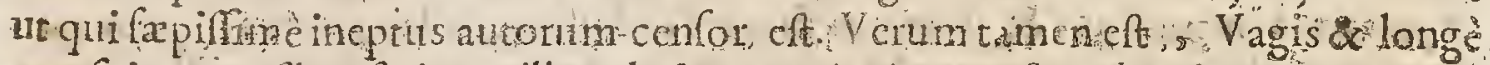
quafris excutibus fatigate illum lectores. Sixti Seneinfis Bibliothecain Sanrian. pall at vellicat, qua tamen viris doctifitnis: in pretio eft. Apparatus ejus Sacer majore in pretionontulis habetur, multaque habet de Scriptoribus Veteribus \& novis judicia, ex alion m lepe fenfu formata. Utilirmum tamen ill 1 bocem fuccpit, in quo aliqua condonari debent. $b$ silletus fuadet, ut correcio erorum, abalinuo viro docto filcipintur. Annectir Catalogos Manufcriptonum, quaad res Ecclefafticas pertincut magno Audio ex omnibus erudici Orbisibliotrecis conquiftos ; cuif fimiles increris difciplinis colletiones haberemus, magno profecto ufui efft. Judic cjus, de . Machiovelio nagnam ipfus of citantiam \& imprudentiam argunt, ut ofte dit in Prafatione Principis Mathinellici Conring ins. Dun. Georg. Borbof. I olyhift. 17 s's

Urilem magis (Gefnero) deditoperam Ecclefu Antoniw l'ffevinus, è Cocie tare Iefit, in ApparatuSacro; quanquam scis; homo ltains, hallucinetur interdum, \& ferc circa nomenau cognomen Scrip nis cxeri Valex. Andreas in Prafat. Bibliotb. Belgic.

Pofievini Biblinbera felecta, quamvis admodimmenca \& mutila fexlivore fcil. \& protenfo odio Hare Cewn quo fit ut ininumeros prefantifiuos autares

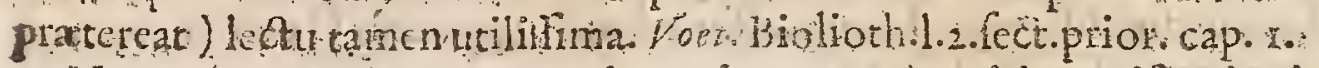

Neque hoc tantictar at verbo artingeretur à nobis : nif mirari fubiffer, Poleri hn dum in Apparatw Sacro, moréfo, Suffridurn exlcribit, non correxilfe illud levichlum. Yolt de Hift. Liat $\mathrm{p}, 274$.

Doctor $R$ aynoldus illum vacat $G$ a quis; \& de codern dicere Colcbat, , copis illi opus effe. Angl.

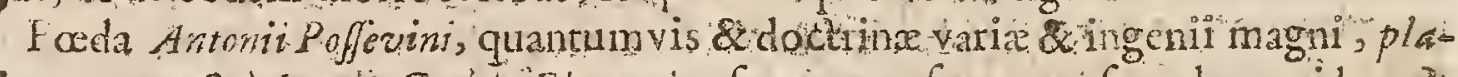
gia qucrum \& a acobo $G$ addo "Florentino fueritacculatus, ac fupe ba quidem frafidentia, iniqua amen, deque rebus \& viris fiba ignotis improba judicia cuebro fedepreherdife aitceleberrimus Cónringims dedicatione in Machiavelíb Principem. Thomal de lag - num.68g.

Ne vidit quidem $M$ achiavelturn, quem refutavis, vitio ipfi familiariffmo:

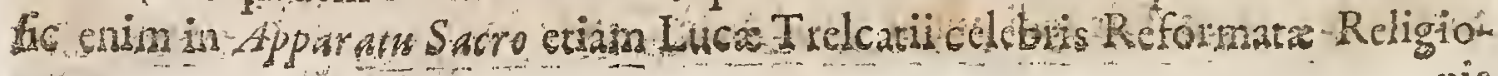


sis Theologi Sywopfun methodi Sacrat Theologix 5 criptis Catlolicis anume

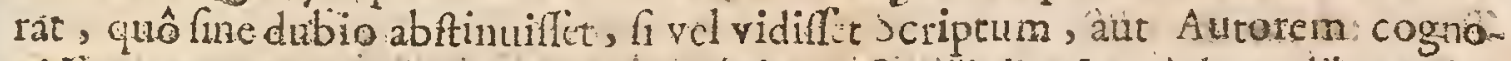

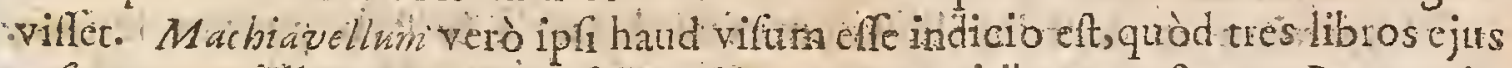
arcfutct , cumilletantum unus fit \& exigutus -26. capitibas conftans. Becman. in Meditat. polit.cap.s.fcet.6:"

Extat Bibliotheca felecta, ale Ratione, ftudiorum, 2. Tomis Roma $1593.2 \mathrm{Com}$ Losia Agripprize $160 \%$

Extat Apparatus Sacer de Scriptoribus Ecclefiafticis, 2. Tomis, Tentat603, 13606. ErCoi. Agrip.

\section{SCCAYILA SAMARTHANUS。}

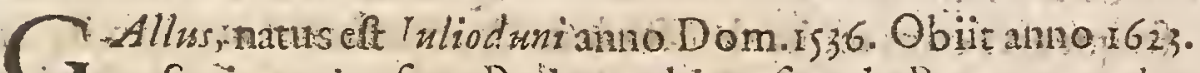

3 Scripta ejus fulte:Prdotrophix, five de Pueroru meducationelibrittes Clar.An.D. $\mathrm{MDXC}$ - Lyricorum lib.2. -. Sylvarum lib. 3. El giaum lib. I. - Epigrammatum Mibri z. - Sacra Cantica. - Elogia Gaillơnur doçrinâ illuftrium.

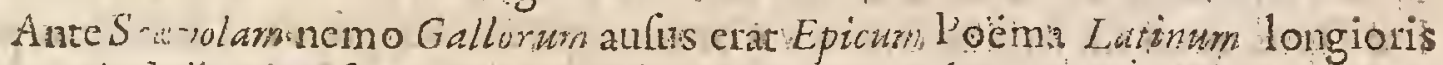
- contextûsificipere faltemlectione dignum saut quale iltud, in quo omnes numeri artis Poëica, omnes gratize elegantiarum, omnes doctz antigutatés rẹgld conficiuntin: unde acceptitfimum eváfit apud omnes cultionis ingenii wiros, \& præa aliis apped Italos. Ioan. Vigzt. Mugir. in vitâ Scavcl. Sarnarthim.

Diibonit quem mihi Libium mififti ànofro Samarthano confcriptum? tron hiber eft, fed ipfe Mufä; totum motrum Hslionateftemappello. Quin \& fide co judicium mihiconcefferm fit a velim equiden illum omnibus hitgus feculi Poëtis anteponere; vel fi Bembus, Hawgerius, divinufque Fracaforius agrè Jatuif fint. Wum enim perpendo quàm apte fuavitatem Carminis purx terfaque

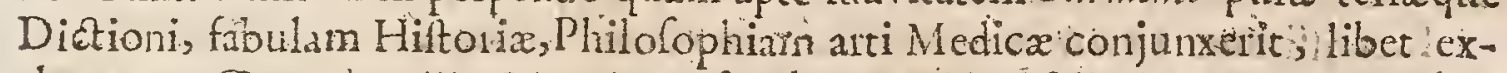
clamare-Deus, densille, Menulco. - feculumque iftud felix dicere, quiod nobis

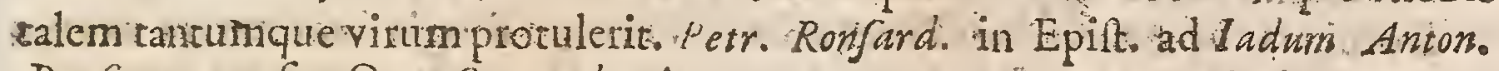
Bayfrim, prafix. Opp. Samaribani.".

$\because$ Nihil in Carminibus tuis video, quod omnem noftritemporis $P$ oettren non longè exfuperet: ctiam / indarica plantè divina funt. Padotrophia tua nobilionis quidem tela quàm Venatio Bargei eft, quamvis \& ille Poëta fit non inconcirnus: fed dulcedolilla quam tantopere profequitur, mafculo verfun tuorum robore deftituta eft. Vicuri proculdubio funt \& ego quoquevitam ab illis hau riam. Iof. Scalig. in Epift. Iugd. Bat. foriptâ MenfFeb.1593.

Samartbani:Poẹmata \& Elogia vidi; illa doctè, hæc \& prudenter fcripta. Feficem etiam filiis patrem? galdeat $\&$ fruatur. $L$ ipf. in Epift. ad Dorrinic. Barb diuzis.

Samarthanus vil, sim ob morum canderemac fummam integritatem, tum $\therefore 1.9 P P P^{2}$ 
ob raram eruditionem \& excellentem ingen folicitarem, mili charifimus Thuan.ad annum 1588 .

Elogia viroum doctrinâ illuftrium tantâ elegantiâ \& Atyli puritate fcripfitz ut quàm proximè accedat; \& fi aufim dicere, vix cedat quidem eloquentiffmis. prifcorum temporum Scriptoribus $M$ agir. in vir. ejus.

"Hac Opus valde laudar Losephus Scaliger qui dixit: "Beatos illos qui lauor dantur à taudato vito, etiam fermone tam terfo ac nitido.

: A Alidua ipfus pro latria falute follicitudo, non obftitit quin identidem illis præatatibus scriptis opcram navaret, quæ in Eruditonum manibus jugiter for rebunt. Ejus de Pedorrophia feu Puerorum celucatione. Poema Latinum optimis

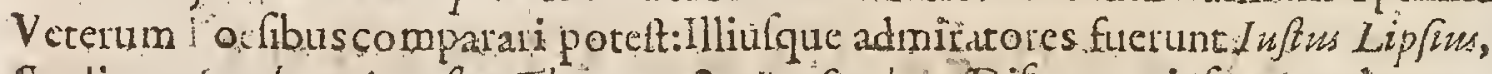
Sculiger, facobus Auguftus T buanus \& Ronfardus. Difcrtum infuper calamum exercuit in Latmis $O$ dis $P$ indaricis confcribendis : Quarum lectio Poniffrem Urbanum ViI/ frequenter cum multa delêctatione \& attẹtione occupavit In Gallica Poefi non fuît minus felix: Chrifiana Metamorphafes, quás rhythmico carmine contexuit, ejus in hoc forbendi genere peritiam fais argunn. Sed an s dum verba facio de fublimibus illis fotibus, flentio preteream praclarum illud Oputs quod illuntum Galize Virorum . qui feculo ipfus in Literarum profeffone excellierune, memoria confecravit Doctorum gloria munquam ma jori pompấ \& reverentiâ fuit celebrata. Quoniam ingenii ùnaginem tantum delineat, cjus togia fuccileta quidem fuint, fcd fplendidiflimis Loquentia. Latinu veneribus condccorata. Et Gane ii hacce labore non minùs propila famz quàm magnoum iftorum Difciplinarum Genorum cel britati litavit: Quandoquiden horum nomina Honoris Templo infcribens, eidem furm infculpfit, colplendore quentempus delere nunquam poterit If: Bultart. Acad. Scientium rum. Gall.

Noltorum vitas Samarthanus fcriplit, verfu, quàm prosâ inclior., cujus lon luta orntio etiam poëfm wedolet. Rol. Mare S.1.2. epitt. 25. .:

Latiniffmum ecentioribus anthorem yocat Bulakn..

Divinum Roetam appellat Borrichius, p. II 8 .

Dominus Sar-Martbanus Preclirorm Virorum Elogia, non autem eorum vitam confcubere aggrellits, de iis eloquenterut Orator loquutus eft, non ain-

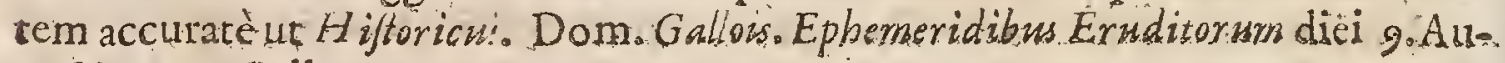
gufti 1666. Gall.

Sccula Samartbani fuàiffuma Mufa. Scaligerana z.?

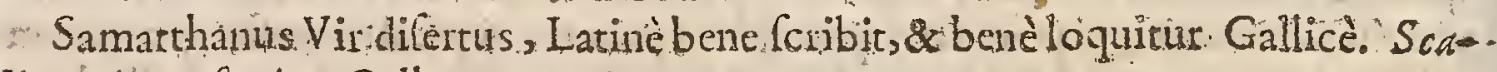
ligeriana pofterior. Gall.

Extant Scavola \& Abeliz ejus Filii Opera Latina \& Gallica, Parifis r.633.4\%.

Sccovola Sanmarthanus una cum Frarre Ludovico, additamenta dedit ad Clau. dii Roberti Galliarn Chriflionam, quibus feriés omnium Archiepifcoportm. Epilcoporum \& Abbarmm totus Gaus deducitur. Tomis 4 . Parifis in fol. an 16.560

FRAN 


\section{FRANCISCUS JUNIUS。}

N] Obili genere natus. Biturigibus, Anno Chr. 1545: Obile peft Anno 160 zo ClarnitA.D. Tandem Lugduni Bat. Fidem poluit, ibique per decennium profefloris munus

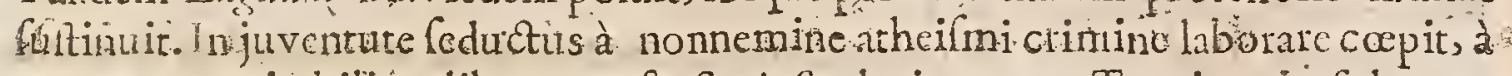
quo tamen mir biliter liberatus eft. S6ripfi plurima, qua $T$ - Tomis 2 in fol prodieruno Geneve, ans. 160.7 .

Certè Francifrus I unins, Biturix, non temerè hấ xtate cumpreftantif mis five Theologis five Philologis contendendus videture Gajp. Sciopp. dé AntCrit.p.iso...

llle vir mangus quern jure läudàs, Innium intelligo: Cui tu an Gyutere, adhære, \& recondita multa hauri ex arcano illo uberique penu. Lipf Epitt Cent. 2. Milccll. Epint:9r.ad Regnerum Gruterum.

Quis pauló humanior te non novit? Et qui hovit quis non amet At "tu tamen affectum in me largiter farrè declaraft cùm epiftolầ fuavilfimè . Srriptân y tum

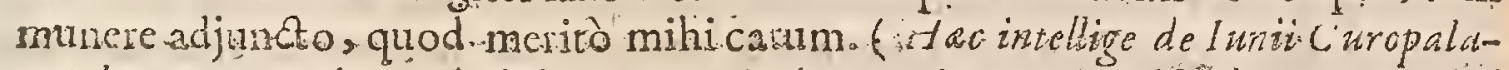
te jub nomine tiebrio Nadabi Agmonit ab eo vulgato A. I588. Le quo prolixe

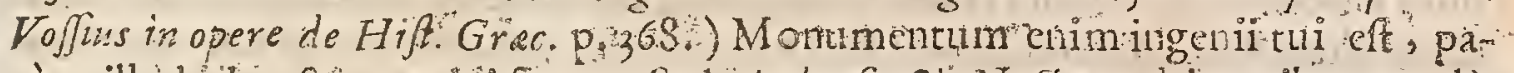
xủm illud ad guftum vulgi fateor: Scd Ambrofla 2 N Nectar nobis, quibus paule acrior judicii illc fenfus. Sanè in implicatifimo fcripto ntilem fubtilèmque

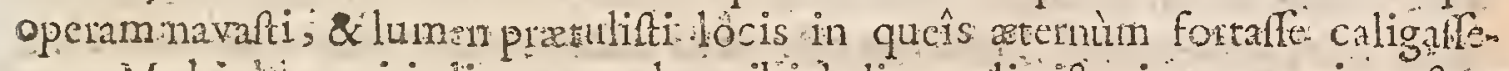
mus. Multiplex notitia hinguarum ho tibi dedir ur talia ifta interpretar nofto ævo poffis unice, ac dixeram pene unus. De iis quze Epittolis ad Atticum obfer-

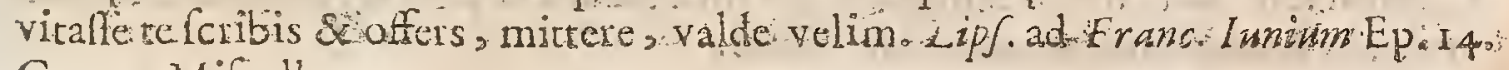
Cent.2. Milcell.

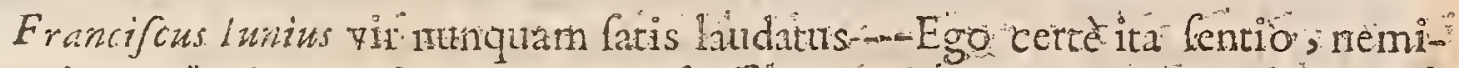
nem inter Theologor noftros tepertum fuilfe qui minus jurarie in zerba crajuf

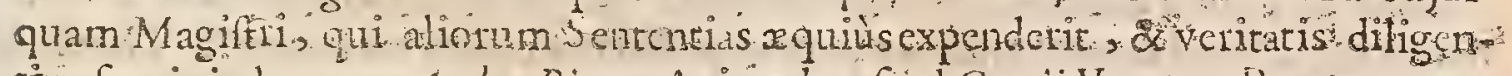
tror fuerit.indagator. And'r. Rivet. Animadverfoad Groiii Vot.pro Pace.

Pollem Tertultanum fufespere explicandum; fed camproviticin maudio jam a Francifro I wnio efléfufceptam; qui fracerrimo illi, quo poller ; ingenio minus inidulferit, non alium ille Afer vindicem pofcre debet.lff Cafinb. in Epint.ad Gacob. Bongarfium, Gen. I8: Kal. Jan. Is95.

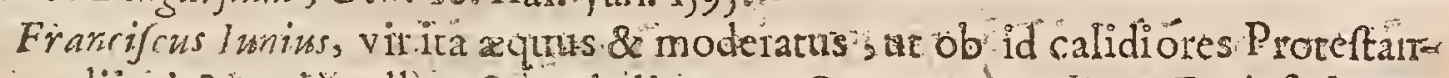
gium alii, ci \& male vellent \& maledicerent Grot vor pro Pace Ecclefiant.

Francifco Iur is nultum debeo; fed dicam qu od tes eft:Mntlcum illè vir vidir

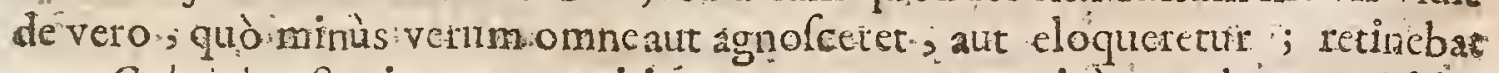

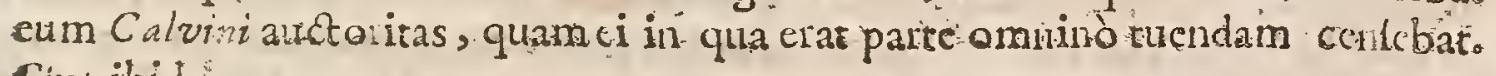
Grat. ibid.

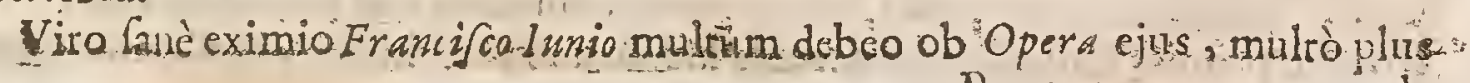
Ppppp 3 ob 
ob vita excmplum, quod milii perpetuò ob oculos verfatur. Idem in Epift. ad Ger. Lown. Vojjisurn, Lutet. 2I.Jan. I645.

Erancifcus I unius Leydenfis civitatis decus, Oraculum Textulis \& Scholafticx Theologix, Linguarm dives, in diftinctionibus fubrilis, in Argumentis invictus. Doctoris Hall. Dec. Epilt. Enilt.7. Angl.

Tranlatio illa Veteris Teftamenti edita Capiùs, \& quâ hodiè utuntur multi, magnum ap nomen pepexit. Lac. Verbeiden.

Fruncifcrinni Scholia, brevia quidem, fed eruditione multifaria \& fummo judicio limata,cujus vel pauca verbangentia aquant aliorum volumina. Inniz lubores non pernendos dixit Hugo Grotiur : Rectéfact; at addere petuiffet, \&e addent quotquot lunit labore: rquis oculis ulurpaverint, pluvimi altimandos, \&inprimis Interpretum fublelliis collocandos. Math. Palus Prafat. Vol. F. Synops. Crit.

Superelt ut examinemus Eatinam Tremellit: Iunit Verfonem, qux apud Proteliantes, in Anglia prefertim, initioplirimi aftimata fuit Drufurs qui inter do diffunos \& Cagacifimos P roteftuntium Scriptores clartit, non potuit temperare ab illa damnanda plurium locorum refpcetu. Qued moleftias ipfi creavit, guoniam hujus Verfionis plurimi erantapprobatores. Hanc tamen ad incudem revocare \& in accuratiore verfionem reformare coacti fuerunt: ed quia metho dum vitiolam, fecuti funt, infua Tranlatio c ritè procedere son poterant. Unde ctiam alcera hac Editio damnata fuit à Confintino l'Errpereur qui \& iple Proteftans crat \& in Hebraicis crudicus. Hic Author atieverat fe à Tremellit \& IUnii Verfone recedere teneri, quia modo yuodam vertendi utuntur, quo fapius In errorem abducuntur. Presbyter Oratorii Rich. Simon Hit. Crit. V. T.1.20 cap.21. Gall.

Nihil ferè Innio magis familiare, quàm oblcuritas. Dr: Tho. Troiffus Animadverf. ad Arminizcollationem cuin Tunio:

Francifcus Innius, wirdefultorio ingenio: qui multa conatis, an adlecurus fit quod moliebarur, Doctorum cric judicium. Thuan.ad Ann. 1602 .

Hare de I unio Thuanus, à quo tamcu mutri egregiam lauden retulere, cum nec alterm Innianarum witutum partem polladerent-_-Inniw autem Theologorum, qui, iifdem quidem Caftris, in hoc R ligionis per orben diffdio, nili-

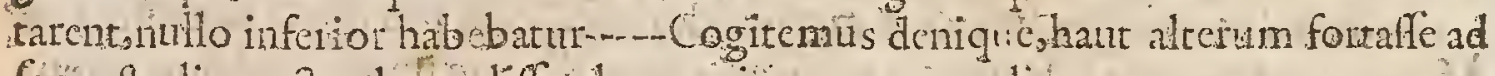
facia ftudia tractanda attuliffe plura majoraquetum adjumeratasum ornamenta; quàm à I zrito factum fuit. Quippe qui diligenter Iegiffe jam puer Latinos, Gracos, Grammaticos, Oratores, oetas, Hiftoricos, thilofophos : qui I uris feien-

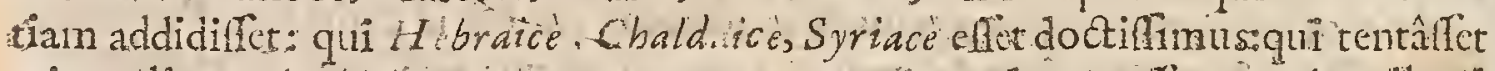
esiam aliqua ir bic quanquam eo tempore, quo ardum chet reperire ultad linguam hanc lubfidia, quze poftè Divinâbonitate fuppeditânunt multa magnam

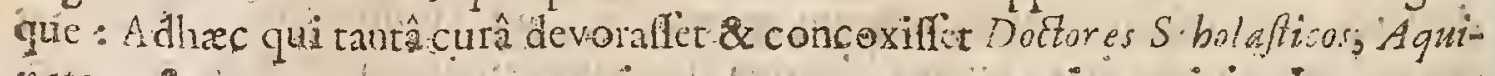
natem, of ante omies: quique, ut recures magni nominis Interpretes legiffet ita affuduè penèverfaffet $S 3$. Patres; innumera ad eos oblervaffet; in Gracis inprimis; Cujus rei tetimonia luculenta, tum in Nicani Concilii libris 
ab co trannatis ; tum in toro Iofepho Clemente integro, ac pliribus aliis ab co illuftratis, corredifque oftendere ipfi poffumus, ac polfunt item frmilia alii in alis. Sed quid his infito? Sane ingenium viri, \& diffufrfimam eruditionem, multifacilius caspent, quàm æmulabuntur.Voff. praf.ad lib.de Hift. Lat.

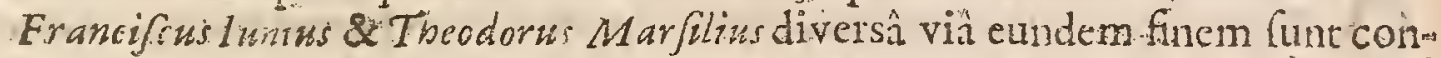
fecuti, ignorantiam. Hic omnialégendo, ille nihil, cum tamen do stimum fe exifinarct; doctiorem eriam in Gracis Cafaubeno \& $S$ tephan quos nihili fam sibbat. Ejus Refponfones in Bellarisinum bonx; led facilè eft taliu feribere, \& mendacium refellere:-

7uniws omns fpernebat se praclarifimum fui fcculi, pracedentum \& fusarorum efe opinabatur. Flurium linguarum peritus ecufcri volxbat;ur \& $\mathrm{Me}^{2}$ dicus, Jurícontultus Soli ejus difcipuli eum magifaciunt, ignari qui nefciun

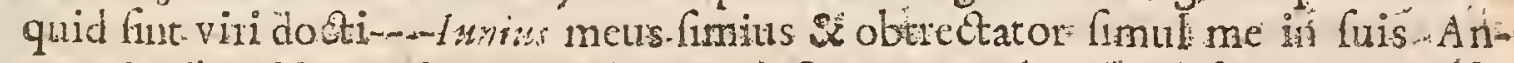
notationibusin Genefon imini tentavit. O quantasineptias in fua Biblia infeinit. Nihil legerat, cateris tamen doctior elfe volebat, fibique fidem haberi. J e-

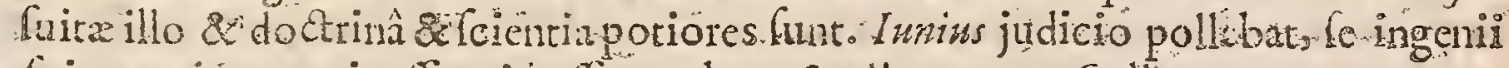
fui actmine omnia alfequi polfe putabate Scaligerana 2. Gall:"

Feruneillum in humaniaibus literis verfatum fuite. Puto euth inter $\mathrm{H}_{\mathrm{t}}$ maniorimfudiorumfeatares Theologia peritum, inter Theologas vero Humaniorum lirerarum callentem exiftimatum fuilce. Perroniana. $G$ all

* Erancr cus I uniw inter Hareticos prima Claflis lóctin habct. Erancifci Iu

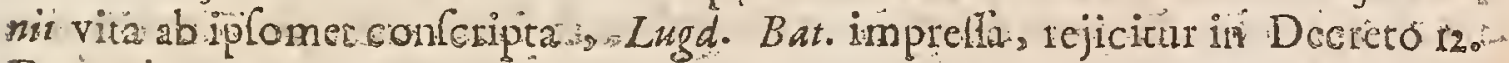
Diccembr. $1624:-$

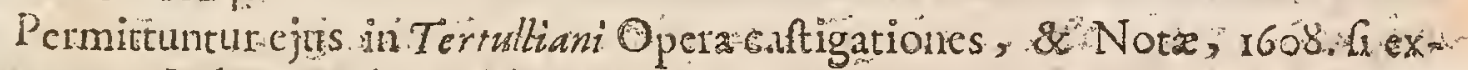
purgentur. Index M adrit. edit. ant. $16 \% 0^{\circ}$

Hoc ejus Epitaphim, Auctoreloane Menrifo-?

$\mathrm{J}$ unuis ergo abitt, Hatavxitux awrea genti:

Et quen wät orbis, nunc brevis urna capit

Quis lamentamibididet, quis fobile carmen.

Atroposs inque mum non bona wata caput?

Siccine tarn Sando tollis de aerrice crinem:

Diosque s queis potesas parciere, filia fecass.

En, facinus pulat Ecelefialuget amitero

Et fua Gymnafum a bile dahnogenits..

El plorat pickas, op parfos.fiffa capillos

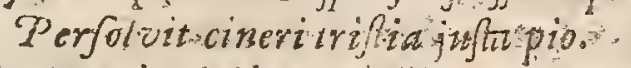

Sartaque dat lachngmis Vuttis ranantix, mittist.

I: anferias turali on vertice cana Fides,

Sie tainen aterno decurrastord ine fata:

Vertitur arbitriofors sua cosigne Dei.

Illague adbuc ratio eft, aniroum que ternperet agrum:

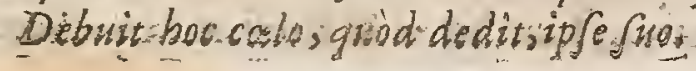




\section{A NDREA S S CHOTTUS, SOC.Jer.}

- Mar. An. D. Ntverpic natus eft Am. Dom.rs52. Obiit anno I636. xtatis 84. Toletre Wu. C. A Cafarangufte eloquentiam, Hifteriam; \& Gracas liceras dacuit. Vocatus in.I taliam Orateriam tribus annis Romo profeffus eft. Reliquum tempus Antverpic tranlegit.

Scripta cjus funt: Obfervationum humanatum libsi quinque---Adagia facra Novi Teftamenti---Note in Senece controverfias...-Nota in Fomponium, Melam, Aurelium Vietorcm, "in esmilium, Probum, in Procli Cbreforsusthiam, \&c. Pbotiz Bibizotbecarn Lative trantulit---Adagia Grecorum ex Zenobio, Diogeniano, Suida \& alis collegit, Scholif́que neceffátiis illuftravit. Multaque alia: Cripfit \& tranftulit.

Vir fuit ob candorem animi \& bonitatem ac manluetudinem narure, quam. -religiosầ modeltîâa ac.comitatecxomaverat, ipfis ctiam fidè hoftibus carus , \& in pretio ac veneratione; quorum laudes Schotto dicere, fcriptxque o paffim in ore \& manibus funt. Heroés ctiam non fecularis duntaxat dignitatis vili.; led is Ecclefix principes, Schotturn unicè cóluertnt. IpLe ctiam 7ürbunus VIII. Pontifex Opt. Max. S'chottum extremis vite, diebus per, Cardinalem Nepotem Er.ncéfcum Barberinum, literis datis, magnâ benevolentix \& amolis teftificarione, peramantcr falutari a fe voluit. Aleganbe.

And. Schottus \& lanus Drufuss, excmplo fuo \& libris. Criticis, quidm non negligenda fint Theologo Philologica, preclare docuetunto siopp. de Art.Crito pag. IG.

Vir fuit de Latinis Grecifque literis, actam fachis, quàm exteriis preclarè meirus. Voff. de Scient. Mathem.c.70.Sect.29.

Andreas Schottu vîr non une nomine præclarè meritus de Rep. Literariâ. Idem de Philolog:c.6.Sect. 2 .

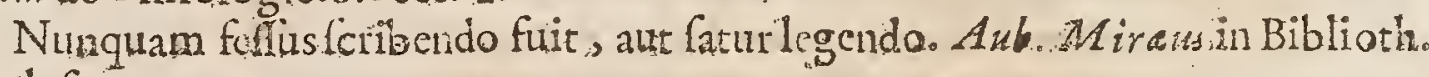
Ecelef.

Andreas Schottus; in quiô viro prxter pictatcm in Deum , anirni candorcmo humanitatem, \& multam accurarámque doct inam incxplicabile proilus:\& incredibîle quoddam fudîm. remliterariam omnimodis adjuvandi. Pbil. Rubenires I.I. Elector:G.I2.

Amicus nofter Andreas Schottus, vir de literis immortaliter benè meritus. Barth. Animadverfo ad Phoebadizcap.28.

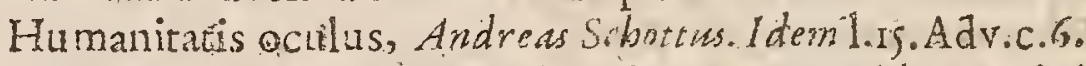

Vir ad literartm ntudia promovendanatus. David Hoefckel. Not. ad P'hotid Biblioth.

Quem virum (Andrean Schootum) jam olim novi, \& quia movi., amo. Eft

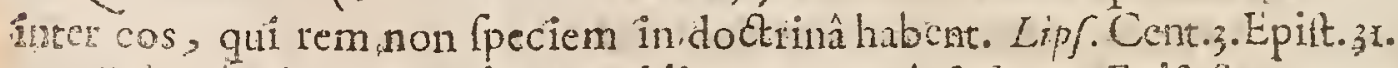

Andre as shottus, vit bono publico natus. I ipf. Cent.s. Epifr.8g.

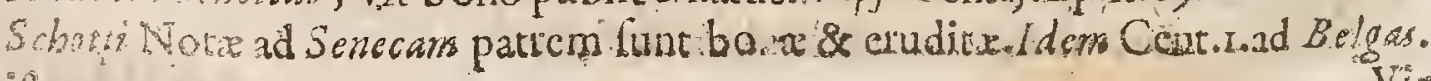
Bpinto $2 \varepsilon_{0}$ 


\section{CELEBRIORUM ALTHORUM.}

$V$ ir admodum Reverendus Toammes Pearfonws illum ignoraitia accufare non dubitat, quippe qui in rebuls $\%$ bilofophicis haud benè verfatus fit, \& ine explicandis Autoribus milcrrimè lapius fit. Yoan.Pearfon. prolegom. ad Hierocl. de l'rovid. \& Fato.

Andreas Schottus, homo qquidem bonus \& eruditus, fed quem fuccelfus (Commentario in Pomponium Melam) potius, quàm voluntas deftituit. If. Voff. Præ: fat. in Pompon. Melars.

Vir alta eruditionis audit Andreas Schottus apud Cafaubonum Prefat. in Athen.

Andreas Schotuts, vir clarifimus, qui omnem Aintiquitatem callet, eamque lotis manibus contrectare amat;parum tamen \& ipfe felix in exfcribcudo. Laurent. Pignor. in Epit.;o.

Andreas Schottus maximum inter omnes fuo feculo commercium coluit quoad politiorem literaturam, Omnefque Eruditi ad ipfum cx ommibus Europe plagis referebantur, iplumque quafífum centrum fpectabant. Et fanè omnibus dotibus inttructus erat, necelfaivis ad refpondendum utiliter corum expectationi, corunque indigentix, multa cruditione $\&$ honstate, candore, fincerirate, gencrofitate, folida pictate, \& fummo ftudio quofvis homines, cujufcumque Regionis \& Religionis libi demciendi \& literarum perfectionem promovendi. Jum dicia Eruditonum per Bailletwn, Paril.1685. Gall.

Sincere fatendum eft glo iam quam celcbris ille Scriptor in Republica litewatia fibi pepcit aliunde quam ab ejus Verfionzbus ipfi advenire. ibid.

Photii Bibit thecrm pertunctoric admodum in Latinum fermonem vertit vir aliàs doctifimus Andreas Schottus; adcò ut Thomas Gatakerus, vir laude major, tralationem hanc (licèt Schott nomen præferat) cjus fuilfe vix crediderit. Colomef. in Paralip. ad Chartophyl.Ecclefiaft. p. 38.

Vatiacjus Opera variis in locis atq̨ue temporibus funt impreffa.

\section{FAMIA NUS STRA D A, Soc.Ies:} Atione Italus, Patriâ Romanus. Artis Rbetoricr per annos quindecim pu-
blicus Rome Magifter.

Scripfit Prolufionum Academicarum libros tres-m-De Bello Belgicc--n--Oran - tiones Varias----1' 'oëmata---.-De Artificio contexenda Orationis Libros IV. ----De Aftcetibus Oratoriè concitundis lib.I.-.---Epitaphiorum à fe compofitorum lib. I. Et alia quredam.

Foamines Baptifft Saccus, Senatus Mediolanenfss à Secretis, librorumque pro Regiis Cenfor, Anefor Prrefidi fcribens, de Prolufowum Academicarum libris hoc judicium tnlit: ' Qureris quid de Strada fentiam ? Vir hic fublimi admo- Clar. A. D. "dum ingenioelt, \& excello, quodque de Angelo Politiano difertifini olim MDXC. ' homines tradidcre, verfatili \& ad omnia facto: Judicio acri \& perpolito : do-

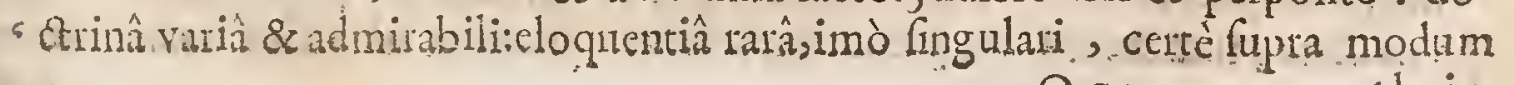
Qqqqq "jujus 
" hujus ævi: prudentiâ \& terum cognitione tantâ, tit hitmanarum Actionum \& 'calum nihil profus eum fngere vidiatur. P'roten eftnovafque fubinde formas - invenit, in quas fe vertat. Illud verò palmarium ei effe duco; quòd ubique $S_{c r i m}$ 'perrarr fuorum joca funul \& feria milcet, \& cum lepidus fit, \& feftivus, joco"fufeyte ad effufos ufque rifus provocandos, niliil tamen interim ci deperit de - pistate, modeftiâ, gravitate vel decoro: adeo ut omne ferat punctum.

Magnus ill:, \& verè Heroicus Hiftoriarum Scriptor, ille famâ nofter Eamiznius. Siruda, res Belgicas Latinâ ftyli Majeftate complexus, turbatx Europe caufas, initia, progrellus, tam accuratè expofuit,ut fum non fuo xvo, ornare vifus fit, noftrum antiquo. Habent fum Romani Saluftium, Livium, Taciturn, nos Stradam, qui it $B$ elgas defcriberet; Rornanzes effe debuit, ingenio, judicio eloquio intructifimus. Libera,plena, \& elegans ubique natratio eft, aurum eft: Civiles autem fententix, velut gernme intedlucent, tam aptè collocatx, ut fine tumore emincant, fune affectatione cx furgant. Aqualitas interim fumma eft, gravi. tas moderata, fubtilitas facilis, veritas incorrupta. Eryc. Putean in Epilt. ad Sylveftrum Petrafanctam.

Viringenus, liber, \& veritatis hiltoricx ammtifimus. $G . . b$. Naud. in Epil. $84 \cdot$. p. 636 :

Liviani, Salufiani, Ciceroniani in folutâ otatione, Oviti.ni, Sta ini, Virgis liani in Carmin ftyli, cum libet, imitato e, inter pluimos caltigatx Latinitatis Scriptores delectus eft unus, quo Magni Alex indri Parm \& Whentia Ducis, Belgique domitoris, res preclarè gette hiftoicâ, câquéprud nui , \& eleganci narratione pofterorum memorix tradantur. Andr. Victor ell.

Jam verò de politroris Lireratura parente, totrufque antiquicat is aichctypo Farniano Stradâ Romano Patrum Jefuincomparabilifocio, quid attinct pluia dicere? Quis ejus libellis vel parumper legendis addictus, non fentiat animum inufitatâ comptifina lectionis dulcedine titillail Suada ipfi verè connatas ac fermonis lenocinium, quo dum aureifuminis infur exubrat, veturioum exaguat laudes, recentionm cxuperat. Nihil pulchrius, poëtx; vel oratonis ftylum efthgere. Nihil dignius quàm optimële confingendo præccllere, quod utrun pue vir xternâ colendus memoriâ, incredibili commendatione adcptus eft. I oan Imperial in Mul. Hif.

Strada merctur laudari à prudentià \& eloquentiâ,tametfi in nonnullis Latinitatem non oblervavenit, \& meruerit fcuticam magni Gramatici, Gajparis $S$ iow pii, cujus liber eft Infarmia Famiani; attanen fcriptorille eft praclutus. Herm. Conr. de Rep. Belgic.

Meretu: magnam ludem Famianus Strada, qui non dubitavit Roma de Bello Belgïco praclaros edere Commentarios; fcripfit duobus Tomis res à Parmenfa geftas : dim verò favear Hipanie, illius fides interdum cladicat. Idern.in Hipen.

- Stylus ex variis ftylus mixtus vitiofus femper eft.Hoc autem Jefuita:Strada - in ejus Belgica Hifto ria vitio laborar; quippequi tum propria imaginationis - venuftate tum mulorum authorum lectione mentem diverfis clanacteribus 
tibi repleverat. Illa autem farrago que in ejus fribendi ratione occurit, quantumyis jucundu, cjus tanen perfectionem minuit. Rapin. Animad, in Hiftolian. Sect. ro. Gall.

Quantum potuiffet Famianus Strada Epicc carmine praftare nû̀ Hiltorix \& eloquentix eum cura aliò avertiffet, liquidò declaravit in Proluf. fuis Acud in quibus jam Lucanm inducit cancntem, jam Luretimm,jam Clauduanm, jam Ovicium, jam Statium, jam denique Niaronem, co judicio, illâ proprictate dictionis fingulorum retentâ, ut fi ipfi in vivis cifent, non puderet eofdem humaniffimi officii. Prafertim verò certamen "'bzlomela \& Fidicinis dextcritate admirabili rçddidit. Rorrii h de Poët. p. ro6.

Quifquis Parris Famiani Strada J cfuitz labores ernditos attenderit, ablque manifetti livoris notanon poterit linguamab ejus laudibus cohibere. Laurentius Crafjus. Ital.

Extat de Bello Belgico Decas prior ab exceffu Caroli V.ad aln. I579. Rome fol. 1640

Extat Decas pofterior ad annurn 1590. ibid. fol. 1647.

Italice prodiit idem opus in $4^{\circ}$. Korna amno $1 / 38$.

\section{F R A N CIS C.US VIE T A:}

CAllus, vivere defiit Anno 1603. Extant cjus continuatio Algcbra proI portionalis: Harmonicon Colefte: relatio Calendarii Gregorsani : adClar. An. Ina verfus Chriffophorum Clavium expoftulatio : Pfeudomefolabum: Apollonius Gallus: Munimen adverfus novam C'yclometricam, ơc.

Initio anni 1603.7. Kalend. Mart. Lutetia Pariforum anno Climacterico fuo ad Deum migravit Erancifcus Vieta Fontenaio in inferiore Pidlonum provinciâ 11atus, vir inge: iosầ \& profundâ meditatione : Cujus vi nihil illi îlacceffum in abftrufioribus lcicntiis ; nihil, quod acumine mentis poffet confici,dififile confectu fuit. In Marberiatiz r. pracipuè induttriam, inter alias occupationes \& negotia, (à quibus capax \& indefatigabilc ejus ingenium nunquam vacavit) totâ vitâ cxercuit. In quibus adeò excelluit, ut quicquid ab Aktighib in eo genere illventum, \& Scriptis ( quæ temporis iujuriâ aut perierunt, alt obfolverunt) proditum memoratur, ipfe affiduâ cogitatione invenerit \& renovarit; \& multa ex fuo ad illorum ingeniofa repertaaddidcrit. Tam profundâ autem meditatione fuit, ut fapiüs yifus fit totum triduum continum in cogitatione defixus ad menfam lutcubratoriam federe, fine cibo \& formen nifi quem cubito innixus, nec fe loco movens, ad refocillandam per intervalla naturam, capiebat. Scripta ejus rara, neque tamen pauca, quòd ea fumptu fuo cudenda curaret, \& exemalari penes fe retineret: qux amicis homo longè ab omni avaritiâ pofitus, \& harum rerum peritis liberaliter diftribuebat. Thu:tno ad An. 1603 .

Francifcus Wieta, fubtilitate \& inventionum acumine Matbematicorum nofti feculi facilè Princeps. If.Cas aub. Epift, , 66 .ad Thuanum. 
Vietam Matbernatisorum noftri Ceculi Coryphoum appellat David Rivalius à Flwranti. Prolegom. in Archimeder.

A mo is90. magnum menitò Francifci Vietce nomen fuit. Cujus utinam füpereflet Hurmonicon c'alefle. Voff. de Mathemat.p.'ig6.

Anno rggr. Eraneifrus Vieta Gallus publici jurisfecit Munimen fuum adverfus novan Cyclometricann Quo opere Scaligeri in Cyclornetricis paralogifnos detexit, unde acris initio contentio fuit: Sed poltquam, quantus effet Vieta, Scaliger perfpesit, fio quidem pretio eum cum animo fuo attimavit: Sed fic, ut humanitas aliquid patiens,non multu m ejus laudes predicaret. Idem de Scient.Mathem. p.337.

Victam ingeniofifimum hominem vocat Seth.Calvijus in Elcncho Calendarii Gregoriani cap.30.

Vieta, excelfi inftar Gigantis, omnes alios vaftis meditationum fuarum paffibus videtur fuperalfe. Iacob. de Billy prafat. in Algebrom fuam.

Continuationem ilgebroproporionalis, quam Vieta reliquit, acutiffinum Opus vocat iofephis Blancanus in Chronolog. Mathematicorum.

Inter eos, qui libcralinm Artium culturầ cateros antec illuerunt Mortalcs, atque praclaris Monumentis fuis apud Poftros glo:iam fibi paraverunt im moltalem, minimè poltremis annumerandus eft Vir infignis Francifcus Vretay" Fontenxenfss. Analyfeos fpeciolx Autor primus. Quantum enim ex hoc aliifque Inventis ipfus colligere liceat frucum, $v$ cl inde pare, g a re, quo viri endiri ejus Analyfincubuerunt, fcicntia hac ampliffimum incrementum ceperit, ac Matbefis tanqu rm fepultaè tencbis lucidum caput cxtulcirit. Francè Schooten in Epit.ad D. Iacoburn Golium Oper.Viet prefix.

Hadrianus Romanus, cùm problema omnibus totius Orbis Mathematicis conftrucndum propofuiffet, Viete illud continto folvir, \& cum caftigationibus \&auctario, \& A pollonis præxtereà Gallo ad Ronanum remifit , tantâ cum Ronani admiratione, nt confentim ille iter in Galliam conipucrit, ut hominem fibi antè ignotum conveniret, \& poftcì atctam cum co amiciriam colstet. Thuani ad alln. I 03 .

Extant cjus Opera Mathematica Imgd. Bat'1646. Alia cjus Opera variis in locis at qृue temporibus funt imprefis.

$$
\text { B. ONAVENT:URA V U"LCANIUS. }
$$

Clar.A.D. $M D X C$

T Atus eft Brogis Flandrorwo Anno I5 8. Obiit anno 1610. I cide Grecam 1. linguam per triginta duos annos magno cum fructu profeffus eft. Verten-
do Gracos autores optimè de Re liverara meruit. Inter alios Cyrillurs de Adcratione in Spirtiu e Veritate primus tranfulit: :rrianu de Geftis Alexandri Magri novấ Interprètatione donavit : Alutbiam Grecè \& Eatine cum Notis edidit. Carmina varia feripft. Konts in Biblioth.

A nciquitatum \& politiotis literaturex indagator frgaciffimus, cum veterum Auctorum Optimorum monumenta plurima integritati \& prittino nitori reftisuit, atque Grerorar I atinitate sonavit, tum ipfe pixclara Opera in omui genere Artium \& Difciplinarum feripfit. Gefner. in Eiblioth, ... 
Bonaventurs Wiccnii Grscarum literarum in Leidanâ Academiâ Profefforis, nobile ingenium nunquam feriari aut quiefcere oportuit'; qui fimul editione Callimachi, Bionis, \& Mof:bi, Ifidori, MartizniCapella, Agatbia, \& Apuleii denique, incredibilem omnium de fe expectationem concitavit \& accendit. Sciop. de Art. Crit.p. is.

Bonaventura Vulcanius, amicus meus fummus, plurima in co labore (Interpretis ) ingenii fui \& dotrinz monmenta edidir;in verbis quidem parum fe tor quet, breviter tamen \& prefsè, fplendidè quoque ac pereleganter interpretatury ut cum Scriptiones ejus perlcgas, vix melius ullum Inierpretan genus elle pu. tes : \& in co quidem ftudio totum ferè longiflimx vitz tempus contrivit. Huet. de Clar. Interpret.

Callimachur, Bionem, $M$ frbum,jam nunc à Te accepi:uno partu trigeminos, rarum \& felicem ingenii tui. fæutum. Publicâ causâ (vere dícam) tibì debco: privata magis, quia duos ex iis mihi infcribis, hoc cf, immortalem me facis. Quô quid homini ab homine majus dari poteft? Vivent enim ancuiffini l'ö. tx illi, quamdiu $M$ uf : \& $\mathrm{cum}$ is tuus labor, \& cum labore tuo meum

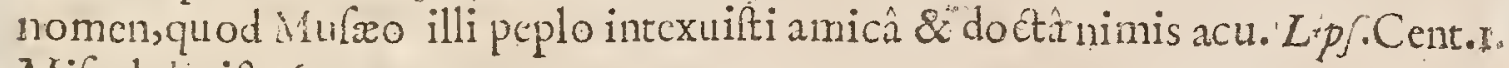
Mifcel. Epirt. 6 .

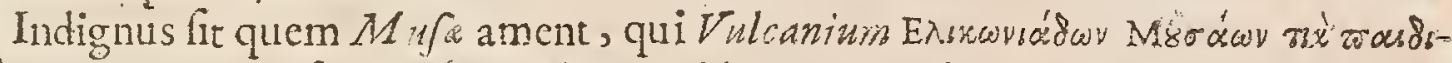
wà non amct. Ego facio, \& ex animo quidem. Cataban. Epift. 249.

Bonsvin wra Vulcanius virde bonis liters optimè meritus. Pignor. Symbol. Epilt. pag. 2Ir.

Cujus fit Religionis iple nefcit, Religionumque difcimen ignorat. Feliciter fatis cxprimir quacunque interpretatur. caligerana 2. Gall.

Bonivenura Vutcariw homo rediflimè de literis merens. Marc. Velfer, in Epift. ad Sralig: p: 795 .

Incer plutimas infignes qualitates qux Brugenfer in Flandria. Civitatis famam \& cclcbitatem augent pracipua fapicntiotum judicio, eft quod Orbi produ-

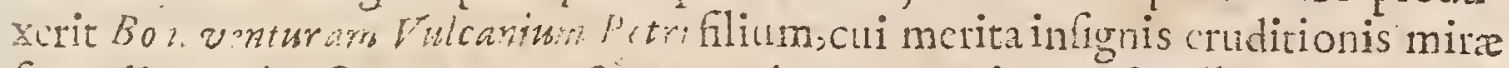
facundia conjunces, amorcm \& renetationem omnium vafta illius Provincia primarionu Literatorum ipfi conciliaverunt. Gbilini, ltalicè.

Carmina cjus fervantur Tomo 2. Delit. Belg. pag 562 . Alia cjus Opera variis in locis atque Tcmpo:ibus funt impreff.

$$
C \text { E S A R B A R O N I U S. }
$$

Ardinalis, Annalium Ecclefaficorum conditor, Sora in Regno Neapolitano Clar An. D. natuseft tricefmo Octobris 1538 . Obiit Roma tricefmo Junii, Anno MDXC. Dom. Iso7.

Mifit in rvorum, pecenititem A nalium Ecclefafiticorum. Tomos 12. SpifSum Opus \& Operolum, cui gloriosè immortuus eft, Tomo duodecimo à decellu ipfus cdito. Nomenritt. Cardin. Rman. Ecclef.

Annales fuos amplius quadragintannorum fudio clucubravit. Rainoldus.

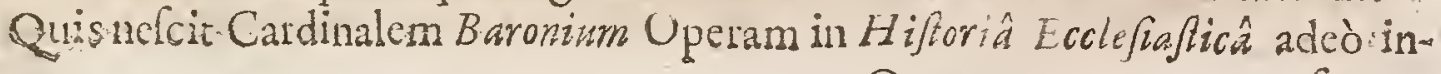

$$
\text { Qqqqu } 3 \text { fouram }
$$


lignem pofuiffe, ut omnibus fuâdiligentiâ palmam præripuerit:Hic enim cft, $q u$ primus omnium, totius $O_{1}$ bis hriftiani res gettas, prefertim autem qua ad Ecclefiam pertincbant, in continuam fricm annorum fic digefit, ut finius UiLis laftos concinnaret: qui nefcio unde ex abdito,tam multa planè pritus ignota, primus prompfit in lucem; qui intiquorum Epilcoporum in magnis Urbibus fuccefiones; Vcterum Harefcun originem progrodium \& fincm; teirpora Ecclefire,five tranguilla, five tubulenta tam accuratâ diligentiâ explicuit; qui denique merita fua in Ecclcfiam, fi immoderato partium ftudio non compiffct, dignus erat fine controverfiâ,cui omnes, \& veteres \& recentiores, qui illata eruditionis partem unquam attigerunt, affurgerent, \& fafces fubmitterent. If. Cafaub. in I'rolegom. ad Excrcitat. ad Burnin. Annal.

Neque tamen fic immenfrlabo:is (Baronii) Annaliwm pretium elevamus, utnon quantum cjus Arti Roma debet ac ingenio, tantum diligcntia propemodum debere univerfum Orbem Chritianum agnofcamus, ob illa tot ab eo crita mont-mentalicet in corum cenfum non pauca fubleftr nimis fidei relata fint 'quæ(fine illo fuilfet) xternis forte damnata tenebris latuif(ent. Qui nec ita partum fudio ducimur, ut Dostrine Temporum conditorem laude fraudatuin fuà vclimus, abeffet modò fuccus loliginis \& rrugo. Nan qux tandem Ars inchoata fimul \& perfecta eft? Quin eum inter principes Cbronologos non illibenter putamus, $\&$ verfarile hominis irgenium, \& eruditionem fanè multijugam, \& bcnè Latinum, ac rotundum Elóquii genus complectimur, nec arbiramur ei parem tum fuife, poltquam à Sirmonco difcefferis, illius Ordins virum:eumyue adeò magis interdum quàm Scaligerwr Cequimur. Alex. $M$ cr in Prefat.prefix. Eufeb.C hronico.

Hiftoriam Ecclefiafticam Baroniu's quantâ potuir maximâ diligentiâ cxcolụi \& fedulitate. Erat autem illa fumma, etiam penè prodigiofa. Univerfam enim Hiftoria Ecclefiaftic molem feptenis vicibus retractavit:totics illum Orbem ftudiorum, confcetum refumpfit inchoandum, priufquam manum admoliretur, confcribendis, quas meditabitur \& apparabut,Fiftoriis, \& Annalibus Ecclefiaf: cis. Plane novo \& inaudito exemplo, b omni retrò antiquitate, heroico conatu, \& pradicando.- ---Inftituti ifius ratio,illa fuic,ut qui confefloni Komane adhærerent, haberent in promptu, \& ad manum, qued enturiis $M$ agdeburgicorum opponere pollent. Montacut. Prafat.ad A pparat. Cect. $58,59$.

Nihil cortm quod caufam Fontificiam juvare viderctur,omifit. Majori tamę̧ ferè fuo difpendio, quàm caufx commodo. Partium enim ftudium immenfo las borimultùm detraxit. Hottinger. Biblioth.Quadripartit.p.413.

In Hiftoricis Baronio encomium ad fuperfitionem laboriofifimi feriptoris nemo adjudicabit;nifi compedes ei aliundè injectre libertatem ademiffent, magnus effe potuiffet. Idern ibid. p. 419 .

Quis inter Pontificios celebrior Author Baronio, \& magis factus a Papz nutum? MolinaiHyperafpilt.

Cui in Hiftoriâ texendấ,iftevidetur unicus effe propolitus fcopus, ut quax-m cunque fabula faciunt ad Papifni commodum, eas flo nomine confirmet. Dan. Ghamier. 
Cáfar Baronius vir facra prophanaque doctus. Lipf. in Not. ad lib. 2. dés Cruce.

Baronius vir quem merito boni \& docti amant. Idem in Epif. Cent. ad Ital. \& Hipan. Epirt.6:

Baronium ob incomparabilem in Hiftorî̀ Ecclesalficâ concinnandâ diligentiam magnís laudibus accumulant non tantùm Scaliger \& Cafaubonus, fed ctiam: alii nòoftrorum: Omes tamen tefantur ipfum non tantù crcberrimè in veritatem, Hiftorue veram vitam, crafsè peccare, fed etiam penè femper in Chronologicis errare pueriliter. Rob. Bailins i.l Op. fuo thitt. \& Chronolog. Ímpreflo, Amflelod. 1668. Fol.

Judicio verò non exiguo opus eft in Centuriatoribus legnndis; nec in Baronio minori; quem interea negare non polfimus praclarè meritum cffe de Antiguitate Esclefezzlftcâ Voffo de Philolog.p. 78.

Cui intima totius vetuftatis penetralia tam erant cognita \& familiaria, quam eft mihi domus mea. Montacut. Apparat.9.fect. 48 .

Utinam magnus ille Cafaubonus examini Armalium fupervixifet, ut purgatam ab erroribus \& corruptione Hiftorian Sacram legeremus. Plus cnin, ut rectè notatum à quodam, Annales Baronii, quàm Controverfice Bellarmini nocuerunt. Georg. Horn. Prafat.ad Lector.Sulpit.Severi.

$B$ aronius fabularum rigidus eft affertor \& defenfor-m- - Hodic Papa pretendir Dominium directum in siciliarn. Fateor aliçuandö Ponificenn habuille jus directiDominii, verùm pòft mutatum. Reges enim Arragonia dicunt fibi abVrbano l'apâ jus plenum conceffum effe. Curia Romana hoc negat. Rex Hispa-

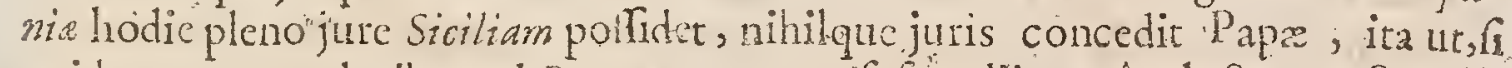

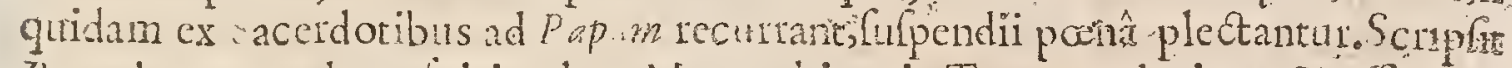
Baroniz contra hare firicualem Monarchiam in Tomo undecimo, \& affirmat, quod Bu'las quam piimo Regi Neapoit ıno \& Sirilic Rogerio donatam afferulit, falla \& fuppofititia fit. Quod shilippitm ad o offendit,ut non dubitaverit manu Carnificis Tomum illum x. comburi curare, quamvis effect Pape ftudiofrinmus Rex. Hic Tomus tam Neapoli, quà n in Siciliâ, Nobilibus fub pæenû tran-

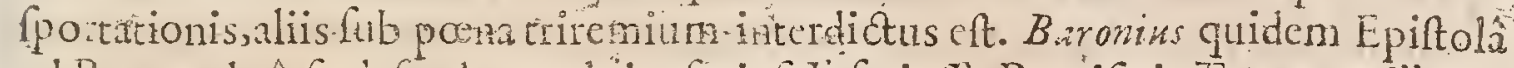
ad Regem datâ, fe defendsre voluit, feripfile fe juffu Pontificis Tomum illum, fed uihil effecit, exculiverat nempe fe, quafif Petrus \& Clemens VII. hoc jufferit.

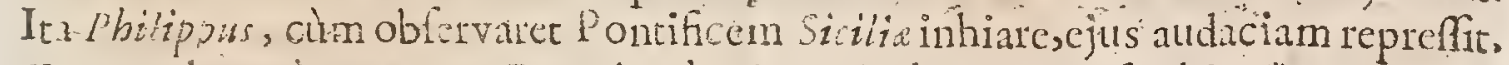
Quomodo verò excepeus Baro izit ab Etipanis, el ganter defcribit Thasanus libro 334. Ob:inuifet Paputuin Baronius , quo tempore cligebatur Paulus V.'ni obftitiflent Hifpuni. Herman. Conring. in Hi

Baronius frriptor parum accuratus; \& rerum veteris populi Indaici non adsmodum intelligens. Cafunt. fxercit. ad Baron p. 537 :num.92.

Hac temeritas $B$ ar mio farmiliaris eft, ut, in rebus etiam non magni monienti, qux fibi in Patrum libris difplicent, illa aud cter affrmet effe alienâ manu contum verbis affuta. Dallour de Ufir. Parr.c.4.P.IIg.

Baronius optimus elt q̨uatcor: Rozage Evangeliftarum. Alii nihil habent quàm Gubtilitates 
fubtilitates \& Sophifticos Cermones. Ejus prefertim Annalium liber ptimus innumeris fatuitatibus \& falfitatibus fcatet. Baronius Hiftoria eft, bonus eft, fed catiùs conftat. Sxpe hallucinatur, nulla tempora obfervat. Tot errores commifit ufque ad Juftiniani tempora: Baronizs negotiistractandis ineptus eft'; ad Papatum parum eft idoneus. (lact. Gallicè.) Buronius meliof Bellarmino, nam falem contexuit Hiftoriam, \& omnis Hiftoria bona cft,docet me aliquid, non Bellarminus. Barcnus fi mihi daretur,acciperem, fed non emam. Nihil habee quàm quod Centwriatores fecerunt : \& illos perpetuò reprehendit; putat ita tegere fua furta. Baronius eft Bibliuthecarius nihila; in Grages intelligitis. Baronins quo magis procedet, eô minora falla dicet in Hifrorià; fed prima illa tempora Apoftolorum, \& pòft, funt valdè oblcura; deinde alia funt valde ficta, ut EpifroLa Chriftiad quendam Abgarum Regem. Baronius citat Epiftolas Symmachi; videntur Chrifiane, fed tamen non fuit; fapiunt vetgfatcm, fed nihil habent fimile illis quas Iuretus edidit. Baronius fine ullo judicio componit Hiftoriam. Scaligerana pofterior.

Dominus $N$ audaus qui minimè mendax erat dixit mihi fe audivilfe à $L u c$ Holfenio Hamburgenfi, qui Rome, Canonicus eft S. Iobannis Latcrinenjos, plufqum bis mille falitates apud Baronium ab illo indicari polfe, imò \& probar per Manufripta Bibliotbece Vaticanecujus hodie curtos eft. Guido Pann Epiitolis Celect. Ep. 8 g. Gall.

Laudanda fanè fungularis illa Baronit diligentia in Anno Chrift matalitio, que vera. Annaliur Chriflianorum bafis, eruendo,ubi enudita multa \& operosè conquifita. Frid.Spanbem. part.2.Dub. Evangelic.p. 47.

Extant cjus Annales Ecclefaftici r2. Tomis Antverpia cx officinâ Plantiniañ. qux editio prantantifima eft.

Epitaphium Taurufie Baronii Card. Rome in S. Marie de Vallicellâ:

Francife Maria Tamrufio o Cxari Baronio Sorano ex Congregatione Ora torii $S . R . E$. Presbyteris $C$ ardinalibus, nie corpora disjungerentur in morte, guorum animi divinis virtutibus infignes, in vitâ conjunctiffrmi fuerant, eadem Congregatio unumutrique monumentum pofuit. Taurufus vixit annos 82 . menfes 9. dies 14 obiit 3 . I dus 7unii 1608 . Barolius vixit annos 68 . menses 8 . obiit pridie Calendas: 7unit 507 .

\section{P A U L U S S A R I I U S, Ord. Servorim,}

Clar. A. D. T Enetiis natus eft Anno Dom. 1552. Septuagefimo primo ætatis anno Vené tiis a Sicariis confoffus eft.

Struxit Hiftoriam Veneti interdicti feptem libris : item Hiftoriam Concilit Tridentiai fub nomine Petri Survis Polani.

Ad decimam lextam Centuriam Magdeburgicam peltinet Hiforia Conciliz Tridentini, anno 1542 indicti, ann. 545 . inchorti, \& ad ann. 1563 . producti. Hiltolia 
EI ittoria meherculè auro[ [dicam? ] imogemmis pretiofitumis contra, non cara, \& omni xre diutiùs per nuatura; a P. M. Paulo Veneto Ordinis Servortm fcripta:viro eruditionis admiraridx, exquiftiffimi judicii, indefarigabilis induftrię, rodeftix deniq e \& intcgritatis vix æeq iparandx. Q od q.idem Elogi m, vir -\& dignicate, pariter "\& er ditione perilutris, fidiffimus ej is interpres Anglicus D.Nathaniel Brent, Eg es Auratus., Collegii. UM ertonensettrefect s, ( q i

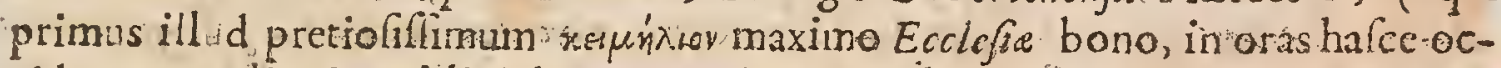
cid as prot lit, \& publicầ luce donavit) ei praliminari-fuá Epittolâ merivifi"mò tribuit; idq enon temerè ; "tpote qui licerară ej ıs conf et dine, ac propiori familiaritate aliquandiu fruitus , penitus cum noverat. Sed \& Ophs ipf m tantundem l:culenter pextat; ex libell is memorialibus, Commentariif e Legatorum; ex. Princèp m; \& Rerumpublicarum Epifolis, aliifó e feriptis;á præ'tulibus, Theologis, E egatifque ipfis, qui eidem" Conventusi interfuere, diligenter adfervatis concinnatum; tanto labore, tanta accuratione, fudio \& fide, (ficuti doctifimu s idem "\& chriffimus Eques ibidem oblervavit) ut omnes in ea genere Hifforiat, five veteres five recentiores, facilè provocate poiflit. Whear. in Relect.Hyem:tect +5 .

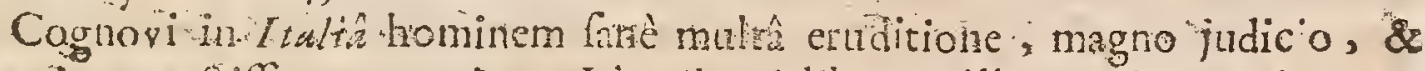
integritat ectifimogue animo, Licer haud libenter illos audiret, $q$ i Romanam Ecelcjarm nimis sdeptimunt; nihilominus ab illis etiam abhorrebat, qui ejus

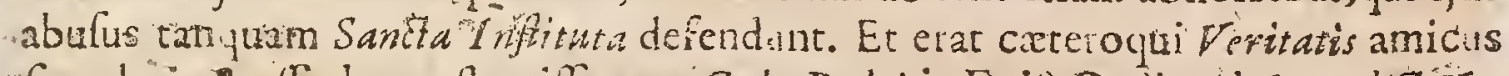
fingularis, \&.affecla-conltantilimus. Gul. Bedelin Epilt.Dedic.ad Interdict.Vem Bet. Hiff.

Veneilis cagnovimus R.A1.Pan! um Venetum, à quò aliqua didicife non eru-

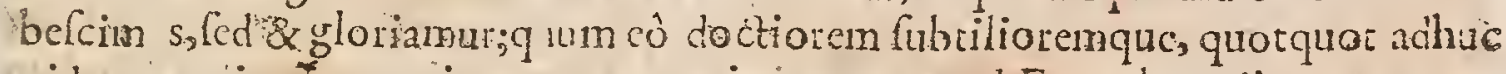
videre contigcrit, neminem cogineverimus, natum ad Encyclopædian, non tantùm Venetæ Unbisnut Italix, fed Orbis fplendor \& ornamentum.7o. Bapt.Porta Mib.7.Magie Natural.

Neque verò meo is preconio indiget, quem Opus pquin loquirer ingenii felicem, magni rectique judiciivirum, omni genere do ztrina liberalirer eruditum, atque ad maxłmam probitatem animique manfuerudinem utiáque prudentiâ,di-

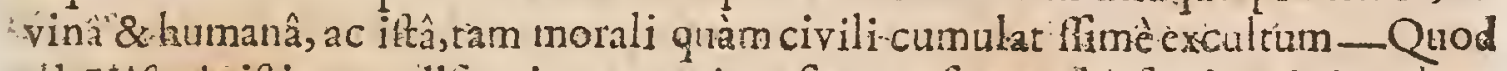
2d Hifforie iftius exxdificationem attinet, five res five verba fpectes, \& in rebus, fitcmporam ordinem, fi cenfilia, acta, eventus : 2 in rebus:geftis, fi declarari non folum defideras, quid actum aut dictum fit, fed etiam quomodo: \& cùm de eventu dicitur, ut caulfe explicentur omnes:vel casûs, vel fap entix, vel temeritatis; $H a c, \&$ alia ejufrodi, qua diccndi fcribendique $M a_{s}$ istri requir unt in $H$ iforiaran Scriptore, ille adeo plenè accuraté coagmentatione, omnes Hisforia confcribend $x$ numeros impleffe, atque hac nomine majorum gentium Hiftoricis accenfendus mericiffnò credatur. Adarn Neviton. Eques Aitrat.InterpresLatin.

Magna Authoris ingen itas, qui multa Sydodi Tridentina arcana derexit. Dignus proinde Cardinali Pallàvicino vifus, qui $i_{i \text { i pugnaretur }}$ Arrs poritis 
potiùs quadm refutaretur. Nihilque Cardinalis aliud ferè obrinuilfe dicî́. tur, quàim quòd in ipsâ Italiâ avidıùs legeretur. Hottinger Biblioh. Quadriparr. P.329.

Iobannes Leonicenus ait Patrem Paulum Sanguinis C'irculationem invenilfe, Venarumque Valvulas, fed rem propalare non effe aulum, ne quam in fe pro: celiain excitaret. Jam plus fatis fulpectus erat., illoque uno Paradoxo nihil ulteriùs fuiffet opus ad illum in Hxreticum transformandum in Inguifutionis Regionibus : Adeo urarcaumum fumm unico Aguapendenticrediderit, qui livori fele e ponere refugiens \& moleftis eventibus qui poterant. fequi Dogma guod ab innumeris Viris ut capitale adverfus Antiquos crimen traductum fuilfet, fecretum à Patre Paulo fibi concreditum follicitè cavit revelare fuff pectis Hominibus. Obitûs fui horam præftolatus eft ad librum de Vulvulis \& Venis à le compofitum in Venete Reipublicx manus tradendum: quoniam antem in illis plagis vel minima novitates animos terrent, liber in $S_{0}$. Marci Biblioihecam recondicus fuit. Sed cum Aquapendens Anglico cuidam juveni cui nomen Harveius admodum curio $\mathfrak{C}^{\circ}$, qui, Patavii: fub le ftudebat, rem aperire non dubitaffer, eodemque tempore Pater Paulus, idem eAnglie Legato. amicè detexiffet, duo illi Angli in Pat riam reduces in Libera Regione verfantes Dogma it ûd propalárunt, eoqurepluribus experimentis confirmato, ejufdem integram gloria n fibi vendicarunt. Novelle Gallica Reip. Literarix.Tom. I. pag. $3 i 5 \cdot 336$. Gall.

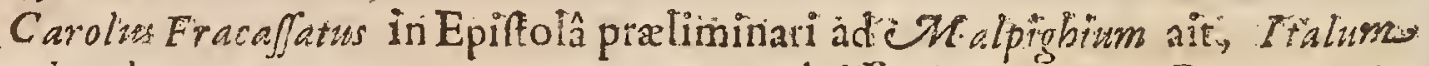
quendam hoc Inventum ante Harvarum excoluiffe. Is nempe i Pater Paulus. Servita, quera foannes Walaus (epift. x.ad Bartbolinum y, etiam in fcenam. protraxi, Circulatzonis yuc hujus primum aretorem pradicat. Nimirum nec lux eft abfque unbrî̀, neque gloria fine invidiâ. Iftins:antem commenti fabulam: jampridem die mihi narratam memini: Nempe, Legatum Venetwm, ad fuos redirum pazanten, libro tue de Circulatione Sangunis à te do'tratum friffe, eundemque pofteà Patri Paulo legendum exhibuiffe: : Indeque virum hunc celebrem,

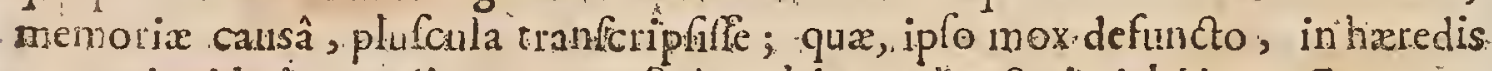
manus incidetint: creditur que pofteà multís, eundem Scripti hijus auctorem exsitiffe: habereque re literas. a $P$ atre Eulgentio, ip fius fodali, ad te fcriptas, qux rem eanden clas è exprimerent.Georg. Entain cpiftad.Gul. Haxuam, profix, Apolog. pro Circul:Sang.

Pater. Paulus Vir fuit vafta eruditione confummatifimaque Erendentia aque clatus: (unulque fuit $\&$ unus è maximis Theologis \& ex feculi fui fapientifí mis viris. Verum celebren Concilii Tridentini H.istoricum commendare adeo. furpervacaneum eft, ut plura in ejus laudem loqui meritò definere poffiñ. Verum hụ̂c Bedellı digniras multùm augeri necelfariò hinc debet; quòd I talus Vii, qui, præer caucelam in illa Regione fingulis ingenitam, \& prndentiam quâ quis in fua agendi, ratione ad cuilibet plufquam quivis alius., diffidendum adigitur, cum omnitum gentium hominibus cautifimè verfari cogebazur, rigido illo reginine quo adminiltratur Refpubliça cujus civis erat , Be- 
dellum tamen ad intimum affetum \& confortum admiferit, eique ut Henticus Wotton defuncto Regi alleveravit, reconditifimas cordis fui cogitationes apesuerit ; adeo ut Bedellus palàm profiteretur fe plus ab eo didicifie in omnibus Thcologix cum Speculativa, tun Practicx partibus quànà quovis alio quicu n per totam vitam ubivis verfatus effet-Pater Paulus Bedello tradidit inxitimabilia Manufcripta. Hiforix Tridentini Concilii, fir ul cum Hiftoria Interdicti \& Inquifitionis. Horum prius cenfebitur in avum Exen plar primarium illis omnibus imicandum, qui in Hiltöria quavls ritè conícribenda felicen fuccellum exoptant. Doctor Burnetius in Vita Epifcopi Bedelli. Anglicè.

P. Paulws omian qui Humanitatis limiribus circumferipti funt humillimus fuit. Genuinam Exemplar pixcepti celebris Quanto dorlior, tanto fub-

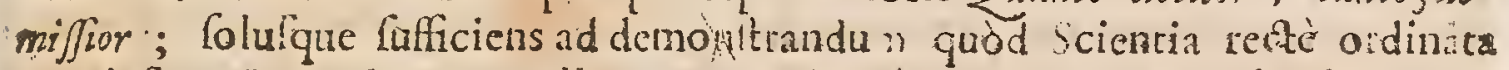
non inflet. In Pofitiva excellens, in Sobolatica \& Politica Theologia excellens : Rarus Mathematicus, etiam in abttrufinmis Difciplinx partibus, qualia funt élgebra \& Tbeorica; \& tamen inul ita pericus Hiftorix Plastarum, ac fi precer Nacurar nullum unquan ibum legilet : Denique Magnus Canouiftr, qui titulus fuit ejus Ordinarii Minifterii in Republica. Et fanè Interdi i Pontícii rempore pracipua conlilia Senarus ab ip:o hauriebat. Quando feorfm legebat vel f́cribebat, cjus mos erat federe characeo caltello tedili \& capite circumfeptis ; in ea cnim opinione enat, cu n noftrare Domiso à S. Albano, quódomnis aer pradno ins tit \& fpecialiter nocivus quando firitus cum maxima cerebil contentione occupantur. Equi tis Henrici Wottoni Chanacter P.Pauti. Angl.

Quanus vir Paulus Sarpizs fucrit, non ignotum effe poteft illis, qui interiorem reiliterarie notiriam habent Fuir ille facri o dinis homo, Monachers, Minorita, Ced fummi Ingenii. Extat ejus Hiftoria Concilii Tridontini, magnâ prudentià \& ingenuitate fcripta, fub nomine Suavis Polani, quam inter abfolutiflma Hifto ire Spccinina numeiat Guido Patinus epift. 70 . Tatum Reip. Venete ftatum moderatus fuit confilis fuis. Vindicarir jura cjus adverfus Pontificem, qui de causấ fummè invilus fuï Pontificiis, \& in mortem ejus aliqnoties confpiratum, ut Sicariorum manibus per vim vix exrorqueretur. Illum enim omnibus Hereticis pejorem habuerunt, ut qui arcanorum Pontificii Statûs Prodico: erat. Spargebatur de ipfo fama, quid abitum ad Reformatos meditaretur, qux non omninò de nihilo eft : Scio enim fupercfe epiltolas manu ejus feriptas, ad Ifaacum Cafaubonum, quibus follicitat ipfun de gratiâ Rrgis e Anglia fibi conciliandâ ; fi forté illic fortuna iniquior ipfum abigeret. Vita cjus confcripta elt Itaticâ Ling ıâ ; polteâ in Linguam Gallicam converfa prodiic Lugduni Batavor.in $12^{\circ}$. anno 1661 . fub titulo La Vie dus Pere Paul. Multa funt in hâc defcriptione merorabilia ad omnem rem literariam : habuit enim excellentifmum Ingenium, quod per omnes Scientias, artes, \& linguas fe diffuderat. Promptus erat confilio, anino femper prælens, extrema yitx pericula fummâ generolitate contemnens, \&. 
w brexirer dicam, fui trmperis. Phonix. Multa enim ille in Phyficis \& Mathemaricis demontrant extemporali penè coleria, qua de perata aliis videbantur. Celebratan apud Medicos Crrculationum primus ille ante Harvet tempora oftendi," quod cum objiceret Burtholinus Anglis, xgrè admodum tulerunt, ejus inventionis gloram d biam fibi reddi. Sed dolendum elt, omnes illius viri chartas periille, ac diftactas polt mortcm ejus fuife : nithil enim horum ferio fcripfr, \& data-operá; fed guaf aliud agendo, cim vacario elfet à publicis nego-m tis. DrizGeorg. Morbofin Polyhint. pa.222. 223.

Ineptum eft \&maligum Cardinalis Perronit de Panlo Sarpió judicium in excerpus illis fuis; qui de illo ita Gallicè loquicur, In ilto viro nibil eminentis animadverto, fudi io intelligentia fanus est, fed infgnem orudivionem nul

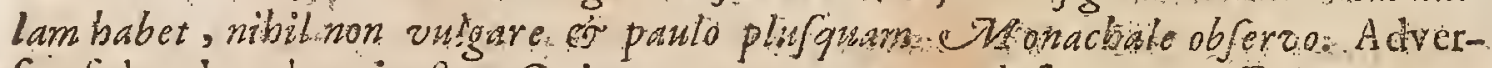
fus lolcm hoc loqui elt. Qui norme, quantas qualefque res gelferit Sarpius, quibus ille do trinis excelluerit, illi ron fupra conachans, fed \& fupra Cardinalem, acipfuin hunc Perronim, fapuife largientur Ldem ibidem pag. 293.294 .

* Hiftoriadel Concilio Trident.óc' da Pietro Soave Polanoedita in lucen per Marcum Antonium de Dorninis A rchiepifc. olin Spalat. cum ejufdem Prasfarione, \& Dedicatoriâ,plohibetur in Decreto 22. Noyembris $16 \%$ g.

\section{N.I C.OLA U S S E R R RE U S Socier. Jef.}

Clar. Bu. D. Atrone Lotharingus, patri. Raxbervillarus, quod oppidum ef in Weten

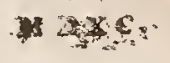

1 fis Epifcopi ditione. Natus eft A nno IssT. Societati J efu nouncn dedit An-

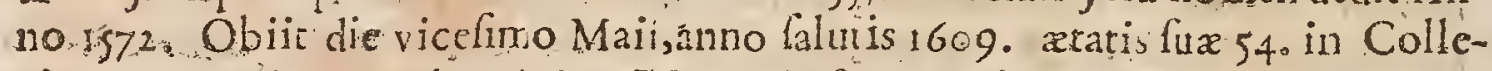

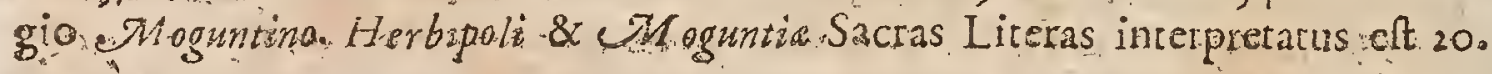
prupè annos.

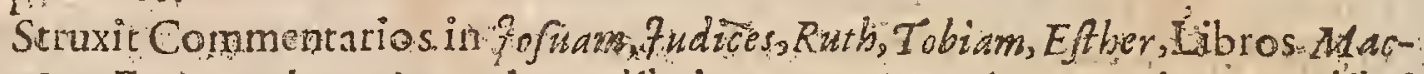
cab. \&ce Extàn etian ejus quinque libriterum Moguntacarazn: itemstres libri

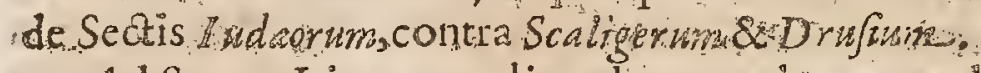

Ad Sacras Literas explicandas, tuendas, omandas, non difputamice modö ill $\mathrm{m}$ Theologian, verum etiam omnium Philofophonen, Ontonm, Hiftoricorum atque adeò Poëtanum lectionem conferebat. Itaque aiebat fe mul torum. ho inum miferari vicem, qui cum hifce velut Agypti Spoliis, De A Acam exornare polfent,atatem in is fine fructu contererent. Cum his etiam Latinas: Grace, Hebraice, Syriace Linguarum cognitionem copularat, qux ip frs quoq;adverfarii ejus commendationem expreflit. His ille quidem armis vincere holtem poterat, qui ut $\mathrm{fe}$ vinei quoque fineret, admirabili candore anim $x$, moru mque dura itate, quá 3 Sermones omnes temperabat, adnifus eft Id quod admirabilius. fude quoque at, quòd fervidus naturâ, \&az nif longâ atque acri meditatione fe 
fregilfet, ad iram eflet proclivior. A legambe.

Nicolaws Serarius, Hebraarwm Antiguitatum callentiffinus vir, urinam patlò modeftior: Mtortacut.c. erc, $\therefore$.ect.2.

Lucis I ubar Ecclefise Germanica, dicere non iubitavit Caf. Baronitss ad Ann. Chrisize.

Nicolaus Serariws Ecclefiaftice Antquitati- diligertiffmuss perveftigntor, Koft is Hereicorum. Io. Card. Bonk.

Nicolazs Serarius, dum lảe fribimus, vivit, vitâ langiore dignus, magrìis

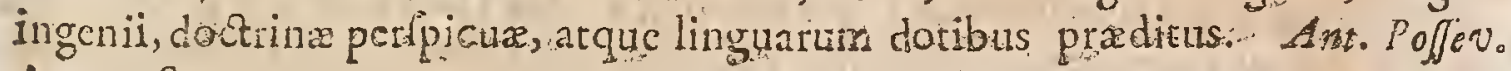
Appair. Sac....

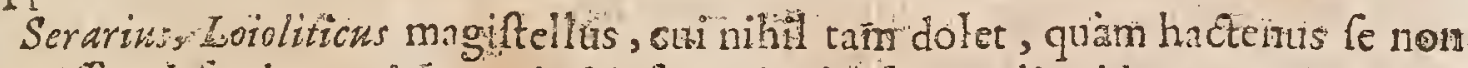
potuife perfladere euiquain docto fe Hebraice Ccire, aliquid cornicatus elt in no ira Eufebiana; de Succeflione Herodiadarum. Et initum in modum effuat, ut prober Partes meliüs gentis Herodis feiviffe quàm Iffepham. Tanta eft im-

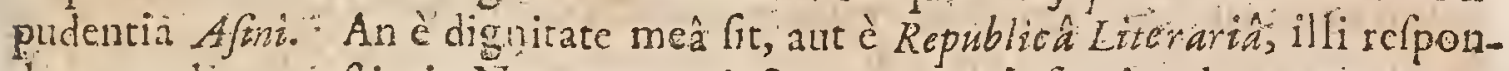
derc,nondum conftitui. Nim magna jactura temporis fuerit ad olmnes canum

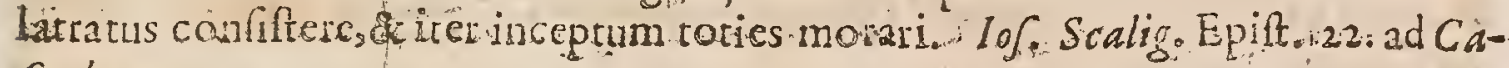
Sartbonum.

Cùn friphifer Scaliger, Heyodemalienigenam fàtsô fuilte creditum à Vète-

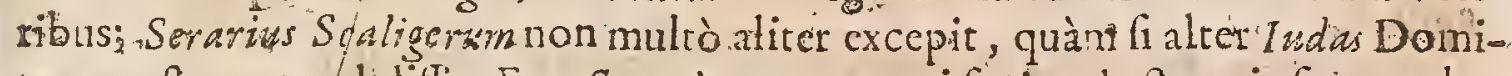
num noftum prod diffet. Ege Serarinm non parvi facio ; doetus vir fuit, multa-

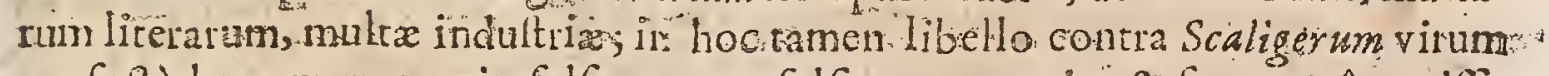
piofectù berum thon egit, falfá tuetur, fallis argumentis, \& fine caúsâ veriffi-

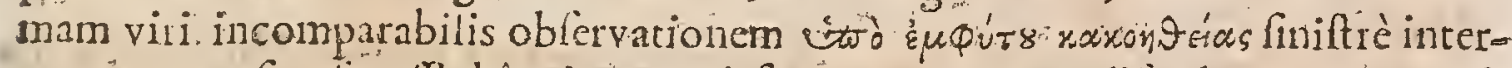
pretatur, quafi urctas eflèthâc in pante à fententià Veterum dilcedes e If Ca arbo. Epilt.698..nd Thuans.

Senarius Jefuita omnibus Scripturarum Interprezi necelfariis dotibus inftuEtus fuit:praterquàm enim quòd Linguarum Grace \& Latine fufficienter fciehs: érat, \& multò melins quàn folent qui Commentarios ita Scripturas elucu-

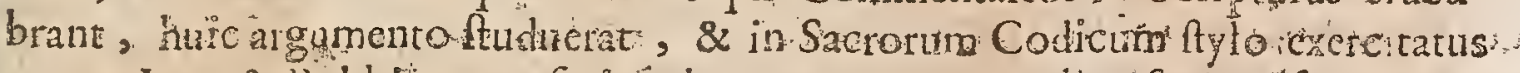
erat : Imo \& Rabbihorum" fcripta legerte poterat; at palant fecit DH putationibus fuis cum Druffo \&. Scatigero Werùm ejus Methodus fatis criticanon ent, ni-

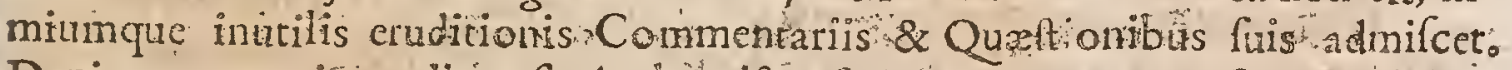
Denique quamvis eruditus fit Auther ifte, fatis accuratus non eft ; Judicium ejus \& doctrina fuis in Biblia $\mathbb{P}$ iólegomenis magis elucent', ubi plures te fert Quxttiones, quas folidè paucifue verbis pertractato OratoritPresbyter Rists? Simon Hift.Crit.V.T.I.3.c.12. Gall.

Upera ejus edica funt tribus Tom:fol: Moguntza $1627 \ldots$

RISI 3 AARCUS 


\section{MARCUS YELSERUS}

Mak 0. ZS DXC V.
$\mathrm{P}$ Atricius, \& Duumvir Augustanus, bono publico matus eft anno Chrifi :sj8. die vicefimo I nni: Obiit anno 1614 . die I3. Iunii. A teneris A:tram ac virtutum ftudiis excoctus, macuritatem ingenii, judicii , \& doctrinxfeliciter eft confecutus, nec imitatus eos, quilibi nati ac fuis Camunis ing o: 1o in ocio confenefcunt, omnemque feientiam vità umbratic finiunt, aut bracteatis naniis metiuntur. Vivido hic victutis ardore farim fe in lucen protulic, patrixque Reip.ac Literaria totum impendit. itaque ut mens generofa culo annis motu gaudet : ita \& ipfe in Italiam progrellus, edidit Antagutates Argustanas, felix fame furgentis aupicium \& pium. Exinde aliis atque aliis ad unguem fa. ctis monumentis obligavic fibi rem literariam. Annales Boicos feripfic libris quinque tantầ perfpicuitate, cancâ fide, tantâ prudentia, tanto nitorç ut meditanti videantur adititile hinc $M$ ufa \& Gratia; hinc, Conjus, Apollo, Suada, Venus. Melch. Adam.in vit.cjus. epift. 13.

Feiferus nofter, illud Margaritum Germanis fuat. Pignor. Symbol.Epilt.

Reipublice Augufane xernum.decus. Montacut. Antidiat.

Me tacente, Scripta illus,omnelque vili erudici, open iphus munificam,paratiflmamque experti, quantus vir fuerit, fatis lo quantar.Gajend.in Vir.Peireskir,p.: 8 .

M. Ve berus vir illufrifimus , \& propter fummam eruditionem merito fuo omnibus venerabilis. Meric. Cajaub. picras.

Marcus Velferus, nomen omni poltericativenerandum. Eisthat. Sovert. 1.t. Analcet.p.s8.cap.13.

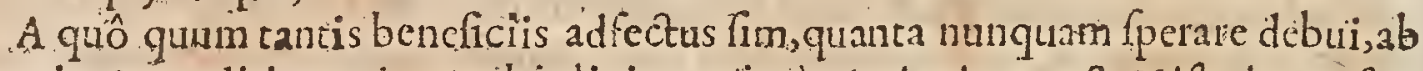
ingenio \& eruditione ejus multiplici, maxinè Antiquitatum \& Hiforid um fudio, in prefens pradicando, me abftinebo; ue beneficia fumma verbis compolicis compenfare velle videar. Sciop.de Art.Crit.p.19.

Quotufquilque enim erudiorzin eft, qui nonopine confulum putet rei Literaria, reculs acpublico velut redonatis egregit trelferi monumentis, qux longo jam tempore nullo pretio potucrunt comparari,ac legi tamen ac pervolvi diligenter ab omnibus omnino merebantur? Nonfert in ituri rario, ut in laudariones claro:um virorum excuranns: aftic tanen nobilcumomnes lentient, quibus Felferii Commenteriss infpicere contigit, ut fuit vir in omni vità literarum amantifimas, ac in ornandis iis promovendifque incredibili fuctio, ira $B$ oi cas pracipuè Antigutates neminem eo certius cruiffe, aut illuftralfe rectius. AEta Erudit.Calend. Jun.an.1682 vol.1.p.169.

Cujus -riri [Velferi] ufumfruetum pané equidem tibi invideo: in quo thefarum caum rerum habes, qua hamini ingenuo apperendx fut, vel amandx. Yeruftes 
Vetuftas, inquam, vel artium vel morum: \& uter oque titulo in Europấ noftrâ claset. Lipf.Cent.4.Milcel.ep.97.

Maguns ille vir etiam in prifco \& magno ævo fuifet. Toto animo eum amo. Eipf: Cent.ad German.8s Gallos, Epift.80.ad Martin.Delriwm.

Accepi Anrales veftros, eruditionis, clegantix \& optime frugis plenos. . Iof. Scalig.cp: +3 .

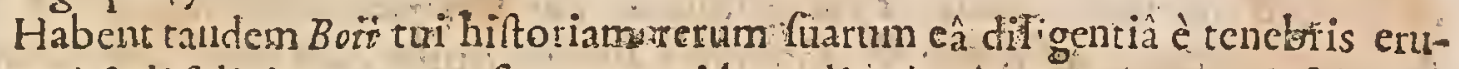

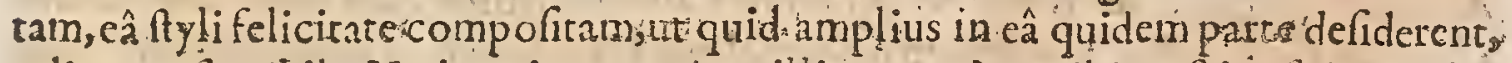
reliquum fit nithil. Utri potius gratuler, illine genti,an tibi, nefciós: fed gratulor sertè utri ue ex animo; tibisqu d opus fufceptum, ut erat te dignum, graviter \&

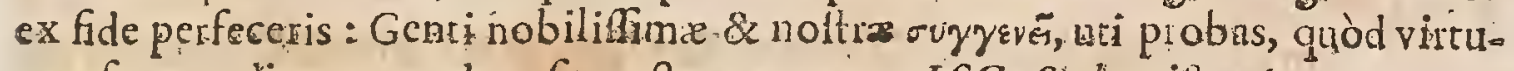

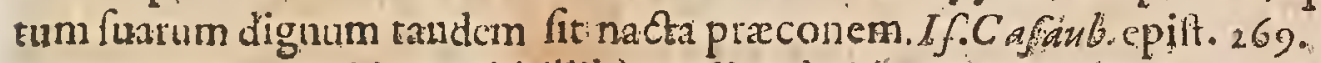

Eoica Velferi dev o:avi, inhil jam diu ent, ita me rapuit in admirationem:Mirum mibi, quod tories eftimilizm veftrum notet, quì tamen accuratus val dè Scriptor; lèd iftuis hominis diligentiamnihil fugit.Georg. Mich.Lingellshem in ep. 38 . ad Borgarfaram.

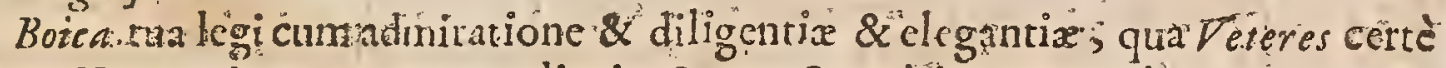
xquas; Vètercs inquam notx melioris : Itaque \& quód ine excmplo privatim donaveris,exzlto; \& quod tamacceratum Opits publicum feceris; huic feculo noftro gratulor, I he Biongar sin ep. ad Velifer:rGo2.

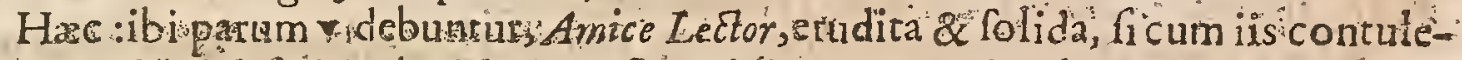
ris, qua dini pòft fcripar legi ejus: Hi iforic initio, quam de rebus Boicis prudenter, dactè \& eleganter fummo judiciv viŕ,atqute doctrini, cum pari Nubilitate con-

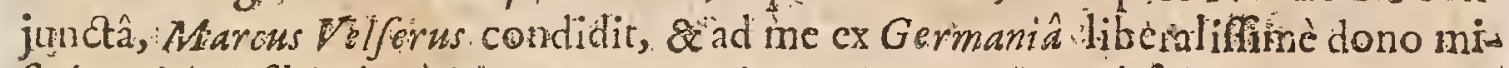

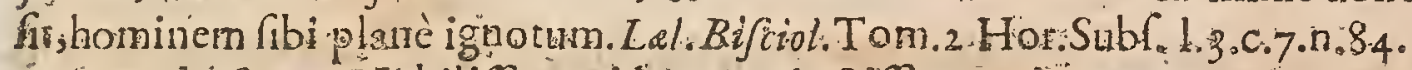

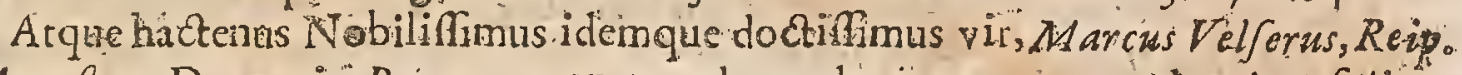

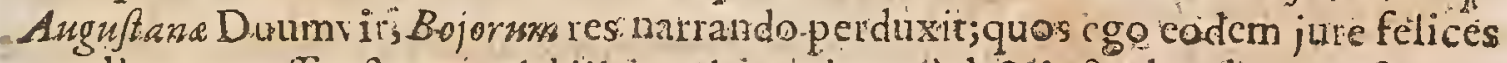
appellem; neceffe et, quo Acbillem Alexandcr; quiod \& ipfi talem laudum fuarum

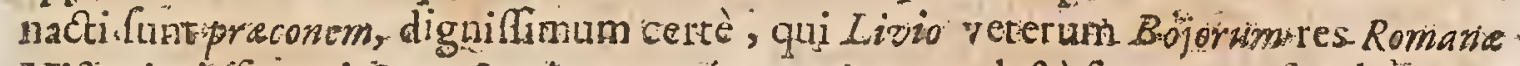

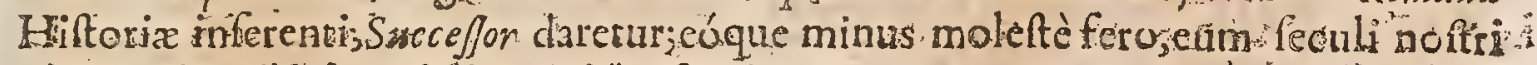
Tacitum à quiburdain indigitari " etfi enim eo nomine non amplifimè laludatum

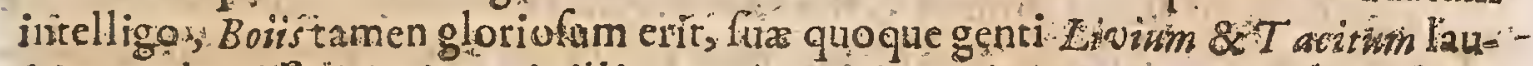
datoves obrigiffe. Artenim quia illi egregiè coepti cursûs metan mors invidit, noss quo polfumus pede;certiflimo duce deftituri, sujus manibàs bènè precarnur, itè profequemur: Andr. Bromner.in Boictso

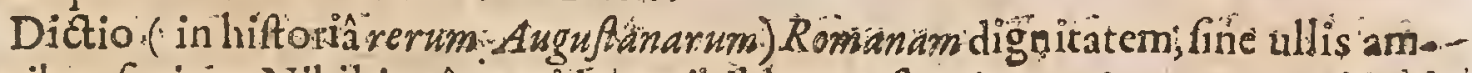
bảgibus, fapiens. Nihil in eâ turgịdum, nihil laxum: fr quâ in re immoratur, id ad sem folidè explicandam facit. Poffezin. Biblioth. felect.

Exrant rerum Arouffanarum lib.8.Venetiis is94. fol.

Extant teium Boicarum lib. Angula Tindel.í602.in 40:

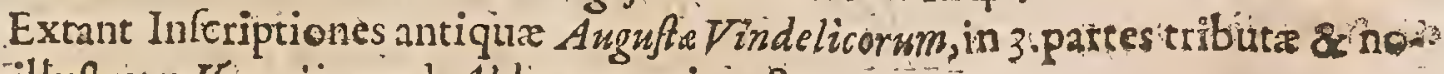

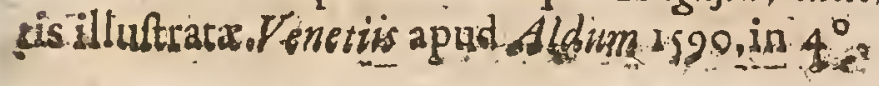




\section{PHILIPPUS MORNAUS}

Clar.An-D. Allus, Pleffiaci Dominus, Theologus, Jurifconfultus, \& Philologis MDXér. nis inter Reformatos Gallie vit vix quífquam Pontificiorum cumeo congredi in Religionis negotio aufus fuerit. Condidit librum ritulo MIf yferii Iniquitatis: alium de Eucharifiâ: Opus irem de Rel yione Cobriftianâ. Exaravic ciamadmonitionem de Mefjia ad I udaos. Obiit undecimo Novembiis, Anno 162, . xtatis 74 . Konig.

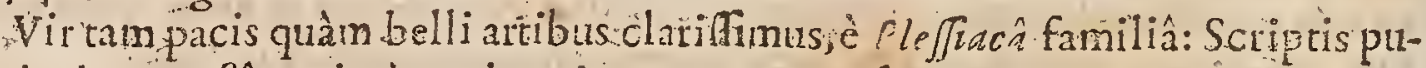
blicis, de Ecclefia optimè meritus: inter qua Chiyflerium Iniquitatis : de Eucharifîa, \&c. qui poftremus liber, ling !a vernacula fcriptus, cumob fyli elcgantiam, per omaium vol taret manus, Theologi Pontigci periculum veriti,palfm in Concionibus in cum invehebantur. Hinc cum collatione inftitut Rege prefcnceac Proceribus, David Perronizs Epifcopus Ebroicenfis, quädan falsè, quadatn verbis truncatis in illo, ex Patribus \& Scholasicicis allegata a Morneo, contenderet, Anno 1600 .hic libi à Perronio edirionibus caltratis ne mutatis impoli-

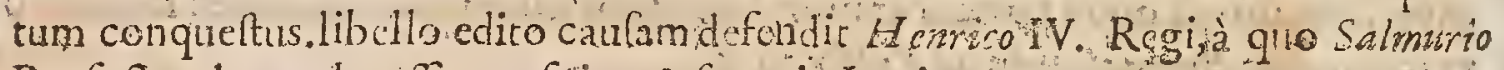
Prefectus datu, charifi us fuit. Hofusanin Lexic.

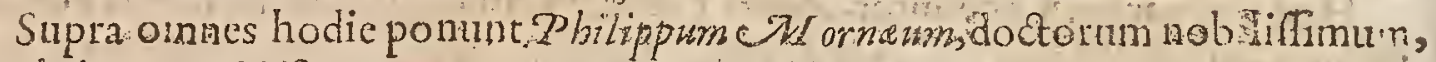
\& nobilium doctifimun:quem virum? quem unum : Platonis, Dernofthenis, "\& Angufini, finul compoftorum Idea vix exprimat.Thorn.Lanfon Orat pro Gall. pag 175.

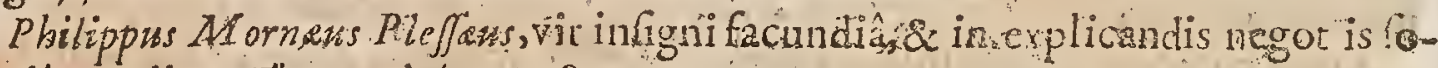
lertiâ præditus. Thuan ad Ann.i589.

Non ignoras quantum excoluerintifam materiam phỏofophicâ Gubilinate Raimundus Sebundus; Dialogorum varietate Ludivives;maximu autem cum ertm ditione tum facundiâ ventras Mornaus. Bug. Grotoin Lim. Oper.de Yerit. R. C. Fieron.B.gnonio dicati, Last.IGgio.

Quantus vir fuerit illutis Bornas Ple faciDoninus, quantumgue, ille Conflio gladio, calamo, pro tuend vera religionis \&patria diberate fub dizcta lerenili i Regis Navarreni, pofea Galliarum Henrici V. geiferit, nemi-

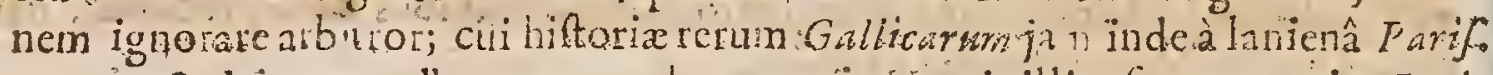

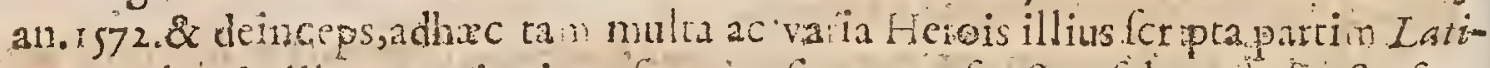
na, partim Gallica atenitati confecria, finon perfpecta faltem infpecta fuerint: Ne quiddicande vit cjuden non itapridem a viro erucito \& diferto. Gal-

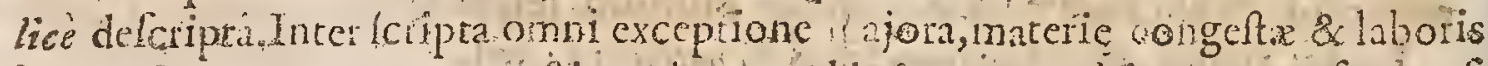

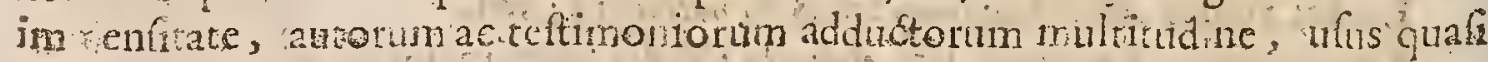
univerfalis ad quo cunque literatonm ortines \& fatus, ad quacunque Reipublica \& cclefiz negotia ac conflia extenfone, Pyligravicate, fe maximè com-

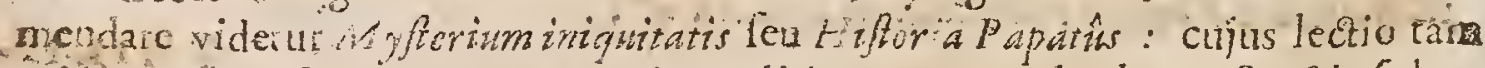
avide certation frequentata, utomnium editionum exen plaribus diftratis, folum defice- 


\section{CELEBRIORUM AUTHORUM.}

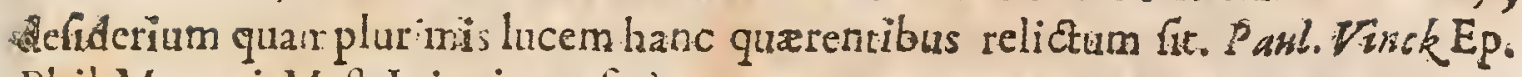
Phil Mornxi Mylt. Iniquit prafixà.

Tu ex iis, quibus Hebraorum ir oni enta io pretio, ut preclara tua fcripta fatis fuperque teltantur. Vehe renter fanè, polt aliorum tuorum lectionem, delecta-

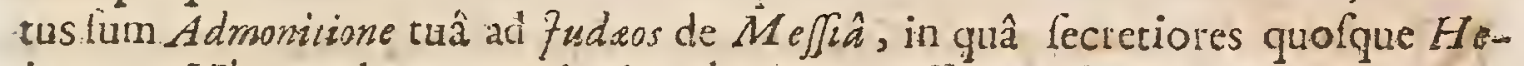
braorusn Libros, ad argumenti tui probationer, ąfluentilfimé producis. Buxtorfo

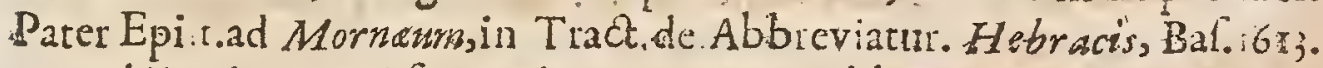

Fbilippi Mornai fententia:ne exponam ex libro cjus Gallicè fcripto de Veritate Religionis Chriftiana,cui fir ilis in hoc argumenti genere nullus antchac prodirt.To.Leunclar. in Pandect Hitt. Turc.

Quod ad D.Plej]li Perfona r atinet, addietifimus ei far ulus fur, tot us $G$ allie 1 citifimum Scriptorem illum cenfco, cum de Retigione non agiour ; rarifimum \& excellentifimum Ingeninon, agt eque liceratura. Iubl. Caf. Buling. fcribens adwerfus Prafationem libri de Eucharistia. Gall.

Quandoquide $n$ ante aliquot dies tumore in fparferunt quidan Irr poftorés quòd Neraci D. Pleffao dixerim eum nihil fire neque Gracè neque Latinè neque Hebraice, tam effionti ac impudenti calumnic perferipto hoc tellin onio volui occurrere. In cos eitin eo non min s indignor quam $\mathrm{i}_{\mathrm{i}}$ fi teprehenfione digni funt, vel potius cátigarione, fi dcbitè ju iria exerccretur, qui d me quantum in ipfis eft, tam rurpi probro implicuerint., quo magis offendor quàm ipfe Do.r inurs Plefferts. Cum eni n tanta fint ejus merita, uc nerro aifio o niro perfricte frontis fuerit illa diffiteri audeat, iis in pudentior effem, fi dotes quibus illum exornavit Deus non agnoleeren, cxcus fin quod unicuique patet non vidercm, malignus fi guod diffiteri nequeo non faterer-D Q Quomodo dixilfem enm clfe Linguaran rudem, cùm preclara ejus Scriptas qua pra umnibus hujus fec li demiror, contranii me arguerent? Praterquam quòd ejus condifcipuli mecertiorem fecerune, quod propryis fumptibus I udeos ce nduxerit in Italia ad Hebraifrnatra accuratè perdilcendum, imo null m Poëtan Grecum quantumvis arduum extare, quein à ft: diorum primordiis non didicerit. Sed quorfum probationes ejufmodi ? Id in ejus Scriptis perfpicio, id in mea. Confcientia lego: $\mathrm{q}$ :apropter rem hanc aliter referre non valeo. Pancis verbis dicam, Deus autem cordis mei teftis eft, eum bonarum lirerarum fientior $m$ effé, érumque fenfu \& experientia antecellere vel celeberrimos \& facundiffimos Adverfarior $m$ : Er hoc unicum adeo ipfos urit. Iof.Scalig. in Judicio MS.ap . d D. de la Renandrere Cadomensem Medicum, olim affervato. Gall.

${ }^{*}$ Híc Author inter Hareticos Primæ Claffas rejicitur in Indice Roma impreffo Anno 168 . Ej fdem liber infcriptus Mysterium I niquitatis prohibetur in Decreto Roma 16 1\%. Ejufdem de SacrấEucbariffiâ , freur \& alia omnia ejus Opera prohibentur in decreto 16. Martii tó s.

Extant ejus Opera vasiis in locis atque temperibus imprelfa. 


\section{JOANAES MARIANA, Soc. Jef.}

Char. A.D. $M \cap \mathrm{D} \in \mathrm{q}$.

J Atione Hisfanus, patriâ Talabricenfis, feptendecimannos natus, fe So cietati Iefu dedicavit. Toleti obiit die 17. Fcbruarii, Anno: 624 . xtatis 87 .

Reliquät 3.libros de Rege \& Regis Inftitutione: De Monetx muratione: Triginta Libros Rer um Hapanicarum: Scholia in V.\&N.T. ut \& 7 .Traetatus de. adventu S.I acobi in Hijpaniam. Multaque al ia.

Ioannes Mariana, maximo vir ingenio, peracri judicio, fingulari memoriâ, multorum annorum ftudio, omne difciplinarum genus diligentifi rè exculeity \& ad S. Thcologiam, raram omnium Liberalium Artium, \& Hiftorix tur: Ecclefuafticx, tum Prophane cognitionem; \& pratered Latina, Greck atque Hebraice Linguze peritiam adj nxit. Alegambè.

Ioannes Mariana, fingulari virji dicio, fcripfit 30 . Annalium Hifpansalibros wifertè adu odum gravique fylo $\mathrm{o}_{\text {: }}$ ur Thucydrdis prudentiam ac Taciti acumen unus 60 plexus effe videarur. Hifpan. Biblioth

foannes Mariana veritatis amalor: \& pietatis optimus cultor, qui érudito Atylo poftremam man mappoluit resw Hifpanicanum Hiftorix, Hippanus \& iple, led affectu privato carens, dignus Profelfor Socistatis. Iefwo. Baronad An mim Chr.688.

Idemquc Baronius Tomo 3. ait illum Res Hifpanicas accuratifimè perfeciziz. tum.

Inter Leatizios omnibus palmam praripuit Toannes Mariana Hifpänus, rerum Hifp:nicarum cognitione nemini fecundilis: Valuir verò Mariana infigni cloquentiâ, pr dentiâ, \& magnâ libertare dicendi, hịc \& libertatis ftudiofinimus in Re gès fuess. frpè eft mordax. Elt itidem fiperftitiolufirmus homo, quo nomine etiam inter fuos malè andit. Tantam libertatem fibiaffumpfit, ut \& Iibellum edideri:- de membris Societatis, quem licèt fupprimerent Jel. itre, tamen in mediâ. Româ editurn elfe conftar, rariffmus hodicelt inventu. Prodiit \& alius ejus li bellus, De infitintione Regis, mulka prxclara continens, in quo liberrimè judicats quomodo Reges inftitueis dii fint: Non dubitavit a tem \& apertè quoque docere; GRex vel anathemate factus vel excommunicatus, ae uonnibil receffr z̀ Romanâ Ecclefiâ, licere in illum gladio, igne fcilicer:an madvertere. Eâtamen pierate videri voluit, tur dixeris, Regem veneno tolli non licere, quafi vero. Combuftus verò hic ett liber ob talem doctrinam hurrendam Paxifirs, \& coacti fuere J cluitz diffenf m profiteri. Non dubitavit \& Mariana Sicarsuin Henri. IV. Regis Gallia inter Sanctos memorare. Hermà. Conring.ele Regno Hijpan.

Mariana in ejus Hiftoria: Hifpania z acoticorum nemine ftrperatus fuit, nec incepti magnitudine, nec ftyli nobijlitate, Cateris accuratior eft ; fanaq; mente de Asngul is judicat. Rapin. Animadv .in Hift.Sect.28. Gallo?

Joamis M Marians Scholia a exgua quidem mole fed bu aen cotemnen- 
da, \& cum jadicio exarata. Cy atth. Pol.Przfat. ad Lcetor.Vol.r.

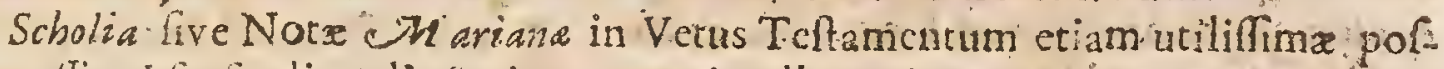
funt elle ad fon litcralis Scripurarum intelligentum quonam ad propriam vocum Hebraicarsm fignificacionem exprimendan htidium pracipuim adibuit. Sic in princ pio Genefews fagaciter obfervavit yerbum Hicbraicum bate quod Creare verti folet, propia fignificatione non défignarc ex nthilo fecere. ut vulgò creditur; imò iplos Authorcs Gracos of Lainos qui in luis Lir guis ve: cembreare excogitârunt, hunc fením ei alligare non potuillic, quandoquịiem quod nune Creatio feu ex nihila productio dicitur, iiś penitus incognitum: fuic. Quamvis cjus Notz breves admodum fine, aliquas tamen abfervationes ptætemittere potullèt qux mara lunt etudicionis, nihilque ad Texiús ipfus elucidationem confcrunt. Ejtifnodi digreffones rà tamen apud iplim occurrune, dicique poreft Marinam accenfendum elfe peritilimis \& fagacifrmis Scholiaftis qui a nobis in Bibliz legantur. Verm quiden illum mediocriter tancum calluifts Linguas Crecam \&. Hebraicam, led illum defectum quadantcnu fupplent ungenii sjus ac men \& magna animi cjus contentio. Optimum fenfum plerumque deligic \& nequidem in diverfis qua, sefert interprctationibus, tadiofus elt. Frequenrer admodum citar Verus Vulgara exemplar quod Gotticum denominat \& cujus in Hípanicis Ecclefiis ufus olim elat. Or. Pr. Rich. Simors. Hilt.Crit:V.T L.i.c.12. Call.

* Fonmir Marina Tractutus Seprem prohibenur donec corrignntur. Totus inte Tractatus de Mutarione Monetxe pungatur. Tractat us de Morte, \& Immortalitate, cxpurgand.s.Index Madrit.edir.an.r667.

Extat Historia Hifpania 3 .Libris. Toleti 1592 typis fo. Roderici. Moguntice anno I Ge s.\&in Hijpinia Illutratî Tomo 2.

Extat de Ponderibus \& Menluris Tractatus. Toleti $4^{\circ} \cdot 1599$.apud Thom.Gufmanium.

\section{J ANUS DOUZA, Filius,}

Dilologus ac Pö̈ra, \& quod in tenerâ adhuc xtate mireris, Philofophus ac ClaY.A.D. Marhematicus infignis, primufque Bibliotheca Lugdunom $B$ atrve Prafectus, AS I I C Y : : patcrnis filtens veftigiis. Obiit anno 1597 nondum expleto 26 . etatis anno, $H$ ga Comitis. Val. Andreas.

Scripta c jus funt: Note in Catullum, Tibullwars, Propertium-Spicilcgium in Petroniz Arbitri Satyricon-An-Anadverfones breves in Plauti Comodias-Declamutio in laudem umbre: addito rerum Colefinm Lib 0 ...-Annales Bata. vie Patris lui prosâ o:arione pertexuit----Poëmata varia.

Hic acceptam à parente nominis claricatem ingenii lui luce illuftravit. Trimm linguarum exquifita cognitio, Antiquitatis logunque Romanarum intelligencia \& Marhematica totius, totiufque Philofophix notitia. Meurf. Atbers. Batav.

Larms Donza filius, juvenis admirabili ingenio, excelleni doctriná cum rar

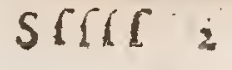

n.orw 


\section{ENSNRA}

morum tuavịate conjunctâ prxditus, cùm ex peregrinatione longinguẩ redinct to. q ali in portu naufragium fecit, anno xtatis 26 . ereptus. Thuan.ad Ann.1596.

Cùm elfem apud D. Scaligerum, multus nobis ultro citroque fermo fuit de $\mathrm{Te}_{\text {; }}$ ac parte tuo;nec parcus veftrarum laudum. Tuam de $C$ celo l'oërin in colum effere homo, \& optimus talium æftimator, \& minimè à naturâ aut di ciplinâ faetus ad? alfentandum. Valdè irem capirur îs verfibus, quos in cifigiem fuam \& parris conpoluifti. Mihi quidem, yu nec omuium hebetifimus ad ea fludia fum, nec multùm acutus, ita placene, ut negem quidquam el cgantius fieri polfe,quodique propius accedat ad genium purx pur $x$ antiquitaris;ex quo myrorhecio promendum eft, quidquid probabitur probis.Baud.Cent. E Epift.27ad Fan. Donz. fil.

Certe omnia magna mihi de Te fpondeo, fupra cos qui nune, \& qui fuere in Batavìi ( non inflandi cui causâ di. crim:) vive tantum, \& curfun hunc quem copifti tene Lipf.in Epilt. Cent.3.ad Belg.Ep.2.

Cum ab co termone dilcelli, quicquid: fupereft admirationis in te confumo, adolefcens doetifime; Facilè enim ex is qux adhuc vidi, quam frugem factura fit bec leges, qux a dhuc in herbà eft, auguroi. Deus oprimus Maximus (adolefcens. nobiliirime) tua ftudia profperet, tuam juventusem regat, vitam totam omnibus. bonis cur.ulet. If. Cafauba, in Epift.1.5.

Patrem xamulatus fanus Douza filius, anno xtatis fux, fifatis funcerèmemini, 16. novam eanque pulcherrimam Plauti cditionem dedit: IHos Amorwm Trium-

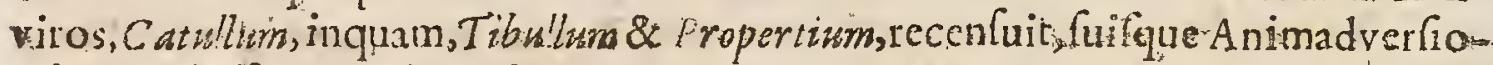
nibus doctifimis explanavit: Et, quod omnes, me tamen tacente, intelligint nimio plura ejs $s$ in rem Litcrariam bene promerita futura fuerant, nif Deus super optimum illum, \& fummx fpei juvenem, heu! præmaturè nimis \& patri nobiJilfmo \& nobis omibus er puiffet. Galp. Sciop.De Art.Crit.p.17.

Lunus Douza mirabilis erat ingenii, quo felicirer perficere potuiffer quicquid aggred voluifer. Qmamentum uaiverfi o bis illum vocat Iofephis Scaliger, dixitque in xtaris floce cum ad lapientix \& eruditionis gradum ejufinodi alcendiffe, adquem virtute aceruditione charifimi viri, vix atate provecta perpingere pozuerunt Grotius Annalium libra.j. nobis alfeverat, cjus Poërica fripta-paternis longe praftare, quamvis tantam in Republica literaria Poëf fua Pater ejus: famam fibi paravel is. Imo hunc ab illa adjutum fuite in Hollandicorwm AnnaJum compolitione. An Teifjer Elog Viror End: Gall?

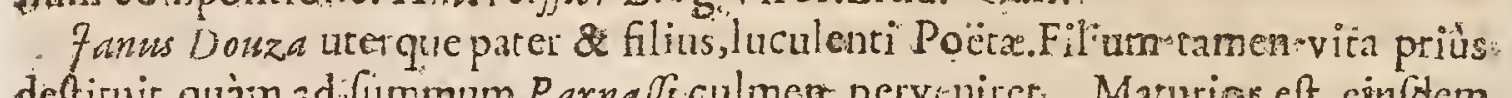
defticuir, quàn ad fummum $P$ arnafsculmen perviniret Maturior eft cjufdem.

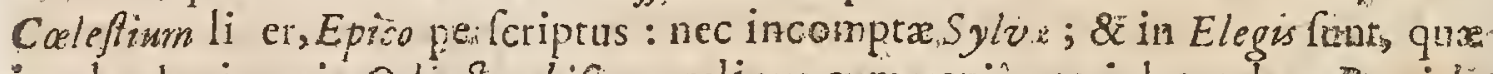
jure laudes, item in Odis, fambifque:reliqua ctm wenia xtatis legenda Zorrisb. de Poër.p. '41. 42 .

* Ejus libri Rerum Coleftium, \& in laudem Umbra, jus oratio funebris, A fint; cjufque oratio funeb is, $P$ ediculi;inter $l$ bros expurgandos numerantur in Indice. Madrit.ed tánno 1667.

Extar Declamatioin laudem Vmbre Lugd: Bat. I6!8.8०.

Extant Batayia \& Hellandie Annales, inchoati; à Pacre verò adhuc fuperftite 


\section{CELEBRIORUM AUTHORUM.}

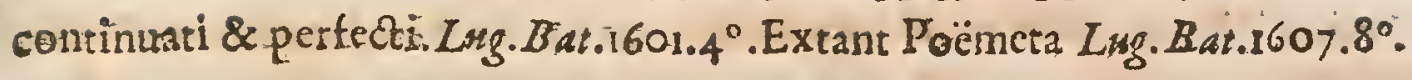

Conditus elt $H_{\text {agd }}$ Comitis unà cam $P$ atre fuo, ubi hoc Epitaphium reperitur:

\section{D. $S_{\text {。 }}$.}

7.Douza Jani F. hic cubat, qui wixit Ann.25. Arenf. Ir. Dies 4. Jaui Douzz Patris, of foiti.

Jierque Douzza, ztergite Janus hic cublut;

Patergue, filinfque: Morte quâ, rogas?:

Pater dolore, shatus afthmatc, è vix.

Sibiliabore quod crear at, occidit.

Precari at ipfe ne gravare mortuis,

2Eegata vivo utrizue que fuit quies.

\section{DOMINICOS BAUDIUS}

Hoc cjus Symbolum.

\section{AIEN E I IETEYETN。}

T F̈lulcnfis Flander, Jurifconfultus, Hifftoricus, \& Pöëtådoctifimus. Natus eft anno 561 . Obiit anno: 613. Prinò Theologix Opxeräm dedit:mox eâ defertà, Clar. An.D: $M D G$. at Jưris ftudium fefe tranfulit, cui cùm per quindecim menfes ftrenuè incubuiffet, Doctoris gradu dignus habifus, eoque inaugukatus eft. Lugduni eloquentiam. profellus eft. Scripfrt Pö̈mata.ltem:tres libros de Iriduciits Belli.Belgici; Epiftot las, \&c. Kanig. in Biblioth.

In Baudiovivente memoriam, ingeniumque pletrque admirati funt $\because$ geniumque hominis Epiffole ejus pafim produnt, quas feribere ad amicos incredibili fe licate folet, in quibus ira exe expreflit, ut in iis vivere adhuc \& firarevideatur. Valer. Axdr. in Biblioth: B.ligic.

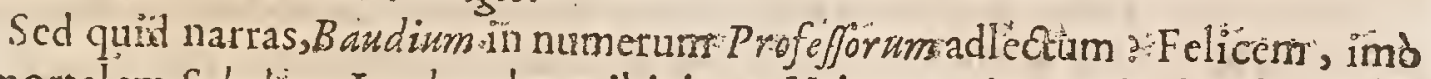
inmortalem Scholam-Eugdun, hoc tibicine! Utinam ad vos advolare liceret $\$$.

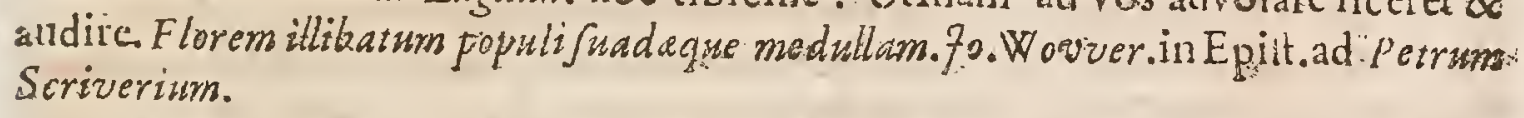

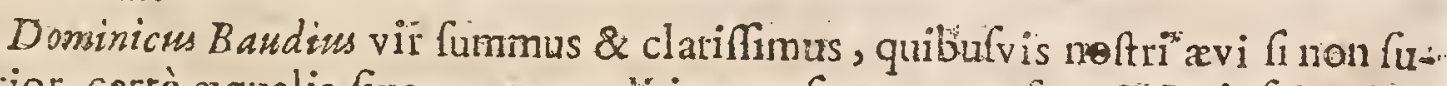
perior, certè aqualis, five veram eruditionem, five rerum ufum, \& Juris fcientiara:

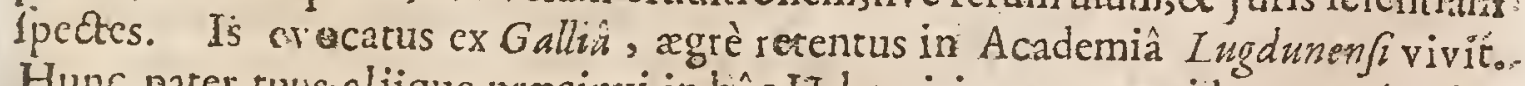
Hunc pater tuus aliique pracipui in hâc Urbe viri penes me videiunt; cjus incredibilem eruditionem, memoriam, ingeniumque, fupra mortales admirati funt. Idem in Epift.ad cognatum fum ANuh a $F$ echta.

$$
\text { STSE } 3 \quad \text { Legi: }
$$


- Legi, mi Baudi,quam miffti orationem, qua vel filliade prolixior fuifet; - tamen cupidos adhuc nos dimifflet, nec planè dum fatiatos. Equidem hoc milii - non lumo, ut de talibus judicium puten ferre me polle: Si quid tamen ufi lon'go confecusi fumus, neque in totum lingux Latzne fumas áuúntos, quid fit Lati" nè Cribere non fcimus, niff hoc eft ita loqui,ut tu lo yucris. Sive prosa aratione - a te fcripti lego, video: colloquentem mecum audire, fine fuco, fine cincinn 1 s - \& mèrctriciis ornamentis quibus infana hac juventus Sermonis elegantiam me"ticur, If.cia aub.Epilt.2-6.

Legi his dicbus incredibili cum voluptate Carmen aurewh, quo virum diviaum[S caligerum] \& novum cjus opus Eufcbianum laudafti. Nihil poterat neque elegantius, neque Latinius.Jam fententiarum gravitas cum perficilitate ita certat ut nelciam utrum potius mirer; taceo pictatem quam totum carmen lipirat.1 derm Epilt. 46 ;.

Baudiumauditorem tuum hî́c vidi,cujus dootiffimis poëmatiis valdè captus Sum Iof.Scalig. Epitt.5. ad Iuf.Lipf.

8 win doctus ett Budires habet fylum non Ciceroniansm, fed feculi Domitiani; omnes Baydii Epiftolas alfervo Scalig. 2. Gall.

Amicus veró nofter dum viveret, \& qundo Dordrechim divertillet, holpes fuaviRimus, Dominicus Baudius, Pö̈ta idem clegantifimus \& difertifimus. Voff. de Analog l.I.C.42,

Donizicus $B$ audius, Infulenfisf Flander, Jambis potifimùn inclaruit, immo omnibus ferè in hoc articulo nunerofior; non infel ixtamen five Epico, five Elegiaco verfu. In Gromis tamen Iambicis fecuriòs regnat, \& difertius philolophatur. Barrich. de Poërc. p.410.

Epifzolas Bandii I quis legerit propter egregium ftylum, operam non Iuferit; alioquin vixulla re, lectu \& icin dignte ibi comparent. Vöt. Biblioth.fudiof. Theolog.1.2.c.4.p. 284 .

His adde Dominicum Batdium, virum ingenii felicitatecum vetcribus com-

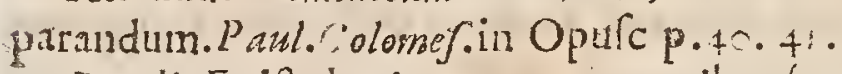

$B$ audir Epifola in tyronum manibus funt. Nemini ignoius $B$ andius, Calibus * facetiis ubique diffuens. Vir fuir doctiffmus, Doëra inprimis in Jambis felicillimus. Dictio ejus, fi judicium $S$ catiger in Excerptzs Pateanats audimus, fapir phrafn Neronimi temporis. Et enim in ilio quidam flos lermonis ad poc̈rimum aliquantum accedens, \& colorem aliquem è Plauti arguriis trahens, qui ipli fori-

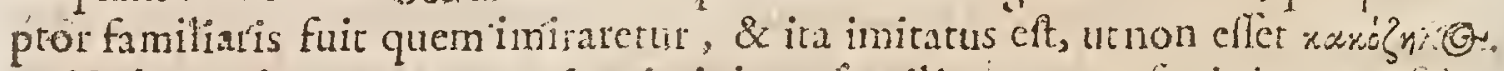
Epiftolare cnim argumentum inprimis iner familiates non refpuic jocos \& fales. Vir fuit meliore fortun dignus, fi iple faber ejus efre portiller. Habitit familiaria vicia,qux vehementer iph abtiterunt ad altiora tendenti, Venerem \& Bacchum; amoribus enim paulò plus, quàm licébat per honeftatem \& ordinem, deditus fuit; Quod occafionem dedic el ganti 11 i Centoni, Virgiliano quem Dan. Heinfurs in ipium difimulato nonine fcripfrt, qui reperitur inter Poëmata ejus p. +26 . Accellit pofted,vel in famam vel in infamiam Baudii, qued Petrus Scriverivederet tibrum cum riculo:Dominici $B$ ardit Amores, in quo ille congentic onnes, qua de 
hôc argumento habentur in $B$ andio, Epiftolas; ; adjectis aliis fimilis argumenti, non omilfo etiam Centone illo Heinfiano, cui Dom. Bandii nomen prefcripfit, quod difimulârat in Poëmatibus fuis Heinfius. Umnia in illo libro lepida,grara futura ris, quos trahit illa voluptas; amatoribus fcilicet, fed eruditis. Nec mixum eft, delectatum fuilfe hôc. Iabore Petrum Scriverium, qui \& iple totus ad has delicias compofitus fuit, fr fides habenda eft illis, que narrat Colomefuns in Opufculis tuis; illic cnim mirabilis hiftoria de illo habetur, p. IOs. quam illic vise. Dan.Georg. Morbof. Polyhift.p.306.

Peirws Scriverius de Effigie Dominici Bandit hec Carmina compofuit:

rane, anid affectas osmagni reddere. Baudi,

pittor? ad bunc homzzemison fatis apius eras.:

Nullus Apolleis color eft geniuf.gue tabelis,

Lylipunom frustrat axitelemgue voles.

Optrmus ipse fui pictor, morumque fuorum,

Quos joens of docti compo fivere Sales.

Ona vel in mediun procedat Epiffola Baudi;

Vera redicfacies, affimilata perit。

Iil eundem fegucntia compofuit Higho Grotivs::

puem legis; \& landas, $\sqrt{i}$ vis noviffe, Pö̈tam.

Verrfbus of vitâ Baulitis unzs erat.

Vidimus hunc ipfum qualem tibi carmina manfirant:

Ingenium Domini lata papyrus babet.

Talisierat, fen cum fluitarent profpera, fen cum.

Immeritum premeret Javior aur a caput.

Liber ơ intrepidus, nec qui concederet zunguame.

Fortuneanagnis Regibus effe minor:

Nulli ponte nocens, ơ amabilis bostibus ipfis,

In quo, fo noffes, perderet ira locum: :

Iñjenfus.Sceleri: fed non ut lege. fever â

Viveret, antigua fimplicitatis amans.

Mrelle madens; quo non incorruptius altes.

THifcuitinnumeris Seria mille jocis:

Ei ficunita fimul permittis dicere, vates:

Tejus arguta mifrus Ariltophani.

* Döminici Bärdit Orationes, ejufdemque Poëmatum nova Editio, inter lis",

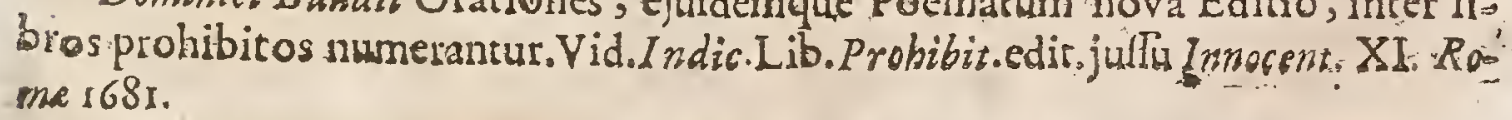

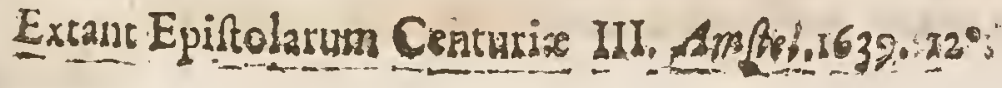


Extant Orationes aliquor, morte Baudii fimul editx, $1619.8 \%$

Extant de Induciis Belli Belgici libri n11.1613. $4^{\circ}$.

\section{«U U I L M US C AMDENUS, Clarentius,}

ClaP. A.D MDC.

T Ondini natus eft Anno Dom. 1550.Obiit 19ono die Novembris ann.162\% Scripfit Hitoriam Britannicam : item Hiftoriam de Rebus Elizabethe
Regina.

Criticus accuratus, Philofophus omnibus numeris abfolutus, Linguarum Grace \& Latina, ncc non rei 4 ifforic a peritifimus, maximè autem retum antiquarum cognicione inftructus erat Camdenus; quibus nominibus non tantum apud $A$ nglos, gener e \& er: ditione claros, in pretio fuit, verùm apud exteros quo que celeberrimos fimmo in honore verfabatur; quales fucre Orielius, Lipfius, Douza, Scaliger, Thuanus, Gruterus, Peireskius, \&c. quorum perinde \& aliorum haud paucorum è literis, ad Carndenum quidem datis mihique perlettis, facilè colligendum, coævis mnibus, prifcorum leculorum monumenta rimancibus, ip fum fuifte antehabitum. Enimvero popularibus Anglis, quotquor eandera materiam nquam i Luftrarunt, longè viderur antecelluiffe, \& proinde Infularum Britannicarum Panfanias merirò à quib ldam nuncupatur, utpore cujus famâ diuturnius non erit Gentis Bricannie nomen. Anton. à Wood. in Autiq. Univerf. Oxon.p. 27 c.

Antiquitatis ftudiofus \& impenfus amans, prefertim fuz Patrie, nihil quod ad ejus veritatem eruendam momenti aliquid habere videretur omifit ; tandemque Hifroriam Britanniam publicavit. Unicum illid \& incomparabile Opus, quo Britannice noltre Antiquitatem, \& f a antiquitati Britanniam reftituit, quo pulcherrimam terră(à toto orbe divifam)toti terrarum orbi confícuam \& illufttem reddidit: hôc uno opere quid luculentus ? quid lirratius ? quid accurarius, vel Paufanias, vel Strabo, vel quivis alius vererum Geographorum dare poruit? Vetutis induit novitatem, obfcuris lucem accendit, dubii. fidem conciliavitAnnales Rerum Anglicarum, \& Hibernicarum, regnante Elizabeib., acsreditur, fuo tempore abfolvit, ejulque primam partem edidir; in quo opere, we tecta Hiftorix numeros omnes reperiri, haud credo quenquam elle qui diffircbitur, nifi judicium prajudicio obnoxium nimis habeat \& occratum. Whear. in Commer.cut. Gul.Carden.

Annales Elizabetbe fufcipit Camdenus, perficitque fylo tam plenè Regio, tam undequaque \& rei \& fibi confono, quifi virginalem tanta Majeftatis iplendorem libro luo maritare tatuifet; ut pari fame confortio polteris femper audian, Elizabetha \& Camdenus. Tounleius Orat in Memorian Camder.

Strabo Britannicus, \& Panfanias Anglicus à plurimis vocatur.

Gulielmus Camdenus, vir in reconditis Antiquntatum apothecis longè periffmers. Brian.T Tuynde Acad. Oxon.p.2.

Camdenus vir impen è doctus. Bocbart. in Geog. Sac.

Camdenus nobilis Britannis Lux illutraror. Bartb.Adverf, l.x.c. 17.

Camdeni 


\section{CELEBRTORUM AUTHORUM.}

Camdeni Britannia bona Scaligerana 2.

Limatiffna Camdeni noliri.Britannia. Donza lib.r. Annal.Holland.

Extat praclara Hiftoria Wilhelrin Camdeni de rebus gettis Elizabcth .Primam Hiltoria partem edidit dum vixit;pofteriorem edere noluit ob odii metum; altcsam ver partem debemus Nicolao Peireskio, Baroni Gallico, cruditorum ad ftutporem Parrono. Lectu digua illa Hiftoria, quia mira multa invenia * Hermain. Conring.

Non Anglos folùm tuos, vir doetiflime, opere illo tuo (Hifbrià -Britannicâ) femper vikturo tibi obitrinxilti, fed omnes quotquor ubique finnt vetel is Hiffovis amantes'\& cupidi_. Omnia in tuis feriptis mirificè mihi placent, ingenium,

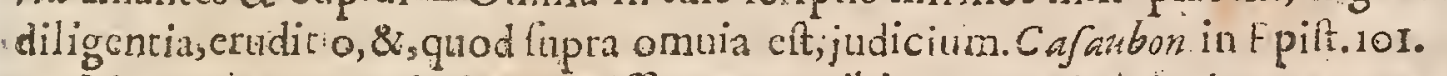

Munus a te accepi, vir ornatifime, per mihi gratum, Britanniam tuam:quam illuftrafti ingenii \& induftrix clarâ facc. Multum Pâtriutibi deber;multum extera hos; qui per te pulcherrimam Infulam videmus, etiam cùm non videmus. Perge in hoc \& fmili ttudiorum genere , quod abefle nun poreft quin tibi famam,pofter is reternum ferat fructum. Lipf.in Epitt:ad Carsden.

Camdenumauchorem hâc fequor, friptorem longè gravifinum Mir arc.Zür. Boxborn.in Epitt.p.138.

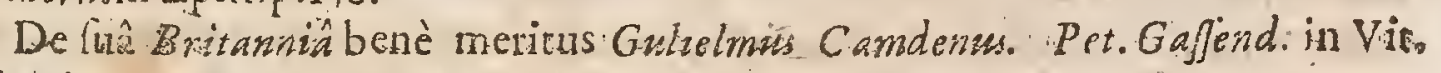
Peiresk.p.ja.

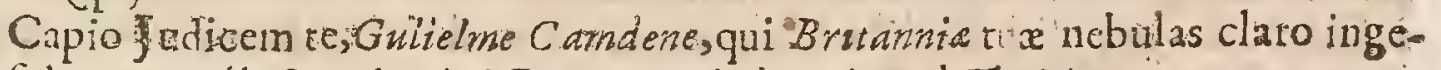
nii fole nemper illuftrati. Lipf.Comment. in I.I2. Annal.Taciti.

In Caindeno ur eluxic veritatis ftudium, dos apprimè requifita Hiftoriam fcribenei, fic maxime valựic Oratione ad Hiftoria compofitioners accommodatâ: nam nec mellihtuas Cafaris stylus, nec lepos Curtiz, nec acumen Tacitidefunt il${ }^{2} i_{\text {i }}$ ira ejas Stylns naturali pulchricudine exurgit, fententiarum punctis tanquam duminihus âpergitur,\& in animos legentium placidè fedinitrit. Lud.Molinam Orat.habir.in Regiâ Acad Cxon in laud. Gul:Camdent.

Cambdenu cuditus \& fagáxille Vir Hiltoriam Elizabetbe Regni conferipfit. ea fidelitate eaguc curnztam terfo ltylo tamque acri judicio, ut ablque controverfia ea fir potifims pars Anglica nottrix Hiftoria. Sed iple pafirn profitctur fe multa illis reliquilfe, qui Ecclefix Eliftoriam aggrefturi elf́ent. Qnapropter qưod ad hujus Regui exordia (pectar, ur ill tum, ea fide, qux tam infigni Scriptori debetursin omibus fequturus fum, fic etiam cum in quxdam inciderim, qua vel ip= funs latuertunt, vel qui in Hiftoria tam fuccincta prolixius enarrare minimè necelfarium dexiryon verebor prater ea que fcripfir aliquid fuperacedere, quamvis fama merito ipli debita liuperfuum videri faciat; aliud quicquam rebus ab iplo tractatis adficere. Doct.Burnettus. Fux Reformationis. Hiftorix parte 2, lib. 3. 18. 377. Angl.

Dominus de Thou, cum generalem Hiftoriam contexcre in animo habetet cominercium colere cœpit cum omnibus Eraropa Viris qui maxime idonei etan qux vera effent ad ipfum tranfinittere: Magnum itaque cum Camden combiner-

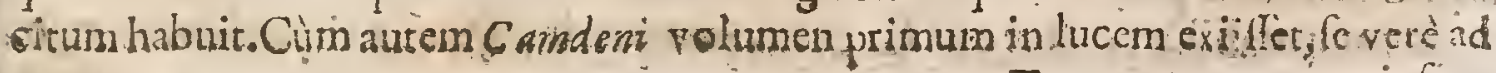

$$
\text { Toto dist }
$$


ipfum fcripfix deprehendens id adeo difcrepans efle ab is, qux in mutuis ipforum Ep ftolis exarata fuerant, præfertim réfpectu Scotorum Keginæ. De quibus quod verum erat ipfi confeffus eft Camdenus, Icilicet Regem facubum illud necellariò tevifere volulfe, idemque poftea tradidiffe in manus Comitis Northampioniz, qui. erat Ducis Norfotcice frater, qui propter illam reginam capice truncatus füerat, \& pluima ex illo erafa, pluimaque alcerata fuille Hoc moleftifi ium fuit Camsdcno, qui follicitus fuir neponterionis partis idem effet fatum: Et ea proprer illam extra Angliam ad puxturstem illum Virum tranfmifit, ut poff fum obitum fideliter typís mandari poffet. Hoc in Anglia notifimum eft' Er Secunde Parivs,ultra mare ad Extraneum tran /mifio, facile quemvis inducie ad credendum cam hijus veram rationem fuilfe.D. Burnetti Replicatio ad D.I arillas p.59.Angl.

* Gulielmi CamdeniBritannia, cjufdemqie Annales Elizabetha cum Expurgasionibus permirtuntur. Ejuidem vero Actio in Henricum Garnetum Soc. Ielii, \& $c_{\text {. }}$ verfa in Latinum ab codem $C$ dmdeno, omninà prohibetur. Irdex Madrit:

Extant Annales Rerum A Anglicarwn \& Hibernicarum tegnante Elizabetbâ. Lugdwni Bat.ex Offic.Ëzevirianâ 1625.î 8\%.

Extat Defcriptio Britannich. Londini aptd Georg Bishop.1607\% cum Tabulis Chorographicis, Fol.

Sepultus eft in Ecclefia S.. Petri-Wefmonafterienfs porticu Auftrali; Choro: proximâ, 10 . Novemb. Anno Dom. 623. Parieti vero Occidentali, fupra tumulum, Infixa eft Effigies. Viri dimidiata, ex marmore albo dedolata, \& cjufmodiunfriprione inferius pofitâ,ornata.

Qui fide Antiquâ \& operâ afiduâ Britannicam antiquicatem indagayit, fimplicítatem innatam honeftis ftidiis excoluit: Animi folertia n Candore illuftravit Gulichnu Carndenus ab Elizabetha R.ad Regis:Armonu(Clarentititilo). diguitatem evocarus. Hîc fpe cert refurgendi in Chriffo S. E.Q. Ubir Auno. Dom.16.23. Noy smbig. atacisilux 74 .

\section{ISA A C.U.S CASA U:BO N:U S}

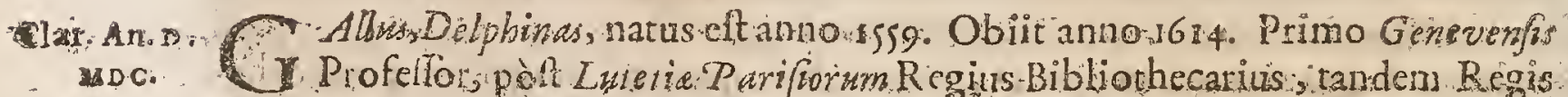
Iacobi Magui Bratania Confliarius tactus eft.

Confecir Exercitationes contra Baronium Cardinalem Comment in Hif Aug, Seriptares, Swetonizm, Strabonem, Theopbraftum, Diegenend Lertiun, Theocri-

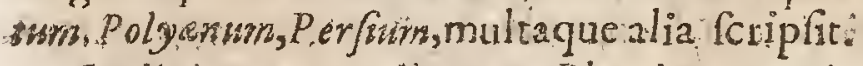

Scaliger eum endivorum P bonicem, Heinfuns enditionis Solem \& xtaris de-

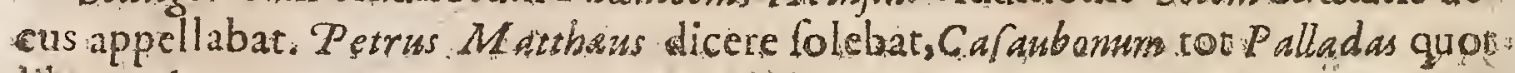
inbros edere:

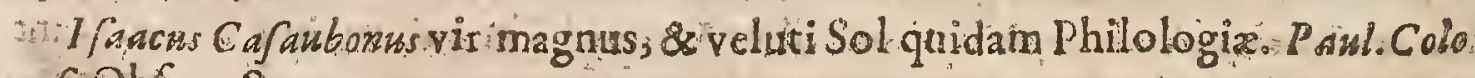
mef Obrerv.Sac.p.25.

Incomparabilis yir \& feculi cui decus inmortale, Ifugns Gajaubonus, nun quans: 


\section{CELEBRIORUM AUTHORUM.}

quam fine laride nominandus, nunquam fatis laudatus Salmaf. Praf.ad Hilf. Aut guit.Script.

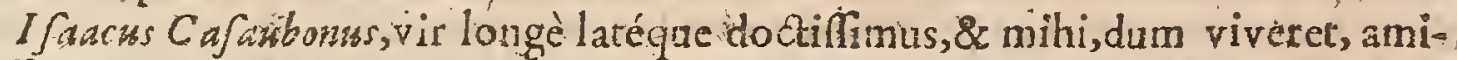
cifimus, meritifue in rem lieerariam clarifhmus, in Hiltoryeis recendis verfatiffumus. Salmaf. Nor.in = Elit Spartian. Hadrian.

Cujus ertıditio praconium meum longè fupergreffa eft: equidem feculo graculor quòd habeat , quem antiquis opponat. Iobanta. Wouver. de Polymath. cap. I2.

Erat invictus operis \& laboris, \& in omnes de publico benè merendi occa- frones femper intentus. 'Meric. Caufeub.de iv. ling.p 47.

Cafaubono ftatim à tcheris unguiculis fincero veræpietatis lade imbuto lupsipetebat tara Linguarum Orientalinm cognitio, in Grasiâ vix fecundum, nedum parem habebat:Non deerat facre, non de erat Hitto ice veritatis illuftrandx Itutdium.Iac.Capel.Ptezfat.ad Vindic.pro If.CaJaub.

Vir Nectare \& Ambrof Remus in Themift.p.159.

Imınortale Gallix decus, quô digniorem omni laude alium ne Hiftorix quidem continent. Rittershufin Salvian.

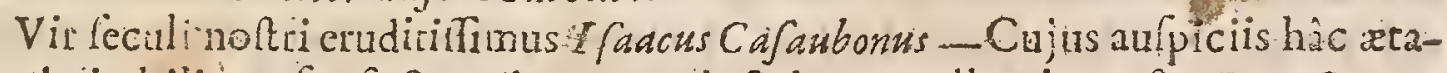
te admirabilis curfus factus ad omnem doctrinxe excellentiam eft. Petr.Cunans Repub. Hebrear. p. $33: 54$.

Cafaribonus, vir ille plurima fcic, pauca ignoat. Quàm multa quotidie etuit, qua fruttrd alibi requiras! Dominic. Band.in Epitt.Cenr. 2. Epint.9. ad Ioham. aे Wow

Ifarcus $C$ a faubonus vir æatate noftrâ vix cuiquam comparandus. Gasp. Sciopp. Sufpect.Lect.1.4. Epilt.I3.

Virum magnumac doctifimum fapiùs eum appellas Bochartus in Sacrâ Geographì.

Mufarum favus Taacus Cafarbonus. Toff:1. Inftit.'Orator. p.218.

Aniinadverfionibus.I saaci Cafauboni in Philologum Nawcratztam nihil hic Sol co in genere vider crudicius. Idem ibid.l.4.p.214!

Nihil vidi ab colutius Commentatio Cafauboni in Suetonium. 7 of.Scalig. Epitt. 2.x.Ep.29.ad Ian.Douzam F.

Quum primurn mihi falivam movitfent Theophraftei Charatlerestui; dicam feriò, de poteftate mei exivis, nequire me continere porui, quin ea dete predicarem qux \& meritum tuum; \& amor meus poftulabant: quanquam quicquid de te dixero, omne infra virtutes ingenil tui fuerit: Onaria me tua delectant,eruditio, jadjsium, Oratio.I dern Epiti. 35 .

Cafauboniad Suetonium vidi cruditum Opus.Adol efcentem magni ingenii, \&

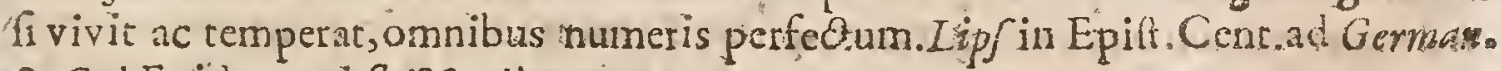
\& Gal.Epi.t.24.ad 7oj.Scalig.

Animadverfiones tuas in Atheniartmaccepi, gratum fane donum te mittente: Agnofco anorem, quem jure tamen deberi mi hi foio amanti. Quod ad iphos.

$$
\text { Ttrot quid }
$$


quid nif te digna fint? nec vel conetur aliquis tale, nif interiòre quadim \& va ria doctrinâ, quam tibi confenfu tributum imus, (a) awbone, qui aliquid tapimus aut judicanis.Lipfin Epit. Centad Germ \& Gall.Ep.69.

Magnus ille literarum vindex If: Cafaubonus tam luculentis \& eruditis An imadverfonibus Suctonism illultravit, ut nihil à quoquam adjici potnifievideaeur; ab co tarnen frve majoribus negotiis di:tricto, live humani ingenii lege, nonnulla pratermiffa fuifle dubitari non debet. Boxborn.in Lit ad Dan Heing.dato. Lugd.Bat. Annor63r.Kal. Aug.

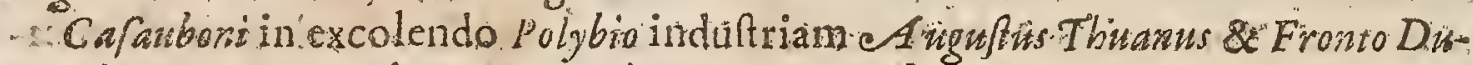
caus fummopere extulerunt:ea verò utrique potiflimum plácuit interpretandi ratio, quam hoc Opere transferendo tẹnillet, ut non facilè dici polle crederent.

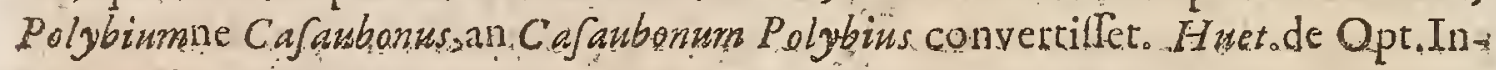
terpret.Gen.

Prxter Cafabonum hod e nullus doutus apud Calviniftas. In Cafaboni Peros. fo condimentum pifce fapidius elt. Theophrafit Charateres \& Athenous Cafauboni optimi tunt. D. Cafaubonus eleganter Latinè fcribir:. Affectu peccat in Epiftola quamide Serarii libro ad mefcr bit. Ejus Epiltolas femper alfervo Cafaubo

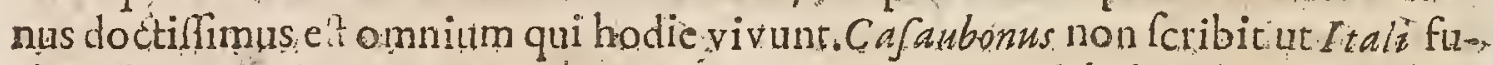
sè.Plurima novit que Lapfins ignorat. Ca fawbonus non debcbat intereffe colloquio Plefiaano, erat Afnus, inter Sinias, doctus inter imperitos. Scalig poltecior: Gall:

Jelf Vuaffor obfervavit Cafaubono fapius excidere Gillicifnos at errores Grananaitcos in ejus: Latinitate.D. Motteus le $V$ ayer ipfum culpar quod tenero. nimis affect amaverit Authotes in quos laboravit, quodque pravum roorm fe-

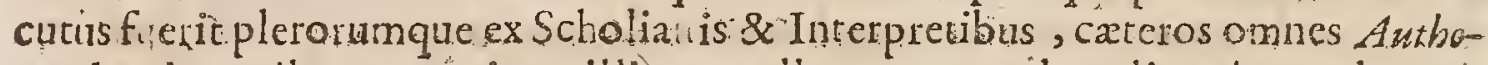
res deprimentibus ut meritum illius extollant, quem vel explicandum vel inter pretandum fuccipiunt; Inter alios verò contenditeum de Cornelia: Tarito contemptim locutun elfe, ad hocsanum ur Polybio famam coneiliare Iudicis Ermdito rum F arifir 685 . Gall.

Augustus Bu bherus referbat, Cafaubonum pro Exercitationibus contra Bat rontinm à Rege Anglia quolidiè coronatum vel ducatum accepilfe: Konig.in Bi blioth:

Petrus Molina iss, in liceris ad Fac. Montacutium, Bathonien fern EpiCcopum, an. 16:0:Cafanbonum arguit, giod ad $P$ aptmasn inclinet, ejufque apoltafia menenda fit, 1 ili in Angina fervetur.

Multa funt in Cafauboni Epinolis fughlariagua tam ad hiftoriam literaian quam Civilem illius temporis pertinent:Stylus familiaribus fcatens elegantiis \& argutiis; Grxce ling ra fiores, adagia ubique apparent. Conpofitio qu dem Cireromiana non elt, neque, ut ipfe fatern, femulrùm cruciavir in verbonum dele fed tamen miram omnia elegantiam fpirant Erenim compofitio interdum omnem

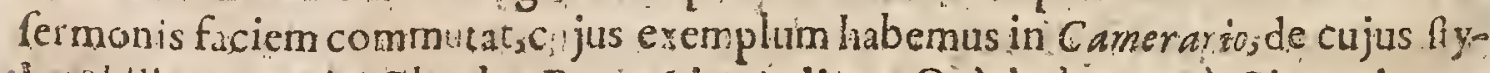
lo Philippus Metahethon 1.4. Ep.2cG.ita judicat: Quòdscùm antea Ciceronis ver. bis \& phrabus uteretwr, compofitionena yeióperiodonm al iam habetet, pof - 


\section{CELEBRIORVM AVTHORVM.}

eà)cumetiam hainc ad Ciceronis normam inftitueret, feipfum quafi fuperânit. Quỉ Gracis formulis in fcribendis Epitolis delectantur, multas tum cx Cafamboni,

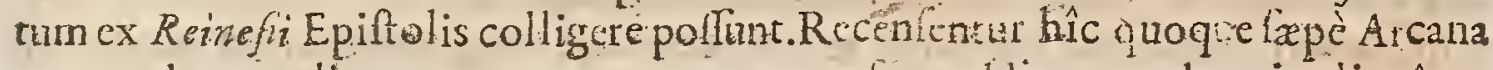
quorundam erudito um, quarum nom na, non funt ad́dita, qua detexir aliquâ ex. parte Colomefrus in Clave Epittolarum Scaligeri \& Canfaubonis, qua addita eft corpu'culis ejus literariis.Non tamen ille omnia notavir.Rittershufizus in Epiftolâ ad Richterumb fcribir, fe plures habere Cafanboni Epi!: olas,p.: or. Ab eo crecio impetravit plurimas Gronovius quas editioni fux adjecit. Extar ad Ricbterum ejus

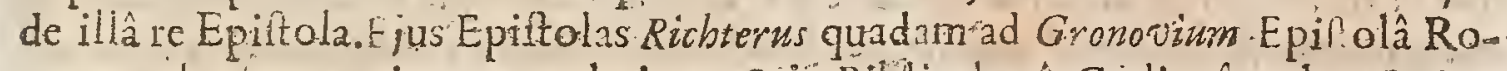
mæ combultas nunciat, p.240. latitant \& in Bibliothecâ Girdìanầ mulex Cafäsboni Epitola.Dan.Georg.Morbof.Polyhift.p.287.288.

* Ifact Cafanboni Epit olx quotquot reperiri potuentut : item Epillola de morbi ejus mortifque causà in Decrero.26.Oetob.1 64c.Ejufdem Corona Regia ab:Eupliormione inlucen edita, in Decreto 18 . Decemb: $16+6$.Item in primum Tomum Annalinm Baronit in Decreto :2.Decembir624. prohibentir. Vide Indo Librotum prohibit. Alexandri VII.P.M.juffu edit.Rome. 1664. .

Varia ejus Opera variis in locis atque temporibus funt impreffa.

Hoc ejus Epitaphium; quale legitur Londini in Templo Westimonafterieng

$$
\text { IS } A A C \cup S C A S A \cup B O N U B
$$

[O Doction quidquid eft alturgite:

Huic tam colcndo Nomini ].

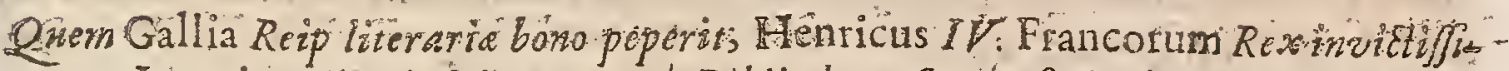

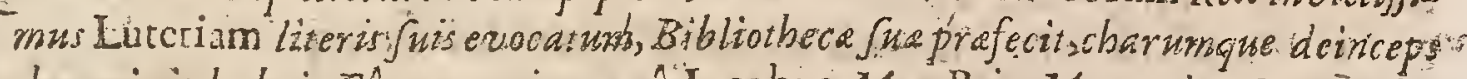

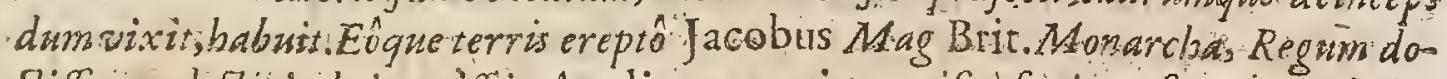

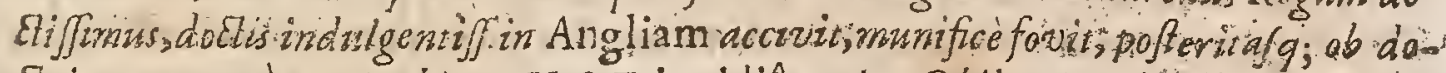
Itrinal atcrnims mirabitur.H.S.E. invidiâ major. Obizt"etern. in Chriltowitam

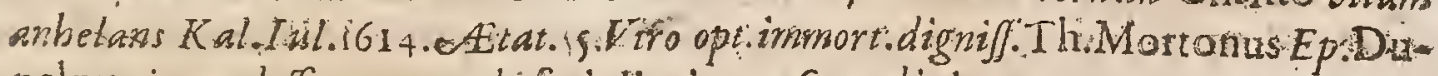

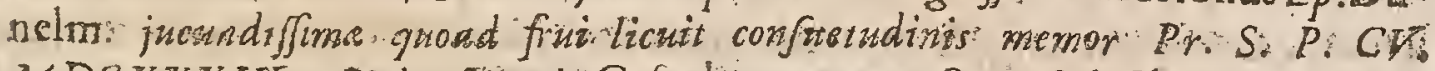
MDCXXXIN. Quinoffe wtalt Cafabonum, non Saxa fed Charras legat for

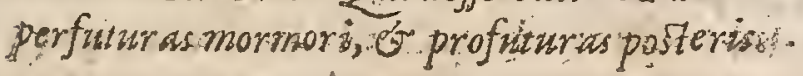

\section{MARTINUS ANTONIUS DELRIOZ,}

Sóc. Jê:

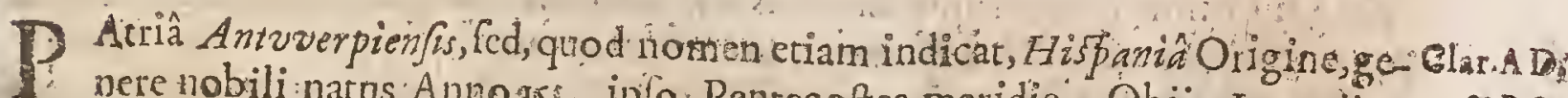

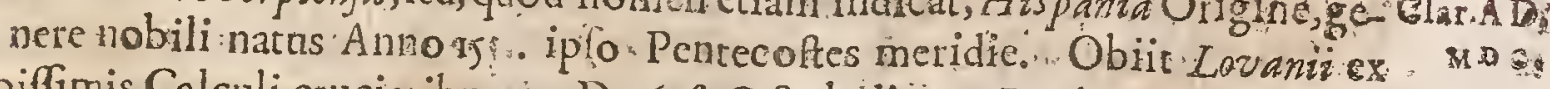

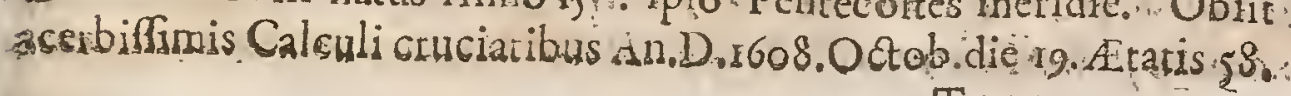

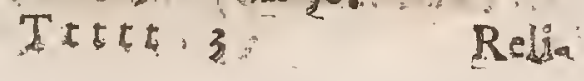


Reliquit Adagia Sacra Ver:\& N.T.Difquiftiones Magicas:Notas in Genefin, Canticum, Ithrenos: Comment.in Senecam Tragicum, \&c.

Ipío pueririx exordio vegerum, acre emicuit ejus ingenium, ad literas aptum atque incitatum:cui cim accefillet contumax ftudium, cü brevi evafit doctrine; wt annos.12. natus, plus mius mille \& c ntum Auctorum Sententias acti judicio expenfas congelferit in unis Adverfariis ad Senecam:quem ideo fustus Lip fur ævi o tri mirachilbs appellans, negabat le lcire an lint non pauci eorum Scriproium quos ille diligenter evolitos pioferebat. Greca, Latinaque adjunxit linguas He-

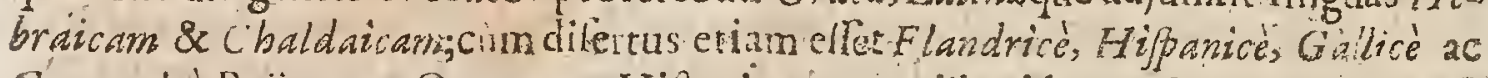
Germanicè.Pötarum, Oratorum, Hiftoricorum quidquid toto Belgio erat, excufferat. Fuit vir animi candorc funmo,ur, quod ab eo dicebarur, fincerum, confitmatumque omnes arbitrarentur. Nullus fuit co nhquam magis integrè virtuti amicu, \& honeftati,ubicunque ea demum effet, in quocunque ellet. In ipfis hoftibus yuidquid non illaudarum elfet, ingenuè amplectebatur, \& efferebar. Non opinionibus vulgi rapicbatur in omnibus rationem fequebatur ducem, cætera firfque deque habebat. Alegambe.

Delrius, Latinè, Grace, Hebraicé, Chaldaicè, Flandrice, Hispanicè, Italice, Gullicé,Germanicè ita loquebatur ( fune diltincte novem Idiomata) ut in plerifque eloquentifínus, in nullo holpes effet. Quintus Ennius, te Re Gellio, rria corda har bere dicebat, quod loqui Grace, Ofcè, \& Latiné fciret. Num igitur non novem corda habuerk $D$ elrizss qui novem linguas percalluit? --.-P podigio fimile eft vel ipfa fola Auctornin in Lure nomina meminilfe, quos ille Epiftolâ ad Parenten fum fe perlegife commontrat. Furt were ( quod Tultius de Catone) librorumhelIuo.Drexell.Aurifod.part.1.c. .

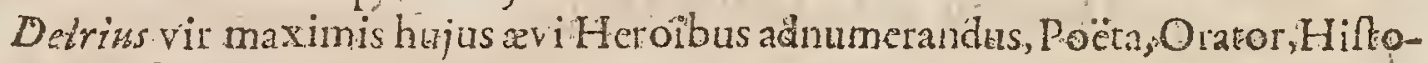
ricus, Jurifconfultus, Thoologus, variorum item Idiomatum lcientifimus, $A$ it. Sander.de Brugenf.erud iclaris.

Mulcijuga lectionis vir, Ant.Delrio.Vofll. ide Idolol.c; 44 .

Doctas, Oratores, Hiftoricos omnes, cum facros, tum prophanos, wilo: ophos, Theologos, omnium denique diciplinarum Scriptores fic e hatherat, nihil ut ignorare, \&; quod difcerct, dectie viderctur. Sacrarum literarum lectione poiffimún fub viuze exitum delectabatur; ut ciolendum profecto fit, yirum Hebrais Grecis, Liatinif que linguis apprimè inftuctum, in medio illutirandz Scriptura divinz ctufi, Orthodoxie Ecclefixerptum. Sed \& nos' Belge naginum certè lumen patiogue decus amifimus, quodad funelti bujus Belli. Hiforiam, quam ad Foanis Auftriz exceflum deduxerat, es fide prolequendam, horro term ulu, ju-

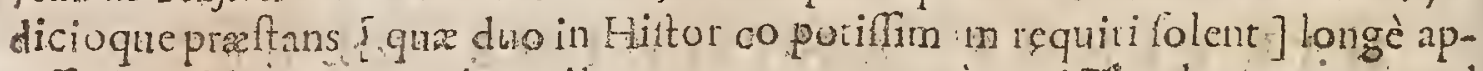
tiflmus videretur. Inter ingenii monumenti, qux cumad Theolog am, tum ad Jurifprudentiam lireraque human iones illuftrandas varia pofteris reliquit, maxime, laudantur ternurque manibus Diffrifationes $M$ agica; novun feilicet, atque, rit Lipjus appellatsdodtimopus Aubert. Nircus.

Plerague ex in is obalfo olim me c:o $M$. AntDelrio (eum honoris \& amo-

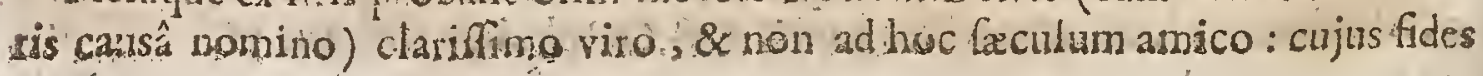




\section{CELEBRIORUIM AUTHOR UIM.}

cerca mihi, fuit, rebus incertis. Lips: l.i. Elect. $є .26$.

M. Ant.Delrio jurifconlultopro adverariis in enecam;pro Noris in Clán dianum, i Senecam, Solinsm, alios denique, quum multùm antè deberemus, nune nuper Latina Tragadix nomine plurimum debere cepimus. Sciopp. de Art. Crit.p'4.

Lutum \& ftęrcus Generis Humani Xfartinus Delrio---Quô invidentiorem maledicentiotem, arogantiorem bipedem hodie neminem credo vivere. for.Scam lig. in epit. $13 \cdot 134$.

Sulmajus ejus. Editionem Solini non magni xtimat. Salmaf, Protegom. in Ful.Solin.Polyhif. .

Varia ejus Opera variis in locis atque temponibus funt impreflá.

\section{JOANNES: DRUSIUS}

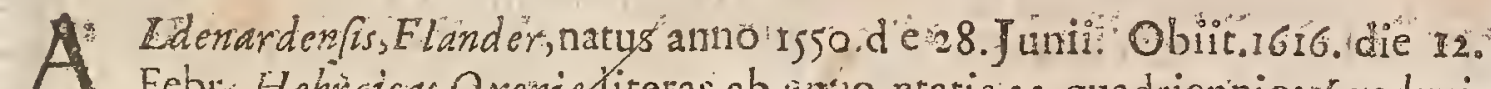
A Febr. Hebraicas Oxonig iteras ab amo xtatis: 22.quadricnnio Lugduni,

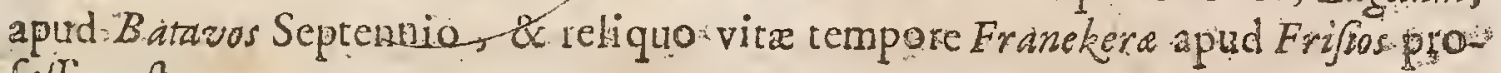
fellus eft:

Seripfrt Praterita in Novum Tefamentum:Notas in Siracidem:Commentin loen difficiliora Pentatemchi:Obferyationes Sacras: Luafita per-Epiftolas ; inul-. raque alia.".

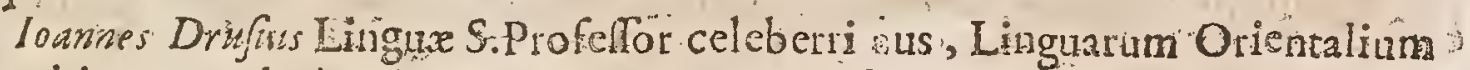
cognitione apprimè imbutus: Opela cjus nota funt. Quenfledt.

Vir Lingua Hebraice peritimus, \& in Scriptis Rabbinorusin verfatifimus Leigh in Tract.de Erudition.8 Erud.

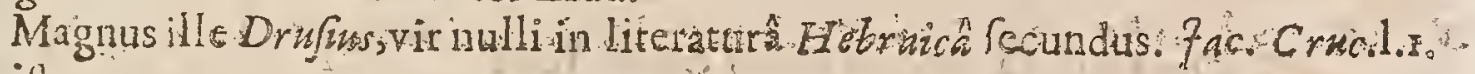
Epirt.ep.r.

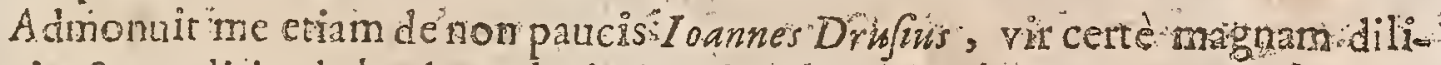
gentix \& enditionis laudem plurimis edit is Tratatibus merito anonfecutas.".

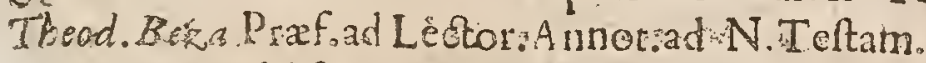

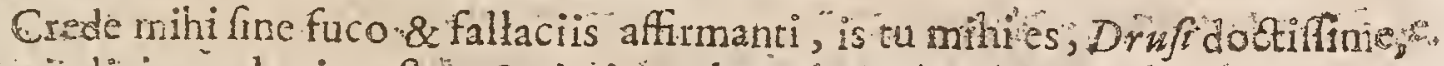

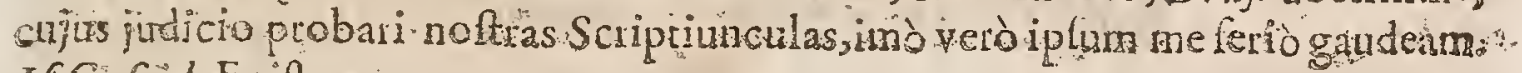
If.C.ajausb.Epitt.7r:

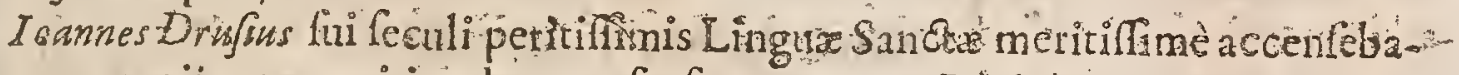
sur , proprique meriti adeo perfuafus erat ut Divinz Grammatici no-3men fibi tribuilfet---Multi dieunt sum Serarno-Hebraicë Lingux callentionem

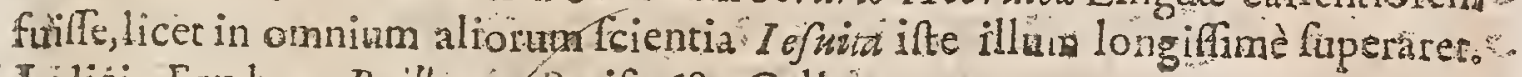
Judicia Erud. per Baillettim Parif.169s. Gall:

Rabbinos non legir a .ub adverfus Serarium libro hune, lenter nimis tractat." Qunm miferum elt Drufii judicium. Nihil prater fuam Grammaticam novit. Sqraritm doctrina non exaquat nifi quoad Hebranm Grammaticam Libar ejus 
de Nomine Dei Tetragrammate febova prxclarus eft. Filius eft Patre doctior in Hebrais. Drufus Lipfii Simius miram haber Latinitatem: non Latinè licibic.

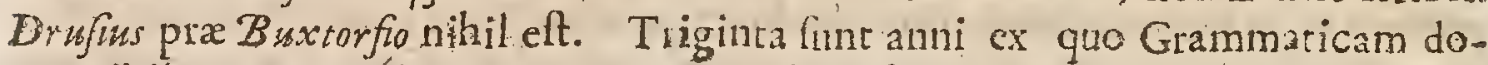
cet,nihilque preteréa novit, \& mirum elfé nifíciret optimè. Ego benè "fcio quid fit Drujus, eft doctus in Grarnmatiers \& in Textu Flebreo. Drwfos noluit unquam lufcribere confeffioninoltrx, \& proptereailli malè volunt fui Collegx. Orufus nefcir quid fit Religio. Noitrx Confefloni non fuffagatur.Lovani inter Papilas educatus eft. Diufus non eft Doctus, licet feputer elfe doctillmum. Seatig. polterior. Gall.

Drufus, qu: feptimum inter Cricicos illos locum orcupat, cateris omnibus, meo quidem judicio, anteponenduselt; nam praterquàm quod in Lingua Hebrä́ca doctus erat, \& per fe iplum Judä̈cos libros confulere pocerat, Veteres Gracos Tranflato:es accuratè legcrat, adco ut meliotem fibi formaviffet ideam Lingux Sacræx quàm cæeri Critici, qui unicè Rabbinorurn lectioni incubuerunt. Ad qund addi poret uòd Divi Hieronymi \& quorundam aliorum Parrum Opera perlegiffet. Verbô ut abfolvam, Drufius omninm Criticorum, qui in hac Synopic compichenduntur, doctrine \& judicio praftantifimus eft. Or.Pr.Kich.S:mon.Hilt.Crit.V.T.lib.j.c.15. Gall.

* Toanni Brufi Opera probibentur, donec emendentur. Vid.Indicem Rom imprelf.ann.1681.80.

Extant in Ruth \& Estheram Annotationes cum Scholis. Amfel. $1632.4^{\circ}$ ". Extant in Iobum Scholia: Amftel. 1636.4n.

Extant in Prophetas un inores Comment five lectiones. Amfrel. $1627.4^{\circ}$

\section{Hoc ejus Epiraṕhum, Auctore Paulo Bufio JC.}

Quiprifcos ritus, qui mores Gentis Judx

Norat, s haud ulli cefleratingciio:

Qui doctus Latîn, Graingue, of quotque ab Ortu

Lingue wnguaris note. Drulius unus erat.

Aft idem, baud alins qrio Vaturn oracula nuper

Terfus explicuit, conditur bô turnto.

\section{Aliud, Auctore S. Sicrama.}

CH aximus exigno tegitur fub marmore Diulus.

Si iamen Heroes mirmoris urna zegit.

Drufus Hebrex vindex of gloria lingas,

per suems obfcura monus pagina fucra cluit.

Pignore quo tantima Franckela culta superbit,

euantum Scaligero Leida Difertagüo. 


\section{Quivite fatur of fame gua circuit orbem.}

Dum fuldirin of pietas crefcere pofje negant

Crefcere guo poffet colum reftabąt avinum,

Cocluin adit, of parrio fella receptapolo eft.

Filia cum genero tanix cognominis beres

Hîc cineres pojuit: satera faria tenet.

\section{JACOBUS DAVYUS PERRONIUS:}

C Ardinalis, Magnus Francze Elccmofynaius, Epifcopus Ebroicenjis, dein Archiepifcopus senonenfr, natus eft vicufino quinto Novembi is Anno 556. Obiit Parijus quinto die Septembris anno Dom 1618.

Scripfit varia, qua duobus magnis voluminibus continentur. Gallice.

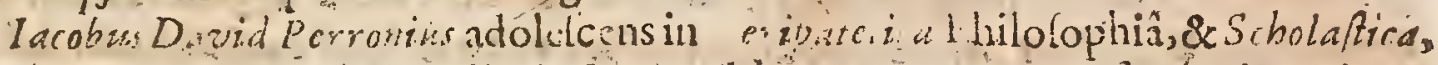
ex câ natâ, Theologià egregiè doctus", ad lixi peramceno \& faceto ingenio \& verfibus Gallic pangendis tilici, qui brlp "yit optimi \& opima fortunâ, quam adcptus clt, dignifimi commendacione in allam fe infinuaverat, cjerațâ, in quâ eduçatus fucrat, "roteffali isin doct inâ. Thits. ad ann. 1591 .

Cardinalis : id ftuporem doetus, velut forbudi ambiguus pucuc emifit fer-

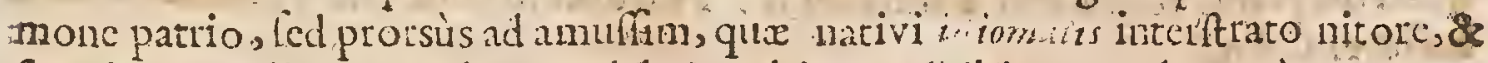
fingulari expolitione verborum dd ctu ubique adhibito, multoperè connendentur. Nomen l.2. 3. R. E. Cardinalium.

lacobus Perrown, virfane pratantilimus, ingenio \& erudicione admirandus, facundia Neflor, atque ut I heologus nemini lecundus, fic \& Pocta Latino ac vernaculo fermone elcgancifimus. wh. Nireti.

lacol su erro: ins doctus \& cloquens ad miraculum: quem fi amplius taudare volucro, fucosfaciam, cum tit major omni läde. Spuntain in Amnal. ad Ann. 3618.

Auctorizate es inter tuos, \& ingenii atyue doctrinx fama apud omnes. If. Casant 710.9 .900 .

Cardinalis Perronius, maguus ille \& curiolus Antiguitatis indagator. Ioan. Dallezus de ver. ur. Patr. p. iss.

Cujus nominc aullum ferè cft apud adverfarios illutrius. Tdem de Pleudepig: Apoftol.l. I. c I.

Cardinalu '" erronus Gallicani Clcri ac Romañe purpurx decus fingulare. Phit. Labbe de Script. Ecclef. Tom. 2. p. $48 \%$.

Petrus Molineur in 'refatione libris adversis Cardinalem Perroritum, cui cie tulus, Novitas Patifm de errorit Refponfione ad Regem laroburn fic judicat: Nullum inter Adverfarios Opus tam elaboritum, reperio. Scd modica ejus Lingux Gra: \& humanio: u Lirerarum peritia, facit ut frequenter celpitct. Gall. Circa amu in 1623. ptodit iadinalis Perronii liber contra fercnifimum Regem lacobum. Liber quem fontificir iminewfum quantan laudibus extollums.

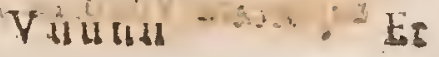


Et eft fanc̀ omnium, qui. Romanain fidem Gallicè propugnaveruat, erudiififimus \& Libtilifimus, Gul.Bates,ir vit. Petr. Molin. p. 716 .

De $S_{2} / 2 j$ judicium ferre polfum a quoniam totos 25 . annes probatos omnes Authores Latinos, $G$ urecos \& Italos evolvi ; totis If. annis Ciceronis Orato. rem in perula Cemper geftavi. Perronzana p.306.307 - Gall,

Omnia illa fun ex ufu aula, inter Aulicos 2 Faminas; : ut de Cardinali Perronio dicebar Iofephus Scaliger, qui ute in Aula doctus exiftimarctur,apud Mulicres differebarde Fluxu \& Refutu Maris; de Ente Metaphy fiç \& de prinspio Lndividuationi. Guido Patin Epift, 67. Gall:

Cardinalis ille Ebroicenfis magna laborat ambitione. Dodus non eft, locurulejus, Faminisgratus eft Parijirs cù degerem Perronius umbia mea fuit, me contiư lequebatur cum Magnares convenicbäm; hoc inficias non ibit. Scaligerana polterioi: Gall:

Perronins Mornei infiguem de Eucharifia librum fiuftà aggreffus , caftratis: mutatifq; editionibus cestui impofuit; Morna edito foripto caulan fuam defendente. Hofmain.

Dominus Faulkand vocar eum Magnum, Eloquentem, \&o Sagacem Cardinalem P.rroniurn, cumque Bellarmino atque Buront antcponit, aff titque de cjus.

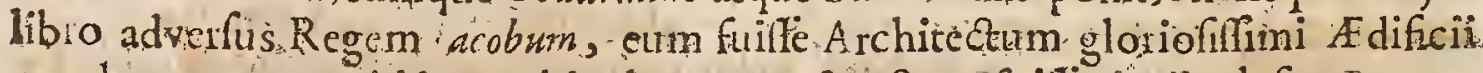

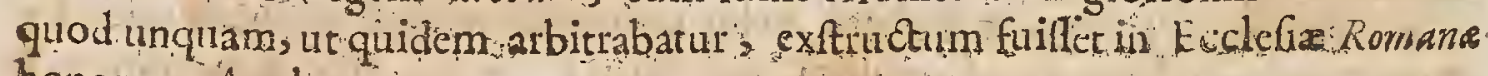
honorem. Angl:

Quod Bicherellur qui Ecclefix R omance erro iblus valde addiotis non erats ab hac pulatm dilfenferit in Tranfubitantiationis Dógmate 2 non admodum mirardim eft: Nirari magis fubit, quòd Vir adeo eminens iner Romanos, fcili-

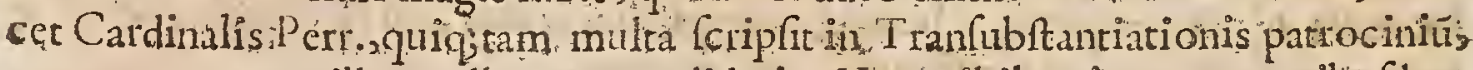
nunq̨uan tamen illam ullatenus crediderit. Hoc nihilominus eum quibuddam Amicis paulò ante mortem confeffum liquidò nobis conttat ; quòd nimirum hanc Doetrinam mouftolan cenfurct; fe quidem omnes adhibuiffeconatus ad illan, quantum freri poterat, infucandam in Scripris fuis $s_{2}$ ed malx caulx pasocinium fe fufcepiffe quamque nemo tueri polfet I faaci KV Vake l'ratatio præa milla differtationi fua de Sacra Euchar. Angl:

Hoc ejus Epitaphitum in Cathedrali Senonum: :

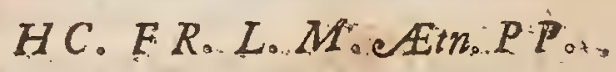

Jacet hîc quodclaindi potuit lacobi Davii:Perronii, qui S. R. E.TT. S.Agnes tzs in ag one Presbyter Card annos quaterdenøs, Archiepifcopus Senonum Galliarum \& Germani. Primas, Magnus Francie Eleëmolynaius duodonos, inter homines mortales ternos \& fexagenos mortalis homo vixit; mortalis elle defit Non. Sept. An. Chrifti 1619: At vivet polthac, xternumque apud omnes gentes atque nationes gloria immortalis, quam ex Hrefitoties

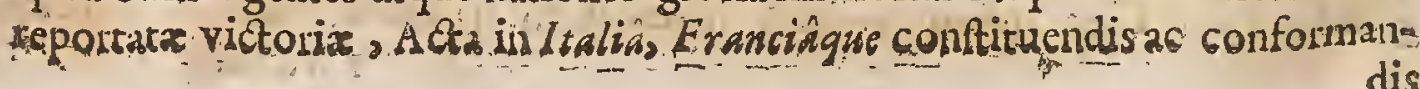


dis Ecclefix nutantis rebus felicia, intta, \& preclata ; Libri denique quos plurimos at que divinifimos incomparabilis ingenii clarifima nonusicute reliquit s ei meritifimè pcpererunt.

\section{ARENOLUS PONTACUS.}

Allus Burdegalengis, è nobili Pontacionum familia : Epircopus Vajatengis
fuit. Obiti Anno rGos. Clar.An. D. $\mathrm{MDC}$.

Anno 604 . Annoldus Pontacus preclarè de Chronologiâ meritus eft Notis \&

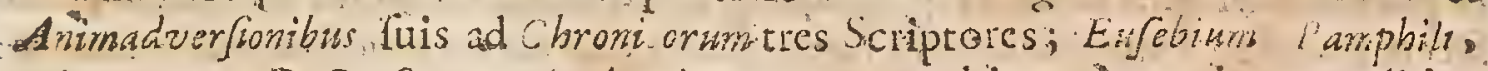

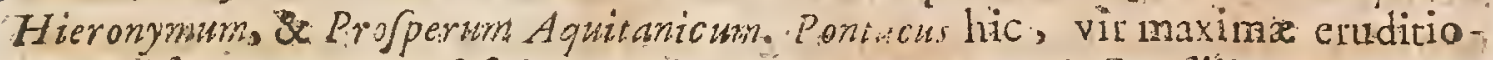

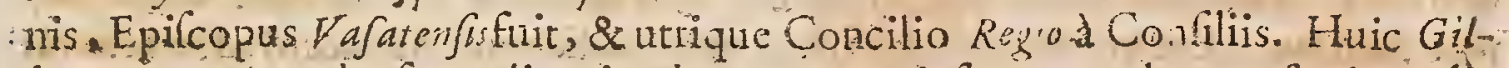
bertus Genebrardus fuan dicavit Cbronologiam; ipfe autem duos pofteriores libros emendavit, \& adauxit. Iof: de fcient. Marhemat.

Quum ha Note propè ad exitum perducta ellint Chronicon Eafebia zum. тй

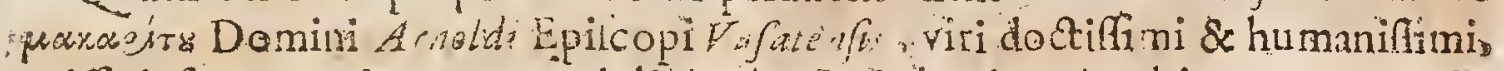
miffu ipfus accepimus, qưd liête eâ animi alacritate à nabis exccptum êt, quam \& Awh horis yirtus \& Uperis meritum exigcbat; tamen hoc noftum gaudium proprium efre repentinus de cjus vidi mortc nuncius non paffus eft Quanti cgo illius mores doatrinamque fecerim, facioque;, fciunt atque teftari pollunt, qui hominem de facie fibi ignotum ex folà pradicatione noltrầ, arque folam fidem noftram fequuti, amare atque obfervare coperunt Quum igitır. alle optimus, modeftifinus \& dafifimus vir, tantum diligentix \& laboris ad, Eufebii Chroni, i reftirutionem attulerit, quartum in hoc genere feribendi, att nemo autpanci antecem preftxe powuerunt, faccre non polfum quin \& cjus Editioneri, \& fuldium incredibile quo illam excoluit, diligcntian indeferlam quâ tot fcriptos iadices inter fc contulit, quibus polfum laudibus commenden. lof. Sealig. ad Eufeb. Chron. in addcind.

Mirati eramus paulò antè, \& muritiflumè quìem, viri preftantiflimi, longéque doctifimi Arnaldi Pontaci Epi fcopi Vafaten $/$ s. fiècm, induftriam, \& in affectà paritcr atare diligentiam propè frue exemplo, in totconfercndisantiquis merabranis, ex quibus pulcherrinam illam fian ejufdein Eufebii cditionem concinnavit : qux pritus ab ipfo fulcepta, quàm de tuo confilio quicquam relciffet, (ut fapius jpfum milhi lizeris fignificafe teneo). codem ferè tempore cdi copta eft, cum Tuâ. Sed Preful is amplifimi immathrus obitus, \& tibi fructum vel jucundifimum anicitix "quấ cratis invicem junct; \& ipfi gaudiu ma ademir, que nunc fungcretur inattimabili, cùm viderct Opus a fe feliciter inchoatum, feliciflimè à Te cffe confummatum. Conftat mihi, ipfum, fi jam viveret, quầ eruditione fuit, quiô erga Te affectu, $\beta$ candore in xétimandis tuis virtutibus, non minus acrem Operis tui adversìs invidos \& obtrcetatores vindicem futurum; quàm affidum tuarum laudum apud bonos preconem. $I f . C_{a *}$ Saub. ad Iof. Scalig. S. Kal. Sextil. an. $160 \%$ 
"Arnoldws Pontacus in is, qua adi. Hieronymi Cbronicon magnâ induftrix. nec doct inâ minore, annotavit, Wof. de vit. Serm.1.2.c. 3:

Ut abtervavit doctifimus \& diligentifindus Am noldus Pontacus in fiiis ad Chronicum lrofperi notis. Voj. de Hilt. Pelag. p. jI. .

Árnolcus Epifcopus $r a$ atenfis Poniactir, enjus fape mentionem habuimus. vir

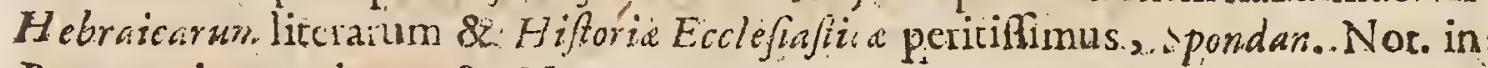
Baran.epitom. ad ann. 339 Num: 6 .

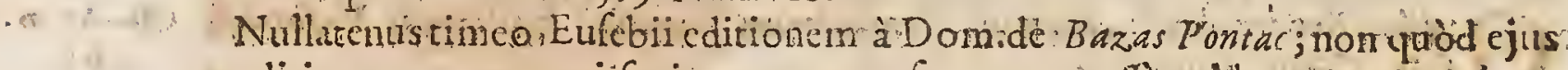
craditionem non magni faciam, ncc agnolcam : en elfe valle perium Hebraica pralertim lingux Hiftorixq; Ecclefuffica: Sed quod Tu faciesille nequaquam facerc potcrit, imo yeamvis id facere poltet, id tamen non facere aut faceret non aulit. Eufbius liberè tractari debet:, \& a Viris qui nullam cenfuram perimefant. Extant Excmplaria rebus quas addiderune Monachiadeo referta:

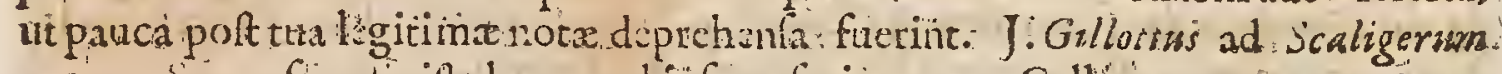
pag.95: Synopfos Epittolarum ad ipfum fcriptarum: Galls:

\section{GONRADUS: RITIERHUSIUS:}

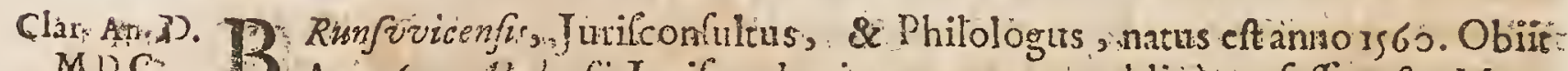
$M \mathrm{C}_{\text {s. }}$.

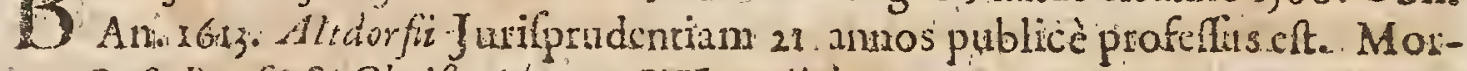
tio Capol’anfa \& Crrift. Adamus VVenzelick parentaverunt..

Puxter uridica Scripta, Commentarium in Oppianum, Salvänm, Gunthe-

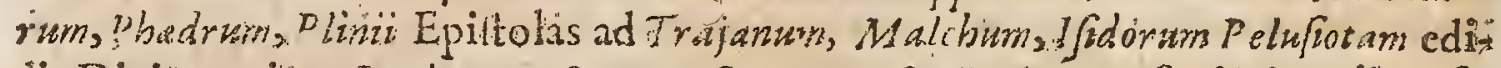

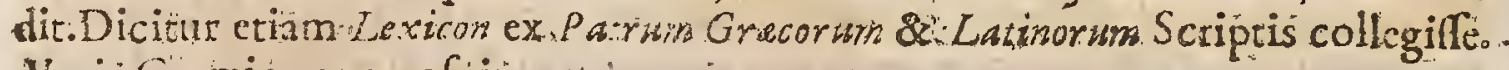
Varia Carmina compoluit:

Verèfuitvir hicinfignis, alter fii fxculi Scxvola, Orator, Pöta, Philologus \& Philofophus cximias, Graca \& Laine Lingua: callentiffmus: ita ut perpetuó cum Literarum Priticipibus, fid wero, Platone, friftotelc, Dernofla.

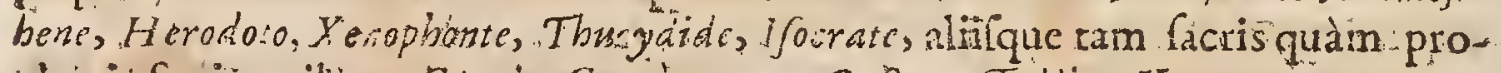
ghanis Scriptonibus, Graris, Grace : cum Cafare, Tullio, Varrone, Aarome, Horano: \&aliis Latmi 1 diomatis proceribus Lative fcribendo \& dicendo certare follct. Linguxectian $H$ ébrá non hofpitem fuille, inde appatet, qu òd palmorum Duvianconur maxinam partem ềfelicitate metris Romanis expreffi, , ut

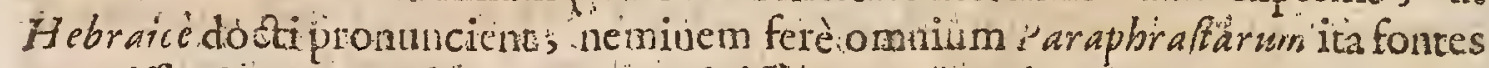
aperuife, dacu, quod aiune rem tetigif:. Melsh. Adamo in vita cjus.

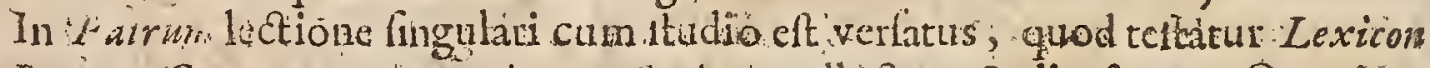
ex Patrum Grecorum tuin Latinorum Scriptz collcaum \& digefum .. Opus ínmortalitate \& lice publicâ dignum. I dem ibid ?

De omni literatuâ preclarifinè meritis eft Conradus Rütterbufus. Ioan. Andr. Quenfted.

Grutern gemmam omnium dóctorum atque bonorum inatimabilem; eum

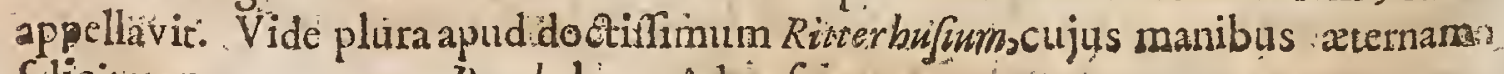

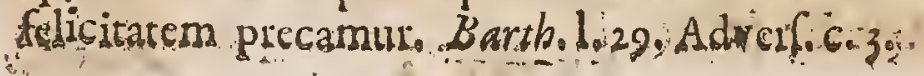

Urijiamg; 
Utinam, mi Rittershufi, interiora animi mei noffes! fcires quàm folcat mihi. effe gratum quic yuid à te fuerit profectum. Salvanumis verò qui pluris faciat quam ipfé facio, non facile invenias. Itaque pro câ, operâ, qux illi optrimo "r riţtori à te eft impenfa, ago tibi pro meâ. virili grat 's gratiffinas. Bene de literis meritus es, bene de ftudiis pictatis, bine de nomine ciallice. If. Cafoub.in Epift. 6oj.

Tu mihi mittis elegantifimos elegos tuos, mihi in Ambroful loco gratos, tanquam prilcâ illâ \& nativâtyerborum fignificatione, variatum quoque Sententia ru in intertexturî nitidifimos. Sriopp 1.; fufpect. lection: epift. 20.

kitrershingus Vir ef honeftus \& doctus Rigaltizs inomerito ipfum laceffrvit in. ejus Phxdrus: Scaligerana pofterior. Sall!

* Curradi Rittershufii differentiarum Iuris Cävilis, \& Canonici,fcu Pontifcii, libri feptem prohibentur. Ejufdem. liber cui 'T itulus. I us Infivianeum, hoc eft. Novellatum Imp. Infiniani Angufisi expofitio Methodicá prohibetur in Decreto . 10. Martii 10. 16rg

Extant Carmina ejus Tom: 5. Delit. Germ. $4 \$$ 3. Aliz ejus Opera variis in loais atque remporibus funt imprefla.

\section{JACOBUS AUGUSTUS THUANUS}

( Allus, meus eft: Parifis anno Dom. Is53:Obiit anno 16 r

1. CondiditHitoriam resum per totum O b in geftrum ab A. C.1545. Clar. An.D. MDC. ufque ad An: 1603: ftilo luculento: Extant ejufdem Hieracofophion five de re acuipirarià libri tes; item, Conftantia Iobi, Ecclefufter, Threni, Ieremia, \&c.

Virgenere, doctrinâ, dignitate maximus, \&inter liujus ax Hiftoricos principe loco dignus: VVheur. in Meth. Leg. Hilt. fect. 45.

Incomparabilis nofti tomporis Hiforicis nuncupatur Conrado Röttersbufio ad Salvianati..

lacobus Arguffus Thunus fux xtat is Hiftoriam fummo judicio \& fide, fine' odio \& ga:iñ, ad Deigloriam \& \&ublicam utilitatcm prudentifimè confcripfit:Opus \& ityli clegantia's. \& gravinimarum remm copia ac majeftite cum qui-bufvis five vetum five recentium in co genere Scriptis conferendum: Lanfiz Urat. pro Gall. p. 177 ?

Toucrnirn cgo virum divinitus datum cenfeo faculo ifti in exemplum pietas

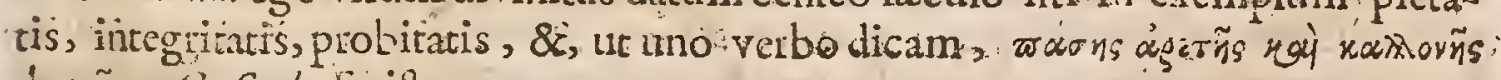

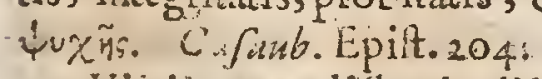

Vir immontali lauda dignus, \& Hiftoricz veritatis limeno. Montacut. Antidiat.

Iärobus Aiguftus Thuanus, vir illinfris, lingenii celfifimi, ac juris publici optimè confultus. Quenfed.

Vir non minus eruditione quam offici dignitate nobilis; 8 fl juis alius $\%$ revifudiolus. Mortor. Caula Keg. c.3.-

$$
\text { Y. แแ แ } 3 ; \text { ' De: }
$$


De praclariflimo Hiftoriarum monumento quod feculo imputanti, valdè omnes boni te amant. Ego aliter quâm filendo prontunciarc non pollum, omnia cnim infra dignitatem verb, ertunt. Cùm catcra tacitus admiraror, - tum imprimis dignam fummo Senatore fidem, veritatem, libertatem. Band. Centur. I. Epift. 86 .

Inter multa qux in te admiratura eft pofteritas, ego illud unicè obftupefco, unde tibi modô in fori arce, modò in fummâ Republicâ verlanti otium, unde vis indefeffa animi, ut res tot ac tantas aut lcribendas cognolceres, aut cognitas fcriberes. Grot in Epilt. 16. Non. Jun. An. IGIg. Roterdami.

Oibis totius Hiftoriam ita complexus es, ut talem nemo vel ab otioffimo homine unquam expectaverit: Tanta rcrum copia, tantus verborum nitor Tum illud yironm maxime, opus immortale, quamquam \& lermonis clegantiam ab ipsâaliquitate reduxir, \& renm varietatc placere nemini non poteft, nullá tamen in parte melius merctur de legentibus, quàm quod eos viros bonos

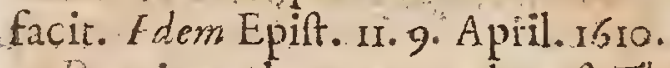

Pigecipuo loco poncndus ef Thuanus, Parlamenti Parifienfis Preles, Scripror clouluentiâ, doctrinâ, libertate, prudentiâ \& fide nemini inferior, pralertim in rebus Galticis, quibus ipleinterfuit; in reliquarum gentium hiftonia non parem ubique fidem meretur, quid alios fequi necellum fabuit. Unde faetum, ut etiam ftylus ejus alicubi diverfus deprehendattr. Verba namque Autorum, quibus ufus ef, plerumque rerintit. Qux ad Religionis Hiftoriam pertinent, fummâ zequitate ac moderatione quanquam Raligioni "ontifcic addictus tractavit, , idcircò Politico-Catbolicus appellatur: à quibuldam etiam ut Athens \& profanus traducitur. Auctor. Anonyn. in. Biblioth. Politicî Curiosâ.

Thuanus ut laboris compendium facerct, dum ex variorum adiplum mifis chartis libcllifque opus contexit, retentis autoram verbis, Hittoriam nobis dedit non cjufdern genii \& lingux. Cafp.Barlens iu Epift.jo4.ad Petr. C. Ho fi.

Dominus de Thon cum gencralem Hitoriam contexere in animo haberet commcrcium colere copir cum omnilbss Europa Viris qui maximè idonei erant que vera effent ad ipfum tranfmitrere: Magnum inque cum canden commercium hablit. Cùm autem Candeni volumen primum in lucem exiiffet, feverèd ipfum lctiplit, deprehendensid adeo difcrepans ete ab is qux in mutuis cortion Epifolis exarata fuerant prelcrtip refpectu Scoturum Regina. De quibus quod crat verum ipf cenfeflus oft Cambdenus, fcilicet, Regem tarobum illud neceflario revilere voluille, idemaue pofea tradidife in manus Comitis Nortamptorii, quit erat Ducis Norfolit frater, quipropter illam Reginam capite truncatus fuerat, \& plurima ex illoverala. plurimaque alterata fuifle. Hoc molettifmum fuit camdenos qui collicirus, fuir ne porten rioris partis idem cfit fatum : Eapropter illam extra Angliam at preftantem illum rilum tranfmifit, at poft fum obitumeypis fid liter mandari portet. Hoc in Arglianotiffmum elt: Et lecunda partis, ultra mate ad extraneum tranfmiffio, factle quemvis inducit ad credendum eam lujus veram rationcm fuife. Doctois Burneti Replicatio ad Dom. Varillas pag. 59. Anglicè.

Cumprimis 
Cumprimis laboravit Thuanus odio zelotarum Religionis Pontifcie, licèt ipfe fluerit Poniff, in:; fd quia fcelera fuorum non :dubitaflet divulgare adeo verè, 8E ufquc adcò veritatis habitâ ratione, ut ne Pap. quidem pepercerit, incurrit in odium imprimis. Iefuitarum. Primum ejus Volumen iil Lndicen Expurgatg: riwn relatum erat Rom s, in Indice tamen Colonic edito non confpexi: Illud." $\mathrm{Ja}_{\mathrm{a}}$ Eant plurique id factum effe propter Præfationem doctiflinam, quæ Pontiffcios vehementer mordet. Thuanus autem eft me quidem judice hujus \& fuperioris feculi 'Hiftoricu maxinus,' ob infignem wapphoiav, \&eftudihm veritatis. Dolen-

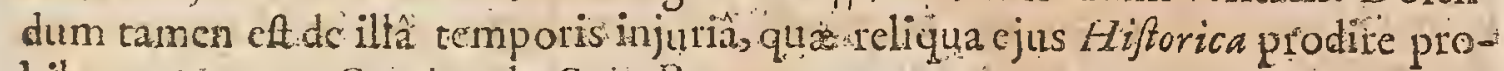
hibec.- Hermani Gonring de Gall. Regn.

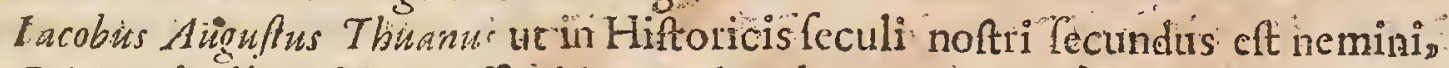
ita Poëfece gloriấcedit paucifrmis; quod vel ex tribirs ejufdem De Re Accipi-

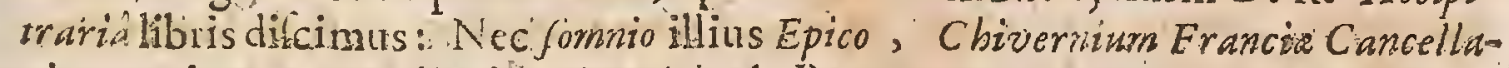
rium, quicquan vigilianilis. Borrich. de Poër.p. ing."

E: junioubus stes tibros De Re Accipitrariô elegantifino Carmine feripfit I acobits Augustus Thuanus. Voff. de Philofophr.p. 58.

Inter plinimos ejus lihborés cum immortali celebritate circumferuntur pra-

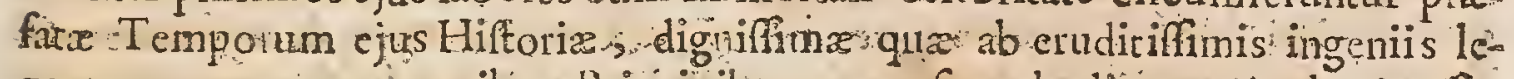
gantur; nontamen omnibus Principibus gratz; fre ob aliquam A uthoris affectum naturalem raut ob immodicam calami ejus libèrtatem circa hoininum actiones, aut quod alicnas Iuxifdietiones nimis aceuratè déçibar. Ardenti quodam Gallica Gentis ftudio Pakriz multum aduatu's ent: Non defuetunt qui à Catholicifmo ipfum exiltimarint alienum; - Sed defenfione \& in vita \& in morte non caruito... Mundo non autem fame mortusseft anno $26_{1} \sigma_{0} \therefore$. Latren tins cräflus. Ital.

Chytræum fequith in plerifique retrm Germanicarum ndrationibus, verbis ejur non nifileviter mutatis. C'onring rp de urbibus Germani Sect. ns:

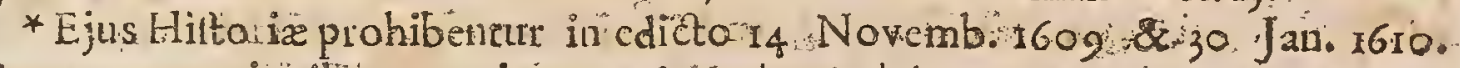
Cum expurgarionibits permirtuntur inlend. Madrit. á.67:

Præferendæ funt Editiones Parifina, ab ipfo Thuano procturate prima editio

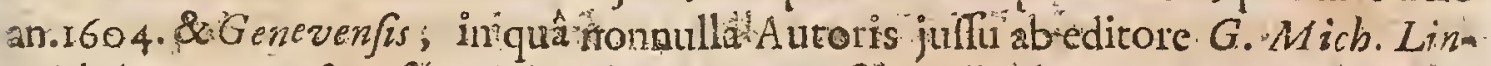
gelsbeimic expuncti, fringulieque lib is premiffǘs Indiculus Scriptorum, quibus

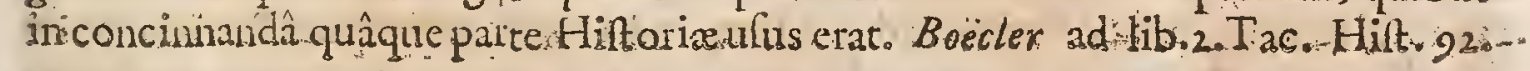

\section{Hoc ejus Epitaphium:-:}

Jacobe Augufto Thuano, Chriftophoriflio in Regni Conflitis Adfeffori, Amo

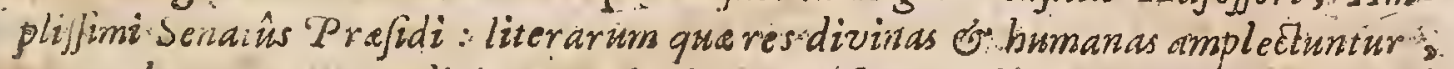

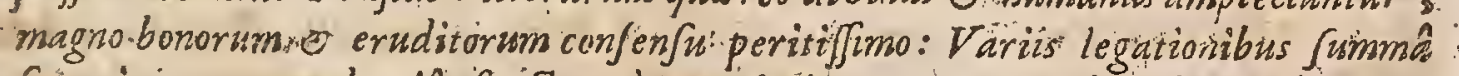

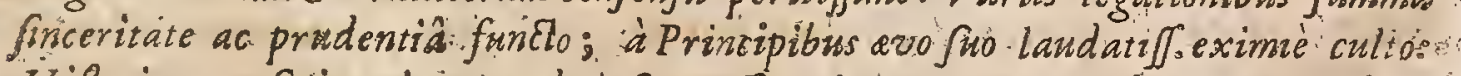
Hifloritum friptori, guod ipfe paffim logunntur; celeberrimo: CbriBituna-Pietatis antigua retinentiffrmo. Parciflamè cenfuijfe videtur, qui tali. ziro fecwlum defuifle dixit. Jacobus Auguftus Thuanus, Jacobir Auguti fim 
lius, Ampliffimi Ordinis Senator So Prafes, tam fui, graim Fratrum ac Sorox. ruin affecious objeguens facieridum curavit.

\section{SETHUS CALVISIUS,}

Clar. A. $M D C V$.
Ermanus, natus ef anno I556. Obiit anmo 1615 .

1 . Anno Dom.1605. Setbris Caluifin juris publici faciebat Chronotogiam fuam: in quầ iof phis salgeri imprimis inftitit veftigiis. Atque iỏem anno 16 rix. \& lequenti, in lucem dabat Elenchurn Calendarii à 1'apâ Gregorio s. comprobati. Duo hrc verò fibi Calvifus in Elencho illo propoluit: ut ex fundamcntis Ajtrologic refellerce alendarium Gregcrianum; atquc ut novam alentarie rationem, camque verioiem, \& expeditiorem adferret. Visf. de Mathemat.

solus ille optimus \& cruditifimus vir repertus eft, qui inter $C$ bronologos nugaridefiverir. Opus ct preftantifimum, utilifimum, \& ommi doctrinấ refertilsimum : iof. Scalig. in tpift. 240 .

Unus tandem, qui inftar omnium erie, accuratifsimus \& harum litcrarum peritilsimus 'etbus Calvijur, Germanur, nuper cruditifsimum \& confummatif fumum Chronicon edidit, guod torum rationt m noftrarum infitit monumentis: Opus Heroicum, \& atchitate dignum. Scalic. Lpilt. 439.

Vivet igitur, vivet opus hoc. Sacrarium Temporum, Scrin ium atenitatis perpctuorum Faftorum condirorium. Jam defitum eft in Cbronelogi nugari, Nihil in eo incptum, nihil futilc. Omnia plana, perfpicua, ita inter fe apta; ut ultimo à primis pendeant, media utrifque hercant. Omnia denique inter fe refpondent, \& paria cum rationibus noitris faciuat. ldem Epift;08.

Vidifuperioribus dicbus rccentem scriptorem, cujus nomen ex tuis literis

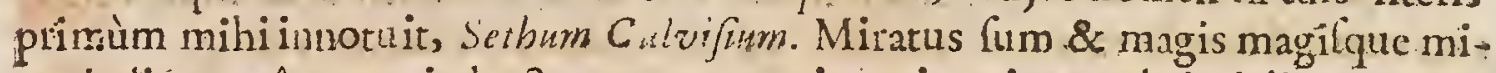
ror indics, quî potucrit hactenus tantum ingcuium in tcnebris delitere. Sca mihi videtur hom fimplex, de nominis fplendore parìn cogitalle. Itaque totus femel in lucemprodicus majore miraculo nos perculit. Suntitamen nonnulla in ejus divino opere, de quo vcliun à te iplum moneri. Nam quid attinchat $N$ atalery à contitur, \& icliquos id genus mperos seriptors, cuorum pars etiamatm vivit, torics land rit hoc nos iniyuo animo fercbamus, in ram erudito viro, \& tam recondite do trinix. Quf fi nobis effet notus, perliteras

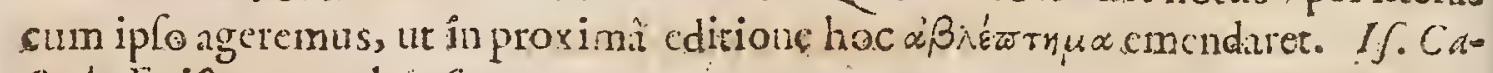
surb. Epift. 444. ad $i \cdot \int \cdot, g$.

Accondit cupidintem ream tursille Serbus Caljifars : cujus ingenium quo-

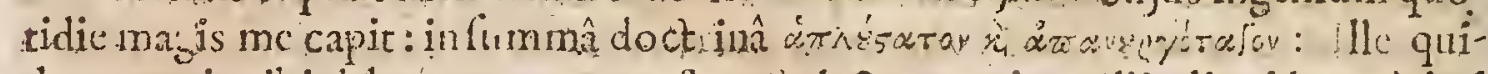
dem omnia tibi deber, quantus eft: Sid \& tu opinorilli aliquid: quod ad

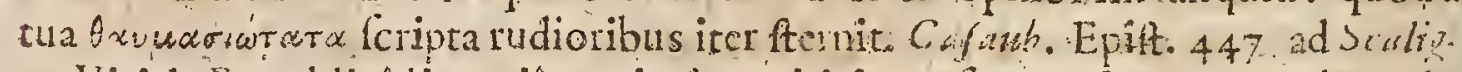

Viride Republicíliterariâ optimè meriti in co femper fuerunt, ut hac duo Rudia (Hifurirum \& Chronologrsm) amicè conjungcrentur, conjunct, mutuâ diligentiâ excolerentur, te forte alterum fine alterius culturâ aliquid amitterct lucis, 
lucis aut debitre dignitatis. In horum numero profectò haud ultimum fibi vent dicare videtur locum excellentiffimus \& famigeratifimus Chronologus Seibus Calvifur, dum ante luftra aliquot boni publici caufa ejufmodi opus $C$ bronologicum elaboravit, quod, tefte Scaligero, diu fuit in expectatione, quod multo habuit admiratores, plurimos emprores. Epift. prefix. edit. $4 \mathfrak{x}$ Calvif.

Setbus Calvifinus tantam in exquifitiffimo opere fno Clronilo oftendit ingenii acrimoniam ac judicii dexteritatem, ut fi pares aliquos in hoc genere, fuperiores fanè æyo noftro nullos habuiffe videatur. Totos viginti annos accuratæ opexis fui Cbronologici impendit elaborationi, idque ejufmodi firmavit $D$ emonftretionibur, ut non folim in totâ Germaniâ, fed etiam apud exteras Nationes mirificè commendata fit Viri induftria, nec quifquam in tantis Cbronologorum difo fenfionibus facilè inventus fuerit, quicraffa cujuldam falfitatis Calvifiz Chro= soligian arguere, aut convincere Aftronomicá potuerit veritate. Theod. Spizel. in Templo Honor. referat.

Serbus Calojifus nupera fuæ Cbronologie editione, operofam adè diligentiam adhibuit, ut nihil quicquam omiferit, quô verum Hiltoriarum tempus exquifitè doceatur. V Vhear.6.in Meth. Leg. Hift. Civ. Sect.6.

Setbus Calvifuns, vir citra controverfram in re Chronologicâ verfatifimus, fed nimiùm pronus ad innovandum. Montacut. Apparat. II. Sect. 4I.

* Inter Hareticos primx Clafis rejicitur Sethus Calvifrus in Ind. Madrito edit. 1667 .

\section{GALILEUSAALILEI.}

F Lorentinus, celeberrimus Mathematicus, fuperioribus annis claruit. Patan Clar An. D. 1 vi difciplinas Mathematicas docuit. Iide Pijas à Magno Hetrurie duce vocatus eft, à quo fingulis menfibus centenos argenteos nummos magnos, quos Laminas vocant, Calarii loço accepit. Condidit librum, titulo Nuncii fiderei : item, Dialogum de Syftemate mundi, in quo fententiam fuam de Terræ circa Coali orbes, 1ullo agitatos motn converfione aperuit. A quafitoribus Fidei: Romam evocatus \& palinodiam publicè canere juffus eft. Eidém inventionem fellarum Nedicearum tribuunt. Vixit 84 . annos, luminibus, ut aiunt, tandem orbatus. Konig.

Inter eos, qui benè atque placlarè, virtute ing enii, maximarumque rerum, fcientiâ, noftrâ memoriầ, de Florentine. Civitatis nomine ac dignitate meruerunt, primum fune dubio locum ac numerum obtinet Galilaus Galilai, Florentie nobili ac vetere profapiâ, non tapen legitimo toro natus. Etenim quifnam eft in toto Orbe terrarum locus ita remotus, itaà nobis locorum intervallo disjunctus, qux natio tam efferata, tam barbara, ubi aliquis fit bonis literis honor, in quâ Galilai nomen, omnium fermonibus ac literis, fummo cum ejus patrix, qux talem virum genuit, honore ac laúde non ufurpetur; Ian. Nic. Ergthr. in Pinacoth.

MDCiV.

$\mathrm{X} \times \times \times \times \quad$ Etid 
Etfi Galilew pre aliis ad res Aftronomicas impetu quodam fercbatur, in Philo. fophî̀̂̀ tamen nuturali magnâ cumn laude verfatus eft, \& ìn naturam motûs (cui: fidem faciunt (cuipta cedro diguifima) fupra Antiquıos longilfimè penctravit. Vit. Hobbian. Alctar. p. 49 .

Inter admiratores fi me dixcro fcmper fuife, nihil mentiar. Hug. Grot. in. Epitt, ad Galilaum, Septembr. 1636 .

$\mathrm{Ab}$ Archimedc nihil fuc̀ actum eft in Geometriâ Mechanicâ ufque ad Galileum, qui exacto judicio magnâque interioris Geometru notitiâ inftructus, pomoria fcicntia protulit primus;, idenque solidorum refitentiam ad Geometrie leges revocare copit. Adla Eradit. An.1694. p.319.

Interomnes Philolophos rccentiores, qui celeberrimi fuerunt, funt Galileus Italus; Bacon, Hobbes, Bcile Angli; Gafendi, Des Cartes Galli, Van Helinont Belga. Galilæus omnium folertifmi ingenii clfe videtur. Hinc, meo quidem judicio, Neoterica Philolophia latens vocuri potcft. Ejus Methodus cum illa Platonicorum valde affinis eft; jucundus cft cjus ftylus, \& mul tos tegit nxvos fuo feribendi modo. Quamvis è prioribus thilolophis non pauca exfcripferit, omnia ex proprio penu defumpefife videtur, coruxa we velut autographum cenletur, pluribuslocis ubi merum apographum tradit. Rapir. Animadv. in Philolophiam. Sect. 18. Gall.

Tanti apud $G$ allos xettimatus fuit, ut nonnulli illius tantùm videndi cau sâ, itc $r$ in Italiam inftuerint; \& à fide digno viro accepi, Diod: tu quendam nobilem, literis ac virtutibus clarum, Florentiam è $G$ al iz co folum nomine contendiffe; \&. cum pertredecion dies fummâ animi oblectatione, de variis Na'ure Arcanis fermonem cum Galilao habuiffet, fat fibi effe proper cum Italism vidiffe ratus, catcris aliis negotiis neglectis, in Galliam quâm maximis itineibus celeralre. Leo Allat. Apcs Urbanz.

Nulla in toto orbe Gens exiftit apudquam aliquo in pretio fint Literx, cui Gailat nomen non innotucrit, quaque gloriam quam praclaris ingenii ejus inventionibus meruit ei non tribuat. Admodum inffignem locun metitò tenere potef inter Viros enditos qui Florentinan Civitatem celebrem reddiderunt, Cui natales debet, (ed ex illegitimo concubitu, cùm ope Tubi, cujus Adinventor eft, immenfis. Atheris Regiones pervagatus fir, ablque Oculorum pertriatione fplcndidam Solisluccm intuitus fit, Lune Spharan penctrarerit, maculafque in hac \& umbras cxploraveit, in Firmamento novas repererit \& incognitas Stellas, quas Medices, à Principum fuorum cognominc, denominavito. If.Bullar, Acad. Scicntiarum. Gall.

Nullus unquam Marhefos Profeffor extitit qui Scientiam adeo necefrariam. \&adeo nobilem explanaverit cum. majori perficuitate \& puritate, quam. Galileus, hodie Elerentiamurbem Patriam incolens, flius Vincentii Gublat, Nobilis politiorum Literarum notitia fatis celebris, ob va: iacjus ciica Muticam opera. Nemo faciliori ratione majorigue effeacia refolvit dabia difficilia \& intricata, qua in cjufmodi Diciphinis occurunt; quod cifacillimum: crat propter continua ftudia \& publicas illius Scintix laturas, quibus fclicift- 
mum, \& acutiffimum ingenium femper occupavit, quam cxp'icavic non modo Pifatribus annis, rogatu Ferdinandi Primi Tufora Magni Ducis, cui notiffima exant cjus promerita, Sed etiam Patavit toto 8 . annorum fpatio, magno Difcipulorum confuxu ex variis Gentibus, prafertim vero Nobilium \& Ma gnarum infigniorum Gibilini, Iralicè.

Ille mihi videtur meliùs Philofophari quàm Philofophorum vulgus, quatenus ab Erroribus Scholx, quantum poteft, recedit, \& materias Phyficas rationibus Mathomaticis examinare comatur. Eatenus fanè illi omninoaftipulor, \& puto nullam aliam inveftigandi ver rationem effe. Sed mihi videtur in hoc graviter erare, quòd Digreflones tbique faciat nullique materix explicandælat is immoretur; quod irdicio eft illum non examinaffe ordine materias omnes, fed guorundam tantum particularium effectuum rationcs ind:igalfe, omiffis primis Naturæcaufis, \& fic ablque fundamento xdificalfe. Porro quia ejus Philofophandi modus eft vero propior, è faciliùs errores ejus cognolci polfunt, quemadmodum facilius eft judicare utrum à rectâ viâ reccdant, qui illain nonnunquam fequuntur, quàm quinunquam. Renat. Defcart. part.2.Epilt. Epift.gr.

Vir in omni Matbernatum parte fummus, in Philofophiầ caterâ non infimus Galilens Galilai, Jefuitarum in ipfum odio ac Principis Thu $c r$, fub quo vixit focordi metu coactus Romam ire, ideo quòd Terram moviffet, non vetante veftro Fiortenfio, durè habitus ut majus vitarct malum, quafi ab Ecclefia edoctus fua Scita refcidit. Hing. Grot. in Epift. ad VofJ: Lut. 17. Maii 1635.

Extant Opera ejus omnia ltalicè in Bologná 1656 . in to.

Extat Syterna Cofmicum. Ex Italuco Latine redditum per $M$ azthiam Bernegges surn Profellotem Argentorat. Londini apud Thomam Dicas 1663. in $8 \%$

Hoc cjus Epitaphium:

Galileo Galulai Florentino, Thilofopho \& Geometre verè Iynceo, Natura Oedipo, Mirabilium femper inventorum Machinatori; qui inconceffà adhuc Mortalibus glorî̀ Colorum Provincias auxit, \& Univerfo dedit incrementum. Non enim vitreos Sphrrarnm Orbes, fragilefque ftellas conflavit, fed xterna Mundi corpora Medicea beneficentix dedicavit, cujus inextincta Glorix cupiditas, ut oculos Nationum, feculorumque omnium videre doceret, proprios impendit oculos; cum jam nil ąmplius haberet Natura quod ipfe videret. Cujus inventa vix intra rerum limites comprehenfa. Fimamentum ipfum non folùm continet, fed etiam recipit. Qui relictis rot fcientiarum monimentis, plurafecum tulit, quàm reliquit. Gravi enim fed nondum affectâ fenctute novis contemplationibus majorem gloriam affectans inexplebilem fapientix Animam, immatuio nobis obitu, exhalavit, Anno Dom.1642. Etatis fux 78. 


\section{DAVID HOESCHELIUS.}

Clar.An.D. Crmanus Bibliothecarius Augufanus, celebris Philologus; natus eft ann. M. CV. Autores (Procopium, photium, \&c.) in lucem protraxit, adeoque de re literariâ optimè meruit. Konig.

Fuit Hofcheliwatque elfe nunquam definet in Doctorum memoriâ lucidifimum, non Germanic tantum, fed \& totius Europe fidus, quod fummi paffim viri magnifecerunt, \& admirati fitnt. Omnes Davidem Hoefchelizin fufpexdrunt, ejufque certatim ambierunt amicitiam, \& familidritatem, hunc Grecarum literarum Phofphorum, hunc ruenti Gracie divinitus Jufitatum:ibicinem, hunc vetem rum librorurs refitutorem

\section{[Lateri propior quó nemo Minerve, Gratior aut Phobi Pieridumve cliens Fuerit]}

crebrò falutaverunt, hunc immortali laude dignifimum effe judicarunt, eò quòd egregium de Republicâ Literariâ benè merendi animum nunquam depofuilfet. Theoph. Spizel. in Templo Honor. relerat.

David Hoefchelius, vir Grecarum literarum peririffmus, \& judicii recti. CaSaitb Epilt: 482 .

Vir cruditus \& induftrius." Dovid Hoefchelizs. Lipf.

Quantum \& hoc prefens, \& futura fecula, tot bonis auctoribus, quos cdidiIti, demerearis, fcriberem tibi, niff fcirem te hoc non fincurum, nifi intelligeres, quantum eo iplo literas juves, qux per negligentiam quotidiè pereunt. Iof. Scalig. Epilt. 389 .

Davide Hoefchio nemo unquam magis idoneus extitit ad Bibliothecx gun bernarionem-----Plures Grecos Authores ipfi debemus, cum Notulis quæ nihil inutile ufquam continent. Colomiez. Biblioth. Scled.p. 1 gs Ig 6 Gall.

Hoefchrlius Lutheranus quidem fed Doetus. Nifi ipfum tucretur Velgerus, jam expulius fuiflet. Pragogicam admodum fapit, Sed bonus vir eft: Hoef chelitu: infuo Procopio Epiftolarum mearum \& Cafaboni frag menta quadam excudi curavit. Hoef helizts non elt magnus Grecus, fed diligentillimus. Scaligerana pofterior. Gallicè.

Preclarum quoque in Interpretando Cibi paravit nomen David Hoefbelius, quô quum nemo eruendis Antiquorum fcriptis feliciùs incubuerit, tum in is Latine quandoquc reponendis vix ulli primas co:ccifrt: quòd fifententias non aliquando compleret de fuo, qux aliàs ejus eft in rependendis verbis diligentia, cxterorum luminibus obftucret. Huet. de Clar. Interpret.

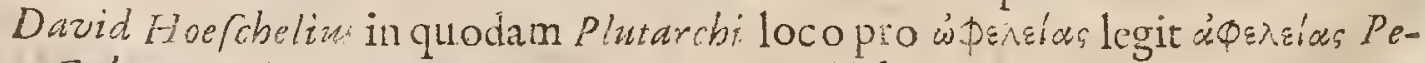
trus Eaber, qui ante annos viginti eandem inti loco medicinam adhibuerat, ipium 
ipfum proptereà, licèt blandis verbis, infimulat $P$ lagii. Nobis illa infintulatio admodum preceps videtur. Thomas de Plag.num. $467^{\circ}$

* Auctorifte, Duvid Hoefchelius, Lutheranus licèt, varia cdidit veterum Auctorum Grerorum Opufcula cum Scholiis, in quibus vix occurrit, quod offendat: exceptis Epiftolis Dedicatoriis, qux plerumque funt ad Hxeticos. Vid. Ind. Mudrit. Edit. ann. 1667.

Varia ejus Opera variis in locis atque temporibus impreffa funt.

\section{FRIDERICUS TAUBMANNUS.}

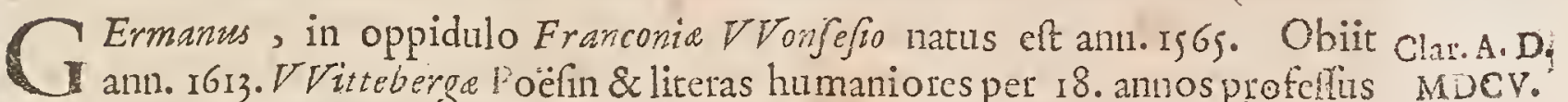
eft. Compofuit Commentarios in Plauturn \& Virgilium. Scriplitetiam Difler-

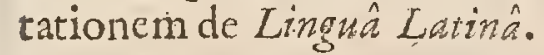

Literarum Gracarum \& Latinarum vindex acerrimus, barbariei extifpator longè felicifimus, Poëta incomparabilis, ut habet Lapis Sepulchralis. I'rincipum ob fales amor \& delicium, charus æqualibus, jucundus amicis, magnus omnibus, benè de bonis literis clucubratis Operibus nulli non notis meritus eft, inprimis lucubrationibus eruditifimis in Tlautum \& Virgilium. Quenfed.

Magnus Apollo vocatur Pareo.

Feftivitatis \& Salinarum Arbiter, fi quis alius mortalium. Band. in Epift. quadam.

Homo hominum in illo tact ? (Saxonia) ) literatiflimus. Lips. Centur.s.Mifcel. Epilt. 87.

Certè induftria \& clegantia fimul ingenii tui in concinnando hoc opere (Plautimo ) fic apparent, ut alii omnes, qui conati, ad tuam accurationem $8 \mathrm{x}$ lucem lufcitiof videantur. Lipf. ibid.

Taubrannus, omnium Incerpretum longè optimus. Tanaquíl. Fab. lib.2. Epift. I6.

De ilto attemtuo opere [ Plautino] nihil aliud dicam, quàm, in eo ubique \& judicii \& ingenii, \& indufrix tux manifctta extare veftigia: ut, cum in illud omnium fuperioum laterprentam labores contribueris plus praftiteris, quàm ipfi: quòdii quilque pro parte fuâ Plautum fibi deviuxerunt; tu ex omnium illorum lucubrationibus totum tuum fecift. Iof. Soalig. in Epift. 465 .

Id unum agcbat femper T.imbrannus, ut divina Poëleos penetralia juventuti refcrarct; linguam Latinam perpurgaret; \& bonorum Auctorum editione illuftaret. P'rattitit hoc omnium doctorum calculo egregiè, fr quifquam unquam, in Plauto \& Virgilio. Melch. Adam. in Vit.cjus.

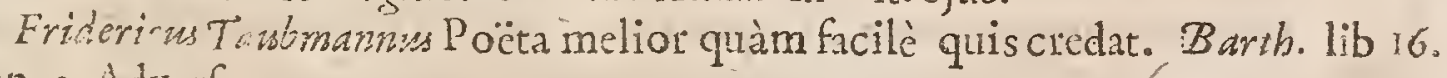
cap. 3. Adverfar.

Virdoctus, probus, ingenuus, Fridcricus Taubmannus. Idem 1. 16.c. I4.

Erat T aubmamns nofter humanus, affibilis, comis, facundus, placidus, candidus, omnium horaum homo, in feriis gravis \& ferius, in aliis jucundus, \& $\mathrm{Xx \times x \times 3}$ cirra 
citra omnem affectationem, qux fultorum index eft, non fine naturalibus quibufdam gratiis ac vencribus, liberaliter eruditéque jocofus, candido femper Merourii, nunquam nigro Momi fale fermones fuos confpergens, aut dicacitel alios perftringens, vel mordaciter infectans; led præfentibus omnibus honeftam hilaritatem felicitate fingulari concilians, ut non immeritò, finongeneris humani, falteng virorum cruditorum, aut Acadcmix noltre Delicic appellaripotuerit. Quo nomine cum aliorum quorumvis, tum in primis principum multorum gratian \& amorem fingularem promeruit. Erat pratereà pro modo facultatum liberalis erga cgenos, maximé ftudiolos, quorum non pauci, benè merendi \& juvandi ftudium ejus funt experti. Sæpè alicui opitulaturus, ipfe aliunde mutuo numulos accepit. Erat \& officiofus, cum in cxpediundis aliorum negotiis, tum intercedendo, tum commendando, tum ad interrogata refpondendo, tum modis quibufcunque aliis. Erafm. Smidius in ejus Parentatione.

Preceflit obitum ejus fignw quoddam non contemnendum, aut filentio involvchdum. Inter primos ftatim dies morbi fui, quo extinctus eft. manè expergefactus vifus eft fibi videre prope lectum fuum arcam oblongars, \& in eâ virum fabi fimilem jacentem. Cúmque initio deceptionem visûs aut imaginarionem inanem effe putaret, clcvato capite prodigium artentiùs afpexit, \& rem fefe aliter non liabere deprehendit. Quo vifo tantum abeft ut exterritus fuerit, ut hilariter aliis referrer, \& pramonitionem divinam agnoferet. Cui cventus etiam nimis verè refpondit, ldemibid.

Qux in Virgilium fcriph mera ferè eft Compilatio corum qux ex Scaliger Poetica \& ex duobus Ioviani Pontani Dialogis, Adtio, feilicet \& Antonio corraferat, juxta obfervationem Authoris Anonymi Bibliagraphi. Tam timidus autem tamque parum proprix peritix fibi confius crat, ut de fuo iis ferè nihil addere fit aufus. Opus pofthumum eft. Hujus alitem refpectus haberi debet cum vitia quxdam in iis occurrant. Indicia Erwditorum Parifis I6.85. per Baillettum. Gall.

Fridericus Taubmannus prater alia Opera, quibus meruir immortalis effe, in Poëfi quoque multum vera glorix fibi pepcrit, ut in Epicis, \& Elegiacis, itapra fcrtim in Lyrico genere: Una fortalis poliyioribus minus probabitur audacior: in fabricandis novis, \& Latio inufutatis vecibus libertas, quam tamen in lepido, \& jocolo metro excufabit lectoris ingenuitas, Borrich. de Poẹt, p. Isy. 1667 .

* Friderici Iambrnanni Opera, fi corrigartur, permittuntu. Index Madri.

Varia ejus Opcra varis in locis atçuc temporibus funt imprelia.

Hoc ejus Epitaphium in Templo Parochiali VYitteberga crectum:

Friderico Taubmano Wofenati Franco, viropietatis zelo publice notiffmo, li-

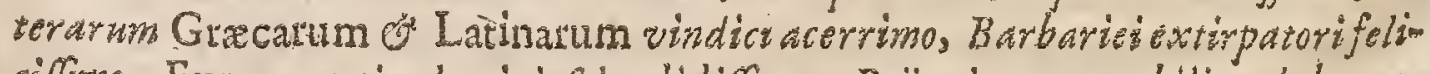
Cifmo. Europe totiws lumini plendidifino, Poëte incomparabili, of bwats nivatis 
nitatis in celeberrimaW ittebergenfum Academia Profefjori clariflmo, marito os patri defoderatifinno Anno C'briftiano 1613. die 24. Martii, atatis 48 . pie in Clbrifo defunto monumentum boc vidua o liberimxfiffurn affectu pio of grato P.C.

\section{FRANCISCUS BACONUS.}

B

Aro de Verulam, Vice-Comes Sancti Albani, fummus Anglix Cancella- Clar. A. D. rius. Natus eft Londini in Palatio Eboracenfi, vicefmo fecundo Januari, MDCX. Ann. 1560. Obiit nono die Aprilis, ana. 1626. in xdibus Comitis Armodella in Villầ de Highgate prope Londinum.

\section{Symbolum cjus:}

\section{MEDIOCRIA FIRMA.}

Scripfit Hiltoriam Regni Henrici VII. Regis Anglie: Hitoriam Ventorum: De Augmenzis Scientiarum: Sermones Fideles: Sylvam: Sylvarum. Multaque alia.

Seculi, \& gentis fui decus, ornator \& ornamentum literarum - Illi Philofophia Arifotelica infipida vifa fuit, non propter vilipendium Auctoris, quem lummis femper laudibus evehere in more habuit, Ced propter inefficacitatem vix; cjufmodi nimirum cùm effet hre Philolophir , qux ad Dilputationes \& Contentiones folùm nata, ad productionem autem Operum, qux vitæ humanæ comm oda effent, Aterilis omninò effet. Vit. Bacon. prafix. Opp.

Ille magnus Peireskius qui in rebus Naturx maximè verfatus eft, fufpexit Genitum, comprobavitque Inftitutum Cancellarii Anglorum Magni, Francifci Verulamii, quem lapiùs doluitnon conveniffe, fuperltitem adhuc' cim fuit; venitque poltremùm Parifis. Gaffend. in Vit. Teiresk. 1. 6.p. 237.

Henrici Septimi vitam \& res geftas, hand ita pridem nobis reprafentavit Nobilifimus Vice-Comes Sancti Albani, adéo feliciter adeóque plenè, ut Hîtori corum ptatintiffimos, fi. non fuperaverit; certò prorsùs xquaverit. Vthear. in Meth. Leg. Hiit. Civil.

Hentrici Sepizini Hitoriam perfecutus eft feorsìm, eleganter admodùm, Canceliarius Regni snglia Baco de Verulamio, qui multum prudentix inferuit, etianfin non fit facundus \& probè Latïnus Scriptor. Merito verò legeinda Hifto ria ejus Henrici Septimn, utpotè qui prudentịfimè rexir Rempublicam. Herman. Conring.

Barnat habemus librum fane magno jidicio Ccriptum de rebus Hesrici VIT.

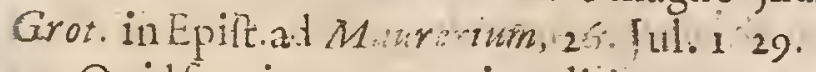

Quidfuavius aut magis politicum Francifì Baconi de Verulamio hiftoriâ,

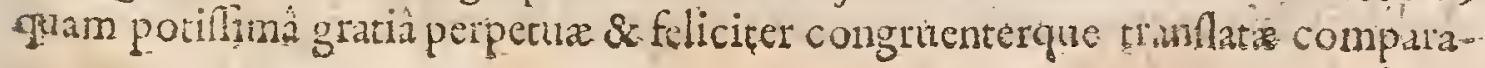


riones condiunt? hoc enim de induttriâ exemplum nominare libet rei, quam defciptione, ctiam curiosâ, vix Lais commendaveris. Renovatur denique antiqui moris ufus; qucm in Augufi vitâ Tranquillus defcripfit. Iob. Boecler. de cloquent. Politici n. 39.

sapicntifimus quondam Angliæ Cancellarius; qui præcipuè noftrố feculố velut clafficum cecinife \& fignum fultuliffe videtur, ut in rebus Philofophicis aliquid ulterius \& exquifititius inveftigarctur, quàm quô hactenus Scholarum parietes refonucrant. Sic ut fi quæ elt pulchrius noftro tempore efflorefcentis Philofophia gratia, itti viro non minimâex parte debeatur. Sam.Pufendorf. Specim. Controverf. cap. r. fect. s.

In ejus effigiem ita $H$. Conringius:

\section{Magnus bonore tuis, fed major; Baco, fuifi Ingenio atgue atque anfis; ars trbi fola deeft.}

Magnus ille Cancellarius dici poteft unus ex iis qui Scicntiis promovendis maximè allaborarunt. Cum enim illas imperfectiflimas à Vetcribus nobis effe traditas animadverteret, Recentiores verò modicos tantùm progreflus in is feciffe, duos conferipfit libros ut doceret quibus modis exdcm perfici polfent. Prior infcribitur;, De Augmentis Scientiarurn, in quo:ftatum prefentem in quoverfantur Scientix nobis exhibet, quxque defiderentur ut ad perfectionem adducantur nobis oftendit. Verum afferit magnum profectum non effe fperandum in his adjuveniendis nifi adhibeantur alia media quàm que hactenus adhibita fucre: demonftrat enim Logicam qua nunc utimur aptiorem effe ad $S_{\text {c }}$ boLarum Difputationes fovendas quàm ad veritatcm elucidandam, câque nos po tuis doceri de vocibus vitilitigare quàm rerum fubrantiam penctrarc. Unde etian dicit Arifotelem, cui artem hanc acceptam ferimus, Phyficarif fitam Logica fux accommodafle, chim contra Eogicarn fuam Phyfi a debuiffet attcmperare, illumque naturalem ordinem invertendo, finem mediis fubicciffe. Ad hujufmodi confufionem tollendam magnus hic Cancellarius alterum Librtum claboravit, quem Nownm Organum infcripfit, quo novam, Logicam docet; cujus precipuns fcopus elt bonam Inductionem cóntexere, quemadmodum Logicre Ariftotelic finis principalis eft bonum formarc Syllogifrum. Præclarum ent hoc Opus, fuitque femper ab hoc Authore confideratum ut omnium "qux clucubravit exquifitifimum. Imo illum in hoc claborando oatodecim "annosinfudaffe perhibent, ante illius evulgationem. Eruditorum Ephemerides. Gall. 8 . Martii 1666.

Opus illud Nowi Organi (cui iple inter opera fua primas tribuit) neutiquam fanè cogitatio umbratilis aut cerebri proprii Commentum fuit; fed veluti fixa \& radicata notio, multorum annorum, \& laboris improbi proles. Vid. in Vit. Baconis.

In libris fuis componendis, verborum vigorem \& perfpicuitatem precipué fectabaturs' 
Cectabatur, non elgantiam aut concimitatem fermonis: Inter fcribendum aut dictandum, fape interrogavit, num fenfus ejus clare fatis \& pertpicuè vedditus eflet? quippe qui fciret, aqum che, ut verba famularentur rebus, non res verbis. Neque verò verborum minutis \& allifionibuscapicbatur, fed cas lemper excompofito \& de indufria efugit, probe Cciens, ejumoditutilitates nihil aliud effe, quàm deviationes \& aberrationes a fcopo propofito, \& gravituti \& dignitati fyli, non modiclm officere \& detraliere. siouiden apul tuos elo-

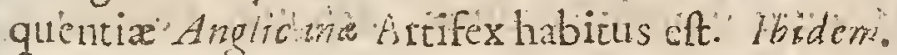

Baconus eft ingenium vagum qui de rebus nunguam enuclcatè differit: Nimia ejus doutina eum accuratum efre non finit. Heraque ejus dogmata ulterioris meditationis potius anfam prebent, quàm fiximata qua fequi teneamur. Ljus Opiniones aliquid acuti \& f plendentis habent; \& fi verum de ipfis dicere velimus, ignis Scintillas potiùs quan conftantem o nativan lucem teferunt. Rapir. Animadv. in Philof. Seet as. Gall.

Plus elucetingenui in Baconi Mórlibus quam in exteis ejus Opcribus. Omia ibi Scite cogitata, fed nefcio an emila vera." Kapinu in Etbicdm Sed. Gall.

Baconusamórem Philofophic apud Angles excitavit Ingenium fuit vaftum quoad Phyficam, non tamen in is qua de hyficis pertrabavit felicior fuit quàm in lua Ventorum Hittoria; quamvis paulò ninitim credulus dici debcat relaeionibus hujus materia fibi fubminiftatis. Idem. Animadv. in Phycim Sect. 9. Gall.

Eques Nicolaus Beconus primas fuir Magni igilli Cuftos in quem tota dignitas \& anthontas Magni Cancellanii collata fuerit. Ncc tamen ad altiorcm hune honorcm evectus, nativa modeftir limites exceflt: Licct mim Dodtiffinis Pientifimis noftrx Gentifg accentendus flet in illa tamen amplitudine modeAim fervavit qua cum fuis concivibus in altifimum gradum evedis verfaban-

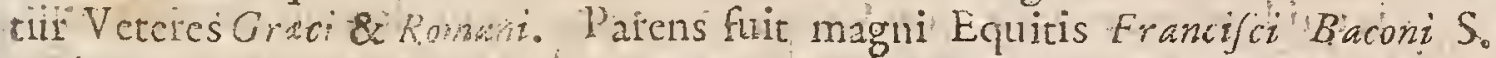
Albani Vicecomitis \& Magni Angla Canceluarii; qui Anglice Gunis decus fummum extitit fi qutis alius. Burnetti Hiftor. Reform. Par.2.1. 3 pagin. 380. Angl.

Quando quis fupcrioris Secili Scriptores, cum illis confert, quin noftro Sectlo excellunt, valde confpicuum eft inter utrofure difcrimen. Iple ctiam Eques Erancifcus Baconu, quiprimus idiomate noftro purèferiplit, ut etiamnum op timis Authorum noftatium cenfetur, quibuldam locis tamen infolentibus

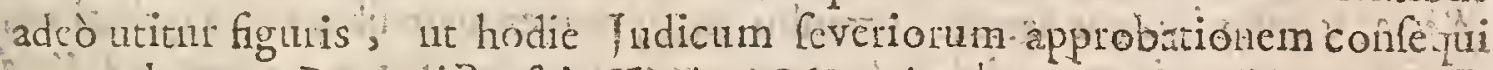
non valerent. Burietil Praf.in Vtopiarn Mórr. Angl.

Quoadicribendi elegantiam, claruit Eques Francifcus Baconus S. AbaniVice-Comes, quipreter ejus $N$ ovi Orgni eru ditiflumos libros, Regmum Hen

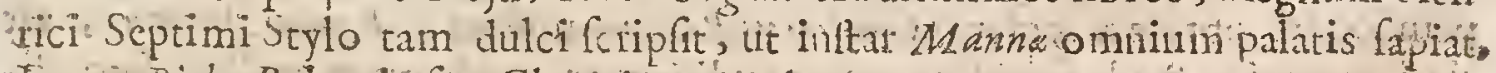
Equics Rich. Baker in Luo Chrônico Angl:

Extant omnia ejis Opera in fol. Francofurti ad Mernin anno 1665 . 
HHoc ejus Epirapbium, in Cancello Ecclefar S. Mich. apud S. Albanum :-

Francifcus Bacon Baro de. Vèrulam, Sancti Albani Vicccomes ; Ceurnotioribus. Titulis Scientiarum lumen, Facundia lex fic fédebat. Qui poftaum omnia Naturalis fapientix \& civilis. Arcana evolvilfet, Natura decretum explevir, compolita! Lolvantur. Anno Dom. M. DCXXVI. Atatis LX V I.. I anti: viri Mem. Thornas Meautus fupertitis culcor, defuncti. Admiratoz. H. P.

\section{GUAITERUS. RAULAUS.}

Glar. A. D. T Ques Auratus, in Parochiâ de Budeley, in Agro Divonienf mas r. inter MDCX. IC Commenfales Orielenfes effe copit Anno Dom.1574 atatis i6. ubi rempus Gradum Baccalaurei in Artibus requifitum propemodum complèvir ith diis Acadenicis, maxime autem polition literaturâ quàm optinè mintructis. Ne fingula perfequar, fub Elizabethâ Regii Satellicii Capitanès, Quinque Portunem Guardanur fuit , illam verò Indice Occidentalis partem detexit quam in Domilix Regina honowem Virginiam nuncupavit. In T urim denique Lonái- zenferm proprer fulceptam quam iple Scriptis mandavit expeditionem, compingirur. Demum pravaluce Comitis Gundamauri, Hipanorum legati, artes, is

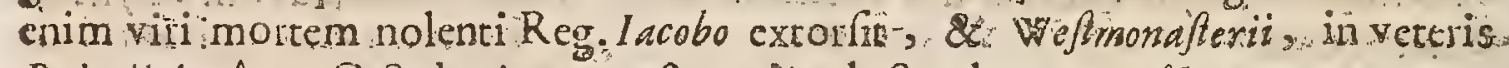
Palatii. Areâ, 29. O ctob. Anno r618. capite plectendum curavit.

Scriplit Tradatum qui adminiftrandi. Regni:Artem continet Güand Def criptionem Obleryationes in Artem $N$ autucam, aliqque ad Mare fpectantia: Pro. expeditione fuâ Guianenfâ Apologiảm :- Monita tho fuo Polterifque confcripta:Prerogarivam Parliamentorum in Angliâ : Orbis Terrarum Hiftoriam.

Vir quidem erat eximiis tam Coupous quàm Animi dotibus locupletatus. cui Ingenium, Judicium, \& facundiam, vix alibi Tparfimreperienda, prodiga quafi in cumulum congeffr $N$ atura. His accefft prefracta Induftia, quâ mentẹr deni jue Doctriize tenacillimam omnimodâ fcientiâ mirificè excoluit. Ut

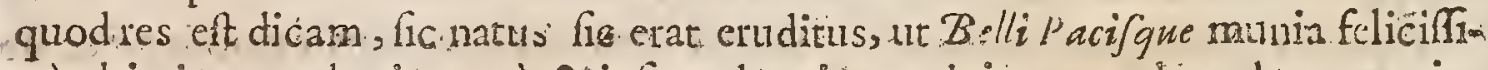
mè obierit, quod enim verò \& ipfi tandem in perniciem vertebat dum tam infilitis meritis \& exteris metnm incutetes \& Gentiltion fuorum invidiam ex citaret. Orbern non modò errarum, fed \& literarium peragravit, \& in utroque Regiores prits ignotas detexit, omnibus utilis prarerquam fibi, vir, fo quis alius, preteriti temporis exemplis, \& lequentium imitatione major. Antor. à. IVood il Hift. \& Antiquit. Vniverf. Oxen. p. rogo:

- Hos autem féqui pofünt nonulli ex recentioribus: quos inter, principern locum obrinere meretur Gualterus Rauldus nofras, Eques Auratus, vir clai nominis, \& ob fingularem fortitudinem ac prudentiam metion fato diInus. Is Vniver falem Hiftoriamabinitio Mundi ufque ad Macedonci Imperiis Ave tertix M onarchie occafum, ex probatilimàs Axctoribus coagmentavit, no. 
Clar.An.D. Ardinalis, Natione Italis, patria Politianus, natus eft çarto die Octo MDCX. rembris anno falutis 1560 . 2tatis fura 18 Obiit anno Dom.1621. die 17. Septembris xtatis luæ 79.

Reliquit Libros Controverfarum, quibus prelertim fibi purpure honorem \& gloiiam peperit, tum Conciones, Refponfionem \& Apologiam ad lacobum Angli Regem, deinde de Scriptoribus Ecclefraftisis volumen. Davidici Palo terit interpetationem, acpoltemis vitafure mis. deGemitu Columba, de Arte bence Molendi, aliague Opufcula cdidit

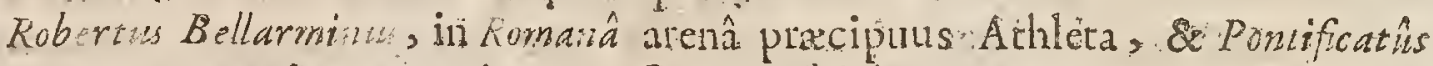
propugnatoracerrimus, qui contra Ordinis fui decreta \& voum initiationis

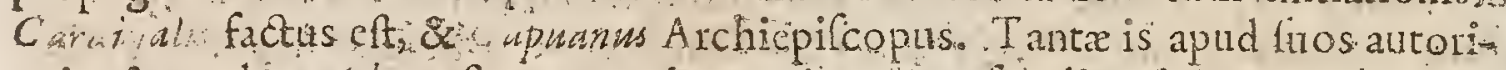

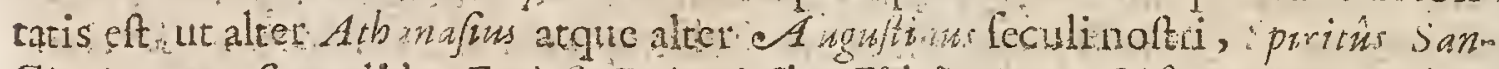

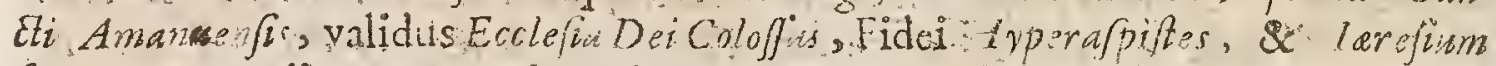

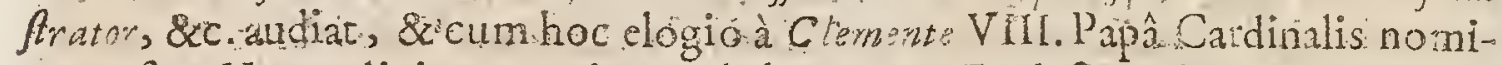
natus fit: Hurc eligimus, quia non haber parem Ecclefr Dei; quoad doctrinam, \& yuia eft nepos optimi \& an tirimi ontificis (nempe $M$ arcelli 11.$)$

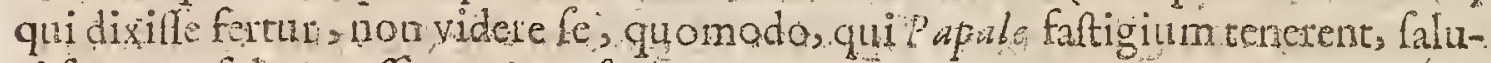
tifuze confulere polint Quenfed.

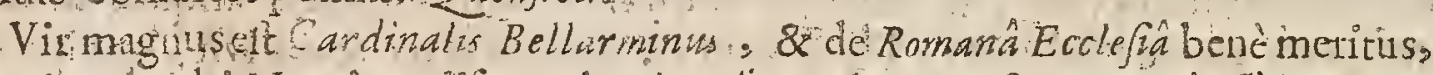

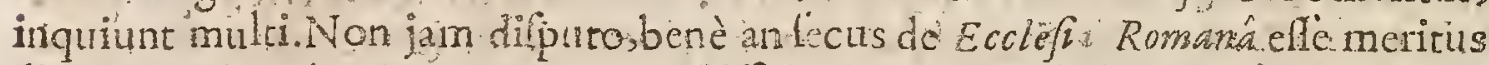

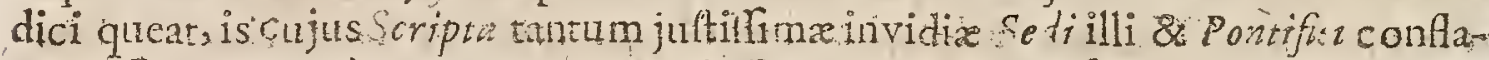
runt Poteratcertè Bellarminus \& - de R. E. \& de univerfo nomines Cbrifiano mereri haut patlò melịs, fingenium quol excellit \& döckinam pio charitatis fervore fuccenfus ad tollendam porius quàm augendam Ecclefe Coiftram contulill i f quanco fudio \& diligencià Principibus terribilem Pape onnipotentiam, \& piritum Supcrbizeclefa cxirabilem; tot lucubationbus fuis acerrimé propugray ir tantum fudil \& diligentia inpendifut, ut malis Ecclefix per aliquot jam feculaafrdue gcments, \& ad priltinam dilciplinam revocarigeftientis, alicyod pro fuâ virili, remedium procuraflet. Tunc verè $M a-$ gnus Bellarmina abuniveda Orbis Chriftanis audiret tunc unami concentu, Prin ipes pariter \& Principum fubditi laudes ejus nomenque celebrarent. Nunc quo pacto fine pe fidia notâ fideles Pxincipurn fubditi landabunt; qux contra Rénm Iura \&in Pritcipur curtam perniciem Card. Bellarrinus fcripfit tam multa? Cafaut. Epift. 624.ad Frontonem ruceum $p \cdot 723$.

Virerat, hald inficior, admiranda induftrix, doctrinz, lectionisftupende Bellarminus: qui ut primus iti folus immanem illam molem, \& immenium chaos controverfarum, ftipendâ ingenii dexteri felicitate, artificio fingulari excoluit, in ordinem redegit confufum prius : ac uratâ diligentiä, \&i inultorum anorum ttudio eleganter expolivit: pracipuit ille palmam fecuturis omnibus 
\& fibi defponfatam vel deftinatam cuicunque laudem abfulit. Nam ab illo, qui trackan: hodie Controverfax, ut ab ab.Homero Poëta, Cua omnia ferèmutudntur. Montacut. praf. ad Apparar. fcét: 6.

Methodus quin fuo in $r$ falmos Commentario fecutus eft Cardinalis Bellarminus bona cft coque digna. Hcbraicum T(xtum examinat, quil cft Prototypum, deinde duas Verliones veteres quas authenticas declaravit Leclefia. Non eft tamen criticus, \& mediocrizer tantum Hebraice Lingux peritum fe prodit: adeo ut quandoque labazur. Qúoniam poft Genebrarum faipfit, ab illo canfumfit ferè omnia qua Grammaticam \& riticen fpectant, paucis tartum immutetis. Sunterizm loca qux magis ad literam \& juxp fenfum Hilto-

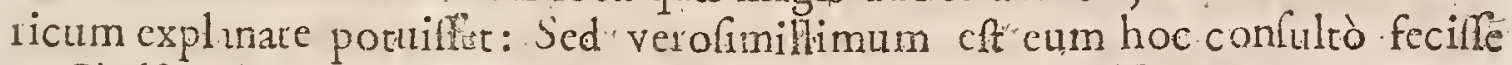
ut Chriftanis utilio forct Commentarius fuus. Oratorí Presbyter Rich. Simon. Hift. Crit. V.T.1 3: C. I.. Gallicè.

Bellammorib judico vinun doctum, ingenio felici, judició fubrili, lectione multiplici praditun, quilolet aperiùs \& limpliciùs agere, quàm reliqui $\mathrm{Pa}_{\mathrm{a}}$ pitze conilueverunt, \& argnmentum preffus urget, \& arctivs ad caufam adharefcit. $V$ biuk, in profat.de Scriptoribus.

Staturâ:fuir pufllixproximâ, collô brevi, nec fanè nimis elçañi formâ: quamvis jus animingeniique probitas pulchritudoque in ore emicaret. $i$. I i $i$ cins in Pinacoth.

Bellarmi us nhilin Hebraicis feivit confderatu dignum. Ferunt eumadornalle Grammaticam quabona perhibetur. Liot mihi dono darentur Bcllarmini Opcra, é relpuetem sectorum cnim oculos pertungere conatur. Bellarminu nithil corum credit qua fcribit; planè eft Athcuss. S’aligerana poftèrior. Gal!.

Cardinalis Bellarminus egregiieftingenii \& dilucidiffmi ; cum incidit in aliquod. roumentum accurate difculfum \& examinatumab aliis, hoc mirifice al lutravit, ing nii fui acumine ac puritate; $S c d$ cum Argumentum acperitadhuc intricatrm, \& valde confufum, mens ejus sin ea perftringitur. Sapius utitur Verfianibus, 'atrum Grecorum, ipjos fontes negligendo ; quod mitor ; $;$ Grece cnim eruditus erat." Perromma, Callicé.

Magnam fibi paravi famam libo fuo de Scriptoribus Ecclefafficis : cujus

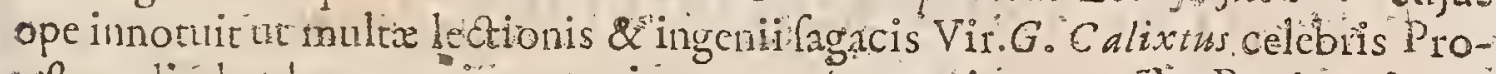
seftans dicebar hoc omnitim scriprolum ejus optimum efle.. Partim Atudio

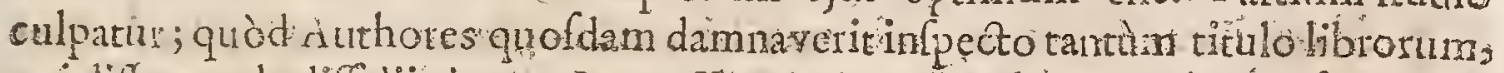
qui differunt de difidiis inter "Papas 8 Prnsipes Seculares; quod duafdam Verfones improbaverit Authonm bonx nota eo pratcxtu quodab Hatericis elum cubratx fullent, quamvis in ris fidi fuerint Inteppretes. Fatendim etiam eum quandoque in Criticis hallucinari \& Cbronologict. Verùn duo ift nevi ultim venia digni funt, fi attendaturingens obfervationum ejus egregiarum ntumerus, Optandum effer ur uthorum probatis cditionibus ufus efre; plus folaminis 2auxilii ex ipfis percepiffer. Judicium Ertaditorum Parilis per Baillettam. 168. Gall. 
Sapienter Patres Curid Parfisenfs fecere; qui I rfitutionem Mariand Jefuitz nltricibus flammis addixerunt: fcd Capicnifime quòd Roberti Bellagrnini Cardinalis, cujus ore tota Iefuitica Societur loquitur, libum de tcmporali potetate Papx adversus Gulielmum Barclaims, librum SC to, damnaverunt, \& fub poenâ $1 \mathfrak{x}$ Majeftatis habere, rceinere, communicarc, excudere, vendere veruerunt. Hoc decretum eft Anno I6ro. Herman. Conring.

In Elenticis primx jure dibentur, fr Audum Cpectes, \& eruditionem, Bellar min. Hottinger. Biblioth. Quadipart. p. 419 .

Eft tamen Baronius Bellarminomelior, homine ad Strophas, Sophifmata, Mendaciat apto, nulli alii rei idoneo. Norma ulli veri eftnon Sara Scmpsura, lcd libicto Pape, quem ut Denm interris contiuat, quàm licelcftè, quàm frè mentitur. Cuaub. Epint. ad N. N. Lonóni w. Eid. Mart. 26I3.

Sub initium porrò hu us Cxculi Robertm Bellarminus librum didit de Scriptoribus Eccle falicis, qui inter precipuos hujus argumenti libros non immerito

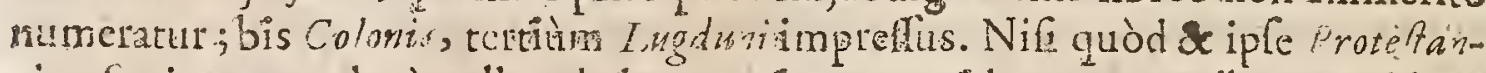
tiun Scriptorum planè nullam habear rationem, idque ex omnibus manitere odio. Vertin ter. Vogler. Introduct. Univenfal. in Notit. Scriptor. c. 6.

* Tractarus de Poteftate Pontificis Romani in Temporalibus adverfus Guliclmum Barclaium, ccufurân notatus \& vititus in $G a l i a \hat{~}$.

Extant Opera ejus 7. Tomis, Ingolft. 1601.\& Col. Agr. I617.

Hoc ejus Epitaphium, quodin Collegio Cardinalium reperitur:

Die 7 . Septembris 162. Reverendiffmins Dom.Robertus Bellarminus, Presbyter. Cardinalis, de Monte Politiano, sx Venerabili Socieinte Jefu, bâc die sorâ du. adecimâ de regione mortuorum tranfovit ad regiones zivorum. Vir Clariflimus, Theologus eminentifimus, acfidei Catbolica propugnator acerrimus, Hareticoruminallews, aque pius, prudens, bumilis ac fummè eleëmofynarius: Sacrum Collegium Cardinalium, ac wniversa Curia Romana tanti viri amifsonem, non fane lacrymis maximè indoluếre.

\section{JOANNES BUXTORFIUS, Senior}

Ciar. A. D. MDCX

7 Ammonia VVeftphalus, ex familiâ inter fuos illuftri: cùm Bafilca fudioI rum causî degerer, ob cximiam in 4 ebraigâ literaturà perititiam, S.Lin gux hujus Carhediz ibi tum vacanti admotus, Cpem de fc conceptam tam nagnificè implevit, ut brevi Rabbinorum $M$ agifter, meritò audiret. Obiit anno 1629. Etat. 65. Rafilex Hofman. in Lexic.

Scripfit Epitomen Grammatices - Manuale Hebraicurn-Lexicon HebraiconChaldaicum-Thcfaurum - Grammaticam Chaldaico-Syriacam - Synago gam Iudaicam - Abbreviaturas Hebreorismu - Epiftolas Hebraicas - Prex- 
fuit Operi Biblico, cui Tiberiadem adjunxit. Affecit Concordantias, \& Lexicon* Chaldarco-Rublivicc-Thalmudicum, \&c. Reliquit Babyloniarib, adhuc àvén8orovo Ioannes Buxtorfur, Lingux Hebraa in Academiâ Bafleenfil rofeffor , $H E m$ braifmi Pboenix, doctiflimus.Cbriftianorum Rabbi. Quenfed.

Doctiffimus. Buxtorfur; \& Lcxicographorum doctiffimus; fapifimè vocasur à $B$ oc bux:o in Geogiaph. Sac.

Bux orfut in admirando Opcre: Syntadico, guod Clurifunus Ludovicus de Dien fibi Clavem Scripturx: Biolica effe adfitmat;-; ac omnibus. Theologix ftudiofis commendat: Dilber. Tom.2. Difputat. Academic..

Buxtorfiii LexiconChaldaicum, Talv, uticum, \& Rabbinicum, Opus trignitat annorum, : cui inihil tale Sol lunquam afpexit aut fimile. Edm. Leigho.

Ut nuper obfervatum eftà doctiffmo amico noftro loäne Buxtorfo, Lingux Hicbraica \& omnium Iudaicorum Intitutorum pcritiffino. If. - Cafanb. ad Annal: Baron.An, 34, num. 127.

Quố [ B Buxtorfio] H:bruicarum líterarum intelligentiorem, magifque in: Rabbinicus \&. Talmudicis exercitatum Europa habct. neminem. Voffo. in Orat. ina obit. Thom Erpenito..

Butorfins Synagygam Tudaicam elaboravit qux bona eft, fed plurcs voces non intelligit, quas yerperam incerpretatur. Buxtorfius allus planè Vir ent qua in: VVafirus. Dootris eft, imö unicus Doetus-Hebraicè. Hadie nullum prater eum

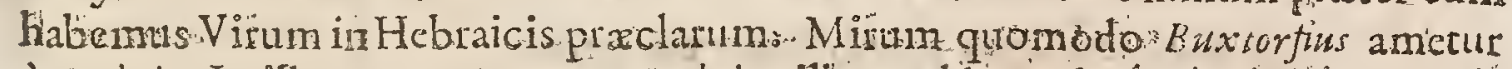
à:I duis: In ifla tamen Synagoga Iudaita illos valde perftringition Reliquit mul tos errores.in Epittolis Indaicis. Scaligerana 2. Gall:

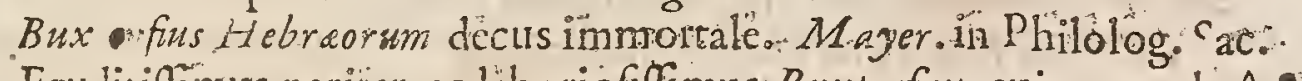

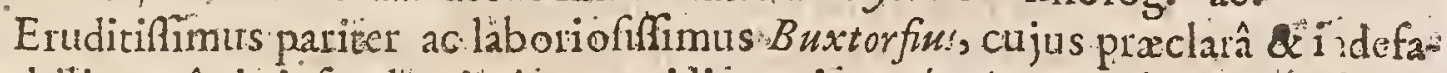
rigabili opcrâs in ipfa adyta intimaque idiomatis Hebrai penerralia in dies fing los ftudiof magis femper magifque deducuntur. Edv.Leggh, Nor. ir Crit: Sac. prrafar:ad Lector.

Suis Lucubsationibus tantan nominis celebritatem fuit confecurts; ut not ${ }^{3}$ tantum omuza Exemplaria brcvi tempore diftracta, \& aliquoties magno numn. ro recula, verum etiam, wr nullis in Orbe Chriftiano locus daretur in quo $B u x-$

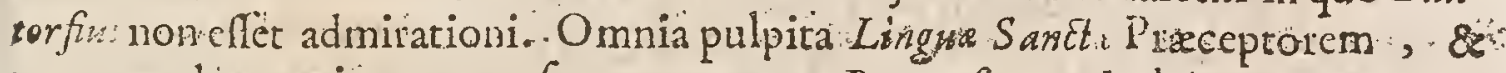
propemodum unicum agnofcere caperrine - Buxtorfurmo. Indai per totim Gerinaniam, Poloniam, Moraviam, Buberniam, Inaliam creberrimis illím literis fam tigatunt; adeò ut non Centurias, fed Myriadas Hebraicarum Epiftolartm à di

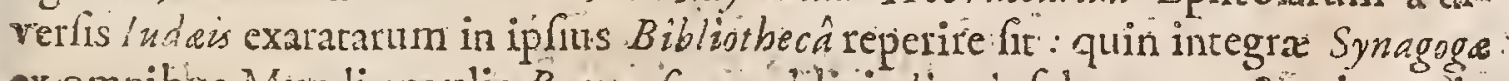
ex omnibus Mundi angulis $B$ uxiorfinm publicis literis fal lutarunt, \& mirum in: modum depradicarunt. Dan. Tollan in Orat de Vit. \& Obito Loan. Buxtorf, vido? Henning.VVitte in Memor. Philoloph. p. $3 \mathrm{r}_{3}$.

Buo Buxtorfi-qui multam, inter proteftantes cumprimis, famam fibì peperernnt; in plerifque Scriptorum fuorum nihil nif praconceptam exiftimationem Rabbinicarum opinionum cxhibentsceteris Auth otibus uninimècenfúltis.Qr. Prcsb. Kigh. Simon, Prxfat.Hift. Crib Y.. I. Gallo.

Plexigitu 
Plerique corum qui hodie fuam in Hebräla lingua peritiam Venditant, nulIum ferè magiftum alium habent quam $B$ uxtorfi Lexicon, quod omnibus praftare cenfuerunt, quia omnium compendiofifimum \& maximè methodicum eft. Omnium tamen angufiffimum eft in Hebratcarum vocum fignifica tione. Normam fibi prefixit Rabbinorum libros. Idem Hift. Crit. V. 1. I.3.c. 2. Gall.

Cavendum autem à quibuldam Rabbinorum \& Cabalifarmm commentis \& fabellis, quas inter explicandas Hebraicas voces fparfim mifcet Buxtorfius. In dex Madrit. $1667 \cdot \mathrm{p} \cdot 5.6$.

* Lexicon Buxtorfi; cjuldemque liber, cui titulus, loannos Buxtorfit Thelaurus Grammaticus Linguæ Sanetz Hebraici duebus libiis methodicè propof.tus, expunetis autem Litrenis Dedicatoriis, permittitur in Decrto 4 Julii 166 . in 12 .

Extat Manuale Hcbraicin \& Cbaldaicun. Bufl. 1602. 1613. 1630. 1658.

Extat Synagoga Indaica. Bafil, 1603 . 1641. 266.1. in So Fanov. 1614. 1622.2. in $12 \%$

Extat exicon Hebraicum \& Chaldaicmm. Amftelod. $16 y_{4}$ in 8\%.

In obitum Summi Viri Loan. Buxtorfit fre cecinit Ludovicus de Diew.

Siccine Mufarum priciafic luce parentem

Tetra twes? nunguarn lux 'ea morte perit.

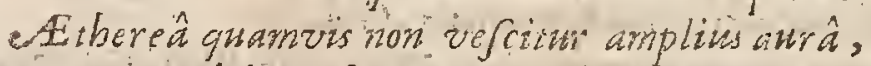

EAtcrna bunc farna vivere fata valunt to

Tumea mens moritor, tu fanclam defere linguam:

Tu Targium, Talmud, abjice, perde, cave:

Si tibi quando viri moritur nomcnque decufque.

Qiilibi, durn vixit, vivore inente dedit.

Plangite, Judxi, qui veleram dicere linguam

os docuit recidita net rediturus abeft.

Plangite Rabbini, qui vobis veftra reclufix

Abatia, jurn trato abfondidit illa Dco.

Plangite, quos Chrifus carâ fibi morie recie it

Dax vobis, doztor, lixigue decufgue jacet.

Hoc'ejus Epitapbiurn:

C. $S$.

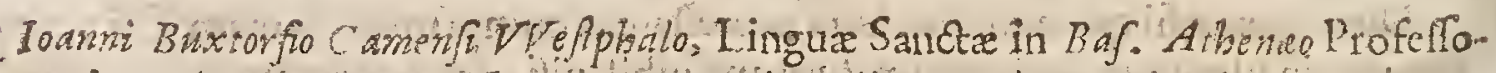

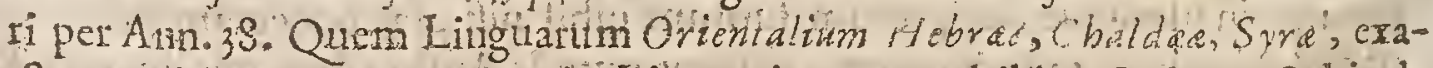
a cognitio cum Monument Literar incomparabilibus U bi \& Orbi admiabilem rcddiderunt, Lue peltifera magnis Laboribus chen! prama- 
turè erepto, Margareta Curionid Conjux Liberique moentir. Marito. Parente defideratil. C. L. P.P. B. Ann. 6g. $\odot$. Ann.1629. Idib. Sept.

\section{JOANNES AUDOENUS, vUlgo OVVEN,}

T. Atus in Villâ Armon, in Comir tu Caernarvanienfi, bonarum literarum elementa, aufpiciis Dostoris Bilfon, in Scholâ VV intonienfih haufit; - ColleClar. A. Do MDCX. gii verò Novi Socius emicuit Anno Is 84. eundemque exuit anno i59r. quấ tempore LI. Baccalaureatu ornatus companit, \& Ludo deinceps Literarion Tryleyis haud procul ab urbe Monumethenfis prafuiffe perhibetur. Epigrammat. ta fcripfit.

Virum hunc Ingenii eximii dotibus inftuxerat Natura; Arte verò Poëtică. inter Coævos prefertim cxcelluit, id quod Epigrammatum libri ab ipfo editi fao tis teftantur; in quibus liberius quidem jocatur, vitiaque humana haud infu'sè plerum que notat; falibus \& facetiis feculi quo vixit ingenio accommoditaris: Morbo l'oëtas inter epidemico, egeftate nimirum, graviffimè conflictabatur, Dodtoris antem Ioaninis VViliamas, Epifcopi Lincalnienjus, magnique Sigillt cum ftodis, popularis verò fui, patrocinio fublevatus, annis benè multis melius habuit. Porrò dicitur, ipfum ab hæreditate admodum amplâ dimotum, quaram ab Avunculo locuplete expectaverat, ob hrec ipfa qux fuperiùs appofui $C$ armitna: adeò fatali lege Mendicitas Poëtas confequitur, \& Vates ingenio, acuto ni: mis telo, pereunt fio Ant. à VVood in Hirt. \& Antiquit. Oxon.

Loannem Ovvenum Cambro-Britannum ipfe Mufa enutriilfe videntur, adeo ing Epigrammatis ejus plerifque nervi, argutiæe, venuftas inter fe de palmâ conten dunt. Non turget, non inhorrefcit, non anxiè quærit $S_{a l e s}$ fuos, ut qui fponte fe offerunt, \& calamo currenti propemodum innafcuntur. Sed, ne quid difimulemus, in fordibus \& obfcœenis frequentius volutatur, caftofque animos [ax pè cxulcerat. Quoties ipfracumen parit furcities? quoties furtum meretricusIx: quoties cavilla! Viciffet Martialem, nifi hâc parte ad cum acceffiffet propiús. Eft \& , quanquam rarius, ubi in Quantitate Syllabarum, th ubi in: Dis Etionis Latine munditiem impingit, quod ipfi cum celebratiffimo aliàs Barclaio commune. Sed hos næevos magnis redimit virtutibus. Borrich. de Por̈t. p.55०

Multa ingeniosè fcripfit Orvenus in ifto Carminum genere: fed intercurrung non pauca vilioris moniex. Magno applaufu apud Anglos leguntur.Cafp. Baya lens in Epift. 883.

Notetur proprium ejus de feipfo judicium:

\section{Qui legis ifta, tuam reprebendo, fimea landas. Omriia, finlitiam: fr nibil, invidiam.}

Ingeniis fui feculi elegantifimis accenfendus erat, quodque Poeter tard con ingit, ejusid fuit judicium; eaque prudentia ut animadverterer genium \&

$$
\mathrm{Zz} \mathrm{zz} \text { dore }
$$


dotes ejus Epigrammatis limitibus coerceri debere, fuique fatis compos fueri ut illos non tranfilturit. Indicia Eruditorum Parijizs 168. Per Baillettun. Gall.

Iobannes Ovvenenius Oxonienfis Britannus, Poeta falaciflmus hunc honorem Seculo noftro confecutus eft, ut inter prima ingenia collocaretur quoad argutorum Epigrammatum Latinam compofitionem. In gloria ejus incrementum, à luis Conterraneis frequentifime Martialis Anglicus cognuminatus fuit, ob fententiarum acumen, carminumque jucunditatem, quippe qua non legantur quin feftivitas cum Satyra in eorum contextu fociata mirifice leCtorem delectent. Periti artis Pocticx retimatores qui hujus ingenii pondus ex cjus evulgatorum lectione trutinaverunt, judicârunt eum efle P̉ectam argutifimum, undequaque floridam, parum tamen cultorem genuinarum Latinæ Poefews phrafewn, quibus vel Veteres vel neoterici ipforum imitatores ufi funt: Quia fcilicet loannes de fyli fublimitate \& puritate, verborumque ad locution nis exornationem delefu parum follicitus. fuit, mentis conceptus quocumque tandem modo exprimeie contentus. Si verò debitis circumftantiis scripta fua stipaviffet, Poetis innumeris palmam dubio procul praripuiffet. Laurentzus Crosfjus. Italicè.

* Hic Author propter Epigrammata varia rejicitur inter $H$ areticos prima Clafjis, maximè autem propter Difichon illud:

An Petrus fuerit Roma jub judice lis eft;

Simonem Romæ nerno frifje negat.

E vivis migravit eodem ferè tempore quo eruditiffmus $C$ amdenus, an.nimiw rum I623. Inque Navi Ecclefia Cathredralis Pauline Londini terra mandatus eft, funere Antilitis prafari [ Lobannis VVilians, Epifc. Lincolnien/is ] impenfis folennem in modum deducto, qui viri porro effigiem, lauro tempora! redimitam, Columux tumulo propinqux affigendam curavit, Epitapbio ifto ïn ferius appofito.

Parva iibi fatua eft, quia parva fatura, fupellex Parva, volat parvus magna per ora liber:

Sed, non parvus bonos, non parva cft Gloria, quippe

Ingenpo band quicquam ef majus in orbe tuo.

Parva doxus texit. Templum fed grande; Poëts

Ium rerè vitam, quum moriuntur, agunt.

\section{THOMAS DEMPSTERUS:}

Clar.An. D. C Cotus, nobili Rtemmate.profatus, amiflis in patrii fortunis, cùm ea Religio MDCX. ni Reformata I'ontificiam judicaret polthabendam. Lutetiam Parijurum venit. 
venit. Juris peritus, humanioribus in eâ urbe literís, quas juventuti tradebat, rem gloriamque confequebatur. Tandem in Bononienforum Academiâ. Profeflor. obiit anno Dom. I625.

Scripta ejus funt: Commentarii in Rofinum, de Antiquitatibus RomanorumCommentarii in Corippum Poctam Africanum, \& Clandianum - Epifolarum libri quatuordecim - Colmographia - Mythologia - Judicium de unoquoque æatis cujulvis Hitorico - Libri quinque \& triginta Hifforia Sco tia, \&ce.

Erat Thomas Dempfterus, uti refert Mattheus Peregrinus, indefeffus in legen* do, ita ut quatnordecim dici foras in librorum lectione continuare foleret. Mentis acumine fatis valuit, fed memorix tenacitate longè plurimùm, adeo ut multoties diceret, ignorare fe quid fit oblivio. Nihil adeo abditum in Antiquitatis monumentis, cujus non meminifet; ita ut Frazsifosus Cöfuius, vir in literis omni comparatione major, De, sapplerum magnam Bibliothecam loquent tem compcllare confueverit. Stylus ei copiofus, confragofus tamen. Moriw bus apertus \& fimulandi nefcius ; five amore odiove quempiam profequeretur; utrumque palam. Ut amicis obfequentiflimus, ita inimicis maximè infeńfus. Aub. Miraus.

Aicins Erytbraus refert, hominem admodum contentiofum fuiffe, \& leviter re vel verbo laceffirum, continuò ad arma rixafque decurriffe : unde factum, ut omnibus formidabilis fíteret. Illi verò glo iam ( ut ait Erytbraks.) multiplex rerum fcicntia, recondita exquifitæque liter , \& incredibilis memorix magnitudo confccerat. Ian. Nic. Erytbr. in Pinacoth.

Neque snim hîc alfentior Demptere, reconditx alioquin doct rinx\& multiplicis eruditionis viro. Fel. Ofuns in Not. ad Albertini Muffati prolog. Hift, Auguit.

Benè de Corippo meritum eruditifipum virum Thomam Dempfterum, nullat" atas negabit. Barth. Adverfar. 1.21. c. r3.

In Galliis enm [Claudranum] tractat Thomas Dempfferus, cujus nuper Antiquitates commodo fanè optimo juventutis publicatz funt. Enffuth. Svvart. l. $_{\text {. }}$ 2. Analcet.c. II.

Multifiæi lectionis \& eruditionis vir DempRerms. Dilber. Difput. Acad.

Thomas Dempfterus, cruditus Scotus, beneque de literis meritus $F^{T}$ (f). de Vit:" Serm.1.1.c. Io.

Ecclefiafticam Scotia Hiftoriam x. libris nobis tradidit ubi de Regionis illius Literatis multa refert. Sed quamvis cxtera doctus effet, non ideo zequioris animi cenfor, nec folidioris judicii, nec fincerioris confcientix Vir fuit. Optaffet Eruditos omnes Scotos effe: Librorum qui nunquam extiterunt ticulos commentus eft ad Patrix fux gloriam illuftrandam, variafune ali.s f faudes commifit, quibus apud Literatos nomen fuum infame reddidit, Indivia Eruditorum. Parif. 1595. per Baillettum. Gallicè.

Verùm Angli, atque Hiberni arguune Dempferum commentum elfe pleraque.

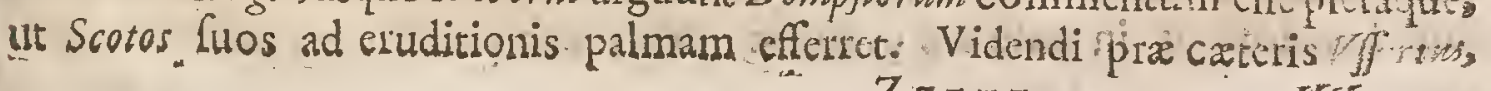


VVoar as, ac. Amt. Teifler in Catal. Auctor, \& Bibliothec.

Dermplerus infuum Scriptorum Scotie Catalogum, prolibidine fuâ Anglos, Wallos \& Hibernos paffm retulit, \& ad aflerriones fuas frmandas, finxitfapiffimè anthores, Opera, locos, \& tempora. Iac. Warrbatus de Scripror. Hibern. p.IIg.

-Commenti genus eft illi homini (Dempftero) non minus familiare, quàm libiorum qui nunquam feripti funt ex ipfius otiofo deprompta cerebro recenfio. Isc. Vfjer. de Britan. Ecclef. Primord. 463.

Thonas Demplterus, kowo multa lectionis, fed nullius planè judicii. Yfler. Antiquit. Britan. Ecclef.c.x.

Quod verò Dempflerus Hift. Scot. lib.6. num. 336 ,affirmat, Faftidium noftrum Scotorum Cbronicon. fcripfiffe, id homini nugivendulo, \& in Gentis fux rebuspesè femper ineptienti condonandum eft. Gul. Cave ad Ann. Chr. 420.

Praterco Mufam ejus, lepidum Carmen, Ced non indoctum, \& in quo eas Dempfterus fignavit lineas, quæ manum Apelleam clarè teftentur. Borrich. de Pö̈. p. Isr.

* Scotra illuftrior Thoma Dempfteri prohibetur. Liber queque infcriptus $H$ i. Germie, five Artiquioris Scotic vindicix adverfus immodeftam Parecbafm Thoma Dempfteri in Decreto 17. Decembris 1623. prohibitus fuic. Thome Demferi te antiquitate Romanormm liber, prohibetur, donec corrigatur, in decreto $x$. Martii I62I.

Extant ejus Hiftorix Ecclefraftica Gentis Scotormm lib. Ig. Bononia Typis. Nicol. Thebaldini $1627 \cdot 4^{\circ}$.

Extat Romanarum Antiquitatum Auctarium ad look. Rofinmm, unà cum Ro/26xo excufum Collonic Allogobrum Typis Gabr. Cartierii 1613. in $4^{\circ}$. Colonice

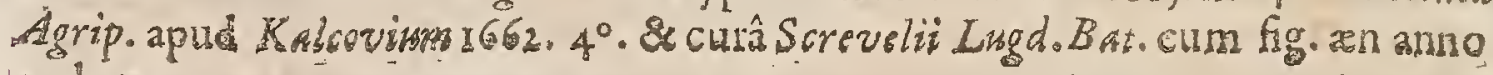
codem.

\section{Hoc cjus Epitaphium:}

2ugete Boni, ingere Doti, Thomas Dempterus inclytus ille weffer hic conditur asbi Aftream, Poëfm, literas fatius condifuerat. Scotiagloriosé genait, I talia provide rapuit, Felfusa pie tumulavit. A Athere spritus, boe lapide cinis, scrip-

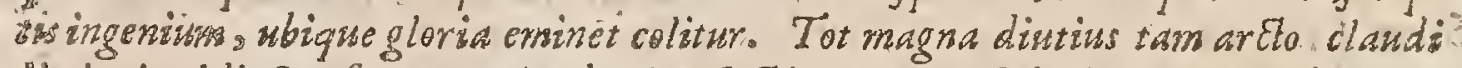
ilimite invidiofum fuerat, Academia Noctis tatitivi fyderis occafurm deflens. Hescrymatrum vitali ore magis quàm celsè lo quacem vabis exponit lapidern.

\section{F RONTO DUCEUS, soc. fes.}

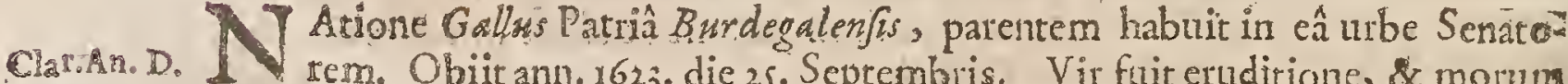
MLEX. 1em. Obiit ann.162j. die 25. Septembris. Vir fuit eruditione, \& morum flavitate carus etiam iis, qui iniquiore animo in Socictatem, crant; vt vulgò parm à malcdictis in noftum ordinem vibratis exceptum cum efle vellent. 
Antíquitatis totius cognitione maximè nobilis fuit. Certè ad laborem fuit impigerrimus, perdius in libris \& pernox, tantâ fui abjectione \& defpicientiâ. uh nullum domi tenuiorem crederes. Phil. Alegambe.

Multa S. Patrum Opera recenfuit Notifque illuftravit, ut Gregorii Nazianad zeni, Nyfeni, Bafilit, Chryfofami. Scriplit pratercà Collectanez in Clementizem Alexandrinum. Denique etiam edicuravit Bibliethecam Gracorums Patram.

Fronto Duceus Theologus, dectrinâ \& candore morum vir infignis. If: Casz Saub. Epif. 496. ad los. Scalig.562.

Fronto nofter, vir profectô melior, quàm ut pro germano Loiolita polfir hà beri. Is te fingulari reverentiâ femper coluit, \& prærtantian eruditionis rug cum omnibus bonis miratur: neque fuorum Sycophantias moracur, fed, quu candore eft, abominatur: "Utinam hoc ingenio omnes familiz illius Codalcs ef -

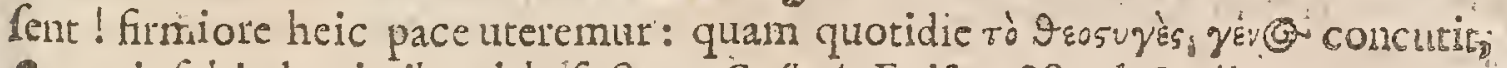
\& novis fubinde arietibus labefactat. C $C_{\text {af }}$ fub. Epitt. 488. ad Scalig.

Fronto Duceus, vir Ecclefiafticarum Antiquitatum ftudiofifimus - Vir infin-4 gnis doctrine ac pietatis. Baron. Vol.g.

Eronto Ducaus, Vir doctiffimus, \& cui Chryfoftomis nofter phiurimum de: bet. Henric. Savil. Not. in Pfalm. Chryfoft.

Homo eximiè eruditus Fronto Duceus. Montacut. A pparat, g. Sect. g.

Fronto Dwians aft honeftifimus Iefuita. Omnes illi Senatores P'arifenfes

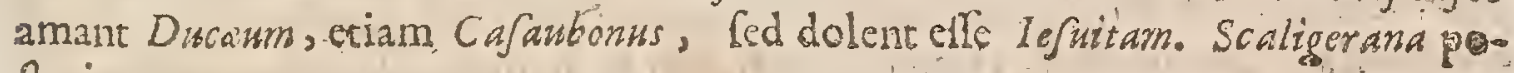
Aterior.

Fronto Ducatts, Jefuita, vir omnigenâ cenditione pollens. Paul. Colomes. Obferv. Sac. p. rg.

Magnus ille vir Pbilippus Mornetos Pleflius, ingenuè faretur ab alio fe nullo adverfario, inter multos, acerbiorem ac luculentiorem q̨uàm ab illo plagan accepiffe:

Jefuita Fronto inter feculi fui praftantifimos Viros claruit cum ob ingenio cjus clegantiam, tum ob judicii ejus foliditatem, infignemque fapientiam 3t modertiam, Ubique eximiam Lingux Greca notitiam, amplamque in Eeclefrafticis eruditionem prodit. Indicia Eradit. Parifis s685. per Baillety tum. Gall.

\section{UBBO EM MIUS:}

CRethanus, Frifus, Hitoriarum \& Gracx Linguæ Profeffor, primufque Xector Academix Groningnax: Natus eft Anno 1547 . die 5. Decemburis. Clax. An D D Mosid Deceflit anno I625. die 9. Decembris.

Scripta cjus hæe Cunt : Frifcarum Rerum Hiftoria, in Decades feptem diffin: A2 - De Frifiâ \& Frifiorum Republicâ, deque Civitatibus, Foris, \&c. - De Agro Frifre, deque urbe-Groning $\hat{a}$ - Opus Chrọologicum novum, cum $C_{g-}$ none Chronico - Chronologia Rerum Romanarum-Gracia vetus, five de Gr: corum Refpublicis:

$$
\underline{2 z z z} 3 \text { posg }
$$


Dotes ingenii \& vis ignea in hîtoriâ fcribendâ maximè effulfeiunt. In co cnim fcriptionis genere ingenium habuit planè fubactum. Nam in omni omnium populorum ac gentium hiftoriâ verfatifimus, de cujufque gentis ac cujullibet temporis hiftoriî rogatus extempore differebat, recitatis omnibus locorum, temporis; \& perfonarum circumftantiis, haud fecus ac"il premeditatus \& paratus accederet ad hiftorias iftas exponendas. Nec erat fuperficiaria hæc (Hiftoriartum) cognitio, qux multis contigit, Ced qux paucis, exact, folid, ad interiora penetrans atque defcendens. Nic. Muler. in Elog. Emmii.

Moliebatur divinum illud Opus Chronologicum,novâ formâ, nec ulli hactenus ufurpata conceptum in quô illuftriores omnium hiftoriarú eventus in fua tempora digefti inter Ce comparantur haud minore labore quàm induftriâ. Ejus lìber de Rebus Græcix eft opus rei literarix utilifimum, præfertim viris ad Reiproblice Clavum fedentibus, aut Principum conflia regentibus gratifimum. Idemibid.

Nec in Frifonum gettis recenfendis leetoris otio abutemur; fupervacuum exiftimantes ea iterare, qua ab Vobone Emmio, lcgitimo Frifie fux Hiftorico fidelifime perferipta. Cujus ea in Patrix Lux Antiquitatibusi inveftigandis curiom fitas, ea religio fuit, ut meo quidem animo, parum, feu potius nihil, aliorum unduftiz reliqum feciffe videater. fan. Douf.1. I. Annal. Hollandic.

Citra affentationem dicam, quare enim apud te Nihil fimile tuis Scriptis poft Buchananum in eo genere melegere memini, Ceu fides, prudentia, ac ingenualibertas; Greorationis elegans fimplicitas ac perfpicua brevitas fpectetur. Thuan. in Lit. ad Emmium an I604. Ccript.

A Erifer ordinibus invitatus [ juffidus Petrejus] origines, Colonias, nobilicatem, libertatem, jura gentis fux illuftranda fufcepit, in quibus altiùs repetendis, dum admiftis fabularum figmentis nimium ftylo indulget, multorum repre henfiones incurrit, ut Vbboni Emmio, qui candem provinciam fummâ fide ac admirandâ fimplicitate pottea exfecutus êt, poriùs lampada tradidiffe, yuàm ei în feribendâ hiftoriâ Patriâ præluxiffe videatur. Thuan. ad Ann. $1597^{\circ}$

Frifica gens mea Hiftoricum accepit Vbbonem Emmium, nulli, quamvis veterum, temerè fecundum, judicio politico, ttyli elcgantiâ \& accuratè tractatâ narratione $H$. Conring. de C. P. sep. I4.

Difertiflimus Frifrcarunterum explicator, condignus utique patriâ fuâ Hiftoricus, parque tanta rerum inolifutinendx. Dossa Fil. annot. Holland. ro.

Vir eruditifimus, cujus prater Opus Genealogicum, veterem Greciam, of defcriptionem Frifix, extat, Hiftoria rerum Erificarum ab anno Chrifi CC.CCXLIX. ufque ad 5 5 64. tantâ prudentiâ ac elegantiâ leripta, ut palmam cunctis prioribus preripiat, coque digna, qux frequentius fudioforum hominum manibus teratur. Variè primùm \& particulatim, fed pofteà unô volumine juncta excufa eft in Batavia Lugduni 1616. Ioh. Andr. Bofins de compar. Prud. Civ. n. 55 .

Quanti \& probitatem tuam \& doetrinam femper fecerim, non folum ego mihi confius fum, fed \& illi, qui me de te ea nartantem fxpiffimè audiverunt, qua virtus tua \& mecitum á me expreflit. Certè a fu nihil aliud faltem divina Hiflo- 
riatua Frifica hoc à me exigcbat , quam ego judico non folù iis, qui fimilem fcribere volent, conatum, fed \& iis, qui jam fcripferunt, laudem præripuiffe. Iof. Scalig. in lit. ad Emminm ann. 1608. Ccript.

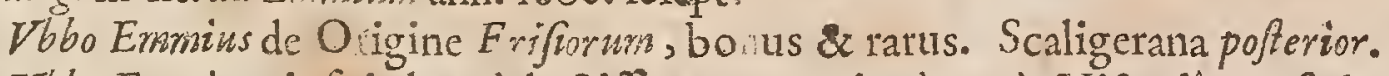

$V b b o$ Emmiur vir fuir longè doctiflimus: præcipuè verò Hiftoriâ Frzfia incla ruit. Vof. de Mathemat. p. 237.

Suffridus Petrivir benè doaus, fed qui in Frifice rebus, atque omni lireratura laude longè ccdat Emmio. I dern de Kiift. Lat. 1.2. c. 40.

* Emrnii Opcra, appofitâ notâ Auctoris damnati, permittuntur, fi expurgen tur. Index Madrit. Edit. ann. I667.

Extat Hiftoria Renurn Frificarum, \& Frifie Orientalis defcriptio Chorographica. Lugd. Bat. in Fol. ann. 3616 . Progreditur autem ab Anno 449. ad an. 1564:

Extat Opus Chronologicum novum libris, diftinctum, cum Canone Chronologico. Groninge 1619. in Fol.

Extat Gracia Vetus, five de Gracorum Rebufpublicis $1628.8^{\circ}$. Lingd. Bat.

Extat de Agro Frifia inter \& Amafurn \& Lavicam $\mathrm{A}$ deque Urbe Graning $a \hat{~ i n}$ codem agro, \& de jure utriufque Syntagma, cum ferie Magiftratum præcipuew xum, 8: Groninge 1646

Conditx funt corporis exuvix in inferiore parte Templi Academici Gropningẹfis juxta liberos: Conditorio Saxum inftratum; cui họ Epitaphium memorix causâ incifum:

Immortali Nemoric Clarif. o Pientif. Senis Ubbonis Emmii, Frifi Grethani, Primi Acad. Gronning. Rectoris, Theologi fnceri, Philologi eximin, Historici abjoluti, viri prudentice Jingularis; Qui per onsern vitarn fû́ forte contentus, labore indefeflo, de Ecclefía \& Republ. patriâ quam op tisnè meritus. Verè piâ demim ac placidifluna morte defunctus beic corpare quiefoit. Margaretha à Bergen vidua $\&$ laberifuperfites moerentes $H: M: P$. vixit in terris Ann. LXXVIII. dies 4. Abiit in Calos anno Chriftiano MDCXXV. die 9. Decemb.Iul. Nix col. Mullerus M.D. Author.

\section{GULIEIMUS GILBERTUS.}

Eocefrenfs, Philofophus \& Medicus Londinenfistres amplifinios Com- Clar. A.D.
mentarios de Naturâ Magnetis edidit. Quibus Imagis mihi probavit do MDCXa Arinam fuam, quàm Magnetis Naturam. Nam incertior fum, quam dudum. Iof. Scalig. in Epilt.200.

Quidam Anglus ante triennium libro de Magnete ediro, nihil dignum expe: ctatione eâ, quuam excitârat, protulit. Icf. Scaligg. Epift. ad Cafoub. Gilbertu: noftras, cùm Natuam Magnetis laboriofilfimè. \& magnâ judicii
firmitudine \& conftantiâ, nec non experimentorum magno comitatu \& fere agmine perfcutatus eflet, confinxir ftatin Thilofophiam confentaneam rei apu iplum 
ipfumpirepollenti. Eranci. Bacon.in Var. Inc.

Equidem fcio neminem in hâc materiâ (de Magnetis Natura) fanè difficillimâ, illum fibi habere parem: Nam quod alii vix attingunt verbo, illud ciilbertw nofter amplinimè diduxit, \& ab ovo quafí rem inchoavit, \& clariflme ac acutiffunè explicavit. Scaliger quanģuam cetera omnialubtiliter, tamen non fatisfacere potuit rei veritati in hac quxRione. Ad occultas qisalitates cum crtcris provocat Philofophis. Verim ignoranti nihil non occultum \& abfonditum eft. YVolfgang. Locbrnan. prafix. de Magnet.

Axthori noftro nec acumen nec argumentum deficit, quo non tantù dcle? atare, fed \&erudire folcrtem Natura indagacorem valeat. Ibid.

Dolete Peireskius folebat non agnitos fibi Gutielmum Gilbertum audoremi Mibri de Magnete, nec Thomam Lydiatum cclebrem Mathematicum.

Gafjendus in Vitî Peireskeci Gilbertum magni facit.

Mirabilis illenatura Magnetis Scrutator, Doctor Guberturs,cujus \& Doctowis Harvai beneficio, Gens noftra fibiarrogare potelt, quòd ulrimo hoc feculo Coronam meruerit ob Philofop hix folidam Doctrinam, ut anteha pluribus continuis feculis ob acutas fubrilef Digby Tractat. de Corporibus.c.20. Angl.

Proprictatum Magnetis notitia cerra fufficientique deftiruebamur, ufque ad tempusquo Deo vifum ef unum e Popularibus nofris excitare; fcilicet Docorem Gilbertum, qui novum ad perpetuam fui gloriam tramitem ad Philolophiam ingreffus eft, \&infigne Trophaum fuper Magnetem erexit, qua laude perenni apud Pofteros celebratetur. Vide-plura apud Carpent. Geographizlib. 1. cap. 3. Anglicè.

Gibertus meliùs quàm cateri Magnetis experimenta elucidavit. Rapixi: Animadv. in Phyficam, \$.9. Gall.

Poftremò ex hac apud Ptolemoum de Lapide Herculeo narratiunculâ intelligi mis, non folum in India Magnetem nafci, fedibi ctiam natum, fingulari effcacitate valere. Clara \& tcftata hre quoque res eft, certifimo recentiorm eriam Authorum expenimento, nominatim verò doctiflini Gilberti nofri, artis Tam Magnetica, quam $M$ edica fcientiffini: qui exIndiâ Orientali, Chinâ, Bengalâ, Magnetes omnium pratantiflimos peri allerit. Nic.Fuller. 1.4. c. Ig. Mifel. Sacr.

-mo-Nec ur recentiores illos commemorem, acumine fimiles Antroyis, \& propè pares, Galiloum, Gajfendum, Gilbertm, Merfennum, Curtefum; Ifaac. Barrowo Opurc. pag. 87 .

In hunc Auctorem hoc Epigramma compoluit Ioannes Ovven:

Stare negas Terpari, ; nobis miracula narras:

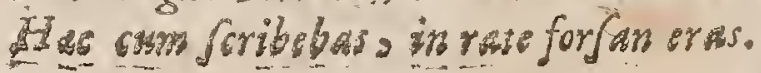

Liv. I. Epigram. 94 


\section{DANIEL SENNERTUS.}

T. Atus Uratiflavix Anno Chr. I572. Patte Nicolao Sennerto, Calceario \& 1 Cive:VVitteberga 1599. Philofophiæ Magiter, \& ibidcm r6or. MediciClar. An.D. MDCX. ne Doctor, pauloque poft anno nempe 1602 . ejufdem Profeffor Publicus, nec non randem etiam Electoris $S$ axori. Archiater conftitutus eft. Obiit VVitteberga 1637.65. Opera ejus omnia, in fex Tomos divifa, prodiere Lugduni, an. 1676. in Fol.

Verùm quoniam quædam in Liddelio deficiunt, ideò maximoperè fuaferim Clariflimi sennertifnfi. uiones Medicas his conjungi, ex quibus hoc commodi habere poteris, it \& fine Interprete eas intelligere, \& plurimorum Anctorum fententias cognofcere, atque dubia quoque quxdam non levia, qua artem nofram obfcuram faciunt, pervidere peffis : qux omnia cùm fine gravi labore $\&$ judicio præftare non potucrit, nactus eft admiratores \& laudatores plurimos, aliquos verò ita infatuavit, ut eum fufpiciant tanquam artis noftre fupremum Ditzatorem, pancos verò ad invidiam concitavit. Ego quid de ennerti cenfeam laboribus ingenuè \& liberè proferam, neque cujufquam verebor judicium. Confeo Scripua ejus plurimis laboribus fuiffe congelta ex vaiis Autoribus, ue ideò Locorum Cornrnuniurn inftar elfe poffint : addo, plurima ab ipfo benè fuifCe annotata, quæa alii Autores malè propofuetunt : addo \& hoc, quxdam abipfo quoque primùm inventa fuiffe, eaque non mala: atque id of cujufquam Autcm ris, ccrtè ejus lectionen proficuam fore tyronibus Medicina, atque etiam in arte provectio ibus planè \& fine metu ediffero. Sed tamen eo inlaniz nunquam pevenero, ut eum numcris omnibus abfolutum cenfeam; fcio hominem eum fuiffe, atque ideo in plurimis errare potuiffe : fcio \& hoc plurimabrevius, acuratiùs, ordnatè magis, ac veriùs proponi polfe, quàm ab ipfo factum eft; led Ii hac gloriam magni viri obfcurare debent, quis tandem famam merebitur? Proptereà virulentix \& invidire plenum pronuncio Plempii elfe judicium quod Auditoribur Cuis commuricavit, in Epiftolâ quadam, quam Lindanus in $\mathrm{Me-}$ dullâ Juâ Medicinæ Manuductioni fux propofuit. Albert. Kyper. Kyper. Method edic. Lngd.Bat. 1643.12\%. p. 291. 292.

' Judicia Virorum quorundam Clarill. preféna Sennerti Operibus editis 'Lugduni 1666. in Fol.

Ingenii divini Monumentis in eam pronpifti famam, ut \& Itali ipfi Germani hominis judicium æftimare \& venerari fe publicè dicant. Quod iertè têtimonium tanto habendum eft potius, quantò majorem elfe horum ambitionem fcimus. Dan. Bucret. D. M. Venet. 1617 die. Pafch.

Pervolve, \& nodurnâ diurnâque verlato manu Inftitutiones Don.Sennerti, in quibus prolixiori Orationis ferie fundamenta artis pleniffimè enarrantur, \& longè fortè Colidiùs, quàn factitatum à Fuch/en, Valleriolâ, Riolano, Heurnio Duncane, Liddelio, caterifque de genere hoc. Unus ifte erit tibi inftar omnium, quem finoris, omnes nôris. Petr. Lauremberg. in Lauru Delphicâ. 
Recreavit me mirificè iftius (Part. 1. r. Pratica) Lectio: utque animi mei fenfa ex candido tibi per tot annos perfpceto pectore explicem, nihil habeo ( \& Confcientiam teftor) quod in eo defiderem. Perfpicuitas in ombus, dusesßris decifio Controverfarum Quxltionum, methodus accurata quidem, interim perfacilis, materia Medica indicationibus curativis in totum correfpondens mihi plurimum arridet. Perge itaque, clariflime Sennerte, nec dubita te laborem Deo Reipubl.' Literaria gratum \& utilem fufcepilfe; cum ut matures etiam atque etiam te rogo.Immortalem inde apud Bonos laudem confequeris. Gratulor facultati Medicx \& cjus ftudiofis quod nucleu'n M'edicine Dogmaticum tam facili labore, te duce, confequuntur. Ioan.Georg. Magnus D.r4. Jan. 1624 . Berlini.

Librum tuum de Febribus denuò \& diligenter quidem nunc perlegi, \& deprehendi quxcunque ibi fcripta funt optimis rationibus, ilfquc frmifimis omnia effe munita. Utinam verò Autbores parem ad iftam materiam diligentiam, vel faltem confimile judicium attuliffent. Quxfo te per falutem $M$ edice $A$ r. tis, ut porrò in aliis quoque idem prâtes. Sic fanè talentum colitùs commiffum non defodies, fed oprimè ufurpabis cum magno fanè tuo lucro. Georg. Low thiss D.\& Proferf Med. Aulicus Regiomont. 28. Novemb. 2629 .

Ut taceam reliquos, foli Inftrtutionum libri, \& nobilis ture Praxeos pars prima, aded me affecerunt, \& tan profundè ad animum penetrarunt, ut jurarem ipfe mihi, prater Biblia Sacra nullum amplius Authorem Medicumalium, pro Praxeos mex Scipione \& irineris comite, domi forifque me ufurpaturum, fi modò mihi tam beato refiduos quoque libros videre contingeret. Philip. Tufcher M. D. \& Suvibofuana DiøceL. Ordinarius. Svvib $\int 21$. Sept 1628 .

Tantus vir, qualem Sennerturn efle omnibus in confelfo eft. Gabr. Naud. in Ep. 7 8. ubi libuin ejus Hypornernáturn præclarum opus vocat.

* Ejus Pbysca Hyporninemata inter libros prohibitos numerantur in Indice Expurgatorio. Vid. Ind. Rom. Imprefl: Anno 1681.

\section{JANUS GRUTERUS。}

\section{Per Anagr. \\ $G R A T \cup S$ in $V E R S \mho$.}

Clar.An.D. R Rabantus Jurifconfultus, \& Philologus celebris, Antverpic natus et MDCX. B ann.1560. Obiit ann 1627. Heidelberge literas amceniores tractavit, ubi \& Bibliothcce prefuit, quam libris rariflimis, Hebraicis, Chaldaicis, Aran bicis, Gracts atque Latinis auxit atque locupletavit. Konig.

Scripfit Poëmata varia - Sufpicionum libros 9. in quibuis varia Scriptorum loca emendata \& explicata -...- Notas Criticas in Seneca Philofophi Opera omnia: In Senece Tragcedias: In Statii Papinii I'öemata : In Martialis Epigrammata: In Sallufium: In Livium: In Tacitum: In Florum: In Velleium Pa- 
terculum: In Plinii Epiftolas : In Panegyristas Veteres : In Hifforia Augufte Scripeores: In Flantum: In Querolum, incerti Comodiam : In Mimos Pum bli Syri - Infriptionum Veterum Roman. ingens vaftumque volumenLampadem five Thefaurum Criticum, hoc eft, scriptores Criticos, Tomisfex diftinctos - Chronicon Chronicorum-Florilegium Magnum-Ethico-Pow liticorum Tomostres - Bibliothecam exulum, five Enchinididion Divinx humanxque prudentix.

Vir fuir Gracè Latinè, omnifque adeò Antiquitatis, admodum peritus. Valer: Andreas in Biblioth. Belgic.

Vir multx eruditionis ac Poëta fuavis: Iuffo Lipf $\int_{\text {Io }}$ ab ingenii amcenitate ac doctrinâ charifimus. Sander, de Clar. Gandavenfibus.

Ianus Grwterus incomparabilis judicii \& lectionis Criticus, feculi noftri als ter TJarro, Bonifac. in Ludic. Hift. p. sgI.

Præftantiflimus Gruterm, vir intimè bonus, prudens, \& fupra quam credibi. le, cruditus, \& acutus. Barth. in Adverfar. p.852.

Summi limatiffimipue judicii vir I anus Gruterus. Idem ibid. p. I420.

Vir emendandi prudentiflimus ac perfpicaciffimus. Ider/s lib. I2. Adverfar: cap. Io.

Vir eruditifimus \& de bonis literis optimè meritus. Scalig. Animadverfo its Eufeb.

Cafaubonos Notis in Elium Lampridium illum ut enditiflimum \& clariffmum virum celebrat.

Sufcipionum tuarum libros vidimus, nec pauca in iis peracuta. Lips. Epift. Cent.ad Gerrisan. \& Gall.Epitt. 6.

Gruterus luculentam Operam navavit $M$ artiali. Vix eft, ut quifquam me. liùs de prifco aliquo autore fit meritus. Scalig. Epift. 216.

Ianus Gruterus Senecam cum libris prifcis \& Chirographis contulit: quod

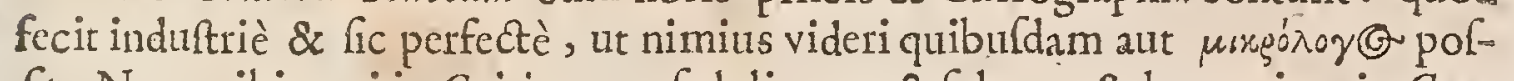
fit. Non mihi, qui in Critico amo fedulitatem \& fidem: \& hancetiam in Gru tero Operam, quod aliorum paffim notas aut Interpretationes adjecit. Ufui mihi fuit, ingenuè fateor : \&amo virum è meâ olim dif́ciplinâ, nunc \& docendo factum. Lipr. Introduct. Lector. Sener. r. Vol.

De nobilifimo ano Grutero, etfi ille omnibus bonis \& doctis, qui jam in ore famæ funt, amicis utitur, quantum fibi bonas literas fcriptis fuis, edito prafertim poft Pincianum \& alios Senec $\hat{a}, \&$ novem Inforiptionum libris, devinxe rit, nemini non conftare potef. Sciopp. de Crit. p. í.

Cujus inter laudes eximias non minimum ea locum meretur, quòd nullus hôc virô, nec diffitente invidiâ, praclariǹs fit meritus de tot Scriptoribus Ro: manis. I.G.Voff. in Orat. memorix Th. Erpenii dictâ.

Vidi quæ Iamus Gruterus ad Tacitum annotavit. Diligentiam ejus in colligend dis varièêntentiis improbare nefas fir. Sed (quodliberè licear) commifliones merz funt, \&, ut flagitiofiffimi Caligule non abfonum dictum in re fimiliufur: pem arena fine calce. Videtur fibi propoluiffe ad imitandum rationem illam.

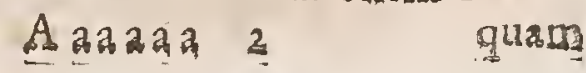


quam fecutus eft Lipintu in admirabili \& præftantifimo opere de Civili Doctri nâ. Sed Dii bon! ! quàm longo intervallo, quàm non paffibus æquis veltigia fectatur. Baud in Cent. 2. Epift. Epilt. 13.

Grutteru non curat utrum Charta fit cacata, modo libros excudat. Omninò idoneus eft ad Veteres libros revifendos : in Martialem \& in Senecam Tragicum optimè laboravit; in Philo fophum verò ex aliis corrafit. Comralinus retulit mili Gruterum ftultum imò valde fultum efle. Dum ftudendo aliquid non capit, ftomachatur, fuofque libros in humum abjicit Scaligerana pofterior. Gallicè.

Leguntur illius Carmina variæ ætatis, varii generis, fed quæ venuftate quadam peculiariac propriâ femper uni refpondent authori. Ubique enim elegantiarum \& fapientiæ tantım mifcuit, quantum Poëtæ antiquo \& Romano effet fatis, \& cuivis Philolophorum non parum. Et hæc tamen pleraque per ludum tantùm in jocum codicillis inferebat. Ut cætera quibus amicis gratulatus eft, non attingam, Cola Bibliotheca Exulum, non multò priùs luci data, quàm luci Author ereptus, planè talis eft, ut non Hominis, fed ipfus Virtut is manibus videatur perfcripta. Singuli verfus, fingula funt oracula. Quod fifecundum Neopiolernum Navianum, paucis eft Pbiloropbandum, cx hoc libro eft Philofophandum, quippe molis tam exigux, ut vix manum, fapientiæ verò tantæ, ut titulum fuum non impleat modò, fed etiam fuperet. Jam Infcriptiones Veteres, cum etiam in saxis, \& Marmoribus confenefcerent, nec in illâ duriffimâ materiâ durabiles effent, eternitatem, fiqua poteft efle in rebus burnanis, à Grutcro acceperunt. Balthaf.Venator. in Panegyr. Ian. Gruter. fcripto, p. 258. 259. Tom. r. Memor. Philofophor.11oltri Sec. per Henning. Vítten.

* Quxdam corrigendafunt tam in Iani Gruteri Notis in Hiftorix Augufe Scriptores, quàm in ejufdem Annotationibus in Salluftiurn. Index Madrit. Imprefl.ann. 1667 .

Extant Sufpicionum lib.9 VVitteb. Is9r. in 8?.

Extat Bibliotheca Exulum. Argent.1624. in $12^{\circ}$. Francof. 625. in $8 \circ$. Extat Lampas, five Thefaurus Criticus, Vol. 7 . Francof. $1607.8^{\circ}$. Extant Infcriptiones totius Orbis Ronani Antiqua. Francof. 1616. in Fol:

In hunc Auctorem hæc Carmina compofuit Sam. Rofenbornins:

Gratus es in Verfu, Grutere diferte, fonoro,

$v_{t}$ te vix alter gratior effe queat.

De locuplete penu tu cuncta recondita promis, Ore Jufurrante $\hat{\imath}$ ac imitaris apes.

Que veluti Nectar delibant nobile florum,

Et fipunt liguidis cerea regna favis.

sic th, quicquid babet Latium, vel Gracia quicguid.

Congeris ingeni fertilioris Opus.

Hujus opes quoties fummis degufto labellis 


\section{HENRICUS SAVILIUS.}

F Ques Anglus, Eliðabethe Anglorum Regina à Ptudiis Grecis \& Anagnofta, E Mertonenfis apud Oxonienfes Collegii Prafes fuit. Obiit Anno 1621. SepClar.Antor MDCX: *uagenario major.

Pralectrones in Euclidem confecit. Idem Operum S.Chryfoftomi opt mam \& pulcherrimam editionem procuravit. Extat ejufdem traêtatus de Militiâ Romanâ. Editio Chryfoftorni octo mille libris Anglicanis Savilio confitit.

Vir preftantiffmus, \& ad miraculum eruditus Savilius. Rich Moztacut. Not. ad Phot. Epirt. 2.

Nobiliffimus Henricus Savilius, inter fplendidiffima hujus Academic ornaw. menta ærernum memorandus. VV hear. in Meth. Leg. Hift $\$ .27$.

Vir nobilitate atque eruditione juxta celeberrimus Henricus Savilius. Idem. ibid. $\$ .28$.

Savilius vir doctiffimus. Iof. Scaliz. in Epirt. 232.

H. Savilius, vir \& eruditionis diffufifime, \& fi dei optima.Ioan.Dall.de libr? Suppol. Diony. Areop.\&Ignat. Antioch. p. 38 .

Henricus Savilius, excellcntis ingenii \& admirand eruditionis vir. If. Ca $=$

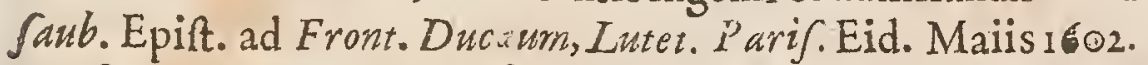

Sanè quanti Savilum faciam, non ignoras tu, qui ad eruditiffima ipfus Scripta intelligenda tantầ me operâ juvifti. I dem ad Loan.Coceron Lond.prid. Id. Sept. 1596.

Hic Cbryfoftomus à Savilio editur, privatâ impensâ, animo regio. Ejus feré lem Otione ærumnas meas levare foleo. Idem ad David. Hoefchelium. Lond. Kal. Aug. I6rr.

In Notis tuis nihil difplicet prater breviratem \& paucitatem. Cærterùm cùm cogito \& fumptuum, quos fecifi, immenfitatem , \& non ferendos labores, quos per aliquot annos, quà Exemplaria Cbryfoftcmi conquirens, quà legens \& relew gens, qua emendans, quà invicem comparans fuftinuifti, abfolvo te $a b$ omni culpâ, imò miror potiûs quòd reliquis laboribus ( qui alium quemvis non invicti planè animi oppreffiffent) hunc etiam Notas tuas fcribendi \& alienas corrigendi addere voluifti. Lom. Bor. Not. in Homil. in Gerzes.

Quòd doctè \& accuratè obfervavit Savilitim, ut pleraque alia in his $\mathrm{Hifto-}$ riarum libris, quà illuftrandx Taci. i hiftorix, quà oftendendo in quibus Tacitus ipfe incuriofiùs aut minus explicavit rerum geftarum ord'nem, aut contraria fibi ipfi \& repugnantia fcripferit. Quæ omniấlummâ induftria, diligentiâ, judìcio, ab eo relata. $7 u$. Mercer. in Not. ad Trci. 1. I. Hit.

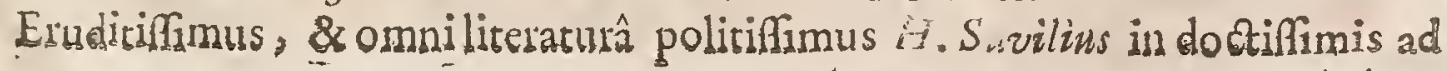
A 2aaa 3 Iacitum 
Tacitum Notis : quas Reip.intererat, aliâ etiam linguâ, quàm Anglicâ in vulgus dari. I dem in Not. ad Tacit.1. r. Annal. c. 74.

Annus \& hic apud nos abftulit Henricum Savilium, Equitem omni viredtum, o mniumque Ccientiarum genere inftructiffmum, qui plurima eruditiønis fingulatis monumenta edidit - Sicut boni omnes vivum fummoperè dilexerunt propter doctrinam qux in eo eximia fuit ; íta in mortuo ornando, mutuâ amulatione certarunt. Robert. Iobnfon. de Reb, Britann. 1. I8.

Nofter utrâque arenâ ( \& Theologicầ \& Philofophicâ ) inter exercitatiffimos valens Atbleta, Graca \& Romàne lingux , omnifque in eâ elegantix a biter fcientiffimus, \& per cuncta legi ac fciri digna acerrimo graffatus judicio. Ifaac. Gruter. in Lit ad Lect. quas Henr. Savil. Comment. in Tacit. premifit.

Anno IGro. Henricus Savilius, Eques Britannus, fuas in Euclihem prelectuIras juris faciebat publici. Vir co nomine de ftudiis benè meritus; magisautem, quòd Profeffronem Mathernaticam de fuo inftituerit in Academiâ Cantabrigienfi: \& quòd, magno Ecclefix bono, Etonenfi prelo dederit longe optimam, \& pulcherrimam editionem B. Chry fostorni. Vof. de Scient. Mathemat! p. 339 .

Dominus Savilius B. Chryfoftomi Opera fummâ curâ recognovit, ad normam plurium Veterum Manufcriptorum magno labore \& ingentibus expenfis conquifitorum per totam Europarm, imo \& in ipfa Grecia, in quan homines data opera ablegaverat. Sed quantumvis accuratè lanc edicionem emendatam evulgare conatus fucrit, plura tamen ejus locácorrupta remanfcrunt, quorum genuinum fenfum divinari difficile poteft. Ephemeriá. Exuditorum Kal. Febr. I666. per Gallois. Gall.

Eques ifte prachlarus optima B. Chryfofomi exemplaria follícitè conquifivit, eruditorumque Virorum operam adhibuit ad illa tranfcribenda \& Annotationibus illuftranda, quo facto eadem propriis fumptibus luculcntiffimis characteribus impreflia evulgavit; Quod onus fubivit \& geftavit nunquam fub ipfo fatifens, quamvis tanti fuerit ponderis ut cujufvis vulgaris hominis' ilia fracturum fuiffet. Sed Papiftæ Parifienfes fuos il Anglia Emifjarios habuerunt, qui Equitis hujus eruditos labores clam furreptos fchedarin fingulis hebdomadibus prout è pirelo prodibant in Galliam tranfmiferunt. Tune Fronto $D u=$ cans (Cardinalis Gallus, ut quidem arbitror, ) illorum impreflionem ibi accum ravit, cum implicita Fide atque Obedientia caca, ideft totidem Literis prout illos ex Anglia recipiebat, adjunctis tantum Latina Translatione \& quibufdam aliis parvi momenti Additionibus. Gemina itaque B. Chryfofomi Editionęs ftadium eodem tempore per Orbem decurrerunt, certantes utra alteram tanquam acceptior \& publicè vendibilior pravertere poffet. Equitis Hsnrici Editio aliquot menfibus ante $P$ arifinam licem vidit; fed hae illam preffo pede fecuta eft, '\& ob additam Verfionem Latinam, quamvis cariù ideo conftaret, priorem venditionis prompritudine anteivit. Sed nuper Cbryfoftormus Savnlianu gradum valde acceleravit, adeo ut patuca hrijus impreffionis exemplaria remanfexint. Doctor Thornas Euller, de Praclaris Angliz Viris. Vide Eboracenfem Camitarm. Anglicè. 
Extat Commentarius de Militiâ Romanâ. Heid.r6or. in $8^{\circ}$. in $4^{\circ}$.

Extant Prxlectiones 13, in Principium Elementorum, Euclidis. Oxon. 1621。?

Non longè à Sepulchro Alexandri. Fisher, è regione autem Bodleiani, collocatur Monumentum [Henrici Savilii] Honorarium, fplendidum abundè ac magnificum, ubi dimidìtam viri Imaginem depictam confpicis, cogân induti; manumqute libro claulo imponentis. Ex utroque cjus latere furgit Columna è Marmore nigro dedolata, viri effigiem urrinque habens. Virorum ad dextram póftorum primus, qui manu libum tenet, D. Chryfoftomus; alter verò, qui virga Sphxiam monftrat 'toloma elle dignolcitur, quod Infcriptiones fupra eofdem pofita oltendunt. Reliquorum duorum, ad Columnam utiquie finiftram comparentium, primus manu alterâ virgam, alterâ circinum habct, \& Euclides infcribitur, uti novifimus ille, qui manu librum tenet, $C$. Tacitus. Supra hos omnes cernuntmr Genii bini, fedentes; quorum alter faciem viri primitus dicti in fpeculo intuctur, alter verò cjufdem nomen in Libirum Vite redigit. Denique in fuprema Monumenti parte confpicitur Famæ Imago, Clypeo Saviliano incumbentis, luccinamque inflantis; \& fub omnibus hilce fimulachris comparet ejufmodi Infcriptio.

\section{S.}

Henricus Savile Miles Collegii $\left\{\begin{array}{l}\text { Mertonenfis Cuftos. } \\ \text { Etonenfis Prapofitus. }\end{array}\right.$

$$
\text { Fui. }
$$

Exuvias corporis fruftrì fit qui bic querat,

Servat Prinobile depofitum Etona,

Perenners virtuturs ac Benefactorum memoriam

Quibus Collegium utrurnque, Academiam imprimis.

Oxonienlem complexus eft, ipsumque adeo

Mundwas babet fibi debendi reum.

Affedtus infuper pientifirn uxoris

PoJjidet ifte lapis.

B.M. P. Margareta conjux obfequentijlma;

In boc uno guod po fuit piè immorigera.

Obiit anno CIDIวCXXI. Feb. 19:

Anton. aे VVod de Colleg. Mertonen $\sqrt{b}$.

TRAJANUS BOCALINUS.

D Omanus, vir acri ingenio, ad jocandum cum aliquo maledicto facerus, Clar. An. omni elegantiâ doctiina excultus, fcripfit librum, in quem o mnia in mon- 
te Parnaffo actr, ac Romam perlata referuntur. Idem librum, cui Lydii Lapidis nomen fecit, edidit, qui ipf ultimum exitium attulit. Quia enim in eo libro oftendere conabatur, Regis cujuldam potentifimi Opes non effe tam validas, ue labefactari non pollent, die quodam Venetits, ubi fe tutum fore fperabat, a quatuor validis hominibus facculis, arenâ plenis, ita contufus committigarutque eft, ut ex eâ verberatione fupremum diem obicrit, nec Apollo eum incolumen præftare potuerit, cui fummam rerum omnium tribuerat. Inepti funt, qui in Boccalini libris artem Chymicam contineri, aliis perfuadere conantur.Konig. in Bibliothecî.

In Trajano Boccalino Cive Romano enituit Hermatbena multiplicis esuditionis, \& orbiculata illa feries omnium Scientiarum, quam Graci appellant Ency-a clopediam. Inter has excellebat Polntices cognitio fingularis; hinc Trajamusal omnis erudiri conventûs, \& fpirans liber: Principibus, ac fenatoribus editus Linguâ, calamoque liberior, quâm ferret xuum adeò fervum. Ridens plerumque verum dixit, Ceriò pupugitludens Boccalinus in Orbis Theatro Satyrus palliatus acuminibus, \& Calibus facetiarum callidètemperans gravitatem fententiam rum. Complura Opera immortalitati confecravit, quibus cenfura delapfi prafens tempus damnabat pona mortuorum culpas viventium flagellans. Prudette ter ille quidem, fi gencratim Cemper fcribens peperciffet fingularibus: quos aliquando tenui, atque perfpicuo velo porius ornatos, quàm tectos lacefiviv。 Iac. Gadd. in 1 log.

Elegansadmodum atque amónum dे naturâ ingenium obtinuit Boccalinus: quod etiam multarum rerum cruditione ac fcientiâ expolivit atq auxit. At in eâ prxlertim Arte fuit excellens, qux in Rebufpub. in Civitatibus rectè adminiftrandis tota verfatur. Et in quadam ad Sipionem Card. Burgbefumfcriptî EpiItolâ, fe Commentarios in Cornelunn Tacitum edituxum fpondet, qui nondum apm paruerunt; quos ego Commentarios, pro fingulari hominis ingenio, omni elegantiâ doctrinâque refertiflimos elfe, non ambigo. Ian. Nic. Erytbr. in Pinacoth.

Manufcriptum alias Commentarium ejus in Tacitum legi, fed in co tam parum reperi quod quærebam, ut à me imperrare nequiverim eundem typis mandatum relegere, ne oleum \& operam denù perderem. Memini me tunc hoc de illojudicium tuliffe, quòd Oratoris potius quam Politici more Tacitum commentetur, cùmque $I$ acitus plura paucis, Bocalinus paucr pluribus verbis dicat. Nefcio an excufus liber ad artis normam accuratiùs elaboratus fit. Vide Taciti Moralia Domini Amelot de la Honfj.ite. Gall.

Omnes Politici Opus hoc magni xftimant, nimirum Boccalini Commenta: rium in Corn. Tacitum Imò non defunt qui afferant neminem hactenus hoc Authore Politicx adytaintimiùs penetrâffe, nec Taciti fenfum feliciùs alfecucutum:elle; à quo Paulus II. \& Clemens VIII. Exemplar Politica defumferint unde tantam in fuo Regimine celcbritatem fibi paraverunt. Eruditorum Ephemeridum Gall. Tom. 7.p.24:

Becalinks admodum yarius ac volubilis eft in fuis de Authoribus judiciis, uc Cribit 
Ccribit Gabriel Naudaus Confilio fuo de fuo Bibliotheca conftuenda. Alii verø ctiam obfervarunt eum præconceptas ferè tantum opiniones fuas fecutum elff. Indicia Eruditorum Parif. per Bailletum 1689. Gall.

Eques Ifaacus VV ake vocat Bocalini Collectiones Parnafs primam in Profa Satyram. Celcbris verò Seldenus ait fe Humani cujufvis librì quàm iftus jau Eturam patientiùs quoad ftudia fua tolératurum. Angl.

Cum Ingeniofis seeuli noftri Scriptoribus, qui Antiquorum quoad Invenw. tiones xmuli fuerunt, de fuperioritate jure merito contendere potelt Trajanus Boccalinus Romanus, Architecti cujufdam Filius. Is licet liberaliter à Natur folettiffimo ingenio ditatus, ad laborem nihilo minùs fero fe accinxit, donec rerum, multis labentibus annis acquifita notitia, animum cjus ad ftudium appulit; Quò forfitan impulfus fuit, vel qúòd res effet angufta domi, vel quòd multos 1 tudiofos literartm iter ingreffos in favore apud Magnates effe animadverte? ret. Laurentius Craffibs. Italicè.

* Boccalini Parnafjus, ejufque Commentarii in Tacitum, prohibentur in Iss. dice Rome imprelfo anno $168 \mathrm{r}$.

Prodiit Boccalini Parnafiss Italice. Venet. $1630.4^{\circ}$.

Pietradel Paragone politico. Colmopoli $1652.3^{\circ}$

\section{CHRISTOPHORUS HELVICUS:}

Ermanus, Sprenlinga natus eft Arno ig S. die 26. Decembris." Obiit año Clar An. Bu

I 1617. Marpurgi Gracam \& Hebraicam Linguam, tandem etiam Theolo- MiCXV, giam profeflits eft.

Scripta ejus multa \& varia, palmam verò hæc cateris præripiunc: Syftema

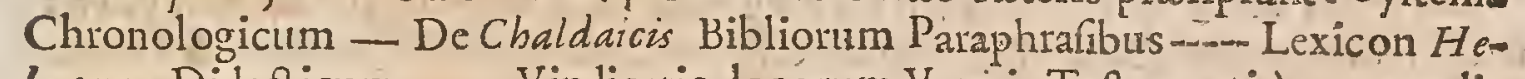
braum Didacticum -..... Vindicatio locorum Veteris Teftamenti à corruptelis Pontificiorum --.- De Carminibus atque Dialectis Gracorum ....- Elementale Hebraicum 3 Cbaildaicwm-.--Libri Didactici, Grammaticx UniverGalis, Latina, Grece, Hebraica \& Chaldaica.

Precelfum ac planè Coelefte ingenium $N$ atura huic viro concelferat, cujus ope fupremum illum eruditioniịs gradum attigit, quô noftrâ xtate latè confpicuum \& nirentem vidimus -.-.- Tantos in ftudiis fublimioribus fecit progetfus, ut five Linguarum Cardinalizm \& Orientalizm peritiam quis fpectet, five omnium Gentium Hiftoriam, \& qux illius lumen eft, infignem Chronologia notitiam, ipfamque cruditionem Theclooicam refpiciat, haud facilè quempiam inveniat Helvico anteponendum, friquidem in Pbilofophicist etiam Dilciplinis tantam fibi paravit Scientiam, ut cum quovis viro docto de Argumento quolibet acutè \& eruditè conferre fententias potuérit, ita perfectam, ita exquifitam trium linguarum intelligentiam eft affecutus, ut in iis natus potius, quàm edoctus vi: deretur. Theod. Spizel.in Templ. Honor. referat.

Quanta fuerit ingenii ejus felicitas, in pueritia patuit, de quâ, qua eum in B bbbb b prigile 
primis literis erudiverunt, ingentem concepere $f \mathrm{pem}$, nec fefellit cos expectatio. Prater enim fummos in jeientiâ Theologicâ honores; quos inagno.cum applaufu confecutus eft, \& Profefforii muneris dignitatem, admirandos fecit profectus in exactâ cognitione Ling larum, Greca, Hebraice, Chaldaica \& Syriaca; quibufcum conjunxit Hiftoriarum $S_{a c r a r u m}$ Prophanarumque cognítionem, \& Rerum Aftronomicarum ac Arithmetices tantam Scientiam, quanta in hominem cadere poteft. Acquifivit autem hæc omnia plurimâ lectione \& vigiliis ac labore incredibili, ut abundè apparet ex Theatro cjus Hiftorico five Syltemate Chronologix, quo quidem Opere vix quicq:am ufquam in eo genere fol adspexit perfectius concinnius, limatiufque, quod cum omnium propè Doctorum teratur manibus, aliquoties excufum \& recufum, noftro non eget preconio. Boiffard. in Icon.

Chriftophorus Helveticus fuit homo multarum lectionum, laboris patiens, in Aftronomicis \& Arithmeticis exercitatus, rerum \& circumftatiarum obfervacor accuratus, Linguarum (Latine, Grece; Hebraice, Chaldaica \& Syriaca) peritifimus, in Scriptis rum Sacris, tum Profanis verfatiflimus. Ioan. Schup. in Dedicat. prafix. Helvico.

A mifimustalem virum, cui Deus omnia cumulatifimé dona cónceffiffe videtur, fundamentam rerum Theologicarum notitiam, in Religione finceritatatem, in doecndo dexteritatem, acutam in Philofophicis Scientiis fubtilitatem, in conferendo gravitatem cum manfuetudine \& animi prafentiâ conjunctam, ingenii \& judicii felicitatem, infignem in rebus Criticis \& Pbilologicis perfpicaciam, accuratam in Chronologicis \& Hiftoricis diligentiam, eximiam Linguarum Latina, Graca, Hebraïca, Chaldaice Syriace peritiam. Henning. VVitte in Memor. Theolog.

De ipfus in Chronologicis accuratâ diligentiâ \& haud vulgari fcientiâ, præeter Icripta edita, literæab excellentiffmis Chronologicis, Setho Calvifo, \& Ioanne Bébrnio, ad ipfum fcriptæ teftantur; in quibus ingenii \& judicii acumen admirati de multis cum ipfo contulerunt. I dern ibid.

Vir eruditilfimus, cujus Theatrum Chronologicum fi rectè adhibeatur, ftudiofis magno poterit elfe ufui. G. Calixt. in Appar. Theolog.p 173.

Quantum ei in Hebraicis praftantiflimus Hebraus, loannes Buxtorfius, Prod feffor Bafleenfis, tribuerit, ex literis ipfus ad Helvicum datis abundè fatis patet.

Primùm hoc mihic redas velim, Helvicum non fatislocupletis elfe fidei in hac Chronologix parte, qux Virorum Scriptis illuftium atatem fignat : Dein hoc quoque habet Helvicus, quòd ferè plerumq; recentiores Scriptores fequatur, ur Eclogarios, Bibliothecarios, \&c. quale aliquid quoq; in Calvifio improb irac $S$ cam liger quemadmodum ex Epiftolis e usapparet; quamvis Calvifi opus, ex quo rotus ef Helvicus, mirifice laudaret. Tanaquill. Faber Epilt. 1. I. epift. 63.

Tractatum Helvi i de Chaldaic í Bibliorwm P araphrafi fummoperè commendat Andreas Rivetus in Ifagoge ad fac. Scriptur. c.9.

* Chriftophori Helvici Theatrum Hiftóricum \& Chronologicum, inter libros expurgandos recenfetur : ejuldé catcraprohibentur in Ind.Madrit odit an.1667. 
Extant cjus Theatrum Hiftor cum \& Chronologicum. Francof. in fol. 1666. Alia ejus Opera variis in locis atque temporibus funt impreffa.

\section{In hujus Auctoris cffigiem hæc carmina compoluit Iaccbus Boifjardus:}

Helvici bac facies : genio gui infignis Hcbræus,

Theiologus, Latius, Grxcus of Hiforicus.

Prob dolor! boc Patria Decus ingens niorte peremptum

Heu jacet! at Scriptis vivit ubique Juis.

PHILIPIUS CLUVERIUS.

A Nu 1580.Gedani, ccleberrimo in Boruffía emporio, parre, ibidem rei Clar.A.D. A monetarix prxfceto, ex nobili antiquâ, in Bremenfiun agro, Cluveriorum MDCXVI: gente, natus eft. Obiit anno Dom. I523. atatis 4?. Italzarn, Germaniann \& Sciliam antiquam ampliffimo commentario illuftravit.

Magnum Germania Onamentum doctiflimus Cluverius nofter.IofJ. in Hift: Pelag.

Cluverius vir tupendx lectionis \& curæ. Dilher. Difput. Acad.

Vir accuratiflmus Pbilippus Cluverius. Laurent. Pignor. in Epif. 26.

Philippus Cluverius vir fingulariter eruditus, de antiqư̂a \& novâ Geographia optimè meritus. Ioan. Card. Bona.

Gcographorum tix atatis habitus cft princeps: prafertim quatenus in Gec* graphid hiftoriam potius attcidimus, quàm Mathefin. Nulli unquam labori pepercit in evolvendis Scriptoribus, vel antiquis, vel novis, unde Geographiam luccm capere poffe arbitraretur. Viff. de Mathom.

Inter veteris autem illius Geographic cxcultores equidem familiam ducere, \& omnium Principem arbitror Pbilippum Cluverium. Nec dubito, idem mecum Cenfuros, qui quidem animo defacato volumina illius, faltem illa, quibus Germaniam, Italiar̃ \& Siciliam antiquam illuftravit, lcgerunt : aliter cnim alios nomnullos in Batavis judicalfe, non me fugit: fcio vero etiam illos partium \& certaminum quorundam ftudio nimium fuille deditos. P'odunt certe Scripta illa viri induftriam in Geographico illo ftudio incomparabilem. Er quidni, cùm non gravatus fuerit, pedes univerfam I taliam \& Siciliam luftrare, quò utramque eò accuratiùs polfct enarrare. Produnt eadem lcetionem infinitam, judicium acre fimul \& clegans. Nec tamen ab omnibus illa crroribus vacua dixerim. Ego fatcor, in haud paucis a Cinverio, in Germania cumprimis rebus, dillentio : yuas meas fententias tibi etiam, clarilfime Buno, video probari. Nec tamen minus principatum in hoc doctrinæ genere illi tribuerc, vel tantillum dubito: idy; quandoquidem in longè plurimis, imò in propè infinitis, non tantùm conatus omnium antcgrelfos fuperaverit, me judice, fed etiam meliorum fpem praceperit: ad quam doctrinæ vim collati, errores nihil funt, nifi navi cxigui in corpore formofifimo. Herman. Conring.in lit. ad loax.Bunon. ans. 66r. fript. Phil. Cluver. Gcogr. pramillis.

Bbbbbb

is

Fuille 
Fuife autem Cluverium, non duntaxat antiqux, fed \& recentis"noftra Geos graphix longè peritifimum, luculéntiffimo fanè argumento eft pofthumus. ille libellus, quố per epitomen veteris noftrique Orbis defcriptionem eft perfccutus. Nec verò vel huic quicquam fimile videas. Quis enim alius veterem novamq; geographiam unâ operâ docuit ? Utut haud negaverim, múlta fatis etiam hîc reperiri perquam mendofa: qua tamen jute excularioncm mereantur, quoniam ultima manus non accelferit, fed futum immatutum mors præpropera informem propemodum multis partibus reliquerit. Fdem ibid.

Quantum Germaniarn Cluverianarn infpexi, neque poffum non probare diligentian, qua egregii aliquid folet parturite, ubi vires fuas colligens uni Opori affigitur. Cæterum etfialiquid remififfe videtur de ferociâ, qua in libcllo antehac edito apparebat, vultum tamen audacix retinet. Cujus infigne documentum eft. quòd frè voces delet, aut immutat, nullis librorum veftigiis, folâ ingenii fui fiduciâ. Reprehende ndi quoque alios magna eum tenet prurigo, quem morbum eò patientiùs in ipfo qui vivunt ferre dcbent, quòd Cefar, quod Strabo, aliique preftantiflimi Auctores fæpe ab illo fupinæ ignotantiæa aguntur rei : cum quibus unà culpari, id verò mihi videtur effe laudari. Hzog. Grot. in epilt. ad Joar.I Jaac. Pontanum, Rotterod.20. Jan. 1616.

In quo fcripto, enudito admodum ac operofo, de Germanic limitibus ac terminis, de habitu ac cultu, de Religione Gentis, pietate, armis, jure, oppidis ac po pulis, adverfus ipfam fapè Anciquitatem, ea vel excogitavit, vel ex difciplinæe lux fundamentis, maximo ingenio produxit; qux, ut eam, cui fpiritum ac lucem fe debere exiftimabat, in polfeffionem veræ laudis ponunt, fic autoti,quanrum eruditionis, tantum pietatis adfruxerunt. Dan. Hein. in otat. quam in obit. Phil. Clwaer. confcripfit.

Dominus Chriftophorus Cellarius libro fuo, qui infcribitur Geographia antiqua \&c. non fine caufa obfervat Cluverium ea accuratione'non elaborafte fuam Geographia Epitomen, quæ in ejus Antiqua Germania deprehenditur, ut \& in cjus Italia ejufque Sicilia. Qui illa Eprtome ad Geographiam addifcendam uf funt obfervare potuerunt enm frequenter locorum limites petperam defignare, cum intra eadem confinia duas diverlas Nationes concludat, quod notari poteft illis Capitibus quibus de Pannonia, de Dacia, imò \& de. Italia Cribit, fi cum hujus quam ipfe adornavit Tabula conferantur. Sxpe incognita loca vel exiguos pagos memorat, infignefque praterit Urbes. Quia tamen magnam fibi paravit famam, factum eit ut qui poft illum Gcographix compcindia contexucrunt, illum abfque pravio examine tranfcripferint fapiufque cofdem quos ipfe crrores erraverint. Ipfa Editiones̃ Cluverii Epitomes cui $T$ abcllæ fuerunt adjunctr, præterauam quod mendis fcatent, ufque adeo neglectx funt, ut Tabell ris defcriptionibus minimè refpondeant: adco ut pateat Tabulas illas à quibufdam aliis . nullo C lwverii refpectu habito, tranfumptas fuilfe. Biblioth. Univerf. Tom. 12.p.392.393. Gall.

Intrepidıs omnium, yux ipf exhibita funt, affervator; \& fub antigne Germaw nia titulo novator maximus. Grot in prolegom. Hiftor.Goth. 
Leetor Ptatim in Defcriptione Sicilia animadverteret, me Cluverium maxime fequi, qui de veteri Siciliês o mnium doctiflimè \& luculentifimè fcripfit. Bochart. i11 1. 1. Geogr. Sac.27.p 558 .

Ejus ad literas nuatum ingenium prafertim verò ad Linguas omnibus admiram tioni fuit. Denas magna cum facilitate loquebatur, nimirum Gracarr, Lainarra Germanicam, Gallicam, Anglicam, Hollandicam, Italicam, Hungaricann, Polonio cam, Bobernicam. Morcri Diction. Gallico.

Extant Italie anciqux Libri 4 . editore Dan. Heinfo. Lugd. Bat. in fol. 1624.

Extat Germania Antiqua item Vindelicia Noricum ibid in fol. apud Lud. ElZevir. anno I616.

Extant Sicilia : Sardinia : Corfica antiqua. ibid. IGig. fol. apud eundem.

\section{JOANNES BARCLAIUS.}

Acus eft Aberdonicex Antiquifimâ Scotorum familiâ, vicefimo oftavo
Janual: Anno Dom. 82 . Ubiit iz. die Aprilis, Anno Dom. 262x. Scripta ejus funt: Euphormionis Lufinini five Satyricon lib. S. Argenidis lib.s. Clar: An.D: MDCXX Icon Animorum: Carminum lib. 3. Alizque Opp.MS.

Quis fuerit, aurea ejus Monumenta fatis produnt; $G$ allia predicat, promulgat Anglia, Roma eloquiicur. Dignus planè quem omnium Gentium vota optent in Civem----Ad immortalitatem Barclaii una fufficiet llius Argenis; quam Richelexus ævi noftri miraculum afiduis (ut aiunt) verfabat manibus, habcbatque quaf præcepricem ac directricem illius regiminis, quo deinceps Galliam venerabilem juxra terribilemque gentibus cateris fecit. Sed herclè nemo nifi forte non anans, aut ignarus optimarum artium, divini, utita loquar, iftius Operis admicatione non rapiatur: nam ficum rerum gravitate majeftatem iharacteris ponderas, mirabere in unâ Argenide Pandorarr donis omnibus à Diis auctam: apiculam variorum florum fucco gravidam undequaque delibato; habet enim Hcroicum Tulli vigorem, Laconifmuri, \& politicam Tacili, Livii antiquitatem, Hofculos puros Petronii, fales fabulofos $N$ a fonis, poëticam $M$ aronicâ vix inferio. rem. Ubi folutâ, nemo penè difertius; ubiftrictât, nemo folertius. Seria jocis,prophanis facra fic temperat, nemo ut fit ex templo, ex foro, qui non imbutus modò optimis artibus, fed \& optimis moribus intritutus ab hac Argenizis lectione abeat. Sed quàm fuaviter fulpenfos animos fallit ! Quàm folerter triumphantem de vitio, fortunaque ludo virtutem fub fictis nominibus, \&ad fuftinendas perfonas idoneis in fcenam inducit. Vita Barclaii præfix. Argenid.

Saryricon fcriplit: quo Angluca, Gallica, Belgica, Lotharinge Aula veram fui temporis delineavit Iconem, tantam apud omnes gratiam promeruit, ut non folum omnes hujus avi parentes eloquentia, fed veterum in hoc genere fcriptas -ipfufque Petronii Satyricon fuperafie cenleretur. Hocabieptus faftu adversùs $S_{c-}$ - Elarios invehondi munus fulcepit, fed haufta è Cardinalis Bellarmini fcriptis doctrinâ 2.vix.jple Thoologicis sudimontis imbutus effudit oleum \& operam. $\mathrm{Bb} b \mathrm{bb} 3$ Pariter 
Pariter fraudatus honoris, meliorilque ltatûs acceflone, humana jam cedens iniquitati, ad viridarii cujufdam fui culturam animum appulit, ubirranfumpris undique floribus pretioforibus, jucundiffímo afpectu temporis radium fallere nitebatur. Ioan. Imperial. in MuL. Hitt.

Fuit enim verò hic morum facilitate præditusy $\&$ ingenio fucis aulicis, urbanifque diffimulationibus æquè apto : hinc Romani proceres hac ejus indolis imbibiti opinione, graviter ufque adeo fenfere de iplo; ut Catholicam fidem haud ex animo, verùm difimulanter profiteri fufpicarentur; illius nempe fectatorem hrerefis, cujus infitutum eft religioni fe locorum pront occafio, ac res propria culerit, devovere. Neque concepta hac ipfus vel defuncti evanuit nota, quippe Infcriptionem ac Statwarn, quam ejus glorix filius, in Ecclcfiâ $S$. Laureñii extra muros erexerat, cantiore Patres conflio fublatam, ac deletam voluerunt: Idem ibid.

Amœniffrmi ingenii vir, \& quem fû́ meritô omnis elegantix compendium mihi vocate videor. Forftner. ad lib. 2. Tacit. Annal.

Argenis Barclaii pleniflima bonx frugis. Conring. de civ. prud.cap.14.ubi \& pag 322. Ejus Iconem Animorum ita Laliè elegantem dicit, ut \& æmulandi comatus omnibus videatur præreprus.

Barclaii Argenis haud dubiè precellit, quicquid placcat illis, quibus lubido eft, pulcherrimos vultus accufarc, quòd non fint pulchriores. Prefidium illí viro ingens ex arcanâ ingeniorum animorumque difciplinâ, cujus eximium fpecimen dedit in Icone Animorum, libello exquilf 2 fubtilitatis \&elegantiz-mIn Barc'aio Regii amores caltiflimè, negotia regni graviffumè, fubrilitates vitz ac. curatiflimè, tractantur. Ioh. Hen. Boecler. in fpecim. Cubrilit. polit.n. 3940.

Acutiffimus Politicus Burclaius, juvenis vigiuti annorum fib Euphormionis nomine eâ prudentiâ \& majeftate omnium Europe Rerumpublicarum vitia \& virtures Saryricofale perftrinxit, ut univerfum Orbem in ftuporem dederic. Iob. Andr. Bofws introduct. in notit. Rerump. cap. S. Lect.ro.

Scription deditus fuavi ftylo Argenidem confcriplit. Opus varium, inventiós ne 8 clocutione præclarum, Cententiifque plenum. Meditabundus multa pratered contexuit, fingularum in primis Gentium mores. Earum characteres dedit eleganti libcllo, quem Iconem Animorum inlcripfrt. Nec minori in Carminibus facilitate cruditorum fuffragia promeruit: quos conciliaverat fibi grata converCatio, argutus fermo, fed \& jocofis fine fale adco face:us; ut multi dubitaverint, iplum Euphormionis auCtorem. Nec minus Gregorio XV. charus, \& $M$ apheo $B$ arberino pirpuratorum Principi, literarum acerrimo eltimatori gratifimus fuit: quorum liberalitate familiam fuam in dies loctplctiorem percepit. Thoma: fir. in Elog.

Ioannes Barclaius Latinus oppido Scriptor \& elegans, Iconem Animorum Argenidem edidit; foluta orationi ligatam hinc illinc mifcuit; tres infuper libros infripfit Euphormionis Lufnini Satyricon: Hoc Scriptum in omnes ferè tam politicos quâm Lacros hominum ordines pugnavit; Ced acculationibus id urgere, infticuti mei non eft : lunamus manes quiefcere. Hoctifu dignifimum. $A$ B ar. clatis 
claii morte homines fimplices \& prorfus albæ mentis quædam præfixo cjus nomine obftruferuntedita, ( vifum tenearis amici?) ac fi literarum hoc ævum 2 plumbo nefcirct aurum diftinguere. Drexell. in Aurifod. p. 258.

Gallus quidam Satyricon ad "Eetronii imitationem, Styloque Petroniano compofuit, Plures illi errores inexiftunt, quos plurimi non animadvertent, ut in Domini Beze Carminibus, plures occurrunt Gallicifini. Scaligerana 2. Gall.

Eft \& quamquam rarius, ubi in quantitates fyllabarum, eft ubi in dictionis Latine munditiem impingit Loannes Ovvenus, quod ipfi cum celebratiffimo aliàs Barclaio commune. Borrich. de Pöèt p. Iss.

Prodiit tandem, velut aurum ex Marchafitâ, \& uniones ex Matrice conchâ, Icon animorum Joannis Barclaii. Cui ego aucto:i, non modò præittanti facundiâ, fed omni genere laudis, qux ex litcrarum ftudiis elegantioribus provenire folet, ne ex illis quidem veteribus Romanis quenquam antepono. Gab. Nowds Bibliograph. Polit.

Quis fuerit Iob. Barclaius dicit compendio Hugo Grotius:

Gente Caledonius, Gallus natalibus bic ef,

Romam Romano qui docet ore logui.

* Ioannis Barclaii Euphormio Lufninizs, five Satyricon in variis editionibus corrigitur Indice Madrit. Impreff. ann. 1667.

Exrant libri 3. Argenidis, cum Notis Variorum Lugd.Bat. ex officinâ Hac' kianâ Vol. $28^{\circ} .1664$ \& 1674.

Extat Satyricon, nunc primùm in 6. partes difpertitum, \& Notis illuftratum cum Clavi Acceffit Confpiratio Anglicara. Lugd. Bato ex Officinâ Hackỉanâ.: 674.80.

Hoc ejus Epiraphium:

Heuplangit, meminitgue fui Parnaffus alumni

Sicque gemit Jparfis Mufa Secuta comis.

- fatum! Ab! noftre cecidiffi gemma corone:

Occidit ante furm noffer Apollo diem.

Parcite Pierides lachrymis, in latius ora.

Fingite; namterris vefter Apollo micat.

Dum vivent aterna tui monimenta libelli,

Barclai, vives cuncta per ora virûm.

Hac twa per totam te pradicat Argenis orbem?

Cum fcelus imperii, fed fore dente notas.

Caftaliis puras bauffifie é fontibus undas,

Quas modó digestas ecce propino libens.

Has quicungue tumens prono non appetet ore 3

Tauzalus in mediis ardeat alter agmis 
Fercula diverfis dapibus condita miniflro, Hoc fine non Sapiet docla Minerva fale.

\section{THOMAS CAMPANELLA:}

Clar. A. D. Alaber, Stylenfis, Ordinis Predicatorum, natus eft s. die Septembris, An $M D C X X$. 1568. Obiit Lutetiis Menfe Maii Anno 1639.

Hoc ejus Symbolum,

\section{PROPTER SION NONTACEBO.}

Scripta cjushac funt: Phyfiologia : Quxftiones Phyfiologicx: Defenfid Rerum : Opufcula Phyfica: Metaphyfica: Poëcica : Atheifmus Triumpha rus: Tractatus Aftrologicus: Monarchia Hippania: Tractatus varri Medicinalium.

Scripfit ab.anno ætatis vigefimo, non que ab aliis feripta erant, fed in hoc incumbens, ut nova in omnibus ferè Ccientiis excogitarct. Leo Allat. Ap. Urban.

- Scripfrt ingens Opus, de Reformatione Scientidrum, decem in Codices divifum, gizorim finguli, plures in partes diftribuuntur; unde, nihil acurifimo ingenio homini tam fuiffe propofitum apparet, quàm relictis veteribus viis ad omnium fcientiarum notitiam, novum atque directum iter aperire. Scripfit etiam alia permulta, partím edita, partim nondum imprelfa, quorum index à. 1 acobo $G$ affa rello recenfetur. Ian. Nic. Eryth. in Pinacoth.

Amicus eriam nofter Thomas $C$ ampanella juxta doctrinam fuarum Primalitatum Etbicam novam compofuit, qux fub Epilogifmi nomine cum Philofophiâ' fuâ Naturali , \& Polticic rypis commilfa fuit à Tobia Adamo, Atylo quidem non itacompto delineata, ut Cuceronianis arridere poffit, fed eâ nobilitate cogitatio* num, rationumque fubtilitate, itt omnibus fapientix MyRis non polfit effe non fummoperè gratifima. Gab. Naud. An Kibliograph. Polit.

Secundus ab ip ro fuit Thomas Campanella, ardentis penitùs s. \& portentofi vir ingenii, qui dum in tenebris, \& padore carceris vitasn traduceret, Civitatem folis delineavit, eâ cogítationum novitate, \& fublimitare fenfuum, ut prater Philofophicas fpeculariones multa etiam contineat queis Reipublica ráeliùs adminiAtrari poffent, \& Homines ipfi meliores evadere. Idem ibid.

Campanella philofophatur magnâ feveritate, fed fuâ Metaphyfcâ Methodo; proinde moleftâ. Docet, ebteftatur, blandicur, ut res tulit, $\dot{x}$ tractationis ordo: dum fappius magis fuaforiis, qu $m$ fortibus \& heroicis argumentis armatus in pralium, magisluetam dixeris fuiffe, defcendit; in arduis cefpitat, hoftem armis fermè exurtum jam dimittit, aut negligit Cxpius; cui periculo fultinendo, prajudicio orbis Chrifliani fe commilerito Ioan. Deskler. Icript. Adefpot. 1686. p. 323: 
Thoma Campanella Civitas folis latide quidem digua, multùn cht tamen infra Th. MoriUtopiam. H. Conring de Civ. Prudc it.

Ornibus hifce (Cyriaci Strozze Supplementó, Eranc. Patricii Senenfis Opere de Republicâ, Adovardi Gualandilibris de civili fucultate esc. ) prextant licet mole exigui \& in earcere fine ommi libronm auxilio alicnum ad calamum diEati, Potitici Aphorifmi Thome Campanelle, quos Latinè yerfos partem tertiam Philofophice Realis inferipfir Tobias Adami : argune fanè capax atque verfutum Ancto is ing ninum; perinde atque liber de Morarcbià Hifpanicá prodit admi-

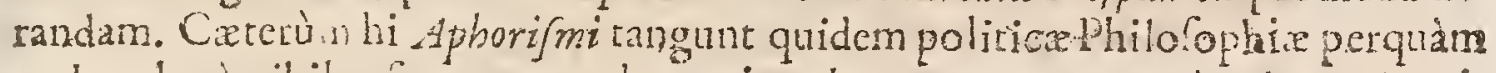
mulca, plenè nihil exie uuntur: plura etiam docent perperam, quàm à Grotio animadverfa funt.Conring.de Civ.prud.p.358.

Camparella ille homo fuit callidus, fine ulla religione \& fide, Machiavelli dogmatum acerrinus pariter teprehenfor,\& fucatus Doftor A c.I4. Ufque ad 3I. ejus Monarchia Hifpanica lectorem curiofum meretur. Seripfir hoc opus decennali miferiâin padorecarceris, \& rg rotus, nullos in fubfidium habuit libros imò pla Sacra Fibiza ipfi adempta funt, ut ipfi ignofendum fit, ficubi quedam delirans dixir.Herm.Conting.de.Hippan.

Monachusifte Gampanellas wir ttupendi \& portentofingenii, in libro fuo de Monarchid Yifpanice docetçuemodo Rex Hispanie poriri polite toto terraatum orbe. Varia ille luggerit conflia, nec srobat reginein rigidum Hifpania, \&

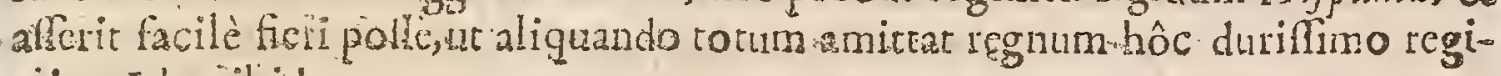
mine.Idcrisibid.

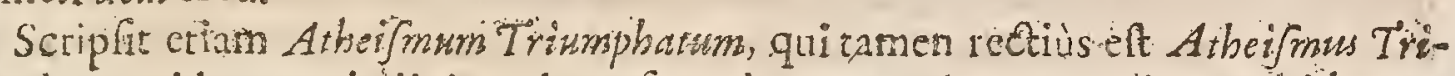
smphans, idemque judicium de eo fercndum, quod Barlaus de Amphicheatro Vamini vulit. Idem ibid.

Cardinalis Richetius magna beneficia in ipftrm contulit. Philofophiam tradidit qua patteorum palato fapuit, quamvis ejus Profelfor per o:bem in ma gha eflet exiltimatione. Ejus quidempopularis qui ełogium ejus odo navit, fatetur cum ingenii acumine, exigro vero judicio praditum fuiffe, moderationifquic ac folidicatis indigum exticilfè. Morert Biction. Gall.

Prachara fravirure ac eruditione dignum fe praftititsqui Seculi fui Philofospliorum Princeps audirctolfadc Bullarto. Acad. Scientiarum. Gall.

* Obfing ilarem doitrinam invidiam fibi confavit, apud inquifitores delatus, quafi cam ex inferorum fontibus hauffeet : Neapoli etiam perduellionis reus factus, quòd regnum ill led holtbus prodere conatus effet: Unde in carcerem cons jectus, 8 25.mn.miferrimè tractatus eft. Tandem vinculis elapfus; in Galliam tainquam in Portum confugit, Regique illi \& Regni Ptoceribiss, quoad vixitsaccep? Eiffinius fuit. Kong.

Extant lib.4. de fenfu Rerum \& Magià. Parif. $1637.4^{\circ}$.

Extat Athe fmus Triumphatus. Roma 1630.4 . \& Parif.1636.

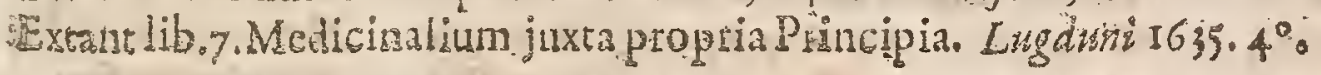

Cosec ith 
In Effigiem ejus hxc Carmina compoluit fo. Bened.P erax zo

Exprimit elate Sat Nomen mentis Abyfsum.

Exprimit Agnomen farne os ubique fonum.

Multiplici partum portendit codice plaufum.

Quan cupidè eximit cernis Imago viri.

A urminis ofores perdit, fidufque revelat.

Abdita queve Polo, condita quave folo.

Call uit ingenio cunttas ornifcius Artes;

Fit Cous Medicissefl Apollo Cygnis:

\section{PETRUS CUNAUS:}

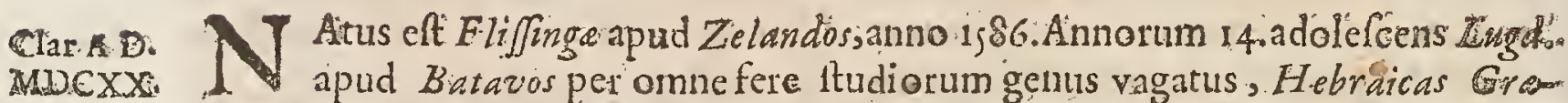

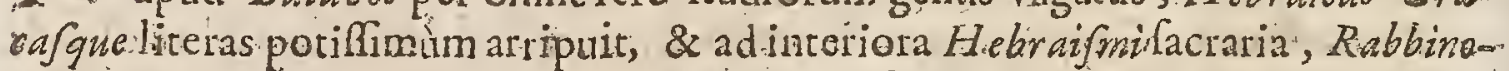
rumque Commentarios manuduetore ufus eft 7oanne Drufo, qui Eranekera Erofiorum Linguas, HA, ebräitam, Chaldaiom,ac Syriacam profitebaturibidemque z:

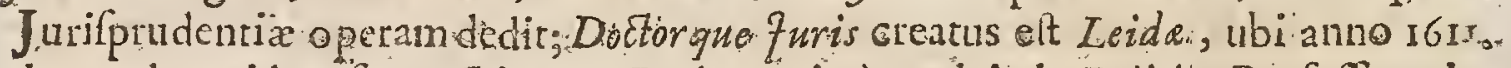
demandata eidem E erat Lingure Latini primùm, deinde Politica Profeflio; do. cretumque ab Academia ( uratoribus anno: 1655 . ut prater politica, fus: quoque Civile interpretasetur, quam Provinciam ad extremum vitx futt nuit. Vivere defit anno 1638 . mení Novembri. Faler.eAndreas in Biblioth. Belgic:

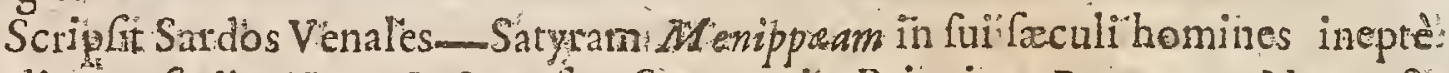
eruditos - Zuliani Imp.Cafares, live Satyam in Principes Rornanos - Natas 8 Animadverfiones in Donni Panopolite Dionyfiaca-De Republicâ. Hebrcorum libros tres-Exercitationum Qratoriarum Inaugurationem-Orationum Librum:

Petrus Cunsus vir Liatinè, Gracè, Hiebraicélcientiffmus, arque idem eloquentiflimus, \& jurifconfaltilfmus V.oj. de Hift. Grecil.2.c.I8. .

Petsus Cuneus, EliJinganus, orientalium Iinguarum, \& Rabbinicorum Arcamorum: fientiffmis. Hofman.

Cunxus eft bene doctus fed melancholicus. Scalig. pofterior.

Peracrís judiciivir Perns Cunous. Paul Colomef? Oblery:Sac.p.7.

Cunaus ftupendum, \& portentofum ingenium. Beverovic. de Vit. Term. Rig, 46 .

Diu eft, vir eruditifime, ex quo tuum mihi nomen innotuit, \& fingularis.

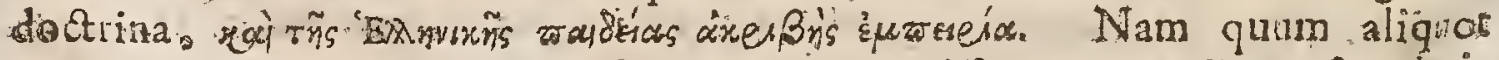
Greca tua Epigrammata in ochlos meos incurriffent, advertit me fingularis, legantia \& purit as dietionis, ut non nntè quief $6 \mathrm{crem}, q u a ̀ m$ de te \& tuis itudiis 
Eos, qui iffinc veniebant, fedulè elfem percontatus. Omnes ea narrabans, qux me facilè tibi conciliarent---In his ego nomen profiteor meum: Qui tingenué profiteor, à tuorum lectione \& meliorem me difceffiffe \& doctiorem. If. Casazbb. in Epift.578.

Libros tuos de Republicâ Hebreorum, tr omnia tua, ex of culatus fum.Magnum illorum hîc apud non valgariter doctos precium eft tum ob obleryationes Thalmudicas, quas apud ipios Autores legere cujufvis nen eit, tum ob dictionis Romana, quâ omnibus hujus faculirdoctis precellis, puritatem. Cafp. Barlaus in Epift.194.

Cunaum de Republic ấ Hicbrvorum legi, neque partm inde, quod fateor, profeci:quanquam intercurrunt nonnulla, que malin judicii fererioris limà ab ilLo admorfa fuiffe, quxdam etiam, in quibus lauro tibï opus effet, cujus clie

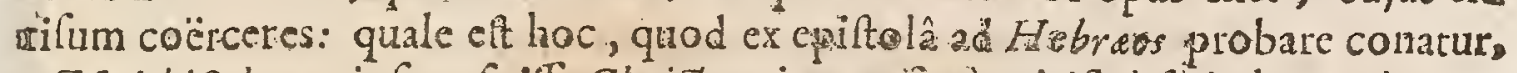

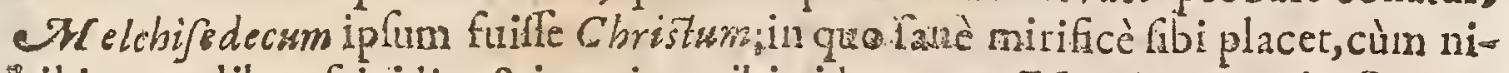
Hil in toro libro frigidius \& ineptius mihi videarar. Mrartirs. Ruar. in Cent. so Epift.p.41.

Vidi librum de Mari Clanfo,magro molimine \&apparatu è Seldeno fcriptum. sed non difficile erit tibi, cui has partes derandatas aiunt, Claufun Mare aperiine,utpote \& hiforix veteris, ac juris diviai pariter humanique peritifimo. Di Snum eft te argumentum, quo demereberis Batavos omnes, \& quotquot fortus. an libero Mari experiri amant. Cafp. Barlass in - Epift.3I7.

Quid Cuneum, virum ernditifimum, retineat, que minus Seldeno refpondeat' miror. Hug.Grot.in Epitt.ad Lud.Camerar.30.Maii 1636.

Cunai judicium magni feci femper, \& puto fuilfe $\varphi_{1} \lambda$ owarér $8 \alpha$, eo pue magis doleo quòd in eo Academia fecit damnum. I dern in Epilad Ger. Ioanma Voffo Cal.jan.1638.

Erat illi [Petro Cundo ] dictio tam caltigata, tam concinna,tam pura ac perfpicua, \& minimè affectata, ut aureum illud Latini fermonis feculum, qrod fub. Augreffo, \& I ulii Cafanis ac Ciceronis temporibus fuit, in eo non defiderares-Equidem appatuit unagnis minimifque rebus, quàm cordatus elfet. Si in Senatus fi in foro dicenda effet fertentia, fiex fuggefto laboranti Academia faccurrendum, fiad Ordinum confelfum confugiendum, fi commendandis aliquis elfete apud eos quirebus cum Imperio prafunt, femper fe catum, femper virum oftendit, \& admirationem fui vel invitis extorfit. eAdolph.Yorfizus in Orat. Funeb.ad diem 6.Decemb.16;8.

Juri Confultotum eminentifimus, Petrus $C$ wnaus, vir profunda eruditionis, $\&$, propter purifinm diction is elegantiam \& venuftatem, feculi noftri Cicero, \& f f quid in (icerone elo quentius effe poserit. Steph. fo. Stephanus in not.ad Saxonis Gramm.hift.Dan.lib.6.

${ }^{*}$ Cunai de Repúblicâ Hebrcorum libri tres, cum expurgatione permittuntur ire Ind.Madrit.edit.ann.1667.

Extant Sardi Venales, Lugd. 3 at.1616.in $24^{\circ}$. Extat Satyra Mepippea.Lugd.Bat.1632,in $12^{\circ}$ :

$\operatorname{Ceccc} \&$ Ixtane 
Eant libri 3.de Republicâ Hebræorum.Amstelod.1632.in $24^{\circ}$

Extat exercitationum oratoriarum Inauguratio. Anstel.1621.in 4:

Extant orationes Varii Argumenti,Lugd.Bat.1640. Witeb.in 8०.

Extat Animadverfonum Liber in. 2 Voni Biony faca.H annov.1610.in 8.

In noctem, quâ extinctus eft vir incomparabilis Petr. Cunauss, hac carriaina compoluit M.Z.Boxhornius.

Nox fuit, of nondum perluftrat Pholphorus orbem.

Nox fuit, of nondurn red didit ille diem.

Nox manet, of fiertit Phobus, languetque, fumgues.

$U_{t}$ folet, auraturn non finit effe caput.

Nec Jovis Hetculeis. iterum lafcivia natis

Tam vacat; infenfos credimus effe Deos.

Cunxo aternam indixit mors invida noctem:

Hac guemvis nobis abfitilit illa diem.

\section{T HO MAS ERPENIU:S}

Clar.A.D. M. D. $\Sigma x$.

7 Ulgo ab Erpe, Batavus, nafitur Gorcomii anno 1584.30 Idts Septembi. Prima literatum tyrocinia pofuit Lugduni Batavorum, ibidemque ftudia abfolvir Philofophica, fimul linguis orientalibus dans operam, quod ftudium aufpicatus erat porifimùm hortatu fof cphi Scaligeri, qui jam tum facilè perfpiciebat, quantum aliquando virum daturus effet. Unde inftitutâ peregrinatione in Galliam, Germaniam, Italiamque ubique admiratores fui invenit. Fenetics Fudeorum eruditorum ac Turcarum copiam nactus, preter Arabicam etiam Turcitam, Perficam atque Atbiopicam linguas didicit, reverfufque in Patriam. Lugduni apud Batavos anno 16 13. Lingux Arabice \& cxterarum Orientaliurn Piofellor a Curatoribus illius Academix conftitutus fuit Spartamque fibi oblatam egregié adornavit, quâ docendo, quà fribendo \& excudendo, inltitutâ ab ipfo Erpenio Typographiâ earundem Linguarum. Vir fuit ftudi confantis \& perrinacis, n orum elegantiâ atque humanitate fungulari praditus. Obiị Leida anno 262.4. Waler. Andreas in Biblioth. Belgic.

Scripfit Grammaticam Arabicam-Lexicon Arabion-Proverbiorum Arabicorum Centutias-_-Locmanni fapientis Fabulas ex Arabico-Tefamenrum Novum Arabicè-Canones de Litteram Evi. apude A rabes naturâ \& permutatione - Rudimenta lingua Arabice - Grammaticam Hebraam - ArCanum Punctationis revelatum - Orationes tres de Linguarum Hebras atgue Arabica dignitate-Pentateuchü, Arabice-Hiforiam Iofephi Patriarcha, Arabice-DClterium Syriacum, cum Verfone Erpenzi--Hifteriam Saracenicam.

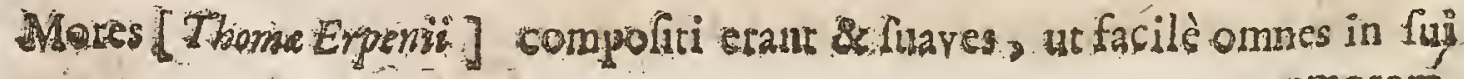
omorexia 
anorem pelliceret. Ingenium felix, non modò ad aliquid capiendum; fed etiam refervandun: amicitiam Londini init cum Gulielmo Bedello, viro longè dostiffimo, atque Orientalium Linguarum peritiflno: qui Erpenium ad ealdem excolendas plurimum hortabatur-fuada quadam infidebat viri illius labris qux fic Orationem temperabat, ut non folùm qua tetrica viderentur, perfpicuè.tractaret; fed auditorum etiam animos incredibili quâdam perfunderet voluptate Vo:J\% Orat.in Obit. Erpenit:

Thornas Erpenius cùm aliarum literarum \& Philofophiz callens, tum Arabifmi \& Grammaticarum ejus Lingux Ob fervationum mirificè curielus \& intelligens.Casäub.Epift. 86.ad Thuan.p.663。.

Ille vir [Thornas Erpenius] videtur mihi divinitus náetus effe fpartam ornandi linguas exoticas, prafertim Arabicam; cnjus cam cognitionem labore improbo \& magnis impenfes cf confecutus, ut ipfis Arabibus fuerit miraculo jam ante unum aut alterum annum: Ego certè ftupere defigor, quoties de illo portentolo ingenio cogito. Cafaub.in Epilt.ad Heinfiurn.

Quanta in rebus Orientalibus caligo fuit,antequam fidus illud Batavia, Thomas Erpenius Arabicam literarum orbi noltro inferret!Georg. Horn.in Præfat.ad Lector. Sever.Sulpitii:

Vir de inftaurandx A rabicx Linguę fudio apprinè follicitus \& praclarè me ritus.G.Calixt.de V.R.C.n.:8...

Tharas Expenius, linguarum, dum wiveret, Oriëntalium decus \& 'deftina. Megic. Cafaub.de quat.Ling.p.45.

Vir fummus, Orientalium Linguarum, maximè Arabicx, in occidente Parens, dum vixit, colendifimus.Selden. in Defat.ad Eutychï Patriarch. Alex, Eccl. fuat origines . 7.

-Quenvis tamen Arbitrum per me Leetor ftatuat, nom ination verd fum ip:fus $D_{\text {rufii }}$ Conterraneum, Thomam Erpenium, integerrimum doctifimumque visum, Lingua Arabica non peritiorem tantùr, fed etiam rul tò peritifimum, id que de Philarabibus univerfis (expertus loquor) quam optainèneritum, \&.6 fiduè merenten.Nic. Euller.in Append. ad Mifcell.Sac.

Erpenii mors rajus eft damnun Literarum quam a!t dici, aut cogitari queat. Spero non defuturos qui merr oriam ejus ut par elt celebrent. Hug. Grot.ir Epift: ad fo. Grotium, Lutet.28. Novemb. 1624 .

${ }^{+}$Hic Author fi expurgetur, permittitur in Tid. Madrit editanno $1667 \%$

Extat Grammatica e 1 rabica Amftelod.16;6.21656. in $4^{\circ}$.

Extat Arcanum Punctationis revelatum. Lugd.Ras.1 624.in A $0^{\circ}$

Extat Hifloria Saracenica. Lugd.Bat.1622.\& 162 g.in fol.

In obitum viri Clariff. Thome Expeniz Orientalium literarum in Acadenia Lugdunenfi Indtauratcris incomparabilis.

Omnia dum Leida Phobus concedit, habebas

Quas bebrit Graius, griag gue Latiuus, opes: 
Intulit Erpenius Muas Oriente petisas:

Hac deerat Batavis gloria fola meis.

Sublato Domino patrias rediere fub oras,

Et fugit Batavos gloria tanta aseos.

- Lugdunenfis data cui tutela Mînerva est.

Et vatum vatés diceris efje pater,

Hefperias faltem, Phobe, $\hat{o}$ defende Camoenas,

I am wiltifpoliummors Orientis baber.

Joannes Rutgerfius:

\section{IE NRICUS SPELMANAUS}

19.8.

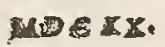

A Nglus, Eques Auratus, obit Antso Dom. 1641. xtatis 78. Compofuit Are. 1 chrologum, five Glofarium-Librum de Concil is----Librum de Decin. mis--Denon temerandis Ecclefis.

Eruditifimus \& nobilifimus A Antiquitatum ferutator Henricus Spelman: Eques a nglo-Britannus, amicis nofter honorandus. Olai Wormii Licerar. Da2ic.C.I.

De prifcâ literaturâ benê meritus Henricus Spelman. I dem.

D. Hear. Spelmannus infignis \& acurillimus Anquitatum Britannicarum ext plorator.Duck. de Author.Jur.Civil.Rornen.L.2.c.8.

Nefio quo fatorum confilio, huic ultimo feculo nec merenti, nec talid

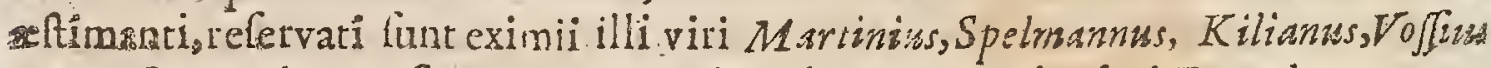

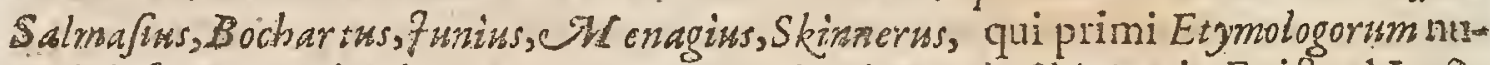
gari de.Perunt.VidaEdis. Etyrnologici Ling.Anglic.Steph. Skinnor.in Epift.ad Lect. Ann.16gi.fol.

De Spelmanni Lexíco, partem prorem vidimus farè utilem, \& in Saxonicis maximé yocibus accuratam.Grot ad Peireskitum, Lat. 16.Sept. 630.

Sed de ito \& aliis, malo adiri enditum Spelmanni Gloffarium:quod, hactenus dimidiatum, wrinam aliquando, modò, fuperfar, integrum publici faciat juris. $V_{0}$ of: de Vic.Serm.1.2.c.9.

Gloffarii deinde Spelmanniani prodiit pars potterior, quxe etfi multa obfervatu digna licèt indigefa contineat, priore tamen longè inferior: ut mirum fe virum doctiflimum Operi, quod eruditi quique tot votis tantoque fudio expeterent, extremam manum non appofuilfe, cum prioris partis editioni qua anno 1626 . prodiut, annis 15. fuperfurerit. Obiit enim anno 1641 . 2tatis 78 . Cujus quidem rei caufam elfe aliam nón arbitror, quâm quìd Angliçana Ecclefra Concilionum Collectioni ac Editioni, veteribufque eruendis monumentis, totum dedifet feLe $e_{\text {a }}$ lo Jarimm verò quantum exigebat dignitas argumenti abfolvere, immenli nia

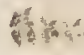

maiqus 


\section{CELEBRIORVM AVTHORVM:}

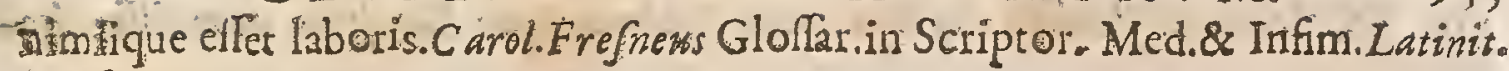
Prefat.p.55,56.

Henrici Spelmannii Vocabularizm utiliffmum eft illis qui corrupte Latinizatis Authores legunt, titulofque veteres \& Chartas antiquas enucleare aggrediuntur. Id typis mandandum curaverat Spelmannus dum viveret ufque ad lire$\operatorname{sam} M$. Poft ejus obirum in iplius Seriptis ad ejus perfectionem neceffaria fuiffe seperta perfuadere voluertunt ejus amici; verùm præcedentibus minimè refpondet ejufmodi fupplementum. Nobis etiain idem Athor Conciliorum Anglia co piam fecir, qux imperfecta quoque remanferunt. Ferunt eorum impreffonem. ex iis qux fcripta reliquir ablolvi. Sed Authoris hujus Opera polthuma vix (perari pollunt; cum enim atatis, tantùm anno quinquagefimo ad fudia fe accilnxerir, prelo fubjicere feftinavit, quxeumque digna cenfuit publica lace. Cumque brevi poltea diem obierit, multùm laborare ipfinon vacarit, nee nllit opesum inceptorum ultimam odmoverc manum. Ephenderides Gall. Eruditorum 5 . Jan.1665.p.2.

Tertium MS. accommodavit Nobilis ille dectifimafque Dominus Henricus Spelmannus eques Auratus, eruditionis reconditionis. „Judicii aceribin vir, Noftræ Britannic lumen gloriaque; amicus infuper megs. fingularis, in: ftudiis adjutor precipuns ; \& yui me primus ad Antiquitates ernendas täm ver-

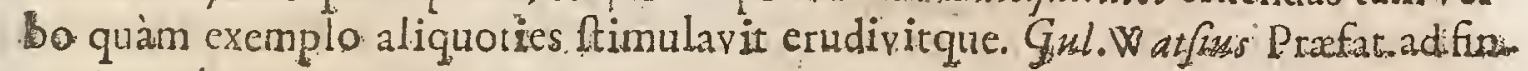
M.Paris.

Eninens meritum \& dignitas pientifimi hujus Equirtis, , cujufvis landibis: aut calamo nen indigent. Praftantiflma ejus Doctrina, Pietas \& Sapientia optimis quibufque cortaneis ejut notifina fuerunt: Ejufque Operarev vivene in lureem emiffa, frrul cum magno applaufiu quo:illum tum populares, cum exteri Nobiles enuditi, magnique 12 rincipes condecorarunt, omir exceptione majora funt te? im onia. Inter omnia catera ejus merita \& Opera null ium eft illutrius quàm ejus erga Dicum Pietas, comprobata tùm fancto ejus vite curricul@, tum fueciatim erudit \& pio ejus Tractatu de furibus \& Veneratione que debentur Ecclefits: In @ụ tam accuratè probavic quid Deo debcatur, ipfique reddendum fir, tum quead tempus cultui cjus deftioatum, tum quoadimedia \& loca, quíbus ejus cultus eft peragendus, ut aemo verè Chriftianus, qui Evangeliun amplectirur, lubens non prædicet fingularia cjus merita infignemghe ejus pietarem. Magna ejus in Regnin noftri Jure Municipali notitia, ut \& i

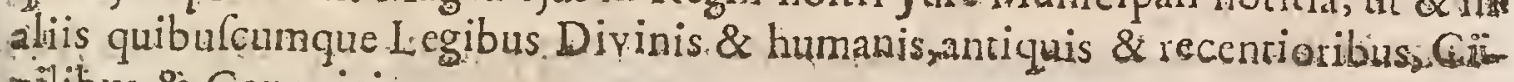
vilibus \& Canonicis,

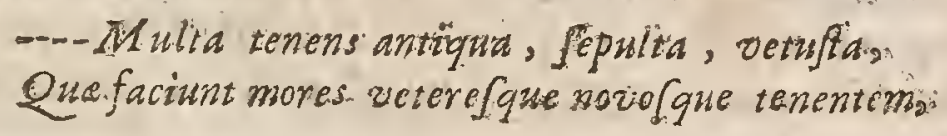

num frnglari judicio pluribus aliis pracellentem redduna $x$ id

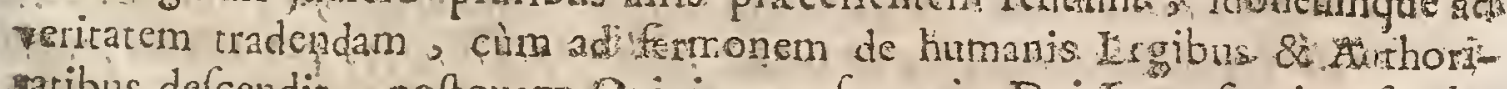
rabus defcendit portguant Opinionem Inam in Dei. Ing fumiter funciayito 
vit. Fer. Stephani Prefatione Trakatui Spelmanni de Decimis pramilla Anglice.

Henrieus Speimatros, vir nobilifimus ac illufte Britannia fuxe derus. Vide Steph. in Ploleg. Nor.ad Hifor.Dan.Sax.Gr.

Variarm anriquituram periflimus. I dem ad lib.8.

Maxmingenii Eques. Hachenb. Germ.Med.dilp.4.Sed.Ig.

Maximm Equeftris ordinis decus. Itid. difp.s. Sea.6.

\section{THOMAS IA MES}

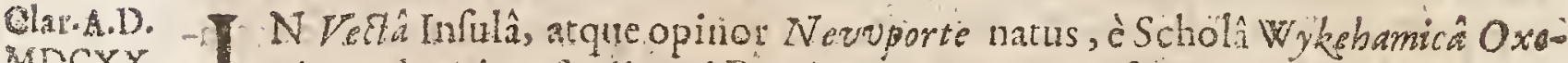
MDCXX.

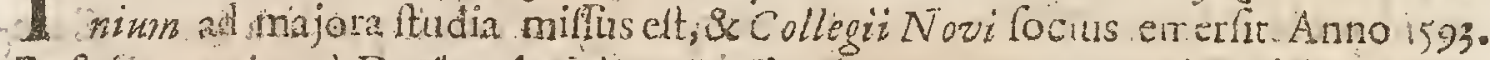

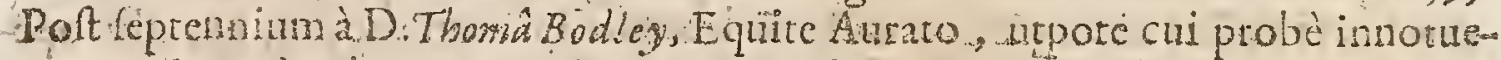
rant viti merira, in Proto-Bibliothecarium fum cooptatus, ea praticit qux ad Artium ingenuatum frucum cgregium hatd parmiconducerent; fruidem fupellectlem l terariam mundiorem reddidit librofque omes in Catalogos bis redegit. Anno 1614. Thieologix Doctoratum fufcepit in fobdecanum Wellez-

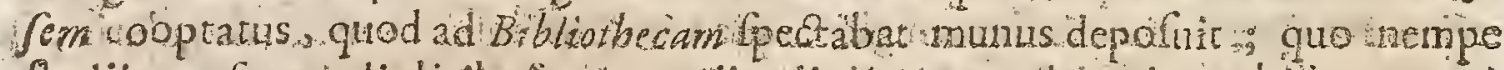

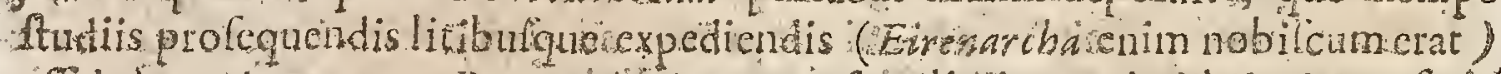
affiduc mag is vacaret. Patum Antiquorum familiariserat in libris Manucripris prefertim (quorum corruptelas nemo nelius apenit) kevolvendisindefefis, Statutorum poriò 8 confictudinum Academicarum rimatoreculatifimus.

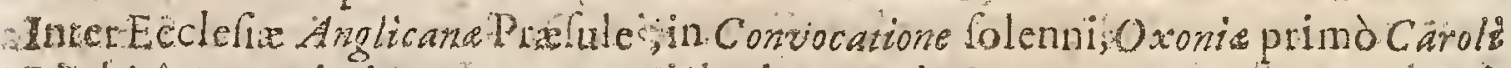
IVabirâ, (quo nimirum tempore cel chabantur"ibidem Comitia Partiamentaria) confidebat; athorque fuitut certis qubufdam viris demandaretur Manufcripta Patrum Sacrorumoperaper Biblio hecasomnes.Anglicanas, five publicas five

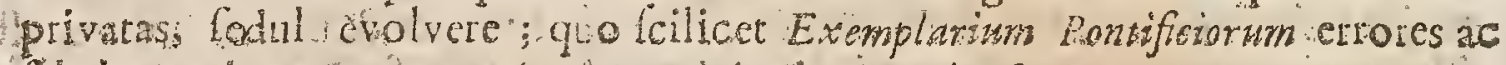
fphalmatadetgerentur, Ant Wood.Antiq. Oronienf.

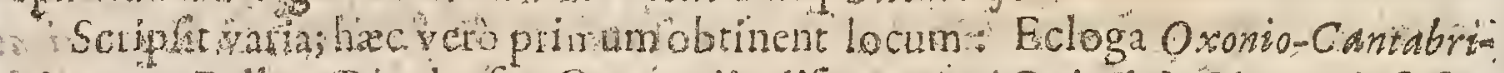

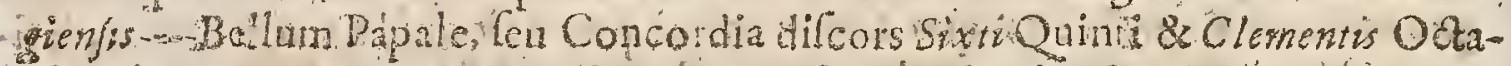

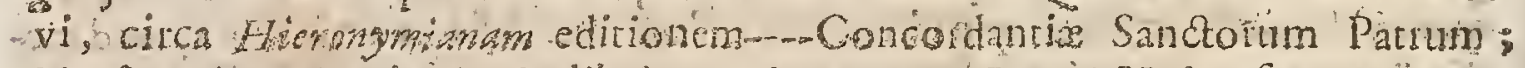

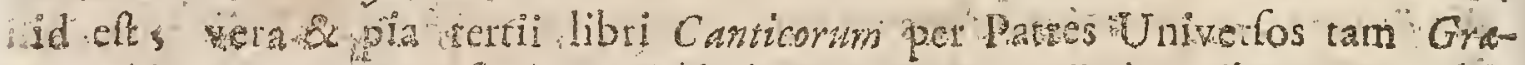

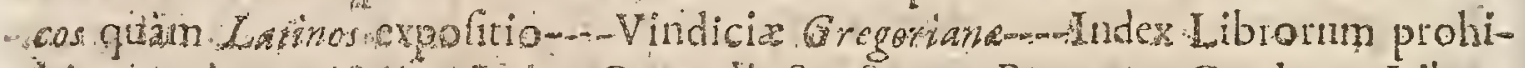

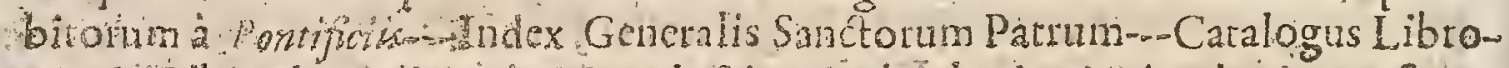

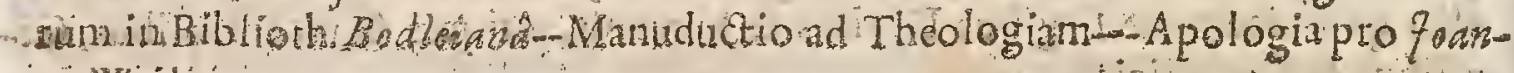
sre Wiélévio.

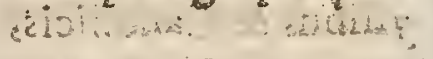

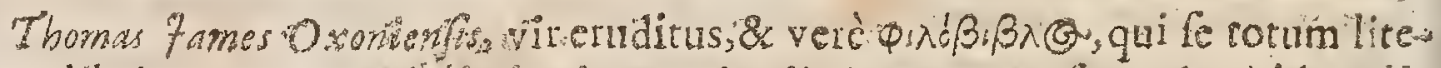
ris \& libris, in Angliabibhohecis cxcuriendis (Deus opus fecundet) id molisur, quod Reipublics Literartimprimis crit ufit.Camdenin Britan.vid.Comit. Mounnouths.

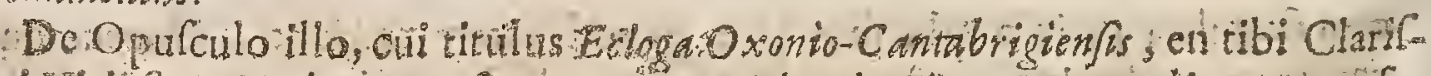

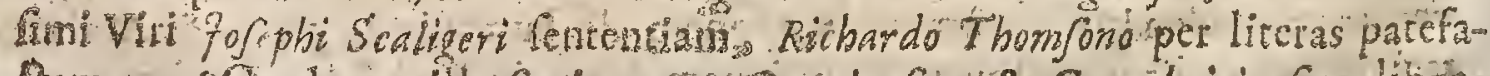

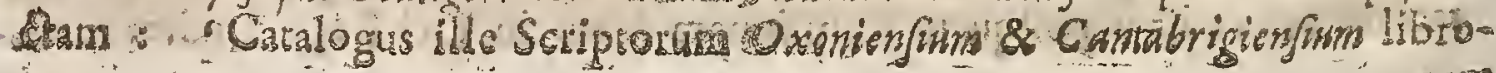


tum mirificè me affecit ; præfertim quum videam multa in - t2 cffe, quibus res Gallica \& Regni Francorum illuftrati polfint. Et praterea - non minorem numerum corum quibus Tyramis Pontificia manifeftò depre- hendi poffit; tum qux doceant quando cloacx illa \& collivies Monachorum - Sele in Europam effuderint: ut Loiolite hodiè \& Capucini. Habetis quoque Origenem in Celfum, atiofque eximios Gracos nondum editos; quos parum vexari ab iis puto qui in illis Collegiis degunt. A me certè non raro reviferentur, $f$ - ibi adellem.

Fama obtinet libri ejus, qui Fifcus Papalis infcribitur, edicufque Londini en ann. 1621. Authorem fuille, quem alii tamen Gulielmo Crashave Cantabrigienfo. tribuunt. Utcunque, de famefio nolt ro conftat, ad induftriam \& memeriam haud vulgarem judicinm planè impar adjecille. Ant. d Wood.

Sunt qui in Bibliothecis ut Blattæ verfantur, qui libris meliores non evadunt, fed à quibus libri deteriores funt, ut qui digitis fuis illos tantùm fordident. Sed cum Doctore fames non ita comparatum erat: quippe qui in proprium \& Publicuin bonum libris utebatur. Manu-fcripti cujufvis atatem fola faciei cjus infpectione dignofcebat, \& ex Characteris forma tempus quo confcriptum fucrat defignare poterat. Thomas Fuller de Praclaris Angliz Viris. Angl.

Extat Catalogus Univerfalis Librorum Bibliothecx Badleiana ordine alphabetico.Oxenii in $4^{\circ}$.ann.1620. Appendix ad enndem ibid.1635. $4^{\circ}$.

Extat Ecloga Oxonio-Cantabrigiensis in r.libros tribura, quorum prior continet confulim librorum MSS. in Bibliothecis Academiarum Oxonic \& Cantabrigia: pofterior verò Catalogım eorundem difpofitum fec. 4 . facultates, ordine Alphabetico. Losdins 1600 . in $4^{\circ}$.

\section{HUGO GROTIUS}

R Atavus, Parriâ Delphenfis, natus eft Anno Dom.1583. Iv. Id Aprilis. Obiit Rostocbii Anno Dom.16 4 .

Hoc cjus Symbolum:

\section{$R \cup I T \cdot H$ O $R A$}

Scripta ejus hre funt: De Veritate Religionis Chriftienem-n-Mare liberuni -De Jure Belli ac Pacis lib. 3.----De Antiquitate Reipublica BatdoricaDe Imperio fummarum Poteftatum circa facra Commentarius-..-Annales \& Hittorix de Rebus Belgicis----Hiftoria Gothoram,Vandalorum, \& Longobardoru ---Dilfertatio de Origne Gentium Americandrum---De Satisfactione Chrifge adverfus Socinum--A pologeticus-..-Comment. in omnes Veteris \& Novi TeAamenti libros----In Confultationem $C$ affandri-_-_Florum Sparfio ad Jus ftse

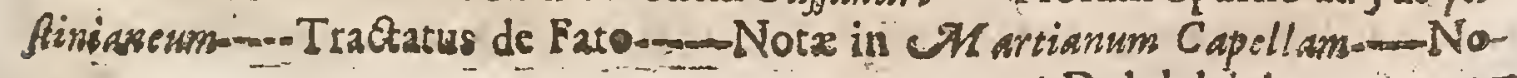


ta in Lucani Pharfaliam--..-Syntagma A sateorum-...-.-Florilegium Stohng -...-Notabreves \& Emendationes in Tacitum-...-Adamns exul, \& Chri-

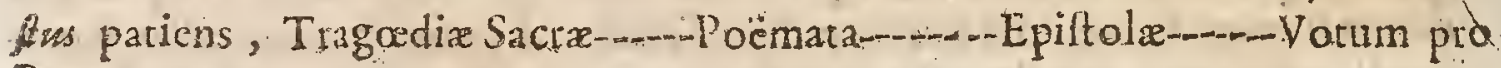
Pace.

Vir fummi \& incorruptifimi judicii vocatur. Heinfio in Animadv. ad Senec Traged.p. 512 .

Criticus acutus \& infignis. Dempfter. $\forall \cdot \int \delta$

Non divinarum minus., quàm humanarum renum fcientiffmus.

Seculi fui Phonix yocatur Hofriano.

Grotiun , virum excellentifime doctrina in omni genee literarum vocat Salmafims Excrcitat.in Solinim.

Virum acuminis \& omnigena doctrina preftantià incomparabilem appellat Seldenus in Mar.Clous.

Seculi nofri grande onamentum, vel miraculum potilis, vocatur Voffo de Poët.p.82.

Eternum Batavix \& feculi fui decus immortale Idem lib. 9. de Idololatr. Eap. 7 .

In omnibus fuis lucubrationibus magnus fuit $H$ ugo Grotius fed in Epiftolis uti $\&$ in Carminibus, incomparabilis ac Divinus. Claud. Sarrawin Prifat prefix.Grot: Epit.

Offertur inter alios viventim primarius Hugo Grotius Grect Lintinie fer monis, nec non furris Cafarei penirioni fcientiâ perpolitus. Fo. Imperial.

Summus virorum $H$ ugo Grotius, lumen illud ac columen literarum : de quo wihil tam magnificum dici aut fcribi potel, quin vircus \& eruditio id linperaret fua. Io.Mibon. Mecrnas, c.4.

Quo Batnvo [Augone Grotio] alcero ejus terre cum Magno EFafwo lumine nithil inunc undique eruditi us, vel fol videt, vel, folum fultinet. Tojf.de. Hift . Lat. p.713.

Inter primarios habendus eft $H$ ngo Grotivs, quin eximis illis de fure Belli ac Pacus libris ipfarn Ebreorum, quam exhibituri fumus, difciplinam è Talmudicis angit, aliaque ex eorm fcitis ad augendam etiam nomullis C hristianifini rebus lucem prudenter adfert. Fo. Selden.de Jur.Gent.l.I.c.2.

Eò quòd confuetudiue maximi viri Hugonis Grotiinterdum fruar felicirarem meam fatis pradicare non pollum. U. virum admirabilem! Equidem fivi hoc etiam antè fed praftantiam divini illus ingeni nemo fat is capict, nifi qui vultum prefents viderit, \& fernones loquent is andierit. In vultu probibitas habität fermones doctrinx exquifutfimx; \& pietatis fincerifama:funtindices. Neč putes folùme-illius viri admiratione captum elfe:omnes docti \& pii quibus ille innotuit, fmiliter funt affeeti. If.Cafaub. Epilt.738. da Dan. Heinfun.

Nolo nefcias, doctifime Thuane, vidife me hîn Hugonem Grotzism, virtum pro-

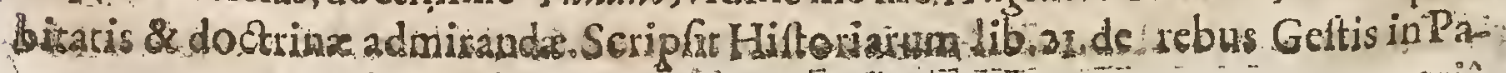




\section{CELEBRIORVM AVTHORVM. 947}

triâ âb annis circiter 5 pauca adhuc legi,fed qux valde mithi funt probata. Sunt alix virrures illius, propter quas pluris etiam illum ficio. Nam do hodicrnis contentionibus in negorio Religionis \& doctè \& piè judicar, \& inveneratione Antiquitatis cum iis fentit, qui optimè fentiunt. Idern Epift.739.

Omnes verò quii de Bello Bèlgicó fcriplerunt, (uperar(meo quidem judicio) Hugo.Grotzres, fi quis velit integritrem judicii $x$ frimare : Hic depolitis omnibus affectibus unicè fectatus eft veritaten, è eloquentiâ \& nervoli brevitate, ut cum Trociso optimè mereatur comparari. Felicifinè imitatus elt Tacitum Grotius. Interim nemo temerè ex Grotio Hiftoriam difcere porerit, qui planè rerum Bclgicarum non haber aliquam notitiam: Obfcurus enim aque eft, ac Tacitus: hinc qui jam pralibấrunt Hiftoriam Belti Belgici, cum yolfunt facilè allequi: Tribus enim verbis interdum totam Hiforiam aliquam habet. Herman. Conrng. de Rep.Batav, foder.

Âd res Hollandicas feorfim nofcendas inter alia multùm conducit liber $H$. Crotii de Anguâ Rep. Elollandic, qui lcetu elt dignus, nifi quidille plulculum nonnihil patcix indulferir, \& de antiquo ejus ttatu q ardam min s vera radiderit, qualifilicet Hollandi non adeò plenèfuerine fub Francis. fed quo delegerint Comites pro Arbitrio \& nominetcnus tantum Francos fint reverici. De catero autcm elt elegans liber fcriptufque a Gratio admodum adolefcente. Cons ring.de Rep. Batav foeder, MSS.

Ap :d Belgas Reformatos feripruset libellus ille perquam egregius de Impèrio furmmarum Poteflatizn cêrca facra ab viro illo tù doctrinâ omnigenâ longè

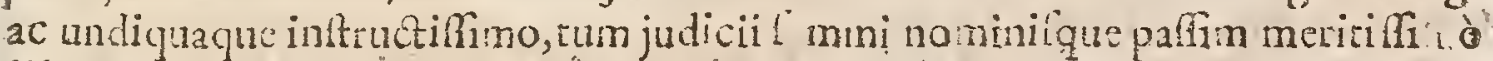

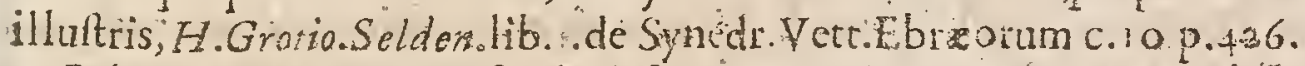

Palmambatenus in difciplinâfuris Naturalis or Geatimm rulile judicatus fụit non preter meritum $H$. Orotzus qui \& primus feculumad ifam diciplinam xltimandam evocâfe videtur, \& ita in eadern efe verhatus, ut circa magnam üprus partem corteris nil nitr Spicilegii laborem reliquerit.Quantumcunque tamen ejus viri famanobis cordi lit, qui \& peculiari noinine ejuldem filis obtticti fum s, fatcindun tamen elt, nón pauca ab jó planè cfé preteita, quxdam levi duptaxar brachio tractata, quædam denique admifta, quæ \& iplumhominen fuille argüerent. Imprimis autem non exiguam nobilitimo operi labem adfpergunt, queis paffin a recepris orthodoxe Ecclefix fententiis diverfus abit. $Q$ quidem magnorum ingeniorum infelicifimus labor mifi femper vilus fuit, circa divina aliquid novare; cùm tanta al larum renm fuperfr copia, in qua alicui innoxiè cornicum oculos configete licear. Etper itthec erian verè ac utiliter di- Etis auctoritas derrahit ir ac plurimorum afperrime cenfure provacant $r$, $q$ if aliàs conrra tales Virọs nẹ hifcere quidem digni erant.Sam. Pufendorf.in Prxfat. lib.de J.N.\& G.

D. I. E. in Grotio hoc taxar, quò adductis aliquot locis, vel ex Poëtâ; vèl ex Hiftorico; ftarim inde univerfale aliquod reate rationis dictarum \& Gentium jus velit extruere ; deinde, q"òd fxpius etiam decipi fe à Jurifconfultris Romanis pallus fit , \& nimis leviter illud juris Naturalis dixerit, qued hi pru caliha$D d d d d$ benth 
Bent. Tobias Magirusin Eponymolog. Critic.

$\checkmark$ ir fine controverfia do diffmus, fed Juris, imprimis J untiniane, alibi paffrm Cenfo: iniquior. Rebban.Præfat.ad Inftit. Locam.

Laudo \&admiror Grotium, led Theologiam ejus deploro, vel cum interpretaaur Scripuras, vel cùn de Interpretibus fententiam dicit. 7o. Boecler.in I'refato Comment ad lib.de J.B.\& P?.

Vir fune controverfiâ maximus, \& de Rep.literaràa inter paucos meritus, fed in

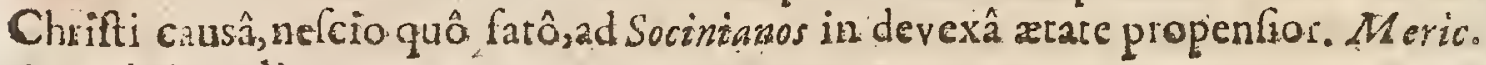
Cafaub de w.lingg.p.10;.

Nobis relatum eft Dominum Grotim Rof okii ex Suedia redeuntem febre continua extinet m el[e. Pcrhibent it non contigilfe abfque fufpicione veneni Lutberanis propinati, ob ea qux in gratiam Pape de Antichrifo ferip ferat; Verum in illis Rcgionibus homines veneno tolli nou arbitror, ut in quibufdam Italix locìs. Ejus religio a 20 . retrò angis perfpicue mota non fuít. In fura cum Domino Rivetzo altercatione Catholicorum Romanorum partibus favere videbatur. Hollandrü erat, \& Arminii Scetator fuerat. Regina Lutheranx Legatus erat. In Lutherana Ciritate inter Lutherani Miniti Brachia diem fupremum obiir, ille, inquam, cui \& Lutherus \& Calvinus adeo invifi erant. Quidam perhibent eum Socinianifno infectum $\approx$ vita migralte, talemque in animo fuilfe, quic quid extrinfecus funularet.Guide Patin. Epilt.7. Parif. fcripta 24 . Octobris 2645 Gall.

De Grotio reckè fentis, neminem finctenus eruditius cuntra Socinum feripfif fe. Martin.Ruar.in Cenr.I.Epift.P:59.

Dominus Btondeltus Trackntu luo de Sibytis de eo fcribit quad Vir pra?antiffmus fuerit, frve refpedu fublimis cjus ingenii, ejufque eruditionis univerfalitatis, quam nemo fat magnifacere porcrat; five refpectu diver fuaris Scriptorum ejus. Gall.

Dominus Balzacius air, prater doctrina fermonis Veneres, befcio: quem obfervar probieats charaterem in prxclar Illius. Viri Serip is omnibus; Id antem de Sealigers \& Salmafal Q preribus nemi-

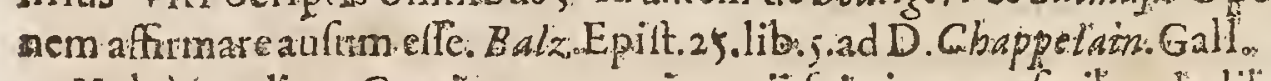

Vulgò crediter Grorium omnes ingenii fui vires conferibendo libro de furea

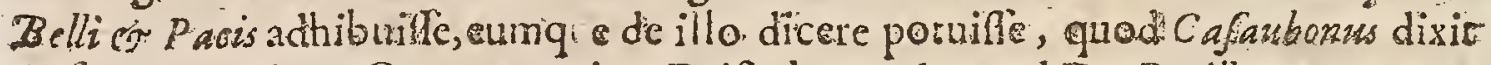
ate fuo in Perficun Commentario: Epiftola quadam ad D. Beraillau cognatum fuum, quax typis mandatg non fuit, In Perfio omom ingenii conatzm effudimus. Grotii Opuspræclarifimum fane Scriptum ef, nec mirati fubit quòd in Germa-

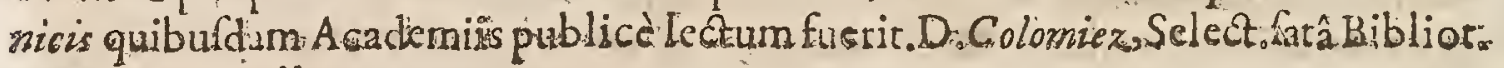
p.1 8.129. Gall.

Inter onnia literatorum Siềera, in Belgio nullum felicius, quấm Grotianum illuxit. Hic ob acumen Magm ingeni i meric eft tanquan Aguila in n bibuss guanvis etiam in multis creutiac Phut.Andx.Oldenburg. in Thelaur.Rewanp. part.3.

In Religione varius erat, \& in quibufdam cuan Pontificiwa in aliis cum Lutheransive 


\section{CELEBRIORUM AUTHORUM.}

ranis, in nonnullis cum Remonfrantibus \& Photinianis faciebat. Hinc vir dubize atque variar: Religionis vocatur. Voètio in Biblioth.ftudiol. Theolog.

Grotii Norx locum etian ibi invenerunt: Cirmque in pretio fins apud omnes, elogio noftro peculiari hon indigent.Hoc tantùm obfervabo, quod fcilicet in Poèrasum citarionibus nimium quandoque diffurus fit, aliortunque innumerorum Authorum profanorum, in quo doctum \& eruditione praftantem virum fe oltentare, potius quans fagacem \& Criticuim, affectalle videttirt. Hunc fi vitaf-

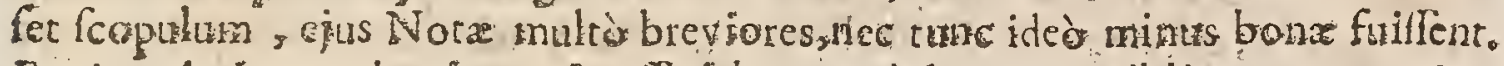
Eo imprimis nomine in pretio che debent, quòd Veteres Bibliorum Gracos Inserpretes cum Hebraico T extu frequenter conferat, wee Malfora nimia exiltimatione imbutus frt. Varias tamen Lectiones abfque necefftate interdum inaltiplio cat; quamy is autem ut plarimum optiman Textus explicationen deligat, advertendum tancin eft, quod presconceptis' A Amínanorum \& Socinianorum opi pinionibus plenus cùn eflet , duabus illis Seetis quandoque fav erit . Carerum quanvis quadam in Grotii Notis carp?erim,in eo prefertim quod profanos anthores crebro nimis citet, plura tamen interdum in eja fnodi citationibus optima occurrunt, quibus plures Scripturarum difficuleares explanari polfint. Hoc tantum optaffem ut feilicet juxta Critices regulas profanorum hortm Authorum teftimonia non atrulefet, prafertim verò Poëtarum, nifi iltis in locis que 7.jufmodi illuftrationibus. indigebant. Nec enim crat necefiarium rexempli gratria, ut ad vocis.Jghna explicationem, Genefews C. r.verf. 1 4. Homeri verfus tuos, Arati pero quirtque adducerct. Nec etiam video necelfe fuille, in fequentem vo cem terspora, dicere quòt Proclus in fua Theologia vocet aft ra Temporis organ

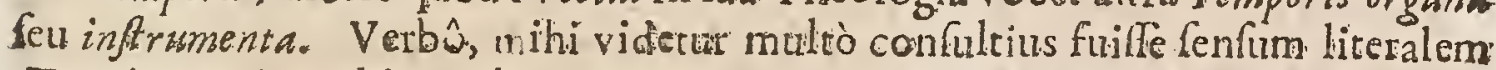
Textûs pancis verbis explicare, nec authoritates ullas citare nifi ad illas diffi-cultates qua huphinodí elucidatione indigebant. Uratorii Presbyter Rich.Simoan Hit.C.iit.V.T.I.3.c.15. Gall.

Hugonis Grotii Epiftolx à vî́r maximo prefecta fummo in pretio effe onniburs debent. Tot ceitè tantaque vir ille feripfit, ut feculi noftri phenix merit dicendus fre. Paucaz ejus Epiftola edize primùn fuerunt, quaruma ipfum tamew

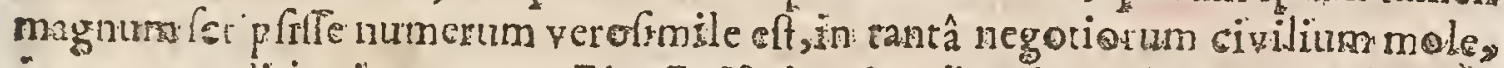

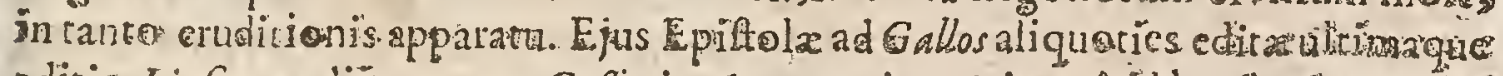

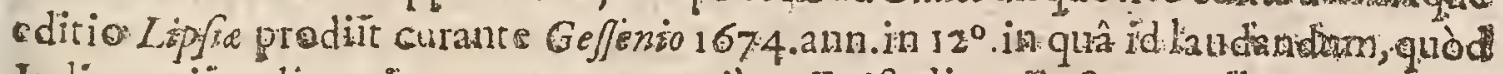
Indicem iis adjeceris, quen ego onmibus Epittolis adjectzm ₹ellam : Nam \& ntilifimns eft, \&z multo labor levat legentes. Nune tädem opus waftum Epiftolarum Grotianarum prodiit, quod hacterns in Bibliothecis. Wiroxum illu-

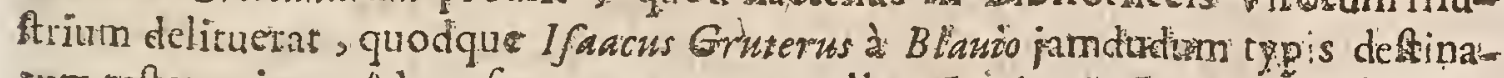

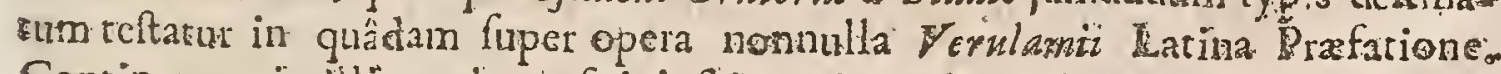
Continentur in illis yaria, ur fuit ipfi ingenium ast omnia narum, Politica, Ecclefraftica, Thcologica, Juridica, Philologica, Judicia de libris. Nec deeftilli Orationis culcus., quanquam ftylus ipfi interdum ex argumento fordes aliquas trahar, \& fe ad hominum, quibus tcribir, indolem componat. Reperiuntur enima

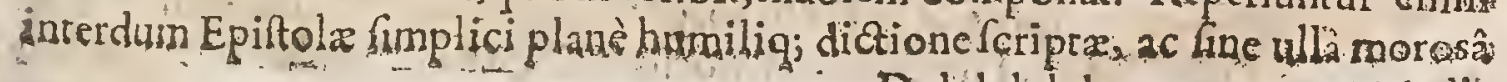
Ddd d d d

Madion 
Meditatione.Sed cum rem aliquam zunicè agit' nemo ipfo vol dulcior eft Poëtas vel elegantior Oratorjaut netvolion Hiftoriographus. Adeo ubig̣ie vir ille domi elt, \& velut in fundo fuo dommatur: Quam in Politicis Epittolis ingenio terum attemperare calamum debeat earum Sctiptor, ille novit, qui in hor negotio verfatur: ubi verborum cura fipertitiola quidem non elt, fed debent illa ad rei expreffionem fingulari rarione effeaciommodata. In his Grotii Epitolis multa funt, quz ftatum Univerfa Europętro ternpore denudant, qux alininde dificulte petuntur. Si ii; quiopus hoc Eputolicum edidenne, Indicem rerum quoque adjecilTent, optime fane de nobis metiti fuillent : Nunc in illo vato opere mula latent, qux non nifr magno labore erui poffint. Sunt tamen \& fecundum temporum leriem Epilola dilpolite quod ad Hi loriam magnoperè conducie Pucaverim ego fanè plures etiamnum incditas elfe vin hijus Epiltolas ac vidi ego non paucas in Bibliothec $G$ udiana quas ego in illo opere extarc non credo. Dan. Seorg. Morhof. in Polyhit.p.294,295.

Poefis una eft Plotellonum qua Grotium ab ingenti primx notx Doctorum numero ditingueie fecerunt, eumque fupra Lipfros, Ca aubonos, Salmafios \& Voflos extulecunt.Bailhet Judiciis Endit. Poet. Parif. 686. Gall.

Hugo Grotivs \& Daniel Heinfus Carmine Latino non ignobiliter feripferunt; nifi quòd ingens illa, qua memo ian onerarting liceratira impediat utrumque ne res modo illo delicato concipiant, in quo tota ver latur clegantia. Renatus Rapinus, Animadv in poeticam, pare 2. feu Animad.pecul.16. Gall.

Quid H.Groio undiquaque dequs, ctiam in his Sacris? Nibil comptius, aut magis mafculum hiftoria fone cpicis ab iplo expreffa; nil caltus eleg s, qubus incufata fe purgat Smana ; nil gravius yeminâ ill Tragoediâfacra, in quarum

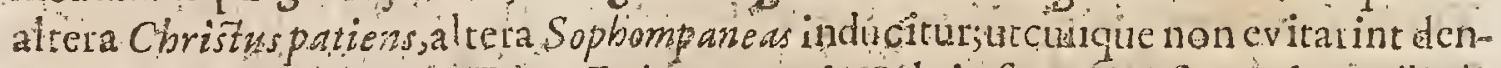
tes Criricoram o mnium, E \& Epigra matis, Sylvis, farragini fum dec s, licet in ompibus nequaquam idem calor. Porrich. de Poët p. I 42 .

Hug.Grotii Opera fequentia incer libros prohibitos numeratur: Apologeticus eorum qui Hallandue Weffrifectuc \& vicinâs quibufan nationibus ex legibus prefueruat ante matationcm, nux evenit anno IGI 8. cun refutatione corum, qua adverfus iplum, arque alios acta, ac judicara lunt, In Decrero 4 . Feb. I6 -7. prohibeturoe tive Belli \& Pacis ibid.:Porma collcta, \& edita a Fratre Guliet. Grotio ibid.: Pe Imperio fummarmm Po eitatum sirca Sacra Comment.Po? humus prohiberur in Decreto $0 . J$ m 68 . Annales \& Hiltorix de rebus Belgicis prohibentur in Decreto 4.Jul 1661 . Difiertatio ejudem Anctoris, \& alioum de

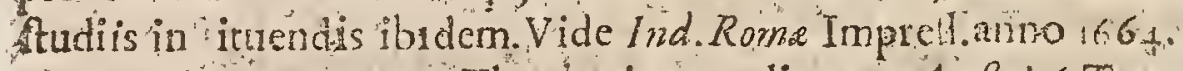

Groti opera ompia Theologica padierunt Ambel. Go Tom fol

\section{CORNELIUS A LA P I DE, Soc.Jel.}

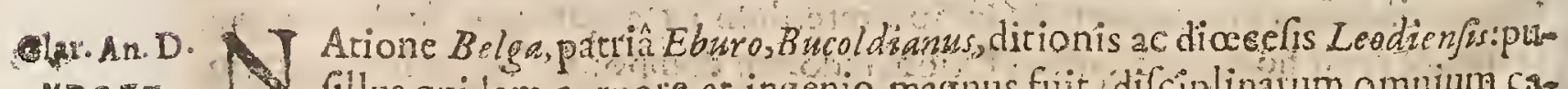
Hog. Gilus quidem curpote, ingenio manus fuit, difciplinarum omnium calo pax, Orator bhilo ophus, Theologus, Hinoricus, linguarum Grece atg; Hebraics 
peritus:cujus In lucubrando, cornmentatido, fcribendo, in legendis evolvendifque SS. Parrum atque Interpiem variorim fcriptis ftudium concinum \& indefeffum meritò ornn busadmitationi elle deber. In Sacris Litcris enat perdius \& pernós, tametfi valctudo plerumque infirma \& dubia, virefque debiles elient : quas in Collegio S.J.cum Lovanien't ( ubi \& linquam Hebraicam unà profitebatur) tum Rorisano, quadraginta, \& co amplitus annos pari celebrikate doctrinæac nominis interpretatus en, icriplicque in plerolque libros lacros Comment.commendara in primis à foliditate, brevitate, clavitate, ac methodo Namq; ei hoc propofitumerat vel maxi è; quemadinodumad Epillolas Panlinas profando ipfe de fe teftatur,ato; id ipfum aliàs non fenel rcpetir \& inculcat, ut fcil. folide brevitcrq; methodicè \& clatè S.Scripturę univerfá(fi ita Dco vifum effet) fenfun traderet, maximè genuinum ac licealcm, fylo ad hoculus didactico \& methódico. Obit Rome an. 1637.12.die Mart.axatis 71.Valer. Andreas in Bibliokt.Belgit.

Nihilllo videri potuir mitius, nihil modeftus, nihil temperantius. Obedientia illi femper, \& veritar amor præ vitâ fuic. Hanc in omni fcriptione primam habuit ; illam verò ductuicem ad proferendas Scriptiones ad publicam lucengquas alio quin fuerar zerro damnaturus filentio: Alegambe.

Enarrationes ejus pias, dodafque in Pentateuchum, in Bropheras Majores, in D.Pantum obviis ulnis Clmiltianus Orbis excepie. In Propheras alios, in Apocalyp frmin. Epifulas Canonicas, al ialque in alios facros libsos brevi vuigandas non minus letè excipiet: And.Vietorell.

In cujus Commentaris, inter multa áte aliena non parca reperi doctrina at que acumine plufquam vulggi confripra. Matth.Pol.Praf. ivol. Synopl. Crit.

Extant ejus Commentario in pentateuchum, Prophetas majores \& minores, Prom terbia. Ecclefiaftén, Cantica, \& A pocryptim Syracidern \& barucbitozum N.Teft. Sed quid in iis defideremus brevirer dicemus. I. Interpretationes Pontificiorum fuorum, \& Patram non femper omnes refert. 2. Noltorum rarò refert, aut non ex profeffo:aut ficubi hoc facrat, tantum occafionem quxrit calumnix. 3 In plurimis locis difficilibus \& illantri as prolixo commentario ilhutrandis, læpe jejunus ent a ir ònurus magis quàmpifcis: 4. In Plilologicis facris holpes eft, \&

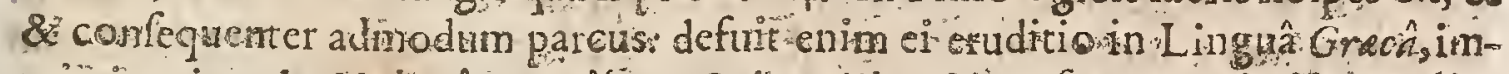
primis etiam in Hebrea, crterilque Orientalibus, \& confequcrter iniftam linguarum idiotifnis, elgantils, antiquitatibus. s. In moralibirs \& praticis, poftillitticas quilquitias, \& carbones pro thefaris, ex Contipraten/3. Difcipulo de zempore, legendis, vitis Patrum \& inilibus fabularum promis condis plerumgue oberudir.Vö̈.Biblioth 1.2.C.4.P.5०4.

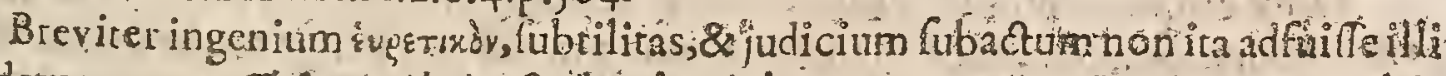

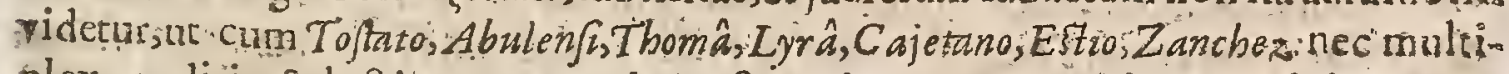

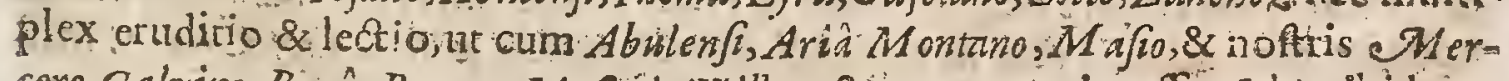
cero, Calvino, Bezâ, Bucero, Mufcülo, Willeto, \&c.compatari poffit. Idem.ibid.

Adinodum folemne et illis qui Cominentarios in Biblia elucubrant, eruditionem \& Qurftiones a fuo Contextu remotas, is admifcere. Hoc etiam vitio laboran Commentaria Cornelij Lapide : Et tamen Authosille in Operis fin 
principio profitetur fe velle brevem effe paucíque verbis complecti , qua diffis: fiori fty lo jam oblervarunt alii. Scio quidem hujufmodi Commentaria, eruditionis plena, hominibus innumeris pralertin yer concionatoribus, arridere, fed fagacium virorum palato fapere ne queunt, quippe qui fing la fcorfim \& fuo loco tractari volunt. Or.Pr.Rich.Simon. Hift.Crir.V.T.I.j.c.ín. Gall.

Cornelius a Lapide integra ferè Biblia 12. Tom.commentatus eft, fed duo primi in Mofis Libros \& in Divi $P$ absli Epiltolas plus eruditionis quam alia decem in fe continent.Gidio Patin. Epint. fel, Ep.17: Gall.

Corderii commentarium in Lucars compilalfe à nonncmine arg itur. Korig.

\section{JOSIAS MERCERUS}

Clas. An. D. MDCXX.

(Allus, Ioarnistilius, obiit circiter annum 1628. Edidit Nonium: Arifanet Iofias Mercerns, Galliarmm lumen, tanto patre dignifimos filins. Montacus. in Antidiat.

Fofas Mercerus vireruditifim:s, ragni illius foannis filius tali parente dignifimus.If.Cafaub. Not.in Spartian.p: 70.

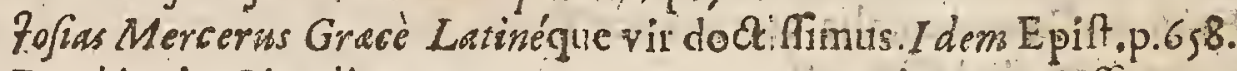
fimum.

Bartbins in Clawdianum pag. 1244 . eum vocat virum acuit fimum \& eriditif-

Iofas Superftes, tanto patre digniflimus filius, qui præter exactam utriufque Lingux peritiam, \& raram purioris Antiquitat is cognitionen acerrimo judicio excelluit.Thuan.ad.ann. 1570 .

Fofas Mercerus praftantifimi ingenii vir,nec doctrinâ tantùm \& eruditione, fed \& Gingulari rerum agendarum Colertiâ clarus.Defider. Herald.in Anixadv.in oblerv. Salmajiz in Fus Attic.\& Roman.l.4.c.1.

Iofam Mercerum jam olim inter infignes Gollia viros habui,\& valdè fe mihi nune probavit, eruditis, \& probi animi judicique,ad Tacitum Notis. Vidi enim. Er quamquam a me interim divertit, laudare \& anare virum debeo:quia \& cum causâ \& cum modo facit. Utinam lic in ltudiis noftris alii ! utinam ne Critice hrec ludus fiat, \& arena, ut fic dicam. beftiariorum! At bona hæc via, conferre fine livore, fine amulatione, in publicum:nec detractum ire ingeniis, ut tuum attollas.Lipf.Epift.Cent.ad German.\& Gal.ep.5 r.ad Bäudium.

Fame aliquis radius te quoque illucet à magno illo Patre; cujus cruditio \& virtus, clara apud omnes. Et tu luccedes, imò pixcedes, fr pergis modò in hoc laudis ftadio, quod currere copilti recto \& felici pede. Nam $\vec{N}$ ore tux ad Cornelinm noftrum quas mittis (verè non blandè dicam) vix tux ærtatis. Lips. Cent. 1. Mifcell.ep. 32 .

Fofam M ercerum, virum ingeniofifimum, \& Gracè ac Latinè doctifimum, pxinê præterieram, quòd ipfitis, modeftiâ credo \& verecundiâ inftinctus, nomen Guis libris prafcribere adhuc noluit. Edidit autem Nonism cun Annorationibus virorum 

virorim doetifinorum, \& nuper Ariflaneti Epiftolas recenfuit, elegantifinè \&e inimitabili fuavitate Latine convert:t, notis quoque perg am eruditis magis itluftravir Gafp.Sciopp.de Art.Crit.p. 8.

Maximus vir fofias CMercerus in edendo Nonio longè polt fe reliquit $H_{a-}$ driani I unit,Dionyfii Gothofredi, aliorumque induftriam. Voffo de Philolog. c.so fect.I3.

Inter omnes novifimorum "horum temporum Criticos D. Colomiezait neaminern fibi notum elfe, cujus tam certa fuerint conjecture quànilla fof foc $M$ Mer cerit, nequitidem D. Salmafio excepto.Precipuus ejus labor cft editio Noni Mar"celli quem: Divinâ folertiâ correxit. Paulus. Colomiez, fuis Mifcellaneis Hiftor.p. $35.36 \cdot$ Gall.

Amo te, Alercere, amabilem multis de caufis, fed imprimis quia $P$ atrem habuilti de linguâ ât cbraicâ optimè meritum, \& quir daternis veftigiis infiftens, dignum te praftas qui ab omnibus ameris. 1o. Druf.in cpitt.p.I4.

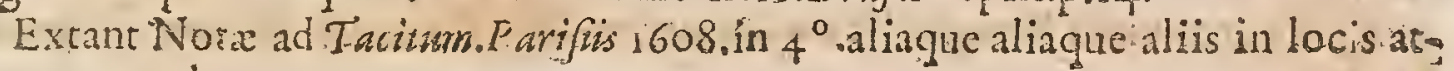
gue tcmponbus.

\section{JOANNES MEURSIUS}

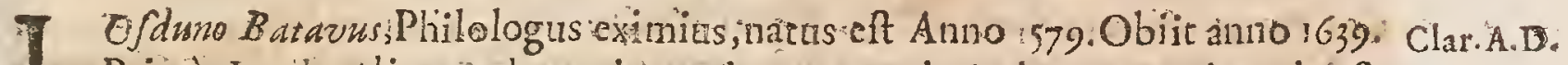

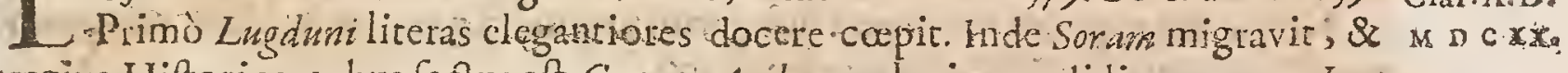
Regius Hiftoriographus factus eft, Grucos' Ańthores plurimos edidit, quos ant La-

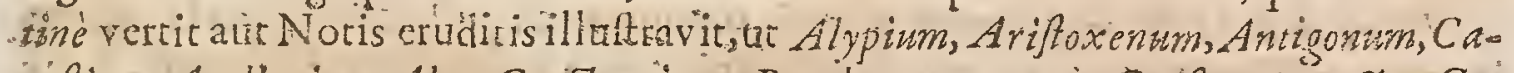

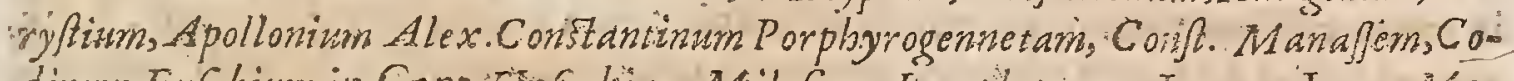

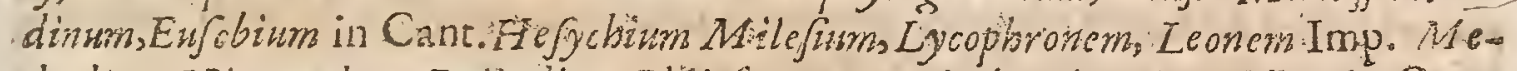

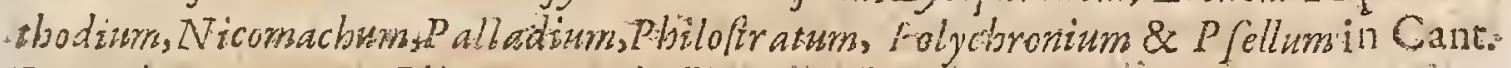
Procopinm, Gazeum, Piblegonters Trallianum, Theodorum Metocbitan, Theophyla87um, Theorritums\&c. De A thenienfum rebus imprimis benè mereri voluit, edendo Regnum Atticum, Archentes Atben. Fertunam Atticam, Cecropiam, streopa:

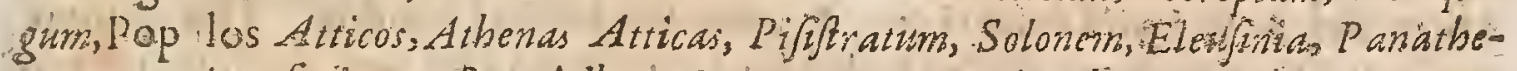
mea, Greciam feriatam, \&c. Adhrec Lat antores, ut Arnobitum, Apuleium, Cato-

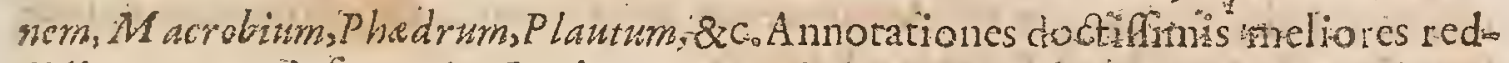
didit. Extant infuper ejus Lexicon Graco-barbarmsorcheftra, Greciatudibun- da, Mifellanea Laconica, librit de puerperio \& funere, tractat. de l'xu Romanorum, Gtilh. A uriacus, Ferdinandus $A$ lbanus, Hiftoria Danied, \&c. Scripta certè dignifhma, ur de novo recudantur'\& in certos tonros diftribuantur. Konig. in Bilstioth.

Unus hic [ 70, Meirfsus] verendus Antiquitatis Arbiter,atque delitefcentium ejus Scriptorum indagator, \& helluo, plura ex Gracis revocavit in lacem Latinaque icddidit, ac Notis auxit, quàn alii centenis tetrò annis praftieiffe dicantur. 7o.Imperial.in Mur.Hift.

Cujus meritis in rem licerariam omnia verba funt inferiora. Eugthat. Svivartl. 3.Analeet.c.2. 
Toannes Marrfins vir multis nominibus praclarè meritus de Literis Grecis. Fofj.de Scient, Mathemat, c,22. Sect.4.

Ioannes Mi eur/âns vir, prę cateris de Gracâ Antiquitate benè meritus. Ióars. Ionf.l.z. de Script.Hilt.Philo\{oph.c.'9.

Ioannes $\mathcal{M}$ errirus Antiquitatis Grace, Attice tamen imprimis, peritilimus fuit, cui \& ipfe Albene, \& Aticarum Antiquitatum ftudiofi plurimum debent. Idem ibid. c. 20.

De Gracormm Feftis feripfr libros fex maximo cum licerarum emolumento, \& literatorum plaufí Ioannes MHeurfins, Hiftorię Grxeç apud Batazos Profellor fideliffimus ac diligentillumus. Nic.Pinell. in additament.ad Onuph. Panvin.de lud.Circenf.l.2.c.!:

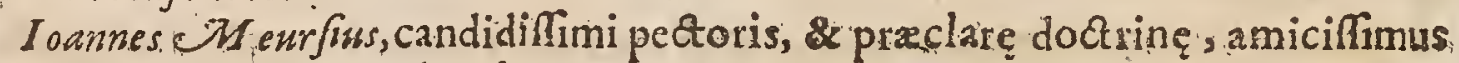
Collega meus, quô yix alius literas ininori tractabat ambitione. Voff.de Vit.Serm. 1.2.c.2.

Virmeritorum ia Rempublicam literariam clariflimoram Dilber. Difputat. Academ.

Vir fuit inexhauta lectionis; \& laboris conftantis. Waler. Andreas in Bibliot: Beglgici

Io. Mexrfrus, döaifimus adolefcèns, quem fxpe miror: \& certè fupra fuos ans nos, literarum dote ditefeit: Nic. Rigalt. Not din Lib. r. Pbadri, Eab.4.

Neque enim poreft me fugere quicquam tuorum, à quarum lectione nun quam recell nifi doctior. If. Cafaub in Epift.390.

Vidco te in Hiftoria, \& omnis generis monumentis poterioris Gracia mirum in modum elfe verfatum, quę pars eruditionis cum à paucis adhuc fit culta, bene proculdubio de lireris mereris, quando ea profers in lucem, que etiam doctifimi viri prius ignorabant. Idem in Epilt 748

Tot jam fcriptis illuftratti literanum tenebras, tor jam monumentis a e Eternitatem y ocalti genus humanum, ut non viviere eum dicam, qui indoctus ef ; non fapere, gui feliciffmam ingeriił; rudicionifque tuę induttriam non intelligito Mitto Belgas, in lialiâ celebris ies, \& inter lumina avi haberis: Jam quoque crefcunt iti radil; \& vel ab Orcbefrêtua, ad me milsâ,emicant. Sed fi fic pergis nox in omni Antiquitate effe definetsteque folem fum faculi confenfus appelläbit:Eryc.Putean. Epift.Centur. Epilt.83.

Mewrfus in Groeis: Linguę \& Antiquitatum notitia prefertin excellebat, nee ullus unguam tam infigne beneficium, hoc quidem capite, Literis praftitit, quippe qui indefelfo labore ac infolita prorfus diligentia ad varia $x$ eterum Opafcus Ja è tenebris eruenda, emendanda Notis elucidanda, vertenda \& erulgauda, animum appuleric Baillez. Indiciis Eruditorum, PParifis 1685. Gall.

Qua contigerunt in Belgio, Ferdinando Albuno imperante, fingulatim perle: cutus eft, ( I0: Menrfus) peregregiè;item que gefta func Wilhelmo Auriaco vivo infigni Commentario lliufravis, nif quod in nonnullis credacur iniguior for-

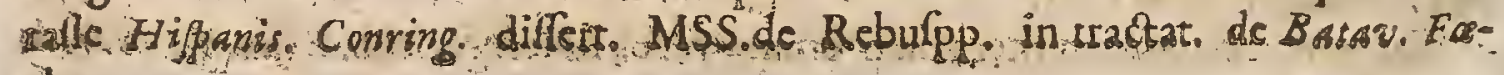
der 
Vir de Atticis rebus omnium optimè meritus.I dem de antiquitat. Acad.Sup. plem.7.

Polt Ubbonem Emmium multùm adeò laboravit in Atticis I oannes $M$ e:brfü: ut omnium diligentiam longo intervallo Cuperaverit ; in Grammaricum tamen -ufum potius, quam politicum, cui folo fuo Areopagitico \& Solone commodum te pratitit.I dern ac Civ.prud.c.I4p.309. feq.

Dania Fatavis duobus deber fapientem fuarum retum hiltoriam, Teanti Meurfo \& Iobanni IJascro Pontaro I dem ibid.p.i34.

De Antiquitatibus Grevapalum jampridem in erciditorum manibus, indu-

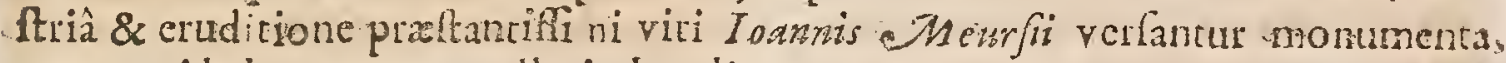
quę tanti habentur, ut nulla in hoc literatum genere is anteponancux, pauca

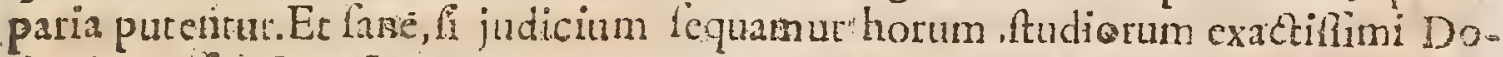

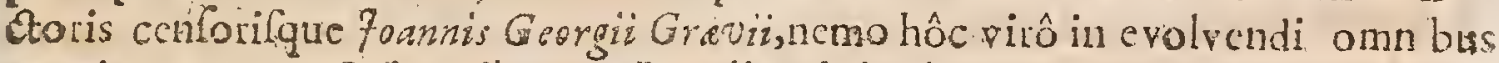
omnium etatum fcriptoribus', qui ex illxtabili illâ barbariei nocte halvi in lim cem horum temporum emerferunt, fuit diligentior, \& in obfervando \& conyulirendo, quicquid ad veterem Græciam illuftrabdampertinet, ftudiofor. Alta Erss4.An.1684, P.55I,553.

\section{Hoc Symbolum ejus, \\ ESTERNITATEN COGITH.}

* Athese Barava, five de Urbe Leidenfi, \& Academiă, viríque claris, \&e. Ito. Teurfir. libri duo, prohibentur in Indice Rorna ImprelT.1681.

Varia ejus Opera variis in locis atque remporibus impteffa fune.

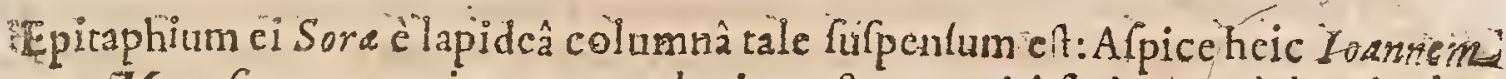
Wh eurfun, nec majora quarc elogia, teltantur viri fcripta, quod majus thec nomine-nihil habuit Sora.

\section{JOANNES BAPTISTA Van HELMONT.}

7 Arus ef Brusellis, Anno Chr. 1577. Anno atatis fue 17.totum Philofophie Clas. An. Di I curfum abfolvit.Ipfe fe vocare folitus eft Philofophum per.lgnem.Obiit. AH. M Chr.I644.etatis Lue 67. Onmia ejus Opera prodiêre I667. fol.

\&ohannes Caramuel Lobkovvizita de eo Cribit: Helmontiss(novithominem) fiir pius, do ctus ae celeber:Galeni \& Arifotelis yratus hoftis : Sub quo $x g$ non labordbant diù.Nam.2.aut 3. ad fummum die carcbant vitî́ ant morbo. Vocabatur pracipuè adillos, qui ab aliis Medicis deferebantur, è quibus non paucos refti tuit, vel frendentibus illis, à quibus fuerant condemnati. Prodicrunt jam-randen ejus Opera, \&in iplis continuscontra $P$ erepatericos \& Galenifas Latyra, mule 


\section{6.}

\section{ENS U R A}

tis onufta foliis, fructu tenui, \&c. Hxc ille. Vide Konig.

Sed \& alii novas Sectas inftituere coperune. Qualis cumprimis eft foanne. Baptifta Helmontius, ille quifefe per Ignem Philofophum nuncupare infolenti ti. tulo vo'uit, ac fi hujus benefic o P bilofophus evafiffet. Ex parte autem hic $F$ os racelf wm fectatur, ex parte veì̀ nova multa \& hactenus nunquam audita commentas eft. Idcoque in univerfum omnibus, quotquot hacenus vixerunt, $\mathscr{M}$ - dicis convicium dicere, fe verò unicum verum CMedicum à Deo iplo conditum, atque adeo illum quem Siracides honerandum dixir, pronunciare, rid culè \& ineptè, non dubiravit. Luamvis verò nonnulla habear haud contemnenda, pleraque tamen Non fani efje bominis non fanus juret Orestes. Multùn certè fallirur qui ejus credit jactabundis vocibus. Ufu tamen Chemicorum operum fic faris videtur valuilfe: at ille neminem verè Medicum facit, prout notum elt. Sebafto Scheff.in Introduct.ad Medic. p.43.

Inter quos doatifimus \& celeberrimus re \& famâ Medicus \& Philolophus. Helmontiws cenfendus $\in \mathbb{R}$, vir acris ingenii", \& prxcellentis literatura. Sed fua nihilominus deliquiá \& Eclipfes. fultinuit hoc fidus, quod fuper Candelabrum guidem confliturum, ut arderer \& luceret; fcientix tamen radios pofteritati fub Itraxit, \& prapofterà charitate fub modio occultavir. Ui proinde merico Pofbus ma ejus Scripta, ad qux, veluti folicifmi ominis Cynofuram, literatorum animi confugere debebant, tanguam funefti ominis fidus, crinitum ac portentolum Cometam effugiant, qui inter umbras \& tenebras triftilumine emicat. Quàm enim hic bon memorix -vir multa \& preclata de Sale volatili ipfus Tartari, adducit! ejus tamen modum \& parandi dexte itatem occultavit, duro ac novercali in polteritatem animo, quam velut Orphanos inter fufpiria \& lach ymas defolatam defolfo in terram talento virtâ excedens dereliquit. To.Zvoelfer. Pharmacopo. Reg. Edir.Dordrelti 1672 in $4^{\circ} \cdot p \cdot 720$.

Nè quis puter me hîc venari occafionem clainfrimun Helmontium fuggillandi, dicam me neque hîc, neque alibi (nullitis licèt in verba jurarum) ejus judiciumparvi facere. Eum lubenter lego, \& ex ejus Lectione me profec lfe fateor. Quin \& agnofcu eum frille virum magnum, magnx indutisę, accerrio mi ingenii, fedulum veritatis Indagatorem. Utinam verò ab coindecoro, in omnes propè alios ante fe, pruritu invehendi abltinuiffet : Profectò, meo juo dicio, fibifamrque fux melius confulueraco Non quòd cuivis fas non fit errores, five aliorum, five fuos, corrigere: fed quorfum attinet in alios fuo xvo celebres jamdiu defunctos involâle ? Efto, cos in plurimis lapfos elfe: faris fit coldem fuife eatenus infelices. Tu felicior es, fruere forte tuâ Veritas in multis temporis filia eft. Nam quid irideamus Féteres quòd nefciverint Circuitum Sanguinis, Fenas Lacleas, Tasa Lymphatica, aut ca qua ad hre nccelario confequuntur? Multa hoc feculum accurato Natura ferutinio deditum, hujumodi, tum Feteribus, tum ipti Helrbontio :gnota, adinvenit. An proprerea virum alioqui folertem defpicatui habeam ? Apage. In aliquibus forlitan erravinus omnes. Gaveamus igitur, nè duriore cenfurâ alios per-

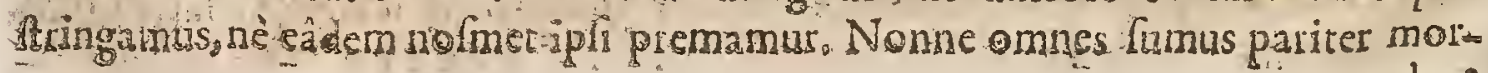
tales?: 


\section{CELEBRIORVM AVTHORVM.}

tales? Eequis Dhilofophorum è tripode diatat, aut fpiritu infallibilitatis in rebus naturalibus aftlatur: Satis fcio de mciplo, me facilli mè crrare polfe. In arduis $N a-$ tura, cogitationes primx ferè lecundis, factà pleniore inductione, cedere cogmntur. Cauto opus eft, nè præpropere defnias, aut de alis judices. Nonhac nune dico, quòd difplicat Helmoniti Latex, quin potiùs quòd in multis approbem: Ita tamen ut Scholis quod fuum eft, \& Flelmontio quod fuum eft, refervetur. Dedit faltem nomen priore commodius, nec non alia multa de:eudem fcitu digna. Eranc.Gliffon. Trąatr.de Ventric. \& Inteftin. Edit. Lond. I677.in $4^{\circ} \cdot \mathrm{p} .236$.

Profectò, ut mihi videcur hic Author [Helmontius fcil.] Gutcunque acerrimi ingenii, in co fuit minùs felix, quòd Teterum placit is rariffine èffentitur, \&e vix, nifa in is rebus in quibus illi, ex certifimis \& demontratis $N$ cotericorum oblerva. tionibus, manifretè coarguuntur. Negat cnim Circuitum Sanguinis, Sangrification nem Hepatis afferit, Lateas non agnofit, Lymphe dudtus ignorat, Lienis humo. rem acidum in Fentruculum effundit. Franc.Giufton.ibidip. $280,28 \%$

Pollcm tibi dicere quàm acerbè exceptus etiam fuerit Helmontius cùm primùm in lucem prodiit, cum ut Enthufraftes \& Eymphatus fuerit tradiutus; quamvis apud te profiteri tenear, Hypothefes ab iplo traditas, ad morborum cfientias detegendas, mediaque ad corum curationem idonea invenienda, oftendere eum folida ratione $\&$ infigni perfpicacitate terum Naturalium adyta pen etrare : Imò ego, qui annifus fun, ut annitendum cfle fateor, ejus intelligentiamalkeguí, quamvis ejus Medicamenta intelligi nequeant, expertus dicere polfum ejus Do. drinam talem elfe, ut fi frequenter confulatur, Medico peritiam acquifitura lis Moborum curacionem riteinftituendi, plus quam quacun fuein hanc:rem hactenus dicta fuere. M. NeedhamiMedela Medicine. p.15. Angt.

Multum jam laboravit acutus \& perfpicax. Helmontius, cujus lectionem $\mathrm{Pa}$ pularibus noftris fatis commendare non pollum, nunc ex quo Anglica civitate donatus eft. Sed fcito perfunctoriam ejus lectionem nihil profuturam: Decies repetita non fufficit, quamvis preceptorem à quo dirigatur quis habuerit. Si ad hut jufmodi molimen aptus efficm nullum unquam Orbi praclarius oficium preAare valcrem quàm fr accurata metiodo diverfas $S c_{1}$ iptorum illius partes in meliorem quendam ordinem redigercm, quo fubtilifini ejus Cenceptus-familiariotes, \& faciliores evaderent. Et fanè eo attétius penficulanda funt ea quię fcribit, quod ficut nobilis Igniarius Philofophus fuit, fic anteguam novtim intud Studii ftadium decurreret, indefeffus veterum fudiofus fuerat, quippe qui bis perlegillet Galcni Opera tædiofa, femel veró Hippocrätem [ ejus Apborifnos memoriter addifcens] \& totum Avicennam, omnefque cùm Griccos, tum Arabas \& complures neotericos Authorcs, non pauciores fexcentis, Notafque ex is omnibus collegilfet. Sed tandem profitetur, dum quid in eo profeciffet fecum reputat, fe deprehendere, quòd nihil prater labolum ponitudinem adeptus effet, paxumque utiliter tot annos impendiffet... Totam in Galemm cnlpan: conjicit Corruptorem infignem omnium qux apud Hippocratem \& in Scholis toleabilia erant. Galenus ifte glorinm illorum qui fe antecellerant fibiarrogans, Me dicinz Artem, paucis Rigulis priùs comprehentam, in vafta volumina amplia.

$$
\text { Ecece } 3 \text { vit. }
$$




\section{8}

vit. Idemiliadem pag. 239.240. Angl.

Helmont pater tant fiebar Bruxellis, ut non nifi defperati ad illum cuafial Sacram Linchoram confugetent, quorum non exiguum ab Orci faucibus cripiebat mumerum. At Zoili cornm nonullos quoque fato cedere objiciebants id guod prudenti nulli mirum obtinget, frquiden

\section{Non eft Medico Semperrelevetur at ager:}

Interdum docta plus walet arte mailum.

- fuerit Haimont fatis, plurimos a Zoitis morti adjudicatos, vivos repetiilfe Lares, Theocica qua bobet alca funt, eruta è Nature Principiis, ingenii dotc, ipsà Nats-

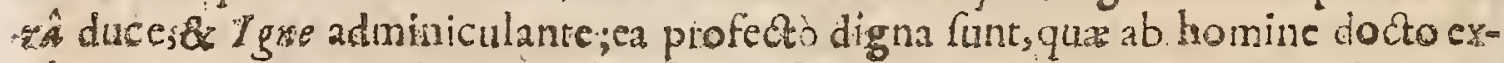
planentur. Nic. Eranchintront in Epidt. prafix. Franc Ofveld Grembs Arbori. In regre \& Ruinolre Hominis.

\section{In J.B. Helmontio Opera contra Calenstatio}

Clawide Scholas, Galche, thas: Satis occiformm eft.

Oke jam Satis cfi: plena Sepulchra fonant:!

Namgre arwor clystergue tibifunt pharmaca: fepe

Das wilals in Critico fostibifola die.

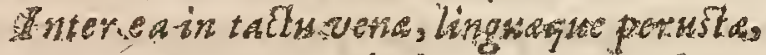

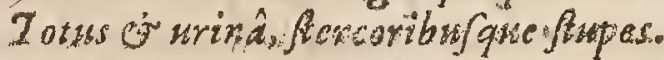

Non egrum juv.zt boe:illi Medicina paranda

Nil opus eft rostbi teltibus: at Medico.

Attamen exppeclas pretism poft funera rnagnum:

Sic eanis agrotum.jpectat, arnatgue pecus.

(3)us Apolineâ potis eft Helmontus arte.

Quos alter morti liquerat, eriperé?

Tdn. Walhornius D.Majelt.fize Confliarios.

\section{DIRUS MOLINAUS}

Clax.An. D. Allusnarus eft anno 1568. Oatob.18.in agro Pexinati. Paftor primố Eccle-

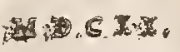
candem tranllaius elt, obiit Sedani 16,8 . xtatis 90.

Scripta cjus funt Elementa Logica-Meditationes in Pfal.12:- - Novitas Pa-

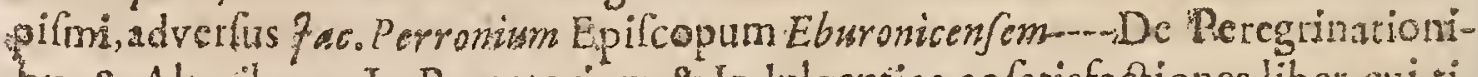
bus \& Altaribus--In Purgatorium, \& Indulgentias,ac fatisfactiones liber,cui ti

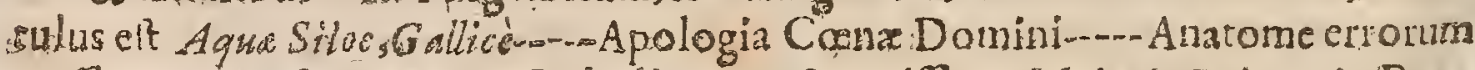
Cuffetelli--Defenfo Fidei Cacholica pro Serenifimo Majoris Britannie Rege 7o $6060=-$ Medirationes de Vanitate \& de Amore Dei-a-Refponfio ad 32. Quafita 
Peitri Cottoni, unà cum 64. Quxaftionibus Cottono.regeftis-n-Acta Difputationis cum Petro Cayerio, excepta ab. Amannenfibus ex ore Difputantium. Er quaedam alia minutula.

Molineus quidem multis artibus pollebat; (ed omnium eminentilima fuit difputandiperitia, inul to ufu confirmata, mirum ingeniiiacamen, ferenu in judicium non unquam irâ aut impatientiầ obturbatum, qux difputationes garavifimè in Aticutas folent abrumpere. Dr.Gul.Bates in Vit.Petr.Mislin.

Magnus: 9ofephus Scaliger Molinanm fecit maximi. Quando Molineus Logio cam fuam Leyda. edidit anno 1596. Scaliger, perlectâ. ejus Prafatione ad Juventutem Itudiofam, de eâ pronnnciävis, Hiao Epistola non ef bujus avi. Fuit Logich. ilta tredecies intra pancos annos praló commifla \& in pluximis Academis pus blicè pralectajutpote intimam (inquit Bates) rationalis Philofophiz Medule lam, in Topicis prafertim, aperiens.

Semel cum Penronitus in pradio fuo Nobiles vicinos in̈yitâffety rum Römane: tum Reformate. Confeflionis, \& fermo de Molineo incidilfet; quidam Prafídens Chevelier dixit eum elfe Afonwm. Commotus Perronitus, Minime (inquit) cenfendus eft inter Afonos Molineus;nullus:fefe illiafino affricuit, qui non ab eo calce perculfus abievit:

Cim viringenio \& eloquentiâ infignis Cuffetellis tibrum edidiffer contra Serenifimi Regisiacobifidei confeffronem, Molinaus Regia Confeffionis Defenfio. nem libro fingulari frrfcepit. Liber Regi \& Clëro Anglitano fuir acceptifimis? Rexque fuper hä ofcafione copit ad Molinasm fcribere, \& eum poftea literis fuis fapiùs dignatus elt; mutuas ab co líteras po?tulans. Affervatur in Regis Scríniis, quem ego me vidiffe memini, MT alinai ad Regem. Epith olarum Codex. Gub Bates in Viro ejuso...

In libra cui titulus eft Novitas Papifmi, Cuam in Grecis literis peritiam da mul \& Perronii ignorantiam fatis oftendit. Idem ibid.

Noltrâ ærate \&eftyli perficuitas, \& rẹtum varičtas maximè commendàvit Wrölinean,communem Gallix preceptorem. Hottinger.Bibliothec Quadripart. pag. 197 .

Acutiffimum \& extitiffinum. Theologum. Petrum Molinatw rocat Eriderizsus Spashernius parte primà Dub. Evangel.p.280.

Miferas mihimureolum Vatem Vereris in Philofophia..Doctoris mei", nune etiam in Canonicosum Cantuarienfium Collegio, College honoratiffmi.' Mae gni Triolituei nomen adderem, hocinter nos effer opus, qui taciti etiam vene. ramur nomen, quod:orbis pradicat univerfus:Ger. Fo.Vojfon Epilt.ad Andr. Rivet. pag. 75 :

Iptum miror de Eucháritfia \& de Purgatorio: Cor meum poffidet dum lego eju's Cónfolationes adFratres fios. Ecclefix Galliqanz; ut \& Tractatum ejus de Amo. re erga Derm. Enixè optarem Gallicam ling uam addifcere ad hec unum ut ifLum intelligerem; Er jam pridem in voris habui ac etiamoum habeo ut inih - comparem aliquid eorum qua fcripfit.Dost. Tuviffe. Angl.

* Hic Autior inter Horeticos Primz Clatis rejicitur in I nd. Tridentino. 
Varia ejus Opera varis in locis atque temporibus funt imprefle.

\section{NIC, CLAUD. FABRIC. PEIRESCIUS}

CIst. An: D.

Allus, Natus aft in Belgenferizcaltro prope Totonem, rimo die Decertb. I58a. Senator Parlamenti Provincia, ingenio inter pring fui Seculi: PhiIn Academià Romanâ funebri Oratione, aliquor Cardinalibus prefentibus, in literatorum pancgyrijonoracus. Elogia ejus, linguis quadraginta expreffa, in uno volumine baburur, cuiticulus Renglo flo. Hofrian.

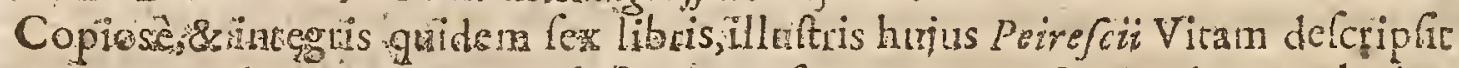

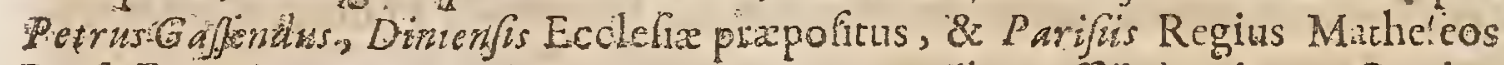
Profelfor, cujus jan tertia Edirio eruditorum manibus affiduè teritur. Catalo: nectit, quò nos lecturem remitrimus.

Nunguan fatis laudandus vis Nicolaus Peirefcius. Salmaf. de Primat. pag.104.

Nucolaus Fabritius Peireskizus vir aternâ famâ dignilfumus.Sarrav.in Epift. a 7acoburis Palmarturn, Rothorrag. Non. Ang. 1640.

Vir \& eruditione \& genere nobilifimus, nec fune honoris prafatione nomi-

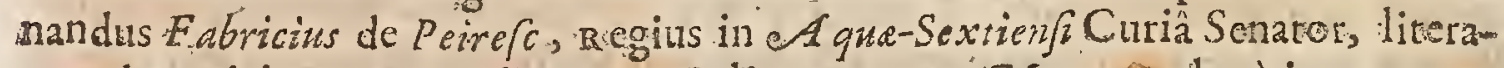
rum, dum vixit, magnus infaurator, \& literatorum ex ecunas lanè incompara bilis. Ant.Clement.in Vir. Salmafir.

Amplifimus Vir \& Anciguiraris Profana \& Ecckefnatica ftudiofifrme PeiRefcius.Io.cex orin. in Opuĺc. Hebrao-Samarit.p. 95 .

Vir amplirimus Nicolaus P.eirefcius, in cujus morte \& literx \& literati omnes dammm incredibile fecerunt. Grot. in Annotat. ad lib.de Veritat. R. C. cap.r. fсc. I6.

Porrò in hoftimentum Camalerus Peireskinobfervavit, maximi fecit, eumq; Notis ad Britannorum Numifmata, yocat Iuvenem nabiliffrnum, \& in re nummo-

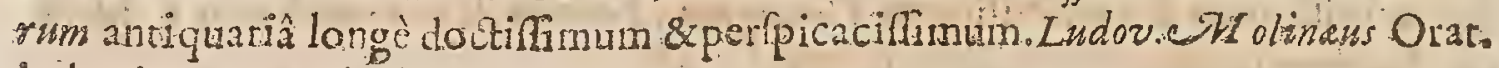
in Jaud.Gul.Canderi.

Vir dignitate, entitione \& virtureillufts. Conring.in cenfur. d:plom Lindiv. Luriov. . .5.

Nobilis Gallus, vir immortalium meritorum. Rupert. ad lib.2.H.de O.J. pag.j7.

Vit ad ornandas $8 x$ adjutwandas literas omnis gencrịs factus à naturâ, à doctrinâ eruditus, à forrinâ inftuctus. fo. soëcler.in Prafar. Comment.ad Grot. de J. B. ap.s.

Heu renm vices! hen fata infand heu mors acerba \& infenfa bonis omnibus, qua geftienti latitize interceflit, Viro illo incomparabili, $P$ eirefcro,tunc,cum nibil minus quam de cjus occafu timebatur, èvivis fublato: ubi cnim crinitum

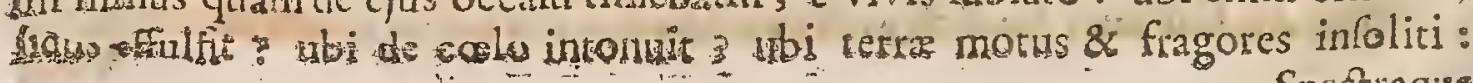




\section{CELEBRIORUM AUTHORUM.}

Spectraq; \& portenta apparuerunt in ejus viri omnium maximi, omnium optimi fapientifnmique interitu ? Vide Naud. Epift. 56.ad Pct. Gaifend.

Ego vesò clarifimum P'erreskium ejus loco lemper habui, in quo vires fuas Natura potiffinum experta eft, ut hominem produceret, cui nihil decffet, quod eximium, honckumque Mortalibu concedi in hâc vitâ poffit : illumque pro co, ac dcbeo, verbis ornare non poffim, quorum me pauperen reddit copia me-

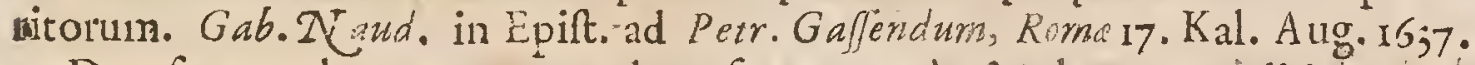

Duo funt, ob qux commendatus fummoperè cet, 'alterum exuditio magna, ac omnigena, cum ardore fciendi inexplcbili : altcrum cura indefeffa promovendi arteis ingenuas, cum regiâ planè erga umneis litetatos munificentiâ. Gafiend. Epilt. Dedicat. ad Vit. ejus.

Omitto alia, quả in reliquâ literaturâ fecit Opera. Ejustantùm Epirtolas, in adıirationis cumulum addam, que quidem funt ita multx, atqục eruditix, ut ff nullum aliud feriptionis genus unquam attigiffet, univerfum tamen omnium doctrinarum, \& liberalium difciplinarum orbem impleviffe, dici poruerit. Nullum enim adeo præclarum, vel rarum, in bonis artibus nafi porct argumentum, de quo "'eirefciu confultus, ad eruditifimum quemque non fcripferit; doctè, fiequenter, \& copiosè admodum, ut omneis omnium provinciarum urbeis, fuis, non dicam Epiltolis, [cd voluminibus oppleviffe videatur. Buccord. in laudat. Peireskii, p. $27 \mathrm{I}$.

Si quis eft pro quo liceat inverecundum effe petitorem, is fuit Peirefcitu, folitus benefacere \& ignotis \& non petentibus. Celcbratus in Itaitî eft Orationibus. Nunc etiam Carmina ex toto Orbe ad ornandam ejus memoriain colliguntur, quadraginta, quod nunquam factum eft, linguis. Ego, majoribus operum impai, Epigrammate Latizo profecutus fum viri, de publico, ac de me quoque optime eneriti, nomen. Hugo Grot. in Epift. MS. ad Cajp. Barlaums Lut. I6 April.rizg.

De Antonianâ Columnâa, fcriptum nuper mihi eft à Senatore Aquenfitalium curiofiffino, qui multa ad inftitutum pertinentia fubmifit ex ditifimâ fuâ antiquariâ fupellectile, extare ejus in his locis pleraque exemplaria manu expreffa \& tranfcripta. Salmaf. in Epift ad Voff. L. yd. i 4 . Kal. Jan. I634.

Quemadmodum nemo unquam tam dilectus fuit quam ipfe, fic etiam neministantum poft mortem univerforum fuit defiderium. E us obitum doluit taRome Academia, funcbi Oratione audita, quam in infignis illius Geniigloriam, coramillo celebri confeffu pronunciavit iacabus Bourburd cruditus $\mathrm{Pa}$ rifienfis. Docti omnes mortem illius deplorarunt ut liberi mortem patris deplorant; feque orphanos poit Mecanatis fui jacturam reputantes, in calamitate illa exclamaverunt, Orcidit igitur pes noftra? Occidit Sol nofter ? Occidêre generis humani delicix ? Occidit ille, folus, qui triftes hàc tempettate $\mathrm{C}_{a}$ menas refpexit? Gabri:l Nandaus Româ fcribens ad "etrum Gafèn ì circaillam moitem dolorem fuum fic exprimit. Heurerum vices! heil fata infanda! heu mors acerba, \& infenfa bonis omnibus qux g ftienti læritix int $\approx$ reffit, viro illo incomparabili, tunc cùm nihil minus, quàm de ejus obitu timebatur; è vivis Ffffe Cublato! 
fub'ato ! Ubi enin crinitum fids cffulft ? Ubi de crelointonuit? UoiTera motus ac flagores infolici , Cpeetraque \& portenta apparuerunt in ejus Viriomnium maximi, onnium optimi , fapientiflumique interitu? If. Bullârt. Acad. Scientiar. Lat. \& Gall.

\section{Hoc cjus Epitaphium à Nicolao Rigaltio fcriptum :}

Hic fitus Nicolaus Fabui Peirefcius, Ampliffimi Ordinis in A quar. Sext. CH: rî̉ Senator Chriftianam Refurrectionem expectat: Reconditiffrros Antiquaris Supelletilis thefauros faga itate, conflitio, liberalitate, cunctis orbe toto difiplinarum fitudiofis, aperuit, doctiffrmis unde proficerent fapè monfravit, wirâ beaitiate felix, feculo fatis rixofo notiffimus fine querelầ vixit. 8. Kal. Iul. Cbr. 1637 . etaits jua 57. Optirno viro, Bonos omnes benè apprecare decet.

\section{LAURENTIUS PIGNORIUS.}

Clar.An. D. D Atavit natts eft Anno Dom. I571. die 12. Octobris. Obiir Anno I631. die MLCXX. Is. Tulii.

Opera ejus Latina funt: Menfa I fara, quâ facrorum apud Egyptios natio \& fimulacra lubjectis tabulis xn is fimul exhibentur \& cxplicantur - De fervis, \& corum apud Veteres Minifteriis - Notulx extemporarix in Emblemata Andrax Alcisti - Profopopoin Aldine Catelle - Magnx Desm Matris Idaee \& A tidis Inicia -. Carmen ad Urbanurris vir. P. M. - Mifcclla Elogiorum, Adclamationum, Adlocutionum, Conclamationum, Epitaphioum - Symbo. larum Epiftolicarum liber. Italic varia fcripht.

Totius Antiquitatis ind.gator acerimus, $\&$ in Veterum Numímatibus in rerpretandis oculatifunus in heroico carminevera hu farurb \& Apolinis proles alidir. Elogiographus egregius paffim ab omnibus falutatur. Iac. Phil.Tcu. majar. in Vit. Lignor.

Laurentius igurans vir verè eximius \& qui prifcam illam, propriamque Italorum laudem, five prosâ five verfu fcribit, fortitcr it teftitutum.Dar. Hcinf.

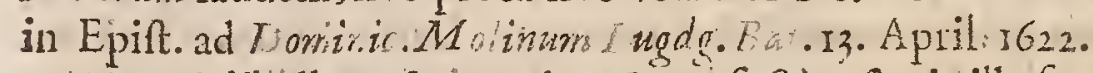

- Pigrorir libellus eft egregius, \& profectò eft vir ille fummum omninò Italia

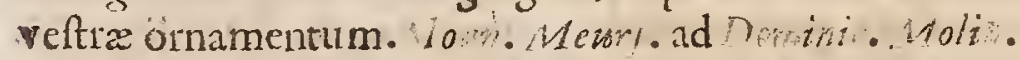

Cujus ego [ ignorii ] omnia \&avidè lego, \& maximi facio, uti rara ejus eruditio meretur. Voft ad Dorsini . $N_{1}$ ols . LuE . B i. prid. Id. Sept.1625.

Ob eximian eruditione $n$, atque humanitatem mihi charifimus vir, Laurentius Pignorius. Laeri de Hift. Lat. 1. :.p.550

Hac omnia $M$ anufript. fuperfunt satavi, apud clarifnum, \& diffufe rem conditayue eruditionis virum Laurentium "gurn. larn ibid.

ileant marmora, taceant xra, obmutefcant picta, fculpta, crelata monumenta: omia ære ac marmore finnius, \& perennits , lignuri doctifine tropham istid 
întud erit, abs te fapientiffimo, prudentiffimo, fcliciflimo Antonio Priolo Principi erectum -...- Salve interim, Piguor, , pignore quolibetcarior, ac pretiofior, qui dum aliis immortalitatis fpecimen impertis, tui memoriam in omnem po-

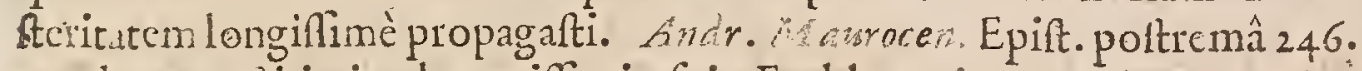

idem prattitit in elegantifimis fuis Emblematis H-adrianus lanius, fcd in Al. i. tinzs ante me adhuc riullus: nifi quòd Pignorims plurimas figuras $\mathrm{ex}$ venerandæ Antiquitatis monumentis paffim correxit, \& feliciter rcftituit, cuilanè hac in parte multum debemus. loan. Thuilius Præfat. Emblem. Licati.

Vir clarifimus anentius Pignoritus rerum antiquarum rariorumque, ut $I$ in dex, ita \& Vindex excellentifinus. Felix Ofuns in Caftig.in Auguft.Hift. MufJas ti pag. IgI.

VIr amicifimus, multarum, atquc adeo reconditarum rerum notitiâ perine fignis Laurentium Tignorius. Idem in Utbe Ftern. I. I. c. I.

A quò monumenta propemodum omnia vetera non exculfa modò fed extrita penè funto Iders ibid.

Pignorii induftriam immostali vitâ inter mortales digniffimam nunc jacere, quis tam alienus ab humanitate eft, ut æquo animo fiftincat? Nam \& eum vixiffe, idem mihi $M$ aximiliarans nofter conftanter affirmavit, \& tuâ quiden fide. Sed erramus : non vixit, fed vivit, \& cumbeatis calitibu fruitur aurâ divinx contemplationis. Neque enim aliter ut lemiamus, ingenium, candor, finoeritas, probitas, fides, qux in feriptis ejus elucefcunt, mihiq; aliunde fatis cognita, perfpectaque fuerunt, permittunt. Mélch. Haiminsfeld. Golä daft. in Epift. ad D, irizic. olizum:

Extat de Servis , \& coram apud Veteres Minifteriis Commentarius $\dot{p}_{\text {atari }}$ 4". Anno 1656. \& Ambitclodami apud Andr. Fr? Junri 1674:16\%.

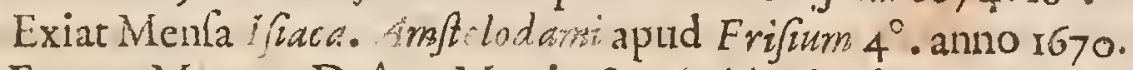

Extant Magnæe Deûm Matris \& Attidis initia. Parifirs apud Nicol. Buorn? 1623. in $4^{\circ}:$

\section{Hoc ejus Epitaphim}

\section{O. M.}

Laurentio Pignorio, alteri bijus Ecclésa primum Parocbo, deinde Tarvifil canö. nico, pietate ac morim fanclitate SpeCtatiffrmo, literarums omnium, itum graviorum, tum politiorum, peritifjimo, pentioris Antiquitatis non mivits certo quàm curiofo indagateri, Patrie, Amicorum, \& fui ipfus Memoria liculentijfmis Scriptionibus propagatori, Mufarum denique \& Gratiarum corculo, \& oceilo, Dominicus Molinis Sen.Ven. Amico, ac. Hofpiti cariffimo, of jucundiff: $\mathrm{P}^{\circ} . \mathrm{Ob}$. Ann. 1613. idib. Lunii, vixit Annos 59. Menf. 8 . 


\section{PETRUS GASSENDUS}

Clar. A.D. Allus, Dinienfis Ecclefix Prapolitus, \& Parifis Rcgius Mathefeos Pre? MDCXXV. I fellor, necnon Phil@ophix Epicurea intaurator:obiit anno 1655 . xtatis 64 .

Scripfit S. Exercitationes adverfus Arifoteleos : Oetolibros de Vitâ Epicuri: Inftitutionem Aftonomicam: Vitus Tychonis Brabe, Nicol. opernici, G. Puro bachii \& Iob.Keguonontani: Vitam Ni-Claud.Peirefcii: Calendarium Rom \&c. Petrus Gaffendus Dinienfis Ecclefiæ Theologus, vir primarius, qui novo ingeniiacumine, difertâ Orationis texturâ \& admiandorum monumentorum copiâ Europe innotuit I,eon. Allat. Ap. Urban. p. 70.

In eo [Petro Gaffendo] peracre ingenium \& judicium, incredibile Rudium; labor indefertus, fingulatis in afferendâ veritate methodus, va ia eruditio, caque excuifitifima , terfa \& claborata $\ell_{\text {iptio, }}$, bonitas eximia \& pietas, vitæ gravitas, morumque integritas fumma, frugalitas prifca, Theologtis infignis, \& in Academiâ ariflenfi Kegius Mathematum Profeffor. Ión. Launoy in Epint quad.de Gajend.

Petrus ille Gaffendur, vir profectò capitalis, \& mirâ ingcuii felicitare, quâ per omnes fcientias aquè fe diffundit, haud abfque ftupore fpectandus. Gab. Nand. in Epift. ad Len. Allatium, Urbini die I8. Aug. 163i.

-...- Nec ut recentiores illos commenorem, acumine fimiles Antiguis, \& propè pares, Galilaim, Gafjendiri, Gilbertum; Merfennum, Cartefium. I Jaac. Barrove in Opufe.p 87.

Nemo aut acriùs aut uberiùs, aut quidem feliciùs Epicuri apologiam confecir quàm Petrus Gafjendus, vir quidem magnus, omnique, fi quis alius doctrinâ eruditus, nec tamen eruditione, quàm aut judicio, aut candore nobilios. Same: Parker. Difputat. de $\mathcal{D}$ to, Difput. 1 \$.12.

Quis eruditorum eft hominum (Audifye- Ceverioribus deditorum) cui $\mathrm{Tu}$ ignotus, qui tibi imotefcere non fummo mentis ardore cupiat? Nempe frculi noftri decus fummum efle te, judicant ii omnes qui in Natura atque foicutiarum fcrutinio paulo profundiùs verfantur. Illud certè habes peculiare atque tibi proprium, guodin o min literarum genere adeo excellas, ut in quât to parte maximè verfatus lis, planè dificile fr decernere. Ita enim Marhematicas Difciplinas Philofophix ftudis ac linguatum adjunxift, ira his omnibus fty li nitorem induifti, ita ingenuum ubique animi candorem, eximiamque gencrofe mentis grariam, peromnia tua ( qux plurima funt) elucefcere facis, ut impofibile effe judicem, tua vidiffe, \& te non fufpicere atque amare. Ego certiab Adolefcente ita tui ipfus amore exarf, ut fape mihi in animo fucit $G$ alliam tuam proficici,co aut folo fine aut prxcipuo, ut pafcerem oculos te intuendo. seth. VV ard. in De dicat. prafix. lib.cui Tit. Afronmia Geometrica.

¿ Jue merito ( vis clafifime) doctus exiftimais, utpote qui Philolophiam, \& Marhematicas 
Mathematicas Scientias calles, eafque lorgè aliter quiàm vulgus Profefforum, doces. Relietâ enim illâ viâ, qua ab aliquot faculis obtinuit, \& in Scholas barbaram quandam thilofophiam induxit, de rcbus pulcherrimis eleganter, quantum matc ix difficultas patitur, diffet is, nec res um fublimitatem verbis fordidis dehoncftari finis. Quod teftantur egregia tua monumenta, ex quibus altioruim fcientiarum notitiam cum politioribus literis te conjunxilfe manifefteapparet. Roland. Mir. S. epift.1. I. epift.33.

Anno 1628.ac deinceps, variâ doctrinâ, imprimis Matbe Gaffentus, Gallus: cujus fingularem, \& multi jigam eruditionem, non potui non mirari, cùm, Belgicam hanc luftrans, anno 1629. me non femel falutatione, * alloquio fuavifimo, dignarctur. $V_{0}:$ de $M$ athernat.

Gallendi quatuor Epiftolas de apparente magnitudine Solis humilis, \& fubli-

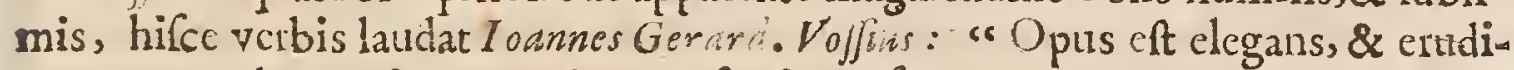
Is tum; quodque animum pariter, \& fructu pafcat, \& recre et voluptate. Vo $\int /$. de Mathem. c. 6r. fect. 12.

Petrus Gafjendus Anno 1624. edebat Exercitationes Paradoxicas octo adverIus Arifoteleos. In quibus Ramiftarn fe prodit \& acerrimum Arifotelis calum niatorem, quanguam nihil minus fe facturum Prixfatione pollicetur. Sed puduit Giffendutur cœpti infolentis, ut fex libros reliquos tenebris æternis damnaverit, \& cim Ariftotelem vituperare fune dedecore non polfet, ad alterum extremum delapfus, Epicurrum laudace, ejufque Philofophiam illuftrare coepit, ide

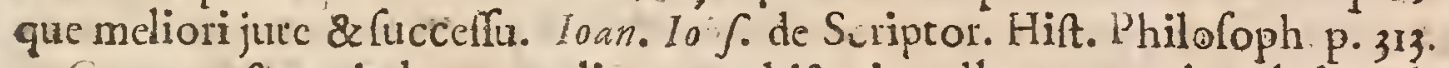

Certum cft nos in bonarum literarum hiftoria nullum exemplum habere lucidioris, doctioris \& acutionis difcursûs ; nec fubactioris judicii, vitæquéregiminis fapientioris \& moderatioris quam in hoc thilolopho. Sorbiere Epift. 49 Gallicè.

GuJje ndus eft Author qui fat is laudari nequit. In rota Vetuftate nullus reperizar. Phi ofophus qui fex ampla volumina tam nervosè confcripferit. Rapin. Animadv. in Phyficam. Scct. g. Gall.

- Gafjendus, qui cenferi tantum voluit Democritice Epicuraeg; Philofophix ReAtanrator pauca è proprio peum loquitur, de fuio ferè nihil habet prater fyli venuftatem, qux Authoris milifici famam ipfi facilc conciliavit. Ad ipfum in cjus Phyfica refutandum, fufficiunt Ariftotelis adverfus Densocritur in ejufque Difcipulos Argumenta. Idem in Rhilofophiam, Animadv. I8. Gall.

Opera cjus omnia in 6 . Tomos diftributa, Lugduni auno 1658 . prodierunt.

Hoc ejus Epitaphium folido marmore albo \& nigro pofitum I utetid in Ec.

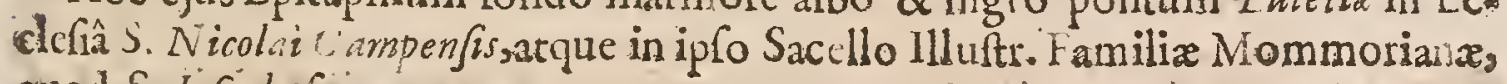
guod S. Iojepho facrum.

Potrus Gaffendus, Dinienfis Civis, Precbyter, ejufdem Ecclefix Prapofutus, $S$ : Theologie Doctor, in Acadermia Parifienfi Regitus Mathemutice Profeffor bic

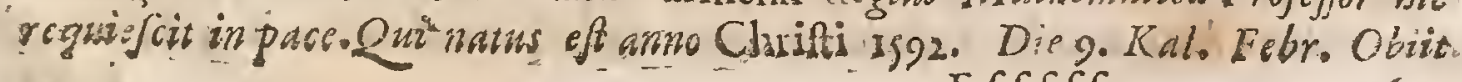
Efffff 16ss: 
r655. die 9. Kal. Novidepofetus eft $7 . K$ al. Henricus Ludovicus Habertus de Montmor. Libell. Suppl. Magifter: viropio, Sapienti, docto, arnico Juo Hospiti polwit.

\section{Aliud Epitaphium :}

Hîc jacet, ñon unus è Septem Sapientibus, verùn tota Sapientum familia, Pbilofo: phi omnes, Pclitici, Pbilologi, Matbernatici, Theologi eodern tumulo teguniur; Academix veteris novk, Ly:ai, Stox, bortorum rudera, veftigia, équibus pamjan reparanda of mul to Splendidius reftauranda edita doctrina Sapientum templa ferena. Vbi veluti toudemo a ula, fiftendi erant redivivi 0 audiendi Thales, Anaxagoras, Pythagoras, Hippocrates, Democritus, Socrates, Plato, Ariftoteles, Zeno, Epicurus, Lucretius, Cicero, Sencca, Plutarchus . Sextus of quot quot bujufcernods Heroum ad noltra ufque ternpora extitere, bic jacent cum Mujis, Pallade $e^{\circ}$ Apolline, Pudor of justrtia foror incorrupta fin des nudagueveritas. Que univerfa magnum Petri Gallendi nomen complectitur. TuViator erudite! luge fortem generi, humani, cui mors invida eripuit fidiffrnum, diligentiffmum Nature Interpretem, Virtutis, folida Pietatis, bone Mentis Cultorem, Vindicem, Propagatorem integerrimum, acerrimum, felicife. fimum. Vixit fine querela, forte fuâ contentus, interioris nota amicis jucundifjmus viris imperio, auctoritate, doctrinâ, Sapientiâ praftantiffmis acceptiffimus, charifirnus; non apud exteros folum, sed of in patriâ $\int u \hat{a}$ amorexn \& venerationemmeritus, consequutus. Annos $L X I I I$. men $\int e s I X$. dies XIII. aternum Sui defiderium relinquens Lutetix Parifiorum A.D.I X. Kal. Nov. 1655. Abrahamus Pratxus, Thomas Mortellus, Samuel Sorberius, Francifcus Bernerius, Amico veteri, Preceptoribene merito, grati animi monumenturis M. M.P.P.

Iu Effigiem ejus hæc carmina compofuit Auctor Anonymus:

Hic eft ille, dedit cuife Natura videndam,

Et Sophia aternas cui referavit opes:

Invida non totum rapuifis fidera. Vultum

Nantolius. Mentem pagina docta refert.

\section{JACOBUS SIRMONDUS, Soc. JeL.}

Clar.An.D. AT Atione Gallus, patriâ Arvernus Ricomagen Is , Rector olim Collegii $P$ a MDCXXV. rifienfis, obiit anno Dom. 165 - xtatis 93 .

Varios autores edidit notifque eruditis illuftravit, ut. Sidoñum Apollinarem, Gofrioum Vindocinenfem, Ennodium Ticinenferr, etrum Cellenfem, Idaii \& Aarcellini Chronica, \&c. Theodereti Cyrenenfis Epifcopi operds in 4.'Tomos di- 
tyrannide fua dehoneftabat, \& odiofam vilemque reddidilfet, fi nullibi nif ir. ejus Scriptis extitilfet. Ider\% ibid.

Doctifimum ac candidifimum Sirmondum Jefuitum jam fupra edidimus. hon modd confitentem, fedetiam pugnantem, ac veris validifque argumentis vihcentem Dionyfi Martyrium fub Dorti iano Principe contigilfe - Qui Sirmundi vel acumen \& judicium, vel candorem \& fidem norit, no: dubitabit , quin ille hæc, \& viderit, . \& fccutus fit; ac ne hoc quidem obfcurum, vel apud cordatos ambiguum eft hunc virum five eruditionem, five judicium fpectas. pluris efle unum, quam trecentos fiyc Delrios, five Halloixios. Ioan. Dall. de libr. Luppol. Dionys. Areop. \& gnat. Antioch. 1. . . c. 36.

Magna verò lacobi Sirnonci in Humanioribus Difiplinis praftantia: venuftâ quadam \& nativâ floret facundiâ, \& legentium animos mira volıptatis fuavitate perfundit. Hanc tamen dicendi facultatem ad Auctoris exemplum cö̈rcet. plufque Interpretationis fidei, \& recepto apud Chriftianos homines verborum ufui, quàm elegantia Cermonis \& munditix tribuit. F1uet. de clar. Incerpret.

Extant Concilid antiqua Gallie omnia hu unum collcat. Voluminibus 3. Pas rifis 1629 .

Extat Pradeftinatus five de Predefinatianorum Haref Tractatus. Amfelod in 8\%. 2645 . \& deinde Parifir anno 1649.

Extant Operadogmatica Veterum quinque Scriptorim. Parifris 16:0.80.

Extant alia ejus Opera yariis in locis arque temporibus imprefla.

Lutetic P arifrorum in Collegio Claromontano Societaris lefu exictero, 1 quem Regium morbumvocant decefit firmâ adhuc valekudine vividus fenex, Nonis Octobris anno reparare per Chriftum falutis 1651 . vixit annos $9 j \cdot$ minùs dicbus g.llatus 4. Idus Octobris annc Cuperioris feculi 59.

Hoc ejus Epitaphium:

Sirmondum rapuit vegetos fuffufa per artus. Aurigo: nec mors credidit effe fenem.

$B$ is confecta novem vite poft luftra beata, Telo ufa eft, juvenes quo fuperare folet.

Exornant tumulos aliorum marmora of aurum:

Sirmondus tumuli fit decus ip e fui.

Aurea mens vivo, facta aurea, of aurea dicla?

Nec defundi alius debuit effe color.

Phil. Labbe in Thefaur. Epitaphs 


\section{GERARDUS JOHANNES VOSSIUS.}

A Rcbipalatirus, eloquentiâ \& eruditione feculi hujus inter principes. Naw Clar. A. D tus anno 1977. Dortraci literis incubuit, cum Erycio Puicano. Dein eru- MDCXXV. ditarum linguarum notitiâ exactè imbutus, præcipuas Europe urbes invifit, ubique magnâ veneratione cultus. Reverfus, Dordraci, Lugduni Batavorum, \& Amftelodami docuit, Obiit anno IGSO. Elofman.

Extant ejus Grammatica Latina: Rhetorica: Liber de naturậ Logices: Liber de naturâ Rhetorices : Infitutiones Poetica : Etymologicon Lẩina Liur guz: Liber de Philofophî̀ \& Sectis i’hilofophorum: Iiber de Hiftoricis Gracis \& Latinis: De quatuor Artibus popularibus : De Scicntiis IMathematicis: Tractatus de Gloffematis vitiifque Latizi Sermonis : Theologia Gentilium: Thefes Theologica: Harmonia Paffonis Chrifti: Hiftoria Pelagiana: Tractatus de Baptifmo: Detribus Symbolis: De Arte Hiftoricâ : Chronologize Sacra ifagoge: Tractatus duo, de cognitione fui, \& deftudiorum ratione: in fitutionum Oratoriarum libri 6 .

Ego certè itafentio, neminem inter Theologos noftros repertum fuiffe, qui mints urarit in verba cujufquam.Magiftri, qui aliorum fententias æquitus expendcrit, \& qui veritatis diligentior fuerit indagator. Andr.Rivet. Apologet, pro veriâ pace Ecclel.

Lofephus Scaliger cùm Voffi intitutionum Oratoriarum libros perlegiffet; ingenue profelius eft, fe ab eẩ lectione doctiorem evafifle, nec à veteribus ipfis quenquam extare, qui in eo argumento Vofjo palmam prariperet. Cafraboni vero hoc de Vo/fio erat judicium, nihil ejus Rbetoricis effe perfectius, nihil nitidius, fingularem eruditionem, lectionem multiplicem, retum judiciumubique elucere. Konig in Biblioth.

Non potueras melius confulere liberis tuis, quàm quòd eorum fpem Voffio commendas, rarx tum probitatis, tum eruditionis viro. Memini à Cafaubono fummislaudibus predicari Oraiorias ejus Inftimi ines. Tum qua de Plagiana Hiftoriâ confcriplit, maximi hîc ab omnibus fiunt. Grot. Epift. 38 ad $A u b$. Maurérium.

Eft mihi vir ille (Voffins) optimè notus, nec quidquam tam magnificum dixero, quin ejus doetrina virtulque fuperet. Band.26. Centur, 2. Epift. 26

Iobannes Gerardus Vofjius, omni doctrinarum genere atque omni eruditione mirabiliter excultus. Utinam Orthodoxâ Fide imbutus fuillet. Ioan. Card. Bona.

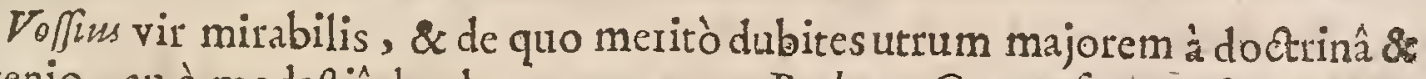
ingenio, an à modeftî laudem mereatur. Bochart. Geegr. fac $p \cdot 485$.

Ejus liber de Hiftoricis Gracis opus miræ eruditionis, ex cujus lectione nos profecille non parùm ingenuè profitemur. Idem ibid.p. 864

Gerardus Iohannes.Voffus tot fcripfit \& tanta utilitatis libros; ut ejù merita paucialfequantus. Quante cnim in Hifloricorum Grecorum \& Latinorum cogni- 
rione tenebræ per eum funt difpulf $x$ doetiffmis libris de Hiftoricis Gracis Latinis ! ut jute deleamus non abfolutum ab eo effe laborem fimilem quo Poètas Gracos \& Latinos variis tenebris \& difficulcatibus itidem liberate conabatur: quo imperfecto labore tantifper fruimur dum à felici al iquo ingenio is perficiatur. Iongrus de Scriptor. Hitt. Philofophic. p. 3 I3 314.

Vir Clarifimus loannes Vo/fus, quô ncmo rem Grammaticam accuratiùs excuffit \& explicuit. Gaiaker de Nov. Inftumentiftylo Differt.c.23.

Tumm de Grammaica Arte accepi, exactidimu in hoc genere Opus,ac cui nullum priorum vel prifci evi vel nofti poffir comparari. Non pucris tantum hre Scripta; Ced viris, qui hinc haurirent unde doctiores evadant, quacue aliunde doceri non poffent. Salmaf. 1. r. epilt. 74 .

Quantum me, bone Deus! (ut reliquajun taceam) ultimi de Hifroricis Gracis libuiceperunt! Tam felici induftitî ulus es, ut quicquid à veteri avo Grecin fudavit, ignorare jam docti indoctiquc definant, quod omnes unus docuift. Quædivitix! quæ delicix! Nihil tam abditum, quod non legeris; tam dubium, quod non expenderis; tam oblcurum, quod non illuftrâris. Eric. Pum tean. in Litter.

Proximis dicbus aliquid nactus otii , legi eâ ; quâ omnia tua foleo, aviditate ac animi affeetu, tua de $I$ dololatri $\hat{\imath}$ : in quo contra fecilti, quàm nunc fieri folet, plerique enim titulos fuos operenon implent: tu aliter nos decipis, plus dando quàm eras pollicitus. Nam præter omnium Gentiurs hiftoriam, nature nobis pandis mytteria, \& in tantâ rertm congerie Cervas; quod dificillimum eft, ordinem. Prreterea quoties Vetersm aut Scriptura aut fenfus in dubium venit, oftendis quàm exacta fit judicii tui trutina. Tum verò pietatis ac probitatis lemina ita ubique infpergis, ut non alium nôrim librum efficaciorem comigendisfeculi moribus. Hug. Grot. in Epift.

Inter tot libros quos celtbris Gerardus Voffizs confcipfit,nullus ifto ccleb:ior fuit \& etiamnmm eft (qui fcil. Theologia Gentilis infcribitur.) Caterùm quantumvis egregium fit hoc Opus imperfectum tamen, ut \& alia ejufdem Authoris complura remanfit: hoc tamen difcrimine, quòd iftud eifemper honorificum fit futurum, cxtera verò dedecori erunt ipfr. Hujufmodi funt imprimis ejus Etymologicum, ejus de Poetis Gracis \& Latinis bini Tractatus, ejufque ad Chronologiam introdnatio, quæ nunquam evulgari confultum fuilfet. D. Colorniez Biblioth. Clect. p.87. \& c. Gallice.

In quo Opere Etymologico, utin aliis ejus Scriptis", $110 n$ pauca font quæ miram properantian argutunt. Hactamen in quibuldam feltinatio, viri illius exiftimationem haud pinuit, dignifimi fanè, quem, ob tot præclara in vulgus emiffas omnis amet $\&$ adiniretur pofteritas Ider in obfervat. fac.p. 31 .

Gerardus Iobames Voflun, magnum in bouis literis nomen, cujuique adeò di*itiis facilius credas inhiafe fures lierarios, de quibus \& conquercntem videmus, quàn iplum fmile quid patiaviffe. Tamen quod forf fur [ de Scripr.HiR. Philof.p.49.] obfervavit, Vhoverim fuppreffo illius nomine quandaque fecutus ett. Thornal. de Plag num. $57^{8}$. 
minime veró iis quifupra vulgus fapiunt. Contentus eft magnis potiùs quam multis laudatoribus. Hug. Groi in epift. 174 .

Capelluri, vi um in Hebrai is literis Sacrâque Hiforiâ egreginm, maximi facio Hug. Grot. in Epif. ad l'incipem de Luterc. Lut.24. Odtob. 1640.

Hanc fententiam (de Punctorum vocalium inventione) poft P. Martirizum tuctur eruditè Ludovicus Capellus vir clarifimus in eximio Tractatu de Puretcrwm Hebroorum antiquitate. Frid.Spabern.3. part. Dub. Evangelic.Dub.129.

Erudito fanè Lud. Capelli Tractatu pugna de Punclorurn Aniquitate ita depu-

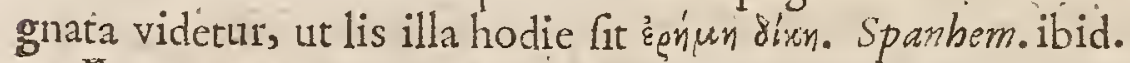

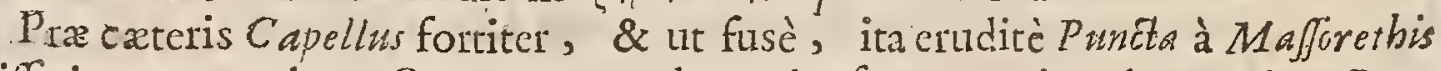
fuiffe inventa probat, Opere co, quod nominefuo praterito, de Revelato Pun Etorum Arcano infcripfit - Facilè adlentio doctiffimo Capello, qui accentuum, we vocant, punctorum yue omnium doctrine extremam manum additam exiftimat à nobili Mafjorethä Ben A cher.Vofl. de Art. Grammatic.1. I.

Communis fere eft doctorum Cententia, luculentifimè à $R$. viro Lud. Capello proprio opere demontrata, $P$ uncti illa qua vocant $H$ ebraica, non nifi ferò \& aliquot poft Christimanifeftationem feculis, jam extincto Hieronymo, in ufu elle copilfe. Ioan. Da!l. Epift. ad N. N. I ut. Kal. April. 1636.

De Punitorum Antiquitate adcat qui volet, librum cui titulus eft Arcanum \&c. à Thomâ Erpenio amici nomine non diu editum in luccm, quo in libro Quæftio hæc non minus lıculenter quàm copiosè pertractarur, novitalque $P$ unctón rum exquifitiffmis \& validilfimis rationibus adturuitur. Simeo Muifus in $\mathrm{C}_{2-}$ ftigat. Animadverfion. Morini, p. Is9.

De Punctis poft mortem Cbrifti auditis, omnium diligentiam fuperavit Anow nymirs Author Diatribes de verâ Antiquitate Vocalium, quam clarifimus Erpenius 1624 . edidit. "Ille enim fententiam iltam ddeo validè confirmavit, rationefque qua in contrarium vulgò afferuntur, adeò folidè refutayit, ut doctiffimorum Theolngorum qui anteà contrariæe fententiæ mordicus hærebant, alios in Guam lententiam perraxerit, alios verò non parùm dubios reddiderit. Sixtin. Amama in Dilfertat. de Nom. Ichova, p. 326

Quoad tuam (in tuo Arcano) conjecturam aquod filicet Iudai fua puncta defumpferint ab Arabibus, hanc verifimam autumo, méque demonftrare polfe rcor. Sed hac omnia longam differtationem exigunt. Iobann.Morinus in Epift. 72. ad Ludovic. Capellum. Gall.

Vir Hebraicarum liccrarum callentiffimus Eudovicus. Capellus. Dr. Iac. Duport. prafat. ad Metaph. Pralm.

Ludovicus Capellus vir doctiffimus, \& in Thalmudicis verfatillimis. Meric. Cafanb. de quat. Linguis, p. I21.

Vir exacti judicii. H. Conring. de num. Ebrzor. paradox. cap. 5.

Hactenus in Pinctorum Hebraic. origine aftruendâ duo maximi magiłtri deGudant, quorum alter Arcani Punctaiionis Author ( cui nos multum profitemur debcre limatifimo vir judicio \& undecunque doetiflimus eft. Alexand. Mo gubs in exercit. de Scripturâ S. p. 69 :

Argumen:a 
Argumenta de punctorum novitate Clariffmi Lud.Cepelli Antagoniftarum facilè $P^{\prime}$ rincipis, non tanti fanè funt roboris, quali celcbrantur, imo pleraque. funt prorfus inania. Cafp. Ledebur. Pref. ad Lect. in Tractat. de Accentibus $H \cdot b .1547$.

Luduvicus Capellus prius cvulgaverat præclarum Tractatum quem infcriplerat Arcanum Punctationis, quo invictis argumentis demonftrat Punctorum $\mathrm{He}$ brai contextûs novitatem. 'Yrimum illud Capelli Opus, quod in Hollandia typis mandatum fuit, magnos inter Protefantes rumores excitavit, imò jang antequam prelo fubjiceretur ipfos terruerat, ac fr Religionis eorum principiis prorfus adverfaretur. Alexander Morus qui ipfum antequam in lucem ederetur jam vidcrat, non potuit ex æquo de Authore non judicare. Limatiffirno vir judicio, inquir de Capello loquens, \& undecungue doctiffimus; codemque loco de hoc libro verba faciens fubdit, Opus quantivis prctii, fed à multis Zeu lo Dei flagrantibus etiam bic Gerrcva reformidatum. Idem Morus clarè Catis oftendic hunc Genevenfum Proteftantium zelum non fuiffe ficundum verita tem, quandoquidem fatetur Capelli opinionem Lutheri, Calrom, Zvvinglits Fagi, Merceri, Drufi, Cafeuboni, Scaligeri, Erpenii, Salmafii, Grotii \& Heinfif fententix conformem effe: Adeoque novitatem à Capello introductam effe dici nequit, fed ab co fortiùs tantìm ftabilitam fuiffe Opinionem à fagacioribus \& doctioribus Protestantibus jam approbatam. Nec dubium, inquit Morks quin ejus caufa viccrit, fi res Doctorum fuffragiis \& aurhoritate tranfigatur, Vcrum meris prajudicatis meraque' ignorantia peccant plerigute horum Genevenfrusm Miniftrorum, qui confulere debuiffent l'ræfationem prat fixam fronti Bibliorum Gallicornon cx Hcbraico Textu verforum ibique reperiffent quòd Robertus Olivetanus primx illius Verfionis' Author, Quæetionem prolixè agitavcrit, ncc à Capcllo quidquam prattitum fuerie nif quòd Olnvew tani opinionem majori luce donaverit. Prajudicati hujus quo Germaniorum \& Genevenfurm Protctantium plcrique imbuti lunt origo petenda eft ex eo quòd cxco impetu fecuti funt utriulque Buxxorfii opinionem de Bibliorum Textûs Hcbraici finceritate. Oratorii P'resbyt. Rich. Simon. Hift. Crit. V.T. lib 3. cap. 20. Gall.

* Ludovicus Capella inter Hæreticos primæ Clafis numeratur in Indice Madrit. Edit. an. I667.

Extant Critica Sacta. Tarffirs 1650. fol.

Extat Arcanum Punctationis Revelatum. Lingd. Bat, 1624.40\%

Extat Hiftoria Apoftolica. Geneve $164_{4} 4^{\circ}$.

Extat Chronologia Sacra. Paris. $1655.4^{\circ}$.

\section{IUDOVICUS de DIEU:}

T Liflingenfis Zelandus, Natis eft amno 1590. Obiit anno 1642. Mortuo Clar.An.D. Ioannes Polyander parentavis. Linguarum Orientalium ad ftuporem eru- MDCXXX. Gggggg dirus 
ditus, atque indefell diligentix, qux \& mortis accelerandx, atque immaturæ eicaula fuit. Valer. Andreas.

Scripta ejushæc funt: Compendium Grammaticæ Hebrax - Rudimenta Lingua Arabica \& Perfice - Crammatica Linguarum Orientalium, Hebraices Chaidaica, \& Syriaca inter fe collatarum - Animadverfiones ad Vetus Teftamentum, præfertim Syracusm - Animadvcrfones in A Ea Apoftolorum, quibus vulgattm Interpretem cum Textu Greco, Syro, Arabico contendit, \& ex co tuetui - - In: Apocalypfin S. Iohannis Syriace, Hebraice, \& Yatine, cum Notis -... Hiftoria Christi \& S. Petri ab Hieronymo Xaverio S. J. Zerfice Ccrip. tas à fe Latiné reddita.

1lle Phonix facre Theologix. Dilher. Difput. Acad. Tom. I.

Vir in Linguâ Syriacâ incomparabilis. Idern Tom. 2.

Optimus, \& cùm omnis egregiæ doctrinæ, tum literarum Orientalium peri* tifimus vir, Ludovicus de Dien. Marc. Zuer. Buxhorn. in epift. ad Brunonem.

Quem quotiefcunque ipfus in Scriptis meis mentionem facio, per confcientiam nequeo, quin encomils extollam, qui tantâ pietate, Theologix yeræ, arri! $1 \mathrm{~m}$, \&linguarum fermè omnium cognitione, fyderis inftar ex alto corufcantis eminet. Confantin. l'Empereur Epift Dedicat. ad Itinerar. Benjaminis.

Singularis humanitas ac modeftia ita propria tibi funt, ue non minus eximiis his naturæ dotibus, quàm virtutis tuæ; ac doctrinæ merito, in amorem tui, \& admirationem accendas, te quotquot de proximo norûnt. In quorum numero, ut me effe, non invisus agnofco; ita non polfum, non ea veneral i dona, quæ magnus ille Deus largâ manu in te cumulavit. Iac. Crmizs. 1. 3. epift. ep. I.

Critica Nota quas evulgavit Ludouicus de Dien fub nomine Animadverfonum in Veteris Teftamenti Libros ownes, quxdam tantum felectiora Bibliorum loca refpiciunt, quibus novas elucidationes afferre fibi arrogavit. Cum verò cxterorum explicationibus aliquid novi Luperaddere affectaverit, interdum evenit ut ad minimas ufque Grammaticx minutias defcendat, plufque fubtilitatis quàm foliditatis of tentent novæillius interpretationes. Ad Linguras Hebraico affines frequenter confugit, ut è meliùs vocum Hebraicarum fignificationem propriam cliciat. Cùm illas Obfervationes Criticas in Biblia molitus eft, perfectiorem reddere meditabatur novam Verfionem Belgicam totius Scripturæ qux ex Synodi Dordracene decreto erat elaboranda. Primum tamen confilium fum quandoque deferit, pleraque in fuas Notas inferendo qua merz funt erm ditionis, quxque ad Criticam minime pertinent: ut ftatim à primis Notarum fuarum verbis, ubi oblervatquod juxta Cabbalam qux Germatria dicitur, probetur ex primis Genefew vocibus Mundum initio anni, id eft menle Septembri con'litum fuife. Deinde eodem loco addit, quòd fecundum aliam Cabbalre fpeciem qux Temura vocatur feu Literarum metathefis, Mundus Calendis Septembris creatus deprehendatur. Verum hujufmodi obfervatio plurefque idgenus alia, quas Operi fuo inferuit Author, prorfus inutiles funt ad literalis fensû́s explicationem \& àd genuinam Bibliorum Verfionem adornandam. Adia Judworum delinia Notis fuis admifcuit ur cum hanc quaftionem cum Doctoribus 


\section{CELEBRIORUM AUTHORUM.}

Doctoribus Thalmudicis movit in hec e jufden Capitis verba Deus creavit hominem: Cur feilicet unicum in Orbe hominem creaverit Deus? Ad quod refpondet cum Thalmude, Deum unicum homincm creaffe, ut nos doceret quod fi quis vel unum Ifraclitan deftruat, idem id fir ac fi totum Orbem deftrueret: fi contra quis illum confervet, idem id fir ac fi $\mathrm{O}$ bem integrum confervaret. Ejulmodi animadverfiones in Opere tam compendiofo locum habere non deberent. Sed ufu ferè femper venit ut qui aliqua eruditione inftructi funt, eâ libros fuos repleant, minimè pérpendentes an ad $\mathrm{r}$ m faciat ejulmodi eruditio. Cæterum illæ Notæ Ludovici de Dien admodum utiles effe poffunt illis qui ad Grammaticum Scripture fenfum applicant animum; In hoc autem prefertim excelluit; quamvis nimiam interdum fubtilitatem oftentet. Or: Presb. Rich. Sia mon. Hift. Crit. V. T.1.3. C. 14. Gallicè.

Rudimenta Lingure Perfice, qux Ludovicus de Dien adornavit \& evulgaví in $4^{3}$. 1639. cum Verfone Hifforic Chrifi à Xaverio, apud omnes univerim in in pretio funt, quoniam opinio eft quòd fí in omnium Oricntalium linguarum perititia aquales haberct, faltem co fuperioremullum reperini vix poffe. Iudicia Eruditor. Parifiris 1685 . per Bailletium. Gall.

* Ludovici de Disu Opera numerantur incer libros prohibitos in Decreto is. Decembris 1646 .

Extant ejus in omnes V. Tett. libcos Animalvecfiones $4^{\circ}$. Lugd. Bat. 1648.

Extant in quatuor Evang. Animadv. $4^{\circ}$. ibid. I $/ 3 \mathrm{I}$.

Extant in tfif:Chriff. Perfic. conlcriptain; \& ab illo Lat. veddit. Animiadvo $4^{\circ}$. ibid. 1639 .

Extant in Alta Comment. $4^{\circ}$. ibid. 1634 .

Extant in Epiff. S. pauli, except. ad Pbilem. $4^{\circ}$. ibid.1645.

Extant in Epif. Canon \& Apoc. 4. ibid. 1646.

Extant in Apoc.Syr. Hebr. Lat. $4^{\circ}$. ibid. 1627.

\section{JOANNE'S KIRCHMANNUS.}

TIE YS. Januarii , Anno Dom.1575. natus cft Lubeca. Die 20. Martii, Anno 1643 obiit Labeca.

Clax. A. D: MDCXXX:

Scripfit de Funeribus Romanorum libros-4, Be Annulis Librum fingularem: Drationes varias: Rudimenta Rhetorica, Rudimenta Logicx Peripatetica.

Cùm viderim Cogitationes tuas de Ritú Sepelicndorum Cadaverum Romatu nortum, cáfque dignififinas judicem, ut à cunctis leganticur, ne diffetas in ip is edendis, etiam atque etiam te hortor. Præterquam enim, quòd omnes eruditos juvabis, tibi quoque retenum nomen comparabis. Hieronym. Alercurial. in Epift. $2^{3} i \hat{j}_{s}$ Scriptâ ann. 1602 .

Funeralis tua vidi, vel potius bafio excepi. Nihil dabo auribus: verè me cepit fimplex \& inornara venus, \& ratio differendi inaffectata. Loan.VVosver. in Epift. 54 . Cent. I. 
Munus tuum de Anrulis ab antore co eft profectum, quem ex accuratis de Funere antiquorum libris pridem admiratus lum. Dan. Heins. in Epift. fcript. ann. 1624 .

Ecce ribieruditum Opus, à loanne Kirchmanno Lubecenfi claboratum accepimus, qui, fortaffe alpcrnatur Porcachii exiles in eâ materielabores (Ced plurimi faciendos, quòd primus in arcnam defcendit) uberiùs abfolvit, qux ille inchoavit. Nihil eft, quod amplius defideres. Ex oprimis quibuqque Lainis Gracifgue autoribus, effolfis cæmentis, nobililfmum Sepulchrorum dificium condidit. Iul. Caf. Capacius Elog 1.2.

I'erlegi, vir clarifime, \& ira me Deus amet, perlegiffe jucundum fuit, ca folia, quæ è tuo de Annulis liballo ad me mifinti. Tam enim accuratè, tantâque cum erudirione tota ejus hiftoria à te tradita eft, ut neque ei ad perfectionem, neque ribi ad lammam laudem quicquam deelle videatur. Ian. Rurger f.in Litt. fcript. an. 1623 .

Dono etiam obfringere me tibi voluifi, libro nimirum de Annuis, mon'umento ingenii tui docto fanè \& Laboricfo. Quod quanto ego accuratiùs lego, tantò magis jucundâ cjus, nec fructuosâ minus lectione oblector. Voff. in Litt. ad Kirchrow. Ictipt. anu. 1628.

De quibus Kirchnannus, folertilimus ritum funebrium indagator confula. cur. Sertor. Jrfat. L. I. Monument. Patavin. G. 2.

Kirchmannus de funere bonus eft. Saligerana 2.

Scaligero notto quantum placueric Opus tum de Euneribus, non facile

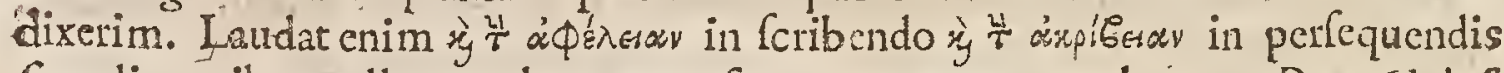
fingulis, quibus nullum volumen par futurum omnes putabamus. Dan. Heinf. in Epirt. Ccript. an, 1605 .

Poftquam libros illos tuos reconditx eruditionis de Funere Romano atque "Annulis fummâ animi oblectatione perlegi, in penitifima \& Sacra \& Secularis Literature adyta te perrupiffe animadverti. Alter famam tuam rogo funereo cripiet; alter nomini tuo annos addet inumerabiles. Iohan. Mich. Dilher. in Epilt. Ience prid: Calend. Octob. 1636.

Ex quo doctiffimos tuos de Funere Romanorum \& Annulis libros videre datum eft, quod adolefcente ante annos nifi fallor 30 - contigit, amare equidem te cœpi \& colere. Dexteritatem enim judicii cum mulriplici lectione conjunctam. mirabar \& olculabar. Georg. Calixt. in Epift. Flensburgi poftrid. Kal. Jan. 1635:

Tuum de Annulis Commentariun ut omnia tta, perexpecto cupidè. I Suác.Cafaub. in Epift. Lut. Parif. 8. Kal. April.1608.

Kirchmannw in libro de Funeribus Romanorum multa defumpfit ex Kornman zilibro de Diraculis Mortuorm. Anton. Berremanf. lib. Var. Lect. cap. 4 pag. 32 .

Vir ad omnem humanitatem fretus \& reconditx eruditionis. Stephan ad 1. fo? Sax. Gramm. Hiftor. Dan.

Kirchrsannus optimum optimi ingenii foetum edidit, $\&$ in publicum prodis: Sit ialeum nempè \& omnibus numerís ablolutum librum de Funeribus Roma 


\section{CELEBRIORUM AUTHORUIM.}

ñorum, quem uti omnes horridx Antiguitatis periti ofculo \& complexu acceperunt, ita fummis in Ccelum laudibus extulerunt. Nullum enim volumen huic par futurum fcribit Heinfuns, vir tanta eruditionis, quantam in unum hominem cadere poffe vix quifquam putet. Et fanè, fi nilhil aliud ad egregium publis cum Kirchmannus, , prater elaboratifimum hoc opus, contuliffet, Gatis fuper. que tamen feciffet, \&unomen fuum à funerea oblivione egregie vindicalfet. I aw cob. Stolterfbot. in Orat. Funeb. Kirchman. vide Henning. VVitte in Philof. mes, mor.p. 530 .

* Ejus libri de Funeribus Rormanorum, fi expurgentur, permittuntur in Iredid ce Madrit.ann.1667.

Extant de Funeribus Romanorum libri 4. Lugd. Bat. 1672 . in 120.

Extat de Annulis liber fingularis. Lugd. Bat. 1672. in $12^{\circ}$.

Extant Rudimenta Rhetorica. Breme 1652. in $\mathrm{I}^{\circ}$.

Extant Rudimenta Logica Peripatetica. Lubece 1669 . \& Lxpiùs in 8:?

In Cl. Viri Iobannis Kirchmanni de Funeribus Romanorum libros

Funera dum Scribis Veterum, Kirchmanne, Quiritum,

Luce bears ritus tam longâ nocle fepultos,

Hec te funeribus Subducun funera, jannque

Consiliant nullo perituram tempore famam.

Radulphus Forneriou Antecefor Aurelius"

\section{A UBER_T US MIREUS。}

R Ruxcllenfis, nams eft Anno Dom. 1573. prid. Kal. Decembris Decanus Clar. An.Dä Antverpienfis obiit 1640.xIv. kal. Novembris.

Struxit Faftos facros Belgicos ac Burgundicos: Item, Chronicon rerum Belgiearum à Iul.Cafaris adventu ufque ad anum 1635. Elogia Illuftrium Belgia Seriptorum. Multaque alia.

Vir fuit de Ecclefiaficis in Belgio prafertim Antignitatibus optimè meritus: qui hoc unum àgebat maximè ut ảvér\&ora hactenus, \& cum blattis tincifque luctantia, in lucem afpectumque publicum proferret, ut Écclefixeftatum ac regimen ob oculos poneret; ut Sacrorum Ordinum initiasprogreffufque erueret; ut Principatuum Belgit Origines hactenus obfcuras illuftraret, ac pleraque alia Belgica Antiquitatis Arcana hactenus abdita recluderet, idque non ex conjecturis aut fabellis popularibus, fed ex probatz notæ Hiftoricis ac Chronographis, quinimò ex ipfis Principum Diplomatibus, quæ in eam rem ex publicis privatifque Bibliotbecis atque Arčbivis plurima ingenti labore, ac fumptu collegit \& publici juris fecit. Valer.Andreas in Biblioth. Belgic.

Rerum Belgicarmin ac totius Hiftorix Ecclefiaftica eximiè peritus. Gaffend. de Vit. Peiresk.1.2. 
Aubertus Mirans vir Hiftorix Ecclefix cogaitione inprimis excellens. Franc. Swert. Aiben. Belgic.

Aubertus Miraus, Sol Belgarwm, inter tot Sidera; caliginem, torporem, frigus pellens. Inf. Iipf.

In tabulis veteris ævi utilem operam pofuit. Conring. cenfur.diplom. Lindav. p. II 7 .

Antiquitatum fequioris ævi curiolus indagator. Conring. de Antiquit. Acad. Supplem:32.

Geographiani tuam Ecclefafticam accepi, gratum profecto munus; quia \& curiofum \& utile. Simul Cemelque reprafentas, quicquid à Sarrus Injulis in Uube terrarum regitur: nec poreft am tuum angutio ibus limicibus nomen daudi. Ubicunque -pifropifunt, Mirkus queque erit, ingenio, labore, doctrinâ mirus, \& jam dignus iner illos cenferi. Amplius eft, fic defcribere omnes Urbes, quàm uni praeffe. T'uus fanc̀ calamus nihil Pedo Epif upuli cedir : \& corona tamen laborum ( permitte ut dicam ) Mitra erit. Eryc. Putear. Epift. Apparat. Cent. 2. Epift. 6z.

Plurimùm mihi gratulator, quòd tibi viro in omni fcientiarum genere verfatiffimo placent Exercirationes meæ; eâ enim es eruditione, \& apud omnes erum ditos afimatione, ut nulli aut pauci improbaturi fint quæ tuo calculo comprobas. Ioan. Morin.in Epilt. I2.

Cateris accuratior eft elegantiúfque loquitur in fuis Elogiis'Belgicis, fed tenerum \& quodammodo crecum amorem in Patriam \& Populares patefacit. Quapropter ad ipfus excufationem dici poteft unicum ejus fcopum fuife Elogi. fimpliciter contexere, non examinatis Authorum quos laudat promeritis. Jud. Enud. per Baillet Parif. 1635. Gall.

Magnam ejus eruditionem ornabant folida pietas animique grata lenitas, qux omnium amorem ipfi conciliabant. Hic character in ejus qux nobis fuperfunt Operibus fatis manifeftus eft. Integram poffent Bibliothccam inftruere; nec ullus unquam utiliores difquiftiones elucubravit. Moreri Diction. majore Gallico.

Revercndiffime \& Clariflime Domine, Bibliothecam Ecclefafficam abs te mihi milfam reverenter accepi, uti munus facrum ab homine facro. Admiratus fum in eî̀ cruditionem; judicium, perfpicuiratem. Quàm multa lcgiffe, opurs eft eum, qui hac fcripferit ! qua prudentia vigere, qui de fingulisita judicaverit! qu ingenii facilitare, qui res adeo implexas tam clare digefferit! Debuimus ad hanc diem ic iptores Exciefiaficor illis feptem Nomenclaroibus viz.

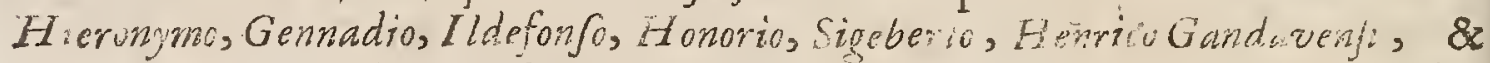
Ifidoro Hijpalenfi: jam incipimus eos aliofque deber \& tibi, cujus operâ illum ftriores accipimus. Ut meritò tibi, tales inter viros adfcribendo gratulari non vanâ anticipatione poffimus. Fum. Stratic in Epift dat: Fuma 21. Jan. $16_{4} 0$.

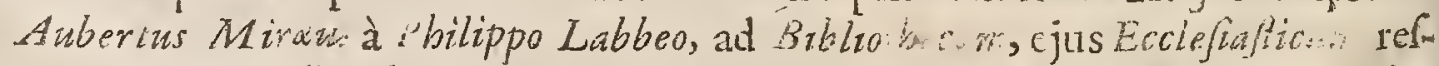
piciente, non modd bamaleon i comparatur, uti variis infidet autoribus, ita diverlos colores induenci, fed stiam nominatim ut Bellarmivi, VoJjii, R yzandi, 
Sirmondi exfcriptor fugillatur. Hîc, uti non abnuo, folere Miram pafim ta cere quos deferibit: iranec ubique mutum agit pifcem, ut aftuiffe malignitatem credam, certè non tantam fuiffic, cui tories etiam ubi cirat per quos profecit, odiofum exfcriptori nomen imponi, prefertim optimè alioqui meito,debuerit. Sed nota eft Labbei rabies. Quem fi quis forte ex ambiguitate vocabuli exculandum putet, is nihil aliud profecerit, "nifi ut Lapino furori Vulpenatrs quoque verfiriam ferviiffe intelligalatus. Thomas. de Plag. num. 508.509 .

Varia ejus Opera variis in locis atque temporibus funt impreffa.

Obiit Antverpie, ubi hoc ejus Epitaphium; in ambitu Chori :

\section{O. M. S.}

'Auberto Mirro H. Cath. Eccles. Decano, fudiis friptifgue Clariflimo,qui Ora dinibus Religiofis origines, Annalibus gefia, piis Fundatcribus fariam, Hijporiis incer, fcriptorzbusper elogia vitam, Patria claritudinem, Ecclefac buic Decus afferuit: quibus afsdue laboranti, ac feliciter operanit es perennare digniflmo Morsmanum injecit Anno 1640. Menf. Oct. die Ig. vite ejus 67. Joan. Carol. Franchemius Miraus ex afse heres Avunculo magro, Proparenti opt. in. H. E. Choro condito, Gratitudinis ergô. monumentum P..C.

\section{DIONYSIUS PETAVIUS, Soc. Jef.}

17 Arione Gallus, Patriâ Aurelianenjis, natus eft Anno I583. obiit Anno

Emift I3. libros de doetrinâ temporum, quos duobus Tomis complexus eft: item, Rationarium Temporum. Compofuit ctiam ingens opus de Dogmatibus Theologicis, 5. Tomis conftans. Synefi, Themigiz, Epiphonit, Iuliawi, aliorumque opera Latinétranfulit \& utilifimis notis illuftavit. Extat cjuLdem Paraphrafis Ifalmorum Gracis verfibus exprella: item, Lyrica, \&c.

Quô virô [Petavio] nefcio an habeat erudita lefo Societas doctiorem. Gafjent.in Vit. Peiresk. p. Iog.

Quô [ Petavio ] nemo hodie vivit in eâ, quam falsò vocant, Iefu Societrete; eruditionis ac' doctrinæ nominibus clarior. Dallaus de Pfeudepigr. Apoltol 1. I. cap. I.

Quem ego virum [ Petavium ] cum praftantiflimis quiburque omnium xta-1 tum, varictate \& copiâ doctrinæ, comparo. Vaval de Ludic. Dict. p. 24 I.

Petavius vir diligentix exactiflima, \& judicii folidifimi in Chronologicis. Montacubt. Apparat. 2. \$.9r.

Secundùm accuratifimos Chronologos, in quibus precipuo loco habeovirum vere eruditionis ac pietatis Dionyfum Petavium. Grot.3. Vol. p.948.

Permulta poft Scaligerum optimè obfervavir. Sed, quia adhuc fupercft, nolim judicium interponere inter eos, quortm uterque preclárè adeò de C'bronom H.hhLh 2 logia 
logiâ meritùs eft, ut nullis plus hre fcientia debeat. Tofjo de Scient. Mathemate. p. 238 .

Nune Uranologiumverfo Petari! opus, etiam in hoc utile, quòd Scriptores optimos repertu raros promifcui ufûs fecit. Vellem literarum causâ quas non immeritò tiumanas dicimus, ne vir ille indefefl laboris funem rixofa contentionis cum erudirifimo Salmafio duceret. Grot. ad Nic. Peiresk. Lut. I6. Sept. I 30 .

Uranologii caudam non totam quidem, fed tamen infpexi. Inter alia miror: quòd Seldenum à quo nominatus honorificè fuerat, quædam etiam placita ipfus defenfa, tanti non fecerir ut nomen cjus poneret. Tantum \& in libro \& in Indice Marmorum Arundelianorum enditorem appellat, nimirum quia $H$ areticos nifi contumelix causâ nominare piaculum eft. Idern in Epift.II. ad Claud. Salmas.

Diony furs Petavizs vir fanè doctiflmus, \& cùm multifariâ eruditione pradi tus, tum Grece inprimis Linguæ Scientî̀ non leviter imbutus. Is igitur , inter complura alia egrrgia tam in Theologicis quâm in Pbilologicts doctrinx fux mo numenta, etiam Metricam P falmorum Paraphrajin poft fe reliquit, eruditam certè, \&, meo quidem judicio, elegantem. Iac. Dupori. in Prxfat.ad Metaphraf. Pfalm.

Vir in Hebraicis haud leviter verfatus, fed, quod dolendum, viris fummis, quofqueverè dixerim Reip. Literarix Heroas, valdè iniquus, Poul.Colomefo Gall. Oriental.

Qui ad omnia, non folum falfa aut inania, fed etiam vera, certa \& omnium confenti approbata, vellicanda \& carpenda natus effe videtur. Croii Obfervat. in N.T.c.g.

Fucus ille (Petavius) qui omnes reptehendit, ab omnibus reprehendcndus, quique inter omnes Scaligerum quacunque occafone vexandum arripit, jure an äjuriâ niliil penfi habens. Salmog.in Solinur, 313 .

At Scaliger peccavit in rebus iplis, nec in verbis tantùn', quod fepè demon'Rravit Doctrinz Temporum Pater. Scio, nec enim Dews fuit, nec humania fe quicquam alicnum putavit. Sed qui taın duriter \& acerbè caftigat alios Pater, nunquamne caftigandus ipfe eft? Nunquamne ad Epiphanium, nunquamne in Dogmasibus'T beologicis dormitat! Nihil dicemus gravius in mortuum, quanquam nec vivum \& videntem niminm reveriti fumus is in libellis, quos contra ipfum à nobis confcriptos in lucem tertia mox editio proferet. Memini cum viveret, atque ad eum invifendi causâ itaremus, ne nominari quidem Scaligerum ferre poterat, quin excandefceret, ac ftomachum in contumeliolas voces, ut how mine partibus addicto, quàm erudito magis dignas crumperet. Alex. Morus præfat. ad Leet in fecund. Eufeb. Scaligeriuni edit. 16,8 .

- Tefuita ille Petavius inter Societatis fux dodtifimos numerandus eft, fed vir fuit morofits, mordax \& obtrectator, qui nunquam nif ad aliquem refellendem fcripfit. Duo confarcinavit Volumina in folio ad lofephum Scaligerum refutundum, in quem tota convitiorum plauntra evomuit, quamvis 20. jam retrò 


\section{CELEBRIORUM AUTHORUM.}

annis diem hic obiiffet. Meminifine ejus quod dicit Plinius, Hifforid fua Natralis Præfatione, folos fcilicet Lernures cum hominum Manibus dimica1.. In Epiphanium non Ccripfit nifi ut Cardinalem $B$ aronium fingulis paginis cor riperet. Guido Patin. Epiftolis fele et. Epift. 2. Gall.

Magno conatu, nihil magnum in Epiphanio præfitit Petavius Montacut. Apparat.5. Sect. 74 .

Multum debemus diligentiffmo Petavio ob Epiphanit editionem, \& ob erus ditas in eum notas. Paul. Colornef. in Paralipom. ad Chartophyl. Ecclef.

Nec ullum ferè eft Carminis genus in quo non feliciter luferit : quippe qui Tragredras etiam fcriptitarit, nec Latinos modò, verùm etiam Gracos atque Hebraicos verfus fcitifimè procuderit. Certè Hugo Grotius hujufmodi operum judex fimul atque artifex peritifimus, Dionyfir Petavii Carmina magnoperè pros bare \& laudare confueverat. Henr. Valef. Orat. in obit. Diony/. Petavii.

Extant Dogmata Theologica. Parifies I644.5. Vol. fol.

Exat opus de Dodtrinâ Temporum. Parifirs $1627 \cdot 3 \cdot \mathrm{vol}$. fol.

Extat Epiphanius Verfone ac Notis illuftratus: Parf $f .1622: 2$. vol. fol. I

Extat Appendix ad Epiphan. Animadverfiones. 1624. $3^{\circ}$. Parif.

Extat Synefins cum Verfone \& Notis. Lutetix primò editus 16I. dein 1633. \&. tandem 1640 . fol.

Extat Rationarium Temporum. Parifis 1652 . $12^{\circ}$.

Extant Pö̈mata Lat. Grac. \& Hebca. Parifits $1642.8^{\circ}$.

In Obitum P.Dionyf. Petavii, Soc. I ef. Presbyteri, cultui

B. Virginis Genowefe addictifimi :

Paulatim lentâ es fubductus morte, Petavi,

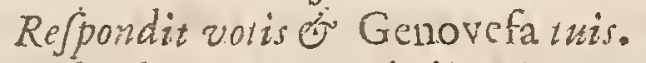

Optafic vitam, longa dedit otia vita.

Optafi morterm, mors tibi longa data est.

Sed que mortalis protraxit tempora vita,

Et mortem variis mortibus implicuit;

Immortalem eadem concefjo nurizine vitam

Prabuit, ofnullis gandia mifa malis.

Pbil. Labbe in Thefaur. Epitaph:

\section{ERYCIUS PUTEANUS.}

T Geldria Verlos natus anno 1574. Mediolani Eloquentia Profeffor fuit, Clar An.D: I ac Regii Hifrorici titulo ornatus. Inde in Belgicam accerfitus Iufto Lipfo in MDCXXX Catlyedrầ Lovanienflucceffit. Lovanii per annos 36 . cum docuilfet, obiit, anno Dom. I646. Mortum daudavit Nicol.Vernuleus. 
Edidit circulum Vrbanicurn: Librum de bilfexto; Hiftoriam Infubria; Sermones Geniales: Orationes : Epiftolas, \&c.

Viris principibus ac Magnatibus, ceterifque omnis ordinis Primoribus in Belgio, \& extra imprimis gratus, vel modeftix ac doctrinæ gratiâ, ut vel Epiftolarumingens moles atque apparatus fidem facit. Superavit omnia encomia; $A$ tticumque ftyliacumen parielegantiâa \& facilitate ufurpans, oltendere non minus vivendo, quàm docendo femper ftuduit, in literis etiam Sapientice ac Vir. tutis frudium contiverr. Aliquid infir Lipfir ctiam in vultu ac voce ejus elle, plures confelfifunt, præletrin qui Lip inuri eâ xtate noverunt. Una ei cura lemper. fuit, benè de 7 wentute \& Republic ̂̀ mereri. Valer. Antreas in Biblioth. Belo.

In co [? uteano] omnes ingenium, elegantiam, facilitatem, modefiam admirantur \& amant. Natus ad omnes Artes videtur, \&r ad virtutem compofitus. Talem illum fcripta tcitantur, piofeflio exhibet a converfatio probat. Nic. Vermul. 1. 3. de Acad. Lovan. C. I3.

Erycius Prteanus, vir admodum doctus \& eruditus. Ioan. Bona Card.

Vir clariffmus, ac in pueritiâ condifcipulus, \&cx fudiorum conjunctione amicifimus femper, Erycius Puteanzs. Voff. de Scient. Mathemat p.9r.

De Puteano fic fcribit Borhornius : "Eximium feculi noltriomamentum fuit, - \& lequentium omnium, fi virtutiac literis quod debecur decus, maneat, im 5 mortale erit.

Erycius Pateanus, vir dodifimus \& difertiflimus. Barth. I.r. Adv. c. 20.

Inter precipua Gallic ornamenta, dum viveret; merito fuo Cemper habitus eft Erycius Puteanus .15. Cafaub. prafat. ad Hif. Auguft.

Erycius Puteanus juvenis raris ingenii dotibus, \& animi vitaque candore. Zips. Cent. I. ad Belgar, Epilt. 70.

Unio hujus feculi vocatur $P$ areo.

Erycius $P$ uteanus ingenio ad optimas artes facili \& tenaci, in utravis lingu Gracâ \& Latinâ peritus, verf \& prosâ bonus, vitâ moriburyue modeftus: \& plura etiam reperienda in co, fr quis pernoverit, quàm hîc dicam. Habet $M a-$ thefm, Philo ophiar, M ufram quoque : \& plané dignifimus eft, cui bene velit , five benè faciat, quifquis doctriñam, elegantiam, aut virtutem amat. Iuft, LipSin Teftimon. de Puteara, affix. Epift. 57 . Cent. ad Ita! \& E Bifpan.

Tuquidem, Eryci Puteane Leovanienfrs Gymnafii decus infigne, allicis juvenum undique confuentium agmina, folidiffmâ reconditæ literaturæ peritiâ: Sed Italoriur voces Tuo nomini applaudentes, propria tibi referant Scripta, ipforum perfepe trita manibus, \& comprobata confenfu. Te unum merito magno Lipfo antecelfori fufrectum pradicat Belgiura. Te Eifforiographi regii peramplo

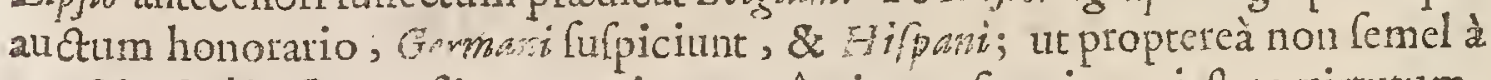
cunctis Orbis Gymnafiisconcupitus, eâ vivens fruaris majeftate virtutum, quam non ingrata poferitas, multorum etiam curriculo faculorum confervat: Eura fit. Ioun! Irap ris! in parerg. Viror. Illuft:

Quod ad ejus eruditione:n attinet, tam luculenta cjus figna in preclaris fuis Scriptis teliquit , ut Poftritas nonquam dibitatura fit quin ea \& lolidifina 8 emincntifram 
eminentilima fuerit. Quamvis ejus calamus ad argumenta quæ gloriâ cjus indigna crant fe quandoque demiferit, hac tamen ftyli fui robore ulque adeo extulic ut neminis palato non fapiant, omniumque applaufum excitent. IJaac Bullart. Acad. Scientiar. Gall.

Eryius Puteanus, VToverius Antwerpienfis ; nugatores Scaligerana : Gall.

Dominus Vofzus mihi dixit Cy oretturs celebrem iserpic Ty uthetam; dum Erario Puteano aliquando exprobraret, quod libcllos tantum cs fcriberet, refponfum ab ipfo accepiffe quòd Plutarchus aliic; Antiquitetis duthotes tales etian compoluilfent. Tum reg fic ei $M$ orettus putas-ne tuos libros, quos divendere non poffum, a harib: lib is efle xuiparandos? Quo dicto Puieanus iram tus ex $M$ cretti taberna exivit. Paul. Colome $\int$ O puic. I2j. Gall.

Extant Geniales Sermoncs. Mediol. 1598. 4n. Franeof. ad M. 1602.8․

Extant Hifolia 'nfubrice. Lovan.130. Lipf.1676.in fol.

Extat irculus Vib nianti. Lovan.1632. 4". Alia ejus opera variis in locis atqä, temporibus Cunt impreffa.

Hoc ejus Epitaphium:

\section{Eryci Prsteani Memorix Eternx.}

Candor ipse, lex amoris, ipfa lex Modefice, lex Juavitatis ipsa, vera lex fan cundia, lumen Orbis eruditi, Jeculi fulgor fui, nemini invidere natus, major. invidentibus, occidit mortigue ceffit, nefcius tarnen mori. Hunc verere of. amulare, livor, aut vittus tace.

\section{Viro Summo.}

Juft Lipfi fucceffori, candoris of bumanitatis Medulle, in exemplumberuditio niss aut virtutis nato, Baravii Amice pofuerunt.

Hoc Epitaphium iple fibi vivus compofuit:

$$
\Sigma \Pi O Y \Delta A I \Omega \Sigma \Sigma H N A P I \Sigma T O N !
$$

Audire vivus panca verba mortui

Sinon imes, quod bactenus feci, loguar.

Putcanus :go furr, fizna guers circumfluit

In liberis riabifuperftes, of libris.

Hanc effe lucern umbram fuifje sogita:

Durn navigas, vel Scylla: vel Churybdis eft:

Poft fata portus: vitu wo.te naficiur.

Quid ergos vive fe licebi non isuri.

Vixiffe pulcbre in rebus eft eternitas. 
Wortun audis: ut ego te vioum

Benè precare mortuo.

\section{NICOLAUS, RIGALTIUS:}

Mar.A.D. D Arifienfis, Jurifconfultus, Regi à Confliis, \& Bibliothecx Regix prafe ¿DCXXX. I ctus, fenex obiit Anno Dom. I652.

Seripta ejus funt: Obfervationes \& Notæ in Auctores Finium regundo: rum - In Glolfas Agrimenforias Gloflarium - Funus Parafiticum - Vi. ta S. Romani - Notæ in Martialem, Cyprianum, Tertullianum, Phadrum, Onow

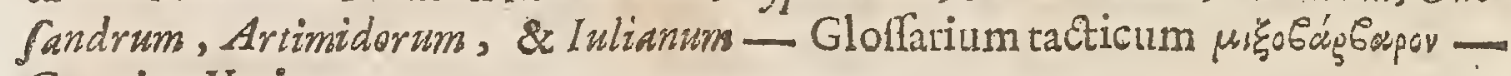
Carmina Varia.

Phadrus me tuus, clarifime vir, humaniffimè aliquando interpellavit, non liber, fed The Saurus; fed qui à tuo ingenio pretii incrementum accepit. Ut nunquam ab oculis meis elegantiflimus hic, non tam Augufti, quàm tuus libertus recedit : ita Rigaltii nomen \& fimul affectum continuò mihi fuggerit. Eryc. Putean. Cent. 4. Epirt.37.

Certèex interiore literaturâ, \&, ut fic dicam, xeturiı́ors earum ifta funt, qua eu ingenio \& induftriâ in lucem proculiti, victura in tuam famam; \& publicum uLum. Inf. Lip\}. Cent. ad Gerran. \& Gall. Epift.95.

Nicolaus Rigaltius vir eruditione perrarâ confuicuus. Gafend. de Vit. Peì resk. 1. 4 .

Nicolaus Rigaltius, politiore doctrinâ, judiciqque elegantiâ, \& incorruptâ Latini Cermonis integritate, omnibus antecellens: Cui nos, fi modò in hoc gene re literarum aliquid profecimus, id totum debere gloriamur. Ioan. Iacob. Bus card.inlaudat. Peiresk.

Nicolaus Rigaltius vir ille praftans eruditionis \& ingenii. Barth.1.12.c.3.

Cui plurimum omnis bumanitas deber. Idem 1. 28. c. 20.

Omnes eruditi te ex promilfo conveniunt, \& à te Plinii emendationem quafi pro fuo jure expolcunt: Nec jam tibi tergiverfari liberum eft, pracipuè cùm fis tam arduo negotio par, \& idoneus. Igitur fi laudi literariis tuis laboribus parte non parvum negotio par, \& idoneus. Igitur fi laudi literariis tuis laboribus parte non parvum cumulun addere cupis, incumbe operi, quod immortalem nomini tuo gloriam conciliaturum efle tibi affeverare audeo. Roland. Maref. 1. 20. Epift. 40. ad Nicol. Rigalt.

Rigaltio pro Tertulliano plurimum debeo. Edirio eft elegans, Notx breves fed exacti judiciii, \&, ut monueras, interfparsâ libertate: præfationes nicidæ \& cultr. Grot. Epift. ad Petr. Puteanum Hawburg. 26. Apr. 1634.

Indatior [Iacobo Sirmondo] Nicolaus Rigaltius \& elatior, verborum neglis gens, laborat in fententiis, eafque pil:gui, ut ita dicam, interpretatione conveRit. Huet. de Chr. Interpret.

Nicolams Rigaltius Parificnfis, Regius in Mediomatricum Senatu Confiliarius Regixqus 
Regixque Bibliothecx Cuftos, ob eruditionem celebuis fuit, \& ob fingularem Doctorum Linguarum, præfertim verò Græcæ peritiam. Præclariomnes Viri ejus contemporanci ei Amici fuerunt: Petrus verò du Puy ; cujus Vitam fcripfit, unus ex præcipuis fuit. Vix quis tam infignia merita animadvertere poterat, quin ea magni faceret. Dominus Rigaltius fingulares quandoque fovebat opiniones. Moreri. Gall.

Dominus Naudaus dicit eum fuilfe Corypheum omnium quotquot ejus $S_{x}$ culo Humaniores Literas colcbant; Criticumque nemini fecundum. Gall.

Si qua detur occafio aliquas Notarwin ejus Theologicar rum carpendi, ceterà fatcri rcnemur Notas \& Objêrvationes ejus circa Criticam, Grammaticam, \& explanationem locorum Tertullianidifficiliorum, praftantifimas effe. Ell.du Prn.
Nova Biblioth.p. 293. Gall.

Dominus Henricus Dodvvll afferit Dominum Rigaltium quamvis cartera Do. Etum \& peritum Criticum, parum effe accuratum iniis qux ediffenit, eum quamvis Romanam Communionem colat, Caivinißarum partes utpluiimum tueri; cùm apud Authores quos in lucem edcbat aliquid videbatur adverfans vedum ejus Ecclefá fed \&c Vaiverfalìs Ecclefar ritibus, id follicitè admodum ab co fuiffe obfervatum, forfitan ut cô lectu jucundiores per novitatem fierent ejus Cbfervationes. Biblioth.Vniverfal. \& Fifforic. Amn.1697. Tom. 4 pagin. 97. Gallicè.

Carmina ejus leguntur Tom.3. Delit. Gall. 23r.

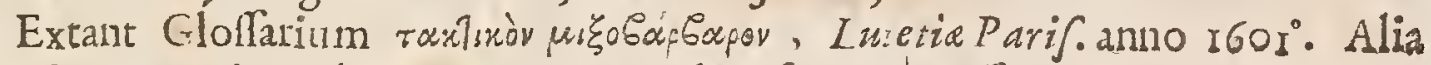
ejus Opera variis in locis atqque temporibus funt impreffa.

\section{GASPAR SCIOPPIUS,}

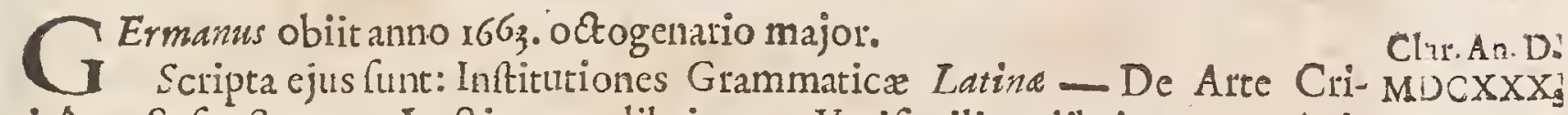
ticấ - Sufpectarum Leetionum libri s. - Verifimilium libri 4. -..-- Animadverfiones in Vofiz librum de Viitis Sermonis --_-- Animadverfiones in Thud-

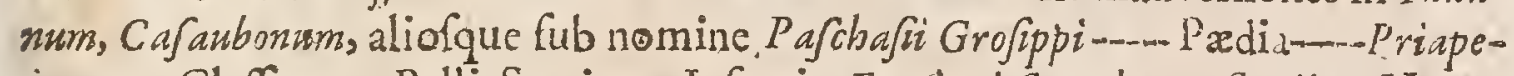
ia -..-Clafficum Belli Sacri-m--Infamia Eamiani Strada-m-Scaliger Hypo-
bolimæus, \&cc.

Neque tuos, Gafpar: Scioppi, reticere faftus poffim, qui generis nobilitati, praftantiocum quarumqne doctrinarum notitiam addidifti, ob quam Germanie cux fpectabilis, Italie admirandus, Pontificibus, Regibus, ac l'rincipibus fingulis acceptifimus, privilegia nulli ampliùs tot amplitudine meritorum conceffa obtinuifti. Ioan. Impcrial. in Mufro Hir.

Nobis dilectus Confiliarius nofter $G$ asp. Scioppins, inter $x$ vi hujus eruditos meritò recenfendus. Ferdinand. II. Imp.Roman. in Liplomate.

Nos fanè de ftudio, \& doctrinâ variấque eruditione, \& prudentiâ Gaparis Scioppii eximiam quandam opinionem, non magis ex aliorum relatione, quà $n$ 
proprio judicio conceptam femper habuimus. I dern in alio Diplom.

Odtav. Ferrarius in præluf. p. 202. Scioppium vocat virum in omni licerarum genere eminentiffmum, quiabineunte atate ita totus literis affixus fuerit, ut fexto decimo anno libros evulgarit, quos fenes admirarentur. I dem p.22s. duo. in eo pracipuè commendat, miram \& exactam vim judicii in aftimandis alio rum Scriptis, \& Cummam Sacrarum Literarumperitiam, ut, quod olim de Efdra dictum eft, deperditos Linguæ Sanct: Codices folus reparare potucrit. Addit, plures libros à Scioppio confectos, quàm annos numeraret, ejuíque Opera vel magnam Bibliothecam inftruere poffe.

Scioppius nihil nif miferabilis literator fuit, ué opera ejus inepta \& maligna oftendunt, ac extremâ Cenectâ, fcriptis Patavin Leidam Literis, tranfitionem iterum ad Evangelicos offerebat, fi in gratiam reciperetur: Sed rejectus $A p o f a-$. ta contemptufque ob vanitatem fuit. Horn. in Hift. Ecclefiaft.!p.226.

Inter illos qui Blatphemias contra Sasrem Scripturem Ccriplerunt, ducit how die familiam ifte hoftis Deicertiffrnus Scioppius; in cujus Ecclefiaftico leviter infpecto , multas legifuperioribus diebusadverfus $\tau \alpha^{\prime}$ Asowvés 5 s Scripturas blatphemias longè diriffumas capite 90 . in difputarionibus de Eidei articulis, non vult adhiberi verbum Dei, de que extat vox Domini, Inquirite Scripmeras. CaSaub.ad Apparat. Annal. Baron. num.93.

Scaligeri duo, Pater \& Filius, in utraque linguâ, \& in omnibus difciplinis pé ritiffmi, quibus incalsum, ut Lune Cenis, oblatrauit Scioppius. Bonifac. Lud. Hif. p. 602 .

Gaspar Scioppius, vir'defultoriz levitatis. Pbil. Labbe part. 2. Bibliothec. Nummar.

Valla omnes Grammaticos, qui ante ipfum vixerunt, aggreditui. Gafpar Scioppius non mitiol eft, necipfi Ciceroni Farroni parcit. Annotat. ad Relig. Medic. p. 356.

Paucula illa, qux Robertellus \& Scioppius de Arte Criticâ fcriplere, tumultuariafunt, \& hujus rei fundum omnem non emetiuntur. Dan. Georg. Morbof. Polyhift.

Quoadilla qux in Apuleium fcripfit quorum titulus Symbola Critica, negarm dumlnon eft eum inillis feliciorem fuiffe cxtcris qui ante ippum hujus Authom ris difficilis elucidationi allaboraverane. Sed, hoc concelfo., Critica ejus $V_{\text {b }}-$ riarum Lestionum limites ferè non excedit . quas pleriquie parvi faciunt. Si enim hujufmodi laborisfcopus effet, ut aliquis fructus ex illo perciperetur, opus effet ut peritus aliquis $V$ ir examinaret, quid rationi magis confentaneum in hac Critica diverfitate occurrat, utque in textum infereret, qux optima \& Authoris Senfui maximè conformia cenferet. Ephemerid. Eruditor. diei Lunæ 16. Martii 3665. Gallicè.

Homo, ut notiffmum eft, ingenii maligni \& oris maledicentiffmi, qui propter praftantifimorum, \& de re literatiâ optimè meritorum virorum invi las ac injuriofas calumniationes meritò Canis Grammaticus appellatur. Lambec. li di to 


\section{CELEBRIORUM AUTHORUM.}

Monfrum ex omni fpurcitiarum \& $\&$ celeum colluvic concretum. Baud. cent. 3. epift. 27 .

Famolus ifte turbo \& publica tempeftas pacis. Sprinfeld. de apanag. cap. 4: n. 38 .

Multa fripfit Scioppius doctè \& laboriosè, fed pleraque co animo \& ftylo, ut ad f commata \& convicia factus videretur. Limneus in add. d. cap. 5 11. 99.

Quis, quxfo, magnorum ejus \& antecedentis ætatis virorum, cujus Scripta \& famam ipre [ Gafp. Scioppirs ] non majori cum infamiâ polluiflet? Loan. Den cker. de Script. Adefpotis, P. 94.1686.

Quid Scioppius Gipbanio harpagânit, notum eft doctis, inquit Rittershufus in Epift. ad Georg.Richterum, p. 205 .

Nam quòd fufpicatur Schoppius ignoraffe Phedrum leges metricas, cui quxfo, perfuaferic ? cadem operâ P. Syrum, cadem operâ Plautum, Terentium, veterés

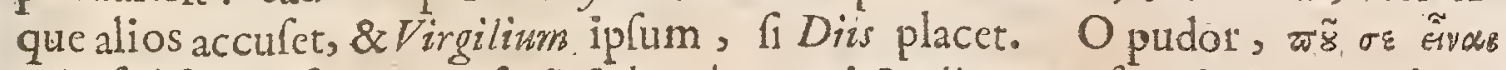
фü; fed folens fuo more facit Schoppius, qui Scaligeros aufus crt, \& Cafaubonos

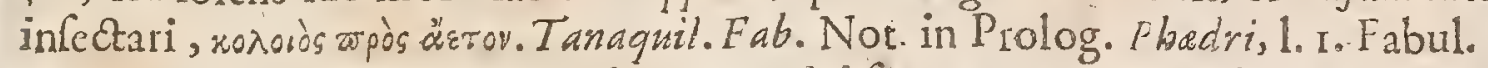

De Salmafo non queror, qui cum nemini fuorum remporum literato pepercerit, non magis quàm ille Scboppius, quem infignis maledicentia Zoilo quovis nobiliorem reddidit, nihil profectò rationis elt, cur parentis mei caufam potiorem ducam, quàm cxtcrorum omnium, qui xtate noltrâ claruere, quorum ne= mo virulentum ejus dentem evafit. Nic.Heinfins Not. in Ovid. librum 2. de Art. Amand. verf.660.

Ciceronis Accufator, de quo ut ad te fcribam me rogas, eft formidandus ille Scioppius. Mediolani librum prelo fubmifit, in quo Ciceroner incongruitatis \& barbarifmi arguit. Hxc erga Ceceronem injuftitia Scaligerum frevivifceret folaretsw. Sed fpero Scioppin cundem librum alterum confcripturum quo evincendum fufcipiet Catonem Virum minimèfrugi, I uliumgue Cafarem ignavun militem fuiffe. Bulzacius Epift. I2. ad Dominum Chapelain. lib. I8. Gall.

Varia ejus Opera variis in locis arque temporibus funt impreffa.

\section{GUIIEIMUS HARVEIUS}

A Ifgiur, I acobi Caroligue Regum Anglid, Medicus primarius; in ColleA gio Medicorum Londinen Jum Anatomes \& Chirurgix Profeflor, motu Sanguinis circulari reperto nobilis. Obiit 3. Junii Ann. Dom. I657 annoque xtatis So.

Scriplit Exercitationes Anatomicas de Circulatione Sanguinis, \& de Motu Cordis : item. Exercitationes de Generatione Animalium.

Carolus Fracafjatus aic, Italum quendam hoc Inventum ante Harvizm excoluilfe. Is nempe eft $P$ ater $P$ oulus Servita, quem Iodnnes VV aleus etiam in fce. nam protraxit, Circulationifque hujus primum Auctorem pradicat. Nimirum nec lux eft abfque umbrâ, neque gloria fine invidiâ. Iftius autem commenti fa-

$$
\text { Iijiil z bulam }
$$


bulam jampridem àte mihi natratam memini. Nempè Legatum Venetum, ad Guos reditum parantem, libro tuo de Cirulatione Sanguinis a te donatum fuiffe; eundemque pofteà Patri Paslo legendum exhibuiffe: Indeque virum hunc cew lebrem, memorix causâ, plufcula trancripflfe, quæ, iplo mox defuncto, in Haredis manus incidcrint : creditumque poltea multis, eundem Scripri hujus Auctorem extitiffe: habcreque te literas à Patre Fulgentio, ipfuslodali, ad te fcriptas, quæ rem eandem clarè ex primerent. Georg. Ent. in epift. prafix. Apolog. pro Circuit: Sang.

Penfitatis hactenus æquâ lance inter Ce rationibus Amilui Parifani, \& Gul. Harvai, concludere demum licet Circulationem Sanguinis effe veriffimam, atque Harveo immortales gratias à pofteris deberi, quod ipfis rem adeo fubtilem ac proficuam communicaverit; eandemque firmiffmis undequaque conquifitis rationibus tatan fecerit, humaniter verò ignolcendum, fi alicubi (ur in re tenebricosâ fierifolet ) cefpitaverit:\& quod iplemet x turus fuerit: Parifano autem gratias quoque debitas elfe, vel co nomine; quod commento ab VImo mutuato, reliquifque elumbibus argumentis, veritatem eandem uberiùs confirmaverit. Georg.Ent.200 in A polog. fect. 200.

Ultimo demum loco ex Anglo-Britannis prxcipuè commendandus venit, Gulislmus Harvejus, Circulari Sanguinis motu reperto nobilis Quamvis enim novam hanc \& omnibus retrò feculis inauditam ejus doctrinam cùm alii tum Aimylius Parifanus, \& Fortunatus Plempius convellere conati fucrint; ita tamen Amplitf. Dn. Prefes juxta cum aliis eos exceperunt, ut paffim,per e1"uditum orbem magis magifque Harveiana fententia alfenfum inveniat. Sebaft. Scheffer Introd. ad Mcd.p.j.

Præomnibus tamen eminet immortalis Guil. Havveius Anglo-Britannur, re-i rum ad Animalium $\gamma^{\prime} \varepsilon \varepsilon \sigma \omega$ pertinentium fcrutator indefellus \& felix, ceu ex ejufdem aureis Exercitationibus fatis fuperque perfpıcitur, queis xternum applatfum, ac minimè perituram taudem eft promeritus. Veruntamen cùm elegans ifte libellus decenti ordine careat; cùm Obfervationes in eodem enarrata non fint unius generis, variéque difperle; cùm denique plurima differtationes fint immixta, atque fic omnia in unum quafi acervum permiftim collata, vix legifur cum eo fructu qualem tot infignes Obfervationes aliàs ex fefe afferre queant. Inff.Schrader. in Prefat ad G. Harv. Obfervat. de Generat.

Guil. Harveius cum ex invento, deprehenfoque Sanguinis motugloriofifimum egiffet triumphum, ad inveftigandam Animalium Generationem animum adjunxit. Quamobrem adhibitâ frequenti Zootomiâ (nam ingens illi cujulvis generis Animantium copia, \& diffecandi opportunitas abunde fuppetiit ) permulta in lucem protulit, à fe primùm animadverfa atque notata; quæ mihi jamdiufaxü hoc volventimagno, fateor, adjumento fuere, \&cc. Interea non diffim inlabo Harvein in ejufmodiftudio ita fe praftitiffe, ut cùm fummă in obfervando experiêdoq; diligentiam exhibuerit, in judicădo tame11 perfape labarur:quippe experimenta magno labore atque induftiâ conquifita ad præconceptas Opiniopes ( quod dolenter potius, quàm contumeliosè dictum velimi ) perperam tradu- 


\section{CELEBRIORUM AUTHORUM.}

cit. Thom. Cornel. Progymnafm. V. de Generat. edit. Lipf. 1683 , in $12^{\circ}$, p. 168.

Noltro feculo Grii . Havvjus, Anglur, fingulari induftriâ \& ingenii ad Ccrutandum nati acumine, hunc Sanguinis per arteriasitum, \& per venas reditum, è tenebris in licem protraxit, \& anno 1628. ertuditornm cenfurx primus publice propoluit; eundemque firmis fundamentis ita probavit, ut veritas non quafi in crepufculo micet, fed eeu in medio conttitura colo fulgentibus radiis totum literarinm orbem illuftret. Protanto beneficio à plurimis Artis Medica primoribus meritis traetatur laudibus, quorundan tamen infimul mordetur calculis, fortunam Columbi experiens, qui pro laudabili Novi Orbis inventione, etiam à plurimis gloriam, à quibufdain fuiftra judicis \& fugillationes reportavit. Pautis autem iifque bonis placere optima laus eft. Gothofred. Moebii Fun-

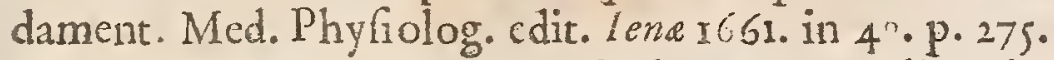

Nuper Anglia novam peperit de Motu Cordis opinionem, quam invulgavit Gul. Harveins Medicus Regis Anglia \& Anatomes in Collegio Londinenjî Profeffor, ediro eâ de re peculiari libello - Hoc fuum Commentum multis verifi $\rightarrow$ milibus rationibus adftruit; adeò ut jam multis doctis hodiè adridere incipiat; nomineturque honoris causầ à quodam populari fuo Circulator Microcofyri, ad diltinctionem alterius Angli, qui primus Macrofcomum circicuit. Primùm mihi inventum hoc non plactit, quod \& voce \& fcripto publicè reftatus fum : fed dum pofteà ei refutando \& explodendo vehementiùs incumbo, refutor ipfe \& explodor; adeo funt rationes ejus non perfuadentes, fcd cogentes : diligenter omnes examinavi, \& in vivis aliquor canibus eum ä finem à $\mathrm{mc}$ dilfectis veriflimas comperi. Plempii fundam. Medic fol. pagin. 128 .

Ex recentioribus Ariffotei felicitate par, induftriâque non minor, fed ingenii acumine, gloriâque Inventorum citra dubium major, in Angliâ noftro rempore inclauit Harveius. Hic enim quantum in Zootome praferrim profecem rit, eruditiffima ejus de Circulatorio metu Sanguinis, \& Generatione Animalium fcripta fat teltantur. Ioan. Mair. Majoris Chinurg.Infufor. edit.Kiloni $1667.4^{\circ}$.

Eft tanta cximii viri Guil. Harveii in Natura penctralia fcrutando diligentia \& Gagaciras: \& in Obfervata tradendo tam candida finceritas, ut ejus tradita, quæ omnium fidem facilè merentur, amplecti non erubefcamus; in perpetuam ip fi laudem cedet, quód invenerit, communique commodo liberaliter țadiderat de Sanguinis motu \& Animalium Generatione

\section{Que longa vetufas
Occulit arcanis Oracula merfa senebris.}

Iac. de Back Differtat. de Corde Alloq̣. ad Leet.

Scientiam Humani Corperis, Phyficæ partem utiliflumam in libris fuis de Motu Sanguinis, \& de Generatione Aniwalium, mirabili fagacitate detexit \& demonftravir Gulielmus Harymus R. R. Aacobi Caroligue Medicusprimarius; folns Iijii 3

(quog 
(quod fciam) qui doctrinam novam fuperatâ invidiâ vivens fabilivit. Thomo' Hobb. præfat. ad Elcm. Philol. Cect. I. de Corpore.

Statua ejus confpicitur in Collegio Medicorum Iondinenfum, cum hac Info criptione:

Induferiâ, Sagacitate, Succeffu Nobilis, perpetuos Sanguinis eAfus circulari Gy ro fugientis primus promulgavit Mundo, Nec pafjus ultra Mortales fua ignow rare Primordia. Auremn cdidit de ovo atque pullo librum: foc novis inventis apollineam amspliavit artem $=-m-M$ Meruitque efje fator perpetuus.

\section{JOANNES SELDENUS.}

Symbolum ejus fuit:

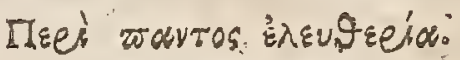

OHar. A. D: A Nglus,celebris Jurifconfultus, natus eft decimo Cexto Decemb. An.rs 4 . MDCXXX. A Sabvintonie in Conitatu Sufjexia. Obiit ultimo die Novembris Anno 1654 :

Reliquit infignem Tractatum de Ju1e Natu'æ-m-Alium de Diis Syrorum-man Librum de Synedris Hebreorurn--.-De Succeflionibus \& Pontificatum-..De Anno Civili veterum Indeornps- --De Decimis, vernaculo Sermone---Marmord Arundeliana-m-Liber cjufdem extat de Nummis. Oblervationesporio in Fle tam Ccripfit.

Ioannes Seldenus ad Iuris Patrii exactam fcientiam, Legum Mofaicarum. reliquarumque Gentium; \& literarum porrò omnium, non Latinarurn modò \& Gracarum, fed Hebraicarum \& Gentium Orientalium fingularem cognitionem adjecir. Arth. Duck de Authoritat. Jur. Civil.1.2.8. p. 193.

Seldeni doctrinam \& eruditionem non fufpicio modò \& veneror, fed etiam admiror \& exofculor planè, Cappell. in diatrib. de Nom. Iehovedh.

Magnum honorem Seldeno deferunt extranci, prafertim verò Grotine, qui eum vocat Honore Britannies Annotat. ad c. 2.1.2. de Jur. Bell. \& Pac.

Videatur de iis doctiflmus Jurifconfultus Iobnnes Seldenus, qui in his Sacris per medium fundum Antiquitatis peregrinatur, ut, ubi Sacros Scripturx locos quàm multos,ad Prifcos Deos remittunt, nobis det cnodatos: qui vir etiam fi præterea aliud nihil præftitifer, eft tamen, cur ei Antiquitatis amatores multum Ie debere fateantur. Dilber. Difputat. Acad. Tom. 1o. p. 248.

Anno 1644. Ionnes Seldenus, Anglus, Jurifconfultus, ut tot aliis pulcherrimis Scriptis, ita Differtatione de Anno Civili, \& Calendario Veteris Ecclefix, Geu Reip. Indaica, præclarè admodum de ftudiis /meritus fuit. Voff. de Scient. Mathem.p. $4^{\text {th }}$.

Per idem tempus accepit aureum eruditi Seldeni librum de Arundellianis

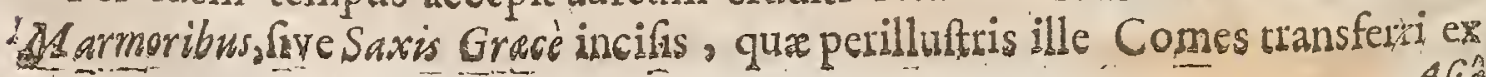


Afia in Angliam, hortofque fuos curaverat. Gajjend.de vit, Peiresk.lib.4. p. 140 .

De Noachidarum Preceptis, ex Talmudicorum fcriniis, toto demenfa horre congeffic vir Praftantiffimus Ioannes Seldenus, libris 7. de I wre Naturali, \& Gentium, juxta difciplinam Flebreormm: Qui cùm fint fummâ diligentiâ \& mirâ eruditione confcripti; nemini, falrem è doctioribus, non funt fedulò evolvendi. Ex illo fonte nos fitim Laturavimus. Ioan. Marsham. in Chronic. Secul. 9. p. IGr.

De DoctrinâThahmudicâ quid in genere cenfen̂dum fit, \& quibus ea cautionibus amplectenda, confulant ftudiofi profundie fimul eruditionis \& judicii virum, Iobannem Seldenum, in opere exinio de Iure N aturali Hebreorwin, \& jus nos judicio libenter fubmittimus. Meric.Cafaub. de 4. Linguis,p.II.

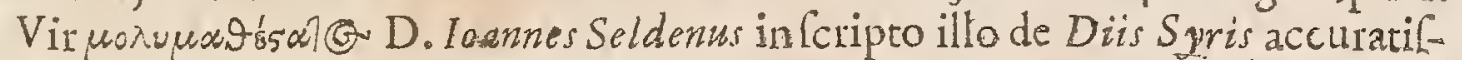
fimo; exuditionifque reconditionis cumprimis foeto. Gataker de Tetragram.

Hoc Opus de Dis Syris aureum libellum vocat Bochart. in Geogx. Sacr.

Inter omnia Deldeni Opera Ecce, (librum de Düis Syris) meo quidem calcuzlo, ompium jucundifimum \& utiliflimum. Gerardo Voffo ufque adco gratum fuit ut illud infuam Theologiam Ethnican ferè totum ejns Authorem ubique laudans, infertuerit. Tam univerfim laudatur Seldenus ut fingulorum teftimonia huc referre minimè decreverim, unicum Ludovici Mólinai Mcdici Londinenfis in ejus Apologia ad Renatums Verdexum, qui eft Andreas Rivettus enarrare fufficiat, Tantum abeft, inquit, ut me ñoffrorum $\$$ inautia ceperit, ut maximè concefferim imo viltrò agnoverim Gallia nof tram vix habere Seldeno, in fuo genere eruditiow nis, fuperiorem; at Ufferio Archiepifcopo Armachano neparem quiders. Quibus pater Dominum Molineum, quamvis Seldenum impensè laudet, eum tamen Arihiepifcopo Vfferio inferiorem agnofcere. Qua in re ipfincquaquamalfentior, 'Paul.Colome. Sel: Biblioth. p. I97 198. Gall.

Vir Clarifimus Loannes Seldenus aternum noftri feculi decus. Marshamo. Canon. pag. is.

Vir doctifrmus - Opus futum de Jure N. \& G.eruditâ \& modeftâæmulatione Grotiani Operis fcripfit. Boecler. in Praf. Comment. Grot. de J.B. \& P.

Equidem Seldeni opera landare velle, nihilalind effet, quam Soli teftimonium lplendoris meditari, \&zc. Vid. Boecler. in dedicat. Operis Seldeni de J. N.\& G.

Vir Canè non vulgari cruditione preditus. Arsold. Vinnius ad Sect. I. Inftit. de R.D. 11. 4. ubi tamenlibium ejus, quem Mare Claufur inforipfit, improbat, ejufque fentenciam Paradoxam dicit.

Quare igitur Rich. Simson non recenfuir celebris Seldeni Opera, qui Latinè non minus benè quam Anglice (cripfir, quique nobis tor infignes elucidationes tradidit innumerorum Veteris Teftamentis locorum in libris de Diis Syris, de Decimis, Vxore Hebraica, de Synedriis Indeorum? Dices forfitan Seldezurn adeo cognitum clfe ut epus non elfet illum Rich. Sirson: commemorari: Sed plurimi lunt alii, de quibus eadem ratione tacere debuiffet. Iudicis plurium Theologorum Holldandicorum fuper CriticaRich. Simonis. p.378. Gall. 
Iobannes Seldenus fuit unus è maximis Viris quos unquäm Anglica Gens habuerit. Arundeliana Marmora mirabili fuccelfu emendavit eorumq; dificultates enodavit; iilque tam excellentes Notas addidit, ut ideo dictum fuerit Lapides pro ipfo locuturos, etf homines elogia ipfi debita reticerent. Indicia Eruditor. Parif. $169 ;$ per Baillettum. Gallicè.

D. Seldeni præclara jam habuimus ex Hebroorum Ccriptis deprompta; quare in animo illi effe novis nos muneribus fuis ditare gaudco. De Synedrio pauca pro materix ubertate dedit nobis Cocbius. Non dubito quin D. Seldenuspro iftâ fuâ multijugi lectione plurima fcitu utilia ac jucunda poffit velitque addere. Nee minus placet alterum reconditæ eruditionis argumentum de Iure Gentium, quale Hebrxi coluere. - tug. Grot, in Epift. ad Samfon. I obnfin. Lutet. ${ }_{30}^{20}$ Sept.x 638.

Eruditiffimus Dominus Seldenus, unus è praclariffimis Viris quos ulla eftas unquam produxerit. Eurnetti Hilt. Reform. lib.3. 1539. p.264. Anglicè.

Magna erat ejus induftria, qua maturinis horis utebatur in fuis ftudiis Philofephicis, pomeridiano antem tempore Materiam coacervabat eorum Argumentorum circa qua fibi fatisfacere tentabat. Robuftum hab ebat corpus, fidem lem Memoriam naturalem \& artificialem, Mentis conceptum tardum ( લ̧uamvis identidem in Poeticam \& Otatoriam excurreret, tum ad animum à gravioribus meditationibus relaxandum, tum ad expoliendum \& connexiorem reddendum Stylum fuum, interruptum \& afperum (qux vitia contrahebat ob immenfam materiam quam is illum amplecti adigebat) edoctus à Benj. Iobna fono, ut quidem gloriabarur, Horatium imitari) Ced judicium Lolidum. Indon les ejus ad communicationem propenfa, Scutoriarum Imaginum eximius Interpres, ut patet ex ejus Honoris Titulis : Magnus Antiquarius, ut oftendunt Marmora ejus Arundeliana; Tractatus in Draytoni Eadmerum, plurima cjus prifca Numifmara, multóque plura neoterica; dives tum Mufro, tum Arcis; Juris-Confultifinias, quem talem demonftant ejus Obfervationes in Fletas in Tenuras, in Fortifcuti Modum tenendz Parliansentum, ejufque Argumenta, quippe qui, fi quis in toto Regno alius, Documenta in promptu haberet, $D_{e}$ cimis, qua omnem Indaicam, Etbricam \& Cbriftianam in hujufmodi Argumenrum Doctritram complcetitur : Ejws Mare Clanfwr adverfus Grotii Mare Li. berum, quo continenrur omnes Leges, Confuetudines \& Ufus Orbis univerfi circa hoc Caput; Ejus Vxor Hebraica, de Synedriits, I ex Natura Se undum confuetudines r tebrairas, qux toridem funt Monumenta ejus in Doctrina I udaica perficicacitatis; Libri ejus de Diis Syrzs, quibus evincitur quam bò noverit quomodo Ethnicorum Fabula mera fuerint corruptio Veritatum criptura $S_{a}$ Crx, \& quomodò Gentilium Doctrina Chriffiane Religioni pofit conciliari; Liber ejus de Decimis impreffus anno 1616 .offendiculo fuit , tum ob ejus Præfationem, quoniam Cleri noftri famam \& Authoritatem minuebat refpectu. Doatrinæ; tum ob ejus Materiam qua commodo ejuldem detrimentum afferebat refpectu utilitatis(quamvis ad eum refponderit Eques lobannes Temple, quoad legalem \& Hiftoricam partem; Dominus Nettles infignis Talmudifta in Regina Collegio Cantabrrgia, quoad partem Indaicam: Dominus Montacutus \& Dr.Tilfere 
Tilley' Rocheffrie Archidiaconus, quoad Grase \& Latina linguæe, ut \& Ecclefiafticx Hiftorix perititiam; ) Særvifima procella (inquit ille) quax polt Reformationem Beneficiorum Ecclefiafticorum horrea concufferit: Sed omifit, quoddic 28. Januarii 1618 coram quatuor Epifcopis \& quatuor luris Doctoribus publicoque Norario fubmiffionem fuam conteftatus fit, \& culpam agnoverit temerie tatis fux, Confuffoni fure manu proprix fubfcribens. Doctor Lloyd in luis Ads. verfariis. Anglicè.

Extat Mare Claufum Londini 1636.8?.

Extat de Jure Naturali \& Gentium, Londini 1540.

Extat de Synedriis \& Iræafecturis Juridicis Veterum Hebraorum, Londin I650. \& Reqg. annis, 4 :

Extalit Vindicix Miaris Claufi contra Burgum, Londini $1653.4^{\circ}$.

Hoc cjus Epitaphium:

\section{Ioannes Seidenus.}

Heic juxta fitus, natus eft 16. Decemb. I584. Salvingtonix qui viculus eft Fera ring occidentalis in Sulfexix maritimis, larentibus honeftis Johanne Seldeno, Thomæ Filio, è Quiris Jecundo anno I54. nato.

\section{E T}

Margaretâ Filiâ, ơ harede unicâ Tho. Bakeri de Rullington ex Equeftri Bake: rorurn in Cantu farmiliâ, filius è cunis fuperfitum unicus, etatis fer 70 . annow rum, Denatus eft ultimo die Novembris Anno Salutis reparata I654. per guam expectat heic Refurrectionem felicem.

\section{DA NIEL HEINSIUS:}

Symbolum ejus fuit :

\section{Quantum eft quod nefimus:}

Cindavenfis, natus eft anno is 80 . Studiorum fuorum rectore Iofepho Sca- Clap. a s: Autores intepretatus eft: tandem Politices \& Hiftoriarum profeffiones fufcepit: queis \& Secretarii cad \& Bibliothecarii nobile munus acceffit. A Guftuvo Adolphr, Suecie Rege in Confiliariorbmb numerum afcicus \& à Cerenifi mâ Vénem toram Rep. Equeftri D. Marci dignitate ornatus, ipfum Vrbanum ViIi. Pontifo Rom. eruditionis fux admiratorem habuit, ampliffimo honoratio Romam, ut cam à barbarie vindicarct, invitatus. Obiit ann 1655 .

Struxit Ariftarchum facrum in N onnum: irem Exercitationes in Novum Te$\mathrm{Kkkkkk}$ ftamestum 
ftamentum. Plurimaque alia, quorum Catalogum videre eft apud Valerium Andrear in Bibliothecâ $B$ ! lgicá.

Vir verè magnus, fummus, ac dodifimus vocatur Bocharto in Geogr Sac. Tam levroriorum quam amœniorum literarum Sol. Selden: Prafat.ad lib. de Diis Syr.

Magnum feculi noftri ormamentum Daniel Heinfus, vir admirabili cloquen* tiâ. altiflımâ eruditione, \& nultiplici linguarum Oricntalium atque Occidentalium peritia à Deo exomatus: Loban. Polyand. in Epif. ad Ladn. Beverovic. Leim de 24. Jul. 1635 .

Heinfio viro incomparabili, \& in quem ut Zetwis in fuam Venerem, aut Pbydias in Clypeurn Minerve, natura contuliffe videtur, quicquid eft Veneruris \& Gratiarum à me falutem. Iacob. Cruc. in lit. ad Doniel. Co.onium.

Vir abfque pari ingeniofus, eruditus, \& difcrtus, Daniel Heinfuns, fcriptor hujus fcculi primarius, veterum nonpaucisfuperior, paucis omninò inferior, cujus Gracas Lainafyue Mulas, cujus eruditionem \& eloquentiam,omnis Pofteritas \& amabit \& venerabitur; cujus lepor \& gratia nulla non praconia merentur, Catis autem extolli nequeunt. Barth. in Adverfar. p. 28.03 .

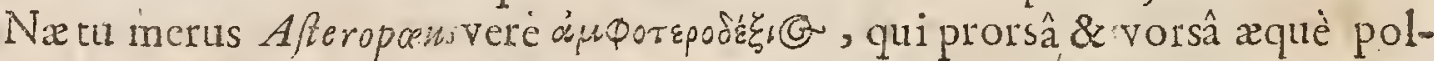
leas. Cùm verfus Grecos tuos lego, Homernm inon Heinfiurn puto me legere: cùm Latinos, Ovidium aut Propertiun. Casaub. Epin. 318.

Somnium tuum, Clarifime Heinfi, vidi, legi, relegi. Sciebam quantus effes in feriò tractandis literis; quantus in omni genere ftrix fcriptionis. Tantum ineffe tibi lepôris, tantum amœnitatis ac venuftifimæ venuftatis, neque ego fciebam, neque fortaffe quifquam alius eorum, quiè tuis fcriptis te norunt. Deum immortalem ! quàm ingeniofa fermonis ftructura ac difpofitio ; quàm ron è trivio, fed nefcio unde ex abdito petiti joci : quàm docti \&z falfi fales: quàm alta denique \& profunda atque effluens eruditio tua in fingulis propè verbis apparet! Idem in Epift. 526 .

Anacreontica tua Graca indicant quantus in hoc genere futurus fis. Certè nihil in illis verficulis tuis vidi, quod non \&laudabile, \& generofr camæna auram non fpirct. Iof. Scalig. in Epift. 277.

Heinfurus elt ingenium extra alcam, prxfertim in eâxtate. I dem Epilt gr.

Quod ad Hyrnisus tuum attinet : hoc. auro ottendis, ferrum efse quicquid alii cuderunt. Admiror penitus fcriptum, \& fic cajior̈, ut è manibus non deponam. Belga autem nifi te agnolcant Apollinarm fuum, nce lingram, nec Poëfin intelligunt. Mihi Poëmata hæc omnia videntur admiranda clec; in admirandis Hymow illum eminere. Sicutillufriffmum argumestum eft, ita preftitit $M u-$ fil fua, yuod nemo hactenus allecutus. Eric. Putean. Epift. Apparat. Epil.z2. Heinfit no nen mihi propè divinum eft. Gabr.Naud.59. Epint 59.

Heinfuns \& Grotius rarum par \& czemplum antique virtutis \& fidei. Baud. Centrir. 4. Epift.r.

O litere tux, O libri : In litcris, ipfe mihi præfons es, quas aureas, quas gemmeas appeilo: \& in libis, qui admirationem feculo, licet duro ac ferreo, in- 
cutiunt. Arifrarchus tuus ex oculis meis non recedit, quot verbis, tot documentis fertilis, omuem oftendens unius ing cnii doctrinam ac feicntiam comprehendi. Et quis te ant non novit, aut orbis amore dignum non pronuncict ? Iderr in Epif. $82 \cdot$. .82 .

Ego cum voluptatc fxpè legere folco maximorum virorum Hugonis Grotii \& Danielis Hcinfi puerilia L armina, qux initio hujus feculi edita, poftcà Opcribus ipfis non fint inferta. Qux etfr à Virilibus illis multùm difcrepant, dclectat tamcn florum illa luxuries, quos tam pixclari fructus poftea fecuti funt. Dan. Georg. Morbof. Polybift. p. 62 .

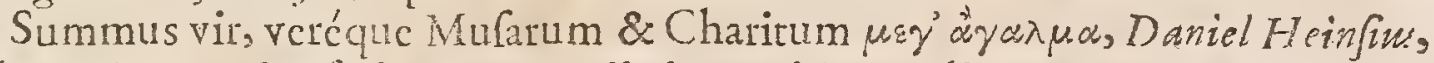
inlaudatione $]$ frit, fcripto, ut genii, ita penitiorum literarum, ac civilis prudentia plenifimo. V fl.de Hift. Lat.p. 138 .

Heinglacra Exercitationes, opus ingens \& eruditum. Boxhorn. in Epif. p. 106.

Incredibile quanto amorc illum profecuri fucrint Iofepbus Scaliger, Ianus Bou$z a$, alique viri doctifmi. Naturî ipsî̀ infructus ad Pö̈ticam facultatem, patrio ctiam rythmo exccllit, ut paucis agam. Quxcunque ab co profecta funt, limam fapiunt politiorcm : Phrafis terfa \& elaborata : conccptus fublimes : ita ut cum illis prifci fermonis Scriptoribus certarc velle vidcatur. Svvertii Athen. Belgic.

Daniel Hcinfuze in fummis vatibus meritò aftimandus, orbem eruditum fibi devinxit varii generis, varii argumenti loëmatis, in quibus nihil humile aut jcjunum, omnia terfa, folida, fonora. Dum apothcofin condit Thuano, Scaligeroque verfu Epico, tcrtiam ipfe mcretur; nec mori poteft, qui de contemptu mortis tam cecinit vitalitcr. Quàm lecta in ejus Hipponacte dictio? Sed \& quàm hinc idde aculcata? quàm fcliciter audct in Herode Infanticida? Nec Elegis ejus quicquam venuftus. Borrich. de Poët.p. I千3.

Dominus Balzacius affeverat duos Heinfii Tractatus in Horatii Satyricon effe duo preftantifima opera. Ait fe non opinari fe unquam majorem rcnovatæ Antiquitatis copiam fimul collckam vidiffe, ut ncc plus continuatæ rationis, plufque fubrilitatis majori roborc ftatuminatæ. Intutilem, pergit idcm, non navat operam in extrucndo trophæo locortm proffus fimilium fuper voccm quampiam nulla difficultate implicatam, corum more qui Notas confcribunt, quique loca in invicem coaccrvant, \& in fua? Scripta nihil nifi Lcationis fuæ cruditatem conftifionemque inferunt. $B$ alzac. Epift. in Infanticidium p.r42.143. Gallicè.

D. Voffias mihi dixit Heinfii Patris fylum hinc facilè cognofci poffe quòd plufquam quis alius pronomine Qui, qux, quod utcretur. Id non fme voluptate verum eftc oblcrvavi. Panlus Colomes. Opulc. I28. Gall.

* Danielis Heinfii Sacrarum excitationum ad Novum Tcftamentum libri 20. cjuldcmque Ariftarcbus, five ad Nonni in Ioannem Metaphrafin exercitationes cmendatiores nunc, \& auctiores editæ prohibentur in Decreto 19. Mart. $16, j$. in Decreto IS. Decembris I646. 
Extant ejus in Novum Teftamentum exercitationes fol. Lngd. Bat. $1639.4^{\circ}$ : Cantabrigia 1640 .

Extat Ariftarchus Sacer. 8.. Lugd. 1627. Alia ejus opera variis in locis atque temporibus lunt impieffa.

Morti proximus omnium penè rerum oblitus fuit; unde Conft. Hugenim Epigrarmata in ejus morbum \& mortem modulatus eft:

Sciverat Heinfiades, guantum nefcire fatentur, Quos nefore nibul credere fama jubet.

Vltima lento fubrepens infitia morbo Reddidit infantem, ner fine laude fenem:

Succeffit melior fugiente fcicntia; poftquarn

Ornnia déscivit, fcire mori didacit.

\section{In ejus Effigiem :}

Cernitis ? Hic Mundi Pboenix, ille alter Apollo, Heinfus, ut pingi corpore, $\mathcal{F}$ ore poteft. Parte fui meliore, animo tranfendit Olympum, Iarnque diu Divos inter of Astra fut. Qui plureis doctè fcripfit, quàr viximus annos; Et, pratextatus, Neftore major erat. Livor, abi. Palmam Batava meruiftis Athena, Nec regio vatem viderat ulla parem.

\section{Reincrius Neufus $/ . C$.}

\section{EDWARDUS HERBERTUS.}

Clar.An. D. MDCXXX.

A Nglus, ad Caftrum Montgomerienfe natus dicitur, inter Collegii VnizuerfoA tatis Commenfales, poltremis Elizabetbe temporibus (prout ex Aliznnom rum Catalogo, illâ tcmpeftate compofito, edoctus fum) litcras percepir; Annoque 1603 cùm Auree Perifcelidis Eques crearetur Henricus VV allix 'jrinceps, Equies de Balneo ficbat. Sunt qui credant è Collegio Regineng fuilfe Herbertum illum, verùm in errore proculdubio verfantur, atque pradicto pofteriorem fatelldumet Edvvardum Herbert Agri Montgomerienfis Armigeri Filium, qui in Reginenfurm numerum inque Album Academicum, primo Lulii die, anno Dom. I6r8: ætat.17. admiflus reperitur. Utcunque Artium Linguarumque peritifimus fuit, tantamque à Caroloprimo gratiam inivit, ut Baro Caftri Infule de Kerry', apud Hibernos, paucifque poft annis Baro de Cberbury in Anglia crearetur. De illo plura referre fuperfedeo, utpote qui ubique apud feculi hujus fcriptores memosatu:. Anton. aेVVood in Hift, \& Antiquit. Univerf! Oxon. 
Scripfit de veritate. De caufis errorum, \& de Religione laici. Expeditionem in Rearn Infulam. Vitam Henricr Octavi. De Religione Gentilium.

Tradidit mihi librum tuum de Veritate doctiffmus Doreflans. Exolculatus fum munusitud Literarurs non uno nomine. Pretium illi conciliat autor, titus lus, \& ille,per quem voluifti ad me deferri opus graviffmum, exactifimumque. Gaudeo in Britanna PhilofophariBaro :e; \&ad ftudia noftra fe demittere grandes illuftrefque animas. Gaudeo philo oppbiar non illis folùm cordi effe, qui longâ - Atolâ ambulant, hoc eft, Umbaricis Doctoribus, fed \& viris in lucem pofitis, quofque dignior fortuna fecrevit populo. Nec minus recreor Augufto Veritam tus vocabulo, ad quam aflurgat ipfe è Curuli fellâ Cato. Demerfam illam in prom fundo puteo dicebat Plato: Inveniri nó porte Pyrrbesprobabilem folùm efle Academicus. Inveniri polfe, cerramque clfe \& immobile Dogmaticn. Tu, vir fumme, Dogrmaticorum fententix affinis, non inveniri folum eam poffe doces, fed \& ocum lis Letlorum nudam objicis. Legi pleraque; nec alienate dicere \& fentire ab Arim Stotele \& Peripateticis ftatuo, licèt aliâ formâ orationis \& mutatis vocabulis, quorum majeftate \& clegantiâ gratior es lectori, \& admirabilis magis. Ubi dif fentis, facilè te diffentientem fero, cùm \& hoc inter Veritates co ismunes fit, $N$ on idemomesfentire. Philofopharis liberè nec in aliorwm verba juras, ut non folüm in tertitorio tuo, led \& Philofophorum Regno Baronatum excıceas. Qui uti libertatis civilis ctt ftudiofifimus, ita pari libertare de Vero judicas, nulli beneficio vcl metu obnoxius. Quibus Stipendiaria eft veritas, anxiè loquuntur; \& licèt fentiant fecus, linguam ca'amumque falso mancipant. Ideo utilia fibi loqui malunt, quàm vera. Tu in libertatir regno narus ea furibis, qua nec foedan fervitutem, nec licentiam effrenem fapiunt. Simul \& candidè 1 bilof cpharis \& pruden-

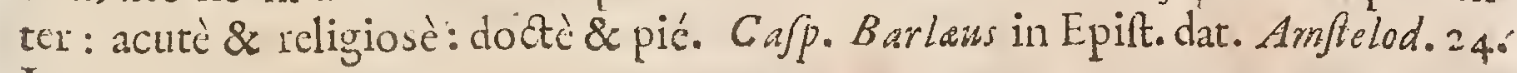
I $u_{11} .1635$.

Quamvis hæc Hiftoria [De Vitâ Henrici VIII. Anglice Regis] jam anno 1649 . evulgata, fapiufque deinde recula, initium Collectionis noftra longè antevertat, ob tudtorit tanien celebritatem non indignam judicavimus, quæ per oc. calionem muperx editionis [Anno 1683.] nobis ante paucos demum menfes oblatx, his AEti infererctur. Adeo enim, non modò apud inglos fuos, fed exteras etiam gentes inclartit ievbertw, ue cjusde ve itate libri ( fi Lloydo in obfervationibus ad vitas Azi.iffrorum Anglicorum credimus Bibliothecx Vaticane fummo cum honore illati fuerint; Hacque ipfa Henrici VIIL. Hiftoria (VVoodo in Hif.Oxon. atfirmante) in Archivis Bibliotheca Bodlcianc manufcripta prctiof alicujus ?mmelii inftar, affervetur. Enim verò fi, prater mirificam fentenciarum concinnitatem, fingulatem in judicando dexteritatem, fummumque quod ubiq; pra fe fert, veritatis fudium fpectemus, optimo fane jure hunc feriptorem inter prattuntifrmos xtatis noltra referemus. Orditur autem annales fuos ab Ann. I49I. quo lucem adipexit Henricu, definitque in anno 1547 . quo fato conceflit I'rinceps ing ntibus vitiis, que magnis virturibus redemir, famofus. Videtur ve xô argumcntum tam nobile de indultrî̀ clegiffe terbortur, in quo fuam in dicen-

akkkk 3 cendo 
cendo vim exereret, cưm non folùm infignis rerum Getmanicarum, Gallicarum, \& Hispanicarum inclinatio, fed religionis etiam per Angliam memorabilis mutatio illo rempore facta fuerit, quæ ex Ä̈tis fecretioribus fumnâ curâ perlütra* tis, \& Hiftoricis fcculi fuperioris fide digniffimis diligentifimè cruta, Lectori in compendio quafi ante oculos ponit. AEta Eruditor. Menfis Mare. 1686.

Aliquot ab hinc annis edidit librum de veritate, prout difinguitur à revelatione, àverifrrili, à paffebili for a falfo, item librum de caufis errorum; nec non de, Religione Giniliurn errorumque apud eos cauff. (Nain cxtera, qux hinc inde Auctor promittit, num lucem huc ufque confpexcrint, non conftat) quibus Commentariis fuis mirum eft quàm fibi plaudat elatiffmi animi Scriptor, \& c. Omnem movet lapidem $B$ aro, ut in odium, invidiam \& contemptum adducatcommuniter receptam doctrinam, eamuque cum fuâ collatam novitcr repertâfapien-

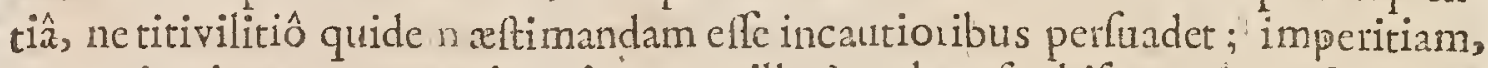
prævaricationem, nugas, incptias, cavilla trophas, fophifmata, impofturas, \& nelcio qux non, paffim Scholis exprobrans. Qux tamen Evpruata fi paulò infpectentur acriuts, nonnifi perfonatas fubtilitates effe, aut, fi quid folid $x$ fubfit fapientix, vix aliter, quàm vocum novitate, à receptâ fcholarum doctuina difcordare, dudum harum rerum peritifimisfuit animadverfum. Kortbolt. de tribus Impoftor.Sect. 2 .

Aliquot dunc effuxere Menfes, Nobilifime \& Generofifime Baro,quòd librum tuum acceperim de Religione Gentilium, erroruma; apnd eos Canfr;idy unat cum literis Serenifini Electoris \& tuis. Et pro libro \& pro literis non polfum non gratias agere quàm maximas. Delectatus fum plurimùm \& Argumento, \& Scriptionis genere. Vix itaque dixerim, quàm avidè, quantoque cum fructu illum devolârim. Nam jam animus êt, ut fribam tibi, quid de hoc Opere fenriam. Scio quàm difflultcraudirc laudes tuas poffis. Audiant has illi, quibufcumfepè de hôc fcripto colloquor, cum tempus \& occafio patitur, quæ nunquam non fefe offert. Dum itaque fapius lego, \& rel go, illos tuos Commentarios, animadverti verum clfe iftud, nullam in bonis rebus effe fatictatem. Ger. 1oh. Voflo in Epiredat. Amstelod.1645.3. Kal. Tan.

Holingshead, ped, \& Stove, meras rerum publicè cognitarum relationes tradiderunt, plurefque errores committunt. Eorum veftigia premunt fere omnes neoterici noftri Scriptores, eaque tantum excerpunt \& repetunt quæ ab ipfis fcripta funt. Dominus $H$ erberd Se minime dignum autumavit ut alii fecerant nugari, ideoque diligcntius exquifivit autographa Monumenta quàm ullus eorum qui.ipfum præcefferant, fummaque fidelitate ac indufria Henrici VIII. Hiftoriam nobis tradidit; verim rebus Religioncm fpectantibus tamdiù non immoraturut argumcitum poftularet, hac fcilicet Viris diverfa à fe profeffionis relinquens, \& forfitan exiftimans minus congrum fux conditionis viro, hujufmodiargumentorum plenam \& accuratam tractationem perfequi. Burnetti Praf.adfuam Hit. Reform. part. I. Angl.

Excellcntilfmus fuit Artifex, Polyglottus eximius, tam Virorum quam Lin brorum ftudiis operam navavit, ipfeque duorum valde infignium Operum Author 
thor fuit, qux funt Traetatus de Veritate Gallicè confcriptus,tanto apud Tranfmarinos in pretio habitus, \& etiamnum (ut perhibent) pcihononificè in Papa Biblioth. Vaticana exiftés; jus Hiftoria Hentici VIII.ubi ejus Collectiones plenæ funt \& authenticx. Ejus Obfervationes fagacitatem fipirantes, ejus Connexis vallidd \& cohxrens, totum verò opus accuratum. Da. Lloydi diverfarin. Anglicè:

* Ejus libii de Veritate inter libros prohibitos numerantur in Zndice Ruma impreffo $168 \mathrm{I}$.

Obiit 20./ Augufti Anno Dom. 1648. inque Ecclefix S. Egy dii, extra urbem Londinenerr, Adyto Repultus requielcit.

Exrat Tractatus de Veritate, unà cum libro de Caufis errorum, \& de Religione Laici. Lond. an110 I645, Lat.

Extat Vita Henrici Octavi. Lond. Anno 1649.Angl.

\section{A.C O B U S USSER I US.}

D Atriâ Dublinienfis in Hiberniâ, in Parochiâ S. Nîcolai natus Anno 1580. quarto die Ianuarii, quafi Strene loco in orbem miffus; magnum centè futurus, cum latrie fure decus, tum Ecclḉr Dei beneficium. Clun familiâ fuit, Archicpifcopus Arnoricharms, \& totius Hibernia Primas. Obiit viccfmo primo Martii, anno 1655 .

Opera ejus Laiziza hre funt: De Ecclefrarum Chrittianarum fucceffione \& ftatu - Hiftoria Gottefbalci - Epiftolarum Hibernicarm Sylloge - De Primordiis Ecclef.Brtanicicarum - Ignatii Epiltolx cum Annotationibus Appendix Igratiana - De Romana Ecclefire fymbolo A poltolico vetere, \& aliis fidei romulis - De anno folari Macedonm - Epiltola ad Capellum de variantibus textûs Hebraict lectionibus - Annales Veteris Teltamenti - Annales Noui Teftrmenti - De Grećl leptuaginta Interpretum verfione fyntagma - De Cainane fupenddito dilfertatio-...-. Chronologia facra. Scripfit plurima Anglican fermone.

Iacolus VJferius valte lectionis \& eruditionis Theologus, inque Antignitate

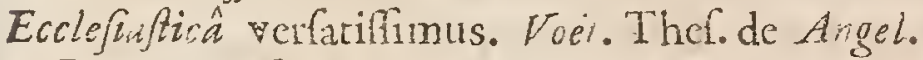

Reverendilmmus Antiftes lac. 7) ficrins, Arch. Armachinus, vir fummâ pietate, julicio fingulari, ufque ad miraculum doctus, \& literis feverioribus promovendis nat s. Losn. aelden. Marmo: Aruidel.

Non opus elfe arbitror, ut quod $V$ eriano nomini infcriptum prodit, Lectori datâ operâ commelidem. Norunt quotquot liceras meliores colunt, nûrunt $\&$ femidocti; quanta fuerit VJjeri, \& quàm diffula crudicio, quàm infinita lcctio, quantajudicii graviras. Inter tot ceitè litcrature Inftauratores \& O1thodoxæ

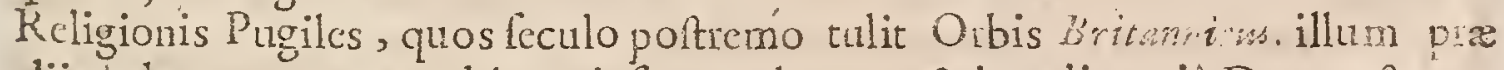
aliis habernus quem nobismetiplis gratulemui, \& in re literariâ Duccm facuamus. Henr $V$ barto in Prefat. ad lac Vjjer. Hiftor. Dogmatic controverfo inter Orthod. \& Pontif. de Scriptur. \& Sair. Terna ulis.

Multum equidem debeo, quod non cefles augere \& Bibliothecam noftram libris, \& nos doctrinâ. Ut mitran quæ mileras priùs, quàm gratum acceptum- 
que aureolum, five aureum potiùs munus tuun de Britannicarum Ecclefarum Anitipuitetibus. In quibus ambigo, magifine mirari conveniat fingularem Induftriam, an fummam eruditionem \& judicium exaetum, quod etiam tuin elucet, cùm fatius judicas judicio fuperfedcre. Ger. Ioh.Vof! in Epift. p. 375 .

-..- Quo de viro, rerum divinarum humararumque peritiflimo, nihil pof fum dicere tam fublime, quin ejus id virtus fuperet. Vof]. de Mather. p.392.

Vir vafta eruditionis, nec fine laude nominandus. Iderm ibid.p. 446.

Summa fummi viri, \& undccunque doctiffimi merita de Ecclefîa, \& totâ Rep. Licerariá, nunquam finent, ut non æternù m ab omnibus lizeraruri amantibus memoriâ gratâ celebretur. Idern de Vit. Scrm.c. o.

I arobus Vjeerius Archiepifcopus Armacbanus, totius dibernis Primas, Anti-

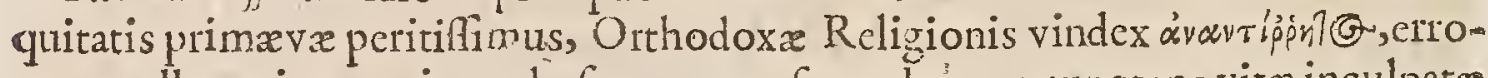
rum malleus, in concionando frequens, facundus, præpotens vitæ inculpatæ exemplar fpectabile. Rob.P ink. Vice-Cancellar. Oxon.publicis Almæ Academix fuffragiis in convocatione A.D 1644

Iacobum VJjerium locupletiffimum folidæe eruditionis \& totius Antiquitatis Gazopbyllacium appellat Prid.aux, Epifc. Virgorn. in Apocal. de Mille Annis.

Virum fingularis pictatis, \& omnigenæeruditionis laude cumulatum VJ]erium vocat Davenant Epifc. Sarisber. Exhortat. ad Pacem.

Alexander Moru in oratione Geneva habitâ, Vfferingue infcriptâ, illum vocat excellentifimum Dei fervum, Reverendifimum virum Dei, Ceculi noftri Athanafiur, tuum pectus eft Bibliotheca fpians; tu Britannid, quod Ang hatiTus Hipponi, vale, Maxinum 'Britannia decus. Anno 1648.

Iacobus VJjerius omnigenæ ac recondite eruditionis laude, linguarum orientalium peritiâ planè fingulari inclytus -...- Illud venerabile toti Europa caput--Sepofitâ authoritate illầ, quâ apud omnes pollet maximâ, \&c. Arnold. Boot. Epif.comra Iu C Capell \& Append ad Buxtr.rf.

Ingentes tuæ virtutes, fumme U fieri, non veftro tantùm Orbi notx lunt, fed \& noftro, \& ubicunque terrarum pietati fuum decus $\&$ eruditioni fum pretium conftat. Spanber.. Epift. Dedicat.3.part. Dub. Evangel.

acatbolicormer doctiffimus vocaturVJJerius à Fitz-S nons Ie fuitâ.

Quod \& dignifimo Axchiepifcopo Armacbano debemus, in quo,cum incredibili doct inâ \& râa purionis Antiquitati cognitione, (quam norunt \& Tagus \& Ganges, forfan of Anipodes) Morum eximius candor, \& in inftuendo imperitiores mira fuavitas, feriâ quadam \& Epifcopali mixta gravitate, certare dignofcuntur; à quo non parìm me in hoc opere prov hendo adjutum profite or, utpote qui luto herentem frpiùs extraxit , \& deviantern in vitam reduxit. Rog. 'Tuvijd. Lpif. Lector. Hitt. Anglic. Script. Io

-. Archic pilcopus Hibernie VJerius, magnæ diligentix judiciique Vir. Grot. in Proleg. Hiltor. Goth.

Confciaeft Hibernia, intelligit Anolia, novit Orbir Chriftianusuniuerfus qu? \& quanti fuerint ejus pro Ecclefia Dei fufcepti labores quantx curæ \& folicitudines. Nota funt Regum I acobi Caroligue de co judicia. Diligentiam ejus \& induftian 
induftriam quis non mirabitur? Ego certè quoties eam cogito, non polfum quin exclamem( quod de Cefare Cicero) ô horribilem diligentiam! Gul. Batef. in Vit. Ujer.

1 Reverendifimus Lac. U ferius, Archiepifcopus Armachanus, fuo merito ob infignem literarum omnium lcientiam, inter Britannie Noltra Urnamenta annumerandus eft. Arth.Duck.de Authorit.Jur.Civil.Roman.

Fac. Uferizu, vir admirande tum p etatis, tum eruditionis, Colomes.in Paral:pom.ad Chartoph.Ecclefiaft.p. 43 .

De tanto Pixfule filere preftat, quàm pauca dicere:cùm talis fit [quod olim de Antonino Philolopho dixit Hiltoricus] Quers mirari facilius quis, quàn lawdare poffut.Pietatem ejus infgnem, perpetuam in legendo, (cribendo, concionando, induftram, eruditionem in re antiquaria , Theologia, \& omni humanioris literasuræ genere fummam, cum æquali modeftiâ conjunctam, fufùs laudare nec opus, nec mihi animus; Hiftoriam enim non fcribo; fed Epifrolam, Virtus enim V/feriana eft fui ipfus Panegyrica, laudis noltræ non indiga.Vivitaternumque vivet in Scripturis tuis Cedro dignis, in ore \& corde Doetorum, in memoriâ hominum, \& monumentis temporum; illumque [ quem Hibernia parens ingrata, tali flio \& Prefule indigna, bonis (praterquam animi) omnibus exutum in exilium mifit ] Poftertas [era venerabitur.

Quô nibil majus, meliufveterris
Fate donavere, bonique Divi;
Nec daburt, quamois redeant in aurum
Tempora prifum:

Thom. Earlovr, nunc Epilc. Lincolnienfis in Epilt. Dedic. Dom. Timoth. Tyrill, prafix. Ujeer. Chronol. Sacr.

Dono tuo accepi Diatribam tuam de Symbolis Veteris Ecclefar. Pro iftis tuis etga me meritis; debitas rependó gratiarum actiones. Magnâ cum voluptate, nec fine fructu, legi poltrema ifta opufcula;in quibus igneum ingenii vigorem, \& reconditam eruditionem, abtrufifrma quxque rimantem, \& bono publico eruentem, ex animi fententià dico, fum admiratus.Clausd.Sarrav.ad I ac. Vjer. Armac. Lut.Parif.28.Octob.1647.

Tantum abeft ut me noftrorum фiraurís ceperit, ut facilè concelferim, imò ultrò agnoverim Galliam noltram vix habere Seldeno in fuo genere enditionis fuperiorem;at Vjerio Archiepifcopo Armachano ne parem quidem. Lud.c Molinaus, Med.in Apolog.ad Andr.Rivet.

Ex quibus patet, quamvis a Molineo magnis efferatur laudibus Seldenus ab ipfo tamen infra Epifcopum U Je erium collocari : Qua in re me fibi fuffragantem non habet, Colomies.Bibliorh, felect. Gall.

Neceffarium non puto Uferii Armachani opinionem feu potius paradoxum L $11 ! 11$ confutare, 
confutare, qui duplicem rüv Septuaginta nomine infcriptam Verfronem Gracam extitilfe arbicracur. Priorem $\tau$ ẅy Sepinaginta verè fuilfe putat, hanc lub Ptolonnco Philadelpho continuatam fuile; fed alteram, q a Ale xandrie parite fub Prolomæo Phifcone fuerat elabo:ata, queque genuina non elt, eam elle qux hodiedum nubis fupereft. Dominus Valois novum hoc Syftena optimè confutavit, Epitola in hanc rem ad UTerium confcripta.Otatorii Presbyter. Richard. Simon. Hilt. Crit.V.T.1.2.c.3. Gall.

Inter quos. ( filicet ejus Operis fautores ) primas meritò tenet, Primas ille Reverendifimus Hibernise facobus Uferius, Archicpifcopus A Armacbarus ¿ uxudérms vir doetrinâ multifariâ, pietate, modellia omnibus confpicuus, cui propria hæc laus erat nil proprium habere, fed ex effus bonitate omnia, in Reipublice literarix boum communicare; qui inftuctifimâ fủ Bibliothecâ libros plurimos MSS. vel imprelfos variorum Idiomarum nobis libenter commodavir, confliumque funm quando ipfum convenirem libenterimpertivit, quô in multis me adjutum proficeor. Brian. Walton.prafat.in Bibl.POJyglott.

Deus bonc! quàm reconditâ literaturâ refertus. Stupebunt exteri, gratulabuntur pofteri hanc feliciratem. Fo eph.Hall. (Epifc.Norvvic.) in Epift. Gratulat. pro libris Annaliwn dono mifiss.

Reverendus hic Author, præter magnam fuam peritiam in omnigena utiliore \& politiore literatura, immenfam fuam lectionem, fuanque ficilitatem in ufum quavis occafione revocandi quicquid legerat, fibi adeo univerfam celebritatem paraverat ob piam \& ordinatam fuam vitam, lenitatem \& moderationem, ut \& fuam humilitatem, afrabilitatem, hiberimque acceflum in omnibus converfationibus, fimul cum fua facilitate atque luberitia ad gratam confuetudinem continuandam cum is quibufami verfatus crat, ut vel merum ejus nomen authoritatem fccum gereret, \& ad reverentiam atque exifimationem \& Perfonx \& judicii fui adigeret vel illos iplos, qui neminis nif proprio fui ipforum judicio facilè fe fe fubmittere folent. Hac Doftor Sanderfon Epifcopus Lincolnienfis, Prafatione pramilla Trada tui poftbumo Domini Primatis de Poteftate Principis, \& Obedientia Subditi. Anglicè.

Clementia tua eruditos Labores tuos dignata eft mecum communicare pro quibus verè profiteri polium, Ecclefiam in porterum non moris reverentix Memoria tux debitricem fore illâ quâ nos hodieno tempore Perfon:m tuam colere tenemur. Gul. Londinenfis Epifcop. po teaque Centuarienfis Archiepifc. Epittola qua nunc in manibus eft illitis Eruditi ac Solertis Nobilis facobi Tyrelli Uferii Epifcopi ex. filia Neporis. Anglicè.

Nat rales ejus dotes tam varix, tamque infignes fuerunt ut ratò in uno codemque homine tales concurrant; Nimirum inventio focunda, Memoria tenax cum Judicio: quorum ope jam ah adolefcentia illicò paratus crat ad quodvis exercitinm fibi impofitum, quodque ambitu fudiorum ad qux appulifet andmum comprehenderetur. Verboque ut quod ies eft dicam, optimè illi po- 
reft applicari Character quo B. Auguftinus infignicus eft, videlicet. Infignis erat fanetifimi Préfulis manfuetudo, ac miranda animi lenitas, \& quædam invincibilis clementia: Linguam habebat ab omni petulantiâ \& convitiis puran; Ingenii felicitas prorfus erat incomparabilis, five fpectes Ingenii acumen, vel obicurifina facilè penetrans, five capacis memorix fidem, five vim quandam mentis indefatigabilem. Vide Vitam Archiepifcopi Ujeriz fcriptam à Doctore Par, ejus quondam Capellano, prefixam nupero Volumini Epifolarum ad prafatum Primatem \& ab ipfomet foriptarum. Anglicè.

Sinul cum ingenti atque vata eruditione fua (Epifc: Uiferius ) nemo unquam meliorem Animam, Mentenque magis Apo tolicam habuit. Infla Converfatione vera n Cbrifiani fimplicitatem exhibuit. Nam Iracundie, Arro. gantix, Obtinationis, vel Amoris Mundi ne minimulum quidem veftigium in illo Viro ubfervabarul : adeò te tota columba innocentia in ipfo exilteret. Modo quodam hominum corda fibi lucrifaciendi, horumque Confcientias afficiendi utebatur, qui redivivam Etatem Apoltolicam quadantenus fpirabat. In duobus hilce optimis exercitiis magnam temporis fui partem infumebat, Arcana videlicet Precatione, alienarur que Conlcientiarum Directione, tum publicis concionibus, tmm privatis fermonib s ; temporis antem refiduum Studiis fuis dicabat; In quibus quàm Atpenda fuerit ejus diligentia \& accuratio, cum judicio fubacto ex multitudine Voluminum ab iplo confcriptorum liquidà conftat. Adco ut clarifimis, \& optimis Viris quos Seculum,-imò Univerfus forfitan Orbis tulerit, certifimè fit annumerandus. Verum nemoelt omnibus numeris abfolutus, ad Muneris fui partem regiminis functiones fpectantem minimè natus erat; nimia erat Animi ejus lenitas ad alperum opus reformationis Abufum promovendums, quaproper in ftatu quo res invenerat illas relinquebat. Reformationis tempus venturum effe fperabat: Plurimos abufus refcindendi necellitatemanimadvertcbat, \& fatchatur tolerantiam abominandarum corruptionum à Canonifizs invectarum adeo fœdam maculam elfe in Ecclefra optimè omnium alio quovis refpectu teformata, ut metuerer ne hinc in totam Confitutionem maledictio \& exitium accerferetur. Sed quamvis Deum precaretur ut aufpicatior opportunitas affulgeret, \& animitus cuperet ad horum reformationem concurrere, non tamen eum adhibebat conatum quo illam ex fuo munere fufcipere tenebatur. Admodum autem verofmile eft hanc negligentiam animum ejus, gravafe dum moribundus decamberet; identidem enim fubmiffifimè precabatur ut Deus peccata omifrionis fibi condonaret, fuaque in officio fro delicta. Non fune magna repugnantia id la me tandem impetrare potui ut aliquid dicerem quod characterem minuere videbatur Viri tam eximii, qui in cxteris omnibus guofvis fios contemporaneos antecellebat, fed hac tantum in parte infra fe ipfum deprefus eft : Et illi qui omni alio refpectu ipfum amabant \&admirabantur, hunc in ipfo defectum deplotaverunt, qui unicus nævus in ipfo remanflfe videbatur, \& abfque quo majori forfitan quàm conveniret venerationi apud homines fuiffet. Burnetti Vita Epifcopi Bedelli p. $8,56,87$. Angl. 
* Iacobi Ufferii liber Gravifimæ Qúxtionis Chriftianarum Ecclefarum in occidentis pralertim partibus, Hitorica explicatio, ab A poftolo um temporibus ad nofram ulque ætatem continuâ fuceeflione, \& ftatu, omnino prohibetur in Decreto S.Martii. 1616.

Varia ejus Opera variis in locis atque temporibus funt impreffa.Vide Catalogumad Calcem vitæ Rev. Primatis à Richardo Par, S. T. P. Sacellano olim duo fideliter confcriptum.

En ejus Epitaphium à Richardo $P$ ar, S. T. P. ad calcem vitæ non minus verc̀ quàm argutè fcriptum, quamvis nullum nifi in operibus, ejus memoria anhuc politum eft Monumcntum:

\section{S.}

Zacobus Ujerius,

Archiepifcopus Armachanus

Hic Jitus est.

ob

Praclaram Profapiam,

Raraineruditionem,

Ingenii acumen,

Dicendi, ơ Scribendi facundiam,

M orum gravitatem fuavitate conditarns-

Vita candorem, of integritatem,

Equabilem in utrague fortunâ animi constantiams

Orbi Christiaus, \& piis omnibus charus;

Orniungue judicio, praierquam $\int \mathrm{wo}$

Preful veré magnus.

Qui Ecclefiam veterum infitutis,

Clerum exemplo,

Populum concionibus,

Ajsidue inftruxit:

Cbronologiam Sacrampriftino nitori reftituit:

Bonarumb A rtium Profefores,

Inopiâ afflittos,

Munificentia Jublevavit:

Denique qui Herefes repullulantes calamo erudito contudit.

His ingenii datibus, bis animi virtutibus ornatus,

Praful optimus,piiffinus, meritiffinus,

Cum inter Bella Civilia, or Ecclefia, o Patria Juefunesta,

Sibique luctuofa,

Nec Ecclefie, nec Patria diutius prodefle poterats

In Chriffo Pacis Autbore placide obdormivit?

Amno Era Gbrifiane MDCLV: 
Atatis Jue 76 .

Rigate in Comitatu Surreice

Martii 21. obiit.

A pud W eftmonafterium in Capella S.Erafmi fepultus.

April.s. 1656.

\section{ROBERTUSSANDERSON.}

R Otheramia, in A gro Eboracenfi, Miniftro patre natus, 19 . Septembris anno Clax.A.D. Baccalaurei in Artibus gradum, in Socinm electus eft. Sed relicto mox Cullegio, Rector de $B_{0}$ tbby-Paganelli in Agro Lincolnienji, necnon Ecclefix ejuf dem $C$ athedralis Prabendarius factus eft, $\&$ tandem longo poft rempore $S$. Theologia Doctor, ejufdemque Facultatis in Academiâ Oxor. Profelfor Regius. His omnibus, Regiarum partium fudio, quibus femper haferat fidelis, à Parliamento privatus eft; fed in Caroli II. reditu Epifcoparu Lincolnienfiremuneratus.

Scripfit Logicæ \& Phyficx Compendium. De Juramenti Promilforii obligatione Prælectiones feprem. De obligationc Confcientix Pralectiones decem. Epifcopatum prout nunc in Angliâ litabilitur, Regie poteltati, nequaquam prajudicare, Angl. Quættiones duas practicas folutas, Angl. Quinque alias ejufdem generis Quxtiones practicas, ab eodem, variis temporibus, folutas, $A$ ngl. Sermones triginta, \& amplius. Creteros, quos publici juris fecit, libros, cu m in Catalogo Bodleiano recenfeantur non heic operx pretium erit enumerare. Quamplurimos infuper Tradtarus apud fe confervaros, quanquam multorum judicio in publicam lucem prodire dignos, cumfuprema \& faralis hora inftaret, ipfe Aammis tradidir, ne fcilicet iplo defuncto, imperfecti quæftûs grariâ evulgarentur.

Ab ipsâ juventute prxgnanti fuit, necnon capaci intellectu, fidelifimá memorià, judicioque folidifimo; qux quidem omnia, methodo, \& multâ cogitatione mirum in modum excoluerar. Hifce Nature dotibus, maturus jam annis, prudentiam, \& induftriam ipfe addiderat, fimul \& fagacitatem in quærendo, \& perfpicuitatem in explicando; animo íerenus, \& fedatus, vitâ \& moribus gravis \& fobrius. In Fidei \& Religionis Controverfis exercitatifimus ; P atrum \& Scbolafticorum Scriptis volvendis verfarifimus, fuique Seculi Cafuifarum (quos vocant) facilè princeps. Neque quilquam ferè eft, alicujus laltem apud Nofrates in Literis fame, qui non honorificentifmè femper illius mentionem fecerit. Uferiut Armachanus persficacis ipfum compellatione infignivit, \& accepto ab illo cujuldam à fe propofitx Quaftionis refponfo, omnes ejus apices, \& circumftantias, ab illo tam felicirer confideratas fatetur, omnemque dubitandi anfam adeo precifan effe, ut ne minimus quidem ulteriori fcrupulo locus re-

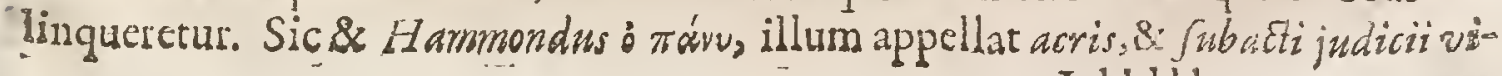


rum, químeditato loguitur,prudenter. cognoscit, exactè difinguit, decretoriéfert sen tentiam, Senfa animi liquido, aptè, veraciter expromit. A nt.à Wood. in Hilt. \& Antiquit. Univerl.oxon.

Propter mite ingểium, ănimum æquabilem, mores candidos., do Arinam fingularem, bonis omnibus femper acceptilimus-...-. Edidit alia quxdam qux à viris doctis \& prudentibus admodum probantur; de Confcientiâ verò acutè, difinctè, perfpicuè , fummuque cum judicio fcripfit--.---In Controverfis dirimendis verfatifimus erat. Rob. Grov. in Refponf. ad Celengma, paq. $38,39$.

Aliam hiltoriolam filentio praterice non debeo, quippe quâ Doetoris San-. derfoni Pietas, ejulque quatenus $C$ afuite eximia peritia \& acre judicium arguntur. Gum aliquando colloquerer cum Illunti Equite Roberto Boile (cujus Pietarem pluris atimo quam ejus nobilitatem \& enditionem, quamvis urraque infignis exiftat) de Cafi Confcientix circa furamenta \& Vota corumque naturam \& obligationem, in qux peculiaribus de caufis, intimiùs tunc penetrare cupiebat, Sanderfoni Libum de far amento apud ipfum laudavi, cujus lechione cum fibi abund fatisfactum ellet, à me petiit nùn arbitrarer, Doctorem illum induci polle ad furibendum de cafbus Confcientia, fi honoraria penfio ipfi affognarcur, ut Libri ad hunc finem necelfarii fibi fubminiftarentur. Ipf refpondi me putare cum id facurum : Epittolà vero ad Doctorem fcripta,ipfí retuli, quanto cum delectamento Praclarus ille Vir \& plures alii legillent librum ejus De.furamento; ipfumque rogavi num ipfi liberer ad emolumentum Ecclefra aliquem elaborare Tractatum de Cafibus Confcienize. Mihi refpondic fe gaudere quòd aliquis aliquem è fuis libris fruetum percepilfet, addens infuper, fi futurus aliquis fur Trabatus tantum emolumenti cuipiam allaturus foret, quantùm videbamur dicere à priori fuo allatum fuifre, fe manum ad opus illud libentifimè admoliturum, quamvis abfque ulla penfione. Hoc cim accepillem refponfum, præfatus illeVir illuftris quinquaginta Libras per manus meas tranfmitti curavit ad bonum illum Dodtorem, cujus conditio, ut plurimorum tunc temporis bonorum admodum tenuis crat ; Iple autem extemplò recognoyit, abfolvit \& evulgavit eximium illum librum De Confcientia. Qui liber mole quidem exigutus eft, non autem pretio, fi beneficium confideremus quod exillo ad peritum Lectorem redire potel. Ibi enim occurrunt tot generales Propofitiones circa Confientian, circa ejus Naturam \& Obligationem., explanatæ atque probatæ tam folida Coníquentia \& tanta Rationis evidentia, ut qui illas legit, memoria retinet \& poteft prudenter bic \& nunc, \& appofitè ad particulares Cafus applicare, illarum auxilio ac luce,poffit rationabiliter mille patticularia Confcientix dubia vel fcrupulos refolvere. Hxc Doctor Thorn. Barlove nunc Epifcopus Lincolnienfis, Epiftola ad Dom. If. Waltonum. Dat.Londini Io.Maii I678.Imprefsâ cum. D.Waltuni Relatione vitw Doctoris Sanderfoni. Angl.

Quamvis iplum acriori Iudicio quam alios Natuma beavillet, ei tamen ufque adeo 
adeo diffidebat, ut iterum atquie iterum retractaret Confegnentias, \& adeo differret ac fecum recoleret quid determinaturus elfer, ut quar vis nemo meli's unquam determinaret, attamen quando campanx Ggno in Auditorium advocabatur, ut Oxoniz Theolagicas fuas Lediones haberet, omnefques-Dilcipuli expectarent ad illum andiendim, nondun co tempore, aut falcm tunc demum ternporis Iatuiffet \& fcripflfer quod deterrinandum prxcogitaverat; Adeo ut id verithmum effe videretur, quod antiquus \& intimus amicus ejus Doctor Scbeldon frepius dixerat, nimirum, quò Jud cium ejus hantafian adeo luperaret ut quicquid ab hac fuggeretur ab illo faftidiretur \& improbaretum conctite \& rependendo, donec tantum fluxillet temporis ut fribere cogeretur, non quod optimum, ut verofimile eft, fed quod ultimum animo volverat.IS. Walton in Vita Doctoris Sanderfoni. Angl.

Doßtor Robertus Sanderfon ex Nobili Familia Sanderfonorum in Eboracenfa \& Lincolnienfi Comitatibus, in Schola Licolnienfi eduencus, fub Methodico Magifto, \& fedizlo Praceptore in ejufdem Loci Athenao; gui acre illius ingenium, capacen cjus intellectum, fidelem ejus Memoriam, folidum ejus fudicium, cui vires addiderunt Method.s \& profunda Apprehenfio, magna fpei gravitatem ejus, fileutem, fedentariam \& ftupendam cjus Induftriam, ad exquifitam illam perfectonem dcduxit, qua fque ad ultimam vitæmetam onatus fuit (hanc autein fed litate itrictanve accurationem ob crvare voluit in jaciendis Dootrina fundamentis, th hac vicitim in ea que f, pertruerentur inAluerent.) In adolícentia Me oria Artem didiçit; cu nenin in pueritia juberecur memoria mandare, qua non intelligebat, frmilitudinibus uti cogebatur, \& mente recolere qux ignora hbi erant, cogirando de quibuldam is que noverat affinib s. Scrius exat in fuis propolitis, prudens in fudiis fais, indultrius in fua Merhodo; ; clarus in conceptibus, Gagax in fuis Difquifit onibus; ferenus ordinarus \& methodic s, in cogiratis his ; Sobeus \& comis in fuis moribus, quoniam ejus educatio praclaris ejus dotibus addiderat eam humilitatem,imanfuetuedinem, modeftam,obfequentian, \& urbanitarem, qua laudabili eju, difpofirione adaucta iplum in atate proveca reddiderant fuperioribus morigerum, crga requales officiofum, eiga inferiores indulgentem, affabilem, munifcum, ( bona in juventute difciplina Obcdientix habitum in atatc matura generat.) Sollicitus ejus Animus confictabatur cum tricis, perplexiratibus, obfcuritate atq e conf frone Naturæ; \& intentus erat genuinæ termappelienfoni, potius quàn operofx verboum collectioni, excepta Grammaricx periria qua ad mentis cogitata congruè, \& Rhetorica ad eadem perfuafibiliter proferenda fuficerer, coque Loyice ú quo fuos conceprus methodice ordinari, duci ac dirigi poltent; res di inetè apprehendendo, de is fanè judicando, yeritatem in iis hatententem feliciter cruendo, crtores, deceptiories, \& fallacias, qux citca ilo lam nobis oxuduntur evidentcr confurando : veritatefque detectas rationibus omni exceptione na joribus urgendo. Dan.Lloidi Adverlaria. Angl.

${ }_{5}^{*}$ Ejus Libri de Confcientiâ,feu de Obligatione Confcientix, \& de Juramenti Promilio= 
Promilfotii Obligatione, inter Libros prohibitos numerantur in Ind. Rom. Imä prelt.Anno $168 \mathrm{I}$.

In Choro Ecclefia fuæ Bugdenenfis in Agro Huntingtonia inhamatur, cui fe. quens Epitaphium fic inferibitur:

Depofitum Roberti Sandexfon, nuper Lincolnienfis Epilcopi, qui obiit Jan.2o. anno Dom.M.DC.LXII.\& ætatis fux feptuâgefino fexto, hîc requielcit ing fpe beâte Refurrectionis.

Varia ejus Opera variis in locis atque temporibus impreffa funt.

\section{PETRUS HEYLINUS}

Clak.A.D. he $\operatorname{cxx} \times \mathrm{r}$.

$\mathrm{N}$ Atrse êt Burfordie,ágri Oxonienfis Oppidi Mercatorii 29.Novemb. Anno I599. In Collegio $M$ agdalenenfi educatus eft. Anno Dom. I631. Novembris primo Prabendarius Weftmonasterienfes in loco Docturis Darrell defuncti factus eft. Anno 1638 . per commutationem cum Magittro e A thingon Collegii S. Foannis Baptista Ecclefix de I Ilip juxta Oxoniwm, Rector de Warn borongh Auftrali in Agro Hiantonien/i evafit, \& ejufdem Comicatûs pro pace confervandâ fuftitiarius, afcitus eft. Anno 1639. Apr. 10. in Convocationem Cleri pro Ecclefia Wefmonaffafcitus eft. Anno 1642. defertis omnibus ad Regem Oxonii commorantem fe contulit, à quo Mercurios Auticos fingulis feptimanis confcribendi cusa ipfi demandata cft : In hoc munere per integ cum penè annum pertitit, in eodern à Magittro qoann. Birkenhead è Coll. Omnium Animaram tum fuccenturiatus. Paulo polt à Parlian ento inter Delinquentes declaratus, bonis ornnibus, \& libris totầq e re Ecclefinfticâ multatus êt. Anno 1644. Patrono fuo Laudo, \& deinde ipfo Rege in anno 1648. immani fententia è medio fublatis, primò in pagum, quem $\mathcal{M}$ infter Lovellorum vocant, juxta Burfordiam, inde ad Curiam Laceranam Abendonic fe recepit, utrobique in Ecclefix Anglicane defenfiones fcribendo totus; ufque duin redeunte Carolo I I. ad onnes, quibus excidilfet, in Ecclefiâ promotiones reftitutis fit.

Scrip̧ frt varia, cæeteris verò palmam præripiunt Hiforia S. Georgii de Capi padocia. Hiltoria Sabbati. Expofitio Symboli. Colmographia. Hittoria Epifcopatûs. Hîtoria Reformationis Ecclefix Anglicana ab Henrico VIII. ad Reginam Elizabetam.Vita Gulielmi Land Archiep. Cantuar. Hittoria Presbyteriana.

Vir eximiis Naturx dotibus, ingenio \& memoriâ inftruetiflimus. Poëta, Hiftoricus, Orator (etiam extemporameus) addo \& Satyricus infignifimus. Hoc folum infelix, quòd aliquammultos, priufquam obiret, annos, ex acri quấlaborabat febre, oculos amifit. Hoc illi ad altiosa in Ecclefâa Lurgenti fimul \& 


\section{CELEBRTORVM AVTHORVM.}

majora in fudiis molienti fufflaminavit. Ant.à Wood in Hift.\& Ant.UnivOxor.

Doct. Heylin Vir fuit eximiis dotibus ac eruditione pradirns, quique Hiftoriam ucunde fatis feripfit; [ed in quibufdam nimio partiam ftudio ducebatur, quod bon hiltorici fame repugnat : Cumque iplemet quibuldam controverfis adnodam implicitus ellet, omniacjus circa Ecclefiam.noltram Scripta clare oftendunt utras partes tucretur, quod, ut mihi quidem videtur, Hit oricum minimè decet, qui neurri partium addictus ellè deber. Et fi modô infamià pollet afpergere quos Puritanorum Sectam nominabat, ab initio Reformationis, non admodum curabat an univeriæ Reformation is fam hinc coinquinaretur. Stillingflecti Dialogi inter Rom. Sacerdotem, Fanaticum Ecclefraften, \& Ecclefix Anglicanw Theologum. Anglicè.

Bini Authores Ecclefiafticam Hiftoriam agggreffi funt, Fuller \& Heylin. In prioris manus inciderunt fcripta quadam paica, antequam ab illo evulgarentur nond m vifa ; fed quoniam phantafticus erat $\&$ infolitum fribendi modum affectabat, ejus opus Leetori parum fatisfacit : Sed DoEtor Heylin comiter \& venuftè fcripfit, methodo ye ac fylo laudabili, ejúque Opus ab omnibus libentiùs legebatur quàm ullum aliud ańte illud editum. Sed aut rerum ignarus admodum fuit, aut affectibus valde indulfr, cüq; violentifimis præjudiciis exacerbatus effet in Viros quofdan, qui rerum tunc temporis geftarum pars magna fuerant, multa tam infolenti modo iefert, ut clam ad id inftiga=tus videatur ab Ecclefure.Romane Sectatoribus, quamvis illum Poteftantem fincerum fuilfe nullus dubitem, fed quibuldam propriis opinionibus obliquè abductum. In uno fanè nequaquam excufari poteft, quèd nulla unquam authoritate firmat qux fcribit, quod cuivis candonari nequit fcribenti de rebus ante fuan atatem geftis, novaque \& eatenus incognita referenti. Adeo ut quibus fundarentis nixus majorem libri fui partem contexuerit conjectaie tantùm nobis ilceat, plures autem in fuis conjecturis ad ipfi favendum haud multùn proclives fint.Burnetti. Praf.ad :part. Hilt Reform. Angl.

In omnibus ejus.Libris Stylus ejus blandus \& tamen mafculus eft; fenfus ejus plenus \& copiofus, ejus verba clara \& intellectu facilia, ejus notiones nur erofxac perfpicur, ejus Argumenta appofita, nomentofa, \& evincentia. Hujufmodi perfectiones, qux in uno Individuo rarifimè concurrunt, Doctori Heylin inerant in emine:ti \& fupremo gradu, videlicet judicium folidum, acutum ingenium, foeta \& ópulenta phantalia, Merroria sam prodigióa, prompta \& tenax, ut plerarunque omnitim Artium \& Scientiarum Apotheca fuerit. Q odque maximè mirum eft, neque atas, neque æurumna detrimentum ei attulerant. Nam plura erudita volumina, quæ nomen ejus præfe ferunt, poftguam vifu orbatus elfer, fcripta fuerunt. Hic autem praterire nequeo debitum illum characterem quem illi tribuit Doctifimus quidam vir, nunc vero Ecclefræ noftra Prælul, quòd nimirum Doct. Heylin nullum unquam fcripferit librum, quantumvis mediocre $a c$ è trivio fumptum foret $\epsilon j$ s arg mentum, quin dignus idem fuerit qui d Doctis legereur. A lius verò celebratifímus Profelfor, jam, Oxonien $f_{1}$, cum ipfum officiosè aliquando invifiltet, domum rediit fumma cum admirat one incomparabì- 
lis ej: ss peritiæ, dicens fe nullum unquam Academicx Cathedræ Doctorem aut diviffe qui copiofius magifque dilucidè de novis Argumento judicium ferret quàm Doctor noiter fecerat, de variis Theologici, capitibus fibi propolitis. Adeo ur quod de Catone Livius afferit,abfque ullo veritacis difpendio de hoc venerando Viro.affimari poffet, $N$ atum ad iddiceres, quodcurnque ageret. Georgius Vernon Recton Bortoni ad Aquam in Comitatu Gloceftrie, in Vita Petri Heylin excufa Londini anno 1682.p.253, is4. Angl.

Ejus Hitoria S. Georgii a Doctore Hakezivill agri Surreienfis Archidiacono multum impugnata eft, in Libello, quem contra eam fcripfit, calumnis referto. Polteà vero Hakevillus in libro cui Natur a Apologium titulum fecir,omnia à fe in libello predicto, contra hanc Hiltoriam prolata, aquillimo animo retractavit.

Obiit Wefmonafterii 8. Maii, in ipro Afcenfonis die $1662 . \&$ in ejurdem Ecclefix Choso fepultus eft, juxta fedem Subdecani.Verùm Cenotaphium ad Aquilonarem parietem extra Chorum erigitur,cum hoc Elogio à Doctore Fohanne Earles ejuldern Ecclefix tunc temporis Decano compofitó:

Hîc jacet è propinquo Dépofitum mortale Petri Heylin S.T.D. hujus Ecclefia Prabendarii \& Subdecani, viri planè me orabilis, egregiis doribus inftruAifimi, ingenio acri \& fuecundo judicio fubacto, memorià ad prodigium tenaci; cui adjuxit incredibilem in fudiis patientiam; qux, ceffantibus oculis, non ceffarunt. Scripfit varia \& plurima, quæ jam manibus hominum reruntur, \& argumentis non vulgaribus fylo non vulgari fuffecit. Conftans ubique Ecclefix \& Majeftatis R egix Alfertor, nec florentis magis ucriufque quàm afflictæ : Idemque perduellium \& Chifmaticx Factionis Impugnator accerrimus: Contemptor Invidix, \& animo infracto. Pl ra ejufmodi meditanti mors indixit flentium; ur flearur efficere non poteft. Obiit anno Atat. 63. Pofuic hoc illi mœftiffima conjux.

\section{CASPAR BARTHIUS.}

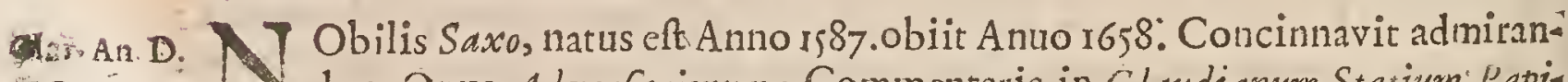
- DCxixr 1 dum Opus Adverfariorum: Commentaria in Claudianum, Statium Papinium, Guilhe Imurn Britonem, $\mathcal{Y}$ amertum, \& alios. Pietatem ejus faris oftendit elegantifimum Opus Soliloguiorum. Aiunt ipfum cxx.Adverfariorum libros reliquiffe,prioribus multo : elio:es. Konig. Acad.

Gafpar Barthius, immortale Germanic ornamentum. Dilber.in Difputat.

Clarifimum illud Germanie lumen Bartbius incomparabili Adverfariorum. Idem ibid. Tom. 2.

Gapar Bartbius Criticus, \& Philologus multæ eruditionis.I o.Card.Bona. Bartbins 


\section{CELEBRIORUM AUTHORUM.}

Bartbius vir multæ quidem lectionis, fed naris haud prorfus emunetx. Paul. Colomef. Opulc.p.250.

Casphar Barthizs, vir dootifrmus, \& propè infinita lectionis.VofJ. Inftit, Dö̈to lib.2. p.30.

Virum [Bartbium ] narramus generis \& famæ claritudine, elegantifimarum Artium tum Gracarum tum Latinarum cognitione, verreque fapientix Profellionc exculiffunum, cui parem inexhaufx Doctrinx Opibus Germania vix habuir \& quo in prime, medix, infimæ Antiquitatis Scriptoribus, iifque five Chriftianis five Gentilibus luculentiùs verfatum Exteri vix poterunt oftendere, imò cujus virtutem juvenilem ac cordatos aufus forephus Scaliger fuppexir adeò, ut divinationis inftar hanc illi de Barthio vocen excidific compertum fit, N'aium efje adbucunwm aternitati ingeniurs, quod $\int \mathrm{i}$ ad maturitatem pervesiset, literas ali-. quandin vivere poffe. Theodor. Spizel. in Templo Honor. Referat.

Quanta in talibus, \& præcipuc̀, quod Auctores ip os attinet, major hodie Philologorum pars ignoraret, abligue co [Barthio] fuilfet? Etiam eo adolefcenti uti Doctore non crubucrunt Taubmannus, Siberus, Scbnidius. Qux Gruteri, aliorumque apud cxteros Virorum de eo tum lata fuerine judicia, domi corum liter afo fervate partim, partim lecte docent. Diligentia \& labor in co fupendus, fi tantum ${ }^{\circ}$ gogito quæ habeo \& vidi inedita, nee unquam edenda. Chrifoph.Dawrnits in Epift. ad Thom.Reine farat. dic 28.Decemb. Anni $: 650$.

In funt gaudco, frivola mea eâ fclicitatc fuiffe, ut incidercnt in Cenfoiem talem.Cl. enim Barthinm, at quem virum! elfe cerris document's feire videor. Judicium verò ejus, qui de omni genere Scriptomn pronunciare prafumplit fecitque luculentifime, fuftinere non eft in laude ultima. Thom. Reines. in Epift. dat. Alienburgi dic s. Ang. 1637 :

Pauci Critici plures Authores quàm ipfe mendis expurgaverunt. Hæc publica ejus profefio fuit atque occupatio. Commentarios reliquit in Claudianum, Statium, Gulielnn Britonum, Ramertum \&c. In Trogilium etian laboravit, in Petronium, Rutilium, Epifolas Pliniz junionis, aliofque Authores, fed pracipum ejus Opus funt ejus Adverfaria in 6o. libros divifa, quæ apud plurimos, pirferim verò apud Germanos in pretio \& exiftimatione funt. Barthius, ut perhibent, 120, alia Adverjaria prioribus adhuc preftanio moriens reliquit; Er in omnibus ejus imprefis opcribus honefatis \& mode!tix charam cterem quendam cernere eft, qui eorum merimm illuftrat. Quidam tamen animadverterunt eum, quando judicia fua format, memoria defectu in contradictones interdum labi. Judicia Eruditor. per Bailletum; Parif. 1685. Galo, licè.

Ingens apud Barthim occurrit numerus Citarionum qux nihil continent, queque ad hoc tantum confarcinatę vidcneur,ut valtam ledioncm \&felicen memoriam oltentent. Biblioth. Univer falis \& Historicasanni 168 . Tom. 5.pag. $27 \%$
Gallicè.

Copiâ lectionis ineshauftà, memorix promptitudine fupendà, judicingravi tatefummâ , \& ingenii pleftantià incomparabili Philologus excellentilimus". $\mathrm{Mmmmm} \quad 2$

Oninis 
Omnis etuditionis antiqux penu. Quemadmodum vel unicum illud Adverfariorurn volumen, cujus fimile nunquam ab uno homine in literas milfum, teftacur. Varro alter, fr quifquam, meritò dicendus, qui tam multa legit, ut aliquid ei fcribere vacarem iremul, tam mulra fcribit, quam vix quendam legere polfe credamus. Tobias Magirus in Eponymol. Cririco.

Gafpar Barthius de omni eruditione humaniori benè meritus, \& prefertim de Clavdiano. Cenfere aliorum poëmata maluit, quàm multa iple fcribere:quoties tamen iftuc eum rapuit impetus, fatis docuit nihil fibi in arte universâ invium effe.Borrich.de Pö̈r.p.Izj.

Extant Adverfariorun libri 60. Franc.1624.Fol.Alia ejus Opera varios in $10=$ cis atque temporibus imprefla funt.

\section{DAVID BLONDELLUS}

Clar.A.D.

(I) Alus, obiit A Anstellodami, fexto die Aprilis Anno Dom. 1655. anno: Scripea ejus funt:Libellus de foannâ Papijsâ-Apologia pro fententià S. Hie- onymi de Epifcopo \& Presbyteris_De Primatu Ecclefix-Affertio Genealogira Erancie - Tractatus de Sibyllis -De Formulâ regnante Chrifo-_-I fidorus Vapulans-De Eucharifià̃,\&c.

David Blondellus, Gente Gallus Cabilone in Campania ortus eft.A tener is annis miram in Literas propeufionem oftendit, in iis fatis felicem fuccelfum nactus eft: Eruditas enim addidicit Linguas ac Theologiann: fed Hiftorix prefertion fefe addixit.Dominus Blondellus feliciffima, fi quis al us, memotia pollebat, id ei maximo ad propofitum iftud emolumento fuit; magno ctiam ingenii acumine præditus erat, quo utiliter ad novas detectiones ufus eft-Vir frugi erat, lectionis prodigiofe, rerum maximarum capax; \& quamvis nec Gallicè, nec Latinè ritè fcripferit, ejus tamen opera eruditione mirifica fota func qua illa reddic digna Eruditorum curioficate. Moreri Dietion. Gall.

Blondellus vir inter Religionis fux confortes parem in Criticis fortaffe non agnofcebat, fi verò errores in illis commiferit ejus fortunx commodis potius quàm vel ignorantix, vel prxjudiciis, ii funt afcribendi. Fudic. Eruditorum. $P_{2}$ rif.168;. Gall.

"Doctiflimus ille temporum magifter Blondellus. Tanaq. Faber. part.r.Epift. P.I48.

Nunquam Graca Eeclefaratantum Zonare, Balfamoni,Nilo, Grecifque aliis debuit, quantum nunc Blondello. Præter lectionem \& multiplicem \& diligentem amo valdè methodum \& perfpicuitatem. Hug.Grot.in Epift.ad Sarravium, Lum cet.17.Jul.1639.

Blondellus, magne vir diligentia, fed fuxparti fupra aqum addious. Hugt Grot.in Epift.ad Voff.Lutet.22.Aug.1643.

Blondelli omaia videre defidero. Eft enim peritifimus Hiftorixe fed nonnun- 
April.1645.

Davad Blondellus, vir doctiffimus, adversis Chifletium feribere julfus, non ras rò facit, quod in adverfario reprehendit, neque lemper penfi habet, quid fcribat, dummodò caufæ fux ferviat:quanquam profeetò hoc non eft caufx fervire, fed nocere, fi quis fudio cortandi proxima quequearripit, cenfet, vexat, neque de ulcerioribus \& citer ioribus cogitat.Io.Boecler.in differt.de S.R.J.

Privatâ auctoritate Itylum publicum tocius Europæ corrigere aufus.Ibid.Voc. Romanum.

Prout in partes fibi invilas aut dilectas incidit, in contraria quafi ventô circumagitur. 16id.

Incomparabili labore confcripfit accuratifinam Cenfuram Decretalitum If fe. dori.Conring.de O.J.G.c.16.ubi \& c.19. Opus iltud praclarifimum vocat.

Stupend. vir induftrix. 7 dem ad part. 3. Lampadic.6.

Spirans illa Bibliotheca omnilque antiquitatis hiforicx thefaurus, eleberriw D. David.Blondellus.Schoock. in Fab.Hamel.p.9r.

David Blondellaws, vir Antiquitaris Hiltorixque Ecclefrafice fingulatiter peritus. Faient. Henr.Vogler. Intrond. Univerf.in Notit. Scripr.c.6.

Nemo fere et eruditorum, facrapreferim tractantium, qui vel ex ipfis tuis dơtifimis laudatifimifque lucubrationibus non perfpexerit, vel ex famâ faltem non didicerit, quanta tua fit in omni literarum genere exeellentia, \& quàm accurata Antiqui arum, maximè Ecclefiaficarum nocitia:quarum tamen omnium Auctores fic trivift, omnes finus atque anfractus fic explorafti, omnia fecula, tempora, ac penè momenta fic ad unguem indagata calles, ut prodigii inttar fit, unum hominem res tam ab ditas eruere, tam involutas explicare, tam diverfas, tamque innumerabiles animo omnes amplecti ac memoria tenere potuilfe. Io.Dallaus Præfat.Apolog.pro Ecclef.Reform.

Percurri cum voluptate D. Blondelli Diatribam de Suburbicariis: de ipsâ ré inunquam aliud quàm iple fenfi. Non polfum faris laudare viri fummam diligen-, ciam defxcatumque indicium.Hug.OProt. Epilt.183.ad Claud.Sarravium.

Blondelli diligentian pridem admiratus; quo plura ejus lego, eu adniror magis. Grót.Epilt.ad Sarrav.18. Jan.1640.

In Antiquitate Ecclefialticâ verfatillimus fuit Blondellus.Rivet.Grot.defcript. dialyl.\$.10.

David Blondellus,inter omnes Minittos, qui Reformatos fe vorant, Hiftorie Veteris peritiffimus. Rivet. Apologet,Difcuft:

Blondellus vir piifimus, \& fupra fidem in rebus Ecclefiafticis doctus. Bochart. in Epirt.

Ac Sibyllina quidem Carmina, \& prifcis Urbis ad Siricium Epifcopis affictas (impudentià an fultitiâ majore incertum) à Lucumone neício quo Epiftolas Rlon-

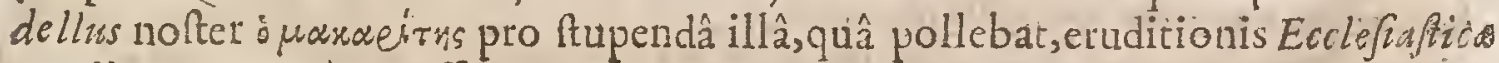
copiâ ita accuratè excufirt, ita omnia novitatis \& impofturę argumenta patefe it, ut omnibus \& noltrarum, \& alterarum partium hominibus, æquis quidem \& can- 
1014

\section{$C E N S U R A$}

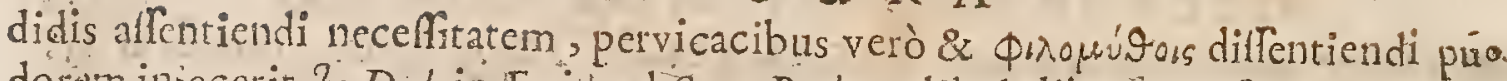
dorem injecerit. Fo.Dal.in Epittad Sam.Bochart.lib.de libr.fuppof Dionyf.Arcopay. \& Ignat.Antioch.præfix.

Extat de foannà Papisâ Latinè, Amstelod.1657. $8^{\circ}$.

Extant Pfeud-Ifidorus \& Turrianus vapulantes, Genova 1628. 4-.

Extat Apologia pro fententiâ Hieronymi de Pteshyteris \& Epifcopis: Amfiem lod.1646. $4^{\circ}$

\section{RENATUS des CARTES, five CARTESIUS}

Clar. A.D. DCXI.

1 Obilis Gallws, Philofophus hujus féculi celeberri : us. In Turonibus natus, firpe fuit,in Aremoricâ,\& Paclonibus, illuftri:à primâ juventà ftudis deditus, in Philofophia, \& Mathematicis, ftupendos fecit progrellis : $\mathrm{Ar}_{\mathrm{i}}$ a dein in Germanì \& Hingaria feliciter circumtulit. Hinc Philofophia fecelum polcente, Egmontium in Hollandiam conceffit, ibi annos 25. comoratus; Edidic hic primò Meditationes prima Philolophie, quibus cùm varia objicerentur, on nibus. eruditè \& folidè fatisfecit:Intereà ex omnibus orbis partibus per Epiftolas laceffitus, ut velut Oraculum quoddam relponfa daret. Dein Parifios veniens, à Ludovico XIIl.\& Card.Xichelio inviratus eit, ur ibi fedem figeret: Sed Aulam Mufis non convenientem ratus excufavit le. Nihilominus C'brifina Suecorum Regina frequenti rogatu Holmiam venit, ut fingulis diebus horà quinti matutinâ in Bibliothecâ ejus illaminftrueret. Sed paulò polt obiit vir incomparabilis Anno 1650.æatatis 54. Hofman.

Scripfit Dioptr'cam: Gcomeriam: Principia Philofophix : Metcorologica: Epiftolas:De Homine: De Pafionibus, \&c.

Nobilis Cartefus, Thilofopboum hoc avo Coryphais, omni laude dignus. propter acumen \& folertiam, \& Heroicos conarus in promovendo Philofophico tudio. Sam. Mares. Theol. Elenchic. Nor.Synopl. Tom.2. Controverf.2r.

Fortunatus Plempius eum Renatum Democritum vocare folebat.

Fuit profect Cartefo ingenium crectum, \& indagande Veritatis avidum, \& filcepto par negotio, nifi viventi prefidia, tandemque vita defuiffet fumma fuit Mathermaticarum difiplinarum peritia, quarum tam immodico Hagrabar fudio, crieras ut omues fub earum $P_{1}$ ictipra redactas vellet ; id quod optandum, led materia conditione vix fperandum permittitur: fuic acre limatumgue judicium, \& nifi liquidx ac prope dixi rractabili dew o ntraioni cedere nelcium, fed nimis anxium in rebus pracipuè Metaphy/firs \& Ethicis, quas $M$ atbematzcâ períequi

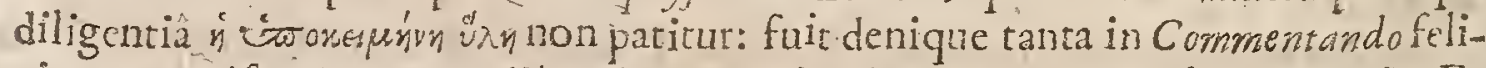
citas, ut Ariftetele commodiùs, acido \& verius, in hy ficis permulta docuesit. Et hoc negare non eft niî malignomm: Sed an ideò Aristotelì comparandus? Rilum vix renebam, nuper, cum in Aulicos incidifén, qui de A riftotele contemptiùs - quàm de Dificipulo, de Cartefío magnificenciùs quàm de Niagiftro loquebanutu. 
Et ita judicare Sciolorum demum 'elt. Nos latidamus Cártefum, Arifrotelemadmiramuc. Ábrit invidia dicto:non dicam centum, fed compluria ta en ex fuminis xat is noftrę ngeniis in unum conflari oporteret, ut Ariftotelem redderent. Alex. Morus in Prefat.prefix. Enfebii Chronic.

Renatus Cartefus: vir proculdubiò optimus atq; ingeniofiffimus, ac ferio Philofophus, \& qui videtur ad Philofophix hajus [De Materia \& Motw] contemplationem ea artuliffe auxilia, qualia fortaffis nemu unquam alius; intelligo eximia is Matbematicis peritiam; animum naturâ atque affuefactione medicationis patienti frmum; judicium prejudicis omnibus \& ; popularium erroum laqueis exutum, extricatumque, quinetiam plurimis iifque non nifi certiffimis \& felectifimis experimentis intructum;abundans otium, ab inutilium libroru, le. ctione,\& avo amentis leculi electione propriâ immune, ne memorem incomparabile ingenii acuinen, \& facultates quibus præeftabat eximiis tam clarè \& diftintzè coitandr, quan mentem fuam paucis verbis admodum plenè ac dilucide explicandi: Ifaac. Barrowr.in Opufc.p.156.

Cartefii Epitolx pleræque Phyfici Argumenti Cunt. Novæ Philofophiæautor fuit Cartefurs, quax tamennon ita nova eft, ut non apud Antiquos ejus Dogmata appareant, ut per fingula capita facilè demonftrari polfet. Fuit qui illa ex Mofe deducere voluit, primis fcilicet Genefeos capiribus,quod ipfi Cartefro ne quidem per tomnium in mentem veniffe opinor. Ejus Hypothefes vix perfe funt intelligibiles, nifi illuftrentur vivầ doctinà. MTathematicas certè corporum affectiones, \& quicquid ab iis operationum dependet in natur $\hat{a}$, ut funt permulta, nemo profundiùs \& exquifitiùs demonftivavit, quàm Cartefuns. Poft motem ejus edicx funt Epitolx in $4^{\circ}$. Lugd. Batav.qux ad viros doctos feripte funt fuper dubiis : hilo ophix fux locis. Nullo itaque ex Commentario meliùs intelligi poreft doctrina Cartefrana, quam ex iftô, quein prabent Epittolx. Multa illic pioponuntur ratiora nature $\varphi$ xuvóphuos, in quibus explicandis illic fuum exercuit ingenium. Gallicâ etiam linguâ plures icriptx. DaniGeorg. Morbof. Po-, lyhift. p.2.7.

Domini Cartefii acumen admirationi meritò fuit. Et fanè Geniis qui hoc poftremò feculo claruerunt fupra vulgus elarifirmis accenfendus eft, ingenii fæecundi reconditæque cruditionis. Ejus Syttemo ritè difpofitum, Doctrinæ ip- frus concatenatiu ad ejus fcopurn tellders, ejufque ordo bene excogitatus deprehenditur.eMrereri Dict:on. Gallico.

Me titationes cjus Metaphyficie, ad Seculi noltri gloriam arguunt neminem ante ipf Im hoc A gumentum ( quid nimirum Deus exiftat, Animagne noftrainzmortalis fit tam profundè, tam evidenter tamque folidè pertractavifíe. Et fanè quemadmodaun Poëtx CM inervam è Jovis cerebro nafci finxerunt, ille Principia fua è naturali rariocinio deducit, pbilafopbiamgue intra I deas noftras nafci facit. Hoc pacto liberat illam ab opinione cui à Sophiftis, mancipata decincba- ru, ut in Cerritudine illam fundet. Illam ingeniofis fưis dubiis infallibilem reddir;detractoq"e velo, quo menti noftrx occultabatur, faciéi ejus apertum inruisum nobis permittit-Methodus ejus præclarillima Europæingenia ftupefecir. 
qux Argumentationibus Scholr alfueta, cjus Axiomata prima fonte ægrè quo: dammodo deguftaverunt.Qui illa oppugnaverunt funt Caterus Belgii Theologus crudicus, Hobbes celebris Philofophus Anglus. Arnaldiss Andillius Sorbona DoCtor unus è preclariffmis Galliz geniis. Petras Gaffendus Vir in humanioribus literis \& in Philolophia verfatiffmus; poltremus, ifque onnium concitatifimus Loyolica quidam. His plures alii Theologi atque 3 hilofophi operam fuam addiderunt. Objectionibús fuis fubruere annifi funt recentiorem hanc Philofophinm quam Cartefuns antiquæe ruderibus fupertruebat, verùm poft multos co. natus irrios plurimi fundamenta ejus inconcuffa deprehenderunt. If. Bullart. in Acad.Scient. Gall.

Hunc Tractatum( de Homine) ufque adeo confufum reliquerat D. Cartefus, ut à nemine intelligi pollet nifi D. Clercelier ejus materiam ordine difpofuiffer, eundemque Dom.de Forge \& Gufcoven figuris illuftraflent. Erudit. Ephemerides Gallice, dici Luna 5.Jan.166g.

Ultrajectini quidam Theologi Cartefura infamare moliti, publicè fcriplerunt ejus Philofophiam effrani vitæ favere $\&$ ad Atheifmum deduccre. Nullo fundamento nitebatur ejufmodi calumnia; nullus cnim Philofophus tantam adhibuit operam ad Dei exiftentiam \& Anime rationalis immortalitatem demonftrandam; omnefque vira fux actiones tam ritè compofuit, ut ejus mores boCtrinæ fux conformes femper fuerint. Illum tamen in Publicis Thefibus impietatis accufarunt, plures ejus Opiniones ab Vniverfutate Civitatis fux damnari curaverunt; quoniam autem illis paulo vehementius refpondit, criminis litem ipf intentârunt, plurefque adverfus ipfum judiciales fententias obtinucrunt ; fed criminationem prorfus diluit, amplâ A pologià in qua apud Ultrajectinos Magiftratus de iniquis judiciis in fe latis conquericur. Ibidem die Lunæ 31. Jan. 1667 . Gall.

Ex omnibus qui in ejus Dioptricam fcripferunt, nemo illam tam acriter impugnavit ac D.de Format: Ibid.

Iis qux de Adverfariorum furorum Operibus dicit nimia non eftadhibenda fides : Fatendum eft enim illum ex animi impotentia nimis conter ptim de illis quandoque loqui, omnefque alios eruditos judicium valde diverfum de iifdem prouluncialfe. Ibics.

Denique ut Genti noftre \& Cartefir memorix debitam laudem tribuzmus, fateamur Phyficam ejus fubtiliffmis \& abfolutifimis recentioribus annumerandam elfe; curiofas ideas \& \& cgregios mentis conceptus continet; cumque artentius eadem confideratur, melius ordinatum Doctrina Syfema quàm apud Galilaum \& apud Anglos in ea reperitur: imò plus novitatis \& inventionis quàm apud Gaffendum in ea occurrit. Verbo ut abfolvam Opus hac eft, cujus ordo oprimè excogitatus eft. Methodus ejus penitus eft Geometrica, quxe à principiis ad principia, à propoficionibus ad propolitiones procedit. Rapinus. Animadverl. in Phyficam 5. Gall.

Verum 
Verum quidem eft illum dubitationem nimis docere cujufmodi exemplar imitandum ingeniis natura fua incredulis haud aptè proponitur. Idem in Philolophiam \$. Is.

Cartefius o nia in dubium revocari voluit, ut câ ratione fụmam de ominibus certitudinem inveftigaret; at exitu tam infelici, ut tandem magno fudorc atque majori apparat! nihil nifi féefje probaverit. Quod tamen opinor fimplici intuitu, fine folenni iftâ dici indictione, fune prolixầ meditationum ferie, fine tanto fyllogifmorum ftrepitu, fat notum fibi liabcre potuiifct. Sam. Parker. in Difputat. de Dec, \& Provident. Divin. Difput. C. \$.16.

* Renati des Cartes Opera fequentia prohibentur, donec corrigantur: De Pri mâ Philofophiâ, in quâ Dei Exiftentia, \& Animæ Humanx à Corporé diftinctio demontratur - Notx in programma quoddam fub finem Anni 1654 . in Belgio editum - Explicatio mentis Humana - Epiftola ad Petrum Dinet Soc. Jefu per Francian P repofitum Provincialem - Epiftola ad cclebcrimum virum D. Gisbertum Voëtium, in quâ examinantur duolibri, \&c. - Paffiones Anima - Opera PhiloLophica. Index Rome I mprell: Anno I68I.

Varia ejus Opera variis in locis atque temporibus funt impreffa.

Hco ejus Epitaphium:

$$
\begin{aligned}
& \text { D. O. M. } \\
& \text { Regnante. }
\end{aligned}
$$

Chriftuna, Guttavi primi Pronepte, Magni fliâ, Avorumincepta, Parriague terminos victoriis'novis promovente, pacem demitm armis quaftam Artibus or nante: accitis undigue Terrarum Sapientia Maglfris, ip sa in exemplum futh$r a$, Renatus Delcartes ex Eremo Pbilofophicâ in lucem, Go ornamentum aule vocatus, poft guartum $M$ enferm morbo interiit, fub boc lapide mortalitatem religuit Anno Cbrift c I O. I O c L. vita Jux 54.

In Effigiem Cartefin hæc Carmina compofuit Anonymus quidam :

Talis erat vuliu Natura filius : unus

Qui menti in matris vifcera pandit iter:

Afgrians gue fuis quevis miracula caufis,

Miraculum reliquum Jolus in orbe fuit.

\section{JOHANNES D,ALIEUS:}

Cclefix Reformatx Parifen fis, qux Carentone fuos cetus habuit, Paftor. Clar. A. D. In Galliâ natus eft Cexto die Iamuarii, Auno Dom. I594. Obiit Parifir is. MDCXL 
die April. Anno Dom. 1670. xtatis 77 .

\section{CEN S U R A}

IScripfit de Ufu Patrum. Multaque alia.

Dallaus, Theologus, pietate \& eruditione nulli fecundus. Fofman.

Dalleus vir multa ac variz Lectionis. Tanaqtil. Faber l. r. epilt.p. 140.”

Iohannes Dallans Ecclefiaftes Parifrenfis in erudito fuo opere, cujufmodi funt? omnia illius, de VJu Patrum Sam. Maréf: Theol. Elench. Nov. Syn. Tom.2?

Vir Antiquitatis Ecclefiatic promus condus feliciffimus, Iob. Dallaws. Hotsinger. Biblioth. Quadipart. p. 218.

Ioannes Dallaus, in SS. Pareum monumentis diligenter verfatus, in difcemendis operibus furiis adinodum acucus. I oan. Pearjon. in Vindic. Epift. S. Ignat. pag. I.

Dallesiom magno in honore habuerunt, incomparabiles illi viri $B$ aro de. Fav'land, \& Gulielnibs Chillingovorib: qui in Scriptis fuis adverfus Pontificios lroc Autore fapius ufi funt.

Protefantem Terronium vocat Baro de Faulkiand.

Dallaum quidem fumo ingenio, preftanti eruditione ac doztinâ, nec minori pietate vitum fuille, \& de Ecclefhẩ Reformat plurimis in rebus optimè meritum, ultrò o mnes hîc confircmur. Verim id malè nos habet, quòdille contra Ecclefarn Rornanain difputans, noftram ctiam, tanquam iildem erroribus obnoxiam, fub communi Latinorun nomine in lilcimintim oppugnarit, nufquam diftinguens inter: coldem ritus ut à Romanâ atque à n/frâ E-clelị̂ ufratos, etiamfr plurimum intereffe, benè nôrit. Gu! Bevereg. in Proæin. Cod. Canon. Ecclef. Primitiv.

Francifcts Turrianus, Jefuita, librum fingulatem edidit, quo probare çona tus eft Canoués vulgo Apoftolorum dictos, ab iplis Apoftolis conftitutos, \& à fartceirino eorum difcipulo Clemente Rorna literis mandatos, atque in eam, qum hodie trabemus, formam redatos effe. Hanc Opinionem vir egregiè docus, \& in

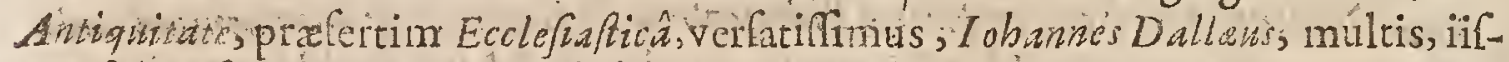
que folidiffmis àgumentis lefutavit. Sed quod commune ef hominum etiam crudirifimorum fatum, in refellendâ iftâ Turriani fententiâ fummè occupatus, prx nimio incenfi in cam animi ardore, eò tandem devenit, ut omni affeveratione affirmatit, hanc Canonum Colledionemnon tantum non ab ipfis Apoftolis, vel à viris Apoftolicis compolitam effe, Ced ab Heretico nefcio quo tenebrione confarcinatam, eamque nec ante quiuntum illud fue adultum à Chrifo incarnato feculum Ecclefu Christiand inotille, \& quinto excunte jam primùm extiriffe, publicarique coptam effe. Quod quidem non eft à delirâ Turriani opinione tantùm recedere, verum etiam in aliatn ci ex diametro contraliamfele precipitare - Nos quidem mediam inter duas iftas extremas, Turrianiam filicet \& Dallaanam, opinionesatrplexifumus: Hos fcilicet Canones nec ab ipfs Domini Apofolis Anno Dom. XLV. ut vult Turrianus, conftitutos efle, nec tamen quinto exentute feculo cos primum extitife, vel publicari coptos eff; ut hatioJatis cet $D$ illest ; fed modio inter ca tempore; Cecundo videlicer exeunte, vel tertio 
Eertio Caltem ineunte feculo conftitutos pariter edirofq̨ue fuiffe, Idem in Cod. Canon. Eccle.. Primitiv. \&c.1. r. c. r.

In diverfas admodum fententias abeunt Operis de VJit P.atrum cenfores. Id magni faciüit Presbyteriani: Angli verò Epifcopales idem parvi eftimant. LeEtori utras ipfilibuerit partes amplecti permitto. Paulus Colornies in fua Sel. Bi* bliotheca. Gall

Cum aliquando Parifiis Dominum Valefum primogenitum conveniffem', in ter alia milhi dixit, plurimos efle qui libros confcribere fibi fumebant, fed-perpaucos fibi notos qui Dallawn in Cribendo æquarent. P'aulus Colornies. Opufc. p. 95 . ( all.

Licèt quidquid operum hactenus edidift, vir Reverende, mihi plutimùm placuei it, tuaque omnia, cùm Latin tum Gali, elcripta, æquali planfu ab eiruditis, atque ad ò piis omnibus, excepta fint, diffiteri tamen non polfum, laborum tuorum plimitias, Tractatum nempe tuum de Patrum in decidendis de Keligion $n \in$ Controverfis $V / u$, me plurimùm. Emper cepilfe. Non folùm enim $O$ ptis iftud milá rcru . lectu \& fcitu juctundiffimatumque varietare refertum eft, ven rùm ctiam cloquentia orationíque nitor cum rebus ipfis certant, tantâque erthdition \& facundiâ argumentum illud pertractafti, ut vix quicquam magis elaboratum ęudito hoc ficulo prodiiffe videatur. Loamn. Mettayer in Epilt ad Dulluw , quain pramil. lib. de.Ver UC. PP.

* Ioanrize Dallei de duobus Latinoruriz ex V́nftione Sacramentis, Confirmatione, \& extremâ, quam dicunt, Vnetione, Difputatio, inter Prohibitos häbetur li: bros in Indice Rome impreffo Anno $168 \mathrm{I}$.

Varia ejus Opera variis in locis atque Temporibus funt impreffa.

\section{HENRICUS HAMMONDUS.}

A Nnglus, Surbrien is, natus anno Dom.1605.dic 18. Augufti, apud Cherfeg', elar.A. D: Scripfit Annotationcs in 1 falmos, atque in Novum I ctamentum, multaque alia.

Ex omni illo Commontatorum numero, qui in P Palmos fcripferunt (de Neotericis loquor) ut Calvinur, Mufcuilum, Liti in, Mollernim, alios nnittain, duos precipuè \& præ aliis maximè adjumento fuiffe fateor. Ii funt, Simeon de Wuirs,

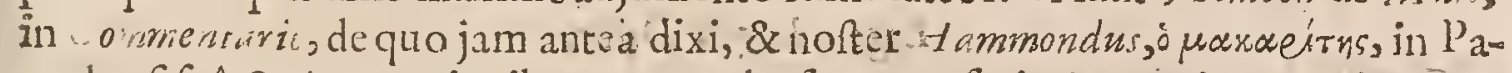
raphrafifuâ \& Annotationibus vernaculo fermone fcriptis: (utił̧am verò tra \& illæa altere in Novurb Fodu, Latine loquerentur; quò \& ad'cx éro; etiam dimanaret tantus thefautus: ) nobile par Interpretum, me quidein judice, \& qui in indagando eruendoque literali (quem vocant) fenfu $T$, $x, \hat{u}$ s D w vidici, Lagacifimi

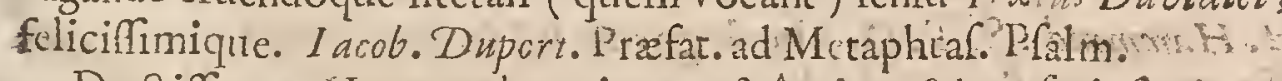

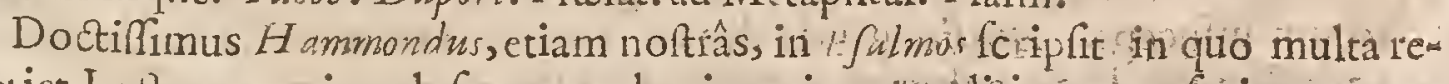
peliet Lector acumine plufquam vulgari, parique ëruditionie, confcripta, nonNanna 2 nulla 
nulla ctiam fingularia. Matth. Po'w Pirfat. Tom. 2. Synopl. Critic.

ClariRimus Harmondus noftras, anteà fuo merito laudatus, in eruditiffimis ipfus Annotatio ibus in N T. in quibus non pura fun planè fingular a. I dem Prafat. Tom. 4. Synopl. Cric.

- Neque enirr fi quod extaret, omififet hoc loco doetiffinus 4 ammondus,cui omnis Ecclefafira Antiquitits æquè ac domus fua, nota erat. Ioan. Dall. de lib. fuppol. Diony. \& $\mathrm{g} \cdot \mathrm{lat}$. p: 346

Orat. Presbyt. Simon mentionem quoque nullam fecit celebis 1 ammondi, qui in P falmos \& in Proverbir tam docte fcripfit, ne quid de ceteris ejus Operibus dicam. Author ifte qui dubio procul inter peritifimos feculi noftri Criticos non ultimus eft, dignus erat qui inter $y$ cripturæ Interpretes collocaretur, in quos Criticen fuam exercere libuit Presbytcro Simoni, nedum propter magnam apud Aiglos Operum ejus celebritatem, fed etiam quia Fauci revera funt om. mentatores apud quos adeo fingulares Oblervationes repeciantur ac apud itum. Plerique omnes ineri Exfcriptores funt vel Epitomatores corum qui ante illos fcripferunt. Hammondus verò quxcunque dicit è proprio penu ferè depromit. Indicia Theologor allundortin 377 : Gall.

Praclara naturalis ejus folertia, prechrior acquilita. Per totam Artium Encyclopadiam in linguis accurat!s \& eloquetis erat, Edus refpectu Veterum \& recentiorum Scriptorum, in Philolophia verfatus admodum, in Philologia verfatior, in Theologia Scholaltica eruditus, in Ecclciaftica Antiquirate Magifter, contummatus in Parrum, Conciliorum, Hiftoricorum Ecclefiaficorum; \& Liturgiconm notitia. Reverâ eminens intellc otualibus fuis Virtutibus, eminentior vertò in Moralibus fuit. D avidis Lloid. Adverfaria. Anglicè.

Henricus Harnrnondus: vir planéfummus, Theologus omnium confumman tiflimus, eruditæ pictatis decus fimul, \& exemplar; Sacui Codicis Interpres facilè omnum oculitiffimus, Errortum milleus. Pof homines natos felicifrmus; venitatis Hyperafpiftes fupra quàm dici poteft nervolus; In cujus Scciptis elucelcunt ingenii gravitas \& acumen, judiciis ublimitas \& árpibeia, Cententraitum

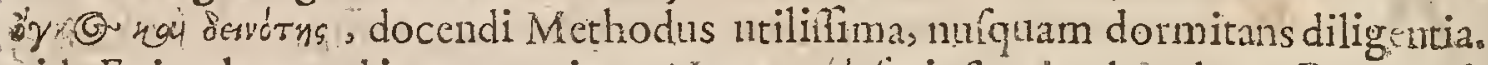
vid. Epitaph quod in memoriam Harmond. lcripfit vir admodum Revercnd. Thom. Pierce S.T.D.

Epitaphium ejus tals legitur in Opufculis lfaci Barrove, $\rho .30$ s.

$$
\text { Lege, Luge, Difce. }
$$

Ne te pratergrefum poniteat, fifte pedem Hic o animums Viator. Etenim,

Hic jacet H. Hammand, S. T. D. Theologorum fui feculi Coryphaus. Litera to um princeps. Ariglice gentis dccus Eccle a columen. Veritatis allicror

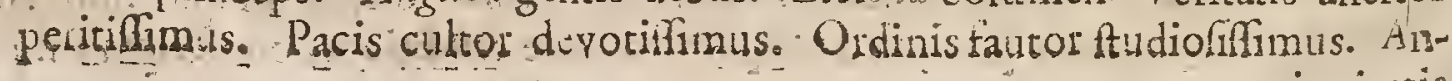
tiquitatis. 
tiquitatis genuine fidifimus Interpres, \& propugnator acerrimus. Sanctitatis Magifter preftantifimus. Omnibus omamentis inftudifrmus. Philofophus Colidèacutns, dilucidéfubtilis. Orator inaffetatè poltuss,nervosè copiofus. Difputator vehemens, extracetbiratem. Egregius Criticus, abfque fuperbia tamen aut lizpercilio. Lectionis infinitæ, Led cxquiftè digettre Maximi ing Majoris judicii, confummatx cruditionis cum pari modeftia; $T$ antis dotibus ufus præclarifinè. De Ecciefâ, Principe, "atriâ optimò meritus. Utriufue Tabulx Lcgum praco, obferuator, vindex. Ecclefia A alizara enfis \& Cly peus: quam à falli chifmatis labe purgavit, à veri contagio munivit; Romanis holtibus, \& perfugis $S$ :Etari, fulis, fugatis. Sinccræ doctrine radio veteres tenebias 1 fend-Catbolicus difpulit, nova lumina Anri-Catbohce cxtinxie. i'resbyurianam paritatem proftavit. Fanaticam licentian coercuit. Temporum iniquitatem expugnavit Scriptis victoribus, paticntî̀ triumphali, Ecclefiaftici ordinis, jurifque vindex fortilimus, ac felicifinus. Limrgic patronus confultiffmus. Theologicorum dogmatum fcrutator fedulus. Difficultatum enodato accuratus. Veritatum explorator fagax. Novnm Tefamentum, Tfalterium Davidicum, luculentâ Paraphrafi, eximio Commentarzo, fancto exema plo illuftavit. Calamo fcripfrt, vitâ edidit ratinum Catechignurn. ChritiaHe fortitudinis, patientix, manfuetudinis illuftre Exemolar. Mentis infigni

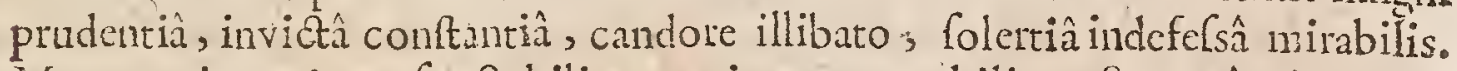
Morum integritate fpectabilis, gravitate venerabilis. Summâ pietate in Deum; extremâ Fide in Principern; propcnsâ charitate in Onnes confpiculs. $V$ ir, Scholafficus, Theologur, planè incomparabilis, omni Epitheto major, quolibet Elogio potior. Meruit haberi $M$ artyr affiduis pro Ecclefin curis $x$ vigiliis confectus. Occidit diei nofti / wifer, Anno 1660. Calutis partx, primo.Regis Restituti, Ratrix liberatx, Ecclefix inftauratæ qux à fe ftrentê promota, $\&$ ardenter concupita prefagit animo, fed oculo non adpectavit, in hoc felicinimè infelix.

\section{Vade, Cogita, Imitare:}

Nec Magnum :amen Hammondum Satis ulla loguantwr

Saxa, nec a morfut temporis wlla tegant:

Clarius oftendit Scriptis je illufirtbits, illo

Digna fici tantirio Junt Monumenta Libri.

Pluta de co fcire cupientem ad libellum de Vitâ ejus à Doctore lohanne Felly Reverendo sEdis Chrifti Decano, polted verò Epifcopo Oxonienfa, confcripm
tum temitrimus.

Omnia ejus Gpera in 4 . Vol. in fol. continentur. 


\section{GABRIEL NAUDAUS:}

Clar An D. D Arifnus, Eminentillimorum Cardinalium, Francifci à Balneo, Francifci MDCXL. I Barberini, lulii MaZarini, ac demum Sereniflima Cbriffina Reginz Sue corum, Go borum \& Vandalorur; Bibliothecarius. Natus eft IV. Non Feb!uarii 1600. Obiit 29 Tulii Anno Dom. 1653.

Edidit Pentadem Quxtionum iatrophilologicarum: Bibliographiam Politicam : De Seudio liberali jyntagma: Conflium de Bibliotheea ftruenda.

Gabriel Nancans Parifuns, nominis inter literatos magni. Gajénd. de Vit. Peiresk. p. Is3.

Librorum ifte Cux xtatis telluc doctiflimus Gabricl Nandaus. Annotator in lib. I6. c.4. Anlicicllizcum Not. Var.

Quæad infignem erudition m comparandam præfidia conferunt, Gabrieli Nandao', fermè univerla adfuerunt; Patrix \& Ceculi erudirio, folers ingenium, indefcfus in ftudio labor, otium, librosum copia, cultifimorum hominum confuetudo, \& mirain lcribendo facilitas. Elog Naura prefix.epift. Naud.

Cæterùm te hîc appello, Gabriel Naudae, inclytam Pariforum fobolem, ac non vulgarium florentis ingenii fœtuum varietare focundam. Probantur, le guntur à doctis omnibus tua quctidie monumenta litcrarum. Angit eos ctiam atque etiam expectatio cæterorum, quæ nordum completa rerum pulcherrimarum divitias pollicentur. Ioan. Imperial. in Muf. Hift. p. 202.

Audio Naudarm noftum, Galluce probitatis exemplum, tuique amantiflimum, nova fubinde moliri monumenta lirerarum; èquibus, qua jam luci imminet, Polituca Bibliographia, opinione Doctorum hominum diu concepta, partum haud ferò decus admittat meritiffima laudis; quam is. \& editâ nuper de Venenis Differtatione praftanter adè comparavit, ut fermè dixerim, $N$ andeum f1bi gloriam Venentipfis aluiffe, infigni doctrina miraculo. Virum novi liberalibus doctrinis politifimum; novi in omni vetuftatis ratione cum induftiâ verfatum; quò ad ea qua publica fecit, ornamenta fudionum, diligentix, ac laboris plurimum contuliffe haud dubi videri poffit: verùm illuftre illıd de ftudio liberail fyntag ma, quo nobiliffun um dol fcentem egregiè inftitutum voluit, fcimus aulicis curis penè dintracto, fublicivis horis, raptim excidiff; ; th incredibile cuiquam fit, pottiffe illum, nullo commentandi otio, nullo lib orum adjumento, tam multis ex antiquitate erutis rationibus, \& exemplis, quid ad omnem ing nuum morem, erudito difciplinarum culru, cum laude faciat, apto Atudiorum, atque exercitationum d lectu, difertè adeò, \& accommodâte prafcribere: nififottè in whaufâ illâ, qux Catons olim fuit, legendi aviditate ita pridem nobilis belu ingenium ex leverit, ut is carere libris nufquam poffit, dum fuo non carcat ingenio, feque unum ipfe cicumferat. Gaspar de sirneorib. Epirt. ad Leon. Allat. 
Vir ingenio, judicio, \& multâ lcotione præpollens clarifimufque. Conring. Cupplein. 30 .

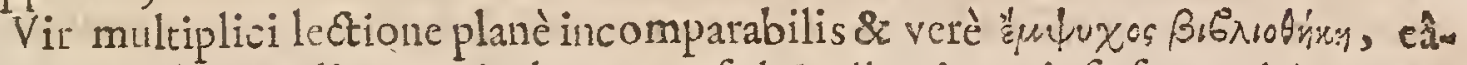
que de causânon olim Gallia duntaxat, fed I talia etiam, ipfiufque adeò Rome, imo univer orbis enditi in admiratione. Conring. cap. 19. Cenfur. diplom. Lindav.

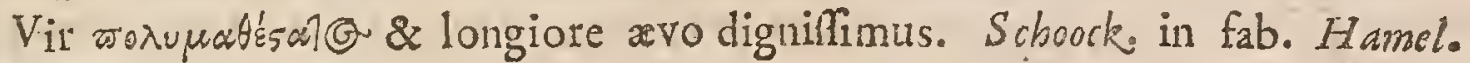
pag. 26.

In $N$ audao oblervare licèt, eum interdum ftudio" partium odioque Nationis aut Religionis quibufdan iniquiorem effe, multos ctiam Auctores egregios ob eafdem caulas, ut videtur, plane preterire. Excmplo elfe pollunt, qux de Clapmario, Grutero, Forfmero, Scipione Gentili, \& quibufdam aliis fatis frigidè aut etiam malignè Ccripfrt. Anonym. Auctor. vid Koniz.

Iatro-Philologicam ertuditifmi $N$ audet differtarionem adverfus nacurâ $A l a t$ foras cum Cummo applaufu percurri. Utinam plura ab ingenio illo videamus. Casp. Gevart. Epift. ad loan. Francifi. Slingelandurn.

Extat Syntagma de fudio Militari. Rome $1637 \cdot 4^{\circ}$.

Extat Bibliographia Politica. Venetis $1633.9^{\circ}$. \& Lugd. Bat. I642. 8?"

Extant Epigramatum libri 2. Parifbis $1650.8^{\circ}$.

\section{S A M U E L P E T I T U S.}

N Atione Gallus, Sacrx Theologix apud Nemanfenses Profelfor, obiic Anno Dom.1654.

Hujus sripta funt: Mifcellanea, $4^{\circ}$...- Eclogx Chronologice, $4^{\circ}$ Clar.An. D: MDCXL。

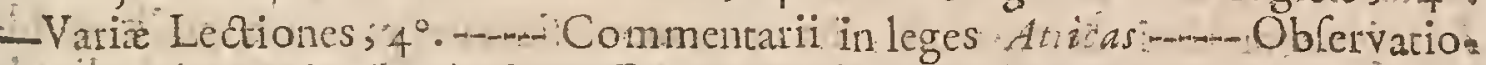
nes, $4^{\circ}$-- Diatriba de - Dure, Pricipum ediatis, \&c. 8:...- Verus Latin in obitum W. Schikardi.

Ingeniofitrmus Petitus, vir non fui nominis, Ced verè inter Gallorum liseratorum maximos numerandus. Thom. Reines:1. I. Var. Lect. c. 25 .

-Cui magnopere obfric exopto exinio Petito. Gerard.toan. VojJ. ac Sam. Sorberinmi Amfiel. Kal. Jan, $563^{3} \cdot$

Samuel Petitur, vit Hebraicé \& Coptice doctifimus, \& in omni Antiquitate, Ecclefiaticâ praferim, ocularifinus. Paul. Colbissof:Gill: Oriental:

Salmafur, "etrufgue ex paucislibriscommunicatis in Linghâ Copticâ pluris mùm profecerunt. Gafend, in vit. Peiresk, p. 168.

Petizus hic nomine, doct inâ Magrus.cft; - nam \& Coriptis multis jam inça ruit, quibus enditifimum fe linguarum Oxitentalumn oftendit, 8 in omni artiquitate Ecclefrafticâ verfatifimum, ne de Theologia ac Pbilófapbia dicam, cujus elt peritiflmus. Salmas.ad Guir.m. Stadk mann. Leyd. 3.Id. Jan. 1635 .

Vir doctus Samuel $P$ etitns, fed hatd dubiè minus folir in emendandis Veterum scriptis 
Scriptis. Tanaquil. Fabor. Epift. 1. 1. Ep.10.

Leges Atticas edidit, à fe, quo voluerat, modo collcetas \& concinnatas, ad quas Commentarium addiderar. Erat vir probus, \& doctus, fed iis prafidiis, qux ad opus hujus argumenti elaborandum necelfaria erant, deftitutus. Defder. Kierald. ad laf. Attic. \& Roman.1.2 c. I2.

Petiti leges Atticas videre avco, ut cognofcam an fupra Scaligeri collectionem, đuâ ufum me memini, aliquid præititerit. Hug. Grot. ad Cordefunm, 30. Octob. 1634 .

Exiguus nofter, vir bonus eruditufque, nodum in fcirpo quxrit, non metuenda metuens. Nam fi Nov: Foderis auctoritari non obftant tot qux olim deprehenfafunt, \& quotidic deprehenduntur, difcrepantes Scriptura, quid mali facit qui in Veteri, Faderi. libris five ex Orientalioribus Iudais Give ex Interpretibus antiquis, aliquas fuilfe prater eas in quas inciderunt. $M$ aforeta, fedulo obfervat \& verccundè docet? Idernàd Claud. Sarrav. IS. Jan. 1640.

Nulla quippe eft ex omnibus Correctionibus Plantinis quam pro verâ ac probarâ fumere aufim; multxablurdiffimx. Quas in Gresis Aathoribus cxcogitam vit nihilo meliores. Legem Senarii l ambici apud Gracos Cornicos non videtur tenuiffe, adeò lape contra Metri menfuram offendit. SalmaS. ad Hug. Grot. 8. Id. Maii 1630.

De Punisis Plautinis tecum fentio, vel Plutone cxciorum in plerifque deprehendi. Idem ad eund. Divione Kal. Ian. Í́zo.

De Sermone Punico apud Plautum Cripfi, polfe ad Ebraifmum reduci, \& fore, ut, fi monftra Lectionum \& incptias Libraciorum inde refigamus, ifta Punic planè 'Ebran effe certò fimus depreh nfuri. Hoc verò omnium effe veriffumum, intereà dum mea eduntur, oftendit elegante ingeniô homo Samuel Petitus, qui omnium iftorum Plawtino-Tunicorcm à doctis depofitorum veras lectiones ex Ebraifmo conftituit \& expofuit, ita ut nemo defiderare pratereà poffit quidquam, adcum omninò remitto, fi qui ultrà dubitent. Thom. Reines. in Epift. quadaun dat. Altenburgi s. Ang. 1637 .

Eximix doćtrine vir, Samuel Petitus, Anno 1632 edidit Eclogas Chronologicas. Opas eft pereruditum. Vofj. de Matbernat. p. 238 .

Cum lofephum interpretandum fufceperit Petitus, magnx vir diligentix Lin guarumgue fciens, multum eo nomine gaudeo, paratus conferre quicquid potero quod in hoc negotiorum aftu fanè exiguum eft. Grot. ad Peiresk. Lut.22. Maii, 1637.

Petit unus cft fex illuftrium illorum I'roteftantium, quos Dominus Colomiez folos cenfet magna valuifle literatura inter fuos Confectaneos. Vide Mifcellanea Hiftorica p.73. Gallicè.

Extant Mifcellanea. Parif. $1630.4^{\circ}$ :

Extant Eclogi Chronologica. Parif. 1631. $4^{\circ}$

Extant Varia Lectiones. Parif. $1633 \cdot 4^{\circ}$.

Extant Commentarii in Leges Atticas. Parif. 1535 . fol.

Extant Obferyationes. Parif.1642.4\% 


\section{CLAUDIUS SALMASIUS:}

$\mathrm{D}$

Ivionenfis, natus eft Anno r596. obiit anno I652. Eum adhuc Iuyenem Iofephus Sraliger \& I caacus Cafaubonus adritati, imò profelfi lunt, fe à Clas. An. D? MDC XL.

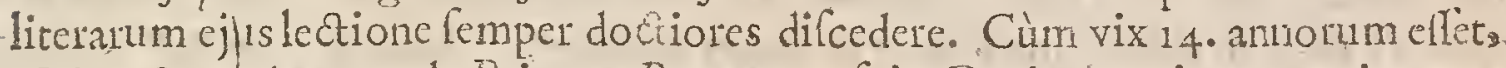
Nilum \& flamsm de Primatu Papa recenfuit. Decimo quinto xtatis anno Florm ediditunà cum Notis, $81 \mathrm{hb}$. Gruero dedicavit. Hac fcripta pofta pluca aliz lecuta funt, quz omnia enumerare diffcile foret. Inter precipua funt

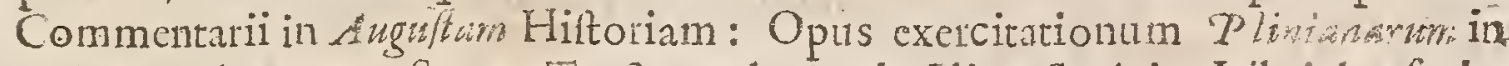
Solimm: Apparatus Sacer: Tractatus de Annis Climactericis : Libri de ufuris, modo ufurarum \& fanore trapezitico: Defenfio Regiapro Carolo I. Liber de Tranfibltantiatione, \&c. Reliqua ejus opufcula Anionius Clcmentius in Vita Salmaji pag. 64. recenfet. A Veneits, multis aureorum millibus promifis inviratis eft, ut ter tantum in anro publicè prelegeret: quod modeftè recufavit. A $x e \lg$ folus dignus aftimatus eft, ut magni Scaligeri locum licè longo tem- pore poftimplerct. Mortus eft non fine veneni fufpicione. Poft mortem multa cjus fcripta ( fic enim julferat) ab uxore combufta funt, ynòd in iis durius in. viros doctos invectus fuillet. Viri ertiditi fateri coguntui, fuilfe eum doctillmum Theologum, foletrifimum Iurifconfultum, exquififinmum Medicum, mbilifinum Philofophum, admirabilem Philologum. Linguarum notitix adco aviduserat, ut Arabicam, Egyinacam, Perjiarn, Chinism, \& Indicam, cateris Europeis, quas anteà callebat, adjungere non dubitaverit. O feculi miracu um! Hugoni Grotic audic optimus interpres veteris Salmafus avi. Scioppins appellat literarun principen. Glonovius Uarronem \& Eratofbenem feculi nofiri. Reinefou in Var. Lect. 1. 6.

Salra fiz exquifinima entitioni tantum tribuo, ut non modò, qua doctè ad bonos antores notavit \& ingeniosé iftorum medelis exccgitavit, tantum non exofculer longéque meis abortivis praferam: Ced ultro fivolis meis cedere paratus fim, fi ipfi contrà videri videtín. Konig. in Biblioth.

Vir nobilifinnus, idemque celeberimus Polyhiftor, in anriquis fcriptoribus atque antiquituribus verfatifimus Salmajm. Gisbert.Vö̈t. par.. I. Difput.Sclect. p. $7 \tilde{2}_{2}$

Vir fupendx \& ad miraculum recondita cruditionis excellentifinus Salmad fius. Iac. Ouzel. ad Minut. Felic. p. 9.1652.

Afrentio Claudio Salmafo, viro nunquam fatis laudato. Vofj. de Hift. Grec. cap. 17.

Ingens illudliterarum columen Claudius Salmajus. Idem de Hift. Lat. p 693: in Etbico.

Vide maximi illius viri [ I f. Scaligeri] Epinolim 240.ad Claudium Salmafum, tum magnam Reip. Literarize pem, nunc eximium ejus, \& incomparbile onamentum. Idem lib.j. Intit. l'oütic.c. 20. Sect. 7 . 
Vir nuncquam fatis laudaus, nce temerè finc laude nominandus. Idem de Idolulat. 1 4.c. 9 r.

Eft quidem Iuvenis Divionen is Selmafure, ad miraculum doetus. If. Cafaub. in Lit. ad Sarig. Lut. 15. Kal. Mart. 1607.

Eftprofectò dignifimus, quem omnes boni ament. Omitto incredivilem eruditionem pari modeltiâ conditam : Illud equidem pluris facio, quòd puriorem religionem palam non dubitavit nuper profitcri. Idem in Liţt. ad Georg. Mich. Lingelsbersw, Bretor. 4. Non Sept.1606.

Viriclarifimi Clasdii Salmafir entiditionem confummatifinam filentio venerari malo, guàm laudes ejus ingenii mei culpâ detercre. Hug.Grot.limine No: tar. ad Stobit lorileg. Parif. I623.

Vir infinitz Lectionis Cl. Salmafus. Idem in Annot. ad lib.de Verit. R. C. $1640 \cdot$. 308 .

Cloudius Salofirs, vir undecunque doctiffmus, \& qui divinis in omni difciplinâ lucubrationibus hoc confecutus eft, ut jum non hominis, fed ipfurmet fcicntia Sulafus nomen habeatur. Atgid. Menag. ad Serenifl. Chriftinam in Epift. Balzacii, I6s I

Is [Snlos frus] elt fanè, incujus fententiam omnes boni boctiqutu libenter eant, adeo in literis fuo merito principarum tenet. 'Claud. Sarrav. in litt.ad Vincent. Fabricinats.

Quanto gaudio perfulus effes'audiendo Bochartum, de mille arcanis [Salma fuw ] folicitc̀ \& curiosè interrogantem, nunquam in.snem recedere; juraffes non defeciffe Oracule. Uno in homine miratus elles piifimum \& do siffimum Theologm, elogtentifimum Orators, folertifsimum Iurifonfulus, Medicum exquifitifsimum, $\mathrm{B}$ hilofophum nobilifsimum, \& omnigenælinguæ, Ccientia

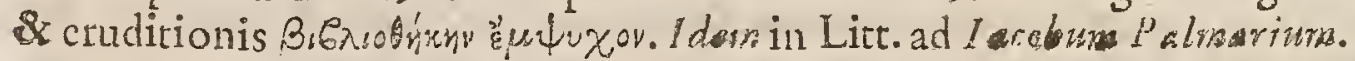

Hxc cumita lufiferrus, \& conjecturis o niatentalfemus, Clarifsimus vir, omni literaru'x gencre excultilsimus, \& in difusâ eruditione : Egyptìce etiam Lingue peritifsimus Clasudizs Sal safus uno vabo nos expedivit. Lud. de Dien in Animadverfion. ad A ct. Apolt.c. 7 . Sect. 43.

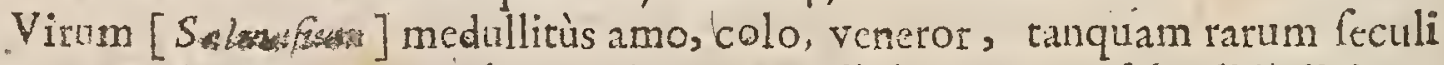
decus, \& doctrinx miraculum, deque eo nihil à metam fplendidè dici po. reft, ut ad meritorum fublimitatem alfurgat. Iac. Cruc. in litt. ad Theod. Schreveintara.

Dominus Salmatur Criticis fuis fagacibus fuaque in obfcuri simam Antiquitatem penctratione tantam fibi paravit ramam, ut vcl unicum ejus nomen in 'Lecto'is mente Literatura ac Enuditionis magnas excitet ideas. Res fic le habetquadilluftres illos Doctos ut quoad Populorum Domitores in Hiftoria, quorum nomina omnia fupra vulgus mentibus ingerunt \& quavis Elogia fupewant. Sic nempe Domini Salmafin no men libri cujufpiam fronti prefixum ejus magnificum Panegyricum efficir. Viele Dominum Bewval, in Operum eruditorum Hittoria. Februar. 1689 . Gall.

Nuperdectsit Clandius Salmafrws vix in omi' literarum genere eminentifi- 


\section{CELEBRIORUM AUTHORUM.}

mus, ac fine controverfiầ hujus ævi fummus. Sed quæfitâ meritis Lupcibiầ immodicus fii æeftimator, aliorumque contemptor, omnilque fententix, cujus ipfe autor non effet, inimicus. Oethve,Eerrar. in litt. ad lcetor. quas pofteriori libror. parti de re Ve firiniâ præmilit.

Vir alioguin ad literas fummo hohore tractandas, \& illuftrandas natus, fi modeftiam adhibere, \& arroganti de fe perfizhlone, ac erga alios malignitate excufsâ, mentem animi in iis fedulò occupare potuilfet. Defider. Herald. Animadverf. in Salmas.obfervat. in lus Atric. \& Rom. 1. 2.c.7.

$S a^{\prime}$ mof frus nemini fuorum temportum literato pepercit;nemo omnium qui $x$ tate noftrâ claruere, virulentum ejus dentem evafit. Nic. Heing. Not. ad Ovid.

Habebat hoc vir ille incomparabilis, ut uberrimo ingenio nulla fufficeret manus, \& ubi inftituerat fcribere, nec rerum nec verborum modum noffet. "Loan. Frì. Gronov. in lib. de Seftertits, $1655^{\prime}$. p. 46. 47.

Scripfit librum pro Corrolol. Rege Anglia magni nominis vir Claudins $S_{a l-}$ mafin; ;ed, ne quid difimulem, non refpondet expectationi,admodum enim tuw

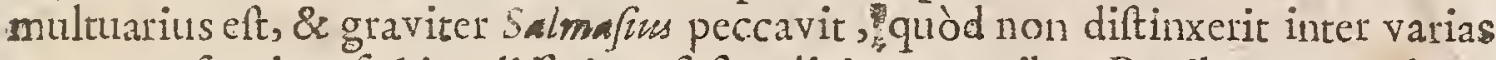
Regnorum fpecies; fed ita differit as fi fimpliciter $ه$ mnibus Regibus una eadem que poreftas; \& quæ reperit apud Autorcs de Regibus, illa omnia uni Regi aps plicut; cum tamen Arifoteles plures ponat Regni fpecies, licèt minus plenas vel mixtas. Debuiffet potiths argumentati ex legibus \& confuetudinibus Regni Anglicani, non ex iis. qux in hiftoriis legerat. Excepit eum mordax Scriptor Miltonu, fed in quo defidcres prudentiam \& $x$ quitatem judicii : in Sarcafmo eft artifex, unde petulans ejus ingenium fatis fe prodidit. 'Herman. Conring. de Regn.' Angl.

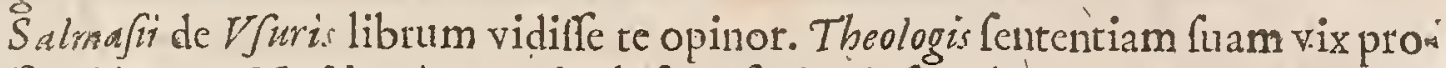
baffe videtur. Nofti quàm periculofum fit in ejufmodi argumentis ingenium excrcere; prafertim cùm contra receptam ab omnibus fententiam in aliam, \& no: vam itur. MArc. Zuer. Boxhorn. in Litt. ad Ioan. Ifaac. Pontanum, p. $\$ 4$.

Salmafir Epiftole prodierunt poft mortem iftius viri, doctrinâ variâ plenæ; ut fuit ille vir diffuf $x$ lectionis \& ingcnii; fed paucæ illax funt, quarum egolongè plures ab illo fcriptas effe exiltimo. In tantâ enim celcbritate hominum vi-

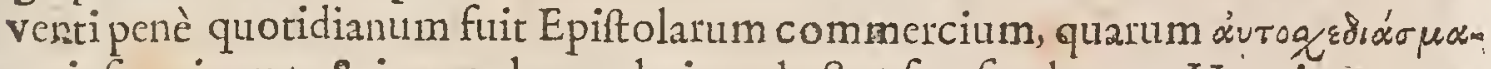
ta ipfi perierunt, \& in angulo apud viros doctos fparfim latent. Ut enim extemporalis Kị it in omni lectione fuâ, omniaque, prout femel conceperat, in typon gtaphiam miferat: ita vix credibile eft, Epiftolas illum defcripfife: dolendum tamein eft, intercidiffe illas in quibus fortaffe multa fuerunt, qua prodeffe orbi literario potuerint. Apud Sarraviurs non paućx ejus Epiftolæ leguntur, quas in opere illo Epiftolarum non deprehendas. Reperiuntur \& in Bibliothecâ Gudias; nầ nonullix. Disny Georg. Morbof. P.olyhilt. pag. 292.

Salmajens Notas ad Khodii aras defcripfit ex Holobolo Rhetore.Colomef. Opulc? p. 13S. If. Vef. ad Pornp. Mel.p. 213.

* Claudii Salmafii Opera prohibentur in Decreto I8. Decemb. 1646.

Varia cjus Opera variis in locis atque temeribus funt impreffa. 
In Effigicm C. Sulmafin hac Carmina compofuit C. Barleus:

Gallia guo nuper, jam fidere Leyda fuverbit, Pralucet magnis artibus ifta Plasros.

Hec Junt perspecti, LeEtor, comperdia Mundi,

Fronte Sub bac Pallas prodigiofa latet.

Partimur doclitinam alii. Hî Se tota recondit:

Immenfof gue babitat mens Jpatioga Lares.

Scribite.fcriptories. Cui pagina fcripia Solini eft. Iudice the, fripti. Circulus orbis crit.

\section{FRIDERICUS SPANHEMIUS:}

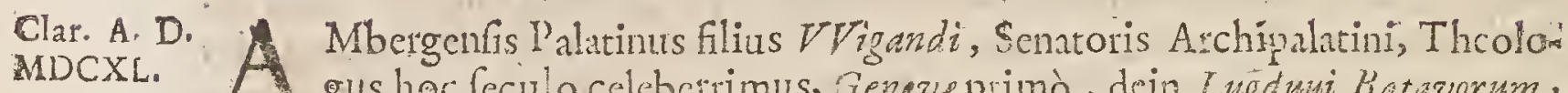
Profelfor. Edidit varia, inter qua eminent Dubra Evangelica, Exercitationes de Gratiâ Univerfali, Miles Swecicus, \&c. Obiit Aruo Chr. I6 49. xtatis 49.Heim. dan. Oratione funebri.

Accuratifimus Ceriptor Fridericus Spanbemius' in eximio illo Opere de Dw biis Evangelicis. Rochart. in Geograph. p. 104 .

Spanbemius, vir planè eximitus, fluperioribus diebus Profefsionem Theologicam feliciter apud nos eftauficatus. Talis Atles illud ccelum debebat futtinere. Marr.Zurr.Boxborn. in Litt.ad Atrian. Hofferipr, Lugd. Bat.1642 Novemb.I2. Gloriofifsimum mercputo quòd bene de me Dominus Spanbersins cxiftimet; Virum enim illum maximi facio. Bulzacius, Epifola 2S.ad D. Chapelain. 1.20. Gallicè.

Vir magne, docta ing cnii tuỉ monumenta magno labore, magnifque vigiliis elucubrata, fummâ cùm voliptate, fü̈mo cum fructu, vidi \& legi. De Repłblicâ celtè litterariâ mereri magis non poteras, quàm Dubiis tuis Evangelicis, dignis memoriâ, \&laude feculornm. Non quod vel Dubia ftatuatur Veritas Evangelica, vel de e ambigendum cenfeas. Abfit ab homine Cloriftiano qui ali- quo pietatis fenfuducitur tam impia cogitatio. Sed dubia, qua vcl profanorum furor, vel infirmortum imbecillitas non inveuit in Scripintâ, fed in scripinram invexit, à radice revellere tibi fuit animus. Éudabili meherculè inftituto ! Namnon scetariorum folum, fed \& r boniorum ac Ábeorum funeita agmina paffim occurtunt, qui facrilegâ prorsùstemeritate, Teritatem Evannéitcam infelicitcr fub iles, vel convitiis apertè lacelfunt, vel per cuniculos lab factant, judicafti quâ polles piudentiâ, hoc fcribsindi genn:s non utile folùm, fed \& neceffirium effe, \& fine crimine non debere negligi. Exemplo Patrum, Tertulitunt, Origenis, Epiphanii, Eieronywh, Anignfina, \& aliorum, qui firophas AdverfarioSurn datectas folidè eliferunt, \& S. Scriptura dignitatem mafculè tutati funt , ne hominum 
hominum impiorum protervia ullo modo fraudi effet Ecclefa Chriftiana, fed ut in luce \& oculis omnium, Fentas clariùs fplendefceret. Iecob. Crur. in Evitt.

Quàm eft laudabile, multis linguis loqui polfe \& fcriberc. Uni genti nati vis dentur: quibus frimplex ett lingua; quibus bifulca \& trilulca, pluribus. Inter hos nomen mereris, Clariffime Spanherit, dum iis vocibus loqueris quibus fe maximè cxplicat hodierna facundia. Latizass innuo \& Galleas, quarum documenta dedift criptis luculentifimis. Capp.Barl.in Epit. ad Lrid. Spunberm. Am Ateld. I8. Mart. 1645 .

Plurimum me tibi debere proficcor, quòd Tomis fecundo \& Tertio Dubicz "rum Evang /icum liberaliter me donaveris. Legi tos quampiimum potui maximâcum aviditatc. Satis mirari ncqueo diligentiam tuam in evolvendis tor Interpretivar, partim antiyuis, partion novis, quibuldarn etiam horum milis ignotis hactenus; tum verò non pallca Chronologia, Hifirra preceptorum video abste quàm ab aliis enuclcatiùs expofita. Neque doleo quadam, 'qux cgo prídem annotaveram, mihi tuo labore plærepta. Quin gaudeo potius metum judicium tuo, viri tam entiti, judicio confirmari. Hiwg. Grot, in Litt. dat. Luteto 16. F $c b$ ' 1639 .

Facultas Theologica per obitum Sphanhemii adhuc vacat. Majorcm ccrtè olbitatcm pai non potuit Acaderais. Utinam illa illucefcat aliquando dies, quà furrogetur in locum defuncti, qui cum co paria faciat, fed mihi crede facilins reperictur qui locum fubibir,quàm qui implebir. Dolo fäpe mecum extinctum hoc lumen feculi, decus virtutum, \& principern ingenii, \& doofrine, omnique. fcicntiarum gencre cumulatifimum. Sed ita Deo vifum, cujus voluntati no-

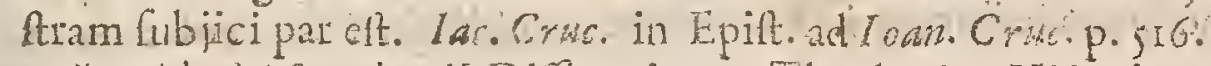

* Eriderici Spanbemit Differtationes Theologico-Hiftonica omninò prohtbentur. Index Roma impreft. $168 \mathrm{i}$.

Extant Dubia Evangelica 2. Vol. in $4^{\circ}$. Genevo 1639.

\section{HENRICUS VALESIUS.}

T. Iftoriographus Regins, natus cet Lutctia Parifun amo Che $160340^{\circ}$ 1 Idus Septembris, dic Mercurii. Obiir Nonis Maii Anno Chrifi í́76.

ScripfrNotas \& Annotationesin Arsianim: Marcellimum, in Eufebium, Socrato tem, \& Evgrium, \&c. Multa in Serinis volumina moriens reliquit, pattin abfoluta, partim imperfecta. Ejus Note in Taleriz Harpocrationis Lexicon edita funt Lugd.Batav. I682. 4. Unum ocilum amifrat.

Vir fummus fummos Gammivos, \& Rhetoricos, atque adco Oratores ipfos plurimum fupergrefus ef: quippe qui Gracas, Romanas \& barbaras notas haben batantiguitates, cui crat Hifloria facra prophanaque comperta, qui Gracush La:inumgue formonem tamquam "atrum noverat; quildenique ad magnitudi-

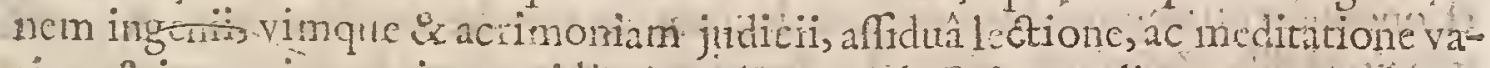
riam \& interminatam omni literawm genere doetrinam adjunxerat. Hadrian. Veleg. fratcr in Vit. Hen. Valefo:

$$
\text { O०Q000 } 3 \quad \text { Nemo }
$$

Clar.An.D. MDCXL; 
Nemo Criticom Profefionem fuam magis condecoravit quam Dominus Valefur, onnibus ad illam rite exercondam necelfariis dotibus inftuctus erat, ejufque dignitatem magno çu (plendore tuitus eft imo \& adauxit. Iudicia Erum ditor. Parif. IE 8 ;. Gall.

Dominus Valois inter totius Regni Græcæ lingux cultares excelluit, \& in Ecclefix ac Imperii Hiftoria verfatifimus erat, in omribufque argumentis ab $E_{u} / e_{\text {e. }}$ bio Socratc, Sozomene. Theodereto Evagrio pertractatis. Quapropter ex omni patte refpondit expectarioni juffique Cleri Gallısi, qui ei ut totius Seculi viro ad hoc maximè idonco gloriofam demandaverat provinciam Hiforicos vertendi, fi mandatum idem non exequeretur Dominus de Morchal Tholofa Archicpifcopus. Certóque affirmari poteft illum nedum obfeuravilfe \& diclevilfe omnes illorum Authorum verfiones ante fe elucubratas, fed etiam patmcifimos Imterpretes iplum nec fuperare imò nec adæquare poffe. Quxdam tamen loca occurrunt in aliquibus harum Verfion ubi Doctus ille vir, Criticorum hodiernorum judicio, ambobus fuis oculis opus habuiflet. Idem. Gallicè.

Eruditus Honricus Udefus omnium Enfebit Verfonum vitiis obfervatis aliam is abfolutiorem elaborare molitus ef. Illam adjunxic Graco contextui 2d quamer manufcripta recognito, Doctifimalque Notas eidem addidit. Ejus Verfo Literarix Reipublicx applanfum omniumgue Eruditorum promeruit. Dnobus attributis parum vulgaribus ornari poteft, quod nimirum \& elegans \& literalis fit. Critici quidam aliquos tamen lapfus in illa obfervaverunt; Sed omnibus fatisfacere impelfibile eft, difficillimumque in tantx pron lixitatis opere nufquam hallucinari. El. du Pin. in Biblioth. Nov. Vol. 2.pag.9. Gallicè.

Negari non poteft, quò in Notis Valefinnis in Harpoerationis Lexicon plurima occurrant, quæ Seripturam non intellectam aliis aperiunt, teterrima Scrip. torn loca reftituunt, Latinos Grocorwm interpretes corrigunt, Hiforian multis partibus illuftrant, obfcurifima Fabularm deridicula, \& nativum Verborum atque dicteriorum leporem, qui in Fabularum fcenis difcitur, revelant; Po:etarum quoque \& oratorum lufus ac dclicias, fuavitate Graca conditas elégantia, fine fuco fiftunt. Ut taccamus, quix in cognitione Autorum, Grectrum prefertim, in doctrinâ Gréce lingux, in tribunalis Graciformulis \& harum Origine, in contractum, \& forensum AEtionum generibus, necnon in rebus Geographicis \& Cbronologicis illuftrata ab eodem hîc reperiuntur. Alla Eruáitór vol. I.p. 250.25 r.

Ediderat anno 1636. Parifis Marcellinum Henricus Valefins, vir de literis égregiè meritus, ex manufcriptorum Codicum fide doctifque conjecturis, quanrum fieri potuit, emendatifimum, notifque illufratnm perquam eruditis. Ex quo tempore \& familiaris magis reddi hic Autor eruditis copit, à cujus leCtione antea quamplurimos tot in eo lacunx ac mendx ablterruerant: \&.Editio pracipuè illa Velofnna, diftractis brevi tempore exemplaribus, fummo apúd dectos omues in pretio fuit. Ibid. ut fupra p.13.14. 
Henricus Valefus, vir eruditiøne cum maximis hujus ac fuperioris atatis $F$ bilologis comparandus. Colome .44 . in Paralipom. ad Chartoph. Ecclef. Gul.Cave p.44.

Henricus Valefans virfummus, cujus mors nuper rei literarie ingentem inpofuit \& irreparabilem plagam, omnibus cruditis diutiflmè lugendam. Ioan. Georg. Grav. Pretfat. ad Ciceron. Epitt. cum Not. Var.

Ingeniorum noftra atatis plincipem yocat idem Gravius Tom. 2. Not. in Ep. C'iceron.p. 407 .

\section{J.OHANNES IUDOVICUS GUEZIUS BALSACIUS:}

CAllus, Poëta Latinus, obiit anno Dom. 1694. Reliquit tres libros CarmiThum, itcm Epitolas, \&cc.

Ioanmes Ludovicus Gagits Balzaent, celebris ille fcilicet, cni nemonon Galli. cè modò, fed Latraè etiam feribentium elegantix palmam non facilé cedat. Gaffend. de Vir. Peire k. p. 250.

Balzaci litere felectx, valite fermone fcriptx, Amfelodami apud Elzevirios editx an: $1656.1112^{\circ}$. Apud popnlares fuos varia expertus eft judicia ob novnm aliquod dictionis genus in Gallico fermone: Eft enim argutus, flovidus, Mctaphoris aliquantulum indulgens; qux fcribendi ratio quiburdam, qui cantigariores videri volebant, difplicuit. Nam Satyrx adverfus illum fcripta \& integrilibri, quos ipfe tamen valide fatis excepit \& retudit. Latinas Epiftolas fcripfit; qux rarx funt, in quibus fingularis quidam Lingux Latinx nitor, \& Gallick quxdam facundia, optimè ad fermonis Latini genium applicata. oIn $G$ allicis Epifow lis habentur fingula ia de rebus litetariis \& auctoribus judicia. Non has tan-

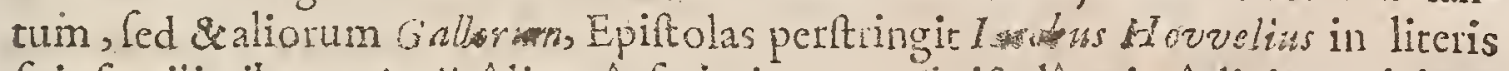
Guis familiaribus, Anglicể linguâ fcripris; nam Epiftolâ primâ dicit, vicinos

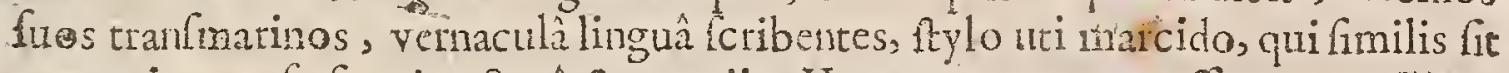
corpori carnofo fine juncturâ \& arteriis. Vocat cornm exprefliones Hecticas, \& meris verbis fatulentas, aranearum telas, quix non ftringant Lectores - lllie

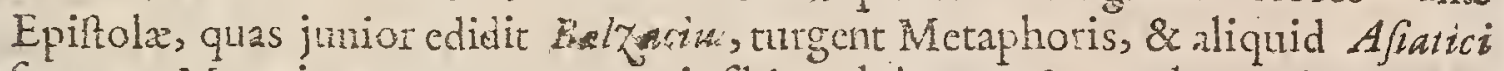
fonant. Maturiore atate temperavit fibi panlulum, \& quod tumidum anteà videbatur, in mollius dicendi genus commutavit. Si quid ego judico Gallice illius eloquentix, vel porius orrandiloquentix, quam Genti illi familiatem in Sulpitio Severo, Eucherio aliqui, in 33 at Eo Erafmusnotavit, fpecimen inillo quoque oblervare mihi videor. Magna interim partium ftudia fuerunt in Galliâadveifus hujus viri eloquentiam, aliis ut novam integris libris damnantibus; aliis ne perfectifluai fermonis cxemplum imitantibits. Hiftoriam omnem cjus rei prolixâ differtatione complexus cet Sorelltzis in Bibliothecî Gallicâ. In Balzarì Epiftolis notari merentur, qux habet de lire inter Guietury \& Groinum fuper pireltantià vin: \& cerevifa pay. 3Ij. Errancifi Grieti Rufticum Epigramma pro wino adverfus Batovos Cerevifa potores illic legatus. Grotii Phalencus pro

Clar.An. Da MDCXI. 
Cerevifá inter poèmata cjus reperitu1. Dan. Georg. Morhof.Polyhift. p. 295. 296.

Nec vercer Balzeit Latinas Epifolas cum Epifolis Antionarum compa rate, ac nefcio, an etiam preferre debeam: Ciceronin as excipio, nihil enim illis in co genere perfectis. Sunt tamen, quibus alique nimis culte \& compofitx, nec fatis faciles a familiares ex Balzaciants iftis videantur. efgid. Monag. in Epit. ad Chifianam Sudorum Regin. prefix. Carminib. Balzac.

Epifolarum tuarum conctptus graves lunt \& à vulgaribus cogitatis non minus remoti lunt quam conformes fenfui communi virortum qui peracri judicio valent: Earum dictio pura eft, verba verò ejus funt delectûs qui cum lat1dabilifimplicirate confifere poteft, earum fenfus perfpicuus \& nitidus, \& periodi fuis omnibus numeris abfolute. Cardinalis Richelins Epiftola ad Balzacium, Parifins 4. Febr. 1624 . Gall.

Stylus cjus argumentorum adeo jucundormm nature tam congruus ef, ut Axiomata cjus Politisầvel iplarum frominarum captuiattemperentur, ejus verò Amatoric Epiftolx Philolophorum gravitatem non offendant. Apologia pro D. Balizacio. Gall.

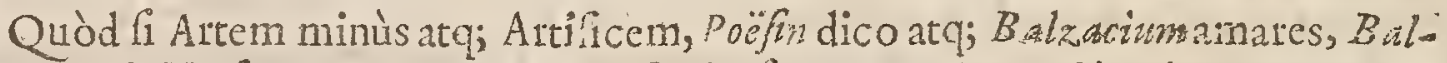
zacii centè Verfus non amare non poffes;ita funt Lätini \& caftigati;itacanori atq; rotundi,adeo abhorrent ab omni verborum vilitate, adeò in iis omnia vivunt, \& moventur; tanta vis eft atque fublimiras; tam felix audacia; tam nihil pueile, nihil otiolum atque arcefitum. Propter qui, $H$ ugo Grotizs, Nicolaus Borbonius, Francifc.Guietus, Hadrianus Valefibu, Carolus Feramufusu, ut sumi Poeta, ita Poetarum judices exactinimi, Balzacium inter eximios hujus feculi oëtas collocarunt. Etgid.henag. in Epitt.ad Chrifir. Sued.Regin.prafix. Carmin. Balzact.

Si Bulfaro tuo vifum fuillet, Nobilifime Virorum, intra patrium fermonem; cui exornando totum fe impendit, nominis exifimationem cohibere, nemo tam praclaro infituto non faveret. Majoris verò eruditionis famam cum ambiret, ne difertus magis, credo, quàm eruditus videretur,fummum decus feculi aggreffus eft, qui ingenio fublimi, néc judicio minori, tum fcientiarum omnium cognitione, \& antiquitatis utriufque inftuctus, nufquam jam hrere poteft. Id tenrandum interim fufcepit; quod cum omnia fint fum ma, inter prima ejus mon!tmenta numeramus; Herodern feilicet, Infantiridam: Tragediam, ut breviter hoc dicam, excitatan \& coleftem: quam univerfus ordo Literatus cum fuporeadmirationis legit, pradicatque. Quæ Aniqumitatis ita vim omném genium que expreffit, ut (ne quid dicam ampliùs) xquarit. Marc.Zuer. Bos:born. in. Epift. ad Confaritin. Hugenium, Lugd. Bai. 1636. Jul. I2.

Superat utrumque [loannem Auratum \& loannem Bachotium] Io. Ludovicus Guezins Balzacius, cujus in verfibus felix audacia; nihil jejunum, otiofum, accerfitum. Solcbat diccre Ioannes Saracenas fuperari Balzacium à paucis in genere levi \& xquabili, in gravi \& fublimi à nullo æquari. Nexum tamen Poëticum alicubi requirct Lector, \&alicubi collifiones verború afperiores forfan averfabitur; urcung; catera ejus fcupta ulimam propemodum limam receperint. Tres $C$ ari aninum ejus libros ccidit illuftris e Agidins Menagin, 'varii argumenti in quibus 
Epica cum Elegis de principatu certant. Inter Epica praptat Chrifius Victor, inter Elegias propemodum Amyntas. Borrich.de Poër. P.II, I: 2.

Vir ingenio compto, \& Gallica eloquentix laude clarus, Balzacus, ,ed in Res ligione plus quàm infans. Molnaus Prafat.ad Hyperafpitt.

Extant opera ejus Gallicè Tom.2, in fol.'Parif.1665.

\section{CASPAR BARIAUS}

'A Ntverpianus, Dootor Medicus, primùm Logices in Academiấ Lugdunow A Batavâ,put Philofophię Moralis apud Amfelod. Profefler, obiji Anno Clarín. Dis $M D C X L$. I647 Reliquit.Carmina, Drationes, \&s Epiftolas. lib.ı.c.3.

Cafparus Barlaus, dubium Poëta melior,an Philofophus. Voff. de Grammat. $\operatorname{man}$.

Barlans, Orator \& Poëta Batavus, cuivis Antiquorim comparandus. Hof-

Barleo valetudinem epto profperior em, vel Poëleos causâ quam ornat. HHug. Grot.in Epift.ad Vof!.Cal.Jan.16;8.

Poëil plurimuin valet, vinétâque numeris oratione fublimè incedit; fed nee Colutâ minus difertus eft. Valer. Andr.in Biblioth. Belgic.

Ita admirando planè art ficio, \& incredibili Auditorum delectatione ac fruetu,apud Amfel. Logicam exponit vir fummus, \& clariffimus Cafpar Barlaus, quem meritò numerare foles inter primarios Reip. Laterarie proceres. $70 . B^{2}$ everovic. ad 70.Wefterburgium de Vit.term.p.íg.

Magni viri [Barlei] infignem doctrinam ilunquam non veneror, laudo, praxdico. Fo. Wefferburg.ad I0.Beverovic. p. 179.

Ille vatuin noltri feculi Princeps Barlatus. Marc. Zuer. Boxhorn. in Epift.ad Pontanum, p.4.

Nec in Belgis defecit Genius Poëticus, fed nonnunquam gloriam Veterum propenodum obfcuravit. Sanè Cafpar Barlaus Antverpianus, \& inventionum artificio, 8:cultu dictionis, optimo cuique Antiquorm, etiam ipfi Claudiano palmam dubiam facit, in quocunque argumento, quocunque Poëratuin genere oppidò nitidus, facundus, exquifitus: digms qui ab omnibus Heliconis alumnis in finu geftetur, ità piè \& fuaviter Sacra emodulatur, malcule Heronm gefta, opportuinè \& convenienter varietatem Actionum Humanarum; ubique experrectx induftria, cui accedit nativa quadam facilitas, copia, majeftas. Ag: ovit illam dexteritarem Card.Rishelius, \& lecto $P$ anegyrico cujus exordium, $N$ unc nova purpureîfument exordiat fafces, planè Regi i munificentiâ profecutus eft. Ad fummam, in wao Barleo oftendere voluit Natura, Phoobum femper juvenem effe, nec cum mundo effoto confenu. ffe. Borrich.de Poët. p. 140 .

Barlai Epifolæ facetiis \& Calibus perfperfæ multa iftus temporis notabilia fxpè memorant. Fuit Barlaus Philofophus \& Poëra preftantifimus, quanquam a $B$ aravis ipfis non magni aftimatus;ingenium foecundifimum \& fellivifimu

$$
\text { PPPP P }
$$


habuit, in Elegia, Scazonte \& P baleucis mirè fuav is \& argutus, in Epico carmine luxurià nimia penè molefus : Quam cjus loquacitatem conterpcim habuere Heinfus aliique caftigariores Poctæ. Id certè verum elt, in delectu verborum non multum fe crucialfe, fed ptimos impetus plerumque efle fecutum, \& ingenii fui ubertatem. Mifero fato periit, puteo fubmerfus; an fponte, an cafu, incertum. Ejus extant Epiltolæx, quas noin adeò ob dictionem legi velim, quàm ob argutias \& urbanitatem : Facetiatum plenifimus eft, ubique jocis circumfluens; ac incidunt nonnunquam, qua ad Hitorian literariam fui temporis, præcipue in Bataviz, pertinent. Lapida inter alia Eittola eft LXXI.quam ad Petrum Gruterum Ludinagiftum fcripft, hominem in ftylo xaxo nnov \& antiquarium, ubi per mimefin perperuam eum cum tylo fuo exagitat. Ett verò Gru-

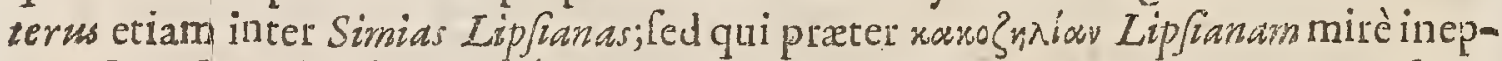
tus eft in frigidis Allulionnibus \& verbis Antiquitatis. Dan.Georg.Morbof.Polyhift. $\cdot 300,30 \mathrm{r}$.

In Barlei Epiftolis habent Lectores quod difcant, Fiftorici quiod notent, Theologi quod animadvertant. De rebus facris, de veritate pacificâ, de Religionis libertate differit Auctor tam piè quàm animosè:de Philesophorum arcanis fagyciter \& perfpicuâ fubtilitate. Erga familiares oficiolus eft fcriptor, in fautores gratus, cum gaudentibus gaudet, \& dolentibus prebet folatium. Sic mifcet urile dulci, rerum argumentorumque varietate, nonitis, jocis, falibufque. Plura adderem, fed non eget domeltico teite.Gerard.Brandt.in Epift.ad Arnold.Hooft,præfix.Epift.Barlai.

Barlæi jactura,cujus aliquas circunftantias à me petis, cum Walai \& Veflingiz interitu non eft conferenda, quamvis præclarus vir fueric ille; plures enim femper exiltent eximii Poete quam eximii Medici. Amfelodarni cum degeren de vitęillius exitu variifpargebantur rumores, ac fo melancholia quædam iplum accelerallet. Verum quidem eft quod cum in Principis $A$ uraici obitum Funebrem Orationem carmine concinnalfet, Doctor autem Spanbemius alteràm profa pronunciaffet, impatientiflimè renumerationis inxqualitatem toleraverit, ut enin feltivè dixit Dom. Salmajuss, mira hac fuit hallucinatio, quod Equitis ftipendium Pediti, Peditis vero Equiti perfolveretur: Barlaus quingentas tantum libras,alter verò quingentos nummos accepit. Sorbiere Epift.ad Dom. Patin pag. 442. Gall.

Socinianus nec fum,nec fui, vellent quidem me effe, qui explendi in me odii materiam folicitè quarunt.Sed his innocentiam meam pro fcuto opponam.Barl. iple in Epift.ad Petr.Cunaum, 12.Septemb.16\%6.

Extant ejus Poëmata, Lúgd.Batav.1628.8०.

Extant ejus Epitola, Amftel.apud 7o.Blaew. I6 67.80. 


\section{JOANNES MORINUS}

Atione Gallus, Patriâ Blefenfiss, Congregationis Oratorii Presbyter; Obiit
ann.1659.æatis 68 .

Edidit Biblia Graca Interpretum LXX. Item Exercitationes Ecclefafficicas in Clar.A.0. MOCXI utrumque Samaritanom Pentatenchum : Tractatum de Sinceritare Hebraci Graciqute Textus dignofcendâ, contra Taylerum,Bootium,ac Muifum, Grammaticam Samaritanarn, \&c.

Vir impensè doctus Ioannes Morinus è Congregatione Oratorii. Gafferd. in Vir.Peiresk -68 .

Orientalium literarum peritifrmus Ioannes Morinus. Voff.in Harmon Evang. pag. 550.

Io.Morinum Congregationis Oratorii $P_{1}$ esbyterum, in linguis Orientalibus fuilfe veratifimum, fed i entateucbo Samaritano nimis addiEtum fcripta clamanto Pawl.Colome T Gal.Orient.p.166.

A Domino Patin audivi, Cardinalem Richelium, cum aliquando de Io. Morino Oratorii Presbytero incideret fermo, dixife ipfum egregium effe ingenium, feque illum timere. $P$ aul Colorbef.Opufc.par29. Gall.

Nunquam interituram fibi peperit famam, quia vero merito fupertucta erat: Pauci profunde ejus eruditioni parem alfecutifunt. Prafantis erat ingenii, foecundx phantafix, memorixque tam fidelis ut nihil unquam ipfi elaberetur eorum qua ipfi concredita fuerant. CNioreri Majoi Dictionario Gallico.

foannes. Morinus vir dottiflimus, cui multum ob labores in Samaritano Pent. docti omnes debent. Brian. Walton in Dillert. de Iing. Oriental. I658. p. 41 .

Mirum eft fo. Morinum virum aliàs doctifimum, fatuere tam Grocam LXX. quàm vulgatam Latinam divinx authoritatis effe, cùm inter fe fa, ifrmè dilcrepent \& contraria affrment. I demibid.0. 1.8.

Si Capellum cum Morino comparate liceat in is quę uterque de rebus Biblicis compoluit, in hujus quidem libris plus eruditionis apparer, fed que fapiis fit extra ien, at in illo plus ingenia atque judicii qui nunquam à fcopoaberret, \& id quod fibi propolut frmilimis rationibus comprobet. Vit. fo. Norini prafix. Antiquit.Eccle! O ienc.1682.p.69.

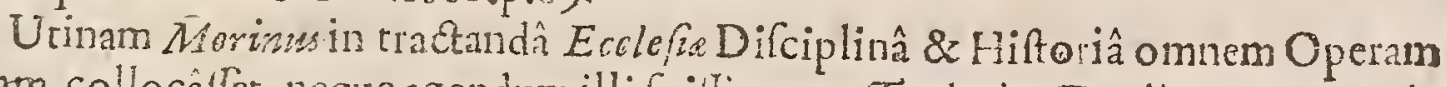
fuam collocatlet, neque agendumilli fuilet cum Tayloris, Bootiis, Hotingeris,

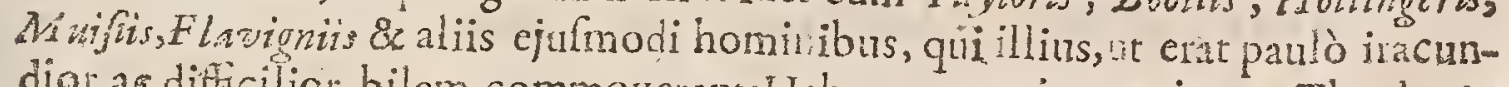
dior ae difhcilior, bilem commoverant:Haberemus enim maximam Theolog parcem ab co graviffmè tractatam, \& non ex more Scholaficorum qui temetè \& fine judicio de rebus magni ponderis fenten iam fermn, nihilque edunt in Theoloziam preter fophifmata \& argutias qux viros doctos ad tifum \& colltcmpun incitent.I bid. $\$ .99 .100$.

$$
\text { Pppppp 2 Nemg }
$$


Nemo in Bibliorum Criticen plura imò nec ertuditus fcripfit quám foann. Morinus Oratorii Presbyter. Quoniam plurimos hodie fequaces habet, qui cjus Opiniones minus accuratè exculfas creco impetu fectantur, non abs re fuerit fi eafdem majoy fedulitare penficulemus. "Cum apud fe ftatuillet alteram

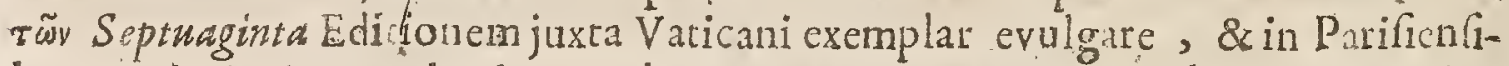
bus Polyglottis exeudendum Hebraico-Samaritanum exemplar Pentateuchi, jam abillo tempore anino molitus elt hodiernum contextum Hebraicum quantum polfet deftruete, ut eò magis r w̃y Septuaginta Verfonem \& HebræoSamaritanum Pentateuchum commendaret, quali depravatus ellet textus Hebraicus Judrorum plurimus in locis, in quibus dif́crepat à Verfone Greca

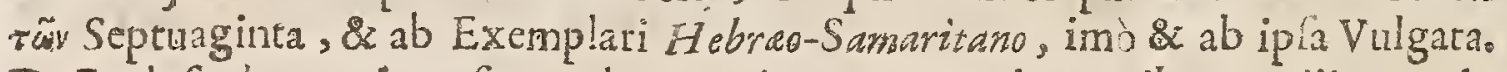
DeEcclefia hac ratione fe preclare meriturum putavit, omnibus mediis tuendo Veteres Verfiones, quas ufu diuturno approbaverat. Verum fortaflis non ani-

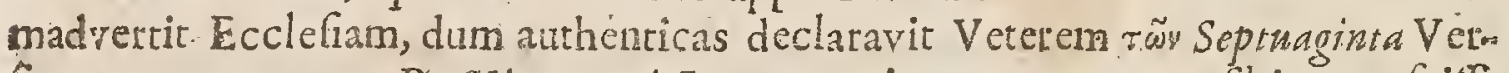
fronem, novamque B. Hieronymi Interpretationem, nunquam fibi propofuite Hebraicum Textum damnare, nec Judxos quod eundem depravaverint accufare. In ejus Libris innumera funt utilia, altifimaq;occurrit erudi io. Protefanres quidam Morino relpondere conari furt. Sed praterquam quod prajudiciis. in grariam Judæorum pleni erant, adeo infirma funt eorum refi onfa, ut facilè crediturus fit Lector ratione nixum fuilfe Morinm in omnibus q adverfus cT afforetarum textum Hebraicum in hilce libris attulit. Dominus de $M$ uis fagaciùs multò Hebrai Textus Apologiam fcripfit, eademque opera quibufdam foann. Morini propolitionibus refpondit. Optandum tamen elfét eum moderatiorem fuilfe, nec confilium pratexendo : Morinum acr ùs oppugnandi, qui nimiu n oftentavit Zelum pro Veterum Verfionum ab Ecclefia approbatarum propugnatione, ad alterum extremum tam prope illum non acceffifle, $M$ a f $\int_{0}$ ra acribendo plura ipf minimè debita. Quamvis D.de $M$ uis Hebræx Lingue peritus eflet, totam tamen non videtur habuiffe eruditionem nece rariam ad bonum refponfum Morini Libris opponendum. Orat.Presb.Rich.Simon. Hift. Crit, V.T.1.3.c.18.

foannet Buxtorfus in Differtatione de Literarum Hebraicarum genuinâ An: tiquitate, Morini Exercitariones vocat Librum crudâ \& indigeftâ materia mole infertum \& confertum.

Extant Biblia LXX. Interpret.cum Prafat.ac Prolegomenis , Parif.3. vol. fol. 1628 .

Extant Exercitationes in utrumque Samaritanorum Pentateuchum. Parif: I631.40.

Extant Exercitationes Ecclefiaficx. Parif. $1626.4^{\circ}$.

\section{SAMUEL BOCHARTUS}

Clar.A.D. D Flotomagen/2s, Anno I599.natus,anno 1667.0biit. Fuit Theologus \& Philo? MDCL: I logus eximius. 


\section{CELEBRIORVM AVTHORVM.}

Scripfit Hierozoicon, \& Geographiam Sacram, \&c.

Samuel Bochartus Proteftancis Religionis apud Cadomenfes Minifter fuic. Ejus propenfio erat in politiores lirteras, quarum callentifimus erat, affiduèque Poetas Gracos \& Latinos Veterelq e Patres legerar. Dom. Bochartus Lin-" guarum ctiam peritilimus erat, Latinâ, Gracâ, \& Hebraicâ loquebatur \& fcribebat, Arabicaque latis gnarus erat. Ejus merita nedum apud ejus partium homines exiltimationem ipli conciliarunt, fed etiam apud omnes apud quos probitss \& Doctrina in pretio eraht. Eorum illuftrifimos indigitare haud dificile foret; fed obfervalfe finficiet eum à Regina Suecic Stokolmiam accitum fuife anno $6 j 2$ ibig̣ue publicis fignis cam oltendile quanti ejus eruditionem faceret: Moreri, Diction. Gall.

Samuel Bochartus, illud faculi noftri Miraculum, cujus fi quis fit qui nomen ignoret, aut ftupendam cum fummâ mode iâ conjunctam erudicione non fúpiciat,na illum penitus «̌furov elfe oportet. Fo. Lud.Fabrit.in Orat.inaugnral.de Anim.immortalitat.

Samuel Bochartus erudicionis licèt Abyflus, adè tamen proprix opinionis \& xitimationis expers fuit, ut hand femel commilfos in fcriptis fuis errores publicè lit protelfus : Irigenuè agnofco (dicit inter alia Geograph. Sacr. lib. 2. c. I4.) nos in its erraffe, qua de Calpiis portis \& Nifro C'ampo drximus. Adeo ut fummo jure Apuleianum hoc convenire Viro huic dixeris quòd inter do tos nobiliffimus, inter nobiles do diffimus, inter utrolque optimus, \&, quod merito addas, inter omnes modellifimus frerit. Cul. Salden.de Ufu \& Abufu Librorum.

Doctifimus, Linguarmimque Oricatalium peritifimus vir $S$. Bochartus in admirando opere, Geographia Sacra. Ouzel. Animadverf. ad Minut.Felic, pag. 34 .

Vir longè doctifrmus in illo diffufx eruditionis opere; Geographia Sacra.Po cock.in portam Mof.c. j.

Opus laboriolim, fcilicet Geographia Sacra, \& vàriâ eruditione refertum.Vö̈t. in Biblioth.lui, p. 420 .

Qux autem Tarfis, \& ubi fuerit, nuper in immortali Opere demonftravit, quod tute Icis, longè doctifimus Bocbartus. Tanaq. Faber. Epil.1.1.p. 36.

Samuel Bochartus, doctiflimus \& judicii abqque controverfia limatifimi. Lambec. . Hit.lit.prodr.4.

De quo adenudus Bochartus in ad nirando opere de Animalibus Biblicis: Bochartus, inquam, quem ut, dum viveret, veneratione fingulari coluimus, it nune fato functum lugemus, cum omnibus bonis, quibus nota erat viri illins, in fummâ omnium ferè linguarum \& univerfæantiquitatis peritiâ admirabilis rorum probitas, pari modeftia juncta. Paul.Colomef. Obfervat. Sac. pag.i27.

Samuel Bochartus, vir Punice Lingux ad miraculum peritus, fed (profi dolor! ) maximo Reip. Literaria damno nuper ereptis. Colomef. in opule. pag. 205 :

$$
\text { PPPPP }
$$

Vis 
Vir eruditionis cumulatifimx Sarnuel Bochartus. Petr.Gaffend.in epin.ad M. Neuraurn,Parif.7. Kal. Novem. 1653.

Batanea eadem eft qux Bafan, quod bene obfervat feculi noftri ornamedrum Samuel Bochartus in Geographiâ S. Fo. Forr. de Scripror. Hift. Philofoph.p.286.

Samueli Bocharto divini ingenii viro, \& pro tali jam olim mihi noto, \& ex quo noto, culto fempĕr \& amato, haud invicus accedam. CHeric. Cafanbad Lä̈rt.p.4.

Oblervatione dignum eft illud Doctifimi Bocharti, qui multa de linguis anti juis nobis fuppeditavit; Babylonem femper Hebraica Lingua fatalem fui? $\mathrm{e}$, tum ob Ling arum Confusonem ibi factam, tum q od fudai captivi ibi linguam patriam dedidicerint. Brian. Walton. in Dillert. de Ling. Oriental pag. 20 .

De hoc Homeri loco Athenaws, 1. 2. Ced Samuel Bochartus facinrum humanarumque literarum lumen çarifimu n, rem pio fuá fingúlari doctrinâ longè aliter trictavit in admirando opere, cui nomen eft Pbaleg. Tanag. Faber Not. in Longinurn, p. 288.

Hominum quotquot vivunt doctifirms Bochartus, If.Voff:n obierv.ąd Mebarn, p. I97.

Idem non femel affirmat Menagius Not.ad Laerium, \& 7oannes Schefferus in op.de Milit.Navali, p.34I.

Sed ncfcio quo fatorum confilio, huic ultimo feculo nec metenti, nec talia enimant, refervati funt eximii illi viri $M$ artinius, Spelmannus, Kilionus, Voffus, Solmafus, Bocharms, 7 unius, Menagiws, Skimerus, qui piimi Etymologorkin nugas ri deflerunt.vid.Editor. Etymol. Ling. Anglican.Steph. Skinntri,in Epilt.ad Lca. Anno 1671 .

Cadornenfis Bochardus eruditifimum Commentarium ad Genefeos cap. 10. perfecit: in quo Geographice Sacra illuftris \& nova tractatio c: m omnigenà doatrinâ conjuncta fuaviter te afficiet. Cl.Sarrav. ad Salmas. Lut.Parif. 15.Marto 1645 .

En mihi relatam mortem Viri, fi quis ufquam gentium, in Orientalibus Linguis doctiflimi. Is erat Dom. Bochartus Cadomi in Normannia Ecclefinftes, quem paucis horis ablulit Apoplexia. Annum feptuagefimun nondum attigerat. Nimia animi contentio \& in ftudiis intcmpcrantia obıtum ejus unicè accclerârunt. Propediem Librum fum de Paradifo Terrestri pralo fubmittere decreverat. Apud me habeo praclaros duos libros ab illo elucubratos de Geograpbia Sacra \& de Animalibus Biblicis, colque interdum cum voluptate lego. Ejufmodi homines nunquam mori deberent. Guido Patin. Epilt. fcl. Epiit. iss. Gall.

Bochartus duo ingentia volumina compo?uit quorum untm Phaleg alterum verò de Animalibus Scripturce Sacre inferibirur in quibus multa Bibliorum loca elucidavit: Verum quoniam diffufus, adrodum eftille Author , \& vir Qootus, ac enditione potius guam judicio valens haberi viderur affectalle, 


\section{CELEBRIORUM AUTHORVM.}

optandum elfet ut duo illa Opera in compendium redigerentur, ea tantum retinendo quæ ad Librorum Sacrorum intelligentiam conferre poffunt. Verum quidem elt quòd pleraque eorum qua referuntur cùm in Phaleg, tum in libro de Animalibus quorum mentio in Scriptura occurrit, meris utplurimùm conjecturis nitantur: Sed id genus conjectura utiles quandoque funt, quatenus fi per illas non femper detegatur veritas, ad errorem præcavendum faltem conducunt : Hac autem in re polterior Liber,qui agit de Animalibus apud Authores Sacros memoratis, utilifimus effe poteft ; quamvis enim vera ignorentur nomina plerorumque A nimalium, quorum Biblia ir eminerunt, fatis quandoque lucis a fert ad animalia quxdam excludenda, quibus eadem nomina convenire neque int. Rich.Simon.Hift.Crit.V.T. 1.3.c.20. Gall.

Liber quem Bocbartus in lucem emifit cui titulus Phaleg, preferri debet differtationibus quas idem A rias Montanusevulgavit etian fub nominibus $P$ haleg \& Canaam, quæque Apparatûs ejus partera conftituunt. Idem ibid. lib. 3 ; c.17.

Extat Geographia facra, Cadomi 16 5 1. fol.

Extat Hierozoicon, Londini I6 63.2. vol.fol.

Ultimum diem obiir loquens in Cadomenfis Adademiæ confeffu, die Lunæ 16. Maii 1667.quæ fuit occafio cur D. de Brieux eleganti hoc Epitaphio ipfum decoraverit :

\section{Scilicet bac cuique eft data fors aquiflima, talis \\ $U_{t}$ fit mors, qualis vita peracta fuit. \\ Musarumingremio teneris qui vixit ab annis, IMuJarurning gremio debuit ifte mori.}

Dominus Bochart opulentus erat, opimum reliquit patrimonium filia unicx quam-Rotamagenfis Curię Senator quidam uxorem duxerat. Verùm ingenii ejus filiis multò Colidioribus opibus gaudet. "Potiflimi funt duo illa egregia Opera $\mathrm{q} \rightsquigarrow$ adhuc in vivis publici juris fecit. Prius eft Phaleg feu Geographia Sacra : altelum vero de Anirnalibus Sacre Scriptura. Operam preterea navaverat in Tractatu de Mineralibus, Plantis \& Gemmis, quorum in Sacris Codicibus mentio; in alio de Paradifo Terreftri, in Commentariis in Genefin \& in volumine Differtationum. Omnia ejufmodi Fragmenta cum plurimis Epiftolis eruditione refertis in Domini Le Aoine amici ejus intimi manus pervenerunt; à quo quædan corum evulgaium iri fperabatur; fed ob moleftum quoddam negotium regno extorris factus, id nordum praltare potuit; Profelfor nunc Lugduni Batavorum electus hac de re forfitan cogitabit, Id tanquam certum mihi dictum eft. Moreri Diction. Gallico. 


\section{JOANNES IAUNOIUS}

Clar.A.D. Onstantienfis, Theologus Parienfis, natus eft vicefimo primo Decemb. $M B D$.

Scripta ejus multa funt \& varia: cæteris verò palmam praripiunt, Quinque Tomi Epiftolarum: Opufculum de Dionyfiz: Tractatus de variâ Aristotelis in Academiâ Parifinâ fortunâ: Differtatio de rectâ Nicani Canonis 6.intelligentiâ: De mente Concilvi Tridentini circa fatisfactionem in Sacramento Ponicentix:De Commentitio Lazari, Magdalena, \& Marthe in Provinciam appulfu: Deverâ causâ fecefsûs Brunonis in Defertum: Difertatio de Auctoritate negalstis Argumenti:Judicium de Hadr. Valefir difeptatione de Baflicis.

Martinus Schoockius part.2.fab. Harnel.c.20. ait. Launoium elle ferium \& en1ditum Veritatis antiftem,ac vindicem : Scriptaque illins uni veritati eruenda dicata elfe.

Goannes Launoius, vir' [ex elogio eEgidii Menagii ] doctifimus, humanifrmus, \& inter Theologos Parifienfes (namtalemelle Launoinm, ne vel ipfe livor negaverit) celeberrimus. Utinam verò dintiùs vixiflet Autor non minus doctilimus quàm diligentiffimus, ut multos labores fios utilifimos continuare abfolvereque potuiller! Ađta Erudit. Menf.Jul.I686.

Nemo eft inter hujus feculi Scriptores qui merito fuo apud cordatos omnes majori in pretio fit habitus, quàm foannes Launoius. Quineriam citra invidiam dixerimus, vix alium inveniri, qui majore um candore, tum ingenii acumine, fepofito omni partium ftudio, res facras tract rit, atque imperiti vulgi errores animofiùs impıgnârit, aut etiam feliçius proftraverit. Elog.Ioann.Iawn.12 ${ }^{\circ}$, Impreff. Lond.1685.vid. prxfat.

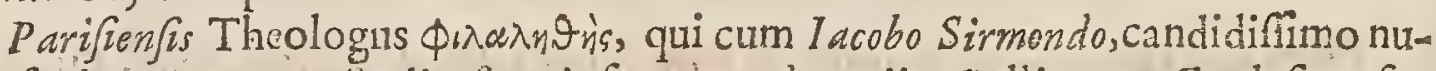
per fociorum, magno teudio, fpretis fuorum caluminis, Gallicanam Ecclefiam fabulis liberare hodie nicitur. Coning.præfat.in Caffand.\& Wicel.

Multum tribuo Viri judicio, utpore quod abundè ille mihi probavit eximiis al quot libellis, quibus fabulas nonnullas Ecclefiaticas in vulgus receptas mafo culè explofit.I derm de Antiq. Ácad. Supplem.39.

Clarifimus Sorbona Doctor vocatur Daleode Cultu Relig.in Præfat.pag.9. Ubi differtatio illius de Audtoritáte negantis Argumenti anno 1662. edita doCiffrma quoque dicitur.

Dominus Launoius bonus erat Criticus; Ad hoc autem magno fuerunt ei emolumentu familiaria cum Jefuita Sirmondo colloquia. Omnes ferè Gallicanarum Ecclefiarum Veteres Traditiones impugnavit, fententiam fuam Sulpitii Severi \& Gregorii Turonen/is Epocbis fuperftuendo, quæ tamen omninò falfe funt, ut peritifimis pluribus Criticis perfuafum eft. Moreri Diction. Gall.

Nulli forfican Critici inter Catholicos extiterunt, qui tanto cum emolumante tantoque fuccellu libertate illa ufus fit, qux tam necelfaria elt iis omni- 


\section{CELEBRIORUM AUTHORUM. 1041}

Bus qui de aliornm Scriptis fanum judicium ferre volunt. Hujufmodilibertàs audaciam cam in illo produxit, qun quifquam alius impunè fortaftis agere non effet aufus: Hanc veio audaciam fecura eft paulo nimia confidentia in propria fua authoritate, qua ipfum ad pracipitata quandoque impulit judiciade Scriptis feu Opcribus quibufdam non femper à fe examinatis accuratione \&acumine Gbi folitis. Catera tamen nunquam fatis laudari polfet Vir ille øuoad forti andinem illam qua promovit Pofutive liberationem à jugo fervitutis qua premebaturà Scbolaftica. 7rdicia Eruditorum per Bailletwm Parifiss 168.5. Gallicè.

Extat de Variâ Arifotelis in Academia Parigna fortunâ. Haga Comitis $1656.4^{\circ}$.

Extat de recâ Canọnis Nicani 6.intelligentiâ. Parif.1662.8\%

Reliquz ejus Opera variis in locis atque temporibus funt impreffa.

Epitaphum ejus hoe eft:

D. O. ML.

Wic jace Launoius Contantienfis, Parifienfis Theologus: Quiveritatis affertor parpetuns, Iurium Ecclefie of Regis acerrimus vindex, vitam snnoxiarn exegzt: Opes neglexit, o quantulumcungue, in relidturus, fatis babuit . Multa fcripfit milla spe, nullo trmore: Opizinam famam maxiviamque renerationem apud probos

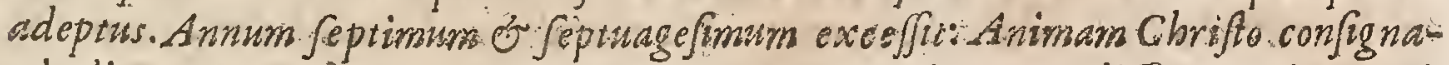
vit die Io. Mart. Ann.167\%. Hoc monumentum amico jucundifsmo poni curavit Nicolaus le Camus, supremesubjidionim Curia Princeps...

\section{JOANNES LIGHTFOOT}

N Atus eft in adibus. Pattoris Stoke ad Trentam in Comitatu Staffordienfi, Clar. An. D: die.Veneris 29.Martii 1602. Obiit Elia 6.Decemb. 1675 . Compofuit Harmoniam Vet.\& Nowi.Teftamenti: Horas Hebraicas in quaver Evangeliltas, mulaque alia fcripfit, qua duobus Tomis fol. impreffa funt Latinè Roterodami 1686.

Ejus cruditio optimè ex Operibus ab eo editis nota eft. Sita prafertim erat in Hiltoriâ, Chronologiầ, Theologiâ Syftematicâ:, Oriéntalibus Linguis, fed præfertim in Rabbinorum \& Thalmudicorsa Scriptorum leatione ac cognitione. In hifce ultimis fine dubio multum temporis ac laboris impendit, ac puto me polle dicere, quantum quidem ex ejus Scriptis apparet, iil utroque. Thalmude, (in quorum imelligentia fita eft potifimum eruditio fudxormm, guippe quibus eorum Ius Eanonicum \& Civile continetur) Euille eum verfacifinum \& pericifimum omnium Europaormm-Stylus 


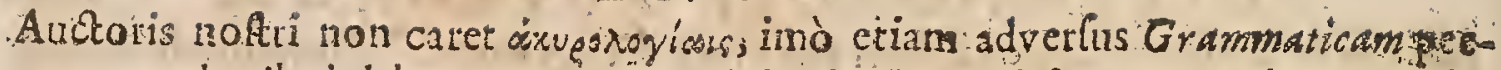
calt; qued tribui debet perpecuae vertationi Thalmudiftarum Rabbinorum, librorumque al is Linguis Orientalibus confcriptosum, quorum genius valde diftar ob Occidantalitim genio; \& rare lectioni Auctorum noftorum gi lin guâ vernaculâ ufínt, qu d compofrionibus luis ac cogirationibus fatis occuparcur; \&aliquando ciam furte hoc inde orirur, qued fingulares adinodum fint ejus Opiniones. Qbfervari ciam potelt, eum fxpè multùn differrè plerifyuc ompibus Chronologes, ut in temporc Nativitains Cbrifi, tempore a Chrifi Bapritmate ajus marten, duobufque terminis feptuaginta Hebdo-

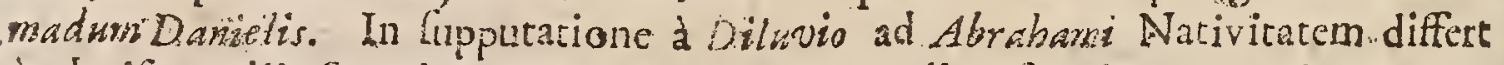
à plevilgue aliis fexaginta annis, idque propter diverfam interpretaionem Ge= nef 1. $26 \%$ \& quia pobat Abrahamum non fulte maximumntu flioum Therachi. Vid:Georg. Lright Prafar.ad Opera jo Lightf. Impreilovol, fol Raterod. 1686.

De le Moinecrudicus Minifter Ecclefix Reformatx Rothomagenfis, in epiltad Doctorem orthingtonum, verba faciensde Notis fürs \& exercitationibus in. Iofephum,ait; In îs utor fapifimè notis Lighifootiz. Thalmudice doctifrni, quem inter Philcbraorum familiam ducemutixero, nihil cerè dixero, quodaflurgat ulera meritumerudirifimi illins viri. Quę de Templo, de Chorogiaphiâ frcrầin Matthaum, in AEtus, ervitie \& feliciter confcriplit, diu eft quod illapoladeo, iifque praslaris Operibus Bibliodhecamea fiperbit.

Exboris ojus. Thalmudicis incepillius doctrinam \& diligentiam valdè amare. Illę laliyam mihi moverunt, ut propedien ab jpio fimilia videre defider $\mathrm{cm}$ \&

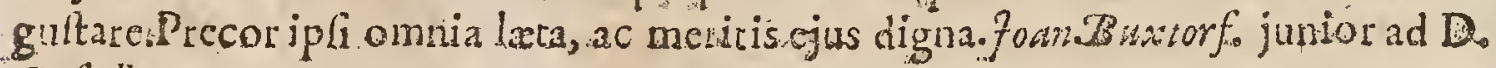
Cafellism.

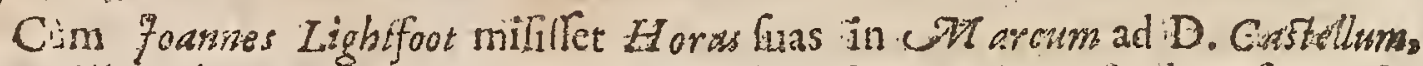
virum illum linguarum adco peritum : refcripfit Castellus, le ab ipfo ineffabilidevincun Beneficio; id erkditum elle \& diu expectum Opus; eumque ditalte ipfus exiguam Bibliohecam, additione tam eximîa \& jucurdâ. Et acceptis Horis in ${ }^{2}$ osmem, accepi, inquit, preterit hebdomad, tho juffu, donum auro quovis, gemmilque contra non charum; quod omnes orientis d vitię aquare non valcant ; taleopus, ut dignum fit qued iecenfatur inter ea monumenta, quę proxima funt infallibilibus Scriptis. A.c certè rara tua inventa in coleftibus veritatibus, videntur mihi omia lupra onnen dubitaioners, aut biefrationem polita.

In Hanponia Evangelica, Harmoñico-Chronico, He Horis Hebraicis Clarif funi Lightroot, plum \& nova \& fructiola reperiet Lector, exintinis Hebraorum penerchlibus cruta. Matt.Pol.Synopr. Critic. Tom. 4 . Prafat.

Cur etian Rich. Simoni invilus et famigeratus Jigtfootiws, qui felicilime in Verus Tetamenta operam pofuit, quod ejus ne minimam quidem mentionem feceait? Ejus Hamonia Vet. Tefanienti, ejus in Genefn Obfervationes \& in Exodum plurefgric alii Tractatus ad Bibliorum intelligentian utiles, digni fanis crant qui obics faltem menoracentur, quod fo quis praftare teneretur, is vide- 
mareffe Rich. Simon, cùm huic Authori hoc cumillo commune fir, quod innumeros Rabbinos citet ;.. fed quibus admodnm felicius utitur quam Rich. Simon. Verum Authores ifti (Hammondus \& Lightvootius) Anglicè fcripferunt:Ideoque hec videtur effe caufa cur illi minùs quam cxteri innotuerint. Theologorum Hallardia fontentia.p.797:"

\section{Hoc ejüs Epitaphiin:}

\section{Joannes Lightfoot; S. T. P:}

Agro Staffordienfi orimaduis, Eccleffie Magne Mundonia in Agro Hertfordienf Rector. Aulæ S.Catharinę apud Cantabrigien fes Prafeltus, e̛ Elienfis Canonicus. Eruditione omnifariâ, prafcrtim Orientali, inffrucliffimus. Qui Thalmudicam doctrinam miro judicis:acumine tractavit, of Rabbirica literatura venam. exhibuit (quod rarum) fine Scariis: S. Scripturis Ob.curioribus lucem dedit, con-

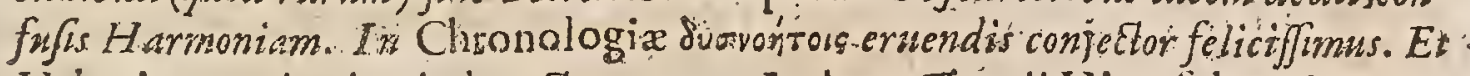
Hebraicx veritatis vindex strenums. Intimus. Templi Hierololytani e My. Aes; Q Qui fecretiors Adyta penetravit, Sacra ordinavit. Atriamenfus eft calamoinere Angelico. Terram Canaaniticam, injurizût temporzs magnä patrte

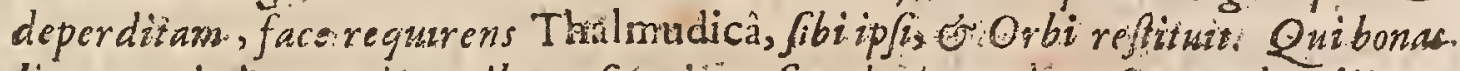

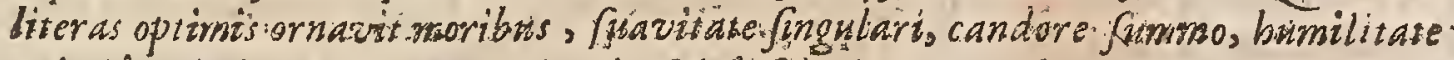
eximiâ. Amicis maximum religui wi defiderium, omnibus extmplium. SenteEtutevegetâ, fudendo, fribiendo, concionando lubenter impensâ, depofuit tanders quicquid erat mortale. Hovis verò Hebraicè O. Thalmudicè impenfis Noon.

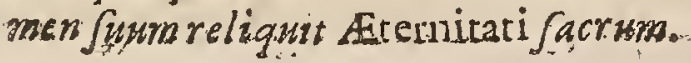

\section{THOMAS, HOB BES}

TI Atus eft CMalmesburie, Agri Wiltonienfis, Nonis A pri is,Anirs88. Obiit I 1679.die sto. Decembuis, xtatis fux 9I. Opera ejus Philofophica amo Clàr. An: $D_{2}^{+}$ 1668. Amfterod. in quarto prodierunt.. In eis continentur problemata Phyfica:Dialogi fex de emendatione hodiernx Geometrix : Libri rres de corpore : Liber de tomine: Libri tres de cive: Tract.de naturâ aëris : Tract. de : Irincipiis \& ratiocinationibus Geometrarum: Leviathan five de materiâ, formâ \& poteftate civitatis Ecclefiafticæ \& civilis.Anno 1671. prodiit ciufdera Rofetum Gcomericum.

Thomas Hobbes in operibus fuis âd Civilem Scientiam Pectantibus pluirima luaber quantivis pretii; \& nemo, cui rerum ejufmodi ent incsllectus, negaverit ram profundè iptum Sociètatis H umana \& Civilis compagem timatum tuiffe, uEparici priotum cum iplo heic comparati queans. Et quà à veróaberrats occafio sem tamen ad talia meditanda fuggerit, qux fortaffe aliàs nemini in mentem ye-

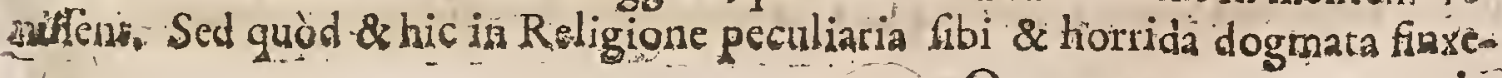

$$
\text { Qg9g. } 2 \text {. xitg. }
$$


rit, hoc ipio apud multos non citra rationem fui averfationem excitavit: $Q$ uanquam \& illud non rare contingere videas, ut ab ilis maximo cum fupercilio condemnctur, abs quibus minime lectus fuir aut intellectus. Sam.Pufendorf, de Jur.Nat. \& Gent.vide Prafat.ad Lect.

Magnam Linguarum Grece Latineque peritian \& in hodiernis exercitationem haud mediucrem tanto viro adturuere fupervarancum facilè cenfeatur; certè Anglicani fermonis Genium adeò feliciter expreffrt, ut sum preftantilimis Gentis notra feriptoribus conferendus veniat. Excmplo fit gravifinus Hiftoricus Thucydides, quem vel ipfis veteribus fubobicurmm adeo perfoicues. adco venufte \& elganter tranlulit, ut nitil fupra. Vin Thom. Hobb.in Praloq. ad Lector.

Hobbes, Gaffendus \& Cartefus tres funt Viri quos ommibus illis quotquot

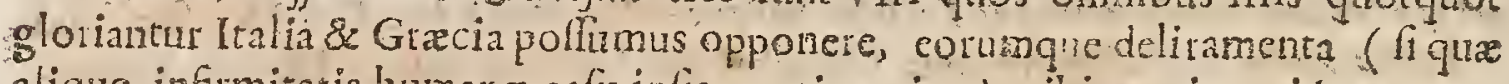
aliquo infmitatis humanx cafu iplis contingerint) mihi magis arrident, quam velgraviflima quorundam aliorum Philolophorum dog nata. Sorbiere Epilt.32. pag. 216. Gal.

Gafjendo fuit charifimus Thomas Hobbes, ctijus libellum De Corpore, manibus pratai noftri, paucis ante obicum menfibus accipiens, of culatus et? fubjungens, Mole quidem parvaset itte liber, werum torus, u opinor, Mcallia fratect. Sam. Sorbieg. Prefin Opp. Gaffend.

Liber de Cive certe eft non v Igaris", dignufque, qui onnium, qui alriora fa piunt, manibus teratur, neque (filla lepoluero, qua Rcligionem, in quâ fumus (t) protundius. Peir.Gafend in Epitad Sam. Sorberium.

Neque parim debere nos profitemur Thora Hobbs, cujus Hypothelis in li-

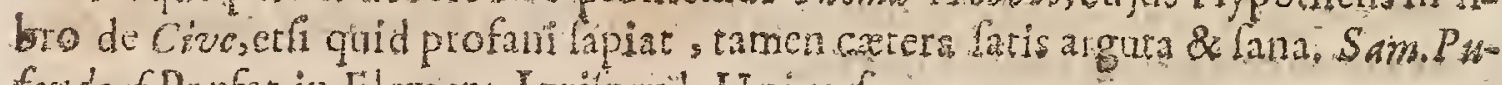
ferdorf. Prefat.in Element. Joriprid. Univerf.

Hoc probel lcio Hobbim nihil nobis obulte, nif guod and veteres in Epicuro reprehenfum Henianus. Us enim Epictows ounia à Domocrito furipuife

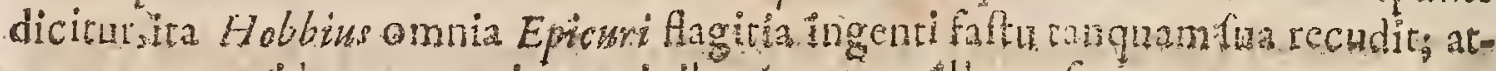

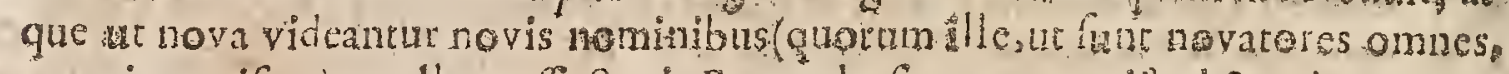
eg:egins artifex app llare afechait. Exemplo fr magnum iftud \& primum on-

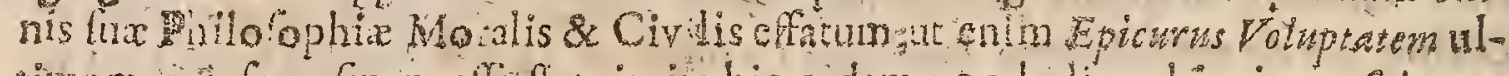

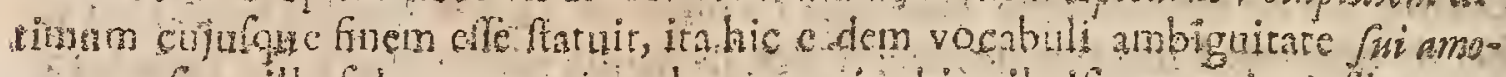
rem, at ficur ille folam corpo is voluptaten, ir hic vil nif corpors ejuidemgue

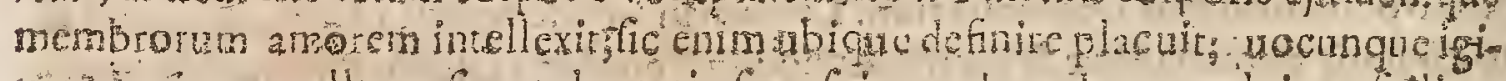

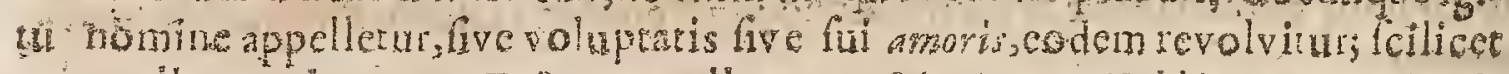

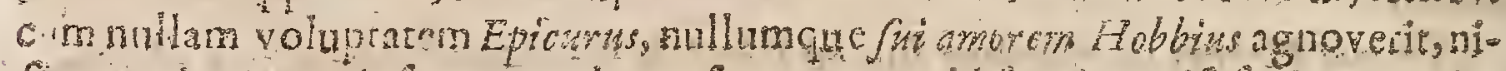

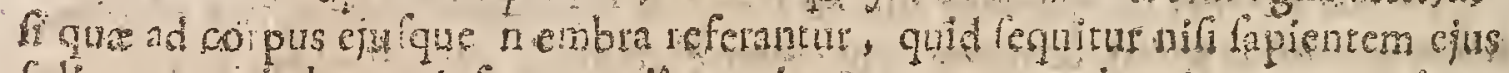
folins curam habere, cinfque gratia omnia noce, atque adeo ab utre we vitam

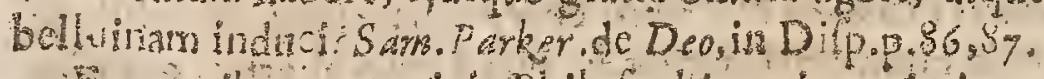

Ex omibusneotericis Philofophis, qui maximi nominis fuerunt, funt Galli-

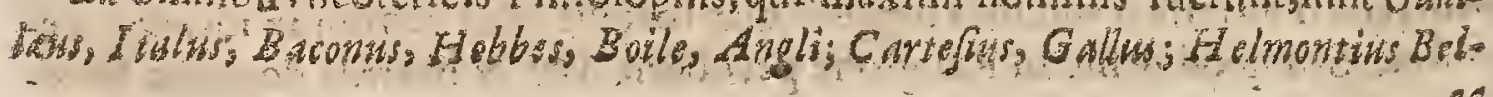


ga-jobbes obfcurus eft gratiatumguc expers, in fuis Ideis fingularis, eruditus, parum amen folidus, in fua dodtina inceaftans, mods cnim Epicuram,

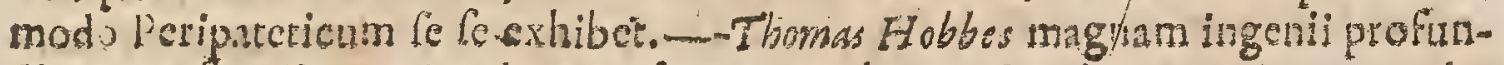
ditatem oftendit, ut etiam inter poftemomm harum Seculoum Epicureos audacifrmus eft, corumg;inomnibus principia, nequaquam fibi temperans, fectatur. In omnibus qux mentem ejufque principales operationes refpiciunt perperam ratiocinatus cft, hotum fcilicer principium Phantalmatibus \& Imaginationi tribuens. Rapin. Animadverfionibus in Vererem \& novam Philol.Sect.19.\& Animadvin Phyf.Sect.9. Gall.

Hoc judicium nuper Galeottus Galeatius Karlsbergius de Hobbiontulit : Famam quam numcrotum proportionumque feicitiâ comparavit, prudentia Itudiis adeo non auxit, ur guoque labefactoverit maximè. Nam justum \& injufum perperam afimat, legem malè defuit, Prinsipemimpiê folvit lege. Civitatem cum adornat, aut deformat, at evertic. Pactorum religione non multim tangitas, Societates Civiles non confiderat, ut debet; jamque princisia nova confingit, jam vetera, majori, d. bium, libidine, an coneradicendi procacinte dellurit. Abfolutum Principi Imperi nallerit; Civem non jur , fed mero Principis arbitrio lubjicit, aftimans, faciendum, paticnd $m$, chin facere, pati, agere, omirtere, pro frudét velir jubieat Princeps. Vercor, ne hic Cyclopicâ licentià Cyclopicam Remp. condar: Vivat in ế Habbefun fi velicmobis longè alia placer. Foam. Decker. de Scripe Adefpot.p.328,329:Am,1686.

Inter Pufendorfum a Grotium medius quafi elt Thomas Hobbes, Anglus, qui in Elementis /hitofopbicis de Civejuris naturalis \& Gentum inticuriones molicus eit fed hie quidem propret Hypotheles quamplurimas maxime para doxas non tantùm exterorum, fed \& civium fuorum indignationem meruir. Ec Lanè, licet Scriptor ille Catis acuti judicii linguzque faris polite fuerit, tamen illi ufrata fcribendi ratio ftupenda n aliquam animi perverfitarcm arguit; Nam Statum Naturatem is proponit talem qualis nququam fuir, nec unquam effe porer. Et falfirmum et quod in Annotatione ad C.I.Sect Io dicit inj frita erga homines Guponit.leges humanas, \&c. foan. Eifenhart. initit. jui. nat. C.2. Sed.1.

Unus Hobbefus, quamvis nova fecta principarum affcans, Logicam fuo viderur attimaffe pretio, folamgue illam ex omnibus difiplinis viteres poffidere art : Utut pefimus in formandis demontratiqnibus artifex \& magnus ac meus plemmque paralogina, atque ex arbirarits ac fetis Hypothefbus juxra cum amulis fuis veram pepriéque dictam fcientiam. Lectori vanè atque finperbè pollicitus. Val. Hem. Fogler de Audionm hodiernis conupelis $37.8 \mathrm{req}$.

Angus Bobbes librố Elementorum Philofopharam de Civecdito non dubitaw

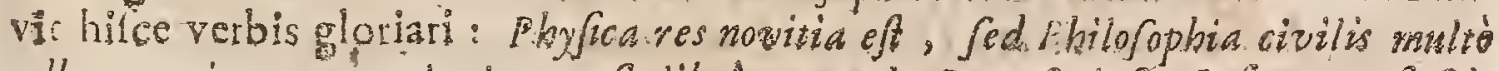

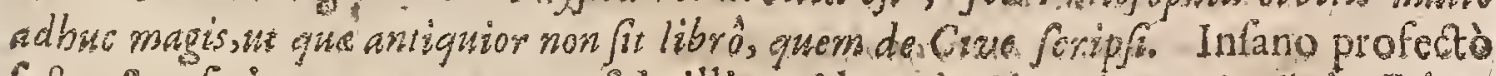
fatu, \&c. fatis autem apertum elt in illis quidem de Cove elements nihil elfe bo ni, quod non ab omn retò memoria fuerienotum Nequidem illud aurem po.

$$
\text { Qg9g9 } 3 \text { nuifet }
$$




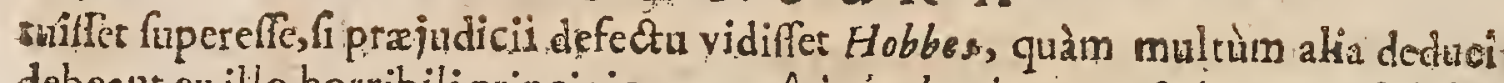
debeant ex illo horribili principio, naturâ inter bornines non focietatem, sed difcordiam inftitutarn effe; \& verd illo pofito omuis focietas humana contra Natusx fuerit intitutum. Qua adfertonelcio num quid excogicari poffit abfurdan magis \& improbum. Sed relinquinus hominem illum intanicni fux fapientim Conring. de Civ. prud.c.!4.fin.

Nifi ipfe fummus admirator fui, quadm Auditor veterum effe maluiffer, ad maximorum ingeniorum gloriam perventurus erat. Ioan. Bö̈ler.in Prefat ad leć. Comment.Grot.

Periculofis ac malè cohærentibus axiomatibus fuis præftantifinam feientiam politicam non parum conturbat. Vö̈t.lib.2.Bibl. Theol.c.22.

De libro cui ticulus eft Leviathan, hife verbis exclamat foan. Arrovvifmitho - Dic lodes, amice lector, ecquis unquam liber ad omne genus irreligionis pa- rentiorem januam aperuille compertus eft Credo equidem neminem, fi de eis. - Cermo fit, qui nomen Christi pra le ferunt.Vid.Tact. Sac. p. 12.4.

Hoc unicum in onnifuâ Philofophia fategiffe videtur Malmesburienfiss, ut. om ques quotquot videmis effectus, tum $N$ ature communis, tum humand, folis materiz viribus afcribantur. Sam. Parker.de:Deo,p \&8.

Samul SMarefus part.2. Controverf.contra Tirinum p.476. Roliticam Hób. befi patria fux morbis exulcerandisquam mitigand is magis accommodatamefs fe exiltimat

\section{In Libellum ejus de 2 Eaturâ Hominis:}

Qua magna. Coli menia, or trattus Maris, Terreque fines foguid ant ulira $e f t$, capit; Mens ipfa tandem capitur: Omnia bactenus-:Que noffe potuit, nota jam primsun efs fibi. A ccede, Lector, difce guis demum fre es; Et Inquititan jecoris agnoscas tui, Quâ propiùs bieret nil tibi, es nil tam procul. Non bî́ Scholarum frivola, aw Cafli Logi

Quales per annos fortéplus Jeptern legits Ot folle pleno prodeat, Rixie Artifex: Kianas gue merces futili lingua crepet: Sed fandia, rerum pondera, o senfus graves: Quales parari decuit, ipfa cum fuit. Pingenda Ratio, r. Vindici fuo adstitit. Panduntur omnes Machinx Gyri tue;. Animarue vesles, Trochler, Cunei, Rotosa. Qua concitetur ante; qua fufflamine. Sificitur illa rux zes; or constet fibi :

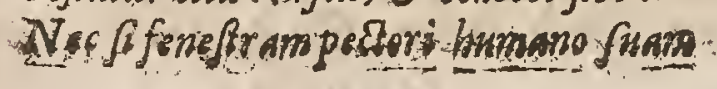


A ptaffet ipfe Momus, infpiceret magis.

Hic cerno levia Affectum yeftigia.

Gracile gque Sensû, lineas; video quibu

Vebantur ális blanduli Cupidines.

Quibugherfimulis urgeant Ira graves:

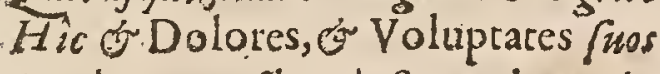

Erodumt recefius: ip se nec timer latet.

Has nôrit artes quifguis in foro velit

Animorum babenas flectere, of popiles chipis

Aptis ligatos nexibus jungt foti.

Hic Archimedes Publicus fgat pedem.

Si quando Regna Machinis Politicis

Urgere fatagit, feras gentes cit\&,

I mifgue Motum fedibus Mundurn quati:

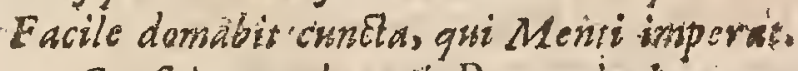

Confultor audax, of Promethripotens

Eacinoris Arime! quis Tibi dedir Deu

Hac inturifaculis longe abditas

Oculof gue luce tinxit Ambrofia tuos?

Tha mentis omitis, at ina nislla eft capax.

Hac laude folus fruere: Divinum est opios

Animaw creare; proximum tanic, Oltendere.

$$
\begin{aligned}
& \text { Rad. Dathurf,A.M. } \\
& \text { Col.Tron.Oxon.Soc. }
\end{aligned}
$$

Sequentia in Dom. Hobbes laudem Anglico carmine cecinir ejus Admirator Abrabam Cowvley, qux ob elegantian Lectori gracum nos facore pustavimus, fir verbation Latinè repofuerimus, guamvis denativo nirore multura ejus allegoria Es deriahi facearnur.

\section{Pro Dom. Hobbes.}

\section{I.}

T Asta Philofophia Corpora

Sepius vidi ac legi:

Sed ea ominia Junt Corpora morttas

Vel Fabricata Corpora:

wadesus autem Vivam Animan contemplavi non licus mo

Precerquan in this Libris \& in Te ipfo.

Deo wnice datur nolfe.

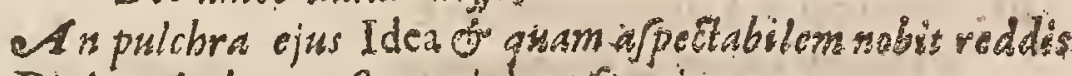

Divino Archstapo fit omnine conforrnissnec ne.

Hoc falietn rudacter profitebots

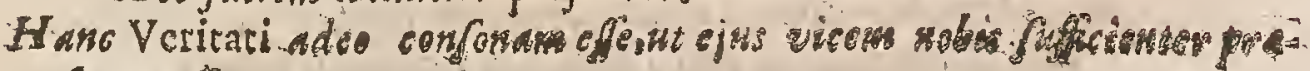
fitarepolit. 
Hand fecus, ac in Natura funt the Proportiones,

Asque ac concors est earum. Varietas,

Tam firmiter guarn pories in Juo guiefount Centro:

Omnia denique tam folida fint,

Ut non minss quarm Natura abhorreant à Vacuo.

\section{II:}

Stagiritapotens diutinum exercuit

Imperium in Univerlas mentes.

Beaxú Leopardus natalem fuam Regionem fubätam viditi.

Fortior Aquila Romana coolavit,

Frequentius atatem fuam renovavit, eamque extinetam vidit.

Ip a Mecha, invito Mahumete occupata,

Horrendogue Diluvio ab Oriente fingata,

Monarchiam $\int$ uam in Occidente denuo condidit.

Sed quernadmodwm vafficujuf vis I mperivetas labilis eft,

Tandernque noom aliud alignod ex ejus ruderibus exurgere fotet:

Sic nobile boc Imperium

Gradatim labisejugque gloria jplendorem marcefcere contigitis.

Fandernque in Scholatticorum manibus omnino interitt..

Tunc mera fuccreverunt verbas.

Eague amnis Rarbara.

Interiit, inquam o evanuit,

Yita ejus ơ Anima exbalatain Aera wacumk abiverunt:

\section{III:}

Arva qua quondan colonorum Aratrocopiosé refpondebants.

Exbaufa of effeta nullam nun $M$ effern exbibent:

Sterilem ac ingloriarn, pinifgue tantim borridam fetatem nusc vivimus.

Prateritamque Abundantiam jactamus,

Unde prafens Pauperies parum lovaninis accipit.

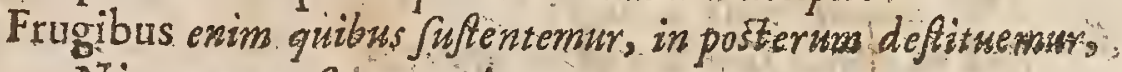

Ni novos conferamins Agros:

Manu facrilega veterum tumulos violamus.

Ipforuris Rudera foruitamur,

Lo Eorum Ruinis ut inanes Uinbra vagari amanxas:

Bacillorumque fulta divinatione

In Defunctorum esfonumentis

Defolfos "rimamur. Thefauros.

Dum Munifica Tellus etiamnum tegit

To intaltas fodinar Auro batenus ireperto footas 
I V.

Tr are Balticrim, Pontus Euxinus or Marp Cafpium. Et ängufti litioris Mediterraneum, Retrufi tenturn Sinus tibi videntur .

Quos perrerent mifella Mentis Horiolą:

Sed ampla tua Navis per Oceanum vaftum velificatur.

Nibilque quam Equcr of Ethera conficatur;

- Donec incognitas Terras exploraverit.

Tin preclarus alter Columbus Aurifera Regionis nova Pbilojoghis:

Quin rovitio audacius quam ille Jufcepifi facinus.

Docla evirn America twa,

Non modo à Te primum detecta,

$\mathbb{N}$ ec inculta futur indufrice relicta fuit:

Sed Facundià tuâ, tuâque folertîn

Blantariis, Coloniis, Edificiis, legibusgue iltam excoluifito.

V.

Raulöantebac putaveram.

( Nec,ufque adeo angusta eft mea chiens.

Tantam opulentiam capere poteram)

Quod quantumvis Eloquentix Promptuarium,

$\mathrm{Ne}$ rnediam quidem partemb fufficere waleret.

Splendidi, novi of durabilis texti,

Ad valida Membra Giganteorum tuorum Senfun veftiends.

Solida tua Ratio, ut Clypeus ille de Cato miffus.

Ad Trojanum illum Heroa.:

Quibufois mortalium telis impenetrabitis,

Auro of Gemmis totus pratere fulgidus eft,

Et mirabilibus geftis : Artis docta manu colatus:

Clypeus, qui conspectus delectamentum affert

Vel ipformin Hostumn oculis,

Tirom etiarn curs certo provident.fe per.illum in pralio fuccubituros:

\section{V. $I_{0}^{\prime}$}

Nec poteft Nix illà, guâ frigida Senectus confpergi

Tuurn venerabile caput,

Fél reftinguere,vel ullatenus languefacere nobilem Ignemgut in illo are deto.

Sed guicguid olim fisisti. 
Et quicgrid poteft effe Juventa, etiarnam in te peresatut.

USgue adeó perfect:

Erueris robore virilis atatis, $\rightarrow$ ividogue Anini flore,

Totogue nacivo calose, Sed eo nullatenus Febriculofo.

Quemadmodumin Eenao vertice, contraria fic conppirantu

$V_{t}$ codsm loco cernere liceat pruin ts \& erumpentes ignesi

Et tarnguan fideles vicini tranquillam pacem colant

Rigens Nix \& Flamma vorax; adeo.utillla prope iftam fecure dormias.

Sed fi tecum exarninemsis

Naturam e. Caufas, concludernus

Rem aliter se habere non pofje:

Rebus Immorcalibus rugas Teinpus induere nequit:

Quodgue morituruin nuinguam eft juventute per enis floreat oportet.

Abrahain Corvley.

\section{PHILIRPUS LABBE, Soc. JeT.}

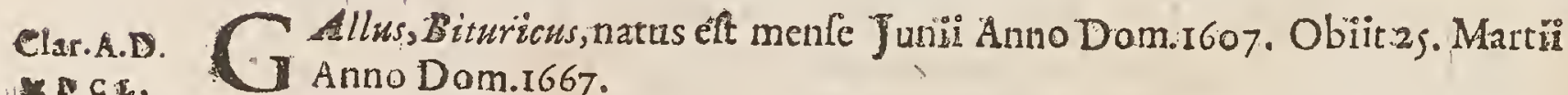

Scripta cius hre funt: Nova Bibliotheca MSS.librorum, Vol.2.Fol.-..De Byzantine Hiftoria Scriptoribus - Galleni Vita - Bibliotheca Bibliothecarum- Concordia Chronologica - De Scriproribus Ecclefiatticis Bellarmini Philologica \& Hitorica Diffètatio - Bibliographir Patrun Sncietatis felu in Francia - Bibliotheca Anti-faneniana - Synoplis Conciliorum - Nocitia dignitatum Imperii Romani. Aliaque edidifet Opera, qux propemodum abiolverat, fillum mors non áblutiriet.

Fhilippus Labbe Soc. Jefu, vir infinita lectionis, \& eruditionis, atque acerrimi judicii in veterum fcriptis recenfendis. To.Bona Card.

Summæ doctina vir thilippus Labbaus. DofJ.de Hilt. Grac.1.4.C.2T.

Pbilippus Labbe, homo plurima utique le Cionis \& induntix, ac merito laudandus, nîf in viros à Papicolis alienos, co!que g aves, pietate $\&$ doctrinâ prafantes, effusè nimis debacchatus elfer.Henning. Witten. Preftat.ad Memor. Theo$\log$.Clarifip. 24.

Jef. Labbeus in duarum Linguram Grace nimirum \& Latina notitia pręfertim excelluit, ut \& Authorum, ac Librorum, Hiltorixque. Sed ejus eruditio longe inferiot fuit ejus diligentię; llleque labo is amor famam ejus utcunque minuit ; quippe qui ad Scriptorum fuorum numer $m$ multiplicandum porius quàm ad eadem expolienda ipfum impulerit, folertifimumque Exferiprotem iplum reddiderit, fed valde mediocrem Authorem in iis qua marte proprio elaboravit, fi que duas Linguas fpectant excipiantur.I udic. Erud. Baillet. Gall.

Quod ad illum Librum attinet, quem je.. Labbens confcripst , cui titulus 
Ipecimar nove Ribliotbeca Mannfriptorum librorum, fatendum eft eum \& utilem frimul \& curiofum elfe: Sed prarterquam quòd admodism imperfectus eft, paulè etiam fiecior \&macilentior quam par effet deprehenditur, illifque explicarionibus, nimium nudarusqua ad indtituti cjus intelligęutiam requi esentur. Ibid.

Jel.Labbei Differtationes in Bellarmini Tractatum de Scripteribus Ecclefiaft: cis, inter Scripta quax:ab co funt evulgata optimis arcenfentur; Que caufa eft, cus: qui ipfum non amant dixerine cum è Jefisirmondi Manufcriptis haufife quxcimque in illa Libro laudabilia occurrunt. Id verum quidem elfe polfet; ; Cum tamen Jef.Lobbeus plures fibi excitaret inimicos fuperbo \& impotenti qua fe gerebat animo, quis dubitet quin probrum hoc in illum gratis cudi potuerit? 20 velle de Republ.Literaria.Jan.1686.p.106. Gallo..

Bellarminzilibrum de Scriptoribus Ecclefrafticis recenfivit nuper, \& Differtationibus Philologicis auxit Philsppus Labbabs, feriptor biliofus, qui planè If maeliticâ remeritate optimis quibufvis, mullâ religionis habità ratione, infultat feriptoribis. Eft feriptum cinus, quod non diffitcor, ager: laboriosè quidem culzus;fed in quo fpinx \& urricx ita luxuriant, ut ne quidem, quod bonæ: frugis effe: videatur,aliundè ceprompzum, deccrpi queat. Hotsinger. Biblioth. Quadri p.p.2.

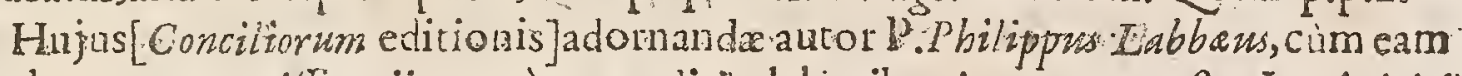
multum promoviffet, piis æquè ac eruditis laboribus immortuus eft. Is Aviricä

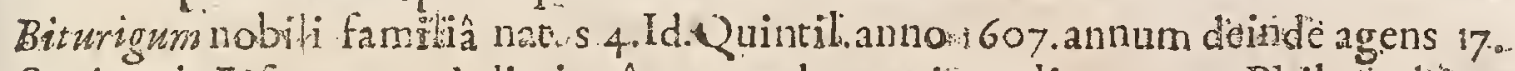
Societari J Jến nomen dedit:in eâque tum hamaniores literas, tum Philolophiam ac Thsologiam, magna doctriiiz commendatione ducuit:ac deinde in légendo: feribendoque totus, egrcgiam in omni eruditionis genere laudèm, ingenti librorum, quos edidit mulitudine, adeptus eft. Vir labotis affiduitate, facilitate ingenii,memoria tenacitare, paucis fecunduis. Ggobriel.Coffart.in Præfat. ad Lect.SS.

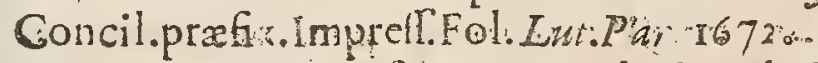

Pbilippus Labbe, fcriptar ut plarima lectionis \& exquifita dodrina; fien ordacis admodum, prefertim in alienos à fuâ, hoc elt Pontifiçiấ, religione calami quos in illo de Exclefiaficic S'Scriptoribus Opere fuo paffim pentlantiffmè criminatur. Sed quod uni alterique impingit plagium, fibi objectum vicifim audit ipfe videlicet C'ornieula efffopicas, \& paffim dicta aliis, eriam nominibus diffmulatis., in rhapfodiam illam ${ }^{2}$ am tranfcribens, ut jam Hitzingerus monuit in. Enneade Differtationum Philologico-Theologicarum Difputat.8. Thomaf.dp Plag. 470 .

Extat Caralogus librorum à Philippo Labbao emillorum, ab amico colleatus. PArif.1662.4\%

\section{FRANCISCUS VAVASSOR; SOC. Jef."}

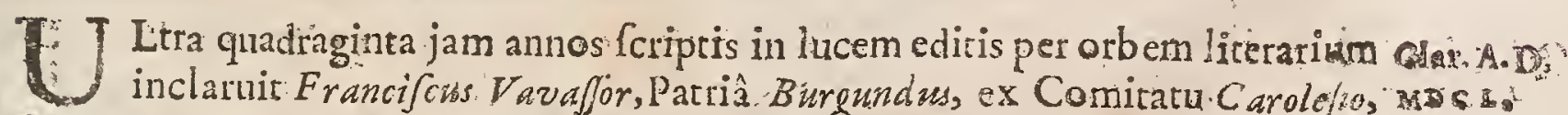
anno atatis I4. fcculi hujus 2I. ili Societatem Jeftlut vocant, cooptatus, \& poltquam Parn liss Humaniora duosiRheroricam quin que, \& Theologiam pofiti-

$$
\text { RTEI } 5 \text { 2. }
$$


yam feu expolitivam fex \& triginta annos docuerat, ibid. Anno 168 , die 16. Decemb.non fine ingenti literatorum marore his terris ereptus. Ala Eridit. Vol. 2. $2.267,268$.

Scripfit trés libro's Epigrammatum: libellum de Epigrain rate: Tractatum de Iudicrâ Dictione:librum de Formâ Chrifti in diebus Carnis.alium de Miraculis Chrifti: l'oëmata varia.

Vir diferifhinus, \& fummi ingenii ac doctinie Erancifous Vavafior fo.Georg. Grav.part.2.Not.in Epitt.Ciceron.p.6r.

Is cettè quidem I udex, cujus perfpicacitatem nihil fugeret, integ ritatem nihil corrumperce. Fo. Lueas in Epift prafix.Petr.70.Perpinan Epif.

Francifcus Vavajjor, vir in altimandis Veterum recentzormane friptis accermi judicii,eruditione mulciplici, Grece \& Hebraice Lingure lciens, ut pauci; Latine ut nemo magisab omni memorî̀. Orator comptilimus, loëtaperelegans, Interpres Scriptura Cemper fidus. fo.Lwc. in Teftimon prafix. Vavajörs Multipl. \& Var.Poërí

Jel. Bowbours ait Vavefforem peracri jud cio, fiquis alius, inter xyi fui Criticos fuille, quamvis ei non altentretur, circa judicium quod ex animi creca imporentia de quibuldam Libris tulerat. Sermones Arifi \& Engeni, Dialc go 2. pag. 169. Gall.

Francifcus Vavaffor ap d fuos Sodales a nnefque Dodos magno fuit in pretio. Eximins Posta, praclaruque fuit Orator, Theologiamque lofitivam toris

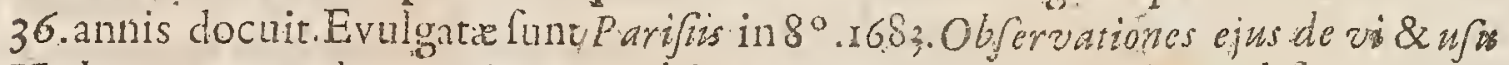
Verborum quorwindam Latinosum. Ibi extant ducente vel circiter Obfervationes Grammatice, ex quibus nob s conftat eum magna aninini contentione Vereres Authores legilfe, plurimafque circa verborum \& phalcon encrgiam fubtilifi. mas explorationes acceptas ipli ferendas effe. Admodum reddidit confpicuam rempus, quo plurima vaces in Lingum Latinam incroduci coperunt, multaque nota fecir dilcrimina inter vocabula qua vulgò idem figra icare putantur. NovelLe de Repub. Literaria.Septemb.1684.p.1320" Gall.

Jef. Vavafjor cujus jacturam Erudici omnes ace bifimè indoluerunt, nus eft fingularin horum ho ninum, de quorum Scriptis n hil deperdi polteritatis intereft. Citra omnem exaggerationem dici potelt eum fi alius quilquam hoc feculo \& in tora Europ.a, omnes Lingure Latinx motos \& argutias optimè calluilfe; Imo nounulli profiteri non dubitannt neminem forfan ab Augufi feculo illam purits \& elegantius efe locutum. De veterum \& recentioun Author m genio perpicacinmè dijudicabat; Mente fana, judicio folido, accuratione incomprehenfibili, Veritatis amore inufutato fammaque ad laborandum contentione commendabilis erat. Teftimonium quo Critices ejus bonitatem limatumque ejus ingenium ornat Yel. Pètavins Epiftolarum furum lib. 5 . Epilt. $34,36,37$. Elogiointcgro xquivalcus eft; sed ex Operibus clatins adhuc innotelcit Autboris meritum. Ephemerides Eruditorm Gallice. 22. Febr.1683.

Liber ille de Lidicra DiCtione qui fo:ulares Poëtas noltros laceffit, mirificus eft in fuo genere, nec folidius ingeniofufque tatiocinari potef quifpiam quam illuftis 


\section{CELEBRIORUIM ALTHORUIM.}

Auftris ille fefuita. Quid dicam de gratiis \& veneribus ftyli ejus, de Critices ejus argutiis, de judicio crod circa celeberrimos, Anriquitaris Authorcs nobis pronunciat? Sanè erudicus Dom. Grevinus nullis dignioribus Laudibus Scriptum illud ornare poterat quàm cuin ipfum fuis in Hefiodum Notis, denominat Librum omnibus Gratiis es Verreribuss condîtum. Si verò difertus Do:n. Balzacius paulo diutius fuperfes fuifet incomparabilemillum Tractatum totis viribus laudaffet. Paulus Colomies fuâ Biblioth.Selèctâ.p.I, 2. Gal.

Francifcus Yaviffor non Jobum modò, fed \& miracula Chrifti heroico verfix extulit, foridior in expingendis Miraculis quàm in fobi Hiforì, ut in quầ arctionbus fefe limitibus incluferat, utrobique tamen purus, planus, emendatus. Borrich.de Poët. p.izo.

Erat Vavaffor bon comptus tantùm"Orator, atque Pö̈ta elegans, fed \& Latisis literature tam fciens, ut new o magis;unde \& tale illi à Io. Commirio, J fuitâspo. ditum eft Epitaphium:

\section{Vavallor jacet hic, guem poffguam fata tulermit, Aulonix Chartes dedidicere logui. \\ Asta Eruditor. Cal. Jul. I683.}

\section{ZUCAS HOLSTENIUS}

I Amburgenfrs, Vaticane Bibliothecx prafectus, obiit Anno Dom.18610 anIl nogue etatis 65 .

Multos Icripteres nondum editos in lucem protraxit. Porphyriz Crrịpta IIEe "גæox $\tilde{4}$ s nitidifímè edi curavit.

Jampridem clarum eft per Orbem \& illuftre Luce Holftenii nomen , \& immortalia cjufdem habentur in rem literariam merita dum eleganti ftudio ariores Aubtores expolivit, corumque memoriam ab oblivione \& interitu, integritatemque à corruptelis vindicavit, reconditas quoque Antiquitates profanas juxta \& factas recenfuit : quarum exacta cura eruditorum omnium admirationem, Magnatum amorem, cumprimis auten Rome Purpuratorum favorem fibi conciliavir,à Erancifco Barberino Cardinale doctiffino ( quem Bi bliotheca \& Facultatum fuarum Heredem ex Afe fcriplerat, Anno 1661.annos fexaginta quinque natus vità difcedens egregio fepulch ra li monumento in Ecclefiẩ

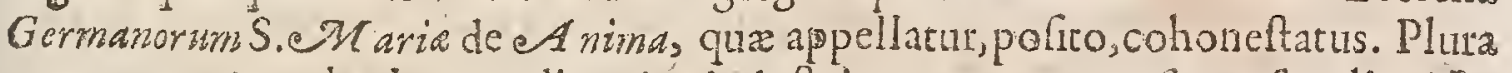
autem extarent plæclara eruditæ ejus induftrix monumenta, fi per fata licuifet abfolvere, \& in publicum emictere, qua affecta habuit. Acta Eruditor. Ann。 $1684 \cdot \mathrm{P} \cdot 487$. lib.4.

Lucas Holfenius Hamburgenfis, eruditorum ocellus. Gaffend. de Vit.Peiresk. 
Lucas Holfenius Hamburgenfis, vir clariflimus fingularis doetrina, \& ading rande eruditionis in onni genere literaturs. To. Card. Bona.

Germanorum, uno aut altero excepto, doctiffimus Lucas. Holstenius.Paul. Cos lome/.in Paralipo n.ad Chartoph.Ecclefialt.p.6.

Leo Allatius \& Lucas Holstenius pra cæreris in Grecorum Aulorum lectione G. Manufcriptorum tractatione verfatiffimi funt. Gab. Naud. in Epilt. ad Pet. Gafjend. Rorne 6.Mart 1 G32.

Holftenum doctiflmum itineris fui Italici comitem vacavit Philippus Cluverizs I tal. Antig.lib.2.

Lucas $H$ olftenius vir fuit qui cum valta eruditione, \& peracri judicio, infolitâ Geographix peritia praditus erat. Novelle de literaria Rep. Torn. I. pag.495. Gallicè.

Publici juris fecit varia de Ecclefantica \& profana Antiquitate Scripta cum Ctiticis Noris, quibus innotuit magna cjus in Antiquitatibus experientia, jud cii ejus loliditas, erudicionifque ejus valtitas Sed pleraque Opera ejus Pofthurna qux in lucem prodierunt, imperfecta vientur, parumque accurata, feu quod morte preventus ultimam ip fis manum non adhibuerit, feu quòd nimis negligentes fuernt qui editiones ejus accuraverunt. Z udicimm Erudit per Baillettum $\mathrm{Pa}$ rifiri635. Gall.

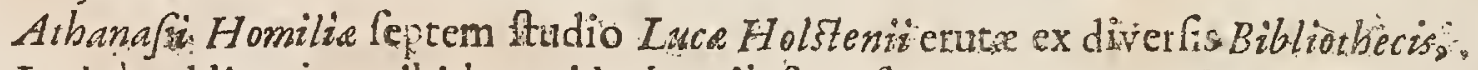
\& Latiné redditx, ita mihi languida, humilefque, funt, nt magno Atbanafo doctis viris indigna prorsùs videantur. Has ego femel arque iterum lcgi, fed pueriles: valdè nihilque veteris fucci continere adveri. Cafornir. Oudim in Supplem. de: Scriptor.vel Script Eccler.à Bellarm. omilf.p. 38.

Extant Emendationes in Eenfebii librum contra Hieroclem. Parif.1628.

Extat Dillertatio de Vitâ \& Scriptis Porphyrii, \&Oblervationes ad Vitam $P_{y-\text { - }}$ thagore, Roma 1 ́́30.80.

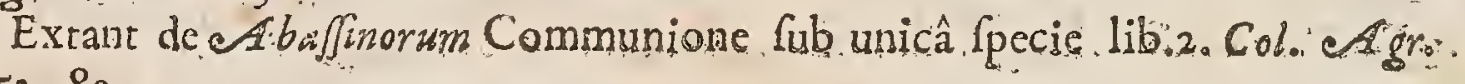
1653.80 .

Hoc ci Epitaphium Atruxit Francifcus Bäberinus: Cardỉalis:

$$
\text { D. O. M. }
$$

Luce Holftenio, Saxoni Hambitegenf, gutclarus in Galliis, Roma clarior, gen tium omniumque tatum Hiltorias \&. Ecclefia res mente complexus, diverfis regionibus peragratis, diverfos eorum fines of nomina probè, tenuit, varias guogue. linguas, preter Gracam Latinamque, quarum: criptoribus plurimum lucis.attua, lit. Antiquam Phitofophiamcalluit. Ab. U band IX. Canonicatu Bafil.Vatic.ab. Innocentio X. prafectura Bibliothecæ ornatus, ab Alexandro VH. Sapienter unus eleclus, ut occurreret Suecorum Gothorumgue Regine incomparabili, qus miram in tanto viro fumm ingenid furmmaque modefiz conjunctionem fufp?xit

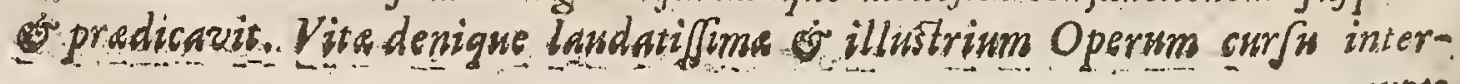


- ottpto, eximins patria Germanix amator propugnatorgue Religionis Catholicx obiit 4.Non. Febr. Anno MDCLXI.

\section{JOANNES HENRICUS HOTTINGERUS}

T Igrinars, Philologus, \& Theologus interprimos noftri feculi.Natus Anno Clar.A.D. 1 Dom.1620. Tancam mulcijug k eruditionis fur Famam voce fcriptiqque in MDCLX. "exteras oras (parfit, ut à Gallis, Germanis, Belgis, Anglis, Sutcis, Danis, Itatis, per literas quoridie adiretur. Ipfe Serenif.Elect. Palatinus Anno Chrift.655. ufuram ejus à Proceribus Tigurinz Reip.petit \& impetravit,ad tempus:quo exacto, fruftra ab Hafiss, Amplelodamenfibus, Bremenfibus, aliis expecitus, rediit in Patriam Anno i661.quas m porro illuttrare perrexit, donec à Cuzatoribus Academia Lugduno-Batave vocatus, veni.um eò difcedendi ad annos aliquor à Magiftratu Tí gur.impetravit. Cui itineri dum fe parat, in Limagi trajectu,undis merfus, obiit Anno 1667 . Hofman.in Lexic.

Scripfit plurima, hace vern palmaria funt: Thefaurus Philologicus feu Clavis S. Scripture-_- Hiftoriz Ecclefiaticie Novi Tellamenti Toni 9. Gra matica quaruor linguarum - Juris Hebreorum leges-Collegium Sapientix Re'litutum-Smegma Orientale - Promptuarium Ieu Bibl orheca Orientalis -Cippi Hebraici-Schola Carolina -Speculum Tïgurinam-Prinirix Heidelbergenfes-Lexicon Harmonicum Pentaglotron-Bibliotheca Hittorico-Theologi-

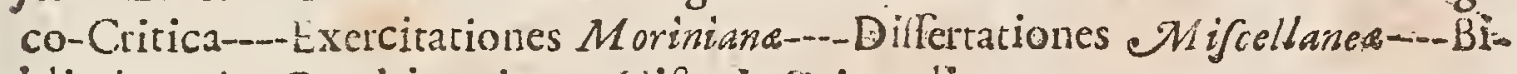
bliohecarius Quadripartitus--iHite in Orientalis.

Fortiflmus Religionis vindex, aby (fus eruditionis, \& literatorum facilè Prin ceps. Io Henr.Heidegger in Vit.cjus.

Haud ita pridem, no vun veluti aliquod Sydus, inter wos exertus D. $\$ 0$. Henr. Hottingerus, amicus mihi exoptatilimus, ad Linguarum Orientalium \& Antiquitatis ormamentum \& incrementum vobis datus \& natus. Addat ei fupremus dies, \&egregiis ejus cenaribus uberiin ex al to bonedicar.fo.Buxtorf.fil.in Epitt.Differr.Philologico-Theolog. pr: fix.

Fo.Henr.Hottingerm non admodum accurtatus eft in fua Orientali Bibliotheca,ut nec in cxteris a e confertip.is. Quamvis ejus libri avidè quadantenus lecti fuerint ob curiolarum rerum quam in illis fabi propofuit tractationem, preclari tamen Scriptoris nomine non gaudet, nec aptud Religionis fur confortes, neC apud populares fuos, ut à Do s. ino Morello celebri Antiquario Bernate milhi relatum eit. Fudicia Eruditorum.16.89. Gall.

Vir-Orientalis literaturx fine exemplo peritifimus, fimulque inufitate indus: Atrix \& probitatis. Conring. de Antiquit. A cad.Supplem. 20.

Nec verò habuit temerè hoc leculum quenquam, cui Hottingerus fueric fe-

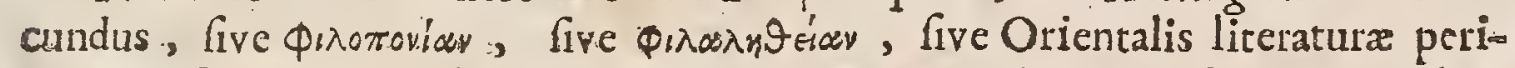
tiam in iftis annis inufitatam videamus. Conring. de num. Ebrzor. paradox sap. $x_{0}$ 
P. Angelus à S. Ioseph taxat Hottingerum, quùd iverbliotbeca Orientali jejunam nimis notitiam circa $P$ erfice Bibliothec Catalogum habuerit, cum in omni: facultate vererum pariter ac recentiorum exhibere potuerit elucubrationes. Adta: Erud.Anni $1684 \cdot p \cdot 4.42$.

Hottingerus fuum Catalogum Scriptorim Ecclefiafticorum Suppofititionum inepriffu è corrafit ex Andrea Riveto \& Roberto Coco. Labbe in Biblioth. Bibliothec.

Si modum aliquem in fuis Operibus fervalfet Hottingerus, nec minutiis ufque adeo inhafffet, aliquid in ipfis ad fensûs Scripturarum literalis intelligentiam. utile reperiri polfet. Sed quoniam ferè femper part um ftudio ducitur, nimifque præcipicanter libros fuas compofuit, frequencibus hallucinationibus elt obm noxius. Unum ex ejus in hoc argumentum Scriptis illudelt, quod adverfis Morini Exercitationes Samaritanas contexulit; led nequidem in hoc Opere omnino accuratus eft. Orat. Presbyt. Rich. Simon, in Hittor Critic. V Telt. 1. z. cap.19. - Gall.

* Hiftoria Orientalis, \& Thefaurus Philologicus, feu Clavis S. Scripturæ, inrer libros prohibitos recententur in Indice Roma edit. anno 1681 ,

Extat Thefaurus Philologicus, feu Clavis S.Scripture, Tigur.1649.4\%

Extat Hiftoria Orientalis. Ibid.

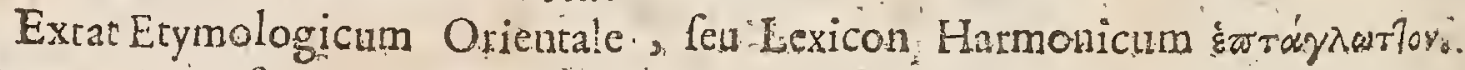
Franc. $1661.4^{\circ}$. in $8^{\circ}$.

Extat Hiftoria Ecclefiaficx Novi:Telt. Enneas feu pars prima. Tigur. I6g.30.

Extat Hiftorix Ecclefaltica pars fecunda. Tigur.1651. 80.

\section{JOANNES FREDERICUS GRONOVIUS.}

Ciar. A. D. Trifconfultus, \& Polyhiftor celeberrimus, Patriàn Hamburgum habuit, ubi: MDCIX. primam lucem afpesit Anno $16 \%$. Mufas ftatim à puero. incredibiliter. amare coepic, feliciterque excoluit. Juvenis factus Germaniam, I'taliam, Galliam. que peragravit, nec non clarifimorum vilorum favore $\&$ amicitia inclaruit. In: Belginm delatus Daventrice fedem poluit: inde in Batevarn A cademiam à potenriflimis Hollandra Statibus in Dan.Heinfui locum evocatus eft. Obiit Leyder. Anno 1672. magno rei literarix difpendio. Konig.

Scripta ejus lunt: Diatriba in Papinii Sylvas---_- Tres Obfervarionum libri-_-Monobiblus Obfervationum in Ecclcfiafficis Scriproribus-_-_Liber de Sefteriis, five de vetere pecuniâ-----Plurimos Clafficos Autores recenfuit emendaYitque, ut Plautum, Salistium, Livium, Senecam, Plinium, Qumilianum, Agellium, \&c. plures emaculaturus fuoque nitori reftiuturus, nifi morte prxvenius, eeptam abrumpere telam coactus fuiflet. 
Gronovius criticus eft eruditionis magnæ, \&, quod ralifimum, judicii paris. Boxhorn. in Epift. ad Ioan.Pontan. Lugd. Bat.1637. Yul. 8.

In vetcrum monumentis reftituendis eximiam notris temporibus navavit operam, doctrinæ copiâ, ingenii acumine, \& indagandi felicitate præftantiffimus vir Lonnes Fridericus Gronivius. Acta eruditor. Vol. 2. p.49.

Gaudeo in expofitione hujus loci confentientem mihi habere virum maximum Ioannem Fridericum Gronovium. loan. Scheffer. Not. in libr. 3. Fab. 3. Phadri.

Gronovii librun de Seftertir, felicifimi ingenii ac profundiffima eruditionis Opus vocat idem Schefferus Notis in lib 4 . Fah. V. hed.

O factum bene ! Gronovi praftantiffine. Quanta lux literis Gresis propediem acceffura eft, poftquam tu illarum interpretandarum provinciam fufcepifti. Nunc demum habet florentillina Acadernia virum, Scriptorum editorum copiâ nobilem, \& cujus fplendore tam clara per fe Profefjio illuftretur -...-. Tu omnes numeros confummatx eruditionis jampridem implevifi. Tanaquil. $F a-$ ber in Epift. 75 .

Tanta funt fuavitatis, Gronovi doctifine, Obfervationes tux, ut lemel in manus fumptas quanquam in multis negotiis deponere nunquam potuerim. Sunt omnia plena emendationibus ingeniofis, explicationibus pereruditis. Ipfa tot scriptorum, de quibus bene mereris, varietas mire oblectat animum; mei quoque quòd benignam fecilti mentionem pergratum elt. Hug. Grot. in Epift. Lutet. 25 - Mart. 1639.

Edidere Senecarn Tragitum varii : Omnibus tamen accuratior hactenus illa editio, qux è pluteis loannis FredericiGronovii exiit, ut qua textum exhibeat curiofifimè enendatum, \& notas cruditas. Borrich. de Poët. p. 57.

Cronoviopra reliquis Statius tantum debet, quantum cateris omuibus, qui aliquid lucis ei affuderunt. Ioan.Veenbuf. in Prafat. pazfix. Stat. Opp.

Remitto cum laryis gratiis Gronovii Papininm. Valde me delectarunt notx tam accurarx, \& in pondere non magno fatis ponderof $x$ Viri ad reftituendum genuinum Autoribus fencum peculiari quopiam Genio nati, à Charitibusque educati. Chr.Daumius in Epitt. ad Thom. Reinef. Dat. Cygnea die 2r. Feb. 1654 .

Ejus in Titum Livium Commentarii magnain exiftimationefunt; Eos evulgavit tribus Voluminibus in $8^{\circ}$. ann. 1665 . Sed Dominus Colonies arbitratur confultum fore fi eis adjicerentur. Epiftolx flii cjus, qui parum provecta retate Patris menfuram, inquit, jam impleverar ; additque plura in iis occurreré loca Geographiam Spectantia mirifice emendatata. Nefcio cur Dominus Fureterius Fobannem Fridcricum Gronovium incommodis Padagogis \& imperitis Critucis an numeraverit. Dominus Baillet, Iudiciis Eruditorum. Pari 5 . 168 g. Gallicè.

Gronovius Livio fuo xternum addictus implebit Patavium fuo momine. Tor eximia in unum caput congerit, ut pulchrè Tumebum referre mihi vid atur; non antem jejunos illos, qui ut plurimum leves ungas magno \& prolixótudio SIIIS 
p. spello venditant. Claud. Sarrav. in Epift. ad Alex. Morum Lut. Par. Prid. Non. Nov. 1643 .

Quàm gaudeo de munere tuo, molem fi libellifpectes, minuto; fin füctum, ingenti.ita multa bona de Seftertio, obiter etiam de aliis doces vel doctifimos; in. his etiam heroas illos Budeum, Hottomannum, Scaligerum, \& tot alios in Rep. literariâ principem obtinentes locum. Gratulor ingenio tuo; gratulator Urbi veft: imò Orbi, quando ut voce urbem, fic orbem calamo doces. Deus diutiffimè te confervet, prafertim feculo hốc ad barbariem non fenfim eunte, fed gradu adeò præcipiri grallante. Quæ è fidcntiùs fcribo, quia nihil periculi eft ne fermo cujufquam inflare polfet; quando non minus modeftiam nirari folco, quàm ingenio acri, acre additum judicium, \& utrique raram eruditionem \& multijugam. Ger. Iob.Vol. in Epir. CCCCLXXXV.

Extat Diatribe in Pap. Statii Sylvarum libros 5. Haga Comitis $16378^{\circ}$.

Extat Monobiblos Obfervatorum in Scriptoribus Ecclefiaficis. Daventric IGjI. I $2^{\circ}$.

Extant Obfervationum libri 3. Lug. Bat. 1639. S'.

Extat de Seftertiis, Ceu veteri pecuniâ Grecâ \& Romaná. Daventrie I643. 8": Et Amiftel. 1656.8 .

\section{THOMAS-WIIIIS.} MDCLXX. An. Atus honefto loco, circa A. C. I620. Patre Philofophiz Magiftro in Academiî Anglomu Oxomenfi creato : ipfe vierò primùn Thcologix operam dedit in eadem Academ iâ : Sed poltea mutato confilio ad Medicinam converfus, ejus Doctor \& Profeflor Philofophix Naruralis Oxonic renunciatus eft: circa A. C. 1667. Londintrin ad Medicinam faciendam evocatus eft, ibique obiit A. C. $1677 . x$ tatis fux circiter 57.

Scriplit de Ferunentatione, de Fcbribus, de Cerebri Anatome, de Anima Bruntolum, 'harmaceuticen Ration.lem, multaque alia qua ad rem Medicam pertincnt.

Nuperrimè Thomas VVI!lir Anglice Academix Dynaftes, cui cùm Fermentatione Febrium Doctrinam clarius quàn fecerint veteres reclufilfet, in Cercbrum tam diligenti incubuit fectione ut demeacula medullaria fucci nervei, fpirituumque aptas ad Cerebri ac interiorum fenfuum motus operationes, \& collaris diverforum animantium Cerebri ftucturis, non confantes imaginationis, Phantafre, appetituum, ac memorix modos, ac demum vel ip am animam brutorum, quàm graphicè oculis ipfis ulteriùs fubditurum promittit, fingulari aufu \& nobili co. tu fitaffecutus. Car. Fracafjat. Differt. Epiftolic. de Cercbro ad Marcell. Mab pighium, p. 177. 17 8. edit. Amftel. I 69. in $12^{\circ}$.

Submilsè ac reverenter veni um polco,quòd Doetori VVillis non affentiar. Nemo fagacis ingenii Praxin ejus culpare poteft: Methodos authenticas non altexavit, fed novas \& plaufbiles pro antiquua rationes attulit. Is in eo Character 
eft agnofcendus, quòd vix quifquam iu ejus fcntentiis dum vigilat cum fuperet; \& hac eft peculianis ejus felicitas quod vel ejus fomnia jucunditate atque coharentia non careant. Genr. Stwbbe, Differtatione de Pilcboromia, adverfus G. Thonfoem p. 4.45. imprella Londini 67 r. in 4 . Angl.

Semper confideravi Diffutationem erudiri illius Viri (nimirum Doctoris VVillis) de Febribus, ut unum è maximi judicii Scriptis yuod acultas noftra unquam produxeric. Succircta eft fine oblcuritate \& fine omiflione ullarum circunftantiarum, qux five frequenter, five rarò fub Mcdici confiderationem radunt, \& cùm Praxis tum Medicamenta tam integra tradunturabeo, tamque ufu comprobata fccrndum Artis \& practicarum C bfervationum Regulas, à nobis obfervatas, ut ab omnibus invidix atque malitix telis fecura fit.ibid.p.172.

Liber ille (Pharmaceutice Rationalis) Donini VVilits poftremum opus non effet nif mors illum abfuliffet in medio glorix, quam Doctis fuis Scripris fibi paraverat. Anglia tumultus obftiterunt ne in Scenam prodiret ftatim ac cjus merita id jure poftulabant: Sed bella non impediverunt quinprivatim pace profun da frueretur, cujus mirifici fructus, animique cjus ptimi fortus fucte Traitatus de Fermentatione, de Fcbribus, \& de Vrinis. Tractatus ejus de Cerebri Anatow miat, de Scorbuto \& de Morbis quos fipant convulfones, in lucem venerunt, haud diù poftquam Philofophiæ profefrone condecoratus fuit. Sed Oxonienfi Univerfitate ampliori Theatro dignus erat. Anno 1667. Londinum Evocatus eft ad Medicinam exerccndam, idque ineffabili gloria \& fuccelfupraftitit. Egrorum a quibus accer ebatur multitudo nunquam tamen fecit ut mufrum fuum defereret, \& poltquam omnem his tulerat opem, Sanis doctrinæ fux lucem imperticbat, nec magnus Prefcriptionum ynmerus quas quotidie tenebatur exarare, non obftabat quin libros confcriberet. Ille quem elaboravit in infolitum Sanguinis ardorem, \& in Mufculorwm motum, in lucem prodiit initio urgentifimarum ejus Occafionum, huncque fecuti funt alii de Anima Brutorum, de $C_{e-}$ rebrimorbis, tamdemque ejus Harmacentice. Ephemerides Gallica Eruditorum. Dici Lunæ20. Julii 1676. Gall.

Triftiffmus affertur nuncius, Autorem immortalitate digniflimum, Pleuritidis incluctabili impetu oppreffum, è vivis exceffffe, nec profuiffe Domino Artes, qux aliis omnibus profuerun Dabit veniam Lector, fi memoria tam facræ aliquantifper parentemus; nec fupervacuum ducet paucis audire, qualis.ille vir fuerat, qui talia fcripferat : porrò intelligere gettiet, quâm bonus erat ille quitam doctus, quàm etiam in pietatis praxi exercitatıs, qui in Praxi Medicâ verfatilimus - Circa Annum I 667. Londinum ad Medicinam facielidam evocatus, minum dictu, quàm citò, \& quantâ cum lande inclaruerit, prælertim cum ita elfet naturâ \& moribus factus, ut nec verbis ad fucum faciendum compoftis, nec vafris Agyrtarum technis fe venditare poflit. Sed licèt totos dies, \& tantùm non noctes in zgrotantium curâ exhauriret, Arti fuxe excolendx librifque confribendis ufque vacavit, unde inter mille interpellationes nati funt Tractatus De Sangninis Accenfione, \& Motu Mufculari, De Animâ Brutorum, De suobis Cerebri, Pharmaceutices Rationalis pars prior, \& demumaltera - 
Porrò pientiflimæ Animæ Divini Numinis cultus eadem ufque cura infederat, \& quandoquidem horis Canonicis in Ecclefâ Parochiali Edibus fuis vicinâa precibus publicis per negotia intereffe non liceret; ut officia facra primo mane \& Cero vefpere ibidem celebiarentur, procuravit; iifque, negotiis quibufcunq; fruft à reclamantibus femper ferè vacavit. Infuper cùm videret inftitutum illud utile ad odum fuiffe pluribus, qui in viciniá pariter toto die in Mercaturâ aliifque artibus excrendis diftingebantur, Sacerdotem id munus per furura fecula obiturum idonco falario dotavit. Vit. Thorn. VVillis,prefix. Opp. ejufdem, Impreff. Geneve apud S. De Tournes $4^{\circ}$.

\section{TANAQUILLUS FABER.}

Vixir\& friIit Ann. $\mathrm{N}$. MDCLXXXV.

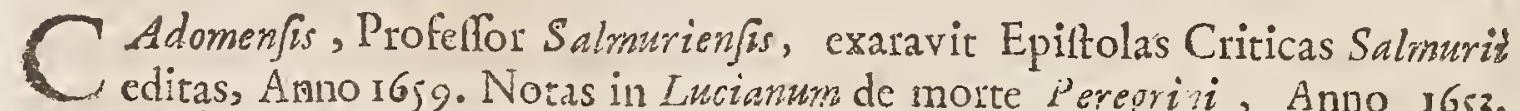
itcm in Elianum, Anacreontem, Dionyfum. Alexandrinum, Apollodoritm, Loriginum, Terentium, Lucretium, Phedrum, I uftinur, \&c.

Tanaquillus Faber Cadonenfis, non Colùm Gracis \& Iatinis Iiteris egregiè eft imbutus, fed \& rarâ valet áyxivola. Sarn. Bochart. in Hicrozoic. 2.18 .

Tanaguillus Faber, homo dum vixit, perfacetus fuit, omnique Gracâ \& Lam tina urbanitate mirificè excultur. Iac. Tollii. Foutuit. p. 320.

Quantum in Linguâ Grasâ \& Latinâ fupra Doctorum vulgus fapias, \& valeas, nemo fere hic ignorat. Cl. Sarrav. in Epif. ad Tan. Fabr. Lut.Par. 29. Mart. IGgI.

Tanaguillus Eaber præclarus vir eft primæque hodicrnorum Eruditorum Claffis. Guido Patin, Epitt. 148. Gallicè.

Tannaguillus Faber Vitas quorimdam Grecorum Poetarum idiomate nofto contexuit. Author Epheweridum Eruditorum ait illas jucundifimo ftylo fcriptás efle, eòque gratiùs exceptas fuiffe, quòd de hujufmodi materia nihil hactchus lingua noftra fcriptum effet. Sed ut diverfi guttûs funt homines, idem ille ftylus qui quibufdam anidet , aliis naufeam ovet quoniam illum nimis humilem deprehonderunt, quique padagogicam ut quidem arbitrantur, affectationem fapiat. Praterea plura narrare poterat quàm ab co facum eft. Multam tamen eruditionem continet illa synopfss, dolendumque eft quòd nihil nobis dixerit de infigni auxilio quod ex Opere Iilii Gregorii Giraldi accepit. Indicis Eruditoru per Bailletturr Paris.1635. Gallicè.

Tanaquilus Faber duo evulgavit Volumina Epifolarur Pbilologicarum 4. Tomis. Omnia quz illis pertractat Argumenta ferè funt Critica. Ilurima in illis viluncur Veterum loca quæ admodum eruditè ab ipfo explicantur, ingeniofe Conjectura ad loca reftituenda qux depravata videntur, eximix que obfervationes circa Hifteriam \& Chronologanrm. Sed difficile eft dicere an magis 
proficua quàm nocua, fit Authoribus de qubus loquitur, ill Domini Fabri Critica. si cuim plura operumillorum loca elucidavit, pluces in iidem notabiles nævos propalavit, imo etiam contendit demonfrare illos frequenter linguam non intellexiffe qua in fuis Libris uf funt, ncc Authores quos in illis citant, \& inter alios in exemplum adducit Titur Livim, Terentiven Arifotelem, Horatium, Tarinum, Eufébium; Euthativor \&c. Satis ei non fuit Hifloricor \& Poem tas emendare, Crilicem fuum in ipfam Scripturam Sucr:m convertit, pluraque tetigit loca in quibus voces mutavit, periodos tranfpofuit, \& quandoque lineas integtas erafit: idque nullam ejus quod alferit probationcm afferens, nifi quòd fibi videatur fenfum hac ratione meliorem \& pleniorem fore. Ephemerides Eriiditorwan Gallicx, Diei Lunæ 3. Maii 1666..

Extat praterea in hoc altcro Epiftolacum Volumine Aristophanis Comedia una, quam recèns Latinè reddidit doctifiméque commentarus eft Dom. Le Fevre. Potuifet tamentam follicitè non explicare quadam in quibus ipfe Arim Eoph nnes aliquam obicuritatem affectafe videtur. Abfurdum faltem videbitu quòd eodem Volumine ocurrat explicatio plurium Scripiure Sacra locorum \& fpurcifinorum Arifophanis dictorum, ideft, corum qua in Ethnicorum libris impurifima funt, \& coium qux in Chrificnifmo ut fanctifima fufpicimtur. Ibidem.

Qua cim ita fefe habeant, miror extitilfe nuper admodum Tanaquillum $F$ am brum, virum catcra eruditum \& ingeniofum, fed præ nimio fui amore caligantem haudrarò, quod ferendum utcunque effet, fi hrec $\Psi_{\text {b } \lambda \text { ou }}$ lios \& immoderata fui oftentatio cum malignitate \& contemptu alieno non conjungeretur. Hunc, inquam, Tanaquillum Labrum miror in Epifolis nuper cditis aufum affumare, næy fum, nedum fublatum fuiffe, cumvix alius in toto $\mathrm{N}$. fone locus occumat, qui ingenia noftri temporis plura excrcuerit, atque in fe converterit, ut jam vidimus. Nec monere id neglcxit meus pater in editione fuâ, quâ fe ufum elfe Faber ipfe non diffictur. Iftud verò magis mirandum tam fecurè \& confidenter Salrn fra a crivia à Fabro compilari, \& cumpulva culo, quod ajunt, hoc efts

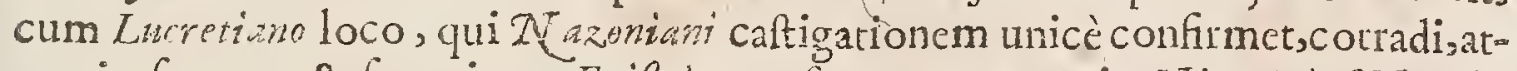
que in fuccum \& fanguinem Epifolarm fuarum converti. Nic.Heinf.Not. in Ovid.lib.2. De Art. Amand. verf.660.

\section{Sit gracilis, macie qua malè viva fuâ eft.}

Tanaquillus Faber vir dootifimus fuit, Philologus, Græcarum literarum peritiflimus, velocis fed \& auáacioris ingenii, Salmurienfis Academia Profef for: multa ex ingenio fuo in Autoribus repofuit, etf Manufcriptis Libris deftitutus; qux tamen ipf temecitas nonnunquam feliciter ceffit ingenii folcrtiâ $\mathfrak{c}_{x-}$ pè percipienti, quod alii magno labore in Manufcriptis requirmnt. Non femel cancn aliis ob audaciam fuam vapulat Scriptoríbus : nam corrigit Lepè pro

$$
\sec 3 \int_{3} \text { Jubirt }
$$


lubitu mendofa loca, deftruit, adificat, mutat quadrata rotundis. Multa fuarum conjecturarum complexus eft Epiftolis fuis, quarum libri duo funt, quibus autorum veterum loca adverfus omnium fententias explicat, ob feftivitatem ingenii \& acumen magno in pretio habendus. Aliquem Epiftolarum illarum locum, ubi Livium reprehendit, ut qui quondam Latinæ Linguæ vocem non fatis intellexiffet, fugillarunt Epherneridum scriptores Gallici, qui tamen ab ipfo probè depexi libro quodam Gallico, cui titulus : Iournal du lournal.

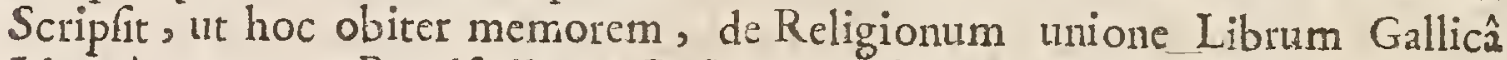
Linguâ, quo nec Pontificiis nec Reformatis placuit, illorum vitia in nuditate fuâfiftens, horum verò invidiam incurrens, quiod jungere Gryphes Equis lasboraret: qui liber $\&$ in Belgicam Linguam converfus eft. Cæterùm magna fuerunt iftus Viri Calamitates domefticx, de quibus frepè conqueritur.- Filiam doctam habuit, qua hodie libros fcribic in gratiam Delphini, qux \& ipla dicitur imitari Patrem. Edidit quoque prima Scaligerana, quibus Præfationem pramittit, in qua de fatis fwis queritus. Dan. Georg. Morbof. Polyhift. pag. $297,298$. 


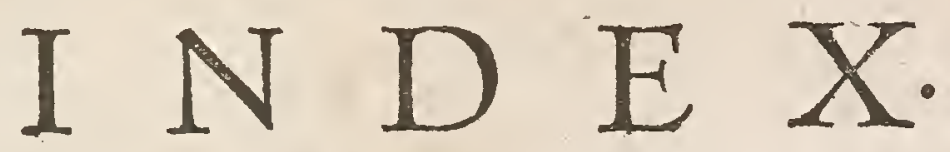

Prima Columna continet Indicem Alphabeticum Auborum qui in boe libro recenfeniur; Secunda defgnat Jeculum Authorum qui ante Chriftum floruerunt; Tertia feculum corum qui poft Chriftum floruerunt ; Q Quarta Paginam libri in qua jingul Autbores reperiri pofunt.

\section{A}

A Ccurfius Francifcus Acolta Iosepbirs Alianus

Amilius Panlus

Afchines

Afchylus

Agathias

Agricola Georgins

Agricola Rodrb!phus

Agripoa Henr. Cornelius

Albertus Magnus

Andreas Alciatus

Alcvinus

Aldrovandus Viyjes

de Alliaco Petrus

D. Ambrofius

Amiotus iscobus

Ammianus Marcellinus

Andeftafius

Anfelmus

Antoninus $M$. Aurrelius

Apollonius Pergxus

Apollonius Rhodius

Appianus

Apulejus

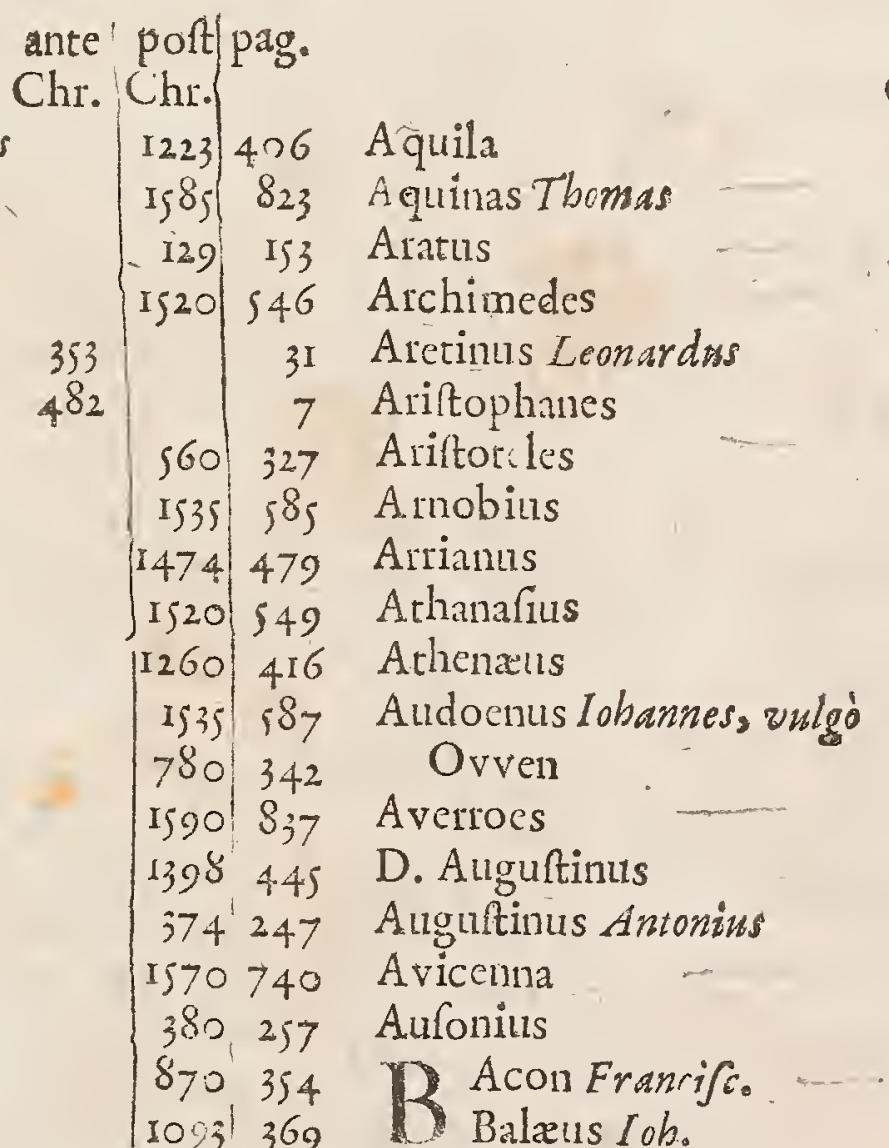

ante poftpag

Chr. Chr.

$128, \quad 155$

I25: 4 I3

\begin{tabular}{l|l}
271 & 39
\end{tabular}

2.2 I

$400 \quad$\begin{tabular}{r|r}
1410 & 453 \\
& 21
\end{tabular}

343

$303 \quad 213$

I47 166

$3 2 6 \longdiv { 2 2 3 }$

ISS. 167

16 IO 913

$1150 \quad 385$

396270

1570741

$1040 \quad 357$

390268

I6IO 903

1552683

1560) 708

1400447

1640 I03I

$1180 \quad 396$

163 I70 Larbarus Hermolans 
Barclajus lob.

Barlaus Caspar

Baronius Cafar

Barthius Cajpar

Bartolus de Saxoferrato

Bafili:is

Baudius Dominicus

Becanus Ioh. Goropius

Beda

Bellarminus

Bembus Petrus

Bernardus

Beroaldus Philippus

Berolus

Beza

Billius I acobus.

Blefenfis Petrus

Blondus Flavius

Blondellus David

Bocatius Iob.

Boccalinus Trajan.

Bochartus Samuel

Bodinus Loh.

Boëthius

Bradv vardinus Thomas

Brahe Tycbo

Barnabas Briffonius

Brodxus Ioh.

Bucerus Martinus

Buchananus Georgius

Bucholecrus Ababam."

Budxus Gul.

Busbequius

Buxtolfus, Iob. fenior

$\mathrm{C}$

C Iulius Cafar

Cajetanus

Tob. Calvinus

Calvifus eibus

Gul. Camdenus

Camesarius Loachim

\section{N D E X}

ante poftpag.

Chr. Chr.

I 620

16401033

1590 86I

16351010

I350 435

$370 \quad 241$

$1600 \quad 877$

1560712

703339

$1610-908$

I520. 554

IIIS 372

I500 515

257

I560 710

I575 771

II $60 \quad 392$

I $440 \quad 465$

1640 IOI2

$1366 \quad 437$

I610 927

16501036

ISTO 744

$510 \quad 317$

I 348 S 430

I 58 , 789

I5SO 791

1550658

I530 575

I5 $45 \quad 654$

I576. 787

$15: 0 \quad 565$

I575 786

I6IO 910

46

6

:66

I $20 \quad 547$

I5 $45 \quad 646$

Irog 896

1600880

I535 520
Campanclla Thomas

Cantacuzenus Iob.

Canterus Gul.

Canus Melchior

Capella Martianus

Capellus Ludovicus

Capitolinus I ulius

Cardanus Hieronymis

Cartefus Renatus

Cafalob.

Cafaubonus Ifaac.

Calfander Georgius

Caffiodorus M. Aurelins

Caltalio Sebafizan.

Cato M. Porcius

Catullus .Valerius

Cedrentus Georgains

Chaucerus Galfred.

Chemnitius Martin.

Chryfoftomus

Ciacconius Petrus

Cicero M. Tullius

Cinnamus Iob.

Claudianus Clandius

Clavius Chrifloph.

Alexandrinus Clemens

Cluverius Pbilippus

Columella

Cominæus Pbilippus

Comnena Anna

Contarenus Gajpar

Copernicus $N^{\top}$ icolaus

Cujacilis Iacobus

Cunzus Petrus

Q. Curtius

Cufanus Nicolaus

Cufpinianus roh.

Cyprianus

Cyrillus Alexandrinus ante poftpag.

Chr.Chr.

I620.936

I34I 428

1570748

I530 569

490307

1630.971

298211

$154464 I$

I 640 , OI4

IS 45643

$1600 \quad 882$

$1560 \times 727$

514319

IS5S 700

90

44

1057361

I $380 \quad 443$

I5.70 768

$398 \quad 276$

I570 750

57

II $60 \quad 394$

$388 \quad 263$

I5SO $S_{2 \mathrm{I}}$

I92 178

I6I6 931

58 107

1490510

IIIS 375

I535 606

I536 609

I570 752

$1620 \quad 938$

Sol 121

1448,467

I5IS 538

248201

4I 287. 


\section{N D E X}

D.

D Allaus lob. Dantes Aligerus Delrio Martin. Anton. Demorthenes Demplterus Thomas de Dieu Ludovicus. Dio Caffius

Dio Chryfoftomus Diodonus Siculus Diogenes Lä̈rtius Dionyfius Halicarnaff. Doufa, Pater Ianus Doufa, Filius I anus Drufius loh. Duarenus Francifco Ducaus Fronto

E

E I ias, Levita

Ennius Quintus

Epictetus

Epiphanius

Erafmus

Erigena lob: Erpenius Thomas

Evagrius Scholafticus

Eviclides.

Eunapius

Euripides

Eufebius

Ezra Aben

F

\section{TA Aber lacobus \\ I Faber Petrus}

Faber Tanaquillus

Fabricius Georgius

Paysils baulus ante poit pag.

Chr.' Chr.

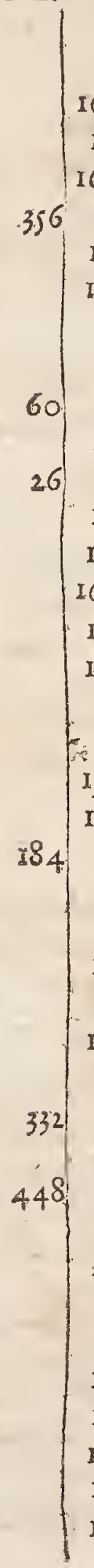

6

1595824

I $597 \quad 875$

$1600 \quad 887$

I550. 660

1610216

540611

1610

49

82

370

I23

239

I5.10 $52 \%$

8,83349

1620940

380

$3 \mathrm{I}_{5}$
Fallopius Gabriel

Fernelius Iob.

640 ror7 Ficinus Marfilius

I310 42 Flacius Illyricus, $M_{\text {att }}$.

1600885 Flaccus C. Valeritus

29 Florus 2. Anneus

1610 914 Folieta Hubertus

16;0 97; Fracaftorins Hieronym.

230194 Frontinus Sext.Iul.

III I45 Fulgentius Afer

62 Fulgentitts Grammaticus

140.158

917

595333

35

260

$I_{2}$

II 4538 Gregorius Magnus

Gregorius Nazianzenus.

Gregorius Thumaturgus.

I5O3 521 Gregorius Nyflenus

I5 $59 \$_{26}$ Gronovius.loh. Frid.

I5851060 Grolteft Robertus.

Is65 729 Grotius Hugo

I545 645 Gruterus fanzs

Itt.t5 ante poft pag:

Chr.'Chr.

1535.596

$1540 \quad 623$

1430,492

$1560 ; 714$

73 ' 116

201 I 184

I565 737

I530. $58 \mathrm{I}$

S5. 128

$508 \quad 318$

510 3is

$1494 \quad 513$

143165

IISI 358

1605.897

1625964

1455473

I5 4565 I

II2 146

I5SO 793

492309

$\mathrm{T}_{4} 4 \mathrm{O}_{4} 449$

I.550 66:

$1590 \quad 8 ; 8$

$1610 \quad 919$

$581 \quad 328$

$\begin{array}{lll}1530 & 584\end{array}$

I570 755

Is5o 666

II3I 380

590.330

370244

254204 .

375. 250

1660 1056

I235 408

1620945

161022 
Grynzus Simon

Gualter. da Hemmingford

Guicciardinus Francisc.

Guilandinus Melcbior

Gulielmus ! anus

Gyraldus Lilius Gregorins

$\mathrm{H}$.

TI Ammoudus Henric.

II Harvcius Gul.

Heinfus Demiel

van Helmont Yoh. Baptifte

Helvicus Chriftoph.

Herbertus Edvvardus.

Hermogenes

Herodianus

Herodotus

Hefiodus

Hefychius

Heurnius Iob:

Heylin Petrus

Hicrocles

Hieronymus

Hilarius

Hincrnarus

Hippocrates

Hirtius Aulus

Hobbes Thomas

Hoefchelius David

Holftenius Lucas

Homerus

Hooker Richardus

Horatius

Hotomannus Francisc.

Hottingerus Iob: Henric.

Hoveden Rogerius

Huntingtonenfis Henricus

Hyginus C. Intius
INDEX

ante'poft $($ pag.
Chr. Chr.

\begin{tabular}{|c|c|c|}
\hline $\begin{array}{r}1530 \\
1335\end{array}$ & $\begin{array}{l}570 \\
426\end{array}$ & I \\
\hline 1520 & $55 \mathrm{r}$ & Amblicus \\
\hline Is 80 & 795 & Jamefius Thomas \\
\hline $25^{8} 4$ & 830 & Janfenius Cornelius. \\
\hline 1530 & 577 & $\begin{array}{l}\text { Ignatius } \\
\text { Jofephus Flavius } \\
\text { Jovius Poulus }\end{array}$ \\
\hline 1640 & rorg & Irenæus \\
\hline 1630 & 987 & Ifrus \\
\hline 1630 & 993 & Ifidorus Hifpalenfis - \\
\hline 620 & 955 & Ifidorus Pelufiota \\
\hline 1615 & 929 & Ifocrates \\
\hline 1630 & 996 & Juellus Iob. \\
\hline 156 & 168 & Julianus \\
\hline 24. & 192 & Julius A fricanus \\
\hline & 15 & $\begin{array}{l}\text { Junius Francifc. } \\
\text { Tunius Hadrian: }\end{array}$ \\
\hline 500 & 310 & Juftinianus \\
\hline rgso & 799 & Juftinus, Hiftoricus \\
\hline 1635 & 1008 & Juftinus Martyr \\
\hline 302 & $2 I_{2}$ & Juvenalis \\
\hline 378 & 252 & $\mathbf{K}$ \\
\hline $\begin{array}{l}354 \\
345\end{array}$ & 344 & TT Empis à Thomas \\
\hline & to & Kimchii David \\
\hline & 68 & Kirchmannus \\
\hline 165 & 1043 & L: \\
\hline $\begin{array}{l}1605 \\
1650\end{array}$ & $\begin{array}{l}900 \\
1053\end{array}$ & Abbe Philionus \\
\hline & & L Lactantius \\
\hline Is & 1845 & Lamber. Schafnaburgenfis \\
\hline & 75 & Lambinus Dionyfing \\
\hline 1575 & 773. & Lampridius eAlins \\
\hline 1660 & IOSS & Lanfrancus \\
\hline IIg9 & 400 & Langton Stepbanus \\
\hline IIS & 397 & à Lapide Cornelins \\
\hline & 90 & Lafcaris Ioh. Andreas \\
\hline & & $\begin{array}{l}\text { Latinus Latinius } \\
\text { Launoius Ioh. }\end{array}$ \\
\hline & & Lazíus VVolfgangus \\
\hline
\end{tabular}

ante polt pag:

Chr. Chr.

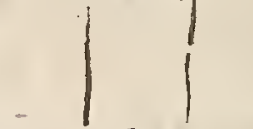

$345 \quad 228$

1620944

1555,684

$100 \quad 137$

$94 \quad 135$

I $540 \quad 633$

179 $\quad 174$

380

$595 \quad 334$

412.296

394

I559 705

361235

$220 \quad 195$

$\begin{array}{lll}1590 & 857\end{array}$

$1545 \quad 652$

$527 \quad 320$

142 I. 6 I

140.599

95 I3S

$1450 \quad 469$

Iigo 398

$1630 \quad 975$

16501050

$303 \quad 216$

1077366

1560715

296209

$1070 \quad 32$

$\mathrm{I}_{2} \mathrm{O}_{4} 4 \mathrm{O} 2$

1620,950

I 490,494

I565 733

16501040

I555, 686 
Lelandus 1oh:

Leonicenus Nicolaus

Lcunclavius Ioh.

Libanius

Lightfoot $10 h$.

Linacer Thomas

Lind'vyood $G u l$.

Lipfus Iuftus

Livius Titus

Lombardus Petrus

Longinus Dionyfirus

Lucanus M. Annaws

Lucianus

Lucilius

Lucretilis

Lullus Rainundus

Lutherus Martin.

Lyranus Nicolaus

Lyfias

\section{M.}

M Acrobius Maimonides.

Maldonatus lob.

Malmesburienfis Gul.

M. Manilius

Manutiıs Paulus

Mariana loh.

Martialis

Martyl Petrus

Mafius Andreàs

Mela Pomponias

Philippus Melanothori

Mercator Gevardus

Mercerus Iob.

Mercerus Iofas

Mercurialis Hieronsmus

Meurfius (oh).

Minutius Felix

Mirandula iob. Picus

Miszus Aubertus

\section{N D E X}

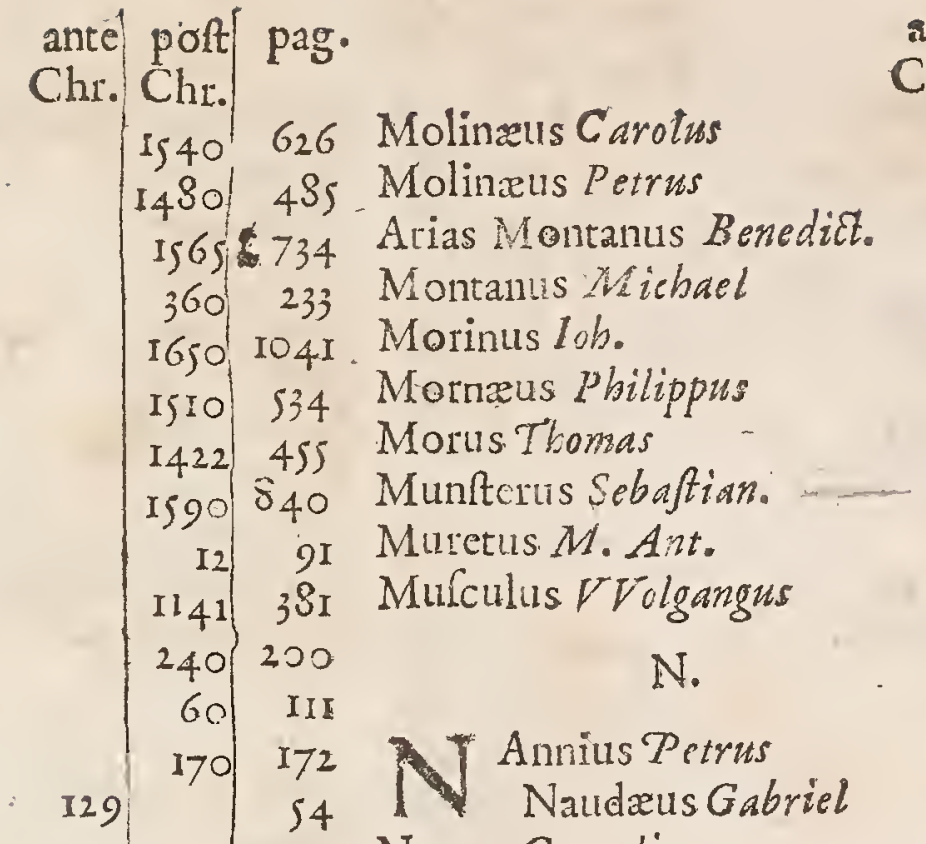

Nepos Cornelius

105

1300.420

I517 540

I320 424

406

Neu brigenfis $G u l$.

Nicetas Acominatus

N.

Cellus Lucanus Incertx Oecolampadius Ioh. xtatis

344 226 Oecumenius

I160 390 Onuphrius Panvinius

I570 $75^{8}$ Oppianus

32

II.3O 378

77

I560 718

Origenes

Orofus Paulus

Ortelius Abrabam

Ovidius

P.

$1540 \quad 613$

I555 703 D Agninu: Sanctes

45104 Pamelius lacobus

I540 615 Pancirolus Guido

1570,770 Papinianus

Isss 697 Paracelfus.

${ }^{1620} 952$ laris $M$ atthous

I580 800 Pafferatius Ioh.

1620 953 Patercnlus Co Vellejus

220 189 Patricius Francife.

1484,497 Paufanias

1630 977. Peirefcius antec poft pag:

Chr.'Chr.

I540 618

$1620 \quad 958$

I575 774

IjSO 8ry

$1640 \quad 1035$

I $595 \quad 872$

$1525561^{\circ}$

$1530 \quad 579$

I575 777

$1540 \quad 621$

I520 544

$990 \quad 356$

$1565.73 \mathrm{I}$

217,187

$230 \quad 197$

$416 \quad 290$

1575780

7

85

$1510 \quad 536$

I575 779

$1570 \quad 757$

$200 \cdot 183$

I535 597

I240 410

$1,85 \quad 831$

27. $10 I$

580797

I39 159

$1620 \quad 260$ 
Pererius Benedictus

Perronius Iac. Davyus

Perottus Nicolaus

Perfitis

Petavius Dionyfus

Petitus Samuel

Petrarcha Francife.

T. Petronius Arbiter

Peucer Caspar

Phadrus

Philelphus Eranife.

P'nilo

Philoftorgius

Philoftratus

Photius

Pichercllus

Pierius Valerianus 1ob.

Pighius Albertus

Pighius Stephanus

Pignorius Laurentius

Pindarus

Pinellus

Pintianus

Pithæus Petrus

Platina Bartbolomaus

Plato

Plautus

Plinius, fenior

Plinius, junior.

Plotinus

Plutarchus

Poggius

Politianus Angelus

Pollux Iuliuss

Polws Reginaldus

Polybius

Polycarpus

Pomponius Iatus I ulius

Pontacus Arnoldus

Pontanus Iob. Iovian.

Rosphyriug

\section{N D E X X}

anté poft pag.

Chr. Chr.

I585 834 Poffevinus Antonins

1600889 Poftellus Gul.

I460 477 Prifcianus

57 105 Proclus

I630 979 Procopius

1640 102; Propertius

I350 432 ProfperTiro

64. II3 Prudentius

I565 735 Pfellus Michael

20 96 Ptolomxus Clandius

1450 47I Puteanus Erycius

40.102

$425 \quad 295$

204 I86

$858,35 \mathrm{I}$

2560,725

I520 557

I535 592

$15,80,802$

1620

476

1580804

I535 607

Is 80 SOS

$1474 \quad 481$

366

182

75

250,203

$104 \mathrm{I}_{43}$

1407451

$1490 \quad 507$

185176

$1540 \quad 627$

4.6

$94 \quad 133$

$14.80 \quad 495$

1600891

$148 ; 500$

$270 \mid 206$
D Abanus Maurus

R。

1. Rabelafus Francifc.

Rainoldus Iot.

Ramus Petrus

Raulxus Gualter

Rhenanus Beatus

Rhodiginus

Rigaltius Nicolaus

Ritterluufius Conradus

Robertellus Francifcus

Rondeletius Gul.

Rufinus

ante $\mid$ poft pag.

Chr.Chr.

I590 849

$\begin{array}{lll}1550 & 667\end{array}$

528326

500.312

$527 \quad 323$

a)

446. 304

405282

$1050 \quad 359$

140156

1630 98.

83

I2T.

847346

$1540 \quad 63 I$

$1590 \quad 847$

I5 60721

1610906

I535 594

I5IO 531

$16309_{93}$

$1600 / 892$

\begin{tabular}{l|l}
1555 & 693
\end{tabular}

II55 695

390,265

\section{S}

C Abellicus

- Sadoletus

Salmafius

Salviantus

Saluftius

Samarthanis Sccuola

49

1490505

$5530 \quad 573$

1640 1025

440,302

Sambucus Ioh.

Sanderfon Robertus

Sannazarius I acobus

Sarisburienfis Iob. \begin{tabular}{l|l} 
& 64 \\
1590 & 851
\end{tabular}

$1575 \quad 7 \div 2$

$1630) 1006$

I500 516

1172395 


\section{N D E \&}

Sarpius P:Paulus

Savanarola Hieronym.

Savilius tenricus

Scaliger Iul. Cafar

Scaliger lofephers

Schottus Andreas

Scioprius Gajpar.

Scotus Ioh. Duns

Scldenus Iob.

Seneca M. Anneus

Sence $L$. Annaus

Sennertus Baniel

Senenfis Sixtiss

Serarius Nicolaus

Severus Sulpicius

Sidonius

Sigebertus

Sigonius Carolus

C. Silius Italicus

Simlerus Iojias

Sirmondus lacobus

Sleidanus Iob.

Socrates Scholafticus

Sophocles

Sozomenes Hermias

Sphanhemius Fridericus

Spartianus : Elius

Spelmannus Henricus

Statius Publius Papinius

Steplianus Robertus

Stephanus Henricus

Strabo

Strada Famianus

C. Suctonius Tranguillus

Suidas

Sydnæus Pbilippus

Szlburgius Fridericus

Sylvius eneas

Symmachus

Syuefius ance poft pag.

Chr. Chr.

I595 864

1480490

$1610 \quad 225$

1535600

I5 80808

I590 856

1630985

$1300 \quad 418$

$1630 \cdot 990$

$20 \quad 98$

6) 109

3610,921 Theophylactus

I5s) 69I Theophylactus Simocatta

I595 868 Thuanus Iac. Anguftus.

$400: 250$ Thucydides

472306 Tibullus

II० 371 Tiraquellus Andrcas

1570760 Toletus Franife.

72 II Torquatus Taffus

Is 70 7.62 Torrentius Lavinus

1625966 Toltatus Alphonfus

I540 628 Trapezuntius Georgius

440 299 Tremellius

$\begin{array}{rll} & \text { I } 4 \text { Trithemius } \\ 440 & 301 & \text { Trifmegiftus Hermes }\end{array}$

Mofi coxvus

Turnebus Adrianus

293 208 Turianus Erancifous

I620 942

85129

I540 636 T Alerius Maximus

I580 Sir Valefius Henricus

Valla Laurentizs

II I48 Vatablus Francifcus

I08 I 367 Vavafor Erancifc.

I586 32.8 Velferus Marcus

I530 813 Vefalius Andreas

${ }^{1} 45^{8} 475$ Victor Aurelius

$39_{4}$ 26I Victorinus Afer.

$4 \mathrm{IO}_{2} \mathrm{~S}_{4}$ Victorius Petrus

Yida $M$. Hieronymus

Ittet 3 ante polt pag.

Chr. Chr.

100.139

1605901

$154 \quad 52$

192180

352,229

$272 \quad 38$

423292

$5 ; 8 \quad 6$

$303 \quad 36$

$1071 \quad 364$

611337

$1600 \quad 89$

$429 \quad 18$

I3 83

$1550: 67$

$1580 \quad 814$

1535835

I 800 8ry

I $440 \quad 458$

1440,460

I56O 723

503

I

688

I55O $68 \mathrm{I}$

27

16401029

$1440 \quad 462^{\circ}$

68

60

153560

I65O $105 \mathrm{I}$

I595 870

I5SO 678

$396 \quad 275$

$352 \quad 237$

1550 673.

1550675 
Vinta Francife.

de illa Nova Arnoldus

Vincutnius Bellovacenfis

Vimcentius Lerinenfis

Virgilius Polyctor.

Virgilius Maro $P$ nb.

Viterbienfis Iob. Arnius

Vitruvius

Vives iob. Luduvi:us

Volaterranus Raphael

Voffius Ger. Iob.

Uifinus Fulvius

Uffrius I acobus

Vulcanius Bonaventura

W.

TT Eftmonafter. Matt. Whothamfead. Ioh.

\section{$I N D E X$}

ante poftpag.

Chr.eihr.

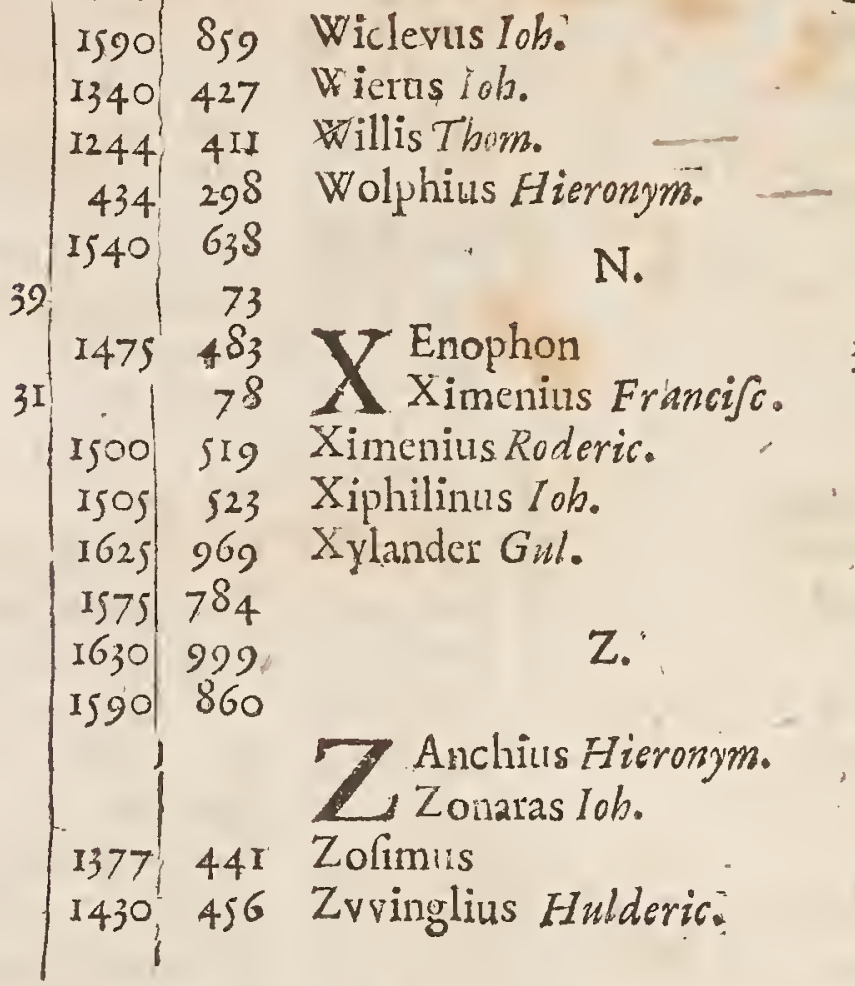

ante' polt pag.

Chr. Chr.

$1370 \quad 439$

I57O 764

$1670^{\circ} 1508$

I570 766

387

I5O6 24

1208

405

$1073 \quad 365$

I5 65 7j8

$F I N I S$.

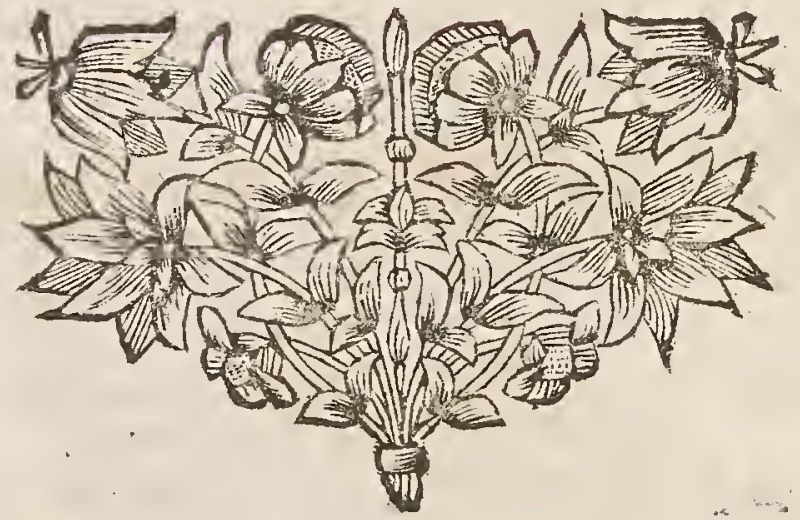




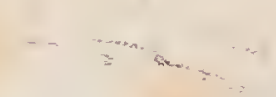








$+$

$+4$

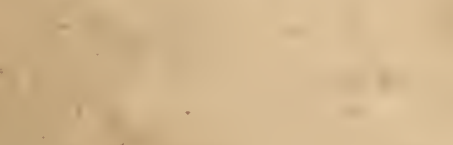

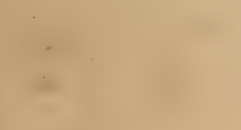

$+$

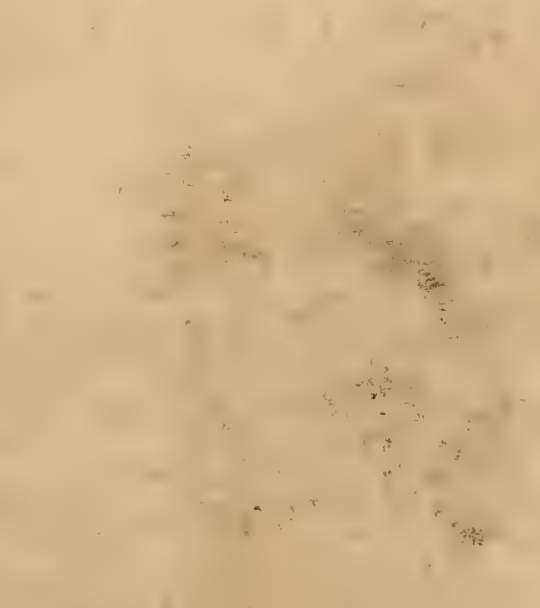

$\cdots$
$\cdots$
$\cdots$

$$
-x+\frac{1}{2+\infty}
$$
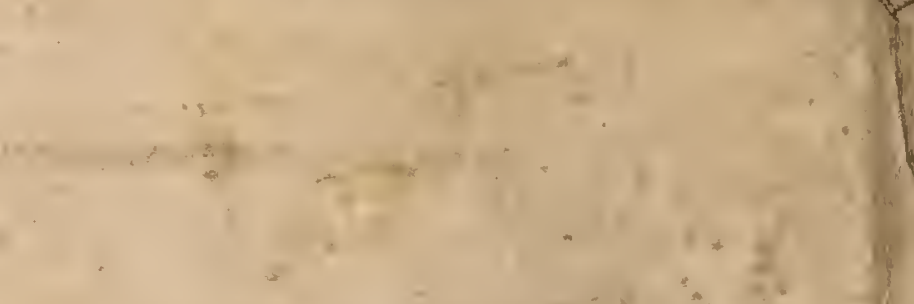

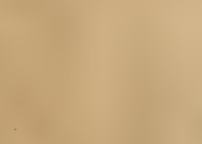

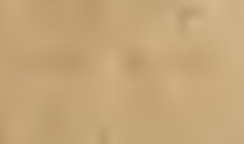

$\ldots$.

$\because$

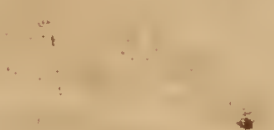

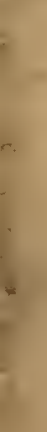
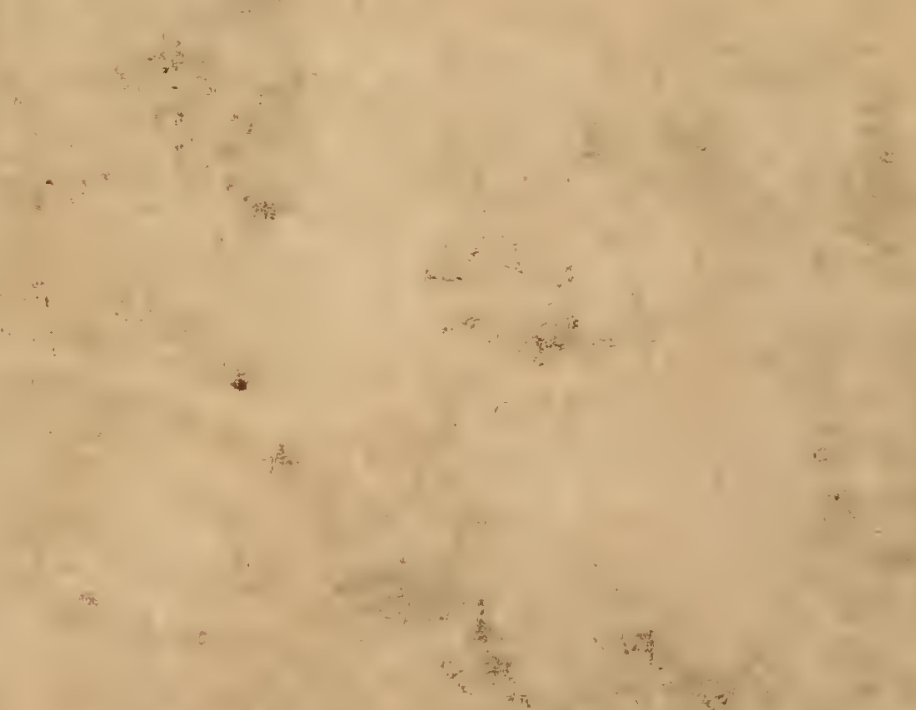

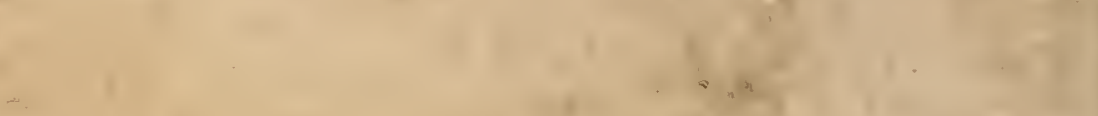
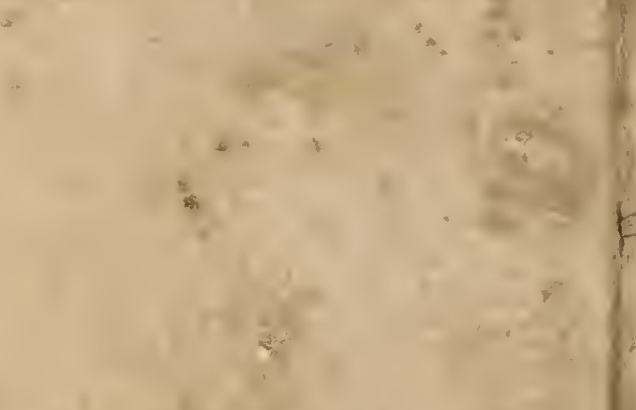

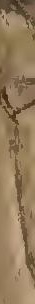
, $\left(\frac{1}{2}\right.$

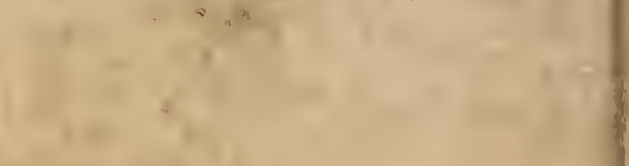

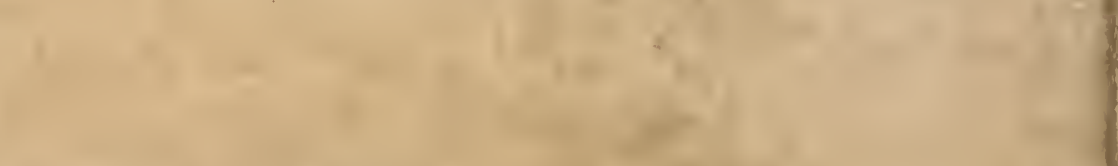

